\title{
Water-Loss Investigations:
}

Lake Hefner Studies,

Base Data Report

GEOLOGIGAL SURVEY PROFESIONAL PAPER 270

Prepared in collaboration with the U.S. Department of the Navy, Bureau of Ships, Navy Electronics Laboratory; U.S. Department of the Interior, Bureau of Reclamation; U.S. Department of Commerce, Weather Bureau

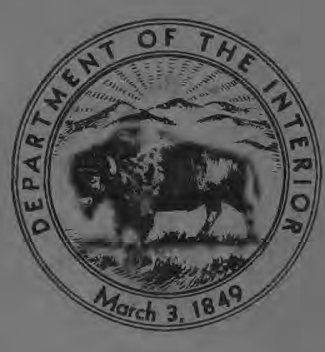




\section{Water-Loss Investigations:}

Lake Hefner Studies,

Base Data Report

GEOLOGICAL SURVEY PROFESIONAL PAPER. 270

Prepared in collaboration with the $U . S$. Department

of the Navy, Bureau of Ships, Navy Electronics

Laboratory; U.S. Department of the Interior, Bureau of Reclamation; U.S. Department of

Commerce, Weather Bureau

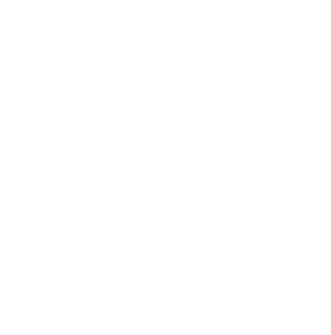

Prepared for reproduction by the Geological Survey and Weather Bureau Part of the edition issued as N. E. L. Report 328, San Diego 52, Calif.

UNITED STATES GOVERNMENT PRINTING OFFICE, WASHINGTON : 1954 


\section{UNITED STATES DEPARTMENT OF THE INTERIOR}

Douglas McKay, Secretary

GEOLOGICAL SURVEY

W. E. Wrather, Director

For sale by the Superintendent of Documents, U. S. Government Printing Office Washington 25, D. C. - Price $\$ 1.75$ (paper cover) 


\section{PREFACE}

This compilation of the basic data obtained in connection with the Lake Hefner water-loss studies was assembled in the Water Resources Division of the U. S. Geological Survey, C. G. Paulsen, Chief Hydraulic Engineer, under the administrative supervision of R. W. Davenport, Chief, Technical Coordination Branch.
The brief text describing the water-budget, masstransfer, and energy-budget data was prepared by G. Earl Harbeck, Jr., Geological Survey, and the text pertaining to the evaporation-pan studies was prepared by Max A. Kohler, U. S. Weather Bureau. The tabulations of the mass-transfer data were prepared by the Weather Bureau from punchcard records. 


\section{CONTENTS}

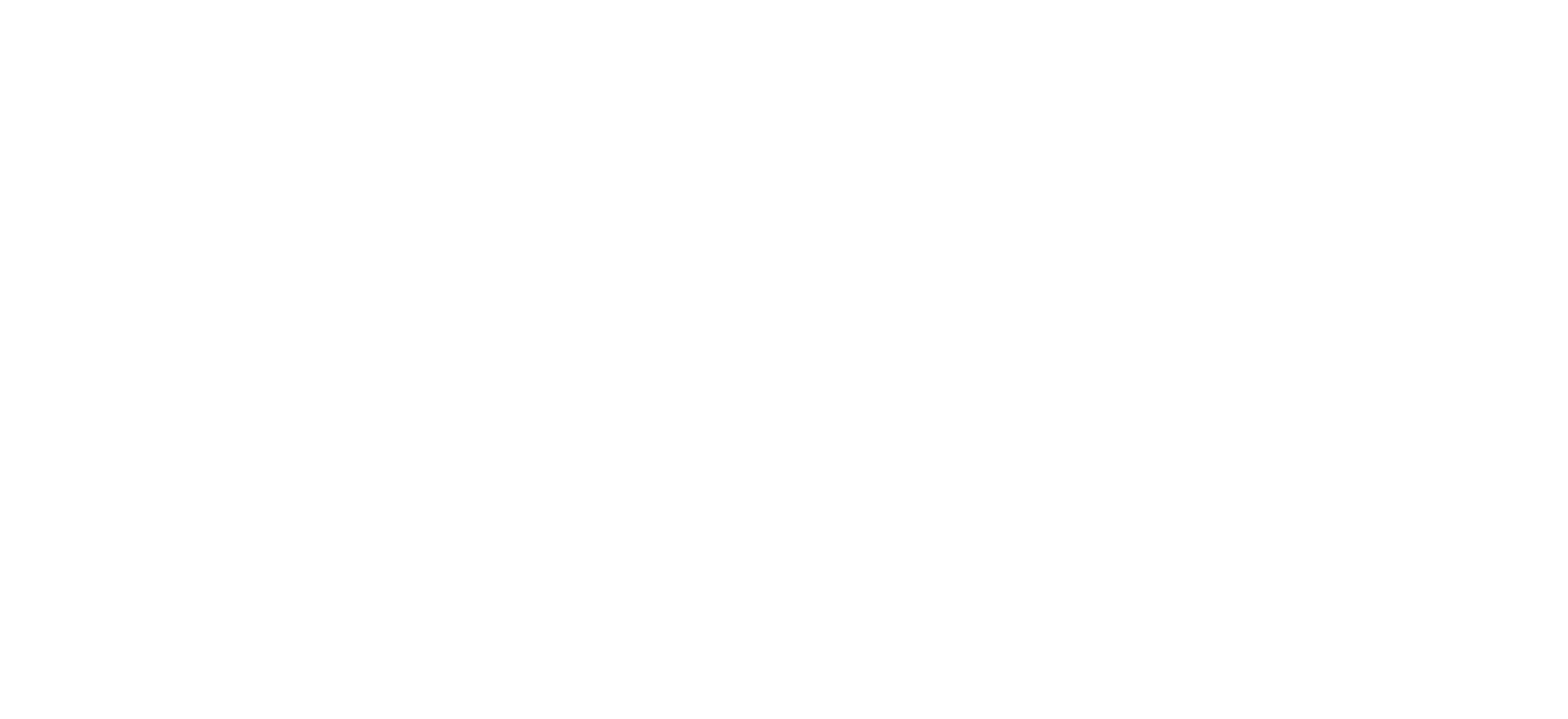

\section{TABLES}

Table 1. Daily water-budget evaporation from Lake Hefner.

2. Monthly water-budget evaporation from Lake Hefner adjusted for thermal expansion.................... 17

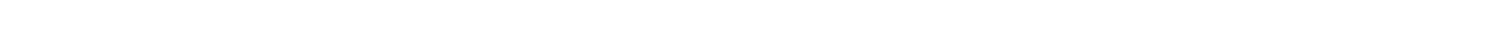

4. Daily flow of Bluff Creek above Lake Hefner near Oklahoma City........................................ 20.

5. Combined daily flow at gages $A, B, D, E, F, G, H$, and $J$, and estimated flow from ungaged area.. 21

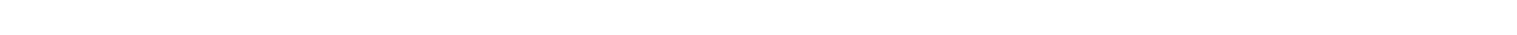

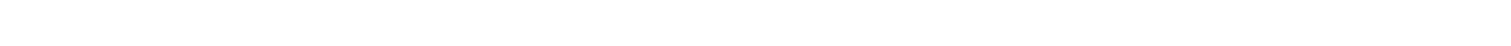

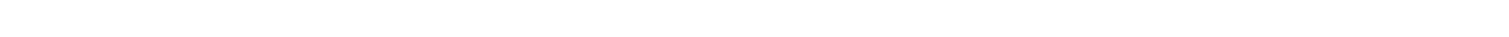

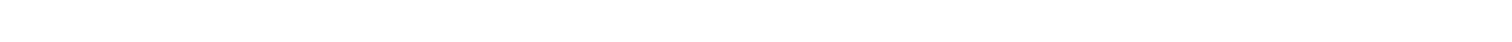

10. Three-hour averages of air and wet-bulb temperatures, water-surface temperatures, and wind

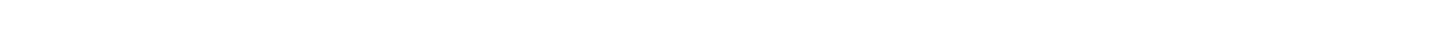

11. Daily averages of air and wet-bulb temperatures, water-surface temperatures, and wind speeds.... 223

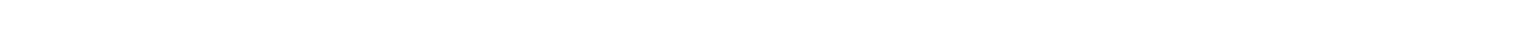

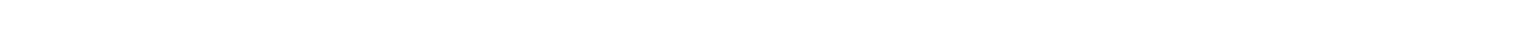

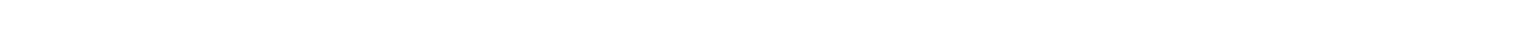

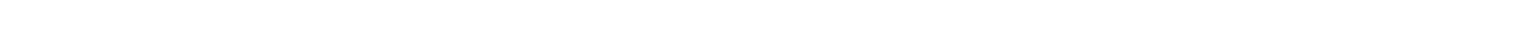

16. Mean water temperatures for 1 -meter layers at thermal-survey points............................. 260

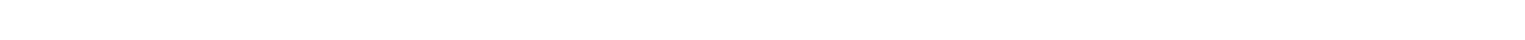

18. Evaporation and temperature data for Cummings radiation integrator and Lake Hefner............... 284

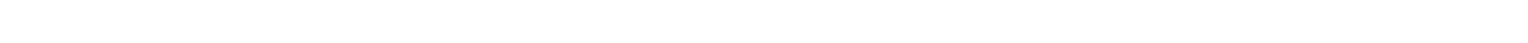




\section{WATER-LOSS INVESTIGATIONS: LAKE HEFNER STUDIES}

\section{BASE DATA REPORT}

\begin{abstract}
This report is the second of two reports on the Lake Hefner water-loss studies. It contains tables of waterbudget, mass-transfer, energy-budget, and pan-evaporation data, accompanied by a brief explanatory text.

\section{INTRODUCTION}

When the Lake Hefner studies were first visualized, it was decided that one of the primary objectives should be the publication of the basic data. Although it was planned that the analysis of data, made by scientists and engineers of collaborating agencies, should be thorough, it was recognized that no one group of analysts could hope to extract all possible information from the vast quantity of data to be collected. How ever, by making these data available, it was hoped that others studying evaporation might utilize them to expand the knowledge of this subject, thereby benefiting all interested parties. Moreoyer, it was believed that these data may be useful in studies having little, if any, relationship to evaporation.
\end{abstract}

The first report in this series 1 (originally published as U. S. Geol. Survey Circ. 229 and as U. S. Navy Electronics Lab. Rept. 327, 1952; reprinted in 1954 as U. S. Geol. Survey Prof. Paper 269) contains, in addition to the results of the technical studies, descriptions of the instrumentation, field methods, and data-processing procedures, with discussions of instrumental limitations and the accuracy of measurements.

\section{GENERAL DESCRIPTION OF DATA PRESENTED}

The data presented in this report include observations required for the determination of evaporation

${ }^{1}$ Two other reports relating to this investigation are: Anderson, E. R., Anderson, L. J., and Marciano, J. J., 1950, A review of evaporation theory and development of instrumentation, Lake Mead Water-Loss Investigations, Interim Report: U. S. Navy Electronics Lab. Rept. 159. Harbeck, G. Earl, Jr., and others, 1951, Utility of selected western reservoirs for water-loss studies: U. S. Geol. Survey Circ. 103. from Lake Hefner for the water-budget, mass-transfer, energy budget, and evaporation-pan methods. A tremendous quantity of data has been accumulated-approximately $1,325,000$ items were recorded in connection with the mass-transfer studies alone. Publication of each observation was considered impracticable. Moreover, the sheer quantity of data would overwhelm the average user, unless he had high-speed computing equipment at his disposal.

Therefore, it was believed desirable to publish summaries, or averages, of the field observations. The period of time over which the data were averaged was determined on consideration of the following factors: Besides unduly lengthening the report, short periods are subject to error and emphasize erratic or spurious variations. Long periods, on the other hand, tend to hide or obscure significant variations. In some tables, the nature of the data or other practical matters dictated the period for which the data are presented.

Daily values are presented of each of the items required for the computation of evaporation using the water-budget me thod. One day was the shortest period of time for which evaporation from Lake Hefner could be computed accurately-the governing factor was the determination of changes in storage in the lake.

Three-hour and daily averages of the mass-transfer data are presented. Wet-and dry-bulb temperatures and wind speeds at four levels, plus water-surface temperatures, are given for each of the four meteorological stations. The most frequent wind direction at the barge station during each 3 -hour period is also listed. The 3-hour data, rather than the daily, were used in testing the various mass-transfer theories; that is, evaporation was computed for each 3-hour period, and the results for the eight 3 -hour periods in each day were totaled to give a computed daily evaporation for comparison with the water-budget figure.

Daily means of the various radiation items of the energy budget (solar radiation, reflected solar radia- 
tion, and atmospheric radiation) are shown. Practical considerations prevented publication of the half-hour data that were used in the computations. It was believed that 3-hour averages would not be suitable, for example, because of the rather large short-period fluctuations in solar radiation and the seasonal change in time of sunrise and sunset. Data from the thermal surveys of the lake also are presented.

Temperatures, measured in connection with the operation of the Cummings radiation integrator, are listed for each of the periods between CRI servicings, and the evaporation and energy-storage data obtained at these times also are given. Water-budget data for these same periods are tabulated.

\section{WATER-BUDGET DATA}

\section{EXPLANATION OF TABLES}

The daily water-budget data for Lake Hefner for the period April 25, 1950, to August 31, 1951, are presented in table 1 (p. 9). Evaporation was computed using the formula for inflow-outflow ehange in storage (Harbeck and Kennon, 1952, p. 17 and fig. 22). The basic computational unit was the acre-foot. Daily evaporation was computed in acre-feet and converted to inches and centimeters. Daily figures were classified as to their relative accuracy (Harbeck and Kennon, 1952, p. 33) and the classification of each daily figure is given.

It should be emphasized that the accuracy-classification scheme, al though objective, is not infallible. From statistical theory alone, one would expect to find certain days actually in error either more or less than indicated by the classification scheme. Also, it must be kept in mind that there are possible sources of error other than those taken into account. For example, precipitation during the period February $13-15$ was in the form of snow; winds on February 13 and 14 averaged approximately 16 knots. The average catch in all 22 rain gages for the entire storm was slightly more than half an inch. It is quite probable that indicated amounts of precipitation for this storm are in error because of blowing snow. Because there appeared to be nological method of adjusting or correcting the observed catches that is independent of the results or correlations being tested, no such correction was made. Possibly, other sources of error went unrecognized, but it is believed that scientific research is better served by presenting the basic observations, with the hope that the equipment and methods used have been sufficiently well described to enable the user of the data to make adjustments if believed warranted.

All computed daily figures of evaporation, regardless of accuracy class ification, were included in the monthly totals given in table 2 (p. 17). The inclusion of even a very few daily figures subject to rather large errors sometimes may have a considerable effect on monthly totals which are, therefore, of ten less accurate than most of the daily figures, because, large er rors being infrequent, it is not certain that they are compensating over a period as short as 1 month. Adjustments for thermal expansion were made (Harbeck and Kennon, 1952, p. 19-20). Because of the occasional cumulative effect of rounding-off errors, monthly totals given in acre-feet may not be in precise agreement with those given in inches and centimeters.

Daily figures of mean lake stage and contents are listed in table 3 (p. 18). Daily mean lake $s$ tages were obtained by graphically averaging the recorder trace for the entire day. Daily mean contents then were taken from the capacity table. It should be noted that the daily stage changes listed in table 1 are midnightto-midnight changes and therefore are not the same as the difference between two successive daily mean stages.

Tables 4-9, inclusive (p. 20), contain daily figures of the various items of inflow and outflow. The unit employed throughout was the acre-foot, except that, in table 8, daily and storm rainfall are reported in inches. Mean rainfall, in acre-feet, on the lake surface was computed by multiplying the depth of rainfall by the water-surface area at the time of the storm.

\section{AVAILABILITY OF DATA}

The basic water-budget data (not published in this report) include water-stage recorder charts for the four lake gages and the gages on Bluff Creek and on the intake canal, original discharge-moasurement notes, and fathometer records obtained during the resurvey of the lake. Water-stage recorder charts for the lake gages (see fig. 1) and the fathcmeter records are in the Denver office of the Technical Coordination Branch, Water Resources Division, U, S. Geological Survey. The recorder charts for Bluff Creek and the intake canal, and the discharge-measurement notes, are on file at the Oklahoma City office of the Surface Water Branch, Water Resources Division, U. S. Geological Survey. Any, or all, of these data will be made available on microfilm (at cost) by the pertinent office, listed above.

\section{MASS-TRANSFER DATA}

\section{EXPLANATION OF TABLES}

The method used in processing the meteorological data is described by Marciano and Harbeck (1952, p. 61-62). Little additional explanation is believed necessary, except possibly in connection with the computations of 3 -hour and daily averages. Some loss of record occurred because of occasional malfunctioning of equipment.

When a temperature recorder stopped, all temperature records were lost at that station. More frequently one, or more, of the nine recorcied temperatures was obviously incorrect-for example, when a single wet-bulb reservoir went dry. Occasionally, it was evident that one anemometer or another was not operating correctly. Wind and temperature records were carefully scanned, both in the fielc and in the office, to detect and eliminate faulty otservations. Ordinarily, a 3-hour average was computed from the six half-hour observations, but if some cbservations 


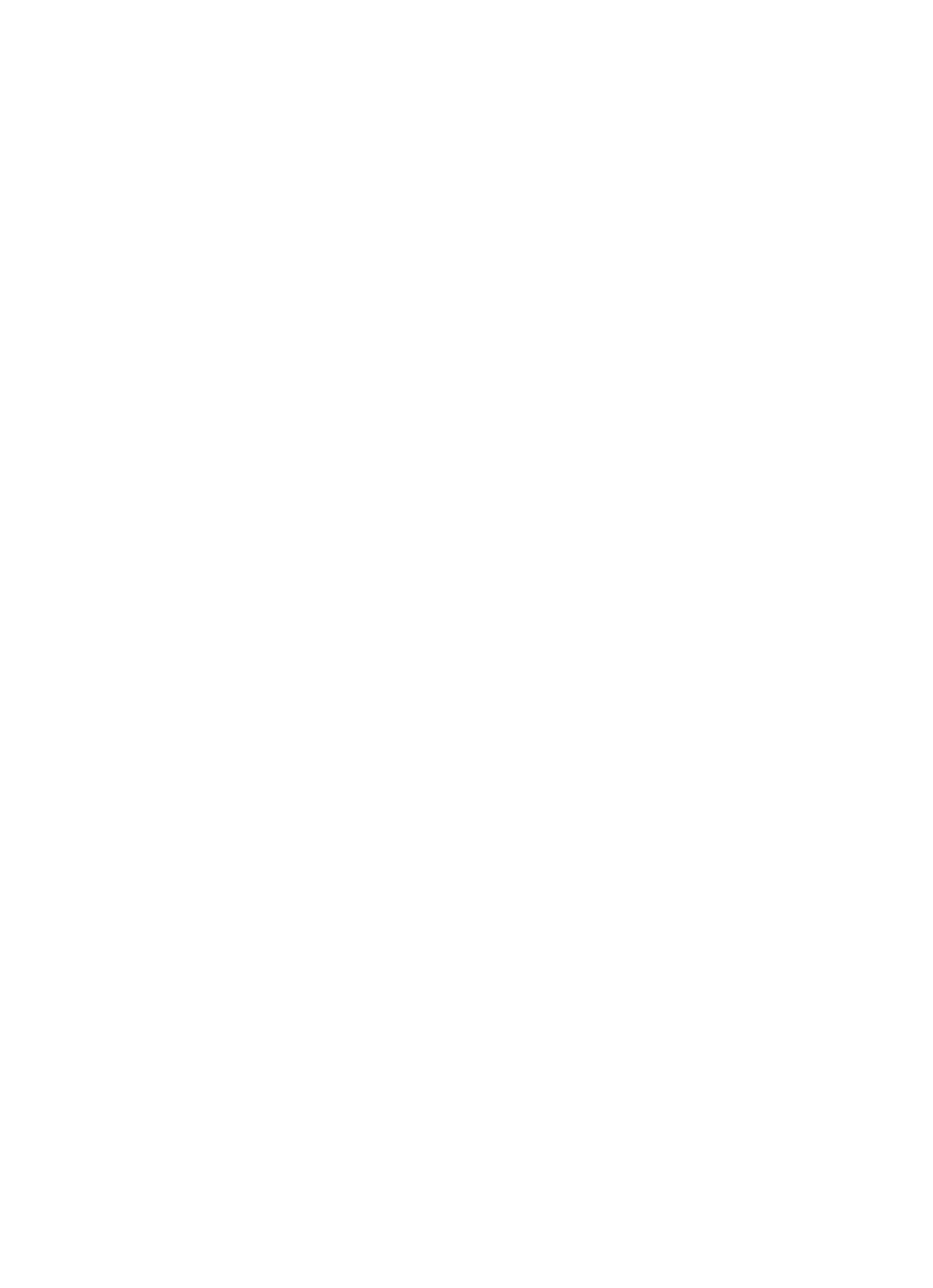


were missing, the 3 -hour average was computed from the remaining observations.

If a wet-bulb reservoir went $\mathrm{dry}$, it remained dry until the station was next visited, which might have been a few minutes or 1 day or more. Thus, in tabulations of, 3-hour averages (see table 10, p. 27), it is possible that the items immediately preceding and immediately following a period of missing record are based on less than six observations. Where there is no break in the 3-hour tabulations, it is unlikely that any average is based on less than six observations.

Daily averages were computed for the period July 1 , 1950 , to August 31,1951 , and are listed in table 11 (p. 223). Each daily figure is the average of the eight 3-hour. averages. A daily average was not computed unless all eight 3 -hour figures were available but, as mentioned above, a few 3-hour averages were based on less than six observations.

\section{AVALAABITTY OF DATA}

The original Esterline-Angus recorder charts, which contain the basic temperature and wind measurements, have been deposited in the National Archives and thus a re available for $s$ tudy. (Specimens of temperature and wind charts are shown in figs. 2 and 3.) One complete set of punchcards, containing half-hour observations of wind and temperature data, have also been deposited in the National Archives and are available for tabulating or for statistical analysis. (A specimen chart is shown in fig. 4.) A complete set of punchcards containing the 3-hour data and a set containing the daily averages have been retained by the U. S. Navy Electronics Laboratory. If desired, duplicate sets can be obtained for the cost of duplication.

\section{ENERGY.BUJDGET DATA}

\section{EXPLANATION OF TABLES}

The observational program at Lake Hefner and the data-processing procedure employed are described by E. R. Anderson (1952, p. 73-74). Daily mean figures of solar radiation, reflected solar radiation, atmospheric radiation, and water-temperature data are given in tables 12-16, inclusive.

The radiation data in tables 12-14 were recorded on an Esterline-Angus 1-mil recorder, using a 15-point programming switch. The following elements were recorded: solar radiation (table 12, p. 251), reflected solar radiation (table 13, p. 252) flat-plate radiometer reading, and the temperature of the flat-plate. The daily average data on atmospheric radiation (table 14 , p. 253) were based upon the night measurements indicated by the flat-plate radiometer.
The data were processed by constructing a continuous diurnal curve for each element and reading values of each element at half-hour intervals. These 48 readings were averaged to obtain a daily ralue, which was used in the heat-energy budget for computation of evaporation by the methods described in Circular 229.

The temperature data given in tables 15 and 16 (p. 254 and 260) were obtained from the temperature profile records (TPR), or from the bathythermograph (BI), as indicated. There were two series of observations: Table 15 lists the daily profiles at 1 -meter levels made at either station 6 or station 2 , and table 16 lists the thermal surveys at 1 -meter lovels at the 16 stations in the lake, made at 7-or 1C-day intervals, as indicated.

\section{AVAILABILITY OF DATA}

In addition to the tables of daily averages of solar radiation, reflected solar radiation, and a tmospheric radiation, tabulations of half-hour values of each of these items have been prepared, but they have not been published. The original recorder charts, from which these data were taken, have been deposited in the National Archives. (See fig. 5 for specimen of radiation-recorder chart.) The original thermalsurvey data, which are contained in Esterline-Angus charts from the TPR recorder, have been retained by the U. S. Navy Electronics Laboratory. Copies of the half-hour tabulations of radiation data, and of the thermal-survey charts, are available from the laboratory for the cost of microfilming.

\section{CUMMINGS RADIATION INTEGRATOR [ ATA}

\section{EXPLANATION OF TABLES}

The basic data obtained in connection with the operation of the CRI are presented in tables 17 and 18 (p. 283 and 284). Observational techniques are described by G. Earl Harbeck, Jr., (1952, p. 121). Although CRI servicing data (table 17) are sh own for the entire period of operation of the CRI, continuous records of water, soil, and rain temperatures were obtained, starting with May 1951. Average temperatures for the periods tested, which are shown in table 18 , were computed from daily average temperatures, which in turn were obtained by graphicall" averaging the continuous diurnal curve constructed for each temperature.

\section{AVAILABLITY OF DATA}

The original charts for the Esterline-Angus recorder that was used to record the various temperatures have been retained by the Technical Coordination 

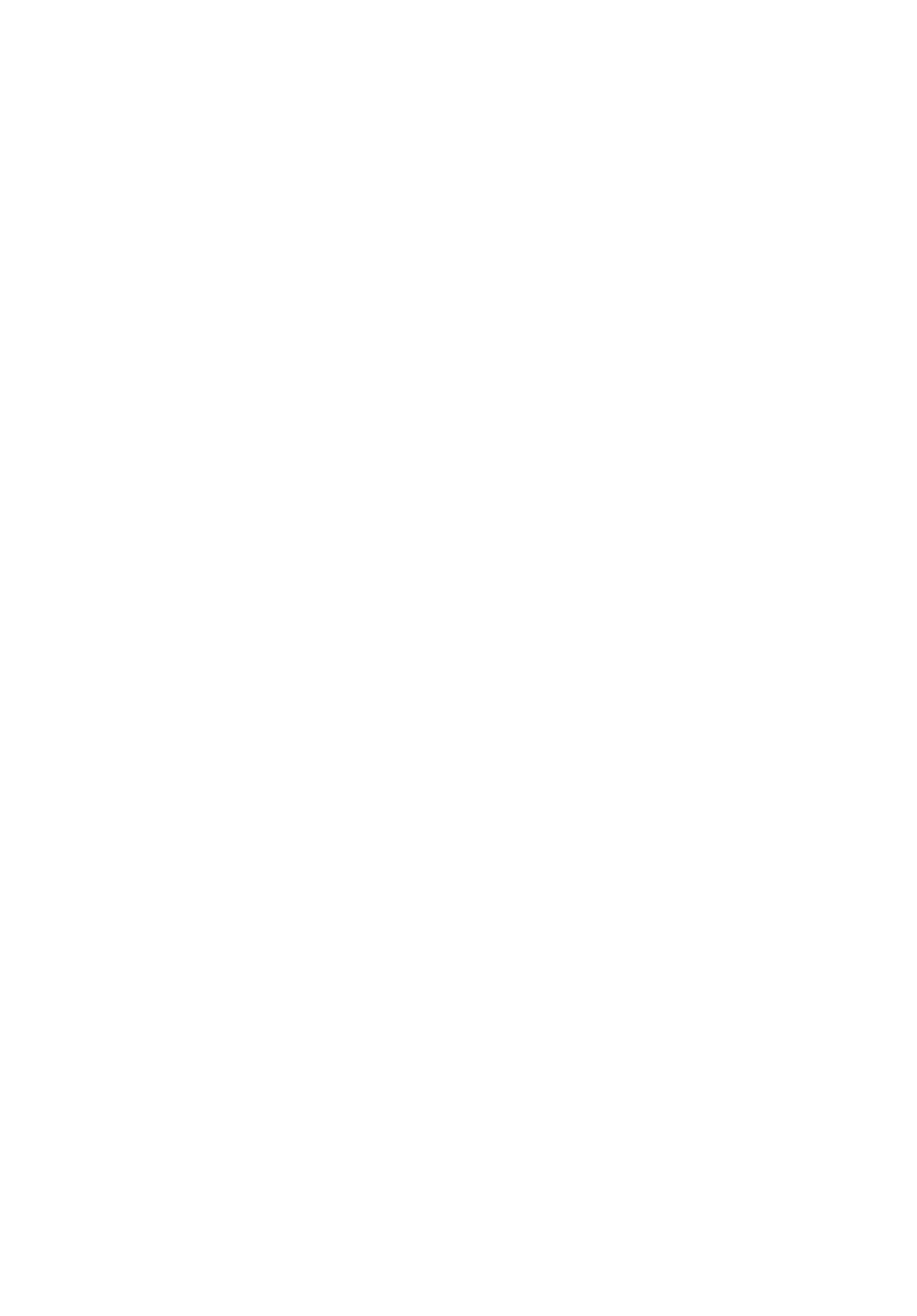

Figure 2.-Temperature recorder chart. 


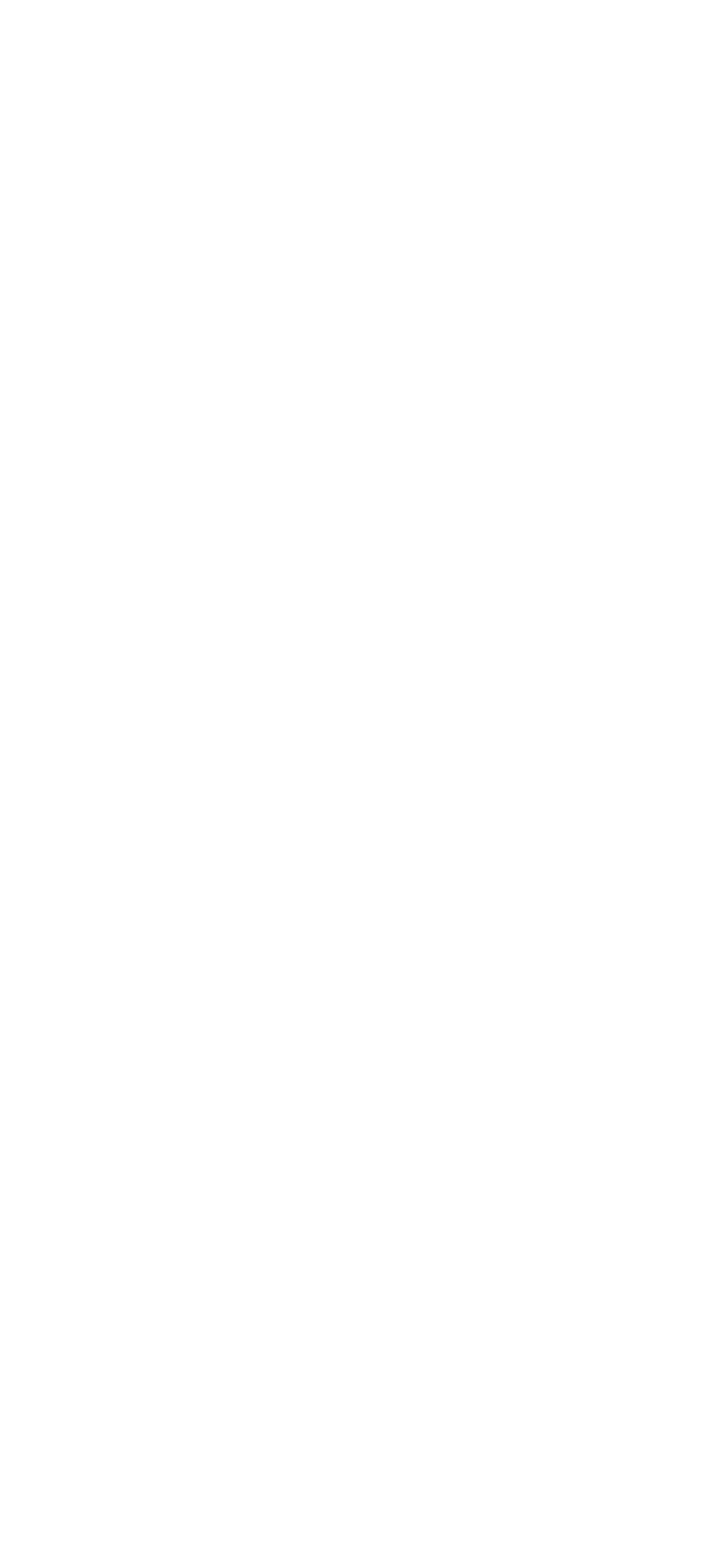


Branch, Water Resources Division, U. S. Geological Survey, Denver, Colo., and copies are available for the cost of microfilming. (A specimen of a chart is shown in $\mathrm{fig}$. 6.)

\section{PAN-EVAPORATION DATA}

EXPLANATION OF TABLE

The basic data collected for the pan-evaporation study at Lake Hefner are presented in table 19 (p. 285). The instrumentation and operational procedures are described by Max A. Kohler (1952, p. 127-132). The data in table 19 consist of the following: Daily evaporation for each of the seven pans; daily maximum and minimum water temperature for each pan; daily wind movement for the Class A pans; and daily maximum and minimum air temperature at each of the three separate stations.

In order to clarify the presentation of the data in table 19, the following items should be noted:

(1) The observed evaporation for the 24-hour period ending at the time of observation is tabulated, except in those instances when the pan overflowed. In

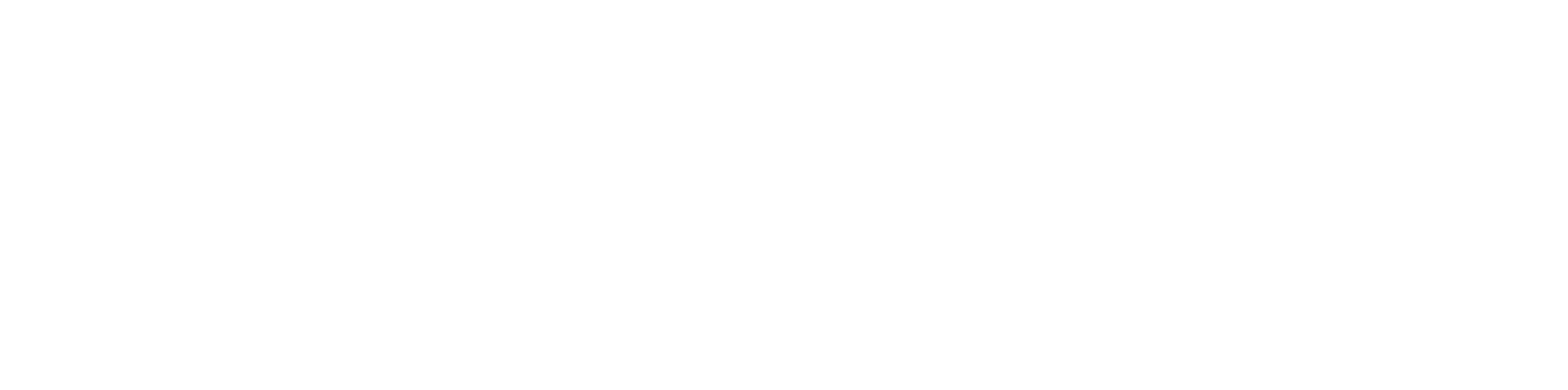

Figure 5. -Radiation recorder chart.

Time, in hours

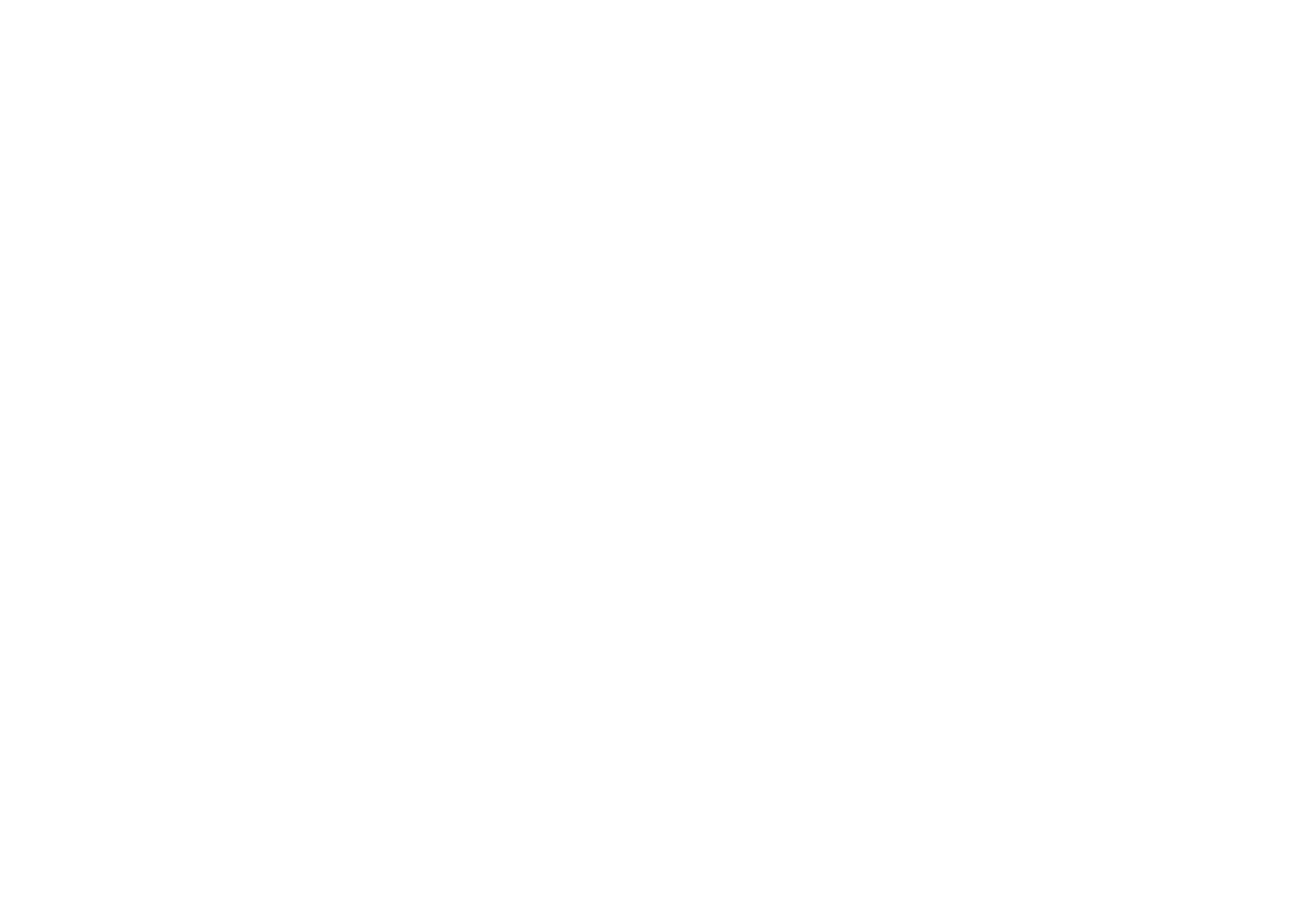

Figure 6. Cummings radiation integrator recorder chart. 
these cases, an estimated value was substituted.

Two values of monthly evaporation are shown.

The first one is a summation of the tabulated data.

The second value, Adjusted total, consists of tabu-

lated data for days without precipitation and of data adjusted for splash-out and overflow on days with precipitation (Kohler, 1952, p. 139-141).

(2) Observations for May 1950 through June 10, 1950 were made at about $1500 \mathrm{c}$.s.t. Beginning on June 11,1950 , the time of observation was changed to about 0900 (Kohler, 1952, p. 127).

(3) Subsequent to June 10, 1950, the maximum and minimum air- and water-temperature data apply to the 24-hour period prior to the time of observation. In general, therefore, the maximum temperature, tabulated for a specific date, occurred during the afternoon of the previous day, and the minimum temperature occurred in the morning of the observation date.

Prior to June 10, 1950, in several cases the observed maximum and minimum temperature data were adjusted according to thermograph records to make them consistent with the subsequent data, as previously described. The adjustment was required because of the difficulty in interpreting the maximum temperatures when the time of observation was about 1500 .

(4) Wind data are expressed in terms of total miles of movement during the 24-hour period prior to the time of observation.

\section{AVALABILITY OF DATA}

In addition to the data presented in table 19 , the following records are available: Hygrothermorraph records at northeast, southwest, and south stations; Gotham gas-bulb thermograph charts for Class A pan at south station; recording rain-gage charts for northeast station; and soil-moisture and soil-temperature data at south station.

The original copies of the data presented in table 19 and the additional data listed above are on file in the Hydrologic Services Division of the Weather Bureau in Washington, D. C. Photostat or microfilm copies are available on request, at cost of reproduction.

\section{LITERATURE CITED}

[All of the following references are obtained from Water-loss investigations: Lake Hefnerstudies, technical report: U. S. Geol. Survey Circ. 229, 1952, and U. S. Geol. Survey Prof. Paper 269, 1954] Anderson, Ernest R., Energy-budget studies.

Harbeck, G. Earl, Jr., Cummings radiation integrator. Harbeck, G. Earl, Jr., and Kennon, Frank W., The water-budget control.

Kohler, Max A., Lake and pan evaporatior.

Marciano, J. J., and Harbeck, G. Earl, Jr., Masstransfer studies. 
TABLE 1

Table 1. -Daily water-budget evaporation from Lake Hefner, Okla., Apr. 26, 1950, to Aug. 31, 1951

\begin{tabular}{|c|c|c|c|c|c|c|c|c|c|c|c|c|c|}
\hline \multirow[b]{3}{*}{ Day } & \multicolumn{5}{|c|}{ Change in stage, in feet } & \multirow{3}{*}{$\begin{array}{c}\text { Aver- } \\
\text { age } \\
\text { surface } \\
\text { area } \\
\text { (acres) }\end{array}$} & \multirow{3}{*}{$\begin{array}{c}\text { Change } \\
\text { in } \\
\text { content } \\
\text { (acre-ft) }\end{array}$} & \multirow[b]{3}{*}{$\underset{\text { (acre-ft) }}{\text { Inflow }}$} & \multirow[b]{3}{*}{$\begin{array}{l}\text { Outflow } \\
\text { (acre-ft) }\end{array}$} & \multirow{2}{*}{\multicolumn{3}{|c|}{ Evaporation }} & \multirow[b]{3}{*}{$\begin{array}{l}\text { Accuracy } \\
\text { classification }\end{array}$} \\
\hline & \multicolumn{4}{|c|}{ Gages } & \multirow[b]{2}{*}{$\begin{array}{c}\text { Aver- } \\
\text { age }\end{array}$} & & & & & & & & \\
\hline & North & South & East & West & & & & & & $\begin{array}{c}\text { Acre- } \\
\text { feet }\end{array}$ & Inches & $\begin{array}{l}\text { Centi- } \\
\text { meters }\end{array}$ & \\
\hline \multicolumn{14}{|c|}{ April 1950} \\
\hline $\begin{array}{l}26 \\
27 \\
28 \\
29 \\
30 \\
\end{array}$ & $\begin{array}{r}-0.043 \\
-.047 \\
-.006 \\
-.052 \\
-.030 \\
\end{array}$ & $\begin{array}{r}-0.040 \\
-.025 \\
-.020 \\
-.010 \\
-.060 \\
\end{array}$ & $\begin{array}{l}- \\
- \\
- \\
-\end{array}$ & $\begin{array}{l}- \\
\overline{-} \\
-\end{array}$ & $\begin{array}{r}-0.042 \\
-.036 \\
-.013 \\
-.031 \\
-.045 \\
\end{array}$ & $\begin{array}{l}2,163 \\
2,162 \\
2,160 \\
2,159 \\
2,157 \\
\end{array}$ & $\begin{array}{l}-90.8 \\
-77.8 \\
-28.1 \\
-66.9 \\
-97.1 \\
\end{array}$ & $\begin{array}{l}1.0 \\
1.0 \\
1.0 \\
1.1 \\
1.2 \\
\end{array}$ & $\begin{array}{l}35.5 \\
34.7 \\
38.0 \\
35.9 \\
26.6 \\
\end{array}$ & $\begin{array}{r}+56.3 \\
+44.1 \\
-8.9 \\
+32.1 \\
+71.7 \\
\end{array}$ & $\begin{array}{r}+0.312 \\
+.245 \\
-.049 \\
+.178 \\
+.399 \\
\end{array}$ & $\begin{array}{r}+0.793 \\
+.622 \\
-.126 \\
+.453 \\
+1.013\end{array}$ & $\begin{array}{l}\mathbf{A} \\
\mathbf{D} \\
\mathbf{D} \\
\mathbf{D} \\
\mathbf{D}\end{array}$ \\
\hline \multicolumn{14}{|c|}{ May 1950} \\
\hline $\begin{array}{l}1 \\
2 \\
3 \\
4 \\
4 \\
5\end{array}$ & $\begin{array}{r}-0.024 \\
-.004 \\
-.004 \\
-.018 \\
-.047\end{array}$ & $\begin{array}{r}-0.025 \\
-.048 \\
+.005 \\
-.009 \\
-.023\end{array}$ & $\begin{array}{l}\overline{-} \\
\bar{z}\end{array}$ & $\begin{array}{l}\overline{-} \\
\overline{-} \\
-\end{array}$ & $\begin{array}{r}-0.024 \\
-.026 \\
-.014 \\
-.035\end{array}$ & $\begin{array}{l}2,155 \\
2,154 \\
2,153 \\
2,153 \\
2,152\end{array}$ & $\begin{array}{c}-51.7 \\
-56.0 \\
0 \\
-30.1 \\
-75.3\end{array}$ & $\begin{array}{r}1.8 \\
2.0 \\
2.2 \\
1.8 \\
14.8\end{array}$ & $\begin{array}{l}38.0 \\
46.7 \\
46.3 \\
43.1 \\
44.8\end{array}$ & $\begin{array}{l}+15.5 \\
+11.3 \\
-44.1 \\
-11.2 \\
+45.3\end{array}$ & $\begin{array}{r}+0.086 \\
+.063 \\
-.246 \\
-.062 \\
+.253\end{array}$ & $\begin{array}{r}+0.219 \\
+.160 \\
-.624 \\
-.157 \\
+.642\end{array}$ & $\begin{array}{l}\mathbf{A} \\
\mathbf{D} \\
\mathbf{C} \\
\mathbf{C} \\
\mathbf{D}\end{array}$ \\
\hline $\begin{array}{r}6 \\
7 \\
8 \\
9 \\
10\end{array}$ & $\begin{array}{c}-.033 \\
+.020 \\
-.038 \\
- \\
-\end{array}$ & $\begin{array}{c}-.034 \\
-.071 \\
+.022 \\
- \\
-\end{array}$ & $\begin{array}{l}- \\
\overline{-} \\
-\end{array}$ & 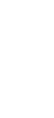 & $\begin{array}{l}-.034 \\
-.026 \\
-.008 \\
- \\
-\end{array}$ & $\begin{array}{l}2,150 \\
2,149 \\
2,148 \\
2,148 \\
2,154\end{array}$ & $\begin{array}{c}-73.1 \\
-55.9 \\
-17.2 \\
- \\
-\end{array}$ & $\begin{array}{c}1.2 \\
1.4 \\
1.6 \\
- \\
-\end{array}$ & $\begin{array}{c}45.9 \\
35.8 \\
37.2 \\
- \\
-\end{array}$ & $\begin{array}{c}+28.4 \\
+21.5 \\
-18.4 \\
- \\
-\end{array}$ & $\begin{array}{l}+.158 \\
+.120 \\
-.103 \\
- \\
-\end{array}$ & $\begin{array}{c}+.403 \\
+.305 \\
-.261 \\
- \\
-\end{array}$ & $\begin{array}{l}\mathbf{A} \\
\mathbf{D} \\
\mathbf{D} \\
\mathbf{D} \\
\mathbf{D}\end{array}$ \\
\hline $\begin{array}{l}11 \\
12 \\
13 \\
14 \\
15\end{array}$ & $\begin{array}{c}\overline{-} \\
\overline{-} \\
-\overline{0} \\
-.012\end{array}$ & $\begin{array}{c}- \\
- \\
-.005 \\
-.017\end{array}$ & $\begin{array}{l}\overline{-} \\
\overline{-} \\
\overline{-}\end{array}$ & $\bar{z}=$ & $\begin{array}{c}- \\
- \\
-\overline{0} 008 \\
-.016\end{array}$ & $\begin{array}{l}2,165 \\
2,187 \\
2,196 \\
2,196 \\
2,195\end{array}$ & $\begin{array}{r}- \\
- \\
- \\
-17.6 \\
-35.1\end{array}$ & $\begin{array}{r}- \\
- \\
16.9 \\
5.3\end{array}$ & $\begin{array}{c}- \\
- \\
23.6 \\
31.0\end{array}$ & $\begin{array}{r}\bar{z} \\
\overline{10.9} \\
+9.4\end{array}$ & $\begin{array}{c}\bar{z} \\
\overline{-} \\
+.060 \\
+.051\end{array}$ & $\begin{array}{c}\overline{-} \\
\bar{E} \\
+. \overline{151} \\
+.130\end{array}$ & $\begin{array}{l}\mathbf{D} \\
\mathbf{D} \\
\mathbf{D} \\
\mathbf{C} \\
\mathbf{A}\end{array}$ \\
\hline $\begin{array}{l}16^{a} \\
17^{2} \\
18 \\
19 \\
20\end{array}$ & $\begin{array}{c}-.023 \\
-.017 \\
- \\
\overline{-} \\
+.016\end{array}$ & $\begin{array}{c}-.027 \\
-.012 \\
- \\
+.017\end{array}$ & $\begin{array}{l}\overline{-} \\
\overline{-}\end{array}$ & $\begin{array}{l}\bar{z} \\
\bar{z}\end{array}$ & $\begin{array}{c}-.025 \\
-.014 \\
- \\
- \\
+.016\end{array}$ & $\begin{array}{l}2,194 \\
2,193 \\
2,204 \\
2,232 \\
2,241\end{array}$ & $\begin{array}{r}-54.8 \\
-30.7 \\
- \\
- \\
+35.9\end{array}$ & $\begin{array}{c}4.2 \\
3.6 \\
- \\
- \\
78.0\end{array}$ & $\begin{array}{c}33.9 \\
36.6 \\
- \\
- \\
22.4\end{array}$ & $\begin{array}{r}+25.1 \\
-2.3 \\
- \\
+\overline{9} .7\end{array}$ & $\begin{array}{c}+.137 \\
-.013 \\
- \\
- \\
+. \overline{105}\end{array}$ & $\begin{array}{c}+.349 \\
-.032 \\
- \\
+.268\end{array}$ & $\begin{array}{l}\mathbf{B} \\
\mathbf{D} \\
\mathbf{D} \\
\mathbf{D} \\
\mathbf{A}\end{array}$ \\
\hline $\begin{array}{l}21 \\
22 \\
23 \\
24 \\
25\end{array}$ & $\begin{array}{l}-.011 \\
-.032 \\
-.046 \\
-.035 \\
-.011\end{array}$ & $\begin{array}{r}-.026 \\
-.056 \\
-.032 \\
-.044 \\
+.023\end{array}$ & $\begin{array}{l}- \\
\overline{-} \\
-\end{array}$ & $\begin{array}{l}\overline{-} \\
\bar{z}\end{array}$ & $\begin{array}{r}-.018 \\
-.044 \\
-.039 \\
-.040 \\
+.006\end{array}$ & $\begin{array}{l}2,240 \\
2,238 \\
2,236 \\
2,234 \\
2,233\end{array}$ & $\begin{array}{l}-40.3 \\
-98.5 \\
-87.2 \\
-89.4 \\
+13.4\end{array}$ & $\begin{array}{r}6.7 \\
4.6 \\
5.1 \\
3.6 \\
50.4\end{array}$ & $\begin{array}{l}22.8 \\
40.8 \\
42.2 \\
39.7 \\
34.8\end{array}$ & $\begin{array}{l}+24.2 \\
+62.3 \\
+50.1 \\
+53.3 \\
+11.2\end{array}$ & $\begin{array}{r}+.130 \\
+.334 \\
+.269 \\
+.286 \\
+.060\end{array}$ & $\begin{array}{r}+.329 \\
+.848 \\
+.683 \\
+.727 \\
+.153\end{array}$ & $\begin{array}{l}\mathbf{D} \\
\mathbf{D} \\
\mathbf{D} \\
\mathbf{C} \\
\mathbf{D}\end{array}$ \\
\hline $\begin{array}{l}26 \\
27 \\
28 \\
29 \\
30 \\
31\end{array}$ & $\begin{array}{l}+.043 \\
-.024 \\
+.048 \\
-.031 \\
-.018 \\
-.037\end{array}$ & $\begin{array}{l}+.042 \\
-.029 \\
+.033 \\
-.015 \\
-.021 \\
-.025\end{array}$ & $\begin{array}{l}\overline{-} \\
\overline{-} \\
\overline{-} \\
-\end{array}$ & $\begin{array}{l}\overline{-} \\
\overline{-} \\
\overline{-}\end{array}$ & $\begin{array}{l}+.042 \\
-.026 \\
+.040 \\
-.023 \\
-.020 \\
-.031\end{array}$ & $\begin{array}{l}2,236 \\
2,235 \\
2,236 \\
2,236 \\
2,235 \\
2,233\end{array}$ & $\begin{array}{l}+93.9 \\
-58.1 \\
+89.4 \\
-51.4 \\
-44.7 \\
-69.2\end{array}$ & $\begin{array}{r}172.0 \\
6.4 \\
115.0 \\
7.4 \\
4.7 \\
3.4\end{array}$ & $\begin{array}{l}27.1 \\
29.8 \\
16.9 \\
32.4 \\
25.1 \\
33.8\end{array}$ & $\begin{array}{r}+51.0 \\
+34.7 \\
+8.7 \\
+26.4 \\
+24.3 \\
+38.8\end{array}$ & $\begin{array}{l}+.274 \\
+.186 \\
+.047 \\
+.142 \\
+.130 \\
+.210\end{array}$ & $\begin{array}{l}+.697 \\
+.473 \\
+.119 \\
+.360 \\
+.331 \\
+.530\end{array}$ & $\begin{array}{l}\text { A } \\
\text { B } \\
\text { D } \\
\text { D } \\
\text { A } \\
\text { C }\end{array}$ \\
\hline
\end{tabular}

a 22-hour period $(0000-2200)$.

June 1950

\begin{tabular}{|c|c|c|c|c|c|c|c|c|c|c|c|c|c|}
\hline $\begin{array}{l}1 \\
2 \\
3 \\
4 \\
5\end{array}$ & $\begin{array}{l}-0.014 \\
+\quad .009 \\
-\quad .041 \\
-\quad .024 \\
-\quad .021\end{array}$ & $\begin{array}{l}-0.040 \\
+\quad .021 \\
-\quad .028 \\
-\quad .098 \\
-\quad .030\end{array}$ & $\begin{array}{c}- \\
- \\
- \\
-0.025 \\
-\quad .035\end{array}$ & $\begin{array}{l}- \\
\overline{-} \\
\overline{-}\end{array}$ & $\begin{array}{r}-0.027 \\
+\quad .015 \\
-\quad .034 \\
-\quad .027 \\
-\quad .029\end{array}$ & $\begin{array}{l}2,232 \\
2,232 \\
2,231 \\
2,230 \\
2,228\end{array}$ & $\begin{array}{l}-60.3 \\
+\quad 33.5 \\
-\quad 75.9 \\
-\quad 60.2 \\
-\quad 64.6\end{array}$ & $\begin{array}{r}3.2 \\
110.0 \\
13.2 \\
5.3 \\
5.0\end{array}$ & $\begin{array}{l}37.3 \\
38.7 \\
30.8 \\
30.3 \\
35.5\end{array}$ & $\begin{array}{l}+26.2 \\
+37.8 \\
+58.3 \\
+35.2 \\
+34.1\end{array}$ & $\begin{array}{r}+0.141 \\
+\quad .203 \\
+\quad .314 \\
+\quad .189 \\
+\quad .184\end{array}$ & $\begin{array}{r}+0.358 \\
+\quad .516 \\
+\quad .796 \\
+\quad .481 \\
+\quad .466\end{array}$ & $\begin{array}{l}\mathrm{D} \\
\mathrm{C} \\
\mathrm{C} \\
\mathrm{B} \\
\mathrm{C}\end{array}$ \\
\hline $\begin{array}{r}6 \\
7 \\
8 \\
9 \\
10\end{array}$ & $\begin{array}{l}-.028 \\
-.034 \\
-.014 \\
-\quad .030 \\
+\quad .037\end{array}$ & $\begin{array}{l}-\quad .027 \\
-\quad .039 \\
-\quad .020 \\
-\quad .012 \\
+\quad .040\end{array}$ & $\begin{array}{l}-\quad .030 \\
-\quad .040 \\
-\quad .015 \\
-.015 \\
+\quad .035\end{array}$ & $\begin{array}{l}- \\
\overline{-} \\
-\end{array}$ & $\begin{array}{l}-\quad .028 \\
-\quad .038 \\
-\quad .016 \\
-.019 \\
+\quad .037\end{array}$ & $\begin{array}{l}2,226 \\
2,225 \\
2,224 \\
2,223 \\
2,223\end{array}$ & $\begin{array}{l}-\quad 62.3 \\
-\quad 84.6 \\
-\quad 35.6 \\
-\quad 42.2 \\
+\quad 82.3\end{array}$ & $\begin{array}{r}5.4 \\
3.4 \\
3.0 \\
2.8 \\
122.1\end{array}$ & $\begin{array}{l}37.6 \\
41.8 \\
38.7 \\
46.8 \\
32.5\end{array}$ & $\begin{array}{l}+30.1 \\
+46.2 \\
-\quad .1 \\
-1.8 \\
+\quad 7.3\end{array}$ & $\begin{array}{l}+.162 \\
+.249 \\
-.001 \\
-.010 \\
+.039\end{array}$ & $\begin{array}{r}+.412 \\
+.633 \\
+.002 \\
+.025 \\
+.100\end{array}$ & $\begin{array}{l}\text { A } \\
\text { A } \\
\text { A } \\
\text { C } \\
\text { B }\end{array}$ \\
\hline $\begin{array}{l}11 \\
12 \\
13 \\
14 \\
15\end{array}$ & $\begin{array}{l}-.004 \\
-\quad .018 \\
-.031 \\
-.034 \\
-\quad .033\end{array}$ & $\begin{array}{l}-\quad .020 \\
-\quad .024 \\
-\quad .023 \\
-.024 \\
-.033\end{array}$ & $\begin{array}{l}-\quad .020 \\
-\quad .005 \\
-\quad .035 \\
-.025 \\
-\quad .040\end{array}$ & $\begin{array}{l}- \\
\overline{-} \\
\overline{-}\end{array}$ & $\begin{array}{l}-.015 \\
-.016 \\
-.030 \\
-.028 \\
-\quad .035\end{array}$ & $\begin{array}{l}2,224 \\
2,223 \\
2,222 \\
2,220 \\
2,218\end{array}$ & $\begin{array}{l}-\quad 33.4 \\
-\quad 35.6 \\
-\quad 66.7 \\
-\quad 62.2 \\
-\quad 77.6\end{array}$ & $\begin{array}{l}6.8 \\
3.5 \\
2.6 \\
2.2 \\
2.1\end{array}$ & $\begin{array}{l}22.8 \\
33.9 \\
37.0 \\
41.3 \\
42.5\end{array}$ & $\begin{array}{r}+17.4 \\
+\quad 5.2 \\
+32.3 \\
+23.1 \\
+37.2\end{array}$ & $\begin{array}{l}+.094 \\
+.028 \\
+.174 \\
+.125 \\
+\quad .201\end{array}$ & $\begin{array}{l}+.238 \\
+.071 \\
+.443 \\
+.317 \\
+.511\end{array}$ & $\begin{array}{l}\text { C } \\
\text { C } \\
\text { B } \\
\text { B } \\
\text { B }\end{array}$ \\
\hline $\begin{array}{l}16 \\
17 \\
18 \\
19 \\
20\end{array}$ & $\begin{array}{l}-.035 \\
-\quad .034 \\
-\quad .049 \\
-.023 \\
+\quad .025\end{array}$ & $\begin{array}{l}-.032 \\
-\quad .040 \\
-\quad .041 \\
-\quad .015 \\
+\quad .005\end{array}$ & $\begin{array}{l}-.035 \\
-\quad .040 \\
-\quad .045 \\
-\quad .025 \\
+.025\end{array}$ & $\begin{array}{l}\overline{-} \\
\overline{-} \\
\overline{-}\end{array}$ & $\begin{array}{l}-.034 \\
-.038 \\
-.045 \\
-.021 \\
+\quad .018\end{array}$ & $\begin{array}{l}2,216 \\
2,215 \\
2,213 \\
2,210 \\
2,210\end{array}$ & $\begin{array}{l}-\quad 75.3 \\
-\quad 84.2 \\
-\quad 99.6 \\
-\quad 46.4 \\
+\quad 39.8\end{array}$ & $\begin{array}{r}2.5 \\
2.3 \\
2.1 \\
1.9 \\
98.5\end{array}$ & $\begin{array}{r}48.2 \\
46.1 \\
39.4 \\
6.5 \\
29.3\end{array}$ & $\begin{array}{l}+29.6 \\
+40.4 \\
+62.3 \\
+41.8 \\
+29.4\end{array}$ & $\begin{array}{l}+.160 \\
+\quad .219 \\
+\quad .338 \\
+\quad .227 \\
+\quad .160\end{array}$ & $\begin{array}{r}+\quad .407 \\
+\quad .556 \\
+\quad .858 \\
+\quad .576 \\
+\quad .405\end{array}$ & $\begin{array}{l}\text { A } \\
\text { A } \\
\text { B } \\
\text { B } \\
\text { C }\end{array}$ \\
\hline $\begin{array}{l}21 \\
22 \\
23 \\
24 \\
25\end{array}$ & $\begin{array}{l}+.139 \\
+.249 \\
-.058 \\
-\quad .040 \\
-\quad .055\end{array}$ & $\begin{array}{l}+.103 \\
+\quad .258 \\
-\quad .035 \\
-\quad .036 \\
-\quad .057\end{array}$ & $\begin{array}{l}+.145 \\
+\quad .230 \\
-\quad .045 \\
-\quad .040 \\
-\quad .050\end{array}$ & $\begin{array}{l}- \\
\overline{-} \\
\overline{-}\end{array}$ & $\begin{array}{l}+.129 \\
-\quad .246 \\
-.046 \\
-\quad .039 \\
-\quad .054\end{array}$ & $\begin{array}{l}2,211 \\
2,228 \\
2,229 \\
2,227 \\
2,225\end{array}$ & $\begin{array}{r}+285.2 \\
+548.1 \\
-102.5 \\
-\quad 86.9 \\
-120.2\end{array}$ & $\begin{array}{r}478.0 \\
550.0 \\
5.4 \\
3.4 \\
3.2\end{array}$ & $\begin{array}{l}46.0 \\
42.6 \\
44.6 \\
31.4 \\
36.3\end{array}$ & $\begin{array}{l}+146.8 \\
-40.7 \\
+63.3 \\
+58.9 \\
+87.1\end{array}$ & $\begin{array}{l}+.797 \\
+\quad .219 \\
+\quad .341 \\
+\quad .317 \\
+\quad .470\end{array}$ & $\begin{array}{l}+2.024 \\
-\quad .557 \\
+\quad .866 \\
+\quad .806 \\
+1.193\end{array}$ & $\begin{array}{l}\text { D } \\
\text { D } \\
\text { C } \\
\text { A } \\
\text { B }\end{array}$ \\
\hline $\begin{array}{l}26 \\
27 \\
28 \\
29 \\
30\end{array}$ & $\begin{array}{l}-\quad .047 \\
-\quad .035 \\
-\quad .016 \\
-\quad .033 \\
-\quad .031\end{array}$ & $\begin{array}{l}-\quad .038 \\
-\quad .037 \\
-\quad .005 \\
-\quad .037 \\
-\quad .042 \\
\end{array}$ & $\begin{array}{l}-.040 \\
-\quad .040 \\
-\quad .005 \\
-\quad .035 \\
-\quad .030\end{array}$ & $\begin{aligned} &- \\
&+ \overline{0} .025 \\
&-\quad .070 \\
&-\quad .045\end{aligned}$ & $\begin{array}{r}-.042 \\
-\quad .037 \\
-\quad .044 \\
-\quad .037\end{array}$ & $\begin{array}{l}2,223 \\
2,220 \\
2,220 \\
2,219 \\
2,216 \\
\end{array}$ & $\begin{array}{c}-93.4 \\
-\quad 82.1 \\
-\quad 97.6 \\
-\quad 82.0\end{array}$ & $\begin{array}{r}2.7 \\
2.4 \\
73.2 \\
9.9 \\
2.6\end{array}$ & $\begin{array}{l}51.2 \\
50.5 \\
47.3 \\
39.9 \\
43.0\end{array}$ & $\begin{array}{l}+44.9 \\
+34.0 \\
+25.9 \\
+67.6 \\
+41.6\end{array}$ & $\begin{array}{l}+\quad .242 \\
+\quad .184 \\
+\quad .140 \\
+\quad .366 \\
+\quad .225 \\
\end{array}$ & $\begin{array}{r}+.616 \\
+\quad .467 \\
+.356 \\
+.929 \\
+\quad .572 \\
\end{array}$ & $\begin{array}{l}\text { B } \\
\text { A } \\
\text { D } \\
\text { D } \\
\text { B }\end{array}$ \\
\hline
\end{tabular}


TABLE 1

Table 1. -Daily water-budget evaporation from Lake Hefner, Okla., Apr. 26, 1950, to Aug. 31, 1951

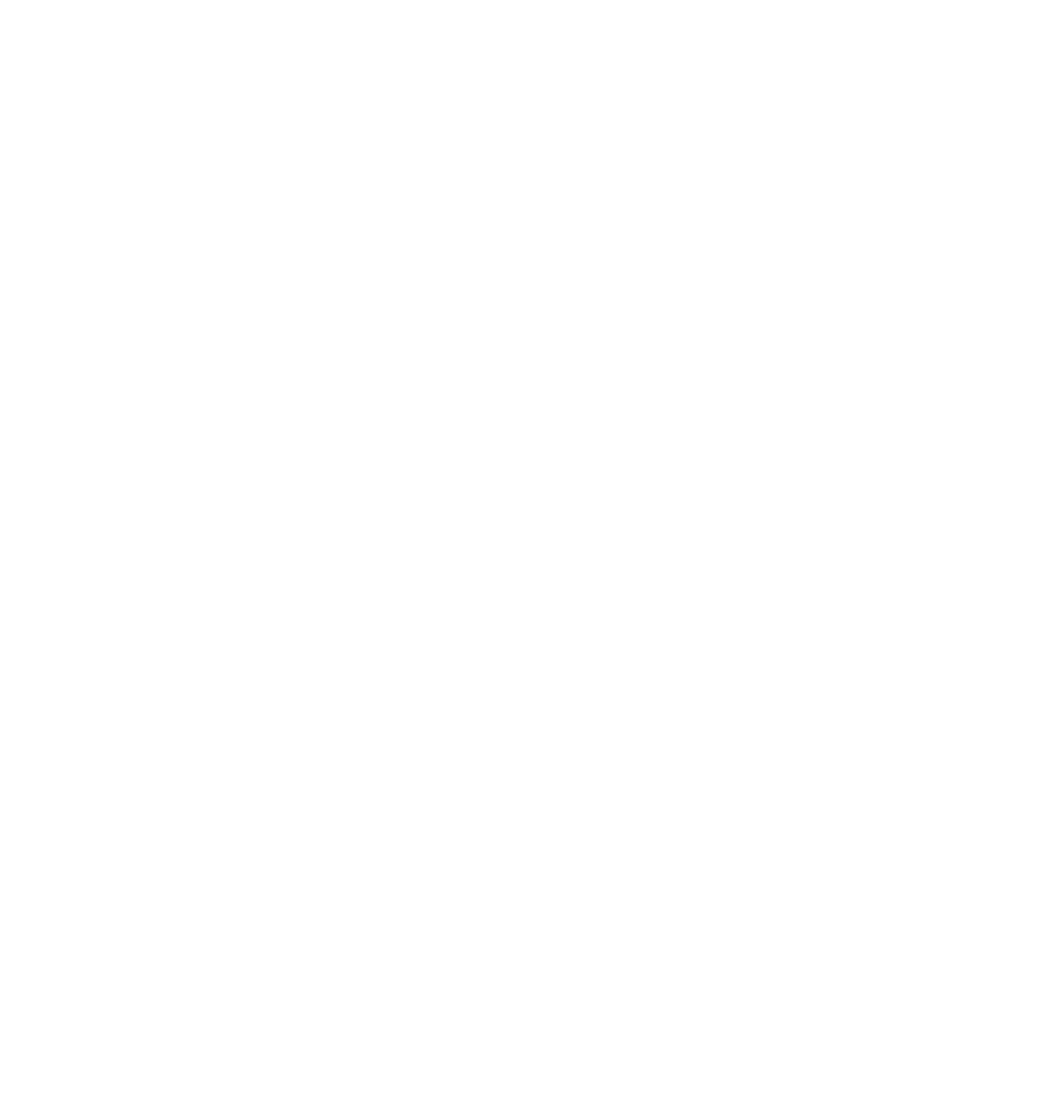


TABLE 1

Table 1. - Daily water-budget evaporation from Lake Hefner, Okla., Apr. 26, 1950, to Aug. 31, 1951-Continued

\begin{tabular}{|c|c|c|c|c|c|c|c|c|c|c|c|c|c|}
\hline \multirow{3}{*}{ Day } & \multicolumn{5}{|c|}{ Change in stage, in feet } & \multirow{3}{*}{$\begin{array}{c}\text { Aver- } \\
\text { age } \\
\text { surface } \\
\text { area } \\
\text { (acres) }\end{array}$} & \multirow{3}{*}{$\begin{array}{c}\text { Change } \\
\text { in } \\
\text { content } \\
\text { (acre-ft) }\end{array}$} & \multirow{3}{*}{$\begin{array}{l}\text { Inflow } \\
\text { (acre-ft) }\end{array}$} & \multirow{3}{*}{$\begin{array}{l}\text { Outflow } \\
\text { (acre-ft) }\end{array}$} & \multicolumn{3}{|c|}{ Evaporation } & \multirow{3}{*}{$\begin{array}{c}\text { Accuracy } \\
\text { classification }\end{array}$} \\
\hline & \multicolumn{4}{|c|}{ Gages } & \multirow{2}{*}{$\begin{array}{l}\text { Aver- } \\
\text { age }\end{array}$} & & & & & \multirow{2}{*}{$\begin{array}{l}\text { Acre- } \\
\text { feet }\end{array}$} & \multirow{2}{*}{ Inches } & \multirow{2}{*}{$\begin{array}{l}\text { Centi- } \\
\text { meters }\end{array}$} & \\
\hline & North & South & East & West & & & & & & & & & \\
\hline \multicolumn{14}{|c|}{ September 1950} \\
\hline $\begin{array}{l}1 \\
2 \\
3 \\
4 \\
5\end{array}$ & $\begin{array}{r}-0.044 \\
-.037 \\
-.021 \\
+.059 \\
-.031\end{array}$ & $\begin{array}{r}-0.043 \\
-.038 \\
-.024 \\
+.059 \\
-.029\end{array}$ & $\begin{array}{r}-0.037 \\
-.042 \\
-.027 \\
+.055 \\
-.030\end{array}$ & $\begin{array}{r}-0.041 \\
-.031 \\
-.028 \\
+.065 \\
-.036\end{array}$ & $\begin{array}{r}-0.041 \\
-.037 \\
-.025 \\
+.060 \\
-.032\end{array}$ & $\begin{array}{l}2,369 \\
2,367 \\
2,365 \\
2,365 \\
2,367\end{array}$ & $\begin{array}{r}-97.1 \\
-87.6 \\
-59.1 \\
+141.9 \\
-75.7\end{array}$ & $\begin{array}{r}1.6 \\
4.4 \\
6.7 \\
165.7 \\
4.6\end{array}$ & $\begin{array}{l}34.7 \\
36.3 \\
23.2 \\
28.5 \\
27.2\end{array}$ & $\begin{array}{r}+64.0 \\
+55.7 \\
+42.6 \\
-4.7 \\
+53.1\end{array}$ & $\begin{array}{r}+0.324 \\
+.282 \\
+.216 \\
-.024 \\
+.269\end{array}$ & $\begin{array}{r}+0.823 \\
+.717 \\
+.549 \\
\because .061 \\
+.684\end{array}$ & $\begin{array}{l}\text { A } \\
\text { B } \\
\text { A } \\
\text { C } \\
\text { A }\end{array}$ \\
\hline $\begin{array}{r}6 \\
7 \\
8 \\
9 \\
10\end{array}$ & $\begin{array}{l}-.035 \\
-.026 \\
-.036 \\
-.025 \\
-.023\end{array}$ & $\begin{array}{l}-.038 \\
-.025 \\
-.036 \\
-.029 \\
-.027\end{array}$ & $\begin{array}{l}-.035 \\
-.020 \\
-.030 \\
-.028 \\
-.028\end{array}$ & $\begin{array}{l}-.034 \\
-.027 \\
-.035 \\
-.030 \\
-.027\end{array}$ & $\begin{array}{l}-.036 \\
-.024 \\
-.034 \\
-.028 \\
-.026\end{array}$ & $\begin{array}{l}2,365 \\
2,363 \\
2,362 \\
2,360 \\
2,359\end{array}$ & $\begin{array}{l}-85.1 \\
-56.7 \\
-80.3 \\
-66.1 \\
-61.3\end{array}$ & $\begin{array}{l}1.9 \\
1.7 \\
1.4 \\
1.4 \\
1.4\end{array}$ & $\begin{array}{l}30.1 \\
34.0 \\
36.3 \\
36.3 \\
33.5\end{array}$ & $\begin{array}{l}+56.9 \\
+24.4 \\
+45.4 \\
+31.2 \\
+29.2\end{array}$ & $\begin{array}{l}+.289 \\
+.124 \\
+.231 \\
+.159 \\
+.149\end{array}$ & $\begin{array}{l}+.733 \\
+.315 \\
+.586 \\
+.403 \\
+.377\end{array}$ & $\begin{array}{l}\text { A } \\
\text { A } \\
\text { A } \\
\text { A } \\
\text { A }\end{array}$ \\
\hline $\begin{array}{l}11 \\
12 \\
13 \\
14 \\
15\end{array}$ & $\begin{array}{l}-.043 \\
-.016 \\
-.002 \\
-.006 \\
-.003\end{array}$ & $\begin{array}{l}-.039 \\
-.012 \\
-.005 \\
-.010 \\
-.001\end{array}$ & $\begin{array}{l}-.044 \\
-.018 \\
-.007 \\
-.007 \\
-.002\end{array}$ & $\begin{array}{l}-.044 \\
-.012 \\
0 \\
-.005 \\
-.003\end{array}$ & $\begin{array}{l}-.042 \\
-.014 \\
-.004 \\
-.007 \\
-.002\end{array}$ & $\begin{array}{l}2,357 \\
2,355 \\
2,355 \\
2,355 \\
2,355\end{array}$ & $\begin{array}{r}-99.0 \\
-33.0 \\
-9.4 \\
-16.5 \\
-4.7\end{array}$ & $\begin{array}{r}1.2 \\
51.9 \\
47.4 \\
49.6 \\
35.3\end{array}$ & $\begin{array}{l}25.1 \\
32.5 \\
28.1 \\
30.4 \\
30.5\end{array}$ & $\begin{array}{r}+75.1 \\
+52.4 \\
+28.7 \\
+35.7 \\
+9.5\end{array}$ & $\begin{array}{l}+.382 \\
+.267 \\
+.146 \\
+.182 \\
+.048\end{array}$ & $\begin{array}{l}+.971 \\
+.678 \\
+.371 \\
+.462 \\
+.123\end{array}$ & $\begin{array}{l}\text { A } \\
\text { B } \\
\text { B } \\
\text { B } \\
\text { A }\end{array}$ \\
\hline $\begin{array}{l}16 \\
17 \\
18 \\
19 \\
20\end{array}$ & $\begin{array}{l}-.020 \\
-.019 \\
-.022 \\
-.015 \\
-.027\end{array}$ & $\begin{array}{l}-.016 \\
-.024 \\
-.024 \\
-.022 \\
-.022\end{array}$ & $\begin{array}{l}-.022 \\
-.017 \\
-.027 \\
-.012 \\
-.017\end{array}$ & $\begin{array}{l}-.022 \\
-.020 \\
-.023 \\
-.019 \\
-.027\end{array}$ & $\begin{array}{l}-.020 \\
-.020 \\
-.024 \\
-.017 \\
-.023\end{array}$ & $\begin{array}{l}2,354 \\
2,353 \\
2,351 \\
2,350 \\
2,349\end{array}$ & $\begin{array}{l}-47.1 \\
-47.1 \\
-56.4 \\
-40.0 \\
-54.0\end{array}$ & $\begin{array}{l}2.0 \\
1.6 \\
1.5 \\
1.6 \\
3.7\end{array}$ & $\begin{array}{l}22.4 \\
29.3 \\
36.7 \\
27.8 \\
\mathbf{3 5 . 5}\end{array}$ & $\begin{array}{l}+26.7 \\
+19.4 \\
+21.2 \\
+13.8 \\
+22.2\end{array}$ & $\begin{array}{l}+.136 \\
+.099 \\
+.108 \\
+.070 \\
+.113\end{array}$ & $\begin{array}{l}+.346 \\
+.251 \\
+.275 \\
+.179 \\
+.288\end{array}$ & $\begin{array}{l}\text { A } \\
\text { A } \\
\text { A } \\
\text { B } \\
\text { B }\end{array}$ \\
\hline $\begin{array}{l}21 \\
22 \\
23 \\
24 \\
25\end{array}$ & $\begin{array}{l}-.049 \\
-.031 \\
-.032 \\
-.021 \\
-.035\end{array}$ & $\begin{array}{l}-.029 \\
-.037 \\
-.026 \\
-.031 \\
-.038\end{array}$ & $\begin{array}{l}-.039 \\
-.035 \\
-.024 \\
-.038 \\
-.041\end{array}$ & $\begin{array}{l}-.041 \\
-.034 \\
-.027 \\
-.025 \\
-.043\end{array}$ & $\begin{array}{l}-.040 \\
-.034 \\
-.027 \\
-.029 \\
-.039\end{array}$ & $\begin{array}{l}2,348 \\
2,346 \\
2,344 \\
2,343 \\
2,341\end{array}$ & $\begin{array}{l}-93.9 \\
-79.8 \\
-63.3 \\
-67.9 \\
-91.3\end{array}$ & $\begin{array}{l}1.1 \\
1.0 \\
1.2 \\
.9 \\
1.9\end{array}$ & $\begin{array}{l}36.2 \\
31.6 \\
28.5 \\
31.2 \\
30.8\end{array}$ & $\begin{array}{l}+58.8 \\
+49.2 \\
+36.0 \\
+37.6 \\
+62.4\end{array}$ & $\begin{array}{l}+.300 \\
+.252 \\
+.184 \\
+.193 \\
+.320\end{array}$ & $\begin{array}{l}+.763 \\
+.639 \\
+.468 \\
+.489 \\
+.812\end{array}$ & $\begin{array}{l}\text { C } \\
\text { A } \\
\text { A } \\
\text { B } \\
\text { A }\end{array}$ \\
\hline $\begin{array}{l}26 \\
27 \\
28 \\
29 \\
30 \\
\end{array}$ & $\begin{array}{l}- \\
\overline{-} \\
-\end{array}$ & $\begin{array}{l}-.042 \\
-.029 \\
-.022 \\
-.029 \\
-.022 \\
\end{array}$ & $\begin{array}{l}-.034 \\
-.022 \\
-.028 \\
-.030 \\
-.020 \\
\end{array}$ & $\begin{array}{l}-.031 \\
-.028 \\
-.030 \\
-.017 \\
-.019 \\
\end{array}$ & $\begin{array}{l}-.036 \\
-.026 \\
-.027 \\
-.025 \\
-.020 \\
\end{array}$ & $\begin{array}{l}2,339 \\
2,337 \\
2,336 \\
2,334 \\
2,333 \\
\end{array}$ & $\begin{array}{l}-84.2 \\
-60.8 \\
-63.1 \\
-58.4 \\
-46.7 \\
\end{array}$ & $\begin{array}{r}17.9 \\
1.1 \\
1.2 \\
1.1 \\
1.1 \\
\end{array}$ & $\begin{array}{l}33.9 \\
25.3 \\
27.7 \\
30.3 \\
19.8 \\
\end{array}$ & $\begin{array}{l}+68.2 \\
+36.6 \\
+36.6 \\
+29.2 \\
+28.0 \\
\end{array}$ & $\begin{array}{l}+.350 \\
+.188 \\
+.188 \\
+.150 \\
+.144 \\
\end{array}$ & $\begin{array}{l}+.889 \\
+.477 \\
+.478 \\
+.381 \\
+.366 \\
\end{array}$ & $\begin{array}{l}\text { B } \\
\text { B } \\
\text { B } \\
\text { C } \\
\text { A } \\
\end{array}$ \\
\hline \multicolumn{14}{|c|}{ October 1950} \\
\hline $\begin{array}{l}1 \\
2 \\
3 \\
4 \\
5\end{array}$ & $\begin{array}{r}- \\
- \\
+0.038 \\
-.031 \\
-.034\end{array}$ & $\begin{array}{r}-0.029 \\
+.592 \\
+.045 \\
-.043 \\
-.035\end{array}$ & $\begin{array}{r}-0.030 \\
+.590 \\
+.044 \\
-.039 \\
-.035\end{array}$ & $\begin{array}{r}-0.031 \\
+.563 \\
+.057 \\
-.033 \\
-.038\end{array}$ & $\begin{array}{r}-0.030 \\
+.582 \\
+.046 \\
-.036 \\
-.036\end{array}$ & $\begin{array}{l}2,332 \\
2,348 \\
2,364 \\
2,364 \\
2,362\end{array}$ & $\begin{array}{r}-70.0 \\
+1,366.5 \\
+108.7 \\
-85.1 \\
-85.0\end{array}$ & $\begin{array}{r}14.2 \\
1,423.2 \\
175.1 \\
4.0 \\
2.7\end{array}$ & $\begin{array}{l}21.1 \\
24.4 \\
24.7 \\
19.2 \\
22.0\end{array}$ & $\begin{array}{l}+63.0 \\
+32.3 \\
+41.7 \\
+69.9 \\
+65.7\end{array}$ & $\begin{array}{r}+0.324 \\
+.165 \\
+.212 \\
+.355 \\
+.334\end{array}$ & $\begin{array}{r}+0.823 \\
+.419 \\
+.538 \\
+.901 \\
+.848\end{array}$ & $\begin{array}{l}\text { A } \\
\text { D } \\
\text { C } \\
\text { B } \\
\text { A }\end{array}$ \\
\hline $\begin{array}{r}6 \\
7 \\
8 \\
9 \\
10\end{array}$ & $\begin{array}{l}-.026 \\
-.049 \\
-.036 \\
-.020 \\
-.037\end{array}$ & $\begin{array}{l}-.055 \\
-.010 \\
-.038 \\
-.033 \\
-.037\end{array}$ & $\begin{array}{l}-.040 \\
-.030 \\
-.038 \\
-.034 \\
-.036\end{array}$ & $\begin{array}{l}-.045 \\
-.030 \\
-.032 \\
-.029 \\
-.031\end{array}$ & $\begin{array}{l}-.042 \\
-.030 \\
-.036 \\
-.029 \\
-.035\end{array}$ & $\begin{array}{l}2,359 \\
2,358 \\
2,356 \\
2,354 \\
2,352\end{array}$ & $\begin{array}{l}-99.1 \\
-70.7 \\
-84.8 \\
-68.3 \\
-82.3\end{array}$ & $\begin{array}{l}2.1 \\
1.6 \\
1.3 \\
1.2 \\
1.2\end{array}$ & $\begin{array}{l}31.4 \\
26.4 \\
19.3 \\
26.2 \\
30.1\end{array}$ & $\begin{array}{r}+69.8 \\
+45.9 \\
+66.8 \\
+43.3 \\
+53.4\end{array}$ & $\begin{array}{l}+.355 \\
+.234 \\
+.340 \\
+.221 \\
+.272\end{array}$ & $\begin{array}{l}+.902 \\
+.593 \\
+.864 \\
+.561 \\
+.692\end{array}$ & $\begin{array}{l}\text { C } \\
\text { D } \\
\text { A } \\
\text { B } \\
\text { A }\end{array}$ \\
\hline $\begin{array}{l}11 \\
12 \\
13 \\
14 \\
15\end{array}$ & $\begin{array}{l}-.024 \\
-.018 \\
-.029 \\
-.029 \\
-.030\end{array}$ & $\begin{array}{l}-.011 \\
-.035 \\
-.037 \\
-.026 \\
-.033\end{array}$ & $\begin{array}{l}-.012 \\
-.025 \\
-.035 \\
-.025 \\
-.035\end{array}$ & $\begin{array}{l}-.018 \\
-.031 \\
- \\
-\end{array}$ & $\begin{array}{l}-.016 \\
-.027 \\
-.034 \\
-.027 \\
-.033\end{array}$ & $\begin{array}{l}2,351 \\
2,350 \\
2,348 \\
2,347 \\
2,345\end{array}$ & $\begin{array}{l}-37.6 \\
-63.4 \\
-79.8 \\
-63.4 \\
-77.4\end{array}$ & $\begin{array}{r}1.2 \\
1.1 \\
1.0 \\
1.0 \\
.9\end{array}$ & $\begin{array}{l}33.2 \\
27.2 \\
29.1 \\
24.8 \\
31.4\end{array}$ & $\begin{array}{r}+5.6 \\
+37.3 \\
+51.7 \\
+39.6 \\
+46.9\end{array}$ & $\begin{array}{l}+.029 \\
+.190 \\
+.264 \\
+.202 \\
+.240\end{array}$ & $\begin{array}{l}+.073 \\
+.484 \\
+.671 \\
+.514 \\
+.610\end{array}$ & $\begin{array}{l}\text { B } \\
\text { B } \\
\text { B } \\
\text { A } \\
\text { A }\end{array}$ \\
\hline $\begin{array}{l}16 \\
17 \\
18 \\
19 \\
20\end{array}$ & $\begin{array}{l}-.041 \\
-.023 \\
-.023 \\
-.020 \\
-.022\end{array}$ & $\begin{array}{l}-.028 \\
-.024 \\
-.018 \\
-.017 \\
-.021\end{array}$ & $\begin{array}{l}-.040 \\
-.020 \\
-.020 \\
-.020 \\
-.012\end{array}$ & $\begin{array}{l}-.032 \\
-.026 \\
-.020 \\
-.019 \\
-.017\end{array}$ & $\begin{array}{l}-.035 \\
-.023 \\
-.020 \\
-.019 \\
-.018\end{array}$ & $\begin{array}{l}2,343 \\
2,342 \\
2,341 \\
2,340 \\
2,339\end{array}$ & $\begin{array}{l}-82.0 \\
-53.9 \\
-46.8 \\
-44.5 \\
-42.1\end{array}$ & $\begin{array}{l}.7 \\
.7 \\
.7 \\
.9 \\
.8\end{array}$ & $\begin{array}{l}28.2 \\
29.8 \\
30.9 \\
25.6 \\
27.9\end{array}$ & $\begin{array}{r}+54.4 \\
+24.8 \\
+16.6 \\
+19.8 \\
+15.0\end{array}$ & $\begin{array}{l}+.279 \\
+.127 \\
+.085 \\
+.102 \\
+.077\end{array}$ & $\begin{array}{l}+.709 \\
+.323 \\
+.216 \\
+.258 \\
+.195\end{array}$ & $\begin{array}{l}\text { B } \\
\text { A } \\
\text { A } \\
\text { A } \\
\text { A }\end{array}$ \\
\hline $\begin{array}{l}21 \\
22 \\
23 \\
24 \\
25\end{array}$ & $\begin{array}{l}-.028 \\
-.039 \\
-.021 \\
-.034 \\
-.013\end{array}$ & $\begin{array}{l}-.027 \\
-.028 \\
-.035 \\
-.031 \\
-.029\end{array}$ & $\begin{array}{l}-.028 \\
-.030 \\
-.035 \\
-.030 \\
-.025\end{array}$ & $\begin{array}{l}-.025 \\
+.017 \\
-.051 \\
-.033 \\
-.047\end{array}$ & $\begin{array}{l}-.027 \\
-.020 \\
-.036 \\
-.032 \\
-.028\end{array}$ & $\begin{array}{l}2,338 \\
2,336 \\
2,334 \\
2,333 \\
2,331\end{array}$ & $\begin{array}{l}-63.1 \\
-46.7 \\
-84.0 \\
-74.7 \\
-65.3\end{array}$ & $\begin{array}{l}.8 \\
.8 \\
.6 \\
.7 \\
.6\end{array}$ & $\begin{array}{l}25.6 \\
26.6 \\
22.6 \\
28.3 \\
32.6\end{array}$ & $\begin{array}{r}+38.3 \\
+20.9 \\
+62.0 \\
+47.1 \\
+33.3\end{array}$ & $\begin{array}{l}+.197 \\
+.107 \\
+.319 \\
+.242 \\
+.171\end{array}$ & $\begin{array}{l}+.499 \\
+.273 \\
+.810 \\
+.615 \\
+.435\end{array}$ & $\begin{array}{l}\text { A } \\
\text { D } \\
\text { C } \\
\text { A } \\
\text { C }\end{array}$ \\
\hline $\begin{array}{l}26 \\
27 \\
28 \\
29 \\
30 \\
31\end{array}$ & $\begin{array}{l}-.073 \\
-.027 \\
-.017 \\
-.030 \\
-.021\end{array}$ & $\begin{array}{l}-.051 \\
-.028 \\
-.014 \\
-.036 \\
-.024 \\
-.036\end{array}$ & $\begin{array}{l}-.047 \\
-.038 \\
-.020 \\
-.025 \\
-.025 \\
-.015\end{array}$ & $\begin{array}{l}-.045 \\
-.023 \\
-.028 \\
-.030 \\
-.033 \\
-.026\end{array}$ & $\begin{array}{l}-.048 \\
-.028 \\
-.022 \\
-.027 \\
-.028 \\
-.024\end{array}$ & $\begin{array}{l}2,329 \\
2,327 \\
2,326 \\
2,324 \\
2,323 \\
2,322\end{array}$ & $\begin{array}{r}-111.8 \\
-65.2 \\
-51.2 \\
-62.7 \\
-65.0 \\
-55.7\end{array}$ & $\begin{array}{l}.7 \\
.6 \\
.6 \\
.3 \\
.3 \\
.6\end{array}$ & $\begin{array}{l}25.8 \\
27.9 \\
26.6 \\
26.2 \\
28.3 \\
28.3\end{array}$ & $\begin{array}{l}+86.7 \\
+37.9 \\
+25.2 \\
+36.8 \\
+37.0 \\
+28.0\end{array}$ & $\begin{array}{l}+.447 \\
+.195 \\
+.130 \\
+.190 \\
+.191 \\
+.145\end{array}$ & $\begin{array}{r}+1.135 \\
+.496 \\
+.330 \\
+.483 \\
+.485 \\
+.368\end{array}$ & $\begin{array}{l}\text { A } \\
\text { C } \\
\text { B } \\
\text { C } \\
\text { B } \\
\text { C }\end{array}$ \\
\hline
\end{tabular}


Table 1. - Daily water-budget evaporation from Lake Hefner, Okla., Apr. 26, 1950, to Aug. 31, 1951-Continued

\begin{tabular}{|c|c|c|c|c|c|c|c|c|c|c|c|c|c|}
\hline \multirow{3}{*}{ Day } & \multicolumn{5}{|c|}{ Change in stage, in feet } & \multirow{3}{*}{$\begin{array}{c}\text { Aver- } \\
\text { age } \\
\text { surface } \\
\text { area } \\
\text { (acres) }\end{array}$} & \multirow{3}{*}{$\begin{array}{c}\text { Change } \\
\text { in } \\
\text { content } \\
\text { (acre-ft) }\end{array}$} & \multirow{3}{*}{$\begin{array}{l}\text { Inflow } \\
\text { (acre-ft) }\end{array}$} & \multirow{3}{*}{$\begin{array}{l}\text { Outflow } \\
\text { (acre-ft) }\end{array}$} & \multirow{2}{*}{\multicolumn{3}{|c|}{ Evaporations }} & \multirow{3}{*}{$\begin{array}{c}\text { Accuracy } \\
\text { classification }\end{array}$} \\
\hline & \multicolumn{4}{|c|}{ Gages } & \multirow{2}{*}{$\begin{array}{l}\text { Aver- } \\
\text { age }\end{array}$} & & & & & & & & \\
\hline & Noprth & South & East & West & & & & & & $\begin{array}{c}\text { Acre- } \\
\text { feet }\end{array}$ & Inches & $\begin{array}{l}\text { Centi- } \\
\text { meters }\end{array}$ & \\
\hline \multicolumn{14}{|c|}{ November 1950} \\
\hline $\begin{array}{l}1 \\
2 \\
3 \\
4 \\
5\end{array}$ & $\begin{array}{l}-0.053 \\
-.027 \\
-.005 \\
-021 \\
-.046\end{array}$ & $\begin{array}{r}-0.021 \\
-0030 \\
-.003 \\
-046 \\
-.047\end{array}$ & $\begin{array}{l}-0.043 \\
-.027 \\
0 \\
-.045 \\
-.040\end{array}$ & $\begin{array}{l}-0.065 \\
-.011 \\
-0.039 \\
-.041\end{array}$ & $\begin{array}{r}-0.039 \\
-.028 \\
-.005 \\
-.038 \\
-.044\end{array}$ & $\begin{array}{l}2,320 \\
2,318 \\
2,319 \\
2,316 \\
2,314\end{array}$ & $\begin{array}{r}-90.5 \\
-64.9 \\
-11.6 \\
-88.0 \\
-101.8\end{array}$ & $\begin{array}{r}1.2 \\
9.2 \\
127.1 \\
1.1 \\
.8\end{array}$ & $\begin{array}{l}29.7 \\
26.7 \\
28.8 \\
27.2 \\
24.1\end{array}$ & $\begin{array}{r}+62.0 \\
+47.4 \\
+109.9 \\
+61.9 \\
+78.5\end{array}$ & $\begin{array}{r}-0.321 \\
+.245 \\
+.569 \\
+.321 \\
+.407\end{array}$ & $\begin{array}{r}+0.815 \\
+.623 \\
+1.444 \\
+.815 \\
+1.034\end{array}$ & $\begin{array}{l}\mathbf{D} \\
\mathbf{A} \\
\mathbf{B} \\
\mathbf{C} \\
\mathbf{A}\end{array}$ \\
\hline $\begin{array}{r}6 \\
7 \\
8 \\
9 \\
10\end{array}$ & $\begin{array}{l}-.034 \\
-.017 \\
-.046 \\
-.062 \\
-.029\end{array}$ & $\begin{array}{l}-.013 \\
-.017 \\
-.007 \\
-.072 \\
-.052\end{array}$ & $\begin{array}{l}-.030 \\
-.015 \\
-.035 \\
-.065 \\
-.035\end{array}$ & $\begin{array}{l}-.019 \\
-.016 \\
- \\
-\end{array}$ & $\begin{array}{l}-.024 \\
-.016 \\
-.029 \\
-.066 \\
-.039\end{array}$ & $\begin{array}{l}2,312 \\
2,311 \\
2,310 \\
2,308 \\
2,304\end{array}$ & $\begin{array}{r}-55.5 \\
-37.0 \\
-67.0 \\
-152.3 \\
-89.9\end{array}$ & $\begin{array}{l}.7 \\
.6 \\
.6 \\
.3 \\
.5\end{array}$ & $\begin{array}{l}29.6 \\
26.9 \\
29.9 \\
29.7 \\
27.4\end{array}$ & $\begin{array}{r}+26.6 \\
+10.7 \\
+37.7 \\
+122.9 \\
+63.0\end{array}$ & $\begin{array}{l}+.138 \\
+.056 \\
+.196 \\
+.639 \\
+.328\end{array}$ & $\begin{array}{r}+.351 \\
+.141 \\
+.497 \\
+1.623 \\
+.833\end{array}$ & $\begin{array}{l}\text { C } \\
\text { A } \\
\text { D } \\
\text { B } \\
\text { C }\end{array}$ \\
\hline $\begin{array}{l}11 \\
12 \\
13 \\
14 \\
15\end{array}$ & $\begin{array}{l}-.038 \\
-.037 \\
-.027 \\
-.007 \\
-.018\end{array}$ & $\begin{array}{l}-.043 \\
-.036 \\
-.018 \\
-.010 \\
-.001\end{array}$ & $\begin{array}{l}-.040 \\
-.038 \\
-.027 \\
-.005 \\
-.009\end{array}$ & $\begin{array}{l}- \\
- \\
-.007\end{array}$ & $\begin{array}{l}-.040 \\
-.037 \\
-.024 \\
-.007 \\
-.009\end{array}$ & $\begin{array}{l}2,303 \\
2,301 \\
2,299 \\
2,298 \\
2,298\end{array}$ & $\begin{array}{l}-92.1 \\
-85.1 \\
-55.2 \\
-16.1 \\
-20.7\end{array}$ & $\begin{array}{r}.8 \\
.9 \\
1.1 \\
1.0\end{array}$ & $\begin{array}{l}28.8 \\
22.5 \\
28.4 \\
27.9 \\
30.4\end{array}$ & $\begin{array}{r}+64.1 \\
+63.5 \\
+27.9 \\
-11.0 \\
-8.7\end{array}$ & $\begin{array}{l}+.334 \\
+.331 \\
+.146 \\
-.057 \\
-.045\end{array}$ & $\begin{array}{l}+.848 \\
+.841 \\
+.370 \\
-.146 \\
-.115\end{array}$ & $\begin{array}{l}\text { A } \\
\text { A } \\
\text { B } \\
\text { A } \\
\text { C }\end{array}$ \\
\hline $\begin{array}{l}16 \\
17 \\
18 \\
19 \\
20\end{array}$ & $\begin{array}{l}-.026 \\
-.007 \\
-.024 \\
-.038 \\
-.017\end{array}$ & $\begin{array}{l}-.034 \\
-.039 \\
-.009 \\
+.028 \\
-.083\end{array}$ & $\begin{array}{l}-.029 \\
-.027 \\
-.013 \\
-.005 \\
-.057\end{array}$ & $\begin{array}{l}- \\
- \\
-.014 \\
-.012 \\
-.043\end{array}$ & $\begin{array}{l}-.030 \\
-.024 \\
-.015 \\
-.007 \\
-.050\end{array}$ & $\begin{array}{l}2,296 \\
2,295 \\
2,294 \\
2,294 \\
2,292\end{array}$ & $\begin{array}{r}-68.9 \\
-55.1 \\
-34.4 \\
-16.1 \\
-114.6\end{array}$ & $\begin{array}{r}.6 \\
.7 \\
.9 \\
1.1 \\
. \quad .5\end{array}$ & $\begin{array}{l}28.7 \\
13.1 \\
27.6 \\
24.3 \\
22.5\end{array}$ & $\begin{array}{r}+40.8 \\
+42.7 \\
+7.7 \\
-7.1 \\
+92.6\end{array}$ & $\begin{array}{l}+.213 \\
+.223 \\
+.040 \\
-.037 \\
+.485\end{array}$ & $\begin{array}{r}+.542 \\
+.567 \\
+.102 \\
-.094 \\
+1.231\end{array}$ & $\begin{array}{l}\text { B } \\
\text { D } \\
\text { B } \\
\text { D } \\
\text { D }\end{array}$ \\
\hline $\begin{array}{l}21 \\
22 \\
23 \\
24 \\
25\end{array}$ & $\begin{array}{l}-.030 \\
-.019 \\
-.047 \\
-.024 \\
-.027\end{array}$ & $\begin{array}{l}-.024 \\
-.021 \\
-.026 \\
-.045 \\
-.016\end{array}$ & $\begin{array}{l}-.025 \\
-.024 \\
-.031 \\
-.030 \\
-.015\end{array}$ & $\begin{array}{l}-.026 \\
-.019 \\
-.048 \\
-.030 \\
-.027\end{array}$ & $\begin{array}{l}-.026 \\
-.021 \\
-.038 \\
-.032 \\
-.021\end{array}$ & $\begin{array}{l}2,290 \\
2,289 \\
2,287 \\
2,285 \\
2,284\end{array}$ & $\begin{array}{l}-59.5 \\
-48.1 \\
-86.9 \\
-73.1 \\
-48.0\end{array}$ & $\begin{array}{l}.8 \\
.8 \\
.7 \\
.5 \\
.9\end{array}$ & $\begin{array}{l}28.3 \\
30.3 \\
17.9 \\
19.1 \\
27.3\end{array}$ & $\begin{array}{l}+32.0 \\
+18.6 \\
+69.7 \\
+54.5 \\
+21.6\end{array}$ & $\begin{array}{l}+.168 \\
+.098 \\
+.366 \\
+.286 \\
+.113\end{array}$ & $\begin{array}{l}+.426 \\
+.247 \\
+.929 \\
+.727 \\
+.288\end{array}$ & $\begin{array}{l}\text { A } \\
\text { A } \\
\text { C } \\
\text { C } \\
\text { B }\end{array}$ \\
\hline $\begin{array}{l}26 \\
27 \\
28 \\
29 \\
30 \\
\end{array}$ & $\begin{array}{l}-.013 \\
-.015 \\
-.029 \\
-.013 \\
-.012 \\
\end{array}$ & $\begin{array}{l}-.028 \\
-.014 \\
-.019 \\
-.022 \\
-.014 \\
\end{array}$ & $\begin{array}{l}-.022 \\
-.018 \\
-.016 \\
-.026 \\
-.014 \\
\end{array}$ & $\begin{array}{l}-.015 \\
-.015 \\
-.020 \\
-.018 \\
-.015 \\
\end{array}$ & $\begin{array}{l}-.020 \\
-.016 \\
-.021 \\
-.020 \\
-.014 \\
\end{array}$ & $\begin{array}{l}2,283 \\
2,282 \\
2,281 \\
2,280 \\
2,279 \\
\end{array}$ & $\begin{array}{l}-45.7 \\
-36.5 \\
-47.9 \\
-45.6 \\
-31.9 \\
\end{array}$ & $\begin{array}{r}1.0 \\
.9 \\
1.1 \\
1.0 \\
.9 \\
\end{array}$ & $\begin{array}{l}20.8 \\
24.2 \\
32.9 \\
32.0 \\
23.9 \\
\end{array}$ & $\begin{array}{r}+25.9 \\
+13.2 \\
+16.1 \\
+14.6 \\
+8.9 \\
\end{array}$ & $\begin{array}{l}+.136 \\
+.069 \\
+.085 \\
+.077 \\
+.047 \\
\end{array}$ & $\begin{array}{l}+.346 \\
+.176 \\
+.215 \\
+.195 \\
+.119 \\
\end{array}$ & $\begin{array}{l}\text { B } \\
\text { A } \\
\text { B } \\
\text { B } \\
\text { A } \\
\end{array}$ \\
\hline \multicolumn{14}{|c|}{ December 1950} \\
\hline $\begin{array}{l}1 \\
2 \\
3 \\
4 \\
5\end{array}$ & $\begin{array}{r}-0.016 \\
-.034 \\
-.010 \\
-.044 \\
-.053\end{array}$ & $\begin{array}{l}-0.025 \\
-.010 \\
-037 \\
-0020 \\
-.015\end{array}$ & $\begin{array}{r}-0.018 \\
-.026 \\
-.026 \\
-.031 \\
-.021\end{array}$ & $\begin{array}{r}-0.015 \\
-.024 \\
-.016 \\
-.043 \\
-.039\end{array}$ & $\begin{array}{r}-0.018 \\
-.024 \\
-.022 \\
-.034 \\
-.032\end{array}$ & $\begin{array}{l}2,278 \\
2,277 \\
2,276 \\
2,274 \\
2,273\end{array}$ & $\begin{array}{l}-41.0 \\
-54.6 \\
-50.1 \\
-77.3 \\
-72.7\end{array}$ & $\begin{array}{r}1.2 \\
1.2 \\
.8 \\
.9 \\
.6\end{array}$ & $\begin{array}{l}29.0 \\
24.1 \\
21.5 \\
31.3 \\
25.2\end{array}$ & $\begin{array}{l}+13.2 \\
+31.7 \\
+29.4 \\
+46.9 \\
+48.1\end{array}$ & $\begin{array}{r}+0.070 \\
+.167 \\
+.155 \\
+.247 \\
+.254\end{array}$ & $\begin{array}{r}+0.177 \\
+.424 \\
+.394 \\
+.629 \\
+.645\end{array}$ & $\begin{array}{l}B \\
C \\
C \\
C \\
D\end{array}$ \\
\hline $\begin{array}{r}6 \\
7 \\
8 \\
9 \\
9 \\
10\end{array}$ & $\begin{array}{l}-.021 \\
-.019 \\
-.021 \\
-.024 \\
-.013\end{array}$ & $\begin{array}{l}-.057 \\
-.036 \\
-.020 \\
-.018 \\
-.025\end{array}$ & $\begin{array}{l}-.042 \\
-.036 \\
-.016 \\
-.016 \\
-.026\end{array}$ & $\begin{array}{l}-.034 \\
-.001 \\
-.053 \\
-.020 \\
-.010\end{array}$ & $\begin{array}{l}-.038 \\
-.023 \\
-.028 \\
-.020 \\
-.018\end{array}$ & $\begin{array}{l}2,270 \\
2,269 \\
2,268 \\
2,266 \\
2,265\end{array}$ & $\begin{array}{l}-86.3 \\
-52.2 \\
-63.5 \\
-45.3 \\
-40.8\end{array}$ & $\begin{array}{r}.1 \\
.1 \\
1.8 \\
1.1\end{array}$ & $\begin{array}{l}30.2 \\
28.7 \\
35.3 \\
37.8 \\
28.3\end{array}$ & $\begin{array}{r}+56.2 \\
+23.6 \\
+29.0 \\
+8.8 \\
+13.6\end{array}$ & $\begin{array}{r}+.297 \\
+.125 \\
+.153 \\
+.047 \\
+.072\end{array}$ & $\begin{array}{r}+.755 \\
+.317 \\
+.390 \\
+.118 \\
+.183\end{array}$ & $\begin{array}{l}\text { D } \\
\text { C } \\
\text { D } \\
\text { A } \\
\text { B }\end{array}$ \\
\hline $\begin{array}{l}11 \\
12 \\
13 \\
14 \\
15\end{array}$ & $\begin{array}{l}-.023 \\
-.017 \\
-.018 \\
-.015 \\
-.025\end{array}$ & $\begin{array}{l}-.013 \\
-.018 \\
-.018 \\
-.015 \\
-.022\end{array}$ & $\begin{array}{l}-.011 \\
-.021 \\
-.024 \\
-.015 \\
-.025\end{array}$ & $\begin{array}{c}- \\
-\overline{0} \\
-.019 \\
-.017 \\
-.021\end{array}$ & $\begin{array}{r}-.016 \\
-.019 \\
-.020 \\
-.016 \\
-.023\end{array}$ & $\begin{array}{l}2,264 \\
2,264 \\
2,263 \\
2,262 \\
2,261\end{array}$ & $\begin{array}{l}-36.2 \\
-43.0 \\
-45.3 \\
-36.2 \\
-52.0\end{array}$ & $\begin{array}{r}1.0 \\
1.1 \\
.9 \\
.9 \\
1.0\end{array}$ & $\begin{array}{l}34.2 \\
30.2 \\
36.1 \\
35.2 \\
37.3\end{array}$ & $\begin{array}{r}+3.0 \\
+13.9 \\
+10.1 \\
+1.9 \\
+15.7\end{array}$ & $\begin{array}{l}+.016 \\
+.074 \\
+.054 \\
+.010 \\
+.083\end{array}$ & $\begin{array}{r}+.040 \\
+.187 \\
+.136 \\
+.026 \\
+.212\end{array}$ & $\begin{array}{l}\text { B } \\
\text { A } \\
\text { A } \\
\text { A } \\
\text { A }\end{array}$ \\
\hline $\begin{array}{l}16 \\
17 \\
18 \\
19 \\
20\end{array}$ & $\begin{array}{l}-.017 \\
-.023 \\
-.018 \\
-.023 \\
-.019\end{array}$ & $\begin{array}{l}-.019 \\
-.021 \\
-.022 \\
-.015 \\
-.020\end{array}$ & $\begin{array}{l}-.015 \\
-.025 \\
-.015 \\
-.015 \\
-.020\end{array}$ & $\begin{array}{l}-.018 \\
-.020 \\
-.022 \\
-.022 \\
-.023\end{array}$ & $\begin{array}{l}-.017 \\
-.022 \\
-.019 \\
-.019 \\
-.020\end{array}$ & $\begin{array}{l}2,260 \\
2,259 \\
2,257 \\
2,256 \\
2,255\end{array}$ & $\begin{array}{l}-38.4 \\
-49.7 \\
-42.9 \\
-42.9 \\
-45.1\end{array}$ & $\begin{array}{l}1.0 \\
1.0 \\
1.0 \\
1.0 \\
1.1\end{array}$ & $\begin{array}{l}36.1 \\
34.9 \\
34.5 \\
35.3 \\
37.1\end{array}$ & $\begin{array}{r}+3.3 \\
+15.8 \\
+9.4 \\
+8.6 \\
+9.1\end{array}$ & $\begin{array}{l}+.018 \\
+.084 \\
+.050 \\
+.046 \\
+.048\end{array}$ & $\begin{array}{l}+.044 \\
+.213 \\
+.127 \\
+.116 \\
+.123\end{array}$ & $\begin{array}{l}\text { A } \\
\text { A } \\
\text { A } \\
\text { A } \\
\text { A }\end{array}$ \\
\hline $\begin{array}{l}21 \\
22 \\
23 \\
24 \\
25\end{array}$ & $\begin{array}{l}-.013 \\
-.020 \\
-.015 \\
-.009 \\
-.019\end{array}$ & $\begin{array}{l}-.022 \\
-.016 \\
-.011 \\
-.021 \\
-.014\end{array}$ & $\begin{array}{l}-.018 \\
-.017 \\
-.015 \\
-.010 \\
-.025\end{array}$ & $\begin{array}{l}-.015 \\
-.013 \\
-.015 \\
-.009 \\
-.017\end{array}$ & $\begin{array}{l}-.017 \\
-.016 \\
-.014 \\
-.012 \\
-.019\end{array}$ & $\begin{array}{l}2,254 \\
2,254 \\
2,253 \\
2,252 \\
2,251\end{array}$ & $\begin{array}{l}-38.3 \\
-36.1 \\
-31.5 \\
-27.0 \\
-42.8\end{array}$ & $\begin{array}{r}1.0 \\
1.0 \\
1.0 \\
1.0 \\
.9\end{array}$ & $\begin{array}{l}35.6 \\
34.9 \\
27.9 \\
22.4 \\
22.4\end{array}$ & $\begin{array}{r}+3.7 \\
+2.2 \\
+4.6 \\
+5.6 \\
+21.3\end{array}$ & $\begin{array}{r}+.020 \\
+.012 \\
+.024 \\
+.030 \\
+.114\end{array}$ & $\begin{array}{r}+.050 \\
+.030 \\
+.062 \\
+.076 \\
+.288\end{array}$ & $\begin{array}{l}\text { B } \\
\text { A } \\
\text { A } \\
\text { B } \\
\text { B }\end{array}$ \\
\hline $\begin{array}{l}26 \\
27 \\
28 \\
29 \\
30 \\
31\end{array}$ & $\begin{array}{l}-.037 \\
-.014 \\
-.021 \\
-.012 \\
-.007 \\
-.022\end{array}$ & $\begin{array}{l}-.013 \\
-.041 \\
-.019 \\
-.014 \\
-.025 \\
-.032\end{array}$ & $\begin{array}{l}-.025 \\
-.023 \\
-.019 \\
-.013 \\
-.017 \\
-.028\end{array}$ & $\begin{array}{l}-.024 \\
-.021 \\
-.019 \\
-.018 \\
-.009 \\
-.029\end{array}$ & $\begin{array}{l}-.025 \\
-.025 \\
-.020 \\
-.014 \\
-.014 \\
-.028\end{array}$ & $\begin{array}{l}2,250 \\
2,249 \\
2,247 \\
2,247 \\
2,246 \\
2,244\end{array}$ & $\begin{array}{l}-56.2 \\
-56.2 \\
-44.9 \\
-31.5 \\
-31.4 \\
-62.8\end{array}$ & $\begin{array}{r}.7 \\
.3 \\
.8 \\
2.8 \\
1.0 \\
.9\end{array}$ & $\begin{array}{l}27.6 \\
28.7 \\
28.7 \\
34.5 \\
30.3 \\
31.3\end{array}$ & $\begin{array}{r}+29.3 \\
+27.8 \\
+17.0 \\
-.2 \\
+2.1 \\
+32.4\end{array}$ & $\begin{array}{r}+.156 \\
+.148 \\
+.091 \\
-.001 \\
+.011 \\
+.173\end{array}$ & $\begin{array}{r}+.397 \\
+.377 \\
+.231 \\
-.003 \\
+.028 \\
+.440\end{array}$ & $\begin{array}{l}\text { C } \\
\text { C } \\
\text { A } \\
\text { A } \\
\text { C } \\
\text { B }\end{array}$ \\
\hline
\end{tabular}


TABLE 1

Table 1. -Daily water-budget evaporation from Lake Hefner, OkIa., Apr. 26, 1950, to Aug. 31, 1951-Continned

\begin{tabular}{|c|c|c|c|c|c|c|c|c|c|c|c|c|c|}
\hline \multirow{3}{*}{ Da } & \multicolumn{5}{|c|}{ Change in stage, in feet } & \multirow{3}{*}{$\begin{array}{c}\text { Aver- } \\
\text { age } \\
\text { surface } \\
\text { area } \\
\text { (acres) }\end{array}$} & \multirow{3}{*}{$\begin{array}{c}\text { Change } \\
\text { in } \\
\text { content } \\
\text { (acre- }-5 t)\end{array}$} & \multirow{3}{*}{$\begin{array}{c}\text { Inflow } \\
\text { (acre-ft) }\end{array}$} & \multirow[b]{3}{*}{$\begin{array}{l}\text { Outfliow } \\
\text { (acre-ft) }\end{array}$} & \multirow{2}{*}{\multicolumn{3}{|c|}{ Evaporation }} & \multirow{3}{*}{$\begin{array}{l}\text { Accuracy } \\
\text { classification }\end{array}$} \\
\hline & \multicolumn{4}{|c|}{ Gages } & \multirow{2}{*}{$\begin{array}{l}\text { Aver- } \\
\text { age }\end{array}$} & & & & & & & & \\
\hline & North & South & East & West & & & & & & $\begin{array}{l}\text { Acre- } \\
\text { feet }\end{array}$ & Inches & $\begin{array}{l}\text { Cent- } \\
\text { meters }\end{array}$ & \\
\hline & & & & & & & January 1 & & & & & & \\
\hline $\begin{array}{l}1 \\
2 \\
3 \\
4 \\
5\end{array}$ & $\begin{array}{r}-0.017 \\
+.009 \\
-0.020 \\
-.009 \\
-0.031\end{array}$ & $\begin{array}{r}+0.009 \\
+.024 \\
-0.025 \\
-031 \\
+.019\end{array}$ & $\begin{array}{l}0 \\
+.020 \\
-.028 \\
-.024 \\
-.013\end{array}$ & $\begin{array}{r}-0.010 \\
+.015 \\
-0.018 \\
-0.013 \\
-.024\end{array}$ & $\begin{array}{r}-0.004 \\
+.011 \\
-.023 \\
-.019 \\
-.012\end{array}$ & $\begin{array}{l}2,244 \\
2,245 \\
2,244 \\
2,243 \\
2,242\end{array}$ & $\begin{array}{r}-9.0 \\
+38.2 \\
+51.6 \\
-42.6 \\
-26.9\end{array}$ & $\begin{array}{r}2.8 \\
63.0 \\
1.9 \\
1.2 \\
1.0\end{array}$ & $\begin{array}{l}27.5 \\
32.0 \\
39.9 \\
33.9 \\
24.9\end{array}$ & $\begin{array}{r}-15.7 \\
-7.2 \\
+13.6 \\
+9.9 \\
+3.9\end{array}$ & $\begin{array}{r}-0.084 \\
-.038 \\
+.073 \\
+.053 \\
+.016\end{array}$ & $\begin{array}{r}-0.213 \\
-.098 \\
+.185 \\
+.135 \\
+.041\end{array}$ & $\begin{array}{l}\text { C } \\
\text { B } \\
\text { B } \\
C\end{array}$ \\
\hline $\begin{array}{r}6 \\
7 \\
8 \\
9 \\
10\end{array}$ & $\begin{array}{l}-.021 \\
-.017 \\
-.015 \\
-.027 \\
-.023\end{array}$ & $\begin{array}{l}-.039 \\
-.024 \\
-\therefore 021 \\
-.014 \\
-.033\end{array}$ & $\begin{array}{l}-.020 \\
-.020 \\
-.027 \\
-.014 \\
-0.032\end{array}$ & $\begin{array}{l}-.019 \\
\therefore .021 \\
-\because 017 \\
-020 \\
-0.032\end{array}$ & $\begin{array}{l}-.022 \\
-\because 022 \\
-.022 \\
-0019 \\
-030\end{array}$ & $\begin{array}{l}2,241 \\
2,240 \\
2,239 \\
2,238 \\
2,237\end{array}$ & $\begin{array}{r}-56.0 \\
-44.8 \\
-44.8 \\
-42.5 \\
-67\end{array}$ & $\begin{array}{r}.6 \\
: 4 \\
: 8 \\
.9 \\
1.0\end{array}$ & $\begin{array}{r}7.7 \\
27.3 \\
21.9 \\
28.0 \\
34.1\end{array}$ & $\begin{array}{l}+48.9 \\
+41.9 \\
+23.9 \\
+15.7 \\
+34.4 \\
+34.0\end{array}$ & $\begin{array}{r}+.262 \\
+.096 \\
+.1177 \\
+.083 \\
+.182\end{array}$ & $\begin{array}{r}+.665 \\
+.244 \\
+.323 \\
+.210 \\
+.463\end{array}$ & $\begin{array}{l}\text { C } \\
\text { A } \\
\text { B } \\
\text { B } \\
\text { B }\end{array}$ \\
\hline $\begin{array}{l}11 \\
12 \\
13 \\
14 \\
15\end{array}$ & $\begin{array}{l}-.011 \\
-.023 \\
+.0013 \\
+.0011 \\
-.019\end{array}$ & $\begin{array}{l}-.033 \\
-\because 003 \\
+.026 \\
+.016 \\
-.020\end{array}$ & $\begin{array}{l}-.024 \\
-.007 \\
+.019 \\
+.024 \\
-.024\end{array}$ & $\begin{array}{l}-.011 \\
-.027 \\
+.012 \\
+.030 \\
-.015\end{array}$ & $\begin{array}{l}\because 020 \\
\because .015 \\
+.018 \\
+.022 \\
-020\end{array}$ & $\begin{array}{l}2,235 \\
2,234 \\
2,234 \\
2,236 \\
2,235\end{array}$ & $\begin{array}{l}-44.7 \\
-33.5 \\
+40.2 \\
+50.9 \\
-44.7\end{array}$ & $\begin{array}{r}.6 \\
2.9 \\
26.6 \\
42.5 \\
2.5\end{array}$ & $\begin{array}{l}26.6 \\
28.8 \\
20.0 \\
24.0 \\
35.3\end{array}$ & $\begin{array}{r}+18.7 \\
+5.6 \\
-33.6 \\
-3.47 \\
+11.5\end{array}$ & $\begin{array}{r}+100 \\
+.030 \\
-.180 \\
-.201 \\
+.062\end{array}$ & $\begin{array}{r}+.255 \\
+.076 \\
-.458 \\
-.5110 \\
+.157\end{array}$ & $\begin{array}{l}\text { C } \\
\text { C } \\
\text { B } \\
\text { B } \\
B\end{array}$ \\
\hline $\begin{array}{l}16 \\
17 \\
18 \\
19 \\
20\end{array}$ & $\begin{array}{l}-.012 \\
-.028 \\
-.013 \\
-.017 \\
-.035\end{array}$ & $\begin{array}{l}-.036 \\
-.003 \\
-.013 \\
-.021 \\
-.015\end{array}$ & $\begin{array}{l}-.020 \\
-0012 \\
-0018 \\
-0023 \\
-.027\end{array}$ & $\begin{array}{l}-.020 \\
-.021 \\
-.012 \\
-.013 \\
-.030\end{array}$ & $\begin{array}{l}-.022 \\
-.011 \\
-.011 \\
-\because 011 \\
-.027\end{array}$ & $\begin{array}{l}2,234 \\
2,233 \\
2,233 \\
2,232 \\
2,231\end{array}$ & $\begin{array}{l}-49.1 \\
-35.7 \\
-31.3 \\
-310.2 \\
-60.2 \\
-60.2\end{array}$ & $\begin{array}{l}1.3 \\
1.2 \\
1.1 \\
1.0 \\
7\end{array}$ & $\begin{array}{l}24.7 \\
30.6 \\
25.7 \\
25.6 \\
27.0\end{array}$ & $\begin{array}{r}+25.7 \\
+\quad+6.3 \\
+66.7 \\
+65.6 \\
+33.9 \\
+33.9\end{array}$ & $\begin{array}{l}+.138 \\
+.034 \\
+.036 \\
+.0084 \\
+.182\end{array}$ & $\begin{array}{l}+.351 \\
+.086 \\
+.091 \\
+.+213 \\
+.463\end{array}$ & $\begin{array}{l}\text { C } \\
\text { A } \\
\text { A } \\
\text { C }\end{array}$ \\
\hline $\begin{array}{l}21 \\
22 \\
23 \\
24 \\
25\end{array}$ & $\begin{array}{l}-.009 \\
-\because 032 \\
-.013 \\
-.023 \\
-.020\end{array}$ & $\begin{array}{l}-.033 \\
-.010 \\
-\therefore 029 \\
-\therefore 018 \\
-.033\end{array}$ & $\begin{array}{l}-.023 \\
-.010 \\
-\because 032 \\
-.015 \\
-0.030\end{array}$ & $\begin{array}{l}-.019 \\
-.030 \\
-.016 \\
-.020 \\
-.009\end{array}$ & $\begin{array}{l}-.021 \\
-.022 \\
-.022 \\
-.0219 \\
-.023\end{array}$ & $\begin{array}{l}2,229 \\
2,228 \\
2,227 \\
2,226 \\
2,225\end{array}$ & $\begin{array}{l}-46.8 \\
-44.6 \\
-49.0 \\
-42.3 \\
-51.3\end{array}$ & $\begin{array}{l}.4 \\
.5 \\
.6 \\
.5 \\
5\end{array}$ & $\begin{array}{l}26.9 \\
26.3 \\
26.3 \\
29.4 \\
29.5\end{array}$ & $\begin{array}{r}+20.3 \\
+18.8 \\
+\quad 23.3 \\
+13.4 \\
+22.2\end{array}$ & $\begin{array}{r}+109 \\
+.101 \\
+.126 \\
+.0722 \\
+.120\end{array}$ & $\begin{array}{r}+.278 \\
+.257 \\
+.+197 \\
+.183 \\
+.304\end{array}$ & $\begin{array}{l}\mathrm{C} \\
\mathrm{C} \\
\mathrm{C} \\
\mathrm{A} \\
\mathrm{C}\end{array}$ \\
\hline $\begin{array}{l}26 \\
26 \\
28 \\
29 \\
30 \\
31\end{array}$ & 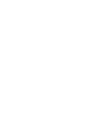 & 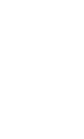 & $\begin{array}{l}\vdots \\
\vdots \\
-0025 \\
\therefore .005\end{array}$ & $\begin{array}{l}-.036 \\
-.024 \\
-.030 \\
- \\
-\end{array}$ & $\begin{array}{l}-.030 \\
-.016 \\
-\therefore 033 \\
-.032 \\
-.0217 \\
-0217\end{array}$ & $\begin{array}{l}2,224 \\
2,223 \\
2,221 \\
2,219 \\
2,218 \\
2,217 \\
2,217\end{array}$ & $\begin{array}{l}-66.7 \\
-35.6 \\
-73.3 \\
-71.0 \\
-46.0 \\
-47.6 \\
-37.7\end{array}$ & $\begin{array}{r}.7 \\
.6 \\
.1 \\
.1 \\
3.4\end{array}$ & $\begin{array}{l}30.6 \\
27.4 \\
23.7 \\
33.7 \\
33.4 \\
30.8 \\
30.8\end{array}$ & $\begin{array}{r}+36.8 \\
+8.8 \\
+49.8 \\
+40.8 \\
+13.8 \\
+10.3 \\
+10.3\end{array}$ & $\begin{array}{l}+.199 \\
+.048 \\
+.269 \\
+.221 \\
+.072 \\
+.056 \\
+.056\end{array}$ & $\begin{array}{r}+.504 \\
+.121 \\
+.683 \\
+.5650 \\
+.1183 \\
+.142 \\
+.142\end{array}$ & $\begin{array}{l}\text { D } \\
\text { D } \\
\text { C } \\
C \\
\text { D } \\
\end{array}$ \\
\hline & & & & & & & February 1 & & & & & & \\
\hline $\begin{array}{l}1 \\
2 \\
3 \\
4 \\
5\end{array}$ & $\begin{array}{r}-0.022 \\
-.016 \\
-.028 \\
-0.010 \\
+.004\end{array}$ & $\begin{array}{r}-0.038 \\
-0.020 \\
-0.010 \\
-0.013 \\
0\end{array}$ & $\begin{array}{r}-0.005 \\
-\therefore .052 \\
-.028 \\
-.010 \\
-.010\end{array}$ & $\begin{array}{c}- \\
-0.032 \\
-0.012 \\
-.002\end{array}$ & $\begin{array}{r}-0.022 \\
-.022 \\
\because .02 \\
\because .011\end{array}$ & $\begin{array}{l}2,216 \\
2,215 \\
2,213 \\
2,212 \\
2,211\end{array}$ & $\begin{array}{r}-48.8 \\
-64.2 \\
-53.1 \\
-24.3 \\
-2.2 .2\end{array}$ & $\begin{array}{r}0.1 \\
.1 \\
.3 \\
1.0 \\
1.4\end{array}$ & $\begin{array}{l}37.5 \\
34.4 \\
33.7 \\
22.8 \\
30.2\end{array}$ & $\begin{array}{r}+11.4 \\
+29.9 \\
+19.7 \\
+2.5 \\
-26.6\end{array}$ & $\begin{array}{r}+0.062 \\
+.162 \\
+.107 \\
+.014 \\
-.144\end{array}$ & $\begin{array}{r}+0.157 \\
+.411 \\
+.271 \\
+.034 \\
-.367\end{array}$ & $\begin{array}{l}\text { D } \\
\text { D } \\
\text { A } \\
\text { B }\end{array}$ \\
\hline 6 & -.030 & -.020 & -.008 & -.019 & -.018 & 2,211 & -42.0 & 1.4 & 31.7 & +11.7 & +.064 & +.161 & c \\
\hline 8 & $\begin{array}{l}-023 \\
-021\end{array}$ & $\begin{array}{r}-015 \\
-0156\end{array}$ & -.021 & $\because 018$ & -.019 & $\begin{array}{l}2,210 \\
2,209\end{array}$ & $\begin{array}{l}-42.0 \\
-42,0\end{array}$ & .46 & $\begin{array}{l}28.9 \\
30.1\end{array}$ & $\begin{array}{l}+12.5 \\
+12.5\end{array}$ & $\begin{array}{l}+.073 \\
+.068\end{array}$ & $\begin{array}{l}+.186 \\
+.172\end{array}$ & ${ }_{\mathrm{A}}^{\mathrm{B}}$ \\
\hline 10 & $\begin{array}{l}-.012 \\
-.013\end{array}$ & $\begin{array}{l}-.036 \\
-.020\end{array}$ & $\begin{array}{l}-.030 \\
-.010\end{array}$ & -.013 & $\because .014$ & $\begin{array}{l}\begin{array}{l}2,208 \\
2,207\end{array} \\
2,2\end{array}$ & $\begin{array}{l}-48.6 \\
-30.9\end{array}$ & $\begin{array}{l}.6 \\
.6\end{array}$ & $\begin{array}{l}30.7 \\
30.6\end{array}$ & $\begin{aligned}+18.5 \\
+.9\end{aligned}$ & $\begin{array}{l}+.101 \\
+.005\end{array}$ & $\begin{array}{l}+.255 \\
+.012 \\
+.25\end{array}$ & ${ }_{B}^{C}$ \\
\hline $\begin{array}{l}11 \\
12\end{array}$ & $\begin{array}{l}+.001 \\
-.029\end{array}$ & $\begin{array}{l}-.007 \\
+.040\end{array}$ & $\begin{array}{l}0 \\
+.008\end{array}$ & $\begin{array}{l}0 \\
-.018\end{array}$ & $a^{-.002}$ & $\begin{array}{l}2,206 \\
2,207\end{array}$ & $\begin{array}{c}-4.4 \\
0\end{array}$ & $\begin{array}{l}.6 \\
.6\end{array}$ & $\begin{array}{l}26.8 \\
29.6\end{array}$ & $\begin{array}{l}-21.8 \\
-29.0\end{array}$ & $\begin{array}{l}-\because 119 \\
\because .158\end{array}$ & $\begin{array}{l}-.301 \\
-.400\end{array}$ & $\begin{array}{l}\text { A } \\
\text { D }\end{array}$ \\
\hline $\begin{array}{l}13 \\
14\end{array}$ & $\begin{array}{l}-.002 \\
+.034\end{array}$ & $\begin{array}{l}+.007 \\
-.002\end{array}$ & $\begin{array}{r}-.005 \\
+025\end{array}$ & $\begin{array}{l}+.004 \\
+.025\end{array}$ & +.001 & $\begin{array}{l}2,206 \\
2,207\end{array}$ & $\begin{array}{r}+2.2 \\
+44.1\end{array}$ & 4.3 & $\begin{array}{l}25.7 \\
30.7\end{array}$ & $\begin{array}{l}-23.6 \\
-2.6\end{array}$ & $\begin{aligned}-128 \\
-014\end{aligned}$ & $\begin{array}{l}-3266 \\
\because 336\end{array}$ & B \\
\hline & +.009 & +.006 & +.002 & +.012 & $\begin{aligned}+.027 \\
+.002\end{aligned}$ & 2,208 & $\begin{array}{l}+44.1 \\
+15.5\end{array}$ & $\begin{array}{l}71.6 \\
26.0\end{array}$ & $\begin{array}{l}30.1 \\
31.3\end{array}$ & $\begin{array}{l}-2.6 \\
-20.8\end{array}$ & $\because 113$ & -.287 & B \\
\hline $\begin{array}{l}16 \\
17\end{array}$ & $\begin{array}{l}-.010 \\
-.010\end{array}$ & $\begin{array}{l}-.033 \\
-.008\end{array}$ & $\begin{array}{l}-.017 \\
-.013\end{array}$ & $\begin{array}{l}-.015 \\
-.007\end{array}$ & $\begin{array}{l}-.019 \\
-.010\end{array}$ & $\begin{array}{l}2,207 \\
2,206\end{array}$ & $\begin{array}{l}-41.9 \\
-22.1\end{array}$ & $\begin{array}{r}.8 \\
5.8\end{array}$ & $\begin{array}{l}29.8 \\
28.6\end{array}$ & $\begin{array}{r}+12.9 \\
-7\end{array}$ & $\begin{array}{l}+.070 \\
-.004\end{array}$ & $\begin{array}{r}+.178 \\
-010\end{array}$ & $\stackrel{c}{A}$ \\
\hline $\begin{array}{l}18 \\
19\end{array}$ & $\begin{array}{r}-.003 \\
+.056\end{array}$ & $\begin{array}{r}+.033 \\
+.067\end{array}$ & $\begin{array}{l}+.010 \\
+.058\end{array}$ & $\begin{array}{l}-.001 \\
+056\end{array}$ & $\begin{array}{l}+.002 \\
+.059\end{array}$ & $\begin{array}{l}2,206 \\
2,206\end{array}$ & $\begin{array}{r}+4.4 \\
+130\end{array}$ & $\begin{array}{r}7.6 \\
1097\end{array}$ & $\begin{array}{l}19.7 \\
28.3\end{array}$ & $\begin{array}{l}-16.5 \\
-4.8 \\
-4.8\end{array}$ & $\begin{aligned}-0900 \\
-\quad 265\end{aligned}$ & $\begin{aligned}-228 \\
-6674\end{aligned}$ & $\begin{array}{l}B \\
B \\
B\end{array}$ \\
\hline & +.184 & +.179 & +.185 & +.184 & +.183 & 2,211 & +404.6 & 434.8 & 30.4 & $\begin{array}{l}-48.8 \\
-.2 \\
-.2\end{array}$ & $\begin{array}{l}\because 001 \\
\because .001 \\
\end{array}$ & $\begin{array}{l}-.003 \\
-.003\end{array}$ & D \\
\hline 21 & $\begin{array}{r}+.169 \\
-006\end{array}$ & $\begin{array}{r}.171 \\
-009\end{array}$ & $\begin{array}{r}.170 \\
-.005 \\
-170\end{array}$ & +.172 & +.170 & 2,225 & +378.2 & 387.1 & 29.1 & -20.2 & -.109 & -.277 & c \\
\hline $\begin{array}{l}23 \\
23 \\
24\end{array}$ & $\begin{aligned}-005 \\
-004\end{aligned}$ & $\begin{array}{r}+.002 \\
+0.015 \\
-0\end{array}$ & $\begin{array}{l}-007 \\
-0008\end{array}$ & $\begin{aligned}-0004 \\
-0033\end{aligned}$ & $\begin{aligned}-.004 \\
-.004\end{aligned}$ & $\begin{array}{l}2,228 \\
2,227\end{array}$ & $\begin{array}{l}-15.6 \\
-8.9\end{array}$ & $\begin{array}{r}6.2 \\
21.7\end{array}$ & 28.1 & $\begin{array}{l}-6.1 \\
+2.5 \\
+2.5\end{array}$ & $\begin{array}{r}-.033 \\
+.013\end{array}$ & $\begin{aligned}-.0833 \\
+.034\end{aligned}$ & ${ }_{B}^{A}$ \\
\hline & $\begin{aligned}-.004 \\
+.010 \\
+010\end{aligned}$ & $\begin{aligned}-.015 \\
+.013\end{aligned}$ & $\begin{aligned} & .008 \\
&+.010\end{aligned}$ & $\begin{aligned} & .0033 \\
+.004 & \end{aligned}$ & $\begin{aligned}-.008 \\
+.009\end{aligned}$ & $\begin{array}{l}2,227 \\
2,227\end{array}$ & $\begin{array}{l}-17.8 \\
+20.0\end{array}$ & $\begin{array}{r}3.7 \\
21.4\end{array}$ & $\begin{array}{l}28.1 \\
21.5\end{array}$ & $\begin{array}{rl} & -6.6 \\
-20.1 & 1\end{array}$ & $\begin{aligned}-. .036 \\
-.108\end{aligned}$ & $\begin{array}{r}-.090 \\
-.275\end{array}$ & ${ }_{\mathrm{B}}^{\mathrm{B}}$ \\
\hline 26 & -.015 & $\because 004$ & $\because 009$ & -.016 & -.011 & 2,227 & -24.5 & $\begin{array}{l}3.4 \\
2.9\end{array}$ & 27.7 & +.2 & +.001 & $\begin{array}{r}+003 \\
+.03\end{array}$ & B \\
\hline & $\begin{array}{r}-.023 \\
-.024\end{array}$ & $\begin{array}{r}-.001 \\
-.001 \\
\end{array}$ & $\begin{array}{l}-.000 \\
-.006 \\
\end{array}$ & $\begin{array}{r}-.052 \\
-.022\end{array}$ & $\begin{aligned}-.007 \\
-.013\end{aligned}$ & $\begin{array}{l}2,227 \\
2,226 \\
\end{array}$ & $\begin{array}{l}\begin{array}{l}15.6 \\
-28.6\end{array} \\
-2\end{array}$ & $\begin{array}{l}2.9 \\
2.3\end{array}$ & $\begin{array}{r}28.0 \\
28.3 \\
\end{array}$ & $\begin{array}{r}-9.5 \\
+2.9 \\
+2\end{array}$ & $\begin{array}{r}.0 .015 \\
+.016\end{array}$ & $\begin{array}{r}r 130 \\
+.040\end{array}$ & $\begin{array}{l}\mathrm{C} \\
\mathrm{C}\end{array}$ \\
\hline
\end{tabular}


TABLE 1

Table 1. - Daily water-budget evaporation from Lake Hefner, Okla., Apr. 26, 1950, to Aug. 31, 1951-Continued

\begin{tabular}{|c|c|c|c|c|c|c|c|c|c|c|c|c|c|}
\hline \multirow[b]{2}{*}{ Day } & \multicolumn{5}{|c|}{ Change in stage, in feet } & \multirow{2}{*}{$\begin{array}{l}\text { Aver- } \\
\text { age } \\
\text { surface } \\
\text { 2rea } \\
\text { (acres) }\end{array}$} & \multirow{2}{*}{$\begin{array}{c}\text { Change } \\
\text { in } \\
\text { content } \\
\text { (acre-ft) }\end{array}$} & \multirow[b]{2}{*}{$\begin{array}{l}\text { Inflow } \\
\text { (acre-ft) }\end{array}$} & \multirow[b]{2}{*}{$\begin{array}{c}\text { Outflow } \\
\text { (acre-ft) }\end{array}$} & \multicolumn{3}{|c|}{ Evaporation } & \multirow[b]{2}{*}{$\begin{array}{l}\text { Accuracy } \\
\text { classification }\end{array}$} \\
\hline & \multicolumn{3}{|c|}{ Gages } & West & $\begin{array}{l}\text { Aver- } \\
\text { age }\end{array}$ & & & & & $\begin{array}{l}\text { Acre- } \\
\text { feet }\end{array}$ & Inches & $\begin{array}{l}\text { Centi- } \\
\text { meters }\end{array}$ & \\
\hline \multicolumn{14}{|c|}{ March 1951} \\
\hline $\begin{array}{l}1 \\
2 \\
3 \\
4 \\
5\end{array}$ & $\begin{array}{l}-0.011 \\
-.022 \\
-.034 \\
-.007 \\
-.050\end{array}$ & $\begin{array}{l}-0.021 \\
0 \\
-.021 \\
-.042 \\
-.027\end{array}$ & $\begin{array}{r}-0.020 \\
+.020 \\
-.048 \\
-.022 \\
-.035\end{array}$ & $\begin{array}{r}-0.009 \\
-.001 \\
-.028 \\
\because 017 \\
-.044\end{array}$ & $\begin{array}{r}-0.015 \\
+.004 \\
-.033 \\
-.022 \\
-.039\end{array}$ & $\begin{array}{l}2,226 \\
2,225 \\
2,224 \\
2,223 \\
2,222\end{array}$ & $\begin{array}{r}-33.4 \\
+8.9 \\
-73.4 \\
-48.9 \\
-86.7\end{array}$ & $\begin{array}{l}1.8 \\
2.1 \\
1.1 \\
1.1 \\
1.0\end{array}$ & $\begin{array}{l}26.4 \\
27.3 \\
27.8 \\
31.1 \\
30.2\end{array}$ & $\begin{array}{r}+8.8 \\
-34.1 \\
+46.7 \\
+18.9 \\
+57.5\end{array}$ & $\begin{array}{r}+0.047 \\
-.184 \\
+.252 \\
+.102 \\
+.311\end{array}$ & $\begin{array}{r}+0.120 \\
-.467 \\
+.640 \\
+.259 \\
+.789\end{array}$ & $\begin{array}{l}B \\
C \\
C \\
C \\
C\end{array}$ \\
\hline $\begin{array}{r}6 \\
7 \\
8 \\
9 \\
10\end{array}$ & $\begin{array}{l}-.013 \\
-.021 \\
-.033 \\
+.017 \\
+.043\end{array}$ & $\begin{array}{l}-.001 \\
-.028 \\
-.016 \\
-.010 \\
+.043\end{array}$ & $\begin{array}{l}-.011 \\
-.021 \\
-.030 \\
+.007 \\
+.043\end{array}$ & $\begin{array}{l}-.020 \\
-.021 \\
-.025 \\
+.009 \\
+.046\end{array}$ & $\begin{array}{l}-.011 \\
-.023 \\
-.026 \\
+.006 \\
+.044\end{array}$ & $\begin{array}{l}2,2: 20 \\
2,219 \\
2,218 \\
2,217 \\
2,218\end{array}$ & $\begin{array}{l}-24.4 \\
-51.0 \\
-57.7 \\
+13.3 \\
+97.6\end{array}$ & $\begin{array}{r}1.0 \\
.8 \\
.8 \\
36.4 \\
150.0\end{array}$ & $\begin{array}{l}26.8 \\
29.3 \\
27.8 \\
23.9 \\
25.1\end{array}$ & $\begin{array}{r}-1.4 \\
+22.5 \\
+30.7 \\
-.8 \\
+27.3\end{array}$ & $\begin{array}{l}-.008 \\
+.122 \\
+.166 \\
-.004 \\
+.148\end{array}$ & $\begin{array}{l}-.019 \\
+.309 \\
+.422 \\
-.011 \\
+.375\end{array}$ & $\begin{array}{l}\text { C } \\
\text { A } \\
\text { B } \\
\text { C } \\
\text { A }\end{array}$ \\
\hline $\begin{array}{l}11 \\
12 \\
13 \\
14 \\
15\end{array}$ & $\begin{array}{l}+.007 \\
-.032 \\
-.024 \\
-.020 \\
-.011\end{array}$ & $\begin{array}{l}+.074 \\
-.071 \\
-.041 \\
-.023 \\
-.014\end{array}$ & $\begin{array}{l}+.040 \\
-.051 \\
-.035 \\
-.017 \\
-.020\end{array}$ & $\begin{array}{l}+.012 \\
-.031 \\
-.028 \\
-.016 \\
-.015\end{array}$ & $\begin{array}{l}+.033 \\
-.046 \\
-.032 \\
-.019 \\
-.015\end{array}$ & $\begin{array}{l}2,223 \\
2,220 \\
2,218 \\
2,217 \\
2,216\end{array}$ & $\begin{array}{r}+73.4 \\
-102.1 \\
-71.0 \\
-42.1 \\
-33.2\end{array}$ & $\begin{array}{r}82.0 \\
2.7 \\
2.4 \\
2.1 \\
1.9\end{array}$ & $\begin{array}{l}23.5 \\
31.1 \\
27.3 \\
24.2 \\
28.1\end{array}$ & $\begin{array}{r}-14.9 \\
+73.7 \\
+46.1 \\
+20.0 \\
+7.0\end{array}$ & $\begin{array}{r}-.080 \\
+.398 \\
+.249 \\
+.108 \\
+.038\end{array}$ & $\begin{array}{r}-.204 \\
+1.012 \\
+.633 \\
+.275 \\
+.096\end{array}$ & $\begin{array}{l}\text { D } \\
\text { D } \\
\mathbf{B} \\
\mathbf{A} \\
\mathbf{B}\end{array}$ \\
\hline $\begin{array}{l}16 \\
17 \\
18 \\
19 \\
20\end{array}$ & $\begin{array}{l}-.015 \\
-.043 \\
-.016 \\
-.016 \\
-.034\end{array}$ & $\begin{array}{l}-.023 \\
+.029 \\
-.075 \\
-.027 \\
-.016\end{array}$ & $\begin{array}{l}-.012 \\
+.004 \\
-.057 \\
-.027 \\
-.025\end{array}$ & $\begin{array}{l}-.014 \\
-.039 \\
-.016 \\
-.023 \\
-.030\end{array}$ & $\begin{array}{l}-.016 \\
-.012 \\
-.041 \\
-.023 \\
-.026\end{array}$ & $\begin{array}{l}2,2: 15 \\
2,2115 \\
2,213 \\
2,211 \\
2,21.0\end{array}$ & $\begin{array}{l}-35.4 \\
-26.6 \\
-90.7 \\
-50.9 \\
-57.5\end{array}$ & $\begin{array}{r}2.0 \\
1.4 \\
.9 \\
1.2 \\
1.1\end{array}$ & $\begin{array}{l}34.1 \\
31.3 \\
22.0 \\
30.0 \\
32.3\end{array}$ & $\begin{array}{r}+3.3 \\
-3.3 \\
+69.6 \\
+22.1 \\
+26.3\end{array}$ & $\begin{array}{r}+.018 \\
-.018 \\
+.377 \\
+.120 \\
+.143\end{array}$ & $\begin{array}{r}+.045 \\
-.045 \\
+.959 \\
+.305 \\
+.363\end{array}$ & $\begin{array}{l}\text { B } \\
\text { D } \\
\text { D } \\
\text { B } \\
\text { C }\end{array}$ \\
\hline $\begin{array}{l}21 \\
22 \\
23 \\
24 \\
25\end{array}$ & $\begin{array}{l}-.014 \\
-.021 \\
-.037 \\
-.016 \\
-.019\end{array}$ & $\begin{array}{l}-.032 \\
-.034 \\
-.016 \\
-.030 \\
-019\end{array}$ & $\begin{array}{l}-.016 \\
-.020 \\
-.029 \\
-.019 \\
-.022\end{array}$ & $\begin{array}{l}-.021 \\
-.022 \\
-.027 \\
-.023 \\
-.018\end{array}$ & $\begin{array}{l}-.021 \\
-.024 \\
-.027 \\
-.022 \\
-.020\end{array}$ & $\begin{array}{l}2,209 \\
2,208 \\
2,207 \\
2,205 \\
2,204\end{array}$ & $\begin{array}{l}-46.4 \\
-53.0 \\
-59.6 \\
-48.5 \\
-44.1\end{array}$ & $\begin{array}{r}.7 \\
1.0 \\
.8 \\
.8 \\
.9\end{array}$ & $\begin{array}{l}30.7 \\
32.6 \\
31.1 \\
31.9 \\
23.6\end{array}$ & $\begin{array}{l}+16.4 \\
+21.4 \\
+29.3 \\
+17.4 \\
+21.4\end{array}$ & $\begin{array}{r}+.089 \\
+.116 \\
+.159 \\
+.095 \\
+.117\end{array}$ & $\begin{array}{r}+.226 \\
+.295 \\
+.405 \\
+.241 \\
+.296\end{array}$ & $\begin{array}{l}\text { C } \\
\text { B } \\
\text { C } \\
\text { B } \\
\text { A }\end{array}$ \\
\hline $\begin{array}{l}26 \\
27 \\
28 \\
29 \\
30 \\
31\end{array}$ & $\begin{array}{l}+.004 \\
-.005 \\
-.034 \\
-.020 \\
-.019 \\
-.028\end{array}$ & $\begin{array}{l}-.013 \\
+.001 \\
+.053 \\
-.085 \\
-.021 \\
-.014\end{array}$ & $\begin{array}{r}-.025 \\
-.001 \\
+.025 \\
-.066 \\
-.019 \\
-.018\end{array}$ & $\begin{array}{l}+.008 \\
-.002 \\
-.027 \\
-.026 \\
-.019 \\
-.020\end{array}$ & $\begin{array}{l}-.006 \\
-.002 \\
+.004 \\
-.049 \\
-.020 \\
-.020\end{array}$ & $\begin{array}{l}2,203 \\
2,203 \\
2,203 \\
2,202 \\
2,200 \\
2,199\end{array}$ & $\begin{array}{r}-13.2 \\
-4.4 \\
+8.8 \\
-107.9 \\
-44.0 \\
-44.0\end{array}$ & $\begin{array}{r}36.5 \\
2.2 \\
15.1 \\
1.1 \\
1.2 \\
.9\end{array}$ & $\begin{array}{l}30.8 \\
30.2 \\
25.2 \\
27.5 \\
28.5 \\
29.9\end{array}$ & $\begin{array}{l}+18.9 \\
-23.6 \\
-18.9 \\
+81.5 \\
+16.7 \\
+15.0\end{array}$ & $\begin{array}{r}+.103 \\
-.129 \\
-.103 \\
+.444 \\
+.091 \\
+.082\end{array}$ & $\begin{array}{r}+.261 \\
-.327 \\
-.261 \\
+1.128 \\
+.231 \\
+.208\end{array}$ & $\begin{array}{l}\text { C } \\
\text { A } \\
\text { D } \\
\text { D } \\
\text { A } \\
\text { B }\end{array}$ \\
\hline
\end{tabular}

April 1951

\begin{tabular}{|c|c|c|c|c|c|c|c|c|c|c|c|c|c|}
\hline $\begin{array}{l}1 \\
2 \\
3 \\
4 \\
5\end{array}$ & $\begin{array}{r}-0.020 \\
-.018 \\
-.015 \\
-.016 \\
-.006\end{array}$ & $\begin{array}{r}-0.023 \\
-.027 \\
-.020 \\
-.037 \\
+.023\end{array}$ & $\begin{array}{r}-0.015 \\
-.024 \\
-.015 \\
-.034 \\
+.018\end{array}$ & $\begin{array}{r}-0.023 \\
-.021 \\
-.015 \\
-.015 \\
-.012\end{array}$ & $\begin{array}{r}-0.020 \\
-.022 \\
-.016 \\
-.026 \\
+.006\end{array}$ & $\begin{array}{l}2,198 \\
2,197 \\
2,196 \\
2,195 \\
2,194\end{array}$ & $\begin{array}{l}-44.0 \\
-48.3 \\
-35.1 \\
-57.1 \\
+13.2\end{array}$ & $\begin{array}{r}0.6 \\
1.7 \\
.8 \\
.9 \\
28.4\end{array}$ & $\begin{array}{l}16.6 \\
28.5 \\
32.5 \\
32.7 \\
28.1\end{array}$ & $\begin{array}{r}+28.0 \\
+21.5 \\
+3.4 \\
+25.3 \\
-12.9\end{array}$ & $\begin{array}{r}+0.153 \\
+.117 \\
+.019 \\
+.138 \\
-.071\end{array}$ & $\begin{array}{r}+0.388 \\
+.298 \\
+.047 \\
+.351 \\
-.179\end{array}$ & $\begin{array}{l}\text { A } \\
\text { B } \\
\text { A } \\
\text { C } \\
\text { C }\end{array}$ \\
\hline $\begin{array}{r}6 \\
7 \\
8 \\
9 \\
10\end{array}$ & $\begin{array}{l}-.018 \\
-.030 \\
-031 \\
-024 \\
-029\end{array}$ & $\begin{array}{l}-.010 \\
-.029 \\
-.035 \\
-.031 \\
-.005\end{array}$ & $\begin{array}{l}-.012 \\
-.034 \\
-.025 \\
-.037 \\
-.021\end{array}$ & $\begin{array}{l}-.011 \\
-.028 \\
-.029 \\
-.032 \\
-.029\end{array}$ & $\begin{array}{l}-.013 \\
-.030 \\
-.030 \\
-.031 \\
-.021\end{array}$ & $\begin{array}{l}2,194 \\
2,193 \\
2,191 \\
2,189 \\
2,188\end{array}$ & $\begin{array}{l}-28.5 \\
-65.8 \\
-65.7 \\
-67.9 \\
-45.9\end{array}$ & $\begin{array}{r}1.4 \\
.9 \\
.7 \\
.7 \\
4.2\end{array}$ & $\begin{array}{l}25.4 \\
26.6 \\
28.0 \\
32.1 \\
32.5\end{array}$ & $\begin{array}{r}+4.5 \\
+40.1 \\
+38.4 \\
+36.5 \\
+17.6\end{array}$ & $\begin{array}{l}+.025 \\
+.219 \\
+.210 \\
+.200 \\
+.097\end{array}$ & $\begin{array}{r}+.063 \\
+.557 \\
+.534 \\
+.508 \\
+.245\end{array}$ & $\begin{array}{l}\text { A } \\
\text { A } \\
\text { B } \\
\text { B } \\
\text { C }\end{array}$ \\
\hline $\begin{array}{l}11 \\
12 \\
13 \\
14 \\
15\end{array}$ & $\begin{array}{l}-.035 \\
-.037 \\
-.026 \\
-.036 \\
-.035\end{array}$ & $\begin{array}{l}\because .055 \\
-.038 \\
-.032 \\
-.032 \\
-.032\end{array}$ & $\begin{array}{l}-.027 \\
-.044 \\
-.038 \\
-.023 \\
-.037\end{array}$ & $\begin{array}{l}-.037 \\
-.033 \\
-.026 \\
-.031 \\
-.038\end{array}$ & $\begin{array}{l}-.038 \\
-.038 \\
-.030 \\
-.030 \\
-.036\end{array}$ & $\begin{array}{l}2,187 \\
2,184 \\
2,183 \\
2,181 \\
2,179\end{array}$ & $\begin{array}{l}-83.1 \\
-83.0 \\
-65.5 \\
-65.4 \\
-78.4\end{array}$ & $\begin{array}{r}2.2 \\
.7 \\
.5 \\
.6 \\
.4\end{array}$ & $\begin{array}{l}28.3 \\
26.4 \\
33.4 \\
32.8 \\
30.4\end{array}$ & $\begin{array}{r}+57.0 \\
+57.3 \\
+32.6 \\
+33.2 \\
+48.4\end{array}$ & $\begin{array}{r}+.313 \\
+.315 \\
+.179 \\
+.183 \\
+.267\end{array}$ & $\begin{array}{r}+.794 \\
+.800 \\
+.455 \\
+.464 \\
+.677\end{array}$ & $\begin{array}{l}\text { C } \\
\text { B } \\
\text { B } \\
\text { B } \\
\text { A }\end{array}$ \\
\hline $\begin{array}{l}16 \\
17 \\
18 \\
19 \\
20\end{array}$ & $\begin{array}{l}-.024 \\
-.026 \\
-.035 \\
-.013 \\
+.101\end{array}$ & $\begin{array}{l}-.029 \\
-.062 \\
+.010 \\
-.020 \\
+.070\end{array}$ & $\begin{array}{l}-.032 \\
-.046 \\
-.007 \\
-.025 \\
+.090\end{array}$ & $\begin{array}{l}-.028 \\
-.037 \\
-.023 \\
-.013 \\
+.092\end{array}$ & $\begin{array}{l}-.028 \\
-.043 \\
-.014 \\
-.018 \\
+.088\end{array}$ & $\begin{array}{l}2,178 \\
2,176 \\
2,174 \\
2,173 \\
2,174\end{array}$ & $\begin{array}{r}-61.0 \\
-93.6 \\
-30.4 \\
-39.1 \\
+191.3\end{array}$ & $\begin{array}{r}.5 \\
.5 \\
6.7 \\
1.4 \\
193.3\end{array}$ & $\begin{array}{l}33.2 \\
33.3 \\
36.2 \\
34.8 \\
28.3\end{array}$ & $\begin{array}{r}+28.3 \\
+60.8 \\
+.9 \\
+5.7 \\
-26.3\end{array}$ & $\begin{array}{r}+.156 \\
+.335 \\
+.005 \\
+.031 \\
-.145\end{array}$ & $\begin{array}{r}+.396 \\
+.852 \\
+.013 \\
+.080 \\
-.369\end{array}$ & $\begin{array}{l}\text { A } \\
\text { D } \\
\text { D } \\
\text { B } \\
\text { C }\end{array}$ \\
\hline $\begin{array}{l}21 \\
22 \\
23 \\
24 \\
25\end{array}$ & $\begin{array}{l}-.036 \\
-.026 \\
\because .013 \\
-029 \\
-030\end{array}$ & $\begin{array}{l}+.016 \\
-.050 \\
-.041 \\
-.026 \\
+.004\end{array}$ & $\begin{array}{l}-.012 \\
-.031 \\
-.027 \\
-.024 \\
-.012\end{array}$ & $\begin{array}{l}-.017 \\
-.035 \\
-.011 \\
-.025 \\
-.029\end{array}$ & $\begin{array}{l}-.012 \\
-.036 \\
-.023 \\
-.026 \\
-.017\end{array}$ & $\begin{array}{l}2,178 \\
2,176 \\
2,174 \\
2,173 \\
2,172\end{array}$ & $\begin{array}{l}-26.1 \\
-78.3 \\
-50.0 \\
-56.5 \\
-36.9\end{array}$ & $\begin{array}{r}4.4 \\
1.2 \\
1.0 \\
1.7 \\
.6\end{array}$ & $\begin{array}{l}29.2 \\
25.6 \\
23.4 \\
35.7 \\
36.2\end{array}$ & $\begin{array}{r}+1.3 \\
+53.9 \\
+27.6 \\
+22.5 \\
+1.3\end{array}$ & $\begin{array}{l}+.007 \\
+.297 \\
+.152 \\
+.124 \\
+.007\end{array}$ & $\begin{array}{r}+.018 \\
+.755 \\
+.387 \\
+.316 \\
+.018\end{array}$ & $\begin{array}{l}\text { D } \\
\text { C } \\
\text { C } \\
\text { C } \\
\text { C }\end{array}$ \\
\hline $\begin{array}{l}26 \\
27 \\
28 \\
29 \\
30\end{array}$ & $\begin{array}{l}+.014 \\
-.015 \\
-.011 \\
+.117 \\
+.185\end{array}$ & $\begin{array}{l}-.022 \\
-.003 \\
-.011 \\
+.105 \\
+.239\end{array}$ & $\begin{array}{l}-.020 \\
-.002 \\
-.010 \\
+.100 \\
+.210\end{array}$ & $\begin{array}{l}+.009 \\
-.015 \\
-.012 \\
+.117 \\
+.201\end{array}$ & $\begin{array}{l}-.005 \\
-.009 \\
-.011 \\
+.110 \\
+.209\end{array}$ & $\begin{array}{l}2,172 \\
2,171 \\
2,171 \\
2,172 \\
2,178\end{array}$ & $\begin{array}{r}-10.9 \\
-19.5 \\
-23.9 \\
+238.9 \\
+455.2\end{array}$ & $\begin{array}{r}.5 \\
.7 \\
.5 \\
215.1 \\
418.4\end{array}$ & $\begin{array}{l}13.9 \\
35.7 \\
33.6 \\
22.0 \\
35.1\end{array}$ & $\begin{array}{r}-2.5 \\
-15.5 \\
-9.2 \\
-45.8 \\
-71.9\end{array}$ & $\begin{array}{l}-.014 \\
-.086 \\
-.051 \\
-.253 \\
-.396\end{array}$ & $\begin{array}{r}-.035 \\
-.218 \\
-.129 \\
-.043 \\
-1.006\end{array}$ & $\begin{array}{l}\text { D } \\
\text { B } \\
\text { A } \\
\text { B } \\
\text { D }\end{array}$ \\
\hline
\end{tabular}


Table 1. - Daily water-budget evaporation from Lake Hefner, Okla., Apr. 26, 1950, to Aug. 31, 1951- Continued

\begin{tabular}{|c|c|c|c|c|c|c|c|c|c|c|c|c|c|}
\hline \multirow{3}{*}{ Day } & \multicolumn{5}{|c|}{ Change in stage, in feet } & \multirow{3}{*}{$\begin{array}{c}\text { Aver" } \\
\text { age } \\
\text { surface } \\
\text { area } \\
\text { (acres) }\end{array}$} & \multirow{3}{*}{$\begin{array}{c}\text { Change } \\
\text { in } \\
\text { content } \\
\text { (acre-ft) }\end{array}$} & \multirow{3}{*}{$\begin{array}{l}\text { Inflow } \\
(\text { acre-ft) }\end{array}$} & \multirow{3}{*}{$\begin{array}{l}\text { Outflow } \\
(\text { acre-ft) }\end{array}$} & \multicolumn{3}{|c|}{ Evaporation } & \multirow{3}{*}{$\begin{array}{l}\text { Accuracy } \\
\text { classification }\end{array}$} \\
\hline & \multicolumn{4}{|c|}{ Gages } & \multirow{2}{*}{$\begin{array}{l}\text { Aver- } \\
\text { age }\end{array}$} & & & & & Acre - & & Centi- & \\
\hline & North & South & East & West & & & & & & feet & Inches & meters & \\
\hline
\end{tabular}

May 1951

\begin{tabular}{|c|c|c|c|c|c|c|c|c|c|c|c|c|c|}
\hline $\begin{array}{l}1 \\
2 \\
3 \\
4 \\
5\end{array}$ & $\begin{array}{r}+0.021 \\
-.038 \\
-.026 \\
-.030 \\
-.019\end{array}$ & $\begin{array}{l}-0.008 \\
-.030 \\
-.024 \\
-.032 \\
-.023\end{array}$ & $\begin{array}{r}+0.020 \\
-.033 \\
-.023 \\
-.029 \\
-.031\end{array}$ & $\begin{array}{r}+0.012 \\
-.034 \\
-.031 \\
-.036 \\
-.010\end{array}$ & $\begin{array}{r}+0.011 \\
-.034 \\
-.026 \\
-.032 \\
-.021\end{array}$ & $\begin{array}{l}2,188 \\
2,187 \\
2,185 \\
2,183 \\
2,182\end{array}$ & $\begin{array}{l}+24.1 \\
-74.4 \\
-56.8 \\
-69.9 \\
-45.8\end{array}$ & $\begin{array}{r}83.1 \\
6.0 \\
3.4 \\
2.6 \\
2.0\end{array}$ & $\begin{array}{l}29.4 \\
33.1 \\
36.6 \\
40.2 \\
36.3\end{array}$ & $\begin{array}{l}+29.6 \\
+47.3 \\
+23.6 \\
+32.3 \\
+11.5\end{array}$ & $\begin{array}{r}+0.162 \\
+.260 \\
+.130 \\
+.178 \\
+.063\end{array}$ & $\begin{array}{r}+0.412 \\
+.659 \\
+.329 \\
+.451 \\
+.161\end{array}$ & $\begin{array}{l}\text { C } \\
\text { A } \\
\text { A } \\
\text { A } \\
\text { C }\end{array}$ \\
\hline $\begin{array}{r}6 \\
7 \\
8 \\
9 \\
10\end{array}$ & $\begin{array}{l}-.051 \\
-.019 \\
-.024 \\
+.168 \\
+.415\end{array}$ & $\begin{array}{l}-.041 \\
-.024 \\
-.042 \\
+.179 \\
+.420\end{array}$ & $\begin{array}{l}-.042 \\
-.020 \\
-.034 \\
+.180 \\
+.410\end{array}$ & $\begin{array}{l}-.025 \\
-.026 \\
-.025 \\
+.165 \\
+.433\end{array}$ & $\begin{array}{l}-.040 \\
-.022 \\
-.031 \\
+.173 \\
+.420\end{array}$ & $\begin{array}{l}2,180 \\
2,179 \\
2,178 \\
2,178 \\
2,192\end{array}$ & $\begin{array}{r}-87.2 \\
-47.9 \\
-67.5 \\
+376.8 \\
+920.6\end{array}$ & $\begin{array}{r}1.3 \\
1.3 \\
1.3 \\
357.2 \\
1,018.1\end{array}$ & $\begin{array}{l}23.9 \\
35.2 \\
30.8 \\
30.4 \\
26.8\end{array}$ & $\begin{array}{l}+64.6 \\
+14.0 \\
+38.0 \\
-50.0 \\
+70.7\end{array}$ & $\begin{array}{l}+.356 \\
+.077 \\
+.209 \\
-.275 \\
+.387\end{array}$ & $\begin{array}{l}+.903 \\
+.196 \\
+.532 \\
-.700 \\
+.983\end{array}$ & $\begin{array}{l}\text { C } \\
\text { A } \\
\text { C } \\
\text { C } \\
\text { D }\end{array}$ \\
\hline $\begin{array}{l}11 \\
12 \\
13 \\
14 \\
15\end{array}$ & $\begin{array}{l}+.178 \\
-.019 \\
-.040 \\
-.036 \\
-.011\end{array}$ & $\begin{array}{l}+.176 \\
-.033 \\
-.041 \\
-.034 \\
+.004\end{array}$ & $\begin{array}{l}+.176 \\
-.031 \\
-.039 \\
-.032 \\
-.005\end{array}$ & $\begin{array}{l}+.171 \\
-.027 \\
-.029 \\
-.037 \\
-.010\end{array}$ & $\begin{array}{l}+.175 \\
-.028 \\
-.037 \\
-.035 \\
-.006\end{array}$ & $\begin{array}{l}2,216 \\
2,216 \\
2,215 \\
2,213 \\
2,211\end{array}$ & $\begin{array}{r}+387.8 \\
-62.0 \\
-82.0 \\
-77.5 \\
-13.3\end{array}$ & $\begin{array}{r}411.0 \\
5.8 \\
3.4 \\
2.4 \\
17.0\end{array}$ & $\begin{array}{l}29.8 \\
32.4 \\
33.3 \\
33.6 \\
34.5\end{array}$ & $\begin{array}{r}-6.6 \\
+35.4 \\
+52.1 \\
+46.3 \\
-4.2\end{array}$ & $\begin{array}{l}-.036 \\
+.192 \\
+.282 \\
+.251 \\
-.023\end{array}$ & $\begin{array}{l}-.091 \\
+.487 \\
+.717 \\
+.638 \\
-.058\end{array}$ & $\begin{array}{l}\text { D } \\
\text { B } \\
\text { B } \\
\text { A } \\
\text { B }\end{array}$ \\
\hline $\begin{array}{l}16 \\
17 \\
18 \\
19 \\
20\end{array}$ & $\begin{array}{r}+.023 \\
+.761 \\
+1.140 \\
+.527 \\
+.339\end{array}$ & $\begin{array}{r}+.018 \\
+.756 \\
+1.144 \\
+.496 \\
+.369\end{array}$ & $\begin{array}{r}+.019 \\
+.743 \\
+1.145 \\
+.515 \\
+.376\end{array}$ & $\begin{array}{r}+.024 \\
+.766 \\
+1.139 \\
+.882\end{array}$ & $\begin{array}{r}+.021 \\
+.756 \\
+1.142 \\
+.513 \\
+.361\end{array}$ & $\begin{array}{l}2,211 \\
2,226 \\
2,287 \\
2,327 \\
2,353\end{array}$ & $\begin{array}{r}+46.4 \\
+1,682.8 \\
+2,611.8 \\
+1,193.8 \\
+849.4\end{array}$ & $\begin{array}{r}75.4 \\
1,713.8 \\
2,703.9 \\
1,204.3 \\
802.6\end{array}$ & $\begin{array}{l}32.3 \\
30.2 \\
29.3 \\
23.2 \\
26.4\end{array}$ & $\begin{array}{r}-3.3 \\
+.8 \\
+62.8 \\
-12.7 \\
-73.2\end{array}$ & $\begin{array}{l}-.018 \\
+.004 \\
+.330 \\
-.065 \\
-.373\end{array}$ & $\begin{array}{l}-.045 \\
+.011 \\
+.837 \\
-.166 \\
-.948\end{array}$ & $\begin{array}{l}\text { B } \\
\text { D } \\
\text { D } \\
\text { D } \\
\text { D }\end{array}$ \\
\hline $\begin{array}{l}21 \\
22 \\
23 \\
24 \\
25\end{array}$ & $\begin{array}{l}+.014 \\
0 \\
-.011 \\
-.012 \\
-.014\end{array}$ & $\begin{array}{l}+.021 \\
+.014 \\
-.028 \\
-.009 \\
-.018\end{array}$ & $\begin{array}{l}+.024 \\
-.001 \\
-.025 \\
-.005 \\
-.020\end{array}$ & $\begin{array}{l}+.882 \\
-.018 \\
-.008 \\
-.017\end{array}$ & $\begin{array}{l}+.020 \\
+.004 \\
-.020 \\
-.008 \\
-.017\end{array}$ & $\begin{array}{l}2,359 \\
2,361 \\
2,360 \\
2,359 \\
2,359\end{array}$ & $\begin{array}{r}+47.2 \\
+9.4 \\
-47.2 \\
-18.9 \\
-40.1\end{array}$ & $\begin{array}{r}99.4 \\
59.8 \\
10.1 \\
50.4 \\
8.5\end{array}$ & $\begin{array}{l}35.2 \\
34.6 \\
32.5 \\
27.1 \\
34.5\end{array}$ & $\begin{array}{l}+17.0 \\
+15.8 \\
+24.8 \\
+42.2 \\
+14.1\end{array}$ & $\begin{array}{l}+.086 \\
+.080 \\
+.126 \\
+.215 \\
+.072\end{array}$ & $\begin{array}{l}+.220 \\
+.204 \\
+.320 \\
+.545 \\
+.182\end{array}$ & $\begin{array}{l}\text { C } \\
\text { C } \\
\text { B } \\
\text { A } \\
\text { A }\end{array}$ \\
\hline $\begin{array}{l}26 \\
27 \\
28 \\
29 \\
30 \\
31\end{array}$ & $\begin{array}{r}-.030 \\
- \\
+.001 \\
-.022 \\
+.004 \\
-.030\end{array}$ & $\begin{array}{c}-.023 \\
- \\
-.001 \\
-.016 \\
-.024 \\
-.031\end{array}$ & $\begin{array}{c}-.027 \\
- \\
-.006 \\
-.005 \\
-.019 \\
-.035\end{array}$ & $\begin{array}{c}- \\
- \\
+.003 \\
-.013 \\
-.013 \\
-.025\end{array}$ & $\begin{array}{r}-.027 \\
-.001 \\
-.014 \\
-.013 \\
-.030\end{array}$ & $\begin{array}{l}2,357 \\
2,364 \\
2,372 \\
2,371 \\
2,371 \\
2,370\end{array}$ & $\begin{array}{r}-63.6 \\
- \\
-2.4 \\
-33.2 \\
-30.8 \\
-71.1\end{array}$ & $\begin{array}{r}5.8 \\
- \\
48.9 \\
16.6 \\
9.8 \\
6.6\end{array}$ & $\begin{array}{r}32.8 \\
- \\
31.0 \\
40.4 \\
40.6 \\
37.2\end{array}$ & $\begin{array}{r}+36.6 \\
- \\
+20.3 \\
+9.4 \\
0 \\
+40.5\end{array}$ & $\begin{array}{l}+.186 \\
+.103 \\
+.048 \\
0 \\
+.205\end{array}$ & $\begin{array}{l}+.473 \\
+.261 \\
+.121 \\
0 \\
+.521\end{array}$ & $\begin{array}{l}\text { B } \\
\text { D } \\
\text { B } \\
\text { B } \\
\text { C } \\
\text { B }\end{array}$ \\
\hline
\end{tabular}

June 1951

\begin{tabular}{|c|c|c|c|c|c|c|c|c|c|c|c|c|c|}
\hline $\begin{array}{l}1 \\
2 \\
3 \\
4 \\
5\end{array}$ & $\begin{array}{r}+0.007 \\
-.051 \\
-.032 \\
-.030 \\
-.018\end{array}$ & $\begin{array}{r}+0.005 \\
-.010 \\
-.043 \\
-.030 \\
-.031\end{array}$ & $\begin{array}{r}+0.012 \\
-.032 \\
-.030 \\
-.032 \\
-.025\end{array}$ & $\begin{array}{r}+0.005 \\
-.038 \\
-.034 \\
-.035 \\
-.010\end{array}$ & $\begin{array}{r}+0.007 \\
-.033 \\
-.035 \\
-.032 \\
-.021\end{array}$ & $\begin{array}{l}2,369 \\
2,368 \\
2,367 \\
2,365 \\
2,363\end{array}$ & $\begin{array}{l}+16.6 \\
-78.1 \\
-82.8 \\
-75.7 \\
-49.6\end{array}$ & $\begin{array}{r}83.5 \\
8.9 \\
9.1 \\
5.2 \\
5.6\end{array}$ & $\begin{array}{l}41.1 \\
25.5 \\
19.3 \\
35.1 \\
37.5\end{array}$ & $\begin{array}{l}+25.8 \\
+61.5 \\
+72.6 \\
+45.8 \\
+17.7\end{array}$ & $\begin{array}{r}+0.131 \\
+.312 \\
+.368 \\
+.232 \\
+.090\end{array}$ & $\begin{array}{r}+0.332 \\
+.792 \\
+.935 \\
+.590 \\
+.228\end{array}$ & $\begin{array}{l}\text { B } \\
\text { D } \\
\text { B } \\
\text { A } \\
\text { C }\end{array}$ \\
\hline $\begin{array}{r}6 \\
7 \\
8 \\
9 \\
10\end{array}$ & $\begin{array}{l}-.012 \\
-.016 \\
-.007 \\
-.026 \\
+.082\end{array}$ & $\begin{array}{l}-.012 \\
-.018 \\
-.012 \\
-.004 \\
+.077\end{array}$ & $\begin{array}{l}-.003 \\
-.032 \\
+.002 \\
-.025 \\
+.083\end{array}$ & $\begin{array}{l}-.025 \\
-.019 \\
+.002 \\
-.018 \\
+.080\end{array}$ & $\begin{array}{l}-.013 \\
-.021 \\
-.004 \\
-.018 \\
+.080\end{array}$ & $\begin{array}{l}2,363 \\
2,361 \\
2,360 \\
2,360 \\
2,362\end{array}$ & $\begin{array}{r}-30.7 \\
-49.6 \\
-9.4 \\
-42.5 \\
+189.0\end{array}$ & $\begin{array}{r}44.0 \\
11.7 \\
46.6 \\
7.2 \\
213.0\end{array}$ & $\begin{array}{l}37.5 \\
37.9 \\
37.8 \\
39.9 \\
21.1\end{array}$ & $\begin{array}{r}+37.2 \\
+23.4 \\
+18.2 \\
+9.8 \\
+2.9\end{array}$ & $\begin{array}{r}+.189 \\
+.119 \\
+.093 \\
+.050 \\
+.015\end{array}$ & $\begin{array}{l}+.480 \\
+.302 \\
+.235 \\
+.127 \\
+.037\end{array}$ & $\begin{array}{l}\text { C } \\
\text { B } \\
\text { B } \\
\text { C } \\
\text { A }\end{array}$ \\
\hline $\begin{array}{l}11 \\
12 \\
13 \\
14 \\
15\end{array}$ & $\begin{array}{l}+.042 \\
-.022 \\
-.020 \\
-.021 \\
-.018\end{array}$ & $\begin{array}{l}+.039 \\
-.013 \\
-.028 \\
-.027 \\
-.018\end{array}$ & $\begin{array}{l}+.040 \\
-.021 \\
-.032 \\
-.014 \\
-.014\end{array}$ & $\begin{array}{l}+.048 \\
-.023 \\
-.029 \\
-.012 \\
-.024\end{array}$ & $\begin{array}{l}+.042 \\
-.020 \\
-.027 \\
-.018 \\
-.018\end{array}$ & $\begin{array}{l}2,365 \\
2,365 \\
2,364 \\
2,363 \\
2,362\end{array}$ & $\begin{array}{l}+99.3 \\
-47.3 \\
-63.8 \\
-42.5 \\
-42.5\end{array}$ & $\begin{array}{r}158.5 \\
11.9 \\
6.6 \\
24.7 \\
17.5\end{array}$ & $\begin{array}{l}34.7 \\
38.1 \\
36.6 \\
39.5 \\
42.6\end{array}$ & $\begin{array}{l}+24.5 \\
+21.1 \\
+33.8 \\
+27.7 \\
+17.4\end{array}$ & $\begin{array}{l}+.124 \\
+.107 \\
+.172 \\
+.141 \\
+.088\end{array}$ & $\begin{array}{l}+.316 \\
+.272 \\
+.436 \\
+.357 \\
+.225\end{array}$ & $\begin{array}{l}\text { B } \\
\text { B } \\
\text { B } \\
\text { B } \\
\text { B }\end{array}$ \\
\hline $\begin{array}{l}16 \\
17 \\
18 \\
19 \\
20\end{array}$ & $\begin{array}{l}-.024 \\
-.023 \\
-.030 \\
-.015 \\
+.029\end{array}$ & $\begin{array}{l}-.029 \\
-.016 \\
-.025 \\
-.017 \\
-.008\end{array}$ & $\begin{array}{l}-.024 \\
-.032 \\
-.026 \\
-.017 \\
+.003\end{array}$ & $\begin{array}{l}-.029 \\
-.014 \\
-.021 \\
-.027 \\
+.019\end{array}$ & $\begin{array}{l}-.026 \\
-.021 \\
-.026 \\
-.019 \\
+.011\end{array}$ & $\begin{array}{l}2,361 \\
2,360 \\
2,358 \\
2,357 \\
2,358\end{array}$ & $\begin{array}{r}-61.4 \\
-49.6 \\
-61.3 \\
-44.8 \\
+25.9\end{array}$ & $\begin{array}{r}4.2 \\
4.1 \\
22.2 \\
8.5 \\
111.8\end{array}$ & $\begin{array}{l}42.1 \\
34.3 \\
36.9 \\
36.6 \\
31.5\end{array}$ & $\begin{array}{r}+23.5 \\
+19.4 \\
+46.6 \\
+16.7 \\
+54.4\end{array}$ & $\begin{array}{r}+.119 \\
+.099 \\
+.237 \\
+.085 \\
+.277\end{array}$ & $\begin{array}{l}+.303 \\
+.251 \\
+.602 \\
+.216 \\
+.703\end{array}$ & $\begin{array}{l}\text { A } \\
\text { C } \\
\text { B } \\
\text { B } \\
\text { D }\end{array}$ \\
\hline $\begin{array}{l}21 \\
22 \\
23 \\
24 \\
25\end{array}$ & $\begin{array}{l}-.031 \\
-.031 \\
-.034 \\
-.034 \\
-.028\end{array}$ & $\begin{array}{l}-.013 \\
-.017 \\
-.039 \\
-.039 \\
-.034\end{array}$ & $\begin{array}{l}-.010 \\
-.022 \\
-.042 \\
-.032 \\
-.030\end{array}$ & $\begin{array}{l}-.025 \\
-.025 \\
-.039 \\
-.037 \\
-.029\end{array}$ & $\begin{array}{l}-.020 \\
-.024 \\
-.038 \\
-.036 \\
-.030\end{array}$ & $\begin{array}{l}2,357 \\
2,355 \\
2,354 \\
2,352 \\
2,350\end{array}$ & $\begin{array}{l}-47.1 \\
-56.5 \\
-89.5 \\
-84.7 \\
-70.5\end{array}$ & $\begin{array}{r}15.0 \\
3.6 \\
2.8 \\
2.2 \\
2.2\end{array}$ & $\begin{array}{l}37.8 \\
36.7 \\
37.7 \\
36.8 \\
37.5\end{array}$ & $\begin{array}{l}+24.3 \\
+23.4 \\
+54.6 \\
+50.1 \\
+35.2\end{array}$ & $\begin{array}{r}+.124 \\
+.119 \\
+.278 \\
+.256 \\
+.180\end{array}$ & $\begin{array}{l}+.314 \\
+.303 \\
+.707 \\
+.649 \\
+.457\end{array}$ & $\begin{array}{l}\text { C } \\
\text { B } \\
\text { A } \\
\text { A } \\
\text { A }\end{array}$ \\
\hline $\begin{array}{l}26 \\
27 \\
28 \\
29 \\
30\end{array}$ & $\begin{array}{l}-.045 \\
-.051 \\
-.033 \\
-.045 \\
-.052\end{array}$ & $\begin{array}{l}-.044 \\
-.050 \\
-.035 \\
-.040 \\
-.036\end{array}$ & $\begin{array}{l}-.040 \\
-.058 \\
-.032 \\
-.045 \\
-.044\end{array}$ & $\begin{array}{l}-.042 \\
-.052 \\
-038 \\
-.041 \\
-.046\end{array}$ & $\begin{array}{l}-.043 \\
-.053 \\
-.034 \\
-.043 \\
-.044\end{array}$ & $\begin{array}{l}2,348 \\
2,346 \\
2,343 \\
2,341 \\
2,339\end{array}$ & $\begin{array}{r}-101.0 \\
-124.3 \\
-79.7 \\
-100.7 \\
-102.9\end{array}$ & $\begin{array}{l}1.9 \\
1.6 \\
1.2 \\
1.2 \\
2.3\end{array}$ & $\begin{array}{l}42.7 \\
48.0 \\
48.7 \\
46.7 \\
38.4\end{array}$ & $\begin{array}{r}+60.2 \\
+77.9 \\
+32.2 \\
+55.2 \\
+66.8\end{array}$ & $\begin{array}{l}+.308 \\
+.398 \\
+.165 \\
+.283 \\
+.343\end{array}$ & $\begin{array}{r}+.781 \\
+1.012 \\
+.419 \\
+.719 \\
+.870\end{array}$ & $\begin{array}{l}\text { A } \\
\text { A } \\
\text { A } \\
\text { A } \\
\text { B }\end{array}$ \\
\hline
\end{tabular}


Table 1. - Daily water-budget evaporation from Lake Hefner, Okla., Apr. 26, 1950, to Aug. 31, 1951-Continued

\begin{tabular}{|c|c|c|c|c|c|c|c|c|c|c|c|c|c|}
\hline \multirow{3}{*}{ Day } & \multicolumn{5}{|c|}{ Change in stage, in feet } & \multirow{3}{*}{$\begin{array}{l}\text { Aver- } \\
\text { age } \\
\text { surface } \\
\text { area } \\
\text { (acres) }\end{array}$} & \multirow{3}{*}{$\begin{array}{c}\text { Change } \\
\text { in } \\
\text { content } \\
\text { (acre-ft) }\end{array}$} & \multirow[b]{3}{*}{$\begin{array}{l}\text { Inflow } \\
\text { (acre-ft) }\end{array}$} & \multirow{3}{*}{$\begin{array}{l}\text { Outflow } \\
\text { (acre-ft) }\end{array}$} & \multicolumn{3}{|c|}{ Evaporation } & \multirow{3}{*}{$\begin{array}{c}\text { Accuracy } \\
\text { classification }\end{array}$} \\
\hline & \multicolumn{4}{|c|}{ Gages } & \multirow{2}{*}{$\begin{array}{l}\text { Aver- } \\
\text { age }\end{array}$} & & & & & & & & \\
\hline & North & South & East & West & & & & & & $\begin{array}{l}\text { Acre- } \\
\text { feet }\end{array}$ & Inches & $\begin{array}{l}\text { Centi- } \\
\text { meters }\end{array}$ & \\
\hline \multicolumn{14}{|c|}{ July 1951} \\
\hline $\begin{array}{l}1 \\
2 \\
3 \\
4 \\
5\end{array}$ & $\begin{array}{l}-0.016 \\
-.017 \\
-.025 \\
+.059 \\
-.018\end{array}$ & $\begin{array}{l}-0.018 \\
-.029 \\
-.013 \\
+.058 \\
-.043\end{array}$ & $\begin{array}{l}-0.015 \\
-.026 \\
-.020 \\
+.068 \\
-.033\end{array}$ & $\begin{array}{c}\overline{\overline{0}} \\
-0.020\end{array}$ & $\begin{array}{l}-0.016 \\
-.024 \\
-.020 \\
+.062 \\
-.031\end{array}$ & $\begin{array}{l}2,338 \\
2,336 \\
2,335 \\
2,337 \\
2,337\end{array}$ & $\begin{array}{r}-37.4 \\
-56.1 \\
-46.7 \\
+144.9 \\
-72.4\end{array}$ & $\begin{array}{r}57.2 \\
5.3 \\
1.5 \\
207.9 \\
2.1\end{array}$ & $\begin{array}{l}28.8 \\
33.1 \\
39.4 \\
36.8 \\
33.9\end{array}$ & $\begin{array}{r}+65.8 \\
+28.3 \\
+8.8 \\
+26.2 \\
+40.6\end{array}$ & $\begin{array}{r}+0.338 \\
+.145 \\
+.045 \\
+.135 \\
+.208\end{array}$ & $\begin{array}{r}+0.858 \\
+.369 \\
+.115 \\
+.342 \\
+.530\end{array}$ & $\begin{array}{l}\text { A } \\
\text { B } \\
\text { B } \\
\text { C } \\
\text { C }\end{array}$ \\
\hline $\begin{array}{r}6 \\
7 \\
8 \\
9 \\
10\end{array}$ & $\begin{array}{l}-.044 \\
-.036 \\
-.045 \\
-.038 \\
-.046\end{array}$ & $\begin{array}{l}-.030 \\
-.046 \\
-.039 \\
-.042 \\
-.040\end{array}$ & $\begin{array}{l}-.041 \\
-.043 \\
-.038 \\
-.044 \\
-.042\end{array}$ & $\begin{array}{l}-.037 \\
-.039 \\
-.045 \\
-.043\end{array}$ & $\begin{array}{l}-.038 \\
-.040 \\
-.040 \\
-.042 \\
-.043\end{array}$ & $\begin{array}{l}2,335 \\
2,333 \\
2,331 \\
2,329 \\
2,327\end{array}$ & $\begin{array}{r}-88.7 \\
-93.3 \\
-93.2 \\
-97.8 \\
-100.1\end{array}$ & $\begin{array}{l}1.1 \\
.8 \\
.7 \\
.6 \\
.5\end{array}$ & $\begin{array}{l}42.4 \\
39.2 \\
27.6 \\
48.9 \\
53.7\end{array}$ & $\begin{array}{l}+47.4 \\
+54.9 \\
+66.3 \\
+49.5 \\
+46.9\end{array}$ & $\begin{array}{l}+.244 \\
+.282 \\
+.341 \\
+.255 \\
+.242\end{array}$ & $\begin{array}{l}+.619 \\
+.717 \\
+.867 \\
+.648 \\
+.614\end{array}$ & $\begin{array}{l}\text { C } \\
\text { B } \\
\text { A } \\
\text { A } \\
\text { A }\end{array}$ \\
\hline $\begin{array}{l}11 \\
12 \\
13 \\
14 \\
15\end{array}$ & $\begin{array}{l}-.041 \\
-.042 \\
-.042 \\
-.005 \\
-.028\end{array}$ & $\begin{array}{l}-.038 \\
-.043 \\
-.027 \\
-.015 \\
-.035\end{array}$ & $\begin{array}{l}-.048 \\
-.036 \\
-.033 \\
-.014 \\
-.030\end{array}$ & $\begin{array}{l}-.043 \\
-.041 \\
-.029 \\
-.011 \\
-.030\end{array}$ & $\begin{array}{l}-.042 \\
-.040 \\
-.033 \\
-.011 \\
-.031\end{array}$ & $\begin{array}{l}2,325 \\
2,322 \\
2,320 \\
2,319 \\
2,318\end{array}$ & $\begin{array}{l}-97.6 \\
-92.9 \\
-76.6 \\
-25.5 \\
-71.9\end{array}$ & $\begin{array}{r}.4 \\
.4 \\
.4 \\
48.1 \\
5.4\end{array}$ & $\begin{array}{l}51.2 \\
50.8 \\
46.7 \\
36.7 \\
34.3\end{array}$ & $\begin{array}{l}+46.8 \\
+42.5 \\
+30.3 \\
+36.9 \\
+43.0\end{array}$ & $\begin{array}{l}+.242 \\
+.220 \\
+.157 \\
+.191 \\
+.223\end{array}$ & $\begin{array}{l}+.614 \\
+.558 \\
+.398 \\
+.485 \\
+.565\end{array}$ & $\begin{array}{l}\text { B } \\
\text { A } \\
\text { B } \\
\text { B } \\
\text { A }\end{array}$ \\
\hline $\begin{array}{l}16 \\
17 \\
18 \\
19 \\
20\end{array}$ & $\begin{array}{l}-.036 \\
-.029 \\
-.041 \\
-.040 \\
-.046\end{array}$ & $\begin{array}{l}-.038 \\
-.032 \\
-.045 \\
-.032 \\
-.064\end{array}$ & $\begin{array}{l}-.034 \\
-.033 \\
-.046 \\
-.036 \\
-.062\end{array}$ & $\begin{array}{l}-.042 \\
-.035 \\
-.035 \\
\because .032 \\
-.048\end{array}$ & $\begin{array}{l}-.038 \\
-.032 \\
-.042 \\
-.035 \\
-.055\end{array}$ & $\begin{array}{l}2,316 \\
2,315 \\
2,313 \\
2,311 \\
2,308\end{array}$ & $\begin{array}{r}-88.0 \\
-74.1 \\
-97.1 \\
-80.9 \\
-126.9\end{array}$ & $\begin{array}{r}.2 \\
.2 \\
10.2 \\
.6 \\
.1\end{array}$ & $\begin{array}{l}51.5 \\
50.9 \\
51.2 \\
56.1 \\
53.6\end{array}$ & $\begin{array}{l}+36.7 \\
+23.4 \\
+46.1 \\
+35.4 \\
+73.4\end{array}$ & $\begin{array}{l}+.190 \\
+.121 \\
+.239 \\
+.184 \\
+.382\end{array}$ & $\begin{array}{l}+.483 \\
+.308 \\
+.607 \\
+.467 \\
+.969\end{array}$ & $\begin{array}{l}\text { A } \\
\text { A } \\
\text { B } \\
\text { A } \\
\text { C }\end{array}$ \\
\hline $\begin{array}{l}21 \\
22 \\
23 \\
24 \\
25\end{array}$ & $\begin{array}{l}-.073 \\
-.057 \\
-.034 \\
-.041 \\
-.014\end{array}$ & $\begin{array}{l}-.062 \\
-.040 \\
-.027 \\
+.031 \\
-.021\end{array}$ & $\begin{array}{l}-.061 \\
-.044 \\
-.032 \\
+.038 \\
-.028\end{array}$ & $\begin{array}{l}-.076 \\
-.049 \\
-.032 \\
+.036 \\
-.017\end{array}$ & $\begin{array}{l}-.068 \\
-.048 \\
-.031 \\
+.036 \\
-.020\end{array}$ & $\begin{array}{l}2,305 \\
2,302 \\
2,300 \\
2,299 \\
2,300\end{array}$ & $\begin{array}{r}-156.7 \\
-110.5 \\
-71.3 \\
+82.8 \\
-46.0\end{array}$ & $\begin{array}{c}0 \\
0 \\
14.5 \\
141.8 \\
18.8\end{array}$ & $\begin{array}{l}54.4 \\
48.9 \\
51.9 \\
36.5 \\
34.3\end{array}$ & $\begin{array}{r}+102.3 \\
+61.6 \\
+33.9 \\
+22.5 \\
+30.5\end{array}$ & $\begin{array}{r}+.533 \\
+.321 \\
+.177 \\
+.117 \\
+.159\end{array}$ & $\begin{array}{r}+1.352 \\
+.816 \\
+.449 \\
+.298 \\
+.404\end{array}$ & $\begin{array}{l}\text { B } \\
\text { B } \\
\text { A } \\
\text { D } \\
\text { B }\end{array}$ \\
\hline $\begin{array}{l}26 \\
27 \\
28 \\
29 \\
30 \\
31\end{array}$ & $\begin{array}{l}-.025 \\
+.017 \\
-.034 \\
-.035 \\
-.039 \\
-.037\end{array}$ & $\begin{array}{l}-.029 \\
+.030 \\
-.032 \\
-.040 \\
-.042 \\
-.035\end{array}$ & $\begin{array}{l}-.021 \\
+.021 \\
-.032 \\
-.039 \\
-.038 \\
-.033\end{array}$ & $\begin{array}{l}-.024 \\
+.016 \\
-.031 \\
-.027 \\
-.048 \\
-.036\end{array}$ & $\begin{array}{l}-.025 \\
+.021 \\
-.032 \\
-.035 \\
-.042 \\
-.035\end{array}$ & $\begin{array}{l}2,299 \\
2,300 \\
2,299 \\
2,297 \\
2,295 \\
2,293\end{array}$ & $\begin{array}{l}-57.5 \\
-48.3 \\
-73.6 \\
-80.4 \\
-96.4 \\
-80.3\end{array}$ & $\begin{array}{r}53.6 \\
104.2 \\
4.1 \\
2.4 \\
1.9 \\
3.3\end{array}$ & $\begin{array}{l}40.7 \\
40.7 \\
46.0 \\
37.3 \\
50.3 \\
38.2\end{array}$ & $\begin{array}{r}+70.4 \\
+15.2 \\
+31.7 \\
+45.5 \\
+48.0 \\
+45.4\end{array}$ & $\begin{array}{r}+.367 \\
+.079 \\
+.165 \\
+.238 \\
+.251 \\
+.238\end{array}$ & $\begin{array}{r}+.933 \\
+.201 \\
+.420 \\
+.604 \\
+.637 \\
+.603\end{array}$ & $\begin{array}{l}\text { B } \\
\text { B } \\
\text { A } \\
\text { B } \\
\text { B } \\
\text { A }\end{array}$ \\
\hline
\end{tabular}

August 1951

\begin{tabular}{|c|c|c|c|c|c|c|c|c|c|c|c|c|c|}
\hline $\begin{array}{l}1 \\
2 \\
3 \\
4 \\
5\end{array}$ & $\begin{array}{l}-0.027 \\
-.044 \\
-.047 \\
-.035 \\
-.046\end{array}$ & $\begin{array}{r}-0.029 \\
-.048 \\
-.041 \\
-.043 \\
-.063\end{array}$ & $\begin{array}{r}-0.039 \\
-.036 \\
-.044 \\
-.042 \\
-.053\end{array}$ & $\begin{array}{r}-0.028 \\
-.051 \\
-.041 \\
-.040 \\
-.052\end{array}$ & $\begin{array}{r}-0.031 \\
-.045 \\
-.043 \\
-.040 \\
-.054\end{array}$ & $\begin{array}{l}2,291 \\
2,289 \\
2,287 \\
2,285 \\
2,282\end{array}$ & $\begin{array}{r}-71.0 \\
-103.0 \\
-98.3 \\
-91.4 \\
-123.2\end{array}$ & $\begin{array}{r}1.4 \\
1.0 \\
.7 \\
.7 \\
.5\end{array}$ & $\begin{array}{l}47.4 \\
51.8 \\
51.9 \\
51.9 \\
50.7\end{array}$ & $\begin{array}{r}+25.0 \\
+52.2 \\
+47.1 \\
+40.2 \\
+73.0\end{array}$ & $\begin{array}{r}+0.131 \\
+.274 \\
+.247 \\
+.211 \\
+.384\end{array}$ & $\begin{array}{r}+0.333 \\
+.695 \\
+.628 \\
+.536 \\
+.975\end{array}$ & $\begin{array}{l}\text { B } \\
\text { B } \\
\text { A } \\
\text { A } \\
\text { B }\end{array}$ \\
\hline $\begin{array}{r}6 \\
7 \\
8 \\
9 \\
10\end{array}$ & $\begin{array}{l}-.059 \\
-.067 \\
-.054 \\
-.023 \\
+.049\end{array}$ & $\begin{array}{l}-.044 \\
-.081 \\
-.045 \\
-.010 \\
+.045\end{array}$ & $\begin{array}{r}-.052 \\
-.072 \\
-.055 \\
-.007 \\
+.051\end{array}$ & $\begin{array}{r}-.056 \\
-.071 \\
-.060 \\
-.015 \\
+.049\end{array}$ & $\begin{array}{r}-.053 \\
-.073 \\
-.054 \\
-.014 \\
+.048\end{array}$ & $\begin{array}{l}2,279 \\
2,276 \\
2,272 \\
2,271 \\
2,272\end{array}$ & $\begin{array}{r}-120.8 \\
-166.1 \\
-122.7 \\
-31.8 \\
+109.1\end{array}$ & $\begin{array}{r}.2 \\
.1 \\
.1 \\
55.7 \\
156.0\end{array}$ & $\begin{array}{l}51.8 \\
65.8 \\
63.6 \\
35.0 \\
27.1\end{array}$ & $\begin{array}{r}+69.2 \\
+100.4 \\
+59.2 \\
+52.5 \\
+19.8\end{array}$ & $\begin{array}{r}+.364 \\
+.529 \\
+.313 \\
+.277 \\
+.105\end{array}$ & $\begin{array}{r}+.925 \\
+1.345 \\
+.794 \\
+.705 \\
+.266\end{array}$ & $\begin{array}{l}\text { B } \\
\text { B } \\
\text { B } \\
\text { B } \\
\text { B }\end{array}$ \\
\hline $\begin{array}{l}11 \\
12 \\
13 \\
14 \\
15\end{array}$ & $\begin{array}{l}-.024 \\
-.016 \\
-.037 \\
-.048 \\
-.064\end{array}$ & $\begin{array}{l}-.020 \\
-.018 \\
-.047 \\
-.053 \\
-.034\end{array}$ & $\begin{array}{l}-.022 \\
-.028 \\
-.035 \\
-.054 \\
-.046\end{array}$ & $\begin{array}{l}-.022 \\
-.018 \\
-.040 \\
-.052 \\
-.050\end{array}$ & $\begin{array}{l}-.022 \\
-.020 \\
-.010 \\
-.052 \\
-.048\end{array}$ & $\begin{array}{l}2,272 \\
2,271 \\
2,270 \\
2.267 \\
2,265\end{array}$ & $\begin{array}{r}-50.0 \\
-45.4 \\
-90.8 \\
-117.9 \\
-108.7\end{array}$ & $\begin{array}{r}1.8 \\
.7 \\
.4 \\
.2 \\
.1\end{array}$ & $\begin{array}{l}25.2 \\
14.5 \\
33.9 \\
40.2 \\
47.6\end{array}$ & $\begin{array}{l}+26.6 \\
+31.6 \\
+57.3 \\
+77.9 \\
+61.2\end{array}$ & $\begin{array}{r}+.140 \\
+.167 \\
+.303 \\
+.412 \\
+.324\end{array}$ & $\begin{array}{r}+.357 \\
+.424 \\
+.769 \\
+1.047 \\
+.824\end{array}$ & $\begin{array}{l}\text { A } \\
\text { B } \\
\text { B } \\
\text { A } \\
\text { C }\end{array}$ \\
\hline $\begin{array}{l}16 \\
17 \\
18 \\
19 \\
20\end{array}$ & $\begin{array}{l}-.028 \\
-.056 \\
-.019 \\
-.026 \\
-.053\end{array}$ & $\begin{array}{l}-.046 \\
-.052 \\
-.017 \\
-.041 \\
-.049\end{array}$ & $\begin{array}{l}-.044 \\
-.045 \\
-.028 \\
-.034 \\
-.047\end{array}$ & $\begin{array}{l}-.042 \\
-.051 \\
-.021 \\
-.037 \\
-.043\end{array}$ & $\begin{array}{l}-.0 \times 0 \\
-.051 \\
-.021 \\
-.034 \\
-.048\end{array}$ & $\begin{array}{l}2,262 \\
2,260 \\
2,258 \\
2,257 \\
2,254\end{array}$ & $\begin{array}{r}-90.5 \\
-115.3 \\
-47.4 \\
-76.7 \\
-108.2\end{array}$ & $\begin{array}{r}0 \\
18.4 \\
4.4 \\
.4 \\
.1\end{array}$ & $\begin{array}{l}46.6 \\
44.1 \\
35.3 \\
35.3 \\
48.9\end{array}$ & $\begin{array}{r}+43.9 \\
+89.6 \\
+16.5 \\
+41.8 \\
+59.4\end{array}$ & $\begin{array}{l}+.233 \\
+.476 \\
+.088 \\
+.222 \\
+.316\end{array}$ & $\begin{array}{r}+.592 \\
+1.208 \\
+.223 \\
+.564 \\
+.803\end{array}$ & $\begin{array}{l}\text { C } \\
\text { B } \\
\text { B } \\
\text { B } \\
\text { B }\end{array}$ \\
\hline $\begin{array}{l}21 \\
22 \\
23 \\
24 \\
25\end{array}$ & $\begin{array}{l}-.014 \\
-.029 \\
-.005 \\
-.041 \\
-.044\end{array}$ & $\begin{array}{l}+.001 \\
-.037 \\
-.019 \\
-.037 \\
-.043\end{array}$ & $\begin{array}{l}-.004 \\
-.035 \\
-.013 \\
-.037 \\
-.044\end{array}$ & $\begin{array}{l}-.007 \\
-.029 \\
-.011 \\
-.041 \\
-.039\end{array}$ & $\begin{array}{l}-.006 \\
-.032 \\
-.012 \\
-.039 \\
-.042\end{array}$ & $\begin{array}{l}2,253 \\
2,252 \\
2,251 \\
2,249 \\
2,247\end{array}$ & $\begin{array}{l}-13.5 \\
-72.1 \\
-27.0 \\
-87.7 \\
-94.4\end{array}$ & $\begin{array}{r}84.7 \\
.5 \\
49.5 \\
.3 \\
.2\end{array}$ & $\begin{array}{l}31.2 \\
27.9 \\
39.2 \\
42.2 \\
41.0\end{array}$ & $\begin{array}{r}+67.0 \\
+44.7 \\
+37.3 \\
+45.8 \\
+53.6\end{array}$ & $\begin{array}{r}+.357 \\
+.238 \\
+.199 \\
+.244 \\
+.286\end{array}$ & $\begin{array}{l}+.906 \\
+.605 \\
+.505 \\
+.621 \\
+.727\end{array}$ & $\begin{array}{l}\mathrm{B} \\
\mathrm{A} \\
\mathrm{B} \\
\mathrm{A}\end{array}$ \\
\hline $\begin{array}{l}26 \\
27 \\
28 \\
29 \\
30 \\
31\end{array}$ & $\begin{array}{l}-.039 \\
-.051 \\
-.059 \\
-.058 \\
-.054 \\
-.048\end{array}$ & $\begin{array}{l}-.037 \\
-.053 \\
-.064 \\
-.054 \\
-.048 \\
-.048\end{array}$ & $\begin{array}{l}-.035 \\
-.064 \\
-.063 \\
-.050 \\
-.051 \\
-.042\end{array}$ & $\begin{array}{l}-.037 \\
-.042 \\
-.063 \\
-.059 \\
-.053 \\
-.037\end{array}$ & $\begin{array}{l}-.037 \\
-.052 \\
-.062 \\
-.055 \\
-.052 \\
-.044\end{array}$ & $\begin{array}{l}2,245 \\
2,243 \\
2,240 \\
2,237 \\
2,234 \\
2,232\end{array}$ & $\begin{array}{r}-83.1 \\
-116.6 \\
-138.9 \\
-123.0 \\
-116.2 \\
-98.2\end{array}$ & $\begin{array}{l}.1 \\
.1 \\
0 \\
0 \\
0 \\
0\end{array}$ & $\begin{array}{l}37.8 \\
51.2 \\
49.8 \\
51.2 \\
51.0 \\
51.6\end{array}$ & $\begin{array}{r}+45.4 \\
+65.5 \\
+89.1 \\
+71.8 \\
+65.2 \\
+46.6\end{array}$ & $\begin{array}{l}+.243 \\
+.350 \\
+.477 \\
+.385 \\
+.350 \\
+.251\end{array}$ & $\begin{array}{r}+.616 \\
+.890 \\
+1.212 \\
+.978 \\
+.890 \\
+.636\end{array}$ & $\begin{array}{l}\text { A } \\
\text { B } \\
\text { A } \\
\text { B }\end{array}$ \\
\hline
\end{tabular}




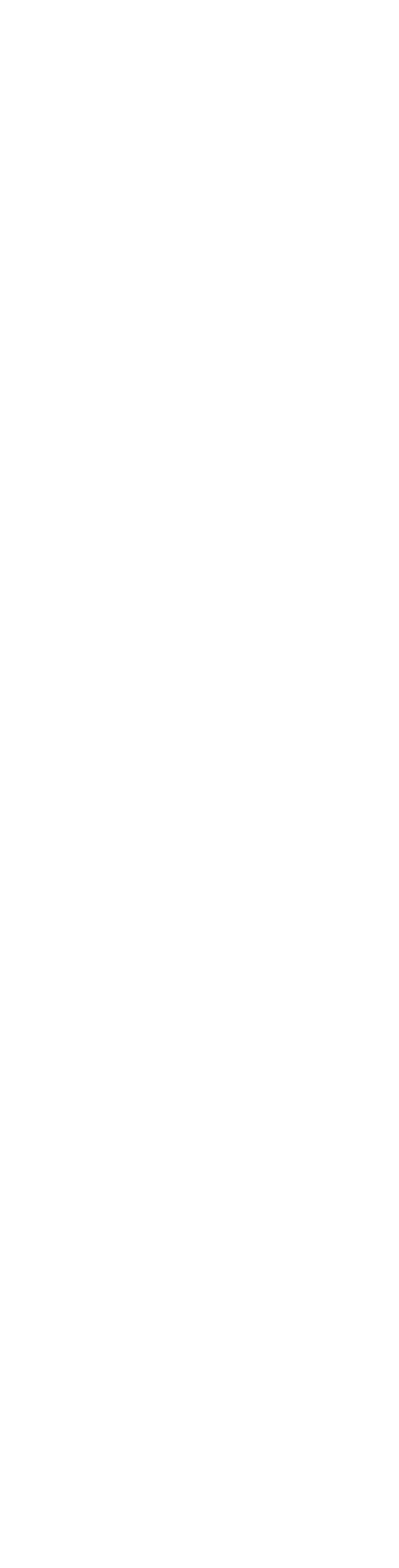




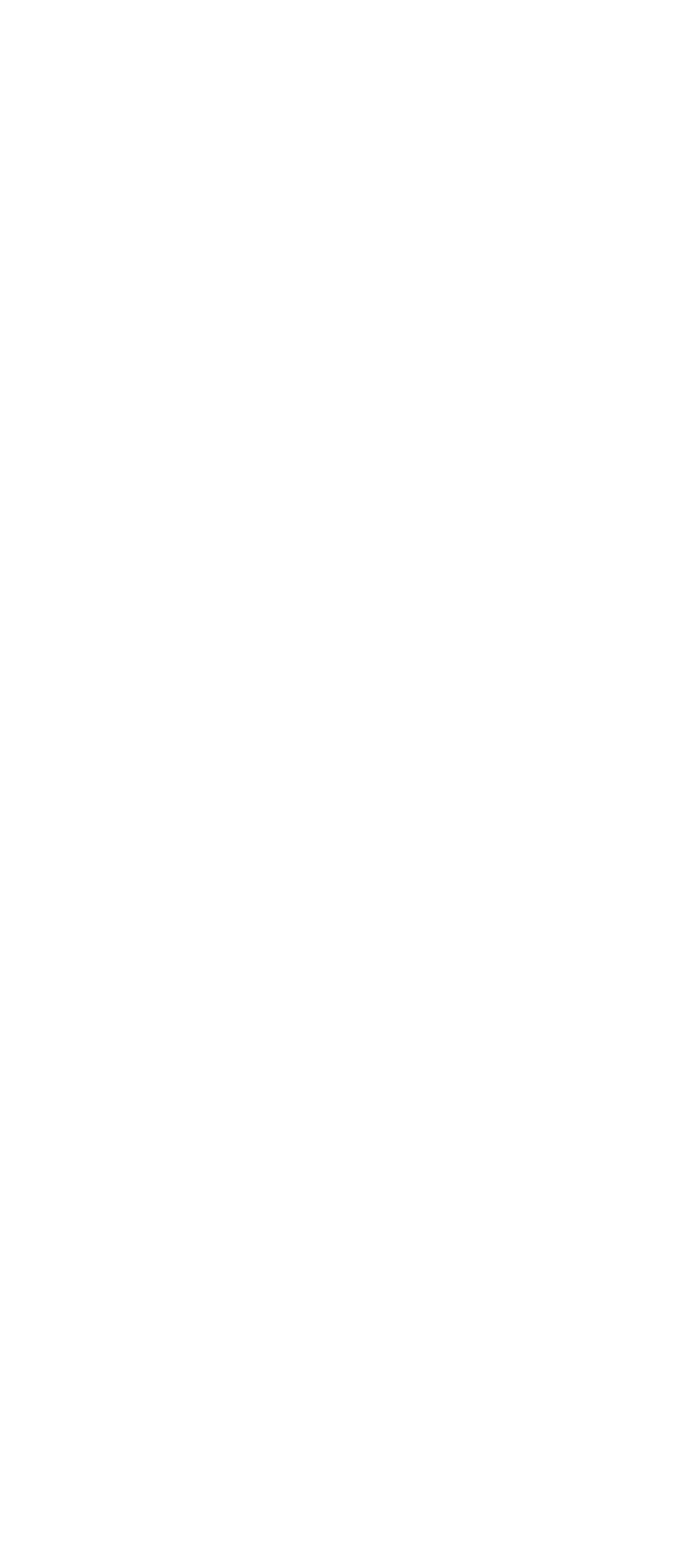




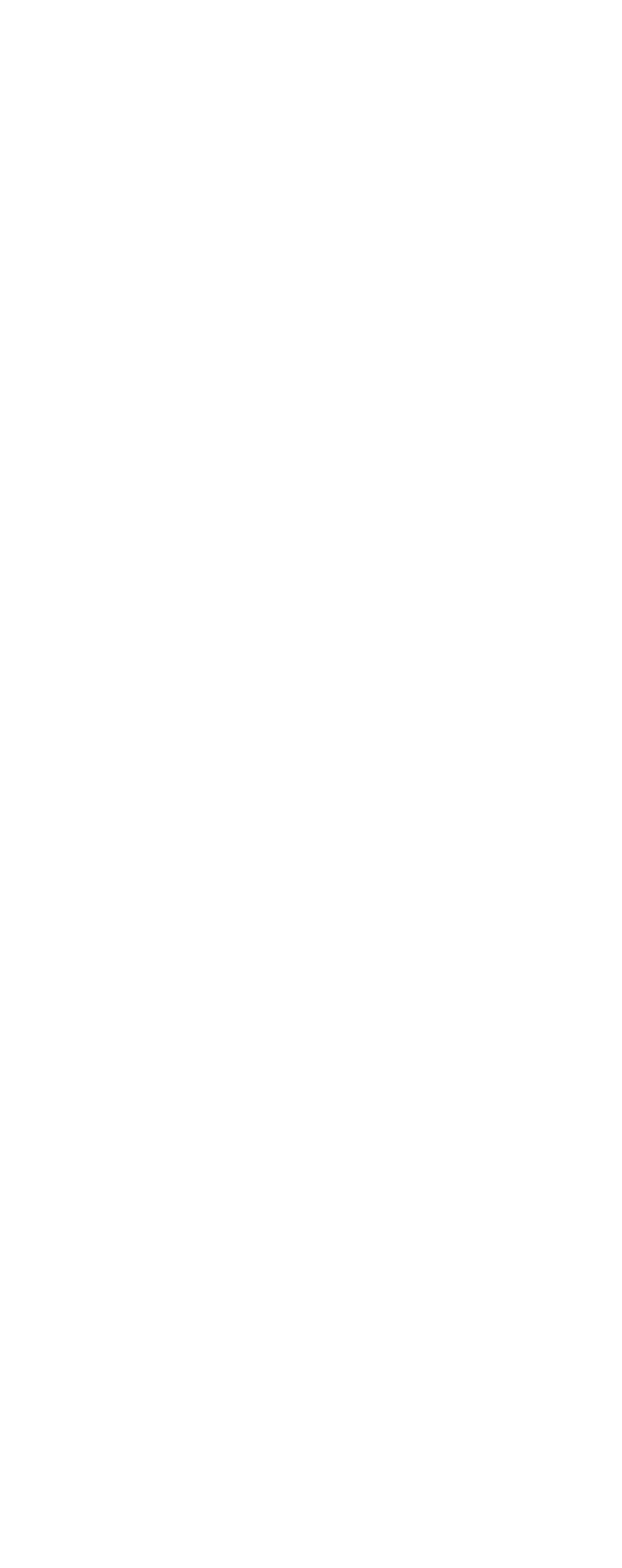


Table 4. -Daily flow of Bluff Creek above Lake Hefner near Oklahoma City, in acre-feet

\begin{tabular}{|c|c|c|c|c|c|c|c|c|c|c|c|c|c|c|c|c|c|}
\hline \multirow{2}{*}{ Day } & \multicolumn{9}{|c|}{1950} & \multicolumn{8}{|c|}{1951} \\
\hline & Apr. & May & June & July & Aug. & Sept. & Oct. & Nov. & Dec. & Jan. & Feb. & Mar. & Apr. & May & June & July & Aug. \\
\hline 1 & & 0.52 & 0.81 & 0.46 & 1.7 & 0.10 & 0.12 & 0.93 & 0.52 & 0.32 & 0.10 & 0.62 & 0.50 & 12.0 & 4.84 & 0.75 & 1.07 \\
\hline 2 & & .72 & 1.45 & .34 & 3.71 & .10 & .30 & .18 & .54 & .75 & .14 & .64 & .46 & 1.86 & 3.17 & .67 & .58 \\
\hline 3 & & 1.02 & 4.17 & 36 & 2.50 & .12 & 1.61 & .64 & .50 & .58 & .24 & .52 & .46 & 1. 37 & 2.20 & .48 & .42 \\
\hline 4 & & .88 & 2.46 & 2.16 & 2.10 & 1.21 & .46 & .30 & .44 & .42 & .62 & .52 & .52 & 1.11 & 1.77 & 3. 55 & .42 \\
\hline 5 & & .72 & 2.62 & 1.25 & 1. 79 & .99 & .32 & .22 & .26 & .40 & .93 & .40 & .71 & .88 & 2. 70 & .71 & .18 \\
\hline 6 & & .34 & 3.05 & .71 & 1.45 & .36 & .24 & .16 & .12 & .32 & .79 & .46 & .71 & .79 & 3. 33 & .36 & .02 \\
\hline 7 & & .45 & 1.19 & .67 & 1.17 & .28 & .22 & .20 & .12 & .30 & .40 & .48 & .54 & .67 & 2.50 & .32 & 0 \\
\hline 8 & & 38 & 1. 19 & .61 & 1.09 & .22 & .12 & .22 & .30 & .32 & .48 & .48 & .42 & .67 & 2.74 & .20 & 0 \\
\hline 9 & & a2.24 & 1. 19 & .61 & 1.19 & .22 & .10 & .20 & .58 & .36 & .46 & .75 & .40 & 2.10 & 2.62 & .10 & .01 \\
\hline 10 & & 230.9 & 3.05 & .58 & 1. 17 & .16 & .12 & .28 & .48 & .42 & .50 & 1.27 & .46 & 4.03 & 7.76 & .08 & 1.43 \\
\hline 11 & & a8. 63 & 3.55 & .69 & .93 & .12 & .16 & .28 & .46 & .34 & .48 & 6.78 & .42 & 1.47 & 10.28 & .06 & .67 \\
\hline 12 & & a2.18 & 1.45 & .85 & .61 & .22 & .12 & .28 & .42 & .36 & .40 & 1.17 & .36 & 1.03 & 3.19 & .04 & .30 \\
\hline 13 & & a3. 95 & .97 & .87 & .42 & .32 & .10 & .56 & .42 & .48 & .22 & .93 & .32 & .77 & 2.34 & .02 & .14 \\
\hline 14 & & 1.51 & .62 & .56 & .56 & .48 & .12 & .28 & .42 & 1.23 & .22 & .75 & .32 & .62 & 2.10 & .20 & .08 \\
\hline 15 & & 1.48 & .58 & .52 & .58 & .63 & .06 & .38 & .40 & .79 & .79 & .75 & .30 & .71 & 2.18 & .14 & .04 \\
\hline 16 & & 1. 39 & 1.11 & .42 & 1.33 & .36 & .02 & .34 & .42 & .58 & .79 & .79 & . 32 & .85 & 1.69 & .04 & .01 \\
\hline 17 & & 1.45 & .93 & 2.0 & .97 & .24 & .06 & .42 & .44 & .52 & 1.77 & .67 & . 34 & 32.4 & 1.33 & .02 & .04 \\
\hline 18 & & $\mathrm{a} 31.3$ & .61 & 2.0 & .83 & .23 & .08 & .44 & .40 & .52 & 2.60 & .58 & .83 & 39.2 & 1.33 & .01 & .02 \\
\hline 19 & & a2.26 & .52 & 10.8 & .63 & .25 & .12 & .46 & .40 & .52 & 1.55 & .52 & 1. 33 & 6.33 & 1.67 & .01 & .01 \\
\hline 20 & & 2.59 & 1.49 & 7.91 & .54 & .22 & .14 & .26 & .40 & .44 & 3.77 & .52 & 4.15 & 4.58 & 7.24 & 0 & 0 \\
\hline 21 & & 1.77 & 1.45 & 3.85 & .54 & .13 & .16 & .30 & .42 & .36 & 1.23 & .52 & 1.73 & 3.01 & 1.57 & 0 & .08 \\
\hline 22 & & .95 & .79 & 2.64 & .58 & .10 & .12 & .32 & .42 & .40 & .87 & .58 & .58 & 9.28 & 1.33 & 0 & .12 \\
\hline 23 & & .58 & .67 & 1. 31 & 1.45 & .12 & .08 & . 32 & .44 & .36 & .71 & .46 & .71 & 2.66 & 1.23 & 0 & .36 \\
\hline 24 & & .58 & .48 & 1.02 & .36 & .09 & .10 & .24 & .40 & .42 & .83 & .46 & 1.39 & 2.70 & 1.07 & 12,30 & .12 \\
\hline 25 & & .48 & .81 & 16.8 & .32 & .06 & .12 & .32 & 36 & .44 & .75 & .50 & .42 & 2.58 & .93 & 5.50 & .02 \\
\hline 26 & $0.42 \mid$ & 7.64 & .62 & 3. 39 & .20 & .22 & .10 & .36 & .28 & .48 & .87 & .48 & .42 & 1.82 & .75 & .42 & 0 \\
\hline 27 & & 1.91 & .43 & 1.51 & .14 & .24 & .16 & .34 & .24 & .46 & .73 & .87 & .40 & a78. 5 & .62 & 9.11 & 0 \\
\hline 28 & .40 & 4.58 & .76 & 2.18 & .12 & .34 & .12 & .36 & .30 & .22 & .71 & .71 & .32 & 14.6 & .52 & 2.50 & 0 \\
\hline 29 & & 1.77 & .72 & 14.0 & .30 & .20 & .04 & .42 & .34 & .10 & & .66 & 2.70 & 5.98 & .48 & 1.33 & 0 \\
\hline 30 & & 1.23 & .59 & 2.94 & .22 & .20 & .02 & .46 & .38 & .12 & & .58 & 12.7 & 3.53 & .62 & 1.17 & 0 \\
\hline 31 & & $\begin{array}{r}.60 \\
.69\end{array}$ & & 1.39 & .20 & & .30 & & .34 & .10 & & .52 & & 2.34 & & 1.33 & 0 \\
\hline Tota & 2.51 & 35.63 & 40.33 & 85.40 & 39.70 & 8.53 & 5.91 & 10.47 & 11.96 & 13.43 & 23,95 & 25.94 & 35.24 & 180.84 & 76.10 & 41.42 & 6.14 \\
\hline Average & .30 & 1.48 & 1. 34 & 2. 75 & 1.28 & .28 & .19 & .35 & .39 & .43 & .86 & .84 & 1.17 & 60.28 & 2.54 & 1.34 & .20 \\
\hline
\end{tabular}

a Not used in computing mean; daily evaporation not determined. 
Table 5.-Combined daily flow, in acre-feet, at gages A, B, D, E, F, G, H, and J, and estimated flow from ungaged area

[Drainage area above culvert gages 1,377 acres. Ungaged area 1,224 acres at lake stage of 1,191 feet; 1,012 acres at lake stage of 1,195 feet]

\begin{tabular}{|c|c|c|c|c|c|c|c|c|c|c|c|c|c|c|c|c|c|}
\hline \multirow[t]{2}{*}{ Day } & \multicolumn{9}{|c|}{1950} & \multicolumn{8}{|c|}{1951} \\
\hline & Apr. & May & June & July & Aug. & Sept. & Oct. & Nov. & Dec. & Jan. & Feb. & Mar. & Apr. & May & June & July & Aug. \\
\hline 1 & & 0 & 56 & 0 & 47.10 & 0 & 0 & 0 & 0 & & 0 & 0.12 & 0 & 34.80 & 6.88 & 0.47 & 0 \\
\hline 2 & & 0 & .70 & 0 & 9.37 & 0 & 0.37 & 0 & 0 & 0.64 & 0 & .10 & 0 & 3.14 & 4. 39 & .40 & 0 \\
\hline 3 & & 0 & 4.77 & 0 & 2.50 & 0 & 2.45 & 0.44 & $\theta$ & .48 & 0 & 0 & 0 & 1.50 & 2.76 & .21 & 0 \\
\hline 4 & & 0 & .96 & 1.68 & 1. 56 & 2.39 & .38 & .21 & 0 & .29 & 0 & 0 & 0 & 1.00 & 2.08 & 5.29 & 0 \\
\hline 5 & & 0 & .59 & .73 & .72 & 1.99 & .22 & .10 & 0 & .15 & 0 & 0 & .20 & .63 & 1.66 & .52 & 0 \\
\hline 6 & & 0 & .47 & 0 & 1.02 & .34 & .10 & 0 & 0 & 0 & 0 & 0 & .20 & .22 & 3.73 & .18 & 10 \\
\hline 7 & & 0 & .32 & 0 & .82 & .16 & .10 & 0 & 0 & c & 0 & 0 & .10 & .17 & 2.62 & .03 & 0 \\
\hline 8 & & 0 & .11 & 0 & .64 & 0 & 0 & 0 & 0 & & 0 & 0 & 0 & .12 & 2.97 & .02 & 0 \\
\hline 9 & & - & .04 & 0 & .50 & 0 & 0 & 0 & 0 & 0 & 0 & .30 & 0 & 48.21 & 3.07 & .01 & 0 \\
\hline 10 & & - & 2.59 & 0 & .35 & 0 & 0 & 0 & 0 & 0 & 0 & 1.06 & 0 & 14.08 & 19.27 & 0 & 0.52 \\
\hline 11 & & - & 1.00 & 0 & .24 & 0 & 0 & 0 & 0 & 0 & 0 & 13.00 & 0 & 3.17 & 29.15 & 0 & .13 \\
\hline 12 & & - & .34 & .10 & .11 & 0 & 0 & 0 & 0 & 0 & 0 & 1.08 & 0 & 1.38 & 6.87 & 0 & 0 \\
\hline 13 & & - & .09 & .30 & 0 & .10 & 0 & 0 & 0 & .17 & 0 & .72 & 0 & .61 & 2.90 & 0 & 0 \\
\hline 14 & & 1.24 & 0 & 0 & 0 & .69 & 0 & 0 & 0 & 1.02 & 0 & .50 & 0 & .23 & 2.07 & 0 & 0 \\
\hline 15 & & 1.14 & 0 & 0 & .21 & .85 & 0 & 0 & 0 & .62 & 0 & .48 & 0 & .26 & 2.53 & 0 & 0 \\
\hline 16 & & & 0 & 0 & .79 & .28 & 0 & 0 & 0 & .30 & 0 & .48 & 0 & .33 & 1.12 & 0 & 10 \\
\hline 17 & & a. 25 & 0 & 1.00 & .51 & .14 & 0 & 0 & 0 & .12 & 2.00 & .30 & 0 & 103.39 & .94 & 0 & 0 \\
\hline 18 & & - & 0 & 1.60 & .26 & .13 & 0 & 0 & 0 & 0 & 3.04 & . 14 & 0 & 129.59 & 2.52 & 0 & 0 \\
\hline 19 & & - & 0 & 11.30 & .03 & .11 & 0 & 0 & 0 & 0 & 1.80 & .12 & 0 & 13.80 & 1.20 & 0 & 0 \\
\hline 20 & & 3.11 & 1. 78 & $\theta .60$ & 0 & 0 & 0 & 0 & 0 & 0 & 3.75 & 0 & 4.72 & 11.38 & 17.31 & 0 & 0 \\
\hline 21 & & 1.69 & .59 & 5.97 & 0 & 0 & 0 & 0 & c & 0 & .91 & 0 & 1.46 & 4.99 & 2.50 & 0 & 0 \\
\hline 22 & & .90 & .11 & 5.08 & 0 & 0 & 0 & 0 & 0 & 0 & .42 & 0 & .38 & 19.02 & 1. 22 & 0 & 0 \\
\hline 23 & & .49 & 0 & 1.52 & 3.27 & 0 & 0 & 0 & 0 & 0 & .13 & 0 & .12 & 4.91 & .64 & 0 & 10 \\
\hline 24 & & .27 & 0 & .77 & .26 & 0 & 0 & 0 & 0 & 0 & .20 & 0 & 0 & 4.43 & .42 & 19.44 & 0 \\
\hline 25 & & .49 & 0 & 43.70 & .15 & 0 & 0 & 0 & 0 & c & .55 & 0 & 0 & 3.79 & .36 & 11.43 & 0 \\
\hline 26 & 0 & 12.40 & 0 & 6.42 & 0 & .10 & 0 & 0 & 0 & 0 & .64 & .36 & 0 & 2.32 & .23 & .93 & 0 \\
\hline 27 & 0 & . 30 & 0 & 2.04 & 0 & .10 & 0 & 0 & 0 & 0 & .45 & .50 & 0 & - & .16 & 4.85 & 0 \\
\hline 28 & 0 & 12.2 & 0 & .92 & 0 & .10 & 0 & 0 & 0 & 0 & .26 & .28 & 0 & 23.62 & 0 & .77 & 0 \\
\hline 29 & 0 & 3.3 & 0 & 27.00 & .22 & .10 & 0 & 0 & 0 & 0 & & .16 & 8.17 & 8.26 & 0 & .32 & 0 \\
\hline 30 & 0 & 1.51 & 0 & 6.18 & .10 & .10 & 0 & 0 & 0 & 0 & & .12 & 44.10 & 4.59 & 0 & .11 & 0 \\
\hline 31 & & .87 & & 2.29 & .10 & & & & 0 & & & 0 & & 2.92 & & 0 & 0 \\
\hline Total & 0 & 42.75 & 15.02 & 128.20 & 70.83 & 7.68 & $3.62 \mid$ & .75 & 0 & 3.79 & 14.15 & $\mid 19.82$ & 59.45 & 446.86 & 121.57 & 44.98 & .65 \\
\hline Average & 0 & 1.78 & .50 & 4.14 & 2.28 & .26 & .12 & .02 & 0 & .12 & .51 & . .64 & 1.98 & 14.90 & 4.05 & 1.45 & .02 \\
\hline
\end{tabular}

a Covers 22-hour period (0000-2200); heavy rain thereafter. 


\begin{tabular}{|c|c|c|}
\hline & 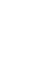 & 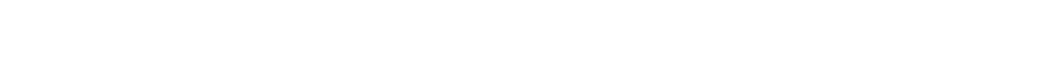 \\
\hline & 尝 & 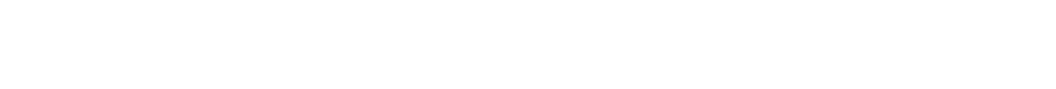 \\
\hline & $\overbrace{5}^{2}$ & 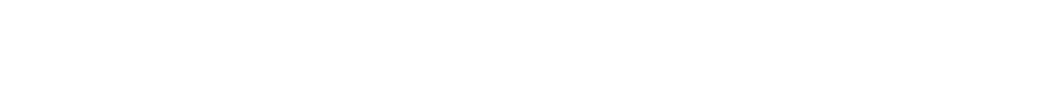 \\
\hline : & 㞼 & 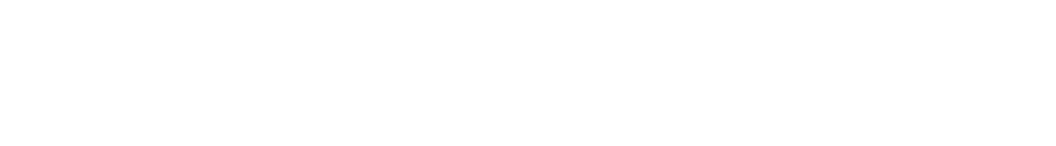 \\
\hline$\Rightarrow$ & : & 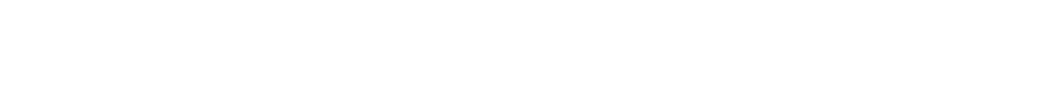 \\
\hline & $\stackrel{\dot{\sigma}}{\Sigma}$ & 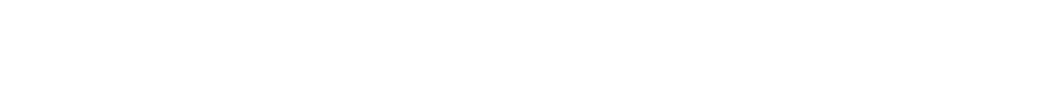 \\
\hline & $\stackrel{\dot{0}}{\dot{0}}$ & 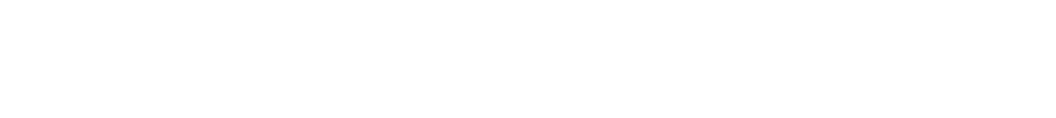 \\
\hline & ๘্் & 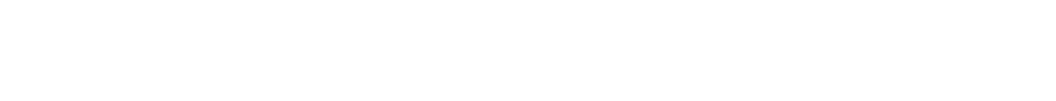 \\
\hline & نّ̊ & 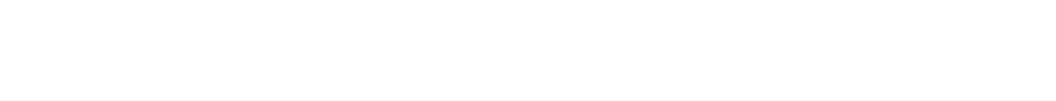 \\
\hline & $\dot{z}$ & 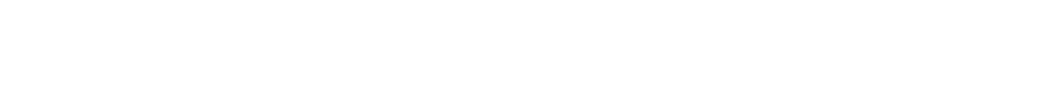 \\
\hline & $\dot{\ddot{\delta}}$ & 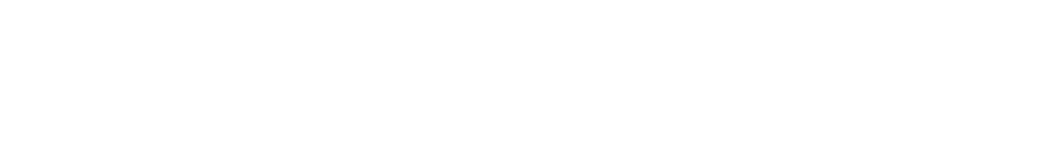 \\
\hline & 苔 & 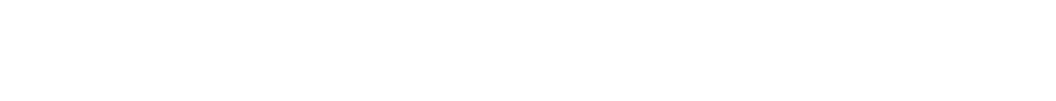 \\
\hline 号 & $\begin{array}{l}\dot{s 0} \\
\dot{4}\end{array}$ & 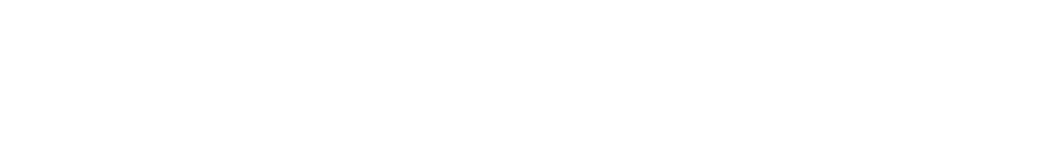 \\
\hline & ફ & 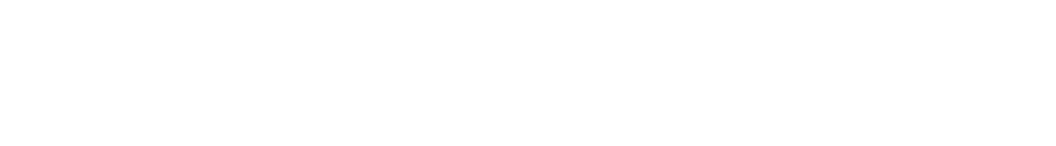 \\
\hline & 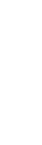 & 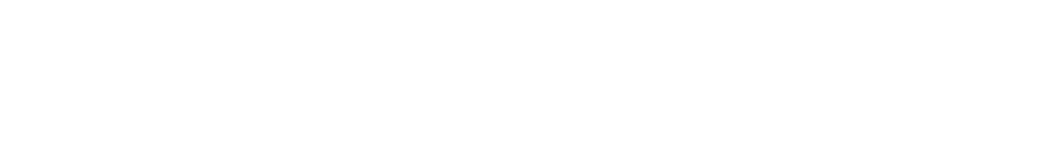 \\
\hline & 要 & 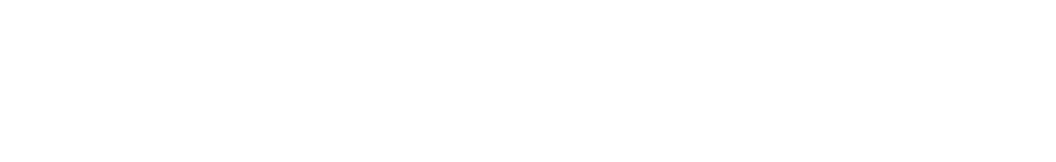 \\
\hline & 菑 & 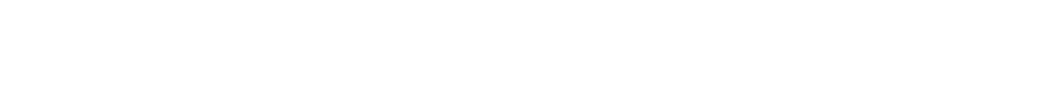 \\
\hline 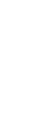 & ఫొ & 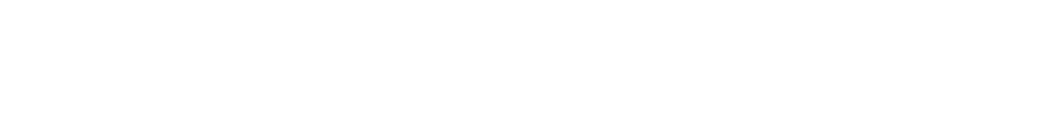 \\
\hline
\end{tabular}


TABLE 7

\begin{tabular}{|c|c|c|}
\hline & $z_{4}^{\infty}$ & 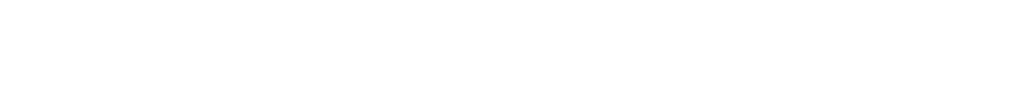 \\
\hline & ? & 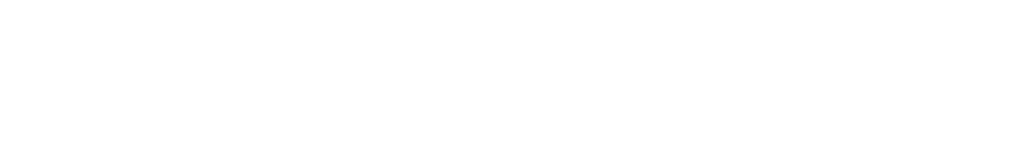 \\
\hline & 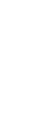 & 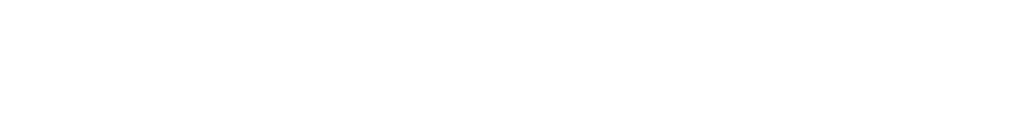 \\
\hline & & 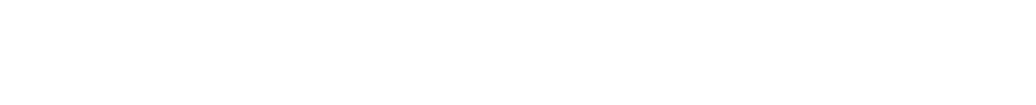 \\
\hline & |cta & 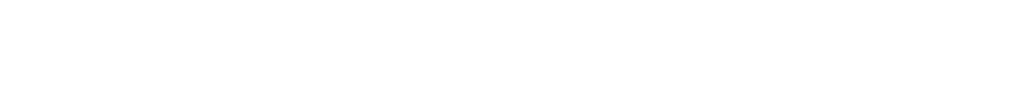 \\
\hline & & 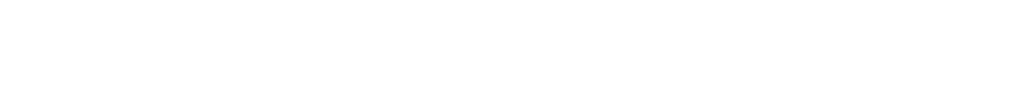 \\
\hline & & 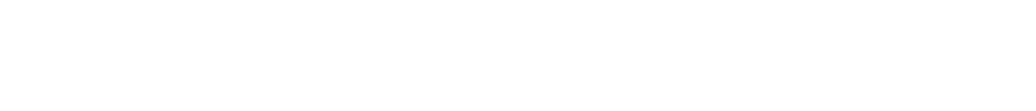 \\
\hline & ⿷匚ّ & 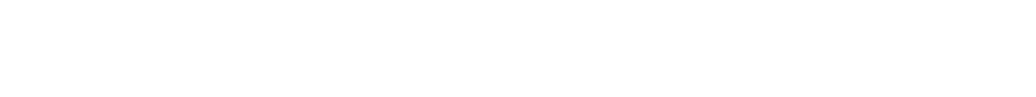 \\
\hline & & 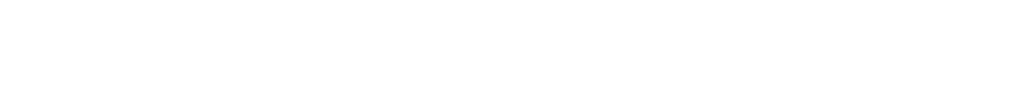 \\
\hline & 蛋 & 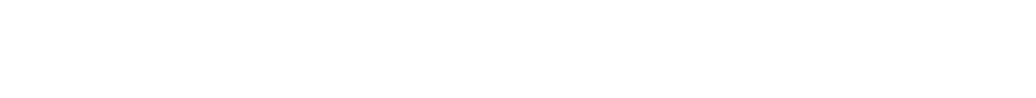 \\
\hline & & 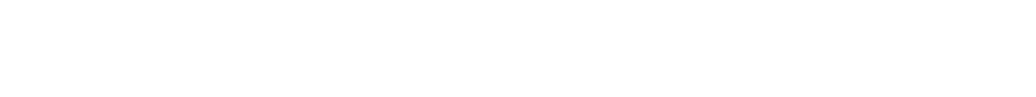 \\
\hline & & 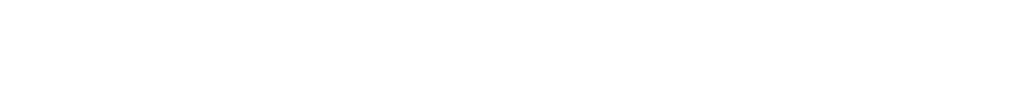 \\
\hline$\left|\begin{array}{ll}0 \\
0 \\
\vdots \\
\hdashline\end{array}\right|$ & & 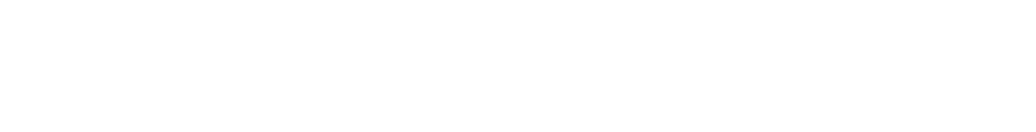 \\
\hline & & 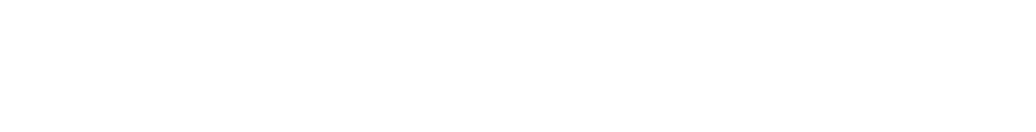 \\
\hline & ș & 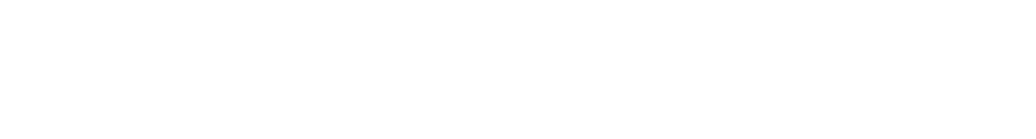 \\
\hline & $\overbrace{}^{\frac{\pi}{2}}$ & 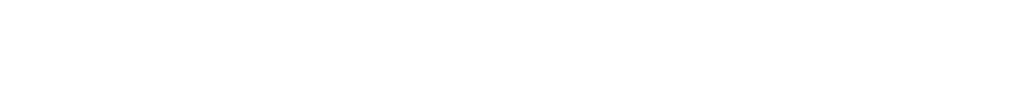 \\
\hline & 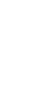 & 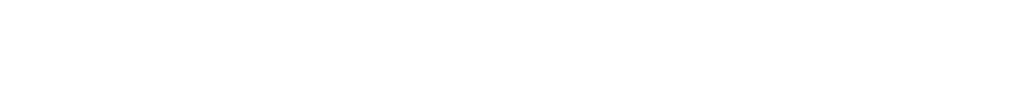 \\
\hline Д็ & & Nm nu以 \\
\hline
\end{tabular}




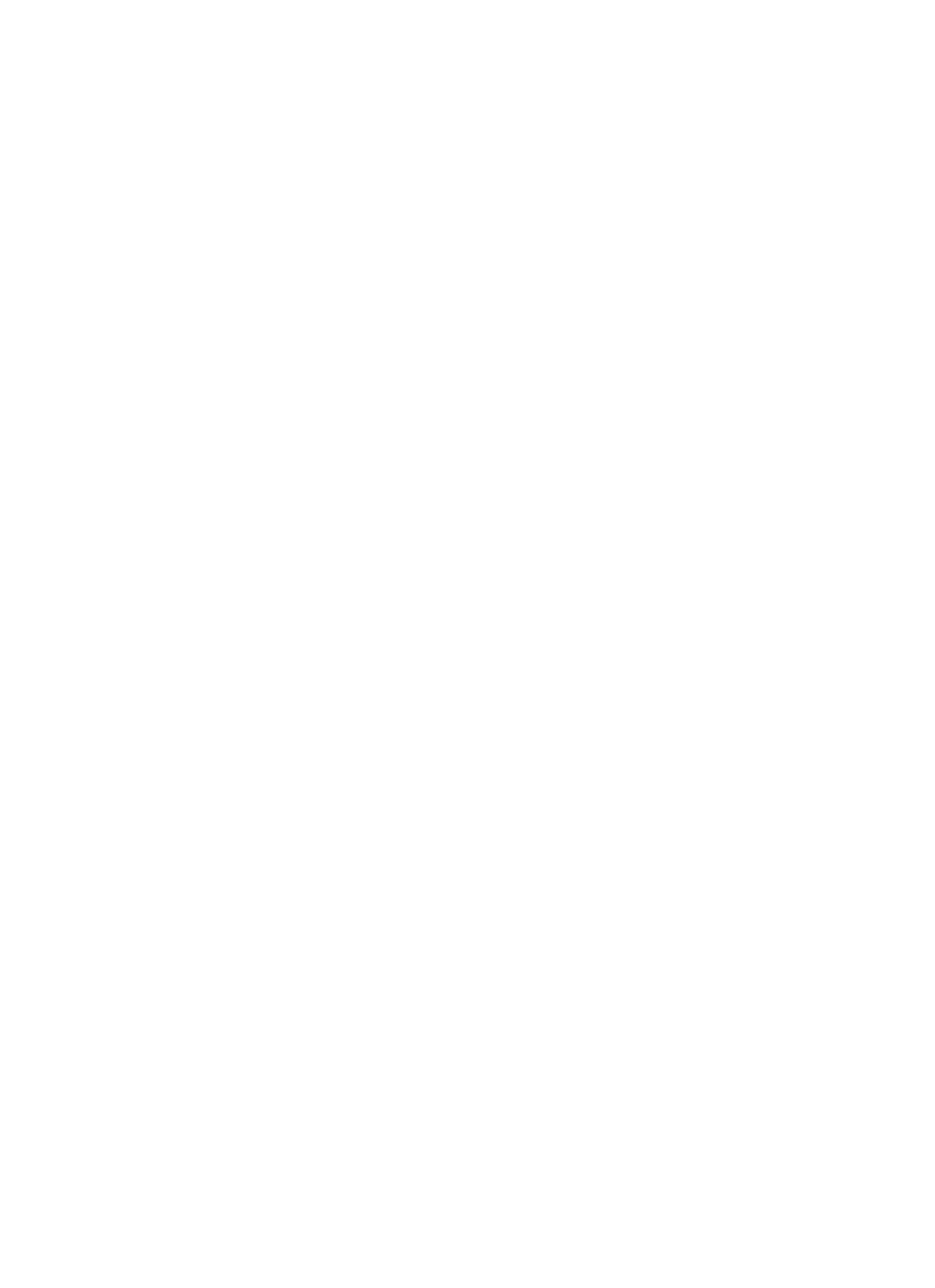


TABLE 8

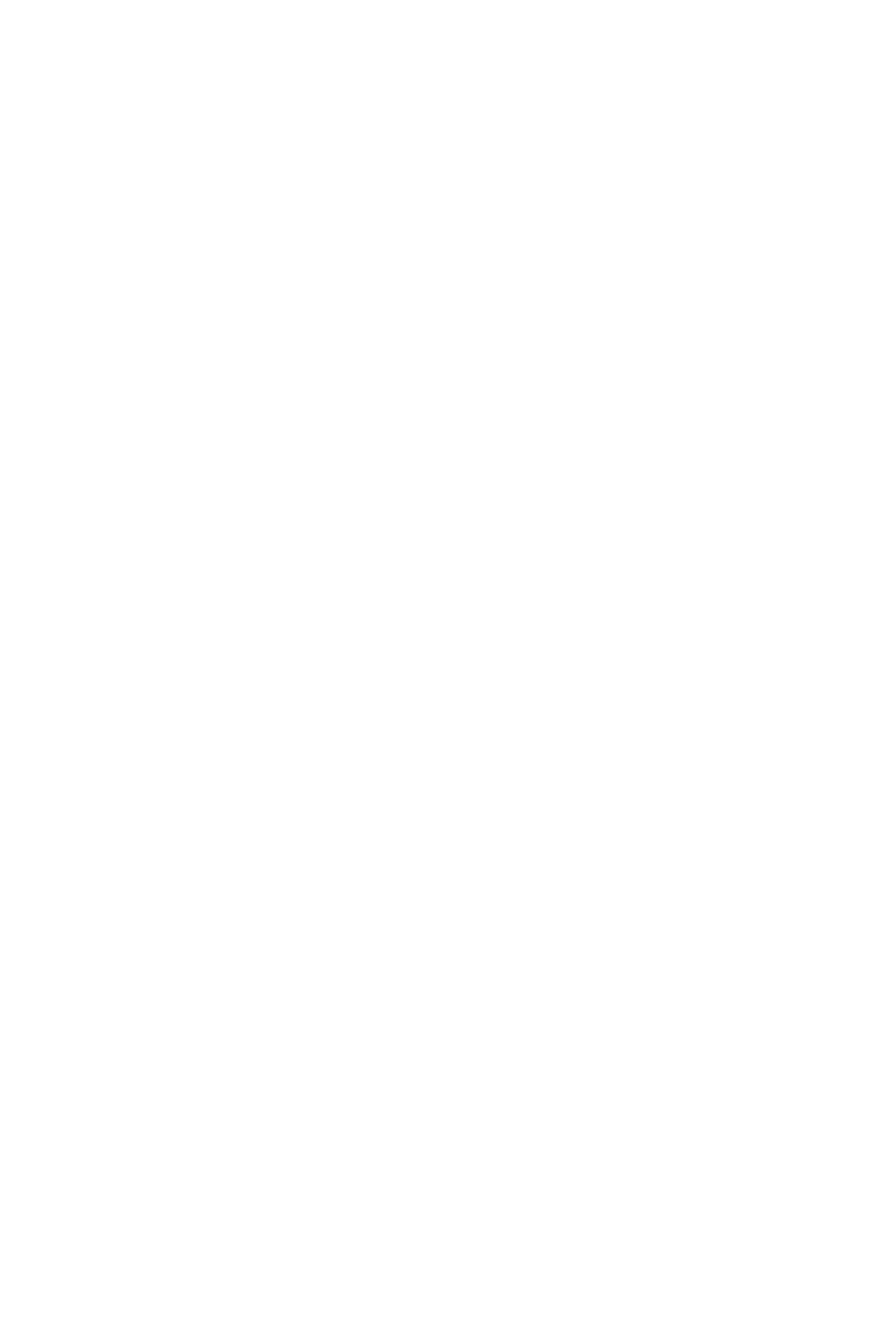


Table 9.-Daily withdrawals for golf-course irrigation, in acre-feet

\begin{tabular}{|c|c|c|c|c|c|c|c|c|c|c|c|c|c|c|c|c|c|}
\hline \multirow[t]{2}{*}{ Day } & \multicolumn{9}{|c|}{1950} & \multicolumn{8}{|c|}{1951} \\
\hline & Apr. & May & June & July & Aug. & Sept. & Oct. & Nov. & Dec. & Jan. & Feb. & Mar. & Apr. & May & June & July & Aug. \\
\hline 1 & & 0 & 0 & 0 & 0 & 0.1 & 0 & 0.1 & 0 & 0 & 0 & 0 & 0 & 0 & 0 & 0 & 0 \\
\hline 2 & & 0 & 0 & 0.1 & 0 & 0 & 0 & 0 & 0 & 0 & 0 & 0 & 0 & 0 & 0 & 0 & 0 \\
\hline 3 & & 0 & 0 & 0 & 0 & 0 & 0 & 0 & 0 & 0 & 0 & 0 & 0 & 0 & 0 & 0.1 & 0 \\
\hline 4 & & 0 & 0 & 0 & 0 & 0 & 0 & 0 & 0 & 0 & 0 & 0 & 0 & 0 & 0 & 0 & 0 \\
\hline 5 & & 0 & 0 & 0 & 0 & 0 & 0 & 0 & 0 & 0 & 0 & 0 & 0 & 0 & 0.1 & 0 & 0.1 \\
\hline 6 & & 0 & 0 & 0 & 0 & 0 & 0 & 0 & 0 & 0 & 0 & 0 & 0 & 0 & 0 & .1 & .1 \\
\hline 7 & & 0 & 0.1 & 0 & 0.1 & 0 & 0 & 0 & 0 & 0 & 0 & 0 & 0.1 & 0.1 & 0 & .1 & .1 \\
\hline 8 & & 0 & .1 & .1 & 0 & 0 & 0 & 0 & 0 & 0 & 0 & 0 & 0 & 0 & 0 & .1 & .1 \\
\hline 9 & & - & .1 & 0 & .1 & 0 & 0 & 0 & 0 & 0 & 0 & 0 & 0 & 0 & 0 & .1 & 0 \\
\hline 10 & & - & 0 & .1 & 1 & .1 & 0 & 0 & 0 & 0 & 0 & 0 & 0 & 0 & 0 & .1 & 0 \\
\hline 11 & & - & 0 & .2 & 0 & .1 & 0 & 0 & 0 & 0 & 0 & 0 & 0 & 0 & 0 & .1 & 0 \\
\hline 12 & & - & 0 & .1 & .1 & 0 & 0.1 & 0 & 0 & 0 & 0 & 0 & 0 & 0 & 0 & .1 & .1 \\
\hline 13 & & - & 0 & 0 & .1 & 0 & 0 & 0 & 0 & 0 & 0 & 0 & 0 & .1 & 0 & .1 & .1 \\
\hline 14 & & 0 & .1 & .1 & .1 & 0 & 0 & .1 & 0 & 0 & 0 & 0 & 0 & .1 & 0 & 0 & .1 \\
\hline 15 & & 0 & 0 & .2 & .1 & 0 & .1 & 0 & 0 & 0 & 0 & 0 & 0 & 0 & 0 & .1 & .1 \\
\hline 16 & & 0 & 0 & 0 & 0 & 0 & 0 & 0 & 0 & 0 & 0 & 0 & 0 & 0 & 0 & .1 & .1 \\
\hline 17 & & 0 & .1 & 0 & 0 & 0 & 0 & 0 & 0 & 0 & 0 & 0 & .1 & 0 & 0 & .1 & 0 \\
\hline 18 & & - & 0 & 0 & .1 & 0 & .1 & 0 & 0 & 0 & 0 & 0 & 0 & 0 & 0 & .1 & 0 \\
\hline 19 & & - & 0 & 0 & .1 & .1 & 0 & 0 & 0 & 0 & 0 & 0 & 0 & 0 & 0 & .1 & .1 \\
\hline 20 & & 0 & .1 & 0 & .1 & 0 & .1 & .1 & 0 & 0 & 0 & 0 & 0 & 0 & 0 & .2 & .1 \\
\hline 21 & & 0 & 0 & 0 & .1 & 0 & 0 & 0 & 0 & 0 & 0 & 0 & 0 & 0 & 0 & .2 & 0 \\
\hline 22 & & 0 & 0 & 0 & 0 & 0 & .1 & 0 & 0 & 0 & 0 & 0 & 0 & 0 & 0 & .2 & 0 \\
\hline 23 & & 0 & .1 & 0 & 0 & .1 & 0 & 0 & 0 & 0 & 0 & 0 & 0 & 0 & .1 & .2 & 0 \\
\hline 24 & & 0 & 0 & 0 & 0 & 0 & .1 & 0 & 0 & 0 & 0 & 0 & 0 & 0 & .1 & .1 & .1 \\
\hline 25 & & 0 & .1 & 0 & 0 & 0 & .1 & 0 & 0 & 0 & 0 & 0 & 0 & 0 & .1 & 0 & .1 \\
\hline 26 & 0 & 0 & .1 & 0 & .1 & 0 & .1 & 0 & 0 & 0 & 0 & 0 & 0 & 0 & .1 & .1 & .1 \\
\hline 27 & 0 & 0 & .1 & 0 & .1 & 0 & .1 & 0 & 0 & 0 & 0 & 0 & 0 & - & .1 & 0 & .1 \\
\hline 28 & 0 & 0 & .1 & 0 & .1 & 0 & .1 & 0 & 0 & 0 & 0 & 0 & 0 & 0 & .1 & .1 & .1 \\
\hline 29 & 0 & 0 & 0 & 0 & 0 & 0 & 0 & 0 & 0 & 0 & & 0 & 0 & 0 & .1 & .2 & .1 \\
\hline 30 & 0 & 0 & 0 & 0 & 0 & .1 & .1 & .1 & 0 & 0 & & 0 & 0 & .1 & .1 & .1 & .1 \\
\hline 31 & & 0 & & 0 & .1 & & .1 & & 0 & 0 & & 0 & & .1 & & 0 & .1 \\
\hline Total & 0 & 0 & 1.1 & .9 & 1.5 & .6 & 1.2 & .4 & 0 & 0 & 0 & 0 & .2 & .5 & .9 & 2.8 & 1.9 \\
\hline Average & 0 & 0 & .04 & .03 & .05 & .02 & .04 & .01 & 0 & 0 & 0 & 0 & .01 & .02 & .03 & .09 & .06 \\
\hline
\end{tabular}


TABLE 10

Table 10. - Three-hour averages of air and water-surface temperatures and wind directions and speed, April 1950-August 1951, Lake Hefner

STATION I

THREE-HOURLY AVERAGES

APRIL, 1950

\begin{tabular}{|c|c|c|c|c|c|c|c|c|c|c|c|c|c|c|c|}
\hline \multirow{3}{*}{ 勇 } & \multirow{3}{*}{ 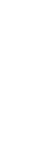 } & \multicolumn{8}{|c|}{ Average air temperature $\left({ }^{\circ} \mathrm{C}\right)$ at indicated height } & \multirow{3}{*}{$\begin{array}{c}\text { Average } \\
\text { water- } \\
\text { surface } \\
\text { tempera- } \\
\text { ture } \\
\text { (०) }\end{array}$} & \multirow{3}{*}{$\begin{array}{c}\begin{array}{c}\text { Average } \\
\text { wind } \\
\text { direction }\end{array} \\
\text { (coded) }\end{array}$} & \multicolumn{4}{|c|}{$\begin{array}{l}\text { Average wind speed (knots) } \\
\text { at indicated height }\end{array}$} \\
\hline & & \multicolumn{2}{|c|}{$\begin{array}{c}2 \\
\text { meters }\end{array}$} & \multicolumn{2}{|c|}{$\begin{array}{c}4 \\
\text { meters }\end{array}$} & \multicolumn{2}{|c|}{$\begin{array}{c}8 \\
\text { meters }\end{array}$} & \multicolumn{2}{|c|}{$\begin{array}{c}16 \\
\text { meters }\end{array}$} & & & 2 & 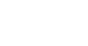 & 8 & 18 \\
\hline & & $\begin{array}{l}\text { Dry } \\
\text { bulb }\end{array}$ & $\begin{array}{l}\text { Wet } \\
\text { bulb }\end{array}$ & $\begin{array}{l}\text { Dry } \\
\text { bulb }\end{array}$ & \begin{tabular}{|l|}
$\begin{array}{l}\text { Wet } \\
\text { bulb }\end{array}$ \\
\end{tabular} & $\begin{array}{l}\text { Dry } \\
\text { bulb }\end{array}$ & $\begin{array}{l}\text { Wet } \\
\text { bulb }\end{array}$ & $\begin{array}{l}\text { Dry } \\
\text { bulb }\end{array}$ & $\begin{array}{l}\text { Wet } \\
\text { bulb }\end{array}$ & & & meters & meters & meters & \\
\hline $\begin{array}{l}25 \\
25 \\
25 \\
25 \\
25 \\
25 \\
25 \\
25\end{array}$ & $\begin{array}{r}0 \\
3 \\
6 \\
9 \\
12 \\
15 \\
18 \\
21\end{array}$ & $\begin{array}{l}10.6 \\
14.1 \\
16.2 \\
15.8 \\
12.9\end{array}$ & $\begin{array}{l}5.0 \\
6.5 \\
8.0 \\
8.7 \\
7.3\end{array}$ & $\begin{array}{l}10.6 \\
14.1 \\
16.4 \\
15.7 \\
12.9\end{array}$ & $\begin{array}{l}4.3 \\
5.8 \\
7.4 \\
8.3 \\
.7 .1\end{array}$ & $\begin{array}{l}10.5 \\
14.1 \\
16.3 \\
15.7 \\
12.7\end{array}$ & $\begin{array}{l}4.0 \\
5.7 \\
7.4 \\
8.3 \\
6.6\end{array}$ & $\begin{array}{l}10.5 \\
14.1 \\
16.4 \\
15.9 \\
12.9\end{array}$ & $\begin{array}{l}3.8 \\
5.4 \\
6.5 \\
6.9 \\
6.0\end{array}$ & $\begin{array}{l}15.2 \\
15.5 \\
15.1 \\
15.0 \\
15.0\end{array}$ & $\begin{array}{l}3 \\
3 \\
3 \\
2 \\
2 \\
2 \\
2 \\
2\end{array}$ & $\begin{array}{r}8.2 \\
9.2 \\
5.8 \\
12.8 \\
13.6 \\
12.8 \\
13.4 \\
16.4\end{array}$ & $\begin{array}{r}13.4 \\
.14 .0 \\
8.4 \\
14.4 \\
15.6 \\
14.4 \\
15.4 \\
18.2\end{array}$ & $\begin{array}{r}15.8 \\
14.8 \\
8.2 \\
15.0 \\
16.8 \\
15.2 \\
16.8 \\
19.4\end{array}$ & $\begin{array}{l}15.8 \\
17.6 \\
16.4 \\
18.2 \\
21.0\end{array}$ \\
\hline $\begin{array}{l}26 \\
26 \\
26 \\
26 \\
26 \\
26 \\
26 \\
26\end{array}$ & $\begin{array}{r}0 \\
3 \\
6 \\
9 \\
12 \\
15 \\
18 \\
21\end{array}$ & $\begin{array}{l}21.5 \\
19.9 \\
17.7\end{array}$ & $\begin{array}{l}12.3 \\
12.7 \\
12.1\end{array}$ & $\begin{array}{l}22.1 \\
20.2 \\
17.9\end{array}$ & $\begin{array}{l}12.2 \\
12.3 \\
11.9\end{array}$ & $\begin{array}{l}22.2 \\
20.5 \\
18.1\end{array}$ & \begin{tabular}{l|}
11.8 \\
11.8 \\
11.4
\end{tabular} & $\begin{array}{l}22.6 \\
20.8 \\
18.1\end{array}$ & $\begin{array}{l}11.8 \\
11.8 \\
11.2\end{array}$ & $\begin{array}{l}14.7 \\
14.3 \\
14.5\end{array}$ & $\begin{array}{l}2 \\
2 \\
2 \\
2 \\
2 \\
2 \\
2 \\
2 \\
2\end{array}$ & $\begin{array}{r}9.8 \\
12.8 \\
14.8 \\
18.6 \\
15.8 \\
12.6 \\
7.8 \\
7.8\end{array}$ & $\begin{array}{r}10.6 \\
14.0 \\
16.8 \\
22.6 \\
18.2 \\
14.4 \\
9.2 \\
9.2\end{array}$ & $\begin{array}{l}11.0 \\
14.6 \\
17.8 \\
24.6 \\
19.4 \\
15.6 \\
10.2 \\
10.4\end{array}$ & $\begin{array}{l}11.8 \\
15.6 \\
18.6 \\
26.0 \\
20.2 \\
16.4 \\
11.4 \\
11.6\end{array}$ \\
\hline $\begin{array}{l}27 \\
27 \\
27 \\
27 \\
27 \\
27 \\
27 \\
27\end{array}$ & $\begin{array}{r}0 \\
3 \\
6 \\
9 \\
12 \\
15 \\
18 \\
21\end{array}$ & $\begin{array}{l}16.6 \\
12.8 \\
10.7 \\
12.0 \\
13.5 \\
14.3 \\
1400 \\
11.7\end{array}$ & $\begin{array}{r}11.8 \\
9.4 \\
6.1 \\
7.0 \\
8.6 \\
9.1\end{array}$ & $\begin{array}{l}16.9 \\
12.7 \\
10.6 \\
11.8 \\
13.4 \\
14.3 \\
14.0 \\
11.7\end{array}$ & $\begin{array}{r}11.6 \\
8.8 \\
5.5 \\
6.2 \\
8.0 \\
8.8 \\
8.4 \\
7.0\end{array}$ & $\begin{array}{l}16.9 \\
12.4 \\
10.3 \\
11.8 \\
13.4 \\
14.3 \\
13.7 \\
11.4\end{array}$ & $\begin{array}{r}11.0 \\
8.3 \\
5.0 \\
5.9 \\
7.6 \\
8.5 \\
8.1 \\
6.7\end{array}$ & $\begin{array}{l}16.7 \\
12.0 \\
10.1 \\
11.6 \\
13.3 \\
14.2 \\
13.6 \\
11.2\end{array}$ & $\begin{array}{r}11.0 \\
7.7 \\
4.5 \\
5.6 \\
7.4 \\
8.2 \\
7.9 \\
6.5\end{array}$ & & $\begin{array}{l}2 \\
3 \\
3 \\
3 \\
3 \\
3 \\
3 \\
3 \\
3\end{array}$ & $\begin{array}{r}7.6 \\
13.4 \\
16.8 \\
15.6 \\
14.8 \\
12.8 \\
11.6 \\
9.8\end{array}$ & $\begin{array}{r}8.4 \\
15.2 \\
19.6 \\
18.0 \\
15.8 \\
13.6 \\
12.0 \\
10.0\end{array}$ & & $\begin{array}{r}9.6 \\
17.2 \\
22.2 \\
20.4 \\
17.8 \\
15.2 \\
13.2 \\
11.0\end{array}$ \\
\hline $\begin{array}{l}28 \\
28 \\
28 \\
28 \\
28 \\
28 \\
28 \\
28\end{array}$ & $\begin{array}{r}0 \\
3 \\
6 \\
9 \\
12 \\
15 \\
18 \\
21\end{array}$ & $\begin{array}{l}11.1 \\
11.6 \\
13.2 \\
15.2\end{array}$ & $\begin{array}{l}18.4 \\
16.4 \\
17.2\end{array}$ & $\begin{array}{l}11.2 \\
11.7 \\
13.3 \\
15.7\end{array}$ & $\begin{array}{r}6.9 \\
7.4 \\
10.3 \\
15.5\end{array}$ & $\begin{array}{l}10.9 \\
11.3 \\
13.2 \\
15.6 \\
23.3 \\
19.5 \\
19.9\end{array}$ & $\begin{array}{r}6.7 \\
7.3 \\
10.5 \\
15.6\end{array}$ & $\begin{array}{l}10.7 \\
11.3 \\
13.3 \\
15.6\end{array}$ & $\begin{array}{r}6.6 \\
7.2 \\
10.6 \\
15.5\end{array}$ & $\begin{array}{l}14.2 \\
14.2 \\
14.1 \\
13.2\end{array}$ & $\begin{array}{l}3 \\
3 \\
2 \\
2 \\
2 \\
2 \\
2 \\
2 \\
2\end{array}$ & $\begin{array}{r}7.2 \\
5.2 \\
5.0 \\
8.2 \\
14.4 \\
9.2 \\
8.4 \\
12.6\end{array}$ & $\begin{array}{r}7.4 \\
5.2 \\
5.6 \\
9.4 \\
18.4 \\
10.4 \\
10.4 \\
14.4\end{array}$ & $\begin{array}{r}7.5 \\
7.2 \\
5.8 \\
10.2 \\
19.8 \\
11.8 \\
11.4 \\
16.2\end{array}$ & $\begin{array}{r}6.0 \\
10.8 \\
21.2 \\
12.0 \\
12.4 \\
16.6\end{array}$ \\
\hline $\begin{array}{l}29 \\
29 \\
29 \\
29 \\
29 \\
29 \\
29 \\
29\end{array}$ & $\begin{array}{r}0 \\
3 \\
6 \\
9 \\
12 \\
15 \\
18 \\
21\end{array}$ & $\begin{array}{r}17.1 \\
16.6 \\
17.6 \\
18.2 \\
11.5 \\
10.6 \\
11.3 \\
9.5\end{array}$ & $\begin{array}{r}14.4 \\
14.0 \\
15.0 \\
15.9 \\
10.1 \\
9.0 \\
9.0 \\
7.4\end{array}$ & $\begin{array}{l}17.2 \\
16.6 \\
17.9 \\
18.5 \\
11.3 \\
10.3 \\
10.9 \\
9.1\end{array}$ & $\begin{array}{r}14.3 \\
14.0 \\
15.9 \\
16.2 \\
9.9 \\
8.6 \\
8.6 \\
7.1\end{array}$ & $\begin{array}{r}17.1 \\
16.6 \\
17.8 \\
18.6 \\
10.5 \\
9.9 \\
10.7 \\
8.7\end{array}$ & $\begin{array}{r}14.2 \\
13.9 \\
15.9 \\
16.1 \\
9.1 \\
8.3 \\
8.2 \\
6.6\end{array}$ & $\begin{array}{r}17.2 \\
16.7 \\
18.2 \\
19.0 \\
10.5 \\
10.0 \\
10.5 \\
8.5\end{array}$ & $\begin{array}{r}14.2 \\
13.9 \\
15.9 \\
16.1 \\
8.9 \\
8.1 \\
8.0 \\
6.3\end{array}$ & $\begin{array}{l}13.9 \\
13.9 \\
13.9 \\
13.9 \\
14.2 \\
14.3 \\
14.4 \\
14.3\end{array}$ & $\begin{array}{l}2 \\
2 \\
2 \\
2 \\
4 \\
3 \\
3 \\
3\end{array}$ & $\begin{array}{r}10.6 \\
14.2 \\
14.0 \\
12.4 \\
16.0 \\
10.4 \\
9.4 \\
10.4\end{array}$ & $\begin{array}{l}12.0 \\
15.8 \\
16.6 \\
14.6 \\
20.0 \\
18.4 \\
18.2 \\
18.4\end{array}$ & $\begin{array}{l}13.4 \\
17.2 \\
18.2 \\
16.2 \\
19.0 \\
21.4 \\
20.6 \\
22.0\end{array}$ & $\begin{array}{l}1400 \\
18.0 \\
19.0 \\
16.8 \\
22.2\end{array}$ \\
\hline $\begin{array}{l}30 \\
30 \\
30 \\
30 \\
30 \\
30 \\
30 \\
30\end{array}$ & $\begin{array}{r}0 \\
3 \\
6 \\
9 \\
12 \\
15 \\
18 \\
21\end{array}$ & $\begin{array}{r}7.7 \\
6.0 \\
5.2 \\
7.0 \\
10.8 \\
13.8 \\
13.7 \\
11.9\end{array}$ & $\begin{array}{l}5.8 \\
4.6 \\
3.9 \\
5.0 \\
7.1 \\
9.4 \\
9.77 \\
9.3\end{array}$ & $\begin{array}{r}7.0 \\
5.8 \\
4.8 \\
6.7 \\
10.5 \\
13.6 \\
13.5 \\
11.6\end{array}$ & $\begin{array}{l}5.2 \\
4 \cdot 0 \\
3.2 \\
4.3 \\
6.8 \\
9.2 \\
9.5 \\
9.0\end{array}$ & $\begin{array}{r}6.7 \\
5.4 \\
4.2 \\
6.7 \\
10.4 \\
13.0 \\
13.3 \\
11.5\end{array}$ & $\begin{array}{l}4 \cdot 5 \\
3.5 \\
2.9 \\
4.3 \\
6.7 \\
8.8 \\
9.3 \\
8.9\end{array}$ & $\begin{array}{r}6.3 \\
4.9 \\
4.1 \\
6.6 \\
10.6 \\
13.6 \\
13.3 \\
11.4\end{array}$ & $\begin{array}{l}4.3 \\
3.1 \\
3.0 \\
4.2 \\
6.5 \\
8.7 \\
9.0 \\
8.7\end{array}$ & $\begin{array}{l}14.1 \\
14.0 \\
13.9 \\
13.9 \\
14.0 \\
13.9 \\
13.7 \\
13.6\end{array}$ & $\begin{array}{l}3 \\
3 \\
3 \\
3 \\
3 \\
3 \\
3 \\
3\end{array}$ & $\begin{array}{r}9.6 \\
9.8 \\
9.6 \\
10.0 \\
7.8 \\
7.6 \\
8.2 \\
8.2\end{array}$ & $\begin{array}{r}18.8 \\
18.0 \\
15.8 \\
12.6 \\
9.2 \\
8.2 \\
9.2 \\
8.4\end{array}$ & $\begin{array}{r}22.4 \\
21.6 \\
18.6 \\
13.4 \\
10.0 \\
8.4 \\
9.8 \\
8.8\end{array}$ & $\begin{array}{r}13.4 \\
10.4 \\
8.8 \\
10.0 \\
9.0\end{array}$ \\
\hline
\end{tabular}


TABLE 10

\begin{tabular}{|c|c|c|c|c|c|c|c|c|c|c|c|c|c|c|c|}
\hline \multicolumn{2}{|c|}{ STATION } & \multicolumn{4}{|l|}{1} & \multicolumn{6}{|c|}{ THREE-HOURLY AVERAGES } & \multirow{2}{*}{\multicolumn{4}{|c|}{$\begin{array}{l}\text { MAY, } 1950 \\
\text { speed (knots) } \\
\text { d height }\end{array}$}} \\
\hline \multirow{3}{*}{ 突 } & \multirow{3}{*}{ 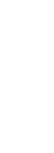 } & \multicolumn{8}{|c|}{ Average air temperature $\left({ }^{\circ} \mathrm{C}\right)$ at indicated height } & \multirow{3}{*}{$\begin{array}{l}\text { Average } \\
\text { water- } \\
\text { surface } \\
\text { tempera- } \\
\text { ture } \\
\text { ("C) }^{\circ}\end{array}$} & \multirow{3}{*}{$\begin{array}{c}\text { Average } \\
\text { wind } \\
\text { direction } \\
\text { (coded) }\end{array}$} & & & & \\
\hline & & \multicolumn{2}{|c|}{$\begin{array}{c}2 \\
\text { meters }\end{array}$} & \multicolumn{2}{|c|}{$\begin{array}{c}4 \\
\text { meters }\end{array}$} & \multicolumn{2}{|c|}{$\begin{array}{c}8 \\
\text { meters }\end{array}$} & \multicolumn{2}{|c|}{$\begin{array}{c}16 \\
\text { meters }\end{array}$} & & & 2 & 4 & 8 & 16 \\
\hline & & $\begin{array}{l}\text { Dry } \\
\text { bulb }\end{array}$ & $\begin{array}{l}\text { Wet } \\
\text { bulb }\end{array}$ & $\begin{array}{l}\text { Dry } \\
\text { bulb }\end{array}$ & $\begin{array}{l}\text { Wet } \\
\text { bulb }\end{array}$ & $\begin{array}{l}\text { Dry } \\
\text { bulb }\end{array}$ & $\begin{array}{l}\text { Wet } \\
\text { bulb }\end{array}$ & $\begin{array}{l}\text { Dry } \\
\text { bulb }\end{array}$ & $\begin{array}{l}\text { Wet } \\
\text { bulb }\end{array}$ & & & meters & meters & meters & meters \\
\hline $\begin{array}{l}1 \\
1 \\
1 \\
1 \\
1 \\
1 \\
1 \\
1\end{array}$ & $\begin{array}{r}0 \\
3 \\
6 \\
9 \\
12 \\
15 \\
18 \\
21\end{array}$ & $\begin{array}{r}10.8 \\
10.2 \\
9.8 \\
11.4 \\
13.8 \\
14.8 \\
14.4 \\
13.2\end{array}$ & $\begin{array}{r}9.0 \\
9.0 \\
8.3 \\
9.3 \\
11.3 \\
12.5 \\
12.5 \\
12.5\end{array}$ & $\begin{array}{r}10.5 \\
10.1 \\
9.6 \\
11.2 \\
13.7 \\
14.9 \\
14.3 \\
13.2\end{array}$ & $\begin{array}{r}8.9 \\
8.9 \\
8.1 \\
9.1 \\
11.4 \\
12.6 \\
12.6 \\
12.5\end{array}$ & $\begin{array}{r}10.0 \\
9.6 \\
9.1 \\
10.9 \\
13.2 \\
14.5 \\
13.7 \\
13.0\end{array}$ & $\begin{array}{r}8.6 \\
8.5 \\
7.7 \\
9.1 \\
11.2 \\
12.3 \\
12.3 \\
12.4\end{array}$ & $\begin{array}{r}10.3 \\
9.9 \\
9.3 \\
11.3 \\
13.6 \\
14.8 \\
14.1 \\
13.1\end{array}$ & $\begin{array}{r}8.3 \\
8.4 \\
7.7 \\
8.0 \\
11.2 \\
12.3 \\
12.2 \\
12.3\end{array}$ & $\begin{array}{l}13.5 \\
13.4 \\
13.3 \\
13.4 \\
13.6 \\
13.1 \\
13.2 \\
13.0\end{array}$ & $\begin{array}{l}3 \\
3 \\
3 \\
3 \\
3 \\
3 \\
3 \\
3 \\
3\end{array}$ & $\begin{array}{l}7.8 \\
9.2 \\
8.4 \\
5.8 \\
6.6 \\
5.8 \\
8.02 \\
5.0\end{array}$ & $\begin{array}{l}8.4 \\
9.2 \\
9.6 \\
6.0 \\
6.8 \\
6.2 \\
8.0 \\
5.6\end{array}$ & $\begin{array}{r}8.4 \\
10.0 \\
10.0 \\
6.2 \\
7.6 \\
6.6 \\
9.2 \\
5.8\end{array}$ & $\begin{array}{r}8.8 \\
20.2 \\
20.8 \\
6.6 \\
6.8 \\
9.4 \\
6.0\end{array}$ \\
\hline $\begin{array}{l}2 \\
2 \\
2 \\
2 \\
2 \\
2 \\
2 \\
2\end{array}$ & $\begin{array}{r}0 \\
3 \\
6 \\
0 \\
19 \\
15 \\
18 \\
21\end{array}$ & $\begin{array}{l}12.3 \\
11.0 \\
11.2 \\
14.1 \\
18.5 \\
20.2\end{array}$ & $\begin{array}{l}11.9 \\
11.0 \\
11.2 \\
13.3 \\
15.3 \\
16.0\end{array}$ & $\begin{array}{l}12.2 \\
11.1 \\
11.3 \\
14.3 \\
18.8 \\
70.2\end{array}$ & $\begin{array}{l}11.7 \\
11.0 \\
11.2 \\
13.5 \\
16.0 \\
16.3\end{array}$ & $\begin{array}{l}11.9 \\
11.0 \\
11.04 \\
14.2 \\
18.5 \\
20.0\end{array}$ & $\begin{array}{l}11.6 \\
11.0 \\
11.4 \\
13.5 \\
15.5 \\
16.2\end{array}$ & $\begin{array}{l}11.9 \\
10.9 \\
11.9 \\
15.1 \\
19.5 \\
21.6\end{array}$ & $\begin{array}{l}11.5 \\
10.9 \\
11.4 \\
13.7 \\
15.6 \\
16.5\end{array}$ & $\begin{array}{l}17.09 \\
12.1 \\
11.4 \\
12.05 \\
12.8 \\
13.0\end{array}$ & $\begin{array}{l}3 \\
2 \\
2 \\
2 \\
2 \\
2 \\
2 \\
2 \\
2\end{array}$ & $\begin{array}{r}6.0 \\
4.4 \\
7.2 \\
13.6 \\
15.8 \\
16.0 \\
15.8 \\
21.4\end{array}$ & $\begin{array}{r}6.0 \\
4.8 \\
7.8 \\
15.2 \\
17.6 \\
18.0 \\
18.0 \\
24.2\end{array}$ & $\begin{array}{r}6.2 \\
4.8 \\
7.6 \\
16.2 \\
29.2 \\
19.2 \\
19.8 \\
26.0\end{array}$ & $\begin{array}{r}6.2 \\
4.8 \\
8.0 \\
27.0 \\
20.2 \\
20.8 \\
21.0 \\
27.8\end{array}$ \\
\hline $\begin{array}{l}3 \\
3 \\
3 \\
3 \\
3 \\
3 \\
3 \\
3\end{array}$ & $\begin{array}{r}0 \\
3 \\
6 \\
3 \\
12 \\
15 \\
18 \\
21\end{array}$ & & & & & & & & & & $\begin{array}{l}2 \\
2 \\
2 \\
2 \\
3 \\
2 \\
2 \\
2\end{array}$ & $\begin{array}{l}19.6 \\
17.6 \\
20.4 \\
22.8 \\
19.4 \\
18.0 \\
18.0 \\
18.8\end{array}$ & $\begin{array}{l}22.0 \\
19.6 \\
23.2 \\
25.4 \\
22.0 \\
20.2 \\
20.8 \\
21.2\end{array}$ & $\begin{array}{l}23.6 \\
21.6 \\
25.0 \\
27.6 \\
23.8 \\
22.4 \\
22.4 \\
23.0\end{array}$ & $\begin{array}{l}25.4 \\
23.0 \\
26.2 \\
29.0 \\
24.8 \\
24.0 \\
24.0 \\
24.4\end{array}$ \\
\hline $\begin{array}{l}4 \\
4 \\
4 \\
4 \\
4 \\
4 \\
4 \\
4\end{array}$ & $\begin{array}{r}0 \\
3 \\
6 \\
9 \\
12 \\
15 \\
18 \\
21\end{array}$ & $\begin{array}{l}23.3 \\
24.7 \\
24.9 \\
24.1 \\
73.7\end{array}$ & $\begin{array}{l}20.7 \\
21.0 \\
21.0 \\
20.8\end{array}$ & $\begin{array}{l}23.7 \\
25.5 \\
25.0 \\
24.5 \\
23.9\end{array}$ & $\begin{array}{l}21.0 \\
21.4 \\
21.4 \\
20.9 \\
20.1\end{array}$ & $\begin{array}{l}24.1 \\
25.7 \\
25.3 \\
24.8 \\
24.2\end{array}$ & $\begin{array}{l}21.5 \\
21.7 \\
21,5 \\
21.1 \\
20.6\end{array}$ & $\begin{array}{l}24.7 \\
25.8 \\
25.9 \\
25.1 \\
24.6\end{array}$ & & & $\begin{array}{l}2 \\
2 \\
2 \\
2 \\
2 \\
2 \\
2 \\
2 \\
2\end{array}$ & $\begin{array}{l}16.6 \\
14.2 \\
15.8 \\
18.2 \\
21.2 \\
22.0 \\
25.6\end{array}$ & $\begin{array}{l}18.6 \\
15.8 \\
17.4 \\
19.6 \\
20.0 \\
23.0 \\
24.8 \\
29.2\end{array}$ & $\begin{array}{l}20.6 \\
17.0 \\
19.0 \\
21.4 \\
21.2 \\
25.0 \\
27.2 \\
31.2\end{array}$ & $\begin{array}{l}22.2 \\
28.2 \\
20.4 \\
22.6 \\
23.0 \\
26.6 \\
29.2 \\
34.2\end{array}$ \\
\hline $\begin{array}{l}5 \\
5 \\
5 \\
5 \\
5 \\
5 \\
5 \\
5\end{array}$ & $\begin{array}{r}0 \\
3 \\
6 \\
0 \\
12 \\
15 \\
18 \\
21\end{array}$ & $\begin{array}{l}18.4 \\
16.5 \\
14.8 \\
15.2 \\
18.3 \\
19.9 \\
18.5 \\
15.6\end{array}$ & $\begin{array}{r}10.3 \\
10.3 \\
11.1 \\
9.9\end{array}$ & $\begin{array}{l}18.3 \\
16.5 \\
14.8 \\
15.1 \\
18.6 \\
20.2 \\
18.5 \\
15.8\end{array}$ & $\begin{array}{r}12.0 \\
9.3 \\
8.8 \\
9.8 \\
9.9 \\
10.8 \\
9.5\end{array}$ & $\begin{array}{l}13.2 \\
16.2 \\
14.6 \\
15.1 \\
18.6 \\
20.0 \\
18.5 \\
15.6\end{array}$ & $\begin{array}{r}11.3 \\
8.6 \\
8.2 \\
9.1 \\
9.9 \\
9.9 \\
9.9 \\
9.2\end{array}$ & $\begin{array}{l}18.0 \\
16.1 \\
14.4 \\
15.1 \\
18.7 \\
20.6 \\
18.9 \\
15.7\end{array}$ & $\begin{array}{l}9.1 \\
9.7 \\
9.5 \\
8.9\end{array}$ & $\begin{array}{l}17.2 \\
16.9 \\
16.9 \\
16.7\end{array}$ & $\begin{array}{l}2 \\
2 \\
2 \\
4 \\
4 \\
4 \\
2 \\
2\end{array}$ & $\begin{array}{r}16.0 \\
18.8 \\
18.0 \\
17.4 \\
14.2 \\
4.6 \\
5.6 \\
6.8\end{array}$ & $\begin{array}{r}17.8 \\
22.0 \\
21.0 \\
19.6 \\
16.2 \\
5.4 \\
5.8 \\
8.0\end{array}$ & $\begin{array}{r}19.8 \\
23.6 \\
23.4 \\
20.6 \\
16.8 \\
5.4 \\
6.8 \\
8.4\end{array}$ & $\begin{array}{r}20.6 \\
24.2 \\
24.0 \\
21.6 \\
17.8 \\
5.8 \\
7.6 \\
9.4\end{array}$ \\
\hline $\begin{array}{l}6 \\
6 \\
6 \\
6 \\
6 \\
6 \\
6 \\
6\end{array}$ & $\begin{array}{r}0 \\
3 \\
6 \\
9 \\
12 \\
15 \\
18 \\
21\end{array}$ & $\begin{array}{l}15.0 \\
14.5 \\
15.0 \\
20.0 \\
23.8 \\
24.3 \\
21.0 \\
17.7\end{array}$ & $\begin{array}{r}9.6 \\
9.7 \\
10.2 \\
12.4 \\
13.5 \\
15.1 \\
16.0 \\
16.5\end{array}$ & $\begin{array}{l}14.9 \\
14.8 \\
15.3 \\
21.7 \\
7.8 .8 \\
74.7 \\
21.3 \\
17.9\end{array}$ & $\begin{array}{r}0.1 \\
9.2 \\
10.0 \\
12.3 \\
13.7 \\
25.0 \\
16.0 \\
16.5\end{array}$ & $\begin{array}{l}14.9 \\
14.4 \\
15.3 \\
21.6 \\
24.6 \\
25.0 \\
21.4 \\
18.0\end{array}$ & $\begin{array}{r}9.0 \\
8.9 \\
9.8 \\
12.1 \\
13.4 \\
14.8 \\
16.1 \\
16.6\end{array}$ & $\begin{array}{l}15.0 \\
14.4 \\
15.6 \\
21.9 \\
25.1 \\
25.5 \\
21.7 \\
18.2\end{array}$ & $\begin{array}{r}8.9 \\
8.9 \\
0.8 \\
12.3 \\
13.9 \\
15.0 \\
16.2 \\
16.8\end{array}$ & $\begin{array}{l}16.8 \\
16.7 \\
16.6 \\
16.9 \\
17.5 \\
17.3 \\
17.1 \\
17.0\end{array}$ & $\begin{array}{l}2 \\
2 \\
2 \\
2 \\
2 \\
2 \\
2 \\
2 \\
2\end{array}$ & $\begin{array}{r}8.4 \\
9.6 \\
10.2 \\
10.2 \\
6.2 \\
10.6 \\
9.6 \\
6.8\end{array}$ & $\begin{array}{r}9.4 \\
10.6 \\
11.2 \\
11.4 \\
7.2 \\
12.0 \\
11.0 \\
7.6\end{array}$ & $\begin{array}{r}10.0 \\
11.2 \\
12.0 \\
12.0 \\
7.8 \\
13.2 \\
12.2 \\
8.2\end{array}$ & $\begin{array}{r}10.6 \\
11.8 \\
12.4 \\
12.6 \\
8.0 \\
14.0 \\
13.0 \\
9.2\end{array}$ \\
\hline $\begin{array}{l}7 \\
7 \\
7\end{array}$ & $\begin{array}{l}0 \\
3 \\
6\end{array}$ & $\begin{array}{l}17.3 \\
17.7\end{array}$ & $\begin{array}{l}16.7 \\
17.4\end{array}$ & $\begin{array}{l}17.5 \\
18.1\end{array}$ & $\begin{array}{l}16.7 \\
17.5\end{array}$ & $\begin{array}{l}17.7 \\
18.3\end{array}$ & $\begin{array}{l}16.8 \\
17.7\end{array}$ & $\begin{array}{l}17.9 \\
18.4\end{array}$ & $\begin{array}{l}17.1 \\
18.1\end{array}$ & $\begin{array}{l}17.0 \\
17.0\end{array}$ & $\begin{array}{l}2 \\
2 \\
2\end{array}$ & $\begin{array}{l}8.2 \\
9.4 \\
8.6\end{array}$ & $\begin{array}{r}8.8 \\
10.4 \\
9.8\end{array}$ & $\begin{array}{r}9.4 \\
11.4 \\
10.6\end{array}$ & $\begin{array}{l}10.0 \\
11.6 \\
11.4\end{array}$ \\
\hline $\begin{array}{l}7 \\
7 \\
7 \\
7 \\
7\end{array}$ & $\begin{array}{r}9 \\
12 \\
15 \\
18 \\
21\end{array}$ & $\begin{array}{l}21.9 \\
22.1 \\
23.1 \\
22.1 \\
22.9\end{array}$ & $\begin{array}{l}20.5 \\
21.0 \\
21.8 \\
21.4 \\
20.9\end{array}$ & $\begin{array}{l}22.6 \\
23.1 \\
23.6 \\
23.1 \\
23.1\end{array}$ & $\begin{array}{l}20.9 \\
21.4 \\
22.0 \\
21.7 \\
21.0\end{array}$ & $\begin{array}{l}23.0 \\
23.5 \\
24.0 \\
23.3 \\
24.1\end{array}$ & $\begin{array}{l}21.2 \\
21.8 \\
22.4 \\
22.2 \\
21.6\end{array}$ & $\begin{array}{l}23.9 \\
24 \cdot 3 \\
24.9 \\
24 \cdot 1 \\
25.1\end{array}$ & $\begin{array}{l}22.1 \\
23.0 \\
23.7 \\
23.3 \\
22.5\end{array}$ & $\begin{array}{l}16.8 \\
16.9 \\
17.0 \\
16.8\end{array}$ & $\begin{array}{l}2 \\
2 \\
3 \\
2 \\
2\end{array}$ & $\begin{array}{r}8.4 \\
7.0 \\
12.0 \\
12.2 \\
18.8\end{array}$ & $\begin{array}{r}9.6 \\
8.4 \\
13.6 \\
13.6 \\
21.2\end{array}$ & $\begin{array}{r}10.8 \\
9.2 \\
15.2 \\
15.0 \\
23.4\end{array}$ & $\begin{array}{r}11.2 \\
9.8 \\
16.0 \\
15.4 \\
25.0\end{array}$ \\
\hline $\begin{array}{l}8 \\
8 \\
8 \\
8 \\
8 \\
8 \\
8 \\
8 \\
8\end{array}$ & $\begin{array}{r}0 \\
3 \\
6 \\
9 \\
12 \\
15 \\
18 \\
21\end{array}$ & $\begin{array}{l}22.6 \\
21.3 \\
21.4 \\
23.6 \\
24.8 \\
25.9 \\
24.8 \\
23.3\end{array}$ & $\begin{array}{l}20.1 \\
19.2 \\
19.7 \\
20.6 \\
21.1 \\
21.6 \\
21.0 \\
20.1\end{array}$ & $\begin{array}{l}23.1 \\
21.7 \\
21.3 \\
24.0 \\
25.4 \\
26.3 \\
25.2 \\
23.5\end{array}$ & $\begin{array}{l}20.4 \\
19.4 \\
19.9 \\
20.8 \\
21.2 \\
21.8 \\
21.1 \\
20.1\end{array}$ & $\begin{array}{l}23.3 \\
21.6 \\
22.1 \\
24.7 \\
25.9 \\
26.9 \\
25.8 \\
24.1\end{array}$ & $\begin{array}{l}20.8 \\
19.7 \\
20.3 \\
21.1 \\
21.8 \\
22.0 \\
21.6 \\
20.4\end{array}$ & $\begin{array}{l}24 \cdot 2 \\
22.5 \\
23.2 \\
25.7 \\
27.1 \\
27.1 \\
26.7 \\
25.0\end{array}$ & $\begin{array}{l}21.1 \\
20.8 \\
21.7 \\
22.6 \\
22.8 \\
23.3 \\
22.4 \\
21.2\end{array}$ & $\begin{array}{l}16.6 \\
17.0 \\
17.0 \\
17.5 \\
17.8 \\
18.0 \\
18.0 \\
18.0\end{array}$ & $\begin{array}{l}2 \\
2 \\
2 \\
2 \\
2 \\
2 \\
2 \\
2\end{array}$ & $\begin{array}{l}23.4 \\
19.0 \\
18.2 \\
21.2 \\
18.5 \\
19.2 \\
21.2 \\
21.2\end{array}$ & $\begin{array}{l}26.6 \\
21.2 \\
20.4 \\
24.0 \\
21.0 \\
21.8 \\
24.0 \\
24.0\end{array}$ & $\begin{array}{l}29.2 \\
23.0 \\
21.8 \\
26.0 \\
22.6 \\
23.6 \\
26.2 \\
26.2\end{array}$ & $\begin{array}{l}31.0 \\
24.4 \\
23.2 \\
27.8 \\
24.2 \\
25.2 \\
27.8 \\
28.0\end{array}$ \\
\hline $\begin{array}{l}9 \\
9 \\
9\end{array}$ & $\begin{array}{l}0 \\
3 \\
6\end{array}$ & $\begin{array}{l}22.6 \\
21.3\end{array}$ & $\begin{array}{l}19.3 \\
18.9\end{array}$ & $\begin{array}{l}22.8 \\
21.5\end{array}$ & $\begin{array}{l}19.4 \\
19.0\end{array}$ & $\begin{array}{l}23.3 \\
21.9\end{array}$ & $\begin{array}{l}19.8 \\
19.4\end{array}$ & $\begin{array}{l}24.2 \\
22.9\end{array}$ & $\begin{array}{l}20.6 \\
20.5\end{array}$ & $\begin{array}{l}17.9 \\
17.7\end{array}$ & $\begin{array}{l}2 \\
2 \\
2\end{array}$ & $\begin{array}{l}20.0 \\
18.2 \\
12.0\end{array}$ & $\begin{array}{l}22.8 \\
20.6 \\
13.2\end{array}$ & $\begin{array}{l}24.0 \\
22.0 \\
13.4\end{array}$ & $\begin{array}{l}26.0 \\
23.2 \\
14.6\end{array}$ \\
\hline $\begin{array}{l}9 \\
9 \\
9 \\
9 \\
9\end{array}$ & $\begin{array}{r}9 \\
12 \\
15 \\
18 \\
21\end{array}$ & $\begin{array}{l}16.2 \\
17.4 \\
18.2\end{array}$ & $\begin{array}{l}14.7 \\
15.2 \\
16.1\end{array}$ & $\begin{array}{l}16.2 \\
17.5 \\
18.2\end{array}$ & $\begin{array}{l}14.4 \\
1.4 .9 \\
15.9\end{array}$ & $\begin{array}{l}16.7 \\
17.8 \\
18.7\end{array}$ & $\begin{array}{l}14.6 \\
15.2 \\
16.1\end{array}$ & $\begin{array}{l}17.1 \\
18.5 \\
19.5\end{array}$ & $\begin{array}{l}15.2 \\
16.0 \\
16.8\end{array}$ & $\begin{array}{l}16.9 \\
17.2 \\
17.5\end{array}$ & $\begin{array}{l}3 \\
3 \\
3 \\
3 \\
3\end{array}$ & $\begin{array}{r}7.0 \\
6.6 \\
6.8 \\
10.2 \\
6.4\end{array}$ & $\begin{array}{r}11.2 \\
10.0 \\
8.2 \\
10.6 \\
7.4\end{array}$ & $\begin{array}{r}11.6 \\
11.0 \\
8.8 \\
11.2 \\
7.8\end{array}$ & $\begin{array}{r}10.0 \\
9.0 \\
11.6 \\
7.4\end{array}$ \\
\hline $\begin{array}{l}10 \\
10 \\
10 \\
10 \\
10 \\
10 \\
10 \\
10\end{array}$ & $\begin{array}{r}0 \\
3 \\
6 \\
9 \\
12 \\
15 \\
18 \\
21\end{array}$ & 15.3 & 15.3 & 15.4 & $15 \cdot 1$ & 16.5 & 26.0 & 16.5 & 16.5 & 15.0 & $\begin{array}{l}3 \\
3 \\
3 \\
3 \\
3 \\
3 \\
3 \\
3 \\
3\end{array}$ & $\begin{array}{r}6.0 \\
9.4 \\
8.4 \\
10.8 \\
9.4 \\
11.0 \\
7.8 \\
8.4\end{array}$ & $\begin{array}{r}7.6 \\
9.8 \\
9.8 \\
11.0 \\
10.0 \\
12.6 \\
9.0 \\
9.8\end{array}$ & $\begin{array}{r}7.8 \\
10.4 \\
10.6 \\
11.4 \\
10.6 \\
13.4 \\
9.8 \\
10.2\end{array}$ & $\begin{array}{r}7.6 \\
10.6 \\
10.2 \\
12.0 \\
10.8 \\
13.8 \\
9.4 \\
10.4\end{array}$ \\
\hline
\end{tabular}


TABLE 10

Table 10. -Three-hour averages of air and water-surface temperatures and wind directions and speed, April 1950-August 1951, Lake Hefner-Continued

STATION 1

THREE-HOURLY AVERAGES

MAY, 2950

\begin{tabular}{|c|c|c|c|c|c|c|c|c|c|c|c|c|c|c|c|}
\hline \multirow{4}{*}{ · 悹䓌 } & \multirow{4}{*}{ 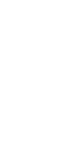 } & \multicolumn{8}{|c|}{ Average air temperature $\left({ }^{\circ} \mathrm{C}\right)$ at indicated height } & \multirow{4}{*}{\begin{tabular}{|} 
Average \\
water- \\
surface \\
tempera- \\
ture \\
$\left({ }^{\circ} \mathrm{C}\right)$
\end{tabular}} & \multirow{4}{*}{$\begin{array}{c}\begin{array}{c}\text { Average } \\
\text { wind } \\
\text { direction } \\
\text { (coded) }\end{array}\end{array}$} & \multirow{2}{*}{\multicolumn{4}{|c|}{$\begin{array}{l}\text { Average wind speed (knots) } \\
\text { at indicated height }\end{array}$}} \\
\hline & & \multirow{2}{*}{\multicolumn{2}{|c|}{$\begin{array}{c}2 \\
\text { meters }\end{array}$}} & \multirow{2}{*}{\multicolumn{2}{|c|}{$\begin{array}{c}4 \\
\text { meters }\end{array}$}} & \multirow{2}{*}{\multicolumn{2}{|c|}{$\begin{array}{c}8 \\
\text { meters }\end{array}$}} & \multirow{2}{*}{\multicolumn{2}{|c|}{$\begin{array}{c}16 \\
\text { meters }\end{array}$}} & & & & & & \\
\hline & & & & & & & & & & & & 2 & 4 & 8 & 16 \\
\hline & & $\begin{array}{l}\text { Dry } \\
\text { bulb }\end{array}$ & $\begin{array}{l}\text { Wet } \\
\text { bulb }\end{array}$ & $\begin{array}{l}\text { Dry } \\
\text { bulb }\end{array}$ & $\begin{array}{l}\text { Wet } \\
\text { bulb }\end{array}$ & $\begin{array}{l}\text { Dry } \\
\text { bulb }\end{array}$ & $\begin{array}{l}\text { Wet } \\
\text { bulb }\end{array}$ & $\begin{array}{l}\text { Dry } \\
\text { bulb }\end{array}$ & $\begin{array}{l}\text { Wet } \\
\text { bulb }\end{array}$ & & & meters & meters & meters & meters \\
\hline $\begin{array}{l}11 \\
11 \\
21 \\
11 \\
11 \\
11 \\
11 \\
11\end{array}$ & $\begin{array}{r}0 \\
3 \\
6 \\
09 \\
12 \\
15 \\
18 \\
21\end{array}$ & $\begin{array}{l}16.2 \\
17 \cdot 8 \\
17 \cdot 6 \\
15.7\end{array}$ & $\begin{array}{l}15.0 \\
15.9 \\
16.1 \\
15.1\end{array}$ & $\begin{array}{l}16.2 \\
17.8 \\
17.6 \\
15.7\end{array}$ & $\begin{array}{l}14.8 \\
15.7 \\
16.0 \\
14.7\end{array}$ & $\begin{array}{l}16.6 \\
18.3 \\
18.1 \\
16.0\end{array}$ & $\begin{array}{l}15.1 \\
16.2 \\
16.5 \\
15.1\end{array}$ & $\begin{array}{l}17.7 \\
19.4 \\
19.2 \\
16.8\end{array}$ & $\begin{array}{l}16.4 \\
17 \cdot 2 \\
17 \cdot 6 \\
16.1\end{array}$ & $\begin{array}{l}16.8 \\
17 \cdot 1 \\
17 \cdot 2 \\
16.9\end{array}$ & $\begin{array}{l}3 \\
3 \\
3 \\
3 \\
3 \\
3 \\
3 \\
3\end{array}$ & $\begin{array}{l}7.0 \\
9.2 \\
6.8 \\
9.2 \\
6.0 \\
6.6 \\
6.0 \\
7.0\end{array}$ & $\begin{array}{r}10.0 \\
10.6 \\
9.4 \\
11.0 \\
8.0 \\
8.4 \\
6.2 \\
7.2\end{array}$ & $\begin{array}{r}10.2 \\
11.2 \\
10.4 \\
11.6 \\
8.8 \\
9.6 \\
6.6 \\
7.6\end{array}$ & $\begin{array}{r}9 \cdot 8 \\
11: 4 \\
12.6\end{array}$ \\
\hline $\begin{array}{l}12 \\
12 \\
12 \\
12 \\
12 \\
12 \\
12 \\
12\end{array}$ & $\begin{array}{r}0 \\
3 \\
6 \\
9 \\
12 \\
15 \\
18 \\
21\end{array}$ & $\begin{array}{l}13.9 \\
12.4 \\
12.4 \\
16.1 \\
20.4 \\
22.3 \\
20.5 \\
18.1\end{array}$ & $\begin{array}{l}13.4 \\
12.4 \\
12.3 \\
14.0 \\
16.0 \\
16.8 \\
17.4 \\
16.9\end{array}$ & $\begin{array}{l}13.9 \\
12.4 \\
12.3 \\
16.2 \\
20.3 \\
21.9 \\
20.5 \\
18.1\end{array}$ & $\begin{array}{l}13.2 \\
12.3 \\
12.2 \\
14.0 \\
15.6 \\
16.9 \\
17.3 \\
16.8\end{array}$ & $\begin{array}{l}24.2 \\
12.06 \\
12.6 \\
17.4 \\
21.6 \\
23.1 \\
21.0 \\
18.7\end{array}$ & $\begin{array}{l}13.7 \\
12.5 \\
12.5 \\
14 \cdot 6 \\
16.6 \\
17.8 \\
17.8 \\
17.1\end{array}$ & $\begin{array}{l}14.9 \\
13.6 \\
13.7 \\
18.6 \\
23.3 \\
25.6 \\
22.4 \\
19.7\end{array}$ & $\begin{array}{l}14.6 \\
13.5 \\
13.5 \\
16.1 \\
18.3 \\
20.0 \\
19.0 \\
18.4\end{array}$ & $\begin{array}{l}16.9 \\
16.5 \\
16.5 \\
17.8 \\
19.3 \\
2.00 \\
18.5 \\
17.7\end{array}$ & $\begin{array}{l}3 \\
3 \\
3 \\
2 \\
2 \\
2 \\
2 \\
2\end{array}$ & $\begin{array}{l}3.4 \\
3.4 \\
4.8 \\
2.4 \\
1.2 \\
3.8 \\
6.2 \\
7.2\end{array}$ & $\begin{array}{l}4.4 \\
5.2 \\
5.6 \\
1.8 \\
0.8 \\
3.8 \\
7.0 \\
7.8\end{array}$ & $\begin{array}{l}5.2 \\
5.4 \\
5.6 \\
2.6 \\
1.0 \\
4.2 \\
7.4 \\
8.4\end{array}$ & $\begin{array}{l}5.6 \\
2.8 \\
1.4 \\
4.2 \\
7.8 \\
8.8\end{array}$ \\
\hline $\begin{array}{l}13 \\
13 \\
13 \\
13 \\
13 \\
13 \\
13 \\
13\end{array}$ & $\begin{array}{r}0 \\
3 \\
6 \\
9 \\
12 \\
15 \\
18 \\
21\end{array}$ & $\begin{array}{l}16.8 \\
16.2 \\
15.2 \\
17.3 \\
20.0 \\
21.8 \\
20.7 \\
18.8\end{array}$ & $\begin{array}{l}16.4 \\
15.5 \\
14.9 \\
15.5 \\
16.2 \\
17.2 \\
17.9 \\
17.8\end{array}$ & $\begin{array}{l}16.7 \\
16.2 \\
15.2 \\
17.3 \\
20.2 \\
22.0 \\
21.0 \\
18.9\end{array}$ & $\begin{array}{l}16.2 \\
15.4 \\
14.6 \\
15.1 \\
15.9 \\
16.8 \\
17.4 \\
17.8\end{array}$ & $\begin{array}{l}17.2 \\
16.06 \\
15.6 \\
17.9 \\
20.9 \\
22.8 \\
21.09 \\
19.6\end{array}$ & $\begin{array}{l}16.6 \\
15.8 \\
15.0 \\
15.5 \\
16.3 \\
17.3 \\
17.5 \\
18.1\end{array}$ & $\begin{array}{l}18 \cdot 2 \\
17 \cdot 7 \\
16.5 \\
19 \cdot 0 \\
22 \cdot 0 \\
24 \cdot 2 \\
23 \cdot 3 \\
21.3\end{array}$ & $\begin{array}{l}17.9 \\
16.8 \\
16.0 \\
16.5 \\
17.6 \\
18.5 \\
18.7 \\
18.3\end{array}$ & $\begin{array}{l}17.9 \\
17.0 \\
17.0 \\
18.2 \\
18.7 \\
18.8 \\
18.7 \\
18.4\end{array}$ & $\begin{array}{l}2 \\
2 \\
3 \\
3 \\
3 \\
3 \\
3 \\
2\end{array}$ & $\begin{array}{r}5.4 \\
11.0 \\
6.04 \\
5.8 \\
4.6 \\
4.2 \\
1.8 \\
2.0\end{array}$ & $\begin{array}{r}5.8 \\
12.2 \\
9.0 \\
9.4 \\
7.0 \\
6.8 \\
3.2 \\
2.2\end{array}$ & $\begin{array}{r}5.8 \\
12.2 \\
9.8 \\
10.0 \\
7.4 \\
7.4 \\
4.0 \\
2.4\end{array}$ & $\begin{array}{r}6.0 \\
13.0\end{array}$ \\
\hline $\begin{array}{l}14 \\
14 \\
14 \\
14 \\
14 \\
14 \\
14 \\
14\end{array}$ & $\begin{array}{r}0 \\
3 \\
6 \\
9 \\
12 \\
15 \\
18 \\
21\end{array}$ & $\begin{array}{l}18.1 \\
17.7 \\
16.6 \\
20.1 \\
21.9 \\
22.7 \\
18.7 \\
16.8\end{array}$ & $\begin{array}{l}17.1 \\
16.6 \\
15.5 \\
16.4 \\
16.4 \\
16.5 \\
15.8 \\
15.3\end{array}$ & $\begin{array}{l}18.1 \\
17.5 \\
16.6 \\
20.2 \\
22.2 \\
23.2 \\
18.7 \\
16.8\end{array}$ & $\begin{array}{l}17.0 \\
16.5 \\
15.3 \\
16.2 \\
16.0 \\
16.4 \\
16.0 \\
15.1\end{array}$ & $\begin{array}{l}18.7 \\
18.00 \\
17.12 \\
21.1 \\
22.8 \\
23.5 \\
19.02 \\
17.1\end{array}$ & $\begin{array}{l}17.7 \\
16.7 \\
15.9 \\
16.7 \\
16.5 \\
17.0 \\
16.6 \\
15.5\end{array}$ & $\begin{array}{l}20.0 \\
18.9 \\
18.1 \\
22.0 \\
24.0 \\
24.7 \\
20.1 \\
17.9\end{array}$ & $\begin{array}{l}18.6 \\
17.6 \\
16.9 \\
17.7 \\
17.6 \\
18.0 \\
17.2 \\
16.4\end{array}$ & $\begin{array}{l}18.5 \\
18.3 \\
18.2 \\
19.2 \\
19.9\end{array}$ & $\begin{array}{l}2 \\
2 \\
4 \\
4 \\
3 \\
2 \\
2 \\
2\end{array}$ & $\begin{array}{r}1.8 \\
4.4 \\
4.6 \\
3.4 \\
4.2 \\
10.6 \\
2.2 \\
5.2\end{array}$ & $\begin{array}{r}1.8 \\
4.6 \\
5.0 \\
4.6 \\
6.4 \\
12.6 \\
2.4 \\
5.8\end{array}$ & $\begin{array}{r}2.4 \\
4.6 \\
4.8 \\
4.6 \\
6.4 \\
13.8 \\
2.4 \\
6.8\end{array}$ & $\begin{array}{r}13.8 \\
2.4 \\
6.8\end{array}$ \\
\hline $\begin{array}{l}15 \\
15 \\
15 \\
15 \\
15 \\
15 \\
15 \\
15\end{array}$ & $\begin{array}{r}0 \\
3 \\
6 \\
9 \\
12 \\
15 \\
18 \\
21\end{array}$ & $\begin{array}{l}16.7 \\
15.4 \\
16.6 \\
21.8 \\
25.6 \\
26.5 \\
23.8 \\
20.6\end{array}$ & $\begin{array}{l}15.1 \\
14.6 \\
15.2 \\
16.8 \\
17.8 \\
17.1 \\
18.5 \\
17.8\end{array}$ & $\begin{array}{l}16.8 \\
15.3 \\
16.7 \\
22.1 \\
25.4 \\
26.3 \\
23.8 \\
20.6\end{array}$ & $\begin{array}{l}14.9 \\
14.3 \\
15.1 \\
16.7 \\
16.7 \\
17.1 \\
18.2 \\
17.5\end{array}$ & $\begin{array}{l}17.0 \\
15.8 \\
17.5 \\
23.3 \\
26.3 \\
27.2 \\
24.7 \\
21.2\end{array}$ & $\begin{array}{l}15.2 \\
14.7 \\
15.6 \\
17.3 \\
17.8 \\
17.8 \\
18.8 \\
17.8\end{array}$ & $\begin{array}{l}17.9 \\
16.5 \\
18.2 \\
24.6 \\
28.0 \\
29.1 \\
26.3 \\
22.6\end{array}$ & $\begin{array}{l}15.9 \\
15.5 \\
15.8 \\
19.0 \\
19.4 \\
19.9 \\
18.8\end{array}$ & $\begin{array}{l}18.7 \\
18.6 \\
18.9 \\
21.0 \\
23.5 \\
23.2 \\
21.4 \\
19.5\end{array}$ & $\begin{array}{l}2 \\
4 \\
4 \\
3 \\
2 \\
2 \\
2 \\
2\end{array}$ & $\begin{array}{l}4.6 \\
4.2 \\
2.6 \\
2.0 \\
1.6 \\
3.4 \\
3.6 \\
6.0\end{array}$ & $\begin{array}{l}4.8 \\
4.2 \\
3.0 \\
2.0 \\
2.2 \\
3.4 \\
4.4 \\
6.6\end{array}$ & $\begin{array}{l}5.4 \\
4.6 \\
2.6 \\
2.2 \\
1.6 \\
3.8 \\
4.8 \\
7.2\end{array}$ & $\begin{array}{l}5.8 \\
4.8 \\
3.0 \\
2.4 \\
1.8 \\
3.86 \\
5.6 \\
8.2\end{array}$ \\
\hline $\begin{array}{l}16 \\
16 \\
16 \\
16 \\
16 \\
16 \\
16 \\
16\end{array}$ & $\begin{array}{r}0 \\
3 \\
6 \\
9 \\
12 \\
15 \\
18 \\
21\end{array}$ & $\begin{array}{l}19.1 \\
18.2 \\
19.3 \\
23.2 \\
25.4 \\
25.5 \\
23.9 \\
21.9\end{array}$ & $\begin{array}{l}16.7 \\
16.3 \\
16.9 \\
17.9 \\
19.2 \\
20.6 \\
20.2 \\
19.1\end{array}$ & $\begin{array}{l}19.2 \\
18.2 \\
19.6 \\
23.6 \\
25.7 \\
26.1 \\
24.0 \\
22.0\end{array}$ & $\begin{array}{l}16.6 \\
16.2 \\
17.0 \\
17.9 \\
19.3 \\
20.4 \\
20.2 \\
19.1\end{array}$ & $\begin{array}{l}19.7 \\
18.5 \\
20.4 \\
24.6 \\
26.8 \\
27.1 \\
24.9 \\
22.8\end{array}$ & $\begin{array}{l}17.0 \\
16.7 \\
17.2 \\
18.4 \\
19.8 \\
21.01 \\
20.7 \\
19.5\end{array}$ & $\begin{array}{l}21.1 \\
19.6 \\
21.5 \\
25.9 \\
28.2 \\
28.7 \\
26.4 \\
24.4\end{array}$ & $\begin{array}{l}17.8 \\
17.5 \\
18.3 \\
19.5 \\
21.1 \\
22.6 \\
22.9 \\
20.5\end{array}$ & $\begin{array}{l}18.8 \\
18.8 \\
18.8 \\
19.5 \\
20.3 \\
20.6 \\
20.7 \\
20.2\end{array}$ & $\begin{array}{l}2 \\
2 \\
2 \\
2 \\
2 \\
2 \\
2 \\
2\end{array}$ & $\begin{array}{r}4.0 \\
6.4 \\
6.2 \\
9.8 \\
10.8 \\
12.0 \\
7.6 \\
6.2\end{array}$ & $\begin{array}{r}4.4 \\
7.0 \\
6.8 \\
11.0 \\
11.8 \\
13.6 \\
8.6 \\
7.0\end{array}$ & $\begin{array}{r}4.6 \\
7.2 \\
7.2 \\
11.8 \\
12.6 \\
14.4 \\
9.8 \\
8.0\end{array}$ & $\begin{array}{r}5.6 \\
7.8 \\
7.6 \\
12.2 \\
13.4 \\
15.0 \\
10.8 \\
9.0\end{array}$ \\
\hline $\begin{array}{l}17 \\
17 \\
17 \\
17 \\
17 \\
17 \\
17 \\
17\end{array}$ & $\begin{array}{r}0 \\
3 \\
6 \\
9 \\
12 \\
15 \\
18 \\
21\end{array}$ & $\begin{array}{l}19.9 \\
18.9 \\
19.4 \\
24.1 \\
27.8 \\
28.5 \\
26.2 \\
23.7\end{array}$ & $\begin{array}{l}17.9 \\
17.08 \\
18.00 \\
20.1 \\
22.0 \\
21.8 \\
22.03 \\
21.00\end{array}$ & $\begin{array}{l}20.0 \\
19.0 \\
19.7 \\
24.5 \\
28.1 \\
28.8 \\
26.6 \\
23.6\end{array}$ & $\begin{array}{l}17.9 \\
17.6 \\
18.3 \\
20.2 \\
22.1 \\
21.7 \\
22.1 \\
21.2\end{array}$ & $\begin{array}{l}20.6 \\
19.4 \\
20.2 \\
25.1 \\
29.1 \\
29.7 \\
27.6 \\
24.9\end{array}$ & $\begin{array}{l}18.3 \\
18.0 \\
18.5 \\
20.8 \\
22.6 \\
21.8 \\
22.7 \\
22.1\end{array}$ & $\begin{array}{l}22.0 \\
20.3 \\
21.6 \\
26.8 \\
30.5 \\
31.8 \\
29.5 \\
26.0\end{array}$ & $\begin{array}{l}19.4 \\
18.9 \\
19.8 \\
22.2 \\
24.3 \\
24.0 \\
24.6 \\
23.1\end{array}$ & $\begin{array}{l}20.0 \\
19.6 \\
19.9 \\
22.0 \\
24.5 \\
23.7 \\
22.3 \\
21.9\end{array}$ & $\begin{array}{l}2 \\
2 \\
2 \\
2 \\
2 \\
2 \\
2 \\
2\end{array}$ & $\begin{array}{l}4.0 \\
6.2 \\
5.0 \\
2.2 \\
2.4 \\
6.0 \\
4.8 \\
6.4\end{array}$ & $\begin{array}{l}4.2 \\
6.6 \\
5.4 \\
2.4 \\
2.8 \\
6.8 \\
5.8 \\
8.6\end{array}$ & $\begin{array}{l}5.0 \\
7.0 \\
5.6 \\
2.6 \\
3.0 \\
7.6 \\
6.4 \\
9.8\end{array}$ & $\begin{array}{l}5.6 \\
7.4 \\
6.0 \\
2.8 \\
3.0 \\
8.0 \\
7.6 \\
9.6\end{array}$ \\
\hline $\begin{array}{l}18 \\
18 \\
18 \\
18 \\
18 \\
18 \\
18 \\
18\end{array}$ & $\begin{array}{r}0 \\
3 \\
6 \\
9 \\
12 \\
15 \\
18 \\
21\end{array}$ & 20.2 & 19.7 & 20.4 & 19.5 & 20.2 & 20.0 & 23.0 & & & $\begin{array}{l}3 \\
2 \\
2 \\
2 \\
2 \\
2 \\
2 \\
2\end{array}$ & $\begin{array}{r}7.2 \\
17.4 \\
12.4 \\
15.4 \\
16.2 \\
18.8 \\
17.2 \\
16.2\end{array}$ & $\begin{array}{r}8.8 \\
19.6 \\
14.0 \\
17.6 \\
18.6 \\
21.4 \\
20.0 \\
18.4\end{array}$ & $\begin{array}{l}9.4 \\
21.2 \\
15.6 \\
19.6 \\
20.0 \\
23.2 \\
21.2 \\
19.6\end{array}$ & $\begin{array}{r}9.2 \\
22.6 \\
15.8 \\
20.2 \\
21.0 \\
24.6 \\
22.8 \\
21.0\end{array}$ \\
\hline $\begin{array}{l}19 \\
19 \\
19 \\
19 \\
19 \\
19 \\
19 \\
19\end{array}$ & $\begin{array}{r}0 \\
3 \\
6 \\
9 \\
12 \\
15 \\
18 \\
21\end{array}$ & $\begin{array}{l}22.9 \\
22.5 \\
21.5 \\
23.0 \\
26.4 \\
25.4 \\
23.7 \\
21.3\end{array}$ & $\begin{array}{l}20.6 \\
21.01 \\
21.01 \\
21.03 \\
22.03 \\
22.2 \\
20.07 \\
18.9\end{array}$ & $\begin{array}{l}23.1 \\
22.5 \\
21.6 \\
23.4 \\
26.8 \\
25.7 \\
23.8 \\
21.03\end{array}$ & $\begin{array}{l}20.6 \\
21.1 \\
21.2 \\
21.2 \\
22.7 \\
22.2 \\
20.6 \\
18.8\end{array}$ & $\begin{array}{l}23.6 \\
23.0 \\
22.2 \\
24.2 \\
27.5 \\
26.7 \\
24.6 \\
22.1\end{array}$ & $\begin{array}{l}21.0 \\
21.9 \\
21 \bullet 9 \\
21 \bullet 9 \\
23.1 \\
23: 0 \\
21: 0 \\
19.3\end{array}$ & $\begin{array}{l}24.9 \\
24 \cdot 4 \\
23.9 \\
25.8 \\
29 \cdot 3 \\
28.4 \\
26.3 \\
23.5\end{array}$ & $\begin{array}{l}22.3 \\
23.2 \\
23.3 \\
23.2 \\
25.1 \\
24.6 \\
22.5 \\
20.6\end{array}$ & $\begin{array}{l}20.0 \\
19.9 \\
20.0 \\
20.5 \\
20.5 \\
20.4 \\
20.4 \\
20.0\end{array}$ & $\begin{array}{l}2 \\
2 \\
2 \\
3 \\
3 \\
3 \\
3 \\
3\end{array}$ & $\begin{array}{r}16.0 \\
13.6 \\
2.8 \\
7.2 \\
11.6 \\
13.4 \\
11.8 \\
9.8\end{array}$ & $\begin{array}{r}18.0 \\
15.2 \\
3.02 \\
8.8 \\
12.4 \\
14.2 \\
12.4 \\
10.2\end{array}$ & $\begin{array}{r}19.4 \\
16.4 \\
3.2 \\
9.2 \\
13.6 \\
15.6 \\
13.6 \\
11.0\end{array}$ & $\begin{array}{r}20.6 \\
17.2 \\
3.4 \\
9.6 \\
14.4 \\
16.4 \\
14.6 \\
11.8\end{array}$ \\
\hline $\begin{array}{l}20 \\
20 \\
20 \\
20 \\
20 \\
20 \\
20 \\
20\end{array}$ & $\begin{array}{r}0 \\
3 \\
6 \\
9 \\
12 \\
15 \\
18 \\
21\end{array}$ & $\begin{array}{l}20.1 \\
18.6 \\
16.1 \\
18.8 \\
22.4 \\
24.8 \\
23.7 \\
19.5\end{array}$ & $\begin{array}{l}18.4 \\
17.4 \\
15.6 \\
16.9 \\
17.9 \\
19.5 \\
21.02 \\
18.4\end{array}$ & $\begin{array}{l}20.0 \\
18.4 \\
16.0 \\
13.9 \\
22.6 \\
25.1 \\
23.8 \\
19.9\end{array}$ & $\begin{array}{l}18.2 \\
16.7 \\
15.03 \\
16.4 \\
18.0 \\
19.1 \\
21.0 \\
18.3\end{array}$ & $\begin{array}{l}20.5 \\
18.8 \\
16.3 \\
19.5 \\
23.3 \\
25.8 \\
24.4 \\
20.1\end{array}$ & $\begin{array}{l}18.9 \\
17.1 \\
15.8 \\
17.2 \\
18.3 \\
19.7 \\
21.6 \\
18.8\end{array}$ & $\begin{array}{l}21.6 \\
19.5 \\
17.4 \\
20.9 \\
24.6 \\
27.3 \\
26.0 \\
21.3\end{array}$ & $\begin{array}{l}20.0 \\
18.6 \\
16.8 \\
18.4 \\
19.6 \\
21.01 \\
23.5 \\
20.0\end{array}$ & $\begin{array}{l}19.9 \\
19.8 \\
19.1 \\
19.9 \\
21.2 \\
21.3 \\
21.7 \\
21.2\end{array}$ & $\begin{array}{l}3 \\
4 \\
3 \\
3 \\
2 \\
4 \\
3 \\
3\end{array}$ & $\begin{array}{r}8.6 \\
14.6 \\
9.2 \\
5.0 \\
4.8 \\
5.6 \\
4.6 \\
4.6\end{array}$ & $\begin{array}{r}9.4 \\
15.6 \\
10.0 \\
6.0 \\
5.4 \\
6.2 \\
5.6 \\
6.0\end{array}$ & $\begin{array}{r}10.2 \\
16.0 \\
10.6 \\
6.04 \\
5.08 \\
7.0 \\
6.2 \\
5.6\end{array}$ & $\begin{array}{l}10.4 \\
17.2 \\
10.6 \\
5.8 \\
7.4 \\
6.6 \\
5.6\end{array}$ \\
\hline
\end{tabular}


Table 10. - Three-hour averages of air and water-aurface temperatures and wind directions and speed, April 10s0-August 951, Lake Hefner-Continued

STATION 1 THREE-HOURLY AVERAGES

MAY. 2930

\begin{tabular}{|c|c|c|c|c|c|c|c|c|c|c|c|c|c|c|c|}
\hline \multirow{4}{*}{ 总葛 } & \multirow{4}{*}{ 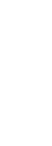 } & \multicolumn{8}{|c|}{ Average air temperature $\left({ }^{\circ} \mathrm{C}\right)$ at indicated height } & \multirow{4}{*}{$\begin{array}{l}\text { Average } \\
\text { water- } \\
\text { surface } \\
\text { tempera- } \\
\text { ture } \\
\text { (॰C) }\end{array}$} & \multirow{4}{*}{$\begin{array}{c}\text { Averáge } \\
\text { wind } \\
\text { direction } \\
\text { (coded) }\end{array}$} & \multirow{2}{*}{\multicolumn{4}{|c|}{$\begin{array}{l}\text { Average wind speed (knots) } \\
\text { at indicated height }\end{array}$}} \\
\hline & & \multirow{2}{*}{\multicolumn{2}{|c|}{$\begin{array}{c}2 \\
\text { meters }\end{array}$}} & \multirow{2}{*}{\multicolumn{2}{|c|}{$\begin{array}{c}4 \\
\text { meters }\end{array}$}} & \multirow{2}{*}{\multicolumn{2}{|c|}{$\begin{array}{c}8 \\
\text { meters }\end{array}$}} & \multirow{2}{*}{\multicolumn{2}{|c|}{$\begin{array}{c}16 \\
\text { meters }\end{array}$}} & & & & & & \\
\hline & & & & & & & & & & & & 2 & 4 & 8 & 16 \\
\hline & & $\begin{array}{l}\text { Dry } \\
\text { bulb }\end{array}$ & $\begin{array}{l}\text { Wet } \\
\text { bulb }\end{array}$ & $\begin{array}{l}\text { Dry } \\
\text { bulb }\end{array}$ & $\begin{array}{l}\text { Wet } \\
\text { bulb }\end{array}$ & $\begin{array}{l}\text { Dry } \\
\text { bulb }\end{array}$ & $\begin{array}{l}\text { Wet } \\
\text { bulb }\end{array}$ & $\begin{array}{l}\text { Dry } \\
\text { bulb }\end{array}$ & $\begin{array}{l}\text { Wet } \\
\text { bulb }\end{array}$ & & & & & & meters \\
\hline
\end{tabular}

\begin{tabular}{|c|c|c|c|c|c|c|c|c|c|c|c|c|c|c|c|}
\hline $\begin{array}{l}21 \\
21 \\
21 \\
21 \\
21 \\
21 \\
21 \\
21\end{array}$ & $\begin{array}{r}0 \\
3 \\
6 \\
9 \\
12 \\
15 \\
18 \\
21\end{array}$ & $\begin{array}{l}17.0 \\
15.2 \\
15.8 \\
19.1 \\
21.9 \\
24.2 \\
22.8 \\
19.5\end{array}$ & $\begin{array}{l}16.9 \\
15.2 \\
14.8 \\
14.8 \\
14.4 \\
15.0 \\
15.9 \\
15.5\end{array}$ & $\begin{array}{l}17.0 \\
15.3 \\
15.8 \\
19.3 \\
22.1 \\
24.1 \\
22.8 \\
19.4\end{array}$ & $\begin{array}{l}16.8 \\
15.0 \\
14.0 \\
14.3 \\
14.0 \\
14.8 \\
15.9 \\
15.2\end{array}$ & $\begin{array}{l}17.4 \\
15.5 \\
16.3 \\
19.4 \\
22.1 \\
23.9 \\
22.8 \\
19.4\end{array}$ & $\begin{array}{l}17.1 \\
15.3 \\
15.1 \\
13.9 \\
13.7 \\
14.7 \\
15.7 \\
15.1\end{array}$ & $\begin{array}{l}18.5 \\
16.3 \\
17.3 \\
19.8 \\
22.3 \\
24.4 \\
22.9 \\
19.6\end{array}$ & $\begin{array}{l}18.4 \\
16.2 \\
26.0 \\
14.1 \\
14.1 \\
13.1 \\
15.2 \\
14.8\end{array}$ & $\begin{array}{l}20.7 \\
20.4 \\
20.5 \\
20.9 \\
21.5 \\
22.8 \\
22.1 \\
21.1\end{array}$ & $\begin{array}{l}4 \\
3 \\
4 \\
3 \\
3 \\
2 \\
2 \\
2\end{array}$ & $\begin{array}{l}7.0 \\
5.8 \\
4.2 \\
5.4 \\
2.6 \\
1.4 \\
3.2 \\
6.8\end{array}$ & $\begin{array}{l}8.0 \\
8.0 \\
5.0 \\
8.2 \\
4.2 \\
1.4 \\
3.4 \\
7.0\end{array}$ & $\begin{array}{l}8.2 \\
4.6 \\
8.8 \\
4.4 \\
1.4 \\
3.6 \\
7.8\end{array}$ & $\begin{array}{l}7.8 \\
5.0\end{array}$ \\
\hline $\begin{array}{l}22 \\
22 \\
22 \\
22 \\
22 \\
22 \\
22 \\
22\end{array}$ & $\begin{array}{r}0 \\
3 \\
6 \\
9 \\
12 \\
15 \\
18 \\
21\end{array}$ & $\begin{array}{l}18.3 \\
18.3 \\
20.2 \\
23.1 \\
25.2 \\
25.9 \\
23.0 \\
21.2\end{array}$ & $\begin{array}{l}17.6 \\
16.3 \\
17.2 \\
16.6\end{array}$ & $\begin{array}{l}18.2 \\
19.0 \\
20.5 \\
23.6 \\
25.6 \\
25.9 \\
23.3 \\
21.5\end{array}$ & $\begin{array}{l}14.7 \\
14.5 \\
15.1 \\
17.4 \\
17.1 \\
16.0 \\
16.9 \\
16.4\end{array}$ & $\begin{array}{l}18.2 \\
18.5 \\
20.5 \\
23.9 \\
25.8 \\
26.4 \\
23.5 \\
21.5\end{array}$ & $\begin{array}{l}14.7 \\
14.3 \\
14.9 \\
17.4 \\
17.2 \\
16.0 \\
16.8 \\
16.3\end{array}$ & $\begin{array}{l}18.2 \\
18.8 \\
20.8 \\
24.2 \\
26.1 \\
26.7 \\
23.9 \\
21.8\end{array}$ & $\begin{array}{l}14.5 \\
14.3 \\
15.0 \\
17.2 \\
17.1 \\
15.8 \\
16.7 \\
16.2\end{array}$ & $\begin{array}{l}20.7 \\
20.3 \\
20.0 \\
20.3 \\
20.5 \\
20.5 \\
20.3 \\
20.1\end{array}$ & $\begin{array}{l}2 \\
2 \\
2 \\
2 \\
2 \\
2 \\
2 \\
2\end{array}$ & $\begin{array}{r}8.4 \\
12.2 \\
13.4 \\
16.4 \\
16.0 \\
13.8 \\
8.8 \\
12.6\end{array}$ & $\begin{array}{r}9.0 \\
13.6 \\
14.8 \\
18.2 \\
17.8 \\
15.4 \\
9.8 \\
14.2\end{array}$ & $\begin{array}{r}9.2 \\
14.8 \\
15.8 \\
19.4 \\
19.0 \\
16.6 \\
10.8 \\
15.2\end{array}$ & $\begin{array}{r}9.8 \\
15.4 \\
16.4 \\
20.2 \\
19.4 \\
17.2 \\
12.2 \\
16.4\end{array}$ \\
\hline $\begin{array}{l}23 \\
23 \\
23 \\
23 \\
23 \\
23 \\
23 \\
23\end{array}$ & $\begin{array}{r}0 \\
3 \\
6 \\
9 \\
12 \\
15 \\
18 \\
21\end{array}$ & $\begin{array}{l}21.0 \\
19.3 \\
20.2 \\
23.6 \\
24.9 \\
27.9 \\
26.0 \\
23.8\end{array}$ & $\begin{array}{l}16.3 \\
16.3 \\
17.0 \\
18.7 \\
18.9 \\
18.4 \\
19.1 \\
17.9\end{array}$ & $\begin{array}{l}21.0 \\
19.3 \\
20.4 \\
23.9 \\
27.1 \\
28.3 \\
26.3 \\
24.2\end{array}$ & $\begin{array}{l}16.1 \\
16.0 \\
16.9 \\
18.5 \\
18.7 \\
18.2 \\
19.0 \\
17.7\end{array}$ & $\begin{array}{l}21.2 \\
19.4 \\
20.7 \\
24.4 \\
28.1 \\
28.7 \\
26.4 \\
24.2\end{array}$ & $\begin{array}{l}16.1 \\
16.0 \\
17.1 \\
18.7 \\
18.6 \\
18.5 \\
19.0 \\
17.5\end{array}$ & $\begin{array}{l}21.6 \\
19.7 \\
21.4 \\
24.9 \\
28.7 \\
29.2 \\
26.7 \\
24.4\end{array}$ & $\begin{array}{l}16.2 \\
16.2 \\
17.9 \\
19.2 \\
18.9 \\
18.5 \\
19.0 \\
17.6\end{array}$ & $\begin{array}{l}20.2 \\
20.0 \\
20.1 \\
20.3 \\
20.2\end{array}$ & $\begin{array}{l}2 \\
2 \\
2 \\
2 \\
2\end{array}$ & $\begin{array}{l}16.4 \\
13.8 \\
15.0 \\
17.2 \\
17.2 \\
14.2 \\
16.4\end{array}$ & $\begin{array}{l}18.4 \\
15.2 \\
17.0 \\
19.0 \\
19.0 \\
16.0 \\
18.4\end{array}$ & $\begin{array}{l}19.6 \\
25.8 \\
18.2 \\
21.4 \\
21.2 \\
18.2 \\
20.0\end{array}$ & $\begin{array}{l}20.6 \\
17.0 \\
19.0 \\
22.6 \\
22.2 \\
19.4 \\
21.4\end{array}$ \\
\hline $\begin{array}{l}24 \\
24 \\
24 \\
24 \\
24 \\
24 \\
24 \\
24\end{array}$ & $\begin{array}{r}0 \\
3 \\
6 \\
9 \\
12 \\
15 \\
18 \\
21\end{array}$ & $\begin{array}{l}21.5 \\
20.3 \\
21.7 \\
23.8 \\
26.7 \\
27.3 \\
25.6 \\
24.0\end{array}$ & $\begin{array}{l}17.3 \\
17.6 \\
18.3 \\
19.3 \\
20.1 \\
19.3 \\
19.6 \\
19.3\end{array}$ & $\begin{array}{l}21.6 \\
20.4 \\
21.6 \\
24.0 \\
27.2 \\
27.7 \\
25.7 \\
24.7\end{array}$ & $\begin{array}{l}18.1 \\
19.3 \\
19.8 \\
19.3 \\
19.5 \\
19.1\end{array}$ & $\begin{array}{l}21.8 \\
20.6 \\
21.7 \\
24.5 \\
27.5 \\
28.1 \\
26.0 \\
24.3\end{array}$ & $\begin{array}{l}17.2 \\
17.4 \\
17.6 \\
19.3 \\
19.9 \\
20.3 \\
20.4 \\
20.1\end{array}$ & $\begin{array}{l}22.0 \\
20.7 \\
22.0 \\
25.0 \\
28.1 \\
28.5 \\
25.3 \\
24.9\end{array}$ & $\begin{array}{l}17.4 \\
17.5 \\
18.1 \\
19.4 \\
20.0 \\
19.4 \\
19.7 \\
19.1\end{array}$ & $\begin{array}{l}20.4 \\
20.7 \\
20.8 \\
20.7 \\
20.8\end{array}$ & $\begin{array}{l}2 \\
2 \\
2 \\
2 \\
2 \\
2 \\
2 \\
2\end{array}$ & $\begin{array}{l}16.0 \\
15.0 \\
18.6 \\
15.0 \\
19.0 \\
20.8 \\
16.6 \\
17.4\end{array}$ & $\begin{array}{l}17.8 \\
16.8 \\
20.8 \\
17.2 \\
21.8 \\
23.6 \\
18.8 \\
19.6\end{array}$ & $\begin{array}{l}19.0 \\
18.2 \\
22.6 \\
18.8 \\
23.8 \\
26.0 \\
20.0 \\
21.4\end{array}$ & $\begin{array}{l}20.4 \\
19.2 \\
23.8 \\
19.8 \\
25.4 \\
27.8 \\
22.2 \\
23.0\end{array}$ \\
\hline $\begin{array}{l}25 \\
25 \\
25 \\
25 \\
25 \\
25 \\
25 \\
25\end{array}$ & $\begin{array}{r}0 \\
3 \\
6 \\
9 \\
12 \\
15 \\
18 \\
21\end{array}$ & $\begin{array}{l}22.8 \\
\geqslant 1.9 \\
21.7 \\
23.5 \\
23.4 \\
21.2 \\
19.3 \\
16.8\end{array}$ & $\begin{array}{l}20.1 \\
19.7 \\
18.4 \\
17.3 \\
15.7\end{array}$ & $\begin{array}{l}22.9 \\
22.0 \\
22.0 \\
23.9 \\
23.7 \\
21.0 \\
19.2 \\
16.3\end{array}$ & $\begin{array}{l}18.5 \\
18.6 \\
19.1 \\
20.0 \\
19.2 \\
18.0 \\
16.9 \\
15.1\end{array}$ & $\begin{array}{l}22.9 \\
22.1 \\
22.0 \\
24.3 \\
23.8 \\
21.0 \\
19.2 \\
16.3\end{array}$ & $\begin{array}{l}19.2 \\
19.1 \\
19.8 \\
21.0 \\
20.2 \\
18.7 \\
17.4 \\
15.4\end{array}$ & $\begin{array}{l}23.0 \\
22.1 \\
22.4 \\
24.5 \\
24.0 \\
21.1 \\
19.3 \\
16.3\end{array}$ & $\begin{array}{l}18.4 \\
18.6 \\
19.3 \\
20.3 \\
19.6 \\
18.1 \\
17.0 \\
15.1\end{array}$ & $\begin{array}{l}20.7 \\
20.4 \\
20.3 \\
20.5 \\
20.9 \\
20.7 \\
20.7 \\
20.5\end{array}$ & $\begin{array}{l}2 \\
2 \\
2 \\
2 \\
4 \\
4 \\
3 \\
4\end{array}$ & $\begin{array}{r}18.0 \\
14.4 \\
10.2 \\
7.8 \\
5.8 \\
10.4 \\
9.8 \\
15.8\end{array}$ & $\begin{array}{r}20.2 \\
16.0 \\
11.6 \\
9.2 \\
7.4 \\
13.8 \\
13.2 \\
19.6\end{array}$ & $\begin{array}{r}22.0 \\
27.6 \\
12.6 \\
9.8 \\
9.2 \\
13.4\end{array}$ & $\begin{array}{r}23.6 \\
18.6 \\
13.2 \\
10.2 \\
9.6 \\
14.2 \\
12.8 \\
20.6\end{array}$ \\
\hline $\begin{array}{l}26 \\
26 \\
26 \\
26 \\
26 \\
26 \\
26 \\
26\end{array}$ & $\begin{array}{r}0 \\
3 \\
6 \\
9 \\
12 \\
15 \\
18 \\
21\end{array}$ & $\begin{array}{l}13.9 \\
13.3 \\
12.0 \\
12.0 \\
12.6 \\
12.9 \\
14.1 \\
13.9\end{array}$ & $\begin{array}{l}13.8 \\
13.0 \\
11.5 \\
10.9 \\
11.8 \\
12.0 \\
12.8 \\
17.8\end{array}$ & $\begin{array}{l}13.6 \\
13.0 \\
11.5 \\
11.5 \\
12.5 \\
12.9 \\
13.9 \\
13.7\end{array}$ & $\begin{array}{l}13.4 \\
12.5 \\
10.7 \\
10.8 \\
11.3 \\
11.8 \\
12.0 \\
12.2\end{array}$ & $\begin{array}{l}13.7 \\
12.7 \\
11.4 \\
11.7 \\
12.6 \\
12.9 \\
13.9 \\
13.7\end{array}$ & $\begin{array}{l}13.6 \\
12.5 \\
10.9 \\
11.0 \\
12.0 \\
12.1 \\
12.7 \\
12.7\end{array}$ & $\begin{array}{l}14.1 \\
12.7 \\
11.4 \\
11.9 \\
12.7 \\
13.1 \\
14.0 \\
13.8\end{array}$ & $\begin{array}{l}14.1 \\
12.6 \\
10.8 \\
10.9 \\
11.5 \\
111.9 \\
12.3 \\
12.3\end{array}$ & $\begin{array}{l}21.7 \\
19.9 \\
19.8 \\
19.8 \\
19.4 \\
19.5 \\
19.8 \\
19.6\end{array}$ & $\begin{array}{l}3 \\
3 \\
4 \\
4 \\
4 \\
4 \\
4 \\
4\end{array}$ & $\begin{array}{r}8.8 \\
12.6 \\
13.8 \\
8.8 \\
5.8 \\
7.8 \\
6.6 \\
6.0\end{array}$ & $\begin{array}{r}13.0 \\
16.8 \\
17.4 \\
11.4 \\
7.0 \\
8.4 \\
9.6 \\
8.0\end{array}$ & $\begin{array}{r}19.4 \\
11.6 \\
7.4 \\
10.6 \\
9.8 \\
8.0\end{array}$ & $\begin{array}{r}11.2 \\
19.0 \\
17.8 \\
12.6 \\
7.8 \\
10.6 \\
11.0 \\
9.0\end{array}$ \\
\hline $\begin{array}{l}27 \\
27 \\
27 \\
27 \\
27 \\
27 \\
27 \\
27\end{array}$ & $\begin{array}{r}0 \\
3 \\
6 \\
9 \\
12 \\
15 \\
18 \\
21\end{array}$ & $\begin{array}{r}13.2 \\
12.0 \\
9.9 \\
10.1 \\
14.2 \\
18.8 \\
18.0\end{array}$ & $\begin{array}{r}12.2 \\
11.2 \\
9.6 \\
9.6 \\
12.5 \\
14.5 \\
15.6\end{array}$ & $\begin{array}{r}13.0 \\
11.8 \\
9.7 \\
9.9 \\
14.5 \\
18.8 \\
18.7\end{array}$ & $\begin{array}{r}11.5 \\
10.6 \\
9.0 \\
9.1 \\
11.9 \\
14.1 \\
14.8\end{array}$ & $\begin{array}{r}13.0 \\
11.6 \\
9.6 \\
9.9 \\
14.5 \\
18.7 \\
18.9\end{array}$ & $\begin{array}{r}12.1 \\
10.7 \\
9.2 \\
9.5 \\
12.6 \\
14.6 \\
15.4\end{array}$ & $\begin{array}{r}13.0 \\
11.5 \\
9.5 \\
10.1 \\
14.9 \\
19.5 \\
19.1\end{array}$ & $\begin{array}{r}11.7 \\
10.6 \\
8.9 \\
9.5 \\
13.4 \\
14.8 \\
14.9\end{array}$ & $\begin{array}{l}19.6 \\
19.6 \\
19.2 \\
19.6 \\
20.1 \\
20.5 \\
20.2\end{array}$ & $\begin{array}{l}4 \\
4 \\
4 \\
4 \\
4 \\
2 \\
2 \\
2\end{array}$ & $\begin{array}{l}6.2 \\
8.0 \\
8.2 \\
6.0 \\
3.8 \\
1.6 \\
4.6 \\
5.6\end{array}$ & $\begin{array}{r}8.4 \\
8.6 \\
10.6 \\
6.8 \\
4.6 \\
1.8 \\
4.8 \\
5.8\end{array}$ & $\begin{array}{r}8.2 \\
10.6 \\
12.2 \\
8.2 \\
5.0 \\
1.8 \\
5.2 \\
6.0\end{array}$ & $\begin{array}{r}9.6 \\
10.6 \\
13.0 \\
8.4 \\
5.4 \\
1.8 \\
5.2 \\
6.2\end{array}$ \\
\hline $\begin{array}{l}28 \\
28 \\
28 \\
28 \\
29 \\
28 \\
28 \\
28\end{array}$ & $\begin{array}{r}0 \\
3 \\
6 \\
9 \\
12 \\
15 \\
18 \\
21\end{array}$ & $\begin{array}{l}14.8 \\
15.1 \\
17.0 \\
19.9 \\
21.1 \\
21.7 \\
20.9\end{array}$ & $\begin{array}{l}14.5 \\
14.6 \\
15.9 \\
17.9 \\
19.2 \\
20.0 \\
19.0\end{array}$ & $\begin{array}{l}14.6 \\
15.2 \\
17.2 \\
19.9 \\
21.1 \\
21.7 \\
20.9\end{array}$ & $\begin{array}{l}14.2 \\
14.3 \\
15.5 \\
17.5 \\
18.8 \\
19.7 \\
19.8\end{array}$ & $\begin{array}{l}14.5 \\
15.3 \\
1.7 \cdot 3 \\
20.1 \\
21.4 \\
21.9 \\
21.3\end{array}$ & $\begin{array}{l}14.4 \\
14.5 \\
15.9 \\
18.1 \\
19.5 \\
20.2 \\
20.2\end{array}$ & $\begin{array}{l}14.8 \\
15.4 \\
17.5 \\
20.5 \\
22.0 \\
22.5 \\
22.1\end{array}$ & $\begin{array}{l}14.7 \\
14.4 \\
15.7 \\
18.1 \\
19.5 \\
20.2 \\
20.6\end{array}$ & $\begin{array}{l}18.8 \\
18.9 \\
19.0 \\
19.6 \\
19.8 \\
19.7 \\
19.4\end{array}$ & $\begin{array}{l}2 \\
2 \\
2 \\
2 \\
2 \\
2 \\
2 \\
2\end{array}$ & $\begin{array}{r}6.4 \\
10.2 \\
10.4 \\
13.4 \\
14.4 \\
12.4 \\
12.2 \\
13.4\end{array}$ & $\begin{array}{r}7.0 \\
11.6 \\
11.4 \\
14.8 \\
16.2 \\
13.8 \\
13.6 \\
14.8\end{array}$ & $\begin{array}{r}7.2 \\
13.2 \\
12.0 \\
16.2 \\
17.4 \\
15.0 \\
15.0 \\
16.2\end{array}$ & $\begin{array}{r}7.2 \\
13.6 \\
12.2 \\
16.4 \\
18.2 \\
15.8 \\
15.8 \\
17.0\end{array}$ \\
\hline $\begin{array}{l}29 \\
29 \\
29 \\
29 \\
29 \\
29 \\
29 \\
29\end{array}$ & $\begin{array}{r}0 \\
3 \\
6 \\
9 \\
12 \\
15 \\
18 \\
21\end{array}$ & $\begin{array}{l}20.4 \\
23.1 \\
23.5 \\
21.7 \\
21.3\end{array}$ & $\begin{array}{l}19.8 \\
21.0 \\
20.6 \\
18.6 \\
17.0\end{array}$ & $\begin{array}{l}20.7 \\
23.6 \\
24 \cdot 0 \\
21.8 \\
21.6\end{array}$ & $\begin{array}{l}19.7 \\
20.9 \\
20.0 \\
17.7 \\
16.9\end{array}$ & $\begin{array}{l}21 \cdot 1 \\
24 \cdot 0 \\
24 \cdot 3 \\
22.0 \\
71.9\end{array}$ & $\begin{array}{l}20.4 \\
21.7 \\
20.9 \\
18.5 \\
17.6\end{array}$ & $\begin{array}{l}21 \cdot 8 \\
24 \cdot 7 \\
24 \cdot 8 \\
22.5 \\
22 \cdot 4\end{array}$ & $\begin{array}{l}20.8 \\
21.6 \\
20.8 \\
17 \cdot 9 \\
17.0\end{array}$ & $\begin{array}{l}17.9 \\
18.3 \\
19.4 \\
17.7 \\
17.2\end{array}$ & $\begin{array}{l}2 \\
2 \\
2 \\
2 \\
4 \\
4 \\
3 \\
2\end{array}$ & $\begin{array}{r}16.6 \\
19.6 \\
12.6 \\
10.4 \\
7.6 \\
11.2 \\
5.2 \\
4.0\end{array}$ & $\begin{array}{r}18.6 \\
22.0 \\
14.0 \\
11.6 \\
10.8 \\
15.6 \\
7.2 \\
4.2\end{array}$ & $\begin{array}{r}20.0 \\
23.8 \\
15.2 \\
12.8 \\
12.2 \\
15.6 \\
9.6 \\
4.6\end{array}$ & $\begin{array}{r}21.2 \\
25.2 \\
15.8 \\
13.0 \\
12.8 \\
19.0 \\
10.0 \\
5.2\end{array}$ \\
\hline $\begin{array}{l}30 \\
30 \\
30 \\
30 \\
30 \\
30 \\
30 \\
30\end{array}$ & $\begin{array}{r}0 \\
3 \\
6 \\
9 \\
12 \\
15 \\
18 \\
21\end{array}$ & $\begin{array}{l}17.5 \\
20.3 \\
23.6 \\
25.8 \\
24.6 \\
20.9\end{array}$ & $\begin{array}{l}15.1 \\
16.5 \\
17.9 \\
18.7 \\
19.4 \\
18.3\end{array}$ & $\begin{array}{l}17.5 \\
20.3 \\
23.9 \\
26.2 \\
24.7 \\
21.1\end{array}$ & $\begin{array}{l}14.2 \\
15.7 \\
16.7 \\
17.1 \\
18.8 \\
17.8\end{array}$ & $\begin{array}{l}17.9 \\
20.8 \\
24.4 \\
26.9 \\
25 \cdot 2 \\
21.2\end{array}$ & $\begin{array}{l}15.0 \\
16.3 \\
17.2 \\
18.2 \\
19.1 \\
18.1\end{array}$ & $\begin{array}{l}18.2 \\
21: 3 \\
25.1 \\
27.2 \\
26.2 \\
21.9\end{array}$ & $\begin{array}{l}14.6 \\
15.8 \\
16.8 \\
17.9 \\
18.2 \\
17.8\end{array}$ & $\begin{array}{l}16.4 \\
16.5 \\
16.7 \\
16.7 \\
16.7 \\
17.0\end{array}$ & $\begin{array}{l}2 \\
2 \\
4 \\
4 \\
3 \\
2 \\
2 \\
2\end{array}$ & $\begin{array}{l}6.06 \\
9.0 \\
7.0 \\
7.6 \\
7.0 \\
1.6 \\
2.8 \\
4.2\end{array}$ & $\begin{array}{l}7.0 \\
9.4 \\
8.8 \\
9.8 \\
8.8 \\
1.8 \\
3.4 \\
4.8\end{array}$ & $\begin{array}{r}7.4 \\
12.8 \\
9.0 \\
11.0 \\
10.0 \\
1.8 \\
4.0 \\
5.4\end{array}$ & $\begin{array}{r}7.8 \\
12.0 \\
10.6 \\
12.2\end{array}$ \\
\hline $\begin{array}{l}31 \\
31 \\
31 \\
31 \\
31 \\
31 \\
31 \\
31\end{array}$ & $\begin{array}{r}0 \\
3 \\
6 \\
9 \\
12 \\
15 \\
18 \\
21\end{array}$ & $\begin{array}{l}19.4 \\
18.2 \\
18.3 \\
20.5 \\
21.7 \\
22.2 \\
19.7 \\
16.6\end{array}$ & $\begin{array}{l}17.3 \\
16.9 \\
16.0 \\
16.4 \\
16.8 \\
17.0 \\
16.5 \\
14.9\end{array}$ & $\begin{array}{l}19.4 \\
18.1 \\
18.3 \\
20.5 \\
21.9 \\
22.4 \\
19.6 \\
16.3\end{array}$ & $\begin{array}{l}17.1 \\
16.7 \\
15.9 \\
15.1 \\
15.3 \\
15.9 \\
15.8 \\
14.3\end{array}$ & $\begin{array}{l}19.6 \\
18.6 \\
18.5 \\
20.8 \\
22.1 \\
22.7 \\
19.8 \\
16.4\end{array}$ & $\begin{array}{l}17.6 \\
17.1 \\
15.4 \\
15.9 \\
15.9 \\
16.3 \\
16.0 \\
14.5\end{array}$ & $\begin{array}{l}20.2 \\
19.2 \\
19.0 \\
21.2 \\
22.5 \\
22.9 \\
19.7 \\
16.4\end{array}$ & $\begin{array}{l}17.3 \\
16.9 \\
16.2 \\
15.2 \\
15.8 \\
16.0 \\
15.7 \\
14.4\end{array}$ & $\begin{array}{l}16.7 \\
16.8 \\
16.4 \\
16.3 \\
16.2\end{array}$ & $\begin{array}{l}2 \\
3 \\
3 \\
3 \\
3 \\
3 \\
3 \\
3\end{array}$ & $\begin{array}{r}4.0 \\
3.4 \\
10.6 \\
13.0 \\
13.0 \\
11.8 \\
10.4 \\
9.8\end{array}$ & $\begin{array}{r}4.4 \\
3.6 \\
11.2 \\
13.8 \\
14.0 \\
12.6 \\
11.0 \\
10.0\end{array}$ & $\begin{array}{r}4.6 \\
3.8 \\
11.6 \\
14.6 \\
14.6 \\
13.4 \\
11.4 \\
10.04\end{array}$ & $\begin{array}{r}5.4 \\
3.8 \\
12.2 \\
15.2 \\
15.4 \\
13.8 \\
12.2 \\
10.8\end{array}$ \\
\hline
\end{tabular}


TABLE 10

Table 10. - Three-hour averages of air and water-surface temperatures and wind directions and speed, April 1950-August station 1951, Lake Hefner-Continued

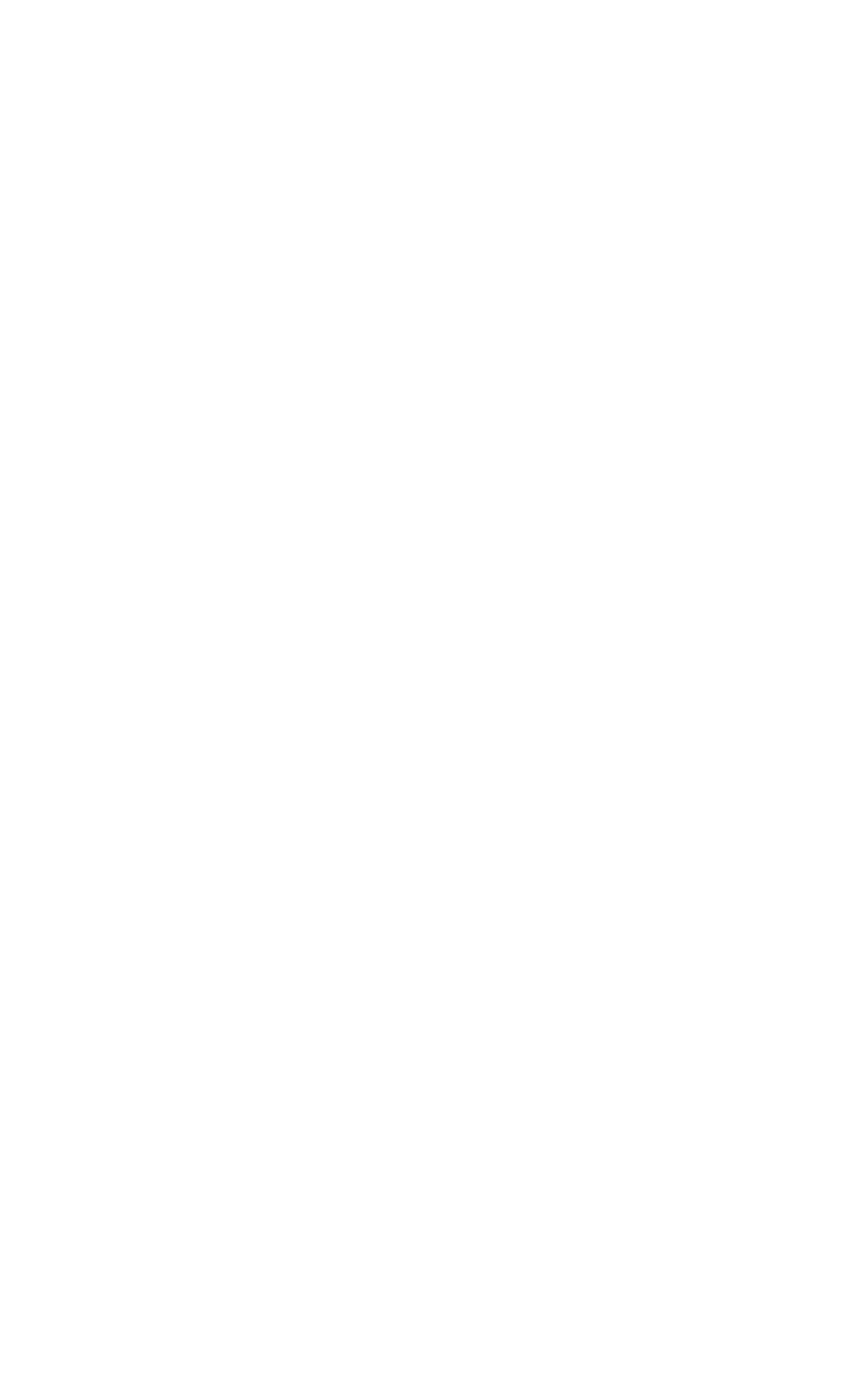


Table 10. - Three-hour averages of air and water-surface temperatures and wind directions and speed, April 1950-August 1951, Lake Hefner-Continued

FHREE-HOURLY AVERAGES

JUNE, 1950

\begin{tabular}{|c|c|c|c|c|c|c|c|c|c|c|c|c|c|c|c|}
\hline \multirow{4}{*}{ 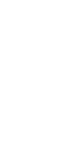 } & \multirow{4}{*}{ 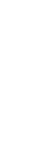 } & \multicolumn{8}{|c|}{ Average air temperature $\left({ }^{\circ} \mathrm{C}\right)$ at indicated height } & \multirow{4}{*}{$\begin{array}{l}\text { Average } \\
\text { water- } \\
\text { surface } \\
\text { tempera- } \\
\text { ture } \\
\text { (ㄷ) }\end{array}$} & \multirow{4}{*}{$\begin{array}{c}\text { Average } \\
\text { wind } \\
\text { direction } \\
\text { (coded) }\end{array}$} & \multirow{2}{*}{\multicolumn{4}{|c|}{$\begin{array}{l}\text { Average wind speed (knots) } \\
\text { at indicated height }\end{array}$}} \\
\hline & & \multirow{2}{*}{\multicolumn{2}{|c|}{$\begin{array}{c}2 \\
\text { meters }\end{array}$}} & \multirow{2}{*}{\multicolumn{2}{|c|}{$\begin{array}{c}4 \\
\text { metera }\end{array}$}} & \multirow{2}{*}{\multicolumn{2}{|c|}{$\begin{array}{c}8 \\
\text { meters }\end{array}$}} & \multirow{2}{*}{\multicolumn{2}{|c|}{$\begin{array}{c}16 \\
\text { meters }\end{array}$}} & & & & & & \\
\hline & & & & & & & & & & & & 2 & 4 & 8 & 16 \\
\hline & & $\begin{array}{l}\text { Dry } \\
\text { bulb }\end{array}$ & $\begin{array}{l}\text { Wet } \\
\text { bulb }\end{array}$ & $\begin{array}{l}\text { Dry } \\
\text { butb }\end{array}$ & $\begin{array}{l}\text { Wet } \\
\text { bulb }\end{array}$ & $\begin{array}{l}\text { Dry } \\
\text { bulb }\end{array}$ & $\begin{array}{l}\text { Wet } \\
\text { bulb }\end{array}$ & $\begin{array}{l}\text { Dry } \\
\text { bulb }\end{array}$ & $\begin{array}{l}\text { Wet } \\
\text { bulb }\end{array}$ & & & & & & \\
\hline
\end{tabular}

\begin{tabular}{|c|c|c|c|c|c|c|c|c|c|c|c|c|c|c|c|}
\hline $\begin{array}{l}11 \\
11 \\
11 \\
11 \\
11 \\
11 \\
11 \\
11\end{array}$ & $\begin{array}{r}0 \\
3 \\
6 \\
9 \\
12 \\
15 \\
18 \\
21\end{array}$ & $\begin{array}{l}20.6 \\
19.4 \\
20.4 \\
23.0 \\
24.5 \\
24.5 \\
23.6 \\
22.7\end{array}$ & $\begin{array}{l}18.7 \\
18.6 \\
19.0 \\
20.2 \\
21.3 \\
21.6 \\
21.1 \\
21.3\end{array}$ & $\begin{array}{l}20.5 \\
19.3 \\
20.1 \\
23.1 \\
24.5 \\
24.7 \\
23.7 \\
22.6\end{array}$ & $\begin{array}{l}18.6 \\
18.5 \\
18.8 \\
20.2 \\
21.3 \\
21.6 \\
21.0 \\
21.2\end{array}$ & $\begin{array}{l}20.7 \\
19.5 \\
20.5 \\
23.4 \\
25.0 \\
24.7 \\
23.9 \\
22.9\end{array}$ & $\begin{array}{l}18.9 \\
18.7 \\
19.2 \\
20.4 \\
21.5 \\
21.7 \\
21.1 \\
21.3\end{array}$ & $\begin{array}{l}21 \cdot 1 \\
20.2 \\
21 \cdot 0 \\
24 \cdot 0 \\
25.7 \\
24 \cdot 9 \\
24 \cdot 4 \\
23.1\end{array}$ & $\begin{array}{l}19.4 \\
19.3 \\
19.6 \\
20.8 \\
22.2 \\
21.7 \\
21.5 \\
21.6\end{array}$ & $\begin{array}{l}22.3 \\
22.5 \\
22.4 \\
23.0 \\
23.1 \\
22.6 \\
22.4 \\
22.4\end{array}$ & $\begin{array}{l}2 \\
3 \\
2 \\
2 \\
2 \\
2 \\
2 \\
2\end{array}$ & $\begin{array}{r}6.4 \\
5.2 \\
6.2 \\
3.6 \\
5.6 \\
13.0 \\
11.2 \\
11.2\end{array}$ & $\begin{array}{r}7.0 \\
5.6 \\
6.6 \\
4.2 \\
6.4 \\
14.4 \\
12.4 \\
12.6\end{array}$ & $\begin{array}{r}7.6 \\
5.8 \\
6.8 \\
4.6 \\
6.6 \\
15.8 \\
13.6 \\
13.6\end{array}$ & $\begin{array}{r}7.6 \\
6.6 \\
6.8 \\
4.6 \\
6.6 \\
16.4 \\
14.2 \\
14.2\end{array}$ \\
\hline $\begin{array}{l}12 \\
12 \\
12 \\
12 \\
12 \\
12 \\
12 \\
12\end{array}$ & $\begin{array}{r}0 \\
3 \\
6 \\
9 \\
12 \\
15 \\
18 \\
21\end{array}$ & $\begin{array}{l}22.2 \\
21.7 \\
22.7 \\
26.1 \\
27.9 \\
28.6 \\
26.7 \\
25.7\end{array}$ & $\begin{array}{l}21.0 \\
20.8 \\
21.0 \\
22.4 \\
22.2 \\
22.6 \\
22.9 \\
22.0\end{array}$ & $\begin{array}{l}22.2 \\
21.6 \\
22.8 \\
26.5 \\
28.3 \\
29.0 \\
26.9 \\
25.6\end{array}$ & $\begin{array}{l}20.9 \\
20.8 \\
21.1 \\
22.2 \\
22.2 \\
22.4 \\
23.0\end{array}$ & $\begin{array}{l}22.3 \\
21.7 \\
23.2 \\
26.7 \\
28.7 \\
29.6 \\
28.1 \\
25.6\end{array}$ & $\begin{array}{l}21.0 \\
20.9 \\
21.1 \\
22.4 \\
22.5 \\
22.7 \\
23.0 \\
21.8\end{array}$ & $\begin{array}{l}22.4 \\
21.8 \\
23.5 \\
27.4 \\
29.4 \\
30.2 \\
28.6 \\
25.9\end{array}$ & $\begin{array}{l}21.2 \\
20.9 \\
21.3 \\
23.0 \\
22.7 \\
22.9 \\
23.1 \\
22.1\end{array}$ & $\begin{array}{l}22.5 \\
22.3 \\
22.3 \\
22.9 \\
22.9 \\
23.0 \\
23.1 \\
23.0\end{array}$ & $\begin{array}{l}2 \\
2 \\
2 \\
2 \\
2 \\
2 \\
2 \\
2\end{array}$ & $\begin{array}{r}9.2 \\
12.6 \\
14.4 \\
13.4 \\
14.2 \\
14.2 \\
12.2 \\
14.4\end{array}$ & $\begin{array}{l}11.2 \\
11.0 \\
16.6 \\
15.4 \\
16.2 \\
16.2 \\
13.8 \\
16.4\end{array}$ & $\begin{array}{l}12.0 \\
15.2 \\
18.0 \\
16.8 \\
18.2 \\
18.0 \\
15.4 \\
17.8\end{array}$ & $\begin{array}{l}13.0 \\
15.8 \\
18.6 \\
17.0 \\
18.8 \\
18.8 \\
16.2 \\
18.8\end{array}$ \\
\hline $\begin{array}{l}13 \\
13 \\
13 \\
13 \\
13 \\
13 \\
13 \\
13\end{array}$ & $\begin{array}{r}0 \\
3 \\
6 \\
9 \\
12 \\
15 \\
18 \\
21\end{array}$ & $\begin{array}{l}23.8 \\
23.6 \\
24.2 \\
26.7 \\
29.0 \\
29.1 \\
28.0 \\
25.8\end{array}$ & $\begin{array}{l}21.1 \\
20.7 \\
21.4 \\
22.6 \\
23.0 \\
23.0 \\
23.1 \\
22.2\end{array}$ & $\begin{array}{l}23.7 \\
23.5 \\
24.3 \\
27.0 \\
29.8 \\
29.5 \\
27.9 \\
25.8\end{array}$ & $\begin{array}{l}22.9 \\
23.0 \\
23.1 \\
21.9\end{array}$ & $\begin{array}{l}23.9 \\
23.7 \\
24.5 \\
27.5 \\
29.8 \\
30.0 \\
28.2 \\
26.1\end{array}$ & $\begin{array}{l}20.9 \\
20.7 \\
21.4 \\
22.8 \\
22.9 \\
23.2 \\
23.2 \\
22.0\end{array}$ & $\begin{array}{l}24 \cdot 3 \\
24.0 \\
25.0 \\
27.9 \\
30.2 \\
30.7 \\
28.6 \\
26.2\end{array}$ & $\begin{array}{l}21.2 \\
20.9 \\
21.8 \\
22.6 \\
23.0 \\
23.5 \\
23.5 \\
22.3\end{array}$ & $\begin{array}{l}23.0 \\
23.0 \\
23.0 \\
23.2 \\
23.7 \\
23.5 \\
24.7 \\
23.7\end{array}$ & $\begin{array}{l}2 \\
2 \\
2 \\
2 \\
2 \\
2 \\
2 \\
2\end{array}$ & $\begin{array}{l}14.8 \\
12.8 \\
13.8 \\
12.4 \\
14.6 \\
16.4 \\
13.0 \\
12.8\end{array}$ & $\begin{array}{l}16.6 \\
14.2 \\
15.4 \\
14.8 \\
16.6 \\
18.6 \\
14.6 \\
14.4\end{array}$ & $\begin{array}{l}18.0 \\
15.4 \\
16.8 \\
16.4 \\
18.4 \\
20.4 \\
16.2 \\
15.8\end{array}$ & $\begin{array}{l}18.8 \\
16.2 \\
17.2 \\
17.0 \\
19.0 \\
21.6 \\
17.2 \\
16.6\end{array}$ \\
\hline $\begin{array}{l}14 \\
14 \\
14 \\
14 \\
14 \\
14 \\
14 \\
14\end{array}$ & $\begin{array}{r}0 \\
3 \\
6 \\
9 \\
12 \\
15 \\
18 \\
21\end{array}$ & $\begin{array}{l}24.0 \\
22.9 \\
24.4 \\
27.0 \\
28.4 \\
28.8 \\
27.5 \\
25.0\end{array}$ & $\begin{array}{l}21.4 \\
21.1 \\
21.8 \\
22.4 \\
22.8 \\
22.2 \\
22.8 \\
22.2\end{array}$ & $\begin{array}{l}23.9 \\
22.8 \\
24.6 \\
27.3 \\
28.9 \\
29.1 \\
27.5 \\
25.3\end{array}$ & $\begin{array}{l}21.2 \\
20.9 \\
21.6 \\
22.4 \\
22.7 \\
22.3 \\
22.8 \\
22.0\end{array}$ & $\begin{array}{l}24.1 \\
22.99 \\
24.7 \\
27.7 \\
29.2 \\
29.5 \\
27.9 \\
25.4\end{array}$ & $\begin{array}{l}21.1 \\
21.0 \\
21.9 \\
22.6 \\
22.6 \\
22.1 \\
22.9 \\
22.1\end{array}$ & $\begin{array}{l}24.2 \\
23.2 \\
25.1 \\
28.2 \\
29.8 \\
29.8 \\
28.3 \\
25.7\end{array}$ & $\begin{array}{l}21 \cdot .5 \\
21 \cdot 3 \\
22 \cdot 0 \\
22 \cdot 0 \\
23 \cdot 9 \\
22 \cdot 1 \\
23.3 \\
22.3\end{array}$ & $\begin{array}{l}23.4 \\
23.4 \\
23.4 \\
23.8 \\
24.0 \\
24.0 \\
24.0 \\
24.0\end{array}$ & $\begin{array}{l}2 \\
2 \\
2 \\
2 \\
2 \\
2 \\
2 \\
2\end{array}$ & $\begin{array}{r}13.8 \\
11.6 \\
14.4 \\
13.2 \\
13.4 \\
13.8 \\
12.0 \\
9.8\end{array}$ & $\begin{array}{l}15.8 \\
14.4 \\
16.4 \\
14.8 \\
15.4 \\
16.2 \\
13.4 \\
10.6\end{array}$ & $\begin{array}{l}16.8 \\
14.4 \\
18.2 \\
16.4 \\
17.0 \\
17.8 \\
14.8 \\
11.6\end{array}$ & $\begin{array}{l}18.0 \\
15.0 \\
18.6 \\
17.4 \\
17.6 \\
18.6 \\
15.6 \\
12.4\end{array}$ \\
\hline $\begin{array}{l}15 \\
15 \\
15 \\
15 \\
15 \\
15 \\
15 \\
15\end{array}$ & $\begin{array}{r}0 \\
3 \\
6 \\
9 \\
12 \\
15 \\
18 \\
21\end{array}$ & $\begin{array}{l}23.8 \\
22.5 \\
23.6 \\
27.2 \\
28.8 \\
29.1 \\
27.6 \\
25.3\end{array}$ & $\begin{array}{l}21.7 \\
20.8 \\
21.2 \\
21.6 \\
22.0 \\
21.8 \\
22.0 \\
21.6\end{array}$ & $\begin{array}{l}23.7 \\
22.4 \\
23.6 \\
27.3 \\
29.0 \\
29.1 \\
27.6 \\
25.3\end{array}$ & $\begin{array}{l}21.5 \\
20.6 \\
21.0 \\
21.9 \\
21.9 \\
21.8 \\
21.9 \\
21.2\end{array}$ & $\begin{array}{l}23.8 \\
22.5 \\
23.8 \\
27.7 \\
29.3 \\
29.8 \\
27.9 \\
25.4\end{array}$ & $\begin{array}{l}21.5 \\
20.6 \\
21.1 \\
21.9 \\
21.9 \\
21.9 \\
22.0 \\
21.03\end{array}$ & $\begin{array}{l}24 \cdot 1 \\
22.7 \\
24.3 \\
28.2 \\
29.9 \\
30.1 \\
28.3 \\
25.8\end{array}$ & $\begin{array}{l}21.8 \\
20.9 \\
21.5 \\
22.0 \\
22.4 \\
22.0 \\
22.2 \\
21.6\end{array}$ & $\begin{array}{l}23.9 \\
23.8 \\
23.9 \\
24.3 \\
25.5 \\
24.9 \\
24.6 \\
24.6\end{array}$ & $\begin{array}{l}2 \\
2 \\
2 \\
2 \\
2 \\
2 \\
2 \\
2\end{array}$ & $\begin{array}{r}10.4 \\
10.2 \\
11.8 \\
13.2 \\
12.6 \\
12.8 \\
10.8 \\
7.2\end{array}$ & $\begin{array}{r}11.0 \\
11.4 \\
13.2 \\
15.0 \\
14.4 \\
14.4 \\
12.2 \\
8.0\end{array}$ & $\begin{array}{r}12.6 \\
12.2 \\
14.4 \\
16.4 \\
15.8 \\
16.2 \\
13.4 \\
9.0\end{array}$ & $\begin{array}{r}13.0 \\
12.6 \\
14.6 \\
16.8 \\
16.4 \\
16.6 \\
14.2 \\
9.8\end{array}$ \\
\hline $\begin{array}{l}16 \\
16 \\
16 \\
16 \\
16 \\
16 \\
16 \\
16\end{array}$ & $\begin{array}{r}0 \\
3 \\
6 \\
9 \\
12 \\
15 \\
18 \\
21\end{array}$ & $\begin{array}{l}27.2 \\
29.0 \\
29.5 \\
28.2 \\
25.5\end{array}$ & $\begin{array}{l}22.6 \\
22.5 \\
22.6 \\
22.1 \\
21.3\end{array}$ & $\begin{array}{l}27.4 \\
29.5 \\
29.8 \\
28.4 \\
25.5\end{array}$ & $\begin{array}{l}22.5 \\
22.3 \\
22.4 \\
22.0 \\
21.1\end{array}$ & $\begin{array}{l}27.8 \\
29.8 \\
30.3 \\
28.6 \\
25.8\end{array}$ & $\begin{array}{l}22.7 \\
22.1 \\
22.6 \\
21.9 \\
21.0\end{array}$ & $\begin{array}{l}28.3 \\
30.3 \\
30.7 \\
29.1 \\
26.2\end{array}$ & $\begin{array}{l}23 \cdot 1 \\
22.5 \\
22 \cdot 8 \\
22.3 \\
21.3\end{array}$ & $\begin{array}{l}25.8 \\
26.1 \\
25.4 \\
26.0 \\
25.1\end{array}$ & $\begin{array}{l}2 \\
2 \\
2 \\
2 \\
2 \\
2 \\
2 \\
2\end{array}$ & $\begin{array}{r}8.8 \\
9.6 \\
11.6 \\
10.6 \\
9.8 \\
11.0 \\
9.6 \\
5.6\end{array}$ & $\begin{array}{r}11.6 \\
12.6 \\
14.0 \\
11.8 \\
11.0 \\
12.0 \\
10.8 \\
6.4\end{array}$ & $\begin{array}{r}12.4 \\
13.6 \\
15.2 \\
13.0 \\
12.0 \\
14.0 \\
12.0 \\
7.44\end{array}$ & $\begin{array}{r}13.2 \\
14.0 \\
15.8 \\
13.2 \\
12.4 \\
14.4 \\
12.8 \\
8.4\end{array}$ \\
\hline $\begin{array}{l}17 \\
17 \\
17 \\
17 \\
17 \\
17 \\
17 \\
17\end{array}$ & $\begin{array}{r}0 \\
3 \\
6 \\
9 \\
12 \\
15 \\
18 \\
21\end{array}$ & $\begin{array}{l}24.2 \\
23.5 \\
24.1 \\
27.6 \\
29.1 \\
29.8 \\
28.3 \\
25.4\end{array}$ & $\begin{array}{l}21.1 \\
20.9 \\
21.1 \\
21.7 \\
21.8 \\
21.7 \\
21.2 \\
21.1\end{array}$ & $\begin{array}{l}24.1 \\
23.4 \\
24.2 \\
27.7 \\
29.5 \\
29.9 \\
28.4 \\
25.5\end{array}$ & $\begin{array}{l}20.9 \\
20.7 \\
21.0 \\
21.7 \\
21.6 \\
21.7 \\
21.4 \\
20.9\end{array}$ & $\begin{array}{l}24.5 \\
23.5 \\
24.5 \\
28.2 \\
29.7 \\
30.4 \\
28.7 \\
25.8\end{array}$ & $\begin{array}{l}21.0 \\
20.8 \\
21.0 \\
21.6 \\
21.8 \\
21.5 \\
21.1 \\
20.8\end{array}$ & $\begin{array}{l}24.9 \\
23.7 \\
25.0 \\
28.7 \\
30.4 \\
30.8 \\
29.1 \\
26.2\end{array}$ & 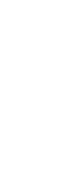 & $\begin{array}{l}25.0 \\
24.9 \\
25.2 \\
26.2 \\
26.5 \\
25.7 \\
25.2 \\
25.2\end{array}$ & $\begin{array}{l}2 \\
2 \\
2 \\
2 \\
2 \\
2 \\
2 \\
2\end{array}$ & $\begin{array}{r}6.8 \\
11.2 \\
12.0 \\
12.2 \\
10.6 \\
13.0 \\
10.0 \\
7.4\end{array}$ & $\begin{array}{r}7.6 \\
12.4 \\
13.2 \\
13.6 \\
12.2 \\
14.8 \\
11.4 \\
8.2\end{array}$ & $\begin{array}{r}8.2 \\
13.4 \\
13.4 \\
15.0 \\
13.4 \\
16.2 \\
12.8 \\
9.2\end{array}$ & $\begin{array}{r}9.0 \\
14.0 \\
14.8 \\
15.2 \\
13.8 \\
17.0 \\
13.4 \\
10.0\end{array}$ \\
\hline $\begin{array}{l}18 \\
18 \\
18 \\
18 \\
18 \\
18 \\
18 \\
18\end{array}$ & $\begin{array}{r}0 \\
3 \\
6 \\
9 \\
12 \\
15 \\
18 \\
21\end{array}$ & $\begin{array}{l}23.1 \\
23.0 \\
23.5 \\
26.1 \\
28.7 \\
29.1 \\
28.1 \\
25.6\end{array}$ & $\begin{array}{l}19.2 \\
19.7 \\
20.0 \\
20.3 \\
20.6 \\
20.5 \\
21.3 \\
20.8\end{array}$ & $\begin{array}{l}23.0 \\
23.0 \\
23.6 \\
26.5 \\
28.9 \\
29.3 \\
28.2 \\
25.6\end{array}$ & $\begin{array}{l}19.1 \\
19.3 \\
19.8 \\
20.2 \\
20.4 \\
20.3 \\
21.0 \\
20.7\end{array}$ & $\begin{array}{l}23.1 \\
23.1 \\
23.8 \\
26.7 \\
29.3 \\
29.6 \\
28.5 \\
25.6\end{array}$ & $\begin{array}{l}19.0 \\
19.4 \\
20.0 \\
20.3 \\
20.5 \\
20.3 \\
21.0 \\
20.6\end{array}$ & $\begin{array}{l}23.3 \\
23.3 \\
24.2 \\
27.5 \\
29 \cdot 7 \\
30.1 \\
29 \cdot 0 \\
26.1\end{array}$ & $\begin{array}{l}19.3 \\
19.6 \\
20.1 \\
20.4 \\
20.9 \\
20.7 \\
21.5 \\
21.0\end{array}$ & $\begin{array}{l}24.2 \\
24.4 \\
24.9 \\
25.1 \\
25.5 \\
25.0 \\
25.1 \\
24.6\end{array}$ & $\begin{array}{l}2 \\
2 \\
2 \\
2 \\
2 \\
2 \\
2 \\
2\end{array}$ & $\begin{array}{r}14.0 \\
13.8 \\
14.2 \\
15.6 \\
15.8 \\
15.4 \\
9.6 \\
11.6\end{array}$ & $\begin{array}{l}15.4 \\
15.6 \\
15.8 \\
17.4 \\
17.8 \\
17.4 \\
10.8 \\
13.0\end{array}$ & $\begin{array}{l}16.8 \\
16.8 \\
17.4 \\
19.4 \\
19.6 \\
19.4 \\
12.0 \\
24.2\end{array}$ & $\begin{array}{l}17.4 \\
17.4 \\
17.6 \\
19.8 \\
20.2 \\
20.2 \\
12.6 \\
14.8\end{array}$ \\
\hline $\begin{array}{l}19 \\
19 \\
19 \\
19 \\
19 \\
19 \\
19 \\
19\end{array}$ & $\begin{array}{r}0 \\
3 \\
6 \\
9 \\
12 \\
15 \\
18 \\
21\end{array}$ & $\begin{array}{l}25.0 \\
23.4 \\
21.0 \\
22.5 \\
24.7 \\
25.1\end{array}$ & $\begin{array}{l}20.2 \\
20.2 \\
19.0 \\
19.4 \\
20.6 \\
20.9\end{array}$ & $\begin{array}{l}25.0 \\
23.3 \\
20.7 \\
22.3 \\
24.4 \\
25.0\end{array}$ & $\begin{array}{l}20.0 \\
20.0 \\
18.6 \\
19.2 \\
20.4 \\
20.0\end{array}$ & $\begin{array}{l}25.2 \\
23.4 \\
20.7 \\
22.7 \\
24.9 \\
25.0\end{array}$ & $\begin{array}{l}20.1 \\
20.0 \\
18.8 \\
19.4 \\
20.6 \\
20.5\end{array}$ & $\begin{array}{l}25 \cdot 6 \\
23 \cdot 7 \\
20.9 \\
22.8 \\
24 \cdot 9 \\
25.4\end{array}$ & $\begin{array}{l}20.3 \\
20.3 \\
19.0 \\
19.8 \\
20.8 \\
20.9\end{array}$ & $\begin{array}{l}24.6 \\
25.0 \\
25.4 \\
26.5 \\
27.6 \\
26.8\end{array}$ & $\begin{array}{l}2 \\
2 \\
3 \\
3 \\
3 \\
3 \\
3 \\
2\end{array}$ & $\begin{array}{r}12.2 \\
4.8 \\
9.4 \\
4.0 \\
5.0 \\
5.6 \\
7.2 \\
6.6\end{array}$ & $\begin{array}{r}13.6 \\
5.0 \\
10.6 \\
4.4 \\
5.6 \\
6.4 \\
7.6 \\
7.0\end{array}$ & $\begin{array}{r}15.0 \\
5.6 \\
11.2 \\
5.0 \\
6.0 \\
6.8 \\
7.6 \\
7.2\end{array}$ & $\begin{array}{r}15.8 \\
6.0 \\
11.4 \\
4.8 \\
6.0 \\
6.8 \\
8.0 \\
7.4\end{array}$ \\
\hline $\begin{array}{l}20 \\
20 \\
20 \\
20 \\
20 \\
20 \\
20 \\
20\end{array}$ & $\begin{array}{r}0 \\
3 \\
6 \\
9 \\
12 \\
15 \\
18 \\
21\end{array}$ & $\begin{array}{l}30.2 \\
29.5 \\
19.9 \\
21.0\end{array}$ & $\begin{array}{l}22.9 \\
23.3 \\
17.9 \\
19.1\end{array}$ & $\begin{array}{l}30.4 \\
29.7 \\
19.9 \\
20.8\end{array}$ & $\begin{array}{l}23.0 \\
23.2 \\
17.8 \\
18.9\end{array}$ & $\begin{array}{l}31.0 \\
30.1 \\
20.1 \\
20.9\end{array}$ & $\begin{array}{l}22.2 \\
23.1 \\
18.0 \\
19.0\end{array}$ & $\begin{array}{l}31 \cdot 5 \\
30 \cdot 3 \\
20 \cdot 2 \\
21 \cdot 1\end{array}$ & $\begin{array}{l}23.4 \\
23.4 \\
18.3 \\
19.3\end{array}$ & $\begin{array}{l}28.3 \\
26.2 \\
25.9 \\
25.9\end{array}$ & $\begin{array}{l}2 \\
2 \\
3 \\
2 \\
2 \\
2 \\
2 \\
2\end{array}$ & $\begin{array}{l}8.44 \\
7.0 \\
4.6 \\
4.4 \\
7.2 \\
7.8 \\
7.00 \\
6.4\end{array}$ & $\begin{array}{l}9.0 \\
7.8 \\
4.8 \\
4.8 \\
8.0 \\
9.0 \\
7.6 \\
7.0\end{array}$ & $\begin{array}{r}9.4 \\
8.02 \\
5.0 \\
5.2 \\
8.8 \\
10.0 \\
8.0 \\
7.4\end{array}$ & $\begin{array}{r}9.6 \\
8.4 \\
4.8 \\
5.2 \\
9.2 \\
10.6 \\
8.0 \\
7.4\end{array}$ \\
\hline
\end{tabular}


TABLE 10

Table 10. - Three-hour averages of air and water-surface temperatures and wind directions and speed, April 1950-August 1951, Lake Hefner-Continued

STATION 2

THREE - HOURLY AVERAGES

JUNE, 1950

\begin{tabular}{|c|c|c|c|c|c|c|c|c|c|c|c|c|c|c|c|}
\hline \multirow{4}{*}{ 总 } & \multirow{4}{*}{ 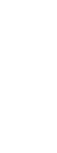 } & \multicolumn{8}{|c|}{ Average air temperature $\left({ }^{\circ} \mathrm{C}\right)$ at indicated height } & \multirow{4}{*}{$\begin{array}{l}\text { Average } \\
\text { water- } \\
\text { surface } \\
\text { tempera- } \\
\text { ture } \\
\text { ('C) }\end{array}$} & \multirow{4}{*}{$\begin{array}{c}\text { Average } \\
\text { wind } \\
\text { direction } \\
\text { (coded) }\end{array}$} & \multirow{2}{*}{\multicolumn{4}{|c|}{$\begin{array}{l}\text { A verage wind speed (knots) } \\
\text { at indicated height }\end{array}$}} \\
\hline & & \multirow{2}{*}{\multicolumn{2}{|c|}{$\begin{array}{c}2 \\
\text { meters }\end{array}$}} & \multirow{2}{*}{\multicolumn{2}{|c|}{$\begin{array}{c}4 \\
\text { meters }\end{array}$}} & \multirow{2}{*}{\multicolumn{2}{|c|}{$\begin{array}{c}8 \\
\text { meters }\end{array}$}} & \multirow{2}{*}{\multicolumn{2}{|c|}{$\begin{array}{c}16 \\
\text { meters }\end{array}$}} & & & & & & \\
\hline & & & & & & & & & & & & 2 & 4 & 8 & 16 \\
\hline & & $\begin{array}{l}\text { Dry } \\
\text { bulb }\end{array}$ & $\begin{array}{l}\text { Wet } \\
\text { bulb }\end{array}$ & $\begin{array}{l}\text { Dry } \\
\text { bulb }\end{array}$ & $\begin{array}{l}\text { Wet } \\
\text { bulb }\end{array}$ & $\begin{array}{l}\text { Dry } \\
\text { bulb }\end{array}$ & $\begin{array}{l}\text { Wet } \\
\text { bulb }\end{array}$ & $\begin{array}{l}\text { Dry } \\
\text { bulb }\end{array}$ & $\begin{array}{l}\text { Wet } \\
\text { bulb }\end{array}$ & & & meters & meters & meters & meters \\
\hline $\begin{array}{l}21 \\
21 \\
21 \\
21 \\
21 \\
21 \\
21 \\
21\end{array}$ & $\begin{array}{r}0 \\
3 \\
6 \\
9 \\
12 \\
15 \\
18 \\
21\end{array}$ & $\begin{array}{l}21.2 \\
20.9 \\
21.3 \\
24.3 \\
26.5 \\
27.0 \\
25.9 \\
24.1\end{array}$ & $\begin{array}{l}19.5 \\
19.8 \\
19.6 \\
19.7 \\
20.9 \\
21.5 \\
21.5 \\
21.6\end{array}$ & $\begin{array}{l}21.0 \\
20.9 \\
21.02 \\
24.3 \\
26.5 \\
27.0 \\
25.8 \\
24.0\end{array}$ & $\begin{array}{l}19.3 \\
19.7 \\
19.5 \\
19.6 \\
20.9 \\
21.2 \\
21.5 \\
21.5\end{array}$ & $\begin{array}{l}21.1 \\
21.0 \\
21.04 \\
24.6 \\
26.7 \\
27.02 \\
25.9 \\
24.02\end{array}$ & $\begin{array}{l}19.5 \\
19.7 \\
19.4 \\
19.6 \\
20.6 \\
20.9 \\
21.4 \\
21.4\end{array}$ & $\begin{array}{l}21.03 \\
21.1 \\
21.7 \\
24.9 \\
27.1 \\
27.6 \\
26.2 \\
24.4\end{array}$ & $\begin{array}{r}19.8 \\
20.0 \\
19.8 \\
19.9 \\
21.2 \\
21.6 \\
21.7 \\
21.9\end{array}$ & $\begin{array}{l}25.5 \\
25.02 \\
26.0 \\
27.6 \\
28.5 \\
26.5 \\
25.9 \\
26.0\end{array}$ & $\begin{array}{l}2 \\
2 \\
2 \\
2 \\
2 \\
2 \\
2 \\
2\end{array}$ & $\begin{array}{r}7.2 \\
5.4 \\
7.4 \\
6.4 \\
8.6 \\
10.2 \\
8.2 \\
8.2\end{array}$ & $\begin{array}{r}7.8 \\
5.6 \\
7.6 \\
6.8 \\
10.0 \\
11.02 \\
9.0 \\
9.0\end{array}$ & $\begin{array}{r}8.4 \\
6.2 \\
8.0 \\
7.4 \\
10.4 \\
12.2 \\
9.8 \\
9.6\end{array}$ & $\begin{array}{r}8.4 \\
6.2 \\
8.0 \\
7.4 \\
10.6 \\
12.6 \\
10.2 \\
10.0\end{array}$ \\
\hline $\begin{array}{l}.22 \\
22 \\
22 \\
22 \\
22 \\
22 \\
22 \\
22\end{array}$ & $\begin{array}{r}0 \\
3 \\
6 \\
9 \\
12 \\
15 \\
18 \\
21\end{array}$ & $\begin{array}{l}23.4 \\
23.2 \\
23.9 \\
26.9 \\
28.9 \\
28.9 \\
27.4 \\
25.7\end{array}$ & $\begin{array}{l}21.9 \\
22.5 \\
22.9 \\
23.6 \\
23.8 \\
23.6 \\
23.0 \\
22.6\end{array}$ & $\begin{array}{l}23.3 \\
23.22 \\
23.9 \\
27.1 \\
29.2 \\
29.0 \\
27.04 \\
25.7\end{array}$ & $\begin{array}{l}21.9 \\
22.4 \\
22.9 \\
23.5 \\
23.7 \\
23.5 \\
22.9 \\
22.5\end{array}$ & $\begin{array}{l}23.4 \\
23.3 \\
24.1 \\
27.4 \\
29.4 \\
29.4 \\
27.6 \\
25.9\end{array}$ & $\begin{array}{l}21.9 \\
22.5 \\
22.9 \\
23.7 \\
23.9 \\
23.5 \\
22.9 \\
22.5\end{array}$ & $\begin{array}{l}23.6 \\
23.5 \\
24.4 \\
27.8 \\
29.9 \\
29.7 \\
27.0 \\
26.9\end{array}$ & $\begin{array}{l}22.2 \\
23.0 \\
23.2 \\
23.9 \\
24.2 \\
24.0 \\
23.2 \\
22.9\end{array}$ & $\begin{array}{l}25.8 \\
25.6 \\
26.0 \\
26.8 \\
27.2 \\
26.1 \\
25.6 \\
25.5\end{array}$ & $\begin{array}{l}2 \\
2 \\
2 \\
2 \\
2 \\
2 \\
2 \\
2\end{array}$ & $\begin{array}{l}10.2 \\
9.2 \\
15.6 \\
16.2 \\
16.4 \\
16.6 \\
16.0 \\
18.6\end{array}$ & $\begin{array}{l}11.0 \\
10.2 \\
17.6 \\
18.2 \\
18.4 \\
18.6 \\
18.2 \\
22.2\end{array}$ & $\begin{array}{l}11.8 \\
11.0 \\
19.4 \\
20.6 \\
20.4 \\
20.8 \\
20.0 \\
24.0\end{array}$ & $\begin{array}{l}12.2 \\
11.2 \\
20.0 \\
20.6 \\
21.0 \\
21.6 \\
20.8 \\
25.0\end{array}$ \\
\hline $\begin{array}{l}23 \\
23 \\
23 \\
23 \\
23 \\
23 \\
23 \\
23\end{array}$ & $\begin{array}{r}0 \\
3 \\
6 \\
9 \\
12 \\
15 \\
18 \\
21\end{array}$ & $\begin{array}{l}25 \cdot 7 \\
24 \cdot 9 \\
24 \cdot 9\end{array}$ & $\begin{array}{l}22.7 \\
22.6 \\
22.9\end{array}$ & $\begin{array}{l}25.7 \\
24.8 \\
24.9\end{array}$ & $\begin{array}{l}22.5 \\
22.5\end{array}$ & $\begin{array}{l}25.9 \\
25.0 \\
25.0\end{array}$ & $\begin{array}{l}22.6 \\
22.6 \\
22.8\end{array}$ & $\begin{array}{l}26 \cdot 1 \\
25 \cdot 2 \\
25.2\end{array}$ & $\begin{array}{l}22.9 \\
22.9 \\
23.1\end{array}$ & $\begin{array}{l}25.2 \\
25.1 \\
25.6\end{array}$ & $\begin{array}{l}2 \\
2 \\
2 \\
2 \\
2 \\
2 \\
2 \\
2\end{array}$ & $\begin{array}{l}21.0 \\
20.0 \\
19.6 \\
20.4 \\
20.0 \\
19.2 \\
17.6 \\
18.8\end{array}$ & $\begin{array}{l}23.6 \\
22.8 \\
22.0 \\
23.0 \\
22.6 \\
21.2\end{array}$ & $\begin{array}{l}26.0 \\
25.6 \\
24.0 \\
25.6 \\
25.0 \\
27.8 \\
27.8 \\
23.0\end{array}$ & $\begin{array}{l}27.0 \\
26.6 \\
25.0 \\
26.4 \\
26.0 \\
24.2\end{array}$ \\
\hline $\begin{array}{l}24 \\
24 \\
24 \\
24 \\
24 \\
24 \\
24 \\
24\end{array}$ & $\begin{array}{r}0 \\
3 \\
6 \\
9 \\
12 \\
15 \\
18 \\
21\end{array}$ & $\begin{array}{l}28.7 \\
29.7\end{array}$ & $\begin{array}{l}23.8 \\
24.3\end{array}$ & & & $\begin{array}{l}28.9 \\
30.5\end{array}$ & $\begin{array}{l}23.8 \\
24.5\end{array}$ & $\begin{array}{l}29.3 \\
31.1\end{array}$ & $\begin{array}{l}24.1 \\
24.9\end{array}$ & $\begin{array}{l}27.3 \\
27.7\end{array}$ & $\begin{array}{l}2 \\
2 \\
2 \\
2 \\
2 \\
2 \\
2 \\
2\end{array}$ & $\begin{array}{l}18.2 \\
18.8 \\
19.2 \\
19.4 \\
17.8 \\
18.6 \\
16.6 \\
16.8\end{array}$ & $\begin{array}{l}20.2 \\
21.0 \\
21.6 \\
22.00 \\
20.0 \\
21.0 \\
18.8 \\
19.0\end{array}$ & $\begin{array}{l}22.02 \\
23.0 \\
24.0 \\
24.02 \\
22.02 \\
23.4 \\
20.8 \\
20.8\end{array}$ & $\begin{array}{l}23.2 \\
24.0 \\
24.6 \\
25.0 \\
23.0 \\
24.8 \\
21.5 \\
21.8\end{array}$ \\
\hline $\begin{array}{l}25 \\
25 \\
25 \\
25 \\
25 \\
25 \\
25 \\
25\end{array}$ & $\begin{array}{r}0 \\
3 \\
6 \\
9 \\
12 \\
15 \\
18 \\
21\end{array}$ & & & & & & & & & & $\begin{array}{l}2 \\
2 \\
2 \\
2 \\
2 \\
2 \\
2 \\
2\end{array}$ & $\begin{array}{l}16.6 \\
18.2 \\
20.4 \\
20.2 \\
16.2 \\
18.6 \\
12.2 \\
13.0\end{array}$ & $\begin{array}{l}18.8 \\
20.4 \\
22.8 \\
22.6 \\
18.4 \\
21.2 \\
13.6 \\
14.6\end{array}$ & $\begin{array}{l}20.6 \\
22.6 \\
25.4 \\
25.4 \\
20.4 \\
23.4 \\
15.0 \\
16.0\end{array}$ & $\begin{array}{l}21.6 \\
23.2 \\
26.0 \\
26.4 \\
21.2 \\
24.6 \\
15.6 \\
16.8\end{array}$ \\
\hline $\begin{array}{l}26 \\
26 \\
26 \\
26 \\
26 \\
26 \\
26 \\
26\end{array}$ & $\begin{array}{r}0 \\
3 \\
6 \\
9 \\
12 \\
15 \\
18 \\
21\end{array}$ & $\begin{array}{l}30.5 \\
31.8 \\
32.1 \\
29.5 \\
26.0\end{array}$ & $\begin{array}{l}22.8 \\
23.5 \\
23.9 \\
23.5 \\
21.9\end{array}$ & $\begin{array}{l}30.6 \\
32.3 \\
32.6 \\
30.0 \\
25.8\end{array}$ & $\begin{array}{l}22,5 \\
23.2 \\
23.5 \\
23.1 \\
21.4\end{array}$ & $\begin{array}{l}32.2 \\
32.7 \\
32.9 \\
30.6 \\
25.8\end{array}$ & $\begin{array}{l}22.7 \\
23.4 \\
23.4 \\
23.0 \\
21.4\end{array}$ & $\begin{array}{l}31.8 \\
33.4 \\
33.6 \\
31.1 \\
26.0\end{array}$ & $\begin{array}{l}23.3 \\
24.0 \\
24.3 \\
23.5 \\
21.9\end{array}$ & $\begin{array}{l}27.7 \\
27.9 \\
26.6 \\
26.2 \\
26.1\end{array}$ & $\begin{array}{l}2 \\
2 \\
2 \\
2 \\
2 \\
2 \\
2 \\
3\end{array}$ & $\begin{array}{r}13.4 \\
11.8 \\
12.2 \\
11.2 \\
10.8 \\
13.6 \\
6.0 \\
10.8\end{array}$ & $\begin{array}{r}15.0 \\
13.2 \\
13.6 \\
12.4 \\
12.4 \\
15.6 \\
7.2 \\
11.6\end{array}$ & $\begin{array}{r}16.2 \\
14.2 \\
14.8 \\
13.8 \\
13.8 \\
17.2 \\
8.4 \\
12.6\end{array}$ & $\begin{array}{r}17.0 \\
14.8 \\
15.0 \\
13.8 \\
14.2 \\
18.0 \\
8.6 \\
13.0\end{array}$ \\
\hline $\begin{array}{l}27 \\
27 \\
27 \\
27\end{array}$ & $\begin{array}{l}0 \\
3 \\
6 \\
9\end{array}$ & $\begin{array}{l}24.1 \\
21.8\end{array}$ & $\begin{array}{l}20.6 \\
29.5\end{array}$ & $\begin{array}{l}23.9 \\
21.6\end{array}$ & $\begin{array}{l}20.3 \\
29.2\end{array}$ & $\begin{array}{l}24.0 \\
21.5\end{array}$ & $\begin{array}{l}20.3 \\
19.2\end{array}$ & $\begin{array}{l}24.0 \\
21.8\end{array}$ & $\begin{array}{l}20.7 \\
19.8\end{array}$ & $\begin{array}{l}26.0 \\
25.9\end{array}$ & $\begin{array}{l}3 \\
3 \\
2 \\
2\end{array}$ & $\begin{array}{r}6.0 \\
10.0 \\
11.8 \\
6.2\end{array}$ & $\begin{array}{r}6.6 \\
10.6 \\
12.6 \\
6.8\end{array}$ & $\begin{array}{r}6.8 \\
11.0 \\
13.4 \\
7.4\end{array}$ & $\begin{array}{r}7.0 \\
11.2 \\
13: 6 \\
7.6\end{array}$ \\
\hline $\begin{array}{l}27 \\
27 \\
27 \\
27 \\
27\end{array}$ & $\begin{array}{r}12 \\
15 \\
18 \\
21\end{array}$ & $\begin{array}{l}30.9 \\
31.2 \\
29.5 \\
27.9\end{array}$ & $\begin{array}{l}22.6 \\
22.6 \\
23.3 \\
21.8\end{array}$ & $\begin{array}{l}31.5 \\
31.8 \\
29.8 \\
27.9\end{array}$ & $\begin{array}{l}22 \cdot 4 \\
22 \cdot 3 \\
22 \cdot 8 \\
22 \cdot 4\end{array}$ & $\begin{array}{l}31.8 \\
32.2 \\
30.3 \\
28.0\end{array}$ & $\begin{array}{l}21.3 \\
22 \cdot 0 \\
22.6 \\
21.2\end{array}$ & $\begin{array}{l}32 \cdot 2 \\
32 \cdot 6 \\
30 \cdot 7 \\
28 \cdot 3\end{array}$ & $\begin{array}{l}22 \cdot 8 \\
22 \cdot 7 \\
23 \cdot 1 \\
21.9\end{array}$ & $\begin{array}{l}27.9 \\
26.7 \\
26.4 \\
26.3\end{array}$ & $\begin{array}{l}2 \\
2 \\
2 \\
2 \\
2\end{array}$ & $\begin{array}{l}0.2 \\
8.4 \\
8.0 \\
7.4 \\
9.6\end{array}$ & $\begin{array}{r}9.8 \\
9.6 \\
8.4 \\
10.8\end{array}$ & $\begin{array}{l}10.4 \\
10.4 \\
10.0 \\
11.6\end{array}$ & $\begin{array}{l}10.8 \\
11.0 \\
10.8 \\
12.4\end{array}$ \\
\hline $\begin{array}{l}28 \\
28 \\
28 \\
28 \\
28 \\
28 \\
28 \\
28\end{array}$ & $\begin{array}{r}0 \\
3 \\
6 \\
-9 \\
12 \\
15 \\
18 \\
21\end{array}$ & $\begin{array}{l}25.9 \\
21.1 \\
20.2 \\
22.2 \\
28.1 \\
28.0 \\
26.3 \\
24.0\end{array}$ & $\begin{array}{l}21.8 \\
19.3 \\
18.8 \\
19.3 \\
20.9 \\
21.4 \\
21.7 \\
21.3\end{array}$ & $\begin{array}{l}25.9 \\
20.8 \\
19.9 \\
22.1 \\
26.8 \\
27.6 \\
25.9 \\
23.8\end{array}$ & $\begin{array}{l}21.4 \\
18.8 \\
18.4 \\
19.1 \\
20.5 \\
20.4 \\
21.3 \\
21.1\end{array}$ & $\begin{array}{l}25.9 \\
20.5 \\
19.9 \\
22.2 \\
27.2 \\
27.8 \\
25.9 \\
23.9\end{array}$ & $\begin{array}{l}21.3 \\
18.8 \\
18.3 \\
19.1 \\
21.1 \\
20.6 \\
21.3 \\
21.0\end{array}$ & $\begin{array}{l}26.1 \\
20.6 \\
20.0 \\
22.4 \\
27.6 \\
27.9 \\
26.02 \\
24.02\end{array}$ & $\begin{array}{l}21.8 \\
18.6 \\
18.6 \\
19.4 \\
21.6 \\
20.9 \\
21.6 \\
21.4\end{array}$ & $\begin{array}{l}26.1 \\
25.9 \\
26.0 \\
27.2 \\
28.6 \\
27.4 \\
26.0 \\
25.8\end{array}$ & $\begin{array}{l}2 \\
3 \\
2 \\
2 \\
3 \\
3 \\
3 \\
3\end{array}$ & $\begin{array}{r}9.8 \\
14.0 \\
11.2 \\
8.8 \\
2.4 \\
7.6 \\
6.2 \\
4.4\end{array}$ & $\begin{array}{r}11.0 \\
15.6 \\
12.0 \\
9.8 \\
2.8 \\
8.4 \\
6.6 \\
4.6\end{array}$ & $\begin{array}{r}11.8 \\
16.2 \\
12.6 \\
10.4 \\
3.2 \\
8.8 \\
7.4 \\
5.0\end{array}$ & $\begin{array}{l}12.4 \\
17.2 \\
12.8 \\
10.6\end{array}$ \\
\hline $\begin{array}{l}29 \\
29 \\
29 \\
29 \\
29 \\
29 \\
29 \\
29\end{array}$ & $\begin{array}{r}0 \\
3 \\
6 \\
9 \\
12 \\
15 \\
18 \\
21\end{array}$ & $\begin{array}{l}23.4 \\
22.8 \\
21.7 \\
23.3 \\
24.6 \\
24.5 \\
23.4 \\
22.0\end{array}$ & $\begin{array}{l}21.1 \\
20.8 \\
20.6 \\
20.7 \\
19.6 \\
27.5 \\
17.7 \\
17.0\end{array}$ & $\begin{array}{l}23.3 \\
22.8 \\
21.5 \\
22,9 \\
24.4 \\
24.3 \\
23.3 \\
21.9\end{array}$ & $\begin{array}{l}21.0 \\
20.7 \\
20.3 \\
20.3 \\
19.1 \\
17.2 \\
17.4 \\
16.9\end{array}$ & $\begin{array}{l}23.4 \\
22.8 \\
21.5 \\
23.2 \\
24.5 \\
24.4 \\
23.3 \\
21.8\end{array}$ & $\begin{array}{l}21.1 \\
20.7 \\
20.4 \\
20.4 \\
19.0 \\
16.9 \\
17.3 \\
16.8\end{array}$ & $\begin{array}{l}23.5 \\
22.9 \\
21.6 \\
23.0 \\
24.7 \\
24.5 \\
23.5 \\
21.9\end{array}$ & $\begin{array}{l}21.6 \\
21.2 \\
20.9 \\
20.8 \\
19 \cdot 2 \\
17.1 \\
17.6 \\
17.0\end{array}$ & $\begin{array}{l}25.8 \\
25.7 \\
26.1 \\
26.6 \\
26.0 \\
26.2 \\
25.9 \\
25.9\end{array}$ & $\begin{array}{l}2 \\
2 \\
3 \\
3 \\
3 \\
3 \\
3 \\
2\end{array}$ & $\begin{array}{r}4.0 \\
5.0 \\
6.6 \\
4.8 \\
10.0 \\
8.6 \\
5.2 \\
4.2\end{array}$ & $\begin{array}{r}4.4 \\
5.4 \\
7.2 \\
5.6 \\
10.4 \\
9.0 \\
5.4 \\
4.4\end{array}$ & $\begin{array}{r}4.6 \\
5.6 \\
7.8 \\
6.2 \\
10.8 \\
9.2 \\
5.6 \\
4.6\end{array}$ & $\begin{array}{r}4.8 \\
5.2 \\
7.6 \\
6.0 \\
11.0 \\
9.2 \\
5.6 \\
4.6\end{array}$ \\
\hline $\begin{array}{l}30 \\
30 \\
30 \\
30 \\
30 \\
30 \\
30 \\
30\end{array}$ & $\begin{array}{r}0 \\
3 \\
6 \\
9 \\
12 \\
15 \\
18 \\
21\end{array}$ & $\begin{array}{l}20.8 \\
20.7 \\
21 \cdot 7 \\
24 \cdot 3 \\
26.6 \\
27.2 \\
26.1 \\
23.7\end{array}$ & $\begin{array}{l}16.7 \\
16.9 \\
16.6 \\
17.0 \\
19.0 \\
20.0 \\
20.1 \\
19.3\end{array}$ & $\begin{array}{l}20.7 \\
20.7 \\
21.7 \\
24.3 \\
26.8 \\
27.3 \\
26.0 \\
23.6\end{array}$ & $\begin{array}{l}16.4 \\
16.7 \\
16.2 \\
16.6 \\
18.8 \\
19.5 \\
19.8 \\
19.0\end{array}$ & $\begin{array}{l}20.7 \\
20.7 \\
21.7 \\
24.6 \\
27.0 \\
27.4 \\
26.1 \\
23.5\end{array}$ & $\begin{array}{l}16.4 \\
16.5 \\
16.2 \\
16.6 \\
18.8 \\
19.4 \\
19.6 \\
18.9\end{array}$ & $\begin{array}{l}20.9 \\
20.7 \\
22.17 \\
24.6 \\
27.0 \\
27.7 \\
25.3 \\
23.7\end{array}$ & $\begin{array}{l}16.5 \\
16.9 \\
16.8 \\
17.0 \\
21.0 \\
20.0 \\
19.8 \\
29.1\end{array}$ & $\begin{array}{l}25.5 \\
25.03 \\
26.0 \\
27.12 \\
28.3 \\
27.6 \\
26.4 \\
25.8\end{array}$ & $\begin{array}{l}2 \\
2 \\
2 \\
2 \\
2 \\
2 \\
2 \\
2\end{array}$ & $\begin{array}{l}4.0 \\
2.8 \\
5.6 \\
6.4 \\
3.0 \\
6.8 \\
7.6 \\
8.0\end{array}$ & $\begin{array}{l}4.4 \\
3.0 \\
6.0 \\
6.4 \\
3.4 \\
7.8 \\
8.4 \\
8.8\end{array}$ & $\begin{array}{l}4.6 \\
3.2 \\
6.6 \\
6.6\end{array}$ & $\begin{array}{l}5.0 \\
3.2 \\
6.4 \\
7.2 \\
3.6 \\
8.4 \\
9.6 \\
9.8\end{array}$ \\
\hline
\end{tabular}


TABLE 10 Table 10.-Three-hour averages of air and water-surface temperatures and wind directions and speed, April 1950-August
1951, Lake Hefner-Continued

STATION 1 THREE-HOURLY AVERAGES

JULY, 1950

\begin{tabular}{|c|c|c|c|c|c|c|c|c|c|c|c|c|c|c|c|}
\hline \multirow{4}{*}{ 总 } & \multirow{4}{*}{ 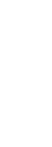 } & \multicolumn{8}{|c|}{ Average air temperature $\left({ }^{\circ} \mathrm{C}\right)$ at indicated height } & \multirow{4}{*}{$\begin{array}{l}\text { Average } \\
\text { water- } \\
\text { surface } \\
\text { tempera- } \\
\text { ture } \\
\text { ('C) }\end{array}$} & \multirow{4}{*}{$\begin{array}{l}\text { Average } \\
\text { wind } \\
\text { direction } \\
\text { (coded) }\end{array}$} & \multirow{2}{*}{\multicolumn{4}{|c|}{$\begin{array}{l}\text { Average wind speed (knots) } \\
\text { at indicated height }\end{array}$}} \\
\hline & & \multirow{2}{*}{\multicolumn{2}{|c|}{$\begin{array}{c}2 \\
\text { meters }\end{array}$}} & \multirow{2}{*}{\multicolumn{2}{|c|}{$\begin{array}{c}4 \\
\text { meters }\end{array}$}} & \multirow{2}{*}{\multicolumn{2}{|c|}{$\begin{array}{c}8 \\
\text { meters }\end{array}$}} & \multirow{2}{*}{\multicolumn{2}{|c|}{$\begin{array}{c}16 \\
\text { meters }\end{array}$}} & & & & & & \\
\hline & & & & & & & & & & & & 2 & 4 & 8 & 16 \\
\hline & & $\begin{array}{l}\text { Dry } \\
\text { bulb }\end{array}$ & $\begin{array}{l}\text { Wet } \\
\text { bulb }\end{array}$ & $\begin{array}{l}\text { Dry } \\
\text { bulb }\end{array}$ & $\begin{array}{l}\text { Wet } \\
\text { bulb }\end{array}$ & $\begin{array}{l}\text { Dry } \\
\text { bulb }\end{array}$ & $\begin{array}{l}\text { Wet } \\
\text { bulb }\end{array}$ & $\begin{array}{l}\text { Dry } \\
\text { bulb }\end{array}$ & $\begin{array}{l}\text { Wet } \\
\text { bulb }\end{array}$ & & & & & & \\
\hline
\end{tabular}

\begin{tabular}{|c|c|c|c|c|c|c|c|c|c|c|c|c|c|c|c|}
\hline $\begin{array}{l}1 \\
1 \\
1 \\
1 \\
1 \\
1 \\
1 \\
1\end{array}$ & $\begin{array}{r}0 \\
3 \\
6 \\
9 \\
12 \\
15 \\
18 \\
21\end{array}$ & $\begin{array}{l}21.9 \\
21.0 \\
22.8 \\
25.9 \\
28.0 \\
28.7 \\
27.4 \\
24.7\end{array}$ & $\begin{array}{l}18.6 \\
18.1 \\
18.7 \\
19.9 \\
20.4 \\
20.9 \\
20.3 \\
19.9\end{array}$ & $\begin{array}{l}21.7 \\
20.8 \\
22.9 \\
25.9 \\
28.2 \\
29.0 \\
27.4 \\
24.7\end{array}$ & $\begin{array}{l}18.2 \\
18.0 \\
18.4 \\
19.5 \\
20.2 \\
20.7 \\
19.9 \\
19.7\end{array}$ & $\begin{array}{l}21.8 \\
20.8 \\
23.0 \\
26.2 \\
28.4 \\
29.2 \\
27.5 \\
24.7\end{array}$ & $\begin{array}{l}18.3 \\
17.8 \\
18.4 \\
19.5 \\
20.1 \\
20.6 \\
19.8 \\
19.5\end{array}$ & $\begin{array}{l}22.0 \\
20.7 \\
23.3 \\
26.5 \\
28.7 \\
29.5 \\
27.7 \\
24.8\end{array}$ & $\begin{array}{l}18.4 \\
18.1 \\
18.7 \\
19.8 \\
20.7 \\
21.2 \\
20.3 \\
19.8\end{array}$ & $\begin{array}{l}25.5 \\
25.7 \\
26.3 \\
26.9 \\
27.0 \\
26.3 \\
25.9 \\
25.7\end{array}$ & $\begin{array}{l}2 \\
2 \\
2 \\
2 \\
2 \\
2 \\
2 \\
4\end{array}$ & $\begin{array}{r}7.1 \\
7.1 \\
11.2 \\
13.9 \\
13.4 \\
14.7 \\
10.0 \\
7.2\end{array}$ & $\begin{array}{r}7.7 \\
7.4 \\
12.2 \\
15.4 \\
15.0 \\
16.5 \\
11.2 \\
7.9\end{array}$ & $\begin{array}{r}8.3 \\
8.3 \\
13.4 \\
17.0 \\
16.6 \\
18.2 \\
12.2 \\
8.7\end{array}$ & $\begin{array}{r}8.8 \\
8.9 \\
13.6 \\
17.3 \\
16.7 \\
18.9 \\
12.9 \\
8.7\end{array}$ \\
\hline $\begin{array}{l}2 \\
2 \\
2 \\
2 \\
2 \\
2 \\
2 \\
2\end{array}$ & $\begin{array}{r}0 \\
3 \\
6 \\
9 \\
12 \\
15 \\
18 \\
21\end{array}$ & $\begin{array}{l}23.7 \\
22.1 \\
23.3 \\
25.8 \\
28.1 \\
29.5 \\
28.6 \\
26.3\end{array}$ & $\begin{array}{l}19.2 \\
18.4 \\
19.2 \\
20.5 \\
21.6 \\
22.6 \\
22.1 \\
21.2\end{array}$ & $\begin{array}{l}23.6 \\
21.9 \\
23.3 \\
25.8 \\
28 \% 3 \\
30 \% 0 \\
28.7 \\
26.3\end{array}$ & $\begin{array}{r}18.9 \\
18.1 \\
19.0 \\
20.2 \\
21.5 \\
22.4 \\
21.7 \\
21.0\end{array}$ & $\begin{array}{l}23.6 \\
21.9 \\
23.5 \\
26.0 \\
28.6 \\
30.1 \\
28.8 \\
26.4\end{array}$ & $\begin{array}{l}18 \cdot 8 \\
18 \cdot 0 \\
19 \cdot 0 \\
20.2 \\
21.4 \\
22 \cdot 4 \\
21.7 \\
20.9\end{array}$ & $\begin{array}{l}23.9 \\
22.0 \\
23.7 \\
26.4 \\
29.1 \\
30.5 \\
29.0 \\
26.6\end{array}$ & $\begin{array}{l}19.1 \\
18.3 \\
19.4 \\
20.8 \\
22.2 \\
23.0 \\
22.4 \\
21.5\end{array}$ & $\begin{array}{l}25.7 \\
25.4 \\
25.8 \\
26.7 \\
27.2 \\
26.3 \\
25.7 \\
25.7\end{array}$ & $\begin{array}{l}2 \\
2 \\
2 \\
2 \\
2 \\
2 \\
2 \\
2\end{array}$ & $\begin{array}{r}8.2 \\
13.3 \\
11.8 \\
10.3 \\
9.2 \\
12.6 \\
11.6 \\
10.2\end{array}$ & $\begin{array}{r}9.0 \\
14.7 \\
12.9 \\
11.4 \\
10.3 \\
14.3 \\
13.0 \\
11.1\end{array}$ & $\begin{array}{r}9.5 \\
15.9 \\
14.0 \\
12.5 \\
11.3 \\
15.7 \\
14.4 \\
12.4\end{array}$ & $\begin{array}{r}9.8 \\
16.2 \\
14.0 \\
12.7 \\
11.7 \\
16.3 \\
15.1 \\
13.0\end{array}$ \\
\hline $\begin{array}{l}3 \\
3 \\
3 \\
3 \\
3 \\
3 \\
3 \\
3\end{array}$ & $\begin{array}{r}0 \\
3 \\
6 \\
9 \\
12 \\
15 \\
18 \\
21\end{array}$ & $\begin{array}{l}24.3 \\
23.4 \\
23.8 \\
25.8 \\
27.8 \\
28.9 \\
27.6 \\
25.4\end{array}$ & $\begin{array}{l}20.4 \\
20.6 \\
21.2 \\
21.9 \\
22.4 \\
22.6 \\
22.8 \\
22.3\end{array}$ & $\begin{array}{l}24.2 \\
23.3 \\
23.8 \\
25.8 \\
27.8 \\
28.8 \\
27.8 \\
25.4\end{array}$ & $\begin{array}{l}20.1 \\
20.3 \\
21.0 \\
21.5 \\
22.4 \\
22.0 \\
22.7 \\
22.2\end{array}$ & $\begin{array}{l}24.3 \\
23.3 \\
23.9 \\
26.1 \\
28.1 \\
29.4 \\
27.8 \\
25.4\end{array}$ & $\begin{array}{l}20.1 \\
20.3 \\
21.0 \\
21.5 \\
22.2 \\
22.0 \\
22.7 \\
22.0\end{array}$ & $\begin{array}{l}24 \cdot 4 \\
23.4 \\
24.1 \\
26.2 \\
28 \cdot 3 \\
29.6 \\
28.1 \\
25.5\end{array}$ & $\begin{array}{l}20.5 \\
21.0 \\
21 . .5 \\
22.1 \\
22.4 \\
22.0 \\
22.9 \\
22.3\end{array}$ & $\begin{array}{l}25.6 \\
25.6 \\
25.9 \\
26.7 \\
27.2 \\
27.7 \\
26.9 \\
26.6\end{array}$ & $\begin{array}{l}2 \\
2 \\
2 \\
2 \\
4 \\
4 \\
2 \\
2\end{array}$ & $\begin{array}{r}12.2 \\
9.8 \\
8.6 \\
6.2 \\
5.0 \\
2.9 \\
4.0 \\
3.2\end{array}$ & $\begin{array}{r}13.4 \\
10.8 \\
9.2 \\
6.8 \\
5.0 \\
2.7 \\
4.5 \\
3.1\end{array}$ & $\begin{array}{r}14.4 \\
11.7 \\
10.2 \\
7.4 \\
5.7 \\
3.4 \\
5.0 \\
3.6\end{array}$ & $\begin{array}{r}15.3 \\
11.9 \\
10.4 \\
7.6 \\
5.3 \\
2.9 \\
5.1 \\
3.7\end{array}$ \\
\hline $\begin{array}{l}4 \\
4 \\
4 \\
4 \\
4 \\
4 \\
4 \\
4\end{array}$ & $\begin{array}{r}0 \\
3 \\
6 \\
9 \\
12 \\
15 \\
18 \\
21\end{array}$ & $\begin{array}{l}23.9 \\
22.6 \\
20.8 \\
22.9 \\
24,9 \\
23.7 \\
23.4 \\
22.3\end{array}$ & $\begin{array}{l}20.7 \\
20.9 \\
19.7 \\
20.8 \\
21.3 \\
20.9 \\
21.4 \\
21.2\end{array}$ & $\begin{array}{l}23.7 \\
22.6 \\
20.7 \\
22.8 \\
24.7 \\
23.6 \\
23.3 \\
22.3\end{array}$ & $\begin{array}{l}20.6 \\
20.8 \\
19.5 \\
20.6 \\
21.2 \\
20.7 \\
21.3 \\
21.1\end{array}$ & $\begin{array}{l}23.8 \\
22.5 \\
20.4 \\
22.8 \\
24.7 \\
23.6 \\
23.3 \\
22.5\end{array}$ & $\begin{array}{l}20.8 \\
20.8 \\
19.4 \\
20.6 \\
21.1 \\
20.6 \\
21.4 \\
21.3\end{array}$ & $\begin{array}{l}23.9 \\
22.6 \\
20.9 \\
23.2 \\
25.1 \\
23.6 \\
23.3 \\
22.5\end{array}$ & $\begin{array}{l}20.9 \\
20.9 \\
19.5 \\
20.5 \\
21.5 \\
20.5 \\
21.5 \\
21.5\end{array}$ & $\begin{array}{l}26.3 \\
26.1 \\
26.0 \\
26.5 \\
27.2 \\
26.1 \\
26.1 \\
25.7\end{array}$ & $\begin{array}{l}2 \\
2 \\
2 \\
3 \\
3 \\
2 \\
3 \\
3\end{array}$ & $\begin{array}{l}3.7 \\
5.9 \\
7.2 \\
5.6 \\
3.0 \\
4.1 \\
5.0 \\
4.1\end{array}$ & $\begin{array}{l}3.9 \\
6.3 \\
7.1 \\
5.9 \\
4.1 \\
7.1 \\
5.4 \\
4.1\end{array}$ & $\begin{array}{l}4.2 \\
6.4 \\
7.9 \\
6.1 \\
4.2 \\
4.5 \\
5.3 \\
4.3\end{array}$ & $\begin{array}{l}4.2 \\
6.6 \\
7.6 \\
6.0 \\
4.3 \\
5.0 \\
5.2 \\
4.4\end{array}$ \\
\hline $\begin{array}{l}5 \\
5 \\
5 \\
5 \\
5 \\
5 \\
5 \\
5\end{array}$ & $\begin{array}{r}0 \\
3 \\
6 \\
9 \\
12 \\
15 \\
18 \\
21\end{array}$ & $\begin{array}{l}22.6 \\
22.4 \\
22.6 \\
23.3 \\
27.1 \\
29.6 \\
28.3 \\
23.6\end{array}$ & $\begin{array}{l}21.7 \\
21.5 \\
21.7 \\
21.4 \\
21.2 \\
22.2 \\
22.6 \\
22.0\end{array}$ & $\begin{array}{l}22.7 \\
22.5 \\
22.5 \\
23.5 \\
27.7 \\
29.7 \\
27.9 \\
23.5\end{array}$ & $\begin{array}{l}21.6 \\
21.4 \\
22 \cdot 3 \\
21 \cdot 1 \\
21.0 \\
21.9 \\
22.2 \\
22.0\end{array}$ & $\begin{array}{l}22.7 \\
23.0 \\
23.0 \\
23.5 \\
26.4 \\
30.1 \\
27.9 \\
23.5\end{array}$ & $\begin{array}{l}21 \cdot 8 \\
21 \bullet 6 \\
21.5 \\
21 \bullet 2 \\
20.5 \\
21.9 \\
22 \cdot 1 \\
22.0\end{array}$ & $\begin{array}{l}22.9 \\
22,6 \\
22.6 \\
23.4 \\
26.9 \\
29.7 \\
28.0 \\
23.5\end{array}$ & $\begin{array}{l}22.0 \\
21.7 \\
21.8 \\
20.9 \\
21.1 \\
22.1 \\
22.4 \\
22.3\end{array}$ & $\begin{array}{l}25.8 \\
25.7 \\
25.6 \\
26.6 \\
27.7 \\
28.0 \\
26.8 \\
26.0\end{array}$ & $\begin{array}{l}2 \\
2 \\
2 \\
3 \\
3 \\
4 \\
4 \\
3\end{array}$ & $\begin{array}{l}3.2 \\
3.1 \\
4.7 \\
9.2 \\
3.6 \\
0.6 \\
3.2 \\
8.4\end{array}$ & $\begin{array}{l}3.3 \\
3.0 \\
4 \cdot 1 \\
8.7 \\
4 \cdot 3 \\
1.1 \\
3.1 \\
8.8\end{array}$ & $\begin{array}{r}3.5 \\
3.3 \\
5.3 \\
10.1 \\
4.4 \\
1.6 \\
3.8 \\
9.0\end{array}$ & $\begin{array}{r}3.6 \\
3.7 \\
5.0 \\
10.2 \\
4.9 \\
1.6 \\
3.9 \\
9.2\end{array}$ \\
\hline $\begin{array}{l}6 \\
6 \\
6 \\
6 \\
6 \\
6 \\
6 \\
6\end{array}$ & $\begin{array}{r}0 \\
3 \\
6 \\
9 \\
12 \\
15 \\
18 \\
21\end{array}$ & $\begin{array}{l}22.7 \\
21.3 \\
21.8 \\
24.5 \\
26.1 \\
26.4 \\
26.0 \\
24.4\end{array}$ & $\begin{array}{l}21.9 \\
20.7 \\
20.5 \\
20.9 \\
20.9 \\
20.9 \\
21.5 \\
21.7\end{array}$ & $\begin{array}{l}22.6 \\
21.1 \\
21.4 \\
24.0 \\
25.8 \\
26.3 \\
25.9 \\
24.3\end{array}$ & $\begin{array}{l}21 \cdot 7 \\
20.5 \\
20.1 \\
20.5 \\
20.6 \\
20.6 \\
21.4 \\
21.6\end{array}$ & $\begin{array}{l}22.5 \\
21.2 \\
21.6 \\
24.1 \\
25.9 \\
26.5 \\
26.0 \\
24.4\end{array}$ & $\begin{array}{l}21.8 \\
20.5 \\
20.3 \\
20.6 \\
20.6 \\
20.7 \\
21.4 \\
21.5\end{array}$ & $\begin{array}{l}22.6 \\
21.0 \\
21.7 \\
24.3 \\
26.7 \\
26.8 \\
26.2 \\
24.5\end{array}$ & $\begin{array}{l}22.0 \\
20.8 \\
20.5 \\
20.8 \\
20.8 \\
21.0 \\
21.7 \\
21.8\end{array}$ & $\begin{array}{l}25.9 \\
25.5 \\
26.1 \\
27.3 \\
27.4 \\
27.0 \\
26.4 \\
26.1\end{array}$ & $\begin{array}{l}3 \\
3 \\
3 \\
3 \\
3\end{array}$ & $\begin{array}{l}6.4 \\
5.4 \\
5.5 \\
5.8 \\
5.2 \\
4.9 \\
4.4 \\
3.8\end{array}$ & $\begin{array}{l}6.3 \\
5.7 \\
5.9 \\
6.2 \\
5.6 \\
5.2 \\
4.6 \\
3.8\end{array}$ & $\begin{array}{l}6.8 \\
5.8 \\
6.4 \\
6.4 \\
5.7 \\
5.6 \\
4.8 \\
4.1\end{array}$ & $\begin{array}{l}6.8 \\
5.9 \\
6.1 \\
6.5 \\
5.8 \\
6.0 \\
5.2 \\
4.4\end{array}$ \\
\hline $\begin{array}{l}7 \\
7 \\
7 \\
7 \\
7 \\
7 \\
7 \\
7\end{array}$ & $\begin{array}{r}0 \\
3 \\
6 \\
9 \\
12 \\
15 \\
18 \\
21\end{array}$ & $\begin{array}{l}23.2 \\
21.08 \\
22.6 \\
25.6 \\
27.5 \\
25.5 \\
26.0 \\
23.3\end{array}$ & $\begin{array}{l}20.8 \\
20.2 \\
20.9 \\
21.6 \\
21.5 \\
22.0 \\
22.1 \\
21.3\end{array}$ & $\begin{array}{l}22.9 \\
21.7 \\
22.6 \\
25 \cdot 7 \\
27.7 \\
25.5 \\
25.8 \\
23.3\end{array}$ & $\begin{array}{l}20.7 \\
20.1 \\
20 \cdot 8 \\
21.5 \\
21.0 \\
21.8 \\
22.1 \\
21.1\end{array}$ & $\begin{array}{l}23.0 \\
21.8 \\
22.8 \\
25.9 \\
27.9 \\
25.9 \\
25.8 \\
23.4\end{array}$ & $\begin{array}{l}20.0 \\
20.1 \\
21.0 \\
21.5 \\
21.0 \\
21.6 \\
21.8 \\
21.0\end{array}$ & $\begin{array}{l}23.1 \\
21.8 \\
23.2 \\
25.2 \\
28.2 \\
25.5 \\
25.9 \\
23.5\end{array}$ & $\begin{array}{l}20.9 \\
20.4 \\
21.3 \\
21.8 \\
21.4 \\
21.8 \\
22.2 \\
21.6\end{array}$ & $\begin{array}{l}26.0 \\
25.9 \\
26.3 \\
27.5 \\
28.0 \\
27.1 \\
26.2 \\
25.9\end{array}$ & $\begin{array}{l}2 \\
2 \\
2 \\
2 \\
2 \\
3 \\
2 \\
2\end{array}$ & $\begin{array}{r}3.8 \\
5.2 \\
6.0 \\
7.8 \\
5.6 \\
12.1 \\
8.2 \\
5.7\end{array}$ & $\begin{array}{r}3.8 \\
6.5 \\
6.4 \\
8.7 \\
7.3 \\
23.0 \\
9.0 \\
6.1\end{array}$ & $\begin{array}{r}3.9 \\
6.8 \\
6.7 \\
9.4 \\
7.8 \\
13.7 \\
0.6 \\
6.4\end{array}$ & $\begin{array}{r}3.6 \\
6.7 \\
6.7 \\
9.4 \\
8.0 \\
13.9 \\
9.8 \\
6.6\end{array}$ \\
\hline $\begin{array}{l}8 \\
8 \\
8 \\
8 \\
8 \\
8 \\
8 \\
8\end{array}$ & $\begin{array}{r}0 \\
3 \\
6 \\
9 \\
12 \\
15 \\
18 \\
21\end{array}$ & $\begin{array}{l}23.0 \\
22.2 \\
23.0 \\
25.3 \\
26.6 \\
27.2 \\
26.5 \\
25.4\end{array}$ & $\begin{array}{l}21.8 \\
21.4 \\
21.4 \\
22.1 \\
22.7 \\
22.9 \\
22.7 \\
22.2\end{array}$ & $\begin{array}{l}22.9 \\
22 \cdot 1 \\
23.0 \\
25 \cdot 3 \\
26 \cdot 7 \\
27 \cdot 3 \\
26 \cdot 4 \\
25.4\end{array}$ & $\begin{array}{l}21 \cdot 6 \\
21 \cdot 1 \\
21 \cdot 3 \\
21 \bullet 9 \\
22 \cdot 6 \\
22 \cdot 8 \\
22 \cdot 7 \\
22.0\end{array}$ & $\begin{array}{l}22.9 \\
22.1 \\
23.1 \\
25.6 \\
26.9 \\
27.6 \\
26.5\end{array}$ & $\begin{array}{l}21.5 \\
21.1 \\
21.4 \\
21.9 \\
22.6 \\
22.8 \\
22.6\end{array}$ & $\begin{array}{l}23,0 \\
22.1 \\
23,4 \\
25.8 \\
27,0 \\
27,9 \\
26,6\end{array}$ & $\begin{array}{l}21.9 \\
21.5 \\
21.7 \\
22.1 \\
22.9 \\
23.0 \\
22.9\end{array}$ & $\begin{array}{l}26.0 \\
26.0 \\
26.5 \\
25.5 \\
26.6 \\
26.6 \\
25.9\end{array}$ & $\begin{array}{l}2 \\
2 \\
2\end{array}$ & $\begin{array}{r}6.3 \\
7.9 \\
10.7 \\
13.7 \\
12.9 \\
12.8 \\
11.9 \\
12.7\end{array}$ & $\begin{array}{r}6.9 \\
8.6 \\
11.7 \\
15.6 \\
14.6 \\
14.1 \\
13.2 \\
14.1\end{array}$ & $\begin{array}{r}7.0 \\
9.0 \\
12.5 \\
17.3 \\
15.7 \\
15.4 \\
14.2 \\
15.2\end{array}$ & $\begin{array}{r}7.3 \\
9.2 \\
12.7 \\
17.6 \\
16.3 \\
16.0 \\
14.7 \\
16.2\end{array}$ \\
\hline $\begin{array}{l}9 \\
9 \\
9 \\
9 \\
9 \\
9 \\
9 \\
9\end{array}$ & $\begin{array}{r}0 \\
3 \\
6 \\
9 \\
12 \\
15 \\
18 \\
21\end{array}$ & & & & & & & & & & $\begin{array}{l}2 \\
2 \\
2 \\
2\end{array}$ & $\begin{array}{l}13.4 \\
15.4 \\
16.0 \\
12.7 \\
15.7 \\
16.8 \\
16.3 \\
14.8\end{array}$ & $\begin{array}{l}14.8 \\
17.0 \\
17.3 \\
14.1 \\
17.3 \\
18.6 \\
18.0 \\
16.1\end{array}$ & $\begin{array}{l}16.0 \\
18.3 \\
18.7 \\
15.1 \\
18.8 \\
20.1 \\
19.5 \\
17.6\end{array}$ & $\begin{array}{l}15.4 \\
19.3 \\
19.3 \\
15.5 \\
19.9 \\
20.9 \\
20.4 \\
18.2\end{array}$ \\
\hline $\begin{array}{l}10 \\
10 \\
10 \\
10 \\
10 \\
10 \\
10 \\
10\end{array}$ & $\begin{array}{r}0 \\
3 \\
6 \\
9 \\
12 \\
15 \\
18 \\
21\end{array}$ & $\begin{array}{l}23 \cdot 1 \\
24 \cdot 8 \\
25 \cdot 7 \\
24 \cdot 7 \\
23 \cdot 2\end{array}$ & $\begin{array}{l}20.7 \\
21.5 \\
21.8 \\
21.6 \\
21.1\end{array}$ & $\begin{array}{l}22.9 \\
24.8 \\
25.9 \\
24.7 \\
23.1\end{array}$ & $\begin{array}{l}20.7 \\
21.0 \\
21.6 \\
21.4 \\
20.9\end{array}$ & $\begin{array}{l}22.8 \\
25.1 \\
25.1 \\
24.7 \\
23.2\end{array}$ & $\begin{array}{l}20.7 \\
21.1 \\
21.6 \\
21.3 \\
21.1\end{array}$ & $\begin{array}{l}23 \cdot 1 \\
25 \cdot 2 \\
26 \cdot 1 \\
24 \cdot 8 \\
23 \cdot 3\end{array}$ & $\begin{array}{l}20.9 \\
21.4 \\
21.9 \\
21 \cdot 6 \\
21.2\end{array}$ & $\begin{array}{l}26.2 \\
26.5 \\
25.8 \\
25.4 \\
25.2\end{array}$ & $\begin{array}{l}2 \\
2 \\
2 \\
2 \\
2 \\
2 \\
2\end{array}$ & $\begin{array}{r}12.4 \\
12.8 \\
13.3 \\
12.9 \\
14.2 \\
10.1 \\
9.5 \\
8.5\end{array}$ & $\begin{array}{r}13.4 \\
13.8 \\
14.3 \\
14.2 \\
15.9 \\
10.9 \\
10.3 \\
9.2\end{array}$ & $\begin{array}{r}14.7 \\
14.5 \\
15.0 \\
15.2 \\
17.3 \\
11.6 \\
10.9 \\
9.9\end{array}$ & $\begin{array}{r}15.2 \\
14.8 \\
25.2 \\
15.9 \\
17.8 \\
11.9 \\
11.3 \\
9.9\end{array}$ \\
\hline
\end{tabular}


TABLE 10

Table 10. - Three-hour averagea of air and water-surface temperatures and wind directions and speed, April 1950-August 1951, Lake Hefner-Continued

STATION 1

THREE-HOURLY AVERAGES

JULY, 1950

\begin{tabular}{|c|c|c|c|c|c|c|c|c|c|c|c|c|c|c|c|}
\hline \multirow{3}{*}{ 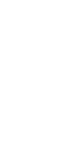 } & \multirow{3}{*}{ 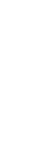 } & \multicolumn{8}{|c|}{ Average air temperature $\left({ }^{\circ} \mathrm{C}\right)$ at indicated height } & \multirow{3}{*}{$\begin{array}{c}\text { Average } \\
\text { water- } \\
\text { surface } \\
\text { tempera- } \\
\text { ture } \\
\left.{ }^{\circ} \mathrm{C}\right)\end{array}$} & \multirow{3}{*}{$\begin{array}{c}\text { Average } \\
\text { wind } \\
\text { direction } \\
\text { (coded) }\end{array}$} & \multirow{2}{*}{\multicolumn{4}{|c|}{$\begin{array}{l}\text { Average wind speed (knots) } \\
\text { at indicated height }\end{array}$}} \\
\hline & & \multicolumn{2}{|c|}{$\begin{array}{c}2 \\
\text { meters }\end{array}$} & \multicolumn{2}{|c|}{$\begin{array}{c}4 \\
\text { meters }\end{array}$} & \multicolumn{2}{|c|}{$\begin{array}{c}8 \\
\text { meters }\end{array}$} & \multicolumn{2}{|c|}{$\begin{array}{c}16 \\
\text { meters }\end{array}$} & & & & & & \\
\hline & & $\begin{array}{l}\text { Dry } \\
\text { bulb }\end{array}$ & $\begin{array}{l}\text { Wet } \\
\text { bulb }\end{array}$ & $\begin{array}{l}\text { Dry } \\
\text { bulb }\end{array}$ & $\begin{array}{l}\text { Wet } \\
\text { bulb }\end{array}$ & $\begin{array}{l}\text { Dry } \\
\text { bulb }\end{array}$ & $\begin{array}{l}\text { Wet } \\
\text { bulb }\end{array}$ & $\begin{array}{l}\text { Dry } \\
\text { bulb }\end{array}$ & $\begin{array}{l}\text { Wet } \\
\text { bulb }\end{array}$ & & & meters & $\begin{array}{c}\mathbf{4} \\
\text { meters }\end{array}$ & meters & meters \\
\hline $\begin{array}{l}11 \\
11 \\
11 \\
11 \\
11 \\
11 \\
11 \\
11\end{array}$ & $\begin{array}{r}0 \\
3 \\
6 \\
9 \\
12 \\
15 \\
18 \\
21\end{array}$ & $\begin{array}{l}22.1 \\
21.8 \\
21.6 \\
23.3 \\
25.3 \\
25.5 \\
25.3 \\
23.7\end{array}$ & $\begin{array}{l}20.9 \\
20.8 \\
20.5 \\
21.0 \\
21.7 \\
22.3 \\
22.2 \\
21.7\end{array}$ & $\begin{array}{l}21.9 \\
21.8 \\
21.6 \\
23.2 \\
25.4 \\
25.6 \\
25.3 \\
23.7\end{array}$ & $\begin{array}{l}20.9 \\
20.7 \\
20.4 \\
20.9 \\
21.6 \\
22.2 \\
22.1 \\
21.6\end{array}$ & $\begin{array}{l}22.1 \\
21.7 \\
21.7 \\
23.4 \\
25.3 \\
25.9 \\
25.3 \\
23.7\end{array}$ & $\begin{array}{l}21.00 \\
20.9 \\
20.5 \\
21.0 \\
21.6 \\
22.44 \\
22.4 \\
21.8\end{array}$ & $\begin{array}{l}22.00 \\
21.99 \\
21.8 \\
23.7 \\
25.5 \\
26.2 \\
25.6 \\
23.9\end{array}$ & $\begin{array}{l}21.2 \\
21.00 \\
20.8 \\
21.1 \\
21.6 \\
22.3 \\
22.02 \\
21.8\end{array}$ & $\begin{array}{l}25.2 \\
25.22 \\
25.44 \\
25.0 \\
26.1 \\
26.0 \\
25.03 \\
25.2\end{array}$ & $\begin{array}{l}2 \\
2 \\
2 \\
2 \\
2 \\
2 \\
2 \\
2\end{array}$ & $\begin{array}{l}6.6 \\
7.00 \\
7.7 \\
8.5 \\
7.2 \\
8.2 \\
8.2 \\
6.4\end{array}$ & $\begin{array}{l}7.2 \\
7.5 \\
8.3 \\
9.5 \\
8.0 \\
9.1 \\
9.0 \\
6.9\end{array}$ & $\begin{array}{r}7.5 \\
7.8 \\
8.7 \\
10.1 \\
8.7 \\
9.7 \\
9.7 \\
7.3\end{array}$ & $\begin{array}{r}7.6 \\
7.7 \\
8.9 \\
10.3 \\
8.9 \\
10.0 \\
10.0 \\
7.6\end{array}$ \\
\hline $\begin{array}{l}12 \\
12 \\
12 \\
12 \\
12 \\
12 \\
12 \\
12\end{array}$ & $\begin{array}{r}0 \\
3 \\
6 \\
9 \\
12 \\
15 \\
18 \\
21\end{array}$ & $\begin{array}{l}23.1 \\
22.2 \\
23.1 \\
26.1 \\
27.0 \\
27.4 \\
23.9 \\
20.5\end{array}$ & $\begin{array}{l}21.0 \\
20.4 \\
20.7 \\
21.6 \\
22.1 \\
22.4 \\
21.06 \\
20.1\end{array}$ & $\begin{array}{l}23.0 \\
22.2 \\
23.2 \\
26.1 \\
27.1 \\
27.7 \\
23.9 \\
20.5\end{array}$ & $\begin{array}{l}20.7 \\
20.1 \\
20.7 \\
21.3 \\
21.8 \\
22.3 \\
21.3 \\
19.9\end{array}$ & $\begin{array}{l}23.1 \\
22.2 \\
23.3 \\
26.3 \\
27.6 \\
27.9 \\
23.9 \\
20.6\end{array}$ & $\begin{array}{l}21.0 \\
20.3 \\
20.8 \\
21.4 \\
22.0 \\
22.3 \\
21.4 \\
20.1\end{array}$ & $\begin{array}{l}23.3 \\
22.3 \\
23.6 \\
26.7 \\
27.8 \\
28.2 \\
23.3 \\
20.8\end{array}$ & $\begin{array}{l}21.1 \\
20.5 \\
21.0 \\
21.5 \\
22.2 \\
22.4 \\
21.2 \\
20.3\end{array}$ & $\begin{array}{l}25.1 \\
25.3 \\
25.06 \\
26.7 \\
26.3 \\
26.1 \\
25.03 \\
25.5\end{array}$ & $\begin{array}{l}2 \\
2 \\
2 \\
2 \\
2 \\
2 \\
2 \\
3\end{array}$ & $\begin{array}{l}6.4 \\
6.7 \\
7.3 \\
8.3 \\
6.1 \\
5.19 \\
6.9 \\
3.9\end{array}$ & $\begin{array}{l}6.9 \\
7.2 \\
8.0 \\
7.0 \\
6.7 \\
6.7 \\
8.5 \\
4.7\end{array}$ & $\begin{array}{l}7.3 \\
7.7 \\
8.4 \\
7.6 \\
7.3 \\
7.3 \\
9.3 \\
5.0\end{array}$ & $\begin{array}{r}8.1 \\
7.9 \\
8.6 \\
7.8 \\
7.5 \\
7.5 \\
-9.5 \\
5.0\end{array}$ \\
\hline $\begin{array}{l}13 \\
13 \\
13 \\
13 \\
13 \\
13 \\
13 \\
13\end{array}$ & $\begin{array}{r}0 \\
3 \\
6 \\
9 \\
12 \\
15 \\
18 \\
21\end{array}$ & $\begin{array}{l}21.3 \\
20.8 \\
19.9 \\
21.5 \\
23.1 \\
24.0 \\
23.1 \\
19.9\end{array}$ & $\begin{array}{l}20.8 \\
19.6 \\
17.6 \\
17.7 \\
17.7 \\
17.7 \\
17.8 \\
17.03\end{array}$ & $\begin{array}{l}21.1 \\
20.6 \\
19.6 \\
21.02 \\
22.8 \\
23.7 \\
22.8 \\
19.6\end{array}$ & $\begin{array}{l}20.3 \\
19.0 \\
17.2 \\
16.8 \\
17.0 \\
16.8 \\
17.4 \\
16.9\end{array}$ & $\begin{array}{l}21.3 \\
20.6 \\
19.5 \\
21.3 \\
22.8 \\
23.8 \\
22.9 \\
19.6\end{array}$ & $\begin{array}{l}20.3 \\
19.0 \\
17.0 \\
16.6 \\
16.9 \\
16.9 \\
17.3 \\
16.9\end{array}$ & $\begin{array}{l}22.5 \\
20.6 \\
19.6 \\
21.4 \\
23.1 \\
23.9 \\
23.0 \\
19.7\end{array}$ & $\begin{array}{l}20.6 \\
19.2 \\
17.2 \\
16.9 \\
16.9 \\
17.0 \\
17.6 \\
16.9\end{array}$ & $\begin{array}{l}25.5 \\
25.2 \\
25.5 \\
26.5 \\
26.4 \\
25.5 \\
25.1 \\
25.0\end{array}$ & $\begin{array}{l}3 \\
3 \\
3 \\
3 \\
3 \\
3 \\
3 \\
3\end{array}$ & $\begin{array}{r}8.3 \\
10.8 \\
13.9 \\
13.2 \\
10.0 \\
8.3 \\
6.6 \\
6.3\end{array}$ & $\begin{array}{r}9.1 \\
12.0 \\
15.6 \\
14.6 \\
11.3 \\
9.0 \\
7.2 \\
6.7\end{array}$ & $\begin{array}{r}9.3 \\
12.2 \\
15.9 \\
15.1 \\
11.6 \\
9.4 \\
7.3 \\
6.8\end{array}$ & $\begin{array}{r}10.0 \\
13.1 \\
17.1 \\
15.9 \\
12.1 \\
9.9 \\
7.6 \\
7.1\end{array}$ \\
\hline $\begin{array}{l}14 \\
14 \\
14 \\
14 \\
14 \\
14 \\
14 \\
14\end{array}$ & $\begin{array}{r}0 \\
3 \\
6 \\
9 \\
12 \\
15 \\
18 \\
21\end{array}$ & $\begin{array}{l}17.7 \\
16.5 \\
18.0 \\
22.2 \\
26.3 \\
27.2 \\
26.03 \\
24.1\end{array}$ & $\begin{array}{l}16.1 \\
15.2 \\
15.6 \\
17.0 \\
19.0 \\
20.5 \\
21.04 \\
22.0\end{array}$ & $\begin{array}{l}17.5 \\
16.04 \\
18.0 \\
22.1 \\
25.7 \\
27.0 \\
26.1 \\
24.0\end{array}$ & $\begin{array}{l}15.9 \\
15.0 \\
15.6 \\
16.9 \\
19.0 \\
20.05 \\
21.03 \\
22.0\end{array}$ & $\begin{array}{l}17.5 \\
16.3 \\
18.2 \\
22.8 \\
26.2 \\
27.03 \\
26.2 \\
24.0\end{array}$ & $\begin{array}{l}15.9 \\
15.0 \\
15.5 \\
17.3 \\
19.0 \\
20.2 \\
21.03 \\
22.0\end{array}$ & $\begin{array}{l}17.5 \\
16.4 \\
18.5 \\
22.9 \\
26.1 \\
27.6 \\
26.5 \\
24.2\end{array}$ & $\begin{array}{l}16.1 \\
15.3 \\
15.7 \\
17.6 \\
19.3 \\
20.4 \\
21.4 \\
22.2\end{array}$ & $\begin{array}{l}24.9 \\
24.8 \\
25.2 \\
26.8 \\
28.0 \\
26.9 \\
25.05 \\
25.4\end{array}$ & $\begin{array}{l}3 \\
3 \\
3 \\
3 \\
2 \\
2 \\
2 \\
2\end{array}$ & $\begin{array}{l}5.9 \\
3.9 \\
6.7 \\
3.7 \\
3.1 \\
5.1 \\
6.4 \\
7.8\end{array}$ & $\begin{array}{l}5.9 \\
4.1 \\
6.8 \\
3.7 \\
3.3 \\
5.4 \\
7.0 \\
8.5\end{array}$ & $\begin{array}{l}8.0 \\
4.0 \\
7.0 \\
3.9 \\
3.4 \\
5.9 \\
7.5 \\
9.2\end{array}$ & $\begin{array}{l}6.0 \\
4.0 \\
6.09 \\
3.8 \\
3.1 \\
6.5 \\
8.1 \\
9.5\end{array}$ \\
\hline $\begin{array}{l}15 \\
15 \\
15 \\
15 \\
15 \\
15 \\
15 \\
15\end{array}$ & $\begin{array}{r}0 \\
3 \\
6 \\
9 \\
12 \\
15 \\
18 \\
21\end{array}$ & $\begin{array}{l}23.1 \\
22.5 \\
23.3 \\
25.7 \\
28.2 \\
29.5 \\
28.04 \\
26.6\end{array}$ & $\begin{array}{l}22.0 \\
21.05 \\
22.00 \\
22.7 \\
23.01 \\
23.3 \\
23.06 \\
23.02\end{array}$ & $\begin{array}{l}23.0 \\
22.4 \\
23.4 \\
25.9 \\
28.5 \\
29.8 \\
28.5 \\
26.7\end{array}$ & $\begin{array}{l}21.9 \\
21.01 \\
21.8 \\
22.6 \\
23.1 \\
23.3 \\
23.5 \\
23.0\end{array}$ & $\begin{array}{l}23.0 \\
22.4 \\
23.5 \\
26.0 \\
28.9 \\
29.9 \\
28.7 \\
26.8\end{array}$ & $\begin{array}{l}21.9 \\
21.2 \\
21.9 \\
22.7 \\
23.2 \\
23.4 \\
23.5 \\
23.0\end{array}$ & $\begin{array}{l}23.1 \\
22.4 \\
23.7 \\
26.5 \\
29.5 \\
30.1 \\
29.0 \\
27.1\end{array}$ & $\begin{array}{l}22.1 \\
21.6 \\
22.1 \\
22.8 \\
23.4 \\
23.6 \\
23.7 \\
23.2\end{array}$ & $\begin{array}{l}25.2 \\
25.0 \\
25.1 \\
26.1 \\
26.3 \\
25.7 \\
25.6 \\
25.3\end{array}$ & $\begin{array}{l}2 \\
2 \\
2 \\
2 \\
2 \\
2 \\
2 \\
2\end{array}$ & $\begin{array}{l}10.2 \\
12.2 \\
11.1 \\
13.0 \\
15.9 \\
15.6 \\
14.5 \\
16.1\end{array}$ & $\begin{array}{l}11.0 \\
13.2 \\
12.1 \\
14.3 \\
17.6 \\
17.6 \\
15.8 \\
17.8\end{array}$ & $\begin{array}{l}11.8 \\
14.1 \\
13.2 \\
15.7 \\
19.4 \\
19.2 \\
17.6 \\
19.4\end{array}$ & $\begin{array}{l}12.3 \\
14.4 \\
13.5 \\
26.1 \\
20.1 \\
20.1 \\
18.5 \\
20.1\end{array}$ \\
\hline $\begin{array}{l}16 \\
16 \\
16 \\
16 \\
16 \\
16 \\
16 \\
16\end{array}$ & $\begin{array}{r}0 \\
3 \\
6 \\
9 \\
12 \\
15 \\
18 \\
21\end{array}$ & $\begin{array}{l}25.5 \\
24.5 \\
25.0 \\
27.2 \\
29.0 \\
29.1 \\
28.2 \\
27.03\end{array}$ & $\begin{array}{l}22.0 \\
22.0 \\
22.6 \\
22.9 \\
23.3 \\
23.4 \\
23.0 \\
22.7\end{array}$ & $\begin{array}{l}25.5 \\
24.5 \\
25.0 \\
27.3 \\
29.3 \\
29.3 \\
28.4 \\
27.4\end{array}$ & $\begin{array}{l}21.9 \\
21.9 \\
22.5 \\
22.8 \\
23.2 \\
23.3 \\
22.9 \\
22.5\end{array}$ & $\begin{array}{l}25.6 \\
24.6 \\
25.0 \\
27.6 \\
29.6 \\
29.5 \\
28.7 \\
27.5\end{array}$ & $\begin{array}{l}21.7 \\
22.0 \\
22.5 \\
22.8 \\
23.3 \\
23.3 \\
22.8 \\
22.7\end{array}$ & $\begin{array}{l}25.8 \\
24 \cdot 8 \\
25.4 \\
28 \cdot 2 \\
30.1 \\
29.8 \\
28.9 \\
27.8\end{array}$ & $\begin{array}{l}22.0 \\
22.1 \\
22.8 \\
23.1 \\
23.4 \\
23.5 \\
22.9 \\
22.7\end{array}$ & & $\begin{array}{l}2 \\
2 \\
2 \\
2 \\
2 \\
2 \\
2 \\
2\end{array}$ & $\begin{array}{l}18.3 \\
18.1 \\
20.8 \\
17.7 \\
16.7 \\
20.2 \\
16.7 \\
18.6\end{array}$ & $\begin{array}{l}19.8 \\
19.9 \\
23.0 \\
19.6 \\
18.6 \\
22.6 \\
18.4 \\
20.4\end{array}$ & $\begin{array}{l}21.06 \\
21.06 \\
25.03 \\
21.07 \\
20.7 \\
25.0 \\
20.02 \\
22.3\end{array}$ & $\begin{array}{l}22.5 \\
22.6 \\
26.3 \\
22.4 \\
21.5 \\
26.5 \\
21.0 \\
23.5\end{array}$ \\
\hline $\begin{array}{l}17 \\
17 \\
17 \\
17 \\
17 \\
17 \\
17 \\
17\end{array}$ & $\begin{array}{r}0 \\
3 \\
6 \\
9 \\
12 \\
15 \\
18 \\
21\end{array}$ & $\begin{array}{l}26.2 \\
24.4 \\
20.7 \\
20.9\end{array}$ & $\begin{array}{l}22.5 \\
21.6 \\
19.8 \\
20.2\end{array}$ & $\begin{array}{l}26.3 \\
24.3 \\
20.4 \\
20.8\end{array}$ & $\begin{array}{l}22.2 \\
21.5 \\
19.4 \\
20.0\end{array}$ & $\begin{array}{l}26.4 \\
24.3 \\
20.4 \\
21.0\end{array}$ & $\begin{array}{l}22.3 \\
21.3 \\
19.5 \\
20.0\end{array}$ & $\begin{array}{l}26.6 \\
24.3 \\
20.4 \\
21.2\end{array}$ & $\begin{array}{l}22.4 \\
21.4 \\
19.8 \\
20.1 \\
21.5 \\
22.1 \\
21.4\end{array}$ & $\begin{array}{l}25.3 \\
25.2 \\
25.1 \\
25.0 \\
25.5 \\
25.2 \\
25.1\end{array}$ & $\begin{array}{l}2 \\
2 \\
2 \\
3 \\
2 \\
2 \\
3 \\
3\end{array}$ & $\begin{array}{r}18.9 \\
15.1 \\
10.4 \\
2.8 \\
9.4 \\
7.0 \\
7.8 \\
9.3\end{array}$ & $\begin{array}{r}20.8 \\
16.7 \\
11.0 \\
3.0 \\
9.9 \\
7.04 \\
8.0 \\
9.7\end{array}$ & $\begin{array}{r}23.0 \\
18.1 \\
12.2 \\
3.1 \\
10.2 \\
7.8 \\
8.1 \\
10.1\end{array}$ & $\begin{array}{r}24.0 \\
18.8 \\
12.6 \\
3.3 \\
10.3 \\
7.9 \\
8.1 \\
10.2\end{array}$ \\
\hline $\begin{array}{l}18 \\
18 \\
18 \\
18 \\
18 \\
18 \\
18 \\
18\end{array}$ & $\begin{array}{r}0 \\
3 \\
6 \\
9 \\
12 \\
15 \\
18 \\
21\end{array}$ & $\begin{array}{l}25.8 \\
27.0 \\
27.0 \\
21.2\end{array}$ & $\begin{array}{l}21.8 \\
21.5 \\
23.1 \\
23.0 \\
22.7 \\
18.0\end{array}$ & $\begin{array}{l}26 \cdot 0 \\
27 \cdot 1 \\
27 \cdot 0 \\
21 \cdot 2\end{array}$ & $\begin{array}{l}23.0 \\
23.0 \\
22.5 \\
17.8\end{array}$ & $\begin{array}{l}26 \cdot 3 \\
27.5 \\
27.3 \\
21.3\end{array}$ & $\begin{array}{l}23.2 \\
23.0 \\
22.5 \\
17.8\end{array}$ & $\begin{array}{l}26 \cdot 4 \\
27 \cdot 7 \\
27 \cdot 6 \\
21.5\end{array}$ & $\begin{array}{l}22.0 \\
21.4 \\
23 \cdot 2 \\
23.2 \\
22.6 \\
17.9\end{array}$ & $\begin{array}{l}25.0 \\
25.0 \\
25.3 \\
25.2 \\
25.0 \\
20.8\end{array}$ & $\begin{array}{l}2 \\
2 \\
2 \\
3 \\
2 \\
2 \\
2 \\
2\end{array}$ & $\begin{array}{r}9.0 \\
9.17 \\
7.8 \\
6.3 \\
10.7 \\
11.0 \\
10.3 \\
9.8\end{array}$ & $\begin{array}{r}9.3 \\
10.4 \\
8.4 \\
6.8 \\
11.9 \\
12.8 \\
11.3 \\
10.7\end{array}$ & $\begin{array}{r}9.7 \\
11.02 \\
8.8 \\
7.0 \\
12.7 \\
14.2 \\
12.3 \\
11.7\end{array}$ & $\begin{array}{r}9.6 \\
11.04 \\
9.02 \\
7.01 \\
13.2 \\
14.7 \\
13.0 \\
12.4\end{array}$ \\
\hline $\begin{array}{l}19 \\
19 \\
19 \\
19 \\
19 \\
19 \\
19 \\
19\end{array}$ & $\begin{array}{r}0 \\
3 \\
6 \\
9 \\
12 \\
15 \\
18 \\
21\end{array}$ & $\begin{array}{l}22.7 \\
22.9 \\
22.6 \\
22.6 \\
25.4 \\
27.5 \\
25.5\end{array}$ & $\begin{array}{l}20 \cdot 2 \\
20 \cdot 7 \\
21 \cdot 3 \\
21 \cdot 0 \\
22 \cdot 8 \\
24 \cdot 0 \\
23.3\end{array}$ & $\begin{array}{l}22.7 \\
22.8 \\
22.5 \\
22.5 \\
25.5 \\
27.5 \\
25.7\end{array}$ & $\begin{array}{l}19.9 \\
20.5 \\
21.2 \\
20.9 \\
22.7 \\
23.8 \\
23.3\end{array}$ & $\begin{array}{l}22.7 \\
22.8 \\
22.6 \\
22.6 \\
25.8 \\
27.8 \\
24.8\end{array}$ & $\begin{array}{l}19.9 \\
20.5 \\
21 \cdot 3 \\
21.0 \\
23.4 \\
23.9 \\
22.3\end{array}$ & $\begin{array}{l}22 \cdot 8 \\
22 \cdot 8 \\
22 \cdot 8 \\
22 \cdot 7 \\
26 \cdot 2 \\
28 \cdot 2 \\
24 \cdot 7\end{array}$ & $\begin{array}{l}20.0 \\
20.8 \\
21.2 \\
20.7 \\
23.2 \\
24 \cdot 3 \\
22.4\end{array}$ & $\begin{array}{l}24.9 \\
24.9 \\
25.0 \\
25.0 \\
25.4 \\
25.1 \\
25.0\end{array}$ & $\begin{array}{l}2 \\
2 \\
2 \\
2 \\
2 \\
2 \\
3 \\
2\end{array}$ & $\begin{array}{r}11.0 \\
6.1 \\
5.5 \\
12.8 \\
12.5 \\
8.1 \\
10.3 \\
8.2\end{array}$ & $\begin{array}{r}11.5 \\
6.6 \\
5.9 \\
13.9 \\
13.8 \\
9.1 \\
11.8 \\
8.6\end{array}$ & $\begin{array}{r}12.5 \\
7.1 \\
6.2 \\
15.2 \\
15.2 \\
10.1 \\
12.8 \\
9.1\end{array}$ & $\begin{array}{r}13.2 \\
7.5 \\
6.3 \\
15.5 \\
15.6 \\
10.4 \\
13.5 \\
9.3\end{array}$ \\
\hline $\begin{array}{l}20 \\
20 \\
20 \\
20 \\
20 \\
20 \\
20 \\
20\end{array}$ & $\begin{array}{r}0 \\
3 \\
6 \\
9 \\
12 \\
15 \\
18 \\
21\end{array}$ & $\begin{array}{l}21.5 \\
20.9 \\
22.9 \\
25.9 \\
26.6 \\
25.4 \\
23.8\end{array}$ & $\begin{array}{l}19.7 \\
20.0 \\
20.6 \\
21.7 \\
21.9 \\
22.7 \\
22.4\end{array}$ & $\begin{array}{l}21.2 \\
20.8 \\
23.3 \\
25.2 \\
26.6 \\
25.4 \\
23.7\end{array}$ & $\begin{array}{l}19.5 \\
19.9 \\
20.5 \\
21.2 \\
21.7 \\
22.5 \\
22.2\end{array}$ & $\begin{array}{l}21.3 \\
21.0 \\
23.5 \\
25.6 \\
26.4 \\
25.4 \\
23.7\end{array}$ & $\begin{array}{l}19.4 \\
20.0 \\
20.8 \\
21.3 \\
22.0 \\
22.5 \\
22.2\end{array}$ & $\begin{array}{l}21 \cdot 3 \\
21 \cdot 2 \\
23 \cdot 1 \\
25 \cdot 6 \\
26 \cdot 6 \\
25 \cdot 6 \\
23.9\end{array}$ & $\begin{array}{l}19 \cdot 5 \\
20.2 \\
20.6 \\
21.4 \\
22 \cdot 1 \\
22.7 \\
22.4\end{array}$ & $\begin{array}{l}24.9 \\
24.9 \\
25.7 \\
26.5 \\
27.0 \\
26.0 \\
25.0\end{array}$ & $\begin{array}{l}2 \\
2 \\
2 \\
2 \\
3 \\
3 \\
3 \\
2\end{array}$ & $\begin{array}{r}14.03 \\
10.4 \\
4.0 \\
2.3 \\
2.2 \\
1.4 \\
4.8 \\
6.5\end{array}$ & $\begin{array}{r}15.5 \\
11.1 \\
4.1 \\
2.5 \\
2.4 \\
2.1 \\
4.9 \\
6.8\end{array}$ & $\begin{array}{r}16.9 \\
11.9 \\
4.2 \\
2.6 \\
2.6 \\
2.02 \\
5.00 \\
7.1\end{array}$ & $\begin{array}{r}27.3 \\
12.3 \\
4.3 \\
2.3 \\
2.5 \\
2.1 \\
5.2 \\
7.2\end{array}$ \\
\hline
\end{tabular}


TABLE 10

Table 10. - Three-hour averages of air and water-surface temperatures and wind directions and speed, April 1950-August 1951, Lake Hefner-Continued

STATION

THREE-HOURLY AVERAGES

JULY, 1950

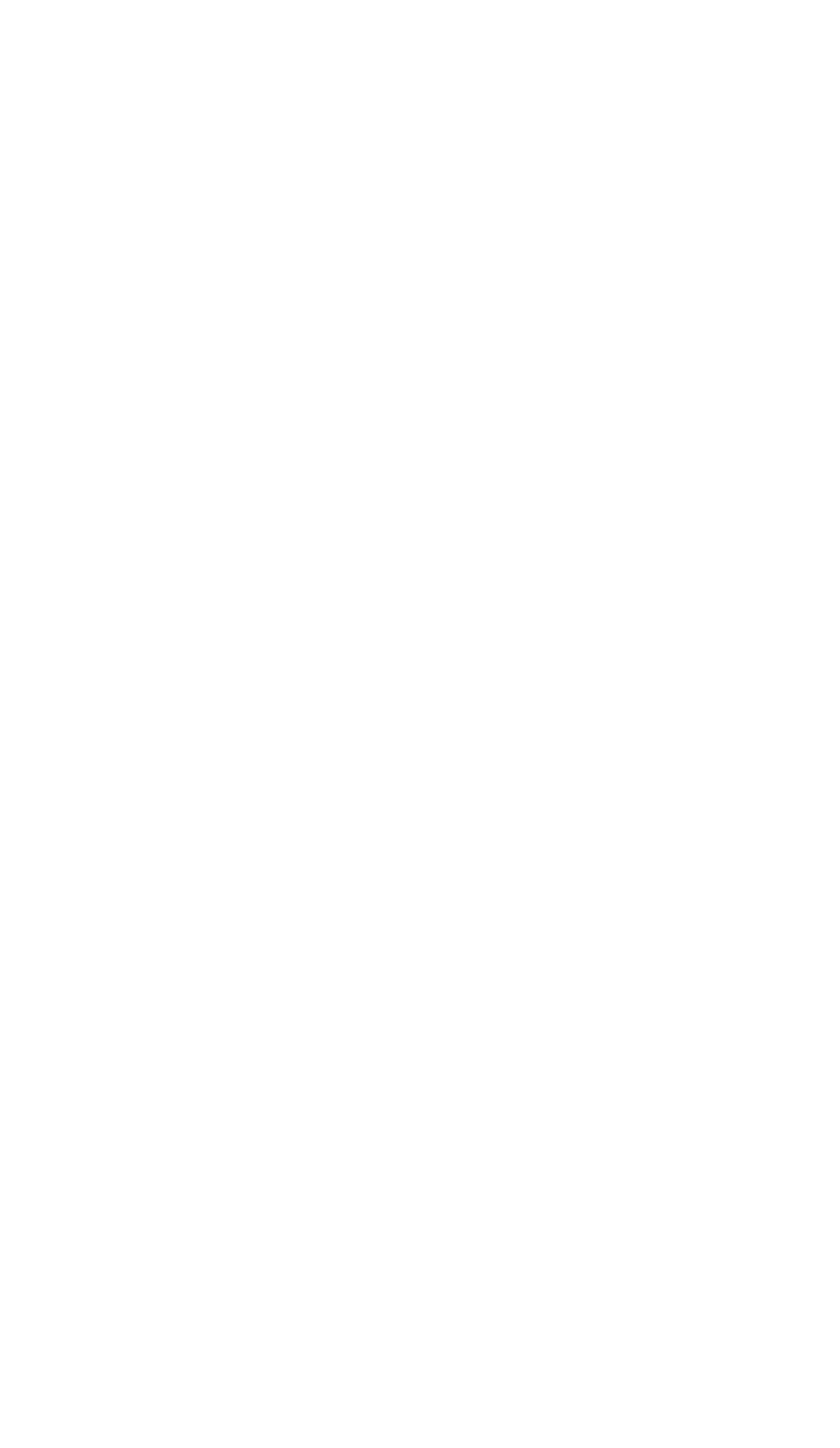


TABLE 10

Table 10. -Three-hour averages of air and water-surface temperatures and wind directions and speed, April 1950-August 1951, Lake Hefner-Continued

STATION :

THREE-HOURLY AVERAGES

AUGUST, 1950

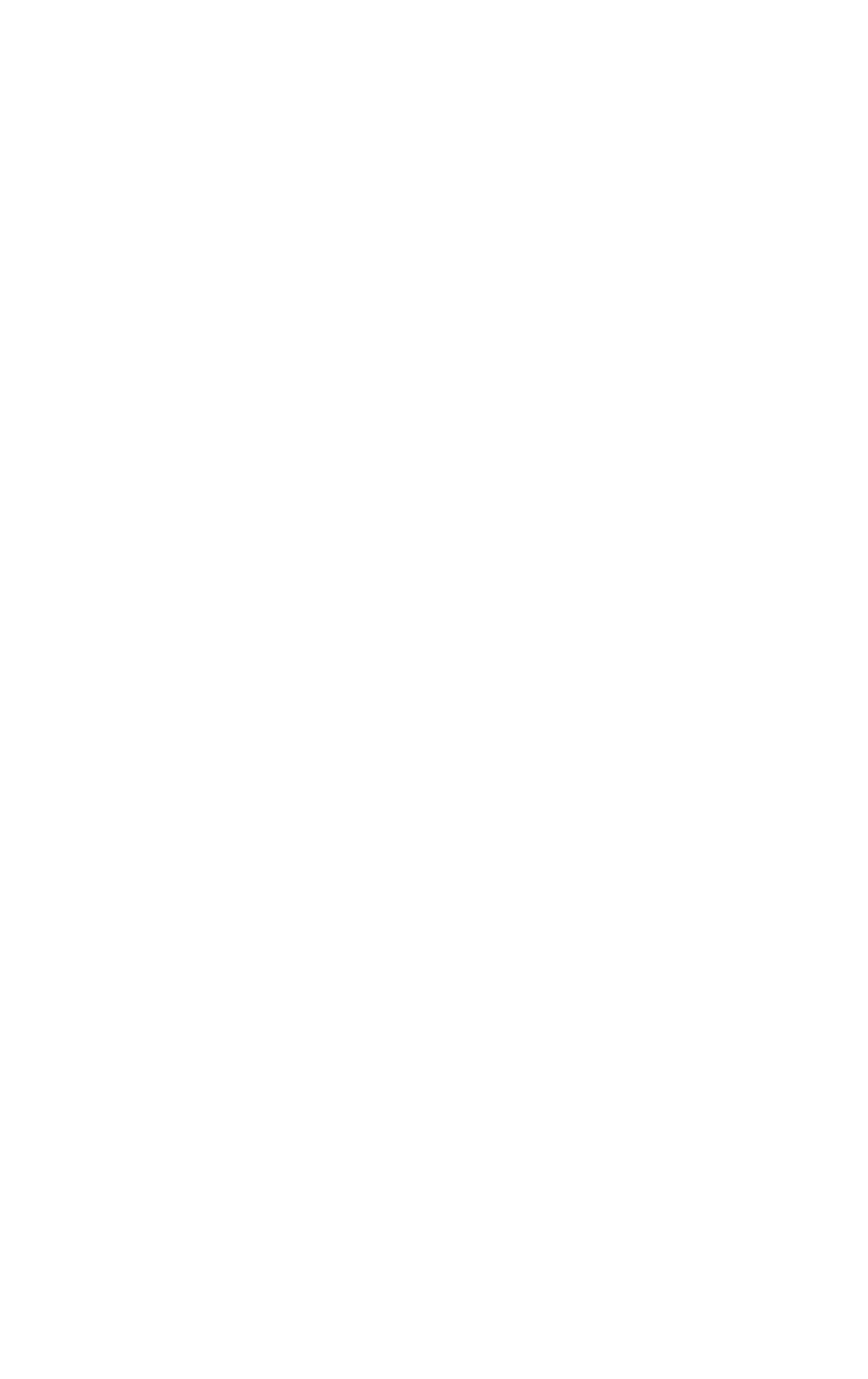


TABLE 10

\begin{tabular}{|c|c|c|c|c|c|c|c|c|c|c|c|c|c|c|c|}
\hline \multicolumn{2}{|c|}{ STATION } & \multicolumn{5}{|l|}{1} & \multicolumn{7}{|c|}{ THREE-HOURLY AVERAGES } & \multirow{3}{*}{\multicolumn{2}{|c|}{$\begin{array}{l}\text { AUGUST, } 1950 \\
\text { speed (knots) } \\
\text { ted height }\end{array}$}} \\
\hline \multirow{3}{*}{ 悉 } & \multirow{3}{*}{ 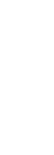 } & \multicolumn{8}{|c|}{ Average air temperature $\left({ }^{\circ} \mathrm{C}\right)$ at indicated height } & \multirow{3}{*}{$\begin{array}{c}\text { Average } \\
\text { water- } \\
\text { surface } \\
\text { tempera- } \\
\text { ture } \\
\left({ }^{\circ} \mathrm{C}\right)\end{array}$} & \multirow{3}{*}{$\begin{array}{c}\text { Average } \\
\text { wind } \\
\text { direction } \\
\text { (coded) }\end{array}$} & \multirow{2}{*}{\multicolumn{2}{|c|}{$\begin{array}{l}\text { Average wind speed (knots) } \\
\text { at indicated height }\end{array}$}} & & \\
\hline & & \multicolumn{2}{|c|}{$\begin{array}{c}2 \\
\text { meters }\end{array}$} & \multicolumn{2}{|c|}{$\begin{array}{c}4 \\
\text { meters }\end{array}$} & \multicolumn{2}{|c|}{$\begin{array}{c}8 \\
\text { meters }\end{array}$} & \multicolumn{2}{|c|}{$\begin{array}{c}16 \\
\text { meters }\end{array}$} & & & & & & \\
\hline & & $\begin{array}{l}\text { Dry } \\
\text { bulb }\end{array}$ & $\begin{array}{l}\text { Wet } \\
\text { butb }\end{array}$ & $\begin{array}{l}\text { Dry } \\
\text { bulb }\end{array}$ & $\begin{array}{l}\text { Wet } \\
\text { bulb }\end{array}$ & $\begin{array}{l}\text { Dry } \\
\text { bulb }\end{array}$ & $\begin{array}{l}\text { Wet } \\
\text { bulb }\end{array}$ & $\begin{array}{l}\text { Dry } \\
\text { bulb }\end{array}$ & $\begin{array}{l}\text { Wet } \\
\text { bulb }\end{array}$ & & & $\begin{array}{c}2 \\
\text { meters }\end{array}$ & $\begin{array}{c}4 \\
\text { meters }\end{array}$ & \begin{tabular}{|c|}
8 \\
meters
\end{tabular} & $\begin{array}{c}16 \\
\text { meters }\end{array}$ \\
\hline $\begin{array}{l}11 \\
11 \\
11 \\
11 \\
11 \\
11 \\
11 \\
11\end{array}$ & $\begin{array}{r}0 \\
3 \\
6 \\
9 \\
12 \\
15 \\
18 \\
21\end{array}$ & $\begin{array}{l}25.2 \\
24.2 \\
24.0 \\
26.4 \\
29.6 \\
31.2 \\
29.2 \\
26.5\end{array}$ & $\begin{array}{l}22.8 \\
21: 9 \\
21.8 \\
22.4 \\
23.5 \\
24.0 \\
24.7 \\
23.9\end{array}$ & $\begin{array}{l}25.2 \\
24.0 \\
24.0 \\
26.4 \\
29.9 \\
31.7 \\
29.2 \\
26.5\end{array}$ & $\begin{array}{l}22.5 \\
21.7 \\
21.6 \\
22.3 \\
23.2 \\
23.8 \\
24.5 \\
23.5\end{array}$ & $\begin{array}{l}25.2 \\
24.0 \\
24.1 \\
26.8 \\
30.3 \\
31.9 \\
29.4 \\
26.6\end{array}$ & $\begin{array}{l}22.5 \\
21: 7 \\
21.7 \\
22.5 \\
23.3 \\
23.7 \\
24.5 \\
23.7\end{array}$ & $\begin{array}{l}25 \cdot 5 \\
24.5 \\
24.3 \\
27.1 \\
30.5 \\
32.5 \\
29.7 \\
26.2\end{array}$ & $\begin{array}{l}22.7 \\
21.9 \\
21.9 \\
22.6 \\
23.5 \\
23.7 \\
24.8 \\
23.9\end{array}$ & $\begin{array}{l}26.0 \\
25.8 \\
26.2 \\
27.8 \\
29.0 \\
27.7 \\
26.8 \\
26.2\end{array}$ & $\begin{array}{l}2 \\
2 \\
2 \\
2 \\
2 \\
2 \\
2 \\
2\end{array}$ & $\begin{array}{r}10.5 \\
9.8 \\
9.1 \\
3.5 \\
8.5 \\
8.3 \\
11.3 \\
13.6\end{array}$ & $\begin{array}{r}11.6 \\
10.9 \\
10.0 \\
3.9 \\
9.5 \\
9.4 \\
12.7 \\
15.2\end{array}$ & $\begin{array}{r}12.5 \\
11.5 \\
10.6 \\
4.2 \\
10.3 \\
10.3 \\
13.9 \\
16.4\end{array}$ & $\begin{array}{l}13.2 \\
12.3 \\
11.02 \\
40.4 \\
10.8 \\
11.0 \\
14.8 \\
17.3\end{array}$ \\
\hline $\begin{array}{l}12 \\
12 \\
12 \\
12 \\
12 \\
12 \\
12 \\
12\end{array}$ & $\begin{array}{r}0 \\
3 \\
6 \\
9 \\
12 \\
15 \\
18 \\
21\end{array}$ & $\begin{array}{l}24.9 \\
23.1 \\
23.4 \\
28.3 \\
31.5 \\
32.0 \\
29.5 \\
26.9\end{array}$ & $\begin{array}{l}22.1 \\
21.2 \\
21.0 \\
21.6 \\
22.1 \\
22.7 \\
23.0 \\
22.5\end{array}$ & $\begin{array}{l}24.9 \\
22.9 \\
23.3 \\
28.5 \\
31.5 \\
32.4 \\
29.6 \\
26.8\end{array}$ & $\begin{array}{l}21.8 \\
20.9 \\
20.8 \\
21.2 \\
21.6 \\
22.1 \\
22.6 \\
22.2\end{array}$ & $\begin{array}{l}24.9 \\
22.9 \\
23.5 \\
28.9 \\
31.9 \\
32.7 \\
29.7 \\
26.8\end{array}$ & $\begin{array}{l}21.7 \\
20.8 \\
20.6 \\
20.9 \\
21.1 \\
21.9 \\
22.3 \\
22.1\end{array}$ & $\begin{array}{l}25.1 \\
23.0 \\
23.0 \\
29.2 \\
32.3 \\
33.2 \\
30.3 \\
27.0\end{array}$ & $\begin{array}{l}21.8 \\
21.0 \\
20.8 \\
21.3 \\
21.7 \\
22.1 \\
22.3 \\
22.3\end{array}$ & $\begin{array}{l}28.0 \\
25.9 \\
26.6 \\
27.7 \\
29.1 \\
28.4 \\
27.6 \\
27.3\end{array}$ & $\begin{array}{l}2 \\
2 \\
2 \\
2 \\
2 \\
2 \\
2 \\
2\end{array}$ & $\begin{array}{r}14.8 \\
12.7 \\
13.2 \\
10.2 \\
7.7 \\
8.3 \\
7.4 \\
10.9\end{array}$ & $\begin{array}{r}16.1 \\
14.1 \\
14.6 \\
11.5 \\
8.6 \\
9.7 \\
8.6 \\
12.2\end{array}$ & $\begin{array}{r}17.3 \\
15.0 \\
15.6 \\
12.6 \\
9.4 \\
10.9 \\
9.7 \\
13.2\end{array}$ & $\begin{array}{l}18.3 \\
15.9 \\
16.4 \\
13.1 \\
9.9 \\
11.7 \\
11.1 \\
14.4\end{array}$ \\
\hline $\begin{array}{l}13 \\
13 \\
13 \\
13 \\
13 \\
13 \\
13 \\
13\end{array}$ & $\begin{array}{r}0 \\
3 \\
6 \\
9 \\
12 \\
15 \\
18 \\
21\end{array}$ & $\begin{array}{l}25.4 \\
24.0 \\
24.5 \\
28.9 \\
30.5\end{array}$ & $\begin{array}{l}22.4 \\
21.6 \\
21.4 \\
22.1 \\
22.5\end{array}$ & $\begin{array}{l}25.3 \\
24.0 \\
24.6 \\
29.0 \\
30.8\end{array}$ & $\begin{array}{l}22 \cdot 1 \\
21 \cdot 3 \\
21 \cdot 1 \\
21.7 \\
22: 0\end{array}$ & $\begin{array}{l}25.3 \\
24.0 \\
24.8 \\
29.3 \\
31.2\end{array}$ & $\begin{array}{l}22.0 \\
21: 2 \\
21.0 \\
21.7 \\
22.0\end{array}$ & $\begin{array}{l}25.4 \\
24.1 \\
25.2 \\
29.7 \\
31.5\end{array}$ & $\begin{array}{l}22.2 \\
21.4 \\
21.2 \\
27.0 \\
22.3\end{array}$ & $\begin{array}{l}26.4 \\
26.1 \\
27.1 \\
28.3 \\
28.8\end{array}$ & $\begin{array}{l}2 \\
2 \\
2 \\
2 \\
2 \\
2 \\
2 \\
2\end{array}$ & $\begin{array}{r}12.2 \\
9.4 \\
7.1 \\
10.4 \\
7.0 \\
8.9 \\
8.9 \\
6.4\end{array}$ & $\begin{array}{r}13.6 \\
10.3 \\
7.9 \\
11.6 \\
7.9 \\
10.1 \\
9.8 \\
6.9\end{array}$ & $\begin{array}{r}14.4 \\
11.2 \\
8.5 \\
12.6 \\
8.7 \\
11.1 \\
10.8 \\
7.5\end{array}$ & $\begin{array}{r}15.4 \\
11.8 \\
8.8 \\
13.1 \\
9.1 \\
11.7 \\
11.8 \\
8.5\end{array}$ \\
\hline $\begin{array}{l}14 \\
14 \\
14 \\
14 \\
14 \\
14 \\
14 \\
14\end{array}$ & $\begin{array}{r}0 \\
3 \\
6 \\
9 \\
12 \\
15 \\
18 \\
21\end{array}$ & $\begin{array}{l}30.0 \\
30.3 \\
29.5\end{array}$ & $\begin{array}{l}22.7 \\
22.9 \\
22.9\end{array}$ & $\begin{array}{l}30.2 \\
30.5 \\
29.6\end{array}$ & $\begin{array}{l}22.2 \\
22.4 \\
22.4\end{array}$ & $\begin{array}{l}30.2 \\
30.8 \\
29.7\end{array}$ & $\begin{array}{l}21.6 \\
22.1 \\
22.2\end{array}$ & $\begin{array}{l}30.2 \\
31.1 \\
30.0\end{array}$ & $\begin{array}{l}22.2 \\
22.4 \\
22.5\end{array}$ & $\begin{array}{l}29.4 \\
28.6 \\
28.2\end{array}$ & $\begin{array}{l}2 \\
2 \\
2 \\
2 \\
2 \\
2 \\
2 \\
2\end{array}$ & $\begin{array}{l}6.5 \\
5.2 \\
5.4 \\
7.1 \\
4.0 \\
7.0 \\
6.5 \\
6.0\end{array}$ & $\begin{array}{l}7.0 \\
5.6 \\
5.9 \\
7.8 \\
4.4 \\
8.6 \\
7.2 \\
6.6\end{array}$ & $\begin{array}{l}7.4 \\
5.9 \\
6.3 \\
8.4 \\
4.8 \\
9.4 \\
8.0 \\
7.1\end{array}$ & $\begin{array}{l}8.2 \\
6.3 \\
6.6 \\
8.7 \\
5.0 \\
9.8 \\
9.0 \\
8.0\end{array}$ \\
\hline $\begin{array}{l}15 \\
15 \\
15 \\
15 \\
15 \\
15 \\
15 \\
15\end{array}$ & $\begin{array}{r}0 \\
3 \\
6 \\
9 \\
12 \\
15 \\
18 \\
21\end{array}$ & $\begin{array}{l}28.7 \\
30.7 \\
31.2 \\
25.5 \\
22.0\end{array}$ & $\begin{array}{l}22.2 \\
22.9 \\
23.0 \\
23.6 \\
20.4\end{array}$ & $\begin{array}{l}28.8 \\
30.9 \\
31.7 \\
25.0 \\
21.7\end{array}$ & $\begin{array}{l}21.6 \\
22.2 \\
22.8 \\
21.8 \\
20.3\end{array}$ & $\begin{array}{l}29.2 \\
31.3 \\
31.7 \\
24.7 \\
21.7\end{array}$ & $\begin{array}{l}21.6 \\
22.1 \\
22.4 \\
21 \cdot 7 \\
20.2\end{array}$ & $\begin{array}{l}29.5 \\
31.7 \\
32.1 \\
24 \cdot 3 \\
21.8\end{array}$ & $\begin{array}{l}22.2 \\
22.6 \\
23.1 \\
21.0 \\
20.5\end{array}$ & $\begin{array}{l}28.2 \\
28.9 \\
28.2 \\
27.5 \\
26.7\end{array}$ & $\begin{array}{l}2 \\
2 \\
2 \\
2 \\
2 \\
2 \\
2 \\
2\end{array}$ & $\begin{array}{r}6.7 \\
10.2 \\
10.3 \\
11.6 \\
9.4 \\
8.1 \\
10.5 \\
12.2\end{array}$ & $\begin{array}{r}7.4 \\
11.3 \\
11.3 \\
12.7 \\
10.4 \\
9.1 \\
11.6 \\
13.5\end{array}$ & $\begin{array}{r}7.8 \\
12.1 \\
12.2 \\
13.9 \\
11.5 \\
10.0 \\
12.3 \\
14.2\end{array}$ & $\begin{array}{r}8.6 \\
13.0 \\
12.6 \\
14.5 \\
11.9 \\
10.5 \\
13.2 \\
14.9\end{array}$ \\
\hline $\begin{array}{l}16 \\
16 \\
16 \\
16 \\
16 \\
16 \\
16 \\
16\end{array}$ & $\begin{array}{r}0 \\
3 \\
6 \\
9 \\
12 \\
15 \\
18 \\
21\end{array}$ & $\begin{array}{l}22,5 \\
22,1 \\
22,1 \\
24.4 \\
26.6 \\
25.4 \\
24,5 \\
23.7\end{array}$ & $\begin{array}{l}20.6 \\
20.2 \\
20.7 \\
21.7 \\
22.6 \\
22.1 \\
22.0 \\
22.6\end{array}$ & $\begin{array}{l}22.5 \\
22.0 \\
22.0 \\
24.6 \\
26.6 \\
25.3 \\
24.4 \\
23.6\end{array}$ & $\begin{array}{l}20.3 \\
20.0 \\
20.4 \\
21.5 \\
22.4 \\
21.9 \\
21.9 \\
22.3\end{array}$ & $\begin{array}{l}22.6 \\
22.0 \\
22.0 \\
24.9 \\
26.8 \\
25.3 \\
24.4 \\
23.6\end{array}$ & $\begin{array}{l}20 \cdot 3 \\
20.0 \\
20 \cdot 5 \\
21 \cdot 5 \\
22 \cdot 5 \\
21 \cdot 7 \\
21 \cdot 8 \\
22: 3\end{array}$ & $\begin{array}{l}22 \cdot 7 \\
22 \cdot 1 \\
22 \cdot 1 \\
24 \cdot 7 \\
26.9 \\
25 \cdot 5 \\
24 \cdot 5 \\
23.7\end{array}$ & $\begin{array}{l}20 \cdot 5 \\
20.2 \\
20 \cdot 9 \\
21 \cdot 9 \\
22 \cdot 7 \\
22 \cdot 1 \\
22.1 \\
22.6\end{array}$ & $\begin{array}{l}26.2 \\
26.2 \\
26.6 \\
27.0 \\
27.7 \\
26.9 \\
26.5 \\
26.4\end{array}$ & $\begin{array}{l}2 \\
2 \\
3 \\
2 \\
2 \\
2 \\
2 \\
2\end{array}$ & $\begin{array}{l}6.3 \\
4.6 \\
5.0 \\
2.8 \\
6.6 \\
8.2 \\
5.2 \\
5.3\end{array}$ & $\begin{array}{l}7.2 \\
4.9 \\
5.3 \\
3.1 \\
7.3 \\
9.1 \\
5.7 \\
5.8\end{array}$ & $\begin{array}{l}7.7 \\
5.0 \\
5.4 \\
3.3 \\
7.9 \\
9.7 \\
8.1 \\
6.0\end{array}$ & $\begin{array}{r}8.2 \\
5.1 \\
5.5 \\
3.2 \\
8.3 \\
10.0 \\
6.2 \\
6.2\end{array}$ \\
\hline $\begin{array}{l}17 \\
17 \\
17 \\
17 \\
17 \\
17 \\
17 \\
17\end{array}$ & $\begin{array}{r}0 \\
3 \\
6 \\
9 \\
12 \\
15 \\
18 \\
21\end{array}$ & $\begin{array}{l}22.5 \\
22.2 \\
21.7 \\
23.3 \\
23.8 \\
24.1 \\
22.1 \\
21.0\end{array}$ & $\begin{array}{l}21.4 \\
20.7 \\
20.6 \\
20.6 \\
20.7 \\
20.9 \\
20.1 \\
19.9\end{array}$ & $\begin{array}{l}22.4 \\
22.1 \\
21.7 \\
23.2 \\
23.5 \\
23.7 \\
21.8 \\
20.8\end{array}$ & $\begin{array}{l}21.2 \\
20.5 \\
20.4 \\
19.9 \\
20.2 \\
20.4 \\
19.3 \\
19.6\end{array}$ & $\begin{array}{l}22.4 \\
22.0 \\
21.9 \\
23.3 \\
23.6 \\
23.6 \\
21.7 \\
20.7\end{array}$ & $\begin{array}{l}21.1 \\
20.4 \\
20.3 \\
19.8 \\
20.2 \\
20.4 \\
19.3 \\
19.5\end{array}$ & $\begin{array}{l}22.5 \\
22.0 \\
22.0 \\
23.4 \\
23.8 \\
23.0 \\
21.9 \\
20.9\end{array}$ & $\begin{array}{l}21.4 \\
20.6 \\
20.7 \\
20.1 \\
20.5 \\
20.6 \\
19.6 \\
19.7\end{array}$ & $\begin{array}{l}26.4 \\
26.3 \\
26.7 \\
27.7 \\
27.2 \\
26.9 \\
26.4 \\
26.3\end{array}$ & $\begin{array}{l}2 \\
2 \\
2 \\
3 \\
3 \\
3 \\
3 \\
3\end{array}$ & $\begin{array}{r}5.3 \\
7.3 \\
5.7 \\
6.3 \\
9.6 \\
14.2 \\
9.5 \\
7.9\end{array}$ & $\begin{array}{r}5.7 \\
7.8 \\
5.7 \\
7.0 \\
10.6 \\
16.7 \\
10.5 \\
8.6\end{array}$ & $\begin{array}{r}6.1 \\
3.2 \\
6.0 \\
7.5 \\
11.6 \\
18.1 \\
11.0 \\
9.5\end{array}$ & $\begin{array}{r}6.4 \\
8.5 \\
5.9 \\
7.8 \\
12.0 \\
19.3 \\
11.3 \\
9.8\end{array}$ \\
\hline $\begin{array}{l}18 \\
18 \\
18 \\
18 \\
18 \\
18 \\
18 \\
18\end{array}$ & $\begin{array}{r}0 \\
3 \\
6 \\
9 \\
12 \\
15 \\
18 \\
21\end{array}$ & $\begin{array}{l}20.3 \\
19.6 \\
19.1 \\
21.7 \\
24.6 \\
26.3 \\
24.9 \\
22.0\end{array}$ & $\begin{array}{l}19.6 \\
18.9 \\
18.2 \\
18.8 \\
18.2 \\
18.0 \\
18.5 \\
17.5\end{array}$ & $\begin{array}{l}20.1 \\
19.2 \\
18.9 \\
21.6 \\
24.5 \\
25.9 \\
24.5 \\
21.9\end{array}$ & $\begin{array}{l}19.3 \\
18.7 \\
17.8 \\
18.5 \\
18.0 \\
17.1 \\
18.0 \\
17.1\end{array}$ & $\begin{array}{l}20.0 \\
19.0 \\
18.8 \\
21.6 \\
24.6 \\
26.0 \\
24.6 \\
21.9\end{array}$ & $\begin{array}{l}19.0 \\
18.3 \\
17.6 \\
18.1 \\
17.1 \\
16.9 \\
17.9 \\
17.0\end{array}$ & $\begin{array}{l}20.1 \\
19.1 \\
19.0 \\
21.9 \\
24: 9 \\
26.3 \\
24: 9 \\
22.2\end{array}$ & $\begin{array}{l}19.4 \\
18.6 \\
17.8 \\
18.2 \\
17.7 \\
17.3 \\
17.8 \\
17.2\end{array}$ & $\begin{array}{l}26.1 \\
26.0 \\
26.3 \\
27.3 \\
27.4 \\
26.7 \\
26.1 \\
25.9\end{array}$ & $\begin{array}{l}3 \\
3 \\
3 \\
3 \\
3 \\
3 \\
3 \\
2\end{array}$ & $\begin{array}{r}8.2 \\
10.1 \\
9.6 \\
10.0 \\
9.7 \\
8.4 \\
4.8 \\
4.4\end{array}$ & $\begin{array}{r}9.4 \\
11.6 \\
10.7 \\
10.9 \\
10.9 \\
9.4 \\
5.0 \\
4.6\end{array}$ & $\begin{array}{r}9.9 \\
12.2 \\
11.5 \\
12.0 \\
11.8 \\
10.1 \\
5.0 \\
4.8\end{array}$ & $\begin{array}{r}10.1 \\
12.3 \\
11.8 \\
12.5 \\
12.3 \\
10.4 \\
5.5 \\
5.1\end{array}$ \\
\hline $\begin{array}{l}19 \\
19 \\
19 \\
19 \\
19 \\
19 \\
19 \\
19\end{array}$ & $\begin{array}{r}0 \\
3 \\
6 \\
9 \\
12 \\
15 \\
18 \\
21\end{array}$ & $\begin{array}{l}25 \cdot 1 \\
25 \cdot 1 \\
27 \cdot 1 \\
25 \cdot 4 \\
21.5\end{array}$ & $\begin{array}{l}17.0 \\
16.9 \\
18.4 \\
19.6 \\
19.0\end{array}$ & $\begin{array}{l}24.6 \\
26.0 \\
27.1 \\
25.2 \\
21.3\end{array}$ & $\begin{array}{l}17.2 \\
17.0 \\
18.1 \\
19.3 \\
18.4\end{array}$ & $\begin{array}{l}25.4 \\
26.3 \\
27.1 \\
25.0 \\
21.2\end{array}$ & $\begin{array}{l}17.5 \\
16.8 \\
18.3 \\
19.4 \\
18.1\end{array}$ & $\begin{array}{l}25 \cdot 3 \\
26 \cdot 3 \\
27 \cdot 4 \\
25 \cdot 3 \\
21 \cdot 2\end{array}$ & $\begin{array}{l}16.9 \\
17.1 \\
18.3 \\
19.1 \\
18.2\end{array}$ & $\begin{array}{l}28.8 \\
29.1 \\
27.6 \\
26.1 \\
25.8\end{array}$ & $\begin{array}{l}2 \\
2 \\
2 \\
2 \\
3 \\
3 \\
3 \\
3\end{array}$ & $\begin{array}{l}2.8 \\
1.7 \\
1.1 \\
1.3 \\
4.7 \\
6.0 \\
5.9 \\
11.4\end{array}$ & $\begin{array}{r}3.1 \\
1.09 \\
1.4 \\
1.6 \\
5.0 \\
6.4 \\
6.2 \\
11.0\end{array}$ & $\begin{array}{r}3.2 \\
1.0 \\
1.5 \\
1.5 \\
5.2 \\
6.6 \\
6.5 \\
12.2\end{array}$ & $\begin{array}{r}3.2 \\
1.7 \\
1.2 \\
1.5 \\
5.2 \\
6.8 \\
7.3 \\
12.7\end{array}$ \\
\hline $\begin{array}{l}20 \\
20 \\
20 \\
20 \\
20 \\
20 \\
20 \\
20\end{array}$ & $\begin{array}{r}0 \\
3 \\
6 \\
9 \\
12 \\
15 \\
18 \\
21\end{array}$ & $\begin{array}{l}17.7 \\
16.0 \\
14.7 \\
14.7 \\
15.0 \\
14.5 \\
14.5 \\
14.6\end{array}$ & $\begin{array}{l}14.8 \\
13.3 \\
12.2 \\
12.6 \\
12.8 \\
12.9 \\
12.9 \\
13.5\end{array}$ & $\begin{array}{l}17.3 \\
15.6 \\
14.2 \\
14 \cdot 3 \\
14.5 \\
13.9 \\
14.2 \\
14.4\end{array}$ & $\begin{array}{l}14.3 \\
12.5 \\
11.1 \\
11.8 \\
12.3 \\
12.4 \\
12.7 \\
13.4\end{array}$ & $\begin{array}{l}17.1 \\
15.4 \\
14.1 \\
14.3 \\
14.3 \\
13.8 \\
14.2 \\
14.3\end{array}$ & $\begin{array}{l}13.8 \\
12.2 \\
10.7 \\
11.5 \\
12.2 \\
12.1 \\
12.6 \\
13.1\end{array}$ & $\begin{array}{l}17.2 \\
15.5 \\
14.0 \\
14 \cdot 3 \\
14 \cdot 4 \\
13.9 \\
14.4 \\
14 \cdot 6\end{array}$ & $\begin{array}{l}13.9 \\
12.3 \\
10.7 \\
11.7 \\
12.5 \\
17.4 \\
12.8 \\
13.5\end{array}$ & $\begin{array}{l}25.5 \\
25.3 \\
25.4 \\
25.4 \\
25.3 \\
25.0 \\
24.7 \\
24.5\end{array}$ & $\begin{array}{l}3 \\
3 \\
3 \\
3\end{array}$ & $\begin{array}{r}11.3 \\
11.5 \\
12.5 \\
8.3\end{array}$ & $\begin{array}{r}12.5 \\
12.8 \\
13.8 \\
9.1\end{array}$ & $\begin{array}{r}13.2 \\
13.8 \\
14.4 \\
9.4\end{array}$ & $\begin{array}{r}13.7 \\
14 \cdot 3 \\
14 \cdot 7 \\
9.8\end{array}$ \\
\hline
\end{tabular}


TABLE 10

Table 10. - Three-hour averages of air and water-surface temperatures and wind directions and speed, April 1950-August 1951, Lake Hefner-Continued

STATION 1 THREE-HOURLY AVERAGES

AUGUST, 1950

\begin{tabular}{|c|c|c|c|c|c|c|c|c|c|c|c|c|c|c|c|}
\hline \multirow{4}{*}{ 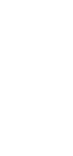 } & \multirow{4}{*}{ 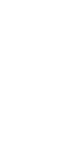 } & \multicolumn{8}{|c|}{ Average air temperature $\left({ }^{\circ} \mathrm{C}\right)$ at indicated height } & \multirow{4}{*}{\begin{tabular}{|c} 
Average \\
water- \\
surface \\
tempera- \\
ture \\
$\left({ }^{\circ} \mathrm{C}\right)$
\end{tabular}} & \multirow{4}{*}{$\begin{array}{c}\text { Average } \\
\text { wind } \\
\text { direction } \\
\text { (coded) }\end{array}$} & \multirow{2}{*}{\multicolumn{4}{|c|}{$\begin{array}{l}\text { Average wind speed (knots) } \\
\text { at indicated height }\end{array}$}} \\
\hline & & \multirow{2}{*}{\multicolumn{2}{|c|}{$\begin{array}{c}2 \\
\text { meters }\end{array}$}} & \multirow{2}{*}{\multicolumn{2}{|c|}{\begin{tabular}{|c|}
4 \\
meters \\
\end{tabular}}} & \multirow{2}{*}{\multicolumn{2}{|c|}{\begin{tabular}{|c|}
$\mathbf{8}$ \\
meters \\
\end{tabular}}} & \multirow{2}{*}{\multicolumn{2}{|c|}{$\begin{array}{c}16 \\
\text { meters }\end{array}$}} & & & & & & \\
\hline & & & & & & & & & & & & 2 & 4 & 8 & 16 \\
\hline & & $\begin{array}{l}\text { Dry } \\
\text { bulb }\end{array}$ & $\begin{array}{l}\text { Wet } \\
\text { bulb }\end{array}$ & $\begin{array}{l}\text { Dry } \\
\text { bulb }\end{array}$ & $\begin{array}{l}\text { Wet } \\
\text { bulb }\end{array}$ & $\begin{array}{l}\text { Dry } \\
\text { bulb }\end{array}$ & $\begin{array}{l}\text { Wet } \\
\text { bulb }\end{array}$ & $\begin{array}{l}\text { Dry } \\
\text { bulb }\end{array}$ & $\begin{array}{l}\text { Wet } \\
\text { bulb }\end{array}$ & & & meters & meters & & meters \\
\hline $\begin{array}{l}21 \\
21 \\
21 \\
21 \\
21 \\
21 \\
21 \\
21\end{array}$ & $\begin{array}{r}0 \\
3 \\
6 \\
9 \\
12 \\
15 \\
18 \\
21\end{array}$ & $\begin{array}{l}14.5 \\
14.3 \\
14.9 \\
18.9 \\
23.9 \\
24.4 \\
23.2 \\
21.8\end{array}$ & $\begin{array}{l}13.8 \\
13.8 \\
13.8 \\
15.2 \\
18.3 \\
19.0 \\
19.7 \\
19.8\end{array}$ & $\begin{array}{l}14.3 \\
14.1 \\
14.8 \\
19.0 \\
24.4 \\
24.4 \\
23.0 \\
21.6\end{array}$ & $\begin{array}{l}13.4 \\
13.5 \\
13.7 \\
15.1 \\
18.2 \\
18.8 \\
19.4 \\
19.7\end{array}$ & $\begin{array}{l}14.2 \\
14.0 \\
14.9 \\
19.1 \\
24.1 \\
24.3 \\
23.1 \\
21.6\end{array}$ & $\begin{array}{l}13.1 \\
13.1 \\
13.4 \\
15.2 \\
18.0 \\
18.9 \\
19.5 \\
19.7\end{array}$ & $\begin{array}{l}14.4 \\
14.2 \\
15.2 \\
19.4 \\
23.9 \\
24.5 \\
23.2 \\
21.7\end{array}$ & $\begin{array}{l}13.8 \\
13.7 \\
13.9 \\
15.5 \\
18.3 \\
19.8 \\
20.1 \\
19.9\end{array}$ & $\begin{array}{l}24.7 \\
24.5 \\
24.7 \\
26.3 \\
26.8 \\
26.0 \\
25.7 \\
25.7\end{array}$ & $\begin{array}{l}3 \\
3 \\
2 \\
2 \\
2 \\
3\end{array}$ & $\begin{array}{l}5.2 \\
2.8 \\
4.3 \\
2.4 \\
4.7\end{array}$ & $\begin{array}{l}5.4 \\
3.6 \\
4.8 \\
2.7 \\
4.9\end{array}$ & $\begin{array}{l}5.8 \\
3.7 \\
5.1 \\
2.7 \\
4.9\end{array}$ & $\begin{array}{l}5.0 \\
5.6 \\
3.7 \\
5.1 \\
2.7 \\
5.1\end{array}$ \\
\hline $\begin{array}{l}22 \\
22 \\
22 \\
22 \\
22 \\
22 \\
22 \\
22\end{array}$ & $\begin{array}{r}0 \\
3 \\
6 \\
9 \\
12 \\
15 \\
18 \\
21\end{array}$ & $\begin{array}{l}20.2 \\
20.0 \\
20.6 \\
22.4 \\
27.2 \\
27.4 \\
25.9 \\
23.5\end{array}$ & $\begin{array}{l}19.2 \\
19.2 \\
19.9 \\
19.9 \\
20.6 \\
21.0 \\
21.1 \\
20.3\end{array}$ & $\begin{array}{l}20.1 \\
20.0 \\
20.6 \\
22.3 \\
27.2 \\
27.5 \\
25.9 \\
23.3\end{array}$ & $\begin{array}{l}19.0 \\
19.2 \\
19.8 \\
19.8 \\
20.4 \\
20.8 \\
20.7 \\
20.0\end{array}$ & $\begin{array}{l}20.0 \\
20.0 \\
20.6 \\
22.5 \\
27.1 \\
27.7 \\
26.0 \\
23.3\end{array}$ & $\begin{array}{l}19.0 \\
19.2 \\
19.9 \\
19.7 \\
20.4 \\
20.7 \\
20.7 \\
20.1\end{array}$ & $\begin{array}{l}20.1 \\
20.0 \\
20.7 \\
22.9 \\
27.3 \\
27.8 \\
26.2 \\
23.5\end{array}$ & $\begin{array}{l}19.3 \\
19.5 \\
20.1 \\
20.0 \\
21.5 \\
21.0 \\
20.8 \\
20.3\end{array}$ & $\begin{array}{l}25.2 \\
24.9 \\
25.0 \\
25.5 \\
26.8 \\
26.7 \\
25.5 \\
25.0\end{array}$ & $\begin{array}{l}2 \\
2 \\
2 \\
2 \\
3 \\
2 \\
2 \\
2\end{array}$ & $\begin{array}{l}4.2 \\
4.4 \\
6.7 \\
7.1 \\
1.5 \\
4.6 \\
8.3 \\
9.5\end{array}$ & $\begin{array}{r}4.4 \\
4.6 \\
7.2 \\
7.9 \\
1.7 \\
5.1 \\
9.4 \\
10.7\end{array}$ & $\begin{array}{r}4.4 \\
4.7 \\
7.4 \\
8.3 \\
2.0 \\
5.4 \\
10.1 \\
11.1\end{array}$ & $\begin{array}{r}4.5 \\
4.6 \\
7.7 \\
8.7 \\
2.6 \\
6.3 \\
10.8 \\
11.7\end{array}$ \\
\hline $\begin{array}{l}23 \\
23 \\
23 \\
23 \\
23 \\
23 \\
23 \\
23\end{array}$ & $\begin{array}{r}0 \\
3 \\
6 \\
9 \\
12 \\
15 \\
18 \\
21\end{array}$ & $\begin{array}{l}19.5 \\
18.7 \\
18.3 \\
21.0 \\
25.4 \\
26.4 \\
25.4 \\
22.8\end{array}$ & $\begin{array}{l}18.3 \\
17.8 \\
17.7 \\
19.1 \\
20.9 \\
21.8 \\
22.0 \\
21.4\end{array}$ & $\begin{array}{l}19.2 \\
18.5 \\
18.2 \\
20.8 \\
25.3 \\
26.4 \\
25.3 \\
22.7\end{array}$ & $\begin{array}{l}18.1 \\
17.6 \\
17.4 \\
18.9 \\
20.6 \\
21.7 \\
21.8 \\
21.0\end{array}$ & $\begin{array}{l}19.4 \\
19.7 \\
18.2 \\
21.0 \\
25.8 \\
26.6 \\
25.2 \\
22.7\end{array}$ & $\begin{array}{l}17.8 \\
17.7 \\
17.6 \\
19.1 \\
20.4 \\
21.6 \\
21.8 \\
21.1\end{array}$ & $\begin{array}{l}19.6 \\
18.6 \\
18.4 \\
21.3 \\
25.7 \\
26.9 \\
25.3 \\
22.0\end{array}$ & $\begin{array}{l}17.9 \\
17.9 \\
27.9 \\
10.5 \\
20.9 \\
21.9 \\
27.0 \\
21.3\end{array}$ & $\begin{array}{l}24.7 \\
24.7 \\
24.7 \\
25.9 \\
26.9 \\
25.8 \\
25.0 \\
25.0\end{array}$ & $\begin{array}{l}2 \\
2 \\
2 \\
2 \\
2 \\
2 \\
2 \\
2\end{array}$ & $\begin{array}{r}10.2 \\
6.5 \\
6.7 \\
4.8 \\
6.2 \\
7.0 \\
7.2 \\
9.0\end{array}$ & $\begin{array}{r}11.3 \\
7.2 \\
7.3 \\
5.2 \\
6.9 \\
7.9 \\
7.9 \\
9.8\end{array}$ & $\begin{array}{r}11.4 \\
7.5 \\
7.7 \\
5.3 \\
7.4 \\
8.6 \\
8.4 \\
10.3\end{array}$ & $\begin{array}{r}12.3 \\
7.7 \\
7.8 \\
5.5 \\
7.6 \\
9.0 \\
9.0 \\
10.8\end{array}$ \\
\hline $\begin{array}{l}24 \\
24 \\
24 \\
24 \\
24 \\
24 \\
24 \\
24\end{array}$ & $\begin{array}{r}0 \\
3 \\
6 \\
9 \\
12 \\
15 \\
18 \\
21\end{array}$ & $\begin{array}{l}22.3 \\
21.7 \\
21.9 \\
25.8 \\
29.0 \\
29.9 \\
28.1 \\
26.8\end{array}$ & $\begin{array}{l}20.9 \\
20.5 \\
20.7 \\
22.1 \\
23.2 \\
24.1 \\
24.4 \\
23.6\end{array}$ & $\begin{array}{l}22.1 \\
21.5 \\
21.9 \\
26.1 \\
29.3 \\
30.1 \\
28.4 \\
26.9\end{array}$ & $\begin{array}{l}20.7 \\
20.4 \\
20.6 \\
22.0 \\
23.0 \\
24.0 \\
24.4 \\
23.4\end{array}$ & $\begin{array}{l}22.1 \\
21.6 \\
22.0 \\
26.3 \\
29.7 \\
30.5 \\
28.7 \\
27.2\end{array}$ & $\begin{array}{l}20.8 \\
20.4 \\
20.7 \\
22.1 \\
23.1 \\
24.2 \\
24.4 \\
23.4\end{array}$ & $\begin{array}{l}22 \cdot 2 \\
21 \cdot 6 \\
22 \cdot 3 \\
26 \cdot 9 \\
30 \cdot 3 \\
30: 9 \\
29: 0 \\
27.4\end{array}$ & $\begin{array}{l}20.9 \\
20.6 \\
20.9 \\
22.4 \\
23.3 \\
24.6 \\
24.8 \\
23.6\end{array}$ & $\begin{array}{l}24.8 \\
24.7 \\
25.1 \\
26.0 \\
26.2 \\
25.7 \\
25.5 \\
25.4\end{array}$ & $\begin{array}{l}2 \\
2 \\
2 \\
2 \\
2 \\
2 \\
2 \\
2\end{array}$ & $\begin{array}{r}9.8 \\
10.1 \\
9.4 \\
9.2 \\
11.1 \\
12.4 \\
7.0 \\
12.0\end{array}$ & $\begin{array}{r}10.6 \\
11.0 \\
10.3 \\
10.3 \\
12.8 \\
14.2 \\
8.1 \\
13.3\end{array}$ & $\begin{array}{r}11.1 \\
11.5 \\
11.0 \\
11.2 \\
14.0 \\
15.7 \\
9.2 \\
14.4\end{array}$ & $\begin{array}{l}11.7 \\
12.0 \\
11.2 \\
11.8 \\
14.9 \\
16.7 \\
10.3 \\
15.6\end{array}$ \\
\hline $\begin{array}{l}25 \\
25 \\
25 \\
25 \\
25 \\
25 \\
25 \\
25\end{array}$ & $\begin{array}{r}0 \\
3 \\
6 \\
9 \\
12 \\
15 \\
18 \\
21\end{array}$ & $\begin{array}{l}25.2 \\
23.6 \\
24.0 \\
28.1 \\
30.6 \\
31.4 \\
28.3 \\
25.6\end{array}$ & $\begin{array}{l}22.1 \\
21.1 \\
20.6 \\
22.0 \\
22.9 \\
23.6 \\
24.0 \\
23.3\end{array}$ & $\begin{array}{l}25.2 \\
23.6 \\
24.0 \\
28.4 \\
30.8 \\
31.7 \\
28.3 \\
25.6\end{array}$ & $\begin{array}{l}21.9 \\
20.8 \\
20.4 \\
21.8 \\
23.0 \\
23.5 \\
23.8 \\
23.1\end{array}$ & $\begin{array}{l}25.2 \\
23.7 \\
24.3 \\
28.7 \\
31.2 \\
31.9 \\
28.7 \\
25.6\end{array}$ & $\begin{array}{l}21.9 \\
20.8 \\
20.5 \\
21.5 \\
23.0 \\
23.5 \\
23.8 \\
23.1\end{array}$ & $\begin{array}{l}25 \cdot 4 \\
23.9 \\
24 \cdot 7 \\
29 \cdot 4 \\
31 \cdot 6 \\
32.4 \\
29.0 \\
25.0\end{array}$ & $\begin{array}{l}22.1 \\
20.9 \\
20.6 \\
22.0 \\
23.3 \\
23.8 \\
24 \cdot 2 \\
23.4\end{array}$ & $\begin{array}{l}25.1 \\
25.0 \\
25.3 \\
26.1 \\
26.6 \\
26.2 \\
25.8 \\
25.9\end{array}$ & $\begin{array}{l}2 \\
2 \\
2 \\
2 \\
2 \\
2 \\
2 \\
2 \\
2\end{array}$ & $\begin{array}{r}10.0 \\
7.8 \\
7.1 \\
10.3 \\
10.1 \\
11.1 \\
6.1 \\
5.4\end{array}$ & $\begin{array}{r}11.1 \\
8.8 \\
7.9 \\
11.6 \\
11.4 \\
12.4 \\
7.1 \\
6.1\end{array}$ & $\begin{array}{r}12.0 \\
9.4 \\
8.4 \\
12.7 \\
12.5 \\
13.9 \\
8.3 \\
6.6\end{array}$ & $\begin{array}{r}12.8 \\
10.0 \\
8.9 \\
13.2 \\
13.1 \\
14.6 \\
9.4 \\
7.6\end{array}$ \\
\hline $\begin{array}{l}26 \\
26 \\
26 \\
26 \\
26 \\
26 \\
26 \\
25\end{array}$ & $\begin{array}{r}0 \\
3 \\
6 \\
9 \\
12 \\
15 \\
18 \\
21\end{array}$ & $\begin{array}{l}24 \cdot 5 \\
23 \cdot 4 \\
23 \cdot 5 \\
27 \cdot 3 \\
30 \cdot 3 \\
30 \cdot 9 \\
28 \cdot 4 \\
22 \cdot 3\end{array}$ & $\begin{array}{l}22.7 \\
21.04 \\
21.0 \\
21.9 \\
23.0 \\
23.5 \\
23.8 \\
19.5\end{array}$ & $\begin{array}{l}24.4 \\
23.5 \\
23.5 \\
27.4 \\
31.0 \\
30.9 \\
28.6 \\
22.2\end{array}$ & $\begin{array}{l}22.4 \\
21.1 \\
20.8 \\
21.8 \\
22.7 \\
23.5 \\
23.7 \\
18.9\end{array}$ & $\begin{array}{l}24.4 \\
23.6 \\
23.7 \\
27.7 \\
31.2 \\
31.4 \\
28.6 \\
22.0\end{array}$ & $\begin{array}{l}22.4 \\
21.1 \\
20.9 \\
21.7 \\
22.8 \\
23.3 \\
23.1 \\
18.7\end{array}$ & $\begin{array}{l}24 \cdot 6 \\
23.8 \\
24.0 \\
28 \cdot 2 \\
31.5 \\
31.9 \\
28.8 \\
22.0\end{array}$ & $\begin{array}{l}22 \cdot 6 \\
21 \cdot 3 \\
21 \cdot 0 \\
22 \cdot 1 \\
23 \cdot 1 \\
23 \cdot 6 \\
23.3 \\
19 \cdot 2\end{array}$ & $\begin{array}{l}25.7 \\
25.2 \\
25.6 \\
26.5 \\
26.7 \\
26.4 \\
25.9 \\
25.8\end{array}$ & $\begin{array}{l}2 \\
2 \\
2 \\
2 \\
2 \\
2 \\
2 \\
2 \\
2\end{array}$ & $\begin{array}{r}10.3 \\
4.6 \\
7.1 \\
9.1 \\
11.1 \\
10.9 \\
8.3 \\
11.1\end{array}$ & $\begin{array}{r}11.4 \\
5.0 \\
7.6 \\
10.2 \\
12.5 \\
12.4 \\
9.4 \\
11.9\end{array}$ & $\begin{array}{r}12.3 \\
5.2 \\
8.0 \\
11.2 \\
14.0 \\
13.8 \\
10.5 \\
12.5\end{array}$ & $\begin{array}{r}13.1 \\
5.4 \\
8.3 \\
11.7 \\
14.6 \\
14.8 \\
11.6 \\
13.3\end{array}$ \\
\hline $\begin{array}{l}27 \\
27 \\
27 \\
27 \\
27 \\
27 \\
27 \\
27\end{array}$ & $\begin{array}{r}0 \\
3 \\
6 \\
9 \\
12 \\
15 \\
18 \\
21\end{array}$ & $\begin{array}{l}21.1 \\
20.1 \\
20.4 \\
24.0 \\
27.0 \\
26.8 \\
26.2 \\
23.4\end{array}$ & $\begin{array}{l}19.2 \\
19.0 \\
19.2 \\
21.0 \\
21.3 \\
21.5 \\
21.2 \\
21.04\end{array}$ & $\begin{array}{l}20.8 \\
19.9 \\
20.0 \\
23.4 \\
27.4 \\
26.7 \\
26.0 \\
23.4\end{array}$ & $\begin{array}{l}18.9 \\
18.9 \\
18.9 \\
20.7 \\
21.0 \\
20.9 \\
21.0 \\
21.3\end{array}$ & $\begin{array}{l}20.7 \\
19.9 \\
20.2 \\
23.7 \\
27.1 \\
27.2 \\
25.7 \\
23.4\end{array}$ & $\begin{array}{l}18.9 \\
18.8 \\
19.1 \\
21.0 \\
21.0 \\
21.3 \\
20.9 \\
21.3\end{array}$ & $\begin{array}{l}20.7 \\
20.0 \\
20.3 \\
24.3 \\
26.7 \\
27.6 \\
26.0 \\
23.6\end{array}$ & $\begin{array}{l}19.0 \\
19.1 \\
19.4 \\
21.3 \\
21.2 \\
21.8 \\
21.1 \\
21.6\end{array}$ & $\begin{array}{l}25.7 \\
25.5 \\
25.7 \\
26.7 \\
27.3 \\
26.7 \\
26.5 \\
26.2\end{array}$ & $\begin{array}{l}3 \\
3 \\
3 \\
2 \\
4 \\
3 \\
3 \\
3\end{array}$ & $\begin{array}{l}9.0 \\
6.8 \\
5.5 \\
2.8 \\
3.4 \\
3.2 \\
2.2 \\
3.6\end{array}$ & $\begin{array}{l}9.6 \\
7.3 \\
6.2 \\
3.1 \\
3.6 \\
3.2 \\
2.3 \\
4.1\end{array}$ & $\begin{array}{r}10.1 \\
7.4 \\
6.3 \\
3.1 \\
4.4 \\
3.8 \\
2.3 \\
4.1\end{array}$ & $\begin{array}{r}10.4 \\
7.8 \\
6.7 \\
3.1 \\
4.2 \\
3.0 \\
2.3 \\
4.1\end{array}$ \\
\hline $\begin{array}{l}28 \\
28 \\
28 \\
28 \\
28 \\
28 \\
28 \\
28\end{array}$ & $\begin{array}{r}0 \\
3 \\
6 \\
9 \\
12 \\
15 \\
18 \\
21\end{array}$ & $\begin{array}{l}22.0 \\
21.3 \\
21.9 \\
24.7 \\
28.5 \\
28.2\end{array}$ & $\begin{array}{l}21.1 \\
20.5 \\
20.7 \\
21.4 \\
21.8 \\
21.8\end{array}$ & $\begin{array}{l}22.0 \\
21.2 \\
21.9 \\
24.9 \\
28.3 \\
28.5\end{array}$ & $\begin{array}{l}21.0 \\
20.2 \\
20.5 \\
21.3 \\
21.8 \\
21.7\end{array}$ & $\begin{array}{l}22.0 \\
21.1 \\
21.8 \\
24.9 \\
28.0 \\
28.3\end{array}$ & $\begin{array}{l}21.0 \\
20.3 \\
20.6 \\
21.4 \\
21.6 \\
21.5\end{array}$ & $\begin{array}{l}22 \cdot 1 \\
21 \cdot 3 \\
22 \cdot 1 \\
25 \cdot 0 \\
27 \cdot 9 \\
28 \cdot 4\end{array}$ & $\begin{array}{l}21 \cdot 2 \\
20.6 \\
20 \cdot 9 \\
21 \cdot 7 \\
21 \cdot 7 \\
21.6\end{array}$ & $\begin{array}{l}25.9 \\
25.9 \\
26.0 \\
27.0 \\
28.5 \\
28.0\end{array}$ & $\begin{array}{l}2 \\
2 \\
2 \\
2 \\
2 \\
2 \\
2 \\
2\end{array}$ & $\begin{array}{l}4.0 \\
5.2 \\
6.3 \\
2.6 \\
3.5 \\
6.5 \\
8.3 \\
6.8\end{array}$ & $\begin{array}{l}4.3 \\
5.7 \\
6.8 \\
3.0 \\
3.8 \\
7.0 \\
9.1 \\
7.4\end{array}$ & $\begin{array}{l}4.5 \\
6.0 \\
7.0 \\
3.1 \\
4.0 \\
7.4 \\
9.6 \\
7.8\end{array}$ & $\begin{array}{r}4.6 \\
5.2 \\
7.2 \\
3.6 \\
4.1 \\
7.7 \\
10.2 \\
8.4\end{array}$ \\
\hline $\begin{array}{l}29 \\
29 \\
29 \\
29 \\
29 \\
29 \\
29 \\
29\end{array}$ & $\begin{array}{r}0 \\
3 \\
6 \\
9 \\
12 \\
15 \\
18 \\
21\end{array}$ & $\begin{array}{l}22 \cdot 3 \\
24 \cdot 9 \\
27 \cdot 2 \\
25 \cdot 1 \\
22 \cdot 5\end{array}$ & $\begin{array}{l}18.7 \\
19.3 \\
20.1 \\
20.1 \\
20.1 \\
20.4\end{array}$ & $\begin{array}{l}20.2 \\
22.2 \\
24 \cdot 7 \\
27 \cdot 1 \\
24: 9 \\
22.3\end{array}$ & $\begin{array}{l}18.9 \\
19.0 \\
19.5 \\
19.6 \\
19.7 \\
20.1\end{array}$ & $\begin{array}{l}20.5 \\
22.5 \\
24 \cdot 5 \\
27.2 \\
24.8 \\
22.3\end{array}$ & $\begin{array}{l}18.8 \\
19.2 \\
19.8 \\
19.8 \\
19.8 \\
20.2\end{array}$ & $\begin{array}{l}20 \cdot 9 \\
22: 8 \\
24 \cdot 9 \\
27 \cdot 2 \\
24 \cdot 9 \\
22 \cdot 5\end{array}$ & $\begin{array}{l}19.4 \\
19.4 \\
20.1 \\
20.2 \\
20.1 \\
20.3\end{array}$ & $\begin{array}{l}26.4 \\
26.1 \\
27.0 \\
27.2 \\
26.5 \\
26.0\end{array}$ & $\begin{array}{l}2 \\
2 \\
3 \\
2 \\
3 \\
3 \\
3 \\
3\end{array}$ & $\begin{array}{l}9.1 \\
8.8 \\
4.3 \\
4.4 \\
2.5 \\
1.2 \\
4.4 \\
5.7\end{array}$ & $\begin{array}{r}10.1 \\
9.7 \\
4.8 \\
4.9 \\
3.0 \\
1.3 \\
4.6 \\
6.7\end{array}$ & $\begin{array}{r}10.7 \\
10.1 \\
4.9 \\
5.1 \\
3.1 \\
1.3 \\
5.0 \\
7.0\end{array}$ & $\begin{array}{r}11.3 \\
10.7 \\
5.0 \\
5.3 \\
3.0 \\
1.2 \\
5.0 \\
7.3\end{array}$ \\
\hline $\begin{array}{l}30 \\
30 \\
30 \\
30 \\
30 \\
30 \\
30 \\
30\end{array}$ & $\begin{array}{r}0 \\
3 \\
6 \\
9 \\
12 \\
15 \\
18 \\
21\end{array}$ & $\begin{array}{l}20.7 \\
19.0 \\
19.0 \\
21.0 \\
23.0 \\
23.0 \\
21.7 \\
19.2\end{array}$ & $\begin{array}{l}19.8 \\
18.6 \\
17.7 \\
17.7 \\
18.3 \\
18.5 \\
18.0 \\
17.2\end{array}$ & $\begin{array}{l}20.4 \\
18.9 \\
18.7 \\
20.8 \\
22.9 \\
23.4 \\
21.4 \\
19.0\end{array}$ & $\begin{array}{l}19.4 \\
18: 3 \\
17.2 \\
17.2 \\
17.8 \\
17.9 \\
17.5 \\
16.8\end{array}$ & $\begin{array}{l}20.4 \\
18.7 \\
18.6 \\
20.7 \\
22.0 \\
23.4 \\
21.03 \\
18.9\end{array}$ & $\begin{array}{l}19.5 \\
18.1 \\
17.2 \\
17.2 \\
17.6 \\
17.8 \\
17.3 \\
16.7\end{array}$ & $\begin{array}{l}20.4 \\
18.8 \\
18.7 \\
21.0 \\
23.2 \\
23.5 \\
21.3 \\
19.0\end{array}$ & $\begin{array}{l}19.7 \\
18.3 \\
17.4 \\
17.2 \\
17.7 \\
17.0 \\
17.4 \\
16.9\end{array}$ & $\begin{array}{l}25.7 \\
25.4 \\
25.6 \\
26.9 \\
27.2 \\
26.4 \\
25.5 \\
25.3\end{array}$ & $\begin{array}{l}3 \\
3 \\
3 \\
3 \\
3 \\
3 \\
3 \\
3\end{array}$ & $\begin{array}{r}7.1 \\
9.6 \\
10.2 \\
10.7 \\
12.0 \\
12.6 \\
9.0 \\
7.1\end{array}$ & $\begin{array}{r}8.3 \\
10.8 \\
11.1 \\
11.9 \\
13.3 \\
14.0 \\
10.1 \\
7.7\end{array}$ & $\begin{array}{r}8.6 \\
11.5 \\
12.4 \\
12.9 \\
14.9 \\
15.5 \\
10.6 \\
8.1\end{array}$ & $\begin{array}{r}8.7 \\
11.7 \\
12.7 \\
13.4 \\
15.5 \\
16.2 \\
11.0 \\
8.4\end{array}$ \\
\hline $\begin{array}{l}31 \\
31 \\
31 \\
31 \\
31 \\
31 \\
31 \\
31\end{array}$ & $\begin{array}{r}0 \\
3 \\
6 \\
9 \\
12 \\
15 \\
18 \\
21\end{array}$ & $\begin{array}{l}17.5 \\
16.7 \\
16.5 \\
30.0 \\
22.0 \\
23.5 \\
22.7 \\
20.1\end{array}$ & $\begin{array}{l}16.3 \\
15.9 \\
16.0 \\
17.0 \\
17.7 \\
18.6 \\
18.4 \\
17.5\end{array}$ & $\begin{array}{l}17.3 \\
16.3 \\
16.3 \\
19.0 \\
21.8 \\
33.4 \\
27.4 \\
19.9\end{array}$ & $\begin{array}{l}16.0 \\
15.3 \\
15.6 \\
16.5 \\
17.6 \\
18.0 \\
18 \bullet 0 \\
17.4\end{array}$ & $\begin{array}{l}17.1 \\
16.2 \\
16.3 \\
19.0 \\
22.0 \\
23.4 \\
22.04 \\
19.9\end{array}$ & $\begin{array}{l}15.9 \\
15.3 \\
15.4 \\
16.3 \\
17.4 \\
77.9 \\
18.0 \\
17.3\end{array}$ & $\begin{array}{l}17.2 \\
35.3 \\
16.5 \\
20.1 \\
22.2 \\
24.5 \\
22.5 \\
20.0\end{array}$ & $\begin{array}{l}15.9 \\
15.4 \\
15.7 \\
16.3 \\
17.4 \\
17.9 \\
11.1 \\
17.4\end{array}$ & $\begin{array}{l}25.1 \\
25.0 \\
25.2 \\
26.1 \\
26.2 \\
25.3 \\
24.8 \\
24.7\end{array}$ & $\begin{array}{l}3 \\
3 \\
3 \\
3 \\
3 \\
3 \\
3 \\
3\end{array}$ & $\begin{array}{r}7.5 \\
9.0 \\
10.5 \\
15.5 \\
13.7 \\
12.0 \\
7.8 \\
6.4\end{array}$ & $\begin{array}{r}8.3 \\
10.4 \\
11.5 \\
17.3 \\
15.8 \\
13.3 \\
8.3 \\
7.0\end{array}$ & $\begin{array}{r}8.9 \\
10.7 \\
12.5 \\
19.2 \\
17.4 \\
14.7 \\
0.4 \\
7.7\end{array}$ & $\begin{array}{r}9.2 \\
11.0 \\
12.7 \\
20.2 \\
18.3 \\
15.4 \\
9.9 \\
8.0\end{array}$ \\
\hline
\end{tabular}


Table 10. - Three-hour averages of air and water-surface temperatures and wind directions and speed, April 1950-August STATION, THREE-HOURLY AVERAGES

SEPTEMBER, 1950

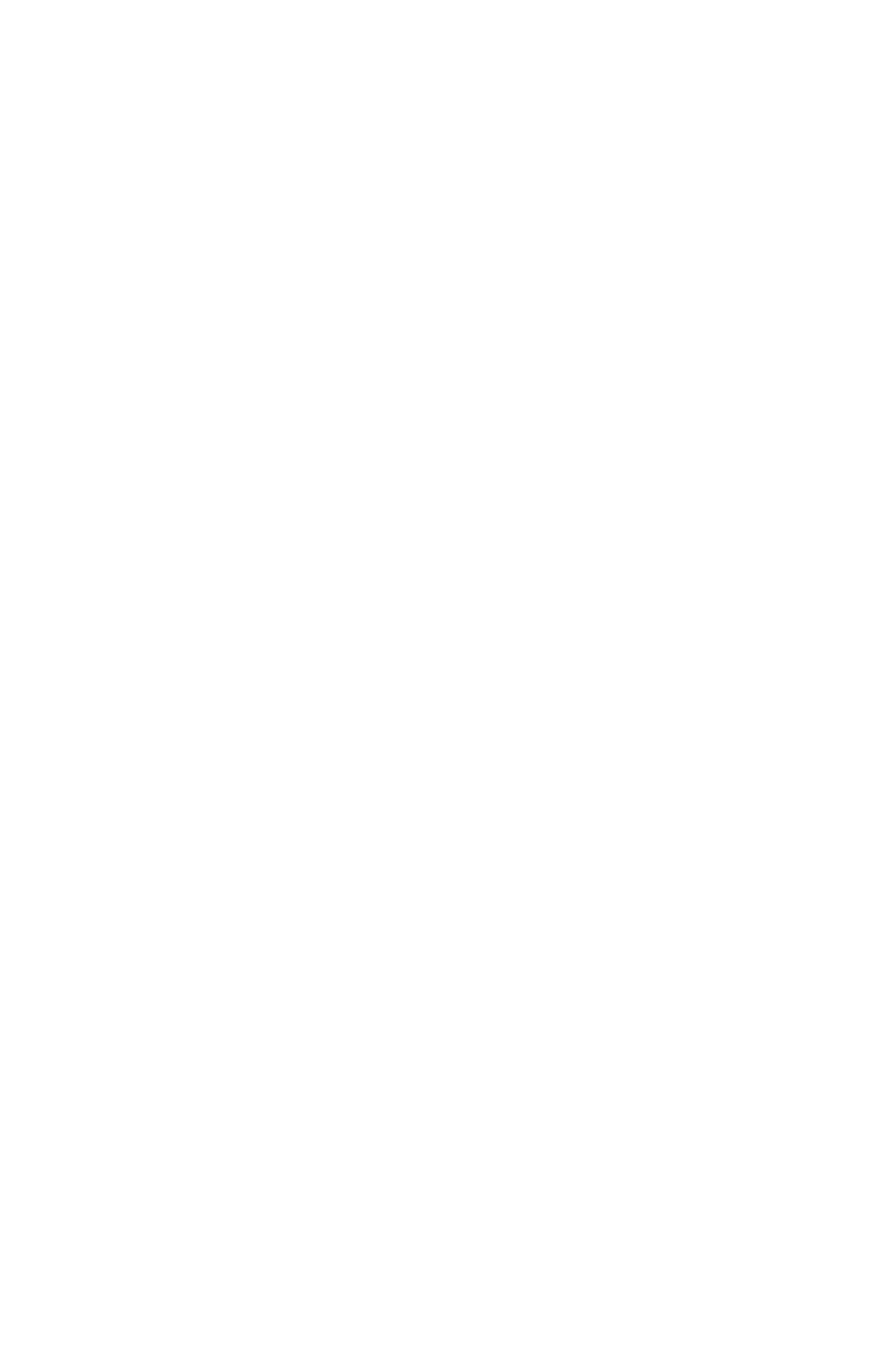


TABLE 10

Table 10, - Three-hour averages of air and water-surface temperatures and wind directions and speed, April 1950-August 1951, Lake Hefner-Continued

STATION 1

THREE-HOURLY AVERAGES

SEPTEMBER, 1950

\begin{tabular}{|c|c|c|c|c|c|c|c|c|c|c|c|c|c|c|c|}
\hline \multirow{3}{*}{ 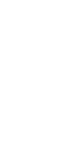 } & \multirow{3}{*}{ 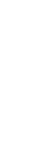 } & \multicolumn{8}{|c|}{ Average air temperature $\left({ }^{\circ} \mathrm{C}\right)$ at indicated height } & \multirow{3}{*}{$\begin{array}{l}\text { Average } \\
\text { water- } \\
\text { surface } \\
\text { tempera- } \\
\text { ture } \\
\left({ }^{\circ} \mathrm{C}\right)\end{array}$} & \multirow{3}{*}{$\begin{array}{c}\text { Average } \\
\text { wind } \\
\text { direction } \\
\text { (coded) }\end{array}$} & \multicolumn{4}{|c|}{$\begin{array}{l}\text { Average wind speed (knots) } \\
\text { at indicated height }\end{array}$} \\
\hline & & \multicolumn{2}{|c|}{$\begin{array}{c}2 \\
\text { meters }\end{array}$} & \multicolumn{2}{|c|}{$\stackrel{4}{4}$} & \multicolumn{2}{|c|}{$\begin{array}{c}8 \\
\text { meters }\end{array}$} & \multicolumn{2}{|c|}{$\begin{array}{c}16 \\
\text { meters }\end{array}$} & & & & & & \\
\hline & & $\begin{array}{l}\text { Dry } \\
\text { bulb }\end{array}$ & $\begin{array}{l}\text { Wet } \\
\text { bulb }\end{array}$ & $\begin{array}{l}\text { Dry } \\
\text { bulb }\end{array}$ & $\begin{array}{l}\text { Wet } \\
\text { bulb }\end{array}$ & $\begin{array}{l}\text { Dry } \\
\text { bulb }\end{array}$ & $\begin{array}{l}\text { Wet } \\
\text { buib }\end{array}$ & $\begin{array}{l}\text { Dry } \\
\text { bulb }\end{array}$ & $\begin{array}{l}\text { Wet } \\
\text { bulb }\end{array}$ & & & meters & meters & meters & meters \\
\hline $\begin{array}{l}11 \\
11 \\
11 \\
11 \\
11 \\
11 \\
11 \\
11\end{array}$ & $\begin{array}{r}0 \\
3 \\
6 \\
9 \\
12 \\
15 \\
18 \\
21\end{array}$ & $\begin{array}{l}20.2 \\
17.4 \\
16.0 \\
16.0 \\
17.6 \\
20.7 \\
19.5 \\
17.2\end{array}$ & $\begin{array}{l}17.7 \\
15.0 \\
13.8 \\
13.2 \\
14.5 \\
16.3 \\
15.9 \\
14.8\end{array}$ & $\begin{array}{l}20.2 \\
17.2 \\
15.6 \\
15.4 \\
17.4 \\
20.4 \\
19.3 \\
17.0\end{array}$ & $\begin{array}{l}17.4 \\
14.7 \\
13.2 \\
12.9 \\
14.0 \\
15.8 \\
15.5 \\
14.6\end{array}$ & $\begin{array}{l}19.9 \\
16.9 \\
15.3 \\
15.3 \\
17.4 \\
20.4 \\
19.1 \\
16.9\end{array}$ & $\begin{array}{l}17.1 \\
14.0 \\
12.0 \\
12.4 \\
13.8 \\
15.5 \\
15.2 \\
14.3\end{array}$ & $\begin{array}{l}19.8 \\
16.5 \\
15.1 \\
15.2 \\
17.4 \\
20.4 \\
19.0 \\
26.7\end{array}$ & $\begin{array}{l}17.1 \\
13.7 \\
12.7 \\
12.3 \\
14.0 \\
15.8 \\
15.3 \\
14.4\end{array}$ & $\begin{array}{l}22.9 \\
22.9 \\
22.9 \\
23.0 \\
23.0 \\
22.9 \\
22.5 \\
22.0\end{array}$ & $\begin{array}{l}2 \\
3 \\
3 \\
3 \\
3 \\
3 \\
3 \\
3\end{array}$ & $\begin{array}{r}8.2 \\
14.6 \\
13.8 \\
13.2 \\
6.8 \\
7.4 \\
6.2 \\
5.6\end{array}$ & $\begin{array}{r}7.8 \\
17.7 \\
15.4 \\
14.5 \\
9.7 \\
8.2 \\
6.9 \\
6.5\end{array}$ & $\begin{array}{r}6.8 \\
18.5 \\
16.7 \\
16.2 \\
10.7 \\
9.1 \\
7.3 \\
6.9\end{array}$ & $\begin{array}{r}7.3 \\
20.2 \\
17.1 \\
16.6 \\
10.9 \\
9.3 \\
7.7 \\
7.0\end{array}$ \\
\hline $\begin{array}{l}12 \\
12 \\
12 \\
12 \\
12 \\
12 \\
12 \\
12\end{array}$ & $\begin{array}{r}0 \\
3 \\
6 \\
9 \\
12 \\
15 \\
18 \\
21\end{array}$ & $\begin{array}{l}15 \cdot 3 \\
14 \cdot 9 \\
15 \cdot 3 \\
17 \cdot 3 \\
17 \cdot 6 \\
19 \cdot 7 \\
18.2 \\
17.9\end{array}$ & $\begin{array}{l}13.9 \\
13.8 \\
14.0 \\
15.7 \\
16.7 \\
18.2 \\
17.8 \\
17.5\end{array}$ & $\begin{array}{l}35.1 \\
14.8 \\
25.1 \\
17.5 \\
17.4 \\
19.4 \\
18.0 \\
17.8\end{array}$ & $\begin{array}{l}13.5 \\
13.7 \\
13.8 \\
15.0 \\
15.3 \\
17.9 \\
17.4 \\
17.2\end{array}$ & $\begin{array}{l}14.8 \\
14.8 \\
15.0 \\
17.0 \\
17.5 \\
19.4 \\
17.9 \\
17.6\end{array}$ & $\begin{array}{l}13.4 \\
13.5 \\
13.7 \\
15.1 \\
16.3 \\
17.8 \\
17.3 \\
16.9\end{array}$ & $\begin{array}{l}14 \cdot 6 \\
14 \cdot 7 \\
14 \cdot 9 \\
16.8 \\
17.3 \\
19.3 \\
17.6 \\
17.3\end{array}$ & $\begin{array}{l}13.3 \\
13.5 \\
13.7 \\
15.2 \\
16.3 \\
17.8 \\
17.3 \\
16.9\end{array}$ & $\begin{array}{l}22.1 \\
22.1 \\
22.0 \\
22.05 \\
22.8 \\
22.5 \\
22.4 \\
22.03\end{array}$ & $\begin{array}{l}2 \\
2 \\
2 \\
3 \\
3 \\
2 \\
2\end{array}$ & $\begin{array}{l}5.8 \\
3.8 \\
4.0 \\
7.1 \\
9.9 \\
6.6 \\
6.9 \\
8.5\end{array}$ & $\begin{array}{r}6.3 \\
4.2 \\
4.4 \\
7.6 \\
10.8 \\
7.0 \\
7.4 \\
9.0\end{array}$ & $\begin{array}{r}6.9 \\
4.4 \\
4.5 \\
7.9 \\
12.2 \\
7.2 \\
7.5 \\
9.3\end{array}$ & $\begin{array}{r}7.0 \\
4.4 \\
4.5 \\
7.9 \\
13.8 \\
7.5 \\
7.5 \\
9.4\end{array}$ \\
\hline $\begin{array}{l}13 \\
13 \\
13 \\
13 \\
13 \\
13 \\
13 \\
13\end{array}$ & $\begin{array}{r}0 \\
3 \\
6 \\
9 \\
12 \\
15 \\
18 \\
21\end{array}$ & $\begin{array}{l}17.4 \\
16.7 \\
16.6 \\
17.2 \\
19.3 \\
21.5 \\
20.4 \\
19.9\end{array}$ & $\begin{array}{l}17.0 \\
16.4 \\
15.8 \\
16.5 \\
18.4 \\
19.5 \\
19.4 \\
19.0\end{array}$ & $\begin{array}{l}17.2 \\
16.6 \\
16.4 \\
17.0 \\
19.2 \\
21.5 \\
20.3 \\
19.8\end{array}$ & $\begin{array}{l}16.7 \\
16.0 \\
15.3 \\
16.1 \\
18.2 \\
19.2 \\
19.1 \\
18.8\end{array}$ & $\begin{array}{l}17.1 \\
16.3 \\
16.7 \\
16.9 \\
19.0 \\
21.03 \\
20.2 \\
19.7\end{array}$ & $\begin{array}{l}16.6 \\
15.8 \\
15.2 \\
16.2 \\
18.1 \\
19.2 \\
18.9 \\
18.7\end{array}$ & $\begin{array}{l}16.9 \\
16.1 \\
16.0 \\
16.8 \\
19.0 \\
21.2 \\
20.1 \\
19.5\end{array}$ & $\begin{array}{l}16.6 \\
16.0 \\
15.2 \\
16.2 \\
19.1 \\
19.1 \\
18.9 \\
18.7\end{array}$ & $\begin{array}{l}22 \cdot 2 \\
22 \cdot 1 \\
22 \cdot 1 \\
22 \cdot 5 \\
22 \cdot 7 \\
2 ? \cdot 8 \\
22 \cdot 3 \\
22 \cdot 2\end{array}$ & $\begin{array}{l}3 \\
3 \\
3 \\
3 \\
3 \\
3 \\
3 \\
3\end{array}$ & $\begin{array}{l}7.3 \\
8.3 \\
8.1 \\
8.7 \\
6.5 \\
6.5 \\
9.3 \\
6.8\end{array}$ & $\begin{array}{l}7.5 \\
8.7 \\
8.7 \\
9.6 \\
6.9 \\
6.8 \\
9.8 \\
7.1\end{array}$ & $\begin{array}{r}7.7 \\
8.9 \\
9.0 \\
10.0 \\
7.2 \\
7.1 \\
10.0 \\
7.5\end{array}$ & $\begin{array}{r}7 \cdot 8 \\
9 \cdot 1 \\
9 \cdot 1 \\
10 \cdot 1 \\
7 \cdot 3 \\
7 \cdot 2 \\
10 \cdot 2 \\
7 \cdot 5\end{array}$ \\
\hline $\begin{array}{l}14 \\
14 \\
14 \\
14 \\
14 \\
14 \\
14 \\
14\end{array}$ & $\begin{array}{r}0 \\
3 \\
5 \\
9 \\
12 \\
15 \\
18 \\
21\end{array}$ & $\begin{array}{l}18.8 \\
16.4 \\
16.2 \\
17.9 \\
18.9 \\
70.1 \\
19.9 \\
19.4\end{array}$ & $\begin{array}{l}18.3 \\
15.7 \\
15.4 \\
16.9 \\
17.5 \\
18.7 \\
19.0 \\
19.3\end{array}$ & $\begin{array}{l}18.6 \\
16.0 \\
15.9 \\
17.7 \\
18.6 \\
20.0 \\
39.7 \\
19.3\end{array}$ & $\begin{array}{l}18.0 \\
15.1 \\
15.1 \\
16.5 \\
17.4 \\
18.4 \\
18.7 \\
19.1\end{array}$ & $\begin{array}{l}18.5 \\
16.0 \\
15.8 \\
17.7 \\
18.6 \\
19.9 \\
19.6 \\
19.6\end{array}$ & $\begin{array}{l}17.7 \\
15.0 \\
15.1 \\
16.3 \\
17.3 \\
18.3 \\
18.6 \\
19.1\end{array}$ & $\begin{array}{l}18.0 \\
15.4 \\
15.7 \\
17.5 \\
18.5 \\
19.9 \\
19.3 \\
19.2\end{array}$ & $\begin{array}{l}17.6 \\
14.9 \\
15.1 \\
16.2 \\
17.3 \\
18.4 \\
18.6 \\
10.2\end{array}$ & $\begin{array}{l}22.0 \\
22.0 \\
22.0 \\
22.4 \\
22.7 \\
22.1 \\
22.0 \\
21.0\end{array}$ & $\begin{array}{l}3 \\
3 \\
3 \\
3 \\
3 \\
3 \\
3 \\
3\end{array}$ & $\begin{array}{r}10.9 \\
12.5 \\
6.9 \\
8.0 \\
7.5 \\
6.6 \\
7.7 \\
5.7\end{array}$ & $\begin{array}{r}12.1 \\
13.3 \\
7.3 \\
8.6 \\
7.9 \\
7.0 \\
8.0 \\
6.1\end{array}$ & $\begin{array}{r}12.8 \\
13.8 \\
7.4 \\
9.0 \\
8.3 \\
7.2 \\
8.2 \\
6.2\end{array}$ & $\begin{array}{r}13.2 \\
14.2 \\
7.5 \\
9.2 \\
8.4 \\
7.4 \\
8.4 \\
6.3\end{array}$ \\
\hline $\begin{array}{l}15 \\
15 \\
15 \\
15 \\
15 \\
15 \\
15 \\
15\end{array}$ & $\begin{array}{r}0 \\
3 \\
6 \\
9 \\
12 \\
15 \\
18 \\
21\end{array}$ & $\begin{array}{l}20.3 \\
19.7 \\
10.8 \\
20.9 \\
25.3 \\
27.0 \\
24.4 \\
20.9\end{array}$ & $\begin{array}{l}19.7 \\
19.1 \\
10.2 \\
20.1 \\
22.1 \\
22.0 \\
22.4 \\
19.7\end{array}$ & $\begin{array}{r}20.3 \\
19.6 \\
19.5 \\
21.0 \\
25.8 \\
27.7 \\
24.1 \\
20.8\end{array}$ & $\begin{array}{l}19.6 \\
18.9 \\
19.0 \\
20.0 \\
22.1 \\
22.7 \\
22.1 \\
19.4\end{array}$ & $\begin{array}{l}20.9 \\
19.3 \\
19.4 \\
20.9 \\
25.8 \\
28.0 \\
23.8 \\
20.6\end{array}$ & $\begin{array}{l}19.5 \\
18.9 \\
18.9 \\
20.0 \\
22.2 \\
22.0 \\
22.0 \\
19.3\end{array}$ & $\begin{array}{l}20.3 \\
19.5 \\
19.3 \\
21.0 \\
26.0 \\
28.4 \\
23.8 \\
20.4\end{array}$ & $\begin{array}{l}10.8 \\
10.0 \\
10.1 \\
20.2 \\
29.3 \\
22.0 \\
22.0 \\
10.2\end{array}$ & $\begin{array}{l}21.9 \\
21.9 \\
22.0 \\
22.5 \\
23.0 \\
22.7 \\
22.3 \\
22.03\end{array}$ & $\begin{array}{l}2 \\
2 \\
2 \\
2 \\
2 \\
2 \\
3 \\
3\end{array}$ & $\begin{array}{r}5.3 \\
8.6 \\
8.7 \\
12.5 \\
8.4 \\
4.8 \\
7.5 \\
7.6\end{array}$ & $\begin{array}{r}6.7 \\
9.3 \\
9.5 \\
14.0 \\
9.6 \\
5.8 \\
8.1 \\
8.1\end{array}$ & $\begin{array}{r}7.2 \\
9.7 \\
10.1 \\
15.1 \\
10.6 \\
6.8 \\
8.7 \\
8.3\end{array}$ & $\begin{array}{r}7.4 \\
10.0 \\
10.5 \\
15.7 \\
11.2 \\
7.0 \\
8.8 \\
8.6\end{array}$ \\
\hline $\begin{array}{l}16 \\
16 \\
16 \\
16 \\
16 \\
16 \\
16 \\
16\end{array}$ & $\begin{array}{r}0 \\
3 \\
6 \\
9 \\
12 \\
15 \\
18 \\
71\end{array}$ & $\begin{array}{l}20.5 \\
20.0 \\
29.9 \\
20.1 \\
21.7 \\
23.0 \\
21.6 \\
20.6\end{array}$ & $\begin{array}{l}10.1 \\
19.0 \\
13.0 \\
19.1 \\
10.0 \\
20.3 \\
30.1 \\
19.7\end{array}$ & $\begin{array}{l}20.5 \\
19.9 \\
19.9 \\
20.0 \\
? 1.7 \\
23.4 \\
? 1.06 \\
20.5\end{array}$ & $\begin{array}{l}18.9 \\
13.7 \\
18.6 \\
18.9 \\
10.7 \\
20.0 \\
10.9 \\
19.5\end{array}$ & $\begin{array}{l}20.3 \\
19.5 \\
19.5 \\
20.0 \\
21.8 \\
23.4 \\
21.5 \\
20.3\end{array}$ & $\begin{array}{l}18.9 \\
18.6 \\
18.6 \\
18.8 \\
10.5 \\
20.0 \\
19.8 \\
19.4\end{array}$ & $\begin{array}{l}20.2 \\
19.6 \\
19.6 \\
19.9 \\
31.8 \\
? 3.4 \\
21.4 \\
30.2\end{array}$ & $\begin{array}{l}18.8 \\
19.5 \\
18.6 \\
18.9 \\
10.5 \\
20.0 \\
19.8 \\
10.4\end{array}$ & $\begin{array}{l}22.1 \\
22.0 \\
22.0 \\
22.0 \\
22.4 \\
22.1 \\
22.0 \\
21.9\end{array}$ & $\begin{array}{l}2 \\
2 \\
3 \\
3 \\
2 \\
2 \\
3 \\
3\end{array}$ & $\begin{array}{r}11.4 \\
13.5 \\
10.1 \\
9.9 \\
15.0 \\
9.6 \\
9.5 \\
5.7\end{array}$ & $\begin{array}{r}12.4 \\
14.6 \\
10.9 \\
10.5 \\
16.5 \\
10.5 \\
10.0 \\
6.1\end{array}$ & $\begin{array}{r}13.3 \\
15.4 \\
11.5 \\
11.1 \\
17.8 \\
11.2 \\
10.6 \\
6.3\end{array}$ & $\begin{array}{r}13.7 \\
16.0 \\
11.7 \\
11.3 \\
18.6 \\
11.7 \\
11.0 \\
6.8\end{array}$ \\
\hline $\begin{array}{l}17 \\
17 \\
17 \\
17 \\
17 \\
17 \\
17 \\
17\end{array}$ & $\begin{array}{r}0 \\
3 \\
6 \\
9 \\
12 \\
15 \\
18 \\
21\end{array}$ & $\begin{array}{l}19.5 \\
19.7 \\
19.4 \\
22.1 \\
34.4 \\
25.2 \\
23.1 \\
? 2.1\end{array}$ & $\begin{array}{l}19.0 \\
18.5 \\
18.7 \\
19.4 \\
19.6 \\
20.4 \\
20.4 \\
19.9\end{array}$ & $\begin{array}{l}19.4 \\
19.6 \\
19.4 \\
22.02 \\
24.5 \\
25.5 \\
23.3 \\
22.1\end{array}$ & $\begin{array}{l}18.7 \\
18.2 \\
18.4 \\
18.8 \\
19.3 \\
20.1 \\
20.1 \\
10.7\end{array}$ & $\begin{array}{l}19.3 \\
19.5 \\
19.4 \\
22.3 \\
24.5 \\
25.6 \\
23.6 \\
37.1\end{array}$ & $\begin{array}{l}18.5 \\
18.1 \\
18.4 \\
18.7 \\
19.2 \\
20.0 \\
19.8 \\
19.6\end{array}$ & $\begin{array}{l}19.2 \\
19.3 \\
19.4 \\
22.4 \\
24.6 \\
25.8 \\
24.0 \\
? 2.2\end{array}$ & $\begin{array}{l}18.7 \\
13.2 \\
18.4 \\
18.9 \\
19.2 \\
20.1 \\
19.7 \\
19.6\end{array}$ & $\begin{array}{l}21.9 \\
21.9 \\
21.9 \\
22.5 \\
23.1 \\
22.5 \\
22.2 \\
22.4\end{array}$ & $\begin{array}{l}2 \\
2 \\
2 \\
2\end{array}$ & $\begin{array}{l}5.3 \\
5: 1 \\
7.1 \\
6.9\end{array}$ & $\begin{array}{l}5.7 \\
5.6 \\
7.8 \\
7.6\end{array}$ & $\begin{array}{l}5.9 \\
6.0 \\
3.3 \\
7.9\end{array}$ & $\begin{array}{l}6.2 \\
6.2 \\
8.5 \\
8.0\end{array}$ \\
\hline $\begin{array}{l}18 \\
18 \\
18 \\
18 \\
18 \\
18 \\
18 \\
18\end{array}$ & $\begin{array}{r}0 \\
3 \\
6 \\
9 \\
12 \\
15 \\
28 \\
21\end{array}$ & $\begin{array}{l}20.8 \\
20.2 \\
20.5 \\
24.1 \\
25.8 \\
26.5 \\
24.4 \\
22.3\end{array}$ & $\begin{array}{l}19.4 \\
19.1 \\
10.5 \\
20.6 \\
20.7 \\
20.6 \\
20.9 \\
20.8\end{array}$ & $\begin{array}{l}20.8 \\
20.2 \\
20.5 \\
24.5 \\
26.2 \\
26.9 \\
24.5 \\
22.3\end{array}$ & $\begin{array}{l}10.1 \\
18.0 .9 \\
10.4 \\
20.4 \\
20.5 \\
20.0 \\
20.9 \\
20.7\end{array}$ & $\begin{array}{l}30.7 \\
20.1 \\
30.5 \\
3.4 .6 \\
26.5 \\
27.0 \\
24.05 \\
22.03\end{array}$ & $\begin{array}{l}18.9 \\
18.9 \\
20.3 \\
20.5 \\
20.4 \\
20.4 \\
20.7 \\
20.5\end{array}$ & $\begin{array}{l}20.6 \\
20.0 \\
20.7 \\
24.8 \\
26.6 \\
27.1 \\
24.6 \\
22.3\end{array}$ & $\begin{array}{l}18.9 \\
18.9 \\
19.5 \\
20.5 \\
20.4 \\
20.4 \\
20.7 \\
20.5\end{array}$ & $\begin{array}{l}22.1 \\
21.8 \\
22.0 \\
22.7 \\
22.9 \\
22.8 \\
22.7 \\
22.3\end{array}$ & $\begin{array}{l}2 \\
2 \\
2 \\
2 \\
2\end{array}$ & $\begin{array}{r}10.4 \\
7.6 \\
8.2 \\
6.3 \\
6.4\end{array}$ & $\begin{array}{r}11.8 \\
8.7 \\
9.5 \\
7.3 \\
7.2\end{array}$ & $\begin{array}{r}13.1 \\
9.7 \\
10.6 \\
8.3 \\
7.9\end{array}$ & $\begin{array}{r}13.7 \\
10.3 \\
11.4 \\
9.0 \\
8.9\end{array}$ \\
\hline $\begin{array}{l}19 \\
19 \\
19 \\
19 \\
19 \\
19 \\
19 \\
19\end{array}$ & $\begin{array}{r}0 \\
3 \\
6 \\
9 \\
12 \\
15 \\
18 \\
31\end{array}$ & $\begin{array}{l}21.9 \\
20.7 \\
21.00 \\
24.3 \\
24.5 \\
24.1 \\
22.3 \\
21.6\end{array}$ & $\begin{array}{l}20.5 \\
19.9 \\
20.2 \\
21.7 \\
21.9 \\
20.9 \\
20.4 \\
20.6\end{array}$ & $\begin{array}{l}21.9 \\
20.7 \\
21.1 \\
24.4 \\
24.6 \\
24.2 \\
22.3 \\
21.6\end{array}$ & $\begin{array}{l}20.4 \\
19.9 \\
20.2 \\
31.7 \\
21.8 \\
20.8 \\
20.2 \\
20.6\end{array}$ & $\begin{array}{l}21.8 \\
20.5 \\
21.00 \\
24.5 \\
24.7 \\
24.2 \\
22.2 \\
21.6\end{array}$ & $\begin{array}{l}20.2 \\
19.8 \\
20.02 \\
21.06 \\
21.07 \\
20.5 \\
20.1 \\
20.5\end{array}$ & $\begin{array}{l}21: 7 \\
20: 4 \\
21 \cdot 1 \\
24: 5 \\
24: 8 \\
24: 3 \\
22: 1 \\
21: 5\end{array}$ & $\begin{array}{l}20.2 \\
19.7 \\
20.3 \\
21.6 \\
21.6 \\
20.6 \\
20.1 \\
20.5\end{array}$ & $\begin{array}{l}22.4 \\
22.2 \\
22.5 \\
22.9 \\
23.0 \\
22.5 \\
22.3 \\
22.4\end{array}$ & $\begin{array}{l}2 \\
2 \\
2 \\
2\end{array}$ & $\begin{array}{l}7.4 \\
5.6 \\
5.9\end{array}$ & $\begin{array}{l}8.4 \\
6.2 \\
6.5\end{array}$ & $\begin{array}{l}9.2 \\
6.7 \\
7.0\end{array}$ & $\begin{array}{l}9.8 \\
7.3 \\
7.2\end{array}$ \\
\hline $\begin{array}{l}20 \\
20 \\
20 \\
20 \\
20 \\
20 \\
20 \\
20\end{array}$ & $\begin{array}{r}0 \\
3 \\
6 \\
9 \\
12 \\
15 \\
18 \\
21\end{array}$ & $\begin{array}{l}21.5 \\
20.6 \\
20.6 \\
23.7 \\
28.0 \\
29.4 \\
26.6 \\
24.2\end{array}$ & $\begin{array}{l}20.8 \\
20.2 \\
20.0 \\
21.1 \\
22.1 \\
22.6 \\
22.1 \\
21.3\end{array}$ & $\begin{array}{l}21.5 \\
20.5 \\
20.7 \\
23.9 \\
28.6 \\
29.9 \\
26.9 \\
24.5\end{array}$ & $\begin{array}{l}20.7 \\
20.1 \\
39.9 \\
21.1 \\
32.2 \\
22.5 \\
22.2 \\
21.11\end{array}$ & $\begin{array}{l}21.4 \\
20.4 \\
20.6 \\
24.3 \\
28.9 \\
30.0 \\
27.1 \\
24.5\end{array}$ & $\begin{array}{l}20.6 \\
20.0 \\
19.8 \\
21.1 \\
22.1 \\
22.4 \\
22.0 \\
21.5\end{array}$ & $\begin{array}{l}21 \cdot 3 \\
20: 3 \\
20.5 \\
24.4 \\
20.0 \\
30.2 \\
27.0 \\
25.0\end{array}$ & $\begin{array}{l}20.5 \\
19.9 \\
19.9 \\
21.0 \\
21.9 \\
22.5 \\
22.2 \\
21.4\end{array}$ & $\begin{array}{l}22.2 \\
22.1 \\
22.3 \\
22.9 \\
23.0 \\
23.0 \\
22.5 \\
22.3\end{array}$ & $\begin{array}{l}2 \\
2 \\
2 \\
2 \\
2\end{array}$ & $\begin{array}{r}13.0 \\
12.4 \\
12.7 \\
9.6 \\
8.1\end{array}$ & $\begin{array}{r}14.7 \\
14.0 \\
14.3 \\
11.1 \\
9.3\end{array}$ & $\begin{array}{l}16.3 \\
15.5 \\
16.0 \\
12.7 \\
10.5\end{array}$ & $\begin{array}{l}17.1 \\
16.2 \\
16.7 \\
13.7 \\
11.6\end{array}$ \\
\hline
\end{tabular}


TABLE 10 Table 10. - Three-hour averages of air and water-surface temperatures and wind directions and speed, April 1950-August
1951, Lake Hefner-Continued

STATION 1 THREE-HOURLY AVERAGES

SEPTEMBER, 1950

\begin{tabular}{|c|c|c|c|c|c|c|c|c|c|c|c|c|c|c|c|}
\hline \multirow{3}{*}{ 秃 } & \multirow{3}{*}{ 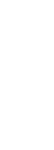 } & \multicolumn{8}{|c|}{ Average air temperature $\left({ }^{\circ} \mathrm{C}\right)$ at indicated height } & \multirow{3}{*}{$\begin{array}{l}\text { Average } \\
\text { water- } \\
\text { surface } \\
\text { tempera- } \\
\text { ture } \\
\text { ('C) }\end{array}$} & \multirow{3}{*}{$\begin{array}{c}\text { Average } \\
\text { wind } \\
\text { direction } \\
\text { (coded) }\end{array}$} & \multicolumn{4}{|c|}{$\begin{array}{l}\text { Average wind speed (knots) } \\
\text { at indicated height }\end{array}$} \\
\hline & & \multicolumn{2}{|c|}{$\begin{array}{c}2 \\
\text { meters }\end{array}$} & \multicolumn{2}{|c|}{$\begin{array}{c}4 \\
\text { meters }\end{array}$} & \multicolumn{2}{|c|}{$\begin{array}{c}8 \\
\text { meters }\end{array}$} & \multicolumn{2}{|c|}{$\begin{array}{c}16 \\
\text { meters }\end{array}$} & & & & & & \\
\hline & & $\begin{array}{l}\text { Dry } \\
\text { bulb }\end{array}$ & $\begin{array}{l}\text { Wet } \\
\text { bulb }\end{array}$ & $\begin{array}{l}\text { Dry } \\
\text { bulb }\end{array}$ & $\begin{array}{l}\text { Wet } \\
\text { bulb }\end{array}$ & $\begin{array}{l}\text { Dry } \\
\text { bulb }\end{array}$ & $\begin{array}{l}\text { Wet } \\
\text { bulb }\end{array}$ & $\begin{array}{l}\text { Dry } \\
\text { bulb }\end{array}$ & $\begin{array}{l}\text { Wet } \\
\text { bulb }\end{array}$ & & & meters & meters & meters & meters \\
\hline $\begin{array}{l}21 \\
21 \\
21 \\
21 \\
21 \\
21 \\
21 \\
21\end{array}$ & $\begin{array}{r}0 \\
3 \\
6 \\
9 \\
12 \\
15 \\
18 \\
21\end{array}$ & $\begin{array}{l}23.9 \\
22.1 \\
18.4\end{array}$ & $\begin{array}{l}17.3 \\
16.6 \\
15.0\end{array}$ & $\begin{array}{l}24.2 \\
22.2 \\
18.1\end{array}$ & $\begin{array}{l}16 \cdot 4 \\
16 \cdot 2 \\
14 \cdot 6\end{array}$ & $\begin{array}{l}24.1 \\
22.1 \\
17.9\end{array}$ & $\begin{array}{l}16.3 \\
15.9 \\
14.5\end{array}$ & $\begin{array}{l}24 \cdot 1 \\
22 \bullet 0 \\
17 \bullet 8\end{array}$ & $\begin{array}{l}16.2 \\
16.0 \\
14.6\end{array}$ & $\begin{array}{l}22.4 \\
22.2 \\
22.1\end{array}$ & $\begin{array}{l}2 \\
4 \\
3 \\
3 \\
3 \\
3 \\
3 \\
3\end{array}$ & $\begin{array}{r}5.6 \\
10.0 \\
12.7 \\
10.7 \\
11.0 \\
10.1 \\
9.8 \\
8.4\end{array}$ & $\begin{array}{r}6.1 \\
12.0 \\
15.4 \\
12.3 \\
12.4 \\
11.8 \\
11.1 \\
9.0\end{array}$ & $\begin{array}{r}7.0 \\
13.6 \\
15.9 \\
13.4 \\
14.1 \\
13.1 \\
12.1 \\
10.3\end{array}$ & $\begin{array}{l}7.7 \\
23.6 \\
26.6 \\
13.9 \\
14.5 \\
13.5 \\
13.0 \\
10.5\end{array}$ \\
\hline $\begin{array}{l}22 \\
22 \\
22 \\
22 \\
22 \\
22 \\
22 \\
22\end{array}$ & $\begin{array}{r}0 \\
3 \\
6 \\
9 \\
12 \\
15 \\
18 \\
21\end{array}$ & $\begin{array}{l}16.3 \\
15.1 \\
15.2 \\
18.7 \\
20.6 \\
21.9 \\
20.4 \\
19.2\end{array}$ & $\begin{array}{l}14.5 \\
14.0 \\
14.1 \\
15.7 \\
15.5 \\
15.8 \\
15.4 \\
15.0\end{array}$ & $\begin{array}{l}16.0 \\
14.8 \\
14.9 \\
18.5 \\
20.5 \\
21.7 \\
20.2 \\
19.2\end{array}$ & $\begin{array}{l}14 \cdot 1 \\
13.6 \\
13.7 \\
14 \cdot 9 \\
15.3 \\
15.0 \\
14 \bullet 8 \\
14.3\end{array}$ & $\begin{array}{l}15.8 \\
14.6 \\
15.0 \\
16.5 \\
20.6 \\
? 3.5 \\
20.2 \\
19.4\end{array}$ & $\begin{array}{l}13.9 \\
13.4 \\
13.7 \\
14.8 \\
14.9 \\
14.8 \\
14.9 \\
14.2\end{array}$ & $\begin{array}{l}15.6 \\
14.5 \\
14.8 \\
18.4 \\
20.5 \\
21.3 \\
20.1 \\
19.3\end{array}$ & $\begin{array}{l}14.0 \\
13.5 \\
13.6 \\
14.6 \\
14.8 \\
14.9 \\
15.0 \\
14.6\end{array}$ & $\begin{array}{l}21.9 \\
21: 8 \\
22.2 \\
22.9 \\
23.0 \\
22.2 \\
22 \cdot 1 \\
22.1\end{array}$ & $\begin{array}{l}3 \\
3 \\
3 \\
3 \\
3 \\
3 \\
3 \\
3 \\
3\end{array}$ & $\begin{array}{r}8.2 \\
8.7 \\
10.4 \\
8.0 \\
7.8 \\
6.0 \\
3.7 \\
1.1\end{array}$ & $\begin{array}{r}9.3 \\
10.3 \\
12.2 \\
9.0 \\
8.8 \\
6.7 \\
4.1 \\
1.2\end{array}$ & $\begin{array}{r}9.9 \\
10.8 \\
12.7 \\
9.8 \\
9.6 \\
7.4 \\
4.8 \\
1.3\end{array}$ & $\begin{aligned} 10.1 \\
11: 1 \\
13: 1 \\
10.1 \\
9.9 \\
7.6 \\
5.0 \\
1.5\end{aligned}$ \\
\hline $\begin{array}{l}23 \\
23 \\
23 \\
23 \\
23 \\
23 \\
23 \\
23\end{array}$ & $\begin{array}{r}0 \\
3 \\
6 \\
9 \\
12 \\
15 \\
18 \\
21\end{array}$ & $\begin{array}{l}17.1 \\
16.0 \\
17.6 \\
22.6 \\
25.3 \\
25.6 \\
22.2 \\
20.2\end{array}$ & $\begin{array}{l}14.7 \\
14.5 \\
14.7 \\
15.6 \\
15.7 \\
16.9 \\
17.3 \\
16.8\end{array}$ & $\begin{array}{l}17 \cdot 1 \\
15 \cdot 9 \\
17 \cdot 6 \\
22.7 \\
24 \cdot 8 \\
24 \cdot 9 \\
22.2 \\
20.1\end{array}$ & $\begin{array}{l}14.4 \\
14.3 \\
14.4 \\
15.4 \\
15.2 \\
15.6 \\
16.8 \\
16.0\end{array}$ & $\begin{array}{l}17.0 \\
16.1 \\
17.7 \\
23.2 \\
25.0 \\
34.9 \\
22.5 \\
20.1\end{array}$ & $\begin{array}{l}14.4 \\
14.2 \\
14.3 \\
15.0 \\
15.2 \\
15.6 \\
16.6 \\
15.9\end{array}$ & $\begin{array}{l}17.0 \\
16.2 \\
17.8 \\
22.7 \\
25.7 \\
25.2 \\
22.7 \\
20.4\end{array}$ & $\begin{array}{l}14.6 \\
14.0 \\
14.3 \\
15.1 \\
15.4 \\
16.0 \\
16.2 \\
15.9\end{array}$ & $\begin{array}{l}22.0 \\
21.9 \\
21.8 \\
22.8 \\
23.8 \\
23.1 \\
22.5 \\
22.2\end{array}$ & $\begin{array}{l}2 \\
2 \\
2 \\
4 \\
3 \\
3 \\
3 \\
2\end{array}$ & $\begin{array}{l}2.6 \\
5.9 \\
6.7 \\
3.6 \\
3.4 \\
4.8 \\
2.3 \\
2.0\end{array}$ & $\begin{array}{l}2.6 \\
6.0 \\
6.8 \\
3.6 \\
3.6 \\
5.4 \\
2.5 \\
2.1\end{array}$ & $\begin{array}{l}3.1 \\
6.3 \\
7.2 \\
3.9 \\
3.9 \\
5.8 \\
2.9 \\
2.3\end{array}$ & $\begin{array}{l}3.4 \\
6.8 \\
7.6 \\
4.00 \\
4.0 \\
6.02 \\
3.8 \\
2.9\end{array}$ \\
\hline $\begin{array}{l}24 \\
24 \\
24 \\
24 \\
24 \\
24 \\
24 \\
24\end{array}$ & $\begin{array}{r}0 \\
3 \\
6 \\
9 \\
12 \\
15 \\
18 \\
21\end{array}$ & $\begin{array}{l}17.9 \\
16.9 \\
16.1 \\
30.8 \\
23.5 \\
23.7 \\
20.6 \\
18.0\end{array}$ & $\begin{array}{l}15.4 \\
15.1 \\
13.7 \\
14.7 \\
15.7 \\
16.2 \\
16.5 \\
16.1\end{array}$ & $\begin{array}{l}17.7 \\
17.2 \\
15.6 \\
21.1 \\
23.3 \\
23.6 \\
20.3 \\
17.8\end{array}$ & $\begin{array}{l}15.4 \\
14.9 \\
13.4 \\
14.4 \\
15.1 \\
15.9 \\
16.1 \\
15.7\end{array}$ & $\begin{array}{l}17.9 \\
17.2 \\
15.5 \\
21.1 \\
23.2 \\
23.6 \\
20.1 \\
17.7\end{array}$ & $\begin{array}{l}15.0 \\
14.9 \\
13.3 \\
14.3 \\
15.0 \\
15.5 \\
15.9 \\
15.5\end{array}$ & $\begin{array}{l}17.8 \\
17.1 \\
15.4 \\
21.2 \\
23.4 \\
23.7 \\
20.1 \\
17.5\end{array}$ & $\begin{array}{l}15.0 \\
14.7 \\
13.3 \\
14.6 \\
15.2 \\
15.7 \\
16.1 \\
15.5\end{array}$ & $\begin{array}{l}22.1 \\
21.8 \\
22.0 \\
23.0 \\
23.4 \\
22.9 \\
22.0 \\
21.7\end{array}$ & $\begin{array}{l}3 \\
3 \\
3 \\
3 \\
3 \\
3 \\
3 \\
3\end{array}$ & $\begin{array}{l}3.7 \\
3.6 \\
4.0 \\
3.9 \\
6.4 \\
6.5 \\
6.7 \\
7.2\end{array}$ & $\begin{array}{l}3.9 \\
4.1 \\
4.3 \\
4.2 \\
6.8 \\
7.0 \\
7.0 \\
7.7\end{array}$ & $\begin{array}{l}4 \cdot 0 \\
4.1 \\
4.3 \\
4.4 \\
7.1 \\
7.3 \\
7.4 \\
8.0\end{array}$ & $\begin{array}{l}4.2 \\
4.4 \\
4.4 \\
4.6 \\
7.3 \\
7.7 \\
8.4 \\
8.4\end{array}$ \\
\hline $\begin{array}{l}25 \\
25 \\
25 \\
25 \\
25 \\
25 \\
25 \\
25\end{array}$ & $\begin{array}{r}0 \\
3 \\
6 \\
9 \\
12 \\
15 \\
18 \\
21\end{array}$ & $\begin{array}{l}16.1 \\
15.2 \\
15.6 \\
17.7 \\
20.1 \\
70.4 \\
18.7 \\
18.0\end{array}$ & $\begin{array}{l}14.8 \\
14: 5 \\
14: 0 \\
14.0 \\
15.3 \\
15.8 \\
16.1 \\
15.1\end{array}$ & $\begin{array}{l}15.8 \\
15.1 \\
15.5 \\
17.7 \\
20.1 \\
20.3 \\
19.5 \\
17.8\end{array}$ & $\begin{array}{l}14.5 \\
14.3 \\
13.5 \\
13.5 \\
14.7 \\
15.4 \\
15.9 \\
14.9\end{array}$ & $\begin{array}{l}15.7 \\
14.9 \\
15.4 \\
17.6 \\
20.0 \\
20.2 \\
11.05 \\
17.7\end{array}$ & $\begin{array}{l}14.5 \\
14.2 \\
13.4 \\
13.5 \\
14.6 \\
15.2 \\
15.8 \\
14.6\end{array}$ & $\begin{array}{l}15.6 \\
14.9 \\
15.2 \\
17.7 \\
20.0 \\
20.1 \\
18.2 \\
17.5\end{array}$ & $\begin{array}{l}14.5 \\
14.3 \\
13.3 \\
13.5 \\
14.8 \\
15.3 \\
15.7 \\
14.8\end{array}$ & $\begin{array}{l}21.7 \\
21.6 \\
21.6 \\
22.4 \\
22.3 \\
21.9 \\
21.5 \\
21.7\end{array}$ & $\begin{array}{l}3 \\
2 \\
3 \\
2 \\
2 \\
3 \\
3 \\
3\end{array}$ & $\begin{array}{r}5.4 \\
6.3 \\
10.9 \\
9.3 \\
8.2 \\
8.8 \\
7.2 \\
9.3\end{array}$ & $\begin{array}{r}5.8 \\
6.8 \\
12.1 \\
10.3 \\
9.1 \\
9.6 \\
7.7 \\
10.1\end{array}$ & $\begin{array}{r}6.0 \\
7.0 \\
12.8 \\
10.9 \\
9.9 \\
10.1 \\
8.0 \\
10.6\end{array}$ & $\begin{array}{r}6.1 \\
7.3 \\
13.2 \\
11.2 \\
10.0 \\
10.05 \\
8.2 \\
10.9\end{array}$ \\
\hline $\begin{array}{l}26 \\
26 \\
26 \\
26 \\
26 \\
26 \\
26 \\
26\end{array}$ & $\begin{array}{r}0 \\
3 \\
6 \\
9 \\
12 \\
15 \\
18 \\
21\end{array}$ & $\begin{array}{l}16.5 \\
15.3 \\
15.0 \\
15.9 \\
19.3 \\
20.6 \\
19.5 \\
18.1\end{array}$ & $\begin{array}{l}14.7 \\
13.8 \\
13.4 \\
15.1 \\
16.5 \\
16.7 \\
16.8 \\
15.8\end{array}$ & $\begin{array}{l}16.2 \\
15.0 \\
14.8 \\
15.8 \\
19.3 \\
20.6 \\
19.4 \\
18.0\end{array}$ & $\begin{array}{l}14.4 \\
13.6 \\
12.8 \\
14.6 \\
16.0 \\
16.4 \\
16.6 \\
15.2\end{array}$ & $\begin{array}{l}15.2 \\
14.8 \\
14.6 \\
15.9 \\
19.2 \\
20.6 \\
19.3 \\
17.7\end{array}$ & $\begin{array}{l}14.5 \\
13.4 \\
12.6 \\
14.6 \\
15.9 \\
16.4 \\
16.4 \\
15.1\end{array}$ & $\begin{array}{l}16.0 \\
14.7 \\
14.3 \\
15.9 \\
19.3 \\
20.5 \\
19.1 \\
17.5\end{array}$ & $\begin{array}{l}14.4 \\
13.5 \\
12.7 \\
14.6 \\
15.8 \\
16.4 \\
16.3 \\
15.0\end{array}$ & $\begin{array}{l}21.6 \\
21.3 \\
21.4 \\
22.2 \\
22.3 \\
22.0 \\
21.8 \\
21.7\end{array}$ & $\begin{array}{l}2 \\
2 \\
2 \\
2 \\
2 \\
2 \\
2 \\
2 \\
2\end{array}$ & $\begin{array}{r}8.2 \\
8.1 \\
10.8 \\
12.3 \\
13.5 \\
11.4 \\
9.7 \\
13.0\end{array}$ & $\begin{array}{r}9.0 \\
8.9 \\
11.7 \\
13.7 \\
15.0 \\
12.9 \\
10.7 \\
14.5\end{array}$ & $\begin{array}{r}9.4 \\
9.3 \\
12.3 \\
14.5 \\
16.1 \\
13.8 \\
11.4 \\
15.4\end{array}$ & $\begin{array}{r}9.8 \\
9.4 \\
12.7 \\
14.9 \\
16.9 \\
14.4 \\
12.0 \\
16.0\end{array}$ \\
\hline $\begin{array}{l}27 \\
27 \\
27 \\
27 \\
27 \\
27 \\
27 \\
27\end{array}$ & $\begin{array}{r}0 \\
3 \\
6 \\
9 \\
12 \\
15 \\
18 \\
21\end{array}$ & $\begin{array}{l}15.9 \\
17.8 \\
18.0 \\
19.4 \\
22.8 \\
23.0 \\
22.2 \\
20.5\end{array}$ & $\begin{array}{l}16.2 \\
17.2 \\
17.6 \\
18.1 \\
19.4 \\
20.0 \\
19.4 \\
18.9\end{array}$ & $\begin{array}{l}16.7 \\
17.8 \\
18.0 \\
19.4 \\
23.0 \\
24.0 \\
22.2 \\
20.4\end{array}$ & $\begin{array}{l}15.9 \\
17.0 \\
17.2 \\
18.0 \\
19.3 \\
19.8 \\
19.2 \\
18.7\end{array}$ & $\begin{array}{l}16.6 \\
17.6 \\
17.9 \\
19.4 \\
23.1 \\
24.0 \\
22.1 \\
20.3\end{array}$ & $\begin{array}{l}15.8 \\
16.9 \\
17: 1 \\
17.9 \\
19.3 \\
19.7 \\
19: 0 \\
18.7\end{array}$ & $\begin{array}{l}16.4 \\
17.4 \\
17.7 \\
19.4 \\
23.1 \\
24.0 \\
22.0 \\
20.1\end{array}$ & $\begin{array}{l}15.7 \\
16.9 \\
17.0 \\
17.9 \\
19.3 \\
19.8 \\
19.0 \\
18.7\end{array}$ & $\begin{array}{l}21 \cdot 7 \\
21.6 \\
21.6 \\
22.2 \\
22 \cdot 3 \\
21.8 \\
21.5 \\
21.4\end{array}$ & $\begin{array}{l}2 \\
2 \\
2 \\
2 \\
2 \\
2 \\
2 \\
2 \\
2\end{array}$ & $\begin{array}{l}15.0 \\
13.2 \\
13.5 \\
14.7 \\
14.3 \\
15.4 \\
12.3 \\
14.5\end{array}$ & $\begin{array}{l}16.8 \\
14.7 \\
15.1 \\
16.4 \\
16.1 \\
17.3 \\
13.9 \\
16.1\end{array}$ & $\begin{array}{l}18.0 \\
15.7 \\
16.1 \\
17.8 \\
17.5 \\
18.8 \\
15.0 \\
17.3\end{array}$ & $\begin{array}{l}18.7 \\
16.4 \\
16.9 \\
18.6 \\
18.4 \\
19.8 \\
15.9 \\
18.2\end{array}$ \\
\hline $\begin{array}{l}28 \\
28 \\
28 \\
28 \\
28 \\
28 \\
28 \\
28\end{array}$ & $\begin{array}{r}0 \\
3 \\
6 \\
9 \\
12 \\
15 \\
18 \\
21\end{array}$ & $\begin{array}{l}19.7 \\
19.4 \\
19.7 \\
21.5 \\
24.4 \\
25.0 \\
22.5 \\
20.8\end{array}$ & $\begin{array}{l}18.7 \\
18.5 \\
18.5 \\
19.3 \\
20.1 \\
20.5 \\
19.7 \\
19.9\end{array}$ & $\begin{array}{l}19.5 \\
19.4 \\
19.6 \\
21.6 \\
24.7 \\
25.2 \\
22.5 \\
20.7\end{array}$ & $\begin{array}{l}18.5 \\
18.2 \\
18.2 \\
10.1 \\
20.3 \\
20.3 \\
19.5 \\
18.7\end{array}$ & $\begin{array}{l}19.4 \\
19.2 \\
19.5 \\
71.8 \\
24.8 \\
25.3 \\
22.4 \\
20.7\end{array}$ & $\begin{array}{l}18.3 \\
18.2 \\
18.2 \\
19.1 \\
19.9 \\
20.2 \\
19.4 \\
18.6\end{array}$ & $\begin{array}{l}19.1 \\
19.1 \\
19.4 \\
21.8 \\
24.9 \\
25.3 \\
22.3 \\
20.6\end{array}$ & $\begin{array}{l}18.3 \\
18.1 \\
18.2 \\
19.1 \\
20.1 \\
20.3 \\
10.4 \\
18.6\end{array}$ & $\begin{array}{l}21.4 \\
21.3 \\
21.4 \\
21.8 \\
22.1 \\
21.7 \\
21.5 \\
21.4\end{array}$ & $\begin{array}{l}2 \\
2 \\
2 \\
2 \\
2 \\
2 \\
2 \\
2\end{array}$ & $\begin{array}{l}15.5 \\
13.9 \\
14.7 \\
16.1 \\
15.1 \\
15.9 \\
13.5 \\
12.9\end{array}$ & $\begin{array}{l}17.4 \\
15.5 \\
16.4 \\
18.1 \\
17.1 \\
17.7 \\
15.2 \\
14.4\end{array}$ & $\begin{array}{l}18.8 \\
16.6 \\
17.7 \\
19.7 \\
18.7 \\
19.4 \\
16.3 \\
15.6\end{array}$ & $\begin{array}{l}19.6 \\
17.4 \\
18.6 \\
20.7 \\
19.8 \\
20.5 \\
17.4 \\
16.4\end{array}$ \\
\hline $\begin{array}{l}29 \\
29 \\
29 \\
29 \\
29 \\
29 \\
29 \\
29\end{array}$ & $\begin{array}{r}0 \\
3 \\
6 \\
9 \\
12 \\
15 \\
18 \\
21\end{array}$ & $\begin{array}{l}19.9 \\
20.3 \\
21.0 \\
22.9 \\
25.3 \\
25.9 \\
23.9 \\
21.9\end{array}$ & $\begin{array}{l}18.9 \\
19.5 \\
19.8 \\
20.3 \\
20.7 \\
20.7 \\
20.0 \\
20.2\end{array}$ & $\begin{array}{l}19.8 \\
20.3 \\
21.0 \\
22.9 \\
25.6 \\
26.1 \\
24.0 \\
22.0\end{array}$ & $\begin{array}{l}18.7 \\
19.4 \\
19.7 \\
20.1 \\
20.6 \\
20.6 \\
19.9 \\
20.2\end{array}$ & $\begin{array}{l}19.7 \\
20.3 \\
21.0 \\
23.0 \\
25.9 \\
26.3 \\
24.0 \\
22.0\end{array}$ & $\begin{array}{l}18.7 \\
19.4 \\
19.6 \\
20.1 \\
20.5 \\
20.5 \\
29.9 \\
20.2\end{array}$ & $\begin{array}{l}19.6 \\
20.2 \\
20.9 \\
23.1 \\
26.0 \\
26.4 \\
23.0 \\
21.9\end{array}$ & $\begin{array}{l}18.7 \\
19.4 \\
19.6 \\
20.2 \\
20.6 \\
20.5 \\
19.9 \\
20.2\end{array}$ & $\begin{array}{l}21 \cdot 3 \\
21.2 \\
21.4 \\
22.0 \\
22.0 \\
21.6 \\
21.5 \\
21.6\end{array}$ & $\begin{array}{l}2 \\
2 \\
2 \\
2 \\
2 \\
2 \\
2 \\
2\end{array}$ & $\begin{array}{l}12.7 \\
13.5 \\
14.3 \\
14.9 \\
12.8 \\
13.1 \\
11.1 \\
14.1\end{array}$ & $\begin{array}{l}14.2 \\
15.1 \\
16.0 \\
16.8 \\
14.6 \\
15.0 \\
12.4 \\
15.7\end{array}$ & $\begin{array}{l}15.2 \\
16.4 \\
17.4 \\
18.4 \\
16.0 \\
16.3 \\
13.6 \\
17.0\end{array}$ & $\begin{array}{l}16.0 \\
17.2 \\
18.2 \\
19.5 \\
16.9 \\
17.3 \\
14.3 \\
17.9\end{array}$ \\
\hline $\begin{array}{l}30 \\
30 \\
30 \\
30 \\
30 \\
30 \\
30 \\
30\end{array}$ & $\begin{array}{r}0 \\
3 \\
6 \\
9 \\
12 \\
15 \\
18 \\
21\end{array}$ & $\begin{array}{l}21.8 \\
20.9 \\
20.9 \\
22.4 \\
24.0 \\
24.8 \\
23.2 \\
20.6\end{array}$ & $\begin{array}{l}20.3 \\
19.7 \\
19.9 \\
20.5 \\
20.7 \\
20.7 \\
20.3 \\
19.3\end{array}$ & $\begin{array}{l}21.8 \\
20.8 \\
20.9 \\
22.6 \\
24.2 \\
24.9 \\
23.2 \\
20.5\end{array}$ & $\begin{array}{l}20.2 \\
19.5 \\
19.8 \\
20.4 \\
20.6 \\
20.7 \\
20.2 \\
19.1\end{array}$ & $\begin{array}{l}21.7 \\
20.7 \\
20.9 \\
22.7 \\
24.4 \\
25.0 \\
23.1 \\
20.2\end{array}$ & $\begin{array}{l}20.2 \\
19.4 \\
19.8 \\
20.4 \\
20.5 \\
20.6 \\
20.1 \\
18.9\end{array}$ & $\begin{array}{l}21.7 \\
20.6 \\
20.9 \\
22.7 \\
24.3 \\
25.1 \\
23.0 \\
20.2\end{array}$ & $\begin{array}{l}20.1 \\
19.4 \\
19.8 \\
20.3 \\
20.5 \\
20.6 \\
20.0 \\
18.7\end{array}$ & $\begin{array}{l}21.5 \\
21.5 \\
21.5 \\
21.8 \\
21.9 \\
21.7 \\
21.6 \\
21.6\end{array}$ & $\begin{array}{l}2 \\
2 \\
2 \\
2 \\
2 \\
2 \\
2 \\
2\end{array}$ & $\begin{array}{l}15.7 \\
13.6 \\
12.5 \\
12.8 \\
15.0 \\
14.1 \\
13.4 \\
15.2\end{array}$ & $\begin{array}{l}17.7 \\
15.3 \\
13.9 \\
14.0 \\
16.8 \\
16.0 \\
15.0 \\
16.9\end{array}$ & $\begin{array}{l}19.2 \\
16.4 \\
14.9 \\
15.8 \\
18.5 \\
17.5 \\
16.2 \\
18.2\end{array}$ & $\begin{array}{l}20.2 \\
17.3 \\
15.7 \\
16.6 \\
19.5 \\
18.5 \\
17.2 \\
19.1\end{array}$ \\
\hline
\end{tabular}


TABLE 10

Table 10. - Three-hour averages of air and water-surface temperatures and wind directions and speed, April 1950-August STATION 1

THREE-HOURLY AVERAGES

OCTOBER, 1950

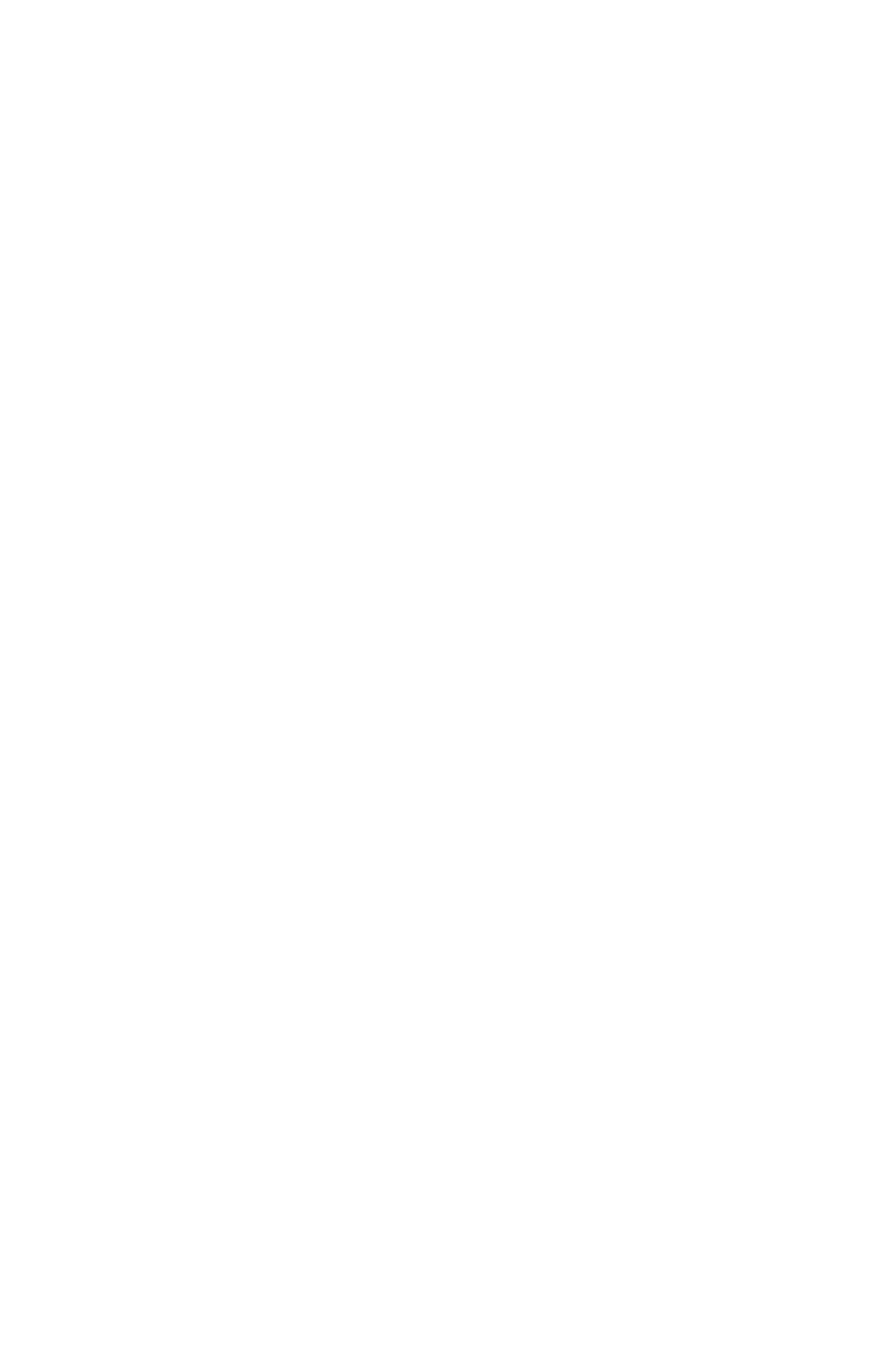


Table 10. - Three-hour averages of air and water-surface temperatures and wind directions and speed, April 1950-August 1951, Lake Hefner-Continued

THREE-HOURLY AVERAGES

OCTOBER, 1950

\begin{tabular}{|c|c|c|c|c|c|c|c|c|c|c|c|c|c|c|c|}
\hline \multirow{3}{*}{ 宽 } & \multirow{3}{*}{ 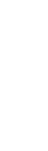 } & \multicolumn{8}{|c|}{ Average air temperature $\left({ }^{\circ} \mathrm{C}\right)$ at indicated height } & \multirow{3}{*}{$\begin{array}{c}\text { Average } \\
\text { water- } \\
\text { surface } \\
\text { tempera- } \\
\text { ture } \\
\text { ('C) }\end{array}$} & \multirow{3}{*}{$\begin{array}{c}\text { Average } \\
\text { wind } \\
\text { direction } \\
\text { (coded) }\end{array}$} & \multirow{2}{*}{\multicolumn{4}{|c|}{$\begin{array}{l}\text { Average wind speed (knots) } \\
\text { at indicated height }\end{array}$}} \\
\hline & & \multicolumn{2}{|c|}{$\begin{array}{c}2 \\
\text { meters }\end{array}$} & \multicolumn{2}{|c|}{$\begin{array}{c}4 \\
\text { meters }\end{array}$} & \multicolumn{2}{|c|}{$\begin{array}{c}8 \\
\text { meters }\end{array}$} & \multicolumn{2}{|c|}{$\begin{array}{c}16 \\
\text { meters }\end{array}$} & & & & & & \\
\hline & & $\begin{array}{l}\text { Dry } \\
\text { bulb }\end{array}$ & $\begin{array}{l}\text { Wet } \\
\text { buib }\end{array}$ & $\begin{array}{l}\text { Dry } \\
\text { bulb }\end{array}$ & $\begin{array}{l}\text { Wet } \\
\text { bulb }\end{array}$ & $\begin{array}{l}\text { Dry } \\
\text { bulb }\end{array}$ & $\begin{array}{l}\text { Wet } \\
\text { bulb }\end{array}$ & $\begin{array}{l}\text { Dry } \\
\text { bulb }\end{array}$ & $\begin{array}{l}\text { Wet } \\
\text { bulb }\end{array}$ & & & $\begin{array}{c}2 \\
\text { meters }\end{array}$ & $\begin{array}{c}4 \\
\text { meters }\end{array}$ & $\begin{array}{c}8 \\
\text { meters }\end{array}$ & $\begin{array}{c}16 \\
\text { meters }\end{array}$ \\
\hline $\begin{array}{l}11 \\
11 \\
11 \\
11 \\
11 \\
11 \\
11 \\
11\end{array}$ & $\begin{array}{r}0 \\
3 \\
6 \\
0 \\
12 \\
15 \\
18 \\
21\end{array}$ & $\begin{array}{l}16.6 \\
15.1 \\
14.5 \\
21.1 \\
26.4 \\
30.3 \\
22.4 \\
20.2\end{array}$ & $\begin{array}{l}13.5 \\
13.00 \\
12.9 \\
16.0 \\
17.0 \\
18.4 \\
17.7 \\
15.5\end{array}$ & $\begin{array}{l}16.5 \\
15.1 \\
14.4 \\
20.5 \\
26.9 \\
30.0 \\
23.0 \\
20.4\end{array}$ & $\begin{array}{l}13.3 \\
12.8 \\
12.7 \\
15.2 \\
16.4 \\
17.3 \\
16.5 \\
14.7\end{array}$ & $\begin{array}{l}16.4 \\
14.9 \\
14.4 \\
21.3 \\
27.3 \\
30.6 \\
23.6 \\
20.4\end{array}$ & $\begin{array}{l}13.3 \\
12.9 \\
12.8 \\
15.3 \\
16.5 \\
17.1 \\
16.2 \\
14.5\end{array}$ & $\begin{array}{l}16.7 \\
14.9 \\
14.6 \\
22.2 \\
27.4 \\
30.6 \\
24.4 \\
20.7\end{array}$ & $\begin{array}{l}13.2 \\
12.5 \\
12.5 \\
15.3 \\
17.1 \\
18.1\end{array}$ & $\begin{array}{l}18.7 \\
18.7 \\
18.8 \\
20.7 \\
23.7 \\
22.7 \\
20.4 \\
19.4\end{array}$ & $\begin{array}{l}2 \\
2 \\
2 \\
2 \\
2 \\
3 \\
3 \\
3\end{array}$ & $\begin{array}{l}2.4 \\
2.5 \\
2.4 \\
0.8 \\
2.0 \\
1.4 \\
2.1 \\
7.6\end{array}$ & $\begin{array}{l}2.6 \\
2.6 \\
2.7 \\
1.5 \\
2.1 \\
1.9 \\
2.9 \\
8.1\end{array}$ & $\begin{array}{l}5.4 \\
3.9 \\
8.8\end{array}$ & $\begin{array}{r}3.7 \\
3.0 \\
2.7 \\
1.5 \\
3.4 \\
4.6 \\
10.7\end{array}$ \\
\hline $\begin{array}{l}12 \\
12 \\
12 \\
12 \\
12 \\
12 \\
12 \\
12\end{array}$ & $\begin{array}{r}0 \\
3 \\
6 \\
9 \\
12 \\
15 \\
18 \\
21\end{array}$ & $\begin{array}{l}17.6 \\
16.4 \\
16.4 \\
21.3 \\
24.6 \\
24.9 \\
19.8 \\
17.6\end{array}$ & $\begin{array}{l}13.9 \\
12.5 \\
13.3 \\
13.4 \\
14.5 \\
15.3 \\
14.5 \\
13.1\end{array}$ & $\begin{array}{l}17.8 \\
16.4 \\
16.4 \\
21.5 \\
24.9 \\
25.3 \\
20.0 \\
17.6\end{array}$ & $\begin{array}{l}13.5 \\
12.1 \\
12.7 \\
12.9 \\
14.2 \\
14.7 \\
13.8 \\
12.9\end{array}$ & $\begin{array}{l}17.8 \\
16.4 \\
16.6 \\
21.7 \\
25.2 \\
75.8 \\
20.0 \\
17.4\end{array}$ & $\begin{array}{l}13.3 \\
12.0 \\
12.7 \\
12.7 \\
13.7 \\
14.6 \\
13.2 \\
12.8\end{array}$ & $\begin{array}{l}17.7 \\
16.2 \\
16.4 \\
22.0 \\
25.2 \\
25.7 \\
20.8 \\
17.6\end{array}$ & $\begin{array}{l}12.4 \\
13.4 \\
14.5 \\
14.9 \\
13.3 \\
12.9\end{array}$ & $\begin{array}{l}18.8 \\
18.8 \\
19.0 \\
20.3 \\
21.1 \\
19.9 \\
19.2 \\
19.3\end{array}$ & $\begin{array}{l}3 \\
3 \\
3 \\
2 \\
2 \\
2 \\
2 \\
2\end{array}$ & $\begin{array}{l}1.7 \\
2.6 \\
3.4 \\
6.8 \\
5.1 \\
5.6 \\
4.2 \\
7.0\end{array}$ & $\begin{array}{l}2.1 \\
2.7 \\
3.7 \\
7.7 \\
5.9 \\
6.9 \\
4.9 \\
7.8\end{array}$ & $\begin{array}{l}1.7 \\
2.4 \\
3.5 \\
8.2 \\
6.3 \\
8.2 \\
6.1 \\
8.5\end{array}$ & $\begin{array}{l}2.8 \\
3.2 \\
4.1 \\
8.9 \\
6.8 \\
8.7 \\
8.2 \\
9.7\end{array}$ \\
\hline $\begin{array}{l}13 \\
13 \\
13 \\
13 \\
13 \\
13 \\
13 \\
13\end{array}$ & $\begin{array}{r}0 \\
3 \\
6 \\
9 \\
12 \\
15 \\
18 \\
21\end{array}$ & $\begin{array}{l}17.4 \\
16.3 \\
16.8 \\
22.0 \\
25.9 \\
26.4 \\
23.1 \\
20.5\end{array}$ & $\begin{array}{l}12.9 \\
12.5 \\
12.6 \\
15.4 \\
17.9 \\
18.6 \\
17.5 \\
16 . ?\end{array}$ & $\begin{array}{l}17.4 \\
16.3 \\
16.9 \\
22.3 \\
26.8 \\
27.0 \\
23.3 \\
20.6\end{array}$ & $\begin{array}{l}12.6 \\
12.0 \\
12.3 \\
15.3 \\
17.7 \\
18.3 \\
17.2 \\
16.0\end{array}$ & $\begin{array}{l}17.2 \\
16.2 \\
16.9 \\
22.7 \\
27.1 \\
27.5 \\
23.6 \\
20.5\end{array}$ & $\begin{array}{l}12.5 \\
11.09 \\
12.2 \\
15.3 \\
17.7 \\
18.4 \\
17.2 \\
15.9\end{array}$ & $\begin{array}{l}17.2 \\
16.2 \\
17.0 \\
23.1 \\
27.2 \\
27.8 \\
23.8 \\
20.5\end{array}$ & $\begin{array}{l}12.5 \\
12.0 \\
12.2 \\
15.9 \\
18.6 \\
19.2 \\
17.4 \\
16.0\end{array}$ & $\begin{array}{l}18.9 \\
18.8 \\
19.1 \\
20.2 \\
20.2 \\
19.3 \\
18.9 \\
19.0\end{array}$ & $\begin{array}{l}2 \\
2 \\
2 \\
2 \\
2 \\
2 \\
2 \\
2\end{array}$ & $\begin{array}{r}7.6 \\
10.6 \\
11.1 \\
14.4 \\
12.8 \\
10.8 \\
10.6 \\
13.4\end{array}$ & $\begin{array}{r}8.5 \\
12.1 \\
12.5 \\
15.6 \\
15.0 \\
12.8 \\
12.3 \\
15.4\end{array}$ & $\begin{array}{r}9.2 \\
13.2 \\
13.6 \\
18.7 \\
16.9 \\
14.6 \\
13.8 \\
17.1\end{array}$ & $\begin{array}{l}10.2 \\
13.9 \\
14.3 \\
19.9 \\
18.1 \\
15.9 \\
15.0 \\
18.3\end{array}$ \\
\hline $\begin{array}{l}14 \\
14 \\
14 \\
14 \\
14 \\
14 \\
14 \\
14\end{array}$ & $\begin{array}{r}0 \\
3 \\
6 \\
9 \\
12 \\
15 \\
18 \\
21\end{array}$ & $\begin{array}{l}18.9 \\
18.9 \\
19.4 \\
23.9 \\
28.9 \\
28.3 \\
22.6 \\
21.1\end{array}$ & $\begin{array}{l}15.4 \\
15.0 \\
15.2 \\
17.0 \\
18.2 \\
18.5 \\
17.2 \\
16.5\end{array}$ & $\begin{array}{l}18.9 \\
18.9 \\
19.5 \\
24.4 \\
29.4 \\
29.3 \\
23.2 \\
21 . ?\end{array}$ & $\begin{array}{l}15.1 \\
14.8 \\
15.1 \\
16.8 \\
18.1 \\
18.2 \\
16.8 \\
16.3\end{array}$ & $\begin{array}{l}18.8 \\
18.8 \\
19.5 \\
24.7 \\
30.0 \\
30.0 \\
23.8 \\
21.2\end{array}$ & $\begin{array}{l}15.0 \\
14.7 \\
15.1 \\
16.9 \\
18.1 \\
18.2 \\
16.5 \\
16.1\end{array}$ & $\begin{array}{l}18 \cdot 8 \\
18 \cdot 8 \\
19 \cdot 8 \\
25.2 \\
30 \cdot 2 \\
30.2 \\
24.3 \\
21.3\end{array}$ & $\begin{array}{l}15.0 \\
14.8 \\
15.1 \\
17.3 \\
19.3 \\
19.4 \\
17.0 \\
16.4\end{array}$ & $\begin{array}{l}18.9 \\
18.9 \\
19.2 \\
20.2 \\
20.4 \\
19.6 \\
19.1 \\
19.1\end{array}$ & $\begin{array}{l}2 \\
2 \\
2 \\
2 \\
2 \\
2 \\
2 \\
2\end{array}$ & $\begin{array}{r}11.3 \\
12.5 \\
14.2 \\
13.0 \\
11.6 \\
8.9 \\
6.2 \\
10.6\end{array}$ & $\begin{array}{r}12.8 \\
14.1 \\
16.0 \\
14.6 \\
13.2 \\
10.8 \\
7.8 \\
12.2\end{array}$ & $\begin{array}{r}14.1 \\
15.7 \\
18.0 \\
16.2 \\
14.9 \\
12.6 \\
9.6 \\
13.8\end{array}$ & $\begin{array}{l}15.3 \\
16.7 \\
18.9 \\
17.0 \\
15.6 \\
13.4 \\
11.6 \\
15.4\end{array}$ \\
\hline $\begin{array}{l}15 \\
15 \\
15 \\
15 \\
15 \\
15 \\
15 \\
15\end{array}$ & $\begin{array}{r}0 \\
3 \\
6 \\
9 \\
12 \\
15 \\
18 \\
21\end{array}$ & $\begin{array}{l}19.2 \\
18.0 \\
17.7 \\
22.8 \\
26.0 \\
26.5 \\
73.5 \\
71.3\end{array}$ & $\begin{array}{l}15.7 \\
14.5 \\
14.3 \\
16.7 \\
17.8 \\
18.0 \\
17.3 \\
15.7\end{array}$ & $\begin{array}{l}19.2 \\
17.9 \\
17.7 \\
23.2 \\
26.7 \\
26.9 \\
74.0 \\
21.3\end{array}$ & $\begin{array}{l}15.4 \\
14.2 \\
14.1 \\
16.5 \\
17.4 \\
17.9 \\
17.0 \\
15.4\end{array}$ & $\begin{array}{l}10.1 \\
17.8 \\
17.7 \\
23.5 \\
27.3 \\
77.4 \\
24.1 \\
71.03\end{array}$ & $\begin{array}{l}15.3 \\
14.0 \\
13.9 \\
16.5 \\
17.3 \\
17.9 \\
16.8 \\
15.0\end{array}$ & $\begin{array}{l}19.1 \\
17.8 \\
17.8 \\
24.0 \\
27.5 \\
27.8 \\
24.4 \\
21.4\end{array}$ & $\begin{array}{l}15.3 \\
14.0 \\
14.0 \\
16.9 \\
17.9 \\
18.5 \\
17.2 \\
15.4\end{array}$ & $\begin{array}{l}19.0 \\
19.0 \\
19.3 \\
20.3 \\
20.3 \\
19.3 \\
19.0 \\
19.0\end{array}$ & $\begin{array}{l}2 \\
2 \\
2 \\
2 \\
2 \\
2 \\
2 \\
2 \\
2\end{array}$ & $\begin{array}{r}10.1 \\
10.5 \\
10.6 \\
9.9 \\
12.8 \\
11.6 \\
10.5 \\
13.4\end{array}$ & $\begin{array}{l}11.5 \\
11.9 \\
11.9 \\
11.4 \\
15.0 \\
13.7 \\
11.9 \\
15.3\end{array}$ & $\begin{array}{l}12.6 \\
13.0 \\
13.0 \\
12.9 \\
17.0 \\
15.5 \\
13.3 \\
16.9\end{array}$ & $\begin{array}{l}13.9 \\
14.1 \\
13.8 \\
13.6 \\
18.2 \\
16.7 \\
14.6 \\
18.1\end{array}$ \\
\hline $\begin{array}{l}16 \\
16 \\
16 \\
16 \\
16 \\
16 \\
16 \\
16\end{array}$ & $\begin{array}{r}0 \\
3 \\
6 \\
9 \\
12 \\
15 \\
18 \\
21\end{array}$ & $\begin{array}{l}19.4 \\
17.7 \\
17.6 \\
72.9 \\
25.7 \\
25.7 \\
22.7 \\
18.7\end{array}$ & $\begin{array}{l}14.8 \\
14.5 \\
14.8 \\
16.9 \\
16.7 \\
16.4 \\
15.4 \\
14.7\end{array}$ & $\begin{array}{r}19.5 \\
17.5 \\
.17 .5 \\
2.3 .0 \\
26.0 \\
26.1 \\
22.7 \\
18.6\end{array}$ & $\begin{array}{l}14.5 \\
14.1 \\
14.5 \\
16.6 \\
16.4 \\
16.0 \\
14.9 \\
14.3\end{array}$ & $\begin{array}{l}19.3 \\
17.04 \\
17.6 \\
23.5 \\
26.6 \\
76.04 \\
22.8 \\
18.6\end{array}$ & $\begin{array}{l}14.2 \\
130.9 \\
14.3 \\
16.6 \\
16.3 \\
15.7 \\
14.7 \\
1400\end{array}$ & $\begin{array}{l}19.3 \\
17.3 \\
17.8 \\
23.8 \\
26.8 \\
26.8 \\
22.7 \\
18.7\end{array}$ & $\begin{array}{l}14.4 \\
13.9 \\
14.5 \\
16.9 \\
17.0 \\
16.4 \\
15.0 \\
14.2\end{array}$ & $\begin{array}{l}18.9 \\
18.9 \\
19.3 \\
20.3 \\
20.3 \\
19.4 \\
19.0 \\
18.9\end{array}$ & $\begin{array}{l}3 \\
3 \\
3 \\
3 \\
3 \\
3 \\
3 \\
3\end{array}$ & $\begin{array}{r}12.4 \\
10.6 \\
11.9 \\
15.8 \\
13.5 \\
12.2 \\
10.5 \\
6.7\end{array}$ & $\begin{array}{r}14.0 \\
12.0 \\
13.4 \\
18.2 \\
15.6 \\
14.3 \\
11.9 \\
7.5\end{array}$ & $\begin{array}{r}15.5 \\
13.0 \\
14.7 \\
20.6 \\
17.8 \\
16.0 \\
13.3 \\
8.3\end{array}$ & $\begin{array}{r}16.5 \\
14.0 \\
15.6 \\
21.8 \\
18.9 \\
17.2 \\
14.6 \\
9.7\end{array}$ \\
\hline $\begin{array}{l}17 \\
17 \\
17 \\
17 \\
17 \\
17 \\
17 \\
17\end{array}$ & $\begin{array}{r}0 \\
3 \\
6 \\
9 \\
12 \\
15 \\
18 \\
21\end{array}$ & $\begin{array}{l}17.7 \\
17.0 \\
17.2 \\
22.7 \\
25.8 \\
25.7 \\
21.1 \\
19.9\end{array}$ & $\begin{array}{l}14.4 \\
14.2 \\
14.3 \\
16.7 \\
17.7 \\
18.0 \\
16.9 \\
16.0\end{array}$ & $\begin{array}{l}17.6 \\
16.4 \\
17.0 \\
23.0 \\
26.5 \\
26.5 \\
21.9 \\
20.0\end{array}$ & $\begin{array}{l}14.0 \\
13.9 \\
14.1 \\
16.3 \\
17.3 \\
17.2 \\
16.3 \\
15.6\end{array}$ & $\begin{array}{l}17.5 \\
16.8 \\
17.3 \\
73.3 \\
26.6 \\
27.2 \\
72.7 \\
20.2\end{array}$ & $\begin{array}{l}14.0 \\
13.8 \\
14.0 \\
16.4 \\
17.4 \\
17.2 \\
16.1 \\
15.2\end{array}$ & $\begin{array}{l}17.5 \\
16.8 \\
17.4 \\
23.7 \\
26.8 \\
27.4 \\
23.5 \\
20.6\end{array}$ & $\begin{array}{l}14.0 \\
13.8 \\
14.0 \\
16.7 \\
17.9 \\
18.2 \\
16.6 \\
15.5\end{array}$ & $\begin{array}{l}19.0 \\
19.0 \\
19.3 \\
20.3 \\
20.4 \\
19.5 \\
19.1 \\
19.1\end{array}$ & $\begin{array}{l}2 \\
2 \\
2 \\
2 \\
2 \\
2 \\
2 \\
2 \\
2\end{array}$ & $\begin{array}{r}8.1 \\
9.0 \\
10.4 \\
10.3 \\
8.4 \\
5.8 \\
4.2 \\
5.5\end{array}$ & $\begin{array}{r}9.0 \\
10.1 \\
11.8 \\
11.9 \\
9.7 \\
7.3 \\
5.3 \\
6.4\end{array}$ & $\begin{array}{r}9.8 \\
10.9 \\
12.8 \\
13.5 \\
10.9 \\
3.9 \\
6.5 \\
7.6\end{array}$ & $\begin{array}{r}10.8 \\
12.1 \\
13.7 \\
14.2 \\
11.5 \\
9.1 \\
8.4 \\
9.6\end{array}$ \\
\hline $\begin{array}{l}18 \\
18 \\
18 \\
18 \\
18 \\
18 \\
18 \\
18\end{array}$ & $\begin{array}{r}0 \\
3 \\
6 \\
9 \\
12 \\
15 \\
18 \\
21\end{array}$ & $\begin{array}{l}18.0 \\
17.0 \\
16.9 \\
22.3 \\
24.4 \\
22.6 \\
19.8 \\
18.1\end{array}$ & $\begin{array}{l}15.1 \\
14.7 \\
14.8 \\
17.0 \\
15.8 \\
17.3 \\
16.6 \\
16.0\end{array}$ & $\begin{array}{l}18.1 \\
16.9 \\
17.0 \\
22.5 \\
24.8 \\
23.0 \\
19.8 \\
18.2\end{array}$ & $\begin{array}{l}14.9 \\
14.3 \\
14.6 \\
16.5 \\
15.9 \\
16.9 \\
16.3 \\
15.8\end{array}$ & $\begin{array}{l}18.0 \\
16.8 \\
17.1 \\
22.8 \\
24.9 \\
23.3 \\
30.0 \\
18.2\end{array}$ & $\begin{array}{l}14.6 \\
14.0 \\
14.5 \\
16.5 \\
15.3 \\
17.0 \\
16.0 \\
15.5\end{array}$ & $\begin{array}{l}18.1 \\
16.8 \\
17.6 \\
22.8 \\
24.9 \\
23.3 \\
20.3 \\
18.4\end{array}$ & $\begin{array}{l}14.8 \\
14.1 \\
14.6 \\
16.6 \\
16.6 \\
17.2 \\
16.3 \\
15.6\end{array}$ & $\begin{array}{l}19.1 \\
19.0 \\
19.2 \\
20.5 \\
20.3 \\
19.5 \\
19.0 \\
18.9\end{array}$ & $\begin{array}{l}3 \\
3 \\
3 \\
3 \\
3 \\
3 \\
3 \\
3\end{array}$ & $\begin{array}{l}6.1 \\
4.2 \\
4.9 \\
4.9 \\
4.4 \\
6.4 \\
2.5 \\
2.2\end{array}$ & $\begin{array}{l}7.2 \\
4.6 \\
5.3 \\
5.8 \\
5.2 \\
7.6 \\
3.1 \\
2.5\end{array}$ & $\begin{array}{l}7.9 \\
4.8 \\
5.8 \\
6.4 \\
5.7 \\
8.7 \\
3.9 \\
2.8\end{array}$ & $\begin{array}{l}9.3 \\
5.6 \\
6.6 \\
6.9 \\
6.1 \\
9.4 \\
4.8 \\
3.7\end{array}$ \\
\hline $\begin{array}{l}19 \\
19 \\
19 \\
19 \\
19 \\
19 \\
19 \\
19\end{array}$ & $\begin{array}{r}0 \\
3 \\
6 \\
9 \\
12 \\
15 \\
18 \\
21\end{array}$ & $\begin{array}{l}17.4 \\
17.6 \\
16.5 \\
18.4 \\
22.1 \\
22.4 \\
20.6 \\
19.1\end{array}$ & $\begin{array}{l}15.6 \\
15.5 \\
14.8 \\
15.3 \\
16.2 \\
16.7 \\
16.4 \\
15.0\end{array}$ & $\begin{array}{l}17.4 \\
17.8 \\
16.6 \\
18.4 \\
22.4 \\
23.1 \\
21.1 \\
19.0\end{array}$ & $\begin{array}{l}15.4 \\
15.2 \\
14.6 \\
15.2 \\
15.9 \\
15.8 \\
15.7 \\
14.4\end{array}$ & $\begin{array}{l}17.4 \\
17.7 \\
16.6 \\
18.6 \\
22.7 \\
23.6 \\
21.5 \\
19.0\end{array}$ & $\begin{array}{l}15.1 \\
15.0 \\
14.4 \\
15.2 \\
15.6 \\
15.4 \\
15.1 \\
14.3\end{array}$ & $\begin{array}{l}17.6 \\
17.7 \\
16.02 \\
18.7 \\
22.9 \\
23.8 \\
21.7 \\
19.0\end{array}$ & $\begin{array}{l}15.2 \\
15.0 \\
14.3 \\
15.3 \\
15.5 \\
15.6 \\
15.02 \\
14.2\end{array}$ & $\begin{array}{l}19.1 \\
19.1 \\
19.3 \\
19.8 \\
20.0 \\
19.7 \\
19.02 \\
19.1\end{array}$ & $\begin{array}{l}2 \\
2 \\
3 \\
4 \\
3 \\
3 \\
3 \\
3\end{array}$ & $\begin{array}{l}2.2 \\
2.7 \\
2.4 \\
2.4 \\
4.1 \\
4.2 \\
2.9 \\
3.5\end{array}$ & $\begin{array}{l}2.2 \\
3.0 \\
3.6 \\
3.8 \\
4.9 \\
5.4 \\
3.9 \\
4.0\end{array}$ & $\begin{array}{l}2.6 \\
3.2 \\
4.0 \\
4.4 \\
5.5 \\
6.3 \\
4.8 \\
4.5\end{array}$ & $\begin{array}{l}3.5 \\
4.2 \\
3.9 \\
4.8 \\
6.2 \\
7.2 \\
6.4 \\
5.4\end{array}$ \\
\hline $\begin{array}{l}20 \\
20 \\
20 \\
20 \\
20 \\
20 \\
20 \\
20\end{array}$ & $\begin{array}{r}0 \\
3 \\
6 \\
9 \\
12 \\
15 \\
18 \\
21\end{array}$ & $\begin{array}{l}17.8 \\
16.2 \\
15.3 \\
17.4 \\
20.9 \\
20.4 \\
18.7 \\
16.7\end{array}$ & $\begin{array}{l}13.6 \\
13.1 \\
13.1 \\
14.1 \\
15.7 \\
16.1 \\
14.6 \\
12.8\end{array}$ & $\begin{array}{l}17.7 \\
16.1 \\
15.1 \\
17.3 \\
21.0 \\
20.8 \\
19.0 \\
16.7\end{array}$ & $\begin{array}{l}13.2 \\
12.9 \\
12.8 \\
13.5 \\
15.4 \\
15.2 \\
14.0 \\
12.5\end{array}$ & $\begin{array}{l}17.7 \\
15.9 \\
15.1 \\
17.4 \\
21.0 \\
21.0 \\
19.1 \\
16.6\end{array}$ & $\begin{array}{l}13.0 \\
12.8 \\
12.8 \\
13.6 \\
15.03 \\
14.07 \\
13.5 \\
12.2\end{array}$ & $\begin{array}{l}17.6 \\
15.8 \\
14.9 \\
17.4 \\
21.5 \\
21.03 \\
19.2 \\
16.5\end{array}$ & $\begin{array}{l}13.0 \\
12.8 \\
12.7 \\
13.8 \\
15.5 \\
14.8 \\
13.5 \\
12.2\end{array}$ & $\begin{array}{l}19.0 \\
18.09 \\
18.9 \\
19.3 \\
19.4 \\
19.0 \\
18.9 \\
18.9\end{array}$ & $\begin{array}{l}3 \\
3 \\
3 \\
3 \\
3 \\
3 \\
3 \\
3\end{array}$ & $\begin{array}{l}3.4 \\
4.7 \\
5.6 \\
4.1 \\
4.0 \\
3.03 \\
2.5 \\
3.9\end{array}$ & $\begin{array}{l}3.4 \\
5.3 \\
6.3 \\
4.8 \\
5.1 \\
4.2 \\
3.2 \\
4.1\end{array}$ & $\begin{array}{l}4.2 \\
6.4 \\
7.1 \\
5.1 \\
5.8 \\
5.2 \\
3.8 \\
4.2\end{array}$ & $\begin{array}{l}4.5 \\
6.7 \\
7.5 \\
5.3 \\
5.9 \\
6.0 \\
5.1 \\
4.8\end{array}$ \\
\hline
\end{tabular}


TABLE 10

Table 10. - Three-hour averages of air and water-surface temperatures and wind directions and speed, April 1950-August 1951, Lake Hefner-Continued

STATION 1 THREE-HOURLY AVERAGES

OCTOBER, 1950

\begin{tabular}{|c|c|c|c|c|c|c|c|c|c|c|c|c|c|c|c|}
\hline \multirow{4}{*}{ 委 } & \multirow{4}{*}{ 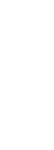 } & \multicolumn{8}{|c|}{ Average air temperature $\left({ }^{\circ} \mathrm{C}\right)$ at indicated height } & \multirow{4}{*}{$\begin{array}{c}\text { Average } \\
\text { water- } \\
\text { surface } \\
\text { tempera- } \\
\text { ture } \\
\left({ }^{\circ} \mathrm{C}\right)\end{array}$} & \multirow{4}{*}{$\begin{array}{c}\text { Average } \\
\text { wind } \\
\text { direction } \\
\text { (coded) }\end{array}$} & \multirow{2}{*}{\multicolumn{4}{|c|}{$\begin{array}{l}\text { Average wind speed (knots) } \\
\text { at indicated height }\end{array}$}} \\
\hline & & \multirow{2}{*}{\multicolumn{2}{|c|}{$\begin{array}{c}2 \\
\text { meters }\end{array}$}} & \multirow{2}{*}{\multicolumn{2}{|c|}{$\begin{array}{c}4 \\
\text { meters } \\
\end{array}$}} & \multirow{2}{*}{\multicolumn{2}{|c|}{$\begin{array}{c}8 \\
\text { meters }\end{array}$}} & \multirow{2}{*}{\multicolumn{2}{|c|}{$\begin{array}{c}16 \\
\text { meters }\end{array}$}} & & & & & & \\
\hline & & & & & & & & & & & & 2 & 4 & 8 & 16 \\
\hline & & $\begin{array}{l}\text { Dry } \\
\text { bulb }\end{array}$ & $\begin{array}{l}\text { Wet } \\
\text { bulb }\end{array}$ & $\begin{array}{l}\text { Dry } \\
\text { bulb }\end{array}$ & \begin{tabular}{|l} 
Wet \\
bulb
\end{tabular} & $\begin{array}{l}\text { Dry } \\
\text { bulb }\end{array}$ & \begin{tabular}{|l|} 
Wet \\
bulb
\end{tabular} & $\begin{array}{l}\text { Dry } \\
\text { bulb }\end{array}$ & $\begin{array}{l}\text { Wet } \\
\text { bulb }\end{array}$ & & & meters & & & meters \\
\hline $\begin{array}{l}21 \\
21 \\
21 \\
21 \\
21 \\
21 \\
21 \\
21\end{array}$ & $\begin{array}{r}0 \\
3 \\
6 \\
9 \\
12 \\
15 \\
18 \\
21\end{array}$ & $\begin{array}{l}15.0 \\
13.6 \\
12.4 \\
17.9 \\
21.8 \\
22.8 \\
18.2 \\
17.0\end{array}$ & $\begin{array}{l}11.4 \\
10.8 \\
10.1 \\
12.1 \\
13.1 \\
14.0 \\
12.6 \\
11.5\end{array}$ & $\begin{array}{l}14.9 \\
13.5 \\
12.2 \\
17.8 \\
21.7 \\
22.1 \\
18: 3 \\
16.7\end{array}$ & $\begin{array}{r}11.0 \\
10.6 \\
9.8 \\
11.8 \\
12.5 \\
12.1 \\
11.7 \\
11.1\end{array}$ & $\begin{array}{l}14.9 \\
13.2 \\
12.4 \\
18.1 \\
21.9 \\
22.4 \\
18.4 \\
16.8\end{array}$ & $\begin{array}{r}11.1 \\
10.3 \\
9.7 \\
11.4 \\
12.0 \\
11.4 \\
11.4 \\
10.8\end{array}$ & $\begin{array}{l}14.8 \\
13.2 \\
12.2 \\
18.2 \\
21.9 \\
22.6 \\
19.0 \\
16.7\end{array}$ & $\begin{array}{r}11.1 \\
10.4 \\
9.9 \\
11.8 \\
12.2 \\
12.2 \\
11.5 \\
11.1\end{array}$ & $\begin{array}{l}18.8 \\
18.7 \\
18.8 \\
19.8 \\
19.9 \\
19.2 \\
18.8 \\
18.7\end{array}$ & $\begin{array}{l}3 \\
4 \\
4 \\
3 \\
3 \\
3 \\
3 \\
3\end{array}$ & $\begin{array}{l}2.9 \\
4.9 \\
5.9 \\
4.0 \\
6.02 \\
5.6 \\
3.02 \\
2.0\end{array}$ & $\begin{array}{l}3.0 \\
4.1 \\
5.0 \\
4.4 \\
7.1 \\
6.6 \\
3.6 \\
2.9\end{array}$ & $\begin{array}{l}3.1 \\
5.4 \\
7.1 \\
5.3 \\
7.9 \\
7.3 \\
4.1 \\
2.9\end{array}$ & $\begin{array}{l}6.3 \\
8.3 \\
8.2 \\
5.8 \\
3.2\end{array}$ \\
\hline $\begin{array}{l}22 \\
22 \\
22 \\
22 \\
22 \\
22 \\
22 \\
22\end{array}$ & $\begin{array}{r}0 \\
3 \\
6 \\
9 \\
12 \\
15 \\
18 \\
21\end{array}$ & $\begin{array}{l}14.9 \\
12.3 \\
10.1 \\
14.1 \\
19.3 \\
21.0 \\
17.5 \\
12.8\end{array}$ & $\begin{array}{r}10.2 \\
9.1 \\
8.1 \\
11.1 \\
13.0 \\
14.0 \\
12.7 \\
10.5\end{array}$ & $\begin{array}{r}14.6 \\
11.7 \\
9.6 \\
14.0 \\
10.4 \\
21.00 \\
17.2 \\
12.3\end{array}$ & $\begin{array}{r}9.8 \\
8.5 \\
7.4 \\
10.2 \\
12.2 \\
13.2 \\
12.2 \\
9.6\end{array}$ & $\begin{array}{r}14.5 \\
11.6 \\
9.4 \\
14.1 \\
19.5 \\
21.0 \\
17.1 \\
11.9\end{array}$ & $\begin{array}{r}9.6 \\
8.2 \\
7.2 \\
10.2 \\
12.1 \\
13.0 \\
11.9 \\
9.3\end{array}$ & $\begin{array}{r}14.4 \\
11.5 \\
9.3 \\
14.2 \\
19.6 \\
21.1 \\
16.9 \\
11.6\end{array}$ & $\begin{array}{r}9.8 \\
8.2 \\
7.3 \\
10.4 \\
12.3 \\
13.3 \\
13.1 \\
9.4\end{array}$ & $\begin{array}{l}18.6 \\
18.5 \\
18.7 \\
19.5 \\
19.6 \\
18.9 \\
18.6 \\
18.5\end{array}$ & $\begin{array}{l}4 \\
4 \\
3 \\
3 \\
3 \\
3 \\
3 \\
3\end{array}$ & $\begin{array}{r}5.0 \\
8.1 \\
10.5 \\
10.4 \\
9.5 \\
9.4 \\
9.0 \\
12.0\end{array}$ & $\begin{array}{r}4.8 \\
7.9 \\
12.1 \\
12.1 \\
11.1 \\
10.5 \\
10.7 \\
13.3\end{array}$ & $\begin{array}{r}5.2 \\
9.1 \\
12.9 \\
12.5 \\
12.2 \\
12.3 \\
11.3 \\
14.8\end{array}$ & $\begin{array}{l}10.0 \\
13.4 \\
13.1 \\
12.7 \\
13.0 \\
12.0 \\
15.1\end{array}$ \\
\hline $\begin{array}{l}23 \\
23 \\
23 \\
23 \\
23 \\
23 \\
23 \\
23\end{array}$ & $\begin{array}{r}0 \\
3 \\
6 \\
9 \\
12 \\
15 \\
18 \\
21\end{array}$ & $\begin{array}{r}9.4 \\
7.8 \\
7.6 \\
11.0 \\
16.6 \\
19.4 \\
16.2 \\
14.0\end{array}$ & $\begin{array}{r}8.4 \\
7.0 \\
7.1 \\
8.9 \\
11.5 \\
13.6 \\
12.4 \\
11.1\end{array}$ & $\begin{array}{r}9.0 \\
7.2 \\
7.0 \\
11.0 \\
16.0 \\
18.9 \\
16.0 \\
13.8\end{array}$ & $\begin{array}{r}7.7 \\
6.5 \\
6.4 \\
8.5 \\
11.0 \\
12.6 \\
12.1 \\
10.7\end{array}$ & $\begin{array}{r}8.7 \\
6.9 \\
6.5 \\
11.0 \\
16.2 \\
18.7 \\
15.9 \\
13.7\end{array}$ & $\begin{array}{r}7.4 \\
6.2 \\
6.4 \\
8.1 \\
11.0 \\
12.6 \\
11.8 \\
10.5\end{array}$ & $\begin{array}{r}8.5 \\
6.7 \\
6.8 \\
11.1 \\
15.7 \\
18.7 \\
15.8 \\
13.6\end{array}$ & $\begin{array}{r}7.5 \\
6.2 \\
6.4 \\
8.4 \\
11.4 \\
12.9 \\
11.9 \\
10.7\end{array}$ & $\begin{array}{l}18.4 \\
18.2 \\
18.3 \\
19.2 \\
20.0 \\
19.3 \\
18.4 \\
18.1\end{array}$ & $\begin{array}{l}3 \\
3 \\
3 \\
3 \\
4 \\
2 \\
2 \\
2\end{array}$ & $\begin{array}{r}10.0 \\
8.6 \\
7.7 \\
4.8 \\
1.6 \\
3.0 \\
5.0 \\
4.9\end{array}$ & $\begin{array}{r}11.7 \\
30.0 \\
8.6 \\
5.3 \\
1.7 \\
3.4 \\
6.2 \\
5.4\end{array}$ & $\begin{array}{r}12.1 \\
10.5 \\
9.4 \\
5.4 \\
1.7 \\
3.5 \\
6.4 \\
.5 .6\end{array}$ & $\begin{array}{r}12.6 \\
10.7 \\
9.6 \\
5.8 \\
1.7 \\
3.7 \\
7.3 \\
6.3\end{array}$ \\
\hline $\begin{array}{l}24 \\
24 \\
24 \\
24 \\
24 \\
24 \\
24 \\
24\end{array}$ & $\begin{array}{r}0 \\
3 \\
6 \\
9 \\
12 \\
15 \\
18 \\
21\end{array}$ & $\begin{array}{l}13.7 \\
15.6 \\
16.2 \\
21.3 \\
24.8 \\
24.9 \\
20.1 \\
16.9\end{array}$ & $\begin{array}{l}11.0 \\
12.0 \\
12.8 \\
14.7 \\
15.9 \\
16.6 \\
15.1 \\
13.6\end{array}$ & $\begin{array}{l}13.6 \\
15.5 \\
15.2 \\
21.6 \\
25.7 \\
26.1 \\
20.2 \\
16.8\end{array}$ & $\begin{array}{l}10.6 \\
11.6 \\
12.5 \\
14.5 \\
15.2 \\
16.0 \\
14.6 \\
13.1\end{array}$ & $\begin{array}{l}13.5 \\
15.5 \\
15.2 \\
21.9 \\
25.9 \\
26.6 \\
20.4 \\
16.7\end{array}$ & $\begin{array}{l}10.6 \\
11.6 \\
12.5 \\
14.4 \\
15.2 \\
16.0 \\
14.3 \\
12.0\end{array}$ & $\begin{array}{l}13.4 \\
15.5 \\
16.1 \\
22.2 \\
26.1 \\
26.9 \\
20.5 \\
16.6\end{array}$ & $\begin{array}{l}10.7 \\
11.5 \\
12.5 \\
14.8 \\
16.0 \\
16.7 \\
14.3 \\
12.9\end{array}$ & $\begin{array}{l}18.1 \\
18.0 \\
18.1 \\
18.8 \\
19.0 \\
18.5 \\
18.2 \\
18.1\end{array}$ & $\begin{array}{l}2 \\
2 \\
2 \\
2 \\
2 \\
2 \\
4 \\
3\end{array}$ & $\begin{array}{r}7.8 \\
15.6 \\
16.2 \\
13.1 \\
9.4 \\
5.6 \\
5.6 \\
4.9\end{array}$ & $\begin{array}{r}8.7 \\
17.6 \\
18.3 \\
14.9 \\
10.8 \\
7.4 \\
6.0 \\
5.4\end{array}$ & $\begin{array}{r}9.3 \\
10.7 \\
20.5 \\
16.7 \\
12.1 \\
8.7 \\
7.4 \\
6.1\end{array}$ & $\begin{array}{r}10.0 \\
20.7 \\
21.3 \\
17.4 \\
12.7 \\
9.5 \\
9.2 \\
6.7\end{array}$ \\
\hline $\begin{array}{l}25 \\
25 \\
25 \\
25 \\
25 \\
25 \\
25 \\
25\end{array}$ & $\begin{array}{r}0 \\
3 \\
6 \\
9 \\
17 \\
15 \\
18 \\
21\end{array}$ & $\begin{array}{l}14.3 \\
12.0 \\
11.1 \\
14.3 \\
19.8 \\
22.1 \\
18.7 \\
18.4\end{array}$ & $\begin{array}{l}12.1 \\
10.9 \\
10.3 \\
12.5 \\
15.6 \\
17.0 \\
16.2 \\
14.9\end{array}$ & $\begin{array}{l}14.0 \\
11.8 \\
10.8 \\
14.2 \\
19.7 \\
22.1 \\
18.8 \\
18.4\end{array}$ & $\begin{array}{r}11.7 \\
10.3 \\
9.8 \\
12.3 \\
14.9 \\
16.4 \\
15.7 \\
14.6\end{array}$ & $\begin{array}{l}13.7 \\
11.6 \\
10.8 \\
14.5 \\
30.5 \\
77.3 \\
19.3 \\
18.5\end{array}$ & $\begin{array}{r}11.4 \\
10.2 \\
9.6 \\
12.3 \\
15.1 \\
15.9 \\
15.3 \\
14.4\end{array}$ & $\begin{array}{l}13.4 \\
11.44 \\
10.6 \\
14.5 \\
20.6 \\
22.1 \\
20.2 \\
18.5\end{array}$ & $\begin{array}{r}11.4 \\
10.1 \\
9.7 \\
12.2 \\
15.2 \\
16.3 \\
15.6 \\
14.5\end{array}$ & $\begin{array}{l}18.1 \\
18.1 \\
18.1 \\
18.9 \\
19.5 \\
19.0 \\
18.4 \\
18.0\end{array}$ & $\begin{array}{l}3 \\
3 \\
3 \\
3 \\
2 \\
2 \\
2 \\
2\end{array}$ & $\begin{array}{l}6.2 \\
5.9 \\
7.2 \\
6.1 \\
2.9 \\
1.7 \\
4.2 \\
9.1\end{array}$ & $\begin{array}{r}7.3 \\
8.2 \\
7.2 \\
6.4 \\
3.1 \\
2.0 \\
4.7 \\
10.4\end{array}$ & $\begin{array}{r}7.3 \\
8.4 \\
8.7 \\
6.8 \\
3.2 \\
2.3 \\
6.2 \\
11.7\end{array}$ & $\begin{array}{r}7.8 \\
8.8 \\
8.5 \\
6.8 \\
3.4 \\
2.6 \\
7.6 \\
13.2\end{array}$ \\
\hline $\begin{array}{l}26 \\
26 \\
26 \\
26 \\
26 \\
26 \\
26 \\
26\end{array}$ & $\begin{array}{r}0 \\
3 \\
6 \\
9 \\
12 \\
15 \\
18 \\
? 1\end{array}$ & $\begin{array}{l}18.2 \\
18.6 \\
19.5 \\
24.1 \\
27.8 \\
27.4 \\
24.1 \\
22.5\end{array}$ & $\begin{array}{l}14.7 \\
13.9 \\
13.9 \\
14.2 \\
15.9 \\
16.4 \\
14.9 \\
13.1\end{array}$ & $\begin{array}{l}18.2 \\
18.6 \\
19.6 \\
24.6 \\
28.3 \\
28.3 \\
24.6 \\
22.8\end{array}$ & $\begin{array}{l}14.2 \\
13.4 \\
13.4 \\
13.7 \\
15.1 \\
15.8 \\
14.3 \\
12.6\end{array}$ & $\begin{array}{l}18.2 \\
18.7 \\
20.0 \\
25.1 \\
29.0 \\
28.9 \\
24.8 \\
23.1\end{array}$ & $\begin{array}{l}14.1 \\
13.2 \\
13.3 \\
13.7 \\
15.3 \\
15.8 \\
14.1 \\
17.2\end{array}$ & $\begin{array}{l}18.3 \\
18.8 \\
20.3 \\
25.4 \\
29.5 \\
29.2 \\
25.2 \\
23.3\end{array}$ & $\begin{array}{l}14.2 \\
13.3 \\
12.7 \\
14.2 \\
15.9 \\
15.6 \\
14.7 \\
12.9\end{array}$ & $\begin{array}{l}17.8 \\
17.8 \\
17.9 \\
18.7 \\
18.8 \\
18.2 \\
17.9 \\
17.8\end{array}$ & $\begin{array}{l}2 \\
2 \\
2 \\
2 \\
2 \\
2 \\
2 \\
2 \\
2\end{array}$ & $\begin{array}{l}10.9 \\
12.3 \\
14.0 \\
16.0 \\
16.6 \\
14.4 \\
13.5 \\
14.4\end{array}$ & $\begin{array}{l}12.5 \\
13.8 \\
15.9 \\
18.2 \\
19.3 \\
16.8 \\
15.8 \\
16.5\end{array}$ & $\begin{array}{l}13.9 \\
15.6 \\
17.9 \\
20.4 \\
21.9 \\
19.4 \\
17.8 \\
18.8\end{array}$ & $\begin{array}{l}15.2 \\
16.9 \\
19.0 \\
21.4 \\
23.2 \\
20.9 \\
19.5 \\
20.2\end{array}$ \\
\hline $\begin{array}{l}27 \\
27 \\
27 \\
27 \\
27 \\
27 \\
27 \\
27\end{array}$ & $\begin{array}{r}0 \\
3 \\
6 \\
9 \\
12 \\
15 \\
18 \\
23\end{array}$ & $\begin{array}{l}20.4 \\
19.2 \\
16.7 \\
19.1 \\
24.2 \\
25.1 \\
20.3 \\
10.2\end{array}$ & $\begin{array}{l}12.3 \\
11.5 \\
10.5 \\
13.2 \\
15.4 \\
15.6 \\
14.3 \\
13.7\end{array}$ & $\begin{array}{l}20.5 \\
19.2 \\
16.7 \\
19.4 \\
24.4 \\
25.8 \\
20.8 \\
19.1\end{array}$ & $\begin{array}{l}11.7 \\
10.6 \\
10.0 \\
12.4 \\
14.6 \\
14.5 \\
13.4 \\
13.2\end{array}$ & $\begin{array}{l}20.6 \\
19.2 \\
16.7 \\
19.7 \\
24.7 \\
26.1 \\
21.6 \\
10.3\end{array}$ & $\begin{array}{l}11.4 \\
10.4 \\
10.0 \\
12.2 \\
14.7 \\
14.4 \\
13.0 \\
12.9\end{array}$ & $\begin{array}{l}20.7 \\
19.2 \\
16.3 \\
19.9 \\
25.0 \\
26.6 \\
22.5 \\
19.5\end{array}$ & $\begin{array}{l}12.0 \\
11.2 \\
10.1 \\
12.7 \\
15.1 \\
15.4 \\
13.5 \\
13.3\end{array}$ & $\begin{array}{l}17.8 \\
17.7 \\
17.7 \\
19.7 \\
19.6 \\
18.6 \\
18.0 \\
17.7\end{array}$ & $\begin{array}{l}2 \\
2 \\
2 \\
2 \\
2 \\
2 \\
2 \\
2\end{array}$ & $\begin{array}{r}14.8 \\
13.0 \\
9.5 \\
5.1 \\
4.1 \\
5.5 \\
5.5 \\
8.4\end{array}$ & $\begin{array}{r}17.0 \\
14.7 \\
10.4 \\
5.7 \\
4.6 \\
6.9 \\
6.7 \\
9.7\end{array}$ & $\begin{array}{r}19.2 \\
16.6 \\
11.4 \\
6.4 \\
5.2 \\
7.8 \\
8.7 \\
11.1\end{array}$ & $\begin{array}{r}20.5 \\
17.7 \\
12.3 \\
6.8 \\
5.7 \\
8.9 \\
10.9 \\
12.7\end{array}$ \\
\hline $\begin{array}{l}28 \\
28 \\
28 \\
28 \\
28 \\
28 \\
28 \\
28\end{array}$ & $\begin{array}{r}0 \\
3 \\
6 \\
9 \\
12 \\
15 \\
18 \\
21\end{array}$ & $\begin{array}{l}19.2 \\
19.0 \\
15.6 \\
20.2 \\
25.3 \\
25.4 \\
19.9 \\
17.2\end{array}$ & $\begin{array}{l}15.7 \\
15.1 \\
12.7 \\
14.2 \\
16.5 \\
16.6 \\
15.7 \\
15.0\end{array}$ & $\begin{array}{l}19.4 \\
17.9 \\
15.7 \\
20.2 \\
25.7 \\
26.5 \\
20.05 \\
17.0\end{array}$ & $\begin{array}{l}15.5 \\
14.9 \\
12.3 \\
13.8 \\
15.3 \\
16.0 \\
14.7 \\
14.3\end{array}$ & $\begin{array}{l}19.6 \\
37.8 \\
15.7 \\
20.7 \\
26.3 \\
26.7 \\
21.6 \\
17.6\end{array}$ & $\begin{array}{l}15.5 \\
14: 7 \\
12.1 \\
13.7 \\
15.1 \\
16.0 \\
14.5 \\
13.4\end{array}$ & $\begin{array}{l}19.7 \\
17.8 \\
15.9 \\
20.9 \\
26.4 \\
26.9 \\
23.2 \\
18.9\end{array}$ & $\begin{array}{l}15.7 \\
14.7 \\
11.9 \\
13.9 \\
15.6 \\
16.3 \\
15.1 \\
13.6\end{array}$ & $\begin{array}{l}17.7 \\
17.5 \\
17.7 \\
18.4 \\
18.9 \\
18.4 \\
18.0 \\
17.7\end{array}$ & $\begin{array}{l}2 \\
2 \\
2 \\
3 \\
3 \\
3 \\
3 \\
3\end{array}$ & $\begin{array}{r}11.2 \\
9.2 \\
7.1 \\
8.8 \\
7.7 \\
4.3 \\
1.6 \\
1.4\end{array}$ & $\begin{array}{r}12.7 \\
10.4 \\
7.3 \\
10.4 \\
8.6 \\
5.2 \\
2.2 \\
1.6\end{array}$ & $\begin{array}{r}14.4 \\
11.7 \\
8.0 \\
11.5 \\
9.1 \\
5.6 \\
2.6 \\
1.6\end{array}$ & $\begin{array}{r}15.7 \\
12.6 \\
7.9 \\
12.1 \\
9.6 \\
6.1 \\
4.6 \\
1.3\end{array}$ \\
\hline $\begin{array}{l}29 \\
29 \\
29 \\
29 \\
29 \\
29 \\
29 \\
29\end{array}$ & $\begin{array}{r}0 \\
3 \\
6 \\
6 \\
12 \\
15 \\
18 \\
21\end{array}$ & $\begin{array}{l}15.9 \\
16.0 \\
15.6 \\
22.1 \\
27.6 \\
27.62 \\
22.5 \\
20.6\end{array}$ & $\begin{array}{l}13.5 \\
12.7 \\
13.4 \\
16.0 \\
17.3 \\
17.6 \\
16.7 \\
15.9\end{array}$ & $\begin{array}{l}15.8 \\
16.0 \\
15.5 \\
22.7 \\
28.2 \\
27.7 \\
22.9 \\
20.7\end{array}$ & $\begin{array}{l}13.2 \\
12.3 \\
13.1 \\
15.7 \\
15.7 \\
17.0 \\
16.3 \\
15.4\end{array}$ & $\begin{array}{l}15.7 \\
16.0 \\
15.6 \\
23.3 \\
28.8 \\
28.3 \\
23.3 \\
20.9\end{array}$ & $\begin{array}{l}13.0 \\
12.0 \\
13.2 \\
15.8\end{array}$ & $\begin{array}{l}17.1 \\
16.0 \\
15.8 \\
24.0 \\
29.2 \\
28.7 \\
23.7 \\
71.0\end{array}$ & $\begin{array}{l}12.8 \\
12.1 \\
13.3 \\
16.1 \\
17.3 \\
17.7 \\
15.5 \\
15.5\end{array}$ & $\begin{array}{l}17.7 \\
17.7 \\
17.8 \\
18.5 \\
18.5 \\
18.1 \\
17.9 \\
17.8\end{array}$ & $\begin{array}{l}2 \\
2 \\
2 \\
2 \\
2 \\
2 \\
2 \\
2 \\
2\end{array}$ & $\begin{array}{r}2.2 \\
5.7 \\
8.0 \\
10.3 \\
12.9 \\
12.3 \\
10.7 \\
12.5\end{array}$ & $\begin{array}{r}2.3 \\
6.4 \\
9.0 \\
11.7 \\
15.0 \\
14.6 \\
12.7 \\
14.2\end{array}$ & $\begin{array}{r}3.2 \\
6.9 \\
9.7 \\
13.3 \\
17.4 \\
17.1 \\
15.1 \\
16.4\end{array}$ & $\begin{array}{r}4.9 \\
8.2 \\
10.7 \\
14.1 \\
18.0 \\
18.3 \\
16.6 \\
18.0\end{array}$ \\
\hline $\begin{array}{l}30 \\
30 \\
30 \\
30 \\
30 \\
30 \\
30 \\
30\end{array}$ & $\begin{array}{r}0 \\
3 \\
6 \\
9 \\
12 \\
15 \\
18 \\
21\end{array}$ & $\begin{array}{l}19.8 \\
12.7 \\
18.3 \\
22.4 \\
35.3 \\
25.5 \\
21.7 \\
20.0\end{array}$ & $\begin{array}{l}16.1 \\
15.8 \\
15.3 \\
16.5 \\
17.1 \\
17.5 \\
16.5 \\
16.3\end{array}$ & $\begin{array}{l}19.0 \\
18.7 \\
18.4 \\
22.9 \\
25.8 \\
26.0 \\
22.1 \\
20.2\end{array}$ & $\begin{array}{l}15.8 \\
15.4 \\
15.1 \\
16.4 \\
15.9 \\
17.2 \\
16.2 \\
16.2\end{array}$ & $\begin{array}{l}20.0 \\
18.7 \\
18.5 \\
23.1 \\
26.1 \\
26.4 \\
22.5 \\
20.2\end{array}$ & $\begin{array}{l}15.1 \\
15.1 \\
16.3 \\
16.9 \\
17.1 \\
16.1 \\
16.1\end{array}$ & $\begin{array}{l}20.1 \\
18.6 \\
18.2 \\
23.3 \\
26.5 \\
26.8 \\
22.6 \\
20.3\end{array}$ & $\begin{array}{l}15.9 \\
15.4 \\
14.9 \\
16.4 \\
17.2 \\
17.5 \\
15.3 \\
16.2\end{array}$ & $\begin{array}{l}17.8 \\
17.7 \\
17.8 \\
18.6 \\
18.7 \\
18.1 \\
17.9 \\
17.8\end{array}$ & $\begin{array}{l}2 \\
2 \\
2 \\
2 \\
2 \\
2 \\
2 \\
2\end{array}$ & $\begin{array}{r}13.7 \\
14.0 \\
13.6 . \\
13.1 \\
15.0 \\
11.6 \\
6.7 \\
11.1\end{array}$ & $\begin{array}{r}15.7 \\
16.0 \\
15.4 \\
14.6 \\
17.3 \\
13.6 \\
8.0 \\
13.1\end{array}$ & $\begin{array}{r}17.8 \\
17.9 \\
17.3 \\
16.3 \\
19.5 \\
15.8 \\
9.5 \\
14.3\end{array}$ & $\begin{array}{l}19.1 \\
19.0 \\
18.2 \\
17.0 \\
20.6 \\
16.8 \\
11.0 \\
15.8\end{array}$ \\
\hline $\begin{array}{l}31 \\
31 \\
31 \\
31 \\
31 \\
31 \\
31 \\
31\end{array}$ & $\begin{array}{r}0 \\
3 \\
6 \\
9 \\
12 \\
15 \\
18 \\
21\end{array}$ & $\begin{array}{l}19.4 \\
19.3 \\
19.1 \\
23.3 \\
26.1 \\
26.1 \\
22.7 \\
20.7\end{array}$ & $\begin{array}{l}17.4 \\
17.7 \\
17.1 \\
18.2 \\
18.3 \\
17.7 \\
15.7 \\
14.8\end{array}$ & $\begin{array}{l}10.5 \\
10.3 \\
19.3 \\
23.6 \\
26.1 \\
26.4 \\
23.1 \\
20.8\end{array}$ & $\begin{array}{l}17.3 \\
17.6 \\
17.0 \\
18.0 \\
18.1 \\
17.4 \\
15.2 \\
14.3\end{array}$ & $\begin{array}{l}14.6 \\
19.3 \\
19.3 \\
24.0 \\
26.7 \\
26.7 \\
23.2 \\
20.9\end{array}$ & $\begin{array}{l}17.3 \\
17: 5 \\
17: 0 \\
18.1 \\
17.8 \\
17.2 \\
14.9 \\
14.3\end{array}$ & $\begin{array}{l}19.7 \\
19.4 \\
19.6 \\
24.2 \\
27.2 \\
27.1 \\
23.3 \\
21.2\end{array}$ & $\begin{array}{l}17.5 \\
17.6 \\
17.1 \\
19.3 \\
19.2 \\
17.5 \\
15.0 \\
14.5\end{array}$ & $\begin{array}{l}17.8 \\
17.8 \\
18.0 \\
18.7 \\
18.9 \\
18.5 \\
13.0 \\
18.0\end{array}$ & $\begin{array}{l}2 \\
2 \\
2 \\
2 \\
2 \\
2 \\
2 \\
2\end{array}$ & $\begin{array}{l}12.3 \\
12.6 \\
12.5 \\
17.3 \\
19.9 \\
15.3 \\
12.2 \\
13.7\end{array}$ & $\begin{array}{l}14.0 \\
14.4 \\
14.2 \\
19.8 \\
22.6 \\
17.8 \\
14.1 \\
15.6\end{array}$ & $\begin{array}{l}15.7 \\
16.2 \\
16.0 \\
22.5 \\
25.9 \\
20.4 \\
15.9 \\
17.4\end{array}$ & $\begin{array}{l}16.9 \\
17.2 \\
16.8 \\
23.9 \\
27.5 \\
21.6 \\
17.1 \\
18.7\end{array}$ \\
\hline
\end{tabular}


TABLE 10

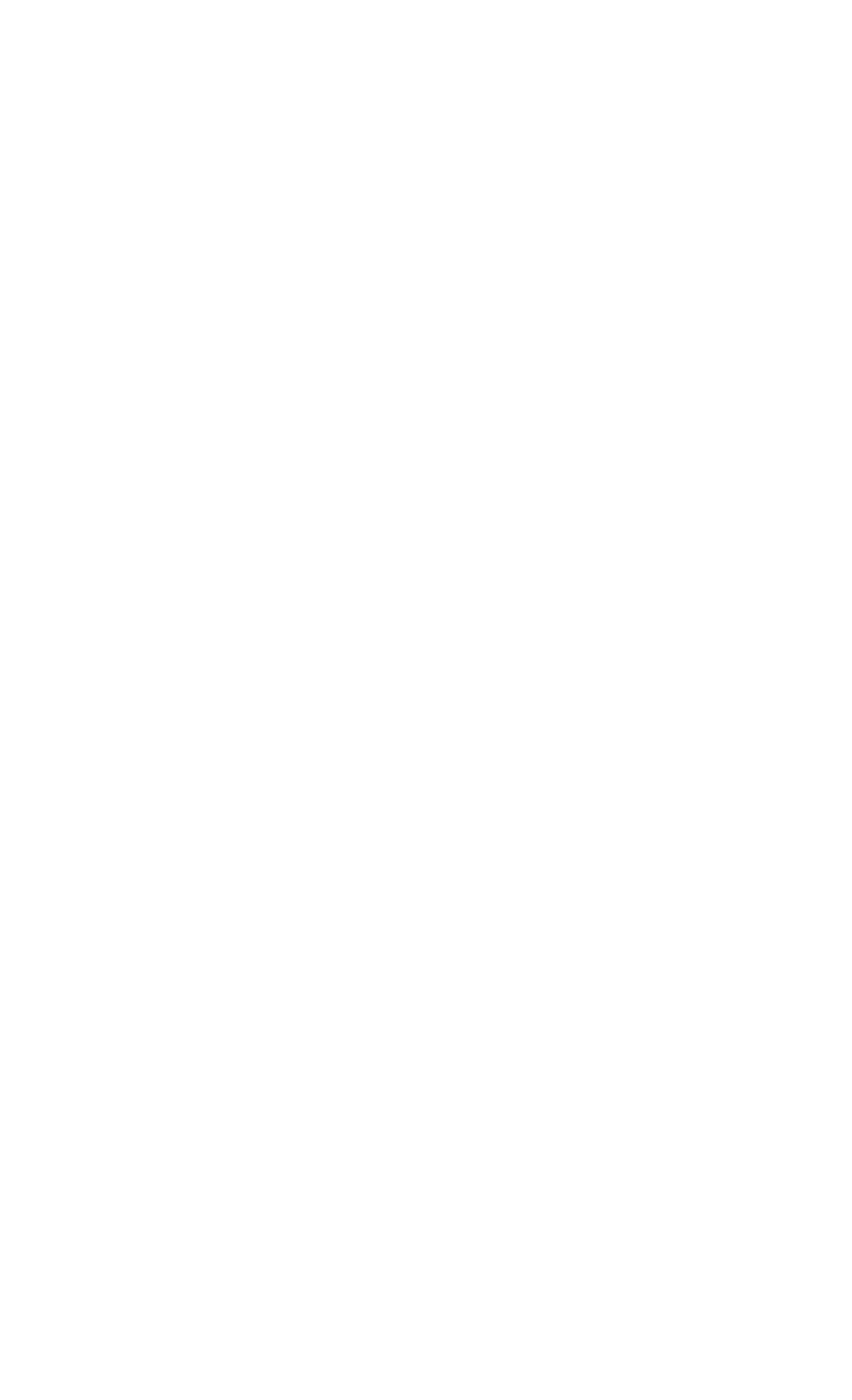


TABLE 10

Table 10. - Three-hour averages of air and water-surface temperatures and wind directions and speed, April 1950-August 1951, Lake Hefner-Continued

STATION 1

THREE-HOURLY AVERAGES

NOVEMBER, 1950

\begin{tabular}{|c|c|c|c|c|c|c|c|c|c|c|c|c|c|c|c|}
\hline \multirow{4}{*}{ 秀 } & \multirow{4}{*}{ 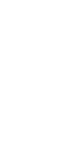 } & \multicolumn{8}{|c|}{ Average air temperature $\left({ }^{\circ} \mathrm{C}\right)$ at indicated height } & \multirow{4}{*}{$\begin{array}{c}\text { Average } \\
\text { water- } \\
\text { surface } \\
\text { tempera- } \\
\text { ture } \\
\left({ }^{\circ} \mathrm{C}\right)\end{array}$} & \multirow{4}{*}{$\begin{array}{c}\text { Average } \\
\text { wind } \\
\text { direction } \\
\text { (coded) }\end{array}$} & \multirow{2}{*}{\multicolumn{4}{|c|}{$\begin{array}{l}\text { Average wind speed (knots) } \\
\text { at indicated he ight }\end{array}$}} \\
\hline & & \multirow{2}{*}{\multicolumn{2}{|c|}{$\begin{array}{c}2 \\
\text { meters }\end{array}$}} & \multirow{2}{*}{\multicolumn{2}{|c|}{$\begin{array}{c}4 \\
\text { meters }\end{array}$}} & \multirow{2}{*}{\multicolumn{2}{|c|}{\begin{tabular}{|c|}
$\mathbf{8}$ \\
meters
\end{tabular}}} & \multirow{2}{*}{\multicolumn{2}{|c|}{$\begin{array}{c}16 \\
\text { meters }\end{array}$}} & & & & & & \\
\hline & & & & & & & & & & & & & & & 16 \\
\hline & & $\begin{array}{l}\text { Dry } \\
\text { bulb }\end{array}$ & $\begin{array}{l}\text { Wet } \\
\text { bulb }\end{array}$ & $\begin{array}{l}\text { Dry } \\
\text { bulb }\end{array}$ & $\begin{array}{l}\text { Wet } \\
\text { bulb }\end{array}$ & $\begin{array}{l}\text { Dry } \\
\text { bulb }\end{array}$ & $\begin{array}{l}\text { Wet } \\
\text { bulb }\end{array}$ & $\begin{array}{l}\text { Dry } \\
\text { bulb }\end{array}$ & $\begin{array}{l}\text { Wet } \\
\text { bulb }\end{array}$ & & & meters & meters & meters & meters \\
\hline $\begin{array}{l}11 \\
11 \\
11 \\
11 \\
11 \\
11 \\
11 \\
11\end{array}$ & $\begin{array}{r}0 \\
3 \\
6 \\
9 \\
12 \\
15 \\
18 \\
21\end{array}$ & $\begin{array}{r}-2.4 \\
=2.9 \\
-2.0 \\
2.8 \\
7.33 \\
8.6 \\
5.7 \\
4.2\end{array}$ & $\begin{array}{r} \\
1.2 \\
2.1 \\
2.09 \\
1.00 \\
-0.1\end{array}$ & $\begin{array}{l}2.8 \\
3.2 \\
2.3 \\
3.0 \\
7.0 \\
8.3 \\
5.5 \\
3.9\end{array}$ & $\begin{array}{l}0.1 \\
1.9 \\
2.8 \\
0.8 \\
0.3\end{array}$ & $\begin{array}{r}-3.0 \\
-3.5 \\
-2.4 \\
2.7 \\
7.1 \\
8.4 \\
5.3 \\
3.7\end{array}$ & $\begin{array}{r}1.2 \\
0.9 \\
1.9 \\
-0.8\end{array}$ & $\mid \begin{array}{r}-3.2 \\
-3.7 \\
-2.5 \\
2.1 \\
5.9 \\
8.2 \\
5.0 \\
3.5\end{array}$ & $\begin{array}{r}2.0 \\
2.9 \\
20.7 \\
-0.2\end{array}$ & $\begin{array}{l}11.7 \\
11.4 \\
11.5 \\
12.2 \\
12.0 \\
11.03 \\
10.9 \\
10.8\end{array}$ & $\begin{array}{l}2 \\
2 \\
2 \\
2 \\
2 \\
2 \\
2 \\
2\end{array}$ & $\begin{array}{l}8 \cdot 3 \\
11.7 \\
11.9 \\
15 \cdot 2 \\
13.9 \\
11 \cdot 2 \\
10.1 \\
12.3\end{array}$ & $\begin{array}{r}9.1 \\
12.9 \\
13.2 \\
17.1 \\
15.8 \\
12.5 \\
11.2 \\
13.6\end{array}$ & $\begin{array}{r}9.7 \\
14.0 \\
14.2 \\
18.8 \\
17.3 \\
13.7 \\
11.9 \\
14.6\end{array}$ & $\begin{array}{l}10.0 \\
14.3 \\
14.6 \\
19.5 \\
18.0 \\
14.4 \\
12.5 \\
15.3\end{array}$ \\
\hline $\begin{array}{l}12 \\
12 \\
12 \\
12 \\
12 \\
12 \\
12 \\
12\end{array}$ & $\begin{array}{r}0 \\
3 \\
6 \\
9 \\
12 \\
15 \\
18 \\
21\end{array}$ & $\begin{array}{r}2.5 \\
2.0 \\
2.3 \\
6.3 \\
11.2 \\
12.3 \\
9.4 \\
7.5\end{array}$ & $\begin{array}{r}-1.0 \\
-1.2 \\
-1.0 \\
1.06 \\
4.5 \\
5.1 \\
3.5 \\
2.0\end{array}$ & $\begin{array}{r}2.1 \\
1.7 \\
2.0 \\
6.1 \\
11.3 \\
12.3 \\
9.1 \\
7.4\end{array}$ & $\begin{array}{l}1.1 \\
1.3 \\
1.3 \\
1.2 \\
4.6 \\
5.4 \\
3.8 \\
3.0\end{array}$ & $\begin{array}{r}1.9 \\
1.6 \\
2.0 \\
6.3 \\
11.5 \\
12.3 \\
9.0 \\
7.3\end{array}$ & $\mid \begin{array}{r}-1.6 \\
-2.0 \\
-1.7 \\
1.0 \\
3.5 \\
4.1\end{array}$ & $\begin{array}{r}1.5 \\
1.4 \\
1.7 \\
6.3 \\
11.5 \\
12.3 \\
8.9 \\
7.2\end{array}$ & $\mid \begin{array}{r}-1.4 \\
-1.5 \\
-0.9 \\
2.0 \\
5.4 \\
5.4 \\
3.9 \\
3.3\end{array}$ & & $\begin{array}{l}2 \\
2 \\
2 \\
2 \\
2 \\
2 \\
2 \\
2\end{array}$ & $\begin{array}{l}11.5 \\
11.5 \\
13.5 \\
13.2 \\
14.4 \\
13.0 \\
10.1 \\
12.6\end{array}$ & $\begin{array}{l}12.8 \\
12.7 \\
15.0 \\
14.8 \\
15.6 \\
14.7 \\
11.2 \\
13.9\end{array}$ & $\begin{array}{l}13.7 \\
13.6 \\
16.2 \\
16.0 \\
17.2 \\
16.2 \\
12.1 \\
14.9\end{array}$ & $\begin{array}{l}14.2 \\
14.1 \\
16.8 \\
16.6 \\
18.2 \\
17.1 \\
12.9 \\
15.7\end{array}$ \\
\hline $\begin{array}{l}13 \\
13 \\
13 \\
13 \\
13 \\
13 \\
13 \\
13\end{array}$ & $\begin{array}{r}0 \\
3 \\
6 \\
9 \\
12 \\
15 \\
18 \\
21\end{array}$ & $\begin{array}{r}6.0 \\
5.0 \\
3.6 \\
8.3 \\
13.1 \\
15.3 \\
12.5 \\
11.7\end{array}$ & $\begin{array}{l}2.1 \\
1.8 \\
1.2 \\
4.8 \\
7.6 \\
9.0 \\
9.0 \\
9.6\end{array}$ & $\begin{array}{r}5.8 \\
4.7 \\
3.5 \\
8.4 \\
13.5 \\
15.6 \\
12.8 \\
11.9\end{array}$ & $\begin{array}{l}2.2 \\
1.6 \\
1.2 \\
4.4 \\
7.1 \\
8.7 \\
8.8 \\
9.3\end{array}$ & $\begin{array}{r}5.6 \\
4.5 \\
3.5 \\
8.5 \\
13.9 \\
15.8 \\
13.0 \\
11.8\end{array}$ & $\begin{array}{l}4.4 \\
7.2 \\
8.8 \\
8.9 \\
9.4\end{array}$ & $\begin{array}{r}5.4 \\
4.2 \\
3.0 \\
8.6 \\
14.0 \\
16.1 \\
13.2 \\
11.0\end{array}$ & $\begin{array}{l}2.2 \\
1.3 \\
1.1 \\
4.4 \\
7.7 \\
9.4 \\
9.3 \\
9.9\end{array}$ & $\begin{array}{l}10.5 \\
10.3 \\
10.4 \\
11.7 \\
11.8 \\
10.5 \\
10.2 \\
10.2\end{array}$ & $\begin{array}{l}2 \\
2 \\
2 \\
2 \\
2 \\
2 \\
2 \\
2\end{array}$ & $\begin{array}{r}13.1 \\
13.0 \\
8.9 \\
10.5 \\
9.5 \\
9.4 \\
7.8 \\
12.3\end{array}$ & $\begin{array}{r}14.3 \\
14.0 \\
9.4 \\
11.8 \\
10.9 \\
11.3 \\
9.1 \\
14.0\end{array}$ & $\begin{array}{r}9.9 \\
13.7 \\
12.8 \\
13.3 \\
11.4 \\
16.2\end{array}$ & $\begin{array}{l}16.0 \\
15.3 \\
10.1 \\
14.0 \\
12.8 \\
13.5 \\
11.8 \\
16.4\end{array}$ \\
\hline $\begin{array}{l}14 \\
14 \\
14 \\
14 \\
14 \\
14 \\
14 \\
14\end{array}$ & $\begin{array}{r}0 \\
3 \\
6 \\
9 \\
12 \\
15 \\
18 \\
21\end{array}$ & $\begin{array}{l}13.1 \\
13.0 \\
13.7 \\
15.0 \\
16.4 \\
18.0 \\
16.9 \\
16.6\end{array}$ & $\begin{array}{l}10.2 \\
11 . .4 \\
11.9 \\
12.5 \\
13.0 \\
14.9 \\
15.1 \\
14.9\end{array}$ & $\begin{array}{l}13.4 \\
14.1 \\
14.0 \\
15.2 \\
16.8 \\
18.2 \\
17.6 \\
17.3\end{array}$ & $\begin{array}{l}10.0 \\
11.4 \\
11.8 \\
12.5 \\
13.1 \\
15.2 \\
15.8 \\
16.4\end{array}$ & $\begin{array}{l}13.5 \\
14.3 \\
14.2 \\
15.4 \\
17.2 \\
18.8 \\
18.0 \\
17.5\end{array}$ & $\begin{array}{l}10.0 \\
11.5 \\
12.0 \\
12.6 \\
13.2 \\
15.3 \\
15.9 \\
16.5\end{array}$ & $\begin{array}{l}13.7 \\
14: 5 \\
14: 2 \\
15: 7 \\
17.4 \\
19.3 \\
18.2 \\
18.0\end{array}$ & $\begin{array}{l}10.8 \\
11.2 \\
10.8 \\
12.1 \\
13.2 \\
15.3 \\
15.6 \\
15.5\end{array}$ & $\begin{array}{l}10.4 \\
10.4 \\
10.4 \\
10.9 \\
11.2 \\
10.8 \\
10.8 \\
10.8\end{array}$ & $\begin{array}{l}2 \\
2 \\
2 \\
2 \\
2 \\
2 \\
2 \\
2\end{array}$ & $\begin{array}{l}14.5 \\
15.6 \\
16.9 \\
18.1 \\
19.2 \\
17.2 \\
15.0 \\
14.1\end{array}$ & & & $\begin{array}{l}19.6 \\
21.5 \\
23.0 \\
25.1 \\
26.9 \\
23.5 \\
21.2 \\
20.0\end{array}$ \\
\hline $\begin{array}{l}15 \\
15 \\
15 \\
15 \\
15 \\
15 \\
15 \\
15\end{array}$ & $\begin{array}{r}0 \\
3 \\
6 \\
9 \\
12 \\
15 \\
18 \\
21\end{array}$ & $\begin{array}{l}17.2 \\
18.0 \\
17.3 \\
19.8 \\
21.8 \\
20.5 \\
16.7 \\
12.9\end{array}$ & $\begin{array}{r}16.1 \\
16.0 \\
16.1 \\
16.8 \\
14.5 \\
12.6 \\
9.9 \\
7.5\end{array}$ & $\begin{array}{l}18.1 \\
18.6 \\
18.1 \\
20.6 \\
22.6 \\
22.1 \\
17.4 \\
13.0\end{array}$ & $\begin{array}{r}17.3 \\
17.8 \\
17.0 \\
17.6 \\
14.4 \\
12.3 \\
9.1 \\
6.7\end{array}$ & $\begin{array}{l}18 \cdot 3 \\
18.8 \\
18.3 \\
20.8 \\
23 \cdot 4 \\
23.2 \\
18.0 \\
12.9\end{array}$ & $\begin{array}{r}17.0 \\
17.4 \\
16.9 \\
17.7 \\
14.3 \\
12.5 \\
9.0 \\
6.3\end{array}$ & $\begin{array}{l}19.0 \\
19 \cdot 4 \\
18 \cdot 7 \\
21.3 \\
23 \cdot 7 \\
23.7 \\
18.2 \\
13 \cdot 0\end{array}$ & $\begin{array}{r}16.9 \\
17.2 \\
16.9 \\
17.9 \\
16.3 \\
14 \cdot 9 \\
10.9 \\
7.5\end{array}$ & $\begin{array}{l}10.8 \\
12.0 \\
11.0 \\
12.2 \\
12.6 \\
11.6 \\
11.2 \\
11.1\end{array}$ & $\begin{array}{l}2 \\
2 \\
2 \\
2 \\
2 \\
2 \\
3 \\
4\end{array}$ & $\begin{array}{r}14.8 \\
16.3 \\
14.4 \\
18.6 \\
14.9 \\
8.7 \\
9.3 \\
8.4\end{array}$ & $\begin{array}{r}17.2 \\
18.9 \\
16.7 \\
21.2 \\
16.6 \\
9.9 \\
10.8 \\
7.7\end{array}$ & $\begin{array}{l}19.6 \\
21.7 \\
19.3 \\
24.3 \\
19.2 \\
11.9 \\
13.2 \\
11.8\end{array}$ & $\begin{array}{l}21.4 \\
23.3 \\
20.7 \\
25.8 \\
20.3 \\
12.0 \\
15.4 \\
12.1\end{array}$ \\
\hline $\begin{array}{l}16 \\
16 \\
16 \\
16 \\
16 \\
16 \\
16 \\
16\end{array}$ & $\begin{array}{r}0 \\
3 \\
6 \\
9 \\
12 \\
15 \\
18 \\
21\end{array}$ & $\begin{array}{r}9.7 \\
7.8 \\
5.4 \\
7.8 \\
10.3 \\
11.1 \\
9.4 \\
7.7\end{array}$ & $\begin{array}{l}5.5 \\
4.2 \\
2.4 \\
3.8 \\
4.9 \\
5.3 \\
4.5 \\
4.1\end{array}$ & $\begin{array}{r}9.6 \\
7.5 \\
5.0 \\
7.5 \\
10.2 \\
11.0 \\
9.4 \\
7.8\end{array}$ & $\begin{array}{l}4.6 \\
3.4 \\
1.8 \\
2.8 \\
3.6 \\
4.3 \\
3.7 \\
3.6\end{array}$ & $\begin{array}{r}9.6 \\
7.3 \\
5.0 \\
7.6 \\
10.2 \\
10.9 \\
3.2 \\
7.3\end{array}$ & $\begin{array}{l}4.3 \\
3.1 \\
1.7 \\
2.5 \\
3.5 \\
4.0 \\
3.5 \\
3.6\end{array}$ & $\begin{array}{r}9.6 \\
7.3 \\
5.0 \\
7.5 \\
10.2 \\
10.8 \\
9.1 \\
7.8\end{array}$ & 2.2 & $\begin{array}{l}11.0 \\
11.0 \\
11.2 \\
12.1 \\
12.4 \\
11.1 \\
10.9 \\
20.9\end{array}$ & $\begin{array}{l}3 \\
3 \\
3 \\
3 \\
3 \\
3 \\
3 \\
3\end{array}$ & $\begin{array}{l}7.6 \\
6.7 \\
7.7 \\
9.4 \\
8.4 \\
7.3 \\
3.4 \\
1.3\end{array}$ & $\begin{array}{r}9.1 \\
7.3 \\
8.4 \\
10.5 \\
9.7 \\
8.1 \\
4.0 \\
1.5\end{array}$ & $\begin{array}{r}9.6 \\
8.1 \\
9.5 \\
11.7 \\
10.5 \\
9.2 \\
4.0 \\
1.4\end{array}$ & $\begin{array}{r}10.8 \\
8.2 \\
9.7 \\
12.0 \\
11.1 \\
9.5 \\
4.5 \\
1.8\end{array}$ \\
\hline $\begin{array}{l}17 \\
17 \\
17 \\
17 \\
17 \\
17 \\
17 \\
17\end{array}$ & $\begin{array}{r}0 \\
3 \\
6 \\
9 \\
12 \\
15 \\
18 \\
21\end{array}$ & $\begin{array}{r}6.4 \\
4.8 \\
5.6 \\
8.8 \\
12.2 \\
13.3 \\
11.4 \\
10.0\end{array}$ & $\begin{array}{l}3.6 \\
2.7 \\
2.7 \\
4.5 \\
6.0 \\
6.7 \\
6.2 \\
6.1\end{array}$ & $\begin{array}{r}6.4 \\
4.7 \\
5.5 \\
8.8 \\
12.3 \\
13.3 \\
11.3 \\
9.9\end{array}$ & $\begin{array}{l}3.1 \\
2.6 \\
2.1 \\
4.2 \\
5.4 \\
6.1 \\
5.6 \\
5.3\end{array}$ & $\begin{array}{r}6.0 \\
4.7 \\
5.5 \\
8.9 \\
12.4 \\
13.4 \\
11.2 \\
9.9\end{array}$ & $\begin{array}{l}3 \cdot 2 \\
2.3 \\
1.0 \\
4.1 \\
5.1 \\
5.9 \\
5.3 \\
5.1\end{array}$ & $\begin{array}{r}6.5 \\
5.2 \\
5.5 \\
9.0 \\
12.5 \\
13.4 \\
11.2 \\
9.0\end{array}$ & $\begin{array}{l}3.0 \\
2.7\end{array}$ & & $\begin{array}{l}2 \\
2 \\
2 \\
2 \\
2 \\
2 \\
2 \\
2\end{array}$ & $\begin{array}{r}2.2 \\
2.5 \\
6.4 \\
12.4 \\
14.2 \\
12.6 \\
8.0 \\
13.2\end{array}$ & $\begin{array}{r}2.3 \\
2.7 \\
7.3 \\
14.5 \\
16.2 \\
14.7 \\
9.0 \\
14.8\end{array}$ & $\begin{array}{r}2.5 \\
3.0 \\
8.4 \\
16.6 \\
19.0 \\
16.7 \\
10.5 \\
17.3\end{array}$ & $\begin{array}{r}2.3 \\
3.1 \\
8.3 \\
16.6 \\
19.1 \\
17.0 \\
10.8 \\
17.4\end{array}$ \\
\hline $\begin{array}{l}18 \\
18 \\
18 \\
18 \\
18 \\
18 \\
18 \\
18\end{array}$ & $\begin{array}{r}0 \\
3 \\
6 \\
9 \\
12 \\
15 \\
18 \\
21\end{array}$ & $\begin{array}{r}9.3 \\
9.1 \\
10.2 \\
13.7 \\
16.7 \\
17.7 \\
15.9 \\
15.8\end{array}$ & $\begin{array}{r}5.9 \\
6.2 \\
7.5 \\
10.7 \\
13.1 \\
14.2 \\
13.8 \\
13.9\end{array}$ & $\begin{array}{r}9.2 \\
9.1 \\
10.2 \\
14.0 \\
17.2 \\
18.3 \\
16.5 \\
16.1\end{array}$ & $\begin{array}{r}5.5 \\
5.7 \\
7.2 \\
10.5 \\
13.0 \\
14.3 \\
14.1 \\
14.5\end{array}$ & $\begin{array}{r}9.1 \\
9.0 \\
10.3 \\
14.2 \\
17.7 \\
18.7 \\
16.8 \\
16.1\end{array}$ & $\begin{array}{c}5.1 \\
5.6 \\
7.2 \\
10.6 \\
13.2 \\
14.5 \\
14.4 \\
14.8\end{array}$ & $\begin{array}{r}9.0 \\
8.9 \\
10.3 \\
14.5 \\
17.9 \\
19.0 \\
17.2 \\
16.8\end{array}$ & $\begin{array}{l}3.2 \\
8.9\end{array}$ & & $\begin{array}{l}2 \\
2 \\
2 \\
2 \\
2 \\
2 \\
2 \\
2\end{array}$ & $\begin{array}{r}13.7 \\
14.1 \\
13.1 \\
16.6 \\
15.3 \\
10.1 \\
9.4 \\
11.8\end{array}$ & & & $\begin{array}{l}18.2 \\
18.6 \\
17.3 \\
22.9 \\
21.2 \\
14 \bullet 9 \\
14.1 \\
17.2\end{array}$ \\
\hline $\begin{array}{l}19 \\
19 \\
19 \\
19 \\
19 \\
19 \\
19 \\
19\end{array}$ & $\begin{array}{r}0 \\
3 \\
6 \\
9 \\
12 \\
15 \\
18 \\
21\end{array}$ & $\begin{array}{r}15.5 \\
14 \cdot 8 \\
15.2 \\
17.6 \\
20.8 \\
13.4 \\
4.6 \\
3.4\end{array}$ & $\begin{array}{r}13.8 \\
13.4 \\
13.8 \\
14.0 \\
13.4 \\
9.0 \\
2.6 \\
1.1\end{array}$ & $\begin{array}{r}16.0 \\
15.3 \\
15.6 \\
18.0 \\
21.4 \\
13.1 \\
4.3 \\
3.4\end{array}$ & $\begin{array}{r}14.3 \\
14.0 \\
14.2 \\
14.2 \\
13.4 \\
8.8 \\
2.9 \\
1.2\end{array}$ & $\begin{array}{r}16.0 \\
15.2 \\
15.5 \\
18.2 \\
22.0 \\
12.8 \\
3.9 \\
2.6\end{array}$ & $\begin{array}{r}14.6 \\
14.3 \\
14.6 \\
14.5 \\
13.5 \\
8.7 \\
2.7 \\
1.0\end{array}$ & $\begin{array}{r}16.6 \\
15.6 \\
16.0 \\
18.9 \\
22.4 \\
12.5 \\
3.7 \\
2.5\end{array}$ & $\begin{array}{l}4.5 \\
2.0 \\
0.4\end{array}$ & & $\begin{array}{l}2 \\
2 \\
2 \\
2 \\
2 \\
2 \\
3 \\
3\end{array}$ & $\begin{array}{l}11.3 \\
11.3 \\
11.6 \\
14.2 \\
13.7 \\
18.1 \\
20.0 \\
20.4\end{array}$ & $\begin{array}{l}13.2 \\
13.0 \\
13.4 \\
16.4 \\
16.1 \\
18.0 \\
23.0 \\
23.5\end{array}$ & $\begin{array}{l}16.0 \\
15.4 \\
15.9 \\
19.0 \\
17.8 \\
22.0 \\
23.6 \\
24.0\end{array}$ & $\begin{array}{l}16.7 \\
16.0 \\
16.5 \\
19.7 \\
18.7 \\
22.5 \\
27.5 \\
27.0\end{array}$ \\
\hline $\begin{array}{l}20 \\
20 \\
20 \\
20 \\
20 \\
20 \\
20 \\
20\end{array}$ & $\begin{array}{r}0 \\
3 \\
6 \\
9 \\
12 \\
15 \\
18 \\
21\end{array}$ & $\begin{array}{r}1.8 \\
-0.7 \\
-2.0 \\
0.2 \\
4.1 \\
6.4 \\
5.4 \\
4.3\end{array}$ & $\begin{array}{l}0.4 \\
1.5 \\
1.0 \\
1.0\end{array}$ & $\begin{array}{l}1.5 \\
1.0 \\
2.5 \\
0.1 \\
3.9 \\
6.6 \\
5.3 \\
4.2\end{array}$ & $\begin{array}{l}0.5 \\
2.0 \\
0.3 \\
0.9 \\
0.8 \\
0.6\end{array}$ & $\left|\begin{array}{r}0.4 \\
-1.3 \\
-2.8 \\
-0.6 \\
3.1 \\
3.0\end{array}\right|$ & $\left|\begin{array}{r}-0.6 \\
\\
1.5 \\
1.4 \\
1.3 \\
1.0\end{array}\right|$ & $\begin{array}{r}0.7 \\
-1.8 \\
-3.0 \\
-0.3 \\
3.9 \\
6.4 \\
5.0 \\
3.9\end{array}$ & -1.5 & $\begin{array}{l}10.7 \\
10.4 \\
10.4 \\
11.3 \\
11.6 \\
10.7 \\
10.4 \\
10.3\end{array}$ & $\begin{array}{l}3 \\
3 \\
3 \\
3 \\
3 \\
3 \\
2 \\
2\end{array}$ & $\begin{array}{r}19.5 \\
17.0 \\
12.8 \\
10.5 \\
6.3 \\
3.0 \\
2.4 \\
5.1\end{array}$ & $\begin{array}{r}22.2 \\
18.2 \\
14.6 \\
11.5 \\
6.8 \\
3.1 \\
2.6 \\
5.6\end{array}$ & $\begin{array}{r}24.9 \\
21.1 \\
15.7 \\
12.7 \\
7.5 \\
3.5 \\
2.8 \\
5.9\end{array}$ & $\begin{array}{r}25.5 \\
21.8 \\
15.8 \\
13.1 \\
7.7 \\
4.8 \\
2.8 \\
6.3\end{array}$ \\
\hline
\end{tabular}


Table 10. - Three-hour averages of air and water-surface temperatures and wind directions and speed, April 1950-August 1951, Lake Hefner-Continued

STATION

THREE-HOURLY AVERAGES

NOVEMBER, 1950

\begin{tabular}{|c|c|c|c|c|c|c|c|c|c|c|c|c|c|c|c|}
\hline \multirow{3}{*}{ 宽 } & \multirow{3}{*}{ 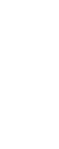 } & \multicolumn{8}{|c|}{ Average air temperature $\left({ }^{\circ} \mathrm{C}\right)$ at indicated height } & \multirow{3}{*}{$\begin{array}{l}\text { Average } \\
\text { water- } \\
\text { surface } \\
\text { tempera- } \\
\text { ture } \\
\left({ }^{\circ} \mathrm{C}\right)\end{array}$} & \multirow{3}{*}{$\begin{array}{c}\text { Average } \\
\text { wind } \\
\text { direction } \\
\text { (coded) }\end{array}$} & \multicolumn{4}{|c|}{$\begin{array}{l}\text { Average wind speed (knots) } \\
\text { at indicated height }\end{array}$} \\
\hline & & \multicolumn{2}{|c|}{$\stackrel{2}{\text { meters }}$} & \multicolumn{2}{|c|}{$\begin{array}{c}4 \\
\text { meters }\end{array}$} & \multicolumn{2}{|c|}{$\begin{array}{c}8 \\
\text { meters }\end{array}$} & \multicolumn{2}{|c|}{$\begin{array}{c}16 \\
\text { meters }\end{array}$} & & & & & 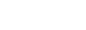 & \\
\hline & & $\begin{array}{l}\text { Dry } \\
\text { bulb }\end{array}$ & $\begin{array}{l}\text { Wet } \\
\text { bulb }\end{array}$ & $\begin{array}{l}\text { Dry } \\
\text { bulb }\end{array}$ & $\begin{array}{l}\text { Wet } \\
\text { bulb }\end{array}$ & $\begin{array}{l}\text { Dry } \\
\text { bulb }\end{array}$ & $\begin{array}{l}\text { Wet } \\
\text { bulb }\end{array}$ & $\begin{array}{l}\text { Dry } \\
\text { bulb }\end{array}$ & $\begin{array}{l}\text { Wet } \\
\text { bulb }\end{array}$ & & & meters & meters & meters & meters \\
\hline $\begin{array}{l}21 \\
21 \\
21 \\
21 \\
21 \\
21 \\
21 \\
21\end{array}$ & $\begin{array}{r}0 \\
6 \\
3 \\
9 \\
12 \\
15 \\
18 \\
21\end{array}$ & $\begin{array}{r}3.6 \\
4.3 \\
3.5 \\
8.0 \\
12.5 \\
14.6 \\
10.3 \\
10.3\end{array}$ & $\begin{array}{l}0.1 \\
1.0 \\
0.3 \\
3.3 \\
5.9 \\
7.5 \\
6.5 \\
6.3\end{array}$ & $\begin{array}{r}3.3 \\
4.0 \\
3.2 \\
7.6 \\
12.9 \\
14.2 \\
10.3 \\
10.3\end{array}$ & $\begin{array}{l}0.1 \\
0.6 \\
0.1 \\
2.8 \\
5.9 \\
6.8 \\
5.7 \\
5.7\end{array}$ & 11.9 & $\begin{array}{l}0.5 \\
0.1 \\
3.0 \\
6.2 \\
7.1 \\
5.5 \\
6.1\end{array}$ & $\begin{array}{r}3.0 \\
3.7 \\
3.1 \\
7.7 \\
13.4 \\
15.4 \\
12.0 \\
10.6\end{array}$ & & $\begin{array}{l}10.2 \\
10.0 \\
10.1 \\
11.1 \\
11.3 \\
10.3 \\
10.0 \\
9.9\end{array}$ & $\begin{array}{l}2 \\
2 \\
2 \\
2 \\
2 \\
2 \\
2 \\
?\end{array}$ & $\begin{array}{r}8.0 \\
17.9 \\
11.3 \\
15.3 \\
10.1 \\
4.3 \\
3.0 \\
5.2\end{array}$ & $\begin{array}{r}8.8 \\
19.9 \\
12.7 \\
17.4 \\
11.7 \\
5.7 \\
3.8 \\
6.0\end{array}$ & $\begin{array}{r}0.8 \\
2 ? .9 \\
14.3 \\
20.0 \\
13.5 \\
5.4 \\
5.1 \\
7.4\end{array}$ & $\begin{array}{r}9.8 \\
22.8 \\
14.5 \\
20.2 \\
13.9 \\
7.0 \\
6.7 \\
8.4\end{array}$ \\
\hline $\begin{array}{l}22 \\
22 \\
22 \\
22 \\
22 \\
22 \\
22 \\
22\end{array}$ & $\begin{array}{r}0 \\
3 \\
6 \\
9 \\
12 \\
15 \\
18 \\
21\end{array}$ & $\begin{array}{r}9.5 \\
\\
+12.3 \\
16.4 \\
17.1 \\
10.7 \\
10.3\end{array}$ & $\begin{array}{l}7.6 \\
9.6 \\
9.5 \\
7.4 \\
6.3\end{array}$ & $\begin{array}{l}12.2 \\
16.0 \\
17.3 \\
11.1 \\
10.7\end{array}$ & $\begin{array}{l}7.3 \\
9: 2 \\
8.9 \\
6.6 \\
5.0\end{array}$ & $\begin{array}{l}12.4 \\
16.2 \\
16.8 \\
12.8 \\
10.4\end{array}$ & $\begin{array}{l}7.4 \\
9.5 \\
9.1 \\
6.5 \\
5.9\end{array}$ & $\begin{array}{l}17.6 \\
17.2 \\
17.7 \\
15.7 \\
11.8\end{array}$ & & $\begin{array}{l}11.4 \\
11.9 \\
11.2 \\
10.8 \\
10.0\end{array}$ & $\begin{array}{l}2 \\
2 \\
2 \\
3 \\
3 \\
2 \\
2 \\
2\end{array}$ & $\begin{array}{l}7.0 \\
4.6 \\
7.3 \\
8.8 \\
1.9 \\
1.3 \\
2.6 \\
4.3\end{array}$ & $\begin{array}{l}7.9 \\
4.5 \\
6.3 \\
7.9 \\
2.4 \\
1.0 \\
3.1 \\
5.1\end{array}$ & $\begin{array}{l}0.3 \\
5.2 \\
7: 0 \\
8: 1 \\
2.3 \\
2.1 \\
4.6 \\
6.5\end{array}$ & $\begin{array}{l}9.8 \\
6.0 \\
9.7 \\
9.2 \\
3.5 \\
2.4 \\
8.0 \\
7.0\end{array}$ \\
\hline $\begin{array}{l}23 \\
23 \\
23 \\
23 \\
23 \\
23 \\
23 \\
23\end{array}$ & $\begin{array}{r}0 \\
3 \\
6 \\
9 \\
12 \\
15 \\
18 \\
21\end{array}$ & $\begin{array}{r}11.2 \\
12.0 \\
4.04 \\
=0.3 \\
=0.1 \\
=1.05 \\
=4.3 \\
=4.8\end{array}$ & $\begin{array}{l}6.3 \\
6.9 \\
1.9\end{array}$ & $\begin{array}{r}11.2 \\
11.9 \\
4.1 \\
0.5 \\
0.3 \\
2.3 \\
4.8 \\
5.1\end{array}$ & $\begin{array}{l}6.1 \\
6.9 \\
1.5\end{array}$ & $\begin{array}{r}11.1 \\
11.6 \\
3.1 \\
-1.2 \\
-\quad 0.9 \\
=2.8 \\
-5.4 \\
-5.6\end{array}$ & $\begin{array}{l}6.3 \\
7.0 \\
1.4\end{array}$ & $\begin{array}{r}11.9 \\
12.1 \\
3.8 \\
-1.4 \\
-1.4 \\
-3.3 \\
-5.7 \\
-\quad 5.9\end{array}$ & & $\begin{array}{r}10.0 \\
9.9 \\
9.9 \\
10.5 \\
10.0 \\
9.4 \\
0.1 \\
9.0\end{array}$ & $\begin{array}{l}2 \\
2 \\
2 \\
3 \\
3 \\
3 \\
3 \\
3 \\
3\end{array}$ & $\begin{array}{r}7.7 \\
9.1 \\
17.7 \\
22.2 \\
21.4 \\
19.1 \\
13.0 \\
13.0\end{array}$ & $\begin{array}{r}8.9 \\
10.4 \\
20.1 \\
25.0 \\
24.5 \\
22.1 \\
14.5 \\
14.3\end{array}$ & $\begin{array}{l}10.2 \\
11.9 \\
22.9 \\
23.1 \\
27.0 \\
23.6 \\
15.7 \\
15.8\end{array}$ & $\begin{array}{l}12.2 \\
13.2 \\
23.3 \\
29.4 \\
28.2 \\
24 \cdot 5 \\
16 \cdot 3 \\
16.2\end{array}$ \\
\hline $\begin{array}{l}24 \\
24 \\
24 \\
24 \\
24 \\
24 \\
24 \\
24\end{array}$ & $\begin{array}{r}0 \\
3 \\
0 \\
9 \\
12 \\
15 \\
18 \\
21\end{array}$ & $\begin{array}{r}-5.7 \\
-6.2 \\
=6.9 \\
-\quad 4.5 \\
0.0 \\
2.3 \\
1.6 \\
0.4\end{array}$ & & $\begin{array}{l}6.5 \\
5.8 \\
7.5 \\
4.7 \\
0.4 \\
1.5 \\
1.4 \\
0.0\end{array}$ & & $\begin{array}{r}-5.8 \\
-7.0 \\
-7.5 \\
-5.1 \\
-0.3 \\
1.5 \\
1.2 \\
0.0\end{array}$ & & $\mid \begin{array}{r}-7.1 \\
-7.2 \\
-\quad 8.0 \\
-5.2 \\
-0.6 \\
1.4 \\
0.9\end{array}$ & 0.0 & $\begin{array}{l}8.8 \\
8.7 \\
8.6 \\
9.3 \\
9.5 \\
8.5 \\
8.1 \\
8.3\end{array}$ & $\begin{array}{l}3 \\
3 \\
3 \\
3 \\
3 \\
3 \\
2 \\
2\end{array}$ & $\begin{array}{r}10.1 \\
9.0 \\
11.6 \\
13.5 \\
12.1 \\
8.9 \\
4.4 \\
3.0\end{array}$ & $\begin{array}{r}11.2 \\
10.0 \\
13.7 \\
15.3 \\
12.9 \\
9.4 \\
4.5 \\
3.2\end{array}$ & $\begin{array}{l}12.2 \\
11.2 \\
14.4 \\
16.3 \\
15.2 \\
11.0 \\
5.3 \\
3.4\end{array}$ & $\begin{array}{r}12 \cdot 3 \\
11 \cdot 3 \\
14: 7 \\
17.0 \\
14 \cdot 3 \\
11.0 \\
5.1 \\
3.3\end{array}$ \\
\hline $\begin{array}{l}25 \\
25 \\
25 \\
25 \\
25 \\
25 \\
25 \\
25\end{array}$ & $\begin{array}{r}0 \\
3 \\
6 \\
9 \\
12 \\
15 \\
18 \\
21\end{array}$ & $\begin{array}{r}-0.9 \\
-0.9 \\
5.0 \\
11.3 \\
12.2 \\
9.1 \\
6.0\end{array}$ & $\begin{array}{l}1.9 \\
4.8 \\
6.5 \\
4.9 \\
3.0\end{array}$ & $\begin{array}{r}1.1 \\
1.2 \\
0.5 \\
5.0 \\
11.7 \\
12.7 \\
9.2 \\
5.9\end{array}$ & $\begin{array}{l}2.0 \\
4.6 \\
6.0 \\
4.4 \\
2.8\end{array}$ & $\begin{array}{r}-1.3 \\
-1.4 \\
-0.7 \\
4.9 \\
11.6 \\
12.5 \\
8.9 \\
5.3\end{array}$ & $\begin{array}{l}1.6 \\
4.9 \\
5.9 \\
4.3 \\
2.7\end{array}$ & $\begin{array}{r}-1.5 \\
-1.5 \\
-\quad 0.8 \\
5.2 \\
12.3 \\
13.1 \\
9.4 \\
5.5\end{array}$ & & $\begin{array}{l}8.5 \\
8.4 \\
8.4 \\
9.4 \\
9.5 \\
8.6 \\
8.2 \\
8.1\end{array}$ & $\begin{array}{l}2 \\
2 \\
2 \\
2 \\
2 \\
3 \\
3 \\
3\end{array}$ & $\begin{array}{r}5.5 \\
8.3 \\
10.5 \\
12.2 \\
10.9 \\
6.3 \\
5.7 \\
8.5\end{array}$ & $\begin{array}{r}5.0 \\
9.1 \\
11.6 \\
13.3 \\
11.9 \\
7.3 \\
6.9 \\
9.4\end{array}$ & $\begin{array}{r}6.5 \\
9.9 \\
12.6 \\
14.5 \\
13.1 \\
9.4 \\
7.9 \\
10.6\end{array}$ & $\begin{array}{r}6.8 \\
10.2 \\
13.0 \\
14.9 \\
14.7 \\
10.1 \\
9.4 \\
11.5\end{array}$ \\
\hline $\begin{array}{l}26 \\
26 \\
26 \\
26 \\
26 \\
26 \\
26 \\
26\end{array}$ & $\begin{array}{r}0 \\
3 \\
6 \\
9 \\
12 \\
15 \\
18 \\
21\end{array}$ & $\begin{array}{r}2.3 \\
0.3 \\
-0.1 \\
2.3 \\
6.0 \\
9.0 \\
6.5 \\
4.7\end{array}$ & $\begin{array}{l}0.4 \\
2.1 \\
4.3 \\
3.3 \\
2.5\end{array}$ & $\begin{array}{l}2.3 \\
0.1 \\
0.7 \\
2.0 \\
6.7 \\
8.7 \\
6.5 \\
4.7\end{array}$ & $\begin{array}{l}0.0 \\
1.3 \\
0.8 \\
1.9 \\
3.6 \\
2.9 \\
2.5\end{array}$ & $\begin{array}{r}1.7 \\
-0.3 \\
-0.8 \\
2.0 \\
6.2 \\
9.0 \\
6.4 \\
4.7\end{array}$ & $\begin{array}{l}2.2 \\
3.6 \\
2.7 \\
2.2\end{array}$ & $\begin{array}{r}1.8 \\
-\quad 0.4 \\
-0.0 \\
1.8 \\
6.1 \\
8.9 \\
6.8 \\
5.2\end{array} \mid$ & $\left|\begin{array}{r}-1.1 \\
-1.5 \\
4.1\end{array}\right|$ & $\begin{array}{l}8.0 \\
7.9 \\
8.0 \\
8.8 \\
9.9 \\
8.2 \\
7.9 \\
7.9\end{array}$ & $\begin{array}{l}3 \\
3 \\
3 \\
3 \\
3 \\
3 \\
3 \\
3\end{array}$ & $\begin{array}{l}7.9 \\
8.9 \\
9.7 \\
9.3 \\
7.0 \\
3.2 \\
2.1 \\
1.5\end{array}$ & $\begin{array}{r}8.8 \\
9.7 \\
11.0 \\
10.3 \\
7.1 \\
3.5 \\
2.2 \\
1.7\end{array}$ & $\begin{array}{r}9.6 \\
10.9 \\
11.7 \\
11.5 \\
8.2 \\
3.8 \\
2.5 \\
1.4\end{array}$ & $\begin{array}{r}9.9 \\
11.1 \\
13.2 \\
11.7 \\
8.1 \\
3.9 \\
3.0 \\
1.6\end{array}$ \\
\hline $\begin{array}{l}27 \\
27 \\
27 \\
27 \\
27 \\
27 \\
27 \\
27\end{array}$ & $\begin{array}{r}0 \\
3 \\
6 \\
9 \\
12 \\
15 \\
18 \\
21\end{array}$ & $\begin{array}{r}3.8 \\
3.5 \\
3.9 \\
7.3 \\
12.8 \\
15.0 \\
9.0 \\
7.2\end{array}$ & $\begin{array}{l}1.8 \\
1.4 \\
1.4 \\
4.0 \\
6.1 \\
8.0 \\
5 . ? \\
3.1\end{array}$ & $\begin{array}{r}3.7 \\
3.3 \\
3.6 \\
7.7 \\
12.8 \\
13.9 \\
9.3 \\
7.2\end{array}$ & $\begin{array}{l}1.3 \\
1.3 \\
1.3 \\
3.2 \\
5.8 \\
7.0 \\
4.4 \\
2.9\end{array}$ & $\begin{array}{r}3.6 \\
3.2 \\
3.6 \\
8.0 \\
13.3 \\
14.2 \\
10.0 \\
7.1\end{array}$ & $\begin{array}{l}1.2 \\
1.0 \\
0.6 \\
3.1 \\
5.6 \\
6.2 \\
3.7 \\
2.4\end{array}$ & $\begin{array}{r}4.3 \\
2.9 \\
3.6 \\
8.3 \\
13.3 \\
14.1 \\
10.8 \\
7.4\end{array}$ & & $\begin{array}{r}7.9 \\
7.8 \\
7.9 \\
9.5 \\
10.7 \\
9.7 \\
8.7 \\
8.1\end{array}$ & $\begin{array}{l}2 \\
2 \\
2 \\
2 \\
2 \\
3 \\
2 \\
?\end{array}$ & $\begin{array}{l}1.6 \\
1.7 \\
1.1 \\
1.5 \\
2.1 \\
2.2 \\
2.8 \\
3.7\end{array}$ & $\begin{array}{l}1.7 \\
2.3 \\
1.5 \\
1.7 \\
2 . ? \\
2.9 \\
3.4 \\
4 . ?\end{array}$ & $\begin{array}{l}1.7 \\
2.4 \\
1.7 \\
1.5 \\
2.6 \\
3.1 \\
4.7 \\
4.9\end{array}$ & $\begin{array}{l}2.0 \\
2.44 \\
1.7 \\
0.8 \\
2.9 \\
3.6 \\
6.7 \\
6.7\end{array}$ \\
\hline $\begin{array}{l}28 \\
28 \\
28 \\
28 \\
28 \\
28 \\
28 \\
28\end{array}$ & $\begin{array}{r}0 \\
3 \\
6 \\
9 \\
12 \\
15 \\
18 \\
21\end{array}$ & $\begin{array}{r}6.2 \\
4.2 \\
2.4 \\
7.3 \\
12.5 \\
12.0 \\
7.3 \\
5.1\end{array}$ & $\begin{array}{r}2.3 \\
0.9 \\
-0.4 \\
3.1 \\
5.5 \\
6.2 \\
3.2 \\
1.5\end{array}$ & $\begin{array}{r}5.9 \\
3.9 \\
2.3 \\
7.5 \\
12.8 \\
12.7 \\
7.3 \\
5.0\end{array}$ & $\begin{array}{l}2.0 \\
0.7 \\
0.7 \\
2.3 \\
5: 0 \\
5.5 \\
2.8 \\
1.0\end{array}$ & $\begin{array}{r}5.9 \\
3.7 \\
2.3 \\
8.2 \\
13.1 \\
13.0 \\
7.2 \\
4.8\end{array}$ & $\begin{array}{r}1.5 \\
0.1 \\
-0.9 \\
2.4 \\
4.7 \\
4.8 \\
2.3 \\
0.7\end{array}$ & $\begin{array}{r}6.3 \\
3.9 \\
2.0 \\
8.01 \\
13 . ? \\
13.2 \\
7.5 \\
4.6\end{array}$ & & $\begin{array}{l}7.8 \\
7.8 \\
7.8 \\
8.8 \\
9.1 \\
8.4 \\
7.9 \\
8.3\end{array}$ & $\begin{array}{l}2 \\
2 \\
3 \\
2 \\
2 \\
3 \\
3 \\
3\end{array}$ & $\begin{array}{l}3.4 \\
3.3 \\
5.3 \\
5.8 \\
3.5 \\
5.1 \\
6.0 \\
4.9\end{array}$ & $\begin{array}{l}3.7 \\
3.4 \\
5.4 \\
6.4 \\
4.1 \\
5.0 \\
6.5 \\
5.5\end{array}$ & $\begin{array}{l}4.3 \\
3.4 \\
5.6 \\
6.6 \\
4.4 \\
7.0 \\
7.2 \\
5.6\end{array}$ & $\begin{array}{r}5.8 \\
4: 0 \\
5: 1 \\
7.0 \\
4.7 \\
7: 8 \\
.9 .1 \\
5.5\end{array}$ \\
\hline $\begin{array}{l}29 \\
29 \\
29 \\
29 \\
29 \\
29 \\
29 \\
29\end{array}$ & $\begin{array}{r}0 \\
3 \\
6 \\
9 \\
12 \\
15 \\
18 \\
21\end{array}$ & $\begin{array}{r}3.4 \\
1.8 \\
1.5 \\
6.7 \\
11.7 \\
12.8 \\
8.2 \\
7.3\end{array}$ & $\begin{array}{r}0.5 \\
-0.5 \\
-0.3 \\
2.4 \\
5.6 \\
6.5 \\
5.0 \\
3.9\end{array}$ & $\begin{array}{r}3.3 \\
1.6 \\
1.4 \\
6.4 \\
11.0 \\
13.0 \\
8.7 \\
7.4\end{array}$ & $\begin{array}{l}0.1 \\
0.7 \\
0.7 \\
2.1 \\
4.9 \\
6.1 \\
4.3 \\
3.6\end{array}$ & $\begin{array}{r}3.2 \\
1.5 \\
1.5 \\
6.5 \\
12.2 \\
13.3 \\
9.8 \\
7.3\end{array}$ & $\begin{array}{r}0.0 \\
-1.0 \\
-\quad 0.8 \\
1.9 \\
4.7 \\
5.8 \\
4.1 \\
3.2\end{array}$ & $\begin{array}{r}3.0 \\
1.3 \\
1.5 \\
6.7 \\
12.4 \\
13.6 \\
10.9 \\
7.8\end{array}$ & -1.4 & $\begin{array}{l}7.7 \\
7.7 \\
7.8 \\
8.7 \\
8.9 \\
8.0 \\
7.7 \\
7.7\end{array}$ & $\begin{array}{l}3 \\
3 \\
2 \\
2 \\
2 \\
2 \\
2 \\
2\end{array}$ & $\begin{array}{l}3.2 \\
2.7 \\
2.3 \\
4.5 \\
5.2 \\
6.1 \\
2.7 \\
3.9\end{array}$ & $\begin{array}{l}3.6 \\
2.8 \\
2.4 \\
5.0 \\
7.3 \\
7.6 \\
3.4 \\
4.4\end{array}$ & $\begin{array}{l}3.7 \\
3.4 \\
2.8 \\
6.3 \\
8.3 \\
0.1 \\
4.6 \\
5.8\end{array}$ & $\begin{array}{r}3.8 \\
3.2 \\
3.3 \\
5.7 \\
8.8 \\
10.0 \\
6.5 \\
7.1\end{array}$ \\
\hline $\begin{array}{l}30 \\
30 \\
30 \\
30 \\
30 \\
30 \\
30 \\
30\end{array}$ & $\begin{array}{r}0 \\
3 \\
6 \\
9 \\
12 \\
15 \\
18 \\
21\end{array}$ & $\begin{array}{r}6.1 \\
5.7 \\
2.2 \\
7.0 \\
12.1 \\
14.3 \\
8.8 \\
7.4\end{array}$ & $\begin{array}{l}3.5 \\
3.9 \\
0.7 \\
4.8 \\
8.1 \\
9.0 \\
6.3 \\
5.3\end{array}$ & $\begin{array}{r}6.1 \\
5.5 \\
2.1 \\
7.0 \\
12.4 \\
15.0 \\
9.3 \\
7.2\end{array}$ & $\begin{array}{l}4.8 \\
8.0 \\
9.0 \\
6.4 \\
5.2\end{array}$ & $\begin{array}{r}6.0 \\
5.0 \\
2.0 \\
7.1 \\
12.8 \\
15.4 \\
10.8 \\
7.6\end{array}$ & $\begin{array}{l}2.8 \\
8.0 \\
9.0 \\
6.6 \\
5.2\end{array}$ & $\begin{array}{r}6.1 \\
5: 2 \\
2: 1 \\
7: 2 \\
13.0 \\
15.8 \\
12.3 \\
7.7\end{array}$ & 4.3 & $\begin{array}{l}7.8 \\
7.8 \\
7.7 \\
8.5 \\
8.8 \\
8.1 \\
7.8 \\
7.8\end{array}$ & $\begin{array}{l}2 \\
2 \\
3 \\
3 \\
2 \\
2 \\
2 \\
2\end{array}$ & $\begin{array}{l}5.2 \\
6.0 \\
4.3 \\
4.8 \\
6.9 \\
3.1 \\
1.1 \\
3.3\end{array}$ & $\begin{array}{l}5.7 \\
6.6 \\
4.5 \\
5.7 \\
7.7 \\
4.1 \\
1.7 \\
4.0\end{array}$ & $\begin{array}{l}6.2 \\
7.0 \\
4.6 \\
5.4 \\
8.3 \\
5.0 \\
1.9 \\
4.3\end{array}$ & $\begin{array}{l}7.1 \\
7.7 \\
5.0 \\
5.7 \\
8.8 \\
5.8 \\
3.9 \\
5.0\end{array}$ \\
\hline
\end{tabular}


TABLE 10

Table 10. -Three-hour averages of air and water-surface temperatures and wind directions and speed, April 1950-August 1951, Lake Hefner-Continued

STATION 1 THREE-HOURLY AVERAGES

DECEMBER, 1950

\begin{tabular}{|c|c|c|c|c|c|c|c|c|c|c|c|c|c|c|c|}
\hline \multirow{3}{*}{ 茺 } & \multirow{3}{*}{ 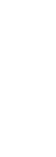 } & \multicolumn{8}{|c|}{ Average air temperature $\left({ }^{\circ} \mathrm{C}\right)$ at indicated height } & \multirow{3}{*}{\begin{tabular}{|c|} 
Average \\
water- \\
surface \\
tempera- \\
ture \\
$\left({ }^{\circ} \mathrm{C}\right)$
\end{tabular}} & \multirow{3}{*}{$\begin{array}{l}\begin{array}{c}\text { Average } \\
\text { wind } \\
\text { direction }\end{array} \\
\text { (coded) }\end{array}$} & \multirow{2}{*}{\multicolumn{4}{|c|}{$\begin{array}{l}\text { Average wind speed (knots) } \\
\text { at indicated height }\end{array}$}} \\
\hline & & \multicolumn{2}{|c|}{$\begin{array}{c}2 \\
\text { meters }\end{array}$} & \multicolumn{2}{|c|}{\begin{tabular}{c|}
4 \\
meters
\end{tabular}} & \multicolumn{2}{|c|}{$\begin{array}{c}8 \\
\text { meters }\end{array}$} & \multicolumn{2}{|c|}{$\begin{array}{c}16 \\
\text { meters }\end{array}$} & & & & & & \\
\hline & & $\begin{array}{l}\text { Dry } \\
\text { bulb }\end{array}$ & $\begin{array}{l}\text { Wet } \\
\text { bulb }\end{array}$ & $\begin{array}{l}\text { Dry } \\
\text { bulb }\end{array}$ & $\begin{array}{l}\text { Wet } \\
\text { bulb }\end{array}$ & $\begin{array}{l}\text { Dry } \\
\text { bulb }\end{array}$ & $\begin{array}{l}\text { Wet } \\
\text { bulb }\end{array}$ & \begin{tabular}{|l|} 
Dry \\
bulb
\end{tabular} & $\begin{array}{l}\text { Wet } \\
\text { bulb }\end{array}$ & & & meters & meters & meters & meters \\
\hline $\begin{array}{l}1 \\
1 \\
1 \\
1 \\
1 \\
1 \\
1 \\
1\end{array}$ & $\begin{array}{r}0 \\
3 \\
6 \\
9 \\
12 \\
15 \\
18 \\
21\end{array}$ & $\begin{array}{r}4.3 \\
4.7 \\
8.1 \\
15.1 \\
18.5 \\
19.5 \\
15.7 \\
14.7\end{array}$ & $\begin{array}{r}3.1 \\
3.5 \\
6.5 \\
10.2 \\
10.7 \\
10.4 \\
8.7 \\
8.2\end{array}$ & $\begin{array}{r}4.5 \\
5.4 \\
8.6 \\
14.8 \\
1901 \\
2009 \\
1700 \\
15.5\end{array}$ & $\begin{array}{r}3.4 \\
4.1 \\
6.9 \\
10.2 \\
10.6 \\
10.2 \\
8.5 \\
8.1\end{array}$ & $\begin{array}{r}4.3 \\
5.3 \\
8.5 \\
15.2 \\
20.1 \\
21.9 \\
18.4 \\
16.1\end{array}$ & $\begin{array}{r}3.4 \\
4.0 \\
7.0 \\
10.4 \\
10.6 \\
10.4 \\
8.0 \\
8.1\end{array}$ & $\begin{array}{r}4.7 \\
5.6 \\
8.8 \\
15.6 \\
20.5 \\
22.2 \\
19.1 \\
16.6\end{array}$ & & $\begin{array}{l}7.7 \\
7: 7 \\
7: 8 \\
8: 7 \\
8.9 \\
8.3 \\
8.2 \\
8.2\end{array}$ & $\begin{array}{l}2 \\
2 \\
2 \\
2 \\
2 \\
2 \\
2 \\
2\end{array}$ & $\begin{array}{r}2.6 \\
7: 9 \\
12.9 \\
16.6 \\
17.2 \\
11.2 \\
7.3 \\
10.0\end{array}$ & $\begin{array}{r}2.8 \\
8.9 \\
14.7 \\
19.7 \\
20.0 \\
13.4 \\
9.3 \\
12.1\end{array}$ & $\begin{array}{r}3.0 \\
9.9 \\
16.8 \\
22.0 \\
23.2 \\
15.6 \\
11.8 \\
14.5\end{array}$ & $\begin{array}{r}3.5 \\
10.8 \\
17.9 \\
23.0 \\
24.5 \\
17.1 \\
13.3 \\
16.4\end{array}$ \\
\hline $\begin{array}{l}2 \\
2 \\
2 \\
2 \\
2 \\
2 \\
2 \\
2\end{array}$ & $\begin{array}{r}0 \\
3 \\
6 \\
9 \\
12 \\
15 \\
18 \\
21\end{array}$ & $\begin{array}{r}15.4 \\
14.7 \\
9.0 \\
5.5 \\
8.1 \\
7.3 \\
4.7 \\
1.7\end{array}$ & $\begin{array}{r}8.6 \\
7.1 \\
4.6 \\
3.3 \\
4.0 \\
3.9 \\
1.9 \\
-0.6\end{array}$ & $\begin{array}{r}16.1 \\
15.1 \\
8.4 \\
5.4 \\
8.1 \\
7.2 \\
4.4 \\
1.3\end{array}$ & $\begin{array}{l}8.5 \\
6.9 \\
4.1 \\
3.0 \\
4.5 \\
3.4 \\
1.3 \\
1.1\end{array}$ & $\begin{array}{r}16.5 \\
15.3 \\
8.2 \\
5.4 \\
8.1 \\
7.0 \\
4.2 \\
0.9\end{array}$ & $\begin{array}{r}3.5 \\
6.9 \\
3.0 \\
2.9 \\
4.3 \\
3.1 \\
0.9 \\
-1.4\end{array}$ & $\begin{array}{r}17.2 \\
15.5 \\
7.8 \\
5.4 \\
7.0 \\
6.9 \\
3.8 \\
0.8\end{array}$ & & $\begin{array}{l}8.1 \\
8.0 \\
8.0 \\
8.7 \\
8.8 \\
8.1 \\
8.0 \\
7.8\end{array}$ & $\begin{array}{l}2 \\
2 \\
2 \\
3 \\
3 \\
3 \\
3 \\
3\end{array}$ & $\begin{array}{r}13.4 \\
12.8 \\
10.9 \\
10.7 \\
12.8 \\
12.9 \\
11.8 \\
9.7\end{array}$ & $\begin{array}{l}15.6 \\
14.5 \\
10.0 \\
11.5 \\
14.3 \\
15.0 \\
14.5 \\
11.5\end{array}$ & $\begin{array}{l}18.1 \\
16.7 \\
13.8 \\
13.6 \\
16.6 \\
16.3 \\
14.5 \\
11.7\end{array}$ & $\begin{array}{l}19.4 \\
17: 9 \\
13.5 \\
14: 0 \\
17: 1 \\
17: 4 \\
15: 6 \\
12.2\end{array}$ \\
\hline $\begin{array}{l}3 \\
3 \\
3 \\
3 \\
3 \\
3 \\
3 \\
3\end{array}$ & $\begin{array}{r}0 \\
3 \\
6 \\
9 \\
12 \\
15 \\
18 \\
21\end{array}$ & $\begin{array}{r}-0.5 \\
-2.03 \\
=3.7 \\
-0.2 \\
5.55 \\
7.7 \\
4.9 \\
5.1\end{array}$ & $\mid \begin{array}{r}-2.2 \\
-3.1 \\
-0.5 \\
1.6 \\
3.2 \\
1.5 \\
1.6\end{array}$ & $\begin{array}{l}0.9 \\
2.9 \\
3.9 \\
0.2 \\
5.5 \\
7.5 \\
4.6 \\
5.0\end{array}$ & $\begin{array}{l}2.7 \\
2.6 \\
0.9 \\
1.3 \\
2.6 \\
1.1 \\
1.1\end{array}$ & {$\left[\begin{array}{r}-1.1 \\
-3.0 \\
-3.9 \\
0.6 \\
5.4 \\
7.4 \\
4.6 \\
4.9\end{array}\right.$} & $\begin{array}{r}-3.0 \\
-3.9 \\
-0.9 \\
1.2 \\
2.4 \\
0.8 \\
0.9\end{array}$ & $\begin{array}{r}-1.3 \\
-\quad 3.3 \\
-\quad 4.3 \\
0.5 \\
5.4 \\
7.4 \\
4.5 \\
4.8\end{array} \mid$ & 0.2 & $\begin{array}{l}7.7 \\
7.5 \\
7.3 \\
8.4 \\
3.7 \\
8.0 \\
7.6 \\
7.5\end{array}$ & $\begin{array}{l}3 \\
3 \\
4 \\
2 \\
2 \\
2 \\
2 \\
2\end{array}$ & $\begin{array}{r}7.2 \\
8.1 \\
7.9 \\
3.1 \\
3.3 \\
7.3 \\
7.14 \\
11.7\end{array}$ & $\begin{array}{r}9.1 \\
9.3 \\
7.9 \\
2.2 \\
3.7 \\
8.3 \\
8.1 \\
13.2\end{array}$ & $\begin{array}{r}8.6 \\
9.0 \\
8.5 \\
3.3 \\
4.0 \\
9.2 \\
8.9 \\
14.3\end{array}$ & $\begin{array}{r}9.7 \\
10.1 \\
9.7 \\
1.5 \\
4.3 \\
10.1 \\
9.7 \\
15.4\end{array}$ \\
\hline $\begin{array}{l}4 \\
4 \\
4 \\
4 \\
4 \\
4 \\
4 \\
4\end{array}$ & $\begin{array}{r}0 \\
3 \\
6 \\
9 \\
12 \\
15 \\
18 \\
21\end{array}$ & $\begin{array}{r}5.3 \\
5.8 \\
6.0 \\
7.8 \\
9.8 \\
10.8 \\
8.1 \\
4.6\end{array}$ & $\begin{array}{l}1.7 \\
2.0 \\
1.8 \\
2.7 \\
4.3 \\
5.1 \\
3.5 \\
1.6\end{array}$ & $\begin{array}{r}5.3 \\
5.8 \\
5.9 \\
7.2 \\
10.0 \\
10.7 \\
8.0 \\
4.4\end{array}$ & $\begin{array}{l}1.2 \\
1.5 \\
1.3 \\
2.3 \\
3.9 \\
4.2 \\
3.0 \\
1.1\end{array}$ & \begin{tabular}{|r|}
5.2 \\
5.7 \\
5.8 \\
7.5 \\
10.3 \\
10.8 \\
7.0 \\
4.3
\end{tabular} & $\begin{array}{l}1.0 \\
1.2 \\
1.1 \\
2.1 \\
3.6 \\
3.0 \\
2.7 \\
0.7\end{array}$ & $\begin{array}{r}5.0 \\
5.5 \\
5.7 \\
7.2 \\
10.4 \\
10.8 \\
7.8 \\
4.1\end{array}$ & 1.0 & $\begin{array}{l}7.4 \\
7: 5 \\
705 \\
7: 7 \\
7.8 \\
7: 5 \\
702 \\
7.1\end{array}$ & $\begin{array}{l}2 \\
2 \\
2 \\
2 \\
2 \\
2 \\
3 \\
3\end{array}$ & $\begin{array}{r}16.0 \\
19.9 \\
18.6 \\
16.2 \\
10.0 \\
9.8 \\
12.6 \\
8.2\end{array}$ & $\begin{array}{r}18.1 \\
22.6 \\
21.1 \\
18.3 \\
11.3 \\
11.0 \\
13.2 \\
9.1\end{array}$ & $\begin{array}{r}19.9 \\
24.6 \\
23.2 \\
20.1 \\
12.4 \\
11.5 \\
13.9 \\
9.8\end{array}$ & $\begin{array}{l}20.8 \\
26.6 \\
24.3 \\
21.1 \\
13.2 \\
12.2 \\
14.5 \\
10.2\end{array}$ \\
\hline $\begin{array}{l}5 \\
5 \\
5 \\
5 \\
5 \\
5 \\
5 \\
5\end{array}$ & $\begin{array}{r}0 \\
3 \\
6 \\
9 \\
12 \\
15 \\
18 \\
21\end{array}$ & $\begin{array}{r}2.7 \\
-0.5 \\
-4.02 \\
-5.9 \\
-6.4\end{array}$ & $\begin{array}{l}0.4 \\
1.2\end{array}$ & $\begin{array}{l}2.5 \\
0.1 \\
4.9 \\
6.8 \\
7.4\end{array}$ & $\begin{array}{l}0.0 \\
0.3\end{array}$ & $\begin{aligned} & 2.3 \\
- & 0.6 \\
= & 5.2 \\
- & 7.3 \\
- & 8.1\end{aligned}$ & $=0.22$ & $\begin{array}{r}2.1 \\
-1.3 \\
-5.0 \\
-7.0 \\
-8.7\end{array}$ & & $\begin{array}{l}7.1 \\
7.1 \\
6.8 \\
6.7 \\
6.5\end{array}$ & $\begin{array}{l}3 \\
3 \\
3 \\
3 \\
3 \\
3 \\
3 \\
3\end{array}$ & $\begin{array}{l}11.3 \\
22.4 \\
24.6 \\
22.8 \\
20.6 \\
21.3 \\
20.6 \\
18.2\end{array}$ & $\begin{array}{l}12.5 \\
26.6 \\
29.6 \\
28.8 \\
27.6 \\
27.7 \\
25.3 \\
22.4\end{array}$ & $\begin{array}{l}13.8 \\
29.4 \\
32.5 \\
32.6 \\
30.3 \\
30.7 \\
28.3 \\
24.7\end{array}$ & $\begin{array}{l}13.9 \\
31.0 \\
34.4 \\
34.2 \\
31.6 \\
32.0 \\
28.6 \\
25.1\end{array}$ \\
\hline $\begin{array}{l}6 \\
6 \\
6 \\
6 \\
6 \\
6 \\
6 \\
6\end{array}$ & $\begin{array}{r}0 \\
3 \\
6 \\
9 \\
12 \\
15 \\
18 \\
21\end{array}$ & & & & & & & & & & $\begin{array}{l}3 \\
3 \\
3 \\
3 \\
4 \\
3 \\
3 \\
3 \\
3\end{array}$ & $\begin{array}{r}15.4 \\
14.7 \\
13.2 \\
13.8 \\
12.3 \\
9.1 \\
7.1 \\
6.0\end{array}$ & $\begin{array}{r}19.2 \\
19.0 \\
16.8 \\
16.7 \\
13.8 \\
10.4 \\
8.5 \\
6.9\end{array}$ & \begin{tabular}{|r|}
20.4 \\
19.0 \\
17.2 \\
18.1 \\
15.8 \\
11.5 \\
8.9 \\
7.4
\end{tabular} & $\begin{array}{r}20.6 \\
20.0 \\
18.6 \\
18.8 \\
16.7 \\
11.2 \\
9.1 \\
7.5\end{array}$ \\
\hline $\begin{array}{l}7 \\
7 \\
? \\
? \\
7 \\
7 \\
7 \\
7\end{array}$ & $\begin{array}{r}0 \\
3 \\
6 \\
9 \\
12 \\
15 \\
18 \\
21\end{array}$ & $\begin{array}{l}=4.2 \\
=4.5 \\
-5.4\end{array}$ & & $\begin{array}{l}4.2 \\
4.6 \\
5.5\end{array}$ & & & & {$\left[\begin{array}{l}-4.6 \\
-4.9 \\
-5.8\end{array}\right]$} & & $\begin{array}{l}4.5 \\
4.4 \\
4.2\end{array}$ & $\begin{array}{l}2 \\
2 \\
2 \\
2 \\
2 \\
2 \\
2 \\
2\end{array}$ & $\begin{array}{r}6.3 \\
9.3 \\
8.6 \\
10.5 \\
7.8 \\
6.5 \\
7.0 \\
6.4\end{array}$ & $\begin{array}{r}6.4 \\
9.5 \\
8.9 \\
10.8 \\
8.1 \\
6.8 \\
7.8 \\
7.0\end{array}$ & $\begin{array}{r}6.8 \\
9.8 \\
9.3 \\
11.6 \\
8.5 \\
7.7 \\
8.4 \\
7.7\end{array}$ & $\begin{array}{r}6.8 \\
10.1 \\
9.2 \\
11.6 \\
8.8 \\
7.8 \\
8.6 \\
7.8\end{array}$ \\
\hline $\begin{array}{l}8 \\
8 \\
8 \\
8 \\
8 \\
8 \\
8 \\
8\end{array}$ & $\begin{array}{r}0 \\
3 \\
6 \\
9 \\
12 \\
15 \\
18 \\
21\end{array}$ & $\begin{array}{r}-6.2 \\
=6.8 \\
-6.4 \\
-0.4 \\
4.8 \\
7.1 \\
3.1 \\
2.5\end{array}$ & $\begin{array}{l}1.8 \\
3.6 \\
1.8 \\
0.9\end{array}$ & $\begin{array}{l}6.2 \\
6.9 \\
6.4 \\
0.0 \\
5.5 \\
7.6 \\
3.3 \\
2.4\end{array}$ & $\begin{array}{l}1.3 \\
2.7 \\
1.03 \\
0.0\end{array}$ & $\begin{array}{l}5.9 \\
7.8 . \\
5.0 \\
2.5\end{array}$ & $\begin{array}{r}1.4 \\
2.6 \\
1.1 \\
-0.1\end{array} \mid$ & $\begin{array}{r}-6.6 \\
-7.1 \\
-6.5 \\
99.7 \\
5.6 \\
8.0 \\
6.3 \\
3.5\end{array}$ & & $\begin{array}{l}4.2 \\
3.5 \\
3.4 \\
3.7 \\
4.6 \\
4.0 \\
3.9 \\
4.0\end{array}$ & $\begin{array}{l}2 \\
2 \\
2 \\
2 \\
4 \\
3 \\
3 \\
2 \\
2\end{array}$ & $\begin{array}{l}6.4 \\
7.3 \\
7.1 \\
9.0 \\
7.2 \\
3.4 \\
1.8 \\
3.4\end{array}$ & $\begin{array}{l}7.1 \\
8.1 \\
7.8 \\
9.8 \\
8.8 \\
4.8 \\
2.2 \\
3.9\end{array}$ & $\begin{array}{r}7.7 \\
8.8 \\
8.5 \\
10.6 \\
8.8 \\
5.1 \\
2.4 \\
4.9\end{array}$ & $\begin{array}{r}7.9 \\
8.9 \\
8.6 \\
10.9 \\
11.2 \\
0.0 \\
2.5 \\
7.0\end{array}$ \\
\hline $\begin{array}{l}9 \\
9 \\
9 \\
9 \\
9 \\
9 \\
9 \\
9\end{array}$ & $\begin{array}{r}0 \\
3 \\
6 \\
9 \\
12 \\
15 \\
18 \\
21 .\end{array}$ & $\begin{array}{r}2.0 \\
2.3 \\
2.7 \\
6.2 \\
10.6 \\
10.6 \\
6.5 \\
4.0\end{array}$ & $\begin{array}{l}0.4 \\
0.8 \\
1.1 \\
3.1 \\
5.5 \\
5.3 \\
3.2 \\
1.3\end{array}$ & $\begin{array}{r}1.9 \\
2: 2 \\
2.6 \\
6.5 \\
11: 2 \\
11: 9 \\
7: 1 \\
4: 0\end{array}$ & $\begin{array}{l}0.0 \\
0.3 \\
0.06 \\
3.2 \\
5.3 \\
4.09 \\
2.06 \\
0.7\end{array}$ & $\begin{array}{r}2.0 \\
2.03 \\
2.7 \\
6.9 \\
12.0 \\
12.2 \\
7.6 \\
3.0\end{array}$ & $\mid \begin{array}{r}-0.1 \\
0.2 \\
0.5 \\
3.2 \\
5.5 \\
5.0 \\
2.4 \\
0.4\end{array}$ & \begin{tabular}{r|}
2.8 \\
2.8 \\
2.9 \\
7.3 \\
12.3 \\
12.7 \\
7.7 \\
4.0
\end{tabular} & & $\begin{array}{l}3.9 \\
3.9 \\
3.9 \\
4.5 \\
4.7 \\
4: 3 \\
4: 1 \\
4: 0\end{array}$ & $\begin{array}{l}2 \\
2 \\
2 \\
3 \\
3 \\
4 \\
4 \\
4\end{array}$ & $\begin{array}{r}6.8 \\
4.3 \\
3.8 \\
7.9 \\
11.5 \\
8.9 \\
4.2 \\
5.7\end{array}$ & $\begin{array}{r}7.2 \\
4.6 \\
4.2 \\
6.0 \\
13.3 \\
11.6 \\
4.2 \\
5.7\end{array}$ & $\begin{array}{r}8.2 \\
5.2 \\
4.6 \\
10.8 \\
14.9 \\
13.3 \\
6.9 \\
7.2\end{array}$ & $\begin{array}{r}10.3 \\
6.5 \\
5.7 \\
8.5 \\
16.8 \\
17.4 \\
9.3 \\
9.8\end{array}$ \\
\hline $\begin{array}{l}10 \\
10 \\
10 \\
10 \\
10 \\
10 \\
10\end{array}$ & $\begin{array}{r}0 \\
3 \\
6 \\
9 \\
12 \\
15 \\
18 \\
21\end{array}$ & $\begin{array}{l}2.0 \\
1.2 \\
0.4 \\
3.6 \\
6.6 \\
8.2 \\
4.5 \\
4.0\end{array}$ & $\begin{array}{r}-0.3 \\
=-1.3 \\
-1.7 \\
0.8 \\
2.8 \\
3.4 \\
1.8 \\
0.9\end{array}$ & $\begin{array}{l}1.9 \\
1: 0 \\
0.1 \\
3: 7 \\
7: 0 \\
8.9 \\
4: 9 \\
4: 1\end{array}$ & $\begin{array}{l}0.7 \\
1.3 \\
2.1 \\
0.3 \\
2.3 \\
3.1 \\
1.02 \\
0.7\end{array}$ & $\begin{array}{l}1.8 \\
0.9 \\
0.1 \\
3.9 \\
7.4 \\
9.4 \\
5.8 \\
4.2\end{array}$ & 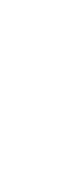 & $\begin{array}{l}1.7 \\
0.7 \\
0: 0 \\
4: 0 \\
7.4 \\
9.7 \\
6.5 \\
4.4\end{array}$ & $\begin{array}{l}0.5 \\
2.0 \\
3.1 \\
0.5\end{array}$ & $\begin{array}{l}4: 0 \\
4: 1 \\
3: 9 \\
4: 9 \\
5: 1 \\
4: 4 \\
4: 0 \\
4: 0\end{array}$ & $\begin{array}{l}4 \\
4 \\
4 \\
2 \\
2 \\
2 \\
2 \\
2\end{array}$ & $\begin{array}{r}8.1 \\
10.0 \\
8.2 \\
7.0 \\
5.5 \\
2.3 \\
3.6 \\
6.3\end{array}$ & $\begin{aligned} & 11.2 \\
& 77.6 \\
& 8.2 \\
& 5.6 \\
& 2.5 \\
& 4.5 \\
& 7.2\end{aligned}$ & $\begin{array}{r}9.2 \\
11.2 \\
10.5 \\
9.0 \\
7.4 \\
3.1 \\
6.0 \\
8.3\end{array}$ & $\begin{array}{l}9.6 \\
5.6 \\
3.3 \\
6.8 \\
9.6\end{array}$ \\
\hline
\end{tabular}


Table 10. -Three-hour averages of air and water-surface temperatures and wind directions and speed, April 1950-August 1951, Lake Hefner-Continued

STATION 1

THREE-HOURLY AVERAGES

DECEMBER, 1950

\begin{tabular}{|c|c|c|c|c|c|c|c|c|c|c|c|c|c|c|c|}
\hline \multirow{3}{*}{ 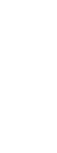 } & \multirow{3}{*}{ 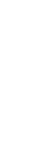 } & \multicolumn{8}{|c|}{ Average air temperature $\left({ }^{\circ} \mathrm{C}\right)$ at indicated height } & \multirow{3}{*}{$\begin{array}{l}\text { Average } \\
\text { water- } \\
\text { surface } \\
\text { tempera- } \\
\text { ture } \\
\text { () }\end{array}$} & \multirow{3}{*}{$\begin{array}{c}\text { Average } \\
\text { wind } \\
\text { direction } \\
\text { (coded) }\end{array}$} & \multicolumn{4}{|c|}{$\begin{array}{l}\text { A verage wind speed (knots) } \\
\text { at indicated height }\end{array}$} \\
\hline & & \multicolumn{2}{|c|}{$\begin{array}{c}\mathbf{a} \\
\text { meters }\end{array}$} & \multicolumn{2}{|c|}{$\begin{array}{c}4 \\
\text { meters }\end{array}$} & \multicolumn{2}{|c|}{$\begin{array}{c}\mathbf{8} \\
\text { meters }\end{array}$} & \multicolumn{2}{|c|}{$\begin{array}{c}16 \\
\text { meters }\end{array}$} & & & & & & \\
\hline & & $\begin{array}{l}\text { Dry } \\
\text { bulb }\end{array}$ & $\begin{array}{l}\text { Wet } \\
\text { bulb }\end{array}$ & $\begin{array}{l}\text { Dry } \\
\text { bulb }\end{array}$ & $\begin{array}{l}\text { Wet } \\
\text { bulb }\end{array}$ & $\begin{array}{l}\text { Dry } \\
\text { bulb }\end{array}$ & $\begin{array}{l}\text { Wet } \\
\text { bulb }\end{array}$ & $\begin{array}{l}\text { Dry } \\
\text { bulb }\end{array}$ & $\begin{array}{l}\text { Wet } \\
\text { bulb }\end{array}$ & & & meters & meters & meters & meters \\
\hline $\begin{array}{l}11 \\
11 \\
\text { 11 } \\
\text { i1 } \\
\text { 11 } \\
11 \\
11\end{array}$ & $\begin{array}{r}0 \\
3 \\
6 \\
9 \\
12 \\
15 \\
18 \\
21\end{array}$ & $\begin{array}{r}4.5 \\
4.1 \\
3.1 \\
8.6 \\
12.1\end{array}$ & $\begin{array}{l}1.2 \\
1.1 \\
0.7 \\
4.9 \\
6.9\end{array}$ & $\begin{array}{r}4.5 \\
4.1 \\
2.9 \\
8.9 \\
12.8\end{array}$ & $\begin{array}{l}0.9 \\
0.8 \\
0.5 \\
4.6 \\
6.6\end{array}$ & $\begin{array}{r}4.5 \\
3.9 \\
3.1 \\
9.5 \\
13.5\end{array}$ & $\begin{array}{l}0.8 \\
0.6 \\
0.6 \\
4.8 \\
7.0\end{array}$ & $\begin{array}{r}4.7 \\
4.0 \\
3.7 \\
10.2 \\
14.1\end{array}$ & & $\begin{array}{l}4 \cdot 1 \\
4 \cdot 1 \\
4 \cdot 1 \\
4.9 \\
5.4\end{array}$ & $\begin{array}{l}2 \\
2 \\
2 \\
3 \\
3 \\
3 \\
2 \\
2\end{array}$ & $\begin{array}{r}9.3 \\
6.4 \\
8.3 \\
11.4 \\
11.6 \\
8.9 \\
3.1 \\
2.4\end{array}$ & $\begin{array}{r}10.6 \\
7.1 \\
8.5 \\
14.1 \\
14.5 \\
12.5 \\
4.2 \\
3.1\end{array}$ & $\begin{array}{r}12.0 \\
8.0 \\
10.2 \\
15.0 \\
16.5 \\
14.2 \\
5.4 \\
4.2\end{array}$ & $\begin{array}{r}13.2 \\
9.0 \\
11.2 \\
18.2 \\
18.8 \\
16.4 \\
7.4 \\
4.8\end{array}$ \\
\hline $\begin{array}{l}12 \\
12 \\
12 \\
12 \\
12 \\
12 \\
12 \\
12\end{array}$ & $\begin{array}{r}0 \\
3 \\
6 \\
9 \\
12 \\
15 \\
18 \\
21\end{array}$ & $\begin{array}{l}4.6 \\
5.8 \\
6.2 \\
3.4 \\
2.0\end{array}$ & $\begin{array}{l}1.7 \\
2.5 \\
2.8 \\
1.1 \\
0.3\end{array}$ & $\begin{array}{l}4.7 \\
5.9 \\
6.2 \\
3.4 \\
1.8\end{array}$ & $\begin{array}{l}1.9 \\
2.4 \\
2.6 \\
0.9 \\
0.0\end{array}$ & $\begin{array}{l}4.8 \\
6.2 \\
6.3 \\
3.4 \\
1.4\end{array}$ & $\begin{array}{r}1.8 \\
2.3 \\
2.5 \\
0.9 \\
-0.3\end{array}$ & $\begin{array}{l}4 \cdot 8 \\
6.1 \\
6.5 \\
3.4 \\
1.6\end{array}$ & & $\begin{array}{l}4.9 \\
4.8 \\
4.4 \\
4.2 \\
4.1\end{array}$ & $\begin{array}{l}2 \\
3 \\
3 \\
2 \\
2 \\
3 \\
2 \\
2\end{array}$ & $\begin{array}{l}1.5 \\
3.0 \\
1.8 \\
3.3 \\
4.3 \\
5.3 \\
3.6 \\
3.6\end{array}$ & $\begin{array}{l}1.5 \\
3.3 \\
2.3 \\
3.7 \\
4.8 \\
6.1 \\
4.1 \\
4.1\end{array}$ & $\begin{array}{l}1.9 \\
4.0 \\
2.5 \\
3.7 \\
5.1 \\
6.8 \\
4.6 \\
4.4\end{array}$ & $\begin{array}{l}2.9 \\
5: 0 \\
3.0 \\
4.0 \\
5.4 \\
7.5 \\
5.8 \\
5.1\end{array}$ \\
\hline $\begin{array}{l}13 \\
13 \\
13 \\
13 \\
13 \\
13 \\
13 \\
13\end{array}$ & $\begin{array}{r}0 \\
3 \\
6 \\
9 \\
12 \\
15 \\
18 \\
21\end{array}$ & $\begin{array}{r}0.2 \\
-1.4 \\
-0.7 \\
1.9 \\
7.2 \\
8.4 \\
3.9 \\
2.5\end{array}$ & $\begin{array}{r}-0.8 \\
-2.1 \\
-1.5 \\
0.4 \\
3.7 \\
4.2 \\
2.1 \\
1.5\end{array}$ & $\begin{array}{l}0.2 \\
1.5 \\
0.7 \\
1.7 \\
6.8 \\
8.9 \\
4.4 \\
2.5\end{array}$ & $\begin{array}{l}0.8 \\
2.5 \\
1.5 \\
0.0 \\
2.9 \\
3.7 \\
1.9 \\
1.4\end{array}$ & $\begin{array}{r}0.1 \\
-1.9 \\
-0.7 \\
1.8 \\
7.1 \\
9.2 \\
5.1 \\
3.0\end{array}$ & 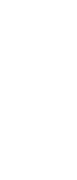 & $\begin{array}{r}0.2 \\
-2.1 \\
-0.8 \\
2.0 \\
7.3 \\
9.3 \\
6.0 \\
3.0\end{array}$ & $\begin{array}{r}-0.9 \\
-1.1 \\
1.4\end{array} \mid$ & $\begin{array}{l}4.0 \\
4.1 \\
4.0 \\
4.7 \\
5.2 \\
4.4 \\
3.9 \\
4.0\end{array}$ & $\begin{array}{l}2 \\
3 \\
2 \\
3 \\
3 \\
2 \\
2 \\
2\end{array}$ & $\begin{array}{l}2.4 \\
4.9 \\
3.3 \\
6.4 \\
6.0 \\
4.3 \\
1.0 \\
0.7\end{array}$ & $\begin{array}{l}2.8 \\
5.5 \\
3.6 \\
7.0 \\
6.6 \\
5.2 \\
1.9 \\
1.2\end{array}$ & $\begin{array}{l}3.0 \\
5.8 \\
3.7 \\
7.5 \\
7.1 \\
5.9 \\
2.0 \\
1.3\end{array}$ & $\begin{array}{l}3.3 \\
6.0 \\
4: 0 \\
7.6 \\
7.4 \\
6.3 \\
2.7 \\
1.2\end{array}$ \\
\hline $\begin{array}{l}14 \\
14 \\
14 \\
14 \\
14 \\
14 \\
14 \\
14\end{array}$ & $\begin{array}{r}0 \\
3 \\
6 \\
9 \\
12 \\
15 \\
18 \\
21\end{array}$ & $\begin{array}{r}1.6 \\
0.8 \\
0.9 \\
5.2 \\
9.0 \\
10.9 \\
5.4 \\
5.2\end{array}$ & $\begin{array}{l}0.4 \\
0.0 \\
0.1 \\
3.5 \\
5.6 \\
6.6 \\
3.7 \\
3.6\end{array}$ & $\begin{array}{r}1.5 \\
0.6 \\
0.9 \\
5.5 \\
9.2 \\
10.5 \\
6.5 \\
5.8\end{array}$ & $\begin{array}{l}0.3 \\
0.1 \\
0.0 \\
3.9 \\
5.9 \\
6.5 \\
4.1 \\
3.9\end{array}$ & $\begin{array}{r}1.7 \\
0.7 \\
0.9 \\
5.7 \\
11.2 \\
11.4 \\
7.6 \\
6.7\end{array}$ & $\begin{array}{r}0.3 \\
-0.1 \\
0.0 \\
3.6 \\
6.4 \\
6.8 \\
4.8 \\
4.6\end{array}$ & $\begin{array}{r}2.3 \\
1.0 \\
1.5 \\
5.5 \\
11.0 \\
12.1 \\
9.3 \\
7.8\end{array}$ & & $\begin{array}{l}4.0 \\
3.0 \\
4.0 \\
5.1 \\
6.2 \\
4.9 \\
4.7 \\
4.7\end{array}$ & $\begin{array}{l}2 \\
2 \\
2 \\
2 \\
2 \\
2 \\
2 \\
2\end{array}$ & $\begin{array}{l}0.7 \\
1.4 \\
3.3 \\
4.6 \\
0.6 \\
0.6 \\
1.7 \\
1.8\end{array}$ & $\begin{array}{l}1.5 \\
1.8 \\
3.8 \\
5.7 \\
1.3 \\
1.2 \\
2.5 \\
2.6\end{array}$ & $\begin{array}{l}1.5 \\
2.0 \\
4.1 \\
6.4\end{array}$ & $\begin{array}{l}2.7 \\
2.7 \\
5.5 \\
.6 .7\end{array}$ \\
\hline $\begin{array}{l}15 \\
15 \\
15 \\
15 \\
15 \\
15 \\
15 \\
15\end{array}$ & $\begin{array}{r}0 \\
3 \\
6 \\
9 \\
12 \\
15 \\
18 \\
21\end{array}$ & $\begin{array}{l}3.6 \\
2.1 \\
0.3 \\
3.8 \\
7.8 \\
7.5 \\
3.1 \\
2.2\end{array}$ & $\begin{array}{r}2.6 \\
1.00 \\
-0.4 \\
1.2 \\
2.6 \\
-3.1 \\
-0.1 \\
-0.9\end{array}$ & $\begin{array}{l}3.9 \\
2.1 \\
0.4 \\
3.7 \\
5.7 \\
6.9 \\
3.2 \\
2.2\end{array}$ & $\begin{array}{l}3.0 \\
1.2 \\
0.4 \\
0.5 \\
1.6 \\
1.8 \\
0.4 \\
1.1\end{array}$ & $\begin{array}{l}4.3 \\
1.9 \\
0.1 \\
3.8 \\
7.0 \\
6.9 \\
3.0 \\
2.1\end{array}$ & $\begin{array}{r}3.3 \\
1.33 \\
-0.44 \\
0.14 \\
1.6 \\
-1.5 \\
-0.6 \\
-1.33\end{array} \mid$ & $\begin{array}{l}4.0 \\
2.1 \\
0.1 \\
4.0 \\
7.1 \\
6.0 \\
3.1 \\
1.0\end{array}$ & & $\begin{array}{l}4 \cdot 3 \\
4 \cdot 2 \\
4 \cdot 2 \\
5 \cdot 2 \\
5 \cdot 3 \\
4 \cdot 5 \\
4 \cdot 2 \\
4 \cdot 2\end{array}$ & $\begin{array}{l}2 \\
2 \\
3 \\
3 \\
3 \\
3 \\
3 \\
3\end{array}$ & $\begin{array}{l}1.6 \\
3.0 \\
5.2 \\
9.9 \\
6.7 \\
5.9 \\
3.6 \\
2.6\end{array}$ & $\begin{array}{r}2.2 \\
3.2 \\
6.8 \\
11.1 \\
7.6 \\
6.9 \\
4.1 \\
3.0\end{array}$ & $\begin{array}{r}2.4 \\
3.3 \\
7.4 \\
11.7 \\
8.1 \\
7.8 \\
4.4 \\
3.1\end{array}$ & $\begin{array}{r}3.2 \\
3.4 \\
8.0 \\
12.1 \\
8.5 \\
8.5 \\
5.2 \\
3.3\end{array}$ \\
\hline $\begin{array}{l}16 \\
16 \\
16 \\
16 \\
16 \\
16 \\
16 \\
16\end{array}$ & $\begin{array}{r}0 \\
3 \\
6 \\
9 \\
12 \\
15 \\
18 \\
21\end{array}$ & $\begin{array}{l}0.9 \\
0.4 \\
0.7 \\
2.3 \\
5.7 \\
9.1 \\
5.5 \\
5.4\end{array}$ & $\begin{array}{r}-1.8 \\
-2.0 \\
=1.09 \\
-0.6 \\
2.8 \\
5.2 \\
3.0 \\
3.0\end{array}$ & $\begin{array}{l}0.7 \\
0.3 \\
0.4 \\
2.3 \\
5.7 \\
9.6 \\
5.8 \\
5.4\end{array}$ & $\begin{array}{l}2.0 \\
2.3 \\
2.3 \\
0.7 \\
2.7 \\
5.1 \\
2.9 \\
2.9\end{array}$ & $\begin{array}{l}0.6 \\
0.2 \\
0.4 \\
2.2 \\
5.9 \\
9.9 \\
6.3 \\
5.7\end{array}$ & $\left|\begin{array}{r}-2.2 \\
=2.3 \\
=2.1 \\
-0.3 \\
2.3 \\
5.1 \\
2.09 \\
2.8\end{array}\right|$ & $\begin{array}{l}0.6 \\
0.2 \\
0.4 \\
2.3 \\
6.3 \\
9.5 \\
7.1 \\
6.1\end{array}$ & & $\begin{array}{l}4 \cdot 2 \\
4 \cdot 1 \\
4 \cdot 1 \\
4 \cdot 3 \\
5 \cdot 3 \\
4 \cdot 6 \\
4 \cdot 2 \\
4 \cdot 1\end{array}$ & $\begin{array}{l}3 \\
3 \\
2 \\
2 \\
2 \\
2 \\
2 \\
2\end{array}$ & $\begin{array}{l}3.7 \\
2.5 \\
2.3 \\
3.8 \\
3.3 \\
3.4 \\
5.4 \\
7.8\end{array}$ & $\begin{array}{l}4.3 \\
3.0 \\
2.8 \\
4.3 \\
4.0 \\
4.3 \\
6.4 \\
8.7\end{array}$ & $\begin{array}{r}4.3 \\
3.0 \\
2.8 \\
4.5 \\
4.4 \\
5.2 \\
8.3 \\
10.3\end{array}$ & $\begin{array}{r}4.6 \\
3.2 \\
2.8 \\
4.5 \\
4.6 \\
5.8 \\
10.8 \\
12.5\end{array}$ \\
\hline $\begin{array}{l}17 \\
17 \\
17 \\
17 \\
17 \\
17 \\
17 \\
17\end{array}$ & $\begin{array}{r}0 \\
3 \\
5 \\
9 \\
12 \\
15 \\
18 \\
21\end{array}$ & $\begin{array}{r}4.0 \\
2.5 \\
-0.8 \\
1.9 \\
5.0 \\
5.0 \\
2.5\end{array}$ & $\begin{array}{r}2.2 \\
0.7 \\
-1.8 \\
-0.2 \\
1.3 \\
1.8 \\
0.1\end{array}$ & $\begin{array}{l}4.0 \\
2.2 \\
1.0 \\
0.7 \\
4.2 \\
4.7 \\
2.6\end{array}$ & $\begin{array}{l}2.0 \\
0.4 \\
2.3 \\
1.3 \\
0.7 \\
1.0 \\
0.2\end{array}$ & $\mid \begin{array}{r}4.1 \\
2.2 \\
-1.3 \\
0.6 \\
4.3 \\
4.6 \\
2.6\end{array}$ & $\left|\begin{array}{r}2.0 \\
0.1 \\
-2.6 \\
-2.5 \\
0.5 \\
-0.8 \\
-0.4\end{array}\right|$ & $\begin{array}{r}4.3 \\
2.0 \\
-1.5 \\
0.6 \\
4.2 \\
4.5 \\
2.6\end{array}$ & & $\begin{array}{l}4 \cdot 1 \\
4 \cdot 1 \\
4 \cdot 1 \\
5 \cdot 0 \\
5 \cdot 3 \\
4.4 \\
4.0\end{array}$ & $\begin{array}{l}2 \\
3 \\
3 \\
3 \\
3 \\
3 \\
3 \\
3\end{array}$ & $\begin{array}{l}4.1 \\
7.2 \\
7.2 \\
6.4 \\
4.7 \\
6.0 \\
6.3 \\
8.0\end{array}$ & $\begin{array}{l}4.8 \\
7.4 \\
8.4 \\
7.2 \\
5.3 \\
6.0 \\
6.7 \\
8.2\end{array}$ & $\begin{array}{l}5.9 \\
8.4 \\
8.7 \\
7.4 \\
6.0 \\
7.5 \\
6.8 \\
8.3\end{array}$ & $\begin{array}{l}6.6 \\
9.6 \\
9.0 \\
7.7 \\
6.2 \\
8.0 \\
8.0 \\
8.7\end{array}$ \\
\hline $\begin{array}{l}18 \\
18 \\
18 \\
18 \\
18 \\
18 \\
18 \\
18\end{array}$ & $\begin{array}{r}0 \\
3 \\
6 \\
9 \\
12 \\
15 \\
18 \\
21\end{array}$ & $\begin{array}{l}0.0 \\
4.8 \\
5.7 \\
3.3 \\
2.8\end{array}$ & $\begin{array}{l}1.7 \\
2.5 \\
1.3 \\
0.6\end{array}$ & $\begin{array}{l}0.3 \\
3.9 \\
5.7 \\
3.4 \\
2.7\end{array}$ & $\left|\begin{array}{r}-1.9 \\
0.8 \\
2.3 \\
0.9 \\
0.3\end{array}\right|$ & $\left|\begin{array}{r}-0.5 \\
4.3 \\
5.9 \\
3.6 \\
2.7\end{array}\right|$ & $\begin{array}{r}-3.4 \\
1.2 \\
1.9 \\
0.6 \\
0.1\end{array} \mid$ & $\left|\begin{array}{r}-0.3 \\
4.8 \\
6.0 \\
4.1 \\
2.7\end{array}\right|$ & & $\begin{array}{l}5.0 \\
5.6 \\
4.2 \\
4.0 \\
4.0\end{array}$ & $\begin{array}{l}3 \\
2 \\
3 \\
2 \\
2 \\
2 \\
2 \\
2\end{array}$ & $\begin{array}{l}8.0 \\
5.7 \\
3.5 \\
3.5 \\
2.5 \\
4.8 \\
4.7 \\
5.8\end{array}$ & $\begin{array}{l}8.4 \\
5.0 \\
3.8 \\
4.0 \\
2.9 \\
5.7 \\
5.2 \\
6.5\end{array}$ & $\begin{array}{l}3.4 \\
6.0 \\
3.7 \\
4.3 \\
3.4 \\
6.7 \\
6.3 \\
7.3\end{array}$ & $\begin{array}{l}8.7 \\
0.2 \\
3.5 \\
4.3 \\
4.6 \\
7.5 \\
8.0 \\
8.3\end{array}$ \\
\hline $\begin{array}{l}19 \\
19 \\
19 \\
19 \\
19 \\
19 \\
19 \\
19\end{array}$ & $\begin{array}{r}0 \\
3 \\
6 \\
9 \\
12 \\
15 \\
18 \\
21\end{array}$ & $\begin{array}{r}2.5 \\
1.0 \\
-0.2 \\
3.4 \\
7.6 \\
7.1 \\
4.5 \\
2.1\end{array}$ & $\begin{array}{r}0.2 \\
-0.5 \\
-1.5 \\
1.04 \\
3.9 \\
3.9 \\
2.6 \\
0.6\end{array}$ & $\begin{array}{l}2.5 \\
0.9 \\
0.5 \\
3.1 \\
7.4 \\
7.0 \\
4.8 \\
2.0\end{array}$ & $\begin{array}{r}0.1 \\
-0.7 \\
-1.7 \\
1.0 \\
3.3 \\
3.6 \\
2.0 \\
0.1\end{array}$ & $\begin{array}{r}2.3 \\
0.7 \\
-0.7 \\
3.3 \\
7.7 \\
8.2 \\
5.0 \\
3.0\end{array}$ & $\begin{array}{r}0.0 \\
-0.8 \\
-1.1 \\
1.4 \\
3.4 \\
3.6 \\
1.09 \\
-0.1\end{array}$ & $\begin{array}{r}2.44 \\
0.6 \\
-0.7 \\
3.4 \\
7.7 \\
8.2 \\
5.4 \\
2.2\end{array}$ & & $\begin{array}{l}4.0 \\
3.9 \\
3.9 \\
4.6 \\
4.7 \\
4.3 \\
3.9 \\
3.8\end{array}$ & $\begin{array}{l}2^{\prime} \\
2 \\
2 \\
2 \\
2 \\
3 \\
3 \\
3\end{array}$ & $\begin{array}{l}8.2 \\
5.6 \\
6.3 \\
3.9 \\
3.4 \\
5.0 \\
4.0 \\
5.5\end{array}$ & $\begin{array}{l}8.4 \\
6.3 \\
7.0 \\
4.0 \\
4.5 \\
6.1 \\
4.7 \\
5.8\end{array}$ & $\begin{array}{r}10.5 \\
7.1 \\
7.9 \\
5.0 \\
4.8 \\
5.9 \\
6.0 \\
6.4\end{array}$ & $\begin{array}{r}11.3 \\
7.3 \\
8.0 \\
5.1 \\
5.3 \\
7.5 \\
7.6 \\
8.2\end{array}$ \\
\hline $\begin{array}{l}20 \\
20 \\
20 \\
20 \\
20 \\
20 \\
20 \\
20\end{array}$ & $\begin{array}{r}0 \\
3 \\
6 \\
9 \\
12 \\
15 \\
18 \\
21\end{array}$ & $\begin{array}{r}0.6 \\
-0.5 \\
-1.2 \\
1.0 \\
4.8 \\
5.2 \\
4.6 \\
4.0\end{array}$ & $\begin{array}{l}0.5 \\
2.1 \\
2.4 \\
2.3 \\
2.0\end{array}$ & $\begin{array}{l}0.3 \\
0.9 \\
1.8 \\
0.0 \\
4.1 \\
5.3 \\
4.7 \\
4.0\end{array}$ & $\left|\begin{array}{r}-1.2 \\
2.5 \\
0.1 \\
0.9 \\
2.0 \\
1.7 \\
1.6\end{array}\right|$ & $\begin{array}{r}0.2 \\
-1.2 \\
-2.1 \\
0.0 \\
4.1 \\
5.5 \\
4.8 \\
4.1\end{array}$ & $\left|\begin{array}{r}-1.4 \\
-0.5 \\
0.9 \\
1.0 \\
1.4 \\
1.1\end{array}\right|$ & $\begin{array}{r}0.0 \\
-1.2 \\
-2.1 \\
0.2 \\
4.2 \\
5.5 \\
4.8 \\
4.1\end{array} \mid$ & -1.8 & $\begin{array}{l}3.9 \\
3.9 \\
3.5 \\
4.7 \\
4.3 \\
4.0 \\
3.9 \\
3.9\end{array}$ & $\begin{array}{l}3 \\
3 \\
3 \\
3 \\
3 \\
3 \\
3 \\
3\end{array}$ & $\begin{array}{l}7.0 \\
7.0 \\
5.6 \\
5.4 \\
5.1 \\
4.9 \\
2.5 \\
3.4\end{array}$ & $\begin{array}{l}7.8 \\
7.7 \\
6.2 \\
5.3 \\
5.8 \\
5.6 \\
3.2 \\
4.3\end{array}$ & $\begin{array}{l}8.2 \\
7.9 \\
6.4 \\
6.1 \\
6.3 \\
6.1 \\
3.5 \\
4.7\end{array}$ & $\begin{array}{l}8.6 \\
0.0 \\
6.8 \\
6.3 \\
6.6 \\
6.5 \\
3.8 \\
4.9\end{array}$ \\
\hline
\end{tabular}


TABLE 10

Table 10. - Three-hour averages of air and water-surface temperatures and wind directions and speed, April 1950-August 1951, Lake Hefner-Continued

STATION 1

THREE-HOURLY AVERAGES

DECEMBER, 1950

\begin{tabular}{|c|c|c|c|c|c|c|c|c|c|c|c|c|c|c|c|}
\hline \multirow{3}{*}{ 总 } & \multirow{3}{*}{ 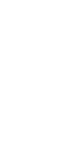 } & \multicolumn{8}{|c|}{ Average air temperature $\left({ }^{\circ} \mathrm{C}\right)$ at indicated height } & \multirow{3}{*}{$\begin{array}{c}\text { Average } \\
\text { water- } \\
\text { surface } \\
\text { tempera- } \\
\text { ture } \\
\left({ }^{\circ} \mathrm{C}\right)\end{array}$} & \multirow{3}{*}{$\begin{array}{c}\text { Average } \\
\text { wind } \\
\text { direction } \\
\text { (coded) }\end{array}$} & \multicolumn{4}{|c|}{$\begin{array}{l}\text { Average wind speed (knots) } \\
\text { at indicated height }\end{array}$} \\
\hline & & \multicolumn{2}{|c|}{$\begin{array}{c}2 \\
\text { meters }\end{array}$} & \multicolumn{2}{|c|}{$\begin{array}{c}4 \\
\text { meters }\end{array}$} & \multicolumn{2}{|c|}{$\begin{array}{c}8 \\
\text { meters }\end{array}$} & \multicolumn{2}{|c|}{$\begin{array}{c}16 \\
\text { meters }\end{array}$} & & & 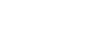 & 4 & 8 & 16 \\
\hline & & $\begin{array}{l}\text { Dry } \\
\text { bulb }\end{array}$ & $\begin{array}{l}\text { Wet } \\
\text { bulb }\end{array}$ & $\begin{array}{l}\text { Dry } \\
\text { bulb }\end{array}$ & $\begin{array}{l}\text { Wet } \\
\text { bulb }\end{array}$ & $\begin{array}{l}\text { Dry } \\
\text { bulb }\end{array}$ & $\begin{array}{l}\text { Wet } \\
\text { bulb }\end{array}$ & $\begin{array}{l}\text { Dry } \\
\text { bulb }\end{array}$ & $\begin{array}{l}\text { Wet } \\
\text { bulb }\end{array}$ & & & meters & meters & meters & meters \\
\hline $\begin{array}{l}21 \\
21 \\
21 \\
21 \\
21 \\
21 \\
21 \\
21\end{array}$ & $\begin{array}{r}0 \\
3 \\
6 \\
9 \\
12 \\
15 \\
18 \\
21\end{array}$ & $\begin{array}{l}4.0 \\
3.8 \\
3.3 \\
7.1 \\
8.9 \\
8.6 \\
4.8 \\
3.9\end{array}$ & $\begin{array}{l}1.9 \\
1.9 \\
1.2 \\
4.0 \\
5.5 \\
5.9 \\
3.8 \\
2.8\end{array}$ & $\begin{array}{l}4.0 \\
3.8 \\
3.4 \\
6.9 \\
8.7 \\
9.2 \\
5.5 \\
3.9\end{array}$ & $\begin{array}{l}1.7 \\
1.5 \\
1.0 \\
3.0 \\
5.5 \\
6.3 \\
4.0 \\
2.7\end{array}$ & $\begin{array}{l}4.1 \\
3.8 \\
3.4 \\
7.1 \\
9.1 \\
9.5 \\
6.1 \\
3.9\end{array}$ & $\begin{array}{l}1.3 \\
1.2 \\
1.0 \\
3.8 \\
5.5 \\
6.2 \\
4.3 \\
2.7\end{array}$ & $\begin{array}{l}4.1 \\
3.8 \\
3.4 \\
7.0 \\
8.9 \\
9.5 \\
6.6 \\
3.9\end{array}$ & & $\begin{array}{l}3.9 \\
3.9 \\
3.9 \\
5.1 \\
5.5 \\
4.5 \\
4.4 \\
4.1\end{array}$ & $\begin{array}{l}2 \\
3 \\
2 \\
2 \\
2 \\
2 \\
2 \\
2\end{array}$ & $\begin{array}{l}2.2 \\
1.0 \\
2.1 \\
2.9 \\
4.9 \\
5.3 \\
3.2 \\
7.2\end{array}$ & $\begin{array}{l}2.6 \\
2.1 \\
2.5 \\
3.4 \\
6.0 \\
6.4 \\
4.2 \\
8.3\end{array}$ & $\begin{array}{l}2.8 \\
2.2 \\
2.8 \\
3.9 \\
6.7 \\
7.5 \\
5.3 \\
9.5\end{array}$ & $\begin{array}{r}2.9 \\
2.3 \\
2.9 \\
4.3 \\
7.3 \\
8.0 \\
6.0 \\
10.7\end{array}$ \\
\hline $\begin{array}{l}22 \\
22 \\
22 \\
22 \\
22 \\
22 \\
22 \\
22\end{array}$ & $\begin{array}{r}0 \\
3 \\
6 \\
9 \\
12 \\
15 \\
18 \\
21\end{array}$ & $\begin{array}{r}2.9 \\
2.8 \\
2.1 \\
6.3 \\
10.8 \\
11.6 \\
7.7 \\
5.8\end{array}$ & $\begin{array}{l}2 \cdot 3 \\
2.2 \\
1.6 \\
5 \cdot 0 \\
7.5 \\
7.8 \\
5.7 \\
4.7\end{array}$ & $\begin{array}{r}3.0 \\
2.8 \\
2.2 \\
6.6 \\
11.8 \\
12.4 \\
8.2 \\
6.1\end{array}$ & $\begin{array}{l}2.4 \\
2.4 \\
1.8 \\
5.0 \\
7.7 \\
7.6 \\
5.9 \\
4.9\end{array}$ & $\begin{array}{r}3.0 \\
2.8 \\
2.1 \\
6.9 \\
12.4 \\
12.8 \\
8.7 \\
6.5\end{array}$ & $\begin{array}{l}2 \cdot 3 \\
2.4 \\
1.8 \\
5.5 \\
7.7 \\
7.8 \\
6.2 \\
5.0\end{array}$ & $\begin{array}{r}3.1 \\
2.9 \\
2.2 \\
7.6 \\
12.4 \\
12.8 \\
9.4 \\
7.3\end{array}$ & & $\begin{array}{l}4.0 \\
4.0 \\
3.9 \\
5.1 \\
5.6 \\
4.7 \\
4.6 \\
4.4\end{array}$ & $\begin{array}{l}2 \\
2 \\
2 \\
2 \\
2 \\
2 \\
2 \\
2\end{array}$ & $\begin{array}{l}7.4 \\
6.0 \\
5.0 \\
5.6 \\
9.0 \\
5.6 \\
6.1 \\
7.2\end{array}$ & $\begin{array}{r}8.4 \\
6.7 \\
5.5 \\
5.5 \\
10.6 \\
6.9 \\
7.9 \\
8.9\end{array}$ & $\begin{array}{r}9.5 \\
7.6 \\
6.2 \\
7.2 \\
12.1 \\
8.0 \\
10.0 \\
11.1\end{array}$ & $\begin{array}{r}10.4 \\
8.3 \\
7.1 \\
7.6 \\
12.5 \\
8.5 \\
11.7 \\
12.9\end{array}$ \\
\hline $\begin{array}{l}23 \\
23 \\
23 \\
23 \\
23 \\
23 \\
23 \\
23\end{array}$ & $\begin{array}{r}0 \\
3 \\
6 \\
9 \\
12 \\
15 \\
18 \\
21\end{array}$ & $\begin{array}{r}5.4 \\
4.4 \\
4.1 \\
7.3 \\
11.5 \\
11.7 \\
8.0 \\
7.0\end{array}$ & $\begin{array}{l}4.5 \\
3.8 \\
3.7 \\
6.1 \\
7.8 \\
7.8 \\
5.9 \\
4.9\end{array}$ & $\begin{array}{r}5.7 \\
4.8 \\
4.7 \\
6.8 \\
11.9 \\
12.2 \\
8.2 \\
7.0\end{array}$ & $\begin{array}{l}4.9 \\
4.5 \\
4.4 \\
6.3 \\
7.8 \\
8.1 \\
5.2 \\
5.0\end{array}$ & $\begin{array}{r}5.7 \\
4.8 \\
4.8 \\
7.7 \\
12.5 \\
12.6 \\
8.8 \\
7.6\end{array}$ & $\begin{array}{l}4 \cdot 9 \\
4 \cdot 7 \\
4 \cdot 5 \\
6 \cdot 5 \\
7 \cdot 9 \\
8 \cdot 2 \\
6 \cdot 3 \\
5 \cdot 2\end{array}$ & $\begin{array}{r}5.8 \\
4.9 \\
4.9 \\
8.3 \\
12.7 \\
12.7 \\
9.0 \\
8.0\end{array}$ & & $\begin{array}{l}4.3 \\
4.3 \\
4.4 \\
5.4 \\
5.8 \\
5.1 \\
4.5 \\
4.5\end{array}$ & $\begin{array}{l}2 \\
2 \\
2 \\
2 \\
2 \\
2 \\
2 \\
2\end{array}$ & $\begin{array}{r}8.9 \\
10.3 \\
13.5 \\
10.5 \\
12.0 \\
8.4 \\
5.7 \\
8.2\end{array}$ & $\begin{array}{r}10.6 \\
11.9 \\
15.4 \\
12.0 \\
14.0 \\
10.0 \\
7.1 \\
9.5\end{array}$ & $\begin{array}{r}12.4 \\
13.5 \\
17.6 \\
13.7 \\
16.0 \\
11.8 \\
8.7 \\
11.3\end{array}$ & $\begin{array}{l}13.8 \\
14.6 \\
18.6 \\
14.5 \\
16.7 \\
12.5 \\
10.1 \\
13.4\end{array}$ \\
\hline $\begin{array}{l}24 \\
24 \\
24 \\
24 \\
24 \\
24 \\
24 \\
24\end{array}$ & $\begin{array}{r}0 \\
3 \\
6 \\
9 \\
12 \\
15 \\
18 \\
21\end{array}$ & $\begin{array}{r}6.1 \\
4.0 \\
2.9 \\
5.7 \\
11.2 \\
14.6 \\
8.3 \\
6.8\end{array}$ & $\begin{array}{l}4.1 \\
2.4 \\
0.8 \\
3.1 \\
6.0 \\
7.7 \\
4.6 \\
4.0\end{array}$ & $\begin{array}{r}6.1 \\
3.9 \\
2.6 \\
6.0 \\
12.0 \\
15.3 \\
9.4 \\
7.4\end{array}$ & $\begin{array}{l}4.1 \\
2.4 \\
0.5 \\
2.8 \\
6.2 \\
7.6 \\
4.7 \\
4.0\end{array}$ & $\begin{array}{r}6.6 \\
4.1 \\
3.0 \\
6.2 \\
13.1 \\
15.5 \\
10.9 \\
8.1\end{array}$ & $\begin{array}{l}4.1 \\
2.1 \\
0.5 \\
2.7 \\
6.5 \\
7.8 \\
5.2 \\
4.0\end{array}$ & $\begin{array}{r}6.9 \\
4.4 \\
2.8 \\
6.2 \\
13.7 \\
15.9 \\
12.3 \\
8.8\end{array}$ & & $\begin{array}{l}4.4 \\
4.0 \\
4.1 \\
5.4 \\
5.4 \\
5.7 \\
5.4 \\
4.8\end{array}$ & $\begin{array}{l}2 \\
2 \\
2 \\
3 \\
3 \\
2 \\
2 \\
2\end{array}$ & $\begin{array}{l}7.3 \\
3.1 \\
4.4 \\
2.5 \\
2.3 \\
1.4 \\
2.4 \\
4.1\end{array}$ & $\begin{array}{l}8.3 \\
3.4 \\
4.3 \\
2.8 \\
2.8 \\
2.3 \\
3.4 \\
5.4\end{array}$ & $\begin{array}{l}9.8 \\
4.2 \\
5.0 \\
3.3 \\
3.4 \\
2.4 \\
4.4 \\
7.0\end{array}$ & $\begin{array}{r}11.6 \\
5.0 \\
3.6 \\
4.0 \\
3.4 \\
5.6 \\
9.0\end{array}$ \\
\hline $\begin{array}{l}25 \\
25 \\
25 \\
25 \\
25 \\
25 \\
25 \\
25\end{array}$ & $\begin{array}{r}0 \\
3 \\
6 \\
9 \\
12 \\
15 \\
18 \\
21\end{array}$ & $\begin{array}{r}6.3 \\
6.2 \\
5.5 \\
10.5 \\
16.9 \\
17.5 \\
13.8 \\
11.9\end{array}$ & $\begin{array}{l}3.7 \\
3.6 \\
3.3 \\
5.5 \\
7.8 \\
8.1 \\
6.6 \\
6.0\end{array}$ & $\begin{array}{r}6.7 \\
5.5 \\
5.6 \\
11.1 \\
17.9 \\
18.2 \\
14.4 \\
12.4\end{array}$ & $\begin{array}{l}3.6 \\
3.5 \\
3.2 \\
5.5 \\
7.6 \\
7.6 \\
5.2 \\
5.6\end{array}$ & $\begin{array}{r}7.2 \\
6.7 \\
5.6 \\
11.8 \\
18.5 \\
18.9 \\
15.0 \\
112.7\end{array}$ & $\begin{array}{l}3.5 \\
3.4 \\
3.1 \\
5.5 \\
7.7 \\
7.7 \\
6.2 \\
5.5\end{array}$ & $\begin{array}{r}7.9 \\
6.7 \\
5.8 \\
12.3 \\
18.8 \\
10.1 \\
15.4 \\
12.9\end{array}$ & & $\begin{array}{l}4.4 \\
4.2 \\
4.3 \\
5.3 \\
6.0 \\
5.0 \\
4.8 \\
4.9\end{array}$ & $\begin{array}{l}2 \\
2 \\
2 \\
2 \\
2 \\
2 \\
2 \\
2\end{array}$ & $\begin{array}{r}6.8 \\
9.0 \\
9.3 \\
11.4 \\
17.8 \\
14.6 \\
13.6 \\
11.7\end{array}$ & $\begin{array}{r}8.4 \\
10.5 \\
11.0 \\
13.3 \\
20.4 \\
17.2 \\
15.9 \\
13.7\end{array}$ & $\begin{array}{l}10.4 \\
12.1 \\
12.8 \\
15.3 \\
23.3 \\
19.7 \\
18.6 \\
15.9\end{array}$ & $\begin{array}{l}12.2 \\
13.4 \\
14.2 \\
16.2 \\
24.4 \\
20.9 \\
20.1 \\
17.4\end{array}$ \\
\hline $\begin{array}{l}26 \\
26 \\
26 \\
26 \\
26 \\
26 \\
26 \\
26\end{array}$ & $\begin{array}{r}0 \\
3 \\
6 \\
9 \\
12 \\
15 \\
18 \\
21\end{array}$ & $\begin{array}{r}8.5 \\
-4.0 \\
-1.0 \\
-0.7 \\
-0.1 \\
-0.6 \\
-2.8 \\
-4.6\end{array}$ & $\begin{array}{r}4.6 \\
-1.6 \\
-1.7 \\
\end{array}$ & $\begin{array}{l}9.1 \\
4.0 \\
1.4 \\
1.7 \\
0.9 \\
1.3 \\
3.5 \\
5.5\end{array}$ & $\begin{array}{r}4.2 \\
-\quad 2.2 \\
-2.4 \\
\end{array}$ & $\begin{array}{r}9.3 \\
-3.5 \\
-2.0 \\
-1.9 \\
-1.2 \\
-1.8 \\
-4.0 \\
-5.9\end{array}$ & $\begin{array}{r}4.1 \\
0.2 \\
-\quad 2.9 \\
\end{array}$ & $\begin{array}{r}9.4 \\
3.1 \\
-2.1 \\
-2.1 \\
-1.5 \\
-2.11 \\
-\quad 4.1 \\
-\quad 6.2\end{array}$ & & $\begin{array}{l}4.7 \\
4.7 \\
4.6 \\
5.4 \\
5.6 \\
4.6 \\
4.2 \\
4.1\end{array}$ & $\begin{array}{l}2 \\
3 \\
3 \\
3 \\
3 \\
3 \\
3 \\
3\end{array}$ & $\begin{array}{l}10.4 \\
19.6 \\
19.3 \\
19.0 \\
18.1 \\
17.2 \\
15.4 \\
13.7\end{array}$ & $\begin{array}{l}12.0 \\
22.6 \\
22.3 \\
21.8 \\
20.8 \\
19.9 \\
17.3 \\
15.7\end{array}$ & $\begin{array}{l}13.9 \\
25.0 \\
24.2 \\
23.5 \\
22.7 \\
21.4 \\
18.1 \\
16.2\end{array}$ & $\begin{array}{l}15.5 \\
26.6 \\
25.4 \\
24.6 \\
23.9 \\
22.2 \\
18.7 \\
16.8\end{array}$ \\
\hline $\begin{array}{l}27 \\
27 \\
27 \\
27 \\
27 \\
27 \\
27 \\
27\end{array}$ & $\begin{array}{r}0 \\
3 \\
6 \\
9 \\
12 \\
15 \\
18 \\
21\end{array}$ & $\begin{array}{l}=6.1 \\
=5.0 \\
=4.9 \\
=2.7 \\
=2.2 \\
=1.2 \\
=3.1 \\
-3.7\end{array}$ & & $\begin{array}{l}6.8 \\
5.8 \\
5.9 \\
5.1 \\
3.3 \\
2.1 \\
3.5 \\
3.9\end{array}$ & & $\begin{array}{l}-7.0 \\
-6.0 \\
-6.1 \\
-5.4 \\
-3.5 \\
-2.4 \\
-3.8 \\
-4.1\end{array}$ & & $\left|\begin{array}{l}-7.3 \\
-5.1 \\
-6.3 \\
-5.3 \\
-3.5 \\
-2.0 \\
-4.0 \\
-4.3\end{array}\right|$ & & $\begin{array}{l}4.0 \\
4.0 \\
4.0 \\
4.7 \\
4.8 \\
4.0 \\
3.8 \\
3.8\end{array}$ & $\begin{array}{l}3 \\
3 \\
3 \\
3 \\
3 \\
3 \\
3 \\
2\end{array}$ & $\begin{array}{r}10.4 \\
10.7 \\
8.6 \\
4.7 \\
5.4 \\
5.6 \\
5.7 \\
4.9\end{array}$ & $\begin{array}{r}12.0 \\
12.2 \\
9.5 \\
5.2 \\
6.0 \\
6.2 \\
6.2 \\
5.4\end{array}$ & $\begin{array}{r}12.4 \\
12.4 \\
9.5 \\
5.5 \\
6.6 \\
6.6 \\
6.3 \\
5.6\end{array}$ & $\begin{array}{r}12.6 \\
12.7 \\
9.6 \\
5.7 \\
6.7 \\
6.7 \\
5.9 \\
5.6\end{array}$ \\
\hline $\begin{array}{l}28 \\
28 \\
28 \\
28 \\
28 \\
28 \\
28 \\
28\end{array}$ & $\begin{array}{r}0 \\
3 \\
6 \\
9 \\
12 \\
15 \\
18 \\
21\end{array}$ & $\begin{array}{r}-4.3 \\
-5.0 \\
-5.0 \\
-5.9 \\
3.2 \\
5.6 \\
2.3 \\
1.0\end{array}$ & $\begin{array}{r} \\
\\
0.4 \\
1.4 \\
-0.1 \\
-1.5\end{array}$ & $\begin{array}{l}4 \cdot 6 \\
5.3 \\
5.3 \\
1.0 \\
3.3 \\
5.5 \\
2.4 \\
1.1\end{array}$ & $\begin{array}{r} \\
0.5 \\
-1.2 \\
-0.3 \\
-1.7\end{array}$ & {$\left[\begin{array}{r}-4.7 \\
-5.3 \\
-5.4 \\
-1.0 \\
3.4 \\
5.8 \\
2.8 \\
0.9\end{array}\right.$} & $\begin{array}{r} \\
0.1 \\
-0.5 \\
-0.3\end{array}$ & $\mid \begin{array}{r}-4.9 \\
-5.4 \\
-5.7 \\
-1.0 \\
3.5 \\
5.0 \\
3.2 \\
0.9\end{array}$ & & $\begin{array}{l}3.8 \\
3.7 \\
3.7 \\
4.7 \\
4.9 \\
3.6 \\
3.2 \\
3.2\end{array}$ & $\begin{array}{l}2 \\
2 \\
2 \\
2 \\
2 \\
2 \\
2 \\
2\end{array}$ & $\begin{array}{l}5.5 \\
6.9 \\
5.4 \\
8.2 \\
7.1 \\
4.2 \\
3.7 \\
5.3\end{array}$ & $\begin{array}{l}6.3 \\
7.6 \\
6.0 \\
8.9 \\
7.3 \\
5.3 \\
4.4 \\
5.9\end{array}$ & $\begin{array}{l}5.9 \\
8.4 \\
6.6 \\
9.7 \\
8.5 \\
5.3 \\
5.8 \\
6.8\end{array}$ & $\begin{array}{r}9.5 \\
6.8 \\
10.9 \\
8.9 \\
6.8 \\
7.1 \\
7.3\end{array}$ \\
\hline $\begin{array}{l}29 \\
29 \\
29 \\
29 \\
29 \\
29 \\
29 \\
29\end{array}$ & $\begin{array}{r}0 \\
3 \\
6 \\
9 \\
12 \\
15 \\
18 \\
21\end{array}$ & $\begin{array}{l}0.2 \\
0.3 \\
0.2 \\
2.2 \\
3.4 \\
3.7 \\
1.5 \\
0.9\end{array}$ & $\mid \begin{array}{r}-2.1 \\
-2.0 \\
-2.0 \\
-0.3 \\
0.0 \\
1.3 \\
1.0 \\
0.9\end{array}$ & $\begin{array}{l}0.0 \\
0.1 \\
0.2 \\
1.9 \\
3.4 \\
3.6 \\
1.8 \\
1.1\end{array}$ & $\begin{array}{r}-2.3 \\
-2.4 \\
-1.0 \\
-0.5 \\
0.0 \\
1.2 \\
1.1 \\
1.1 \\
1.0\end{array}$ & $\begin{array}{l}0.1 \\
1.8 \\
3.4 \\
3.6 \\
1.8 \\
1.1\end{array}$ & $-\begin{array}{r}0.1 \\
0.0 \\
0.8 \\
1.0 \\
1.0\end{array}$ & $\begin{array}{ll}0.1 & 1 \\
0.2 \\
1.8 \\
3.4 \\
3.5 \\
1.6 \\
1.0\end{array}$ & & $\begin{array}{l}3.1 \\
3.1 \\
3.2 \\
3.8 \\
3.7 \\
3.4 \\
3.3 \\
3.3\end{array}$ & $\begin{array}{l}2 \\
2 \\
2 \\
2 \\
3 \\
3 \\
2 \\
2\end{array}$ & $\begin{array}{l}4.6 \\
3.7 \\
2.3 \\
1.3 \\
4.8 \\
4.1 \\
3.4 \\
4.6\end{array}$ & $\begin{array}{l}5.3 \\
4.2 \\
2.8 \\
1.8 \\
5.3 \\
4.6 \\
3.8 \\
5.2\end{array}$ & $\begin{array}{l}5.9 \\
4.6 \\
2.9 \\
2.0 \\
5.7 \\
4.8 \\
4.0 \\
5.6\end{array}$ & $\begin{array}{l}5.2 \\
5.0 \\
3.0 \\
2.4 \\
6.1 \\
5.1 \\
4 \cdot 0 \\
5.7\end{array}$ \\
\hline $\begin{array}{l}30 \\
30 . \\
30 \\
30 \\
30 \\
30 \\
30 \\
30\end{array}$ & $\begin{array}{r}0 \\
3 \\
6 \\
9 \\
12 \\
15 \\
18 \\
21\end{array}$ & & & & & & & & & & $\begin{array}{l}2 \\
2 \\
2 \\
4 \\
4 \\
2 \\
2 \\
2\end{array}$ & $\begin{array}{r}5.7 \\
5.1 \\
6.2 \\
6.0 \\
3.8 \\
2.5 \\
3.9 \\
10.0\end{array}$ & $\begin{array}{r}6.6 \\
5.7 \\
6.7 \\
5.7 \\
3.8 \\
3.0 \\
5.0 \\
11.3\end{array}$ & $\begin{array}{r}7.2 \\
6.1 \\
7.1 \\
6.7 \\
4.8 \\
3.7 \\
5.9 \\
12.6\end{array}$ & $\begin{array}{r}7.6 \\
6.5 \\
7.3 \\
3.0 \\
4.6 \\
4.2 \\
7.2 \\
13.8\end{array}$ \\
\hline $\begin{array}{l}31 \\
31 \\
31 \\
31 \\
31 \\
31 \\
31 \\
31\end{array}$ & $\begin{array}{r}0 \\
3 \\
5 \\
9 \\
12 \\
15 \\
18 \\
21\end{array}$ & $\begin{array}{l}3.0 \\
4.5\end{array}$ & $\begin{array}{l}0.9 \\
2.0\end{array}$ & $\begin{array}{l}2.9 \\
4.5\end{array}$ & $\begin{array}{l}0.8 \\
2.2\end{array}$ & $\begin{array}{l}2.5 \\
3.3\end{array}$ & $\begin{array}{l}0.5 \\
1.9\end{array}$ & $\begin{array}{l}2.9 \\
5.6\end{array}$ & & $\begin{array}{l}3.7 \\
4.4\end{array}$ & $\begin{array}{l}2 \\
2 \\
2 \\
2 \\
2 \\
2 \\
2 \\
2 \\
2\end{array}$ & $\begin{array}{l}12.9 \\
14.6 \\
16.4 \\
19.6 \\
21.9 \\
19.2 \\
19.2 \\
19.8\end{array}$ & $\begin{array}{l}14.6 \\
16.7 \\
18.9 \\
22.6 \\
25.3 \\
22.3 \\
22.1 \\
23.0\end{array}$ & $\begin{array}{l}16.1 \\
18.4 \\
21.1 \\
25.6 \\
29.0 \\
25.3 \\
25.0 \\
25.8\end{array}$ & $\begin{array}{l}17.3 \\
19: 6 \\
22: 0 \\
27: 3 \\
31.3 \\
27.5 \\
26.8 \\
27.7\end{array}$ \\
\hline
\end{tabular}


Table 10. - Three-hour averages of air and water-surface temperatures and wind directions and speed, April 1950-August 1951, Lake Hefner-Continued

THREE-HOURLY AVERAGES

JANUARY, 1951

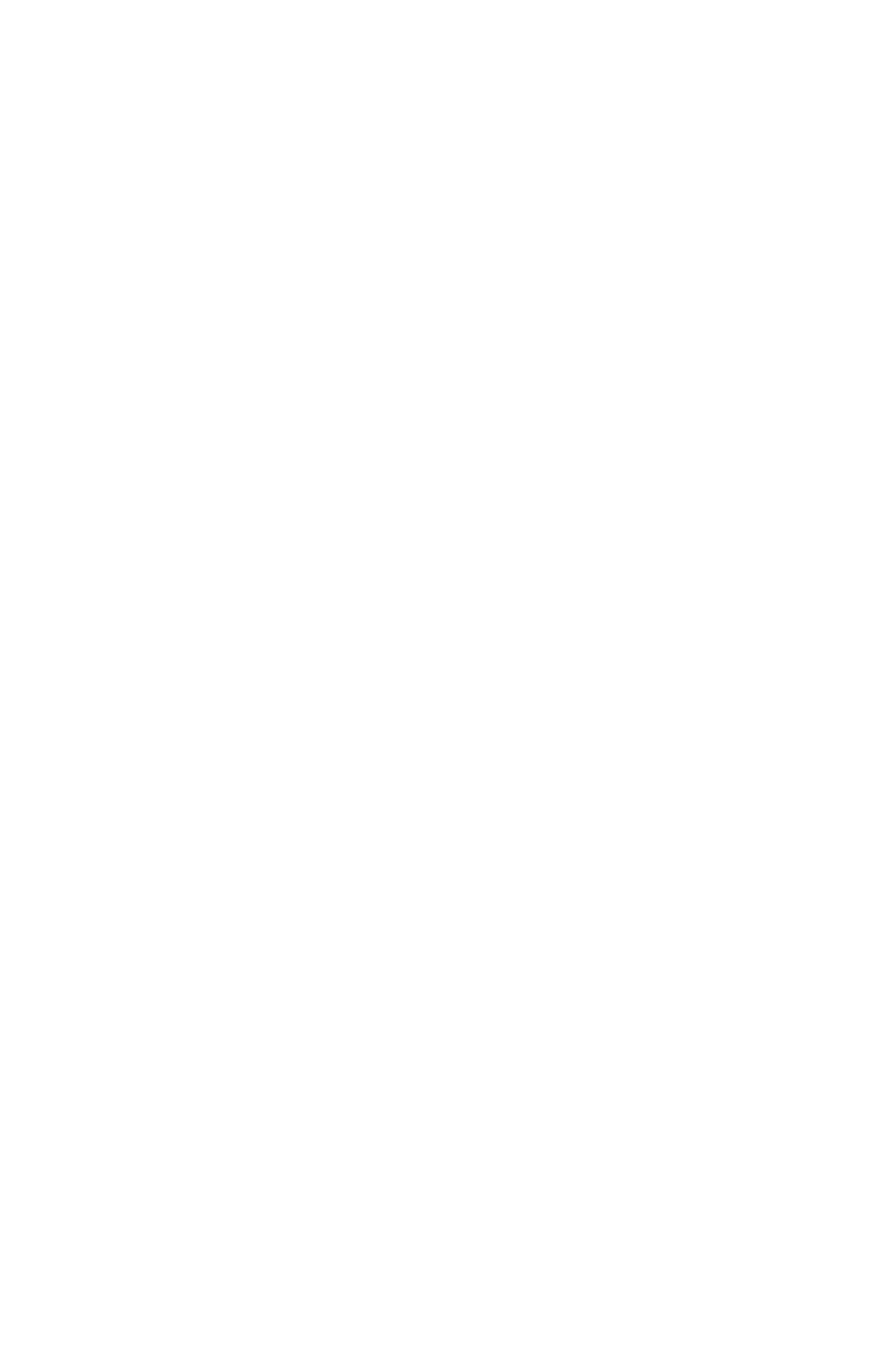


TABLE 10

Table 10. -Three-hour averages of air and water-surface temperatures and wind directions and speed, April 1950-August 1951, Lake Hefner-Continued

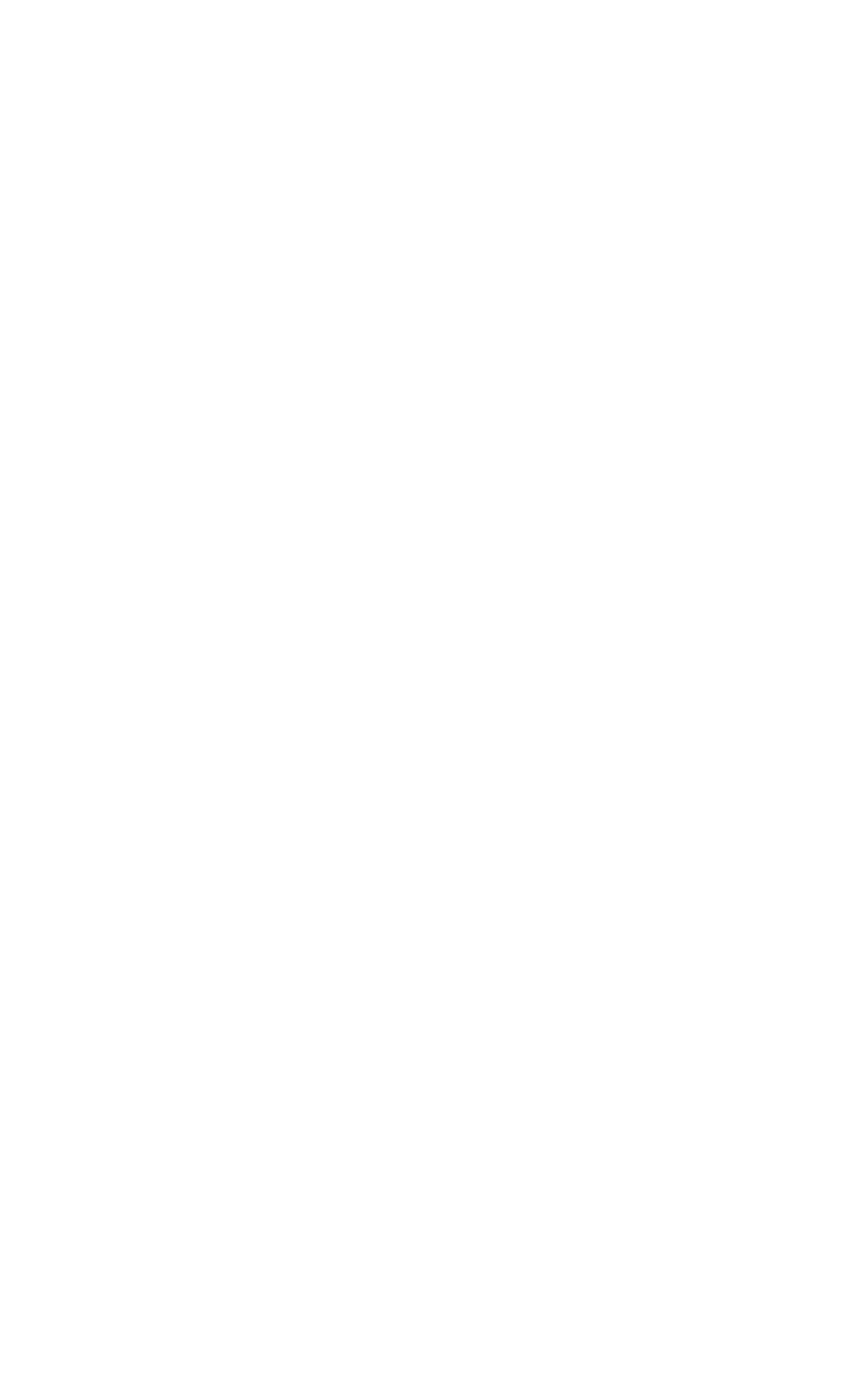


TABLE 10

Table 10. - Three-hour averages of air and water-surface temperatures and wind directions and speed, April 1950-August STATION 1 1951, Lake Hefner-Continued

JANUARY, 1951

\begin{tabular}{|c|c|c|c|c|c|c|c|c|c|c|c|c|c|c|c|}
\hline \multirow{4}{*}{ 宽 } & \multirow{4}{*}{ 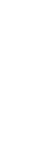 } & \multicolumn{8}{|c|}{ Average air temperature $\left({ }^{\circ} \mathrm{C}\right)$ at indicated height } & \multirow{4}{*}{$\begin{array}{l}\text { Average } \\
\text { water- } \\
\text { surface } \\
\text { tempera- } \\
\text { ture } \\
\left({ }^{\circ} \mathrm{C}\right)\end{array}$} & \multirow{4}{*}{$\begin{array}{c}\text { Average } \\
\text { wind } \\
\text { direction } \\
\text { (coded) }\end{array}$} & \multirow{2}{*}{\multicolumn{4}{|c|}{$\begin{array}{l}\text { Average wind speed (knots) } \\
\text { at indicated height }\end{array}$}} \\
\hline & & \multirow{2}{*}{\multicolumn{2}{|c|}{$\begin{array}{c}2 \\
\text { meters }\end{array}$}} & \multirow{2}{*}{\multicolumn{2}{|c|}{$\begin{array}{c}4 \\
\text { meters }\end{array}$}} & \multirow{2}{*}{\multicolumn{2}{|c|}{$\begin{array}{c}8 \\
\text { meters }\end{array}$}} & \multirow{2}{*}{\multicolumn{2}{|c|}{$\begin{array}{c}16 \\
\text { meters }\end{array}$}} & & & & & & \\
\hline & & & & & & & & & & & & 2 & 4 & 8 & 16 \\
\hline & & $\begin{array}{l}\text { Dry } \\
\text { bulb }\end{array}$ & $\begin{array}{l}\text { Wet } \\
\text { bulb }\end{array}$ & $\begin{array}{l}\text { Dry } \\
\text { bulb }\end{array}$ & $\begin{array}{l}\text { Wet } \\
\text { bulb }\end{array}$ & $\begin{array}{l}\text { Dry } \\
\text { bulb }\end{array}$ & $\begin{array}{l}\text { Wet } \\
\text { bulb }\end{array}$ & $\begin{array}{l}\text { Dry } \\
\text { bulb }\end{array}$ & $\begin{array}{l}\text { Wet } \\
\text { bulb }\end{array}$ & & & meters & meters & meters & meters \\
\hline $\begin{array}{l}21 \\
21 \\
21 \\
21 \\
21 \\
21 \\
21 \\
21\end{array}$ & $\begin{array}{r}0 \\
3 \\
6 \\
9 \\
12 \\
15 \\
18 \\
21\end{array}$ & $\begin{array}{r}=3.7 \\
=5.6 \\
=6.4 \\
=4.6 \\
=0.4 \\
2.8 \\
1.1 \\
0.0\end{array}$ & $\begin{array}{r} \\
-0.0 \\
0.00 \\
-1.1\end{array}$ & $\begin{array}{l}4.0 \\
5.9 \\
6.9 \\
5.3 \\
0.7 \\
2.7 \\
0.9 \\
0.2\end{array}$ & $\begin{array}{r} \\
-1.0 \\
-0.1\end{array}$ & $\begin{array}{r}-4.2 \\
=6.2 \\
-7.0 \\
-5.44 \\
-0.8 \\
2.6 \\
0.0 \\
-0.3\end{array} \mid$ & & $\begin{array}{l}-4.5 \\
-6.4 \\
-7.1 \\
-5.4 \\
-1.0 \\
2.6 \\
0.9 \\
-0.5\end{array}$ & $\begin{array}{l}-0.1 \\
=0.8\end{array}$ & $\begin{array}{l}3.7 \\
3.5 \\
3.3 \\
4.0 \\
5.0 \\
3.9 \\
3.5 \\
3.5\end{array}$ & $\begin{array}{l}3 \\
3 \\
3 \\
3 \\
4 \\
2 \\
2 \\
2\end{array}$ & $\begin{array}{l}9.5 \\
8.0 \\
6.7 \\
3.7 \\
1.4 \\
4.6 \\
6.5 \\
9.6\end{array}$ & $\begin{array}{r}10.3 \\
9.0 \\
7.5 \\
4.1 \\
1.7 \\
5.5 \\
7.3 \\
10.7\end{array}$ & $\begin{array}{r}11.4 \\
9.7 \\
8.1 \\
4.5 \\
1.8 \\
6.0 \\
7.9 \\
11.6\end{array}$ & $\begin{array}{r}11.7 \\
10.0 \\
8.3 \\
4.7 \\
2.6 \\
7.2 \\
8.6 \\
12.0\end{array}$ \\
\hline $\begin{array}{l}22 \\
22 \\
22 \\
22 \\
22 \\
22 \\
22 \\
22\end{array}$ & $\begin{array}{r}0 \\
3 \\
6 \\
9 \\
12 \\
15 \\
18 \\
21\end{array}$ & $\begin{array}{l}7.6 \\
9.7 \\
8.2 \\
7.0\end{array}$ & $\begin{array}{l}3.0 \\
4.7 \\
3.9 \\
3.5\end{array}$ & $\begin{array}{r}7.8 \\
10.3 \\
8.5 \\
7.1\end{array}$ & $\begin{array}{l}2.7 \\
4.1 \\
3.5 \\
3.0\end{array}$ & $\begin{array}{r}8.1 \\
10.6 \\
8.7 \\
7.2\end{array}$ & $\begin{array}{l}2.7 \\
4.0 \\
3.3 \\
3.0\end{array}$ & $\begin{array}{r}8.5 \\
10.6 \\
8.8 \\
7.2\end{array}$ & & $\begin{array}{l}4.9 \\
3.9 \\
3.8 \\
3.6\end{array}$ & $\begin{array}{l}2 \\
2 \\
2 \\
2 \\
2 \\
2 \\
2 \\
2\end{array}$ & $\begin{array}{l}12.1 \\
15.9 \\
17.0 \\
21.0 \\
18.9 \\
15.3 \\
14.0 \\
15.3\end{array}$ & $\begin{array}{l}13.5 \\
18.0 \\
19.4 \\
24.3 \\
21.8 \\
17.8 \\
16.0 \\
17.3\end{array}$ & $\begin{array}{l}14.7 \\
19.8 \\
21.3 \\
27.0 \\
24.8 \\
20.2 \\
10.2 \\
19.6\end{array}$ & $\begin{array}{l}15.4 \\
20.6 \\
22.4 \\
28.9 \\
26.3 \\
21.6 \\
19.5 \\
20.9\end{array}$ \\
\hline $\begin{array}{l}23 \\
23 \\
23 \\
23 \\
23 \\
23 \\
23 \\
23\end{array}$ & $\begin{array}{r}0 \\
3 \\
6 \\
9 \\
12 \\
15 \\
18 \\
21\end{array}$ & $\begin{array}{l}3.8 \\
1.2 \\
1.4 \\
4.0 \\
6.8 \\
8.2 \\
4.0 \\
2.0\end{array}$ & $\begin{array}{r}1.8 \\
-0.2 \\
0.1 \\
2.4 \\
3.0 \\
3.3 \\
1.44 \\
0.0\end{array}$ & $\begin{array}{l}3.8 \\
1.1 \\
1.2 \\
4.2 \\
7.1 \\
8.8 \\
4.6 \\
2.3\end{array}$ & $\begin{array}{r}1.2 \\
-0.8 \\
-0.2 \\
2.5 \\
2.7 \\
2.9 \\
0.8 \\
-0.3\end{array}$ & $\begin{array}{l}3.6 \\
1.0 \\
1.2 \\
4.8 \\
7.4 \\
9.1 \\
5.7 \\
2.7\end{array}$ & $\begin{array}{r}0.9 \\
-1.0 \\
-0.2 \\
2.3 \\
2.7 \\
2.09 \\
0.7 \\
-0.5\end{array}$ & $\begin{array}{l}3.4 \\
0,5 \\
1.2 \\
4: 3 \\
7.5 \\
9.1 \\
6.5 \\
4.1\end{array}$ & & $\begin{array}{r}3.2 \\
3.2 \\
3.3 \\
4.7 \\
-4.6 \\
3.8 \\
2.9 \\
3.0\end{array}$ & $\begin{array}{l}3 \\
3 \\
3 \\
3 \\
3 \\
3 \\
2 \\
2\end{array}$ & $\begin{array}{r}8.7 \\
10.8 \\
10.1 \\
11.2 \\
8.9 \\
6.7 \\
2.0 \\
2.6\end{array}$ & $\begin{array}{r}10.5 \\
11.4 \\
12.0 \\
13.0 \\
10.7 \\
8.5 \\
2.7 \\
3.0\end{array}$ & $\begin{array}{l}11.3 \\
13.7 \\
12.7 \\
14.7 \\
12.1 \\
9.7 \\
3.4 \\
3.8\end{array}$ & $\begin{array}{r}12.6 \\
14.3 \\
13.8 \\
15.6 \\
13.4 \\
10.8 \\
3.4 \\
4.9\end{array}$ \\
\hline $\begin{array}{l}24 \\
24 \\
24 \\
24 \\
24 \\
24 \\
24 \\
24\end{array}$ & $\begin{array}{r}0 \\
3 \\
6 \\
9 \\
12 \\
15 \\
18 \\
21\end{array}$ & $\begin{array}{l}1.7 \\
1.8 \\
2.2 \\
5.1 \\
9.2 \\
8.1 \\
3.6 \\
1.0\end{array}$ & $\begin{array}{r}-0.7 \\
-0.5 \\
-0.02 \\
1.7 \\
3.7 \\
3.12 \\
0.8 \\
-0.8\end{array}$ & $\begin{array}{l}1.6 \\
1.9 \\
2.3 \\
5.4 \\
9.6 \\
8.3 \\
3.7 \\
1.1\end{array}$ & $\begin{array}{r}-1.0 \\
-0.8 \\
-0.4 \\
1.5 \\
3.5 \\
3.0 \\
0.4 \\
-1.1\end{array}$ & $\begin{array}{r}1.8 \\
1.9 \\
2.3 \\
5.6 \\
10.1 \\
5.5 \\
3.6 \\
0.9\end{array}$ & $\begin{array}{r}-0.9 \\
-0.9 \\
-0.4 \\
1.5 \\
3.8 \\
2.09 \\
0.03 \\
-1.4\end{array}$ & $\begin{array}{r}2.0 \\
2.6 \\
2.4 \\
5.8 \\
10.3 \\
8.4 \\
3.6 \\
0.8\end{array}$ & & $\begin{array}{l}3.0 \\
3.0 \\
3.1 \\
4.6 \\
5.0 \\
4.0 \\
3.4 \\
3.3\end{array}$ & $\begin{array}{l}2 \\
2 \\
2 \\
2 \\
2 \\
3 \\
3 \\
3\end{array}$ & $\begin{array}{r}2.7 \\
4.2 \\
3.6 \\
8.7 \\
13.8 \\
14.0 \\
6.5 \\
5.4\end{array}$ & $\begin{array}{r}3.1 \\
4.8 \\
4.0 \\
9.5 \\
14.6 \\
15.1 \\
7.4 \\
6.2\end{array}$ & $\begin{array}{r}3.7 \\
5.8 \\
4.6 \\
11.3 \\
17.3 \\
18.4 \\
3.2 \\
5.5\end{array}$ & $\begin{array}{r}4.9 \\
7.8 \\
5.3 \\
11.9 \\
17.2 \\
19.8 \\
9.2 \\
7.0\end{array}$ \\
\hline $\begin{array}{l}25 \\
25 \\
25 \\
25 \\
25 \\
25 \\
25 \\
25\end{array}$ & $\begin{array}{r}0 \\
3 \\
6 \\
9 \\
12 \\
15 \\
18 \\
21\end{array}$ & $\begin{array}{r}0.0 \\
0.1 \\
-0.2 \\
1.5 \\
5.4 \\
7.3 \\
4.3 \\
3.3\end{array}$ & $\mid \begin{array}{r}-2.1 \\
=2.1 \\
-2.0 \\
-0.9 \\
1.44 \\
2.5 \\
1.2 \\
0.3\end{array}$ & $\begin{array}{l}0.3 \\
0.0 \\
0.5 \\
1.7 \\
5.5 \\
7.5 \\
4.4 \\
3.3\end{array}$ & $\begin{array}{r}-2.4 \\
=-2.4 \\
-2.2 \\
-1.4 \\
1.2 \\
2.1 \\
0.8 \\
0.0\end{array}$ & $\left|\begin{array}{r}-0.5 \\
-0.2 \\
-0.6 \\
1.5 \\
5.7 \\
7.5 \\
4.5 \\
3.2\end{array}\right|$ & $\begin{array}{r}-2.7 \\
-2.55 \\
-2.2 \\
-1.55 \\
1.00 \\
2.00 \\
0.04 \\
-0.2\end{array}$ & $\left|\begin{array}{r}-0.5 \\
-0.3 \\
-0.5 \\
1.5 \\
5.5 \\
7.5 \\
4.8 \\
3.2\end{array}\right|$ & & $\begin{array}{l}3.3 \\
3.2 \\
3.2 \\
4.5 \\
4.9 \\
4.0 \\
3.6 \\
3.6\end{array}$ & $\begin{array}{l}3 \\
2 \\
2 \\
2 \\
2 \\
2 \\
2 \\
2\end{array}$ & $\begin{array}{r}7.8 \\
4.2 \\
2.3 \\
0.3 \\
10.6 \\
10.5 \\
5.1 \\
10.0\end{array}$ & $\begin{array}{r}8.2 \\
4.5 \\
2.5 \\
10.5 \\
12.2 \\
12.2 \\
6.2 \\
12.4\end{array}$ & $\begin{array}{r}9.5 \\
4.7 \\
2.7 \\
11.6 \\
13.6 \\
13.9 \\
7.5 \\
13.9\end{array}$ & $\begin{array}{r}9.4 \\
4.9 \\
2.8 \\
21: 9 \\
14: 1 \\
14: 6 \\
9: 0 \\
25: 1\end{array}$ \\
\hline $\begin{array}{l}26 \\
26 \\
26 \\
26 \\
26 \\
26 \\
26 \\
26\end{array}$ & $\begin{array}{r}0 \\
3 \\
6 \\
9 \\
12 \\
15 \\
18 \\
21\end{array}$ & $\begin{array}{r}2.4 \\
2.5 \\
1.9 \\
7.8 \\
13.7 \\
16.5 \\
13.4 \\
14.0\end{array}$ & $\begin{array}{r}-0.1 \\
-0.13 \\
-0.6 \\
3.5 \\
6.6 \\
8.0 \\
7.4 \\
8.2\end{array}$ & $\begin{array}{r}2.4 \\
2.4 \\
1.9 \\
7.6 \\
14.4 \\
17.4 \\
14.3 \\
14.5\end{array}$ & $\begin{array}{r}-0.6 \\
-0.8 \\
-0.9 \\
3.1 \\
6.8 \\
8.2 \\
7.6 \\
8.4\end{array}$ & $\begin{array}{r}2.3 \\
2.3 \\
1.8 \\
8.02 \\
25.1 \\
17.7 \\
15.1 \\
15.0\end{array}$ & $\begin{array}{r}-0.8 \\
-\quad 0.8 \\
-1.0 \\
3.1 \\
6.9 \\
8.2 \\
7.8 \\
8.5\end{array}$ & $\begin{array}{r}2.3 \\
2.2 \\
1.7 \\
8.5 \\
15.6 \\
18.3 \\
15.8 \\
15.6\end{array}$ & & $\begin{array}{l}3.4 \\
3.2 \\
3.3 \\
4.6 \\
5.2 \\
4.2 \\
4.0\end{array}$ & $\begin{array}{l}2 \\
2 \\
2 \\
2 \\
2 \\
2 \\
2 \\
2\end{array}$ & $\begin{array}{r}12.6 \\
8.7 \\
10.0 \\
15.6 \\
15.4 \\
18.7 \\
14.5 \\
19.5\end{array}$ & $\begin{array}{r}14.2 \\
9.9 \\
12.4 \\
18.0 \\
18.2 \\
21.9 \\
17.2 \\
22.6\end{array}$ & $\begin{array}{l}16.0 \\
10.8 \\
13.8 \\
20.6 \\
21.0 \\
25.5 \\
20.4 \\
26.3\end{array}$ & $\begin{array}{l}17 \cdot 1 \\
11.6 \\
14: 5 \\
21.7 \\
22.2 \\
27.1 \\
22.5 \\
28.3\end{array}$ \\
\hline $\begin{array}{l}27 \\
27 \\
27 \\
27 \\
27 \\
27 \\
27 \\
27\end{array}$ & $\begin{array}{r}0 \\
3 \\
6 \\
9 \\
12 \\
15 \\
18 \\
21\end{array}$ & & & & & & & & & & $\begin{array}{l}2 \\
3 \\
3 \\
3 \\
3 \\
3 \\
3 \\
3 \\
3\end{array}$ & $\begin{array}{l}16.7 \\
13.4 \\
16.5 \\
18.4 \\
16.6 \\
14.7 \\
14.0 \\
14.4\end{array}$ & $\begin{array}{l}19.1 \\
15.8 \\
17.9 \\
20.3 \\
18.5 \\
16.4 \\
15.6 \\
16.2\end{array}$ & $\begin{array}{l}22.0 \\
17.4 \\
20.7 \\
23.2 \\
21.1 \\
18.4 \\
17.3 \\
18.1\end{array}$ & $\begin{array}{l}23.3 \\
18 \cdot 3 \\
21.8 \\
24 \cdot 3 \\
21.8 \\
19.1 \\
18.1 \\
18.6\end{array}$ \\
\hline $\begin{array}{l}28 \\
28 \\
28 \\
28 \\
28 \\
28 \\
28 \\
28\end{array}$ & $\begin{array}{r}0 \\
3 \\
6 \\
9 \\
12 \\
15 \\
18 \\
21\end{array}$ & & & & & & & & & & $\begin{array}{l}3 \\
3 \\
3 \\
3 \\
3 \\
3 \\
3 \\
3\end{array}$ & $\begin{array}{l}17.0 \\
17.0 \\
15.6 \\
16.3 \\
14.9 \\
15.7 \\
14.8 \\
15.6\end{array}$ & $\begin{array}{l}18.9 \\
19.2 \\
17.5 \\
18.5 \\
17.0 \\
18.0 \\
17.0 \\
18.1\end{array}$ & $\begin{array}{l}21.6 \\
21.5 \\
19.5 \\
20.6 \\
18.8 \\
19.8 \\
18.4 \\
20.0\end{array}$ & $\begin{array}{l}22.4 \\
22.3 \\
20.0 \\
21.3 \\
19.5 \\
20.5 \\
19.0 \\
20.7\end{array}$ \\
\hline $\begin{array}{l}29 \\
29 \\
29 \\
29 \\
29 \\
29 \\
29 \\
29\end{array}$ & $\begin{array}{r}0 \\
3 \\
6 \\
9 \\
12 \\
15 \\
18 \\
21\end{array}$ & & & & & & & & & & $\begin{array}{l}3 \\
3 \\
3 \\
3 \\
3 \\
3 \\
3 \\
3 \\
3\end{array}$ & $\begin{array}{l}15.2 \\
15.3 \\
16.5 \\
15.0 \\
13.3 \\
13.4 \\
12.2 \\
13.3\end{array}$ & $\begin{array}{l}17.7 \\
17.6 \\
19.0 \\
17.03 \\
15.5 \\
16.0 \\
14.3 \\
15.3\end{array}$ & $\begin{array}{l}19.0 \\
19.2 \\
20.9 \\
18.7 \\
16.5 \\
17.1 \\
15.1 \\
15.8\end{array}$ & $\begin{array}{l}19 \cdot 7 \\
19: 7 \\
21.5 \\
19.3 \\
17: 0 \\
17: 3 \\
15: 3 \\
15.1\end{array}$ \\
\hline $\begin{array}{l}30 \\
30 \\
30 \\
30 \\
30 \\
30 \\
30 \\
30\end{array}$ & $\begin{array}{r}0 \\
3 \\
6 \\
9 \\
12 \\
15 \\
18 \\
21\end{array}$ & $\begin{array}{l}-8.6 \\
=7.6 \\
=9.2 \\
-10.5\end{array}$ & & $\begin{array}{r}9.8 \\
8.7 \\
9.7 \\
11.1\end{array}$ & & $\left|\begin{array}{l}-10.0 \\
-9.1 \\
-10.2 \\
-11.4\end{array}\right|$ & & 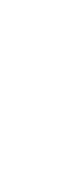 & & $\begin{array}{l}2.7 \\
1.8 \\
1.4 \\
1.1\end{array}$ & $\begin{array}{l}3 \\
3 \\
3 \\
3 \\
3 \\
3 \\
3 \\
3\end{array}$ & $\begin{array}{r}13.8 \\
12.6 \\
11.5 \\
9.0 \\
10.2 \\
9.8 \\
111.5 \\
11.9\end{array}$ & $\begin{array}{l}15.9 \\
14.7 \\
13.2 \\
10.2 \\
11.3 \\
10.8 \\
13.0 \\
13.2\end{array}$ & $\begin{array}{l}16.5 \\
15.5 \\
13.7 \\
11.0 \\
12.0 \\
11.4 \\
13.8 \\
14.3\end{array}$ & $\begin{array}{l}16.8 \\
15.7 \\
14: 0 \\
11.2 \\
12.7 \\
11.8 \\
14.0 \\
14.7\end{array}$ \\
\hline $\begin{array}{l}31 \\
31 \\
31 \\
31 \\
31 \\
31 \\
31 \\
31\end{array}$ & $\begin{array}{r}0 \\
3 \\
6 \\
9 \\
12 \\
15 \\
18 \\
21\end{array}$ & $\begin{array}{l}-10.9 \\
-11 \\
-11.1 \\
-11.2 \\
=9.1 \\
=8.3 \\
=9.1 \\
-10.7\end{array}$ & & $\begin{array}{r}11.7 \\
11.7 \\
11.9 \\
11.5 \\
9.9 \\
8.9 \\
9.8 \\
11.5\end{array}$ & & $\left|\begin{array}{l}-12.0 \\
-12.0 \\
-12.4 \\
-11.4 \\
-10.6 \\
-9.9 \\
-10.4 \\
-11.9\end{array}\right|$ & & $\begin{array}{l}-12.3 \\
-12.4 \\
-12.6 \\
-12.6 \\
-10.8 \\
-9.9 .7 \\
-10.6 \\
-12.3\end{array}$ & & $\begin{array}{l}0.8 \\
0.4 \\
0.5 \\
1.0 \\
1.2 \\
0.6 \\
0.3 \\
0.1\end{array}$ & $\begin{array}{l}3 \\
3 \\
3 \\
3 \\
3 \\
3 \\
3 \\
3\end{array}$ & $\begin{array}{l}11.5 \\
11.6 \\
13.0 \\
13.7 \\
15.6 \\
16.2 \\
17.1 \\
15.0\end{array}$ & $\begin{array}{l}12.7 \\
12.8 \\
14.3 \\
15.0 \\
17.9 \\
18.0 \\
19.2 \\
16.9\end{array}$ & $\begin{array}{l}13.6 \\
13.9 \\
16.1 \\
16.9 \\
10.8 \\
20.5 \\
21.9 \\
.19 .0\end{array}$ & $\begin{array}{l}13.9 \\
14.3 \\
16: 4 \\
17.4 \\
20.3 \\
21.3 \\
22.5 \\
19.5\end{array}$ \\
\hline
\end{tabular}


TABLE 10

Table 10. - Three-hour averages of air and water-surface temperatures and wind directions and speed, April 1950-August STATION 2 THREE-HOURLY AVERAGES

FEBRUARY, 1951

\begin{tabular}{|c|c|c|c|c|c|c|c|c|c|c|c|c|c|c|c|}
\hline \multirow{3}{*}{ 害 } & \multirow{3}{*}{ 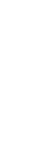 } & \multicolumn{8}{|c|}{ Average air temperature $\left({ }^{\circ} \mathrm{C}\right)$ at indicated height } & \multirow{3}{*}{$\begin{array}{c}\text { Average } \\
\text { water- } \\
\text { surface } \\
\text { tempera- } \\
\text { ture } \\
\left({ }^{\circ} \mathrm{C}\right)\end{array}$} & \multirow{3}{*}{$\begin{array}{c}\text { Average } \\
\text { wind } \\
\text { direction } \\
\text { (coded) }\end{array}$} & \multirow{2}{*}{\multicolumn{4}{|c|}{$\begin{array}{l}\text { Average wind speed (knots) } \\
\text { at indicated height }\end{array}$}} \\
\hline & & \multicolumn{2}{|c|}{$\begin{array}{c}2 \\
\text { meters }\end{array}$} & \multicolumn{2}{|c|}{$\begin{array}{c}4 \\
\text { meters }\end{array}$} & \multicolumn{2}{|c|}{$\begin{array}{c}8 \\
\text { meters }\end{array}$} & \multicolumn{2}{|c|}{$\begin{array}{c}16 \\
\text { meters }\end{array}$} & & & & & & \\
\hline & & $\begin{array}{l}\text { Dry } \\
\text { bulb }\end{array}$ & $\begin{array}{l}\text { Wet } \\
\text { bulb }\end{array}$ & $\begin{array}{l}\text { Dry } \\
\text { bulb }\end{array}$ & $\begin{array}{l}\text { Wet } \\
\text { bulb }\end{array}$ & $\begin{array}{l}\text { Dry } \\
\text { bulb }\end{array}$ & $\begin{array}{l}\text { Wet } \\
\text { bulb }\end{array}$ & $\begin{array}{l}\text { Dry } \\
\text { bulb }\end{array}$ & $\begin{array}{l}\text { Wet } \\
\text { bulb }\end{array}$ & & & meters & meters & $\mid \begin{array}{c}8 \\
\text { meters }\end{array}$ & $\begin{array}{c}16 \\
\text { meters }\end{array}$ \\
\hline $\begin{array}{l}1 \\
1 \\
1 \\
1 \\
1 \\
1 \\
1 \\
1\end{array}$ & $\begin{array}{r}0 \\
3 \\
6 \\
9 \\
12 \\
15 \\
18 \\
21\end{array}$ & $\begin{array}{l}-12.0 \\
-13.8 \\
-15.8 \\
-14.44 \\
-11.44 \\
=7.7 \\
=7.9 \\
-10.1\end{array}$ & & $\begin{array}{r}13.0 \\
14.9 \\
16.5 \\
15.2 \\
11.5 \\
8.0 \\
8.3 \\
10.4\end{array}$ & & $\begin{array}{r}-13.44 \\
-15.3 \\
49.9 \\
-15.5 \\
-11.5 \\
-8.3 \\
-8.3 \\
-10.5\end{array}$ & & 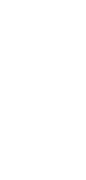 & & $\begin{array}{l}0.4 \\
0.7 \\
0.2\end{array}$ & $\begin{array}{l}3 \\
3 \\
3 \\
3 \\
3 \\
3 \\
3 \\
2\end{array}$ & $\begin{array}{l}14.3 \\
12.6 \\
13.3 \\
13.3 \\
12.6 \\
9.3 \\
3.9 \\
5.7\end{array}$ & $\begin{array}{l}17.9 \\
14.9 \\
14.8 \\
15.6 \\
12.8 \\
9.8 \\
4.3 \\
7.2\end{array}$ & $\begin{array}{r}18.3 \\
16.1 \\
17.5 \\
16.9 \\
14.2 \\
11.1 \\
4.5 \\
7.8\end{array}$ & $\begin{array}{r}19.0 \\
8.8 \\
4.4 \\
8.4\end{array}$ \\
\hline $\begin{array}{l}2 \\
2 \\
2 \\
2 \\
2 \\
2 \\
2 \\
2\end{array}$ & $\begin{array}{r}0 \\
3 \\
6 \\
9 \\
12 \\
15 \\
18 \\
21\end{array}$ & $\begin{array}{l}-11.1 \\
-11.4 \\
-10.4 \\
=5.1 \\
-0.8 \\
0.8 \\
-1.1 \\
-2.4\end{array}$ & & $\begin{array}{rl}11 & 1.4 \\
11 & .6 \\
10.6 \\
5.1 \\
0.8 \\
11.0 \\
1.1 \\
2.6\end{array}$ & & 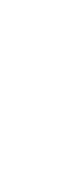 & & 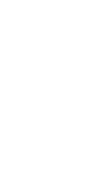 & & $\begin{array}{l}0.6 \\
0.9 \\
0.7 \\
0.1 \\
0.1\end{array}$ & $\begin{array}{l}2 \\
2 \\
2 \\
2 \\
2 \\
2 \\
2 \\
2\end{array}$ & $\begin{array}{r}7.7 \\
9.0 . \\
10.6 \\
15.2 \\
14.6 \\
10.8 \\
9.1 \\
13.2\end{array}$ & $\begin{array}{r}8.2 \\
10.0 \\
11.4 \\
16.7 \\
16.2 \\
12.1 \\
10.3 \\
14.9\end{array}$ & $\begin{array}{r}9.0 \\
10.9 \\
12.4 \\
18.3 \\
17.9 \\
13.6 \\
11.7 \\
16.4\end{array}$ & $\begin{array}{l}10.2 \\
11.7 \\
13.4 \\
18.8 \\
18.2 \\
14.1 \\
13.0 \\
17.3\end{array}$ \\
\hline $\begin{array}{l}3 \\
3 \\
3 \\
3 \\
3 \\
3 \\
3 \\
3\end{array}$ & $\begin{array}{r}0 \\
3 \\
6 \\
9 \\
12 \\
15 \\
18 \\
21\end{array}$ & $\begin{array}{r}-4.1 \\
=-4.8 \\
=5.0 \\
-0.6 \\
3.7 \\
4.5 \\
1.0 \\
-0.8\end{array}$ & $\begin{array}{r} \\
0.2 \\
0.5 \\
-1.3 \\
-2.6\end{array}$ & $\begin{array}{l}4.3 \\
4.9 \\
5.2 \\
0.4 \\
3.9 \\
4.7 \\
1.4 \\
1.1\end{array}$ & $\begin{array}{r} \\
0.4 \\
0.3 \\
-1.4 \\
-2.8\end{array}$ & $\begin{array}{r}-4.4 \\
-5.0 \\
-5.3 \\
-0.2 \\
4.2 \\
5.2 \\
1.6 \\
-1.1\end{array}$ & $\begin{array}{r} \\
0.5 \\
0.8 \\
-1.2\end{array}$ & $\left|\begin{array}{r}-4.6 \\
-5.1 \\
-5.4 \\
-\quad 0.1 \\
4.3 \\
5.5 \\
2.1 \\
-1.0\end{array}\right|$ & -1.0 & $\begin{array}{l}0.1 \\
0.8 \\
1.2 \\
0.8 \\
0.3 \\
0.2\end{array}$ & $\begin{array}{l}2 \\
2 \\
2 \\
2 \\
2 \\
2 \\
2 \\
2\end{array}$ & $\begin{array}{r}13.1 \\
12.4 \\
12.9 \\
15.9 \\
10.3 \\
5.9 \\
6.8 \\
8.2\end{array}$ & $\begin{array}{r}14.6 \\
13.7 \\
14.3 \\
17.9 \\
11.9 \\
8.4 \\
8.1 \\
9.3\end{array}$ & $\begin{array}{r}15.8 \\
15.0 \\
15.5 \\
19.7 \\
13.3 \\
9.9 \\
9.5 \\
10.5\end{array}$ & $\begin{array}{l}16.6 \\
15.5 \\
16.1 \\
18.4 \\
13.8 \\
10.8 \\
10.8 \\
11.4\end{array}$ \\
\hline $\begin{array}{l}4 \\
4 \\
4 \\
4 \\
4 \\
4 \\
4 \\
4\end{array}$ & $\begin{array}{r}0 \\
3 \\
6 \\
9 \\
12 \\
15 \\
18 \\
21\end{array}$ & $\begin{array}{r}-1.7 \\
-1.2 \\
-0.1 \\
3.3 \\
11.0 \\
9.4 \\
3.9 \\
4.1\end{array}$ & $\begin{array}{l}1.1 \\
4.6 \\
3.6 \\
0.9 \\
1.2\end{array}$ & $\begin{array}{r}1.8 \\
1.4 \\
0.1 \\
3.9 \\
10.3 \\
10.5 \\
5.8 \\
4.9\end{array}$ & $\mid \begin{array}{r}-3.4 \\
-3.0 \\
-1.5 \\
1.0 \\
4.6 \\
4.0 \\
1.3 \\
1.3\end{array}$ & $\mid \begin{array}{r}-1.9 \\
-1.8 \\
0.4 \\
5.0 \\
9.4 \\
10.6 \\
7.6 \\
6.1\end{array}$ & $\begin{array}{l}1.8 \\
5.0 \\
4.5 \\
3.0 \\
2.8\end{array}$ & $\mid \begin{array}{r}-1.8 \\
-1.1 \\
0.6 \\
5.0 \\
10.7 \\
10.8 \\
8.7 \\
6.8\end{array}$ & & $\begin{array}{l}0.2 \\
0.1 \\
0.3 \\
1.6 \\
1.7 \\
0.4 \\
0.2 \\
0.7\end{array}$ & $\begin{array}{l}2 \\
2 \\
4 \\
3 \\
3 \\
3 \\
2 \\
2\end{array}$ & $\begin{array}{l}5.9 \\
4.9 \\
6.9 \\
3.5 \\
0.8 \\
1.1 \\
2.2 \\
6.7\end{array}$ & $\begin{array}{l}6.7 \\
5.5 \\
7.1 \\
4.8 \\
0.9 \\
1.7 \\
3.5 \\
8.2\end{array}$ & $\begin{array}{r}8.0 \\
6.7 \\
8.6 \\
5.3 \\
1.1 \\
1.9 \\
5.0 \\
10.3\end{array}$ & $\begin{array}{r}8.9 \\
8.2 \\
9.6 \\
5.4 \\
1.5 \\
1.2 \\
6.4 \\
11.8\end{array}$ \\
\hline $\begin{array}{l}5 \\
5 \\
5 \\
5 \\
5 \\
5 \\
5 \\
5\end{array}$ & $\begin{array}{r}0 \\
3 \\
6 \\
9 \\
12 \\
15 \\
18 \\
21\end{array}$ & $\begin{array}{l}4.8 \\
4.3 \\
3.6\end{array}$ & $\begin{array}{l}2.0 \\
1.4 \\
1.2\end{array}$ & $\begin{array}{l}5.3 \\
4.5 \\
3.7\end{array}$ & $\begin{array}{l}2.1 \\
1.4 \\
1.1\end{array}$ & $\begin{array}{l}5.6 \\
4.8 \\
3.6\end{array}$ & $\begin{array}{l}3.0 \\
2.5 \\
2.0\end{array}$ & $\begin{array}{l}5.7 \\
5.0 \\
3.6\end{array}$ & & $\begin{array}{l}0.8 \\
0.8 \\
0.7\end{array}$ & $\begin{array}{l}2 \\
2 \\
2 \\
2 \\
2 \\
2 \\
2 \\
2 \\
2\end{array}$ & $\begin{array}{r}9.2 \\
12.5 \\
13.9 \\
19.6 \\
19.7 \\
17.5 \\
18.6 \\
17.7\end{array}$ & $\begin{array}{l}10.8 \\
14.2 \\
15.7 \\
21.9 \\
22.6 \\
20.2 \\
21.2 \\
20.2\end{array}$ & $\begin{array}{l}12.0 \\
15.7 \\
17.2 \\
23.7 \\
25.5 \\
22.7 \\
24.0 \\
22.8\end{array}$ & $\begin{array}{l}13.1 \\
16.6 \\
18.2 \\
25.7 \\
27.3 \\
24 \cdot 5 \\
26.1 \\
24.2\end{array}$ \\
\hline $\begin{array}{l}6 \\
6 \\
6 \\
6 \\
6 \\
6 \\
6 \\
6\end{array}$ & $\begin{array}{r}0 \\
3 \\
6 \\
9 \\
12 \\
15 \\
18 \\
21\end{array}$ & & & & & & & & & & $\begin{array}{l}3 \\
3 \\
3 \\
3 \\
3 \\
3 \\
3 \\
3\end{array}$ & $\begin{array}{r}9.6 \\
10.4 \\
14.2 \\
20.9 \\
18.4 \\
15.0 \\
9.7 \\
8.6\end{array}$ & $\begin{array}{r}11.7 \\
12.2 \\
16.4 \\
24.0 \\
20.8 \\
16.6 \\
11.1 \\
9.5\end{array}$ & $\begin{array}{l}14.6 \\
14.5 \\
18.2 \\
26.6 \\
24.1 \\
19.7 \\
12.5 \\
10.4\end{array}$ & $\begin{array}{l}10.0 \\
16.3 \\
19.6 \\
28.4 \\
25.9 \\
21.1 \\
13.7 \\
11.2\end{array}$ \\
\hline $\begin{array}{l}7 \\
7 \\
7 \\
7 \\
7 \\
7 \\
7 \\
7\end{array}$ & $\begin{array}{r}0 \\
3 \\
6 \\
9 \\
12 \\
15 \\
18 \\
21\end{array}$ & $\begin{array}{l}-4.1 \\
-1.3 \\
0.5 \\
-0.5 \\
-2.2\end{array}$ & & $\begin{array}{l}5.1 \\
2.3 \\
0.3 \\
0.6 \\
2.3\end{array}$ & & $\mid \begin{array}{r}-5.2 \\
-2.2 \\
0.2 \\
-0.7 \\
-3.5\end{array}$ & & $\left|\begin{array}{l}-5.3 \\
-2.3 \\
0.2 \\
-0.8 \\
-2.7\end{array}\right|$ & & $\begin{array}{l}1.9 \\
2.0 \\
1.3 \\
1.0 \\
1.0\end{array}$ & $\begin{array}{l}3 \\
3 \\
3 \\
3 \\
3 \\
3 \\
2 \\
2\end{array}$ & $\begin{array}{r}8.6 \\
9.4 \\
10.0 \\
8.9 \\
5.0 \\
5.3 \\
6.1 \\
7.3\end{array}$ & $\begin{array}{r}9.6 \\
10.0 \\
11.5 \\
9.9 \\
6.8 \\
6.0 \\
6.5 \\
7.7\end{array}$ & $\begin{array}{r}10.5 \\
11.4 \\
12.2 \\
10.3 \\
7.4 \\
6.3 \\
6.8 \\
8.2\end{array}$ & $\begin{array}{r}10.9 \\
11.7 \\
12.6 \\
11.0 \\
7.6 \\
7.4 \\
7.2 \\
8.3\end{array}$ \\
\hline $\begin{array}{l}8 \\
8 \\
8 \\
8 \\
8 \\
8 \\
8 \\
8\end{array}$ & $\begin{array}{r}0 \\
3 \\
6 \\
9 \\
12 \\
15 \\
18 \\
21\end{array}$ & $\begin{array}{l}-2.8 \\
=1.8 \\
-1.0\end{array}$ & $\begin{array}{l}6.0 \\
5.9 \\
3.6 \\
1.7\end{array}$ & $\begin{array}{r}2.9 \\
2.0 \\
1.1 \\
13.0 \\
12.2 \\
8.6 \\
5.3\end{array}$ & $\begin{array}{l}6.1 \\
6.1 \\
3.9 \\
2.2\end{array}$ & \begin{tabular}{r|}
12.8 \\
13.3 \\
0.8 \\
6.1
\end{tabular} & $\begin{array}{l}6.0 \\
6.4 \\
3.7 \\
1.9\end{array}$ & $\begin{array}{l}-3.3 \\
-2.4 \\
-1.3\end{array}$ & & $\begin{array}{l}0.9 \\
0.9 \\
1.0 \\
2.5 \\
1.8 \\
1.3 \\
1.1\end{array}$ & $\begin{array}{l}2 \\
2 \\
2 \\
2 \\
2 \\
2 \\
2 \\
3\end{array}$ & $\begin{array}{r}9.4 \\
12.8 \\
16.4 \\
18.5 \\
14.1 \\
5.9 \\
2.1 \\
5.7\end{array}$ & $\begin{array}{r}10.2 \\
14.1 \\
18.5 \\
21.0 \\
16.4 \\
7.5 \\
3.2 \\
8.1\end{array}$ & $\begin{array}{r}11.0 \\
15.1 \\
20.2 \\
23.1 \\
18.4 \\
8.7 \\
4.4 \\
9.1\end{array}$ & $\begin{array}{r}11.1 \\
15.6 \\
21.3 \\
24.6 \\
19.3 \\
9.5 \\
5.1 \\
9.5\end{array}$ \\
\hline $\begin{array}{l}9 \\
9 \\
9 \\
9 \\
9 \\
0 \\
0 \\
0\end{array}$ & $\begin{array}{r}0 \\
3 \\
6 \\
9 \\
12 \\
15 \\
18 \\
21\end{array}$ & $\begin{array}{r}1.6 \\
-1.3 \\
-4.9 \\
-3.2 \\
0.6 \\
6.1 \\
3.3 \\
3.0\end{array}$ & $\left|\begin{array}{r}-0.6 \\
-2.4 \\
-1.8 \\
1.9 \\
0.2 \\
0.1\end{array}\right|$ & $\begin{array}{l}1.5 \\
0.8 \\
5.3 \\
3.5 \\
0.6 \\
5.0 \\
3.8 \\
3.1\end{array}$ & $\begin{array}{r}-1.1 \\
-3.2 \\
-0.1 \\
\\
1.3 \\
0.2 \\
0.0\end{array}$ & $\begin{array}{r}1.3 \\
-1.0 \\
-5.4 \\
-3.5 \\
0.7 \\
5.6 \\
4.4 \\
3.2\end{array}$ & $\begin{array}{l}1.4 \\
0.9 \\
0.4\end{array}$ & $\left|\begin{array}{r}1.0 \\
-\quad 1.0 \\
-5.5 \\
-3.7 \\
1.6 \\
5.8 \\
4.8 \\
3.3\end{array}\right|$ & & $\begin{array}{l}1.1 \\
1.0 \\
1.7 \\
2.8 \\
3.4 \\
1.8 \\
1.5 \\
1.6\end{array}$ & $\begin{array}{l}3 \\
3 \\
3 \\
3 \\
2 \\
2 \\
2 \\
2\end{array}$ & $\begin{array}{r}10.2 \\
12.4 \\
10.7 \\
7.7 \\
2.3 \\
2.2 \\
3.2 \\
6.9\end{array}$ & $\begin{array}{r}12.4 \\
15.0 \\
13.0 \\
8.8 \\
2.4 \\
3.0 \\
4.4 \\
9.5\end{array}$ & $\begin{array}{r}13.2 \\
15.6 \\
13.2 \\
8.6 \\
2.5 \\
3.6 \\
6.0 \\
12.6\end{array}$ & $\begin{array}{r}15.0 \\
16.7 \\
13.9 \\
9.9 \\
1.7 \\
3.9 \\
7.7 \\
14.1\end{array}$ \\
\hline $\begin{array}{l}10 \\
10 \\
10 \\
10 \\
10 \\
10 \\
11 \\
10\end{array}$ & $\begin{array}{r}0 \\
3 \\
5 \\
9 \\
12 \\
15 \\
18 \\
21\end{array}$ & $\begin{array}{r}2.9 \\
2.8 \\
2.8 \\
10.4 \\
17.3 \\
19.7 \\
12.6 \\
11.2\end{array}$ & $\begin{array}{r}0.1 \\
0.2 \\
0.4 \\
5.4 \\
0.0 \\
11.0 \\
5.1 \\
0.8\end{array}$ & $\begin{array}{r}3.1 \\
2.09 \\
2.09 \\
10.6 \\
17.3 \\
19.08 \\
13.5 \\
11.5\end{array}$ & $\begin{array}{r}0.0 \\
0.0 \\
0.3 \\
5.4 \\
9.8 \\
10.9 \\
3.5 \\
110.0\end{array}$ & $\begin{array}{r}3.2 \\
3.0 \\
3.2 \\
10.7 \\
17.3 \\
19.8 \\
14.5 \\
11.7\end{array}$ & $\begin{array}{r}6.4 \\
9.8 \\
10.9 \\
8.0 \\
10.1\end{array}$ & $\begin{array}{r}3.3 \\
3.1 \\
3.4 \\
10.7 \\
17.1 \\
17.6 \\
15.4 \\
11.3\end{array}$ & & $\begin{array}{l}1.7 \\
1.6 \\
1.7 \\
2.9 \\
4.2 \\
3.3 \\
2.6 \\
2.7\end{array}$ & $\begin{array}{l}2 \\
2 \\
2 \\
2 \\
2 \\
2 \\
2 \\
2\end{array}$ & $\begin{array}{r}10.8 \\
10.9 \\
11.3 \\
12.6 \\
12.1 \\
7.1 \\
1.09 \\
0.4\end{array}$ & $\begin{array}{r}13.1 \\
13.2 \\
13.6 \\
14.6 \\
14.2 \\
8.5 \\
3.2 \\
11.3\end{array}$ & $\begin{array}{r}15.6 \\
15.8 \\
15.4 \\
16.9 \\
16.1 \\
10.1 \\
4.0 \\
14.4\end{array}$ & $\begin{array}{r}17.8 \\
18.0 \\
17.8 \\
18.1 \\
17.5 \\
11.2 \\
6.4 \\
16.5\end{array}$ \\
\hline
\end{tabular}


TABLE 10

Table 10. - Three-hour averages of air and water-surface temperatures and wind directions and speed, April 1950-August
1951, Lake Hefner-Continued STATION I THREE-HOURLY AVERAGES FEBRUARY, 1951

\begin{tabular}{|c|c|c|c|c|c|c|c|c|c|c|c|c|c|c|c|}
\hline \multirow{4}{*}{ 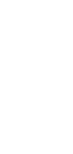 } & \multirow{4}{*}{ 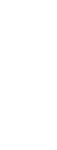 } & \multicolumn{8}{|c|}{ Average air temperature $\left({ }^{\circ} \mathrm{C}\right)$ at indicated height } & \multirow{4}{*}{$\begin{array}{c}\text { Average } \\
\text { water- } \\
\text { surface } \\
\text { tempera- } \\
\text { ture } \\
\left({ }^{\circ} \mathrm{C}\right)\end{array}$} & \multirow{4}{*}{$\begin{array}{c}\text { Average } \\
\text { wind } \\
\text { direction } \\
\text { (coded) }\end{array}$} & \multirow{2}{*}{\multicolumn{4}{|c|}{$\begin{array}{l}\text { Average wind speed (knots) } \\
\text { at indicated height }\end{array}$}} \\
\hline & & \multirow{2}{*}{\multicolumn{2}{|c|}{$\begin{array}{c}2 \\
\text { meters }\end{array}$}} & \multirow{2}{*}{\multicolumn{2}{|c|}{$\begin{array}{c}4 \\
\text { meters }\end{array}$}} & \multirow{2}{*}{\multicolumn{2}{|c|}{$\begin{array}{c}8 \\
\text { meters }\end{array}$}} & \multirow{2}{*}{\multicolumn{2}{|c|}{$\begin{array}{c}16 \\
\text { meters }\end{array}$}} & & & & & & \\
\hline & & & & & & & & & & & & 2 & 4 & 8 & 16 \\
\hline & & $\begin{array}{l}\text { Dry } \\
\text { bulb }\end{array}$ & $\begin{array}{l}\text { Wet } \\
\text { bulb }\end{array}$ & $\begin{array}{l}\text { Dry } \\
\text { bulb }\end{array}$ & $\begin{array}{l}\text { Wet } \\
\text { bulb }\end{array}$ & $\begin{array}{l}\text { Dry } \\
\text { butb }\end{array}$ & $\begin{array}{l}\text { Wet } \\
\text { bulb }\end{array}$ & $\begin{array}{l}\text { Dry } \\
\text { bulb }\end{array}$ & $\begin{array}{l}\text { Wet } \\
\text { bulb }\end{array}$ & & & meters & meters & meters & meters \\
\hline $\begin{array}{l}11 \\
11 \\
11 \\
11 \\
11 \\
11 \\
11 \\
11\end{array}$ & $\begin{array}{r}0 \\
3 \\
6 \\
9 \\
12 \\
15 \\
18 \\
21\end{array}$ & $\begin{array}{r}9.4 \\
8.7 \\
9.0 \\
15.1 \\
19.1 \\
22.3 \\
19.0 \\
17.1\end{array}$ & $\begin{array}{r}8.9 \\
8.1 \\
8.3 \\
11.9 \\
13.9 \\
14.8 \\
13.4 \\
12.8\end{array}$ & $\begin{array}{r}9.6 \\
9.0 \\
9.3 \\
15.3 \\
19.2 \\
22.5 \\
19.0 \\
17.1\end{array}$ & $\begin{array}{r}9.3 \\
8.5 \\
8.6 \\
12.1 \\
13.8 \\
14.6 \\
13.3 \\
12.7\end{array}$ & $\begin{array}{r}9.8 \\
9.1 \\
9.4 \\
15.7 \\
18.7 \\
22.0 \\
19.0 \\
17.3\end{array}$ & $\begin{array}{r}9.3 \\
8.4 \\
12.4 \\
14.7 \\
14.4 \\
13.3 \\
12.6\end{array}$ & $\begin{array}{r}9.7 \\
9.1 \\
9.6 \\
15.5 \\
20.3 \\
22.0 \\
19.2 \\
17.3\end{array}$ & & $\begin{array}{l}2.8 \\
2.8 \\
3.1 \\
4.9 \\
7.8 \\
4.8 \\
4.4 \\
4.7\end{array}$ & $\begin{array}{l}2 \\
2 \\
2 \\
2 \\
2 \\
2 \\
2 \\
i \\
2\end{array}$ & $\begin{array}{r}8.7 \\
9.5 \\
14.2 \\
14.9 \\
13.6 \\
12.4 \\
14.5\end{array}$ & $\begin{array}{l}11.8 \\
10.8 \\
11.5 \\
16.8 \\
17.6 \\
16.3 \\
14.7 \\
17.2\end{array}$ & $\begin{array}{l}14.7 \\
13.1 \\
13.5 \\
10.2 \\
20.1\end{array}$ & $\begin{array}{l}16.5 \\
15.2 \\
15.5 \\
21.1 \\
22.5 \\
22.0 \\
18.1 \\
24.9\end{array}$ \\
\hline $\begin{array}{l}12 \\
12 \\
12 \\
12 \\
12 \\
12 \\
12 \\
12\end{array}$ & $\begin{array}{r}0 \\
3 \\
6 \\
9 \\
12 \\
15 \\
18 \\
21\end{array}$ & $\begin{array}{r}17.4 \\
15.9 \\
14.5 \\
16.4 \\
10.1 \\
4.0 \\
-\quad 0.3 \\
-2.0\end{array}$ & $\begin{array}{l}12.0 \\
11.0 \\
11.0\end{array}$ & $\begin{array}{r}17.5 \\
16.0 \\
14.6 \\
17.2 \\
10.8 \\
4.1 \\
0.8 \\
2.4\end{array}$ & $\begin{array}{r}11.8 \\
11.3 \\
11.0 \\
11.8 \\
6.0 \\
2.2 \\
-0.3\end{array}$ & $\begin{array}{r}17.5 \\
15.9 \\
14.7 \\
16.8 \\
9.8 \\
3.6 \\
-1.00 \\
-2.6\end{array}$ & $\begin{array}{r}11.8 \\
11.3 \\
11.0 \\
11.7 \\
5.7 \\
2.0 \\
-0.7\end{array}$ & $\begin{array}{r}17.5 \\
15.8 \\
14.5 \\
16.9 \\
9.4 \\
3.1 \\
-1.3 \\
-3.0\end{array}$ & & $\begin{array}{l}4.8 \\
4.9 \\
5.0 \\
5.9 \\
6.0 \\
5.1 \\
4.5 \\
4.2\end{array}$ & $\begin{array}{l}2 \\
2 \\
2 \\
2 \\
4 \\
4 \\
3 \\
3\end{array}$ & $\begin{array}{l}15.1 \\
19.3 \\
18.0 \\
13.9 \\
14.8 \\
16.8 \\
19.1 \\
18.0\end{array}$ & $\begin{array}{l}18.1 \\
22.9 \\
20.9 \\
16.4 \\
14.3 \\
16.7 \\
18.1 \\
17.9\end{array}$ & $\begin{array}{l}19.4 \\
16.5 \\
19.0 \\
22.2 \\
21.0\end{array}$ & \\
\hline $\begin{array}{l}13 \\
13 \\
13 \\
13 \\
13 \\
13 \\
13 \\
13\end{array}$ & $\begin{array}{r}0 \\
3 \\
6 \\
9 \\
12 \\
15 \\
18 \\
21\end{array}$ & $\begin{array}{l}=3.9 \\
=5.3 \\
=6.1 \\
=7.0 \\
=7.4 \\
-7.0\end{array}$ & & $\begin{array}{l}4.3 \\
5.5 \\
6.7 \\
7.3 \\
7.0 \\
7.5\end{array}$ & & $\begin{array}{l}4.6 \\
-6.1 \\
-7.0 \\
-7.7 \\
-8.2 \\
-7.8\end{array}$ & & $\begin{array}{l}-4.7 \\
-6.4 \\
-7.3 \\
-8.1 \\
-8.5 \\
-8.0\end{array}$ & & $\begin{array}{l}4.0 \\
3.6 \\
3.1 \\
2.7 \\
2.2 \\
1.8\end{array}$ & $\begin{array}{l}3 \\
3 \\
3 \\
3 \\
3 \\
3 \\
3 \\
3\end{array}$ & $\begin{array}{l}17.8 \\
17.5 \\
18.0 \\
19.1 \\
18.5 \\
18.6 \\
19.0 \\
20.0\end{array}$ & $\begin{array}{l}19.2 \\
20.8 \\
23.9\end{array}$ & $\begin{array}{l}21.3 \\
20.3 \\
20.6 \\
23.3 \\
23.7 \\
25.4 \\
26.9 \\
27.3\end{array}$ & \\
\hline $\begin{array}{l}14 \\
14 \\
14 \\
14 \\
14 \\
14 \\
14 \\
14\end{array}$ & $\begin{array}{r}0 \\
3 \\
6 \\
9 \\
12 \\
15 \\
18 \\
21\end{array}$ & $\begin{array}{l}=7.8 \\
=8.0 \\
=7.1 \\
=7.1 \\
=6.4 \\
=6.5 \\
=6.5\end{array}$ & & $\begin{array}{l}8.0 \\
8.4 \\
7.0 \\
7.0 \\
6.4 \\
6.5 \\
6.5\end{array}$ & & $\begin{array}{l}8.3 \\
-8.5 \\
-7.8 \\
-7.1 \\
-6.8 \\
-6.7 \\
-6.7\end{array}$ & & $\left|\begin{array}{l}-8.7 \\
-8.7 \\
-7.9 \\
-7.5 \\
-6.9 \\
-6.9 \\
-6.9\end{array}\right|$ & & & $\begin{array}{l}3 \\
3 \\
3 \\
3 \\
3 \\
3 \\
3 \\
3 \\
3\end{array}$ & $\begin{array}{r}19.6 \\
18.4 \\
16.8 \\
16.2 \\
15.3 \\
13.6 \\
12.0 \\
9.0\end{array}$ & $\begin{array}{r}23.1 \\
22.0 \\
18.9 \\
15.5 \\
14.2 \\
12.0 \\
7.8\end{array}$ & $\begin{array}{l}26.7 \\
24.0 \\
22.2 \\
19.3 \\
20.6 \\
18.0 \\
15.6 \\
10.7\end{array}$ & 4 \\
\hline $\begin{array}{l}15 \\
15 \\
15 \\
15 \\
15 \\
15 \\
15 \\
15\end{array}$ & $\begin{array}{r}0 \\
3 \\
6 \\
9 \\
12 \\
15 \\
18 \\
21\end{array}$ & $\begin{array}{l}=6.5 \\
=7.1 \\
=6.8 \\
=4.9 \\
=3.8 \\
=3.7 \\
=3.9 \\
-3.8\end{array}$ & & $\begin{array}{l}6.3 \\
6.6 \\
6.3 \\
4.8 \\
4.2 \\
3.8 \\
3.8 \\
3.7\end{array}$ & & $\begin{array}{r}-6.6 \\
=-6.8 \\
=-5.6 \\
=-4.5 \\
-\quad 4.0 \\
-\quad 4.0 \\
-3.9\end{array}$ & & $\begin{array}{l}-6.8 \\
-7.0 \\
-\quad 6.7 \\
=5.4 \\
=-4.6 \\
=-4.1 \\
=\quad 4.1 \\
-\quad 4.0\end{array}$ & -5.5 & & $\begin{array}{l}3 \\
2 \\
2 \\
2 \\
2 \\
2 \\
2 \\
2\end{array}$ & $\begin{array}{l}7.3 \\
8.0 \\
9.1 \\
7.8 \\
8.2 \\
8.2 \\
3.6 \\
1.1\end{array}$ & $\begin{array}{r}9.6 \\
9.6 \\
10.8 \\
9.6 \\
9.2 \\
8.9 \\
4.1 \\
1.4\end{array}$ & $\begin{array}{r}12.3 \\
9.5 \\
\\
10.7 \\
10.5 \\
5.0 \\
2.1\end{array}$ & \\
\hline $\begin{array}{l}16 \\
16 \\
16 \\
16 \\
16 \\
16 \\
16 \\
16\end{array}$ & $\begin{array}{r}0 \\
3 \\
6 \\
9 \\
12 \\
15 \\
18 \\
21\end{array}$ & $\begin{array}{r}-6.4 \\
-6.8 \\
-7.3 \\
-2.8 \\
2.5 \\
5.1 \\
2.5 \\
1.5\end{array}$ & & $\begin{array}{l}5.9 \\
6.5 \\
7.0 \\
2.7 \\
3.1 \\
5.7 \\
3.1 \\
2.1\end{array}$ & $\begin{array}{l}1.5 \\
2.7 \\
1.2 \\
0.3\end{array}$ & $\begin{array}{r}5.8 \\
-6.4 \\
-6.5 \\
-2.7 \\
3.0 \\
5.3 \\
3.1 \\
1.9\end{array}$ & $\begin{array}{l}1.5 \\
2.8 \\
1.4 \\
0.3\end{array}$ & $\mid \begin{array}{r}-5.3 \\
-6.0 \\
-6.4 \\
-\quad 2.8 \\
3.0 \\
5.4 \\
3.6 \\
2.0\end{array}$ & & $\begin{array}{l}0.4 \\
0.2\end{array}$ & $\begin{array}{l}2 \\
2 \\
2 \\
2 \\
2 \\
2 \\
2 \\
2 \\
2\end{array}$ & $\begin{array}{l}2.7 \\
3.5 \\
4.1 \\
7.3 \\
5.0 \\
3.9 \\
3.6 \\
7.6\end{array}$ & $\begin{array}{l}3.9 \\
4.5 \\
4.9 \\
8.7 \\
6.1 \\
4.9 \\
4.7 \\
9.5\end{array}$ & $\begin{array}{r}6.3 \\
6.0 \\
6.0 \\
10.1 \\
7.1 \\
6.0 \\
6.5 \\
12.1\end{array}$ & \\
\hline $\begin{array}{l}17 \\
17 \\
17 \\
17 \\
17 \\
17 \\
17 \\
17\end{array}$ & $\begin{array}{r}0 \\
3 \\
6 \\
9 \\
12 \\
15 \\
18 \\
21\end{array}$ & $\begin{array}{l}1.2 \\
1 \cdot 2 \\
1.6 \\
3.5 \\
8.2 \\
9.3 \\
5.9 \\
5.5\end{array}$ & & $\begin{array}{l}1.8 \\
1.8 \\
2.1 \\
4.0 \\
8.4 \\
9.5 \\
6.4 \\
6.3\end{array}$ & $\begin{array}{l}0.3 \\
0.8 \\
1.11 \\
2.4 \\
5.5 \\
6.5 \\
4.7 \\
5.6\end{array}$ & $\begin{array}{l}1.6 \\
1.6 \\
2.1 \\
3.9 \\
8.5 \\
9.4 \\
6.1 \\
6.1\end{array}$ & $\begin{array}{l}0.4 \\
0.9 \\
1.1 \\
2.3 \\
5.4 \\
6.0 \\
4.5 \\
5.6\end{array}$ & $\begin{array}{l}1 \cdot 1 \\
1.8 \\
2.1 \\
4: 0 \\
8.7 \\
9.04 \\
6.2 \\
6.2\end{array}$ & & $\begin{array}{l}0.1 \\
0.7 \\
0.9 \\
0.3 \\
0.1 \\
0.3\end{array}$ & $\begin{array}{l}2 \\
2 \\
2 \\
2 \\
2 \\
2 \\
2 \\
2 \\
2\end{array}$ & $\begin{array}{r}10.7 \\
10.3 \\
10.5 \\
9.6 \\
7.5 \\
8.5 \\
10.1 \\
10.3\end{array}$ & $\begin{array}{r}12.8 \\
12.5 \\
12.3 \\
11.6 \\
9.4 \\
10.4 \\
12.5 \\
12.8\end{array}$ & $\begin{array}{l}14.9 \\
14.2 \\
14.5 \\
13.4 \\
11.3 \\
13.6 \\
16.0 \\
14.5\end{array}$ & \\
\hline $\begin{array}{l}18 \\
18 \\
18 \\
18 \\
18 \\
18 \\
18 \\
18\end{array}$ & $\begin{array}{r}0 \\
3 \\
6 \\
9 \\
12 \\
15 \\
18 \\
21\end{array}$ & $\begin{array}{l}13.0 \\
15.3\end{array}$ & $\begin{array}{l}10.3 \\
11.3\end{array}$ & $\begin{array}{r}6.9 \\
8.2 \\
8.2 \\
13.0 \\
15.4\end{array}$ & $\begin{array}{r}6.8 \\
6.7 \\
5.3 \\
10.2 \\
11.0\end{array}$ & $\begin{array}{r}6.9 \\
7.9 \\
7.6 \\
13.3 \\
15.5\end{array}$ & $\begin{array}{l}10.4 \\
10.9\end{array}$ & $\begin{array}{r}7.6 \\
9.2 \\
9.0 \\
13.1 \\
15.4\end{array}$ & & $\begin{array}{l}3.6 \\
4.0\end{array}$ & $\begin{array}{l}2 \\
2 \\
2 \\
2 \\
2 \\
2 \\
2 \\
2\end{array}$ & $\begin{array}{r}8.7 \\
6.8 \\
8.5 \\
8.0 \\
10.1 \\
8.5 \\
3.5 \\
5.3\end{array}$ & $\begin{array}{r}30.7 \\
8.4 \\
10.3 \\
9.5 \\
12.2 \\
10.2 \\
5.1 \\
7.0\end{array}$ & $\begin{array}{r}12.5 \\
10.2 \\
12.8 \\
31.3 \\
14.3 \\
12.3 \\
7.3 \\
9.2\end{array}$ & $\begin{array}{r}12.1 \\
16.2 \\
13.9 \\
9.5 \\
11.4\end{array}$ \\
\hline $\begin{array}{l}19 \\
19 \\
19 \\
19 \\
19 \\
19 \\
19 \\
19\end{array}$ & $\begin{array}{r}0 \\
3 \\
6 \\
9 \\
12 \\
15 \\
18 \\
21\end{array}$ & $\begin{array}{l}16.3 \\
15.9 \\
12.9\end{array}$ & $\begin{array}{r}9.1 \\
12.8 \\
12.2\end{array}$ & $\begin{array}{l}16.6 \\
16.1 \\
14.1\end{array}$ & $\begin{array}{r}9.1 \\
12.9 \\
13.2\end{array}$ & $\begin{array}{l}14.1 \\
16.3 \\
16.4 \\
14.6\end{array}$ & $\begin{array}{r}7.8 \\
8.9 \\
14.2 \\
13.4\end{array}$ & $\begin{array}{l}13.8 \\
16.3 \\
16.4 \\
14.5\end{array}$ & & $\begin{array}{l}4.5 \\
5.0 \\
4.4 \\
4.4\end{array}$ & $\begin{array}{l}2 \\
2 \\
2 \\
2 \\
2 \\
2 \\
3 \\
3\end{array}$ & $\begin{array}{r}7.0 \\
6.8 \\
6.9 \\
8.5 \\
8.6 \\
9.3 \\
5.0 \\
10.1\end{array}$ & $\begin{array}{r}8.8 \\
8.4 \\
8.6 \\
10.3 \\
10.2 \\
11.3 \\
6.1 \\
10.3\end{array}$ & $\begin{array}{r}11.9 \\
11.6 \\
12.1 \\
13.3 \\
12.3 \\
13.6 \\
7.00 \\
12.1\end{array}$ & $\begin{array}{r}12.9 \\
12.8 \\
12.8 \\
14.6 \\
12.8 \\
14.3 \\
8.2 \\
13.6\end{array}$ \\
\hline $\begin{array}{l}20 \\
20 \\
20 \\
20 \\
20 \\
20 \\
20 \\
20\end{array}$ & $\begin{array}{r}0 \\
3 \\
6 \\
9 \\
12 \\
15 \\
18 \\
21\end{array}$ & $\begin{array}{l}3.7 \\
4.4 \\
5.4 \\
4.9 \\
3.6\end{array}$ & $\begin{array}{l}3.2 \\
3.7 \\
4.4 \\
4.3 \\
3.2\end{array}$ & $\begin{array}{l}3.6 \\
4.4 \\
5.4 \\
4.9 \\
3.6\end{array}$ & $\begin{array}{l}3.1 \\
3.6 \\
4.4 \\
4.3 \\
3.2\end{array}$ & $\begin{array}{l}3.3 \\
4.1 \\
5.2 \\
4.6 \\
3.5\end{array}$ & $\begin{array}{l}3.3 \\
3.9 \\
4.6 \\
4.4 \\
3.4\end{array}$ & $\begin{array}{l}3.7 \\
4.4 \\
5.3 \\
5.0 \\
3.7\end{array}$ & & $\begin{array}{l}4.0 \\
4.3 \\
4.4 \\
4.2 \\
3.9\end{array}$ & $\begin{array}{l}3 \\
4 \\
4 \\
4 \\
4 \\
4 \\
3 \\
3\end{array}$ & $\begin{array}{r}5.9 \\
17.9 \\
20.6 \\
17.0 \\
17.4 \\
11.5 \\
6.5 \\
4.1\end{array}$ & $\begin{array}{r}6.9 \\
19.3 \\
21.9 \\
18.1 \\
18.3 \\
11.9 \\
6.4 \\
3.0\end{array}$ & $\begin{array}{r}8.0 \\
21.0 \\
24.1 \\
20.0 \\
20.2 \\
13.3 \\
7.7 \\
5.5\end{array}$ & $\begin{array}{r}8.6 \\
23.2 \\
26.1 \\
21.5 \\
21.8 \\
15.0 \\
8.7 \\
5.7\end{array}$ \\
\hline
\end{tabular}


TABLE 10

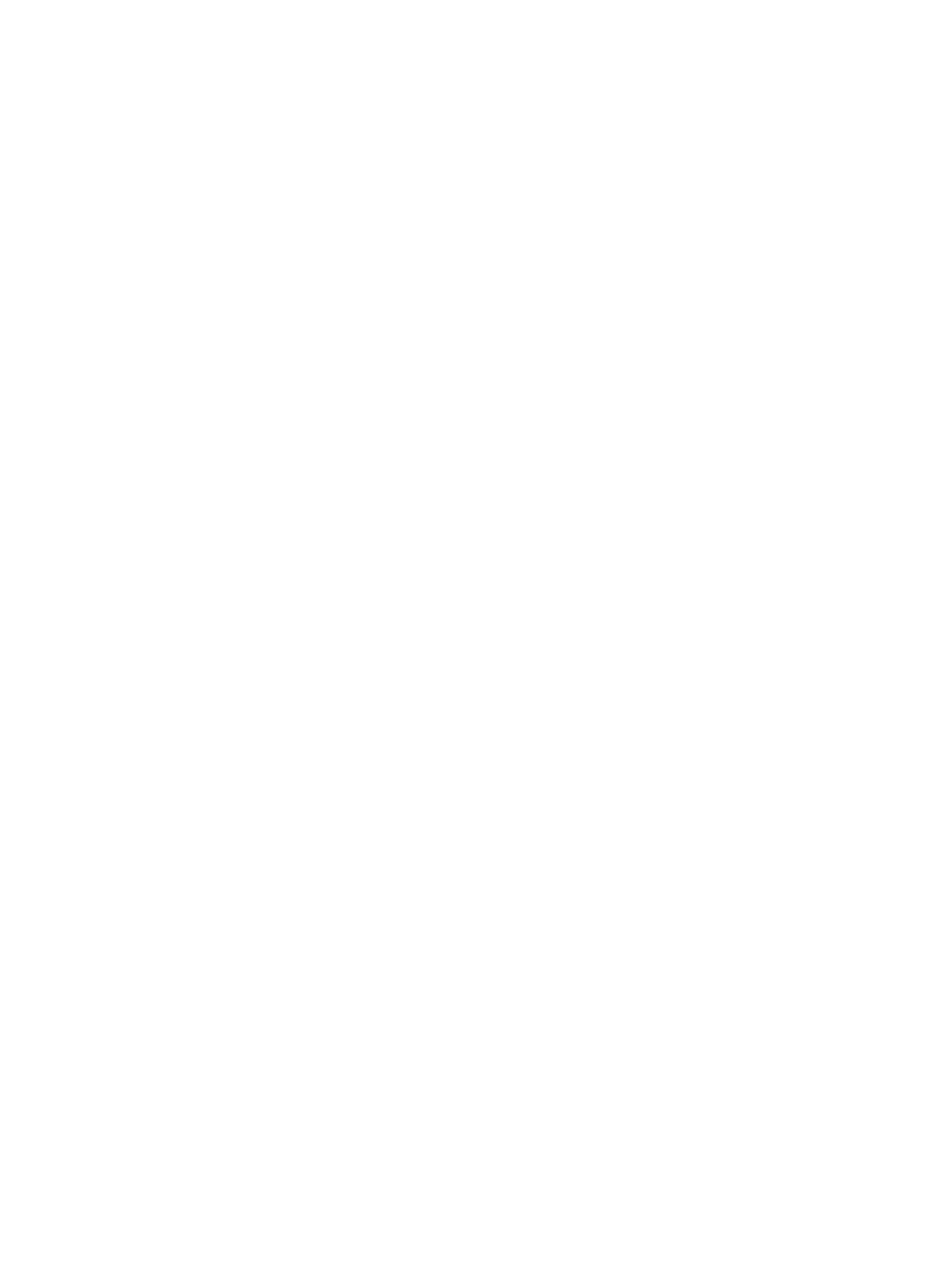


Table 10. - Three-hour averages of air and water-surface temperatures and wind directions and speed, April 1950-August 1951, Lake Hefner-Continued

STATION 1

THREE-HOURLY AVERAGES

MARCH, 1951

\begin{tabular}{|c|c|c|c|c|c|c|c|c|c|c|c|c|c|c|c|}
\hline \multirow{3}{*}{ 咅 } & \multirow{3}{*}{ 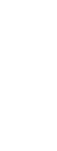 } & \multicolumn{8}{|c|}{ Average air temperature $\left({ }^{\circ} \mathrm{C}\right)$ at indicated height } & \multirow{3}{*}{$\begin{array}{l}\text { Average } \\
\text { water- } \\
\text { surface } \\
\text { tempera- } \\
\text { ture } \\
\text { (ㄷ) }\end{array}$} & \multirow{3}{*}{$\begin{array}{c}\text { Average } \\
\text { wind } \\
\text { direction } \\
\text { (coded) }\end{array}$} & \multirow{2}{*}{\multicolumn{4}{|c|}{$\begin{array}{l}\text { Average wind speed (knots) } \\
\text { at indicated height }\end{array}$}} \\
\hline & & \multicolumn{2}{|c|}{$\begin{array}{c}2 \\
\text { meters }\end{array}$} & \multicolumn{2}{|c|}{$\begin{array}{c}4 \\
\text { meters }\end{array}$} & \multicolumn{2}{|c|}{$\begin{array}{c}8 \\
\text { meters }\end{array}$} & \multicolumn{2}{|c|}{$\begin{array}{c}16 \\
\text { meters }\end{array}$} & & & & & & \\
\hline & & $\begin{array}{l}\text { Dry } \\
\text { bulb }\end{array}$ & $\begin{array}{l}\text { Wet } \\
\text { bulb }\end{array}$ & $\begin{array}{l}\text { Dry } \\
\text { bulb }\end{array}$ & $\begin{array}{l}\text { Wet } \\
\text { bulb }\end{array}$ & $\begin{array}{l}\text { Dry } \\
\text { bulb }\end{array}$ & $\begin{array}{l}\text { Wet } \\
\text { bulb }\end{array}$ & $\begin{array}{l}\text { Dry } \\
\text { bulb }\end{array}$ & $\begin{array}{l}\text { Wet } \\
\text { bulb }\end{array}$ & & & meters & $\begin{array}{c}4 \\
\text { meters }\end{array}$ & meters & meters \\
\hline $\begin{array}{l}1 \\
1 \\
1 \\
1 \\
1 \\
1 \\
1 \\
1\end{array}$ & $\begin{array}{r}0 \\
3 \\
6 \\
9 \\
12 \\
15 \\
18 \\
21\end{array}$ & $\begin{array}{r}4.7 \\
3.5 \\
3.2 \\
5.7 \\
11.5 \\
14.1 \\
13.2 \\
13.1\end{array}$ & $\begin{array}{l}3.2 \\
2.4 \\
2.2 \\
3.8 \\
5.3 \\
7.7 \\
7.7 \\
8.0\end{array}$ & $\begin{array}{r}4.7 \\
3.3 \\
3.2 \\
6.7 \\
11.8 \\
15.2 \\
14.1 \\
13.6\end{array}$ & $\begin{array}{l}3.0 \\
2.2 \\
2.1 \\
3.7 \\
6.4 \\
7.7 \\
7.8 \\
8.2\end{array}$ & $\begin{array}{r}4.6 \\
3.3 \\
3.2 \\
6.9 \\
12.2 \\
15.7 \\
14.8 \\
14.2\end{array}$ & $\begin{array}{l}2.9 \\
2.0 \\
2.0 \\
3.8 \\
6.3 \\
7.8 \\
7.8 \\
8.3\end{array}$ & $\begin{array}{r}4.8 \\
3.2 \\
3.2 \\
7.0 \\
12.5 \\
16.1 \\
15.1 \\
14.7\end{array}$ & & $\begin{array}{l}6.1 \\
6.2 \\
6.7 \\
7.7 \\
7.8 \\
7.1 \\
6.8 \\
6.8\end{array}$ & $\begin{array}{l}3 \\
3 \\
3 \\
3 \\
2 \\
3 \\
3 \\
3 \\
3\end{array}$ & $\begin{array}{r}3.7 \\
7.6 \\
7.5 \\
9.7 \\
7.5 \\
10.0 \\
8.4\end{array}$ & $\begin{array}{r}3.9 \\
8.0 \\
8.0 \\
10.8 \\
8.4 \\
11.7 \\
9.8\end{array}$ & $\begin{array}{r}4.4 \\
8.5 \\
8.4 \\
11.4 \\
9.3 \\
11.0\end{array}$ & $\begin{array}{r}5.6 \\
9.5 \\
9.0 \\
11.8 \\
9.7 \\
13.7 \\
14.4\end{array}$ \\
\hline $\begin{array}{l}2 \\
2 \\
2 \\
2 \\
2 \\
2 \\
2 \\
2\end{array}$ & $\begin{array}{r}0 \\
3 \\
6 \\
9 \\
12 \\
15 \\
18 \\
21\end{array}$ & $\begin{array}{l}12.8 \\
13.3 \\
14.2 \\
14.5 \\
18.7 \\
20.5 \\
17: 9 \\
18.9\end{array}$ & $\begin{array}{r}8.9 \\
10.9 \\
12.6 \\
13.5 \\
14.8 \\
15.1 \\
14.5 \\
9.0\end{array}$ & $\begin{array}{l}13.3 \\
13.7 \\
14.5 \\
15.4 \\
20.0 \\
22.0 \\
19.7 \\
19.7\end{array}$ & $\begin{array}{r}9.2 \\
11.3 \\
13.3 \\
14.1 \\
15.4 \\
15.9 \\
15.4 \\
8.9\end{array}$ & $\begin{array}{l}13.8 \\
14.0 \\
14.9 \\
16.0 \\
20.4 \\
22.8 \\
21.2 \\
20.5\end{array}$ & $\begin{array}{r}16.4 \\
16.5 \\
16.0 \\
8.7\end{array}$ & $\begin{array}{l}14.0 \\
14.4 \\
15.0 \\
15.8 \\
19.4 \\
22.1 \\
20.9 \\
20.9\end{array}$ & $\begin{array}{l}17.2 \\
18.1 \\
17.4 \\
11.5\end{array}$ & $\begin{array}{l}6.9 \\
6.8 \\
7.0 \\
7.3 \\
8.1 \\
8.1 \\
8.4 \\
8.1\end{array}$ & $\begin{array}{l}2 \\
2 \\
2 \\
2 \\
2 \\
2 \\
2 \\
2 \\
2\end{array}$ & $\begin{array}{l}14.6 \\
16.7 \\
13.2 \\
10.1 \\
16.9\end{array}$ & $\begin{array}{l}17.0 \\
19.7 \\
15.8 \\
12.5 \\
18.4\end{array}$ & $\begin{array}{l}20.5 \\
23.0 \\
18.6 \\
15.4 \\
20.6\end{array}$ & $\begin{array}{l}20.8 \\
23.8 \\
19.5 \\
16.1 \\
22.8\end{array}$ \\
\hline $\begin{array}{l}3 \\
3 \\
3 \\
3 \\
3 \\
3 \\
3 \\
3\end{array}$ & $\begin{array}{r}0 \\
3 \\
6 \\
9 \\
12 \\
15 \\
18 \\
21\end{array}$ & $\begin{array}{r}14.5 \\
10.7 \\
7.9 \\
4.7 \\
5.3 \\
6.7 \\
5.2 \\
3.2\end{array}$ & $\begin{array}{l}6.3 \\
4.2 \\
3.0 \\
2.6 \\
2.2 \\
3.1 \\
2.5 \\
1.1\end{array}$ & $\begin{array}{r}14.7 \\
10.9 \\
8.0 \\
4.5 \\
5.1 \\
6.3 \\
5.0 \\
3.0\end{array}$ & $\begin{array}{l}6.1 \\
3.9 \\
3.0 \\
2.4 \\
2.0 \\
2.8 \\
2.1 \\
0.9\end{array}$ & $\begin{array}{r}15.1 \\
10.9 \\
7.8 \\
4.4 \\
5.1 \\
6.3 \\
4.9 \\
2.8\end{array}$ & $\begin{array}{l}5.0 \\
3.6 \\
2.6 \\
1.9 \\
1.9 \\
2.6 \\
1.8 \\
0.7\end{array}$ & $\begin{array}{r}15.1 \\
11.0 \\
7.5 \\
4.3 \\
5.0 \\
6.3 \\
4.8 \\
2.7\end{array}$ & $\begin{array}{l}3.1 \\
1.8 \\
2.6\end{array}$ & $\begin{array}{l}7.2 \\
7.2 \\
7.3 \\
8.2 \\
8.3 \\
7.6 \\
7.4 \\
7.4\end{array}$ & $\begin{array}{l}2 \\
2 \\
2 \\
3 \\
4 \\
3 \\
3 \\
3\end{array}$ & $\begin{array}{r}14.2 \\
13.7 \\
11.6 \\
12.0 \\
8.4 \\
4.9 \\
7.3 \\
6.5\end{array}$ & $\begin{array}{r}14.7 \\
14.9 \\
12.5 \\
13.9 \\
9.7 \\
7.0 \\
7.8 \\
6.7\end{array}$ & $\begin{array}{r}16.9 \\
15.5 \\
13.1 \\
15.1 \\
10.7 \\
7.7 \\
8.0 \\
6.8\end{array}$ & $\begin{array}{r}18.4 \\
17.0 \\
14.2 \\
15.9 \\
11.0 \\
8.0 \\
8.5 \\
7.2\end{array}$ \\
\hline $\begin{array}{l}4 \\
4 \\
4 \\
4 \\
4 \\
4 \\
4 \\
4\end{array}$ & $\begin{array}{r}0 \\
3 \\
6 \\
9 \\
12 \\
15 \\
18 \\
21\end{array}$ & 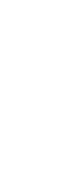 & $\begin{array}{r}0.2 \\
-0.1 \\
-0.1 \\
2.3 \\
4.9 \\
5.7 \\
5.4 \\
4.6\end{array}$ & $\begin{array}{r}1.3 \\
0.8 \\
0.7 \\
4.9 \\
9.0 \\
11.5 \\
11.4 \\
10.5\end{array}$ & $\begin{array}{r}0.0 \\
-0.4 \\
-0.4 \\
1.08 \\
4.03 \\
5.66 \\
5.2 \\
4.4\end{array}$ & $\begin{array}{r}1.2 \\
0.6 \\
0.4 \\
4.6 \\
9.1 \\
12.0 \\
11.6 \\
10.7\end{array}$ & $\begin{array}{r}-0.1 \\
-0.17 \\
-0.6 \\
2.0 \\
4.6 \\
5.6 \\
5.0 \\
4.4\end{array}$ & $\begin{array}{r}1.1 \\
0.5 \\
0.4 \\
5.0 \\
9.4 \\
12.2 \\
11.8 \\
10.9\end{array}$ & $\begin{array}{r}0.1 \\
-0.4 \\
-0.2 \\
2.8 \\
5.6 \\
6.9 \\
6.3 \\
5.6\end{array}$ & $\begin{array}{r}7.3 \\
7.3 \\
7.5 \\
8.9 \\
10.5 \\
8.5 \\
7.4 \\
7.2\end{array}$ & $\begin{array}{l}3 \\
3 \\
3 \\
3 \\
2 \\
2 \\
2 \\
2\end{array}$ & $\begin{array}{r}6.3 \\
7.4 \\
5.5 \\
2.1 \\
2.0 \\
7.4 \\
8.1 \\
14.1\end{array}$ & $\begin{array}{r}6.6 \\
7.6 \\
7.0 \\
2.2 \\
2.0 \\
8.5 \\
9.6 \\
16.2\end{array}$ & $\begin{array}{r}6.6 \\
7.7 \\
7.5 \\
2.4 \\
2.1 \\
9.7 \\
11.2 \\
18.4\end{array}$ & $\begin{array}{r}6.9 \\
8.1 \\
7.0 \\
2.3 \\
2.1 \\
10.2 \\
12.5 \\
19.5\end{array}$ \\
\hline $\begin{array}{l}5 \\
5 \\
5 \\
5 \\
5 \\
5 \\
5 \\
5\end{array}$ & $\begin{array}{r}0 \\
3 \\
6 \\
9 \\
12 \\
15 \\
18 \\
21\end{array}$ & $\begin{array}{r}9.0 \\
7.4 \\
7.5 \\
11.9 \\
18.0 \\
20.0 \\
15.9 \\
13.1\end{array}$ & $\begin{array}{l}4.0 \\
3.3 \\
3.3 \\
5.1 \\
7.3 \\
8.4 \\
3.1 \\
7.0\end{array}$ & $\begin{array}{r}9.0 \\
7.4 \\
7.5 \\
12.5 \\
18.9 \\
21.0 \\
17.2 \\
13.3\end{array}$ & $\begin{array}{l}3.7 \\
3.1 \\
3.1 \\
5.4 \\
7.3 \\
3.4 \\
8.3 \\
6.9\end{array}$ & $\begin{array}{r}9.1 \\
7.4 \\
7.5 \\
13.8 \\
19.6 \\
21.7 \\
17.8 \\
13.6\end{array}$ & $\begin{array}{l}3.8 \\
3.1 \\
2.9 \\
5.0 \\
7.4 \\
8.5 \\
8.3 \\
6.7\end{array}$ & $\begin{array}{r}9.1 \\
7.5 \\
7.8 \\
14.3 \\
20.1 \\
22.1 \\
16.5 \\
13.9\end{array}$ & & $\begin{array}{l}7.2 \\
7.2 \\
7.8 \\
8.8 \\
8.6 \\
8.2 \\
7.8 \\
7.7\end{array}$ & $\begin{array}{l}2 \\
2 \\
2 \\
2 \\
2 \\
2 \\
2 \\
2\end{array}$ & $\begin{array}{l}12.8 \\
14.0 \\
15.9 \\
18.3 \\
17.6 \\
14.4 \\
10.2 \\
15.4\end{array}$ & $\begin{array}{l}14.6 \\
16.0 \\
18.1 \\
21.0 \\
20.6 \\
16.8 \\
12.4 \\
17.3\end{array}$ & $\begin{array}{l}16.3 \\
17.8 \\
20.2 \\
23.6 \\
23.5 \\
19.4 \\
14.5 \\
20.4\end{array}$ & $\begin{array}{l}17.5 \\
19.0 \\
21.3 \\
25.3 \\
24.7 \\
20.4 \\
15.9 \\
22.0\end{array}$ \\
\hline $\begin{array}{l}6 \\
6 \\
6 \\
6 \\
6 \\
6 \\
6 \\
6\end{array}$ & $\begin{array}{r}0 \\
3 \\
6 \\
9 \\
12 \\
15 \\
18 \\
21\end{array}$ & $\begin{array}{r}10.4 \\
10.2 \\
11.7 \\
14.5 \\
16.7 \\
18.4 \\
12.2 \\
9.1\end{array}$ & $\begin{array}{r}7.1 \\
7.6 \\
9.5 \\
10.7\end{array}$ & $\begin{array}{r}10.7 \\
10.5 \\
12.1 \\
15.1 \\
17.8 \\
19.7 \\
12.6 \\
9.1\end{array}$ & $\begin{array}{r}7.1 \\
7.6 \\
9.7 \\
11.2 \\
12.1 \\
13.0 \\
7.3 \\
4.9\end{array}$ & $\begin{array}{r}10.9 \\
10.7 \\
12.6 \\
15.6 \\
18.6 \\
21.2 \\
13.8 \\
8.8\end{array}$ & $\begin{array}{r}7.0 \\
7.5 \\
10.1 \\
11.3 \\
12.0 \\
13.5 \\
8.6\end{array}$ & $\begin{array}{r}11.2 \\
11.1 \\
12.9 \\
16.0 \\
19.5 \\
21.8 \\
13.0 \\
8.2\end{array}$ & & $\begin{array}{l}7.5 \\
7.7 \\
7.8 \\
8.3 \\
8.9 \\
8.3 \\
8.1 \\
7.8\end{array}$ & $\begin{array}{l}2 \\
2 \\
2 \\
2 \\
2 \\
2 \\
3 \\
3\end{array}$ & $\begin{array}{r}8.1 \\
9.8 \\
11.6 \\
12.7 \\
12.4 \\
9.7 \\
10.4 \\
9.5\end{array}$ & $\begin{array}{r}9.4 \\
11.5 \\
13.5 \\
14.8 \\
14.9 \\
12.0 \\
11.3 \\
10.2\end{array}$ & $\begin{array}{l}11.1 \\
13.5 \\
15.7 \\
17.3 \\
17.6 \\
14.2 \\
14.1 \\
12.1\end{array}$ & $\begin{array}{l}12.4 \\
15.1 \\
17.0 \\
18.3 \\
18.5 \\
15.2 \\
15.1 \\
12.8\end{array}$ \\
\hline $\begin{array}{l}7 \\
7 \\
7 \\
7 \\
7 \\
7 \\
7 \\
7\end{array}$ & $\begin{array}{r}0 \\
3 \\
6 \\
9 \\
12 \\
15 \\
18 \\
21\end{array}$ & $\begin{array}{r}4.1 \\
1.8 \\
0.4 \\
3.3 \\
8.0 \\
10.5 \\
8.8 \\
6.6\end{array}$ & $\begin{array}{l}0.8 \\
4.1 \\
6.4 \\
5.5 \\
4.0\end{array}$ & $\begin{array}{r}4.0 \\
1.5 \\
0.0 \\
2.0 \\
8.2 \\
10.4 \\
9.3 \\
6.6\end{array}$ & $\begin{array}{r}1.8 \\
0.1 \\
-1.0 \\
0.4 \\
4.02 \\
5.3 \\
5.2 \\
3.9\end{array}$ & $\begin{array}{r}3.6 \\
1.11 \\
-0.2 \\
2.6 \\
8.65 \\
10.6 \\
9.6 \\
6.6\end{array}$ & $\begin{array}{r}1.7 \\
-0.1 \\
-1.2 \\
0.4 \\
4.5 \\
5.2 \\
4.8 \\
3.7\end{array}$ & $\begin{array}{r}3.4 \\
0.9 \\
-0.4 \\
2.6 \\
8.6 \\
10.6 \\
10.0 \\
6.7\end{array}$ & $\begin{array}{r}1.8 \\
-1.3 \\
0.8 \\
3.7\end{array}$ & $\begin{array}{l}7.6 \\
7.5 \\
7.7 \\
9.0 \\
9.2 \\
8.3 \\
8.0 \\
8.1\end{array}$ & $\begin{array}{l}3 \\
4 \\
4 \\
4 \\
2 \\
3 \\
3 \\
3\end{array}$ & $\begin{array}{r}9.9 \\
10.3 \\
9.4 \\
8.0 \\
4.1 \\
2.2 \\
3.6 \\
4.8\end{array}$ & $\begin{array}{r}11.6 \\
12.5 \\
11.2 \\
9.1 \\
4.7 \\
2.6 \\
4.4 \\
5.0\end{array}$ & $\begin{array}{r}12.2 \\
12.6 \\
11.7 \\
9.7 \\
5.1 \\
3.2 \\
5.4 \\
5.5\end{array}$ & $\begin{array}{r}13.2 \\
13.6 \\
12.6 \\
11.5 \\
4.2 \\
3.2 \\
6.6 \\
6.6\end{array}$ \\
\hline $\begin{array}{l}8 \\
8 \\
8 \\
8 \\
8 \\
8 \\
8 \\
8\end{array}$ & $\begin{array}{r}0 \\
3 \\
6 \\
9 \\
12 \\
15 \\
18 \\
21\end{array}$ & $\begin{array}{l}5.9 \\
4.4 \\
3.2 \\
4.3 \\
5.7 \\
4.8 \\
3.9 \\
3.8\end{array}$ & $\begin{array}{l}3.5 \\
2.5 \\
1.4 \\
2.0 \\
2.2 \\
1.6 \\
1.0 \\
0.3\end{array}$ & $\begin{array}{l}5.7 \\
4.1 \\
3.0 \\
3.9 \\
5.3 \\
4.3 \\
3.8 \\
3.3\end{array}$ & $\begin{array}{r}3.1 \\
2.2 \\
0.1 \\
1.4 \\
1.8 \\
1.3 \\
0.8 \\
-0.2\end{array}$ & $\begin{array}{l}5.4 \\
3.9 \\
2.9 \\
3.7 \\
4.5 \\
4.2 \\
3.6 \\
2.2\end{array}$ & $\begin{array}{r}3.0 \\
2.2 \\
0.7 \\
1.1 \\
1.08 \\
0.9 \\
0.5 \\
-0.5\end{array}$ & $\begin{array}{l}5.3 \\
3.8 \\
2.6 \\
3.6 \\
4.3 \\
3.9 \\
3.4 \\
2.0\end{array}$ & $\begin{array}{l}1.2 \\
0.8 \\
1.2 \\
1.5 \\
0.7\end{array}$ & $\begin{array}{l}7.9 \\
8.0 \\
8.3 \\
8.8 \\
8.5 \\
8.1 \\
7.6 \\
7.6\end{array}$ & $\begin{array}{l}3 \\
3 \\
3 \\
3 \\
3 \\
3 \\
3 \\
3\end{array}$ & $\begin{array}{r}4.0 \\
7.3 \\
13.7 \\
16.2 \\
15.0 \\
15.2 \\
10.4 \\
13.5\end{array}$ & $\begin{array}{r}4.2 \\
8.0 \\
15.6 \\
18.2 \\
16.9 \\
17.4 \\
11.6 \\
15.0\end{array}$ & $\begin{array}{r}4.9 \\
8.5 \\
16.7 \\
19.5 \\
18.9 \\
19.0 \\
12.6 \\
16.4\end{array}$ & $\begin{array}{r}5.3 \\
9.2 \\
17.2 \\
20.9 \\
19.7 \\
19.8 \\
13.0 \\
16.8\end{array}$ \\
\hline $\begin{array}{l}9 \\
9 \\
9 \\
9 \\
9 \\
9 \\
9 \\
9\end{array}$ & $\begin{array}{r}0 \\
3 \\
6 \\
9 \\
12 \\
15 \\
18 \\
21\end{array}$ & $\begin{aligned} & 1.4 \\
&- 0.9 \\
&- 1.7 \\
&-1.2 \\
& 0.0 \\
& 0.7 \\
& 1.0\end{aligned}$ & $\begin{array}{l}-0.6 \\
-1.5 \\
-2.1\end{array}$ & $\begin{array}{l}1.1 \\
0.2 \\
1.5 \\
2.5 \\
1.6 \\
0.5 \\
0.2 \\
0.7\end{array}$ & $\begin{array}{l}-1.1 \\
-2.1 \\
-2.5\end{array}$ & $\begin{array}{r}0.6 \\
-\quad 0.6 \\
=-1.77 \\
=2.11 \\
=1.6 \\
-\quad 0.99 \\
0.22 \\
0.8\end{array}$ & $\mid \begin{array}{l}-1.5 \\
-2.3 \\
-2.0 \\
\end{array}$ & $\begin{array}{r}0.4 \\
-1.0 \\
-1.09 \\
-2.6 \\
-1.7 \\
-0.0 \\
0.1 \\
0.8\end{array}$ & $\begin{array}{l}-1.0 \\
-2.0\end{array} \mid$ & $\begin{array}{l}7.44 \\
7.3 \\
7.03 \\
7.1 \\
7.1 \\
6.9 \\
6.9 \\
6.9\end{array}$ & $\begin{array}{l}3 \\
3 \\
3 \\
3 \\
3 \\
3 \\
3 \\
2\end{array}$ & $\begin{array}{r}14.0 \\
12.4 \\
11.9 \\
9.5 \\
6.7 \\
3.7 \\
3.6 \\
4.3\end{array}$ & $\begin{array}{r}15.8 \\
13.7 \\
13.0 \\
10.3 \\
8.0 \\
4.3 \\
3.6 \\
3.5\end{array}$ & $\begin{array}{r}16.9 \\
15.0 \\
14.6 \\
11.4 \\
8.4 \\
4.5 \\
3.6 \\
3.0\end{array}$ & $\begin{array}{r}17.5 \\
15.4 \\
14.7 \\
11.1 \\
9.1 \\
4.9 \\
3.8 \\
3.6\end{array}$ \\
\hline $\begin{array}{l}10 \\
10 \\
10 \\
10 \\
10 \\
10 \\
10 \\
10\end{array}$ & $\begin{array}{r}0 \\
3 \\
6 \\
9 \\
12 \\
15 \\
18 \\
21\end{array}$ & $\begin{array}{r}1.7 \\
1.9 \\
2.8 \\
5.6 \\
8.4 \\
12.7 \\
11.3 \\
7.9\end{array}$ & $\begin{array}{r}1.2 \\
5.1 \\
8.0 \\
10.0 \\
10.0 \\
7.2\end{array}$ & $\begin{array}{r}1.0 \\
1.1 \\
2.2 \\
5.8 \\
8.8 \\
13.2 \\
11.5 \\
7.7\end{array}$ & $\begin{array}{r}2.5 \\
5.4 \\
8.2 \\
11.1 \\
10.6 \\
7.2\end{array}$ & $\begin{array}{r}1.1 \\
1.3 \\
2.4 \\
4.9 \\
7.7 \\
13.5 \\
11.9 \\
7.2\end{array}$ & $\begin{array}{r}3.2 \\
4.4 \\
7.9 \\
11.2 \\
10.9 \\
6.8\end{array}$ & $\begin{array}{r}1.4 \\
1.6 \\
2.9 \\
5.8 \\
8.3 \\
13.3 \\
12.0 \\
7.1\end{array}$ & & $\begin{array}{l}6.9 \\
6.8 \\
6.9 \\
7.8 \\
7.9 \\
7.7 \\
7.4 \\
7.4\end{array}$ & $\begin{array}{l}2 \\
2 \\
2 \\
2 \\
2 \\
2 \\
3 \\
4\end{array}$ & $\begin{array}{r}5.1 \\
3.2 \\
6.4 \\
12.6 \\
11.6 \\
8.1 \\
4.6 \\
10.9\end{array}$ & $\begin{array}{r}5.5 \\
3.4 \\
6.8 \\
14.3 \\
13.4 \\
9.4 \\
-5.5 \\
17.3\end{array}$ & $\begin{array}{r}5.8 \\
3.9 \\
7.5 \\
15.8 \\
15.1 \\
10.8 \\
6.6 \\
19.3\end{array}$ & $\begin{array}{r}6.5 \\
3.6 \\
7.7 \\
16.5 \\
15.9 \\
11.4 \\
7.3 \\
19.7\end{array}$ \\
\hline
\end{tabular}


TABLE 10

Table 10. -Three-hour averages of air and water-surface temperatures and wind directions and speed, April 1950-August 951, Lake Hefner-Continued

STATION 1 THREE-HOURLY AVERAGES

MARCH, 2952

\begin{tabular}{|c|c|c|c|c|c|c|c|c|c|c|c|c|c|c|c|}
\hline \multirow{4}{*}{ 虽 } & \multirow{4}{*}{ 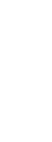 } & \multicolumn{8}{|c|}{ Average air temperature $\left({ }^{\circ} \mathrm{C}\right)$ at indicated height } & \multirow{4}{*}{$\begin{array}{l}\text { Average } \\
\text { water- } \\
\text { surface } \\
\text { tempera- } \\
\text { ture } \\
\left.{ }^{\circ} \mathrm{C}\right)\end{array}$} & \multirow{4}{*}{$\begin{array}{l}\text { Average } \\
\text { wind } \\
\text { direction } \\
\text { (coded) }\end{array}$} & \multirow{2}{*}{\multicolumn{4}{|c|}{$\begin{array}{l}\text { Average wind speed (knots) } \\
\text { at indicated height }\end{array}$}} \\
\hline & & \multirow{2}{*}{\multicolumn{2}{|c|}{$\begin{array}{c}2 \\
\text { meters }\end{array}$}} & \multirow{2}{*}{\multicolumn{2}{|c|}{$\begin{array}{c}4 \\
\text { meters }\end{array}$}} & \multirow{2}{*}{\multicolumn{2}{|c|}{$\begin{array}{c}8 \\
\text { meters }\end{array}$}} & \multirow{2}{*}{\multicolumn{2}{|c|}{$\begin{array}{c}16 \\
\text { meters }\end{array}$}} & & & & & & \\
\hline & & & & & & & & & & & & & & 8 & 16 \\
\hline & & $\begin{array}{l}\text { Dry } \\
\text { butb }\end{array}$ & $\begin{array}{l}\text { Wet } \\
\text { bulb }\end{array}$ & $\begin{array}{l}\text { Dry } \\
\text { bulb }\end{array}$ & $\begin{array}{l}\text { Wet } \\
\text { bulb }\end{array}$ & $\begin{array}{l}\text { Dry } \\
\text { bulb }\end{array}$ & $\begin{array}{l}\text { Wet } \\
\text { bulb }\end{array}$ & $\begin{array}{l}\text { Dry } \\
\text { bulb }\end{array}$ & $\begin{array}{l}\text { Wet } \\
\text { bulb }\end{array}$ & & & & & & \\
\hline
\end{tabular}

\begin{tabular}{|c|c|c|c|c|c|c|c|c|c|c|c|c|c|c|c|}
\hline $\begin{array}{l}12 \\
11 \\
11 \\
11 \\
11 \\
12 \\
11 \\
11\end{array}$ & $\begin{array}{r}0 \\
3 \\
6 \\
9 \\
12 \\
15 \\
18 \\
21\end{array}$ & & & & & & & & & $\begin{array}{l}7.0 \\
7.0 \\
7.0 \\
7.0 \\
7.1 \\
6.9 \\
6.8 \\
6.7\end{array}$ & $\begin{array}{l}3 \\
3 \\
3 \\
3 \\
3 \\
3 \\
3 \\
3\end{array}$ & $\begin{array}{l}17.4 \\
20.5 \\
19.6 \\
18.4 \\
19.0 \\
20.0 \\
21.1 \\
21.00\end{array}$ & $\begin{array}{l}20.8 \\
25.7 \\
23.1 \\
22.0 \\
23.6 \\
22.3 \\
23.3 \\
24.1\end{array}$ & $\begin{array}{l}22.3 \\
25.9 \\
24.9 \\
22.7 \\
25.7 \\
25.3 \\
25.8 \\
27.0\end{array}$ & $\begin{array}{l}23.7 \\
28.6 \\
25.1 \\
23.5 \\
26.3 \\
27.0 \\
28.0 \\
28.1\end{array}$ \\
\hline $\begin{array}{l}12 \\
12 \\
12 \\
12 \\
12 \\
12 \\
12 \\
12\end{array}$ & $\begin{array}{r}0 \\
3 \\
6 \\
9 \\
12 \\
15 \\
18 \\
21\end{array}$ & & & & & & & & & $\begin{array}{l}6.6 \\
6.3 \\
6.5 \\
7.0 \\
7.0 \\
6.4 \\
5.8 \\
5.6\end{array}$ & $\begin{array}{l}3 \\
3 \\
3 \\
3 \\
3 \\
3 \\
3 \\
3\end{array}$ & $\begin{array}{l}19.9 \\
20.5 \\
20.1 \\
19.5 \\
21.2 \\
21.7 \\
15.7 \\
13.8\end{array}$ & $\begin{array}{l}23.5 \\
24.8 \\
24.7 \\
24.4 \\
25.9 \\
26.0 \\
19.0 \\
16.4\end{array}$ & $\begin{array}{l}25.8 \\
26.4 \\
25.7 \\
25.2 \\
28.0 \\
28.3 \\
19.9 \\
16.8\end{array}$ & $\begin{array}{l}26.9 \\
27.5 \\
27.3 \\
27.4 \\
29.5 \\
29.9 \\
20.5 \\
17.6\end{array}$ \\
\hline $\begin{array}{l}13 \\
13 \\
13 \\
13 \\
13 \\
13 \\
13 \\
13\end{array}$ & $\begin{array}{r}0 \\
3 \\
5 \\
9 \\
12 \\
15 \\
18 \\
21\end{array}$ & & & & & & & & & $\begin{array}{l}5.6 \\
5.3 \\
6.0 \\
7.1 \\
0.8 \\
5.7 \\
5.0 \\
5.0\end{array}$ & $\begin{array}{l}3 \\
4 \\
4 \\
4 \\
4 \\
4 \\
3 \\
3\end{array}$ & $\begin{array}{r}15.2 \\
15.6 \\
16.6 \\
17.9 \\
17.8 \\
16.0 \\
8.7 \\
7.3\end{array}$ & $\begin{array}{r}18.9 \\
19.4 \\
19.3 \\
21.8 \\
20.7 \\
19.4 \\
10.7 \\
8.1\end{array}$ & $\begin{array}{r}19.2 \\
20.1 \\
22.3 \\
23.6 \\
24.3 \\
21.02 \\
10.8 \\
8.8\end{array}$ & $\begin{array}{r}20.1 \\
21.8 \\
23.3 \\
25.1 \\
24.9 \\
22.5 \\
11.5 \\
9.2\end{array}$ \\
\hline $\begin{array}{l}14 \\
14 \\
14 \\
14 \\
14 \\
14 \\
14 \\
14\end{array}$ & $\begin{array}{r}0 \\
3 \\
6 \\
9 \\
12 \\
15 \\
18 \\
21\end{array}$ & $\begin{array}{l}1.9 \\
4.5 \\
7.2 \\
5.4 \\
3.7\end{array}$ & $\begin{array}{l}0.0 \\
1.3 \\
2.2 \\
2.8 \\
1.4\end{array}$ & $\begin{array}{l}2.7 \\
4.5 \\
7.2 \\
5.4 \\
3.7\end{array}$ & $\begin{array}{l}0.5 \\
1.5 \\
2.7 \\
3.0 \\
1.7\end{array}$ & $\begin{array}{l}2.5 \\
4.6 \\
7.4 \\
6.1 \\
3.9\end{array}$ & $\begin{array}{l}0.8 \\
1.7 \\
2.3 \\
2.0 \\
1.1\end{array}$ & $\begin{array}{l}2.2 \\
4.6 \\
7.5 \\
6.4 \\
4 \cdot 5\end{array}$ & $\begin{array}{l}2.4 \\
2.4\end{array}$ & $\begin{array}{l}4.9 \\
5.1 \\
5.7 \\
6.6 \\
6.5 \\
5.7 \\
5.3 \\
5.2\end{array}$ & $\begin{array}{l}4 \\
4 \\
4 \\
4 \\
4 \\
4 \\
4 \\
2\end{array}$ & $\begin{array}{r}6.9 \\
10.1 \\
11.5 \\
10.9 \\
9.3 \\
6.4 \\
1.5 \\
2.2\end{array}$ & $\begin{array}{r}7.2 \\
9.6 \\
11.8 \\
12.5 \\
9.7 \\
6.5 \\
1.3 \\
2.5\end{array}$ & $\begin{array}{r}7.6 \\
11.4 \\
14.2 \\
13.8 \\
12.2 \\
7.3 \\
2.0 \\
2.8\end{array}$ & $\begin{array}{r}8.2 \\
17.1 \\
14.6 \\
14.4 \\
8.0 \\
2.6 \\
3.3\end{array}$ \\
\hline $\begin{array}{l}15 \\
15 \\
15 \\
15 \\
15 \\
15 \\
15 \\
15\end{array}$ & $\begin{array}{r}0 \\
3 \\
6 \\
9 \\
12 \\
15 \\
18 \\
21\end{array}$ & $\begin{array}{l}2.4 \\
0.4 \\
0.6 \\
3.9 \\
8.0 \\
7.9 \\
5.5 \\
3.5\end{array}$ & $\begin{array}{r}0.2 \\
-1.0 \\
-0.5 \\
1.6 \\
3.9 \\
3.8 \\
3.44 \\
1.8\end{array}$ & $\begin{array}{l}2.1 \\
0.1 \\
0.0 \\
3.0 \\
6.7 \\
7.7 \\
5.7 \\
3.4\end{array}$ & $\begin{array}{r}0.2 \\
-0.08 \\
-0.5 \\
1.00 \\
3.0 \\
3.09 \\
3.3 \\
1.08\end{array}$ & $\begin{array}{l}2.9 \\
6.2 \\
7.8 \\
6.0 \\
3.1\end{array}$ & $\left|\begin{array}{r}-0.1 \\
-1.0 \\
-0.7 \\
0.9 \\
2.6 \\
3.03 \\
2.08 \\
1.4\end{array}\right|$ & $\begin{array}{l}1.8 \\
0.0 \\
0.0 \\
3.2 \\
5.5 \\
7.9 \\
6.5 \\
3.4\end{array}$ & $\begin{array}{r}0.1 \\
-0.9 \\
-0.6 \\
1.3 \\
3.3 \\
4.2 \\
3.4 \\
1.8\end{array}$ & $\begin{array}{l}5.0 \\
4.9 \\
5.4 \\
5.7 \\
6.7 \\
5.8 \\
5.1 \\
5.2\end{array}$ & $\begin{array}{l}4 \\
3 \\
3 \\
3 \\
3 \\
3 \\
3 \\
3\end{array}$ & $\begin{array}{l}3.6 \\
3.1 \\
2.5 \\
5.9 \\
4.3 \\
5.8 \\
2.6 \\
5.1\end{array}$ & $\begin{array}{l}3.7 \\
\\
6.4 \\
4.6 \\
6.6 \\
4.9 \\
5.9\end{array}$ & $\begin{array}{l}3.7 \\
3.4 \\
2.8 \\
7.3 \\
5.4 \\
5.9 \\
3.5 \\
6.5\end{array}$ & $\begin{array}{l}4.2 \\
3.7 \\
2.9 \\
6.8 \\
5.8 \\
7.3 \\
5.5 \\
7.8\end{array}$ \\
\hline $\begin{array}{l}16 \\
16 \\
16 \\
16 \\
16 \\
16 \\
16 \\
16\end{array}$ & $\begin{array}{r}0 \\
3 \\
6 \\
9 \\
12 \\
15 \\
18 \\
21\end{array}$ & $\begin{array}{r}2.2 \\
2.6 \\
3.3 \\
9.3 \\
14.6 \\
18.7 \\
16.4 \\
12.9\end{array}$ & $\begin{array}{r}0.9 \\
0.9 \\
1.6 \\
6.9 \\
10.4 \\
10.8 \\
9.7 \\
8.4\end{array}$ & $\begin{array}{r}2.3 \\
2.5 \\
3.3 \\
9.5 \\
15.7 \\
20.0 \\
18.3 \\
14.0\end{array}$ & $\begin{array}{r}0.8 \\
0.9 \\
1.7 \\
8.7 \\
11.1 \\
12.1 \\
10.9 \\
9.3\end{array}$ & $\begin{array}{r}2.0 \\
2.3 \\
3.2 \\
10.1 \\
16.1 \\
21.2 \\
19.4 \\
14.9\end{array}$ & $\begin{array}{r}0.7 \\
0.7 \\
1: 0 \\
8.0 \\
11.3 \\
11.9 \\
10.8 \\
9.3\end{array}$ & $\begin{array}{r}2.0 \\
2.3 \\
3.5 \\
11.1 \\
16.8 \\
21.8 \\
20.1 \\
15.7\end{array}$ & $\begin{array}{l}0.8 \\
0.8 \\
1.8\end{array}$ & $\begin{array}{l}5.0 \\
5.0 \\
5.5 \\
6.5 \\
6.5 \\
5.1 \\
5.0 \\
6.0\end{array}$ & $\begin{array}{l}2 \\
3 \\
2 \\
2 \\
2 \\
2 \\
2 \\
2\end{array}$ & $\begin{array}{r}8.3 \\
10.2 \\
13.1 \\
15.7 \\
15.7 \\
13.6 \\
8.6 \\
8.5\end{array}$ & $\begin{array}{r}9.1 \\
10.9 \\
14.5 \\
18.1 \\
18.4 \\
16.4 \\
11.0 \\
10.8\end{array}$ & $\begin{array}{r}9.7 \\
11.7 \\
15.7 \\
20.1 \\
21.1 \\
19.1 \\
13.2 \\
13.1\end{array}$ & $\begin{array}{l}10.2 \\
12.1 \\
16.2 \\
21.3 \\
22.5 \\
20.8 \\
14.7 \\
14.8\end{array}$ \\
\hline $\begin{array}{l}17 \\
17 \\
17 \\
17 \\
17 \\
17 \\
17 \\
17\end{array}$ & $\begin{array}{r}0 \\
3 \\
5 \\
9 \\
12 \\
15 \\
12 \\
21\end{array}$ & $\begin{array}{r}13.2 \\
8.7 \\
5.6 \\
4.6 \\
7.7 \\
8.1 \\
6.4\end{array}$ & $\begin{array}{l}7.7 \\
6.4 \\
4.9 \\
3.7 \\
5.0 \\
4.9 \\
3.8\end{array}$ & $\begin{array}{r}14.0 \\
9.2 \\
6.1 \\
4.9 \\
7.9 \\
8.2 \\
6.1 \\
1.8\end{array}$ & $\begin{array}{l}8.2 \\
5.1 \\
5.4 \\
4.1 \\
\\
2.8 \\
0.2\end{array}$ & $\begin{array}{r}14.4 \\
9.1 \\
5.8 \\
4.9 \\
8.0 \\
8.2 \\
5.8 \\
1.4\end{array}$ & $\begin{array}{l}7.9 \\
6.8 \\
5.4 \\
4.0 \\
5.0 \\
4.8 \\
3.1 \\
0.1\end{array}$ & $\begin{array}{r}15.2 \\
9.4 \\
5.8 \\
4.8 \\
8.1 \\
8.3 \\
5.7 \\
1.2\end{array}$ & $\begin{array}{r}6.1 \\
5.2 \\
4.1 \\
\\
1.8 \\
-0.2\end{array}$ & $\begin{array}{l}6.0 \\
5.9 \\
6.0 \\
6.2 \\
7.2 \\
6.4 \\
6.1 \\
6.0\end{array}$ & $\begin{array}{l}2 \\
2 \\
4 \\
4 \\
4 \\
4 \\
4 \\
4\end{array}$ & $\begin{array}{l}13.6 \\
13.2 \\
15.2 \\
13.5 \\
11.7 \\
14.6 \\
16.4 \\
20.1\end{array}$ & $\begin{array}{l}26.1 \\
13.6 \\
16.6 \\
16.1 \\
14.5 \\
18.0 \\
20.6 \\
24.8\end{array}$ & $\begin{array}{l}18.8 \\
16.0 \\
19.9 \\
17.6 \\
16.1 \\
19.4 \\
21.7 \\
25.6\end{array}$ & $\begin{array}{l}20.7 \\
18.9 \\
20.7 \\
16.9 \\
17.2 \\
21.2 \\
24.2 \\
29.2\end{array}$ \\
\hline $\begin{array}{l}18 \\
18 \\
18 \\
18 \\
18 \\
18 \\
18 \\
18\end{array}$ & $\begin{array}{r}0 \\
3 \\
6 \\
9 \\
12 \\
15 \\
18 \\
21\end{array}$ & $\begin{array}{r}-2.6 \\
0.2 \\
3.8 \\
5.5 \\
3.9 \\
2.2\end{array}$ & $\begin{array}{r} \\
0.1 \\
1.0 \\
0.1 \\
-0.7\end{array}$ & $\begin{array}{l}0.5 \\
1.5 \\
2.0 \\
0.9 \\
3.7 \\
4.9 \\
3.8 \\
2.0\end{array}$ & $\begin{array}{r} \\
0.9 \\
0.9 \\
0.3 \\
-0.7\end{array}$ & $\begin{array}{l}-0.6 \\
=1.5 \\
-1.9 \\
0.8 \\
3.6 \\
4.8 \\
3.5 \\
1.8\end{array}$ & $\begin{array}{r} \\
\\
0.44 \\
0.2 \\
-0.3 \\
-1.4\end{array}$ & $\left|\begin{array}{r}-0.9 \\
-1.8 \\
-2.2 \\
1.0 \\
3.6 \\
4.9 \\
3.03 \\
1.8\end{array}\right|$ & & $\begin{array}{l}5.8 \\
5.6 \\
5.9 \\
6.9 \\
6.8 \\
6.0 \\
5.6 \\
5.5\end{array}$ & $\begin{array}{l}3 \\
3 \\
3 \\
3 \\
3 \\
3 \\
3 \\
3\end{array}$ & $\begin{array}{r}19.8 \\
15.3 \\
15.5 \\
17.4 \\
16.4 \\
14.6 \\
7.07 \\
5.0\end{array}$ & $\begin{array}{r}23.4 \\
16.7 \\
27.0 \\
19.6 \\
18.3 \\
16.3 \\
8.8 \\
5.5\end{array}$ & $\begin{array}{r}25.3 \\
19.3 \\
19.3 \\
22.0 \\
21.0 \\
18.0 \\
10.0 \\
5.5\end{array}$ & $\begin{array}{r}26.8 \\
19.6 \\
19.9 \\
23.2 \\
21.8 \\
19.5 \\
10.5 \\
6.1\end{array}$ \\
\hline $\begin{array}{l}19 \\
19 \\
19 \\
19 \\
19 \\
19 \\
19 \\
19\end{array}$ & $\begin{array}{r}0 \\
3 \\
6 \\
9 \\
12 \\
15 \\
18 \\
21\end{array}$ & $\begin{array}{r}0.9 \\
-0.1 \\
0.3 \\
4.5 \\
5.5 \\
8.0 \\
6.4 \\
4.4\end{array}$ & $\left|\begin{array}{r}-1.55 \\
-2.0 \\
-2.0 \\
1.00 \\
2.2 \\
2.09 \\
3.6 \\
2.02\end{array}\right|$ & $\begin{array}{l}0.7 \\
0.4 \\
0.0 \\
4.3 \\
6.5 \\
8.2 \\
6.5 \\
4.3\end{array}$ & $\left|\begin{array}{r}-1.0 \\
-1.9 \\
\\
3.4\end{array}\right|$ & $\begin{array}{r}0.7 \\
-0.7 \\
-0.1 \\
4.4 \\
6.7 \\
8.5 \\
7.1 \\
4.4\end{array}$ & $\left|\begin{array}{r}-1.6 \\
-2.3 \\
-2.0 \\
0.9 \\
2.1 \\
3.1 \\
2.5 \\
1.8\end{array}\right|$ & $\begin{array}{r}0.7 \\
-0.6 \\
0.0 \\
4.5 \\
6.7 \\
8.5 \\
7.7 \\
5.2\end{array}$ & & $\begin{array}{l}5.2 \\
5.1 \\
6.1 \\
6.9 \\
6.7 \\
5.9 \\
5.6 \\
5.6\end{array}$ & $\begin{array}{l}3 \\
2 \\
2 \\
2 \\
4 \\
2 \\
4 \\
2\end{array}$ & $\begin{array}{r}2.4 \\
2.4 \\
8.4 \\
10.3 \\
10.8 \\
7.3 \\
2.3 \\
3.5\end{array}$ & $\begin{array}{r}2.3 \\
2.2 \\
8.9 \\
11.1 \\
21.3 \\
7.9 \\
2.6 \\
3.8\end{array}$ & $\begin{array}{r}2.2 \\
2.6 \\
9.8 \\
11.8 \\
12.8 \\
8.5 \\
3.3 \\
4.4\end{array}$ & $\begin{array}{r}2.3 \\
2.6 \\
10.2 \\
12.8 \\
15.8 \\
\\
3.9 \\
6.1\end{array}$ \\
\hline $\begin{array}{l}20 \\
20 \\
20 \\
20 \\
20 \\
20 \\
20 \\
20\end{array}$ & $\begin{array}{r}0 \\
3 \\
6 \\
9 \\
12 \\
15 \\
18 \\
21\end{array}$ & $\begin{array}{r}3.9 \\
3.1 \\
4.2 \\
9.3 \\
12.9 \\
13.9 \\
8.4 \\
3.2\end{array}$ & $\begin{array}{l}1.2 \\
0.7 \\
1.1 \\
3.3 \\
5.0 \\
5.8 \\
3.5 \\
0.8\end{array}$ & $\begin{array}{r}3.7 \\
2.8 \\
4.2 \\
9.7 \\
13.2 \\
14.8 \\
8.4 \\
2.8\end{array}$ & 4.1 & $\begin{array}{r}3.7 \\
2.6 \\
4.1 \\
9.6 \\
13.4 \\
15.2 \\
8.3 \\
2.5\end{array}$ & $\begin{array}{r}1.00 \\
0.2 \\
0.9 \\
3.4 \\
5.0 \\
5.0 \\
3.0 \\
-0.1\end{array}$ & $\begin{array}{r}3.7 \\
2.5 \\
4: 3 \\
10.1 \\
13.7 \\
15.4 \\
7.6 \\
2.2\end{array}$ & & $\begin{array}{l}5.7 \\
5.7 \\
6.0 \\
7.3 \\
7.1 \\
6.4 \\
6.0 \\
5.9\end{array}$ & $\begin{array}{l}2 \\
2 \\
2 \\
2 \\
2 \\
2 \\
3 \\
3\end{array}$ & $\begin{array}{r}8.2 \\
10.3 \\
12.7 \\
18.3 \\
15.4 \\
9.8 \\
13.5 \\
13.3\end{array}$ & $\begin{array}{l}9.0 \\
11.6 \\
14.2 \\
20.8 \\
17.4 \\
11.3 \\
15.7 \\
15.4\end{array}$ & $\begin{array}{l}10.1 \\
13.2 \\
16.2 \\
23.0 \\
19.4 \\
12.4 \\
20.8 \\
16.2\end{array}$ & $\begin{array}{l}11.2 \\
13.6 \\
17.6 \\
24.3 \\
20.6 \\
13.4 \\
18.5 \\
17.0\end{array}$ \\
\hline
\end{tabular}



Table 10. -Three-hour averages of air and water-surface temperatures and wind directions and speed, April 1950-August
1951, Lake Hefner-Continued

STATION

THREE-HOURLY AVERAGES

MARCH, 1951

\begin{tabular}{|c|c|c|c|c|c|c|c|c|c|c|c|c|c|c|c|}
\hline \multirow{4}{*}{ 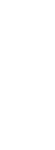 } & \multirow{4}{*}{ 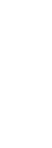 } & \multicolumn{8}{|c|}{ Average air temperature $\left({ }^{\circ} \mathrm{C}\right)$ at indicated height } & \multirow{4}{*}{$\begin{array}{c}\text { Average } \\
\text { water- } \\
\text { surface } \\
\text { tempera- } \\
\text { ture } \\
\text { ('C) }\end{array}$} & \multirow{4}{*}{$\begin{array}{c}\text { Average } \\
\text { wind } \\
\text { direction } \\
\text { (coded) }\end{array}$} & \multirow{2}{*}{\multicolumn{4}{|c|}{$\begin{array}{l}\text { Average wind speed (knots) } \\
\text { at indicated height }\end{array}$}} \\
\hline & & \multirow{2}{*}{\multicolumn{2}{|c|}{$\begin{array}{c}2 \\
\text { meters }\end{array}$}} & \multirow{2}{*}{\multicolumn{2}{|c|}{$\begin{array}{c}4 \\
\text { meters }\end{array}$}} & \multirow{2}{*}{\multicolumn{2}{|c|}{$\begin{array}{c}8 \\
\text { meters }\end{array}$}} & \multirow{2}{*}{\multicolumn{2}{|c|}{$\begin{array}{c}16 \\
\text { meters }\end{array}$}} & & & & & & \\
\hline & & & & & & & & & & & & 2 & 4 & 8 & 16 \\
\hline & & $\begin{array}{l}\text { Dry } \\
\text { bulb }\end{array}$ & $\begin{array}{l}\text { Wet } \\
\text { bulb }\end{array}$ & $\begin{array}{l}\text { Dry } \\
\text { bulb }\end{array}$ & $\begin{array}{l}\text { Wet } \\
\text { bulb }\end{array}$ & $\begin{array}{l}\text { Dry } \\
\text { bulb }\end{array}$ & $\begin{array}{l}\text { Wet } \\
\text { bulb }\end{array}$ & $\begin{array}{l}\text { Dry } \\
\text { bulb }\end{array}$ & $\begin{array}{l}\text { Wet } \\
\text { bulb }\end{array}$ & & & & meters & meters & \\
\hline
\end{tabular}

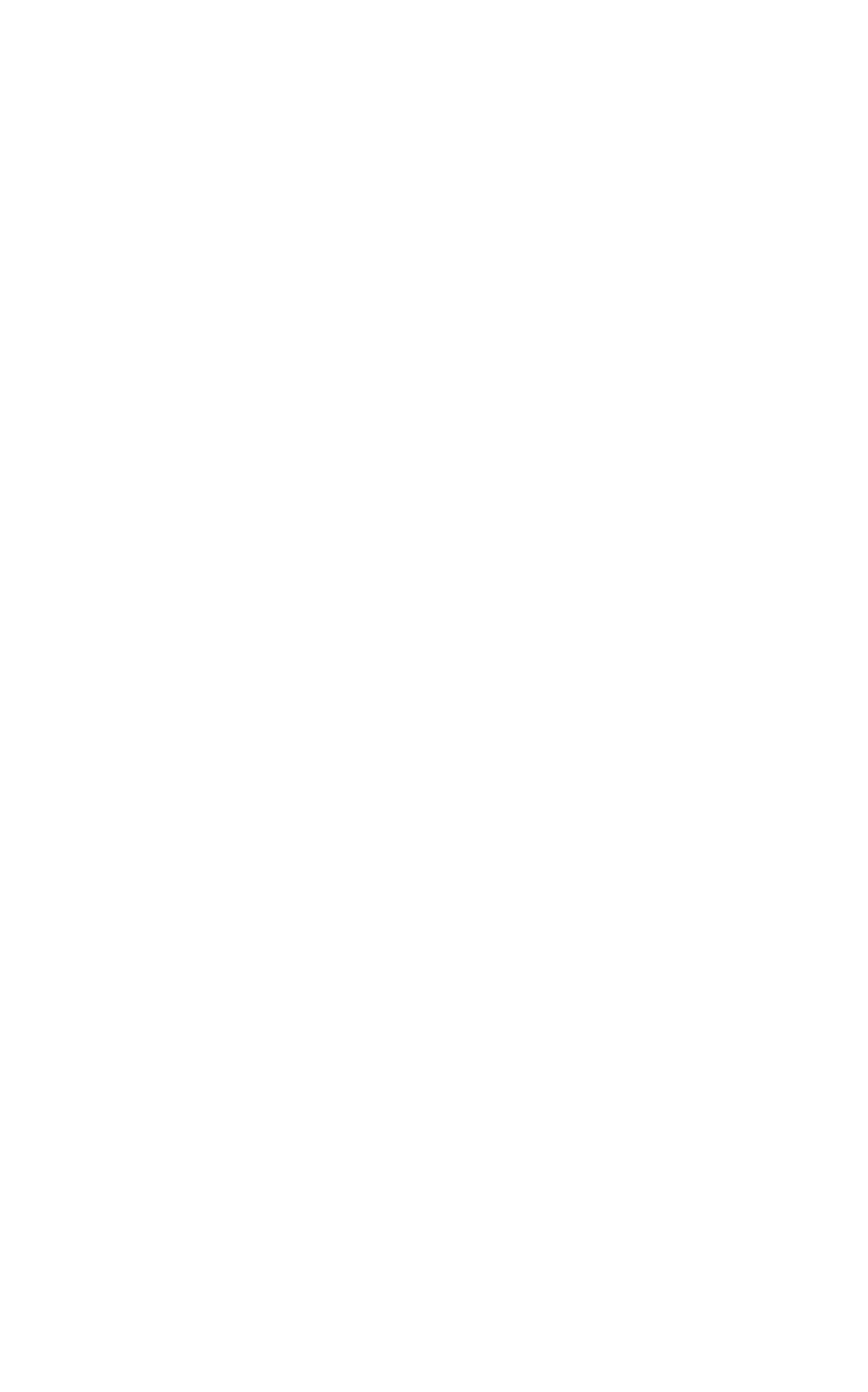


TABLE 10

Table 10. - Three-hour averages of air and water-surface temperatures and wind directions and speed, April 1950-August 951, Lake Hefner Continued

THREE-HOURLY AVERAGES

APRIL, 1951

\begin{tabular}{|c|c|c|c|c|c|c|c|c|c|c|c|c|c|c|c|}
\hline \multirow{4}{*}{ 窘 } & \multirow{4}{*}{ 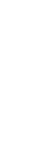 } & \multicolumn{8}{|c|}{ Average air temperature $\left({ }^{\circ} \mathrm{C}\right)$ at indicated height } & \multirow{4}{*}{$\begin{array}{c}\text { Average } \\
\text { water- } \\
\text { surface } \\
\text { tempera- } \\
\text { ture } \\
\left({ }^{\circ} \mathrm{C}\right)\end{array}$} & \multirow{4}{*}{$\begin{array}{c}\text { Average } \\
\text { wind } \\
\text { direction } \\
\text { (coded) }\end{array}$} & \multirow{2}{*}{\multicolumn{4}{|c|}{$\begin{array}{l}\text { Average wind speed (knots) } \\
\text { at indicated height }\end{array}$}} \\
\hline & & \multirow{2}{*}{\multicolumn{2}{|c|}{$\stackrel{2}{\text { meters }}$}} & \multirow{2}{*}{\multicolumn{2}{|c|}{$\begin{array}{c}4 \\
\text { meters }\end{array}$}} & \multirow{2}{*}{\multicolumn{2}{|c|}{$\begin{array}{c}8 \\
\text { meters }\end{array}$}} & \multirow{2}{*}{\multicolumn{2}{|c|}{$\begin{array}{c}16 \\
\text { meters }\end{array}$}} & & & & & & \\
\hline & & & & & & & & & & & & 2 & 4 & 8 & 16 \\
\hline & & $\begin{array}{l}\text { Dry } \\
\text { bulb }\end{array}$ & $\begin{array}{l}\text { Wet } \\
\text { bulb }\end{array}$ & $\begin{array}{l}\text { Dry } \\
\text { bulb }\end{array}$ & $\begin{array}{l}\text { Wet } \\
\text { bulb }\end{array}$ & $\begin{array}{l}\text { Dry } \\
\text { bulb }\end{array}$ & $\begin{array}{l}\text { Wet } \\
\text { bulb }\end{array}$ & $\begin{array}{l}\text { Dry } \\
\text { bulb }\end{array}$ & $\begin{array}{l}\text { Wet } \\
\text { bulb }\end{array}$ & & & meters & meters & meters & meters \\
\hline $\begin{array}{l}1 \\
1 \\
1 \\
1 \\
1 \\
1 \\
1 \\
1\end{array}$ & $\begin{array}{r}0 \\
3 \\
6 \\
9 \\
17 \\
15 \\
18 \\
21\end{array}$ & $\begin{array}{l}8.7 \\
8.4 \\
7.7 \\
6.5 \\
5.6 \\
5.7 \\
5.2 \\
4.3\end{array}$ & $\begin{array}{l}5.0 \\
4.0 \\
4.7 \\
4.1 \\
3.4 \\
3.8 \\
3.7 \\
3.0\end{array}$ & $\begin{array}{l}8.7 \\
8.4 \\
7.5 \\
6.3 \\
5.4 \\
5.7 \\
5.0 \\
4.3\end{array}$ & $\begin{array}{l}4.9 \\
4: 9 \\
4.5 \\
4: 0 \\
3.3 \\
4.0 \\
3.6 \\
3.1\end{array}$ & $\begin{array}{l}7.5 \\
6.9 \\
4.9 \\
4.9 \\
4.6 \\
4.1\end{array}$ & $\begin{array}{l}4.4 \\
4.2 \\
3.9 \\
3.5 \\
2.8 \\
2.9 \\
3.2 \\
3.0\end{array}$ & $\begin{array}{l}8.6 \\
8.3 \\
7.2 \\
6.0 \\
5.0 \\
5.3 \\
4.6 \\
4.0\end{array}$ & $\begin{array}{l}4.8 \\
4.5 \\
4.1 \\
3.5 \\
3.0 \\
3.4 \\
3.2 \\
2.9\end{array}$ & $\begin{array}{l}8.3 \\
8.4 \\
8.5 \\
8.5 \\
8.7 \\
8.5 \\
8.2 \\
8.0\end{array}$ & $\begin{array}{l}3 \\
3 \\
3 \\
3 \\
3 \\
3 \\
4 \\
4\end{array}$ & $\begin{array}{r}11.2 \\
8.02 \\
11.01 \\
12.7 \\
15.6 \\
14.1 \\
13.2 \\
8.2\end{array}$ & $\begin{array}{r}12.7 \\
10.3 \\
12.7 \\
14.0 \\
18.8 \\
16.4 \\
15.6 \\
8.0\end{array}$ & $\begin{array}{r}13.6 \\
10.6 \\
13.4 \\
15.6 \\
20.2 \\
18.0 \\
17.1 \\
9.3\end{array}$ & $\begin{array}{l}14 \cdot 2 \\
11 \cdot 2 \\
14 \cdot 1 \\
16 \cdot 2 \\
21: 5 \\
19 \cdot 1 \\
18: 2 \\
11 \cdot 1\end{array}$ \\
\hline $\begin{array}{l}2 \\
2 \\
2 \\
2 \\
2 \\
2 \\
2 \\
2 \\
2\end{array}$ & $\begin{array}{r}0 \\
3 \\
6 \\
9 \\
12 \\
15 \\
13 \\
21\end{array}$ & $\begin{array}{l}4.5 \\
3.1 \\
2.9 \\
6.7 \\
8.3 \\
9.4 \\
8.2 \\
6.2\end{array}$ & $\begin{array}{l}3.3 \\
2.2 \\
2.3 \\
3.1 \\
4.5 \\
5.5 \\
5.4 \\
4.2\end{array}$ & $\begin{array}{l}4.4 \\
3.0 \\
2.3 \\
6.5 \\
8.2 \\
9.1 \\
8.0 \\
6.2\end{array}$ & $\begin{array}{l}3.3 \\
2.2 \\
1.9\end{array}$ & $\begin{array}{l}4.2 \\
2.7 \\
2.8 \\
6.5 \\
8.2 \\
9.0 \\
7.8 \\
6.1\end{array}$ & $\begin{array}{l}3.0 \\
1: 7 \\
1: 9 \\
2: 4 \\
4: 1 \\
4.9 \\
4.5 \\
4.0\end{array}$ & $\begin{array}{l}4.1 \\
2.3 \\
2.7 \\
6.4 \\
8.2 \\
9.2 \\
7.9 \\
6.2\end{array}$ & $\begin{array}{l}2.9 \\
1.6 \\
1.8 \\
2.4\end{array}$ & $\begin{array}{l}8.0 \\
7.9 \\
8.2 \\
9.5 \\
9.3 \\
3.8 \\
8.2 \\
8.1\end{array}$ & $\begin{array}{l}4 \\
4 \\
4 \\
3 \\
3 \\
3 \\
3 \\
2\end{array}$ & $\begin{array}{r}10.4 \\
10.5 \\
9.3 \\
15.2 \\
12.8 \\
10.6 \\
5.2 \\
2.7\end{array}$ & $\begin{array}{r}11.0 \\
14.2 \\
9.8 \\
17.0 \\
14.8 \\
12.1 \\
5.8 \\
3.3\end{array}$ & $\begin{array}{r}12.7 \\
12.4 \\
10.8 \\
19.5 \\
16.4 \\
13.6 \\
6.3 \\
3.5\end{array}$ & $\begin{array}{l}13.8 \\
15.6 \\
14.6 \\
20.7 \\
17.3 \\
14.4 \\
7.3 \\
4.2\end{array}$ \\
\hline $\begin{array}{l}3 \\
3 \\
3 \\
3 \\
3 \\
3 \\
3 \\
3\end{array}$ & $\begin{array}{r}0 \\
3 \\
6 \\
0 \\
0 \\
12 \\
15 \\
18 \\
21\end{array}$ & $\begin{array}{r}4.3 \\
3.3 \\
3.7 \\
9.9 \\
14.8 \\
16.8 \\
33.7 \\
12.1\end{array}$ & $\begin{array}{l}3.1 \\
2.4 \\
2.6 \\
5.7 \\
7.6 \\
8.0 \\
7.8 \\
7.6\end{array}$ & $\begin{array}{r}4.1 \\
3.2 \\
3.9 \\
9.5 \\
14.5 \\
17.1 \\
14.4 \\
12.9\end{array}$ & & $\begin{array}{r}3.9 \\
3.1 \\
4 \cdot 1 \\
10.3 \\
14.0 \\
17.3 \\
14.9 \\
13.5\end{array}$ & $\begin{array}{l}2.8 \\
2.1 \\
2.7 \\
5.8 \\
7.4 \\
8.0 \\
7.8 \\
7.5\end{array}$ & $\begin{array}{r}4.2 \\
3.0 \\
4.3 \\
11.2 \\
14.8 \\
1.7 .4 \\
16.3 \\
14.1\end{array}$ & & $\begin{array}{r}8.1 \\
8.0 \\
8.4 \\
10.4 \\
13.5 \\
11.3 \\
9.7 \\
9.5\end{array}$ & $\begin{array}{l}2 \\
2 \\
2 \\
3 \\
3 \\
2 \\
2 \\
2\end{array}$ & $\begin{array}{l}4.3 \\
6.1 \\
4.8 \\
2.0 \\
2.5 \\
4.8 \\
2.9 \\
5.8\end{array}$ & $\begin{array}{l}4.5 \\
6.5 \\
5.3 \\
2.2 \\
3.0 \\
5.5 \\
4.0 \\
7.2\end{array}$ & $\begin{array}{l}5.1 \\
6.9 \\
5.7 \\
2.1 \\
3.0 \\
6.5 \\
5.2 \\
8.7\end{array}$ & $\begin{array}{r}6.4 \\
7.6 \\
5.9 \\
2.4 \\
2.7 \\
7.4 \\
6.8 \\
10.0\end{array}$ \\
\hline $\begin{array}{l}4 \\
4 \\
4 \\
4 \\
4 \\
4 \\
4 \\
4\end{array}$ & $\begin{array}{r}0 \\
3 \\
6 \\
9 \\
12 \\
15 \\
18 \\
21\end{array}$ & $\begin{array}{l}11.6 \\
11.0 \\
11.0 \\
15.3 \\
18.7 \\
20.2 \\
19.8 \\
19.3\end{array}$ & $\begin{array}{r}6.6 \\
6.3 \\
6.4 \\
8.9 \\
1.0 .8 \\
11.4 \\
11.00 \\
11.03\end{array}$ & $\begin{array}{l}11.8 \\
11.11 \\
11.02 \\
16.1 \\
19.8 \\
21.5 \\
20.03 \\
19.0\end{array}$ & & $\begin{array}{l}11.8 \\
111.1 \\
11.2 \\
16.4 \\
20.4 \\
22.2 \\
20.9 \\
19.3\end{array}$ & & $\begin{array}{l}12.0 \\
11.4 \\
11.4 \\
17.2 \\
20.9 \\
22.7 \\
21.5 \\
19.9\end{array}$ & & $\begin{array}{r}9.0 \\
8.7 \\
9.0 \\
9.8 \\
10.2 \\
9.5 \\
9.7 \\
9.4\end{array}$ & $\begin{array}{l}2 \\
2 \\
2 \\
2 \\
2 \\
2 \\
2 \\
2\end{array}$ & $\begin{array}{r}9.4 \\
12.4 \\
15.2 \\
14.6 \\
12.3 \\
8.4 \\
7.2 \\
13.8\end{array}$ & $\begin{array}{r}10.3 \\
14.0 \\
17.3 \\
17.6 \\
14.5 \\
10.3 \\
9.0 \\
15.6\end{array}$ & $\begin{array}{l}11.8 \\
15.6 \\
19.3 \\
19.3 \\
16.5 \\
11.9 \\
10.6 \\
17.9\end{array}$ & $\begin{array}{l}13.0 \\
16.6 \\
20.3 \\
20.5 \\
17.3 \\
12.4 \\
11.5 \\
19.2\end{array}$ \\
\hline $\begin{array}{l}5 \\
5 \\
5 \\
5 \\
5 \\
5 \\
5 \\
5\end{array}$ & $\begin{array}{r}0 \\
3 \\
6 \\
9 \\
12 \\
15 \\
18 \\
21\end{array}$ & $\begin{array}{l}16.7 \\
14.4\end{array}$ & $\begin{array}{l}11.4 \\
10.4\end{array}$ & $\begin{array}{l}16.4 \\
14.6\end{array}$ & 12.6 & $\begin{array}{l}17.7 \\
14.4\end{array}$ & 12.7 & $\begin{array}{l}18.0 \\
14.4\end{array}$ & 12.4 & $\begin{array}{r}9.4 \\
9.2 \\
9.3 \\
9.5 \\
10.2 \\
10.5 \\
10.0 \\
0.9\end{array}$ & $\begin{array}{l}2 \\
2 \\
2 \\
2 \\
2 \\
2 \\
3 \\
2\end{array}$ & $\begin{array}{r}16.9 \\
14.6 \\
17.3 \\
16.3 \\
14.7 \\
11.6 \\
11.6 \\
5.0\end{array}$ & $\begin{array}{r}19.5 \\
17.1 \\
19.5 \\
18.6 \\
16.6 \\
13.2 \\
12.7 \\
6.2\end{array}$ & $\begin{array}{r}21.8 \\
18.8 \\
21.7 \\
20.5 \\
18.2 \\
14.7 \\
13.7 \\
7.1\end{array}$ & $\begin{array}{r}23.2 \\
20.0 \\
22.9 \\
21.1 \\
19.2 \\
15.4 \\
15.2 \\
7.8\end{array}$ \\
\hline $\begin{array}{l}6 \\
6 \\
6 \\
6 \\
6 \\
6 \\
6 \\
6\end{array}$ & $\begin{array}{r}0 \\
3 \\
6 \\
9 \\
12 \\
15 \\
18 \\
21\end{array}$ & $\begin{array}{l}11.7 \\
11.7 \\
10.03 \\
11.4 \\
12.5 \\
12.5 \\
11.55 \\
10.5\end{array}$ & $\begin{array}{r}1.1 .1 \\
11.1 \\
9.7 \\
9.4 \\
9.6 \\
9.7 \\
9.4 \\
9.1\end{array}$ & $\begin{array}{l}12.7 \\
12.0 \\
10.3 \\
11.6 \\
12.6 \\
12.7 \\
11.6 \\
10.7\end{array}$ & $\begin{array}{r}11.7 \\
11.4 \\
9.7 \\
9.6\end{array}$ & $\begin{array}{l}11.6 \\
12.9 \\
12.8 \\
11.7 \\
10.7\end{array}$ & $\begin{array}{r}11.8 \\
11.5 \\
9.8 \\
9.5 \\
9.4 \\
9.5 \\
9.2 \\
8.8\end{array}$ & $\begin{array}{l}12.5 \\
11.9 \\
10.5 \\
11.8 \\
12.9 \\
12.8 \\
11.5 \\
10.6\end{array}$ & $\begin{array}{c}11.0 \\
8.8 \\
9.1\end{array}$ & $\begin{array}{r}9.9 \\
9.9 \\
10.1 \\
10.5 \\
11.1 \\
10.2 \\
10.1 \\
10.2\end{array}$ & $\begin{array}{l}2 \\
4 \\
4 \\
4 \\
4 \\
4 \\
4 \\
4\end{array}$ & $\begin{array}{r}9.8 \\
12.4 \\
9.8 \\
11.7 \\
12.6 \\
11.7 \\
10.8 \\
9.8\end{array}$ & $\begin{array}{l}10.6 \\
15.5 \\
11.6 \\
12.1 \\
13.7 \\
13.9 \\
13.2 \\
11.9\end{array}$ & $\begin{array}{l}11.7 \\
16.1 \\
13.1 \\
15.2 \\
17.0 \\
15.9 \\
14.3 \\
12.8\end{array}$ & $\begin{array}{l}10.1 \\
19.2 \\
15.6 \\
14.3 \\
17.4 \\
17.4 \\
16.4 \\
14.3\end{array}$ \\
\hline $\begin{array}{l}7 \\
7 \\
7 \\
7 \\
7 \\
7 \\
7 \\
7\end{array}$ & $\begin{array}{r}0 \\
3 \\
6 \\
0 \\
1.2 \\
1.5 \\
18 \\
71\end{array}$ & $\begin{array}{r}9.1 \\
7.2 \\
7.1 \\
0.3 \\
10.8 \\
11.0 \\
9.0 \\
8.6\end{array}$ & $\begin{array}{l}8.0 \\
6.5 \\
6.2 \\
6.0 \\
5.5 \\
6.0 \\
4.9 \\
4.3\end{array}$ & $\begin{array}{r}8.9 \\
7.1 \\
7.1 \\
9.3 \\
10.9 \\
11.2 \\
0.7 \\
8.5\end{array}$ & $\begin{array}{l}7.9 \\
6.4 \\
5.9\end{array}$ & $\begin{array}{r}8.8 \\
7.00 \\
7.0 \\
9.3 \\
31.0 \\
11.03 \\
9.06 \\
3.3\end{array}$ & $\begin{array}{l}7.6 \\
6.0 \\
5.7 \\
5.6 \\
5.1 \\
5.3 \\
4.2 \\
3.6\end{array}$ & $\begin{array}{r}8.5 \\
6.7 \\
6.9 \\
9.2 \\
10.9 \\
11.2 \\
9.5 \\
3.2\end{array}$ & $\begin{array}{l}7.1 \\
5.5 \\
5.2\end{array}$ & $\begin{array}{l}10.1 \\
10.0 \\
10.4 \\
11.7 \\
11.03 \\
10.5 \\
10.0 \\
10.0\end{array}$ & $\begin{array}{l}4 \\
4 \\
3 \\
3 \\
4 \\
4 \\
4 \\
4\end{array}$ & $\begin{array}{r}9.6 \\
11.1 \\
12.9 \\
16.4 \\
14.6 \\
16.1 \\
12.4 \\
10.0\end{array}$ & $\begin{array}{l}10.6 \\
13.0 \\
15.5 \\
19.0 \\
17.5 \\
17.8 \\
11.7\end{array}$ & $\begin{array}{l}13.5 \\
14.4 \\
17.1 \\
21.3 \\
19.3 \\
21.6 \\
14.6 \\
11.6\end{array}$ & $\begin{array}{l}14 \cdot 2 \\
17 \cdot 2 \\
18 \cdot 1 \\
22 \cdot 5 \\
20 \cdot 7 \\
22 \cdot 0 \\
11 \cdot 2\end{array}$ \\
\hline $\begin{array}{l}8 \\
8 \\
8 \\
8 \\
8 \\
8 \\
8 \\
8\end{array}$ & $\begin{array}{r}0 \\
3 \\
6 \\
0 \\
12 \\
15 \\
18 \\
21\end{array}$ & $\begin{array}{r}6.7 \\
4.9 \\
5.9 \\
9.0 \\
11.5 \\
12.9 \\
11.4 \\
8.3\end{array}$ & $\begin{array}{l}3.3 \\
2.2 \\
2.4 \\
3.8 \\
5.2 \\
6.2 \\
5.3 \\
3.9\end{array}$ & $\begin{array}{r}6.5 \\
4.9 \\
5.8 \\
9.0 \\
11.7 \\
13.2 \\
11.5 \\
8.3\end{array}$ & & $\begin{array}{r}6 \cdot 3 \\
4.5 \\
5.9 \\
9 \cdot 2 \\
11.9 \\
13.4 \\
11.5 \\
3.1\end{array}$ & $\begin{array}{l}2.7 \\
1.6 \\
2.0 \\
3.2 \\
4.8 \\
5.4 \\
4.5 \\
3.4\end{array}$ & $\begin{array}{r}6.2 \\
4.4 \\
5.8 \\
8.7 \\
11.6 \\
13.5 \\
11.5 \\
8.2\end{array}$ & & $\begin{array}{r}9.9 \\
9.8 \\
10.3 \\
11.5 \\
11.5 \\
10.6 \\
10.0 \\
9.8\end{array}$ & $\begin{array}{l}2 \\
2 \\
2 \\
4 \\
4 \\
4 \\
3 \\
2\end{array}$ & $\begin{array}{r}7.8 \\
10.9 \\
14.2 \\
17.1 \\
16.5 \\
15.6 \\
6.6 \\
4.9\end{array}$ & $\begin{array}{r}7.5 \\
11.5 \\
14.0 \\
17.3 \\
16.6 \\
16.2 \\
7.8 \\
4.8\end{array}$ & $\begin{array}{r}8.4 \\
12.3 \\
15.6 \\
20.5 \\
19.1 \\
18.4 \\
3.1 \\
5.4\end{array}$ & $\begin{array}{r}19.6 \\
10.0 \\
6.1\end{array}$ \\
\hline $\begin{array}{l}9 \\
9 \\
9 \\
9 \\
9 \\
9 \\
9 \\
9\end{array}$ & $\begin{array}{r}0 \\
3 \\
6 \\
9 \\
12 \\
15 \\
18 \\
21\end{array}$ & $\begin{array}{r}7.0 \\
5.4 \\
6.4 \\
11.1 \\
13.5 \\
15.3 \\
12.6 \\
10.4\end{array}$ & $\begin{array}{l}3.1 \\
2.0 \\
2.3 \\
4.8 \\
5.7 \\
6.8 \\
7.3 \\
5.4\end{array}$ & $\begin{array}{r}6.6 \\
5.2 \\
6.3 \\
11.4 \\
13.8 \\
15.6 \\
13.0 \\
10.5\end{array}$ & & $\begin{array}{r}6.4 \\
5.1 \\
6.9 \\
11.8 \\
14.3 \\
15.8 \\
13.6 \\
10.7\end{array}$ & $\begin{array}{l}2.2 \\
1.4 \\
2.2 \\
4.1 \\
5.1 \\
6.2 \\
5.7 \\
4.7\end{array}$ & $\begin{array}{r}6.3 \\
5.0 \\
6: 9 \\
11: 7 \\
14: 2 \\
15.9 \\
14.0 \\
10.7\end{array}$ & & $\begin{array}{r}9.8 \\
9.7 \\
10.4 \\
11.6 \\
11.07 \\
10.9 \\
10.2 \\
10.1\end{array}$ & $\begin{array}{l}2 \\
2 \\
2 \\
4 \\
4 \\
3 \\
3 \\
2\end{array}$ & $\begin{array}{r}7.7 \\
8.5 \\
9.02 \\
10.6 \\
10.9 \\
8.6 \\
3.8 \\
5.1\end{array}$ & $\begin{array}{r}8.0 \\
8.7 \\
10.2 \\
14.2 \\
11.9 \\
10.1 \\
4.7 \\
5.6\end{array}$ & $\begin{array}{r}8.8 \\
9.03 \\
10.8 \\
12.0 \\
13.6 \\
11.6 \\
6.0 \\
6.7\end{array}$ & $\begin{array}{r}14.0 \\
12.2 \\
7.3 \\
8.1\end{array}$ \\
\hline $\begin{array}{l}10 \\
10 \\
10 \\
10 \\
10 \\
10 \\
10 \\
10\end{array}$ & $\begin{array}{r}0 \\
3 \\
6 \\
9 \\
12 \\
15 \\
18 \\
2 \mathrm{I}\end{array}$ & $\begin{array}{r}8.6 \\
8.0 \\
7.5 \\
10.8 \\
12.2\end{array}$ & $\begin{array}{l}5.5 \\
5.9 \\
5.6 \\
6.4\end{array}$ & $\begin{array}{r}8.3 \\
7.9 \\
7.5 \\
11.2 \\
8.2\end{array}$ & 4.5 & $\begin{array}{r}8.7 \\
7.8 \\
7.4 \\
11.0 \\
12.2 \\
7.5 \\
6.0 \\
5.4\end{array}$ & $\begin{array}{l}5.2 \\
5.6 \\
5.1 \\
6.5 \\
7.6 \\
6.1 \\
5.0 \\
4.1\end{array}$ & $\begin{array}{r}8.1 \\
7.6 \\
7.4 \\
13.0 \\
11.8 \\
6.87 \\
5.5 \\
4.8\end{array}$ & & $\begin{array}{l}10.3 \\
10.3 \\
10.5 \\
12.6 \\
10.6 \\
10.7 \\
10.5 \\
10.0\end{array}$ & $\begin{array}{l}2 \\
3 \\
3 \\
3 \\
3 \\
3 \\
3 \\
3\end{array}$ & $\begin{array}{r}9.8 \\
9.2 \\
11.0 \\
15.0 \\
16.0 \\
20.2 \\
18.0 \\
17.8\end{array}$ & $\begin{array}{r}10.6 \\
9.7 \\
11.4 \\
16.2 \\
18.6 \\
23.3 \\
20.5 \\
19.5\end{array}$ & $\begin{array}{l}11.3 \\
10.1 \\
11.8 \\
16.8 \\
20.0 \\
25.8 \\
23.2 \\
22.9\end{array}$ & $\begin{array}{l}11.7 \\
10.5 \\
12.1 \\
17.6 \\
21.0 \\
26.8 \\
24.1 \\
23.8\end{array}$ \\
\hline
\end{tabular}


TABLE 10 Table 10. -Three-hour averages of air and water-surface temperatures and wind directions and speed, April 1950-August
1951, Lake Hefner-Continued

STATION 1

THREE-HOURLY AVERAGES

APRIL, 1951

\begin{tabular}{|c|c|c|c|c|c|c|c|c|c|c|c|c|c|c|c|}
\hline \multirow{3}{*}{ 声 } & \multirow{3}{*}{ 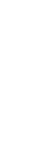 } & \multicolumn{8}{|c|}{ Average air temperature $\left({ }^{\circ} \mathrm{C}\right)$ at indicated height } & \multirow{3}{*}{\begin{tabular}{|c} 
Average \\
water- \\
surface \\
tempera- \\
ture \\
('C)
\end{tabular}} & \multirow{3}{*}{$\begin{array}{l}\text { Average } \\
\text { wind } \\
\text { direction } \\
\text { (coded) }\end{array}$} & \multirow{2}{*}{\multicolumn{4}{|c|}{$\begin{array}{l}\text { Average wind speed (knots) } \\
\text { at indicated height }\end{array}$}} \\
\hline & & \multicolumn{2}{|c|}{$\begin{array}{c}2 \\
\text { meters }\end{array}$} & \multicolumn{2}{|c|}{$\begin{array}{c}4 \\
\text { meters }\end{array}$} & \multicolumn{2}{|c|}{$\begin{array}{c}8 \\
\text { meters }\end{array}$} & \multicolumn{2}{|c|}{$\begin{array}{c}16 \\
\text { meters }\end{array}$} & & & & & & \\
\hline & & $\begin{array}{l}\text { Dry } \\
\text { bulb }\end{array}$ & $\begin{array}{l}\text { Wet } \\
\text { bulb }\end{array}$ & $\begin{array}{l}\text { Dry } \\
\text { bulb }\end{array}$ & & $\begin{array}{l}\text { Dry } \\
\text { bulb }\end{array}$ & $\begin{array}{l}\text { Wet } \\
\text { bulb }\end{array}$ & $\begin{array}{l}\text { Dry } \\
\text { bulb }\end{array}$ & $\begin{array}{l}\text { Wet } \\
\text { bulb }\end{array}$ & & & & & & \\
\hline
\end{tabular}

\begin{tabular}{|c|c|c|c|c|c|c|c|c|c|c|c|c|c|c|c|}
\hline $\begin{array}{l}11 \\
11 \\
11 \\
11 \\
11 \\
11 \\
11 \\
11\end{array}$ & $\begin{array}{r}0 \\
3 \\
6 \\
9 \\
12 \\
15 \\
18 \\
21\end{array}$ & $\begin{array}{l}4.9 \\
4.0\end{array}$ & ' & 4.7 & & $\begin{array}{l}4.7 \\
3.4 \\
3.5 \\
6.1 \\
6.7 \\
6.7 \\
5.3 \\
3.3\end{array}$ & $\begin{array}{l}3.3 \\
1.9 \\
1.3 \\
1.9 \\
1.6 \\
1.9 \\
1.9 \\
0.9\end{array}$ & $\begin{array}{l}4.4 \\
3.1 \\
2.4\end{array}$ & & $\begin{array}{r}9.9 \\
9.8 \\
10.3 \\
11.0 \\
10.9 \\
10.4 \\
9.7 \\
9.4\end{array}$ & $\begin{array}{l}4 \\
4 \\
4 \\
4 \\
4 \\
4 \\
4 \\
2\end{array}$ & $\begin{array}{l}12.5 \\
12.9 \\
16.3 \\
19.6 \\
18.9 \\
20.6 \\
13.3 \\
11.4\end{array}$ & $\begin{array}{l}15.0 \\
18.6 \\
21.9 \\
21.2 \\
22.8 \\
13.8 \\
11.1\end{array}$ & $\begin{array}{l}15.8 \\
16.3 \\
21.4 \\
26.6 \\
25.3 \\
26.4 \\
15.3 \\
12.1\end{array}$ & $\begin{array}{l}26.0 \\
27.5 \\
26.2 \\
28.2 \\
21.2 \\
12.7\end{array}$ \\
\hline $\begin{array}{l}12 \\
12 \\
12 \\
12 \\
12 \\
12 \\
12 \\
12\end{array}$ & $\begin{array}{r}0 \\
3 \\
6 \\
9 \\
12 \\
15 \\
18 \\
21\end{array}$ & & ' & & $\begin{array}{r}-0.7 \\
-0.9 \\
0.2 \\
3.3 \\
5.2 \\
5.1 \\
3.5\end{array}$ & $\begin{array}{r}1.9 \\
1.1 \\
2.2 \\
4.1 \\
7.3 \\
10.4 \\
9.6 \\
7.0\end{array}$ & $\begin{array}{r}-0.3 \\
-\quad 1.0 \\
-0.7 \\
0.4 \\
3.0 \\
4.8 \\
4.8 \\
3.3\end{array}$ & & & $\begin{array}{r}9.4 \\
9.6 \\
10.1 \\
10.8 \\
10.6 \\
10.2 \\
9.3 \\
9.1\end{array}$ & $\begin{array}{l}2 \\
2 \\
4 \\
4 \\
4 \\
4 \\
4 \\
2\end{array}$ & $\begin{array}{r}13.7 \\
16.4 \\
20.7 \\
21.0 \\
17.5 \\
16.4 \\
10.0 \\
9.8\end{array}$ & $\begin{array}{r}13.2 \\
18.1 \\
20.6 \\
22.0 \\
18.7 \\
17.0 \\
8.1 \\
9.6\end{array}$ & $\begin{array}{l}14 \cdot 8 \\
18.0 \\
22.6 \\
27.8 \\
21.9 \\
21.5 \\
13.1 \\
10.8\end{array}$ & $\begin{array}{l}14.8 \\
17.8 \\
29.0 \\
22.6 \\
10.0 \\
11.2\end{array}$ \\
\hline $\begin{array}{l}13 \\
13 \\
13 \\
13 \\
13 \\
13 \\
13 \\
13\end{array}$ & $\begin{array}{r}0 \\
3 \\
6 \\
9 \\
12 \\
15 \\
18 \\
21\end{array}$ & $\begin{array}{r}5.7 \\
8.9 \\
12.1 \\
14.4 \\
12.8 \\
10.5\end{array}$ & $\begin{array}{l}2.7 \\
4.3 \\
5.5 \\
6.7 \\
7.5 \\
6.0\end{array}$ & $\begin{array}{l}3.7 \\
3.6\end{array}$ & $\begin{array}{l}2.0 \\
0.9 \\
1.8 \\
4.3 \\
5.0 \\
6.3 \\
6.9 \\
5.2\end{array}$ & $\begin{array}{r}5 \cdot 3 \\
3.7 \\
5.3 \\
9.4 \\
12 \cdot 7 \\
16.1 \\
14.7 \\
11.1\end{array}$ & $\begin{array}{l}1.7 \\
0.7 \\
1.7 \\
3.7 \\
4.8 \\
6.1 \\
6.1 \\
4.8\end{array}$ & $\begin{array}{r}5.4 \\
9.2 \\
12.6 \\
16.1 \\
15.6 \\
11.7\end{array}$ & 1.7 & $\begin{array}{r}9.0 \\
9.0 \\
9.7 \\
10.9 \\
11.0 \\
10.1 \\
9.6 \\
9.4\end{array}$ & $\begin{array}{l}2 \\
2 \\
4 \\
4 \\
4 \\
4 \\
2 \\
2\end{array}$ & $\begin{array}{r}10.1 \\
9.9 \\
12.6 \\
14.0 \\
11.5 \\
7.0 \\
2.5 \\
5.6\end{array}$ & $\begin{array}{r}7.3 \\
12.5 \\
13.7 \\
11.3 \\
6.5 \\
2.9 \\
6.6\end{array}$ & $\begin{array}{r}11.1 \\
9.5 \\
14.1 \\
16.3 \\
13.3 \\
8.6 \\
4.1 \\
8.9\end{array}$ & $\begin{array}{l}7.8 \\
9.8\end{array}$ \\
\hline $\begin{array}{l}14 \\
14 \\
14 \\
14 \\
14 \\
14 \\
14 \\
14\end{array}$ & $\begin{array}{r}0 \\
3 \\
6 \\
9 \\
12 \\
15 \\
18 \\
21\end{array}$ & $\begin{array}{l}10.5 \\
10.8 \\
12.1 \\
18.3 \\
20.3 \\
18.1 \\
15.6 \\
11.7\end{array}$ & $\begin{array}{r}5.9 \\
5.9 \\
6.4 \\
9.1 \\
10.7\end{array}$ & 13.5 & $\begin{array}{r}5.4 \\
5.2 \\
5.9 \\
8.5 \\
10.7 \\
10.5 \\
9.5 \\
7.5\end{array}$ & $\begin{array}{l}10.9 \\
10.8 \\
13.9 \\
19.9 \\
21.9 \\
19.2 \\
16.1 \\
12.0\end{array}$ & $\begin{array}{r}5.1 \\
4.9 \\
5.7 \\
8.3 \\
10.4 \\
10.3 \\
9.1 \\
7.3\end{array}$ & $\begin{array}{l}11.1 \\
11.1 \\
14.2 \\
20.2 \\
22.0 \\
19.3 \\
16.1 \\
12.1\end{array}$ & & $\begin{array}{r}9.5 \\
9.6 \\
10.2 \\
11.0 \\
11.6 \\
10.6 \\
10.1 \\
10.1\end{array}$ & $\begin{array}{l}2 \\
2 \\
2 \\
2 \\
4 \\
3 \\
3 \\
3\end{array}$ & $\begin{array}{r}11.5 \\
14.1 \\
18.0 \\
12.9 \\
8.2 \\
8.8 \\
9.3 \\
9.6\end{array}$ & $\begin{array}{l}13.1 \\
15.9 \\
20.0 \\
14.7 \\
11.5 \\
17.4 \\
15.0 \\
10.9\end{array}$ & $\begin{array}{l}14.9 \\
18.1 \\
22.6 \\
16.5 \\
13.6 \\
20.8 \\
17.0 \\
12.0\end{array}$ & $\begin{array}{l}16.5 \\
19.5 \\
24.0 \\
17.0 \\
14.0 \\
22.0 \\
18.4 \\
13.1\end{array}$ \\
\hline $\begin{array}{l}15 \\
15 \\
15 \\
15 \\
15 \\
15 \\
15 \\
15\end{array}$ & $\begin{array}{r}0 \\
3 \\
6 \\
9 \\
12 \\
15 \\
18 \\
21\end{array}$ & $\begin{array}{r}9.7 \\
7.6 \\
7.0 \\
8.9 \\
10.1 \\
10.0 \\
8.1 \\
5.8\end{array}$ & & & $\begin{array}{l}6.3 \\
4.4 \\
2.5 \\
3.4 \\
3.8 \\
3.6 \\
2.8 \\
1.6\end{array}$ & $\begin{array}{l}9.7 \\
7.4 \\
6.4 \\
8.5 \\
9.7 \\
9.8 \\
7.6 \\
5.5\end{array}$ & $\begin{array}{l}5.9 \\
3.9 \\
2.1 \\
3.2 \\
3.2 \\
3.3 \\
2.3 \\
1.5\end{array}$ & $\begin{array}{l}9.6 \\
7.1 \\
6.3 \\
8.4 \\
9.6 \\
9.6 \\
7.4 \\
5.5\end{array}$ & & $\begin{array}{r}10.0 \\
9.9 \\
10.4 \\
11.5 \\
11.4 \\
10.3 \\
9.8 \\
9.5\end{array}$ & $\begin{array}{l}3 \\
3 \\
3 \\
3 \\
3 \\
3 \\
3 \\
3\end{array}$ & $\begin{array}{r}8.1 \\
14.3 \\
15.5 \\
16.5 \\
15.4 \\
14.8 \\
11.8 \\
5.2\end{array}$ & $\begin{array}{r}9.2 \\
16.3 \\
17.9 \\
19.9 \\
17.7 \\
16.9 \\
12.7 \\
5.5\end{array}$ & $\begin{array}{r}9.9 \\
17.5 \\
19.2 \\
21.0 \\
19.5 \\
18.9 \\
14.8 \\
6.1\end{array}$ & $\begin{array}{r}11.0 \\
18.3 \\
20.0 \\
22.0 \\
20.4 \\
19.8 \\
15.4 \\
6.5\end{array}$ \\
\hline $\begin{array}{l}16 \\
16 \\
16 \\
16 \\
16 \\
16 \\
16 \\
16\end{array}$ & $\begin{array}{r}0 \\
3 \\
6 \\
9 \\
12 \\
15 \\
18 \\
21\end{array}$ & $\begin{array}{r}6.3 \\
5.0 \\
4.3 \\
6.7 \\
9.0 \\
11.5 \\
10.0 \\
7.5\end{array}$ & $\begin{array}{l}1.0 \\
2.1 \\
3.8 \\
5.1 \\
4.9 \\
3.3\end{array}$ & $\begin{array}{r}5.0 \\
5.8 \\
8.9 \\
10.8 \\
9.8 \\
7.2\end{array}$ & $\begin{array}{l}2.1 \\
0.8 \\
0.5 \\
0.9 \\
2.6 \\
3.9 \\
3.9 \\
2.3\end{array}$ & $\begin{array}{r}6.0 \\
4.5 \\
3.9 \\
5.9 \\
9.0 \\
10.8 \\
9.9 \\
7.1\end{array}$ & $\begin{array}{r}1.9 \\
0.6 \\
-0.3 \\
0.6 \\
2.0 \\
3.4 \\
3.4 \\
2.2\end{array}$ & $\begin{array}{r}6.0 \\
4.3 \\
3.7 \\
5.9 \\
8.9 \\
10.8 \\
9.1 \\
7.0\end{array}$ & & $\begin{array}{r}9.5 \\
9.5 \\
9.8 \\
10.9 \\
11.3 \\
10.6 \\
10.0 \\
10.0\end{array}$ & $\begin{array}{l}4 \\
3 \\
3 \\
3 \\
3 \\
3 \\
3 \\
3 \\
2\end{array}$ & $\begin{array}{l}4.9 \\
7.9 \\
6.1 \\
8.8 \\
8.5 \\
6.8 \\
4.3 \\
6.1\end{array}$ & $\begin{array}{r}5.4 \\
9.1 \\
7.4 \\
10.0 \\
10.0 \\
7.7 \\
4.6 \\
6.6\end{array}$ & $\begin{array}{r}6.0 \\
9.3 \\
7.3 \\
10.8 \\
11.2 \\
8.5 \\
5.2 \\
7.0\end{array}$ & $\begin{array}{r}6.1 \\
9.7 \\
8.0 \\
11.3 \\
11.6 \\
9.0 \\
6.2 \\
7.7\end{array}$ \\
\hline $\begin{array}{l}17 \\
17 \\
17 \\
17 \\
17 \\
17 \\
17 \\
17\end{array}$ & $\begin{array}{r}0 \\
3 \\
6 \\
9 \\
12 \\
15 \\
18 \\
21\end{array}$ & $\begin{array}{r}6.5 \\
6.2 \\
7.0 \\
13.3 \\
17.5 \\
18.7 \\
17.0 \\
15.7\end{array}$ & $\begin{array}{l}2.7 \\
2.1 \\
1.8\end{array}$ & $\begin{array}{r}5.4 \\
6.0 \\
7.0 \\
13.7 \\
17.8 \\
19.0 \\
17.5 \\
16.1\end{array}$ & $\begin{array}{l}3.9 \\
1.5 \\
2.3 \\
5.7 \\
8.1 \\
9.3 \\
9.0 \\
8.6\end{array}$ & $\begin{array}{r}6.3 \\
5.9 \\
7.1 \\
14.1 \\
18.3 \\
19.5 \\
18.0 \\
16.2\end{array}$ & $\begin{array}{l}1.7 \\
1.3 \\
2.2 \\
5.5 \\
7.9 \\
9.1 \\
8.9 \\
8.4\end{array}$ & $\begin{array}{r}6.2 \\
5.9 \\
7.2 \\
14.4 \\
19.0 \\
19.9 \\
18.0 \\
16.3\end{array}$ & & $\begin{array}{r}9.9 \\
9.8 \\
10.3 \\
11.5 \\
11.5 \\
10.7 \\
10.1 \\
10.2\end{array}$ & $\begin{array}{l}2 \\
2 \\
2 \\
2 \\
2 \\
2 \\
2 \\
2\end{array}$ & $\begin{array}{r}7.9 \\
11: 3 \\
14: 3 \\
17.4 \\
17.0 \\
17.2 \\
14.0 \\
19.1\end{array}$ & $\begin{array}{r}8.6 \\
12.6 \\
16.0 \\
19.8 \\
19.2 \\
20.0 \\
16.2 \\
21.8\end{array}$ & $\begin{array}{r}9.2 \\
13.6 \\
17.7 \\
22.4 \\
22.0 \\
22.8 \\
18.2 \\
24.6\end{array}$ & $\begin{array}{l}10.0 \\
14.3 \\
18.4 \\
23.5 \\
23.1 \\
24.3 \\
19.3 \\
26.2\end{array}$ \\
\hline $\begin{array}{l}18 \\
18 \\
18 \\
18 \\
18 \\
18 \\
18 \\
18\end{array}$ & $\begin{array}{r}0 \\
3 \\
6 \\
9 \\
12 \\
15 \\
18 \\
21\end{array}$ & $\begin{array}{l}14.9 \\
14 \cdot 3 \\
14.8 \\
19.3 \\
24.4 \\
23.7\end{array}$ & $\begin{array}{l}19.0 \\
10.4 \\
11.6 \\
14.0 \\
14.9 \\
14.4\end{array}$ & $\begin{array}{l}15.3 \\
14.4 \\
15.7 \\
20.3 \\
25.5 \\
24.8\end{array}$ & $\begin{array}{r}8.9 \\
9.6 \\
11.02 \\
13.4 \\
13.5 \\
13.1\end{array}$ & $\begin{array}{l}15.4 \\
14.5 \\
15.6 \\
20.7 \\
25.8 \\
25.3\end{array}$ & $\begin{array}{r}8.9 \\
9.5 \\
11.4 \\
13.5 \\
13.7 \\
12.7\end{array}$ & $\begin{array}{l}15.4 \\
14.5 \\
15.7 \\
20.9 \\
26.1 \\
25.4\end{array}$ & & $\begin{array}{l}10.1 \\
10.1 \\
10.8 \\
11.9 \\
12.0 \\
10.9\end{array}$ & $\begin{array}{l}2 \\
2 \\
2 \\
2 \\
2 \\
3 \\
3 \\
3\end{array}$ & $\begin{array}{r}17.7 \\
19.1 \\
19.1 \\
15.9 \\
8.4 \\
7.6 \\
8.3 \\
7.6\end{array}$ & $\begin{array}{r}21.8 \\
21.8 \\
21.0 \\
17.5 \\
9.8 \\
10.7 \\
12.8 \\
11.3\end{array}$ & $\begin{array}{l}24.7 \\
24.6 \\
24.0 \\
20.5 \\
11.1 \\
12.5 \\
16.6 \\
13.1\end{array}$ & $\begin{array}{l}26.4 \\
26.3 \\
25.5 \\
20.7 \\
11.6 \\
11.6 \\
18.2 \\
15.2\end{array}$ \\
\hline $\begin{array}{l}19 \\
19 \\
19\end{array}$ & $\begin{array}{l}0 \\
3 \\
6\end{array}$ & & & & & & & & . & & $\begin{array}{l}3 \\
3 \\
3\end{array}$ & $\begin{array}{l}7.3 \\
6.6 \\
8.3\end{array}$ & $\begin{array}{l}8.6 \\
7.6\end{array}$ & $\begin{array}{r}10.1 \\
8.6 \\
10.1\end{array}$ & $\begin{array}{r}11.3 \\
9.7 \\
10.6\end{array}$ \\
\hline $\begin{array}{l}19 \\
19\end{array}$ & $\begin{array}{r}9 \\
12\end{array}$ & $\begin{array}{l}17.7 \\
18.9\end{array}$ & $\begin{array}{l}12.7 \\
13.9\end{array}$ & $\begin{array}{l}16.8 \\
19.5\end{array}$ & $\begin{array}{l}12.8 \\
14.0\end{array}$ & $\begin{array}{l}17.0 \\
20.1\end{array}$ & 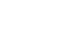 & $\begin{array}{l}17.0 \\
20.0\end{array}$ & 11.5 & $\begin{array}{l}12.6 \\
12.9\end{array}$ & $\begin{array}{l}3 \\
3\end{array}$ & $\begin{array}{l}7.3 \\
7: 9\end{array}$ & $\begin{array}{l}8.2 \\
8.5\end{array}$ & $\begin{array}{l}8.7 \\
9.0\end{array}$ & $\begin{array}{l}9.1 \\
9.3\end{array}$ \\
\hline 19 & 15 & 20.8 & 14.9 & 21.6 & 14.9 & 22.0 & 14.0 & 22.0 & & 12.4 & 3 & 8.6 & 9.7 & 10.5 & 10.9 \\
\hline $\begin{array}{l}19 \\
19\end{array}$ & $\begin{array}{l}18 \\
21\end{array}$ & $\begin{array}{l}18.4 \\
16.3\end{array}$ & $\begin{array}{l}14.1 \\
13.0\end{array}$ & $\begin{array}{l}19.8 \\
16.9\end{array}$ & $\begin{array}{l}14.3 \\
13.0\end{array}$ & $\begin{array}{l}30.3 \\
17.4\end{array}$ & $\begin{array}{l}13.6 \\
12.4\end{array}$ & $\begin{array}{l}20.4 \\
17.5\end{array}$ & 12.0 & $\begin{array}{l}11.8 \\
11.4\end{array}$ & $\begin{array}{l}3 \\
3\end{array}$ & $\begin{array}{l}7.2 \\
8.9\end{array}$ & $\begin{array}{l}8.5 \\
9.9\end{array}$ & $\begin{array}{r}9.4 \\
11.0\end{array}$ & $\begin{array}{l}10.4 \\
12.0\end{array}$ \\
\hline $\begin{array}{l}20 \\
20 \\
20 \\
20 \\
20 \\
20 \\
20 \\
20\end{array}$ & $\begin{array}{r}0 \\
3 \\
6 \\
9 \\
12 \\
15 \\
18 \\
21\end{array}$ & $\begin{array}{l}14.5 \\
15.9 \\
14.7\end{array}$ & $\begin{array}{l}12.2 \\
14.3 \\
13.5\end{array}$ & $\begin{array}{l}14.9 \\
16.4 \\
15.0\end{array}$ & $\begin{array}{l}12.3 \\
14.7 \\
13.1\end{array}$ & $\begin{array}{l}15.3 \\
16.8 \\
15.8\end{array}$ & $\begin{array}{l}11.08 \\
14.3 \\
13.4\end{array}$ & $\begin{array}{l}15.4 \\
17.0 \\
15.0\end{array}$ & $\begin{array}{l}12.2 \\
14.8\end{array}$ & $\begin{array}{l}11.2 \\
11.2 \\
11.1\end{array}$ & $\begin{array}{l}2 \\
2 \\
2 \\
2 \\
2 \\
2 \\
2 \\
2\end{array}$ & $\begin{array}{r}8.3 \\
13.5 \\
12.1 \\
17.3 \\
18.8 \\
11.3 \\
7.2 \\
13.2\end{array}$ & $\begin{array}{r}9.5 \\
15.3 \\
13.7 \\
19.5 \\
21.3 \\
12.7 \\
8.4 \\
15.0\end{array}$ & $\begin{array}{r}11.0 \\
16.8 \\
15.3 \\
21.5 \\
23.6 \\
14.4 \\
9.5 \\
16.8\end{array}$ & $\begin{array}{r}12.0 \\
18.2 \\
16.1 \\
22.8 \\
25.1 \\
15.2 \\
9.9 \\
17.8\end{array}$ \\
\hline
\end{tabular}


TABLE 10

Table 10. -Three-hour averages of air and water-surface temperatures and wind directions and speed, April 1950-August 1951, Lake Hefner-Continued

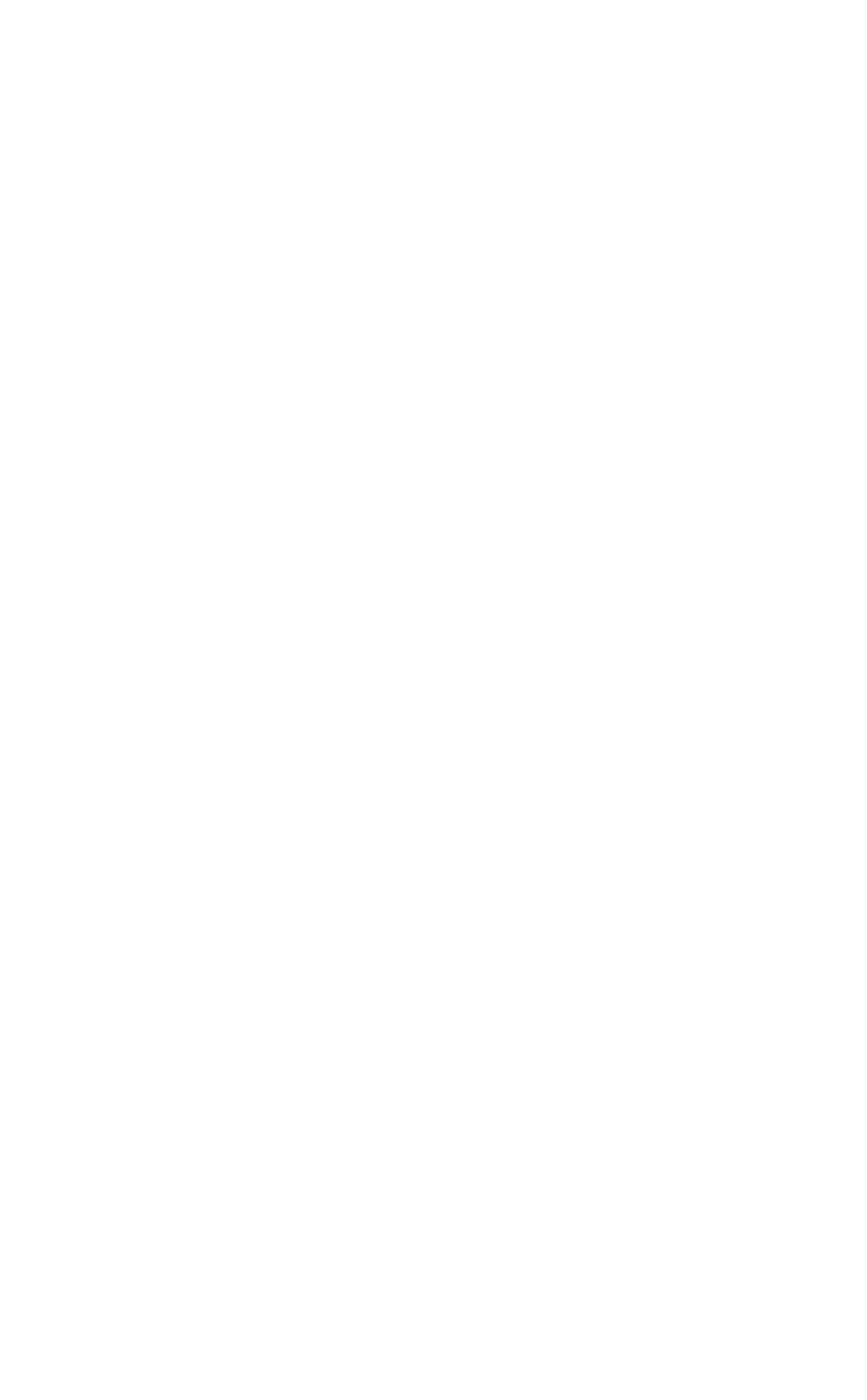


TABLE 10 Table 10. - Three-hour averages of air and water-surface temperatures and wind directions and speed, April 1950-August
1951, Lake Hefner-Continued

STATION 1 THREE-HOURLY AVERAGES

MAY, 1951

\begin{tabular}{|c|c|c|c|c|c|c|c|c|c|c|c|c|c|c|c|}
\hline \multirow{3}{*}{ 焉 } & \multirow{3}{*}{ 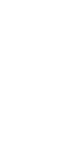 } & \multicolumn{8}{|c|}{ Average air temperature $\left({ }^{\circ} \mathrm{C}\right)$ at indicated height } & \multirow{3}{*}{$\begin{array}{l}\text { Average } \\
\text { water- } \\
\text { surface } \\
\text { tempera- } \\
\text { ture } \\
\text { (०) }\end{array}$} & \multirow{3}{*}{$\begin{array}{c}\text { Average } \\
\text { wind } \\
\text { direction } \\
\text { (coded) }\end{array}$} & \multirow{2}{*}{\multicolumn{4}{|c|}{$\begin{array}{l}\text { Average wind speed (knots) } \\
\text { at indicated height }\end{array}$}} \\
\hline & & \multicolumn{2}{|c|}{\begin{tabular}{c|c}
2 \\
meters
\end{tabular}} & \multicolumn{2}{|c|}{$\begin{array}{c}4 \\
\text { meters }\end{array}$} & \multicolumn{2}{|c|}{$\begin{array}{c}8 \\
\text { meters }\end{array}$} & \multicolumn{2}{|c|}{$\begin{array}{c}16 \\
\text { meters }\end{array}$} & & & & & & \\
\hline & & $\begin{array}{l}\text { Dry } \\
\text { bulb }\end{array}$ & $\begin{array}{l}\text { Wet } \\
\text { bulb }\end{array}$ & $\begin{array}{l}\text { Dry } \\
\text { bulb }\end{array}$ & $\begin{array}{l}\text { Wet } \\
\text { bulb }\end{array}$ & $\begin{array}{l}\text { Dry } \\
\text { bulb }\end{array}$ & $\begin{array}{l}\text { Wet } \\
\text { bulb }\end{array}$ & $\begin{array}{l}\text { Dry } \\
\text { bulb }\end{array}$ & $\begin{array}{l}\text { Wet } \\
\text { bulb }\end{array}$ & & & $\begin{array}{c}2 \\
\text { meters }\end{array}$ & $\begin{array}{c}4 \\
\text { meters }\end{array}$ & $\begin{array}{c}8 \\
\text { meters }\end{array}$ & $\begin{array}{c}16 \\
\text { meters }\end{array}$ \\
\hline $\begin{array}{l}1 \\
1 \\
1 \\
1 \\
1 \\
1 \\
1 \\
1\end{array}$ & $\begin{array}{r}0 \\
3 \\
6 \\
9 \\
12 \\
15 \\
18 \\
21\end{array}$ & $\begin{array}{l}11.4 \\
12.9 \\
15.8 \\
18.0 \\
19.8 \\
18.7 \\
16.4\end{array}$ & $\begin{array}{l}10.1 \\
20: 9 \\
10.8 \\
11: 6 \\
11.9 \\
11.9 \\
11.2\end{array}$ & $\begin{array}{l}11.7 \\
12.1 \\
15.5 \\
18.0 \\
20.1 \\
18.7 \\
16.4\end{array}$ & $\begin{array}{l}10.6 \\
10.8 \\
10.2 \\
11.0 \\
11.5 \\
11.6 \\
10.9\end{array}$ & $\begin{array}{l}12.7 \\
15.9 \\
18.3 \\
19.9 \\
13.8 \\
16.4\end{array}$ & $\begin{array}{l}10.7 \\
10.2 \\
10.8 \\
11.3 \\
11.0 \\
10.4\end{array}$ & $\begin{array}{l}12.0 \\
15.5 \\
17.9 \\
19.9 \\
18.7 \\
16.1\end{array}$ & $\begin{array}{r}0.9 \\
10.0 \\
10.8 \\
12.5 \\
11.0 \\
10.4\end{array}$ & $\begin{array}{l}15.3 \\
15.4 \\
15.3 \\
16.0 \\
16.4 \\
16.2 \\
15.9 \\
15.7\end{array}$ & $\begin{array}{l}4 \\
2 \\
2 \\
2 \\
2 \\
2 \\
2 \\
2 \\
2\end{array}$ & $\begin{array}{r}6.5 \\
5.3 \\
11.3 \\
17.9 \\
18.3 \\
16.4 \\
12.0 \\
12.5\end{array}$ & $\begin{array}{r}8.4 \\
7.0 \\
12.5 \\
20.3 \\
20.2 \\
18.6 \\
13.2 \\
14.2\end{array}$ & $\begin{array}{r}9.4 \\
7.1 \\
13.9 \\
22.9 \\
22.9 \\
21.1 \\
14.9 \\
15.7\end{array}$ & $\begin{array}{l}10.5 \\
7.0 \\
14.4 \\
23.8 \\
23.9 \\
22.9 \\
16.1 \\
16.9\end{array}$ \\
\hline $\begin{array}{l}2 \\
2 \\
2 \\
2 \\
2 \\
2 \\
2 \\
2\end{array}$ & $\begin{array}{r}0 \\
3 \\
6 \\
9 \\
12 \\
15 \\
18 \\
21\end{array}$ & $\begin{array}{l}14.4 \\
12.7 \\
13.3 \\
18.4 \\
22.5 \\
23.2 \\
20.5 \\
17.8\end{array}$ & $\begin{array}{l}11.1 \\
10.2 \\
10.5 \\
12.3 \\
12.4 \\
13.1 \\
14 . ? \\
13.1\end{array}$ & $\begin{array}{l}14.4 \\
12.7 \\
13.4 \\
18.9 \\
23.0 \\
23.6 \\
20.8 \\
17.7\end{array}$ & $\begin{array}{l}10.8 \\
10.0 \\
10.2 \\
12.0 \\
12.0 \\
12.8 \\
14.0 \\
12.9\end{array}$ & $\begin{array}{l}14.3 \\
12.3 \\
13.5 \\
10.4 \\
23.3 \\
24.1 \\
21.4 \\
17.9\end{array}$ & $\begin{array}{r}10.3 \\
9.5 \\
10.0 \\
11.8 \\
11.5 \\
12.5 \\
14.5 \\
12.5\end{array}$ & $\begin{array}{l}13.9 \\
11.09 \\
13.1 \\
19.0 \\
23.0 \\
23.7 \\
21.0 \\
17.6\end{array}$ & $\begin{array}{r}10.3 \\
0.4 \\
10.1 \\
11.9 \\
11.8 \\
13.0 \\
14.0 \\
12.7\end{array}$ & $\begin{array}{l}15.7 \\
15.6 \\
15.8 \\
16.1 \\
16.2 \\
16.2 \\
15.1 \\
15.9\end{array}$ & $\begin{array}{l}2 \\
2 \\
2 \\
2 \\
2 \\
2 \\
2 \\
2 \\
2\end{array}$ & $\begin{array}{r}12.1 \\
10.3 \\
14.2 \\
15.0 \\
16.6 \\
15.1 \\
8.4 \\
8.5\end{array}$ & $\begin{array}{r}13.5 \\
11.3 \\
16.0 \\
17.1 \\
18.9 \\
17.4 \\
10.0 \\
9.7\end{array}$ & $\begin{array}{l}14.9 \\
12.4 \\
17.6 \\
10.2 \\
21.5 \\
20.0 \\
11.3 \\
11.3\end{array}$ & $\begin{array}{l}15.9 \\
13.2 \\
18.03 \\
20.3 \\
22.6 \\
21.0 \\
13.2 \\
12.7\end{array}$ \\
\hline $\begin{array}{l}3 \\
3 \\
3 \\
3 \\
3 \\
3 \\
3 \\
3\end{array}$ & $\begin{array}{r}0 \\
3 \\
6 \\
9 \\
12 \\
15 \\
18 \\
21\end{array}$ & $\begin{array}{l}15.6 \\
15.6 \\
15.1 \\
18.9 \\
22.6 \\
22.8 \\
20.6 \\
17.2\end{array}$ & $\begin{array}{l}12: 1 \\
11.7 \\
11.6 \\
13.0 \\
12.8 \\
12.6 \\
13.6 \\
13.4\end{array}$ & $\begin{array}{l}15.7 \\
15.4 \\
15.0 \\
19.3 \\
22.9 \\
23.0 \\
20.7 \\
17.6\end{array}$ & $\begin{array}{l}11.9 \\
11.3 \\
11.03 \\
12.04 \\
12.0 \\
11.8 \\
12.8 \\
12.7\end{array}$ & $\begin{array}{l}15.6 \\
15.3 \\
65.2 \\
19.7 \\
23.2 \\
23.8 \\
21.4 \\
18.0\end{array}$ & $\begin{array}{l}11.04 \\
11.00 \\
11.5 \\
17.1 \\
11.07 \\
11.01 \\
12.02 \\
11.8\end{array}$ & $\begin{array}{l}15.5 \\
15.1 \\
15.2 \\
19.3 \\
22.9 \\
23.4 \\
21.4 \\
19.1\end{array}$ & $\begin{array}{l}11.7 \\
11.4 \\
11.3 \\
12.4 \\
11.9 \\
11.8 \\
12.5 \\
11.6\end{array}$ & $\begin{array}{l}15.8 \\
15.7 \\
15.9 \\
16.7 \\
16.9 \\
16.6 \\
16.4 \\
16.5\end{array}$ & $\begin{array}{l}2 \\
2 \\
4 \\
3 \\
3 \\
3 \\
3 \\
3 \\
2\end{array}$ & $\begin{array}{l}8.1 \\
8.0 \\
5.6 \\
7.2 \\
7.9 \\
6.2 \\
2.9 \\
1.0\end{array}$ & $\begin{array}{l}9.2 \\
9.0 \\
5.8 \\
8.7 \\
9.2 \\
7.2 \\
3.6 \\
2.5\end{array}$ & $\begin{array}{r}10.5 \\
10.5 \\
7.0 \\
9.8 \\
10.7 \\
5.6 \\
4.6 \\
3.2\end{array}$ & $\begin{array}{r}11.9 \\
12.8 \\
9.2 \\
10.4 \\
11.3 \\
9.2 \\
5.7 \\
4.6\end{array}$ \\
\hline $\begin{array}{l}4 \\
4 \\
4 \\
4 \\
4 \\
4 \\
4 \\
4\end{array}$ & $\begin{array}{r}0 \\
3 \\
6 \\
9 \\
12 \\
15 \\
18 \\
21\end{array}$ & $\begin{array}{l}15.7 \\
14.4 \\
15.3 \\
18.2 \\
20.7 \\
21.5 \\
19.5 \\
16.7\end{array}$ & $\begin{array}{l}12.5 \\
11.0 \\
10.9 \\
12.6 \\
13.3 \\
13.7 \\
15.1 \\
13.4\end{array}$ & $\begin{array}{l}15.5 \\
14.2 \\
15.3 \\
18.4 \\
21.1 \\
21.7 \\
19.9 \\
16.7\end{array}$ & $\begin{array}{l}12.3 \\
10.7 \\
10.8 \\
12.4 \\
12.9 \\
13.4 \\
13.7 \\
12.9\end{array}$ & $\begin{array}{l}15.7 \\
14.1 \\
15.5 \\
18.7 \\
21.5 \\
22.5 \\
20.2 \\
17.3\end{array}$ & $\begin{array}{l}11.0 \\
10.04 \\
10.8 \\
12.0 \\
12.5 \\
12.8 \\
12.0 \\
12.0\end{array}$ & $\begin{array}{l}16.2 \\
14.3 \\
15.0 \\
18.3 \\
21.02 \\
22.0 \\
20.1 \\
18.3\end{array}$ & $\begin{array}{l}11.2 \\
10.4 \\
10.7 \\
12.2 \\
12.7 \\
13.3 \\
13.2 \\
17.2\end{array}$ & $\begin{array}{l}16.6 \\
16.4 \\
16.6 \\
17.02 \\
17.4 \\
17.9 \\
17.0 \\
16.9\end{array}$ & $\begin{array}{l}2 \\
2 \\
4 \\
3 \\
3 \\
3 \\
3 \\
2\end{array}$ & $\begin{array}{r}4.7 \\
5.9 \\
7.9 \\
9.6 \\
12.0 \\
12.2 \\
5.3 \\
2.9\end{array}$ & $\begin{array}{r}5.0 \\
7.0 \\
7.8 \\
11.3 \\
14.4 \\
14.0 \\
6.9 \\
3.4\end{array}$ & $\begin{array}{r}5.7 \\
7.7 \\
0.5 \\
12.7 \\
16.7 \\
16.3 \\
8.4 \\
4.3\end{array}$ & $\begin{array}{r}7.4 \\
9.8 \\
9.2 \\
13.6 \\
17.9 \\
17.4 \\
9.7 \\
5.4\end{array}$ \\
\hline $\begin{array}{l}5 \\
5 \\
5 \\
5 \\
5 \\
5 \\
5 \\
5\end{array}$ & $\begin{array}{r}0 \\
3 \\
6 \\
9 \\
12 \\
15 \\
18 \\
21\end{array}$ & $\begin{array}{l}15.4 \\
14.1 \\
15.5 \\
20.4 \\
22.9 \\
23.5 \\
21.4 \\
18.5\end{array}$ & $\begin{array}{l}13.1 \\
12.2 \\
12.5 \\
14.4 \\
14.3 \\
14.9 \\
14.7 \\
13.5\end{array}$ & $\begin{array}{l}15.5 \\
14.1 \\
15.4 \\
19.7 \\
23.1 \\
23.8 \\
21.7 \\
18.6\end{array}$ & $\begin{array}{l}12.8 \\
12.0 \\
12.2 \\
13.9 \\
14.0 \\
14.3 \\
14.4 \\
13.3\end{array}$ & $\begin{array}{l}15.6 \\
14.1 \\
15.5 \\
20.7 \\
23.4 \\
24.2 \\
21.9 \\
18.7\end{array}$ & $\begin{array}{l}12.4 \\
11.8 \\
12.2 \\
13.8 \\
13.9 \\
13.8 \\
14.0 \\
13.0\end{array}$ & $\begin{array}{l}17.0 \\
14.4 \\
15.4 \\
20.3 \\
23.1 \\
24.0 \\
21.8 \\
18.6\end{array}$ & $\begin{array}{l}11.6 \\
11.5 \\
12.3 \\
13.7 \\
14.0 \\
14.1 \\
14.2 \\
13.1\end{array}$ & $\begin{array}{l}16.8 \\
16.7 \\
16.9 \\
18.6 \\
19.0 \\
18.7 \\
17.3 \\
16.6\end{array}$ & $\begin{array}{l}2 \\
2 \\
2 \\
3 \\
2 \\
2 \\
3 \\
3\end{array}$ & $\begin{array}{r}1.9 \\
5.7 \\
2.8 \\
2.5 \\
4.4 \\
5.0 \\
7.3 \\
10.1\end{array}$ & $\begin{array}{r}2.3 \\
5.9 \\
3.5 \\
2.9 \\
5.0 \\
5.9 \\
8.3 \\
10.9\end{array}$ & $\begin{array}{r}2.5 \\
6.5 \\
3.5 \\
3.0 \\
5.6 \\
6.6 \\
9.2 \\
12.0\end{array}$ & $\begin{array}{r}3.8 \\
7.7 \\
3.8 \\
3.3 \\
5.9 \\
6.9 \\
10.0 \\
12.0\end{array}$ \\
\hline $\begin{array}{l}6 \\
6 \\
6 \\
6 \\
6 \\
6 \\
6 \\
6\end{array}$ & $\begin{array}{r}0 \\
3 \\
6 \\
9 \\
12 \\
15 \\
18 \\
21\end{array}$ & $\begin{array}{l}16.2 \\
14.3 \\
12.2 \\
12.3 \\
11.8 \\
12.7 \\
13.1 \\
12.2\end{array}$ & $\begin{array}{r}12.8 \\
11.6 \\
9.8 \\
8.8 \\
8.1 \\
8.1 \\
8.8 \\
8.8\end{array}$ & $\begin{array}{l}16.1 \\
14.2 \\
11.7 \\
11.8 \\
11.4 \\
12.3 \\
12.9 \\
12.1\end{array}$ & $\begin{array}{r}12.4 \\
10.9 \\
8.8 \\
7.8 \\
7.0 \\
7.8 \\
8.6 \\
8.6\end{array}$ & $\begin{array}{l}16.1 \\
13.8 \\
11.5 \\
11.6 \\
11.1 \\
12.2 \\
12.8 \\
11.9\end{array}$ & $\begin{array}{r}12.1 \\
10.5 \\
8.4 \\
7.3 \\
6.6 \\
7.2 \\
8.0 \\
8.2\end{array}$ & $\begin{array}{l}15.8 \\
13.5 \\
11.2 \\
11.1 \\
10.9 \\
11.0 \\
12.6 \\
11.7\end{array}$ & $\begin{array}{r}12.1 \\
10.4 \\
8.3 \\
7.1 \\
6.4 \\
7.2 \\
8.1 \\
8.3\end{array}$ & $\begin{array}{l}16.4 \\
16.3 \\
16.6 \\
16.3 \\
16.1 \\
16.0 \\
15.8 \\
15.7\end{array}$ & $\begin{array}{l}3 \\
3 \\
3 \\
3 \\
3 \\
3 \\
3 \\
3\end{array}$ & $\begin{array}{r}6.7 \\
15.4 \\
18.0 \\
18.7 \\
15.2 \\
14.7 \\
11.4 \\
8.1\end{array}$ & $\begin{array}{r}7.3 \\
17.6 \\
20.9 \\
21.3 \\
17.3 \\
16.8 \\
12.5 \\
8.9\end{array}$ & $\begin{array}{r}7.8 \\
18.2 \\
21.8 \\
22.2 \\
13.0 \\
17.4 \\
13.1 \\
9.0\end{array}$ & $\begin{array}{r}8.4 \\
19.3 \\
23.0 \\
23.6 \\
19.0 \\
19.0 \\
14.5 \\
10.1\end{array}$ \\
\hline $\begin{array}{l}7 \\
7 \\
7 \\
7 \\
7 \\
7 \\
7 \\
7\end{array}$ & $\begin{array}{r}0 \\
3 \\
6 \\
9 \\
12 \\
15 \\
18 \\
21\end{array}$ & $\begin{array}{r}10.5 \\
9.6 \\
10.6 \\
13.0 \\
16.9 \\
18.1 \\
16.7 \\
14.7\end{array}$ & $\begin{array}{r}8.3 \\
7.9 \\
8.1 \\
8.9 \\
9.8 \\
1164 \\
1068 \\
1067\end{array}$ & $\begin{array}{r}10.2 \\
9.2 \\
9.9 \\
12.5 \\
15.8 \\
17.6 \\
16.6 \\
14.6\end{array}$ & $\begin{array}{r}8.0 \\
7.5 \\
7.3 \\
8.3 \\
9.4 \\
10.2 \\
10.8 \\
10.5\end{array}$ & $\begin{array}{r}10.1 \\
9.1 \\
9.7 \\
12.4 \\
15.7 \\
18.1 \\
16.6 \\
14.5\end{array}$ & $\begin{array}{r}7.8 \\
7.04 \\
7.0 \\
7.9 \\
9.0 \\
10.1 \\
10.5 \\
10.1\end{array}$ & $\begin{array}{r}9.7 \\
8.9 \\
9.5 \\
12.3 \\
15.2 \\
17.6 \\
16.4 \\
14.4\end{array}$ & $\begin{array}{r}7.6 \\
7.3 \\
6.9 \\
7.8 \\
8.9 \\
10.2 \\
10.3 \\
9.8\end{array}$ & $\begin{array}{l}15.7 \\
15.6 \\
15.8 \\
16.4 \\
17.4 \\
18.1 \\
16.9 \\
16.6\end{array}$ & $\begin{array}{l}3- \\
3 \\
3 \\
3 \\
3 \\
2 \\
2 \\
2\end{array}$ & $\begin{array}{l}7.2 \\
5.3 \\
7.4 \\
7.2 \\
2.5 \\
2.2 \\
4.3 \\
4.2\end{array}$ & $\begin{array}{l}8.0 \\
5.8 \\
8.0 \\
7.8 \\
2.7 \\
2.4 \\
4.6 \\
4.5\end{array}$ & $\begin{array}{l}8.5 \\
5.8 \\
8.1 \\
8.2 \\
2.9 \\
2.6 \\
5.0 \\
4.8\end{array}$ & $\begin{array}{l}8.7 \\
5.9 \\
8.3 \\
8.4 \\
3.0 \\
2.7 \\
5.2 \\
5.2\end{array}$ \\
\hline $\begin{array}{l}8 \\
8 \\
8 \\
8 \\
8 \\
8 \\
8 \\
8\end{array}$ & $\begin{array}{r}0 \\
3 \\
6 \\
9 \\
12 \\
15 \\
18 \\
21\end{array}$ & $\begin{array}{l}13.5 \\
12.5 \\
13.9 \\
17.0 \\
19.4 \\
20.6 \\
20.2 \\
18.6\end{array}$ & $\begin{array}{l}10.0 \\
10.6 \\
11.8 \\
12.8 \\
14.7 \\
16.0 \\
15.6 \\
15.0\end{array}$ & $\begin{array}{l}13.3 \\
12.3 \\
14.2 \\
17.1 \\
19.7 \\
20.8 \\
20.2 \\
18.7\end{array}$ & $\begin{array}{r}9.9 \\
10.0 \\
11.7 \\
12.8 \\
14.8 \\
16.2 \\
15.8 \\
15.0\end{array}$ & $\begin{array}{l}13.2 \\
12.2 \\
14.3 \\
17.02 \\
20.0 \\
21.1 \\
20.5 \\
18.8\end{array}$ & $\begin{array}{r}9.6 \\
10.0 \\
11.6 \\
12.4 \\
14.8 \\
16.0 \\
15.5 \\
14.0\end{array}$ & $\begin{array}{l}13.0 \\
12.1 \\
14.02 \\
17.02 \\
19.9 \\
21.0 \\
20.5 \\
18.7\end{array}$ & $\begin{array}{r}9.5 \\
10.0 \\
11.6 \\
13.3 \\
14.7 \\
16.1 \\
15.5 \\
14.9\end{array}$ & $\begin{array}{l}16.5 \\
16.3 \\
16.3 \\
16.7 \\
16.9 \\
16.8 \\
16.6 \\
16.6\end{array}$ & $\begin{array}{l}2 \\
2 \\
2 \\
2 \\
2 \\
2 \\
2 \\
2\end{array}$ & $\begin{array}{r}6.0 \\
6.4 \\
9.0 \\
14.3 \\
14.5 \\
14.4 \\
12.6 \\
14.1\end{array}$ & $\begin{array}{r}6.5 \\
6.9 \\
10.1 \\
16.5 \\
16.5 \\
16.5 \\
14.4 \\
16.0\end{array}$ & $\begin{array}{r}7.0 \\
7.6 \\
11.0 \\
19.0 \\
18.5 \\
18.6 \\
16.1 \\
17.8\end{array}$ & $\begin{array}{r}7.5 \\
7.8 \\
11.4 \\
19.0 \\
19.3 \\
19.7 \\
17.1 \\
18.8\end{array}$ \\
\hline $\begin{array}{l}9 \\
9 \\
9 \\
9 \\
9 \\
9 \\
9 \\
9\end{array}$ & $\begin{array}{r}0 \\
3 \\
6 \\
9 \\
12 \\
15 \\
18 \\
21\end{array}$ & $\begin{array}{l}16.9 \\
16.1 \\
17.1 \\
19.6 \\
21.8 \\
22.9 \\
22.0\end{array}$ & $\begin{array}{l}14.6 \\
14.9 \\
15.7 \\
15.8 \\
17.6 \\
18.0 \\
16.3\end{array}$ & $\begin{array}{l}16.9 \\
16.2 \\
17.1 \\
19.9 \\
22.5 \\
23.5 \\
19.7\end{array}$ & $\begin{array}{l}14.6 \\
14.9 \\
15.8 \\
16.9 \\
17.7 \\
18.2 \\
16.3\end{array}$ & $\begin{array}{l}16.8 \\
16.1 \\
17.1 \\
20.2 \\
22.7 \\
23.7 \\
19.2\end{array}$ & $\begin{array}{l}14.4 \\
14.9 \\
15.8 \\
16.9 \\
17.7 \\
18.01 \\
16.02\end{array}$ & $\begin{array}{l}16.7 \\
16.0 \\
17.1 \\
20.3 \\
22.8 \\
23.9 \\
19.4\end{array}$ & $\begin{array}{l}14.2 \\
14.7 \\
15.4 \\
16.7 \\
17.6 \\
18.2 \\
18.4\end{array}$ & $\begin{array}{l}16.4 \\
16.4 \\
16.8 \\
17.5 \\
17.7 \\
17.0 \\
17.0\end{array}$ & $\begin{array}{l}2 \\
2 \\
2 \\
2 \\
2 \\
2 \\
2 \\
4\end{array}$ & $\begin{array}{r}14.6 \\
11.9 \\
11.5 \\
15.4 \\
14.3 \\
12.6 \\
8.2 \\
7.4\end{array}$ & $\begin{array}{l}16.5 \\
13.4 \\
12.9 \\
17.5 \\
16.5 \\
14.6 \\
13.9\end{array}$ & $\begin{array}{r}19.3 \\
14.7 \\
14.4 \\
20.0 \\
18.9 \\
16.6 \\
10.6 \\
9.1\end{array}$ & $\begin{array}{l}19.4 \\
15.5 \\
15.0 \\
21.2 \\
19.9 \\
17.6 \\
11.2\end{array}$ \\
\hline $\begin{array}{l}10 \\
10 \\
10 \\
10 \\
10 \\
10 \\
10 \\
10\end{array}$ & $\begin{array}{r}0 \\
3 \\
6 \\
9 \\
12 \\
15 \\
18 \\
21\end{array}$ & $\begin{array}{l}14.7 \\
15.8 \\
17.5 \\
16.5 \\
13.5\end{array}$ & & $\begin{array}{l}14.5 \\
15.6 \\
17.7 \\
16.2 \\
13.2\end{array}$ & $\begin{array}{l}12.8 \\
13.0 \\
13.5 \\
13.5 \\
11.9\end{array}$ & $\begin{array}{l}14.6 \\
15.8 \\
17.6 \\
16.2 \\
13.3\end{array}$ & $\begin{array}{l}12.6 \\
12.8 \\
13.2 \\
13.2 \\
11.6\end{array}$ & & & $\begin{array}{l}17.0 \\
17.4 \\
17.0 \\
16.8 \\
16.6\end{array}$ & $\begin{array}{l}4 \\
4 \\
4 \\
4 \\
4 \\
3 \\
3 \\
3\end{array}$ & $\begin{array}{r}10.9 \\
12.9 \\
12.2 \\
12.3 \\
13.4 \\
12.6 \\
8.4 \\
7.4\end{array}$ & $\begin{array}{r}11.1 \\
14.6 \\
11.5 \\
13.5 \\
15.4 \\
14.7 \\
9.5 \\
8.3\end{array}$ & $\begin{array}{r}13.9 \\
16.7 \\
14.6 \\
16.1 \\
18.0 \\
16.3 \\
10.6 \\
8.8\end{array}$ & $\begin{array}{r}27.1 \\
18.9 \\
17.5 \\
11.2 \\
9.5\end{array}$ \\
\hline
\end{tabular}


TABLE 10

Table 10. - Three-hour averages of air and water-surface temperatures and wind directions and speed, April 1950-August 1951, Lake Hefner-Continued

STATION 1

THREE-HOURLY AVERAGES

MAY, 2951

\begin{tabular}{|c|c|c|c|c|c|c|c|c|c|c|c|c|c|c|c|}
\hline \multirow{3}{*}{ 宽 } & \multirow{3}{*}{ 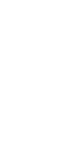 } & \multicolumn{8}{|c|}{ Average air temperature $\left({ }^{\circ} \mathrm{C}\right)$ at indicated height } & \multirow{3}{*}{$\begin{array}{l}\text { Average } \\
\text { water- } \\
\text { surface } \\
\text { tempera- } \\
\text { ture } \\
\text { ("C) }\end{array}$} & \multirow{3}{*}{$\begin{array}{c}\text { Average } \\
\text { wind } \\
\text { direction } \\
\text { (coded) }\end{array}$} & \multicolumn{4}{|c|}{$\begin{array}{l}\text { Average wind speed (knots) } \\
\text { at indicated height }\end{array}$} \\
\hline & & \multicolumn{2}{|c|}{$\begin{array}{c}2 \\
\text { meters }\end{array}$} & \multicolumn{2}{|c|}{$\begin{array}{c}4 \\
\text { meters }\end{array}$} & \multicolumn{2}{|c|}{$\begin{array}{c}8 \\
\text { meters }\end{array}$} & \multicolumn{2}{|c|}{$\begin{array}{c}16 \\
\text { meters }\end{array}$} & & & & & & \\
\hline & & $\begin{array}{l}\text { Dry } \\
\text { bulb }\end{array}$ & $\begin{array}{l}\text { Wet } \\
\text { bulb }\end{array}$ & $\begin{array}{l}\text { Dry } \\
\text { bulb }\end{array}$ & $\begin{array}{l}\text { Wet } \\
\text { bulb }\end{array}$ & $\begin{array}{l}\text { Dry } \\
\text { bulb }\end{array}$ & $\begin{array}{l}\text { Wet } \\
\text { bulb }\end{array}$ & $\begin{array}{l}\text { Dry } \\
\text { bulb }\end{array}$ & $\begin{array}{l}\text { Wet } \\
\text { bulb }\end{array}$ & & & meters & meters & meters & meters \\
\hline $\begin{array}{l}11 \\
11 \\
11 \\
11 \\
11 \\
11 \\
11 \\
11\end{array}$ & $\begin{array}{r}0 \\
3 \\
6 \\
9 \\
12 \\
15 \\
18 \\
21\end{array}$ & $\begin{array}{l}11.9 \\
10.7 \\
11.9 \\
15.5 \\
18.8 \\
19.6 \\
18.6 \\
16.1\end{array}$ & $\begin{array}{l}13.0 \\
13.3 \\
13.8 \\
14.5 \\
13.4\end{array}$ & $\begin{array}{l}11.5 \\
10.5 \\
12.1 \\
15.5 \\
18.0 \\
19.6 \\
18.5 \\
16.0 .\end{array}$ & $\begin{array}{l}10.9 \\
10.1 \\
10.5 \\
11.8 \\
12.4 \\
13.2 \\
13.5 \\
12.6\end{array}$ & $\begin{array}{l}11.7 \\
10.7 \\
12.4 \\
15.1 \\
18.0 \\
19.7 \\
13.4 \\
15.9\end{array}$ & $\begin{array}{l}10.7 \\
10.00 \\
10.6 \\
11.5 \\
12.4 \\
12.8 \\
12.9 \\
12.3\end{array}$ & $\begin{array}{l}16.4 \\
10.0 \\
17.0 \\
15.4\end{array}$ & & $\begin{array}{l}16.6 \\
16.5 \\
17.3 \\
19.0 \\
19.9 \\
19.1 \\
18.1 \\
17.7\end{array}$ & $\begin{array}{l}3 \\
3 \\
2 \\
3 \\
3 \\
3 \\
3 \\
2\end{array}$ & $\begin{array}{l}4.5 \\
2.8 \\
1.7 \\
2.7 \\
3.9 \\
3.3 \\
5.5 \\
4.9\end{array}$ & $\begin{array}{l}5.0 \\
3.1 \\
2.0 \\
3.2 \\
4.2 \\
3.5 \\
6.0 \\
5.6\end{array}$ & $\begin{array}{l}5.2 \\
3.2 \\
2.0 \\
3.4 \\
4.5 \\
3.7 \\
6.5 \\
5.8\end{array}$ & $\begin{array}{l}6.1 \\
3.2 \\
2.1 \\
2.6 \\
4.7 \\
3.9 \\
7.3 \\
6.5\end{array}$ \\
\hline $\begin{array}{l}12 \\
12 \\
12 \\
12 \\
12 \\
12 \\
12 \\
12\end{array}$ & $\begin{array}{r}0 \\
3 \\
6 \\
9 \\
12 \\
15 \\
18 \\
21\end{array}$ & $\begin{array}{l}15.4 \\
14.9 \\
15.1 \\
17.4 \\
19.3 \\
20.4 \\
18.9 \\
17.0\end{array}$ & $\begin{array}{l}12.8 \\
12: 9 \\
13.0 \\
14.3 \\
15.2 \\
15.8 \\
15.1 \\
14.1\end{array}$ & $\begin{array}{l}15.0 \\
14.9 \\
15.0 \\
27.5 \\
19.5 \\
20.5 \\
19.0 \\
16.9\end{array}$ & $\begin{array}{l}12.2 \\
12.2 \\
12.2 \\
12.9 \\
13.4 \\
14.0 \\
13.6 \\
12.8\end{array}$ & $\begin{array}{l}15.3 \\
15.0 \\
15.1 \\
17.7 \\
19.8 \\
20.8 \\
19.0 \\
16.9\end{array}$ & $\begin{array}{l}12.2 \\
12.00 \\
12.0 \\
12.6 \\
13.2 \\
13.5 \\
13.03 \\
12.05\end{array}$ & $\begin{array}{l}14.8 \\
14.5 \\
14.7 \\
17.3 \\
19.4 \\
20.4 \\
18.7 \\
16.6\end{array}$ & & $\begin{array}{l}16.9 \\
16.7 \\
17.2 \\
17.4 \\
17.9 \\
17.3 \\
16.8 \\
16.7\end{array}$ & $\begin{array}{l}2 \\
2 \\
2 \\
2 \\
2 \\
2 \\
2 \\
2\end{array}$ & $\begin{array}{r}5.9 \\
7.8 \\
11.0 \\
13.3 \\
11.9 \\
12.6 \\
9.5 \\
13.3\end{array}$ & $\begin{array}{r}6.6 \\
8.4 \\
11.7 \\
14.5 \\
13.4 \\
14.2 \\
10.7 \\
15.0\end{array}$ & $\begin{array}{r}7.1 \\
9.0 \\
13.5 \\
16.0 \\
14.6 \\
15.8 \\
12.0 \\
16.4\end{array}$ & $\begin{array}{r}7.3 \\
9.2 \\
12.7 \\
16.4 \\
15.3 \\
16.5 \\
12.6 \\
17.3\end{array}$ \\
\hline $\begin{array}{l}13 \\
13 \\
13 \\
13 \\
13 \\
13 \\
13 \\
13\end{array}$ & $\begin{array}{r}0 \\
3 \\
6 \\
9 \\
12 \\
15 \\
18 \\
21\end{array}$ & $\begin{array}{l}15.7 \\
14.6 \\
15.8 \\
19.7 \\
21.6 \\
22.5 \\
21.2 \\
20.0\end{array}$ & $\begin{array}{l}13.6 \\
13.1 \\
13.7 \\
16.3 \\
17.0 \\
17.0 \\
16.6 \\
15.9\end{array}$ & $\begin{array}{l}15.6 \\
14.65 \\
15.9 \\
19.9 \\
21.0 \\
22.6 \\
21.5 \\
20.1\end{array}$ & $\begin{array}{l}12.6 \\
12.2 \\
12.6 \\
15.3 \\
15.5 \\
15.2 \\
14.9 \\
14.4\end{array}$ & $\begin{array}{l}15.6 \\
14.5 \\
16.1 \\
20.2 \\
22.2 \\
22.9 \\
21.6 \\
20.2\end{array}$ & $\begin{array}{l}12.2 \\
11.8 \\
12.3 \\
14.7 \\
15.0 \\
14.7 \\
14.3 \\
13.8\end{array}$ & $\begin{array}{l}15.2 \\
14: 1 \\
15.8 \\
10: 9 \\
21: 2 \\
22.8 \\
21.3 \\
19.9\end{array}$ & & $\begin{array}{l}16.7 \\
16.8 \\
17.6 \\
18.5 \\
18.5 \\
17.9 \\
17.1 \\
17.3\end{array}$ & $\begin{array}{l}2 \\
2 \\
2 \\
2 \\
2 \\
2 \\
2 \\
2\end{array}$ & $\begin{array}{l}12.8 \\
12.4 \\
16.2 \\
17.9 \\
18.9 \\
17.8 \\
15.4 \\
16.2\end{array}$ & $\begin{array}{l}14.3 \\
13.9 \\
18.1 \\
20.4 \\
20.7 \\
20.0 \\
17.2 \\
18.2\end{array}$ & $\begin{array}{l}15.5 \\
15.0 \\
19.8 \\
22.5 \\
22.8 \\
22.3 \\
19.1 \\
20.0\end{array}$ & $\begin{array}{l}16.3 \\
15.7 \\
20.8 \\
23.6 \\
24.2 \\
23.4 \\
20.2 \\
20.9\end{array}$ \\
\hline $\begin{array}{l}14 \\
14 \\
14 \\
14 \\
14 \\
14 \\
14 \\
14\end{array}$ & $\begin{array}{r}0 \\
3 \\
6 \\
9 \\
12 \\
15 \\
18 \\
21\end{array}$ & $\begin{array}{l}19.3 \\
18.1 \\
18.1 \\
20.6 \\
22.7 \\
24.2 \\
22.6 \\
21.4\end{array}$ & $\begin{array}{l}15.3 \\
14.8 \\
15.6 \\
16.5 \\
17.6 \\
18.7 \\
18.7 \\
18.6\end{array}$ & $\begin{array}{l}19.6 \\
18.0 \\
18.2 \\
21.0 \\
23.2 \\
24.6 \\
23.0 \\
21.6\end{array}$ & $\begin{array}{l}14.0 \\
13.9 \\
14.9 \\
15.5 \\
16.5 \\
17.4 \\
17.9 \\
18.3\end{array}$ & $\begin{array}{l}19.6 \\
18.1 \\
18.4 \\
21.2 \\
23.7 \\
24.8 \\
23.2 \\
21.5\end{array}$ & $\begin{array}{l}13.4 \\
13.0 \\
14.7 \\
15.0 \\
15.8 \\
16.7 \\
17.3 \\
18.0\end{array}$ & $\begin{array}{l}19.0 \\
17: 7 \\
17.9 \\
21.0 \\
23.6 \\
24.7 \\
23.2 \\
21.5\end{array}$ & & $\begin{array}{l}17.2 \\
17.2 \\
17.8 \\
18.1 \\
18.4 \\
17.8 \\
17.5 \\
17.6\end{array}$ & $\begin{array}{l}2 \\
2 \\
2 \\
2 \\
2 \\
2 \\
2 \\
2\end{array}$ & $\begin{array}{l}15.6 \\
16.4 \\
19.0 \\
17.8 \\
15.7 \\
16.8 \\
16.6 \\
18.1\end{array}$ & $\begin{array}{l}17.6 \\
118.4 \\
21.4 \\
20.5 \\
17.9 \\
19.0 \\
18.8 \\
20.7\end{array}$ & $\begin{array}{l}10.1 \\
20.0 \\
23.9 \\
22.8 \\
19.8 \\
21.2 \\
20.8 \\
22.9\end{array}$ & $\begin{array}{l}20 \cdot 1 \\
21: 0 \\
25: 2 \\
24 \cdot 1 \\
20.9 \\
22 \cdot 5 \\
21 \cdot 9 \\
24 \cdot 2\end{array}$ \\
\hline $\begin{array}{l}15 \\
15 \\
15 \\
15 \\
15 \\
15 \\
15 \\
15\end{array}$ & $\begin{array}{r}0 \\
3 \\
6 \\
9 \\
12 \\
15 \\
18 \\
21\end{array}$ & $\begin{array}{l}20.4 \\
19.1 \\
19.9 \\
20.5 \\
20.9 \\
21.0 \\
20.1 \\
19.0\end{array}$ & $\begin{array}{l}18.8 \\
18.1 \\
18.5 \\
18.9 \\
19.5 \\
19.2 \\
18.6 \\
18.0\end{array}$ & $\begin{array}{l}20.5 \\
18.7 \\
20.0 \\
20.7 \\
20.9 \\
21.0 \\
20.2 \\
18.9\end{array}$ & $\begin{array}{l}18.5 \\
17.5 \\
18.5 \\
18.9 \\
19.0 \\
18.9 \\
18.3 \\
17.9\end{array}$ & $\begin{array}{l}20.5 \\
18.8 \\
20.0 \\
20.9 \\
21.0 \\
21.1 \\
20.2 \\
19.0\end{array}$ & $\begin{array}{l}18.2 \\
18.0 \\
18.2 \\
18.7 \\
18.9 \\
18.6 \\
18.0 \\
17.6\end{array}$ & $\begin{array}{l}20.4 \\
19.3 \\
20.1 \\
20.3 \\
21.1 \\
21.1 \\
20.2 \\
19.2\end{array}$ & $\begin{array}{l}18.5 \\
18.3 \\
18.6 \\
18.8 \\
18.2 \\
18.7 \\
18.1 \\
17.8\end{array}$ & $\begin{array}{l}17.6 \\
17.4 \\
17.7 \\
17.8 \\
18.2 \\
17.8 \\
17.7 \\
17.7\end{array}$ & $\begin{array}{l}2 \\
2 \\
2 \\
2 \\
2 \\
2 \\
2 \\
2\end{array}$ & $\begin{array}{l}17.2 \\
12.9 \\
15.8 \\
14.1 \\
15.9 \\
15.7 \\
13.7 \\
10.6\end{array}$ & $\begin{array}{l}19.5 \\
14.5 \\
17.8 \\
16.0 \\
17.9 \\
17.7 \\
15.4 \\
11.9\end{array}$ & $\begin{array}{l}21.6 \\
16.0 \\
19.6 \\
17.5 \\
19.8 \\
19.6 \\
17.0 \\
13.0\end{array}$ & $\begin{array}{l}22.7 \\
17.0 \\
20.9 \\
18.6 \\
20.6 \\
20.6 \\
18.0 \\
13.8\end{array}$ \\
\hline $\begin{array}{l}16 \\
16 \\
16 \\
16 \\
16 \\
16 \\
16 \\
16\end{array}$ & $\begin{array}{r}0 \\
3 \\
6 \\
9 \\
12 \\
15 \\
18 \\
21\end{array}$ & $\begin{array}{l}19.4 \\
19.0 \\
18.6 \\
19.7 \\
22.1 \\
22.6 \\
21.01 \\
20.4\end{array}$ & $\begin{array}{l}18.2 \\
18.02 \\
17.7 \\
18.0 \\
18.6 \\
19.4 \\
19.02 \\
18.5\end{array}$ & $\begin{array}{l}19.5 \\
19.0 \\
18.5 \\
19.7 \\
22.3 \\
22.9 \\
21.3 \\
20.5\end{array}$ & $\begin{array}{l}17.9 \\
18.1 \\
16.7 \\
17.8 \\
18.4 \\
18.7 \\
18.9 \\
17.8\end{array}$ & $\begin{array}{l}19.5 \\
19.1 \\
18.3 \\
19.9 \\
22.8 \\
23.1 \\
21.3 \\
20.5\end{array}$ & $\begin{array}{l}17.8 \\
17.9 \\
17.2 \\
17.5 \\
18.3 \\
18.7 \\
18.8 \\
17.8\end{array}$ & $\begin{array}{l}19.6 \\
19.0 \\
18.6 \\
10.9 \\
22.7 \\
23.2 \\
21.3 \\
20.2\end{array}$ & $\begin{array}{l}17.8 \\
17.9 \\
17.3 \\
17.2 \\
18.1 \\
28.8 \\
18.9 \\
17.6\end{array}$ & $\begin{array}{l}17.7 \\
17.7 \\
17.8 \\
18.5 \\
18.4 \\
18.0 \\
18.0 \\
17.9\end{array}$ & $\begin{array}{l}2 \\
2 \\
2 \\
2 \\
2 \\
2 \\
2 \\
2\end{array}$ & $\begin{array}{r}9.2 \\
12.0 \\
15.3 \\
17.0 \\
14.1 \\
11.6 \\
10.7 \\
14.2\end{array}$ & $\begin{array}{l}10.5 \\
13.5 \\
17.1 \\
19.5 \\
16.1 \\
13.2 \\
12.0 \\
16.5\end{array}$ & $\begin{array}{l}11.6 \\
14.9 \\
18.6 \\
21.9 \\
18.4 \\
14.7 \\
13.5 \\
18.0\end{array}$ & $\begin{array}{l}12.4 \\
15.7 \\
20.0 \\
22.9 \\
19.4 \\
15.5 \\
14.1 \\
18.8\end{array}$ \\
\hline $\begin{array}{l}17 \\
17 \\
17 \\
17 \\
17 \\
17 \\
17 \\
17\end{array}$ & $\begin{array}{r}0 \\
3 \\
6 \\
9 \\
12 \\
15 \\
18 \\
21\end{array}$ & $\begin{array}{l}17.7 \\
18.0 \\
17.8 \\
16.9 \\
15.6\end{array}$ & $\begin{array}{l}15.9 \\
16.3 \\
16.6 \\
15.9 \\
15.3\end{array}$ & $\begin{array}{l}17.0 \\
17.2 \\
17.1 \\
15.9 \\
15.3\end{array}$ & $\begin{array}{l}15.6 \\
16.0 \\
16.5 \\
15.5 \\
14.9\end{array}$ & $\begin{array}{l}17.3 \\
17: 9 \\
17: 1 \\
17: 0 \\
15.3\end{array}$ & $\begin{array}{l}15.5 \\
16.1 \\
16.2 \\
15.4 \\
14.5\end{array}$ & $\begin{array}{l}17.3 \\
17.6 \\
16.0 \\
16.4 \\
15.7\end{array}$ & & $\begin{array}{l}17.9 \\
17.9 \\
17.8 \\
17.8 \\
17.9\end{array}$ & $\begin{array}{l}3 \\
3 \\
2 \\
2 \\
2 \\
2 \\
2 \\
2\end{array}$ & $\begin{array}{r}5.2 \\
8.2 \\
9.8 \\
12.9 \\
12.9 \\
8.3 \\
19.6 \\
18.4\end{array}$ & $\begin{array}{r}6.2 \\
8.8 \\
11.2 \\
14.5 \\
14.4 \\
9.1 \\
21.6 \\
20.1\end{array}$ & $\begin{array}{r}6.6 \\
9.3 \\
12.1 \\
16.1 \\
16.0 \\
10.1 \\
23.9 \\
21.9\end{array}$ & $\begin{array}{r}6.8 \\
9.4 \\
12.6 \\
16.7 \\
16.5 \\
10.6 \\
24.8 \\
22.6\end{array}$ \\
\hline $\begin{array}{l}18 \\
18 \\
18 \\
18 \\
18 \\
18 \\
18 \\
18\end{array}$ & $\begin{array}{r}0 \\
3 \\
6 \\
9 \\
12 \\
15 \\
18 \\
21\end{array}$ & $\begin{array}{l}16.2 \\
13.0 \\
14.1 \\
17.1 \\
19.3 \\
20.0 \\
19.5 \\
18.8\end{array}$ & $\begin{array}{l}14.9 \\
14.9 \\
13.3 \\
15.6 \\
17.4 \\
18.4 \\
18.5 \\
18.1\end{array}$ & $\begin{array}{l}16.4 \\
19.1 \\
20.0 \\
19.2 \\
18.4\end{array}$ & $\begin{array}{l}14.2 \\
12.5 \\
13.1 \\
15.3 \\
17.0 \\
17.9 \\
18.2 \\
17.8\end{array}$ & $\begin{array}{l}15.7 \\
13.3 \\
14.0 \\
17.2 \\
19.6 \\
20.2 \\
19.7 \\
18.9\end{array}$ & $\begin{array}{l}14.0 \\
12.6 \\
17.9 \\
14.8 \\
16.7 \\
17.7 \\
18.0 \\
17.5\end{array}$ & $\begin{array}{l}25.4 \\
12.8 \\
13.9 \\
16.9 \\
19.2 \\
19.9 \\
19.2 \\
18.5\end{array}$ & & $\begin{array}{l}17.5 \\
17.5 \\
17.5 \\
18.2 \\
18.0 \\
18.0 \\
17.9 \\
17.9\end{array}$ & $\begin{array}{l}3 \\
3 \\
2 \\
2 \\
2 \\
2 \\
2 \\
2\end{array}$ & $\begin{array}{r}11.7 \\
9.2 \\
13.2 \\
15.6 \\
14.9 \\
15.0 \\
11.7 \\
9.6\end{array}$ & $\begin{array}{r}12.7 \\
9.6 \\
14.4 \\
17.7 \\
16.9 \\
17.1 \\
13.2 \\
11.3\end{array}$ & $\begin{array}{l}13.4 \\
10.7 \\
15.5 \\
19.5 \\
19.2 \\
19.1 \\
14.7 \\
12.7\end{array}$ & $\begin{array}{l}13.8 \\
10.8 \\
15.9 \\
20.4 \\
20.1 \\
20.2 \\
15.5 \\
13.5\end{array}$ \\
\hline $\begin{array}{l}19 \\
19 \\
19 \\
19 \\
19 \\
19 \\
19 \\
19\end{array}$ & $\begin{array}{r}0 \\
3 \\
6 \\
9 \\
12 \\
15 \\
18 \\
21\end{array}$ & $\begin{array}{l}17.9 \\
17.8 \\
28.9 \\
21.4 \\
23.7 \\
23.9 \\
20.7 \\
19.2\end{array}$ & $\begin{array}{l}16.7 \\
17.0 \\
17.9 \\
19.4 \\
20.4 \\
20.5 \\
18.6 \\
16.3\end{array}$ & $\begin{array}{l}19.3 \\
21.4 \\
24.1 \\
24.4 \\
20.5 \\
18.8\end{array}$ & $\begin{array}{l}16.4 \\
16.8 \\
17.8 \\
19.4 \\
20.4 \\
20.03 \\
18.3 \\
15.7\end{array}$ & $\begin{array}{l}17.9 \\
17.7 \\
19.1 \\
21.9 \\
24.5 \\
24.7 \\
20.8 \\
19.5\end{array}$ & $\begin{array}{l}16.2 \\
16.6 \\
17.7 \\
19.4 \\
20.4 \\
20.2 \\
18.1 \\
15.5\end{array}$ & $\begin{array}{l}17.6 \\
16.9 \\
18.8 \\
21.5 \\
24.1 \\
24.3 \\
20.4 \\
18.7\end{array}$ & & $\begin{array}{l}17.7 \\
17.6 \\
17.9 \\
18.6 \\
19.2 \\
18.4 \\
18.2 \\
18.3\end{array}$ & $\begin{array}{l}2 \\
2 \\
2 \\
2 \\
2 \\
2 \\
3 \\
2\end{array}$ & $\begin{array}{r}9.1 \\
10.1 \\
13.2 \\
9.7 \\
9.6 \\
12.7 \\
12.2 \\
18.9\end{array}$ & $\begin{array}{l}10.2 \\
11.8 \\
15.0 \\
10.7 \\
11.1 \\
14.8 \\
14.0 \\
21.4\end{array}$ & $\begin{array}{l}11.7 \\
13.4 \\
18.7 \\
12.1 \\
12.7 \\
16.8 \\
15.3 \\
23.8\end{array}$ & $\begin{array}{l}12.6 \\
14.2 \\
21.6 \\
12.6 \\
13.3 \\
18.0 \\
15.7 \\
22.0\end{array}$ \\
\hline $\begin{array}{l}20 \\
20 \\
20 \\
20 \\
20 \\
20 \\
20 \\
20\end{array}$ & $\begin{array}{r}0 \\
3 \\
6 \\
9 \\
12 \\
15 \\
18 \\
21\end{array}$ & $\begin{array}{l}28.1 \\
16.7 \\
17.2 \\
22.3 \\
23.9\end{array}$ & $\begin{array}{l}16.0 \\
15.2 \\
16.0 \\
18.2 \\
19.6\end{array}$ & $\begin{array}{l}18.0 \\
16.7 \\
16.9 \\
21.2 \\
23.2\end{array}$ & $\begin{array}{l}15.4 \\
15.0 \\
15.5 \\
17.5 \\
19.4\end{array}$ & $\begin{array}{l}18.0 \\
16.7 \\
17.2 \\
21.6 \\
23.0\end{array}$ & $\begin{array}{l}15.1 \\
14.9 \\
15.5 \\
17.6 \\
19.1\end{array}$ & $\begin{array}{l}17.6 \\
16.4 \\
16.6 \\
21.6 \\
23.0\end{array}$ & $\begin{array}{l}15.1 \\
15.6 \\
17.7 \\
29.2\end{array}$ & $\begin{array}{l}18.0 \\
17.9 \\
18.2 \\
20.6 \\
22.7\end{array}$ & $\begin{array}{l}2 \\
2 \\
3 \\
3 \\
2 \\
2 \\
2 \\
2\end{array}$ & $\begin{array}{r}12.0 \\
2.1 \\
3.1 \\
1.7 \\
3.0 \\
6.8 \\
8.3 \\
8.2\end{array}$ & $\begin{array}{r}13.5 \\
2.8 \\
3.9 \\
2.1 \\
3.8 \\
8.0 \\
9.8 \\
9.9\end{array}$ & $\begin{array}{r}14.9 \\
3.1 \\
3.8 \\
2.4 \\
3.8 \\
9.2 \\
11.2 \\
11.2\end{array}$ & $\begin{array}{r}15.6 \\
3.2 \\
4.1 \\
2.3 \\
4.0 \\
9.7 \\
12.0 \\
12.3\end{array}$ \\
\hline
\end{tabular}


TABLE 10

Table 10. - Three-hour averages of air and water-surface temperatures and wind directions and speed, April 1950-August 1951. Lake Hefner-Continued

STATION 1 THREE-HOURLY AVERAGES

MAY, 1951

\begin{tabular}{|c|c|c|c|c|c|c|c|c|c|c|c|c|c|c|c|}
\hline \multirow{3}{*}{ 密 } & \multirow{3}{*}{ 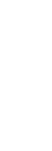 } & \multicolumn{8}{|c|}{ Average air temperature $\left({ }^{\circ} \mathrm{C}\right)$ at indicated height } & \multirow{3}{*}{$\begin{array}{l}\text { Average } \\
\text { water- } \\
\text { surface } \\
\text { tempera- } \\
\text { ture } \\
\text { ("C) }\end{array}$} & \multirow{3}{*}{$\begin{array}{c}\text { Average } \\
\text { wind } \\
\text { direction } \\
\text { (coded) }\end{array}$} & \multirow{2}{*}{\multicolumn{4}{|c|}{$\begin{array}{l}\text { Average wind speed (knots) } \\
\text { at indicated height }\end{array}$}} \\
\hline & & \multicolumn{2}{|c|}{$\begin{array}{c}2 \\
\text { meters }\end{array}$} & \multicolumn{2}{|c|}{$\begin{array}{c}4 \\
\text { meters }\end{array}$} & \multicolumn{2}{|c|}{$\begin{array}{c}8 \\
\text { meters }\end{array}$} & \multicolumn{2}{|c|}{$\begin{array}{c}16 \\
\text { meters }\end{array}$} & & & & & & \\
\hline & & $\begin{array}{l}\text { Dry } \\
\text { bulb }\end{array}$ & $\begin{array}{l}\text { Wet } \\
\text { bulb }\end{array}$ & $\begin{array}{l}\text { Dry } \\
\text { bulb }\end{array}$ & $\begin{array}{l}\text { Wet } \\
\text { bulb }\end{array}$ & $\begin{array}{l}\text { Dry } \\
\text { bulb }\end{array}$ & $\begin{array}{l}\text { Wet } \\
\text { bulb }\end{array}$ & $\begin{array}{l}\text { Dry } \\
\text { bulb }\end{array}$ & $\begin{array}{l}\text { Wet } \\
\text { bulb }\end{array}$ & & & meters & $\begin{array}{c}4 \\
\text { meters }\end{array}$ & meters & meters \\
\hline $\begin{array}{l}21 \\
21 \\
21 \\
21 \\
21 \\
21 \\
21 \\
21\end{array}$ & $\begin{array}{r}0 \\
3 \\
6 \\
9 \\
12 \\
15 \\
18 \\
21\end{array}$ & $\begin{array}{l}24.1 \\
25.5 \\
25.3 \\
21.7 \\
17.3\end{array}$ & $\begin{array}{l}19.9 \\
20.3 \\
20.3 \\
18.9 \\
16.3\end{array}$ & $\begin{array}{l}24.3 \\
26.0 \\
25.8 \\
22.0 \\
17.4\end{array}$ & $\begin{array}{l}19.9 \\
20.5 \\
20.2 \\
18.5 \\
16.0\end{array}$ & $\begin{array}{l}24.7 \\
26.5 \\
26.1 \\
21.6 \\
17.0\end{array}$ & $\begin{array}{l}19.7 \\
20.4 \\
20.0 \\
18.2 \\
15.7\end{array}$ & $\begin{array}{l}24 \cdot 5 \\
26.4 \\
26.1 \\
21 \cdot 3 \\
16.8\end{array}$ & $\begin{array}{l}20.2 \\
20.7 \\
20.3 \\
18.2 \\
15.9\end{array}$ & $\begin{array}{l}20.3 \\
20.3 \\
19.5 \\
19.3 \\
19.2\end{array}$ & $\begin{array}{l}2 \\
2 \\
2 \\
2 \\
2 \\
2 \\
2 \\
3\end{array}$ & $\begin{array}{r}5.2 \\
2.5 \\
5.6 \\
6.2 \\
11.6 \\
17.2 \\
12.9 \\
12.8\end{array}$ & $\begin{array}{r}6.3 \\
3.1 \\
6.5 \\
7.4 \\
13.5 \\
19.8 \\
14.5 \\
13.5\end{array}$ & $\begin{array}{r}7.4 \\
3.8 \\
7.5 \\
8.6 \\
15.5 \\
22.1 \\
16.5 \\
14.7\end{array}$ & $\begin{array}{r}8.1 \\
4.2 \\
7.9 \\
8.9 \\
16.6 \\
23.6 \\
17.3 \\
14.7\end{array}$ \\
\hline $\begin{array}{l}22 \\
22 \\
22 \\
22 \\
22 \\
22 \\
22 \\
22\end{array}$ & $\begin{array}{r}0 \\
3 \\
6 \\
9 \\
12 \\
15 \\
18 \\
21\end{array}$ & $\begin{array}{l}14.5 \\
15.1 \\
17.4 \\
19.6 \\
19.6 \\
17.8 \\
17.3 \\
15.8\end{array}$ & $\begin{array}{l}14.1 \\
14.6 \\
15.8 \\
16.7 \\
16.8 \\
16.1 \\
15.6 \\
14.8\end{array}$ & $\begin{array}{l}15.2 \\
15.2 \\
17.4 \\
19.8 \\
19.5 \\
17.6 \\
17.0 \\
15.4\end{array}$ & $\begin{array}{l}14.8 \\
14.9 \\
15.5 \\
16.7 \\
16.5 \\
15.5 \\
15.2 \\
14.5\end{array}$ & $\begin{array}{l}15.0 \\
15.03 \\
17.4 \\
19.9 \\
19.4 \\
17.6 \\
16.9 \\
15.4\end{array}$ & $\begin{array}{l}14.7 \\
14.9 \\
15.5 \\
17.0 \\
16.0 \\
15 . ? \\
15.1 \\
14.3\end{array}$ & $\begin{array}{l}15.4 \\
15.5 \\
17.1 \\
19.8 \\
19.1 \\
17.2 \\
16.6 \\
15.1\end{array}$ & $\begin{array}{l}14.8 \\
15.0 \\
15.6 \\
16.5 \\
16.1 \\
15.2 \\
15.0 \\
14.3\end{array}$ & $\begin{array}{l}19.2 \\
19.2 \\
10.7 \\
20.5 \\
20.6 \\
20.7 \\
20.0 \\
19.8\end{array}$ & $\begin{array}{l}3 \\
2 \\
2 \\
4 \\
4 \\
3 \\
3 \\
3\end{array}$ & $\begin{array}{r}6.9 \\
5.5 \\
8.1 \\
16.3 \\
19.1 \\
16.5 \\
10.8 \\
6.3\end{array}$ & $\begin{array}{r}7.3 \\
5.4 \\
8.8 \\
16.0 \\
20.7 \\
19.2 \\
11.8 \\
7.5\end{array}$ & $\begin{array}{r}7.7 \\
6.1 \\
0.6 \\
18.5 \\
25.3 \\
21.3 \\
13.4 \\
7.4\end{array}$ & $\begin{array}{r}7.8 \\
6.0 \\
9.7 \\
26.3 \\
22.3 \\
13.9 \\
7.9\end{array}$ \\
\hline $\begin{array}{l}23 \\
23 \\
23 \\
23 \\
23 \\
23 \\
23 \\
23\end{array}$ & $\begin{array}{r}0 \\
3 \\
6 \\
9 \\
12 \\
15 \\
18 \\
? 1\end{array}$ & $\begin{array}{l}14.9 \\
14.3 \\
14.9 \\
19.9 \\
22.0 \\
20.9\end{array}$ & $\begin{array}{l}13.9 \\
13.2 \\
13.8 \\
14.0 \\
15.6 \\
14.6\end{array}$ & $\begin{array}{l}14.7 \\
14.1 \\
15.0 \\
19.0 \\
20.8 \\
20.8\end{array}$ & $\begin{array}{l}13.6 \\
13.0 \\
13.5 \\
13.7 \\
14.5 \\
14.3\end{array}$ & $\begin{array}{l}20.8 \\
21.0\end{array}$ & $\begin{array}{l}13.4 \\
13.0 \\
14.0 \\
14.2 \\
14.0\end{array}$ & $\begin{array}{l}14.3 \\
13.8 \\
14.9 \\
19.0 \\
20.5 \\
20.3\end{array}$ & $\begin{array}{l}13.5 \\
13.0 \\
13.7 \\
13.9 \\
14.2 \\
14.1\end{array}$ & $\begin{array}{l}19.5 \\
19.4 \\
19.9 \\
22.1 \\
22.7 \\
22.0\end{array}$ & $\begin{array}{l}4 \\
4 \\
4 \\
4 \\
4 \\
2 \\
2 \\
2\end{array}$ & $\begin{array}{l}5.0 \\
3.6 \\
3.5 \\
1.2 \\
1.7 \\
5.2 \\
5.4 \\
5.5\end{array}$ & $\begin{array}{l}6.1 \\
3.5 \\
3.5 \\
1.3 \\
1.8 \\
5.7 \\
6.0 \\
6.0\end{array}$ & $\begin{array}{l}6.4 \\
3.6 \\
3.8 \\
1.4 \\
1.9 \\
6.3 \\
6.7 \\
6.4\end{array}$ & $\begin{array}{l}6.8 \\
2.8 \\
4.0 \\
1.3 \\
1.7 \\
6.4 \\
7.3 \\
6.8\end{array}$ \\
\hline $\begin{array}{l}24 \\
24 \\
24 \\
24 \\
24 \\
24 \\
24 \\
24\end{array}$ & $\begin{array}{r}0 \\
3 \\
6 \\
9 \\
12 \\
15 \\
18 \\
21\end{array}$ & $\begin{array}{l}17.1 \\
18.2 \\
16.0 \\
15.5 \\
15.0 \\
15.7\end{array}$ & $\begin{array}{l}14.0 \\
14.9 \\
15.2 \\
15.2 \\
15.2 \\
14.7\end{array}$ & $\begin{array}{l}17.1 \\
18.1 \\
16.1 \\
15.8 \\
15.5 \\
15.8\end{array}$ & $\begin{array}{l}13.7 \\
14.7 \\
15.0 \\
15.1 \\
15.0 \\
14.4\end{array}$ & $\begin{array}{l}17.2 \\
18.0 \\
16.0 \\
15.8 \\
15.5 \\
15.8\end{array}$ & $\begin{array}{l}13.0 \\
13.6 \\
14.6 \\
14.9 \\
15.1 \\
14.9 \\
14.4\end{array}$ & $\begin{array}{l}16.5 \\
17: 0 \\
17.9 \\
15.7 \\
15.7 \\
15.3 \\
15.6\end{array}$ & $\begin{array}{l}13.0 \\
13.5 \\
14.5 \\
14.8 \\
15.1 \\
15.0 \\
14.4\end{array}$ & $\begin{array}{l}18.0 \\
19.0 \\
19.1 \\
18.9 \\
18.8 \\
18.8 \\
18.8\end{array}$ & $\begin{array}{l}2 \\
2 \\
2 \\
2 \\
2 \\
2 \\
2 \\
3 \\
2\end{array}$ & $\begin{array}{r}8.2 \\
9.6 \\
12.6 \\
13.1 \\
10.2 \\
8.0 \\
6.2 \\
5.9\end{array}$ & $\begin{array}{r}9.0 \\
10.8 \\
14.0 \\
14.8 \\
11.3 \\
8.7 \\
6.4 \\
6.5\end{array}$ & $\begin{array}{r}9.6 \\
11.7 \\
15.7 \\
16.4 \\
12.3 \\
9.3 \\
6.6 \\
7.0\end{array}$ & $\begin{array}{r}10.1 \\
12.2 \\
15: 7 \\
17: 0 \\
12.7 \\
9.4 \\
6.8 \\
7.2\end{array}$ \\
\hline $\begin{array}{l}25 \\
25 \\
25 \\
25 \\
25 \\
25 \\
25 \\
25\end{array}$ & $\begin{array}{r}0 \\
3 \\
6 \\
9 \\
12 \\
15 \\
18 \\
21\end{array}$ & $\begin{array}{l}15.0 \\
14.2 \\
15.2 \\
17.5 \\
19.2 \\
20.6 \\
20.2 \\
18.2\end{array}$ & $\begin{array}{l}14.0 \\
13.8 \\
14.1^{\prime} \\
15.3 \\
16.5 \\
17.2 \\
17.6 \\
16.9\end{array}$ & $\begin{array}{l}15.0 \\
14 . ? \\
15.3 \\
17.6 \\
19.2 \\
20.7 \\
20.1 \\
18 . ?\end{array}$ & $\begin{array}{l}13.9 \\
13.6 \\
14.0 \\
15.1 \\
16.2 \\
17.0 \\
17.2 \\
16.8\end{array}$ & $\begin{array}{l}15.0 \\
14.3 \\
15.6 \\
17.8 \\
19.4 \\
20.8 \\
20.2 \\
18.1\end{array}$ & $\begin{array}{l}13.9 \\
13.8 \\
13.9 \\
14.9 \\
15.2 \\
17.0 \\
17.2 \\
16.6\end{array}$ & $\begin{array}{l}14.8 \\
14: 0 \\
15: 1 \\
17: 5 \\
19: 0 \\
20.6 \\
20.0 \\
18.1\end{array}$ & $\begin{array}{l}13.8 \\
13.7 \\
13.8 \\
15.0 \\
16.2 \\
16.9 \\
17.2 \\
16.7\end{array}$ & $\begin{array}{l}18.6 \\
18.7 \\
19.0 \\
19.0 \\
20.1 \\
19.9 \\
10.7 \\
19.7\end{array}$ & $\begin{array}{l}2 \\
2 \\
3 \\
2 \\
2 \\
2 \\
2 \\
2 \\
2\end{array}$ & $\begin{array}{l}3.7 \\
4.8 \\
6.0 \\
7.8 \\
7.5 \\
8.7 \\
7.8 \\
6.0\end{array}$ & $\begin{array}{l}3.9 \\
4.0 \\
6.6 \\
8.9 \\
8 . ? \\
9.6 \\
8.8 \\
6.7\end{array}$ & $\begin{array}{r}4.1 \\
5.0 \\
7.1 \\
3.6 \\
9.1 \\
10.8 \\
9.8 \\
7.3\end{array}$ & $\begin{array}{r}4.1 \\
5.1 \\
7.2 \\
9.5 \\
9.4 \\
11.1 \\
10: 4 \\
7.8\end{array}$ \\
\hline $\begin{array}{l}26 \\
26 \\
26 \\
26 \\
26 \\
26 \\
26 \\
26\end{array}$ & $\begin{array}{r}0 \\
3 \\
6 \\
9 \\
12 \\
15 \\
18 \\
21\end{array}$ & $\begin{array}{l}17.5 \\
17.5 \\
18.4 \\
21.5 \\
23.1 \\
24.8 \\
22.8 \\
18.7\end{array}$ & $\begin{array}{l}16.6 \\
16.9 \\
15.9 \\
14.3 \\
14.4 \\
15.0 \\
16.2 \\
14.3\end{array}$ & $\begin{array}{l}17.5 \\
17.4 \\
17.9 \\
21.1 \\
22.6 \\
23.5 \\
21.4 \\
18.7\end{array}$ & $\begin{array}{l}16.5 \\
16.7 \\
15.2 \\
13.2 \\
13.6 \\
13.6 \\
14.8 \\
13.9\end{array}$ & $\begin{array}{l}17.5 \\
17.4 \\
17.7 \\
21.1 \\
22.5 \\
23.4 \\
21.7 \\
18.8\end{array}$ & $\begin{array}{l}15.5 \\
16.6 \\
15.0 \\
13.9 \\
13.5 \\
13.1 \\
14.9 \\
13.6\end{array}$ & $\begin{array}{l}17: 5 \\
17: 03 \\
17: 06 \\
21: 0 \\
21.0 \\
23.5 \\
21.0 \\
19.00\end{array}$ & $\begin{array}{l}16.5 \\
16.6 \\
14.7 \\
12.4 \\
13.5 \\
13.1 \\
13.5 \\
12.9\end{array}$ & $\begin{array}{l}19.5 \\
10.6 \\
20.1 \\
20.5 \\
20.8 \\
20.7 \\
19.9 \\
19.5\end{array}$ & $\begin{array}{l}2 \\
3 \\
3 \\
3 \\
3 \\
3 \\
3 \\
3\end{array}$ & $\begin{array}{r}5.8 \\
5.7 \\
9.5 \\
10.5 \\
7.0 \\
4.5 \\
3.1 \\
3.8\end{array}$ & $\begin{array}{r}6.4 \\
7.4 \\
11.2 \\
11.7 \\
8.0 \\
5.5 \\
3.9 \\
4.0\end{array}$ & $\begin{array}{r}7.0 \\
7.5 \\
11.8 \\
12.2 \\
3.4 \\
5.8 \\
4.6 \\
4.4\end{array}$ & $\begin{array}{r}7.4 \\
8.5 \\
12.1 \\
12.7 \\
8.7 \\
6.2 \\
5.5 \\
5.7\end{array}$ \\
\hline $\begin{array}{l}27 \\
27 \\
27 \\
27 \\
27 \\
27 \\
27 \\
27\end{array}$ & $\begin{array}{r}0 \\
3 \\
6 \\
9 \\
12 \\
15 \\
18 \\
21\end{array}$ & $\begin{array}{l}17.6 \\
17.0 \\
18.5 \\
17.2 \\
16.0 \\
20.3 \\
20.4 \\
18.2\end{array}$ & $\begin{array}{l}13.4 \\
12.9 \\
13.8 \\
14.6 \\
14.9 \\
17.8 \\
18.6 \\
17.5\end{array}$ & $\begin{array}{l}17.5 \\
17.0 \\
18.5 \\
16.7 \\
15.7 \\
20.1 \\
20.3 \\
18.1\end{array}$ & $\begin{array}{l}13.1 \\
12.4 \\
12.9 \\
13.9 \\
14.8 \\
17.6 \\
18.3 \\
17.2\end{array}$ & $\begin{array}{l}17.5 \\
17.0 \\
19.6 \\
16.7 \\
15.5 \\
20.6 \\
20.3 \\
18.1\end{array}$ & $\begin{array}{l}12.7 \\
12.3 \\
12.9 \\
13.9 \\
15.6 \\
17.7 \\
18.1 \\
17.1\end{array}$ & $\begin{array}{l}17.5 \\
17.0 \\
18.5 \\
17.5 \\
16.4 \\
20.5 \\
20.1 \\
18.0\end{array}$ & $\begin{array}{l}12.4 \\
12.0 \\
12.7 \\
13.7 \\
15.6 \\
17.8 \\
18.2 \\
17.1\end{array}$ & $\begin{array}{l}19.7 \\
19.5 \\
19.6 \\
10.3 \\
19.4 \\
20.1 \\
10.7 \\
19.4\end{array}$ & $\begin{array}{l}2 \\
2 \\
2 \\
2 \\
2 \\
2 \\
3 \\
3\end{array}$ & $\begin{array}{r}4.6 \\
5.7 \\
7.7 \\
11.4 \\
9.5 \\
4.2 \\
5.3 \\
4.7\end{array}$ & $\begin{array}{r}5.0 \\
6.1 \\
8.6 \\
12.7 \\
10.3 \\
4.7 \\
5.8 \\
5.0\end{array}$ & $\begin{array}{r}5.4 \\
5.5 \\
0.3 \\
13.9 \\
11.1 \\
5.2 \\
6.2 \\
5.2\end{array}$ & $\begin{array}{r}6.0 \\
7.0 \\
9.6 \\
14.8 \\
11.9 \\
5.4 \\
6.6 \\
5.4\end{array}$ \\
\hline $\begin{array}{l}28 \\
28 \\
28 \\
28 \\
28 \\
28 \\
28 \\
28\end{array}$ & $\begin{array}{r}0 \\
3 \\
6 \\
9 \\
12 \\
15 \\
18 \\
21\end{array}$ & $\begin{array}{l}17.9 \\
18.1 \\
18.9 \\
21.5 \\
22.8 \\
24.0 \\
23.3 \\
22.2\end{array}$ & $\begin{array}{l}17.1 \\
16.9 \\
16.0 \\
17.7 \\
19.6 \\
20.8 \\
20.8 \\
20.6\end{array}$ & $\begin{array}{l}17.8 \\
18.0 \\
18.9 \\
21.8 \\
23.1 \\
24.8 \\
23.9 \\
22.5\end{array}$ & $\begin{array}{l}16.8 \\
16.6 \\
15.7 \\
17.5 \\
19.5 \\
20.7 \\
20.9 \\
20.6\end{array}$ & $\begin{array}{l}17.8 \\
18.0 \\
19.1 \\
22.1 \\
23.3 \\
25.3 \\
74.4 \\
22.6\end{array}$ & $\begin{array}{l}16.7 \\
16.4 \\
15.6 \\
17.4 \\
19.5 \\
20.8 \\
21.0 \\
20.6\end{array}$ & $\begin{array}{l}17.7 \\
17.9 \\
19.0 \\
22.1 \\
23.4 \\
25.5 \\
? 4.5 \\
22.7\end{array}$ & $\begin{array}{l}16.6 \\
16.4 \\
15.5 \\
17.5 \\
19.6 \\
21.0 \\
21.2 \\
20.7\end{array}$ & $\begin{array}{l}10.3 \\
19.3 \\
19.3 \\
19.9 \\
20.4 \\
20.2 \\
20.2 \\
20.2\end{array}$ & $\begin{array}{l}3 \\
3 \\
3 \\
3 \\
3 \\
2 \\
2 \\
2\end{array}$ & $\begin{array}{r}7.1 \\
7.6 \\
11.3 \\
10.8 \\
8.8 \\
8.0 \\
6.9 \\
9.3\end{array}$ & $\begin{array}{r}7.3 \\
8.1 \\
12.1 \\
11.8 \\
9.7 \\
9.3 \\
8.1 \\
10.5\end{array}$ & $\begin{array}{r}7.2 \\
7.8 \\
12.5 \\
12.5 \\
10.6 \\
10.6 \\
9.6 \\
11.8\end{array}$ & $\begin{array}{r}7.9 \\
8.9 \\
13.3 \\
13.1 \\
11.1 \\
11.3 \\
10.4 \\
12.9\end{array}$ \\
\hline $\begin{array}{l}29 \\
29 \\
29 \\
29 \\
29 \\
29 \\
29 \\
29\end{array}$ & $\begin{array}{r}0 \\
3 \\
5 \\
9 \\
12 \\
15 \\
18 \\
21\end{array}$ & $\begin{array}{l}21.3 \\
20.7 \\
21.2 \\
25.2 \\
27.8 \\
28.0 \\
25.3 \\
22.7\end{array}$ & $\begin{array}{l}19.8 \\
18.5 \\
13.6 \\
20.2 \\
21.0 \\
21.9 \\
22.9 \\
22.0\end{array}$ & $\begin{array}{l}21.4 \\
20.8 \\
21.5 \\
25.7 \\
28.0 \\
29.1 \\
26.1 \\
2 ? .9\end{array}$ & $\begin{array}{l}19.7 \\
18.3 \\
18.5 \\
20.0 \\
21.0 \\
22.1 \\
2 ? .8 \\
? ? .0\end{array}$ & $\begin{array}{l}21.5 \\
20.8 \\
21.7 \\
25.1 \\
28.1 \\
29.8 \\
26.9 \\
73.2\end{array}$ & $\begin{array}{l}19.7 \\
13.2 \\
12.5 \\
20.1 \\
21.0 \\
21.8 \\
22.9 \\
22.0\end{array}$ & $\begin{array}{l}21.3 \\
20.8 \\
21.0 \\
28.0 \\
28.2 \\
20.0 \\
26.0 \\
23.3\end{array}$ & $\begin{array}{l}10.7 \\
18.2 \\
12.7 \\
30.1 \\
21.3 \\
23.03 \\
23.0 \\
? 2.1\end{array}$ & $\begin{array}{l}20.0 \\
19.9 \\
20.1 \\
20.5 \\
21.4 \\
21.8 \\
22.2 \\
72.1\end{array}$ & $\begin{array}{l}2 \\
2 \\
2 \\
2 \\
2 \\
2 \\
4 \\
4\end{array}$ & $\begin{array}{r}8.5 \\
12.9 \\
14.6 \\
10.9 \\
6.7 \\
5.4 \\
4.1 \\
7.0\end{array}$ & $\begin{array}{r}9.7 \\
14.5 \\
16.6 \\
12.7 \\
3.0 \\
7.1 \\
5.8 \\
2.9\end{array}$ & $\begin{array}{r}10.9 \\
16.4 \\
18.9 \\
14.5 \\
0.3 \\
8.4 \\
2.0 \\
4.0\end{array}$ & $\begin{array}{r}11.8 \\
17.5 \\
10.9 \\
15.2 \\
9.6 \\
8.9 \\
8.9 \\
5.5\end{array}$ \\
\hline $\begin{array}{l}30 \\
30 \\
30 \\
30 \\
30 \\
30 \\
30 \\
30\end{array}$ & $\begin{array}{r}0 \\
3 \\
6 \\
9 \\
12 \\
15 \\
18 \\
21\end{array}$ & $\begin{array}{l}21.4 \\
20.5 \\
21.3 \\
25.0 \\
28.6 \\
28.1\end{array}$ & $\begin{array}{l}21.3 \\
20.4 \\
20.3 \\
22.3 \\
23.5 \\
23.7\end{array}$ & $\begin{array}{l}21.6 \\
20.7 \\
20.5 \\
24.9 \\
29.3 \\
29.2\end{array}$ & $\begin{array}{l}21.3 \\
20.4 \\
19.9 \\
21.9 \\
23.1 \\
23.6\end{array}$ & $\begin{array}{l}21.6 \\
20.4 \\
20.6 \\
25.2 \\
28.8 \\
29.7\end{array}$ & $\begin{array}{l}21.2 \\
20.2 \\
19.8 \\
21.9 \\
23.0 \\
23.5\end{array}$ & $\begin{array}{l}21.5 \\
20.3 \\
20.7 \\
25.0 \\
28.6 \\
29.0\end{array}$ & $\begin{array}{l}21.1 \\
20.1 \\
19.0 \\
22.0 \\
23.2 \\
23.9\end{array}$ & $\begin{array}{l}22.1 \\
21: 9 \\
21: 8 \\
23.1 \\
24: 2 \\
23.1\end{array}$ & $\begin{array}{l}3 \\
3 \\
3 \\
2 \\
2 \\
2 \\
2 \\
2\end{array}$ & $\begin{array}{r}3.1 \\
5.5 \\
5.1 \\
3.1 \\
4.6 \\
5.9 \\
6.0 \\
11.1\end{array}$ & $\begin{array}{r}3.7 \\
6.6 \\
5.5 \\
3.3 \\
5.4 \\
7.3 \\
7.6 \\
12.6\end{array}$ & $\begin{array}{r}4.2 \\
7.3 \\
5.2 \\
4.2 \\
6.1 \\
7.6 \\
9.4 \\
14.6\end{array}$ & $\begin{array}{r}4.9 \\
7.8 \\
6.4 \\
4.8 \\
6.4 \\
9.8 \\
10.6 \\
16.2\end{array}$ \\
\hline $\begin{array}{l}31 \\
31 \\
31 \\
31 \\
31 \\
31 \\
31 \\
31\end{array}$ & $\begin{array}{r}0 \\
3 \\
6 \\
9 \\
12 \\
15 \\
18 \\
21\end{array}$ & $\begin{array}{l}23.6 \\
25.5 \\
27.4 \\
28.6 \\
26.7 \\
25.0\end{array}$ & $\begin{array}{l}20.5 \\
20.4 \\
20.6 \\
20.7 \\
20.0 \\
21.2\end{array}$ & $\begin{array}{l}23.6 \\
25.0 \\
27.8 \\
29.2 \\
27.0 \\
25.4\end{array}$ & $\begin{array}{l}20.4 \\
20.0 \\
20.1 \\
20.2 \\
20.6 \\
20.9\end{array}$ & $\begin{array}{l}24.1 \\
26.3 \\
28.3 \\
29.5 \\
27.6 \\
25.7\end{array}$ & $\begin{array}{l}20.5 \\
20.2 \\
20.0 \\
20.3 \\
20.6 \\
20.8\end{array}$ & $\begin{array}{l}24.2 \\
26.5 \\
28.5 \\
29.7 \\
27.8 \\
25.7\end{array}$ & $\begin{array}{l}20.7 \\
20.4 \\
20.3 \\
20.5 \\
20.8 \\
21.7\end{array}$ & $\begin{array}{l}20.9 \\
20.7 \\
21.4 \\
21.7 \\
21.5 \\
21.8\end{array}$ & $\begin{array}{l}2 \\
2 \\
2 \\
2 \\
2 \\
2 \\
2 \\
2\end{array}$ & $\begin{array}{l}11.8 \\
12.3 \\
12.7 \\
15.0 \\
15.0 \\
16.0 \\
11.2 \\
10.6\end{array}$ & $\begin{array}{l}13.5 \\
13.9 \\
14.6 \\
18.9 \\
17.4 \\
18.4 \\
12.9 \\
12.2\end{array}$ & $\begin{array}{l}15.5 \\
15.8 \\
16.5 \\
18.1 \\
10.8 \\
20.8 \\
14.9 \\
13.6\end{array}$ & $\begin{array}{l}16.9 \\
17.0 \\
17.4 \\
20.9 \\
21.1 \\
22.1 \\
16.2 \\
14.6\end{array}$ \\
\hline
\end{tabular}


TABLE 10

Table 10. - Three-hour averages of air and water-surface temperatures and wind directions and speed, April 1950-August 1951, Lake Hefner-Continued

STATION 1

THREE-HOURLY AVERAGES

JUNE, 1951

\begin{tabular}{|c|c|c|c|c|c|c|c|c|c|c|c|c|c|c|c|}
\hline \multirow{3}{*}{ 害 } & \multirow{3}{*}{ 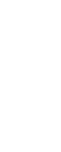 } & \multicolumn{8}{|c|}{ Average air temperature $\left({ }^{\circ} \mathrm{C}\right)$ at indicated height } & \multirow{3}{*}{\begin{tabular}{|} 
Average \\
water- \\
surface \\
tempera- \\
ture \\
$\left({ }^{\circ} \mathrm{C}\right)$
\end{tabular}} & \multirow{3}{*}{$\begin{array}{c}\begin{array}{c}\text { Average } \\
\text { wind } \\
\text { direction } \\
\text { (coded) }\end{array} \\
\text { (a) }\end{array}$} & \multicolumn{4}{|c|}{$\begin{array}{l}\text { Average wind speed (knots) } \\
\text { at indicated height }\end{array}$} \\
\hline & & \multicolumn{2}{|c|}{$\begin{array}{c}2 \\
\text { meters }\end{array}$} & \multicolumn{2}{|c|}{$\begin{array}{c}4 \\
\text { meters }\end{array}$} & \multicolumn{2}{|c|}{$\begin{array}{c}8 \\
\text { meters }\end{array}$} & \multicolumn{2}{|c|}{$\begin{array}{c}16 \\
\text { meters }\end{array}$} & & & & & & \\
\hline & & $\begin{array}{l}\text { Dry } \\
\text { bulb }\end{array}$ & $\begin{array}{l}\text { Wet } \\
\text { bulb }\end{array}$ & $\begin{array}{l}\text { Dry } \\
\text { bulb }\end{array}$ & $\begin{array}{l}\text { Wet } \\
\text { bulb }\end{array}$ & $\begin{array}{l}\text { Dry } \\
\text { bulb }\end{array}$ & $\begin{array}{l}\text { Wet } \\
\text { bulb }\end{array}$ & $\begin{array}{l}\text { Dry } \\
\text { bulb }\end{array}$ & $\begin{array}{l}\text { Wet } \\
\text { bulb }\end{array}$ & & & meters & meters & meters & meters \\
\hline $\begin{array}{l}1 \\
1 \\
1 \\
1 \\
1 \\
1 \\
1 \\
1\end{array}$ & $\begin{array}{r}0 \\
3 \\
6 \\
9 \\
12 \\
15 \\
18 \\
21\end{array}$ & $\begin{array}{l}23.9 \\
22.4 \\
22.4 \\
24.4 \\
26.2 \\
26.4 \\
22.0 \\
24.2\end{array}$ & $\begin{array}{l}20.6 \\
20.0 \\
19.6 \\
20.3 \\
21.3 \\
21.7 \\
20.4 \\
20.5\end{array}$ & $\begin{array}{l}24.1 \\
22.5 \\
22.7 \\
24.6 \\
26.6 \\
26.7 \\
22.8 \\
24.3\end{array}$ & $\begin{array}{l}20.2 \\
19.8 \\
19.3 \\
20.3 \\
21.3 \\
21.6 \\
20.6 \\
20.4\end{array}$ & $\begin{array}{l}24.1 \\
22.5 \\
22.9 \\
25.0 \\
26.9 \\
27.1 \\
22.7 \\
23.6\end{array}$ & $\begin{array}{l}20.2 \\
19.6 \\
19.2 \\
20.2 \\
21.4 \\
20.3 \\
20.9 \\
20.3\end{array}$ & $\begin{array}{l}24.1 \\
22: 3 \\
22.8 \\
24.9 \\
2609 \\
27.3 \\
2.308 \\
24.4\end{array}$ & $\begin{array}{l}20.3 \\
19.7 \\
29.3 \\
20.3 \\
21.5 \\
20.4 \\
20.9 \\
20.2\end{array}$ & $\begin{array}{l}21.2 \\
21.0 \\
21.1 \\
21.5 \\
21.9 \\
21.3 \\
21.6 \\
21.7\end{array}$ & $\begin{array}{l}2 \\
2 \\
2 \\
2 \\
2 \\
2 \\
2 \\
2\end{array}$ & $\begin{array}{r}14.3 \\
12.4 \\
15.6 \\
19.1 \\
17.3 \\
15.3 \\
8.9 \\
14.5\end{array}$ & $\begin{array}{l}16.3 \\
13.8 \\
17.8 \\
21.8 \\
19.8 \\
17.2 \\
10.0 \\
15.8\end{array}$ & $\begin{array}{l}18.1 \\
15.5 \\
20.0 \\
24.7 \\
22.4 \\
19.8 \\
11.4 \\
18.4\end{array}$ & $\begin{array}{l}19.3 \\
15: 4 \\
21.0 \\
26.3 \\
24.0 \\
21.2 \\
12.4 \\
19.8\end{array}$ \\
\hline $\begin{array}{l}2 \\
2 \\
2 \\
2 \\
2 \\
2 \\
2 \\
2\end{array}$ & $\begin{array}{r}0 \\
3 \\
6 \\
9 \\
12 \\
15 \\
18 \\
21\end{array}$ & $\begin{array}{l}23.5 \\
22.3 \\
21.4 \\
16.9 \\
15.3 \\
15.3 \\
15.5 \\
15.1\end{array}$ & $\begin{array}{l}19.6 \\
19.3 \\
18.7 \\
15.3 \\
13.6 \\
13.7 \\
13.9 \\
13.7\end{array}$ & $\begin{array}{l}23.6 \\
22.5 \\
21.1 \\
16.7 \\
14.9 \\
15.0 \\
15.2 \\
14.8\end{array}$ & $\begin{array}{l}19.5 \\
19.2 \\
18.6 \\
14.8 \\
13.0 \\
13.1 \\
13.4 \\
13.2\end{array}$ & $\begin{array}{l}23.7 \\
22.4 \\
21.0 \\
16.3 \\
14.6 \\
14.8 \\
15.0 \\
14.6\end{array}$ & $\begin{array}{l}19.1 \\
18.9 \\
18.02 \\
14.4 \\
12.6 \\
12.7 \\
13.0 \\
13.0\end{array}$ & $\begin{array}{l}23.7 \\
22.4 \\
20.6 \\
16.0 \\
14.4 \\
14.6 \\
14.9 \\
14.3\end{array}$ & $\begin{array}{l}19.1 \\
19.0 \\
18.0 \\
14.0 \\
12.5 \\
12.6 \\
13.0 \\
12.8\end{array}$ & $\begin{array}{l}21.1 \\
20.9 \\
21.7 \\
21.6 \\
21.8 \\
21.5 \\
21.3 \\
21.0\end{array}$ & $\begin{array}{l}2 \\
2 \\
2 \\
4 \\
3 \\
3 \\
3 \\
3\end{array}$ & $\begin{array}{r}15.0 \\
12.0 \\
9.9 \\
11.1 \\
12.8 \\
11.7 \\
10.7 \\
9.5\end{array}$ & $\begin{array}{l}17.2 \\
13.2 \\
11.0 \\
12.2 \\
14.9 \\
13.2 \\
11.8 \\
10.4\end{array}$ & $\begin{array}{l}19.1 \\
1409 \\
1205 \\
14.0 \\
16.0 \\
14.5 \\
13.0 \\
11.3\end{array}$ & $\begin{array}{l}20.2 \\
16.0 \\
13.2 \\
14.7 \\
16.9 \\
14.8 \\
13.3 \\
11.3\end{array}$ \\
\hline $\begin{array}{l}3 \\
3 \\
3 \\
3 \\
3 \\
3 \\
3 \\
3\end{array}$ & $\begin{array}{r}0 \\
3 \\
6 \\
9 \\
12 \\
15 \\
18 \\
21\end{array}$ & $\begin{array}{l}14.5 \\
13.5 \\
13.8 \\
14.4 \\
15.7 \\
16.9 \\
15.7 \\
13.6\end{array}$ & $\begin{array}{l}13.3 \\
12.8 \\
12.4 \\
11.7 \\
12.5 \\
13.0 \\
13.3 \\
12.3\end{array}$ & $\begin{array}{l}14.0 \\
13.2 \\
13.2 \\
13.9 \\
14.8 \\
15.9 \\
15.2 \\
13.3\end{array}$ & $\begin{array}{l}12.8 \\
12.3 \\
11.6 \\
10.8 \\
11.8 \\
12.4 \\
12.5 \\
11.9\end{array}$ & $\begin{array}{l}13.7 \\
12.9 \\
13.1 \\
13.5 \\
14.7 \\
15.7 \\
14.8 \\
13.0\end{array}$ & $\begin{array}{l}12.6 \\
12.2 \\
11.4 \\
10.6 \\
11.4 \\
12.1 \\
12.3 \\
11.7\end{array}$ & $\begin{array}{l}13.6 \\
12.7 \\
12.8 \\
13.2 \\
14.4 \\
15.6 \\
14.6 \\
13.0\end{array}$ & $\begin{array}{l}12.5 \\
11.9 \\
10.8 \\
10.3 \\
11.3 \\
11.8 \\
12.1 \\
11.6\end{array}$ & $\begin{array}{l}20.9 \\
20.9 \\
20.9 \\
20.9 \\
20.9 \\
20.7 \\
20.5 \\
20.2\end{array}$ & $\begin{array}{l}3 \\
3 \\
3 \\
3 \\
3 \\
3 \\
3 \\
3\end{array}$ & $\begin{array}{r}12.0 \\
11.4 \\
15.3 \\
14.6 \\
11.9 \\
10.6 \\
9.1 \\
5.6\end{array}$ & $\begin{array}{r}13.3 \\
12.5 \\
17.0 \\
16.1 \\
13.1 \\
12.0 \\
9.8 \\
6.0\end{array}$ & $\begin{array}{r}13.7 \\
13.1 \\
17.8 \\
17.0 \\
13.7 \\
12.2 \\
10.1 \\
6.1\end{array}$ & $\begin{array}{r}15.0 \\
14.6 \\
19.6 \\
18.8 \\
14.9 \\
13.2 \\
10.3 \\
6.2\end{array}$ \\
\hline $\begin{array}{l}4 \\
4 \\
4 \\
4 \\
4 \\
4 \\
4 \\
4\end{array}$ & $\begin{array}{r}0 \\
3 \\
6 \\
9 \\
12 \\
15 \\
18 \\
21\end{array}$ & $\begin{array}{l}12.8 \\
12.0 \\
12.5 \\
15.9 \\
18.4 \\
20.3 \\
19.6 \\
17.1\end{array}$ & $\begin{array}{l}12.1 \\
11.7 \\
11.2 \\
12.4 \\
13.4 \\
14.4 \\
15.1 \\
15.1\end{array}$ & $\begin{array}{l}12.6 \\
11.8 \\
11.7 \\
14.8 \\
17.1 \\
19.4 \\
19.2 \\
17.0\end{array}$ & $\begin{array}{l}11.6 \\
11.0 \\
10.1 \\
11.3 \\
12.6 \\
14.1 \\
14.8 \\
14.9\end{array}$ & $\begin{array}{l}12.5 \\
11.5 \\
11.4 \\
14.5 \\
16.8 \\
19.8 \\
19.1 \\
16.9\end{array}$ & $\begin{array}{r}11.3 \\
10.8 \\
9.7 \\
11.2 \\
12.4 \\
14.0 \\
14.7 \\
14 \cdot 9\end{array}$ & $\begin{array}{l}12.3 \\
11.3 \\
11.4 \\
14.4 \\
17.0 \\
19.7 \\
19.0 \\
16.8\end{array}$ & $\begin{array}{r}11.2 \\
10.4 \\
9.5 \\
11.3 \\
12.4 \\
14.0 \\
14.7 \\
14.9\end{array}$ & $\begin{array}{l}20.3 \\
20.2 \\
20.3 \\
20.9 \\
21.3 \\
21.4 \\
20.7 \\
20.4\end{array}$ & $\begin{array}{l}3 \\
3 \\
3 \\
3 \\
3 \\
3 \\
3 \\
2\end{array}$ & $\begin{array}{r}6.3 \\
9.9 \\
10.0 \\
6.5 \\
5.3 \\
3.6 \\
5.1 \\
5.9\end{array}$ & $\begin{array}{r}6.9 \\
11.0 \\
11.0 \\
7.2 \\
5.7 \\
3.9 \\
5.3 \\
6.2\end{array}$ & $\begin{array}{r}7.4 \\
12.0 \\
11.5 \\
7.7 \\
6.1 \\
4.0 \\
5.6 \\
6.5\end{array}$ & $\begin{array}{r}7.4 \\
12.1 \\
11.5 \\
7.9 \\
6.5 \\
4.4 \\
5.7 \\
6.7\end{array}$ \\
\hline $\begin{array}{l}5 \\
5 \\
5 \\
5 \\
5 \\
5 \\
5 \\
5\end{array}$ & $\begin{array}{r}0 \\
3 \\
6 \\
9 \\
12 \\
15 \\
18 \\
21\end{array}$ & $\begin{array}{l}16.3 \\
15.8 \\
16.1 \\
18.5 \\
20.8 \\
21.8 \\
20.8 \\
20.0\end{array}$ & $\begin{array}{l}15.0 \\
14.9 \\
15.4 \\
16.5 \\
17.4 \\
18.3 \\
18.6 \\
18.6\end{array}$ & $\begin{array}{l}16.3 \\
15.8 \\
16.1 \\
18.4 \\
20.8 \\
21.9 \\
20.8 \\
20.0\end{array}$ & $\begin{array}{l}14.9 \\
14.9 \\
15.4 \\
16.3 \\
17.0 \\
18.0 \\
18.3 \\
18.3\end{array}$ & $\begin{array}{l}26.2 \\
15.6 \\
16.1 \\
18.6 \\
20.9 \\
21.9 \\
20.8 \\
20.0\end{array}$ & $\begin{array}{l}14.8 \\
14.8 \\
15.3 \\
16.2 \\
16.9 \\
17.9 \\
18.2 \\
18.3\end{array}$ & $\begin{array}{l}16.0 \\
15.5 \\
15.9 \\
18.5 \\
20.7 \\
21.7 \\
20.7 \\
20.1\end{array}$ & $\begin{array}{l}14.8 \\
14.7 \\
15.3 \\
16.2 \\
16.8 \\
17.8 \\
18.1 \\
17.9\end{array}$ & $\begin{array}{l}20.4 \\
20.3 \\
20.5 \\
20.9 \\
21.0 \\
20.9 \\
20.7 \\
20.8\end{array}$ & $\begin{array}{l}2 \\
2 \\
2 \\
2 \\
2 \\
2 \\
2 \\
2\end{array}$ & $\begin{array}{l}3.6 \\
4.6 \\
4.1 \\
7.3 \\
8.5 \\
8.9 \\
7.6 \\
8.0\end{array}$ & $\begin{array}{r}3.8 \\
5.0 \\
4.5 \\
7.9 \\
9.5 \\
10.0 \\
8.5 \\
8.8\end{array}$ & $\begin{array}{r}4.0 \\
5.1 \\
4.8 \\
3.5 \\
10.5 \\
11.1 \\
0.3 \\
9.5\end{array}$ & $\begin{array}{r}4.0 \\
5.2 \\
4.9 \\
8.8 \\
10.9 \\
11.5 \\
9.9 \\
10.1\end{array}$ \\
\hline $\begin{array}{l}6 \\
6 \\
6 \\
6 \\
6 \\
6 \\
6 \\
6\end{array}$ & $\begin{array}{r}0 \\
3 \\
6 \\
9 \\
12 \\
15 \\
18 \\
21\end{array}$ & $\begin{array}{l}19.3 \\
19.3 \\
19.0 \\
21.8 \\
20.4 \\
23.0 \\
23.1 \\
22.3\end{array}$ & $\begin{array}{l}18.5 \\
18.4 \\
17.9 \\
19.8 \\
18.8 \\
20.5 \\
28.5 \\
20.0\end{array}$ & $\begin{array}{l}19.2 \\
19.0 \\
19.0 \\
22.0 \\
20.5 \\
23.3 \\
23.2 \\
22.4\end{array}$ & $\begin{array}{l}18.4 \\
18.1 \\
17.7 \\
10.6 \\
18.4 \\
20.2 \\
20.1 \\
19.8\end{array}$ & $\begin{array}{l}18.2 \\
19.0 \\
19.0 \\
22.0 \\
20.6 \\
23.5 \\
22.7 \\
22.0\end{array}$ & $\begin{array}{l}18.3 \\
18.1 \\
17.6 \\
19.7 \\
18.5 \\
20.4 \\
20.2 \\
19.8\end{array}$ & $\begin{array}{l}10.1 \\
18.8 \\
19.0 \\
22.2 \\
20.7 \\
23.5 \\
23.14 \\
22.4\end{array}$ & $\begin{array}{l}18.2 \\
19.0 \\
17.6 \\
10.6 \\
18.5 \\
20.3 \\
20.3 \\
10.9\end{array}$ & $\begin{array}{l}20.8 \\
20.5 \\
20.7 \\
20.7 \\
20.8 \\
20.9 \\
20.7 \\
20.6\end{array}$ & $\begin{array}{l}2 \\
2 \\
2 \\
2 \\
3 \\
2 \\
2 \\
2\end{array}$ & $\begin{array}{l}15.1 \\
15.0 \\
11.1 \\
13.5 \\
12.0 \\
10.7 \\
14.3 \\
14.3\end{array}$ & $\begin{array}{l}17.0 \\
16.9 \\
12.4 \\
15.2 \\
13.1 \\
12.0 \\
16.2 \\
16.1\end{array}$ & $\begin{array}{l}18.8 \\
18.7 \\
13.8 \\
17.1 \\
14.0 \\
13.4 \\
18.1 \\
13.1\end{array}$ & $\begin{array}{l}19.7 \\
19.5 \\
14.3 \\
18.0 \\
14.4 \\
13.9 \\
19.1 \\
19.2\end{array}$ \\
\hline $\begin{array}{l}7 \\
7 \\
7 \\
7 \\
7 \\
7 \\
7 \\
7\end{array}$ & $\begin{array}{r}0 \\
3 \\
6 \\
9 \\
12 \\
15 \\
18 \\
21\end{array}$ & $\begin{array}{l}20.2 \\
18.5 \\
18.1 \\
20.3 \\
25.4 \\
25.8 \\
24.9 \\
20.4\end{array}$ & $\begin{array}{l}16.9 \\
16.4 \\
16.5 \\
18.8 \\
22.0 \\
22.4 \\
21.8 \\
17.5\end{array}$ & $\begin{array}{l}20.1 \\
18.4 \\
18.1 \\
20.3 \\
26.0 \\
26.5 \\
25.3 \\
20.5\end{array}$ & $\begin{array}{l}16.6 \\
15.9 \\
16: 1 \\
18.7 \\
21.8 \\
21.9 \\
21.4 \\
16.8\end{array}$ & $\begin{array}{l}20.4 \\
18.4 \\
17.9 \\
30.2 \\
26.7 \\
26.7 \\
25.5 \\
20.3\end{array}$ & $\begin{array}{l}16.5 \\
15.8 \\
16.0 \\
18.6 \\
22.0 \\
22.2 \\
23.3 \\
16.8\end{array}$ & $\begin{array}{l}20.3 \\
13.5 \\
17.8 \\
20.3 \\
26.2 \\
26.8 \\
25.5 \\
20.2\end{array}$ & $\begin{array}{l}16.5 \\
15.6 \\
15.5 \\
18.6 \\
21.7 \\
73.0 \\
21.5 \\
16.4\end{array}$ & $\begin{array}{l}20.6 \\
20.4 \\
20.3 \\
20.8 \\
21.3 \\
20.9 \\
20.9 \\
20.7\end{array}$ & $\begin{array}{l}2 \\
2 \\
3 \\
3 \\
2\end{array}$ & $\begin{array}{r}13.9 \\
11.1 \\
8.3 \\
9.2 \\
8.6\end{array}$ & $\begin{array}{r}15.4 \\
12.4 \\
8.4 \\
8.7 \\
10.1\end{array}$ & $\begin{array}{r}17.0 \\
13.5 \\
0.1 \\
10.2 \\
11.4\end{array}$ & $\begin{array}{r}18.0 \\
14.2 \\
9.8 \\
10.3 \\
11.9\end{array}$ \\
\hline $\begin{array}{l}8 \\
8 \\
8 \\
8 \\
8 \\
8 \\
8 \\
8\end{array}$ & $\begin{array}{r}0 \\
3 \\
6 \\
9 \\
12 \\
15 \\
18 \\
21\end{array}$ & $\begin{array}{l}20.9 \\
20.9 \\
22.4 \\
25.7 \\
27.8 \\
27.4 \\
25.6 \\
21.2\end{array}$ & $\begin{array}{l}18.5 \\
19.6 \\
20.9 \\
22.5 \\
23.5 \\
23.7 \\
22.9 \\
17.9\end{array}$ & $\begin{array}{l}21.1 \\
20.9 \\
22.5 \\
26.1 \\
28.2 \\
28.0 \\
26.2 \\
21.7\end{array}$ & $\begin{array}{l}18.0 \\
19.3 \\
20.7 \\
22.2 \\
22.8 \\
23.3 \\
22.7 \\
17.6\end{array}$ & $\begin{array}{l}21.1 \\
20.9 \\
22.7 \\
26.4 \\
28.5 \\
28.0 \\
26.4 \\
21.6\end{array}$ & $\begin{array}{l}18.2 \\
19.4 \\
20.8 \\
22.5 \\
23.1 \\
23.7 \\
2.9 \\
17.5\end{array}$ & $\begin{array}{l}21 \cdot 1 \\
20: 3 \\
22.9 \\
26 \cdot 3 \\
23.5 \\
28.5 \\
26 \cdot 3 \\
21.3\end{array}$ & $\begin{array}{l}17.0 \\
19.3 \\
20.8 \\
27.3 \\
23.0 \\
23.6 \\
2 ? .3 \\
17.6\end{array}$ & $\begin{array}{l}20.8 \\
20.9 \\
21.1 \\
21.5 \\
22.0 \\
22.0 \\
21.6 \\
21.02\end{array}$ & $\begin{array}{l}2 \\
2 \\
2 \\
2 \\
2 \\
2\end{array}$ & $\begin{array}{l}17.4 \\
18.0 \\
17.0 \\
15.6 \\
11.7 \\
12.2\end{array}$ & $\begin{array}{l}19.8 \\
21.4 \\
19.4 \\
17.9 \\
13.6 \\
13.9\end{array}$ & $\begin{array}{l}22.6 \\
24.4 \\
22.3 \\
20.6 \\
15.4 \\
15.6\end{array}$ & $\begin{array}{l}23.5 \\
25.4 \\
23.3 \\
21.5 \\
15.5 \\
16.7\end{array}$ \\
\hline $\begin{array}{l}9 \\
9 \\
9 \\
9 \\
9 \\
9 \\
9 \\
9\end{array}$ & $\begin{array}{r}0 \\
3 \\
6 \\
9 \\
12 \\
15 \\
18 \\
21\end{array}$ & $\begin{array}{l}19.8 \\
17.6 \\
18.6 \\
22.4 \\
25.2 \\
25.4 \\
23.2 \\
20.7\end{array}$ & $\begin{array}{l}17.9 \\
16.7 \\
17.1 \\
19.0 \\
20.1 \\
20.4 \\
20.1 \\
19.2\end{array}$ & $\begin{array}{l}19.8 \\
17.4 \\
18.0 \\
21.8 \\
24.1 \\
25.0 \\
23.2 \\
20.7\end{array}$ & $\begin{array}{l}17.7 \\
16.4 \\
16.7 \\
18.1 \\
19.0 \\
19.5 \\
19.5 \\
18.8\end{array}$ & $\begin{array}{l}10.6 \\
17.3 \\
18.7 \\
21.9 \\
24 \cdot 7 \\
25.4 \\
23.4 \\
20.6\end{array}$ & $\begin{array}{l}17.5 \\
16.2 \\
16.6 \\
18.2 \\
19.0 \\
19.3 \\
19.5 \\
18.8\end{array}$ & $\begin{array}{l}10.6 \\
17: ? \\
17.0 \\
21.8 \\
2402 \\
25.3 \\
23.04 \\
20.6\end{array}$ & $\begin{array}{l}17.1 \\
16.0 \\
16.5 \\
18.1 \\
19.1 \\
10.5 \\
10.3 \\
18.6\end{array}$ & $\begin{array}{l}21.0 \\
21.1 \\
21.6 \\
22.6 \\
23.0 \\
21.9 \\
21.7 \\
21.8\end{array}$ & $\begin{array}{l}2 \\
3 \\
3 \\
3 \\
3 \\
3 \\
3 \\
3\end{array}$ & $\begin{array}{l}4.0 \\
7.4 \\
7.3 \\
6.5 \\
7.6 \\
9.9 \\
6.4 \\
6.1\end{array}$ & $\begin{array}{r}4.6 \\
7.9 \\
7.7 \\
7.3 \\
8.6 \\
11.0 \\
7.00 \\
6.6\end{array}$ & $\begin{array}{r}4.8 \\
9.2 \\
8.2 \\
7.8 \\
9.1 \\
12.7 \\
7.4 \\
7.1\end{array}$ & $\begin{array}{r}5.4 \\
7.8 \\
8.4 \\
8.4 \\
9.5 \\
12.3 \\
8.8 \\
8.0\end{array}$ \\
\hline $\begin{array}{l}10 \\
10 \\
10 \\
10 \\
10 \\
10 \\
10 \\
10\end{array}$ & $\begin{array}{r}0 \\
3 \\
6 \\
9 \\
12 \\
15 \\
18 \\
21\end{array}$ & $\begin{array}{l}19.0 \\
18.7 \\
18.2 \\
19.1 \\
22.9 \\
22.8 \\
21.0 \\
19.9\end{array}$ & $\begin{array}{l}18.2 \\
18.0 \\
17.7 \\
17.1 \\
18.7 \\
19.3 \\
20.0 \\
18.6\end{array}$ & $\begin{array}{l}19.0 \\
18.5 \\
18.1 \\
19.0 \\
22.4 \\
22.7 \\
22.0 \\
19.8\end{array}$ & $\begin{array}{l}18.0 \\
17.8 \\
17.5 \\
16.5 \\
18.4 \\
19.0 \\
19.8 \\
18.3\end{array}$ & $\begin{array}{l}19.0 \\
18.5 \\
18.0 \\
10.1 \\
22.6 \\
22.6 \\
22.1 \\
19.7\end{array}$ & $\begin{array}{l}17.9 \\
17.8 \\
17: 3 \\
16.6 \\
18.3 \\
18.9 \\
19.6 \\
18.1\end{array}$ & $\begin{array}{l}18.9 \\
18.3 \\
17.8 \\
18.9 \\
22.3 \\
22.5 \\
22.0 \\
19.5\end{array}$ & $\begin{array}{l}17.9 \\
17.6 \\
16.9 \\
16.5 \\
18.3 \\
18.9 \\
19.5 \\
18.0\end{array}$ & $\begin{array}{l}21.9 \\
22.0 \\
22.0 \\
22.2 \\
23.3 \\
22.5 \\
22.0 \\
21.9\end{array}$ & $\begin{array}{l}3 \\
3 \\
3 \\
3 \\
3 \\
3 \\
3 \\
3\end{array}$ & $\begin{array}{r}4.0 \\
7.2 \\
15.5 \\
15.7 \\
4.7 \\
8.4 \\
4.4 \\
7.3\end{array}$ & $\begin{array}{l}4 \cdot 3 \\
6.6\end{array}$ & $\begin{array}{r}4.5 \\
7.7 \\
13.7 \\
17.4 \\
5.7 \\
9.3 \\
4.9 \\
3.3\end{array}$ & $\begin{array}{r}4.8 \\
7.9 \\
19.9 \\
18.3 \\
6.2 \\
9.7 \\
5.6 \\
8.7\end{array}$ \\
\hline
\end{tabular}


Table 10. -Three-hour averages of air and water-surface temperatures and wind directions and speed, April 1950-August 1951, Lake Hefner-Continued

STATION

THREE-HOURLY AVERAGES

JUNE, 1951

\begin{tabular}{|c|c|c|c|c|c|c|c|c|c|c|c|c|c|c|c|}
\hline \multirow{3}{*}{ 点 } & \multirow{3}{*}{ 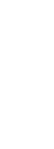 } & \multicolumn{8}{|c|}{ Average air temperature $\left({ }^{\circ} \mathrm{C}\right)$ at indicated height } & \multirow{3}{*}{$\begin{array}{l}\text { Average } \\
\text { water- } \\
\text { surface } \\
\text { tempera- } \\
\text { ture } \\
\text { (ैC) }^{\circ}\end{array}$} & \multirow{3}{*}{$\begin{array}{l}\text { Average } \\
\text { wind } \\
\text { direction } \\
\text { (coded) }\end{array}$} & \multicolumn{4}{|c|}{$\begin{array}{l}\text { Average wind speed (knots) } \\
\text { at indicated height }\end{array}$} \\
\hline & & \multicolumn{2}{|c|}{$\begin{array}{c}2 \\
\text { meters }\end{array}$} & \multicolumn{2}{|c|}{$\begin{array}{c}4 \\
\text { meters }\end{array}$} & \multicolumn{2}{|c|}{$\begin{array}{c}8 \\
\text { meters }\end{array}$} & \multicolumn{2}{|c|}{$\begin{array}{c}16 \\
\text { meters }\end{array}$} & & & & & & \\
\hline & & $\begin{array}{l}\text { Dry } \\
\text { bulb }\end{array}$ & $\begin{array}{l}\text { Wet } \\
\text { bulb }\end{array}$ & $\begin{array}{l}\text { Dry } \\
\text { bulb }\end{array}$ & $\begin{array}{l}\text { Wet } \\
\text { bulb }\end{array}$ & $\begin{array}{l}\text { Dry } \\
\text { bulb }\end{array}$ & $\begin{array}{l}\text { Wet } \\
\text { bulb }\end{array}$ & $\begin{array}{l}\text { Dry } \\
\text { bulb }\end{array}$ & $\begin{array}{l}\text { Wet } \\
\text { bulb }\end{array}$ & & & meters & meters & meters & meters \\
\hline $\begin{array}{l}11 \\
11 \\
11 \\
11 \\
11 \\
11 \\
11 \\
11\end{array}$ & $\begin{array}{r}0 \\
3 \\
6 \\
9 \\
12 \\
15 \\
18 \\
21\end{array}$ & $\begin{array}{l}19.1 \\
18.9 \\
17.9 \\
18.5 \\
20.1 \\
21.3 \\
20.7 \\
19.7\end{array}$ & $\begin{array}{l}18.1 \\
17.7 \\
27.8 \\
17.7 \\
17.8 \\
18.6 \\
18.9 \\
18.6\end{array}$ & $\begin{array}{l}19.1 \\
18.7 \\
17.9 \\
18.4 \\
20.1 \\
21.3 \\
20.8 \\
19.7\end{array}$ & $\begin{array}{l}18.1 \\
17.4 \\
17.5 \\
17.3 \\
17.6 \\
18.6 \\
18.8 \\
18.5\end{array}$ & $\begin{array}{l}19.1 \\
18.6 \\
17.7 \\
18.3 \\
20.2 \\
21.4 \\
20.7 \\
19.6\end{array}$ & $\begin{array}{l}18.0 \\
17.3 \\
17.4 \\
17.1 \\
17.3 \\
18.5 \\
18.7 \\
19.4\end{array}$ & $\begin{array}{l}18.9 \\
18.5 \\
17.5 \\
18.2 \\
20.1 \\
21.3 \\
20.6 \\
19.5\end{array}$ & $\begin{array}{l}17.7 \\
17.2 \\
17.3 \\
17.1 \\
17.4 \\
18.6 \\
18.7 \\
18.4\end{array}$ & $\begin{array}{l}21.8 \\
21.7 \\
21.6 \\
22.0 \\
22.3 \\
21.9 \\
22.0 \\
27.0\end{array}$ & $\begin{array}{l}2 \\
2 \\
3 \\
3 \\
2 \\
2 \\
2 \\
2 \\
2\end{array}$ & $\begin{array}{r}5.1 \\
10.1 \\
7.7 \\
10.5 \\
9.0 \\
3.4 \\
5.5 \\
4.1\end{array}$ & $\begin{array}{r}10.8 \\
11.4 \\
9.9 \\
3.7 \\
6.0 \\
4.5\end{array}$ & $\begin{array}{r}6.1 \\
12.5 \\
11.4 \\
11.0 \\
10.8 \\
5.1 \\
6.3 \\
5.0\end{array}$ & $\begin{array}{r}6.0 \\
13.0 \\
11.8 \\
12: 2 \\
11.0 \\
4.2 \\
6.6 \\
5.0\end{array}$ \\
\hline $\begin{array}{l}12 \\
12 \\
12 \\
12 \\
12 \\
12 \\
12 \\
12\end{array}$ & $\begin{array}{r}0 \\
3 \\
6 \\
9 \\
12 \\
15 \\
18 \\
21\end{array}$ & $\begin{array}{l}18.7 \\
17.9 \\
18.4 \\
20.2 \\
22.1 \\
23.7 \\
23.7 \\
20.6\end{array}$ & $\begin{array}{l}17.3 \\
17.2 \\
17.5 \\
18.5 \\
18.6 \\
18.3 \\
19.4 \\
18.5\end{array}$ & $\begin{array}{l}18.6 \\
17.8 \\
28.2 \\
20.3 \\
22.0 \\
23.5 \\
22.7 \\
20.6\end{array}$ & $\begin{array}{l}17.9 \\
17.1 \\
17.5 \\
18.1 \\
18.2 \\
17.5 \\
18.5 \\
18.3\end{array}$ & $\begin{array}{l}18.5 \\
17.8 \\
18.2 \\
20.3 \\
22.3 \\
23.6 \\
22.8 \\
20.5\end{array}$ & $\begin{array}{l}17.9 \\
17.0 \\
17.4 \\
18.2 \\
18.0 \\
17.6 \\
18.6 \\
18.1\end{array}$ & $\begin{array}{l}18.4 \\
17.7 \\
18.2 \\
20.2 \\
22.1 \\
23.6 \\
22.8 \\
20.5\end{array}$ & $\begin{array}{l}17.7 \\
17.0 \\
17.2 \\
18.0 \\
17.8 \\
17.7 \\
18.2 \\
18.0\end{array}$ & $\begin{array}{l}21.9 \\
21.08 \\
22.0 \\
22.5 \\
23.0 \\
23.0 \\
22.5 \\
22.7\end{array}$ & $\begin{array}{l}2 \\
2 \\
4 \\
4 \\
4 \\
3 \\
3 \\
2\end{array}$ & $\begin{array}{l}7.1 \\
4.5 \\
7.6 \\
6.0 \\
8.1 \\
4.9 \\
3.7 \\
5.4\end{array}$ & $\begin{array}{l}7.8 \\
5.0 \\
8.2 \\
6.3 \\
8.7 \\
5.6 \\
4.2 \\
5.7\end{array}$ & $\begin{array}{l}8.8 \\
5.4 \\
8.7 \\
6.4 \\
9.8 \\
6.0 \\
4.4 \\
6.1\end{array}$ & $\begin{array}{r}9.4 \\
5.4 \\
9.1 \\
6.5 \\
11.7 \\
6.4 \\
5.0 \\
6.4\end{array}$ \\
\hline $\begin{array}{l}13 \\
13 \\
13 \\
13 \\
13 \\
13 \\
13 \\
13\end{array}$ & $\begin{array}{r}0 \\
3 \\
6 \\
9 \\
12 \\
15 \\
18 \\
21\end{array}$ & $\begin{array}{l}19.9 \\
18.9 \\
20.6 \\
23.6 \\
25.5 \\
25.2 \\
21.5 \\
21.8\end{array}$ & $\begin{array}{l}17.8 \\
17.9 \\
19.1 \\
19.7 \\
20.1 \\
20.0 \\
18.0 \\
18.6\end{array}$ & $\begin{array}{l}19.7 \\
18.8 \\
20.8 \\
23.9 \\
25.7 \\
25.2 \\
21.4 \\
21.8\end{array}$ & $\begin{array}{l}17.7 \\
17.8 \\
19.1 \\
19.5 \\
19.8 \\
19.6 \\
17.4 \\
18.5\end{array}$ & $\begin{array}{l}19.7 \\
18.9 \\
21.0 \\
24.0 \\
25.9 \\
25.0 \\
21.3 \\
21.8\end{array}$ & $\begin{array}{l}17.5 \\
17: 7 \\
19.1 \\
19.5 \\
19.8 \\
19.2 \\
17.3 \\
18.4\end{array}$ & $\begin{array}{l}19.7 \\
18.0 \\
20.9 \\
23.9 \\
25.9 \\
24.9 \\
211.5 \\
21.7\end{array}$ & $\begin{array}{l}17.4 \\
17.6 \\
19.2 \\
19.4 \\
10.7 \\
19.5 \\
17.3 \\
18.3\end{array}$ & & $\begin{array}{l}2 \\
2 \\
2 \\
2 \\
2 \\
2 \\
3 \\
2\end{array}$ & $\begin{array}{r}4.7 \\
4.9 \\
5.5 \\
7.6 \\
8.3 \\
11.2 \\
13.9 \\
11.3\end{array}$ & $\begin{array}{r}4.9 \\
5.3 \\
6.1 \\
8.3 \\
9.3 \\
12.3 \\
15.3 \\
12.7\end{array}$ & $\begin{array}{r}5.1 \\
5.7 \\
6.6 \\
9.2 \\
10.4 \\
9.9 \\
16.0 \\
14.7\end{array}$ & $\begin{array}{r}5.5 \\
6.3 \\
6.8 \\
9.5 \\
10.8 \\
13.7 \\
26.6 \\
14.7\end{array}$ \\
\hline $\begin{array}{l}14 \\
14 \\
14 \\
14 \\
14 \\
14 \\
14 \\
14\end{array}$ & $\begin{array}{r}0 \\
3 \\
6 \\
9 \\
12 \\
15 \\
18 \\
21\end{array}$ & $\begin{array}{l}20.1 \\
18.7 \\
18.7 \\
21.7 \\
24.0 \\
25.3 \\
24.8 \\
22.8\end{array}$ & $\begin{array}{l}17.6 \\
17.3 \\
17.4 \\
18.9 \\
19.8 \\
21.0 \\
21.6 \\
21.6\end{array}$ & $\begin{array}{l}20.0 \\
18.5 \\
18.7 \\
21.7 \\
24.3 \\
25.5 \\
24.9 \\
22.8\end{array}$ & $\begin{array}{l}17.5 \\
16.9 \\
17.2 \\
18.7 \\
19.6 \\
20.8 \\
21.2 \\
21.4\end{array}$ & $\begin{array}{l}19.8 \\
18.4 \\
18.7 \\
21.8 \\
24.3 \\
25.6 \\
23.8 \\
22.8\end{array}$ & $\begin{array}{l}17.2 \\
16.9 \\
17.1 \\
18.6 \\
19.7 \\
20.5 \\
21.1 \\
21.3\end{array}$ & $\begin{array}{l}19.4 \\
18.4 \\
18.6 \\
21.8 \\
24.7 \\
26.0 \\
25.5 \\
22.7\end{array}$ & $\begin{array}{l}17.0 \\
16.8 \\
17.1 \\
18.5 \\
10.6 \\
20.7 \\
21.1 \\
21.3\end{array}$ & $\begin{array}{l}22.2 \\
2 ? .7 \\
23.8 \\
22.9 \\
23.7 \\
23.6 \\
23.4 \\
33.4\end{array}$ & $\begin{array}{l}4 \\
3 \\
2 \\
2 \\
2 \\
2 \\
3 \\
2\end{array}$ & $\begin{array}{r}9.1 \\
7.4 \\
9.5 \\
10.3 \\
5.4 \\
3.8 \\
4.4 \\
8.8\end{array}$ & $\begin{array}{r}9.6 \\
8.0 \\
10.2 \\
11.2 \\
6.0 \\
4.3 \\
4.0 \\
9.3\end{array}$ & $\begin{array}{r}10.7 \\
8.4 \\
11.0 \\
12.2 \\
5.6 \\
4.7 \\
5.2 \\
10.4\end{array}$ & $\begin{array}{r}3.6 \\
9.5 \\
11.1 \\
12.5 \\
7.0 \\
5.1 \\
5.0 \\
10.9\end{array}$ \\
\hline $\begin{array}{l}15 \\
15 \\
15 \\
15 \\
15 \\
15 \\
15 \\
15\end{array}$ & $\begin{array}{r}0 \\
3 \\
6 \\
9 \\
12 \\
15 \\
18 \\
21\end{array}$ & $\begin{array}{l}21.9 \\
17.9 \\
18.5 \\
21.5 \\
25.1 \\
26.9 \\
25.4 \\
23.4\end{array}$ & $\begin{array}{l}21.3 \\
17.0 \\
17.6 \\
18.6 \\
19.9 \\
21.0 \\
21.5 \\
20.5\end{array}$ & $\begin{array}{l}21.9 \\
17.8 \\
18.7 \\
21.7 \\
25.0 \\
26.9 \\
25.6 \\
23.4\end{array}$ & $\begin{array}{l}20.4 \\
16.7 \\
17.4 \\
18.5 \\
19.5 \\
20.5 \\
21.0 \\
20.3\end{array}$ & $\begin{array}{l}21.4 \\
17.6 \\
18.7 \\
21.8 \\
25.1 \\
27.0 \\
25.7 \\
23.3\end{array}$ & $\begin{array}{l}20.3 \\
16.6 \\
17.4 \\
18.4 \\
19.6 \\
20.1 \\
20.7 \\
20.1\end{array}$ & $\begin{array}{l}21.2 \\
17.4 \\
18.7 \\
21.7 \\
24: 6 \\
26.9 \\
25.8 \\
24.2\end{array}$ & $\begin{array}{l}20.1 \\
16.5 \\
17.3 \\
18.7 \\
19.7 \\
20.4 \\
20.5 \\
20.2\end{array}$ & & $\begin{array}{l}2 \\
3 \\
2 \\
2 \\
2 \\
2 \\
2 \\
2\end{array}$ & $\begin{array}{r}10.4 \\
20.0 \\
5.6 \\
6.0 \\
3.1 \\
4.8 \\
4.8 \\
6.7\end{array}$ & $\begin{array}{r}11.5 \\
11.0 \\
6.1 \\
6.4 \\
3.3 \\
5.2 \\
5.5 \\
7.4\end{array}$ & $\begin{array}{r}12.4 \\
1 . .5 \\
6.3 \\
5.7 \\
3.5 \\
5.6 \\
6.4 \\
8.2\end{array}$ & $\begin{array}{r}13.0 \\
12.1 \\
6.6 \\
7.0 \\
3.7 \\
5.9 \\
7.9 \\
8.9\end{array}$ \\
\hline $\begin{array}{l}16 \\
16 \\
16 \\
16 \\
16 \\
16 \\
16 \\
16\end{array}$ & $\begin{array}{r}0 \\
3 \\
6 \\
9 \\
12 \\
15 \\
18 \\
21\end{array}$ & $\begin{array}{l}22.1 \\
21: 0 \\
21.6 \\
24.7 \\
27.2 \\
28.7 \\
26.8 \\
23.9\end{array}$ & $\begin{array}{l}20.2 \\
19.0 \\
19.0 \\
20.2 \\
20.6 \\
20.7 \\
21.7 \\
21.3\end{array}$ & $\begin{array}{l}21.9 \\
20.7 \\
21.8 \\
25.0 \\
26.8 \\
28.8 \\
26.9 \\
24.0\end{array}$ & $\begin{array}{l}20.0 \\
18.9 \\
18.8 \\
19.8 \\
20.2 \\
20.3 \\
21.3 \\
21.0\end{array}$ & $\begin{array}{l}22.0 \\
20.7 \\
21.3 \\
25.1 \\
28.0 \\
29.0 \\
27.2 \\
24.0\end{array}$ & $\begin{array}{l}19.9 \\
18.6 \\
18.7 \\
19.9 \\
20.1 \\
20.1 \\
21.0 \\
20.8\end{array}$ & $\begin{array}{l}21.9 \\
20: 7 \\
21: 3 \\
25: 2 \\
27: 7 \\
29 \cdot 1 \\
27.4 \\
24: 1\end{array}$ & $\begin{array}{l}19.9 \\
18.5 \\
18.7 \\
19.9 \\
19.9 \\
19.7 \\
20.7 \\
20.8\end{array}$ & $\begin{array}{l}23.7 \\
23.4 \\
23.5 \\
23.9 \\
25.0 \\
25.3 \\
24.9 \\
24.8\end{array}$ & $\begin{array}{l}2 \\
2 \\
2 \\
2 \\
2 \\
2 \\
2 \\
2 \\
2\end{array}$ & $\begin{array}{l}5.4 \\
5.7 \\
9.5 \\
8.4 \\
4.3 \\
6.5 \\
4.2 \\
5.9\end{array}$ & $\begin{array}{r}6.1 \\
6.2 \\
10.1 \\
9.2 \\
4.8 \\
7.2 \\
4.9 \\
6.6\end{array}$ & $\begin{array}{r}6.5 \\
6.7 \\
11.0 \\
10.1 \\
5.2 \\
3.0 \\
5.0 \\
7.4\end{array}$ & $\begin{array}{r}7.1 \\
7.2 \\
11.3 \\
10.5 \\
5.6 \\
8.5 \\
7.4 \\
8.7\end{array}$ \\
\hline $\begin{array}{l}17 \\
17 \\
17 \\
17 \\
17 \\
17 \\
17 \\
17\end{array}$ & $\begin{array}{r}0 \\
3 \\
6 \\
9 \\
12 \\
15 \\
18 \\
21\end{array}$ & $\begin{array}{l}22.8 \\
22.3 \\
23.5 \\
27.0 \\
30.3 \\
29.3 \\
27.0 \\
24.3\end{array}$ & $\begin{array}{l}20.8 \\
20.5 \\
20.6 \\
21.7 \\
22.8 \\
23.2 \\
23.0 \\
22.4\end{array}$ & $\begin{array}{l}22.7 \\
22.4 \\
23.6 \\
26.6 \\
29.3 \\
29.0 \\
27.0 \\
24.4\end{array}$ & $\begin{array}{l}20.6 \\
20.3 \\
20.4 \\
21.4 \\
22.0 \\
22.7 \\
22.8 \\
22.2\end{array}$ & $\begin{array}{l}22.7 \\
22.5 \\
23.8 \\
26.7 \\
29.9 \\
29.0 \\
27.2 \\
24.5\end{array}$ & $\begin{array}{l}20.6 \\
20.2 \\
20.4 \\
21.6 \\
22.4 \\
22.5 \\
22.7 \\
22.1\end{array}$ & $\begin{array}{l}22 \cdot 6 \\
22 \cdot 4 \\
23 \cdot 7 \\
26 \cdot 5 \\
29 \cdot 5 \\
29 \cdot 1 \\
27 \cdot 3 \\
24.5\end{array}$ & $\begin{array}{l}20 \cdot 5 \\
20 \cdot 3 \\
20 \cdot 4 \\
21 \cdot 5 \\
22 \cdot 5 \\
22 \cdot 8 \\
22 \cdot 8 \\
22 \cdot 1\end{array}$ & $\begin{array}{l}24.1 \\
24.5 \\
25.1 \\
25.8 \\
29.1 \\
25.0 \\
25.1 \\
24.4\end{array}$ & $\begin{array}{l}2 \\
4 \\
2 \\
3 \\
2 \\
3 \\
3 \\
3\end{array}$ & $\begin{array}{l}5.3 \\
2.6 \\
3.1 \\
4.0 \\
2.2 \\
6.8 \\
7.7 \\
5.7\end{array}$ & $\begin{array}{l}6.3 \\
3.0 \\
3.8 \\
4.2 \\
2.6 \\
7.7 \\
8.0 \\
6.3\end{array}$ & $\begin{array}{l}5.8 \\
3.5 \\
4.1 \\
4.4 \\
2.4 \\
7.5 \\
0.4 \\
6.9\end{array}$ & $\begin{array}{l}7.8 \\
3.3 \\
4.3 \\
4.3 \\
2.8 \\
8.0 \\
9.6 \\
8.0\end{array}$ \\
\hline $\begin{array}{l}18 \\
18 \\
18 \\
18 \\
18 \\
18 \\
18 \\
18\end{array}$ & $\begin{array}{r}0 \\
3 \\
6 \\
9 \\
12 \\
15 \\
18 \\
21\end{array}$ & $\begin{array}{l}23.4 \\
22.3 \\
24.0 \\
25.8 \\
24.2 \\
26.5 \\
25.7 \\
23.5\end{array}$ & $\begin{array}{l}22.1 \\
21.6 \\
21.4 \\
21.5 \\
20.7 \\
21.3 \\
22.1 \\
21.7\end{array}$ & $\begin{array}{l}23.3 \\
22.2 \\
24.1 \\
25.7 \\
24.2 \\
26.6 \\
25.7 \\
23.5\end{array}$ & $\begin{array}{l}21.9 \\
21.4 \\
21.3 \\
21.4 \\
20.2 \\
21.0 \\
21.8 \\
21.6\end{array}$ & $\begin{array}{l}23.3 \\
22.1 \\
24.1 \\
26.0 \\
24.2 \\
26.6 \\
25.9 \\
23.5\end{array}$ & $\begin{array}{l}21: 9 \\
21: 3 \\
21: 2 \\
21: 1 \\
19: 9 \\
21: 0 \\
21: 5 \\
21: 4\end{array}$ & $\begin{array}{l}23.2 \\
2.1: 0 \\
24: 3 \\
25.6 \\
24: 2 \\
26.9 \\
26.1 \\
23.5\end{array}$ & $\begin{array}{l}21.9 \\
21.2 \\
21.1 \\
20.9 \\
20.0 \\
20.9 \\
21.7 \\
21.3\end{array}$ & $\begin{array}{l}24.9 \\
24.9 \\
23.2 \\
24.4 \\
25.0 \\
24.8 \\
24.4 \\
24.3\end{array}$ & $\begin{array}{l}3 \\
2 \\
2 \\
3 \\
3 \\
3 \\
3 \\
2\end{array}$ & $\begin{array}{r}6.0 \\
6.0 \\
10.9 \\
9.2 \\
8.7 \\
6.9 \\
4.5 \\
4.3\end{array}$ & $\begin{array}{r}6.5 \\
7.7 \\
12.2 \\
10.7 \\
9.5 \\
7.5 \\
5.0 \\
5.0\end{array}$ & $\begin{array}{r}7.1 \\
-.0 \\
13.5 \\
12.0 \\
10.0 \\
8.0 \\
5.5 \\
5.3\end{array}$ & $\begin{array}{r}7.5 \\
8.4 \\
14.0 \\
12.7 \\
10.4 \\
8.3 \\
6.7 \\
6.1\end{array}$ \\
\hline $\begin{array}{l}19 \\
19 \\
19 \\
19 \\
19 \\
19 \\
19 \\
19\end{array}$ & $\begin{array}{r}0 \\
3 \\
6 \\
9 \\
12 \\
15 \\
18 \\
21\end{array}$ & $\begin{array}{l}22.4 \\
20.5 \\
22.4 \\
26.0 \\
28.5 \\
30.1 \\
28.0 \\
26.3\end{array}$ & $\begin{array}{l}21.0 \\
19.4 \\
19.8 \\
20.6 \\
22.1 \\
22.9 \\
23.6 \\
23.3\end{array}$ & $\begin{array}{l}22.3 \\
20.4 \\
22.7 \\
26.3 \\
29.0 \\
30.1 \\
28.0 \\
26.4\end{array}$ & $\begin{array}{l}20.9 \\
19.1 \\
19.5 \\
20.4 \\
21.9 \\
22.8 \\
23.5 \\
23.1\end{array}$ & $\begin{array}{l}22.2 \\
20.5 \\
22.7 \\
26.5 \\
29.1 \\
30.2 \\
28.2 \\
26.5\end{array}$ & $\begin{array}{l}20.7 \\
19.1 \\
19.3 \\
20.2 \\
21.9 \\
22.6 \\
23.3 \\
23.0\end{array}$ & $\begin{array}{l}22.1 \\
20.1 \\
22.8 \\
26.4 \\
29.3 \\
30.2 \\
28.1 \\
26.6\end{array}$ & $\begin{array}{l}20.7 \\
18.8 \\
19.5 \\
20.3 \\
22.0 \\
22.7 \\
23.3 \\
23.0\end{array}$ & & $\begin{array}{l}3 \\
2 \\
2 \\
2 \\
2 \\
2 \\
2 \\
2\end{array}$ & $\begin{array}{r}5.9 \\
10.2 \\
10.5 \\
8.6 \\
4.3 \\
5.3 \\
6.6 \\
6.4\end{array}$ & $\begin{array}{r}6.2 \\
11.2 \\
11.3 \\
9.3 \\
4.6 \\
6.1 \\
7.5 \\
7.3\end{array}$ & $\begin{array}{r}6.2 \\
12.3 \\
12.0 \\
10.2 \\
4.7 \\
6.7 \\
8.4 \\
9.9\end{array}$ & $\begin{array}{r}6.6 \\
12.7 \\
12.6 \\
10.4 \\
5.3 \\
7.2 \\
9.2 \\
9.8\end{array}$ \\
\hline $\begin{array}{l}20 \\
20 \\
20 \\
20 \\
20 \\
20 \\
20 \\
20\end{array}$ & $\begin{array}{r}0 \\
3 \\
6 \\
9 \\
12 \\
15 \\
18 \\
21\end{array}$ & $\begin{array}{l}25.0 \\
23.3 \\
23.7 \\
25.8 \\
27.1 \\
28.1 \\
27.1\end{array}$ & $\begin{array}{l}20.1 \\
21.1 \\
22.0 \\
23.8 \\
23.9 \\
23.8 \\
23.8\end{array}$ & $\begin{array}{l}24.1 \\
23.2 \\
23.9 \\
25.8 \\
27.2 \\
28.3 \\
27.3\end{array}$ & $\begin{array}{l}19.6 \\
21.0 \\
22.0 \\
23.6 \\
23.8 \\
23.7 \\
23.7\end{array}$ & $\begin{array}{l}23.7 \\
23.3 \\
23.8 \\
25.9 \\
27.4 \\
28.5 \\
27.4\end{array}$ & $\begin{array}{l}19.4 \\
20.8 \\
22.1 \\
23.7 \\
23.8 \\
23.8 \\
23.7\end{array}$ & $\begin{array}{l}24.5 \\
23.2 \\
23.8 \\
26.0 \\
27.6 \\
28.7 \\
27.5\end{array}$ & $\begin{array}{l}19.0 \\
20.8 \\
21.9 \\
23.8 \\
23.8 \\
23.8 \\
23.7\end{array}$ & $\begin{array}{l}24 \cdot 8 \\
24.9 \\
25 \cdot 3 \\
25 \cdot 1 \\
25.1 \\
24 \cdot 9 \\
24.9\end{array}$ & $\begin{array}{l}2 \\
2 \\
3 \\
3 \\
2 \\
2 \\
2 \\
2\end{array}$ & $\begin{array}{r}12.7 \\
9.4 \\
8.1 \\
10.9 \\
13.4 \\
12.4 \\
11.4 \\
14.5\end{array}$ & $\begin{array}{r}14.4 \\
10.4 \\
8.7 \\
11.9 \\
14.8 \\
14.0 \\
12.7 \\
15.8\end{array}$ & $\begin{array}{r}16.0 \\
11.5 \\
8.8 \\
13.0 \\
16.5 \\
15.6 \\
14.1 \\
17.5\end{array}$ & $\begin{array}{r}17.2 \\
12.3 \\
9.3 \\
13.3 \\
16.9 \\
16.4 \\
14.7 \\
17.9\end{array}$ \\
\hline
\end{tabular}


TABLE 10

Table 10. - Three-hour averages of air and water-surface temperatures and wind directions and speed, April 1950-August 1951, Lake Hefner-Continued

STATION I THREE-HOURLY AVERAGES

JUNE, 1951

\begin{tabular}{|c|c|c|c|c|c|c|c|c|c|c|c|c|c|c|c|}
\hline \multirow{3}{*}{ 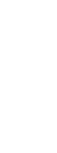 } & \multirow{3}{*}{ 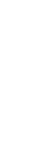 } & \multicolumn{8}{|c|}{ Average air temperature $\left({ }^{\circ} \mathrm{C}\right)$ at indicated height } & \multirow{3}{*}{\begin{tabular}{|c|} 
Average \\
water- \\
surface \\
tempera- \\
ture \\
$\left({ }^{\circ} \mathrm{C}\right)$
\end{tabular}} & \multirow{3}{*}{$\begin{array}{c}\begin{array}{c}\text { Average } \\
\text { wind } \\
\text { direction }\end{array} \\
\text { (coded) }\end{array}$} & \multirow{2}{*}{\multicolumn{4}{|c|}{$\begin{array}{l}\text { Average wind speed (knots) } \\
\text { at indicated height }\end{array}$}} \\
\hline & & \multicolumn{2}{|c|}{$\begin{array}{c}2 \\
\text { meters }\end{array}$} & \multicolumn{2}{|c|}{$\begin{array}{c}4 \\
\text { meters }\end{array}$} & \multicolumn{2}{|c|}{$\begin{array}{c}8 \\
\text { meters }\end{array}$} & \multicolumn{2}{|c|}{$\begin{array}{c}16 \\
\text { meters }\end{array}$} & & & & & & \\
\hline & & $\begin{array}{l}\text { Dry } \\
\text { bulb }\end{array}$ & $\begin{array}{l}\text { Wet } \\
\text { bulb }\end{array}$ & $\begin{array}{l}\text { Dry } \\
\text { bulb }\end{array}$ & $\begin{array}{l}\text { Wet } \\
\text { bulb }\end{array}$ & $\begin{array}{l}\text { Dry } \\
\text { bulb }\end{array}$ & $\begin{array}{l}\text { Wet } \\
\text { bulb }\end{array}$ & $\begin{array}{l}\text { Dry } \\
\text { bulb }\end{array}$ & $\begin{array}{l}\text { Wet } \\
\text { bulb }\end{array}$ & & & $\begin{array}{c}2 \\
\text { meters }\end{array}$ & $\begin{array}{c}4 \\
\text { meters }\end{array}$ & $\begin{array}{c}8 \\
\text { meters }\end{array}$ & $\begin{array}{c}16 \\
\text { meters }\end{array}$ \\
\hline $\begin{array}{l}21 \\
21 \\
21 \\
21 \\
21 \\
21 \\
21 \\
21\end{array}$ & $\begin{array}{r}0 \\
3 \\
6 \\
9 \\
12 \\
15 \\
18 \\
21\end{array}$ & $\begin{array}{l}23.8 \\
24.2 \\
26.1 \\
27.4 \\
26.7 \\
26.1\end{array}$ & $\begin{array}{l}22 \cdot 3 \\
22.3 \\
23.0 \\
23.5 \\
24 \cdot 2 \\
23.9\end{array}$ & $\begin{array}{l}23.9 \\
24.3 \\
26.2 \\
27.6 \\
26.9 \\
26.2\end{array}$ & $\begin{array}{l}22.0 \\
22.2 \\
22.7 \\
23.4 \\
24 \cdot 1 \\
23.7\end{array}$ & $\begin{array}{l}23.9 \\
24.3 \\
2.6 .4 \\
27.7 \\
25.9 \\
26.3\end{array}$ & $\begin{array}{l}22.0 \\
22.2 \\
22.5 \\
23.5 \\
24 \cdot 1 \\
23.6\end{array}$ & $\begin{array}{l}23.8 \\
24.3 \\
26.4 \\
27.4 \\
27.0 \\
26.2\end{array}$ & $\begin{array}{l}21.9 \\
22.1 \\
22.7 \\
23.4 \\
24.0 \\
23.4\end{array}$ & $\begin{array}{l}24 \cdot 7 \\
24: 9 \\
25 \cdot 2 \\
25 \cdot 1 \\
25 \cdot 1 \\
25 \cdot 2\end{array}$ & $\begin{array}{l}2 \\
2 \\
2 \\
2 \\
2 \\
2 \\
2 \\
2\end{array}$ & $\begin{array}{r}10.8 \\
14.5 \\
6.2 \\
10.0 \\
8.7 \\
6.8 \\
4.5 \\
10.1\end{array}$ & $\begin{array}{r}12.6 \\
16.8 \\
6.8 \\
11.1 \\
9.9 \\
7.8 \\
5.1 \\
11.6\end{array}$ & $\begin{array}{r}13.7 \\
18.5 \\
7.3 \\
12.1 \\
11.0 \\
8.8 \\
5.7 \\
12.9\end{array}$ & $\begin{array}{r}14.4 \\
19.4 \\
7.6 \\
12.5 \\
11.6 \\
9.3 \\
6.4 \\
13.8\end{array}$ \\
\hline $\begin{array}{l}22 \\
22 \\
22 \\
22 \\
22 \\
22 \\
22 \\
22\end{array}$ & $\begin{array}{r}0 \\
3 \\
6 \\
9 \\
12 \\
15 \\
18 \\
21\end{array}$ & $\begin{array}{l}24.9 \\
24.5 \\
24.2 \\
25.8 \\
27.7 \\
28.2 \\
26.8 \\
25.0\end{array}$ & $\begin{array}{l}23.2 \\
22.4 \\
22.3 \\
22.8 \\
23.0 \\
22.9 \\
22.5 \\
22.9\end{array}$ & $\begin{array}{l}24.9 \\
24.5 \\
24: 2 \\
25.8 \\
27 \cdot 9 \\
28 \cdot 1 \\
27.0 \\
25 \cdot 0\end{array}$ & $\begin{array}{l}23.0 \\
22.2 \\
22: 1 \\
22.7 \\
22.7 \\
22.7 \\
22.2 \\
22.5\end{array}$ & $\begin{array}{l}24.9 \\
24.5 \\
24.4 \\
26.1 \\
28.0 \\
28.5 \\
27.1 \\
25.1\end{array}$ & $\begin{array}{l}22: 8 \\
22: 1 \\
27: 2 \\
22: 7 \\
22: 0 \\
22.5 \\
22: 1 \\
22.4\end{array}$ & $\begin{array}{l}25.1 \\
24.4 \\
24: 4 \\
26.1 \\
23.1 \\
23.7 \\
27.2 \\
? 5.1\end{array}$ & $\begin{array}{l}23.1 \\
22 \cdot 1 \\
22.1 \\
22.7 \\
22.8 \\
22.6 \\
22.0 \\
22.4\end{array}$ & $\begin{array}{l}24.9 \\
25 \cdot 0 \\
24: 7 \\
25.2 \\
25.7 \\
25.4 \\
25.1 \\
25.3\end{array}$ & $\begin{array}{l}2 \\
2 \\
2 \\
2 \\
2 \\
2 \\
2 \\
2 \\
2\end{array}$ & $\begin{array}{r}6.0 \\
15.3 \\
10.7 \\
8.5 \\
8.5 \\
10.2 \\
6.0 \\
4.4\end{array}$ & $\begin{array}{r}7.3 \\
17.2 \\
12.0 \\
9.6 \\
9.7 \\
11.6 \\
7.8 \\
5.0\end{array}$ & $\begin{array}{r}7.9 \\
18.8 \\
13.2 \\
10.6 \\
10.9 \\
12.9 \\
9.0 \\
6.0\end{array}$ & $\begin{array}{r}8.4 \\
19.8 \\
13.8 \\
11.1 \\
11.4 \\
13.7 \\
9.9 \\
6.1\end{array}$ \\
\hline $\begin{array}{l}23 \\
23 \\
23 \\
23 \\
23 \\
23 \\
23 \\
23\end{array}$ & $\begin{array}{r}0 \\
3 \\
6 \\
9 \\
12 \\
15 \\
18 \\
21\end{array}$ & $\begin{array}{l}23.9 \\
23.9 \\
23.9 \\
26.0 \\
26.9 \\
26.6 \\
26.7 \\
25.8\end{array}$ & $\begin{array}{l}22 \cdot 0 \\
21: 5 \\
21: 3 \\
21: 7 \\
21: 3 \\
22: 1 \\
22: 0 \\
22: 4\end{array}$ & $\begin{array}{l}23.8 \\
23.8 \\
24.0 \\
26.1 \\
27.1 \\
26.0 \\
26.0 \\
25.8\end{array}$ & $\begin{array}{l}21 \cdot 8 \\
21 \cdot 2 \\
71: 1 \\
20: 8 \\
21 \cdot 3 \\
21: 9 \\
22.7 \\
22.1\end{array}$ & $\begin{array}{l}23.9 \\
23.7 \\
24.1 \\
26.7 \\
27.7 \\
26.7 \\
27.1 \\
26.0\end{array}$ & $\begin{array}{l}21.8 \\
21.1 \\
21.0 \\
20.8 \\
21.1 \\
21.9 \\
22.6 \\
21.8\end{array}$ & $\begin{array}{l}23.9 \\
23.5 \\
24: 1 \\
26: 7 \\
27: 2 \\
26: 7 \\
27: 1 \\
25.1\end{array}$ & $\begin{array}{l}21.3 \\
21.1 \\
21.0 \\
20.5 \\
21.1 \\
21.9 \\
27.6 \\
21.7\end{array}$ & & $\begin{array}{l}3 \\
2 \\
2 \\
? \\
2 \\
2 \\
2 \\
?\end{array}$ & $\begin{array}{r}5.8 \\
12.0 \\
15.1 \\
16.7 \\
16.0 \\
13.5 \\
4.8 \\
7.6\end{array}$ & $\begin{array}{r}6.1 \\
13.3 \\
17.0 \\
19.0 \\
18.2 \\
15.3 \\
5.5 \\
8.4\end{array}$ & $\begin{array}{r}6.2 \\
14.6 \\
13.9 \\
21.4 \\
20.4 \\
17.2 \\
6.0 \\
9.3\end{array}$ & $\begin{array}{r}6.6 \\
15.2 \\
19.6 \\
22.6 \\
21.4 \\
18.1 \\
6.7 \\
10.0\end{array}$ \\
\hline $\begin{array}{l}24 \\
24 \\
24 \\
24 \\
24 \\
24 \\
24 \\
24\end{array}$ & $\begin{array}{r}0 \\
3 \\
6 \\
9 \\
12 \\
15 \\
18 \\
71\end{array}$ & $\begin{array}{l}24.3 \\
22.4 \\
20.9 \\
24.0 \\
26.4 \\
27.5 \\
26.1 \\
24.9\end{array}$ & $\begin{array}{l}21.2 \\
20.5 \\
17.7 \\
19.9 \\
21.6 \\
21.8 \\
22.4 \\
22.3\end{array}$ & $\begin{array}{l}24.3 \\
22.0 \\
20.8 \\
24.1 \\
26.6 \\
27.5 \\
26.1 \\
74.0\end{array}$ & $\begin{array}{l}21.0 \\
20.2 \\
17.3 \\
19.4 \\
21.4 \\
21.4 \\
22.2 \\
22.1\end{array}$ & $\begin{array}{l}24.1 \\
22.0 \\
20.5 \\
24.2 \\
26.5 \\
27.7 \\
25.2 \\
24.8\end{array}$ & $\begin{array}{l}20.8 \\
20.0 \\
17.0 \\
10.4 \\
21.4 \\
21.4 \\
22.1 \\
22.0\end{array}$ & $\begin{array}{l}24.0 \\
21.9 \\
20.6 \\
24 \cdot 7 \\
26.7 \\
27.8 \\
26.3 \\
24.8\end{array}$ & $\begin{array}{l}20.7 \\
20.0 \\
16.0 \\
19.2 \\
21.1 \\
21.4 \\
22.0 \\
22.0\end{array}$ & & $\begin{array}{l}2 \\
3 \\
3 \\
3 \\
2 \\
2 \\
2 \\
2\end{array}$ & $\begin{array}{r}8.3 \\
9.4 \\
13.5 \\
15.0 \\
11.8 \\
9.4 \\
4.9 \\
10.8\end{array}$ & $\begin{array}{r}9.0 \\
10.5 \\
14.5 \\
16.1 \\
12.9 \\
10.6 \\
5.5 \\
11.9\end{array}$ & $\begin{array}{r}9.7 \\
10.9 \\
15.2 \\
16.9 \\
14.3 \\
11.5 \\
6.0 \\
13.0\end{array}$ & $\begin{array}{r}10.3 \\
11.5 \\
15.7 \\
17.5 \\
14.6 \\
12.1 \\
6.8 \\
13.7\end{array}$ \\
\hline $\begin{array}{l}25 \\
25 \\
25 \\
25 \\
25 \\
25 \\
25 \\
25\end{array}$ & $\begin{array}{r}0 \\
3 \\
6 \\
9 \\
12 \\
15 \\
18 \\
21\end{array}$ & $\begin{array}{l}23.8 \\
23.0 \\
33.2 \\
25.1 \\
25.6 \\
27.8 \\
27.3 \\
25.9\end{array}$ & $\begin{array}{l}22.2 \\
22: 0 \\
21: 9 \\
22: 4 \\
23.0 \\
23.4 \\
23.5 \\
23.3\end{array}$ & $\begin{array}{l}23.7 \\
22.0 \\
23.4 \\
25.1 \\
26.7 \\
27.9 \\
27.4 \\
26.0\end{array}$ & $\begin{array}{l}22.1 \\
21 \\
21.9 \\
22.8 \\
22.3 \\
22.8 \\
23.3 \\
23.5 \\
23.1\end{array}$ & $\begin{array}{l}23.6 \\
22.8 \\
23.3 \\
25.1 \\
25.9 \\
28.1 \\
27.6 \\
26.0\end{array}$ & $\begin{array}{l}22.0 \\
21.8 \\
21.0 \\
27.2 \\
22.8 \\
23.2 \\
23.5 \\
23.0\end{array}$ & $\begin{array}{l}23.5 \\
22.8 \\
23.3 \\
25.7 \\
27.0 \\
28.1 \\
27.5 \\
25.0\end{array}$ & $\begin{array}{l}22.0 \\
21.7 \\
21.07 \\
22.5 \\
23.9 \\
23.3 \\
23.4 \\
23.9\end{array}$ & & $\begin{array}{l}2 \\
2 \\
2 \\
2 \\
2 \\
2 \\
2 \\
2\end{array}$ & $\begin{array}{r}12.1 \\
15.4 \\
12.2 \\
9.5 \\
10.4 \\
12.2 \\
10.5 \\
12.7\end{array}$ & $\begin{array}{l}13.6 \\
17.2 \\
13.7 \\
10.6 \\
11.8 \\
13.8 \\
11.9 \\
14.3\end{array}$ & $\begin{array}{l}15.0 \\
18.9 \\
15.3 \\
11.9 \\
13.3 \\
15.6 \\
13.3 \\
16.0\end{array}$ & $\begin{array}{l}15.5 \\
19.7 \\
15.7 \\
12.4 \\
13.7 \\
16.4 \\
14.2 \\
16.8\end{array}$ \\
\hline $\begin{array}{l}26 \\
26 \\
26 \\
26 \\
26 \\
26 \\
26 \\
26\end{array}$ & $\begin{array}{r}0 \\
3 \\
6 \\
9 \\
1 ? \\
15 \\
18 \\
71\end{array}$ & $\begin{array}{l}25.0 \\
24.2 \\
24.4 \\
26.8 \\
29.0 \\
29.9 \\
28.4 \\
26.0\end{array}$ & $\begin{array}{l}21.8 \\
21.1 \\
21.5 \\
22.3 \\
23.0 \\
22.9 \\
22.1 \\
21.1\end{array}$ & $\begin{array}{l}25.0 \\
24: ? \\
24.4 \\
27.0 \\
29.2 \\
29.5 \\
28.5 \\
26.0\end{array}$ & $\begin{array}{l}21.6 \\
20: 9 \\
23 \cdot 3 \\
22: 1 \\
22: 9 \\
22: 9 \\
21.8 \\
20.8\end{array}$ & $\begin{array}{l}25.0 \\
24.1 \\
24.5 \\
27.2 \\
29.4 \\
30.2 \\
25.6 \\
26.0\end{array}$ & $\begin{array}{ll}21 & : 4 \\
20 & : 5 \\
21 & 3 \\
22 & : 1 \\
22 & 0 \\
22 & 7 \\
21 & 0 \\
20 & 0\end{array}$ & $\begin{array}{l}25.0 \\
24: 0 \\
24: 5 \\
27.0 \\
29: 5 \\
30.5 \\
20.07 \\
25.0\end{array}$ & $\begin{array}{l}21.3 \\
20.8 \\
? 1.4 \\
22.0 \\
22.8 \\
22.8 \\
21.4 \\
20.5\end{array}$ & $\begin{array}{l}24.9 \\
24.8 \\
24.9 \\
25.7 \\
25.9 \\
25.6 \\
25.1 \\
25.0\end{array}$ & $\begin{array}{l}2 \\
2 \\
2 \\
2 \\
2 \\
2 \\
2 \\
2 \\
2\end{array}$ & $\begin{array}{l}14.9 \\
13.9 \\
14.1 \\
15.5 \\
16.2 \\
17.2 \\
13.5 \\
14.4\end{array}$ & $\begin{array}{l}16.9 \\
15.6 \\
15.8 \\
16.5 \\
18.4 \\
19.5 \\
15.5 \\
16.3\end{array}$ & $\begin{array}{l}18.8 \\
17.4 \\
17.6 \\
13.3 \\
20.9 \\
22.3 \\
17.4 \\
18.1\end{array}$ & $\begin{array}{l}19.7 \\
18.1 \\
19.2 \\
19.1 \\
21.7 \\
23.5 \\
12.3 \\
19.1\end{array}$ \\
\hline $\begin{array}{l}27 \\
27 \\
27 \\
27 \\
27 \\
27 \\
27 \\
27\end{array}$ & $\begin{array}{r}0 \\
3 \\
6 \\
9 \\
12 \\
15 \\
18 \\
21\end{array}$ & $\begin{array}{l}25 \cdot 0 \\
24 \cdot 3 \\
24 \cdot 1 \\
26 \cdot 9 \\
29: 3 \\
29 \cdot 7 \\
27 \cdot 9 \\
26.0\end{array}$ & $\begin{array}{l}20.6 \\
20.4 \\
20.4 \\
21.5 \\
22.2 \\
21.5 \\
21.5 \\
21.7\end{array}$ & $\begin{array}{l}25.1 \\
24.1 \\
74.0 \\
27 \cdot 1 \\
29.6 \\
29 \cdot 8 \\
28.0 \\
26.1\end{array}$ & $\begin{array}{l}20.5 \\
20.0 \\
20.1 \\
21 \cdot 3 \\
22.1 \\
21.3 \\
21.3 \\
21.5\end{array}$ & $\begin{array}{l}25.1 \\
24.1 \\
24.3 \\
27.4 \\
20: 8 \\
30.3 \\
23.1 \\
26.1\end{array}$ & 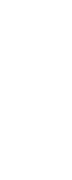 & $\begin{array}{l}25: 3 \\
24: 0 \\
34: 4 \\
27: 5 \\
20: 0 \\
30.4 \\
28: 2 \\
26.0\end{array}$ & $\begin{array}{l}20.1 \\
19.8 \\
20.0 \\
21.0 \\
21.8 \\
21.0 \\
21.1 \\
21.2\end{array}$ & $\begin{array}{l}24.8 \\
24.4 \\
24.5 \\
25.2 \\
25.5 \\
25.1 \\
24.7 \\
24.6\end{array}$ & $\begin{array}{l}2 \\
2 \\
2 \\
2 \\
2 \\
2 \\
2 \\
2\end{array}$ & $\begin{array}{l}15.2 \\
13.5 \\
13.2 \\
16.7 \\
16.5 \\
15.5 \\
12.5 \\
13.4\end{array}$ & $\begin{array}{l}17.1 \\
15.0 \\
14.7 \\
10.0 \\
19.1 \\
17.8 \\
14.2 \\
15.0\end{array}$ & & $\begin{array}{l}20.0 \\
17.5 \\
27.1 \\
22.6 \\
23.5 \\
21.1 \\
16.8 \\
17.8\end{array}$ \\
\hline $\begin{array}{l}28 \\
28 \\
28 \\
28 \\
28 \\
28 \\
28 \\
28\end{array}$ & $\begin{array}{r}0 \\
3 \\
6 \\
9 \\
12 \\
15 \\
18 \\
21\end{array}$ & $\begin{array}{l}24.5 \\
23.3 \\
24 \cdot 0 \\
26.2 \\
28.6 \\
29.4 \\
27.7 \\
26.3\end{array}$ & $\begin{array}{l}21.1 \\
20.5 \\
21.1 \\
21.9 \\
22.5 \\
22.3 \\
22.5 \\
21.8\end{array}$ & $\begin{array}{l}24.5 \\
23.3 \\
23.9 \\
26.4 \\
28.7 \\
29.6 \\
27.9 \\
26.5\end{array}$ & $\begin{array}{l}21.0 \\
20: 5 \\
20.8 \\
21: 7 \\
22: 0 \\
22.2 \\
22.2 \\
21.6\end{array}$ & $\begin{array}{l}24.5 \\
23.3 \\
24.7 \\
36.5 \\
29.0 \\
29.9 \\
29.1 \\
36.5\end{array}$ & $\begin{array}{l}20.8 \\
20.3 \\
20.8 \\
21.6 \\
21.8 \\
21.7 \\
22.1 \\
21.4\end{array}$ & $\begin{array}{l}24.5 \\
23.5 \\
23.0 \\
26.5 \\
20.0 \\
30.1 \\
28.2 \\
26.5\end{array}$ & $\begin{array}{l}20.7 \\
20.2 \\
20.7 \\
21.5 \\
21.6 \\
21.8 \\
22.0 \\
21.3\end{array}$ & & $\begin{array}{l}2 \\
2 \\
2 \\
2 \\
2 \\
2 \\
2 \\
2\end{array}$ & $\begin{array}{r}14.3 \\
9.8 \\
9.6 \\
4.5 \\
5.6 \\
9.0 \\
8.7 \\
11.3\end{array}$ & $\begin{array}{r}16.1 \\
10.9 \\
10.5 \\
5.0 \\
6.4 \\
10.4 \\
10.0 \\
12.7\end{array}$ & $\begin{array}{r}17.8 \\
12.0 \\
11.7 \\
5.9 \\
7.1 \\
11.8 \\
11.4 \\
14.0\end{array}$ & $\begin{array}{r}18.7 \\
12.7 \\
12.1 \\
5.7 \\
7.6 \\
12.5 \\
12.3 \\
15.0\end{array}$ \\
\hline $\begin{array}{l}29 \\
29 \\
29 \\
29 \\
29 \\
29 \\
29 \\
29\end{array}$ & $\begin{array}{r}0 \\
3 \\
5 \\
9 \\
12 \\
15 \\
18 \\
21\end{array}$ & $\begin{array}{l}25.3 \\
23.7 \\
24.5 \\
25.5 \\
28.2 \\
29.7 \\
28.1 \\
26.7\end{array}$ & $\begin{array}{l}21.9 \\
21.5 \\
21.9 \\
22: 7 \\
23.1 \\
23.1 \\
22.4 \\
21.9\end{array}$ & $\begin{array}{l}25.2 \\
23.7 \\
24.5 \\
25.7 \\
28.6 \\
29.9 \\
28.5 \\
26.8\end{array}$ & $\begin{array}{l}21.7 \\
21.3 \\
21.8 \\
22.4 \\
22: 9 \\
23.0 \\
22.2 \\
21.8\end{array}$ & $\begin{array}{l}25.7 \\
23.7 \\
24.8 \\
25.8 \\
28.8 \\
30.0 \\
28.5 \\
26.8\end{array}$ & $\begin{array}{l}21 \cdot 6 \\
21: 1 \\
21 \cdot 8 \\
22 \cdot 4 \\
22 \cdot 7 \\
22 \cdot 7 \\
22 \cdot 1 \\
21 \cdot 6\end{array}$ & $\begin{array}{l}25.2 \\
23.6 \\
24.9 \\
25.0 \\
28.0 \\
30.5 \\
28.6 \\
26.7\end{array}$ & $\begin{array}{l}21.4 \\
21.0 \\
21.7 \\
23.4 \\
23.7 \\
27.8 \\
21.9 \\
21.4\end{array}$ & & $\begin{array}{l}2 \\
2 \\
2 \\
2 \\
2 \\
2 \\
2 \\
2 \\
2\end{array}$ & $\begin{array}{r}14.0 \\
11.1 \\
13.5 \\
8.1 \\
8.5 \\
13.4 \\
10.8 \\
14.3\end{array}$ & $\begin{array}{r}15.8 \\
12.4 \\
15.2 \\
9.0 \\
9.7 \\
15.2 \\
12.4 \\
16.1\end{array}$ & $\begin{array}{l}17.6 \\
13.7 \\
17.0 \\
10.1 \\
10.8 \\
17.1 \\
14.0 \\
17.7\end{array}$ & $\begin{array}{l}18.6 \\
14.7 \\
17.6 \\
10.6 \\
11.5 \\
18.0 \\
14.8 \\
18.6\end{array}$ \\
\hline $\begin{array}{l}30 \\
30 \\
30 \\
30 \\
30 \\
30 \\
30 \\
30\end{array}$ & $\begin{array}{r}0 \\
3 \\
6 \\
9 \\
12 \\
15 \\
18 \\
21\end{array}$ & $\begin{array}{l}24.2 \\
20.4 \\
19.8 \\
20.9 \\
20.8 \\
21.7 \\
21.0 \\
19.0\end{array}$ & $\begin{array}{l}21.3 \\
19.4 \\
18.9 \\
19.4 \\
19.0 \\
18.6 \\
17.2 \\
16.5\end{array}$ & $\begin{array}{l}24.1 \\
20.1 \\
19.8 \\
20.4 \\
20.3 \\
21.2 \\
20.7 \\
18.8\end{array}$ & $\begin{array}{l}21.0 \\
18.8 \\
18.4 \\
18.9 \\
18.6 \\
18.0 \\
15.5 \\
16.4\end{array}$ & $\begin{array}{l}23.5 \\
19.9 \\
19.4 \\
20.1 \\
20.2 \\
21.0 \\
20.3 \\
18.7\end{array}$ & $\begin{array}{l}20.3 \\
18.6 \\
18.2 \\
18.8 \\
18.2 \\
17.6 \\
16.5 \\
16 . ?\end{array}$ & $\begin{array}{l}23.4 \\
19.8 \\
19.3 \\
19.0 \\
20.0 \\
20.9 \\
20.2 \\
18.6\end{array}$ & $\begin{array}{l}20.4 \\
18.4 \\
17.9 \\
18.6 \\
18.0 \\
17.3 \\
16.1 \\
16.1\end{array}$ & $\begin{array}{l}24.8 \\
24.6 \\
24.6 \\
25.0 \\
25.0 \\
24.6 \\
24.1 \\
24.0\end{array}$ & $\begin{array}{l}2 \\
3 \\
3 \\
3 \\
3 \\
3 \\
3 \\
3\end{array}$ & $\begin{array}{r}13.6 \\
9.9 \\
12.0 \\
9.8 \\
14.5 \\
13.5 \\
8.7 \\
6.6\end{array}$ & $\begin{array}{r}15.4 \\
11.9 \\
13.0 \\
10.9 \\
16.4 \\
15.6 \\
10.2 \\
6.8\end{array}$ & $\begin{array}{r}16.8 \\
12.5 \\
13.3 \\
11.3 \\
17.0 \\
16.2 \\
10.6 \\
6.8\end{array}$ & $\begin{array}{r}18.0 \\
13.0 \\
13.7 \\
12.0 \\
18.5 \\
17.3 \\
10.9 \\
7.0\end{array}$ \\
\hline
\end{tabular}


TABLE 10

Table 10. -Three-hour averages of air and water-surface temperatures and wind directions and speed, April 1950-August 1951, Lake Hefner-Continued

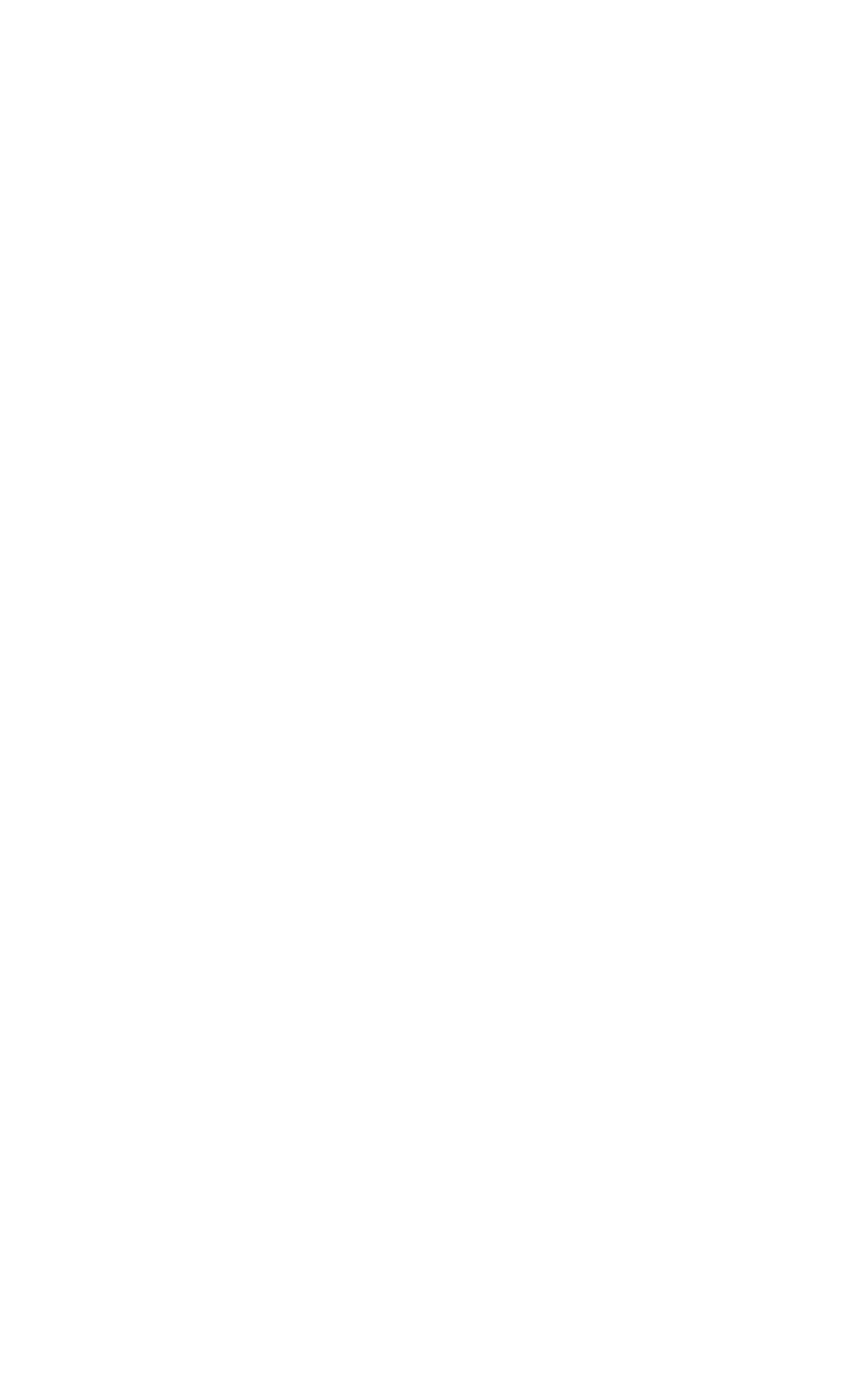


TABLE 10 Table 10. - Three-hour averages of air and water-surface temperatures and wind directions and speed, April 1950-August
1951, Lake Hefner-Continued

STATION

THREE-HOURLY AVERAGES

JULY, 1951

\begin{tabular}{|c|c|c|c|c|c|c|c|c|c|c|c|c|c|c|c|}
\hline \multirow{3}{*}{ 害葛 } & \multirow{3}{*}{ 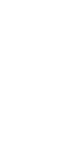 } & \multicolumn{8}{|c|}{ Average air temperature $\left({ }^{\circ} \mathrm{C}\right)$ at indicated heigbt } & \multirow{3}{*}{$\begin{array}{l}\text { Average } \\
\text { water- } \\
\text { surface } \\
\text { tempera- } \\
\text { ture } \\
\text { ("C) }\end{array}$} & \multirow{3}{*}{$\begin{array}{c}\text { Average } \\
\text { wind } \\
\text { direction } \\
\text { (coded) }\end{array}$} & \multirow{2}{*}{\multicolumn{4}{|c|}{$\begin{array}{l}\text { Average wind speed (knots) } \\
\text { at indicated height }\end{array}$}} \\
\hline & & \multicolumn{2}{|c|}{$\begin{array}{c}2 \\
\text { meters }\end{array}$} & \multicolumn{2}{|c|}{$\begin{array}{c}4 \\
\text { meters }\end{array}$} & \multicolumn{2}{|c|}{$\begin{array}{c}8 \\
\text { meters }\end{array}$} & \multicolumn{2}{|c|}{$\begin{array}{c}16 \\
\text { meters }\end{array}$} & & & & & & \\
\hline & & $\begin{array}{l}\text { Dry } \\
\text { bulb }\end{array}$ & $\begin{array}{l}\text { Wet } \\
\text { bulb }\end{array}$ & $\begin{array}{l}\text { Dry } \\
\text { bulb }\end{array}$ & $\begin{array}{l}\text { Wet } \\
\text { bulb }\end{array}$ & $\begin{array}{l}\text { Dry } \\
\text { bulb }\end{array}$ & $\begin{array}{l}\text { Wet } \\
\text { bulb }\end{array}$ & $\begin{array}{l}\text { Dry } \\
\text { bulb }\end{array}$ & $\begin{array}{c}\text { Wet } \\
\text { bulb }\end{array}$ & & & meters & meters & meters & meters \\
\hline $\begin{array}{l}11 \\
11 \\
11 \\
11 \\
11 \\
11 \\
11 \\
11\end{array}$ & $\begin{array}{r}0 \\
3 \\
6 \\
9 \\
12 \\
15 \\
18 \\
21\end{array}$ & $\begin{array}{l}25.7 \\
24.6 \\
24.8 \\
27.6 \\
29.2 \\
29.8 \\
28.2 \\
26.0\end{array}$ & $\begin{array}{l}22.4 \\
22.1 \\
22.2 \\
22.2 \\
22.1 \\
22.7 \\
23.1 \\
22.7\end{array}$ & $\begin{array}{l}25.8 \\
24.6 \\
24.9 \\
28.0 \\
29.4 \\
30.1 \\
28.2 \\
26.0\end{array}$ & $\begin{array}{l}22.2 \\
21.9 \\
22.0 \\
21.9 \\
21.8 \\
22.5 \\
22.9 \\
22.6\end{array}$ & $\begin{array}{l}25.8 \\
24.5 \\
25.0 \\
28.0 \\
29.8 \\
30.2 \\
28.4 \\
26.0\end{array}$ & $\begin{array}{l}22.2 \\
21.9 \\
22.0 \\
21.8 \\
21.8 \\
22.3 \\
22.8 \\
22.4\end{array}$ & $\begin{array}{l}25.7 \\
24 \cdot 3 \\
25.1 \\
28.3 \\
29.7 \\
30.3 \\
28.3 \\
26.0\end{array}$ & $\begin{array}{l}22 \cdot 0 \\
21 \cdot 6 \\
21.8 \\
21 \cdot 6 \\
21.6 \\
22.6 \\
22.7 \\
22 \cdot 3\end{array}$ & $\begin{array}{l}25.4 \\
25.3 \\
25.9 \\
26.6 \\
25.7 \\
25.9 \\
25.7 \\
25.6\end{array}$ & $\begin{array}{l}2 \\
2 \\
2 \\
2 \\
2 \\
2 \\
2 \\
2\end{array}$ & $\begin{array}{r}11.8 \\
13.7 \\
15.2 \\
12.5 \\
10.8 \\
12.3 \\
10.2 \\
7.1\end{array}$ & $\begin{array}{r}13.2 \\
15.4 \\
17.1 \\
14.1 \\
11.6 \\
14.1 \\
11.7 \\
7.8\end{array}$ & $\begin{array}{r}14.4 \\
17.1 \\
19.2 \\
15.9 \\
13.9 \\
15.8 \\
13.0 \\
7.4\end{array}$ & $\begin{array}{r}15.2 \\
17.8 \\
20.0 \\
16.5 \\
14.4 \\
16.6 \\
13.9 \\
9.1\end{array}$ \\
\hline $\begin{array}{l}12 \\
12 \\
12 \\
12 \\
12 \\
12 \\
12 \\
12\end{array}$ & $\begin{array}{r}0 \\
3 \\
6 \\
9 \\
12 \\
15 \\
18 \\
21\end{array}$ & $\begin{array}{l}24.7 \\
23.8 \\
24.9 \\
28.9 \\
30.4 \\
30.8 \\
29.3 \\
27.4\end{array}$ & $\begin{array}{l}22.3 \\
22.0 \\
22.2 \\
22.6 \\
23.0 \\
23.1 \\
23.2 \\
23.0\end{array}$ & $\begin{array}{l}24.7 \\
23.8 \\
24.9 \\
29.0 \\
30.7 \\
31.2 \\
29.5 \\
27.5\end{array}$ & $\begin{array}{l}22 \cdot 0 \\
21.7 \\
22: 0 \\
22 \cdot 3 \\
22.5 \\
22: 5 \\
22: 9 \\
22.7\end{array}$ & $\begin{array}{l}24.7 \\
23.7 \\
25.0 \\
29.2 \\
31.1 \\
31.5 \\
29.8 \\
27.6\end{array}$ & $\begin{array}{l}21.9 \\
21.6 \\
21.8 \\
22 \cdot 8 \\
22.3 \\
22.6 \\
22.8 \\
22.7\end{array}$ & $\begin{array}{l}24.6 \\
23.6 \\
25.1 \\
29.3 \\
31.0 \\
31.6 \\
29.8 \\
27.6\end{array}$ & $\begin{array}{l}21.8 \\
21.5 \\
21.8 \\
22.2 \\
22.3 \\
22.5 \\
22.7 \\
22.6\end{array}$ & $\begin{array}{l}25.6 \\
25.5 \\
26.0 \\
26.8 \\
27.4 \\
26.5 \\
26.0 \\
26.0\end{array}$ & $\begin{array}{l}2 \\
2 \\
2 \\
2 \\
2 \\
2 \\
2 \\
2\end{array}$ & $\begin{array}{r}10.0 \\
11.8 \\
13.1 \\
13.6 \\
8.9 \\
10.0 \\
8.1 \\
8.5\end{array}$ & $\begin{array}{r}11.0 \\
13.2 \\
14.7 \\
15.2 \\
10.0 \\
11.5 \\
9.4 \\
9.6\end{array}$ & $\begin{array}{l}12.1 \\
14.5 \\
16.4 \\
17.1 \\
11.4 \\
13.0 \\
10.8 \\
10.8\end{array}$ & $\begin{array}{l}12.5 \\
15: 1 \\
17.0 \\
17.6 \\
11.7 \\
13.6 \\
11: 8 \\
11.6\end{array}$ \\
\hline $\begin{array}{l}13 \\
13 \\
13 \\
13 \\
13 \\
13 \\
13 \\
13\end{array}$ & $\begin{array}{r}0 \\
3 \\
6 \\
9 \\
12 \\
15 \\
18 \\
21\end{array}$ & $\begin{array}{l}25.7 \\
22.5 \\
23.9 \\
26.1 \\
27.3 \\
30.2 \\
26.1 \\
23.5\end{array}$ & $\begin{array}{l}22.6 \\
21.2 \\
21.7 \\
22.9 \\
23.0 \\
24.1 \\
23.6 \\
22.2\end{array}$ & $\begin{array}{l}25.6 \\
22.4 \\
23.8 \\
25.4 \\
27.3 \\
29.6 \\
25.8 \\
23.4\end{array}$ & $\begin{array}{l}22.4 \\
21.0 \\
21.5 \\
22.5 \\
23.5 \\
23.7 \\
23.2 \\
21.9\end{array}$ & $\begin{array}{l}25.6 \\
22.2 \\
23.8 \\
25.5 \\
27.5 \\
29.5 \\
25.6 \\
23.3\end{array}$ & $\begin{array}{l}22.3 \\
20.9 \\
21.5 \\
22.5 \\
22.9 \\
23.8 \\
23.2 \\
21.8\end{array}$ & $\begin{array}{l}25.4 \\
22.0 \\
23.8 \\
25.3 \\
27.4 \\
29.4 \\
25.3 \\
23.2\end{array}$ & $\begin{array}{l}22.2 \\
20.8 \\
21.5 \\
22.4 \\
22.8 \\
23.6 \\
22.9 \\
21.6\end{array}$ & $\begin{array}{l}25.9 \\
25.9 \\
26.3 \\
27.3 \\
27.5 \\
27.5 \\
26.5 \\
26.3\end{array}$ & $\begin{array}{l}2 \\
2 \\
3 \\
3 \\
3 \\
3 \\
3 \\
3 \\
3\end{array}$ & $\begin{array}{r}6.1 \\
8.6 \\
4.6 \\
8.5 \\
6.7 \\
5.0 \\
10.1 \\
6.7\end{array}$ & $\begin{array}{r}6.8 \\
9.3 \\
4.9 \\
9.5 \\
7.1 \\
5.5 \\
11.2 \\
7.9\end{array}$ & $\begin{array}{r}7.2 \\
9.5 \\
5.1 \\
10.3 \\
7.5 \\
6.1 \\
11.7 \\
8.1\end{array}$ & $\begin{array}{r}8.6 \\
9.7 \\
5.2 \\
12.4 \\
7.7 \\
7.09 \\
12.0 \\
8.3\end{array}$ \\
\hline $\begin{array}{l}14 \\
14 \\
14 \\
14 \\
14 \\
14 \\
14 \\
14\end{array}$ & $\begin{array}{r}0 \\
3 \\
6 \\
9 \\
12 \\
15 \\
18 \\
21\end{array}$ & $\begin{array}{l}22.5 \\
21.6 \\
22.0 \\
22.2 \\
23.1 \\
26.9 \\
26.9 \\
24.1\end{array}$ & $\begin{array}{l}21 \cdot 6 \\
21 \cdot 2 \\
21 \cdot 7 \\
21 \cdot 7 \\
21.8 \\
23 \cdot 1 \\
23.6 \\
22.3\end{array}$ & $\begin{array}{l}22.4 \\
21: 4 \\
21: 9 \\
22: 0 \\
22.9 \\
27 \cdot 0 \\
26 \cdot 9 \\
24 \cdot 1\end{array}$ & $\begin{array}{l}21 \cdot 3 \\
20.9 \\
21 \cdot 4 \\
21.4 \\
21 \cdot 3 \\
23.0 \\
23.3 \\
22 \cdot 2\end{array}$ & $\begin{array}{l}22.2 \\
21 \cdot 3 \\
21.8 \\
22.0 \\
22 \cdot 8 \\
27.1 \\
26.9 \\
24.0\end{array}$ & $\begin{array}{l}21.2 \\
20.8 \\
21.4 \\
21.2 \\
21.4 \\
22.9 \\
23.0 \\
22.1\end{array}$ & $\begin{array}{l}22 \cdot 1 \\
21 \cdot 1 \\
21 \cdot 9 \\
22 \cdot 7\end{array}$ & $\begin{array}{l}21 \cdot 2 \\
20 \cdot 8 \\
21 \cdot 2 \\
21.4\end{array}$ & $\begin{array}{l}26.1 \\
26.0 \\
26.1 \\
26.2 \\
26.9 \\
26.4 \\
26.0 \\
25.9\end{array}$ & $\begin{array}{l}3 \\
3 \\
3 \\
3 \\
3 \\
2 \\
3 \\
3\end{array}$ & $\begin{array}{r}4.4 \\
4.6 \\
11.6 \\
13.1 \\
11.7 \\
9.3 \\
7.4 \\
8.0\end{array}$ & $\begin{array}{r}4.9 \\
5.4 \\
12.1 \\
14.1 \\
12.4 \\
10.3 \\
8.0 \\
8.7\end{array}$ & $\begin{array}{r}4.5 \\
5.2 \\
12.4 \\
14.1 \\
13.0 \\
11.4 \\
8.2 \\
8.8\end{array}$ & $\begin{array}{r}4.7 \\
5.3 \\
12.7 \\
14.4 \\
13.3 \\
11.7 \\
8.8 \\
9.0\end{array}$ \\
\hline $\begin{array}{l}15 \\
15 \\
15 \\
15 \\
15 \\
15 \\
15 \\
15\end{array}$ & $\begin{array}{r}0 \\
3 \\
6 \\
9 \\
12 \\
15 \\
18 \\
21\end{array}$ & $\begin{array}{l}23.6 \\
22.9 \\
23.4 \\
25.5 \\
28.5 \\
29.4 \\
27.5 \\
74.9\end{array}$ & $\begin{array}{l}22.6 \\
21.8 \\
22.3 \\
22.5 \\
22.9 \\
23.7 \\
22.6 \\
22.2\end{array}$ & $\begin{array}{l}23.6 \\
22.9 \\
23.5 \\
25.4 \\
28.8 \\
29.6 \\
27.5 \\
24.8\end{array}$ & $\begin{array}{l}22.5 \\
21.7 \\
22.3 \\
22.3 \\
22.9 \\
23.5 \\
22.4 \\
21.9\end{array}$ & $\begin{array}{l}23.5 \\
22.8 \\
23.5 \\
25.4 \\
29.0 \\
29.7 \\
27.4 \\
24.7\end{array}$ & $\begin{array}{l}22.4 \\
21.5 \\
22 \cdot 3 \\
21 \cdot 9 \\
22.7 \\
23 \cdot 2 \\
22 \cdot 3 \\
21.9\end{array}$ & $\begin{array}{l}22 \cdot 8 \\
22 \cdot 2 \\
22 \cdot 9 \\
24 \cdot 8 \\
28 \cdot 4 \\
29 \cdot 3 \\
26 \cdot 9 \\
24 \cdot 3\end{array}$ & & $\begin{array}{l}25.9 \\
25.9 \\
26.4 \\
26.9 \\
27.2 \\
25.6 \\
26.2 \\
26.2\end{array}$ & $\begin{array}{l}2 \\
2 \\
3 \\
3 \\
2 \\
2 \\
2 \\
2\end{array}$ & $\begin{array}{r}7.9 \\
6.4 \\
6.4 \\
11.7 \\
10.7 \\
11.3 \\
10.5 \\
10.4\end{array}$ & $\begin{array}{r}8.7 \\
7.1 \\
6.7 \\
12.7 \\
12.0 \\
12.8 \\
11.8 \\
11.6\end{array}$ & $\begin{array}{r}9.3 \\
7.5 \\
7.0 \\
13.1 \\
13.2 \\
14.2 \\
13.0 \\
12.7\end{array}$ & $\begin{array}{r}9.6 \\
7.8 \\
6.8 \\
13.7 \\
13.6 \\
15.1 \\
13.7 \\
13.3\end{array}$ \\
\hline $\begin{array}{l}16 \\
16 \\
16 \\
16 \\
16 \\
16 \\
16 \\
16\end{array}$ & $\begin{array}{r}0 \\
3 \\
6 \\
9 \\
12 \\
15 \\
18 \\
21\end{array}$ & $\begin{array}{l}23.5 \\
22.3 \\
24.3 \\
28.6 \\
30.8 \\
31.2 \\
29.4 \\
26.6\end{array}$ & $\begin{array}{l}21 \cdot 5 \\
20.7 \\
21.7 \\
22 \cdot 5 \\
22.7 \\
22 \cdot 3 \\
23.5 \\
23.2\end{array}$ & $\begin{array}{l}23.4 \\
22.3 \\
24.4 \\
28.5 \\
31.1 \\
31.6 \\
29.5 \\
26.5\end{array}$ & $\begin{array}{l}21.2 \\
20.7 \\
21.6 \\
22.1 \\
22.1 \\
21.7 \\
23.0 \\
23.1\end{array}$ & $\begin{array}{l}23.2 \\
22.1 \\
24.7 \\
29.1 \\
31.2 \\
31.8 \\
29.8 \\
20.6\end{array}$ & $\begin{array}{l}21.1 \\
20.5 \\
21.5 \\
22.0 \\
22.1 \\
21.7 \\
22.8 \\
22.9\end{array}$ & $\begin{array}{l}22.8 \\
21.7 \\
24.4 \\
28.9 \\
30.0 \\
31.7 \\
29.7 \\
26.4\end{array}$ & & $\begin{array}{l}25.1 \\
26.0 \\
26.6 \\
27.5 \\
28.1 \\
27.7 \\
27.1 \\
27.0\end{array}$ & $\begin{array}{l}2 \\
2 \\
2 \\
2 \\
2 \\
2 \\
2 \\
2\end{array}$ & $\begin{array}{l}7.5 \\
5.7 \\
8.9 \\
7.8 \\
5.7 \\
5.3 \\
4.9 \\
5.0\end{array}$ & $\begin{array}{l}8.2 \\
6.5 \\
9.6 \\
8.7 \\
6.4 \\
7.1 \\
5.4 \\
5.9\end{array}$ & $\begin{array}{r}8.9 \\
6.7 \\
10.9 \\
9.8 \\
7.4 \\
8.2 \\
7.1 \\
6.0\end{array}$ & $\begin{array}{r}9.8 \\
7.0 \\
11.2 \\
10.4 \\
7.8 \\
8.7 \\
7.6 \\
7.4\end{array}$ \\
\hline $\begin{array}{l}17 \\
17 \\
17 \\
17 \\
17 \\
17 \\
17 \\
17\end{array}$ & $\begin{array}{r}0 \\
3 \\
6 \\
9 \\
12 \\
15 \\
18 \\
21\end{array}$ & $\begin{array}{l}24 \cdot 8 \\
23.6 \\
24.3 \\
28.6 \\
31.7 \\
31.9 \\
30.2 \\
27.0\end{array}$ & $\begin{array}{l}22 \cdot 5 \\
21.8 \\
21 \cdot 8 \\
22 \cdot 7 \\
22 \cdot 3 \\
22 \cdot 7 \\
23.4 \\
23.3\end{array}$ & $\begin{array}{l}24.7 \\
23.5 \\
24.5 \\
28.6 \\
28.4 \\
28.5 \\
30.4 \\
26.9\end{array}$ & $\begin{array}{l}22.3 \\
21.6 \\
21.5 \\
22.5 \\
22.2 \\
22.4 \\
23.1 \\
23.1\end{array}$ & $\begin{array}{l}24.6 \\
23.4 \\
24.6 \\
23.8 \\
30.1 \\
32.1 \\
30.5 \\
76.9\end{array}$ & $\begin{array}{l}22.0 \\
21 \\
21.5 \\
22.5 \\
22.0 \\
22.0 \\
22.6 \\
23.1\end{array}$ & $\begin{array}{l}24 \cdot 4 \\
23.1 \\
24: 4 \\
28.5 \\
31.1 \\
32.0 \\
30.6 \\
26.9\end{array}$ & 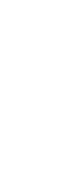 & $\begin{array}{l}26.8 \\
26.5 \\
27.1 \\
28.4 \\
30.0 \\
29.4 \\
28.5 \\
28.5\end{array}$ & $\begin{array}{l}2 \\
2 \\
2 \\
2 \\
2 \\
2 \\
2 \\
2 \\
2\end{array}$ & $\begin{array}{l}6.0 \\
7.0 \\
6.0 \\
3.1 \\
3.4 \\
4.7 \\
3.5 \\
4.02\end{array}$ & $\begin{array}{l}6.3 \\
6.9 \\
5.7 \\
3.4 \\
3.8 \\
5.3 \\
3.4 \\
4.2\end{array}$ & $\begin{array}{l}7.2 \\
8.3 \\
7.0 \\
3.8 \\
4.2 \\
5.0 \\
4.8 \\
5.1\end{array}$ & $\begin{array}{l}8.6 \\
8.8 \\
7.3 \\
5.3\end{array}$ \\
\hline $\begin{array}{l}18 \\
18 \\
18 \\
18 \\
18 \\
18 \\
18 \\
18\end{array}$ & $\begin{array}{r}0 \\
3 \\
6 \\
9 \\
12 \\
15 \\
18 \\
21\end{array}$ & $\begin{array}{l}25.3 \\
24.1 \\
25.5 \\
29.2 \\
32.0 \\
32.2 \\
30.2 \\
28.3\end{array}$ & $\begin{array}{l}21.9 \\
21.0 \\
21.3 \\
22.1 \\
22.2 \\
22.1 \\
23.0 \\
22.6\end{array}$ & $\begin{array}{l}25.2 \\
24: 0 \\
25.6 \\
29.7 \\
31: 9 \\
32.0 \\
30.2 \\
28.6\end{array}$ & $\begin{array}{l}21.7 \\
20.7 \\
21.1 \\
21.8 \\
20.9 \\
22.2 \\
22.8 \\
22.6\end{array}$ & $\begin{array}{l}25.2 \\
23.9 \\
25.6 \\
29.8 \\
31.9 \\
32.4 \\
30.2 \\
28.5\end{array}$ & $\begin{array}{l}21.5 \\
20.6 \\
21.0 \\
21.9 \\
20.6 \\
21.5 \\
22 \cdot 1 \\
22.1\end{array}$ & $\begin{array}{l}25.0 \\
23.8 \\
25.6 \\
29.8 \\
31.9 \\
32.0 \\
30.3 \\
28.4\end{array}$ & $\begin{array}{l}21.4 \\
20.4 \\
21.0 \\
21.5 \\
20.5 \\
21.5 \\
22.0 \\
22.0\end{array}$ & $\begin{array}{l}27.5 \\
26.8 \\
27.6 \\
28.7 \\
30.1 \\
29.5 \\
28.2 \\
27.8\end{array}$ & $\begin{array}{l}2 \\
2 \\
2 \\
2 \\
2 \\
2 \\
2 \\
2\end{array}$ & $\begin{array}{l}6.7 \\
5.6 \\
7.6 \\
4.5 \\
2.3 \\
5.6 \\
6.8 \\
6.4\end{array}$ & $\begin{array}{l}7.0 \\
6.2 \\
7.9 \\
3.4 \\
2.3 \\
6.0 \\
7.8 \\
7.1\end{array}$ & $\begin{array}{l}8.1 \\
6.9 \\
9.3 \\
5.7 \\
2.9 \\
6.7 \\
8.5 \\
7.9\end{array}$ & $\begin{array}{l}8.8 \\
7.6 \\
9.6 \\
6.0 \\
3.8 \\
7.8 \\
9.2 \\
8.6\end{array}$ \\
\hline $\begin{array}{l}19 \\
19\end{array}$ & $\begin{array}{l}0 \\
3\end{array}$ & & & & & & & & & & $\begin{array}{l}2 \\
3\end{array}$ & $\begin{array}{l}4.3 \\
4.4\end{array}$ & 5.2 & $\begin{array}{l}5.0 \\
4.7\end{array}$ & $\begin{array}{l}5.4 \\
5.9\end{array}$ \\
\hline 19 & $\begin{array}{r}6 \\
9 \\
9\end{array}$ & $\begin{array}{l}24.9 \\
78.5\end{array}$ & $\begin{array}{l}23.1 \\
22.7\end{array}$ & $\begin{array}{l}24.5 \\
28.4\end{array}$ & $\begin{array}{l}22 \cdot 6 \\
22 \cdot 4\end{array}$ & $\begin{array}{l}25.0 \\
29.0\end{array}$ & $\begin{array}{l}22.8 \\
2.2 .3\end{array}$ & $\begin{array}{l}24.7 \\
28.7\end{array}$ & & & $\begin{array}{l}3 \\
2\end{array}$ & $\begin{array}{l}3.4 \\
2.0\end{array}$ & $\begin{array}{l}3.3 \\
2.1\end{array}$ & $\begin{array}{l}3.6 \\
2.3\end{array}$ & 4.6 \\
\hline $\begin{array}{l}19 \\
19\end{array}$ & $\begin{array}{l}12 \\
15\end{array}$ & $\begin{array}{l}31.4 \\
32.0\end{array}$ & $\begin{array}{l}22.6 \\
23.5\end{array}$ & $\begin{array}{l}31 \cdot 5 \\
32.2\end{array}$ & $\begin{array}{l}22.4 \\
23.4\end{array}$ & $\begin{array}{l}32.0 \\
32.2\end{array}$ & $\begin{array}{l}22.1 \\
22.6\end{array}$ & $\begin{array}{l}31.5 \\
32.4\end{array}$ & 22.2 & $\begin{array}{r}29 \\
29\end{array}$ & 2 & 2.7 & 3.0 & & \\
\hline $\begin{array}{l}19 \\
19\end{array}$ & $\begin{array}{l}18 \\
21\end{array}$ & $\begin{array}{l}30.4 \\
27.4\end{array}$ & $\begin{array}{l}24.5 \\
24.3\end{array}$ & $\begin{array}{l}30.5 \\
27.4\end{array}$ & $\begin{array}{l}24 \cdot 2 \\
23.8\end{array}$ & $\begin{array}{l}30.7 \\
27.4\end{array}$ & $\begin{array}{l}24 \cdot 4 \\
23 \cdot 6\end{array}$ & $\begin{array}{l}30.9 \\
27.4\end{array}$ & $\begin{array}{l}23.4 \\
23.5\end{array}$ & $\begin{array}{l}28.2 \\
27.2\end{array}$ & $\begin{array}{l}3 \\
3 \\
3\end{array}$ & $\begin{array}{l}7.4 \\
5.2 \\
5.9\end{array}$ & $\begin{array}{l}8.00 \\
8.2 \\
7.0\end{array}$ & $\begin{array}{l}8.5 \\
6.8 \\
6.9\end{array}$ & $\begin{array}{l}8.8 \\
8: 0 \\
7.6\end{array}$ \\
\hline $\begin{array}{l}20 \\
20 \\
20 \\
20 \\
20 \\
20 \\
20 \\
20\end{array}$ & $\begin{array}{r}0 \\
3 \\
6 \\
9 \\
12 \\
15 \\
18 \\
21\end{array}$ & $\begin{array}{l}26 \cdot 1 \\
24.6 \\
25.6 \\
29.0 \\
31.8 \\
32.4 \\
30.0 \\
28.7\end{array}$ & $\begin{array}{l}23.2 \\
22.9 \\
23.0 \\
23.6 \\
23.1 \\
23.3 \\
23.2 \\
23.7\end{array}$ & $\begin{array}{l}26 \cdot 0 \\
24 \cdot 6 \\
25 \cdot 7 \\
29 \cdot 3 \\
32 \cdot 0 \\
32.7 \\
31.1 \\
28.8\end{array}$ & $\begin{array}{l}23.0 \\
22.6 \\
23.0 \\
23.7 \\
23.2 \\
23.5 \\
23.4 \\
23.6\end{array}$ & $\begin{array}{l}25.9 \\
24.6 \\
25.8 \\
29.5 \\
32.5 \\
33.0 \\
31.3 \\
28.7\end{array}$ & $\begin{array}{l}22.7 \\
22.4 \\
22.7 \\
23.1 \\
22.4 \\
22.8 \\
22.5 \\
23.1\end{array}$ & $\begin{array}{l}25.8 \\
24.3 \\
25.7 \\
29.7 \\
32.4 \\
33.0 \\
31.5 \\
28.6\end{array}$ & $\begin{array}{l}22.7 \\
22.3 \\
22.8 \\
23.2 \\
23.3 \\
22.7 \\
22.5 \\
23.0\end{array}$ & $\begin{array}{l}27.4 \\
27.0 \\
27.5 \\
28.1 \\
28.4 \\
27.7 \\
27.5 \\
27.4\end{array}$ & $\begin{array}{l}2 \\
2 \\
2 \\
2 \\
2 \\
2 \\
2 \\
2\end{array}$ & $\begin{array}{r}7.4 \\
8.6 \\
10.2 \\
11.3 \\
10.8 \\
12.5 \\
9.0 \\
13.7\end{array}$ & $\begin{array}{r}8.2 \\
10.1 \\
12.2 \\
13.0 \\
12.5 \\
14.3 \\
10.2 \\
15.2\end{array}$ & $\begin{array}{r}8.9 \\
10.3 \\
12.5 \\
14.6 \\
13.9 \\
16.2 \\
11.6 \\
16.7\end{array}$ & $\begin{array}{r}9.4 \\
10.8 \\
13.0 \\
15.1 \\
14.6 \\
17.1 \\
12.5 \\
17.5\end{array}$ \\
\hline
\end{tabular}


Table 10. - Three-hour averages of air and water-surface temperatures and wind directlons and speed, April 1950-August 1951, Lake Hefner-Continued

STATION I

THREE-HOURLY AVERAGES

JULY, 2951

\begin{tabular}{|c|c|c|c|c|c|c|c|c|c|c|c|c|c|c|c|}
\hline \multirow{4}{*}{ 总 } & \multirow{4}{*}{ 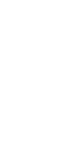 } & \multicolumn{8}{|c|}{ Average air temperature $\left({ }^{\circ} \mathrm{C}\right)$ at indicated height } & \multirow{4}{*}{$\begin{array}{l}\text { Average } \\
\text { water- } \\
\text { surface } \\
\text { tempera- } \\
\text { ture } \\
\text { ("C) }\end{array}$} & \multirow{4}{*}{$\begin{array}{c}\text { Average } \\
\text { wind } \\
\text { direction } \\
\text { (coded) }\end{array}$} & \multirow{2}{*}{\multicolumn{4}{|c|}{$\begin{array}{l}\text { Average wind speed (knots) } \\
\text { at indicated height }\end{array}$}} \\
\hline & & \multirow{2}{*}{\multicolumn{2}{|c|}{$\begin{array}{c}2 \\
\text { meters }\end{array}$}} & \multirow{2}{*}{\multicolumn{2}{|c|}{$\begin{array}{c}4 \\
\text { meters }\end{array}$}} & \multirow{2}{*}{\multicolumn{2}{|c|}{$\begin{array}{c}8 \\
\text { meters }\end{array}$}} & \multirow{2}{*}{\multicolumn{2}{|c|}{$\begin{array}{c}16 \\
\text { meters }\end{array}$}} & & & & & & \\
\hline & & & & & & & & & & & & 2 & 4 & 8 & 16 \\
\hline & & $\begin{array}{l}\text { Dry } \\
\text { bulb }\end{array}$ & $\begin{array}{l}\text { Wet } \\
\text { bulb }\end{array}$ & $\begin{array}{l}\text { Dry } \\
\text { butb }\end{array}$ & $\begin{array}{l}\text { Wet } \\
\text { bulb }\end{array}$ & $\begin{array}{l}\text { Dry } \\
\text { bulb }\end{array}$ & $\begin{array}{l}\text { Wet } \\
\text { bulb }\end{array}$ & $\begin{array}{l}\text { Dry } \\
\text { bulb }\end{array}$ & $\begin{array}{l}\text { Wet } \\
\text { bulb }\end{array}$ & & & meters & meters & meters & meters \\
\hline $\begin{array}{l}21 \\
21 \\
21 \\
21 \\
21 \\
21 \\
21 \\
21\end{array}$ & $\begin{array}{r}0 \\
3 \\
6 \\
9 \\
12 \\
15 \\
18 \\
21\end{array}$ & $\begin{array}{l}26.8 \\
25.9 \\
27.5 \\
31.2 \\
33.0 \\
33.4 \\
31.9 \\
? 9.1\end{array}$ & $\begin{array}{l}23.1 \\
22.6 \\
22.1 \\
23.0 \\
23.5 \\
23.7 \\
23.6 \\
22.6\end{array}$ & $\begin{array}{l}26.7 \\
25.9 \\
27.8 \\
31.6 \\
33.8 \\
33.9 \\
32.9 \\
29.3\end{array}$ & $\begin{array}{l}23.0 \\
22.5 \\
21.8 \\
22.7 \\
23.2 \\
23.4 \\
23.3 \\
37.1\end{array}$ & $\begin{array}{l}26.7 \\
25.8 \\
27.9 \\
31.8 \\
33.8 \\
34.1 \\
32.3 \\
79.4\end{array}$ & $\begin{array}{l}22.5 \\
22.0 \\
21.6 \\
22.5 \\
23.1 \\
23.2 \\
23.1 \\
22.2\end{array}$ & $\begin{array}{l}26.6 \\
25.8 \\
28.0 \\
32.0 \\
34.2 \\
34.4 \\
32.3 \\
39.3\end{array}$ & $\begin{array}{l}22.4 \\
21.8 \\
21.7 \\
22.7 \\
23.3 \\
23.5 \\
23.1 \\
22.1\end{array}$ & $\begin{array}{l}27.0 \\
27.0 \\
27.2 \\
23.1 \\
28.3 \\
27.7 \\
27.3 \\
27.0\end{array}$ & $\begin{array}{l}2 \\
2 \\
2 \\
2 \\
2 \\
2 \\
2 \\
2 \\
2\end{array}$ & $\begin{array}{l}13.8 \\
14.1 \\
15.8 \\
15.9 \\
14.9 \\
14.0 \\
12.3 \\
12.8\end{array}$ & $\begin{array}{l}15.5 \\
15.9 \\
17.8 \\
17.9 \\
16.9 \\
16.1 \\
14.1 \\
14.4\end{array}$ & $\begin{array}{l}16.6 \\
17.6 \\
20.0 \\
20.4 \\
19.4 \\
18.4 \\
15.8 \\
15.9\end{array}$ & $\begin{array}{l}17.8 \\
18.5 \\
20.7 \\
21.1 \\
20.1 \\
19.3 \\
16.9 \\
10.7\end{array}$ \\
\hline $\begin{array}{l}22 \\
22 \\
22 \\
22 \\
22 \\
22 \\
22 \\
22\end{array}$ & $\begin{array}{r}0 \\
3 \\
6 \\
0 \\
12 \\
15 \\
18 \\
21\end{array}$ & $\begin{array}{l}26.8 \\
25.6 \\
26.3 \\
29.6 \\
30.8\end{array}$ & $\begin{array}{l}21.9 \\
21.6 \\
22.0 \\
2365 \\
24.0\end{array}$ & $\begin{array}{l}26.8 \\
25.5 \\
26.3 \\
20.9 \\
31.1\end{array}$ & $\begin{array}{l}? 1.5 \\
21.0 \\
? 1.8 \\
23.2 \\
23.8\end{array}$ & $\begin{array}{l}26.3 \\
25.5 \\
26.4 \\
30.0\end{array}$ & $\begin{array}{l}21.4 \\
20.9 \\
21.8 \\
23.2\end{array}$ & $\begin{array}{l}25.7 \\
25.3 \\
26.6 \\
30.1\end{array}$ & $\begin{array}{l}21.4 \\
21.0 \\
22.0 \\
23.4\end{array}$ & $\begin{array}{l}26.9 \\
26.7 \\
27.5 \\
28.6\end{array}$ & $\begin{array}{l}2 \\
2 \\
2 \\
2 \\
2 \\
2 \\
2 \\
2 \\
2\end{array}$ & $\begin{array}{r}10.2 \\
9.8 \\
9.3 \\
9.5 \\
8.9 \\
7.4 \\
9.8 \\
8.6\end{array}$ & $\begin{array}{r}11.4 \\
11.0 \\
10.4 \\
10.7 \\
10.3 \\
8.5 \\
11.1 \\
9.7\end{array}$ & $\begin{array}{r}12.6 \\
12.1 \\
11.6 \\
12.1 \\
11.6 \\
9.7 \\
11.4 \\
10.8\end{array}$ & $\begin{array}{l}13.3 \\
12.7 \\
12.0 \\
12.5 \\
12.2 \\
10.2 \\
13.1 \\
11.7\end{array}$ \\
\hline $\begin{array}{l}23 \\
23\end{array}$ & $\begin{array}{l}0 \\
3\end{array}$ & & & & & & & & & & $\begin{array}{l}2 \\
3\end{array}$ & $\begin{array}{l}7.4 \\
8.3\end{array}$ & $\begin{array}{l}8.2 \\
9.5\end{array}$ & $\begin{array}{r}9.1 \\
10.1\end{array}$ & $\begin{array}{r}9.7 \\
10.7\end{array}$ \\
\hline 23 & 6 & 24.2 & 22.1 & 23.7 & 2.1 .2 & 23.6 & 21.2 & 23.3 & 21.0 & 27.8 & 3 & 10.5 & 11.9 & $12 \cdot 1$ & 13.0 \\
\hline 23 & 9 & 27.2 & 2269 & 27.2 & 22.6 & $27 \cdot 3$ & 22.7 & 27.2 & 27.8 & 28.7 & 3 & $5 \cdot 3$ & 5.6 & & 6.4 \\
\hline $\begin{array}{l}23 \\
33\end{array}$ & $\begin{array}{l}12 \\
15\end{array}$ & $\begin{array}{l}30.4 \\
76.9\end{array}$ & $\begin{array}{l}23.8 \\
23.1\end{array}$ & $\begin{array}{l}30.6 \\
27.1\end{array}$ & $\begin{aligned} 23.4 \\
32.8\end{aligned}$ & $\begin{array}{l}30.7 \\
27.1\end{array}$ & $\begin{array}{l}23.4 \\
22.7\end{array}$ & $\begin{array}{l}30.1 \\
26.5\end{array}$ & $\begin{array}{l}2.3 .5 \\
2.2 .6\end{array}$ & $\begin{array}{l}29.4 \\
27.6\end{array}$ & 3 & $\begin{array}{l}4.6 \\
8.2\end{array}$ & 5. & 6.0 & $\begin{array}{r}8.1 \\
10.0\end{array}$ \\
\hline 33 & 13 & 2409 & 23.1 & 3.408 & $? ? .9$ & 34.6 & 22.7 & 24.2 & 22.06 & 27.1 & 3 & $\begin{array}{l}8.2 \\
4.5\end{array}$ & $\begin{array}{l}9.1 \\
4 \cdot 7\end{array}$ & $\begin{array}{l}9.3 \\
5.0\end{array}$ & 4.9 \\
\hline 23 & 21 & 34.3 & $2 ? 69$ & 24.2 & 32.7 & 74.2 & 22.6 & 24.1 & 22.7 & 27.0 & 2 & 4.1 & $4 \cdot 5$ & 408 & 409 \\
\hline $\begin{array}{l}24 \\
24 \\
24 \\
24 \\
24 \\
24 \\
24 \\
24\end{array}$ & $\begin{array}{r}0 \\
3 \\
6 \\
9 \\
12 \\
15 \\
19 \\
21\end{array}$ & $\begin{array}{l}22.7 \\
22.0 \\
22.7 \\
24.6 \\
27.3 \\
30.7 \\
28.0 \\
23.9\end{array}$ & $\begin{array}{l}22.1 \\
21.2 \\
21.4 \\
22.6 \\
23.0 \\
23.6 \\
23.5 \\
22.5\end{array}$ & $\begin{array}{l}32.5 \\
32.0 \\
22.6 \\
24.4 \\
27.0 \\
29.7 \\
38.1 \\
23.9\end{array}$ & $\begin{array}{l}21 \cdot 7 \\
20: 9 \\
21 * 2 \\
22: 3 \\
22: 8 \\
23.1 \\
23: 1 \\
21.9\end{array}$ & $\begin{array}{l}22.3 \\
21.8 \\
22.5 \\
24.3 \\
27.6 \\
29.7 \\
28.0 \\
23.5\end{array}$ & $\begin{array}{l}21 \cdot ? \\
20.6 \\
21 \cdot 3 \\
22 \bullet 2 \\
22 \cdot 8 \\
22 \cdot 7 \\
22 \bullet 9 \\
21 \bullet 9\end{array}$ & $\begin{array}{l}? 2.1 \\
? 1.7 \\
22.4 \\
24.2 \\
27.2 \\
29.3 \\
? 7.8\end{array}$ & $\begin{array}{l}21 \cdot 3 \\
21.1 \\
21 \cdot 3 \\
22.4 \\
23.1 \\
23.2 \\
23.2 \\
22.8\end{array}$ & $\begin{array}{l}27.0 \\
27.0 \\
27.0 \\
27.3 \\
29.1 \\
29.4 \\
28.5 \\
27.4\end{array}$ & $\begin{array}{l}3 \\
3 \\
3 \\
3 \\
3 \\
3 \\
3 \\
3\end{array}$ & $\begin{array}{r}7.3 \\
4.9 \\
2.8 \\
4.8 \\
3.8 \\
3.4 \\
5.9 \\
11.9\end{array}$ & $\begin{array}{r}8.4 \\
5.1 \\
2.9 \\
5.0 \\
3.1 \\
3.6 \\
6.2 \\
12.7\end{array}$ & $\begin{array}{r}8.9 \\
5.2 \\
3.0 \\
5.1 \\
3.5 \\
3.9 \\
6.5 \\
12.8\end{array}$ & $\begin{array}{r}9.2 \\
5.2 \\
3.1 \\
5.2 \\
4.0 \\
4.0 \\
6.7 \\
13.9\end{array}$ \\
\hline $\begin{array}{l}25 \\
25 \\
25 \\
25 \\
25 \\
25 \\
25 \\
25\end{array}$ & $\begin{array}{r}0 \\
3 \\
6 \\
9 \\
12 \\
15 \\
18 \\
71\end{array}$ & $\begin{array}{l}22.3 \\
22.7 \\
23.2 \\
26.9 \\
29.7 \\
30.2 \\
29.2 \\
? 6.6\end{array}$ & $\begin{array}{l}21.6 \\
22.0 \\
22.5 \\
23.1 \\
22.5 \\
23.4 \\
24.2 \\
23.0\end{array}$ & $\begin{array}{l}22.5 \\
22.6 \\
23.2 \\
26.7 \\
29.6 \\
30.1 \\
29.2 \\
26.5\end{array}$ & $\begin{array}{l}21.4 \\
21.8 \\
22.3 \\
22.9 \\
22.6 \\
23.0 \\
23.9 \\
23.6\end{array}$ & $\begin{array}{l}22.3 \\
22.6 \\
23.3 \\
26.9 \\
29.5 \\
30.1 \\
29.1 \\
? 6.5\end{array}$ & $\begin{array}{l}20.6 \\
21 \cdot 1 \\
22: 3 \\
22: 8 \\
22: 3 \\
22.9 \\
23.7 \\
23.6\end{array}$ & & & $\begin{array}{l}26.9 \\
26.8 \\
27.4 \\
29.1 \\
30.0 \\
29.5 \\
28.5 \\
27.5\end{array}$ & $\begin{array}{l}2 \\
3 \\
2 \\
2 \\
2 \\
3 \\
3 \\
3\end{array}$ & $\begin{array}{l}2.5 \\
2.7 \\
4.6 \\
3.4 \\
3.5 \\
6.2 \\
5.8 \\
5.3\end{array}$ & $\begin{array}{l}2.6 \\
2.5 \\
5.0 \\
3.7 \\
3.8 \\
6.7 \\
6.1 \\
6.6\end{array}$ & $\begin{array}{l}2.6 \\
2.7 \\
5.3 \\
3.9 \\
4.2 \\
6.8 \\
6.2 \\
7.1\end{array}$ & $\begin{array}{l}2.6 \\
2.7 \\
5.3 \\
4.0 \\
4.2 \\
7.5 \\
6.9 \\
7.5\end{array}$ \\
\hline $\begin{array}{l}26 \\
26 \\
26 \\
26 \\
26 \\
26 \\
26 \\
26\end{array}$ & $\begin{array}{r}0 \\
3 \\
6 \\
9 \\
12 \\
15 \\
18 \\
21\end{array}$ & $\begin{array}{l}26.0 \\
25.0 \\
25.6 \\
26.9\end{array}$ & $\begin{array}{l}23.5 \\
22.8 \\
22.6 \\
23.1\end{array}$ & $\begin{array}{l}25.9 \\
24.9 \\
25.5 \\
27.1\end{array}$ & $\begin{array}{l}23.3 \\
22.6 \\
22.4 \\
23.0\end{array}$ & $\begin{array}{l}25 \cdot 8 \\
24.9 \\
25.5 \\
27.3\end{array}$ & $\begin{array}{l}23.1 \\
22.4 \\
22.3 \\
23.1\end{array}$ & & & $\begin{array}{l}27 \cdot 2 \\
27 \cdot 1 \\
27 \cdot 3 \\
27 \cdot 7\end{array}$ & $\begin{array}{l}2 \\
2 \\
2 \\
2 \\
2 \\
2 \\
2 \\
2 \\
2\end{array}$ & $\begin{array}{r}7.6 \\
8.1 \\
8.7 \\
6.6 \\
7.2 \\
10.2 \\
11.9 \\
9.7\end{array}$ & $\begin{array}{r}8.4 \\
8.8 \\
9.7 \\
7.5 \\
7.9 \\
11.1 \\
12.6 \\
10.4\end{array}$ & $\begin{array}{r}9.1 \\
9.5 \\
10.6 \\
8.4 \\
6.5 \\
12.1 \\
12.2 \\
11.1\end{array}$ & $\begin{array}{r}9.5 \\
9.8 \\
10.8 \\
8.7 \\
8.9 \\
12.3 \\
13.5 \\
11.3\end{array}$ \\
\hline $\begin{array}{l}27 \\
27 \\
27 \\
27 \\
27 \\
27 \\
27 \\
27\end{array}$ & $\begin{array}{r}0 \\
3 \\
6 \\
9 \\
12 \\
15 \\
18 \\
21\end{array}$ & $\begin{array}{l}24.0 \\
29.2 \\
32.8 \\
31.8 \\
29.4 \\
26.9\end{array}$ & $\begin{array}{l}22.2 \\
23.8 \\
24.8 \\
24.7 \\
25.3 \\
23.8\end{array}$ & $\begin{array}{l}24.1 \\
28.8 \\
32.5 \\
31.4 \\
29.4 \\
25.8\end{array}$ & $\begin{array}{l}22 \cdot 1 \\
23 \cdot 3 \\
24 \cdot 0 \\
24 \cdot 0 \\
24 \cdot 6 \\
23.5\end{array}$ & $\begin{array}{l}24 \cdot 3 \\
28.9 \\
32.2 \\
31.4 \\
29.4 \\
26.7\end{array}$ & $\begin{array}{l}22.0 \\
23.2 \\
23.8 \\
23.7 \\
24.2 \\
23.3\end{array}$ & & & $\begin{array}{l}27.4 \\
29.0 \\
30.3 \\
30.2 \\
23.8 \\
28.6\end{array}$ & $\begin{array}{l}2 \\
2 \\
2 \\
2 \\
3 \\
3 \\
3 \\
2\end{array}$ & $\begin{array}{l}9.0 \\
8.7 \\
3.5 \\
1.3 \\
2.1 \\
8.0 \\
6.0 \\
5.1\end{array}$ & $\begin{array}{l}9.7 \\
9.8 \\
3.7 \\
1.4 \\
2.3 \\
8.3 \\
7.4 \\
5.4\end{array}$ & $\begin{array}{r}10.3 \\
10.8 \\
4.0 \\
1.4 \\
2.5 \\
3.1 \\
7.8 \\
5.8\end{array}$ & $\begin{array}{r}10.5 \\
11.1 \\
4.7 \\
1.3 \\
2.5 \\
9.0 \\
8.4 \\
6.2\end{array}$ \\
\hline $\begin{array}{l}28 \\
28 \\
28 \\
28 \\
28 \\
28 \\
28 \\
28\end{array}$ & $\begin{array}{r}0 \\
3 \\
6 \\
9 \\
12 \\
15 \\
18 \\
21\end{array}$ & $\begin{array}{l}25.8 \\
24.5 \\
25.4 \\
29.6\end{array}$ & $\begin{array}{l}23.4 \\
22.9 \\
23.1 \\
23.7\end{array}$ & $\begin{array}{l}25.7 \\
24.5 \\
25.4 \\
30.0\end{array}$ & $\begin{array}{l}23.1 \\
22.7 \\
22.8 \\
23.6\end{array}$ & $\begin{array}{l}25.6 \\
74.4 \\
25.7 \\
30.7\end{array}$ & $\begin{array}{l}22.9 \\
22.4 \\
22.0 \\
23.3\end{array}$ & & & $\begin{array}{l}28.5 \\
28.1 \\
25.4 \\
30.3\end{array}$ & $\begin{array}{l}2 \\
2 \\
2 \\
2 \\
3 \\
3 \\
3 \\
3\end{array}$ & $\begin{array}{l}3.2 \\
2.8 \\
3.1 \\
1.3 \\
4.3 \\
6.8 \\
3.8 \\
6.4\end{array}$ & $\begin{array}{l}3.4 \\
3.1 \\
3.4 \\
1.5 \\
4.6 \\
7.4 \\
4.1 \\
6.6\end{array}$ & $\begin{array}{l}3.6 \\
3.3 \\
3.5 \\
1.4 \\
4.8 \\
7.7 \\
4.4 \\
6.7\end{array}$ & $\begin{array}{l}3.6 \\
3.5 \\
3.5 \\
1.6 \\
5.0 \\
8.3 \\
4.9 \\
7.8\end{array}$ \\
\hline $\begin{array}{l}29 \\
29 \\
29 \\
29 \\
29 \\
29 \\
29 \\
29\end{array}$ & $\begin{array}{r}0 \\
3 \\
6 \\
9 \\
12 \\
15 \\
18 \\
21\end{array}$ & & & & & & & & & & $\begin{array}{l}3 \\
3 \\
3 \\
3 \\
3 \\
3 \\
3 \\
3\end{array}$ & $\begin{array}{l}4.7 \\
3.0 \\
4.5 \\
3.7 \\
5.8 \\
6.0 \\
5.5 \\
5.4\end{array}$ & $\begin{array}{l}4.9 \\
3.0 \\
4.4 \\
3.8 \\
6.1 \\
6.3 \\
5.8 \\
5.5\end{array}$ & $\begin{array}{l}4.9 \\
3.0 \\
4.5 \\
3.9 \\
6.3 \\
5.8\end{array}$ & $\begin{array}{l}5.2 \\
3.2 \\
4.5 \\
3.9 \\
5.6 \\
7.0 \\
6.9 \\
6.3\end{array}$ \\
\hline $\begin{array}{l}30 \\
30\end{array}$ & $\begin{array}{l}0 \\
3\end{array}$ & & & & & & & & & & $\begin{array}{l}3 \\
2\end{array}$ & $\begin{array}{l}5.7 \\
7.0\end{array}$ & $\begin{array}{l}7.0 \\
7.4\end{array}$ & $\begin{array}{l}7.9 \\
8.0\end{array}$ & $\begin{array}{l}7.7 \\
8.4\end{array}$ \\
\hline 30 & 6 & 26.3 & 23.2 & 26.3 & 23.0 & 26.2 & 22.9 & 25 & 22 . & 28 & 2 & 8.5 & 9.4 & 10.3 & 10.5 \\
\hline 30 & 9 & 28.4 & 230 & & & 23. & 23 & & & & 2 & & & & \\
\hline 30 & 12 & 30. & 23. & 29.0 & 23. & 30.1 & 23 & 30. & 23. & & 2 & & & & \\
\hline 30 & 15 & 32.1 & 23.1 & 31.6 & 22.8 & 31.6 & 22.8 & 31.7 & 22.5 & 30.1 & 3 & & & 4.7 & \\
\hline $\begin{array}{l}30 \\
30\end{array}$ & $\begin{array}{l}18 \\
21\end{array}$ & $\begin{array}{l}30.3 \\
27.3\end{array}$ & $\begin{array}{l}24 \cdot 2 \\
23.8\end{array}$ & $\begin{array}{l}30.2 \\
27.3\end{array}$ & $\begin{array}{l}23.6 \\
23.5\end{array}$ & $\begin{array}{l}30.2 \\
27.2\end{array}$ & $\begin{array}{l}23,3 \\
23,2\end{array}$ & $\begin{array}{l}30.3 \\
27.1\end{array}$ & $\begin{array}{l}23.1 \\
22.9\end{array}$ & $\begin{array}{l}29.7 \\
29.0\end{array}$ & $\begin{array}{l}3 \\
3\end{array}$ & $\begin{array}{l}5.2 \\
6.0\end{array}$ & & $\begin{array}{l}5.8 \\
6.6\end{array}$ & $\begin{array}{l}6.4 \\
7.2\end{array}$ \\
\hline 31 & 0 & $26 . ?$ & 22.5 & $26 \cdot 2$ & 22. & 26.1 & 210 & 26. & 220 & & 2 & & & & \\
\hline 31 & 3 & 24.7 & 21.7 & 34.6 & 21.4 & 24.6 & $21 \cdot 2$ & $\begin{array}{l}20.0 \\
24.4\end{array}$ & $\begin{array}{l}21.0 \\
21.2\end{array}$ & & 2 & $\begin{array}{l}2.4 \\
5.3\end{array}$ & 5. & & \\
\hline 31 & 6 & $25 \cdot 5$ & 22.0 & $25 p 5$ & 21.9 & 25.5 & 21.7 & 35.5 & 21.7 & 28. & 2 & $6+2$ & & 7. & \\
\hline 31 & 9 & $27 \cdot 1$ & 23.0 & 27.0 & 22.6 & $26 . \varepsilon$ & 22.4 & 26.7 & 22.3 & 28.6 & 2 & $8 \times 3$ & & 9.6 & 10.2 \\
\hline 31 & 12 & 25.7 & 23.6 & 25,5 & 20.7 & 25.4 & $22 \cdot 3$ & 25.4 & 23.3 & & 3 & 566 & & 7.5 & \\
\hline 31 & 15 & 27.5 & & 26.8 & & & 28.7 & 26.7 & 22.7 & & 3 & 5.5 & & 6. & 6.7 \\
\hline $\begin{array}{l}31 \\
31\end{array}$ & $\begin{array}{l}28 \\
21\end{array}$ & $\begin{array}{l}26.4 \\
24.7\end{array}$ & $\begin{array}{l}23.7 \\
23.0\end{array}$ & 26.3 & 23,3 & $? 6.2$ & $? \cdot 2$ & 20.1 & 23.1 & $\begin{array}{l}28.2 \\
280\end{array}$ & 3 & 406 & 40 & 40 & 4.8 \\
\hline & & & & & 700 & 74.01 & & 34.6 & $2 ? 2.4$ & & 3 & 3.2 & 3.3 & 3.3 & 384 \\
\hline
\end{tabular}


TABLE 10 Table 10. - Three-hour averages of air and water-surface temperatures and wind directions and speed, April 1950-August

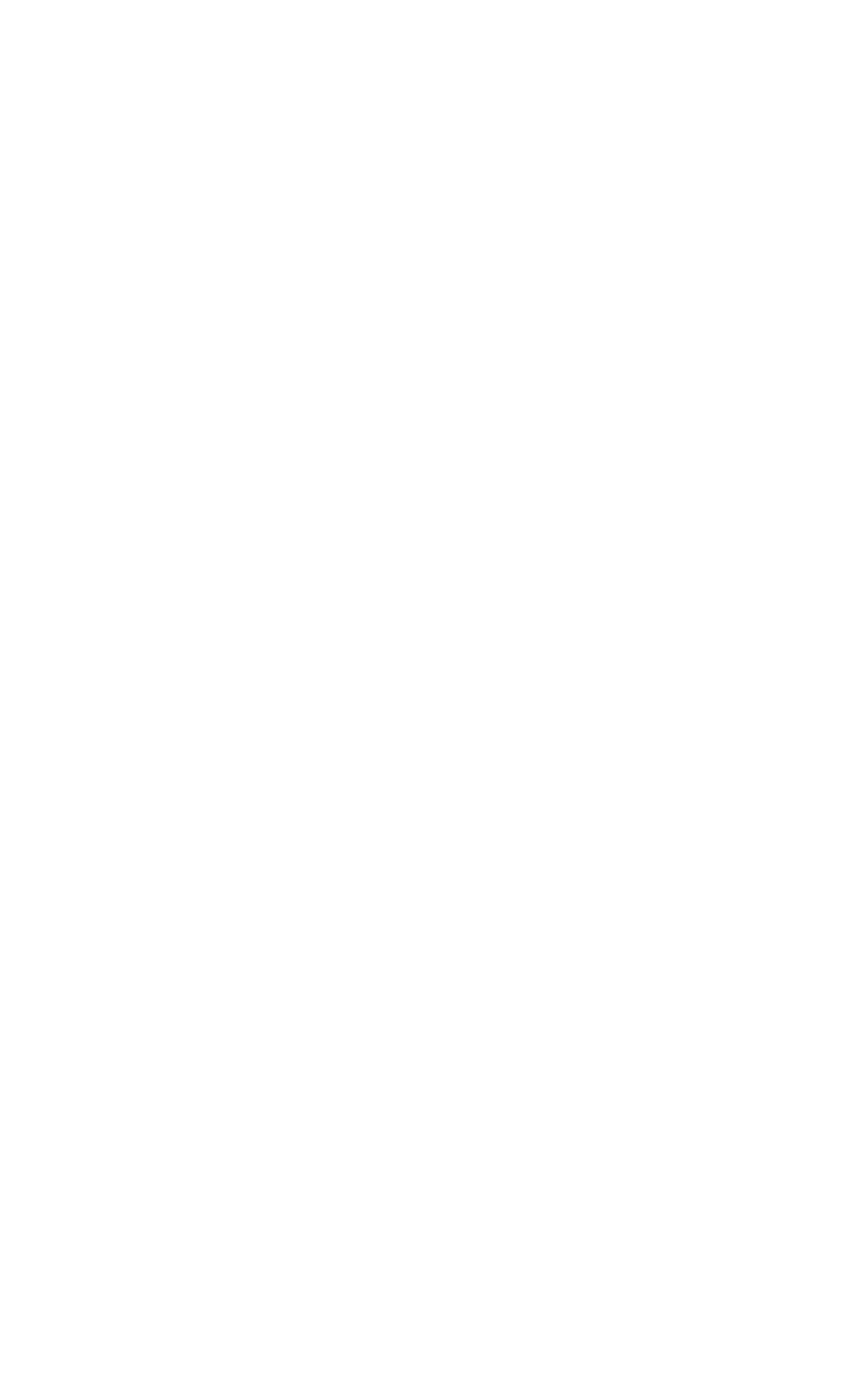




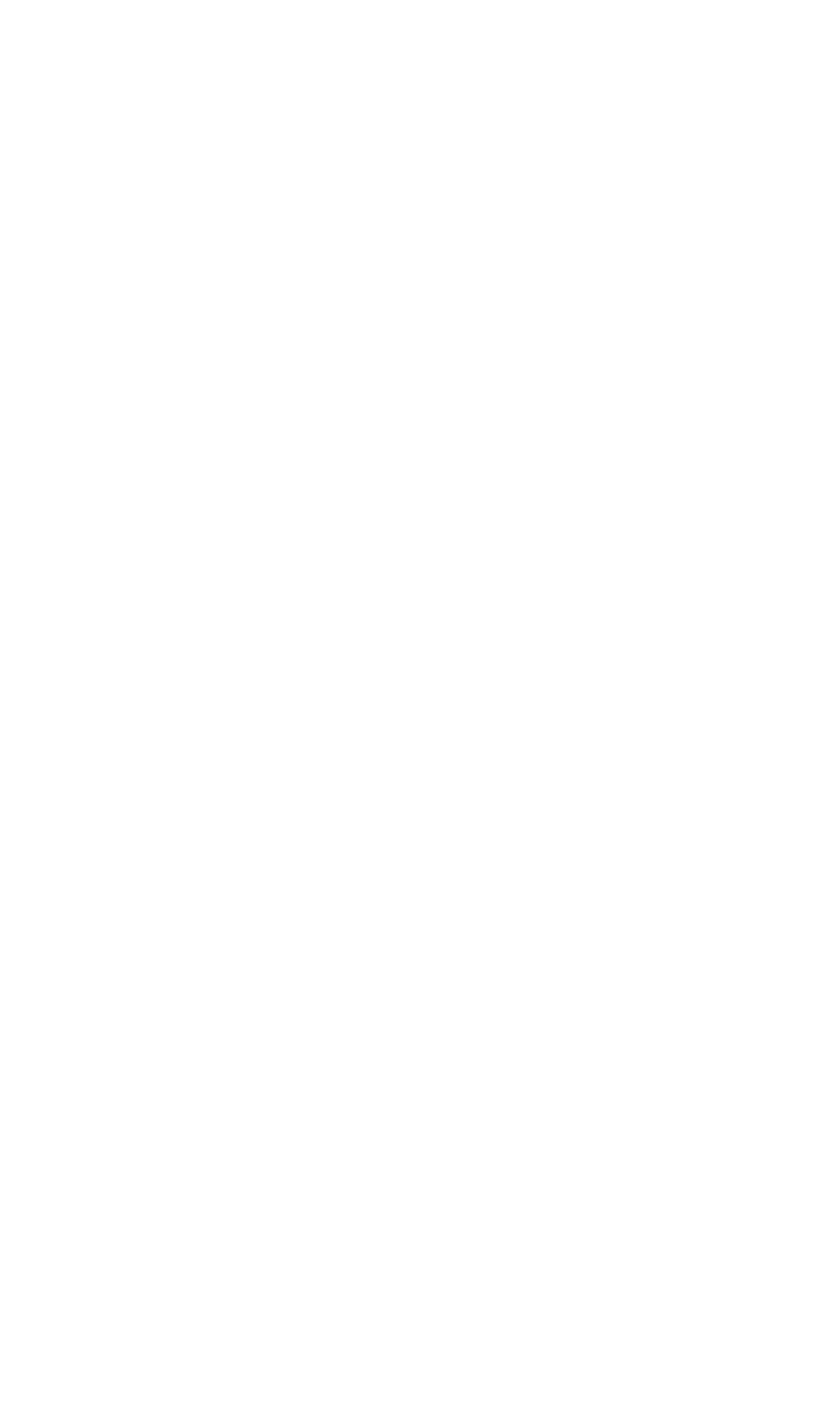


TABLE 10

Table 10. - Three-hour averages of air and water-surface temperatures and wind directions and speed, April 1950-August 951, Lake Hefner-Continued

STATION 1

THREE-HOURLY AVERAGES

AUGUST, 1951

\begin{tabular}{|c|c|c|c|c|c|c|c|c|c|c|c|c|c|c|c|}
\hline \multirow{4}{*}{ 解 } & \multirow{4}{*}{ 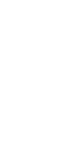 } & \multicolumn{8}{|c|}{ Average air temperature $\left({ }^{\circ} \mathrm{C}\right)$ at indicated height } & \multirow{4}{*}{$\begin{array}{c}\text { Average } \\
\text { water- } \\
\text { surface } \\
\text { tempera- } \\
\text { ture } \\
\left({ }^{\circ} \mathrm{C}\right)\end{array}$} & \multirow{4}{*}{$\begin{array}{c}\text { Average } \\
\text { wind } \\
\text { direction } \\
\text { (coded) }\end{array}$} & \multirow{2}{*}{\multicolumn{4}{|c|}{$\begin{array}{l}\text { Average wind speed (knots) } \\
\text { at indicated height }\end{array}$}} \\
\hline & & \multirow{2}{*}{\multicolumn{2}{|c|}{$\begin{array}{c}2 \\
\text { meters }\end{array}$}} & \multirow{2}{*}{\multicolumn{2}{|c|}{$\begin{array}{c}4 \\
\text { meters }\end{array}$}} & \multirow{2}{*}{\multicolumn{2}{|c|}{$\begin{array}{c}8 \\
\text { meters }\end{array}$}} & \multirow{2}{*}{\multicolumn{2}{|c|}{$\begin{array}{c}16 \\
\text { meters }\end{array}$}} & & & & & & \\
\hline & & & & & & & & & & & & 2 & 4 & 8 & 16 \\
\hline & & $\begin{array}{l}\text { Dry } \\
\text { bulb }\end{array}$ & $\begin{array}{l}\text { Wet } \\
\text { bulb }\end{array}$ & $\begin{array}{l}\text { Dry } \\
\text { bulb }\end{array}$ & $\begin{array}{l}\text { Wet } \\
\text { bulb }\end{array}$ & $\begin{array}{l}\text { Dry } \\
\text { bulb }\end{array}$ & $\begin{array}{l}\text { Wet } \\
\text { bulb }\end{array}$ & $\begin{array}{l}\text { Dry } \\
\text { bulb }\end{array}$ & $\begin{array}{l}\text { Wet } \\
\text { bulb }\end{array}$ & & & meters & meters & meters & meters \\
\hline $\begin{array}{l}21 \\
21 \\
21 \\
21 \\
21 \\
21 \\
21 \\
21\end{array}$ & $\begin{array}{r}0 \\
3 \\
6 \\
9 \\
12 \\
15 \\
18 \\
21\end{array}$ & $\begin{array}{l}25.9 \\
24: 2 \\
21: 7 \\
21 \cdot 3 \\
23.0 \\
24 \cdot 3 \\
22.5 \\
21.1\end{array}$ & $\begin{array}{l}21.5 \\
21.7 \\
21.2 \\
20.9 \\
21 \cdot 7 \\
22.1 \\
20.7 \\
19.1\end{array}$ & $\begin{array}{l}25.9 \\
24.0 \\
21.5 \\
21.2 \\
22.4 \\
23.5 \\
22.1 \\
20.8\end{array}$ & $\begin{array}{l}21.02 \\
21.05 \\
20.3 \\
20.2 \\
21.0 \\
21.04 \\
19.8 \\
18.6\end{array}$ & $\begin{array}{l}25.9 \\
24: 0 \\
21.1 \\
21 \cdot 0 \\
22.2 \\
23.2 \\
21.09 \\
20.6\end{array}$ & $\begin{array}{l}21 \cdot 1 \\
21: 3 \\
20: 1 \\
20.1 \\
20.9 \\
21.1 \\
19 \cdot 7 \\
18.2\end{array}$ & $\begin{array}{l}25.9 \\
23.8 \\
20.9 \\
20.7 \\
22.2 \\
23.1 \\
21.8 \\
20.3\end{array}$ & $\begin{array}{l}20.6 \\
21.1 \\
20.0 \\
20.1 \\
20.9 \\
20.9 \\
19.5 \\
18.0\end{array}$ & $\begin{array}{l}26.9 \\
26.8 \\
26.9 \\
26.9 \\
27.0 \\
26.9 \\
26.6 \\
26.3\end{array}$ & $\begin{array}{l}2 \\
3 \\
3 \\
3 \\
3 \\
3 \\
3 \\
3\end{array}$ & $\begin{array}{r}6.4 \\
7.9 \\
11.2 \\
8.6 \\
9.3 \\
10.8 \\
10.4 \\
8.0\end{array}$ & $\begin{array}{r}7.0 \\
8.9 \\
12.5 \\
9.2 \\
10.0 \\
12.0 \\
11.2 \\
8.8\end{array}$ & $\begin{array}{r}7.8 \\
9.7 \\
13.2 \\
9.5 \\
10.6 \\
12.8 \\
11.8 \\
9.2\end{array}$ & $\begin{array}{r}8.8 \\
9.8 \\
13.5 \\
9.6 \\
10.7 \\
13.1 \\
11.9 \\
9.5\end{array}$ \\
\hline $\begin{array}{l}22 \\
22 \\
22 \\
22 \\
22 \\
22 \\
22 \\
22\end{array}$ & $\begin{array}{r}0 \\
3 \\
6 \\
9 \\
12 \\
15 \\
18 \\
21\end{array}$ & $\begin{array}{l}19.8 \\
19.8 \\
19.3 \\
19.0 \\
22.0 \\
23.3 \\
22.4 \\
21.5\end{array}$ & $\begin{array}{l}17.7 \\
16.9 \\
16.9 \\
17.7 \\
20.0 \\
21 \cdot 3 \\
21.2 \\
21.0\end{array}$ & $\begin{array}{l}19.4 \\
19.4 \\
19.0 \\
18.6 \\
22.0 \\
23.2 \\
22.2 \\
21.4\end{array}$ & $\begin{array}{l}16 \cdot 9 \\
16 \cdot 2 \\
16 \cdot 0 \\
17.4 \\
19 \cdot 7 \\
20.9 \\
20.8 \\
20.6\end{array}$ & $\begin{array}{l}19.2 \\
19.2 \\
18.8 \\
18.4 \\
2.2 .0 \\
2.13 \\
22.1 \\
21.3\end{array}$ & $\begin{array}{l}16.8 \\
16.0 \\
16.0 \\
17.1 \\
19.7 \\
20.8 \\
20.7 \\
20.6\end{array}$ & $\begin{array}{l}19 \cdot 1 \\
19 \cdot 1 \\
18 \cdot 7 \\
18 \cdot 4 \\
22 \cdot 1 \\
23.0 \\
21.9 \\
21.2\end{array}$ & $\begin{array}{l}16.7 \\
15.9 \\
15.8 \\
17.0 \\
19.8 \\
20.8 \\
20.6 \\
20.6\end{array}$ & & $\begin{array}{l}3 \\
3 \\
3 \\
3 \\
3 \\
3 \\
2 \\
3\end{array}$ & $\begin{array}{l}5.8 \\
5.9 \\
5.5 \\
8.5 \\
4.3 \\
6.2 \\
7.3 \\
6.5\end{array}$ & $\begin{array}{l}6.3 \\
6.5 \\
6.5 \\
8.7 \\
4.5 \\
6.4 \\
7.6 \\
6.8\end{array}$ & $\begin{array}{l}6.6 \\
6.7 \\
6.8 \\
8.8 \\
4.6 \\
6.5 \\
8.0 \\
6.9\end{array}$ & $\begin{array}{l}6.7 \\
6.8 \\
6.9 \\
9.0 \\
4.8 \\
6.6 \\
8.0 \\
7.0\end{array}$ \\
\hline $\begin{array}{l}23 \\
23 \\
23 \\
23 \\
23 \\
23 \\
23 \\
23\end{array}$ & $\begin{array}{r}0 \\
3 \\
6 \\
9 \\
12 \\
15 \\
18 \\
21\end{array}$ & $\begin{array}{l}21 \cdot 2 \\
21 \cdot 5 \\
21 \cdot 7 \\
22 \cdot 5 \\
25 \cdot 8 \\
27 \cdot 5 \\
26 \cdot 9 \\
25 \cdot 5\end{array}$ & $\begin{array}{l}20.7 \\
21.1 \\
21.2 \\
21.6 \\
23.1 \\
23.4 \\
23.5 \\
23.2\end{array}$ & $\begin{array}{l}21 \cdot 2 \\
21 \cdot 5 \\
21 \cdot 6 \\
22 \cdot 5 \\
25 \cdot 9 \\
27 \cdot 6 \\
27 \cdot 1 \\
25.5\end{array}$ & $\begin{array}{l}20.4 \\
20.9 \\
21.1 \\
21.5 \\
22.7 \\
23.1 \\
23.3 \\
22.8\end{array}$ & $\begin{array}{l}21.0 \\
21.3 \\
21.5 \\
22.4 \\
26.1 \\
27.8 \\
27.0 \\
25.4\end{array}$ & $\begin{array}{l}20.2 \\
20.8 \\
20.9 \\
21.3 \\
22.6 \\
22.9 \\
23.0 \\
22.6\end{array}$ & $\begin{array}{l}20.0 \\
21.03 \\
21.04 \\
22.4 \\
26.0 \\
27.09 \\
27.0 \\
25.4\end{array}$ & $\begin{array}{l}20.3 \\
20.5 \\
20.8 \\
21.2 \\
22.5 \\
22.9 \\
22.09 \\
2 ? .4\end{array}$ & & $\begin{array}{l}2 \\
2 \\
2 \\
2 \\
2 \\
2 \\
2 \\
2\end{array}$ & $\begin{array}{r}6.3 \\
10.7 \\
7.6 \\
10.5 \\
8.9 \\
9.0 \\
7.2 \\
11.6\end{array}$ & $\begin{array}{r}6.7 \\
11.6 \\
8.2 \\
11.5 \\
10.0 \\
10.1 \\
8.0 \\
12.9\end{array}$ & $\begin{array}{r}7.3 \\
12.4 \\
8.8 \\
12.4 \\
11.0 \\
11.1 \\
9.0 \\
13.9\end{array}$ & $\begin{array}{r}11.4 \\
11.5 \\
9.6 \\
14.6\end{array}$ \\
\hline $\begin{array}{l}24 \\
24 \\
24 \\
24 \\
24 \\
24 \\
24 \\
24\end{array}$ & $\begin{array}{r}0 \\
3 \\
6 \\
9 \\
12 \\
15 \\
18 \\
21\end{array}$ & $\begin{array}{l}24.7 \\
23.3 \\
23.03 \\
26.1 \\
29.7 \\
30.8 \\
28.9 \\
27.5\end{array}$ & $\begin{array}{l}22.6 \\
21.9 \\
21.8 \\
22.8 \\
23.4 \\
23.6 \\
23.8 \\
23.0\end{array}$ & $\begin{array}{l}24.7 \\
23.3 \\
23.03 \\
26.5 \\
29.9 \\
31.1 \\
29.0 \\
27.7\end{array}$ & $\begin{array}{l}22.1 \\
21.6 \\
21.04 \\
22.05 \\
22.9 \\
23.3 \\
23.5 \\
22.7\end{array}$ & $\begin{array}{l}24.6 \\
23.1 \\
23.2 \\
26.6 \\
30.3 \\
31.5 \\
29.6 \\
27.7\end{array}$ & $\begin{array}{l}21.09 \\
21.04 \\
21.04 \\
22.05 \\
23.0 \\
23.02 \\
23.03 \\
22.6\end{array}$ & $\begin{array}{l}24.5 \\
22.9 \\
23.2 \\
26.6 \\
30.5 \\
31.6 \\
29.7 \\
27.6\end{array}$ & $\begin{array}{l}21 \cdot 8 \\
21 \cdot 3 \\
21 \cdot 2 \\
22 \cdot 3 \\
22 \cdot 8 \\
23 \cdot 2 \\
23 \cdot 1 \\
22 \cdot 5\end{array}$ & & $\begin{array}{l}2 \\
2 \\
2 \\
2 \\
2 \\
2 \\
2 \\
2\end{array}$ & $\begin{array}{l}12.6 \\
11.6 \\
14.0 \\
12.0 \\
10.6 \\
10.03 \\
7.4 \\
11.7\end{array}$ & $\begin{array}{r}13.9 \\
12.9 \\
15.7 \\
14.6 \\
11.9 \\
11.8 \\
8.6 \\
13.1\end{array}$ & $\begin{array}{l}15.2 \\
14.0 \\
17.02 \\
16.03 \\
13.4 \\
13.6 \\
10.0 \\
14.5\end{array}$ & $\begin{array}{l}15.8 \\
14.8 \\
17.8 \\
27.3 \\
13.8 \\
14.2 \\
10.9 \\
15.3\end{array}$ \\
\hline $\begin{array}{l}25 \\
25 \\
25 \\
25 \\
25 \\
25 \\
25 \\
25\end{array}$ & $\begin{array}{r}0 \\
3 \\
6 \\
9 \\
12 \\
15 \\
18 \\
21\end{array}$ & $\begin{array}{l}25.6 \\
24 \cdot 8 \\
24.9 \\
27.8 \\
30.8 \\
31.8 \\
28.9 \\
28.4\end{array}$ & $\begin{array}{l}22.3 \\
21.7 \\
21.5 \\
22.5 \\
23.6 \\
23.9 \\
24.0 \\
22.8\end{array}$ & $\begin{array}{l}25.7 \\
24.0 \\
25.0 \\
28.2 \\
31.1 \\
32.0 \\
29.5 \\
28.6\end{array}$ & $\begin{array}{l}22 \cdot 0 \\
21 \cdot 4 \\
21 \cdot 3 \\
22 \cdot 3 \\
23 \cdot 1 \\
23.4 \\
23 \cdot 7 \\
22 \cdot 3\end{array}$ & $\begin{array}{l}25.7 \\
24.7 \\
25.1 \\
28.5 \\
31.6 \\
32.5 \\
30.0 \\
28.7\end{array}$ & $\begin{array}{l}21 \cdot \bullet 8 \\
21.03 \\
21 \cdot \bullet 1 \\
22 \cdot 0 \\
23 \cdot 1 \\
23.05 \\
23 \cdot 02 \\
22 \cdot 0\end{array}$ & $\begin{array}{l}25.5 \\
24.6 \\
25.2 \\
28.5 \\
31.6 \\
31.00 \\
30.7 \\
28.9\end{array}$ & $\begin{array}{l}21.7 \\
21.1 \\
21.0 \\
22.0 \\
23.1 \\
23.3 \\
22.9 \\
21.9\end{array}$ & & $\begin{array}{l}2 \\
2 \\
2 \\
2 \\
2 \\
2 \\
2 \\
2\end{array}$ & $\begin{array}{r}12.6 \\
12.6 \\
15.3 \\
12.1 \\
12.4 \\
9.5 \\
4.6 \\
10.2\end{array}$ & $\begin{array}{r}14.2 \\
14.0 \\
17.2 \\
13.8 \\
14.0 \\
11.0 \\
5.7 \\
11.4\end{array}$ & $\begin{array}{r}15.6 \\
15.3 \\
19.0 \\
15.5 \\
15.8 \\
12.8 \\
7.3 \\
12.7\end{array}$ & $\begin{array}{r}16.4 \\
16.0 \\
19.8 \\
16.1 \\
16.3 \\
13.4 \\
8.7 \\
13.7\end{array}$ \\
\hline $\begin{array}{l}26 \\
26 \\
26 \\
26 \\
26 \\
26 \\
26 \\
26\end{array}$ & $\begin{array}{r}0 \\
3 \\
6 \\
9 \\
12 \\
15 \\
18 \\
21\end{array}$ & $\begin{array}{l}27 \cdot 0 \\
25 \cdot 6 \\
25 \cdot 3 \\
29 \cdot 3 \\
31 \cdot 8 \\
32 \cdot 2 \\
27 \cdot 1 \\
26.7\end{array}$ & $\begin{array}{l}22.0 \\
21.6 \\
21.3 \\
22.7 \\
23.1 \\
23.3 \\
23.8 \\
23.4\end{array}$ & $\begin{array}{l}27.0 \\
25.6 \\
25.4 \\
29.7 \\
32.1 \\
32.4 \\
27.7 \\
26.8\end{array}$ & $\begin{array}{l}21.5 \\
21.0 \\
20.9 \\
22.4 \\
22.5 \\
22.9 \\
23.2 \\
22.9\end{array}$ & $\begin{array}{l}27.0 \\
25.6 \\
25.5 \\
29.9 \\
32.3 \\
33.0 \\
27.1 \\
26.9\end{array}$ & $\begin{array}{l}21.05 \\
20.9 \\
20.7 \\
22.3 \\
22.6 \\
22.8 \\
23.1 \\
22.9\end{array}$ & $\begin{array}{l}26.9 \\
25.5 \\
25.5 \\
30.1 \\
32.4 \\
33.0 \\
26.9 \\
27.1\end{array}$ & $\begin{array}{l}21 \cdot 1 \\
20.5 \\
20.7 \\
22 \cdot 4 \\
22 \cdot 4 \\
22.9 \\
22 \cdot 9 \\
22 \cdot 5\end{array}$ & & $\begin{array}{l}2 \\
2 \\
2 \\
2 \\
2 \\
2 \\
3 \\
2\end{array}$ & $\begin{array}{l}11.4 \\
12.2 \\
10.3 \\
10.6 \\
10.6 \\
7.3 \\
8.1 \\
7.5\end{array}$ & $\begin{array}{r}12.7 \\
13.7 \\
11.5 \\
11.8 \\
11.8 \\
8.3 \\
8.6 \\
8.2\end{array}$ & $\begin{array}{r}14.1 \\
15.1 \\
12.7 \\
13.2 \\
13.2 \\
9.5 \\
9.1 \\
9.3\end{array}$ & $\begin{array}{r}14.9 \\
15.8 \\
13.1 \\
13.6 \\
13.6 \\
9.8 \\
9.5 \\
10.0\end{array}$ \\
\hline $\begin{array}{l}27 \\
27 \\
27 \\
27 \\
27 \\
27 \\
27 \\
27\end{array}$ & $\begin{array}{r}0 \\
3 \\
6 \\
9 \\
22 \\
15 \\
18 \\
21\end{array}$ & $\begin{array}{l}26.5 \\
25.2 \\
25.9 \\
29.7 \\
32.3 \\
32.9 \\
30.04 \\
29.5\end{array}$ & $\begin{array}{l}21.9 \\
21.5 \\
21.6 \\
21 \cdot 9 \\
22.6 \\
22 \cdot 9 \\
23 \cdot 0 \\
21.6\end{array}$ & $\begin{array}{l}26.5 \\
25 \cdot 3 \\
26 \cdot 2 \\
30.1 \\
32 \cdot 7 \\
33.2 \\
31.2 \\
29.7\end{array}$ & $\begin{array}{l}21 \cdot \bullet 4 \\
21 . \bullet 0 \\
21 \cdot \bullet 2 \\
21 \cdot 6 \\
22 \cdot 0 \\
22 \cdot 04 \\
22 \cdot 03 \\
21.02\end{array}$ & $\begin{array}{l}26.6 \\
25.2 \\
26.2 \\
30.3 \\
33.0 \\
33.7 \\
31.5 \\
29.7\end{array}$ & $\begin{array}{ll}21 & .4 \\
21 & 00 \\
21 & 01 \\
21 & 05 \\
22 & 00 \\
22.04 & 4 \\
22 & 01 \\
21 & 0\end{array}$ & $\begin{array}{l}26.6 \\
25.7 \\
26.3 \\
30.4 \\
33.2 \\
33.9 \\
32.0 \\
29.8\end{array}$ & $\begin{array}{l}21.0 \\
20.0 \\
21.0 \\
21.5 \\
22.0 \\
22.4 \\
21.07 \\
20.6\end{array}$ & & $\begin{array}{l}2 \\
2 \\
2 \\
2 \\
2 \\
2 \\
2 \\
2\end{array}$ & $\begin{array}{r}10.2 \\
10.6 \\
12.2 \\
14.7 \\
12.1 \\
11.5 \\
6.9 \\
14.5\end{array}$ & $\begin{array}{r}11.4 \\
11.9 \\
13.7 \\
16.2 \\
13.5 \\
13.2 \\
8.2 \\
15.7\end{array}$ & $\begin{array}{r}12.7 \\
13.1 \\
15.4 \\
18.1 \\
15.4 \\
15.0 \\
9.7 \\
17.5\end{array}$ & $\begin{array}{l}13.6 \\
13.9 \\
16.1 \\
18.7 \\
15.8 \\
15.7 \\
10.8 \\
18.5\end{array}$ \\
\hline $\begin{array}{l}28 \\
28 \\
28 \\
28 \\
28 \\
28 \\
28 \\
28\end{array}$ & $\begin{array}{r}0 \\
3 \\
6 \\
9 \\
12 \\
15 \\
18 \\
21\end{array}$ & $\begin{array}{l}27.8 \\
27.5 \\
27.0 \\
30.4 \\
33.7 \\
34.7 \\
32.0 \\
30.0\end{array}$ & $\begin{array}{l}20.8 \\
20.6 \\
21.01 \\
22.4 \\
23.3 \\
23.5 \\
23.4 \\
22.2\end{array}$ & $\begin{array}{l}27.9 \\
27.6 \\
27.4 \\
30.9 \\
34.3 \\
35.1 \\
32.4 \\
30.3\end{array}$ & $\begin{array}{l}20.4 \\
20.1 \\
20.7 \\
22.1 \\
22.7 \\
23.0 \\
22.9 \\
21.8\end{array}$ & $\begin{array}{l}27.9 \\
27.7 \\
25.6 \\
31.0 \\
34.7 \\
35.6 \\
33.0 \\
30.4\end{array}$ & $\begin{array}{l}20.2 \\
20.0 \\
20.4 \\
22 \cdot 1 \\
22 \cdot 7 \\
23.0 \\
22.7 \\
21.7\end{array}$ & $\begin{array}{l}27 \cdot 9 \\
27 \cdot 7 \\
27 \cdot 4 \\
31 \cdot 2 \\
34 \cdot 9 \\
34 \cdot 3 \\
33 \cdot 4 \\
30 \cdot 4\end{array}$ & $\begin{array}{l}19.9 \\
19.7 \\
20.4 \\
22.0 \\
22.6 \\
23.1 \\
22.5 \\
21.4\end{array}$ & & $\begin{array}{l}2 \\
2 \\
2 \\
2 \\
2 \\
2 \\
2 \\
2\end{array}$ & $\begin{array}{r}13.7 \\
12.5 \\
14.1 \\
15.0 \\
15.4 \\
14.7 \\
9.4 \\
14.3\end{array}$ & $\begin{array}{l}15.7 \\
14.0 \\
16.0 \\
16.9 \\
17.3 \\
16.7 \\
11.1 \\
16.2\end{array}$ & $\begin{array}{l}17.5 \\
15.7 \\
18.0 \\
19.1 \\
19.6 \\
19.2 \\
13.0 \\
18.3\end{array}$ & \\
\hline $\begin{array}{l}29 \\
29 \\
29 \\
29 \\
29 \\
29 \\
29 \\
29\end{array}$ & $\begin{array}{r}0 \\
3 \\
6 \\
9 \\
12 \\
15 \\
18 \\
21\end{array}$ & $\begin{array}{l}28.0 \\
26.5 \\
27.1 \\
31.0 \\
34.1 \\
34.7 \\
30.8 \\
29.8\end{array}$ & $\begin{array}{l}21.0 \\
20.2 \\
20.7 \\
22.5 \\
23.3 \\
23.5 \\
23.5 \\
22.4\end{array}$ & $\begin{array}{l}28.2 \\
26.6 \\
27.2 \\
31.6 \\
34.8 \\
35.2 \\
31.4 \\
30.0\end{array}$ & $\begin{array}{l}20.2 \\
19.9 \\
20.0 \\
22.1 \\
22.9 \\
23.1 \\
22.8 \\
21.9\end{array}$ & $\begin{array}{l}28.3 \\
26.5 \\
27.4 \\
31.8 \\
35.1 \\
36.0 \\
32.5 \\
30.1\end{array}$ & $\begin{array}{l}20.2 \\
19.8 \\
20.5 \\
22.3 \\
22.9 \\
23.0 \\
22.4 \\
21.8\end{array}$ & $\begin{array}{l}28.3 \\
26.06 \\
27.6 \\
32.0 \\
35.2 \\
36.02 \\
33.03 \\
30.5\end{array}$ & $\begin{array}{l}19.9 \\
19.6 \\
20.2 \\
22.1 \\
22.6 \\
23.4 \\
22.4 \\
21.5\end{array}$ & $\begin{array}{l}25.8 \\
25.8 \\
25.9 \\
26.0 \\
26.1 \\
26.2 \\
26.0 \\
26.0\end{array}$ & $\begin{array}{l}2 \\
2 \\
2 \\
2 \\
2 \\
2 \\
2 \\
2\end{array}$ & $\begin{array}{l}13.7 \\
11.1 \\
13.5 \\
15.5 \\
14.0 \\
11.7 \\
5.8 \\
11.4\end{array}$ & $\begin{array}{r}15.5 \\
12.5 \\
15.1 \\
17.3 \\
15.5 \\
13.3 \\
7.6 \\
13.1\end{array}$ & $\begin{array}{r}17.3 \\
14.1 \\
17.0 \\
19.6 \\
17.6 \\
15.4 \\
9.3 \\
14.6\end{array}$ & $\begin{array}{l}18.4 \\
15.1 \\
17.6 \\
20.4 \\
18.2 \\
16.2 \\
10.9 \\
15.9\end{array}$ \\
\hline $\begin{array}{l}30 \\
30 \\
30 \\
30 \\
30 \\
30 \\
30 \\
30\end{array}$ & $\begin{array}{r}0 \\
3 \\
6 \\
9 \\
12 \\
15 \\
18 \\
21\end{array}$ & $\begin{array}{l}27 \cdot 1 \\
31.3 \\
33.7 \\
34.3 \\
30.4 \\
29.0\end{array}$ & $\begin{array}{l}21.3 \\
22 \cdot 1 \\
22.8 \\
22 \cdot 4 \\
22.9 \\
21.7\end{array}$ & $\begin{array}{l}27.6 \\
31.8 \\
34.3 \\
35 \cdot 0 \\
31 \cdot 3 \\
29 \cdot 1\end{array}$ & $\begin{array}{l}21.00 \\
21.07 \\
22: 01 \\
21: 0 \\
22.11 \\
21.5\end{array}$ & $\begin{array}{l}27.8 \\
32.0 \\
34.8 \\
35.5 \\
32.1 \\
29.3\end{array}$ & 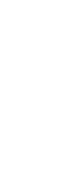 & $\begin{array}{l}28.0 \\
32.3 \\
35.0 \\
35.7 \\
32.5 \\
29.3\end{array}$ & $\begin{array}{l}20.8 \\
21.05 \\
21.0 \\
21.8 \\
21.07 \\
21.00\end{array}$ & & $\begin{array}{l}2 \\
2 \\
2 \\
2 \\
2 \\
2 \\
2 \\
2\end{array}$ & $\begin{array}{r}10.6 \\
10.0 \\
12.3 \\
14.4 \\
12.4 \\
10.9 \\
5.6 \\
9.9\end{array}$ & $\begin{array}{r}12.0 \\
11.02 \\
13.7 \\
15.9 \\
14.5 \\
12.4 \\
7.44 \\
11.4\end{array}$ & $\begin{array}{r}13.4 \\
12.6 \\
15.4 \\
18.0 \\
16.4 \\
14.4 \\
9.2 \\
12.9\end{array}$ & $\begin{array}{l}14.5 \\
13.5 \\
16.0 \\
18.5 \\
17.1 \\
15.1 \\
10.9 \\
14.1\end{array}$ \\
\hline $\begin{array}{l}31 \\
31 \\
31 \\
31 \\
31 \\
31 \\
31 \\
31\end{array}$ & $\begin{array}{r}0 \\
3 \\
6 \\
9 \\
12 \\
15 \\
18 \\
21\end{array}$ & $\begin{array}{l}26.6 \\
24.6 \\
25.8 \\
30.8 \\
34.6 \\
35.0 \\
30.0 \\
27.8\end{array}$ & $\begin{array}{l}21.1 \\
20.4 \\
21.0 \\
21.9 \\
22.3 \\
22.8 \\
22.8 \\
22.2\end{array}$ & $\begin{array}{l}26 \cdot 6 \\
24 \cdot 5 \\
26 \cdot 0 \\
31 \cdot 3 \\
33 \cdot 3 \\
35 \cdot 6 \\
31.3 \\
28.2\end{array}$ & $\begin{array}{l}20.7 \\
20.2 \\
20.6 \\
21.6 \\
21.7 \\
22.0 \\
21.4 \\
21.6\end{array}$ & $\begin{array}{l}26.6 \\
24.4 \\
26.4 \\
30.8 \\
35.5 \\
36.2 \\
32.2 \\
20.0\end{array}$ & $\begin{array}{l}20.3 \\
20.0 \\
20.5 \\
21.5 \\
21.5 \\
21.08 \\
21.0 \\
20.9\end{array}$ & $\begin{array}{l}26 \cdot 6 \\
24 \cdot 4 \\
26 \cdot 2 \\
31 \cdot ? \\
35: 7 \\
36 \cdot 4 \\
32 \cdot 7 \\
30.2\end{array}$ & $\begin{array}{l}19 \cdot 8 \\
20 \cdot 3 \\
21 \cdot 5 \\
21 \cdot 7 \\
21 \cdot 9 \\
21 \cdot 2 \\
20 \cdot 3\end{array}$ & $\begin{array}{l}25.7 \\
25.5 \\
25.7 \\
25.9 \\
25.3 \\
26.3 \\
25.0 \\
35.0\end{array}$ & $\begin{array}{l}2 \\
2 \\
2 \\
2 \\
2 \\
2 \\
2 \\
?\end{array}$ & $\begin{array}{r}10.2 \\
9.04 \\
11.4 \\
11.4 \\
10.2 \\
8.2 \\
3.7 \\
4.1\end{array}$ & $\begin{array}{r}11.5 \\
10.4 \\
12.7 \\
12.8 \\
11.5 \\
9.6 \\
5.0 \\
4.6\end{array}$ & $\begin{array}{r}12.8 \\
11.5 \\
14.2 \\
14.6 \\
13.1 \\
11.1 \\
6.4 \\
6.9\end{array}$ & $\begin{array}{l}13.9 \\
12.3 \\
14.7 \\
14.9 \\
13.6 \\
11.6 \\
7.6 \\
17\end{array}$ \\
\hline
\end{tabular}


TABLE 10

Table 10. - Three-hour averages of air and water-surface temperatures and wind directions and speed, April 1950-August 1951. Lake Hefner-Continued

STATION 2 THREE-HOURLY AVERAGES

APRIL, 1950

\begin{tabular}{|c|c|c|c|c|c|c|c|c|c|c|c|c|c|c|c|}
\hline \multirow{4}{*}{ 秃 } & \multirow{4}{*}{ 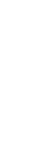 } & \multicolumn{8}{|c|}{ Average air temperature $\left({ }^{\circ} \mathrm{C}\right)$ at indicated height } & \multirow{4}{*}{$\begin{array}{l}\text { Average } \\
\text { water- } \\
\text { surface } \\
\text { tempera- } \\
\text { ture } \\
\left({ }^{\circ} \mathrm{C}\right)\end{array}$} & \multirow{4}{*}{$\begin{array}{c}\text { Average } \\
\text { wind } \\
\text { direction } \\
\text { (coded) }\end{array}$} & \multirow{2}{*}{\multicolumn{4}{|c|}{$\begin{array}{l}\text { Average wind speed (knots) } \\
\text { at indicated height }\end{array}$}} \\
\hline & & \multirow{2}{*}{\multicolumn{2}{|c|}{$\begin{array}{c}2 \\
\text { meters }\end{array}$}} & \multirow{2}{*}{\multicolumn{2}{|c|}{$\begin{array}{c}4 \\
\text { meters }\end{array}$}} & \multirow{2}{*}{\multicolumn{2}{|c|}{$\begin{array}{c} \\
\text { meters } \\
\end{array}$}} & \multirow{2}{*}{\multicolumn{2}{|c|}{$\begin{array}{c}16 \\
\text { meters }\end{array}$}} & & & & & & \\
\hline & & & & & & & & & & & & 2 & 4 & 8 & 16 \\
\hline & & $\begin{array}{l}\text { Dry } \\
\text { bulb }\end{array}$ & $\begin{array}{l}\text { Wet } \\
\text { bulb }\end{array}$ & $\begin{array}{l}\text { Dry } \\
\text { bulb }\end{array}$ & $\begin{array}{l}\text { Wet } \\
\text { bulb }\end{array}$ & $\begin{array}{l}\text { Dry } \\
\text { bulb }\end{array}$ & $\begin{array}{l}\text { Wet } \\
\text { bulb }\end{array}$ & $\begin{array}{l}\text { Dry } \\
\text { bulb }\end{array}$ & $\begin{array}{l}\text { Wet } \\
\text { bulb }\end{array}$ & & & meters & meters & meters & meters \\
\hline $\begin{array}{l}25 \\
25 \\
25 \\
25 \\
25 \\
25 \\
25 \\
25\end{array}$ & $\begin{array}{r}0 \\
3 \\
6 \\
9 \\
12 \\
15 \\
18 \\
21\end{array}$ & $\begin{array}{l}15.8 \\
17.0 \\
13.8 \\
10.4\end{array}$ & $\begin{array}{l}7.5 \\
7.4 \\
6.2 \\
4.5\end{array}$ & $\begin{array}{l}15.7 \\
16.4 \\
15.1 \\
11.1\end{array}$ & $\begin{array}{l}6.7 \\
7.1 \\
6.5 \\
4.9\end{array}$ & $\begin{array}{l}15.3 \\
16.4 \\
15.8 \\
11.7\end{array}$ & $\begin{array}{l}6.7 \\
6.9 \\
6.4 \\
5.1\end{array}$ & $\begin{array}{l}15.2 \\
16.3 \\
16.1 \\
12.6\end{array}$ & $\begin{array}{l}6.3 \\
6.6 \\
6.5 \\
5.3\end{array}$ & $\begin{array}{l}19.4 \\
19.6 \\
18.0 \\
16.0\end{array}$ & & $\begin{array}{r}10.8 \\
12.0 \\
7.2 \\
-9.4 \\
7.8 \\
6.4 \\
2.6 \\
4.8\end{array}$ & $\begin{array}{r}13.8 \\
15.6 \\
8.8 \\
12.2 \\
9.2 \\
7.2 \\
3.2 \\
6.0\end{array}$ & $\begin{array}{r}16.4 \\
16.4 \\
10.0 \\
13.4 \\
11.0 \\
8.4 \\
3.6 \\
7.8\end{array}$ & $\begin{array}{r}16.8 \\
9.8 \\
13.4 \\
11.4 \\
9.2 \\
3.8 \\
10.2\end{array}$ \\
\hline $\begin{array}{l}26 \\
26 \\
26\end{array}$ & $\begin{array}{l}0 \\
3 \\
6\end{array}$ & & 1 & & & & & & & & & $\begin{array}{r}7.0 \\
9.8 \\
13.2\end{array}$ & $\begin{array}{r}8.0 \\
11.2 \\
14.2\end{array}$ & $\begin{array}{r}9.6 \\
12.4 \\
16.0\end{array}$ & $\begin{array}{l}11.8 \\
14.4 \\
17.6\end{array}$ \\
\hline $\begin{array}{l}26 \\
26 \\
26 \\
26 \\
26\end{array}$ & $\begin{array}{r}9 \\
12 \\
15 \\
18 \\
21\end{array}$ & $\begin{array}{l}20.1 \\
23.1 \\
24.0 \\
20.3 \\
17.7\end{array}$ & $\begin{array}{r}9.4 \\
10.9 \\
12.1 \\
11.4 \\
10.8\end{array}$ & $\begin{array}{l}20.0 \\
22.6 \\
23.9 \\
20.4 \\
17.9\end{array}$ & $\begin{array}{r}9.4 \\
10.8 \\
12.1 \\
11.5 \\
10.9\end{array}$ & $\begin{array}{l}19.6 \\
22.2 \\
23.4 \\
20.5 \\
18.0\end{array}$ & $\begin{array}{r}9.2 \\
10.7 \\
11.0 \\
11.5 \\
11.0\end{array}$ & $\begin{array}{l}19.7 \\
21.7 \\
23.2 \\
20.5 \\
18.3\end{array}$ & $\begin{array}{r}9.1 \\
10.6 \\
11.9 \\
11.5 \\
11.0\end{array}$ & $\begin{array}{l}16.5 \\
17.1 \\
17.1 \\
16.2 \\
15.8\end{array}$ & & $\begin{array}{r}19.2 \\
15.2 \\
12.0 \\
6.4 \\
6.6\end{array}$ & $\begin{array}{r}20.8 \\
16.6 \\
13.2 \\
7.6 \\
8.0\end{array}$ & $\begin{array}{r}22.6 \\
18.2 \\
14.4 \\
8.8 \\
9.2\end{array}$ & $\begin{array}{l}24.4 \\
19.8 \\
15.6 \\
10.4 \\
10.8\end{array}$ \\
\hline $\begin{array}{l}27 \\
27 \\
27 \\
27 \\
27 \\
27 \\
27 \\
27\end{array}$ & $\begin{array}{r}0 \\
3 \\
6 \\
9 \\
12 \\
15 \\
18 \\
21\end{array}$ & $\begin{array}{l}16.8 \\
12.4 \\
10.3 \\
12.0 \\
14.0 \\
14.8 \\
13.8 \\
11.5\end{array}$ & $\begin{array}{r}11.2 \\
9.6 \\
4.8 \\
6.1 \\
7.9 \\
8.7 \\
8.3 \\
6.6\end{array}$ & $\begin{array}{l}16.8 \\
12.5 \\
10.3 \\
11.9 \\
13.8 \\
14.6 \\
13.7 \\
11.4\end{array}$ & $\begin{array}{r}11.3 \\
8.4 \\
4.9 \\
5.9 \\
7.8 \\
8.8 \\
8.2 \\
6.6\end{array}$ & $\begin{array}{l}16.9 \\
12.03 \\
10.2 \\
11.9 \\
13.7 \\
14.7 \\
13.6 \\
11.3\end{array}$ & $\begin{array}{r}21.4 \\
3.0 \\
4.8 \\
6.0 \\
7.7 \\
8.7 \\
8.7 \\
6.7\end{array}$ & $\begin{array}{l}17.1 \\
12.02 \\
10.2 \\
11.8 \\
13.6 \\
14.5 \\
13.5 \\
11.3\end{array}$ & $\begin{array}{r}11.4 \\
7.7 \\
4.5 \\
5.8 \\
7.6 \\
8.4 \\
7.8 \\
6.4\end{array}$ & $\begin{array}{l}15.3 \\
14.6 \\
13.6 \\
13.8 \\
14.7 \\
14.8 \\
13.7 \\
12.7\end{array}$ & & $\begin{array}{r}5.0 \\
9.02 \\
12.8 \\
12.0 \\
10.2 \\
8.6 \\
7.04 \\
6.0\end{array}$ & $\begin{array}{r}6.4 \\
11.8 \\
15.2 \\
14.4 \\
13.0 \\
10.4 \\
9.0 \\
7.4\end{array}$ & $\begin{array}{r}7.2 \\
13.4 \\
18.0 \\
16.8 \\
15.2 \\
11.8 \\
10.6 \\
3.2\end{array}$ & $\begin{array}{r}8.4 \\
15.4 \\
19.4 \\
18.2 \\
16.2 \\
12.8 \\
11.0 \\
9.0\end{array}$ \\
\hline $\begin{array}{l}28 \\
28 \\
28 \\
28 \\
28 \\
28 \\
28 \\
28\end{array}$ & $\begin{array}{r}0 \\
3 \\
6 \\
9 \\
12 \\
15 \\
18 \\
21\end{array}$ & $\begin{array}{l}11.1 \\
11.7 \\
13.8 \\
18.0 \\
25.0 \\
24.5 \\
19.7 \\
19.8\end{array}$ & $\begin{array}{r}6.8 \\
7.5 \\
10.6 \\
17.7 \\
19.5 \\
19.3 \\
17.0 \\
17.3\end{array}$ & $\begin{array}{l}11.0 \\
11.7 \\
14.0 \\
18.1 \\
24.9 \\
24.5 \\
20.0 \\
20.0\end{array}$ & $\begin{array}{r}6.7 \\
7.5 \\
10.9 \\
17.6 \\
19.6 \\
19.4 \\
17.0 \\
17.3\end{array}$ & $\begin{array}{l}11.0 \\
11.6 \\
14.0 \\
18.0 \\
24.7 \\
24.4 \\
20.03 \\
20.0\end{array}$ & $\begin{array}{r}6.8 \\
7.5 \\
11.3 \\
17.7 \\
19.2 \\
19.4 \\
17.2 \\
17.1\end{array}$ & $\begin{array}{l}11.00 \\
11.07 \\
14.00 \\
18.2 \\
24.2 \\
24.5 \\
20.04 \\
19.0\end{array}$ & $\begin{array}{r}6.6 \\
7.5 \\
11.5 \\
17.9 \\
19.4 \\
19.5 \\
17.3 \\
17.0\end{array}$ & $\begin{array}{l}13.2 \\
14.0 \\
14.02 \\
14.1 \\
16.9 \\
16.7 \\
16.0 \\
15.7\end{array}$ & & $\begin{array}{r}4.02 \\
3.00 \\
4.44 \\
7.02 \\
16.0 \\
7.4 \\
7.04 \\
10.0\end{array}$ & $\begin{array}{r}5.0 \\
3.6 \\
5.2 \\
8.2 \\
17.6 \\
8.4 \\
8.8 \\
12.0\end{array}$ & $\begin{array}{r}5.8 \\
4.0 \\
5.8 \\
9.0 \\
19.2 \\
9.4 \\
10.2 \\
13.4\end{array}$ & $\begin{array}{r}6.2 \\
4.8 \\
6.2 \\
10.6 \\
20.8 \\
10.6 \\
11.04 \\
15.0\end{array}$ \\
\hline $\begin{array}{l}29 \\
29 \\
29 \\
29 \\
29 \\
29 \\
29 \\
29\end{array}$ & $\begin{array}{r}0 \\
3 \\
6 \\
9 \\
12 \\
15 \\
18 \\
21\end{array}$ & $\begin{array}{r}17.1 \\
16.7 \\
18.7 \\
19.9 \\
11.7 \\
10.6 \\
10.8 \\
9.0\end{array}$ & $\begin{array}{r}14.1 \\
13.9 \\
26.1 \\
16.7 \\
9.9 \\
9.0 \\
8.6 \\
7.03\end{array}$ & $\begin{array}{r}17.1 \\
16.8 \\
18.7 \\
19.8 \\
11.2 \\
10.3 \\
10.6 \\
8.8\end{array}$ & $\begin{array}{l}14.1 \\
13.9 \\
16.1 \\
16.7 \\
9.6 \\
8.6 \\
8.3 \\
6.8\end{array}$ & $\begin{array}{r}17.1 \\
16.8 \\
18.7 \\
19.0 \\
10.8 \\
10.1 \\
10.5 \\
8.5\end{array}$ & $\begin{array}{r}14.0 \\
14.0 \\
16.1 \\
15.6 \\
9.1 \\
8.4 \\
8.4 \\
6.4\end{array}$ & $\begin{array}{r}17.2 \\
16.9 \\
18.6 \\
19.0 \\
10.4 \\
9.9 \\
10.4 \\
8.2\end{array}$ & $\begin{array}{r}14.0 \\
14.0 \\
16.2 \\
15.3 \\
8.8 \\
8.1 \\
7.9 \\
6.3\end{array}$ & $\begin{array}{l}15.6 \\
15.4 \\
15.9 \\
16.8 \\
16.2 \\
14.9 \\
14.4 \\
14.0\end{array}$ & & $\begin{array}{l}8.02 \\
10.8 \\
13.0 \\
11.0 \\
15.6 \\
13.6 \\
12.8 \\
13.8\end{array}$ & $\begin{array}{l}9.8 \\
12.6 \\
14.4 \\
12.2 \\
17.8 \\
17.2 \\
15.0 \\
16.4\end{array}$ & $\begin{array}{l}11.2 \\
14.0 \\
15.0 \\
14.02 \\
21.4 \\
21.00 \\
21.00 \\
22.02\end{array}$ & $\begin{array}{l}12.8 \\
15.8 \\
17.4 \\
15.4 \\
23.0\end{array}$ \\
\hline $\begin{array}{l}30 \\
30 \\
30 \\
30 \\
30 \\
30 \\
30 \\
30\end{array}$ & $\begin{array}{r}0 \\
3 \\
6 \\
9 \\
12 \\
15 \\
28 \\
21\end{array}$ & $\begin{array}{r}6.9 \\
5.4 \\
4.7 \\
7.8 \\
22.5 \\
14.7 \\
13.1 \\
11.2\end{array}$ & $\begin{array}{l}5.4 \\
4.0 \\
3.2 \\
4.8 \\
7.7 \\
9.6 \\
9.1 \\
8.6\end{array}$ & $\begin{array}{r}6.7 \\
5.1 \\
4.3 \\
7.04 \\
12.02 \\
14.4 \\
13.0 \\
11.2\end{array}$ & $\begin{array}{l}5.1 \\
3.8 \\
3.0 \\
4.7 \\
7.7 \\
9.3 \\
9.1 \\
8.6\end{array}$ & $\begin{array}{r}6.3 \\
5.0 \\
4.1 \\
7.6 \\
11.8 \\
14.3 \\
12.8 \\
11.1\end{array}$ & $\begin{array}{l}4.6 \\
3.5 \\
2.9 \\
4.6 \\
7.7 \\
9.5 \\
9.1 \\
8.6\end{array}$ & $\begin{array}{r}6.1 \\
4: 7 \\
4: 0 \\
7.0 \\
11.5 \\
14: 1 \\
12.7 \\
11.0\end{array}$ & $\begin{array}{l}4.4 \\
3.3 \\
2.6 \\
4.3 \\
7.3 \\
9.0 \\
0.0 \\
8.6\end{array}$ & $\begin{array}{l}14.0 \\
12.9 \\
12.9 \\
14.5 \\
16.8 \\
18.2 \\
16.6 \\
15.2\end{array}$ & & $\begin{array}{r}14.2 \\
13.2 \\
12.2 \\
8.6 \\
6.6 \\
5.2 \\
5.4 \\
5.0\end{array}$ & $\begin{array}{r}17.2 \\
15.8 \\
14.0 \\
9.6 \\
7.4 \\
6.2 \\
6.4 \\
6.4\end{array}$ & $\begin{array}{r}22.2 \\
21.0 \\
18.4 \\
10.2 \\
8.2 \\
6.6 \\
7.44 \\
7.4\end{array}$ & $\begin{array}{r}11.4 \\
8.6 \\
7.4 \\
8.0 \\
7.8\end{array}$ \\
\hline
\end{tabular}


TABLE 10

Table 10. - Three-hour averages of air and water-surface temperatures and wind directions and speed, April 1950-August 1951, Lake Hefner-Continued

MAY, 1950

\begin{tabular}{|c|c|c|c|c|c|c|c|c|c|c|c|c|c|c|c|}
\hline \multirow{4}{*}{ 吾 } & \multirow{4}{*}{ 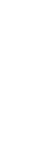 } & \multicolumn{8}{|c|}{ Average air temperature $\left({ }^{\circ} \mathrm{C}\right)$ at indicated height } & \multirow{4}{*}{$\begin{array}{c}\text { Average } \\
\text { water- } \\
\text { surface } \\
\text { tempera- } \\
\text { ture } \\
\left({ }^{\circ} \mathrm{C}\right)\end{array}$} & \multirow{4}{*}{$\begin{array}{c}\text { Average } \\
\text { wind } \\
\text { direction } \\
\text { (coded) }\end{array}$} & \multirow{2}{*}{\multicolumn{4}{|c|}{$\begin{array}{l}\text { Average wind speed (knots) } \\
\text { at indicated height }\end{array}$}} \\
\hline & & \multirow{2}{*}{\multicolumn{2}{|c|}{$\begin{array}{c}2 \\
\text { meters }\end{array}$}} & \multirow{2}{*}{\multicolumn{2}{|c|}{$\begin{array}{c}4 \\
\text { meters }\end{array}$}} & \multirow{2}{*}{\multicolumn{2}{|c|}{$\begin{array}{c}8 \\
\text { meters }\end{array}$}} & \multirow{2}{*}{\multicolumn{2}{|c|}{$\begin{array}{c}16 \\
\text { meters }\end{array}$}} & & & & & & \\
\hline & & & & & & & & & & & & 2 & 4 & 8 & 16 \\
\hline & & $\begin{array}{l}\text { Dry } \\
\text { bulb }\end{array}$ & $\begin{array}{l}\text { Wet } \\
\text { butb }\end{array}$ & $\begin{array}{l}\text { Dry } \\
\text { bulb }\end{array}$ & $\begin{array}{l}\text { Wet } \\
\text { bulb }\end{array}$ & $\begin{array}{l}\text { Dry } \\
\text { bulb }\end{array}$ & $\begin{array}{l}\text { Wet } \\
\text { bulb }\end{array}$ & $\begin{array}{l}\text { Dry } \\
\text { bulb }\end{array}$ & $\begin{array}{l}\text { Wet } \\
\text { bulb }\end{array}$ & & & meters & meters & meters & meters \\
\hline $\begin{array}{l}1 \\
1 \\
1 \\
1 \\
1 \\
1 \\
1 \\
1\end{array}$ & $\begin{array}{r}0 \\
3 \\
6 \\
9 \\
12 \\
15 \\
18 \\
21\end{array}$ & $\begin{array}{r}10.4 \\
10.0 \\
9.9 \\
13.0 \\
14.6 \\
15.9 \\
14.5 \\
13.4\end{array}$ & $\begin{array}{r}8.5 \\
8.5 \\
8.0 \\
10.0 \\
11.5 \\
12.8 \\
12.3 \\
12.5\end{array}$ & $\begin{array}{r}10.4 \\
10.0 \\
9.8 \\
12.7 \\
14.2 \\
15.7 \\
14.5 \\
13.4\end{array}$ & $\begin{array}{r}8.6 \\
8.6 \\
8.1 \\
9.9 \\
11.3 \\
12.8 \\
12.3 \\
12.6\end{array}$ & $\begin{array}{r}10.3 \\
9.9 \\
9.7 \\
12.7 \\
13.7 \\
15.5 \\
14.4 \\
13.4\end{array}$ & $\begin{array}{r}8.6 \\
8.5 \\
7.8 \\
9.9 \\
11.1 \\
12.7 \\
11.2 \\
12.6\end{array}$ & $\begin{array}{r}10.2 \\
9.9 \\
9.5 \\
12.5 \\
14.0 \\
15.4 \\
14.3 \\
13.3\end{array}$ & $\begin{array}{r}8.4 \\
8.4 \\
7.7 \\
9.6 \\
11.2 \\
12.6 \\
12.3 \\
12.6\end{array}$ & $\begin{array}{l}13.9 \\
13.2 \\
13.3 \\
16.6 \\
18.0 \\
19.5 \\
18.2 \\
16.2\end{array}$ & & $\begin{array}{r}5.0 \\
6.0 \\
6.4 \\
4.6 \\
5.6 \\
4.0 \\
13.4 \\
3.2\end{array}$ & $\begin{array}{r}5.8 \\
6.8 \\
7.2 \\
5.2 \\
6.4 \\
4.8 \\
16.6 \\
4.2\end{array}$ & $\begin{array}{r}7.2 \\
7.6 \\
7.6 \\
5.6 \\
7.2 \\
5.4 \\
19.0 \\
4.8\end{array}$ & $\begin{array}{r}8.0 \\
10.2 \\
9.2 \\
6.2 \\
7.6 \\
5.6 \\
20.2 \\
5.4\end{array}$ \\
\hline $\begin{array}{l}2 \\
2 \\
2 \\
2 \\
2 \\
2 \\
2 \\
2\end{array}$ & $\begin{array}{r}0 \\
3 \\
5 \\
9 \\
12 \\
15 \\
18 \\
21\end{array}$ & $\begin{array}{l}16.6 \\
22.0 \\
24.6 \\
22.1 \\
20.5\end{array}$ & $\begin{array}{l}14.2 \\
16.5 \\
17.6 \\
18.0 \\
18.9\end{array}$ & $\begin{array}{l}16.5 \\
21.6 \\
24.1 \\
22.1 \\
20.7\end{array}$ & $\begin{array}{l}14.1 \\
16.2 \\
17.5 \\
18.0 \\
19.1\end{array}$ & $\begin{array}{l}16 \cdot 1 \\
21 \cdot 1 \\
23.9 \\
22.0 \\
20.7\end{array}$ & $\begin{array}{l}14.0 \\
16.3 \\
17.4 \\
17.0 \\
19.1\end{array}$ & $\begin{array}{l}16.0 \\
21.1 \\
23 \cdot 5 \\
22.0 \\
20.8\end{array}$ & $\begin{array}{l}14.1 \\
16.1 \\
17.4 \\
17.9 \\
19.3\end{array}$ & $\begin{array}{l}15.8 \\
18.5 \\
17.9 \\
16.7 \\
16.4\end{array}$ & & $\begin{array}{r}3.4 \\
3.2 \\
5.8 \\
12.4 \\
15.0 \\
14.6 \\
13.8 \\
18.6\end{array}$ & $\begin{array}{r}4.0 \\
4.0 \\
6.8 \\
13.8 \\
16.6 \\
16.2 \\
15.6 \\
20.6\end{array}$ & $\begin{array}{r}4.0 \\
4.4 \\
7.4 \\
15.0 \\
18.0 \\
17.6 \\
17.2 \\
22.4\end{array}$ & $\begin{array}{r}5.2 \\
4.8 \\
8.0 \\
16.2 \\
19.6 \\
19.0 \\
19.0 \\
25.0\end{array}$ \\
\hline $\begin{array}{l}3 \\
3 \\
3 \\
3 \\
3 \\
3 \\
3 \\
3\end{array}$ & $\begin{array}{r}0 \\
3 \\
6 \\
9 \\
12 \\
15 \\
18 \\
21\end{array}$ & $\begin{array}{l}20.7 \\
21.3 \\
23.5 \\
28.2 \\
32.6 \\
31.9 \\
26.2 \\
23.6\end{array}$ & $\begin{array}{l}19.9 \\
20.3 \\
21.1 \\
21.7 \\
20.9 \\
22.1 \\
22.6 \\
21.4\end{array}$ & $\begin{array}{l}21.0 \\
21.5 \\
23.8 \\
28.0 \\
32.4 \\
31.5 \\
26.3 \\
23.7\end{array}$ & $\begin{array}{l}19.9 \\
20.4 \\
21.1 \\
21.5 \\
20.3 \\
21.9 \\
22.6 \\
21.5\end{array}$ & $\begin{array}{l}20.9 \\
21.6 \\
23.7 \\
28.1 \\
31.8 \\
31.0 \\
26.0 \\
23.7\end{array}$ & $\begin{array}{l}19.9 \\
20.5 \\
21.01 \\
21.2 \\
20.4 \\
22.1 \\
22.5 \\
21.5\end{array}$ & $\begin{array}{l}21.00 \\
21.7 \\
23.8 \\
27.6 \\
31.6 \\
30.7 \\
25.9 \\
23.7\end{array}$ & $\begin{array}{l}20.0 \\
20.6 \\
21.2 \\
21.1 \\
20.2 \\
22.0 \\
22.5 \\
21.6\end{array}$ & $\begin{array}{l}16.2 \\
16.2 \\
17.4 \\
19.5 \\
20.2 \\
19.8 \\
18.9 \\
18.3\end{array}$ & & $\begin{array}{l}17.0 \\
14.8 \\
18.4 \\
20.8 \\
18.2 \\
16.6 \\
15.6 \\
16.0\end{array}$ & $\begin{array}{l}18.4 \\
17.4 \\
20.4 \\
23.2 \\
20.2 \\
18.6 \\
17.6 \\
17.8\end{array}$ & $\begin{array}{l}20.6 \\
19.2 \\
22.6 \\
25.6 \\
22.0 \\
20.0 \\
19.4 \\
20.0\end{array}$ & $\begin{array}{l}22 \cdot 4 \\
21.2 \\
25 \cdot 0 \\
28 \cdot 0 \\
23 \cdot 8 \\
22 \cdot 0 \\
21 \cdot 2 \\
21.4\end{array}$ \\
\hline $\begin{array}{l}4 \\
4 \\
4 \\
4 \\
4 \\
4 \\
4 \\
4\end{array}$ & $\begin{array}{r}0 \\
3 \\
6 \\
9 \\
12 \\
15 \\
18 \\
21\end{array}$ & $\begin{array}{l}22.5 \\
22.0 \\
23.5 \\
25.9 \\
27.1 \\
25.2 \\
25.1 \\
24.6\end{array}$ & $\begin{array}{l}21.3 \\
21.2 \\
21.7 \\
21.9 \\
22.1 \\
21.8 \\
21.2 \\
20.4\end{array}$ & $\begin{array}{l}22.6 \\
22.3 \\
23.6 \\
25.6 \\
26.8 \\
26.2 \\
25.2 \\
24.8\end{array}$ & $\begin{array}{l}21.4 \\
21 \cdot 3 \\
21.7 \\
21.8 \\
22.0 \\
21.7 \\
21 \cdot 3 \\
20.5\end{array}$ & $\begin{array}{l}22.7 \\
22.4 \\
23.6 \\
25.5 \\
25.6 \\
26.0 \\
25.1 \\
24.8\end{array}$ & $\begin{array}{l}21 \cdot 4 \\
21 . \cdot 3 \\
21.7 \\
21 \cdot 7 \\
21.9 \\
21.6 \\
21.02 \\
20.5\end{array}$ & $\begin{array}{l}22.7 \\
22.5 \\
23.5 \\
25.2 \\
26.5 \\
25.9 \\
25.2 \\
24.8\end{array}$ & $\begin{array}{l}21.5 \\
21 \cdot 5 \\
21.7 \\
21.4 \\
21.9 \\
21.5 \\
21.3 \\
20.4\end{array}$ & $\begin{array}{l}17.4 \\
16.9 \\
18.0 \\
19.4 \\
19.8 \\
19.4 \\
19.0 \\
19.7\end{array}$ & & $\begin{array}{l}14.8 \\
12.2 \\
14.4 \\
15.6 \\
16.4 \\
18.2 \\
19.4 \\
23.2\end{array}$ & $\begin{array}{l}16.2 \\
13.6 \\
16.0 \\
17.8 \\
18.2 \\
20.2 \\
22.0 \\
25.6\end{array}$ & $\begin{array}{l}18.0 \\
15.2 \\
17.6 \\
19.6 \\
19.8 \\
22.0 \\
24.0 \\
28.4\end{array}$ & $\begin{array}{l}20.0 \\
16.8 \\
19.6 \\
21.2 \\
21.4 \\
24.2 \\
26.0 \\
31.0\end{array}$ \\
\hline $\begin{array}{l}5 \\
5 \\
5 \\
5 \\
5 \\
5 \\
5 \\
5\end{array}$ & $\begin{array}{r}0 \\
3 \\
6 \\
9 \\
12 \\
15 \\
18 \\
21\end{array}$ & $\begin{array}{l}17.2 \\
15.6 \\
14.6 \\
16.4 \\
20.1 \\
21.8 \\
18.0\end{array}$ & $\begin{array}{r}13.3 \\
7.9 \\
7.8 \\
8.9 \\
9.8 \\
10.3 \\
9.2\end{array}$ & $\begin{array}{l}17.2 \\
15.8 \\
14.5 \\
16.0 \\
19.5 \\
21.2 \\
18.3\end{array}$ & $\begin{array}{r}8.7 \\
9.4 \\
10.9 \\
9.5\end{array}$ & $\begin{array}{l}17.2 \\
15.8 \\
14.6 \\
15.8 \\
19.1 \\
21.5 \\
18.6\end{array}$ & $\begin{array}{r}12.5 \\
7.08 \\
7.6 \\
8.4 \\
9.6 \\
10.4 \\
9.6\end{array}$ & $\begin{array}{l}17.4 \\
15.7 \\
14.5 \\
15.6 \\
19.1 \\
21.0 \\
19.3\end{array}$ & $\begin{array}{r}12.2 \\
7.7 \\
7.4 \\
7.9 \\
8.9 \\
10.1 \\
9.5\end{array}$ & $\begin{array}{l}17.8 \\
16.7 \\
16.4 \\
18.0 \\
19.9 \\
21.9 \\
20.9\end{array}$ & - & $\begin{array}{r}13.4 \\
16.0 \\
16.4 \\
15.0 \\
11.6 \\
4.2 \\
3.0 \\
4.0\end{array}$ & $\begin{array}{r}15.0 \\
17.8 \\
18.6 \\
17.0 \\
13.4 \\
5.0 \\
4.2 \\
5.2\end{array}$ & $\begin{array}{r}16.6 \\
19.8 \\
20.4 \\
19.6 \\
16.2 \\
5.4 \\
5.4 \\
6.06\end{array}$ & $\begin{array}{r}18.6 \\
21.8 \\
22.6 \\
21.6 \\
17.6 \\
5.6 \\
6.8 \\
8.6\end{array}$ \\
\hline $\begin{array}{l}6 \\
6 \\
6 \\
6 \\
6 \\
6 \\
6 \\
6\end{array}$ & $\begin{array}{r}0 \\
3 \\
6 \\
9 \\
12 \\
15 \\
18 \\
21\end{array}$ & $\begin{array}{l}25.5 \\
27.2 \\
26.7 \\
21.0 \\
17.3\end{array}$ & $\begin{array}{l}13.2 \\
14.2 \\
14.8 \\
15.2 \\
15.9\end{array}$ & $\begin{array}{l}25.3 \\
27.1 \\
25.0 \\
21.0 \\
17.3\end{array}$ & $\begin{array}{l}13.2 \\
14.0 \\
14.7 \\
15.3 \\
16.0\end{array}$ & $\begin{array}{l}24.0 \\
24.3 \\
25.7 \\
20.8 \\
17.4\end{array}$ & $\begin{array}{l}13.0 \\
15.8 \\
14.5 \\
15.4 \\
16.0\end{array}$ & $\begin{array}{l}24.1 \\
25.8 \\
25.4 \\
20.8 \\
17.4\end{array}$ & $\begin{array}{l}13.5 \\
14.0 \\
14.7 \\
15.7 \\
16.1\end{array}$ & $\begin{array}{l}20.0 \\
20.6 \\
18.9 \\
17.8 \\
17.3\end{array}$ & & $\begin{array}{r}6.4 \\
7.4 \\
9.6 \\
9.6 \\
7.0 \\
10.2 \\
7.0 \\
4.4\end{array}$ & $\begin{array}{r}7.6 \\
8.4 \\
10.8 \\
10.6 \\
7.8 \\
11.4 \\
0.0 \\
5.6\end{array}$ & $\begin{array}{r}9.2 \\
9.8 \\
11.8 \\
11.4 \\
8.4 \\
12.6 \\
9.4 \\
6.6\end{array}$ & $\begin{array}{r}10.8 \\
11.4 \\
13.2 \\
12.0 \\
8.8 \\
13.8 \\
10.8 \\
7.8\end{array}$ \\
\hline $\begin{array}{l}7 \\
7 \\
7 \\
7 \\
7 \\
7 \\
7 \\
7\end{array}$ & $\begin{array}{r}0 \\
3 \\
6 \\
9 \\
12 \\
15 \\
18 \\
21\end{array}$ & $\begin{array}{l}17.4 \\
18.0 \\
19.3 \\
22.9 \\
23.6 \\
24.2 \\
22.7 \\
23.0\end{array}$ & $\begin{array}{l}16.4 \\
17.3 \\
18.9 \\
20.7 \\
21.3 \\
21.9 \\
21.4 \\
20.7\end{array}$ & $\begin{array}{l}17.4 \\
18.0 \\
10.4 \\
23.0 \\
23.4 \\
24.0 \\
22.8 \\
23.1\end{array}$ & $\begin{array}{l}16.5 \\
17.4 \\
19.0 \\
20.7 \\
21.4 \\
21.7 \\
21.4 \\
20.6\end{array}$ & $\begin{array}{l}17.5 \\
18.0 \\
19.5 \\
23.0 \\
23.4 \\
23.8 \\
22.8 \\
23.1\end{array}$ & $\begin{array}{l}16.5 \\
17.4 \\
19.3 \\
20.8 \\
21.5 \\
21.7 \\
21.05 \\
20.7\end{array}$ & $\begin{array}{l}17.5 \\
18.0 \\
19.6 \\
22.9 \\
23.2 \\
23.6 \\
22.9 \\
23.1\end{array}$ & $\begin{array}{l}16.6 \\
17.6 \\
19.4 \\
20.9 \\
21.9 \\
21.9 \\
21.9 \\
20.9\end{array}$ & $\begin{array}{l}17.1 \\
16.7 \\
16.0 \\
18.2 \\
17.8 \\
18.5\end{array}$ & & $\begin{array}{r}5.8 \\
6.8 \\
7.0 \\
8.0 \\
6.4 \\
9.4 \\
8.8 \\
16.6\end{array}$ & $\begin{array}{r}7.6 \\
8.6 \\
8.2 \\
9.0 \\
7.6 \\
12.2 \\
11.0 \\
18.8\end{array}$ & $\begin{array}{r}8.6 \\
9.6 \\
9.0 \\
9.8 \\
8.6 \\
13.6 \\
12.4 \\
21.2\end{array}$ & $\begin{array}{r}9.6 \\
10.8 \\
10.0 \\
10.0 \\
9.0 \\
14.8 \\
13.8 \\
23.0\end{array}$ \\
\hline $\begin{array}{l}8 \\
8 \\
8 \\
8 \\
8 \\
8 \\
8 \\
8\end{array}$ & $\begin{array}{r}0 \\
3 \\
6 \\
9 \\
12 \\
15 \\
18 \\
21\end{array}$ & $\begin{array}{l}22.2 \\
20.6 \\
21.4 \\
24.9 \\
26.5 \\
26.8 \\
24.9 \\
23.0\end{array}$ & $\begin{array}{l}19.7 \\
18.7 \\
19.5 \\
20.7 \\
21.1 \\
21.5 \\
20.5 \\
19.3\end{array}$ & $\begin{array}{l}22 \cdot 2 \\
20.8 \\
21 \cdot 5 \\
24 \cdot 7 \\
26 \cdot 1 \\
26 \cdot 8 \\
25 \cdot 0 \\
23 \cdot 1\end{array}$ & $\begin{array}{l}19.7 \\
18.8 \\
19.5 \\
20.6 \\
21.2 \\
21.5 \\
20.6 \\
19.3\end{array}$ & $\begin{array}{l}22.2 \\
20.8 \\
21.6 \\
24.5 \\
26.0 \\
26.5 \\
24.8 \\
23.1\end{array}$ & $\begin{array}{l}19.8 \\
18.8 \\
19.6 \\
20.6 \\
21.2 \\
21.6 \\
20.6 \\
19.3\end{array}$ & $\begin{array}{l}22.2 \\
20.8 \\
21.5 \\
24.5 \\
25.9 \\
26.6 \\
24.8 \\
23.1\end{array}$ & $\begin{array}{l}19.9 \\
19.2 \\
20.1 \\
26.0 \\
21.5 \\
22.0 \\
21.0 \\
19.8\end{array}$ & $\begin{array}{l}27.7 \\
20.4 \\
20.2 \\
19.5 \\
19.0\end{array}$ & & $\begin{array}{l}19.0 \\
16.4 \\
16.8 \\
19.2 \\
16.8 \\
17.4 \\
19.4 \\
18.6\end{array}$ & $\begin{array}{l}22.0 \\
18.4 \\
18.8 \\
21.0 \\
18.8 \\
19.2 \\
22.0 \\
20.6\end{array}$ & $\begin{array}{l}24.0 \\
20.8 \\
20.4 \\
23.2 \\
20.2 \\
22.4 \\
23.8 \\
22.8\end{array}$ & $\begin{array}{l}26.4 \\
22.4 \\
22.6 \\
25.2 \\
22.2 \\
23.0 \\
26.2 \\
24.8\end{array}$ \\
\hline $\begin{array}{l}9 \\
9 \\
9 \\
9 \\
9 \\
9 \\
9 \\
9\end{array}$ & $\begin{array}{r}0 \\
3 \\
6 \\
9 \\
12 \\
15 \\
18 \\
21\end{array}$ & $\begin{array}{l}22.2 \\
20.9 \\
19.4 \\
15.9 \\
18.0 \\
17.3 \\
15.6 \\
15.0\end{array}$ & $\begin{array}{l}18.6 \\
18.4 \\
17.7 \\
14.3 \\
14.9 \\
15.5 \\
15.0 \\
15.0\end{array}$ & $\begin{array}{l}22: 3 \\
21: 0 \\
19 \cdot 4 \\
15: 8 \\
17: 6 \\
17: 02 \\
15: 7 \\
15: 1\end{array}$ & $\begin{array}{l}18.7 \\
18.4 \\
17.6 \\
14: 3 \\
14.9 \\
15.4 \\
15.0 \\
15.0\end{array}$ & $\begin{array}{l}22.3 \\
21.0 \\
19.3 \\
15: 7 \\
17.3 \\
17.1 \\
15.9 \\
15.2\end{array}$ & $\begin{array}{l}18.7 \\
18.5 \\
17.5 \\
14: 1 \\
14.6 \\
15.9 \\
15.2 \\
15.1\end{array}$ & $\begin{array}{l}22,4 \\
21: 1 \\
19: 2 \\
15: 6 \\
17: 2 \\
17: 1 \\
15: 7 \\
15.3\end{array}$ & $\begin{array}{l}19.1 \\
19.0 \\
17.9 \\
14.3 \\
14.6 \\
15.3 \\
15.2 \\
15.2\end{array}$ & $\begin{array}{l}18.6 \\
17.7 \\
16.6 \\
17.3 \\
20.7 \\
19.0 \\
16.1\end{array}$ & & $\begin{array}{r}18.4 \\
16.6 \\
9.8 \\
8.2 \\
6.8 \\
5.2 \\
6.4 \\
4.4\end{array}$ & $\begin{array}{r}20.0 \\
18.0 \\
10.8 \\
10.6 \\
7.4 \\
6.0 \\
7.6 \\
4.8\end{array}$ & $\begin{array}{r}22.0 \\
20.2 \\
13.2 \\
11.8 \\
9.0 \\
6.4 \\
8.8 \\
6.0\end{array}$ & $\begin{array}{l}24.6 \\
22.2 \\
14.0 \\
11.6\end{array}$ \\
\hline $\begin{array}{l}10 \\
10 \\
10 \\
10 \\
10 \\
10 \\
10 \\
10\end{array}$ & $\begin{array}{r}0 \\
3 \\
6 \\
9 \\
12 \\
15 \\
18 \\
21\end{array}$ & $\begin{array}{l}14.9 \\
14.4\end{array}$ & $\begin{array}{l}14 \cdot 8 \\
14 \cdot 4\end{array}$ & $\begin{array}{l}14 \cdot 9 \\
14 \cdot 5\end{array}$ & $\begin{array}{l}14.8 \\
14.4\end{array}$ & $\begin{array}{l}15.1 \\
14.7\end{array}$ & 15.1 & $\begin{array}{l}15.0 \\
14.7\end{array}$ & 15.5 & & & $\begin{array}{l}5.2 \\
5.8 \\
6.2 \\
6.6 \\
6.4 \\
8.2 \\
5.4 \\
5.2\end{array}$ & $\begin{array}{l}5.8 \\
7.0 \\
7.2 \\
7.8 \\
7.0 \\
9.4 \\
6.4 \\
7.4\end{array}$ & $\begin{array}{r}6.8 \\
8.0 \\
8.4 \\
9.2 \\
7.8 \\
10.4 \\
7.2 \\
8.4\end{array}$ & $\begin{array}{r}6.8 \\
9.0 \\
9.4 \\
10.2 \\
9.6 \\
12.4 \\
8.2 \\
9.2\end{array}$ \\
\hline
\end{tabular}


TABLE 10

Table 10. -Three-hour averages of air and water-surface temperatures and wind directions and speed, April 1950-August 1951, Lake Hefner-Continued

STATION 2 THREE-HOURLY AVERAGES

MAY, 1950

\begin{tabular}{|c|c|c|c|c|c|c|c|c|c|c|c|c|c|c|c|}
\hline \multirow{3}{*}{ 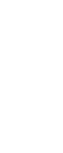 } & \multirow{3}{*}{ 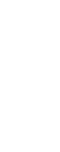 } & \multicolumn{8}{|c|}{ Average air temperature $\left({ }^{\circ} \mathrm{C}\right)$ at indicated height } & \multirow{3}{*}{$\begin{array}{l}\text { Average } \\
\text { water- } \\
\text { surface } \\
\text { tempera- } \\
\text { ture } \\
\text { (॰C) }\end{array}$} & \multirow{3}{*}{$\begin{array}{c}\text { Average } \\
\text { wind } \\
\text { direction } \\
\text { (coded) }\end{array}$} & \multicolumn{4}{|c|}{$\begin{array}{l}\text { Average wind speed (knots) } \\
\text { at indicated height }\end{array}$} \\
\hline & & \multicolumn{2}{|c|}{$\begin{array}{c}2 \\
\text { meters }\end{array}$} & \multicolumn{2}{|c|}{$\begin{array}{c}4 \\
\text { meters }\end{array}$} & \multicolumn{2}{|c|}{$\begin{array}{c}8 \\
\text { meters }\end{array}$} & \multicolumn{2}{|c|}{$\begin{array}{c}16 \\
\text { meters }\end{array}$} & & & & & & \\
\hline & & $\begin{array}{l}\text { Dry } \\
\text { bulb }\end{array}$ & $\begin{array}{l}\text { Wet } \\
\text { bulb }\end{array}$ & $\begin{array}{l}\text { Dry } \\
\text { bulb }\end{array}$ & $\begin{array}{l}\text { Wet } \\
\text { bulb }\end{array}$ & $\begin{array}{l}\text { Dry } \\
\text { bulb }\end{array}$ & $\begin{array}{l}\text { Wet } \\
\text { bulb }\end{array}$ & $\begin{array}{l}\text { Dry } \\
\text { bulb }\end{array}$ & $\begin{array}{l}\text { Wet } \\
\text { bulb }\end{array}$ & & & meters & meters & meters & meters \\
\hline $\begin{array}{l}11 \\
11 \\
11 \\
11 \\
11 \\
11 \\
11 \\
11\end{array}$ & $\begin{array}{r}0 \\
3 \\
6 \\
9 \\
12 \\
15 \\
18 \\
21\end{array}$ & $\begin{array}{l}16.0 \\
16.9 \\
16.4 \\
14.2\end{array}$ & $\begin{array}{l}14 \cdot 1 \\
14.9 \\
14.7 \\
13.3\end{array}$ & $\begin{array}{l}16.0 \\
16.9 \\
16.5 \\
14.3\end{array}$ & $\begin{array}{l}14.2 \\
14.8 \\
14.7 \\
13.2\end{array}$ & $\begin{array}{l}16.0 \\
16.9 \\
16.5 \\
14.4\end{array}$ & $\begin{array}{l}13.9 \\
14.6 \\
14.6 \\
13.1\end{array}$ & $\begin{array}{l}15.8 \\
16.9 \\
16.4 \\
14.2\end{array}$ & $\begin{array}{l}13.9 \\
14.5 \\
14.6 \\
13.2\end{array}$ & $\begin{array}{l}16.1 \\
16.9 \\
16.2 \\
14.1\end{array}$ & & $\begin{array}{l}8.0 \\
6.8 \\
6.8 \\
6.0 \\
5.4 \\
5.8 \\
3.2 \\
3.8\end{array}$ & $\begin{array}{l}9.8 \\
8.2 \\
7.8 \\
6.8 \\
6.0 \\
6.6 \\
4.4 \\
4.6\end{array}$ & $\begin{array}{r}10.8 \\
8.4 \\
8.8 \\
8.0 \\
6.2 \\
7.4 \\
5.0 \\
5.2\end{array}$ & $\begin{array}{r}10.4 \\
10.8 \\
8.8 \\
6.8 \\
7.8 \\
5.6 \\
6.2\end{array}$ \\
\hline $\begin{array}{l}12 \\
12 \\
12 \\
12 \\
12 \\
12 \\
12 \\
12\end{array}$ & $\begin{array}{r}0 \\
3 \\
6 \\
9 \\
12 \\
15 \\
18 \\
21\end{array}$ & $\begin{array}{l}12.5 \\
11.8 \\
12.8 \\
16.2 \\
19.9 \\
20.4\end{array}$ & $\begin{array}{l}12.0 \\
11.6 \\
12.1 \\
13.3 \\
14.7 \\
14.9\end{array}$ & $\begin{array}{l}12.6 \\
11.8 \\
13.0 \\
16.0 \\
19.6 \\
20.2\end{array}$ & $\begin{array}{l}12.0 \\
11.05 \\
12.01 \\
13.5 \\
14.4 \\
15.0\end{array}$ & $\begin{array}{l}12.9 \\
12.0 \\
13.0 \\
16.2 \\
19.4 \\
20.1\end{array}$ & $\begin{array}{l}12.1 \\
11: 7 \\
12.1 \\
13.2 \\
14.3 \\
14.9\end{array}$ & $\begin{array}{l}12.7 \\
12.0 \\
12.9 \\
15.9 \\
19.0 \\
20.2\end{array}$ & $\begin{array}{l}12.0 \\
11.8 \\
12.2 \\
13.1 \\
13.9 \\
14.8\end{array}$ & $\begin{array}{l}13.8 \\
11.7 \\
15.1 \\
18.8 \\
24.6 \\
26.1\end{array}$ & & $\begin{array}{l}3.2 \\
3.4 \\
3.6 \\
2.6 \\
2.8 \\
4.4 \\
4.8 \\
5.2\end{array}$ & $\begin{array}{l}3.8 \\
4.0 \\
4.2 \\
2.4\end{array}$ & $\begin{array}{l}3.8 \\
4.6 \\
4.8 \\
3.2 \\
3.4 \\
5.0 \\
6.4 \\
6.8\end{array}$ & $\begin{array}{l}4.6 \\
4.6 \\
5.0 \\
3.2 \\
504 \\
7.4 \\
8.0\end{array}$ \\
\hline $\begin{array}{l}13 \\
13 \\
13 \\
13 \\
13 \\
13 \\
13 \\
13\end{array}$ & $\begin{array}{r}0 \\
3 \\
6 \\
9 \\
12 \\
15 \\
18 \\
21\end{array}$ & 16.5 & $15 \cdot 4$ & $17 \cdot 3$ & $15 \cdot 5$ & 17.8 & 15.4 & 18.7 & 15.3 & 20.9 & & $\begin{array}{l}3.6 \\
8.2 \\
5.6 \\
6.6 \\
5.4 \\
4.8 \\
1.8 \\
1.2\end{array}$ & $\begin{array}{l}4.4 \\
9.4 \\
6.8 \\
8.2 \\
6.4 \\
5.8 \\
2.4 \\
1.8\end{array}$ & $\begin{array}{r}5.0 \\
11.2 \\
8.2 \\
9.8 \\
7.6 \\
5.8 \\
2.8 \\
2.4\end{array}$ & $\begin{array}{r}5.8 \\
12.6\end{array}$ \\
\hline $\begin{array}{l}14 \\
14 \\
14 \\
14 \\
14 \\
14 \\
14 \\
14\end{array}$ & $\begin{array}{r}0 \\
3 \\
6 \\
9 \\
12 \\
15 \\
18 \\
21\end{array}$ & $\begin{array}{l}26.1 \\
15.9 \\
15.4 \\
20.5 \\
22.4 \\
17.6\end{array}$ & $\begin{array}{l}15.2 \\
15.0 \\
14.5 \\
15.9 \\
15.9 \\
14.3\end{array}$ & $\begin{array}{l}16.7 \\
16.2 \\
15.5 \\
20.3 \\
22.0 \\
18.1\end{array}$ & $\begin{array}{l}15.4 \\
15.0 \\
14.3 \\
15.8 \\
15.4 \\
14.1\end{array}$ & $\begin{array}{l}16.9 \\
16.3 \\
15.4 \\
20.2 \\
21.8 \\
18.7\end{array}$ & $\begin{array}{l}15.3 \\
14.9 \\
14.4 \\
15.4 \\
15,3 \\
13.8\end{array}$ & $\begin{array}{l}17.5 \\
16.5 \\
15.2 \\
19.9 \\
21.6 \\
17.9\end{array}$ & $\begin{array}{l}15.3 \\
15.0 \\
14.2 \\
15.1 \\
14.9 \\
13.2\end{array}$ & $\begin{array}{l}19.9 \\
19.4 \\
19.0 \\
23.1 \\
27.3 \\
24.2\end{array}$ & & $\begin{array}{l}1.2 \\
2.8 \\
3.6 \\
3.8 \\
4.8 \\
8.8 \\
1.4 \\
3.2\end{array}$ & $\begin{array}{r}1.8 \\
3.6 \\
4.4 \\
4.4 \\
5.6 \\
10.2 \\
2.0 \\
4.0\end{array}$ & $\begin{array}{r}2.4 \\
4.4 \\
4.8 \\
5.0 \\
6.0 \\
11.8 \\
2.2 \\
5.0\end{array}$ & $\begin{array}{r}3.2 \\
5.0 \\
5.0 \\
4.8 \\
6.4 \\
12.4 \\
2.6 \\
6.0\end{array}$ \\
\hline $\begin{array}{l}15 \\
15 \\
15 \\
15 \\
15 \\
15 \\
15 \\
15\end{array}$ & $\begin{array}{r}0 \\
3 \\
6 \\
9 \\
12 \\
15 \\
18 \\
21\end{array}$ & 24.9 & 15.0 & $24 \cdot 5$ & $14 \cdot 8$ & 24.1 & $14 \cdot 9$ & $24 \cdot 2$ & 15.0 & 27.7 & & $\begin{array}{l}2.44 \\
2.0 \\
2.2 \\
2.6 \\
2.4 \\
2.6 \\
2.8 \\
4.0\end{array}$ & $\begin{array}{l}3.4 \\
6.0 \\
2.8 \\
3.0 \\
3.0 \\
3.4 \\
3.8 \\
5.0\end{array}$ & $\begin{array}{l}4.6 \\
3.0 \\
3.2 \\
3.4 \\
3.6 \\
5.0 \\
6.6\end{array}$ & $\begin{array}{l}5.2 \\
3.0 \\
3.4 \\
3.2 \\
4.0 \\
6.0 \\
8.8\end{array}$ \\
\hline $\begin{array}{l}16 \\
16 \\
16 \\
16 \\
16 \\
16 \\
16 \\
16\end{array}$ & $\begin{array}{r}0 \\
3 \\
6 \\
9 \\
12 \\
15 \\
18 \\
21\end{array}$ & $\begin{array}{l}25.1 \\
26.9 \\
26.6 \\
23.2 \\
20.2\end{array}$ & $\begin{array}{l}18.1 \\
19.5 \\
20.1 \\
19.0 \\
17.3\end{array}$ & $\begin{array}{l}25.1 \\
26.6 \\
26.4 \\
23.3 \\
20.5\end{array}$ & $\begin{array}{l}17.8 \\
18.9 \\
19: 8 \\
18.8 \\
17.3\end{array}$ & $\begin{array}{l}24.7 \\
26.4 \\
26.1 \\
23.3 \\
20.8\end{array}$ & $\begin{array}{l}17.4 \\
18.7 \\
19.7 \\
18.7 \\
17.1\end{array}$ & $\begin{array}{l}24.5 \\
26.0 \\
26.0 \\
23.3 \\
21.5\end{array}$ & $\begin{array}{l}17.5 \\
18.7 \\
10.6 \\
18.8 \\
17.2\end{array}$ & $\begin{array}{l}20.8 \\
20.7 \\
20.2 \\
19.3 \\
18.7\end{array}$ & & $\begin{array}{r}2.6 \\
3.6 \\
6.6 \\
9.0 \\
10.2 \\
10.6 \\
6.2 \\
4.8\end{array}$ & $\begin{array}{r}3.6 \\
4.4 \\
7.4 \\
10.2 \\
11.4 \\
11.8 \\
7.2 \\
6.0\end{array}$ & $\begin{array}{r}5.0 \\
5.8 \\
8.2 \\
11.2 \\
12.4 \\
13.0 \\
2.04 \\
7.6\end{array}$ & $\begin{array}{r}6.6 \\
7.6 \\
9.2 \\
12.0 \\
13.2 \\
14.0 \\
10.0 \\
8.6\end{array}$ \\
\hline $\begin{array}{l}17 \\
17 \\
17 \\
17 \\
17 \\
17 \\
17 \\
17\end{array}$ & $\begin{array}{r}0 \\
3 \\
6 \\
9 \\
12 \\
15 \\
18 \\
21\end{array}$ & $\begin{array}{l}17.9 \\
17.1 \\
19.1 \\
24.8 \\
28.4 \\
28.5 \\
24.7 \\
21.2\end{array}$ & $\begin{array}{l}16.0 \\
16.0 \\
17.2 \\
19.5 \\
21.0 \\
20.4 \\
20.1 \\
19.0\end{array}$ & $\begin{array}{l}18.6 \\
17.2 \\
19.2 \\
25.0 \\
27.8 \\
28.4 \\
24.9 \\
21.5\end{array}$ & $\begin{array}{l}16.2 \\
16.0 \\
17.2 \\
19.5 \\
20.6 \\
10.9 \\
20.2 \\
19.0\end{array}$ & $\begin{array}{l}19.9 \\
17.4 \\
19.3 \\
24.7 \\
28.3 \\
29.2 \\
25.0 \\
71.8\end{array}$ & $\begin{array}{l}16.3 \\
16.0 \\
17.2 \\
19.3 \\
20.5 \\
19.5 \\
20.1 \\
18.9\end{array}$ & $\begin{array}{l}19.4 \\
17.8 \\
19: 5 \\
24.5 \\
27.5 \\
29.0 \\
25.5 \\
21.5\end{array}$ & $\begin{array}{l}16.5 \\
16.2 \\
17.2 \\
19.2 \\
20.3 \\
19.5 \\
20.3 \\
18.9\end{array}$ & $\begin{array}{l}18.2 \\
18.0 \\
19.3 \\
22.1 \\
23.0 \\
21.2 \\
20.6 \\
20.8\end{array}$ & & $\begin{array}{l}3.8 \\
4.2 \\
4.2 \\
3.4 \\
3.6 \\
5.4 \\
2.4 \\
5.8\end{array}$ & $\begin{array}{r}4.6 \\
5.0 \\
4.8 \\
3.6 \\
4.0 \\
-6.2 \\
3.8 \\
7.0\end{array}$ & $\begin{array}{l}5.8 \\
6.2 \\
5.2 \\
4.0 \\
4.44 \\
6.8 \\
4.8 \\
9.4\end{array}$ & $\begin{array}{l}7.6 \\
7.6 \\
5.6 \\
4.0 \\
4.6 \\
7.6 \\
6.0 \\
9.8\end{array}$ \\
\hline $\begin{array}{l}18 \\
18 \\
18 \\
18 \\
18 \\
18 \\
18 \\
18\end{array}$ & $\begin{array}{r}0 \\
3 \\
6 \\
9 \\
12 \\
15 \\
18 \\
21\end{array}$ & $\begin{array}{l}19.0 \\
21.1 \\
24.5 \\
26.0 \\
26.7 \\
24.5 \\
22.1\end{array}$ & $\begin{array}{l}25.7 \\
16.2 \\
19.4 \\
21.5 \\
20.2 \\
19.9 \\
18.7\end{array}$ & $\begin{array}{l}18.9 \\
21.4 \\
24.5 \\
26.4 \\
26.9 \\
24.6 \\
22.4\end{array}$ & $\begin{array}{l}15.7 \\
16.2 \\
19.5 \\
21.2 \\
20.0 \\
19.9 \\
18.8\end{array}$ & $\begin{array}{l}19.1 \\
21.6 \\
24.5 \\
26.1 \\
26.8 \\
24.6 \\
22.4\end{array}$ & $\begin{array}{l}15.4 \\
16 \cdot 2 \\
19.3 \\
21.0 \\
19.9 \\
19: 8 \\
18.6\end{array}$ & $\begin{array}{l}19.3 \\
21.0 \\
24.5 \\
25.2 \\
26.8 \\
24.5 \\
22.5\end{array}$ & $\begin{array}{l}15.5 \\
16 . ? \\
10.1 \\
20.8 \\
19.7 \\
19.7 \\
18.9\end{array}$ & $\begin{array}{l}19.3 \\
10.9 \\
20.9 \\
20.7 \\
20.1 \\
19.8 \\
19.4\end{array}$ & & $\begin{array}{r}6.0 \\
13.6 \\
9.8 \\
13.6 \\
14.6 \\
16.0 \\
14.4 \\
12.2\end{array}$ & $\begin{array}{l}7 . ? \\
15.2 \\
11.2 \\
15.2 \\
16.4 \\
18.0 \\
16.2 \\
14.4\end{array}$ & $\begin{array}{r}8.8 \\
17.4 \\
12.4 \\
16.8 \\
18.0 \\
19.8 \\
18.0 \\
16.0\end{array}$ & $\begin{array}{l}10.0 \\
20.0 \\
14: 0 \\
17.8 \\
19.6 \\
21.6 \\
20.0 \\
18.0\end{array}$ \\
\hline $\begin{array}{l}19 \\
19 \\
19 \\
19 \\
19 \\
19 \\
19 \\
19\end{array}$ & $\begin{array}{r}0 \\
3 \\
6 \\
9 \\
12 \\
15 \\
18 \\
21\end{array}$ & $\begin{array}{l}21.7 \\
20.9 \\
21.2 \\
23.6 \\
26.6 \\
25.2 \\
22.9 \\
20.4\end{array}$ & $\begin{array}{l}19.4 \\
19.9 \\
20.5 \\
20.9 \\
21.1 \\
21.3 \\
19.1 \\
17.1\end{array}$ & $\begin{array}{l}22.0 \\
21.02 \\
21.03 \\
23.8 \\
26.2 \\
25.2 \\
22.0 \\
20.4\end{array}$ & $\begin{array}{l}19.4 \\
20.0 \\
20.5 \\
20.7 \\
21.5 \\
21.3 \\
18.9 \\
17.1\end{array}$ & $\begin{array}{l}22.1 \\
21.2 \\
21.4 \\
23.6 \\
25.9 \\
25.1 \\
22.8 \\
20.4\end{array}$ & $\begin{array}{l}19.4 \\
19.9 \\
20.4 \\
20.3 \\
20.9 \\
21.0 \\
19.8 \\
17.1\end{array}$ & $\begin{array}{l}22,1 \\
21.3 \\
21.2 \\
23.5 \\
26.0 \\
24 \cdot 9 \\
22.8 \\
20.3\end{array}$ & $\begin{array}{l}19.5 \\
20.1 \\
20.5 \\
20.3 \\
20.9 \\
20.0 \\
18.0 \\
17.2\end{array}$ & $\begin{array}{l}19.5 \\
19.4 \\
20.0 \\
22.4 \\
25.5 \\
26.1 \\
24.6 \\
23.03\end{array}$ & & $\begin{array}{r}13.2 \\
11.2 \\
2.6 \\
6.0 \\
8.0 \\
9.2 \\
7.4 \\
5.8\end{array}$ & $\begin{array}{r}15.0 \\
12.6 \\
3.0 \\
7.6 \\
9.8 \\
11.2 \\
9.2 \\
7.2\end{array}$ & $\begin{array}{r}16.8 \\
14.2 \\
3.6 \\
0.0 \\
11.2 \\
13.6 \\
10.2 \\
8.0\end{array}$ & $\begin{array}{r}18.6 \\
16.0 \\
3.8 \\
10.0 \\
12.2 \\
15.0 \\
11.4 \\
9.4\end{array}$ \\
\hline $\begin{array}{l}20 \\
20 \\
20 \\
20 \\
20 \\
20 \\
20 \\
20\end{array}$ & $\begin{array}{r}0 \\
3 \\
6 \\
9 \\
12 \\
15 \\
18 \\
21\end{array}$ & $\begin{array}{l}24.0 \\
24.4 \\
21.3 \\
18.4\end{array}$ & $\begin{array}{l}17 \cdot 3 \\
18 \cdot 5 \\
19 \cdot 3 \\
17.2\end{array}$ & $\begin{array}{l}23.3 \\
24.6 \\
21.5 \\
18.7\end{array}$ & $\begin{array}{l}17.7 \\
18.2 \\
19.2 \\
17 . ?\end{array}$ & $\begin{array}{l}23.7 \\
24.4 \\
21.6 \\
13.7\end{array}$ & $\begin{array}{l}17.1 \\
17.9 \\
19.1 \\
17.2\end{array}$ & $\begin{array}{l}23.6 \\
24.3 \\
21.6 \\
18.7\end{array}$ & $\begin{array}{l}16.8 \\
17.9 \\
18.0 \\
17.1\end{array}$ & $\begin{array}{l}24.1 \\
22.7 \\
22.9 \\
21.8\end{array}$ & & $\begin{array}{r}5.0 \\
10.2 \\
6.0 \\
4.0 \\
5.2 \\
4.6 \\
2.6 \\
4.0\end{array}$ & $\begin{array}{r}7.2 \\
12.2 \\
7.2 \\
4.8 \\
5.6 \\
5.8 \\
3.8 \\
5.4\end{array}$ & $\begin{array}{r}8.2 \\
14.8 \\
8.4 \\
5.4 \\
5.0 \\
6.8 \\
4.4 \\
6.0\end{array}$ & $\begin{array}{r}8.8 \\
16.4 \\
9.0 \\
5.3 \\
6.4 \\
7.6 \\
5.8 \\
6.0\end{array}$ \\
\hline
\end{tabular}


TABLE 10

Table 10. - Three-hour averages of air and water-surface temperatures and wind directions and speed, April 1950-Angust 1951, Lake Hefner-Continued

STATION 2

THREE-HOURLY AVERAGES

MAY, 1950

\begin{tabular}{|c|c|c|c|c|c|c|c|c|c|c|c|c|c|c|c|}
\hline \multirow{4}{*}{ 吾 } & \multirow{4}{*}{ 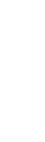 } & \multicolumn{8}{|c|}{ Average air temperature $\left({ }^{\circ} \mathrm{C}\right)$ at indicated height } & \multirow{4}{*}{$\begin{array}{l}\text { Average } \\
\text { water- } \\
\text { surface } \\
\text { tempera- } \\
\text { ture } \\
\left.{ }^{\circ} \mathrm{C}\right)\end{array}$} & \multirow{4}{*}{$\begin{array}{c}\text { Average } \\
\text { wind } \\
\text { direction } \\
\text { (coded) }\end{array}$} & \multirow{2}{*}{\multicolumn{4}{|c|}{$\begin{array}{l}\text { Average wind speed (knots) } \\
\text { at indicated height }\end{array}$}} \\
\hline & & \multirow{2}{*}{\multicolumn{2}{|c|}{$\begin{array}{c}2 \\
\text { meters }\end{array}$}} & \multirow{2}{*}{\multicolumn{2}{|c|}{$\begin{array}{c}4 \\
\text { meters }\end{array}$}} & \multirow{2}{*}{\multicolumn{2}{|c|}{$\begin{array}{c}8 \\
\text { meters }\end{array}$}} & \multirow{2}{*}{\multicolumn{2}{|c|}{$\begin{array}{c}16 \\
\text { meters }\end{array}$}} & & & & & & \\
\hline & & & & & & & & & & & & 2 & 4 & 8 & 16 \\
\hline & & $\begin{array}{l}\text { Dry } \\
\text { bulb }\end{array}$ & $\begin{array}{l}\text { Wet } \\
\text { bulb }\end{array}$ & $\begin{array}{l}\text { Dry } \\
\text { hulb }\end{array}$ & & $\begin{array}{l}\text { Dry } \\
\text { bulb }\end{array}$ & & $\begin{array}{l}\text { Dry } \\
\text { bulb }\end{array}$ & & & & & & & meters \\
\hline
\end{tabular}

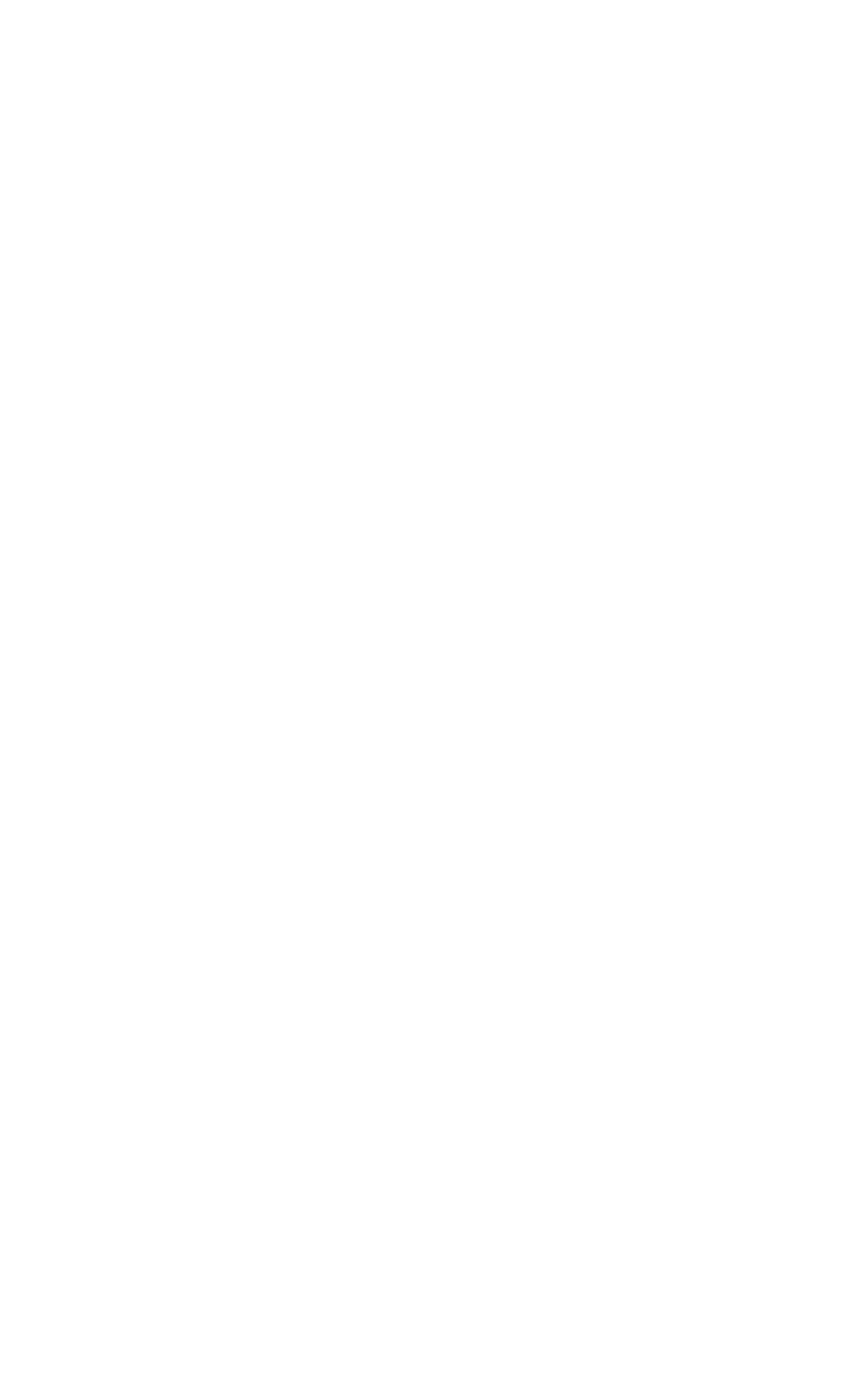


Table 10. -Three-hour averages of air and water-surface temperatures and wind directions and speed, April 1950-August 1951, Lake Hefner-Continued

STATION

THREE-HOURLY AVERAGES

JUNE, 1950

\begin{tabular}{|c|c|c|c|c|c|c|c|c|c|c|c|c|c|c|c|}
\hline \multirow{4}{*}{ 吾 } & \multirow{4}{*}{ 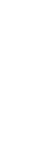 } & \multicolumn{8}{|c|}{ Average air temperature $\left({ }^{\circ} \mathrm{C}\right)$ at indicated height } & \multirow{4}{*}{$\begin{array}{l}\text { Average } \\
\text { water- } \\
\text { surface } \\
\text { tempera- } \\
\text { ture } \\
\left({ }^{\circ} \mathrm{C}\right)\end{array}$} & \multirow{4}{*}{$\begin{array}{c}\text { Average } \\
\text { wind } \\
\text { direction } \\
\text { (coded) }\end{array}$} & \multirow{2}{*}{\multicolumn{4}{|c|}{$\begin{array}{l}\text { Average wind speed (knots) } \\
\text { at indicated height }\end{array}$}} \\
\hline & & \multirow{2}{*}{\multicolumn{2}{|c|}{$\begin{array}{c}2 \\
\text { meters }\end{array}$}} & \multirow{2}{*}{\multicolumn{2}{|c|}{$\begin{array}{c}4 \\
\text { meters }\end{array}$}} & \multirow{2}{*}{\multicolumn{2}{|c|}{$\begin{array}{c}8 \\
\text { meters }\end{array}$}} & \multirow{2}{*}{\multicolumn{2}{|c|}{$\begin{array}{c}16 \\
\text { meters }\end{array}$}} & & & & & & \\
\hline & & & & & & & & & & & & 2 & 4 & 8 & 16 \\
\hline & & $\begin{array}{l}\text { Dry } \\
\text { bulb }\end{array}$ & $\begin{array}{l}\text { Wet } \\
\text { buib }\end{array}$ & $\begin{array}{l}\text { Dry } \\
\text { bulb }\end{array}$ & $\begin{array}{l}\text { Wet } \\
\text { bulb }\end{array}$ & $\begin{array}{l}\text { Dry } \\
\text { bulb }\end{array}$ & $\begin{array}{l}\text { Wet } \\
\text { bulb }\end{array}$ & $\begin{array}{l}\text { Dry } \\
\text { bulb }\end{array}$ & $\begin{array}{l}\text { Wet } \\
\text { bulb }\end{array}$ & & & meters & meters & meters & meters \\
\hline $\begin{array}{l}1 \\
1 \\
1 \\
1 \\
1 \\
1 \\
1 \\
1\end{array}$ & $\begin{array}{r}0 \\
3 \\
6 \\
9 \\
12 \\
15 \\
18 \\
21\end{array}$ & $\begin{array}{l}14.2 \\
13.3 \\
15.9 \\
22.7 \\
25.8 \\
26.0 \\
22.5 \\
20.5\end{array}$ & $\begin{array}{l}12.6 \\
12.2 \\
13.9 \\
18.8 \\
20.6 \\
20.1 \\
18.7 \\
19.0\end{array}$ & $\begin{array}{l}14.3 \\
13.3 \\
15.7 \\
22.3 \\
25.5 \\
25.3 \\
22.5 \\
20.6\end{array}$ & $\begin{array}{l}12.6 \\
12.3 \\
14.0 \\
18.7 \\
20.3 \\
19.9 \\
18.6 \\
19.0\end{array}$ & $\begin{array}{l}14.2 \\
13.3 \\
15.7 \\
22.4 \\
25.2 \\
25.2 \\
22.5 \\
20.6\end{array}$ & $\begin{array}{l}12.5 \\
12.1 \\
14.1 \\
18.6 \\
20.3 \\
19.7 \\
18.7 \\
19.0\end{array}$ & $\begin{array}{l}14.0 \\
13.2 \\
15.8 \\
22.2 \\
25.7 \\
25.1 \\
22.3 \\
20.5\end{array}$ & $\begin{array}{l}12.3 \\
12.1 \\
13.9 \\
18.7 \\
20.0 \\
10.5 \\
1.9 \\
18.9\end{array}$ & $\begin{array}{l}10.9 \\
18.6 \\
18.6 \\
20.5 \\
19.9 \\
19.9 \\
19.2 \\
19.0\end{array}$ & & $\begin{aligned} 4.0 \\
3.6 \\
4.2 \\
7.0 \\
10.4 \\
12.0 \\
11.0 \\
11.2\end{aligned}$ & $\begin{array}{r}4.8 \\
4.4 \\
5.0 \\
8.4 \\
11.8 \\
13.6 \\
12.4 \\
12.8\end{array}$ & $\begin{array}{r}5.4 \\
5.4 \\
5.8 \\
0.4 \\
12.8 \\
14.8 \\
13.8 \\
14.6\end{array}$ & $\begin{array}{r}6.2 \\
6.4 \\
6.0 \\
10.0 \\
13.8 \\
16.2 \\
15.2 \\
16.0\end{array}$ \\
\hline $\begin{array}{l}2 \\
2 \\
2 \\
2 \\
2 \\
2 \\
2 \\
2\end{array}$ & $\begin{array}{r}0 \\
3 \\
6 \\
9 \\
12 \\
15 \\
18 \\
21\end{array}$ & $\begin{array}{l}19.1 \\
18.5 \\
20.1 \\
22.5 \\
23.7 \\
23.7 \\
22.6 \\
18.0\end{array}$ & $\begin{array}{l}18.1 \\
18.0 \\
18.6 \\
19.1 \\
20.1 \\
20.5 \\
20.3 \\
17.4\end{array}$ & $\begin{array}{l}19.2 \\
18.6 \\
20.2 \\
22.5 \\
23.6 \\
23.3 \\
22.6 \\
17.9\end{array}$ & $\begin{array}{l}18.1 \\
18.1 \\
18.7 \\
19.0 \\
10.9 \\
20.3 \\
20.2 \\
17.4\end{array}$ & $\begin{array}{l}19.2 \\
18.7 \\
20.3 \\
22.2 \\
23.2 \\
23.3 \\
22.7 \\
17.2\end{array}$ & $\begin{array}{l}18.2 \\
19.1 \\
18.7 \\
18.9 \\
10.8 \\
20.4 \\
20.2 \\
17.0\end{array}$ & $\begin{array}{l}19.2 \\
19.7 \\
20.2 \\
22.0 \\
23.1 \\
23.0 \\
22.6 \\
17.4\end{array}$ & $\begin{array}{l}18.1 \\
19.0 \\
18.4 \\
18.7 \\
10.8 \\
20.2 \\
20.1 \\
16.8\end{array}$ & $\begin{array}{l}18.8 \\
18.6 \\
18.5 \\
19.5 \\
20.1 \\
20.3 \\
19.9 \\
17.8\end{array}$ & & $\begin{array}{r}9.2 \\
9.2 \\
12.8 \\
11.6 \\
13.2 \\
9.8 \\
6.2 \\
7.0\end{array}$ & $\begin{array}{r}10.5 \\
10.4 \\
14.2 \\
13.0 \\
14.8 \\
11.2 \\
7.2 \\
8.8\end{array}$ & $\begin{array}{r}12.0 \\
11.06 \\
16.7 \\
14.4 \\
15.4 \\
12.0 \\
8 . ? \\
9.2\end{array}$ & $\begin{array}{r}13.0 \\
13.0 \\
17.4 \\
15.0 \\
17.0 \\
13.4 \\
9.4 \\
12.8\end{array}$ \\
\hline $\begin{array}{l}3 \\
3 \\
3 \\
3 \\
3 \\
3 \\
3 \\
3\end{array}$ & $\begin{array}{r}0 \\
3 \\
6 \\
9 \\
12 \\
15 \\
18 \\
21\end{array}$ & $\begin{array}{l}16.9 \\
15.5 \\
15.0 \\
17.7 \\
19.8 \\
20.6 \\
19.0 \\
16.1\end{array}$ & $\begin{array}{l}16.7 \\
15.1 \\
13.5 \\
13.9 \\
14.5 \\
14.8 \\
14.4 \\
13.2\end{array}$ & $\begin{array}{l}16.9 \\
15.5 \\
14.8 \\
17.4 \\
19.4 \\
20.3 \\
18.9 \\
16.3\end{array}$ & $\begin{array}{l}16.7 \\
15.0 \\
13.0 \\
13.5 \\
13.9 \\
14.3 \\
14.1 \\
13.1\end{array}$ & $\begin{array}{l}17.0 \\
15.4 \\
14: 7 \\
17.2 \\
19.3 \\
20.1 \\
13.9 \\
16.2\end{array}$ & $\begin{array}{l}16.6 \\
14.8 \\
12.8 \\
13.4 \\
13.7 \\
13.8 \\
14.0 \\
12.9\end{array}$ & $\begin{array}{l}16.8 \\
15.1 \\
14.5 \\
17.0 \\
18.0 \\
19.0 \\
18.7 \\
16.0\end{array}$ & $\begin{array}{l}16.5 \\
14.4 \\
12.5 \\
12.8 \\
13.2 \\
13.5 \\
13.8 \\
17.8\end{array}$ & $\begin{array}{l}17.1 \\
17.03 \\
17.6 \\
18.4 \\
21.02 \\
21.01 \\
19.5 \\
18.2\end{array}$ & & $\begin{array}{r}7.4 \\
12.6 \\
13.0 \\
12.8 \\
12.7 \\
11.6 \\
7.6 \\
6.2\end{array}$ & $\begin{array}{r}9.4 \\
15.2 \\
14.2 \\
14.4 \\
14.2 \\
13.4 \\
8.8 \\
7.4\end{array}$ & $\begin{array}{l}11.4 \\
10.6 \\
10.2 \\
16.2 \\
18.4 \\
17.0 \\
10.2 \\
10.4\end{array}$ & 15.8 \\
\hline $\begin{array}{l}4 \\
4 \\
4 \\
4 \\
4 \\
4 \\
4 \\
4\end{array}$ & $\begin{array}{r}0 \\
3 \\
6 \\
9 \\
12 \\
15 \\
18 \\
21\end{array}$ & $\begin{array}{l}14.2 \\
12.7 \\
13.5 \\
17.9 \\
20.4 \\
21.3 \\
19.0 \\
15.3\end{array}$ & $\begin{array}{l}12.2 \\
10.8 \\
11.2 \\
12.8 \\
13.4 \\
13.1 \\
13.7 \\
12.9\end{array}$ & $\begin{array}{l}14.3 \\
12.7 \\
13.4 \\
17.4 \\
20.2 \\
20.7 \\
19.1 \\
15.9\end{array}$ & $\begin{array}{l}12.0 \\
10.6 \\
11.1 \\
12.2 \\
12.8 \\
13.2 \\
13.5 \\
13.0\end{array}$ & $\begin{array}{l}14.2 \\
12.7 \\
13.6 \\
17.5 \\
19.8 \\
20.6 \\
19.3 \\
15.3\end{array}$ & $\begin{array}{l}11.8 \\
10.5 \\
10.9 \\
11.9 \\
12.4 \\
13.0 \\
13.4 \\
13.0\end{array}$ & $\begin{array}{l}14.1 \\
12.6 \\
13.3 \\
17.3 \\
19.1 \\
20.3 \\
19.4 \\
16.7\end{array}$ & $\begin{array}{l}11.5 \\
10.2 \\
10.0 \\
11.6 \\
12.4 \\
13.8 \\
13.0 \\
13.7\end{array}$ & $\begin{array}{l}17.7 \\
15.8 \\
17.3 \\
20.6 \\
23.8 \\
24.7 \\
2 ? .8 \\
21.1\end{array}$ & & $\begin{array}{l}6.2 \\
5.8 \\
4.8 \\
3.6 \\
4.8 \\
3.0 \\
1.4 \\
1.8\end{array}$ & $\begin{array}{l}7.2 \\
7.4 \\
5.4 \\
4.0 \\
5.0 \\
3.2 \\
2.0 \\
2.2\end{array}$ & $\begin{array}{l}0.6 \\
8.6 \\
6.2 \\
4.8 \\
7.2\end{array}$ & $\begin{array}{l}3.8 \\
6.4 \\
4.6 \\
6.2 \\
3.8 \\
2.8 \\
4.0\end{array}$ \\
\hline $\begin{array}{l}5 \\
5 \\
5 \\
5 \\
5 \\
5 \\
5 \\
5\end{array}$ & $\begin{array}{r}0 \\
3 \\
6 \\
9 \\
12 \\
15 \\
18 \\
21\end{array}$ & $\begin{array}{l}14.5 \\
14.3 \\
16.1 \\
19.7 \\
21.1 \\
20.8 \\
18.5 \\
15.5\end{array}$ & $\begin{array}{l}12.7 \\
13.0 \\
14.0 \\
15.1 \\
14.6 \\
14.5 \\
15.5 \\
14.9\end{array}$ & $\begin{array}{l}14.8 \\
14.5 \\
16.1 \\
19.8 \\
21.0 \\
20.7 \\
18.5 \\
15.5\end{array}$ & $\begin{array}{l}12.7 \\
12.0 \\
13.8 \\
14.8 \\
14.3 \\
14.6 \\
15.3 \\
14.8\end{array}$ & $\begin{array}{l}15.1 \\
14.6 \\
16.3 \\
19.5 \\
20.7 \\
20.4 \\
18.5 \\
15.7\end{array}$ & $\begin{array}{l}12.8 \\
13.0 \\
13.9 \\
14.9 \\
14.5 \\
14.3 \\
15.3 \\
14.9\end{array}$ & $\begin{array}{l}15.5 \\
14.7 \\
15 . ? \\
10.5 \\
20.7 \\
20.2 \\
18.2 \\
15.7\end{array}$ & $\begin{array}{l}12.7 \\
12.0 \\
13.7 \\
34.8 \\
12.3 \\
14.2 \\
15.1 \\
15.0\end{array}$ & $\begin{array}{l}20.3 \\
20.6 \\
10.4 \\
20.7 \\
21.0 \\
20.4 \\
20.0 \\
17.03\end{array}$ & & $\begin{array}{l}2.8 \\
2.4 \\
2.5 \\
2.2 \\
3.4 \\
3.8 \\
3.4 \\
3.2\end{array}$ & $\begin{array}{l}3.8 \\
3.0 \\
3.0 \\
2.2 \\
4.4 \\
5.2 \\
4.8 \\
4.4\end{array}$ & $\begin{array}{l}6.0 \\
5.6\end{array}$ & $\begin{array}{l}6.8 \\
5.2 \\
3.8 \\
2.4 \\
4.8 \\
6.0 \\
7.2 \\
7.2\end{array}$ \\
\hline $\begin{array}{l}6 \\
6 \\
6 \\
6 \\
6 \\
6 \\
6 \\
6\end{array}$ & $\begin{array}{r}0 \\
3 \\
6 \\
9 \\
12 \\
15 \\
18 \\
21\end{array}$ & $\begin{array}{l}15.4 \\
15.3 \\
16.4 \\
19.5 \\
21.4 \\
22.2 \\
19.9\end{array}$ & $\begin{array}{l}15.2 \\
15.0 \\
15.6 \\
16.4 \\
16.9 \\
17.1 \\
16.6\end{array}$ & $\begin{array}{l}15.5 \\
15.3 \\
16.3 \\
19.3 \\
21.5 \\
21.8 \\
19.9\end{array}$ & $\begin{array}{l}15.3 \\
15.0 \\
15.5 \\
16.2 \\
16.5 \\
17.0 \\
16.5\end{array}$ & $\begin{array}{l}15.6 \\
15.3 \\
16.4 \\
19.1 \\
21.1 \\
21.5 \\
20.1\end{array}$ & $\begin{array}{l}15.3 \\
15.0 \\
15.4 \\
16.1 \\
16.7 \\
17.0 \\
16.6\end{array}$ & $\begin{array}{l}15.4 \\
15.2 \\
16.3 \\
19.1 \\
20.5 \\
21.3 \\
19.0\end{array}$ & $\begin{array}{l}15.2 \\
14.9 \\
15.4 \\
15.0 \\
16.4 \\
16.8 \\
15.5\end{array}$ & $\begin{array}{l}10.7 \\
18.5 \\
18.6 \\
19.4 \\
20.1 \\
70.1 \\
19.3\end{array}$ & & $\begin{array}{l}5.8 \\
6.4 \\
5.8 \\
6.8 \\
8.6 \\
9.2 \\
7.4 \\
6.0\end{array}$ & $\begin{array}{r}7.0 \\
7.2 \\
6.4 \\
7.9 \\
9.6 \\
10.4 \\
8.4 \\
7.0\end{array}$ & $\begin{array}{r}8.0 \\
8.0 \\
7.2 \\
8.6 \\
10.6 \\
11.6 \\
9.6 \\
8.0\end{array}$ & $\begin{array}{r}8.8 \\
9.0 \\
7.8 \\
0.2 \\
11.0 \\
12.6 \\
10.8 \\
9.4\end{array}$ \\
\hline $\begin{array}{l}7 \\
7 \\
7 \\
7 \\
7 \\
7 \\
7 \\
7\end{array}$ & $\begin{array}{r}0 \\
3 \\
6 \\
9 \\
12 \\
15 \\
18 \\
21\end{array}$ & $\begin{array}{l}26.7 \\
26.9 \\
24.5 \\
22.0\end{array}$ & $\begin{array}{l}19.0 \\
19.6 \\
19.3 \\
18.4\end{array}$ & $\begin{array}{l}26.5 \\
26.7 \\
24.4 \\
22.1\end{array}$ & $\begin{array}{l}18.6 \\
19.3 \\
19.2 \\
18.4\end{array}$ & $\begin{array}{l}26.2 \\
25.4 \\
24.4 \\
22.0\end{array}$ & $\begin{array}{l}18.3 \\
18.8 \\
19.5 \\
19.2 \\
18.4\end{array}$ & $\begin{array}{l}24 \cdot 2 \\
25.7 \\
26.3 \\
24 \cdot 3 \\
22.0\end{array}$ & $\begin{array}{l}18.3 \\
18.4 \\
19.3 \\
19.3 \\
19.5\end{array}$ & $\begin{array}{l}20.1 \\
20.6 \\
20.4 \\
19.8 \\
19.1\end{array}$ & & $\begin{array}{r}6.2 \\
7.2 \\
10.0 \\
13.0 \\
13.4 \\
14.0 \\
12.8 \\
11.0\end{array}$ & $\begin{array}{r}7.0 \\
8.4 \\
11.2 \\
14.6 \\
15.0 \\
16.0 \\
14.4 \\
12.8\end{array}$ & $\begin{array}{r}8.4 \\
9.6 \\
12.4 \\
16.2 \\
16.6 \\
17.8 \\
16.0 \\
14.4\end{array}$ & $\begin{array}{r}9.6 \\
11.0 \\
13.0 \\
17.2 \\
18.0 \\
19.4 \\
18.0 \\
16.0\end{array}$ \\
\hline $\begin{array}{l}8 \\
8 \\
8 \\
8 \\
8 \\
8 \\
8 \\
8\end{array}$ & $\begin{array}{r}0 \\
3 \\
6 \\
9 \\
12 \\
15 \\
18 \\
21\end{array}$ & $\begin{array}{l}20.6 \\
20.2 \\
21.8 \\
26.8 \\
28.8 \\
29.5 \\
27.7 \\
25.1\end{array}$ & $\begin{array}{l}18.3 \\
18.3 \\
19.4 \\
22.3 \\
23.7 \\
24.2 \\
23.5 \\
22.7\end{array}$ & $\begin{array}{l}20.6 \\
20.3 \\
22.1 \\
26.7 \\
28.1 \\
29.5 \\
27.8 \\
25.3\end{array}$ & $\begin{array}{l}18.4 \\
18.4 \\
19.4 \\
22.3 \\
23.5 \\
24.3 \\
23.5 \\
22.7\end{array}$ & $\begin{array}{l}20.6 \\
20.4 \\
22.0 \\
26.5 \\
27.6 \\
29.1 \\
27.5 \\
25.1\end{array}$ & $\begin{array}{l}18.3 \\
18.4 \\
19.6 \\
22.3 \\
23.3 \\
23.9 \\
23.4 \\
22.6\end{array}$ & $\begin{array}{l}20.7 \\
20.5 \\
22.1 \\
26.5 \\
27.5 \\
20.2 \\
27.8 \\
25.4\end{array}$ & $\begin{array}{l}13.4 \\
19.5 \\
19.6 \\
22.5 \\
23.5 \\
24.1 \\
23.7 \\
2 ? .9\end{array}$ & $\begin{array}{l}19.0 \\
13.0 \\
19.2 \\
20.5 \\
21.3 \\
21.3 \\
20.8 \\
20.2\end{array}$ & & $\begin{array}{l}12.0 \\
10.0 \\
14.0 \\
15.2 \\
13.6 \\
13.6 \\
12.0 \\
11.4\end{array}$ & $\begin{array}{l}13.8 \\
11.4 \\
16.0 \\
17.0 \\
15.4 \\
15.4 \\
13.5 \\
13.0\end{array}$ & $\begin{array}{l}15.4 \\
12.8 \\
18.0 \\
18.6 \\
17.2 \\
17.0 \\
15.2 \\
14.8\end{array}$ & $\begin{array}{l}17.0 \\
14.2 \\
19.4 \\
20.6 \\
18.4 \\
18.6 \\
16.3 \\
16.6\end{array}$ \\
\hline $\begin{array}{l}9 \\
9 \\
9 \\
9 \\
9 \\
9 \\
9 \\
9\end{array}$ & $\begin{array}{r}0 \\
3 \\
6 \\
9 \\
12 \\
15 \\
18 \\
21\end{array}$ & $\begin{array}{l}23.7 \\
22.9 \\
25.4 \\
28.6 \\
31.7 \\
31.4 \\
28.3 \\
25.9\end{array}$ & $\begin{array}{l}21.5 \\
21.3 \\
23.1 \\
24.8 \\
25.2 \\
25.2 \\
24.3 \\
23.5\end{array}$ & $\begin{array}{l}23.9 \\
23.0 \\
25.5 \\
29.4 \\
31.7 \\
31.1 \\
28.4 \\
26.2\end{array}$ & $\begin{array}{l}21.6 \\
21.5 \\
23.2 \\
24.8 \\
25.1 \\
25.3 \\
24.4 \\
23.6\end{array}$ & $\begin{array}{l}23.7 \\
23.0 \\
25.2 \\
28.8 \\
31.0 \\
30.7 \\
28.2 \\
26.1\end{array}$ & $\begin{array}{l}21.4 \\
21.4 \\
23.1 \\
24.6 \\
24.9 \\
24.9 \\
24.1 \\
23.4\end{array}$ & $\begin{array}{l}2.4 \cdot 1 \\
23.3 \\
25.7 \\
29.4 \\
31.2 \\
31.2 \\
28.6 \\
25.5\end{array}$ & $\begin{array}{l}21 \cdot 8 \\
21 \cdot 9 \\
23 \cdot 4 \\
24 \cdot 9 \\
25 \cdot 3 \\
25.4 \\
24 \cdot 6 \\
23.8\end{array}$ & $\begin{array}{l}20.1 \\
19.06 \\
20.2 \\
21.6 \\
22.7 \\
22.1 \\
21.1 \\
21.0\end{array}$ & & $\begin{array}{r}13.6 \\
13.2 \\
14.8 \\
17.8 \\
10.6 \\
10.5 \\
9.2 \\
7.6\end{array}$ & $\begin{array}{r}15.4 \\
15.2 \\
16.6 \\
14.4 \\
11.8 \\
12.2 \\
10.5 \\
8.8\end{array}$ & $\begin{array}{l}17.2 \\
17.0 \\
18.6 \\
16.0 \\
13.0 \\
13.6 \\
12.0 \\
10.2\end{array}$ & $\begin{array}{l}18.8 \\
18.8 \\
20.6 \\
17.4 \\
14.2 \\
14.6 \\
13.2 \\
11.8\end{array}$ \\
\hline $\begin{array}{l}10 \\
10 \\
10 \\
10 \\
10 \\
10 \\
10 \\
10\end{array}$ & $\begin{array}{r}0 \\
3 \\
6 \\
9 \\
12 \\
15 \\
13 \\
21\end{array}$ & $\begin{array}{l}23.5 \\
21.7 \\
25.1 \\
30.9 \\
33.3 \\
21.6 \\
21.9 \\
22.3\end{array}$ & $\begin{array}{l}22.6 \\
21.4 \\
23.1 \\
24.8 \\
25.3 \\
20.5 \\
19.3 \\
20.0\end{array}$ & $\begin{array}{l}23.8 \\
22.2 \\
25.2 \\
30.3 \\
32.9 \\
22.6 \\
22.7 \\
22.7\end{array}$ & $\begin{array}{l}22.8 \\
21.7 \\
23.2 \\
24.9 \\
25.3 \\
20.8 \\
19.5 \\
20.2\end{array}$ & $\begin{array}{l}23.9 \\
22.5 \\
25.2 \\
30.3 \\
32.2 \\
21.9 \\
22.1 \\
22.2\end{array}$ & $\begin{array}{l}22.8 \\
21.7 \\
22.9 \\
24.7 \\
24.4 \\
20.3 \\
18.9 \\
19.8\end{array}$ & $\begin{array}{l}24.8 \\
23 . ? \\
25.5 \\
30.8 \\
31.9 \\
22.9 \\
23.7 \\
23.5\end{array}$ & $\begin{array}{l}23.2 \\
22.3 \\
23.2 \\
25.0 \\
25.1 \\
20.8 \\
20.0 \\
20.8\end{array}$ & $\begin{array}{l}20.5 \\
20.4 \\
20.8 \\
22.5 \\
22.9 \\
20.5 \\
20.5 \\
20.3\end{array}$ & & $\begin{array}{r}2.0 \\
2.0 \\
2.8 \\
4.4 \\
6.2 \\
13.4 \\
8.0 \\
7.4\end{array}$ & $\begin{array}{r}3.2 \\
2.8 \\
3.6 \\
5.2 \\
7.6 \\
16.2 \\
10.4 \\
8.8\end{array}$ & $\begin{array}{r}3.4 \\
3.8 \\
6.0 \\
2.0 \\
10.4 \\
12.0 \\
10.0\end{array}$ & $\begin{array}{r}4.2 \\
5.2 \\
4: 2 \\
6: 0 \\
8.6 \\
20.6 \\
14: 0 \\
11.2\end{array}$ \\
\hline
\end{tabular}


TABLE 10

Tạble 10. - Three-hour averages of air and water-surface temperatures and wind directions and speed, April 1950-August 1951, Lake Hefner-Continued

STATION 2

THREE-HOURLY AVERAGES

JUNE, 1950

\begin{tabular}{|c|c|c|c|c|c|c|c|c|c|c|c|c|c|c|c|}
\hline \multirow{4}{*}{ 宽 } & \multirow{4}{*}{ 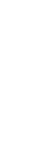 } & \multicolumn{8}{|c|}{ Average air temperature $\left({ }^{\circ} \mathrm{C}\right)$ at indicated height } & \multirow{4}{*}{$\begin{array}{l}\text { Average } \\
\text { water- } \\
\text { surface } \\
\text { tempera- } \\
\text { ture } \\
\left({ }^{\circ} \mathrm{C}\right)\end{array}$} & \multirow{4}{*}{$\begin{array}{l}\text { Average } \\
\text { wind } \\
\text { direction } \\
\text { (coded) }\end{array}$} & \multirow{2}{*}{\multicolumn{4}{|c|}{$\begin{array}{l}\text { Average wind speed (knots) } \\
\text { at indicated height }\end{array}$}} \\
\hline & & \multirow{2}{*}{\multicolumn{2}{|c|}{$\underset{\text { meters }}{2}$}} & \multirow{2}{*}{\multicolumn{2}{|c|}{$\begin{array}{c}4 \\
\text { meters } \\
\end{array}$}} & \multirow{2}{*}{\multicolumn{2}{|c|}{$\begin{array}{c}8 \\
\text { meters }\end{array}$}} & \multirow{2}{*}{\multicolumn{2}{|c|}{$\begin{array}{c}16 \\
\text { meters }\end{array}$}} & & & & & & \\
\hline & & & & & & & & & & & & 2 & 4 & & 16 \\
\hline & & $\begin{array}{l}\text { Dry } \\
\text { bulb }\end{array}$ & $\begin{array}{l}\text { Wet } \\
\text { bulb }\end{array}$ & $\begin{array}{l}\text { Dry } \\
\text { bulb }\end{array}$ & $\begin{array}{l}\text { Wet } \\
\text { bulb }\end{array}$ & $\begin{array}{l}\text { Dry } \\
\text { bulb }\end{array}$ & $\begin{array}{l}\text { Wet } \\
\text { bulb }\end{array}$ & $\begin{array}{l}\text { Dry } \\
\text { bulb }\end{array}$ & $\begin{array}{l}\text { Wet } \\
\text { bulb }\end{array}$ & & & metera & meters & meters & meters \\
\hline $\begin{array}{l}11 \\
11 \\
11 \\
11 \\
11 \\
11 \\
11 \\
11\end{array}$ & $\begin{array}{r}0 \\
3 \\
6 \\
9 \\
12 \\
15 \\
18 \\
21\end{array}$ & $\begin{array}{l}24 \cdot 1 \\
25.4 \\
25.9 \\
23.5 \\
22.1\end{array}$ & $\begin{array}{l}20.3 \\
20.4 \\
21.0 \\
22.1 \\
22.7 \\
21.3 \\
21.1\end{array}$ & $\begin{array}{l}21.9 \\
21.1 \\
24.0 \\
25.3 \\
25.9 \\
23.6 \\
22.3\end{array}$ & $\begin{array}{l}20.7 \\
21: 7 \\
22: 5 \\
21: 1 \\
21.1\end{array}$ & $\begin{array}{l}23.7 \\
25.1 \\
25.2 \\
23.5 \\
22.3\end{array}$ & $\begin{array}{l}20.6 \\
21.6 \\
22.2 \\
21.0 \\
21.1\end{array}$ & $\begin{array}{l}23.0 \\
22.1 \\
23.5 \\
24.9 \\
25.0 \\
23.5 \\
22.3\end{array}$ & $\begin{array}{l}21.02 \\
21.4 \\
20.5 \\
21.4 \\
22.00 \\
21.00 \\
21.01\end{array}$ & $\begin{array}{l}20.6 \\
20.5\end{array}$ & & $\begin{array}{r}4.2 \\
2.6 \\
4.2 \\
3.8 \\
5.6 \\
10.8 \\
8.6 \\
8.6\end{array}$ & $\begin{array}{r}5.0 \\
3.4 \\
5.4 \\
4.4 \\
5.6 \\
12.7 \\
10.0 \\
10.0\end{array}$ & $\begin{array}{l}10.2 \\
14.2 \\
10.6 \\
11.4\end{array}$ & $\begin{array}{r}7.0 \\
5.0 \\
6.4 \\
5.2 \\
14.8 \\
13.0 \\
12.8\end{array}$ \\
\hline $\begin{array}{l}12 \\
12 \\
12 \\
12 \\
12 \\
12 \\
12 \\
12\end{array}$ & $\begin{array}{r}0 \\
3 \\
6 \\
9 \\
12 \\
15 \\
18 \\
21\end{array}$ & $\begin{array}{l}21.3 \\
20.9 \\
22.9 \\
27.8 \\
30.5 \\
31.2\end{array}$ & $\begin{array}{l}20.6 \\
20.5 \\
21.5 \\
23.3 \\
23.6 \\
23.7\end{array}$ & $\begin{array}{l}21.4 \\
21.0 \\
22.9 \\
27.6 \\
30.2 \\
30.9\end{array}$ & $\begin{array}{l}20.6 \\
20.6 \\
21.4 \\
23.1 \\
23.4 \\
22.9\end{array}$ & $\begin{array}{l}21.5 \\
21.0 \\
23.0 \\
27.5 \\
29.8 \\
30.3\end{array}$ & $\begin{array}{l}20.6 \\
20.5 \\
21.4 \\
22.9 \\
23.3 \\
23.0\end{array}$ & $\begin{array}{l}21.5 \\
21: 0 \\
23.2 \\
27: 4 \\
29 \cdot 7 \\
30.7\end{array}$ & $\begin{array}{l}20.7 \\
20.6 \\
21.3 \\
22.9 \\
22.9 \\
22.4\end{array}$ & & & $\begin{array}{r}7.6 \\
10.0 \\
12.0 \\
11.8 \\
12.4 \\
12.2 \\
9.6 \\
11.2\end{array}$ & $\begin{array}{l}8.6 \\
11.4 \\
13.6 \\
13.6 \\
14.2 \\
13.8 \\
11.0 \\
12.8\end{array}$ & $\begin{array}{l}9.8 \\
12.8 \\
15.2 \\
14.8 \\
15.6 \\
15.2 \\
12.6 \\
14.6\end{array}$ & $\begin{array}{l}11.2 \\
14.4 \\
15.6 \\
16.2 \\
17.0 \\
16.6 \\
14.0 \\
16.4\end{array}$ \\
\hline $\begin{array}{l}13 \\
13 \\
13 \\
13 \\
13 \\
13 \\
13 \\
13\end{array}$ & $\begin{array}{r}0 \\
3 \\
6 \\
9 \\
12 \\
15 \\
18 \\
21\end{array}$ & $\begin{array}{l}28.5 \\
31.3 \\
31.7\end{array}$ & $\begin{array}{l}23.2 \\
23.8 \\
23.3\end{array}$ & $\begin{array}{l}28.4 \\
30.8 \\
31.6\end{array}$ & $\begin{array}{l}23.0 \\
23.6 \\
23.4\end{array}$ & $\begin{array}{l}28.1 \\
30.4 \\
31.0\end{array}$ & $\begin{array}{l}22.8 \\
23.4 \\
23.2\end{array}$ & $\begin{array}{l}28.0 \\
30.0 \\
30.8\end{array}$ & $\begin{array}{l}22.9 \\
23.1 \\
23.1\end{array}$ & $\begin{array}{l}25.9 \\
26.9 \\
26.8\end{array}$ & & $\begin{array}{l}11.6 \\
10.4 \\
11.2 \\
11.6 \\
12.8 \\
14.0 \\
11.0 \\
10.0\end{array}$ & $\begin{array}{l}13.2 \\
12.0 \\
12.6 \\
13.2 \\
14.4 \\
16.0 \\
12.6 \\
11.4\end{array}$ & $\begin{array}{l}15.0 \\
13.4 \\
14.2 \\
14.4 \\
16.0 \\
18.0 \\
14.0 \\
13.2\end{array}$ & $\begin{array}{l}16.6 \\
15.0 \\
15.6 \\
16.2 \\
17.4 \\
19.4 \\
15.6 \\
14.6\end{array}$ \\
\hline $\begin{array}{l}14 \\
14 \\
14 \\
14 \\
14 \\
14 \\
14 \\
14\end{array}$ & $\begin{array}{r}0 \\
3 \\
6 \\
9 \\
12 \\
15 \\
18 \\
21\end{array}$ & $\begin{array}{l}29.3 \\
31.3 \\
30.9 \\
27.8 \\
24.9\end{array}$ & $\begin{array}{l}23.0 \\
23.3 \\
22.8 \\
22.6 \\
21.6\end{array}$ & $\begin{array}{l}28.9 \\
30.9 \\
30.5 \\
27.7 \\
24.9\end{array}$ & $\begin{array}{l}22.9 \\
23.2 \\
22.5 \\
22.6 \\
21.6\end{array}$ & $\begin{array}{l}28.7 \\
30.3 \\
30.1 \\
27.6 \\
24.9\end{array}$ & $\begin{array}{l}22.5 \\
22 \cdot 9 \\
22 \cdot 3 \\
22 \cdot 5 \\
21.6\end{array}$ & $\begin{array}{l}28.3 \\
30.0 \\
29 \cdot 9 \\
27.6 \\
25.0\end{array}$ & $\begin{array}{l}22.5 \\
22.9 \\
22.4 \\
22.5 \\
21.6\end{array}$ & $\begin{array}{l}25.9 \\
26.8 \\
26.0 \\
24.4 \\
23.9\end{array}$ & & $\begin{array}{r}9.8 \\
8.6 \\
11.0 \\
10.4 \\
11.2 \\
11.6 \\
8.8 \\
7.0\end{array}$ & $\begin{array}{r}12.2 \\
10.6 \\
13.4 \\
13.2 \\
13.8 \\
14.0 \\
11.0 \\
8.8\end{array}$ & $\begin{array}{l}14.0 \\
12.0 \\
15.2 \\
14.6 \\
15.2 \\
15.6 \\
12.6 \\
10.0\end{array}$ & $\begin{array}{l}15.6 \\
13.8 \\
16.8 \\
16.0 \\
16.4 \\
16.8 \\
14.0 \\
11.4\end{array}$ \\
\hline $\begin{array}{l}15 \\
15 \\
15 \\
15 \\
15 \\
15 \\
15 \\
15\end{array}$ & $\begin{array}{r}0 \\
3 \\
6 \\
9 \\
12 \\
15 \\
18 \\
21\end{array}$ & $\begin{array}{l}23.1 \\
21.6 \\
23.9 \\
28.9 \\
31.3 \\
30.9 \\
27.9 \\
24.4\end{array}$ & $\begin{array}{l}21.0 \\
20.2 \\
21.2 \\
22.3 \\
22.6 \\
22.2 \\
21.8 \\
20.7\end{array}$ & $\begin{array}{l}23.2 \\
21.7 \\
23.9 \\
28 \cdot 7 \\
31.1 \\
30.9 \\
28 \cdot 0 \\
24.6\end{array}$ & $\begin{array}{l}21.0 \\
20.1 \\
21.1 \\
22.0 \\
22.2 \\
21.0 \\
21.07 \\
20.8\end{array}$ & $\begin{array}{l}23.2 \\
21.7 \\
23.9 \\
28.5 \\
30.5 \\
30.4 \\
27.7 \\
24.7\end{array}$ & $\begin{array}{l}21.0 \\
20.1 \\
21 \cdot 0 \\
21.8 \\
22 \cdot 2 \\
21 \cdot 9 \\
21.7 \\
20.7\end{array}$ & $\begin{array}{l}23.3 \\
21.8 \\
23.9 \\
28.4 \\
30.0 \\
30.2 \\
27.7 \\
25.1\end{array}$ & $\begin{array}{l}21.1 \\
20.2 \\
20.9 \\
21.8 \\
22.0 \\
21.5 \\
21.6 \\
20.8\end{array}$ & $\begin{array}{l}23.6 \\
23.3 \\
24.0 \\
25.9 \\
26.9 \\
25.0 \\
24.6 \\
24.1\end{array}$ & & $\begin{array}{r}8.0 \\
7.4 \\
10.0 \\
11.8 \\
11.4 \\
11.2 \\
8.4 \\
5.4\end{array}$ & $\begin{array}{r}9.0 \\
8.06 \\
11.2 \\
13.2 \\
12.0 \\
12.6 \\
9.6 \\
6.4\end{array}$ & $\begin{array}{l}10.4 \\
10.0 \\
12.4 \\
14.8 \\
14.0 \\
14.00 \\
11.00 \\
7.8\end{array}$ & $\begin{array}{r}11.6 \\
11.02 \\
13.6 \\
16.0 \\
15.2 \\
15.4 \\
12.4 \\
9.6\end{array}$ \\
\hline $\begin{array}{l}16 \\
16 \\
16 \\
16 \\
16 \\
16 \\
16 \\
16\end{array}$ & $\begin{array}{r}0 \\
3 \\
6 \\
9 \\
12 \\
15 \\
18 \\
21\end{array}$ & $\begin{array}{l}23 \cdot 3 \\
22.0 \\
24.5 \\
29 \cdot 2 \\
31 \cdot 9 \\
31.6 \\
28.4 \\
24.5\end{array}$ & $\begin{array}{l}20.5 \\
19.9 \\
21.03 \\
23.0 \\
23.1 \\
22.8 \\
21.05 \\
20.2\end{array}$ & $\begin{array}{l}23.4 \\
22.0 \\
24.4 \\
29.0 \\
31.5 \\
31.5 \\
28.4 \\
24.9\end{array}$ & $\begin{array}{l}20.6 \\
19.9 \\
21.3 \\
22.8 \\
22.7 \\
22.6 \\
21.4 \\
20.2\end{array}$ & $\begin{array}{l}23.4 \\
22.01 \\
24.04 \\
22.0 \\
31.3 \\
30.9 \\
28.2 \\
25.1\end{array}$ & $\begin{array}{l}20.6 \\
19.9 \\
21.3 \\
22.9 \\
22.4 \\
22.4 \\
21.4 \\
20.3\end{array}$ & $\begin{array}{l}23.5 \\
22.1 \\
24: 0 \\
28.5 \\
31.0 \\
30.7 \\
28.4 \\
25.7\end{array}$ & $\begin{array}{l}20.6 \\
19.9 \\
21.3 \\
22.6 \\
22.6 \\
22.3 \\
21.4 \\
20.4\end{array}$ & $\begin{array}{l}23.6 \\
23.4 \\
24.4 \\
25.2 \\
20.3 \\
25.0 \\
25.0 \\
24.04\end{array}$ & & $\begin{array}{r}7.8 \\
8.8 \\
10.6 \\
9.2 \\
9.0 \\
9.8 \\
7.0 \\
4.2\end{array}$ & $\begin{array}{r}8.8 \\
10.2 \\
11.8 \\
10.2 \\
10.2 \\
11.0 \\
8.2 \\
5.2\end{array}$ & $\begin{array}{r}10.2 \\
11.06 \\
13.4 \\
11.07 \\
11.2 \\
12.2 \\
9.4 \\
6.6\end{array}$ & $\begin{array}{r}11.8 \\
13.0 \\
14.8 \\
12.2 \\
12.0 \\
13.2 \\
10.8 \\
8.4\end{array}$ \\
\hline $\begin{array}{l}17 \\
17 \\
17 \\
17 \\
17 \\
17 \\
17 \\
17\end{array}$ & $\begin{array}{r}0 \\
3 \\
6 \\
9 \\
12 \\
15 \\
18 \\
21\end{array}$ & $\begin{array}{l}22 \cdot 8 \\
22 \cdot 7 \\
24 \cdot 9 \\
29.7 \\
32 \cdot 0 \\
32.0 \\
28.7 \\
24 \cdot 4\end{array}$ & $\begin{array}{l}20.1 \\
20.3 \\
21.3 \\
22.3 \\
22.3 \\
21.9 \\
20.7 \\
20.1\end{array}$ & $\begin{array}{l}23.2 \\
22.9 \\
25.0 \\
29 \cdot 3 \\
31.6 \\
31.8 \\
28.7 \\
24.8\end{array}$ & $\begin{array}{l}20.2 \\
20.3 \\
21.2 \\
22.0 \\
22.2 \\
21.6 \\
20.7 \\
20.1\end{array}$ & $\begin{array}{l}23.5 \\
22.8 \\
24.5 \\
20 \cdot 1 \\
31.5 \\
31.5 \\
28.4 \\
25.1\end{array}$ & $\begin{array}{l}20.3 \\
20.3 \\
21.2 \\
22.0 \\
21.7 \\
21.4 \\
20.6 \\
20.1\end{array}$ & $\begin{array}{l}24.1 \\
22.7 \\
25.0 \\
29.7 \\
31.1 \\
31.2 \\
28.5 \\
25.4\end{array}$ & $\begin{array}{l}20.4 \\
20.3 \\
21.1 \\
21.7 \\
21.3 \\
21.7 \\
20.7 \\
20.2\end{array}$ & $\begin{array}{l}24.2 \\
23.9 \\
24.5 \\
26.6 \\
27.4 \\
25.7 \\
25.7 \\
25.1\end{array}$ & & $\begin{array}{r}5.0 \\
8.2 \\
9.8 \\
10.2 \\
9.8 \\
11.2 \\
7.4 \\
5.4\end{array}$ & $\begin{array}{r}6.2 \\
9.2 \\
11.2 \\
11.5 \\
11.0 \\
12.4 \\
8.8 \\
6.4\end{array}$ & $\begin{array}{r}7.6 \\
10.8 \\
12.06 \\
12.8 \\
12.00 \\
24.00 \\
10.02 \\
8.00\end{array}$ & $\begin{array}{r}9.4 \\
12.2 \\
13.6 \\
13.6 \\
12.3 \\
15.2 \\
11.6 \\
9.6\end{array}$ \\
\hline $\begin{array}{l}18 \\
18 \\
18 \\
18 \\
18 \\
18 \\
18 \\
18\end{array}$ & $\begin{array}{r}0 \\
3 \\
6 \\
9 \\
12 \\
15 \\
18 \\
21\end{array}$ & $\begin{array}{l}23.5 \\
22.8 \\
24.7 \\
29.7 \\
32.2 \\
32.0 \\
28.4 \\
25.9\end{array}$ & $\begin{array}{l}19.6 \\
19.5 \\
20.5 \\
21.9 \\
22.1 \\
21.2 \\
20.7 \\
20.5\end{array}$ & $\begin{array}{l}23.6 \\
22.9 \\
24.7 \\
29.4 \\
31.8 \\
31.6 \\
28.4 \\
26.0\end{array}$ & $\begin{array}{l}19.6 \\
19.6 \\
20.4 \\
21.4 \\
21.9 \\
21.0 \\
20.7 \\
20.8\end{array}$ & $\begin{array}{l}23.5 \\
23.00 \\
24.07 \\
29.00 \\
31.05 \\
31.03 \\
28.4 \\
36.0\end{array}$ & $\begin{array}{l}19.5 \\
10.06 \\
20.4 \\
21.4 \\
21.7 \\
21.0 \\
20.7 \\
20.9\end{array}$ & $\begin{array}{l}23.8 \\
23.0 \\
24.8 \\
28.0 \\
31.1 \\
31.1 \\
28.1 \\
76.0\end{array}$ & $\begin{array}{l}19.6 \\
19.7 \\
20.5 \\
21.5 \\
21.5 \\
20.9 \\
20.3 \\
20.13\end{array}$ & $\begin{array}{l}24.8 \\
24.7 \\
25.1 \\
25.7 \\
29.4 \\
27.9 \\
26.4 \\
23.9\end{array}$ & & $\begin{array}{r}10.6 \\
10.6 \\
11.6 \\
13.8 \\
13.6 \\
13.4 \\
7.4 \\
9.8\end{array}$ & $\begin{array}{r}12.2 \\
12.0 \\
13.2 \\
15.6 \\
15.2 \\
15.2 \\
8.5 \\
10.4\end{array}$ & $\begin{array}{l}13.6 \\
13.8 \\
14.8 \\
17.6 \\
16.8 \\
16.6 \\
10.0 \\
12.0\end{array}$ & $\begin{array}{l}15.2 \\
15.6 \\
1602 \\
19.0 \\
18.2 \\
13.6 \\
11.4 \\
13.6\end{array}$ \\
\hline $\begin{array}{l}19 \\
19 \\
19 \\
19 \\
19 \\
19 \\
19 \\
19\end{array}$ & $\begin{array}{r}0 \\
3 \\
6 \\
9 \\
12 \\
15 \\
18 \\
21\end{array}$ & $\begin{array}{l}25.2 \\
21.05 \\
21.00 \\
23.5 \\
26.4 \\
26.06 \\
24.9 \\
21.4\end{array}$ & $\begin{array}{l}20.1 \\
19.3 \\
19.1 \\
19.8 \\
21.4 \\
21.5 \\
21.04 \\
20.1\end{array}$ & $\begin{array}{l}25.2 \\
22.0 \\
20.7 \\
23.2 \\
25.3 \\
26.4 \\
24.7 \\
21.5\end{array}$ & $\begin{array}{l}20.1 \\
19.4 \\
19.0 \\
19.8 \\
21.1 \\
21.3 \\
21.4 \\
20.2\end{array}$ & $\begin{array}{l}25.1 \\
22.02 \\
20.5 \\
22.9 \\
25.0 \\
26.0 \\
24.4 \\
21.6\end{array}$ & $\begin{array}{l}20.0 \\
19.4 \\
18.0 \\
19.8 \\
20.9 \\
21.00 \\
21.00 \\
20.1\end{array}$ & $\begin{array}{l}25.3 \\
22.6 \\
20.5 \\
23.0 \\
24.7 \\
25.3 \\
24.5 \\
21.0\end{array}$ & $\begin{array}{l}20.1 \\
19.5 \\
18.7 \\
10.8 \\
20.7 \\
20.9 \\
21.0 \\
20.2\end{array}$ & $\begin{array}{l}25.7 \\
25.1 \\
25.5 \\
23.02 \\
33.5 \\
33.3 \\
31.6 \\
20.1\end{array}$ & & $\begin{array}{l}9.2 \\
2.0 \\
5.8 \\
3.6 \\
4.5 \\
4.6 \\
4.0 \\
3.2\end{array}$ & $\begin{array}{r}10.4 \\
3.2 \\
9.0 \\
3.8 \\
5.5 \\
5.2 \\
5.0 \\
4.8\end{array}$ & $\begin{array}{r}12.0 \\
4.2 \\
11.0 \\
4.4 \\
6.0 \\
6.2 \\
5.8 \\
6.0\end{array}$ & $\begin{array}{r}13.6 \\
5.2 \\
10.5 \\
4.6 \\
6.2 \\
6.4 \\
6.4 \\
7.4\end{array}$ \\
\hline $\begin{array}{l}20 \\
20 \\
20 \\
20 \\
20 \\
20 \\
20 \\
20\end{array}$ & $\begin{array}{r}0 \\
3 \\
6 \\
9 \\
12 \\
15 \\
18 \\
21\end{array}$ & $\begin{array}{l}20.7 \\
21.7 \\
23.2 \\
28.2 \\
31.9 \\
29.3 \\
18.8 \\
19.6\end{array}$ & $\begin{array}{l}20.0 \\
20.3 \\
21.2 \\
22.8 \\
23.1 \\
22.0 \\
17.6 \\
18.5\end{array}$ & $\begin{array}{l}20.9 \\
21.9 \\
23: 3 \\
27.6 \\
31.9 \\
29.0 \\
19.0 \\
19.7\end{array}$ & $\begin{array}{l}20.1 \\
20.4 \\
21.02 \\
22.6 \\
23.0 \\
22.8 \\
17.0 \\
18.4\end{array}$ & 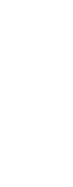 & $\begin{array}{l}20.2 \\
20.5 \\
21.0 \\
22.6 \\
22.9 \\
22.2 \\
17.04 \\
18.3\end{array}$ & $\begin{array}{ll}21.4 & 4 \\
22 & 0 \\
33.0 & 0 \\
27.4 \\
30.3 \\
28.7 \\
18.4 \\
19.4\end{array}$ & $\begin{array}{l}20.2 \\
20.5 \\
21.0 \\
27.5 \\
27.8 \\
23.6 \\
17.4 \\
18.3\end{array}$ & $\begin{array}{l}27.5 \\
25.6 \\
27.0 \\
213.3 \\
29.3 \\
27.3 \\
26.3 \\
25.6\end{array}$ & & $\begin{array}{l}5.4 \\
4.8 \\
2.4 \\
4.4 \\
7.2 \\
6.2 \\
4.0 \\
3.8\end{array}$ & $\begin{array}{l}6.6 \\
5.4 \\
3.4 \\
4.8 \\
8.0 \\
7.4 \\
4.6 \\
4.6\end{array}$ & $\begin{array}{l}7.6 \\
6.4 \\
4.0 \\
5.4 \\
1.8 \\
.06 \\
5.4 \\
5.4\end{array}$ & $\begin{array}{l}9.4 \\
7.2 \\
4.2 \\
5.6 \\
9.4 \\
9.6 \\
6.2 \\
6.4\end{array}$ \\
\hline
\end{tabular}


TABLT 10

Table 10. -Three-hour averages of air and water-surface temperatures and wind directions and speed, April 1950-August statron

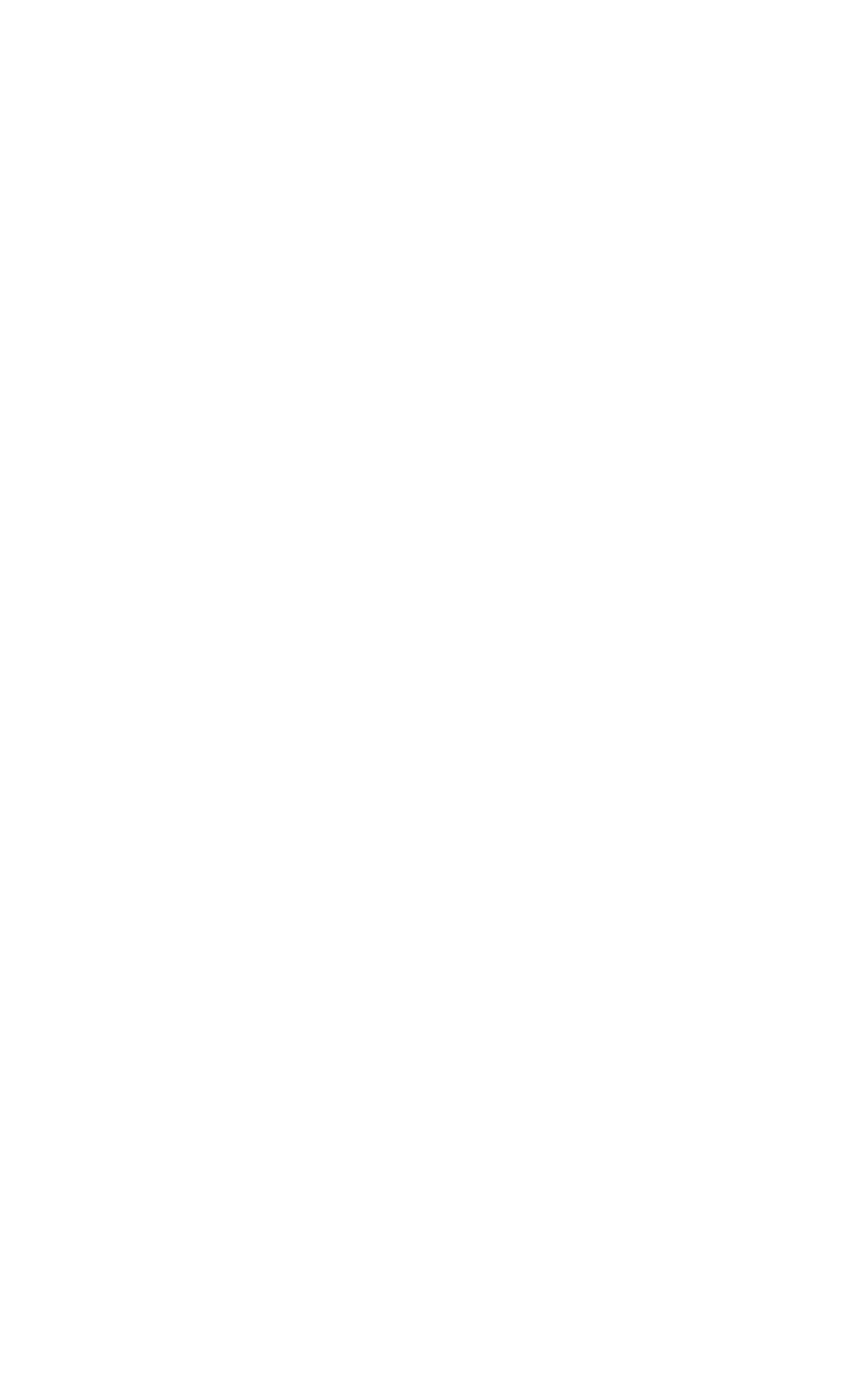


TABLE 10

Table 10. - Three-hour averages of air and water-surface temperatures and wind directions and speed, April 1950-August 1951, Lake Hefner-Continued

STATION 2 THREE-HOURLY AVERAGES

JULY, 2950

\begin{tabular}{|c|c|c|c|c|c|c|c|c|c|c|c|c|c|c|c|}
\hline \multirow{3}{*}{ 总 } & \multirow{3}{*}{ 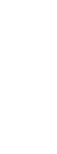 } & \multicolumn{8}{|c|}{ Average air temperature $\left({ }^{\circ} \mathrm{C}\right)$ at indicated height } & \multirow{3}{*}{\begin{tabular}{|} 
Average \\
water- \\
surface \\
tempera- \\
ture \\
$\left({ }^{\circ} \mathrm{C}\right)$
\end{tabular}} & \multirow{3}{*}{$\begin{array}{c}\text { Average } \\
\text { wind } \\
\text { direction } \\
\text { (coded) }\end{array}$} & \multirow{2}{*}{\multicolumn{4}{|c|}{$\begin{array}{l}\text { Average wind speed (knots) } \\
\text { at indicated height }\end{array}$}} \\
\hline & & \multicolumn{2}{|c|}{$\stackrel{2}{\text { meters }}$} & \multicolumn{2}{|c|}{$\stackrel{4}{4}$} & \multicolumn{2}{|c|}{$\begin{array}{c}8 \\
\text { meters }\end{array}$} & \multicolumn{2}{|c|}{$\begin{array}{c}16 \\
\text { meters }\end{array}$} & & & & & & \\
\hline & & $\begin{array}{l}\text { Dry } \\
\text { bulb }\end{array}$ & $\begin{array}{l}\text { Wet } \\
\text { bulb }\end{array}$ & $\begin{array}{l}\text { Dry } \\
\text { bulb }\end{array}$ & $\begin{array}{l}\text { Wet } \\
\text { bulb }\end{array}$ & $\begin{array}{l}\text { Dry } \\
\text { bulb }\end{array}$ & $\begin{array}{l}\text { Wet } \\
\text { bulb }\end{array}$ & $\begin{array}{l}\text { Dry } \\
\text { bulb }\end{array}$ & $\begin{array}{l}\text { Wet } \\
\text { bulb }\end{array}$ & & & $\begin{array}{c}2 \\
\text { meters }\end{array}$ & $\begin{array}{c}4 \\
\text { meters }\end{array}$ & $\begin{array}{c}8 \\
\text { meters }\end{array}$ & $\begin{array}{c}16 \\
\text { meters }\end{array}$ \\
\hline $\begin{array}{l}1 \\
1 \\
1 \\
1 \\
1 \\
1 \\
1 \\
1\end{array}$ & $\begin{array}{r}0 \\
3 \\
6 \\
9 \\
12 \\
15 \\
18 \\
21\end{array}$ & $\begin{array}{l}19.9 \\
18.8 \\
22.2 \\
27.2 \\
30.0 \\
30.0 \\
27.1 \\
23.8\end{array}$ & $\begin{array}{l}17.1 \\
16.8 \\
18.1 \\
19.5 \\
20.5 \\
20.5 \\
19.1 \\
19.1\end{array}$ & $\begin{array}{l}20.0 \\
19.0 \\
22.4 \\
26.8 \\
29.6 \\
29.9 \\
26.9 \\
23.7\end{array}$ & $\begin{array}{l}17.1 \\
16.9 \\
18.0 \\
19.4 \\
20.2 \\
20.2 \\
19.0 \\
19.0\end{array}$ & $\begin{array}{l}20.1 \\
19.2 \\
22.4 \\
26.5 \\
29.3 \\
29.4 \\
26.9 \\
23.8\end{array}$ & $\begin{array}{l}17.1 \\
16.9 \\
18.0 \\
19.2 \\
20.2 \\
20.3 \\
19.0 \\
19.2\end{array}$ & $\begin{array}{l}20.6 \\
19.4 \\
22.4 \\
26 \cdot 3 \\
29 \cdot 1 \\
29 \cdot 3 \\
27.0 \\
24.1\end{array}$ & $\begin{array}{l}17.2 \\
17.0 \\
17.9 \\
19.2 \\
19.9 \\
20.1 \\
18.9 \\
19.0\end{array}$ & & & $\begin{array}{r}4.0 \\
4.3 \\
9.2 \\
11.8 \\
11.4 \\
12.1 \\
7.5 \\
4.9\end{array}$ & $\begin{array}{r}5.4 \\
5.5 \\
10.4 \\
13.4 \\
12.7 \\
13.9 \\
8.7 \\
5.9\end{array}$ & $\begin{array}{r}6.8 \\
6.9 \\
12.0 \\
14.9 \\
14.3 \\
15.6 \\
10.0 \\
7.2\end{array}$ & $\begin{array}{r}8.1 \\
8.6 \\
13.3 \\
16.2 \\
15.5 \\
17.12 \\
11.8 \\
8.5\end{array}$ \\
\hline $\begin{array}{l}2 \\
2 \\
2 \\
2 \\
2 \\
2 \\
2 \\
2 \\
2\end{array}$ & $\begin{array}{r}0 \\
3 \\
6 \\
9 \\
12 \\
15 \\
18 \\
21\end{array}$ & $\begin{array}{l}31.6 \\
28.6 \\
25.6\end{array}$ & $\begin{array}{l}17.8 \\
16.9 \\
18.4\end{array}$ & $\begin{array}{l}31.2 \\
28.6 \\
25.7\end{array}$ & $\begin{array}{l}22.1 \\
21 \cdot 2 \\
20.3\end{array}$ & $\begin{array}{l}30.6 \\
28.5 \\
25.7\end{array}$ & $\begin{array}{l}17.9 \\
17.0 \\
18.4\end{array}$ & $\begin{array}{l}22 \cdot 8 \\
20.8 \\
23.1\end{array}$ & $\begin{array}{l}22.0 \\
21.1 \\
20.4\end{array}$ & & & $\begin{array}{r}5.3 \\
9.4 \\
9.2 \\
8.3 \\
8.6 \\
10.8 \\
8.9 \\
7.6\end{array}$ & $\begin{array}{r}6.5 \\
20.7 \\
10.5 \\
9.5 \\
9.6 \\
12.5 \\
10.0 \\
8.9\end{array}$ & $\begin{array}{r}7.7 \\
12.5 \\
11.9 \\
10.4 \\
10.6 \\
13.9 \\
1102 \\
10.0\end{array}$ & $\begin{array}{r}9.3 \\
14.6 \\
13.0 \\
11.2 \\
11.03 \\
15.2 \\
12.8 \\
12.0\end{array}$ \\
\hline $\begin{array}{l}3 \\
3 \\
3 \\
3 \\
3 \\
3 \\
3 \\
3\end{array}$ & $\begin{array}{r}0 \\
3 \\
6 \\
9 \\
12 \\
15 \\
18 \\
21\end{array}$ & $\begin{array}{l}23.5 \\
22.4 \\
23.4 \\
26.5 \\
29.0 \\
30.0 \\
27.6 \\
23.8\end{array}$ & $\begin{array}{l}19.4 \\
19.8 \\
20.8 \\
21.8 \\
22.9 \\
23.0 \\
22.3 \\
21.5\end{array}$ & $\begin{array}{l}23.5 \\
22.5 \\
23.5 \\
26.5 \\
28.7 \\
29.5 \\
27.4 \\
24.1\end{array}$ & $\begin{array}{l}19.5 \\
19.9 \\
20.8 \\
21.7 \\
22.7 \\
22.8 \\
22.2 \\
21.4\end{array}$ & $\begin{array}{l}23.5 \\
22.4 \\
23.5 \\
26.3 \\
28.5 \\
29.5 \\
27.2 \\
24.3\end{array}$ & $\begin{array}{l}19.6 \\
20.0 \\
21.0 \\
21.7 \\
22.5 \\
22.8 \\
22.1 \\
21.3\end{array}$ & $\begin{array}{l}23.5 \\
22.7 \\
23.6 \\
26.3 \\
28.2 \\
29.2 \\
27.1 \\
24.5\end{array}$ & $\begin{array}{l}10.5 \\
20.0 \\
20.8 \\
21.6 \\
22.2 \\
22.4 \\
22.2 \\
21.3\end{array}$ & & & $\begin{array}{l}8.2 \\
6.0 \\
5.7 \\
4.8 \\
3.9 \\
2.8 \\
3.0 \\
1.8\end{array}$ & $\begin{array}{r}10.5 \\
7.8 \\
7.3 \\
5.8 \\
5.2 \\
3.5 \\
4.0 \\
2.7\end{array}$ & $\begin{array}{r}12.0 \\
8.8 \\
8.4 \\
6.4 \\
5.4 \\
4.3 \\
5.0 \\
3.8\end{array}$ & $\begin{array}{r}13.8 \\
10.5 \\
9.5 \\
6.9 \\
6.9 \\
4.3 \\
5.5 \\
3.8\end{array}$ \\
\hline $\begin{array}{l}4 \\
4 \\
4 \\
4 \\
4 \\
4 \\
4 \\
4\end{array}$ & $\begin{array}{r}0 \\
3 \\
6 \\
9 \\
12 \\
15 \\
18 \\
21\end{array}$ & $\begin{array}{l}22.5 \\
21.05 \\
20.00 \\
23.1 \\
25.4 \\
23.5 \\
23.1 \\
20.9\end{array}$ & $\begin{array}{l}20.2 \\
20.5 \\
19.3 \\
20.8 \\
21.06 \\
20.9 \\
21.05 \\
20.7\end{array}$ & $\begin{array}{l}22.7 \\
21.5 \\
20.1 \\
23.3 \\
25.6 \\
23.1 \\
22.9 \\
21.1\end{array}$ & $\begin{array}{l}20.2 \\
20.5 \\
19.3 \\
20.9 \\
21.4 \\
20.6 \\
21.5 \\
20.8\end{array}$ & $\begin{array}{l}22.7 \\
21.6 \\
20.2 \\
22.9 \\
25.1 \\
22.9 \\
22.8 \\
21.2\end{array}$ & $\begin{array}{l}20.2 \\
20.5 \\
19.3 \\
20.0 \\
21.2 \\
20.7 \\
21.5 \\
20.9\end{array}$ & $\begin{array}{l}23 \cdot 1 \\
21 \cdot 5 \\
20.2 \\
22 \cdot 8 \\
24 \cdot 0 \\
22.7 \\
22.8 \\
21 \cdot 3\end{array}$ & $\begin{array}{l}20.3 \\
20.3 \\
19.2 \\
20.7 \\
21.0 \\
20.4 \\
21.4 \\
20.9\end{array}$ & & & $\begin{array}{l}1.5 \\
2.5 \\
4.1 \\
4.1 \\
2.7 \\
2.4 \\
1.9 \\
1.4\end{array}$ & $\begin{array}{l}2.2 \\
4.2 \\
5.4 \\
4.8 \\
3.7 \\
3.5 \\
2.8 \\
2.3\end{array}$ & $\begin{array}{l}7.7 \\
7.4 \\
5.6 \\
4.5 \\
5.8 \\
4.0\end{array}$ & $\begin{array}{l}3.8 \\
5.3 \\
7.3 \\
5.4 \\
4.5 \\
4.3 \\
3.8 \\
3.6\end{array}$ \\
\hline $\begin{array}{l}5 \\
5 \\
5 \\
5 \\
5 \\
5 \\
5 \\
5\end{array}$ & $\begin{array}{r}0 \\
3 \\
6 \\
9 \\
12 \\
15 \\
18 \\
21\end{array}$ & $\begin{array}{l}20.9 \\
20.7 \\
21.7 \\
23.4 \\
27.7 \\
29.8 \\
27.2 \\
23.0\end{array}$ & $\begin{array}{l}20.8 \\
20.6 \\
21.3 \\
21.7 \\
21 \cdot 5 \\
22 \cdot 0 \\
22.6 \\
22.0\end{array}$ & $\begin{array}{l}21.1 \\
21.0 \\
21.8 \\
23.4 \\
27.1 \\
29.4 \\
27.5 \\
23.0\end{array}$ & $\begin{array}{l}20.9 \\
20.8 \\
21.3 \\
21.3 \\
21.1 \\
21.5 \\
22.5 \\
22.0\end{array}$ & $\begin{array}{l}21.3 \\
21.2 \\
21.9 \\
23.4 \\
27.9 \\
30.0 \\
27.2 \\
23.0\end{array}$ & $\begin{array}{l}20.9 \\
20.9 \\
21.5 \\
21.4 \\
21.3 \\
21.9 \\
22.3 \\
21.9\end{array}$ & $\begin{array}{l}21.8 \\
21.8 \\
22: 0 \\
23.4 \\
27.8 \\
29.9 \\
27.5 \\
23.0\end{array}$ & \begin{tabular}{l|l}
21 & .1 \\
21 & 0 \\
21 & 0 \\
21 & 0 \\
21 & 0 \\
21 & 0 \\
22 & 0 \\
21.09
\end{tabular} & $\begin{array}{l}26.1 \\
29.5 \\
33.8 \\
27.9 \\
26.2\end{array}$ & & $\begin{array}{l}1.3 \\
1.2 \\
2.7 \\
5.9 \\
4.5 \\
2.5 \\
4.2\end{array}$ & $\begin{array}{l}2.0 \\
2.1 \\
3.8 \\
8.0 \\
3.2 \\
1.7 \\
2.7 \\
5.2\end{array}$ & $\begin{array}{r}7.2 \\
10.2 \\
3.6 \\
2.1 \\
3.7 \\
6.2\end{array}$ & $\begin{array}{r}3.5 \\
3.7 \\
5.0 \\
10.7 \\
3.8 \\
2.1 \\
4.4 \\
7.2\end{array}$ \\
\hline $\begin{array}{l}6 \\
6 \\
6 \\
6 \\
6 \\
6 \\
6 \\
6\end{array}$ & $\begin{array}{r}0 \\
3 \\
6 \\
9 \\
12 \\
15 \\
18 \\
21\end{array}$ & $\begin{array}{l}22.4 \\
20.6 \\
21.7 \\
25.2 \\
26.9 \\
27.2 \\
25.0 \\
22.2\end{array}$ & $\begin{array}{r}21.6 \\
20.4 \\
20.5 \\
21.1 \\
21.1 \\
21.3 \\
21.4 \\
20.9\end{array}$ & $\begin{array}{l}22.4 \\
20.5 \\
21.7 \\
25.0 \\
26.3 \\
26.7 \\
25.1 \\
22.7\end{array}$ & $\begin{array}{l}21.6 \\
20.4 \\
20.4 \\
21 \cdot 1 \\
20.9 \\
21 \cdot 1 \\
21.3 \\
21.0\end{array}$ & $\begin{array}{l}22.3 \\
20.5 \\
21.7 \\
25.0 \\
26.3 \\
26.4 \\
25.1 \\
23.2\end{array}$ & $\begin{array}{l}21.5 \\
20.3 \\
20.2 \\
21.0 \\
20.7 \\
20.8 \\
21.1 \\
20.9\end{array}$ & $\begin{array}{l}22 \cdot 3 \\
20 \cdot 4 \\
21 \cdot 5 \\
24 \cdot 3 \\
25 \cdot 8 \\
26 \cdot 2 \\
25 \cdot 3 \\
23 \cdot 7\end{array}$ & $\begin{array}{l}21.5 \\
20.3 \\
20.2 \\
20.7 \\
20.5 \\
20.6 \\
21.0 \\
20.9\end{array}$ & $\begin{array}{l}25.0 \\
23.9 \\
25.0 \\
25.9 \\
28.8 \\
27.5 \\
25.4 \\
24.9\end{array}$ & & $\begin{array}{l}2.9 \\
2.7 \\
2.8 \\
2.7\end{array}$ & $\begin{array}{l}3.7 \\
3.4 \\
4.2 \\
4.6 \\
4.6 \\
4.6 \\
2.6 \\
2.2\end{array}$ & $\begin{array}{l}3.9 \\
4.2 \\
4.8 \\
5.1 \\
5.2 \\
5.2 \\
3.3 \\
2.8\end{array}$ & $\begin{array}{l}5.1 \\
4.9 \\
5.4 \\
6.5 \\
5.7 \\
5.6 \\
4.0 \\
3.9\end{array}$ \\
\hline $\begin{array}{l}7 \\
7 \\
7 \\
7 \\
7 \\
7 \\
7 \\
7\end{array}$ & $\begin{array}{r}0 \\
3 \\
6 \\
9 \\
12 \\
15 \\
18 \\
21\end{array}$ & $\begin{array}{l}20.8 \\
20.3 \\
22.9 \\
26.9 \\
29.3 \\
26.4 \\
27 \cdot 3\end{array}$ & $\begin{array}{l}19.9 \\
19.8 \\
21.1 \\
22.0 \\
22.0 \\
21.8\end{array}$ & $\begin{array}{l}21.4 \\
20.5 \\
23.0 \\
26.5 \\
29.1 \\
25.5\end{array}$ & $\begin{array}{l}20.1 \\
19.8 \\
21.1 \\
21.9 \\
21.5 \\
21.9\end{array}$ & $\begin{array}{l}21.7 \\
20.7 \\
23.0 \\
26.5 \\
29.0 \\
25.2\end{array}$ & $\begin{array}{l}20.0 \\
10.7 \\
20.9 \\
21.6 \\
21.2 \\
21.6\end{array}$ & $\begin{array}{l}22.2 \\
20.8 \\
23.0 \\
26.4 \\
29.8 \\
25 . ?\end{array}$ & $\begin{array}{l}20.1 \\
19.8 \\
20.9 \\
21.4 \\
21.3 \\
21.5\end{array}$ & $\begin{array}{l}24.4 \\
23.9 \\
24.5 \\
26.3 \\
26.6 \\
25.7\end{array}$ & & $\begin{array}{l}4.9 \\
7.0 \\
6.6 \\
7.2 \\
5.6 \\
2.9\end{array}$ & $\begin{array}{l}2.0 \\
3.8 \\
5.2 \\
8.0 \\
6.6 \\
9.8 \\
6.5 \\
3.6\end{array}$ & $\begin{array}{r}2.8 \\
4.7 \\
5.9 \\
8.9 \\
7.3 \\
11.2 \\
7.5 \\
4.8\end{array}$ & $\begin{array}{r}3.7 \\
5.9 \\
6.4 \\
9.5 \\
7.6 \\
12.1 \\
8.8 \\
6.2\end{array}$ \\
\hline $\begin{array}{l}8 \\
8 \\
8 \\
8 \\
8 \\
8 \\
8 \\
8\end{array}$ & $\begin{array}{r}0 \\
3 \\
6 \\
9 \\
12 \\
15 \\
18 \\
21\end{array}$ & $\begin{array}{l}25.4 \\
28.0 \\
28.6 \\
27.7\end{array}$ & $\begin{array}{l}22 \cdot 5 \\
23 \cdot 2 \\
23 \cdot 2 \\
23 \cdot 3\end{array}$ & $\begin{array}{l}26.5 \\
28.0 \\
28.6 \\
27.5\end{array}$ & $\begin{array}{l}22.4 \\
23 \cdot 1 \\
23 \cdot 1 \\
23.3\end{array}$ & $\begin{array}{l}26.2 \\
27.5 \\
28.2 \\
27.3\end{array}$ & $\begin{array}{l}22.2 \\
22.9 \\
22.9 \\
23.0\end{array}$ & $\begin{array}{l}26 \cdot 1 \\
27.2 \\
23.0 \\
27.2\end{array}$ & $\begin{array}{l}22.1 \\
22.8 \\
2.2 \cdot 9 \\
23.0\end{array}$ & $\begin{array}{l}25.5 \\
25.8 \\
25.2 \\
24.0\end{array}$ & & $\begin{array}{r}4.0 \\
4.8 \\
8.4 \\
11.1 \\
10.5 \\
10.2 \\
9.0 \\
9.5\end{array}$ & $\begin{array}{r}4.9 \\
5.8 \\
9.8 \\
12.8 \\
12.1 \\
11.8 \\
10.6 \\
11.1\end{array}$ & $\begin{array}{r}5.8 \\
6.9 \\
10.7 \\
14.2 \\
13.4 \\
13.2 \\
12.0 \\
12.7\end{array}$ & $\begin{array}{r}7.1 \\
8: 0 \\
12: 1 \\
15.6 \\
14.9 \\
14.7 \\
13.3 \\
14.2\end{array}$ \\
\hline $\begin{array}{l}9 \\
9 \\
9 \\
9 \\
9 \\
9 \\
9 \\
9\end{array}$ & $\begin{array}{r}0 \\
3 \\
6 \\
9 \\
12 \\
15 \\
18 \\
21\end{array}$ & $\begin{array}{l}23.7 \\
25.8 \\
25.9 \\
24.7 \\
22.7\end{array}$ & $\begin{array}{l}22 \cdot 1 \\
22 \cdot 9 \\
23 \cdot 1 \\
22 \cdot 3 \\
20.6\end{array}$ & $\begin{array}{l}23.9 \\
25.8 \\
25.8 \\
24.7 \\
22.8\end{array}$ & $\begin{array}{l}21.8 \\
22.9 \\
23.0 \\
22.3 \\
20.6\end{array}$ & $\begin{array}{l}23.9 \\
25.7 \\
25.6 \\
24.6 \\
22.7\end{array}$ & $\begin{array}{l}21.7 \\
22.6 \\
23.0 \\
22.1 \\
20.5\end{array}$ & $\begin{array}{l}24 \cdot 1 \\
25 \cdot 6 \\
25 \cdot 6 \\
24 \cdot 5 \\
22 \cdot 8\end{array}$ & $\begin{array}{l}21.9 \\
22.7 \\
23 \cdot 0 \\
22 \cdot 1 \\
20.6\end{array}$ & $\begin{array}{l}24 \cdot 9 \\
25.3 \\
23.7 \\
22.8 \\
21.9\end{array}$ & & $\begin{array}{r}9.9 \\
11.4 \\
11.9 \\
9.8 \\
32.3 \\
12.6 \\
12.7 \\
10.9\end{array}$ & $\begin{array}{l}11.5 \\
13.3 \\
13.7 \\
11.3 \\
14.4 \\
14.8 \\
14.4 \\
12.9\end{array}$ & $\begin{array}{l}13.1 \\
15.2 \\
15.7 \\
13.1 \\
16.1 \\
15.5 \\
16.5 \\
14.6\end{array}$ & $\begin{array}{l}14.8 \\
16.9 \\
17.4 \\
14.4 \\
17.9 \\
18.4 \\
18.2 \\
16.3\end{array}$ \\
\hline $\begin{array}{l}10 \\
10 \\
10 \\
10 \\
30 \\
10 \\
10 \\
10\end{array}$ & $\begin{array}{r}0 \\
3 \\
6 \\
9 \\
12 \\
15 \\
18 \\
21\end{array}$ & $\begin{array}{l}22.7 \\
21.7 \\
20.5 \\
22.5 \\
25.3 \\
26.3 \\
24.2 \\
22.1\end{array}$ & $\begin{array}{l}20.5 \\
20.1 \\
19.1 \\
20.04 \\
21.02 \\
21.9 \\
20.9 \\
20.5\end{array}$ & $\begin{array}{l}22.8 \\
21.8 \\
20.4 \\
22.5 \\
25.3 \\
26.3 \\
24.2 \\
22.1\end{array}$ & $\begin{array}{l}20.6 \\
20.1 \\
19.1 \\
20.4 \\
21.3 \\
21.7 \\
21.0 \\
20.6\end{array}$ & $\begin{array}{l}22.8 \\
21.7 \\
20.3 \\
22.4 \\
25.0 \\
20.0 \\
24.1 \\
22.1\end{array}$ & $\begin{array}{l}20.5 \\
20.0 \\
19.0 \\
20.2 \\
21.0 \\
21.5 \\
20.8 \\
20.4\end{array}$ & $\begin{array}{l}2 ? .8 \\
21.07 \\
20.02 \\
22.3 \\
24.7 \\
25.8 \\
24.11 \\
22.1\end{array}$ & $\begin{array}{l}20.7 \\
19.9 \\
18.9 \\
20.2 \\
21.1 \\
21.5 \\
20.9 \\
20.6\end{array}$ & $\begin{array}{l}21.8 \\
22.0 \\
22.2 \\
22.9 \\
25.2 \\
23.6 \\
22.1 \\
22.5\end{array}$ & & $\begin{array}{r}9.5 \\
8.3 \\
8.4 \\
10.1 \\
11.7 \\
7.1 \\
6.1 \\
4.8\end{array}$ & $\begin{array}{r}11.1 \\
10.6 \\
10.9 \\
11.9 \\
13.5 \\
8.7 \\
7.7 \\
5.4\end{array}$ & $\begin{array}{r}12.8 \\
12.2 \\
12.3 \\
12.4 \\
9.7 \\
8.8 \\
6.5\end{array}$ & $\begin{array}{r}14.2 \\
13.6 \\
13.4 \\
14.7 \\
16.5 \\
11.0 \\
10.1 \\
8.2\end{array}$ \\
\hline
\end{tabular}


Table 10. - Three-hour averages of air and water-surface temperatures and wind directions and speed, April 1950-August 1951, Lake Hefner-Continued

STATION THREE-HOURLY AVERAGES

JULY, 1950

\begin{tabular}{|c|c|c|c|c|c|c|c|c|c|c|c|c|c|c|c|}
\hline \multirow{3}{*}{ 秥 } & \multirow{3}{*}{ 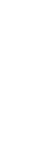 } & \multicolumn{8}{|c|}{ Average air temperature $\left({ }^{\circ} \mathrm{C}\right)$ at indicated height } & \multirow{3}{*}{$\begin{array}{l}\text { Average } \\
\text { water- } \\
\text { surface } \\
\text { tempera- } \\
\text { ture } \\
\left({ }^{\circ} \mathrm{C}\right)\end{array}$} & \multirow{3}{*}{$\begin{array}{l}\text { Average } \\
\text { wind } \\
\text { direction } \\
\text { (coded) }\end{array}$} & \multicolumn{4}{|c|}{$\begin{array}{l}\text { Average wind speed (knots) } \\
\text { at indicated height }\end{array}$} \\
\hline & & \multicolumn{2}{|c|}{$\begin{array}{c}2 \\
\text { meters }\end{array}$} & \multicolumn{2}{|c|}{$\begin{array}{c}4 \\
\text { meters }\end{array}$} & \multicolumn{2}{|c|}{$\begin{array}{c}8 \\
\text { meters }\end{array}$} & \multicolumn{2}{|c|}{$\begin{array}{c}16 \\
\text { meters }\end{array}$} & & & & & & \\
\hline & & $\begin{array}{l}\text { Dry } \\
\text { bulb }\end{array}$ & $\begin{array}{l}\text { Wet } \\
\text { bulb }\end{array}$ & $\begin{array}{l}\text { Dry } \\
\text { bulb }\end{array}$ & $\begin{array}{l}\text { Wet } \\
\text { bulb }\end{array}$ & $\begin{array}{l}\text { Dry } \\
\text { bulb }\end{array}$ & $\begin{array}{l}\text { Wet } \\
\text { bulb }\end{array}$ & $\begin{array}{l}\text { Dry } \\
\text { bulb }\end{array}$ & $\begin{array}{l}\text { Wet } \\
\text { bulb }\end{array}$ & & & meters & meters & meters & meters \\
\hline $\begin{array}{l}11 \\
11 \\
11 \\
11 \\
11 \\
11 \\
11 \\
11\end{array}$ & $\begin{array}{r}0 \\
3 \\
6 \\
9 \\
12 \\
15 \\
18 \\
21\end{array}$ & $\begin{array}{l}21.1 \\
21.1 \\
21.5 \\
23.7 \\
26.0 \\
25.7 \\
25.4\end{array}$ & $\begin{array}{l}20.4 \\
20.4 \\
20.2 \\
21.0 \\
21.9 \\
22.4 \\
21.8\end{array}$ & $\begin{array}{l}21.1 \\
20.9 \\
21.3 \\
23.4 \\
25.9 \\
25.9 \\
25.2\end{array}$ & $\begin{array}{l}20.6 \\
20.5 \\
20.4 \\
21.0 \\
21.5 \\
22.3 \\
21.8\end{array}$ & $\begin{array}{l}21.1 \\
21.0 \\
21.3 \\
23.4 \\
25.5 \\
25.5 \\
25.0\end{array}$ & $\begin{array}{l}20.5 \\
20.3 \\
20.1 \\
21.0 \\
21.5 \\
22.2 \\
21.8\end{array}$ & $\begin{array}{l}21 \cdot 2 \\
21: 0 \\
21 \cdot 2 \\
23 \cdot 3 \\
25 \cdot 3 \\
25: 6 \\
24 \cdot 9\end{array}$ & $\begin{array}{l}20.5 \\
20.4 \\
20.2 \\
20.8 \\
21.3 \\
22.0 \\
21.8\end{array}$ & $\begin{array}{l}21.8 \\
21.6 \\
21.8 \\
24.6 \\
25.4 \\
25.1 \\
22.0\end{array}$ & & $\begin{array}{l}4.5 \\
3.9 \\
5.1 \\
6.7 \\
6.2 \\
6.3 \\
5.1 \\
3.7\end{array}$ & $\begin{array}{l}5.3 \\
5.0 \\
6.5 \\
7.8 \\
7.5 \\
7.5 \\
6.1 \\
4.6\end{array}$ & $\begin{array}{l}5.2 \\
5.8 \\
7.3 \\
8.8 \\
7.9 \\
8.5 \\
7.2 \\
5.7\end{array}$ & $\begin{array}{l}7.2 \\
6.5 \\
8.0 \\
9.5 \\
8.5 \\
9.4 \\
8.4 \\
7.1\end{array}$ \\
\hline $\begin{array}{l}12 \\
12 \\
12 \\
12 \\
12 \\
12 \\
12 \\
12\end{array}$ & $\begin{array}{r}0 \\
3 \\
5 \\
9 \\
12 \\
15 \\
18 \\
21\end{array}$ & 29.1 & $22 \cdot 1$ & 28.8 & 21.7 & $\begin{array}{l}25.7 \\
27.8\end{array}$ & $\begin{array}{l}20.9 \\
21.9\end{array}$ & $\begin{array}{l}26.4 \\
27.9\end{array}$ & $\begin{array}{l}21.0 \\
21.4\end{array}$ & $\begin{array}{l}26.3 \\
28.0\end{array}$ & & $\begin{array}{l}3.6 \\
3.9 \\
5.2 \\
6.0 \\
5.2 \\
4.6 \\
5.4 \\
3.0\end{array}$ & $\begin{array}{l}4.6 \\
4.8 \\
6.2 \\
6.8 \\
5.9 \\
5.4 \\
6.7 \\
3.9\end{array}$ & $\begin{array}{l}5.8 \\
6.0 \\
7.2 \\
7.5 \\
6.5 \\
6.1 \\
8.9 \\
4.8\end{array}$ & $\begin{array}{l}7.3 \\
7.6 \\
7.7 \\
3.0 \\
7.0 \\
6.7 \\
9.6 \\
5.0\end{array}$ \\
\hline $\begin{array}{l}13 \\
13 \\
13\end{array}$ & $\begin{array}{l}0 \\
3 \\
6\end{array}$ & & i & & & & & & & & & $\begin{array}{l}5.3 \\
7.7 \\
9.9\end{array}$ & $\begin{array}{r}6.2 \\
8.8 \\
11.6\end{array}$ & $\begin{array}{r}7.3 \\
9.2 \\
12.2\end{array}$ & $\begin{array}{r}8.4 \\
10.6 \\
14.1\end{array}$ \\
\hline $\begin{array}{l}13 \\
13 \\
13 \\
13 \\
13\end{array}$ & $\begin{array}{r}9 \\
12 \\
15 \\
18 \\
21\end{array}$ & $\begin{array}{l}22.0 \\
23.3 \\
24.5 \\
22.5 \\
19.0\end{array}$ & $\begin{array}{l}17.4 \\
17.5 \\
17.4 \\
17.2 \\
16.5\end{array}$ & $\begin{array}{l}21.3 \\
22.6 \\
23.9 \\
22.2 \\
18.7\end{array}$ & $\begin{array}{l}17.2 \\
17.1 \\
17.1 \\
17.1 \\
16.4\end{array}$ & $\begin{array}{l}21.1 \\
22.8 \\
23.7 \\
21.9 \\
18.6\end{array}$ & $\begin{array}{l}16.8 \\
16.9 \\
16.9 \\
17.1 \\
16.3\end{array}$ & $\begin{array}{l}20.9 \\
22.02 \\
23.3 \\
22.0 \\
18.7\end{array}$ & $\begin{array}{l}16.6 \\
16.5 \\
16.5 \\
16.8 \\
16.3\end{array}$ & $\begin{array}{l}27.1 \\
29.3 \\
29.2 \\
26.9 \\
25.6\end{array}$ & & $\begin{array}{l}8.1 \\
6.7 \\
5.3 \\
3.2 \\
2.8\end{array}$ & $\begin{array}{l}9.4 \\
7.7 \\
6.2 \\
4.4 \\
3.8\end{array}$ & $\begin{array}{r}10.1 \\
8.2 \\
6.9 \\
5.4 \\
4.6\end{array}$ & $\begin{array}{r}14.8 \\
10.7 \\
8.3 \\
6.5 \\
6.0\end{array}$ \\
\hline $\begin{array}{l}14 \\
14 \\
14 \\
14 \\
14 \\
14 \\
14 \\
14\end{array}$ & $\begin{array}{r}0 \\
3 \\
6 \\
9 \\
12 \\
15 \\
18 \\
21\end{array}$ & $\begin{array}{l}15.0 \\
17.9 \\
23.2 \\
28.1 \\
28.5 \\
25.5 \\
22.9\end{array}$ & $\begin{array}{l}14.8 \\
14.1 \\
15.5 \\
17.6 \\
20.0 \\
20.4 \\
20.8 \\
21.4\end{array}$ & $\begin{array}{l}16.2 \\
14.8 \\
17.8 \\
23.1 \\
28.4 \\
28.3 \\
25.6 \\
23.1\end{array}$ & $\begin{array}{l}14.9 \\
14.3 \\
15.4 \\
17.4 \\
19.9 \\
20.0 \\
20.8 \\
21.5\end{array}$ & $\begin{array}{l}16.1 \\
14.9 \\
17.7 \\
22.9 \\
27.4 \\
27.9 \\
25.6 \\
23.3\end{array}$ & $\begin{array}{l}14.8 \\
14.2 \\
15.3 \\
17.0 \\
19.2 \\
20.1 \\
20.7 \\
21.5\end{array}$ & $\begin{array}{l}16.3 \\
15.0 \\
17.8 \\
22.5 \\
26.9 \\
27.3 \\
25.8 \\
23.3\end{array}$ & $\begin{array}{l}14.9 \\
14.3 \\
15.3 \\
17.3 \\
19.5 \\
20.0 \\
20.8 \\
21.7\end{array}$ & $\begin{array}{l}24.4 \\
23.7 \\
25.1 \\
28.8 \\
20.7 \\
28.1 \\
25.3 \\
24.6\end{array}$ & & $\begin{array}{l}1.6 \\
0.8 \\
3.5 \\
3.2 \\
3.7 \\
4.5 \\
4.1 \\
5.1\end{array}$ & $\begin{array}{l}2.3 \\
1.1 \\
4.5 \\
4.0 \\
4 \cdot 1 \\
5.1 \\
5.1 \\
6.0\end{array}$ & $\begin{array}{l}3.2 \\
1.5 \\
5.2 \\
4.6 \\
4.9 \\
5.6 \\
6.1 \\
7.2\end{array}$ & $\begin{array}{l}3.8 \\
2.1 \\
5.6 \\
4.8 \\
5.2 \\
6.2 \\
7.3 \\
8.5\end{array}$ \\
\hline $\begin{array}{l}15 \\
15 \\
15 \\
15 \\
15 \\
15 \\
15 \\
15\end{array}$ & $\begin{array}{r}0 \\
3 \\
6 \\
9 \\
12 \\
15 \\
18 \\
21\end{array}$ & $\begin{array}{l}22.0 \\
21.4 \\
23.1 \\
27.5 \\
30.5 \\
30.9 \\
28.6 \\
26.1\end{array}$ & $\begin{array}{l}21.4 \\
20.8 \\
21.7 \\
22.8 \\
23.6 \\
23.3 \\
23.2 \\
22.7\end{array}$ & $\begin{array}{l}22.1 \\
21.5 \\
23.2 \\
27.1 \\
30.4 \\
30.8 \\
28.6 \\
26.3\end{array}$ & $\begin{array}{l}21.5 \\
20.9 \\
21.7 \\
22.7 \\
23.4 \\
23.2 \\
23.2 \\
22.7\end{array}$ & $\begin{array}{l}27.1 \\
21.5 \\
23.4 \\
26.9 \\
30.1 \\
30.3 \\
28.4 \\
26.3\end{array}$ & $\begin{array}{l}21.3 \\
20.8 \\
21.7 \\
22.6 \\
23.3 \\
23.1 \\
23.1 \\
22.6\end{array}$ & $\begin{array}{l}22.2 \\
21.6 \\
23.1 \\
26.6 \\
29.6 \\
30.2 \\
28.4 \\
26.4\end{array}$ & $\begin{array}{l}21.5 \\
20.8 \\
21.8 \\
23.5 \\
23.1 \\
23.1 \\
23.2 \\
22.7\end{array}$ & $\begin{array}{l}24.1 \\
23.9 \\
24.7 \\
28.2 \\
29.3 \\
27.7 \\
25.3 \\
24.2\end{array}$ & & $\begin{array}{r}7.3 \\
8.5 \\
8.0 \\
10.9 \\
13.3 \\
13.5 \\
11.2 \\
11.9\end{array}$ & $\begin{array}{r}8.6 \\
10.0 \\
9.8 \\
12.4 \\
15.0 \\
15.4 \\
13.4 \\
14.0\end{array}$ & $\begin{array}{l}10.0 \\
11.4 \\
11.2 \\
13.9 \\
16.9 \\
17.2 \\
14.07 \\
16.0\end{array}$ & $\begin{array}{l}11.2 \\
12.7 \\
12.3 \\
14.9 \\
18.3 \\
19.3 \\
16.4 \\
17.8\end{array}$ \\
\hline $\begin{array}{l}16 \\
16 \\
16 \\
16 \\
16 \\
16 \\
16 \\
16\end{array}$ & $\begin{array}{r}0 \\
3 \\
6 \\
9 \\
12 \\
15 \\
18 \\
21\end{array}$ & $\begin{array}{l}25.0 \\
23.8 \\
25.0 \\
28.3 \\
31.0 \\
30.7 \\
28.3 \\
27.0\end{array}$ & $\begin{array}{l}21.4 \\
21.3 \\
22.2 \\
22.8 \\
23.5 \\
23.2 \\
22.5 \\
22.1\end{array}$ & $\begin{array}{l}25.2 \\
23.9 \\
25.0 \\
28.1 \\
30.9 \\
30.5 \\
28.4 \\
27.2\end{array}$ & $\begin{array}{l}21.4 \\
21.4 \\
22.2 \\
22.8 \\
23.5 \\
23.2 \\
22.5 \\
22.2\end{array}$ & $\begin{array}{l}25.1 \\
23.9 \\
25.0 \\
28.0 \\
30.8 \\
30.0 \\
28.4 \\
27.2\end{array}$ & $\begin{array}{l}21.4 \\
21.4 \\
22.2 \\
22.6 \\
23.2 \\
23.0 \\
22.4 \\
22.2\end{array}$ & $\begin{array}{l}25.2 \\
24.0 \\
25.0 \\
28.1 \\
30.5 \\
29.8 \\
28.4 \\
27.2\end{array}$ & $\begin{array}{l}21.5 \\
21.5 \\
22.1 \\
22.7 \\
23.1 \\
23.0 \\
22.4 \\
22.3\end{array}$ & $\begin{array}{l}23.5 \\
23.1 \\
24.6 \\
26.9 \\
29.5 \\
30.1 \\
26.3 \\
25.4\end{array}$ & & $\begin{array}{l}14.2 \\
14.1 \\
16.4 \\
15.0 \\
14.7 \\
17.0 \\
12.6 \\
14.2\end{array}$ & $\begin{array}{l}16.3 \\
16.2 \\
18.8 \\
16.8 \\
16.3 \\
19.4 \\
14.7 \\
16.5\end{array}$ & $\begin{array}{l}18.6 \\
18.3 \\
21.2 \\
19.1 \\
18.2 \\
21.6 \\
16.8 \\
18.8\end{array}$ & $\begin{array}{l}20.6 \\
20.2 \\
23.4 \\
21.0 \\
19.8 \\
23.8 \\
18.6 \\
21.0\end{array}$ \\
\hline $\begin{array}{l}17 \\
17 \\
17 \\
17 \\
17 \\
17 \\
17 \\
17\end{array}$ & $\begin{array}{r}0 \\
3 \\
6 \\
9 \\
12 \\
15 \\
18 \\
21\end{array}$ & $\begin{array}{l}25.9 \\
23.9 \\
19.6 \\
20.2 \\
20.1 \\
24.1 \\
22.9 \\
20.9\end{array}$ & $\begin{array}{l}21.8 \\
21.1 \\
19.4 \\
19.8 \\
19.7 \\
21.8 \\
21.8 \\
20.7\end{array}$ & $\begin{array}{l}26.0 \\
23.9 \\
19.8 \\
20.4 \\
20.1 \\
23.9 \\
22.9 \\
21.0\end{array}$ & $\begin{array}{l}21.9 \\
21.1 \\
19.5 \\
19.9 \\
19.6 \\
21.5 \\
21.7 \\
20.8\end{array}$ & $\begin{array}{l}25.9 \\
23.8 \\
19.9 \\
20.3 \\
20.1 \\
23.6 \\
22.7 \\
21.1\end{array}$ & $\begin{array}{l}21.8 \\
21.0 \\
19.5 \\
19.8 \\
19.5 \\
21.4 \\
21.5 \\
20.7\end{array}$ & $\begin{array}{l}25 \cdot 9 \\
23: 7 \\
19: 9 \\
20.4 \\
20.3 \\
23.7 \\
22,7 \\
21,1\end{array}$ & $\begin{array}{l}21.9 \\
21.0 \\
19.5 \\
19.9 \\
10.7 \\
21.3 \\
21.6 \\
20.7\end{array}$ & $\begin{array}{l}24 \cdot 8 \\
23.4 \\
22.1 \\
24 \cdot 1 \\
24.9\end{array}$ & & $\begin{array}{r}14.4 \\
12.0 \\
7.3 \\
1.7 \\
6.2 \\
5.0 \\
4.0 \\
5.2\end{array}$ & $\begin{array}{r}16.8 \\
13.6 \\
8.4 \\
2.4 \\
7.9 \\
6.0 \\
5.2 \\
7.0\end{array}$ & $\begin{array}{r}19.0 \\
15.5 \\
9.6 \\
2.9 \\
8.9 \\
6.8 \\
5.1 \\
8.4\end{array}$ & $\begin{array}{r}21.0 \\
17.1 \\
10.7 \\
3.3 \\
10.1 \\
7.2 \\
6.7 \\
9.5\end{array}$ \\
\hline $\begin{array}{l}18 \\
18 \\
18 \\
18 \\
18 \\
18 \\
18 \\
18\end{array}$ & $\begin{array}{r}0 \\
3 \\
6 \\
9 \\
12 \\
15 \\
18 \\
21\end{array}$ & $\begin{array}{l}20.1 \\
21.3 \\
21.4 \\
20.4 \\
24.9 \\
27.4 \\
26.8 \\
24.8\end{array}$ & $\begin{array}{l}20.0 \\
20.9 \\
20.8 \\
20.2 \\
22.8 \\
23.4 \\
22.5 \\
21.1\end{array}$ & $\begin{array}{l}20.3 \\
21.4 \\
21.5 \\
20.4 \\
24.8 \\
27.5 \\
27.0 \\
25.0\end{array}$ & $\begin{array}{l}20.2 \\
21.0 \\
20.9 \\
20.3 \\
22.7 \\
23.2 \\
22.4 \\
21.1\end{array}$ & $\begin{array}{l}20.4 \\
21.7 \\
21.8 \\
20.7 \\
25.1 \\
27.4 \\
26.9 \\
25.0\end{array}$ & $\begin{array}{l}20.2 \\
21.1 \\
20.9 \\
20.4 \\
22.7 \\
23.0 \\
22.2 \\
21.0\end{array}$ & $\begin{array}{l}20 \cdot 7 \\
21: 9 \\
21: 8 \\
20: 7 \\
25: 3 \\
27.5 \\
27.0 \\
25.1\end{array}$ & $\begin{array}{l}20.2 \\
21.3 \\
20.9 \\
20.4 \\
22.8 \\
23.1 \\
22.2 \\
21.0\end{array}$ & $\begin{array}{l}24.9 \\
24.1 \\
24.3 \\
25.0 \\
25.0 \\
25.6 \\
24.8 \\
24.2\end{array}$ & & $\begin{array}{l}5.4 \\
5.4 \\
4.9 \\
3.4 \\
7.9 \\
9.2 \\
7.1 \\
8.9\end{array}$ & $\begin{array}{r}7.5 \\
7.7 \\
5.9 \\
4.3 \\
9.4 \\
10.6 \\
8.5 \\
10.4\end{array}$ & $\begin{array}{r}3.7 \\
9.0 \\
7.1 \\
4.9 \\
10.7 \\
12.0 \\
0.8 \\
12.0\end{array}$ & $\begin{array}{r}9.9 \\
10.4 \\
7.9 \\
5.6 \\
11.7 \\
13.1 \\
11.1 \\
13.8\end{array}$ \\
\hline $\begin{array}{l}19 \\
19 \\
19 \\
19 \\
19 \\
19 \\
19 \\
19\end{array}$ & $\begin{array}{r}0 \\
3 \\
6 \\
9 \\
12 \\
15 \\
18 \\
21\end{array}$ & $\begin{array}{l}21.7 \\
21.6 \\
21.3 \\
21.5 \\
26.5 \\
28.4 \\
23.3 \\
19.2\end{array}$ & $\begin{array}{l}19.4 \\
20.1 \\
20.9 \\
20.5 \\
23.4 \\
24.5 \\
21.9 \\
19.1\end{array}$ & $\begin{array}{l}21.8 \\
21.8 \\
21.4 \\
21.5 \\
26.3 \\
28.3 \\
23.4 \\
19.4\end{array}$ & $\begin{array}{l}19.4 \\
20.2 \\
20.9 \\
20.5 \\
23.4 \\
24.3 \\
21.3 \\
19.2\end{array}$ & $\begin{array}{l}21.8 \\
22.1 \\
21.7 \\
21.7 \\
26.2 \\
28.2 \\
22.5 \\
19.6\end{array}$ & $\begin{array}{l}19.2 \\
20.1 \\
20.8 \\
20.5 \\
23.3 \\
24.1 \\
20.8 \\
19.4\end{array}$ & $\begin{array}{l}22.0 \\
22: 3 \\
21: 7 \\
22.0 \\
26.0 \\
28.1 \\
22: 3 \\
19.7\end{array}$ & $\begin{array}{l}19.2 \\
20.2 \\
21.0 \\
20.7 \\
23.3 \\
24.1 \\
20.9 \\
19.5\end{array}$ & $\begin{array}{l}23.9 \\
24.1 \\
24.5 \\
24.7 \\
25.9 \\
25.3 \\
24.9 \\
25.0\end{array}$ & & $\begin{array}{r}7.1 \\
4.2 \\
3.8 \\
9.7 \\
10.3 \\
7.1 \\
7.1 \\
4.3\end{array}$ & $\begin{array}{r}8.4 \\
5.3 \\
4.6 \\
11.1 \\
11.8 \\
8.1 \\
8.6 \\
5.3\end{array}$ & $\begin{array}{r}9.8 \\
6.5 \\
5.5 \\
12.7 \\
13.2 \\
0.2 \\
0.9 \\
6.1\end{array}$ & $\begin{array}{r}11.5 \\
7.9 \\
6.3 \\
14.3 \\
14.4 \\
10.1 \\
12.2 \\
7.2\end{array}$ \\
\hline $\begin{array}{l}20 \\
20 \\
20 \\
20 \\
20 \\
20 \\
20 \\
20\end{array}$ & $\begin{array}{r}0 \\
3 \\
6 \\
9 \\
12 \\
15 \\
18 \\
21\end{array}$ & $\begin{array}{l}19.5 \\
19.8 \\
19.9 \\
23.4 \\
26.2 \\
26.7 \\
24.6 \\
22.7\end{array}$ & $\begin{array}{l}18.5 \\
18.7 \\
19.5 \\
20.5 \\
21.4 \\
22.0 \\
22.2 \\
21.9\end{array}$ & $\begin{array}{l}19.7 \\
19.9 \\
19.9 \\
22.8 \\
25.6 \\
26.7 \\
24.6 \\
22.8\end{array}$ & $\begin{array}{l}18.5 \\
18.8 \\
19.6 \\
20.4 \\
21.2 \\
22.0 \\
22.2 \\
22.1\end{array}$ & $\begin{array}{l}20.0 \\
20.0 \\
20.0 \\
23.3 \\
25.8 \\
26.5 \\
24.7 \\
22.8\end{array}$ & $\begin{array}{l}18.3 \\
18.7 \\
19.4 \\
20.3 \\
21.0 \\
21.8 \\
22.0 \\
21.8\end{array}$ & $\begin{array}{l}20 \cdot 1 \\
20 \cdot 2 \\
20 \cdot 1 \\
22 \cdot 8 \\
24 \cdot 8 \\
26 \cdot 4 \\
24 \cdot 7 \\
22.9\end{array}$ & $\begin{array}{l}18.3 \\
18.9 \\
19.3 \\
20.4 \\
20.7 \\
21.7 \\
22.0 \\
21.8\end{array}$ & $\begin{array}{l}23.9 \\
24.0 \\
23.9 \\
25.1 \\
27.3 \\
28.1 \\
26.9 \\
25.8\end{array}$ & & $\begin{array}{r}10.6 \\
6.9 \\
1.2 \\
1.8 \\
1.2 \\
2.0\end{array}$ & $\begin{array}{r}12.4 \\
8.1 \\
2.6 \\
2.5 \\
2.9 \\
2.4\end{array}$ & $\begin{array}{r}14.2 \\
9.5 \\
3.1 \\
2.7 \\
3.4 \\
2.6\end{array}$ & $\begin{array}{r}16.2 \\
11.1 \\
3.4 \\
2.7 \\
3.7 \\
2.8\end{array}$ \\
\hline
\end{tabular}


TABLE 10

Table 10. -Three-hour averages of air and water-surface temperatures and wind directions and speed, April 1950-August STATION 2 (951, Lake Hefner-Continued

THREE-HOURLY AVERAGES

JULY, 1950

\begin{tabular}{|c|c|c|c|c|c|c|c|c|c|c|c|c|c|c|c|}
\hline \multirow{3}{*}{ 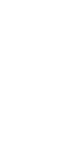 } & \multirow{3}{*}{ 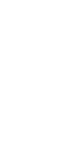 } & \multicolumn{8}{|c|}{ Average air temperature $\left({ }^{\circ} \mathrm{C}\right)$ at indicated height } & \multirow{3}{*}{$\begin{array}{c}\text { Average } \\
\text { water- } \\
\text { surface } \\
\text { tempera- } \\
\text { ture } \\
\left({ }^{\circ} \mathrm{C}\right)\end{array}$} & \multirow{3}{*}{$\begin{array}{c}\text { Average } \\
\text { wind } \\
\text { direction } \\
\text { (coded) }\end{array}$} & \multicolumn{4}{|c|}{$\begin{array}{l}\text { Average wind speed (knots) } \\
\text { at indicated height }\end{array}$} \\
\hline & & \multicolumn{2}{|c|}{$\begin{array}{c}2 \\
\text { meters }\end{array}$} & \multicolumn{2}{|c|}{$\begin{array}{c}4 \\
\text { meters }\end{array}$} & \multicolumn{2}{|c|}{$\begin{array}{c}8 \\
\text { meters }\end{array}$} & \multicolumn{2}{|c|}{$\begin{array}{c}16 \\
\text { meters }\end{array}$} & & & & & & \\
\hline & & $\begin{array}{l}\text { Dry } \\
\text { bulb }\end{array}$ & $\begin{array}{l}\text { Wet } \\
\text { bulb }\end{array}$ & $\begin{array}{l}\text { Dry } \\
\text { bulb }\end{array}$ & $\begin{array}{l}\text { Wet } \\
\text { bulb }\end{array}$ & $\begin{array}{l}\text { Dry } \\
\text { bulb }\end{array}$ & $\begin{array}{l}\text { Wet } \\
\text { bulb }\end{array}$ & $\begin{array}{l}\text { Dry } \\
\text { bulb }\end{array}$ & $\begin{array}{l}\text { Wet } \\
\text { bulb }\end{array}$ & & & meters & $\begin{array}{c}4 \\
\text { meters }\end{array}$ & $\begin{array}{c}8 \\
\text { meters }\end{array}$ & $\begin{array}{c}16 \\
\text { meters }\end{array}$ \\
\hline $\begin{array}{l}21 \\
21 \\
21 \\
21 \\
21 \\
21 \\
21 \\
21\end{array}$ & $\begin{array}{r}0 \\
3 \\
6 \\
9 \\
12 \\
15 \\
18 \\
21\end{array}$ & $\begin{array}{l}21.4 \\
20.8 \\
19.8 \\
21.9 \\
25.5 \\
22.1 \\
19.3 \\
20.1\end{array}$ & $\begin{array}{l}21.1 \\
20.6 \\
19.5 \\
20.7 \\
27.0 \\
20.5 \\
19.0 \\
10.9\end{array}$ & $\begin{array}{l}21.5 \\
20.9 \\
19.8 \\
22.1 \\
25.3 \\
22.1 \\
19.3 \\
20.4\end{array}$ & $\begin{array}{l}21.2 \\
20.7 \\
19.4 \\
20.5 \\
21.8 \\
19.9 \\
19.1 \\
20.0\end{array}$ & $\begin{array}{l}21.5 \\
20.8 \\
19.8 \\
21.7 \\
25.1 \\
21.5 \\
19.4 \\
20.4\end{array}$ & $\begin{array}{l}21.0 \\
20.7 \\
19.2 \\
20.2 \\
21.5 \\
19.9 \\
19.1 \\
20.1\end{array}$ & $\begin{array}{l}21.7 \\
21: 0 \\
19.8 \\
21.09 \\
24.9 \\
21.02 \\
19.6 \\
20.5\end{array}$ & $\begin{array}{l}21.1 \\
20.7 \\
20.3 \\
20.3 \\
21.5 \\
19.8 \\
19.2 \\
20.2\end{array}$ & $\begin{array}{l}25.4 \\
24.9 \\
24.5 \\
25.02 \\
26.5 \\
27.02 \\
26.4 \\
25.8\end{array}$ & & $\begin{array}{l}7.5 \\
6.6 \\
5.3 \\
2.3 \\
1.7\end{array}$ & $\begin{array}{l}9.5 \\
8.3 \\
6.8 \\
3.5 \\
2.9\end{array}$ & $\begin{array}{r}11.0 \\
9.5 \\
8.0 \\
3.9 \\
3.5\end{array}$ & $\begin{array}{r}11.8 \\
10.2 \\
8.9 \\
4.5 \\
4.2\end{array}$ \\
\hline $\begin{array}{l}22 \\
22 \\
22 \\
22 \\
22 \\
22 \\
22 \\
22\end{array}$ & $\begin{array}{r}0 \\
3 \\
6 \\
9 \\
12 \\
15 \\
18 \\
21\end{array}$ & $\begin{array}{l}19.9 \\
18.8 \\
18.6 \\
20.1 \\
23.4 \\
24.2 \\
22.8\end{array}$ & $\begin{array}{l}19.9 \\
18.8 \\
18.4 \\
19.1 \\
20.2 \\
19.5 \\
19.5\end{array}$ & $\begin{array}{l}20.1 \\
18.9 \\
18.7 \\
19.9 \\
23.0 \\
24.0 \\
23.0\end{array}$ & $\begin{array}{l}19.9 \\
18.8 \\
18.6 \\
19.1 \\
20.1 \\
19.3 \\
19.6\end{array}$ & $\begin{array}{l}20.1 \\
19.1 \\
18.8 \\
19.9 \\
23.2 \\
24.0 \\
23.0\end{array}$ & $\begin{array}{l}19.9 \\
18.9 \\
18.4 \\
19.1 \\
19.9 \\
18.8 \\
19.4\end{array}$ & $\begin{array}{l}20.0 \\
19.1 \\
19.3 \\
19.7 \\
23.0 \\
23.9 \\
23.1\end{array}$ & $\begin{array}{l}19.9 \\
18.7 \\
18.5 \\
19.0 \\
19.8 \\
18.7 \\
19.2\end{array}$ & $\begin{array}{l}25.3 \\
24.9 \\
24.7 \\
24.4 \\
25.5 \\
25.7 \\
25.0\end{array}$ & & $\begin{array}{l}2.9 \\
4.0 \\
5.2 \\
3.0\end{array}$ & $\begin{array}{l}3.7 \\
4.9 \\
6.1 \\
3.6\end{array}$ & $\begin{array}{l}4.5 \\
5.6 \\
6.1 \\
3.4\end{array}$ & $\begin{array}{l}5.5 \\
7.0 \\
8.3 \\
5.0\end{array}$ \\
\hline $\begin{array}{l}23 \\
23 \\
23 \\
23 \\
23 \\
23 \\
23 \\
23\end{array}$ & $\begin{array}{r}0 \\
3 \\
6 \\
9 \\
12 \\
15 \\
18 \\
21\end{array}$ & 23.8 & 20.0 & 23.6 & 20.0 & $23 \cdot 1$ & 19.5 & 23.0 & 19.8 & 25.2 & & $\begin{array}{l}2.9 \\
1.3 \\
2.0 \\
1.5 \\
2.5\end{array}$ & $\begin{array}{l}3.8 \\
2.5 \\
2.5 \\
2.4 \\
3.9\end{array}$ & $\begin{array}{l}4.4 \\
2.6 \\
2.9 \\
3.0 \\
5.1\end{array}$ & $\begin{array}{l}4.7 \\
2.5 \\
2.8 \\
400 \\
6.8\end{array}$ \\
\hline $\begin{array}{l}24 \\
24 \\
24 \\
24 \\
24 \\
24 \\
24 \\
24\end{array}$ & $\begin{array}{r}0 \\
3 \\
6 \\
9 \\
12 \\
15 \\
18 \\
21\end{array}$ & $\begin{array}{l}26.7 \\
28.5 \\
28.9\end{array}$ & $\begin{array}{l}22.8 \\
22.9 \\
22.6\end{array}$ & $\begin{array}{l}27.4 \\
28.2 \\
29.1\end{array}$ & $\begin{array}{l}22.7 \\
22.5 \\
22.6\end{array}$ & $\begin{array}{l}26.9 \\
28.0 \\
28.7\end{array}$ & $\begin{array}{l}22 \cdot 8 \\
22 \cdot 1 \\
22 \cdot 3\end{array}$ & $\begin{array}{l}27.4 \\
28.2 \\
28.1\end{array}$ & $\begin{array}{l}27.4 \\
22.0 \\
21.9\end{array}$ & $\begin{array}{l}26.4 \\
25.9 \\
25.0\end{array}$ & & $\begin{array}{l}2.3 \\
1.4 \\
4.0 \\
5: 9 \\
7.8\end{array}$ & $\begin{array}{l}3.4 \\
2.0 \\
1.8 \\
4.7 \\
5.8 \\
7.6 \\
2.1 \\
1.8\end{array}$ & $\begin{array}{l}4.4 \\
2.7 \\
2.0 \\
5.2 \\
6.4 \\
8.5 \\
2.4 \\
2.5\end{array}$ & $\begin{array}{l}6.0 \\
3.2 \\
2.3 \\
5.6 \\
6.9 \\
9.3 \\
2.9 \\
3.2\end{array}$ \\
\hline $\begin{array}{l}25 \\
25 \\
25 \\
25\end{array}$ & $\begin{array}{l}0 \\
3 \\
6 \\
9\end{array}$ & & & & & & & & & & & $\begin{array}{l}4.1 \\
5.4 \\
6.2\end{array}$ & $\begin{array}{l}1.4 \\
4.3 \\
6.1 \\
7.5\end{array}$ & $\begin{array}{l}2.1 \\
5.3 \\
7.3 \\
8.6\end{array}$ & $\begin{array}{l}2.8 \\
6.4 \\
8.3 \\
9.7\end{array}$ \\
\hline $\begin{array}{l}25 \\
25\end{array}$ & $\begin{array}{l}12 \\
15\end{array}$ & $\begin{array}{l}21.9 \\
25.4\end{array}$ & $\begin{array}{l}21.1 \\
22.4\end{array}$ & $\begin{array}{l}22.2 \\
25.1\end{array}$ & 21.0 & 22.0 & 21.1 & 22.4 & 20.9 & $25 \cdot 5$ & & 7.6 & 9.2 & $10 \cdot 4$ & 11.6 \\
\hline $\begin{array}{l}25 \\
25\end{array}$ & $\begin{array}{l}15 \\
18\end{array}$ & $\begin{array}{l}25.4 \\
23.4\end{array}$ & $\begin{array}{l}22.4 \\
22.4\end{array}$ & $\begin{array}{l}25.1 \\
23.5\end{array}$ & $\begin{array}{l}22.2 \\
22.2\end{array}$ & $\begin{array}{l}25.0 \\
23.6\end{array}$ & $\begin{array}{l}21 \cdot 9 \\
22.1\end{array}$ & $\begin{array}{l}25.0 \\
23.8\end{array}$ & $\begin{array}{l}21.0 \\
22.1\end{array}$ & & & $4: 1$ & $\begin{array}{l}5.0 \\
2.2\end{array}$ & 5.6 & 6.1 \\
\hline 25 & 21 & 21.8 & 21.6 & 72.2 & 21.8 & 22.6 & 21.8 & 23.1 & 21.9 & 24.2 & & & $\begin{array}{l}2.2 \\
1.2\end{array}$ & $\begin{array}{l}2.9 \\
2.0\end{array}$ & $\begin{array}{l}3.9 \\
3.1\end{array}$ \\
\hline $\begin{array}{l}26 \\
26 \\
26 \\
26 \\
26 \\
26 \\
26 \\
25\end{array}$ & $\begin{array}{r}0 \\
3 \\
6 \\
9 \\
12 \\
15 \\
18 \\
21\end{array}$ & $\begin{array}{l}21.5 \\
20.3 \\
18.7 \\
20.2 \\
22.7 \\
24.9 \\
23.0 \\
21.2\end{array}$ & $\begin{array}{l}21.2 \\
20.2 \\
18.8 \\
18.9 \\
19.6 \\
20.4 \\
20.4 \\
19.6\end{array}$ & $\begin{array}{l}21.3 \\
20.3 \\
13.8 \\
20.2 \\
22.5 \\
24.8 \\
23.1 \\
21.3\end{array}$ & $\begin{array}{l}21.3 \\
20.2 \\
18.7 \\
18.8 \\
19.7 \\
20.3 \\
20.3 \\
19.5\end{array}$ & $\begin{array}{l}22.0 \\
20.1 \\
18.6 \\
20.0 \\
22.6 \\
25.0 \\
22.9 \\
21.2\end{array}$ & $\begin{array}{l}21.4 \\
20.0 \\
18.5 \\
18.7 \\
19.2 \\
20.1 \\
20.1 \\
19.4\end{array}$ & $\begin{array}{l}22.3 \\
10.9 \\
18.6 \\
20.1 \\
22.6 \\
24 \cdot 8 \\
23.0 \\
21.1\end{array}$ & $\begin{array}{l}21.5 \\
20.0 \\
18.7 \\
18.5 \\
19.1 \\
20.2 \\
20.0 \\
10.3\end{array}$ & $\begin{array}{l}24.2 \\
24.4 \\
24.7 \\
25.0 \\
26.1 \\
26.8 \\
25.9 \\
25.7\end{array}$ & & $\begin{array}{l}4.0 \\
5.1 \\
4.8 \\
3.5 \\
3.4 \\
1.9 \\
2.3 \\
3.7\end{array}$ & $\begin{array}{l}3.3 \\
6.2 \\
6.0 \\
4.4 \\
3.2 \\
2.0 \\
2.7 \\
4.6\end{array}$ & $\begin{array}{l}4.5 \\
6.9 \\
6.9 \\
5.7\end{array}$ & $\begin{array}{l}5.1 \\
8.2 \\
7.9 \\
6.3 \\
3.7 \\
2.6 \\
4.6 \\
6.0\end{array}$ \\
\hline $\begin{array}{l}27 \\
27 \\
27 \\
27 \\
27 \\
27 \\
27 \\
27\end{array}$ & $\begin{array}{r}0 \\
3 \\
6 \\
0 \\
12 \\
15 \\
18 \\
21\end{array}$ & $\begin{array}{l}19.7 \\
18.9 \\
20.5 \\
24.3 \\
27.5 \\
28.4 \\
26.5\end{array}$ & $\begin{array}{l}18.7 \\
18.3 \\
19.0 \\
21.3 \\
22.0 \\
22.1 \\
22.6\end{array}$ & $\begin{array}{l}19.9 \\
10.0 \\
20.5 \\
24.4 \\
27.6 \\
28.8 \\
26.6\end{array}$ & $\begin{array}{l}18.7 \\
18.4 \\
19.1 \\
23: 1 \\
23: 9 \\
22.2 \\
2 ? .4\end{array}$ & $\begin{array}{l}19.9 \\
19.0 \\
20.5 \\
24.1 \\
27.2 \\
29.0 \\
26.5\end{array}$ & $\begin{array}{l}18.6 \\
18.3 \\
19.0 \\
21.0 \\
21.8 \\
22.4 \\
22.5\end{array}$ & $\begin{array}{l}20.1 \\
19.1 \\
20.6 \\
24.3 \\
27.2 \\
28.5 \\
27.1\end{array}$ & $\begin{array}{l}12.6 \\
18.3 \\
19.1 \\
20.9 \\
21.9 \\
21.0 \\
22.0\end{array}$ & $\begin{array}{l}25.2 \\
24.9 \\
25.1 \\
25.9 \\
28.0 \\
25.9 \\
25.9\end{array}$ & & $\begin{array}{l}2.7 \\
4.7 \\
3.8 \\
4.4 \\
3.2 \\
2.0 \\
1.3 \\
2.3\end{array}$ & $\begin{array}{l}3.6 \\
5.7 \\
4.5 \\
4.8 \\
3.5 \\
2.0 \\
2.1 \\
3.3\end{array}$ & $\begin{array}{l}4 \cdot 5 \\
6.8 \\
5.1 \\
5.3 \\
3.8 \\
2.3 \\
2.7 \\
4.3\end{array}$ & $\begin{array}{l}5.9 \\
8.1 \\
5.6 \\
5.8 \\
4.1 \\
2.5 \\
3.6 \\
5.7\end{array}$ \\
\hline $\begin{array}{l}28 \\
28\end{array}$ & $\begin{array}{l}0 \\
3\end{array}$ & & & & & & & & & & & $\begin{array}{l}5.0 \\
3.8\end{array}$ & $\begin{array}{l}5.8 \\
4.6\end{array}$ & $\begin{array}{l}7.0 \\
5.6\end{array}$ & $\begin{array}{l}8.3 \\
6.8\end{array}$ \\
\hline $\begin{array}{l}28 \\
28\end{array}$ & $\begin{array}{l}6 \\
9\end{array}$ & $\begin{array}{l}20.8 \\
24.7\end{array}$ & $\begin{array}{l}20.3 \\
21.9\end{array}$ & $\begin{array}{l}21.4 \\
24.6\end{array}$ & $\begin{array}{l}20.7 \\
2] .5\end{array}$ & $\begin{array}{l}21.5 \\
24.1\end{array}$ & $\begin{array}{l}20.7 \\
21.5\end{array}$ & $\begin{array}{l}21.6 \\
24.4\end{array}$ & $\begin{array}{l}20.8 \\
21.5\end{array}$ & $\begin{array}{l}24.0 \\
25.1\end{array}$ & & $\begin{array}{l}5.2 \\
4.6\end{array}$ & $\begin{array}{l}6.1 \\
5.3\end{array}$ & $\begin{array}{l}6.9 \\
5.9\end{array}$ & $\begin{array}{l}7.5 \\
6.4\end{array}$ \\
\hline 28 & 12 & 25.8 & 22.6 & 25.9 & 22.5 & 25.6 & 22.4 & 25.7 & 27.2 & & & & 5.1 & & $\begin{array}{l}0.4 \\
6.6\end{array}$ \\
\hline 28 & 15 & 23.0 & $22 . ?$ & 23.1 & 21.9 & 23.0 & 21.9 & 23.0 & 21.9 & 28.0 & & 5.1 & 6.1 & 7.0 & \\
\hline $\begin{array}{l}28 \\
28\end{array}$ & $\begin{array}{l}18 \\
21\end{array}$ & $\begin{array}{l}21.8 \\
20.7\end{array}$ & $\begin{array}{l}21 \cdot 1 \\
20.5\end{array}$ & $\begin{array}{l}22.0 \\
20.9\end{array}$ & $\begin{array}{l}23 \cdot 1 \\
20: 4\end{array}$ & $\begin{array}{l}22.0 \\
21.0\end{array}$ & $\begin{array}{l}21.0 \\
20.4\end{array}$ & $\begin{array}{l}22.0 \\
21.0\end{array}$ & $\begin{array}{l}20.9 \\
20.4\end{array}$ & & & $\begin{array}{l}3.6 \\
4.2\end{array}$ & $\begin{array}{l}4.9 \\
5.8\end{array}$ & $\begin{array}{l}5.8 \\
6.9\end{array}$ & $\begin{array}{l}7.0 \\
8.4\end{array}$ \\
\hline $\begin{array}{l}29 \\
29 \\
29 \\
29 \\
29 \\
29 \\
29 \\
29\end{array}$ & $\begin{array}{r}0 \\
3 \\
6 \\
9 \\
12 \\
15 \\
18 \\
21\end{array}$ & $\begin{array}{l}22.1 \\
23.0 \\
20.4 \\
22.03 \\
26.3 \\
26.8 \\
25.5 \\
23.02\end{array}$ & $\begin{array}{l}21.5 \\
21.8 \\
20.1 \\
21.5 \\
23.3 \\
23.8 \\
23.7 \\
22.0\end{array}$ & $\begin{array}{l}22.3 \\
23.1 \\
20.7 \\
22.2 \\
26.2 \\
26.7 \\
25.5 \\
23.2\end{array}$ & $\begin{array}{l}21.5 \\
21.8 \\
20.1 \\
21.6 \\
22.0 \\
23.7 \\
23.6 \\
22.02\end{array}$ & $\begin{array}{l}22.4 \\
22.8 \\
20.5 \\
22.3 \\
25.8 \\
26.7 \\
25.5 \\
23.2\end{array}$ & $\begin{array}{l}21.6 \\
21.5 \\
20.0 \\
21.7 \\
22.8 \\
23.5 \\
23.5 \\
22.1\end{array}$ & $\begin{array}{l}22.6 \\
22.8 \\
20.6 \\
22.5 \\
25.9 \\
26.4 \\
25.4 \\
23.2\end{array}$ & $\begin{array}{l}21.7 \\
21.03 \\
20.0 \\
21.8 \\
22.8 \\
23.5 \\
23.5 \\
22.1\end{array}$ & $\begin{array}{l}23.9 \\
24.9 \\
24.7 \\
24.7 \\
24.5 \\
23.9 \\
23.1 \\
22.7\end{array}$ & & $\begin{array}{l}6.4 \\
6.9 \\
4.4 \\
7.3 \\
8.8 \\
7.1 \\
6.3 \\
8.6\end{array}$ & $\begin{array}{r}7.7 \\
8.2 \\
5.2 \\
9.0 \\
10.3 \\
8.5 \\
7.7 \\
10.2\end{array}$ & $\begin{array}{r}9.0 \\
9.6 \\
6.5 \\
9.3 \\
12.0 \\
9.6 \\
9.00 \\
11.0\end{array}$ & $\begin{array}{r}10.5 \\
12.3 \\
7.3 \\
11.5 \\
12.7 \\
10.6 \\
10.3 \\
13.4\end{array}$ \\
\hline $\begin{array}{l}30 \\
30 \\
30 \\
30 \\
30 \\
30 \\
30 \\
30\end{array}$ & $\begin{array}{r}0 \\
3 \\
6 \\
9 \\
12 \\
15 \\
18 \\
21\end{array}$ & $\begin{array}{l}22.1 \\
21.8 \\
23.0 \\
22.8 \\
28.4 \\
28.7 \\
25.6 \\
24.3\end{array}$ & $\begin{array}{l}21.5 \\
21.3 \\
21.7 \\
22.1 \\
24.3 \\
23.9 \\
23.5 \\
23.1\end{array}$ & $\begin{array}{l}22.2 \\
21.9 \\
23.0 \\
22.9 \\
28.4 \\
28.4 \\
25.7 \\
24.6\end{array}$ & $\begin{array}{l}23 \cdot 4 \\
21 \cdot 0 \\
21.7 \\
22.0 \\
24.1 \\
23.8 \\
23.4 \\
23.1\end{array}$ & $\begin{array}{l}22.1 \\
21.9 \\
22.9 \\
22.9 \\
28.2 \\
28.2 \\
25.7 \\
24.6\end{array}$ & $\begin{array}{l}21.44 \\
21.02 \\
21.7 \\
22.11 \\
23.9 \\
23.7 \\
23.03 \\
23.0\end{array}$ & $\begin{array}{l}22.1 \\
22.0 \\
23.0 \\
23.2 \\
28.1 \\
28.0 \\
25.9 \\
25.1\end{array}$ & $\begin{array}{l}21.4 \\
21.02 \\
21.7 \\
22.3 \\
23.8 \\
23.6 \\
23.4 \\
23.1\end{array}$ & $\begin{array}{l}22.7 \\
22.4 \\
23.0 \\
24.0 \\
23.5 \\
23.4 \\
22.8 \\
22.9\end{array}$ & & $\begin{array}{r}9.5 \\
11.1 \\
6.3 \\
4.7 \\
10.2 \\
10.7 \\
3.4 \\
5.7\end{array}$ & $\begin{array}{r}12.0 \\
12.9 \\
7.5 \\
5.5 \\
11.8 \\
12.2 \\
4.4 \\
6.9\end{array}$ & $\begin{array}{r}13.8 \\
14.8 \\
7.5 \\
13.4 \\
13.9 \\
5.0 \\
8.0\end{array}$ & $\begin{array}{r}16.0 \\
16.6 \\
10.7 \\
7.2 \\
14.7 \\
15.3 \\
6.0 \\
9.2\end{array}$ \\
\hline $\begin{array}{l}31 \\
31 \\
31 \\
31 \\
31 \\
31 \\
31 \\
31\end{array}$ & $\begin{array}{r}0 \\
3 \\
6 \\
9 \\
12 \\
15 \\
18 \\
21\end{array}$ & $\begin{array}{l}24 \cdot 2 \\
23 \cdot 1 \\
23.6 \\
27.0\end{array}$ & $\begin{array}{l}21.6 \\
21.1 \\
21.2 \\
22.9\end{array}$ & $\begin{array}{l}24.4 \\
23.4 \\
23.9 \\
26.8\end{array}$ & $\begin{array}{l}21 \cdot 6 \\
21 \cdot 1 \\
21 \cdot 2 \\
22 \cdot 8\end{array}$ & $\begin{array}{l}24.4 \\
23.6 \\
23.7 \\
26.8\end{array}$ & $\begin{array}{l}21 \cdot 5 \\
21 \cdot 1 \\
21 \cdot 1 \\
22.6\end{array}$ & $\begin{array}{l}24 \cdot 4 \\
23.9 \\
23.9 \\
26.6\end{array}$ & $\begin{array}{l}2] \cdot 5 \\
21.0 \\
21.2 \\
22.4\end{array}$ & $\begin{array}{l}22.6 \\
22.4 \\
22.9 \\
24.0\end{array}$ & & $\begin{array}{r}10.2 \\
4.5 \\
5.2 \\
9.6 \\
9.7 \\
8.1 \\
7.5 \\
5.5\end{array}$ & $\begin{array}{r}12.1 \\
5.6 \\
6.2 \\
10.7 \\
11.1 \\
9.4 \\
9.0 \\
6.8\end{array}$ & $\begin{array}{r}13.9 \\
6.8 \\
7.0 \\
12.6 \\
12.3 \\
10.6 \\
11.3 \\
8.6\end{array}$ & $\begin{array}{r}15.8 \\
8.1 \\
7.7 \\
13.5 \\
13.7 \\
11.7 \\
12.3 \\
10.0\end{array}$ \\
\hline
\end{tabular}


TABLE 10

Table 10. - Three-hour averages of air and water-surface temperatures and wind directions and apeed, April 1950-August 1951, Lake Hefner-Continued

STATION 2

THREE-HOURLY AVERAGES

AUGUST, 1950

\begin{tabular}{|c|c|c|c|c|c|c|c|c|c|c|c|c|c|c|c|}
\hline \multirow{3}{*}{ 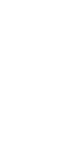 } & \multirow{3}{*}{ 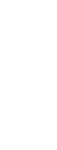 } & \multicolumn{8}{|c|}{ Average air temperature $\left({ }^{\circ} \mathrm{C}\right)$ at indicated height } & \multirow{3}{*}{$\begin{array}{l}\text { Average } \\
\text { water- } \\
\text { surface } \\
\text { tempera- } \\
\text { ture } \\
\left({ }^{\circ} \mathrm{C}\right)\end{array}$} & \multirow{3}{*}{$\begin{array}{l}\text { Average } \\
\text { wind } \\
\text { direction } \\
\text { (coded) }\end{array}$} & \multirow{2}{*}{\multicolumn{4}{|c|}{$\begin{array}{l}\text { Average wind speed (knots) } \\
\text { at indicated height }\end{array}$}} \\
\hline & & \multicolumn{2}{|c|}{$\begin{array}{c}2 \\
\text { meters }\end{array}$} & \multicolumn{2}{|c|}{$\begin{array}{c}4 \\
\text { meters }\end{array}$} & \multicolumn{2}{|c|}{$\begin{array}{c}8 \\
\text { meters }\end{array}$} & \multicolumn{2}{|c|}{$\begin{array}{c}16 \\
\text { meters }\end{array}$} & & & & & & \\
\hline & & $\begin{array}{l}\text { Dry } \\
\text { bulb }\end{array}$ & $\begin{array}{l}\text { Wet } \\
\text { bulb }\end{array}$ & $\begin{array}{l}\text { Dry } \\
\text { bulb }\end{array}$ & $\begin{array}{l}\text { Wet } \\
\text { bulb }\end{array}$ & $\begin{array}{l}\text { Dry } \\
\text { bulb }\end{array}$ & $\begin{array}{l}\text { Wet } \\
\text { bulb }\end{array}$ & $\begin{array}{l}\text { Dry } \\
\text { bulb }\end{array}$ & $\begin{array}{l}\text { Wet } \\
\text { bulb }\end{array}$ & & & meters & meters & meters & meters \\
\hline $\begin{array}{l}1 \\
1 \\
1 \\
1 \\
1 \\
1 \\
1 \\
1 \\
2 \\
2 \\
2 \\
2 \\
2 \\
2 \\
2 \\
2 \\
2\end{array}$ & $\begin{array}{r}0 \\
3 \\
6 \\
9 \\
12 \\
15 \\
18 \\
21 \\
0 \\
3 \\
6 \\
9 \\
12 \\
15 \\
18 \\
21\end{array}$ & $\begin{array}{l}27.1 \\
28.3 \\
28.4 \\
24 \cdot 3 \\
20.0\end{array}$ & $\begin{array}{l}19.3 \\
18.6 \\
19.1 \\
19.6 \\
18.7\end{array}$ & $\begin{array}{l}27 \cdot 1 \\
28 \cdot 2 \\
27.8 \\
25 \cdot 0 \\
21.2\end{array}$ & $\begin{array}{l}19.6 \\
18.7 \\
18.6 \\
19.2 \\
18.8\end{array}$ & $\begin{array}{l}28.2 \\
28.2 \\
28.1 \\
25.0 \\
21.7\end{array}$ & $\begin{array}{l}19.5 \\
18.3 \\
18.4 \\
19.2 \\
18.8\end{array}$ & $\begin{array}{l}26.4 \\
27.4 \\
27.6 \\
25.3 \\
22.3\end{array}$ & $\begin{array}{l}19.4 \\
18.0 \\
18.4 \\
18.7 \\
18.8\end{array}$ & $\begin{array}{l}26.1 \\
26.7 \\
26.2 \\
25.1 \\
25.2\end{array}$ & & $\begin{array}{l}2.6 \\
3.9 \\
4.3 \\
4.7 \\
7.6 \\
5.0 \\
3.04 \\
2.5 \\
1.7 \\
1.5 \\
3.8 \\
3.4 \\
3.2 \\
2.2 \\
1.4 \\
1.7\end{array}$ & $\begin{array}{l}3.3 \\
5.0 \\
5.3 \\
6.2 \\
8.7 \\
5.9 \\
4.0 \\
3.0 \\
2.1 \\
2.1 \\
4.6 \\
4.1 \\
3.5 \\
2.5 \\
1.6 \\
2.9\end{array}$ & $\begin{array}{l}4.0 \\
6.1 \\
6.1 \\
7.1 \\
9.5 \\
7.0 \\
4.1 \\
3.4 \\
2.8 \\
2.7 \\
5.7 \\
5.0 \\
3.9 \\
3.0 \\
2.06 \\
3.8\end{array}$ & $\begin{array}{r}4.7 \\
7.0 \\
7.2 \\
8.0 \\
20.0 \\
9.3 \\
6.2 \\
4.4 \\
3.3 \\
3.4 \\
6.2 \\
5.1 \\
4.0 \\
3.1 \\
3.6 \\
5.4\end{array}$ \\
\hline $\begin{array}{l}3 \\
3 \\
3 \\
3 \\
3 \\
3 \\
3 \\
3\end{array}$ & $\begin{array}{r}0 \\
3 \\
6 \\
9 \\
12 \\
15 \\
12 \\
21\end{array}$ & $\begin{array}{l}18.4 \\
17.9 \\
20.2 \\
24.5 \\
27.8 \\
28.2 \\
24.4 \\
22.3\end{array}$ & $\begin{array}{l}17.8 \\
16.9 \\
18.1 \\
20.0 \\
20.9 \\
20.6 \\
19.7 \\
19.1\end{array}$ & $\begin{array}{l}19.0 \\
18.4 \\
20.4 \\
24.5 \\
27.5 \\
27.6 \\
24.9 \\
22.7\end{array}$ & $\begin{array}{l}17.8 \\
16.09 \\
18.0 \\
19.8 \\
20.5 \\
20.2 \\
19.0 \\
19.1\end{array}$ & $\begin{array}{l}19.3 \\
18.03 \\
20.4 \\
24.4 \\
27.3 \\
27.9 \\
24.0 \\
22.6\end{array}$ & $\begin{array}{l}17.8 \\
17.1 \\
17.9 \\
19.7 \\
20.4 \\
20.3 \\
19.6 \\
19.1\end{array}$ & $\begin{array}{l}19.9 \\
18.8 \\
20.5 \\
24.2 \\
27.4 \\
27.8 \\
25.2 \\
27.8\end{array}$ & $\begin{array}{l}18.0 \\
17.0 \\
18.0 \\
10.6 \\
20.0 \\
20.1 \\
10.6 \\
10.1\end{array}$ & $\begin{array}{l}24.6 \\
24.0 \\
23.9 \\
24.4 \\
25.0 \\
23.1 \\
22.1 \\
22.5\end{array}$ & & $\begin{array}{l}2.3 \\
4.0 \\
6.3 \\
7.4 \\
7.0 \\
7.7 \\
4.2 \\
6.8\end{array}$ & $\begin{array}{l}3.6 \\
5.2 \\
7.6 \\
8.8 \\
8.3 \\
8.9 \\
5.5 \\
8.2\end{array}$ & $\begin{array}{r}4.8 \\
6.6 \\
8.7 \\
9.8 \\
0.2 \\
10.1 \\
6.9 \\
9.8\end{array}$ & $\begin{array}{r}6.8 \\
8.6 \\
9.8 \\
10.6 \\
10.0 \\
11.2 \\
8.5 \\
11.5\end{array}$ \\
\hline $\begin{array}{l}4 \\
4 \\
4 \\
4 \\
4 \\
4 \\
4 \\
4\end{array}$ & $\begin{array}{r}0 \\
3 \\
5 \\
9 \\
12 \\
15 \\
18 \\
21\end{array}$ & $\begin{array}{l}21.6 \\
20.9 \\
31.3 \\
22.9 \\
26.4 \\
26.3 \\
24.0 \\
22.5\end{array}$ & $\begin{array}{l}19.1 \\
18.6 \\
19.1 \\
20.0 \\
21.7 \\
22.2 \\
22.6 \\
21.9\end{array}$ & $\begin{array}{l}22.0 \\
21.2 \\
31.6 \\
23.0 \\
26.0 \\
25.3 \\
25.0 \\
22.6\end{array}$ & $\begin{array}{l}39.0 \\
18.6 \\
18.9 \\
19.8 \\
21.6 \\
22.1 \\
22.6 \\
22.0\end{array}$ & $\begin{array}{l}21.9 \\
21.0 \\
21.4 \\
23.1 \\
25.7 \\
26.0 \\
25.0 \\
27.6\end{array}$ & $\begin{array}{l}19.1 \\
18.6 \\
18.8 \\
19.7 \\
21.3 \\
21.9 \\
22.5 \\
21.9\end{array}$ & $\begin{array}{l}27.0 \\
? .1,1 \\
? 1: 3 \\
? 2: 9 \\
25,7 \\
25: 9 \\
24.9 \\
22.6\end{array}$ & $\begin{array}{l}10.1 \\
12.6 \\
13.9 \\
19.6 \\
21.2 \\
21.7 \\
27.5 \\
21.9\end{array}$ & $\begin{array}{l}22.5 \\
22.2 \\
22.4 \\
22.2 \\
23.0 \\
22.4 \\
22.0 \\
22.2\end{array}$ & & $\begin{array}{r}8.8 \\
8.7 \\
10.3 \\
11.2 \\
9.9 \\
10.0 \\
5.7 \\
6.9\end{array}$ & $\begin{array}{r}10.5 \\
10.3 \\
12.3 \\
13.2 \\
12.0 \\
11.7 \\
7.0 \\
8.7\end{array}$ & $\begin{array}{r}12.1 \\
11.9 \\
14.1 \\
15.1 \\
13.6 \\
13.3 \\
8.2 \\
10.1\end{array}$ & $\begin{array}{r}13.8 \\
13.5 \\
15.8 \\
16.7 \\
15.1 \\
14.6 \\
9.8 \\
11.5\end{array}$ \\
\hline $\begin{array}{l}5 \\
5 \\
5 \\
5 \\
5 \\
5 \\
5 \\
5\end{array}$ & $\begin{array}{r}0 \\
3 \\
5 \\
9 \\
12 \\
15 \\
18 \\
21\end{array}$ & $\begin{array}{l}22.1 \\
21.3 \\
22.1 \\
26.4 \\
27.8 \\
28.0 \\
25.2 \\
23.0\end{array}$ & $\begin{array}{l}21.6 \\
20.9 \\
21.4 \\
22.8 \\
23.3 \\
24.0 \\
23.6 \\
22.4\end{array}$ & $\begin{array}{l}2 ? .3 \\
21.4 \\
? 2.2 \\
26.0 \\
37.4 \\
27.9 \\
25.4 \\
23.1\end{array}$ & $\begin{array}{l}27.7 \\
21.0 \\
21.4 \\
22.6 \\
23.1 \\
24.0 \\
23.0 \\
27.4\end{array}$ & $\begin{array}{l}27.3 \\
21.5 \\
27.0 \\
25.8 \\
26.8 \\
27.4 \\
25.3 \\
23.1\end{array}$ & $\begin{array}{l}21.6 \\
21.0 \\
21.2 \\
22.4 \\
22.8 \\
23.8 \\
23.4 \\
22.3\end{array}$ & $\begin{array}{l}22.3 \\
21.6 \\
21.9 \\
25.6 \\
26.8 \\
27.1 \\
25.2 \\
23.1\end{array}$ & $\begin{array}{l}21.7 \\
21.0 \\
21.2 \\
22.3 \\
22.8 \\
23.8 \\
23.5 \\
77.4\end{array}$ & $\begin{array}{l}22.3 \\
22.3 \\
22.4 \\
23.6 \\
24.3 \\
24.0 \\
23.8 \\
23.4\end{array}$ & & $\begin{array}{l}7.4 \\
7.5 \\
5.0 \\
5.0 \\
6.7 \\
6.0 \\
3.9 \\
5.0\end{array}$ & $\begin{array}{l}9.1 \\
8.9 \\
6.3 \\
6.4 \\
8.6 \\
8.9 \\
5.0 \\
6.8\end{array}$ & $\begin{array}{r}10.7 \\
10.4 \\
7.4 \\
7.4 \\
10.0 \\
10.3 \\
6.1 \\
8.0\end{array}$ & $\begin{array}{r}12.3 \\
22.0 \\
8.1 \\
7.9 \\
20.8 \\
11.3 \\
7.2 \\
9.3\end{array}$ \\
\hline $\begin{array}{l}6 \\
5 \\
6 \\
6 \\
6 \\
6 \\
6 \\
6\end{array}$ & $\begin{array}{r}0 \\
3 \\
6 \\
9 \\
12 \\
15 \\
18 \\
21\end{array}$ & $\begin{array}{l}22.8 \\
22.2 \\
22.3 \\
24.7 \\
26.4 \\
27.7 \\
25.1 \\
23.5\end{array}$ & $\begin{array}{l}21.9 \\
21.3 \\
21.2 \\
21.9 \\
23.0 \\
23.6 \\
23.0 \\
22.7\end{array}$ & $\begin{array}{l}22.8 \\
22.2 \\
22.3 \\
24.5 \\
26.3 \\
77.5 \\
25.2 \\
23.6\end{array}$ & $\begin{array}{l}32.0 \\
21.03 \\
21.1 \\
21.9 \\
22.9 \\
23.6 \\
23.0 \\
22.7\end{array}$ & $\begin{array}{l}22.9 \\
22.2 \\
22.03 \\
24.3 \\
25.0 \\
27.1 \\
25.1 \\
23.6\end{array}$ & $\begin{array}{l}21.9 \\
21.2 \\
21.0 \\
21.7 \\
22.7 \\
23.3 \\
22.9 \\
22.6\end{array}$ & $\begin{array}{l}? 2.8 \\
32.2 \\
22.3 \\
24: 4 \\
25.9 \\
27.1 \\
25.0 \\
? 3.7\end{array}$ & $\begin{array}{l}21.0 \\
21.2 \\
21.0 \\
21.7 \\
22.6 \\
23.1 \\
? 2.9 \\
30.7\end{array}$ & $\begin{array}{l}22.7 \\
22.4 \\
22.4 \\
23.1 \\
23.4 \\
23.1 \\
22.5 \\
22.8\end{array}$ & & $\begin{array}{l}6.7 \\
5.6 \\
5.9\end{array}$ & $\begin{array}{l}8.6 \\
6.9 \\
7.5\end{array}$ & $\begin{array}{l}9,9 \\
8.0 \\
8.4\end{array}$ & $\begin{array}{r}11.2 \\
9.1 \\
9.4\end{array}$ \\
\hline $\begin{array}{l}7 \\
7 \\
7 \\
7 \\
7 \\
7 \\
7 \\
7\end{array}$ & $\begin{array}{r}0 \\
3 \\
6 \\
9 \\
12 \\
15 \\
18 \\
21\end{array}$ & $\begin{array}{l}22.6 \\
21.7 \\
22.4 \\
26.7 \\
31.3 \\
32.5 \\
28.2 \\
24.2\end{array}$ & $\begin{array}{r}21.8 \\
21.0 \\
21.1 \\
22.0 \\
22.9 \\
23.1 \\
22.6 \\
21.4\end{array}$ & $\begin{array}{l}22.6 \\
21.9 \\
22.5 \\
26.6 \\
31.3 \\
32.5 \\
38.2 \\
34.3\end{array}$ & $\begin{array}{l}21 \cdot 8 \\
21 \cdot 0 \\
21 \cdot 0 \\
21 \cdot 8 \\
22.6 \\
22 \cdot 7 \\
? ? \cdot 5 \\
? 1.4\end{array}$ & $\begin{array}{l}22.6 \\
21.9 \\
22.5 \\
26.8 \\
31.0 \\
32.2 \\
28.3 \\
24.5\end{array}$ & $\begin{array}{l}21.7 \\
21.0 \\
21.0 \\
21.9 \\
22.1 \\
22.8 \\
32.5 \\
21.3\end{array}$ & $\begin{array}{l}22.7 \\
21.0 \\
22.5 \\
26.7 \\
30.8 \\
32.0 \\
23.7 \\
3.5 .2\end{array}$ & $\begin{array}{l}21.8 \\
23.0 \\
21.0 \\
21.6 \\
2 ? .0 \\
22.5 \\
20.4 \\
21.4\end{array}$ & $\begin{array}{l}22.9 \\
22.9 \\
22.7 \\
23.2 \\
23.7 \\
23.1 \\
29.0 \\
22.3\end{array}$ & & $\begin{array}{r}12.8 \\
8.9 \\
6.6\end{array}$ & $\begin{array}{r}13.8 \\
10.1 \\
7.4\end{array}$ & $\begin{array}{r}16.2 \\
11.5 \\
8.4\end{array}$ & $\begin{array}{l}17.2 \\
13.0\end{array}$ \\
\hline $\begin{array}{l}8 \\
8 \\
8 \\
8 \\
8 \\
8 \\
8 \\
8\end{array}$ & $\begin{array}{r}0 \\
3 \\
6 \\
9 \\
12 \\
15 \\
18 \\
21\end{array}$ & $\begin{array}{l}22.9 \\
21.1 \\
23.8 \\
28.5 \\
31.0 \\
30.8 \\
27.2 \\
23.1\end{array}$ & $\begin{array}{l}20.4 \\
19.6 \\
21.2 \\
23.2 \\
24.1 \\
22.0 \\
122.5 \\
21.2\end{array}$ & $\begin{array}{l}23.3 \\
21.6 \\
23.0 \\
28.0 \\
30.6 \\
30.7 \\
27.2 \\
23.3\end{array}$ & $\begin{array}{l}20.4 \\
20.0 \\
22 \cdot 2 \\
23 \cdot 1 \\
24 \cdot 1 \\
22 \cdot 2 \\
22 \cdot 6 \\
21 \cdot 2\end{array}$ & $\begin{array}{l}23.4 \\
22.0 \\
23.7 \\
28.1 \\
30.7 \\
30.6 \\
27.1 \\
23.2\end{array}$ & $\begin{array}{l}20.3 \\
20.0 \\
21.1 \\
22.9 \\
23.6 \\
21.7 \\
22.3 \\
2.1 .1\end{array}$ & $\begin{array}{l}33.8 \\
22.7 \\
3.401 \\
27.8 \\
30.4 \\
30.5 \\
27.7 \\
33.5\end{array}$ & $\begin{array}{l}20.4 \\
20.2 \\
21.2 \\
22.9 \\
23.2 \\
21.5 \\
22.3 \\
21.2\end{array}$ & $\begin{array}{l}22.6 \\
23.0 \\
23.8 \\
26.5 \\
27.9 \\
27.4 \\
26.4 \\
26.0\end{array}$ & & $\begin{array}{l}4.4 \\
5.3 \\
4.5 \\
2.5 \\
2.9\end{array}$ & $\begin{array}{l}5.2 \\
6.5 \\
5.6 \\
3.4 \\
3.9\end{array}$ & $\begin{array}{l}5.9 \\
7.5 \\
6.7 \\
4.3 \\
5.0\end{array}$ & $\begin{array}{l}7.3 \\
8.9 \\
7.5 \\
5.6 \\
6.4\end{array}$ \\
\hline $\begin{array}{l}9 \\
9 \\
9 \\
9 \\
9 \\
9 \\
9 \\
9\end{array}$ & $\begin{array}{r}0 \\
3 \\
6 \\
9 \\
12 \\
15 \\
18 \\
21\end{array}$ & $\begin{array}{l}20.3 \\
19.2 \\
21.0 \\
26.0 \\
29.9 \\
29.9 \\
24.0 \\
20.0\end{array}$ & $\begin{array}{l}19.8 \\
19.0 \\
19.9 \\
20.6 \\
21.2 \\
20.8 \\
20.1 \\
13.4\end{array}$ & $\begin{array}{l}20.6 \\
19.4 \\
21.1 \\
25.7 \\
29.5 \\
29.6 \\
25.3 \\
21.4\end{array}$ & $\begin{array}{l}20.0 \\
10.2 \\
10.9 \\
20.5 \\
20.9 \\
20.7 \\
20.1 \\
18.7\end{array}$ & $\begin{array}{l}20.8 \\
19.6 \\
21.1 \\
35.5 \\
29.3 \\
20.2 \\
25.7 \\
27.3\end{array}$ & $\begin{array}{l}20.0 \\
19.2 \\
19.7 \\
20.1 \\
20.7 \\
20.3 \\
20.0 \\
18.8\end{array}$ & $\begin{array}{l}21 \cdot 2 \\
29: 8 \\
21: 0 \\
25.4 \\
29.1 \\
29 \cdot 2 \\
25: 2 \\
23.1\end{array}$ & $\begin{array}{l}20.2 \\
19.3 \\
19.7 \\
20.0 \\
20.2 \\
20.3 \\
20.0 \\
19.0\end{array}$ & $\begin{array}{l}25.9 \\
25.9 \\
25.0 \\
25.8 \\
27.1 \\
26.2 \\
24.8 \\
24.0\end{array}$ & & $\begin{array}{l}1.4 \\
2.1 \\
3.5 \\
4.5 \\
3.9 \\
5.2 \\
1.8 \\
1.8\end{array}$ & $\begin{array}{l}2.2 \\
3.0 \\
4.5 \\
5.7 \\
5.0 \\
5.9 \\
3.0 \\
3.0\end{array}$ & $\begin{array}{l}3.0 \\
3.7 \\
5.1 \\
6.5 \\
5.6 \\
8.0 \\
3.9 \\
4.2\end{array}$ & $\begin{array}{l}4.1 \\
4.6 \\
5.7 \\
7.0 \\
5.0 \\
8.9 \\
4.7 \\
5.6\end{array}$ \\
\hline $\begin{array}{l}10 \\
10 \\
10 \\
10 \\
10 \\
10 \\
10 \\
10\end{array}$ & $\begin{array}{r}0 \\
3 \\
6 \\
9 \\
12 \\
15 \\
18 \\
31\end{array}$ & $\begin{array}{l}18.3 \\
18.6 \\
22.2 \\
26.4 \\
30.7 \\
31.2 \\
27.2 \\
25.1\end{array}$ & $\begin{array}{r}17.9 \\
17.8 \\
19.9 \\
22.2 \\
22.8 \\
22.9 \\
122.7 \\
27.2\end{array}$ & $\begin{array}{l}19.5 \\
19.2 \\
22.1 \\
26.0 \\
30.5 \\
30.9 \\
27.2 \\
25.3\end{array}$ & $\begin{array}{l}18: 1 \\
17: 9 \\
?: 00 \\
? 2: 0 \\
27: 7 \\
? 7: 7 \\
32.8 \\
37.2\end{array}$ & $\begin{array}{l}20.2 \\
10.6 \\
32.0 \\
25.1 \\
30.2 \\
30.4 \\
27.2 \\
25.5\end{array}$ & $\begin{array}{l}18.2 \\
17.9 \\
20.0 \\
21.6 \\
22.6 \\
22.5 \\
23.7 \\
22.2\end{array}$ & $\begin{array}{l}20.8 \\
20.0 \\
22.5 \\
25.9 \\
20.9 \\
30.3 \\
27.4 \\
25.7\end{array}$ & $\begin{array}{l}18.6 \\
18.2 \\
20.2 \\
21.8 \\
22.3 \\
27.3 \\
22.8 \\
22.3\end{array}$ & $\begin{array}{l}23.9 \\
23.8 \\
24.0 \\
25.3 \\
25.8 \\
24.2 \\
23.4 \\
23.7\end{array}$ & & $\begin{array}{l}2.2 \\
2.5 \\
1.5 \\
3.1 \\
3.5 \\
4.0 \\
2.5 \\
4.3\end{array}$ & $\begin{array}{l}3.7 \\
3.9 \\
2.2 \\
4.5 \\
5.0 \\
6.1 \\
4.8 \\
6.5\end{array}$ & $\begin{array}{l}5.0 \\
5.2 \\
2.6 \\
4.5 \\
5.5 \\
6.4 \\
5.7 \\
7.8\end{array}$ & $\begin{array}{l}6.5 \\
7.3 \\
3.0 \\
5.3 \\
6.1 \\
6.7\end{array}$ \\
\hline
\end{tabular}


TABLE 10

Table 10. - Three-hour averages of air and water-surface temperatures and wind directions and speed, April 1950-August 1951, Lake Hefner-Continued

STATION 2 THREE-HOURLY AVERAGES

AUGUST, 1950

\begin{tabular}{|c|c|c|c|c|c|c|c|c|c|c|c|c|c|c|c|}
\hline \multirow{3}{*}{ 宽 } & \multirow{3}{*}{ 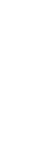 } & \multicolumn{8}{|c|}{ Average air temperature $\left({ }^{\circ} \mathrm{C}\right)$ at indicated height } & \multirow{3}{*}{\begin{tabular}{|l} 
Average \\
water- \\
surface \\
tempera- \\
ture \\
$\left({ }^{\circ} \mathrm{C}\right)$
\end{tabular}} & \multirow{3}{*}{$\begin{array}{c}\text { Average } \\
\text { wind } \\
\text { direction } \\
\text { (coded) }\end{array}$} & \multirow{2}{*}{\multicolumn{4}{|c|}{$\begin{array}{l}\text { Average wind speed (knots) } \\
\text { at indicated height }\end{array}$}} \\
\hline & & \multicolumn{2}{|c|}{$\begin{array}{c}2 \\
\text { meters }\end{array}$} & \multicolumn{2}{|c|}{$\stackrel{4}{\text { meters }}$} & \multicolumn{2}{|c|}{$\begin{array}{c}8 \\
\text { meters }\end{array}$} & \multicolumn{2}{|c|}{$\begin{array}{c}16 \\
\text { meters }\end{array}$} & & & & & & \\
\hline & & $\begin{array}{l}\text { Dry } \\
\text { bulb }\end{array}$ & $\begin{array}{l}\text { Wet } \\
\text { bulb }\end{array}$ & $\begin{array}{l}\text { Dry } \\
\text { bulb }\end{array}$ & $\begin{array}{l}\text { Wet } \\
\text { bulb }\end{array}$ & $\begin{array}{l}\text { Dry } \\
\text { bulb }\end{array}$ & $\begin{array}{l}\text { Wet } \\
\text { bulb }\end{array}$ & $\begin{array}{l}\text { Dry } \\
\text { bulb }\end{array}$ & $\begin{array}{l}\text { Wet } \\
\text { bulb }\end{array}$ & & & meters & $\begin{array}{c}4 \\
\text { meters }\end{array}$ & $\begin{array}{c}8 \\
\text { meters }\end{array}$ & $\begin{array}{c}16 \\
\text { meters }\end{array}$ \\
\hline $\begin{array}{l}11 \\
11 \\
11 \\
11 \\
11 \\
11 \\
11 \\
11\end{array}$ & $\begin{array}{r}0 \\
3 \\
6 \\
9 \\
12 \\
15 \\
18 \\
21\end{array}$ & $\begin{array}{l}24.1 \\
23.1 \\
23.7 \\
27.8 \\
32.0 \\
32.0 \\
28.8 \\
25.8\end{array}$ & $\begin{array}{l}21.9 \\
21: 0 \\
21 \cdot 2 \\
22.8 \\
24 \cdot 1 \\
23.9 \\
24: 2 \\
23.5\end{array}$ & $\begin{array}{l}24.3 \\
23.1 \\
23.7 \\
27.9 \\
31.5 \\
32.6 \\
28.8 \\
25.9\end{array}$ & $\begin{array}{l}21 \cdot 9 \\
21: 0 \\
21 \cdot 2 \\
22.5 \\
23.6 \\
23.8 \\
24: 3 \\
23.4\end{array}$ & $\begin{array}{l}24.2 \\
23.1 \\
23.8 \\
27.4 \\
31.02 \\
32.04 \\
28.7 \\
25.9\end{array}$ & $\begin{array}{l}21.9 \\
21: 0 \\
21 \cdot 0 \\
22.5 \\
23.5 \\
23.5 \\
24: 2 \\
23.3\end{array}$ & $\begin{array}{l}24 \cdot 4 \\
23.2 \\
23: 7 \\
27.6 \\
31 \cdot 3 \\
32 \cdot 3 \\
28: 7 \\
25.9\end{array}$ & $\begin{array}{l}22.0 \\
21.1 \\
21.2 \\
22.4 \\
23.4 \\
23.4 \\
24.4 \\
23.3\end{array}$ & $\begin{array}{l}23.6 \\
23.4 \\
23.6 \\
24.9 \\
25.1 \\
23.7 \\
23.6 \\
23.8\end{array}$ & & $\begin{array}{l}7.1 \\
6.8 \\
6.7 \\
3.6 \\
6.4 \\
6.2 \\
7.1 \\
9.4\end{array}$ & $\begin{array}{r}8.5 \\
8.1 \\
8.0 \\
4.2 \\
8.1 \\
7.7 \\
9.1 \\
11.3\end{array}$ & $\begin{array}{r}10.1 \\
9.5 \\
9.2 \\
4.7 \\
9.2 \\
8.8 \\
10.7 \\
13.2\end{array}$ & $\begin{array}{r}12.4 \\
6.3 \\
9.7 \\
10.4 \\
12.8\end{array}$ \\
\hline $\begin{array}{l}12 \\
12 \\
12 \\
12 \\
12 \\
12 \\
12 \\
12\end{array}$ & $\begin{array}{r}0 \\
3 \\
6 \\
9 \\
12 \\
15 \\
18 \\
21\end{array}$ & $\begin{array}{l}23.9 \\
21.8 \\
23.3 \\
30.2 \\
33.7 \\
33.6 \\
29.1 \\
25.9\end{array}$ & $\begin{array}{l}21.0 \\
20.1 \\
20.5 \\
21.7 \\
22.1 \\
21.9 \\
21.5 \\
21.4\end{array}$ & $\begin{array}{l}24.0 \\
21.9 \\
23.5 \\
29.9 \\
33.2 \\
33.5 \\
29.2 \\
26.1\end{array}$ & $\begin{array}{l}21.1 \\
20: 2 \\
20.5 \\
21.4 \\
21 \cdot 7 \\
21.9 \\
21.5 \\
21.4\end{array}$ & $\begin{array}{l}23.9 \\
21.9 \\
23.5 \\
29.8 \\
33.0 \\
33.1 \\
29.2 \\
26.1\end{array}$ & $\begin{array}{l}21.0 \\
20.1 \\
20.5 \\
21.2 \\
21.6 \\
21.8 \\
21.6 \\
21.4\end{array}$ & $\begin{array}{l}24.0 \\
22.0 \\
23.5 \\
29.7 \\
32.8 \\
33.1 \\
29.5 \\
26.3\end{array}$ & $\begin{array}{l}21.1 \\
20.2 \\
20.5 \\
21.0 \\
21.5 \\
21.5 \\
21.6 \\
21.6\end{array}$ & $\begin{array}{l}23.6 \\
23.5 \\
23.5 \\
24.2 \\
25.1 \\
23.7 \\
23.4 \\
23.8\end{array}$ & & $\begin{array}{r}10.3 \\
8.6 \\
9.9 \\
8.1 \\
6.6 \\
7.1 \\
5.2 \\
7.9\end{array}$ & $\begin{array}{r}12 . ? \\
10.3 \\
11.6 \\
9.2 \\
7.5 \\
8.3 \\
6.4 \\
9.6\end{array}$ & $\begin{array}{r}14.2 \\
12.1 \\
13.2 \\
10.4 \\
8.3 \\
9.5 \\
7.9 \\
11.3\end{array}$ & $\begin{array}{r}11.4 \\
9.1 \\
10.7 \\
9.7 \\
13.2\end{array}$ \\
\hline $\begin{array}{l}13 \\
13 \\
13 \\
13 \\
13 \\
13 \\
13 \\
13\end{array}$ & $\begin{array}{r}0 \\
3 \\
6 \\
9 \\
12 \\
15 \\
18 \\
21\end{array}$ & $\begin{array}{l}24.3 \\
22.4 \\
24.7 \\
30.4 \\
33.0 \\
32.6 \\
28.7 \\
33.7\end{array}$ & $\begin{array}{l}21.3 \\
20.4 \\
20.8 \\
22.0 \\
22.5 \\
22.5 \\
21.3 \\
20.1\end{array}$ & $\begin{array}{l}24.4 \\
22.6 \\
24.7 \\
30.3 \\
32.6 \\
32.2 \\
28.7 \\
23.9\end{array}$ & $\begin{array}{l}21.4 \\
20.4 \\
20.8 \\
21.9 \\
22.2 \\
22.5 \\
21.2 \\
20.1\end{array}$ & $\begin{array}{l}24.4 \\
22.7 \\
24.8 \\
29.9 \\
32.2 \\
32.0 \\
28.6 \\
24.0\end{array}$ & $\begin{array}{l}21.3 \\
20.4 \\
20.7 \\
21.5 \\
22.3 \\
22.2 \\
21.0 \\
20.1\end{array}$ & $\begin{array}{l}24.5 \\
22.8 \\
25.0 \\
29.7 \\
31.9 \\
31.7 \\
28.6 \\
24.5\end{array}$ & $\begin{array}{l}21.5 \\
20.4 \\
20.8 \\
21.6 \\
21.9 \\
22.0 \\
21.1 \\
20.3\end{array}$ & $\begin{array}{l}23.7 \\
23.7 \\
23.8 \\
24.8 \\
25.8 \\
25.0 \\
24.3 \\
24.7\end{array}$ & & $\begin{array}{l}7.8 \\
5: 8 \\
5.8 \\
7.9 \\
6.5 \\
6.7 \\
6.1 \\
3.9\end{array}$ & $\begin{array}{r}10.1 \\
6.9 \\
6.7 \\
8.9 \\
7.5 \\
7.9 \\
7.5 \\
4.9\end{array}$ & $\begin{array}{r}11.7 \\
8.4 \\
7.7 \\
10.1 \\
8.2 \\
9.1 \\
8.9 \\
6.5\end{array}$ & $\begin{array}{r}13.7 \\
10.4 \\
8.7 \\
11.2 \\
8.9 \\
10.0 \\
10.6 \\
8.5\end{array}$ \\
\hline $\begin{array}{l}14 \\
14 \\
14 \\
14 \\
14 \\
14 \\
14 \\
14\end{array}$ & $\begin{array}{r}0 \\
3 \\
6 \\
9 \\
12 \\
15 \\
18 \\
21\end{array}$ & $\begin{array}{l}22.1 \\
20.9\end{array}$ & $\begin{array}{l}20.2 \\
20.0\end{array}$ & $\begin{array}{l}22 \cdot 3 \\
21 \cdot 1\end{array}$ & $\begin{array}{l}20.2 \\
20.0\end{array}$ & $\begin{array}{l}22 \cdot 6 \\
21 \cdot 2\end{array}$ & $\begin{array}{l}20.2 \\
20.1\end{array}$ & $\begin{array}{l}23.0 \\
21.8\end{array}$ & $\begin{array}{l}20.5 \\
20.2 \\
21.0 \\
21.9\end{array}$ & $\begin{array}{l}24.6 \\
24.7 \\
28.4 \\
29.1\end{array}$ & & $\begin{array}{l}3.7 \\
2.5 \\
3.8 \\
6.2 \\
4.3 \\
6.2 \\
3.8 \\
3.8\end{array}$ & $\begin{array}{l}4.7 \\
3.2 \\
4.4 \\
6.8 \\
4.7 \\
7.1 \\
4.9 \\
4.9\end{array}$ & $\begin{array}{l}6.3 \\
4.6 \\
5.0 \\
7.7 \\
5.1 \\
8.1 \\
7.2 \\
6.3\end{array}$ & $\begin{array}{l}8.2 \\
6.3 \\
5.6 \\
8.3 \\
5.0 \\
8.9 \\
7.7 \\
7.9\end{array}$ \\
\hline $\begin{array}{l}15 \\
15 \\
15\end{array}$ & $\begin{array}{l}0 \\
3 \\
6\end{array}$ & & & & & & & & & & & $\begin{array}{l}4.5 \\
6.9 \\
6.9\end{array}$ & $\begin{array}{l}5.6 \\
8.1 \\
8.5\end{array}$ & $\begin{array}{l}6.9 \\
9.6 \\
9.8\end{array}$ & $\begin{array}{r}8.5 \\
11.4 \\
10.9\end{array}$ \\
\hline $\begin{array}{l}15 \\
15 \\
15 \\
15 \\
15\end{array}$ & $\begin{array}{r}9 \\
12 \\
15 \\
18 \\
21\end{array}$ & $\begin{array}{l}29.5 \\
32.1 \\
32.2 \\
23.0 \\
20.1\end{array}$ & $\begin{array}{l}21.8 \\
22.4 \\
22.5 \\
21.4 \\
19.4\end{array}$ & $\begin{array}{l}29.6 \\
32.1 \\
31.8 \\
23.4 \\
20.5\end{array}$ & $\begin{array}{l}21.7 \\
22.1 \\
22.4 \\
21.0 \\
19.4\end{array}$ & $\begin{array}{l}29.6 \\
31.8 \\
31.6 \\
23.3 \\
20.5\end{array}$ & $\begin{array}{l}21.8 \\
22.4 \\
22.2 \\
20.7 \\
19.4\end{array}$ & $\begin{array}{l}29 \cdot 4 \\
31 \cdot 5 \\
31 \cdot 5 \\
23 \cdot 5 \\
20.7\end{array}$ & $\begin{array}{l}21.8 \\
22.1 \\
22.3 \\
20.6 \\
19.7\end{array}$ & $\begin{array}{l}28 \cdot 3 \\
28 \cdot 7 \\
27 \cdot 9 \\
27 \cdot 2 \\
26 \cdot 9\end{array}$ & & $\begin{array}{l}8.4 \\
7.6 \\
6.3 \\
7.4 \\
7.6\end{array}$ & $\begin{array}{l}9.9 \\
8.6 \\
7.1 \\
8.9 \\
9.0\end{array}$ & $\begin{array}{r}11.1 \\
9.7 \\
8.2 \\
10.7 \\
10.7\end{array}$ & $\begin{array}{r}12.4 \\
10.6 \\
9.2 \\
10.6 \\
13.3\end{array}$ \\
\hline $\begin{array}{l}16 \\
16 \\
16 \\
16 \\
16 \\
16 \\
16 \\
16\end{array}$ & $\begin{array}{r}0 \\
3 \\
6 \\
9 \\
12 \\
15 \\
18 \\
21\end{array}$ & $\begin{array}{l}20.8 \\
20.2 \\
21.2 \\
24.8 \\
27.4 \\
25.2 \\
23.4 \\
22.3\end{array}$ & $\begin{array}{l}19.7 \\
19.3 \\
20.2 \\
21.7 \\
23.0 \\
21.7 \\
21.6 \\
21.8\end{array}$ & $\begin{array}{l}21.0 \\
20.4 \\
21.2 \\
24.9 \\
27.5 \\
25.1 \\
23.5 \\
22.5\end{array}$ & $\begin{array}{l}19.5 \\
19.4 \\
20.2 \\
21.9 \\
22.5 \\
22.1 \\
21.4 \\
21.8\end{array}$ & $\begin{array}{l}21.0 \\
20.5 \\
21.3 \\
24.8 \\
27.0 \\
24.9 \\
23.5 \\
22.6\end{array}$ & $\begin{array}{l}19.5 \\
19.3 \\
20.2 \\
21.5 \\
22.3 \\
21.5 \\
21.4 \\
21.8\end{array}$ & $\begin{array}{l}21.4 \\
20.8 \\
21.4 \\
24.6 \\
26.9 \\
24.9 \\
23.6 \\
22.7\end{array}$ & $\begin{array}{l}19.5 \\
19.4 \\
20.3 \\
21.4 \\
21.9 \\
21.5 \\
21.5 \\
22.0\end{array}$ & $\begin{array}{l}26.2 \\
26.1 \\
26.2 \\
27.0 \\
28.2 \\
27.1 \\
26.7 \\
26.5\end{array}$ & & $\begin{array}{l}3.3 \\
1.7 \\
2.1 \\
2.0 \\
6.0 \\
5.4 \\
2.5 \\
2.4\end{array}$ & $\begin{array}{l}4.2 \\
2.4 \\
2.7 \\
3.7 \\
6.7 \\
6.4 \\
3.2 \\
3.1\end{array}$ & $\begin{array}{l}5.0 \\
3.2 \\
3.0 \\
3.7 \\
7.9 \\
7.4 \\
4.0 \\
4.0\end{array}$ & $\begin{array}{l}6.8 \\
4.7 \\
3.8 \\
4.0 \\
8.5 \\
8.6 \\
4.9 \\
5.0\end{array}$ \\
\hline $\begin{array}{l}17 \\
17 \\
17 \\
17 \\
17 \\
17 \\
17 \\
17\end{array}$ & $\begin{array}{r}0 \\
3 \\
6 \\
9 \\
12 \\
15 \\
18 \\
21\end{array}$ & $\begin{array}{l}21.1 \\
20.9 \\
21.3 \\
23.4 \\
23.7 \\
23.8 \\
21.2 \\
20.4\end{array}$ & $\begin{array}{l}20.7 \\
20.1 \\
20.3 \\
20.3 \\
20.6 \\
20.4 \\
10.1 \\
19.4\end{array}$ & $\begin{array}{l}21.3 \\
21.1 \\
21.2 \\
23.3 \\
23.5 \\
23.4 \\
21.2 \\
20.6\end{array}$ & $\begin{array}{l}20.8 \\
20.1 \\
20.2 \\
20.1 \\
20.4 \\
20.6 \\
19.1 \\
19.5\end{array}$ & $\begin{array}{l}21.2 \\
20.9 \\
21.2 \\
23.2 \\
23.4 \\
23.4 \\
21.1 \\
20.4\end{array}$ & $\begin{array}{l}20.7 \\
20.0 \\
20.1 \\
19.9 \\
20.2 \\
20.1 \\
18.9 \\
19.1\end{array}$ & $\begin{array}{l}21 \cdot 4 \\
21: 2 \\
21 \cdot 4 \\
22 \cdot 8 \\
23 \cdot 3 \\
23 \cdot 4 \\
21 \cdot 1 \\
20,4\end{array}$ & $\begin{array}{l}20 \cdot 8 \\
20.0 \\
20 \cdot 3 \\
10 \cdot 7 \\
10.9 \\
10.9 \\
19.0 \\
19 \cdot 2\end{array}$ & $\begin{array}{l}26.2 \\
26.0 \\
26.3 \\
27.7 \\
28.3 \\
27.9 \\
26.5 \\
25.9\end{array}$ & & $\begin{array}{r}3.0 \\
4.0 \\
3.4 \\
5.1 \\
6.3 \\
10.5 \\
6.1 \\
5.8\end{array}$ & $\begin{array}{r}3.7 \\
4.8 \\
4.1 \\
6.0 \\
7.5 \\
12.2 \\
7.5 \\
7.2\end{array}$ & $\begin{array}{r}4.6 \\
5.9 \\
5.1 \\
7.8 \\
9.2 \\
15.5 \\
8.9 \\
10.0\end{array}$ & $\begin{array}{r}5.6 \\
7.2 \\
5.4 \\
7.6 \\
9.6 \\
15.4 \\
10.8 \\
8.5\end{array}$ \\
\hline $\begin{array}{l}18 \\
18 \\
18 \\
18 \\
18 \\
18 \\
18 \\
18\end{array}$ & $\begin{array}{r}0 \\
3 \\
6 \\
9 \\
12 \\
15 \\
18 \\
21\end{array}$ & $\begin{array}{l}20.0 \\
18.9 \\
18.8 \\
22.3 \\
25.6 \\
26.3 \\
22.5 \\
17.7\end{array}$ & $\begin{array}{l}19.1 \\
18.5 \\
17.9 \\
18.9 \\
18.2 \\
17.4 \\
17.3 \\
15.4\end{array}$ & $\begin{array}{l}20.0 \\
19.0 \\
18.8 \\
22.2 \\
25.2 \\
26.1 \\
23.0 \\
19.5\end{array}$ & $\begin{array}{l}19 \cdot 1 \\
18.5 \\
17: 7 \\
18.3 \\
17.8 \\
17.3 \\
17.2 \\
15.8\end{array}$ & $\begin{array}{l}19.9 \\
18.9 \\
18.7 \\
22.0 \\
24.9 \\
25.1 \\
23.02 \\
20.1\end{array}$ & $\begin{array}{l}19.0 \\
18.3 \\
17.5 \\
18.3 \\
17.5 \\
17.0 \\
16.9 \\
15.8\end{array}$ & $\begin{array}{l}19.0 \\
18: 7 \\
18.6 \\
21.7 \\
24.6 \\
25.0 \\
23.8 \\
20.7\end{array}$ & $\begin{array}{l}19.0 \\
18.2 \\
17.5 \\
17.9 \\
16.9 \\
16.4 \\
16.7 \\
16.0\end{array}$ & $\begin{array}{l}25.2 \\
24.8 \\
24.9 \\
26.7 \\
28.1 \\
28.1 \\
27.4 \\
27.0\end{array}$ & & $\begin{array}{l}6.4 \\
7.7 \\
6.8 \\
6.7 \\
6.5 \\
5.2 \\
1.6 \\
1.6\end{array}$ & $\begin{array}{r}8.3 \\
10.4 \\
8.3 \\
7.8 \\
7.5 \\
6.1 \\
2.4 \\
2.3\end{array}$ & $\begin{array}{r}10.3 \\
13.2 \\
10.5 \\
10.2 \\
8.7 \\
6.9 \\
3.5 \\
3.0\end{array}$ & $\begin{array}{l}10.7 \\
12.9 \\
10.1 \\
9.7 \\
9.2 \\
5.1 \\
4.3\end{array}$ \\
\hline $\begin{array}{l}19 \\
19 \\
19 \\
19 \\
19 \\
19 \\
19 \\
19\end{array}$ & $\begin{array}{r}0 \\
3 \\
6 \\
9 \\
12 \\
15 \\
18 \\
21\end{array}$ & $\begin{array}{l}15.5 \\
14.2 \\
20.3 \\
25.2 \\
27.7 \\
27.7 \\
24.1 \\
20.3\end{array}$ & $\begin{array}{l}14.3 \\
13.5 \\
16.4 \\
17.3 \\
17.1 \\
18.1 \\
18.4 \\
17.7\end{array}$ & $\begin{array}{l}17.1 \\
15.3 \\
20.2 \\
24.8 \\
27.1 \\
27.5 \\
24.2 \\
20.4\end{array}$ & $\begin{array}{l}14.9 \\
14.2 \\
16.5 \\
16.6 \\
17.0 \\
18.0 \\
18.4 \\
17.5\end{array}$ & $\begin{array}{l}18.2 \\
16.3 \\
21.3 \\
25.0 \\
26.5 \\
27.0 \\
2.400 \\
20.2\end{array}$ & $\begin{array}{l}14.9 \\
14: 5 \\
16.7 \\
17: 0 \\
16.4 \\
17.5 \\
18.1 \\
17.3\end{array}$ & $\begin{array}{l}19.4 \\
17: 9 \\
21.5 \\
24: 4 \\
26.3 \\
27.1 \\
24.2 \\
20.1\end{array}$ & $\begin{array}{l}15.1 \\
14.9 \\
17.0 \\
16.6 \\
16.6 \\
17.6 \\
18.0 \\
17.2\end{array}$ & $\begin{array}{l}26.6 \\
25.9 \\
26.4 \\
28.3 \\
29.4 \\
29.4 \\
28.4 \\
27.3\end{array}$ & & $\begin{array}{l}1.2 \\
0.9 \\
0.7 \\
2.3 \\
3.7 \\
3.8 \\
2.9 \\
6.1\end{array}$ & $\begin{array}{l}1.4 \\
1.0 \\
0.9 \\
2.6 \\
4.6 \\
4.6 \\
3.8 \\
7.5\end{array}$ & $\begin{array}{l}2.5 \\
0.9 \\
1.1 \\
3.0 \\
4.9 \\
5.4 \\
4.9 \\
0.3\end{array}$ & $\begin{array}{r}2.4 \\
1.3 \\
1.1 \\
3.2 \\
5.7 \\
5.9 \\
6.2 \\
11.4\end{array}$ \\
\hline $\begin{array}{l}20 \\
20 \\
20 \\
20 \\
20 \\
20 \\
20 \\
20\end{array}$ & $\begin{array}{r}0 \\
3 \\
6 \\
9 \\
12 \\
15 \\
18 \\
21\end{array}$ & $\begin{array}{l}16.6 \\
15.3\end{array}$ & $\begin{array}{l}13.7 \\
12.0\end{array}$ & $\begin{array}{l}16.6 \\
15.2\end{array}$ & $\begin{array}{l}13.5 \\
12.0\end{array}$ & $\begin{array}{l}16.4 \\
15.0\end{array}$ & $\begin{array}{l}13.2 \\
12.4\end{array}$ & $\begin{array}{l}16.3 \\
14.8\end{array}$ & $\begin{array}{l}13.1 \\
11.7\end{array}$ & $\begin{array}{l}26 \cdot 1 \\
25.0\end{array}$ & & $\begin{array}{l}7.6 \\
7.5 \\
7.8 \\
7.0 \\
5.2 \\
4.9 \\
2.6 \\
1.5\end{array}$ & $\begin{array}{l}8.6 \\
8.8 \\
9.0 \\
7.7 \\
6.1 \\
5.7 \\
3.3 \\
1.9\end{array}$ & $\begin{array}{r}10.0 \\
10.2 \\
10.3 \\
8.4 \\
6.8 \\
6.4 \\
3.8 \\
2.3\end{array}$ & $\begin{array}{r}11.2 \\
10.5 \\
12.8 \\
10.0 \\
8.1 \\
8.0 \\
4.2 \\
2.6\end{array}$ \\
\hline
\end{tabular}


Table 10. - Three-hour averages of air and water-surface temperatures and wind directions and speed, April 1950-August 1951, Lake Hefner-Continued

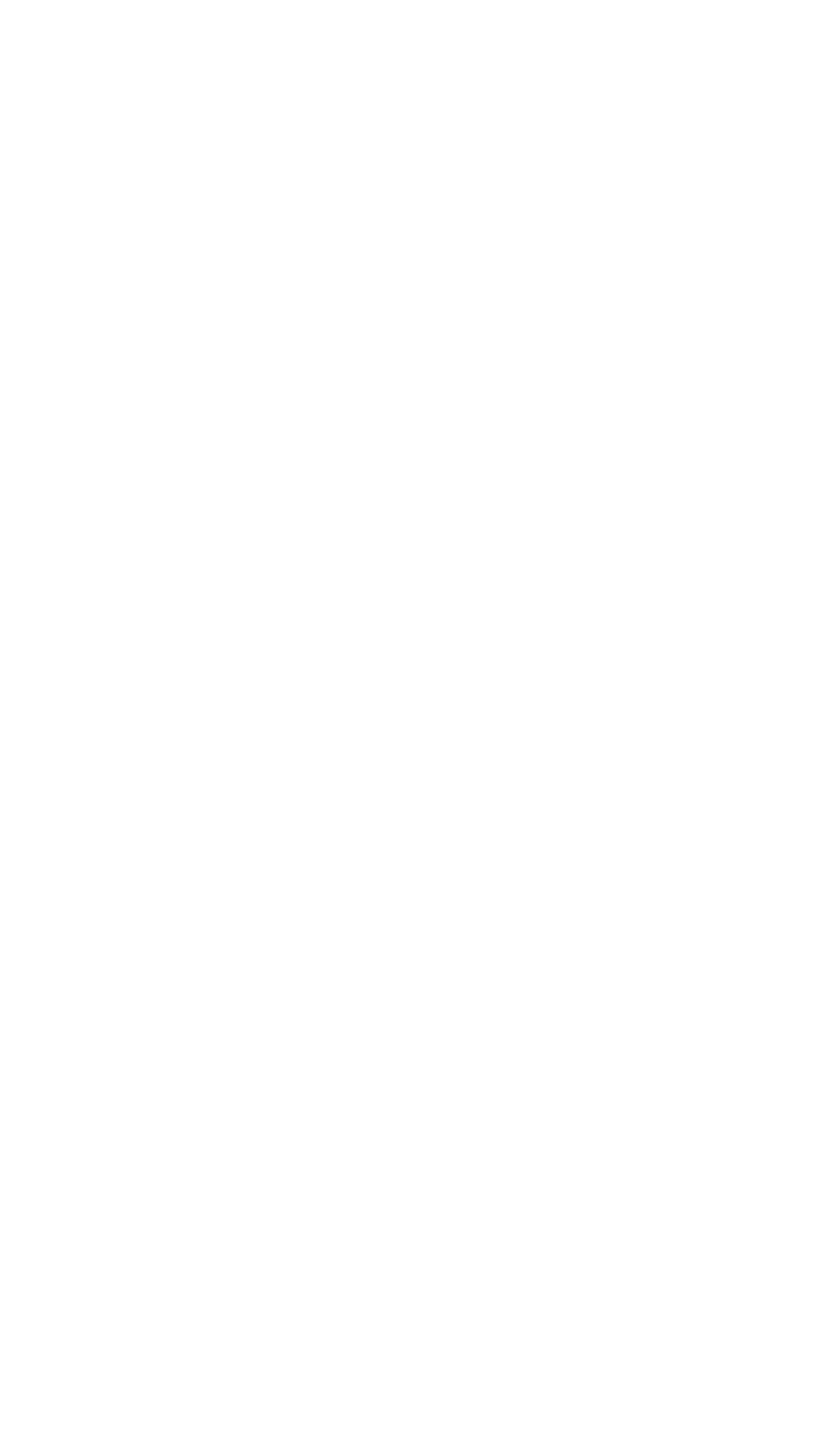


TABLE 10 Table 10. - Three-hour averages of air and water-surface temperatures and wind directions and speed, April 1950-August

STATION 2

THREE-HOURLY AVERAGES

SEPTEMBER, 1950

\begin{tabular}{|c|c|c|c|c|c|c|c|c|c|c|c|c|c|c|c|}
\hline \multirow{3}{*}{ 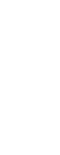 } & \multirow{3}{*}{ 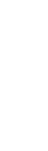 } & \multicolumn{8}{|c|}{ Average air temperature $\left({ }^{\circ} \mathrm{C}\right)$ at indicated height } & \multirow{3}{*}{$\begin{array}{l}\text { Average } \\
\text { water- } \\
\text { surface } \\
\text { tempera- } \\
\text { ture } \\
\left({ }^{\circ} \mathrm{C}\right)\end{array}$} & \multirow{3}{*}{$\begin{array}{c}\text { Average } \\
\text { wind } \\
\text { direction } \\
\text { (coded) }\end{array}$} & \multicolumn{4}{|c|}{$\begin{array}{l}\text { Average wind speed (knota) } \\
\text { at indicated height }\end{array}$} \\
\hline & & \multicolumn{2}{|c|}{$\begin{array}{c}2 \\
\text { meters }\end{array}$} & \multicolumn{2}{|c|}{$\begin{array}{c}4 \\
\text { meters }\end{array}$} & \multicolumn{2}{|c|}{$\begin{array}{c}8 \\
\text { meters }\end{array}$} & \multicolumn{2}{|c|}{$\begin{array}{c}16 \\
\text { meters }\end{array}$} & & & & & & \\
\hline & & $\begin{array}{l}\text { Dry } \\
\text { bulb }\end{array}$ & $\begin{array}{l}\text { Wet } \\
\text { bulb }\end{array}$ & $\begin{array}{l}\text { Dry } \\
\text { bulb }\end{array}$ & $\begin{array}{l}\text { Wet } \\
\text { bulb }\end{array}$ & $\begin{array}{l}\text { Dry } \\
\text { bulb }\end{array}$ & $\begin{array}{l}\text { Wet } \\
\text { bulb }\end{array}$ & $\begin{array}{l}\text { Dry } \\
\text { bulb }\end{array}$ & $\begin{array}{l}\text { Wet } \\
\text { bulb }\end{array}$ & & & meters & meters & meters & meters \\
\hline $\begin{array}{l}1 \\
1 \\
1 \\
1 \\
1 \\
1 \\
1 \\
1\end{array}$ & $\begin{array}{r}0 \\
3 \\
6 \\
9 \\
12 \\
15 \\
18 \\
21\end{array}$ & $\begin{array}{l}18.3 \\
17.0 \\
17.4 \\
22.8 \\
26.5 \\
27.3 \\
24.2 \\
20.4\end{array}$ & $\begin{array}{l}17.0 \\
16.0 \\
15.9 \\
17.6 \\
17.9 \\
18.2 \\
18.8 \\
17.8\end{array}$ & $\begin{array}{l}18.3 \\
17.0 \\
17.6 \\
22.8 \\
25.9 \\
27.4 \\
24.3 \\
20.9\end{array}$ & $\begin{array}{l}16.9 \\
15.9 \\
15.8 \\
17.6 \\
17.9 \\
18.0 \\
18.8 \\
18.0\end{array}$ & $\begin{array}{l}18.2 \\
16.9 \\
17.5 \\
22.6 \\
26.1 \\
27.3 \\
24.4 \\
21.1\end{array}$ & $\begin{array}{l}16.7 \\
15.6 \\
15.6 \\
17.2 \\
17.7 \\
17.9 \\
18.6 \\
17.9\end{array}$ & $\begin{array}{l}18.2 \\
16: 9 \\
17.4 \\
22.4 \\
25.8 \\
27.3 \\
24.6 \\
21.4\end{array}$ & $\begin{array}{l}16.7 \\
15.7 \\
15.7 \\
17.2 \\
17.4 \\
17.9 \\
18.5 \\
19.1\end{array}$ & $\begin{array}{l}24.4 \\
24.1 \\
24.3 \\
25.3 \\
26.6 \\
26.6 \\
26.0 \\
25.5\end{array}$ & & $\begin{array}{l}5.2 \\
6.09 \\
6.09 \\
8.6 \\
7.9 \\
7.3 \\
3.8 \\
3.1\end{array}$ & $\begin{array}{l}7.2 \\
9.0 \\
8.7 \\
9.8 \\
9.1 \\
8.5 \\
4.5 \\
4.3\end{array}$ & $\begin{array}{r}9.0 \\
10.3 \\
11.0 \\
11.1 \\
10.1 \\
9.0 \\
5.7 \\
5.5\end{array}$ & $\begin{array}{r}9.8 \\
10.8 \\
10.8 \\
13.4 \\
13.4 \\
13.4 \\
7.0 \\
5.8\end{array}$ \\
\hline $\begin{array}{l}2 \\
2 \\
2 \\
2 \\
2 \\
2 \\
2 \\
2\end{array}$ & $\begin{array}{r}0 \\
3 \\
6 \\
9 \\
12 \\
15 \\
18 \\
21\end{array}$ & $\begin{array}{l}19.7 \\
18.6 \\
19.6 \\
25.0 \\
27.0 \\
25.3 \\
21.0 \\
20.8\end{array}$ & $\begin{array}{l}17.6 \\
16.8 \\
17.4 \\
19.0 \\
17.8 \\
19.9 \\
20.2 \\
19.8\end{array}$ & $\begin{array}{l}20.0 \\
18.7 \\
20.0 \\
24.9 \\
26.9 \\
25.3 \\
21.0 \\
20.9\end{array}$ & $\begin{array}{l}17.5 \\
16.8 \\
17.4 \\
18.6 \\
17.7 \\
19.9 \\
20.1 \\
10.8\end{array}$ & $\begin{array}{l}20.2 \\
18.8 \\
20.0 \\
24.7 \\
26.7 \\
25.2 \\
20.9 \\
70.9\end{array}$ & $\begin{array}{l}17.5 \\
16.7 \\
17.3 \\
18.5 \\
17.3 \\
19.8 \\
20.0 \\
19.7\end{array}$ & $\begin{array}{l}20.6 \\
19.0 \\
20.0 \\
24.7 \\
26.6 \\
25.0 \\
20.9 \\
20.9\end{array}$ & $\begin{array}{l}17.7 \\
16.9 \\
17.5 \\
18.6 \\
17.4 \\
20.0 \\
20.0 \\
10.8\end{array}$ & $\begin{array}{l}25.1 \\
24.7 \\
24.8 \\
25.9 \\
26.6 \\
26.5 \\
26.1 \\
25.5\end{array}$ & & $\begin{array}{l}3.1 \\
3.6 \\
5.3 \\
6.6 \\
8.2 \\
8.1 \\
5.6 \\
5.4\end{array}$ & $\begin{array}{l}3.9 \\
4.4 \\
6.9 \\
7.8 \\
9.5 \\
9.9 \\
7.1 \\
6.5\end{array}$ & $\begin{array}{r}6.0 \\
6.4 \\
8.4 \\
8.3 \\
10.4 \\
11.4 \\
8.5 \\
8.1\end{array}$ & $\begin{array}{r}7.1 \\
7.5 \\
8.8 \\
10.7 \\
15.6 \\
15.1 \\
9.4 \\
9.6\end{array}$ \\
\hline $\begin{array}{l}3 \\
3 \\
3 \\
3 \\
3 \\
3 \\
3 \\
3\end{array}$ & $\begin{array}{r}0 \\
3 \\
6 \\
9 \\
12 \\
15 \\
18 \\
21\end{array}$ & $\begin{array}{l}19.9 \\
19.3 \\
19.2 \\
20.9\end{array}$ & $\begin{array}{l}19.3 \\
19.1 \\
19 \cdot 2 \\
19.9\end{array}$ & $\begin{array}{l}19.9 \\
19.3 \\
19.3 \\
20.9\end{array}$ & $\begin{array}{l}19.4 \\
19.1 \\
19.2 \\
10.9\end{array}$ & $\begin{array}{l}19.9 \\
19.3 \\
19.2 \\
20.8\end{array}$ & $\begin{array}{l}19.7 \\
19.0 \\
19.1 \\
19.7\end{array}$ & $\begin{array}{l}19.9 \\
19.3 \\
19.3 \\
20.8\end{array}$ & $\begin{array}{l}19.4 \\
19.1 \\
19.2 \\
20.0\end{array}$ & $\begin{array}{l}25 \cdot 1 \\
24 \cdot 9 \\
24 \cdot 8 \\
24 \cdot 1\end{array}$ & & $\begin{array}{l}4 \cdot 2 \\
4 \cdot 3 \\
4 \cdot 2 \\
4: 9 \\
5: 0 \\
6: 7 \\
4: 1 \\
2.3\end{array}$ & $\begin{array}{l}5.4 \\
5.4 \\
4.9 \\
5.7 \\
5.9 \\
8.3 \\
5.2 \\
2.9\end{array}$ & $\begin{array}{r}6.4 \\
5.4 \\
5.3 \\
7.0 \\
6.6 \\
10.2 \\
6.5 \\
3.6\end{array}$ & $\begin{array}{r}7: 1 \\
7: 1 \\
7: 8 \\
9: 3 \\
9: 0 \\
12: 1 \\
7: 7 \\
4: 8\end{array}$ \\
\hline $\begin{array}{l}4 \\
4 \\
4 \\
4 \\
4 \\
4 \\
4 \\
4\end{array}$ & $\begin{array}{r}0 \\
3 \\
6 \\
9 \\
12 \\
15 \\
18 \\
21\end{array}$ & $\begin{array}{l}22.6 \\
26.5 \\
25.5 \\
20.5 \\
21.0\end{array}$ & $\begin{array}{l}21 \cdot 2 \\
22 \cdot 2 \\
21 \cdot 3 \\
20 \cdot 3 \\
20.7\end{array}$ & $\begin{array}{l}22.9 \\
26.0 \\
24.9 \\
20.6 \\
21.0\end{array}$ & $\begin{array}{l}21.2 \\
21.9 \\
21.1 \\
20.2 \\
20.7\end{array}$ & $\begin{array}{l}22.8 \\
25.6 \\
24.6 \\
20.7 \\
21.1\end{array}$ & $\begin{array}{l}21.1 \\
21.7 \\
20.8 \\
19.9 \\
20.8\end{array}$ & $\begin{array}{l}22.4 \\
25.8 \\
24.6 \\
20.8 \\
21.4\end{array}$ & $\begin{array}{l}21.3 \\
21.8 \\
20.7 \\
20.2 \\
21.0\end{array}$ & $\begin{array}{l}24.6 \\
26.8 \\
27.1 \\
26.9 \\
26.5\end{array}$ & & $\begin{array}{l}2.5 \\
2.3 \\
3.1 \\
2.8 \\
3.6 \\
5.5 \\
3.1 \\
1.8\end{array}$ & $\begin{array}{l}2.9 \\
2.8 \\
4.4 \\
3.5 \\
4.3 \\
6.9 \\
3.9 \\
2.2\end{array}$ & $\begin{array}{l}3.6 \\
3.2 \\
5.1 \\
4.0 \\
5.1 \\
8.1 \\
4.7 \\
2.6\end{array}$ & $\begin{array}{l}5.0 \\
4.3 \\
5.5 \\
4.2 \\
5.5 \\
9.7 \\
5.6 \\
3.9\end{array}$ \\
\hline $\begin{array}{l}5 \\
5 \\
5 \\
5 \\
5 \\
5 \\
5 \\
5\end{array}$ & $\begin{array}{r}0 \\
3 \\
5 \\
9 \\
12 \\
15 \\
18 \\
21\end{array}$ & $\begin{array}{l}20.2 \\
18.3 \\
17.5 \\
18.0 \\
21.2 \\
21.3 \\
18.3 \\
16.2\end{array}$ & $\begin{array}{l}19.8 \\
17,9 \\
16.8 \\
16.9 \\
17.9 \\
15.8 \\
14.5 \\
14.1\end{array}$ & $\begin{array}{l}20.2 \\
18.3 \\
17.4 \\
18.0 \\
21.0 \\
21 . ? \\
18.4 \\
16.3\end{array}$ & $\begin{array}{l}19.8 \\
17.9 \\
16.8 \\
16.8 \\
17.6 \\
15.5 \\
14.4 \\
14.1\end{array}$ & $\begin{array}{l}20.2 \\
18.4 \\
17.5 \\
17.9 \\
20.9 \\
21.0 \\
18.3 \\
16.2\end{array}$ & $\begin{array}{l}19.8 \\
17.8 \\
16.7 \\
16.7 \\
17.4 \\
15.4 \\
140 ? \\
14.0\end{array}$ & $\begin{array}{l}20.3 \\
18.3 \\
17.5 \\
17.9 \\
20.7 \\
20.9 \\
18.2 \\
1,6.3\end{array}$ & $\begin{array}{l}20.0 \\
19.0 \\
16.8 \\
16.8 \\
17.3 \\
15.5 \\
14.3 \\
14.1\end{array}$ & $\begin{array}{l}25.7 \\
25.0 \\
24.6 \\
24.7 \\
25.8 \\
25.8 \\
24.9 \\
24.3\end{array}$ & & $\begin{array}{l}4.1 \\
4.4 \\
5.2 \\
5.3 \\
5.1 \\
6.0 \\
3.6 \\
2.7\end{array}$ & $\begin{array}{l}5.2 \\
5.7 \\
6.7 \\
6.7 \\
6.3 \\
7.3 \\
4.5 \\
3.3\end{array}$ & $\begin{array}{l}6.0 \\
6.7 \\
7.7 \\
7.8 \\
7.3 \\
8.9 \\
5.6 \\
4.2\end{array}$ & $\begin{array}{r}7.3 \\
7.4 \\
8.5 \\
8.7 \\
8.3 \\
10.3 \\
6.9 \\
5.7\end{array}$ \\
\hline $\begin{array}{l}6 \\
6 \\
6 \\
6 \\
6 \\
6 \\
6 \\
6\end{array}$ & $\begin{array}{r}0 \\
3 \\
6 \\
9 \\
12 \\
15 \\
18 \\
21\end{array}$ & $\begin{array}{l}14.6 \\
13.0 \\
14.0 \\
13.8 \\
21.4 \\
11.7 \\
18.2 \\
14.1\end{array}$ & $\begin{array}{l}13.5 \\
12.5 \\
12.8 \\
14.2 \\
14.4 \\
14.0 \\
14.3 \\
12.6\end{array}$ & $\begin{array}{l}14.7 \\
13.1 \\
13.0 \\
18.7 \\
20.9 \\
11.4 \\
18.3 \\
14.6\end{array}$ & $\begin{array}{l}13.4 \\
12.5 \\
12.7 \\
13.8 \\
14.0 \\
14.6 \\
14.1 \\
12.6\end{array}$ & $\begin{array}{l}14.7 \\
13.0 \\
13.9 \\
18.5 \\
20.8 \\
21.1 \\
18.2 \\
15.0\end{array}$ & $\begin{array}{l}13.3 \\
12.4 \\
12.6 \\
13.6 \\
14.0 \\
14.4 \\
14.0 \\
12.7\end{array}$ & $\begin{array}{l}14.7 \\
13.0 \\
14.1 \\
18.1 \\
20.0 \\
21.1 \\
18.3 \\
15.6\end{array}$ & $\begin{array}{l}13.5 \\
12.4 \\
12.6 \\
13.8 \\
13.9 \\
14.6 \\
14.0 \\
12.9\end{array}$ & $\begin{array}{l}23.9 \\
23.5 \\
23.7 \\
24.9 \\
25.8 \\
25.9 \\
25.2 \\
24.6\end{array}$ & & $\begin{array}{l}2.0 \\
1.9 \\
3.9 \\
3.4 \\
5.0 \\
4.1 \\
2.6 \\
1.3\end{array}$ & $\begin{array}{l}2.8 \\
2.5 \\
4.9 \\
4.1 \\
5.8 \\
5.0 \\
3.5 \\
2.1\end{array}$ & $\begin{array}{l}3.4 \\
3.0 \\
5.8 \\
4.8 \\
6.7 \\
5.9 \\
4.5 \\
2.9\end{array}$ & $\begin{array}{l}4.2 \\
3.6 \\
6.2 \\
5.3 \\
8.2 \\
6.6 \\
5.7 \\
3.8\end{array}$ \\
\hline $\begin{array}{l}7 \\
7 \\
7 \\
7 \\
7 \\
7 \\
7 \\
7\end{array}$ & $\begin{array}{r}0 \\
3 \\
6 \\
9 \\
17 \\
15 \\
18 \\
21\end{array}$ & $\begin{array}{l}12.2 \\
11.4 \\
13.8 \\
20.7 \\
24.3 \\
24.5 \\
19.1 \\
15.3\end{array}$ & $\begin{array}{l}11.6 \\
11.1 \\
12.6 \\
14.5 \\
15.4 \\
16.0 \\
14.8 \\
13.6\end{array}$ & $\begin{array}{l}13 . ? \\
12.4 \\
14: 3 \\
21.1 \\
24: ? \\
240 ? \\
20.4 \\
16.7\end{array}$ & $\begin{array}{l}12.0 \\
11.8 \\
12.9 \\
14: 6 \\
15.4 \\
16.1 \\
15.0 \\
14.0\end{array}$ & $\begin{array}{l}14.9 \\
33.0 \\
14.8 \\
21.6 \\
23.9 \\
2.4 .1 \\
20.8 \\
37.8\end{array}$ & $\begin{array}{l}12.3 \\
12.1 \\
13.0 \\
14.6 \\
15.7 \\
15.7 \\
14.9 \\
14.1\end{array}$ & $\begin{array}{l}15.0 \\
13.4 \\
14: 0 \\
21.1 \\
23.8 \\
23.6 \\
21.5 \\
18.1\end{array}$ & $\begin{array}{l}12.6 \\
12.8 \\
13.3 \\
14.7 \\
15.3 \\
15.6 \\
14.9 \\
14.3\end{array}$ & $\begin{array}{l}24.0 \\
23.7 \\
24.0 \\
26.2 \\
26.5 \\
25.0 \\
25.2 \\
23.8\end{array}$ & & $\begin{array}{l}0.9 \\
0.8 \\
2.00 \\
1.05 \\
2.44 \\
3.3 \\
1.5 \\
1.5\end{array}$ & $\begin{array}{l}1.8 \\
0.8 \\
2.5 \\
2.0 \\
2.7 \\
4.1 \\
1.9 \\
2.3\end{array}$ & $\begin{array}{l}1.2 \\
0.8 \\
3.0 \\
2.3 \\
3.2 \\
4.7 \\
2.4 \\
2.5\end{array}$ & $\begin{array}{l}0.8 \\
3.2 \\
2.0 \\
3.2 \\
5.3 \\
3.4 \\
3.5\end{array}$ \\
\hline $\begin{array}{l}8 \\
8 \\
8 \\
8 \\
8 \\
8 \\
8 \\
8\end{array}$ & $\begin{array}{r}0 \\
3 \\
6 \\
0 \\
12 \\
15 \\
18 \\
21\end{array}$ & $\begin{array}{l}13.4 \\
12.6 \\
15.4 \\
21.02 \\
24.1 \\
25.0 \\
20.9 \\
17.0\end{array}$ & $\begin{array}{l}12.9 \\
12.1 \\
14.2 \\
15.5 \\
16.3 \\
16.2 \\
15.5 \\
14.2\end{array}$ & $\begin{array}{l}14.5 \\
13.2 \\
15.8 \\
20.7 \\
23.5 \\
24.8 \\
21.1 \\
17.7\end{array}$ & $\begin{array}{l}13.2 \\
12.7 \\
14.0 \\
15.3 \\
15.7 \\
15.9 \\
15.4 \\
14.5\end{array}$ & $\begin{array}{l}15.4 \\
14.1 \\
15.9 \\
20.8 \\
23.8 \\
24.5 \\
21.0 \\
18.0\end{array}$ & $\begin{array}{l}13.4 \\
13.3 \\
14.1 \\
15: 0 \\
16.1 \\
15.8 \\
15.2 \\
14.6\end{array}$ & $\begin{array}{l}15: 6 \\
14: 7 \\
15: 7 \\
21: 0 \\
23.1 \\
24.4 \\
21.4 \\
18.4\end{array}$ & $\begin{array}{l}14.1 \\
13.6 \\
14.1 \\
15.4 \\
15.1 \\
15.3 \\
14.9 \\
14.4\end{array}$ & $\begin{array}{l}23.1 \\
22.6 \\
22.5 \\
23.5 \\
25.0 \\
25.1 \\
24.4 \\
23.8\end{array}$ & & $\begin{array}{l}0.8 \\
1.3 \\
2.5 \\
5.7 \\
5.6 \\
4.6 \\
2.0 \\
1.4\end{array}$ & $\begin{array}{l}1.1 \\
1.9 \\
3.0 \\
6.4 \\
6.4 \\
5.3 \\
2.7 \\
1.9\end{array}$ & $\begin{array}{l}0.9 \\
2.6 \\
3.9 \\
7.4 \\
7.4 \\
6.6 \\
4.2 \\
2.1\end{array}$ & $\begin{array}{l}1.1 \\
3.2 \\
4.0 \\
8.2 \\
8.4 \\
8.3 \\
5.7 \\
3.0\end{array}$ \\
\hline $\begin{array}{l}9 \\
9 \\
9 \\
9 \\
9 \\
0 \\
9 \\
9\end{array}$ & $\begin{array}{r}0 \\
3 \\
5 \\
9 \\
12 \\
15 \\
18 \\
? 1\end{array}$ & $\begin{array}{l}15.8 \\
14.3 \\
15.2 \\
21.9 \\
25: 1 \\
25.4\end{array}$ & $\begin{array}{l}14.1 \\
13.3 \\
13.7 \\
15.2 \\
16.7 \\
17.7\end{array}$ & $\begin{array}{l}17.1 \\
14.4 \\
15: 02 \\
? 1: 07 \\
25.3 \\
26.5\end{array}$ & $\begin{array}{l}14.1 \\
13.0 \\
13.7 \\
15.1 \\
16.4 \\
17.7\end{array}$ & $\begin{array}{l}27.0 \\
14.2 \\
15.2 \\
21.4 \\
25.0 \\
26.9\end{array}$ & $\begin{array}{l}14.0 \\
13 . ? \\
13.8 \\
15.0 \\
16.3 \\
17.4\end{array}$ & $\begin{array}{l}17.1 \\
14.7 \\
15.3 \\
21.2 \\
24: 6 \\
25.9\end{array}$ & $\begin{array}{l}13.8 \\
13.6 \\
13.7 \\
14.7 \\
15.9 \\
17.3\end{array}$ & $\begin{array}{l}23.9 \\
22.4 \\
22.3 \\
23.7 \\
25.6 \\
26.3\end{array}$ & & $\begin{array}{l}2.0 \\
1.6 \\
3.1 \\
3.6 \\
2.9 \\
2.0 \\
1.7 \\
2.2\end{array}$ & $\begin{array}{l}2.6 \\
2.0 \\
3.5 \\
4.0 \\
3.3 \\
2.4 \\
2.6 \\
3.3\end{array}$ & $\begin{array}{l}3.1 \\
2.5 \\
4.3 \\
4.2 \\
3.2 \\
2.6 \\
3.3 \\
4.7\end{array}$ & $\begin{array}{l}4.5 \\
2.9 \\
4.7 \\
4.8 \\
3.9 \\
3.0 \\
4.2 \\
7.0\end{array}$ \\
\hline $\begin{array}{l}10 \\
10 \\
10\end{array}$ & $\begin{array}{l}0 \\
3 \\
6\end{array}$ & & & & & & & & & & & $\begin{array}{l}2.8 \\
3.0 \\
2.8\end{array}$ & $\begin{array}{l}3.8 \\
3.8 \\
3.2\end{array}$ & $\begin{array}{l}5.6 \\
5.1 \\
3.9\end{array}$ & $\begin{array}{l}7.9 \\
7.0 \\
4.4\end{array}$ \\
\hline 10 & 9 & 23.5 & 17.6 & 23.5 & 17.7 & $2 ? .7$ & 17.6 & 22.9 & 17.5 & 23.6 & & 400 & 4.5 & 5.1 & 5.6 \\
\hline $\begin{array}{l}10 \\
10\end{array}$ & $\begin{array}{l}12 \\
15\end{array}$ & $\begin{array}{l}.77 .5 \\
28.2\end{array}$ & $\begin{array}{l}19.0 \\
19.2\end{array}$ & $\begin{array}{l}270 ? \\
28 . ?\end{array}$ & $\begin{array}{l}18.7 \\
19.1\end{array}$ & $\begin{array}{l}26.9 \\
28.5\end{array}$ & $\begin{array}{l}18.7 \\
19.1\end{array}$ & $\begin{array}{l}26.6 \\
28.0\end{array}$ & $\begin{array}{l}19.6 \\
12.0\end{array}$ & $\begin{array}{l}25.9 \\
26.1\end{array}$ & & $\begin{array}{l}2.4 \\
1.6\end{array}$ & $\begin{array}{l}2.7 \\
1.8\end{array}$ & $\begin{array}{l}3 \cdot 2 \\
2.1\end{array}$ & $\begin{array}{l}3.0 \\
2.4\end{array}$ \\
\hline 10 & 18 & 74.2 & 18.8 & 24.5 & 18.9 & 24.6 & 18. & 25.0 & 13.4 & 24.8 & & 1. & & & 3.2 \\
\hline 10 & 21 & 19.4 & 17.6 & 20.3 & 17.7 & 21.0 & 17.9 & 21.9 & 17.9 & 23.7 & & $2 \cdot 2$ & 3.6 & 5.1 & 6.8 \\
\hline
\end{tabular}


Table 10. - Three-hour averages of air and water-surface temperatures and wind directions and speed, April 1950-August 1951, Lake Hefner-Continued

STATION 2 THREE-HOURLY AVERAGES

SEPTEMBER, 1950

\begin{tabular}{|c|c|c|c|c|c|c|c|c|c|c|c|c|c|c|c|}
\hline \multirow{4}{*}{ 点 } & \multirow{4}{*}{ 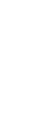 } & \multicolumn{8}{|c|}{ Average air temperature $\left({ }^{\circ} \mathrm{C}\right)$ at indicated height } & \multirow{4}{*}{$\begin{array}{c}\text { Average } \\
\text { water- } \\
\text { surface } \\
\text { tempera- } \\
\text { ture } \\
\text { ("C) }\end{array}$} & \multirow{4}{*}{$\begin{array}{c}\text { Average } \\
\text { wind } \\
\text { direction } \\
\text { (coded) }\end{array}$} & \multirow{2}{*}{\multicolumn{4}{|c|}{$\begin{array}{l}\text { Average wind apeed (knots) } \\
\text { at indicated height }\end{array}$}} \\
\hline & & \multirow{2}{*}{\multicolumn{2}{|c|}{$\begin{array}{c}2 \\
\text { meters }\end{array}$}} & \multirow{2}{*}{\multicolumn{2}{|c|}{$\begin{array}{c}4 \\
\text { meters }\end{array}$}} & \multirow{2}{*}{\multicolumn{2}{|c|}{$\begin{array}{c}8 \\
\text { meters }\end{array}$}} & \multirow{2}{*}{\multicolumn{2}{|c|}{$\begin{array}{c}16 \\
\text { meters }\end{array}$}} & & & & & & \\
\hline & & & & & & & & & & & & 2 & 4 & 8 & 16 \\
\hline & & $\begin{array}{l}\text { Dry } \\
\text { bulb }\end{array}$ & $\begin{array}{l}\text { Wet } \\
\text { bulb }\end{array}$ & $\begin{array}{l}\text { Dry } \\
\text { bulb }\end{array}$ & $\begin{array}{l}\text { Wet } \\
\text { bulb }\end{array}$ & $\begin{array}{l}\text { Dry } \\
\text { bulb }\end{array}$ & $\begin{array}{l}\text { Wet } \\
\text { bulb }\end{array}$ & $\begin{array}{l}\text { Dry } \\
\text { bulb }\end{array}$ & $\begin{array}{l}\text { Wet } \\
\text { bulb }\end{array}$ & & & & & & \\
\hline
\end{tabular}

\begin{tabular}{|c|c|c|c|c|c|c|c|c|c|c|c|c|c|c|}
\hline & & & STES & & wow & octo & Doso & wher & wores & & & ters & foreders & the \\
\hline $\begin{array}{l}11 \\
11 \\
11 \\
11 \\
11 \\
11 \\
11 \\
11\end{array}$ & $\begin{array}{r}0 \\
3 \\
6 \\
9 \\
12 \\
15 \\
18 \\
21\end{array}$ & $\begin{array}{l}19.1 \\
17.0 \\
15.6 \\
15.7 \\
18.2 \\
20.9 \\
18.9 \\
16.5\end{array}$ & $\begin{array}{l}17.1 \\
14.5 \\
13.3 \\
13.0 \\
14.4 \\
16.1 \\
15.3 \\
14.5\end{array}$ & $\begin{array}{l}19.3 \\
16.9 \\
15.5 \\
15.5 \\
17.8 \\
20.6 \\
18.9 \\
16.6\end{array}$ & $\begin{array}{l}17.1 \\
14.5 \\
13.1 \\
12.9 \\
14.3 \\
16.0 \\
15.3 \\
14.4\end{array}$ & $\begin{array}{l}19.2 \\
16.7 \\
15.3 \\
15.2 \\
17.5 \\
20.5 \\
13.8 \\
16.5\end{array}$ & $\begin{array}{l}17.0 \\
14.2 \\
12.9 \\
12.6 \\
14.0 \\
16.0 \\
15.3 \\
14.4\end{array}$ & $\begin{array}{l}19.5 \\
16.5 \\
15.1 \\
15.0 \\
17.3 \\
20.4 \\
18.8 \\
16.5\end{array}$ & $\begin{array}{l}17.0 \\
13.7 \\
12.6 \\
12.2 \\
13.7 \\
15.5 \\
15.1 \\
14.3\end{array}$ & $\begin{array}{l}23.0 \\
22.3 \\
21.6 \\
21.2 \\
21.9 \\
22.3 \\
21.8 \\
21.2\end{array}$ & $\begin{array}{r}4.0 \\
10.3 \\
9.5 \\
9.2 \\
6.1 \\
5.1 \\
3.5 \\
3.1\end{array}$ & $\begin{array}{r}5.1 \\
12.5 \\
11.5 \\
11.1 \\
7.1 \\
5.0 \\
4.1 \\
3.7\end{array}$ & $\begin{array}{r}6.9 \\
16.6 \\
13.0 \\
12.1 \\
7.6 \\
6.6 \\
5.2 \\
4.6\end{array}$ & $\begin{array}{r}8.7 \\
18.1 \\
14.9 \\
23.1 \\
8.1 \\
7.2 \\
6.6 \\
6.0\end{array}$ \\
\hline $\begin{array}{l}12 \\
12 \\
12 \\
12 \\
12 \\
12 \\
12 \\
12\end{array}$ & $\begin{array}{r}0 \\
3 \\
6 \\
9 \\
12 \\
15 \\
18 \\
21\end{array}$ & $\begin{array}{l}14.9 \\
14.1 \\
15.0 \\
17.1 \\
17.2 \\
19.3 \\
17.8 \\
17.2\end{array}$ & $\begin{array}{l}13.7 \\
13.2 \\
13.9 \\
15.2 \\
16.3 \\
17.7 \\
17.5 \\
17.0\end{array}$ & $\begin{array}{l}15.0 \\
14.2 \\
15.0 \\
17.0 \\
17.2 \\
19.3 \\
17.8 \\
17.2\end{array}$ & $\begin{array}{l}13.7 \\
13.2 \\
13.9 \\
15.0 \\
16.3 \\
17.6 \\
17.4 \\
16.9\end{array}$ & $\begin{array}{l}14.9 \\
14.2 \\
15.0 \\
16.8 \\
17.1 \\
19.3 \\
17.5 \\
17.0\end{array}$ & $\begin{array}{l}13.7 \\
13.3 \\
13.9 \\
14.9 \\
16.2 \\
17.7 \\
17.4 \\
17.0\end{array}$ & $\begin{array}{l}140.8 \\
14.3 \\
14.9 \\
16.7 \\
17.0 \\
19.3 \\
17.5 \\
17.1\end{array}$ & $\begin{array}{l}13.5 \\
13.1 \\
13.8 \\
14.9 \\
16.2 \\
17.6 \\
17.2 \\
16.7\end{array}$ & $\begin{array}{l}20.9 \\
20.8 \\
20.8 \\
21.0 \\
21.1 \\
21.0 \\
20.9 \\
20.9\end{array}$ & $\begin{array}{l}3.7 \\
1.7 \\
2.3 \\
4.0 \\
6.3 \\
3.8 \\
3.6 \\
4.6\end{array}$ & $\begin{array}{l}4.2 \\
2.1 \\
2.7 \\
5.1 \\
7.7 \\
5.0 \\
4.3 \\
5.8\end{array}$ & $\begin{array}{l}4.0 \\
2.06 \\
3.2 \\
5.6 \\
8.8 \\
5.0 \\
5.02 \\
7.0\end{array}$ & $\begin{array}{l}5.2 \\
3.0 \\
3.7 \\
6.7 \\
9.8 \\
6.8 \\
6.2 \\
8.3\end{array}$ \\
\hline $\begin{array}{l}13 \\
13 \\
13 \\
13 \\
13 \\
13 \\
13 \\
13\end{array}$ & $\begin{array}{r}0 \\
3 \\
6 \\
9 \\
12 \\
15 \\
18 \\
21\end{array}$ & $\begin{array}{l}16.9 \\
16.2 \\
16.0 \\
16.8 \\
19.8 \\
22.3 \\
20.1 \\
19.4\end{array}$ & $\begin{array}{l}18.6 \\
15.9 \\
15.2 \\
16.4 \\
19.6 \\
19.7 \\
19.0 \\
19.8\end{array}$ & $\begin{array}{l}16.9 \\
16.3 \\
16.0 \\
16.9 \\
19.4 \\
21.9 \\
20.1 \\
10.5\end{array}$ & $\begin{array}{l}16.5 \\
15.8 \\
15.2 \\
16.2 \\
18.3 \\
19.6 \\
18.9 \\
18.7\end{array}$ & $\begin{array}{l}16.7 \\
16.0 \\
15.9 \\
16.5 \\
19.3 \\
21.5 \\
20.0 \\
10.2\end{array}$ & $\begin{array}{l}16.6 \\
15.9 \\
15.2 \\
15.2 \\
18.4 \\
19.5 \\
18.8 \\
18.7\end{array}$ & $\begin{array}{l}16.8 \\
16.2 \\
15.9 \\
16.7 \\
19.3 \\
21.5 \\
19.9 \\
19.3\end{array}$ & $\begin{array}{l}16.4 \\
15.7 \\
15.0 \\
16.1 \\
18.2 \\
19.2 \\
18.8 \\
18.6\end{array}$ & $\begin{array}{l}20.8 \\
20.8 \\
20.7 \\
20.7 \\
21.7 \\
22.6 \\
22.2 \\
22.0\end{array}$ & $\begin{array}{l}4.1 \\
4.1 \\
4.14 \\
5.3 \\
3.2 \\
3.4 \\
4.4 \\
3.6\end{array}$ & $\begin{array}{l}5.1 \\
5.2 \\
5.4 \\
7.1 \\
4.8 \\
4.9 \\
5.7 \\
4.8\end{array}$ & $\begin{array}{l}6.3 \\
6.1 \\
6.8 \\
8.4 \\
6.3\end{array}$ & $\begin{array}{l}6.8 \\
7.0 \\
7.4 \\
8.8 \\
6.4 \\
6.2 \\
7.7 \\
6.4\end{array}$ \\
\hline $\begin{array}{l}14 \\
14 \\
14 \\
14 \\
14 \\
14 \\
14 \\
14\end{array}$ & $\begin{array}{r}0 \\
3 \\
5 \\
9 \\
12 \\
15 \\
18 \\
21\end{array}$ & $\begin{array}{l}18.3 \\
15.3 \\
15.5 \\
17.9 \\
18.9 \\
20.0 \\
19.3 \\
18.9\end{array}$ & $\begin{array}{l}18.1 \\
15.0 \\
15.0 \\
16.6 \\
17.5 \\
18.5 \\
18.5 \\
18.9\end{array}$ & $\begin{array}{l}18.2 \\
15.3 \\
15.4 \\
17.7 \\
18.7 \\
19.9 \\
10.3 \\
19.0\end{array}$ & $\begin{array}{l}17.9 \\
14.9 \\
14.9 \\
16.5 \\
17.4 \\
18.4 \\
18.6 \\
18.8\end{array}$ & $\begin{array}{l}13.0 \\
15.2 \\
15.3 \\
17.7 \\
18.5 \\
19.8 \\
19.1 \\
19.8\end{array}$ & $\begin{array}{l}17.9 \\
14.8 \\
1400 \\
16.4 \\
17.2 \\
18.4 \\
18.6 \\
18.9\end{array}$ & $\begin{array}{l}18.0 \\
15.2 \\
15.4 \\
17.5 \\
18.4 \\
19.7 \\
19.2 \\
19.0\end{array}$ & $\begin{array}{l}17.6 \\
14.6 \\
14.8 \\
16.3 \\
17.2 \\
18.3 \\
18.5 \\
18.9\end{array}$ & $\begin{array}{l}21.6 \\
20.8 \\
20.6 \\
20.9 \\
21.4 \\
21.5 \\
21.2 \\
21.0\end{array}$ & $\begin{array}{l}5.8 \\
6.8 \\
3.8 \\
4.8 \\
4.4 \\
3.5 \\
3.6 \\
2.5\end{array}$ & $\begin{array}{l}6.8 \\
8.7 \\
4.8 \\
5.0 \\
5.8 \\
4.7 \\
4.8 \\
3.5\end{array}$ & $\begin{array}{l}8.8 \\
0.0 \\
6.3 \\
7.0 \\
6.9 \\
5.06 \\
5.3 \\
4.0\end{array}$ & $\begin{array}{r}10.4 \\
11.5 \\
6.2 \\
8.3 \\
7.3 \\
6.1 \\
6.3 \\
4.8\end{array}$ \\
\hline $\begin{array}{l}15 \\
15 \\
15 \\
15 \\
15 \\
15 \\
15 \\
15\end{array}$ & $\begin{array}{r}0 \\
3 \\
6 \\
0 \\
12 \\
15 \\
18 \\
21\end{array}$ & $\begin{array}{l}19.4 \\
18.8 \\
19.0 \\
21.1 \\
27.0 \\
28.8 \\
24.5 \\
30.2\end{array}$ & $\begin{array}{l}19.1 \\
18.7 \\
18.9 \\
20.4 \\
23.0 \\
23.5 \\
22.6 \\
19.2\end{array}$ & $\begin{array}{l}19.5 \\
18.0 \\
19.1 \\
21.3 \\
27.4 \\
28.4 \\
23.0 \\
20.3\end{array}$ & $\begin{array}{l}19.1 \\
18.7 \\
18.9 \\
20.3 \\
22.5 \\
23.3 \\
22.2 \\
19.1\end{array}$ & $\begin{array}{l}19.2 \\
18.7 \\
18.8 \\
21.0 \\
27.3 \\
28.8 \\
23.7 \\
20.1\end{array}$ & $\begin{array}{l}10.2 \\
18.7 \\
18.8 \\
20.3 \\
22.6 \\
23.2 \\
23.1 \\
19.0\end{array}$ & $\begin{array}{l}19.6 \\
18.0 \\
19.0 \\
2.1 .1 \\
27.1 \\
28.5 \\
23.7 \\
20.2\end{array}$ & $\begin{array}{l}19.2 \\
18.8 \\
18.9 \\
20.2 \\
22.9 \\
23.2 \\
22.0 \\
18.9\end{array}$ & $\begin{array}{l}20.9 \\
20.8 \\
20.8 \\
21.4 \\
23.0 \\
23.0 \\
22.2 \\
21.7\end{array}$ & $\begin{array}{l}3.4 \\
4.3 \\
5.4 \\
9.1 \\
7.2 \\
3.4 \\
3.8 \\
4.1\end{array}$ & $\begin{array}{r}4.7 \\
6.1 \\
7.3 \\
10.8 \\
8.6 \\
4.6 \\
5.1 \\
5.4\end{array}$ & $\begin{array}{r}5.7 \\
7.2 \\
8.4 \\
12.5 \\
9.7 \\
5.3 \\
6.3 \\
6.4\end{array}$ & $\begin{array}{r}7.0 \\
8.5 \\
9.5 \\
14.0 \\
10.7 \\
6.1 \\
7.2 \\
7.5\end{array}$ \\
\hline $\begin{array}{l}16 \\
16 \\
16 \\
16 \\
16 \\
16 \\
16 \\
16\end{array}$ & $\begin{array}{r}0 \\
3 \\
6 \\
9 \\
1 ? \\
15 \\
19 \\
21\end{array}$ & $\begin{array}{l}19.6 \\
19.2 \\
19.5 \\
20.1 \\
22.5 \\
23.9 \\
21.4 \\
19.8\end{array}$ & $\begin{array}{l}18.6 \\
18.5 \\
18.7 \\
19.1 \\
20.0 \\
20.3 \\
19.9 \\
19.3\end{array}$ & $\begin{array}{l}19.8 \\
19.2 \\
10.6 \\
20.0 \\
22.3 \\
24.1 \\
21.4 \\
10.0\end{array}$ & $\begin{array}{l}18.5 \\
18.4 \\
18.6 \\
19.0 \\
19.7 \\
20.1 \\
10.8 \\
10.2\end{array}$ & $\begin{array}{l}19.6 \\
19.1 \\
19.5 \\
19.8 \\
22.3 \\
23.7 \\
21.3 \\
19.9\end{array}$ & $\begin{array}{l}18.5 \\
13.5 \\
18.6 \\
19.0 \\
19.3 \\
20.0 \\
19.8 \\
19.3\end{array}$ & $\begin{array}{l}19.7 \\
19.2 \\
19.5 \\
19.9 \\
22.1 \\
23.5 \\
21.3 \\
20.0\end{array}$ & $\begin{array}{l}18.6 \\
18.5 \\
18.6 \\
18.9 \\
19.7 \\
20.0 \\
19.8 \\
19.2\end{array}$ & $\begin{array}{l}21.2 \\
21.0 \\
20.9 \\
21.1 \\
22.0 \\
22.1 \\
21.9 \\
21.0\end{array}$ & $\begin{array}{r}7.6 \\
7.7 \\
6.0 \\
5.7 \\
10.3 \\
5.9 \\
5.2 \\
2.1\end{array}$ & $\begin{array}{r}9.2 \\
10.6 \\
8.5 \\
7.7 \\
13.0 \\
7.7 \\
6.5 \\
2.8\end{array}$ & $\begin{array}{r}10.7 \\
12.1 \\
9.9 \\
9.0 \\
24.1 \\
8.9 \\
7.6 \\
3.4\end{array}$ & $\begin{array}{r}12.4 \\
13.8 \\
11.3 \\
10.2 \\
16.4 \\
10.0 \\
8.8 \\
4.6\end{array}$ \\
\hline $\begin{array}{l}17 \\
17 \\
17 \\
17 \\
17 \\
17 \\
17 \\
17\end{array}$ & $\begin{array}{r}0 \\
3 \\
5 \\
9 \\
12 \\
15 \\
15 \\
21\end{array}$ & $\begin{array}{l}18.9 \\
18.9 \\
19.1 \\
23.6 \\
26.2\end{array}$ & $\begin{array}{l}181.6 \\
18.1 \\
18.4 \\
19.6 \\
20.0\end{array}$ & $\begin{array}{l}10.1 \\
19.0 \\
19 . ? \\
23.3 \\
25.6\end{array}$ & $\begin{array}{l}18.6 \\
18.0 \\
18.3 \\
19.0 \\
19.6\end{array}$ & $\begin{array}{l}19.9 \\
1.3 .9 \\
19.1 \\
23.0 \\
25.2\end{array}$ & $\begin{array}{l}18.6 \\
18.1 \\
18.4 \\
19.2 \\
19.5\end{array}$ & $\begin{array}{l}19.2 \\
18.9 \\
19.2 \\
22.8 \\
25.1\end{array}$ & $\begin{array}{l}19.5 \\
18.0 \\
18.3 \\
19.4 \\
19.6\end{array}$ & $\begin{array}{l}21.4 \\
21.2 \\
21.2 \\
22.4 \\
23.5\end{array}$ & $\begin{array}{r}2.7 \\
3.2 \\
.4 .5 \\
4.5 \\
5.1 \\
4.4 \\
1.8 \\
3.8\end{array}$ & $\begin{array}{l}3.5 \\
3.9 \\
5.3 \\
5.3 \\
6.1 \\
5.4 \\
2.6 \\
4.9\end{array}$ & $\begin{array}{l}4.2 \\
4.0 \\
6.3 \\
5.8 \\
6.7 \\
6.2 \\
4.2 \\
6.1\end{array}$ & $\begin{array}{l}5.2 \\
5.5 \\
7.1 \\
6.4 \\
7.3 \\
7.0 \\
5.3 \\
7.8\end{array}$ \\
\hline $\begin{array}{l}18 \\
18 \\
18 \\
18 \\
18 \\
18 \\
18 \\
18\end{array}$ & $\begin{array}{r}0 \\
3 \\
6 \\
9 \\
12 \\
15 \\
18 \\
? 1\end{array}$ & $\begin{array}{l}28.0 \\
27.9 \\
24.2 \\
21.7\end{array}$ & $\begin{array}{l}21.0 \\
20.7 \\
20.6 \\
20.3\end{array}$ & $\begin{array}{l}27.7 \\
27.8 \\
24.5 \\
21.9\end{array}$ & $\begin{array}{l}20.8 \\
20.7 \\
20.6 \\
20.4\end{array}$ & $\begin{array}{l}27.3 \\
27.8 \\
24.5 \\
72.0\end{array}$ & $\begin{array}{l}20.7 \\
20.8 \\
20.6 \\
20.5\end{array}$ & $\begin{array}{l}27.0 \\
27.6 \\
24.6 \\
22.2\end{array}$ & $\begin{array}{l}20.5 \\
20.7 \\
20.6 \\
20.5\end{array}$ & $\begin{array}{l}22.4 \\
21.6 \\
21.1 \\
21.1\end{array}$ & $\begin{array}{l}3.9 \\
4.9 \\
6.9 \\
8.5 \\
6.4 \\
6.5 \\
4.4 \\
4.4\end{array}$ & $\begin{array}{r}4.8 \\
5.9 \\
8.2 \\
10.0 \\
8.0 \\
7.8 \\
5.5 \\
5.4\end{array}$ & $\begin{array}{r}6.2 \\
7.1 \\
9.4 \\
11.4 \\
9.2 \\
8.9 \\
6.7 \\
6.5\end{array}$ & $\begin{array}{r}8.2 \\
8.6 \\
10.7 \\
12.4 \\
10.2 \\
10.0 \\
8.3 \\
8.1\end{array}$ \\
\hline $\begin{array}{l}10 \\
19 \\
19 \\
19 \\
19 \\
19 \\
19 \\
19\end{array}$ & $\begin{array}{r}0 \\
3 \\
6 \\
9 \\
12 \\
15 \\
18 \\
31\end{array}$ & $\begin{array}{l}21.2 \\
19.7 \\
20.9 \\
25.8 \\
26.5 \\
25.8 \\
22.0 \\
21.4\end{array}$ & $\begin{array}{l}20.1 \\
19.3 \\
20.1 \\
22.2 \\
22.0 \\
21.4 \\
20.4 \\
20.7\end{array}$ & $\begin{array}{l}21.3 \\
19.8 \\
21.0 \\
25.6 \\
26.2 \\
25.4 \\
22.1 \\
21.5\end{array}$ & $\begin{array}{l}20.1 \\
19.3 \\
20.2 \\
2 ? .1 \\
22.5 \\
21.2 \\
20.2 \\
20.7\end{array}$ & $\begin{array}{l}21.4 \\
20.0 \\
21.2 \\
25.7 \\
25.9 \\
25.2 \\
22.2 \\
21.6\end{array}$ & $\begin{array}{l}20.1 \\
19.4 \\
20.2 \\
21.9 \\
22.4 \\
21.0 \\
20.2 \\
20.9\end{array}$ & $\begin{array}{l}21.5 \\
20.2 \\
21.2 \\
25.0 \\
25.3 \\
24.0 \\
22.1 \\
21.6\end{array}$ & $\begin{array}{l}20.1 \\
10.5 \\
20.3 \\
21.9 \\
22.1 \\
20.9 \\
20.2 \\
20.7\end{array}$ & $\begin{array}{l}21.0 \\
20.8 \\
21.1 \\
22.2 \\
22.8 \\
22.6 \\
21.9 \\
21.5\end{array}$ & $\begin{array}{r}4.7 \\
3.2 \\
4.4 \\
6.5 \\
10.3 \\
9.1 \\
5.2 \\
6.6\end{array}$ & $\begin{array}{r}5.7 \\
4.0 \\
5.3 \\
7.6 \\
12.0 \\
10.8 \\
6.3 \\
7.9\end{array}$ & $\begin{array}{r}6.6 \\
5.1 \\
6.1 \\
8.6 \\
13.6 \\
12.1 \\
7.5 \\
9.2\end{array}$ & $\begin{array}{r}8.8 \\
6.9 \\
7.1 \\
9.5 \\
15.2 \\
13.6 \\
8.9 \\
10.6\end{array}$ \\
\hline $\begin{array}{l}20 \\
20 \\
20 \\
20 \\
20 \\
20 \\
20 \\
20\end{array}$ & $\begin{array}{r}0 \\
3 \\
6 \\
9 \\
12 \\
15 \\
18 \\
21\end{array}$ & $\begin{array}{l}21.2 \\
20.2 \\
20.6 \\
25.7 \\
30.9 \\
31.3 \\
27.5 \\
24.7\end{array}$ & $\begin{array}{l}20.7 \\
20.0 \\
10.0 \\
21.0 \\
23.1 \\
23.0 \\
22.4 \\
21.0\end{array}$ & $\begin{array}{l}21.3 \\
20.3 \\
20.7 \\
25.0 \\
30.6 \\
31.1 \\
27.6 \\
24.8\end{array}$ & $\begin{array}{l}20.8 \\
20.0 \\
19.9 \\
21.8 \\
22.9 \\
22.8 \\
22.4 \\
21.9\end{array}$ & $\begin{array}{l}? 1.4 \\
20.3 \\
20.7 \\
35.5 \\
30.4 \\
30.8 \\
27.6 \\
74.9\end{array}$ & $\begin{array}{l}20.8 \\
20.0 \\
20.0 \\
21.5 \\
22.9 \\
22.8 \\
27.5 \\
22.0\end{array}$ & $\begin{array}{l}21.3 \\
20.2 \\
20.7 \\
25.1 \\
30.1 \\
30.5 \\
27.7 \\
25.0\end{array}$ & $\begin{array}{l}20.7 \\
10.9 \\
10.9 \\
21.5 \\
22.4 \\
22.7 \\
22.4 \\
21.9\end{array}$ & $\begin{array}{l}21.3 \\
21.1 \\
21.3 \\
22.5 \\
23.2 \\
22.8 \\
22.1 \\
21.9\end{array}$ & $\begin{array}{r}7.9 \\
5.1 \\
9.1 \\
11.3 \\
10.2 \\
9.8 \\
7.3 \\
6.0\end{array}$ & $\begin{array}{r}9.5 \\
6.0 \\
10.6 \\
13.1 \\
11.8 \\
11.2 \\
8.7 \\
7.1\end{array}$ & $\begin{array}{r}10.9 \\
7.1 \\
12.4 \\
14.6 \\
13.3 \\
12.7 \\
10.3 \\
8.6\end{array}$ & $\begin{array}{r}12.5 \\
8.3 \\
13.8 \\
16.2 \\
14.9 \\
14.4 \\
12.2 \\
10.4\end{array}$ \\
\hline
\end{tabular}


TABLE 10

Table 10. - Three-hour averages of air and water-surface temperatures and wind directions and speed, April 1950-August 1951, Lake Hefner-Continued

STATION 2

THREE-HOURLY AVERAGES

SEPTEMBER, 1950

\begin{tabular}{|c|c|c|c|c|c|c|c|c|c|c|c|c|c|c|c|}
\hline \multirow{3}{*}{ 喿 } & \multirow{3}{*}{ 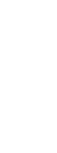 } & \multicolumn{8}{|c|}{ Average air temperature $\left({ }^{\circ} \mathrm{C}\right)$ at indicated height } & \multirow{3}{*}{\begin{tabular}{|c|} 
Average \\
water- \\
surface \\
tempera- \\
ture \\
$\left({ }^{\circ} \mathrm{C}\right)$
\end{tabular}} & \multirow{3}{*}{$\begin{array}{c}\text { Average } \\
\text { wind } \\
\text { direction } \\
\text { (coded) }\end{array}$} & \multirow{2}{*}{\multicolumn{4}{|c|}{$\begin{array}{l}\text { Average wind speed (knots) } \\
\text { at indicated height }\end{array}$}} \\
\hline & & \multicolumn{2}{|c|}{$\begin{array}{c}2 \\
\text { meters }\end{array}$} & \multicolumn{2}{|c|}{$\begin{array}{c}4 \\
\text { meters }\end{array}$} & \multicolumn{2}{|c|}{$\begin{array}{c}\mathbf{8} \\
\text { meters }\end{array}$} & \multicolumn{2}{|c|}{$\begin{array}{c}16 \\
\text { meters }\end{array}$} & & & & & & \\
\hline & & $\begin{array}{l}\text { Dry } \\
\text { bulb }\end{array}$ & $\begin{array}{l}\text { Wet } \\
\text { bulb }\end{array}$ & $\begin{array}{l}\text { Dry } \\
\text { bulb }\end{array}$ & $\begin{array}{l}\text { Wet } \\
\text { bulb }\end{array}$ & $\begin{array}{l}\text { Dry } \\
\text { bulb }\end{array}$ & $\begin{array}{l}\text { Wet } \\
\text { bulb }\end{array}$ & $\begin{array}{l}\text { Dry } \\
\text { bulb }\end{array}$ & $\begin{array}{l}\text { Wet } \\
\text { bulb }\end{array}$ & & & meters & meters & meters & $\begin{array}{c}16 \\
\text { meters }\end{array}$ \\
\hline $\begin{array}{l}21 \\
21 \\
21 \\
21 \\
21 \\
21 \\
21 \\
31 \\
32\end{array}$ & $\begin{array}{r}0 \\
3 \\
6 \\
9 \\
12 \\
15 \\
18 \\
21\end{array}$ & $\begin{array}{l}24.3 \\
24.0 \\
22.6 \\
18.5\end{array}$ & $\begin{array}{l}17.3 \\
17.4 \\
17.0 \\
15.1\end{array}$ & $\begin{array}{l}24 \cdot 1 \\
24.8 \\
22.5 \\
13.5\end{array}$ & $\begin{array}{l}27.0 \\
17.1 \\
16.7 \\
15 . ?\end{array}$ & $\begin{array}{l}23.9 \\
24.8 \\
22.5 \\
13.4\end{array}$ & $\begin{array}{l}21.9 \\
18.3 \\
14.9 \\
15.8 \\
16.8 \\
16.5 \\
14.9\end{array}$ & $\begin{array}{l}23 \cdot 3 \\
21.5 \\
19 \cdot 3 \\
23.6 \\
24 \cdot 7 \\
22 \cdot 3 \\
18 \cdot 2\end{array}$ & $\begin{array}{l}21.8 \\
10.0 \\
14.6 \\
16.5 \\
16.5 \\
16.1 \\
14.8\end{array}$ & $\begin{array}{l}21.8 \\
21.5 \\
21.3 \\
25.4 \\
23.7 \\
22.5 \\
21.5\end{array}$ & & $\begin{array}{r}3.6 \\
7.0 \\
10.0 \\
7.4 \\
8.2 \\
7.4 \\
7.4 \\
6.6\end{array}$ & $\begin{array}{r}4.5 \\
8.6 \\
13.2 \\
9.6 \\
10.3 \\
9.6 \\
9.4 \\
7.7\end{array}$ & $\begin{array}{r}5.8 \\
11.2 \\
14.5 \\
10.8 \\
12.4 \\
11.6 \\
10.4 \\
7.9\end{array}$ & $\begin{array}{r}7.4 \\
12.7 \\
15.8 \\
12.2 \\
13.6 \\
12.9 \\
12.0 \\
9.2\end{array}$ \\
\hline $\begin{array}{l}22 \\
22 \\
22 \\
22 \\
22 \\
22 \\
22 \\
32 \\
? 2\end{array}$ & $\begin{array}{r}0 \\
3 \\
6 \\
9 \\
12 \\
15 \\
18 \\
21\end{array}$ & $\begin{array}{l}20.0 \\
21.0 \\
22.8 \\
18.6\end{array}$ & $\begin{array}{l}14 \cdot 5 \\
14 \cdot 1 \\
15.8 \\
15.7 \\
15.7 \\
14.5\end{array}$ & $\begin{array}{l}19.7 \\
21.5 \\
22.0 \\
19.1\end{array}$ & $\begin{array}{l}15 \cdot 3 \\
15 \cdot 2 \\
15 \cdot 4 \\
14 \cdot 4\end{array}$ & $\begin{array}{l}15.3 \\
15.1 \\
19.4 \\
21.0 \\
21.9 \\
19.2 \\
17.4\end{array}$ & $\begin{array}{l}15.0 \\
14.9 \\
15.1 \\
14.4 \\
13.4\end{array}$ & $\begin{array}{l}19 \cdot 1 \\
20.5 \\
21.7 \\
19.3 \\
17.3\end{array}$ & $\begin{array}{l}14.8 \\
14.7 \\
14.8 \\
14.2 \\
13.5\end{array}$ & $\begin{array}{l}22.6 \\
20.0 \\
22.1 \\
22.9 \\
23.1 \\
22.2 \\
21.9\end{array}$ & & $\begin{array}{l}6.6 \\
7.5 \\
8.2 \\
6.1 \\
5.5 \\
4.0 \\
2.2 \\
0.9\end{array}$ & $\begin{array}{r}8.4 \\
9.8 \\
10.6 \\
7.3 \\
6.5 \\
4.9 \\
2.8 \\
1.5\end{array}$ & $\begin{array}{r}9.2 \\
11.0 \\
11.5 \\
7.8 \\
6.9 \\
5.4 \\
3.4\end{array}$ & $\begin{array}{r}10.8 \\
11.9 \\
12.7 \\
8.9 \\
7.7 \\
6.0 \\
3.8\end{array}$ \\
\hline $\begin{array}{l}23 \\
23 \\
23 \\
23 \\
23 \\
23 \\
23 \\
23\end{array}$ & $\begin{array}{r}0 \\
3 \\
6 \\
9 \\
12 \\
15 \\
13 \\
21\end{array}$ & $\begin{array}{l}14 \cdot 2 \\
15: 7 \\
22.0 \\
24 \cdot 5 \\
23.0 \\
20.7\end{array}$ & $\begin{array}{l}12.5 \\
12.6 \\
13.7 \\
13.6 \\
14.3 \\
14.4\end{array}$ & $\begin{array}{l}14.5 \\
16.0 \\
21.0 \\
24.8 \\
23.6 \\
21.2\end{array}$ & $\begin{array}{l}12.3 \\
12.4 \\
13.3 \\
13.4 \\
14.1 \\
14.5\end{array}$ & $\begin{array}{l}14.8 \\
16.4 \\
21.6 \\
24.1 \\
23.6 \\
21.4\end{array}$ & $\begin{array}{l}12.6 \\
12.5 \\
13.1 \\
13.5 \\
13.9 \\
13.8\end{array}$ & $\begin{array}{l}15.3 \\
16: 6 \\
21: 4 \\
23.6 \\
23: 2 \\
22.2\end{array}$ & $\begin{array}{l}12.5 \\
12.5 \\
12.8 \\
13.0 \\
13.5 \\
13.3\end{array}$ & $\begin{array}{l}20.2 \\
19.0 \\
20.0 \\
22.4 \\
22.7 \\
22.4\end{array}$ & & $\begin{array}{l}1.22 \\
2.0 \\
4.0 \\
2.7 \\
2.2 \\
2.9 \\
1.1 \\
1.0\end{array}$ & $\begin{array}{l}1.8 \\
3.0 \\
4.7 \\
3.3 \\
2.8 \\
3.7 \\
1.8 \\
1.4\end{array}$ & $\begin{array}{l}2.8 \\
4.2 \\
5.9 \\
3.7 \\
3.1 \\
4.8 \\
2.2 \\
1.9\end{array}$ & $\begin{array}{l}3.2 \\
5.4 \\
6.9 \\
4.3 \\
3.3 \\
5.5 \\
3.5 \\
2.6\end{array}$ \\
\hline $\begin{array}{l}24 \\
24 \\
24 \\
24 \\
24 \\
24 \\
24 \\
24 \\
? 4\end{array}$ & $\begin{array}{r}0 \\
3 \\
6 \\
9 \\
12 \\
15 \\
18 \\
21\end{array}$ & $\begin{array}{l}24.8 \\
20.1 \\
16.3\end{array}$ & $\begin{array}{l}16.3 \\
15.0 \\
15.0\end{array}$ & $\begin{array}{l}24.6 \\
20.2 \\
26.5\end{array}$ & $\begin{array}{l}16.0 \\
15.9 \\
15.0\end{array}$ & $\begin{array}{l}24.3 \\
20.1 \\
16.7\end{array}$ & $\begin{array}{l}15.8 \\
15.8 \\
15.0\end{array}$ & $\begin{array}{l}24 . ? \\
20.1 \\
17.1\end{array}$ & $\begin{array}{l}15.9 \\
15.9 \\
15.2\end{array}$ & $\begin{array}{l}25 \cdot 4 \\
24 \cdot 3 \\
23 \cdot 3\end{array}$ & & $\begin{array}{l}1.2 \\
1.1 \\
2.0 \\
3.6 \\
4.3 \\
3.8 \\
3.3 \\
2.0\end{array}$ & $\begin{array}{l}2.0 \\
1.6 \\
2.4 \\
4.6 \\
5.4 \\
4.9 \\
4.4 \\
3.5\end{array}$ & $\begin{array}{l}2.6 \\
2.0 \\
2.8 \\
5.3 \\
6.1 \\
5.7 \\
5.5 \\
4.6\end{array}$ & $\begin{array}{l}3.8 \\
2.9 \\
3.2 \\
5.7 \\
6.8 \\
6.4 \\
6.9 \\
6.0\end{array}$ \\
\hline $\begin{array}{l}35 \\
25 \\
25 \\
25 \\
25 \\
25 \\
75 \\
25 \\
35\end{array}$ & $\begin{array}{r}0 \\
3 \\
6 \\
9 \\
12 \\
25 \\
18 \\
71 \\
71\end{array}$ & $\begin{array}{l}14.0 \\
13.1 \\
14.8 \\
19: 9 \\
22.4 \\
21.0 \\
17.5 \\
16.6\end{array}$ & $\begin{array}{l}13.7 \\
13.0 \\
13.4 \\
14.3 \\
15.6 \\
15.5 \\
14.9 \\
14.3\end{array}$ & $\begin{array}{l}14.3 \\
13.5 \\
14.9 \\
10.4 \\
21.4 \\
20.7 \\
17.7 \\
16.7\end{array}$ & $\begin{array}{l}13.8 \\
13.3 \\
13.2 \\
13.9 \\
15.1 \\
15.4 \\
14.9 \\
14.2\end{array}$ & $\begin{array}{l}14.6 \\
13.8 \\
15.2 \\
19.0 \\
21.0 \\
20.5 \\
17.7 \\
16.8\end{array}$ & $\begin{array}{l}13.9 \\
13.4 \\
13.0 \\
13.9 \\
14.9 \\
15.1 \\
14.3 \\
14 . ?\end{array}$ & $\begin{array}{l}14.9 \\
14.2 \\
15.1 \\
18.7 \\
20.7 \\
20.4 \\
17.8 \\
16.9\end{array}$ & $\begin{array}{l}14.1 \\
13.7 \\
13.2 \\
14.0 \\
15.0 \\
15.2 \\
14.8 \\
14.3\end{array}$ & $\begin{array}{l}22.7 \\
22.0 \\
21.8 \\
22.5 \\
23.1 \\
22.4 \\
21.9 \\
21.3\end{array}$ & & $\begin{array}{l}1.0 \\
2.8 \\
7.2 \\
7.2 \\
6.8 \\
4.7 \\
2.5 \\
4.5\end{array}$ & $\begin{array}{l}2.6 \\
4.3 \\
8.4 \\
8.9 \\
7.8 \\
6.9 \\
4.4 \\
6.3\end{array}$ & $\begin{array}{l}3.9 \\
5.1 \\
9.8 \\
9.8 \\
8.8 \\
8.0 \\
5.7 \\
7.5\end{array}$ & $\begin{array}{r}5.0 \\
7.1 \\
11.2 \\
10.8 \\
9.6 \\
9.0 \\
7.1 \\
8.9\end{array}$ \\
\hline $\begin{array}{l}26 \\
25 \\
26 \\
26 \\
26 \\
26 \\
26 \\
26\end{array}$ & $\begin{array}{r}0 \\
3 \\
6 \\
9 \\
12 \\
15 \\
18 \\
21\end{array}$ & $\begin{array}{l}17.6 \\
20.0 \\
20.8 \\
18.1 \\
16.7\end{array}$ & $\begin{array}{l}16.2 \\
16.2 \\
16.3 \\
15.8 \\
14.5\end{array}$ & $\begin{array}{l}17.8 \\
19.7 \\
20.7 \\
18.3 \\
16.8\end{array}$ & $\begin{array}{l}16.0 \\
16.1 \\
16.3 \\
15.3 \\
14.5\end{array}$ & $\begin{array}{l}17.9 \\
10.8 \\
20.8 \\
18.4 \\
16.9\end{array}$ & $\begin{array}{l}15.7 \\
15.9 \\
16.1 \\
15.9 \\
24.5\end{array}$ & $\begin{array}{l}17.6 \\
19.4 \\
20.5 \\
18.5 \\
16.8\end{array}$ & $\begin{array}{l}15.5 \\
15.0 \\
16.2 \\
15.9 \\
14.5\end{array}$ & $\begin{array}{l}21.3 \\
21.2 \\
20.7 \\
20.3 \\
19.8\end{array}$ & & $\begin{array}{r}4.1 \\
3.1 \\
5.8 \\
8.4 \\
10.2 \\
8.0 \\
5.9 \\
8.7\end{array}$ & $\begin{array}{r}5.2 \\
4.8 \\
7.7 \\
10.4 \\
12.2 \\
9.5 \\
7.2 \\
20.5\end{array}$ & $\begin{array}{r}6.5 \\
5.9 \\
9.7 \\
11.9 \\
13.7 \\
10.8 \\
8.6 \\
12.3\end{array}$ & $\begin{array}{r}8.1 \\
7.2 \\
21.0 \\
13.3 \\
15.3 \\
12.1 \\
10.3 \\
14.0\end{array}$ \\
\hline $\begin{array}{l}27 \\
27 \\
27 \\
? 7 \\
? 7 \\
27 \\
27 \\
77\end{array}$ & $\begin{array}{r}0 \\
3 \\
6 \\
9 \\
12 \\
15 \\
19 \\
21\end{array}$ & $\begin{array}{l}15.0 \\
17: 0 \\
17: 5 \\
20: 3 \\
25: 2 \\
25.1 \\
21.5 \\
19.7\end{array}$ & $\begin{array}{l}15.4 \\
16.6 \\
16.9 \\
18.2 \\
20.2 \\
20.1 \\
19.0 \\
18.5\end{array}$ & $\begin{array}{l}16.0 \\
17.1 \\
17.5 \\
20.2 \\
24.7 \\
24.7 \\
21.6 \\
19.8\end{array}$ & $\begin{array}{l}15.4 \\
16.6 \\
16.9 \\
18.1 \\
19.8 \\
19.9 \\
19.0 \\
18.5\end{array}$ & $\begin{array}{l}16.1 \\
17.1 \\
17.5 \\
20.1 \\
24.3 \\
24.4 \\
21.6 \\
10.8\end{array}$ & $\begin{array}{l}15.5 \\
16.6 \\
16.9 \\
18.2 \\
19.7 \\
19.9 \\
19.0 \\
18.5\end{array}$ & $\begin{array}{l}16.0 \\
17.0 \\
27: 4 \\
20.2 \\
23.0 \\
24.2 \\
21.7 \\
19.8\end{array}$ & $\begin{array}{l}15.5 \\
16.6 \\
16.0 \\
18.0 \\
19.7 \\
19.8 \\
19.1 \\
18.6\end{array}$ & $\begin{array}{l}19.4 \\
19.1 \\
10.2 \\
19.9 \\
21.7 \\
21.9 \\
21.3 \\
20.9\end{array}$ & & $\begin{array}{r}10.9 \\
9.5 \\
10.0 \\
11.2 \\
11.5 \\
11.1 \\
8.1 \\
10.1\end{array}$ & $\begin{array}{l}12.9 \\
11.3 \\
11.8 \\
13.4 \\
13.9 \\
13.9 \\
10.0 \\
12.3\end{array}$ & $\begin{array}{l}14.7 \\
12.9 \\
13.4 \\
15.2 \\
15.7 \\
15.8 \\
11.7 \\
14.3\end{array}$ & $\begin{array}{l}16.7 \\
14.6 \\
15.2 \\
16.8 \\
17.3 \\
17.7 \\
13.4 \\
16.2\end{array}$ \\
\hline $\begin{array}{l}28 \\
? 8 \\
28 \\
28 \\
28 \\
28 \\
28 \\
28\end{array}$ & $\begin{array}{r}0 \\
3 \\
6 \\
9 \\
12 \\
15 \\
18 \\
21\end{array}$ & $\begin{array}{l}18.9 \\
18.7 \\
19.4 \\
23.1 \\
26.8 \\
26.1 \\
21.5 \\
19.8\end{array}$ & $\begin{array}{l}18.1 \\
18.0 \\
18.2 \\
19.6 \\
20.6 \\
20.4 \\
19.0 \\
18.1\end{array}$ & $\begin{array}{l}18.9 \\
18.9 \\
19.4 \\
23.0 \\
25.4 \\
25.8 \\
21.6 \\
19.9\end{array}$ & $\begin{array}{l}18.1 \\
18.0 \\
18.1 \\
19.4 \\
20.4 \\
20.3 \\
19.0 \\
18.1\end{array}$ & $\begin{array}{l}19.0 \\
18.9 \\
19.4 \\
22.6 \\
25.9 \\
25.4 \\
21.6 \\
10.9\end{array}$ & $\begin{array}{l}18.1 \\
18.0 \\
18.1 \\
19.4 \\
20.1 \\
20.3 \\
19.0 \\
18.1\end{array}$ & $\begin{array}{l}18.9 \\
18.9 \\
19: 3 \\
22.5 \\
25.8 \\
25.1 \\
21.6 \\
19.9\end{array}$ & $\begin{array}{l}18.1 \\
18.0 \\
18.2 \\
19.4 \\
20.2 \\
20.3 \\
19.1 \\
18.3\end{array}$ & $\begin{array}{l}20.7 \\
20.4 \\
20.5 \\
21.4 \\
22.1 \\
21.8 \\
21.1 \\
20.7\end{array}$ & & $\begin{array}{r}10.9 \\
9.9 \\
10.8 \\
12.1 \\
11.7 \\
11.5 \\
9.5 \\
8.7\end{array}$ & $\begin{array}{l}13.2 \\
12.3 \\
13.1 \\
14.7 \\
14.4 \\
14.1 \\
11.7 \\
10.6\end{array}$ & $\begin{array}{l}15.0 \\
14.2 \\
14.9 \\
16.6 \\
16.2 \\
16.1 \\
13.6 \\
12.4\end{array}$ & $\begin{array}{l}17.1 \\
16.0 \\
16.9 \\
18.6 \\
18.0 \\
18.0 \\
15.4 \\
14.3\end{array}$ \\
\hline $\begin{array}{l}29 \\
29 \\
29 \\
29 \\
29 \\
29 \\
29 \\
29\end{array}$ & $\begin{array}{r}0 \\
3 \\
6 \\
9 \\
12 \\
15 \\
18 \\
21\end{array}$ & $\begin{array}{l}18.9 \\
19.8 \\
21.0 \\
24.4 \\
27.9 \\
26.9 \\
23.5 \\
21.5\end{array}$ & $\begin{array}{l}18.2 \\
19.3 \\
19.8 \\
20.6 \\
21.1 \\
20.7 \\
19.7 \\
20.1\end{array}$ & $\begin{array}{l}19.0 \\
19.9 \\
21.2 \\
24.2 \\
27.4 \\
26.9 \\
23.5 \\
21.6\end{array}$ & $\begin{array}{l}18.4 \\
19.4 \\
19.8 \\
20.5 \\
21.0 \\
20.6 \\
19.7 \\
20.1\end{array}$ & $\begin{array}{l}10.1 \\
20.0 \\
21.1 \\
24.2 \\
27.3 \\
25.5 \\
23.4 \\
21.6\end{array}$ & $\begin{array}{l}18.4 \\
19.4 \\
19.7 \\
20.5 \\
21.0 \\
20.6 \\
19.7 \\
20.1\end{array}$ & $\begin{array}{l}19.1 \\
20.0 \\
21.1 \\
23.7 \\
26.9 \\
26.5 \\
23.5 \\
21.6\end{array}$ & $\begin{array}{l}18.5 \\
19.4 \\
19.8 \\
20.5 \\
20.9 \\
20.6 \\
19.8 \\
20.1\end{array}$ & $\begin{array}{l}20.5 \\
20.4 \\
20.7 \\
21.6 \\
22.5 \\
22.1 \\
21.9 \\
21.6\end{array}$ & & $\begin{array}{r}8.4 \\
9.4 \\
10.2 \\
11.5 \\
10.2 \\
9.4 \\
7.2 \\
9.7\end{array}$ & $\begin{array}{r}10.4 \\
11.2 \\
12.0 \\
13.6 \\
12.2 \\
11.7 \\
9.0 \\
11.8\end{array}$ & $\begin{array}{l}11.9 \\
12.9 \\
13.7 \\
15.3 \\
13.7 \\
13.4 \\
10.5 \\
13.7\end{array}$ & $\begin{array}{l}13.7 \\
14.6 \\
15.5 \\
17.0 \\
15.1 \\
15.0 \\
12.1 \\
15.5\end{array}$ \\
\hline $\begin{array}{l}30 \\
30 \\
30 \\
30 \\
30 \\
30 \\
30 \\
30\end{array}$ & $\begin{array}{r}0 \\
3 \\
6 \\
9 \\
12 \\
15 \\
18 \\
21\end{array}$ & $\begin{array}{l}21.6 \\
20.6 \\
21.0 \\
23.5 \\
26.0 \\
25.4 \\
22.5 \\
19.8\end{array}$ & $\begin{array}{l}20.2 \\
19.5 \\
19.9 \\
20.7 \\
21.0 \\
20.7 \\
19.7 \\
18.7\end{array}$ & $\begin{array}{l}21.6 \\
20.6 \\
21.0 \\
23.4 \\
25.3 \\
25.4 \\
22.6 \\
19.7\end{array}$ & $\begin{array}{l}20.2 \\
19.5 \\
19.9 \\
20.7 \\
20.8 \\
20.5 \\
19.7 \\
18.6\end{array}$ & $\begin{array}{l}21.6 \\
20.6 \\
20.9 \\
23.3 \\
25.0 \\
25.2 \\
22.6 \\
19.9\end{array}$ & $\begin{array}{l}20.1 \\
19.4 \\
19.8 \\
20.6 \\
20.6 \\
20.4 \\
19.7 \\
18.6\end{array}$ & $\begin{array}{l}21.5 \\
20.6 \\
20.9 \\
23.0 \\
24.6 \\
24.9 \\
22.04 \\
19.6\end{array}$ & $\begin{array}{l}20.1 \\
19.4 \\
10.9 \\
20.5 \\
20.5 \\
20.4 \\
19.7 \\
18.6\end{array}$ & $\begin{array}{l}21 \cdot 5 \\
21 \cdot 3 \\
21 \cdot 2 \\
21 \cdot 2 \\
20.4 \\
20.4 \\
19 \cdot 9 \\
19.7\end{array}$ & & $\begin{array}{r}10.9 \\
8.4 \\
8.6 \\
9.3 \\
11.3 \\
10.1 \\
9.2 \\
10.6\end{array}$ & $\begin{array}{l}13.5 \\
10.7 \\
10.6 \\
11.6 \\
14.0 \\
12.4 \\
11.4 \\
13.0\end{array}$ & $\begin{array}{l}15.4 \\
12.3 \\
12.0 \\
13.1 \\
15.7 \\
14.2 \\
13.2 \\
14.9\end{array}$ & $\begin{array}{l}17.3 \\
13.8 \\
13.6 \\
14.6 \\
17.4 \\
16.0 \\
14.9 \\
16.9\end{array}$ \\
\hline
\end{tabular}


TABLE 10

Table 10. -Three-hour averages of air and water-surface temperatures and wind directions and speed, April 1950-August

STATION 2 THREE-HOURLY AVERAGES

\begin{tabular}{|c|c|c|c|c|c|c|c|c|c|c|c|c|c|c|c|}
\hline \multirow{4}{*}{ 宽 } & \multirow{4}{*}{ 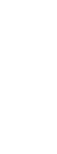 } & \multicolumn{8}{|c|}{ Average air temperature $\left({ }^{\circ} \mathrm{C}\right)$ at indicated height } & \multirow{4}{*}{$\begin{array}{c}\text { Average } \\
\text { water- } \\
\text { surface } \\
\text { tempera- } \\
\text { ture } \\
\text { ("C) }\end{array}$} & \multirow{4}{*}{$\begin{array}{c}\text { Average } \\
\text { wind } \\
\text { direction } \\
\text { (coded) }\end{array}$} & \multirow{2}{*}{\multicolumn{4}{|c|}{$\begin{array}{l}\text { Average wind speed (knots) } \\
\text { at indicated height }\end{array}$}} \\
\hline & & \multirow{2}{*}{\multicolumn{2}{|c|}{$\begin{array}{c}2 \\
\text { meters }\end{array}$}} & \multirow{2}{*}{\multicolumn{2}{|c|}{$\begin{array}{c}4 \\
\text { meters }\end{array}$}} & \multirow{2}{*}{\multicolumn{2}{|c|}{$\begin{array}{c}8 \\
\text { meters }\end{array}$}} & \multirow{2}{*}{\multicolumn{2}{|c|}{$\begin{array}{c}16 \\
\text { meters }\end{array}$}} & & & & & & \\
\hline & & & & & & & & & & & & 2 & 4 & 8 & 16 \\
\hline & & $\begin{array}{l}\text { Dry } \\
\text { bulb }\end{array}$ & $\begin{array}{l}\text { Wet } \\
\text { bulb }\end{array}$ & $\begin{array}{l}\text { Dry } \\
\text { bulb }\end{array}$ & $\begin{array}{l}\text { Wet } \\
\text { bulb }\end{array}$ & $\begin{array}{l}\text { Dry } \\
\text { bulb }\end{array}$ & $\begin{array}{l}\text { Wet } \\
\text { bulb }\end{array}$ & $\begin{array}{l}\text { Dry } \\
\text { bulb }\end{array}$ & $\begin{array}{l}\text { Wet } \\
\text { bulb }\end{array}$ & & & meters & meters & meters & meters \\
\hline $\begin{array}{l}1 \\
1 \\
1 \\
1 \\
1 \\
1 \\
1 \\
1\end{array}$ & $\begin{array}{r}0 \\
3 \\
6 \\
9 \\
12 \\
15 \\
18 \\
21\end{array}$ & $\begin{array}{l}18.6 \\
18.7 \\
19.9 \\
23.0 \\
26.1 \\
25.6 \\
22.6 \\
20.6\end{array}$ & $\begin{array}{l}17.7 \\
17.9 \\
18.7 \\
19.5 \\
20.1 \\
19.7 \\
19.0 \\
18.9\end{array}$ & $\begin{array}{l}18.7 \\
18.8 \\
19.9 \\
22.5 \\
25.4 \\
25.5 \\
22.7 \\
20.7\end{array}$ & $\begin{array}{l}17.6 \\
17.9 \\
18.7 \\
19.5 \\
19.9 \\
18.8 \\
19.0 \\
18.9\end{array}$ & $\begin{array}{l}18.7 \\
18.9 \\
20.0 \\
22.6 \\
25.2 \\
25.4 \\
22.8 \\
20.7\end{array}$ & $\begin{array}{l}17.6 \\
18.0 \\
18.7 \\
19.3 \\
19.7 \\
18.8 \\
19.0 \\
18.9\end{array}$ & $\begin{array}{l}18.6 \\
18.8 \\
19.3 \\
22.2 \\
24.5 \\
25.0 \\
22.6 \\
20.7\end{array}$ & $\begin{array}{l}17.6 \\
13.0 \\
18.6 \\
19.2 \\
19.6 \\
18.7 \\
19.0 \\
10.9\end{array}$ & $\begin{array}{l}19.4 \\
19.1 \\
19.2 \\
19.9 \\
20.5 \\
20.1 \\
19.6 \\
19.5\end{array}$ & & $\begin{array}{r}10.4 \\
10.3 \\
11.2 \\
11.8 \\
12.1 \\
11.1 \\
9.7 \\
10.6\end{array}$ & $\begin{array}{l}13.0 \\
12.6 \\
13.7 \\
14.5 \\
14.9 \\
13.7 \\
11.9 \\
13.1\end{array}$ & $\begin{array}{l}14.8 \\
14.5 \\
15.6 \\
16.4 \\
16.8 \\
15.7 \\
13.8 \\
15.1\end{array}$ & $\begin{array}{l}16.8 \\
16.3 \\
17.5 \\
18.2 \\
18.5 \\
17.7 \\
15.7 \\
17.1\end{array}$ \\
\hline $\begin{array}{l}2 \\
2 \\
2 \\
2 \\
2 \\
2 \\
2 \\
2\end{array}$ & $\begin{array}{r}0 \\
3 \\
6 \\
9 \\
12 \\
15 \\
18 \\
21\end{array}$ & $\begin{array}{l}19.5 \\
19.0 \\
20.0 \\
24.5 \\
19.0 \\
14.1\end{array}$ & $\begin{array}{l}18.7 \\
18.6 \\
19.1 \\
20.1 \\
17.2 \\
13.7\end{array}$ & $\begin{array}{l}19.7 \\
19.0 \\
20.1 \\
24.4 \\
18.6 \\
14.0\end{array}$ & $\begin{array}{l}18.7 \\
18.6 \\
19.1 \\
20.1 \\
16.1 \\
13.6\end{array}$ & $\begin{array}{l}10.8 \\
12.1 \\
20.2 \\
24.3 \\
12.4 \\
13.9\end{array}$ & $\begin{array}{l}18.8 \\
19.6 \\
19.1 \\
19.9 \\
16.7 \\
13.3\end{array}$ & $\begin{array}{l}19.6 \\
10.0 \\
20.0 \\
23.0 \\
17.0 \\
13.4\end{array}$ & $\begin{array}{l}18.7 \\
18.6 \\
19.0 \\
19.9 \\
16.4 \\
12.9\end{array}$ & $\begin{array}{l}19.4 \\
19.1 \\
19.2 \\
19.8 \\
20.1 \\
19.4\end{array}$ & & $\begin{array}{r}10.2 \\
8.4 \\
8.9 \\
10.7 \\
0.9 \\
10.1 \\
8.0 \\
6.1\end{array}$ & $\begin{array}{r}12.6 \\
10.4 \\
10.9 \\
12.5 \\
12.9 \\
12.3 \\
9.3 \\
7.1\end{array}$ & $\begin{array}{r}14.4 \\
11.9 \\
12.3 \\
14.2 \\
14.1 \\
13.4 \\
10.2 \\
8.7\end{array}$ & $\begin{array}{l}16.4 \\
13.6 \\
14.0 \\
15.0 \\
15.4 \\
14.0 \\
10.7 \\
11.0\end{array}$ \\
\hline $\begin{array}{l}3 \\
3 \\
3 \\
3 \\
3 \\
3 \\
3 \\
3\end{array}$ & $\begin{array}{r}0 \\
3 \\
6 \\
9 \\
12 \\
15 \\
18 \\
21\end{array}$ & $\begin{array}{l}10.4 \\
14.0 \\
16.7 \\
15.0 \\
12.8\end{array}$ & $\begin{array}{r}9.4 \\
11.8 \\
13.0 \\
12 . ? \\
10.3\end{array}$ & $\begin{array}{l}10.2 \\
13.7 \\
16.5 \\
15.0 \\
12.8\end{array}$ & $\begin{array}{r}0.2 \\
11.6 \\
12.9 \\
12.0 \\
10.2\end{array}$ & $\begin{array}{l}10.0 \\
13.5 \\
16.5 \\
14.0 \\
12.7\end{array}$ & $\begin{array}{r}9.0 \\
11.3 \\
12.7 \\
11.9 \\
10.1\end{array}$ & $\begin{array}{r}0.6 \\
13.1 \\
16.2 \\
14.7 \\
12.8\end{array}$ & $\begin{array}{r}8.7 \\
11.0 \\
12.4 \\
11.6 \\
9.7\end{array}$ & $\begin{array}{l}18.1 \\
19.4 \\
19.2 \\
18.6 \\
18.0\end{array}$ & & $\begin{array}{l}5.9 \\
7.6 \\
7.5 \\
5.6 \\
5.3 \\
5.1 \\
5.8 \\
4.3\end{array}$ & $\begin{array}{l}6.7 \\
8.6 \\
8.6 \\
7.6 \\
6.2 \\
5.0 \\
6.6 \\
5.1\end{array}$ & $\begin{array}{l}8.2 \\
9.7 \\
9.8 \\
8.2 \\
6.6 \\
8.7 \\
7.3 \\
6.3\end{array}$ & $\begin{array}{r}10.6 \\
10.6 \\
11.1 \\
8.6 \\
7.3 \\
7.6 \\
7.5 \\
8.1\end{array}$ \\
\hline $\begin{array}{l}4 \\
4 \\
4 \\
4 \\
4 \\
4 \\
4 \\
4\end{array}$ & $\begin{array}{r}0 \\
3 \\
6 \\
9 \\
12 \\
15 \\
18 \\
21\end{array}$ & $\begin{array}{r}10.3 \\
8.1 \\
7.8 \\
12.8 \\
16.0 \\
16.0 \\
13.0 \\
11.7\end{array}$ & $\begin{array}{l}9.0 \\
7.5 \\
6.5 \\
8.3 \\
9.7 \\
9.6 \\
9.3 \\
9.2\end{array}$ & $\begin{array}{r}10 . ? \\
8 . ? \\
7.9 \\
12.4 \\
15.3 \\
15.7 \\
23.2 \\
11.8\end{array}$ & $\begin{array}{l}8.8 \\
7.4 \\
6.4 \\
7.8 \\
9.0 \\
9.1 \\
9.0 \\
0.0\end{array}$ & $\begin{array}{r}10.2 \\
8.0 \\
7.9 \\
12.3 \\
15.4 \\
15.6 \\
13.3 \\
11.9\end{array}$ & $\begin{array}{l}8.7 \\
7.3 \\
6.3 \\
7.9 \\
9.1 \\
9.0 \\
8.9 \\
8.9\end{array}$ & $\begin{array}{r}9.9 \\
7.8 \\
7.5 \\
11.9 \\
15.0 \\
15.3 \\
13.4 \\
11.8\end{array}$ & $\begin{array}{l}8.4 \\
6.9 \\
5.9 \\
7.4 \\
8.8 \\
8.7 \\
8.5 \\
8.7\end{array}$ & $\begin{array}{l}17.4 \\
16.7 \\
16.5 \\
17.2 \\
18.3 \\
18.7 \\
18.2 \\
17.7\end{array}$ & & $\begin{array}{l}6.2 \\
6.8 \\
5.9 \\
6.4 \\
4.5 \\
3.6 \\
1.6 \\
1.9\end{array}$ & $\begin{array}{l}7.0 \\
8.1 \\
7.0 \\
7.9 \\
5.4 \\
4.6 \\
2.3 \\
3.4\end{array}$ & $\begin{array}{l}8.3 \\
0.8 \\
8.5 \\
9.1 \\
6.2 \\
5.4 \\
3.1 \\
4.2\end{array}$ & $\begin{array}{r}9.5 \\
11.9 \\
10.8 \\
10.3 \\
7.1 \\
6.0 \\
4.3 \\
5.4\end{array}$ \\
\hline $\begin{array}{l}5 \\
5 \\
5 \\
5 \\
5 \\
5 \\
5 \\
5\end{array}$ & $\begin{array}{r}0 \\
3 \\
6 \\
9 \\
12 \\
15 \\
18 \\
21\end{array}$ & $\begin{array}{l}12.0 \\
11.2 \\
11: 9 \\
17.8 \\
21.5 \\
22.0 \\
18.3 \\
16.2\end{array}$ & $\begin{array}{r}8.7 \\
8.3 \\
9.5 \\
13.9 \\
15.7 \\
16.4 \\
15.0 \\
13.5\end{array}$ & $\begin{array}{l}12.0 \\
11.1 \\
11.9 \\
17.7 \\
21.2 \\
21.9 \\
18.4 \\
16.4\end{array}$ & $\begin{array}{r}8.6 \\
8.1 \\
9.5 \\
13.9 \\
14.7 \\
16.2 \\
14.9 \\
13.4\end{array}$ & $\begin{array}{l}12.00 \\
11.01 \\
12.0 \\
17.7 \\
20.0 \\
21.08 \\
12.05 \\
16.5\end{array}$ & $\begin{array}{r}8.5 \\
8.1 \\
9.6 \\
13.8 \\
14.6 \\
16.1 \\
14.8 \\
13.4\end{array}$ & $\begin{array}{l}11.8 \\
10.5 \\
11.8 \\
17.5 \\
20.5 \\
21.5 \\
18.5 \\
16.3\end{array}$ & $\begin{array}{r}8.2 \\
8.0 \\
9.6 \\
13.6 \\
14.4 \\
16.1 \\
14.8 \\
13.4\end{array}$ & $\begin{array}{l}17.1 \\
16.6 \\
16.2 \\
17.4 \\
18.4 \\
18.3 \\
18.1 \\
17.8\end{array}$ & & $\begin{array}{r}4.7 \\
4.3 \\
8.6 \\
12.5 \\
11.7\end{array}$ & $\begin{array}{r}5.8 \\
5.4 \\
10.1 \\
14.6 \\
14.3\end{array}$ & $\begin{array}{r}6.7 \\
6.4 \\
11.6 \\
16.4 \\
16.8\end{array}$ & $\begin{array}{r}7.8 \\
7.6 \\
13.2 \\
18.3 \\
17.6\end{array}$ \\
\hline $\begin{array}{l}6 \\
6 \\
6 \\
6 \\
6 \\
6 \\
6 \\
5\end{array}$ & $\begin{array}{r}0 \\
3 \\
6 \\
9 \\
12 \\
15 \\
18 \\
21\end{array}$ & $\begin{array}{l}14.5 \\
13.5 \\
14.9 \\
21.7 \\
26.4 \\
26.0 \\
23.4 \\
21.9\end{array}$ & $\begin{array}{l}12.7 \\
11.5 \\
12.7 \\
16.7 \\
19.5 \\
19.7 \\
19.1 \\
18.1\end{array}$ & $\begin{array}{l}14.6 \\
13.6 \\
15.0 \\
21.3 \\
26.1 \\
25.9 \\
23.5 \\
22.1\end{array}$ & $\begin{array}{l}12.1 \\
11.4 \\
12.7 \\
16.7 \\
10.1 \\
19.6 \\
19.1 \\
18.0\end{array}$ & $\begin{array}{l}14.6 \\
13.8 \\
15.1 \\
21.3 \\
26.0 \\
25.9 \\
23.6 \\
22.2\end{array}$ & $\begin{array}{l}12.1 \\
11.5 \\
12.8 \\
16.7 \\
19.1 \\
19.7 \\
19.1 \\
18.0\end{array}$ & $\begin{array}{l}14.6 \\
13.7 \\
15.1 \\
21.7 \\
25.7 \\
25.7 \\
23.4 \\
22.1\end{array}$ & $\begin{array}{l}12.0 \\
11.4 \\
12.8 \\
17.0 \\
19.0 \\
19.4 \\
18.8 \\
17.8\end{array}$ & $\begin{array}{l}17.2 \\
16.3 \\
16.6 \\
18.0 \\
18.9 \\
19.3 \\
18.9 \\
18.6\end{array}$ & & $\begin{array}{l}13.0 \\
15.0 \\
14: 3 \\
12: 3 \\
13.1\end{array}$ & $\begin{array}{l}15.8 \\
18.8 \\
18.3 \\
15.7 \\
16.6\end{array}$ & $\begin{array}{l}18.2 \\
21.0 \\
20.3 \\
17.8 \\
18.8\end{array}$ & $\begin{array}{l}19.8 \\
23.5 \\
23.4 \\
20.2 \\
20.1\end{array}$ \\
\hline $\begin{array}{l}7 \\
7 \\
7 \\
7 \\
7 \\
7 \\
7 \\
7\end{array}$ & $\begin{array}{r}0 \\
3 \\
6 \\
9 \\
12 \\
15 \\
18 \\
21\end{array}$ & $\begin{array}{l}20.8 \\
19.3 \\
16.9 \\
17.5 \\
21.6 \\
22.1 \\
17.6 \\
11.8\end{array}$ & $\begin{array}{r}17.5 \\
17.0 \\
15.2 \\
15.1 \\
13.6 \\
13.2 \\
10.9 \\
7.6\end{array}$ & $\begin{array}{l}20.9 \\
19.4 \\
16.9 \\
17.0 \\
21.7 \\
21.9 \\
17.5 \\
12.6\end{array}$ & $\begin{array}{r}17.6 \\
17.1 \\
15.2 \\
14.9 \\
13.2 \\
12.6 \\
10.9 \\
7.7\end{array}$ & $\begin{array}{l}21.0 \\
19.6 \\
16.8 \\
17.1 \\
21.5 \\
22.0 \\
17.8 \\
13.8\end{array}$ & $\begin{array}{r}17.6 \\
17.1 \\
15.0 \\
15.0 \\
13.0 \\
12.2 \\
10.6 \\
7.8\end{array}$ & $\begin{array}{l}20.9 \\
19.6 \\
16.6 \\
16.7 \\
21.2 \\
22.0 \\
18.5 \\
14.8\end{array}$ & $\begin{array}{r}17.2 \\
16.9 \\
14.4 \\
14.4 \\
12.2 \\
11.7 \\
9.8 \\
7.9\end{array}$ & $\begin{array}{l}18.3 \\
18.1 \\
13.0 \\
17.0 \\
17.9 \\
17.9 \\
17.4 \\
16.8\end{array}$ & & $\begin{array}{r}13.3 \\
6.9 \\
6.8 \\
6.4 \\
7.2 \\
5.4 \\
2.4 \\
2.3\end{array}$ & $\begin{array}{r}16.8 \\
8.9 \\
8.1 \\
7.3 \\
8.2 \\
6.8 \\
3.5 \\
3.8\end{array}$ & $\begin{array}{r}19.1 \\
10.5 \\
10.0 \\
8.6 \\
9.4 \\
7.1 \\
4.0 \\
5.0\end{array}$ & $\begin{array}{r}21.3 \\
12.3 \\
12.1 \\
10.2 \\
11.1 \\
9.1 \\
5.4 \\
6.8\end{array}$ \\
\hline $\begin{array}{l}8 \\
8 \\
8 \\
8 \\
8 \\
8 \\
8 \\
8\end{array}$ & $\begin{array}{r}0 \\
3 \\
6 \\
9 \\
12 \\
15 \\
18 \\
21\end{array}$ & $\begin{array}{l}12.5 \\
11.1 \\
12.7 \\
18.0 \\
20.2 \\
20.4 \\
15.3 \\
10.8\end{array}$ & $\begin{array}{r}7.7 \\
6.8 \\
8.0 \\
11.4 \\
12.2 \\
12.8 \\
10.6 \\
8.4\end{array}$ & $\begin{array}{l}12.6 \\
11.7 \\
12.7 \\
17.7 \\
20.0 \\
20.2 \\
15.6 \\
11.5\end{array}$ & $\begin{array}{r}7.5 \\
6.8 \\
7.7 \\
10.9 \\
12.0 \\
12.4 \\
10.5 \\
8.5\end{array}$ & $\begin{array}{l}13.1 \\
12.1 \\
12.8 \\
17.6 \\
19.9 \\
20.1 \\
15.6 \\
12.3\end{array}$ & $\begin{array}{r}7.7 \\
7.0 \\
7.7 \\
10.8 \\
11.5 \\
12.0 \\
10.5 \\
8.7\end{array}$ & $\begin{array}{l}13.8 \\
12.2 \\
12.8 \\
17.6 \\
19.6 \\
19.9 \\
15.8 \\
12.7\end{array}$ & $\begin{array}{r}7.4 \\
6.8 \\
7.5 \\
10.5 \\
10.9 \\
11.5 \\
10.3 \\
8.7\end{array}$ & $\begin{array}{l}16.2 \\
15.5 \\
15.5 \\
16.3 \\
17.0 \\
16.8 \\
16.3 \\
15.8\end{array}$ & & $\begin{array}{r}3.0 \\
3.3 \\
5.7 \\
8.8 \\
10.3 \\
6.9 \\
2.4 \\
1.2\end{array}$ & $\begin{array}{r}3.9 \\
4.2 \\
6.7 \\
11.6 \\
13.3 \\
8.5 \\
3.2 \\
2.3\end{array}$ & $\begin{array}{r}5.8 \\
5.5 \\
9.4 \\
12.5 \\
15.4 \\
9.2 \\
4.4 \\
3.4\end{array}$ & $\begin{array}{r}6.8 \\
7.1 \\
10.0 \\
14.3 \\
17.0 \\
11.1 \\
6.2 \\
4.9\end{array}$ \\
\hline $\begin{array}{l}9 \\
9 \\
9 \\
9 \\
9 \\
9 \\
9 \\
9\end{array}$ & $\begin{array}{r}0 \\
3 \\
6 \\
9 \\
12 \\
12 \\
18 \\
21\end{array}$ & $\begin{array}{r}8.5 \\
7.5 \\
10.8 \\
18.1 \\
22.6 \\
22.6 \\
17.4 \\
15.4\end{array}$ & $\begin{array}{r}7.1 \\
6.3 \\
8.2 \\
12.2 \\
13.4 \\
13.6 \\
12.3 \\
11.6\end{array}$ & $\begin{array}{r}9.8 \\
8.4 \\
11.0 \\
17.8 \\
22.0 \\
22.4 \\
17.6 \\
15.6\end{array}$ & $\begin{array}{r}7.4 \\
6.5 \\
8.2 \\
12.0 \\
17.8 \\
13.3 \\
12.2 \\
11.5\end{array}$ & $\begin{array}{r}10.8 \\
9.6 \\
11.1 \\
17.7 \\
21.8 \\
22.2 \\
18.0 \\
15.7\end{array}$ & $\begin{array}{r}7.8 \\
7.0 \\
8.2 \\
11.8 \\
12.0 \\
13.3 \\
12.4 \\
11.6\end{array}$ & $\begin{array}{l}11.3 \\
10: 7 \\
11.4 \\
17.5 \\
21.2 \\
21.8 \\
18: 1 \\
15.7\end{array}$ & $\begin{array}{r}8.0 \\
7.4 \\
8.2 \\
11.1 \\
12.8 \\
13.4 \\
12.5 \\
11.6\end{array}$ & $\begin{array}{l}15.4 \\
15.0 \\
15.0 \\
16.4 \\
17.2 \\
17.2 \\
16.7 \\
16.3\end{array}$ & & $\begin{array}{l}1.3 \\
1.2 \\
3.6 \\
7.4 \\
8.00 \\
7.8 \\
5.6 \\
7.4\end{array}$ & $\begin{array}{l}1.7 \\
1.8 \\
4.4 \\
8.4 \\
9.1 \\
9.1 \\
6.9 \\
8.8\end{array}$ & $\begin{array}{r}2.7 \\
3.0 \\
5.7 \\
9.7 \\
10.2 \\
10.1 \\
8.6 \\
10.5\end{array}$ & $\begin{array}{r}4.4 \\
5.2 \\
7.2 \\
10.2 \\
11.2 \\
11.7 \\
10.7 \\
12.3\end{array}$ \\
\hline $\begin{array}{l}10 \\
10 \\
10 \\
10 \\
10 \\
10 \\
10 \\
10\end{array}$ & $\begin{array}{r}0 \\
3 \\
6 \\
9 \\
12 \\
15 \\
18 \\
21\end{array}$ & $\begin{array}{l}13.8 \\
12.5 \\
13.4 \\
17.8 \\
26.4 \\
24.0 \\
17.1 \\
14.3\end{array}$ & $\begin{array}{l}10.7 \\
10.0 \\
10.4 \\
12.3 \\
15.9 \\
16.3 \\
13.8 \\
11.9\end{array}$ & $\begin{array}{l}13.9 \\
12.6 \\
13.6 \\
17.5 \\
26.3 \\
23.7 \\
18.3 \\
16.3\end{array}$ & $\begin{array}{r}10.6 \\
9.9 \\
10.4 \\
12.1 \\
15.4 \\
15.9 \\
13.7 \\
12.3\end{array}$ & $\begin{array}{l}14.0 \\
12.7 \\
13.8 \\
17.6 \\
26.0 \\
23.7 \\
18.9 \\
17.2\end{array}$ & $\begin{array}{l}10.7 \\
10.0 \\
10.5 \\
12.4 \\
15.2 \\
15.7 \\
13.8 \\
12.7\end{array}$ & $\begin{array}{l}13.9 \\
12.7 \\
13.8 \\
17.1 \\
25.2 \\
23.4 \\
19.7 \\
19.2\end{array}$ & $\begin{array}{l}10.7 \\
10.0 \\
10.5 \\
12.2 \\
15.3 \\
15.4 \\
13.9 \\
12.9\end{array}$ & $\begin{array}{l}15.8 \\
15.3 \\
15.0 \\
15.2 \\
16.5 \\
16.5 \\
16.0 \\
16.0\end{array}$ & & $\begin{array}{r}7.5 \\
10.1 \\
9.2 \\
6.3 \\
7.0 \\
6.5 \\
1.5 \\
1.4\end{array}$ & $\begin{array}{r}10.0 \\
11.8 \\
10.7 \\
7.3 \\
8.1 \\
8.0 \\
2.4 \\
2.3\end{array}$ & $\begin{array}{r}11.7 \\
13.4 \\
12.4 \\
8.0 \\
9.1 \\
9.4 \\
3.0 \\
3.2\end{array}$ & $\begin{array}{r}13.8 \\
15.9 \\
14.0 \\
8.9 \\
10.1 \\
10.8 \\
4.2 \\
4.1\end{array}$ \\
\hline
\end{tabular}


TABLE 10

Table 10. - Three-hour averages of air and water-surface temperatures and wind directions and speed, April 1950-August 1951, Lake Hefner-Continued

STATION

THREE-HOURLY AVERAGES

OCTOBER, 1950

\begin{tabular}{|c|c|c|c|c|c|c|c|c|c|c|c|c|c|c|c|}
\hline \multirow{3}{*}{ 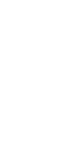 } & \multirow{3}{*}{ 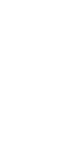 } & \multicolumn{8}{|c|}{ Average air temperature $\left({ }^{\circ} \mathrm{C}\right)$ at indicated height } & \multirow{3}{*}{$\begin{array}{l}\text { Average } \\
\text { water- } \\
\text { surface } \\
\text { tempera- } \\
\text { ture } \\
\left({ }^{\circ} \mathrm{C}\right)\end{array}$} & \multirow{3}{*}{$\begin{array}{c}\text { Average } \\
\text { wind } \\
\text { direction } \\
\text { (coded) }\end{array}$} & \multirow{2}{*}{\multicolumn{4}{|c|}{$\begin{array}{l}\text { Average wind speed (knots) } \\
\text { at indicated he ight }\end{array}$}} \\
\hline & & \multicolumn{2}{|c|}{$\begin{array}{c}2 \\
\text { meters }\end{array}$} & \multicolumn{2}{|c|}{$\begin{array}{c}4 \\
\text { meters }\end{array}$} & \multicolumn{2}{|c|}{\begin{tabular}{c|}
8 \\
meters
\end{tabular}} & \multicolumn{2}{|c|}{$\begin{array}{c}16 \\
\text { meters }\end{array}$} & & & & & & \\
\hline & & $\begin{array}{l}\text { Dry } \\
\text { bulb }\end{array}$ & $\begin{array}{l}\text { Wet } \\
\text { bulb }\end{array}$ & $\begin{array}{l}\text { Dry } \\
\text { bulb }\end{array}$ & $\begin{array}{l}\text { Wet } \\
\text { bulb }\end{array}$ & $\begin{array}{l}\text { Dry } \\
\text { bulb }\end{array}$ & $\begin{array}{l}\text { Wet } \\
\text { bulb }\end{array}$ & $\begin{array}{l}\text { Dry } \\
\text { bulb }\end{array}$ & $\begin{array}{l}\text { Wet } \\
\text { bulb }\end{array}$ & & & $\begin{array}{c}2 \\
\text { meters }\end{array}$ & $\begin{array}{c}4 \\
\text { meters }\end{array}$ & $\begin{array}{c}8 \\
\text { meters }\end{array}$ & $\begin{array}{c}16 \\
\text { meters }\end{array}$ \\
\hline $\begin{array}{l}11 \\
11 \\
11 \\
11 \\
11 \\
11 \\
11 \\
11\end{array}$ & $\begin{array}{r}0 \\
3 \\
6 \\
9 \\
12 \\
15 \\
18 \\
21\end{array}$ & $\begin{array}{l}13.4 \\
12.7 \\
15.1 \\
21.9 \\
29.1 \\
30.7 \\
22.5 \\
20.0\end{array}$ & $\begin{array}{l}11.7 \\
11: 3 \\
13: 1 \\
15.2 \\
17.4 \\
17.6 \\
18.1 \\
14.6\end{array}$ & $\begin{array}{l}14.2 \\
13.0 \\
15.1 \\
22.4 \\
28.9 \\
30.2 \\
23.0 \\
20.1\end{array}$ & $\begin{array}{l}11.9 \\
11: 4 \\
13: 0 \\
15: 6 \\
17.3 \\
17.3 \\
16: 3 \\
14: 3\end{array}$ & $\begin{array}{l}15.1 \\
13.4 \\
15.0 \\
22.5 \\
20.0 \\
30.5 \\
23.5 \\
20.3\end{array}$ & $\begin{array}{l}12.1 \\
11.6 \\
12.6 \\
15.5 \\
17.4 \\
17.5 \\
16.0 \\
14.2\end{array}$ & $\begin{array}{l}15.8 \\
13.7 \\
14.6 \\
21.8 \\
39.1 \\
30.3 \\
24.1 \\
20.2\end{array}$ & $\begin{array}{l}17 \cdot 3 \\
11.8 \\
12.5 \\
15.6 \\
17.5 \\
17.4 \\
16.0 \\
14.0\end{array}$ & $\begin{array}{l}15.8 \\
15.7 \\
15.8 \\
17.0 \\
19.5 \\
20.0 \\
19.1 \\
17.8\end{array}$ & & $\begin{array}{l}1.3 \\
0.8 \\
1.5 \\
2.4 \\
1.8 \\
1.9 \\
4.5\end{array}$ & $\begin{array}{l}1.8 \\
1.22 \\
1.8 \\
2.5 \\
2.3 \\
1.5 \\
2.5 \\
5.8\end{array}$ & $\begin{array}{l}2.3 \\
1.5 \\
1.9 \\
2.6 \\
2.4 \\
2.0 \\
3.4 \\
7.1\end{array}$ & $\begin{array}{l}4.0 \\
2.9 \\
2.8 \\
3.8 \\
1.05 \\
3.00 \\
4.44 \\
8.8\end{array}$ \\
\hline $\begin{array}{l}12 \\
12 \\
12 \\
12 \\
12 \\
12 \\
12 \\
12\end{array}$ & $\begin{array}{r}0 \\
3 \\
6 \\
9 \\
12 \\
15 \\
18 \\
21\end{array}$ & $\begin{array}{l}15.5 \\
12.9 \\
14.9 \\
23.5 \\
27.5 \\
26.2 \\
18.4 \\
16.1\end{array}$ & $\begin{array}{l}12.6 \\
10.6 \\
11.3 \\
13.3 \\
14.5 \\
14.4 \\
12.0 \\
11.4\end{array}$ & $\begin{array}{l}16.3 \\
14.2 \\
14.9 \\
23.0 \\
26.8 \\
25.9 \\
19.1 \\
16.4\end{array}$ & $\begin{array}{l}12.7 \\
11.2 \\
11.1 \\
12.7 \\
13.8 \\
13.9 \\
12.0 \\
11.3\end{array}$ & $\begin{array}{l}17.0 \\
14.9 \\
15.2 \\
22.7 \\
26.6 \\
25.9 \\
19.9 \\
16.8\end{array}$ & $\begin{array}{l}13.1 \\
11: 6 \\
11.4 \\
12.6 \\
13.7 \\
14: 0 \\
12.3 \\
11.5\end{array}$ & $\begin{array}{l}17.0 \\
15.0 \\
15.4 \\
22.5 \\
25.7 \\
25.8 \\
20.4 \\
17.2\end{array}$ & $\begin{array}{l}12.7 \\
11.2 \\
11.2 \\
12.6 \\
13.7 \\
14.0 \\
12.5 \\
11.8\end{array}$ & $\begin{array}{l}17.0 \\
16.7 \\
16.7 \\
17.6 \\
16.6 \\
15.4 \\
15.0 \\
14.8\end{array}$ & & $\begin{array}{l}3.1 \\
0.8 \\
2.5 \\
5.0 \\
4.4 \\
4.8 \\
3.4 \\
5.1\end{array}$ & $\begin{array}{l}1.4 \\
0.7 \\
1.9 \\
7.0 \\
6.1 \\
5.9 \\
4.8 \\
6.5\end{array}$ & $\begin{array}{l}1.8 \\
1.0 \\
2.4 \\
8.3 \\
6.5 \\
6.9 \\
6.6 \\
8.5\end{array}$ & $\begin{array}{l}2.3 \\
1.7 \\
2.9 \\
8.9 \\
7.0\end{array}$ \\
\hline $\begin{array}{l}13 \\
13 \\
13 \\
13 \\
13 \\
13 \\
13 \\
13\end{array}$ & $\begin{array}{r}0 \\
3 \\
6 \\
9 \\
12 \\
15 \\
18 \\
21\end{array}$ & $\begin{array}{l}15.8 \\
14.6 \\
15.9 \\
24.3 \\
28.9 \\
28.7 \\
23 \cdot 1 \\
20.0\end{array}$ & $\begin{array}{l}11.3 \\
10.7 \\
11.3 \\
15.3 \\
18.2 \\
18.6 \\
16.9 \\
15.3\end{array}$ & $\begin{array}{l}15.0 \\
14.8 \\
16.1 \\
23.7 \\
28.6 \\
28.5 \\
23.2 \\
20.1\end{array}$ & $\begin{array}{l}11.2 \\
10.5 \\
11.0 \\
14: 9 \\
18.0 \\
18.4 \\
16.8 \\
15.5\end{array}$ & $\begin{array}{l}16.1 \\
15.0 \\
16.1 \\
23.4 \\
28.4 \\
23.3 \\
23.4 \\
20.2\end{array}$ & $\begin{array}{l}11.3 \\
10.7 \\
11.3 \\
15.2 \\
17.8 \\
13.2 \\
16.7 \\
15.2\end{array}$ & $\begin{array}{l}16.1 \\
14.9 \\
16.1 \\
23.3 \\
27.9 \\
28.0 \\
23.3 \\
20.0\end{array}$ & $\begin{array}{l}11.4 \\
10.7 \\
1=.3 \\
15.0 \\
18.0 \\
13.5 \\
16.9 \\
19.3\end{array}$ & $\begin{array}{l}14.5 \\
14.1 \\
14.0 \\
17.5 \\
18.8 \\
18.1 \\
17.0 \\
16.7\end{array}$ & & $\begin{array}{r}5.2 \\
8.5 \\
9.1 \\
13.0 \\
12.3 \\
9.6 \\
7.5 \\
10.3\end{array}$ & $\begin{array}{r}7.6 \\
9.9 \\
10.9 \\
15.0 \\
13.0 \\
10.9 \\
9.1 \\
12.1\end{array}$ & $\begin{array}{r}9.1 \\
12.8 \\
12.4 \\
16.8 \\
1406 \\
12.5 \\
10.8 \\
13.9\end{array}$ & $\begin{array}{l}18.8 \\
15.5 \\
13.8 \\
12.3 \\
16.1\end{array}$ \\
\hline $\begin{array}{l}14 \\
14 \\
14 \\
14 \\
14 \\
14 \\
14 \\
14\end{array}$ & $\begin{array}{r}0 \\
3 \\
6 \\
9 \\
12 \\
15 \\
18 \\
21\end{array}$ & $\begin{array}{l}18.2 \\
17.9 \\
18.8 \\
25.5 \\
31.3 \\
30.8 \\
23.3 \\
21.0\end{array}$ & $\begin{array}{l}14.5 \\
14.0 \\
14.5 \\
17.1 \\
18.6 \\
18.4 \\
16.2 \\
15.7 .\end{array}$ & $\begin{array}{l}18.3 \\
18.0 \\
18.9 \\
25.6 \\
31.1 \\
30.6 \\
23.9 \\
21.1\end{array}$ & & $\begin{array}{l}18.4 \\
21.8 \\
19.1 \\
25.5 \\
31.0 \\
30.5 \\
24.1 \\
71.2\end{array}$ & $\begin{array}{l}14 \cdot 4 \\
14.0 \\
14.5 \\
16.9 \\
19.2 \\
18.1 \\
16.1 \\
15.7\end{array}$ & $\begin{array}{l}18.3 \\
18.1 \\
19.1 \\
25.3 \\
30.3 \\
30.3 \\
24.6 \\
21.2\end{array}$ & $\begin{array}{l}14.5 \\
14.0 \\
14.6 \\
17.1 \\
19.4 \\
18.5 \\
16.7 \\
15.9\end{array}$ & $\begin{array}{l}16.4 \\
16.4 \\
16.8 \\
13.2 \\
18.9 \\
17.8 \\
16.7 \\
16.5\end{array}$ & & $\begin{array}{r}9.7 \\
9.8 \\
11.7 \\
10.6 \\
10.0 \\
7.9 \\
5.5 \\
8.3\end{array}$ & $\begin{array}{r}11.4 \\
11.4 \\
12.9 \\
12.0 \\
11.2 \\
9.0 \\
6.7 \\
9.9\end{array}$ & $\begin{array}{l}13.1 \\
13.2 \\
14.8 \\
13.6 \\
12.8 \\
10.5 \\
0.1 \\
11.6\end{array}$ & $\begin{array}{l}15.4 \\
15.4 \\
17.0 \\
14.7 \\
13.5 \\
11.7 \\
11.8 \\
14.0\end{array}$ \\
\hline $\begin{array}{l}15 \\
15 \\
15 \\
15 \\
15 \\
15 \\
15 \\
15\end{array}$ & $\begin{array}{r}0 \\
3 \\
6 \\
9 \\
12 \\
15 \\
18 \\
21\end{array}$ & $\begin{array}{l}18.3 \\
17.0 \\
17.1 \\
24.5 \\
29.1 \\
28.4 \\
23.6 \\
20.8\end{array}$ & $\begin{array}{l}14.9 \\
13.3 \\
13.2 \\
16.6 \\
18.0 \\
17.9 \\
16.6 \\
14.7\end{array}$ & $\begin{array}{l}18.5 \\
17.2 \\
17.2 \\
24.3 \\
29.0 \\
28.3 \\
23.7 \\
20.8\end{array}$ & $\begin{array}{l}16.9 \\
17.4 \\
17.5 \\
16.4 \\
14.5\end{array}$ & $\begin{array}{l}18.6 \\
17.3 \\
17.4 \\
24.1 \\
28.7 \\
28.1 \\
23.9 \\
21.8\end{array}$ & $\begin{array}{l}14.8 \\
13.2 \\
13.3 \\
16.2 \\
17.4 \\
17.7 \\
16.4 \\
14.6\end{array}$ & $\begin{array}{l}18.5 \\
17.3 \\
17.3 \\
23.0 \\
28.1 \\
77.9 \\
23.0 \\
21.7\end{array}$ & $\begin{array}{l}14.9 \\
13.3 \\
13.4 \\
16.6 \\
17.9 \\
18.2 \\
16.7 \\
14.0\end{array}$ & $\begin{array}{l}16.5 \\
16.3 \\
16.6 \\
17.9 \\
18.5 \\
17.7 \\
16.7 \\
16.4\end{array}$ & & $\begin{array}{r}7.5 \\
8.3 \\
8.5 \\
9.1 \\
11.3 \\
9.9 \\
7.3 \\
10.0\end{array}$ & $\begin{array}{r}9.0 \\
9.9 \\
10.0 \\
10.3 \\
13.2 \\
11.6 \\
8.9 \\
11.9\end{array}$ & $\begin{array}{l}10.6 \\
11.5 \\
11.7 \\
11.4 \\
14.5 \\
13.2 \\
10.5 \\
13.6\end{array}$ & $\begin{array}{l}12.9 \\
13.7 \\
13.3 \\
12.3 \\
15.8 \\
14.8 \\
12.2 \\
15.7\end{array}$ \\
\hline $\begin{array}{l}16 \\
16 \\
16 \\
16 \\
16 \\
16 \\
16 \\
16\end{array}$ & $\begin{array}{r}0 \\
3 \\
6 \\
9 \\
12 \\
15 \\
18 \\
21\end{array}$ & $\begin{array}{l}18.8 \\
16.5 \\
16.9 \\
24.8 \\
28.6 \\
27.2 \\
22.3 \\
16.6\end{array}$ & $\begin{array}{l}13.6 \\
13.2 \\
13.6 \\
16.0 \\
17.0 \\
16.0 \\
14.1 \\
12.9\end{array}$ & $\begin{array}{l}18.9 \\
16.7 \\
17.0 \\
24.6 \\
28.1 \\
27.0 \\
22.3 \\
17.3\end{array}$ & $\begin{array}{l}13.4 \\
13.0 \\
13.6 \\
16.6 \\
26.5 \\
15.6 \\
14.0 \\
13.0\end{array}$ & $\begin{array}{l}18.9 \\
16.8 \\
17.3 \\
25.1 \\
28.0 \\
27.0 \\
27.3 \\
17.9\end{array}$ & $\begin{array}{l}13.5 \\
13.1 \\
13.7 \\
16.5 \\
16.4 \\
15.5 \\
14.0 \\
13.1\end{array}$ & $\begin{array}{l}18.8 \\
16.8 \\
17.3 \\
22.5 \\
27.4 \\
26.0 \\
22.3 \\
18.5\end{array}$ & $\begin{array}{l}13.9 \\
13.4 \\
13.9 \\
17.0 \\
17.1 \\
16.3 \\
14.7 \\
13.9\end{array}$ & $\begin{array}{l}16.2 \\
16.0 \\
16.1 \\
18.9 \\
19.8 \\
18.5 \\
17.7 \\
17.3\end{array}$ & & $\begin{array}{r}9.6 \\
8.0 \\
0.4 \\
14.1 \\
11.9 \\
9.8 \\
8.1 \\
3.8\end{array}$ & $\begin{array}{r}11.5 \\
9.5 \\
11.1 \\
16.1 \\
13.6 \\
11.6 \\
9.8 \\
5.3\end{array}$ & $\begin{array}{r}13.1 \\
11.0 \\
12.6 \\
18.1 \\
15.2 \\
13.2 \\
11.5 \\
6.8\end{array}$ & $\begin{array}{r}15.1 \\
13.1 \\
14.4 \\
20.2 \\
16.7 \\
14.7 \\
13.5 \\
3.6\end{array}$ \\
\hline $\begin{array}{l}17 \\
17 \\
17 \\
17 \\
17 \\
17 \\
17 \\
17\end{array}$ & $\begin{array}{r}0 \\
3 \\
6 \\
9 \\
12 \\
15 \\
18 \\
21\end{array}$ & $\begin{array}{l}16.1 \\
15.7 \\
16.7 \\
24.6 \\
28.6 \\
27.9 \\
20.3 \\
18.8\end{array}$ & $\begin{array}{l}13.0 \\
13.0 \\
13.5 \\
16.8 \\
18.1 \\
17.7 \\
15.3 \\
14.5\end{array}$ & $\begin{array}{l}16.2 \\
15.9 \\
16.9 \\
24.6 \\
28.3 \\
27.8 \\
21.5 \\
19.3\end{array}$ & $\begin{array}{l}12.9 \\
12.9 \\
13.4 \\
16.5 \\
17.7 \\
17.4 \\
15.5 \\
14.6\end{array}$ & $\begin{array}{l}16.5 \\
16.2 \\
17.0 \\
24.4 \\
28.1 \\
27.7 \\
22.7 \\
19.9\end{array}$ & $\begin{array}{l}13.0 \\
13.0 \\
13.5 \\
16.5 \\
17.6 \\
17.4 \\
15.0 \\
14.8\end{array}$ & $\begin{array}{l}16.9 \\
16.4 \\
17.2 \\
24 \cdot 1 \\
27.4 \\
27.3 \\
23.6 \\
20.5\end{array}$ & $\begin{array}{l}13.5 \\
13 \cdot 3 \\
13.8 \\
17.1 \\
15 \cdot 3 \\
19 \cdot 2 \\
16.7 \\
15.5\end{array}$ & $\begin{array}{l}17.0 \\
16.7 \\
17.0 \\
18.5 \\
19.8 \\
19.8 \\
17.8 \\
17.5\end{array}$ & & $\begin{array}{l}5.3 \\
6.4 \\
8.2 \\
9.4 \\
7.8 \\
4.9 \\
3.3 \\
3.9\end{array}$ & $\begin{array}{r}6.8 \\
7.8 \\
0.7 \\
10.8 \\
8.8 \\
6.0 \\
5.1 \\
5.3\end{array}$ & $\begin{array}{r}9.4 \\
9.4 \\
11.2 \\
12.0 \\
0.7 \\
7.0 \\
6.8 \\
7.2\end{array}$ & $\begin{array}{l}10.5 \\
11.3 \\
12.9 \\
13.1 \\
10.1 \\
7.6 \\
8.7 \\
9.5\end{array}$ \\
\hline $\begin{array}{l}18 \\
18 \\
18 \\
18 \\
18 \\
18 \\
18 \\
18\end{array}$ & $\begin{array}{r}0 \\
3 \\
6 \\
9 \\
12 \\
15 \\
18 \\
21\end{array}$ & $\begin{array}{l}16.7 \\
14.8 \\
15.4 \\
24.0 \\
26.6 \\
23.6 \\
19.0 \\
16.1\end{array}$ & $\begin{array}{l}13.0 \\
13.1 \\
13.6 \\
17.0 \\
17.0 \\
16.9 \\
15.9 \\
14.8\end{array}$ & $\begin{array}{l}17.0 \\
15.3 \\
15.7 \\
24: 5 \\
26.1 \\
23.8 \\
19.4 \\
17.0\end{array}$ & $\begin{array}{l}13.8 \\
13.1 \\
13.6 \\
16.9 \\
16.5 \\
16.8 \\
15.9 \\
14.8\end{array}$ & $\begin{array}{l}17.3 \\
15.6 \\
15.5 \\
23.0 \\
26.1 \\
23.3 \\
10.8 \\
17.7\end{array}$ & $\begin{array}{l}13.9 \\
13.2 \\
14.0 \\
16.7 \\
16.4 \\
16.7 \\
16.0 \\
20.0\end{array}$ & $\begin{array}{l}19.1 \\
16.2 \\
17.2 \\
23.5 \\
25.5 \\
23.3 \\
20.3 \\
13.5\end{array}$ & $\begin{array}{l}14.6 \\
13.7 \\
14.5 \\
17.1 \\
17.0 \\
17.2 \\
16.4 \\
15.6\end{array}$ & $\begin{array}{l}37.1 \\
17.1 \\
17.5 \\
10.7 \\
20.2 \\
18.9 \\
18.6 \\
13.3\end{array}$ & & $\begin{array}{l}4.5 \\
2.44 \\
3.3 \\
5.3 \\
4.6 \\
4.7 \\
1.5 \\
1.1\end{array}$ & $\begin{array}{l}5.9 \\
3.3 \\
3.9 \\
5.0 \\
5.4 \\
5.8 \\
2.5 \\
1.7\end{array}$ & $\begin{array}{l}7.8 \\
4.9 \\
4.9 \\
6.6 \\
5.9 \\
6.9 \\
3.8 \\
2.7\end{array}$ & $\begin{array}{r}10.5 \\
7.1 \\
6.2 \\
6.7 \\
5.8 \\
7.8 \\
5.1 \\
3.6\end{array}$ \\
\hline $\begin{array}{l}19 \\
19 \\
19 \\
19 \\
19 \\
19 \\
19 \\
19\end{array}$ & $\begin{array}{r}0 \\
3 \\
6 \\
9 \\
12 \\
15 \\
18 \\
21\end{array}$ & $\begin{array}{l}15.8 \\
15.5 \\
16.1 \\
18.5 \\
22.5 \\
22.0 \\
19.4 \\
18.4\end{array}$ & $\begin{array}{l}14.5 \\
14.3 \\
14.7 \\
15.5 \\
17.0 \\
16.6 \\
16.4 \\
14.9\end{array}$ & $\begin{array}{l}16.3 \\
16.1 \\
16.3 \\
18.6 \\
22.4 \\
22.1 \\
20.1 \\
18.6\end{array}$ & $\begin{array}{l}14.6 \\
14.3 \\
14.5 \\
15.2 \\
16.1 \\
16.1 \\
16.2 \\
14.6\end{array}$ & $\begin{array}{l}16.9 \\
17.0 \\
16.4 \\
18.6 \\
22.7 \\
22.7 \\
20.3 \\
18.7\end{array}$ & $\begin{array}{l}14 \cdot 8 \\
14: 5 \\
14: 5 \\
15: 3 \\
16: 0 \\
15: 8 \\
16: 1 \\
14.5\end{array}$ & $\begin{array}{l}17.5 \\
17: 7 \\
16: 3 \\
18: 3 \\
22: 5 \\
23.5 \\
20.5 \\
18.5\end{array}$ & $\begin{array}{l}15.0 \\
14.0 \\
14.0 \\
15.5 \\
16.0 \\
15.6 \\
15.6 \\
14.5\end{array}$ & $\begin{array}{l}18.0 \\
17.8 \\
13.0 \\
18.7 \\
19.1 \\
17.4 \\
17.0 \\
16.8\end{array}$ & & $\begin{array}{l}0.7 \\
1.1 \\
1.0 \\
2.8 \\
2.1 \\
2.7 \\
1.0 \\
1.6\end{array}$ & $\begin{array}{l}1.0 \\
2.2 \\
2.3 \\
3.3 \\
2.6 \\
3.7 \\
1.8 \\
2.3\end{array}$ & $\begin{array}{l}1.7 \\
3.3 \\
3.2 \\
4.0 \\
3.1 \\
4.9 \\
3.0 \\
7.8\end{array}$ & $\begin{array}{l}3.0 \\
4.4 \\
3.3 \\
4.0 \\
3.3 \\
5.3 \\
4.2 \\
3.1\end{array}$ \\
\hline $\begin{array}{l}20 \\
20 \\
20 \\
20 \\
20 \\
20 \\
20 \\
20\end{array}$ & $\begin{array}{r}0 \\
3 \\
6 \\
9 \\
12 \\
15 \\
18 \\
21\end{array}$ & $\begin{array}{l}16.0 \\
16.0 \\
15.0 \\
17.6 \\
21.1 \\
20.4 \\
17.2 \\
15.4\end{array}$ & $\begin{array}{l}13.1 \\
13.1 \\
12.9 \\
14 \bullet 1 \\
15.9 \\
15.2 \\
14.11 \\
11.9\end{array}$ & $\begin{array}{l}16.6 \\
16.0 \\
15.0 \\
17.5 \\
21.1 \\
20.4 \\
17.8 \\
15.6\end{array}$ & $\begin{array}{l}13.0 \\
12.9 \\
12.7 \\
13.8 \\
15.8 \\
15.1 \\
13.9 \\
11.8\end{array}$ & $\begin{array}{l}17.1 \\
15.0 \\
15.0 \\
17.3 \\
21.0 \\
20.7 \\
18.2 \\
15.8\end{array}$ & $\begin{array}{l}13.0 \\
12.0 \\
12.7 \\
13.0 \\
15.5 \\
14.8 \\
13.9 \\
11.6\end{array}$ & $\begin{array}{l}17.0 \\
15.7 \\
14: 8 \\
17: 5 \\
21: 2 \\
20.8 \\
18.5 \\
15.8\end{array}$ & $\begin{array}{l}13.3 \\
12.9 \\
12.7 \\
13.8 \\
15.3 \\
14.8 \\
13.9 \\
11.6\end{array}$ & $\begin{array}{l}16.4 \\
16.0 \\
15.9 \\
18.0 \\
19.0 \\
18.7 \\
19.2 \\
17.9\end{array}$ & & $\begin{array}{l}1.3 \\
4.0 \\
4.5 \\
3.2 \\
3.1 \\
2.0 \\
0.7 \\
0.9\end{array}$ & $\begin{array}{l}2.0 \\
5.2 \\
5.7 \\
3.7 \\
3.8 \\
2.6 \\
1.3 \\
1.2\end{array}$ & $\begin{array}{l}5.11 \\
6.0 \\
6.2 \\
4.1 \\
4.8 \\
4.0 \\
1.8 \\
1.9\end{array}$ & $\begin{array}{l}3.5 \\
6.3 \\
6.5 \\
4.4 \\
5.1 \\
5.4 \\
2.0 \\
2.7\end{array}$ \\
\hline
\end{tabular}


TABLE 10

Table 10. -Three-hour averages of air and water-surface temperatures and wind directions and speed, April 1950-August STATION 2 1951, Lake Hefner-Continued

THREE-HOURLY AVERAGES

OCTOBER, 1950

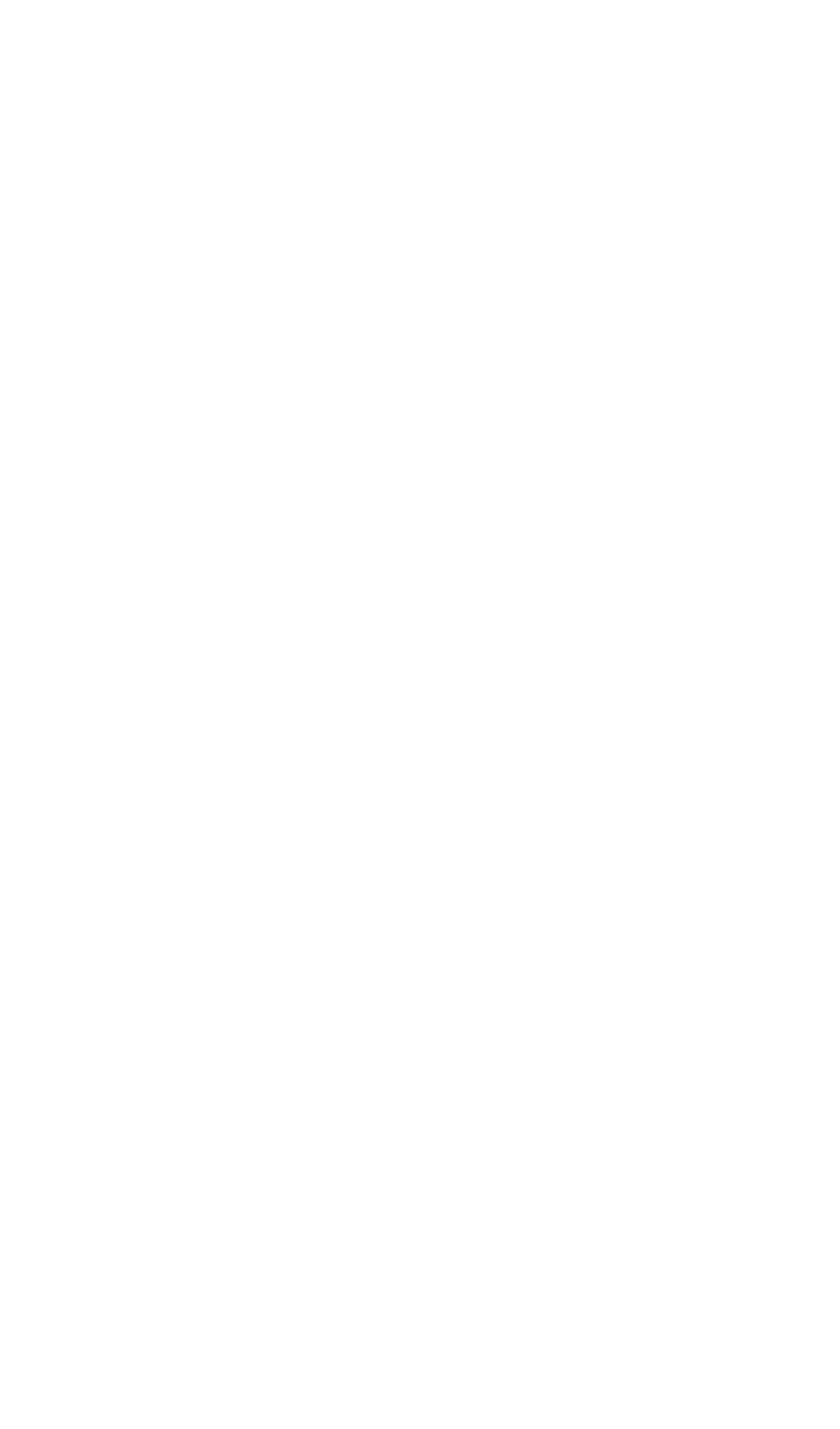


TABLE 10

Table 10. - Three-hour averages of air and water-surface temperatures and wind directions and speed, April 1950-August 1951, Lake Hefner-Continued

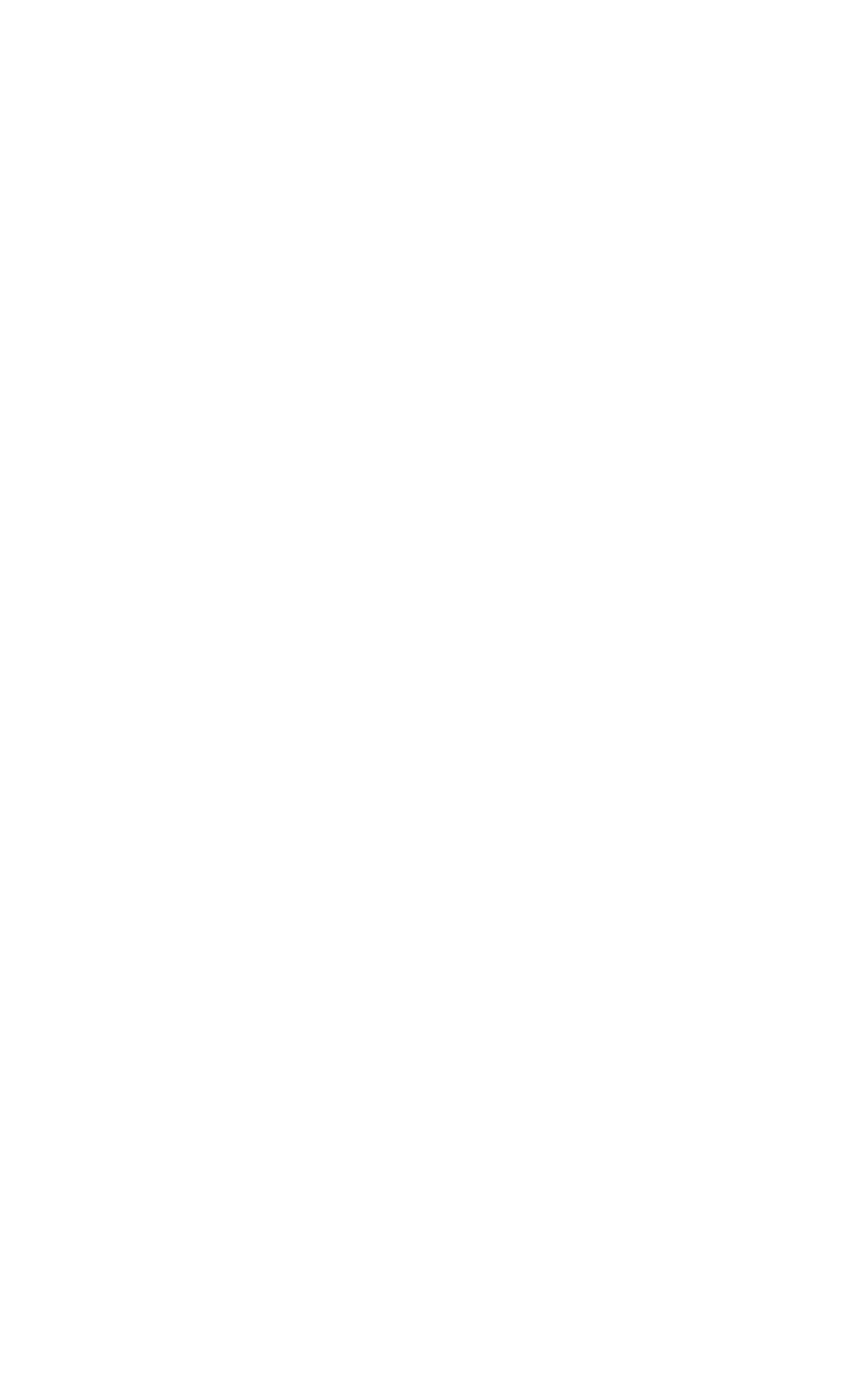


TABLE 10

Table 10, - Three-hour averages of air and water-surface temperatures and wind directions and speed, April 1950-August 1951, Lake Hefner-Continued

STATION 2 THREE-HOURLY AVERAGES

NOVEMBER, 1950

\begin{tabular}{|c|c|c|c|c|c|c|c|c|c|c|c|c|c|c|c|}
\hline \multirow{4}{*}{ 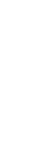 } & \multirow{4}{*}{ 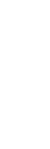 } & \multicolumn{8}{|c|}{ Average air temperature $\left({ }^{\circ} \mathrm{C}\right)$ at indicated height } & \multirow{4}{*}{$\begin{array}{l}\text { Average } \\
\text { water- } \\
\text { surface } \\
\text { tempera- } \\
\text { ture } \\
\text { ("C) }\end{array}$} & \multirow{4}{*}{$\begin{array}{l}\text { Average } \\
\text { wind } \\
\text { direction } \\
\text { (coded) }\end{array}$} & \multirow{2}{*}{\multicolumn{4}{|c|}{$\begin{array}{l}\text { Average wind speed (knots) } \\
\text { at indicated height }\end{array}$}} \\
\hline & & \multirow{2}{*}{\multicolumn{2}{|c|}{$\begin{array}{c}2 \\
\text { meters }\end{array}$}} & \multirow{2}{*}{\multicolumn{2}{|c|}{$\begin{array}{c}4 \\
\text { meters }\end{array}$}} & \multirow{2}{*}{\multicolumn{2}{|c|}{$\begin{array}{c}8 \\
\text { meters }\end{array}$}} & \multirow{2}{*}{\multicolumn{2}{|c|}{$\begin{array}{c}16 \\
\text { meters }\end{array}$}} & & & & & & \\
\hline & & & & & & & & & & & & 2 & 4 & 8 & 16 \\
\hline & & $\begin{array}{l}\text { Dry } \\
\text { bulb }\end{array}$ & $\begin{array}{l}\text { Wet } \\
\text { bulb }\end{array}$ & $\begin{array}{l}\text { Dry } \\
\text { bulb }\end{array}$ & $\begin{array}{l}\text { Wet } \\
\text { bulb }\end{array}$ & $\begin{array}{l}\text { Dry } \\
\text { bulb }\end{array}$ & $\begin{array}{l}\text { Wet } \\
\text { bulb }\end{array}$ & & & & & & & & \\
\hline
\end{tabular}

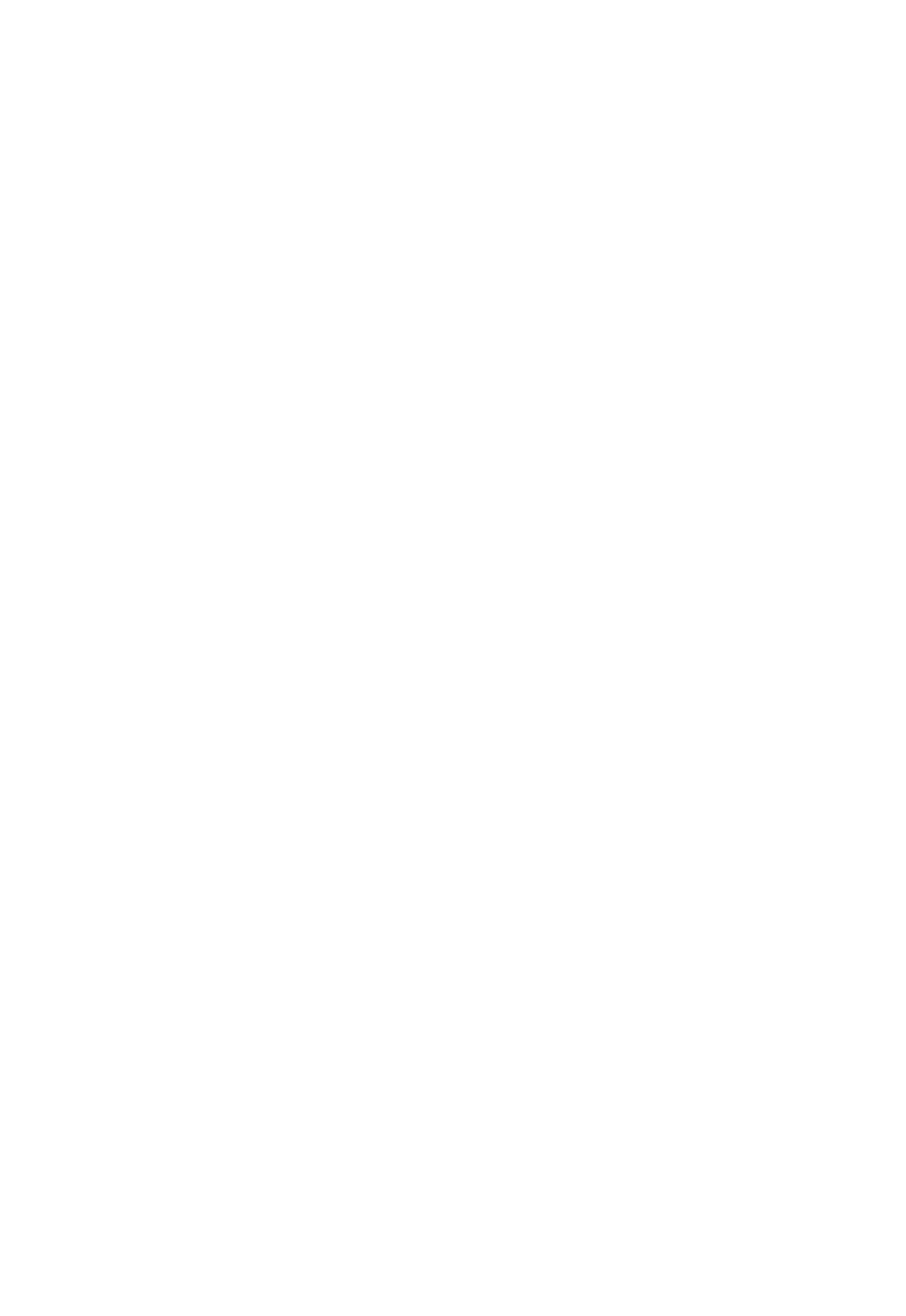


TABLE 10

Table 10, - Three-hour averages of air and water-surface temperatures and wind directions and speed, April 1950-August 1951, Lake Hefner-Continued

STATION 2 THREE-HOURLY AVERAGES

NOVEMBER, 1950

\begin{tabular}{|c|c|c|c|c|c|c|c|c|c|c|c|c|c|c|c|}
\hline \multirow{4}{*}{ 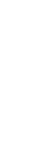 } & \multirow{4}{*}{ 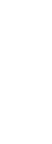 } & \multicolumn{8}{|c|}{ Average air temperature $\left({ }^{\circ} \mathrm{C}\right)$ at indicated height } & \multirow{4}{*}{$\begin{array}{l}\text { Average } \\
\text { water- } \\
\text { surface } \\
\text { tempera- } \\
\text { ture } \\
\left({ }^{\circ} \mathrm{C}\right)\end{array}$} & \multirow{4}{*}{$\begin{array}{c}\text { Average } \\
\text { wind } \\
\text { direction } \\
\text { (coded) }\end{array}$} & \multirow{2}{*}{\multicolumn{4}{|c|}{$\begin{array}{l}\text { Average wind speed (knots) } \\
\text { at indicated height }\end{array}$}} \\
\hline & & \multirow{2}{*}{\multicolumn{2}{|c|}{$\stackrel{2}{\text { meters }}$}} & \multirow{2}{*}{\multicolumn{2}{|c|}{$\begin{array}{c}4 \\
\text { meters }\end{array}$}} & \multirow{2}{*}{\multicolumn{2}{|c|}{$\begin{array}{c}\mathbf{8} \\
\text { meters }\end{array}$}} & \multirow{2}{*}{\multicolumn{2}{|c|}{$\begin{array}{c}16 \\
\text { meters }\end{array}$}} & & & & & & \\
\hline & & & & & & & & & & & & 2 & 4 & 8 & 16 \\
\hline & & $\begin{array}{l}\text { Dry } \\
\text { bulb }\end{array}$ & $\begin{array}{l}\text { Wet } \\
\text { bulb }\end{array}$ & $\begin{array}{l}\text { Dry } \\
\text { buIb }\end{array}$ & $\begin{array}{l}\text { Wet } \\
\text { bulb }\end{array}$ & $\begin{array}{l}\text { Dry } \\
\text { bulb }\end{array}$ & $\begin{array}{l}\text { Wet } \\
\text { bulb }\end{array}$ & $\begin{array}{l}\text { Dry } \\
\text { bulb }\end{array}$ & $\begin{array}{l}\text { Wet } \\
\text { bulb }\end{array}$ & & & & meters & & \\
\hline
\end{tabular}

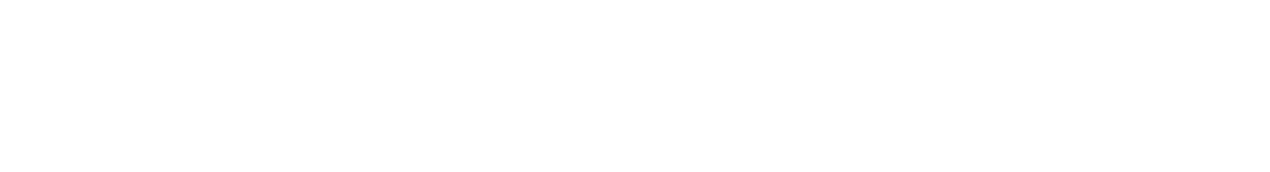

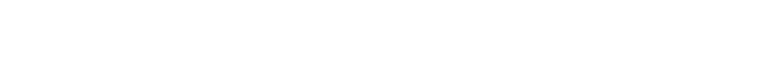

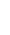

23

23

24

25
25
25
25
25
26
26

21

$9.0 \quad 406$

\begin{tabular}{ll|l|}
3 & 7.8 & 4.9 \\
6 & 6.2 & 4.7
\end{tabular}

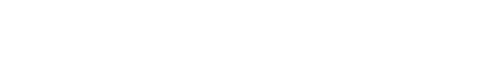

\begin{tabular}{lll|l|l|l|l|l|l}
15 & 17.5 & 9.5 & 17.4 & 9.1 & 17.1 & 9.1 & 16.0 \\
\hline & 9.0 & 17.6 & 8.6 & 18.2 & 8.8 & 18.3
\end{tabular}

\begin{tabular}{|ll|l|l|l|l|l|l|}
21 & 8.9 & 4.1 & 10.8 & 4.9 & 14.1 & 6.3 & 15.9 \\
& & 4.3 & 10.2 & 4.6 & 11.1 & 5.0 & 13.1
\end{tabular}

\begin{tabular}{rr|r|r|r|r|r|r}
0 & 10.5 & 4.9 & 10.9 & 5.0 & 11.4 & 5.1 & 11.6 \\
3 & 11.0 & 5.6 & 11.0 & 5.6 & 11.1 & 5.6 & 11.3 \\
6 & 4.4 & 2.5 & 3.9 & 2.1 & 3.7 & 3.6 & 3.4
\end{tabular}

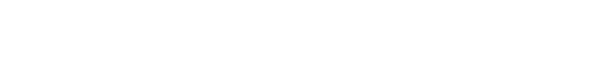

\begin{tabular}{ll|l}
18 & -50 \\
21 & -50
\end{tabular}

$\begin{array}{ll}0 & =6.1 \\ 3 & =6.4\end{array}$

4 \begin{tabular}{r|r}
9 & -4.4 \\
12 & 0.1
\end{tabular}

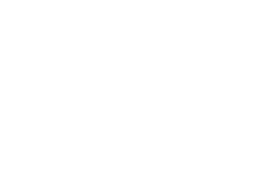

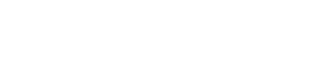

.

5.6
6.8
-7.7

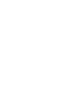

\begin{tabular}{|rr|r|r|r|r|r|r|r|}
15 & 11.7 & 6.3 & 11.9 & 5.9 & 13.0 & 4.4 & 12.7 & \\
18 & 7.8 & 4.0 & 8.2 & 4.3 & 8.5 & 5.6 & 12.5 & 5.7 \\
21 & 5.5 & 2.7 & 5.7 & 2.7 & 5.6 & 2.8 & 8.7 & 3.1 \\
& & & & & & & &
\end{tabular}

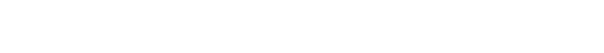

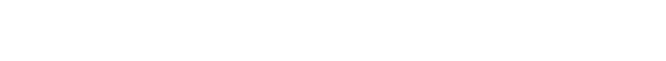

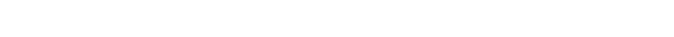

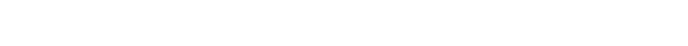

$27 \quad 0 \quad 0.0-1.8 \quad 1.0-0.9 \quad 3.1-0.3$

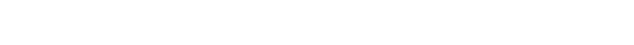

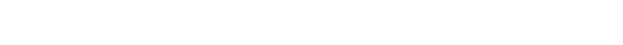

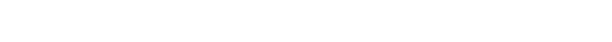

28

28
28

29

29
29
29
29

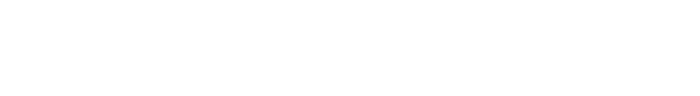

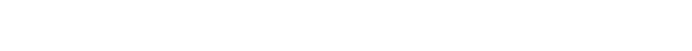

\begin{tabular}{rr|r|r|r|r|r|r|r|r|}
29 & 18 & 6.2 & 2.7 & 8.6 & 3.6 & 9.7 & 3.8 & 10.3 & 4.4 \\
29 & 21 & 3.6 & 0.9 & 4.7 & 1.4 & 5.5 & 1.8 & 7.2 & 2.9
\end{tabular}

\begin{tabular}{lll|l|l|l|l|l|l|l|}
30 & 0 & 2.6 & 1.0 & 3.7 & 1.8 & 4.3 & 2.2 & 5.2 & 3.0 \\
30 & 3 & 4.5 & 3.8 & 4.7 & 3.8 & 4.7 & 3.8 & 4.9 & 3.0
\end{tabular}

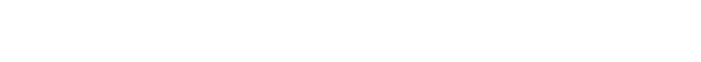

\begin{tabular}{rr|r|r|r|r|r|r|r|r|}
30 & 12 & 15.1 & 5.4 & 8.0 & 5.3 & 8.0 & 5.1 & 8.0 & 5.2 \\
30 & 15 & 16.3 & 9.1 & 14.7 & 8.06 & 14.5 & 8.3 & 14.6 & 8.7 \\
\hline & 7.6 & 5.6 & 10.6 & 16.2 & 10.7 & 16.6 & 9.7
\end{tabular}

\begin{tabular}{r|r|r|r|r|r|r|r|r|r|}
30 & 18 & 7.6 & 5.2 & 10.0 & 6.1 & 10.9 & 6.5 & 11.8 & 7.5 \\
30 & 21 & 5.3 & 3.8 & 5.9 & 4.0 & 6.4 & 4.4 & 7.2 & 5.0
\end{tabular} 
Table 10. -Three-hour averages of air and water-surface temperatures and wind directions and speed, April 1950-August 1951, Lake Hefner-Continued

DECEMBER, 1950

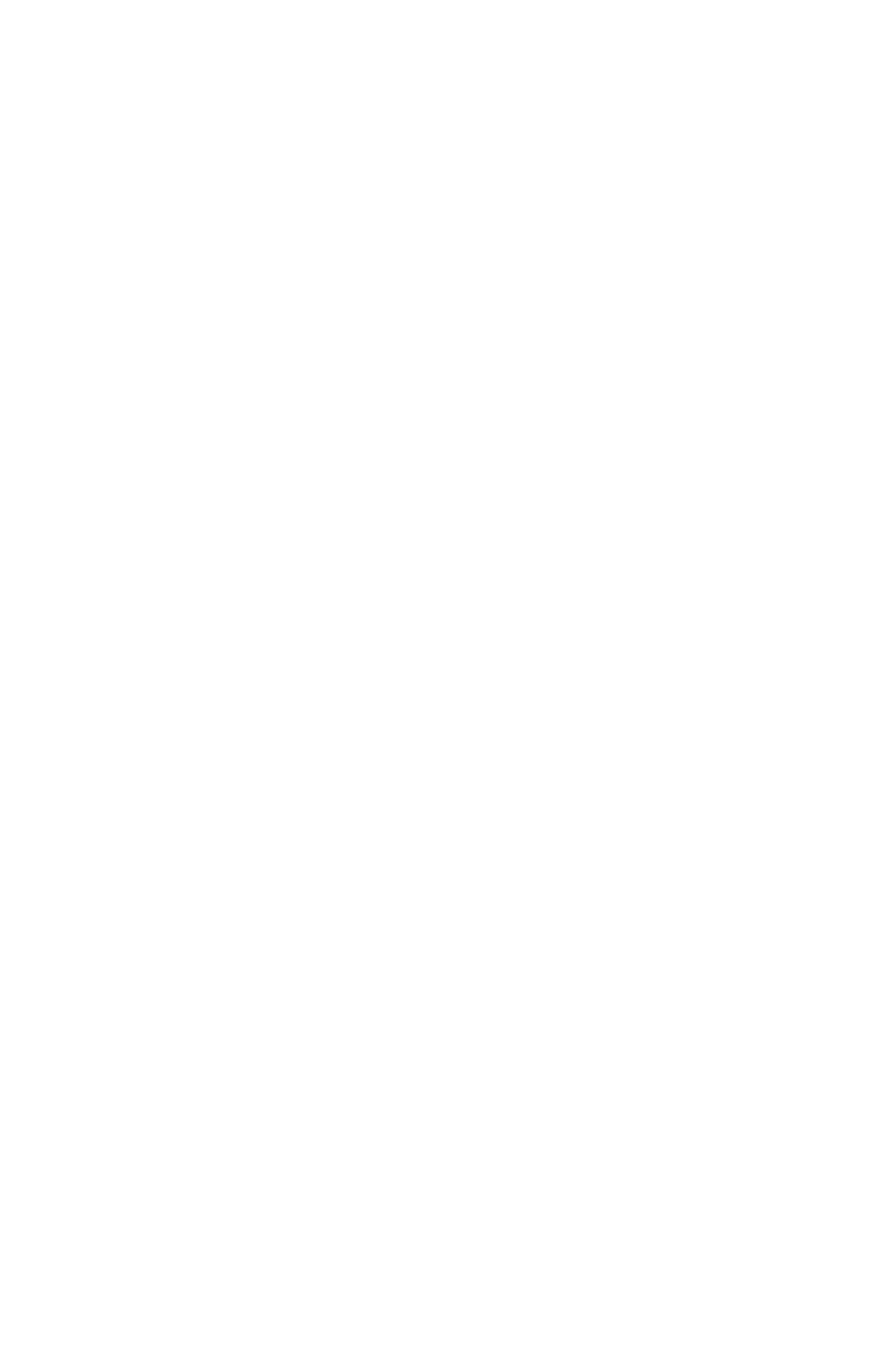


TABLE 10

Table 10. - Three-hour averages of air and water-surface temperatures and wind directions and speed, April 1950-August 1951, Lake Hefner-Continued

STATION 2 THREE-HOURLY AVERRAGS

OECEMBER, 1950

\begin{tabular}{|c|c|c|c|c|c|c|c|c|c|c|c|c|c|c|c|}
\hline \multirow{4}{*}{ 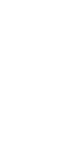 } & \multirow{4}{*}{ 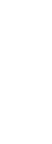 } & \multicolumn{8}{|c|}{ Average air temperature $\left({ }^{\circ} \mathrm{C}\right)$ at indicated height } & \multirow{4}{*}{$\begin{array}{l}\text { Average } \\
\text { water- } \\
\text { surface } \\
\text { tempera- } \\
\text { ture } \\
\left({ }^{\circ} \mathrm{C}\right)\end{array}$} & \multirow{4}{*}{$\begin{array}{c}\text { Average } \\
\text { wind } \\
\text { direction } \\
\text { (coded) }\end{array}$} & \multirow{2}{*}{\multicolumn{4}{|c|}{$\begin{array}{l}\text { Average wind speed (knots) } \\
\text { at indicated height }\end{array}$}} \\
\hline & & \multirow{2}{*}{\multicolumn{2}{|c|}{$\begin{array}{c}2 \\
\text { meters }\end{array}$}} & \multirow{2}{*}{\multicolumn{2}{|c|}{$\begin{array}{c}4 \\
\text { meters }\end{array}$}} & \multirow{2}{*}{\multicolumn{2}{|c|}{$\begin{array}{c}8 \\
\text { meters }\end{array}$}} & \multirow{2}{*}{\multicolumn{2}{|c|}{$\begin{array}{c}16 \\
\text { meters }\end{array}$}} & & & & & & \\
\hline & & & & & & & & & & & & 2 & 4 & 8 & 16 \\
\hline & & $\begin{array}{l}\text { bry } \\
\text { butb }\end{array}$ & $\begin{array}{l}\text { wet } \\
\text { bulb }\end{array}$ & bulb & bulb & bulb & $\begin{array}{l}\text { Wet } \\
\text { bulb }\end{array}$ & $\begin{array}{l}\text { Dry } \\
\text { bulb }\end{array}$ & $\begin{array}{l}\text { Wet } \\
\text { bulb }\end{array}$ & & & meters & meters & meters & meters \\
\hline
\end{tabular}

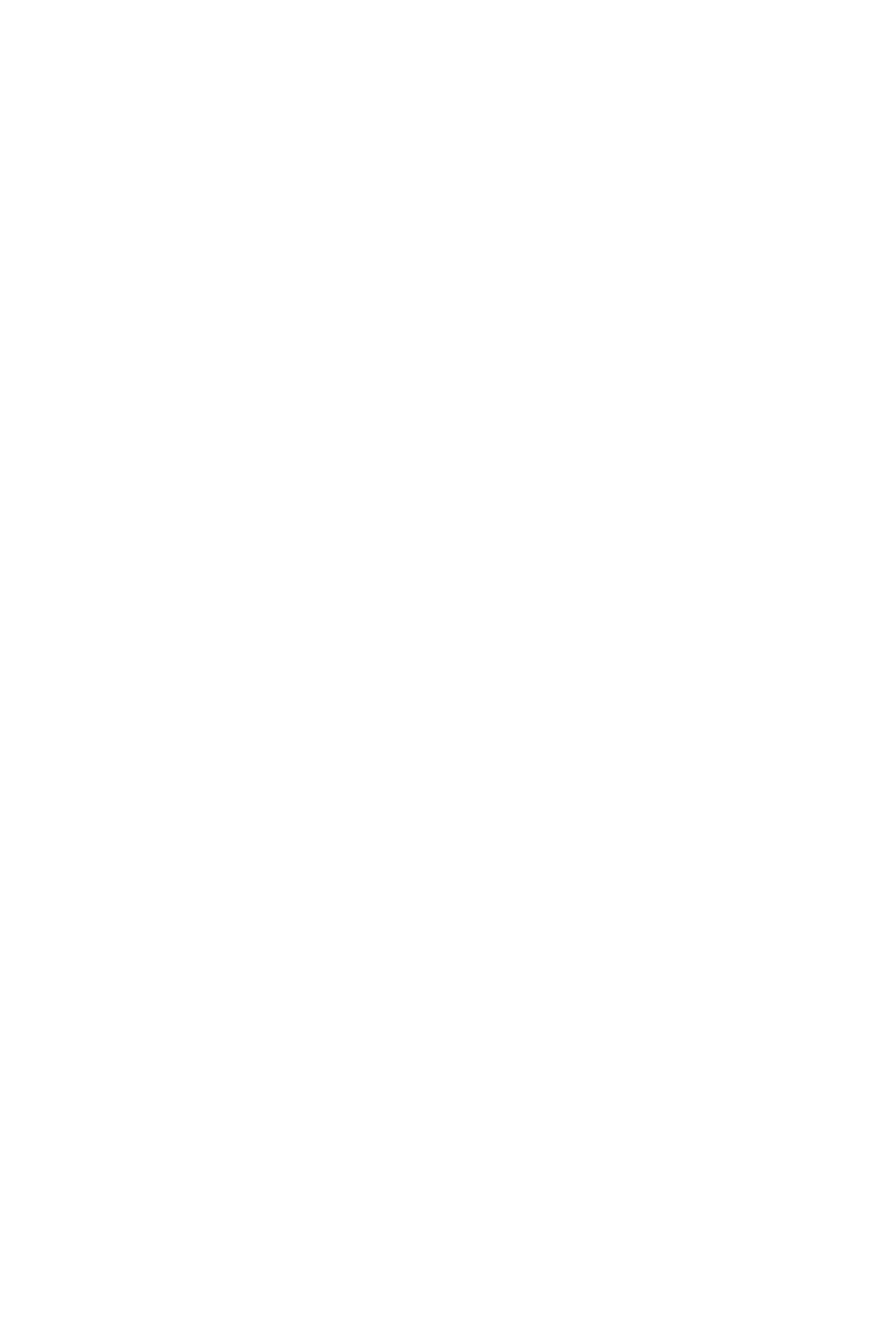


TABLE 10

Table 10. -Three-hour averages of air and water-surface temperaturea and wind directions and speed, April 1950-August 1951, Lake Hefner-Continued

STATION 2

THREE-HOURLY AVERAGES

DECEMBER, 1930

\begin{tabular}{|c|c|c|c|c|c|c|c|c|c|c|c|c|c|c|c|}
\hline \multirow{3}{*}{ 吾吾 } & \multirow{3}{*}{ 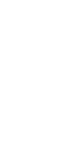 } & \multicolumn{8}{|c|}{ Average air temperature $\left({ }^{\circ} \mathrm{C}\right)$ at indicated height } & \multirow{3}{*}{$\begin{array}{c}\text { Average } \\
\text { water- } \\
\text { surface } \\
\text { tempera- } \\
\text { ture } \\
\left.{ }^{\circ} \mathrm{C}\right)\end{array}$} & \multirow{3}{*}{$\begin{array}{c}\text { Average } \\
\text { wind } \\
\text { direction } \\
\text { (coded) }\end{array}$} & \multicolumn{4}{|c|}{$\begin{array}{l}\text { Average wind speed (knots) } \\
\text { at indicated height }\end{array}$} \\
\hline & & \multicolumn{2}{|c|}{$\stackrel{2}{\text { meters }}$} & \multicolumn{2}{|c|}{$\begin{array}{c}4 \\
\text { meters }\end{array}$} & \multicolumn{2}{|c|}{$\begin{array}{c}8 \\
\text { meters }\end{array}$} & \multicolumn{2}{|c|}{$\begin{array}{c}16 \\
\text { meters }\end{array}$} & & & & & r & \\
\hline & & $\begin{array}{l}\text { Dry } \\
\text { bulb }\end{array}$ & $\begin{array}{l}\text { Wet } \\
\text { butb }\end{array}$ & $\begin{array}{l}\text { Dry } \\
\text { bulb }\end{array}$ & $\begin{array}{l}\text { Wet } \\
\text { bulb }\end{array}$ & $\begin{array}{l}\text { Dry } \\
\text { bulb }\end{array}$ & $\begin{array}{l}\text { Wet } \\
\text { bulb }\end{array}$ & $\begin{array}{l}\text { Dry } \\
\text { bulb }\end{array}$ & $\begin{array}{l}\text { Wet } \\
\text { bulb }\end{array}$ & & & meters & meters & meters & meters \\
\hline $\begin{array}{l}21 \\
21 \\
21 \\
21 \\
21 \\
21 \\
21 \\
21\end{array}$ & $\begin{array}{r}0 \\
3 \\
6 \\
9 \\
12 \\
15 \\
18 \\
21\end{array}$ & $\begin{array}{r}4.3 \\
4.2 \\
3.9 \\
7.9 \\
10.5 \\
9.9 \\
4.6 \\
3.5\end{array}$ & $\begin{array}{l}1.8 \\
2.0 \\
1.3 \\
4.0 \\
6.2 \\
6.3 \\
3.4 \\
2.3\end{array}$ & $\begin{array}{r}4.3 \\
4.1 \\
3.9 \\
7.7 \\
10.4 \\
9.9 \\
5.6 \\
3.5\end{array}$ & $\begin{array}{l}1.7 \\
2.0 \\
1.2 \\
4.0 \\
6.2 \\
6.5 \\
3.9 \\
2.4\end{array}$ & $\begin{array}{r}4.3 \\
4.1 \\
3.9 \\
7.8 \\
10.3 \\
10.00 \\
6.00 \\
3.7\end{array}$ & $\begin{array}{l}1.4 \\
1.8 \\
1.2 \\
3.9 \\
6.1 \\
6.4 \\
4.2 \\
2.4\end{array}$ & $\begin{array}{l}4.3 \\
4.1 \\
3.9 \\
7.8 \\
9.9 \\
9.9 \\
6.7 \\
3.9\end{array}$ & $\begin{array}{l}1.5 \\
1.5 \\
1.3 \\
4.1 \\
6.2 \\
6.6 \\
4.7 \\
2.6\end{array}$ & $\begin{array}{l}4.3 \\
4.3 \\
4.3 \\
4.7 \\
5.5 \\
4.9 \\
4.6 \\
3.9\end{array}$ & & $\begin{array}{l}1.4 \\
1.1 \\
1.7 \\
3.9 \\
5.4 \\
4.7 \\
2.3 \\
5.8\end{array}$ & $\begin{array}{l}2.1 \\
1.7 \\
2.1 \\
4.5 \\
6.0 \\
5.6 \\
3.6 \\
6.9\end{array}$ & $\begin{array}{l}2.7 \\
1.9 \\
2.6 \\
4.5 \\
6.6 \\
6.6 \\
5.0 \\
8.6\end{array}$ & $\begin{array}{l}3.2 \\
2.1 \\
2.8 \\
5.5 \\
6.7\end{array}$ \\
\hline $\begin{array}{l}22 \\
22 \\
22 \\
22 \\
22 \\
22 \\
22 \\
22\end{array}$ & $\begin{array}{r}0 \\
3 \\
6 \\
9 \\
12 \\
15 \\
18 \\
21\end{array}$ & $\begin{array}{r}2.2 \\
2.3 \\
1.6 \\
7.9 \\
14.1 \\
13.3 \\
8.0 \\
5.6\end{array}$ & $\begin{array}{l}1.6 \\
1.8 \\
1.3 \\
5.5 \\
8.6 \\
8.3 \\
5.7 \\
4.5\end{array}$ & $\begin{array}{r}2.2 \\
2.1 \\
1.6 \\
7.9 \\
14.0 \\
13.3 \\
8.3 \\
5.9\end{array}$ & $\begin{array}{l}1.8 \\
1.9 \\
1.5 \\
5.6 \\
8.5 \\
8.3 \\
5.9 \\
4.8\end{array}$ & $\begin{array}{r}2.5 \\
2.4 \\
2.0 \\
8.0 \\
13.7 \\
13.3 \\
8.7 \\
6.3\end{array}$ & $\begin{array}{l}1.9 \\
2.0 \\
1.6 \\
5.6 \\
8.3 \\
8.1 \\
6.1 \\
4.9\end{array}$ & $\begin{array}{r}2.7 \\
2.5 \\
2.4 \\
8.1 \\
13.5 \\
13.3 \\
9.5 \\
7.0\end{array}$ & $\begin{array}{l}2.1 \\
2.1 \\
1.9 \\
5.7 \\
8.2 \\
8.3 \\
6.4 \\
5.4\end{array}$ & $\begin{array}{l}3.3 \\
3.4 \\
3.5 \\
4.4 \\
7.0 \\
5.0 \\
4.9 \\
4.8\end{array}$ & & $\begin{array}{l}5.0 \\
3.4 \\
4.2 \\
7.4 \\
8.6 \\
5.4 \\
4.7 \\
5.3\end{array}$ & $\begin{array}{r}5.9 \\
4.1 \\
5.2 \\
8.3 \\
9.6 \\
6.4 \\
+5.9 \\
6.5\end{array}$ & $\begin{array}{r}7.7 \\
5.1 \\
6.5 \\
9.1 \\
10.6 \\
7.7 \\
7.8 \\
8.6\end{array}$ & $\begin{array}{r}11.7 \\
11.8 \\
9.3 \\
10.9 \\
11.8\end{array}$ \\
\hline $\begin{array}{l}23 \\
23 \\
23 \\
23 \\
23 \\
23 \\
23 \\
23\end{array}$ & $\begin{array}{r}0 \\
3 \\
6 \\
9 \\
12 \\
15 \\
18 \\
21\end{array}$ & $\begin{array}{r}5 \cdot 1 \\
4 \cdot 5 \\
4 \cdot 2 \\
9 \cdot 1 \\
14 \cdot 3 \\
13 \cdot 3 \\
8 \cdot 1 \\
8 \cdot 2\end{array}$ & $\begin{array}{l}4.5 \\
4.3 \\
4.2 \\
7.2 \\
8.9 \\
8.6 \\
6.0 \\
5.6\end{array}$ & $\begin{array}{r}5.1 \\
4.5 \\
4.2 \\
9.0 \\
14.1 \\
13.3 \\
8.3 \\
8.5\end{array}$ & $\begin{array}{l}4.6 \\
4.4 \\
4.3 \\
7.3 \\
8.8 \\
8.6 \\
6.1 \\
5.6\end{array}$ & $\begin{array}{r}5.3 \\
4.6 \\
4.7 \\
9.3 \\
13.8 \\
13.3 \\
8.4 \\
8.7\end{array}$ & $\begin{array}{l}4.7 \\
4.4 \\
4.4 \\
7.2 \\
8.6 \\
8.4 \\
6.2 \\
5.6\end{array}$ & $\begin{array}{r}5.5 \\
4.1 \\
4.0 \\
9.2 \\
13.7 \\
13.3 \\
9.0 \\
9.3\end{array}$ & $\begin{array}{l}4.9 \\
4.5 \\
4.2 \\
7.1 \\
8.6 \\
8.6 \\
6.6 \\
6.1\end{array}$ & $\begin{array}{l}4.8 \\
4.6 \\
4.1 \\
4.5 \\
5.0 \\
5.8 \\
5.2 \\
5.0\end{array}$ & & $\begin{array}{r}8.0 \\
8.5 \\
10.9 \\
10.6 \\
12.1 \\
7.3 \\
5.2 \\
6.6\end{array}$ & $\begin{array}{r}9.3 \\
9.9 \\
12.4 \\
12.1 \\
13.6 \\
8.4 \\
6.4 \\
7.8\end{array}$ & $\begin{array}{l}11.5 \\
11.8 \\
14.2 \\
13.6 \\
15.3 \\
9.0 \\
8.03 \\
9.7\end{array}$ & $\begin{array}{l}14.3 \\
14.2 \\
17.1 \\
15.4 \\
17.1 \\
11.7 \\
11.1 \\
12.3\end{array}$ \\
\hline $\begin{array}{l}24 \\
24 \\
24 \\
24 \\
24 \\
24 \\
24 \\
24\end{array}$ & $\begin{array}{r}0 \\
3 \\
6 \\
9 \\
12 \\
15 \\
18 \\
21\end{array}$ & $\begin{array}{r}6.5 \\
2.7 \\
1.3 \\
6.8 \\
14.4 \\
16.6 \\
7.9 \\
7.5\end{array}$ & $\begin{array}{r}4.2 \\
1.0 \\
-0.2 \\
3.2 \\
7.4 \\
8.3 \\
3.8 \\
3.5\end{array}$ & $\begin{array}{r}6.6 \\
3.5 \\
1.9 \\
6.8 \\
14.2 \\
16.4 \\
10.0 \\
8.3\end{array}$ & $\begin{array}{l}2.9 \\
7.1 \\
8.1 \\
4.8 \\
4.1\end{array}$ & $\begin{array}{r}6.8 \\
3.9 \\
2.2 \\
6.4 \\
13.9 \\
16.9 \\
11.9 \\
9.1\end{array}$ & $\begin{array}{l}4.3 \\
1.5 \\
2.9 \\
6.9 \\
8.2 \\
5.7 \\
4.3\end{array}$ & $\begin{array}{r}7.2 \\
4.6 \\
2.6 \\
6.5 \\
14.2 \\
16.0 \\
13.02 \\
9.9\end{array}$ & $\begin{array}{l}4 \cdot 5 \\
1.9 \\
0.3 \\
3.2 \\
7.7 \\
8.4 \\
6.6 \\
4.9\end{array}$ & $\begin{array}{l}4.9 \\
4.5 \\
4.1 \\
5.3 \\
8.5 \\
8.4 \\
6.9 \\
6.0\end{array}$ & & $\begin{array}{l}5.9 \\
2.1 \\
2.1 \\
2.8 \\
2.3 \\
1.7 \\
2.6 \\
4.6\end{array}$ & $\begin{array}{l}7.0 \\
2.9 \\
2.7 \\
3.4 \\
2.8 \\
2.2 \\
3.8 \\
6.2\end{array}$ & $\begin{array}{l}8.8 \\
3.9 \\
3.6 \\
3.7 \\
2.9 \\
2.6 \\
5.4 \\
8.4\end{array}$ & $\begin{array}{r}11.4 \\
5.6 \\
4.6 \\
4.1 \\
2.9 \\
3.3 \\
6.8 \\
11.2\end{array}$ \\
\hline $\begin{array}{l}25 \\
25 \\
25 \\
25 \\
25 \\
25 \\
25 \\
25\end{array}$ & $\begin{array}{r}0 \\
3 \\
6 \\
9 \\
12 \\
15 \\
18 \\
21\end{array}$ & $\begin{array}{r}6.3 \\
5.7 \\
5.0 \\
12.7 \\
20.0 \\
19.6 \\
15.2 \\
12.9\end{array}$ & $\begin{array}{l}2.8 \\
2.8 \\
2.7 \\
6.2 \\
8.4 \\
8.1 \\
6.3 \\
5.5\end{array}$ & $\begin{array}{r}6.5 \\
5.9 \\
5.2 \\
12.9 \\
19.9 \\
19.6 \\
15.4 \\
13.1\end{array}$ & $\begin{array}{l}3.0 \\
2.9 \\
2.8 \\
6.2 \\
8.3 \\
8.1 \\
6.4 \\
5.6\end{array}$ & $\begin{array}{r}6.9 \\
6.0 \\
5.2 \\
13.1 \\
19.6 \\
19.6 \\
15.6 \\
13.2\end{array}$ & $\begin{array}{l}3.1 \\
2.9 \\
2.7 \\
6.0 \\
8.1 \\
7.7 \\
6.2 \\
5.4\end{array}$ & \begin{tabular}{r|}
7.8 \\
6.4 \\
5.7 \\
13.3 \\
19.7 \\
19.6 \\
15.9 \\
13.3
\end{tabular} & $\begin{array}{l}3.9 \\
3.4 \\
3.1 \\
5.6\end{array}$ & $\begin{array}{l}5.4 \\
5.0 \\
4.9 \\
5.7 \\
6.3 \\
5.7 \\
5.4 \\
5.2\end{array}$ & & $\begin{array}{r}5.1 \\
7.0 \\
8.3 \\
11.9 \\
16.4 \\
12.5 \\
11.8 \\
10.7\end{array}$ & $\begin{array}{r}6.3 \\
8.3 \\
9.6 \\
13.4 \\
18.5 \\
14.3 \\
13.4 \\
12.1\end{array}$ & $\begin{array}{r}8.4 \\
10.1 \\
11.5 \\
15.2 \\
21.1 \\
16.5 \\
15.4 \\
14.1\end{array}$ & $\begin{array}{l}11.2 \\
12.9 \\
14.2 \\
17.0 \\
23.6 \\
19.0 \\
18.3 \\
17.0\end{array}$ \\
\hline $\begin{array}{l}26 \\
26 \\
26 \\
26 \\
26 \\
26 \\
25 \\
26\end{array}$ & $\begin{array}{r}0 \\
3 \\
5 \\
9 \\
12 \\
15 \\
18 \\
21\end{array}$ & $\begin{aligned} & 8.9 \\
& 3.9 \\
- & 1.2 \\
- & 0.8 \\
- & 0.1 \\
- & 1.1 \\
- & 3.6 \\
- & 5.5\end{aligned}$ & $\begin{array}{r}4.1 \\
-1.3 \\
-1.4 \\
\end{array}$ & $\begin{array}{l}9.1 \\
3.8 \\
1.3 \\
1.2 \\
0.6 \\
1.4 \\
3.7 \\
5.7\end{array}$ & $\begin{array}{l}4.1 \\
1.6 \\
\end{array}$ & $\begin{array}{r}9.1 \\
3.5 \\
-1.3 \\
=1.2 \\
=-0.8 \\
=1.5 \\
=3.9 \\
-\quad 5.8\end{array}$ & $\begin{array}{r}4.0 \\
-\quad 0.7 \\
-2.8\end{array}$ & $\left|\begin{array}{r}9.4 \\
-3.2 \\
-1.7 \\
=1.8 \\
=1.1 \\
=1.9 \\
=-4.1 \\
-6.0\end{array}\right|$ & $\begin{array}{r}4.7 \\
0.7 \\
-2.2 \\
\end{array}$ & $\begin{array}{l}5.0 \\
4.7 \\
3.5 \\
3.9 \\
4.8 \\
3.9 \\
2.4 \\
1.7\end{array}$ & & $\begin{array}{r}8.0 \\
14.6 \\
14.2 \\
13.2 \\
13.1 \\
12.9 \\
9.7 \\
9.5\end{array}$ & $\begin{array}{r}9.5 \\
15.09 \\
15.8 \\
15.0 \\
14.5 \\
14.03 \\
11.4 \\
11.0\end{array}$ & $\begin{array}{l}11.8 \\
17.9 \\
18.6 \\
18.9 \\
16.7 \\
16.7 \\
15.0 \\
14.3\end{array}$ & $\begin{array}{l}13.7 \\
18.0 \\
19.8 \\
21.1 \\
18.6 \\
18.4 \\
17.6 \\
17.1\end{array}$ \\
\hline $\begin{array}{l}27 \\
27 \\
27 \\
27 \\
27 \\
27 \\
27 \\
27\end{array}$ & $\begin{array}{r}0 \\
3 \\
6 \\
9 \\
12 \\
15 \\
18 \\
21\end{array}$ & $\begin{array}{l}=7.0 \\
=6.0 \\
=6.0 \\
=4.5 \\
=2.3 \\
=1.8 \\
=4.5 \\
=7.1\end{array}$ & -3.5 & $\begin{array}{l}7.1 \\
6.0 \\
6.0 \\
4.8 \\
2.7 \\
2.1 \\
4.4 \\
6.2\end{array}$ & -3.9 & $\left|\begin{array}{l}-7.1 \\
=6.0 \\
=6.1 \\
=-4.6 \\
-2.9 \\
-2.2 \\
-\quad 4.3 \\
-5.4\end{array}\right|$ & & $\left|\begin{array}{l}-7.2 \\
-6.1 \\
-6.2 \\
-4.9 \\
-3.2 \\
-2.3 \\
-\quad 4.3 \\
-5.0\end{array}\right|$ & & $\begin{array}{l}1.0 \\
0.9 \\
0.9 \\
1.8 \\
3.5 \\
3.4 \\
2.2 \\
1.8\end{array}$ & & $\begin{array}{l}7.1 \\
7.0 \\
5.4 \\
3.9 \\
4.8 \\
4.0 \\
2.9 \\
2.4\end{array}$ & $\begin{array}{l}8.0 \\
8.1 \\
6.5 \\
4.2 \\
5.1 \\
4.6 \\
3.6 \\
3.4\end{array}$ & $\begin{array}{r}10.1 \\
10.3 \\
7.8 \\
4.4 \\
5.4 \\
4.9 \\
4.3 \\
4.5\end{array}$ & $\begin{array}{r}11.1 \\
12.1 \\
8.9 \\
4.9 \\
5.5 \\
5.3 \\
5.9 \\
5.9\end{array}$ \\
\hline $\begin{array}{l}23 \\
28 \\
28 \\
20 \\
20 \\
20 \\
28 \\
28\end{array}$ & $\begin{array}{r}0 \\
3 \\
6 \\
9 \\
12 \\
15 \\
18 \\
21\end{array}$ & $\begin{array}{r}-7.8 \\
-7.7 \\
=8.0 \\
-0.8 \\
4.3 \\
6.3 \\
1.1 \\
-0.3\end{array}$ & $\begin{array}{r} \\
0.8 \\
0.7 \\
-2.5 \\
-3.4\end{array}$ & $\begin{array}{l}7.0 \\
7.5 \\
7.1 \\
1.0 \\
4.3 \\
6.4 \\
3.0 \\
0.1\end{array}$ & \begin{tabular}{r|} 
\\
0.4 \\
1.2 \\
-1.2 \\
-3.0
\end{tabular} & $\mid \begin{array}{r}-6.4 \\
-7.1 \\
-7.1 \\
-1.0 \\
4.3 \\
6.5 \\
3.7 \\
0.8\end{array}$ & $\begin{array}{r}0.1 \\
0.7 \\
-\quad 1.0 \\
-2.8\end{array}$ & $\begin{array}{r}-5.8 \\
-5.5 \\
-6.3 \\
-0.9 \\
4.4 \\
6.6 \\
4.4 \\
1.2\end{array}$ & 0.4 & $\begin{array}{l}1.5 \\
0.9 \\
0.8 \\
2.2 \\
4.1 \\
3.8 \\
2.5 \\
2.3\end{array}$ & & $\begin{array}{l}2.1 \\
3.0 \\
2.8 \\
6.8 \\
5.7 \\
4.2 \\
3.2 \\
3.0\end{array}$ & $\begin{array}{l}3.0 \\
4.1 \\
3.6 \\
7.6 \\
6.8 \\
4.7 \\
4.6 \\
4.3\end{array}$ & $\begin{array}{l}4.1 \\
5.6 \\
4.3 \\
8.4 \\
7.5 \\
5.3 \\
5.7 \\
5.9\end{array}$ & $\begin{array}{l}6.0 \\
8.0 \\
5.7 \\
9.1 \\
8.0 \\
5.9 \\
7.7 \\
8.1\end{array}$ \\
\hline $\begin{array}{l}29 \\
29 . \\
29 \\
29 \\
29 \\
29 \\
29 \\
29\end{array}$ & $\begin{array}{r}0 \\
3 \\
6 \\
9 \\
12 \\
15 \\
18 \\
21\end{array}$ & $\begin{array}{r}-1.3 \\
-1.1 \\
-0.9 \\
2.7 \\
3.8 \\
3.9 \\
1.5 \\
0.9\end{array}$ & $\begin{array}{l}0.4 \\
0.7 \\
1.1 \\
1.0 \\
0.9\end{array}$ & $\begin{array}{l}1.5 \\
1.0 \\
0.6 \\
2.7 \\
3.5 \\
3.9 \\
1.6 \\
1.0\end{array}$ & \begin{tabular}{r|}
-3.3 \\
0.3 \\
0.5 \\
1.1 \\
1.00 \\
0.9
\end{tabular} & $\begin{array}{l}-0.9 \\
-0.4 \\
-0.5 \\
3.0 \\
3.5 \\
3.8 \\
1.6 \\
1.0\end{array}$ & $\begin{array}{l}0.4 \\
0.1 \\
0.0 \\
1.0 \\
1.0\end{array}$ & $\begin{array}{l}2.9 \\
3.5 \\
3.7 \\
1.6 \\
1.1\end{array}$ & $\begin{array}{l}0.6 \\
0.6 \\
1.3 \\
1.1 \\
1.0\end{array}$ & $\begin{array}{l}1.0 \\
1.0 \\
0.9 \\
1.5 \\
2.8 \\
2.3 \\
1.9 \\
1.9\end{array}$ & & $\begin{array}{l}2.2 \\
1.3 \\
1.0 \\
1.4 \\
3.5 \\
2.6 \\
1.4 \\
2.3\end{array}$ & $\begin{array}{l}3.2 \\
2.0 \\
1.6 \\
1.8 \\
4.4 \\
3.5 \\
2.3 \\
3.1\end{array}$ & $\begin{array}{l}4.5 \\
2.8 \\
2.0 \\
1.8 \\
5.6 \\
4.1 \\
2.8 \\
3.8\end{array}$ & $\begin{array}{l}6.9 \\
4.4 \\
2.6 \\
2.2 \\
5.2 \\
4.7 \\
3.6 \\
4.9\end{array}$ \\
\hline $\begin{array}{l}30 \\
30 \\
30 \\
30 \\
30 \\
30 \\
30 \\
30\end{array}$ & $\begin{array}{r}0 \\
3 \\
6 \\
9 \\
12 \\
15 \\
18 \\
21\end{array}$ & $\begin{array}{r}-0.5 \\
=0.9 \\
-0.6 \\
2.3 \\
7.7 \\
9.1 \\
3.4 \\
2.5\end{array}$ & $\begin{array}{r}-0.6 \\
=-1.1 \\
-0.7 \\
1.4 \\
4.7 \\
4.6 \\
1.2 \\
1.0\end{array}$ & $\begin{array}{l}0.6 \\
0.9 \\
0.6 \\
2.2 \\
7.5 \\
9.2 \\
4.6 \\
2.6\end{array}$ & $\begin{array}{r}-0.5 \\
=1.0 \\
-\quad 0.7 \\
1.3 \\
4.5 \\
4.5 \\
1.9 \\
1.1\end{array}$ & $\begin{array}{r}-0.5 \\
-\quad 0.9 \\
-0.6 \\
2.2 \\
7.2 \\
9.5 \\
5.3 \\
2.8\end{array}$ & $\begin{array}{r}-0.5 \\
-0.5 \\
-0.6 \\
1.5 \\
4.3 \\
4.5 \\
2.1 \\
1.1\end{array}$ & $\mid \begin{array}{r}-0.4 \\
-0.9 \\
-0.6 \\
2.3 \\
7.1 \\
9.0 \\
5.9 \\
3.0\end{array}$ & $\begin{array}{r}-0.4 \\
=0.9 \\
-0.6 \\
1.6 \\
4.6\end{array}$ & $\begin{array}{l}1.8 \\
1.9 \\
2.4 \\
4.3 \\
6.0 \\
6.6 \\
5.4 \\
4.3\end{array}$ & & $\begin{array}{l}3.6 \\
4.0 \\
3.4 \\
4.4 \\
3.7 \\
2.2 \\
3.9 \\
8.6\end{array}$ & $\begin{array}{r}4.4 \\
4.8 \\
4.1 \\
4.9 \\
4.2 \\
2.5 \\
5.4 \\
10.2\end{array}$ & $\begin{array}{r}5.6 \\
5.8 \\
4.9 \\
6.3 \\
5.2 \\
3.0 \\
7.1 \\
12.0\end{array}$ & $\begin{array}{r}6.9 \\
7.6 \\
6.0 \\
6.7 \\
5.6 \\
3.6 \\
9.0 \\
14.5\end{array}$ \\
\hline $\begin{array}{l}31 \\
31 \\
31 \\
31 \\
31 \\
31 \\
31 \\
31\end{array}$ & $\begin{array}{r}0 \\
3 \\
6 \\
9 \\
12 \\
15 \\
18 \\
21\end{array}$ & $\begin{array}{r}2.2 \\
2.2 \\
2.3 \\
7.8 \\
23.5 \\
13.3 \\
10.3 \\
8.5\end{array}$ & $\begin{array}{l}0.4 \\
0.2 \\
0.1 \\
3.1 \\
5.5 \\
5.5 \\
4.3 \\
4.0\end{array}$ & $\begin{array}{r}2.3 \\
2.3 \\
2.4 \\
7.9 \\
13.5 \\
13.3 \\
10.4 \\
8.8\end{array}$ & $\begin{array}{l}0.5 \\
0.2 \\
0.1 \\
3.2 \\
5.5 \\
5.7 \\
4.5 \\
4.0\end{array}$ & $\left|\begin{array}{r}2.3 \\
2.2 \\
2.5 \\
8.1 \\
13.4 \\
13.2 \\
10.4 \\
8.7\end{array}\right|$ & $\begin{array}{l}0.4 \\
0.1 \\
0.2 \\
3.0 \\
5.2 \\
5.2 \\
4.3 \\
4.0\end{array}$ & $\begin{array}{r}2.5 \\
2.5 \\
2.7 \\
8.0 \\
13.2 \\
13.1 \\
10.5 \\
8.8\end{array}$ & & $\begin{array}{l}3.8 \\
3.7 \\
3.7 \\
3.8 \\
4.4 \\
4.3 \\
4.2 \\
4.0\end{array}$ & & $\begin{array}{l}10.0 \\
11.4 \\
13.3 \\
17.2 \\
20.6 \\
17.8 \\
16.1 \\
16.8\end{array}$ & $\begin{array}{l}11.8 \\
13.4 \\
15.4 \\
19.9 \\
23.6 \\
20.6 \\
18.7 \\
19.5\end{array}$ & $\begin{array}{l}13.7 \\
15.3 \\
17.5 \\
22.3 \\
26.4 \\
23.2 \\
21.1 \\
22.1\end{array}$ & $\begin{array}{l}16.0 \\
17.5 \\
20.0 \\
25.0 \\
29.5 \\
25.9 \\
23.9 \\
24.9\end{array}$ \\
\hline
\end{tabular}


TABLE 10

101 Table 10. - Three-hour averages of air and water-surface temperatures and wind directions and speed, April 1950-August
1951, Lake Hefner-Continued

STATION 2 THREE-HOURLY AVERAGES

JANUARY, 1951

\begin{tabular}{|c|c|c|c|c|c|c|c|c|c|c|c|c|c|c|c|}
\hline \multirow{4}{*}{ 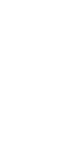 } & \multirow{4}{*}{$\mid$} & \multicolumn{8}{|c|}{ Average air temperature $\left({ }^{\circ} \mathrm{C}\right)$ at indicated height } & \multirow{4}{*}{$\begin{array}{c}\text { Average } \\
\text { water- } \\
\text { surface } \\
\text { tempera- } \\
\text { ture } \\
\left({ }^{\circ} \mathrm{C}\right)\end{array}$} & \multirow{4}{*}{$\begin{array}{l}\text { Average } \\
\text { wind } \\
\text { direction } \\
\text { (coded) }\end{array}$} & \multirow{2}{*}{\multicolumn{4}{|c|}{$\begin{array}{l}\text { Average wind speed (knots) } \\
\text { at indicated height }\end{array}$}} \\
\hline & & \multirow{2}{*}{\multicolumn{2}{|c|}{$\stackrel{2}{\text { meters }}$}} & \multirow{2}{*}{\multicolumn{2}{|c|}{$\begin{array}{c}4 \\
\text { meters }\end{array}$}} & \multirow{2}{*}{\multicolumn{2}{|c|}{$\begin{array}{c}8 \\
\text { meters }\end{array}$}} & \multirow{2}{*}{\multicolumn{2}{|c|}{$\begin{array}{c}16 \\
\text { meters }\end{array}$}} & & & & & & \\
\hline & & & & & & & & & & & & 2 & 4 & 8 & 16 \\
\hline & & $\begin{array}{l}\text { Dry } \\
\text { bulb }\end{array}$ & $\begin{array}{l}\text { Wet } \\
\text { bulb }\end{array}$ & $\begin{array}{l}\text { Dry } \\
\text { bulb }\end{array}$ & $\begin{array}{l}\text { Wet } \\
\text { bulb }\end{array}$ & $\begin{array}{l}\text { Dry } \\
\text { bulb }\end{array}$ & $\begin{array}{l}\text { Wet } \\
\text { bulb }\end{array}$ & $\begin{array}{l}\text { Dry } \\
\text { bulb }\end{array}$ & $\begin{array}{l}\text { Wet } \\
\text { bulb }\end{array}$ & & & meters & meters & meters & meters \\
\hline $\begin{array}{l}2 \\
1 \\
1 \\
1 \\
1 \\
1 \\
1 \\
1\end{array}$ & $\begin{array}{r}0 \\
3 \\
6 \\
9 \\
12 \\
15 \\
18 \\
21\end{array}$ & $\begin{array}{r}7.6 \\
7.9 \\
8.9 \\
9.9 \\
10.9 \\
11.1 \\
10.0 \\
10.0\end{array}$ & $\begin{array}{r}4.7 \\
6.7 \\
8.1 \\
8.9 \\
10.0 \\
10.6 \\
10.0 \\
10.0\end{array}$ & $\begin{array}{r}7.8 \\
8.2 \\
8.9 \\
9.9 \\
10.8 \\
11.1 \\
10.0 \\
10.1\end{array}$ & $\begin{array}{r}4.8 \\
6.8 \\
8.1 \\
9.0 \\
10.0 \\
10.7 \\
10.0 \\
10.1\end{array}$ & $\begin{array}{r}7.8 \\
8.3 \\
8.9 \\
9.7 \\
10.7 \\
11.0 \\
10.0 \\
10.1\end{array}$ & $\begin{array}{r}4.8 \\
6.8 \\
7.9 \\
8.8 \\
9.9 \\
10.6 \\
10.0 \\
10.1\end{array}$ & $\begin{array}{l}11.0 \\
10.8 \\
10.0 \\
10.0\end{array}$ & $\begin{array}{l}10.4 \\
10.6 \\
10.0 \\
10.1\end{array}$ & $\begin{array}{l}4.0 \\
3.7 \\
3.4 \\
4.8 \\
5.3 \\
5.8 \\
6.0 \\
6.0\end{array}$ & & $\begin{array}{r}15.3 \\
14.4 \\
13.3 \\
12.0 \\
9.0 \\
6.1 \\
4.2 \\
6.0\end{array}$ & $\begin{array}{l}17.8 \\
16.6 \\
15.5 \\
14.1 \\
11.1 \\
7.5 \\
5.4 \\
7.1\end{array}$ & $\begin{array}{r}20.0 \\
18.8 \\
17.5 \\
15.9 \\
12.7 \\
8.4 \\
6.2 \\
8.1\end{array}$ & $\begin{array}{r}22.6 \\
21.3 \\
19.8 \\
17.6 \\
14.0 \\
9.4 \\
7.2 \\
9.3\end{array}$ \\
\hline $\begin{array}{l}2 \\
2 \\
2 \\
2 \\
2 \\
2 \\
2 \\
2\end{array}$ & $\begin{array}{r}0 \\
3 \\
6 \\
9 \\
12 \\
15 \\
18 \\
2.1\end{array}$ & $\begin{array}{r}11.9 \\
4.3 \\
2.8 \\
1.5 \\
1.1 \\
1.9 \\
-0.8 \\
-0.1\end{array}$ & $\begin{array}{r}11.9 \\
3.1 \\
2.8 \\
1.5 \\
0.6 \\
1.1 \\
0.1 \\
-0.3\end{array}$ & $\begin{array}{r}12.0 \\
2.9 \\
2.8 \\
1.6 \\
0.9 \\
1.8 \\
0.8 \\
0.1\end{array}$ & $\begin{array}{r}12.0 \\
2.8 \\
2.7 \\
1.3 \\
0.4 \\
0.9 \\
0.2 \\
-\quad 0.5\end{array}$ & $\begin{array}{r}12.2 \\
2.6 \\
2.7 \\
1.4 \\
0.8 \\
1.7 \\
0.6 \\
-0.3\end{array}$ & $\begin{array}{r}12.2 \\
2.6 \\
2.5 \\
1.02 \\
0.2 \\
0.07 \\
0.00 \\
-0.5\end{array}$ & $\begin{array}{r}2.1 \\
2.4 \\
1.3 \\
0.7 \\
1.5 \\
0.5 \\
-0.3\end{array}$ & $\begin{array}{r}12.1 \\
2.3 \\
2.4 \\
1.0 \\
0.1 \\
0.5 \\
0.0 \\
-0.7\end{array}$ & $\begin{array}{r}6.3 \\
6.2 \\
5.2 \\
4.7 \\
4.1 \\
3.5 \\
3.3 \\
3.2\end{array}$ & & $\begin{array}{r}7.6 \\
7.6 \\
8.7 \\
13.8 \\
15.0 \\
11.8 \\
8.7 \\
7.0\end{array}$ & $\begin{array}{r}9.2 \\
8.6 \\
10.0 \\
17.2 \\
18.9 \\
15.0 \\
10.7 \\
8.4\end{array}$ & $\begin{array}{l}10.5 \\
11.8 \\
13.4 \\
19.7 \\
20.1 \\
14.7 \\
11.7 \\
10.9\end{array}$ & $\begin{array}{l}11.9 \\
13.0 \\
14.5 \\
20.6 \\
21.6 \\
16.7 \\
12.6 \\
11.7\end{array}$ \\
\hline $\begin{array}{l}3 \\
3 \\
3 \\
3 \\
3 \\
3 \\
3 \\
3\end{array}$ & $\begin{array}{r}0 \\
3 \\
6 \\
9 \\
12 \\
15 \\
18 \\
21\end{array}$ & $\begin{array}{r}-0.2 \\
=1.4 \\
=2.5 \\
1.4 \\
6.0 \\
7.7 \\
3.2 \\
2.6\end{array}$ & $\begin{array}{l}0.3 \\
2.4 \\
2.9 \\
1.4 \\
1.1\end{array}$ & $\begin{array}{l}0.4 \\
1.3 \\
2.3 \\
1.5 \\
6.1 \\
7.8 \\
4.0 \\
2.8\end{array}$ & $\begin{array}{l}0.6 \\
2.1 \\
2.9 \\
1.7 \\
1.2\end{array}$ & $\begin{array}{r}-0.4 \\
=1.1 \\
-2.0 \\
1.5 \\
5.9 \\
7.8 \\
4.4 \\
3.1\end{array}$ & $\begin{array}{l}0.4 \\
2.0 \\
2.7 \\
1.7 \\
1.1\end{array}$ & $\begin{array}{r}-0.5 \\
-1.1 \\
-1.7 \\
1.4 \\
5.7 \\
7.7 \\
5.0 \\
3.7\end{array}$ & $\begin{array}{l}0.7 \\
1.7 \\
2.9 \\
2.3 \\
1.7\end{array}$ & $\begin{array}{l}2.9 \\
2.5 \\
2.5 \\
3.4 \\
4.5\end{array}$ & & $\begin{array}{r}6.8 \\
3.6 \\
2.6 \\
5.5 \\
10.4 \\
7.7 \\
2.4 \\
3.9\end{array}$ & $\begin{array}{r}8.2 \\
4.5 \\
3.4 \\
6.1 \\
11.8 \\
9.0 \\
3.4 \\
4.9\end{array}$ & $\begin{array}{r}11.1 \\
5.7 \\
4.3 \\
6.7 \\
13.2 \\
10.4 \\
4.8 \\
6.4\end{array}$ & $\begin{array}{r}11.8 \\
6.5 \\
5.6 \\
7.4 \\
14.8 \\
11.9 \\
6.7 \\
8.6\end{array}$ \\
\hline $\begin{array}{l}4 \\
4 \\
4 \\
4 \\
4 \\
4 \\
4 \\
4\end{array}$ & $\begin{array}{r}0 \\
3 \\
6 \\
9 \\
12 \\
15 \\
18 \\
2.1\end{array}$ & $\begin{array}{r}2.6 \\
3.0 \\
2.0 \\
4.1 \\
7.4 \\
10.3 \\
7.1 \\
7.5\end{array}$ & $\begin{array}{l}1.0 \\
1.0 \\
0.2 \\
1.6 \\
3.7 \\
5.5 \\
3.7 \\
3.8\end{array}$ & $\begin{array}{r}2.9 \\
3.5 \\
2.5 \\
3.9 \\
7.2 \\
10.9 \\
8.3 \\
7.8\end{array}$ & $\begin{array}{l}1.1 \\
1.2 \\
0.3 \\
1.4 \\
3.7 \\
5.6 \\
4.1 \\
3.8\end{array}$ & $\begin{array}{r}3.1 \\
3.9 \\
2.5 \\
4.0 \\
7.1 \\
11.4 \\
9.1 \\
8.0\end{array}$ & $\begin{array}{l}1.1 \\
1.3 \\
0.2 \\
1.3 \\
3.5 \\
5.5 \\
4.4 \\
3.8\end{array}$ & $\begin{array}{r}3.6 \\
4.3 \\
2.6 \\
3.9 \\
7.1 \\
11.4 \\
9.9 \\
8.2\end{array}$ & $\begin{array}{l}1.4 \\
1.5 \\
0.3 \\
1.3 \\
3.9 \\
5.8 \\
4.9 \\
4.2\end{array}$ & $\begin{array}{l}2.9 \\
2.8 \\
2.5 \\
3.8 \\
5.9 \\
6.3 \\
4.9 \\
4.2\end{array}$ & & $\begin{array}{l}4.5 \\
5.4 \\
3.0 \\
3.6 \\
2.6 \\
2.7 \\
5.2 \\
8.7\end{array}$ & $\begin{array}{r}5.6 \\
6.6 \\
3.6 \\
4.2 \\
2.7 \\
3.6 \\
6.9 \\
10.3\end{array}$ & $\begin{array}{r}7.2 \\
8.4 \\
4.9 \\
5.0 \\
2.7 \\
4.2 \\
9.0 \\
12.5\end{array}$ & $\begin{array}{r}9.5 \\
10.4 \\
6.2 \\
5.5 \\
3.0 \\
5.0 \\
11.4 \\
14.9\end{array}$ \\
\hline $\begin{array}{l}5 \\
5 \\
5 \\
5 \\
5 \\
5 \\
5 \\
5\end{array}$ & $\begin{array}{r}0 \\
3 \\
6 \\
9 \\
12 \\
15 \\
18 \\
21\end{array}$ & $\begin{array}{r}6.7 \\
4.9 \\
4.7 \\
9.0 \\
10.8 \\
8.1 \\
-\quad 0.9\end{array}$ & $\begin{array}{r}3.4 \\
2.4 \\
2.0 \\
4.6 \\
6.0 \\
5.5 \\
0.07 \\
-0.6\end{array}$ & $\begin{array}{r}6.9 \\
5.0 \\
4.9 \\
9.8 \\
10.5 \\
8.3 \\
1.7 \\
0.5\end{array}$ & $\begin{array}{r}3.4 \\
2.4 \\
2.2 \\
4.2 \\
5.8 \\
5.2 \\
0.5 \\
-0.7\end{array}$ & $\begin{array}{r}7.1 \\
5.1 \\
5.0 \\
9.7 \\
10.0 \\
8.4 \\
0.9 \\
-0.7\end{array}$ & $\begin{array}{r}3.5 \\
2.04 \\
2.02 \\
4.3 \\
5.3 \\
4.88 \\
0.02 \\
-1.2\end{array}$ & $\begin{array}{r}7.3 \\
5.1 \\
5.2 \\
9.5 \\
10.3 \\
8.07 \\
0.06 \\
-1.0\end{array}$ & $\begin{array}{r}3.9 \\
2.5 \\
2.5 \\
4.5 \\
5.8 \\
5.3 \\
0.0 \\
-1.3\end{array}$ & $\begin{array}{l}3.9 \\
3.7 \\
3.6 \\
4.0\end{array}$ & & $\begin{array}{r}9.7 \\
11.6 \\
10.9 \\
8.2 \\
5.5 \\
6.4 \\
13.2 \\
11.7\end{array}$ & $\begin{array}{r}11.5 \\
13.6 \\
12.7 \\
9.2 \\
6.4 \\
8.8 \\
16.7 \\
14.1\end{array}$ & $\begin{array}{r}13.5 \\
15.5 \\
14.8 \\
10.3 \\
8.8 \\
9.2\end{array}$ & $\begin{array}{l}15.8 \\
18.2 \\
17.2 \\
11.4 \\
10.5 \\
11.3 \\
18.3 \\
15.5\end{array}$ \\
\hline $\begin{array}{l}6 \\
6 \\
6 \\
6 \\
6 \\
6 \\
6 \\
6\end{array}$ & $\begin{array}{r}0 \\
3 \\
6 \\
9 \\
12 \\
15 \\
18 \\
21\end{array}$ & $\begin{aligned} & 1.88 \\
= & 2.09 \\
= & 4.5 \\
= & 3.03 \\
- & 0.08 \\
= & 0.05 \\
= & 2.3 \\
- & 4.0\end{aligned}$ & -0.8 & $\begin{array}{l}1.9 \\
3.2 \\
4.8 \\
3.7 \\
1.2 \\
0.7 \\
2.4 \\
4.1\end{array}$ & & $\begin{array}{l}2.1 \\
-3.4 \\
-5.0 \\
-4.0 \\
-1.4 \\
=0.9 \\
-2.5 \\
-4.4\end{array}$ & & $\begin{array}{l}-2.3 \\
-3.7 \\
-5.3 \\
-4.1 \\
=1.6 \\
=1.2 \\
-2.7 \\
-4.5\end{array}$ & & $\begin{array}{l}2.6 \\
1.9 \\
1.4 \\
2.3 \\
3.6 \\
3.2 \\
2.1 \\
1.2\end{array}$ & & $\begin{array}{l}12.3 \\
13.8 \\
16.3 \\
18.2 \\
18.0 \\
14.8 \\
11.4 \\
10.0\end{array}$ & $\begin{array}{l}12.8 \\
15.1 \\
16.8 \\
20.0 \\
20.9 \\
17.8 \\
15.0 \\
12.4\end{array}$ & $\begin{array}{l}14.1 \\
15.8 \\
16.9 \\
19.2 \\
20.8 \\
18.5 \\
14.9 \\
12.5\end{array}$ & $\begin{array}{l}13.8 \\
16.4 \\
17.9 \\
21.4 \\
23.0 \\
19.7 \\
16.0 \\
13.5\end{array}$ \\
\hline $\begin{array}{l}7 \\
7 \\
7 \\
7 \\
7 \\
7 \\
7 \\
7\end{array}$ & $\begin{array}{r}0 \\
3 \\
6 \\
9 \\
12 \\
15 \\
18 \\
21\end{array}$ & $\begin{array}{r}5.0 \\
-6.9 \\
-7.7 \\
-0.5 \\
5.4 \\
5.2\end{array}$ & $\begin{array}{l}1.2 \\
1.1 \\
1.0\end{array}$ & $\begin{array}{l}5.1 \\
7.0 \\
7.4 \\
0.5 \\
5.1 \\
5.2\end{array}$ & $\begin{array}{l}1.5 \\
0.7 \\
0.9\end{array}$ & $\begin{array}{r}5.1 \\
-6.8 \\
-7.1 \\
-0.4 \\
5.1 \\
5.0\end{array}$ & $\begin{array}{l}0.7 \\
0.6\end{array}$ & $\begin{array}{r}5.2 \\
-\quad 6.5 \\
-6.9 \\
-0.4 \\
4.8 \\
4.9\end{array}$ & $\begin{array}{l}0.3 \\
1.0\end{array}$ & $\begin{array}{l}0.4 \\
0.4 \\
1.0 \\
2.3 \\
3.9 \\
4.0\end{array}$ & & $\begin{array}{l}7.5 \\
3.7 \\
4.0 \\
6.0 \\
9.7 \\
6.2 \\
2.01 \\
4.0\end{array}$ & $\begin{array}{r}9.1 \\
4.7 \\
4.9 \\
6.8 \\
11.1 \\
7.7 \\
2.7 \\
5.0\end{array}$ & $\begin{array}{r}10.1 \\
5.7 \\
5.8 \\
7.4 \\
13.5 \\
9.5 \\
3.7 \\
6.6\end{array}$ & $\begin{array}{r}10.6 \\
6.7 \\
7.1 \\
7.8 \\
14.7 \\
10.7 \\
5.5 \\
8.1\end{array}$ \\
\hline $\begin{array}{l}8 \\
8 \\
8 \\
8 \\
8 \\
8 \\
8 \\
8\end{array}$ & $\begin{array}{r}0 \\
3 \\
6 \\
9 \\
12 \\
15 \\
18 \\
21\end{array}$ & $\begin{array}{r}9.5 \\
10.6 \\
4.5 \\
2.8\end{array}$ & $\begin{array}{r}3.1 \\
3.4 \\
0.4 \\
-0.6\end{array}$ & $\begin{array}{r}9.1 \\
10.2 \\
4.7 \\
2.9\end{array}$ & $\begin{array}{r}2.8 \\
3.1 \\
0.4 \\
-0.6\end{array}$ & $\begin{array}{r}8.8 \\
10.3 \\
5.0 \\
3.0\end{array}$ & $\begin{array}{r}2.8 \\
3.0 \\
0.5 \\
-0.5\end{array}$ & $\begin{array}{r}8.6 \\
10.4 \\
5.8 \\
3.2\end{array}$ & 3.0 & $\begin{array}{l}3.9 \\
3.4 \\
2.9 \\
2.6\end{array}$ & & $\begin{array}{r}2.2 \\
2.2 \\
2.3 \\
7.0 \\
10.5 \\
8.2 \\
7.3 \\
8.4\end{array}$ & $\begin{array}{r}2.7 \\
2.8 \\
3.0 \\
7.9 \\
12.0 \\
9.4 \\
8.8 \\
9.9\end{array}$ & $\begin{array}{r}2.9 \\
3.3 \\
3.5 \\
8.8 \\
13.5 \\
11.2 \\
10.8 \\
11.8\end{array}$ & $\begin{array}{r}3.8 \\
4.9 \\
4.4 \\
9.4 \\
14.9 \\
12.8 \\
13.5 \\
14.2\end{array}$ \\
\hline $\begin{array}{l}9 \\
9 \\
9 \\
9 \\
9 \\
9 \\
9 \\
9\end{array}$ & $\begin{array}{r}0 \\
3 \\
6 \\
9 \\
12 \\
15 \\
18 \\
21\end{array}$ & $\begin{array}{r}1.9 \\
0.8 \\
0.2 \\
3.1 \\
9.3 \\
12.0 \\
9.4 \\
7.8\end{array}$ & $\begin{array}{r}-1.7 \\
-2.6 \\
-3.1 \\
=0.8 \\
2.09 \\
4.5 \\
4.3 \\
4.7\end{array}$ & $\begin{array}{r}2.1 \\
0.7 \\
0.2 \\
3.4 \\
9.4 \\
11.9 \\
9.4 \\
7.8\end{array}$ & $\mid \begin{array}{r}-1.7 \\
=2.7 \\
=2.1 \\
-0.7 \\
2.6 \\
4.3 \\
4.2 \\
4.7\end{array}$ & $\begin{array}{r}2.2 \\
0.6 \\
0.4 \\
3.5 \\
9.4 \\
12.0 \\
9.6 \\
7.8\end{array}$ & $\mid \begin{array}{r}-1.7 \\
-2.4 \\
0.1 \\
2.5 \\
4.3 \\
4.2 \\
4.7\end{array}$ & $\begin{array}{r}2.7 \\
0.8 \\
0.6 \\
3.5 \\
9.3 \\
12.0 \\
9.6 \\
8.1\end{array}$ & & $\begin{array}{l}2.4 \\
2.1 \\
2.2 \\
2.8 \\
3.6 \\
3.7 \\
3.4 \\
3.4\end{array}$ & & $\begin{array}{r}10.2 \\
10.4 \\
11.7 \\
12.8 \\
15.9 \\
14.3 \\
9.9 \\
9.9\end{array}$ & $\begin{array}{l}11.9 \\
12.1 \\
13.5 \\
14.9 \\
18.1 \\
16.5 \\
11.8 \\
11.5\end{array}$ & $\begin{array}{l}13.9 \\
14.2 \\
15.6 \\
16.8 \\
20.5 \\
18.8 \\
13.6 \\
13.4\end{array}$ & $\begin{array}{l}16.6 \\
17.0 \\
18.1 \\
18.7 \\
22.8 \\
21.2 \\
15.7 \\
15.7\end{array}$ \\
\hline $\begin{array}{l}10 \\
10 \\
10 \\
10 \\
10 \\
10 \\
10 \\
10\end{array}$ & $\begin{array}{r}0 \\
3 \\
6 \\
9 \\
12 \\
15 \\
18 \\
21\end{array}$ & $\begin{array}{r}1.1 \\
0.8 \\
1.1 \\
3.0 \\
6.4 \\
6.6 \\
2.0 \\
-0.4\end{array}$ & $\begin{array}{r}-0.8 \\
=1.22 \\
-0.13 \\
0.00 \\
1.09 \\
1.09 \\
-1.60 \\
-3.33\end{array}$ & $\begin{array}{l}1.0 \\
0.9 \\
1.1 \\
2.8 \\
6.2 \\
6.5 \\
2.4 \\
0.3\end{array}$ & $\begin{array}{l}-1.00 \\
-1.2 \\
=0.9 \\
-0.1 \\
1.5 \\
1.6 \\
-1.3 \\
-2.6\end{array}$ & $\begin{array}{l}0.9 \\
1.00 \\
1.0 \\
2.8 \\
6.1 \\
6.8 \\
2.8 \\
1.3\end{array}$ & $\begin{array}{r}-1.2 \\
-1.2 \\
-1.00 \\
-0.1 \\
1.3 \\
1.05 \\
-0.9 \\
-2.0\end{array}$ & $\begin{array}{l}0.8 \\
0.9 \\
1.0 \\
2.9 \\
6: 1 \\
7.0 \\
4: 2 \\
1.4\end{array}$ & $\left|\begin{array}{r}0.2 \\
-1.1 \\
0.2 \\
1.2 \\
-1.4 \\
-0.2 \\
-1.2\end{array}\right|$ & $\begin{array}{l}2.9 \\
1.9 \\
1.5 \\
3.0 \\
5.2 \\
4.6 \\
3.4 \\
3.1\end{array}$ & & $\begin{array}{r}10.5 \\
14.0 \\
12.8 \\
12.0 \\
10.2 \\
7.0 \\
1.6 \\
2.0\end{array}$ & $\begin{array}{r}12.3 \\
15.6 \\
14.1 \\
13.6 \\
12.0 \\
8.9 \\
2.4 \\
2.7\end{array}$ & $\begin{array}{r}14.7 \\
23.0 \\
21.8 \\
19.6 \\
16.5 \\
11.7 \\
2.6 \\
3.5\end{array}$ & $\begin{array}{r}16.4 \\
24.8 \\
23.5 \\
21.3 \\
18.2 \\
13.2 \\
3.1 \\
3.8\end{array}$ \\
\hline
\end{tabular}




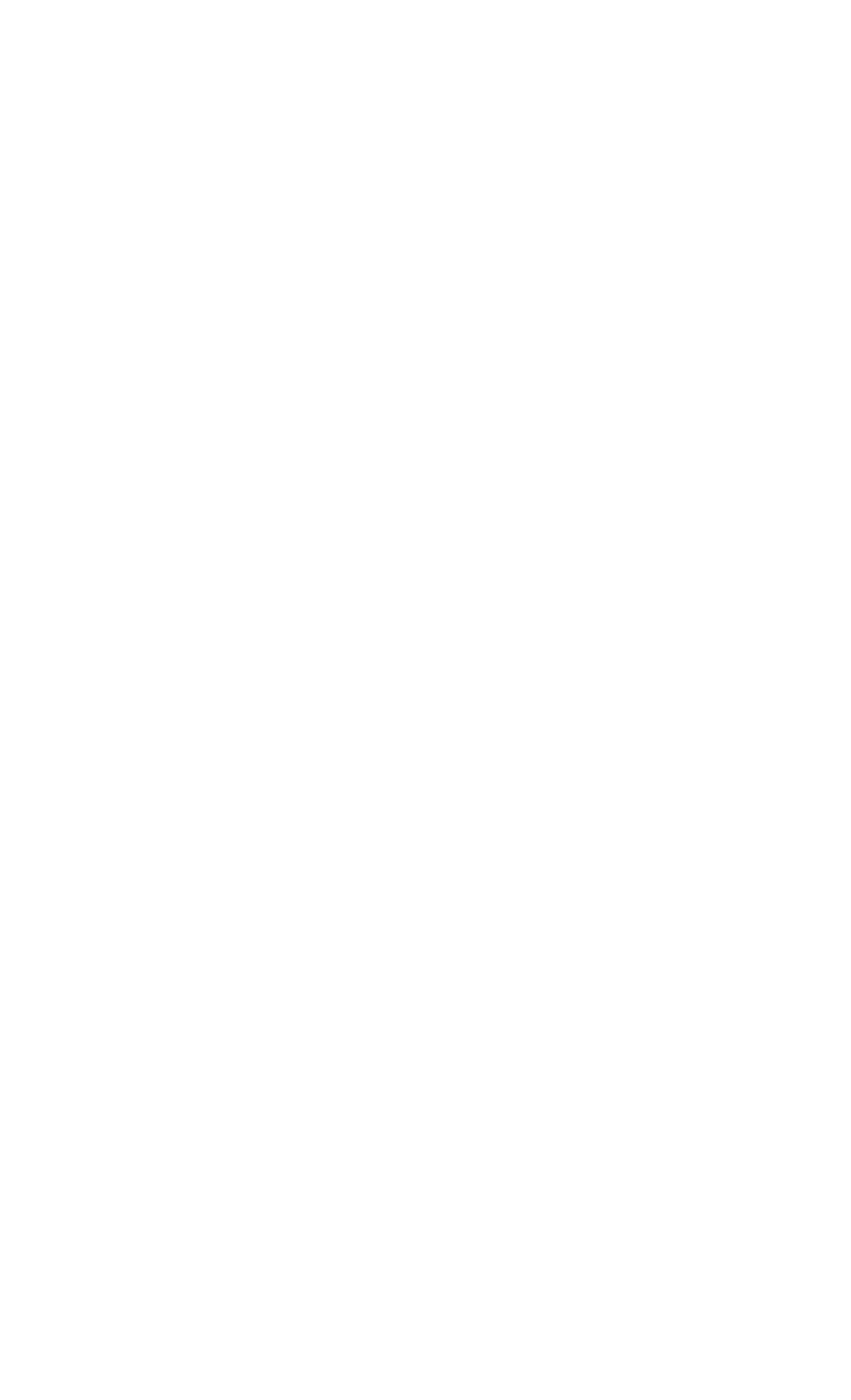


TABLE 10

Table 10. - Three-hour averages of air and water-surface temperatures and wind directions and speed, April 1950-August 1951, Lake Hefner-Continued

STATION 2

THREE-HOURLY AVERAGES

JANUARY, 1951

\begin{tabular}{|c|c|c|c|c|c|c|c|c|c|c|c|c|c|c|c|}
\hline \multirow{3}{*}{ 㤐 } & \multirow{3}{*}{ 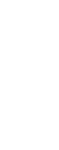 } & \multicolumn{8}{|c|}{ Average air temperature $\left({ }^{\circ} \mathrm{C}\right)$ at indicated height } & \multirow{3}{*}{$\begin{array}{c}\text { Average } \\
\text { water- } \\
\text { surface } \\
\text { tempera- } \\
\text { ture } \\
\left(^{\circ} \mathrm{C}\right)\end{array}$} & \multirow{3}{*}{$\begin{array}{c}\text { Average } \\
\text { wind } \\
\text { direction } \\
\text { (coded) }\end{array}$} & \multirow{2}{*}{\multicolumn{4}{|c|}{$\begin{array}{l}\text { Average wind speed (knots) } \\
\text { at indicated height }\end{array}$}} \\
\hline & & \multicolumn{2}{|c|}{$\begin{array}{c}2 \\
\text { meters }\end{array}$} & \multicolumn{2}{|c|}{$\begin{array}{c}4 \\
\text { meters }\end{array}$} & \multicolumn{2}{|c|}{$\begin{array}{c}8 \\
\text { meters }\end{array}$} & \multicolumn{2}{|c|}{$\begin{array}{c}16 \\
\text { meters }\end{array}$} & & & & & & \\
\hline & & $\begin{array}{l}\text { Dry } \\
\text { bulb }\end{array}$ & $\begin{array}{l}\text { Wet } \\
\text { bulb }\end{array}$ & $\begin{array}{l}\text { Dry } \\
\text { bulb }\end{array}$ & $\begin{array}{l}\text { Wet } \\
\text { bulb }\end{array}$ & $\begin{array}{l}\text { Dry } \\
\text { bulb }\end{array}$ & $\begin{array}{l}\text { Wet } \\
\text { bulb }\end{array}$ & $\begin{array}{l}\text { Dry } \\
\text { bulb }\end{array}$ & $\begin{array}{l}\text { Wet } \\
\text { bulb }\end{array}$ & & & $\begin{array}{c}2 \\
\text { meters }\end{array}$ & $\begin{array}{c}4 \\
\text { meters }\end{array}$ & $\begin{array}{c}8 \\
\text { meters }\end{array}$ & $\begin{array}{c}16 \\
\text { meters }\end{array}$ \\
\hline $\begin{array}{l}21 \\
21 \\
21 \\
21 \\
21 \\
21 \\
21 \\
21\end{array}$ & $\begin{array}{r}0 \\
3 \\
6 \\
9 \\
12 \\
15 \\
18 \\
21\end{array}$ & $\begin{array}{l}-3.8 \\
=5.8 \\
=-6.7 \\
=5.0 \\
=0.2 \\
-3.5 \\
-0.6 \\
-1.1\end{array}$ & 0.9 & $\begin{array}{l}3.9 \\
5.8 \\
6.8 \\
5.2 \\
0.2 \\
3.1 \\
0.2 \\
1.1\end{array}$ & -0.2 & $\begin{array}{r}-4.1 \\
-\quad 6.0 \\
-6.9 \\
-4.9 \\
0.3 \\
3.0 \\
0.2 \\
-1.0\end{array}$ & $\begin{array}{r}-0.2 \\
0.4 \\
\end{array}$ & $\left|\begin{array}{r}-4.2 \\
-6.2 \\
-7.0 \\
-5.0 \\
0.5 \\
2.8 \\
0.7 \\
-0.9\end{array}\right|$ & & $\begin{array}{l}1.0 \\
0.2 \\
1.4 \\
4.1 \\
3.9 \\
2.9 \\
2.6\end{array}$ & & $\begin{array}{l}8.0 \\
7.7 \\
5.5 \\
3.3 \\
2.3 \\
4.0 \\
3.5 \\
6.7\end{array}$ & $\begin{array}{l}8.7 \\
8.7 \\
6.4 \\
3.6 \\
2.4 \\
5.0 \\
4.8 \\
8.0\end{array}$ & $\begin{array}{l}8.9 \\
8.6 \\
6.2 \\
3.6 \\
2.5 \\
5.7 \\
6.5 \\
9.5\end{array}$ & $\begin{array}{r}9.1 \\
9.4 \\
6.9 \\
3.9 \\
2.5 \\
6.0 \\
8.3 \\
11.5\end{array}$ \\
\hline $\begin{array}{l}22 \\
22 \\
22 \\
22 \\
22 \\
22 \\
22 \\
22\end{array}$ & $\begin{array}{r}0 \\
3 \\
6 \\
9 \\
12 \\
15 \\
18 \\
21\end{array}$ & $\begin{array}{r}-1.3 \\
-1.3 \\
0.0 \\
3.8 \\
9.4 \\
11.5 \\
8.7 \\
7.2\end{array}$ & $\begin{array}{l}0.9 \\
3.4 \\
4.7 \\
3.7 \\
3.5\end{array}$ & $\begin{array}{r}1.2 \\
1.2 \\
0.0 \\
3.8 \\
9.5 \\
11.4 \\
8.8 \\
7.5\end{array}$ & $\begin{array}{l}0.5 \\
2.0 \\
4.0 \\
3.0 \\
3.0\end{array}$ & $\mid \begin{array}{r}-1.2 \\
-1.01 \\
0.1 \\
3.0 \\
9.02 \\
11.4 \\
0.0 \\
7.5\end{array}$ & \begin{tabular}{l|} 
\\
0.9 \\
2.6 \\
4.0 \\
3.1 \\
3.0
\end{tabular} & $\mid \begin{array}{r}-1.1 \\
-1.1 \\
0.1 \\
4.0 \\
9.0 \\
11.0 \\
9.0 \\
7.6\end{array}$ & & $\begin{array}{l}2.2 \\
2.2 \\
2.3 \\
3.4 \\
4.2 \\
3.9 \\
3.4 \\
3.3\end{array}$ & & $\begin{array}{l}9.1 \\
11.9 \\
13.8 \\
19.0 \\
18.0 \\
13.4 \\
12.4 \\
12.5\end{array}$ & $\begin{array}{l}10.6 \\
14.0 \\
16.3 \\
21.8 \\
20.3 \\
15.2 \\
14.5 \\
14.1\end{array}$ & $\begin{array}{l}12.3 \\
15.9 \\
18.5 \\
24.6 \\
22.8 \\
17.4 \\
16.6 \\
16.9\end{array}$ & $\begin{array}{l}14.4 \\
18.2 \\
20.6 \\
27.2 \\
25.6 \\
19.6 \\
18.9 \\
19.1\end{array}$ \\
\hline $\begin{array}{l}23 \\
23 \\
23 \\
23 \\
23 \\
23 \\
23 \\
23\end{array}$ & $\begin{array}{r}0 \\
3 \\
6 \\
9 \\
12 \\
15 \\
18 \\
21\end{array}$ & $\begin{array}{l}3.7 \\
1.2 \\
1.3 \\
4.6 \\
7.6 \\
8.2 \\
3.2 \\
0.8\end{array}$ & $\begin{array}{r}1.4 \\
-0.5 \\
0.0 \\
3.1 \\
3.9 \\
3.7 \\
-0.5 \\
-2.0\end{array}$ & $\begin{array}{l}3.6 \\
1.3 \\
1.5 \\
4.5 \\
7.4 \\
8.0 \\
4.6 \\
2.5\end{array}$ & $\begin{array}{r}1.2 \\
-0.6 \\
0.0 \\
2.6 \\
3.2 \\
3.3 \\
0.0 \\
-1.2\end{array}$ & $\begin{array}{l}3.6 \\
1.1 \\
1.5 \\
4.4 \\
7.3 \\
8.7 \\
5.4 \\
3.5\end{array}$ & $\begin{array}{r}1.1 \\
-0.7 \\
0.0 \\
2.5 \\
2.9 \\
2.9 \\
0.4 \\
-0.8\end{array}$ & $\begin{array}{l}3.5 \\
1.7 \\
1.5 \\
4.7 \\
7.9 \\
9.3 \\
6.5 \\
4.7\end{array}$ & $\begin{array}{l}2.9 \\
3.0 \\
1.1 \\
0.1\end{array}$ & $\begin{array}{l}2.8 \\
2.0 \\
1.4 \\
2.8 \\
6.5 \\
6.4 \\
4.7 \\
3.8\end{array}$ & & $\begin{array}{l}6.9 \\
9.0 \\
9.1 \\
9.2 \\
7.1 \\
4.5 \\
2.2 \\
1.9\end{array}$ & $\begin{array}{r}8.8 \\
10.0 \\
11.4 \\
11.7 \\
9.4 \\
6.2 \\
2.8 \\
2.8\end{array}$ & $\begin{array}{r}9.9 \\
13.0 \\
12.0 \\
11.8 \\
10.1 \\
7.8 \\
3.2 \\
3.5\end{array}$ & $\begin{array}{r}11.5 \\
13.9 \\
13.2 \\
13.4 \\
11.5 \\
9.2 \\
4.2 \\
5.0\end{array}$ \\
\hline $\begin{array}{l}24 \\
24 \\
24 \\
24 \\
24 \\
24 \\
24 \\
24\end{array}$ & $\begin{array}{r}0 \\
3 \\
6 \\
9 \\
12 \\
15 \\
18 \\
21\end{array}$ & $\begin{array}{r}0.4 \\
0.2 \\
2.1 \\
6.9 \\
11.5 \\
8.1 \\
3.0 \\
0.3\end{array}$ & $\begin{array}{r}-2.2 \\
=2.3 \\
-0.6 \\
2.2 \\
5.0 \\
3.6 \\
0.1 \\
-1.4\end{array}$ & 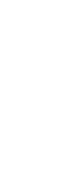 & 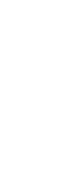 & $\begin{array}{r}2.0 \\
1.9 \\
2.04 \\
6.0 \\
21.1 \\
8.1 \\
3.1 \\
0.4\end{array}$ & $\left|\begin{array}{r}-1.4 \\
-1.4 \\
-1.6 \\
1.9 \\
4.02 \\
2.8 \\
0.0 \\
-1.8\end{array}\right|$ & $\begin{array}{r}3.0 \\
3.4 \\
2.8 \\
6.8 \\
10.9 \\
8.1 \\
3.3 \\
0.6\end{array}$ & $\begin{array}{r}-0.7 \\
-0.5 \\
-0.3 \\
2.0 \\
4.2 \\
2.8 \\
0.0 \\
-1.5\end{array}$ & $\begin{array}{l}3 \cdot 3 \\
3.1 \\
3.1 \\
4.3 \\
5.7 \\
5.1 \\
3.9 \\
2.7\end{array}$ & & $\begin{array}{r}1.8 \\
3.0 \\
3.0 \\
8.0 \\
11.7 \\
10.4 \\
3.5 \\
2.5\end{array}$ & $\begin{array}{r}2.7 \\
4.3 \\
3.5 \\
9.1 \\
13.3 \\
12.8 \\
4.3 \\
2.9\end{array}$ & $\begin{array}{r}3.8 \\
6.0 \\
4.3 \\
10.2 \\
16.3 \\
15.0 \\
6.0 \\
3.8\end{array}$ & $\begin{array}{r}5.8 \\
8.4 \\
5.7 \\
11.1 \\
18.1 \\
17.2 \\
7.4 \\
4.9\end{array}$ \\
\hline $\begin{array}{l}25 \\
25 \\
25 \\
25 \\
25 \\
25 \\
25 \\
25\end{array}$ & $\begin{array}{r}0 \\
3 \\
6 \\
9 \\
12 \\
15 \\
18 \\
21\end{array}$ & $\begin{array}{r}-0.7 \\
-0.8 \\
-2.0 \\
2.8 \\
7.5 \\
8.3 \\
3.7 \\
3.0\end{array}$ & $\begin{array}{r}-3.1 \\
\\
0.4 \\
2.2 \\
2.5 \\
0.0 \\
-0.3\end{array}$ & $\begin{array}{l}0.7 \\
0.7 \\
1.3 \\
2.6 \\
7.2 \\
8.1 \\
4.2 \\
3.3\end{array}$ & $\begin{array}{r}-2.9 \\
-2.9 \\
-3.0 \\
0.3 \\
1.5 \\
2.1 \\
0.0 \\
-0.6\end{array}$ & $\begin{array}{r}-0.6 \\
=0.6 \\
-0.9 \\
2.6 \\
7.2 \\
8.0 \\
4.7 \\
3.3\end{array}$ & $\left|\begin{array}{r}-3.0 \\
-2.8 \\
-2.8 \\
-1.0 \\
1.5 \\
1.0 \\
0.2 \\
-0.6\end{array}\right|$ & $\mid \begin{array}{r}-0.5 \\
-0.5 \\
-0.7 \\
2.3 \\
7.0 \\
7.9 \\
5.1 \\
3.5\end{array}$ & $\begin{array}{r}-2.9 \\
-2.8 \\
-2.7 \\
-1.1 \\
1.6 \\
2.1 \\
0.6 \\
-0.2\end{array}$ & $\begin{array}{l}1.8 \\
2.0 \\
2.3 \\
4.0 \\
5.0 \\
4.2 \\
3.7 \\
3.2\end{array}$ & & $\begin{array}{r}3.9 \\
1.7 \\
2.2 \\
8.8 \\
10.2 \\
8.6 \\
4.5 \\
10.0\end{array}$ & $\begin{array}{r}5.1 \\
2.1 \\
2.7 \\
9.8 \\
11.3 \\
9.8 \\
5.6 \\
11.5\end{array}$ & $\begin{array}{r}5.9 \\
2.5 \\
3.2 \\
10.8 \\
12.5 \\
11.3 \\
7.4 \\
14.0\end{array}$ & $\begin{array}{r}7.4 \\
4.2 \\
3.7 \\
11.8 \\
13.8 \\
13.1 \\
9.4 \\
16.7\end{array}$ \\
\hline $\begin{array}{l}26 \\
26 \\
26 \\
26 \\
26 \\
26 \\
26 \\
26\end{array}$ & $\begin{array}{r}0 \\
3 \\
6 \\
9 \\
12 \\
15 \\
18 \\
21\end{array}$ & $\begin{array}{r}2.2 \\
1.9 \\
1.5 \\
9 \cdot 9 \\
17 \cdot 7 \\
19 \cdot 3 \\
15.6 \\
15.03\end{array}$ & $\begin{array}{r}-1.1 \\
-1.4 \\
-1.3 \\
4.5 \\
8.6 \\
9.5 \\
8.5 \\
9.1\end{array}$ & $\begin{array}{r}2.3 \\
1.9 \\
1.6 \\
10.5 \\
17.6 \\
19.3 \\
15.9 \\
15.4\end{array}$ & $\left|\begin{array}{r}-1.3 \\
-1.6 \\
-1.4 \\
4.1 \\
7.9 \\
8.6 \\
8.1 \\
8.7\end{array}\right|$ & $\begin{array}{r}2.4 \\
1.9 \\
1.7 \\
10.3 \\
17.5 \\
19.2 \\
15.9 \\
15.5\end{array}$ & $\mid \begin{array}{r}-1.3 \\
-1.5 \\
-1.4 \\
3.9 \\
7.8 \\
8.6 \\
8.1 \\
9.7\end{array}$ & $\begin{array}{r}2.5 \\
2: 0 \\
1 * 8 \\
10.1 \\
17.3 \\
19 \cdot 3 \\
16.2 \\
15.8\end{array}$ & $\begin{array}{r}-0.9 \\
-1.1 \\
-1.1 \\
4.1 \\
8.0 \\
9.0 \\
8.7 \\
9.1\end{array}$ & $\begin{array}{l}2.9 \\
2.7 \\
2.7 \\
4.3 \\
5.5 \\
4.7 \\
4.5 \\
4.4\end{array}$ & & $\begin{array}{r}10.6 \\
9.5 \\
11.1 \\
15.6 \\
15.6 \\
17.5 \\
13.2 \\
17.1\end{array}$ & $\begin{array}{l}12.3 \\
11.0 \\
12.8 \\
17.5 \\
17.6 \\
19.6 \\
15.1 \\
19.2\end{array}$ & $\begin{array}{l}14.8 \\
12.8 \\
14.7 \\
19.3 \\
19.8 \\
22.0 \\
17.5 \\
22.0\end{array}$ & $\begin{array}{l}17.9 \\
15.0 \\
17.2 \\
22.0 \\
22.1 \\
25.2 \\
20.3 \\
25.4\end{array}$ \\
\hline $\begin{array}{l}27 \\
27 \\
27 \\
27 \\
27 \\
27 \\
27 \\
27\end{array}$ & $\begin{array}{r}0 \\
3 \\
6 \\
6 \\
12 \\
15 \\
18 \\
21\end{array}$ & $\begin{array}{r}13.5 \\
-3.4 \\
-1.9 \\
=3.6 \\
=3.9 \\
=4.3 \\
=4.4 \\
-4.7\end{array}$ & $\begin{array}{r}8.0 \\
1.1 \\
-2.1 \\
\end{array}$ & $\begin{array}{r}13.5 \\
3.4 \\
1.8 \\
4.0 \\
4.3 \\
4.7 \\
4.7 \\
4.9\end{array}$ & $\begin{array}{r}7.6 \\
0.7 \\
-2.0 \\
\end{array}$ & $\begin{array}{r}13.6 \\
2.5 \\
-2.1 \\
=4.0 \\
=4.7 \\
=4.8 \\
=4.9 \\
-\quad 5.0\end{array}$ & $\begin{array}{r}7.6 \\
0.0 \\
-2.7 \\
\end{array}$ & $\left|\begin{array}{r}13.7 \\
2.1 \\
-2.5 \\
-4.6 \\
-5.0 \\
-5.0 \\
-5.0 \\
-5.3\end{array}\right|$ & $\begin{array}{r}8.3 \\
-0.2 \\
\end{array}$ & $\begin{array}{l}4.4 \\
3.7 \\
2.5 \\
2.9 \\
2.9 \\
2.1 \\
1.2 \\
1.0\end{array}$ & & $\begin{array}{l}12.1 \\
1205 \\
1209 \\
1401 \\
1305 \\
11.1 \\
1100 \\
11.03\end{array}$ & $\begin{array}{l}13.9 \\
15.9 \\
15.5 \\
16.1 \\
16.0 \\
12.5 \\
12.7 \\
12.8\end{array}$ & $\begin{array}{l}16.3 \\
16.4 \\
16.8 \\
16.0 \\
13.6 \\
13.1 \\
13.4\end{array}$ & $\begin{array}{l}19.0 \\
17.5 \\
16.7 \\
17.2 \\
17.0 \\
14.2 \\
13.8 \\
14.0\end{array}$ \\
\hline $\begin{array}{l}28 \\
28 \\
28 \\
28 \\
28 \\
28 \\
28 \\
28\end{array}$ & $\begin{array}{r}0 \\
3 \\
5 \\
9 \\
12 \\
15 \\
18 \\
21\end{array}$ & $\begin{array}{l}-6.2 \\
-10.0 \\
-10.8 \\
-10.7 \\
=9.8 \\
=8.8 \\
=9.8 \\
-10.8\end{array}$ & & 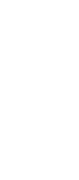 & & $\begin{array}{l}-6.9 \\
-10.8 \\
-11.4 \\
-11.5 \\
-10.4 \\
-10.4 \\
-10.2 \\
-11.3\end{array}$ & & 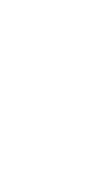 & & $\begin{array}{l}0.9 \\
0.1 \\
0.4 \\
1.1 \\
0.4\end{array}$ & & $\begin{array}{l}13.9 \\
13.4 \\
12.8 \\
13.2 \\
12.1 \\
12.1 \\
11.5 \\
12.6\end{array}$ & $\begin{array}{l}16.4 \\
15.2 \\
14.6 \\
15.5 \\
14.3 \\
13.5 \\
12.9 \\
14.1\end{array}$ & $\begin{array}{l}17.2 \\
15.4 \\
14.9 \\
15.4 \\
14.8 \\
14.7 \\
14.6 \\
15.6\end{array}$ & $\begin{array}{l}17.8 \\
16.7 \\
15.7 \\
16.2 \\
15.1 \\
15.0 \\
17.6\end{array}$ \\
\hline $\begin{array}{l}29 \\
29 \\
29 \\
29 \\
29 \\
29 \\
29 \\
29\end{array}$ & $\begin{array}{r}0 \\
3 \\
6 \\
9 \\
12 \\
15 \\
18 \\
21\end{array}$ & $\begin{array}{l}-11.8 \\
-10.0 \\
=8.5 \\
=9.3 \\
-10.3\end{array}$ & & $\begin{array}{r}13.1 \\
10: 6 \\
8: 8 \\
9: 3 \\
10.4\end{array}$ & & 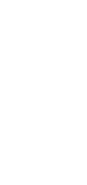 & & 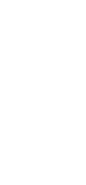 & & $\begin{array}{l}0.9 \\
0.9 \\
0.3 \\
0.1\end{array}$ & & $\begin{array}{r}12.1 \\
11.8 \\
13.6 \\
11 * 9 \\
9.8 \\
9.8 \\
8.2 \\
8.9\end{array}$ & $\begin{array}{r}13.1 \\
13.5 \\
14.5 \\
13.2 \\
10.8 \\
11.3 \\
9.5 \\
10.5\end{array}$ & $\begin{array}{l}14.9 \\
14.9 \\
16.1 \\
15.3 \\
12.6 \\
14.5 \\
12.1 \\
13.6\end{array}$ & $\begin{array}{l}14.4 \\
14.0 \\
15.9 \\
15.3 \\
13.5 \\
15.6 \\
13.5 \\
15.9\end{array}$ \\
\hline $\begin{array}{l}30 \\
30 \\
30 \\
30 \\
30 \\
30 \\
30 \\
30\end{array}$ & $\begin{array}{r}0 \\
3 \\
6 \\
9 \\
12 \\
15 \\
18 \\
21\end{array}$ & $\begin{array}{l}-11.1 \\
-12.3 \\
-12.9 \\
-11.9 \\
-9.9 \\
-8.3 \\
-10.0 \\
-11.0\end{array}$ & & 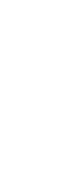 & & 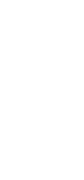 & & $\begin{array}{l}-11.7 \\
-12.9 \\
-13.4 \\
-12.4 \\
-10.3 \\
-9.2 \\
-10.4 \\
-11.6\end{array}$ & & $\begin{array}{l}0.4 \\
0.7 \\
0.2\end{array}$ & & $\begin{array}{l}9.4 \\
9.0 \\
7.7 \\
6.7 \\
7.7 \\
6.7 \\
7.9 \\
8.7\end{array}$ & $\begin{array}{r}10.9 \\
10.6 \\
8.9 \\
7.5 \\
8.8 \\
7.6 \\
9.1 \\
9.7\end{array}$ & $\begin{array}{r}13.5 \\
12.7 \\
11.2 \\
8.3 \\
9.3 \\
9.1 \\
10.5 \\
11.3\end{array}$ & $\begin{array}{r}16.0 \\
14.0 \\
13.1 \\
9.0 \\
9.9 \\
9.7 \\
10.3 \\
12.3\end{array}$ \\
\hline $\begin{array}{l}31 \\
31 \\
31 \\
31 \\
31 \\
31 \\
31 \\
31\end{array}$ & $\begin{array}{r}0 \\
3 \\
6 \\
9 \\
12 \\
15 \\
18 \\
? 1\end{array}$ & $\begin{array}{l}-11.05 \\
-11.6 \\
-11.9 \\
-11.2 \\
-9.6 \\
-8.9 \\
-10.1 \\
-11.6\end{array}$ & & 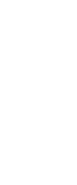 & & 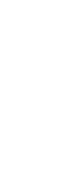 & & $\mid \begin{array}{llll}-1 & 2 & 0 \\
-1 & 2 & 0 \\
-1 & 1 & 1 \\
-1 & 1 & 4 \\
-1 & 0 & 0 \\
-1 & 9 & 0 \\
-1 & 0.6 \\
-1 & 2 & 0 & 0\end{array}$ & & & & $\begin{array}{r}8.1 \\
7.9 \\
10.1 \\
11.1 \\
13.8 \\
14.0 \\
15.7 \\
13.0\end{array}$ & $\begin{array}{r}9.3 \\
9.1 \\
11.6 \\
13.9 \\
17.0 \\
16.5 \\
19.8 \\
16.0\end{array}$ & $\begin{array}{l}10.4 \\
10.1 \\
12.2 \\
13.6 \\
17.7 \\
16.1 \\
19.8 \\
16.6\end{array}$ & $\begin{array}{l}10.9 \\
10.9 \\
12.4 \\
14.5 \\
18.3 \\
17.8 \\
21.3 \\
17.4\end{array}$ \\
\hline
\end{tabular}


TABLE 10

Table 10. - Three-hour averages of air and water-surface temperatures and wind directions and speed, April 1950-August 1951, Lake Hefner-Continued

STATION 2 THREE-HOURLY AVERAGES

FEBRUARY, 1951

\begin{tabular}{|c|c|c|c|c|c|c|c|c|c|c|c|c|c|c|c|}
\hline \multirow{3}{*}{ 宽 } & \multirow{3}{*}{ 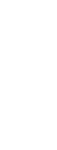 } & \multicolumn{8}{|c|}{ Average air temperature $\left({ }^{\circ} \mathrm{C}\right)$ at indicated height } & \multirow{3}{*}{\begin{tabular}{|l} 
Average \\
water- \\
surface \\
tempera- \\
ture \\
('C)
\end{tabular}} & \multirow{3}{*}{$\begin{array}{c}\text { Average } \\
\text { wind } \\
\text { direction } \\
\text { (coded) }\end{array}$} & \multirow{2}{*}{\multicolumn{4}{|c|}{$\begin{array}{l}\text { Average wind speed (knots) } \\
\text { at indicated height }\end{array}$}} \\
\hline & & \multicolumn{2}{|c|}{$\begin{array}{c}2 \\
\text { meters }\end{array}$} & \multicolumn{2}{|c|}{$\begin{array}{c}4 \\
\text { meters }\end{array}$} & \multicolumn{2}{|c|}{$\begin{array}{c}8 \\
\text { meters }\end{array}$} & \multicolumn{2}{|c|}{$\begin{array}{c}16 \\
\text { meters }\end{array}$} & & & & & & \\
\hline & & $\begin{array}{l}\text { Dry } \\
\text { bulb }\end{array}$ & $\begin{array}{l}\text { Wet } \\
\text { bulb }\end{array}$ & $\begin{array}{l}\text { Dry } \\
\text { bulb }\end{array}$ & $\begin{array}{l}\text { Wet } \\
\text { butb }\end{array}$ & $\begin{array}{l}\text { Dry } \\
\text { bulb }\end{array}$ & $\begin{array}{l}\text { Wet } \\
\text { bulb }\end{array}$ & $\begin{array}{l}\text { Dry } \\
\text { bulb }\end{array}$ & $\begin{array}{l}\text { Wet } \\
\text { bulb }\end{array}$ & & & meters & meters & meters & meters \\
\hline $\begin{array}{l}11 \\
11 \\
11 \\
11 \\
11 \\
11 \\
11 \\
11\end{array}$ & $\begin{array}{r}0 \\
3 \\
6 \\
9 \\
12 \\
15 \\
18 \\
21\end{array}$ & $\begin{array}{r}10.2 \\
9.3 \\
9.5 \\
16.0 \\
21.7 \\
23.1 \\
19.9 \\
17.8\end{array}$ & $\begin{array}{r}9.8 \\
8.9 \\
8.9 \\
12.4 \\
14.4 \\
14.9 \\
13.7 \\
13.1\end{array}$ & $\begin{array}{r}10.2 \\
9.4 \\
9.5 \\
16.3 \\
21.4 \\
23.0 \\
19.9 \\
18.0\end{array}$ & $\begin{array}{r}9.8 \\
8.9 \\
8.9 \\
12.3 \\
14.2 \\
14.7 \\
13.7 \\
13.1\end{array}$ & $\begin{array}{r}10.3 \\
9.8 \\
9.9 \\
16.4 \\
21.3 \\
22.8 \\
20.0 \\
18.1\end{array}$ & $\begin{array}{r}9.8 \\
9.0 \\
9.0 \\
12.4 \\
14.2 \\
14.8 \\
13.8 \\
13.2\end{array}$ & $\begin{array}{r}10.4 \\
9.9 \\
10.2 \\
16.5 \\
21.0 \\
22.8 \\
20.1 \\
18.2\end{array}$ & $\begin{array}{r}9.8 \\
9.0 \\
9.1 \\
12.3 \\
14.2 \\
14.9 \\
13.9 \\
13.2\end{array}$ & $\begin{array}{l}4.2 \\
4.9 \\
4.2 \\
3.6 \\
3.5\end{array}$ & & $\begin{array}{l}12.2 \\
11.4 \\
11.5 \\
16.1 \\
17.1 \\
15.9 \\
13.7 \\
16.2\end{array}$ & $\begin{array}{l}14.2 \\
13.3 \\
13.4 \\
18.1 \\
19.4 \\
18.2 \\
16.3 \\
18.9\end{array}$ & $\begin{array}{l}16.2 \\
15.4 \\
15.5 \\
20.3 \\
21.8 \\
20.3 \\
18.5 \\
21.4\end{array}$ & $\begin{array}{l}18.6 \\
17.7 \\
17.9 \\
22.8 \\
23.9 \\
22.6 \\
20.7 \\
24.4\end{array}$ \\
\hline $\begin{array}{l}12 \\
12 \\
12 \\
12 \\
12 \\
12 \\
12 \\
12\end{array}$ & $\begin{array}{r}0 \\
3 \\
6 \\
9 \\
12 \\
15 \\
18 \\
21\end{array}$ & $\begin{array}{r}17.9 \\
16.3 \\
15.2 \\
16.7 \\
10.1 \\
4.1 \\
-0.2 \\
-2.1\end{array}$ & $\begin{array}{r}12.2 \\
11.7 \\
11.3 \\
12.0 \\
6.2 \\
2.6\end{array}$ & $\begin{array}{r}18.2 \\
16.5 \\
15.3 \\
17.4 \\
9.3 \\
3.7 \\
0.5 \\
2.3\end{array}$ & $\begin{array}{r}11.8 \\
5.7 \\
2.3\end{array}$ & $\begin{array}{r}18.2 \\
16.5 \\
15.3 \\
17.3 \\
8.9 \\
3.3 \\
-0.6 \\
-2.5\end{array}$ & $\begin{array}{r}12.3 \\
11.9 \\
12.0 \\
5.3 \\
1.8 \\
-0.7\end{array}$ & $\mid \begin{array}{r}18.2 \\
16.5 \\
15.3 \\
16.8 \\
8.9 \\
2.09 \\
-1.2 .8 \\
-2.8\end{array}$ & $\begin{array}{r}12.4 \\
12.0 \\
11.2 \\
5.2 \\
1.7 \\
-0.9\end{array}$ & $\begin{array}{l}3.5 \\
3.6 \\
3.7 \\
4.5\end{array}$ & & $\begin{array}{l}17.5 \\
21.9 \\
20.0 \\
15.8 \\
10.8 \\
15.8 \\
15.8 \\
13.8\end{array}$ & $\begin{array}{l}20.3 \\
24.6 \\
22.3 \\
17.8 \\
12.4 \\
19.7 \\
19.5 \\
16.0\end{array}$ & $\begin{array}{l}22.8 \\
27.8 \\
24.5 \\
20.3 \\
17.2 \\
21.2 \\
18.6 \\
16.7\end{array}$ & $\begin{array}{l}25.4 \\
32.4 \\
28.5 \\
22.4 \\
19.3 \\
22.6 \\
21.0 \\
16.9\end{array}$ \\
\hline $\begin{array}{l}13 \\
13 \\
13 \\
13 \\
13 \\
13 \\
13 \\
13\end{array}$ & $\begin{array}{r}0 \\
3 \\
6 \\
9 \\
12 \\
15 \\
18 \\
21\end{array}$ & $\begin{array}{l}=3.8 \\
=5.84 \\
=-6.3 \\
=7.2 \\
=7.6 \\
=7.03 \\
=6.8 \\
=6.8\end{array}$ & & $\begin{array}{l}4.2 \\
5.6 \\
6.4 \\
7.4 \\
7.8 \\
7.4 \\
6.9 \\
6.8\end{array}$ & & $\begin{array}{l}=4.4 \\
=5.8 \\
=6.8 \\
=7.6 \\
=8.0 \\
=7.6 \\
=7.0 \\
-7.0\end{array}$ & & {$\left[\begin{array}{l}-4.6 \\
=-6.2 \\
=7.2 \\
=8.0 \\
=8.4 \\
=7: 0 \\
=7.3 \\
-7.1\end{array}\right.$} & & & & $\begin{array}{l}17.6 \\
17.1 \\
15.7 \\
16.3 \\
14.9\end{array}$ & $\begin{array}{l}18.6 \\
18.2 \\
16.2 \\
17.2 \\
16.8\end{array}$ & $\begin{array}{l}19.3 \\
17.6 \\
18.3 \\
20.5 \\
21.4\end{array}$ & $\begin{array}{l}20.8 \\
20.1 \\
18.4 \\
19.8 \\
21.6\end{array}$ \\
\hline $\begin{array}{l}14 \\
14 \\
14 \\
14 \\
14 \\
14 \\
14 \\
14\end{array}$ & $\begin{array}{r}0 \\
3 \\
6 \\
9 \\
12 \\
15 \\
18 \\
21\end{array}$ & $\begin{array}{l}=6.8 \\
=7.8 \\
=8.1 \\
=7.03 \\
=6.77 \\
=6.22 \\
=-6.4 \\
=6.4\end{array}$ & & $\begin{array}{l}7.0 \\
8.0 \\
8.2 \\
7.3 \\
6.7 \\
6.3 \\
6.5 \\
6.6\end{array}$ & & $\begin{array}{l}-7.1 \\
-8.2 \\
=8.4 \\
=7.4 \\
=6.9 \\
=6.6 \\
=6.7 \\
-6.7\end{array}$ & ${ }^{*}$ & $\begin{array}{l}-7.4 \\
-8.6 \\
=8.7 \\
=7.7 \\
=7.3 \\
=6.9 \\
=6.9 \\
-6.9\end{array}$ & & & & $\begin{array}{r}15.9 \\
17.7 \\
15.6 \\
16.2 \\
14.9 \\
13.7 \\
11.7 \\
8.8\end{array}$ & $\begin{array}{r}17.2 \\
19.8 \\
17.3 \\
18.4 \\
15.3 \\
14.5 \\
12.1 \\
9.7\end{array}$ & $\begin{array}{r}22.2 \\
21.9 \\
19.0 \\
19.2 \\
17.2 \\
15.1 \\
12.6 \\
9.8\end{array}$ & $\begin{array}{l}22.4 \\
22.8 \\
18.5 \\
19.8 \\
16.4 \\
15.4 \\
12.9 \\
10.3\end{array}$ \\
\hline $\begin{array}{l}15 \\
15 \\
15 \\
15 \\
15 \\
15 \\
15 \\
15\end{array}$ & $\begin{array}{r}0 \\
3 \\
6 \\
9 \\
12 \\
15 \\
18 \\
21\end{array}$ & $\begin{array}{l}-4.6 \\
=4.4 \\
=3.9 \\
=3.9 \\
=3.9\end{array}$ & & $\begin{array}{l}4 \cdot 3 \\
4 \cdot 5 \\
4 \cdot 0 \\
4 \cdot 0 \\
3.9\end{array}$ & & $\begin{array}{l}-5.0 \\
=4.0 \\
=4.0 \\
=4.0 \\
=3.9\end{array}$ & & $\left|\begin{array}{l}-5.1 \\
-4.8 \\
=4.1 \\
-4.0 \\
-4.0\end{array}\right|$ & & & & $\begin{array}{r}9.8 \\
10.3 \\
10.8 \\
9.7 \\
8.0 \\
8.9 \\
5.3 \\
1.7\end{array}$ & $\begin{array}{r}11.0 \\
11.9 \\
12.1 \\
11.1 \\
8.7 \\
10.0 \\
5.9 \\
2.2\end{array}$ & $\begin{array}{r}11.4 \\
13.1 \\
13.8 \\
11.8 \\
12.1 \\
11.7 \\
6.9 \\
2.6\end{array}$ & $\begin{array}{r}11.8 \\
13.1 \\
13.7 \\
12.0 \\
12.4 \\
12.2 \\
7.3 \\
2.9\end{array}$ \\
\hline $\begin{array}{l}16 \\
16 \\
16 \\
16 \\
16 \\
16 \\
16 \\
16\end{array}$ & $\begin{array}{r}0 \\
3 \\
6 \\
9 \\
12 \\
15 \\
18 \\
21\end{array}$ & $\begin{array}{r}-5.9 \\
=-8.9 \\
-8.3 \\
-2.5 \\
2.3 \\
5.1 \\
3.1 \\
2.22\end{array}$ & $\begin{array}{l}1.1 \\
2.3 \\
1.5 \\
0.6\end{array}$ & $\begin{array}{l}5.5 \\
6.6 \\
7.4 \\
2.6 \\
2.7 \\
5.5 \\
3.3 \\
2.4\end{array}$ & $\begin{array}{l} \\
1.5 \\
2.7 \\
1.9 \\
0.7\end{array}$ & $\begin{array}{r}-5.3 \\
=-6.3 \\
-\quad 6.9 \\
-2.6 \\
2.5 \\
5.5 \\
3.9 \\
2.4\end{array}$ & $\begin{array}{l} \\
1.6 \\
2.9 \\
1.8 \\
0.7\end{array}$ & $\left|\begin{array}{r}-5.0 \\
=5.7 \\
=6.4 \\
-2.6 \\
2.4 \\
5.7 \\
4.2 \\
2.7\end{array}\right|$ & $\begin{array}{l}1.3 \\
2.7 \\
2.0 \\
0.9\end{array}$ & & & $\begin{array}{r}3.9 \\
4.6 \\
4.0 \\
8.9 \\
6.4 \\
4.8 \\
4.6 \\
10.2\end{array}$ & $\begin{array}{r}4.9 \\
5.6 \\
5.4 \\
9.8 \\
7.1 \\
5.5 \\
5.7 \\
11.8\end{array}$ & $\begin{array}{r}6.4 \\
5.7 \\
6.2 \\
10.7 \\
7.9 \\
6.6 \\
7.1 \\
13.8\end{array}$ & $\begin{array}{r}8.2 \\
8.6 \\
7.5 \\
13.7 \\
8.8 \\
7.9 \\
8.7 \\
15.9\end{array}$ \\
\hline $\begin{array}{l}17 \\
17 \\
17 \\
17 \\
17 \\
17 \\
17 \\
17\end{array}$ & $\begin{array}{r}0 \\
3 \\
6 \\
9 \\
12 \\
15 \\
13 \\
21\end{array}$ & $\begin{array}{r}1.9 \\
1.9 \\
2.2 \\
3.9 \\
8.4 \\
10.1 \\
6.6 \\
6.3\end{array}$ & $\begin{array}{l}0.5 \\
1.00 \\
1.3 \\
2.6 \\
5.8 \\
7.0 \\
5.0 \\
5.0\end{array}$ & $\begin{array}{r}2.0 \\
2.0 \\
2.3 \\
4.1 \\
8.9 \\
10.0 \\
6.7 \\
6.5\end{array}$ & $\begin{array}{l}0.6 \\
1.0 \\
3.4 \\
2.6 \\
5.7 \\
6.8 \\
5.0 \\
6.0\end{array}$ & $\begin{array}{r}2.1 \\
2.1 \\
2.4 \\
4.2 \\
8.9 \\
10.1 \\
6.7 \\
6.5\end{array}$ & $\begin{array}{l}0.7 \\
1.0 \\
1.2 \\
2.5 \\
5.7 \\
6.6 \\
4.9 \\
6.0\end{array}$ & $\begin{array}{r}2.3 \\
2.3 \\
2.5 \\
4.4 \\
9.1 \\
10.1 \\
6.8 \\
6.7\end{array}$ & $\begin{array}{l}0.8 \\
1.2 \\
1.5 \\
2.8 \\
6.0 \\
7.0 \\
5.2 \\
6.2\end{array}$ & & & $\begin{array}{r}12.4 \\
12.3 \\
12.4 \\
11.8 \\
9.3 \\
10.3 \\
12.1 \\
12.9\end{array}$ & $\begin{array}{l}14.1 \\
13.9 \\
14.1 \\
13.2 \\
10.6 \\
12.0 \\
14.1 \\
15.0\end{array}$ & $\begin{array}{l}16.4 \\
16.8 \\
16.1 \\
15.2 \\
12.2 \\
13.9 \\
16.2 \\
17.1\end{array}$ & $\begin{array}{l}19.0 \\
18.6 \\
18.6 \\
17.4 \\
14.3 \\
16.1 \\
18.7 \\
19.8\end{array}$ \\
\hline $\begin{array}{l}18 \\
18 \\
18 \\
18 \\
18 \\
18 \\
18 \\
18\end{array}$ & $\begin{array}{r}0 \\
3 \\
6 \\
9 \\
12 \\
15 \\
18 \\
21\end{array}$ & $\begin{array}{r}7.4 \\
8.2 \\
8.7 \\
12.2 \\
18.0 \\
19.7 \\
12.8 \\
10.1\end{array}$ & $\begin{array}{r}7.4 \\
8.2 \\
8.7 \\
10.4 \\
12.1 \\
11.1 \\
7.9 \\
6.5\end{array}$ & $\begin{array}{r}7.5 \\
8.5 \\
9.0 \\
12.5 \\
18.3 \\
19.6 \\
13.5 \\
10.7\end{array}$ & $\begin{array}{r}7.6 \\
8.5 \\
9.0 \\
10.6 \\
11.5 \\
10.7 \\
8.0 \\
6.6\end{array}$ & $\begin{array}{r}7.4 \\
7.9 \\
8.3 \\
12.7 \\
18.0 \\
19.7 \\
14.4 \\
11.3\end{array}$ & $\begin{array}{r}7.4 \\
7.9 \\
8.3 \\
10.4 \\
11.5 \\
10.7 \\
8.2 \\
6.7\end{array}$ & $\begin{array}{r}7.0 \\
7.1 \\
5.9 \\
12.5 \\
17.8 \\
19.7 \\
15.9 \\
12.5\end{array}$ & 7.0 & $\begin{array}{l}4.9 \\
5.7 \\
4.7 \\
4.0 \\
3.7\end{array}$ & & $\begin{array}{r}10.8 \\
8.1 \\
10.0 \\
9.3 \\
11.8 \\
9.6 \\
4.2 \\
5.9\end{array}$ & $\begin{array}{r}12.4 \\
9.5 \\
11.5 \\
10.5 \\
13.2 \\
10.8 \\
5.8 \\
7.3\end{array}$ & $\begin{array}{r}14.2 \\
11.3 \\
14.0 \\
11.8 \\
14.8 \\
12.6 \\
7.8 \\
9.6\end{array}$ & $\begin{array}{l}16.3 \\
13.2 \\
15.1 \\
13.1 \\
16.4 \\
14.4 \\
10.2 \\
13.1\end{array}$ \\
\hline $\begin{array}{l}19 \\
19 \\
19 \\
19 \\
19 \\
19 \\
19 \\
19\end{array}$ & $\begin{array}{r}0 \\
3 \\
6 \\
9 \\
12 \\
15 \\
18 \\
21\end{array}$ & $\begin{array}{r}9.3 \\
7.8 \\
7.2 \\
11.8 \\
17.2 \\
17.8 \\
14.6 \\
9.5\end{array}$ & $\begin{array}{r}5.9 \\
4.8 \\
4.5 \\
7.7 \\
9.6 \\
13.8 \\
13.6 \\
9.2\end{array}$ & $\begin{array}{r}9.5 \\
8.1 \\
7.5 \\
11.9 \\
17.2 \\
17.7 \\
14.7 \\
9.6\end{array}$ & $\begin{array}{r}5.7 \\
4.6 \\
4.4 \\
7.6 \\
9.1 \\
13.7 \\
13.5 \\
8.6\end{array}$ & $\begin{array}{r}9.8 \\
8 \cdot 1 \\
7: 7 \\
11: 9 \\
17.0 \\
17 \cdot 3 \\
15.2 \\
9.6\end{array}$ & $\begin{array}{r}5.9 \\
4.7 \\
4.5 \\
7.5 \\
0.1 \\
13.7 \\
13.7 \\
8.9\end{array}$ & $\begin{array}{r}10.4 \\
8.6 \\
8.0 \\
12.1 \\
16.7 \\
17.3 \\
15.3 \\
9.3\end{array}$ & & $\begin{array}{l}3.6 \\
3.44 \\
3.5 \\
3.6 \\
3.5 \\
2.9 \\
3.03 \\
5.8\end{array}$ & & $\begin{array}{l}7.5 \\
7.5 \\
8.4 \\
9.9 \\
9.5 \\
9.3 \\
3.0 \\
8.6\end{array}$ & $\begin{array}{r}8.5 \\
8.9 \\
10.0 \\
11.5 \\
10.9 \\
11.1 \\
5.3 \\
10.5\end{array}$ & $\begin{array}{r}10.8 \\
11.0 \\
11.7 \\
12.3 \\
12.0 \\
12.7 \\
6.3 \\
12.3\end{array}$ & $\begin{array}{r}13.7 \\
14.1 \\
14.1 \\
13.9 \\
12.9 \\
14.1 \\
8.0 \\
14.3\end{array}$ \\
\hline $\begin{array}{l}20 \\
20 \\
20 \\
20 \\
20 \\
20 \\
20 \\
20\end{array}$ & $\begin{array}{r}0 \\
3 \\
6 \\
9 \\
12 \\
15 \\
18 \\
21\end{array}$ & $\begin{array}{l}7.8 \\
5.5 \\
3.0 \\
3.5 \\
4.4 \\
5.5 \\
4.0 \\
3.3\end{array}$ & $\begin{array}{l}7.6 \\
5.4 \\
3.0 \\
3.0 \\
3.4 \\
4.4 \\
4.3 \\
3.1\end{array}$ & $\begin{array}{l}7.9 \\
5.5 \\
3.2 \\
3.4 \\
4.0 \\
5.1 \\
4.7 \\
3.2\end{array}$ & $\begin{array}{l}7.6 \\
5.2 \\
3.0 \\
3.1 \\
3.4 \\
4.3 \\
4.3 \\
3.1\end{array}$ & $\begin{array}{l}8.4 \\
5.4 \\
3.3 \\
3.7 \\
4.4 \\
5.5 \\
5.2 \\
3.9\end{array}$ & $\begin{array}{l}8.2 \\
5.2 \\
3.0 \\
3.0 \\
3.2 \\
4.2 \\
4.2 \\
3.5\end{array}$ & $\begin{array}{l}8.4 \\
5.0 \\
2.4 \\
3.4 \\
4.4 \\
5.6 \\
5.3 \\
4.1\end{array}$ & $\begin{array}{l}8 \cdot 3 \\
4.0 \\
2.4 \\
2 \cdot 0 \\
3.3 \\
4 \cdot 2 \\
4 \cdot 3 \\
3.6\end{array}$ & $\begin{array}{l}5.4 \\
4.6 \\
3.7 \\
3.8 \\
3.8 \\
3.5 \\
3.1 \\
2.3\end{array}$ & & $\begin{array}{r}4.4 \\
13.3 \\
15.9 \\
13.5 \\
12.7 \\
8.7 \\
5.3 \\
3.2\end{array}$ & $\begin{array}{r}5.7 \\
15.6 \\
16.4 \\
14.1 \\
1.2 .7 \\
9.3 \\
8.7 \\
4.4\end{array}$ & $\begin{array}{r}7.4 \\
21.8 \\
25.6 \\
20.8 \\
21.4 \\
13.9 \\
7.8 \\
4.3\end{array}$ & $\begin{array}{r}8.9 \\
24.2 \\
28.0 \\
22.1 \\
23.4 \\
19.2 \\
8.2 \\
5.3\end{array}$ \\
\hline
\end{tabular}


Table 10. -Three-hour ave rages of air and water-surface temperatures and wind directions and speed, April 1950-August STATION, 1951, Lake Hefner-Continued

STATION 2 THREE-HOURLY AVERAGES

FEBRUARY, 1951

\begin{tabular}{|c|c|c|c|c|c|c|c|c|c|c|c|c|c|c|c|}
\hline \multirow{4}{*}{ 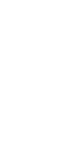 } & \multirow{4}{*}{ 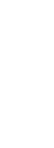 } & \multicolumn{8}{|c|}{ Average air temperature $\left({ }^{\circ} \mathrm{C}\right)$ at indicated height } & \multirow{4}{*}{$\begin{array}{l}\text { Average } \\
\text { water- } \\
\text { surface } \\
\text { tempera- } \\
\text { ture } \\
\text { ("C) }\end{array}$} & \multirow{4}{*}{$\begin{array}{c}\text { Average } \\
\text { wind } \\
\text { direction } \\
\text { (coded) }\end{array}$} & \multirow{2}{*}{\multicolumn{4}{|c|}{$\begin{array}{l}\text { Average wind speed (knots) } \\
\text { at indicated height }\end{array}$}} \\
\hline & & \multirow{2}{*}{\multicolumn{2}{|c|}{$\begin{array}{c}2 \\
\text { meters }\end{array}$}} & \multirow{2}{*}{\multicolumn{2}{|c|}{$\begin{array}{c}4 \\
\text { meters }\end{array}$}} & \multirow{2}{*}{\multicolumn{2}{|c|}{$\begin{array}{c}8 \\
\text { meters } \\
\end{array}$}} & \multirow{2}{*}{\multicolumn{2}{|c|}{$\begin{array}{c}16 \\
\text { meters }\end{array}$}} & & & & & & \\
\hline & & & & & & & & & & & & 2 & 4 & 8 & 16 \\
\hline & & $\begin{array}{l}\text { Dry } \\
\text { bulb }\end{array}$ & $\begin{array}{l}\text { Wet } \\
\text { bulb }\end{array}$ & $\begin{array}{l}\text { Dry } \\
\text { bulb }\end{array}$ & $\begin{array}{l}\text { Wet } \\
\text { bulb }\end{array}$ & $\begin{array}{l}\text { Dry } \\
\text { bulb }\end{array}$ & $\begin{array}{l}\text { Wet } \\
\text { bulb }\end{array}$ & $\begin{array}{l}\text { Dry } \\
\text { bulb }\end{array}$ & $\begin{array}{l}\text { Wet } \\
\text { bulb }\end{array}$ & & & meters & meters & meters & meters \\
\hline $\begin{array}{l}21 \\
21 \\
21 \\
21 \\
21 \\
21 \\
21 \\
21\end{array}$ & $\begin{array}{r}0 \\
3 \\
6 \\
9 \\
12 \\
15 \\
18 \\
21\end{array}$ & $\begin{array}{r}1.4 \\
1.7 \\
2.2 \\
5.3 \\
11.3 \\
7.7 \\
5.3 \\
3.5\end{array}$ & $\begin{array}{l}1.4 \\
1.7 \\
2.2 \\
4.1 \\
7.9 \\
6.7 \\
5.2 \\
3.5\end{array}$ & $\begin{array}{r}1.7 \\
1.9 \\
2.5 \\
5.2 \\
10.9 \\
7.4 \\
5.4 \\
4.1\end{array}$ & $\begin{array}{l}1.8 \\
1.9 \\
2.5 \\
4.4 \\
7.7 \\
6.3 \\
5.2 \\
4.1\end{array}$ & $\begin{array}{r}2.2 \\
1.9 \\
2.5 \\
5.4 \\
10.3 \\
6.8 \\
5.1 \\
4.1\end{array}$ & $\begin{array}{l}2.1 \\
1.8 \\
2.4 \\
4.6 \\
7.0 \\
5.6 \\
4.8 \\
3.9\end{array}$ & $\begin{array}{r}2.3 \\
1.5 \\
2.1 \\
5.4 \\
10.2 \\
5.9 \\
5.3 \\
4.8\end{array}$ & $\begin{array}{l}2.3 \\
1.5 \\
3.1 \\
4.5 \\
6.3\end{array}$ & $\begin{array}{l}1.6 \\
2.6 \\
2.7 \\
3.6 \\
5.3 \\
5.5 \\
4.5 \\
4.0\end{array}$ & & $\begin{array}{l}1.7 \\
2.7 \\
1.2 \\
2.6 \\
5.1 \\
7.8 \\
4.2 \\
1.6\end{array}$ & $\begin{array}{l}2.4 \\
3.7 \\
1.8 \\
3.6 \\
5.2 \\
8.9 \\
5.1 \\
2.4\end{array}$ & $\begin{array}{l}3.2 \\
4.6 \\
2.0 \\
3.9 \\
6.9 \\
0.8 \\
6.0 \\
3.2\end{array}$ & $\begin{array}{r}3.8 \\
5.5 \\
2.4 \\
4.3 \\
7.5 \\
10.9 \\
6.3 \\
4.4\end{array}$ \\
\hline $\begin{array}{l}22 \\
22 \\
22 \\
22 \\
22 \\
22 \\
22 \\
22\end{array}$ & $\begin{array}{r}0 \\
3 \\
6 \\
9 \\
12 \\
15 \\
18 \\
21\end{array}$ & $\begin{array}{r}2.2 \\
3.2 \\
4.2 \\
12.2 \\
16.7 \\
17.0 \\
13.7 \\
10.9\end{array}$ & $\begin{array}{r}2.2 \\
3.2 \\
3.9 \\
8.4 \\
10.9 \\
11.1 \\
9.6 \\
8.1\end{array}$ & $\begin{array}{r}2.9 \\
4.2 \\
5.1 \\
12.2 \\
16.4 \\
17.0 \\
13.9 \\
11.4\end{array}$ & $\begin{array}{r}2.8 \\
4.1 \\
4.6 \\
8.3 \\
10.8 \\
10.9 \\
0.7 \\
8.2\end{array}$ & $\begin{array}{r}3.0 \\
4.5 \\
5.7 \\
11.8 \\
15.8 \\
16.7 \\
13.9 \\
11.5\end{array}$ & $\begin{array}{r}3.0 \\
4.1 \\
4.8 \\
7.8 \\
9.9 \\
10.9 \\
9.3 \\
7.0\end{array}$ & $\begin{array}{r}4.1 \\
5.1 \\
6.6 \\
12.0 \\
16.0 \\
16.5 \\
14.2 \\
11.0\end{array}$ & $\begin{array}{l}4.0 \\
4.8 \\
5.7\end{array}$ & $\begin{array}{l}3.8 \\
3.8 \\
3.8 \\
4.8 \\
6.5 \\
5.3 \\
4.1 \\
3.8\end{array}$ & & $\begin{array}{l}1.1 \\
1.7 \\
4.7 \\
9.8 \\
9.8 \\
9.2 \\
6.7 \\
4.2\end{array}$ & $\begin{array}{r}1.8 \\
2.8 \\
6.2 \\
11.3 \\
11.3 \\
10.7 \\
8.1 \\
5.9\end{array}$ & $\begin{array}{r}2.5 \\
3.9 \\
7.7 \\
12.8 \\
12.6 \\
12.2 \\
0.8 \\
7.3\end{array}$ & \\
\hline $\begin{array}{l}23 \\
23 \\
23 \\
23 \\
23 \\
23 \\
23 \\
23\end{array}$ & $\begin{array}{r}0 \\
3 \\
6 \\
9 \\
12 \\
15 \\
18 \\
21\end{array}$ & $\begin{array}{r}10.2 \\
10.0 \\
9.4 \\
13.0 \\
16.7 \\
15.5 \\
13.2 \\
9.0\end{array}$ & $\begin{array}{r}6.7 \\
6.1 \\
5.8 \\
7.7 \\
10.3 \\
9.5 \\
8.2 \\
8.1\end{array}$ & $\begin{array}{r}10.5 \\
10.2 \\
9.6 \\
13.1 \\
16.6 \\
15.4 \\
13.2 \\
9.5\end{array}$ & $\begin{array}{l}6.7 \\
6.1 \\
5.7 \\
7.6 \\
9.9 \\
9.3 \\
8.1 \\
7.9\end{array}$ & $\begin{array}{r}10.7 \\
10.2 \\
9.5 \\
13.0 \\
15.9 \\
15.1 \\
13.0 \\
9.4\end{array}$ & & $\begin{array}{r}11.0 \\
10.2 \\
9.6 \\
12.8 \\
15.8 \\
15.0 \\
12.0 \\
9.5\end{array}$ & $\begin{array}{l}6.8 \\
6.1 \\
5.6 \\
7.6 \\
0.7 \\
9.1 \\
8.0 \\
7.9\end{array}$ & $\begin{array}{l}4.0 \\
4.0 \\
4.0 \\
5.1 \\
6.1 \\
6.3 \\
5.7 \\
5.7\end{array}$ & & $\begin{array}{r}6.8 \\
9.1 \\
8.2 \\
9.0 \\
10.6 \\
8.8 \\
7.9 \\
8.1\end{array}$ & $\begin{array}{r}8.4 \\
10.8 \\
9.7 \\
10.7 \\
12.4 \\
10.6 \\
9.4 \\
9.7\end{array}$ & $\begin{array}{r}9.9 \\
1204 \\
1102 \\
12.0 \\
14.0 \\
12: 0 \\
11.0 \\
11.2\end{array}$ & $\begin{array}{l}14.0 \\
14.2 \\
12.8 \\
13.1 \\
15.4 \\
13.5 \\
12.7 \\
12.7\end{array}$ \\
\hline $\begin{array}{l}24 \\
24 \\
24 \\
24 \\
24 \\
24 \\
24 \\
24\end{array}$ & $\begin{array}{r}0 \\
3 \\
6 \\
9 \\
12 \\
15 \\
18 \\
21\end{array}$ & $\begin{array}{r}8.3 \\
8.7 \\
9.2 \\
10.3 \\
14.4 \\
17.3 \\
13.9 \\
12.8\end{array}$ & $\begin{array}{r}7.7 \\
7.2 \\
6.3 \\
6.9 \\
10.6 \\
13.0 \\
10.5 \\
8.8\end{array}$ & $\begin{array}{r}8.6 \\
8.9 \\
9.4 \\
10.3 \\
14.1 \\
16.0 \\
14.1 \\
13.0\end{array}$ & $\begin{array}{r}7.3 \\
7.0 \\
6.3 \\
6.8 \\
10.6 \\
12.9 \\
10.4 \\
8.8\end{array}$ & $\begin{array}{r}8.6 \\
8.8 \\
9.3 \\
10.2 \\
14.1 \\
16.6 \\
14.0 \\
12.9\end{array}$ & & $\begin{array}{r}8.0 \\
9.1 \\
9.4 \\
10.3 \\
14.1 \\
16.5 \\
14.1 \\
13.1\end{array}$ & $\begin{array}{r}7.5 \\
6.8 \\
6.2 \\
6.9 \\
10.7 \\
12.7 \\
10.4 \\
3.8\end{array}$ & $\begin{array}{l}5.6 \\
5.6 \\
5.5 \\
5.3 \\
7.0 \\
7.1 \\
6.2 \\
6.1\end{array}$ & & $\begin{array}{r}7.6 \\
7.6 \\
10.0 \\
10.9 \\
11.9 \\
11.8 \\
11.8 \\
11.7\end{array}$ & $\begin{array}{r}0.1 \\
8.9 \\
11.9 \\
13.0 \\
14.0 \\
14.1 \\
14.0 \\
15.0\end{array}$ & $\begin{array}{l}10.5 \\
10.3 \\
13.7 \\
14.8 \\
15.8 \\
15.9 \\
16.0 \\
17.0\end{array}$ & $\begin{array}{l}12.2 \\
11: 9 \\
15.4 \\
16.4 \\
17.3 \\
17.7 \\
17.9 \\
19.4\end{array}$ \\
\hline $\begin{array}{l}25 \\
25 \\
25 \\
25 \\
25 \\
25 \\
25 \\
25\end{array}$ & $\begin{array}{r}0 \\
3 \\
6 \\
9 \\
12 \\
15 \\
18 \\
21\end{array}$ & $\begin{array}{r}12.1 \\
11.6 \\
11.5 \\
14.1 \\
14.9 \\
10.8 \\
9.5 \\
9.2\end{array}$ & $\begin{array}{r}8.9 \\
8.8 \\
10.3 \\
13.0 \\
13.6 \\
10.6 \\
8.5 \\
9.1\end{array}$ & $\begin{array}{l}12.5 \\
21.9 \\
11.9 \\
14.4 \\
15.2 \\
11.3 \\
10.2 \\
10.2\end{array}$ & $\begin{array}{r}8.8 \\
8.7 \\
10.3 \\
12.9 \\
13.5 \\
10.9 \\
10.1 \\
9.1\end{array}$ & $\begin{array}{l}12.6 \\
11: 8 \\
12: 0 \\
14 \cdot 2 \\
15.1 \\
11.1 \\
10.1 \\
10.1\end{array}$ & $\begin{array}{r}8.1 \\
8.1 \\
9.6 \\
21.6 \\
12.2 \\
10.4 \\
9.4 \\
3.4\end{array}$ & $\begin{array}{l}12.7 \\
12.0 \\
12.1 \\
14.2 \\
15.2 \\
11.0 \\
10.0 \\
10.7\end{array}$ & $\begin{array}{r}10.0 \\
9.7\end{array}$ & $\begin{array}{l}5.9 \\
5.3 \\
5.9 \\
5.5 \\
6.7 \\
7.9 \\
7.0 \\
6.4\end{array}$ & & $\begin{array}{r}11.8 \\
11.2 \\
10.0 \\
11.8 \\
12.8 \\
8.3 \\
4.4 \\
6.5\end{array}$ & $\begin{array}{r}13.7 \\
13.0 \\
11.6 \\
13.6 \\
14.8 \\
9.8 \\
5.6 \\
7.7\end{array}$ & $\begin{array}{r}15.6 \\
15.0 \\
13.2 \\
15.2 \\
16.7 \\
11.7 \\
6.8 \\
0.2\end{array}$ & $\begin{array}{r}17.7 \\
17: 0 \\
15: 0 \\
17: 0 \\
18.0 \\
13.3 \\
8.1 \\
11.1\end{array}$ \\
\hline $\begin{array}{l}26 \\
26 \\
26 \\
26 \\
26 \\
26 \\
26 \\
26\end{array}$ & $\begin{array}{r}0 \\
3 \\
6 \\
9 \\
12 \\
15 \\
18 \\
21\end{array}$ & $\begin{array}{r}7.9 \\
6.2 \\
5.1 \\
7.1 \\
11.4 \\
13.4 \\
9.7 \\
6.8\end{array}$ & $\begin{array}{l}7.8 \\
6.2 \\
5.2 \\
5.6 \\
8.5 \\
9.5 \\
8.4 \\
6.5\end{array}$ & $\begin{array}{r}8.7 \\
6.5 \\
5.3 \\
7.2 \\
11.3 \\
13.1 \\
10.4 \\
7.9\end{array}$ & $\begin{array}{l}8.2 \\
6.3 \\
5.1 \\
6.2 \\
8.1 \\
8.9 \\
8.4 \\
7.0\end{array}$ & $\begin{array}{r}8.7 \\
6.1 \\
5.1 \\
7.0 \\
11.7 \\
13.3 \\
10.7 \\
8.2\end{array}$ & $\begin{array}{l}7.1 \\
4: 7 \\
3.8 \\
3.7 \\
6: 7 \\
7.9 \\
7.7 \\
6.6\end{array}$ & $\begin{array}{r}9.4 \\
6.2 \\
5.3 \\
7.0 \\
11.3 \\
12.0 \\
11.5 \\
9.5\end{array}$ & $\begin{array}{l}8.7 \\
6.0 \\
5.0 \\
5.8 \\
8.0 \\
8.8 \\
8.6 \\
7.7\end{array}$ & $\begin{array}{l}6.0 \\
5.7 \\
5.4 \\
6.2\end{array}$ & & $\begin{array}{l}4.5 \\
6.0 \\
5.4 \\
4.2 \\
2.8 \\
2.4 \\
0.8 \\
1.0\end{array}$ & $\begin{array}{l}5.5 \\
8.0 \\
6.9 \\
5.1 \\
3.0 \\
3.0 \\
1.0 \\
1.4\end{array}$ & $\begin{array}{r}7.0 \\
10.8 \\
7.6 \\
4.9 \\
3.4 \\
3.0 \\
1.0 \\
1.9\end{array}$ & $\begin{array}{r}9.0 \\
12.2 \\
8.0 \\
5.9 \\
3.5 \\
3.4 \\
1.3 \\
2.0\end{array}$ \\
\hline $\begin{array}{l}27 \\
27 \\
27 \\
27 \\
27 \\
27 \\
27 \\
27\end{array}$ & $\begin{array}{r}0 \\
3 \\
6 \\
9 \\
12 \\
15 \\
18 \\
21\end{array}$ & $\begin{array}{r}5.3 \\
3.9 \\
5.5 \\
14.7 \\
19.7 \\
20.3 \\
17.4 \\
17.1\end{array}$ & $\begin{array}{r}5.1 \\
3.9 \\
5.3 \\
10.5 \\
13.7 \\
14.7 \\
14.8 \\
16.2\end{array}$ & $\begin{array}{r}6.6 \\
4.6 \\
6.0 \\
14.8 \\
19.5 \\
20.0 \\
17.6 \\
17.2\end{array}$ & $\begin{array}{r}6.0 \\
4.5 \\
5.7 \\
10.5 \\
13.6 \\
14.7 \\
14.9 \\
16.1\end{array}$ & $\begin{array}{r}7.5 \\
5.0 \\
6.5 \\
14.8 \\
19.0 \\
19.9 \\
17.6 \\
17.1\end{array}$ & & $\begin{array}{r}8.2 \\
6: 0 \\
7: 1 \\
14: 6 \\
18: 9 \\
19: 6 \\
17: 6 \\
17.2\end{array}$ & $\begin{array}{r}6.9 \\
5.7 \\
6.3 \\
10.4 \\
13.3 \\
14.6 \\
15.1 \\
16.2\end{array}$ & $\begin{array}{l}6.4 \\
8.0 \\
9.3 \\
8.8 \\
7.8 \\
7.8\end{array}$ & & $\begin{array}{r}1.6 \\
2.3 \\
4.2 \\
8.9 \\
10.5 \\
12.9 \\
8.9 \\
11.0\end{array}$ & $\begin{array}{r}2.4 \\
3.4 \\
5.1 \\
10.3 \\
12.2 \\
15.4 \\
10.6 \\
13.4\end{array}$ & $\begin{array}{r}3.5 \\
4.6 \\
6.4 \\
11.4 \\
14.0 \\
17.04 \\
12.0 \\
15.5\end{array}$ & $\begin{array}{r}4.8 \\
6.1 \\
8.3 \\
12.5 \\
4.9 \\
19.0 \\
1400 \\
17.1\end{array}$ \\
\hline $\begin{array}{l}28 \\
28 \\
28 \\
28 \\
28 \\
28 \\
28 \\
28\end{array}$ & $\begin{array}{r}0 \\
3 \\
6 \\
9 \\
12 \\
15 \\
18 \\
21\end{array}$ & $\begin{array}{r}15.7 \\
15.5 \\
15.6 \\
14.2 \\
14.3 \\
13.4 \\
8.8 \\
5.1\end{array}$ & $\begin{array}{r}13.5 \\
14.8 \\
12.5 \\
6.0 \\
5.8 \\
6.6 \\
5.5 \\
3.3\end{array}$ & $\begin{array}{r}15.9 \\
15.7 \\
15.6 \\
14.1 \\
14.0 \\
13.2 \\
9.0 \\
5.8\end{array}$ & $\begin{array}{r}13.5 \\
14.7 \\
12.1 \\
5.6 \\
5.4 \\
6.2 \\
5.3 \\
3.5\end{array}$ & $\begin{array}{r}15.9 \\
15.6 \\
15.5 \\
13.8 \\
13.6 \\
12.2 \\
8.8 \\
6.2\end{array}$ & & $\begin{array}{r}16.0 \\
15.9 \\
15.6 \\
13.7 \\
13.6 \\
12.2 \\
9.4 \\
6.6\end{array}$ & $\begin{array}{r}15.1 \\
14.9 \\
11.6 \\
5.3 \\
5.2 \\
6.0 \\
5.1 \\
3.8\end{array}$ & $\begin{array}{r}7.6 \\
7.6 \\
8.0 \\
8.9 \\
10.4 \\
10.6 \\
8.6 \\
7.9\end{array}$ & & $\begin{array}{r}13.6 \\
11.7 \\
11.5 \\
14.4 \\
14.6 \\
9.4 \\
3.7 \\
0.9\end{array}$ & $\begin{array}{r}15.8 \\
13.6 \\
13.1 \\
16.3 \\
16.6 \\
11.0 \\
4.5 \\
0.8\end{array}$ & $\begin{array}{r}18.1 \\
15.5 \\
15.2 \\
18.8 \\
10.3 \\
13.9 \\
6.9 \\
0.9\end{array}$ & $\begin{array}{r}20.3 \\
17.5 \\
17.1 \\
20.6 \\
21.3 \\
15.7 \\
7.7 \\
1.6\end{array}$ \\
\hline
\end{tabular}


TABLE 10

Table 10. - Three-hour averages of air and water-surface temperatures and wind directions and speed, April 1950-August 1951, Lake Hefner-Continued

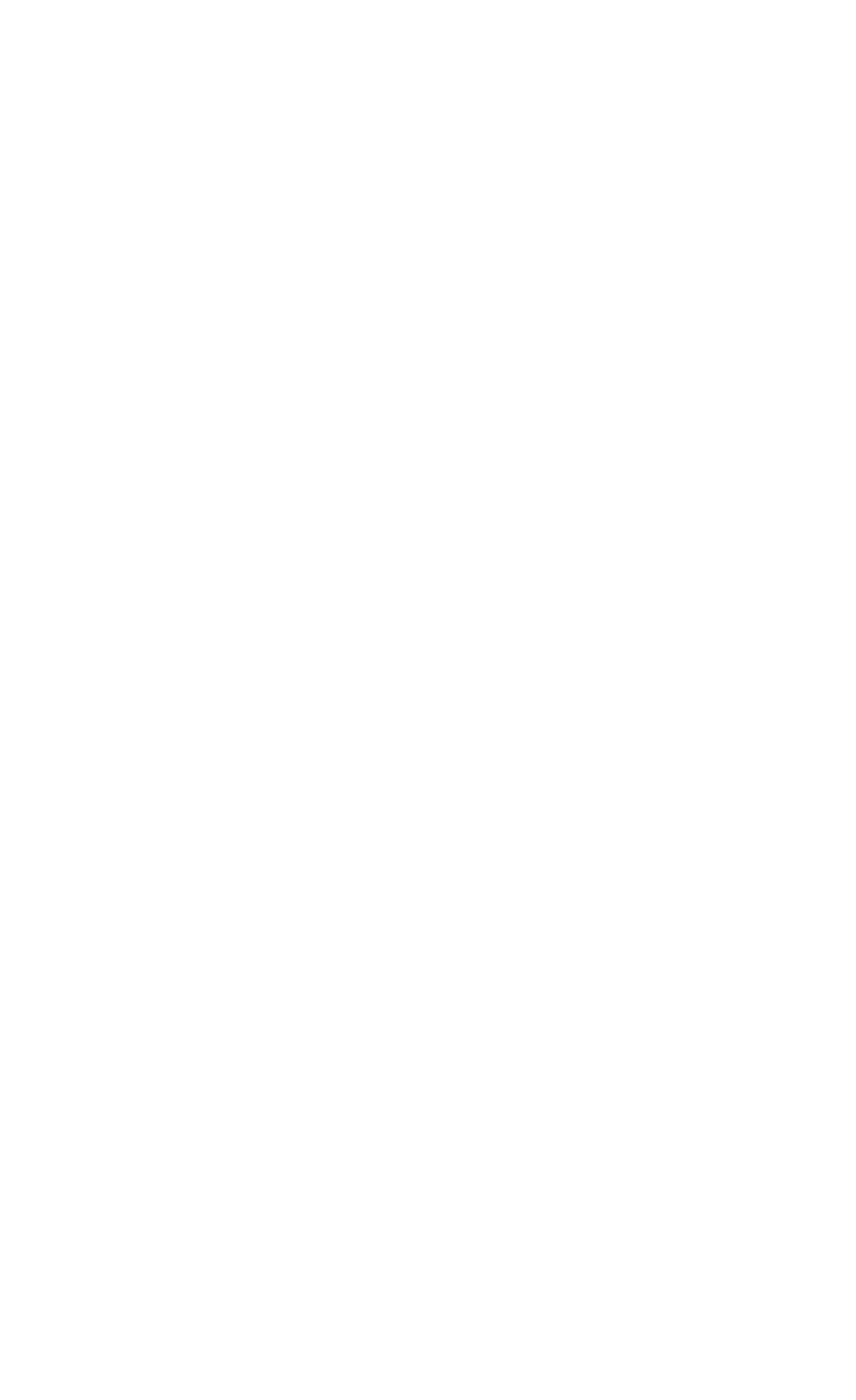


Table 10. - Three-hour averages of air and water-surface temperatures and wind directions and speed, April 1950-August 1951, Lake Hefner-Continued

STATION 2

THREE-HOURLY AVERAGES

MARCH 1951

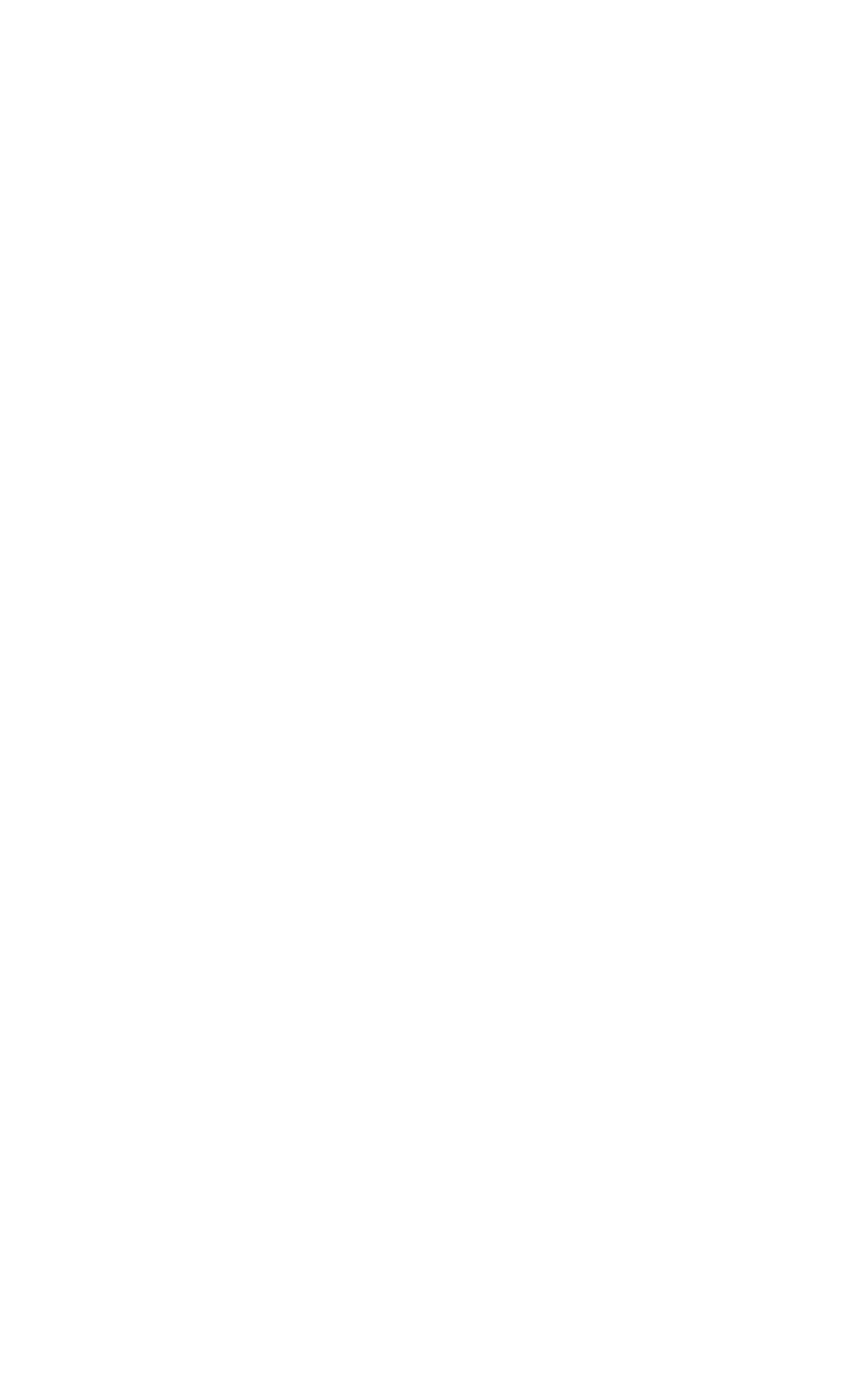


TABLE 10

Table 10. - Three-hour averages of air and water-surface temperatures and wind directions and speed, April 1950-August STATION 2 THREE-HOURLY AVERAGES

MARCH, 1951

\begin{tabular}{|c|c|c|c|c|c|c|c|c|c|c|c|c|c|c|c|}
\hline \multirow{3}{*}{ 壱 } & \multirow{3}{*}{ 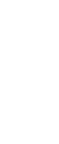 } & \multicolumn{8}{|c|}{ Average air temperature $\left({ }^{\circ} \mathrm{C}\right)$ at indicated height } & \multirow{3}{*}{$\begin{array}{c}\text { Average } \\
\text { water- } \\
\text { surface } \\
\text { tempera- } \\
\text { ture } \\
\text { (ㄷ) }\end{array}$} & \multirow{3}{*}{$\begin{array}{c}\text { Average } \\
\text { wind } \\
\text { direction } \\
\text { (coded) }\end{array}$} & \multicolumn{4}{|c|}{$\begin{array}{l}\text { Average wind speed (knots) } \\
\text { at indicated height }\end{array}$} \\
\hline & & \multicolumn{2}{|c|}{$\begin{array}{c}2 \\
\text { meters }\end{array}$} & \multicolumn{2}{|c|}{$\begin{array}{c}4 \\
\text { meters }\end{array}$} & \multicolumn{2}{|c|}{$\begin{array}{c}8 \\
\text { meters }\end{array}$} & \multicolumn{2}{|c|}{$\begin{array}{c}16 \\
\text { meters }\end{array}$} & & & & & & \\
\hline & & $\begin{array}{l}\text { Dry } \\
\text { bulb }\end{array}$ & $\begin{array}{l}\text { Wet } \\
\text { bulb }\end{array}$ & $\begin{array}{l}\text { Dry } \\
\text { bulb }\end{array}$ & $\begin{array}{l}\text { Wet } \\
\text { bulb }\end{array}$ & $\begin{array}{l}\text { Dry } \\
\text { bulb }\end{array}$ & $\begin{array}{l}\text { Wet } \\
\text { bulb }\end{array}$ & $\begin{array}{l}\text { Dry } \\
\text { bulb }\end{array}$ & $\begin{array}{l}\text { Wet } \\
\text { bulb }\end{array}$ & & & meters & meters & meters $\mathrm{r}$ & meters \\
\hline $\begin{array}{l}21 \\
21 \\
21 \\
21 \\
21 \\
21 \\
21 \\
21\end{array}$ & $\begin{array}{r}0 \\
3 \\
6 \\
9 \\
12 \\
15 \\
18 \\
21\end{array}$ & $\begin{array}{r}-0.6 \\
=2.6 \\
-1.9 \\
5.2 \\
11.6 \\
14.6 \\
10.1 \\
7.0\end{array}$ & $\begin{array}{l}0.8 \\
3.8 \\
5.9 \\
4.1 \\
3.0\end{array}$ & $\begin{array}{r}0.8 \\
2.9 \\
1.9 \\
4.9 \\
10.9 \\
14.1 \\
11.4 \\
8.2\end{array}$ & $\mid \begin{array}{r}-2.4 \\
-3.7 \\
-2.8 \\
0.2 \\
3.2 \\
5.5 \\
4.6 \\
3.4\end{array}$ & $\begin{array}{r}-1.0 \\
-\quad 2.9 \\
-2.0 \\
5.0 \\
11.0 \\
13.9 \\
12.2 \\
9.0\end{array}$ & $\begin{array}{r}-2.2 \\
0.7 \\
3.4 \\
5.4 \\
5.1 \\
3.9\end{array}$ & $\begin{array}{r}-1.1 \\
-1.8 \\
-1.9 \\
4.6 \\
10.4 \\
13.8 \\
12.8 \\
10.0\end{array}$ & $\mid \begin{array}{r}-2.6 \\
=3.6 \\
-3.2 \\
0.9 \\
3.5 \\
5.7 \\
5.4 \\
4.5\end{array}$ & $\begin{array}{l}4.3 \\
3.7 \\
3.3 \\
5.9 \\
6.9 \\
5.7 \\
5.0 \\
4.9\end{array}$ & & $\begin{array}{l}5.2 \\
3.3 \\
3.9 \\
4.6 \\
3.2\end{array}$ & $\begin{array}{l}6.1 \\
4.1 \\
5.2 \\
6.4 \\
5.5 \\
7.9 \\
4.4 \\
4.3\end{array}$ & $\begin{array}{l}7.7 \\
5.1 \\
5.8 \\
7.2 \\
6.1 \\
8.7 \\
5.6 \\
6.3\end{array}$ & $\begin{array}{l}9.2 \\
5.9 \\
6.6 \\
7.8 \\
6.5 \\
9.6 \\
7.0 \\
8.3\end{array}$ \\
\hline $\begin{array}{l}22 \\
22 \\
22 \\
22 \\
22 \\
22 \\
22 \\
22\end{array}$ & $\begin{array}{r}0 \\
3 \\
6 \\
9 \\
12 \\
15 \\
18 \\
21\end{array}$ & $\begin{array}{r}8.4 \\
8.3 \\
8.7 \\
19.3 \\
25.4 \\
28.4 \\
24.6 \\
21.0\end{array}$ & $\begin{array}{r}4.4 \\
5.5 \\
6.2 \\
9.0 \\
11.5 \\
11.5 \\
10.3 \\
10.6\end{array}$ & $\begin{array}{r}9.0 \\
8.4 \\
9.0 \\
19.5 \\
25.6 \\
28.5 \\
24.8 \\
21.4\end{array}$ & $\begin{array}{r}4.5 \\
5.5 \\
6.2 \\
8.5 \\
11.2 \\
11.4 \\
10.2 \\
10.6\end{array}$ & $\begin{array}{r}9.3 \\
8.5 \\
9.2 \\
19.4 \\
25.2 \\
28.4 \\
24.8 \\
21.5\end{array}$ & $\begin{array}{r}4.9 \\
5.6 \\
6.3 \\
8.9 \\
11.1 \\
11.3 \\
10.2 \\
10.6\end{array}$ & $\begin{array}{r}9.7 \\
8.6 \\
9.3 \\
19.2 \\
24.8 \\
28.5 \\
25.1 \\
21.8\end{array}$ & $\begin{array}{r}5.2 \\
5.8 \\
6.4 \\
9.0 \\
11.5 \\
11.9 \\
10.8 \\
11.2\end{array}$ & $\begin{array}{l}4.8 \\
4.9 \\
5.0 \\
5.9 \\
5.6 \\
5.4 \\
5.1 \\
6.5\end{array}$ & & $\begin{array}{r}6.1 \\
8.8 \\
10.0 \\
15.0 \\
15.7 \\
16.1 \\
9.7 \\
11.6\end{array}$ & $\begin{array}{l}7.7 \\
11.1 \\
13.1 \\
17.1 \\
17.4 \\
18.02 \\
11.1 \\
13.3\end{array}$ & $\begin{array}{l}10.0 \\
13.0 \\
15.0 \\
19.4 \\
19.7 \\
21.0 \\
13.1 \\
15.8\end{array}$ & $\begin{array}{l}12.4 \\
15.1 \\
17.0 \\
21.5 \\
21.9 \\
23.4 \\
15.8 \\
18.1\end{array}$ \\
\hline $\begin{array}{l}23 \\
23 \\
23 \\
23 \\
23 \\
23 \\
23 \\
23\end{array}$ & $\begin{array}{r}0 \\
3 \\
6 \\
9 \\
12 \\
15 \\
18 \\
21\end{array}$ & $\begin{array}{r}18.9 \\
14.2 \\
10.2 \\
12.7 \\
13.4 \\
13.4 \\
9.9 \\
6.1\end{array}$ & $\begin{array}{l}9.4 \\
7.4 \\
6.1 \\
5.2 \\
6.2 \\
6.4 \\
4.3 \\
2.4\end{array}$ & $\begin{array}{r}18.9 \\
14.0 \\
10.4 \\
12.5 \\
13.2 \\
13.4 \\
9.9 \\
6.3\end{array}$ & $\begin{array}{l}9.2 \\
7: 2 \\
6: 0 \\
4.7 \\
5.8 \\
5.9 \\
4: 2 \\
2.3\end{array}$ & $\begin{array}{r}19.2 \\
14.4 \\
10.4 \\
12.3 \\
13.1 \\
13.4 \\
9.9 \\
6.5\end{array}$ & $\begin{array}{l}9.2 \\
7.4 \\
5.9 \\
4.6 \\
5.5 \\
5.8 \\
4.0 \\
2.3\end{array}$ & $\begin{array}{r}19.3 \\
14.7 \\
10.7 \\
12.7 \\
13.5 \\
13.7 \\
10.2 \\
6.7\end{array}$ & $\begin{array}{l}0.7 \\
7.5 \\
5.7 \\
4.4 \\
5.5 \\
5.7 \\
3.8 \\
2.2\end{array}$ & $\begin{array}{r}5.4 \\
6.4 \\
6.3 \\
9.3 \\
10.3 \\
9.4 \\
7.8 \\
6.4\end{array}$ & & $\begin{array}{r}13.0 \\
9.0 \\
14.2 \\
17.3 \\
17.1 \\
14.8 \\
6.3 \\
3.2\end{array}$ & $\begin{array}{r}14.5 \\
10.03 \\
14.8 \\
20.3 \\
20.7 \\
18.6 \\
7.6 \\
4.0\end{array}$ & $\begin{array}{l}17.1 \\
14.2 \\
21.1 \\
25.2 \\
23.3 \\
20.9 \\
9.8 \\
5.6\end{array}$ & $\begin{array}{l}19.7 \\
16.3 \\
22.7 \\
27.4 \\
25.5 \\
21.03 \\
11.7 \\
7.7\end{array}$ \\
\hline $\begin{array}{l}24 \\
24 \\
24 \\
24 \\
24 \\
24 \\
24 \\
24\end{array}$ & $\begin{array}{r}0 \\
3 \\
6 \\
9 \\
12 \\
15 \\
18 \\
21\end{array}$ & $\begin{array}{r}3.4 \\
1.0 \\
2.0 \\
9.1 \\
14.3 \\
15.5 \\
11.6 \\
10.0\end{array}$ & $\begin{array}{r}0.5 \\
-0.6 \\
4.0 \\
5.8 \\
6.2 \\
4.6 \\
4.3\end{array}$ & $\begin{array}{r}4.0 \\
1.7 \\
2.4 \\
8.8 \\
14.1 \\
15.7 \\
12.1 \\
10.0\end{array}$ & $\begin{array}{r}0.7 \\
-0.5 \\
0.1 \\
3.5 \\
5.7 \\
6.0 \\
4.6 \\
4.2\end{array}$ & $\begin{array}{r}4.02 \\
2.0 \\
2.6 \\
8.0 \\
14.0 \\
15.2 \\
12.6 \\
10.1\end{array}$ & $\begin{array}{r}0.9 \\
-0.4 \\
0.3 \\
3.2 \\
5.5 \\
5.9 \\
4.7 \\
4.2\end{array}$ & $\begin{array}{r}4.4 \\
2.0 \\
3.0 \\
9.0 \\
13.4 \\
15.0 \\
13.0 \\
10.3\end{array}$ & $\begin{array}{r}0.9 \\
-0.3 \\
0.3 \\
3.1 \\
5.3 \\
5.7 \\
4.8 \\
4.3\end{array}$ & $\begin{array}{l}5.7 \\
5.0 \\
5.0 \\
7.8 \\
8.9 \\
7.9 \\
6.9 \\
5.3\end{array}$ & & $\begin{array}{l}1.4 \\
1.4 \\
2.6 \\
3.2 \\
5.4 \\
6.6 \\
4.2 \\
8.2\end{array}$ & $\begin{array}{l}1.7 \\
1.9 \\
3.1 \\
3.8 \\
5.9 \\
7.5 \\
4.9 \\
9.5\end{array}$ & $\begin{array}{r}2.8 \\
2.02 \\
3.6 \\
4.2 \\
6.5 \\
8.3 \\
6.6 \\
11.3\end{array}$ & $\begin{array}{r}3.9 \\
3.3 \\
4.2 \\
4.4 \\
7.0 \\
9.1 \\
8.2 \\
13.8\end{array}$ \\
\hline $\begin{array}{l}25 \\
25 \\
25 \\
25 \\
25 \\
25 \\
25 \\
25\end{array}$ & $\begin{array}{r}0 \\
3 \\
6 \\
9 \\
12 \\
15 \\
18 \\
21\end{array}$ & $\begin{array}{r}7.6 \\
6.4 \\
5.08 \\
17.0 \\
21.5 \\
21.08 \\
16.2 \\
12.9\end{array}$ & $\begin{array}{l}2.3 \\
2.0 \\
2.1 \\
6.7 \\
8.5 \\
8.2 \\
6.5 \\
5.0\end{array}$ & $\begin{array}{r}7.7 \\
6.5 \\
7.0 \\
16.8 \\
21.7 \\
21.5 \\
16.4 \\
13.2\end{array}$ & $\begin{array}{l}2.3 \\
1.8 \\
2.2 \\
5.8 \\
7.9 \\
7.9 \\
6.3 \\
5.1\end{array}$ & $\begin{array}{r}7.9 \\
6.5 \\
7.5 \\
16.9 \\
21.1 \\
21.2 \\
16.5 \\
13.4\end{array}$ & $\begin{array}{l}2.4 \\
1.9 \\
2.4 \\
6.4 \\
7.7 \\
7.8 \\
6.3 \\
5.1\end{array}$ & $\begin{array}{r}8.2 \\
6.6 \\
7.8 \\
16.5 \\
20.8 \\
21.1 \\
16.9 \\
14.3\end{array}$ & $\begin{array}{l}2.5 \\
1.8 \\
2.4 \\
6.3 \\
7.6 \\
7.8 \\
6.6 \\
5.4\end{array}$ & $\begin{array}{r}5.0 \\
5.8 \\
5.8 \\
7.5 \\
10.5 \\
9.6 \\
7.8 \\
7.3\end{array}$ & & $\begin{array}{l}8.1 \\
5.7 \\
5.7 \\
9.2 \\
7.9 \\
7.0 \\
5.8 \\
5.9\end{array}$ & $\begin{array}{r}9.2 \\
6.7 \\
6.5 \\
10.3 \\
8.7 \\
7.8 \\
6.9 \\
7.1\end{array}$ & $\begin{array}{r}11.2 \\
8.4 \\
7.6 \\
11.6 \\
9.6 \\
8.9 \\
8.8 \\
9.1\end{array}$ & $\begin{array}{r}13.8 \\
10.3 \\
9.1 \\
12.3 \\
10.2 \\
9.7 \\
11.3 \\
12.0\end{array}$ \\
\hline $\begin{array}{l}26 \\
26 \\
26 \\
26 \\
26 \\
26 \\
26 \\
26\end{array}$ & $\begin{array}{r}0 \\
3 \\
6 \\
9 \\
12 \\
15 \\
18 \\
21\end{array}$ & $\begin{array}{r}12.2 \\
9.8 \\
9.4 \\
15.9 \\
17.5 \\
16.0 \\
10.3 \\
8.7\end{array}$ & $\begin{array}{l}4.9 \\
4.5 \\
4.3 \\
7.2 \\
8.6 \\
7.7 \\
8.7 \\
8.6\end{array}$ & $\begin{array}{r}12.4 \\
9.9 \\
9.6 \\
15.6 \\
17.5 \\
16.2 \\
10.2 \\
8.9\end{array}$ & $\begin{array}{l}4.9 \\
4.4 \\
4.2 \\
6.8 \\
8.4 \\
7.4 \\
8.8 \\
8.7\end{array}$ & $\begin{array}{r}12.4 \\
10.0 \\
9.8 \\
15.5 \\
17.1 \\
15.1 \\
9.9 \\
8.9\end{array}$ & $\begin{array}{l}4.9 \\
4.5 \\
4.3 \\
6.8 \\
8.1 \\
7.3 \\
8.8 \\
8.7\end{array}$ & $\begin{array}{r}12.8 \\
10.4 \\
10.2 \\
15.5 \\
16.8 \\
15.0 \\
9.8 \\
8.9\end{array}$ & $\begin{array}{l}5.0 \\
4.3 \\
4.4 \\
6.9 \\
8.0 \\
7.5 \\
8.8 \\
8.5\end{array}$ & $\begin{array}{l}0.9 \\
6.8 \\
7.0 \\
8.0 \\
8.3 \\
8.0 \\
8.1 \\
8.0\end{array}$ & & $\begin{array}{r}9.1 \\
6.8 \\
8.5 \\
12.0 \\
13.2 \\
12.2 \\
11.02 \\
15.3\end{array}$ & $\begin{array}{r}10.4 \\
7.9 \\
10.0 \\
13.9 \\
15.5 \\
13.9 \\
13.3 \\
17.7\end{array}$ & $\begin{array}{r}12.2 \\
9.8 \\
11.6 \\
15.5 \\
17.4 \\
16.0 \\
14.9 \\
20.0\end{array}$ & $\begin{array}{l}15.0 \\
12.5 \\
13.9 \\
17.0 \\
19.2 \\
17.8 \\
16.6 \\
22.1\end{array}$ \\
\hline $\begin{array}{l}27 \\
27 \\
27 \\
27 \\
27 \\
27 \\
27 \\
27\end{array}$ & $\begin{array}{r}0 \\
3 \\
6 \\
9 \\
12 \\
15 \\
18 \\
21\end{array}$ & $\begin{array}{r}8.2 \\
8.0 \\
8.3 \\
11.4 \\
16.9 \\
19.4 \\
16.5 \\
15.0\end{array}$ & $\begin{array}{r}8.2 \\
8.0 \\
8.3 \\
10.9 \\
14.3 \\
15.4 \\
14.4 \\
13.5\end{array}$ & $\begin{array}{r}8.3 \\
8.0 \\
8.3 \\
11.4 \\
16.6 \\
19.0 \\
16.6 \\
15.02\end{array}$ & $\begin{array}{r}8.2 \\
8.0 \\
8.3 \\
10.8 \\
13.7 \\
15.2 \\
14.3 \\
13.5\end{array}$ & $\begin{array}{r}8.2 \\
7.9 \\
8.2 \\
10.6 \\
16.5 \\
18.5 \\
16.5 \\
15.2\end{array}$ & $\begin{array}{r}8.1 \\
7.9 \\
8.2 \\
10.4 \\
13.3 \\
14.6 \\
14.0 \\
13.1\end{array}$ & $\begin{array}{r}7.7 \\
7.0 \\
7.3 \\
10.9 \\
16.2 \\
18.4 \\
10.5 \\
15 . ?\end{array}$ & $\begin{array}{l}10.4 \\
13.6 \\
15.0 \\
14.3 \\
13.4\end{array}$ & $\begin{array}{l}8.0 \\
7.9 \\
8.0 \\
8.9 \\
8.5 \\
9.8 \\
9.1 \\
8.9\end{array}$ & & $\begin{array}{l}15.2 \\
13.7 \\
12.7 \\
14.4 \\
15.6 \\
15.4 \\
13.9 \\
15.2\end{array}$ & $\begin{array}{l}17.4 \\
15.7 \\
14.6 \\
16.4 \\
17.6 \\
17.6 \\
16.2 \\
17.5\end{array}$ & $\begin{array}{l}19.5 \\
27.5 \\
16.3 \\
18.4 \\
19.4 \\
19.8 \\
18.3 \\
19.8\end{array}$ & $\begin{array}{l}21.8 \\
19.5 \\
18.2 \\
20.2 \\
21.3 \\
21.6 \\
20.6 \\
22.1\end{array}$ \\
\hline $\begin{array}{l}28 \\
28 \\
28 \\
28 \\
28 \\
28 \\
28 \\
28\end{array}$ & $\begin{array}{r}0 \\
3 \\
6 \\
9 \\
12 \\
15 \\
18 \\
21\end{array}$ & $\begin{array}{r}14.2 \\
12.9 \\
12.2 \\
11.07 \\
7.03 \\
4.3 \\
2.08 \\
3.0\end{array}$ & $\begin{array}{r}13.1 \\
12.1 \\
9.8 \\
10.1 \\
6.4 \\
3.9 \\
2.8 \\
2.8\end{array}$ & $\begin{array}{r}14.3 \\
12.8 \\
12.4 \\
11.04 \\
7.0 \\
4.2 \\
2.08 \\
3.0\end{array}$ & $\begin{array}{r}13.1 \\
12.0 \\
9.6 \\
9.9 \\
6.3 \\
3.9 \\
2.8 \\
2.8\end{array}$ & $\begin{array}{r}14.4 \\
12.9 \\
12.0 \\
11.0 \\
6.6 \\
4.0 \\
2.4 \\
3.2\end{array}$ & $\begin{array}{r}12.9 \\
11.8 \\
3.4 \\
9.4 \\
5.9 \\
3.4 \\
2.4 \\
2.7\end{array}$ & $\begin{array}{r}14.4 \\
13.1 \\
12.3 \\
10.9 \\
6.9 \\
3.5 \\
2.02 \\
3.1\end{array}$ & $\begin{array}{r}13.0 \\
11.3 \\
0.6 \\
0.5 \\
5.9 \\
3.2 \\
2.2 \\
2.3\end{array}$ & $\begin{array}{l}8.9 \\
9.1 \\
8.6 \\
9.2 \\
9.8 \\
9.0 \\
7.9 \\
7.5\end{array}$ & & $\begin{array}{l}11.7 \\
11.0 \\
13.2 \\
11.04 \\
15.8 \\
17.0 \\
15.3 \\
20.1\end{array}$ & $\begin{array}{l}13.5 \\
12.6 \\
14.9 \\
13.1 \\
18.2 \\
18.5 \\
16.3 \\
22.8\end{array}$ & $\begin{array}{l}15.3 \\
14.4 \\
17.00 \\
14.8 \\
21.5 \\
27.5 \\
25.02 \\
27.04\end{array}$ & $\begin{array}{l}17.3 \\
16.4 \\
19.1 \\
16.1 \\
25.2 \\
29.6 \\
26.7 \\
29.0\end{array}$ \\
\hline $\begin{array}{l}29 \\
29 \\
29 \\
29 \\
29 \\
29 \\
29 \\
29\end{array}$ & $\begin{array}{r}0 \\
3 \\
6 \\
9 \\
12 \\
15 \\
18 \\
21\end{array}$ & $\begin{array}{l}3.9 \\
3.8 \\
3.6 \\
5.4 \\
8.1 \\
8.5 \\
5.9 \\
2.3\end{array}$ & $\begin{array}{r}2.9 \\
2.6 \\
1.6 \\
1.8 \\
2.7 \\
2.7 \\
1.7 \\
-0.2\end{array}$ & $\begin{array}{l}3.7 \\
3.7 \\
3.5 \\
5.3 \\
7.8 \\
8.3 \\
5.9 \\
3.1\end{array}$ & $\begin{array}{l}2.7 \\
2.3 \\
1.2 \\
1.6 \\
1.9 \\
2.4 \\
1.9\end{array}$ & $\begin{array}{l}3.8 \\
3.7 \\
3.5 \\
5.2 \\
7.6 \\
8.0 \\
6.1 \\
3.8\end{array}$ & 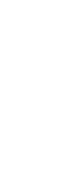 & $\begin{array}{l}3.5 \\
3.5 \\
3: 4 \\
5: 2 \\
7: 5 \\
7.9 \\
5.6 \\
4.0\end{array}$ & $\begin{array}{l}1.9 \\
1.9 \\
0.9 \\
1.3 \\
1.7 \\
1.8 \\
1.5 \\
0.7\end{array}$ & $\begin{array}{l}7.1 \\
6.2 \\
5.8 \\
7.0 \\
9.1 \\
8.0 \\
6.2 \\
6.3\end{array}$ & & $\begin{array}{r}21.8 \\
15.2 \\
15.8 \\
17.6 \\
27.5 \\
15.4 \\
6.0 \\
2.2\end{array}$ & $\begin{array}{r}26.6 \\
17.9 \\
18.4 \\
19.0 \\
19.1 \\
16.8 \\
6.8 \\
2.8\end{array}$ & $\begin{array}{r}27.0 \\
20.05 \\
22.07 \\
28.0 \\
27.0 \\
24.4 \\
0.5 \\
3.6\end{array}$ & $\begin{array}{r}28.8 \\
21.9 \\
24.5 \\
29.7 \\
28.9 \\
26.0 \\
10.4 \\
5.0\end{array}$ \\
\hline $\begin{array}{l}30 \\
30 \\
30 \\
30 \\
30 \\
30 \\
30 \\
30\end{array}$ & $\begin{array}{r}0 \\
3 \\
6 \\
9 \\
12 \\
15 \\
18 \\
21\end{array}$ & $\begin{array}{r}1.6 \\
2.5 \\
4.5 \\
13.0 \\
17.3 \\
18.8 \\
14.0 \\
12.1\end{array}$ & $\begin{array}{l}1.1 \\
4.9 \\
6.5 \\
8.1 \\
7.3 \\
5.9\end{array}$ & $\begin{array}{r}2.2 \\
2.9 \\
4: 9 \\
12.7 \\
16.7 \\
18.5 \\
15.4 \\
12.8\end{array}$ & $\begin{array}{l}5.4 \\
6.0 \\
7.6 \\
7.6 \\
6.1\end{array}$ & $\begin{array}{r}2.7 \\
3.1 \\
5.1 \\
12.7 \\
16.8 \\
18.4 \\
16.0 \\
13.3\end{array}$ & $\begin{array}{l}4.5 \\
5.9 \\
7.4 \\
7.2 \\
5.9\end{array}$ & $\begin{array}{r}3.5 \\
3.4 \\
5.3 \\
12.7 \\
16.5 \\
10.2 \\
16.6 \\
13.8\end{array}$ & $\begin{array}{l}0.2 \\
0.1 \\
1.2 \\
4.4 \\
5.9 \\
7.5 \\
7.6 \\
6.3\end{array}$ & $\begin{array}{l}5.7 \\
4.9 \\
5.3 \\
8.5 \\
9.5 \\
8.7 \\
7.8 \\
7.3\end{array}$ & & $\begin{array}{l}3.7 \\
6.8 \\
8.5 \\
6.3 \\
7.0 \\
7.3 \\
2.0 \\
4.0\end{array}$ & $\begin{array}{l}5.0 \\
7.0 \\
9.6 \\
6.9 \\
7.7 \\
8.2 \\
3.8 \\
6.8\end{array}$ & $\begin{array}{r}5.7 \\
9.7 \\
11.0 \\
7.5 \\
8.4 \\
9.2 \\
4.8 \\
8.6\end{array}$ & $\begin{array}{r}8.5 \\
11.7 \\
12.4 \\
8.0 \\
9.0 \\
10.2 \\
6.1 \\
10.5\end{array}$ \\
\hline $\begin{array}{l}31 \\
31 \\
31 \\
31 \\
31 \\
31 \\
31 \\
31\end{array}$ & $\begin{array}{r}0 \\
3 \\
6 \\
9 \\
12 \\
15 \\
18 \\
21\end{array}$ & $\begin{array}{l}11.7 \\
13.5 \\
12.9 \\
17.3 \\
21.1 \\
18.7 \\
12.9 \\
10.5\end{array}$ & $\begin{array}{r}5.8 \\
7.0 \\
8.1 \\
10.5 \\
12.2 \\
11.1 \\
8.3 \\
5.9\end{array}$ & $\begin{array}{l}12.0 \\
13.5 \\
13.1 \\
17.5 \\
20.5 \\
18.0 \\
12.9 \\
10.6\end{array}$ & $\begin{array}{r}5.9 \\
6.9 \\
8.1 \\
10.3 \\
11.8 \\
10.5 \\
8.0 \\
5.8\end{array}$ & $\begin{array}{l}12.3 \\
13.6 \\
13.0 \\
17.1 \\
30.5 \\
18.0 \\
13.1 \\
10.5\end{array}$ & $\begin{array}{r}5.8 \\
6.8 \\
8.0 \\
10.0 \\
13.4 \\
10.3 \\
7.7 \\
5.5\end{array}$ & $\begin{array}{l}12.5 \\
13.8 \\
13.0 \\
17.0 \\
20.1 \\
13.1 \\
13.03 \\
10.5\end{array}$ & $\begin{array}{r}6.1 \\
7.2 \\
9.3 \\
10.1 \\
11.5 \\
10.1 \\
7.3 \\
5.3\end{array} \mid$ & $\begin{array}{r}7.0 \\
7.03 \\
7.7 \\
9.3 \\
11.4 \\
12.03 \\
11.02 \\
10.0\end{array}$ & & $\begin{array}{r}8.8 \\
10.7 \\
10.8 \\
8.4 \\
3.9 \\
6.7 \\
5.0 \\
6.0\end{array}$ & $\begin{array}{r}10.6 \\
12.5 \\
12.1 \\
9.4 \\
4.2 \\
7.3 \\
5.8 \\
6.8\end{array}$ & $\begin{array}{r}12.4 \\
14.4 \\
13.8 \\
10.4 \\
4.5 \\
10.8 \\
5.7 \\
5.7\end{array}$ & $\begin{array}{r}14.7 \\
16.8 \\
15.6 \\
11.3 \\
4.8 \\
15.8 \\
10.2 \\
11.7\end{array}$ \\
\hline
\end{tabular}


Table 10. - Three-hour averages of air and water-surface temperatures and wind directions and speed, April 1950-August 1951, Lake Hefner-Continued

STATION 2 THREE-HOURLY AVERAGES

APRIL, 1951

\begin{tabular}{|c|c|c|c|c|c|c|c|c|c|c|c|c|c|c|c|}
\hline \multirow{3}{*}{ 秀 } & \multirow{3}{*}{ 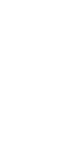 } & \multicolumn{8}{|c|}{ Average air temperature $\left({ }^{\circ} \mathrm{C}\right)$ at indicated height } & \multirow{3}{*}{$\begin{array}{c}\text { Average } \\
\text { water- } \\
\text { surface } \\
\text { tempera- } \\
\text { ture } \\
\left({ }^{\circ} \mathrm{C}\right)\end{array}$} & \multirow{3}{*}{$\begin{array}{c}\text { Average } \\
\text { wind } \\
\text { direction } \\
\text { (coded) }\end{array}$} & \multirow{2}{*}{\multicolumn{4}{|c|}{$\begin{array}{l}\text { Average wind speed (knots) } \\
\text { at indicated height }\end{array}$}} \\
\hline & & \multicolumn{2}{|c|}{$\begin{array}{c}2 \\
\text { meters }\end{array}$} & \multicolumn{2}{|c|}{$\begin{array}{c}4 \\
\text { meters }\end{array}$} & \multicolumn{2}{|c|}{$\begin{array}{c}8 \\
\text { meters }\end{array}$} & \multicolumn{2}{|c|}{$\begin{array}{c}16 \\
\text { meters }\end{array}$} & & & & & & \\
\hline & & $\begin{array}{l}\text { Dry } \\
\text { bulb }\end{array}$ & $\begin{array}{l}\text { Wet } \\
\text { bulb }\end{array}$ & $\begin{array}{l}\text { Dry } \\
\text { bulb }\end{array}$ & $\begin{array}{l}\text { Wet } \\
\text { bulb }\end{array}$ & $\begin{array}{l}\text { Dry } \\
\text { bulb }\end{array}$ & $\begin{array}{l}\text { Wet } \\
\text { bulb }\end{array}$ & $\begin{array}{l}\text { Dry } \\
\text { bulb }\end{array}$ & $\begin{array}{l}\text { Wet } \\
\text { bulb }\end{array}$ & & & meters & meters & meters & meters \\
\hline $\begin{array}{l}1 \\
1 \\
1 \\
1 \\
1 \\
1 \\
1 \\
1\end{array}$ & $\begin{array}{r}0 \\
3 \\
5 \\
9 \\
12 \\
15 \\
18 \\
21\end{array}$ & $\begin{array}{l}9.6 \\
9.0 \\
8.4 \\
7.2 \\
6.0 \\
6.2 \\
5.3 \\
4.7\end{array}$ & $\begin{array}{l}5.1 \\
4.8 \\
4.7 \\
4.3 \\
3.8 \\
4.2 \\
3.8 \\
3.4\end{array}$ & $\begin{array}{l}9.5 \\
9.0 \\
6.4 \\
6.9 \\
5.8 \\
6.0 \\
5.2 \\
4.6\end{array}$ & $\begin{array}{l}4.9 \\
4.5 \\
4.3 \\
4.0 \\
3.5 \\
3.9 \\
3.6 \\
3.3\end{array}$ & $\begin{array}{l}9.5 \\
8.9 \\
8.3 \\
6.8 \\
5.6 \\
6.0 \\
5.1 \\
4.5\end{array}$ & $\begin{array}{l}4.8 \\
4.2 \\
4.2 \\
3.7 \\
3.2 \\
3.7 \\
3.4 \\
3.0\end{array}$ & $\begin{array}{l}9.3 \\
8.9 \\
8.0 \\
6.5 \\
5.4 \\
5.8 \\
409 \\
404\end{array}$ & $\begin{array}{l}4.6 \\
4.1 \\
3.9 \\
3.6 \\
3.0 \\
3.6 \\
3.3 \\
3.0\end{array}$ & $\begin{array}{l}9.1 \\
8.3 \\
8.3 \\
8.5 \\
8.1 \\
7.6 \\
6.6 \\
6.3\end{array}$ & & $\begin{array}{r}7.5 \\
6.0 \\
7.3 \\
9.4 \\
14.4 \\
12.4 \\
11.2 \\
6.9\end{array}$ & $\begin{array}{r}8.6 \\
7.2 \\
8.4 \\
11.2 \\
17.0 \\
16.0 \\
12.2 \\
8.1\end{array}$ & $\begin{array}{l}11.4 \\
8.8 \\
11.1 \\
10.9 \\
19.1 \\
19.2 \\
16.6 \\
10.1\end{array}$ & $\begin{array}{l}13.7 \\
10.02 \\
13.3 \\
12.4 \\
20.1 \\
17.2 \\
17.4 \\
10.6\end{array}$ \\
\hline $\begin{array}{l}2 \\
2 \\
2 \\
2 \\
2 \\
2 \\
2 \\
2\end{array}$ & $\begin{array}{r}0 \\
3 \\
6 \\
9 \\
18 \\
15 \\
18 \\
21\end{array}$ & $\begin{array}{r}4.7 \\
2.7 \\
2.6 \\
7.8 \\
9.9 \\
10.9 \\
8.1 \\
4.0\end{array}$ & $\begin{array}{l}3.5 \\
1.9 \\
1.8 \\
3.8 \\
5.5 \\
6.2 \\
4.9 \\
2.3\end{array}$ & $\begin{array}{r}4.7 \\
2.7 \\
2.8 \\
7.3 \\
9.2 \\
10.1 \\
8.1 \\
5.5\end{array}$ & $\begin{array}{l}3.4 \\
1.7 \\
1.8 \\
3.1 \\
5.0 \\
5.7 \\
4.8 \\
3.1\end{array}$ & $\begin{array}{r}4.5 \\
2.6 \\
2.7 \\
7.0 \\
8.8 \\
10.0 \\
8.0 \\
6.3\end{array}$ & $\begin{array}{l}3.2 \\
1.6 \\
1.7 \\
2.7 \\
4.6 \\
5.5 \\
4.7 \\
3.4\end{array}$ & $\begin{array}{l}4.4 \\
2.4 \\
2.9 \\
6.9 \\
8.7 \\
9.9 \\
8.4 \\
6.8\end{array}$ & $\begin{array}{l}3.0 \\
1.5 \\
1.7 \\
2.7 \\
4.5 \\
5.2 \\
4.6 \\
3.8\end{array}$ & $\begin{array}{r}5.9 \\
5.8 \\
6.1 \\
8.3 \\
11.4 \\
11.6 \\
9.5 \\
8.5\end{array}$ & & $\begin{array}{r}8.8 \\
8.0 \\
6.3 \\
13.2 \\
11.0 \\
8.6 \\
2.8 \\
2.4\end{array}$ & $\begin{array}{r}10.0 \\
9.3 \\
7.1 \\
16.7 \\
13.4 \\
10.5 \\
3.6 \\
3.2\end{array}$ & $\begin{array}{r}12.8 \\
11.2 \\
9.0 \\
15.8 \\
13.0 \\
4.8 \\
4.0\end{array}$ & $\begin{array}{r}13.8 \\
12.0 \\
9.8 \\
17.5 \\
14.8 \\
11.2 \\
6.3 \\
4.5\end{array}$ \\
\hline $\begin{array}{l}3 \\
3 \\
3 \\
3 \\
3 \\
3 \\
3 \\
3\end{array}$ & $\begin{array}{r}0 \\
3 \\
6 \\
9 \\
12 \\
15 \\
18 \\
21\end{array}$ & $\begin{array}{r}2.7 \\
2.0 \\
4.2 \\
12.0 \\
17.2 \\
19.4 \\
14.8 \\
13.1\end{array}$ & $\begin{array}{l}1.5 \\
1.2 \\
2.7 \\
6.4 \\
8.4 \\
8.7 \\
7.0 \\
6.3\end{array}$ & $\begin{array}{r}3.5 \\
2.3 \\
4.5 \\
11.7 \\
17.4 \\
19.3 \\
15.9 \\
13.6\end{array}$ & $\begin{array}{l}1.9 \\
1.3 \\
2.7 \\
6.4 \\
8.2 \\
8.3 \\
7.2 \\
6.3\end{array}$ & $\begin{array}{r}4.2 \\
2.4 \\
4.4 \\
12.4 \\
16.7 \\
18.9 \\
16.7 \\
14.0\end{array}$ & $\begin{array}{l}2.3 \\
1.4 \\
2.7 \\
6.3 \\
7.7 \\
8.1 \\
7.3 \\
6.4\end{array}$ & $\begin{array}{r}5.1 \\
3.0 \\
4.8 \\
12.1 \\
17.0 \\
18.8 \\
17.1 \\
14.6\end{array}$ & $\begin{array}{l}2.6 \\
1.7 \\
2.8 \\
6.2 \\
7.4 \\
8.1 \\
7.6 \\
6.7\end{array}$ & $\begin{array}{r}7.9 \\
7.2 \\
7.2 \\
11.0 \\
13.7 \\
10.2 \\
8.6 \\
8.2\end{array}$ & & $\begin{array}{l}2.8 \\
3.6 \\
3.9 \\
3.0 \\
4.3 \\
5.3 \\
3.3 \\
5.0\end{array}$ & $\begin{array}{l}3.8 \\
4.5 \\
4.5 \\
3.3 \\
4.7 \\
5.9 \\
4.6 \\
6.6\end{array}$ & $\begin{array}{l}5.1 \\
5.6 \\
5.0 \\
3.2 \\
4.9 \\
5.5 \\
5.9 \\
8.1\end{array}$ & $\begin{array}{r}6.7 \\
7.0 \\
5.2 \\
3.3 \\
5.3 \\
7.0 \\
7.3 \\
10.1\end{array}$ \\
\hline $\begin{array}{l}4 \\
4 \\
4 \\
4 \\
4 \\
4 \\
4 \\
4\end{array}$ & $\begin{array}{r}0 \\
3 \\
6 \\
9 \\
12 \\
15 \\
18 \\
21\end{array}$ & $\begin{array}{l}11.8 \\
11.1 \\
11.6 \\
18.8 \\
23.5 \\
23.9 \\
21.8 \\
20.2\end{array}$ & $\begin{array}{r}5.8 \\
5.9 \\
6.4 \\
10.0 \\
12.3 \\
12.5 \\
11.8 \\
11.9\end{array}$ & $\begin{array}{l}12.0 \\
11.3 \\
11.8 \\
18.7 \\
23.4 \\
23.9 \\
22.0 \\
20.4\end{array}$ & $\begin{array}{r}5.8 \\
5.8 \\
6.3 \\
9.9 \\
12.0 \\
12.3 \\
11.7 \\
11.8\end{array}$ & $\begin{array}{l}12.1 \\
11.4 \\
11.8 \\
18.8 \\
23.1 \\
23.8 \\
22.1 \\
20.4\end{array}$ & $\begin{array}{r}5.8 \\
5.9 \\
6.3 \\
9.7 \\
12.0 \\
12.2 \\
11.6 \\
11.8\end{array}$ & $\begin{array}{l}12.4 \\
11.5 \\
11.8 \\
18.0 \\
22.6 \\
23.6 \\
22.2 \\
20.4\end{array}$ & $\begin{array}{r}6.0 \\
6.0 \\
6.5 \\
9.8 \\
12.1 \\
12.3 \\
11.8 \\
12.0\end{array}$ & $\begin{array}{l}7.9 \\
7.7 \\
7.7 \\
8.3 \\
9.2 \\
8.8 \\
8.3 \\
8.4\end{array}$ & & $\begin{array}{r}7.2 \\
10.3 \\
14.0 \\
14.2 \\
12.3 \\
7.6 \\
5.0 \\
10.7\end{array}$ & $\begin{array}{r}8.9 \\
12.4 \\
16.1 \\
16.1 \\
13.8 \\
8.7 \\
7.4 \\
13.6\end{array}$ & $\begin{array}{r}10.9 \\
14.3 \\
13.0 \\
17.0 \\
15.3 \\
10.0 \\
8.8 \\
15.3\end{array}$ & $\begin{array}{l}12.4 \\
16.03 \\
20.4 \\
19.6 \\
16.7 \\
11.01 \\
10.5 \\
17.7\end{array}$ \\
\hline $\begin{array}{l}5 \\
5 \\
5 \\
5 \\
5 \\
5 \\
5 \\
5\end{array}$ & $\begin{array}{r}0 \\
3 \\
5 \\
9 \\
12 \\
15 \\
18 \\
21\end{array}$ & $\begin{array}{l}18.2 \\
13.6 \\
12.2 \\
12.9 \\
13.8 \\
18.2 \\
15.4 \\
15.1\end{array}$ & $\begin{array}{l}12.0 \\
11.2 \\
11.6 \\
12.4 \\
13.3 \\
15.2 \\
14.4 \\
13.0\end{array}$ & $\begin{array}{l}18.3 \\
13.2 \\
12.1 \\
12.7 \\
13.5 \\
17.9 \\
15.4 \\
15.3\end{array}$ & $\begin{array}{l}11.9 \\
11.1 \\
11.6 \\
12.3 \\
13.2 \\
14.9 \\
14.3 \\
13.0\end{array}$ & $\begin{array}{l}18.1 \\
13.1 \\
12.1 \\
12.5 \\
13.4 \\
17.7 \\
15.3 \\
15.4\end{array}$ & $\begin{array}{l}11.9 \\
11.2 \\
11.6 \\
12.2 \\
12.8 \\
14.6 \\
14.1 \\
12.8\end{array}$ & $\begin{array}{l}18.1 \\
13.0 \\
12.3 \\
12.8 \\
13.7 \\
17.7 \\
15.4 \\
15.9\end{array}$ & $\begin{array}{l}12.0 \\
11.1 \\
112.7 \\
12.1 \\
12.9 \\
14.8 \\
14.3 \\
13.0\end{array}$ & $\begin{array}{l}8.6 \\
9.5 \\
9.3 \\
9.0 \\
9.3\end{array}$ & & $\begin{array}{r}13.7 \\
12.1 \\
14.1 \\
13.1 \\
10.6 \\
8.0 \\
7.1 \\
3.2\end{array}$ & $\begin{array}{r}16.0 \\
14.0 \\
16.6 \\
15.5 \\
13.6 \\
11.9 \\
9.8 \\
4.7\end{array}$ & $\begin{array}{r}18.0 \\
16.1 \\
28.8 \\
17.05 \\
15.5 \\
13.0 \\
11.2 \\
5.3\end{array}$ & $\begin{array}{r}20.1 \\
18.1 \\
20.7 \\
19: 5 \\
17.0 \\
14.2 \\
12.8 \\
5.9\end{array}$ \\
\hline $\begin{array}{l}6 \\
6 \\
6 \\
6 \\
6 \\
6 \\
6 \\
6\end{array}$ & $\begin{array}{r}0 \\
3 \\
6 \\
9 \\
12 \\
15 \\
18 \\
21\end{array}$ & $\begin{array}{l}12.6 \\
11.2 \\
10.8 \\
12.9 \\
14.3 \\
13.1 \\
11.8 \\
10.0\end{array}$ & $\begin{array}{r}11.9 \\
110.0 \\
10.1 \\
10.3 \\
10.8 \\
10.2 \\
9.8 \\
9.2\end{array}$ & $\begin{array}{l}12.6 \\
11.4 \\
10.7 \\
12.6 \\
13.6 \\
13.1 \\
11.8 \\
10.9\end{array}$ & $\begin{array}{r}12.0 \\
10.9 \\
10.0 \\
9.9 \\
10.3 \\
9.9 \\
9.6 \\
9.1\end{array}$ & $\begin{array}{l}12.5 \\
11.2 \\
10.5 \\
12.5 \\
13.1 \\
12.7 \\
11.5 \\
10.7\end{array}$ & $\begin{array}{r}11.8 \\
10.6 \\
9.9 \\
9.3 \\
9.4 \\
9.3 \\
9.0 \\
8.6\end{array}$ & $\begin{array}{l}13.0 \\
11.4 \\
10.7 \\
12.7 \\
13.0 \\
12.9 \\
11.7 \\
10.8\end{array}$ & $\begin{array}{r}12.0 \\
10.6 \\
9.9 \\
9.5 \\
9.8 \\
9.7 \\
9.2 \\
8.9\end{array}$ & $\begin{array}{r}9.6 \\
8.9 \\
7.9 \\
12.6 \\
15.5 \\
13.5 \\
11.8 \\
10.7\end{array}$ & & $\begin{array}{l}7.9 \\
9.6 \\
6.7 \\
8.0 \\
9.7 \\
8.8 \\
9.1 \\
8.0\end{array}$ & $\begin{array}{r}9.2 \\
11.1 \\
7.3 \\
10.5 \\
11.1 \\
10.4 \\
10.6 \\
9.2\end{array}$ & $\begin{array}{l}11.1 \\
15.3 \\
11.3 \\
14 \cdot 0 \\
14.6 \\
14.4 \\
14.3 \\
12.5\end{array}$ & $\begin{array}{l}12.9 \\
16.9 \\
12.5 \\
15.3 \\
16.1 \\
15.8 \\
15.4 \\
13.3\end{array}$ \\
\hline $\begin{array}{l}7 \\
7 \\
7 \\
7 \\
7 \\
7 \\
7 \\
7\end{array}$ & $\begin{array}{r}0 \\
3 \\
6 \\
9 \\
12 \\
15 \\
18 \\
21\end{array}$ & $\begin{array}{r}9.0 \\
7.2 \\
7.4 \\
10.2 \\
12.3 \\
12.1 \\
9.8 \\
8.8\end{array}$ & $\begin{array}{l}7.8 \\
6.4 \\
6.2 \\
6.5 \\
7.3 \\
6.3 \\
4.5 \\
4.0\end{array}$ & $\begin{array}{r}8.9 \\
7.2 \\
7.3 \\
9.8 \\
11.7 \\
11.9 \\
9.9 \\
8.8\end{array}$ & $\begin{array}{l}7.8 \\
6.3 \\
6.1 \\
6.0 \\
6.8 \\
5.8 \\
4.3 \\
3.7\end{array}$ & $\begin{array}{r}8.7 \\
6.9 \\
7.1 \\
9.5 \\
11.2 \\
11.6 \\
9.8 \\
8.6\end{array}$ & $\begin{array}{l}7.2 \\
5.8 \\
5.6 \\
5.4 \\
6.0 \\
5.4 \\
4.0 \\
3.5\end{array}$ & $\begin{array}{r}9.0 \\
7: 0 \\
7.1 \\
9.5 \\
11.1 \\
11.3 \\
9.07 \\
8.06\end{array}$ & $\begin{array}{l}7.5 \\
6.0 \\
5.8 \\
5.5 \\
6.3 \\
5.2 \\
4.0 \\
3.5\end{array}$ & $\begin{array}{r}9.4 \\
8.5 \\
9.0 \\
11.3 \\
13.5 \\
12.1 \\
10.0 \\
9.3\end{array}$ & & $\begin{array}{r}7.4 \\
8.7 \\
12.1 \\
13.7 \\
12.8 \\
12.1 \\
9.2 \\
8.5\end{array}$ & $\begin{array}{r}8.9 \\
10.7 \\
14.6 \\
16.6 \\
15.3 \\
14.2 \\
11.02 \\
10.0\end{array}$ & $\begin{array}{l}13.1 \\
13.7 \\
18.0 \\
17.1 \\
17.8 \\
10.0 \\
14.3 \\
11.7\end{array}$ & $\begin{array}{l}14.1 \\
14.9 \\
17.4 \\
18.4 \\
19.0 \\
20.7 \\
15.4 \\
12.6\end{array}$ \\
\hline $\begin{array}{l}8 \\
8 \\
8 \\
8 \\
8 \\
8 \\
8 \\
8 \\
8\end{array}$ & $\begin{array}{r}0 \\
3 \\
6 \\
9 \\
12 \\
15 \\
18 \\
21\end{array}$ & $\begin{array}{r}5.2 \\
3.1 \\
5.6 \\
10.7 \\
13.5 \\
14.3 \\
11.4 \\
6.0\end{array}$ & $\begin{array}{l}2.1 \\
0.5 \\
1.7 \\
4.2 \\
5.9 \\
6.6 \\
5.6 \\
2.2\end{array}$ & $\begin{array}{r}5.5 \\
3.2 \\
5.8 \\
10.4 \\
13.0 \\
14.0 \\
11.6 \\
6.9\end{array}$ & $\begin{array}{l}2.1 \\
0.5 \\
1.7 \\
3: 7 \\
5.4 \\
6.2 \\
5.3 \\
2.3\end{array}$ & $\begin{array}{r}5.6 \\
3.44 \\
5.8 \\
10.0 \\
12.7 \\
13.8 \\
11.6 \\
7.4\end{array}$ & $\begin{array}{l}1.9 \\
0.5 \\
1.6 \\
3.4 \\
5.2 \\
5.8 \\
4.9 \\
2.4\end{array}$ & $\begin{array}{r}5.9 \\
3.8 \\
6.0 \\
9.8 \\
12.8 \\
13.0 \\
11.7 \\
8.3\end{array}$ & $\begin{array}{l}1.9 \\
0.6 \\
1.6 \\
3.1 \\
5.0 \\
5.7 \\
4.6 \\
2.4\end{array}$ & $\begin{array}{r}8.7 \\
7.8 \\
7.7 \\
11.2 \\
14.3 \\
13.5 \\
11.1 \\
9.9\end{array}$ & & $\begin{array}{r}4.7 \\
6.3 \\
11.0 \\
14: 3 \\
13.1 \\
11.7 \\
4.6 \\
3.3\end{array}$ & $\begin{array}{r}5.8 \\
7.6 \\
12.6 \\
16.6 \\
15.7 \\
13.1 \\
5.9 \\
4.5\end{array}$ & $\begin{array}{r}7.3 \\
0.0 \\
15.0 \\
20.4 \\
19.5 \\
18.7 \\
6.8 \\
5.6\end{array}$ & $\begin{array}{r}8.8 \\
10.9 \\
16.4 \\
22.0 \\
21.1 \\
19.9 \\
8.2 \\
7.1\end{array}$ \\
\hline $\begin{array}{l}9 \\
9 \\
9 \\
9 \\
9 \\
9 \\
9 \\
9\end{array}$ & $\begin{array}{r}0 \\
3 \\
6 \\
9 \\
12 \\
15 \\
18 \\
21\end{array}$ & $\begin{array}{r}3.8 \\
2.8 \\
5.8 \\
13.0 \\
15.4 \\
16.4 \\
12.6 \\
7.6\end{array}$ & $\begin{array}{l}0.7 \\
0.2 \\
1.5 \\
5.1 \\
6.7 \\
7.6 \\
5.9 \\
3.1\end{array}$ & $\begin{array}{r}4.4 \\
3.2 \\
5.9 \\
12.6 \\
14.9 \\
15.9 \\
13.3 \\
9.1\end{array}$ & $\begin{array}{l}1.4 \\
4.9 \\
5.0 \\
6.9 \\
5.5 \\
3.3\end{array}$ & $\begin{array}{r}5.0 \\
3.06 \\
6.0 \\
12.0 \\
14.4 \\
15.9 \\
13.7 \\
10.0\end{array}$ & $\begin{array}{l}1.0 \\
0.1 \\
1.7 \\
4.5 \\
5.4 \\
6.3 \\
5.3 \\
3.5\end{array}$ & $\begin{array}{r}5.9 \\
4.4 \\
6.8 \\
12.2 \\
14.7 \\
16.0 \\
14.3 \\
10.9\end{array}$ & $\begin{array}{l}1.1 \\
0.1 \\
1.6 \\
4.4 \\
5.3 \\
6.4 \\
5.5 \\
4.1\end{array}$ & $\begin{array}{r}9.2 \\
8.2 \\
8.2 \\
12.3 \\
15.9 \\
15.7 \\
14.1 \\
12.1\end{array}$ & & $\begin{array}{l}4.5 \\
5.0 \\
7.8 \\
8.5 \\
9.2 \\
6.9 \\
2.3 \\
2.4\end{array}$ & $\begin{array}{r}5.6 \\
6.3 \\
8.8 \\
9.3 \\
10.5 \\
8.5 \\
3.3 \\
4.5\end{array}$ & $\begin{array}{r}7.4 \\
8.0 \\
10.7 \\
12.3 \\
12.9 \\
0.0 \\
4.6 \\
6.1\end{array}$ & $\begin{array}{r}9.6 \\
10.2 \\
11.9 \\
13.1 \\
14.0 \\
10.2 \\
6.0 \\
8.1\end{array}$ \\
\hline $\begin{array}{l}10 \\
10 \\
10 \\
10 \\
10 \\
10 \\
10 \\
10\end{array}$ & $\begin{array}{r}0 \\
3 \\
6 \\
9 \\
12 \\
15 \\
18 \\
21\end{array}$ & $\begin{array}{r}7.3 \\
7.5 \\
7.7 \\
11.7 \\
13.7 \\
8.1 \\
6.4 \\
5.7\end{array}$ & $\begin{array}{l}4.4 \\
5.3 \\
5.3 \\
7.0 \\
8.6 \\
5.4 \\
5.6 \\
4.7\end{array}$ & $\begin{array}{r}7.5 \\
7.06 \\
7.6 \\
11.7 \\
13.3 \\
7.09 \\
6.02 \\
5.6\end{array}$ & $\begin{array}{l}4.4 \\
5.2 \\
5.1 \\
6.9 \\
8.3 \\
6.4 \\
5.4 \\
4.5\end{array}$ & $\begin{array}{r}7.6 \\
7.66 \\
7.55 \\
11.7 \\
12.8 \\
7.6 \\
6.1 \\
5.3\end{array}$ & $\begin{array}{l}4.5 \\
5.2 \\
5.0 \\
6.6 \\
8.0 \\
6.0 \\
5.1 \\
4.0\end{array}$ & $\begin{array}{r}8.0 \\
7.7 \\
7.6 \\
11.6 \\
12.6 \\
7.4 \\
6.0 \\
5.2\end{array}$ & $\begin{array}{l}4.8 \\
5.2 \\
5.0 \\
6.7 \\
7.8 \\
5.9 \\
5.0 \\
4.0\end{array}$ & $\begin{array}{r}10.7 \\
10.0 \\
9.8 \\
9.9 \\
11.3 \\
10.6 \\
9.8 \\
8.4\end{array}$ & & $\begin{array}{r}4.9 \\
5.7 \\
6.7 \\
8.6 \\
11.04 \\
15.0 \\
14.6 \\
15.5\end{array}$ & $\begin{array}{r}7.8 \\
7.8 \\
8.1 \\
10.5 \\
13.1 \\
16.6 \\
17.4 \\
19.5\end{array}$ & $\begin{array}{r}9.5 \\
8.9 \\
9.1 \\
11.9 \\
16.1 \\
21.3 \\
17.8 \\
19.0\end{array}$ & $\begin{array}{r}11.6 \\
10.3 \\
9.9 \\
12.5 \\
18.0 \\
24.0 \\
20.8 \\
19.0\end{array}$ \\
\hline
\end{tabular}


TABLE 10

Table 10. -Three-hour averages of air and water-surface temperatures and wind directions and speed, April 1950-August 1951, Lake Hefner-Continued

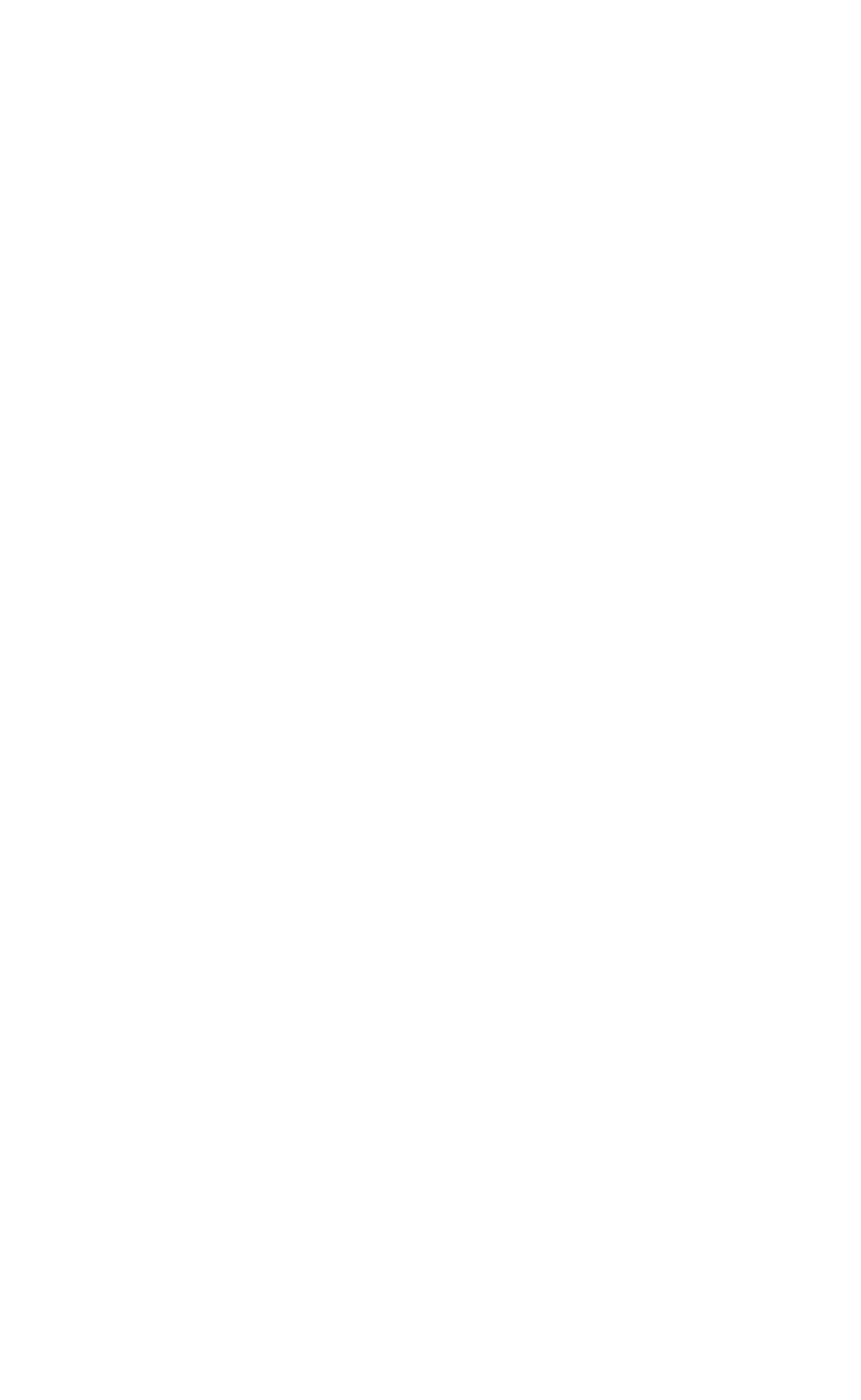



Table 10. -Three-hour averages of air and water-surface temperatures and wind directions and speed, April 1950-August
1951, Lake Hefner-Continued

STATION 2

THREE-HOURLY AVERAGES

APRIL, 1951

\begin{tabular}{|c|c|c|c|c|c|c|c|c|c|c|c|c|c|c|c|}
\hline \multirow{3}{*}{ 总 } & \multirow{3}{*}{ 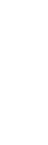 } & \multicolumn{8}{|c|}{ Average air temperature $\left({ }^{\circ} \mathrm{C}\right)$ at indicated height } & \multirow{3}{*}{$\begin{array}{l}\text { Average } \\
\text { water- } \\
\text { surface } \\
\text { tempera- } \\
\text { ture } \\
\text { ("C) }\end{array}$} & \multirow{3}{*}{$\begin{array}{c}\text { Average } \\
\text { wind } \\
\text { direction } \\
\text { (coded) }\end{array}$} & \multirow{2}{*}{\multicolumn{4}{|c|}{$\begin{array}{l}\text { Average wind speed (knots) } \\
\text { at indicated height }\end{array}$}} \\
\hline & & \multicolumn{2}{|c|}{$\begin{array}{c}2 \\
\text { meters }\end{array}$} & \multicolumn{2}{|c|}{$\begin{array}{c}4 \\
\text { meters }\end{array}$} & \multicolumn{2}{|c|}{$\begin{array}{c}8 \\
\text { meters }\end{array}$} & \multicolumn{2}{|c|}{$\begin{array}{c}16 \\
\text { meters }\end{array}$} & & & & & & \\
\hline & & $\begin{array}{l}\text { Dry } \\
\text { bulb }\end{array}$ & $\begin{array}{l}\text { Wet } \\
\text { bulb }\end{array}$ & $\begin{array}{l}\text { Dry } \\
\text { bulb }\end{array}$ & $\begin{array}{l}\text { Wet } \\
\text { bulb }\end{array}$ & $\begin{array}{l}\text { Dry } \\
\text { bulb }\end{array}$ & $\begin{array}{l}\text { Wet } \\
\text { bulb }\end{array}$ & $\begin{array}{l}\text { Dry } \\
\text { bulb }\end{array}$ & $\begin{array}{l}\text { Wet } \\
\text { bulb }\end{array}$ & & & meters & meters & meters & \\
\hline
\end{tabular}

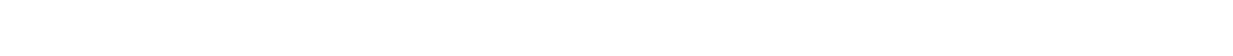

\begin{tabular}{rr|r|r|r|r|r|r|r|r|}
21 & 0 & 13.5 & 12.6 & 12.9 & 12.6 & 13.3 & 12.6 & 13.5 & 12.6 \\
21 & 3 & 12.8 & 12.2 & 12.3 & 12.1 & 12.3 & 12.0 & 12.7 & 12.0 \\
21 & 6 & 8.8 & 7.9 & 8.4 & 7.8 & 8.4 & 7.5 & 8.3 & 7.3
\end{tabular}

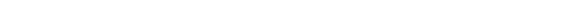

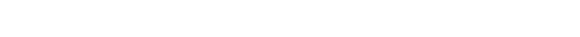

\begin{tabular}{rr|r|r|r|}
\hline .6 & 10.2 & 10.5 & 14.3 & 10.4 \\
8.4 & 10.3 & 8.4 \\
\hline
\end{tabular}

12.5

\begin{tabular}{|c|c|c|c|}
\hline $\begin{array}{r}9.8 \\
3.3 \\
10.9 \\
11.7 \\
8.4 \\
6.3 \\
2.2 \\
6.7\end{array}$ & $\begin{array}{r}11.2 \\
4.4 \\
12.5 \\
13.1 \\
9.2 \\
7.3 \\
2.9 \\
7.7\end{array}$ & $\begin{array}{r}12.8 \\
5.9 \\
17.2 \\
17.6 \\
12.5 \\
9.3 \\
4.2 \\
10.2\end{array}$ & $\begin{array}{r}14.9 \\
6.8 \\
18.5 \\
18.7 \\
13.2 \\
10.1 \\
5.2 \\
13.9\end{array}$ \\
\hline $\begin{array}{r}9.8 \\
14.0 \\
13.7 \\
13.5 \\
9.8 \\
6.8 \\
1.8 \\
1.3\end{array}$ & $\begin{array}{l}10.7 \\
15.8 \\
16.0 \\
15.3 \\
10.9 \\
7.9 \\
2.6 \\
1.8\end{array}$ & $\begin{array}{r}12.8 \\
16.2 \\
15.2 \\
16.0 \\
13.0 \\
9.7 \\
3.7 \\
1.3\end{array}$ & $\begin{array}{r}14.2 \\
17.8 \\
15.9 \\
16.6 \\
14.9 \\
11.2 \\
5.2 \\
2.0\end{array}$ \\
\hline $\begin{array}{r}0.5 \\
2.02 \\
5.0 \\
11.0 \\
13.1 \\
14.03 \\
10.01 \\
13.8\end{array}$ & $\begin{array}{r}1.0 \\
3.3 \\
6.6 \\
12.7 \\
14.7 \\
16.4 \\
11.8 \\
15.8\end{array}$ & $\begin{array}{r}1.5 \\
4.6 \\
7.7 \\
14.1 \\
16.3 \\
18.3 \\
13.6 \\
18.1\end{array}$ & $\begin{array}{r}2.5 \\
6.0 \\
9.0 \\
15.5 \\
18.0 \\
20.0 \\
15.4 \\
20.4\end{array}$ \\
\hline $\begin{array}{l}14.7 \\
14.3 \\
18.7 \\
20.3 \\
21.9 \\
19.3 \\
13.1 \\
19.1\end{array}$ & $\begin{array}{l}16.9 \\
16.5 \\
21.3 \\
23.0 \\
24.3 \\
22.0 \\
15.0 \\
21.8\end{array}$ & $\begin{array}{l}10.1 \\
18.5 \\
23.8 \\
26.0 \\
27.4 \\
24.6 \\
17.1 \\
24.4\end{array}$ & $\begin{array}{l}21.5 \\
20.9 \\
26.5 \\
28.7 \\
30.5 \\
27.2 \\
19.2 \\
27.2\end{array}$ \\
\hline $\begin{array}{r}16.1 \\
12.0 \\
9.7 \\
7.2 \\
5.1 \\
5.5 \\
2.03 \\
3.2\end{array}$ & $\begin{array}{r}18.0 \\
13.8 \\
11.2 \\
9.0 \\
7.6 \\
6.3 \\
3.0 \\
4.1\end{array}$ & $\begin{array}{r}20.8 \\
16.5 \\
14.4 \\
9.4 \\
7.2 \\
7.6 \\
4.4 \\
4.8\end{array}$ & $\begin{array}{r}23.6 \\
18.5 \\
15.6 \\
9.4 \\
8.8 \\
9.9 \\
6.4 \\
6.2\end{array}$ \\
\hline $\begin{array}{r}1.6 \\
3.5 \\
4.1 \\
5.5 \\
7.1 \\
10.8 \\
10.3 \\
12.3\end{array}$ & $\begin{array}{r}2.5 \\
4.3 \\
4.7 \\
6.2 \\
8.2 \\
12.8 \\
12.2 \\
14.4\end{array}$ & $\begin{array}{r}3.5 \\
4.1 \\
5.3 \\
6.8 \\
9.1 \\
14.4 \\
14.0 \\
15.4\end{array}$ & $\begin{array}{r}4.7 \\
5.6 \\
5.1 \\
7.3 \\
9.9 \\
15.9 \\
15.8 \\
18.4\end{array}$ \\
\hline $\begin{array}{l}14.5 \\
10.8 \\
15.6 \\
15.2 \\
13.2 \\
14.4 \\
10.7 \\
11.4\end{array}$ & $\begin{array}{l}17.0 \\
12.5 \\
17.9 \\
16.9 \\
15.1 \\
16.3 \\
12.3 \\
13.5\end{array}$ & $\begin{array}{l}19.3 \\
14.2 \\
19.7 \\
19.1 \\
16.9 \\
13.2 \\
13.9 \\
15.2\end{array}$ & $\begin{array}{l}21.4 \\
16.1 \\
21.8 \\
21.0 \\
18.3 \\
20.2 \\
15.6 \\
16.6\end{array}$ \\
\hline $\begin{array}{l}9.1 \\
10.9 \\
14.1 \\
13.1 \\
14.6 \\
14.7 \\
13.9 \\
11.4\end{array}$ & $\begin{array}{l}10.8 \\
12.7 \\
16.0 \\
14.7 \\
16.3 \\
17.0 \\
16.5 \\
13.6\end{array}$ & $\begin{array}{l}12.3 \\
14.5 \\
10.0 \\
16.4 \\
18.1 \\
18.1 \\
18.6 \\
15.4\end{array}$ & $\begin{array}{l}13.7 \\
16.3 \\
20.0 \\
17.7 \\
19.6 \\
21.0 \\
20.8 \\
17.2\end{array}$ \\
\hline $\begin{array}{l}11.5 \\
11.06 \\
15.5 \\
15.0 \\
12.4 \\
12.7 \\
10.6 \\
15.1\end{array}$ & $\begin{array}{l}13.7 \\
13.7 \\
17.7 \\
17.2 \\
14.3 \\
15.0 \\
12.5 \\
17.8\end{array}$ & $\begin{array}{l}15.6 \\
15.9 \\
10.9 \\
10 . ? \\
16.2 \\
17.0 \\
14 . ? \\
20.1\end{array}$ & $\begin{array}{l}17.3 \\
17.2 \\
22.0 \\
21.1 \\
18.2 \\
10.0 \\
16.1 \\
22.4\end{array}$ \\
\hline $\begin{array}{r}17.1 \\
17.8 \\
13.5 \\
5.1 \\
3.6 \\
4.1 \\
3.8 \\
6.9\end{array}$ & $\begin{array}{r}19.7 \\
20.4 \\
15.6 \\
5.7 \\
4.6 \\
4.8 \\
4.7 \\
8.1\end{array}$ & $\begin{array}{r}22.2 \\
22.9 \\
17.5 \\
6.6 \\
5.0 \\
5.3 \\
4.7 \\
9.1\end{array}$ & $\begin{array}{r}24.7 \\
25.4 \\
19.4 \\
7.2 \\
5.5 \\
5.8 \\
5.4 \\
10.0\end{array}$ \\
\hline
\end{tabular}


TABLE 10

Table 10. - Three-hour averages of air and water-surface temperatures and wind directions and speed, April 1950-August 1951, Lake Hefner-Continued

STATION 2

THREE-HOURLY AVERAGES

MAY, 1951

\begin{tabular}{|c|c|c|c|c|c|c|c|c|c|c|c|c|c|c|c|}
\hline \multirow{3}{*}{ 宛 } & \multirow{3}{*}{ 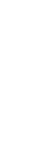 } & \multicolumn{8}{|c|}{ Average air temperature $\left({ }^{\circ} \mathrm{C}\right)$ at indicated height } & \multirow{3}{*}{$\begin{array}{l}\text { Average } \\
\text { water- } \\
\text { surface } \\
\text { tempera- } \\
\text { ture } \\
\text { ('C) }\end{array}$} & \multirow{3}{*}{$\begin{array}{c}\begin{array}{c}\text { Average } \\
\text { wind } \\
\text { direction } \\
\text { (coded) }\end{array}\end{array}$} & \multirow{2}{*}{\multicolumn{4}{|c|}{$\begin{array}{l}\text { Average wind speed (knots) } \\
\text { at indicated height }\end{array}$}} \\
\hline & & \multicolumn{2}{|c|}{$\begin{array}{c}2 \\
\text { meters }\end{array}$} & \multicolumn{2}{|c|}{$\begin{array}{c}4 \\
\text { meters }\end{array}$} & \multicolumn{2}{|c|}{$\begin{array}{c}8 \\
\text { meters }\end{array}$} & \multicolumn{2}{|c|}{$\begin{array}{c}16 \\
\text { meters }\end{array}$} & & & & & & \\
\hline & & $\begin{array}{l}\text { Dry } \\
\text { bulb }\end{array}$ & $\begin{array}{l}\text { Wet } \\
\text { bulb }\end{array}$ & $\begin{array}{l}\text { Dry } \\
\text { bulb }\end{array}$ & $\begin{array}{l}\text { Wet } \\
\text { bulb }\end{array}$ & $\begin{array}{l}\text { Dry } \\
\text { bulb }\end{array}$ & $\begin{array}{l}\text { Wet } \\
\text { bülb }\end{array}$ & $\begin{array}{l}\text { Dry } \\
\text { bulb }\end{array}$ & $\begin{array}{l}\text { Wet } \\
\text { bulb }\end{array}$ & & & $\begin{array}{c}2 \\
\text { meters }\end{array}$ & $\begin{array}{c}4 \\
\text { meters }\end{array}$ & $\begin{array}{c}8 \\
\text { meters }\end{array}$ & $\begin{array}{c}16 \\
\text { meters }\end{array}$ \\
\hline $\begin{array}{l}1 \\
1 \\
1 \\
1 \\
1 \\
1 \\
1 \\
1\end{array}$ & $\begin{array}{r}0 \\
3 \\
6 \\
9 \\
12 \\
15 \\
18 \\
21\end{array}$ & $\begin{array}{l}12.2 \\
11.5 \\
12.6 \\
16.8 \\
19.5 \\
21.1 \\
18.8 \\
16.3\end{array}$ & $\begin{array}{l}11.9 \\
10.5 \\
10.8 \\
11.1 \\
11.7 \\
11.7 \\
11.0 \\
10.1\end{array}$ & $\begin{array}{l}11.7 \\
10.8 \\
11.9 \\
16.8 \\
19.4 \\
21.1 \\
18.8 \\
16.3\end{array}$ & $\begin{array}{l}11.4 \\
10.0 \\
10.5 \\
10.2 \\
11.4 \\
11.4 \\
11.0 \\
10.1\end{array}$ & $\begin{array}{l}11.9 \\
11.6 \\
12.7 \\
16.6 \\
19.0 \\
21.0 \\
19.1 \\
26.3\end{array}$ & $\begin{array}{l}11.7 \\
10.7 \\
10.9 \\
10.2 \\
11.3 \\
11.4 \\
10.9 \\
10.1\end{array}$ & $\begin{array}{l}12.1 \\
12.1 \\
12.9 \\
16.5 \\
18.9 \\
20.9 \\
19.2 \\
16.6\end{array}$ & $\begin{array}{l}11.4 \\
10.8 \\
10.8 \\
10.0 \\
10.7 \\
11.1 \\
10.8 \\
20.0\end{array}$ & $\begin{array}{r}14.3 \\
13.1 \\
10.6 \\
8.3 \\
11.2 \\
16.7 \\
15.1 \\
14.8\end{array}$ & & $\begin{array}{r}6.5 \\
3.7 \\
9.1 \\
16.4 \\
16.1 \\
14.7 \\
8.9 \\
9.5\end{array}$ & $\begin{array}{r}7.7 \\
4.7 \\
10.4 \\
17.9 \\
17.5 \\
16.5 \\
10.6 \\
11.0\end{array}$ & $\begin{array}{r}9.3 \\
5.5 \\
11.8 \\
19.7 \\
19.6 \\
18.5 \\
12.2 \\
12.6\end{array}$ & $\begin{array}{l}10.3 \\
6.3 \\
13.4 \\
22.3 \\
21.7 \\
20.8 \\
14.0 \\
14.6\end{array}$ \\
\hline $\begin{array}{l}2 \\
2 \\
2 \\
2 \\
2 \\
2 \\
2 \\
2\end{array}$ & $\begin{array}{r}0 \\
3 \\
6 \\
9 \\
12 \\
15 \\
18 \\
21\end{array}$ & $\begin{array}{l}13.9 \\
11.5 \\
13.0 \\
20.5 \\
24.5 \\
25.1 \\
21.2\end{array}$ & $\begin{array}{r}10.0 \\
8.8 \\
9.6 \\
12.5 \\
12.6 \\
12.9 \\
13.3\end{array}$ & $\begin{array}{l}14.0 \\
11.6 \\
13.2 \\
19.7 \\
24.5 \\
25.0 \\
21.2\end{array}$ & $\begin{array}{r}10.0 \\
8.8 \\
9.8 \\
12.4 \\
12.4 \\
12.8 \\
13.5\end{array}$ & $\begin{array}{l}14.1 \\
21.7 \\
13.4 \\
19.8 \\
24.2 \\
24.9 \\
21.4\end{array}$ & $\begin{array}{r}10.0 \\
8.8 \\
9.7 \\
12.2 \\
12.3 \\
12.8 \\
13.4\end{array}$ & $\begin{array}{l}14.04 \\
11.9 \\
13.4 \\
19.7 \\
24.0 \\
24.7 \\
21.9\end{array}$ & $\begin{array}{r}9.9 \\
8.8 \\
9.7 \\
11.7 \\
11.8 \\
12.4 \\
13.4\end{array}$ & $\begin{array}{l}14.5 \\
13.8 \\
14.4 \\
15.9 \\
16.6 \\
16.5 \\
15.3\end{array}$ & & $\begin{array}{r}9.4 \\
7.7 \\
11.6 \\
13.0 \\
15.1 \\
13.6 \\
6.5 \\
6.1\end{array}$ & $\begin{array}{r}10.9 \\
9.1 \\
13.3 \\
15.1 \\
17.0 \\
15.5 \\
8.0 \\
7.6\end{array}$ & $\begin{array}{r}12.5 \\
10.7 \\
14.9 \\
16.8 \\
18.8 \\
17.0 \\
9.6 \\
9.3\end{array}$ & $\begin{array}{l}14.3 \\
13.0 \\
16.6 \\
18.4 \\
20.9 \\
19.0 \\
11.3 \\
11.2\end{array}$ \\
\hline $\begin{array}{l}3 \\
3 \\
3 \\
3 \\
3 \\
3 \\
3 \\
3 \\
3\end{array}$ & $\begin{array}{r}0 \\
3 \\
6 \\
9 \\
12 \\
15 \\
18 \\
21\end{array}$ & $\begin{array}{l}14.5 \\
14.3 \\
15.1 \\
19.8 \\
24.1 \\
24.4 \\
20.4 \\
16.1\end{array}$ & $\begin{array}{l}10.8 \\
10.4 \\
11.5 \\
13.2 \\
14.2 \\
13.8 \\
13.2 \\
10.6\end{array}$ & $\begin{array}{l}14.8 \\
13.9 \\
15.2 \\
19.8 \\
23.5 \\
23.7 \\
20.6 \\
18.4\end{array}$ & $\begin{array}{l}10.8 \\
10.6 \\
11.2 \\
13.2 \\
12.8 \\
12.9 \\
12.8 \\
11.0\end{array}$ & $\begin{array}{l}14.8 \\
14.9 \\
15.4 \\
19.2 \\
23.6 \\
23.8 \\
21.3 \\
19.2\end{array}$ & $\begin{array}{l}10.7 \\
21.0 \\
12.9 \\
12.1 \\
12.2 \\
12.6 \\
11.0\end{array}$ & $\begin{array}{l}14.9 \\
15.2 \\
19.5 \\
23.5 \\
24.2 \\
22.2 \\
19.9\end{array}$ & $\begin{array}{l}10.8 \\
10.7 \\
10.8 \\
12.2 \\
11.6 \\
11.1 \\
12.0 \\
11.1\end{array}$ & $\begin{array}{l}14.3 \\
14.1 \\
14.9 \\
19.0 \\
24.2 \\
24.0 \\
21.5 \\
18.4\end{array}$ & & $\begin{array}{l}6.1 \\
5.2 \\
3.5 \\
4.9 \\
6.5 \\
4.9 \\
1.97 \\
2.1\end{array}$ & $\begin{array}{l}7.4 \\
6.9 \\
4.4 \\
7.2 \\
8.4 \\
6.3 \\
2.5 \\
2.8\end{array}$ & $\begin{array}{l}9.2 \\
8.7 \\
5.9 \\
7.6 \\
8.6 \\
6.8 \\
2.8 \\
3.6\end{array}$ & $\begin{array}{r}11.9 \\
11.1 \\
6.5 \\
9.0 \\
10.0 \\
7.7 \\
4.8 \\
5.0\end{array}$ \\
\hline $\begin{array}{l}4 \\
4 \\
4 \\
4 \\
4 \\
4 \\
4 \\
4\end{array}$ & $\begin{array}{r}0 \\
3 \\
6 \\
9 \\
12 \\
15 \\
18 \\
21\end{array}$ & $\begin{array}{l}13.7 \\
12.8 \\
15.2 \\
19.4 \\
22.3 \\
22.6 \\
19.8 \\
15.8\end{array}$ & $\begin{array}{r}9.8 \\
10.0 \\
10.9 \\
13.4 \\
14.1 \\
14.6 \\
13.9 \\
11.8\end{array}$ & $\begin{array}{l}15.1 \\
13.5 \\
15.2 \\
18.5 \\
22.0 \\
22.1 \\
19.8 \\
16.9\end{array}$ & $\begin{array}{r}9.9 \\
10.1 \\
10.7 \\
12.6 \\
13.3 \\
13.8 \\
13.6 \\
11.8\end{array}$ & $\begin{array}{l}16.2 \\
13.6 \\
15.4 \\
18.8 \\
21.6 \\
22.1 \\
19.9 \\
17.8\end{array}$ & $\begin{array}{l}10.0 \\
10.0 \\
10.6 \\
12.4 \\
13.1 \\
13.6 \\
13.5 \\
11.9\end{array}$ & $\begin{array}{l}17.7 \\
14.5 \\
15.5 \\
18.8 \\
21.5 \\
22.03 \\
20.5 \\
18.7\end{array}$ & $\begin{array}{l}10.1 \\
10.0 \\
10.4 \\
12.2 \\
12.7 \\
13.1 \\
13.0 \\
12.0\end{array}$ & $\begin{array}{l}16.8 \\
15.5 \\
16.0 \\
21.3 \\
24.0 \\
21.7 \\
19.0 \\
17.6\end{array}$ & & $\begin{array}{r}2.4 \\
3.9 \\
6.3 \\
8.5 \\
10.6 \\
11.7\end{array}$ & $\begin{array}{r}3.4 \\
4.5 \\
6.7 \\
9.4 \\
11.3 \\
14.4 \\
4.8 \\
3.5\end{array}$ & $\begin{array}{r}4.4 \\
5.8 \\
8.9 \\
11.3 \\
15.4 \\
14.0 \\
5.4 \\
4.0\end{array}$ & $\begin{array}{r}5.9 \\
7.1 \\
10.2 \\
12.3 \\
16.9 \\
14.3 \\
7.4 \\
4.5\end{array}$ \\
\hline $\begin{array}{l}5 \\
5 \\
5 \\
5 \\
5 \\
5 \\
5 \\
5\end{array}$ & $\begin{array}{r}0 \\
3 \\
6 \\
9 \\
12 \\
15 \\
18 \\
21\end{array}$ & $\begin{array}{l}12.9 \\
12.9 \\
15.8 \\
21.7 \\
26.0 \\
20.1 \\
18.6\end{array}$ & $\begin{array}{l}10.6 \\
10.7 \\
12.4 \\
14.6 \\
14.0 \\
14.0 \\
13.2\end{array}$ & $\begin{array}{l}14.2 \\
13.7 \\
15.8 \\
21.1 \\
25.2 \\
20.7 \\
18.7\end{array}$ & $\begin{array}{l}10.9 \\
10.7 \\
12.2 \\
14.2 \\
14.4 \\
14.0 \\
13.2\end{array}$ & $\begin{array}{l}16.3 \\
14.4 \\
16.3 \\
21.5 \\
25.3 \\
20.9 \\
18.9\end{array}$ & $\begin{array}{l}11.0 \\
10.9 \\
12.3 \\
14.2 \\
14.3 \\
13.9 \\
13.1\end{array}$ & $\begin{array}{l}18.4 \\
15.4 \\
16.8 \\
21.1 \\
24.5 \\
21.3 \\
19.6\end{array}$ & $\begin{array}{l}11.3 \\
11.0 \\
12.3 \\
13.8 \\
14.3\end{array}$ & $\begin{array}{l}16.7 \\
15.9 \\
16.8 \\
22.1 \\
21.7 \\
15.4 \\
15.9\end{array}$ & & $\begin{array}{l}4.8 \\
5.9\end{array}$ & $\begin{array}{l}4.8 \\
2.8 \\
3.9 \\
5.2 \\
5.3 \\
5.2 \\
7.6\end{array}$ & $\begin{array}{l}3.1 \\
4.9 \\
3.1 \\
4.6 \\
5.0 \\
5.6\end{array}$ & $\begin{array}{r}3.7 \\
6.3 \\
4.1 \\
4.9 \\
6.1 \\
6.7 \\
8.0 \\
10.6\end{array}$ \\
\hline $\begin{array}{l}6 \\
6 \\
6 \\
6 \\
6 \\
6 \\
6 \\
6\end{array}$ & $\begin{array}{r}0 \\
3 \\
6 \\
9 \\
12 \\
15 \\
18 \\
21\end{array}$ & $\begin{array}{l}12.0 \\
12.5 \\
13.0 \\
12.1\end{array}$ & $\begin{array}{l}7.2 \\
7.9 \\
8.6 \\
8.6\end{array}$ & $\begin{array}{l}11.7 \\
12.5 \\
12.9 \\
12.2\end{array}$ & $\begin{array}{l}7.2 \\
7.6 \\
8.4 \\
8.5\end{array}$ & $\begin{array}{l}11.7 \\
12.4 \\
12.9 \\
12.0\end{array}$ & $\begin{array}{l}7.3 \\
7.5 \\
8.2 \\
8.5\end{array}$ & $\begin{array}{l}11.3 \\
12.2 \\
12.8 \\
12.0\end{array}$ & $\begin{array}{l}6.5 \\
7.0 \\
8.0 \\
8.3\end{array}$ & $\begin{array}{l}15.7 \\
15.4 \\
13.3 \\
12.3\end{array}$ & & $\begin{array}{r}2.6 \\
9.5 \\
11.1 \\
11.0 \\
9.2 \\
9.5 \\
8.5 \\
5.7\end{array}$ & $\begin{array}{r}11.4 \\
13.1 \\
12.6 \\
10.4 \\
12.1 \\
10.6 \\
6.8\end{array}$ & $\begin{array}{r}5.2 \\
13.1 \\
15.2 \\
12.4 \\
12.4 \\
8.6 \\
6.8\end{array}$ & $\begin{array}{r}7.0 \\
18.6 \\
21.6 \\
21.8 \\
16.6 \\
14.3 \\
10.0 \\
6.8\end{array}$ \\
\hline $\begin{array}{l}7 \\
7 \\
7 \\
7 \\
7 \\
7 \\
7 \\
7\end{array}$ & $\begin{array}{r}0 \\
3 \\
6 \\
9 \\
12 \\
15 \\
18 \\
21\end{array}$ & $\begin{array}{r}10.1 \\
8.9 \\
10.2 \\
14.2 \\
18.3 \\
19.4 \\
15.9 \\
12.0\end{array}$ & $\begin{array}{r}8.0 \\
7.3 \\
7.7 \\
8.9 \\
10.5 \\
11.1 \\
10.2 \\
8.8\end{array}$ & $\begin{array}{r}10.1 \\
9.0 \\
10.2 \\
13.4 \\
17.5 \\
19.4 \\
16.4 \\
13.4\end{array}$ & $\begin{array}{r}7.9 \\
7.1 \\
7.3 \\
8.2 \\
9.8 \\
10.4 \\
9.8 \\
8.9\end{array}$ & $\begin{array}{r}10.0 \\
8.9 \\
10.0 \\
13.6 \\
17.6 \\
18.5 \\
16.3 \\
13.9\end{array}$ & $\begin{array}{r}7.8 \\
7.0 \\
7.1 \\
8.2 \\
9.7 \\
30.2 \\
9.8 \\
9.1\end{array}$ & $\begin{array}{r}10.0 \\
8.9 \\
9.9 \\
13.2 \\
17.0 \\
18.5 \\
16.5 \\
14.5\end{array}$ & $\begin{array}{r}7.6 \\
7.0 \\
7.1 \\
8.2 \\
9.9 \\
10.3 \\
9.8 \\
9.1\end{array}$ & & & $\begin{array}{l}4.1 \\
3.0 \\
5.3 \\
5.7 \\
3.7 \\
2.9 \\
2.4 \\
2.3\end{array}$ & $\begin{array}{l}4.8 \\
3.4 \\
5.7 \\
6.2 \\
3.2 \\
3.2 \\
3.0 \\
3.3\end{array}$ & $\begin{array}{l}5.6 \\
4.0 \\
6.6 \\
6.9 \\
3.3 \\
3.4 \\
3.6 \\
4.1\end{array}$ & $\begin{array}{l}6.9 \\
4.9 \\
7.4 \\
7.9 \\
3.6 \\
3.6 \\
4.6 \\
5.5\end{array}$ \\
\hline $\begin{array}{l}8 \\
8 \\
8 \\
8 \\
8 \\
8 \\
8 \\
8\end{array}$ & $\begin{array}{r}0 \\
3 \\
6 \\
9 \\
12 \\
15 \\
18 \\
21\end{array}$ & $\begin{array}{l}11.5 \\
11.5 \\
14.5 \\
18.9 \\
21.8 \\
22.0 \\
20.6 \\
18.4\end{array}$ & $\begin{array}{r}8.6 \\
9.4 \\
11.8 \\
13.2 \\
15.6 \\
16.3 \\
15.5 \\
14.8\end{array}$ & $\begin{array}{l}12.0 \\
11.7 \\
14.5 \\
18.7 \\
21.9 \\
21.9 \\
20.6 \\
18.6\end{array}$ & $\begin{array}{r}8.6 \\
9.4 \\
11.6 \\
12.8 \\
15.2 \\
16.1 \\
15.4 \\
14.7\end{array}$ & $\begin{array}{l}12.4 \\
11.6 \\
14.4 \\
18.4 \\
21.3 \\
21.9 \\
20.6 \\
18.6\end{array}$ & $\begin{array}{r}8.8 \\
9.4 \\
11.4 \\
12.6 \\
15.0 \\
16.0 \\
15.3 \\
14.7\end{array}$ & $\begin{array}{l}13.0 \\
11.9 \\
14.4 \\
18.0 \\
21.0 \\
21.6 \\
20.5 \\
18.5\end{array}$ & $\begin{array}{r}8.9 \\
9.5 \\
11.4 \\
12.6 \\
14.9 \\
15.9 \\
15.3 \\
14.7\end{array}$ & & & $\begin{array}{r}3.4 \\
3.6 \\
7.9 \\
13.8 \\
13.1 \\
12.7 \\
10.5 \\
11.4\end{array}$ & $\begin{array}{r}4.5 \\
4.3 \\
9.1 \\
15.7 \\
14.8 \\
14.5 \\
12.1 \\
13.2\end{array}$ & $\begin{array}{r}5.9 \\
5.4 \\
10.0 \\
17.5 \\
16.4 \\
16.0 \\
13.6 \\
14.9\end{array}$ & $\begin{array}{r}7.7 \\
6.7 \\
11.2 \\
19.0 \\
18.0 \\
17.8 \\
15.2 \\
16.8\end{array}$ \\
\hline $\begin{array}{l}9 \\
9 \\
9 \\
9 \\
9 \\
9 \\
9 \\
9\end{array}$ & $\begin{array}{r}0 \\
3 \\
6 \\
9 \\
12 \\
15 \\
18 \\
21\end{array}$ & $\begin{array}{l}16.5 \\
15.8 \\
17.4 \\
21.6 \\
24.6 \\
24.9 \\
17.4 \\
15.9\end{array}$ & $\begin{array}{l}14.1 \\
14.8 \\
16.1 \\
17.7 \\
18.7 \\
19.0 \\
16.0 \\
15.0\end{array}$ & $\begin{array}{l}16.6 \\
15.9 \\
17.4 \\
21.4 \\
23.8 \\
24.8 \\
16.7 \\
16.3\end{array}$ & $\begin{array}{l}14.1 \\
14.8 \\
16.1 \\
17.7 \\
18.4 \\
18.8 \\
15.2 \\
14.9\end{array}$ & $\begin{array}{l}15.6 \\
15.9 \\
17.4 \\
21.0 \\
23.8 \\
24.7 \\
16.4 \\
16.5\end{array}$ & $\begin{array}{l}14.1 \\
14.7 \\
15.0 \\
17.3 \\
18.3 \\
18.6 \\
14.3 \\
14.7\end{array}$ & $\begin{array}{l}16.6 \\
16.0 \\
17.4 \\
21.1 \\
23.7 \\
24.5 \\
16.2 \\
16.8\end{array}$ & $\begin{array}{l}14.1 \\
14.8 \\
16.0 \\
17.4 \\
18.2 \\
18.6 \\
14.6 \\
14.8\end{array}$ & & & $\begin{array}{r}12.2 \\
9.4 \\
9.8 \\
14.4 \\
13.0 \\
11.5 \\
6.3 \\
5.7\end{array}$ & $\begin{array}{r}14.0 \\
10.8 \\
11.1 \\
15.8 \\
14.7 \\
13.1 \\
7.5 \\
6.6\end{array}$ & $\begin{array}{r}15.7 \\
12.2 \\
12.5 \\
18.1 \\
16.3 \\
14.6 \\
8.8 \\
8.9\end{array}$ & $\begin{array}{r}17.7 \\
13.7 \\
13.9 \\
19.9 \\
17.9 \\
16.1 \\
9.9 \\
10.5\end{array}$ \\
\hline $\begin{array}{l}10 \\
10 \\
10 \\
10 \\
10 \\
10 \\
10 \\
10\end{array}$ & $\begin{array}{r}0 \\
3 \\
6 \\
9 \\
12 \\
12 \\
18 \\
21\end{array}$ & $\begin{array}{l}15.2 \\
13.1 \\
12.8 \\
14.7 \\
16.5 \\
17.8 \\
16.4 \\
13.3\end{array}$ & $\begin{array}{l}13.5 \\
11.2 \\
10.7 \\
12.9 \\
13.8 \\
13.9 \\
13.6 \\
11.7\end{array}$ & $\begin{array}{l}15.2 \\
13.2 \\
12.8 \\
14.6 \\
16.5 \\
17.9 \\
16.4 \\
13.3\end{array}$ & $\begin{array}{l}13.4 \\
11.0 \\
10.6 \\
12.6 \\
13.3 \\
13.6 \\
13.5 \\
11.7\end{array}$ & $\begin{array}{l}15.3 \\
13.1 \\
12.8 \\
14.5 \\
16.2 \\
17.8 \\
16.3 \\
13.2\end{array}$ & $\begin{array}{l}13.1 \\
10.6 \\
10.2 \\
12.2 \\
12.8 \\
13.3 \\
13.1 \\
11.3\end{array}$ & $\begin{array}{l}15.3 \\
13.0 \\
12.8 \\
14.4 \\
16.0 \\
17.5 \\
16.2 \\
13.2\end{array}$ & $\begin{array}{l}13.2 \\
10.7 \\
10.1 \\
12.4 \\
12.9 \\
13.4 \\
13.2 \\
11.4\end{array}$ & & & $\begin{array}{r}8.3 \\
9.7 \\
9.7 \\
9.2 \\
10.0 \\
10.7 \\
6.4 \\
4.7\end{array}$ & $\begin{array}{r}9.3 \\
10.2 \\
11.3 \\
9.9 \\
10.7 \\
12.7 \\
7.4 \\
5.2\end{array}$ & $\begin{array}{r}13.6 \\
16.7 \\
13.8 \\
14.8 \\
16.1 \\
16.2 \\
7.0 \\
6.1\end{array}$ & $\begin{array}{r}14.7 \\
17.7 \\
14.9 \\
15.6 \\
17.5 \\
16.5 \\
7.6 \\
7.2\end{array}$ \\
\hline
\end{tabular}


TABLE 10

Table 10. - Three-hour averages of air and water-surface temperatures and wind directions and speed, April 1950-August 1951, Lake Hefner-Continued

STATION 2 THREE-HOURLY AVERAGES

MAY, 1951

\begin{tabular}{|c|c|c|c|c|c|c|c|c|c|c|c|c|c|c|c|}
\hline \multirow{3}{*}{ 莣 } & \multirow{3}{*}{ 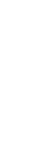 } & \multicolumn{8}{|c|}{ Average air temperature $\left({ }^{\circ} \mathrm{C}\right)$ at indicated height } & \multirow{3}{*}{$\begin{array}{l}\text { Average } \\
\text { water- } \\
\text { surface } \\
\text { tempera- } \\
\text { ture } \\
\text { ("C) }\end{array}$} & \multirow{3}{*}{$\begin{array}{l}\text { Average } \\
\text { wind } \\
\text { direction } \\
\text { (coded) }\end{array}$} & \multirow{2}{*}{\multicolumn{4}{|c|}{$\begin{array}{l}\text { Average wind speed (knots) } \\
\text { at indicated height }\end{array}$}} \\
\hline & & \multicolumn{2}{|c|}{$\stackrel{2}{\text { meters }}$} & \multicolumn{2}{|c|}{$\begin{array}{c}4 \\
\text { meters }\end{array}$} & \multicolumn{2}{|c|}{$\begin{array}{c}8 \\
\text { meters }\end{array}$} & \multicolumn{2}{|c|}{$\begin{array}{c}16 \\
\text { meters }\end{array}$} & & & & & & \\
\hline & & $\begin{array}{l}\text { Dry } \\
\text { bulb }\end{array}$ & $\begin{array}{l}\text { Wet } \\
\text { bulb }\end{array}$ & $\begin{array}{l}\text { Dry } \\
\text { bulb }\end{array}$ & $\begin{array}{l}\text { Wet } \\
\text { bulb }\end{array}$ & $\begin{array}{l}\text { Dry } \\
\text { bulb }\end{array}$ & $\begin{array}{l}\text { Wet } \\
\text { bulb }\end{array}$ & $\begin{array}{l}\text { Dry } \\
\text { bulb }\end{array}$ & $\begin{array}{l}\text { Wet } \\
\text { bulb }\end{array}$ & & & meters & meters & meters & meters \\
\hline
\end{tabular}

\begin{tabular}{|c|c|c|c|c|c|c|c|c|c|c|c|c|c|c|}
\hline & & & & & & & & & & & & & & \\
\hline $\begin{array}{l}11 \\
11 \\
11 \\
11 \\
11 \\
11 \\
11 \\
11\end{array}$ & $\begin{array}{r}0 \\
3 \\
6 \\
9 \\
12 \\
15 \\
18 \\
21\end{array}$ & $\begin{array}{r}11.2 \\
8.5 \\
11.3 \\
15.2 \\
19.2 \\
21.5 \\
18.0 \\
13.8\end{array}$ & $\begin{array}{r}10.8 \\
.9 .1 \\
10.8 \\
12.3 \\
13.4 \\
13.6 \\
13.0 \\
11.6\end{array}$ & $\begin{array}{r}11.3 \\
9.2 \\
11.7 \\
15.0 \\
18.8 \\
21.3 \\
18.0 \\
14.4\end{array}$ & $\begin{array}{r}10.5 \\
9.1 \\
10.5 \\
12.1 \\
12.8 \\
13.4 \\
12.8 \\
11.7\end{array}$ & $\begin{array}{r}11.2 \\
9.4 \\
12.4 \\
14.9 \\
19.0 \\
20.6 \\
18.0 \\
14.9\end{array}$ & $\begin{array}{r}10.1 \\
8.9 \\
10.3 \\
11.5 \\
12.4 \\
12.7 \\
12.5 \\
11.4\end{array}$ & $\begin{array}{l}11.4 \\
10.0 \\
11.9 \\
14.5 \\
18.6 \\
20.2 \\
18.1 \\
15.6\end{array}$ & $\begin{array}{r}10.4 \\
9.4 \\
10.5 \\
12.0 \\
12.8 \\
12.7 \\
12.6 \\
11.6\end{array}$ & & $\begin{array}{l}2.1 \\
0.5 \\
1.5 \\
3.1 \\
3.3 \\
2: 9 \\
2.8 \\
1.8\end{array}$ & $\begin{array}{l}2.8 \\
1.3 \\
2.0 \\
3.5 \\
3.7 \\
3.5 \\
4.0 \\
3.3\end{array}$ & $\begin{array}{l}3.1 \\
1.6 \\
2.1 \\
3 \bullet 6 \\
3.9 \\
3.8 \\
4 \bullet 8 \\
4.4\end{array}$ & $\begin{array}{l}3.8 \\
2.1 \\
2.3 \\
3.8 \\
4.1 \\
4.1 \\
5.9 \\
6.0\end{array}$ \\
\hline $\begin{array}{l}12 \\
12 \\
12 \\
12 \\
12 \\
12 \\
12 \\
12\end{array}$ & $\begin{array}{r}0 \\
3 \\
6 \\
9 \\
12 \\
15 \\
18 \\
21\end{array}$ & $\begin{array}{l}14.1 \\
14.1 \\
15.3 \\
18.5 \\
21.8 \\
22.6 \\
19.0 \\
16.4\end{array}$ & $\begin{array}{l}12.1 \\
11.9 \\
12.4 \\
13.3 \\
14.0 \\
14.4 \\
12.8 \\
12.2\end{array}$ & $\begin{array}{l}14.5 \\
14.3 \\
15.1 \\
18.2 \\
21.2 \\
22.1 \\
19.1 \\
16.6\end{array}$ & $\begin{array}{l}11.9 \\
11.8 \\
12.3 \\
12.9 \\
13.7 \\
13.9 \\
12.7 \\
12.1\end{array}$ & $\begin{array}{l}14.5 \\
14.2 \\
15.0 \\
18.0 \\
21.0 \\
21.7 \\
19.0 \\
16.4\end{array}$ & $\begin{array}{l}11.8 \\
11.7 \\
11.9 \\
12.7 \\
13.1 \\
13.5 \\
12.6 \\
12.0\end{array}$ & $\begin{array}{l}14.8 \\
14.6 \\
15.1 \\
18.1 \\
20.7 \\
21.3 \\
19.2 \\
16.5\end{array}$ & $\begin{array}{l}11.8 \\
11.7 \\
31.9 \\
12.8 \\
13.4 \\
13.7 \\
12.8 \\
12.2\end{array}$ & $\begin{array}{l}16.8 \\
15.9 \\
16.0 \\
16.7 \\
17.6 \\
17.2 \\
15.0 \\
15.4\end{array}$ & $\begin{array}{r}2.9 \\
3.3 \\
5.1 \\
8.2 \\
9.3 \\
9.7 \\
7.5 \\
10.1\end{array}$ & $\begin{array}{r}4.2 \\
5.5 \\
8.3 \\
12.3 \\
11.7 \\
12.3 \\
9.2 \\
12.0\end{array}$ & $\begin{array}{r}5.2 \\
6.6 \\
9.3 \\
13.7 \\
13.0 \\
13.8 \\
10.6 \\
13.7\end{array}$ & $\begin{array}{r}6.6 \\
8.1 \\
10.2 \\
15.2 \\
14.1 \\
15.2 \\
12.1 \\
15.3\end{array}$ \\
\hline $\begin{array}{l}13 \\
13 \\
13 \\
13 \\
13 \\
13 \\
13 \\
13\end{array}$ & $\begin{array}{r}0 \\
3 \\
6 \\
9 \\
12 \\
15 \\
18 \\
21\end{array}$ & $\begin{array}{l}14.8 \\
13.7 \\
16.0 \\
21.5 \\
23.7 \\
24.0 \\
21.5 \\
19.9\end{array}$ & $\begin{array}{l}11.8 \\
11.3 \\
12.3 \\
15.3 \\
15.7 \\
14.9 \\
14.1 \\
13.5\end{array}$ & $\begin{array}{l}14.0 \\
13.8 \\
16.0 \\
21.0 \\
23.6 \\
23.7 \\
21.4 \\
20.0\end{array}$ & $\begin{array}{l}11.8 \\
11.3 \\
12.2 \\
15.3 \\
15.3 \\
14.7 \\
14.0 \\
13.4\end{array}$ & $\begin{array}{l}14.9 \\
13.9 \\
16.1 \\
21.1 \\
22.9 \\
23.5 \\
21.5 \\
19.9\end{array}$ & $\begin{array}{l}11.6 \\
11.1 \\
12.0 \\
14.6 \\
14.9 \\
14.5 \\
13.9 \\
13.3\end{array}$ & $\begin{array}{l}15.1 \\
13.9 \\
16.1 \\
20.6 \\
22.8 \\
23.4 \\
21.5 \\
20.1\end{array}$ & $\begin{array}{l}11.9 \\
11.4 \\
12.3 \\
14.8 \\
14.8 \\
14.5 \\
14.0 \\
13.6\end{array}$ & $\begin{array}{l}14.9 \\
14.8 \\
15.4 \\
17.9 \\
17.9 \\
17.2 \\
16.3 \\
15.9\end{array}$ & $\begin{array}{r}9.4 \\
8.9 \\
12.5 \\
15.0 \\
15.7 \\
14.3 \\
11.8 \\
12.4\end{array}$ & $\begin{array}{l}11.0 \\
10.3 \\
14.5 \\
17.5 \\
18.9 \\
16.7 \\
13.8 \\
14.7\end{array}$ & $\begin{array}{l}12.7 \\
11.8 \\
16.4 \\
19.6 \\
20.5 \\
19.1 \\
15.7 \\
16.5\end{array}$ & $\begin{array}{l}14.5 \\
13.4 \\
18.1 \\
21.6 \\
22.4 \\
20.7 \\
17.5 \\
18.5\end{array}$ \\
\hline $\begin{array}{l}14 \\
14 \\
14 \\
14 \\
14 \\
14 \\
14 \\
14\end{array}$ & $\begin{array}{r}0 \\
3 \\
6 \\
9 \\
12 \\
15 \\
18 \\
21\end{array}$ & $\begin{array}{l}19.1 \\
17.7 \\
18.4 \\
22.2 \\
25.7 \\
26.0 \\
23.4 \\
21.8\end{array}$ & $\begin{array}{l}13.1 \\
12.8 \\
14: 6 \\
15.7 \\
17: 0 \\
17.2 \\
17.6 \\
18.2\end{array}$ & $\begin{array}{l}19.2 \\
17.7 \\
18.4 \\
22.1 \\
25.3 \\
25.8 \\
23.5 \\
21.9\end{array}$ & $\begin{array}{l}13.1 \\
12.8 \\
14.5 \\
15.4 \\
16.5 \\
17.0 \\
17.5 \\
18.2\end{array}$ & $\begin{array}{l}19.3 \\
17.7 \\
18.4 \\
22.3 \\
24.8 \\
25.4 \\
23.4 \\
21.8\end{array}$ & $\begin{array}{l}13.0 \\
12.8 \\
14.4 \\
15.1 \\
16.2 \\
16.9 \\
17.3 \\
17.9\end{array}$ & $\begin{array}{l}19.3 \\
17.7 \\
18.5 \\
22.1 \\
24.5 \\
25.2 \\
23.4 \\
21.7\end{array}$ & $\begin{array}{l}13.1 \\
12.9 \\
14.5 \\
15.2 \\
16.3 \\
16.7 \\
17.5 \\
18.1\end{array}$ & $\begin{array}{l}15.8 \\
15.5 \\
16.5 \\
17.9 \\
18.5 \\
18.1 \\
17.3 \\
17.3\end{array}$ & $\begin{array}{l}11.6 \\
13.2 \\
15.9 \\
14.5 \\
13.3 \\
13.8 \\
13.6 \\
14.8\end{array}$ & $\begin{array}{l}13.8 \\
15.7 \\
18.6 \\
17.3 \\
15.7 \\
16.4 \\
15.8 \\
17.5\end{array}$ & $\begin{array}{l}15.7 \\
17.7 \\
21.3 \\
10.1 \\
17.5 \\
18.2 \\
18.1 \\
19.8\end{array}$ & $\begin{array}{l}17.5 \\
20.1 \\
23.4 \\
21.1 \\
19.2 \\
20.2 \\
20.0 \\
22.1\end{array}$ \\
\hline $\begin{array}{l}15 \\
15 \\
15 \\
15 \\
15 \\
15 \\
15 \\
15\end{array}$ & $\begin{array}{r}0 \\
3 \\
6 \\
9 \\
12 \\
15 \\
18 \\
21\end{array}$ & $\begin{array}{l}20.5 \\
19.5 \\
20.5 \\
21.3 \\
22.8 \\
21.6 \\
20.6 \\
19.2\end{array}$ & $\begin{array}{l}18.4 \\
18.5 \\
18.8 \\
19.3 \\
20.3 \\
19.2 \\
18.5 \\
18.2\end{array}$ & $\begin{array}{l}20.6 \\
19.4 \\
20.3 \\
21.4 \\
22.4 \\
21.5 \\
20.7 \\
19.0\end{array}$ & $\begin{array}{l}18.5 \\
18.2 \\
18.8 \\
19.2 \\
19.9 \\
19.0 \\
18.4 \\
17.9\end{array}$ & $\begin{array}{l}20.6 \\
19.4 \\
20.3 \\
21.3 \\
22.6 \\
21.4 \\
20.6 \\
19.4\end{array}$ & $\begin{array}{l}18.1 \\
18.2 \\
18.6 \\
19.1 \\
19.9 \\
19.0 \\
18.4 \\
18.2\end{array}$ & $\begin{array}{l}20.5 \\
19.5 \\
20.4 \\
21.3 \\
22.0 \\
21.4 \\
20.5 \\
19.4\end{array}$ & $\begin{array}{l}18.2 \\
18.2 \\
18.5 \\
10.0 \\
19.7 \\
18.9 \\
18.3 \\
17.9\end{array}$ & $\begin{array}{l}17.2 \\
17.0 \\
17: 2 \\
17: 8 \\
19.2 \\
18.0 \\
17.2 \\
17.0\end{array}$ & $\begin{array}{r}13.7 \\
10.2 \\
12.6 \\
11.4 \\
11.5 \\
12.3 \\
10.8 \\
7.1\end{array}$ & $\begin{array}{r}16.1 \\
12.1 \\
14.8 \\
13.4 \\
14.5 \\
14.5 \\
12.7 \\
9.1\end{array}$ & $\begin{array}{l}18.3 \\
13.6 \\
16.7 \\
15.0 \\
16.3 \\
16.2 \\
14.3 \\
10.2\end{array}$ & $\begin{array}{l}20.2 \\
15.2 \\
18.6 \\
16.7 \\
18.0 \\
17.9 \\
15.7 \\
11.7\end{array}$ \\
\hline $\begin{array}{l}16 \\
16 \\
16 \\
16 \\
16 \\
16 \\
16 \\
16\end{array}$ & $\begin{array}{r}0 \\
3 \\
6 \\
9 \\
12 \\
15 \\
18 \\
21\end{array}$ & $\begin{array}{l}19.7 \\
19.5 \\
18.8 \\
20.9 \\
24.2 \\
24.2 \\
21.5 \\
19.8\end{array}$ & $\begin{array}{l}18.0 \\
18.4 \\
17.7 \\
18.2 \\
19.4 \\
19.4 \\
19.2 \\
17.6\end{array}$ & $\begin{array}{l}19.8 \\
19.7 \\
18.6 \\
20.8 \\
23.8 \\
23.9 \\
21.7 \\
20.0\end{array}$ & $\begin{array}{l}17.9 \\
18.4 \\
17: 3 \\
17: 9 \\
19.0 \\
19.2 \\
19.1 \\
17.6\end{array}$ & $\begin{array}{l}19.9 \\
19.7 \\
18.8 \\
20.7 \\
23.7 \\
23.8 \\
21.6 \\
19.6\end{array}$ & $\begin{array}{l}18.0 \\
18.4 \\
17.7 \\
17.9 \\
18.8 \\
19.1 \\
19.1 \\
17.2\end{array}$ & $\begin{array}{l}19.9 \\
19.5 \\
18.8 \\
20.5 \\
23.5 \\
23.7 \\
21.6 \\
19.7\end{array}$ & $\begin{array}{l}17.9 \\
18.0 \\
17.2 \\
17.5 \\
18.5 \\
10.1 \\
18.9 \\
16.9\end{array}$ & $\begin{array}{l}16.8 \\
16.8 \\
16.7 \\
19.5 \\
20.7 \\
18.7 \\
17.5 \\
117.3\end{array}$ & $\begin{array}{r}7.0 \\
9.2 \\
12.2 \\
15.0 \\
12.7 \\
8.3 \\
6.9 \\
11.5\end{array}$ & $\begin{array}{r}8.5 \\
10.7 \\
14.2 \\
17.1 \\
14.4 \\
10.8 \\
9.4 \\
13.7\end{array}$ & $\begin{array}{r}9.8 \\
12.2 \\
15.9 \\
19.1 \\
15.9 \\
12.1 \\
10.7 \\
15.6\end{array}$ & $\begin{array}{l}11.0 \\
13.7 \\
17.8 \\
21.1 \\
17.5 \\
13.5 \\
12.0 \\
17.5\end{array}$ \\
\hline $\begin{array}{l}17 \\
17 \\
17 \\
17 \\
17 \\
17 \\
17 \\
17\end{array}$ & $\begin{array}{r}0 \\
3 \\
6 \\
9 \\
12 \\
15 \\
18 \\
21\end{array}$ & $\begin{array}{l}15.2 \\
14.6 \\
14.9 \\
18.2 \\
18.1 \\
18.2 \\
16.5 \\
15.9\end{array}$ & $\begin{array}{l}14.9 \\
14.6 \\
14.6 \\
16.5 \\
16.5 \\
16.9 \\
15.5 \\
15.0\end{array}$ & $\begin{array}{l}15.2 \\
14.7 \\
14.6 \\
17.6 \\
18.2 \\
17.5 \\
16.7 \\
16.0\end{array}$ & $\begin{array}{l}14.6 \\
14.5 \\
14.5 \\
15.5 \\
16.9 \\
16.8 \\
15.5 \\
14.3\end{array}$ & $\begin{array}{l}14.6 \\
14.1 \\
15.4 \\
18.2 \\
18.6 \\
18.0 \\
16.9 \\
16.0\end{array}$ & $\begin{array}{l}14.0 \\
13.6 \\
15.1 \\
16.4 \\
17.0 \\
16.7 \\
16.2\end{array}$ & $\begin{array}{l}15.1 \\
14.4 \\
15.9 \\
18.0 \\
18.6 \\
18.0 \\
17.1 \\
16.0\end{array}$ & $\begin{array}{l}14.7 \\
14.5 \\
15.4 \\
16.4 \\
16.7 \\
16.6 \\
15.8 \\
14.2\end{array}$ & $\begin{array}{l}17.2 \\
16.7 \\
16.1 \\
16.7 \\
16.9 \\
16.9 \\
16.9 \\
16.5\end{array}$ & $\begin{array}{r}3.4 \\
4.4 \\
6.6 \\
10.3 \\
9.2 \\
5.7 \\
12.7 \\
10.4\end{array}$ & $\begin{array}{r}4.3 \\
6.4 \\
8.7 \\
11.9 \\
11.3 \\
7.0 \\
17.0 \\
15.2\end{array}$ & $\begin{array}{r}4.9 \\
7.5 \\
9.7 \\
13.5 \\
12.8 \\
8.1 \\
18.8 \\
17.0\end{array}$ & $\begin{array}{r}5.5 \\
8.5 \\
11.0 \\
14.9 \\
14.3 \\
9.1 \\
21.4 \\
19.2\end{array}$ \\
\hline $\begin{array}{l}18 \\
18 \\
18 \\
18 \\
18 \\
18 \\
18 \\
18\end{array}$ & $\begin{array}{r}0 \\
3 \\
6 \\
9 \\
12 \\
15 \\
18 \\
21\end{array}$ & $\begin{array}{l}15.6 \\
12.9 \\
13.9 \\
18.0 \\
20.5 \\
21.0 \\
19.6 \\
18.7\end{array}$ & $\begin{array}{l}14.4 \\
12.7 \\
13.5 \\
16.1 \\
17.8 \\
18.7 \\
18.3 \\
17.8\end{array}$ & $\begin{array}{l}15.8 \\
12.8 \\
13.7 \\
17.8 \\
20.2 \\
20.9 \\
19.7 \\
18.8\end{array}$ & $\begin{array}{l}14.4 \\
11.9 \\
12.3 \\
15.7 \\
17.6 \\
18.3 \\
18.3 \\
17.7\end{array}$ & $\begin{array}{l}15.9 \\
12.8 \\
14: 2 \\
17.8 \\
20.3 \\
20.8 \\
19.7 \\
18.9\end{array}$ & $\begin{array}{l}13.8 \\
15.4 \\
17.3 \\
18.2 \\
18.1 \\
17.5\end{array}$ & $\begin{array}{l}15.8 \\
12.2 \\
14.2 \\
17.7 \\
20.0 \\
20.6 \\
19.7 \\
18.9\end{array}$ & $\begin{array}{l}14.1 \\
11.8 \\
13.3 \\
15.5 \\
17.3 \\
18.2 \\
18.2 \\
17.4\end{array}$ & $\begin{array}{l}15.6 \\
14.6 \\
14.3 \\
16.0 \\
16.9 \\
17.2 \\
16.8 \\
16.6\end{array}$ & $\begin{array}{r}0.9 \\
7.3 \\
8.1 \\
12.9 \\
12.5 \\
12.3 \\
8.7 \\
8.0\end{array}$ & $\begin{array}{r}9.4 \\
8.9 \\
10.6 \\
15.0 \\
14.1 \\
14.2 \\
10.5 \\
9.0\end{array}$ & $\begin{array}{l}10.7 \\
10.0 \\
11.9 \\
16.8 \\
15.7 \\
15.9 \\
12.1 \\
10.5\end{array}$ & $\begin{array}{l}12.3 \\
11.1 \\
13.5 \\
18.5 \\
17.4 \\
17.7 \\
13.6 \\
12.1\end{array}$ \\
\hline $\begin{array}{l}19 \\
19 \\
19 \\
19 \\
19 \\
19 \\
19 \\
19\end{array}$ & $\begin{array}{r}0 \\
3 \\
6 \\
9 \\
12 \\
15 \\
18 \\
21\end{array}$ & $\begin{array}{l}17.6 \\
17.4 \\
19.7 \\
23.4 \\
26.9 \\
26.2 \\
22.6 \\
18.5\end{array}$ & $\begin{array}{l}16.2 \\
16.8 \\
18.3 \\
20.6 \\
22.1 \\
21.5 \\
19.0 \\
15.5\end{array}$ & $\begin{array}{l}17.7 \\
17.7 \\
19.9 \\
23.4 \\
26.4 \\
26.0 \\
21.2 \\
18.3\end{array}$ & $\begin{array}{l}16.3 \\
16.8 \\
18.2 \\
20.3 \\
21.6 \\
21.3 \\
19.2 \\
15.7\end{array}$ & $\begin{array}{l}17.8 \\
17.8 \\
19.8 \\
23.2 \\
26.0 \\
25.8 \\
21.5 \\
19.2\end{array}$ & $\begin{array}{l}16.2 \\
16.7 \\
18.1 \\
20.2 \\
21.5 \\
21.0 \\
18.8 \\
15.6\end{array}$ & $\begin{array}{l}18.0 \\
17.8 \\
19.6 \\
23.1 \\
25.9 \\
25.6 \\
21.3 \\
19.4\end{array}$ & $\begin{array}{l}16.3 \\
16.7 \\
18.2 \\
20.2 \\
21.2 \\
21.0 \\
18.1 \\
15.6\end{array}$ & $\begin{array}{l}16.3 \\
16.5 \\
16.9 \\
18.3 \\
18.4 \\
17.7 \\
17.3 \\
16.8\end{array}$ & $\begin{array}{r}7.0 \\
8.2 \\
12.2 \\
8.2 \\
9.3 \\
11.4 \\
8.2 \\
15.6\end{array}$ & $\begin{array}{r}8.0 \\
9.5 \\
13.6 \\
9.0 \\
10.6 \\
13.1 \\
9.8 \\
17.9\end{array}$ & $\begin{array}{r}9.3 \\
11.1 \\
25.3 \\
10.1 \\
11.5 \\
14.6 \\
11.2 \\
20.1\end{array}$ & $\begin{array}{l}11.2 \\
13.1 \\
17.1 \\
10.8 \\
12.5 \\
16.2 \\
13.2 \\
22.7\end{array}$ \\
\hline $\begin{array}{l}20 \\
20 \\
20 \\
20 \\
20 \\
20 \\
20 \\
20\end{array}$ & $\begin{array}{r}0 \\
3 \\
6 \\
9 \\
12 \\
15 \\
18 \\
21\end{array}$ & $\begin{array}{l}17.9 \\
15.7 \\
17.5 \\
23.2 \\
25.7 \\
27.1 \\
25.0 \\
22.9\end{array}$ & $\begin{array}{l}15.3 \\
14.5 \\
16.3 \\
18.8 \\
20.5 \\
21.5 \\
21.4 \\
20.1\end{array}$ & $\begin{array}{l}18.0 \\
16.1 \\
17.7 \\
23.2 \\
25.8 \\
26.9 \\
25.3 \\
23.1\end{array}$ & $\begin{array}{l}15.3 \\
14.7 \\
16.1 \\
18.6 \\
20.4 \\
21.2 \\
21.4 \\
20.1\end{array}$ & $\begin{array}{l}18.0 \\
16.2 \\
17.9 \\
23.1 \\
25.4 \\
26.4 \\
25.2 \\
23.1\end{array}$ & $\begin{array}{l}15.2 \\
14.6 \\
15.0 \\
18.0 \\
20.1 \\
21.1 \\
21.2 \\
19.9\end{array}$ & $\begin{array}{l}18.0 \\
16.7 \\
17.7 \\
22.7 \\
25.3 \\
26.5 \\
25.4 \\
23.4\end{array}$ & $\begin{array}{l}15.2 \\
14.8 \\
16.1 \\
18.2 \\
20.2 \\
21.0 \\
21.3 \\
20.1\end{array}$ & $\begin{array}{l}16.8 \\
16.8 \\
17.4 \\
20.5 \\
22.4 \\
20.8 \\
20.2 \\
20.0\end{array}$ & $\begin{array}{l}9.9 \\
1.5 \\
2.4 \\
2.6 \\
4.1 \\
6.6 \\
6.5 \\
6.6\end{array}$ & $\begin{array}{r}11.8 \\
1.9 \\
2.9 \\
3.2 \\
4.5 \\
7.8 \\
8.0 \\
8.2\end{array}$ & $\begin{array}{r}13.5 \\
2.3 \\
3.3 \\
3.4 \\
4.8 \\
8.6 \\
9.2 \\
9.4\end{array}$ & $\begin{array}{r}15.0 \\
2.9 \\
3.7 \\
3.6 \\
5.3 \\
9.4 \\
10.6 \\
10.9\end{array}$ \\
\hline
\end{tabular}


TABLE 10

Table 10. - Three-hour averages of air and water-surface temperatures and wind directions and speed, April 1950-August 951, Lake Hefner Continued

STATION 2 THREE-HOURLY AVERAGES

MAY, 1951

\begin{tabular}{|c|c|c|c|c|c|c|c|c|c|c|c|c|c|c|c|}
\hline \multirow{3}{*}{ 咅 } & \multirow{3}{*}{ 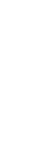 } & \multicolumn{8}{|c|}{ Average air temperature $\left({ }^{\circ} \mathrm{C}\right)$ at indicated height } & \multirow{3}{*}{$\begin{array}{c}\text { Average } \\
\text { water- } \\
\text { surface } \\
\text { tempera- } \\
\text { ture } \\
\left({ }^{\circ} \mathrm{C}\right)\end{array}$} & \multirow{3}{*}{$\begin{array}{c}\text { Average } \\
\text { wind } \\
\text { direction } \\
\text { (coded) }\end{array}$} & \multicolumn{4}{|c|}{$\begin{array}{l}\text { Average wind speed (knots) } \\
\text { at indicated height }\end{array}$} \\
\hline & & \multicolumn{2}{|c|}{$\begin{array}{c}2 \\
\text { meters }\end{array}$} & \multicolumn{2}{|c|}{$\begin{array}{c}4 \\
\text { meters }\end{array}$} & \multicolumn{2}{|c|}{$\begin{array}{c}\mathbf{8} \\
\text { meters }\end{array}$} & \multicolumn{2}{|c|}{$\begin{array}{c}16 \\
\text { meters }\end{array}$} & & & & & & \\
\hline & & $\begin{array}{l}\text { Dry } \\
\text { bulb }\end{array}$ & $\begin{array}{l}\text { Wet } \\
\text { bulb }\end{array}$ & $\begin{array}{l}\text { Dry } \\
\text { butb }\end{array}$ & $\begin{array}{l}\text { Wet } \\
\text { bulb }\end{array}$ & $\begin{array}{l}\text { Dry } \\
\text { bulb }\end{array}$ & $\begin{array}{l}\text { Wet } \\
\text { bulb }\end{array}$ & $\begin{array}{l}\text { Dry } \\
\text { bulb }\end{array}$ & $\begin{array}{l}\text { Wet } \\
\text { bulb }\end{array}$ & & & meters & meters & meters & $\begin{array}{c}16 \\
\text { meters }\end{array}$ \\
\hline $\begin{array}{l}21 \\
21 \\
21 \\
21 \\
21 \\
21 \\
21 \\
21\end{array}$ & $\begin{array}{r}0 \\
3 \\
6 \\
9 \\
12 \\
15 \\
18 \\
21\end{array}$ & $\begin{array}{l}21.0 \\
18.5 \\
22.1 \\
26.5 \\
29.2 \\
27.6 \\
22.6 \\
17.7\end{array}$ & $\begin{array}{l}19.3 \\
18.2 \\
19.8 \\
21.3 \\
22.2 \\
21.2 \\
18.8 \\
16.3\end{array}$ & $\begin{array}{l}21.3 \\
19: 1 \\
22.0 \\
26.5 \\
28.8 \\
27.4 \\
22.1 \\
17.5\end{array}$ & $\begin{array}{l}19.4 \\
18.05 \\
19.7 \\
21.0 \\
22.0 \\
21.00 \\
18.7 \\
15.1\end{array}$ & $\begin{array}{l}21.13 \\
10.03 \\
22.03 \\
26.4 \\
28.7 \\
26.2 \\
21.7 \\
17.5\end{array}$ & $\begin{array}{l}19.2 \\
18.4 \\
19.5 \\
20.8 \\
21.7 \\
20.6 \\
18.4 \\
16.0\end{array}$ & $\begin{array}{l}21.6 \\
20.0 \\
22.5 \\
25: 2 \\
28.3 \\
26.1 \\
21.9 \\
17.5\end{array}$ & $\begin{array}{l}29.4 \\
18.6 \\
19.4 \\
20.6 \\
21.4 \\
20.8 \\
18.2 \\
16.2\end{array}$ & $\begin{array}{l}19.9 \\
19.9 \\
20.3 \\
20.2 \\
20.6 \\
20.2 \\
10.9 \\
10.6\end{array}$ & & $\begin{array}{r}4.0 \\
1.7 \\
5.5 \\
7.0 \\
11.0 \\
14.6 \\
9.2 \\
8.4\end{array}$ & $\begin{array}{r}5.0 \\
2.7 \\
6.2 \\
7.9 \\
12.6 \\
16.3 \\
10.9 \\
10.1\end{array}$ & $\begin{array}{r}6.1 \\
2.9 \\
7.0 \\
8.7 \\
13.8 \\
18.5 \\
12.4 \\
12.1\end{array}$ & $\begin{array}{r}7.4 \\
3.7 \\
10.2 \\
9.4 \\
15.4 \\
20.4 \\
14.5 \\
13.4\end{array}$ \\
\hline $\begin{array}{l}22 \\
22 \\
22 \\
22 \\
22 \\
22 \\
22 \\
22\end{array}$ & $\begin{array}{r}0 \\
3 \\
6 \\
9 \\
12 \\
15 \\
18 \\
21\end{array}$ & $\begin{array}{l}15.7 \\
15.6 \\
18.1 \\
20.4 \\
20.2 \\
18.2 \\
17.5 \\
16.1\end{array}$ & $\begin{array}{l}15.2 \\
15.3 \\
16.1 \\
17.1 \\
17.2 \\
16.1 \\
15.8 \\
15.0\end{array}$ & $\begin{array}{l}15.8 \\
15.8 \\
18.1 \\
20.2 \\
20.1 \\
18.0 \\
17.4 \\
16.2\end{array}$ & $\begin{array}{l}15.1 \\
15.0 \\
15.9 \\
16: 7 \\
16.7 \\
15.6 \\
15.6 \\
14.8\end{array}$ & $\begin{array}{l}15.7 \\
16.0 \\
17.9 \\
20.0 \\
19.0 \\
17.7 \\
17.7 \\
16.0\end{array}$ & $\begin{array}{l}15.0 \\
15.1 \\
15.7 \\
16.3 \\
16.4 \\
15.6 \\
15.3 \\
14.6\end{array}$ & $\begin{array}{l}15.8 \\
15.0 \\
18.0 \\
19.9 \\
19.5 \\
17.7 \\
17.1 \\
16.0\end{array}$ & $\begin{array}{l}15.0 \\
15.1 \\
15.7 \\
16.6 \\
16.2 \\
25.5 \\
15.1 \\
14.7\end{array}$ & $\begin{array}{l}19.6 \\
18.8 \\
18.6 \\
21.3 \\
22.5 \\
21.4 \\
20.3 \\
20.0\end{array}$ & & $\begin{array}{r}4.0 \\
3.6 \\
6.6 \\
13.7 \\
14.3 \\
15.2 \\
9.7 \\
6.7\end{array}$ & $\begin{array}{r}4.8 \\
4.4 \\
7.4 \\
16.0 \\
16.5 \\
18.9 \\
12.8 \\
8.6\end{array}$ & $\begin{array}{r}5.7 \\
6.0 \\
0.3 \\
18.6 \\
22.7 \\
21.0\end{array}$ & $\begin{array}{r}5.5 \\
5.9 \\
9.3 \\
20.3 \\
24.5 \\
21.5 \\
12.5 \\
8.5\end{array}$ \\
\hline $\begin{array}{l}23 \\
23 \\
23 \\
23 \\
23 \\
23 \\
23 \\
23\end{array}$ & $\begin{array}{r}0 \\
3 \\
6 \\
9 \\
12 \\
15 \\
18 \\
21\end{array}$ & $\begin{array}{l}14 \cdot 3 \\
12 \cdot 3 \\
16 \cdot 0 \\
19 \cdot 8 \\
22 \cdot 7 \\
23 \cdot 1 \\
20.0 \\
17.0\end{array}$ & $\begin{array}{l}13.5 \\
11.9 \\
14.4 \\
14.4 \\
15.1 \\
15.2 \\
15.0 \\
14.0\end{array}$ & $\begin{array}{l}14.5 \\
12.8 \\
16.0 \\
19.7 \\
22.2 \\
22.7 \\
20.2 \\
17.5\end{array}$ & $\begin{array}{l}13.5 \\
12.3 \\
14.1 \\
14.4 \\
15.0 \\
14.8 \\
14.9 \\
13.9\end{array}$ & $\begin{array}{l}14.6 \\
13.1 \\
15.8 \\
20.3 \\
22.9 \\
22.5 \\
20.3 \\
18.0\end{array}$ & $\begin{array}{l}13.5 \\
12: 3 \\
13.9 \\
14 \cdot 0 \\
14 \cdot 7 \\
14 \cdot 6 \\
14 \cdot 8 \\
13.8\end{array}$ & $\begin{array}{l}14.7 \\
13.4 \\
15.5 \\
20.2 \\
21.9 \\
22.3 \\
20.7 \\
18.5\end{array}$ & $\begin{array}{l}13.5 \\
12.6 \\
14.0 \\
14.1 \\
14.6 \\
14.3 \\
14.6 \\
13.7\end{array}$ & $\begin{array}{l}19.5 \\
19.6 \\
20.5 \\
24.1 \\
25.7 \\
24.2 \\
20.5 \\
20.0\end{array}$ & & $\begin{array}{l}3.7 \\
1.7 \\
2.3 \\
2.0 \\
2.7 \\
4.8 \\
3.2 \\
2.6\end{array}$ & $\begin{array}{l}4 \cdot 6 \\
2.5 \\
2.8 \\
2.2 \\
3.0 \\
5.3 \\
4 \cdot 2 \\
4.2\end{array}$ & $\begin{array}{l}5.2 \\
3.0 \\
3.3 \\
2.1 \\
3.1 \\
5.8 \\
5.3 \\
5.4\end{array}$ & $\begin{array}{l}5.6 \\
3.4 \\
3.4 \\
2.1 \\
3.2 \\
6.2 \\
6.6 \\
6.9\end{array}$ \\
\hline $\begin{array}{l}24 \\
24 \\
24 \\
24 \\
24 \\
24 \\
24 \\
24\end{array}$ & $\begin{array}{r}0 \\
3 \\
6 \\
9 \\
12 \\
15 \\
18 \\
21\end{array}$ & $\begin{array}{l}16.9 \\
16.9 \\
17.4 \\
18.7 \\
16.5 \\
16.3 \\
16.0 \\
15.6\end{array}$ & $\begin{array}{l}13.2 \\
13.0 \\
13.6 \\
15.0 \\
15.5 \\
15.8 \\
15.5 \\
14.6\end{array}$ & $\begin{array}{l}17.1 \\
17.0 \\
17.4 \\
18.5 \\
16.5 \\
16.3 \\
16.0 \\
15.7\end{array}$ & $\begin{array}{l}13.1 \\
13.0 \\
13.6 \\
14.9 \\
15.2 \\
15.7 \\
15.4 \\
14.5\end{array}$ & $\begin{array}{l}17.2 \\
17.0 \\
17.4 \\
18.4 \\
16.3 \\
16.2 \\
15.9 \\
15.7\end{array}$ & $\begin{array}{l}13.0 \\
13.0 \\
13.5 \\
14.9 \\
15.2 \\
15.5 \\
15.3 \\
14.4\end{array}$ & $\begin{array}{l}17: 5 \\
17: 0 \\
17: 5 \\
13: 6 \\
16: 3 \\
16: 2 \\
16: 0 \\
15.9\end{array}$ & $\begin{array}{l}13.1 \\
13.0 \\
13.5 \\
14.9 \\
15.4 \\
15.6 \\
15.3 \\
14.4\end{array}$ & $\begin{array}{l}19.8 \\
19.4 \\
19.5 \\
19.9 \\
19.9 \\
19.9 \\
19.7 \\
19.1\end{array}$ & & $\begin{array}{r}5.3 \\
6.9 \\
9.3 \\
10.4 \\
7.7 \\
5.5 \\
4.0 \\
3.7\end{array}$ & $\begin{array}{r}5.5 \\
8.5 \\
10.8 \\
11.9 \\
9.0 \\
6.4 \\
4.7 \\
4.7\end{array}$ & $\begin{array}{r}7.7 \\
9.8 \\
17.3 \\
13.5 \\
10.1 \\
7.3 \\
5.5 \\
5.5\end{array}$ & $\begin{array}{r}9.2 \\
11.3 \\
13.9 \\
15.1 \\
11.4 \\
8.1 \\
6.3 \\
6.5\end{array}$ \\
\hline $\begin{array}{l}25 \\
25 \\
25 \\
25 \\
25 \\
25 \\
25 \\
25\end{array}$ & $\begin{array}{r}0 \\
3 \\
6 \\
9 \\
17 \\
15 \\
18 \\
21\end{array}$ & $\begin{array}{l}14.7 \\
13.8 \\
16.6 \\
19.7 \\
21.0 \\
22.0 \\
20.0 \\
17.5\end{array}$ & $\begin{array}{l}14.0 \\
13.5 \\
14.7 \\
16.1 \\
17.0 \\
17.5 \\
17.3 \\
16.4\end{array}$ & $\begin{array}{l}14.8 \\
14.0 \\
16.1 \\
19.2 \\
20.5 \\
21.8 \\
20.1 \\
17.6\end{array}$ & $\begin{array}{l}14.0 \\
13.6 \\
14.5 \\
15.9 \\
15.9 \\
17.5 \\
17.3 \\
16.5\end{array}$ & $\begin{array}{l}14.8 \\
14.0 \\
16.2 \\
18.9 \\
20.4 \\
21.6 \\
20.1 \\
17.7\end{array}$ & $\begin{array}{l}13.9 \\
13.5 \\
14.4 \\
15.6 \\
16.7 \\
17.5 \\
17.1 \\
16.3\end{array}$ & $\begin{array}{l}15.0 \\
14.2 \\
16.2 \\
18.8 \\
20.2 \\
21.8 \\
20.01 \\
17.9\end{array}$ & $\begin{array}{l}14.0 \\
13.7 \\
14.4 \\
15.4 \\
16.8 \\
17.2 \\
17.1 \\
16.5\end{array}$ & $\begin{array}{l}19.0 \\
18.8 \\
19.3 \\
19.8 \\
19.4 \\
20.1 \\
19.0 \\
18.9\end{array}$ & & $\begin{array}{l}1.7 \\
1.5 \\
4.9 \\
7.0 \\
6.7 \\
7.4 \\
5.9 \\
4.2\end{array}$ & $\begin{array}{l}2.4 \\
2.3 \\
6.0 \\
7.9 \\
7.4 \\
8.3 \\
6.8 \\
5.0\end{array}$ & $\begin{array}{l}2.9 \\
2.9 \\
7.2 \\
8.6 \\
8.1 \\
9.1 \\
8.0 \\
6.1\end{array}$ & $\begin{array}{l}3.44 \\
3.7 \\
7.0 \\
9.3 \\
8.7 \\
9.9 \\
9.6 \\
7.5\end{array}$ \\
\hline $\begin{array}{l}26 \\
25 \\
26 \\
26 \\
26 \\
26 \\
26 \\
26\end{array}$ & $\begin{array}{r}0 \\
3 \\
6 \\
9 \\
12 \\
15 \\
18 \\
21\end{array}$ & $\begin{array}{l}17.0 \\
17.3 \\
18.1 \\
22.5 \\
24.5 \\
25.2 \\
21.4 \\
16.9\end{array}$ & $\begin{array}{l}16.2 \\
16.7 \\
15.3 \\
14.0 \\
1409 \\
15.2 \\
15.1 \\
13.2\end{array}$ & $\begin{array}{l}17.2 \\
17.5 \\
18.3 \\
22.4 \\
24.5 \\
24.8 \\
21.8 \\
18.0\end{array}$ & $\begin{array}{l}16.3 \\
16.8 \\
15.3 \\
13.4 \\
15.0 \\
14.9 \\
14.8 \\
13.0\end{array}$ & $\begin{array}{l}37.2 \\
17.4 \\
18.2 \\
22.3 \\
24.1 \\
25.1 \\
21.8 \\
18.4\end{array}$ & $\begin{array}{l}16.2 \\
16.6 \\
15.0 \\
13.1 \\
14.3 \\
14.2 \\
14.2 \\
12.9\end{array}$ & $\begin{array}{l}17.5 \\
17.06 \\
18.1 \\
22.2 \\
23.8 \\
24.5 \\
22.03 \\
19.11\end{array}$ & $\begin{array}{l}16.3 \\
16.7 \\
14.9 \\
12.7 \\
14.2 \\
13.3 \\
13.9 \\
12.9\end{array}$ & $\begin{array}{l}18.8 \\
18.8 \\
18.8 \\
21.9\end{array}$ & & $\begin{array}{l}3.8 \\
3.9 \\
6.8 \\
7.1 \\
4.3 \\
3.5 \\
1.7 \\
1.1\end{array}$ & $\begin{array}{l}4.5 \\
4.8 \\
8.0 \\
8.5 \\
5.1 \\
4.0 \\
2.5 \\
2.3\end{array}$ & $\begin{array}{r}5.3 \\
5.7 \\
9.8 \\
10.1 \\
6.0 \\
4.6 \\
3.5 \\
3.0\end{array}$ & $\begin{array}{r}6.7 \\
6.5 \\
12.1 \\
12.1 \\
7.1 \\
5.1 \\
5.3 \\
4.3\end{array}$ \\
\hline $\begin{array}{l}27 \\
27 \\
27 \\
27 \\
27 \\
27 \\
27 \\
27\end{array}$ & $\begin{array}{r}0 \\
3 \\
6 \\
9 \\
12 \\
15 \\
18 \\
21\end{array}$ & $\begin{array}{l}15.0 \\
14: 7 \\
19.2 \\
17.1 \\
17.6 \\
23.1 \\
21.2 \\
18.5\end{array}$ & $\begin{array}{l}32.0 \\
11.5 \\
33.2 \\
14.5 \\
16.6 \\
18.2 \\
19.1 \\
17.9\end{array}$ & $\begin{array}{l}16.4 \\
15.7 \\
19.2 \\
16.7 \\
17.3 \\
22.6 \\
21.1 \\
18.6\end{array}$ & $\begin{array}{l}12.0 \\
11.5 \\
12.9 \\
13.8 \\
16.2 \\
18.7 \\
18.9 \\
17.9\end{array}$ & $\begin{array}{l}16.9 \\
16.3 \\
19.2 \\
16.7 \\
17.1 \\
22.2 \\
20.9 \\
18.5\end{array}$ & $\begin{array}{l}12.1 \\
11.4 \\
12.9 \\
13.9 \\
16.1 \\
18.4 \\
18.8 \\
17.7\end{array}$ & $\begin{array}{l}17.7 \\
17.2 \\
19.4 \\
16.9 \\
17.2 \\
22.1 \\
20.8 \\
18.5\end{array}$ & $\begin{array}{l}17.2 \\
11.4 \\
17.6 \\
14.0 \\
16.2 \\
18.5 \\
18.8 \\
17.8\end{array}$ & $\begin{array}{l}21.6 \\
21.0 \\
21.1 \\
20.7 \\
20.6 \\
20.8 \\
20.0 \\
20.3\end{array}$ & & $\begin{array}{l}2.3 \\
2.9 \\
5.7 \\
8.9 \\
7.3 \\
4.2 \\
3.2 \\
2.5\end{array}$ & $\begin{array}{r}3.2 \\
4.0 \\
6.9 \\
10.5 \\
8.3 \\
5.0 \\
3.7 \\
2.8\end{array}$ & $\begin{array}{r}4.3 \\
5.3 \\
8.0 \\
12.1 \\
9.3 \\
5.5 \\
4.4 \\
3.5\end{array}$ & $\begin{array}{r}6.0 \\
7.0 \\
9.3 \\
14.0 \\
10.5 \\
5.9 \\
5.2 \\
4.3\end{array}$ \\
\hline $\begin{array}{l}28 \\
28 \\
28 \\
28 \\
28 \\
28 \\
28 \\
28\end{array}$ & $\begin{array}{r}0 \\
3 \\
5 \\
9 \\
12 \\
15 \\
18 \\
21\end{array}$ & $\begin{array}{l}18.3 \\
18.2 \\
19.7 \\
24.3 \\
26.8 \\
27.6 \\
25.5 \\
23.3\end{array}$ & $\begin{array}{l}17.3 \\
16.8 \\
16.4 \\
19.0 \\
21.2 \\
22.4 \\
22.0 \\
21.3\end{array}$ & $\begin{array}{l}18.3 \\
18.3 \\
19.7 \\
24.1 \\
26.2 \\
27.4 \\
25.5 \\
23.4\end{array}$ & $\begin{array}{l}17.2 \\
16.8 \\
16.2 \\
18.5 \\
20.8 \\
22.0 \\
21.9 \\
21.3\end{array}$ & $\begin{array}{l}18.3 \\
18.3 \\
19.6 \\
23.5 \\
25.9 \\
27.0 \\
25.4 \\
23.4\end{array}$ & $\begin{array}{l}17.0 \\
16.0 \\
16.1 \\
18.02 \\
20.6 \\
21.8 \\
21.7 \\
21.1\end{array}$ & $\begin{array}{l}18.3 \\
18.5 \\
19.8 \\
23.4 \\
25.9 \\
26.9 \\
25.5 \\
23.6\end{array}$ & $\begin{array}{l}17.0 \\
16.6 \\
16.2 \\
18.3 \\
20.7 \\
21.9 \\
21.9 \\
21.2\end{array}$ & $\begin{array}{l}19.7 \\
19.1 \\
19.3 \\
20.7 \\
22.6 \\
19.7 \\
19.0 \\
18.8\end{array}$ & & $\begin{array}{l}4.0 \\
5.1 \\
8.8 \\
8.9 \\
7.6 \\
5.8 \\
5.2 \\
6.8\end{array}$ & $\begin{array}{r}4.7 \\
5.0 \\
10.3 \\
10.2 \\
8.8 \\
8.2 \\
6.2 \\
8.2\end{array}$ & $\begin{array}{r}5.5 \\
7.0 \\
11.6 \\
11.3 \\
9.9 \\
9.2 \\
7.3 \\
9.7\end{array}$ & $\begin{array}{r}6.4 \\
8.3 \\
12.9 \\
12.4 \\
10.6 \\
10.0 \\
8.9 \\
11.1\end{array}$ \\
\hline $\begin{array}{l}29 \\
29 \\
29 \\
29 \\
29 \\
29 \\
29 \\
29\end{array}$ & $\begin{array}{r}0 \\
3 \\
6 \\
9 \\
12 \\
15 \\
18 \\
21\end{array}$ & $\begin{array}{l}21.9 \\
21.2 \\
22.6 \\
27.7 \\
30.9 \\
32.3 \\
25.4 \\
23.0\end{array}$ & $\begin{array}{l}20.2 \\
18.5 \\
19.2 \\
21.2 \\
22.7 \\
23.7 \\
23.0 \\
22.2\end{array}$ & $\begin{array}{l}22.2 \\
21.3 \\
22.6 \\
27.8 \\
30.8 \\
32.2 \\
25.8 \\
23.4\end{array}$ & $\begin{array}{l}20.2 \\
18.5 \\
19.1 \\
21.1 \\
22.2 \\
23.3 \\
23.0 \\
22.4\end{array}$ & $\begin{array}{l}22.2 \\
21.3 \\
22.5 \\
27.7 \\
30.6 \\
31.7 \\
26.6 \\
23.5\end{array}$ & $\begin{array}{l}20.0 \\
18.3 \\
19.0 \\
20.8 \\
22.2 \\
23.0 \\
23.1 \\
22.4\end{array}$ & $\begin{array}{l}22.03 \\
21.05 \\
22.8 \\
27.6 \\
30.3 \\
31.5 \\
27.7 \\
23.9\end{array}$ & $\begin{array}{l}20.1 \\
18.5 \\
19.1 \\
20.8 \\
22.3 \\
23.0 \\
23.4 \\
22.6\end{array}$ & $\begin{array}{l}18.9 \\
19.0 \\
19.7 \\
20.7 \\
21.2 \\
21.3 \\
21.6 \\
22.0\end{array}$ & & $\begin{array}{r}7.1 \\
10.9 \\
12.6 \\
9.8 \\
7.0 \\
5.7 \\
3.0 \\
1.5\end{array}$ & $\begin{array}{r}8.6 \\
12.9 \\
14.4 \\
11.0 \\
7.8 \\
6.6 \\
4.4 \\
2.4\end{array}$ & $\begin{array}{r}9.9 \\
14.5 \\
16.4 \\
12.5 \\
8.5 \\
7.4 \\
7.3 \\
3.8\end{array}$ & $\begin{array}{r}11.6 \\
16.8 \\
18.5 \\
13.7 \\
9.2 \\
8.4 \\
9.0 \\
5.3\end{array}$ \\
\hline $\begin{array}{l}30 \\
30 \\
30 \\
30 \\
30 \\
30 \\
30 \\
30\end{array}$ & $\begin{array}{r}0 \\
3 \\
6 \\
9 \\
12 \\
15 \\
18 \\
21\end{array}$ & $\begin{array}{l}21 \cdot 9 \\
21 \cdot 2 \\
21: 8 \\
27: 9 \\
31 \cdot 7 \\
32.5 \\
29.7 \\
26.4\end{array}$ & $\begin{array}{l}21.7 \\
21.00 \\
20.8 \\
23.5 \\
24.7 \\
25.9 \\
24.0 \\
21.4\end{array}$ & $\begin{array}{l}22.0 \\
21.3 \\
21.8 \\
27.9 \\
31.4 \\
32.3 \\
29.8 \\
26.5\end{array}$ & $\begin{array}{l}21.8 \\
21.0 \\
20.8 \\
23.3 \\
24.6 \\
25.6 \\
23.8 \\
21.4\end{array}$ & $\begin{array}{l}22.0 \\
21.1 \\
21.8 \\
27.3 \\
30.8 \\
32.0 \\
29.7 \\
26.4\end{array}$ & $\begin{array}{l}21.7 \\
20.8 \\
20.7 \\
23.2 \\
24 \cdot 2 \\
25 \cdot 3 \\
24 \cdot 4 \\
21.2\end{array}$ & $\begin{array}{l}22.3 \\
21.1 \\
21.8 \\
27.5 \\
30.8 \\
32.0 \\
30.1 \\
26.7\end{array}$ & $\begin{array}{l}21.9 \\
20.8 \\
20.7 \\
23.1 \\
24.3 \\
25.3 \\
24.3 \\
21.1\end{array}$ & $\begin{array}{l}22.6 \\
22.4 \\
22.2 \\
23.8 \\
24.4 \\
21.0 \\
19.8 \\
20.1\end{array}$ & & $\begin{array}{l}1.22 \\
3.9 \\
2.9 \\
3.7 \\
4.9 \\
5.4 \\
5.3 \\
9.0\end{array}$ & $\begin{array}{r}1.6 \\
4.8 \\
3.6 \\
4.1 \\
5.4 \\
6.5 \\
6.6 \\
10.9\end{array}$ & $\begin{array}{r}2.0 \\
2.8 \\
4.3 \\
4.9 \\
6.1 \\
7.3 \\
8.0 \\
12.6\end{array}$ & $\begin{array}{r}2.6 \\
5.7 \\
5.3 \\
5.2 \\
6.6 \\
8.2 \\
9.9 \\
14.7\end{array}$ \\
\hline $\begin{array}{l}31 \\
31 \\
31 \\
31 \\
31 \\
31 \\
31 \\
31\end{array}$ & $\begin{array}{r}0 \\
3 \\
5 \\
9 \\
12 \\
15 \\
18 \\
21\end{array}$ & $\begin{array}{l}29 \cdot 2 \\
30.8 \\
31.2 \\
28.4 \\
26.2\end{array}$ & $\begin{array}{l}21.4 \\
21.5 \\
21.4 \\
21.2 \\
21.3\end{array}$ & $\begin{array}{l}29.0 \\
30.5 \\
31.1 \\
28.5 \\
26.4\end{array}$ & $\begin{array}{l}21: 0 \\
21: 2 \\
20.7 \\
21 \cdot 0 \\
21.0\end{array}$ & $\begin{array}{l}27.4 \\
30.3 \\
30.8 \\
28.5 \\
25.4\end{array}$ & $\begin{array}{l}20.8 \\
21 \cdot 0 \\
20.7 \\
21 \cdot 1 \\
21 \cdot 2\end{array}$ & $\begin{array}{l}28.4 \\
30.1 \\
30.9 \\
28.7 \\
26.6\end{array}$ & $\begin{array}{l}20.8 \\
20.9 \\
20.6 \\
21.0 \\
21.2\end{array}$ & $\begin{array}{l}22.4 \\
22.8 \\
22.1 \\
21.0 \\
21.2\end{array}$ & & $\begin{array}{r}9.9 \\
9.9 \\
10.9 \\
13.2 \\
33.2 \\
13.3 \\
8.2 \\
8.0\end{array}$ & $\begin{array}{r}11.6 \\
11.6 \\
12.4 \\
15.3 \\
15.1 \\
15.6 \\
10.2 \\
9.7\end{array}$ & $\begin{array}{l}13.3 \\
13.3 \\
14.2 \\
17.4 \\
17.0 \\
17.6 \\
11.7 \\
11.2\end{array}$ & $\begin{array}{l}15.5 \\
15.3 \\
15.8 \\
19.1 \\
18.7 \\
19.8 \\
13.5 \\
12.7\end{array}$ \\
\hline
\end{tabular}


TABLE 10

Table 10. - Three-hour averages of air and water-surface temperatures and wind directions and speed, April 1950-August 1951, Lake Hefner-Continued

\begin{tabular}{|c|c|c|c|c|c|c|c|c|c|c|c|c|c|c|c|}
\hline \multicolumn{2}{|c|}{ STATION } & \multicolumn{12}{|c|}{ THREE-HOURLY AVERAGES } & \multirow{3}{*}{\multicolumn{2}{|c|}{$\begin{array}{l}\text { JUNE, } 1951 \\
\begin{array}{l}\text { speed (knots) } \\
\text { ed height }\end{array}\end{array}$}} \\
\hline \multirow{4}{*}{ 咅 } & \multirow{4}{*}{ 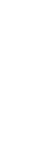 } & \multicolumn{8}{|c|}{ Average air temperature $\left({ }^{\circ} \mathrm{C}\right)$ at indicated height } & \multirow{4}{*}{$\begin{array}{l}\text { Average } \\
\text { water- } \\
\text { surface } \\
\text { tempera- } \\
\text { ture } \\
\text { ('C) }\end{array}$} & \multirow{4}{*}{$\begin{array}{c}\text { Average } \\
\text { wind } \\
\text { direction } \\
\text { (codeḍ) }\end{array}$} & \multirow{2}{*}{\multicolumn{2}{|c|}{$\begin{array}{l}\text { Average wind speed (knots) } \\
\text { at indicated height }\end{array}$}} & & \\
\hline & & \multirow{2}{*}{\multicolumn{2}{|c|}{$\stackrel{2}{\text { meters }}$}} & \multirow{2}{*}{\multicolumn{2}{|c|}{$\begin{array}{c}4 \\
\text { meters }\end{array}$}} & \multirow{2}{*}{\multicolumn{2}{|c|}{$\begin{array}{c}8 \\
\text { meters }\end{array}$}} & \multirow{2}{*}{\multicolumn{2}{|c|}{$\begin{array}{c}16 \\
\text { meters }\end{array}$}} & & & & & & \\
\hline & & & & & & & & & & & & 2 & 4 & 8 & 16 \\
\hline & & $\begin{array}{l}\text { Dry } \\
\text { bulb }\end{array}$ & $\begin{array}{l}\text { Wet } \\
\text { bulb }\end{array}$ & $\begin{array}{l}\text { Dry } \\
\text { bulb }\end{array}$ & $\begin{array}{l}\text { Wet } \\
\text { bulb }\end{array}$ & $\begin{array}{l}\text { Dry } \\
\text { bulb }\end{array}$ & $\begin{array}{l}\text { Wet } \\
\text { bulb }\end{array}$ & $\begin{array}{l}\text { Dry } \\
\text { bulb }\end{array}$ & $\begin{array}{l}\text { Wet } \\
\text { bulb }\end{array}$ & & & meters & meters & meters & meters \\
\hline $\begin{array}{l}1 \\
1 \\
1 \\
1 \\
1 \\
1 \\
1 \\
1\end{array}$ & $\begin{array}{r}0 \\
3 \\
6 \\
9 \\
12 \\
15 \\
18 \\
21\end{array}$ & $\begin{array}{l}24.6 \\
23.0 \\
23.8 \\
26.6 \\
28.9 \\
24.8 \\
23.6 \\
24.6\end{array}$ & $\begin{array}{l}20.8 \\
20.2 \\
20.0 \\
21.5 \\
22.8 \\
20.9 \\
21.8 \\
20.9\end{array}$ & $\begin{array}{l}24.8 \\
23.0 \\
23.8 \\
26.6 \\
28.7 \\
24.7 \\
24.0 \\
24.8\end{array}$ & $\begin{array}{l}20.7 \\
20.0 \\
19.9 \\
21.1 \\
22.4 \\
20.8 \\
21.8 \\
20.9\end{array}$ & $\begin{array}{l}24.7 \\
23.0 \\
23.8 \\
26.4 \\
28.5 \\
25.1 \\
24.2 \\
24.9\end{array}$ & $\begin{array}{l}20.7 \\
20.0 \\
19.9 \\
21.2 \\
22.1 \\
20.4 \\
21.7 \\
20.8\end{array}$ & $\begin{array}{l}24.8 \\
23.1 \\
23.8 \\
26.3 \\
28.3 \\
24.0 \\
24.4 \\
25.1\end{array}$ & $\begin{array}{l}20.6 \\
20.0 \\
19.8 \\
21.0 \\
22.9 \\
20.4 \\
21.7 \\
20.7\end{array}$ & $\begin{array}{l}21.0 \\
20.9 \\
21.7 \\
23.2 \\
23.4 \\
21.6 \\
21.2 \\
20.7\end{array}$ & & $\begin{array}{r}11.1 \\
10.8 \\
12.8 \\
15.5 \\
15.0 \\
12.4 \\
6.5 \\
11.1\end{array}$ & $\begin{array}{r}13.0 \\
12.6 \\
14.9 \\
17.8 \\
17.4 \\
14.3 \\
8.0 \\
13.0\end{array}$ & $\begin{array}{r}14.7 \\
14.3 \\
16.7 \\
20.2 \\
19.3 \\
16.3 \\
9.4 \\
14.9\end{array}$ & $\begin{array}{l}16.7 \\
16.0 \\
18.7 \\
22.4 \\
21.5 \\
18.5 \\
10.9 \\
16.9\end{array}$ \\
\hline $\begin{array}{l}2 \\
2 \\
2 \\
2 \\
2 \\
2 \\
2 \\
2\end{array}$ & $\begin{array}{r}0 \\
3 \\
6 \\
9 \\
12 \\
15 \\
18 \\
21\end{array}$ & $\begin{array}{l}23.9 \\
22.6 \\
22.8 \\
17.3 \\
16.0 \\
16.0 \\
16.0 \\
15.4\end{array}$ & $\begin{array}{l}19.6 \\
19.3 \\
19.9 \\
15.4 \\
13.8 \\
13.9 \\
13.9 \\
13.6\end{array}$ & $\begin{array}{l}24.0 \\
22.8 \\
22.9 \\
17.2 \\
15: 5 \\
15: 7 \\
15.9 \\
15.3\end{array}$ & $\begin{array}{l}19.6 \\
19.3 \\
19.3 \\
15.0 \\
13.5 \\
13.6 \\
13.7 \\
13.5\end{array}$ & $\begin{array}{l}24.1 \\
22.8 \\
22.0 \\
17.0 \\
15.3 \\
15.4 \\
15.8 \\
15.2\end{array}$ & $\begin{array}{l}19.6 \\
19.3 \\
19.1 \\
14.9 \\
13.4 \\
13.2 \\
13.5 \\
13.2\end{array}$ & $\begin{array}{l}24 \cdot 3 \\
22 \cdot 9 \\
21.9 \\
16.8 \\
1409 \\
15.3 \\
15.6 \\
15.0\end{array}$ & $\begin{array}{l}19.5 \\
19.2 \\
19.0 \\
14.4 \\
12.8 \\
13.0 \\
13.4 \\
13.1\end{array}$ & $\begin{array}{l}21.0 \\
21.1 \\
21.3 \\
20.8 \\
21.2 \\
20.7 \\
20.0 \\
29.5\end{array}$ & & $\begin{array}{r}11.3 \\
9.0 \\
8.1 \\
7.4 \\
9.5 \\
8.7 \\
7.3 \\
6.7\end{array}$ & $\begin{array}{r}13.3 \\
10.5 \\
9.4 \\
9.0 \\
13.4 \\
13.2 \\
6.8 \\
7.8\end{array}$ & $\begin{array}{r}15.1 \\
12.0 \\
11.0 \\
12.5 \\
14.2 \\
12.2 \\
8.7 \\
8.1\end{array}$ & $\begin{array}{r}17.0 \\
13.8 \\
12.3 \\
13.2 \\
15.5 \\
12.5 \\
10.1 \\
9.2\end{array}$ \\
\hline $\begin{array}{l}3 \\
3 \\
3 \\
3 \\
3 \\
3 \\
3 \\
3\end{array}$ & $\begin{array}{r}0 \\
3 \\
6 \\
9 \\
12 \\
15 \\
18 \\
21\end{array}$ & $\begin{array}{l}14.6 \\
13.8 \\
13.9 \\
14.6 \\
16.3 \\
17.2 \\
15.5 \\
13.3\end{array}$ & $\begin{array}{l}13.2 \\
12.9 \\
12.4 \\
11.5 \\
12.7 \\
13.2 \\
12.7 \\
11.9\end{array}$ & $\begin{array}{l}14.6 \\
33.6 \\
13.7 \\
14.4 \\
15.9 \\
17.0 \\
15.4 \\
13.4\end{array}$ & $\begin{array}{l}13.2 \\
12.7 \\
12.1 \\
11.3 \\
12.3 \\
12.6 \\
12.6 \\
11.9\end{array}$ & $\begin{array}{l}14.4 \\
13.4 \\
13.5 \\
14.3 \\
15.8 \\
16.7 \\
15.2 \\
13.4\end{array}$ & $\begin{array}{l}13.1 \\
12.6 \\
11.8 \\
10.9 \\
12.0 \\
12.5 \\
12.4 \\
11.7\end{array}$ & $\begin{array}{l}14.2 \\
13.3 \\
13.2 \\
14.0 \\
15.2 \\
16.4 \\
15.0 \\
13.2\end{array}$ & $\begin{array}{l}12.8 \\
12.3 \\
11.2 \\
10.5 \\
11.8 \\
12.2 \\
12.4 \\
11.7\end{array}$ & $\begin{array}{l}19.2 \\
19.0 \\
18.7 \\
20.0 \\
21.6 \\
21.8 \\
20.6 \\
19.7\end{array}$ & & $\begin{array}{r}8.8 \\
9.1 \\
11.7 \\
10.5 \\
8.2 \\
7.0 \\
5.5 \\
3.0\end{array}$ & $\begin{array}{l}11.2 \\
12.3 \\
14.4 \\
12.8 \\
10.1 \\
8.4 \\
6.9 \\
3.8\end{array}$ & $\begin{array}{r}10.6 \\
10.0 \\
15.2 \\
13.5 \\
9.2 \\
8.1 \\
7.8 \\
4.4\end{array}$ & $\begin{array}{r}11.5 \\
9.3 \\
15.4 \\
14.0 \\
11.2 \\
10.0 \\
8.8 \\
5.1\end{array}$ \\
\hline $\begin{array}{l}4 \\
4 \\
4 \\
4 \\
4 \\
4 \\
4 \\
4\end{array}$ & $\begin{array}{r}0 \\
3 \\
6 \\
9 \\
12 \\
15 \\
18 \\
21\end{array}$ & $\begin{array}{l}13.0 \\
12.2 \\
12.1 \\
16.4 \\
19.2 \\
21.7 \\
19.6 \\
15.7\end{array}$ & $\begin{array}{l}11.7 \\
11.5 \\
10.2 \\
12.6 \\
13.5 \\
15.0 \\
15.1 \\
14.4\end{array}$ & $\begin{array}{l}13.1 \\
12.3 \\
12.1 \\
15.9 \\
18.6 \\
21.3 \\
19.6 \\
16.1\end{array}$ & $\begin{array}{l}11.8 \\
11.4 \\
10.2 \\
12.1 \\
13.4 \\
14.8 \\
15.0 \\
14.6\end{array}$ & $\begin{array}{l}13.0 \\
12.1 \\
12.0 \\
16.2 \\
19.1 \\
21.0 \\
19.4 \\
16.4\end{array}$ & $\begin{array}{l}11.7 \\
11.2 \\
10.1 \\
12.0 \\
13.4 \\
14.3 \\
14.8 \\
14.6\end{array}$ & $\begin{array}{l}12.9 \\
11.9 \\
11.8 \\
15.4 \\
18.3 \\
21.0 \\
19.4 \\
16.7\end{array}$ & $\begin{array}{r}11.5 \\
11.0 \\
9.9 \\
11.6 \\
13.2 \\
14.5 \\
14.7 \\
14.7\end{array}$ & $\begin{array}{l}18.6 \\
18.4 \\
18.6 \\
20.8 \\
23.3 \\
23.9 \\
23.0 \\
21.6\end{array}$ & & $\begin{array}{l}4.5 \\
7.1 \\
5.8 \\
4.6 \\
3.8 \\
2.8 \\
2.1 \\
2.2\end{array}$ & $\begin{array}{l}5.3 \\
8.3 \\
6.8 \\
5.5 \\
4.6 \\
3.4 \\
3.0 \\
3.0\end{array}$ & $\begin{array}{l}5.4 \\
9.3 \\
8.5 \\
6.0 \\
4.9 \\
3.9 \\
3.6 \\
3.9\end{array}$ & $\begin{array}{r}6.2 \\
10.6 \\
10.8 \\
6.4 \\
5.6 \\
4.2 \\
4.5 \\
5.3\end{array}$ \\
\hline $\begin{array}{l}5 \\
5 \\
5 \\
5 \\
5 \\
5 \\
5 \\
5 \\
5\end{array}$ & $\begin{array}{r}0 \\
3 \\
6 \\
9 \\
12 \\
15 \\
18 \\
21\end{array}$ & $\begin{array}{l}14.5 \\
14.7 \\
16.5 \\
20.2 \\
23.4 \\
23.8 \\
21.2 \\
20.2\end{array}$ & $\begin{array}{l}14.0 \\
14.4 \\
15.7 \\
17.1 \\
18.3 \\
18.9 \\
18.4 \\
18.5\end{array}$ & $\begin{array}{l}15.0 \\
14.9 \\
16.5 \\
20.1 \\
22.5 \\
23.5 \\
21.2 \\
20.3\end{array}$ & $\begin{array}{l}14.1 \\
14.4 \\
15.7 \\
16.8 \\
17.7 \\
18.5 \\
18.3 \\
18.5\end{array}$ & $\begin{array}{l}15.3 \\
14.9 \\
16.5 \\
20.1 \\
22.3 \\
23.1 \\
21.2 \\
20.3\end{array}$ & $\begin{array}{l}14.2 \\
14.4 \\
15.7 \\
16.5 \\
17.8 \\
18.3 \\
18.3 \\
18.4\end{array}$ & $\begin{array}{l}15.8 \\
15.1 \\
16.6 \\
19.5 \\
22.1 \\
22.9 \\
21.2 \\
20.3\end{array}$ & $\begin{array}{l}14.5 \\
14.4 \\
15.6 \\
16.5 \\
17.5 \\
13.1 \\
18.3 \\
18.4\end{array}$ & $\begin{array}{l}21.0 \\
20.8 \\
20.3 \\
19.8 \\
21.0 \\
20.3 \\
19.8 \\
19.7\end{array}$ & & $\begin{array}{l}1.6 \\
2.3 \\
2.7 \\
6.0 \\
7.3 \\
7.2 \\
4.9 \\
5.1\end{array}$ & $\begin{array}{l}2.3 \\
2.9 \\
3.3 \\
7.0 \\
8.6 \\
8.6 \\
6.0 \\
6.3\end{array}$ & $\begin{array}{l}3.0 \\
3.5 \\
3.6 \\
8.0 \\
9.4 \\
9.5 \\
7.3 \\
7.4\end{array}$ & $\begin{array}{r}3.8 \\
4.4 \\
4.1 \\
8.7 \\
10.1 \\
10.6 \\
8.5 \\
8.7\end{array}$ \\
\hline $\begin{array}{l}6 \\
6 \\
6 \\
6 \\
6 \\
6 \\
6 \\
6\end{array}$ & $\begin{array}{r}0 \\
3 \\
6 \\
9 \\
12 \\
15 \\
18 \\
21\end{array}$ & $\begin{array}{l}19.2 \\
18.9 \\
19.9 \\
23.4 \\
22.8 \\
24.7 \\
23.5 \\
22.6\end{array}$ & $\begin{array}{l}18.7 \\
18.3 \\
18.2 \\
20.4 \\
19.5 \\
21.0 \\
20.5 \\
19.9\end{array}$ & $\begin{array}{l}19.3 \\
19.0 \\
19.8 \\
23.3 \\
22.0 \\
24.6 \\
23.8 \\
22.7\end{array}$ & $\begin{array}{l}18.6 \\
18.2 \\
18.1 \\
20.4 \\
19.1 \\
21.0 \\
20.5 \\
19.9\end{array}$ & $\begin{array}{l}19.2 \\
19.0 \\
19.5 \\
23.1 \\
23.7 \\
24.4 \\
23.6 \\
27.7\end{array}$ & $\begin{array}{l}18.6 \\
18.2 \\
17.9 \\
20.1 \\
10.2 \\
20.9 \\
20.5 \\
19.9\end{array}$ & $\begin{array}{l}19.4 \\
19.0 \\
19.4 \\
23.0 \\
21.6 \\
24.6 \\
23.7 \\
22.9\end{array}$ & $\begin{array}{l}18.6 \\
18.2 \\
17.8 \\
20.2 \\
19.2 \\
20.7 \\
20.5 \\
19.9\end{array}$ & $\begin{array}{l}20.6 \\
20.3 \\
20.2 \\
20.9 \\
21.1 \\
21.0 \\
20.5 \\
20.4\end{array}$ & & $\begin{array}{r}11.1 \\
11.5 \\
9.0 \\
11.5 \\
8.2 \\
7.3 \\
10.7 \\
10.6\end{array}$ & $\begin{array}{r}13.3 \\
13.6 \\
10.4 \\
13.1 \\
11.0 \\
9.7 \\
13.3 \\
12.4\end{array}$ & $\begin{array}{l}14.9 \\
15.2 \\
11.7 \\
14.8 \\
11.8 \\
10.9 \\
14.6 \\
14.0\end{array}$ & $\begin{array}{l}16.9 \\
17.0 \\
13.0 \\
16.3 \\
13.1 \\
12.1 \\
16.8 \\
15.8\end{array}$ \\
\hline $\begin{array}{l}7 \\
7 \\
7 \\
7 \\
7 \\
7 \\
7 \\
7\end{array}$ & $\begin{array}{r}0 \\
3 \\
6 \\
9 \\
12 \\
15 \\
18 \\
21\end{array}$ & $\begin{array}{l}19 \cdot 7 \\
18.1 \\
18.5 \\
21.6 \\
27.8\end{array}$ & $\begin{array}{l}16.2 \\
15.5 \\
16.5 \\
19.3 \\
23.1\end{array}$ & $\begin{array}{l}19.9 \\
19.1 \\
18.4 \\
21.4 \\
27.6\end{array}$ & $\begin{array}{l}16.0 \\
15.4 \\
16.6 \\
19.4 \\
22.8\end{array}$ & $\begin{array}{l}20.0 \\
18.4 \\
18.5 \\
21.6 \\
27.2\end{array}$ & $\begin{array}{l}16.0 \\
15.4 \\
16.6 \\
19.3 \\
22.7\end{array}$ & $\begin{array}{l}20.3 \\
18.5 \\
18.3 \\
21.9 \\
27.4\end{array}$ & $\begin{array}{l}15.9 \\
15.4 \\
16.4 \\
19.4 \\
22.8\end{array}$ & $\begin{array}{l}20.2 \\
20.1 \\
20.0 \\
20.1 \\
19.4\end{array}$ & & $\begin{array}{l}9.6 \\
8.0 \\
4.6 \\
6.5 \\
9.9 \\
9.3 \\
7.7 \\
4.5\end{array}$ & $\begin{array}{r}11.4 \\
9.5 \\
6.0 \\
7.8 \\
11.2 \\
10.8 \\
9.4 \\
7.2\end{array}$ & $\begin{array}{r}13.4 \\
11.1 \\
6.5 \\
8.8 \\
12.5 \\
12.1 \\
10.9 \\
8.2\end{array}$ & $\begin{array}{r}15.4 \\
13.0 \\
7.6 \\
9.5 \\
13.8 \\
13.3 \\
12.5 \\
9.7\end{array}$ \\
\hline $\begin{array}{l}8 \\
8 \\
8 \\
8 \\
8 \\
8 \\
8 \\
8\end{array}$ & $\begin{array}{r}0 \\
3 \\
6 \\
9 \\
12 \\
15 \\
18 \\
21\end{array}$ & $\begin{array}{l}28.3 \\
30.8 \\
30.4 \\
27.3 \\
22.1\end{array}$ & $\begin{array}{l}23.4 \\
24.5 \\
24.8 \\
23.5 \\
17.7\end{array}$ & $\begin{array}{l}28.1 \\
30.5 \\
30.3 \\
27.3 \\
21.0\end{array}$ & $\begin{array}{l}23.3 \\
24.0 \\
24.4 \\
23.5 \\
17.8\end{array}$ & $\begin{array}{l}28.0 \\
30.4 \\
29.8 \\
27.5 \\
21.6\end{array}$ & $\begin{array}{l}22.9 \\
2.4 .1 \\
24.1 \\
23.2 \\
17.4\end{array}$ & $\begin{array}{l}27.6 \\
30.1 \\
29.6 \\
27.5 \\
22.4\end{array}$ & $\begin{array}{l}23.0 \\
24.0 \\
24.1 \\
23.4 \\
17.1\end{array}$ & $\begin{array}{l}20.9 \\
21.4 \\
21.1 \\
20.7 \\
21.2\end{array}$ & & $\begin{array}{r}6.7 \\
8.1 \\
13.3 \\
15.4 \\
14.7 \\
13.6 \\
9.1 \\
9.2\end{array}$ & $\begin{array}{r}8.3 \\
9.7 \\
15.4 \\
17.4 \\
16.5 \\
15.5 \\
10.5 \\
11.0\end{array}$ & $\begin{array}{r}9.7 \\
11.1 \\
17.4 \\
19.7 \\
18.4 \\
17.6 \\
12.1 \\
12.8\end{array}$ & $\begin{array}{l}11.4 \\
12.9 \\
19.5 \\
22.1 \\
20.6 \\
19.6 \\
11.9 \\
10.4\end{array}$ \\
\hline $\begin{array}{l}9 \\
9 \\
9 \\
9 \\
9 \\
9 \\
9 \\
9\end{array}$ & $\begin{array}{r}0 \\
3 \\
6 \\
9 \\
12 \\
15 \\
18 \\
21\end{array}$ & $\begin{array}{l}18.8 \\
18.0 \\
19.0 \\
23.6 \\
26.6 \\
26.9 \\
24.4 \\
21.9\end{array}$ & $\begin{array}{l}17.4 \\
16.7 \\
17.2 \\
19.6 \\
20.7 \\
20.7 \\
20.0 \\
19.1\end{array}$ & $\begin{array}{l}19.3 \\
18.0 \\
19.1 \\
23.2 \\
26.1 \\
26.7 \\
24.4 \\
21.9\end{array}$ & $\begin{array}{l}17.4 \\
16.6 \\
17.1 \\
19.0 \\
20.2 \\
20.5 \\
20.0 \\
19.1\end{array}$ & $\begin{array}{l}19.7 \\
17.9 \\
19.3 \\
23.0 \\
26.0 \\
25.8 \\
24.4 \\
21.0\end{array}$ & $\begin{array}{l}17.2 \\
16.5 \\
17.0 \\
18.8 \\
20.2 \\
19.9 \\
19.7 \\
19.0\end{array}$ & $\begin{array}{l}20.3 \\
17.9 \\
18: 8 \\
22.8 \\
25.6 \\
25.5 \\
24.4 \\
21.2\end{array}$ & $\begin{array}{l}17.2 \\
16.4 \\
16.9 \\
18.6 \\
19.6 \\
20.1 \\
19.6 \\
18.9\end{array}$ & $\begin{array}{l}21.0 \\
21.1 \\
20.7 \\
22.7 \\
23.8 \\
25.9 \\
25.7 \\
24.4\end{array}$ & & $\begin{array}{l}2.8 \\
4.2 \\
4.9 \\
4.4 \\
4.6 \\
6.6 \\
3.6 \\
3.4\end{array}$ & $\begin{array}{l}3.6 \\
5.0 \\
6.0 \\
5.4 \\
5.3 \\
8.2 \\
5.1 \\
4.3\end{array}$ & $\begin{array}{l}4.5 \\
5.9 \\
6.4 \\
5.2 \\
6.3 \\
9.3 \\
6.0 \\
5.1\end{array}$ & $\begin{array}{r}5.5 \\
8.0 \\
6.9 \\
7.2 \\
7.6 \\
11.0 \\
7.1 \\
6.6\end{array}$ \\
\hline $\begin{array}{l}10 \\
10 \\
10 \\
10 \\
10 \\
10 \\
10 \\
10\end{array}$ & $\begin{array}{r}0 \\
3 \\
6 \\
9 \\
12 \\
15 \\
18 \\
21\end{array}$ & $\begin{array}{l}19.4 \\
18.6 \\
18.6 \\
19.4 \\
24.6 \\
24.7 \\
22.6 \\
19.4\end{array}$ & $\begin{array}{l}18.3 \\
38.0 \\
17.8 \\
17.2 \\
19.8 \\
20.2 \\
20.1 \\
18.3\end{array}$ & $\begin{array}{l}19.5 \\
18.7 \\
18.4 \\
19.3 \\
24.3 \\
24.2 \\
22.5 \\
19.6\end{array}$ & $\begin{array}{l}18.3 \\
17.9 \\
17.6 \\
17.0 \\
19.5 \\
20.0 \\
20.1 \\
18.3\end{array}$ & $\begin{array}{l}19.5 \\
18.7 \\
18.3 \\
19.4 \\
24.3 \\
23.9 \\
22.5 \\
19.6\end{array}$ & $\begin{array}{l}18.2 \\
17.9 \\
17.7 \\
16.7 \\
19.4 \\
19.8 \\
20.0 \\
18.1\end{array}$ & $\begin{array}{l}19.5 \\
18.7 \\
18.3 \\
19.4 \\
23.8 \\
23.8 \\
22.6 \\
19.7\end{array}$ & $\begin{array}{l}18.2 \\
17.8 \\
17.6 \\
16.8 \\
18.9 \\
19.6 \\
19.9 \\
18.1\end{array}$ & $\begin{array}{l}24.0 \\
23.3 \\
22.8 \\
21.8 \\
23.5 \\
25.8 \\
24.9 \\
23.1\end{array}$ & & $\begin{array}{r}2.4 \\
4.2 \\
9.9 \\
11.0 \\
4.3 \\
6.6 \\
2.6 \\
4.0\end{array}$ & $\begin{array}{r}2.7 \\
4.6 \\
11.2 \\
12.4 \\
4.9 \\
7.5 \\
3.1 \\
4.9\end{array}$ & $\begin{array}{r}3.3 \\
5.4 \\
12.8 \\
10.9 \\
5.8 \\
8.4 \\
3.7 \\
5.9\end{array}$ & $\begin{array}{r}4.0 \\
6.0 \\
12.5 \\
15.8 \\
5.9 \\
9.1 \\
4.6 \\
7.7\end{array}$ \\
\hline
\end{tabular}


TABLE 10

Table 10. - Three-hour averages of air and water-surface temperatures and wind directions and speed, April 1950-August 1951, Lake Hefner-Continued

STATION 2

THREE-HOURLY AVERAGES

JUNE, 1951

\begin{tabular}{|c|c|c|c|c|c|c|c|c|c|c|c|c|c|c|c|}
\hline \multirow{3}{*}{ 秀 } & \multirow{3}{*}{ 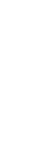 } & \multicolumn{8}{|c|}{ Average air temperature $\left({ }^{\circ} \mathrm{C}\right)$ at indicated height } & \multirow{3}{*}{$\begin{array}{l}\text { Average } \\
\text { water- } \\
\text { surface } \\
\text { tempera- } \\
\text { ture } \\
\text { ('C) }\end{array}$} & \multirow{3}{*}{$\begin{array}{l}\text { Average } \\
\text { wind } \\
\text { direction } \\
\text { (coded) }\end{array}$} & \multicolumn{4}{|c|}{$\begin{array}{l}\text { Average wind speed (knots) } \\
\text { at indicated height }\end{array}$} \\
\hline & & \multicolumn{2}{|c|}{$\begin{array}{c}2 \\
\text { meters }\end{array}$} & \multicolumn{2}{|c|}{$\begin{array}{c}4 \\
\text { meters }\end{array}$} & \multicolumn{2}{|c|}{$\begin{array}{c}8 \\
\text { meters }\end{array}$} & \multicolumn{2}{|c|}{$\begin{array}{c}16 \\
\text { meters }\end{array}$} & & & & & & \\
\hline & & $\begin{array}{l}\text { Dry } \\
\text { bulb }\end{array}$ & $\begin{array}{l}\text { Wet } \\
\text { bulb }\end{array}$ & $\begin{array}{l}\text { Dry } \\
\text { bulb }\end{array}$ & $\begin{array}{l}\text { Wet } \\
\text { butb }\end{array}$ & $\begin{array}{l}\text { Dry } \\
\text { bulb }\end{array}$ & $\begin{array}{l}\text { Wet } \\
\text { bulb }\end{array}$ & $\begin{array}{l}\text { Dry } \\
\text { bulb }\end{array}$ & $\begin{array}{l}\text { Wet } \\
\text { bulb }\end{array}$ & & & meters & $\begin{array}{c}4 \\
\text { meters }\end{array}$ & meters & meters \\
\hline $\begin{array}{l}11 \\
11 \\
11 \\
11 \\
11 \\
11 \\
11 \\
11\end{array}$ & $\begin{array}{r}0 \\
3 \\
6 \\
9 \\
12 \\
15 \\
18 \\
21\end{array}$ & $\begin{array}{l}18.6 \\
18.5 \\
18.1 \\
19.3 \\
21.8 \\
22.7 \\
21.1 \\
19.7\end{array}$ & $\begin{array}{l}18.1 \\
17: 5 \\
17.9 \\
18.1 \\
18.6 \\
19.4 \\
19: 2 \\
18.8\end{array}$ & $\begin{array}{l}18.8 \\
18.5 \\
18.1 \\
19.1 \\
21.4 \\
22.6 \\
21.1 \\
19.7\end{array}$ & $\begin{array}{l}18.0 \\
17.4 \\
17.8 \\
17.8 \\
18.4 \\
19.1 \\
19.1 \\
18.8\end{array}$ & $\begin{array}{l}19.0 \\
18: 5 \\
18: 0 \\
10.0 \\
21.2 \\
22: 2 \\
21: 0 \\
19.7\end{array}$ & $\begin{array}{l}18.0 \\
17.3 \\
17.7 \\
17.6 \\
18.1 \\
19.2 \\
18.9 \\
18.7\end{array}$ & $\begin{array}{l}19.1 \\
18.7 \\
18.0 \\
18.9 \\
20.8 \\
22.0 \\
20.9 \\
19.8\end{array}$ & $\begin{array}{l}18.0 \\
17: 3 \\
17.6 \\
17.4 \\
18.1 \\
19.0 \\
18.8 \\
18.6\end{array}$ & $\begin{array}{l}21.9 \\
20.9 \\
21.1 \\
18: 0 \\
18.0 \\
17.5 \\
16.4 \\
17.1\end{array}$ & & $\begin{array}{l}2.7 \\
7.2 \\
6.4 \\
6.5 \\
7.1 \\
3.2 \\
3.3 \\
1.9\end{array}$ & $\begin{array}{l}3.6 \\
8.8 \\
5.7 \\
8.2 \\
8.9 \\
3.6 \\
4.0 \\
2.8\end{array}$ & $\begin{array}{l}4.3 \\
9.9 \\
2.4 \\
0.3 \\
9.8 \\
4.0 \\
4.7 \\
3.1\end{array}$ & $\begin{array}{r}5.0 \\
11.4 \\
9.6 \\
10.5 \\
10.6 \\
4.3 \\
5.5 \\
3.9\end{array}$ \\
\hline $\begin{array}{l}12 \\
12 \\
12 \\
12 \\
12 \\
12 \\
12 \\
12\end{array}$ & $\begin{array}{r}0 \\
3 \\
6 \\
9 \\
12 \\
15 \\
18 \\
21\end{array}$ & $\begin{array}{l}18.6 \\
17.3 \\
19.1 \\
22.1 \\
23.5 \\
25.4 \\
23.2 \\
19.4\end{array}$ & $\begin{array}{l}18.0 \\
17.0 \\
17.7 \\
18.9 \\
19.2 \\
18.9 \\
19.1 \\
17.8\end{array}$ & $\begin{array}{l}18.5 \\
17.5 \\
18.9 \\
21.6 \\
23.4 \\
24.8 \\
23.3 \\
19.9\end{array}$ & $\begin{array}{l}17: 9 \\
17: 0 \\
17: 6 \\
18: 8 \\
18.7 \\
18.4 \\
19.0 \\
17.8\end{array}$ & $\begin{array}{l}18.5 \\
17.5 \\
23.8 \\
21.03 \\
23.1 \\
24.7 \\
23.3 \\
20.2\end{array}$ & $\begin{array}{l}17.9 \\
16.9 \\
17.4 \\
18.7 \\
18.5 \\
18.5 \\
18.8 \\
17.7\end{array}$ & $\begin{array}{l}18.5 \\
17.7 \\
18.7 \\
21.1 \\
22.0 \\
24.4 \\
23.3 \\
20.7\end{array}$ & $\begin{array}{l}17.7 \\
16.9 \\
17.4 \\
18.4 \\
18.3 \\
18.0 \\
18.5 \\
17.7\end{array}$ & $\begin{array}{l}17.0 \\
17.1 \\
17.1 \\
20.9 \\
22.6 \\
23.0 \\
23.8\end{array}$ & & $\begin{array}{l}4.2 \\
2.3 \\
5.8 \\
4.8 \\
5.9 \\
3.2 \\
2.0 \\
2.4\end{array}$ & $\begin{array}{l}5.1 \\
2.9 \\
6.6 \\
5.5 \\
7.0 \\
4.5 \\
2.7 \\
3.2\end{array}$ & $\begin{array}{l}6.1 \\
3.6 \\
7.4 \\
6.5 \\
9.3 \\
4.8 \\
3.4 \\
4.2\end{array}$ & $\begin{array}{l}7.0 \\
4.5 \\
8.7 \\
7.7 \\
9.9 \\
5.6 \\
4.4 \\
5.5\end{array}$ \\
\hline $\begin{array}{l}13 \\
13 \\
13 \\
13 \\
13 \\
13 \\
13 \\
13\end{array}$ & $\begin{array}{r}0 \\
3 \\
6 \\
9 \\
12 \\
15 \\
18 \\
21\end{array}$ & $\begin{array}{l}18.0 \\
17.5 \\
22.2 \\
26.0 \\
28.1 \\
27.7 \\
21.5 \\
21.9\end{array}$ & $\begin{array}{l}16.8 \\
1.7 .0 \\
19.8 \\
20.6 \\
21.2 \\
21.0 \\
17.5 \\
18.4\end{array}$ & $\begin{array}{l}18.6 \\
17.9 \\
22.2 \\
26.0 \\
28.0 \\
27.1 \\
21.5 \\
22.0\end{array}$ & $\begin{array}{l}16.8 \\
17.1 \\
19.7 \\
20.3 \\
20.9 \\
20.4 \\
17.4 \\
18.4\end{array}$ & $\begin{array}{l}18.9 \\
18.1 \\
22.1 \\
25.8 \\
27.7 \\
26.7 \\
21.5 \\
22.1\end{array}$ & $\begin{array}{l}16.9 \\
17.2 \\
19.6 \\
20.2 \\
20.8 \\
20.0 \\
17.3 \\
13.3\end{array}$ & $\begin{array}{l}19.6 \\
18.7 \\
22: 1 \\
25: 7 \\
27.3 \\
25.1 \\
21: 0 \\
22.2\end{array}$ & $\begin{array}{l}17.0 \\
17.5 \\
10.4 \\
19.9 \\
20.3 \\
19.7 \\
17.4 \\
18.4\end{array}$ & $\begin{array}{l}23.2 \\
22.9 \\
22.4 \\
20.0 \\
20.7 \\
22.4 \\
22.4 \\
22.3\end{array}$ & & $\begin{array}{l}2.4 \\
2.1 \\
4.0 \\
6.5 \\
7.1 \\
8.2 \\
8.8 \\
8.5\end{array}$ & $\begin{array}{r}3.3 \\
2.9 \\
4.7 \\
7.1 \\
8.1 \\
9.7 \\
10.2 \\
10.0\end{array}$ & $\begin{array}{r}4.3 \\
4.1 \\
5.2 \\
7.8 \\
8.9 \\
10.9 \\
11.8 \\
11.3\end{array}$ & $\begin{array}{r}5.9 \\
6.1 \\
5.8 \\
9.8 \\
9.8 \\
10.9 \\
13.6 \\
13.1\end{array}$ \\
\hline $\begin{array}{l}14 \\
14 \\
14 \\
14 \\
14 \\
14 \\
14 \\
14\end{array}$ & $\begin{array}{r}0 \\
3 \\
6 \\
9 \\
12 \\
15 \\
18 \\
21\end{array}$ & $\begin{array}{l}20.4 \\
18.2 \\
19.1 \\
23.9 \\
26.6 \\
28.0 \\
25.6 \\
22.8\end{array}$ & $\begin{array}{l}17.5 \\
17.0 \\
17.8 \\
19.8 \\
20.6 \\
21.9 \\
21.8 \\
21.5\end{array}$ & $\begin{array}{l}20.3 \\
18.4 \\
19.1 \\
23.7 \\
26.6 \\
27.4 \\
25.4 \\
22.9\end{array}$ & $\begin{array}{l}27.5 \\
16.9 \\
17.6 \\
19.6 \\
20.6 \\
21.5 \\
21.5 \\
21.5\end{array}$ & $\begin{array}{l}20.3 \\
18.4 \\
19.1 \\
23.1 \\
26.3 \\
27.5 \\
25.5 \\
22.9\end{array}$ & $\begin{array}{l}17.3 \\
16.8 \\
17.5 \\
19.2 \\
20.3 \\
21.3 \\
21.5 \\
21.5\end{array}$ & $\begin{array}{l}19.9 \\
18.5 \\
19.2 \\
23.1 \\
25.8 \\
27.5 \\
25.5 \\
23.1\end{array}$ & $\begin{array}{l}17.1 \\
16.8 \\
17.4 \\
19.2 \\
20.2 \\
21.2 \\
21.4 \\
21.5\end{array}$ & $\begin{array}{l}21.7 \\
21.2 \\
21.0 \\
23.4 \\
23.8 \\
23.5 \\
22.9 \\
23.1\end{array}$ & & $\begin{array}{l}7.3 \\
4.2 \\
5.8 \\
8.1 \\
4.9 \\
3.8 \\
2.7 \\
5.6\end{array}$ & $\begin{array}{l}8.5 \\
5.3 \\
7.0 \\
9.5 \\
5.8 \\
4.4 \\
3.4 \\
7.0\end{array}$ & $\begin{array}{r}10.2 \\
6.2 \\
7.9 \\
10.6 \\
6.4 \\
4.8 \\
4.3 \\
8.1\end{array}$ & $\begin{array}{r}11.2 \\
8.4 \\
8.9 \\
11.5 \\
6.8 \\
5.2 \\
5.4 \\
9.5\end{array}$ \\
\hline $\begin{array}{l}15 \\
15 \\
15 \\
15 \\
15 \\
15 \\
15 \\
15\end{array}$ & $\begin{array}{r}0 \\
3 \\
6 \\
9 \\
12 \\
15 \\
18 \\
21\end{array}$ & $\begin{array}{l}22.8 \\
26.7 \\
28.6 \\
23.6 \\
22.5\end{array}$ & $\begin{array}{l}19.4 \\
20.5 \\
21.6 \\
20.8 \\
20.1\end{array}$ & $\begin{array}{l}23.0 \\
26.5 \\
28.1 \\
24.2 \\
22.9\end{array}$ & $\begin{array}{l}19.1 \\
20.1 \\
21.1 \\
20.8 \\
20.1\end{array}$ & $\begin{array}{l}22.9 \\
26.7 \\
28.3 \\
24.6 \\
23.0\end{array}$ & $\begin{array}{l}19.1 \\
29.9 \\
20.5 \\
20.6 \\
20.0\end{array}$ & $\begin{array}{l}22 \cdot 8 \\
26: 1 \\
27.9 \\
25.3 \\
23.3\end{array}$ & $\begin{array}{l}18.7 \\
29.9 \\
20.4 \\
20.3 \\
20.0\end{array}$ & $\begin{array}{l}21.1 \\
23.1 \\
23.0 \\
23.8 \\
23.8\end{array}$ & & $\begin{array}{l}7.8 \\
6.2 \\
4.3 \\
4.9 \\
4.0 \\
4.3 \\
3.0 \\
4.4\end{array}$ & $\begin{array}{l}9.3 \\
7.8 \\
4.8 \\
5.4 \\
4.3 \\
4.7 \\
3.9 \\
4.8\end{array}$ & $\begin{array}{r}10.7 \\
10.5 \\
5.3 \\
6.0 \\
4.7 \\
5.4 \\
5.1 \\
6.1\end{array}$ & $\begin{array}{r}11.7 \\
20.8 \\
7.3 \\
5.6 \\
5.1 \\
5.8 \\
6.9 \\
7.0\end{array}$ \\
\hline $\begin{array}{l}16 \\
16 \\
16 \\
16 \\
16 \\
16 \\
16 \\
16\end{array}$ & $\begin{array}{r}0 \\
3 \\
6 \\
9 \\
12 \\
15 \\
18 \\
21\end{array}$ & $\begin{array}{l}21.5 \\
20.1 \\
22.4 \\
26.7 \\
29.8\end{array}$ & $\begin{array}{l}19.9 \\
18.6 \\
19.1 \\
20.5 \\
21.3\end{array}$ & $\begin{array}{l}21.6 \\
20.5 \\
22.2 \\
26.5 \\
29.4\end{array}$ & $\begin{array}{l}20.0 \\
18.6 \\
18.7 \\
20.4 \\
20.5\end{array}$ & $\begin{array}{l}21.7 \\
20.6 \\
22.2 \\
26.4 \\
29.3\end{array}$ & $\begin{array}{l}19.9 \\
18.4 \\
18.8 \\
20.0 \\
20.3 \\
20.8 \\
20.6\end{array}$ & $\begin{array}{l}21.9 \\
20.9 \\
22.4 \\
26.2 \\
29.1 \\
26.5 \\
24.2\end{array}$ & $\begin{array}{l}19.9 \\
18.3 \\
18.7 \\
20.2 \\
20.4 \\
20.9 \\
20.6\end{array}$ & $\begin{array}{l}22.3 \\
21.7 \\
21.1 \\
20.8 \\
22.6 \\
23.3 \\
23.2\end{array}$ & & $\begin{array}{l}3.2 \\
3.2 \\
6.2 \\
6.8 \\
4.6 \\
5.3 \\
3.0 \\
4.0\end{array}$ & $\begin{array}{l}3.8 \\
3.9 \\
7.0 \\
7.5 \\
5.1 \\
6.0 \\
3.9 \\
5.1\end{array}$ & $\begin{array}{l}4.8 \\
5.0 \\
8.1 \\
8.5 \\
5.6 \\
6.7 \\
5.3 \\
6.6\end{array}$ & $\begin{array}{l}6.5 \\
6.8 \\
9.0 \\
9.1 \\
5.0 \\
7.3 \\
6.8 \\
8.8\end{array}$ \\
\hline $\begin{array}{l}17 \\
17 \\
17 \\
17 \\
17 \\
17 \\
17 \\
17\end{array}$ & $\begin{array}{r}0 \\
3 \\
6 \\
9 \\
12 \\
15 \\
18 \\
21\end{array}$ & $\begin{array}{l}22.0 \\
19.6 \\
24.2 \\
28.5 \\
31.9 \\
30.3\end{array}$ & $\begin{array}{l}20.5 \\
19.1 \\
21.0 \\
22.6 \\
23.4 \\
23.5\end{array}$ & $\begin{array}{l}22.6 \\
20.4 \\
24.3 \\
28.3 \\
32.0 \\
30.3\end{array}$ & $\begin{array}{l}20.6 \\
19.7 \\
20.7 \\
22.3 \\
23.1 \\
23.3\end{array}$ & $\begin{array}{l}22.7 \\
21.02 \\
24.4 \\
28.4 \\
31.8 \\
30.3\end{array}$ & $\begin{array}{l}20.5 \\
19.8 \\
20.7 \\
21.9 \\
22.7 \\
23.0\end{array}$ & $\begin{array}{l}22.9 \\
21.9 \\
24 \cdot 3 \\
28 \cdot 2 \\
30.3 \\
30.3\end{array}$ & $\begin{array}{l}20.5 \\
20.0 \\
20.5 \\
22.1 \\
22.8 \\
23.3\end{array}$ & $\begin{array}{l}22.1 \\
22.1 \\
22.4 \\
25.1 \\
27.7 \\
28.7\end{array}$ & & $\begin{array}{l}3.4 \\
1.1 \\
2.8 \\
3.4 \\
2.5 \\
4.4 \\
3.8 \\
1.9\end{array}$ & $\begin{array}{l}4.5 \\
1.9 \\
3.4 \\
3.8 \\
3.0 \\
5.5 \\
5.3 \\
4.1\end{array}$ & $\begin{array}{l}5.8 \\
2.3 \\
3.9 \\
4 \cdot 3 \\
3.3 \\
6.2 \\
6.3 \\
5.2\end{array}$ & $\begin{array}{l}3.4 \\
4.8 \\
3.2 \\
6.3 \\
7.6 \\
6.7\end{array}$ \\
\hline $\begin{array}{l}18 \\
18 \\
18 \\
18 \\
18 \\
18 \\
18 \\
18\end{array}$ & $\begin{array}{r}0 \\
3 \\
6 \\
9 \\
12 \\
15 \\
18 \\
21\end{array}$ & $\begin{array}{l}26.6 \\
24.3 \\
28.1 \\
25.1 \\
22.5\end{array}$ & $\begin{array}{l}22.0 \\
20.8 \\
21.8 \\
21.8 \\
21.2\end{array}$ & $\begin{array}{l}26.1 \\
24.6 \\
27.8 \\
25.4 \\
22.9\end{array}$ & $\begin{array}{l}21.9 \\
20.7 \\
21.5 \\
21.8 \\
21.2\end{array}$ & $\begin{array}{l}25.3 \\
24.7 \\
27.6 \\
25.6 \\
23.0\end{array}$ & $\begin{array}{l}21 \cdot 3 \\
20: 3 \\
21: 4 \\
21: 7 \\
21 \cdot 2\end{array}$ & $\begin{array}{l}25 \cdot 9 \\
24 \cdot 4 \\
27 \cdot 4 \\
25 \cdot 8 \\
23.3\end{array}$ & $\begin{array}{l}21 \cdot 2 \\
20.2 \\
21 \cdot 3 \\
21: 7 \\
21.2\end{array}$ & $\begin{array}{l}23.8 \\
23.5 \\
23.1 \\
23.5 \\
22.2\end{array}$ & & $\begin{array}{l}3.6 \\
4.9 \\
8.2 \\
7.4 \\
4.9 \\
4.1 \\
2.0 \\
2.0\end{array}$ & $\begin{array}{l}5.2 \\
6.4 \\
9.6 \\
9.4 \\
6.0 \\
6.0 \\
3.3 \\
3.1\end{array}$ & $\begin{array}{r}6.3 \\
7.3 \\
11.4 \\
10.5 \\
7.2 \\
6.7 \\
4.2 \\
4.0\end{array}$ & $\begin{array}{r}6.9 \\
8.5 \\
13.9 \\
18.0 \\
11.6 \\
7.1 \\
7.0 \\
5.4\end{array}$ \\
\hline $\begin{array}{l}19 \\
19 \\
19 \\
19 \\
19 \\
19 \\
19 \\
19\end{array}$ & $\begin{array}{r}0 \\
3 \\
6 \\
9 \\
12 \\
15 \\
18 \\
21\end{array}$ & $\begin{array}{l}21.6 \\
19.2 \\
22.3 \\
27.5 \\
31.8 \\
31.9 \\
27.9 \\
26.0\end{array}$ & $\begin{array}{l}20.8 \\
18.8 \\
19.4 \\
21.1 \\
24.7 \\
23.5 \\
23.4 \\
23.0\end{array}$ & $\begin{array}{l}22.0 \\
19.5 \\
22.6 \\
27.3 \\
31.0 \\
31.7 \\
27.8 \\
26.3\end{array}$ & $\begin{array}{l}20.8 \\
18.8 \\
19.4 \\
20.8 \\
24 \cdot 3 \\
23.3 \\
23.1 \\
22.9\end{array}$ & $\begin{array}{l}21.9 \\
19.6 \\
22.8 \\
27.4 \\
30.9 \\
31.4 \\
27.9 \\
26.4\end{array}$ & $\begin{array}{l}20.7 \\
18.6 \\
19.3 \\
20.6 \\
22.7 \\
23.0 \\
23.0 \\
22.9\end{array}$ & $\begin{array}{l}21.9 \\
19.5 \\
22.9 \\
27.1 \\
31.2 \\
29.8 \\
28.2 \\
26.5\end{array}$ & $\begin{array}{l}20.6 \\
18.3 \\
19 \cdot 3 \\
20.5 \\
22.4 \\
22.9 \\
23.0 \\
22.8\end{array}$ & $\begin{array}{l}22.0 \\
22.6 \\
22.2 \\
23.7 \\
25.5 \\
25.2 \\
24.2 \\
24.0\end{array}$ & & $\begin{array}{l}2.3 \\
5.2 \\
7.6 \\
6.7 \\
3.9 \\
4.3 \\
3.6 \\
5.0\end{array}$ & $\begin{array}{l}3.3 \\
7.7 \\
8.7 \\
7.5 \\
4.2 \\
5.1 \\
5.4 \\
6.0\end{array}$ & $\begin{array}{r}3.9 \\
9.0 \\
10.1 \\
8.4 \\
4.7 \\
5.6 \\
7.0 \\
7.3\end{array}$ & $\begin{array}{r}5.4 \\
9.3 \\
14.5 \\
7.6\end{array}$ \\
\hline $\begin{array}{l}20 \\
20 \\
20 \\
20 \\
20 \\
20 \\
20 \\
20\end{array}$ & $\begin{array}{r}0 \\
3 \\
6 \\
9 \\
12 \\
15 \\
18 \\
21\end{array}$ & $\begin{array}{l}23.1 \\
22.5 \\
24.1 \\
27.2 \\
29.0 \\
29.6 \\
27.2 \\
24.9\end{array}$ & $\begin{array}{l}19.3 \\
20.5 \\
22.1 \\
24.5 \\
25.0 \\
24.5 \\
23.6 \\
22.7\end{array}$ & $\begin{array}{l}23.0 \\
22.5 \\
24.3 \\
26.8 \\
28.8 \\
29.5 \\
27.3 \\
25.1\end{array}$ & $\begin{array}{l}29 \cdot 0 \\
20.5 \\
22.0 \\
24 \cdot 2 \\
24.5 \\
24.1 \\
23.5 \\
22.6\end{array}$ & $\begin{array}{l}22.8 \\
22.8 \\
24.2 \\
27.1 \\
28.4 \\
29.2 \\
27.3 \\
25.2\end{array}$ & $\begin{array}{l}18.6 \\
20.5 \\
22.0 \\
24.2 \\
24.2 \\
24.0 \\
23.5 \\
22.6\end{array}$ & $\begin{array}{l}23 \cdot 9 \\
23: 1 \\
24 \cdot 1 \\
26 \cdot 5 \\
28 \cdot 2 \\
29 \cdot 2 \\
27 \cdot 2 \\
25 \cdot 3\end{array}$ & $\begin{array}{l}18,1 \\
20.7 \\
21.9 \\
23.9 \\
24.0 \\
23.8 \\
23.4 \\
22.5\end{array}$ & $\begin{array}{l}23.9 \\
23.7 \\
23.6 \\
22.6 \\
22.3 \\
21.9 \\
21.4 \\
20.1\end{array}$ & & $\begin{array}{r}10.1 \\
5.3 \\
4.7 \\
5.3 \\
8.7 \\
9.7 \\
7.0 \\
7.6\end{array}$ & $\begin{array}{r}11.5 \\
7.5 \\
6.4 \\
10.0 \\
12.5 \\
11.6 \\
9.6 \\
11.9\end{array}$ & $\begin{array}{r}13.8 \\
8.9 \\
7.5 \\
11.3 \\
13.9 \\
13.2 \\
11.0 \\
13.7\end{array}$ & $\begin{array}{r}16.5 \\
11.0 \\
7.6 \\
12.5 \\
15.4 \\
14.8 \\
12.4 \\
15.5\end{array}$ \\
\hline
\end{tabular}


TABLE 10

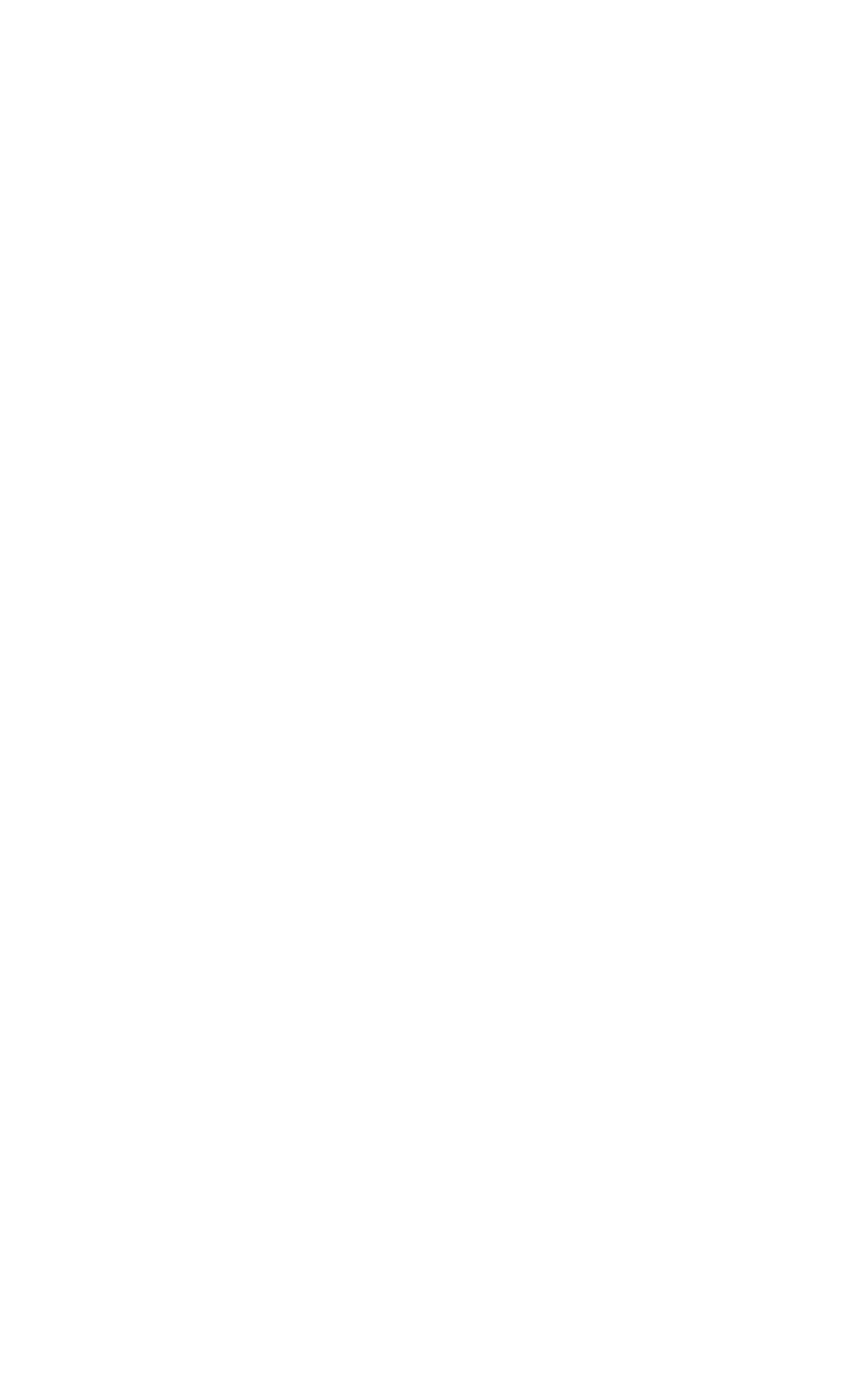


TABLE 10

Table 10. - Three-hour averages of air and water-surface temperatures and wind directions and speed, April 1950-August 1951, Lake Hefner-Continued

STATION 2

THREE-HOURLY AVERAGES

JULY, 1951

\begin{tabular}{|c|c|c|c|c|c|c|c|c|c|c|c|c|c|c|c|}
\hline \multirow{3}{*}{ 岳 } & \multirow{3}{*}{ 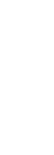 } & \multicolumn{8}{|c|}{ Average air temperature $\left({ }^{\circ} \mathrm{C}\right)$ at indicated height } & \multirow{3}{*}{$\begin{array}{c}\text { Average } \\
\text { water- } \\
\text { surface } \\
\text { tempera- } \\
\text { ture } \\
\text { ("C) }\end{array}$} & \multirow{3}{*}{$\begin{array}{c}\text { Average } \\
\text { wind } \\
\text { direction } \\
\text { (coded) }\end{array}$} & \multirow{2}{*}{\multicolumn{4}{|c|}{$\begin{array}{l}\text { Average wind speed (knots) } \\
\text { at indicated height }\end{array}$}} \\
\hline & & \multicolumn{2}{|c|}{$\begin{array}{c}2 \\
\text { meters }\end{array}$} & \multicolumn{2}{|c|}{$\begin{array}{c}4 \\
\text { meters }\end{array}$} & \multicolumn{2}{|c|}{$\begin{array}{c}\mathbf{8} \\
\text { meters }\end{array}$} & \multicolumn{2}{|c|}{$\begin{array}{c}16 \\
\text { meters }\end{array}$} & & & & & & \\
\hline & & $\begin{array}{l}\text { Dry } \\
\text { bulb }\end{array}$ & $\begin{array}{l}\text { Wet } \\
\text { bulb }\end{array}$ & $\begin{array}{l}\text { Dry } \\
\text { bulb }\end{array}$ & $\begin{array}{l}\text { Wet } \\
\text { bulb }\end{array}$ & $\begin{array}{l}\text { Dry } \\
\text { buib }\end{array}$ & \begin{tabular}{|l|} 
Wet \\
bulb
\end{tabular} & $\begin{array}{l}\text { Dry } \\
\text { bulb }\end{array}$ & $\begin{array}{l}\text { Wet } \\
\text { bulb }\end{array}$ & & & $\begin{array}{c}\mathbf{8} \\
\text { meters }\end{array}$ & $\begin{array}{c}4 \\
\text { meters }\end{array}$ & $\begin{array}{c}8 \\
\text { meters }\end{array}$ & $\begin{array}{c}16 \\
\text { meters }\end{array}$ \\
\hline $\begin{array}{l}1 \\
1 \\
1 \\
1 \\
1 \\
1 \\
1 \\
1\end{array}$ & $\begin{array}{r}0 \\
3 \\
6 \\
9 \\
12 \\
15 \\
18 \\
21\end{array}$ & $\begin{array}{l}18.2 \\
18.0 \\
17.4 \\
15.7 \\
16.6 \\
18.6 \\
18.1 \\
17.8\end{array}$ & $\begin{array}{l}16.0 \\
15.9 \\
15.4 \\
14.8 \\
15.4 \\
17.1 \\
17.5 \\
17.6\end{array}$ & $\begin{array}{l}18.2 \\
18.0 \\
17.4 \\
15.6 \\
16.7 \\
18.4 \\
18.2 \\
17.9\end{array}$ & $\begin{array}{l}16.1 \\
15.8 \\
15.3 \\
14.5 \\
15.4 \\
17.0 \\
17.5 \\
17.6\end{array}$ & $\begin{array}{l}18.2 \\
18.0 \\
17.3 \\
15.4 \\
16.7 \\
18.2 \\
18.1 \\
17.8\end{array}$ & $\begin{array}{l}15.9 \\
15.6 \\
15.3 \\
14.2 \\
15.3 \\
16.8 \\
17.5 \\
17.6\end{array}$ & $\begin{array}{l}18.2 \\
18.0 \\
17.3 \\
15.1 \\
16.6 \\
18.0 \\
18.1 \\
17.8\end{array}$ & $\begin{array}{l}15.9 \\
15.7 \\
15.1 \\
14.1 \\
15.2 \\
16.8 \\
17.5 \\
17.6\end{array}$ & $\begin{array}{l}22.4 \\
22.4 \\
22.7 \\
22.5 \\
22.1 \\
21.8 \\
20.4 \\
19.8\end{array}$ & & $\begin{array}{l}2.5 \\
3.2 \\
5.3 \\
6.4 \\
6.3 \\
6.7 \\
3.5 \\
2.2\end{array}$ & $\begin{array}{l}3.2 \\
4.1 \\
6.6 \\
8.7 \\
8.0 \\
0.5 \\
6.1 \\
3.5\end{array}$ & $\begin{array}{r}3.8 \\
4.7 \\
7.7 \\
10.3 \\
8.8 \\
9.9 \\
7.5 \\
4.5\end{array}$ & $\begin{array}{r}4.6 \\
5.3 \\
9.0 \\
11.8 \\
10.0 \\
20.8 \\
8.4 \\
5.4\end{array}$ \\
\hline $\begin{array}{l}2 \\
2 \\
2 \\
2 \\
2 \\
2 \\
2 \\
2\end{array}$ & $\begin{array}{r}0 \\
3 \\
6 \\
9 \\
12 \\
15 \\
18 \\
21\end{array}$ & $\begin{array}{l}18.1 \\
19.2 \\
19.7 \\
26.7 \\
27.5 \\
27.7 \\
25.8 \\
23.0\end{array}$ & $\begin{array}{l}18.0 \\
18.5 \\
18.9 \\
20.5 \\
22.4 \\
22.4 \\
21.9 \\
21.7\end{array}$ & $\begin{array}{l}18.2 \\
19.0 \\
19.7 \\
26.0 \\
26.5 \\
27.5 \\
25.6 \\
23.1\end{array}$ & $\begin{array}{l}18.0 \\
18.5 \\
18.7 \\
19.9 \\
21.91 \\
22.1 \\
21.9 \\
21.7\end{array}$ & $\begin{array}{l}18.1 \\
18.9 \\
19.7 \\
26.0 \\
26.3 \\
26.9 \\
25.4 \\
23.0\end{array}$ & $\begin{array}{l}17.9 \\
18.05 \\
18.8 \\
19.9 \\
20.9 \\
21.09 \\
21.8 \\
21.7\end{array}$ & $\begin{array}{l}18.1 \\
19.0 \\
19.7 \\
25.7 \\
28.0 \\
26.9 \\
2503 \\
23.1\end{array}$ & $\begin{array}{l}17.9 \\
18.4 \\
18.7 \\
20.0 \\
21.1 \\
21.9 \\
21.8 \\
21.7\end{array}$ & 28.9 & & $\begin{array}{l}4.5 \\
9.7 \\
4.1 \\
2.7 \\
6.6 \\
8.0 \\
7.4 \\
8.8\end{array}$ & $\begin{array}{r}5.1 \\
11.05 \\
4.9 \\
3.2 \\
7.5 \\
9.3 \\
8.8 \\
10.5\end{array}$ & $\begin{array}{r}6.2 \\
13.1 \\
5.9 \\
3.4 \\
8.0 \\
10.0 \\
10.0 \\
12.0\end{array}$ & $\begin{array}{r}7.1 \\
15.0 \\
6.5 \\
3.6 \\
9.1 \\
11.5 \\
11.5 \\
13.7\end{array}$ \\
\hline $\begin{array}{l}3 \\
3 \\
3 \\
3 \\
3 \\
3 \\
3 \\
3\end{array}$ & $\begin{array}{r}0 \\
3 \\
6 \\
9 \\
12 \\
15 \\
18 \\
21\end{array}$ & $\begin{array}{l}22.5 \\
23.11 \\
25.5 \\
28.9 \\
31.0 \\
31.7 \\
29.4 \\
27.3\end{array}$ & $\begin{array}{l}22.0 \\
22.2 \\
23.2 \\
24.7 \\
25.6 \\
25.5 \\
25.0 \\
24.2\end{array}$ & $\begin{array}{l}22.7 \\
23.2 \\
25.5 \\
28.7 \\
30.6 \\
31.6 \\
29.4 \\
27.5\end{array}$ & $\begin{array}{l}22.0 \\
22.0 \\
23.1 \\
24.6 \\
25.3 \\
25.4 \\
25.0 \\
23.5\end{array}$ & $\begin{array}{l}22.7 \\
23.1 \\
25.6 \\
28.8 \\
30.4 \\
31.2 \\
29.3 \\
26.9\end{array}$ & $\begin{array}{l}22 \cdot 1 \\
22 \cdot 2 \\
23 \cdot 2 \\
24 \cdot 5 \\
25 \cdot 0 \\
25 \cdot 2 \\
24 \cdot 9 \\
23.3\end{array}$ & $\begin{array}{l}22.8 \\
23.2 \\
25.5 \\
28.4 \\
30.1 \\
30.9 \\
29.3 \\
27.0\end{array}$ & $\begin{array}{l}22.1 \\
22.1 \\
23.2 \\
24.4 \\
25.1 \\
25.0 \\
25.0 \\
23.5\end{array}$ & $\begin{array}{l}18.3 \\
16.7 \\
15.2 \\
16.8 \\
18.5 \\
20.3 \\
20.0 \\
20.4\end{array}$ & & $\begin{array}{r}9.0 \\
9.3 \\
10.4 \\
13.1 \\
10.6 \\
10.4 \\
7.0 \\
7.7\end{array}$ & $\begin{array}{r}11.2 \\
11.1 \\
12.1 \\
15.2 \\
12.1 \\
12.0 \\
8.4 \\
9.7\end{array}$ & $\begin{array}{r}12.7 \\
12.7 \\
13.4 \\
17.0 \\
13.5 \\
13.4 \\
9.8 \\
11.1\end{array}$ & $\begin{array}{l}14.5 \\
14.4 \\
15.2 \\
19.1 \\
1409 \\
15.0 \\
11.2 \\
12.8\end{array}$ \\
\hline $\begin{array}{l}4 \\
4 \\
4 \\
4 \\
4 \\
4 \\
4 \\
4\end{array}$ & $\begin{array}{r}0 \\
3 \\
6 \\
9 \\
12 \\
15 \\
18 \\
21\end{array}$ & $\begin{array}{l}20.3 \\
19.5 \\
19.3 \\
21.8 \\
28.0 \\
28.5 \\
25.5 \\
24.8\end{array}$ & $\begin{array}{l}18.5 \\
18.1 \\
18.4 \\
19.3 \\
22.3 \\
23.5 \\
23.0 \\
23.6\end{array}$ & $\begin{array}{l}20.5 \\
19.7 \\
19.6 \\
22.0 \\
26.9 \\
28.3 \\
25.6 \\
25.1\end{array}$ & $\begin{array}{l}18.4 \\
18.1 \\
18.1 \\
19.1 \\
21.7 \\
23.3 \\
22.9 \\
23.7\end{array}$ & $\begin{array}{l}20.5 \\
19.7 \\
19.7 \\
21.9 \\
27.2 \\
28.2 \\
25.7 \\
25.3\end{array}$ & $\begin{array}{l}18.4 \\
17.9 \\
18.2 \\
19.1 \\
21.8 \\
23.0 \\
23.0 \\
23.7\end{array}$ & $\begin{array}{l}20.5 \\
19.8 \\
20.0 \\
22.3 \\
27.1 \\
27.8 \\
25.9 \\
25.5\end{array}$ & $\begin{array}{l}18.4 \\
17.8 \\
18.1 \\
19.0 \\
21.3 \\
23.0 \\
23.0 \\
23.7\end{array}$ & $\begin{array}{l}22.0 \\
23.4 \\
23.2 \\
21.5 \\
23.4 \\
25.9 \\
25.0 \\
22.0\end{array}$ & & $\begin{array}{l}6.1 \\
6.6 \\
6.6 \\
6.9 \\
2.8 \\
5.3 \\
2.6 \\
4.4\end{array}$ & $\begin{array}{l}9.4 \\
8.2 \\
8.1 \\
8.1 \\
3.6 \\
6.7 \\
4.8 \\
6.3\end{array}$ & $\begin{array}{r}11.2 \\
10.0 \\
9.4 \\
9.7 \\
3.8 \\
8.0 \\
6.2 \\
7.4\end{array}$ & $\begin{array}{r}12.7 \\
11.9 \\
10.8 \\
10.8 \\
3.8 \\
8.9 \\
7.7 \\
8.9\end{array}$ \\
\hline $\begin{array}{l}5 \\
5 \\
5 \\
5 \\
5 \\
5 \\
5 \\
5\end{array}$ & $\begin{array}{r}0 \\
3 \\
6 \\
9 \\
12 \\
15 \\
18 \\
21\end{array}$ & $\begin{array}{l}24.2 \\
23.4 \\
24.9 \\
29.5 \\
31.7 \\
31.6 \\
28.6 \\
26.1\end{array}$ & $\begin{array}{l}22.5 \\
21.04 \\
22.0 \\
24.1 \\
24.9 \\
23.6 \\
23.0 \\
22.7\end{array}$ & $\begin{array}{l}24.5 \\
23.6 \\
25.0 \\
29.4 \\
31.5 \\
31.5 \\
28.6 \\
26.4\end{array}$ & $\begin{array}{l}22.5 \\
21.5 \\
22.0 \\
23.8 \\
24.3 \\
23.6 \\
23.0 \\
22.8\end{array}$ & $\begin{array}{l}24.6 \\
23.6 \\
25.0 \\
29.2 \\
31.1 \\
31.3 \\
28.6 \\
26.4\end{array}$ & $\begin{array}{l}22.5 \\
21: 4 \\
21.9 \\
23.8 \\
23.9 \\
23.2 \\
23.0 \\
22.7\end{array}$ & $\begin{array}{l}24.7 \\
23.7 \\
25.1 \\
29.0 \\
30.9 \\
31.2 \\
28.6 \\
26.5\end{array}$ & $\begin{array}{l}22.5 \\
21.04 \\
22.00 \\
23.7 \\
24.1 \\
23.0 \\
23.1 \\
22.8\end{array}$ & $\begin{array}{l}21.8 \\
21.8 \\
22.11 \\
23.5 \\
24.6 \\
24.3 \\
24.0 \\
24.1\end{array}$ & & $\begin{array}{r}6.5 \\
8.4 \\
11.11 \\
10.7 \\
9.3 \\
9.0 \\
8.0 \\
9.0\end{array}$ & $\begin{array}{r}8.1 \\
10.1 \\
12.7 \\
12.0 \\
11.0 \\
12.0 \\
9.9 \\
11.1\end{array}$ & $\begin{array}{r}9.5 \\
11.6 \\
14.4 \\
13.5 \\
12.3 \\
13.6 \\
11.3 \\
12.8\end{array}$ & $\begin{array}{l}21.1 \\
13.6 \\
16.3 \\
15.0 \\
13.6 \\
15.6 \\
13.2 \\
14.6\end{array}$ \\
\hline $\begin{array}{l}6 \\
6 \\
6 \\
6 \\
6 \\
6 \\
6 \\
6\end{array}$ & $\begin{array}{r}0 \\
3 \\
6 \\
9 \\
12 \\
15 \\
18 \\
21\end{array}$ & $\begin{array}{l}24.9 \\
23.5 \\
25.4 \\
29.8 \\
32.3 \\
32.3 \\
28.9 \\
25.1\end{array}$ & $\begin{array}{l}21.9 \\
21.2 \\
21.4 \\
23.0 \\
24.7 \\
23.8 \\
23.0 \\
22.0\end{array}$ & $\begin{array}{l}25.0 \\
23.7 \\
25.6 \\
29.8 \\
32.0 \\
32.0 \\
29.0 \\
26.3\end{array}$ & $\begin{array}{l}21.9 \\
21.0 \\
21.4 \\
22.8 \\
23.5 \\
23.6 \\
23.0 \\
22.0\end{array}$ & $\begin{array}{l}25.0 \\
23.7 \\
25.5 \\
29.5 \\
31.6 \\
31.7 \\
28.9 \\
26.4\end{array}$ & $\begin{array}{l}21.9 \\
21.0 \\
21.4 \\
22.6 \\
23.3 \\
23.3 \\
22.8 \\
22.0\end{array}$ & $\begin{array}{l}25.0 \\
23.8 \\
25.7 \\
29.4 \\
31.4 \\
31.6 \\
29.0 \\
26.5\end{array}$ & $\begin{array}{l}22 \cdot 1 \\
21 \cdot 1 \\
21 \cdot 5 \\
22 \cdot 8 \\
23 \cdot 6 \\
23 \cdot 7 \\
23 \cdot 2 \\
22 \cdot 3\end{array}$ & $\begin{array}{l}24.0 \\
24 \cdot 0 \\
23.9 \\
24 \cdot 0 \\
24 \cdot 0 \\
25.0 \\
24 \cdot 0 \\
24 \cdot 4\end{array}$ & & $\begin{array}{r}10.5 \\
10.3 \\
12.0 \\
10.9 \\
11.0 \\
9.7 \\
7.3 \\
8.3\end{array}$ & $\begin{array}{r}12.8 \\
12.2 \\
13.9 \\
12.4 \\
12.7 \\
11.3 \\
9.2 \\
10.3\end{array}$ & $\begin{array}{l}14.5 \\
13.9 \\
15.6 \\
13.9 \\
14.1 \\
12.8 \\
10.6 \\
11.8\end{array}$ & $\begin{array}{l}16.6 \\
15.8 \\
17.6 \\
15.6 \\
15.6 \\
14.3 \\
12.2 \\
13.7\end{array}$ \\
\hline $\begin{array}{l}7 \\
7 \\
7 \\
7 \\
7 \\
7 \\
7 \\
7\end{array}$ & $\begin{array}{r}0 \\
3 \\
6 \\
9 \\
12 \\
15 \\
18 \\
21\end{array}$ & $\begin{array}{l}24.5 \\
23.3 \\
25.1 \\
30.5 \\
32.6 \\
32.4 \\
28.7 \\
26.0\end{array}$ & $\begin{array}{l}21.8 \\
20.8 \\
21.5 \\
23.1 \\
23.8 \\
23.5 \\
21.6 \\
20.5\end{array}$ & $\begin{array}{l}24.7 \\
23.3 \\
25.4 \\
30.3 \\
32.5 \\
32.1 \\
28.8 \\
26.0\end{array}$ & $\begin{array}{l}21.8 \\
20.8 \\
21.4 \\
23.1 \\
23.6 \\
23.3 \\
21.5 \\
20.5\end{array}$ & $\begin{array}{l}24.7 \\
23.44 \\
25.4 \\
30.0 \\
32.0 \\
31.8 \\
28.7 \\
26.1\end{array}$ & $\begin{array}{l}21.7 \\
20.8 \\
21.5 \\
22.9 \\
23.2 \\
23.1 \\
21.4 \\
20.6\end{array}$ & $\begin{array}{l}24.8 \\
23.4 \\
25.4 \\
29.8 \\
31.8 \\
31.7 \\
28.7 \\
26.2\end{array}$ & $\begin{array}{l}22.00 \\
21.00 \\
21.7 \\
23.0 \\
23.8 \\
23.5 \\
22.1 \\
21.1\end{array}$ & $\begin{array}{l}24 \cdot 4 \\
24.0 \\
24 \cdot 1 \\
25.3 \\
26.1 \\
24.6 \\
23.6 \\
23.5\end{array}$ & & $\begin{array}{r}10.1 \\
9.6 \\
10.2 \\
11.6 \\
12.1 \\
12.0 \\
8.9 \\
9.6\end{array}$ & $\begin{array}{l}11.9 \\
11.1 \\
12.2 \\
13.2 \\
13.8 \\
13.8 \\
10.4 \\
11.2\end{array}$ & $\begin{array}{l}13.5 \\
12.7 \\
13.4 \\
14.9 \\
15.6 \\
15.5 \\
12.0 \\
12.8\end{array}$ & $\begin{array}{l}15.4 \\
14.6 \\
15.0 \\
16.7 \\
17.4 \\
17.3 \\
13.8 \\
14.8\end{array}$ \\
\hline $\begin{array}{l}8 \\
8 \\
8 \\
8 \\
8 \\
8 \\
8 \\
8\end{array}$ & $\begin{array}{r}0 \\
3 \\
6 \\
9 \\
12 \\
15 \\
18 \\
21\end{array}$ & $\begin{array}{l}24.1 \\
23.1 \\
25.9 \\
29.9 \\
33.0 \\
33.1 \\
30.11 \\
27.3\end{array}$ & $\begin{array}{l}20.5 \\
19.9 \\
21.2 \\
22.9 \\
23.2 \\
23.3 \\
22.2 \\
22.1\end{array}$ & $\begin{array}{l}24.2 \\
23.3 \\
26.0 \\
29.0 \\
32.7 \\
32.8 \\
30.1 \\
27.3\end{array}$ & $\begin{array}{l}20.5 \\
10.9 \\
21.2 \\
22.6 \\
23.1 \\
23.1 \\
22.0 \\
22.1\end{array}$ & $\begin{array}{l}24.2 \\
23.4 \\
26.1 \\
29.6 \\
32.4 \\
32.7 \\
30.0 \\
27.3\end{array}$ & $\begin{array}{l}20.5 \\
19.9 \\
21.2 \\
22.4 \\
22.8 \\
22.9 \\
22.0 \\
22.0\end{array}$ & $\begin{array}{l}24.3 \\
23.6 \\
26.1 \\
29.7 \\
32.1 \\
32.5 \\
30.0 \\
27.4\end{array}$ & & $\begin{array}{l}23.2 \\
23.2 \\
23.6 \\
24.5 \\
24.5 \\
25.1 \\
23.8 \\
25.0\end{array}$ & & $\begin{array}{r}10.7 \\
9.3 \\
11.7 \\
14.0 \\
14.3 \\
12.5 \\
9.9 \\
10.7\end{array}$ & $\begin{array}{l}12.5 \\
11.1 \\
13.0 \\
16.1 \\
16.8 \\
13.9 \\
11.6 \\
12.4\end{array}$ & $\begin{array}{l}14.2 \\
12.8 \\
15.2 \\
18.2 \\
18.4 \\
15.7 \\
13.2 \\
14.1\end{array}$ & $\begin{array}{l}16.2 \\
14.7 \\
17.2 \\
20.3 \\
20.5 \\
17.6 \\
15.1 \\
16.1\end{array}$ \\
\hline $\begin{array}{l}9 \\
9 \\
9 \\
9 \\
9 \\
9 \\
9 \\
9\end{array}$ & $\begin{array}{r}0 \\
3 \\
6 \\
9 \\
12 \\
15 \\
18 \\
21\end{array}$ & $\begin{array}{l}24.8 \\
23.0 \\
25.5 \\
30.6 \\
33.2 \\
32.4 \\
29.3 \\
27.0\end{array}$ & $\begin{array}{l}21.3 \\
20.5 \\
21.5 \\
23.2 \\
24.1 \\
24.1 \\
22.8 \\
22.4\end{array}$ & $\begin{array}{l}24.8 \\
23.1 \\
25.6 \\
30.4 \\
32.6 \\
32.1 \\
29 \cdot 4 \\
27.1\end{array}$ & $\begin{array}{l}21 \cdot 2 \\
20.5 \\
21.3 \\
22.9 \\
23.7 \\
23.7 \\
22.8 \\
22.4\end{array}$ & $\begin{array}{l}25.0 \\
23.1 \\
25.5 \\
30.1 \\
32.3 \\
31.8 \\
29.3 \\
27.2\end{array}$ & $\begin{array}{l}21.2 \\
20.5 \\
21.3 \\
23.0 \\
23.6 \\
23.4 \\
22.9 \\
2 ? .5\end{array}$ & $\begin{array}{l}24.0 \\
23.03 \\
25.6 \\
30.2 \\
32.2 \\
31.07 \\
29.4 \\
27.2\end{array}$ & $\begin{array}{l}22.8 \\
23.5 \\
23.4 \\
22.9 \\
22.5\end{array}$ & $\begin{array}{l}24.7 \\
24.1 \\
24.8 \\
26.3 \\
26.7 \\
25.6 \\
24.7 \\
24.7\end{array}$ & & $\begin{array}{r}8.5 \\
5.8 \\
10.5 \\
11.02 \\
10.7 \\
9.7 \\
7.7 \\
8.9\end{array}$ & $\begin{array}{r}10.0 \\
6.0 \\
12.0 \\
12.9 \\
12.1 \\
11.03 \\
9.5 \\
10.6\end{array}$ & $\begin{array}{r}11.5 \\
8.02 \\
13.6 \\
14.4 \\
13.5 \\
12.8 \\
11.0 \\
12.02\end{array}$ & $\begin{array}{r}13.4 \\
9.9 \\
15.3 \\
16.0 \\
14.8 \\
14.4 \\
12.4 \\
13.9\end{array}$ \\
\hline $\begin{array}{l}10 \\
10 \\
10 \\
10 \\
10 \\
10 \\
10 \\
10\end{array}$ & $\begin{array}{r}0 \\
3 \\
6 \\
9 \\
12 \\
15 \\
18 \\
21\end{array}$ & $\begin{array}{l}25.9 \\
24.3 \\
26.4 \\
30.3 \\
32.7 \\
32.3 \\
29.2 \\
26.3\end{array}$ & $\begin{array}{l}22.11 \\
21.6 \\
22.4 \\
23.7 \\
24.7 \\
24.3 \\
23.1 \\
22.5\end{array}$ & $\begin{array}{l}26.1 \\
24.9 \\
26.4 \\
30.3 \\
32.0 \\
31.9 \\
29.1 \\
26.5\end{array}$ & $\begin{array}{l}22.2 \\
21.6 \\
22.2 \\
23.3 \\
23.7 \\
23.9 \\
23.0 \\
22.5\end{array}$ & $\begin{array}{l}26.1 \\
24.9 \\
26.2 \\
29.7 \\
31.7 \\
31.7 \\
29.0 \\
? 6.5\end{array}$ & $\begin{array}{l}22 \cdot 2 \\
22 \cdot 6 \\
22 \cdot 3 \\
23 \cdot 2 \\
23 \cdot 6 \\
23 \cdot 8 \\
23 \cdot 1 \\
22 \cdot 5\end{array}$ & $\begin{array}{l}26.2 \\
25.0 \\
26.2 \\
29.5 \\
31.5 \\
31.04 \\
29.0 \\
26.6\end{array}$ & $\begin{array}{l}22 \cdot 2 \\
21 \cdot 6 \\
22 \cdot 6 \\
23 \cdot 2 \\
23 \cdot 7 \\
23.9 \\
23 \cdot 3 \\
22.6\end{array}$ & $\begin{array}{l}25 \cdot 1 \\
24 \cdot 9 \\
25 \cdot 1 \\
25 \cdot 9 \\
26 \cdot 2 \\
25 \cdot 8 \\
25 \cdot 3 \\
24 \cdot 9\end{array}$ & & $\begin{array}{r}10.5 \\
10.06 \\
9.3 \\
9.6 \\
10.9 \\
11.9 \\
7.99 \\
7.3\end{array}$ & $\begin{array}{r}12.2 \\
12.4 \\
10.7 \\
11.2 \\
12.7 \\
13.8 \\
9.5 \\
8.9\end{array}$ & $\begin{array}{l}14.0 \\
14.1 \\
12.0 \\
12.6 \\
14.1 \\
15.6 \\
11.0 \\
10.2\end{array}$ & $\begin{array}{l}16.1 \\
16.1 \\
13.02 \\
13.7 \\
15.5 \\
17.03 \\
12.4 \\
11.6\end{array}$ \\
\hline
\end{tabular}


TABLE 10

Table 10. - Three-hour averages of air and water-surface temperatures and wind directions and speed, April 1950-August 951. Lake Hefner-Continued

STATION 2 THREE-HOURLY AVERAGES

JULY, 295

\begin{tabular}{|c|c|c|c|c|c|c|c|c|c|c|c|c|c|c|c|}
\hline \multirow{4}{*}{ 吾 } & \multirow{4}{*}{ 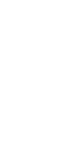 } & \multicolumn{8}{|c|}{ Average air temperature $\left({ }^{\circ} \mathrm{C}\right)$ at indicated height } & \multirow{4}{*}{$\begin{array}{c}\text { Average } \\
\text { water- } \\
\text { surface } \\
\text { tempera- } \\
\text { ture } \\
\text { (') }\end{array}$} & \multirow{4}{*}{$\begin{array}{l}\text { Average } \\
\text { wind } \\
\text { direction } \\
\text { (coded) }\end{array}$} & \multirow{2}{*}{\multicolumn{4}{|c|}{$\begin{array}{l}\text { Average wind speed (knots) } \\
\text { at indicated height }\end{array}$}} \\
\hline & & \multirow{2}{*}{\multicolumn{2}{|c|}{$\begin{array}{c}2 \\
\text { meters }\end{array}$}} & \multirow{2}{*}{\multicolumn{2}{|c|}{$\begin{array}{c}4 \\
\text { meters }\end{array}$}} & \multirow{2}{*}{\multicolumn{2}{|c|}{$\begin{array}{c}8 \\
\text { meters }\end{array}$}} & \multirow{2}{*}{\multicolumn{2}{|c|}{$\begin{array}{c}16 \\
\text { meters }\end{array}$}} & & & & & & \\
\hline & & & & & & & & & & & & 2 & 4 & 8 & 16 \\
\hline & & $\begin{array}{l}\text { Dry } \\
\text { bulb }\end{array}$ & $\begin{array}{l}\text { Wet } \\
\text { bulb }\end{array}$ & $\begin{array}{l}\text { Dry } \\
\text { bulb }\end{array}$ & $\begin{array}{l}\text { Wet } \\
\text { bulb }\end{array}$ & $\begin{array}{l}\text { Dry } \\
\text { bulb }\end{array}$ & $\begin{array}{l}\text { Wet } \\
\text { bulb }\end{array}$ & $\begin{array}{l}\text { Dry } \\
\text { butb }\end{array}$ & $\begin{array}{l}\text { Wet } \\
\text { bulb }\end{array}$ & & & meters & meters & meters & meters \\
\hline $\begin{array}{l}11 \\
11 \\
11 \\
11 \\
11 \\
11 \\
11 \\
11\end{array}$ & $\begin{array}{r}0 \\
3 \\
6 \\
9 \\
12 \\
15 \\
18 \\
21\end{array}$ & $\begin{array}{l}25.6 \\
24.6 \\
25.6 \\
30.3 \\
32.9 \\
32.8 \\
28.9 \\
25.7\end{array}$ & $\begin{array}{l}22.0 \\
21.7 \\
22.2 \\
22.9 \\
23.0 \\
23.5 \\
22.9 \\
22.4\end{array}$ & $\begin{array}{l}25.7 \\
24.7 \\
25.8 \\
30.2 \\
32.5 \\
32.3 \\
28.9 \\
25.9\end{array}$ & $\begin{array}{l}22.0 \\
21.7 \\
22.2 \\
22.5 \\
23.2 \\
23.1 \\
22.9 \\
22.4\end{array}$ & $\begin{array}{l}25.7 \\
24.8 \\
25.7 \\
29.9 \\
32.1 \\
31.9 \\
28.7 \\
25.8\end{array}$ & $\begin{array}{l}22.0 \\
21.8 \\
22.3 \\
22.5 \\
22.8 \\
22.8 \\
22.8 \\
22.4\end{array}$ & $\begin{array}{l}25.9 \\
24.8 \\
25.7 \\
29.8 \\
31.6 \\
31.5 \\
28.7 \\
25.3\end{array}$ & $\begin{array}{l}22.1 \\
21.8 \\
22.3 \\
22.7 \\
23.0 \\
23.4 \\
23.2 \\
22.7\end{array}$ & $\begin{array}{l}24.5 \\
24.5 \\
24.5 \\
26.2 \\
26.7 \\
26.9 \\
26.1 \\
25.4\end{array}$ & & $\begin{array}{r}8.1 \\
9.7 \\
12.4 \\
10.0 \\
9.2 \\
10.2 \\
7.3 \\
4.1\end{array}$ & $\begin{array}{r}9.9 \\
11.6 \\
13.3 \\
11.3 \\
10.6 \\
12.2 \\
9.0 \\
5.4\end{array}$ & $\begin{array}{r}11.4 \\
13.3 \\
14.9 \\
12.7 \\
11.6 \\
13.5 \\
10.5 \\
6.6\end{array}$ & $\begin{array}{r}12.9 \\
15.1 \\
16.6 \\
14.0 \\
12.7 \\
14: 9 \\
12.0 \\
7.9\end{array}$ \\
\hline $\begin{array}{l}12 \\
12 \\
12 \\
12 \\
12 \\
12 \\
12 \\
12\end{array}$ & $\begin{array}{r}0 \\
3 \\
6 \\
9 \\
12 \\
15 \\
18 \\
21\end{array}$ & $\begin{array}{l}24.2 \\
23.5 \\
25.5 \\
31.2 \\
34.2 \\
33.9 \\
30.5 \\
27.5\end{array}$ & $\begin{array}{l}21.9 \\
21.5 \\
22.2 \\
23.3 \\
23.7 \\
23.5 \\
23.0 \\
22.7\end{array}$ & $\begin{array}{l}24.4 \\
23.6 \\
25.7 \\
31.1 \\
33.6 \\
33.6 \\
30.5 \\
27.6\end{array}$ & $\begin{array}{l}21.9 \\
21.4 \\
22.1 \\
23.2 \\
23.4 \\
23.1 \\
22.9 \\
22.7\end{array}$ & $\begin{array}{l}24.4 \\
23.6 \\
25.7 \\
30.7 \\
33.2 \\
33.0 \\
30.3 \\
27.7\end{array}$ & $\begin{array}{l}21.9 \\
21.5 \\
22.1 \\
23.0 \\
23.0 \\
23.0 \\
22.9 \\
22.7\end{array}$ & $\begin{array}{l}24.6 \\
23.6 \\
25.6 \\
30.4 \\
32.6 \\
32.7 \\
30.3 \\
27.8\end{array}$ & $\begin{array}{l}22.0 \\
21.7 \\
22.3 \\
23.4 \\
23.9 \\
23.9 \\
23.7 \\
23.2\end{array}$ & $\begin{array}{l}24.9 \\
24.4 \\
24.8 \\
25.8 \\
25.3 \\
25.9 \\
25.8 \\
25.6\end{array}$ & & $\begin{array}{r}6.2 \\
8.1 \\
10.0 \\
10.5 \\
8.1 \\
8.3 \\
6.1 \\
5.8\end{array}$ & $\begin{array}{r}7.8 \\
9.8 \\
11.4 \\
11.9 \\
9.0 \\
9.9 \\
7.4 \\
7.1\end{array}$ & $\begin{array}{r}9.1 \\
11.2 \\
13.0 \\
13.5 \\
10.0 \\
10.9 \\
8.6 \\
8.4\end{array}$ & $\begin{array}{r}10.7 \\
12.9 \\
14.7 \\
14.9 \\
10.9 \\
12.0 \\
10.0 \\
9.9\end{array}$ \\
\hline $\begin{array}{l}13 \\
13 \\
13 \\
13 \\
13 \\
13 \\
13 \\
13\end{array}$ & $\begin{array}{r}0 \\
3 \\
6 \\
9 \\
12 \\
15 \\
18 \\
21\end{array}$ & $\begin{array}{l}25.2 \\
21.9 \\
24.4 \\
26.9 \\
29.5 \\
31.4 \\
26.1 \\
23.5\end{array}$ & $\begin{array}{l}22.3 \\
20.8 \\
22.0 \\
23.1 \\
23.8 \\
24.7 \\
23.3 \\
22.0\end{array}$ & $\begin{array}{l}25.2 \\
21.9 \\
24.1 \\
26.1 \\
28.7 \\
31.0 \\
26.0 \\
23.5\end{array}$ & $\begin{array}{l}22.2 \\
20.7 \\
22.2 \\
23.1 \\
23.5 \\
24.5 \\
23.3 \\
22.0\end{array}$ & $\begin{array}{l}25.2 \\
21.8 \\
24.2 \\
26.4 \\
28.4 \\
30.7 \\
25.8 \\
23.3\end{array}$ & $\begin{array}{l}22.1 \\
20.8 \\
21.8 \\
23.0 \\
23.2 \\
24.3 \\
23.2 \\
21.9\end{array}$ & $\begin{array}{l}25.4 \\
21.9 \\
24: 2 \\
26: 0 \\
28.5 \\
30.2 \\
2507 \\
23: 3\end{array}$ & $\begin{array}{l}22.4 \\
20.7 \\
21.8 \\
22.9 \\
23.5 \\
24.4 \\
23.1 \\
21.8\end{array}$ & $\begin{array}{l}25.3 \\
24.9 \\
25.6 \\
27.1 \\
29.2 \\
29.4 \\
28.5 \\
27.3\end{array}$ & & $\begin{array}{l}3.3 \\
4.7 \\
3.2 \\
5.5 \\
5.6 \\
3.9 \\
5.5 \\
4.9\end{array}$ & $\begin{array}{l}4.5 \\
5.5 \\
3.6 \\
6.3 \\
6.3 \\
4.3 \\
7.1 \\
5.7\end{array}$ & $\begin{array}{l}5.6 \\
5.6 \\
4.1 \\
7.2 \\
7.2 \\
5.2 \\
8.5 \\
6.5\end{array}$ & $\begin{array}{r}6.8 \\
7.8 \\
4.7 \\
8.7 \\
7.8 \\
5.9 \\
20.3 \\
7.3\end{array}$ \\
\hline $\begin{array}{l}14 \\
14 \\
14 \\
14 \\
14 \\
14 \\
14 \\
14\end{array}$ & $\begin{array}{r}0 \\
3 \\
6 \\
9 \\
12 \\
15 \\
18 \\
21\end{array}$ & $\begin{array}{l}22.0 \\
21.1 \\
22.0 \\
22.0 \\
24.5 \\
29.0 \\
27.0 \\
23.6\end{array}$ & $\begin{array}{l}21.2 \\
20.9 \\
21.4 \\
21.4 \\
22.0 \\
23.8 \\
23.5 \\
22.1\end{array}$ & $\begin{array}{l}22.1 \\
21.1 \\
21.9 \\
21.9 \\
24.0 \\
28.4 \\
26.8 \\
23.6\end{array}$ & $\begin{array}{l}21.2 \\
21.0 \\
21.4 \\
21.4 \\
22.1 \\
23.4 \\
23.3 \\
22.1\end{array}$ & $\begin{array}{l}22.0 \\
21.2 \\
21.9 \\
21.8 \\
23.8 \\
28.1 \\
26.8 \\
23.5\end{array}$ & $\begin{array}{l}21.4 \\
20.9 \\
21.3 \\
21.3 \\
21.8 \\
23.4 \\
23.1 \\
22.1\end{array}$ & $\begin{array}{l}22.1 \\
21.0 \\
21.7 \\
21.6 \\
23.5 \\
28.1 \\
26.7 \\
23.6\end{array}$ & $\begin{array}{l}21.2 \\
20.9 \\
21.4 \\
21.1 \\
21.9 \\
23.6 \\
23.3 \\
22.2\end{array}$ & $\begin{array}{l}26.9 \\
26.5 \\
25.9 \\
25.9 \\
24.5 \\
23.2 \\
22.5 \\
22.5\end{array}$ & & $\begin{array}{l}1.6 \\
2.0 \\
5.6 \\
7.1 \\
7.6 \\
6.6 \\
3.2 \\
2.9\end{array}$ & $\begin{array}{l}2.4 \\
2.8 \\
8.1 \\
8.9 \\
9.7 \\
8.5 \\
5.3 \\
5.2\end{array}$ & $\begin{array}{r}3.0 \\
3.4 \\
9.3 \\
10.2 \\
11.2 \\
9.6 \\
6.8 \\
6.7\end{array}$ & $\begin{array}{r}3.6 \\
4.3 \\
20.3 \\
11.2 \\
12.2 \\
10.7 \\
8.8 \\
8.2\end{array}$ \\
\hline $\begin{array}{l}15 \\
15 \\
15 \\
15 \\
15 \\
15 \\
15 \\
15\end{array}$ & $\begin{array}{r}0 \\
3 \\
6 \\
9 \\
12 \\
15 \\
18 \\
21\end{array}$ & $\begin{array}{l}23.0 \\
22.1 \\
24.1 \\
26.4 \\
31.5 \\
31.9 \\
27.8 \\
24.6\end{array}$ & $\begin{array}{l}22.4 \\
21.4 \\
22.8 \\
23.5 \\
24.0 \\
24.8 \\
22.5 \\
21.8\end{array}$ & $\begin{array}{l}23.0 \\
22.3 \\
23.8 \\
25.9 \\
30.9 \\
31.3 \\
27.8 \\
24.6\end{array}$ & $\begin{array}{l}22.3 \\
21.5 \\
22.6 \\
23.1 \\
23.7 \\
24.3 \\
22.3 \\
21.8\end{array}$ & $\begin{array}{l}23.1 \\
22.3 \\
23.8 \\
25.7 \\
30.3 \\
30.9 \\
27.7 \\
24.5\end{array}$ & $\begin{array}{l}22.4 \\
21.4 \\
22.7 \\
22.9 \\
23.5 \\
24.1 \\
22.3 \\
21.8\end{array}$ & $\begin{array}{l}23.2 \\
22.4 \\
23.8 \\
26.0 \\
30.2 \\
30.7 \\
27.5 \\
24.0\end{array}$ & $\begin{array}{l}22.4 \\
21.5 \\
22.7 \\
22.8 \\
24.0 \\
25.1\end{array}$ & $\begin{array}{l}22.9 \\
21.7 \\
20.1 \\
21.2 \\
26.2 \\
26.1 \\
25.8 \\
24.6\end{array}$ & & $\begin{array}{l}5.2 \\
4.1 \\
4: 1 \\
7.8 \\
8.8 \\
8.7 \\
7.5 \\
7.2\end{array}$ & $\begin{array}{r}6.4 \\
5.1 \\
4.6 \\
8.9 \\
10.8 \\
10.5 \\
9.4 \\
8.8\end{array}$ & $\begin{array}{r}7.6 \\
6.1 \\
5.5 \\
10.4 \\
12.0 \\
11.9 \\
10.8 \\
10.2\end{array}$ & $\begin{array}{r}9.3 \\
7.6 \\
6.1 \\
11.4 \\
13.1 \\
13.1 \\
12.5 \\
11.8\end{array}$ \\
\hline $\begin{array}{l}16 \\
16 \\
16 \\
16 \\
16 \\
16 \\
16 \\
16\end{array}$ & $\begin{array}{r}0 \\
3 \\
6 \\
9 \\
12 \\
15 \\
18 \\
21\end{array}$ & $\begin{array}{l}22.8 \\
21.3 \\
25.0 \\
31.1 \\
34.1 \\
34.3 \\
29.7 \\
24.9\end{array}$ & $\begin{array}{l}21.0 \\
20.3 \\
22.0 \\
23.3 \\
23.0 \\
22.9 \\
22.4 \\
22.0\end{array}$ & $\begin{array}{l}23.0 \\
21.5 \\
25.2 \\
31.0 \\
33.6 \\
33.7 \\
29.7 \\
25.7\end{array}$ & $\begin{array}{l}21.0 \\
20: 3 \\
21.9 \\
22.8 \\
22.7 \\
22.3 \\
22.2 \\
22.1\end{array}$ & $\begin{array}{l}22.9 \\
21.6 \\
25.3 \\
30.7 \\
33.0 \\
33.2 \\
29.9 \\
26.2\end{array}$ & $\begin{array}{l}21.0 \\
20.04 \\
21.9 \\
22.7 \\
22.5 \\
22.2 \\
22.1 \\
22.2\end{array}$ & $\begin{array}{l}23.2 \\
21.9 \\
25.2 \\
29.7 \\
32.8 \\
32.9 \\
30.4 \\
26.8\end{array}$ & $\begin{array}{l}21.3 \\
20.7 \\
22.4 \\
22.5 \\
22.2 \\
21.8 \\
23.8 \\
22.4\end{array}$ & $\begin{array}{l}24.1 \\
24.5 \\
24.2 \\
25.5 \\
27.0 \\
27.1 \\
26.4 \\
26.1\end{array}$ & & $\begin{array}{l}5.4 \\
3.4 \\
6.5 \\
6.2 \\
5.7 \\
5.4 \\
3.6 \\
3.7\end{array}$ & $\begin{array}{l}6.4 \\
4.2 \\
7.4 \\
6.9 \\
6.4 \\
6.4 \\
4.9 \\
4.9\end{array}$ & $\begin{array}{l}7.4 \\
5.3 \\
8.3 \\
7.7 \\
7.0 \\
7.1 \\
6.2 \\
5.3\end{array}$ & $\begin{array}{l}9.3 \\
7.0 \\
9.4 \\
8.3 \\
7.6 \\
7.8 \\
7.66 \\
8.4\end{array}$ \\
\hline $\begin{array}{l}17 \\
17 \\
17 \\
17 \\
17 \\
17 \\
17 \\
17\end{array}$ & $\begin{array}{r}0 \\
3 \\
6 \\
9 \\
12 \\
15 \\
18 \\
21\end{array}$ & $\begin{array}{l}23.9 \\
22.5 \\
24.7 \\
31.4 \\
35.4 \\
34.5 \\
30.0 \\
25.2\end{array}$ & $\begin{array}{l}21.8 \\
21.1 \\
21.8 \\
23.2 \\
23.0 \\
23.0 \\
22.7 \\
22.1\end{array}$ & $\begin{array}{l}24.1 \\
22.7 \\
24.9 \\
30.6 \\
33.6 \\
34.0 \\
30.4 \\
26.2\end{array}$ & $\begin{array}{l}21.8 \\
21.1 \\
21.5 \\
22.9 \\
22.5 \\
22.3 \\
22.3 \\
22.2\end{array}$ & $\begin{array}{l}24.2 \\
22.8 \\
24.9 \\
30.5 \\
33.4 \\
33.6 \\
30.5 \\
26.6\end{array}$ & $\begin{array}{l}21.8 \\
21.01 \\
21.5 \\
22.8 \\
22.5 \\
22.1 \\
22.02 \\
22.03\end{array}$ & $\begin{array}{l}24.7 \\
23.1 \\
25.1 \\
30.4 \\
33.2 \\
33.2 \\
30.9 \\
27.2\end{array}$ & $\begin{array}{l}21.9 \\
21.2 \\
21.6 \\
22.8 \\
22.2 \\
22.5 \\
22.3 \\
22.5\end{array}$ & $\begin{array}{l}25.7 \\
25.3 \\
25.6 \\
26.7 \\
27.6 \\
27.5 \\
26.1 \\
25.9\end{array}$ & & $\begin{array}{l}4.2 \\
3.5 \\
4.1 \\
3.8 \\
3.8 \\
4.3 \\
2.5 \\
2.7\end{array}$ & $\begin{array}{l}5.5 \\
4.3 \\
4.7 \\
4.2 \\
4.4 \\
4.09 \\
3.3 \\
3.8\end{array}$ & $\begin{array}{l}6.6 \\
5.4 \\
5.5 \\
4.5 \\
4.8 \\
5.6 \\
4.2 \\
5.3\end{array}$ & $\begin{array}{l}8.6 \\
7.6 \\
6.1 \\
4.9 \\
5.2 \\
6.02 \\
5.4 \\
7.1\end{array}$ \\
\hline $\begin{array}{l}18 \\
18 \\
18 \\
18 \\
18 \\
18 \\
18 \\
18\end{array}$ & $\begin{array}{r}0 \\
3 \\
6 \\
9 \\
12 \\
15 \\
18 \\
21\end{array}$ & $\begin{array}{l}24.0 \\
22.4 \\
26.0 \\
31.7 \\
34.4 \\
34.8 \\
30.3 \\
26.8\end{array}$ & $\begin{array}{l}20.8 \\
20.1 \\
21.2 \\
22.1 \\
22.3 \\
22.9 \\
22.2 \\
21.5\end{array}$ & $\begin{array}{l}24.1 \\
22.7 \\
26.1 \\
31.8 \\
34.9 \\
34.0 \\
30.0 \\
27.0\end{array}$ & $\begin{array}{l}20.7 \\
20.0 \\
21.0 \\
21.9 \\
21.1 \\
22.0 \\
21.7 \\
21.3\end{array}$ & $\begin{array}{l}24.2 \\
22.9 \\
26.2 \\
31.6 \\
34.6 \\
33.4 \\
30.2 \\
27.3\end{array}$ & $\begin{array}{l}20.7 \\
20.00 \\
21.00 \\
21.4 \\
21.4 \\
21.9 \\
21.7 \\
21.03\end{array}$ & $\begin{array}{l}24 \cdot 9 \\
23.4 \\
26.1 \\
31.4 \\
33.6 \\
33.6 \\
30.4 \\
27.7\end{array}$ & $\begin{array}{l}20.8 \\
20.2 \\
21.2 \\
21.6 \\
21.3 \\
22.2 \\
22.0 \\
21.7\end{array}$ & $\begin{array}{l}25.7 \\
25.2 \\
26.1 \\
26.6 \\
28.4 \\
27.6 \\
27.4 \\
26.6\end{array}$ & & $\begin{array}{l}4.22 \\
2.9 \\
5.9 \\
5.2 \\
3.0 \\
4.4 \\
4.2 \\
3.9\end{array}$ & $\begin{array}{l}5.1 \\
3.7 \\
7.1 \\
5.8 \\
3.4 \\
5.3 \\
5.3 \\
5.1\end{array}$ & $\begin{array}{l}6.6 \\
5.1 \\
8.0 \\
6.4 \\
3.7 \\
6.1 \\
6.7 \\
6.5\end{array}$ & $\begin{array}{l}9.11 \\
7.3 \\
9.1 \\
6.8 \\
4.0 \\
6.7 \\
8.03 \\
8.2\end{array}$ \\
\hline $\begin{array}{l}19 \\
19 \\
19 \\
19 \\
19 \\
19 \\
19 \\
19\end{array}$ & $\begin{array}{r}0 \\
3 \\
6 \\
9 \\
12 \\
15 \\
18 \\
21\end{array}$ & $\begin{array}{l}24.4 \\
23.3 \\
25.5 \\
30.2 \\
35.1 \\
35.6\end{array}$ & $\begin{array}{l}21.1 \\
21.2 \\
23.3 \\
22.8 \\
23.7 \\
24.0\end{array}$ & $\begin{array}{l}24.7 \\
23.4 \\
25.2 \\
30.4 \\
34.1 \\
34.0\end{array}$ & $\begin{array}{l}21.0 \\
21.2 \\
23 \cdot 1 \\
22 \cdot 4 \\
23.1 \\
23.0\end{array}$ & $\begin{array}{l}25.0 \\
23.4 \\
25.6 \\
29.8 \\
33.6 \\
34.0\end{array}$ & $\begin{array}{l}21.1 \\
21 \cdot 1 \\
23.1 \\
22.3 \\
22.8 \\
22.8\end{array}$ & $\begin{array}{l}25.3 \\
23.06 \\
25.3 \\
29.6 \\
33.0 \\
33.8\end{array}$ & $\begin{array}{l}21 \cdot 2 \\
21.2 \\
23 \cdot 1 \\
22 \cdot 4 \\
22 \cdot 8 \\
23.1\end{array}$ & $\begin{array}{l}26.4 \\
26.0 \\
26.5 \\
27.8 \\
30.9 \\
31.0\end{array}$ & $i$ & $\begin{array}{l}2.2 \\
1.5 \\
1.8 \\
2.8 \\
3.7 \\
5.6 \\
3.1 \\
2.9\end{array}$ & $\begin{array}{l}3.0 \\
2.0 \\
2.05 \\
3.0 \\
4.0 \\
0.3 \\
3.9 \\
3.9\end{array}$ & $\begin{array}{l}4.0 \\
2.5 \\
2.9 \\
3.2 \\
4.5 \\
7.5 \\
5.0 \\
5.1\end{array}$ & $\begin{array}{l}5.6 \\
3.0 \\
3.2 \\
3.4 \\
4.8 \\
8.3 \\
6.3 \\
6.8\end{array}$ \\
\hline $\begin{array}{l}20 \\
20 \\
20 \\
20 \\
20 \\
20 \\
20 \\
20\end{array}$ & $\begin{array}{r}0 \\
3 \\
6 \\
9 \\
12 \\
15 \\
18 \\
21\end{array}$ & $\begin{array}{l}32.4 \\
35.8 \\
35.5 \\
31.9 \\
28.9\end{array}$ & $\begin{array}{l}24 \cdot 1 \\
23.7 \\
23.6 \\
22.7 \\
23.0\end{array}$ & $\begin{array}{l}31.9 \\
35.1 \\
34.3 \\
32.0 \\
29.1\end{array}$ & $\begin{array}{l}23 \cdot 6 \\
22 \cdot 7 \\
22 \cdot 6 \\
22 \cdot 2 \\
22 \bullet 7\end{array}$ & $\begin{array}{l}31.5 \\
33.7 \\
33.9 \\
31.9 \\
29.0\end{array}$ & $\begin{array}{l}23.2 \\
23.4 \\
22.4 \\
22.4 \\
22,2 \\
22.7\end{array}$ & $\begin{array}{l}29.1 \\
31.04 \\
33.2 \\
34.4 \\
31.0 \\
29.1\end{array}$ & & $\begin{array}{l}25.8 \\
26.2 \\
26.0 \\
25.5 \\
24.9 \\
25.1\end{array}$ & & $\begin{array}{r}4.7 \\
5.5 \\
7.4 \\
9.3 \\
9.7 \\
10.5 \\
6.4 \\
9.5\end{array}$ & $\begin{array}{r}5.9 \\
7.0 \\
8.6 \\
11.0 \\
11.4 \\
12.1 \\
8.0 \\
11.7\end{array}$ & $\begin{array}{r}7.2 \\
8.2 \\
9.6 \\
12.3 \\
12.5 \\
13.5 \\
9.3 \\
13.3\end{array}$ & $\begin{array}{r}8.9 \\
9.8 \\
10.6 \\
13.4 \\
13.7 \\
15.0 \\
10.8 \\
15.2\end{array}$ \\
\hline
\end{tabular}


TABLE 10

Table 10. - Three-hour averages of air and water-surface temperatures and wind directions and speed, April 1950-August 1951, Lake Heiner-Continued

STATION 2

THREE-HOURLY AVERAGES

JULY, 1951

\begin{tabular}{|c|c|c|c|c|c|c|c|c|c|c|c|c|c|c|c|}
\hline \multirow{3}{*}{ 害 } & \multirow{3}{*}{ 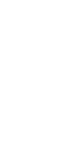 } & \multicolumn{8}{|c|}{ Average air temperature $\left({ }^{\circ} \mathrm{C}\right)$ at indicated height } & \multirow{3}{*}{\begin{tabular}{|} 
Average \\
water- \\
surface \\
tempera- \\
ture \\
(०)
\end{tabular}} & \multirow{3}{*}{$\begin{array}{c}\text { Average } \\
\text { wind } \\
\text { direction } \\
\text { (coded) }\end{array}$} & \multirow{2}{*}{\multicolumn{4}{|c|}{$\begin{array}{l}\text { Average wind speed (knots) } \\
\text { at indicated height }\end{array}$}} \\
\hline & & \multicolumn{2}{|c|}{$\begin{array}{c}2 \\
\text { meters }\end{array}$} & \multicolumn{2}{|c|}{$\begin{array}{c}4 \\
\text { meters }\end{array}$} & \multicolumn{2}{|c|}{$\begin{array}{c}8 \\
\text { meters }\end{array}$} & \multicolumn{2}{|c|}{$\begin{array}{c}16 \\
\text { meters }\end{array}$} & & & & & & \\
\hline & & $\begin{array}{l}\text { Dry } \\
\text { bulb }\end{array}$ & $\begin{array}{l}\text { Wet } \\
\text { bulb }\end{array}$ & $\begin{array}{l}\text { Dry } \\
\text { bulb }\end{array}$ & $\begin{array}{l}\text { Wet } \\
\text { bulb }\end{array}$ & $\begin{array}{l}\text { Dry } \\
\text { bulb }\end{array}$ & $\begin{array}{l}\text { Wet } \\
\text { bulb }\end{array}$ & $\begin{array}{l}\text { Dry } \\
\text { bulb }\end{array}$ & $\begin{array}{l}\text { Wet } \\
\text { bulb }\end{array}$ & & & $\begin{array}{c}2 \\
\text { meters }\end{array}$ & $\begin{array}{c}4 \\
\text { meters }\end{array}$ & $\begin{array}{c}8 \\
\text { meters }\end{array}$ & $\begin{array}{c}16 \\
\text { meters }\end{array}$ \\
\hline $\begin{array}{l}21 \\
21 \\
21 \\
21 \\
21 \\
21 \\
21 \\
21\end{array}$ & $\begin{array}{r}0 \\
3 \\
6 \\
9 \\
12 \\
15 \\
18 \\
21\end{array}$ & $\begin{array}{l}27.0 \\
25.9 \\
28.6 \\
33.7 \\
37.1 \\
36.8 \\
32.9 \\
29.2\end{array}$ & $\begin{array}{l}22.4 \\
21.8 \\
22.1 \\
23.9 \\
24.7 \\
24.5 \\
23.5 \\
22.1\end{array}$ & $\begin{array}{l}27.1 \\
25: 0 \\
28.7 \\
34.0 \\
36.8 \\
36.3 \\
32.6 \\
29.4\end{array}$ & $\begin{array}{l}22.1 \\
21.5 \\
21.5 \\
23.2 \\
23.5 \\
23.4 \\
22.7 \\
21.5\end{array}$ & $\begin{array}{l}27.1 \\
26: 1 \\
28.6 \\
32.0 \\
36.2 \\
36.0 \\
32.7 \\
29.3\end{array}$ & $\begin{array}{l}22.2 \\
21.5 \\
21.6 \\
22.9 \\
23.4 \\
23.3 \\
22.7 \\
21.4\end{array}$ & $\begin{array}{l}27.0 \\
26.1 \\
28.5 \\
33.5 \\
35.8 \\
35.7 \\
32.6 \\
29.3\end{array}$ & & $\begin{array}{l}25.1 \\
25.0 \\
25.3 \\
26.2 \\
27.0 \\
26.7 \\
26.1 \\
25.8\end{array}$ & & $\begin{array}{r}9.9 \\
10.8 \\
12.6 \\
12.7 \\
13.1 \\
12.0 \\
9.5 \\
9.1\end{array}$ & $\begin{array}{l}11.5 \\
12.3 \\
14.3 \\
14.3 \\
14.0 \\
13.6 \\
11.1 \\
10.6\end{array}$ & $\begin{array}{l}13.2 \\
14.2 \\
16.3 \\
16.2 \\
15.8 \\
15.2 \\
12.5 \\
12.1\end{array}$ & $\begin{array}{l}14.9 \\
16.1 \\
18.5 \\
18.1 \\
17.4 \\
16.8 \\
14.2 \\
13.9\end{array}$ \\
\hline $\begin{array}{l}22 \\
22 \\
22 \\
22 \\
22 \\
22 \\
22 \\
22\end{array}$ & $\begin{array}{r}0 \\
3 \\
6 \\
9 \\
12 \\
15 \\
18 \\
21\end{array}$ & $\begin{array}{l}26.3 \\
25.0 \\
27.4 \\
32.4 \\
35.8 \\
36.1 \\
32.0 \\
28.4\end{array}$ & $\begin{array}{l}21.1 \\
20.7 \\
22.1 \\
24.3 \\
24.6 \\
24.8 \\
23.6 \\
22.4\end{array}$ & $\begin{array}{l}26.3 \\
25.1 \\
27 \cdot 3 \\
32.5 \\
35.0 \\
35 \cdot 5 \\
31.9 \\
28.4\end{array}$ & $\begin{array}{l}20.8 \\
20.5 \\
21.7 \\
23.4 \\
23.6 \\
23.4 \\
23.0 \\
21.9\end{array}$ & $\begin{array}{l}26.4 \\
25.1 \\
27.4 \\
31.7 \\
34.8 \\
35.2 \\
31.8 \\
28.7\end{array}$ & $\begin{array}{l}20.8 \\
20.5 \\
21.7 \\
23.3 \\
25.0 \\
23.3 \\
23.0 \\
21.9\end{array}$ & $\begin{array}{l}26.5 \\
25.2 \\
27.4 \\
31.5 \\
34.4 \\
34.7 \\
31.8 \\
28.9\end{array}$ & & $\begin{array}{l}25.5 \\
25.2 \\
25.6 \\
26.5 \\
28.8 \\
27.0 \\
26.4 \\
26.1\end{array}$ & & $\begin{array}{l}7.11 \\
7.0 \\
7.8 \\
8.5 \\
8.6 \\
7.02 \\
6.6 \\
5.7\end{array}$ & $\begin{array}{l}8.2 \\
8.2 \\
8.9 \\
9.5 \\
9.6 \\
8.1 \\
8.4 \\
6.8\end{array}$ & $\begin{array}{r}9.6 \\
9.5 \\
10.0 \\
10.6 \\
10.5 \\
9.0 \\
9.7 \\
8.1\end{array}$ & $\begin{array}{r}11.2 \\
11.3 \\
11.1 \\
11.5 \\
11.4 \\
9.7 \\
21.2 \\
9.9\end{array}$ \\
\hline $\begin{array}{l}23 \\
23 \\
23 \\
23 \\
23 \\
23 \\
23 \\
23\end{array}$ & $\begin{array}{r}0 \\
3 \\
6 \\
9 \\
12 \\
15 \\
18 \\
21\end{array}$ & $\begin{array}{l}26.3 \\
24.9 \\
24.4 \\
29.6 \\
32.6 \\
26.6 \\
24.6 \\
23.9\end{array}$ & $\begin{array}{l}21.3 \\
21.8 \\
21: 8 \\
23.6 \\
24.1 \\
23.1 \\
23.1 \\
22.9\end{array}$ & $\begin{array}{l}28.9 \\
31.8 \\
26.6 \\
24.6 \\
23.9\end{array}$ & $\begin{array}{l}21.0 \\
21.5 \\
23.5 \\
24.1 \\
23.0 \\
23.1 \\
22.9\end{array}$ & $\begin{array}{l}26.5 \\
25.9 \\
28.6 \\
31.8 \\
26.8 \\
24.6 \\
24.0\end{array}$ & $\begin{array}{l}21.1 \\
21.6 \\
21.4 \\
23.1 \\
23.8 \\
22.9 \\
23.2 \\
22.8\end{array}$ & $\begin{array}{l}26.8 \\
24.8 \\
23.9 \\
29.1 \\
30.6 \\
26.3 \\
24.4 \\
24.2\end{array}$ & $\begin{array}{l}22.3 \\
21.9 \\
21.6 \\
23.2 \\
23.3 \\
22.4 \\
22.8 \\
22.6\end{array}$ & $\begin{array}{l}25.9 \\
25.8 \\
25.9 \\
28.4 \\
31.5 \\
29.9 \\
28.7 \\
27.9\end{array}$ & & $\begin{array}{l}4.4 \\
5.8 \\
6.7 \\
4.0 \\
4.03 \\
4.2 \\
2.2 \\
2.3\end{array}$ & $\begin{array}{l}5.7 \\
7.7 \\
8.6 \\
5.1 \\
5.8 \\
5.4 \\
2.9 \\
2.8\end{array}$ & $\begin{array}{l}7.12 \\
8.5 \\
9.5 \\
5.9 \\
5.9 \\
6.6 \\
3.4 \\
3.5\end{array}$ & $\begin{array}{r}8.9 \\
9.7 \\
10.9 \\
6.1 \\
6.5 \\
7.8 \\
3.9 \\
3.8\end{array}$ \\
\hline $\begin{array}{l}24 \\
24 \\
24 \\
24 \\
24 \\
24 \\
24 \\
24\end{array}$ & $\begin{array}{r}0 \\
3 \\
6 \\
9 \\
12 \\
15 \\
18 \\
21\end{array}$ & $\begin{array}{l}22.8 \\
21.6 \\
22.8 \\
25.5 \\
29.4 \\
31.6 \\
29.0 \\
23.4\end{array}$ & $\begin{array}{l}22.1 \\
20.9 \\
21.5 \\
22.9 \\
23.8 \\
23.9 \\
23.3 \\
21.9\end{array}$ & $\begin{array}{l}22.8 \\
21.6 \\
22.7 \\
25.2 \\
28.9 \\
30.9 \\
28.8 \\
23.6\end{array}$ & $\begin{array}{l}21.9 \\
21.0 \\
21.4 \\
22.7 \\
23.7 \\
23.4 \\
23.2 \\
21.9\end{array}$ & $\begin{array}{l}22.6 \\
21.6 \\
22.7 \\
24.9 \\
28.9 \\
31.7 \\
28.6 \\
23.3\end{array}$ & $\begin{array}{l}21.6 \\
21.0 \\
21.3 \\
22.6 \\
23.3 \\
23.4 \\
23.1 \\
21.8\end{array}$ & $\begin{array}{l}22.3 \\
21.6 \\
22.7 \\
24.8 \\
28.3 \\
30.3 \\
28.5 \\
22.5\end{array}$ & $\begin{array}{l}21.3 \\
20.9 \\
21.3 \\
22.5 \\
23.3 \\
23.2 \\
23.1 \\
21.7\end{array}$ & $\begin{array}{l}27.3 \\
26.9 \\
26.5 \\
26.2 \\
26.9 \\
30.5 \\
29.4 \\
28.9\end{array}$ & & $\begin{array}{l}4.8 \\
1.9 \\
2.1 \\
3.3 \\
2.6 \\
2.0 \\
3.0 \\
6.5\end{array}$ & $\begin{array}{l}6.5 \\
2.6 \\
2.0 \\
3.9 \\
3.6 \\
3.3 \\
3.8 \\
8.9\end{array}$ & $\begin{array}{r}6.2 \\
3.2 \\
2.3 \\
4.5 \\
4.0 \\
3.4 \\
4.4 \\
10.4\end{array}$ & $\begin{array}{r}7.6 \\
3.5 \\
2.6 \\
4.8 \\
4.2 \\
3.7 \\
5.1 \\
11.7\end{array}$ \\
\hline $\begin{array}{l}25 \\
25 \\
25 \\
25 \\
25 \\
25 \\
25 \\
25\end{array}$ & $\begin{array}{r}0 \\
3 \\
6 \\
9 \\
12 \\
15 \\
18 \\
21\end{array}$ & $\begin{array}{l}21.4 \\
21.1 \\
23.6 \\
28.7 \\
31.5\end{array}$ & $\begin{array}{l}21.0 \\
21.0 \\
22.5 \\
23.7 \\
23.3\end{array}$ & $\begin{array}{l}21.8 \\
21.5 \\
22.9 \\
28 \cdot 1 \\
30.7\end{array}$ & $\begin{array}{l}21.0 \\
21.1 \\
22 \cdot 2 \\
23.6 \\
22.6\end{array}$ & $\begin{array}{l}21.9 \\
21.6 \\
23.2 \\
27.8 \\
30.5\end{array}$ & $\begin{array}{l}21 \cdot 1 \\
21 \cdot 3 \\
22 \cdot 3 \\
23 \cdot 1 \\
22 \cdot 5\end{array}$ & $\begin{array}{l}22.0 \\
21.9 \\
23.3 \\
27.9 \\
30.1\end{array}$ & $\begin{array}{l}21.1 \\
21.4 \\
22.3 \\
23.1 \\
22.7\end{array}$ & $\begin{array}{l}27.8 \\
27.3 \\
26.1 \\
26.3 \\
27.6\end{array}$ & & $\begin{array}{l}1.1 \\
1.2 \\
3.0 \\
3.5 \\
3.6 \\
4.7 \\
2.9 \\
2.8\end{array}$ & $\begin{array}{l}1.5 \\
1.9 \\
3.7 \\
3.9 \\
4.0 \\
5.3 \\
3.4 \\
3.6\end{array}$ & $\begin{array}{l}1.07 \\
2.22 \\
4 \cdot 3 \\
4 \cdot 3 \\
4 \cdot 3 \\
6.3 \\
4 \cdot 6 \\
4.5\end{array}$ & $\begin{array}{l}1.9 \\
2.8 \\
4.7 \\
4.6 \\
4.7 \\
6.8 \\
5.8 \\
6.3\end{array}$ \\
\hline $\begin{array}{l}26 \\
26 \\
26 \\
26 \\
26 \\
26 \\
26 \\
26\end{array}$ & $\begin{array}{r}0 \\
3 \\
6 \\
9 \\
12 \\
15 \\
18 \\
21\end{array}$ & $\begin{array}{l}30.4 \\
28.9 \\
28.5 \\
25.4 \\
21.8\end{array}$ & $\begin{array}{l}23.9 \\
22.9 \\
23.2 \\
22 \cdot 0 \\
20.1\end{array}$ & $\begin{array}{l}30.6 \\
28.9 \\
27.9 \\
25.2 \\
22.0\end{array}$ & $\begin{array}{l}23.6 \\
22.7 \\
23.2 \\
21.9 \\
20.1\end{array}$ & $\begin{array}{l}27 \cdot 0 \\
30.1 \\
29 \cdot 2 \\
27.7 \\
24.9 \\
21.9\end{array}$ & $\begin{array}{l}23.1 \\
23.5 \\
22.3 \\
23.0 \\
21.5 \\
20.1\end{array}$ & $\begin{array}{l}27.6 \\
29.7 \\
28.5 \\
27.5 \\
24.8 \\
22.0\end{array}$ & $\begin{array}{l}23.0 \\
23.3 \\
21.9 \\
23.0 \\
21.3 \\
20.1\end{array}$ & $\begin{array}{l}24.9 \\
25.5 \\
26.9 \\
25.7 \\
25.4 \\
24.8\end{array}$ & & $\begin{array}{l}4.7 \\
5.0 \\
6.6 \\
6.5 \\
4.0 \\
7.1 \\
5.7 \\
6.1\end{array}$ & $\begin{array}{l}5.9 \\
6.3 \\
7.8 \\
7.4 \\
6.4 \\
8.5 \\
8.6 \\
7.9\end{array}$ & $\begin{array}{r}7.2 \\
7.4 \\
8.8 \\
8.1 \\
7.5 \\
9.8 \\
10.7 \\
9.3\end{array}$ & $\begin{array}{r}8.6 \\
9.0 \\
10.0 \\
8.7 \\
8.7 \\
10.7 \\
12.2 \\
10.9\end{array}$ \\
\hline $\begin{array}{l}27 \\
27 \\
27 \\
27 \\
27 \\
27 \\
27 \\
27\end{array}$ & $\begin{array}{r}0 \\
3 \\
6 \\
9 \\
12 \\
15 \\
18 \\
21\end{array}$ & $\begin{array}{l}21.8 \\
22.2 \\
23.8 \\
29.6 \\
33.8 \\
32.6 \\
29.5 \\
24.8\end{array}$ & $\begin{array}{l}19.9 \\
20.4 \\
22.2 \\
24.1 \\
24.8 \\
24.8 \\
24.5 \\
23.0\end{array}$ & $\begin{array}{l}21.9 \\
22.3 \\
24.0 \\
29.2 \\
32.8 \\
32.4 \\
29.4 \\
25.5\end{array}$ & $\begin{array}{l}19.9 \\
20.5 \\
22.1 \\
23.5 \\
24.1 \\
24.5 \\
24.4 \\
23.0\end{array}$ & $\begin{array}{l}22.0 \\
22.4 \\
24.2 \\
29.8 \\
33.4 \\
32.5 \\
29.4 \\
25.9\end{array}$ & $\begin{array}{l}19.9 \\
20.5 \\
22.1 \\
23.9 \\
24.5 \\
24.1 \\
24.3 \\
22.9\end{array}$ & $\begin{array}{l}22.0 \\
22.4 \\
24.2 \\
30.2 \\
32.3 \\
32.2 \\
29.4 \\
26.4\end{array}$ & $\begin{array}{l}19 \cdot 9 \\
20.5 \\
22.1 \\
23.4 \\
24.1 \\
24 \cdot 1 \\
24.3 \\
22.9\end{array}$ & $\begin{array}{l}24.0 \\
24.7 \\
23.7 \\
24.6 \\
29.6 \\
30.6 \\
30.2 \\
27.4\end{array}$ & . & $\begin{array}{l}5.5 \\
6.1 \\
2.03 \\
1.4 \\
1.9 \\
5.0 \\
3.6 \\
1.5\end{array}$ & $\begin{array}{l}6.7 \\
7.5 \\
2.7 \\
1.6 \\
2.2 \\
6.1 \\
4.8 \\
3.1\end{array}$ & $\begin{array}{l}7.8 \\
8.9 \\
3.1 \\
1.8 \\
2.4 \\
7.0 \\
5.7 \\
4.3\end{array}$ & $\begin{array}{r}9.3 \\
10.6 \\
3.6 \\
1.7 \\
2.5 \\
7.6 \\
6.6 \\
5.8\end{array}$ \\
\hline $\begin{array}{l}28 \\
28 \\
28 \\
28 \\
28 \\
28 \\
28 \\
28\end{array}$ & $\begin{array}{r}0 \\
3 \\
6 \\
9 \\
12 \\
15 \\
18 \\
21\end{array}$ & $\begin{array}{l}23.1 \\
22.1 \\
25.4 \\
31.2 \\
33.0 \\
32.5 \\
29.0 \\
26: 4\end{array}$ & $\begin{array}{l}22.1 \\
21.6 \\
23.0 \\
23.8 \\
24.2 \\
24.2 \\
24.3 \\
23.5\end{array}$ & $\begin{array}{l}23.8 \\
22.6 \\
25.6 \\
30.6 \\
32.4 \\
32.4 \\
29.1 \\
26.6\end{array}$ & $\begin{array}{l}22.2 \\
21.6 \\
22.8 \\
23.6 \\
24.2 \\
24.3 \\
24.0 \\
23.5\end{array}$ & $\begin{array}{l}24.1 \\
22.7 \\
25.7 \\
32.0 \\
33.0 \\
32.3 \\
29.0 \\
26.6\end{array}$ & $\begin{array}{l}22.2 \\
21.8 \\
22.7 \\
23.6 \\
23.9 \\
24.0 \\
23.9 \\
23.4\end{array}$ & $\begin{array}{l}24.6 \\
23.3 \\
25.7 \\
31.1 \\
32.8 \\
32.1 \\
29.1 \\
26.8\end{array}$ & $\begin{array}{l}22 \cdot 2 \\
21.8 \\
22.5 \\
23.5 \\
23.9 \\
24 \cdot 0 \\
23.7 \\
23.4\end{array}$ & $\begin{array}{l}26.0 \\
26.3 \\
25.4 \\
28.4 \\
31.2 \\
32.7 \\
31.2 \\
29.6\end{array}$ & & $\begin{array}{l}0.8 \\
0.9 \\
2.1 \\
1.6 \\
3.1 \\
4.0 \\
2.2 \\
2.7\end{array}$ & $\begin{array}{l}1.7 \\
1.4 \\
2.4 \\
1.8 \\
3.9 \\
5.0 \\
3.1 \\
3.9\end{array}$ & $\begin{array}{l}2.1 \\
1.9 \\
2 \cdot 8 \\
1.9 \\
4 \cdot 2 \\
6.1 \\
3.5 \\
5.0\end{array}$ & $\begin{array}{l}3.0 \\
3.0 \\
3.2 \\
1.7 \\
4.6 \\
7.4 \\
4.4 \\
6.3\end{array}$ \\
\hline $\begin{array}{l}29 \\
29 \\
29 \\
29 \\
29 \\
29 \\
29 \\
29\end{array}$ & $\begin{array}{r}0 \\
3 \\
6 \\
9 \\
12 \\
15 \\
18 \\
21\end{array}$ & $\begin{array}{l}23.5 \\
22.7 \\
24.6 \\
28.3 \\
31.8 \\
32.4 \\
28.6 \\
24.2\end{array}$ & $\begin{array}{l}22.2 \\
21.7 \\
21.9 \\
22.5 \\
22.5 \\
22.8 \\
23.0 \\
21.7\end{array}$ & $\begin{array}{l}23.9 \\
23.2 \\
24.6 \\
28.3 \\
31.2 \\
31.9 \\
28.6 \\
25.0\end{array}$ & $\begin{array}{l}22.3 \\
21: 8 \\
21.8 \\
22.3 \\
22.1 \\
22.3 \\
23.0 \\
21.7\end{array}$ & $\begin{array}{l}24.2 \\
23.3 \\
24.6 \\
28.2 \\
31.0 \\
31.5 \\
28.8 \\
25.5\end{array}$ & $\begin{array}{l}22.2 \\
21.8 \\
21.9 \\
22.1 \\
21.8 \\
21.8 \\
22.8 \\
21.7\end{array}$ & $\begin{array}{l}24.8 \\
23.5 \\
24: 7 \\
27: 9 \\
30: 9 \\
31: 3 \\
29: 1 \\
26.0\end{array}$ & $\begin{array}{l}22.0 \\
21.7 \\
22.0 \\
22.0 \\
21.7 \\
22.2 \\
22.9 \\
21.9\end{array}$ & $\begin{array}{l}28.5 \\
28.0 \\
27.0 \\
27.8 \\
30.6 \\
31.2 \\
29.8 \\
28.0\end{array}$ & & $\begin{array}{l}1.1 \\
0.7 \\
2.1 \\
2.8 \\
4.4 \\
3.5 \\
2.7 \\
1.9\end{array}$ & $\begin{array}{l}2.4 \\
1.0 \\
2.7 \\
3.5 \\
5.5 \\
4.8 \\
3.4 \\
2.9\end{array}$ & $\begin{array}{l}3.3 \\
1.4 \\
3.0 \\
4.0 \\
6.4 \\
5.06 \\
4.3 \\
3.9\end{array}$ & $\begin{array}{l}4: 8 \\
2: 0 \\
3.3 \\
4: 3 \\
6.9 \\
6.2 \\
5.5 \\
5.4\end{array}$ \\
\hline $\begin{array}{l}30 \\
30 \\
30 \\
30 \\
30 \\
30 \\
30 \\
30\end{array}$ & $\begin{array}{r}0 \\
3 \\
6 \\
9 \\
12 \\
15 \\
18 \\
21\end{array}$ & $\begin{array}{l}23.1 \\
23.2 \\
25.3 \\
30.0 \\
32.7 \\
33.5 \\
29.5 \\
25.5\end{array}$ & $\begin{array}{l}21.8 \\
21.8 \\
22.8 \\
23.9 \\
24.0 \\
23.6 \\
23.6 \\
22.7\end{array}$ & $\begin{array}{l}23.6 \\
23.4 \\
25.4 \\
29.6 \\
32.7 \\
33.2 \\
29.7 \\
26.0\end{array}$ & $\begin{array}{l}21.9 \\
21.9 \\
22.7 \\
23.7 \\
23.9 \\
23.3 \\
23.4 \\
22.7\end{array}$ & $\begin{array}{l}23.9 \\
23.8 \\
25.3 \\
29.9 \\
32.2 \\
33.0 \\
29.9 \\
26.4\end{array}$ & $\begin{array}{l}22.0 \\
21.9 \\
22.7 \\
23.3 \\
23.2 \\
23.2 \\
23.2 \\
22.8\end{array}$ & $\begin{array}{l}24 \cdot 5 \\
24: 1 \\
25: 3 \\
28.9 \\
31.8 \\
32.9 \\
30.1 \\
26.9\end{array}$ & $\begin{array}{l}22.1 \\
22.0 \\
22.6 \\
23.1 \\
23.2 \\
23 \cdot 1 \\
23.2 \\
22 \cdot 8\end{array}$ & $\begin{array}{l}26.9 \\
26.2 \\
25.5 \\
25.8 \\
27.6 \\
29.2 \\
28.8 \\
28.1\end{array}$ & & $\begin{array}{l}3.1 \\
3.7 \\
6.7 \\
6.5 \\
4.2 \\
3.0 \\
2.03 \\
2.5\end{array}$ & $\begin{array}{l}3.9 \\
4.9 \\
7.6 \\
7.5 \\
4.5 \\
4.4 \\
2.8 \\
3.4\end{array}$ & $\begin{array}{l}5.2 \\
6.3 \\
8.6 \\
8.1 \\
5.0 \\
5.0 \\
3.8 \\
4.5\end{array}$ & $\begin{array}{l}6.9 \\
8.0 \\
9.7 \\
9.0 \\
5.3 \\
5.5 \\
4.8 \\
6.0\end{array}$ \\
\hline $\begin{array}{l}31 \\
31 \\
31 \\
31 \\
31 \\
31 \\
31 \\
31\end{array}$ & $\begin{array}{r}0 \\
3 \\
6 \\
9 \\
12 \\
15 \\
18 \\
21\end{array}$ & $\begin{array}{l}23.6 \\
23.2 \\
25.3 \\
27.0 \\
25.3 \\
27.0 \\
25.6 \\
22.9\end{array}$ & $\begin{array}{l}21.1 \\
20.6 \\
21.7 \\
23.1 \\
22.7 \\
23.2 \\
23.3 \\
22.1\end{array}$ & $\begin{array}{l}24.5 \\
23.4 \\
25.4 \\
27.2 \\
25.2 \\
26.8 \\
25.6 \\
23.2\end{array}$ & $\begin{array}{l}21.0 \\
20.6 \\
21.6 \\
23.1 \\
22.6 \\
23.0 \\
23.3 \\
22.2\end{array}$ & $\begin{array}{l}25.2 \\
23.5 \\
25.4 \\
25.9 \\
25.1 \\
26.6 \\
25.6 \\
23.3\end{array}$ & $\begin{array}{l}21.0 \\
20.7 \\
21.6 \\
22.7 \\
22.3 \\
23.0 \\
23.2 \\
22.3\end{array}$ & $\begin{array}{l}26.0 \\
23.8 \\
25.6 \\
26.7 \\
25.1 \\
26.7 \\
25.5 \\
23.5\end{array}$ & $\begin{array}{l}20.9 \\
20.6 \\
21.5 \\
22.4 \\
22.2 \\
22.7 \\
23.2 \\
22.2\end{array}$ & $\begin{array}{l}27.4 \\
26.9 \\
26.6 \\
26.3 \\
25.9 \\
26.1 \\
25.9 \\
25.3\end{array}$ & & $\begin{array}{l}2.5 \\
2.5 \\
4.0 \\
5.0 \\
4.04 \\
3.7 \\
1.9 \\
1.02\end{array}$ & $\begin{array}{l}3.6 \\
3.3 \\
4.6 \\
7.0 \\
5.9 \\
4.5 \\
2.6 \\
1.8\end{array}$ & $\begin{array}{l}4.8 \\
4 \bullet 4 \\
5.6 \\
7.0 \\
4.7 \\
5.2 \\
3.2 \\
2.3\end{array}$ & $\begin{array}{l}6.4 \\
6.2 \\
6.7 \\
8.9 \\
6.2 \\
5.8 \\
3.8 \\
2.9\end{array}$ \\
\hline
\end{tabular}


Table 10. - Three-hour averages of air and water-surface temperatures and wind directions and speed, April 1950-August STATION 2

THREE-HOURLY AVERAGES AUGUST, 1951

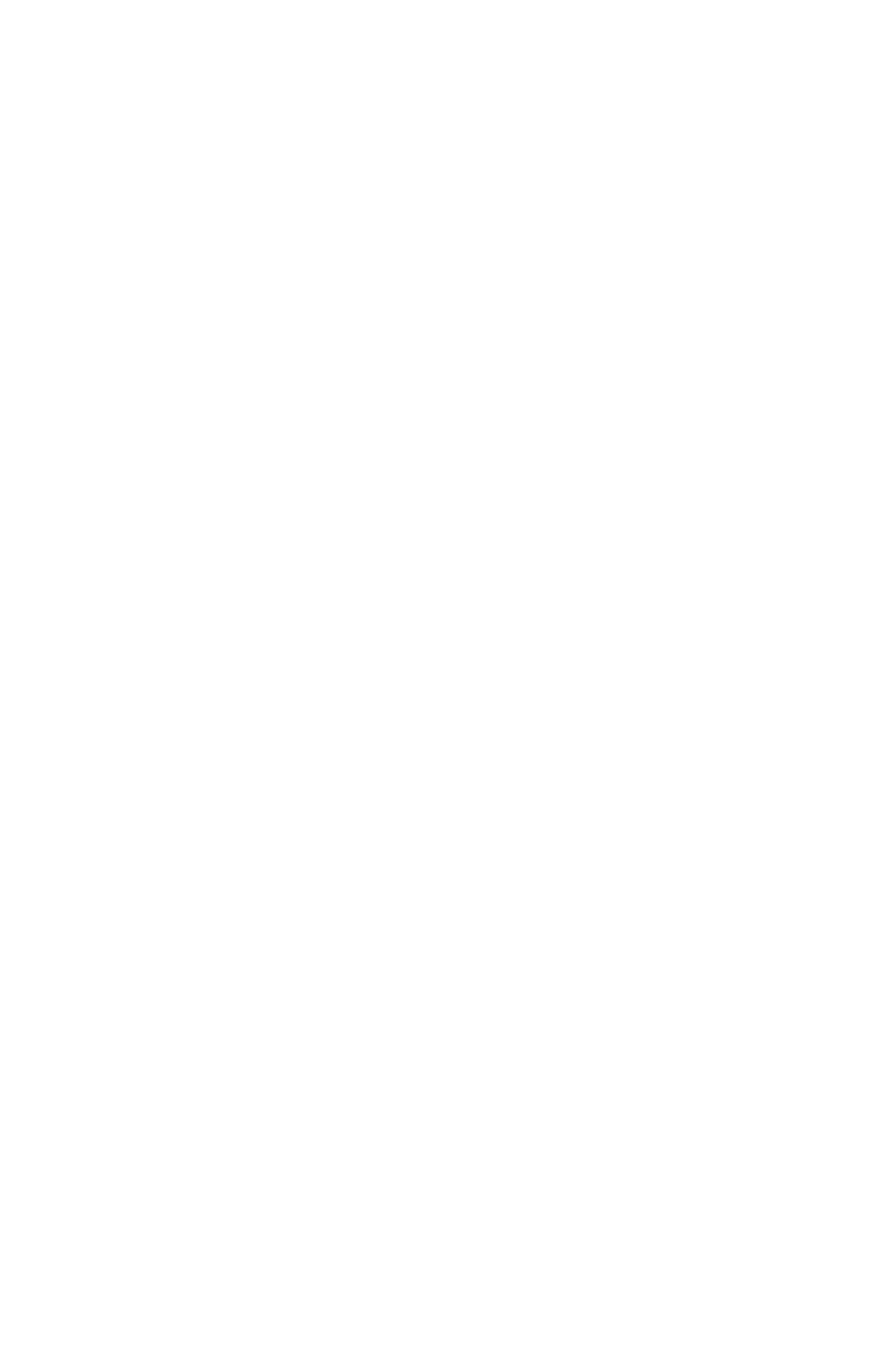


TABLE 10

123

Table 10.-Three-hour averages of air and water-surface temperatures and wind directions and speed, April 1950-August 1951, Lake Hefner-Continued

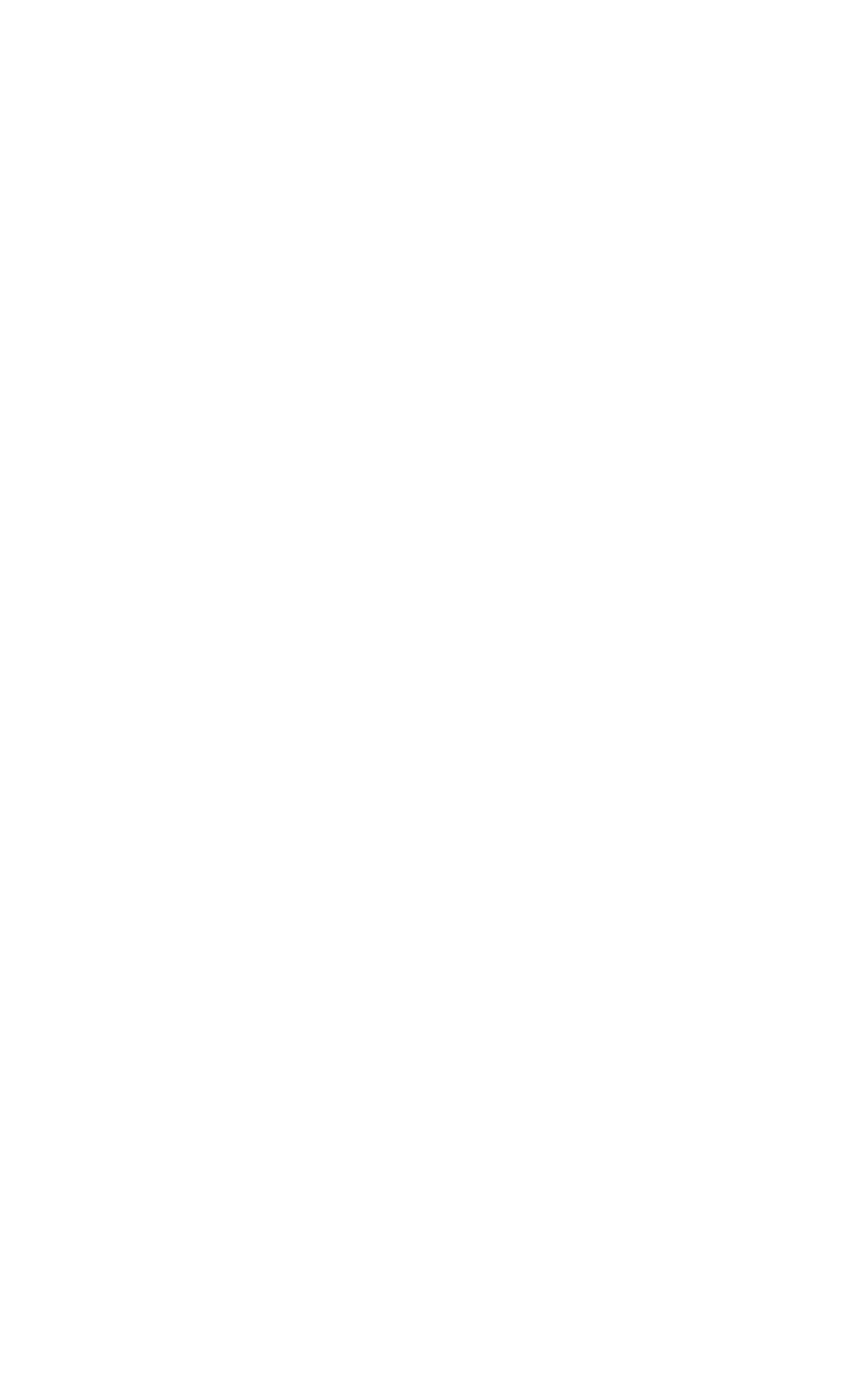


Table 10. -Three-hour averages of air and water-surface temperatures and wind directions and speed, April 1950-August 1951, Lake Hefner-Continued

\begin{tabular}{|c|c|c|c|c|c|c|c|c|c|c|c|c|c|c|c|}
\hline \multicolumn{2}{|c|}{ STATION } & 2 & & & & & THREE & -HOURL & -Y AVER & RAGES & & & & AUGUST, & - 2951 \\
\hline \multirow{4}{*}{ 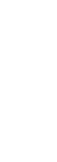 } & \multirow{4}{*}{ 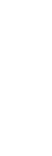 } & \multicolumn{8}{|c|}{ Average air temperature $\left({ }^{\circ} \mathrm{C}\right)$ at indicated height } & \multirow{4}{*}{$\begin{array}{l}\text { Average } \\
\text { water- } \\
\text { surface } \\
\text { tempera- } \\
\text { ture } \\
\text { (ㄷ) }\end{array}$} & \multirow{4}{*}{$\begin{array}{c}\text { Average } \\
\text { wind } \\
\text { direction } \\
\text { (coded) }\end{array}$} & \multirow{2}{*}{\multicolumn{4}{|c|}{$\begin{array}{l}\text { Average wind speed (knots) } \\
\text { at indicated height }\end{array}$}} \\
\hline & & \multirow{2}{*}{\multicolumn{2}{|c|}{$\begin{array}{c}2 \\
\text { meters }\end{array}$}} & \multirow{2}{*}{\multicolumn{2}{|c|}{$\begin{array}{c}4 \\
\text { meters }\end{array}$}} & \multirow{2}{*}{\multicolumn{2}{|c|}{$\begin{array}{c}8 \\
\text { meters }\end{array}$}} & \multirow{2}{*}{\multicolumn{2}{|c|}{$\begin{array}{c}16 \\
\text { meters }\end{array}$}} & & & & & & \\
\hline & & & & & & & & & & & & 2 & 4 & 8 & 16 \\
\hline & & $\begin{array}{l}\text { Dry } \\
\text { bulb }\end{array}$ & $\begin{array}{l}\text { Wet } \\
\text { bulb }\end{array}$ & $\begin{array}{l}\text { Dry } \\
\text { bulb }\end{array}$ & $\begin{array}{l}\text { Wet } \\
\text { bulb }\end{array}$ & $\begin{array}{l}\text { Dry } \\
\text { bulb }\end{array}$ & $\begin{array}{l}\text { Wet } \\
\text { bulb }\end{array}$ & $\begin{array}{l}\text { Dry } \\
\text { bulb }\end{array}$ & $\begin{array}{l}\text { Wet } \\
\text { bulb }\end{array}$ & & & meters & meters & & meters \\
\hline $\begin{array}{l}21 \\
21 \\
21 \\
21 \\
21 \\
21 \\
21 \\
21\end{array}$ & $\begin{array}{r}0 \\
3 \\
6 \\
9 \\
12 \\
15 \\
18 \\
21\end{array}$ & $\begin{array}{l}24.4 \\
23.4 \\
20.5 \\
19.9 \\
21.2 \\
23.0 \\
21.0 \\
19.5\end{array}$ & $\begin{array}{l}19.8 \\
20.9 \\
19.9 \\
19.4 \\
20.4 \\
20.7 \\
19.2 \\
17.7\end{array}$ & $\begin{array}{l}24.5 \\
23.2 \\
20.6 \\
20.0 \\
21.4 \\
22.8 \\
20.9 \\
19.5\end{array}$ & $\begin{array}{l}19.7 \\
20.8 \\
19.7 \\
19.3 \\
20.4 \\
20.7 \\
19.0 \\
17.6\end{array}$ & $\begin{array}{l}24.7 \\
23.3 \\
20.5 \\
19.9 \\
21.4 \\
22.6 \\
20.9 \\
19.4\end{array}$ & $\begin{array}{l}19.8 \\
20.7 \\
19.7 \\
19.3 \\
20.3 \\
20.6 \\
19.0 \\
17.5\end{array}$ & $\begin{array}{l}25.2 \\
23: 2 \\
20: 3 \\
19: 9 \\
21 \cdot 3 \\
22 \cdot 3 \\
20: 7 \\
19.3\end{array}$ & $\begin{array}{l}20.1 \\
20.9 \\
19.4 \\
19.3 \\
20.1 \\
20.3 \\
18.8 \\
17.5\end{array}$ & $\begin{array}{l}24.3 \\
24.4 \\
25.0 \\
24.0 \\
23.4 \\
23.8 \\
23.0 \\
22.6\end{array}$ & & $\begin{array}{l}2.09 \\
5.0 \\
5.8 \\
4.5 \\
5.0 \\
5.3 \\
5.2 \\
3.1\end{array}$ & $\begin{array}{l}4.3 \\
7.1 \\
7.4 \\
5.9 \\
5.9 \\
6.4 \\
6.7 \\
4.7\end{array}$ & $\begin{array}{l}5.9 \\
7.6 \\
9.0 \\
6.9 \\
7.3 \\
8.3 \\
8.3 \\
5.9\end{array}$ & $\begin{array}{r}8.4 \\
8.7 \\
12.0 \\
7.8 \\
9.4 \\
11.7 \\
10.9 \\
7.9\end{array}$ \\
\hline $\begin{array}{l}22 \\
22 \\
22 \\
22 \\
22 \\
22 \\
22 \\
22\end{array}$ & $\begin{array}{r}0 \\
3 \\
6 \\
9 \\
12 \\
15 \\
18 \\
21\end{array}$ & $\begin{array}{l}18.3 \\
18.0 \\
18.0 \\
18.3 \\
22.1 \\
22.7 \\
20.9 \\
19.9\end{array}$ & $\begin{array}{l}16.2 \\
15.4 \\
15.5 \\
17.0 \\
19.6 \\
20.5 \\
19.9 \\
19.7\end{array}$ & $\begin{array}{l}18.3 \\
18.0 \\
18.0 \\
18.7 \\
21.9 \\
22.4 \\
20.9 \\
20.0\end{array}$ & $\begin{array}{l}16.2 \\
15.2 \\
15.4 \\
16.6 \\
19.6 \\
20.3 \\
19.9 \\
19.8\end{array}$ & $\begin{array}{l}18.3 \\
18.1 \\
18.0 \\
18.7 \\
21.6 \\
22.3 \\
20.9 \\
20.0\end{array}$ & $\begin{array}{l}16.0 \\
15.1 \\
15.3 \\
16.6 \\
19.8 \\
20.1 \\
19.9 \\
19.8\end{array}$ & $\begin{array}{l}18.2 \\
18 \cdot 0 \\
18.0 \\
18.5 \\
21.4 \\
2202 \\
20.7 \\
20.0\end{array}$ & $\begin{array}{l}15.9 \\
15.1 \\
15.2 \\
16.7 \\
19.5 \\
20.2 \\
19.8 \\
19.7\end{array}$ & $\begin{array}{l}22.1 \\
21.7 \\
21.5 \\
22.1 \\
22.9 \\
23.5 \\
23.5 \\
23.4\end{array}$ & & $\begin{array}{l}2.8 \\
3.6 \\
3.3 \\
5.3 \\
3.3 \\
4.0 \\
3.6 \\
3.4\end{array}$ & $\begin{array}{l}3.0 \\
3.8 \\
3.7 \\
6.1 \\
3.7 \\
4.6 \\
4.4 \\
3.9\end{array}$ & $\begin{array}{l}3.8 \\
4.8 \\
4.5 \\
7.0 \\
4.02 \\
5.3 \\
5.7 \\
5.0\end{array}$ & $\begin{array}{l}5.2 \\
6.02 \\
5.9 \\
7.5 \\
4.6 \\
5.7 \\
6.7 \\
6.0\end{array}$ \\
\hline $\begin{array}{l}23 \\
23 \\
23 \\
23 \\
23 \\
23 \\
23 \\
23\end{array}$ & $\begin{array}{r}0 \\
3 \\
6 \\
9 \\
12 \\
15 \\
18 \\
21\end{array}$ & $\begin{array}{l}19.5 \\
19.4 \\
20.0 \\
21.6 \\
26.4 \\
28.0 \\
25.4 \\
23.9\end{array}$ & $\begin{array}{l}19.2 \\
19.3 \\
19.8 \\
20.7 \\
22.6 \\
23.0 \\
22.1 \\
21.5\end{array}$ & $\begin{array}{l}19.6 \\
19.7 \\
20.1 \\
21.8 \\
25.5 \\
27.7 \\
25.5 \\
24.3\end{array}$ & $\begin{array}{l}19 \cdot 1 \\
19.5 \\
19 \cdot 8 \\
20.7 \\
22.1 \\
22.5 \\
21.9 \\
21.5\end{array}$ & $\begin{array}{l}19.6 \\
19.8 \\
20.2 \\
21.7 \\
26.3 \\
27.7 \\
25.8 \\
24.4\end{array}$ & $\begin{array}{l}19.1 \\
19.5 \\
19.8 \\
20.6 \\
22.2 \\
22.4 \\
22.0 \\
21.7\end{array}$ & $\begin{array}{l}19.5 \\
19.8 \\
20.0 \\
2107 \\
25.6 \\
27.2 \\
2509 \\
24.4\end{array}$ & $\begin{array}{l}19.1 \\
19.4 \\
19.8 \\
20.5 \\
22.1 \\
22.5 \\
22.0 \\
21.6\end{array}$ & $\begin{array}{l}23.2 \\
22.4 \\
21.8 \\
20.5\end{array}$ & & $\begin{array}{l}3.9 \\
5.3 \\
4.5 \\
0.3 \\
7.4 \\
6.03 \\
3.0 \\
7.2\end{array}$ & $\begin{array}{l}4.7 \\
7.3 \\
6.1 \\
8.6 \\
8.6 \\
8.0 \\
5.3 \\
9.3\end{array}$ & $\begin{array}{r}5.7 \\
8.6 \\
7.0 \\
10.0 \\
9.6 \\
9.1 \\
6.7 \\
10.8\end{array}$ & $\begin{array}{r}6.7 \\
10.1 \\
8.1 \\
11.0 \\
10.5 \\
10.1 \\
8.4 \\
12.5\end{array}$ \\
\hline $\begin{array}{l}24 \\
24 \\
24 \\
24 \\
24 \\
24 \\
24 \\
24\end{array}$ & $\begin{array}{r}0 \\
3 \\
6 \\
9 \\
12 \\
15 \\
18 \\
21\end{array}$ & $\begin{array}{l}23.2 \\
21.6 \\
22.5 \\
27.2 \\
31.0 \\
31.7 \\
28.1 \\
26.4\end{array}$ & $\begin{array}{l}21.0 \\
20.4 \\
20.6 \\
22.3 \\
23.1 \\
22.8 \\
22.4 \\
21.5\end{array}$ & $\begin{array}{l}23.4 \\
21.8 \\
22.3 \\
27.1 \\
30.8 \\
31.8 \\
28.3 \\
26.5\end{array}$ & $\begin{array}{l}20.9 \\
20.4 \\
20.4 \\
22.1 \\
22.5 \\
22.6 \\
22.3 \\
21.5\end{array}$ & $\begin{array}{l}23.5 \\
21.9 \\
22.7 \\
27.0 \\
30.7 \\
31.5 \\
28.5 \\
26.5\end{array}$ & $\begin{array}{l}21.0 \\
20.5 \\
20.5 \\
22.0 \\
22.2 \\
22.5 \\
22.4 \\
21.5\end{array}$ & $\begin{array}{l}23.4 \\
21.9 \\
22.6 \\
26.6 \\
30.4 \\
31.0 \\
28.6 \\
25.6\end{array}$ & $\begin{array}{l}20.9 \\
20.4 \\
20.5 \\
21.8 \\
22 \cdot 4 \\
22 \cdot 2 \\
22.2 \\
21.4\end{array}$ & & & $\begin{array}{r}8.5 \\
8.1 \\
10.2 \\
10.4 \\
8.8 \\
8.2 \\
5.1 \\
8.2\end{array}$ & $\begin{array}{r}9.9 \\
9.6 \\
11.8 \\
12.2 \\
10.1 \\
9.5 \\
6.4 \\
9.7\end{array}$ & $\begin{array}{r}11.5 \\
11.0 \\
13.4 \\
13.4 \\
11.5 \\
10.7 \\
7.7 \\
11.4\end{array}$ & $\begin{array}{r}13.3 \\
12.7 \\
15.1 \\
14.8 \\
12.5 \\
11.9 \\
9.3 \\
12.9\end{array}$ \\
\hline $\begin{array}{l}25 \\
25 \\
25 \\
25 \\
25 \\
25 \\
25 \\
25\end{array}$ & $\begin{array}{r}0 \\
3 \\
6 \\
9 \\
12 \\
15 \\
18 \\
21\end{array}$ & $\begin{array}{l}24.4 \\
23.1 \\
24.0 \\
28.8 \\
32.2 \\
32.7 \\
28.5 \\
26.8\end{array}$ & $\begin{array}{l}20.8 \\
20.0 \\
20.0 \\
21.6 \\
22.8 \\
22.7 \\
22.1 \\
20.7\end{array}$ & $\begin{array}{l}24.5 \\
23.2 \\
24: 0 \\
28.6 \\
31.7 \\
32.4 \\
28.8 \\
27 \cdot 1\end{array}$ & $\begin{array}{l}20.7 \\
20.0 \\
19.8 \\
21.5 \\
22.4 \\
22.4 \\
21.9 \\
20.6\end{array}$ & $\begin{array}{l}24.7 \\
23.3 \\
24.1 \\
28.6 \\
31.5 \\
32.3 \\
29.1 \\
27.3\end{array}$ & $\begin{array}{l}20.7 \\
20.0 \\
19.8 \\
21.4 \\
22.4 \\
22.5 \\
22.0 \\
20.7\end{array}$ & $\begin{array}{l}24.5 \\
23.2 \\
24.0 \\
28.2 \\
31.2 \\
32.0 \\
29.5 \\
27.3\end{array}$ & $\begin{array}{l}20.6 \\
19.9 \\
19.7 \\
21.2 \\
22.0 \\
22.3 \\
21.9 \\
20.7\end{array}$ & & & $\begin{array}{r}8.7 \\
8.7 \\
11.3 \\
9.7 \\
10.1 \\
7.8 \\
3.2 \\
6.8\end{array}$ & $\begin{array}{r}10.3 \\
10.2 \\
13.3 \\
11.2 \\
11.6 \\
9.5 \\
4.7 \\
8.1\end{array}$ & $\begin{array}{r}11.8 \\
11.7 \\
15.1 \\
12.5 \\
13.4 \\
10.8 \\
6.0 \\
9.5\end{array}$ & $\begin{array}{r}13.6 \\
13.5 \\
16.9 \\
13.8 \\
14.8 \\
12.0 \\
7.6 \\
11.4\end{array}$ \\
\hline $\begin{array}{l}26 \\
26 \\
26 \\
26 \\
26 \\
26 \\
26 \\
26\end{array}$ & $\begin{array}{r}0 \\
3 \\
6 \\
9 \\
12 \\
15 \\
18 \\
21\end{array}$ & $\begin{array}{l}25 \cdot 2 \\
24 \cdot 1 \\
24 \cdot 3 \\
30 \cdot 0 \\
32 \cdot 9 \\
32 \cdot 7 \\
26 \cdot 3 \\
24 \cdot 8\end{array}$ & $\begin{array}{l}19.8 \\
19.3 \\
19.5 \\
21.8 \\
22.3 \\
22.2 \\
22.0 \\
21.3\end{array}$ & $\begin{array}{l}25.4 \\
24 \cdot 2 \\
24 \cdot 4 \\
29.9 \\
32.5 \\
32.5 \\
26.3 \\
25.0\end{array}$ & $\begin{array}{l}19.7 \\
19.2 \\
19.5 \\
21.6 \\
21.7 \\
21.9 \\
22.0 \\
21.2\end{array}$ & $\begin{array}{l}25.5 \\
24.3 \\
24.6 \\
29.8 \\
32.4 \\
32.5 \\
26.0 \\
25.4\end{array}$ & $\begin{array}{l}19.8 \\
19.3 \\
19.5 \\
21.3 \\
21.9 \\
21.8 \\
21.9 \\
21.3\end{array}$ & $\begin{array}{l}25.4 \\
24.2 \\
24.5 \\
29.4 \\
32.0 \\
32.2 \\
25.6 \\
25.7\end{array}$ & $\begin{array}{l}19.8 \\
19.3 \\
19.6 \\
21.3 \\
21.7 \\
21.8 \\
21.8 \\
21.1\end{array}$ & & & $\begin{array}{l}7.6 \\
8.6 \\
7.8 \\
8.3 \\
8.4 \\
5.4 \\
3.5 \\
4.7\end{array}$ & $\begin{array}{r}8.9 \\
10.4 \\
9.1 \\
9.5 \\
9.5 \\
6.4 \\
4.8 \\
5.9\end{array}$ & $\begin{array}{r}10.5 \\
11.6 \\
10.2 \\
10.8 \\
11.0 \\
7.4 \\
6.2 \\
7.2\end{array}$ & $\begin{array}{r}12.1 \\
13.4 \\
11.5 \\
11.8 \\
12.0 \\
8.2 \\
7.5 \\
9.3\end{array}$ \\
\hline $\begin{array}{l}27 \\
27 \\
27 \\
27 \\
27 \\
27 \\
27 \\
27\end{array}$ & $\begin{array}{r}0 \\
3 \\
6 \\
9 \\
12 \\
15 \\
18 \\
21\end{array}$ & $\begin{array}{l}25.1 \\
23.6 \\
25.2 \\
30.7 \\
33.9 \\
34.1 \\
30.1 \\
28.6\end{array}$ & $\begin{array}{l}19.8 \\
19.2 \\
19.7 \\
21.4 \\
21.9 \\
21.8 \\
20.7 \\
19.8\end{array}$ & $\begin{array}{l}25.2 \\
23.7 \\
25.3 \\
30.6 \\
33.7 \\
33.9 \\
30.4 \\
? 8.8\end{array}$ & $\begin{array}{l}19.8 \\
19.1 \\
19.6 \\
20.9 \\
21.4 \\
21.4 \\
20.7 \\
19.7\end{array}$ & $\begin{array}{l}25.3 \\
23.3 \\
25.5 \\
30.4 \\
33.5 \\
33.7 \\
30.6 \\
28.8\end{array}$ & $\begin{array}{l}29.8 \\
19.3 \\
19.7 \\
20.9 \\
21.3 \\
21.5 \\
20.8 \\
19.8\end{array}$ & $\begin{array}{l}25.3 \\
23.8 \\
25.4 \\
30.0 \\
32.8 \\
33.2 \\
30.5 \\
28.6\end{array}$ & \begin{tabular}{r|}
19.8 \\
19.3 \\
19.8 \\
21.1 \\
21.5 \\
21.5 \\
21.0 \\
20.0
\end{tabular} \mid & & & $\begin{array}{r}7.0 \\
7.4 \\
9.3 \\
10.8 \\
9.7 \\
9.4 \\
4.7 \\
10.1\end{array}$ & $\begin{array}{r}8.4 \\
8.8 \\
10.8 \\
12.2 \\
11.1 \\
10.9 \\
6.0 \\
11.8\end{array}$ & $\begin{array}{r}9.8 \\
10.2 \\
12.4 \\
14.0 \\
12.8 \\
12.4 \\
7.5 \\
13.5\end{array}$ & $\begin{array}{r}11.5 \\
12.2 \\
14.2 \\
15.4 \\
14.0 \\
13.8 \\
9.1 \\
15.5\end{array}$ \\
\hline $\begin{array}{l}28 \\
28 \\
28 \\
28 \\
28 \\
28 \\
28 \\
28\end{array}$ & $\begin{array}{r}0 \\
3 \\
6 \\
9 \\
12 \\
15 \\
18 \\
21\end{array}$ & $\begin{array}{l}26.5 \\
26.1 \\
26.8 \\
31.4 \\
35.0 \\
35.9 \\
32.1 \\
29.0\end{array}$ & $\begin{array}{l}18.5 \\
18.2 \\
19.3 \\
21.3 \\
22.2 \\
22.2 \\
21.1 \\
20.1\end{array}$ & $\begin{array}{l}26.5 \\
26.1 \\
26.8 \\
31.1 \\
34.8 \\
35.6 \\
32.0 \\
29.1\end{array}$ & $\begin{array}{l}18.5 \\
18.2 \\
19.2 \\
21.2 \\
21.9 \\
21.8 \\
21.0 \\
20.0\end{array}$ & $\begin{array}{l}26.7 \\
26.4 \\
26.9 \\
31.0 \\
34.7 \\
35.4 \\
32.1 \\
29.1\end{array}$ & $\begin{array}{l}18.6 \\
18: 3 \\
19 \cdot 2 \\
21 \cdot 3 \\
21.8 \\
21.9 \\
21.1 \\
20.1\end{array}$ & $\begin{array}{l}26.5 \\
26.3 \\
26.6 \\
30.6 \\
33.9 \\
34.9 \\
31.0 \\
28.8\end{array}$ & $\begin{array}{l}18.8 \\
18.6 \\
19.5 \\
21.3 \\
22.0 \\
22.1 \\
21.4 \\
20.4\end{array}$ & & & $\begin{array}{r}10.2 \\
9.0 \\
10.5 \\
11.8 \\
12.1 \\
11.6 \\
7.5 \\
10.7\end{array}$ & $\begin{array}{r}12.0 \\
10.7 \\
12.3 \\
13.9 \\
13.9 \\
13.4 \\
8.9 \\
12.5\end{array}$ & $\begin{array}{l}13.7 \\
12.3 \\
13.7 \\
15.9 \\
15.9 \\
15.3 \\
10.4 \\
14.3\end{array}$ & $\begin{array}{l}15.7 \\
14.1 \\
15.6 \\
17.6 \\
17.3 \\
17.1 \\
12.2 \\
16.2\end{array}$ \\
\hline $\begin{array}{l}29 \\
29 \\
29 \\
29 \\
29 \\
29 \\
29 \\
29\end{array}$ & $\begin{array}{r}0 \\
3 \\
6 \\
9 \\
12 \\
15 \\
18 \\
21\end{array}$ & $\begin{array}{l}26.9 \\
24.7 \\
26.5 \\
32.4 \\
36.0 \\
36.4 \\
31.3 \\
28.4\end{array}$ & $\begin{array}{l}18.6 \\
17.9 \\
19.1 \\
21.7 \\
22.5 \\
22.1 \\
21.1 \\
19.8\end{array}$ & $\begin{array}{l}27.0 \\
24.9 \\
26.4 \\
32.2 \\
35.6 \\
36.1 \\
31.5 \\
28.6\end{array}$ & $\begin{array}{l}18.5 \\
17.8 \\
19.0 \\
21.7 \\
22.2 \\
21.9 \\
21.1 \\
19.8\end{array}$ & $\begin{array}{l}27.0 \\
25.7 \\
26.7 \\
32.0 \\
35.3 \\
35.9 \\
31.7 \\
28.7\end{array}$ & $\begin{array}{l}21 \cdot 7 \\
22 \cdot 1 \\
21 \cdot 9 \\
21 \cdot ? \\
19 \cdot 8\end{array}$ & $\begin{array}{l}26.9 \\
25.2 \\
26.6 \\
31.3 \\
34.0 \\
35.4 \\
31.0 \\
28.7\end{array}$ & $\begin{array}{l}18.9 \\
18.2 \\
19.4 \\
21.4 \\
22.1 \\
21.9 \\
21.3 \\
19.9\end{array}$ & & & $\begin{array}{r}9.9 \\
8.4 \\
10.8 \\
11.5 \\
10.9 \\
9.4 \\
4.5 \\
8.4\end{array}$ & $\begin{array}{r}11.6 \\
9.9 \\
12.5 \\
13.2 \\
12.6 \\
10.9 \\
5.9 \\
10.0\end{array}$ & $\begin{array}{r}13.3 \\
11.6 \\
14.3 \\
15.2 \\
14.4 \\
12.6 \\
7.5 \\
11.5\end{array}$ & $\begin{array}{r}15.3 \\
13.8 \\
16.2 \\
16.7 \\
15.7 \\
13.7 \\
9.6 \\
13.4\end{array}$ \\
\hline $\begin{array}{l}30 \\
30 \\
30 \\
30 \\
30 \\
30 \\
30 \\
30\end{array}$ & $\begin{array}{r}0 \\
3 \\
6 \\
9 \\
12 \\
15 \\
18 \\
21\end{array}$ & $\begin{array}{l}25.7 \\
23.4 \\
25.5 \\
32.6 \\
36.2 \\
36.3 \\
31.1 \\
28.3\end{array}$ & $\begin{array}{l}18.9 \\
18.8 \\
19.7 \\
21.3 \\
22.1 \\
21.3 \\
20.6 \\
20.1\end{array}$ & $\begin{array}{l}25.9 \\
23.5 \\
25.6 \\
32.4 \\
36.1 \\
35 \cdot 9 \\
31.1 \\
28.3\end{array}$ & $\begin{array}{l}18.9 \\
18.8 \\
19.7 \\
21.2 \\
21.6 \\
21.0 \\
20.5 \\
20.0\end{array}$ & $\begin{array}{l}26.0 \\
23.7 \\
25.7 \\
32.4 \\
35.8 \\
35.8 \\
31.5 \\
28.4\end{array}$ & $\begin{array}{l}18.9 \\
18.8 \\
19.7 \\
21.1 \\
21.5 \\
21.1 \\
20.5 \\
20.1\end{array}$ & $\begin{array}{l}25.3 \\
23.8 \\
25.7 \\
31: 9 \\
34.9 \\
35.3 \\
31.6 \\
28.3\end{array}$ & $\begin{array}{l}19.0 \\
18.9 \\
19.8 \\
21.3 \\
21.3 \\
21.3 \\
21.0 \\
20.4\end{array}$ & & & $\begin{array}{r}7.5 \\
7.3 \\
9.3 \\
10.7 \\
10.6 \\
9.0 \\
5.0 \\
7.3\end{array}$ & $\begin{array}{r}8.8 \\
8.7 \\
10.8 \\
12.2 \\
12.2 \\
10.8 \\
6.3 \\
8.7\end{array}$ & $\begin{array}{r}10.3 \\
10.3 \\
12.3 \\
14.1 \\
13.7 \\
12.3 \\
7.9 \\
10.2\end{array}$ & $\begin{array}{l}12.3 \\
12.5 \\
14.1 \\
15.4 \\
15.0 \\
13.6 \\
10.2 \\
11.9\end{array}$ \\
\hline $\begin{array}{l}31 \\
31 \\
31 \\
31 \\
31 \\
31 \\
31 \\
31\end{array}$ & $\begin{array}{r}0 \\
3 \\
6 \\
9 \\
12 \\
15 \\
18 \\
21\end{array}$ & $\begin{array}{l}25.3 \\
23.0 \\
24.9 \\
32.3 \\
36.3 \\
36.7 \\
29.9 \\
76.9\end{array}$ & $\begin{array}{l}19.1 \\
18.5 \\
19.3 \\
21.3 \\
21.4 \\
21.1 \\
20.1 \\
19.2\end{array}$ & $\begin{array}{l}25.4 \\
23.1 \\
25.0 \\
32.1 \\
36.2 \\
36.3 \\
30.4 \\
27.6\end{array}$ & $\begin{array}{l}19.0 \\
18.4 \\
19.2 \\
21.0 \\
21.0 \\
20.9 \\
19.9 \\
19.0\end{array}$ & $\begin{array}{l}25.5 \\
23.3 \\
25.2 \\
31.8 \\
35.9 \\
36.1 \\
30.9 \\
28.5\end{array}$ & $\begin{array}{l}19.1 \\
18.5 \\
19.4 \\
20.9 \\
20.9 \\
20.8 \\
20.0 \\
19.4\end{array}$ & $\begin{array}{l}25 \cdot 5 \\
23.5 \\
25 \cdot 3 \\
31.6 \\
35 \cdot 3 \\
34 \cdot 6 \\
31.4 \\
29.0\end{array}$ & $\begin{array}{l}19.3 \\
18.6 \\
19.5 \\
21.2 \\
21.3 \\
21.2 \\
20.3 \\
19.8\end{array} \mid$ & & & $\begin{array}{l}7.4 \\
6.4 \\
8.6 \\
9.1 \\
8.2 \\
7.2 \\
2.6 \\
2.9\end{array}$ & $\begin{array}{r}8.9 \\
7.8 \\
10.0 \\
10.4 \\
9.4 \\
8.4 \\
4.2 \\
4.7\end{array}$ & $\begin{array}{r}10.4 \\
9.3 \\
11.5 \\
11.9 \\
10.7 \\
9.6 \\
5.5 \\
6.2\end{array}$ & $\begin{array}{r}12.5 \\
11.5 \\
13.3 \\
12.8 \\
11.5 \\
10.5 \\
7.4 \\
7.9\end{array}$ \\
\hline
\end{tabular}


TABLE 10

Table 10. - Three-hour averages of air and water-surface temperatures and wind directions and speed, April 1950-August 1951, Lake Hefner-Continued

STATION 3

THREE-HOURLY AVERAGES

APRIL, 1950

\begin{tabular}{|c|c|c|c|c|c|c|c|c|c|c|c|c|c|c|c|}
\hline \multirow{3}{*}{ 吉 } & \multirow{3}{*}{ 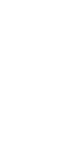 } & \multicolumn{8}{|c|}{ Average air temperature $\left({ }^{\circ} \mathrm{C}\right)$ at indicated height } & \multirow{3}{*}{\begin{tabular}{|c|} 
Average \\
water- \\
surface \\
tempera- \\
ture \\
$\left({ }^{\circ} \mathrm{C}\right)$
\end{tabular}} & \multirow{3}{*}{$\begin{array}{c}\text { Average } \\
\text { wind } \\
\text { direction } \\
\text { (coded) }\end{array}$} & \multirow{2}{*}{\multicolumn{4}{|c|}{$\begin{array}{l}\text { Average wind speed (knots) } \\
\text { at indicated height }\end{array}$}} \\
\hline & & \multicolumn{2}{|c|}{\begin{tabular}{c|}
2 \\
meters
\end{tabular}} & \multicolumn{2}{|c|}{$\begin{array}{c}4 \\
\text { meters }\end{array}$} & \multicolumn{2}{|c|}{$\begin{array}{c}8 \\
\text { meters }\end{array}$} & \multicolumn{2}{|c|}{$\begin{array}{c}16 \\
\text { meters }\end{array}$} & & & & & & \\
\hline & & $\begin{array}{l}\text { Dry } \\
\text { bulb }\end{array}$ & $\begin{array}{l}\text { Wet } \\
\text { bulb }\end{array}$ & $\begin{array}{l}\text { Dry } \\
\text { bulb }\end{array}$ & $\begin{array}{l}\text { Wet } \\
\text { bulb }\end{array}$ & $\begin{array}{l}\text { Dry } \\
\text { bulb }\end{array}$ & $\begin{array}{l}\text { Wet } \\
\text { bulb }\end{array}$ & $\begin{array}{l}\text { Dry } \\
\text { bulb }\end{array}$ & $\begin{array}{l}\text { Wet } \\
\text { bulb }\end{array}$ & & & $\begin{array}{c}2 \\
\text { meters }\end{array}$ & $\begin{array}{c}4 \\
\text { meters }\end{array}$ & $\begin{array}{c}8 \\
\text { meters }\end{array}$ & $\begin{array}{c}16 \\
\text { meters }\end{array}$ \\
\hline $\begin{array}{l}25 \\
25 \\
25 \\
25 \\
25 \\
25 \\
25 \\
25\end{array}$ & $\begin{array}{r}0 \\
3 \\
6 \\
9 \\
12 \\
15 \\
18 \\
21\end{array}$ & $\begin{array}{r}10.6 \\
8.2 \\
7.5 \\
11.6 \\
15.3 \\
16.9 \\
15.1 \\
11.8\end{array}$ & $\begin{array}{l}5.5 \\
3.9 \\
3.2 \\
4.8 \\
6.4 \\
7.1 \\
7.5 \\
6.5\end{array}$ & $\begin{array}{r}10.5 \\
8.2 \\
7.5 \\
11.0 \\
14.7 \\
16.5 \\
15.2 \\
11.7\end{array}$ & $\begin{array}{l}5.3 \\
3.8 \\
3.0 \\
4.02 \\
6.0 \\
6.9 \\
7.6 \\
6.2\end{array}$ & $\begin{array}{r}10.6 \\
8.13 \\
7.44 \\
10.7 \\
14.5 \\
16.4 \\
15.8 \\
12.0\end{array}$ & $\begin{array}{l}5.3 \\
3.7 \\
3.0 \\
4.0 \\
5,5 \\
6.5 \\
7.1 \\
6.1\end{array}$ & $\begin{array}{r}10.4 \\
7.9 \\
7.0 \\
10.5 \\
14.0 \\
16.1 \\
16.0 \\
12.3\end{array}$ & $\begin{array}{l}5.1 \\
3.6 \\
3.0 \\
4.0 \\
5.6 \\
6.6 \\
7.5 \\
5.8\end{array}$ & $\begin{array}{l}13.4 \\
13.1 \\
13.9 \\
14.9 \\
16.2 \\
16.9 \\
16.0 \\
14.9\end{array}$ & & $\begin{array}{r}11.4 \\
11.6 \\
6.8 \\
10.4 \\
10.0 \\
6.6 \\
2.02 \\
5.6\end{array}$ & $\begin{array}{r}12.8 \\
12.2 \\
7.4 \\
11.4 \\
11.2 \\
7.4 \\
2.4 \\
6.2\end{array}$ & $\begin{array}{r}13.6 \\
13.2 \\
8.0 \\
13.0 \\
12.4 \\
8.0 \\
2.6 \\
7.2\end{array}$ & $\begin{array}{l}8.2 \\
3.8 \\
0.6\end{array}$ \\
\hline $\begin{array}{l}26 \\
26 \\
26 \\
26 \\
26 \\
26 \\
26 \\
26\end{array}$ & $\begin{array}{r}0 \\
3 \\
6 \\
9 \\
12 \\
15 \\
18 \\
21\end{array}$ & $\begin{array}{l}10.9 \\
11.0 \\
11.8 \\
17.0 \\
20.1 \\
21.4 \\
19.9 \\
17.4\end{array}$ & $\begin{array}{r}5.9 \\
5.8 \\
6.2 \\
9.0 \\
11.1 \\
12.4 \\
11.8 \\
10.7\end{array}$ & $\begin{array}{l}13.1 \\
17.7 \\
19.8 \\
21.5 \\
20.3 \\
17.7\end{array}$ & $\begin{array}{r}9.9 \\
11.2 \\
12.2 \\
11.9 \\
10.8\end{array}$ & $\begin{array}{l}13.6 \\
17.6 \\
20.5 \\
22.3 \\
20.7 \\
18.0\end{array}$ & $\begin{array}{r}9.1 \\
10.9 \\
11.9 \\
11.8 \\
10.9\end{array}$ & $\begin{array}{l}10.9 \\
10.5 \\
12.2 \\
17.3 \\
20.6 \\
22.04 \\
20.9 \\
17.9\end{array}$ & $\begin{array}{r}5.4 \\
5.0 \\
6.0 \\
8.5 \\
10.6 \\
11.8 \\
11.7 \\
10.9\end{array}$ & $\begin{array}{l}14.2 \\
13.3 \\
13.4 \\
15.1 \\
16.4 \\
17.1 \\
16.0 \\
15.1\end{array}$ & & $\begin{array}{r}10.4 \\
13.6 \\
16.6 \\
21.6 \\
16.6 \\
13.2 \\
7.6 \\
8.0\end{array}$ & $\begin{array}{r}11.0 \\
14.2 \\
17.6 \\
22.6 \\
18.0 \\
14.4 \\
9.0 \\
9.0\end{array}$ & $\begin{array}{l}11.6 \\
15.0 \\
29.8 \\
24.8 \\
20.0 \\
16.2 \\
10.04 \\
10.2\end{array}$ & $\begin{array}{l}12.4 \\
15.6 \\
29.8 \\
26.4 \\
21.4 \\
17.0 \\
12.0 \\
11.8\end{array}$ \\
\hline $\begin{array}{l}27 \\
27 \\
27 \\
27 \\
27 \\
27 \\
27 \\
27\end{array}$ & $\begin{array}{r}0 \\
3 \\
6 \\
9 \\
12 \\
15 \\
18 \\
21\end{array}$ & $\begin{array}{r}16.4 \\
12.0 \\
9.9 \\
11.8 \\
14.0 \\
14.7 \\
13.7 \\
11.2\end{array}$ & $\begin{array}{r}10.8 \\
8.0 \\
4.1 \\
5.4 \\
7.6 \\
8.3 \\
7.7 \\
6.1\end{array}$ & $\begin{array}{r}16.4 \\
12.0 \\
9.9 \\
11.8 \\
13.7 \\
1407 \\
13.6 \\
11.1\end{array}$ & $\begin{array}{r}10.8 \\
7.8 \\
4.1 \\
5.5 \\
7.4 \\
8.2 \\
7.6 \\
6.0\end{array}$ & $\begin{array}{l}16.6 \\
11.9 \\
10.0 \\
11.8 \\
13.7 \\
14.7 \\
13.6 \\
11.2\end{array}$ & $\begin{array}{r}10.9 \\
7.6 \\
4.1 \\
5.4 \\
7.3 \\
8.2 \\
7.7 \\
6.0\end{array}$ & $\begin{array}{r}16.4 \\
11.87 \\
9.8 \\
11.6 \\
13.4 \\
14.03 \\
13.4 \\
10.9\end{array}$ & $\begin{array}{r}10.9 \\
7.5 \\
4.1 \\
5.5 \\
7.3 \\
8.3 \\
7.7 \\
6.1\end{array}$ & $\begin{array}{l}14.8 \\
14.2 \\
13.8 \\
13.8 \\
14.2 \\
14.2 \\
13.8 \\
13.5\end{array}$ & & $\begin{array}{r}6.0 \\
10.4 \\
14.4 \\
13.2 \\
12.0 \\
10.2 \\
8.4 \\
7.0\end{array}$ & $\begin{array}{r}6.6 \\
11.8 \\
16.0 \\
15.2 \\
13.4 \\
11.2 \\
9.2 \\
7.8\end{array}$ & $\begin{array}{r}8.0 \\
13.0 \\
17.8 \\
16.8 \\
14.6 \\
12.4 \\
10.2 \\
8.6\end{array}$ & $\begin{array}{r}8.6 \\
14.8 \\
19.8 \\
18.8 \\
16.6 \\
13.8 \\
12.0 \\
10.0\end{array}$ \\
\hline $\begin{array}{l}28 \\
28 \\
28 \\
28 \\
28 \\
28 \\
28 \\
28\end{array}$ & $\begin{array}{r}0 \\
3 \\
6 \\
9 \\
12 \\
15 \\
18 \\
21\end{array}$ & $\begin{array}{l}11.0 \\
11.5 \\
13.4 \\
17.3 \\
22.2 \\
22.6 \\
19.1 \\
19.9\end{array}$ & $\begin{array}{r}6.2 \\
7.11 \\
10.0 \\
17.02 \\
18.7 \\
18.5 \\
16.5 \\
17.5\end{array}$ & $\begin{array}{l}10.9 \\
11.05 \\
13.4 \\
17.4 \\
22.2 \\
22.0 \\
19.4 \\
20.0\end{array}$ & $\begin{array}{r}6.2 \\
7.0 \\
10.1 \\
17.3 \\
18.8 \\
18.7 \\
16.7 \\
17.5\end{array}$ & $\begin{array}{l}11.0 \\
11.06 \\
13.6 \\
17.06 \\
22.8 \\
24.0 \\
19.09 \\
20.02\end{array}$ & $\begin{array}{r}6.3 \\
7.1 \\
10.5 \\
17.6 \\
18.9 \\
19.2 \\
16.8 \\
17.5\end{array}$ & $\begin{array}{l}10.8 \\
11.3 \\
13.5 \\
17.8 \\
23.3 \\
24.3 \\
19.9 \\
20.0\end{array}$ & $\begin{array}{r}6.3 \\
7.2 \\
10.8 \\
17.6 \\
19.0 \\
19.3 \\
16.8 \\
17.2\end{array}$ & $\begin{array}{l}13.8 \\
13.7 \\
13.9 \\
12.7 \\
16.6 \\
16.5 \\
15.02 \\
14.6\end{array}$ & & $\begin{array}{r}4.8 \\
3.2 \\
4.6 \\
8.8 \\
17.0 \\
8.6 \\
8.0 \\
11.0\end{array}$ & $\begin{array}{r}5.2 \\
3.8 \\
4.8 \\
9.6 \\
18.2 \\
9.6 \\
9.0 \\
12.4\end{array}$ & $\begin{array}{r}6.4 \\
4.4 \\
5.6 \\
10.6 \\
20.4 \\
10.8 \\
10.4 \\
13.8\end{array}$ & $\begin{array}{r}6.8 \\
5.2 \\
6.0 \\
11.6 \\
21.8 \\
12.6 \\
12.2 \\
15.6\end{array}$ \\
\hline $\begin{array}{l}29 \\
29 \\
29 \\
29 \\
29 \\
29 \\
29 \\
29\end{array}$ & $\begin{array}{r}0 \\
3 \\
6 \\
9 \\
12 \\
15 \\
18 \\
21\end{array}$ & $\begin{array}{r}17.1 \\
16.5 \\
17.8 \\
18.9 \\
12.0 \\
10.3 \\
10.6 \\
8.6\end{array}$ & $\begin{array}{r}14.1 \\
13.08 \\
15.7 \\
16.2 \\
10.0 \\
8.02 \\
7.9 \\
6.2\end{array}$ & $\begin{array}{r}17.3 \\
16.6 \\
18.0 \\
18.9 \\
11.5 \\
10.1 \\
10.5 \\
8.4\end{array}$ & $\begin{array}{r}14.1 \\
13.8 \\
15.9 \\
16.2 \\
9.4 \\
8.0 \\
7.8 \\
6.1\end{array}$ & $\begin{array}{r}17.0 \\
16.9 \\
18.3 \\
19.1 \\
11.1 \\
10.1 \\
10.4 \\
8.3\end{array}$ & $\begin{array}{r}14.1 \\
13.9 \\
16.0 \\
16.4 \\
9.3 \\
8.0 \\
7.7 \\
6.0\end{array}$ & $\begin{array}{r}17.3 \\
16.7 \\
18.3 \\
19.0 \\
10.8 \\
9.8 \\
10.2 \\
8.0\end{array}$ & $\begin{array}{r}13.9 \\
13.9 \\
15.9 \\
15.0 \\
8.9 \\
7.8 \\
7.6 \\
5.8\end{array}$ & $\begin{array}{l}14.6 \\
14.5 \\
14.7 \\
15.4 \\
15.3 \\
14.7 \\
14.1 \\
13.2\end{array}$ & & $\begin{array}{r}9.4 \\
12.4 \\
14.8 \\
11.8 \\
15.0 \\
18.0\end{array}$ & $\begin{array}{l}10.6 \\
13.6 \\
16.0 \\
13.2 \\
17.2 \\
20.0\end{array}$ & $\begin{array}{l}11.6 \\
14.8 \\
17.4 \\
13.8 \\
20.2 \\
21.4\end{array}$ & $\begin{array}{l}13.2 \\
16.8 \\
19.0 \\
16.4\end{array}$ \\
\hline $\begin{array}{l}30 \\
30 \\
30 \\
30 \\
30 \\
30 \\
30 \\
30\end{array}$ & $\begin{array}{r}0 \\
3 \\
6 \\
9 \\
12 \\
15 \\
18 \\
21\end{array}$ & $\begin{array}{r}6.3 \\
4.8 \\
4.2 \\
7.6 \\
11.9 \\
14.6 \\
13.0 \\
11.1\end{array}$ & $\begin{array}{l}4.4 \\
3.0 \\
2.4 \\
4.3 \\
7.2 \\
9.1 \\
8.8 \\
8.3\end{array}$ & $\begin{array}{r}6.2 \\
4.6 \\
4.0 \\
7.5 \\
11.6 \\
14.6 \\
12.9 \\
11.1\end{array}$ & $\begin{array}{l}4.2 \\
2.9 \\
2.2 \\
4.1 \\
6.9 \\
8.9 \\
8.8 \\
8.2\end{array}$ & $\begin{array}{r}6.0 \\
4.6 \\
4.0 \\
7.02 \\
11.6 \\
14.5 \\
12.9 \\
11.1\end{array}$ & $\begin{array}{l}4.2 \\
2.9 \\
2.2 \\
4.4 \\
7.0 \\
8.09 \\
8.9 \\
8.3\end{array}$ & $\begin{array}{r}5.7 \\
4.83 \\
3.8 \\
7.8 \\
11.4 \\
14.11 \\
12.8 \\
10.5\end{array}$ & $\begin{array}{l}3.9 \\
2.5 \\
2.1 \\
4.4 \\
7.0 \\
8.9 \\
8.9 \\
8.3\end{array}$ & $\begin{array}{l}12.7 \\
12.0 \\
11.9 \\
13.0 \\
13.9 \\
14.2 \\
13.7 \\
13.2\end{array}$ & & $\begin{array}{l}9.2 \\
7.8 \\
6.2 \\
5.2 \\
5.0\end{array}$ & $\begin{array}{r}10.6 \\
8.6 \\
7.0 \\
7.0 \\
5.8\end{array}$ & $\begin{array}{r}11.8 \\
9.6 \\
7.6 \\
8.2 \\
6.8\end{array}$ & $\begin{array}{r}12.4 \\
10.6 \\
8.0 \\
9.4 \\
7.8\end{array}$ \\
\hline
\end{tabular}


Table 10. - Three-hour averages of air and water-surface temperatures and wind directions and speed, April 1950-August 1951. Lake Hefner Continued

STATION

THREE-HOURLY AVERAGES

MAY, 1950

\begin{tabular}{|c|c|c|c|c|c|c|c|c|c|c|c|c|c|c|c|}
\hline \multirow{4}{*}{ 䓛 } & \multirow{4}{*}{ 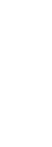 } & \multicolumn{8}{|c|}{ Average air temperature $\left({ }^{\circ} \mathrm{C}\right)$ at indicated height } & \multirow{4}{*}{$\begin{array}{l}\text { Average } \\
\text { water- } \\
\text { surface } \\
\text { tempera- } \\
\text { ture } \\
\text { ("C) }\end{array}$} & \multirow{4}{*}{$\begin{array}{c}\text { Average } \\
\text { wind } \\
\text { direction } \\
\text { (coded) }\end{array}$} & \multirow{2}{*}{\multicolumn{4}{|c|}{$\begin{array}{l}\text { Average wind speed (knots) } \\
\text { at indicated height }\end{array}$}} \\
\hline & & \multirow{2}{*}{\multicolumn{2}{|c|}{$\begin{array}{c}2 \\
\text { meters }\end{array}$}} & \multirow{2}{*}{\multicolumn{2}{|c|}{$\begin{array}{c}4 \\
\text { meters }\end{array}$}} & \multirow{2}{*}{\multicolumn{2}{|c|}{$\begin{array}{c}8 \\
\text { meters }\end{array}$}} & \multirow{2}{*}{\multicolumn{2}{|c|}{$\begin{array}{c}16 \\
\text { meters }\end{array}$}} & & & & & & \\
\hline & & & & & & & & & & & & 2 & 4 & 8 & 16 \\
\hline & & $\begin{array}{l}\text { Dry } \\
\text { bulb }\end{array}$ & $\begin{array}{l}\text { Wet } \\
\text { bulb }\end{array}$ & $\begin{array}{l}\text { Dry } \\
\text { bulb }\end{array}$ & $\begin{array}{l}\text { Wet } \\
\text { bulb }\end{array}$ & $\begin{array}{l}\text { Dry } \\
\text { bulb }\end{array}$ & $\begin{array}{l}\text { Wet } \\
\text { bulb }\end{array}$ & $\begin{array}{l}\text { Dry } \\
\text { bulb }\end{array}$ & $\begin{array}{l}\text { Wet } \\
\text { bulb }\end{array}$ & & & & & & \\
\hline
\end{tabular}

\begin{tabular}{|c|c|c|c|c|c|c|c|c|c|c|c|c|c|c|}
\hline $\begin{array}{l}1 \\
1 \\
1 \\
1 \\
1\end{array}$ & $\begin{array}{r}0 \\
3 \\
6 \\
9 \\
12 \\
15 \\
18 \\
21\end{array}$ & $\begin{array}{r}10.3 \\
9.8 \\
9.6 \\
12.7 \\
14.7 \\
15.7 \\
14.2 \\
13.1\end{array}$ & $\begin{array}{r}8.1 \\
8.1 \\
7.5 \\
9.4 \\
11.6 \\
12.6 \\
12.0 \\
12.1\end{array}$ & $\begin{array}{r}10.2 \\
9.8 \\
9.4 \\
12.4 \\
14.6 \\
15.6 \\
14.2 \\
13.1\end{array}$ & $\begin{array}{r}8.1 \\
8.1 \\
7.4 \\
9.2 \\
11.4 \\
12.4 \\
12.0 \\
12.2\end{array}$ & $\begin{array}{r}10.3 \\
9.9 \\
9.5 \\
12.2 \\
14.4 \\
15.6 \\
14.2 \\
13.2\end{array}$ & $\begin{array}{r}8.2 \\
8.1 \\
7.4 \\
9.3 \\
11.3 \\
12.5 \\
12.0 \\
12.1\end{array}$ & $\begin{array}{r}10.1 \\
9.6 \\
9.2 \\
12.1 \\
1401 \\
15.1 \\
24.0 \\
13.0\end{array}$ & $\begin{array}{r}8.1 \\
8.0 \\
7.3 \\
9.3 \\
11.3 \\
12.4 \\
12.0 \\
12.2\end{array}$ & $\begin{array}{l}13.2 \\
12.9 \\
13.1 \\
14.1 \\
14.5 \\
14.3 \\
13.6 \\
13.1\end{array}$ & $\begin{array}{l}5.4 \\
6.2 \\
6.8 \\
4.8 \\
5.4 \\
4.6 \\
5.8 \\
3.4\end{array}$ & $\begin{array}{l}6.2 \\
6.4 \\
6.8 \\
5.2 \\
5.8 \\
5.0 \\
5.8 \\
3.6\end{array}$ & $\begin{array}{l}6.4 \\
7.6 \\
7.8 \\
5.6 \\
6.4 \\
5.06 \\
7.0 \\
4.02\end{array}$ & $\begin{array}{l}8.4 \\
9.2 \\
9.2 \\
7.0 \\
7.4 \\
7.2 \\
8.6 \\
5.6\end{array}$ \\
\hline $\begin{array}{l}2 \\
2 \\
2 \\
2 \\
2 \\
2 \\
2 \\
2\end{array}$ & $\begin{array}{r}0 \\
3 \\
6 \\
9 \\
12 \\
15 \\
18 \\
21\end{array}$ & $\begin{array}{l}11.7 \\
10.9 \\
11.3 \\
15.0 \\
19.6 \\
22.0 \\
21.3 \\
19.9\end{array}$ & $\begin{array}{l}11.3 \\
10.9 \\
11.2 \\
13.3 \\
15.6 \\
16.7 \\
17.6 \\
18.3\end{array}$ & $\begin{array}{l}12.7 \\
10.9 \\
11.3 \\
14.7 \\
19.4 \\
21.9 \\
21.5 \\
20.0\end{array}$ & $\begin{array}{l}11.3 \\
10.9 \\
11.3 \\
13.4 \\
15.5 \\
16.6 \\
17.7 \\
18.5\end{array}$ & $\begin{array}{l}11.7 \\
10.9 \\
11.4 \\
14.9 \\
19.8 \\
22.5 \\
21.9 \\
20.3\end{array}$ & $\begin{array}{l}11.4 \\
20.9 \\
11.4 \\
13.4 \\
15.7 \\
16.9 \\
17.8 \\
18.7\end{array}$ & $\begin{array}{l}12.7 \\
10.8 \\
11.4 \\
14.0 \\
19.9 \\
22.7 \\
21.9 \\
20.4\end{array}$ & $\begin{array}{l}11.2 \\
10.8 \\
11.3 \\
13.4 \\
15.6 \\
17.7 \\
17.8 \\
18.8\end{array}$ & $\begin{array}{r}12.7 \\
10.5 \\
9.7 \\
14.2 \\
16.4 \\
17.3 \\
16.3 \\
15.8\end{array}$ & $\begin{array}{r}3.8 \\
3.4 \\
6.6 \\
14.4 \\
16.2 \\
16.6 \\
16.4 \\
22.6\end{array}$ & $\begin{array}{r}4.2 \\
3.6 \\
7.4 \\
15.4 \\
17.6 \\
18.0 \\
17.5 \\
24.2\end{array}$ & $\begin{array}{r}5.2 \\
4.2 \\
8.0 \\
16.8 \\
19.2 \\
19.8 \\
19.8 \\
25.6\end{array}$ & $\begin{array}{r}4.8 \\
4.2 \\
8.6 \\
17.8 \\
20.6 \\
22.0 \\
21.6 \\
28.6\end{array}$ \\
\hline $\begin{array}{l}3 \\
3 \\
3 \\
3 \\
3 \\
3 \\
3 \\
3 \\
3\end{array}$ & $\begin{array}{r}0 \\
3 \\
6 \\
9 \\
12 \\
15 \\
18 \\
21\end{array}$ & $\begin{array}{l}20.1 \\
20.4 \\
21.07 \\
24.02 \\
27.5 \\
27.09 \\
24.9 \\
22.8\end{array}$ & $\begin{array}{l}19.0 \\
19.4 \\
19.8 \\
19.9 \\
19.2 \\
20.7 \\
21.7 \\
20.6\end{array}$ & $\begin{array}{l}19.9 \\
20.4 \\
21.9 \\
24.6 \\
27.8 \\
28.3 \\
24.6 \\
22.9\end{array}$ & $\begin{array}{l}29.1 \\
19.5 \\
20.0 \\
20.0 \\
28.8 \\
20.9 \\
21.7 \\
20.7\end{array}$ & $\begin{array}{l}20.3 \\
21.0 \\
22.6 \\
25.3 \\
29.1 \\
29.2 \\
25.2 \\
23.3\end{array}$ & $\begin{array}{l}19.4 \\
19.9 \\
20.2 \\
20.2 \\
19.2 \\
21.3 \\
21.7 \\
20.8\end{array}$ & $\begin{array}{l}20.5 \\
21.1 \\
22.8 \\
25.8 \\
29.7 \\
29.5 \\
25.2 \\
23.2\end{array}$ & $\begin{array}{l}19.6 \\
20.0 \\
20.4 \\
20.3 \\
19.3 \\
21.2 \\
21.7 \\
20.9\end{array}$ & $\begin{array}{l}15.6 \\
15.5 \\
16.4 \\
17.6 \\
19.3 \\
19.9 \\
19.3 \\
18.5\end{array}$ & $\begin{array}{l}20.8 \\
18.6 \\
22.6 \\
24.0 \\
20.0 \\
18.4 \\
19.0 \\
19.4\end{array}$ & $\begin{array}{l}22.4 \\
20.0 \\
24.2 \\
26.0 \\
21.6 \\
20.0 \\
20.6 \\
21.0\end{array}$ & $\begin{array}{l}25.0 \\
22.4 \\
27.2 \\
29.4 \\
25.0 \\
23.0 \\
23.0 \\
23.2\end{array}$ & $\begin{array}{l}26.8 \\
24.0 \\
29.0 \\
32.0 \\
26.4 \\
24.0 \\
25.0 \\
25.0\end{array}$ \\
\hline $\begin{array}{l}4 \\
4 \\
4 \\
4 \\
4 \\
4 \\
4 \\
4\end{array}$ & $\begin{array}{r}0 \\
3 \\
6 \\
9 \\
12 \\
15 \\
18 \\
21\end{array}$ & $\begin{array}{l}21.8 \\
21.1 \\
21.9 \\
23.3 \\
24.8 \\
24.5 \\
24.3 \\
23.7\end{array}$ & $\begin{array}{l}20.4 \\
20.2 \\
20.6 \\
20.6 \\
21.0 \\
21.0 \\
20.9 \\
20.0\end{array}$ & $\begin{array}{l}21.6 \\
21.3 \\
22 \cdot 0 \\
23.4 \\
24 \cdot 8 \\
24 \cdot 8 \\
24 \cdot 4 \\
23.6\end{array}$ & $\begin{array}{l}20.5 \\
20.4 \\
20.7 \\
20.7 \\
21.0 \\
21.0 \\
20.8 \\
20.0\end{array}$ & $\begin{array}{l}22.1 \\
21.8 \\
32.6 \\
23.8 \\
25.2 \\
25.1 \\
24.7 \\
24.2\end{array}$ & $\begin{array}{l}20.8 \\
20.7 \\
20.9 \\
20.7 \\
21.1 \\
21.0 \\
20.8 \\
20.0\end{array}$ & $\begin{array}{l}22.3 \\
21.9 \\
22.7 \\
23.0 \\
25.3 \\
25.2 \\
24.0 \\
24.0\end{array}$ & $\begin{array}{l}20.9 \\
20.9 \\
21.0 \\
20.8 \\
21.3 \\
21.1 \\
20.9 \\
20.1\end{array}$ & $\begin{array}{l}17.7 \\
17.0 \\
17.3 \\
19.3 \\
19.8 \\
19.4 \\
18.7 \\
18.4\end{array}$ & $\begin{array}{l}18.2 \\
14.8 \\
16.4 \\
17.6 \\
18.0 \\
21.2 \\
23.6 \\
28.6\end{array}$ & $\begin{array}{l}19.8 \\
16.0 \\
17.6 \\
18.8 \\
19.6 \\
23.0 \\
25.6 \\
30.6\end{array}$ & $\begin{array}{l}22.6 \\
18.0 \\
18.8 \\
21.2 \\
22.0 \\
25.4 \\
28.0 \\
33.6\end{array}$ & $\begin{array}{l}24.0 \\
19.6 \\
21.2 \\
23.0 \\
23.6 \\
28.0 \\
30.4 \\
36.0\end{array}$ \\
\hline $\begin{array}{l}5 \\
5 \\
5 \\
5 \\
5 \\
5 \\
5 \\
5 \\
5\end{array}$ & $\begin{array}{r}0 \\
3 \\
6 \\
9 \\
12 \\
15 \\
18 \\
21\end{array}$ & $\begin{array}{l}18.3 \\
16.4 \\
24.9 \\
16.0 \\
19.6 \\
21.2 \\
17.4 \\
13.7\end{array}$ & $\begin{array}{r}13.7 \\
9.4 \\
8.8 \\
9.2 \\
9.7 \\
10.0 \\
8.7 \\
7.3\end{array}$ & $\begin{array}{l}17.6 \\
15.3 \\
14.8 \\
15.4 \\
19.1 \\
21.1 \\
17.7 \\
14.2\end{array}$ & $\begin{array}{l}8.3 \\
9.2 \\
9.4 \\
8.5 \\
7.5\end{array}$ & $\begin{array}{l}17.7 \\
16.3 \\
14.7 \\
15.4 \\
18.7 \\
20.9 \\
18.5 \\
14.9\end{array}$ & $\begin{array}{r}12.8 \\
8.4 \\
8.1 \\
7.9 \\
8.8 \\
9.5 \\
8.9 \\
7.7\end{array}$ & $\begin{array}{l}17.2 \\
16.0 \\
14.4 \\
15.1 \\
18.5 \\
20.6 \\
18.0 \\
15.4\end{array}$ & $\begin{array}{r}12.5 \\
8.2 \\
8.9 \\
7.6 \\
8.3 \\
9.4 \\
9.1 \\
7.9\end{array}$ & $\begin{array}{l}17.0 \\
16.5\end{array}$ & $\begin{array}{r}18.6 \\
21.8 \\
20.2 \\
14.0 \\
10.8 \\
5.4 \\
3.8 \\
5.0\end{array}$ & $\begin{array}{r}29.8 \\
23.4 \\
21.4 \\
16.2 \\
13.0 \\
5.6 \\
5.2 \\
6.0\end{array}$ & $\begin{array}{r}22.0 \\
26.2 \\
24.0 \\
14.6 \\
13.0 \\
6.6 \\
6.8 \\
8.0\end{array}$ & $\begin{array}{r}22.8 \\
27.0 \\
24.6 \\
21.4 \\
17.4 \\
6.4 \\
7.4 \\
9.2\end{array}$ \\
\hline $\begin{array}{l}6 \\
6 \\
6 \\
6 \\
6 \\
5 \\
6 \\
6\end{array}$ & $\begin{array}{r}0 \\
3 \\
6 \\
9 \\
12 \\
15 \\
18 \\
21\end{array}$ & $\begin{array}{l}14.1 \\
13.2 \\
14.9 \\
20.4 \\
25.2 \\
25.7 \\
21.2 \\
17.2\end{array}$ & $\begin{array}{r}8.1 \\
8.0 \\
9.3 \\
12.4 \\
14.3 \\
14.8 \\
15.2 \\
15.6\end{array}$ & $\begin{array}{l}14.3 \\
13.6 \\
25.0 \\
20.3 \\
24.8 \\
25.4 \\
21.1 \\
17.3\end{array}$ & $\begin{array}{r}8.0 \\
7.9 \\
9.3 \\
12.0 \\
13.7 \\
14.5 \\
15.1 \\
15.5\end{array}$ & $\begin{array}{l}14.6 \\
13.8 \\
15.2 \\
20.8 \\
25.3 \\
25.5 \\
21.2 \\
17.4\end{array}$ & $\begin{array}{r}7.9 \\
8.0 \\
9.2 \\
12.0 \\
13.5 \\
14.4 \\
25.2 \\
15.8\end{array}$ & $\begin{array}{l}14.8 \\
13.8 \\
15.2 \\
20.7 \\
24.9 \\
25.2 \\
21.0 \\
17.4\end{array}$ & $\begin{array}{r}8.0 \\
8.0 \\
9.2 \\
11.7 \\
13.6 \\
14.3 \\
15.3 \\
15.7\end{array}$ & $\begin{array}{l}18.2 \\
20.0 \\
19.1 \\
17.5 \\
17.1\end{array}$ & $\begin{array}{r}6.6 \\
7.44 \\
10.2 \\
10.8 \\
7.0 \\
10.5 \\
8.4 \\
5.6\end{array}$ & $\begin{array}{r}7.6 \\
8.4 \\
10.8 \\
11.6 \\
7.4 \\
12.0 \\
9.6 \\
6.4\end{array}$ & $\begin{array}{r}8.6 \\
9.4 \\
12.6 \\
12.6 \\
8.2 \\
13.0 \\
10.8 \\
7.4\end{array}$ & $\begin{array}{r}10.0 \\
11.5 \\
13.2 \\
13.4 \\
9.2 \\
14.4 \\
12.6 \\
8.8\end{array}$ \\
\hline $\begin{array}{l}7 \\
7 \\
7 \\
7 \\
7 \\
7 \\
7 \\
7\end{array}$ & $\begin{array}{r}0 \\
3 \\
6 \\
9 \\
12 \\
15 \\
18 \\
21\end{array}$ & $\begin{array}{l}17.1 \\
17.7 \\
18.8 \\
21.8 \\
22.3 \\
23.7 \\
22.3 \\
22.5\end{array}$ & $\begin{array}{l}16.1 \\
17.0 \\
18.5 \\
20.1 \\
20.9 \\
21.7 \\
21.1 \\
20.5\end{array}$ & $\begin{array}{l}17.2 \\
17: 7 \\
19.0 \\
22.8 \\
22.7 \\
23.5 \\
22.4 \\
22.6\end{array}$ & $\begin{array}{l}16.0 \\
17.0 \\
18.5 \\
20.1 \\
20.8 \\
21.4 \\
21.0 \\
20.3\end{array}$ & $\begin{array}{l}17.3 \\
17.8 \\
19.1 \\
22.2 \\
22.9 \\
23.4 \\
22.5 \\
23.0\end{array}$ & $\begin{array}{l}16.2 \\
17.2 \\
18.9 \\
20.4 \\
21.2 \\
21.7 \\
21.5 \\
20.7\end{array}$ & $\begin{array}{l}17.2 \\
27.7 \\
19.8 \\
22.1 \\
22.9 \\
23.0 \\
22.5 \\
22.8\end{array}$ & $\begin{array}{l}16.2 \\
17.3 \\
18.8 \\
20.1 \\
20.8 \\
21.0 \\
21.0 \\
20.1\end{array}$ & $\begin{array}{l}16.6 \\
16.4\end{array}$ & $\begin{array}{r}6.8 \\
8.0 \\
7.6 \\
8.0 \\
6.8 \\
10.8 \\
10.2 \\
18.2\end{array}$ & $\begin{array}{r}7.8 \\
8.8 \\
8.6 \\
8.8 \\
7.6 \\
12.4 \\
11.8 \\
20.0\end{array}$ & $\begin{array}{r}8.8 \\
9.8 \\
9.2 \\
9.8 \\
8.4 \\
13.4 \\
13.4 \\
22.0\end{array}$ & $\begin{array}{r}10.2 \\
11.2 \\
10.6 \\
11.0 \\
9.8 \\
15.6 \\
15.2 \\
24.2\end{array}$ \\
\hline $\begin{array}{l}8 \\
8 \\
8 \\
8 \\
8 \\
8 \\
8 \\
8\end{array}$ & $\begin{array}{r}0 \\
3 \\
5 \\
9 \\
12 \\
15 \\
18 \\
21\end{array}$ & $\begin{array}{l}22.1 \\
20.3 \\
20.3 \\
22.8 \\
24.0 \\
25.4 \\
24.2 \\
22.6\end{array}$ & $\begin{array}{l}19.6 \\
18.5 \\
18.8 \\
19.9 \\
20.3 \\
20.9 \\
20.3 \\
19.2\end{array}$ & $\begin{array}{l}22.0 \\
20.5 \\
20.5 \\
22.8 \\
24.3 \\
25.4 \\
24,3 \\
22.7\end{array}$ & $\begin{array}{l}19.5 \\
18.5 \\
18.9 \\
19.9 \\
20.2 \\
20.9 \\
20.3 \\
19.1\end{array}$ & $\begin{array}{l}22.3 \\
20.6 \\
20.7 \\
23.2 \\
24.5 \\
25.8 \\
24.6 \\
23.0\end{array}$ & $\begin{array}{l}19.9 \\
19.0 \\
19.4 \\
20.1 \\
20.7 \\
22.2 \\
20.5 \\
19.4\end{array}$ & $\begin{array}{l}22.2 \\
20.5 \\
20.7 \\
23.2 \\
24.7 \\
25.8 \\
24.6 \\
23.0\end{array}$ & $\begin{array}{l}19.4 \\
18.5 \\
18.9 \\
19.9 \\
20.5 \\
21.0 \\
20.4 \\
19.2\end{array}$ & & $\begin{array}{l}25.4 \\
17.8 \\
18.2 \\
24.2 \\
19.0 \\
19.8 \\
22.8 \\
23.0\end{array}$ & $\begin{array}{l}27.4 \\
21.2 \\
29.6 \\
24.8 \\
20.6 \\
21.4 \\
24.5 \\
24.8\end{array}$ & $\begin{array}{l}30.6 \\
23.2 \\
22.4 \\
27.2 \\
23.0 \\
23.5 \\
26.8 \\
27.2\end{array}$ & $\begin{array}{l}32.8 \\
25.2 \\
23.2 \\
29.2 \\
24.6 \\
25.6 \\
29.2 \\
29.2\end{array}$ \\
\hline $\begin{array}{l}9 \\
9 \\
9 \\
9 \\
9 \\
9 \\
9 \\
9\end{array}$ & $\begin{array}{r}0 \\
3 \\
6 \\
9 \\
12 \\
15 \\
18 \\
21\end{array}$ & $\begin{array}{l}22.0 \\
20.5 \\
19.0 \\
15.6 \\
17.6 \\
17.2 \\
15.4 \\
14.7\end{array}$ & $\begin{array}{l}18.6 \\
18.2 \\
17.6 \\
14.2 \\
14.5 \\
15.2 \\
14.8 \\
14.7\end{array}$ & $\begin{array}{l}22.0 \\
20: 7 \\
19.1 \\
15.5 \\
17.3 \\
17.1 \\
15.4 \\
14.8\end{array}$ & $\begin{array}{l}28.6 \\
18.2 \\
17.5 \\
24.0 \\
14.3 \\
15.1 \\
14.9 \\
14.8\end{array}$ & $\begin{array}{l}22.2 \\
20.9 \\
19.2 \\
15.6 \\
17.2 \\
17.1 \\
15.5 \\
14.9\end{array}$ & $\begin{array}{l}18.8 \\
18.6 \\
17.9 \\
14.1 \\
14.2 \\
15.3 \\
14.9 \\
14.9\end{array}$ & $\begin{array}{l}22.2 \\
20.9 \\
19.1 \\
15.4 \\
17.2 \\
17.0 \\
15.6 \\
14.9\end{array}$ & $\begin{array}{l}18.7 \\
18.4 \\
17.5 \\
13.9 \\
14.1 \\
15.0 \\
14.8 \\
14.9\end{array}$ & $\begin{array}{l}16.2 \\
17.8 \\
16.5 \\
14.9\end{array}$ & $\begin{array}{r}22.00 \\
20.0 \\
10.4 \\
9.0 \\
7.8 \\
5.8 \\
7.0 \\
4.6\end{array}$ & $\begin{array}{r}23.5 \\
21.5 \\
12.0 \\
10.8 \\
9.0 \\
6.8 \\
8.8 \\
6.0\end{array}$ & $\begin{array}{r}25.6 \\
23.8 \\
13.6 \\
11.8 \\
10.2 \\
7.6 \\
9.4 \\
6.2\end{array}$ & $\begin{array}{r}27.4 \\
25.0 \\
13.6 \\
11.2 \\
11.4 \\
8.4 \\
10.8 \\
7.4\end{array}$ \\
\hline $\begin{array}{l}10 \\
10 \\
10 \\
10 \\
10 \\
10 \\
10 \\
0\end{array}$ & $\begin{array}{r}0 \\
3 \\
6 \\
9 \\
12 \\
15 \\
18 \\
21\end{array}$ & & & & & & & & & ' & $\begin{array}{l}5.6 \\
6.8 \\
6.8 \\
7.2 \\
6.4 \\
8.4 \\
6.0 \\
6.4\end{array}$ & $\begin{array}{r}6.4 \\
7.8 \\
7.8 \\
8.6 \\
7.4 \\
10.2 \\
6.8 \\
7.6\end{array}$ & $\begin{array}{r}7.2 \\
9.0 \\
9.0 \\
9.6 \\
8.4 \\
11.4 \\
7.8 \\
8.4\end{array}$ & $\begin{array}{r}7.6 \\
10.4 \\
10.2 \\
10.8 \\
9.2 \\
12.5 \\
8.6 \\
9.8\end{array}$ \\
\hline
\end{tabular}


TABLE 10 Table 10. - Three-hour averages of air and water-surface temperatures and wind directions and speed, April 1950-August

STATION 3 THREE-HOURLY AVERAGES

MAY, 1950

\begin{tabular}{|c|c|c|c|c|c|c|c|c|c|c|c|c|c|c|c|}
\hline \multirow{4}{*}{ 章 } & \multirow{4}{*}{ 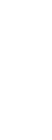 } & \multicolumn{8}{|c|}{ Average air temperature $\left({ }^{\circ} \mathrm{C}\right)$ at indicated height } & \multirow{4}{*}{$\begin{array}{c}\text { Average } \\
\text { water- } \\
\text { surface } \\
\text { tempera- } \\
\text { ture } \\
\text { ('C) }\end{array}$} & \multirow{4}{*}{$\begin{array}{l}\text { Average } \\
\text { wind } \\
\text { direction } \\
\text { (coded) }\end{array}$} & \multirow{2}{*}{\multicolumn{4}{|c|}{$\begin{array}{l}\text { Average wind speed (knots) } \\
\text { at indicated height }\end{array}$}} \\
\hline & & \multirow{2}{*}{\multicolumn{2}{|c|}{$\begin{array}{c}2 \\
\text { meters }\end{array}$}} & \multirow{2}{*}{\multicolumn{2}{|c|}{$\begin{array}{c}4 \\
\text { meters }\end{array}$}} & \multirow{2}{*}{\multicolumn{2}{|c|}{$\begin{array}{c}8 \\
\text { meters }\end{array}$}} & \multirow{2}{*}{\multicolumn{2}{|c|}{$\begin{array}{c}16 \\
\text { meters }\end{array}$}} & & & & & & \\
\hline & & & & & & & & & & & & 2 & 4 & 8 & 16 \\
\hline & & $\begin{array}{l}\text { Dry } \\
\text { bulb }\end{array}$ & $\begin{array}{l}\text { Wet } \\
\text { bulb }\end{array}$ & $\begin{array}{l}\text { Dry } \\
\text { bulb }\end{array}$ & $\begin{array}{l}\text { Wet } \\
\text { bulb }\end{array}$ & $\begin{array}{l}\text { Dry } \\
\text { bulb }\end{array}$ & $\begin{array}{l}\text { Wet } \\
\text { bulb }\end{array}$ & $\begin{array}{l}\text { Dry } \\
\text { bulb }\end{array}$ & & & & & & & \\
\hline
\end{tabular}

\begin{tabular}{|c|c|c|c|c|c|c|c|c|c|c|c|c|c|c|}
\hline & & & & & & & & & & & aeters & geters & JWelera & 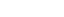 \\
\hline $\begin{array}{l}11 \\
11 \\
11 \\
11 \\
11 \\
11 \\
11 \\
11\end{array}$ & $\begin{array}{r}0 \\
3 \\
6 \\
9 \\
12 \\
15 \\
18 \\
21\end{array}$ & 16.8 & 15.0 & 16.8 & 14.7 & 17.1 & 14.7 & 16.8 & 14.6 & & $\begin{array}{l}7.8 \\
7.0 \\
6.0 \\
6.6 \\
6.0 \\
6.6 \\
3.06 \\
3.06\end{array}$ & $\begin{array}{l}8.8 \\
8.2 \\
7.8 \\
8.0 \\
6.8 \\
7.6 \\
4.0 \\
4.0\end{array}$ & $\begin{array}{l}9.6 \\
9.2 \\
8.8 \\
8.8 \\
7.6 \\
8.6 \\
5.0 \\
5.2\end{array}$ & $\begin{array}{r}9.6 \\
10.4 \\
9.4 \\
9.4 \\
7.6 \\
9.0 \\
6.4 \\
6.8\end{array}$ \\
\hline $\begin{array}{l}12 \\
12 \\
12 \\
12 \\
12 \\
12 \\
12 \\
12\end{array}$ & $\begin{array}{r}0 \\
3 \\
6 \\
9 \\
12 \\
15 \\
18 \\
21\end{array}$ & $\begin{array}{l}17.9 \\
19.4 \\
20.1 \\
19.2 \\
16.8\end{array}$ & $\begin{array}{l}14.3 \\
14.7 \\
14.8 \\
15.8 \\
15.4\end{array}$ & $\begin{array}{l}17.4 \\
19.3 \\
20.0 \\
19.2 \\
16.9\end{array}$ & $\begin{array}{l}14.1 \\
14.4 \\
14.6 \\
15.7 \\
15.3\end{array}$ & $\begin{array}{l}17.4 \\
19.8 \\
20.3 \\
19.3 \\
17.0\end{array}$ & $\begin{array}{l}13.5 \\
14.5 \\
14.9 \\
15.8 \\
15.4\end{array}$ & $\begin{array}{l}17.0 \\
19.3 \\
20.0 \\
19.0 \\
16.8\end{array}$ & $\begin{array}{l}14.0 \\
14.5 \\
15.0 \\
15.6 \\
15.2\end{array}$ & $\begin{array}{l}17.8 \\
20.7 \\
22.2 \\
21.2 \\
28.9\end{array}$ & $\begin{array}{l}2.8 \\
2.4 \\
3.6 \\
2.0 \\
1.8 \\
4.4 \\
6.2 \\
5.6\end{array}$ & $\begin{array}{l}2.6 \\
3.0 \\
4.4 \\
2.6 \\
1.6 \\
4.6 \\
6.6 \\
6.2\end{array}$ & $\begin{array}{l}3.8 \\
3.8 \\
4.4 \\
3.2 \\
2.8 \\
5.0 \\
7.2 \\
7.0\end{array}$ & $\begin{array}{l}4.6 \\
4.6 \\
5.0 \\
3.6 \\
2.8 \\
5.2 \\
8.0 \\
7.4\end{array}$ \\
\hline $\begin{array}{l}13 \\
13 \\
13 \\
13 \\
13 \\
13 \\
13 \\
13\end{array}$ & $\begin{array}{r}0 \\
3 \\
6 \\
9 \\
12 \\
15 \\
18 \\
21\end{array}$ & $\begin{array}{l}15.7 \\
15.0 \\
14.3 \\
17.0 \\
20.2 \\
21.8 \\
19.2 \\
17.7\end{array}$ & $\begin{array}{l}15.3 \\
14.2 \\
13.8 \\
14.7 \\
15.8 \\
16.2 \\
16.0 \\
16.6\end{array}$ & $\begin{array}{l}15.6 \\
15.0 \\
14.4 \\
16.8 \\
20.1 \\
21.5 \\
19.7 \\
18.0\end{array}$ & $\begin{array}{l}15.0 \\
14.1 \\
13.5 \\
14.3 \\
15.1 \\
15.8 \\
15.9 \\
16.5\end{array}$ & $\begin{array}{l}15.8 \\
15.2 \\
14.5 \\
17.0 \\
20.0 \\
21.4 \\
19.9 \\
18.2\end{array}$ & $\begin{array}{l}15.2 \\
14.2 \\
13.7 \\
14.2 \\
14.8 \\
15.4 \\
15.8 \\
16.6\end{array}$ & $\begin{array}{l}15.9 \\
15.3 \\
13.9 \\
16.9 \\
19.7 \\
21.4 \\
20.0 \\
18.3\end{array}$ & $\begin{array}{l}15.0 \\
14.0 \\
13.3 \\
14.0 \\
14.9 \\
15.3 \\
15.6 \\
15.9\end{array}$ & $\begin{array}{l}15.9 \\
16.4 \\
15.6 \\
18.1 \\
18.4 \\
18.0 \\
17.8 \\
17.8\end{array}$ & $\begin{array}{l}4.6 \\
8.8 \\
6.8 \\
8.4 \\
6.8 \\
6.4 \\
1.6 \\
1.4\end{array}$ & $\begin{array}{l}5.0 \\
9.8 \\
7.8 \\
9.2 \\
7.2 \\
6.8 \\
1.8 \\
1.6\end{array}$ & $\begin{array}{r}5.6 \\
10.2 \\
9.4 \\
7.6 \\
7.2 \\
3.0 \\
2.2\end{array}$ & $\begin{array}{r}0.2 \\
11.8 \\
8.8 \\
10.4 \\
8.0 \\
8.0 \\
3.8 \\
2.6\end{array}$ \\
\hline $\begin{array}{l}14 \\
14 \\
14 \\
14 \\
14 \\
14 \\
14 \\
14\end{array}$ & $\begin{array}{r}0 \\
3 \\
6 \\
9 \\
12 \\
15 \\
18 \\
21\end{array}$ & $\begin{array}{l}17.0 \\
16.1 \\
15.8 \\
20.1 \\
22.5 \\
18.2 \\
17.7 \\
16.5\end{array}$ & $\begin{array}{l}15.9 \\
15.1 \\
14.4 \\
15.7 \\
15.8 \\
14.4 \\
14.5 \\
14.4\end{array}$ & $\begin{array}{l}17.2 \\
16.3 \\
15.9 \\
19.8 \\
22.2 \\
18.1 \\
17.8 \\
16.4\end{array}$ & $\begin{array}{l}15.9 \\
15.1 \\
14.2 \\
15.2 \\
15.2 \\
14.0 \\
14.3 \\
14.3\end{array}$ & $\begin{array}{l}17.3 \\
16.4 \\
16.0 \\
20.0 \\
22.0 \\
18.2 \\
17.9 \\
16.5\end{array}$ & $\begin{array}{l}15.9 \\
15.2 \\
14.3 \\
15.0 \\
14.9 \\
13.9 \\
14.3 \\
14.2\end{array}$ & $\begin{array}{l}17.4 \\
10.3 \\
15.9 \\
20.1 \\
21.8 \\
18.6 \\
17.9 \\
16.3\end{array}$ & $\begin{array}{l}15.8 \\
14.9 \\
14.2 \\
15.2 \\
15.0 \\
13.7 \\
14.5 \\
14.1\end{array}$ & $\begin{array}{l}17.8 \\
37.7 \\
27.9 \\
19.2 \\
19.7 \\
18.7 \\
18.2 \\
17.8\end{array}$ & $\begin{array}{r}3.6 \\
3.4 \\
3.8 \\
5.8 \\
11.6 \\
2.2 \\
5.6\end{array}$ & $\begin{array}{r}0.6 \\
2.8 \\
3.8 \\
4.6 \\
6.2 \\
12.6 \\
1.8 \\
6.2\end{array}$ & $\begin{array}{r}1.6 \\
4.2 \\
4.0 \\
5.2 \\
7.4 \\
14.2 \\
2.6 \\
7.0\end{array}$ & $\begin{array}{r}1.8 \\
4.2 \\
4.8 \\
5.2 \\
7.2 \\
14.2 \\
2.8 \\
6.8\end{array}$ \\
\hline $\begin{array}{l}15 \\
15 \\
15 \\
15 \\
15 \\
15 \\
15 \\
15\end{array}$ & $\begin{array}{r}0 \\
3 \\
6 \\
9 \\
12 \\
15 \\
18 \\
21\end{array}$ & $\begin{array}{l}15.3 \\
13.9 \\
16.1 \\
22.1 \\
24.1 \\
34.9 \\
21.1 \\
19.2\end{array}$ & $\begin{array}{l}13.5 \\
12.8 \\
14.3 \\
15.8 \\
15.8 \\
15.7 \\
16.7 \\
16.3\end{array}$ & $\begin{array}{l}15.5 \\
14.0 \\
16.3 \\
22.2 \\
24.1 \\
25.0 \\
21.6 \\
10.3\end{array}$ & $\begin{array}{l}13.6 \\
12.9 \\
14.3 \\
15.4 \\
15.8 \\
15.5 \\
16.4 \\
16.1\end{array}$ & $\begin{array}{l}15.5 \\
14.0 \\
16.3 \\
22.7 \\
24.7 \\
25.1 \\
22.1 \\
19.4\end{array}$ & $\begin{array}{l}13.6 \\
13.0 \\
14.4 \\
15.5 \\
15.4 \\
15.5 \\
16.0 \\
15.9\end{array}$ & $\begin{array}{l}15.5 \\
14.3 \\
16.4 \\
22.1 \\
24.1 \\
24.9 \\
22.3 \\
19.5\end{array}$ & $\begin{array}{l}13.3 \\
13.0 \\
14.3 \\
15.4 \\
15.8 \\
15.6 \\
16.2 \\
15.6\end{array}$ & $\begin{array}{l}17.8 \\
17.6 \\
18.2 \\
19.6 \\
22.4 \\
24.6 \\
22.5 \\
20.7\end{array}$ & $\begin{array}{l}1.8 \\
2.2 \\
2.4 \\
2.8 \\
6.0\end{array}$ & $\begin{array}{l}3.0 \\
2.8 \\
2.0 \\
3.2 \\
2.2 \\
2.0 \\
2.4 \\
5.0\end{array}$ & $\begin{array}{l}2.8 \\
3.4 \\
2.6 \\
3.6 \\
2.8 \\
3.4 \\
3.8 \\
6.4\end{array}$ & $\begin{array}{l}5.6 \\
4.6 \\
3.2 \\
4.2 \\
3.0 \\
3.4 \\
4.0 \\
6.6\end{array}$ \\
\hline $\begin{array}{l}16 \\
16 \\
16 \\
16 \\
16 \\
16 \\
16 \\
16\end{array}$ & $\begin{array}{r}0 \\
3 \\
6 \\
9 \\
12 \\
15 \\
18 \\
21\end{array}$ & $\begin{array}{l}17.5 \\
17.2 \\
18.6 \\
22.9 \\
24.8 \\
24.7 \\
22.7 \\
21.0\end{array}$ & $\begin{array}{l}15.0 \\
15.2 \\
15.9 \\
17.4 \\
18.7 \\
19.4 \\
10.2 \\
17.9\end{array}$ & $\begin{array}{l}17.8 \\
17.3 \\
18.8 \\
22.7 \\
24.9 \\
24.7 \\
22.9 \\
20.9\end{array}$ & $\begin{array}{l}14: 9 \\
15: 1 \\
15: 7 \\
17: 0 \\
18.3 \\
19.1 \\
19: 0 \\
17.7\end{array}$ & $\begin{array}{l}18.3 \\
17.3 \\
18.5 \\
22.9 \\
25.1 \\
25.0 \\
23.1 \\
21.3\end{array}$ & $\begin{array}{l}14.8 \\
15.1 \\
15.6 \\
16.7 \\
1.8 .3 \\
19.1 \\
18.7 \\
17.6\end{array}$ & $\begin{array}{l}18.7 \\
17.2 \\
18.5 \\
23.1 \\
25.1 \\
25.1 \\
3.3 .1 \\
21.4\end{array}$ & $\begin{array}{l}14.7 \\
15.0 \\
15.5 \\
16.5 \\
18.1 \\
19.0 \\
18.6 \\
17.3\end{array}$ & $\begin{array}{l}19.9 \\
19.2 \\
19.2 \\
20.9 \\
22.5 \\
23.0 \\
21.9 \\
21.1\end{array}$ & $\begin{array}{r}3.8 \\
5.4 \\
6.0 \\
10.0 \\
10.4 \\
12.2 \\
7.2 \\
3.6\end{array}$ & $\begin{array}{r}4.2 \\
6.0 \\
6.4 \\
10.4 \\
10.4 \\
11.8 \\
7.8 \\
6.2\end{array}$ & $\begin{array}{r}5.4 \\
7.2 \\
7.4 \\
12.0 \\
12.8 \\
14.8 \\
10.2 \\
8.4\end{array}$ & $\begin{array}{r}6.4 \\
7.8 \\
8.0 \\
12.4 \\
13.6 \\
15.8 \\
11.6 \\
9.4\end{array}$ \\
\hline $\begin{array}{l}17 \\
17 \\
17 \\
17 \\
17 \\
17 \\
17 \\
17\end{array}$ & $\begin{array}{r}0 \\
3 \\
6 \\
9 \\
12 \\
15 \\
18 \\
21\end{array}$ & $\begin{array}{l}19.4 \\
17.7 \\
18.7 \\
24.1 \\
27.3 \\
27.9 \\
24.2 \\
20.9\end{array}$ & $\begin{array}{l}16.9 \\
16.2 \\
16.9 \\
19.4 \\
21.0 \\
20.3 \\
20.0 \\
18.6\end{array}$ & $\begin{array}{l}29.5 \\
17.5 \\
18.8 \\
24.0 \\
27.0 \\
27.7 \\
24.5 \\
21.0\end{array}$ & $\begin{array}{l}16.9 \\
16.1 \\
16.9 \\
18.9 \\
20.4 \\
19.6 \\
20.0 \\
18.7\end{array}$ & $\begin{array}{l}19.5 \\
17.3 \\
19.1 \\
24.7 \\
27.0 \\
27.8 \\
25.0 \\
21.1\end{array}$ & $\begin{array}{l}16.7 \\
16.2 \\
17.0 \\
19.2 \\
20.3 \\
19.6 \\
20.1 \\
18.7\end{array}$ & $\begin{array}{l}19.5 \\
17.6 \\
19.0 \\
24.4 \\
27.3 \\
27.5 \\
25.1 \\
21.0\end{array}$ & $\begin{array}{l}16.5 \\
16.3 \\
17.0 \\
19.4 \\
20.5 \\
19.9 \\
20.2 \\
18.8\end{array}$ & $\begin{array}{l}21.0 \\
20.8 \\
20.5 \\
23.8 \\
27.8 \\
27.0 \\
22.9 \\
21.5\end{array}$ & $\begin{array}{l}1.8 \\
3.0 \\
5.8 \\
3.4 \\
7.4\end{array}$ & $\begin{array}{l}5.4 \\
6.4 \\
4.4 \\
1.8 \\
2.6 \\
6.4 \\
4.2\end{array}$ & $\begin{array}{l}6.2 \\
7.4 \\
5.2 \\
2.4 \\
3.2 \\
7.4 \\
5.8 \\
8.2\end{array}$ & $\begin{array}{r}7.6 \\
8.2 \\
6.0 \\
2.8 \\
3.2 \\
8.2 \\
7.4 \\
10.0\end{array}$ \\
\hline $\begin{array}{l}18 \\
18 \\
18 \\
18 \\
18 \\
18 \\
18 \\
13\end{array}$ & $\begin{array}{r}0 \\
3 \\
6 \\
9 \\
12 \\
15 \\
18 \\
21\end{array}$ & $\begin{array}{l}18.3 \\
19.9 \\
21.1 \\
23.7 \\
25.1 \\
26.1 \\
24.2 \\
22.4\end{array}$ & $\begin{array}{l}16.9 \\
16.5 \\
16.3 \\
19.0 \\
20.8 \\
20.0 \\
19.9 \\
18.9\end{array}$ & $\begin{array}{l}18.4 \\
19.9 \\
21.4 \\
23.6 \\
25.3 \\
26.2 \\
24.4 \\
22.3\end{array}$ & $\begin{array}{l}1 \% .9 \\
16.3 \\
16.1 \\
18.8 \\
20.8 \\
19.8 \\
19.7 \\
10.8\end{array}$ & $\begin{array}{l}18.8 \\
20.3 \\
21.8 \\
24.0 \\
25.7 \\
26.7 \\
24.6 \\
22.6\end{array}$ & $\begin{array}{l}16.7 \\
16.1 \\
16.2 \\
18.9 \\
20.7 \\
19.9 \\
19.8 \\
18.9\end{array}$ & $\begin{array}{l}19.0 \\
20.1 \\
21.6 \\
23.9 \\
25.8 \\
26.6 \\
24.4 \\
22.5\end{array}$ & $\begin{array}{l}18.7 \\
16.1 \\
16.2 \\
18.7 \\
20.8 \\
19.6 \\
19.5 \\
18.7\end{array}$ & $\begin{array}{l}10.7 \\
19.4 \\
19.8 \\
20.7 \\
22.1 \\
22.0 \\
21.3 \\
20.3\end{array}$ & $\begin{array}{r}6.4 \\
18.2 \\
11.4 \\
15.8 \\
16.6 \\
19.0 \\
17.8 \\
17.6\end{array}$ & $\begin{array}{r}7.2 \\
19.8 \\
12.8 \\
17.2 \\
17.8 \\
20.8 \\
19.6 \\
19.0\end{array}$ & $\begin{array}{r}8.2 \\
22.2 \\
14 \cdot 4 \\
10.0 \\
20.2 \\
23.2 \\
21.4 \\
20.8\end{array}$ & $\begin{array}{r}8.8 \\
24.0 \\
16.2 \\
20.6 \\
21.8 \\
25.2 \\
23.6 \\
22.6\end{array}$ \\
\hline $\begin{array}{l}19 \\
19 \\
19 \\
19 \\
19 \\
19 \\
19 \\
19\end{array}$ & $\begin{array}{r}0 \\
3 \\
6 \\
9 \\
12 \\
15 \\
18 \\
21\end{array}$ & $\begin{array}{l}21.6 \\
20.9 \\
20.9 \\
24.0 \\
25.8 \\
24.8 \\
22.2 \\
19.4\end{array}$ & $\begin{array}{l}10.3 \\
10.8 \\
20.1 \\
20.7 \\
21.1 \\
20.7 \\
18.6 \\
16.7\end{array}$ & $\begin{array}{l}21.8 \\
21.0 \\
20.9 \\
23.7 \\
26.0 \\
24.7 \\
22.3 \\
19.5\end{array}$ & $\begin{array}{l}19.2 \\
19.7 \\
20.1 \\
20.1 \\
20.9 \\
20.6 \\
18.4 \\
16.7\end{array}$ & $\begin{array}{l}22.0 \\
21.2 \\
21.2 \\
23.6 \\
25.7 \\
24.5 \\
22.2 \\
10.7\end{array}$ & $\begin{array}{l}19.3 \\
19.8 \\
20.1 \\
20.0 \\
20.8 \\
20.5 \\
18.2 \\
16.7\end{array}$ & $\begin{array}{l}21.9 \\
21.2 \\
20.7 \\
23.8 \\
25.5 \\
24.7 \\
22.1 \\
10.6\end{array}$ & $\begin{array}{l}19.1 \\
19.8 \\
20.0 \\
19.9 \\
20.4 \\
20.5 \\
18.3 \\
16.7\end{array}$ & $\begin{array}{l}19.6 \\
10.0 \\
10.2 \\
20.0 \\
19.8 \\
19.3 \\
18.9 \\
18.7\end{array}$ & $\begin{array}{r}17.2 \\
14.2 \\
2.2 \\
7.4 \\
9.2 \\
10.4 \\
8.2 \\
6.4\end{array}$ & $\begin{array}{r}18.6 \\
15.6 \\
3.2 \\
7.8 \\
10.4 \\
11.6 \\
0.4 \\
7.4\end{array}$ & $\begin{array}{r}20.6 \\
17.0 \\
3.0 \\
10.0 \\
11.6 \\
13.0 \\
10.6 \\
. .6\end{array}$ & $\begin{array}{r}22.0 \\
18.0 \\
3.6 \\
10.0 \\
13.2 \\
15.2 \\
12.8 \\
10.8\end{array}$ \\
\hline $\begin{array}{l}20 \\
20 \\
20 \\
20 \\
20 \\
20 \\
20 \\
20\end{array}$ & $\begin{array}{r}0 \\
3 \\
6 \\
9 \\
12 \\
15 \\
18 \\
21\end{array}$ & $\begin{array}{l}18.0 \\
16.5 \\
14.5 \\
18.8 \\
22.4 \\
23.8 \\
21.3\end{array}$ & $\begin{array}{l}16.2 \\
15.0 \\
13.9 \\
16.1 \\
17.5 \\
18.4 \\
18.9\end{array}$ & $\begin{array}{l}18.1 \\
16.3 \\
14.5 \\
18.8 \\
22.3 \\
23.9 \\
21.3\end{array}$ & $\begin{array}{l}16.2 \\
14.9 \\
13.9 \\
15.8 \\
16.9 \\
18.0 \\
18.8\end{array}$ & $\begin{array}{l}18.2 \\
16.3 \\
14.6 \\
18.7 \\
22.4 \\
24.1 \\
21.3\end{array}$ & $\begin{array}{l}16.2 \\
15.1 \\
14.0 \\
15.4 \\
16.8 \\
17.9 \\
18.7\end{array}$ & $\begin{array}{l}18.2 \\
16.3 \\
14.6 \\
18.6 \\
31 \cdot 1 \\
24 \cdot 0 \\
21.3\end{array}$ & $\begin{array}{l}16.2 \\
14.9 \\
13.7 \\
15.7 \\
16.5 \\
17.7 \\
18.5\end{array}$ & $\begin{array}{l}18.7 \\
16.8 \\
16.1 \\
19.8 \\
21.9 \\
27.7 \\
2210\end{array}$ & $\begin{array}{r}6.0 \\
10.0 \\
5.4 \\
4.8 \\
4.8 \\
4.6 \\
3.4 \\
3.6\end{array}$ & $\begin{array}{r}6.8 \\
12.0 \\
7.6 \\
5.2 \\
5.0 \\
5.4 \\
3.8 \\
4.0\end{array}$ & $\begin{array}{r}8.0 \\
13.6 \\
8.6 \\
6.0 \\
5.2 \\
6.0 \\
4.6 \\
4.6\end{array}$ & $\begin{array}{r}10.0 \\
16.2 \\
9.6 \\
6.8 \\
6.2 \\
7.2 \\
6.2 \\
4.6\end{array}$ \\
\hline
\end{tabular}


TABLE 10

\begin{tabular}{|c|c|c|c|c|c|c|c|c|c|c|c|c|c|c|c|}
\hline \multicolumn{2}{|c|}{ STATION } & 3 & \multicolumn{11}{|c|}{ THREE-HOURLY AVERAGES } & \multicolumn{2}{|c|}{ MAY, 1950} \\
\hline \multirow{3}{*}{ 总 } & \multirow{3}{*}{ 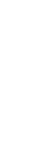 } & \multicolumn{8}{|c|}{ Average air temperature $\left({ }^{\circ} \mathrm{C}\right)$ at indicated height } & \multirow{3}{*}{$\begin{array}{c}\text { Average } \\
\text { water- } \\
\text { surface } \\
\text { tempera- } \\
\text { ture } \\
\text { ("C) }\end{array}$} & \multirow{3}{*}{$\begin{array}{c}\begin{array}{c}\text { Average } \\
\text { wind } \\
\text { direction }\end{array} \\
\text { (coded) }\end{array}$} & \multicolumn{4}{|c|}{$\begin{array}{l}\text { Average wind speed (knots) } \\
\text { at indicated height }\end{array}$} \\
\hline & & \multicolumn{2}{|c|}{$\begin{array}{c}2 \\
\text { meters }\end{array}$} & \multicolumn{2}{|c|}{$\begin{array}{c}4 \\
\text { meters }\end{array}$} & \multicolumn{2}{|c|}{$\begin{array}{c} \\
\text { meters }\end{array}$} & \multicolumn{2}{|c|}{$\begin{array}{c}16 \\
\text { meters }\end{array}$} & & & & & & \\
\hline & & $\begin{array}{l}\text { Dry } \\
\text { bulb }\end{array}$ & $\begin{array}{l}\text { Wet } \\
\text { bulb }\end{array}$ & $\begin{array}{l}\text { Dry } \\
\text { bulb }\end{array}$ & $\begin{array}{l}\text { Wet } \\
\text { bulb }\end{array}$ & $\begin{array}{l}\text { Dry } \\
\text { bulb }\end{array}$ & $\begin{array}{l}\text { Wet } \\
\text { bulb }\end{array}$ & $\begin{array}{l}\text { Dry } \\
\text { bulb }\end{array}$ & $\begin{array}{l}\text { Wet } \\
\text { bulb }\end{array}$ & & & meters & meters & meters & meters \\
\hline $\begin{array}{l}21 \\
21 \\
21 \\
21 \\
21 \\
21 \\
21 \\
21\end{array}$ & $\begin{array}{r}0 \\
3 \\
6 \\
9 \\
12 \\
15 \\
18 \\
21\end{array}$ & & & & & & & & & & & $\begin{array}{l}4.6 \\
4.6 \\
3.6 \\
6.8 \\
3.8 \\
2.0 \\
2.2 \\
6.4\end{array}$ & $\begin{array}{l}5.0 \\
4.4 \\
3.2 \\
7.0 \\
3.4 \\
2.2 \\
6.4\end{array}$ & $\begin{array}{l}6.6 \\
6.0 \\
4.8 \\
8.8 \\
4.6 \\
2.2 \\
3.6 \\
7.8\end{array}$ & $\begin{array}{l}0.2 \\
6.0 \\
5.0 \\
5.2 \\
2.2 \\
4.4 \\
9.0\end{array}$ \\
\hline $\begin{array}{l}22 \\
22 \\
22 \\
22 \\
22 \\
22 \\
22 \\
22\end{array}$ & $\begin{array}{r}0 \\
3 \\
6 \\
9 \\
12 \\
15 \\
18 \\
21\end{array}$ & $\begin{array}{l}21.0 \\
23.0 \\
24.7 \\
25.5 \\
23.0 \\
21.4\end{array}$ & $\begin{array}{l}16.3 \\
17.4 \\
17.4 \\
16.5 \\
17.3 \\
16.3\end{array}$ & $\begin{array}{l}21.1 \\
23.3 \\
25.1 \\
25.7 \\
23.2 \\
21.5\end{array}$ & $\begin{array}{l}17.9 \\
17.0 \\
16.8 \\
16.0 \\
16.9 \\
16.1\end{array}$ & $\begin{array}{l}21.3 \\
23.7 \\
25.3 \\
26.1 \\
23.3 \\
21.7\end{array}$ & $\begin{array}{l}16.5 \\
16.7 \\
16.7 \\
15.7 \\
16.7 \\
16.1\end{array}$ & $\begin{array}{l}21.5 \\
23.7 \\
25.4 \\
26.0 \\
23.5 \\
21.6\end{array}$ & $\begin{array}{l}16.1 \\
16.6 \\
16.7 \\
15.6 \\
16.5 \\
15.8\end{array}$ & $\begin{array}{l}20.4 \\
21.2 \\
32.5 \\
22.5 \\
21.5 \\
20.6\end{array}$ & & $\begin{array}{r}8.4 \\
13.4 \\
14.4 \\
17.6 \\
15.8 \\
13.8 \\
8.8 \\
13.6\end{array}$ & $\begin{array}{r}9.0 \\
14.4 \\
15.0 \\
19.0 \\
17.4 \\
14.8 \\
9.4 \\
14.8\end{array}$ & $\begin{array}{r}9.0 \\
16.0 \\
16.6 \\
21.2 \\
19.8 \\
16.8 \\
11.0 \\
16.4\end{array}$ & $\begin{array}{l}10.2 \\
16.4 \\
17.4 \\
21.8 \\
20.2 \\
17.6 \\
12.4 \\
17.8\end{array}$ \\
\hline $\begin{array}{l}23 \\
23 \\
23 \\
23 \\
23 \\
23 \\
23 \\
23\end{array}$ & $\begin{array}{r}0 \\
3 \\
6 \\
9 \\
12 \\
15 \\
18 \\
21\end{array}$ & $\begin{array}{l}20.6 \\
19.1 \\
19.9 \\
23.5 \\
26.5 \\
27.6 \\
25.4 \\
24.1\end{array}$ & $\begin{array}{l}15.9 \\
15.9 \\
16.4 \\
18.2 \\
18.1 \\
18.4 \\
18.9 \\
17.2\end{array}$ & $\begin{array}{l}20.7 \\
19.1 \\
20.1 \\
23.7 \\
26.8 \\
27.7 \\
25.5 \\
24.1\end{array}$ & $\begin{array}{l}15.8 \\
15.4 \\
16.4 \\
18.2 \\
17.9 \\
18.1 \\
18.7 \\
17.1\end{array}$ & $\begin{array}{l}21.0 \\
19.1 \\
20.3 \\
24.0 \\
27.3 \\
28.2 \\
26.0 \\
24.3\end{array}$ & $\begin{array}{l}15.6 \\
15.3 \\
16.3 \\
18.2 \\
17.9 \\
18.1 \\
18.7 \\
17.0\end{array}$ & $\begin{array}{l}20.8 \\
19.0 \\
20.02 \\
24.0 \\
27.5 \\
28.5 \\
26.1 \\
24.3\end{array}$ & $\begin{array}{l}15.5 \\
15.1 \\
16.3 \\
18.2 \\
17.7 \\
18.0 \\
18.6 \\
16.7\end{array}$ & $\begin{array}{l}19.8 \\
19.3 \\
19.2 \\
20.9 \\
21.8 \\
22.0 \\
21.3 \\
20.4\end{array}$ & & $\begin{array}{l}16.0 \\
13.2 \\
13.6 \\
15.8 \\
18.8 \\
17.6 \\
14.6 \\
17.2\end{array}$ & $\begin{array}{l}17.4 \\
14.0 \\
14: 8 \\
17.0 \\
20: 0 \\
19.0 \\
16.2 \\
18.4\end{array}$ & $\begin{array}{l}19.6 \\
15.2 \\
16.0 \\
19.0 \\
22.4 \\
21.4 \\
18.2 \\
20.6\end{array}$ & $\begin{array}{l}20.6 \\
16.4 \\
16.8 \\
19.6 \\
24.6 \\
23.0 \\
190.6 \\
22.4\end{array}$ \\
\hline $\begin{array}{l}24 \\
24 \\
24 \\
24 \\
24 \\
24 \\
24 \\
24\end{array}$ & $\begin{array}{r}0 \\
3 \\
6 \\
9 \\
12 \\
15 \\
18 \\
21\end{array}$ & $\begin{array}{l}20.9 \\
20.0 \\
21.0 \\
23.7 \\
26.5 \\
26.7 \\
24.7 \\
23.2\end{array}$ & $\begin{array}{l}16.8 \\
17.8 \\
17.8 \\
19.2 \\
19.7 \\
19.0 \\
19.0 \\
18.5\end{array}$ & $\begin{array}{l}21.0 \\
20.2 \\
21.1 \\
23.9 \\
26.5 \\
27.0 \\
24.9 \\
23.5\end{array}$ & $\begin{array}{l}16.7 \\
17.1 \\
17.7 \\
19.1 \\
19.5 \\
18.8 \\
19.0 \\
18.4\end{array}$ & $\begin{array}{l}21.1 \\
20.03 \\
21.03 \\
24.4 \\
26.9 \\
27.2 \\
25.12 \\
23.7\end{array}$ & $\begin{array}{l}16.7 \\
17.1 \\
17.7 \\
19.2 \\
19.6 \\
18.9 \\
19.3 \\
18.5\end{array}$ & $\begin{array}{l}20.8 \\
20.0 \\
21.02 \\
24.5 \\
27.1 \\
27.4 \\
250.1 \\
? 3.7\end{array}$ & $\begin{array}{l}16.5 \\
16.9 \\
17.5 \\
19.1 \\
19.3 \\
18.7 \\
18.9 \\
18.2\end{array}$ & $\begin{array}{l}19.8 \\
19.3 \\
19.3 \\
20.2 \\
21.5 \\
21.9 \\
21.0 \\
20.2\end{array}$ & & $\begin{array}{l}17.0 \\
15.6 \\
19.4 \\
16.4 \\
19.4 \\
21.0 \\
17.0 \\
18.8\end{array}$ & $\begin{array}{l}18.4 \\
16.4 \\
20.4 \\
17.8 \\
21.0 \\
22.8 \\
18.6 \\
20.2\end{array}$ & $\begin{array}{l}20.2 \\
18.4 \\
23.0 \\
10.8 \\
23.6 \\
25.5 \\
20.8 \\
22.2\end{array}$ & $\begin{array}{l}21.4 \\
19.6 \\
23.8 \\
211.4 \\
25.06 \\
277.6 \\
22.6 \\
24.4\end{array}$ \\
\hline $\begin{array}{l}25 \\
25 \\
25 \\
25 \\
25 \\
25 \\
25 \\
25\end{array}$ & $\begin{array}{r}0 \\
3 \\
6 \\
9 \\
12 \\
15 \\
18 \\
21\end{array}$ & $\begin{array}{l}21.9 \\
21.02 \\
210.3 \\
23.6 \\
250.4 \\
21.3 \\
18.6 \\
15.5\end{array}$ & $\begin{array}{l}18.0 \\
18.0 \\
18.6 \\
19.8 \\
20.7 \\
17.9 \\
16.02 \\
14.5\end{array}$ & $\begin{array}{l}21.9 \\
21.3 \\
21.5 \\
23.7 \\
25.2 \\
21.1 \\
18.6 \\
15.4\end{array}$ & $\begin{array}{l}18.0 \\
18.0 \\
18.6 \\
19.8 \\
20.3 \\
17.6 \\
16.3 \\
14.4\end{array}$ & $\begin{array}{l}22.0 \\
21.5 \\
21.8 \\
24.0 \\
25.8 \\
21.0 \\
13.5 \\
15.0\end{array}$ & $\begin{array}{l}18.1 \\
18.0 \\
18.7 \\
19.8 \\
20.2 \\
17.5 \\
16.1 \\
14.2\end{array}$ & $\begin{array}{l}22.1 \\
221.3 \\
21.8 \\
24.0 \\
2500 \\
20.6 \\
18.02 \\
14.9\end{array}$ & $\begin{array}{l}17.9 \\
17.9 \\
18.5 \\
19.9 \\
20.0 \\
17.4 \\
16.0 \\
13.9\end{array}$ & $\begin{array}{l}19.7 \\
19.3 \\
19.6 \\
20.8 \\
21.7 \\
21.5 \\
20.3 \\
20.0\end{array}$ & & $\begin{array}{r}20.0 \\
15.0 \\
11.8 \\
8.0 \\
5.4 \\
9.4 \\
9.2 \\
13.6\end{array}$ & $\begin{array}{r}21.4 \\
16.0 \\
12.6 \\
9.2 \\
6.2 \\
11.2 \\
10.6 \\
15.4\end{array}$ & $\begin{array}{r}23.6 \\
17.6 \\
14.0 \\
8.8 \\
13.8 \\
12.2 \\
18.8\end{array}$ & $\begin{array}{l}25.4 \\
18.8 \\
14.8 \\
10.4 \\
990 \\
12.0 \\
12.2\end{array}$ \\
\hline $\begin{array}{l}26 \\
26 \\
26 \\
26 \\
26 \\
26 \\
26 \\
26\end{array}$ & $\begin{array}{r}0 \\
3 \\
6 \\
0 \\
12 \\
15 \\
18 \\
21\end{array}$ & $\begin{array}{l}12.7 \\
11.7 \\
10.7 \\
11.6 \\
12.1 \\
12.6 \\
13.2 \\
12.9\end{array}$ & $\begin{array}{l}12.7 \\
11.5 \\
10.1 \\
10.4 \\
11.0 \\
11.5 \\
11.7 \\
11.7\end{array}$ & $\begin{array}{l}12.8 \\
11.5 \\
10.6 \\
11.4 \\
12.0 \\
12.6 \\
13.2 \\
17.9\end{array}$ & $\begin{array}{l}17.7 \\
11.3 \\
10.0 \\
10.1 \\
10.8 \\
11.3 \\
11.6 \\
11.5\end{array}$ & $\begin{array}{l}12.7 \\
11.5 \\
10.7 \\
11.5 \\
12.0 \\
12.7 \\
13.2 \\
13.0\end{array}$ & $\begin{array}{r}12.7 \\
11.2 \\
9.9 \\
10.0 \\
10.9 \\
11.3 \\
11.4 \\
11.5\end{array}$ & $\begin{array}{l}12.7 \\
1104 \\
10.3 \\
11.1 \\
11.9 \\
12.0 \\
13.0 \\
12.9\end{array}$ & $\begin{array}{r}12.7 \\
11.2 \\
9.5 \\
9.8 \\
10.6 \\
11.0 \\
11.2 \\
11.2\end{array}$ & $\begin{array}{l}16.1 \\
15.1 \\
17.1 \\
18.7 \\
18.4 \\
18.7 \\
20.0 \\
20.0\end{array}$ & & $\begin{array}{r}7.0 \\
12.0 \\
12.2 \\
7.6 \\
4.6 \\
5.6 \\
6.0 \\
4.8\end{array}$ & $\begin{array}{r}8.0 \\
14.4 \\
14.8 \\
9.0 \\
5.0 \\
7.2 \\
7.2 \\
6.0\end{array}$ & $\begin{array}{r}9.8 \\
16.8 \\
16.6 \\
10.6 \\
6.4 \\
7.4 \\
9.4 \\
7.4\end{array}$ & $\begin{array}{rl}10.44 & \\
70 & 0 \\
10.0\end{array}$ \\
\hline $\begin{array}{l}27 \\
27 \\
27 \\
27 \\
27 \\
27 \\
27 \\
? 7\end{array}$ & $\begin{array}{r}0 \\
3 \\
6 \\
0 \\
12 \\
15 \\
18 \\
21\end{array}$ & $\begin{array}{r}12.3 \\
11.4 \\
9.4 \\
9.9 \\
158.2 \\
18.5 \\
17.4 \\
13.6\end{array}$ & $\begin{array}{r}11.0 \\
10.02 \\
8.08 \\
99.2 \\
12.3 \\
14.02 \\
12.06\end{array}$ & $\begin{array}{r}12.3 \\
11.3 \\
9: 3 \\
9: 7 \\
15: 1 \\
18: 7 \\
17: 7 \\
14: 0\end{array}$ & $\begin{array}{r}10.9 \\
10.0 \\
8.5 \\
8.9 \\
11.9 \\
13.9 \\
14.0 \\
12.8\end{array}$ & $\begin{array}{r}12.4 \\
11.03 \\
9.07 \\
9.7 \\
15.4 \\
18.6 \\
18.1 \\
14.8\end{array}$ & $\begin{array}{r}10.9 \\
9.9 \\
8.4 \\
9.0 \\
12.0 \\
14.0 \\
14.1 \\
13.3\end{array}$ & $\begin{array}{r}12.1 \\
10.0 \\
8.7 \\
995 \\
1489 \\
18.4 \\
18.0 \\
15.4\end{array}$ & $\begin{array}{r}10.5 \\
0.6 \\
8.0 \\
8.8 \\
11.8 \\
14.2 \\
14.2 \\
13.4\end{array}$ & $\begin{array}{l}19.8 \\
19.3 \\
18.1 \\
18.9 \\
20.7 \\
19.0 \\
20.0 \\
19.7\end{array}$ & & $\begin{array}{l}5.2 \\
5.6 \\
6.6 \\
4.6 \\
3.8 \\
2.4 \\
3.2 \\
3.0\end{array}$ & $\begin{array}{l}6.4 \\
7.2 \\
8.4 \\
5.6 \\
4.2 \\
2.6 \\
4: 0 \\
4.0\end{array}$ & $\begin{array}{l}8.0 \\
9.4 \\
5.6 \\
4.6 \\
2.8 \\
4.8 \\
5.8\end{array}$ & $\begin{array}{r}10.2 \\
11.04 \\
7.8 \\
50.4 \\
20.6 \\
506 \\
7.4\end{array}$ \\
\hline $\begin{array}{l}28 \\
28 \\
28 \\
28 \\
28 \\
28 \\
28 \\
28\end{array}$ & $\begin{array}{r}0 \\
3 \\
6 \\
9 \\
12 \\
15 \\
19 \\
21\end{array}$ & $\begin{array}{l}13.2 \\
13.6 \\
14.8 \\
17.6 \\
19.7 \\
20.9 \\
21.1 \\
20.1\end{array}$ & $\begin{array}{l}12.5 \\
13.3 \\
13.9 \\
15.8 \\
17.5 \\
18.7 \\
19.1 \\
18.9\end{array}$ & $\begin{array}{l}13.6 \\
13.6 \\
14.7 \\
17.6 \\
19.7 \\
20.9 \\
31.1 \\
20.3\end{array}$ & $\begin{array}{l}12.6 \\
13.2 \\
13.8 \\
15.7 \\
17.3 \\
18.6 \\
19.1 \\
18.9\end{array}$ & $\begin{array}{l}13.3 \\
13.7 \\
14.9 \\
17.7 \\
10.7 \\
21.0 \\
21.2 \\
20.4\end{array}$ & $\begin{array}{l}12.8 \\
13.5 \\
13.8 \\
15.6 \\
17.4 \\
13.6 \\
19.2 \\
19.0\end{array}$ & $\begin{array}{l}14.0 \\
13.7 \\
14.8 \\
177.4 \\
19.5 \\
300.9 \\
21.2 \\
20.3\end{array}$ & $\begin{array}{l}12.8 \\
13.3 \\
13.7 \\
15.5 \\
17.2 \\
19.5 \\
19.1 \\
18.9\end{array}$ & $\begin{array}{l}18.8 \\
15.6 \\
17.0 \\
19.2 \\
20.1 \\
20.5 \\
20.6 \\
20.1\end{array}$ & & $\begin{array}{r}3.6 \\
7.4 \\
9.6 \\
14.0 \\
13.8 \\
11.8 \\
9.0 \\
10.8\end{array}$ & $\begin{array}{r}4.4 \\
8.8 \\
10.8 \\
15.0 \\
15.2 \\
13.4 \\
11.2 \\
13.2\end{array}$ & $\begin{array}{r}5.8 \\
10.2 \\
11.6 \\
16.2 \\
16.6 \\
14.6 \\
12.4 \\
14.04\end{array}$ & $\begin{array}{r}7.8 \\
12.6 \\
11.6\end{array}$ \\
\hline $\begin{array}{l}29 \\
29 \\
29 \\
29 \\
29 \\
29 \\
29 \\
29\end{array}$ & $\begin{array}{r}0 \\
3 \\
6 \\
9 \\
12 \\
15 \\
18 \\
21\end{array}$ & $\begin{array}{l}19.1 \\
19.0 \\
19.8 \\
22.8 \\
24.7 \\
21.9 \\
20.3 \\
16.8\end{array}$ & $\begin{array}{l}18.1 \\
18.3 \\
19.2 \\
20.2 \\
20.6 \\
17.7 \\
15.9 \\
15.0\end{array}$ & $\begin{array}{l}19.1 \\
19: 0 \\
20.3 \\
33.2 \\
24.5 \\
21.7 \\
20.4 \\
17.5\end{array}$ & $\begin{array}{l}18.1 \\
18.3 \\
10.0 \\
20.1 \\
20.1 \\
17.3 \\
15.7 \\
15.0\end{array}$ & $\begin{array}{l}19.2 \\
190.0 \\
2006 \\
23.6 \\
24.0 \\
21.7 \\
20.7 \\
18.3\end{array}$ & $\begin{array}{l}13.2 \\
1806 \\
10.03 \\
2003 \\
20.0 \\
17.2 \\
150.7 \\
1504\end{array}$ & $\begin{array}{l}10.1 \\
19.0 \\
20.5 \\
23.8 \\
24.1 \\
210.4 \\
20.8 \\
18.7\end{array}$ & $\begin{array}{l}38.0 \\
18.2 \\
19.4 \\
20.3 \\
10.6 \\
17.0 \\
15.6 \\
15.7\end{array}$ & $\begin{array}{l}19.3 \\
18.5 \\
18.6 \\
20.2 \\
21.0 \\
21.5 \\
20.3 \\
19.8\end{array}$ & & $\begin{array}{r}14.0 \\
20.4 \\
12.8 \\
10.0 \\
8.2 \\
11.2 \\
4.8 \\
2.6\end{array}$ & $\begin{array}{r}17.4 \\
22.2 \\
13.6 \\
11.4 \\
10.2 \\
13.4 \\
6.2 \\
3.2\end{array}$ & $\begin{array}{r}10.2 \\
24: 4 \\
14.8 \\
13.0 \\
12.6 \\
17.8 \\
9.0 \\
4.8\end{array}$ & $\begin{array}{r}21.44 \\
260.4 \\
15.8 \\
13.6 \\
13.0 \\
16.8 \\
9.8 \\
6.0\end{array}$ \\
\hline $\begin{array}{l}30 \\
30 \\
30 \\
30 \\
30 \\
30 \\
30 \\
30\end{array}$ & $\begin{array}{r}0 \\
3 \\
6 \\
9 \\
17 \\
15 \\
18 \\
21\end{array}$ & $\begin{array}{l}17.1 \\
15.4 \\
16.5 \\
21.2 \\
35.6 \\
26.1 \\
23.7 \\
20.3\end{array}$ & $\begin{array}{l}15.3 \\
12.8 \\
13.6 \\
110.1 \\
17: 9 \\
18.0 \\
18.8 \\
17.6\end{array}$ & $\begin{array}{l}17.3 \\
15.6 \\
16.6 \\
21.1 \\
25.0 \\
26.1 \\
34.7 \\
21.1\end{array}$ & $\begin{array}{l}15.1 \\
11.7 \\
13.5 \\
150.8 \\
17.7 \\
177.5 \\
17.9 \\
17.5\end{array}$ & $\begin{array}{l}17.2 \\
15.5 \\
16.7 \\
21.2 \\
3501 \\
26.0 \\
25.0 \\
21.2\end{array}$ & $\begin{array}{l}15.0 \\
12.8 \\
13.6 \\
15.5 \\
17.3 \\
16.9 \\
17: 7 \\
17.0\end{array}$ & $\begin{array}{l}17.2 \\
15.3 \\
16.0 \\
20.0 \\
24.8 \\
26.0 \\
25.5 \\
27.0\end{array}$ & $\begin{array}{l}14.5 \\
12.5 \\
13.4 \\
15.0 \\
17.2 \\
17.4 \\
18.1 \\
16.9\end{array}$ & $\begin{array}{l}19.2 \\
19.0 \\
10.2 \\
20.5 \\
21.1 \\
23.2 \\
23.0 \\
21.4\end{array}$ & & $\begin{array}{l}6.4 \\
6.2 \\
5.8 \\
7.0 \\
7.2 \\
2.8 \\
2.4 \\
3.8\end{array}$ & $\begin{array}{l}7.6 \\
8.0 \\
7.2 \\
8.4 \\
8.7 \\
3.0 \\
2.8 \\
4.4\end{array}$ & $\begin{array}{r}8.2 \\
8.2 \\
10.2 \\
9.8 \\
3.6 \\
4.2 \\
7.2\end{array}$ & $\begin{array}{r}8.6 \\
10.8 \\
9.4 \\
11.6 \\
9.8 \\
3.6 \\
5.02\end{array}$ \\
\hline $\begin{array}{l}31 \\
31 \\
31 \\
31 \\
31 \\
31 \\
31 \\
31\end{array}$ & $\begin{array}{r}0 \\
3 \\
6 \\
9 \\
12 \\
15 \\
18 \\
21\end{array}$ & 23.8 & $16 . ?$ & 23.7 & 16.5 & 33.4 & 15.6 & 22.6 & 15.3 & 21.3 & & $\begin{array}{l}4.2 \\
3.2 \\
7.3 \\
9.6 \\
9.6 \\
8.2 \\
6.6 \\
6.0\end{array}$ & $\begin{array}{r}4.4 \\
4.2 \\
4.0 \\
0.0 \\
11.0 \\
11.2 \\
9.6 \\
7.6 \\
6.8\end{array}$ & $\begin{array}{r}102 \\
5.4 \\
5.4 \\
10.2 \\
12.4 \\
12.6 \\
11.0 \\
8.8 \\
3.0\end{array}$ & $\begin{array}{r}6.4 \\
55.6 \\
12.0 \\
14.0 \\
14.2 \\
12.0 \\
10.8 \\
9.6\end{array}$ \\
\hline
\end{tabular}


TABLE 10

Table 10. - Three-hour averages of air and water-surface temperatures and wind directions and speed, April 1950-August 1951, Lake Hefner-Continued

STATION

THREE-HOURLY AVERAGES

JUNE, 1950

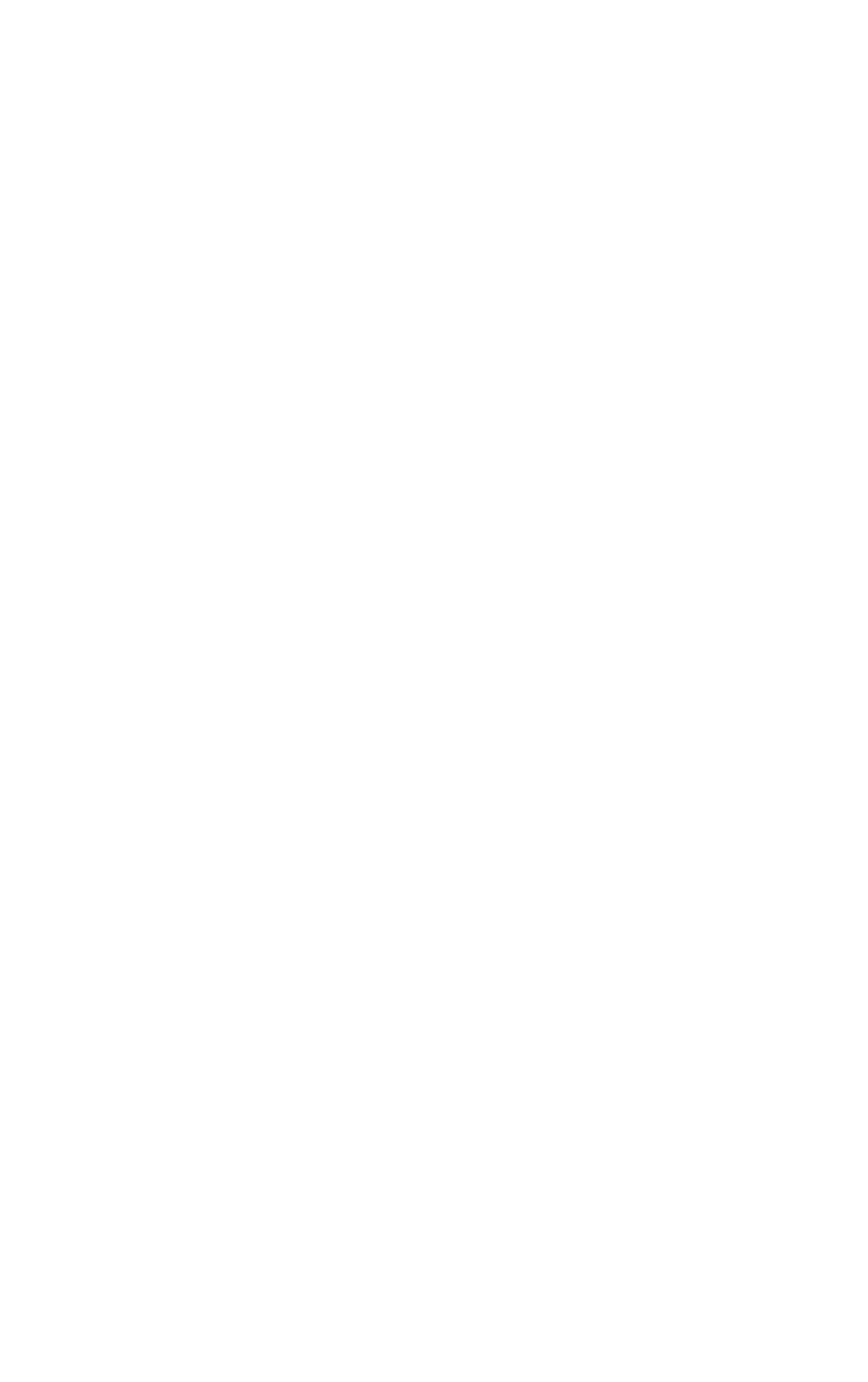


Table 10. - Three-hour averages of air and water-surface temperatures and wind directions and speed, April 1950-August 1951, Lake Hefner-Continued

STATION 3

THREE-HOURLY AVERAGES

JUNE, 1950

\begin{tabular}{|c|c|c|c|c|c|c|c|c|c|c|c|c|c|c|c|}
\hline \multirow{4}{*}{ 秃 } & \multirow{4}{*}{ 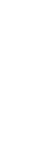 } & \multicolumn{8}{|c|}{ Average air temperature $\left({ }^{\circ} \mathrm{C}\right)$ at indicated height } & \multirow{4}{*}{$\begin{array}{l}\text { Average } \\
\text { water- } \\
\text { surface } \\
\text { tempera- } \\
\text { ture } \\
\left({ }^{\circ} \mathrm{C}\right)\end{array}$} & \multirow{4}{*}{$\begin{array}{c}\text { Average } \\
\text { wind } \\
\text { direction } \\
\text { (coded) }\end{array}$} & \multirow{2}{*}{\multicolumn{4}{|c|}{$\begin{array}{l}\text { Average wind speed (knots) } \\
\text { at indicated height }\end{array}$}} \\
\hline & & \multirow{2}{*}{\multicolumn{2}{|c|}{$\begin{array}{c}2 \\
\text { meters }\end{array}$}} & \multirow{2}{*}{\multicolumn{2}{|c|}{$\begin{array}{c}4 \\
\text { meters }\end{array}$}} & \multirow{2}{*}{\multicolumn{2}{|c|}{$\begin{array}{c}8 \\
\text { meters }\end{array}$}} & \multirow{2}{*}{\multicolumn{2}{|c|}{$\begin{array}{c}16 \\
\text { meters }\end{array}$}} & & & & & & \\
\hline & & & & & & & & & & & & 2 & 4 & 8 & 16 \\
\hline & & $\begin{array}{l}\text { Dry } \\
\text { bulb }\end{array}$ & $\begin{array}{l}\text { Wet } \\
\text { bulb }\end{array}$ & $\begin{array}{l}\text { Dry } \\
\text { bulb }\end{array}$ & $\begin{array}{l}\text { Wet } \\
\text { bulb }\end{array}$ & $\begin{array}{l}\text { Dry } \\
\text { bulb }\end{array}$ & $\begin{array}{l}\text { Wet } \\
\text { bulb }\end{array}$ & $\begin{array}{l}\text { Dry } \\
\text { bulb }\end{array}$ & $\begin{array}{l}\text { Wet } \\
\text { bulb }\end{array}$ & & & meters & meters & meters & meters \\
\hline $\begin{array}{l}11 \\
11 \\
11 \\
11 \\
11 \\
11 \\
11 \\
11\end{array}$ & $\begin{array}{r}0 \\
3 \\
6 \\
9 \\
12 \\
15 \\
18 \\
21\end{array}$ & $\begin{array}{l}19.3 \\
17.4 \\
19.3 \\
22.4 \\
24.0\end{array}$ & $\begin{array}{l}17.9 \\
17.2 \\
18.2 \\
19.7 \\
21.2\end{array}$ & $\begin{array}{l}19.5 \\
17.6 \\
19.4 \\
22.4 \\
23.9\end{array}$ & $\begin{array}{l}17.9 \\
17.2 \\
18.1 \\
19.3 \\
20.7\end{array}$ & $\begin{array}{l}10.6 \\
17.9 \\
19.4 \\
22.6 \\
23.3\end{array}$ & $\begin{array}{l}19.0 \\
17.4 \\
18.3 \\
19.5 \\
20.6\end{array}$ & $\begin{array}{l}19.4 \\
18.0 \\
19.3 \\
22.1 \\
23.5\end{array}$ & $\begin{array}{l}17.8 \\
17.3 \\
18.0 \\
10.4 \\
20.4\end{array}$ & & & $\begin{array}{r}7.0 \\
3.6 \\
4.2 \\
3.2 \\
5.4 \\
10.6 \\
9.6 \\
10.0\end{array}$ & $\begin{array}{r}8.0 \\
4.2 \\
5.4 \\
4.0 \\
6.4 \\
13.0 \\
11.6 \\
12.4\end{array}$ & $\begin{array}{r}8.4 \\
5.2 \\
6.0 \\
4.2 \\
7.0 \\
14.6 \\
13.0 \\
13.4\end{array}$ & $\begin{array}{r}9.0 \\
6.2 \\
6.8 \\
4.6 \\
7.8 \\
16.2 \\
14.6 \\
15.2\end{array}$ \\
\hline $\begin{array}{l}12 \\
12 \\
12 \\
12 \\
12 \\
12 \\
12 \\
12\end{array}$ & $\begin{array}{r}0 \\
3 \\
6 \\
9 \\
12 \\
15 \\
18 \\
21\end{array}$ & $\begin{array}{l}26.1 \\
27.3 \\
28.2 \\
26.7 \\
24.6\end{array}$ & $\begin{array}{l}22.2 \\
22.1 \\
22.5 \\
23.3 \\
21.4\end{array}$ & $\begin{array}{l}26.3 \\
27.4 \\
23.2 \\
26.7 \\
24.9\end{array}$ & $\begin{array}{l}22 \cdot 0 \\
22.9 \\
22 \cdot 0 \\
2 ? \cdot 2 \\
21.3\end{array}$ & $\begin{array}{l}26.6 \\
28.1 \\
28.3 \\
27.0 \\
25.1\end{array}$ & $\begin{array}{l}22: 0 \\
22: 0 \\
22.1 \\
22.2 \\
21.5\end{array}$ & $\begin{array}{l}27.0 \\
28: 2 \\
28: 0 \\
27.1 \\
25: 0\end{array}$ & $\begin{array}{l}22.1 \\
22.0 \\
21.9 \\
22.1 \\
21.2\end{array}$ & & & $\begin{array}{l}10.0 \\
13.2 \\
15.2 \\
14.2 \\
14.8 \\
13.8 \\
10.8 \\
12.8\end{array}$ & $\begin{array}{l}11.4 \\
14.6 \\
17.0 \\
15.6 \\
16.4 \\
15.6 \\
13.6 \\
16.0\end{array}$ & $\begin{array}{l}12.4 \\
15.6 \\
18.4 \\
17.4 \\
18.2 \\
17.4 \\
14.8 \\
17.6\end{array}$ & $\begin{array}{l}13.8 \\
16.6 \\
19.8 \\
18.4 \\
19.4 \\
19.2 \\
16.8 \\
19.6\end{array}$ \\
\hline $\begin{array}{l}13 \\
13 \\
13 \\
13 \\
13 \\
13 \\
13 \\
13\end{array}$ & $\begin{array}{r}0 \\
3 \\
6 \\
9 \\
12 \\
15 \\
18 \\
21\end{array}$ & $\begin{array}{l}23.2 \\
22.5 \\
23.3 \\
25.0 \\
27.8 \\
28.6 \\
26.5 \\
24.4\end{array}$ & $\begin{array}{l}20.7 \\
20.1 \\
20.9 \\
22.1 \\
22.7 \\
22.6 \\
22.3 \\
21.3\end{array}$ & $\begin{array}{l}23.3 \\
22.7 \\
23.4 \\
25.1 \\
27.9 \\
23.8 \\
26.7 \\
24.6\end{array}$ & $\begin{array}{l}20.6 \\
20.0 \\
20.8 \\
21.9 \\
27.2 \\
22.4 \\
22.2 \\
21.1\end{array}$ & $\begin{array}{l}23.4 \\
22.9 \\
23.6 \\
25.5 \\
28.4 \\
28.9 \\
26.8 \\
24.7\end{array}$ & $\begin{array}{l}20 \cdot 6 \\
20: 1 \\
20: 9 \\
22 \cdot 1 \\
22: 2 \\
22 \cdot 4 \\
22 \bullet 2 \\
21 \cdot 1\end{array}$ & $\begin{array}{l}23.3 \\
22.8 \\
23.6 \\
25.7 \\
28.5 \\
29.0 \\
26.0 \\
24 \cdot 7\end{array}$ & $\begin{array}{l}20.5 \\
20.0 \\
20.7 \\
21.8 \\
22.1 \\
22.2 \\
22.0 \\
20.9\end{array}$ & & & $\begin{array}{l}14: 8 \\
12: 0 \\
14: 0 \\
14: 0 \\
14: 6 \\
16: 0 \\
13: 0 \\
12.4\end{array}$ & $\begin{array}{l}16.8 \\
14.2 \\
15.6 \\
15.6 \\
16.4 \\
18.4 \\
14.8 \\
14.4\end{array}$ & $\begin{array}{l}18.8 \\
15.4 \\
17.0 \\
17.2 \\
18.0 \\
20.6 \\
16.4 \\
16.2\end{array}$ & $\begin{array}{l}20.6 \\
16.8 \\
17.8 \\
18.0 \\
19.6 \\
22.8 \\
18.4 \\
18.0\end{array}$ \\
\hline $\begin{array}{l}14 \\
14 \\
14 \\
14 \\
14 \\
14 \\
14 \\
14\end{array}$ & $\begin{array}{r}0 \\
3 \\
6 \\
9 \\
12 \\
15 \\
18 \\
21\end{array}$ & $\begin{array}{l}23.0 \\
21.7 \\
23.4 \\
26.2 \\
28.0 \\
28.1 \\
26.4 \\
24.1\end{array}$ & $\begin{array}{l}20.8 \\
20.4 \\
21.1 \\
21.8 \\
22.5 \\
22.0 \\
22.1 \\
21.4\end{array}$ & $\begin{array}{l}23.1 \\
21.9 \\
23.6 \\
26.2 \\
27.9 \\
28.1 \\
26.4 \\
24.4\end{array}$ & $\begin{array}{l}20.6 \\
20.3 \\
20.9 \\
21.4 \\
22.0 \\
21.6 \\
21.9 \\
21.3\end{array}$ & $\begin{array}{l}23.3 \\
22.0 \\
23.8 \\
26.4 \\
28.1 \\
28.3 \\
26.4 \\
24.5\end{array}$ & $\begin{array}{l}20.7 \\
20.4 \\
21: 0 \\
21: 6 \\
21: 9 \\
21.7 \\
21: 9 \\
21.3\end{array}$ & $\begin{array}{l}23.1 \\
21.8 \\
23.9 \\
26.5 \\
28.4 \\
28.5 \\
26.6 \\
24.4\end{array}$ & $\begin{array}{l}20.4 \\
20.2 \\
20.8 \\
21.4 \\
21.6 \\
21.3 \\
21.8 \\
21.1\end{array}$ & $\begin{array}{l}26.3 \\
27.8 \\
27.1 \\
24.6 \\
23.8\end{array}$ & & $\begin{array}{l}14.2 \\
12.8 \\
15.6 \\
13.8 \\
13.2 \\
13.6 \\
11.6 \\
10.2\end{array}$ & $\begin{array}{l}16.2 \\
14.4 \\
17.2 \\
15.4 \\
15.0 \\
15.8 \\
13.2 \\
11.6\end{array}$ & $\begin{array}{l}17.8 \\
15.8 \\
19.0 \\
16.8 \\
16.8 \\
17.6 \\
15.0 \\
12.8\end{array}$ & $\begin{array}{l}19.8 \\
17.0 \\
19.6 \\
18.0 \\
18.4 \\
19.6 \\
16.6 \\
14.2\end{array}$ \\
\hline $\begin{array}{l}15 \\
15 \\
15 \\
15 \\
15 \\
15 \\
15 \\
15\end{array}$ & $\begin{array}{r}0 \\
3 \\
6 \\
9 \\
12 \\
15 \\
18 \\
21\end{array}$ & $\begin{array}{l}22.8 \\
21.4 \\
22.7 \\
25.6 \\
28.2 \\
28.7 \\
26.8 \\
24.1\end{array}$ & $\begin{array}{l}21.0 \\
20.1 \\
20.7 \\
21.7 \\
22.1 \\
21.9 \\
21.7 \\
20.9\end{array}$ & $\begin{array}{l}22.8 \\
21.5 \\
22.7 \\
26.5 \\
28.1 \\
28.5 \\
26.7 \\
24.3\end{array}$ & $\begin{array}{l}20.8 \\
20.0 \\
20.6 \\
21.4 \\
21.4 \\
21.4 \\
21.6 \\
20.9\end{array}$ & $\begin{array}{l}2.2 .9 \\
21.6 \\
23.0 \\
20.9 \\
75.3 \\
23.8 \\
26.0 \\
24.5\end{array}$ & $\begin{array}{l}20.9 \\
20.0 \\
20.7 \\
21.3 \\
21.4 \\
21.3 \\
21.5 \\
20.8\end{array}$ & $\begin{array}{l}22.8 \\
21.4 \\
22.8 \\
77.1 \\
78.6 \\
28.9 \\
27.0 \\
24.6\end{array}$ & $\begin{array}{l}20.6 \\
19.8 \\
20.5 \\
21.1 \\
21.0 \\
21.0 \\
21.2 \\
20.5\end{array}$ & $\begin{array}{l}23.3 \\
22.8 \\
23.7 \\
26.7 \\
28.9 \\
28.1 \\
25.7 \\
24.6\end{array}$ & & $\begin{array}{r}11.6 \\
10.0 \\
12.6 \\
13.4 \\
12.4 \\
12.4 \\
10.6 \\
6.0\end{array}$ & $\begin{array}{r}13.0 \\
11.6 \\
14.2 \\
15.0 \\
14.0 \\
14.4 \\
12.2 \\
7.6\end{array}$ & $\begin{array}{r}14.0 \\
12.6 \\
15.2 \\
16.6 \\
15.4 \\
16.0 \\
13.6 \\
8.6\end{array}$ & $\begin{array}{l}15.0 \\
13.8 \\
16.0 \\
17.2 \\
16.6 \\
17.6 \\
15.4 \\
10.2\end{array}$ \\
\hline $\begin{array}{l}16 \\
16 \\
16 \\
16 \\
16 \\
16 \\
16 \\
16\end{array}$ & $\begin{array}{r}0 \\
3 \\
6 \\
0 \\
12 \\
15 \\
18 \\
21\end{array}$ & $\begin{array}{l}23.2 \\
21.9 \\
23.5 \\
26.5 \\
29.3 \\
29.0 \\
27.2 \\
24.0\end{array}$ & $\begin{array}{l}20.7 \\
20.0 \\
21.1 \\
22.3 \\
22.9 \\
22.5 \\
21.5 \\
20.4\end{array}$ & $\begin{array}{l}23.3 \\
22.0 \\
23.5 \\
26.7 \\
29.7 \\
29.2 \\
27.3 \\
24.1\end{array}$ & $\begin{array}{l}20.7 \\
19: 9 \\
20.9 \\
21.8 \\
22.1 \\
22.0 \\
21.4 \\
20.4\end{array}$ & $\begin{array}{l}73.3 \\
22.0 \\
23.8 \\
77.2 \\
29.1 \\
20.5 \\
77.5 \\
24.5\end{array}$ & $\begin{array}{l}20.7 \\
20.0 \\
21: 1 \\
21.8 \\
21.9 \\
22.0 \\
21.3 \\
20.3\end{array}$ & $\begin{array}{l}23.1 \\
21.8 \\
23.7 \\
27.1 \\
29.3 \\
29.6 \\
27.6 \\
24.6\end{array}$ & $\begin{array}{l}20.4 \\
19.7 \\
20.8 \\
21.8 \\
21.7 \\
21.7 \\
20.9 \\
20.0\end{array}$ & $\begin{array}{l}23.9 \\
23.4 \\
24.7 \\
27.5 \\
30.0 \\
28.8 \\
26.4 \\
25.2\end{array}$ & & $\begin{array}{r}10.6 \\
11.8 \\
13.4 \\
10.2 \\
9.0 \\
10.4 \\
8.2 \\
4.0\end{array}$ & $\begin{array}{r}12.4 \\
13.6 \\
15.0 \\
11.6 \\
10.6 \\
12.2 \\
9.8 \\
5.2\end{array}$ & $\begin{array}{r}13.6 \\
14.6 \\
16.0 \\
12.8 \\
11.6 \\
13.8 \\
11.2 \\
6.2\end{array}$ & $\begin{array}{r}15.0 \\
15.8 \\
16.6 \\
13.2 \\
12.8 \\
15.4 \\
13.0 \\
8.0\end{array}$ \\
\hline $\begin{array}{l}17 \\
17 \\
17 \\
17 \\
17 \\
17 \\
17 \\
17\end{array}$ & $\begin{array}{r}0 \\
3 \\
6 \\
0 \\
12 \\
15 \\
18 \\
21\end{array}$ & $\begin{array}{l}22.3 \\
22.6 \\
23.6 \\
26.9 \\
29.1 \\
29.4 \\
27.3 \\
24.3\end{array}$ & $\begin{array}{l}20.0 \\
20.4 \\
21.1 \\
21.9 \\
21.9 \\
21.8 \\
20.8 \\
20.1\end{array}$ & $\begin{array}{l}22.6 \\
22.7 \\
23.8 \\
27.1 \\
29.2 \\
29.6 \\
27.4 \\
24.4\end{array}$ & $\begin{array}{l}20.0 \\
20.2 \\
20.8 \\
21.2 \\
21.4 \\
21.3 \\
20.5 \\
20.0\end{array}$ & $\begin{array}{l}22.9 \\
22.8 \\
24.0 \\
27.3 \\
29.3 \\
29.6 \\
27.7 \\
24.6\end{array}$ & $\begin{array}{l}20.0 \\
20.3 \\
20.8 \\
21.1 \\
21.1 \\
21.1 \\
20.4 \\
20.0\end{array}$ & $\begin{array}{l}23.1 \\
22: 6 \\
24: 0 \\
27.4 \\
29.3 \\
29.7 \\
27: 4 \\
24.8\end{array}$ & $\begin{array}{l}19.9 \\
20.1 \\
20.7 \\
20.9 \\
20.9 \\
20.7 \\
20.2 \\
19.9\end{array}$ & $\begin{array}{l}24.8 \\
24.3 \\
25.2 \\
27.4 \\
30.4 \\
29.5 \\
26.8 \\
25.8\end{array}$ & & $\begin{array}{r}4.8 \\
11.4 \\
13.2 \\
12.0 \\
10.4 \\
12.2 \\
9.0 \\
7.0\end{array}$ & $\begin{array}{r}6.4 \\
13.0 \\
14.8 \\
13.8 \\
12.8 \\
14.0 \\
10.6 \\
8.6\end{array}$ & $\begin{array}{r}7.6 \\
14.0 \\
15.8 \\
15.2 \\
13.6 \\
15.6 \\
12.0 \\
10.0\end{array}$ & $\begin{array}{l}10.0 \\
15.0 \\
16.2 \\
15.6 \\
14.6 \\
17.4 \\
13.6 \\
11.8\end{array}$ \\
\hline $\begin{array}{l}18 \\
18 \\
28 \\
18 \\
18 \\
18 \\
18 \\
18\end{array}$ & $\begin{array}{r}0 \\
3 \\
6 \\
9 \\
12 \\
15 \\
18 \\
21\end{array}$ & $\begin{array}{l}23.5 \\
23.0 \\
23.9 \\
26.8 \\
29.0 \\
29.4 \\
27.3 \\
25.3\end{array}$ & $\begin{array}{l}19.9 \\
20.0 \\
20.5 \\
21.5 \\
21.5 \\
21.3 \\
21.0 \\
21.0\end{array}$ & $\begin{array}{l}23.4 \\
23.0 \\
24: 1 \\
27.0 \\
29.2 \\
29.6 \\
26.7 \\
25.5\end{array}$ & $\begin{array}{l}19.8 \\
19.7 \\
20.4 \\
21.0 \\
21.1 \\
20.8 \\
20.7 \\
20.9\end{array}$ & $\begin{array}{l}23.6 \\
23.1 \\
24.0 \\
27.3 \\
29.5 \\
29.9 \\
27.8 \\
25.7\end{array}$ & $\begin{array}{l}19.7 \\
19.7 \\
20.3 \\
21.1 \\
21.0 \\
20.5 \\
20.7 \\
20.9\end{array}$ & $\begin{array}{l}23.3 \\
23.0 \\
24 \cdot 0 \\
27.4 \\
29.6 \\
29.8 \\
27.8 \\
25.7\end{array}$ & $\begin{array}{l}19.2 \\
19.5 \\
20.0 \\
20.8 \\
20.7 \\
20.3 \\
20.4 \\
20.6\end{array}$ & $\begin{array}{l}25.0 \\
24.7 \\
25.9 \\
28.4 \\
30.1 \\
29.7 \\
27.1 \\
26.4\end{array}$ & & $\begin{array}{r}14.4 \\
14.8 \\
15.6 \\
16.0 \\
16.0 \\
15.6 \\
9.2 \\
11.4\end{array}$ & $\begin{array}{l}16.8 \\
17.4 \\
17.2 \\
18.0 \\
18.2 \\
17.8 \\
10.6 \\
13.4\end{array}$ & $\begin{array}{l}18.2 \\
18.6 \\
18.6 \\
20.0 \\
20.2 \\
19.6 \\
12.2 \\
14.6\end{array}$ & $\begin{array}{l}19.8 \\
19.4 \\
19.2 \\
21.0 \\
21.6 \\
21.0 \\
14: 0 \\
16.2\end{array}$ \\
\hline $\begin{array}{l}19 \\
19 \\
19 \\
19 \\
19 \\
19 \\
19 \\
19\end{array}$ & $\begin{array}{r}0 \\
3 \\
6 \\
0 \\
12 \\
15 \\
18 \\
21\end{array}$ & $\begin{array}{l}24.5 \\
22.5 \\
20.5 \\
23.0 \\
26.2 \\
26.0 \\
23.5 \\
20.4\end{array}$ & $\begin{array}{l}20.4 \\
19.8 \\
18.5 \\
19.2 \\
20.7 \\
20.5 \\
20.3 \\
19.2\end{array}$ & $\begin{array}{l}24.7 \\
22.6 \\
20.3 \\
22.5 \\
25.5 \\
25.8 \\
23.4 \\
20.6\end{array}$ & $\begin{array}{l}20.2 \\
19.6 \\
18.4 \\
29.2 \\
20.3 \\
20.3 \\
20.3 \\
19.3\end{array}$ & $\begin{array}{l}24.8 \\
22.7 \\
20.2 \\
22.6 \\
25.1 \\
25.5 \\
23.5 \\
20.9\end{array}$ & $\begin{array}{l}20.1 \\
19.6 \\
18.2 \\
19.0 \\
20.1 \\
20.2 \\
20.3 \\
19.6\end{array}$ & $\begin{array}{l}24 \cdot 7 \\
22.6 \\
20.1 \\
22 \cdot 3 \\
24 \cdot 4 \\
25 \cdot 0 \\
23 \cdot 3 \\
21.0\end{array}$ & $\begin{array}{l}10.8 \\
19.2 \\
18.1 \\
29.1 \\
19.8 \\
20.0 \\
20.1 \\
19.4\end{array}$ & $\begin{array}{l}25.9 \\
25.9\end{array}$ & & $\begin{array}{r}13.6 \\
4.4 \\
7.4 \\
3.4 \\
4.8 \\
4.8 \\
4.0 \\
3.6\end{array}$ & $\begin{array}{r}15.0 \\
5.6 \\
9.2 \\
4.0 \\
5.6 \\
5.8 \\
5.0 \\
4.8\end{array}$ & $\begin{array}{r}16.0 \\
6.0 \\
10.4 \\
4.6 \\
6.6 \\
6.6 \\
5.8 \\
6.4\end{array}$ & $\begin{array}{r}16.6 \\
6.4 \\
10.8 \\
4.8 \\
6.6 \\
7.2 \\
7.4 \\
8.4\end{array}$ \\
\hline $\begin{array}{l}20 \\
20 \\
20 \\
20 \\
20 \\
20 \\
20 \\
20\end{array}$ & $\begin{array}{r}0 \\
3 \\
6 \\
9 \\
12 \\
15 \\
18 \\
21\end{array}$ & $\begin{array}{l}20.0 \\
21.2 \\
21.8 \\
26.6 \\
30.1 \\
27.7 \\
19.1 \\
19.5\end{array}$ & $\begin{array}{l}19.5 \\
20.1 \\
20.4 \\
22.4 \\
23.0 \\
22.8 \\
17.4 \\
18.7\end{array}$ & $\begin{array}{l}20.5 \\
21.1 \\
21.9 \\
26.4 \\
29.5 \\
27.7 \\
19.0 \\
19.6\end{array}$ & $\begin{array}{l}19.6 \\
19.9 \\
20.2 \\
21.9 \\
27.4 \\
22.4 \\
17.4 \\
18.1\end{array}$ & $\begin{array}{l}20.5 \\
21.4 \\
21.9 \\
26.5 \\
29.2 \\
27.0 \\
19.3 \\
19.7\end{array}$ & $\begin{array}{l}19.9 \\
20.2 \\
20.5 \\
22.2 \\
22.1 \\
22.3 \\
17.4 \\
18.1\end{array}$ & 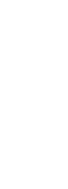 & $\begin{array}{l}19.6 \\
19.9 \\
20.3 \\
21.9 \\
22.0 \\
21.7 \\
17.2 \\
18.0\end{array}$ & & & $\begin{array}{l}5 \cdot 2 \\
6.2 \\
3.2 \\
4 \cdot 0 \\
7 \cdot 0 \\
6.8 \\
6.4 \\
4 * 8\end{array}$ & $\begin{array}{l}6.8 \\
7.4 \\
4.0 \\
4.4 \\
8.02 \\
8.4 \\
7.4 \\
6.0\end{array}$ & $\begin{array}{r}7.8 \\
8.0 \\
4.4 \\
5.0 \\
9.0 \\
10.0 \\
7.6 \\
6.8\end{array}$ & $\begin{array}{r}9.4 \\
8.6 \\
5.0 \\
5.0 \\
9.8 \\
10.8 \\
7.8 \\
7.6\end{array}$ \\
\hline
\end{tabular}


TABLE 10

131

Table 10. -Three-hour averages of air and water-surface temperatures and wind directions and speed, April 1950-August 1951, Lake Hefner-Continued

STATION 3 THREE-HOURLY AVERAGES

JUNE, 1050

\begin{tabular}{|c|c|c|c|c|c|c|c|c|c|c|c|c|c|c|c|}
\hline \multirow{3}{*}{ 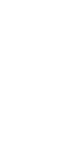 } & \multirow{3}{*}{ 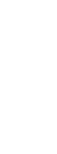 } & \multicolumn{8}{|c|}{ Average air temperature $\left({ }^{\circ} \mathrm{C}\right)$ at indicated height } & \multirow{3}{*}{\begin{tabular}{|l} 
Average \\
water- \\
surface \\
tempera- \\
ture \\
$\left.{ }^{\circ} \mathrm{C}\right)$
\end{tabular}} & \multirow{3}{*}{$\begin{array}{c}\text { Average } \\
\text { wind } \\
\text { direction } \\
\text { (coded) }\end{array}$} & \multicolumn{4}{|c|}{$\begin{array}{l}\text { Average wind speed (knots) } \\
\text { at indicated height }\end{array}$} \\
\hline & & \multicolumn{2}{|c|}{$\begin{array}{c}2 \\
\text { meters }\end{array}$} & \multicolumn{2}{|c|}{$\begin{array}{c}4 \\
\text { meters }\end{array}$} & \multicolumn{2}{|c|}{$\begin{array}{c}8 \\
\text { meters }\end{array}$} & \multicolumn{2}{|c|}{$\begin{array}{c}16 \\
\text { meters }\end{array}$} & & & $x^{a}$ & 然 & 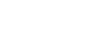 & 16 \\
\hline & & $\begin{array}{l}\text { Dry } \\
\text { bulb }\end{array}$ & $\begin{array}{l}\text { Wet } \\
\text { bulb }\end{array}$ & $\begin{array}{l}\text { Dry } \\
\text { bulb }\end{array}$ & $\begin{array}{l}\text { Wet } \\
\text { bulb }\end{array}$ & $\begin{array}{l}\text { Dry } \\
\text { bulb }\end{array}$ & $\begin{array}{l}\text { Wet } \\
\text { bulb }\end{array}$ & $\begin{array}{l}\text { Dry } \\
\text { bulb }\end{array}$ & \begin{tabular}{|l|} 
Wet \\
bulb
\end{tabular} & & & meters & meters & meters & meters \\
\hline $\begin{array}{l}21 \\
21 \\
21 \\
21 \\
21 \\
21 \\
21 \\
21\end{array}$ & $\begin{array}{r}0 \\
3 \\
6 \\
9 \\
12 \\
15 \\
18 \\
21\end{array}$ & $\begin{array}{l}20.0 \\
19.9 \\
20.8 \\
24.2 \\
26.5 \\
26.6 \\
24.7 \\
22.6\end{array}$ & $\begin{array}{l}19.0 \\
18.9 \\
19.1 \\
19.5 \\
20.9 \\
21.1 \\
20.7 \\
20.4\end{array}$ & $\begin{array}{l}20.0 \\
20.0 \\
20.7 \\
24.1 \\
26.2 \\
26.2 \\
24.8 \\
22.8\end{array}$ & $\begin{array}{l}18.7 \\
18.7 \\
19.7 \\
10.3 \\
20.3 \\
20.5 \\
20.5 \\
20.5\end{array}$ & $\begin{array}{l}20.0 \\
20.1 \\
20.7 \\
24.1 \\
26.0 \\
26.2 \\
24.8 \\
22.8\end{array}$ & $\begin{array}{l}18.7 \\
18.9 \\
18.7 \\
18.9 \\
20.2 \\
20.3 \\
20.4 \\
20.5\end{array}$ & $\begin{array}{l}19.9 \\
19 \cdot 8 \\
20.5 \\
23.0 \\
25.7 \\
26.1 \\
24 \cdot 6 \\
22.7\end{array}$ & $\begin{array}{l}18.6 \\
18.5 \\
18.3 \\
19.1 \\
20.0 \\
20.1 \\
20.2 \\
20.3\end{array}$ & & & $\begin{array}{l}8.0 \\
5.0 \\
6.2 \\
5.0 \\
7.8 \\
8.6 \\
6.8 \\
6.0\end{array}$ & $\begin{array}{r}9.2 \\
6.0 \\
8.2 \\
6.6 \\
9.4 \\
10.8 \\
8.4 \\
8.0\end{array}$ & $\begin{array}{r}9.6 \\
6.4 \\
9.2 \\
6.8 \\
10.4 \\
11.8 \\
9.4 \\
9.0\end{array}$ & $\begin{array}{r}9.8 \\
6.8 \\
9.2 \\
7.2 \\
11.0 \\
13.0 \\
10.6 \\
10.6\end{array}$ \\
\hline $\begin{array}{l}22 \\
22 \\
22 \\
22 \\
22 \\
22 \\
22 \\
22\end{array}$ & $\begin{array}{r}0 \\
3 \\
6 \\
9 \\
12 \\
15 \\
18 \\
2.1\end{array}$ & $\begin{array}{l}22.1 \\
22.3 \\
23.7 \\
25.9 \\
28.2\end{array}$ & $\begin{array}{l}21.1 \\
21.8 \\
22.5 \\
23.0 \\
23.3\end{array}$ & $\begin{array}{l}22.2 \\
22.3 \\
23.8 \\
25.9 \\
28.2\end{array}$ & $\begin{array}{l}21.0 \\
21 \cdot 7 \\
22.3 \\
22.8 \\
23.2\end{array}$ & $\begin{array}{l}22.3 \\
22.3 \\
23.8 \\
26.1 \\
28.4\end{array}$ & $\begin{array}{l}21 \cdot 1 \\
21.8 \\
22 \cdot 4 \\
22 \cdot 8 \\
23.1\end{array}$ & $\begin{array}{l}22.1 \\
22 . ? \\
23.7 \\
26.0 \\
28.5\end{array}$ & $\begin{array}{l}20.9 \\
21.6 \\
22.1 \\
22.6 \\
23.1\end{array}$ & $\begin{array}{l}26 \cdot 2 \\
26 \cdot 8\end{array}$ & & $\begin{array}{r}8.6 \\
9.0 \\
17.2 \\
17.0 \\
16.8 \\
17.6 \\
16.8 \\
20.2\end{array}$ & $\begin{array}{l}10.4 \\
10.8 \\
19.4 \\
18.8 \\
19.0 \\
20.0 \\
18.8 \\
23.0\end{array}$ & $\begin{array}{l}11.4 \\
11.4 \\
21.0 \\
20.6 \\
20.8 \\
21.8 \\
20.6 \\
24.8\end{array}$ & $\begin{array}{l}12.8 \\
12.2 \\
22.0 \\
21.4 \\
22.0 \\
23.2 \\
22.2 \\
27.0\end{array}$ \\
\hline $\begin{array}{l}23 \\
23 \\
23 \\
23 \\
23 \\
23 \\
23 \\
23\end{array}$ & $\begin{array}{r}0 \\
3 \\
6 \\
9 \\
12 \\
15 \\
18 \\
21\end{array}$ & & & & & & & & & & & $\begin{array}{l}22.6 \\
21.8 \\
21.0 \\
21.8 \\
20.4 \\
18.2 \\
16.4 \\
18.4\end{array}$ & $\begin{array}{l}25.0 \\
24.6 \\
23.6 \\
24.6 \\
23.2 \\
20.6 \\
19.0 \\
21.2\end{array}$ & $\begin{array}{l}27.2 \\
26.6 \\
25.8 \\
26.8 \\
25.2 \\
22.8 \\
21.8 \\
23.4\end{array}$ & $\begin{array}{l}28.6 \\
28.0 \\
27.0 \\
28.2 \\
27.4 \\
25.2 \\
24.2 \\
25.8\end{array}$ \\
\hline $\begin{array}{l}24 \\
24 \\
24 \\
24 \\
24 \\
24 \\
24 \\
24\end{array}$ & $\begin{array}{r}0 \\
3 \\
6 \\
9 \\
12 \\
15 \\
18 \\
21\end{array}$ & & & & & & & & & & & $\begin{array}{l}18.2 \\
20.0 \\
21.4 \\
20.6 \\
17.8 \\
18.0 \\
15.6 \\
16.4\end{array}$ & $\begin{array}{l}21.0 \\
22.0 \\
24.0 \\
23.0 \\
20.2 \\
20.8 \\
18.4 \\
19.2\end{array}$ & $\begin{array}{l}22.8 \\
24.2 \\
25.2 \\
25.6 \\
22.6 \\
23.2 \\
20.8 \\
21.2\end{array}$ & $\begin{array}{l}25.0 \\
26.0 \\
27.0 \\
26.6 \\
25.2 \\
26.0 \\
23.2 \\
23.6\end{array}$ \\
\hline $\begin{array}{l}25 \\
25 \\
25 \\
25 \\
25 \\
25 \\
25 \\
25\end{array}$ & $\begin{array}{r}0 \\
3 \\
6 \\
9 \\
12 \\
15 \\
18 \\
21\end{array}$ & & & & & & & & & & & $\begin{array}{l}18.2 \\
20.2 \\
22.4 \\
20.8 \\
16.2 \\
17.6 \\
11.2 \\
12.6\end{array}$ & $\begin{array}{l}20.2 \\
22.4 \\
24.8 \\
23.0 \\
18.2 \\
19.8 \\
13.0 \\
14.4\end{array}$ & $\begin{array}{l}22.2 \\
24.2 \\
27.0 \\
25.0 \\
20.0 \\
21.8 \\
14.6 \\
16.0\end{array}$ & $\begin{array}{l}23.8 \\
25.4 \\
27.8 \\
26.6 \\
21.4 \\
24.2 \\
16.4 \\
18.0\end{array}$ \\
\hline $\begin{array}{l}26 \\
26 \\
26 \\
26 \\
26 \\
26 \\
26 \\
26\end{array}$ & $\begin{array}{r}0 \\
3 \\
6 \\
9 \\
12 \\
15 \\
18 \\
21\end{array}$ & $\begin{array}{l}27.0 \\
28.5 \\
31.0 \\
31.3 \\
28.7 \\
24.8\end{array}$ & $\begin{array}{l}22.2 \\
22.6 \\
23.7 \\
23.6 \\
22.9 \\
20.5\end{array}$ & $\begin{array}{l}27.3 \\
28.9 \\
31.4 \\
31.9 \\
29.8 \\
24.0\end{array}$ & $\begin{array}{l}21.0 \\
22.3 \\
22.9 \\
23.2 \\
22.7 \\
20.4\end{array}$ & $\begin{array}{l}27.2 \\
79.3 \\
31.9 \\
32.3 \\
29.5 \\
74.9\end{array}$ & $\begin{array}{l}21.1 \\
22.1 \\
22.5 \\
23.0 \\
22.4 \\
20.4\end{array}$ & $\begin{array}{l}27 \cdot 2 \\
29: 5 \\
32.1 \\
32 \cdot 3 \\
29: 9 \\
24 \cdot 7\end{array}$ & $\begin{array}{l}21 \cdot 3 \\
21 \cdot 7 \\
22 \cdot 7 \\
22 \cdot 8 \\
27 \cdot 1 \\
20 \cdot 2\end{array}$ & $\begin{array}{l}18.8 \\
25.4 \\
27.0 \\
27.0 \\
25.4 \\
24.0\end{array}$ & & $\begin{array}{r}12.6 \\
10.4 \\
11.6 \\
11.0 \\
10.4 \\
13.2 \\
5.6 \\
6.4\end{array}$ & $\begin{array}{r}14.6 \\
12.4 \\
13.2 \\
12.6 \\
12.0 \\
15.2 \\
7.0 \\
8.4\end{array}$ & $\begin{array}{r}16.0 \\
13.6 \\
14.2 \\
14.0 \\
13.6 \\
17.0 \\
8.2 \\
10.0\end{array}$ & $\begin{array}{r}17.6 \\
15.0 \\
15.4 \\
14.0 \\
14.8 \\
19.0 \\
9.2 \\
12.0\end{array}$ \\
\hline $\begin{array}{l}27 \\
27 \\
27 \\
27 \\
27 \\
27 \\
27 \\
27\end{array}$ & $\begin{array}{r}0 \\
3 \\
6 \\
9 \\
12 \\
15 \\
18 \\
21\end{array}$ & $\begin{array}{l}22.1 \\
20.0 \\
22.6 \\
28.4 \\
31.0 \\
31.4 \\
29.0 \\
27.1\end{array}$ & $\begin{array}{l}19.0 \\
18.1 \\
19.3 \\
22.02 \\
22.8 \\
22.8 \\
22.4 \\
20.0\end{array}$ & $\begin{array}{l}22.2 \\
20.2 \\
22.5 \\
28.0 \\
30.8 \\
31.3 \\
29.3 \\
27.3\end{array}$ & $\begin{array}{l}19.0 \\
18.1 \\
10.3 \\
22.0 \\
22.0 \\
22.0 \\
22.4 \\
20.8\end{array}$ & $\begin{array}{l}22.5 \\
20.3 \\
22.6 \\
20.1 \\
31.1 \\
31.3 \\
29.8 \\
27.7\end{array}$ & $\begin{array}{l}10.1 \\
15.7 \\
19.4 \\
21.8 \\
22.1 \\
21.7 \\
22.0 \\
20.9\end{array}$ & $\begin{array}{l}22.3 \\
20.2 \\
22.5 \\
27: 7 \\
31: 0 \\
31: 0 \\
30.0 \\
27.6\end{array}$ & $\begin{array}{l}19.0 \\
19.1 \\
19.2 \\
21.9 \\
21.5 \\
21.5 \\
21.7 \\
20.8\end{array}$ & $\begin{array}{l}23.4 \\
2 ? .7 \\
23.5 \\
25.3 \\
25.7 \\
27.3 \\
25.8 \\
24.4\end{array}$ & & $\begin{array}{l}3.4 \\
6.4 \\
7.6 \\
5.0 \\
7.8 \\
7.2 \\
5.4 \\
6.8\end{array}$ & $\begin{array}{l}4.4 \\
8.0 \\
9.6 \\
6.6 \\
9.4 \\
8.8 \\
7.6 \\
8.8\end{array}$ & $\begin{array}{r}5.6 \\
9.6 \\
11.6 \\
7.2 \\
10.4 \\
10.0 \\
9.0 \\
10.2\end{array}$ & $\begin{array}{r}7.4 \\
11.6 \\
13.2 \\
8.0 \\
11.4 \\
11.4 \\
11.0 \\
12.2\end{array}$ \\
\hline $\begin{array}{l}28 \\
28 \\
28 \\
28 \\
28 \\
28 \\
28 \\
28 \\
28\end{array}$ & $\begin{array}{r}0 \\
3 \\
6 \\
9 \\
12 \\
15 \\
18 \\
21\end{array}$ & $\begin{array}{l}25.3 \\
19: 7 \\
18.9 \\
21: 0 \\
27.8 \\
28.0 \\
25.1 \\
22.0\end{array}$ & $\begin{array}{l}21.4 \\
18.1 \\
18.0 \\
19.3 \\
21.0 \\
20.8 \\
20.6 \\
20.1\end{array}$ & $\begin{array}{l}25.4 \\
19.8 \\
18.9 \\
22.2 \\
27.4 \\
27.7 \\
25.1 \\
22.2\end{array}$ & $\begin{array}{l}21.1 \\
18.1 \\
17.9 \\
18.8 \\
20.8 \\
20.5 \\
20.6 \\
20.0\end{array}$ & $\begin{array}{l}25.6 \\
19.5 \\
19.0 \\
21.8 \\
27.4 \\
27.6 \\
25.2 \\
22.7\end{array}$ & $\begin{array}{l}21.2 \\
17.8 \\
18.0 \\
18.7 \\
20.7 \\
20.2 \\
20.6 \\
20.2\end{array}$ & $\begin{array}{l}25.4 \\
19.4 \\
19.0 \\
21.6 \\
27.3 \\
27.3 \\
25.3 \\
23.0\end{array}$ & $\begin{array}{l}20.9 \\
17.4 \\
17.7 \\
18.6 \\
20.6 \\
20.1 \\
20.5 \\
20.0\end{array}$ & $\begin{array}{l}24 \cdot 1 \\
23.1 \\
23.1 \\
24.3 \\
27.5 \\
24.6 \\
23.8 \\
23.4\end{array}$ & & $\begin{array}{l}8.2 \\
9.2 \\
7.2 \\
6.8 \\
1.4 \\
4.6 \\
2.8 \\
1.4\end{array}$ & $\begin{array}{r}10.0 \\
11.2 \\
9.0 \\
9.0 \\
2.8 \\
6.8 \\
4.6 \\
2.8\end{array}$ & $\begin{array}{r}11.2 \\
13.4 \\
10.4 \\
10.0 \\
3.2 \\
7.8 \\
5.8 \\
3.8\end{array}$ & $\begin{array}{r}12.4 \\
15.2 \\
12.2 \\
10.6 \\
3.4 \\
8.8 \\
7.8 \\
6.0\end{array}$ \\
\hline $\begin{array}{l}29 \\
29 \\
29 \\
29 \\
29 \\
29 \\
29 \\
29\end{array}$ & $\begin{array}{r}0 \\
3 \\
5 \\
9 \\
12 \\
15 \\
18 \\
21\end{array}$ & $\begin{array}{l}20.9 \\
20.8 \\
20.8 \\
23.2 \\
24.5 \\
23.2 \\
21.3 \\
18.4\end{array}$ & $\begin{array}{l}20.1 \\
20.1 \\
20.1 \\
20.4 \\
10.9 \\
16.3 \\
16.5 \\
15.8\end{array}$ & $\begin{array}{l}21.6 \\
21.1 \\
20.7 \\
22.9 \\
24.1 \\
23.2 \\
21.5 \\
19.4\end{array}$ & $\begin{array}{l}20.2 \\
20.0 \\
20.0 \\
20.1 \\
18.7 \\
16.0 \\
16.5 \\
15.8\end{array}$ & $\begin{array}{l}22 \cdot 1 \\
21 \cdot 3 \\
20.5 \\
22.8 \\
24.0 \\
23.3 \\
22.0 \\
20.3\end{array}$ & $\begin{array}{l}20.3 \\
20.3 \\
20.1 \\
20.0 \\
10.4 \\
16.0 \\
16.4 \\
15.8\end{array}$ & $\begin{array}{l}22.4 \\
21.8 \\
20.8 \\
22.7 \\
23.6 \\
23.1 \\
22.0 \\
20.5\end{array}$ & $\begin{array}{l}20.1 \\
20.0 \\
19.8 \\
20.0 \\
19.0 \\
15.7 \\
16.2 \\
15.6\end{array}$ & $\begin{array}{l}23.3 \\
23.2 \\
23.0 \\
24.3 \\
24.4 \\
23.4 \\
23.1 \\
23.0\end{array}$ & & $\begin{array}{l}0.2 \\
5.0 \\
4 \cdot 2 \\
4 \cdot 6 \\
6.6 \\
5.0 \\
2.2 \\
1.8\end{array}$ & $\begin{array}{l}2.4 \\
5.4 \\
4.6 \\
8.0 \\
6.0 \\
3.4 \\
6.2\end{array}$ & $\begin{array}{l}3.4 \\
6.2 \\
5.4 \\
9.2 \\
7.0 \\
4.2 \\
4.0\end{array}$ & $\begin{array}{r}4.6 \\
5.4 \\
6.2 \\
5.6 \\
10.4 \\
8.6 \\
5.8 \\
5.4\end{array}$ \\
\hline $\begin{array}{l}30 \\
30 \\
30 \\
30 \\
30 \\
30 \\
30 \\
30\end{array}$ & $\begin{array}{r}0 \\
3 \\
6 \\
9 \\
12 \\
15 \\
15 \\
21\end{array}$ & $\begin{array}{l}20.0 \\
19.4 \\
21.0 \\
23.7 \\
27.8 \\
27.0 \\
25.7 \\
23.1\end{array}$ & $\begin{array}{l}16.1 \\
16.1 \\
16.2 \\
17.1 \\
19.2 \\
19.8 \\
19.8 \\
19.1\end{array}$ & $\begin{array}{l}20.2 \\
19.8 \\
21.0 \\
23.0 \\
27.0 \\
26.9 \\
25.7 \\
23.1\end{array}$ & $\begin{array}{l}15.8 \\
15.0 \\
15.6 \\
16.6 \\
18.6 \\
10.2 \\
19.04 \\
18.6\end{array}$ & $\begin{array}{l}20.4 \\
20.0 \\
21.1 \\
23.0 \\
27.2 \\
26.8 \\
25.7 \\
23.2\end{array}$ & $\begin{array}{l}15.9 \\
16.0 \\
15.6 \\
16.1 \\
18.7 \\
15.9 \\
17.3 \\
13.5\end{array}$ & $\begin{array}{l}20.3 \\
19.7 \\
20.0 \\
23.5 \\
27.1 \\
26.7 \\
25.4 \\
22.9\end{array}$ & $\begin{array}{l}15.9 \\
16.1 \\
15.8 \\
16.2 \\
19.0 \\
19.0 \\
10.1 \\
10.4\end{array}$ & $\begin{array}{l}22.8 \\
22.8 \\
23.3 \\
25.7 \\
28.9 \\
27.7 \\
25.9 \\
25.1\end{array}$ & & $\begin{array}{l}4.2 \\
2.3 \\
6.0 \\
5.8 \\
2.4 \\
7.2 \\
8.0 \\
9.0\end{array}$ & $\begin{array}{r}4.8 \\
3.4 \\
6.8 \\
6.8 \\
3.4 \\
8.2 \\
9.2 \\
10.0\end{array}$ & $\begin{array}{r}5.0 \\
3.6 \\
7.0 \\
7.2 \\
3.6 \\
3.6 \\
9.8 \\
10.6\end{array}$ & $\begin{array}{r}5.2 \\
3.8 \\
7.2 \\
7.2 \\
3.6 \\
9.0 \\
10.4 \\
11.0\end{array}$ \\
\hline
\end{tabular}


Table 10. - Three-hour averages of air and water-surface temperatures and wind directions and speed, April 1950-August 1951, Lake Hefner-Continued

THREE-HOURLY AVERAGES

JULY, 1950

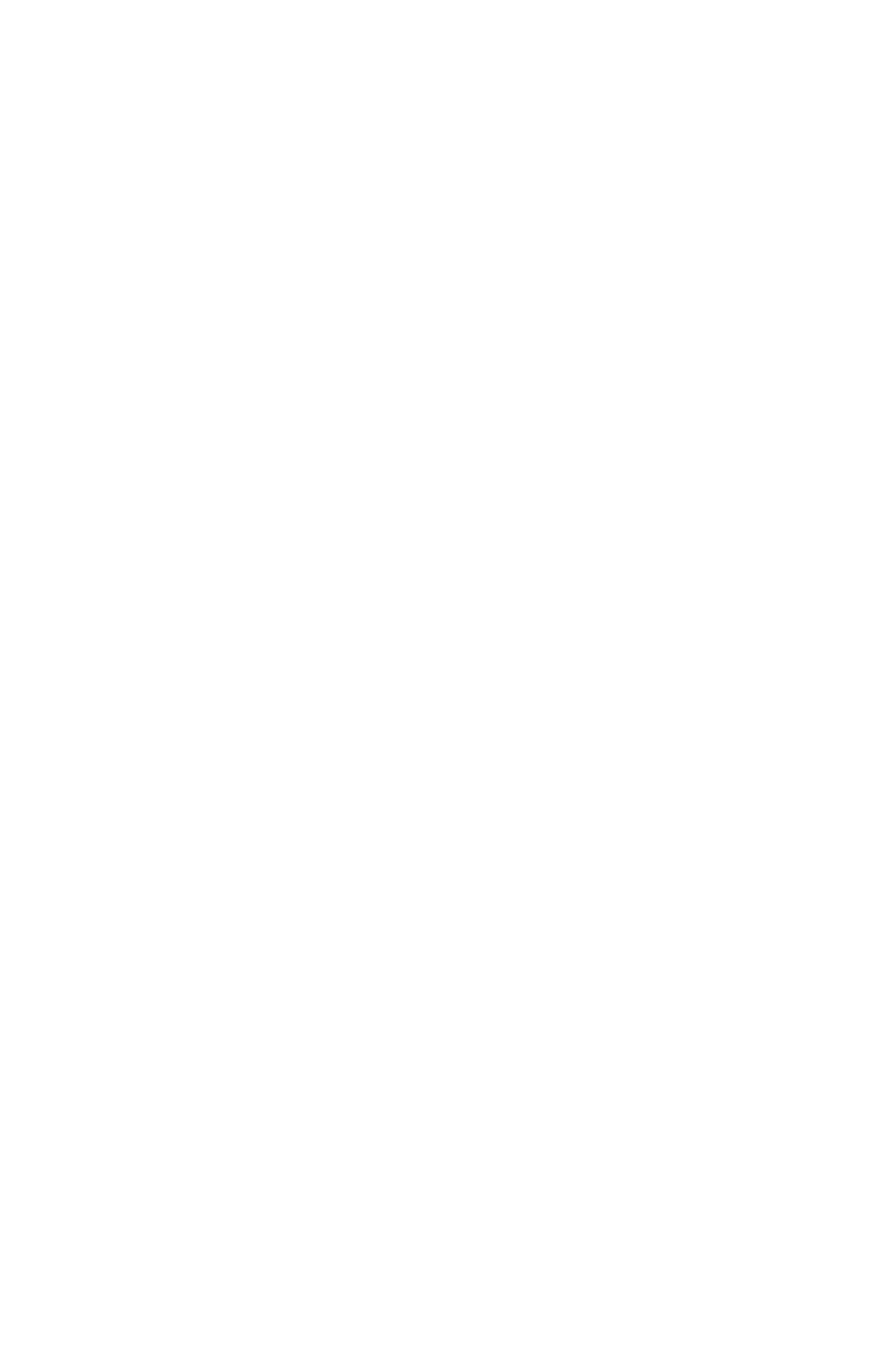


TABLE 10

Table 10. - Three-hour averages of air and water-surface temperatures and wind directions and speed, April 1950-August 951, Lake Hefner-Continued

STATION

THREE-HOURLY Y AVERAGES

JULY, 1850

\begin{tabular}{|c|c|c|c|c|c|c|c|c|c|c|c|c|c|c|c|}
\hline \multirow{3}{*}{ 胥 } & \multirow{3}{*}{ 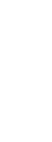 } & \multicolumn{8}{|c|}{ Average air temperature $\left({ }^{\circ} \mathrm{C}\right)$ at indicated height } & \multirow{3}{*}{$\begin{array}{l}\text { Average } \\
\text { water- } \\
\text { surface } \\
\text { tempera- } \\
\text { ture } \\
\text { (C) }\end{array}$} & \multirow{3}{*}{$\begin{array}{c}\text { Average } \\
\text { wind } \\
\text { direction } \\
\text { (coded) }\end{array}$} & \multirow{2}{*}{\multicolumn{4}{|c|}{$\begin{array}{l}\text { Average wind speed (knots) } \\
\text { at indicated height }\end{array}$}} \\
\hline & & \multicolumn{2}{|c|}{$\begin{array}{c}2 \\
\text { meters }\end{array}$} & \multicolumn{2}{|c|}{$\begin{array}{c}4 \\
\text { meters }\end{array}$} & \multicolumn{2}{|c|}{$\begin{array}{c}8 \\
\text { meters }\end{array}$} & \multicolumn{2}{|c|}{$\begin{array}{c}16 \\
\text { meters }\end{array}$} & & & & & & \\
\hline & & $\begin{array}{l}\text { Dry } \\
\text { bulb }\end{array}$ & $\begin{array}{l}\text { Wet } \\
\text { bulb }\end{array}$ & $\begin{array}{l}\text { Dry } \\
\text { bulb }\end{array}$ & $\begin{array}{l}\text { Wet } \\
\text { bulb }\end{array}$ & $\begin{array}{l}\text { Dry } \\
\text { bulb }\end{array}$ & $\begin{array}{l}\text { Wet } \\
\text { bulb }\end{array}$ & $\begin{array}{l}\text { Dry } \\
\text { bulb }\end{array}$ & & & & $\begin{array}{c}2 \\
\text { meters }\end{array}$ & $\begin{array}{c}4 \\
\text { neters }\end{array}$ & 8 & 16 \\
\hline
\end{tabular}

\begin{tabular}{|c|c|c|c|c|c|c|c|c|c|c|c|c|c|c|}
\hline & & DUto & Duid & Duro & Duid & Duto & bulb & bulb & bulb & ("C) & meters & meters & |meters & finets \\
\hline $\begin{array}{l}11 \\
11 \\
11 \\
11 \\
11 \\
11 \\
11 \\
11\end{array}$ & $\begin{array}{r}0 \\
3 \\
6 \\
9 \\
12 \\
15 \\
18 \\
21\end{array}$ & $\begin{array}{l}20.8 \\
20.6 \\
21.0 \\
22.9 \\
24.8 \\
25.9 \\
24.3 \\
22.6\end{array}$ & $\begin{array}{l}20.1 \\
20.0 \\
19.9 \\
20.7 \\
21.4 \\
22.0 \\
21.3 \\
20.8\end{array}$ & $\begin{array}{l}20.8 \\
20.7 \\
20.9 \\
22.8 \\
24 \cdot 6 \\
25.2 \\
24 \cdot 3 \\
22.7\end{array}$ & $\begin{array}{l}20.1 \\
20.0 \\
19.9 \\
20.5 \\
21.2 \\
21.8 \\
21.3 \\
20.8\end{array}$ & $\begin{array}{l}21.0 \\
20.8 \\
21.0 \\
22.8 \\
24.8 \\
25.2 \\
24.4 \\
22.8\end{array}$ & $\begin{array}{l}20.2 \\
20: 0 \\
19: 9 \\
20.4 \\
21.0 \\
21.8 \\
21.3 \\
20.8\end{array}$ & $\begin{array}{l}20.8 \\
20.5 \\
20: 7 \\
22 \cdot 5 \\
24 \cdot 5 \\
25 \cdot 2 \\
24 \cdot 3 \\
22.8\end{array}$ & $\begin{array}{l}20.1 \\
20.0 \\
19.9 \\
20.2 \\
20.9 \\
21.7 \\
21.2 \\
20.8\end{array}$ & $\begin{array}{l}22.8 \\
22.4 \\
22.8 \\
23.5 \\
24.5 \\
25.2 \\
23.6 \\
23.0\end{array}$ & $\begin{array}{l}3.3 \\
3.4 \\
4.7 \\
6.3 \\
6.0 \\
5.8 \\
4.8 \\
4.1\end{array}$ & $\begin{array}{l}4.8 \\
4.6 \\
6.1 \\
8.1 \\
7.3 \\
7.5 \\
6.6 \\
5.4\end{array}$ & $\begin{array}{l}5.6 \\
5.4 \\
7.2 \\
9.0 \\
8.0 \\
8.6 \\
7.0 \\
6.6\end{array}$ & $\begin{array}{r}6.9 \\
6.4 \\
8.2 \\
10.1 \\
8.5 \\
9.8 \\
9.6 \\
8.3\end{array}$ \\
\hline $\begin{array}{l}12 \\
12 \\
12 \\
12 \\
12 \\
12 \\
12 \\
12\end{array}$ & $\begin{array}{r}0 \\
3 \\
6 \\
9 \\
12 \\
15 \\
18 \\
21\end{array}$ & $\begin{array}{l}21.7 \\
20.6 \\
22.3 \\
26.2 \\
26.2 \\
27.6 \\
23.1 \\
19.3\end{array}$ & $\begin{array}{l}20.2 \\
19.5 \\
20.3 \\
21.3 \\
21.9 \\
22.4 \\
21.1 \\
19.1\end{array}$ & $\begin{array}{l}21.9 \\
20.8 \\
22.3 \\
25.9 \\
26.4 \\
27.1 \\
23.0 \\
19.2\end{array}$ & $\begin{array}{l}20.2 \\
19.5 \\
20.2 \\
20.7 \\
21.6 \\
21.9 \\
21.0 \\
19.1\end{array}$ & $\begin{array}{l}22.0 \\
20.9 \\
22.5 \\
25.9 \\
26.6 \\
27.4 \\
23.1 \\
19.4\end{array}$ & $\begin{array}{l}20.2 \\
19.5 \\
20.2 \\
20.7 \\
21.5 \\
21.8 \\
20.7 \\
19.2\end{array}$ & $\begin{array}{l}22 \cdot 0 \\
20: 9 \\
22: 2 \\
25.5 \\
26.2 \\
27.2 \\
22: 3 \\
19.4\end{array}$ & $\begin{array}{l}20.0 \\
19.3 \\
20.0 \\
20.7 \\
21.2 \\
21.6 \\
20.3 \\
19.2\end{array}$ & $\begin{array}{l}22.9 \\
22.6 \\
22.9 \\
24.8 \\
25.5 \\
25.6 \\
24.4 \\
23.5\end{array}$ & $\begin{array}{l}4.0 \\
3.7 \\
5.5 \\
5.9 \\
4.8 \\
5.0 \\
4.7 \\
2.1\end{array}$ & $\begin{array}{l}5.3 \\
4.9 \\
6.5 \\
7.2 \\
6.0 \\
6.1 \\
6.4 \\
3.0\end{array}$ & $\begin{array}{l}6.1 \\
6.0 \\
7.6 \\
7.8 \\
6.8 \\
6.9 \\
7.0 \\
3.5\end{array}$ & $\begin{array}{l}7.5 \\
7.1 \\
8.3 \\
8.5 \\
7.5 \\
7.6 \\
8.0 \\
3.8\end{array}$ \\
\hline $\begin{array}{l}13 \\
13 \\
13 \\
13 \\
13 \\
13 \\
13 \\
13\end{array}$ & $\begin{array}{r}0 \\
3 \\
6 \\
9 \\
12 \\
15 \\
18 \\
21\end{array}$ & $\begin{array}{l}19.8 \\
19.3 \\
18.3 \\
21.2 \\
22.8 \\
24.0 \\
21.4 \\
17.0\end{array}$ & $\begin{array}{l}19.5 \\
18.3 \\
16.2 \\
16.8 \\
17.0 \\
16.9 \\
18.2 \\
15.4\end{array}$ & $\begin{array}{l}19.8 \\
29.2 \\
18.3 \\
21.0 \\
22.8 \\
23.8 \\
21.3 \\
17.2\end{array}$ & $\begin{array}{l}19.5 \\
18.2 \\
16.1 \\
16.8 \\
16.6 \\
16.4 \\
16.4 \\
15.3\end{array}$ & $\begin{array}{l}19.8 \\
19.3 \\
18.3 \\
21.0 \\
22.8 \\
23.5 \\
21.4 \\
17.6\end{array}$ & $\begin{array}{l}19.6 \\
18.2 \\
16.1 \\
16.5 \\
16.4 \\
16.4 \\
16.4 \\
15.4\end{array}$ & 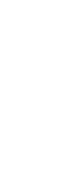 & $\begin{array}{l}19.5 \\
17.8 \\
16.0 \\
16.1 \\
16.2 \\
16.4 \\
16.2 \\
15.4\end{array}$ & $\begin{array}{l}23.0 \\
22.4 \\
22.8 \\
24.0 \\
24.3 \\
24.0 \\
22.6 \\
22.2\end{array}$ & $\begin{array}{l}4.99 \\
6.6 \\
9.3 \\
8.9 \\
7.0 \\
5.9 \\
3.2 \\
1.5\end{array}$ & $\begin{array}{r}6.2 \\
8.1 \\
11.5 \\
11.8 \\
8.7 \\
7.1 \\
4.2 \\
2.9\end{array}$ & $\begin{array}{r}7.6 \\
9.7 \\
13.9 \\
13.4 \\
10.3 \\
8.4 \\
5.2 \\
4.1\end{array}$ & $\begin{array}{r}8.6 \\
11.3 \\
15.3 \\
15.0 \\
11.6 \\
9.2 \\
7.2 \\
6.5\end{array}$ \\
\hline $\begin{array}{l}14 \\
14 \\
14 \\
14 \\
14 \\
14 \\
14 \\
14\end{array}$ & $\begin{array}{r}0 \\
3 \\
6 \\
9 \\
12 \\
15 \\
18 \\
21\end{array}$ & $\begin{array}{l}14.6 \\
13.5 \\
17.2 \\
23.6 \\
26.8 \\
27.6 \\
25.5 \\
23.1\end{array}$ & $\begin{array}{l}14.0 \\
13.2 \\
15.1 \\
17.4 \\
10.4 \\
20.4 \\
21.2 \\
21.4\end{array}$ & $\begin{array}{l}14.8 \\
13.7 \\
17.2 \\
22.8 \\
25.0 \\
26.9 \\
25.6 \\
23.1\end{array}$ & $\begin{array}{l}14.1 \\
13.4 \\
15.0 \\
16.9 \\
18.8 \\
19.8 \\
20.8 \\
21.4\end{array}$ & $\begin{array}{l}15.3 \\
14.2 \\
17.4 \\
22.5 \\
26.0 \\
26.9 \\
25.6 \\
23.3\end{array}$ & $\begin{array}{l}14 \cdot 3 \\
13.6 \\
15.1 \\
16.7 \\
18.9 \\
10.9 \\
20.9 \\
21.5\end{array}$ & $\begin{array}{l}15.6 \\
14.4 \\
17.3 \\
22.6 \\
25.0 \\
26.5 \\
25.4 \\
23.1\end{array}$ & $\begin{array}{l}14.5 \\
13.5 \\
15.0 \\
17.1 \\
19.2 \\
19.7 \\
20.7 \\
21.3\end{array}$ & $\begin{array}{l}22.2 \\
22.2 \\
23.2 \\
25.3 \\
28.0 \\
27.8 \\
25.5 \\
24.4\end{array}$ & $\begin{array}{l}1.6 \\
0.9 \\
3.7 \\
3.2 \\
3.0 \\
4.03 \\
5.00 \\
5.3\end{array}$ & $\begin{array}{l}2.5 \\
2.2 \\
4.6 \\
3.6 \\
4.1 \\
5.1 \\
6.3 \\
7.4\end{array}$ & $\begin{array}{l}3.6 \\
3.0 \\
5.4 \\
4.4 \\
4.5 \\
5.6 \\
7.3 \\
8.3\end{array}$ & $\begin{array}{l}5.7 \\
3.9 \\
6.3 \\
4.7 \\
4.8 \\
5.9 \\
8.7 \\
9.5\end{array}$ \\
\hline $\begin{array}{l}15 \\
15 \\
15 \\
15 \\
15 \\
15 \\
15 \\
15\end{array}$ & $\begin{array}{r}0 \\
3 \\
6 \\
9 \\
12 \\
15 \\
15 \\
21\end{array}$ & $\begin{array}{l}22.2 \\
21.6 \\
22.7 \\
25.6 \\
28.1 \\
29.0 \\
27.8 \\
26.0\end{array}$ & $\begin{array}{l}21 \cdot 4 \\
20.9 \\
21 \cdot 6 \\
22 \cdot 5 \\
23 \cdot 5 \\
23 \cdot 2 \\
23 \cdot 1 \\
22 \cdot 6\end{array}$ & $\begin{array}{l}22 \cdot 2 \\
21 \cdot 6 \\
27 \cdot 0 \\
25 \cdot 3 \\
27 \cdot 9 \\
28 \cdot 9 \\
27 \cdot 9 \\
26: 1\end{array}$ & $\begin{array}{l}21 \cdot 3 \\
20.9 \\
21.4 \\
23.0 \\
23.0 \\
23.0 \\
23.0 \\
22.5\end{array}$ & $\begin{array}{l}22.3 \\
21.7 \\
22.8 \\
25.5 \\
29.2 \\
29.1 \\
27.9 \\
26.2\end{array}$ & $\begin{array}{ll}21 & .4 \\
20.9 \\
21.3 \\
22 & 0 \\
22 & 0 \\
27 & 0 \\
23.0 \\
22.5\end{array}$ & $\begin{array}{l}22.0 \\
21.2 \\
22: 5 \\
25: 5 \\
28: 2 \\
29: 0 \\
27: 0 \\
26: 0\end{array}$ & $\begin{array}{l}21.0 \\
20.5 \\
21.0 \\
21.0 \\
27.7 \\
22.7 \\
22.0 \\
22.03\end{array}$ & $\begin{array}{l}23.7 \\
23.2 \\
23.2 \\
25.6 \\
27.1 \\
26.6 \\
24.5 \\
33.7\end{array}$ & $\begin{array}{r}7.4 \\
10.5 \\
11.2 \\
12.3 \\
14.8 \\
15.5 \\
12.8 \\
12.7\end{array}$ & $\begin{array}{r}9.8 \\
12.8 \\
12.9 \\
13.9 \\
17.6 \\
18.0 \\
15.4 \\
15.9\end{array}$ & $\begin{array}{l}11.0 \\
13.9 \\
13.8 \\
15.3 \\
10.2 \\
10.7 \\
17.0 \\
18 . ?\end{array}$ & $\begin{array}{l}12.1 \\
15.1 \\
14.4 \\
16.5 \\
20.6 \\
21.3 \\
19.0 \\
20.8\end{array}$ \\
\hline $\begin{array}{l}16 \\
16 \\
16 \\
16 \\
16 \\
16 \\
16 \\
16\end{array}$ & $\begin{array}{r}0 \\
3 \\
6 \\
9 \\
12 \\
15 \\
18 \\
21\end{array}$ & $\begin{array}{l}24 \cdot 9 \\
23.9 \\
24 \cdot 4 \\
26.4 \\
28.5 \\
28.7 \\
27.4 \\
26.6\end{array}$ & $\begin{array}{l}21.5 \\
21.5 \\
22.1 \\
22.4 \\
23.4 \\
23.1 \\
22.4 \\
22.0\end{array}$ & $\begin{array}{l}25.0 \\
23.0 \\
24.5 \\
26.6 \\
28.5 \\
28.7 \\
27.5 \\
26.5\end{array}$ & $\begin{array}{ll}21.4 \\
21.4 \\
22: 0 \\
32.2 \\
22.9 \\
22.3 \\
22.2 \\
21.0\end{array}$ & $\begin{array}{l}25.0 \\
24: 0 \\
24: 7 \\
27: 0 \\
20.1 \\
23.9 \\
27.7 \\
26.9\end{array}$ & $\begin{array}{l}21 \cdot 5 \\
21 \cdot 5 \\
22 \cdot 1 \\
22 \cdot 3 \\
22 \cdot 9 \\
22 \cdot 0 \\
22 \cdot 3 \\
22 \cdot 1\end{array}$ & $\begin{array}{l}24.0 \\
23 . c \\
24: 5 \\
27.0 \\
28 . c \\
28.7 \\
27.4 \\
25.6\end{array}$ & $\begin{array}{l}21 \cdot 1 \\
21 \cdot 3 \\
21: 9 \\
72 \cdot 1 \\
27 \cdot 5 \\
23.5 \\
21 \cdot 9 \\
21 \cdot 0\end{array}$ & $\begin{array}{l}23.0 \\
22.4 \\
23.0 \\
24.2 \\
26.0 \\
25.7 \\
23.5 \\
22.0\end{array}$ & $\begin{array}{l}16.0 \\
17.4 \\
19.9 \\
17.7 \\
16.0 \\
19.7 \\
13.7 \\
14.2\end{array}$ & $\begin{array}{l}19.0 \\
20.7 \\
23.5 \\
20.5 \\
18.6 \\
22.5 \\
15.9 \\
19.3\end{array}$ & $\begin{array}{l}21.5 \\
23.5 \\
25.4 \\
22.2 \\
20.5 \\
24.5 \\
13.9 \\
21.6\end{array}$ & $\begin{array}{l}24.0 \\
24.0 \\
27.1 \\
23.1 \\
22.3 \\
26.3 \\
21.4 \\
24.8\end{array}$ \\
\hline $\begin{array}{l}17 \\
17 \\
17 \\
17 \\
17 \\
17 \\
17 \\
17\end{array}$ & $\begin{array}{r}0 \\
3 \\
6 \\
9 \\
12 \\
15 \\
19 \\
21\end{array}$ & $\begin{array}{l}25.5 \\
23.5 \\
19.9 \\
19.7 \\
19.5 \\
23.7 \\
21.9 \\
20.4\end{array}$ & $\begin{array}{l}21.9 \\
21: 0 \\
19.1 \\
19 \cdot 3 \\
19.2 \\
21.2 \\
20.9 \\
20.3\end{array}$ & $\begin{array}{l}25.7 \\
23.5 \\
19.6 \\
19.6 \\
19.4 \\
23.4 \\
21.7 \\
20.4\end{array}$ & $\begin{array}{l}21.8 \\
20.8 \\
18.9 \\
10.1 \\
19.0 \\
20.9 \\
20.8 \\
20.2\end{array}$ & $\begin{array}{l}25.8 \\
23.5 \\
19.8 \\
15.8 \\
19.3 \\
23.1 \\
21.7 \\
20.8\end{array}$ & 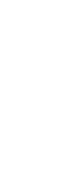 & $\begin{array}{l}25.5 \\
23.2 \\
19.7 \\
19.8 \\
10.4 \\
22.7 \\
21.5 \\
20.5\end{array}$ & $\begin{array}{l}21.5 \\
20.5 \\
13.9 \\
19.1 \\
18.3 \\
20.6 \\
20.7 \\
20.1\end{array}$ & $\begin{array}{l}22.5 \\
22.0 \\
21.3 \\
22.0 \\
32.9 \\
24.8 \\
22.9 \\
21.5\end{array}$ & $\begin{array}{r}15.3 \\
13.0 \\
10.8 \\
1.4 \\
4.0 \\
4.3 \\
4.1 \\
5.0\end{array}$ & $\begin{array}{r}20.0 \\
15.9 \\
12.4 \\
2.5 \\
7.6 \\
5.9 \\
5.6 \\
7.2\end{array}$ & $\begin{array}{r}22.0 \\
17.3 \\
13.1 \\
2.9 \\
0.1 \\
6.9 \\
6.9 \\
8.8\end{array}$ & $\begin{array}{r}24.8 \\
18.8 \\
13.5 \\
3.3 \\
10.2 \\
7.4 \\
8.0 \\
10.2\end{array}$ \\
\hline $\begin{array}{l}18 \\
18 \\
18 \\
18 \\
18 \\
18 \\
18 \\
18\end{array}$ & $\begin{array}{r}0 \\
3 \\
6 \\
9 \\
12 \\
15 \\
13 \\
21\end{array}$ & $\begin{array}{l}24 \cdot 1 \\
26 \cdot 0 \\
25 \cdot 9 \\
24 \cdot 3\end{array}$ & $\begin{array}{l}22.2 \\
22.7 \\
22.0 \\
20.9\end{array}$ & $\begin{array}{l}24 \cdot 1 \\
26.3 \\
36.1 \\
24.6\end{array}$ & $\begin{array}{l}20.7 \\
21.4 \\
21.9 \\
22.3 \\
21.8 \\
20.8\end{array}$ & $\begin{array}{l}21.4 \\
27.2 \\
24.4 \\
26.4 \\
26.4 \\
24.9\end{array}$ & $\begin{array}{l}20.8 \\
21.4 \\
22.0 \\
22.3 \\
21.9 \\
20.8\end{array}$ & $\begin{array}{l}21.3 \\
27.2 \\
24 \cdot 4 \\
26.5 \\
25 \cdot 3 \\
24.5\end{array}$ & $\begin{array}{l}20.5 \\
21.1 \\
21.9 \\
22.3 \\
21.5 \\
20.5\end{array}$ & $\begin{array}{l}22.6 \\
22.3 \\
23.5 \\
23.6 \\
23.1 \\
22.4\end{array}$ & $\begin{array}{l}4.8 \\
6.2 \\
6.3 \\
5.2\end{array}$ & $\begin{array}{r}5.1 \\
8.0 \\
7.0 \\
5.0 \\
11.3 \\
12.7 \\
10.1 \\
13.0\end{array}$ & $\begin{array}{r}7.8 \\
9.3 \\
8.2 \\
5.9 \\
12.5 \\
13.9 \\
11.9 \\
14.8\end{array}$ & $\begin{array}{r}9.0 \\
11.1 \\
8.3 \\
6.6 \\
13.6 \\
15.2 \\
13.5 \\
16.6\end{array}$ \\
\hline $\begin{array}{l}19 \\
19 \\
19 \\
19 \\
19 \\
19 \\
19 \\
19\end{array}$ & $\begin{array}{r}0 \\
3 \\
6 \\
9 \\
12 \\
15 \\
18 \\
21\end{array}$ & $\begin{array}{l}22.1 \\
21.5 \\
21.5 \\
21.8 \\
25.0 \\
26.7 \\
23.0 \\
18.8\end{array}$ & $\begin{array}{l}19.7 \\
20.0 \\
20.6 \\
20.8 \\
22.7 \\
23.6 \\
20.9 \\
18.8\end{array}$ & $\begin{array}{l}22.0 \\
21.5 \\
21: 3 \\
21: 7 \\
25: 0 \\
250.7 \\
? ? \cdot 0 \\
19.0\end{array}$ & $\begin{array}{l}19.4 \\
19.8 \\
20.6 \\
20.5 \\
22.3 \\
23.3 \\
20.6 \\
18.8\end{array}$ & $\begin{array}{l}22.1 \\
21.7 \\
21.6 \\
21.8 \\
25.3 \\
27.0 \\
2 ? \cdot ? \\
19.1\end{array}$ & $\begin{array}{l}19.4 \\
15.9 \\
20.6 \\
20.4 \\
22.3 \\
23.5 \\
20.8 \\
19.7\end{array}$ & 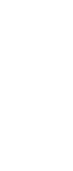 & $\begin{array}{l}10.0 \\
10.7 \\
20.4 \\
20.3 \\
22.2 \\
23.3 \\
20.0 \\
10.7\end{array}$ & $\begin{array}{l}22.0 \\
21.5 \\
21.9 \\
23.2 \\
24.9 \\
24.4 \\
22.5 \\
23.0\end{array}$ & $\begin{array}{r}10.1 \\
4.0 \\
6.0 \\
13.7 \\
11.3 \\
7.5 \\
7.7 \\
6.6\end{array}$ & $\begin{array}{r}12.0 \\
5.2 \\
7.0 \\
15.5 \\
13.4 \\
3.0 \\
9.6 \\
7.7\end{array}$ & $\begin{array}{r}13.1 \\
5.8 \\
7.4 \\
16.6 \\
14.6 \\
0.9 \\
11.8 \\
.6\end{array}$ & $\begin{array}{r}13.6 \\
6.7 \\
7.8 \\
17.1 \\
15.6 \\
10.9 \\
13.4 \\
9.4\end{array}$ \\
\hline $\begin{array}{l}20 \\
20 \\
20 \\
20 \\
20 \\
20 \\
20 \\
20\end{array}$ & $\begin{array}{r}0 \\
3 \\
6 \\
9 \\
12 \\
15 \\
18 \\
21\end{array}$ & $\begin{array}{l}26 \cdot 0 \\
27.2 \\
23.7 \\
21.9\end{array}$ & $\begin{array}{l}21.2 \\
21: 4 \\
21: 7 \\
20.9\end{array}$ & $\begin{array}{l}25 \cdot 9 \\
27 \cdot 2 \\
23 \cdot 8 \\
21.9\end{array}$ & $\begin{array}{l}20.4 \\
21.1 \\
21.5 \\
20.8\end{array}$ & $\begin{array}{l}25.2 \\
26.8 \\
24.1 \\
22.1\end{array}$ & $\begin{array}{l}20,3 \\
21.1 \\
21.6 \\
20.8\end{array}$ & $\begin{array}{l}25.3 \\
26.4 \\
24.0 \\
22.2\end{array}$ & $\begin{array}{l}20.5 \\
21.3 \\
21.3 \\
20.7\end{array}$ & $\begin{array}{l}27.7 \\
27.3 \\
24.0 \\
22.9\end{array}$ & $\begin{array}{r}15.6 \\
9.4 \\
2.7 \\
1.4 \\
2.2 \\
1.5 \\
2.2 \\
3.0\end{array}$ & $\begin{array}{r}17.4 \\
11.0 \\
3.6 \\
1.3\end{array}$ & $\begin{array}{r}18.5 \\
11.7 \\
4.7 \\
1.9 \\
2.5 \\
1.9 \\
3.7 \\
5.4\end{array}$ & $\begin{array}{r}19.4 \\
12.3 \\
4.0 \\
2.5 \\
1.8 \\
4.7 \\
6.9\end{array}$ \\
\hline
\end{tabular}


TABLE 10

Table. 10. - Three-hour averages of air and water-surface temperatures and wind directions and speed, April 1950-August 1951, Lake Hefner Continued

STATION 3 THREE-HOURLY AVERAGES

JULY, 1950

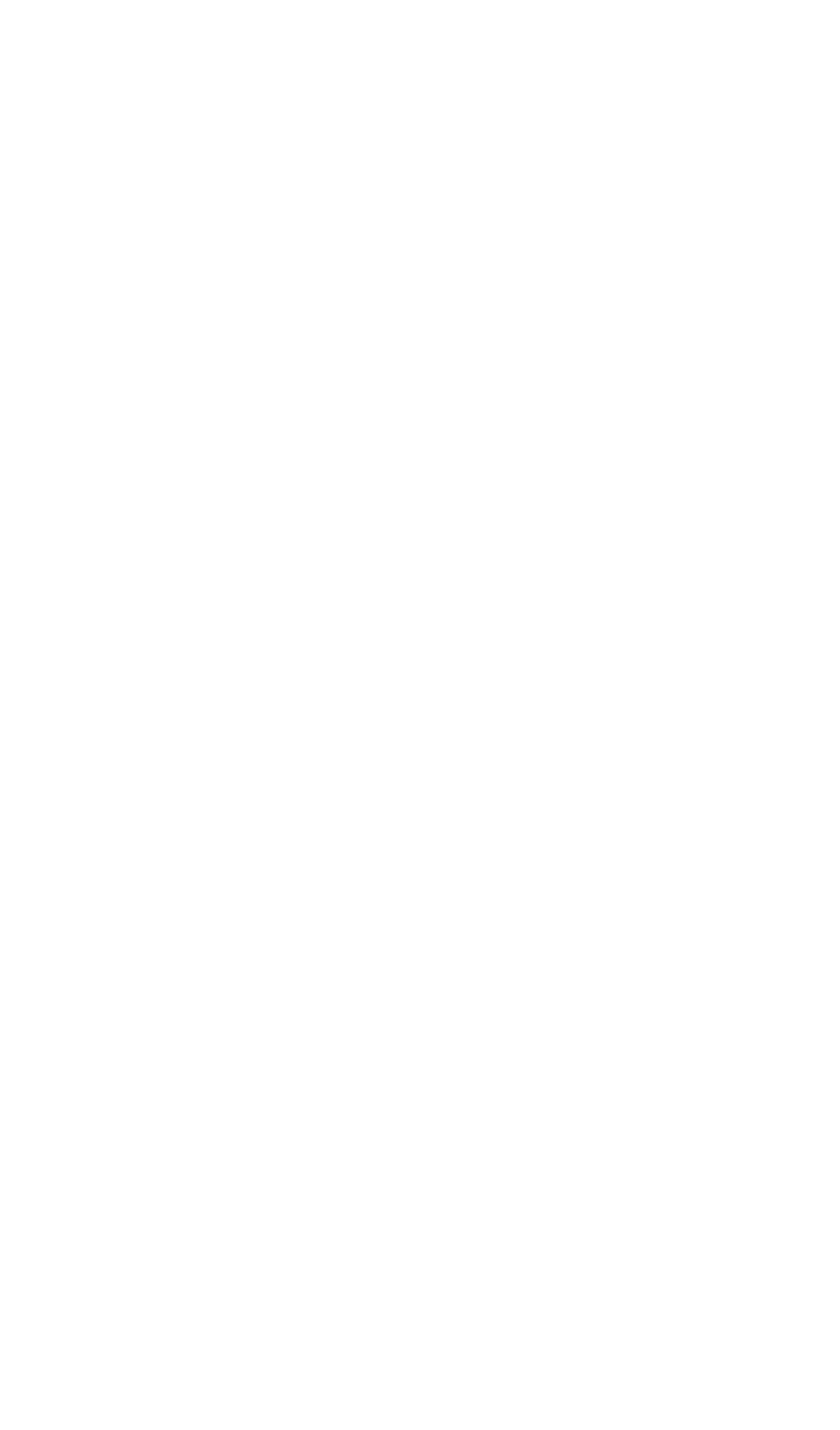


TABLE 10

135

Table 10. - Three-hour averages of air and water-surface temperatures and wind directions and speed, April 1950-August 1951, Lake Hefner-Continued

STATION 3 THREE-HOURLY AVERAGES

AUGUST, 1950

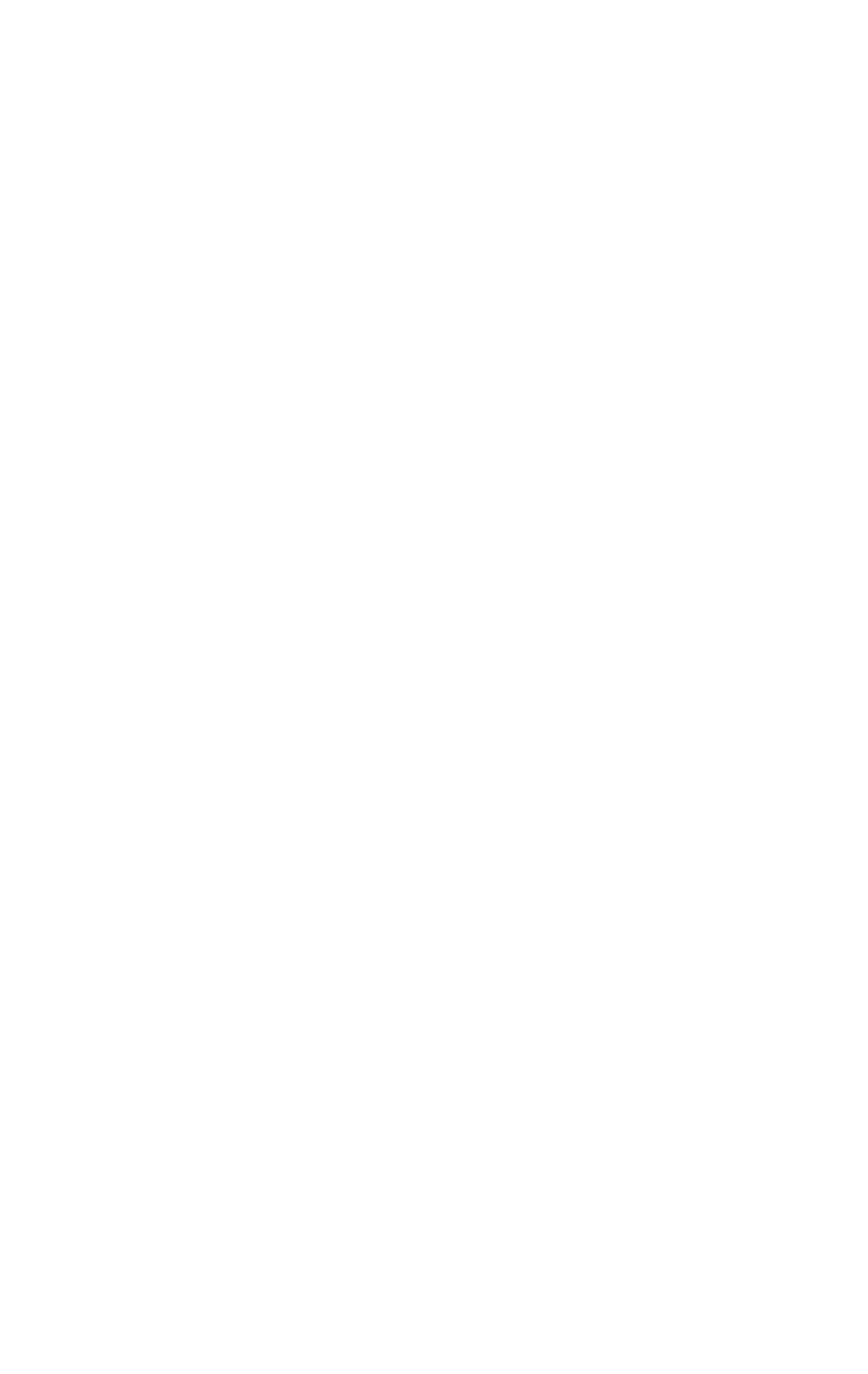


TABLE 10

Table 10. - Three-hour averagea of air and water-surface temperatures and wind directions and speed, April 1950-August 1951, Lake Hefner-Continued

STATION

THREE-HOURLY AVERAGES

AUGUST, 1950

\begin{tabular}{|c|c|c|c|c|c|c|c|c|c|c|c|c|c|c|c|}
\hline \multirow{4}{*}{ 密 } & \multirow{4}{*}{ 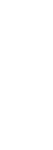 } & \multicolumn{8}{|c|}{ Average air temperature $\left({ }^{\circ} \mathrm{C}\right)$ at indicated height } & \multirow{4}{*}{$\begin{array}{c}\text { Average } \\
\text { water- } \\
\text { surface } \\
\text { tempera- } \\
\text { ture } \\
\left({ }^{\circ} \mathrm{C}\right)\end{array}$} & \multirow{4}{*}{$\begin{array}{c}\text { Average } \\
\text { wind } \\
\text { direction } \\
\text { (coded) }\end{array}$} & \multirow{2}{*}{\multicolumn{4}{|c|}{$\begin{array}{l}\text { Average wind speed (knots) } \\
\text { at indicated height }\end{array}$}} \\
\hline & & \multirow{2}{*}{\multicolumn{2}{|c|}{$\begin{array}{c}2 \\
\text { meters }\end{array}$}} & \multirow{2}{*}{\multicolumn{2}{|c|}{$\begin{array}{c}4 \\
\text { meters }\end{array}$}} & \multirow{2}{*}{\multicolumn{2}{|c|}{$\begin{array}{c}8 \\
\text { meters }\end{array}$}} & \multirow{2}{*}{\multicolumn{2}{|c|}{$\begin{array}{c}16 \\
\text { meters }\end{array}$}} & & & & & & \\
\hline & & & & & & & & & & & & 2 & 4 & 8 & 16 \\
\hline & & $\begin{array}{l}\text { Dry } \\
\text { bulb }\end{array}$ & $\begin{array}{l}\text { Wet } \\
\text { bulb }\end{array}$ & $\begin{array}{l}\text { Dry } \\
\text { bulb }\end{array}$ & $\begin{array}{l}\text { Wet } \\
\text { bulb }\end{array}$ & $\begin{array}{l}\text { Dry } \\
\text { bulb }\end{array}$ & $\begin{array}{l}\text { Wet } \\
\text { bulb }\end{array}$ & $\begin{array}{l}\text { Dry } \\
\text { bulb }\end{array}$ & $\begin{array}{l}\text { Wet } \\
\text { bulb }\end{array}$ & & & meters & meters & meters & meters \\
\hline $\begin{array}{l}11 \\
11 \\
11 \\
11 \\
11 \\
11 \\
11 \\
11\end{array}$ & $\begin{array}{r}0 \\
3 \\
6 \\
9 \\
12 \\
15 \\
18 \\
21\end{array}$ & $\begin{array}{l}25.1 \\
23.8 \\
24.3 \\
27.6 \\
31.4 \\
32.3 \\
28.7 \\
26.1\end{array}$ & $\begin{array}{l}23.0 \\
22.0 \\
22.0 \\
23.1 \\
24.2 \\
24.6 \\
24.6 \\
24.0\end{array}$ & $\begin{array}{l}25.1 \\
23.9 \\
24.4 \\
27.3 \\
31.2 \\
32.1 \\
28.8 \\
26.7\end{array}$ & $\begin{array}{l}22.8 \\
21: 9 \\
21.9 \\
22.6 \\
23.8 \\
24.2 \\
24.6 \\
23.8\end{array}$ & $\begin{array}{l}24.8 \\
23.0 \\
24.0 \\
27.2 \\
31.0 \\
31.0 \\
28.7 \\
26.0\end{array}$ & $\begin{array}{l}22.4 \\
21.4 \\
21.5 \\
22.5 \\
23.4 \\
23.7 \\
24.3 \\
23.5\end{array}$ & $\begin{array}{l}24.8 \\
23.6 \\
24.0 \\
27.1 \\
30.9 \\
31.0 \\
28.6 \\
26.1\end{array}$ & $\begin{array}{l}22.4 \\
21.4 \\
21.5 \\
22.5 \\
23.3 \\
23.6 \\
24.5 \\
23.4\end{array}$ & $\begin{array}{l}27.3 \\
26.8 \\
26.7 \\
27.9 \\
28.3 \\
27.8 \\
26.7 \\
26.6\end{array}$ & & $\begin{array}{r}8.6 \\
8.2 \\
8.4 \\
3.4 \\
6.6 \\
6.2 \\
7.5 \\
10.9\end{array}$ & $\begin{array}{r}10.2 \\
10.1 \\
9.7 \\
4.0 \\
8.4 \\
7.9 \\
9.7 \\
13.3\end{array}$ & $\begin{array}{r}11.5 \\
11.0 \\
10.3 \\
4.4 \\
9.5 \\
9.4 \\
11.5 \\
14.8\end{array}$ & $\begin{array}{r}13.2 \\
12.6 \\
11.4 \\
4.8 \\
10.9 \\
11.0 \\
13.6 \\
17.1\end{array}$ \\
\hline $\begin{array}{l}12 \\
12 \\
12 \\
12 \\
12 \\
12 \\
12 \\
12\end{array}$ & $\begin{array}{r}0 \\
3 \\
6 \\
9 \\
12 \\
15 \\
18 \\
21\end{array}$ & $\begin{array}{l}24.7 \\
23.1 \\
23.7 \\
28.3 \\
31.1 \\
31.8 \\
29.2 \\
26.9\end{array}$ & $\begin{array}{l}22 \cdot 1 \\
21 \cdot 3 \\
21 \cdot 3 \\
22 \cdot 3 \\
23 \cdot 0 \\
24 \cdot 5 \\
24: 2 \\
22 \cdot 9\end{array}$ & $\begin{array}{l}24.7 \\
23.1 \\
23.8 \\
28.6 \\
31.6 \\
31.9 \\
29.5 \\
27.0\end{array}$ & $\begin{array}{l}21.9 \\
21.2 \\
21.1 \\
21.6 \\
22.1 \\
22.7 \\
23.8 \\
22.7\end{array}$ & $\begin{array}{l}24 \cdot 5 \\
27.7 \\
23.7 \\
28.8 \\
31.7 \\
32.2 \\
29.3 \\
26.7\end{array}$ & $\begin{array}{l}21.5 \\
20.8 \\
20.8 \\
20.9 \\
21.4 \\
22.0 \\
23.3 \\
22.3\end{array}$ & $\begin{array}{l}24.4 \\
22.5 \\
23.3 \\
29.1 \\
32.0 \\
32.7 \\
29.5 \\
26.7\end{array}$ & $\begin{array}{l}21.4 \\
20.7 \\
20.8 \\
21.3 \\
21.9 \\
22.1 \\
23.0 \\
27.2\end{array}$ & $\begin{array}{l}26.2 \\
25.8 \\
25.7 \\
26.9 \\
28.9 \\
29.0 \\
28.1 \\
27.7\end{array}$ & & $\begin{array}{r}13.6 \\
17.7 \\
13.8 \\
10.2 \\
7.4 \\
8.7 \\
7.7 \\
11.3\end{array}$ & $\begin{array}{r}15.4 \\
14.0 \\
15.1 \\
11.4 \\
8.4 \\
9.7 \\
8.7 \\
12.6\end{array}$ & $\begin{array}{r}16.5 \\
15.1 \\
16.1 \\
12.5 \\
0.5 \\
11.0 \\
0.9 \\
13.9\end{array}$ & $\begin{array}{r}18.5 \\
16.5 \\
17.5 \\
12.9 \\
9.9 \\
12.2 \\
11.8 \\
15.7\end{array}$ \\
\hline $\begin{array}{l}13 \\
13 \\
13 \\
13 \\
13 \\
13 \\
13 \\
13\end{array}$ & $\begin{array}{r}0 \\
3 \\
6 \\
9 \\
12 \\
15 \\
18 \\
21\end{array}$ & $\begin{array}{l}25.5 \\
24.0 \\
24.8 \\
28.7 \\
30.4 \\
31.3 \\
28.9 \\
25.5\end{array}$ & $\begin{array}{l}22.6 \\
21.8 \\
21.4 \\
22.6 \\
23.4 \\
23.6 \\
22.8 \\
21.8\end{array}$ & $\begin{array}{l}25.5 \\
23.9 \\
25.0 \\
28.9 \\
30.8 \\
31.3 \\
29.1 \\
25.5\end{array}$ & $\begin{array}{l}22.5 \\
21.5 \\
21 \cdot 3 \\
22.1 \\
22.8 \\
23.1 \\
22 \cdot 4 \\
21.3\end{array}$ & $\begin{array}{l}25.1 \\
23.5 \\
24.8 \\
28.9 \\
31.0 \\
31.2 \\
28.8 \\
75.2\end{array}$ & $\begin{array}{l}22.0 \\
21.1 \\
20.9 \\
21.6 \\
22.4 \\
22.6 \\
22.2 \\
21.0\end{array}$ & $\begin{array}{l}25 \cdot 1 \\
23: 5 \\
25: 0 \\
29: 2 \\
31: 1 \\
31 \cdot 2 \\
28: 0 \\
25.1\end{array}$ & $\begin{array}{l}22.0 \\
21.0 \\
21.0 \\
21.7 \\
22.1 \\
22.4 \\
22.0 \\
20.9\end{array}$ & $\begin{array}{l}27.0 \\
26.5 \\
26.7 \\
28.3 \\
29.4 \\
29.8 \\
28.4 \\
27.8\end{array}$ & & $\begin{array}{r}13.0 \\
10.1 \\
7.6 \\
10.2 \\
6.8 \\
8.0 \\
7.6 \\
7.8\end{array}$ & $\begin{array}{r}14.2 \\
10.9 \\
8.4 \\
11.5 \\
7.7 \\
8.1 \\
8.9 \\
8.5\end{array}$ & $\begin{array}{r}15.1 \\
11.6 \\
3.9 \\
12.8 \\
6.4 \\
10.3 \\
9.8 \\
0.1\end{array}$ & $\begin{array}{r}16.3 \\
12.2 \\
9.1 \\
13.1 \\
9.0 \\
11.0 \\
11: 3 \\
10.0\end{array}$ \\
\hline $\begin{array}{l}14 \\
14 \\
14 \\
14 \\
14 \\
14 \\
14 \\
14\end{array}$ & $\begin{array}{r}0 \\
3 \\
6 \\
9 \\
12 \\
15 \\
18 \\
21\end{array}$ & $\begin{array}{l}24.0 \\
23.0 \\
23.4 \\
27.1 \\
30.0 \\
30.4 \\
28.7 \\
26.2\end{array}$ & $\begin{array}{l}21.8 \\
21.5 \\
21.7 \\
22.6 \\
22.8 \\
23.5 \\
23.0 \\
22.7\end{array}$ & $\begin{array}{l}24.0 \\
23.0 \\
23.7 \\
27.1 \\
30.5 \\
30.6 \\
28.8 \\
26.4\end{array}$ & $\begin{array}{l}21.5 \\
21: 3 \\
21: 7 \\
22.3 \\
22.8 \\
22.9 \\
22.7 \\
22.6\end{array}$ & $\begin{array}{l}23.7 \\
22.7 \\
23.4 \\
26.9 \\
30.7 \\
30.5 \\
28.5 \\
26.2\end{array}$ & $\begin{array}{l}21 \cdot 1 \\
21: 0 \\
21 \cdot 3 \\
21: 5 \\
22.6 \\
22: 4 \\
22: 4 \\
22: 2\end{array}$ & $\begin{array}{l}23.7 \\
22.5 \\
23.4 \\
26.9 \\
29.8 \\
30.4 \\
28.8 \\
26.3\end{array}$ & $\begin{array}{l}21 \cdot 2 \\
20 \cdot 9 \\
21.4 \\
21.8 \\
21.9 \\
22.2 \\
27.2 \\
27.1\end{array}$ & $\begin{array}{l}27.3 \\
26.8 \\
27.0 \\
23.7 \\
30.9 \\
30.3 \\
29.5 \\
28.7\end{array}$ & & $\begin{array}{l}7.0 \\
6.1 \\
4.8 \\
6.9 \\
3.5 \\
7.3 \\
5.5 \\
4.9\end{array}$ & $\begin{array}{l}7.5 \\
6.7 \\
5.8 \\
7.7 \\
4.0 \\
8.7 \\
6.5 \\
5.0\end{array}$ & $\begin{array}{l}8.0 \\
6.9 \\
7.4 \\
8.4 \\
4.3 \\
9.0 \\
7.0 \\
6.6\end{array}$ & $\begin{array}{l}9 \cdot 1 \\
7: 5 \\
6.3 \\
8.5 \\
4.5 \\
9.9 \\
9.0 \\
7.9\end{array}$ \\
\hline $\begin{array}{l}15 \\
15 \\
15 \\
15 \\
15 \\
15 \\
15 \\
15\end{array}$ & $\begin{array}{r}0 \\
3 \\
5 \\
9 \\
12 \\
15 \\
18 \\
21\end{array}$ & $\begin{array}{l}25.7 \\
25.1 \\
24.8 \\
28.4 \\
30.4 \\
30.7 \\
24.7 \\
21.8\end{array}$ & $\begin{array}{l}22.9 \\
22.5 \\
22.2 \\
23.0 \\
23.3 \\
24.1 \\
22.0 \\
20.8\end{array}$ & $\begin{array}{l}25.8 \\
25.1 \\
24.9 \\
28.5 \\
30.6 \\
31.1 \\
24.6 \\
21.9\end{array}$ & $\begin{array}{l}22.8 \\
22.1 \\
21.9 \\
22.4 \\
22.7 \\
23.4 \\
21.8 \\
20.6\end{array}$ & $\begin{array}{l}25.5 \\
24.8 \\
24.7 \\
28.4 \\
30.8 \\
31.2 \\
24.3 \\
21.5\end{array}$ & $\begin{array}{l}22 \cdot 3 \\
21 \cdot 7 \\
21 \cdot 5 \\
21 \cdot 8 \\
22 \cdot 2 \\
22 \cdot 6 \\
21 \cdot 4 \\
20 \cdot 3\end{array}$ & $\begin{array}{l}25.5 \\
24: 7 \\
24: 3 \\
28: 6 \\
31: 0 \\
31 \cdot 4 \\
24: 1 \\
21.9\end{array}$ & $\begin{array}{l}22 \cdot 3 \\
21 \cdot 5 \\
21.5 \\
21.5 \\
22 \cdot 1 \\
22.6 \\
21.4 \\
20.4\end{array}$ & $\begin{array}{l}28.2 \\
27.8 \\
27.9 \\
29.9 \\
30.4 \\
30.1 \\
28.3 \\
26.6\end{array}$ & & $\begin{array}{r}6.8 \\
10.5 \\
11.2 \\
10.4 \\
8.8 \\
7.4 \\
8.7 \\
11.3\end{array}$ & $\begin{array}{r}7.8 \\
11.7 \\
12.3 \\
11.9 \\
10.0 \\
8.4 \\
10.5 \\
13.2\end{array}$ & $\begin{array}{r}3.1 \\
12.7 \\
13.1 \\
13.3 \\
11.1 \\
9.3 \\
12.0 \\
14.3\end{array}$ & $\begin{array}{r}9.1 \\
13.9 \\
13.4 \\
13.6 \\
11.5 \\
10.2 \\
13.6 \\
15.7\end{array}$ \\
\hline $\begin{array}{l}16 \\
16 \\
16 \\
16 \\
15 \\
16 \\
16 \\
16\end{array}$ & $\begin{array}{r}0 \\
3 \\
6 \\
9 \\
12 \\
15 \\
18 \\
21\end{array}$ & $\begin{array}{l}23 \cdot 0 \\
21 \cdot 3 \\
21 \cdot 3 \\
24 \cdot 8 \\
27 \cdot 3 \\
25 \cdot 3 \\
24 \cdot 3 \\
23 \cdot 4\end{array}$ & $\begin{array}{l}21.1 \\
20.1 \\
20.6 \\
21.8 \\
23.1 \\
22.1 \\
22.1 \\
22.6\end{array}$ & $\begin{array}{l}22.9 \\
21.05 \\
21.5 \\
24.8 \\
27.0 \\
25.2 \\
24.4 \\
23.5\end{array}$ & $\begin{array}{l}20.7 \\
19.9 \\
20.6 \\
21.8 \\
22.7 \\
21.9 \\
21.9 \\
22.4\end{array}$ & $\begin{array}{l}22.7 \\
21.3 \\
21.3 \\
24.6 \\
26.8 \\
25.0 \\
24.01 \\
23.2\end{array}$ & $\begin{array}{l}20.3 \\
19.8 \\
20.3 \\
21 \cdot 7 \\
22.5 \\
21 \cdot 7 \\
21.5 \\
22.1\end{array}$ & $\begin{array}{l}22: 6 \\
21: 7 \\
21: 4 \\
24: 6 \\
26: 5 \\
24 \cdot 5 \\
23.9 \\
23.2\end{array}$ & $\begin{array}{l}20,3 \\
19 \cdot 8 \\
20.4 \\
21 \cdot 8 \\
22 \cdot 1 \\
21.8 \\
21.6 \\
22 \cdot 1\end{array}$ & $\begin{array}{l}26.9 \\
26.7 \\
26.7 \\
27.2 \\
28.2 \\
27.5 \\
26.8 \\
26.4\end{array}$ & ء & $\begin{array}{l}7.5 \\
3.0 \\
2.6 \\
2.3 \\
6.8 \\
7.9 \\
5.5 \\
4.2\end{array}$ & $\begin{array}{l}8.4 \\
3.8 \\
3.3 \\
3.0 \\
7.5 \\
8.7 \\
6.2 \\
5.4\end{array}$ & $\begin{array}{l}8.8 \\
4.5 \\
4.0 \\
3.3 \\
8.0 \\
9.3 \\
6.6 \\
5.8\end{array}$ & $\begin{array}{r}9.0 \\
5.4 \\
4.9 \\
3.5 \\
8.5 \\
10.0 \\
6.9 \\
6.3\end{array}$ \\
\hline $\begin{array}{l}17 \\
17 \\
17 \\
17 \\
17 \\
17 \\
17 \\
17\end{array}$ & $\begin{array}{r}0 \\
3 \\
6 \\
9 \\
12 \\
15 \\
18 \\
21\end{array}$ & $\begin{array}{l}22.6 \\
22.3 \\
21.6 \\
24.0 \\
23.9 \\
23.6 \\
21.0 \\
19.9\end{array}$ & $\begin{array}{l}21.5 \\
20.9 \\
20.7 \\
20.5 \\
20.7 \\
20.6 \\
19.1 \\
19.1\end{array}$ & $\begin{array}{l}22.5 \\
22.1 \\
21.7 \\
23.6 \\
23.7 \\
23.5 \\
21.0 \\
20.1\end{array}$ & $\begin{array}{l}21.2 \\
20.5 \\
20.4 \\
20.1 \\
20.4 \\
20.3 \\
19.1 \\
19.2\end{array}$ & $\begin{array}{l}22.2 \\
21.5 \\
21.4 \\
23.1 \\
23.3 \\
23.3 \\
20.8 \\
19.8\end{array}$ & $\begin{array}{l}21.0 \\
20.2 \\
20.1 \\
19.4 \\
19.9 \\
19.9 \\
18.8 \\
18.3\end{array}$ & $\begin{array}{l}22.2 \\
21.6 \\
21.4 \\
22.9 \\
23.5 \\
23.2 \\
20.7 \\
19.8\end{array}$ & $\begin{array}{l}21.0 \\
20.2 \\
20.0 \\
19.3 \\
20.0 \\
19.6 \\
16.8 \\
18.3\end{array}$ & $\begin{array}{l}26.1 \\
25.7 \\
25.9 \\
27.5 \\
27.6 \\
25.4 \\
25.9 \\
25.5\end{array}$ & & $\begin{array}{r}6.4 \\
7.0 \\
4.3 \\
5.0 \\
7.0 \\
10.8 \\
5.0 \\
4.7\end{array}$ & $\begin{array}{r}7.4 \\
8.4 \\
5.2 \\
6.1 \\
8.8 \\
13.5 \\
6.5 \\
5.7\end{array}$ & $\begin{array}{r}7.7 \\
8.8 \\
5.7 \\
7.4 \\
10.4 \\
16.3 \\
7.9 \\
6.8\end{array}$ & $\begin{array}{r}7.8 \\
9.2 \\
6.1 \\
7.5 \\
10.8 \\
18.6 \\
8.8 \\
7.8\end{array}$ \\
\hline $\begin{array}{l}18 \\
18 \\
18 \\
18 \\
18 \\
18 \\
18 \\
18\end{array}$ & $\begin{array}{r}0 \\
3 \\
6 \\
9 \\
12 \\
15 \\
18 \\
21\end{array}$ & $\begin{array}{l}19.4 \\
18.5 \\
18.8 \\
22.8 \\
25.9 \\
26.8 \\
22.8 \\
18.8\end{array}$ & $\begin{array}{l}18.9 \\
18.3 \\
17.8 \\
18.8 \\
18.0 \\
17.6 \\
17.1 \\
16.2\end{array}$ & $\begin{array}{l}19.6 \\
18.6 \\
18.8 \\
22.5 \\
25.6 \\
26.7 \\
23.04 \\
20.1\end{array}$ & $\begin{array}{l}18.9 \\
18.3 \\
17.7 \\
18.5 \\
18.0 \\
17.2 \\
17.1 \\
16.4\end{array}$ & $\begin{array}{l}19.3 \\
18.3 \\
18.5 \\
21.9 \\
25.0 \\
26.2 \\
23.7 \\
20.9\end{array}$ & $\begin{array}{l}18.7 \\
17: 0 \\
17: 2 \\
17: 9 \\
17: 2 \\
16.5 \\
16.8 \\
16.3\end{array}$ & $\begin{array}{l}19.2 \\
18.2 \\
18.6 \\
22.0 \\
25: 0 \\
26.2 \\
24 \cdot 3 \\
21.4\end{array}$ & $\begin{array}{l}18.7 \\
17.9 \\
17.4 \\
17.9 \\
17.0 \\
16.7 \\
16.7 \\
16.3\end{array}$ & $\begin{array}{l}25.1 \\
24.9 \\
25.3 \\
26.6 \\
27.1 \\
26.6 \\
25.7 \\
25.5\end{array}$ & & $\begin{array}{l}5.0 \\
6.8 \\
6.8 \\
7.6 \\
7.2 \\
5.8 \\
2.2 \\
2.2\end{array}$ & $\begin{array}{l}6.4 \\
8.4 \\
8.4 \\
9.3 \\
9.1 \\
7.2 \\
2.9 \\
3.3\end{array}$ & $\begin{array}{r}7.6 \\
9.9 \\
9.9 \\
11.4 \\
11.0 \\
8.7 \\
3.9 \\
4.2\end{array}$ & $\begin{array}{r}7.3 \\
9.7 \\
10.7 \\
12.4 \\
11.9 \\
9.6 \\
5.4 \\
6.0\end{array}$ \\
\hline $\begin{array}{l}19 \\
19 \\
19 \\
19 \\
19 \\
19 \\
19 \\
19\end{array}$ & $\begin{array}{r}0 \\
3 \\
6 \\
9 \\
12 \\
15 \\
18 \\
21\end{array}$ & $\begin{array}{l}18.4 \\
16.3 \\
19.4 \\
24.4 \\
27.7 \\
28.1 \\
23.0 \\
20.1\end{array}$ & $\begin{array}{l}16.0 \\
14.7 \\
16.8 \\
17.5 \\
17.3 \\
18.4 \\
18.2 \\
17.4\end{array}$ & $\begin{array}{l}19.0 \\
17.00 \\
19.44 \\
23.9 \\
27.4 \\
27.8 \\
23.5 \\
20.2\end{array}$ & $\begin{array}{l}15.8 \\
14.9 \\
16.9 \\
17.1 \\
16: 9 \\
17.9 \\
18.4 \\
17.4\end{array}$ & $\begin{array}{l}19.6 \\
17.8 \\
19.6 \\
24.3 \\
26.7 \\
27.3 \\
23.7 \\
19.9\end{array}$ & $\begin{array}{l}15.5 \\
14.8 \\
16.5 \\
17.0 \\
16.7 \\
17.8 \\
18.3 \\
17.0\end{array}$ & $\begin{array}{l}20.2 \\
18.8 \\
20.3 \\
24.3 \\
26.3 \\
27.1 \\
24.3 \\
19.0\end{array}$ & $\begin{array}{l}15.7 \\
15.3 \\
16.9 \\
17.3 \\
16.6 \\
17.6 \\
18.2 \\
16.9\end{array}$ & $\begin{array}{l}25.6 \\
25.7 \\
26.1 \\
27.6 \\
28.6 \\
27.0 \\
25.8 \\
25.4\end{array}$ & & $\begin{array}{l}1.4 \\
1.4 \\
1.4 \\
2.0 \\
4.0 \\
4.3 \\
2.6 \\
6.1\end{array}$ & $\begin{array}{l}1.6 \\
1.6 \\
1.4 \\
2.3 \\
4.8 \\
5.3 \\
3.6 \\
7.7\end{array}$ & $\begin{array}{l}2.1 \\
1.4 \\
1.3 \\
2.5 \\
5.5 \\
6.3 \\
4.5 \\
9.2\end{array}$ & $\begin{array}{r}3.2 \\
1.3 \\
1.5 \\
2.5 \\
6.2 \\
7.2 \\
7.2 \\
11.8\end{array}$ \\
\hline $\begin{array}{l}20 \\
20 \\
20 \\
20 \\
20 \\
20 \\
20 \\
20\end{array}$ & $\begin{array}{r}0 \\
3 \\
5 \\
9 \\
12 \\
15 \\
18 \\
21\end{array}$ & $\begin{array}{l}16.4 \\
15.0 \\
13.5 \\
14.7 \\
14.6 \\
14.1 \\
13.9 \\
13.8\end{array}$ & $\begin{array}{l}13.4 \\
11.8 \\
10.4 \\
11.8 \\
12.4 \\
12.3 \\
12.4 \\
12.9\end{array}$ & $\begin{array}{l}16.4 \\
14.09 \\
13.04 \\
14.5 \\
14.4 \\
13.8 \\
13.9 \\
13.9\end{array}$ & $\begin{array}{l}13.2 \\
11.8 \\
10.3 \\
11.5 \\
12.1 \\
12.1 \\
12.3 \\
12.9\end{array}$ & $\begin{array}{l}16.0 \\
14.5 \\
13.0 \\
13.8 \\
14.0 \\
13.5 \\
13.7 \\
13.7\end{array}$ & $\begin{array}{r}12.7 \\
11.3 \\
9.9 \\
11.0 \\
11.8 \\
11.8 \\
12.1 \\
12.7\end{array}$ & $\begin{array}{l}15.8 \\
14.4 \\
13.0 \\
13.9 \\
13.7 \\
13.4 \\
13.7 \\
13.7\end{array}$ & 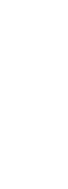 & $\begin{array}{l}25.2 \\
24.9 \\
24.9 \\
24.9 \\
25.0 \\
25.0 \\
24.9 \\
24.9\end{array}$ & & $\begin{array}{l}6.6 \\
7.2 \\
7.4 \\
7.1 \\
5.5 \\
4.6 \\
2.6 \\
2.1\end{array}$ & $\begin{array}{l}8.4 \\
9.0 \\
9.2 \\
8.8 \\
6.9 \\
5.9 \\
3.2 \\
2.6\end{array}$ & $\begin{array}{r}10.1 \\
10.7 \\
11.4 \\
10.6 \\
8.2 \\
7.0 \\
3.3 \\
3.0\end{array}$ & $\begin{array}{r}11.5 \\
12.0 \\
12.8 \\
11.7 \\
9.0 \\
7.6 \\
4.3 \\
2.9\end{array}$ \\
\hline
\end{tabular}


TABLE 10

Table 10. - Three-hour averages of air and water-surface temperatures and wind directions and speed, April 1950-August 1951, Lake Hefner-Continued

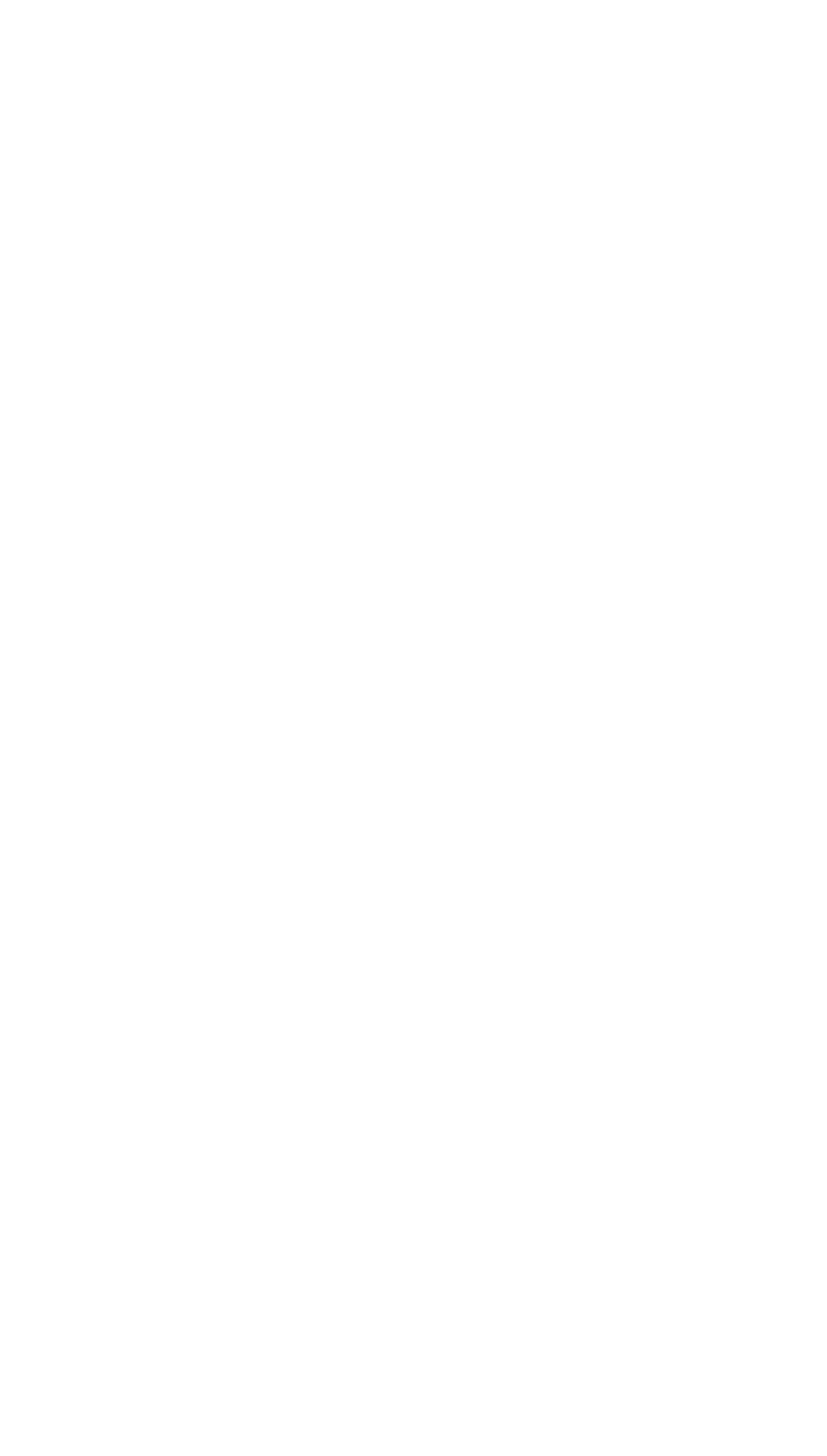


Table 10.-Three-hour averages of air and water-surface temperatures and wind directions and speed, April 1950-August 1951, Lake Hefner-Continued

STATION 3 THREE-HOURLY AVERAGES

SEPTEMBER, 1950

\begin{tabular}{|c|c|c|c|c|c|c|c|c|c|c|c|c|c|c|c|}
\hline \multirow{4}{*}{ 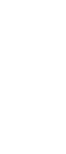 } & \multirow{4}{*}{ 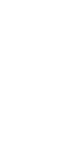 } & \multicolumn{8}{|c|}{ Average air temperature $\left({ }^{\circ} \mathrm{C}\right)$ at indicated height } & \multirow{4}{*}{$\begin{array}{c}\text { Average } \\
\text { water- } \\
\text { surface } \\
\text { tempera- } \\
\text { ture } \\
\left({ }^{\circ} \mathrm{C}\right)\end{array}$} & \multirow{4}{*}{$\begin{array}{l}\text { Average } \\
\text { wind } \\
\text { direction } \\
\text { (coded) }\end{array}$} & \multirow{2}{*}{\multicolumn{4}{|c|}{$\begin{array}{l}\text { Average wind speed (knots) } \\
\text { at indicated height }\end{array}$}} \\
\hline & & \multirow{2}{*}{\multicolumn{2}{|c|}{$\begin{array}{c}2 \\
\text { meters }\end{array}$}} & \multirow{2}{*}{\multicolumn{2}{|c|}{$\begin{array}{c}4 \\
\text { meters }\end{array}$}} & \multirow{2}{*}{\multicolumn{2}{|c|}{$\begin{array}{c}8 \\
\text { meters }\end{array}$}} & \multirow{2}{*}{\multicolumn{2}{|c|}{$\begin{array}{c}16 \\
\text { meters }\end{array}$}} & & & & & & \\
\hline & & & & & & & & & & & & 2 & 4 & 8 & 16 \\
\hline & & $\begin{array}{l}\text { Dry } \\
\text { bulb }\end{array}$ & $\begin{array}{l}\text { Wet } \\
\text { bulb }\end{array}$ & $\begin{array}{l}\text { Dry } \\
\text { bulb }\end{array}$ & $\begin{array}{l}\text { Wet } \\
\text { bulb }\end{array}$ & $\begin{array}{l}\text { Dry } \\
\text { bulb }\end{array}$ & $\begin{array}{l}\text { Wet } \\
\text { bulb }\end{array}$ & $\begin{array}{l}\text { Dry } \\
\text { bulb }\end{array}$ & $\begin{array}{l}\text { Wet } \\
\text { bulb }\end{array}$ & & & meters & meters & meters & meters \\
\hline $\begin{array}{l}1 \\
1 \\
1 \\
1 \\
1 \\
1 \\
1 \\
1\end{array}$ & $\begin{array}{r}0 \\
3 \\
6 \\
9 \\
12 \\
15 \\
18 \\
21\end{array}$ & $\begin{array}{l}16.5 \\
15.4 \\
16.9 \\
23.6 \\
27.3 \\
28.3 \\
24.1 \\
21.2\end{array}$ & $\begin{array}{l}16.0 \\
15.1 \\
15.5 \\
17.8 \\
18.3 \\
18.4 \\
18.1 \\
18.1\end{array}$ & $\begin{array}{l}16.7 \\
15.5 \\
16.8 \\
23.2 \\
26.7 \\
28.1 \\
24.2 \\
21.5\end{array}$ & $\begin{array}{l}16.0 \\
15.0 \\
15.5 \\
17.8 \\
18.2 \\
18.4 \\
18.2 \\
18.1\end{array}$ & $\begin{array}{l}16.6 \\
15.4 \\
16.8 \\
23.0 \\
26.5 \\
27.8 \\
24.1 \\
21.3\end{array}$ & $\begin{array}{l}15.8 \\
14: 7 \\
15: 2 \\
17: 3 \\
17: 9 \\
18.1 \\
17: 9 \\
17.9\end{array}$ & $\begin{array}{l}16.6 \\
15.3 \\
15.9 \\
23.0 \\
26.3 \\
27.7 \\
24.6 \\
21.5\end{array}$ & $\begin{array}{l}15.8 \\
14.7 \\
15.3 \\
17.3 \\
17.7 \\
13.1 \\
17.9 \\
17.9\end{array}$ & $\begin{array}{l}23.9 \\
23.7 \\
23.8 \\
24.7 \\
25.1 \\
24.7 \\
24.0 \\
24.0\end{array}$ & & $\begin{array}{l}3.7 \\
4.6 \\
6.4 \\
9.1 \\
9.4 \\
8.3 \\
3.4 \\
2.9\end{array}$ & $\begin{array}{r}4.7 \\
5.9 \\
8.0 \\
11.6 \\
12.0 \\
11.0 \\
4.2 \\
3.8\end{array}$ & $\begin{array}{r}5.5 \\
7.1 \\
10.6 \\
14.1 \\
14.4 \\
13.4 \\
5.8 \\
5.3\end{array}$ & $\begin{array}{r}6.0 \\
7.3 \\
12.8 \\
15.4 \\
15.8 \\
14.8 \\
7.7 \\
6.3\end{array}$ \\
\hline $\begin{array}{l}2 \\
2 \\
2 \\
2 \\
2 \\
2 \\
2 \\
2\end{array}$ & $\begin{array}{r}0 \\
3 \\
6 \\
9 \\
12 \\
15 \\
18 \\
21\end{array}$ & $\begin{array}{l}19.7 \\
18.2 \\
19.6 \\
25.7 \\
27.2 \\
26.6 \\
21.2 \\
21.1\end{array}$ & $\begin{array}{l}17.3 \\
16.6 \\
17.4 \\
19.2 \\
18.1 \\
20.1 \\
20.1 \\
19.7\end{array}$ & $\begin{array}{l}20.0 \\
18.4 \\
19.6 \\
25.3 \\
27.8 \\
26.2 \\
21.2 \\
21.2\end{array}$ & $\begin{array}{l}17.4 \\
16.7 \\
17.4 \\
19.1 \\
18.2 \\
20.2 \\
20.1 \\
19.8\end{array}$ & $\begin{array}{l}19.8 \\
18.03 \\
19.5 \\
25.0 \\
27.2 \\
25.8 \\
21.1 \\
21.0\end{array}$ & $\begin{array}{l}17.1 \\
16.4 \\
17.1 \\
18.7 \\
17.7 \\
19.9 \\
19.8 \\
19.5\end{array}$ & $\begin{array}{l}19.9 \\
18.3 \\
19.6 \\
25.1 \\
27.2 \\
25.5 \\
20.0 \\
21.0\end{array}$ & $\begin{array}{l}17.1 \\
16.5 \\
17.2 \\
18.7 \\
17.6 \\
20.0 \\
19.9 \\
19.7\end{array}$ & $\begin{array}{l}23.8 \\
23.7 \\
23.8 \\
24.8 \\
24.8 \\
24.4 \\
24.0 \\
23.8\end{array}$ & & $\begin{array}{l}2.7 \\
3.2 \\
4.5 \\
7.2 \\
9.8 \\
9.2 \\
5.8 \\
6.0\end{array}$ & $\begin{array}{r}3.6 \\
4.2 \\
5.7 \\
9.0 \\
12.7 \\
11.6 \\
7.1 \\
7.5\end{array}$ & $\begin{array}{r}5.5 \\
6.3 \\
7.2 \\
11.0 \\
15.4 \\
13.8 \\
3.4 \\
9.0\end{array}$ & $\begin{array}{r}6.2 \\
7.4 \\
7.4 \\
11.7 \\
17.0 \\
16.2 \\
10.1 \\
10.7\end{array}$ \\
\hline $\begin{array}{l}3 \\
3 \\
3 \\
3 \\
3 \\
3 \\
3 \\
3\end{array}$ & $\begin{array}{r}0 \\
3 \\
6 \\
9 \\
12 \\
15 \\
18 \\
21\end{array}$ & $\begin{array}{l}19.7 \\
19.0 \\
19.0 \\
21.2 \\
23.9 \\
24.8 \\
22.7 \\
20.9\end{array}$ & $\begin{array}{l}19.1 \\
19.0 \\
19.0 \\
19.9 \\
20.8 \\
21.0 \\
20.5 \\
20.3\end{array}$ & $\begin{array}{l}19.7 \\
19.1 \\
19.2 \\
21.0 \\
23.5 \\
24.8 \\
22.7 \\
21.0\end{array}$ & $\begin{array}{l}19.2 \\
19.00 \\
19.0 \\
19.9 \\
20.6 \\
20.9 \\
20.5 \\
20.3\end{array}$ & $\begin{array}{l}19.6 \\
19.11 \\
18.09 \\
20.7 \\
23.2 \\
24.1 \\
22.5 \\
20.8\end{array}$ & $\begin{array}{l}18.9 \\
18.9 \\
18.8 \\
19.6 \\
20.3 \\
20.8 \\
20.3 \\
20.1\end{array}$ & $\begin{array}{l}19.5 \\
19 \cdot 1 \\
19.0 \\
20.9 \\
23.3 \\
24 \cdot 1 \\
22.5 \\
21.3\end{array}$ & $\begin{array}{l}19.1 \\
19.0 \\
18.9 \\
19.9 \\
20.4 \\
20.7 \\
20.4 \\
20.4\end{array}$ & $\begin{array}{l}23.6 \\
23.1 \\
22.4 \\
23.1 \\
24.2 \\
24.0 \\
23.8 \\
22.5\end{array}$ & & $\begin{array}{l}4.2 \\
3: 9 \\
4: 2 \\
5.3 \\
6.1 \\
7.5 \\
4: 1 \\
2.3\end{array}$ & $\begin{array}{l}4.6 \\
4.8 \\
5.4 \\
6.8 \\
7.9 \\
9.2 \\
5.0 \\
2.7\end{array}$ & $\begin{array}{r}5.7 \\
5.7 \\
6.6 \\
8.3 \\
9.6 \\
10.9 \\
6.4 \\
3.8\end{array}$ & $\begin{array}{r}7.5 \\
6.9 \\
7.2 \\
9.4 \\
10.5 \\
12.9 \\
8.0 \\
5.1\end{array}$ \\
\hline $\begin{array}{l}4 \\
4 \\
4 \\
4 \\
4 \\
4 \\
4 \\
4\end{array}$ & $\begin{array}{r}0 \\
3 \\
6 \\
9 \\
12 \\
15 \\
18 \\
21\end{array}$ & $\begin{array}{l}20.4 \\
20.1 \\
20.5 \\
22.5 \\
27.3 \\
25.6 \\
20.4 \\
21.0\end{array}$ & $\begin{array}{l}20.3 \\
20.1 \\
20.4 \\
21.4 \\
22.3 \\
21.5 \\
20.2 \\
20.8\end{array}$ & $\begin{array}{l}20.6 \\
20.2 \\
20.6 \\
22.7 \\
26.9 \\
24.9 \\
20.5 \\
21.1\end{array}$ & $\begin{array}{l}20.3 \\
20.00 \\
20.4 \\
21.4 \\
22.1 \\
21.1 \\
20.1 \\
20.8\end{array}$ & $\begin{array}{l}20.5 \\
20.2 \\
20.5 \\
22.6 \\
25.8 \\
24.5 \\
20.6 \\
21.02\end{array}$ & $\begin{array}{l}20.2 \\
20.0 \\
20.3 \\
21.1 \\
22.0 \\
20.8 \\
20.0 \\
20.7\end{array}$ & $\begin{array}{l}21.6 \\
22.6 \\
25.9 \\
24.4 \\
20.7\end{array}$ & $\begin{array}{l}20.9 \\
21.0 \\
22.0 \\
20.8 \\
19.8\end{array}$ & $\begin{array}{l}21 \cdot 3 \\
24 \cdot 1 \\
25 \cdot 0 \\
24 \cdot 3 \\
22.1\end{array}$ & & $\begin{array}{l}2.2 \\
2.1 \\
3.3 \\
3.3 \\
4.2 \\
6.0 \\
2.6 \\
0.9\end{array}$ & $\begin{array}{l}2.7 \\
2.4 \\
4.0 \\
3.9 \\
4.9 \\
7.3 \\
3.3 \\
1.8\end{array}$ & $\begin{array}{l}3.8 \\
3.2 \\
4.8 \\
4.9 \\
5.9 \\
9.0 \\
4.5 \\
2.9\end{array}$ & $\begin{array}{r}4.6 \\
5.9 \\
5.4 \\
5.5 \\
6.5 \\
10.5 \\
5.7 \\
3.8\end{array}$ \\
\hline $\begin{array}{l}5 \\
5 \\
5 \\
5 \\
5 \\
5 \\
5 \\
5 .\end{array}$ & $\begin{array}{r}0 \\
3 \\
6 \\
9 \\
12 \\
15 \\
18 \\
21\end{array}$ & $\begin{array}{l}20.2 \\
18.1 \\
17.6 \\
18.3 \\
21.5 \\
21.8 \\
17.7 \\
15.4\end{array}$ & $\begin{array}{l}19.9 \\
17.8 \\
16.9 \\
17.0 \\
17.8 \\
15.7 \\
14.3 \\
13.7\end{array}$ & $\begin{array}{l}20.2 \\
18.2 \\
17.7 \\
18.1 \\
21.3 \\
21.4 \\
17.8 \\
15.6\end{array}$ & $\begin{array}{l}19.8 \\
17.8 \\
16.9 \\
16.8 \\
17.7 \\
15.5 \\
14.3 \\
13.8\end{array}$ & $\begin{array}{l}20.2 \\
18.1 \\
17.4 \\
17.9 \\
20.9 \\
20.9 \\
17.5 \\
15.6\end{array}$ & $\begin{array}{l}19.5 \\
17.5 \\
16.6 \\
16.5 \\
17.2 \\
15.2 \\
14.0 \\
13.5\end{array}$ & $\begin{array}{l}18.0 \\
17.5 \\
17.0 \\
21.0 \\
20.9 \\
17.9 \\
16.0\end{array}$ & $\begin{array}{l}18.1 \\
16.7 \\
16.5 \\
17.1 \\
15.2 \\
14.0 \\
13.5\end{array}$ & $\begin{array}{l}23.9 \\
23.8 \\
24.0 \\
24.8 \\
24.1 \\
23.8 \\
23.6\end{array}$ & & $\begin{array}{l}4.0 \\
4.3 \\
5.6 \\
5.7 \\
5.4 \\
6.2 \\
2.9 \\
2.5\end{array}$ & $\begin{array}{l}4.7 \\
5.2 \\
6.6 \\
6.9 \\
6.5 \\
7.4 \\
3.6 \\
3.2\end{array}$ & $\begin{array}{l}5.8 \\
6.3 \\
7.8 \\
3.0 \\
7.6 \\
8.8 \\
4.8 \\
4.3\end{array}$ & $\begin{array}{r}7.5 \\
7.9 \\
9.2 \\
9.1 \\
8.5 \\
10.4 \\
7.2 \\
6.3\end{array}$ \\
\hline $\begin{array}{l}6 \\
5 \\
6 \\
6 \\
6 \\
6 \\
6 \\
6\end{array}$ & $\begin{array}{r}0 \\
3 \\
6 \\
9 \\
12 \\
15 \\
18 \\
21\end{array}$ & $\begin{array}{l}14.2 \\
12.4 \\
13.9 \\
19.2 \\
21.1 \\
22.1 \\
17.4 \\
14.0\end{array}$ & $\begin{array}{l}13.3 \\
12.2 \\
12.9 \\
14.3 \\
14.5 \\
14.9 \\
13.8 \\
12.3\end{array}$ & $\begin{array}{l}14.4 \\
12.6 \\
13.8 \\
18.6 \\
20.6 \\
21.7 \\
17.7 \\
14.8\end{array}$ & $\begin{array}{l}13.3 \\
12.02 \\
12.8 \\
13.9 \\
14.1 \\
14.6 \\
13.8 \\
12.6\end{array}$ & $\begin{array}{l}14.2 \\
12.4 \\
1.3 .7 \\
18.1 \\
20.1 \\
21.02 \\
17.5 \\
15.4\end{array}$ & $\begin{array}{l}13.0 \\
11.09 \\
12.4 \\
13.4 \\
13.6 \\
14.4 \\
13.5 \\
12.7\end{array}$ & $\begin{array}{l}14.4 \\
12.6 \\
13.7 \\
18.1 \\
20.1 \\
21.2 \\
18.4 \\
16.5\end{array}$ & $\begin{array}{l}13.1 \\
12.0 \\
12.4 \\
13.6 \\
13.5 \\
14.3 \\
13.5 \\
13.0\end{array}$ & $\begin{array}{l}23.4 \\
23.3 \\
23.5 \\
24.3 \\
24.6 \\
24.1 \\
23.2 \\
23.0\end{array}$ & & $\begin{array}{l}2.3 \\
2.1 \\
4.2 \\
3.8 \\
5.7 \\
4.7 \\
2.4 \\
2.3\end{array}$ & $\begin{array}{l}2.9 \\
2.5 \\
5.2 \\
4.6 \\
7.1 \\
5.8 \\
3.0 \\
3.4\end{array}$ & $\begin{array}{l}3.6 \\
3.4 \\
5.8 \\
5.4 \\
8.4 \\
6.7 \\
4.2 \\
5.1\end{array}$ & $\begin{array}{l}4.0 \\
4: 9 \\
7.1 \\
5: 9 \\
9: 3 \\
7: 6 \\
6.9 \\
7.1\end{array}$ \\
\hline $\begin{array}{l}7 \\
7 \\
7 \\
7 \\
7 \\
7 \\
7 \\
7\end{array}$ & $\begin{array}{r}0 \\
3 \\
6 \\
9 \\
12 \\
15 \\
18 \\
21\end{array}$ & $\begin{array}{l}14.3 \\
12.3 \\
14.7 \\
20.7 \\
24.2 \\
24.8 \\
20.3 \\
16.1\end{array}$ & $\begin{array}{l}12.9 \\
11.7 \\
13.1 \\
15.3 \\
16.2 \\
16.0 \\
14.8 \\
13.7\end{array}$ & $\begin{array}{l}15.5 \\
12.6 \\
15.0 \\
20.7 \\
23.8 \\
24.5 \\
21.4 \\
17.4\end{array}$ & $\begin{array}{l}13.3 \\
11.8 \\
13.1 \\
14.7 \\
15.6 \\
15.8 \\
15.1 \\
14.0\end{array}$ & $\begin{array}{l}15.7 \\
13.0 \\
15.0 \\
20.2 \\
23.5 \\
24.4 \\
21.7 \\
18.4\end{array}$ & $\begin{array}{l}13.2 \\
11.7 \\
12: 9 \\
14: 7 \\
15.2 \\
15.7 \\
15.2 \\
14.3\end{array}$ & $\begin{array}{l}16.2 \\
13.9 \\
15.3 \\
20.4 \\
23.8 \\
24.1 \\
22.1 \\
19.2\end{array}$ & $\begin{array}{l}13.4 \\
12.2 \\
13.1 \\
15.1 \\
15.8 \\
15.5 \\
15.0 \\
14.5\end{array}$ & $\begin{array}{l}23.0 \\
23.0 \\
23.3 \\
24.7 \\
26.4 \\
23.9 \\
22.0 \\
21.9\end{array}$ & & $\begin{array}{l}2.1 \\
1.5 \\
2.2 \\
2.3 \\
2.6 \\
3.4 \\
2.2 \\
2.5\end{array}$ & $\begin{array}{l}1.1 \\
1.9 \\
2.0 \\
2.4 \\
2.8 \\
4.3 \\
3.1 \\
3.9\end{array}$ & $\begin{array}{l}1.6 \\
2.6 \\
3.3 \\
2.7 \\
3.3 \\
4.9 \\
3.7 \\
5.9\end{array}$ & $\begin{array}{l}1.6 \\
2.5 \\
3.2 \\
2.6 \\
3.3 \\
5.5 \\
4.7 \\
6.9\end{array}$ \\
\hline $\begin{array}{l}8 \\
8 \\
8 \\
8 \\
8 \\
8 \\
8 \\
8\end{array}$ & $\begin{array}{r}0 \\
3 \\
6 \\
9 \\
12 \\
15 \\
18 \\
21\end{array}$ & $\begin{array}{l}15.8 \\
13.8 \\
14.9 \\
21.1 \\
24.5 \\
25.5 \\
20.5 \\
17.2\end{array}$ & $\begin{array}{l}14.6 \\
12.7 \\
13.4 \\
15.5 \\
15.9 \\
16.2 \\
15.1 \\
14.2\end{array}$ & $\begin{array}{l}16.4 \\
14.1 \\
14.9 \\
20.8 \\
23.9 \\
25.2 \\
20.8 \\
17.8\end{array}$ & $\begin{array}{l}14.6 \\
12.8 \\
13.3 \\
15.1 \\
15.6 \\
16.1 \\
15.1 \\
14.3\end{array}$ & $\begin{array}{l}16.9 \\
14.9 \\
14.9 \\
20.7 \\
23.7 \\
24.9 \\
20.9 \\
18.0\end{array}$ & $\begin{array}{l}14.7 \\
12.8 \\
13.2 \\
15.0 \\
15.7 \\
16.1 \\
15.1 \\
14.3\end{array}$ & $\begin{array}{l}17.0 \\
14: 2 \\
15.0 \\
20.6 \\
23.7 \\
24.8 \\
21.8 \\
18.6\end{array}$ & $\begin{array}{l}14.5 \\
12.7 \\
13.3 \\
14.8 \\
15.3 \\
15.9 \\
15.1 \\
14.3\end{array}$ & $\begin{array}{l}21.8 \\
21.8 \\
22.0 \\
22.7 \\
23.0 \\
22.2 \\
21.8 \\
21.9\end{array}$ & & $\begin{array}{l}1.2 \\
2.4 \\
3.3 \\
5.4 \\
6.3 \\
5.1 \\
2.2 \\
1.4\end{array}$ & $\begin{array}{l}1.4 \\
3.0 \\
4.0 \\
8.0 \\
8.0 \\
6.6 \\
2.9 \\
1.8\end{array}$ & $\begin{array}{l}2.1 \\
4 \cdot 0 \\
4 \cdot 8 \\
9.3 \\
9.5 \\
8.0 \\
4 \cdot 3 \\
2.8\end{array}$ & $\begin{array}{r}1.9 \\
3.9 \\
4.8 \\
10.4 \\
10.4 \\
9.1 \\
7.1 \\
4.1\end{array}$ \\
\hline $\begin{array}{l}9 \\
9 \\
9 \\
9 \\
9 \\
9 \\
9 \\
9\end{array}$ & $\begin{array}{r}0 \\
3 \\
6 \\
9 \\
12 \\
15 \\
18 \\
21\end{array}$ & $\begin{array}{l}16.1 \\
14.1 \\
15.1 \\
22.2 \\
25.5 \\
26.5 \\
21.8 \\
21.1\end{array}$ & $\begin{array}{l}13.7 \\
13.0 \\
13.8 \\
15.4 \\
16.8 \\
17.8 \\
17.7 \\
17.9\end{array}$ & $\begin{array}{l}16.2 \\
14.6 \\
15.3 \\
21.5 \\
25.3 \\
26.2 \\
22.6 \\
21.0\end{array}$ & $\begin{array}{l}13.7 \\
13.1 \\
13.8 \\
15.0 \\
16.7 \\
18.1 \\
17.5 \\
17.6\end{array}$ & $\begin{array}{l}16.2 \\
14.5 \\
15.3 \\
21.5 \\
24.4 \\
26.4 \\
23.2 \\
21.0\end{array}$ & $\begin{array}{l}13.7 \\
12.9 \\
13.7 \\
15.0 \\
16.4 \\
17.7 \\
17.4 \\
17.2\end{array}$ & $\begin{array}{l}16.3 \\
14.5 \\
15.3 \\
21.4 \\
24.8 \\
25.8 \\
23.8 \\
21.1\end{array}$ & $\begin{array}{l}13.4 \\
13.0 \\
13.5 \\
14.8 \\
16.4 \\
17.5 \\
17.1 \\
17.3\end{array}$ & $\begin{array}{l}21.8 \\
21.8 \\
21.9 \\
22.6 \\
23.6 \\
22.9 \\
21.9 \\
21.8\end{array}$ & & $\begin{array}{l}2.3 \\
2.0 \\
3.0 \\
4.3 \\
3.4 \\
2.3 \\
1.5 \\
4.7\end{array}$ & $\begin{array}{l}3.0 \\
2.6 \\
4.0 \\
5.2 \\
4.2 \\
2.8 \\
2.3 \\
5.4\end{array}$ & $\begin{array}{l}3.9 \\
3.3 \\
4.8 \\
6.4 \\
5.0 \\
3.4 \\
3.4 \\
5.9\end{array}$ & $\begin{array}{l}4.6 \\
3.6 \\
5.2 \\
6.9 \\
5.3 \\
3.8 \\
4.3 \\
6.4\end{array}$ \\
\hline $\begin{array}{l}10 \\
10 \\
10 \\
10 \\
10 \\
10 \\
10 \\
10\end{array}$ & $\begin{array}{r}0 \\
3 \\
6 \\
9 \\
12 \\
15 \\
18 \\
21\end{array}$ & $\begin{array}{l}20.2 \\
19.2 \\
19.5 \\
22.3 \\
27.0 \\
27.2 \\
23.7 \\
20.5\end{array}$ & $\begin{array}{l}17.7 \\
17.8 \\
17.7 \\
17.9 \\
18.7 \\
19.6 \\
18.7 \\
18.0\end{array}$ & $\begin{array}{l}20.1 \\
19.1 \\
19.5 \\
22.3 \\
26.7 \\
27.2 \\
24.1 \\
20.9\end{array}$ & $\begin{array}{l}17.4 \\
17.7 \\
17.5 \\
17.7 \\
18.5 \\
19.3 \\
18.6 \\
18.2\end{array}$ & $\begin{array}{l}20.2 \\
19.2 \\
19.5 \\
22.2 \\
26.5 \\
27.03 \\
24.05 \\
21.7\end{array}$ & $\begin{array}{l}17.2 \\
17.6 \\
17.4 \\
17.5 \\
18.7 \\
19.1 \\
18.8 \\
18.3\end{array}$ & $\begin{array}{l}20.0 \\
18.0 \\
19.4 \\
22.0 \\
27.3 \\
27.5 \\
24.9 \\
22.2\end{array}$ & $\begin{array}{l}17.1 \\
17.5 \\
17.1 \\
17.4 \\
19.4 \\
19.1 \\
18.8 \\
18.3\end{array}$ & $\begin{array}{l}21.8 \\
21.8 \\
22.1 \\
22.5 \\
24.8 \\
24.6 \\
23.4 \\
22.4\end{array}$ & & $\begin{array}{l}6.5 \\
6.6 \\
3.9 \\
4.1 \\
1.7 \\
2.3 \\
2.2 \\
2.9\end{array}$ & $\begin{array}{l}7.0 \\
7.5 \\
4.8 \\
5.3 \\
1.8 \\
2.4 \\
3.0 \\
4.1\end{array}$ & $\begin{array}{l}7.4 \\
7.9 \\
5.2 \\
6.0 \\
2.0 \\
2.9 \\
4.2 \\
5.8\end{array}$ & $\begin{array}{l}7.6 \\
7.9 \\
5: 3 \\
6.0 \\
2.2 \\
3.2 \\
5.4 \\
7.7\end{array}$ \\
\hline
\end{tabular}


TABLE 10

Table 10. - Three-hour averages of air and water-surface temperatures and wind directions and speed, April 1950-August 1951, Lake Hefner-Continued

$\begin{array}{lll}\text { STATION } 3 & \text { THREE-HOURLY AVERAGES SEPTEMBER, } 1950\end{array}$

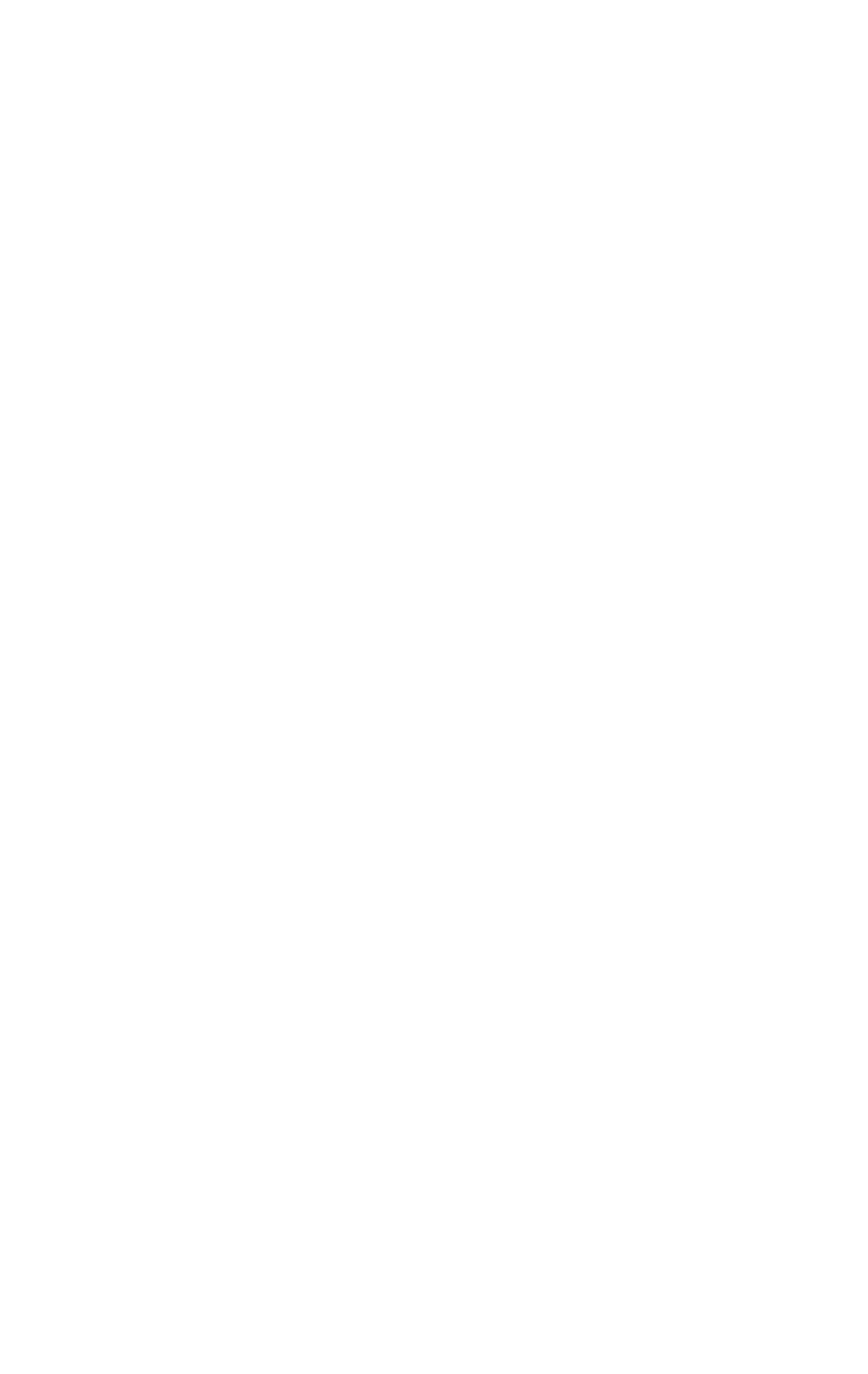


TABLE 10

Table 10. - Three-hour averages of air and water-surface temperatures and wind directiona and speed, April 1950-August 1951, Lake Hefner-Continued

STATION 3

THREE-HOURLY AVERAGES

SEPTEMBER, 1950

\begin{tabular}{|c|c|c|c|c|c|c|c|c|c|c|c|c|c|c|c|}
\hline \multirow{3}{*}{ 竎 } & \multirow{3}{*}{ 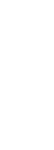 } & \multicolumn{8}{|c|}{ Average air temperature $\left({ }^{\circ} \mathrm{C}\right)$ at indicated height } & \multirow{3}{*}{$\begin{array}{l}\text { Average } \\
\text { water- } \\
\text { surface } \\
\text { tempera- } \\
\text { ture } \\
\left({ }^{\circ} \mathrm{C}\right)\end{array}$} & \multirow{3}{*}{$\begin{array}{c}\text { Average } \\
\text { wind } \\
\text { direction } \\
\text { (coded) }\end{array}$} & \multirow{2}{*}{\multicolumn{4}{|c|}{$\begin{array}{l}\text { Average wind speed (knots) } \\
\text { at indicated height }\end{array}$}} \\
\hline & & \multicolumn{2}{|c|}{$\begin{array}{c}2 \\
\text { meters }\end{array}$} & \multicolumn{2}{|c|}{$\begin{array}{c}4 \\
\text { meters }\end{array}$} & \multicolumn{2}{|c|}{$\begin{array}{c}8 \\
\text { metera }\end{array}$} & \multicolumn{2}{|c|}{$\begin{array}{c}16 \\
\text { meters }\end{array}$} & & & & & & \\
\hline & & $\begin{array}{l}\text { Dry } \\
\text { bulb }\end{array}$ & $\begin{array}{l}\text { Wet } \\
\text { bulb }\end{array}$ & $\begin{array}{l}\text { Dry } \\
\text { bulb }\end{array}$ & $\begin{array}{l}\text { Wet } \\
\text { bulb }\end{array}$ & $\begin{array}{l}\text { Dry } \\
\text { bulb }\end{array}$ & $\begin{array}{l}\text { Wet } \\
\text { bulb }\end{array}$ & $\begin{array}{l}\text { Dry } \\
\text { bulb }\end{array}$ & $\begin{array}{l}\text { Wet } \\
\text { bulb }\end{array}$ & & & meters & meters & $\left|\begin{array}{c}8 \\
\text { meters }\end{array}\right|$ & $\begin{array}{c}16 \\
\text { meters }\end{array}$ \\
\hline $\begin{array}{l}21 \\
21 \\
21 \\
21 \\
21 \\
21 \\
21 \\
21\end{array}$ & $\begin{array}{r}0 \\
3 \\
6 \\
9 \\
12 \\
15 \\
18 \\
21\end{array}$ & $\begin{array}{l}23.1 \\
21.2 \\
19.0 \\
21.8 \\
24.5 \\
25.1 \\
22.0 \\
17.4\end{array}$ & $\begin{array}{l}22.1 \\
18.8 \\
15.2 \\
15.7 \\
17.0 \\
17.2 \\
16.3 \\
14.6\end{array}$ & $\begin{array}{l}23.3 \\
21.03 \\
19.1 \\
21.5 \\
23.9 \\
25.0 \\
22.1 \\
17.4\end{array}$ & $\begin{array}{l}21.9 \\
18: 5 \\
14: 9 \\
15.3 \\
16.5 \\
16.9 \\
1601 \\
14.5\end{array}$ & $\begin{array}{l}23.3 \\
21.3 \\
19.0 \\
21.2 \\
22.8 \\
24.8 \\
22.0 \\
17.4\end{array}$ & $\begin{array}{l}21.8 \\
18.2 \\
14.5 \\
14.7 \\
16.0 \\
16.5 \\
15.8 \\
14.3\end{array}$ & $\begin{array}{l}23.2 \\
21.2 \\
19.0 \\
21.2 \\
22.7 \\
24.9 \\
21.8 \\
17.3\end{array}$ & $\begin{array}{l}21.7 \\
17: 9 \\
14.4 \\
14.7 \\
16.0 \\
16.3 \\
15.6 \\
14.1\end{array}$ & $\begin{array}{l}21.0 \\
21.02 \\
22.1 \\
22.9 \\
23.6 \\
23.4 \\
22.4 \\
21.9\end{array}$ & & $\begin{array}{l}5.0 \\
5: 8 \\
9.5 \\
8: 2 \\
8: 1 \\
7: 2 \\
7: 1 \\
5: 1\end{array}$ & $\begin{array}{r}5.8 \\
7.9 \\
12.1 \\
10.6 \\
10.6 \\
9.4 \\
8.9 \\
6.2\end{array}$ & $\begin{array}{r}6.8 \\
9.5 \\
14.2 \\
13.2 \\
13.8 \\
11.9 \\
10.8 \\
7.6\end{array}$ & $\begin{array}{r}13.6 \\
9.6\end{array}$ \\
\hline $\begin{array}{l}22 \\
22 \\
22 \\
22 \\
22 \\
22 \\
22 \\
22\end{array}$ & $\begin{array}{r}0 \\
3 \\
6 \\
9 \\
12 \\
15 \\
18 \\
21\end{array}$ & $\begin{array}{l}15.3 \\
14.3 \\
15.0 \\
19.3 \\
21.8 \\
22.7 \\
19.3 \\
17.7\end{array}$ & $\begin{array}{l}13.9 \\
13.6 \\
14.0 \\
15.5 \\
15.8 \\
15.8 \\
14.5 \\
14.5\end{array}$ & $\begin{array}{l}15.4 \\
14.4 \\
15.0 \\
19.1 \\
21.4 \\
22.3 \\
19.6 \\
18.0\end{array}$ & $\begin{array}{l}13.9 \\
13.6 \\
13.9 \\
15.2 \\
15.1 \\
15.5 \\
14.6 \\
14.6\end{array}$ & $\begin{array}{l}15.3 \\
14.4 \\
15.0 \\
18.8 \\
20.9 \\
21.9 \\
19.6 \\
18.3\end{array}$ & $\begin{array}{l}13.8 \\
13.5 \\
13.8 \\
14.8 \\
14.8 \\
15.0 \\
14.5 \\
14.5\end{array}$ & $\begin{array}{l}15.2 \\
14.2 \\
14.9 \\
18.6 \\
20.8 \\
21.8 \\
19.0 \\
18.5\end{array}$ & $\begin{array}{l}13.6 \\
13.3 \\
13.6 \\
14.7 \\
14.9 \\
14.9 \\
14.4 \\
14.6\end{array}$ & $\begin{array}{l}21.7 \\
21.1 \\
20.6 \\
21.2 \\
22.5 \\
22.3 \\
21.8 \\
21.8\end{array}$ & & $\begin{array}{l}4.9 \\
5.6 \\
7.6 \\
6.6 \\
6.3 \\
4.3 \\
1.6 \\
0.5\end{array}$ & $\begin{array}{l}6.2 \\
6.8 \\
9.7 \\
8.3 \\
7.7 \\
5.4 \\
2.7\end{array}$ & $\begin{array}{r}7.5 \\
8.2 \\
11.2 \\
9.9 \\
9.4 \\
6.8 \\
2.8 \\
0.9\end{array}$ & $\begin{array}{r}13.0 \\
10.3 \\
9.7 \\
7.2 \\
4.1 \\
1 * 6\end{array}$ \\
\hline $\begin{array}{l}23 \\
23 \\
23 \\
23 \\
23 \\
23 \\
23 \\
23\end{array}$ & $\begin{array}{r}0 \\
3 \\
6 \\
9 \\
12 \\
15 \\
18 \\
21\end{array}$ & $\begin{array}{l}16.2 \\
17.1 \\
18.4 \\
24.5 \\
27.0 \\
26.2 \\
20.9 \\
17.9\end{array}$ & $\begin{array}{l}14.0 \\
15.2 \\
15.5 \\
16.2 \\
16.1 \\
16.4 \\
15.5 \\
15.0\end{array}$ & $\begin{array}{l}16.7 \\
17.0 \\
18.5 \\
24.0 \\
26.4 \\
25.9 \\
22.2 \\
18.7\end{array}$ & $\begin{array}{l}14.0 \\
14.9 \\
15.0 \\
15.9 \\
15.6 \\
16.0 \\
15.7 \\
15.7\end{array}$ & $\begin{array}{l}16.9 \\
16.9 \\
18.4 \\
24.3 \\
25.5 \\
25.6 \\
22.7 \\
19.6\end{array}$ & $\begin{array}{l}14.0 \\
14.6 \\
14.8 \\
15.8 \\
15.2 \\
16.0 \\
15.8 \\
15.1\end{array}$ & $\begin{array}{l}16.9 \\
16.9 \\
18.4 \\
23.9 \\
25.7 \\
25.5 \\
23.4 \\
20.5\end{array}$ & $\begin{array}{l}14.3 \\
14.8 \\
14.9 \\
15.6 \\
15.7 \\
15.8 \\
15.8 \\
15.1\end{array}$ & $\begin{array}{l}21 \cdot 3 \\
21.2 \\
21 \cdot 4 \\
22.7 \\
24 \cdot 2 \\
22.6 \\
21.8 \\
21.6\end{array}$ & & $\begin{array}{l}3.7 \\
5.8 \\
5.8 \\
2.7 \\
3.3 \\
3.5 \\
1.8 \\
1.4\end{array}$ & $\begin{array}{l}2.9 \\
6.8 \\
7.0 \\
3.2 \\
4.0 \\
4.5 \\
2.7 \\
1.9\end{array}$ & $\begin{array}{l}3.8 \\
7.1 \\
7.5 \\
3.9 \\
4.9 \\
5.4 \\
3.7 \\
3.1\end{array}$ & $\begin{array}{l}2.6 \\
6.7 \\
7.5 \\
4.4 \\
5.3 \\
6.2 \\
5.1 \\
4.5\end{array}$ \\
\hline $\begin{array}{l}24 \\
24 \\
24 \\
24 \\
24 \\
24 \\
24 \\
24\end{array}$ & $\begin{array}{r}0 \\
3 \\
6 \\
9 \\
12 \\
15 \\
18 \\
21\end{array}$ & $\begin{array}{l}15.7 \\
14.4 \\
15.0 \\
23.5 \\
25.5 \\
24.8 \\
18.7 \\
15.7\end{array}$ & $\begin{array}{l}14.0 \\
13.5 \\
13.2 \\
15.0 \\
16.0 \\
16.0 \\
15.2 \\
14.6\end{array}$ & $\begin{array}{l}16.2 \\
15.1 \\
15.1 \\
22.7 \\
25.5 \\
24.5 \\
18.0 \\
16.0\end{array}$ & $\begin{array}{l}14.0 \\
13.6 \\
13.2 \\
14.8 \\
15.6 \\
15.9 \\
15.2 \\
14.8\end{array}$ & $\begin{array}{l}16.8 \\
15.03 \\
15.5 \\
22.5 \\
24.8 \\
24.4 \\
19.0 \\
16.4\end{array}$ & $\begin{array}{l}14.2 \\
13.5 \\
13.5 \\
14.9 \\
15.8 \\
15.8 \\
15.5 \\
14.9\end{array}$ & $\begin{array}{l}18.0 \\
16.8 \\
15.7 \\
22.4 \\
24.4 \\
24.0 \\
19.8 \\
16.7\end{array}$ & $\begin{array}{l}14.5 \\
13.9 \\
13.4 \\
14.6 \\
15.4 \\
15.7 \\
15.7 \\
15.0\end{array}$ & $\begin{array}{l}21.4 \\
21.4 \\
22.0 \\
23.1 \\
23.3 \\
22.5 \\
21.8 \\
21.5\end{array}$ & & $\begin{array}{l}2.0 \\
2.3 \\
2.2 \\
3.8 \\
4.7 \\
4.5 \\
3.1 \\
2.9\end{array}$ & $\begin{array}{l}3.1 \\
2.6 \\
2.8 \\
4.6 \\
5.8 \\
5.5 \\
4.3 \\
4.2\end{array}$ & $\begin{array}{l}4.4 \\
4.0 \\
3.4 \\
5.3 \\
6.7 \\
6.6 \\
5.9 \\
5.9\end{array}$ & $\begin{array}{l}6.0 \\
5.8 \\
4.0 \\
5.7 \\
7.5 \\
7.5 \\
8.4 \\
8.2\end{array}$ \\
\hline $\begin{array}{l}25 \\
25 \\
25 \\
25 \\
25 \\
25 \\
25 \\
25\end{array}$ & $\begin{array}{r}0 \\
3 \\
6 \\
9 \\
12 \\
15 \\
18 \\
21\end{array}$ & $\begin{array}{l}13.8 \\
13.5 \\
15.7 \\
18.6 \\
20.7 \\
20.5 \\
17.3\end{array}$ & $\begin{array}{l}13.4 \\
13.4 \\
14.2 \\
14.3 \\
15.5 \\
15.7 \\
15.0\end{array}$ & $\begin{array}{l}14.2 \\
13.8 \\
15.6 \\
18.5 \\
20.7 \\
20.4 \\
17.6\end{array}$ & $\begin{array}{l}13.6 \\
13.5 \\
13.9 \\
14.1 \\
15.3 \\
15.4 \\
14.9\end{array}$ & $\begin{array}{l}14.6 \\
14.0 \\
15.5 \\
18.4 \\
20.7 \\
20.3 \\
17.8\end{array}$ & $\begin{array}{l}13.7 \\
13.7 \\
13.6 \\
14.1 \\
15.1 \\
15.1 \\
14.8\end{array}$ & $\begin{array}{l}15.0 \\
14.3 \\
15.2 \\
18.1 \\
20.4 \\
20.1 \\
18.0\end{array}$ & $\begin{array}{l}14.0 \\
13.8 \\
13.4 \\
14.2 \\
15.1 \\
15.2 \\
14.8\end{array}$ & $\begin{array}{l}21.1 \\
21.0 \\
20.9 \\
21.9 \\
22.9 \\
22.4 \\
21.6\end{array}$ & & $\begin{array}{l}2.3 \\
3.2 \\
9.8 \\
7.9 \\
6.9 \\
5.6 \\
3.5 \\
5.2\end{array}$ & $\begin{array}{r}3.4 \\
4.2 \\
11.3 \\
9.2 \\
8.2 \\
7.3 \\
4.5 \\
6.7\end{array}$ & $\begin{array}{r}5.1 \\
5.1 \\
12.0 \\
9.8 \\
8.9 \\
8.6 \\
6.2 \\
7.8\end{array}$ & $\begin{array}{r}7.2 \\
7.2 \\
13.4 \\
10.7 \\
9.7 \\
9.9 \\
7.8 \\
9.2\end{array}$ \\
\hline $\begin{array}{l}26 \\
25 \\
26 \\
26 \\
26 \\
26 \\
26 \\
26\end{array}$ & $\begin{array}{r}0 \\
3 \\
6 \\
9 \\
12 \\
15 \\
18 \\
21\end{array}$ & $\begin{array}{l}17.3 \\
19.2 \\
20.5 \\
19.0 \\
17.5\end{array}$ & $\begin{array}{l}15.9 \\
16.4 \\
16.8 \\
16.6 \\
15.4\end{array}$ & $\begin{array}{l}17.4 \\
19.3 \\
20.5 \\
19.1 \\
17.6\end{array}$ & $\begin{array}{l}15.8 \\
16.1 \\
16.5 \\
16.3 \\
15.2\end{array}$ & $\begin{array}{l}17.5 \\
19.2 \\
20.4 \\
19.0 \\
17.4\end{array}$ & $\begin{array}{l}15.1 \\
25.9 \\
16.3 \\
16.2 \\
15.0\end{array}$ & $\begin{array}{l}16.8 \\
19.0 \\
20.2 \\
18.9 \\
17.3\end{array}$ & $\begin{array}{l}15.1 \\
15.8 \\
16.3 \\
16.1 \\
14.8\end{array}$ & $\begin{array}{l}21.2 \\
21.1 \\
20.8 \\
20.6 \\
20.1\end{array}$ & . & $\begin{array}{r}6.0 \\
5.3 \\
7.0 \\
9.6 \\
13.1 \\
10.9 \\
7.8 \\
10.6\end{array}$ & $\begin{array}{r}7.4 \\
6.7 \\
8.8 \\
11.6 \\
14.5 \\
12.3 \\
9.5 \\
12.7\end{array}$ & $\begin{array}{r}8.1 \\
7.6 \\
10.0 \\
12.7 \\
15.8 \\
13.3 \\
10.4 \\
13.6\end{array}$ & $\begin{array}{r}9.5 \\
8.8 \\
12.7 \\
14.3 \\
17.2 \\
14.7 \\
12.2 \\
15.4\end{array}$ \\
\hline $\begin{array}{l}27 \\
27 \\
27 \\
27 \\
27 \\
27 \\
27 \\
27\end{array}$ & $\begin{array}{r}0 \\
3 \\
6 \\
9 \\
12 \\
15 \\
18 \\
21\end{array}$ & $\begin{array}{l}24.1 \\
24.1 \\
22.0 \\
20.3\end{array}$ & $\begin{array}{l}20.2 \\
20.1 \\
19.3 \\
18.9\end{array}$ & $\begin{array}{l}24.2 \\
24.2 \\
22.0 \\
20.3\end{array}$ & $\begin{array}{l}20.0 \\
19.9 \\
19.2 \\
18.8\end{array}$ & $\begin{array}{l}24.2 \\
24.2 \\
22.0 \\
20.3\end{array}$ & $\begin{array}{l}19.9 \\
19.9 \\
19.1 \\
18.7\end{array}$ & $\begin{array}{l}24.1 \\
24.0 \\
21.9 \\
20.2\end{array}$ & $\begin{array}{l}20.0 \\
19.8 \\
19.1 \\
18.7\end{array}$ & $\begin{array}{l}21.2 \\
21.0 \\
21.2 \\
20.6\end{array}$ & & $\begin{array}{l}14.0 \\
13.0 \\
13.5 \\
14.1 \\
13.3 \\
13.9 \\
10.8 \\
12.2\end{array}$ & $\begin{array}{l}15.8 \\
14.4 \\
14.8 \\
15.6 \\
15.2 \\
16.3 \\
13.1 \\
14.5\end{array}$ & $\begin{array}{l}16.0 \\
15.4 \\
16.0 \\
17.0 \\
16.7 \\
37.8 \\
14.5 \\
15.8\end{array}$ & $\begin{array}{l}18.8 \\
16.9 \\
17.4 \\
18.7 \\
18.5 \\
20.3 \\
16.6 \\
18.1\end{array}$ \\
\hline $\begin{array}{l}28 \\
28 \\
28 \\
29 \\
23 \\
28 \\
28 \\
28\end{array}$ & $\begin{array}{r}0 \\
3 \\
5 \\
9 \\
12 \\
15 \\
18 \\
21\end{array}$ & $\begin{array}{l}19.3 \\
19.0 \\
19.3 \\
21.4 \\
24.8 \\
24.9 \\
22.3 \\
20.4\end{array}$ & $\begin{array}{l}18.5 \\
18.2 \\
18.3 \\
19.4 \\
20.3 \\
20.5 \\
19.5 \\
18.7\end{array}$ & $\begin{array}{l}19.4 \\
19.0 \\
19.4 \\
21.6 \\
24.7 \\
25.3 \\
22.2 \\
20.4\end{array}$ & $\begin{array}{l}18.5 \\
18.2 \\
13.3 \\
10.3 \\
20.1 \\
20.4 \\
19.4 \\
13.6\end{array}$ & $\begin{array}{l}19.3 \\
19.0 \\
19.5 \\
21.05 \\
24.9 \\
25.3 \\
22.7 \\
20.4\end{array}$ & $\begin{array}{l}18.4 \\
18.1 \\
18.3 \\
19.2 \\
20.0 \\
20.3 \\
19.3 \\
18.5\end{array}$ & $\begin{array}{l}19.1 \\
18.9 \\
19.4 \\
21.7 \\
24.9 \\
25.1 \\
22.1 \\
20.3\end{array}$ & $\begin{array}{l}18.2 \\
18.0 \\
18.1 \\
19.1 \\
20.0 \\
20.4 \\
19.2 \\
18.4\end{array}$ & $\begin{array}{l}19.0 \\
18.5 \\
18.0 \\
19.0 \\
20.5 \\
21.0 \\
21.4 \\
20.8\end{array}$ & & $\begin{array}{l}14.6 \\
11.6 \\
13.6 \\
17.6 \\
14.3 \\
14.0 \\
12.4 \\
11.8\end{array}$ & $\begin{array}{l}16.4 \\
13.2 \\
15.9 \\
18.1 \\
16.3 \\
16.0 \\
14.4 \\
13.5\end{array}$ & $\begin{array}{l}17.5 \\
14.7 \\
17.1 \\
20.0 \\
17.8 \\
17.8 \\
15.7 \\
14.8\end{array}$ & $\begin{array}{l}19.6 \\
16.3 \\
19.1 \\
22.1 \\
20.1 \\
20.2 \\
17.9 \\
16.7\end{array}$ \\
\hline $\begin{array}{l}29 \\
29 \\
29 \\
29 \\
29 \\
29 \\
29 \\
29\end{array}$ & $\begin{array}{r}0 \\
3 \\
6 \\
9 \\
12 \\
15 \\
10 \\
21\end{array}$ & $\begin{array}{l}19.8 \\
20.2 \\
20.0 \\
22.0 \\
25.4 \\
26.02 \\
23.0 \\
21.6\end{array}$ & $\begin{array}{l}18.9 \\
19.5 \\
19.8 \\
20.3 \\
20.8 \\
20.8 \\
10.9 \\
20.1\end{array}$ & $\begin{array}{l}19.9 \\
20.3 \\
21.0 \\
22.8 \\
25.5 \\
26.3 \\
23.7 \\
21.7\end{array}$ & $\begin{array}{l}15.9 \\
19.6 \\
19.8 \\
20.3 \\
20.9 \\
20.7 \\
19.9 \\
20.1\end{array}$ & $\begin{array}{l}19.9 \\
20.4 \\
21.1 \\
22.9 \\
25.9 \\
26.4 \\
23.8 \\
21.7\end{array}$ & $\begin{array}{l}18.9 \\
29.5 \\
29.9 \\
20.3 \\
20.8 \\
20.7 \\
19.9 \\
20.2\end{array}$ & $\begin{array}{l}19.8 \\
20.3 \\
20.9 \\
23.0 \\
26.0 \\
26.4 \\
23.7 \\
21.7\end{array}$ & $\begin{array}{l}18.8 \\
20.5 \\
19.7 \\
20.3 \\
20.8 \\
20.8 \\
10.9 \\
20.2\end{array}$ & $\begin{array}{l}19.2 \\
20.2 \\
20.8 \\
21.4 \\
20.8\end{array}$ & & $\begin{array}{r}12.5 \\
13.1 \\
14.2 \\
15.0 \\
12.7 \\
11.8 \\
8.3 \\
11.1\end{array}$ & $\begin{array}{l}14.0 \\
15.1 \\
15.5 \\
16.3 \\
14.1 \\
13.9 \\
10.5 \\
13.6\end{array}$ & $\begin{array}{l}15.2 \\
16.3 \\
17.0 \\
17.8 \\
15.6 \\
15.5 \\
11.8 \\
15.1\end{array}$ & $\begin{array}{l}17.0 \\
18.0 \\
18.8 \\
19.3 \\
17.3 \\
17.5 \\
13.8 \\
17.5\end{array}$ \\
\hline $\begin{array}{l}30 \\
30 \\
30 \\
30 \\
30 \\
30 \\
30 \\
30\end{array}$ & $\begin{array}{r}0 \\
3 \\
6 \\
9 \\
12 \\
15 \\
18 \\
71\end{array}$ & $\begin{array}{l}24.5 \\
25.2 \\
23.0 \\
20.6\end{array}$ & $\begin{array}{l}21.0 \\
21.0 \\
20.4 \\
19.3\end{array}$ & $\begin{array}{l}24.6 \\
25.3 \\
23.1 \\
20.6\end{array}$ & $\begin{array}{l}20.9 \\
20.9 \\
20.9 \\
20.2 \\
10.2\end{array}$ & $\begin{array}{l}24.0 \\
24.6 \\
25.1 \\
23.2 \\
20.5\end{array}$ & $\begin{array}{l}21.0 \\
20.9 \\
20.9 \\
20.3 \\
19.2\end{array}$ & $\begin{array}{l}24.0 \\
24.5 \\
25.2 \\
23.0 \\
20.4\end{array}$ & $\begin{array}{l}20.9 \\
20.9 \\
20.9 \\
20.3 \\
10.1\end{array}$ & $\begin{array}{l}22.9 \\
22.9 \\
21.6 \\
20.5 \\
19.8\end{array}$ & & $\begin{array}{l}14.9 \\
13.0 \\
11.7 \\
12.7 \\
14.6 \\
13.1 \\
10.1 \\
12.3\end{array}$ & $\begin{array}{l}16.9 \\
14.8 \\
13.3 \\
14.2 \\
16.3 \\
15.1 \\
12.5 \\
14.5\end{array}$ & $\begin{array}{l}18.5 \\
16.1 \\
14.4 \\
15.5 \\
17.9 \\
16.8 \\
14.0 \\
16.0\end{array}$ & $\begin{array}{l}20.7 \\
18.0 \\
16.1 \\
17.3 \\
19.9 \\
19.1 \\
16.2 \\
18.2\end{array}$ \\
\hline
\end{tabular}


TABLE 10

Table 10, - Three-hour averages of air and water-surface temperatures and wind directions and speed, April 1950-August STATION 3

THREE-HOURLY AVERAGES

OCTOBER, 1950

\begin{tabular}{|c|c|c|c|c|c|c|c|c|c|c|c|c|c|c|c|}
\hline \multirow{3}{*}{ 宽 } & \multirow{3}{*}{ 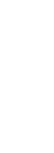 } & \multicolumn{8}{|c|}{ Average air temperature $\left({ }^{\circ} \mathrm{C}\right)$ at indicated height } & \multirow{3}{*}{$\begin{array}{c}\text { Average } \\
\text { water- } \\
\text { surface } \\
\text { tempera- } \\
\text { ture } \\
\left({ }^{\circ} \mathrm{C}\right)\end{array}$} & \multirow{3}{*}{$\begin{array}{c}\text { Average } \\
\text { wind } \\
\text { direction } \\
\text { (coded) }\end{array}$} & \multicolumn{4}{|c|}{$\begin{array}{l}\text { Average wind speed (knots) } \\
\text { at indicated height }\end{array}$} \\
\hline & & \multicolumn{2}{|c|}{$\stackrel{2}{\text { meters }}$} & \multicolumn{2}{|c|}{$\begin{array}{c}4 \\
\text { meters }\end{array}$} & \multicolumn{2}{|c|}{$\begin{array}{c}8 \\
\text { meters }\end{array}$} & \multicolumn{2}{|c|}{$\begin{array}{c}16 \\
\text { meters }\end{array}$} & & & 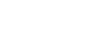 & & & \\
\hline & & $\begin{array}{l}\text { Dry } \\
\text { bulb }\end{array}$ & $\begin{array}{l}\text { Wet } \\
\text { bulb }\end{array}$ & $\begin{array}{l}\text { Dry } \\
\text { bulb }\end{array}$ & $\begin{array}{l}\text { Wet } \\
\text { bulb }\end{array}$ & $\begin{array}{l}\text { Dry } \\
\text { bulb }\end{array}$ & $\begin{array}{l}\text { Wet } \\
\text { bulb }\end{array}$ & $\begin{array}{l}\text { Dry } \\
\text { bulb }\end{array}$ & $\begin{array}{l}\text { Wet } \\
\text { bulb }\end{array}$ & & & meters & meters & meters & meters \\
\hline $\begin{array}{l}1 \\
1 \\
1 \\
1 \\
1 \\
1 \\
1 \\
1\end{array}$ & $\begin{array}{r}0 \\
3 \\
5 \\
9 \\
12 \\
15 \\
18 \\
21\end{array}$ & $\begin{array}{l}19.5 \\
29.6 \\
20.1 \\
21.8 \\
24.1 \\
25.0 \\
23.2 \\
21.3\end{array}$ & $\begin{array}{l}18.4 \\
18.7 \\
19.1 \\
19.6 \\
19.9 \\
20.1 \\
19.5 \\
19.6\end{array}$ & $\begin{array}{l}19.5 \\
19.6 \\
20.2 \\
21.9 \\
24.2 \\
25.4 \\
23.2 \\
21.3\end{array}$ & $\begin{array}{l}18.3 \\
18.6 \\
19.0 \\
19.5 \\
19.8 \\
20.0 \\
19.5 \\
10.5\end{array}$ & $\begin{array}{l}19.4 \\
19.7 \\
20.2 \\
22.0 \\
24.3 \\
25.2 \\
23.3 \\
71.3\end{array}$ & $\begin{array}{l}18.2 \\
18.5 \\
19.0 \\
19.6 \\
19.8 \\
19.9 \\
19.5 \\
19.4\end{array}$ & $\begin{array}{l}19: 3 \\
19: 5 \\
20: 2 \\
22 \cdot 0 \\
24 \cdot 3 \\
25: 1 \\
23: 2 \\
21.1\end{array}$ & $\begin{array}{l}18.1 \\
18.5 \\
19.0 \\
19.3 \\
19.8 \\
19.8 \\
19.5 \\
19.3\end{array}$ & $\begin{array}{l}19.1 \\
18.4 \\
17.9 \\
19.2 \\
20.3 \\
20.0 \\
19.8 \\
19.0\end{array}$ & & $\begin{array}{l}14.2 \\
15.3 \\
14.8 \\
15.9 \\
14.6 \\
13.8 \\
12.0 \\
14.6\end{array}$ & $\begin{array}{l}16.4 \\
17.1 \\
16.5 \\
17.5 \\
16.7 \\
15.8 \\
14.2 \\
16.7\end{array}$ & $\begin{array}{l}17.5 \\
18.3 \\
17.8 \\
19.2 \\
19.2 \\
17.3 \\
15.6 \\
19.1\end{array}$ & $\begin{array}{l}19.9 \\
20.1 \\
19.7 \\
21.2 \\
20.4 \\
19.8 \\
17.9 \\
20.3\end{array}$ \\
\hline $\begin{array}{l}2 \\
2 \\
2 \\
2 \\
2 \\
2 \\
2 \\
2 \\
2\end{array}$ & $\begin{array}{r}0 \\
3 \\
6 \\
9 \\
12 \\
15 \\
18 \\
21\end{array}$ & $\begin{array}{l}20.6 \\
19.9 \\
20.2 \\
23.0 \\
18.3 \\
13.8 \\
13.2 \\
12.5\end{array}$ & $\begin{array}{l}19.7 \\
19.3 \\
19.5 \\
20.1 \\
17.1 \\
13.5 \\
13.1 \\
12.4\end{array}$ & $\begin{array}{l}20.6 \\
20.0 \\
20.3 \\
23.3 \\
18.2 \\
13.8 \\
13.3 \\
12.6\end{array}$ & $\begin{array}{l}19.5 \\
19.2 \\
19.4 \\
20.1 \\
16.8 \\
13.4 \\
13.0 \\
12.4\end{array}$ & $\begin{array}{l}20.6 \\
20.0 \\
20.4 \\
23.5 \\
18.1 \\
14.1 \\
13.7 \\
13.0\end{array}$ & $\begin{array}{l}19.5 \\
19.2 \\
19.5 \\
20.0 \\
16.7 \\
13.4 \\
13: 1 \\
12.8\end{array}$ & $\begin{array}{l}20.4 \\
19: 8 \\
20: 3 \\
23.5 \\
17.0 \\
13.5 \\
13: 0 \\
12.5\end{array}$ & $\begin{array}{l}19.2 \\
19.0 \\
19.0 \\
19.9 \\
16.0 \\
13.0 \\
12.7 \\
12.3\end{array}$ & $\begin{array}{l}17.5 \\
15.9 \\
16.3 \\
17.4 \\
17.0 \\
15.4 \\
15.8 \\
13.6\end{array}$ & & $\begin{array}{r}15.8 \\
13.2 \\
12.3 \\
15.1 \\
10.3 \\
10.4 \\
8.0 \\
5.9\end{array}$ & $\begin{array}{r}17.4 \\
14.5 \\
13.6 \\
16.4 \\
12.4 \\
12.7 \\
9.6 \\
7.8\end{array}$ & $\begin{array}{r}18.9 \\
15.7 \\
14.6 \\
17.9 \\
14.4 \\
14.9 \\
11.3 \\
9.4\end{array}$ & $\begin{array}{l}21.5 \\
17.1 \\
15.9 \\
19.0 \\
12.0 \\
15.6 \\
12.5 \\
10.6\end{array}$ \\
\hline $\begin{array}{l}3 \\
3 \\
3 \\
3 \\
3 \\
3 \\
3 \\
3\end{array}$ & $\begin{array}{r}0 \\
3 \\
6 \\
9 \\
12 \\
15 \\
18 \\
21\end{array}$ & $\begin{array}{l}12.5 \\
11.6 \\
10.4 \\
10.1 \\
14.0 \\
16.6 \\
13.6 \\
10.6\end{array}$ & $\begin{array}{r}12.2 \\
10.6 \\
9.4 \\
9.2 \\
11.6 \\
13.1 \\
11.7 \\
9.7\end{array}$ & $\begin{array}{l}12.6 \\
11.6 \\
10.3 \\
10.0 \\
13.5 \\
16.3 \\
13.6 \\
10.8\end{array}$ & $\begin{array}{r}12.1 \\
10.5 \\
9.2 \\
0.0 \\
11.4 \\
12.7 \\
21.6 \\
9.7\end{array}$ & $\begin{array}{r}12.8 \\
11.4 \\
10.1 \\
9.9 \\
13.1 \\
16.2 \\
13.5 \\
10.6\end{array}$ & $\begin{array}{r}12.2 \\
10.4 \\
9.0 \\
8.9 \\
11.1 \\
12.5 \\
11.4 \\
9.5\end{array}$ & $\begin{array}{r}12.4 \\
11.2 \\
9.8 \\
9.8 \\
13.2 \\
16.2 \\
13.4 \\
10.5\end{array}$ & $\begin{array}{r}11.8 \\
10.0 \\
8.8 \\
3.7 \\
11.1 \\
12.4 \\
10.9 \\
9.2\end{array}$ & $\begin{array}{l}16.1 \\
17.0 \\
17.5 \\
18.0 \\
18.7 \\
18.0 \\
17.8 \\
18.0\end{array}$ & & $\begin{array}{l}5 \cdot 7 \\
6.9 \\
7 \cdot 3 \\
7 \cdot 1 \\
5.0 \\
5.4 \\
4.2 \\
3.2\end{array}$ & $\begin{array}{l}7.6 \\
8.4 \\
9.1 \\
8.7 \\
7.3 \\
6.7 \\
5.0 \\
4.1\end{array}$ & $\begin{array}{r}9.0 \\
10.2 \\
10.7 \\
10.2 \\
8.6 \\
8.0 \\
5.9 \\
4.6\end{array}$ & $\begin{array}{r}10.0 \\
11.1 \\
11.5 \\
10.8 \\
9.1 \\
8.7 \\
7.6 \\
6.5\end{array}$ \\
\hline $\begin{array}{l}4 \\
4 \\
4 \\
4 \\
4 \\
4 \\
4 \\
4\end{array}$ & $\begin{array}{r}0 \\
3 \\
6 \\
9 \\
12 \\
15 \\
18 \\
21\end{array}$ & $\begin{array}{r}9.1 \\
7.3 \\
7.7 \\
13.1 \\
16.3 \\
15.8 \\
12.5 \\
11.8\end{array}$ & $\begin{array}{l}8.4 \\
6.8 \\
6.6 \\
8.3 \\
0.8 \\
9.4 \\
9.1 \\
9.1\end{array}$ & $\begin{array}{r}9.1 \\
7.3 \\
7.7 \\
12.8 \\
15.8 \\
15.7 \\
12.9 \\
11.9\end{array}$ & $\begin{array}{l}8.3 \\
6: 7 \\
6.3 \\
8.0 \\
9.6 \\
9.1 \\
9: 1 \\
9.1\end{array}$ & $\begin{array}{r}9.1 \\
7.2 \\
7.7 \\
22.5 \\
15.5 \\
15.5 \\
13.3 \\
12.0\end{array}$ & $\begin{array}{l}8.1 \\
6.5 \\
6.3 \\
7.8 \\
9.0 \\
9.9 \\
9.0 \\
8.9\end{array}$ & $\begin{array}{r}8.8 \\
6.9 \\
7.6 \\
12.3 \\
15.0 \\
15.3 \\
13.7 \\
12.1\end{array}$ & $\begin{array}{l}7.6 \\
6.3 \\
5.9 \\
7.8 \\
8.9 \\
3.8 \\
8.7 \\
9.0\end{array}$ & $\begin{array}{l}17.9 \\
17.4 \\
18.1 \\
19.3 \\
19.9 \\
19.0 \\
18.8 \\
18.7\end{array}$ & & $\begin{array}{l}5.1 \\
6.6 \\
6.0 \\
6.6 \\
5.0 \\
3.6 \\
2.1 \\
3.5\end{array}$ & $\begin{array}{l}6.3 \\
8.3 \\
7.6 \\
7.8 \\
5.9 \\
4.6 \\
3.0 \\
4.6\end{array}$ & $\begin{array}{r}7.5 \\
10.2 \\
9.1 \\
9.0 \\
6.7 \\
5.3 \\
4.2 \\
5.7\end{array}$ & $\begin{array}{r}8.9 \\
11.6 \\
10.3 \\
10.0 \\
7.5 \\
6.3 \\
5.6 \\
7.1\end{array}$ \\
\hline $\begin{array}{l}5 \\
5 \\
5 \\
5 \\
5 \\
5 \\
5 \\
5\end{array}$ & $\begin{array}{r}0 \\
3 \\
6 \\
9 \\
12 \\
15 \\
18 \\
21\end{array}$ & $\begin{array}{l}12.3 \\
12.3 \\
13.2 \\
17.4 \\
20.1 \\
21.3 \\
18.9 \\
16.9\end{array}$ & $\begin{array}{r}9.2 \\
0.6 \\
11.2 \\
14.5 \\
16.1 \\
16.9 \\
15.7 \\
14.3\end{array}$ & $\begin{array}{l}12.2 \\
12.2 \\
13.0 \\
17.4 \\
20.4 \\
21.5 \\
18.8 \\
16.8\end{array}$ & $\begin{array}{r}9.1 \\
9.2 \\
10.9 \\
14.4 \\
15.8 \\
16.6 \\
15.4 \\
14.0\end{array}$ & $\begin{array}{l}12.1 \\
12.0 \\
13.0 \\
17.5 \\
20.3 \\
21.4 \\
18.8 \\
16.7\end{array}$ & $\begin{array}{r}8.9 \\
9.1 \\
10.7 \\
14.3 \\
15.7 \\
16.4 \\
15.2 \\
13.8\end{array}$ & $\begin{array}{l}12.0 \\
11.9 \\
12.8 \\
17.4 \\
20.4 \\
21.4 \\
18.7 \\
16.6\end{array}$ & $\begin{array}{r}8.9 \\
8.9 \\
10.6 \\
14.0 \\
15.5 \\
16.3 \\
15.1 \\
13.6\end{array}$ & $\begin{array}{l}18.7 \\
18.3 \\
18.0 \\
18.1 \\
18.2 \\
17.4 \\
16.9 \\
16.6\end{array}$ & & $\begin{array}{r}5.2 \\
7.1 \\
13.3 \\
16.6 \\
15.8 \\
12.3 \\
11.0 \\
21.1\end{array}$ & $\begin{array}{r}6.6 \\
8.4 \\
24.5 \\
17.8 \\
16.8 \\
13.2 \\
12.1 \\
12.3\end{array}$ & $\begin{array}{r}7.5 \\
8.9 \\
15.5 \\
19.2 \\
18.1 \\
14.7 \\
13.1 \\
13.4\end{array}$ & $\begin{array}{r}8.6 \\
10.0 \\
16.6 \\
20.3 \\
19.5 \\
16.1 \\
14.8 \\
15.2\end{array}$ \\
\hline $\begin{array}{l}6 \\
6 \\
6 \\
6 \\
6 \\
6 \\
6 \\
6\end{array}$ & $\begin{array}{r}0 \\
3 \\
6 \\
9 \\
12 \\
15 \\
18 \\
21\end{array}$ & $\begin{array}{l}15.8 \\
15.1 \\
15.6 \\
20.7 \\
24.5 \\
24.9 \\
23.3 \\
22.3\end{array}$ & $\begin{array}{l}13.3 \\
13.1 \\
14.0 \\
17.2 \\
19.3 \\
19.9 \\
19.4 \\
18.6\end{array}$ & $\begin{array}{l}15.6 \\
25: 0 \\
16: 1 \\
21.1 \\
24: 9 \\
25.2 \\
23.4 \\
22.3\end{array}$ & $\begin{array}{l}13.1 \\
12.8 \\
13.9 \\
17.1 \\
19.2 \\
19.9 \\
19.5 \\
18.5\end{array}$ & $\begin{array}{l}15.5 \\
14.9 \\
16.02 \\
21.2 \\
25.0 \\
25.2 \\
23.4 \\
22.4\end{array}$ & $\begin{array}{l}12.9 \\
22.6 \\
13.9 \\
17.0 \\
19.3 \\
19.9 \\
19.3 \\
18.4\end{array}$ & $\begin{array}{l}15.3 \\
14 \cdot 8 \\
16.2 \\
21.3 \\
25.2 \\
25.5 \\
23.5 \\
22.5\end{array}$ & $\begin{array}{l}12.7 \\
12.2 \\
13.8 \\
17.0 \\
19.1 \\
19.8 \\
19.2 \\
18.4\end{array}$ & $\begin{array}{l}16.7 \\
16.3 \\
16.5 \\
17.2 \\
17.3 \\
16.5 \\
15.9 \\
15.5\end{array}$ & & $\begin{array}{l}13.5 \\
16.7 \\
18.5 \\
18.3 \\
20.9 \\
20.1 \\
19.2 \\
21.1\end{array}$ & $\begin{array}{l}14.9 \\
17.6 \\
19.9 \\
19.7 \\
22.6 \\
21.8 \\
20.8 \\
22.9\end{array}$ & $\begin{array}{l}16.0 \\
18.9 \\
21.6 \\
21.6 \\
25.2 \\
24.3 \\
23.1 \\
25.3\end{array}$ & $\begin{array}{l}17.6 \\
20.3 \\
23.0 \\
23.3 \\
27.8 \\
26.8 \\
25.4 \\
27.8\end{array}$ \\
\hline $\begin{array}{l}7 \\
7 \\
7 \\
7 \\
7 \\
7 \\
7 \\
7\end{array}$ & $\begin{array}{r}0 \\
3 \\
6 \\
0 \\
12 \\
15 \\
18 \\
21\end{array}$ & $\begin{array}{l}21.2 \\
19.7 \\
15.8 \\
17.8 \\
22.2 \\
22.4 \\
17.7 \\
16.6\end{array}$ & $\begin{array}{l}18.1 \\
17.7 \\
14.6 \\
15.5 \\
13.5 \\
13.5 \\
10.7 \\
10.5\end{array}$ & $\begin{array}{l}21.4 \\
19.8 \\
15.8 \\
17.5 \\
21.8 \\
22.1 \\
18.2 \\
16.0\end{array}$ & $\begin{array}{l}18.1 \\
17.5 \\
14.4 \\
15.4 \\
13.1 \\
12.9 \\
10.6 \\
10.2\end{array}$ & $\begin{array}{l}21.2 \\
20.0 \\
15.7 \\
17.0 \\
21.8 \\
22.2 \\
18.5 \\
16.9\end{array}$ & $\begin{array}{r}17.9 \\
17.5 \\
14.2 \\
15.0 \\
12.8 \\
12.3 \\
10.0 \\
9.0\end{array}$ & $\begin{array}{l}21.4 \\
20.0 \\
25: 6 \\
17.5 \\
21.7 \\
22.02 \\
19.0 \\
16.8\end{array}$ & $\begin{array}{r}17.8 \\
17.3 \\
14: 0 \\
15.0 \\
12.8 \\
12.3 \\
9.7 \\
9.6\end{array}$ & $\begin{array}{l}14.9 \\
14.7 \\
15.5 \\
16.0 \\
18.1 \\
18.8 \\
18.8 \\
18.4\end{array}$ & & $\begin{array}{r}20.5 \\
9.2 \\
8.2 \\
6.8 \\
8.5 \\
6.8 \\
2.7 \\
4.0\end{array}$ & $\begin{array}{r}22.7 \\
11.2 \\
11.6 \\
8.8 \\
10.6 \\
8.4 \\
3.6 \\
5.7\end{array}$ & $\begin{array}{r}14.0 \\
11.7 \\
7.0 \\
7.4\end{array}$ & $\begin{array}{r}25.5 \\
12.2 \\
15.3 \\
11.3 \\
13.6 \\
11.0 \\
6.8 \\
6.9\end{array}$ \\
\hline $\begin{array}{l}8 \\
8 \\
8 \\
8 \\
8 \\
8 \\
8 \\
8\end{array}$ & $\begin{array}{r}0 \\
3 \\
6 \\
9 \\
12 \\
15 \\
18 \\
21\end{array}$ & $\begin{array}{l}13.9 \\
12.4 \\
12.3 \\
12.6 \\
21.3 \\
20.8 \\
14.4 \\
10.8\end{array}$ & $\begin{array}{r}8.3 \\
7.2 \\
7.5 \\
11.4 \\
12.4 \\
12.4 \\
10.0 \\
8.3\end{array}$ & $\begin{array}{l}14.1 \\
12.5 \\
12.5 \\
18.1 \\
20.6 \\
20.5 \\
14: 7 \\
11.9\end{array}$ & $\begin{array}{r}8.2 \\
7.2 \\
7.5 \\
10.9 \\
12.0 \\
12.2 \\
10.1 \\
8.8\end{array}$ & $\begin{array}{l}14.1 \\
12.6 \\
12.6 \\
18.1 \\
20.3 \\
20.4 \\
15.1 \\
12.9\end{array}$ & $\begin{array}{r}7.8 \\
7.0 \\
7.4 \\
10.4 \\
11.4 \\
11.6 \\
10.0 \\
8.9\end{array}$ & $\begin{array}{l}14.0 \\
12.5 \\
12.4 \\
18.2 \\
20.4 \\
20.04 \\
15.8 \\
13.6\end{array}$ & $\begin{array}{r}7.5 \\
6.9 \\
7.3 \\
10.5 \\
11.2 \\
11.6 \\
10.4 \\
9.1\end{array}$ & $\begin{array}{l}18.2 \\
18.0 \\
18.2 \\
19.0 \\
19.9 \\
19.4 \\
18.8 \\
18.5\end{array}$ & & $\begin{array}{r}3.6 \\
3.2 \\
4.4 \\
10.01 \\
10.5 \\
7.09 \\
2.07 \\
2.3\end{array}$ & $\begin{array}{r}4.5 \\
4.4 \\
5.7 \\
22.4 \\
13.2 \\
9.9 \\
3.2 \\
3.7\end{array}$ & $\begin{array}{r}5.4 \\
6.4 \\
15.4 \\
16.2 \\
5.4 \\
4.9\end{array}$ & $\begin{array}{r}7.5 \\
7.0 \\
7.9 \\
14.2 \\
14.9 \\
12.0 \\
7.3 \\
7.0\end{array}$ \\
\hline $\begin{array}{l}9 \\
9 \\
9 \\
9 \\
9 \\
9 \\
9 \\
9\end{array}$ & $\begin{array}{r}0 \\
3 \\
6 \\
9 \\
12 \\
15 \\
18 \\
21\end{array}$ & $\begin{array}{l}10.6 \\
10.9 \\
12.6 \\
16.8 \\
20.3 \\
21.5 \\
18.4 \\
16.7\end{array}$ & $\begin{array}{r}8.6 \\
9.2 \\
9.8 \\
11.9 \\
14.5 \\
14.7 \\
13.8 \\
13.0\end{array}$ & $\begin{array}{l}11.2 \\
11.4 \\
12.7 \\
16.9 \\
20.5 \\
21.6 \\
18.5 \\
16.7\end{array}$ & $\begin{array}{r}8.9 \\
9.2 \\
9.7 \\
11.6 \\
14.5 \\
14.4 \\
13.7 \\
12.7\end{array}$ & $\begin{array}{l}11.9 \\
11.6 \\
12.7 \\
17.0 \\
20.5 \\
21.8 \\
18.4 \\
16.5\end{array}$ & $\begin{array}{r}8.8 \\
9.0 \\
9.6 \\
11.3 \\
13.9 \\
14.1 \\
13.3 \\
12.4\end{array}$ & $\begin{array}{l}12.3 \\
11.9 \\
12.6 \\
17.0 \\
20.5 \\
21.7 \\
18.4 \\
16.4\end{array}$ & $\begin{array}{r}9.0 \\
8.7 \\
9.3 \\
11.1 \\
13.8 \\
13.6 \\
13.0 \\
12.2\end{array}$ & $\begin{array}{l}18.3 \\
18.1 \\
18.4 \\
19.2 \\
20.3 \\
19.8 \\
19.0 \\
18.3\end{array}$ & & $\begin{array}{r}2.3 \\
3.4 \\
7.3 \\
8.9 \\
9.2 \\
10.3 \\
7.9 \\
11.9\end{array}$ & $\begin{array}{r}3.2 \\
4.1 \\
7.8 \\
9.5 \\
10.0 \\
11.1 \\
8.8 \\
13.0\end{array}$ & $\begin{array}{r}4.4 \\
4.7 \\
8.0 \\
10.1 \\
10.9 \\
12.4 \\
9.6 \\
23.8\end{array}$ & $\begin{array}{r}6.0 \\
6.0 \\
8.4 \\
10.6 \\
11.7 \\
13.7 \\
11.3 \\
15.7\end{array}$ \\
\hline $\begin{array}{l}10 \\
10 \\
10 \\
10 \\
10 \\
10 \\
10 \\
10\end{array}$ & $\begin{array}{r}0 \\
3 \\
6 \\
9 \\
12 \\
15 \\
18 \\
21\end{array}$ & $\begin{array}{l}15.6 \\
14.5 \\
14.6 \\
19.0 \\
23.6 \\
22.7 \\
17.0 \\
16.9\end{array}$ & $\begin{array}{l}12.3 \\
12.0 \\
11.8 \\
13.9 \\
15.5 \\
15.9 \\
13.5 \\
14.7\end{array}$ & $\begin{array}{l}15.4 \\
14.0 \\
14.6 \\
19.3 \\
23.4 \\
23.0 \\
17.9 \\
17.2\end{array}$ & $\begin{array}{l}12.1 \\
11.6 \\
11.5 \\
14.0 \\
15.03 \\
15.8 \\
13.6 \\
14.6\end{array}$ & $\begin{array}{l}15.2 \\
14.1 \\
14.6 \\
19.8 \\
23.9 \\
22.9 \\
19.6 \\
17.6\end{array}$ & $\begin{array}{l}11.8 \\
11.1 \\
11.3 \\
13.7 \\
15.1 \\
15.3 \\
13.8 \\
14.1\end{array}$ & $\begin{array}{l}14.9 \\
13.9 \\
14.5 \\
19.6 \\
23.8 \\
23.0 \\
20.5 \\
18.3\end{array}$ & $\begin{array}{l}11.5 \\
10.9 \\
11.1 \\
13.6 \\
15.1 \\
15.2 \\
14.0 \\
13.8\end{array}$ & $\begin{array}{l}17.9 \\
17.2 \\
17.2 \\
18.1 \\
19.0 \\
18.7 \\
18.1 \\
18.0\end{array}$ & & $\begin{array}{r}13.4 \\
15.5 \\
12.7 \\
7.8 \\
8.0 \\
7.2 \\
1.8 \\
2.1\end{array}$ & $\begin{array}{r}14.4 \\
16.6 \\
23.5 \\
8.5 \\
8.9 \\
8.5 \\
2.7 \\
2.7\end{array}$ & $\begin{array}{r}17.8 \\
10.1 \\
3.8 \\
3.1\end{array}$ & $\begin{array}{r}16.8 \\
19.1 \\
15.3 \\
10.0 \\
11.1 \\
10.6 \\
5.0 \\
4.3\end{array}$ \\
\hline
\end{tabular}


Table 10. -Three-hour averages of air and water-surface temperatures and wind directions and speed, April 1950-August STATION

THREE-HOURLY AVERAGES

OCTOBER 1950

\begin{tabular}{|c|c|c|c|c|c|c|c|c|c|c|c|c|c|c|c|}
\hline \multirow{3}{*}{ 悉 } & \multirow{3}{*}{ 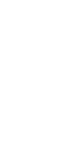 } & \multicolumn{8}{|c|}{ Average air temperature $\left({ }^{\circ} \mathrm{C}\right)$ at indicated height } & \multirow{3}{*}{$\begin{array}{l}\text { Average } \\
\text { water- } \\
\text { surface } \\
\text { tempera- } \\
\text { ture } \\
\left({ }^{\circ} \mathrm{C}\right)\end{array}$} & \multirow{3}{*}{$\begin{array}{c}\begin{array}{c}\text { Average } \\
\text { wind } \\
\text { direction }\end{array} \\
\text { (coded) }\end{array}$} & \multicolumn{4}{|c|}{$\begin{array}{l}\text { Average wind speed (knots) } \\
\text { at indicated height }\end{array}$} \\
\hline & & \multicolumn{2}{|c|}{$\stackrel{2}{2}$} & \multicolumn{2}{|c|}{$\begin{array}{c}4 \\
\text { meters }\end{array}$} & \multicolumn{2}{|c|}{$\begin{array}{c}8 \\
\text { meters }\end{array}$} & \multicolumn{2}{|c|}{$\begin{array}{c}16 \\
\text { meters }\end{array}$} & & & & & & \\
\hline & & $\begin{array}{l}\text { Dry } \\
\text { bulb }\end{array}$ & $\begin{array}{l}\text { Wet } \\
\text { bulb }\end{array}$ & $\begin{array}{l}\text { Dry } \\
\text { bulb }\end{array}$ & $\begin{array}{l}\text { Wet } \\
\text { bulb }\end{array}$ & $\begin{array}{l}\text { Dry } \\
\text { bulb }\end{array}$ & $\begin{array}{l}\text { Wet } \\
\text { bulb }\end{array}$ & $\begin{array}{l}\text { Dry } \\
\text { bulb }\end{array}$ & $\begin{array}{l}\text { Wet } \\
\text { bulb }\end{array}$ & & & meters & meters & meters & meters \\
\hline $\begin{array}{l}11 \\
11 \\
11 \\
11 \\
11 \\
11 \\
11 \\
11\end{array}$ & $\begin{array}{r}0 \\
3 \\
6 \\
9 \\
12 \\
15 \\
18 \\
21\end{array}$ & $\begin{array}{l}15.2 \\
15.44 \\
15.0 \\
21.9 \\
27.8 \\
29.03 \\
21.07 \\
19.0\end{array}$ & $\begin{array}{l}13.4 \\
13.3 \\
13.1 \\
16.2 \\
17.6 \\
18.0 \\
15.8 \\
13.8\end{array}$ & $\begin{array}{l}26.0 \\
15.5 \\
14: 9 \\
21.8 \\
28.5 \\
29.2 \\
22.4 \\
19.2\end{array}$ & $\begin{array}{l}13.4 \\
13.2 \\
13.0 \\
15.6 \\
17.4 \\
17.9 \\
16.2 \\
13.9\end{array}$ & $\begin{array}{l}16.3 \\
15.5 \\
15.0 \\
22.1 \\
29.0 \\
29.6 \\
23.2 \\
19.5\end{array}$ & $\begin{array}{l}23.5 \\
13.0 \\
13.1 \\
25.9 \\
17.8 \\
17.3 \\
1509 \\
13.8\end{array}$ & $\begin{array}{l}16.5 \\
25.4 \\
14.8 \\
22.1 \\
29.3 \\
29.2 \\
23.9 \\
20.0\end{array}$ & $\begin{array}{l}13.3 \\
13.0 \\
12.9 \\
16.0 \\
17.7 \\
17.7 \\
16.2 \\
14.0\end{array}$ & $\begin{array}{l}17.9 \\
17.6 \\
17.9 \\
20.2 \\
23.1 \\
22.2 \\
18.5 \\
17.5\end{array}$ & & $\begin{array}{l}2.1 \\
2.9 \\
2.0 \\
1.4 \\
1.7 \\
1.4 \\
1.6 \\
4.0\end{array}$ & $\begin{array}{l}2.4 \\
3.3 \\
2.6 \\
1.5 \\
1.8 \\
1.8 \\
2.0 \\
5.0\end{array}$ & $\begin{array}{l}2.5 \\
3.4 \\
2.5 \\
1.6 \\
1.6 \\
2.1 \\
3.5 \\
6.6\end{array}$ & $\begin{array}{l}3.2 \\
3.6 \\
2.9 \\
1.97 \\
2.1 \\
2.8 \\
5.1 \\
9.9\end{array}$ \\
\hline $\begin{array}{l}12 \\
12 \\
12 \\
12 \\
12 \\
12 \\
12 \\
12\end{array}$ & $\begin{array}{r}0 \\
3 \\
6 \\
9 \\
12 \\
15 \\
18 \\
21\end{array}$ & $\begin{array}{l}16.1 \\
14.03 \\
14.8 \\
22.5 \\
25.5 \\
25.0 \\
19.4 \\
17.8\end{array}$ & $\begin{array}{l}12.7 \\
11.1 \\
11: 2 \\
13.3 \\
14.4 \\
15.0 \\
14.3 \\
13.7\end{array}$ & $\begin{array}{l}16.6 \\
14.6 \\
15.0 \\
22.2 \\
25.7 \\
24.9 \\
19.7 \\
17.9\end{array}$ & $\begin{array}{l}12.9 \\
11.3 \\
11.5 \\
13.2 \\
14.3 \\
15.4 \\
14.0 \\
13.4\end{array}$ & $\begin{array}{l}26.9 \\
15.1 \\
15.6 \\
22.7 \\
25.8 \\
25.8 \\
19.9 \\
17.8\end{array}$ & $\begin{array}{l}12.6 \\
11.2 \\
11.4 \\
12.9 \\
14 \cdot 2 \\
1407 \\
13.7 \\
13.0\end{array}$ & $\begin{array}{l}17.2 \\
15.4 \\
15.9 \\
22.6 \\
25.4 \\
25.5 \\
20.5 \\
17.9\end{array}$ & $\begin{array}{l}12.5 \\
11.1 \\
11.3 \\
13.2 \\
14.4 \\
14.6 \\
13.2 \\
12.8\end{array}$ & $\begin{array}{l}17.6 \\
17.6 \\
18.0 \\
19.3 \\
20.6 \\
20.1 \\
19.4 \\
18.9\end{array}$ & & $\begin{array}{l}2.3 \\
1.0\end{array}$ & $\begin{array}{l}1.7 \\
1.9 \\
3.0 \\
7.3 \\
5.7 \\
6.4 \\
5.1 \\
7.4\end{array}$ & $\begin{array}{l}2.2 \\
2.5 \\
3.5 \\
8.1 \\
6.2 \\
7.6 \\
6.2 \\
8.1\end{array}$ & $\begin{array}{l}3.5 \\
3.4 \\
4.6 \\
8.9 \\
7.0 \\
8.0 \\
8.5 \\
9.3\end{array}$ \\
\hline $\begin{array}{l}13 \\
13 \\
13 \\
13 \\
13 \\
13 \\
13 \\
13\end{array}$ & $\begin{array}{r}0 \\
3 \\
6 \\
9 \\
12 \\
15 \\
18 \\
21\end{array}$ & $\begin{array}{l}17.0 \\
16.1 \\
16.9 \\
21.6 \\
24.9 \\
25.7 \\
23.0 \\
20.6\end{array}$ & $\begin{array}{l}12.9 \\
12.5 \\
12.6 \\
25.6 \\
17.8 \\
16.6 \\
17.4 \\
26.3\end{array}$ & $\begin{array}{l}17.0 \\
16.1 \\
17.0 \\
22.2 \\
25.8 \\
26.6 \\
23.1 \\
20.7\end{array}$ & $\begin{array}{l}12.8 \\
12.2 \\
12.6 \\
15.6 \\
17.8 \\
18.6 \\
17.3 \\
16.1\end{array}$ & $\begin{array}{l}16.9 \\
16.0 \\
17.00 \\
22.7 \\
26.4 \\
27.1 \\
23.4 \\
20.7\end{array}$ & $\begin{array}{l}12.5 \\
12.0 \\
12.3 \\
15.3 \\
17.6 \\
18.3 \\
17.2 \\
16.0\end{array}$ & $\begin{array}{l}16.9 \\
16.1 \\
17.0 \\
23.0 \\
26.8 \\
27.6 \\
23.6 \\
20.7\end{array}$ & $\begin{array}{l}12.3 \\
11.8 \\
12.2 \\
15.2 \\
17.6 \\
18.3 \\
17.0 \\
15.7\end{array}$ & $\begin{array}{l}18.6 \\
18.3 \\
18.3 \\
19.4 \\
20.4 \\
20.3 \\
19.4 \\
19.0\end{array}$ & & $\begin{array}{l}15.3 \\
13.2 \\
11.7 \\
10.4 \\
14.7\end{array}$ & $\begin{array}{r}8.0 \\
12.2 \\
13.5 \\
16.3 \\
14.5 \\
13.0 \\
11.6 \\
15.8\end{array}$ & $\begin{array}{r}8.8 \\
13.1 \\
14.1 \\
18.1 \\
16.4 \\
14.9 \\
12.9 \\
17.3\end{array}$ & $\begin{array}{r}9.9 \\
14.1 \\
15.0 \\
19.4 \\
18.0 \\
16.9 \\
15.1 \\
18.9\end{array}$ \\
\hline $\begin{array}{l}14 \\
14 \\
14 \\
14 \\
14 \\
24 \\
14 \\
14\end{array}$ & $\begin{array}{r}0 \\
3 \\
6 \\
9 \\
12 \\
15 \\
18 \\
21\end{array}$ & $\begin{array}{l}18.9 \\
18.7 \\
19.0 \\
22.8 \\
26.4 \\
26.8 \\
22.4 \\
21.02\end{array}$ & $\begin{array}{l}15.4 \\
15.1 \\
15.4 \\
17.1 \\
18.3 \\
18.5 \\
17.4 \\
16.8\end{array}$ & $\begin{array}{l}18.9 \\
18.8 \\
19.3 \\
23.4 \\
27.7 \\
27.6 \\
23.0 \\
21.3\end{array}$ & $\begin{array}{l}15.3 \\
14.9 \\
15.3 \\
17.0 \\
10.2 \\
13.4 \\
17.2 \\
16.7\end{array}$ & $\begin{array}{l}19.0 \\
18.8 \\
19.3 \\
24.0 \\
28.6 \\
28.8 \\
23.8 \\
21.5\end{array}$ & $\begin{array}{l}15.1 \\
14.9 \\
15.2 \\
16.9 \\
18.0 \\
18.1 \\
16.8 \\
16.3\end{array}$ & $\begin{array}{l}18.9 \\
18.7 \\
19.5 \\
24.5 \\
29.5 \\
29.6 \\
24.6 \\
21.5\end{array}$ & $\begin{array}{l}14.9 \\
14.6 \\
15.1 \\
16.7 \\
17.9 \\
18.0 \\
16.5 \\
16.1\end{array}$ & $\begin{array}{l}18.5 \\
18.1 \\
18.0 \\
19.3 \\
21.0 \\
20.9 \\
20.0 \\
19.1\end{array}$ & & $\begin{array}{r}11.6 \\
13.6 \\
15.4 \\
12.5 \\
10.7 \\
9.0 \\
7.3 \\
11.6\end{array}$ & $\begin{array}{r}12.4 \\
14.5 \\
16.8 \\
13.9 \\
12.4 \\
10.6 \\
8.4 \\
12.5\end{array}$ & $\begin{array}{l}13.4 \\
15.7 \\
18.0 \\
16.0 \\
14.6 \\
12.9 \\
10.5 \\
13.9\end{array}$ & $\begin{array}{l}14.6 \\
16.6 \\
18.9 \\
16.9 \\
15.4 \\
14.1 \\
12.5 \\
15.7\end{array}$ \\
\hline $\begin{array}{l}15 \\
15 \\
15 \\
15 \\
15 \\
15 \\
15 \\
15\end{array}$ & $\begin{array}{r}0 \\
3 \\
6 \\
9 \\
12 \\
15 \\
18 \\
21\end{array}$ & $\begin{array}{l}19.1 \\
17.09 \\
17.06 \\
22.0 \\
25.1 \\
25.00 \\
23.05 \\
21.03\end{array}$ & $\begin{array}{l}15.9 \\
14.6 \\
14.3 \\
16.7 \\
17.6 \\
18.1 \\
17.2 \\
15.8\end{array}$ & $\begin{array}{l}19.1 \\
17.9 \\
17.8 \\
22.4 \\
26.1 \\
25.7 \\
23.8 \\
21.3\end{array}$ & $\begin{array}{l}15.7 \\
14.5 \\
14.2 \\
16.6 \\
17.7 \\
18.0 \\
17.1 \\
15.6\end{array}$ & $\begin{array}{l}19.2 \\
18.0 \\
17.8 \\
22.0 \\
26.0 \\
27.0 \\
24.0 \\
21.4\end{array}$ & $\begin{array}{l}15.5 \\
14.2 \\
14.0 \\
16.3 \\
17.4 \\
27.9 \\
16.9 \\
15.4\end{array}$ & $\begin{array}{l}19.0 \\
17.9 \\
17.8 \\
23.2 \\
27.1 \\
27.5 \\
24.3 \\
21.5\end{array}$ & $\begin{array}{l}15.2 \\
13.8 \\
13.8 \\
16.4 \\
17.2 \\
17.7 \\
16.8 \\
15.1\end{array}$ & $\begin{array}{l}18.8 \\
18.3 \\
18.2 \\
19.3 \\
20.5 \\
20.3 \\
19.5 \\
18.9\end{array}$ & & $\begin{array}{r}11.2 \\
11.2 \\
11.7 \\
10.1 \\
11.2 \\
12.7 \\
9.9 \\
14.0\end{array}$ & $\begin{array}{l}12.2 \\
12.0 \\
12.4 \\
11.1 \\
14.0 \\
14.0 \\
11.1 \\
15.2\end{array}$ & $\begin{array}{l}13.2 \\
13.1 \\
13.3 \\
12.6 \\
15.9 \\
16.2 \\
12.2 \\
16.7\end{array}$ & $\begin{array}{l}24.6 \\
14.5 \\
24.0 \\
13.5 \\
17.4 \\
18.1 \\
14.4 \\
18.9\end{array}$ \\
\hline $\begin{array}{l}16 \\
16 \\
16 \\
16 \\
16 \\
16 \\
16 \\
16\end{array}$ & $\begin{array}{r}0 \\
3 \\
6 \\
9 \\
12 \\
15 \\
13 \\
21\end{array}$ & $\begin{array}{l}29.6 \\
17.6 \\
17.5 \\
22.1 \\
24.8 \\
25.1 \\
22.3 \\
18.2\end{array}$ & $\begin{array}{l}14.9 \\
14.6 \\
14.6 \\
16.7 \\
16.8 \\
16.2 \\
14.9 \\
14.2\end{array}$ & $\begin{array}{l}19.6 \\
17.5 \\
17.6 \\
22.6 \\
25.5 \\
25.6 \\
22.2 \\
18.2\end{array}$ & $\begin{array}{l}14.7 \\
14.4 \\
14.6 \\
16.7 \\
16.5 \\
15.9 \\
1409 \\
14.1\end{array}$ & $\begin{array}{l}19.6 \\
17.6 \\
17.6 \\
23.1 \\
26.0 \\
25.9 \\
27.2 \\
18.4\end{array}$ & $\begin{array}{l}14.6 \\
14 . ? \\
14.5 \\
16.5 \\
16.4 \\
15.9 \\
14.3 \\
14.1\end{array}$ & $\begin{array}{l}19.4 \\
17.4 \\
17.6 \\
23: 5 \\
26.4 \\
26.3 \\
22.2 \\
18.6\end{array}$ & $\begin{array}{l}14.2 \\
13.9 \\
14.3 \\
16.4 \\
16.1 \\
15.5 \\
14.5 \\
13.8\end{array}$ & $\begin{array}{l}18.4 \\
18.0 \\
18.2 \\
19.1 \\
20.0 \\
19.7 \\
18.6 \\
18.2\end{array}$ & & $\begin{array}{r}13.6 \\
11.4 \\
12.8 \\
17.1 \\
14.3 \\
12.3 \\
9.9 \\
6.5\end{array}$ & $\begin{array}{l}14.6 \\
12.3 \\
13.7 \\
18.6 \\
15.7 \\
13.6 \\
11.0 \\
7.3\end{array}$ & $\begin{array}{r}16.1 \\
13.3 \\
14.8 \\
20.7 \\
17.7 \\
15.3 \\
12.3 \\
8.04\end{array}$ & $\begin{array}{l}17.7 \\
14.7 \\
16.0 \\
22.7 \\
19.1 \\
17.3 \\
140.2 \\
10.6\end{array}$ \\
\hline $\begin{array}{l}17 \\
17 \\
17 \\
17 \\
17 \\
17 \\
17 \\
17\end{array}$ & $\begin{array}{r}0 \\
3 \\
6 \\
9 \\
12 \\
15 \\
18 \\
21\end{array}$ & $\begin{array}{l}17.1 \\
16.7 \\
16.9 \\
20.4\end{array}$ & $\begin{array}{l}14.1 \\
14.2 \\
14.3 \\
16.0\end{array}$ & $\begin{array}{l}17.2 \\
16.7 \\
17.1 \\
20.8\end{array}$ & $\begin{array}{l}14.0 \\
14.1 \\
14.2 \\
15.9\end{array}$ & $\begin{array}{l}17.3 \\
16.7 \\
17.3 \\
20.8\end{array}$ & $\begin{array}{l}14.0 \\
14.0 \\
14.1 \\
15.6\end{array}$ & $\begin{array}{l}17.3 \\
16.6 \\
17.3 \\
21.0\end{array}$ & $\begin{array}{l}13.8 \\
13.8 \\
13.8 \\
15.4\end{array}$ & $\begin{array}{l}17.9 \\
17.7 \\
17.6 \\
18.2\end{array}$ & & $\begin{array}{r}7.5 \\
9.5 \\
10.7 \\
11.0 \\
8.1 \\
5.8 \\
2.7 \\
5.0\end{array}$ & $\begin{array}{r}8.2 \\
10.2 \\
11.5 \\
12.1 \\
9.0 \\
6.8 \\
3.9 \\
5.9\end{array}$ & $\begin{array}{r}8.9 \\
10.9 \\
12.3 \\
13.5 \\
10.4 \\
8.4 \\
6.0 \\
7.3\end{array}$ & $\begin{array}{r}10.5 \\
12.0 \\
13.3 \\
14.4 \\
11.1 \\
9.5 \\
8.3 \\
10.0\end{array}$ \\
\hline $\begin{array}{l}18 \\
18 \\
18 \\
18 \\
18 \\
18 \\
18 \\
18\end{array}$ & $\begin{array}{r}0 \\
3 \\
6 \\
9 \\
12 \\
15 \\
18 \\
21\end{array}$ & $\begin{array}{l}24 \cdot 9 \\
23.2 \\
20.0 \\
18.2\end{array}$ & $\begin{array}{l}17.0 \\
17.1 \\
16.9 \\
16.3\end{array}$ & $\begin{array}{l}25.0 \\
23.2 \\
20.0 \\
18.3\end{array}$ & $\begin{array}{l}26.9 \\
17.0 \\
16.7 \\
16.3\end{array}$ & $\begin{array}{l}25.2 \\
23.2 \\
20.0 \\
18.4\end{array}$ & $\begin{array}{l}16.6 \\
16.9 \\
16.4 \\
16.0\end{array}$ & $\begin{array}{l}25.0 \\
23.1 \\
20.2 \\
18.5\end{array}$ & $\begin{array}{l}16.2 \\
16.8 \\
16.1 \\
15.8\end{array}$ & $\begin{array}{l}21.5 \\
20.6 \\
19.8 \\
19.5\end{array}$ & & $\begin{array}{l}6.0 \\
5.0 \\
4.8 \\
4.8 \\
4.3 \\
5.7 \\
3.2 \\
2.6\end{array}$ & $\begin{array}{l}6.5 \\
5.4 \\
5.2 \\
5.4 \\
5.0 \\
7.0 \\
3.6 \\
2.9\end{array}$ & $\begin{array}{l}7.2 \\
5.8 \\
5.7 \\
6.1 \\
5.6 \\
7.6 \\
4.2 \\
3.1\end{array}$ & $\begin{array}{l}8.6 \\
6.7 \\
6.7 \\
6.6 \\
6.0 \\
9.4 \\
5.3 \\
4.0\end{array}$ \\
\hline $\begin{array}{l}19 \\
19 \\
19 \\
19 \\
19 \\
19 \\
19 \\
19\end{array}$ & $\begin{array}{r}0 \\
3 \\
6 \\
9 \\
12 \\
15 \\
18 \\
21\end{array}$ & $\begin{array}{l}17.8 \\
17.4 \\
16.1 \\
19.1 \\
23.2 \\
23.2 \\
20.3 \\
17.8\end{array}$ & $\begin{array}{l}16.0 \\
15.6 \\
14.5 \\
15.5 \\
16.0 \\
15.7 \\
15.02 \\
14.0\end{array}$ & $\begin{array}{l}17.8 \\
17.7 \\
16.3 \\
18.7 \\
22.0 \\
23.4 \\
20.6 \\
18.1\end{array}$ & $\begin{array}{l}16.0 \\
15.6 \\
14.4 \\
15.4 \\
15.6 \\
15.6 \\
15.0 \\
13.9\end{array}$ & $\begin{array}{l}17.8 \\
17.9 \\
15.9 \\
18.9 \\
22.9 \\
23.6 \\
20.8 \\
18.2\end{array}$ & $\begin{array}{l}15.8 \\
15.5 \\
14.02 \\
15.3 \\
15.2 \\
15.2 \\
14.8 \\
13.6\end{array}$ & $\begin{array}{l}17.9 \\
17.9 \\
15.8 \\
19.3 \\
22.8 \\
23.7 \\
21.2 \\
18.3\end{array}$ & $\begin{array}{l}15.7 \\
15.1 \\
14.0 \\
15.5 \\
15.2 \\
15.1 \\
14.7 \\
13.3\end{array}$ & $\begin{array}{l}19.2 \\
19.0 \\
19.0 \\
19.5 \\
19.8 \\
18.9 \\
18.7 \\
18.5\end{array}$ & & $\begin{array}{l}2.5 \\
2.8 \\
2.4 \\
2.9 \\
3.9 \\
3.6 \\
2.2 \\
2.2\end{array}$ & $\begin{array}{l}2.7 \\
3.2 \\
3.1 \\
3.7 \\
5.0 \\
4.8 \\
3.1 \\
3.0\end{array}$ & $\begin{array}{l}2.7 \\
3.4 \\
3.7 \\
4.9 \\
6.2 \\
6.0 \\
4.4 \\
3.7\end{array}$ & $\begin{array}{l}3.1 \\
4.2 \\
3.7 \\
4.1 \\
6.2 \\
6.3 \\
6.1 \\
4.9\end{array}$ \\
\hline $\begin{array}{l}20 \\
20 \\
20 \\
20 \\
20 \\
20 \\
20 \\
20\end{array}$ & $\begin{array}{r}0 \\
3 \\
6 \\
9 \\
12 \\
15 \\
18 \\
21\end{array}$ & $\begin{array}{l}16.4 \\
14.9 \\
14.4 \\
17.8 \\
21.8 \\
20.6 \\
17.6 \\
14.9\end{array}$ & $\begin{array}{l}12.7 \\
12.4 \\
12.5 \\
13.9 \\
15.4 \\
14.7 \\
23.1 \\
11.3\end{array}$ & $\begin{array}{l}16.5 \\
15.0 \\
14.5 \\
18.0 \\
21.5 \\
20.7 \\
17.9 \\
15.1\end{array}$ & $\begin{array}{l}12.8 \\
12.4 \\
12.5 \\
13.7 \\
15.1 \\
14.5 \\
13.0 \\
11.2\end{array}$ & $\begin{array}{l}16.7 \\
15.1 \\
14.5 \\
17.7 \\
21.05 \\
20.8 \\
13.8 \\
15.4\end{array}$ & $\begin{array}{l}12.7 \\
12.3 \\
12.04 \\
13.7 \\
15.1 \\
14.4 \\
12.7 \\
11.0\end{array}$ & $\begin{array}{l}16.6 \\
15.0 \\
14.4 \\
17.8 \\
21.5 \\
20.9 \\
18.8 \\
15.8\end{array}$ & $\begin{array}{l}12 \cdot 3 \\
12.1 \\
12.2 \\
13.6 \\
15.0 \\
14 \cdot 3 \\
12.5 \\
11.0\end{array}$ & $\begin{array}{l}18.3 \\
18.1 \\
17.9 \\
18.4 \\
18.8 \\
18.5 \\
18.3 \\
18.1\end{array}$ & & $\begin{array}{l}3.9 \\
3.1 \\
3.9 \\
3.4 \\
4.1 \\
2.3 \\
1.7 \\
1.7\end{array}$ & $\begin{array}{l}2.6 \\
4.2 \\
4.8 \\
4 \cdot 2 \\
5.2 \\
3.2 \\
2.6 \\
2.5\end{array}$ & $\begin{array}{l}3.7 \\
4.9 \\
5.8 \\
5.0 \\
6.4 \\
3.6 \\
3.7 \\
3.2\end{array}$ & $\begin{array}{l}4.0 \\
5.9 \\
6.1 \\
4.7 \\
6.7 \\
5.7 \\
4.6 \\
4.8\end{array}$ \\
\hline
\end{tabular}


TABLE 10

143

Table 10. -Three-hour averages of air and water-surface temperatures and wind directions and speed, April 1950-August STATION

THREE HOURLY AVERAGES

OCTOBER, 1950

\begin{tabular}{|c|c|c|c|c|c|c|c|c|c|c|c|c|c|c|c|}
\hline \multirow{3}{*}{ 它 } & \multirow{3}{*}{ 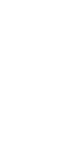 } & \multicolumn{8}{|c|}{ Average air temperature $\left({ }^{\circ} \mathrm{C}\right)$ at indicated height } & \multirow{3}{*}{$\begin{array}{c}\text { Average } \\
\text { water- } \\
\text { surface } \\
\text { tempera- } \\
\text { ture } \\
\left({ }^{\circ} \mathrm{C}\right)\end{array}$} & \multirow{3}{*}{$\begin{array}{c}\text { Average } \\
\text { wind } \\
\text { direction } \\
\text { (coded) }\end{array}$} & \multirow{2}{*}{\multicolumn{4}{|c|}{$\begin{array}{l}\text { Average wind speed (knots) } \\
\text { at indicated height }\end{array}$}} \\
\hline & & \multicolumn{2}{|c|}{$\begin{array}{c}2 \\
\text { meters }\end{array}$} & \multicolumn{2}{|c|}{$\begin{array}{c}4 \\
\text { meters }\end{array}$} & \multicolumn{2}{|c|}{$\begin{array}{c}8 \\
\text { meters }\end{array}$} & \multicolumn{2}{|c|}{$\begin{array}{c}16 \\
\text { meters }\end{array}$} & & & & & & \\
\hline & & $\begin{array}{l}\text { Dry } \\
\text { bulb }\end{array}$ & $\begin{array}{l}\text { Wet } \\
\text { bulb }\end{array}$ & $\begin{array}{l}\text { Dry } \\
\text { bulb }\end{array}$ & $\begin{array}{l}\text { Wet } \\
\text { bulb }\end{array}$ & $\begin{array}{l}\text { Dry } \\
\text { bulb }\end{array}$ & $\begin{array}{l}\text { Wet } \\
\text { bulb }\end{array}$ & $\begin{array}{l}\text { Dry } \\
\text { bulb }\end{array}$ & $\begin{array}{l}\text { Wet } \\
\text { bulb }\end{array}$ & & & $\begin{array}{c}2 \\
\text { meters }\end{array}$ & $\begin{array}{c}4 \\
\text { meters }\end{array}$ & $\begin{array}{c}8 \\
\text { meters }\end{array}$ & $\begin{array}{c}16 \\
\text { meters }\end{array}$ \\
\hline $\begin{array}{l}21 \\
21 \\
21 \\
21 \\
21 \\
21 \\
21 \\
21\end{array}$ & $\begin{array}{r}0 \\
3 \\
6 \\
9 \\
12 \\
15 \\
18 \\
21\end{array}$ & $\begin{array}{l}12.8 \\
11.4 \\
10.9 \\
18.8 \\
2.3 .1 \\
22.8 \\
16.9 \\
14.9\end{array}$ & $\begin{array}{r}9.8 \\
9.3 \\
9.1 \\
12.0 \\
12.6 \\
11.9 \\
10.0 \\
10.1\end{array}$ & $\begin{array}{l}13.1 \\
11.5 \\
11.0 \\
18.9 \\
22.6 \\
22.5 \\
17.2 \\
15.4\end{array}$ & $\begin{array}{r}9.9 \\
9.3 \\
9: 1 \\
11: 9 \\
12.1 \\
11.7 \\
10.2 \\
10.0\end{array}$ & $\begin{array}{l}13.5 \\
11.5 \\
11.1 \\
18.5 \\
22.3 \\
22.4 \\
17.6 \\
15.4\end{array}$ & $\begin{array}{r}10.0 \\
9.4 \\
9.0 \\
11.6 \\
11.8 \\
11.2 \\
10.1 \\
10.0\end{array}$ & $\begin{array}{l}14: 0 \\
11.7 \\
11: 2 \\
18: 7 \\
22.4 \\
22.4 \\
18.5 \\
15.9\end{array}$ & $\begin{array}{r}10.0 \\
9.1 \\
8.9 \\
11.3 \\
11.7 \\
11.3 \\
10.3 \\
9.6\end{array}$ & $\begin{array}{l}18.0 \\
17.7 \\
17.5 \\
18.7 \\
19.3 \\
18.5 \\
18.0 \\
18.0\end{array}$ & & $\begin{array}{l}1.7 \\
2.3 \\
2.7 \\
3.6 \\
5.4 \\
4.0 \\
1.7 \\
1.7\end{array}$ & $\begin{array}{l}2.5 \\
3.3 \\
3.9 \\
4.4 \\
6.8 \\
5.2 \\
2.2 \\
2.5\end{array}$ & $\begin{array}{l}3.4 \\
4.6 \\
5.5 \\
5.2 \\
8.2 \\
6.4 \\
3.2 \\
3.1\end{array}$ & $\begin{array}{l}4.8 \\
5.3 \\
5.7 \\
5.4 \\
8.0 \\
5.09 \\
4.8 \\
3.5\end{array}$ \\
\hline $\begin{array}{l}22 \\
22 \\
22 \\
22 \\
22 \\
22 \\
22 \\
22\end{array}$ & $\begin{array}{r}0 \\
3 \\
6 \\
9 \\
12 \\
15 \\
18 \\
21\end{array}$ & $\begin{array}{r}12.9 \\
9.9 \\
8.6 \\
14.7 \\
20.6 \\
21.4 \\
16.3 \\
11.6\end{array}$ & $\begin{array}{r}8.7 \\
7.2 \\
6.7 \\
10.6 \\
12.6 \\
13.0 \\
11.6 \\
9.2\end{array}$ & $\begin{array}{r}13.1 \\
10.0 \\
8.5 \\
14.4 \\
19.9 \\
21.2 \\
16.4 \\
11.5\end{array}$ & $\begin{array}{r}8.8 \\
7.2 \\
5.8 \\
10.3 \\
12.3 \\
12.8 \\
11.6 \\
9.0\end{array}$ & $\begin{array}{r}13.3 \\
10.0 \\
8.5 \\
14.0 \\
19.7 \\
21.1 \\
16.4 \\
11.2\end{array}$ & $\begin{array}{r}8.6 \\
7.1 \\
6.6 \\
10.0 \\
12.0 \\
12.6 \\
11.3 \\
8.7\end{array}$ & $\begin{array}{r}13.3 \\
10.0 \\
8.5 \\
14.2 \\
19.8 \\
21.0 \\
16.3 \\
10.9\end{array}$ & $\begin{array}{r}8.2 \\
7.0 \\
6.5 \\
9.9 \\
11.8 \\
12.5 \\
11.1 \\
8.6\end{array}$ & $\begin{array}{l}17.0 \\
17.0 \\
16.9 \\
17.4 \\
18.4 \\
18.3 \\
17.8 \\
17.4\end{array}$ & & $\begin{array}{l}2.4 \\
4.1 \\
6.6 \\
8.0 \\
8.2 \\
8.0 \\
6.5 \\
9.0\end{array}$ & $\begin{array}{r}3.4 \\
5.3 \\
8.2 \\
9.9 \\
10.1 \\
9.7 \\
8.1 \\
10.8\end{array}$ & $\begin{array}{r}5.1 \\
7.7 \\
10.1 \\
11.7 \\
11.9 \\
11.5 \\
9.6 \\
12.7\end{array}$ & $\begin{array}{r}5.9 \\
8.4 \\
10.5 \\
12.1 \\
12.1 \\
12.1 \\
11.0 \\
13.5\end{array}$ \\
\hline $\begin{array}{l}23 \\
23 \\
23 \\
23 \\
23 \\
23 \\
23 \\
23\end{array}$ & $\begin{array}{r}0 \\
3 \\
5 \\
9 \\
12 \\
15 \\
18 \\
21\end{array}$ & $\begin{array}{r}7.9 \\
6.1 \\
6.1 \\
11.8 \\
16.3 \\
18.7 \\
14.9 \\
14.3\end{array}$ & $\begin{array}{r}7.1 \\
5.7 \\
5.7 \\
8.6 \\
12.1 \\
13.6 \\
11.8 \\
11.5\end{array}$ & $\begin{array}{r}7.9 \\
6.1 \\
6.2 \\
11.4 \\
15.8 \\
18.4 \\
15.0 \\
14.1\end{array}$ & $\begin{array}{r}7.1 \\
5.7 \\
5.6 \\
8.5 \\
11.8 \\
13.6 \\
11.8 \\
11.2\end{array}$ & $\begin{array}{r}7.9 \\
6.1 \\
6.2 \\
11.1 \\
16.2 \\
18.5 \\
15.2 \\
13.9\end{array}$ & $\begin{array}{r}6.9 \\
5.6 \\
5.6 \\
8.2 \\
11.8 \\
13.5 \\
11.6 \\
10.8\end{array}$ & $\begin{array}{r}7.6 \\
6.0 \\
6.2 \\
11.0 \\
16.1 \\
18.7 \\
15.5 \\
13.8\end{array}$ & $\begin{array}{r}0.6 \\
5.4 \\
5.6 \\
7.9 \\
12.2 \\
13.7 \\
11.4 \\
10.7\end{array}$ & $\begin{array}{l}16.9 \\
16.3 \\
16.3 \\
17.8 \\
19.4 \\
19.5 \\
18.2 \\
17.4\end{array}$ & & $\begin{array}{l}6.5 \\
5.3 \\
5.0 \\
4.3 \\
2.1 \\
2.5 \\
4.0 \\
7.4\end{array}$ & $\begin{array}{l}8.2 \\
6.6 \\
6.2 \\
5.1 \\
2.5 \\
3.0 \\
4.0 \\
7.8\end{array}$ & $\begin{array}{l}9.4 \\
7.6 \\
7.4 \\
5.9 \\
2.6 \\
3.2 \\
5.7 \\
8.2\end{array}$ & $\begin{array}{l}9.9 \\
8.0 \\
7.6 \\
6.0 \\
2.8 \\
3.8 \\
7.8 \\
9.0\end{array}$ \\
\hline $\begin{array}{l}24 \\
24 \\
24 \\
24 \\
24 \\
24 \\
24 \\
24\end{array}$ & $\begin{array}{r}0 \\
3 \\
6 \\
9 \\
12 \\
15 \\
18 \\
21\end{array}$ & $\begin{array}{l}13.4 \\
15.6 \\
16.1 \\
20.4 \\
23.4 \\
23.6 \\
19.4 \\
15.5\end{array}$ & $\begin{array}{l}10.8 \\
12.4 \\
13.0 \\
14.7 \\
15.7 \\
16.6 \\
14.2 \\
12.4\end{array}$ & $\begin{array}{l}13.3 \\
15.5 \\
16.2 \\
21.1 \\
24.3 \\
24.7 \\
19.5 \\
15.6\end{array}$ & $\begin{array}{l}10.6 \\
12.1 \\
12.8 \\
14.7 \\
15.6 \\
16.2 \\
14.2 \\
12.4\end{array}$ & $\begin{array}{l}13.3 \\
15.6 \\
15.2 \\
21.5 \\
25.1 \\
25.6 \\
19.6 \\
15.5\end{array}$ & $\begin{array}{l}10.5 \\
12.0 \\
12.6 \\
14.4 \\
15.4 \\
16.0 \\
13.7 \\
12.1\end{array}$ & $\begin{array}{l}13.2 \\
15.6 \\
16.2 \\
21.8 \\
25.4 \\
26.2 \\
20.0 \\
15.7\end{array}$ & $\begin{array}{l}10.5 \\
11.8 \\
12.5 \\
14.2 \\
15.2 \\
15.9 \\
13.5 \\
12.0\end{array}$ & $\begin{array}{l}17.0 \\
16.9 \\
16.7 \\
17.8 \\
19.2 \\
19.5 \\
18.2 \\
17.5\end{array}$ & & $\begin{array}{r}6.5 \\
17.0 \\
18.0 \\
13.9 \\
9.1 \\
5.8 \\
3.5 \\
3.4\end{array}$ & $\begin{array}{r}7.1 \\
18.2 \\
19.2 \\
15.2 \\
10.2 \\
7.1 \\
4.7 \\
4.5\end{array}$ & $\begin{array}{r}7.6 \\
19.7 \\
20.9 \\
16.7 \\
12.0 \\
9.0 \\
6.1 \\
5.6\end{array}$ & $\begin{array}{r}8.6 \\
20.5 \\
21.6 \\
17.6 \\
12.3 \\
9.9 \\
7.5 \\
6.8\end{array}$ \\
\hline $\begin{array}{l}25 \\
25 \\
25 \\
25 \\
25 \\
25 \\
25 \\
25\end{array}$ & $\begin{array}{r}0 \\
3 \\
6 \\
9 \\
12 \\
15 \\
18 \\
21\end{array}$ & $\begin{array}{l}12.5 \\
10.5 \\
10.1 \\
15.4 \\
20.1 \\
? 1.9 \\
17.5 \\
18.2\end{array}$ & $\begin{array}{r}10.9 \\
9.7 \\
9.4 \\
12.7 \\
15.3 \\
16.4 \\
14.6 \\
15.0\end{array}$ & $\begin{array}{l}12.6 \\
10.7 \\
10.0 \\
15.0 \\
19.9 \\
22.5 \\
18.4 \\
18.3\end{array}$ & $\begin{array}{r}10.8 \\
9.7 \\
9.4 \\
12.6 \\
15.2 \\
16.4 \\
14.8 \\
14.8\end{array}$ & $\begin{array}{l}12.6 \\
10.6 \\
10.0 \\
14.6 \\
20.4 \\
32.3 \\
19.2 \\
13.4\end{array}$ & $\begin{array}{r}10.6 \\
9.5 \\
9.4 \\
12.4 \\
15.1 \\
16.1 \\
15.0 \\
14.6\end{array}$ & $\begin{array}{r}12.5 \\
10.4 \\
9.9 \\
14.4 \\
20.5 \\
22.5 \\
20.1 \\
18.4\end{array}$ & $\begin{array}{r}10.5 \\
9.4 \\
9.2 \\
12.3 \\
15.4 \\
16.3 \\
15.3 \\
14.4\end{array}$ & $\begin{array}{l}17.1 \\
16.9 \\
16.6 \\
17.5 \\
19.2 \\
20.0 \\
18.3 \\
17.5\end{array}$ & & $\begin{array}{l}4.0 \\
4: 8 \\
4: 4 \\
4.6 \\
3.7\end{array}$ & $\begin{array}{r}5.2 \\
6.0 \\
5.6 \\
5.6 \\
4.3 \\
4.8 \\
10.3\end{array}$ & $\begin{array}{r}6.1 \\
6.9 \\
7.1 \\
6.9 \\
5.1 \\
3.4 \\
6.3 \\
11.4\end{array}$ & $\begin{array}{r}6.9 \\
7.5 \\
7.2 \\
7.5 \\
5.0 \\
4.4 \\
8.3 \\
13.0\end{array}$ \\
\hline $\begin{array}{l}26 \\
26 \\
26 \\
26 \\
26 \\
26 \\
26 \\
26\end{array}$ & $\begin{array}{r}0 \\
3 \\
6 \\
9 \\
12 \\
15 \\
18 \\
21\end{array}$ & $\begin{array}{l}18.0 \\
18.4 \\
19.1 \\
23.4 \\
25.5 \\
26.7 \\
23.9 \\
22.1\end{array}$ & $\begin{array}{l}14.7 \\
14.1 \\
13.4 \\
14.3 \\
15.6 \\
16.2 \\
14.9 \\
13.3\end{array}$ & $\begin{array}{l}18.1 \\
18.5 \\
19.5 \\
23.9 \\
27.4 \\
27.3 \\
24.4 \\
22.5\end{array}$ & $\begin{array}{l}14.6 \\
14.0 \\
13.4 \\
14.4 \\
15.8 \\
16.6 \\
15.1 \\
13.4\end{array}$ & $\begin{array}{l}18.1 \\
18.6 \\
19.9 \\
24.7 \\
28.4 \\
27.8 \\
24.6 \\
22.7\end{array}$ & $\begin{array}{l}14.2 \\
13.5 \\
12.9 \\
14.1 \\
15.5 \\
16.1 \\
14.5 \\
12.8\end{array}$ & $\begin{array}{l}18.0 \\
18.8 \\
20.1 \\
24: 9 \\
29.0 \\
28.7 \\
25.1 \\
23.0\end{array}$ & $\begin{array}{l}14.1 \\
13.3 \\
12.6 \\
13.7 \\
14.9 \\
16.0 \\
14.2 \\
12.4\end{array}$ & $\begin{array}{l}17.2 \\
16.9 \\
16.8 \\
18.0 \\
18.9 \\
18.6 \\
18.0 \\
17.3\end{array}$ & & $\begin{array}{l}12.0 \\
14.4 \\
16.4 \\
17.4 \\
17.8 \\
15.6 \\
15.7 \\
16.0\end{array}$ & $\begin{array}{l}12.8 \\
15.4 \\
17.6 \\
19.2 \\
19.6 \\
17.2 \\
17.0 \\
17.3\end{array}$ & $\begin{array}{l}14.0 \\
17.1 \\
19.6 \\
21.8 \\
22.3 \\
20.0 \\
19.0 \\
19.2\end{array}$ & $\begin{array}{l}16.0 \\
18.1 \\
20.8 \\
22.4 \\
23.8 \\
22.0 \\
21.4 \\
21.1\end{array}$ \\
\hline $\begin{array}{l}27 \\
27 \\
27 \\
27 \\
27 \\
27 \\
27 \\
27\end{array}$ & $\begin{array}{r}0 \\
3 \\
6 \\
9 \\
12 \\
15 \\
18 \\
21\end{array}$ & $\begin{array}{l}20.2 \\
19.1 \\
16.5 \\
19.4 \\
23.3 \\
23.5 \\
20.3 \\
19.1\end{array}$ & $\begin{array}{l}12.5 \\
11.7 \\
11.1 \\
13.8 \\
15.9 \\
16.3 \\
14.02 \\
13.7\end{array}$ & $\begin{array}{l}20.4 \\
19.2 \\
16.6 \\
19.0 \\
24.0 \\
24.6 \\
20.6 \\
19.7\end{array}$ & $\begin{array}{l}12.6 \\
11.9 \\
11.0 \\
12.9 \\
15.2 \\
15.6 \\
13.9 \\
13.8\end{array}$ & $\begin{array}{l}20.6 \\
19.2 \\
16.5 \\
10.4 \\
24.5 \\
25.7 \\
21.0 \\
19.2\end{array}$ & $\begin{array}{l}12.0 \\
11.2 \\
10.5 \\
12.6 \\
15.0 \\
14.5 \\
13.5 \\
13.2\end{array}$ & $\begin{array}{l}20.6 \\
19.2 \\
16.5 \\
19.6 \\
24.5 \\
25.3 \\
21.9 \\
19.4\end{array}$ & $\begin{array}{l}11.3 \\
10.7 \\
10.2 \\
12.5 \\
14.8 \\
14.7 \\
13.1 \\
13.3\end{array}$ & $\begin{array}{l}16.9 \\
16.2 \\
16.5 \\
18.1 \\
21.4 \\
21.0 \\
18.9 \\
18.1\end{array}$ & & $\begin{array}{r}17.5 \\
15.0 \\
10.8 \\
4.7 \\
3.1 \\
5.5 \\
4.7 \\
8.9\end{array}$ & $\begin{array}{r}18.9 \\
16.1 \\
11.6 \\
5.6 \\
3.7 \\
6.7 \\
5.4 \\
9.7\end{array}$ & $\begin{array}{r}20.7 \\
17.8 \\
12.7 \\
6.3 \\
4.4 \\
8.4 \\
6.7 \\
11.0\end{array}$ & $\begin{array}{l}22 \cdot 4 \\
24 \cdot 2\end{array}$ \\
\hline $\begin{array}{l}28 \\
28 \\
28 \\
28 \\
23 \\
28 \\
28 \\
28\end{array}$ & $\begin{array}{r}0 \\
3 \\
6 \\
9 \\
12 \\
15 \\
18 \\
21\end{array}$ & $\begin{array}{l}19.1 \\
17.8 \\
16.1 \\
21.1 \\
27.7 \\
27.0 \\
19.4 \\
16.7\end{array}$ & $\begin{array}{l}15.9 \\
15.4 \\
12.6 \\
13.9 \\
15.3 \\
16.1 \\
14.5 \\
15.4\end{array}$ & $\begin{array}{l}19.7 \\
17.5 \\
16.0 \\
21.1 \\
27.7 \\
27.0 \\
20.0 \\
17.3\end{array}$ & $\begin{array}{l}15.9 \\
15.3 \\
12.4 \\
14.0 \\
16.0 \\
16.3 \\
14.9 \\
14.9\end{array}$ & $\begin{array}{l}19.5 \\
17.8 \\
16.0 \\
21.1 \\
27.0 \\
26.9 \\
27.5 \\
17.7\end{array}$ & $\begin{array}{l}15.7 \\
14.9 \\
12.0 \\
13.5 \\
15.3 \\
16.0 \\
14.7 \\
14.5\end{array}$ & $\begin{array}{l}19.5 \\
17.7 \\
15: 0 \\
21.2 \\
27.0 \\
27.0 \\
23.9 \\
18.8\end{array}$ & $\begin{array}{l}15.5 \\
14.6 \\
11.5 \\
13.5 \\
15.5 \\
16.1 \\
14.9 \\
13.8\end{array}$ & $\begin{array}{l}17.9 \\
17.4 \\
17.3 \\
18.3 \\
18.2 \\
17.5 \\
17.0 \\
17.0\end{array}$ & & $\begin{array}{r}12.8 \\
10.3 \\
6.2 \\
7.2 \\
6.2 \\
3.4 \\
1.9 \\
0.9\end{array}$ & $\begin{array}{r}13.6 \\
11.0 \\
7.2 \\
9.1 \\
7.5 \\
4.4 \\
3.1 \\
1.3\end{array}$ & $\begin{array}{r}15.0 \\
12.0 \\
8.0 \\
11.0 \\
8.8 \\
5.2 \\
4.3 \\
1.4\end{array}$ & $\begin{array}{r}16.2 \\
12.8 \\
8.8 \\
11.2 \\
9.7 \\
5.7 \\
6.1\end{array}$ \\
\hline $\begin{array}{l}79 \\
29 \\
29 \\
29 \\
29 \\
29 \\
20 \\
29\end{array}$ & $\begin{array}{r}0 \\
3 \\
6 \\
9 \\
12 \\
15 \\
18 \\
21\end{array}$ & $\begin{array}{l}14.3 \\
15.6 \\
15.3 \\
21.1 \\
25.7 \\
25.5 \\
22.4 \\
20.6\end{array}$ & $\begin{array}{l}13.6 \\
12.9 \\
13.4 \\
15.0 \\
16.9 \\
17.0 \\
16.7 \\
16.0\end{array}$ & $\begin{array}{l}15.4 \\
15.7 \\
15.4 \\
21.08 \\
25.8 \\
26.7 \\
22.8 \\
20.8\end{array}$ & $\begin{array}{l}13.7 \\
12.3 \\
13.3 \\
16.0 \\
16.9 \\
17.3 \\
16.7 \\
16.0\end{array}$ & $\begin{array}{l}15.9 \\
15.7 \\
15.4 \\
27.8 \\
27.9 \\
27.1 \\
33.3 \\
20.9\end{array}$ & $\begin{array}{l}13.6 \\
12.4 \\
13.1 \\
15.8 \\
16.7 \\
17.1 \\
16.4 \\
15.6\end{array}$ & $\begin{array}{l}16.8 \\
15.9 \\
15.6 \\
23.3 \\
28.7 \\
28.1 \\
23.7 \\
21.1\end{array}$ & $\begin{array}{l}13.1 \\
12.1 \\
13.2 \\
15.7 \\
16.7 \\
17.1 \\
16.3 \\
15.4\end{array}$ & $\begin{array}{l}16.9 \\
16.8 \\
16.8 \\
18.1 \\
19.4 \\
19.5 \\
18.5 \\
17.7\end{array}$ & & $\begin{array}{r}1.8 \\
5.7 \\
8.6 \\
8.2 \\
13.1 \\
12.7 \\
12.6 \\
14.5\end{array}$ & $\begin{array}{r}2.2 \\
8.8 \\
9.2 \\
9.2 \\
14.2 \\
14.3 \\
13.7 \\
15.6\end{array}$ & $\begin{array}{r}2.7 \\
6.9 \\
10.1 \\
10.4 \\
17.1 \\
16.8 \\
15.9 \\
17.3\end{array}$ & $\begin{array}{r}5.6 \\
6.5 \\
10.6 \\
11.9 \\
18.4 \\
18.7 \\
18.3 \\
19.2\end{array}$ \\
\hline $\begin{array}{l}30 \\
30 \\
30 \\
30 \\
30 \\
30 \\
30 \\
30\end{array}$ & $\begin{array}{r}0 \\
3 \\
6 \\
9 \\
12 \\
15 \\
18 \\
21\end{array}$ & $\begin{array}{l}19.5 \\
18.5 \\
17.8 \\
21.5 \\
24.1 \\
24.4 \\
21.5 \\
20.0\end{array}$ & $\begin{array}{l}15.0 \\
15.8 \\
15.3 \\
16.5 \\
17.0 \\
15.6 \\
16.7 \\
16.3\end{array}$ & $\begin{array}{l}19.7 \\
18.5 \\
18.0 \\
22.1 \\
24.9 \\
25.0 \\
21.9 \\
20.2\end{array}$ & $\begin{array}{l}15.1 \\
15.9 \\
15.3 \\
16.6 \\
16.9 \\
16.4 \\
16.5 \\
16.4\end{array}$ & $\begin{array}{l}19.8 \\
12.5 \\
18.3 \\
22.7 \\
25.6 \\
25.9 \\
22.3 \\
20.3\end{array}$ & $\begin{array}{l}15.8 \\
15.5 \\
15.1 \\
16.4 \\
16.3 \\
16.3 \\
15.4 \\
16.2\end{array}$ & $\begin{array}{l}19 \cdot 3 \\
18 \cdot 5 \\
18 \cdot 2 \\
23.0 \\
25 \cdot 6 \\
26.4 \\
22.6 \\
20.4\end{array}$ & $\begin{array}{l}15.7 \\
15.3 \\
15.0 \\
16.4 \\
16.8 \\
15.2 \\
16.3 \\
16.2\end{array}$ & $\begin{array}{l}17.3 \\
16.9 \\
16.8 \\
18.1 \\
19.4 \\
19.4 \\
18.5 \\
17.8\end{array}$ & & $\begin{array}{r}16.1 \\
14.9 \\
12.7 \\
12.4 \\
15.2 \\
12.0 \\
7.1 \\
12.7\end{array}$ & $\begin{array}{r}17.1 \\
15.9 \\
13.6 \\
13.6 \\
16.6 \\
13.4 \\
8.0 \\
13.7\end{array}$ & $\begin{array}{r}18.7 \\
17.5 \\
14.9 \\
15.4 \\
19.0 \\
15.4 \\
9.6 \\
15.1\end{array}$ & $\begin{array}{l}20.1 \\
18.5 \\
15.7 \\
16.0 \\
20.1 \\
17.1 \\
12.4 \\
17.0\end{array}$ \\
\hline $\begin{array}{l}31 \\
31 \\
31 \\
31 \\
31 \\
31 \\
31 \\
31\end{array}$ & $\begin{array}{r}0 \\
3 \\
6 \\
9 \\
12 \\
15 \\
13 \\
21\end{array}$ & $\begin{array}{l}29.0 \\
19.0 \\
18.7 \\
22.4 \\
25.0 \\
25.4 \\
22.5 \\
20.4\end{array}$ & $\begin{array}{l}17.2 \\
17.6 \\
17.0 \\
17.9 \\
18.1 \\
17.5 \\
15.5 \\
14.7\end{array}$ & $\begin{array}{l}19.3 \\
19.1 \\
10: 0 \\
22.5 \\
25.4 \\
24.3 \\
22.3 \\
20.4\end{array}$ & $\begin{array}{l}17.3 \\
17.6 \\
17.0 \\
18.0 \\
18.2 \\
17.6 \\
15.5 \\
14.7\end{array}$ & $\begin{array}{l}13.4 \\
13.1 \\
19.1 \\
23.3 \\
25.2 \\
25.0 \\
22.9 \\
20.5\end{array}$ & $\begin{array}{l}17.3 \\
17: 5 \\
17: 0 \\
17: 0 \\
18: 0 \\
17: 3 \\
15: 1 \\
14.2\end{array}$ & $\begin{array}{l}19.4 \\
19.3 \\
19.0 \\
23.6 \\
26.6 \\
26.6 \\
23.1 \\
20.7\end{array}$ & $\begin{array}{l}17.3 \\
17.4 \\
17.0 \\
17.9 \\
17.9 \\
17.1 \\
14.8 \\
14.2\end{array}$ & $\begin{array}{l}17.3 \\
17.1 \\
17.2 \\
18.5 \\
19.3 \\
18.9 \\
18.3 \\
17.6\end{array}$ & & $\begin{array}{l}12.7 \\
14.4 \\
13.2 \\
18.4 \\
20.8 \\
16.8 \\
13.3 \\
13.8\end{array}$ & $\begin{array}{l}13.7 \\
15.4 \\
14.3 \\
20.0 \\
22.7 \\
18.3 \\
14.7 \\
15.0\end{array}$ & $\begin{array}{l}15.2 \\
16.9 \\
15.7 \\
22.6 \\
25.7 \\
20.7 \\
16.6 \\
16.5\end{array}$ & $\begin{array}{l}16.6 \\
18.1 \\
16.6 \\
23.4 \\
26.6 \\
22.4 \\
18.8 \\
18.8\end{array}$ \\
\hline
\end{tabular}


Table 10. - Three-hour averages of air and water-surface temperatures and wind directions and speed, April 1950-August 1951, Lake Hefner-Continue

STATION 3 THREE-HOURLY AVERAGES

NOVEMBER, 1950

\begin{tabular}{|c|c|c|c|c|c|c|c|c|c|c|c|c|c|c|c|}
\hline \multirow{4}{*}{ 壱 } & \multirow{4}{*}{ 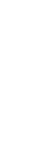 } & \multicolumn{8}{|c|}{ Average air temperature $\left({ }^{\circ} \mathrm{C}\right)$ at indicated height } & \multirow{4}{*}{$\begin{array}{l}\text { Average } \\
\text { water- } \\
\text { surface } \\
\text { tempera- } \\
\text { ture } \\
\left({ }^{\circ} \mathrm{C}\right)\end{array}$} & \multirow{4}{*}{$\begin{array}{l}\text { Average } \\
\text { wind } \\
\text { direction } \\
\text { (coded) }\end{array}$} & \multirow{2}{*}{\multicolumn{4}{|c|}{$\begin{array}{l}\text { Average wind speed (knots) } \\
\text { at indicated height }\end{array}$}} \\
\hline & & \multirow{2}{*}{\multicolumn{2}{|c|}{$\begin{array}{c}2 \\
\text { meters }\end{array}$}} & \multirow{2}{*}{\multicolumn{2}{|c|}{$\begin{array}{c}4 \\
\text { meters }\end{array}$}} & \multirow{2}{*}{\multicolumn{2}{|c|}{$\begin{array}{c}8 \\
\text { meters }\end{array}$}} & \multirow{2}{*}{\multicolumn{2}{|c|}{$\begin{array}{c}16 \\
\text { meters }\end{array}$}} & & & & & & \\
\hline & & & & & & & & & & & & 2 & 4 & 8 & 16 \\
\hline & & $\begin{array}{l}\text { Dry } \\
\text { bulb }\end{array}$ & $\begin{array}{l}\text { Wet } \\
\text { bulb }\end{array}$ & $\begin{array}{l}\text { Dry } \\
\text { bulb }\end{array}$ & $\begin{array}{l}\text { Wet } \\
\text { bulb }\end{array}$ & $\begin{array}{l}\text { Dry } \\
\text { bulb }\end{array}$ & $\begin{array}{l}\text { Wet } \\
\text { bulb }\end{array}$ & $\begin{array}{l}\text { Dry } \\
\text { bulb }\end{array}$ & $\begin{array}{l}\text { Wet } \\
\text { bulb }\end{array}$ & & & meters & meters & meters & meters \\
\hline $\begin{array}{l}1 \\
1 \\
1 \\
1 \\
1 \\
1 \\
1 \\
1\end{array}$ & $\begin{array}{r}0 \\
3 \\
6 \\
9 \\
12 \\
15 \\
18 \\
21\end{array}$ & $\begin{array}{l}20.8 \\
19.3 \\
18.3 \\
17.4 \\
17.6 \\
17.8 \\
13.5 \\
10.2\end{array}$ & $\begin{array}{r}15.8 \\
15.4 \\
15.4 \\
11.3 \\
10.1 \\
10.0 \\
7.6 \\
5.9\end{array}$ & $\begin{array}{l}21.1 \\
19.4 \\
18.4 \\
16.9 \\
17.3 \\
17.7 \\
13.5 \\
10.2\end{array}$ & $\begin{array}{r}15.9 \\
15.4 \\
15.4 \\
10.6 \\
10.0 \\
10.1 \\
7.5 \\
6.0\end{array}$ & $\begin{array}{l}21.3 \\
19.5 \\
13.5 \\
15.6 \\
17.0 \\
17.5 \\
13.4 \\
10.3\end{array}$ & $\begin{array}{r}15.5 \\
15.1 \\
15.0 \\
10.1 \\
9.5 \\
9.7 \\
7.2 \\
5.8\end{array}$ & $\begin{array}{l}21.3 \\
19.5 \\
18.5 \\
16.3 \\
16.8 \\
17.5 \\
13.4 \\
10.2\end{array}$ & $\begin{array}{r}15.3 \\
15.0 \\
14.9 \\
9.8 \\
0.4 \\
9.4 \\
6.9 \\
5.5\end{array}$ & $\begin{array}{l}17.5 \\
17.2 \\
17.0 \\
17.6 \\
17.7 \\
17.0 \\
16.5 \\
16.3\end{array}$ & & $\begin{array}{r}20.0 \\
19.5 \\
14.9 \\
12.3 \\
12.0 \\
10.1 \\
4.6 \\
4.7\end{array}$ & $\begin{array}{r}21.7 \\
21.1 \\
16.1 \\
15.0 \\
14.4 \\
12.1 \\
5.6 \\
5.6\end{array}$ & $\begin{array}{r}24 \cdot 0 \\
23.3 \\
17.9 \\
18.3 \\
17.0 \\
14.2 \\
6.8 \\
6.6\end{array}$ & $\begin{array}{r}25.5 \\
24.4 \\
18.2 \\
19.4 \\
17.6 \\
14.9 \\
8.5 \\
7.8\end{array}$ \\
\hline $\begin{array}{l}2 \\
2 \\
2 \\
2 \\
2 \\
2 \\
2 \\
2 \\
2\end{array}$ & $\begin{array}{r}0 \\
3 \\
6 \\
9 \\
17 \\
15 \\
18 \\
21\end{array}$ & $\begin{array}{r}7.8 \\
6.2 \\
6.2 \\
10.3 \\
13.4 \\
12.7 \\
11.2 \\
8.9\end{array}$ & $\begin{array}{l}4.9 \\
4.3 \\
4.5 \\
6.5 \\
8.1 \\
7.4 \\
7.1 \\
7.7\end{array}$ & $\begin{array}{r}8.0 \\
6.4 \\
6.1 \\
10.3 \\
13.0 \\
12.6 \\
11.2 \\
9.1\end{array}$ & $\begin{array}{l}4.9 \\
4: 5 \\
4: 4 \\
6: 5 \\
7: 9 \\
7.4 \\
7: 1 \\
7: 7\end{array}$ & $\begin{array}{r}7.9 \\
6.6 \\
6.1 \\
9.0 \\
12.9 \\
12.5 \\
11.2 \\
8.8\end{array}$ & $\begin{array}{l}4.9 \\
4.4 \\
4.4 \\
6.5 \\
7.9 \\
7.4 \\
7.1 \\
7.5\end{array}$ & $\begin{array}{r}7.0 \\
6.4 \\
6: 1 \\
10.1 \\
12.8 \\
12.3 \\
11.1 \\
8.5\end{array}$ & $\begin{array}{l}4.6 \\
4.2 \\
4 \cdot 2 \\
6.5 \\
7.7 \\
7.0 \\
5.8 \\
7.1\end{array}$ & $\begin{array}{l}15.8 \\
15.7 \\
15.9 \\
16.3 \\
16.8 \\
16.1 \\
15.9 \\
14.9\end{array}$ & & $\begin{array}{l}3.9 \\
3.3 \\
3.3 \\
3.3 \\
4.2 \\
5.5 \\
5.7 \\
6.7\end{array}$ & $\begin{array}{l}4.7 \\
3.9 \\
4 \cdot 1 \\
3.7 \\
5.7 \\
7.1 \\
6.9 \\
8.2\end{array}$ & $\begin{array}{l}5.5 \\
4.6 \\
5.4 \\
4.7 \\
6.2 \\
0.6 \\
0.1 \\
0.7\end{array}$ & $\begin{array}{l}6.8 \\
5.0 \\
5.5 \\
4.7 \\
5.8 \\
7.7 \\
8.2 \\
9.5\end{array}$ \\
\hline $\begin{array}{l}3 \\
3 \\
3 \\
3 \\
3 \\
3 \\
3 \\
3\end{array}$ & $\begin{array}{r}0 \\
3 \\
6 \\
9 \\
12 \\
15 \\
18 \\
21\end{array}$ & $\begin{array}{l}7.3 \\
4.2 \\
3.6 \\
2.7 \\
3.0 \\
2.7 \\
2.2 \\
0.1\end{array}$ & $\begin{array}{r}7.2 \\
3.9 \\
3.3 \\
2.3 \\
2.7 \\
2.0 \\
-0.8 \\
-0.2\end{array}$ & $\begin{array}{l}7.2 \\
4.1 \\
3.4 \\
2.2 \\
3.0 \\
3.6 \\
2.1 \\
0.2\end{array}$ & $\begin{array}{l}7.0 \\
3.6 \\
3.0 \\
2.1 \\
2.3 \\
1.8 \\
0.6 \\
0.6\end{array}$ & $\begin{array}{l}7.0 \\
3.8 \\
3.2 \\
2.1 \\
2.9 \\
3.4 \\
2.0 \\
0.3\end{array}$ & $\begin{array}{r}0.8 \\
3.4 \\
2.4 \\
1.9 \\
2.0 \\
1.4 \\
0.4 \\
-0.3\end{array}$ & $\begin{array}{l}7.0 \\
3.6 \\
2.0 \\
2.0 \\
2.7 \\
3.1 \\
1.7 \\
0.2\end{array}$ & $\begin{array}{r}6.5 \\
3.0 \\
2.1 \\
1.5 \\
1.6 \\
1.1 \\
0.2 \\
-0.5\end{array}$ & $\begin{array}{l}13.9 \\
13.1 \\
12.4 \\
11.2 \\
11.7 \\
13.0 \\
13.2 \\
12.8\end{array}$ & & $\begin{array}{r}10.4 \\
17.2 \\
20.6 \\
20.0 \\
19.3 \\
16.0 \\
9.2 \\
5.2\end{array}$ & $\begin{array}{r}12.2 \\
20.5 \\
24.3 \\
23.5 \\
22.9 \\
18.4 \\
10.7 \\
6.6\end{array}$ & $\begin{array}{r}13.9 \\
23.3 \\
27.6 \\
25.5 \\
25.4 \\
21.3 \\
12.0 \\
8.7\end{array}$ & $\begin{array}{r}14.7 \\
24.4 \\
29.3 \\
28.0 \\
27.0 \\
22.3 \\
12.8 \\
8.9\end{array}$ \\
\hline $\begin{array}{l}4 \\
4 \\
4 \\
4 \\
4 \\
4 \\
4 \\
4\end{array}$ & $\begin{array}{r}0 \\
3 \\
5 \\
9 \\
12 \\
15 \\
18 \\
21\end{array}$ & $\begin{array}{r}-0.2 \\
-0.5 \\
0.5 \\
5.0 \\
8.6 \\
10.0 \\
7.09 \\
7.07\end{array}$ & $\begin{array}{r}-0.9 \\
-1.2 \\
-\quad 0.6 \\
1.5 \\
3.6 \\
5.2 \\
4.3 \\
4.3\end{array}$ & $\begin{array}{l}0.3 \\
0.7 \\
0.4 \\
4.8 \\
8.0 \\
9.7 \\
7.8 \\
7.4\end{array}$ & $\begin{array}{l}2.2 \\
3.2 \\
4.5 \\
4.0 \\
3.7\end{array}$ & {$\left[\begin{array}{r}-0.2 \\
-0.7 \\
0.4 \\
5.3 \\
8.0 \\
0.5 \\
7.7 \\
7.3\end{array}\right.$} & $\begin{array}{l}2.0 \\
3.2 \\
4.3 \\
3.7 \\
3.2\end{array}$ & $\begin{array}{r}-0.4 \\
-0.8 \\
0.3 \\
5.4 \\
7.4 \\
9.4 \\
7.5 \\
7.0\end{array}$ & $\mid \begin{array}{r}-1.1 \\
-1.6 \\
-1.0 \\
3.7 \\
4.0 \\
3.4 \\
3.1\end{array}$ & $\begin{array}{l}12.8 \\
12.8 \\
12.9 \\
14.5 \\
16.4 \\
15.5 \\
14.2 \\
13.4\end{array}$ & & $\begin{array}{r}4.4 \\
4.5 \\
5.5 \\
2.3 \\
4.7 \\
7.1 \\
9.4 \\
15.4\end{array}$ & $\begin{array}{r}5.5 \\
5.7 \\
5.3 \\
2.8 \\
5.0 \\
7.5 \\
10.2 \\
16.2\end{array}$ & $\begin{array}{r}7.2 \\
7.2 \\
4.9 \\
2.9 \\
5.3 \\
7.8 \\
10.7 \\
17.0\end{array}$ & $\begin{array}{r}7.9 \\
8.5 \\
8.8 \\
3.4 \\
5.3 \\
8.3 \\
11.9 \\
17.6\end{array}$ \\
\hline $\begin{array}{l}5 \\
5 \\
5 \\
5 \\
5 \\
5 \\
5 \\
5\end{array}$ & $\begin{array}{r}0 \\
3 \\
6 \\
9 \\
12 \\
15 \\
18 \\
71\end{array}$ & $\begin{array}{r}7.9 \\
6.7 \\
6.1 \\
11.8 \\
18.5 \\
21.3 \\
16.9 \\
13.8\end{array}$ & $\begin{array}{r}4.1 \\
3.7 \\
3.2 \\
7.1 \\
10.7 \\
12.0 \\
10.5 \\
8.9\end{array}$ & $\begin{array}{r}7.6 \\
6.3 \\
5.8 \\
12.0 \\
10.0 \\
21.7 \\
17.0 \\
13.8\end{array}$ & $\begin{array}{r}3.5 \\
3.1 \\
2: 0 \\
6.9 \\
10.7 \\
1]: 9 \\
10.1 \\
8.5\end{array}$ & $\begin{array}{r}7.2 \\
5.0 \\
5.6 \\
12.3 \\
19.7 \\
32.1 \\
16.9 \\
13.8\end{array}$ & $\begin{array}{r}3.3 \\
2.7 \\
2.5 \\
6.7 \\
10.4 \\
11.9\end{array}$ & $\begin{array}{r}7.0 \\
5.7 \\
5.5 \\
12.5 \\
20.2 \\
22.9 \\
16.9 \\
13.7\end{array}$ & $\begin{array}{r}2.9 \\
2.4 \\
2.5 \\
6.8 \\
10.2 \\
11.4 \\
9.5 \\
8.0\end{array}$ & $\begin{array}{l}12.7 \\
12.3 \\
12.1 \\
13.0 \\
14.8 \\
14.7 \\
13.8 \\
13.0\end{array}$ & & $\begin{array}{l}17.3 \\
16.0 \\
15.0 \\
13.2 \\
14.0 \\
13.5 \\
14.2 \\
15.8\end{array}$ & $\begin{array}{l}18.4 \\
16.9 \\
15.7 \\
14.0 \\
16.3 \\
14.9 \\
15.6 \\
17.0\end{array}$ & $\begin{array}{l}10.4 \\
17.7 \\
16.6 \\
15.1 \\
17.2 \\
17.2 \\
17.4 \\
13.7\end{array}$ & $\begin{array}{l}20.0 \\
18.5 \\
17.1 \\
15.8 \\
10.5 \\
18.9 \\
19.3 \\
20.3\end{array}$ \\
\hline $\begin{array}{l}6 \\
6 \\
6 \\
6 \\
6 \\
6 \\
6 \\
6\end{array}$ & $\begin{array}{r}0 \\
3 \\
6 \\
9 \\
12 \\
15 \\
18 \\
71\end{array}$ & $\begin{array}{r}13.2 \\
11.5 \\
9.7 \\
14.5 \\
17.0 \\
17.8 \\
12.9 \\
10.5\end{array}$ & $\begin{array}{r}8.3 \\
6.8 \\
5.8 \\
7.5 \\
9.7 \\
10.7 \\
8.0 \\
7.0\end{array}$ & $\begin{array}{r}13.2 \\
11.4 \\
9.7 \\
14.4 \\
16.6 \\
17.7 \\
13.5 \\
10.9\end{array}$ & $\begin{array}{l}7.9 \\
6.5 \\
5.6 \\
7.3 \\
8.8 \\
9.8 \\
8.1 \\
7.0\end{array}$ & $\begin{array}{r}13.3 \\
11.3 \\
0.7 \\
14.3 \\
16.8 \\
19.2 \\
14.1 \\
10.9\end{array}$ & $\begin{array}{r}8.2 \\
6.8 \\
+5.9 \\
7.8 \\
8.9\end{array}$ & $\begin{array}{r}13.2 \\
11.1 \\
9.6 \\
13.0 \\
17.0 \\
19.0 \\
14.8 \\
11.4\end{array}$ & $\begin{array}{l}7.2 \\
5.09 \\
5.2 \\
7.3 \\
0.0 \\
7.9 \\
9.0 \\
6.9\end{array}$ & $\begin{array}{l}12.5 \\
12.0 \\
12.0 \\
14.4 \\
17.0 \\
16.4 \\
14.8 \\
14.0\end{array}$ & & $\begin{array}{r}15.1 \\
11.6 \\
8.8 \\
3.5 \\
2.1 \\
1.5 \\
0.5 \\
0.3\end{array}$ & $\begin{array}{r}15.9 \\
12.3 \\
9.3 \\
3.9 \\
2.6 \\
2.0 \\
2.0 \\
1.4\end{array}$ & $\begin{array}{r}17.2 \\
13.0 \\
9.9 \\
4.1 \\
2.6 \\
2.4 \\
3.1 \\
2.0\end{array}$ & $\begin{array}{r}18.8 \\
13.9 \\
10.5 \\
3.9 \\
2.2 \\
2.3 \\
4.1 \\
3.2\end{array}$ \\
\hline $\begin{array}{l}7 \\
7 \\
7 \\
7 \\
7 \\
7 \\
7 \\
7\end{array}$ & $\begin{array}{r}0 \\
3 \\
6 \\
9 \\
12 \\
15 \\
18 \\
21\end{array}$ & $\begin{array}{r}8.8 \\
8.9 \\
6.4 \\
10.5 \\
16.2 \\
17.2 \\
12.6 \\
10.6\end{array}$ & $\begin{array}{r}6.6 \\
7.03 \\
5.4 \\
7.05 \\
11.00 \\
11.6 \\
11.5 \\
9.0\end{array}$ & $\begin{array}{r}9.3 \\
8.8 \\
6.3 \\
9.0 \\
16.0 \\
17.3 \\
13.2 \\
11.5\end{array}$ & $\begin{array}{r}6.8 \\
7.4 \\
5.2 \\
7.3 \\
10.5 \\
11.5 \\
11.6 \\
10.1\end{array}$ & $\begin{array}{r}9.7 \\
8.9 \\
6.3 \\
9.8 \\
15.9 \\
17.3 \\
13.7 \\
12.2\end{array}$ & $\begin{array}{l}7.0 \\
8.0 \\
5.5 \\
5.9\end{array}$ & $\begin{array}{r}9.8 \\
9.1 \\
6.3 \\
9.7 \\
16.1 \\
17.2 \\
14.5 \\
13.0\end{array}$ & $\begin{array}{r}6.5 \\
7.6 \\
5: 2 \\
7.3 \\
10.2 \\
10.5 \\
9.8 \\
8.9\end{array}$ & $\begin{array}{l}13.4 \\
13.0 \\
12.7 \\
13.6 \\
15.1 \\
14.9 \\
14.4 \\
13.8\end{array}$ & & $\begin{array}{l}2 \cdot 3 \\
2 \cdot 7 \\
2 \cdot 2 \\
5 \cdot 4\end{array}$ & $\begin{array}{l}2.2 \\
3.5 \\
3.9 \\
3.4 \\
4.2 \\
4.4 \\
0.7 \\
0.5\end{array}$ & $\begin{array}{l}1.9 \\
3.9 \\
4.3 \\
5.1 \\
4.7 \\
3.8 \\
0.9 \\
1.2\end{array}$ & $\begin{array}{l}2.3 \\
4.6 \\
5.4 \\
5.6 \\
5.8 \\
4.3 \\
2.4\end{array}$ \\
\hline $\begin{array}{l}8 \\
8 \\
8 \\
8 \\
8 \\
8 \\
8 \\
8\end{array}$ & $\begin{array}{r}0 \\
3 \\
6 \\
9 \\
12 \\
15 \\
18 \\
21\end{array}$ & $\begin{array}{r}9.0 \\
9.7 \\
10.7 \\
13.7 \\
17.4 \\
10.4 \\
5.4 \\
3.6\end{array}$ & $\begin{array}{r}7.9 \\
8.6 \\
9.4 \\
11.00 \\
1.2 .0 \\
6.8 \\
2.6 \\
1.1\end{array}$ & $\begin{array}{r}9.4 \\
9.8 \\
10.6 \\
13.9 \\
17.4 \\
9.9 \\
5.1 \\
3.5\end{array}$ & $\begin{array}{r}8.0 \\
8: 7 \\
9.4 \\
10.8 \\
11.8 \\
6.3 \\
2.3 \\
1.0\end{array}$ & $\begin{array}{r}9.9 \\
10.1 \\
10.5 \\
14.0 \\
17.5 \\
9.1 \\
4.8 \\
3.3\end{array}$ & $\begin{array}{r}3.5 \\
8.9 \\
9.6 \\
10.9\end{array}$ & $\begin{array}{r}10.4 \\
10.1 \\
10.7 \\
14.3 \\
17.5 \\
8.5 \\
4.5 \\
3.2\end{array}$ & $\begin{array}{r}8.1 \\
8.3 \\
9.2 \\
10.8 \\
11.2 \\
5.0 \\
1.6 \\
0.2\end{array}$ & $\begin{array}{l}13.1 \\
12.9 \\
12.8 \\
14.0 \\
15.6 \\
14.7 \\
13.4 \\
12.7\end{array}$ & & $\begin{array}{r}5.0 \\
6.7 \\
6.9 \\
5.9 \\
20.9 \\
20.6 \\
16.8\end{array}$ & $\begin{array}{r}3.7 \\
5.6 \\
7.0 \\
8.7 \\
10.2 \\
24.5 \\
23.5 \\
19.3\end{array}$ & $\begin{array}{r}5.0 \\
6.2 \\
7.4 \\
7.9 \\
8.2 \\
28.4 \\
27.6 \\
23.0\end{array}$ & $\begin{array}{r}6.4 \\
7.8 \\
8.0 \\
10.8 \\
16.2 \\
30.1 \\
29.1 \\
23.9\end{array}$ \\
\hline $\begin{array}{l}9 \\
9 \\
9 \\
9 \\
9 \\
9 \\
9 \\
9\end{array}$ & $\begin{array}{r}0 \\
3 \\
6 \\
9 \\
12 \\
15 \\
18 \\
21\end{array}$ & $\begin{array}{r}2.0 \\
0.2 \\
-\quad 0.2 \\
1.2 \\
2.0 \\
2.2 \\
-0.3 \\
-1.0\end{array}$ & $=0.5$ & $\begin{array}{l}1.9 \\
0.1 \\
0.3 \\
0.8 \\
1.8 \\
1.9 \\
0.2 \\
1.1\end{array}$ & -0.5 & $\begin{array}{r}1.7 \\
0.0 \\
-0.5 \\
0.3 \\
1.7 \\
1.6 \\
-1.3\end{array}$ & -0.6 & $\begin{array}{r}1.3 \\
-0.2 \\
-0.7 \\
0.4 \\
1.5 \\
1.4 \\
-0.3 \\
-1.5\end{array}$ & $\mid \begin{array}{l}-1.1 \\
-2.0\end{array}$ & $\begin{array}{l}12.0 \\
11.5 \\
11.0 \\
11.8 \\
12.4 \\
12.1 \\
11.3 \\
10.7\end{array}$ & & $\begin{array}{l}14.0 \\
12.1 \\
13.7 \\
16.7 \\
16.5 \\
14.5 \\
13.1 \\
13.1\end{array}$ & $\begin{array}{l}16.1 \\
14.4 \\
15.5 \\
19.3 \\
19.0 \\
16.8 \\
15.0 \\
15.1\end{array}$ & $\begin{array}{l}18.7 \\
16.1 \\
18.1 \\
22.4 \\
22.1 \\
19.4 \\
17.4 \\
17.4\end{array}$ & $\begin{array}{l}19.7 \\
16.9 \\
18.7 \\
23.1 \\
22.8 \\
20.3 \\
18.3 \\
18.3\end{array}$ \\
\hline $\begin{array}{l}10 \\
10 \\
10 \\
10 \\
10 \\
10 \\
10 \\
10\end{array}$ & $\begin{array}{r}0 \\
3 \\
6 \\
9 \\
12 \\
15 \\
18 \\
21\end{array}$ & 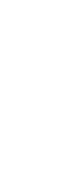 & & $\begin{array}{l}2.7 \\
3.5 \\
5.0 \\
3.5 \\
0.8 \\
0.3 \\
0.0 \\
1.1\end{array}$ & & $\begin{array}{r}-2.9 \\
-3.9 \\
-\quad 5.3 \\
-\quad 4.1 \\
-1.04 \\
0.0 \\
-1.0 \\
-1.04\end{array}$ & & $\begin{array}{l}-3.2 \\
-\quad 4.2 \\
-5.7 \\
-\quad 4.2 \\
-1.5 \\
0.0 .0 \\
-0.2 \\
-1.6\end{array}$ & & $\begin{array}{r}10.1 \\
9.1 \\
8.2 \\
9.5 \\
11.3 \\
10.8 \\
10.5 \\
9.9\end{array}$ & & $\begin{array}{r}12.6 \\
12.9 \\
10.2 \\
7.3 \\
6.6 \\
3.9 \\
4.5 \\
7.9\end{array}$ & $\begin{array}{r}14.6 \\
15.2 \\
12.2 \\
8.6 \\
8.0 \\
4.8 \\
4.7 \\
8.4\end{array}$ & $\begin{array}{r}16.7 \\
17.0 \\
13.7 \\
18.2 \\
9.9 \\
5.6 \\
5.0 \\
3.8\end{array}$ & $\begin{array}{r}17.44 \\
17.8 \\
14.1 \\
10.4 \\
10.6 \\
6.6 \\
5.3 \\
9.3\end{array}$ \\
\hline
\end{tabular}


Table 10, - Three-hour averages of air and water-surface temperatures and wind directions and speed, April 1950-August STATION 3 1951 Lake Hefner-Continued

\begin{tabular}{|c|c|c|c|c|c|c|c|c|c|c|c|c|c|c|c|}
\hline \multirow{4}{*}{ 岳 } & \multirow{4}{*}{ 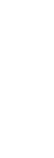 } & \multicolumn{8}{|c|}{ Average air temperature $\left({ }^{\circ} \mathrm{C}\right)$ at indicated height } & \multirow{4}{*}{$\begin{array}{c}\text { Average } \\
\text { water- } \\
\text { surface } \\
\text { tempera- } \\
\text { ture } \\
\text { ("C) }^{\circ} \mathrm{P}\end{array}$} & \multirow{4}{*}{$\begin{array}{c}\text { Average } \\
\text { wind } \\
\text { direction } \\
\text { (coded) }\end{array}$} & \multirow{2}{*}{\multicolumn{4}{|c|}{$\begin{array}{l}\text { Average wind speed (knots) } \\
\text { at indicated height }\end{array}$}} \\
\hline & & \multirow{2}{*}{\multicolumn{2}{|c|}{$\begin{array}{c}2 \\
\text { meters }\end{array}$}} & \multirow{2}{*}{\multicolumn{2}{|c|}{\begin{tabular}{|c|}
4 \\
meters \\
\end{tabular}}} & \multirow{2}{*}{\multicolumn{2}{|c|}{$\begin{array}{c}\mathbf{8} \\
\text { meters } \\
\end{array}$}} & \multirow{2}{*}{\multicolumn{2}{|c|}{$\begin{array}{c}16 \\
\text { meters }\end{array}$}} & & & & & & \\
\hline & & & & & & & & & & & & 2 & 4 & 8 & 16 \\
\hline & & $\begin{array}{l}\text { Dry } \\
\text { bulb }\end{array}$ & $\begin{array}{l}\text { Wet } \\
\text { bulb }\end{array}$ & $\begin{array}{l}\text { Dry } \\
\text { bulb }\end{array}$ & $\begin{array}{l}\text { Wet } \\
\text { bulb }\end{array}$ & $\begin{array}{l}\text { Dry } \\
\text { bulb }\end{array}$ & \begin{tabular}{|l|} 
Wet \\
bulb
\end{tabular} & $\begin{array}{l}\text { Dry } \\
\text { bulb }\end{array}$ & $\begin{array}{l}\text { Wet } \\
\text { bulb }\end{array}$ & & & meters & meters & meters & meters \\
\hline $\begin{array}{l}11 \\
11 \\
11 \\
11 \\
11 \\
11 \\
11 \\
11\end{array}$ & $\begin{array}{r}0 \\
3 \\
6 \\
9 \\
12 \\
15 \\
18 \\
21\end{array}$ & $\begin{array}{r}-1.9 \\
=2.4 \\
-1.7 \\
2.9 \\
7.0 \\
8.3 \\
5.0 \\
3.5\end{array}$ & $\begin{array}{r} \\
0.6 \\
2.0 \\
2.7 \\
0.4 \\
-0.6\end{array}$ & $\begin{array}{l}2.3 \\
2.9 \\
2.1 \\
2.8 \\
7.0 \\
8.2 \\
4.9 \\
3.4\end{array}$ & $\begin{array}{r} \\
\\
1.1 \\
1.7 \\
2.4 \\
0.2 \\
-0.7\end{array}$ & $\begin{array}{r}-2.3 \\
-3.1 \\
-2.3 \\
2.5 \\
6.9 \\
7.9 \\
4.8 \\
3.3\end{array}$ & $\begin{array}{r} \\
1.1 \\
2.2 \\
2.5 \\
0.2 \\
-0.8\end{array}$ & $\begin{array}{r}-2.5 \\
-3.4 \\
-2.4 \\
2.5 \\
5.7 \\
7.8 \\
4.6 \\
3.1\end{array}$ & $\begin{array}{r}1.0 \\
1.8 \\
-0.3 \\
-1.1\end{array}$ & $\begin{array}{r}9.9 \\
8.4 \\
8.0 \\
9.0 \\
10.0 \\
9.7 \\
8.7 \\
8.0\end{array}$ & & $\begin{array}{r}10.6 \\
13.1 \\
14.0 \\
16.5 \\
15.5 \\
12.7 \\
9.8 \\
11.5\end{array}$ & $\begin{array}{l}11.0 \\
13.8 \\
14.7 \\
17.5 \\
16.5 \\
13.5 \\
10.8 \\
12.0\end{array}$ & $\begin{array}{l}11.3 \\
14.4 \\
15.4 \\
18.8 \\
17.7 \\
14.4 \\
11.5 \\
13.4\end{array}$ & $\begin{array}{l}11.9 \\
14.9 \\
16.0 \\
19.8 \\
18.5 \\
15.3 \\
13.3 \\
15.2\end{array}$ \\
\hline $\begin{array}{l}12 \\
12 \\
12 \\
12 \\
12 \\
12 \\
12 \\
12\end{array}$ & $\begin{array}{r}0 \\
3 \\
6 \\
9 \\
12 \\
15 \\
18 \\
21\end{array}$ & $\begin{array}{r}2.3 \\
1.5 \\
1.8 \\
5.9 \\
11.0 \\
11.7 \\
7.9 \\
6.2\end{array}$ & $\begin{array}{r}-1.1 \\
-1.7 \\
-1.1 \\
1.4 \\
4.1 \\
4.4 \\
2.2 \\
1.6\end{array}$ & $\begin{array}{r}2.0 \\
1.4 \\
1.8 \\
5.1 \\
11.1 \\
11.7 \\
8.1 \\
6.4\end{array}$ & $\begin{array}{r}-1.3 \\
-1.8 \\
-1.4 \\
1.4 \\
4.1 \\
4.5 \\
? .4 \\
1.8\end{array}$ & $\begin{array}{r}1.8 \\
1.1 \\
1.6 \\
6.1 \\
11.1 \\
11.7 \\
8.1 \\
6.4\end{array}$ & $\begin{array}{r}-1.5 \\
=2.0 \\
-1.5 \\
0.9\end{array}$ & $\begin{array}{r}1.5 \\
1.0 \\
1.5 \\
0.1 \\
11.1 \\
21.7 \\
8.1 \\
6.3\end{array}$ & $\mid \begin{array}{r}-1.3 \\
-2.3 \\
-1.9 \\
1.1 \\
3.7 \\
3.9 \\
2.1 \\
1.4\end{array}$ & $\begin{array}{l}7.4 \\
8.8 \\
7.4 \\
8.2 \\
9.7 \\
9.6 \\
8.7 \\
8.3\end{array}$ & & $\begin{array}{r}11.9 \\
11.4 \\
13.3 \\
13.9 \\
14.2 \\
12.1 \\
7.4 \\
9.3\end{array}$ & $\begin{array}{r}12.7 \\
12.4 \\
14.4 \\
14.9 \\
15.5 \\
13.5 \\
8.9 \\
11.0\end{array}$ & $\begin{array}{l}13.4 \\
13.1 \\
15.3 \\
15.0 \\
17.0 \\
15.0 \\
10.0 \\
12.3\end{array}$ & $\begin{array}{l}14.7 \\
14.6 \\
16.9 \\
17.3 \\
18.9 \\
17.1 \\
12.2 \\
14.7\end{array}$ \\
\hline $\begin{array}{l}13 \\
13 \\
13 \\
13 \\
13 \\
13 \\
13 \\
13\end{array}$ & $\begin{array}{r}0 \\
3 \\
6 \\
9 \\
12 \\
15 \\
18 \\
21\end{array}$ & $\begin{array}{r}4.4 \\
3.2 \\
1.2 \\
7: 9 \\
13: 0 \\
14: 0 \\
11: 9 \\
11.3\end{array}$ & $\begin{array}{r}0.4 \\
0.0 \\
-0.7 \\
4.5 \\
7.3 \\
8.0 \\
8.3 \\
9.2\end{array}$ & $\begin{array}{r}4.4 \\
3.2 \\
1.4 \\
3.1 \\
13.3 \\
15.2 \\
12.4 \\
11.4\end{array}$ & $\begin{array}{r}0.5 \\
0.1 \\
-0.5 \\
4.8 \\
7.0 \\
0.5 \\
8.8 \\
9.6\end{array}$ & $\begin{array}{r}4.4 \\
3.2 \\
1.7 \\
8.3 \\
13.3 \\
35.3 \\
12.5 \\
11.5\end{array}$ & $\begin{array}{l}5.1 \\
7.5 \\
8.9 \\
8.5 \\
9.3\end{array}$ & $\begin{array}{r}4.5 \\
3.2 \\
2.0 \\
8.3 \\
13.5 \\
15.5 \\
12.5 \\
11.5\end{array}$ & $\begin{array}{r}0.3 \\
-0.1 \\
4.2 \\
7.0 \\
3.5 \\
2.5 \\
0.3\end{array}$ & $\begin{array}{r}7.9 \\
7.5 \\
7.2 \\
3.7 \\
10.0 \\
10.3 \\
0.8 \\
7.3\end{array}$ & & $\begin{array}{r}0.0 \\
8.8 \\
5.3 \\
11.5 \\
9.5 \\
9.3 \\
7.1 \\
13.1\end{array}$ & $\begin{array}{r}10.8 \\
10.7 \\
6.6 \\
12.4 \\
10.6 \\
10.4 \\
8.1 \\
14.2\end{array}$ & $\begin{array}{r}12.2 \\
12.1 \\
7.9 \\
13.6 \\
11.6 \\
11.9 \\
0.5 \\
13.5\end{array}$ & $\begin{array}{r}14.5 \\
14.9 \\
9.5 \\
15.0 \\
13.0 \\
13.8 \\
11.8 \\
17.5\end{array}$ \\
\hline $\begin{array}{l}14 \\
14 \\
14 \\
14 \\
14 \\
14 \\
14 \\
14\end{array}$ & $\begin{array}{r}0 \\
3 \\
6 \\
9 \\
12 \\
15 \\
18 \\
21\end{array}$ & $\begin{array}{l}12.7 \\
13.5 \\
13.2 \\
14.5 \\
16.1 \\
17.0 \\
16.7 \\
16.7\end{array}$ & $\begin{array}{r}9.9 \\
11.1 \\
11.5 \\
12.7 \\
12.7 \\
14.6 \\
15.1 \\
15.8\end{array}$ & $\begin{array}{l}12.8 \\
13.7 \\
13.4 \\
14.8 \\
16.3 \\
13: 1 \\
17.0 \\
16.9\end{array}$ & $\begin{array}{l}10.4 \\
11.6 \\
12.0 \\
12.7 \\
13.4 \\
15.4 \\
15.7 \\
16.2\end{array}$ & $\begin{array}{l}13.1 \\
13.9 \\
13.7 \\
15.1 \\
16.5 \\
18.4 \\
17.4 \\
17.2\end{array}$ & $\begin{array}{l}10.0 \\
11.4 \\
11.7 \\
12.4 \\
13.0 \\
15.1 \\
15.7 \\
16.3\end{array}$ & $\begin{array}{l}13.4 \\
14.0 \\
13.5 \\
15.4 \\
17.2 \\
17.0 \\
17.8 \\
17.5\end{array}$ & $\begin{array}{l}10.0 \\
11.4 \\
11.9 \\
13.4 \\
13.1 \\
15.4 \\
16.0 \\
16.7\end{array}$ & $\begin{array}{r}7.9 \\
10.0 \\
10.2 \\
10.9 \\
11.7 \\
12.0 \\
11.7 \\
11.3\end{array}$ & & $\begin{array}{l}15.1 \\
16.7 \\
17.8 \\
19.2 \\
20.1 \\
17.7 \\
15.6 \\
14.5\end{array}$ & $\begin{array}{l}16.4 \\
18.0 \\
19.4 \\
20.0 \\
21.0 \\
19.4 \\
17.0 \\
16.0\end{array}$ & $\begin{array}{l}13.5 \\
19.9 \\
21.6 \\
23.3 \\
24.5 \\
21.8 \\
19.5 \\
19.0\end{array}$ & $\begin{array}{l}20.3 \\
22: 1 \\
24: 0 \\
26: 0 \\
27: 1 \\
24: 6 \\
22.0 \\
20.7\end{array}$ \\
\hline $\begin{array}{l}15 \\
15 \\
15 \\
15 \\
15 \\
15 \\
15 \\
15\end{array}$ & $\begin{array}{r}0 \\
3 \\
6 \\
9 \\
12 \\
15 \\
18 \\
21\end{array}$ & $\begin{array}{l}17.1 \\
17.7 \\
17.1 \\
18.6 \\
20.1 \\
20.4 \\
16.6 \\
11.8\end{array}$ & $\begin{array}{r}16.1 \\
16.4 \\
16.2 \\
16.3 \\
13.8 \\
12.2 \\
8.8 \\
5.9\end{array}$ & $\begin{array}{l}17.6 \\
18.0 \\
17.7 \\
19.6 \\
21.4 \\
21.4 \\
17.0 \\
11.9\end{array}$ & $\begin{array}{r}16.6 \\
17.1 \\
16.9 \\
16.6 \\
13.9 \\
12.0 \\
8.8 \\
6.0\end{array}$ & $\begin{array}{l}18.2 \\
13.5 \\
18.2 \\
20.2 \\
22.0 \\
22.8 \\
17.4 \\
12.1\end{array}$ & $\begin{array}{r}16.9 \\
17.3 \\
16: 9 \\
16.9 \\
14: 0 \\
12.4 \\
8.7 \\
5.9\end{array}$ & $\begin{array}{l}13 .- \\
19.0 \\
18.5 \\
30.5 \\
22.0 \\
23.0 \\
17.4 \\
12.2\end{array}$ & $\begin{array}{r}17.6 \\
17.8 \\
17.5 \\
17.7 \\
13.9 \\
12.1 \\
8.5 \\
5.7\end{array}$ & $\begin{array}{l}10.8 \\
10.7 \\
10.8 \\
12.3 \\
13.2 \\
12.4 \\
11.9 \\
11.9\end{array}$ & & $\begin{array}{r}16.3 \\
18.5 \\
16.3 \\
19.6 \\
13.4 \\
6.0 \\
7.5 \\
6.1\end{array}$ & $\begin{array}{r}17.8 \\
20.2 \\
17.8 \\
21.8 \\
15.3 \\
7.8 \\
9.5 \\
7.8\end{array}$ & $\begin{array}{r}20.2 \\
22.9 \\
20.1 \\
24.8 \\
18.2 \\
0.2 \\
11.3 \\
9.9\end{array}$ & $\begin{array}{l}22.3 \\
24.5 \\
22.1 \\
25.9 \\
19.3 \\
12.5 \\
12.8 \\
11.2\end{array}$ \\
\hline $\begin{array}{l}16 \\
16 \\
16 \\
16 \\
16 \\
16 \\
16 \\
16\end{array}$ & $\begin{array}{r}0 \\
3 \\
6 \\
9 \\
12 \\
15 \\
18 \\
21\end{array}$ & $\begin{array}{r}8.1 \\
5.8 \\
3.6 \\
8.2 \\
11.2 \\
10.7 \\
8.2\end{array}$ & $\begin{array}{l}3.8 \\
2.4 \\
1.0 \\
3.4 \\
4.5 \\
4.3 \\
3.0\end{array}$ & $\begin{array}{r}8.3 \\
6.0 \\
3.8 \\
7.9 \\
10.7 \\
10.6 \\
8.2\end{array}$ & $\begin{array}{l}3.8 \\
2.4 \\
1.0 \\
3.0 \\
4.0 \\
4.1 \\
3.1\end{array}$ & $\begin{array}{r}3.4 \\
6.1 \\
3.0 \\
7.7 \\
10.3 \\
10.5 \\
8.6\end{array}$ & $\begin{array}{l}3.6 \\
2.03 \\
1.1 \\
2.9 \\
3.9 \\
4.1 \\
3.4\end{array}$ & $\begin{array}{r}8.7 \\
6.3 \\
3.0 \\
7.6 \\
10.4 \\
10.4 \\
8.0\end{array}$ & $\begin{array}{l}3.4 \\
2.1 \\
0.9 \\
? .7 \\
3.7 \\
3.8 \\
3.3\end{array}$ & $\begin{array}{r}11.1 \\
10.5 \\
9.6 \\
10.3 \\
10.9 \\
10.9 \\
10.4\end{array}$ & & $\begin{array}{l}5.8 \\
4.6 \\
5.1 \\
8.2 \\
7.7 \\
6.0 \\
1.3 \\
1.1\end{array}$ & $\begin{array}{l}7.1 \\
5.8 \\
6.5 \\
9.6 \\
9.1 \\
7.0 \\
1.9 \\
1.3\end{array}$ & $\begin{array}{r}8.4 \\
7.4 \\
7.4 \\
11.0 \\
10.7 \\
8.5 \\
2.5 \\
1.7\end{array}$ & $\begin{array}{r}10.3 \\
8.7 \\
8.1 \\
11.0 \\
10.6 \\
8.7 \\
3.0 \\
2.2\end{array}$ \\
\hline $\begin{array}{l}17 \\
17 \\
17 \\
17 \\
17 \\
17 \\
17 \\
17\end{array}$ & $\begin{array}{r}0 \\
3 \\
6 \\
9 \\
12 \\
15 \\
18 \\
21\end{array}$ & $\begin{array}{r}9.7 \\
11.9 \\
12.6 \\
10.6 \\
9.4\end{array}$ & $\begin{array}{l}4.7 \\
5.9 \\
5.7 \\
5.8 \\
5.7\end{array}$ & $\begin{array}{r}9.4 \\
12.1 \\
12.8 \\
10.8 \\
9.6\end{array}$ & $\begin{array}{l}4.8 \\
5.8 \\
5.6 \\
5.7 \\
5.5\end{array}$ & $\begin{array}{r}9.7 \\
12.2 \\
12.9 \\
10.7 \\
9.7\end{array}$ & $\begin{array}{l}4.8 \\
5.8 \\
6.7 \\
5.7 \\
5.5\end{array}$ & $\begin{array}{r}9.5 \\
12.3 \\
13.0 \\
10.7 \\
9.5\end{array}$ & $\begin{array}{l}4.2 \\
5.2 \\
6.0 \\
5.1 \\
5.0\end{array}$ & $\begin{array}{r}10.0 \\
10.6 \\
10.4 \\
9.6 \\
9.2\end{array}$ & & $\begin{array}{r}1.5 \\
2.2 \\
5.0 \\
13.9 \\
15.7 \\
12.7 \\
7.2 \\
13.4\end{array}$ & $\begin{array}{r}1.5 \\
2.5 \\
5.7 \\
15.3 \\
16.9 \\
13.7 \\
8.0 \\
14.5\end{array}$ & $\begin{array}{r}1.8 \\
2.3 \\
6.3 \\
16.6 \\
10.5 \\
15.2 \\
9.0 \\
15.9\end{array}$ & $\begin{array}{r}2.0 \\
3.0 \\
7.5 \\
18.0 \\
19.7 \\
16.9 \\
10.7 \\
17.8\end{array}$ \\
\hline $\begin{array}{l}18 \\
18 \\
18 \\
18 \\
18 \\
18 \\
18 \\
18\end{array}$ & $\begin{array}{r}0 \\
3 \\
6 \\
9 \\
12 \\
15 \\
18 \\
21\end{array}$ & $\begin{array}{r}9.1 \\
9.0 \\
9.8 \\
13.4 \\
16.4 \\
17.0 \\
15.3\end{array}$ & $\begin{array}{r}5.1 \\
5.2 \\
7.5 \\
10.5 \\
13.0 \\
14.1 \\
14.1\end{array}$ & $\begin{array}{r}9.1 \\
9.0 \\
10.0 \\
13.7 \\
16.8 \\
17.6 \\
16.3\end{array}$ & $\begin{array}{r}5 \cdot 7 \\
6.0 \\
7.5 \\
10.7 \\
13.2 \\
14.2 \\
14.2\end{array}$ & $\begin{array}{r}9.1 \\
9.0 \\
10.1 \\
14.0 \\
17.5 \\
17.8 \\
16.4\end{array}$ & $\begin{array}{r}5.6 \\
6.0 \\
7.5 \\
10.8 \\
13.5 \\
14.5 \\
14.3\end{array}$ & $\begin{array}{r}9.0 \\
8.9 \\
10.2 \\
14.3 \\
17.9 \\
18.6 \\
16.7\end{array}$ & $\begin{array}{r}5.1 \\
5.5 \\
7.3 \\
10.7 \\
13.4 \\
14.6 \\
14.4\end{array}$ & $\begin{array}{r}8.9 \\
8.8 \\
8.7 \\
10.3 \\
11.6 \\
12.1 \\
11.1\end{array}$ & & $\begin{array}{r}15.8 \\
15.9 \\
14.0 \\
17.3 \\
16.5 \\
9.3 \\
9.8 \\
12.5\end{array}$ & $\begin{array}{l}16.9 \\
17.0 \\
15.1 \\
18.8 \\
17.9 \\
10.5 \\
10.9 \\
13.7\end{array}$ & $\begin{array}{l}18.3 \\
18.4 \\
16.4 \\
20.7 \\
20.0 \\
12.3 \\
12.4 \\
15.6\end{array}$ & $\begin{array}{l}19.9 \\
20.0 \\
18.4 \\
22.5 \\
21.8 \\
14.3 \\
14: 8 \\
18.0\end{array}$ \\
\hline $\begin{array}{l}19 \\
19 \\
19 \\
19 \\
19 \\
19 \\
19 \\
19\end{array}$ & $\begin{array}{r}0 \\
3 \\
6 \\
9 \\
12 \\
15 \\
18 \\
21\end{array}$ & $\begin{array}{r}19.7 \\
12.4 \\
4.1 \\
2.9\end{array}$ & & $\begin{array}{r}20.4 \\
12.3 \\
3.9 \\
2.6\end{array}$ & $\begin{array}{r}13.2 \\
8.5 \\
2.8 \\
0.7\end{array}$ & $\begin{array}{r}21.8 \\
11.8 \\
3.6 \\
2.5\end{array}$ & $\begin{array}{r}13.3 \\
8.0 \\
2.4 \\
0.3\end{array}$ & 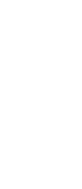 & $\begin{array}{r}13.0 \\
7.6 \\
2.1\end{array}$ & $\begin{array}{l}13.0 \\
11.0 \\
10.9 \\
10.0\end{array}$ & & $\begin{array}{l}12.5 \\
12.1 \\
12.6 \\
14.3 \\
13.1 \\
14.5 \\
17.2 \\
17.6\end{array}$ & $\begin{array}{l}13.7 \\
13.2 \\
13.3 \\
15.5 \\
14.8 \\
17.9 \\
20.8 \\
20.7\end{array}$ & $\begin{array}{l}16.0 \\
14.8 \\
14.9 \\
17.8 \\
17.4 \\
22.02 \\
23.5 \\
23.8\end{array}$ & $\begin{array}{l}17.9 \\
17.0 \\
16.2 \\
19.0 \\
18.0 \\
23.0 \\
24.3 \\
25.3\end{array}$ \\
\hline $\begin{array}{l}20 \\
20 \\
20 \\
20 \\
20 \\
20 \\
20 \\
20\end{array}$ & $\begin{array}{r}0 \\
3 \\
6 \\
9 \\
12 \\
15 \\
18 \\
21\end{array}$ & $\begin{array}{r}1.1 \\
-1.4 \\
-1.8 \\
0.7 \\
5.2 \\
6.4 \\
3.7 \\
3.7\end{array}$ & $\begin{array}{r}1.0 \\
2.0 \\
-0.5 \\
1.0\end{array}$ & $\begin{array}{l}0.9 \\
1.6 \\
2.1 \\
0.4 \\
4: 9 \\
6.0 \\
4.2 \\
3.8\end{array}$ & $\begin{array}{r}-1.0 \\
1.0 \\
0.8 \\
0.8 \\
0.0 \\
1.0\end{array}$ & $\begin{array}{r}0.3 \\
-1.8 \\
-2.2 \\
0.1 \\
3.9 \\
5.8 \\
4.6 \\
4.0\end{array}$ & $\begin{array}{l}0.7 \\
0.0 \\
0.7\end{array}$ & $\left|\begin{array}{r}0.1 \\
-2.0 \\
-2.3\end{array}\right|$ & $\begin{array}{l}0.6 \\
1.1 \\
0.1 \\
0.4\end{array}$ & $\begin{array}{l}9.2 \\
9.0 \\
8.4 \\
8.3 \\
9.5 \\
9.6 \\
9.1 \\
8.6\end{array}$ & & $\begin{array}{r}16.5 \\
13.4 \\
10.2 \\
8.8 \\
5.3 \\
2.5 \\
2.1 \\
4.8\end{array}$ & $\begin{array}{r}19.3 \\
15.2 \\
11.0 \\
10.3 \\
6.1 \\
3.0 \\
2.5 \\
5.2\end{array}$ & $\begin{array}{r}22.4 \\
17.8 \\
13.6 \\
11.0 \\
7.2 \\
3.6 \\
2.6 \\
5.6\end{array}$ & $\begin{array}{r}23.6 \\
18.6 \\
14.2 \\
12.0 \\
7.4 \\
3.8 \\
2.7 \\
6.1\end{array}$ \\
\hline
\end{tabular}


Table 10. - Three-hour averages of air and water-surface temperatures and wind directions and speed, April 1950-August 1951, Lake Hefner-Continued

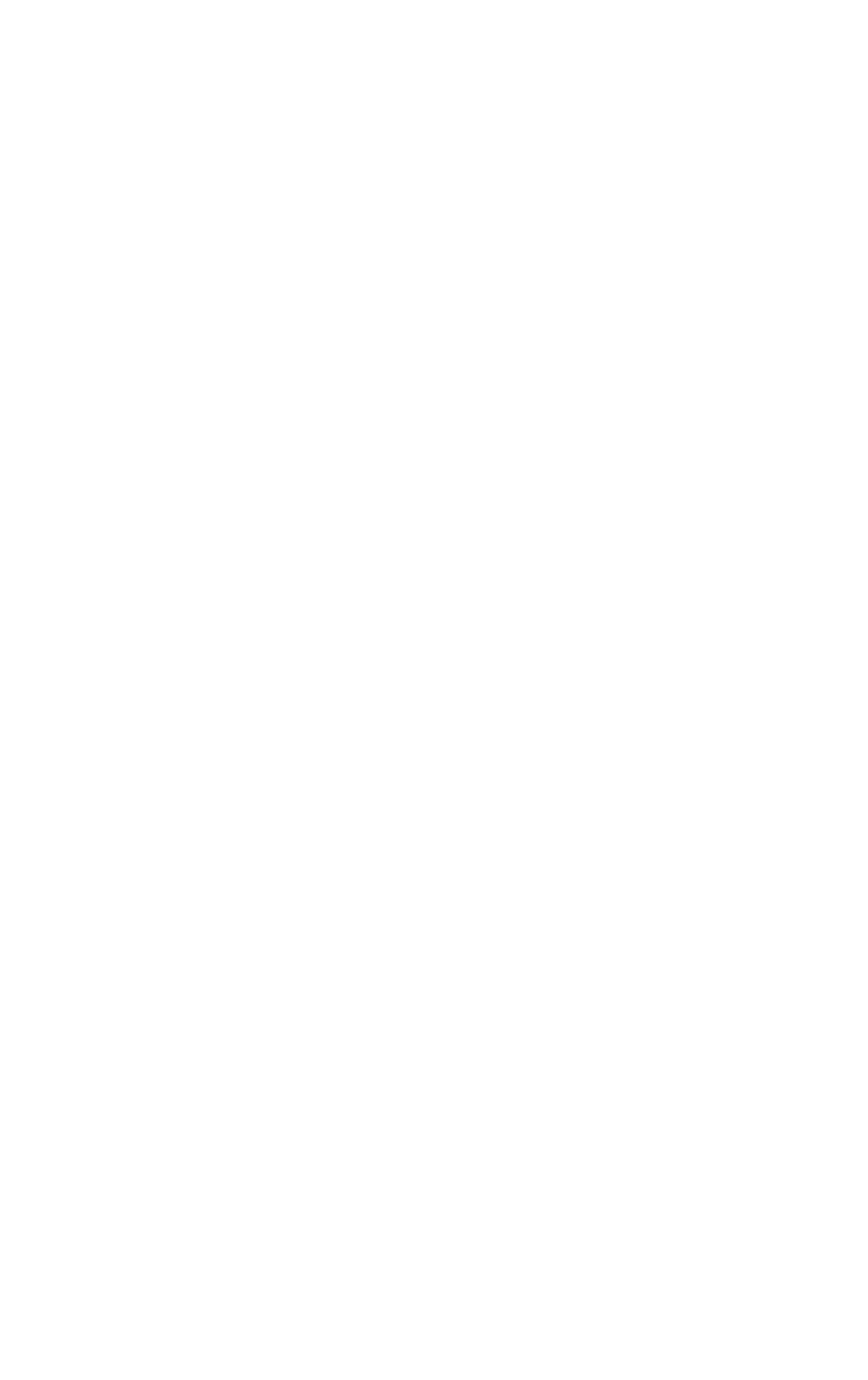


TABLE 10

147

Table 10. -Three-hour averages of air and water-surface temperatures and wind directions and speed, April 1950-August 1951, Lake Hefner-Continued

STATION 3 THREE-HOURLY AVERAGES

DECEMBER, 1950

\begin{tabular}{|c|c|c|c|c|c|c|c|c|c|c|c|c|c|c|c|}
\hline \multirow{3}{*}{ 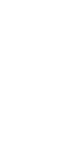 } & \multirow{3}{*}{ 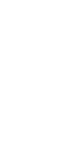 } & \multicolumn{8}{|c|}{ Average air temperature $\left({ }^{\circ} \mathrm{C}\right)$ at indicated height } & \multirow{3}{*}{$\begin{array}{c}\text { Average } \\
\text { water- } \\
\text { surface } \\
\text { tempera- } \\
\text { ture } \\
\left({ }^{\circ} \mathrm{C}\right)\end{array}$} & \multirow{3}{*}{$\begin{array}{c}\text { Average } \\
\text { wind } \\
\text { direction } \\
\text { (coded) }\end{array}$} & \multirow{2}{*}{\multicolumn{4}{|c|}{$\begin{array}{l}\text { Average wind speed (knots) } \\
\text { at indicated height }\end{array}$}} \\
\hline & & \multicolumn{2}{|c|}{$\begin{array}{c}2 \\
\text { meters }\end{array}$} & \multicolumn{2}{|c|}{$\begin{array}{c}4 \\
\text { meters }\end{array}$} & \multicolumn{2}{|c|}{$\begin{array}{c} \\
\text { meters }\end{array}$} & \multicolumn{2}{|c|}{$\begin{array}{c}16 \\
\text { meters }\end{array}$} & & & & & & \\
\hline & & $\begin{array}{l}\text { Dry } \\
\text { bulb }\end{array}$ & $\begin{array}{l}\text { Wet } \\
\text { bulb }\end{array}$ & $\begin{array}{l}\text { Dry } \\
\text { bulb }\end{array}$ & $\begin{array}{l}\text { Wet } \\
\text { bulb }\end{array}$ & $\begin{array}{l}\text { Dry } \\
\text { bulb }\end{array}$ & $\begin{array}{l}\text { Wet } \\
\text { bulb }\end{array}$ & $\begin{array}{l}\text { Dry } \\
\text { bulb }\end{array}$ & $\begin{array}{l}\text { Wet } \\
\text { bulb }\end{array}$ & & & meters & meters & meters & meters \\
\hline $\begin{array}{l}1 \\
1 \\
1 \\
1 \\
1 \\
1 \\
1 \\
1\end{array}$ & $\begin{array}{r}0 \\
3 \\
6 \\
9 \\
12 \\
15 \\
18 \\
21\end{array}$ & $\begin{array}{r}5.0 \\
5.2 \\
8.4 \\
13.2 \\
17.1 \\
17.8 \\
13.7 \\
14.3\end{array}$ & $\begin{array}{r}4.1 \\
3.9 \\
6.9 \\
9.7 \\
11.7 \\
9.8 \\
8.5 \\
8.1\end{array}$ & $\begin{array}{r}4.9 \\
5.3 \\
8.6 \\
14.0 \\
18.3 \\
18.7 \\
15.7 \\
14.9\end{array}$ & $\begin{array}{r}4.0 \\
4.1 \\
7.1 \\
10.1 \\
10.7 \\
10.1 \\
8.6 \\
8.2\end{array}$ & $\begin{array}{r}4.9 \\
5.5 \\
8.7 \\
14.8 \\
19.2 \\
20.7 \\
17.4 \\
15.5\end{array}$ & $\begin{array}{r}4.0 \\
4: 0 \\
7.1 \\
10.1 \\
10.4 \\
10.0 \\
8.5 \\
8.1\end{array}$ & $\begin{array}{r}5.0 \\
5.7 \\
3.8 \\
15.2 \\
19.9 \\
21.8 \\
18.7 \\
16.4\end{array}$ & $\begin{array}{r}3.9 \\
4.2 \\
7.3 \\
10.5 \\
10.8 \\
10.5 \\
8.8 \\
8.3\end{array}$ & $\begin{array}{l}5.6 \\
6.4 \\
5.5 \\
8.4 \\
9.4 \\
9.0 \\
8.6 \\
8.3\end{array}$ & & $\begin{array}{r}3.2 \\
8.6 \\
15.2 \\
18.3 \\
18.1 \\
11.9 \\
8.4 \\
11.4\end{array}$ & $\begin{array}{r}3.3 \\
9.3 \\
16.2 \\
19.8 \\
19.7 \\
13.5 \\
9.9 \\
12.7\end{array}$ & $\begin{array}{r}3.2 \\
10.2 \\
17.6 \\
22.4 \\
22.9 \\
16.4 \\
12.6 \\
15.0\end{array}$ & $\begin{array}{r}3.0 \\
11.5 \\
19.2 \\
23.8 \\
24.6 \\
18.1 \\
14.7 \\
17.6\end{array}$ \\
\hline $\begin{array}{l}2 \\
2 \\
2 \\
2 \\
2 \\
2 \\
2 \\
2\end{array}$ & $\begin{array}{r}0 \\
3 \\
6 \\
9 \\
12 \\
15 \\
18 \\
21\end{array}$ & $\begin{array}{r}14.7 \\
13.8 \\
7.8 \\
6.1 \\
8.8 \\
7.0 \\
3.5 \\
0.4\end{array}$ & $\begin{array}{r}8.5 \\
7.1 \\
4.1 \\
3.5 \\
5.0 \\
3.3 \\
0.8 \\
-1.7\end{array}$ & $\begin{array}{r}15.4 \\
14.4 \\
7.6 \\
5.7 \\
8.5 \\
6.8 \\
3.5 \\
0.2\end{array}$ & $\begin{array}{r}8.6 \\
7.2 \\
4.0 \\
3.3 \\
4.7 \\
3.3 \\
0.8 \\
-1.7\end{array}$ & $\begin{array}{r}16.1 \\
14.7 \\
7.4 \\
5.5 \\
8.1 \\
6.7 \\
3.4 \\
0.2\end{array}$ & $\begin{array}{r}8.4 \\
7.0 \\
3.7 \\
3.1 \\
4.4 \\
3.0 \\
0.5 \\
-1.0\end{array}$ & $\begin{array}{r}16.8 \\
15.1 \\
7.3 \\
5.7 \\
8.1 \\
6.5 \\
3.1 \\
0.0\end{array}$ & $\begin{array}{r}8.4 \\
6.9 \\
3.3 \\
3.1 \\
4.2 \\
2.7 \\
0.2 \\
-2.2\end{array}$ & $\begin{array}{l}8.1 \\
7.8 \\
7.5 \\
8.6 \\
9.1 \\
8.2 \\
7.2 \\
6.6\end{array}$ & & $\begin{array}{r}15.0 \\
13.7 \\
8.0 \\
8.9 \\
11.0 \\
10.9 \\
9.1 \\
6.8\end{array}$ & $\begin{array}{r}16.4 \\
14.9 \\
9.7 \\
10.9 \\
13.4 \\
13.1 \\
10.9 \\
8.1\end{array}$ & $\begin{array}{r}18.9 \\
17.3 \\
13.4 \\
13.1 \\
15.7 \\
14.9 \\
12.3 \\
9.2\end{array}$ & $\begin{array}{l}20.6 \\
18.6 \\
14.0 \\
13.8 \\
16.6 \\
16.1 \\
13.3 \\
10.2\end{array}$ \\
\hline $\begin{array}{l}3 \\
3 \\
3 \\
3 \\
3 \\
3 \\
3 \\
3\end{array}$ & $\begin{array}{r}0 \\
3 \\
6 \\
9 \\
12 \\
15 \\
18 \\
21\end{array}$ & $\begin{array}{r}-1.7 \\
=3.7 \\
-\quad 4.8 \\
0.4 \\
5.5 \\
7.5 \\
4.6 \\
4.8\end{array}$ & $\begin{array}{l}1.5 \\
3.3 \\
1.5 \\
1.4\end{array}$ & $\begin{array}{l}1.9 \\
4.1 \\
4.8 \\
0.6 \\
5.8 \\
7.4 \\
4.6 \\
4.8\end{array}$ & $\begin{array}{r}-3.1 \\
-0.1 \\
2.1 \\
3.0 \\
1.4 \\
1.1\end{array}$ & $\mid \begin{array}{r}-2.1 \\
=-4.3 \\
-4.8 \\
0.5 \\
6.1 \\
7.2 \\
4.7 \\
4.7\end{array}$ & $\begin{array}{l}1.8 \\
2.5 \\
1.2 \\
0.9\end{array}$ & $\left|\begin{array}{r}-2.3 \\
-4.2 \\
-4.8 \\
0.5 \\
5.5 \\
7.2 \\
4.4 \\
4.7\end{array}\right|$ & $\begin{array}{r}-3.6 \\
-0.5 \\
1.5 \\
2.6 \\
0.8 \\
0.8\end{array}$ & $\begin{array}{l}6.0 \\
6.0 \\
5.3 \\
7.1 \\
8.5 \\
9.2 \\
7.1 \\
6.8\end{array}$ & & $\begin{array}{r}5.5 \\
5.3 \\
4.3 \\
2.9 \\
3.5 \\
8.5 \\
7.6 \\
11.7\end{array}$ & $\begin{array}{r}6.6 \\
6.4 \\
5.3 \\
3.3 \\
3.8 \\
8.7 \\
8.3 \\
12.8\end{array}$ & $\begin{array}{r}7.4 \\
7.3 \\
7.1 \\
3.8 \\
3.9 \\
9.4 \\
9.0 \\
13.8\end{array}$ & $\begin{array}{r}8.3 \\
8.0 \\
7.4 \\
4.1 \\
4.0 \\
10.4 \\
10.3 \\
16.0\end{array}$ \\
\hline $\begin{array}{l}4 \\
4 \\
4 \\
4 \\
4 \\
4 \\
4 \\
4\end{array}$ & $\begin{array}{r}0 \\
3 \\
6 \\
9 \\
12 \\
15 \\
18 \\
21\end{array}$ & $\begin{array}{r}4.8 \\
5.5 \\
5.8 \\
7.0 \\
9.9 \\
11.5 \\
7.7 \\
3.3\end{array}$ & $\begin{array}{l}1.2 \\
1.7 \\
1.7 \\
2.5 \\
3.6 \\
4.3 \\
2.5 \\
0.1\end{array}$ & $\begin{array}{r}4.8 \\
5.6 \\
5.8 \\
7.0 \\
9.9 \\
11.0 \\
7.07 \\
3.4\end{array}$ & $\begin{array}{l}1.0 \\
1: 3 \\
1: 1 \\
2: 0 \\
3: 5 \\
4: 1 \\
2: 4 \\
0.1\end{array}$ & $\begin{array}{r}4.8 \\
5.6 \\
5.8 \\
7.1 \\
10.1 \\
10.9 \\
7.6 \\
3.4\end{array}$ & $\begin{array}{l}0.7 \\
1: 0 \\
1.0 \\
2.0 \\
3.0 \\
3.0 \\
2: 0 \\
0.0\end{array}$ & $\begin{array}{r}4.8 \\
5.5 \\
5.7 \\
7.1 \\
10.1 \\
10.7 \\
7.5 \\
3.5\end{array}$ & $\begin{array}{l}0.7 \\
1.00 \\
0.9 \\
1.8 \\
3.7 \\
3.9 \\
2.2 \\
0.0\end{array}$ & $\begin{array}{l}6.5 \\
6.0 \\
5.8 \\
5.9 \\
6.6 \\
6.6 \\
6.3 \\
6.1\end{array}$ & & $\begin{array}{r}15.1 \\
20.5 \\
18.0 \\
15.2 \\
8.7 \\
7.0 \\
8.2 \\
5.6\end{array}$ & $\begin{array}{r}14.9 \\
22.3 \\
19.9 \\
16.9 \\
9.9 \\
8.2 \\
9.7 \\
6.9\end{array}$ & $\begin{array}{r}18.2 \\
24.1 \\
21.7 \\
28.2 \\
10.8 \\
9.3 \\
11.3 \\
8.2\end{array}$ & $\begin{array}{r}20.8 \\
27.1 \\
24.7 \\
21.0 \\
12.5 \\
10.7 \\
13.6 \\
9.9\end{array}$ \\
\hline $\begin{array}{l}5 \\
5 \\
5 \\
5 \\
5 \\
5 \\
5 \\
5\end{array}$ & $\begin{array}{r}0 \\
3 \\
6 \\
9 \\
12 \\
15 \\
18 \\
21\end{array}$ & $\begin{array}{r}1.7 \\
-0.0 \\
-5.2 \\
=7.1 \\
=7.5 \\
-7.6 \\
-9.0 \\
-10.5\end{array}$ & $=0.6$ & $\begin{array}{r}1.7 \\
0.2 \\
5.4 \\
7.1 \\
7.5 \\
7.7 \\
9.1 \\
10.5\end{array}$ & -0.7 & $\begin{array}{r}1.6 \\
-0.6 \\
=-5.8 \\
=7.5 \\
=7.7 \\
=8.1 \\
=9.5 \\
-10.6\end{array}$ & $\left|\begin{array}{l}-0.8 \\
-2.3 \\
\end{array}\right|$ & $\left|\begin{array}{r}1.5 \\
-1.1 \\
-6.1 \\
-7.7 \\
=7.7 \\
-8.3 \\
-9.7 \\
-10.6\end{array}\right|$ & $\left|\begin{array}{l}-0.9 \\
-1.5 \\
\end{array}\right|$ & $\begin{array}{l}5.1 \\
5.8 \\
5.2 \\
5.0 \\
5.0 \\
4.3 \\
3.5 \\
3.0\end{array}$ & & $\begin{array}{r}8.2 \\
29.5 \\
22.0 \\
23.6 \\
21.6 \\
21.8 \\
20.1 \\
16.8\end{array}$ & $\begin{array}{r}9.6 \\
22.9 \\
25.8 \\
27.1 \\
25.1 \\
25.2 \\
23.2 \\
19.6\end{array}$ & $\begin{array}{l}11.1 \\
26.2 \\
29.1 \\
30.9 \\
28.0 \\
28.6 \\
26.3 \\
22.1\end{array}$ & $\begin{array}{l}11.8 \\
27.8 \\
31.0 \\
32.6 \\
30.0 \\
30.0 \\
28.0 \\
23.3\end{array}$ \\
\hline $\begin{array}{l}6 \\
6 \\
6 \\
6 \\
6 \\
6 \\
6 \\
6\end{array}$ & $\begin{array}{r}0 \\
3 \\
6 \\
9 \\
12 \\
15 \\
18 \\
2.1\end{array}$ & $\begin{array}{l}-11.2 \\
-11.3 \\
-11.2 \\
=8.0 \\
=-5.6 \\
=9.1 \\
-11.2\end{array}$ & & $\begin{array}{r}11.3 \\
8.4 \\
6.9 \\
9.1 \\
11.1\end{array}$ & & $\left|\begin{array}{l}-10.8 \\
-11.0 \\
-11 \\
-3.6 \\
-3.7 \\
-7.1 \\
-9.1 \\
-11.3\end{array}\right|$ & & $\begin{array}{l}-10.8 \\
-10.9 \\
-11.5 \\
-8.8 \\
-7.2 \\
-9.3 \\
-11.4\end{array}$ & & $\begin{array}{l}2.2 \\
1.8 \\
3.2 \\
1.1 \\
3.6 \\
3.1 \\
2.6\end{array}$ & & $\begin{array}{r}13.0 \\
12.4 \\
10.9 \\
11.9 \\
10.3 \\
7.0 \\
4.7 \\
3.4\end{array}$ & $\begin{array}{r}16.0 \\
14.6 \\
12.9 \\
14.3 \\
12.4 \\
8.5 \\
5.5 \\
3.0\end{array}$ & $\begin{array}{r}17.9 \\
15.0 \\
14.1 \\
16.9 \\
15.0 \\
10.0 \\
5.0 \\
4.4\end{array}$ & $\begin{array}{r}18.7 \\
16.6 \\
14.6 \\
17.2 \\
15.1 \\
10.3 \\
6.6 \\
5.0\end{array}$ \\
\hline $\begin{array}{l}7 \\
7 \\
7 \\
7 \\
7 \\
7 \\
7 \\
7\end{array}$ & $\begin{array}{r}0 \\
3 \\
5 \\
9 \\
12 \\
15 \\
18 \\
21\end{array}$ & $\begin{array}{l}-11.7 \\
=10.2 \\
=9.4 \\
=-5.0 \\
=4.2 \\
=3.9 \\
=4.4 \\
=5.0\end{array}$ & & $\begin{array}{r}11.7 \\
10.04 \\
9.5 \\
6.3 \\
4.5 \\
4.1 \\
4.5 \\
5.2\end{array}$ & & $\begin{array}{r}-11.6 \\
-10.5 \\
-9.7 \\
-\quad 6.5 \\
-4.5 \\
=4.3 \\
=4.9 \\
-\quad 5.4\end{array}$ & & $\begin{array}{l}-11.8 \\
-10.7 \\
-\quad 9.9 \\
-6.7 \\
-4.9 \\
-4.6 \\
-5.0 \\
-5.6\end{array}$ & & $\begin{array}{l}2.3 \\
2.6 \\
3.2 \\
4.0 \\
3.9 \\
3.3 \\
2.7 \\
2.7\end{array}$ & & $\begin{array}{l}4.5 \\
9.0 \\
8.6 \\
9.1 \\
7.3 \\
7.3 \\
7.5 \\
7.0\end{array}$ & $\begin{array}{r}5.3 \\
10.4 \\
9.4 \\
10.6 \\
7.8 \\
7.5 \\
8.0 \\
7.5\end{array}$ & $\begin{array}{r}5.7 \\
10.8 \\
10.0 \\
8.3 \\
7.8 \\
8.3 \\
7.8\end{array}$ & $\begin{array}{r}6.8 \\
11.3 \\
10.2 \\
12.0 \\
9.0 \\
8.3 \\
9.1 \\
8.2\end{array}$ \\
\hline $\begin{array}{l}8 \\
8 \\
8 \\
8 \\
8 \\
8 \\
8 \\
8\end{array}$ & $\begin{array}{r}0 \\
3 \\
6 \\
9 \\
12 \\
15 \\
18 \\
21\end{array}$ & $\begin{array}{r}-5.6 \\
-\quad 6.0 \\
-5.7 \\
-2.1 \\
7.8\end{array}$ & 3.3 & $\begin{array}{l}5.9 \\
6.2 \\
5.9 \\
2.0 \\
7.9\end{array}$ & 2.7 & $\begin{array}{l}-6.1 \\
-6.3 \\
-6.0 \\
-1.8\end{array}$ & 2.9 & $\begin{array}{l}-6.2 \\
=6.6 \\
=6.1 \\
-1.8\end{array}$ & $\begin{array}{l}2 \cdot 3 \\
2.9\end{array}$ & $\begin{array}{l}2.2 \\
1.2 \\
0.7 \\
1.8 \\
3.5 \\
3.1\end{array}$ & & $\begin{array}{l}7.6 \\
9.6 \\
9.2 \\
8.9 \\
5.4 \\
3.0 \\
1.6 \\
3.8\end{array}$ & $\begin{array}{l}8.1 \\
9.9 \\
9.6 \\
9.6 \\
6.6 \\
3.8 \\
2.1 \\
4.0\end{array}$ & $\begin{array}{r}8.2 \\
10.2 \\
10.0 \\
10.2 \\
8.2 \\
5.6 \\
2.5 \\
4.5\end{array}$ & $\begin{array}{r}8.9 \\
10.4 \\
10.0 \\
10.1 \\
9.2 \\
5.8 \\
3.0 \\
5.9\end{array}$ \\
\hline $\begin{array}{l}9 \\
9 \\
9\end{array}$ & $\begin{array}{l}0 \\
3 \\
6\end{array}$ & & & & & & & & & & & $\begin{array}{l}4.9 \\
3.6 \\
2.8\end{array}$ & $\begin{array}{l}5.3 \\
3.8 \\
3.0\end{array}$ & $\begin{array}{l}5.8 \\
4.1 \\
3.4\end{array}$ & $\begin{array}{l}6.9 \\
4.4 \\
3.7\end{array}$ \\
\hline $\begin{array}{l}9 \\
9\end{array}$ & $\begin{array}{r}9 \\
12\end{array}$ & $\begin{array}{r}9.2 \\
12.6\end{array}$ & $\begin{array}{l}4.9 \\
6.7\end{array}$ & $\begin{array}{r}9 \cdot 1 \\
12 \cdot 5\end{array}$ & $\begin{array}{cc}4.1 \\
5.8\end{array}$ & $\begin{array}{r}9.0 \\
906\end{array}$ & $4 \cdot 1$ & 9.4 & $4 \cdot 2$ & 4.4 & & 6.2 & 7.8 & 11.1 & 11.9 \\
\hline 9 & 15 & 11.8 & 5.8 & $\begin{array}{l}12.5 \\
12.1\end{array}$ & $\begin{array}{l}5.8 \\
5.0\end{array}$ & $\begin{array}{l}12.6 \\
12.5\end{array}$ & $\begin{array}{l}6.0 \\
5.3\end{array}$ & $\begin{array}{l}12.8 \\
1.2 .7\end{array}$ & $\begin{array}{l}6 \cdot 1 \\
5.4\end{array}$ & $\begin{array}{l}5.2 \\
5.0\end{array}$ & & $\begin{array}{l}9.2 \\
5.9\end{array}$ & $\begin{array}{r}11.5 \\
9.0\end{array}$ & $\begin{array}{l}14 \cdot 5 \\
11.9\end{array}$ & $\begin{array}{l}15.7 \\
12.7\end{array}$ \\
\hline $\begin{array}{l}9 \\
9\end{array}$ & $\begin{array}{l}18 \\
21\end{array}$ & $\begin{array}{l}5.5 \\
2.8\end{array}$ & $\begin{array}{l}2.5 \\
0.1\end{array}$ & $\begin{array}{l}7.0 \\
3.0\end{array}$ & $\begin{array}{l}2.2 \\
0.0\end{array}$ & $\begin{array}{l}7.2 \\
3.2\end{array}$ & $\begin{array}{l}2.2 \\
0.0\end{array}$ & $\begin{array}{l}7.8 \\
3.5\end{array}$ & $\begin{array}{l}2.5 \\
0.1\end{array}$ & $\begin{array}{l}4.2 \\
3.9\end{array}$ & & $\begin{array}{l}4.0 \\
3.3\end{array}$ & $\begin{array}{l}5.5 \\
4.5\end{array}$ & $\begin{array}{l}7.3 \\
6.5\end{array}$ & $\begin{array}{l}9.0 \\
8.5\end{array}$ \\
\hline $\begin{array}{l}10 \\
10 \\
10 \\
10 \\
10 \\
10 \\
10 \\
10\end{array}$ & $\begin{array}{r}0 \\
3 \\
6 \\
9 \\
12 \\
15 \\
18 \\
21\end{array}$ & $\begin{array}{r}0.8 \\
0.0 \\
-0.4 \\
4.1 \\
8.5 \\
8.8 \\
3.4 \\
3.5\end{array}$ & $\begin{array}{r}-1.03 \\
-2.0 \\
-2.1 \\
1.0 \\
3.5 \\
3.8 \\
0.3 \\
1.0\end{array}$ & $\begin{array}{l}0.8 \\
0.1 \\
0.4 \\
4.0 \\
8.1 \\
9.4 \\
4.5 \\
3.7\end{array}$ & $\begin{array}{r}-1.5 \\
-2.1 \\
-2.3 \\
2.3 \\
2.3 \\
3.7 \\
0.5 \\
0.7\end{array}$ & $\begin{array}{r}0.3 \\
0.0 \\
-0.4 \\
3.7 \\
7.8 \\
5.5 \\
5.6 \\
4.0\end{array}$ & $\left|\begin{array}{r}-1.4 \\
-2.0 \\
-2.3 \\
0.3 \\
2.3 \\
3.6 \\
1.0 \\
0.6\end{array}\right|$ & $\begin{array}{r}1.0 \\
0.0 \\
-0.4 \\
3.0 \\
7.7 \\
9.5 \\
6.5 \\
4.3\end{array}$ & $\begin{array}{r}-1.4 \\
-2.1 \\
-2.2 \\
0.5 \\
2.4 \\
3.8 \\
1.8 \\
0.7\end{array}$ & $\begin{array}{l}3.2 \\
2.7 \\
2.6 \\
3.6 \\
4.4 \\
4.1 \\
4.0 \\
3.3\end{array}$ & & $\begin{array}{l}4.1 \\
4.9 \\
5.1 \\
6.3 \\
4.6 \\
2.4 \\
3.2 \\
7.2\end{array}$ & $\begin{array}{l}5.5 \\
6.5 \\
6.3 \\
7.6 \\
5.7 \\
3.0 \\
4.5 \\
7.9\end{array}$ & $\begin{array}{l}6.9 \\
9.2 \\
8.7 \\
9.0 \\
7.4 \\
3.2 \\
6.3 \\
3.0\end{array}$ & $\begin{array}{r}9.6 \\
10.4 \\
9.1 \\
9.4 \\
3.0 \\
3.5 \\
8.5 \\
11.0\end{array}$ \\
\hline
\end{tabular}


Table 10, - Three-hour averages of air and water-surface temperatures and wind directions and speed, April 1950-August 1951, Lake Hefner-Continued

STATION 3

THREE-HOURLY AVERAGES

DECEMBER, 1950

\begin{tabular}{|c|c|c|c|c|c|c|c|c|c|c|c|c|c|c|c|}
\hline \multirow{3}{*}{ 点 } & \multirow{3}{*}{ 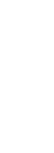 } & \multicolumn{8}{|c|}{ Average air temperature $\left({ }^{\circ} \mathrm{C}\right)$ at indicated height } & \multirow{3}{*}{$\begin{array}{c}\text { Average } \\
\text { water- } \\
\text { surface } \\
\text { tempera- } \\
\text { ture } \\
\left({ }^{\circ} \mathrm{C}\right)\end{array}$} & \multirow{3}{*}{$\begin{array}{c}\text { Average } \\
\text { wind } \\
\text { direction } \\
\text { (coded) }\end{array}$} & \multirow{2}{*}{\multicolumn{4}{|c|}{$\begin{array}{l}\text { Average wind speed (knots) } \\
\text { at indicated height }\end{array}$}} \\
\hline & & \multicolumn{2}{|c|}{$\begin{array}{c}2 \\
\text { meters }\end{array}$} & \multicolumn{2}{|c|}{$\stackrel{4}{\text { meters }}$} & \multicolumn{2}{|c|}{$\begin{array}{c}8 \\
\text { meters }\end{array}$} & \multicolumn{2}{|c|}{$\begin{array}{c}16 \\
\text { meters }\end{array}$} & & & & & & \\
\hline & & $\begin{array}{l}\text { Dry } \\
\text { bulb }\end{array}$ & $\begin{array}{l}\text { Wet } \\
\text { bulb }\end{array}$ & $\begin{array}{l}\text { Dry } \\
\text { bulb }\end{array}$ & $\begin{array}{l}\text { Wet } \\
\text { bulb }\end{array}$ & $\begin{array}{l}\text { Dry } \\
\text { bulb }\end{array}$ & $\begin{array}{l}\text { Wet } \\
\text { bulb }\end{array}$ & $\begin{array}{l}\text { Dry } \\
\text { bulb }\end{array}$ & $\begin{array}{l}\text { Wet } \\
\text { bulb }\end{array}$ & & & $\begin{array}{c}2 \\
\text { meters }\end{array}$ & $\begin{array}{c}4 \\
\text { meters }\end{array}$ & \begin{tabular}{|c|}
8 \\
meters \\
\end{tabular} & $\begin{array}{c}16 \\
\text { meters }\end{array}$ \\
\hline $\begin{array}{l}11 \\
11 \\
11 \\
11 \\
11 \\
11 \\
11 \\
11\end{array}$ & $\begin{array}{r}0 \\
3 \\
6 \\
9 \\
12 \\
15 \\
18 \\
21\end{array}$ & $\begin{array}{r}4.0 \\
3.8 \\
3.4 \\
9.5 \\
14.7 \\
14.4 \\
7.2 \\
3.8\end{array}$ & $\begin{array}{l}1.3 \\
1.4 \\
1.7 \\
5.3 \\
8.8 \\
8.7 \\
4 . ? \\
2.5\end{array}$ & $\begin{array}{r}4.0 \\
3.8 \\
3.7 \\
9.4 \\
14.6 \\
14.7 \\
8.1 \\
4.4\end{array}$ & $\begin{array}{l}1.0 \\
1.0 \\
1.4 \\
4.5 \\
7.8 \\
7.5 \\
4.1 \\
2.5\end{array}$ & $\begin{array}{r}4.0 \\
3.7 \\
30.3 \\
9.0 \\
14.9 \\
14.8 \\
8: 7 \\
6.1\end{array}$ & $\begin{array}{l}0.8 \\
0.9 \\
1.4 \\
4.7 \\
8.0 \\
7.7 \\
4: 7 \\
3.9\end{array}$ & $\begin{array}{r}4.0 \\
3.6 \\
2.2 \\
9.0 \\
15.0 \\
15.0 \\
9.7 \\
0.3\end{array}$ & $\begin{array}{l}0.9 \\
0.3 \\
1.5 \\
5.1 \\
8.03 \\
\vdots .0 \\
.0 \\
4.3\end{array}$ & $\begin{array}{l}3.0 \\
2.5 \\
2.09 \\
4.0 \\
5.6 \\
4.0 \\
3.9 \\
3.0\end{array}$ & & $\begin{array}{r}10.9 \\
7.7 \\
6.1 \\
10.1 \\
11.7 \\
0.3 \\
2.1 \\
1.0\end{array}$ & $\begin{array}{r}11.6 \\
7.8 \\
7.1 \\
12.4 \\
14.4 \\
11.7 \\
2.9 \\
1.5\end{array}$ & $\begin{array}{r}12.7 \\
0.0 \\
0.2 \\
15.3 \\
16.9 \\
13.7 \\
4.1 \\
3.4\end{array}$ & $\begin{array}{r}13.9 \\
9.3 \\
10.5 \\
15.5 \\
17.0 \\
14.8 \\
5.5 \\
4.9\end{array}$ \\
\hline $\begin{array}{l}12 \\
12 \\
12 \\
12 \\
12 \\
12 \\
12 \\
12\end{array}$ & $\begin{array}{r}0 \\
3 \\
6 \\
9 \\
12 \\
15 \\
18 \\
21\end{array}$ & $\begin{array}{r}2.0 \\
0.3 \\
-1.3 \\
1.1 \\
4.3 \\
3.6 \\
-1.6 \\
-3.0\end{array}$ & $\begin{array}{r}1.0 \\
-1.0 \\
-2.5 \\
-0.8 \\
-0.6 \\
-0.1 \\
-3.6 \\
-4.4\end{array}$ & $\begin{array}{l}2.4 \\
0.6 \\
1.5 \\
0.9 \\
4.1 \\
3.4 \\
1.3 \\
3.2\end{array}$ & $\begin{array}{r}1.1 \\
-0.9 \\
-2.5 \\
-1.3 \\
0.00 \\
-0.7 \\
-3.7 \\
-4.6\end{array}$ & $\begin{array}{r}3.1 \\
1.0 \\
-1.0 \\
0.08 \\
4.00 \\
3.02 \\
-1.1 \\
-3.1\end{array}$ & $\begin{array}{r}1.2 \\
-0.8 \\
-2.04 \\
-1.3 \\
0.0 \\
-0.8 \\
=3.6 \\
-4.6\end{array}$ & $\begin{array}{r}5.3 \\
1.0 \\
-0.7 \\
0.5 \\
3.8 \\
3.2 \\
-0.3 \\
-2.4\end{array}$ & $\mid \begin{array}{r}2.5 \\
-0.2 \\
-0.2 \\
-3.0 \\
0.1 \\
-0.5 \\
-3.7 \\
-4.0\end{array}$ & $\begin{array}{l}2.4 \\
2.0 \\
1.7 \\
2.1 \\
2.5 \\
1.4 \\
0.2\end{array}$ & & $\begin{array}{l}1.4 \\
1: 3 \\
1: 0 \\
2: 9 \\
4: 1 \\
3.8 \\
2: 2 \\
1.7\end{array}$ & $\begin{array}{l}1.6 \\
2.07 \\
1.7 \\
3.7 \\
4.7 \\
4.0 \\
3.0 \\
2.7\end{array}$ & $\begin{array}{l}1.9 \\
3.5 \\
2.7 \\
3.7 \\
5.0 \\
5.9 \\
4.6 \\
3.6\end{array}$ & $\begin{array}{l}3.3 \\
6: 0 \\
3 . ? \\
4: 0 \\
5: 7 \\
7: 5 \\
7: 2 \\
5: 3\end{array}$ \\
\hline $\begin{array}{l}13 \\
13 \\
13 \\
13 \\
13 \\
13 \\
13 \\
13\end{array}$ & $\begin{array}{r}0 \\
3 \\
6 \\
9 \\
12 \\
15 \\
18 \\
21\end{array}$ & $\begin{array}{r}-4.7 \\
=-6.4 \\
-5.0 \\
0.0 \\
5.9 \\
8.7 \\
4.3 \\
2.4\end{array}$ & $\begin{array}{r}-5.5 \\
\\
-0.8 \\
1.6 \\
3.8 \\
2.1 \\
2.0\end{array}$ & $\begin{array}{l}4.7 \\
6.5 \\
4.9 \\
0.1 \\
5.7 \\
9.0 \\
4.8 \\
2.6\end{array}$ & $\mid \begin{array}{r}-5.3 \\
\\
-1.2 \\
1.0 \\
3.2 \\
2.0 \\
2.0\end{array}$ & $\begin{array}{r}-4.1 \\
-\quad 5.0 \\
-4.8 \\
0.0 \\
5.6 \\
2.8 \\
5.8 \\
3.1\end{array}$ & $\mid \begin{array}{r}-5.1 \\
-1.2 \\
1.0 \\
3.03 \\
2.4 \\
1.7\end{array}$ & $\begin{array}{r}-3.7 \\
-\quad 6.2 \\
-\quad 4.4 \\
0.0 \\
5.4 \\
8.9 \\
6.7 \\
3.7\end{array}$ & $\mid \begin{array}{r}-4.7 \\
-1.0 \\
1.5 \\
4.0 \\
3.02 \\
1.07\end{array}$ & $\begin{array}{l}0.1 \\
0.4 \\
2.2 \\
3.2 \\
4.4 \\
3.7 \\
2.3\end{array}$ & & $\begin{array}{l}1.4 \\
2.7 \\
1.3 \\
5.2 \\
5.0 \\
3.0 \\
1.4 \\
1.11\end{array}$ & $\begin{array}{l}1.01 \\
3.6 \\
2.3 \\
6 . ? \\
5.0 \\
4.5 \\
1.6 \\
1.3\end{array}$ & $\begin{array}{l}2.4 \\
4: 2 \\
2: 03 \\
7: 1 \\
6: 5 \\
5: 3 \\
2: 3 \\
1.5\end{array}$ & $\begin{array}{l}3.7 \\
4.7 \\
3.5 \\
7.9 \\
7.1 \\
6.2 \\
3.3 \\
2.3\end{array}$ \\
\hline $\begin{array}{l}14 \\
14 \\
14 \\
14 \\
14 \\
14 \\
14 \\
14\end{array}$ & $\begin{array}{r}0 \\
3 \\
6 \\
9 \\
12 \\
15 \\
18 \\
21\end{array}$ & $\begin{array}{r}0.3 \\
0.1 \\
0.8 \\
5.3 \\
10.3 \\
11.0 \\
5.4 \\
4.5\end{array}$ & $\begin{array}{r}-0.4 \\
-0.2 \\
0.3 \\
3.5 \\
6.7 \\
7.2 \\
4.3 \\
3.7\end{array}$ & $\begin{array}{r}1.3 \\
0.3 \\
1.0 \\
5.4 \\
10.3 \\
11.3 \\
6.5 \\
5.5\end{array}$ & $\begin{array}{r}0.3 \\
-0.4 \\
0.3 \\
3.8 \\
6.2 \\
7.1 \\
4.5 \\
4.0\end{array}$ & $\begin{array}{r}1.9 \\
0.5 \\
1.1 \\
5.4 \\
10.7 \\
31.7 \\
8.3 \\
6.5\end{array}$ & $\begin{array}{r}0.3 \\
-0.1 \\
0.4 \\
3.6 \\
6.5 \\
7.1 \\
5.4 \\
4.5\end{array}$ & $\begin{array}{r}2.7 \\
1.0 \\
1.6 \\
5.5 \\
10.7 \\
11.3 \\
9.6 \\
7.0\end{array}$ & $\begin{array}{l}1.2 \\
0.3 \\
0.8 \\
4.4 \\
6.9 \\
7.3 \\
6.7 \\
5.4\end{array}$ & $\begin{array}{l}3.0 \\
2.9 \\
3.4 \\
4.5 \\
6.5 \\
=.0 \\
5.0 \\
4.8\end{array}$ & & $\begin{array}{l}1.9 \\
1.9 \\
3.4 \\
5.2 \\
1.8 \\
0.6 \\
1.9 \\
2.1\end{array}$ & $\begin{array}{l}2.4 \\
2.1 \\
3.7 \\
5.8 \\
1.9 \\
0.7 \\
2.4 \\
2.8\end{array}$ & $\begin{array}{l}2.7 \\
2.44 \\
4.44 \\
5.11 \\
1.0 \\
2.7 \\
3.4 \\
4.0\end{array}$ & $\begin{array}{l}2.9 \\
2.7 \\
5.5 \\
0.6 \\
2.2\end{array}$ \\
\hline $\begin{array}{l}15 \\
15 \\
15 \\
15 \\
15 \\
15 \\
15 \\
15\end{array}$ & $\begin{array}{r}0 \\
3 \\
6 \\
9 \\
12 \\
15 \\
18 \\
21\end{array}$ & $\begin{array}{r}2.9 \\
1.2 \\
-0.8 \\
4.2 \\
8.2 \\
6.7 \\
1.5 \\
0.7\end{array}$ & $\begin{array}{r}2.3 \\
0.5 \\
-1.2 \\
1.3 \\
3.2 \\
2.2 \\
-1.2 \\
-1.8\end{array}$ & $\begin{array}{l}3.4 \\
1.2 \\
0.9 \\
4.2 \\
7.7 \\
6.7 \\
1.7 \\
0.8\end{array}$ & $\begin{array}{r}2.6 \\
0.6 \\
-1.04 \\
0.8 \\
2.10 \\
1.3 \\
-1.6 \\
-2.0\end{array}$ & $\begin{array}{r}3.8 \\
1.03 \\
-1.0 \\
4.3 \\
7.5 \\
6.5 \\
2.00 \\
0.0\end{array}$ & $\begin{array}{r}2.7 \\
0.5 \\
-1.5 \\
0.5 \\
2.0 \\
1.03 \\
-1.5 \\
-2.0\end{array}$ & $\begin{array}{r}4.5 \\
1.5 \\
-0.5 \\
4.3 \\
7.4 \\
6.4 \\
2.4 \\
1.2\end{array}$ & $\begin{array}{r}3.4 \\
0.7 \\
-1.0 \\
0.3 \\
2.3 \\
1.03 \\
-1.01 \\
-1.0\end{array}$ & $\begin{array}{l}4.3 \\
4.1 \\
3.9 \\
5.2 \\
5.7 \\
4.5 \\
3.9 \\
3.7\end{array}$ & & $\begin{array}{l}1.3 \\
2.4 \\
3.4 \\
7.7 \\
5.5 \\
4.2 \\
1.4 \\
1.6\end{array}$ & $\begin{array}{l}1.8 \\
3.0 \\
4.5 \\
9.0 \\
6.7 \\
5.4 \\
2.4 \\
2.0\end{array}$ & $\begin{array}{r}3.5 \\
3.4 \\
5.5 \\
10.3 \\
7.8 \\
5.5 \\
3.1 \\
2.7\end{array}$ & $\begin{array}{r}3.5 \\
4.4 \\
6.2 \\
11.7 \\
8.0 \\
6.7 \\
4.2 \\
3.3\end{array}$ \\
\hline $\begin{array}{l}16 \\
16 \\
16 \\
16 \\
16 \\
16 \\
16 \\
16\end{array}$ & $\begin{array}{r}0 \\
3 \\
6 \\
9 \\
12 \\
15 \\
18 \\
21\end{array}$ & $\begin{array}{r}-0.8 \\
-0.7 \\
0.0 \\
2.2 \\
5.2 \\
7.3 \\
5.1 \\
4.9\end{array}$ & $\begin{array}{r}-3.0 \\
-2.8 \\
-2.1 \\
0.0 \\
3.0 \\
5.0 \\
3.3 \\
3.4\end{array}$ & $\begin{array}{l}1.0 \\
1.1 \\
0.2 \\
2.2 \\
5.5 \\
8.7 \\
5.3 \\
5.1\end{array}$ & $\begin{array}{r}-3.1 \\
-3.0 \\
0.0 \\
2.0 \\
4.8 \\
3.0 \\
3.1\end{array}$ & $\mid \begin{array}{r}-0.8 \\
-0.9 \\
-0.1 \\
2.02 \\
5.9 \\
9.3 \\
5.6 \\
5.3\end{array}$ & $\mid \begin{array}{r}-3.2 \\
-3.1 \\
-2.4 \\
-0.4 \\
2.06 \\
4.0 \\
3.0 \\
3.0\end{array}$ & $\begin{array}{r}-0.2 \\
-0.7 \\
-0.2 \\
2.2 \\
6.1 \\
9.5 \\
6.5 \\
5.7\end{array}$ & $\mid \begin{array}{r}-2.8 \\
-3.0 \\
-2.3 \\
-\quad 0.2 \\
3.1 \\
5.3 \\
3 . .2 \\
3.1\end{array}$ & $\begin{array}{l}3.5 \\
3.3 \\
3.5 \\
3.3 \\
5.0 \\
5.4 \\
4.6 \\
3.9\end{array}$ & & $\begin{array}{l}1.7 \\
0.9 \\
2.3 \\
3.0 \\
3.0 \\
3.5 \\
5.2 \\
6.8\end{array}$ & $\begin{array}{l}2.2 \\
1.9 \\
2.5 \\
4.1 \\
3.5 \\
4.5 \\
6.0 \\
7.5\end{array}$ & $\begin{array}{l}2.9 \\
2.3 \\
2.6 \\
4.3 \\
4.1 \\
5.5 \\
7.7 \\
2.2\end{array}$ & $\begin{array}{r}3.9 \\
2.7 \\
2.6 \\
4.3 \\
4.3 \\
5.1 \\
10.0 \\
10.8\end{array}$ \\
\hline $\begin{array}{l}17 \\
17 \\
17 \\
17 \\
17 \\
17 \\
17 \\
17\end{array}$ & $\begin{array}{r}0 \\
3 \\
6 \\
9 \\
12 \\
15 \\
18 \\
21\end{array}$ & $\begin{array}{r}3.8 \\
1.2 \\
-1.8 \\
1.2 \\
5.2 \\
4.7 \\
0.44 \\
-0.9\end{array}$ & $\begin{array}{r}2.4 \\
0.0 \\
-2.8 \\
-0.5 \\
1.09 \\
-1.5 \\
-1.6 \\
-2.8\end{array}$ & $\begin{array}{l}4.0 \\
1.02 \\
2.3 \\
1.2 \\
4.7 \\
4.6 \\
0.5 \\
1.3\end{array}$ & $\begin{array}{r}2.4 \\
-0.4 \\
-2.9 \\
-1.1 \\
1.3 \\
0.77 \\
-1.9 \\
-3.2\end{array}$ & $\begin{array}{r}4.0 \\
1.0 \\
-2.2 \\
0.0 \\
4.44 \\
4.2 \\
0.6 \\
-1.4\end{array}$ & $\begin{array}{r}2.11 \\
-0.6 \\
-2.09 \\
-1.01 \\
1.00 \\
0.06 \\
-1.8 \\
-3.22\end{array}$ & $\begin{array}{r}4.2 \\
1.0 \\
-2: 2 \\
1.1 \\
4: 5 \\
4: 1 \\
0.9 \\
-1.4\end{array}$ & $\begin{array}{r}1.9 \\
-0.5 \\
-3.0 \\
-1.0 \\
0.9 \\
0.06 \\
-1.44 \\
-3.1\end{array}$ & $\begin{array}{l}3.6 \\
3.2 \\
3.3 \\
4.3 \\
4.9 \\
4.2 \\
3.6 \\
3.1\end{array}$ & & $\begin{array}{l}3.3 \\
4.3 \\
5.2 \\
4.0 \\
4.0 \\
4.0 \\
3.0 \\
3.0\end{array}$ & $\begin{array}{l}4.0 \\
5.9 \\
5 . ? \\
5.9 \\
5.4 \\
5.2 \\
3.7 \\
4.5\end{array}$ & $\begin{array}{l}5.0 \\
3.2 \\
7.2 \\
6.9 \\
5.1 \\
0.4 \\
4.8 \\
5.5\end{array}$ & $\begin{array}{l}6.6 \\
9.2 \\
7.4\end{array}$ \\
\hline $\begin{array}{l}18 \\
18 \\
18 \\
18 \\
18 \\
18 \\
18 \\
18\end{array}$ & $\begin{array}{r}0 \\
3 \\
6 \\
9 \\
12 \\
15 \\
18 \\
21\end{array}$ & $\begin{array}{r}-3.3 \\
-3.1 \\
-3.7 \\
-0.2 \\
5.3 \\
5.4 \\
3.5 \\
2.9\end{array}$ & $\begin{array}{r}-3.7 \\
-1.6 \\
1.3 \\
2.8 \\
1.7 \\
0.8\end{array}$ & $\begin{array}{l}3.5 \\
3.2 \\
3.7 \\
0.4 \\
5.1 \\
5.6 \\
3.5 \\
2.7\end{array}$ & {$\left[\begin{array}{r}-3.9 \\
-1.0 \\
1.1 \\
2.4 \\
1.03 \\
0.4\end{array}\right.$} & $\begin{array}{r}-3.5 \\
-3.3 \\
=3.7 \\
-0.5 \\
4.8 \\
5.7 \\
3.7 \\
2.7\end{array}$ & $\left|\begin{array}{r}-4.2 \\
-1.1 \\
1.1 \\
2.1 \\
1.0 \\
0.2\end{array}\right|$ & $\begin{array}{r}-3.5 \\
-3.4 \\
-3.7 \\
-0.4 \\
4.0 \\
5.8 \\
3.0 \\
2.7\end{array}$ & $\begin{array}{r} \\
-0.9 \\
1.5 \\
2.4 \\
1.2 \\
0.3\end{array}$ & $\begin{array}{l}2.7 \\
2.8 \\
2.8 \\
4.2 \\
6.0 \\
5.1 \\
4.4 \\
3.4\end{array}$ & & $\begin{array}{l}3.6 \\
3.1 \\
1.9 \\
3.7 \\
2.5 \\
5.1 \\
5.5 \\
7.3\end{array}$ & $\begin{array}{l}4.7 \\
3.8 \\
2.2 \\
4.1 \\
2.6 \\
5.7 \\
6.0 \\
7.7\end{array}$ & $\begin{array}{l}5.6 \\
4.2 \\
2.6 \\
4.0 \\
2.0 \\
6.9 \\
6.9 \\
0.2\end{array}$ & $\begin{array}{l}7.3 \\
4.9 \\
3.2 \\
4.3 \\
3.5 \\
7.4 \\
8.4 \\
9.2\end{array}$ \\
\hline $\begin{array}{l}19 \\
19 \\
19 \\
19 \\
19 \\
19 \\
19 \\
19\end{array}$ & $\begin{array}{r}0 \\
3 \\
6 \\
9 \\
12 \\
15 \\
18 \\
21\end{array}$ & $\begin{array}{l}2.6 \\
1.1 \\
0.0 \\
3.7 \\
8.5 \\
8.4 \\
4.2 \\
0.6\end{array}$ & $\begin{array}{r}0.8 \\
-0.4 \\
-1.1 \\
1.8 \\
4.4 \\
4.1 \\
1.6 \\
-1.1\end{array}$ & $\begin{array}{l}2.5 \\
0.9 \\
0.2 \\
3.9 \\
8.4 \\
8.02 \\
4.3 \\
0.6\end{array}$ & $\begin{array}{r}0.4 \\
-0.6 \\
-1.33 \\
1.05 \\
3.8 \\
3.06 \\
1.05 \\
-1.1\end{array}$ & $\begin{array}{r}2.5 \\
0.8 \\
-0.4 \\
3.0 \\
8.3 \\
8.3 \\
4.06 \\
0.5\end{array}$ & $\mid \begin{array}{r}0.3 \\
-0.8 \\
-1.5 \\
1.5 \\
3.8 \\
3.6 \\
1.6 \\
-\quad 1.0\end{array}$ & $\begin{array}{r}2.5 \\
0.5 \\
-0.4 \\
4.1 \\
8.3 \\
8.4 \\
5.1 \\
1.8\end{array}$ & $\begin{array}{r}0.4 \\
-0.7 \\
-1.04 \\
1.9 \\
4.1 \\
4.2 \\
2.07 \\
-0.1\end{array} \mid$ & $\begin{array}{l}3.0 \\
2.8 \\
2.8 \\
3.5 \\
4.5 \\
4.5 \\
3.7 \\
3.1\end{array}$ & & $\begin{array}{l}9.1 \\
8.1 \\
8.2 \\
4.5 \\
4.0 \\
3.8 \\
2.7 \\
2.7\end{array}$ & $\begin{array}{l}9.5 \\
8.5 \\
8.5 \\
4.3 \\
4.9 \\
4.4 \\
3.5 \\
3.5\end{array}$ & $\begin{array}{r}10.2 \\
0.0 \\
8.0 \\
5.0 \\
5.8 \\
5.4 \\
4.5 \\
4.9\end{array}$ & $\begin{array}{r}10.7 \\
9.4 \\
9.4 \\
5.0 \\
5.8 \\
7.3 \\
7.5 \\
3.1\end{array}$ \\
\hline $\begin{array}{l}20 \\
20 \\
20 \\
20 \\
20 \\
20 \\
20 \\
20\end{array}$ & $\begin{array}{r}0 \\
3 \\
6 \\
9 \\
12 \\
15 \\
18 \\
21\end{array}$ & $\begin{array}{r}-0.2 \\
=-1.2 \\
-2.8 \\
0.8 \\
5.0 \\
5.8 \\
4.7 \\
4.1\end{array}$ & $\begin{array}{l}0.3 \\
1.5 \\
2.1 \\
1.5 \\
1.4\end{array}$ & $\begin{array}{l}0.6 \\
1.6 \\
2.9 \\
0.5 \\
4.5 \\
5.8 \\
4.7 \\
4.1\end{array}$ & $\begin{array}{l}1: 1 \\
1: 7 \\
1: 3 \\
1: 1\end{array}$ & $\begin{array}{r}-2.5 \\
-1.6 \\
-3.0 \\
0.4 \\
4.5 \\
5.6 \\
4.7 \\
4.0\end{array}$ & $\begin{array}{l}1.0 \\
1.7 \\
1.3 \\
0.9\end{array}$ & $\begin{array}{r}-0.5 \\
-0.5 \\
-3.0 \\
0.5 \\
4.5 \\
5.5 \\
4.7 \\
4.0\end{array}$ & $\left|\begin{array}{r}-1.9 \\
-3.0 \\
-3.3 \\
0.8 \\
1.5 \\
2.0 \\
1.0 \\
1.1\end{array}\right|$ & $\begin{array}{l}3.2 \\
3.0 \\
2.9 \\
4.4 \\
4.5 \\
4.2 \\
4.0 \\
3.9\end{array}$ & & $\begin{array}{l}4.2 \\
4.6 \\
2.7 \\
4.3 \\
4.4 \\
4.0 \\
1.9 \\
2.6\end{array}$ & $\begin{array}{l}5.2 \\
5.5 \\
3.4 \\
5.0 \\
5.3 \\
4.7 \\
2.3 \\
3.4\end{array}$ & $\begin{array}{l}5.2 \\
6.2 \\
4.1 \\
5.7 \\
0.0 \\
5.4 \\
2.9 \\
3.8\end{array}$ & $\begin{array}{l}7: 2 \\
7: 7 \\
4: 4 \\
0.0 \\
8.2 \\
5.2 \\
4.0 \\
3.9\end{array}$ \\
\hline
\end{tabular}


TABLE 10

Table 10. - Three-hour averages of air and water-surface temperatures and wind directions and speed, April 1950-August 1951, Lake Hefner-Continued

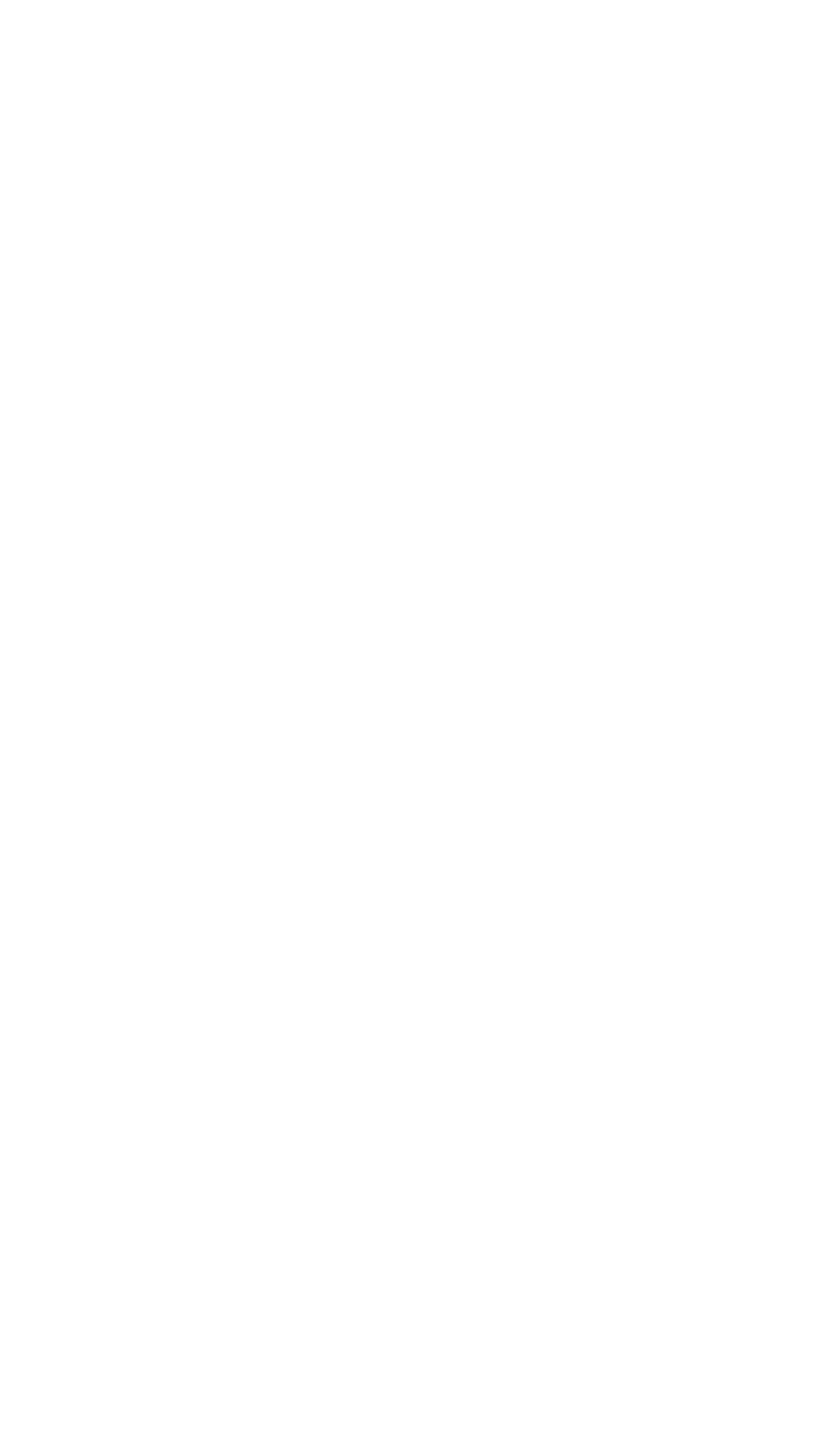


TABLE 10

Table 10. - Three-hour averages of air and water-surface temperatures and wind directions and speed, April 1950-August STATION 3

\begin{tabular}{|c|c|c|c|c|c|c|c|c|c|c|c|c|c|c|c|}
\hline \multirow{4}{*}{ 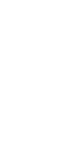 } & \multirow{4}{*}{ 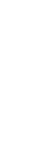 } & \multicolumn{8}{|c|}{ Average air temperature $\left({ }^{\circ} \mathrm{C}\right)$ at indicated height } & \multirow{4}{*}{$\begin{array}{c}\text { Average } \\
\text { water- } \\
\text { surface } \\
\text { tempera- } \\
\text { ture } \\
\text { (॰C) }\end{array}$} & \multirow{4}{*}{$\begin{array}{c}\text { Average } \\
\text { wind } \\
\text { direction } \\
\text { (coded) }\end{array}$} & \multirow{2}{*}{\multicolumn{4}{|c|}{$\begin{array}{l}\text { Average wind speed (knots) } \\
\text { at indicated height }\end{array}$}} \\
\hline & & \multirow{2}{*}{\multicolumn{2}{|c|}{$\begin{array}{c}2 \\
\text { meters }\end{array}$}} & \multirow{2}{*}{\multicolumn{2}{|c|}{$\begin{array}{c}4 \\
\text { meters }\end{array}$}} & \multirow{2}{*}{\multicolumn{2}{|c|}{$\begin{array}{c}8 \\
\text { meters }\end{array}$}} & \multirow{2}{*}{\multicolumn{2}{|c|}{$\begin{array}{c}16 \\
\text { meters }\end{array}$}} & & & & & & \\
\hline & & & & & & & & & & & & 2 & 4 & 8 & 16 \\
\hline & & $\begin{array}{l}\text { Dry } \\
\text { bulb }\end{array}$ & $\begin{array}{l}\text { Wet } \\
\text { bulb }\end{array}$ & $\begin{array}{l}\text { Dry } \\
\text { bulb }\end{array}$ & $\begin{array}{l}\text { Wet } \\
\text { bulb }\end{array}$ & $\begin{array}{l}\text { Dry } \\
\text { bulb }\end{array}$ & $\begin{array}{l}\text { Wet } \\
\text { bulb }\end{array}$ & $\begin{array}{l}\text { Dry } \\
\text { bulb }\end{array}$ & $\begin{array}{l}\text { Wet } \\
\text { bulb }\end{array}$ & & & meters & meters & meters & meters \\
\hline $\begin{array}{l}1 \\
1 \\
1 \\
1 \\
1 \\
1 \\
1 \\
1\end{array}$ & $\begin{array}{r}0 \\
3 \\
6 \\
9 \\
12 \\
15 \\
18 \\
21\end{array}$ & $\begin{array}{l}6.4 \\
6.5 \\
6.9 \\
7.4 \\
7.5 \\
7.6 \\
6.4 \\
5.7\end{array}$ & $\begin{array}{l}3.9 \\
5.3 \\
6.1 \\
6.9 \\
5.8 \\
7.2 \\
6.3 \\
5.7\end{array}$ & $\begin{array}{l}6.4 \\
6.6 \\
7.0 \\
7.7 \\
7.6 \\
7.8 \\
6.3 \\
5.6\end{array}$ & $\begin{array}{l}3.9 \\
5.5 \\
6.3 \\
6.9 \\
7.2 \\
7.4 \\
6.3 \\
5.6\end{array}$ & $\begin{array}{l}6.6 \\
6.9 \\
7.3 \\
7.7 \\
8.2 \\
8.1 \\
6.4 \\
5.7\end{array}$ & $\begin{array}{l}4.1 \\
5.7 \\
6.5 \\
7.0 \\
7.5 \\
7.8 \\
6.3 \\
5.7\end{array}$ & $\begin{array}{l}6.8 \\
7.2 \\
7.8 \\
8.0 \\
8.8 \\
8.3 \\
6.7 \\
6.0\end{array}$ & $\begin{array}{l}4.3 \\
6.0 \\
6.8 \\
7.4 \\
8.0 \\
8.0 \\
5.6 \\
6.0\end{array}$ & $\begin{array}{l}2.9 \\
2.7 \\
2.6 \\
3.0\end{array}$ & & $\begin{array}{l}19.2 \\
17.4 \\
16.3 \\
13.7 \\
11.2 \\
7.5 \\
4.8 \\
6.1\end{array}$ & $\begin{array}{r}20.7 \\
18.7 \\
17.7 \\
15.1 \\
12.4 \\
8.6 \\
5.7 \\
7.3\end{array}$ & $\begin{array}{r}23.0 \\
20.9 \\
19.5 \\
16.6 \\
13.9 \\
9.9 \\
6.7 \\
8.2\end{array}$ & $\begin{array}{r}25.6 \\
23.4 \\
22.0 \\
18.9 \\
15.7 \\
21.6 \\
8.0 \\
10.1\end{array}$ \\
\hline $\begin{array}{l}2 \\
2 \\
2 \\
2\end{array}$ & $\begin{array}{l}0 \\
3 \\
6 \\
9\end{array}$ & & & & & & & & & & & $\begin{array}{r}8.6 \\
8.0 \\
9.0 \\
13.4\end{array}$ & $\begin{array}{r}9.8 \\
9.9 \\
12.0 \\
16.2\end{array}$ & $\begin{array}{l}11.5 \\
13.3 \\
13.9 \\
18.6\end{array}$ & $\begin{array}{l}13.3 \\
14.9 \\
13.7 \\
13.5\end{array}$ \\
\hline $\begin{array}{l}2 \\
2 \\
2 \\
2\end{array}$ & $\begin{array}{l}12 \\
15 \\
18 \\
21\end{array}$ & $\begin{array}{r}1.2 \\
1.7 \\
0.6 \\
-0.1\end{array}$ & $\begin{array}{r}0.7 \\
0.8 \\
0.1 \\
-0.4\end{array}$ & $\begin{array}{l}1.5 \\
1.7 \\
0.5 \\
0.2\end{array}$ & $\begin{array}{r}0.7 \\
0.8 \\
0.0 \\
-0.5\end{array}$ & $\begin{array}{r}1.1 \\
1.5 \\
0.4 \\
-0.3\end{array}$ & $\begin{array}{r}0.4 \\
0.5 \\
-0.2 \\
-0.7\end{array}$ & $\begin{array}{r}1.1 \\
1.4 \\
0.4 \\
-0.3\end{array}$ & $\begin{array}{r}0.3 \\
0.5 \\
-0.3 \\
-0.8\end{array}$ & $\begin{array}{l}3.9 \\
3.3 \\
2.9\end{array}$ & & $\begin{array}{r}13.4 \\
14.7 \\
12.4 \\
8.4 \\
6.2\end{array}$ & $\begin{array}{l}10.6 \\
17.6 \\
14.5 \\
10.0 \\
7.8\end{array}$ & $\begin{array}{r}18.0 \\
20.0 \\
16.6 \\
11.8 \\
9.6\end{array}$ & $\begin{array}{l}1.05 \\
21: 1 \\
17.4 \\
12: 1 \\
10.6\end{array}$ \\
\hline $\begin{array}{l}3 \\
3 \\
3\end{array}$ & $\begin{array}{l}0 \\
3 \\
6\end{array}$ & $\begin{array}{l}=0.3 \\
=0.7 \\
=0.7\end{array}$ & & $\begin{array}{l}0.5 \\
0.8 \\
0.8\end{array}$ & & $\begin{array}{l}-0.6 \\
-0.9 \\
-0.9\end{array}$ & & $\left|\begin{array}{ll}- & 0.6 \\
= & 0.7 \\
- & 0.9\end{array}\right|$ & & $\begin{array}{l}2.5 \\
1.8 \\
1.7\end{array}$ & & $\begin{array}{l}5.8 \\
3.5 \\
7.2\end{array}$ & $\begin{array}{l}7.2 \\
4.3 \\
7.6\end{array}$ & $\begin{array}{l}9.5 \\
5.7 \\
8.0\end{array}$ & $\begin{array}{r}20.0 \\
5.6\end{array}$ \\
\hline $\begin{array}{l}3 \\
3\end{array}$ & 9 & 1.1 & 0.4 & 1.2 & 0.3 & 1.2 & 0.3 & 1.2 & 0.3 & 4.0 & & 7.5 & 7.9 & 8.3 & 9.6 \\
\hline $\begin{array}{l}3 \\
3\end{array}$ & $\begin{array}{l}12 \\
15\end{array}$ & $\begin{array}{l}4.6 \\
6.7\end{array}$ & $\begin{array}{l}1.8 \\
2.9\end{array}$ & $\begin{array}{l}4: 9 \\
7.1\end{array}$ & $\begin{array}{l}1.8 \\
2.8\end{array}$ & $\begin{array}{l}5.1 \\
7.1\end{array}$ & $\begin{array}{l}1.7 \\
2.9\end{array}$ & $\begin{array}{l}5.4 \\
7.4\end{array}$ & 1.9 & $\begin{array}{l}5.4 \\
4.8\end{array}$ & & 13.0 & 13.6 & 15.0 & $\begin{array}{l}16.4 \\
13.8\end{array}$ \\
\hline $\begin{array}{l}3 \\
3\end{array}$ & $\begin{array}{l}18 \\
21\end{array}$ & $\begin{array}{l}4.3 \\
3.3\end{array}$ & $\begin{array}{l}2.4 \\
2.0\end{array}$ & $\begin{array}{l}4.3 \\
3.5\end{array}$ & $\begin{array}{l}2.3 \\
2.0\end{array}$ & $\begin{array}{l}4.4 \\
3.5\end{array}$ & 2.3 & $\begin{array}{l}4.9 \\
3.5\end{array}$ & $\begin{array}{l}2.0 \\
1.4\end{array}$ & 3.7 & & 401 & 4.7 & 5.8 & $\begin{array}{r}130 \\
7.2\end{array}$ \\
\hline $\begin{array}{l}4 \\
4 \\
4 \\
4 \\
4 \\
4 \\
4 \\
4\end{array}$ & $\begin{array}{r}0 \\
3 \\
6 \\
9 \\
12 \\
15 \\
18 \\
21\end{array}$ & $\begin{array}{r}3.4 \\
3.3 \\
2.2 \\
3.8 \\
7.5 \\
11.0 \\
6.9 \\
7.4\end{array}$ & $\begin{array}{l}1.09 \\
1.03 \\
0.44 \\
1.5 \\
4.5 \\
6.2 \\
3.8 \\
3.9\end{array}$ & $\begin{array}{r}3.7 \\
3.6 \\
2.4 \\
3.8 \\
7.8 \\
11.4 \\
7.6 \\
7.8\end{array}$ & $\begin{array}{l}1.9 \\
1.5 \\
0.4 \\
1.2 \\
4.2 \\
6.0 \\
4.1 \\
4.0\end{array}$ & $\begin{array}{r}3.8 \\
3.7 \\
2.3 \\
3.6 \\
8.0 \\
10.9 \\
8.6 \\
8.0\end{array}$ & $\begin{array}{l}1.9 \\
1.4 \\
0.3 \\
1.2 \\
4.0 \\
6.1 \\
4.4 \\
4.1\end{array}$ & $\begin{array}{r}3.9 \\
3.8 \\
2.5 \\
3.6 \\
7.6 \\
12.4 \\
9.8 \\
8.2\end{array}$ & $\begin{array}{l}1.9 \\
1.4 \\
0.4 \\
1.2 \\
3.9 \\
6.4 \\
4.9 \\
4.2\end{array}$ & $\begin{array}{l}3.2 \\
3.0 \\
2.9 \\
3.6 \\
5.6 \\
5.6 \\
4.9 \\
3.9\end{array}$ & . & $\begin{array}{l}5.5 \\
5.1 \\
2.9 \\
4: 0 \\
1.8 \\
2.3 \\
5.2 \\
9.6\end{array}$ & $\begin{array}{r}6.5 \\
6.1 \\
3.9 \\
4.8 \\
2.0 \\
3.3 \\
6.4 \\
10.8\end{array}$ & $\begin{array}{r}7.0 \\
5.0 \\
5.1 \\
5.9 \\
2.0 \\
4.7 \\
8.6 \\
12.4\end{array}$ & $\begin{array}{r}8.7 \\
9.8 \\
7.4 \\
5.2 \\
2.2 \\
4.3 \\
11.3 \\
15.0\end{array}$ \\
\hline $\begin{array}{l}5 \\
5 \\
5 \\
5 \\
5 \\
5 \\
5 \\
5\end{array}$ & $\begin{array}{r}0 \\
3 \\
6 \\
9 \\
12 \\
15 \\
18 \\
21\end{array}$ & $\begin{array}{r}6.7 \\
5.1 \\
4.8 \\
7.1 \\
9.8 \\
9.5 \\
1.11 \\
-0.5\end{array}$ & $\begin{array}{r}3.8 \\
2.8 \\
2.4 \\
3.7 \\
5.7 \\
5.7 \\
0.4 \\
-0.7\end{array}$ & $\begin{array}{r}7.0 \\
5.2 \\
5.0 \\
7.5 \\
10.0 \\
9.3 \\
0.9 \\
0.8\end{array}$ & $\begin{array}{r}3.8 \\
2.8 \\
2.5 \\
3.8 \\
5.8 \\
5.7 \\
0.03 \\
-0.9\end{array}$ & $\begin{array}{r}7.2 \\
5.2 \\
5.1 \\
8.2 \\
10.2 \\
8.9 \\
0.7 \\
-1.0\end{array}$ & $\begin{array}{r}3.8 \\
2.7 \\
2.5 \\
3.9 \\
5.7 \\
5.3 \\
0.0 \\
-\quad 1.2\end{array}$ & $\begin{array}{r}7.4 \\
5.4 \\
5.3 \\
8.4 \\
10.2 \\
8.7 \\
0.5 \\
-1.2\end{array}$ & $\begin{array}{r}3.9 \\
2.7 \\
2.5 \\
4.0 \\
5.9 \\
5.4 \\
-\quad 0.2 \\
-1.4\end{array}$ & $\begin{array}{l}3.7 \\
3.2 \\
2.9 \\
4.4 \\
5.7 \\
4.8 \\
4.1 \\
3.5\end{array}$ & & $\begin{array}{r}13.6 \\
13.7 \\
13.7 \\
9.8 \\
6.0 \\
7.9 \\
13.8 \\
12.7\end{array}$ & $\begin{array}{r}15.0 \\
14.9 \\
14.7 \\
10.8 \\
7.5 \\
9.3 \\
15.9 \\
14.5\end{array}$ & $\begin{array}{r}16.6 \\
16.5 \\
16.2 \\
12.4 \\
9.8 \\
10.8 \\
18.2 \\
16.8\end{array}$ & $\begin{array}{l}19.3 \\
18.7 \\
17.9 \\
12.8 \\
10.3 \\
11.6 \\
19.2 \\
17.6\end{array}$ \\
\hline $\begin{array}{l}6 \\
6 \\
6 \\
6 \\
6 \\
6 \\
6 \\
6\end{array}$ & $\begin{array}{r}0 \\
3 \\
6 \\
9 \\
12 \\
15 \\
18 \\
21\end{array}$ & $\begin{array}{l}=2.02 \\
=3.02 \\
=4.9 \\
=3.7 \\
=0.9 \\
=0.77 \\
=2.77 \\
=4.6\end{array}$ & & $\begin{array}{l}2.5 \\
3.5 \\
5.1 \\
3.9 \\
1.2 \\
0.9 \\
2.9 \\
4.8\end{array}$ & & $\begin{array}{l}-2.0 \\
=3.8 \\
=5.4 \\
=4.1 \\
=1.5 \\
=1.12 \\
=3.1 \\
-4.9\end{array}$ & & $\begin{array}{l}-2.7 \\
=3.0 \\
=5.6 \\
=4.2 \\
=1.7 \\
=1.3 \\
=3.3 \\
-5.1\end{array} \mid$ & & $\begin{array}{l}3.2 \\
3.0 \\
2.6 \\
3.5 \\
4.5 \\
3.4 \\
2.7 \\
2.3\end{array}$ & & $\begin{array}{r}12.8 \\
13.5 \\
15.9 \\
13.4 \\
19.3 \\
14.9 \\
9.9 \\
8.3\end{array}$ & $\begin{array}{r}14.6 \\
15.5 \\
18.0 \\
21.0 \\
22.0 \\
17.3 \\
11.6 \\
9.9\end{array}$ & $\begin{array}{l}17.2 \\
17.9 \\
21.0 \\
24.3 \\
25.4 \\
19.7 \\
13.0 \\
11.0\end{array}$ & $\begin{array}{l}17.6 \\
19.4 \\
22.1 \\
25.4 \\
26.5 \\
20.7 \\
13.9 \\
11.8\end{array}$ \\
\hline $\begin{array}{l}7 \\
7 \\
7 \\
7 \\
7 \\
7 \\
7 \\
7\end{array}$ & $\begin{array}{r}0 \\
3 \\
6 \\
9 \\
12 \\
15 \\
18 \\
21\end{array}$ & $\begin{array}{l}=5.9 \\
=6.2 \\
=4.8 \\
-3.8\end{array}$ & & $\begin{array}{l}6.0 \\
6.2 \\
4.9 \\
4.1\end{array}$ & & $\begin{array}{l}-6.0 \\
-6.2 \\
=4.9 \\
-4.2\end{array}$ & & $\begin{array}{l}-6.1 \\
-6.2 \\
-\quad 4.9\end{array}$ & & $\begin{array}{l}2.0 \\
1.4 \\
1.8\end{array}$ & & $\begin{array}{r}6.0 \\
3.9 \\
6.7 \\
6.9 \\
10.0 \\
6.5 \\
3.0 \\
3.6\end{array}$ & $\begin{array}{r}7.2 \\
5.0 \\
7.4 \\
7.4 \\
12.0 \\
8.2 \\
3.5 \\
4.0\end{array}$ & $\begin{array}{r}8.2 \\
5.8 \\
7.5 \\
7.9 \\
13.7 \\
10.0 \\
3.0 \\
5.7\end{array}$ & $\begin{array}{r}8.8 \\
7.3 \\
7.7 \\
7.9 \\
15.8 \\
10.6 \\
6.0 \\
7.0\end{array}$ \\
\hline $\begin{array}{l}8 \\
8 \\
8 \\
8 \\
8 \\
8 \\
8 \\
8 \\
8\end{array}$ & $\begin{array}{r}0 \\
3 \\
6 \\
9 \\
12 \\
15 \\
18 \\
21\end{array}$ & $\begin{array}{l}7.0 \\
8: 3 \\
5: 1 \\
3.8\end{array}$ & $\begin{array}{l}2.6 \\
3.2 \\
1.6 \\
0.4\end{array}$ & $\begin{array}{l}7.4 \\
8.7 \\
5.3 \\
3.8\end{array}$ & $\begin{array}{l}2.5 \\
3.0 \\
1.5 \\
0.2\end{array}$ & $\begin{array}{l}7.7 \\
9.3 \\
5.5 \\
3.7\end{array}$ & $\begin{array}{l}2.6 \\
3.1 \\
1.4 \\
0.0\end{array}$ & \begin{tabular}{l|l|}
8.1 \\
9.6 \\
5.8 \\
3.8
\end{tabular} & $\begin{array}{l}3.2 \\
3.9 \\
2.1 \\
0.5\end{array}$ & & & $\begin{array}{r}4.0 \\
5.5 \\
5.5 \\
9.9 \\
13.3 \\
10.4 \\
11.7 \\
12.1\end{array}$ & $\begin{array}{r}4.7 \\
6.1 \\
5.7 \\
10.5 \\
14.6 \\
11.6 \\
12.7 \\
13.1\end{array}$ & $\begin{array}{r}4.8 \\
6.3 \\
6.0 \\
11.6 \\
16.7 \\
13.8 \\
14.6 \\
14.4\end{array}$ & $\begin{array}{r}6.3 \\
7.4 \\
5.7 \\
11: 0 \\
17.0 \\
14.7 \\
16.4 \\
16.2\end{array}$ \\
\hline $\begin{array}{l}9 \\
9 \\
9 \\
9 \\
9 \\
9 \\
9 \\
9\end{array}$ & $\begin{array}{r}0 \\
3 \\
6 \\
9 \\
12 \\
15 \\
18 \\
21\end{array}$ & $\begin{array}{r}3.0 \\
2.1 \\
1.3 \\
3.1 \\
7.5 \\
10.1 \\
8.3 \\
6.7\end{array}$ & $\left|\begin{array}{r}-0.1 \\
-1.0 \\
-1.5 \\
-0.3 \\
2.3 \\
4.0 \\
4.0 \\
4.3\end{array}\right|$ & $\begin{array}{r}3.1 \\
1.9 \\
1.2 \\
3.2 \\
7.9 \\
10.5 \\
8.6 \\
6.9\end{array}$ & $\left|\begin{array}{r}-0.3 \\
=1.2 \\
=1.7 \\
-0.4 \\
2.3 \\
4.0 \\
4.1 \\
4.4\end{array}\right|$ & $\begin{array}{r}3.1 \\
1.7 \\
1.3 \\
3.4 \\
3.3 \\
11.0 \\
9.0 \\
7.2\end{array}$ & 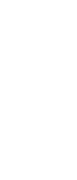 & $\begin{array}{r}3.1 \\
1.7 \\
1.0 \\
3.5 \\
3.3 \\
11.5 \\
9.4 \\
7.3\end{array}$ & & & & $\begin{array}{l}12 \cdot 1 \\
15.4 \\
15.9 \\
17.1 \\
19.4 \\
16.3 \\
14.5 \\
12.2\end{array}$ & $\begin{array}{l}13.1 \\
16.3 \\
16.9 \\
18.3 \\
21.0 \\
18.2 \\
15.0 \\
13.6\end{array}$ & $\begin{array}{l}14.4 \\
17.4 \\
18.0 \\
19.9 \\
23.0 \\
20.2 \\
18.0 \\
16.1\end{array}$ & $\begin{array}{l}15.7 \\
18.3 \\
19.3 \\
21.3 \\
25.0 \\
22.2 \\
20.4 \\
17.5\end{array}$ \\
\hline $\begin{array}{l}10 \\
10 \\
10 \\
10 \\
10 \\
10 \\
10 \\
10\end{array}$ & $\begin{array}{r}0 \\
3 \\
6 \\
9 \\
12 \\
15 \\
18 \\
21\end{array}$ & $\begin{array}{l}0.9 \\
0.3 \\
0.5 \\
3.0 \\
5.0 \\
6.8 \\
2.3 \\
1.0\end{array}$ & $\begin{array}{r}-1.00 \\
-1.5 \\
-1.2 \\
0.00 \\
1.06 \\
-1.30 \\
-1.00 \\
-1.0\end{array} \mid$ & $\begin{array}{l}0.7 \\
0.4 \\
0.6 \\
3.0 \\
6.3 \\
6.7 \\
3.0 \\
1.1\end{array}$ & $\begin{array}{r}-1.00 \\
-1.5 \\
-1.3 \\
0.0 \\
1.03 \\
1.1 \\
-0.08 \\
-1.1\end{array} \mid$ & $\begin{array}{l}0.5 \\
0.3 \\
0.7 \\
2.7 \\
6.0 \\
6.7 \\
3.5 \\
0.9\end{array}$ & $\begin{array}{r}-1.2 \\
-1.0 \\
=1.03 \\
-0.4 \\
1.0 \\
0.0 .9 \\
-0.17 \\
-1.1\end{array}$ & $\begin{array}{l}0.3 \\
0.4 \\
0.5 \\
2.3 \\
6.5 \\
6: 5 \\
4.5 \\
2.1\end{array}$ & & & & 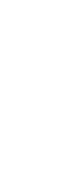 & $\begin{array}{r}10.7 \\
15.7 \\
15.0 \\
15.3 \\
14.5 \\
9.2 \\
1.7 \\
1.6\end{array}$ & $\begin{array}{r}10.8 \\
20.1 \\
20.5 \\
20.5 \\
18.6 \\
11.4 \\
2.6 \\
2.2\end{array}$ & $\begin{array}{r}16.2 \\
22.0 \\
21.3 \\
20.6 \\
18.9 \\
11.8 \\
4.2 \\
2.8\end{array}$ \\
\hline
\end{tabular}


TABLE 10

151

Table 10. - Three-hour averages of air and water-surface temperatures and wind directions and speed, April 1950-August STATION 3

THREE-HOURLY AVERAGES

JANUARY, 1951

\begin{tabular}{|c|c|c|c|c|c|c|c|c|c|c|c|c|c|c|c|}
\hline \multirow{3}{*}{ 总超 } & \multirow{3}{*}{ 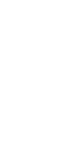 } & \multicolumn{8}{|c|}{ Average air temperature $\left({ }^{\circ} \mathrm{C}\right)$ at indicated height } & \multirow{3}{*}{$\begin{array}{c}\text { Average } \\
\text { water- } \\
\text { surface } \\
\text { tempera- } \\
\text { ture } \\
\left({ }^{\circ} \mathrm{C}\right)\end{array}$} & \multirow{3}{*}{$\begin{array}{c}\begin{array}{c}\text { Average } \\
\text { wind } \\
\text { direction } \\
\text { (coded) }\end{array} \\
\text { (colo }\end{array}$} & \multirow{2}{*}{\multicolumn{4}{|c|}{$\begin{array}{l}\text { Average wind speed (knots) } \\
\text { at indicated height }\end{array}$}} \\
\hline & & \multicolumn{2}{|c|}{$\begin{array}{c}2 \\
\text { meters }\end{array}$} & \multicolumn{2}{|c|}{$\begin{array}{c}4 \\
\text { meters }\end{array}$} & \multicolumn{2}{|c|}{$\begin{array}{c}8 \\
\text { meters }\end{array}$} & \multicolumn{2}{|c|}{$\begin{array}{c}16 \\
\text { meters }\end{array}$} & & & & & & \\
\hline & & $\begin{array}{l}\text { Dry } \\
\text { bulb }\end{array}$ & $\begin{array}{l}\text { Wet } \\
\text { bulb }\end{array}$ & $\begin{array}{l}\text { Dry } \\
\text { bulb }\end{array}$ & $\begin{array}{l}\text { Wet } \\
\text { bulb }\end{array}$ & $\begin{array}{l}\text { Dry } \\
\text { bulb }\end{array}$ & $\begin{array}{l}\text { Wet } \\
\text { bulb }\end{array}$ & $\begin{array}{l}\text { Dry } \\
\text { bulb }\end{array}$ & $\begin{array}{l}\text { Wet } \\
\text { bulb }\end{array}$ & & & meters & meters & meters & meters \\
\hline $\begin{array}{l}11 \\
11 \\
11 \\
11 \\
11 \\
11 \\
11 \\
11\end{array}$ & \begin{tabular}{r|}
0 \\
3 \\
6 \\
9 \\
12 \\
15 \\
18 \\
21
\end{tabular} & $\begin{array}{r}-1.0 \\
-1: 1 \\
0.0 \\
3.0 \\
5.9 \\
8.0 \\
6.9 \\
5.9\end{array}$ & $\left|\begin{array}{r}-2.5 \\
-3.1 \\
=2.5 \\
-0.1 \\
1.4 \\
2.1 \\
1.8 \\
1.7\end{array}\right|$ & $\begin{array}{l}0.6 \\
1.1 \\
0.2 \\
3.1 \\
6.1 \\
8.1 \\
7.0 \\
6.1 \\
0.1\end{array}$ & $=\begin{array}{r}2.6 \\
-3.2 \\
0.2 \\
1.4 \\
2.3 \\
2.1 \\
1.9\end{array}$ & 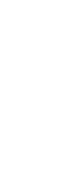 & $\left|\begin{array}{r}-2.44 \\
=3.2 \\
-2.7 \\
-0.3 \\
1.3 \\
2.02 \\
1.9 \\
1.8\end{array}\right|$ & $\begin{array}{r}0.4 \\
-\quad 0.3 \\
0.2 \\
3.2 \\
6.3 \\
8: 4 \\
7.3 \\
6.3\end{array}$ & & & & $\begin{array}{r}3.0 \\
5.3 \\
7.3 \\
12.1 \\
12.6 \\
13.9 \\
10.8 \\
15.4\end{array}$ & $\begin{array}{r}3.7 \\
6.0 \\
8.2 \\
13.3 \\
13.9 \\
15.8 \\
12.1 \\
17.0\end{array}$ & $\begin{array}{r}4.7 \\
7.1 \\
9.2 \\
24.4 \\
15.3 \\
17.5 \\
13.5 \\
18.7\end{array}$ & $\begin{array}{r}7.0 \\
9.8 \\
11.5 \\
16.1 \\
17.2 \\
20.4 \\
16: 0 \\
21.7\end{array}$ \\
\hline $\begin{array}{l}12 \\
12 \\
12 \\
12 \\
12 \\
12 \\
12 \\
12\end{array}$ & $\begin{array}{r}0 \\
3 \\
6 \\
9 \\
12 \\
15 \\
18 \\
21\end{array}$ & $\begin{array}{r}5.4 \\
4.6 \\
4.0 \\
5.8 \\
9.6 \\
11.4 \\
8.3 \\
4.5\end{array}$ & $\begin{array}{l}2.2 \\
2.7 \\
3.5 \\
5.2 \\
6.7 \\
8.2 \\
6.9 \\
4.3\end{array}$ & $\begin{array}{r}5.7 \\
4.8 \\
4.2 \\
8.2 \\
10.3 \\
12.2 \\
8.6 \\
4.8\end{array}$ & $\begin{array}{l}2.3 \\
2.8 \\
3.5 \\
5.3 \\
7.2 \\
8.3 \\
7.0 \\
4.7\end{array}$ & \begin{tabular}{|r|}
5.8 \\
4.8 \\
4.3 \\
6.5 \\
11.1 \\
12.5 \\
8.6 \\
5.4
\end{tabular} & $\begin{array}{l}2.3 \\
2.8 \\
3.6 \\
5.6 \\
7.5 \\
8.5 \\
7.0 \\
5.3\end{array}$ & $\begin{array}{r}5.9 \\
4.9 \\
4.4 \\
6.8 \\
11.5 \\
12.8 \\
8.8 \\
5.8\end{array}$ & & $\begin{array}{l}4.7 \\
3.3 \\
2.3\end{array}$ & & $\begin{array}{r}17.4 \\
16.1 \\
11.9 \\
11.6 \\
12.8 \\
2.6 \\
4.2 \\
2.1\end{array}$ & $\begin{array}{r}18.9 \\
17.2 \\
12.8 \\
12.6 \\
15.1 \\
3.4 \\
5.3 \\
2.8\end{array}$ & $\begin{array}{r}20.9 \\
19.0 \\
14.3 \\
14.0 \\
28.0 \\
4.2 \\
6.6 \\
3.5\end{array}$ & $\begin{array}{r}23.2 \\
21.0 \\
15.6 \\
15.0 \\
19.4 \\
5.00 \\
8.6 \\
3.4\end{array}$ \\
\hline $\begin{array}{l}13 \\
13 \\
13 \\
13 \\
13 \\
13 \\
13 \\
13\end{array}$ & $\begin{array}{r}0 \\
3 \\
5 \\
9 \\
12 \\
15 \\
28 \\
21\end{array}$ & $\begin{array}{l}3.8 \\
4.4 \\
4.04\end{array}$ & $\begin{array}{l}3.8 \\
4.4 \\
4.4\end{array}$ & $\begin{array}{l}3.8 \\
4.4 \\
4.04\end{array}$ & $\begin{array}{l}3.8 \\
4.4 \\
4.4\end{array}$ & $\begin{array}{l}3.9 \\
4.6 \\
4.5\end{array}$ & $\begin{array}{l}3.9 \\
4.6 \\
4.04\end{array}$ & $\begin{array}{l}3.8 \\
4.5 \\
4.4\end{array}$ & $\begin{array}{l}3.8 \\
4.5 \\
4.4\end{array}$ & & & $\begin{array}{l}2.0 \\
2.2 \\
3.1 \\
7.2 \\
8.1 \\
9.1 \\
8.2 \\
8.9\end{array}$ & $\begin{array}{r}2.5 \\
2.8 \\
3.9 \\
8.4 \\
9.4 \\
10.6 \\
10.0 \\
10.5\end{array}$ & $\begin{array}{r}2.8 \\
3.3 \\
4.7 \\
9.4 \\
10.8 \\
12.3 \\
11.8 \\
12.8\end{array}$ & $\begin{array}{r}3.2 \\
3.9 \\
5.0 \\
11.01 \\
12.4 \\
12.5 \\
11.4 \\
12.8\end{array}$ \\
\hline $\begin{array}{l}14 \\
14 \\
14 \\
14 \\
14 \\
14 \\
14 \\
14\end{array}$ & $\begin{array}{r}0 \\
3 \\
6 \\
9 \\
12 \\
15 \\
18 \\
21\end{array}$ & $\begin{array}{l}5.7 \\
6.6 \\
3.8 \\
3.3\end{array}$ & $\begin{array}{l}3.6 \\
3.8 \\
1.9 \\
1.6\end{array}$ & $\begin{array}{l}6.1 \\
7: 3 \\
4.3 \\
3.8\end{array}$ & & $\begin{array}{l}5.8 \\
7.1 \\
3.8 \\
3.7\end{array}$ & $\begin{array}{l}3.2 \\
3.6 \\
1.5 \\
1.4\end{array}$ & $\begin{array}{l}5.8 \\
6.8 \\
3.7 \\
3.6\end{array}$ & $\begin{array}{l}3.1 \\
3.5 \\
1.4 \\
1.4\end{array}$ & & & $\begin{array}{r}11.5 \\
13.5 \\
13.5 \\
8.1 \\
7.8 \\
7.0 \\
8.8 \\
8.9\end{array}$ & $\begin{array}{r}13.6 \\
16.0 \\
15.02 \\
9.6 \\
9.7 \\
8.02 \\
9.7 \\
9.7\end{array}$ & $\begin{array}{l}15.7 \\
18.2 \\
17.2 \\
11.2 \\
12.7 \\
9.7 \\
11.2 \\
10.8\end{array}$ & $\begin{array}{l}16.4 \\
19.1 \\
18.6 \\
12.4 \\
15.02 \\
12.7 \\
11.3 \\
11.7\end{array}$ \\
\hline $\begin{array}{l}15 \\
15 \\
15 \\
15 \\
15 \\
15 \\
15 \\
15\end{array}$ & \begin{tabular}{r|}
0 \\
3 \\
6 \\
9 \\
12 \\
15 \\
18 \\
21
\end{tabular} & $\begin{array}{r}3.6 \\
3.5 \\
2.0 \\
5.8 \\
10.02 \\
10.6 \\
4.4 \\
3.7\end{array}$ & $\begin{array}{l}1.8 \\
1.3 \\
0.5 \\
3.3 \\
5.0 \\
5.8 \\
2.9 \\
2.4\end{array}$ & $\begin{array}{r}4 \cdot 1 \\
3.9 \\
2.3 \\
6.0 \\
10.2 \\
10.9 \\
5.4 \\
4.4\end{array}$ & $\begin{array}{l}4.4 \\
4.9 \\
5.7 \\
3.2 \\
2.8\end{array}$ & $\begin{array}{r}4.1 \\
4.0 \\
2.4 \\
6.1 \\
9.9 \\
11.2 \\
6.9 \\
4.8\end{array}$ & $\begin{array}{l}1.7 \\
1: 3 \\
0.6 \\
2.7 \\
4: 4 \\
5.7 \\
3.6 \\
2.7\end{array}$ & $\begin{array}{r}4.1 \\
3.8 \\
2.2 \\
6.1 \\
9.9 \\
11.2 \\
9.8 \\
5.6\end{array}$ & $\begin{array}{l}1.7 \\
1.3 \\
0.5 \\
3.1 \\
4.5 \\
5.5 \\
5.0 \\
3.3\end{array}$ & $\begin{array}{l}1.2 \\
1: 4 \\
1.1 \\
1.9 \\
2.2 \\
1.5 \\
1.6 \\
1.9\end{array}$ & & & $\begin{array}{l}9.3 \\
9.7 \\
5.3 \\
5.8 \\
9.1 \\
4.2 \\
3.0\end{array}$ & $\begin{array}{r}10.3 \\
12.9 \\
6.0 \\
7.6 \\
11.2 \\
5.8 \\
4.3 \\
5.1\end{array}$ & $\begin{array}{r}11.8 \\
14.0 \\
8.2 \\
8.5 \\
11.5 \\
6.8 \\
5.6 \\
7.0\end{array}$ \\
\hline $\begin{array}{l}16 \\
16 \\
16 \\
16 \\
16 \\
16 \\
16 \\
16\end{array}$ & \begin{tabular}{r|}
0 \\
3 \\
6 \\
9 \\
12 \\
15 \\
18 \\
21
\end{tabular} & $\begin{array}{r}3 \cdot 3 \\
4.0 \\
4.0 \\
8.11 \\
12.7 \\
14.2 \\
11.4 \\
10.6\end{array}$ & $\begin{array}{l}2.0 \\
1.9 \\
1.8 \\
4.2 \\
5.9 \\
5.5 \\
5.3 \\
4.9\end{array}$ & $\begin{array}{r}3.6 \\
4.3 \\
4.5 \\
8.7 \\
13.5 \\
15.2 \\
12.0 \\
11.2\end{array}$ & $\begin{array}{l}2.2 \\
2.01 \\
2.0 \\
4.6 \\
6.03 \\
8.8 \\
5.6 \\
5.3\end{array}$ & $\begin{array}{r}3.8 \\
4.2 \\
4.5 \\
8.7 \\
14.2 \\
16.0 \\
12.6 \\
11.6\end{array}$ & $\begin{array}{l}2.0 \\
1: 8 \\
1: 7 \\
4: 5 \\
6.3 \\
6.8 \\
5.4 \\
5.0\end{array}$ & $\begin{array}{r}4.1 \\
4: 3 \\
4: 5 \\
9: 4 \\
14: 5 \\
16: 7 \\
13.2 \\
12.1\end{array}$ & $\begin{array}{l}2.3 \\
3: 8 \\
1.9 \\
4: 9 \\
7: 5 \\
5.5 \\
5.7\end{array}$ & & & $\begin{array}{r}5.1 \\
10.9 \\
16.7 \\
20.0 \\
18.6 \\
17.6 \\
15.9 \\
20.4\end{array}$ & $\begin{array}{r}5.9 \\
11.9 \\
17.8 \\
21.5 \\
20.5 \\
19.3 \\
17.4 \\
21.7\end{array}$ & $\begin{array}{r}7 \cdot 1 \\
13.3 \\
19.4 \\
24.0 \\
23.2 \\
22.03 \\
20.0 \\
24.6\end{array}$ & $\begin{array}{r}8.6 \\
15.0 \\
21.3 \\
25.6 \\
24.2 \\
24.3 \\
22.7 \\
27.1\end{array}$ \\
\hline $\begin{array}{l}17 \\
17 \\
17 \\
17 \\
17 \\
17 \\
17 \\
17\end{array}$ & \begin{tabular}{r|}
0 \\
3 \\
6 \\
9 \\
12 \\
15 \\
18 \\
21
\end{tabular} & $\begin{array}{r}10.9 \\
9.6 \\
7.5 \\
8.0 \\
10.8 \\
13.1 \\
8.0 \\
6.1\end{array}$ & $\begin{array}{l}4.4 \\
5.6 \\
6.8 \\
4.4 \\
3.4\end{array}$ & $\begin{array}{r}11.5 \\
9.9 \\
7.8 \\
8.2 \\
12.8 \\
15.6 \\
10.3 \\
7.2\end{array}$ & & $\begin{array}{r}12.0 \\
10.0 \\
7.8 \\
8.8 \\
13.6 \\
17.2 \\
11.9 \\
8.5\end{array}$ & $\begin{array}{l}4.9 \\
4: 2 \\
3.0 \\
3.7 \\
6.0 \\
7.6 \\
5.0 \\
3.5\end{array}$ & $\begin{array}{r}12.4 \\
10.2 \\
8.0 \\
8.9 \\
14.2 \\
17.5 \\
13.7 \\
10.1\end{array}$ & $\begin{array}{l}5.2 \\
4.3 \\
3.0 \\
3.9 \\
5.5 \\
8.9 \\
5.7 \\
4.3\end{array}$ & $\begin{array}{l}1.8 \\
1.9 \\
2.1 \\
3.2 \\
4.3 \\
3.9 \\
4.4 \\
3.4\end{array}$ & & $\begin{array}{r}21.2 \\
19.3 \\
15.0 \\
9.1 \\
5.8 \\
4.8 \\
4.5 \\
4.2\end{array}$ & $\begin{array}{l}22.9 \\
20.8 \\
16.2 \\
10.1 \\
7.1 \\
6.5 \\
6.1 \\
5.3\end{array}$ & $\begin{array}{r}25.9 \\
23.6 \\
13.6 \\
11.7 \\
8.7 \\
8.0 \\
9.0 \\
7.4\end{array}$ & $\begin{array}{r}27.6 \\
24.4 \\
19.3 \\
12.5 \\
9.8 \\
8.7 \\
11.4 \\
9.6\end{array}$ \\
\hline $\begin{array}{l}18 \\
18 \\
18 \\
18 \\
18 \\
18 \\
18 \\
18\end{array}$ & \begin{tabular}{r|}
0 \\
3 \\
6 \\
9 \\
12 \\
15 \\
18 \\
21
\end{tabular} & $\begin{array}{r}5.8 \\
4.7 \\
4.9 \\
8.4 \\
16.8 \\
14.0 \\
10.0 \\
8.4\end{array}$ & $\begin{array}{l}3.1 \\
2.4 \\
2.3 \\
4.5 \\
8.3 \\
7.9 \\
5.8 \\
4.9\end{array}$ & $\begin{array}{r}6.4 \\
5.2 \\
5.5 \\
9.3 \\
17.0 \\
16.9 \\
10.8 \\
8.9\end{array}$ & & $\begin{array}{r}7.1 \\
5.5 \\
5.9 \\
9.9 \\
17.3 \\
19.2 \\
12.0 \\
9.7\end{array}$ & $\begin{array}{l}3.0 \\
2.2 \\
2.2 \\
4.9 \\
9.4 \\
8.7 \\
6.2 \\
5.0\end{array}$ & $\begin{array}{r}8.1 \\
6.5 \\
6: 3 \\
10.4 \\
17.5 \\
19.5 \\
13.4 \\
10.7\end{array}$ & $\begin{array}{l}3.2 \\
2.4 \\
2.3 \\
5.3 \\
8.0 \\
9.3 \\
6.0 \\
5.5\end{array}$ & $\begin{array}{l}2.6 \\
2.2 \\
2.2 \\
4.0 \\
8.0 \\
7.7 \\
5.8 \\
4.3\end{array}$ & & $\begin{array}{l}3.9 \\
4.6 \\
4.0 \\
2.5 \\
2.0 \\
4.6 \\
8.4 \\
7.9\end{array}$ & $\begin{array}{l}4.7 \\
5.4 \\
4.6 \\
3.2 \\
2.6 \\
6.1 \\
7.8 \\
9.2\end{array}$ & $\begin{array}{r}6.4 \\
6.7 \\
5.6 \\
4.0 \\
3.1 \\
7.6 \\
10.3 \\
11.5\end{array}$ & $\begin{array}{r}8.8 \\
8.6 \\
6.6 \\
4.7 \\
3.8 \\
8.2 \\
12.6 \\
14.1\end{array}$ \\
\hline $\begin{array}{l}19 \\
19 \\
19 \\
19 \\
19 \\
19 \\
19 \\
19\end{array}$ & $\begin{array}{r}0 \\
3 \\
6 \\
9 \\
12 \\
15 \\
18 \\
21\end{array}$ & $\begin{array}{r}7.9 \\
8.2 \\
6.9 \\
995 \\
14.7 \\
15.9 \\
13.8 \\
12.6\end{array}$ & $\begin{array}{l}4.1 \\
4: 0 \\
3.3 \\
4: 8 \\
6: 7 \\
7.3 \\
6.5 \\
6.0\end{array}$ & $\begin{array}{r}8.7 \\
8.6 \\
7.1 \\
10.7 \\
16.0 \\
17.1 \\
14.8 \\
13.5\end{array}$ & & \begin{tabular}{r|}
8.9 \\
$9: 1$ \\
$7: 5$ \\
$11: 2$ \\
17.3 \\
18.2 \\
$16: 0$ \\
14.1
\end{tabular} & $\begin{array}{l}4: 1 \\
4: 0 \\
3: 3 \\
5: 01 \\
7: 2 \\
7.0 \\
6: 8 \\
6.1\end{array}$ & $\begin{array}{r}9: 3 \\
9: 5 \\
8: 5 \\
12: 2 \\
13: 2 \\
19: 2 \\
17: 0 \\
15: 1\end{array}$ & $\begin{array}{l}4.5 \\
4.2 \\
3.4 \\
5.4 \\
7.0 \\
8.4 \\
7.8 \\
6.8\end{array}$ & $\begin{array}{l}3.9 \\
3.6 \\
3.1 \\
4.8 \\
6.3 \\
5.9 \\
4.6 \\
3.9\end{array}$ & & $\begin{array}{r}5.9 \\
9.2 \\
7.7 \\
9.7 \\
13.4 \\
16.0 \\
14.8 \\
11.9\end{array}$ & $\begin{array}{r}6.8 \\
10.8 \\
8.8 \\
11.0 \\
15.5 \\
17.7 \\
16.4 \\
13.2\end{array}$ & $\begin{array}{r}7.9 \\
12.3 \\
10.9 \\
13.3 \\
18.6 \\
20.8 \\
19.5 \\
16.2\end{array}$ & $\begin{array}{r}9.3 \\
13.6 \\
12.8 \\
14.4 \\
19.0 \\
23.00 \\
21.6 \\
17.8\end{array}$ \\
\hline $\begin{array}{l}20 \\
20 \\
20 \\
20 \\
20 \\
20 \\
20 \\
30\end{array}$ & \begin{tabular}{r|}
0 \\
3 \\
6 \\
9 \\
12 \\
15 \\
12 \\
21
\end{tabular} & $\begin{array}{r}6.3 \\
-0.5 \\
-1.7 \\
-0.8 \\
1.3 \\
4.1 \\
-1.1 \\
-2.0\end{array}$ & $\left.\begin{array}{l}-1.0 \\
-0.1 \\
-0.1 \\
-2.3 \\
-2.3 \\
2.8\end{array}\right]$ & $\begin{array}{l}6.5 \\
0.8 \\
1.8 \\
1.0 \\
1: 3 \\
4: 0 \\
1: 1 \\
2.3\end{array}$ & $-2.8 \mid$ & $\mid \begin{array}{r}6.7 \\
-1: 0 \\
-1: 0 \\
-1.9 \\
1.0 \\
3: 0 \\
-1: 1 \\
-2.3\end{array}$ & $\begin{array}{l}2.1 \\
2.1 \\
0.1 \\
0.9\end{array}$ & $\begin{array}{r}6.2 \\
-1: 2 \\
-2: 0 \\
-2: 0 \\
1: 5 \\
3: 0 \\
3: 0 \\
-2: 0 \\
-2.4\end{array}$ & 3.0 & $\begin{array}{l}3.5 \\
3.5 \\
2.9 \\
3.4 \\
4.1 \\
3.9 \\
3.3 \\
3.0\end{array}$ & & $\begin{array}{r}14.2 \\
15.7 \\
12.7 \\
10.3 \\
5.6 \\
10.2 \\
8.1\end{array}$ & $\begin{array}{r}16.9 \\
18.5 \\
15.8 \\
11.0 \\
8.1 \\
10.9 \\
9.3 \\
8.9\end{array}$ & $\begin{array}{l}20.2 \\
21.0 \\
17.8 \\
15.2\end{array}$ & $\begin{array}{l}21.6 \\
21.88 \\
13.4 \\
13.1 \\
10.8 \\
13.5 \\
12.00 \\
11.3\end{array}$ \\
\hline
\end{tabular}


TABLE 10

Table 10. - Three-hour averages of air and water-surface temperatures and wind directions and speed, April 1950-August 1951, Lake Hefner-Continued

STATION 3

THREE-HOURLY AVERAGES

JANUARY, 1951

\begin{tabular}{|c|c|c|c|c|c|c|c|c|c|c|c|c|c|c|c|}
\hline \multirow{3}{*}{ 西言 } & \multirow{3}{*}{ 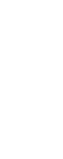 } & \multicolumn{8}{|c|}{ Average air temperature $\left({ }^{\circ} \mathrm{C}\right)$ at indicated height } & \multirow{3}{*}{$\begin{array}{c}\text { Average } \\
\text { water- } \\
\text { surface } \\
\text { tempera- } \\
\text { ture } \\
\text { ('C) } \\
\end{array}$} & \multirow{3}{*}{$\begin{array}{l}\text { Average } \\
\text { wing } \\
\text { direction } \\
\text { (coded) }\end{array}$} & \multirow{2}{*}{\multicolumn{4}{|c|}{$\begin{array}{c}\text { Average wind speed (knots) } \\
\text { at indicated height }\end{array}$}} \\
\hline & & \multicolumn{2}{|c|}{\begin{tabular}{|c|}
2 \\
meters \\
\end{tabular}} & \multicolumn{2}{|c|}{$\begin{array}{c}4 \\
\text { meters } \\
\end{array}$} & \multicolumn{2}{|c|}{\begin{tabular}{|c|}
8 \\
meters \\
\end{tabular}} & \multicolumn{2}{|c|}{$\begin{array}{c}16 \\
\text { meters } \\
\end{array}$} & & & & & & \\
\hline & & \begin{tabular}{|l|} 
Dry \\
bulb
\end{tabular} & $\begin{array}{c}\text { Wet } \\
\text { bulb }\end{array}$ & \begin{tabular}{|l|} 
Dry \\
bulb
\end{tabular} & \begin{tabular}{|l} 
Wet \\
bulb
\end{tabular} & 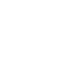 & \begin{tabular}{|c|} 
Wet \\
bulb
\end{tabular} & \begin{tabular}{|c|} 
Dry \\
bulb
\end{tabular} & \begin{tabular}{|l|} 
Wet \\
bulb
\end{tabular} & & & meters & meters & meters & meters \\
\hline $\begin{array}{l}21 \\
21\end{array}$ & & $=4.7$ & & $\begin{array}{c}4.8 \\
6.5\end{array}$ & & {$\left[\begin{array}{l}5.0 \\
-5.6\end{array}\right]$} & & & & & & $\begin{array}{l}6.8 \\
5.8\end{array}$ & & & $9: 1$ \\
\hline $\begin{array}{l}21 \\
21 \\
21\end{array}$ & & $\begin{aligned}-5.9 \\
-5.0\end{aligned}$ & & $\begin{aligned} 7: 0 \\
5.2 \\
0.5\end{aligned}$ & & {$\left[\begin{array}{rl}7.2 \\
-5.3 \\
-5.6\end{array}\right]$} & & $\begin{array}{l}-7.4 \\
-5.1\end{array}$ & & $\begin{array}{l}2.3 \\
3.3\end{array}$ & & & $\begin{array}{l}6.0 \\
3.8\end{array}$ & & $\begin{array}{l}6.8 \\
4.2\end{array}$ \\
\hline $\begin{array}{l}21 \\
21\end{array}$ & $\begin{array}{l}12 \\
15 \\
118\end{array}$ & $\begin{array}{l}0.6 \\
2.8 \\
0.0\end{array}$ & 0.6 & $\begin{array}{r}0.5 \\
3.3 \\
1.0\end{array}$ & & $\left|\begin{array}{r}0.0 \\
3: 0 \\
0.9\end{array}\right|$ & & $\begin{array}{l}0.4 \\
2.7 \\
0.0\end{array}$ & & $\begin{array}{l}4.7 \\
4.22\end{array}$ & & 1.0 & $\begin{array}{l}2.2 \\
5.6\end{array}$ & & $\begin{array}{r}2.4 \\
6.4\end{array}$ \\
\hline 21 & 21 & 0.0 & & $\begin{array}{l}0.00 \\
0.0\end{array}$ & & $\left|\begin{array}{rl}-0.1 \\
-0.1\end{array}\right|$ & & -0.3 & & 2.5 & & 5.8 & 11.8 & & 13.4 \\
\hline 22 & $\begin{array}{l}0 \\
3\end{array}$ & $=0.1$ & & $\begin{array}{lll}0: 2 \\
0.1\end{array}$ & & $=\begin{array}{l}0.4 \\
0.02\end{array}$ & & $=\begin{array}{l}0.5 \\
-8.5\end{array}$ & & $\begin{array}{l}1.9 \\
1.7\end{array}$ & & $\begin{array}{l}15.2 \\
19.7\end{array}$ & $\begin{array}{l}15.2 \\
20.0\end{array}$ & & $\begin{array}{l}17: 2 \\
23: 5\end{array}$ \\
\hline $\begin{array}{lll}22 \\
22\end{array}$ & 9 & 3.5 & 0.6 & $\begin{array}{l}0.6 \\
3.7\end{array}$ & & $\begin{array}{r}0.6 \\
3.8\end{array}$ & 0.8 & $\begin{array}{l}0.5 \\
4.1\end{array}$ & 0.8 & $\begin{array}{l}10.5 \\
2.8\end{array}$ & & $\begin{array}{l}19.4 \\
22.7\end{array}$ & $\begin{array}{l}20.7 \\
24.4\end{array}$ & 26.2 & $\begin{array}{l}24.3 \\
28.8\end{array}$ \\
\hline $\begin{array}{l}22 \\
22\end{array}$ & $\begin{array}{l}12 \\
15\end{array}$ & $\begin{array}{l}7: 3 \\
9: 7\end{array}$ & $\begin{array}{r}2.5 \\
3.0\end{array}$ & $\begin{array}{r}706 \\
10.2\end{array}$ & & $\begin{array}{r}7.3 \\
10.4\end{array}$ & $\begin{array}{l}2.4 \\
3.9\end{array}$ & $\begin{array}{r}\varepsilon \cdot 1 \\
10.6\end{array}$ & $\begin{array}{l}2.5 \\
4.0\end{array}$ & $\begin{array}{l}3.9 \\
3.4\end{array}$ & & $\begin{array}{l}21.0 \\
17.4\end{array}$ & $\begin{array}{l}22.5 \\
18.9\end{array}$ & $\begin{array}{l}24.8 \\
21.1\end{array}$ & $\begin{array}{l}26.6 \\
22.8\end{array}$ \\
\hline $\begin{array}{l}22 \\
22\end{array}$ & $\begin{array}{l}18 \\
21\end{array}$ & $8: 2$ & $\begin{array}{l}3: 3 \\
3: 1\end{array}$ & $\begin{array}{r}8.5 \\
7.2\end{array}$ & & $\begin{array}{l}8.7 \\
7.3\end{array}$ & $\begin{array}{l}3.2 \\
3.2 \\
3.2\end{array}$ & $\begin{array}{l}8.8 \\
7.5\end{array}$ & $\begin{array}{l}3.4 \\
3.1\end{array}$ & $\begin{array}{l}2.8 \\
2.6\end{array}$ & & $\begin{array}{l}14.7 \\
15.4\end{array}$ & $\begin{array}{l}16.1 \\
16.9\end{array}$ & $\begin{array}{l}1709 \\
10.1\end{array}$ & $\begin{array}{l}20.8 \\
21.3\end{array}$ \\
\hline $\begin{array}{l}23 \\
23\end{array}$ & 0 & 3.4 & 0.9 & $\begin{array}{r}3.5 \\
0.3\end{array}$ & 0.9 & $\begin{array}{ccc}3.2 \\
0.2\end{array}$ & 0.6 & 3.1 & 0.4 & 2.3 & & 6.8 & 8.3 & 9.6 & $10 \cdot 4$ \\
\hline 23 & 6 & 0.7 & $\begin{array}{l}0.5 \\
0.7\end{array}$ & $\begin{array}{l}8.3 \\
0.7\end{array}$ & 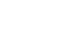 & $\begin{array}{l}0.4 \\
0.9 \\
0.6\end{array}$ & (1.4. & $\begin{array}{l}8.4 \\
0.9\end{array}$ & $\begin{array}{c}1 .: 5 \\
0.4\end{array}$ & 然: 200 & & $\begin{array}{l}7.3 \\
8.6\end{array}$ & $\begin{array}{r}8.9 \\
10.2\end{array}$ & $\begin{array}{l}1100 \\
11: 6\end{array}$ & (12:6 \\
\hline 23 & 12 & 8.3 & 3.4 & $\begin{array}{c}709 \\
0.5 \\
\end{array}$ & 3.7 & $\begin{array}{r}7.8 \\
0.8 \\
5\end{array}$ & 209 & 7.8 & 2.8 & $\begin{array}{ll}3.09 \\
3.9\end{array}-10$ & & 8.7 & $\begin{array}{l}13.0 \\
10.3\end{array}$ & $\begin{array}{l}14.9 \\
12.00\end{array}$ & $\begin{array}{l}15.0 \\
12.4\end{array}$ \\
\hline 23 & $\begin{array}{l}18 \\
21\end{array}$ & $\begin{array}{l}4: 0 \\
2.0\end{array}$ & $\begin{array}{l}1.4 \\
0.5 \\
0.5\end{array}$ & $\begin{array}{lll}4.6 \\
2.04\end{array}$ & $\begin{array}{l}1.5 \\
0.25 \\
0.23\end{array}$ & $\begin{aligned} 5.4 \\
2.06\end{aligned}$ & 0 & $\begin{array}{l}6.0 \\
3.04 \\
3\end{array}$ & $\begin{array}{l}0.5 \\
1.2 \\
0.0\end{array}$ & $\begin{array}{l}3.1 \\
3.1 \\
2.3\end{array}$ & & 1.02 & $\begin{array}{l}80.5 \\
1.9 \\
2.6\end{array}$ & $\begin{array}{r}0.0 \\
2.7\end{array}$ & $\begin{array}{r}3.6 \\
3.6\end{array}$ \\
\hline & & 1.9 & & 2.0 & & 2.2 & & & & 2.7 & & 33 & & & 4.7 \\
\hline $\begin{array}{l}24 \\
24\end{array}$ & $\begin{array}{l}3 \\
6\end{array}$ & $\begin{array}{l}2.4 \\
2.4\end{array}$ & $\begin{array}{l}0.1 \\
0.0\end{array}$ & $\begin{array}{r}2.4 \\
2.5\end{array}$ & 0.1 & $\begin{array}{r}2.5 \\
2.5\end{array}$ & 0.4 & 3.1 & 0.4 & 2.3 & & 4.9 & 5.3 & $\begin{array}{l}6.2 \\
6.2\end{array}$ & 7.98 \\
\hline 24 & $\begin{array}{r}9 \\
12 \\
\end{array}$ & $\begin{array}{l}4.8 \\
8.89 \\
8\end{array}$ & $\begin{array}{l}1.8 \\
3.8\end{array}$ & $\begin{array}{l}5: 1 \\
0.3 \\
0.1\end{array}$ & $\begin{array}{l}2.0 \\
4.3\end{array}$ & $\begin{aligned} 5.5 \\
9.6\end{aligned}$ & $\begin{array}{l}1.5 \\
3.97\end{array}$ & $\begin{array}{r}5.6 \\
10.2\end{array}$ & $\begin{array}{l}205 \\
3.5\end{array}$ & $\begin{array}{l}2.1 \\
3.6 \\
4.5\end{array}$ & & $\begin{array}{r}7.4 \\
7.6 \\
.7 .6\end{array}$ & $\begin{array}{r}4.0 \\
8.5\end{array}$ & $\begin{array}{r}5.0 \\
\quad 0.7 \\
0.7\end{array}$ & $\begin{array}{r}5.6 \\
10.3\end{array}$ \\
\hline & $\begin{array}{l}15 \\
18 \\
\end{array}$ & $\begin{array}{l}8.9 \\
3: 1\end{array}$ & $\begin{array}{r}3.2 \\
0.23\end{array}$ & $\begin{array}{l}8.7 \\
3.2\end{array}$ & 3.6 & $\begin{array}{r}8.6 \\
3.1\end{array}$ & $\begin{array}{r}3.0 \\
-300\end{array}$ & 8.6 & $2: 8$ & 3.4 & & $\begin{array}{l}12.2 \\
12.2\end{array}$ & 14.6 & $\begin{array}{l}1306 \\
17.6 \\
6.5\end{array}$ & $\begin{array}{l}19.5 \\
19.5\end{array}$ \\
\hline 24 & 21 & 0.0 & 1.3 & 0.0 & -2.0 & 0.0 & {$\left[\begin{array}{l}-1.4 \\
\end{array}\right.$} & 0.2 & -2.1 & 2.8 & & $\begin{array}{l}4.0 \\
3.1\end{array}$ & 3.0 & $\begin{array}{l}0.30 \\
5.0\end{array}$ & 4.3 \\
\hline $\begin{array}{l}25 \\
25\end{array}$ & 3 & -1.4 & 3.6 & 1.5 & -3.4 & 1.4 & 3.4 & & -3.2 & $\begin{array}{r}2.9 \\
2.5\end{array}$ & & $\begin{array}{r}3.9 \\
3.9\end{array}$ & 4.8 & 6.2 & 8.8 \\
\hline 25 & 6 & -1.3 & & 0.9 & & -0.7 & 2.6 & 0.6 & & 2.0 & & 2.3 & $\begin{array}{l}4.4 \\
2.6\end{array}$ & $\begin{array}{l}4.5 \\
3.1\end{array}$ & $\begin{array}{l}5.8 \\
3.4\end{array}$ \\
\hline $\begin{array}{l}25 \\
25 \\
25\end{array}$ & 12 & $\begin{array}{l}1.4 \\
5.2\end{array}$ & 1.3 & $\begin{array}{l}1.5 \\
5: 4 \\
\end{array}$ & 3.6 & $\left.\begin{array}{l}1.5 \\
5.5\end{array}\right]$ & $\begin{array}{l}1: 3 \\
1: 0\end{array}$ & $\begin{array}{l}1.4 \\
5.6\end{array}$ & 1.2 & $\begin{array}{l}3.5 \\
5.0 \\
5.0\end{array}$ & & $\begin{array}{l}0.0 .1 \\
11.02\end{array}$ & $\begin{array}{l}10.6 \\
12.0\end{array}$ & $\begin{array}{l}\frac{11.4}{13.4} \\
13.4\end{array}$ & $\begin{array}{l}11.9 \\
13.9\end{array}$ \\
\hline $\begin{array}{l}25 \\
25\end{array}$ & 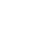 & 4.5 & 104 & 4.5 & 1.3 & $\begin{array}{l}4.5 \\
3.3\end{array}$ & 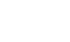 & $5: 1$ & 0.9 & $\begin{array}{r}40.0 \\
3.5\end{array}$ & & $\begin{array}{l}118.8 \\
6.07 \\
6.07\end{array}$ & $\begin{array}{l}12.88 \\
7.1\end{array}$ & $\begin{array}{l}14.6 \\
8.5\end{array}$ & $\begin{array}{l}15.4 \\
10.3\end{array}$ \\
\hline & & 320 & . & 3 & 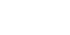 & 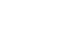 & 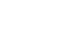 & & & 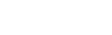 & & 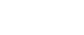 & $10 \%$ & . & 1508 \\
\hline 26 & & 2.5 & 0.4 & 2.7 & $=0.2$ & 2.7 & 0.6 & $\begin{array}{l}2.7 \\
2.7\end{array}$ & $=0.0$ & $\begin{array}{l}2.0 \\
2.1\end{array}$ & & $\begin{array}{l}1309 \\
11.5\end{array}$ & $\begin{array}{l}15.1 \\
12.2\end{array}$ & $\begin{array}{l}16.1 \\
13.03\end{array}$ & $\begin{array}{l}17: 5 \\
140.3\end{array}$ \\
\hline 26 & 9 & 6.8 & 2.7 & 7.3 & 3.1 & 7.7 & 3.1 & 8.3 & 3.4 & 3.7 & & $\begin{array}{l}16.6 \\
16.3\end{array}$ & $\begin{array}{l}130.6 \\
17.6\end{array}$ & $\begin{array}{l}140,5 \\
19.6\end{array}$ & $\begin{array}{l}15.6 \\
20.8\end{array}$ \\
\hline $\begin{array}{l}26 \\
26 \\
26\end{array}$ & $\begin{array}{l}12 \\
15\end{array}$ & $\begin{array}{l}12.7 \\
15.2\end{array}$ & $\begin{array}{l}6.2 \\
7.5 \\
6.5\end{array}$ & $\begin{array}{l}\begin{array}{l}14.0 \\
16.2\end{array} \\
10.2\end{array}$ & $\begin{array}{l}6.5 \\
7.8 \\
\end{array}$ & $\begin{array}{l}14.5 \\
16.7\end{array}$ & $\begin{array}{l}5.7 \\
8.0\end{array}$ & $\begin{array}{l}15.5 \\
18.0\end{array}$ & $\begin{array}{l}7.2 \\
8.5\end{array}$ & $\begin{array}{l}5.2 \\
5.6\end{array}$ & & $\begin{array}{l}17.0 \\
20.4\end{array}$ & $\begin{array}{l}18.6 \\
22.3\end{array}$ & $\begin{array}{l}21.5 \\
25.5\end{array}$ & $\begin{array}{l}23.1 \\
27.8\end{array}$ \\
\hline $\begin{array}{l}26 \\
26 \\
26\end{array}$ & $\begin{array}{l}\frac{18}{21} \\
21\end{array}$ & $\begin{array}{l}13.0 \\
12.0\end{array}$ & $\begin{array}{l}7: 1 \\
7: 6\end{array}$ & $\begin{array}{l}13.8 \\
13.5\end{array}$ & $\begin{array}{l}77.4 \\
7: 9\end{array}$ & $\begin{array}{l}14.7 \\
14.2\end{array}$ & $\begin{array}{l}7.7 \\
8: 1\end{array}$ & $\begin{array}{l}15.7 \\
15: 0\end{array}$ & $\begin{array}{l}8: 2 \\
8.5\end{array}$ & $\begin{array}{l}4.1 \\
3.9\end{array}$ & & $\begin{array}{l}\frac{16.7}{21.0} \\
2.5\end{array}$ & $\begin{array}{l}18.2 \\
23.3\end{array}$ & $\begin{array}{l}21.1 \\
26.5\end{array}$ & $\begin{aligned} 23.5 \\
28.8\end{aligned}$ \\
\hline $\begin{array}{l}27 \\
27\end{array}$ & 0 & 12.4 & $7: 1$ & 12.5 & 7.2 & 13.2 & $7 \cdot 3$ & 13.5 & 7.5 & 3.8 & & 17.7 & 19.4 & 2204 & 23.6 \\
\hline 27 & $\begin{array}{l}3 \\
6\end{array}$ & $\begin{array}{l}3.2 .2 \\
-2.5\end{array}$ & $\begin{array}{l}0.7 \\
2.9\end{array}$ & $\begin{array}{ll}3.2 \\
2.07 \\
2.7\end{array}$ & $\begin{array}{l}0.5 \\
3.3\end{array}$ & $\begin{array}{r}33: 0 \\
-3: 0\end{array}$ & $\begin{array}{l}\begin{array}{l}0.2 \\
3.6\end{array} \\
3.0\end{array}$ & $\begin{array}{r}2.9 \\
-3.3\end{array}$ & $\begin{array}{l}0.1 \\
3.5\end{array}$ & $\begin{array}{l}3.3 \\
3.1\end{array}$ & & $\begin{array}{l}12.3 \\
1404\end{array}$ & $\begin{array}{l}\begin{array}{l}4.3 \\
16.4\end{array}\end{array}$ & $\begin{array}{l}16.3 \\
10.0\end{array}$ & $\begin{array}{l}18.8 \\
19.9\end{array}$ \\
\hline $\begin{array}{l}27 \\
27\end{array}$ & $\begin{array}{r}99 \\
12\end{array}$ & $\begin{array}{l}=4.1 \\
-4.7\end{array}$ & & $\begin{array}{r}4.5 \\
4.9\end{array}$ & & {$\left[\begin{array}{r}4.8 \\
5.3\end{array}\right]$} & & $\begin{array}{r}-4.9 \\
-5.6\end{array}$ & & $\begin{array}{r}3.2 \\
2.8\end{array}$ & & $\begin{array}{l}16.4 \\
15.2\end{array}$ & $\begin{array}{l}18.4 \\
17.4\end{array}$ & $\begin{array}{l}\begin{array}{l}21.3 \\
2000\end{array} \\
\text { ? }\end{array}$ & $\begin{aligned} 22.0 \\
20.7\end{aligned}$ \\
\hline $\begin{array}{l}27 \\
27\end{array}$ & $\begin{array}{l}15 \\
18\end{array}$ & $=\begin{array}{r}5.0 \\
5.3\end{array}$ & & $\begin{array}{l}5.3 \\
5.5 \\
5.5\end{array}$ & & $\begin{array}{l}-5.4 \\
-5.7\end{array}$ & & {$\left[\begin{array}{r}5.7 \\
-5.9\end{array}\right.$} & & $\begin{array}{l}2.4 \\
2.1\end{array}$ & & $\begin{array}{l}12.2 \\
11: 7\end{array}$ & $\begin{array}{l}13.9 \\
13.3\end{array}$ & $\begin{array}{l}16.2 \\
15.04\end{array}$ & $\begin{array}{l}17 \bullet 8 \\
16: 2\end{array}$ \\
\hline 27 & 21 & & & 5.9 & & -6.1 & & -6.2 & & 1.8 & & 12.0 & 13.6 & 15.7 & 15.1 \\
\hline 28 & 3 & $-11: 0$ & & 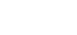 & & $=8.0$ & & $\begin{array}{r}-8.3 \\
-11.8\end{array}$ & & $\begin{array}{l}1.8 \\
1.5\end{array}$ & & 14.8 & 16.8 & 19.5 & 20.4 \\
\hline $\begin{array}{l}28 \\
28 \\
28\end{array}$ & $\begin{array}{l}6 \\
9\end{array}$ & $\begin{array}{l}-11,8 \\
-11,6\end{array}$ & & 1201 & & $\begin{array}{l}-12.3 \\
-12,5\end{array}$ & & $\begin{array}{l}-12.6 \\
-1320\end{array}$ & & 1.4 & & $\begin{array}{l}13.6 \\
14.6\end{array}$ & 15.4 & 17.8 & 18.6 \\
\hline 28 & 12 & $\begin{array}{l}-10.5 \\
-10.0\end{array}$ & & 11.2 & & $\begin{array}{l}-11.6 \\
-1116\end{array}$ & & $-11 \cdot 8$ & & 1.6 & & $\begin{array}{l}13.7 \\
13.5\end{array}$ & $\begin{array}{l}15.5 \\
15.5\end{array}$ & $\begin{array}{l}170 \\
1705\end{array}$ & 18.5 \\
\hline $\begin{array}{l}28 \\
28 \\
28\end{array}$ & $\begin{array}{l}18 \\
21 \\
21\end{array}$ & $\begin{array}{r}-12.0 \\
-13.2\end{array}$ & & $\begin{array}{l}12.2 \\
12.5 \\
1.5\end{array}$ & & $\begin{array}{r}-12.3 \\
-123 \\
-13\end{array}$ & & $\begin{array}{r}-12.5 \\
-13.8\end{array}$ & & 0.5 & & 11.8 & $\begin{array}{l}13.7 \\
14.5\end{array}$ & 15.9 & $\begin{array}{l}15.9 \\
1509\end{array}$ \\
\hline 29 & 0 & -14.3 & & 14.5 & & 14.77 & & & & & & & 13.6 & 150 & \\
\hline & & $\begin{array}{l}-15.2 \\
-160\end{array}$ & & $\begin{array}{c}15.5 \\
16.5\end{array}$ & & $\begin{array}{l}-15.7 \\
-15.5\end{array}$ & & & & & & 12.0 & 13.8 & 16.0 & 1601 \\
\hline $\begin{array}{l}29 \\
29\end{array}$ & 12 & $\begin{array}{l}-14 \cdot 3 \\
-10 ; 8\end{array}$ & & $\begin{array}{l}14: 5 \\
1.10 \\
1.5\end{array}$ & & $\begin{array}{l}-14.8 \\
-1118\end{array}$ & & $\begin{array}{r}-14: 9 \\
-1200\end{array}$ & & $\begin{array}{l}1.5 \\
2.3\end{array}$ & & $\begin{array}{l}12.3 \\
11.3\end{array}$ & $\begin{array}{l}14.4 \\
13.3\end{array}$ & $\begin{array}{l}16.8 \\
15.3\end{array}$ & $\begin{array}{l}18.7 \\
15.8\end{array}$ \\
\hline $\begin{array}{l}29 \\
29 \\
29\end{array}$ & $\begin{array}{l}15 \\
18\end{array}$ & $\begin{array}{l}-10,1 \\
-11,5\end{array}$ & & $\begin{array}{l}10.04 \\
10 \\
10.6\end{array}$ & & $\begin{array}{l}-10.0 \\
-10 \\
-10.7\end{array}$ & & $\begin{array}{l}-110.8 \\
-110.8 \\
-11.09\end{array}$ & & $\begin{array}{l}0.9 \\
0.01\end{array}$ & & $\begin{array}{r}10.4 \\
8.4\end{array}$ & 12.6 & 14.2 & 13.0 \\
\hline 29 & 21 & -12.6 & & 12.7 & & $\begin{array}{l}-12.0 \\
\end{array}$ & & -13.0 & & & & 8.1 & 10.6 & 12.8 & \\
\hline 30 & 0 & -13.5 & & 13.8 & & -13.9 & & -14.1 & & & & 9.2 & 11.6 & 13.6 & \\
\hline $\begin{array}{l}30 \\
30 \\
30\end{array}$ & 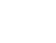 & $\begin{array}{l}-15.07 \\
-150 \\
-150\end{array}$ & & $\begin{array}{l}150 \\
15.3 \\
15\end{array}$ & & $\begin{array}{l}-15.1 \\
-15.4 \\
-15\end{array}$ & & $\begin{array}{l}-15.3 \\
-15.6\end{array}$ & & & & $\begin{array}{l}8: 9 \\
8: 0 \\
8: 0\end{array}$ & $\begin{array}{r}10.7 \\
9.8\end{array}$ & $\begin{array}{l}12.4 \\
11.04\end{array}$ & \\
\hline 30 & 12 & $\begin{array}{l}-11.02 \\
-1102\end{array}$ & & 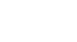 & & $\begin{array}{l}-14.44 \\
-12.2\end{array}$ & & $\begin{array}{l}-14.4 \\
-12.2 .2\end{array}$ & & $0.2^{2}$ & & $\begin{array}{l}781 \\
8.8 \\
8.8\end{array}$ & $\begin{array}{r}807 \\
10.1\end{array}$ & $\begin{array}{l}10.1 \\
11.5\end{array}$ & \\
\hline $\begin{array}{l}30 \\
30 \\
30\end{array}$ & $\begin{array}{l}18 \\
21\end{array}$ & $\begin{array}{l}-12.7 \\
-140\end{array}$ & & $\begin{array}{l}12.9 \\
14 \cdot 2\end{array}$ & & $\begin{array}{r}-13.1 \\
-13 \\
-14.4\end{array}$ & & $\begin{array}{r}-13.3 \\
-14.03\end{array}$ & & & & $\begin{array}{l}801 \\
8.7\end{array}$ & $\begin{array}{r}9.4 \\
10.0\end{array}$ & $\begin{array}{l}1009 \\
1106\end{array}$ & \\
\hline & & & & & & -140 & & & & & & & & & \\
\hline 31 & & -14.6 & & $\begin{array}{l}1407 \\
1450\end{array}$ & & -14.0 & & $\begin{array}{r}-15.1 \\
-15.1\end{array}$ & & & & & 10.2 & 11.7 & 13.4 \\
\hline 31 & & $\begin{array}{r}-11.9 \\
-110.9\end{array}$ & & $\begin{array}{l}12.3 \\
12.03\end{array}$ & & $\begin{array}{l}-12264 \\
-1-106\end{array}$ & & $\begin{array}{l}-12.06 \\
-1206\end{array}$ & & & & & $\begin{array}{l}1108 \\
13.11\end{array}$ & $\begin{array}{l}15.5 \\
15.0\end{array}$ & $\begin{array}{l}14.8 \\
15.6\end{array}$ \\
\hline $\begin{array}{l}31 \\
31\end{array}$ & $\begin{array}{l}12 \\
15 \\
15\end{array}$ & $\begin{array}{r}-10.0 \\
-9.3\end{array}$ & & $\begin{array}{c}10.3 \\
9.0\end{array}$ & & $\begin{array}{l}-10.6 \\
-9.8\end{array}$ & & $\begin{aligned}-10.7 \\
-9.9\end{aligned}$ & & $\begin{array}{l}1: 3 \\
1: 0\end{array}$ & & $\begin{array}{l}13.7 \\
14.97\end{array}$ & $\begin{array}{l}16.0 \\
16.7\end{array}$ & $\begin{array}{l}18.0 \\
18.9\end{array}$ & $\begin{array}{l}18.7 \\
19: 9\end{array}$ \\
\hline $\begin{array}{l}31 \\
32\end{array}$ & $\begin{array}{l}18 \\
21\end{array}$ & $\left|\begin{array}{l}-10.3 \\
-12.1\end{array}\right|$ & & $\begin{array}{l}20.5 \\
12.2 .3\end{array}$ & & $\begin{array}{l}-10.8 \\
-12.05\end{array}$ & & $\begin{array}{l}-11.0 \\
-12.6\end{array}$ & & & & $\begin{array}{l}15.0 \\
13.1\end{array}$ & $\begin{array}{l}17.1 \\
14.7\end{array}$ & $\begin{array}{l}19.3 \\
16.9\end{array}$ & $\begin{array}{l}20.7 \\
17.8\end{array}$ \\
\hline
\end{tabular}


TABLE 10

Table 10. -Three-hour averages of air and water-surface temperatures and wind directions and speed, April 1950-August 1951, Lake Hefner-Continued

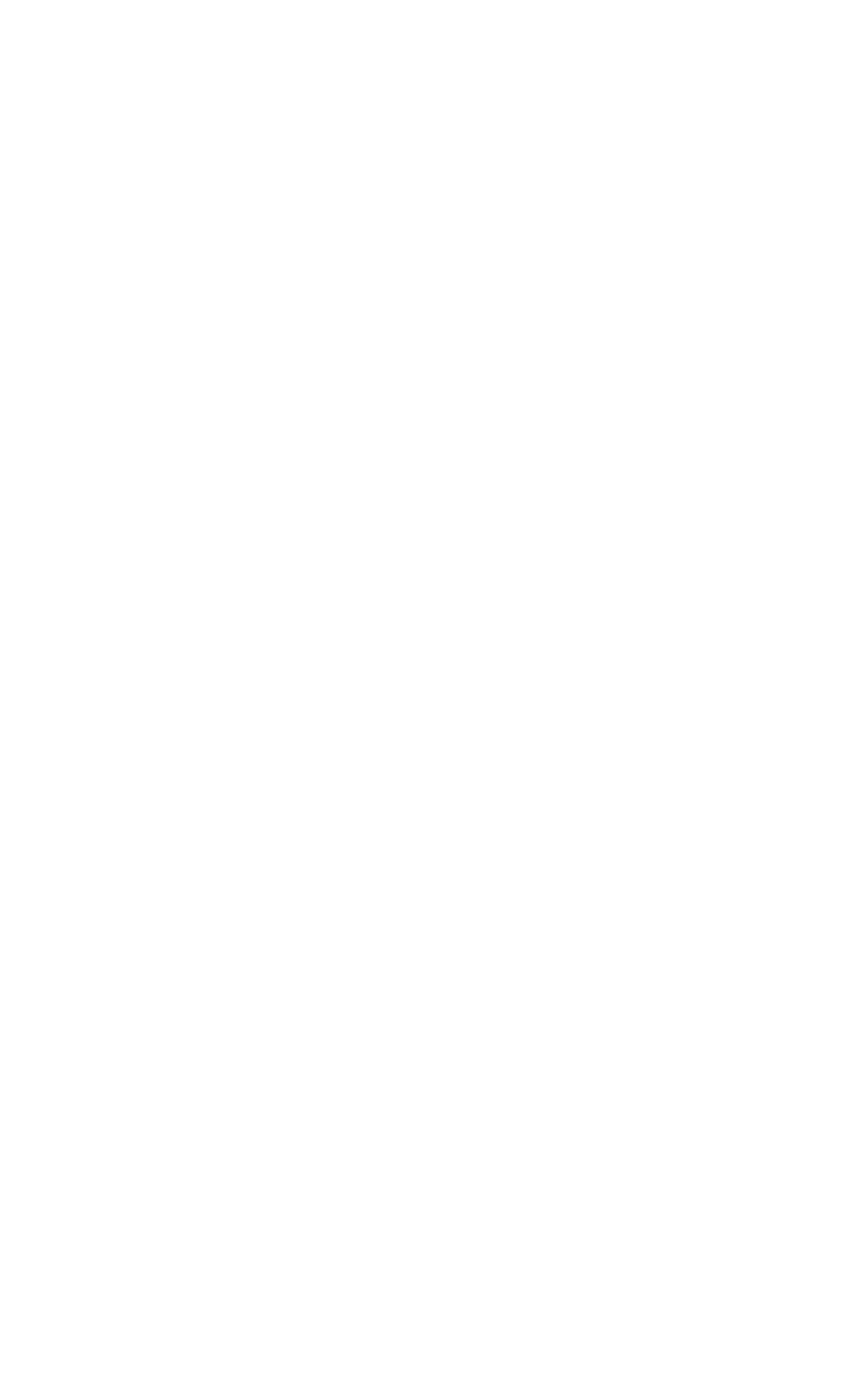


TABLE 10

Table 10. - Three-hour averages of air and water-surface temperatures and wind directions and speed, April 1950-August 1951, Lake Hefner Continued

THREE-HOURLY AVERAGES

FEBRUARY, 1951

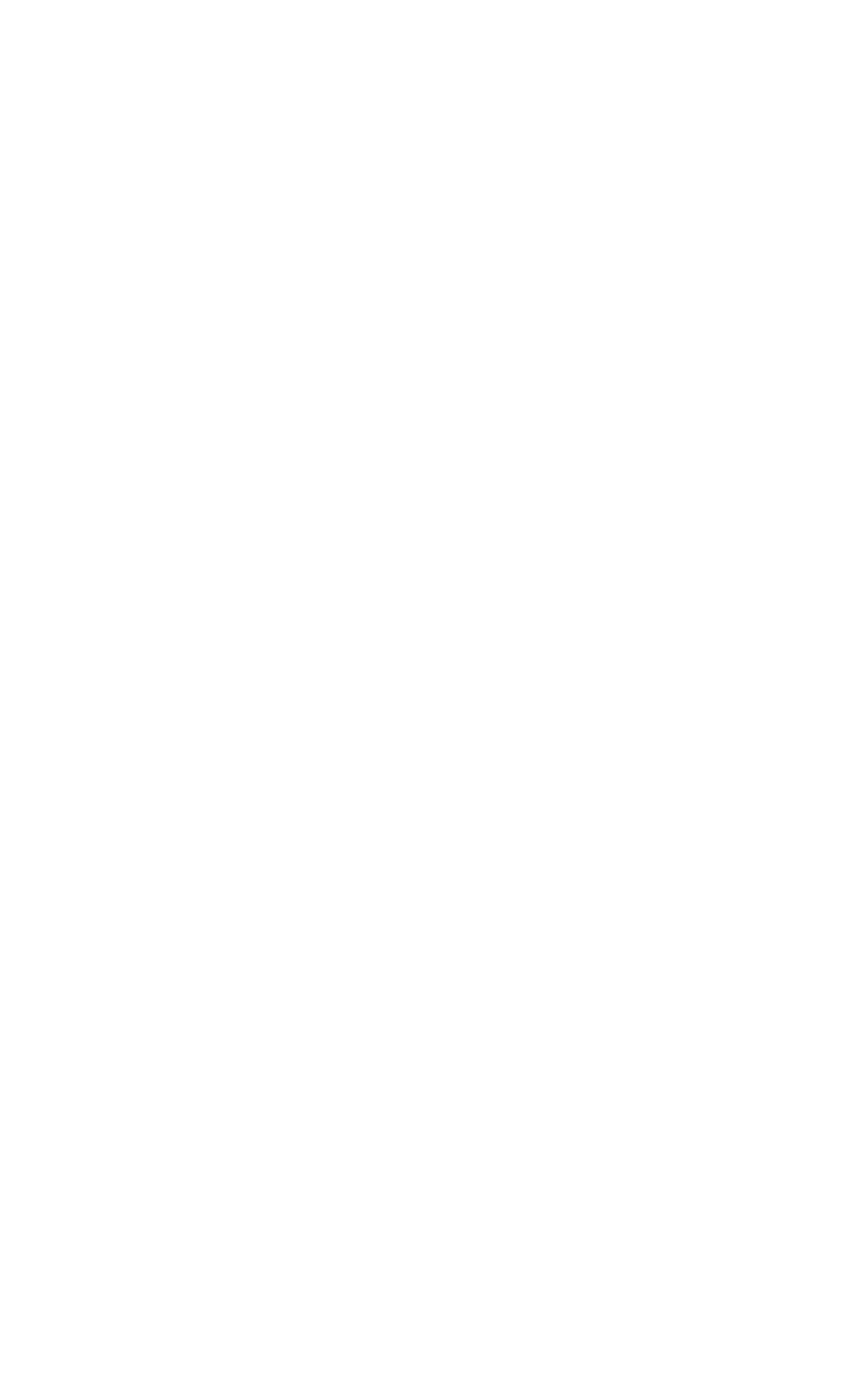


TABLE 10

Table 10. - Three-hour averages of air and water-surface temperatures and wind directions and speed, April 1950-August 1951, Lake Hefner-Continued

STATION

THREE-HOURLY AVERAGES

FEBRUARY, 1951

\begin{tabular}{|c|c|c|c|c|c|c|c|c|c|c|c|c|c|c|c|}
\hline \multirow{4}{*}{ 宽 } & \multirow{4}{*}{ 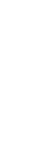 } & \multicolumn{8}{|c|}{ Average air temperature $\left({ }^{\circ} \mathrm{C}\right)$ at indicated height } & \multirow{4}{*}{$\begin{array}{l}\text { Average } \\
\text { water- } \\
\text { surface } \\
\text { tempera- } \\
\text { ture } \\
\left({ }^{\circ} \mathrm{C}\right)\end{array}$} & \multirow{4}{*}{$\begin{array}{c}\text { Average } \\
\text { wind } \\
\text { direction } \\
\text { (coded) }\end{array}$} & \multirow{2}{*}{\multicolumn{4}{|c|}{$\begin{array}{l}\text { Average wind speed (knots) } \\
\text { at indicated height }\end{array}$}} \\
\hline & & \multirow{2}{*}{\multicolumn{2}{|c|}{$\begin{array}{c}2 \\
\text { meters }\end{array}$}} & \multirow{2}{*}{\multicolumn{2}{|c|}{$\begin{array}{c}4 \\
\text { meters }\end{array}$}} & \multirow{2}{*}{\multicolumn{2}{|c|}{$\begin{array}{c}8 \\
\text { meters }\end{array}$}} & \multirow{2}{*}{\multicolumn{2}{|c|}{$\begin{array}{c}16 \\
\text { meters }\end{array}$}} & & & & & & \\
\hline & & & & & & & & & & & & 2 & 4 & 8 & 16 \\
\hline & & $\begin{array}{l}\text { Dry } \\
\text { bulb }\end{array}$ & & & & & & & & & & & & & \\
\hline
\end{tabular}

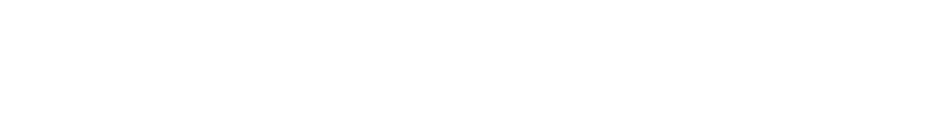

\begin{tabular}{l|l|l|l}
1.7 & 2.2 & 3.2 & 4.3
\end{tabular}

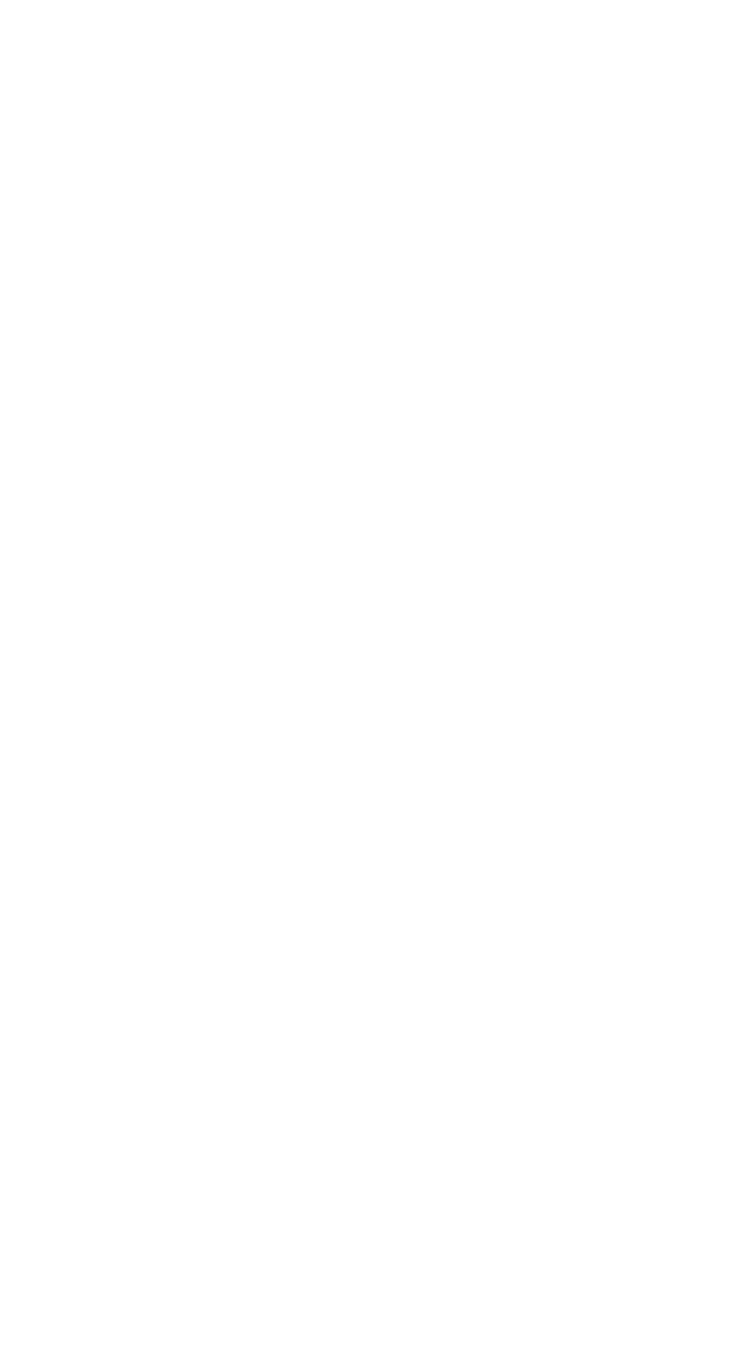

\begin{tabular}{|c|c|c|c|}
\hline $\begin{array}{l}1.7 \\
2.8 \\
1.0 \\
3.0 \\
5.2 \\
9.0 \\
5.2 \\
1.8\end{array}$ & $\begin{array}{r}2.2 \\
3.8 \\
1.4 \\
3.7 \\
6.0 \\
10.0 \\
6.0 \\
2.2\end{array}$ & $\begin{array}{r}3.2 \\
4.5 \\
1.8 \\
4.0 \\
6.5 \\
31.3 \\
6.6 \\
3.2\end{array}$ & $\begin{array}{r}4.3 \\
4.2 \\
2.0 \\
4.5 \\
7.2 \\
12.3 \\
7.5 \\
4.6\end{array}$ \\
\hline $\begin{array}{r}1.7 \\
1.6 \\
5.7 \\
11.5 \\
10.3 \\
10.3 \\
7.4 \\
6.3\end{array}$ & $\begin{array}{r}2.3 \\
2.3 \\
6.6 \\
12.7 \\
11.5 \\
11.8 \\
8.5 \\
7.4\end{array}$ & $\begin{array}{r}3.5 \\
3.4 \\
7.8 \\
14.5 \\
13.4 \\
14.1 \\
10.2 \\
6.9\end{array}$ & $\begin{array}{r}5.5 \\
5.2 \\
10.0 \\
16.1 \\
14.9 \\
15.6 \\
12.4 \\
11.4\end{array}$ \\
\hline $\begin{array}{r}7.3 \\
10.3 \\
10.0 \\
10.2 \\
12.1 \\
10.1 \\
8.5 \\
8.1\end{array}$ & $\begin{array}{r}8.6 \\
11.6 \\
11.4 \\
11.4 \\
13.5 \\
11.4 \\
9.7 \\
9.5\end{array}$ & $\begin{array}{l}10.0 \\
13.1 \\
12.6 \\
12.8 \\
14.8 \\
13.2 \\
11.0 \\
10.7\end{array}$ & $\begin{array}{l}12.3 \\
15.5 \\
14.8 \\
14.5 \\
17.2 \\
15.1 \\
13.0 \\
12.7\end{array}$ \\
\hline $\begin{array}{r}6.8 \\
7.1 \\
10.5 \\
12.9 \\
14.4 \\
13.2 \\
13.8 \\
15.6\end{array}$ & $\begin{array}{r}8.0 \\
8.2 \\
11.9 \\
14.3 \\
15.8 \\
14.6 \\
15.3 \\
17.0\end{array}$ & $\begin{array}{r}9.2 \\
9.2 \\
13.1 \\
15.7 \\
17.6 \\
16.6 \\
17.0 \\
19.0\end{array}$ & $\begin{array}{l}11.0 \\
11.0 \\
15.3 \\
18.3 \\
19.6 \\
18.8 \\
19.6 \\
21.5\end{array}$ \\
\hline $\begin{array}{r}14.7 \\
14.4 \\
12.1 \\
13.4 \\
15.8 \\
8.4 \\
5.3 \\
8.1\end{array}$ & $\begin{array}{r}16.2 \\
15.6 \\
13.4 \\
14.7 \\
17.1 \\
9.8 \\
6.3 \\
9.1\end{array}$ & $\begin{array}{r}18.3 \\
17.9 \\
15.3 \\
16.6 \\
10.7 \\
10.7 \\
7.6 \\
11.0\end{array}$ & $\begin{array}{r}20.9 \\
20.1 \\
17.3 \\
18.7 \\
21.6 \\
14.1 \\
8.8 \\
12.6\end{array}$ \\
\hline $\begin{array}{l}5.6 \\
6.7 \\
5.9 \\
4.9 \\
3.1 \\
1.6 \\
0.3 \\
0.3\end{array}$ & $\begin{array}{l}6.7 \\
8.3 \\
6.9 \\
5.6 \\
3.4 \\
1.8 \\
1.2 \\
1.3\end{array}$ & $\begin{array}{r}5.9 \\
10.1 \\
8.1 \\
6.4 \\
3.7 \\
1.9 \\
1.8 \\
? .1\end{array}$ & $\begin{array}{r}10.3 \\
12.0 \\
8.4 \\
6.9 \\
3.5 \\
2.0 \\
2.5 \\
3.1\end{array}$ \\
\hline $\begin{array}{r}1.4 \\
2.7 \\
4.6 \\
8.6 \\
11.7 \\
14.5 \\
9.9 \\
13.9\end{array}$ & $\begin{array}{r}2.3 \\
3.7 \\
5.6 \\
9.9 \\
13.2 \\
16.5 \\
11.3 \\
15.3\end{array}$ & $\begin{array}{r}3.2 \\
5.3 \\
6.8 \\
10.9 \\
14.7 \\
18.6 \\
12.7 \\
17.1\end{array}$ & $\begin{array}{r}5.2 \\
7.6 \\
9.2 \\
12.4 \\
16.8 \\
21.1 \\
15.2 \\
19.5\end{array}$ \\
\hline $\begin{array}{r}17.6 \\
14.6 \\
12.7 \\
14.6 \\
13.0 \\
8.8 \\
4.9 \\
0.8\end{array}$ & $\begin{array}{r}19.4 \\
16.3 \\
15.6 \\
16.8 \\
14.8 \\
10.4 \\
6.1 \\
1.5\end{array}$ & $\begin{array}{r}21.7 \\
18.8 \\
18.0 \\
18.0 \\
13.6 \\
11.7 \\
7.6 \\
1.9\end{array}$ & $\begin{array}{r}24.1 \\
20.7 \\
29.1 \\
20.3 \\
21.0 \\
15.6 \\
8.9 \\
3.0\end{array}$ \\
\hline
\end{tabular}


Table 10. -Three-hour averages of air and water-surface temperatures and wind directions and speed, April 1950-August 1951, Lake Hefner-Continued

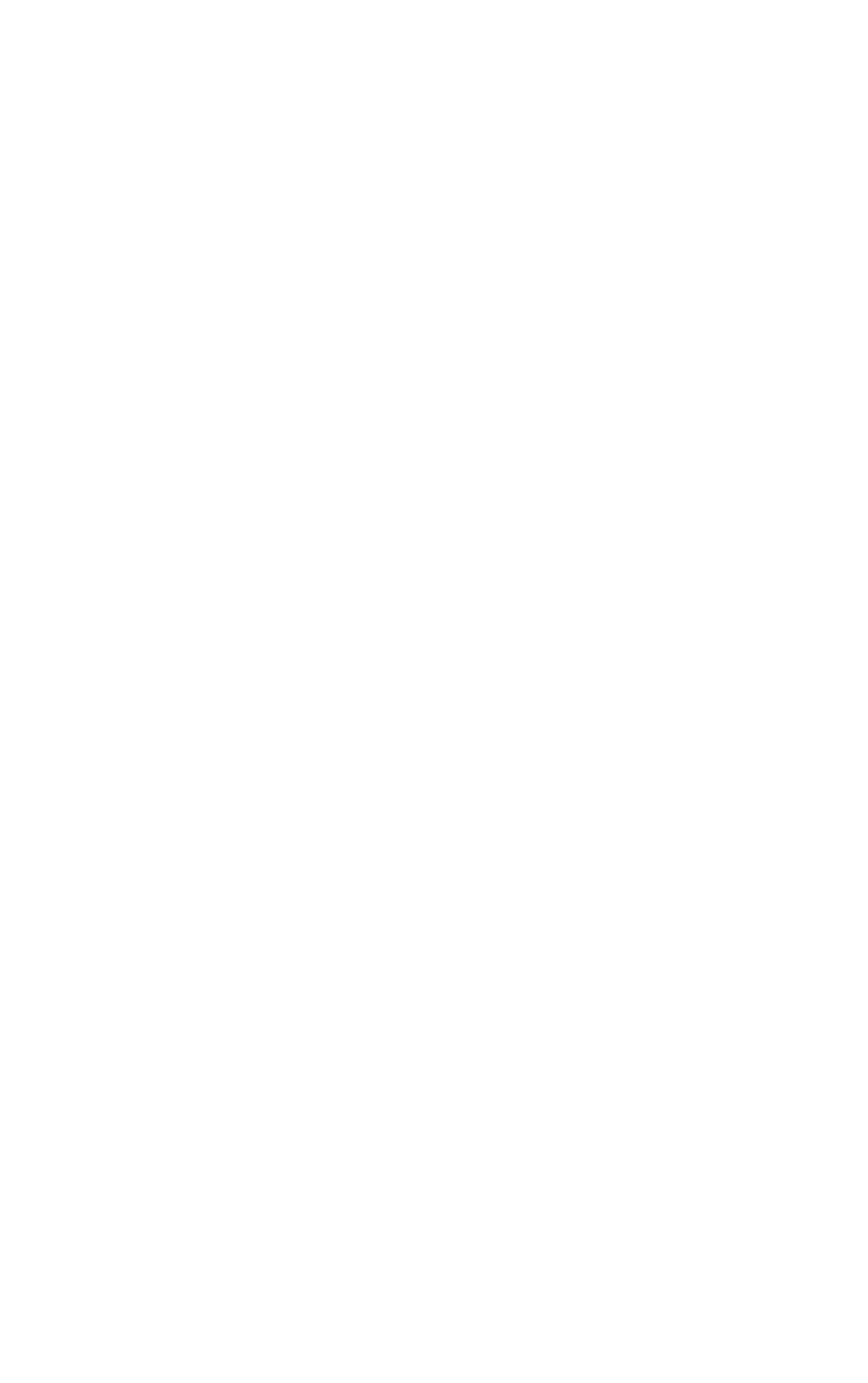


TABLE 10

Table 10. -Three-hour averages of air and water-surface temperatures and wind directions and speed, April 1950-August 1951, Lake Hefner-Continued

STATION 3 THREE-HOURLY AVERAGES

MARCH, 1951

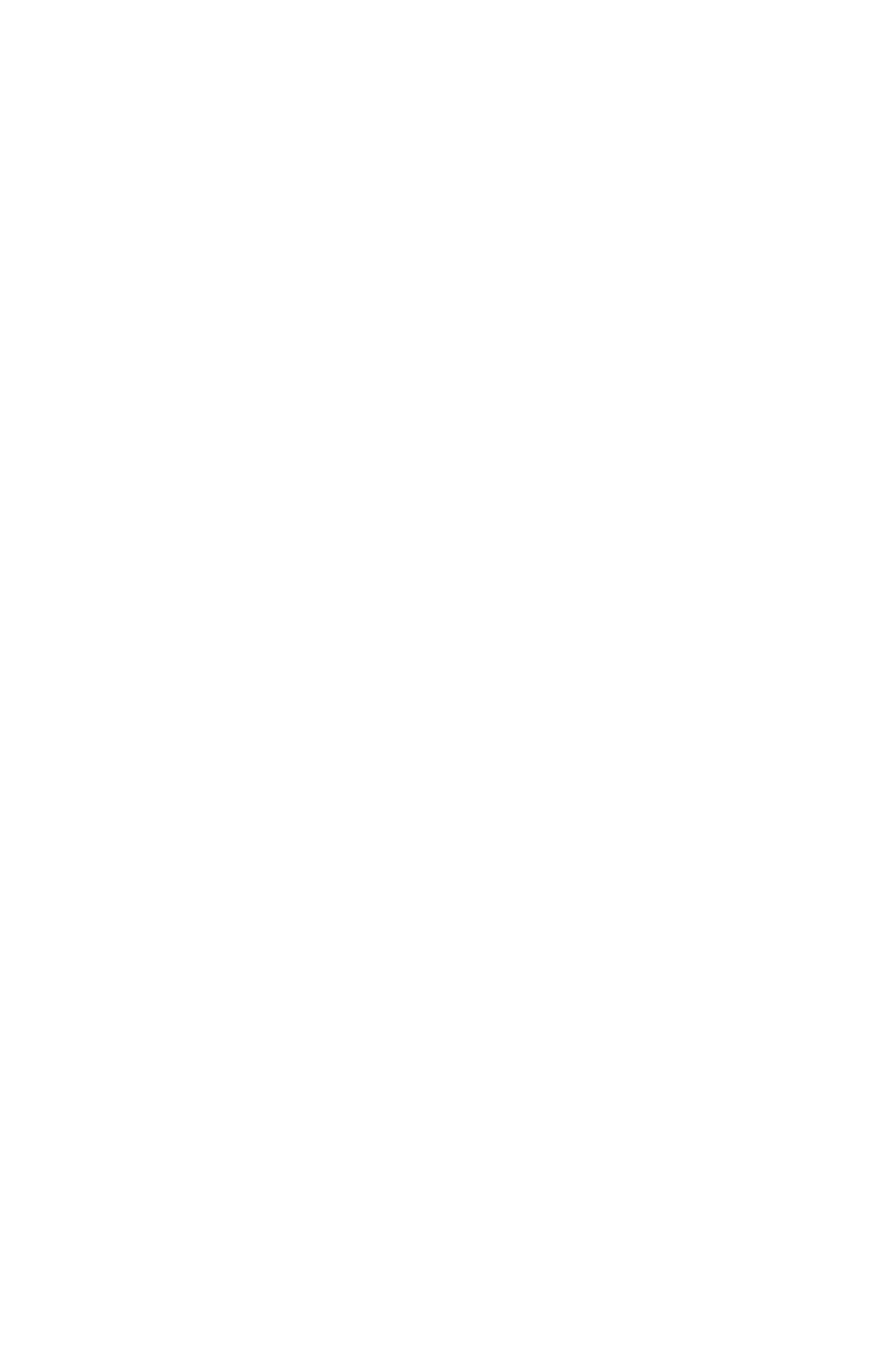


TABLE 10

Table 10. - Three-hour averages of air and water-surface temperatures and wind directions and speed, April 1950-August 1951, Lake Hefner-Continued

STATION 3 THREE-HOURLY AVERAGES

MARCH, 1951

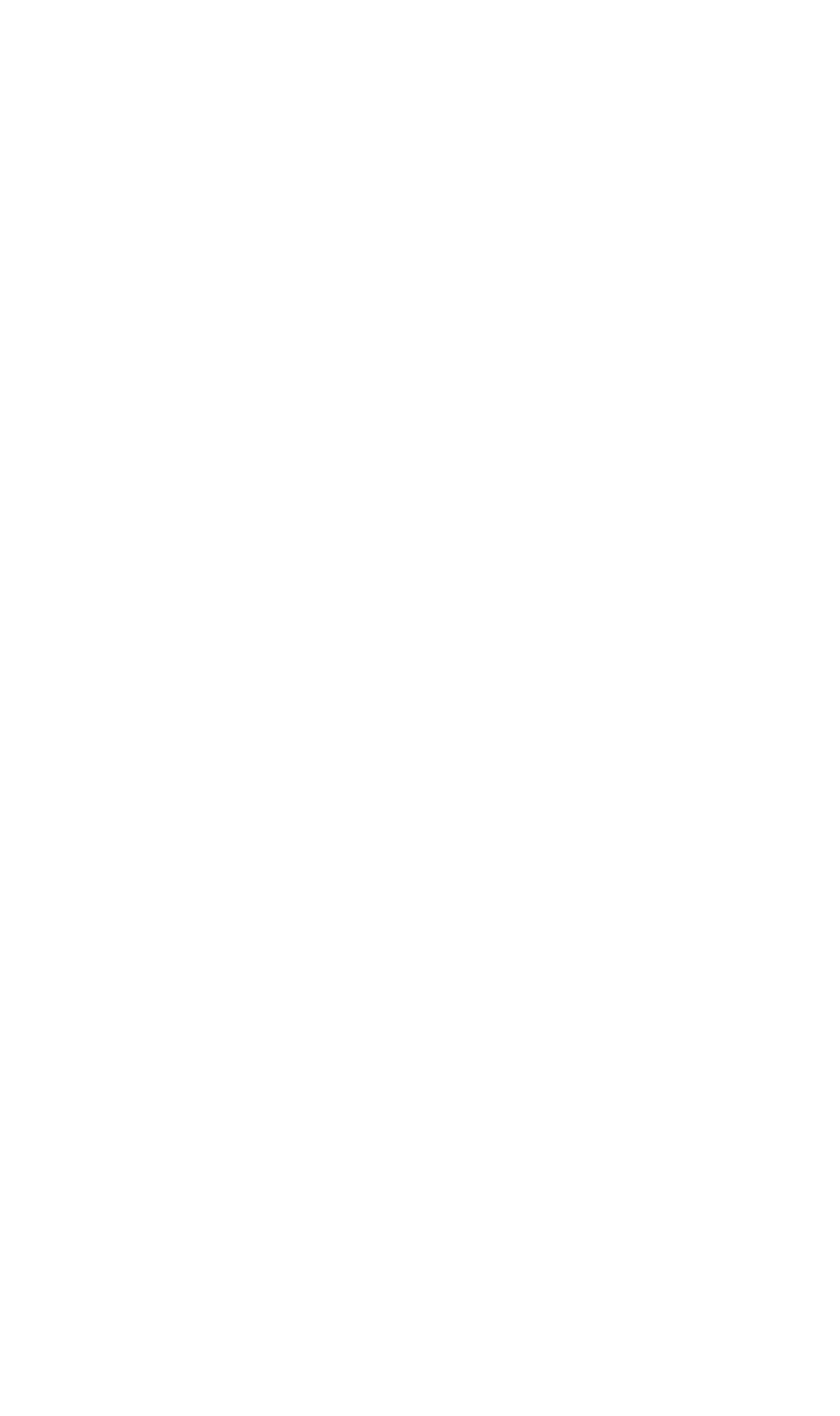


TABLE 10

Table 10.-Three-hour averages of air and water-surface temperatures and wind directions and speed, April 1950-August 1951, Lake Hefner-Continued

STATION 3

THREE-HOURLY AVERAGES

APRIL, 1951

\begin{tabular}{|c|c|c|c|c|c|c|c|c|c|c|c|c|c|c|c|}
\hline \multirow{3}{*}{ 胥 } & \multirow{3}{*}{ 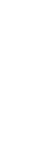 } & \multicolumn{8}{|c|}{ Average air temperature $\left({ }^{\circ} \mathrm{C}\right)$ at indicated height } & \multirow{3}{*}{$\begin{array}{l}\text { Average } \\
\text { water- } \\
\text { surface } \\
\text { tempera- } \\
\text { ture } \\
\left({ }^{\circ} \mathrm{C}\right)\end{array}$} & \multirow{3}{*}{$\begin{array}{c}\text { Average } \\
\text { wind } \\
\text { direction } \\
\text { (coded) }\end{array}$} & \multirow{2}{*}{\multicolumn{4}{|c|}{$\begin{array}{l}\text { Average wind speed (knots) } \\
\text { at indicated height }\end{array}$}} \\
\hline & & \multicolumn{2}{|c|}{$\begin{array}{c}2 \\
\text { meters }\end{array}$} & \multicolumn{2}{|c|}{$\begin{array}{c}4 \\
\text { meters }\end{array}$} & \multicolumn{2}{|c|}{$\begin{array}{c}8 \\
\text { meters }\end{array}$} & \multicolumn{2}{|c|}{$\begin{array}{c}16 \\
\text { meters }\end{array}$} & & & & & & \\
\hline & & $\begin{array}{l}\text { Dry } \\
\text { bulb }\end{array}$ & $\begin{array}{l}\text { Wet } \\
\text { bulb }\end{array}$ & $\begin{array}{l}\text { Dry } \\
\text { bulb }\end{array}$ & $\begin{array}{l}\text { Wet } \\
\text { bulb }\end{array}$ & $\begin{array}{l}\text { Dry } \\
\text { bulb }\end{array}$ & $\begin{array}{l}\text { Wet } \\
\text { bulb }\end{array}$ & $\begin{array}{l}\text { Dry } \\
\text { bulb }\end{array}$ & $\begin{array}{l}\text { Wet } \\
\text { bulb }\end{array}$ & & & meters & $\begin{array}{c}4 \\
\text { meters }\end{array}$ & meters & $\begin{array}{c}16 \\
\text { meters }\end{array}$ \\
\hline $\begin{array}{l}1 \\
1 \\
1 \\
1 \\
1 \\
1 \\
1 \\
1\end{array}$ & $\begin{array}{r}0 \\
3 \\
6 \\
9 \\
12 \\
15 \\
18 \\
21\end{array}$ & $\begin{array}{l}8.9 \\
8.5 \\
7.8 \\
6.7 \\
5.8 \\
6.0 \\
4.9 \\
4.1\end{array}$ & $\begin{array}{l}4.5 \\
4.1 \\
4.0 \\
3.7 \\
3.3 \\
3.8 \\
3.5 \\
3.0\end{array}$ & $\begin{array}{l}8.9 \\
8.6 \\
7.8 \\
6.5 \\
5.6 \\
6.0 \\
5.0 \\
4.1\end{array}$ & $\begin{array}{l}4.3 \\
4.0 \\
3.9 \\
3.4 \\
2.0 \\
3.7 \\
3.3 \\
3.0\end{array}$ & $\begin{array}{l}8.8 \\
8.5 \\
7.6 \\
6.5 \\
5.5 \\
5.9 \\
4.7 \\
4.0\end{array}$ & 3.3 & $\begin{array}{l}8.7 \\
8.4 \\
7.4 \\
6.2 \\
5.3 \\
5.8 \\
4.6 \\
4.0\end{array}$ & $\begin{array}{l}4.2 \\
3.9 \\
3.8 \\
3.3 \\
2.7 \\
3.4 \\
3.1 \\
2.8\end{array}$ & $\begin{array}{l}6.3 \\
6.1 \\
6.3 \\
6.6 \\
6.5 \\
6.3 \\
6.0 \\
5.6\end{array}$ & & $\begin{array}{r}7.8 \\
6.5 \\
8.1 \\
10.9 \\
14.3 \\
13.3 \\
10.7 \\
5.4\end{array}$ & $\begin{array}{r}10.1 \\
8.0 \\
10.4 \\
12.5 \\
16.6 \\
15.1 \\
12.9 \\
6.5\end{array}$ & $\begin{array}{r}11.7 \\
9.1 \\
12.0 \\
14.5 \\
18.7 \\
17.0 \\
15.2 \\
8.3\end{array}$ & $\begin{array}{r}12.0 \\
10.5 \\
8.7 \\
16.0 \\
19.5 \\
17.7 \\
16.5 \\
8.6\end{array}$ \\
\hline $\begin{array}{l}2 \\
2 \\
2 \\
2 \\
2 \\
2 \\
2 \\
2\end{array}$ & $\begin{array}{r}0 \\
3 \\
6 \\
9 \\
12 \\
15 \\
18 \\
21\end{array}$ & $\begin{array}{r}4.1 \\
2.3 \\
2.8 \\
7.9 \\
10.5 \\
11.1 \\
7.7 \\
5.1\end{array}$ & $\begin{array}{l}2.9 \\
1.5 \\
1.8 \\
3.4 \\
5.1 \\
6.0 \\
4.1 \\
3.2\end{array}$ & $\begin{array}{r}4.1 \\
2.2 \\
2.7 \\
7.4 \\
9.6 \\
10.5 \\
7.8 \\
5.8\end{array}$ & $\begin{array}{l}2.8 \\
1.5 \\
1.7 \\
3.2 \\
4.6 \\
5.3 \\
4.0 \\
3.5\end{array}$ & $\begin{array}{r}3.9 \\
2.1 \\
2.7 \\
7.3 \\
9.4 \\
10.1 \\
7.9 \\
6.1\end{array}$ & $\begin{array}{l}1.9 \\
2.8 \\
4.5 \\
5.0 \\
4.1 \\
3.7\end{array}$ & $\begin{array}{r}3.9 \\
2.0 \\
2.8 \\
7.3 \\
9.0 \\
10.0 \\
8.1 \\
6.2\end{array}$ & $\begin{array}{l}2.7 \\
1.2 \\
1.7 \\
2.6 \\
4.4 \\
5.0 \\
4.3 \\
3.8\end{array}$ & $\begin{array}{l}5.3 \\
4.9 \\
5.0 \\
7.3 \\
8.7 \\
8.2 \\
7.0 \\
6.8\end{array}$ & & $\begin{array}{r}7.8 \\
7.0 \\
6.3 \\
15.3 \\
12.8 \\
10.4 \\
3.4 \\
2.5\end{array}$ & $\begin{array}{r}9.4 \\
8.2 \\
8.1 \\
17.6 \\
14.5 \\
11.9 \\
4.4 \\
3.3\end{array}$ & $\begin{array}{r}11.1 \\
9.1 \\
10.5 \\
19.7 \\
16.4 \\
13.5 \\
5.6 \\
4.2\end{array}$ & $\begin{array}{r}11.8 \\
10.5 \\
9.7 \\
20.3 \\
16.9 \\
13.7 \\
5.9 \\
4.6\end{array}$ \\
\hline $\begin{array}{l}3 \\
3 \\
3 \\
3 \\
3 \\
3 \\
3 \\
3\end{array}$ & $\begin{array}{r}0 \\
3 \\
6 \\
9 \\
12 \\
15 \\
18 \\
21\end{array}$ & $\begin{array}{r}5.0 \\
3.5 \\
3.8 \\
12.3 \\
16.7 \\
17.2 \\
14.2 \\
12.6\end{array}$ & $\begin{array}{l}3.8 \\
2.2 \\
2.5 \\
6.6 \\
8.3 \\
9.0 \\
8.1 \\
6.6\end{array}$ & $\begin{array}{r}5.1 \\
3.3 \\
4.0 \\
12.0 \\
16.1 \\
16.6 \\
14.5 \\
12.9\end{array}$ & $\begin{array}{l}3.6 \\
1.9 \\
2.6 \\
6.5 \\
8.2 \\
8.1 \\
8.1 \\
6.5\end{array}$ & $\begin{array}{r}4.9 \\
2.9 \\
4.4 \\
12.2 \\
16.1 \\
17.7 \\
15.8 \\
13.7\end{array}$ & $\begin{array}{l}3.4 \\
1.7 \\
2.7 \\
6.4 \\
8.2 \\
8.0 \\
7.3 \\
6.6\end{array}$ & $\begin{array}{r}4.7 \\
3.1 \\
4.7 \\
12.4 \\
16.4 \\
17.7 \\
16.5 \\
14.3\end{array}$ & $\begin{array}{l}3.3 \\
1.9 \\
2.9 \\
6.9 \\
8.5 \\
8.2 \\
7.9 \\
6.9\end{array}$ & $\begin{array}{r}6.4 \\
6.0 \\
6.3 \\
8.7 \\
11.6 \\
11.8 \\
10.3 \\
8.1\end{array}$ & & $\begin{array}{l}4.7 \\
5.6 \\
4.4 \\
2.2 \\
2.6 \\
4.7 \\
3.0 \\
8.6\end{array}$ & $\begin{array}{l}4.6 \\
6.2 \\
4.7 \\
2.2 \\
2.9 \\
5.3 \\
4.1 \\
7.2\end{array}$ & $\begin{array}{l}5.2 \\
6.8 \\
5.3 \\
2.4 \\
3.0 \\
5.1 \\
5.9 \\
8.9\end{array}$ & $\begin{array}{r}4.9 \\
8.2 \\
4.6 \\
2.3 \\
3.1 \\
6.5 \\
7.4 \\
11.1\end{array}$ \\
\hline $\begin{array}{l}4 \\
4 \\
4 \\
4 \\
4 \\
4 \\
4 \\
4\end{array}$ & $\begin{array}{r}0 \\
3 \\
6 \\
9 \\
12 \\
15 \\
18 \\
21\end{array}$ & $\begin{array}{l}12.0 \\
11.1 \\
11.2 \\
15.8 \\
18.9 \\
19.8 \\
20.8 \\
19.5\end{array}$ & $\begin{array}{r}6.2 \\
6.1 \\
6.6 \\
9.3 \\
11.00 \\
111.4 \\
11.04 \\
11.05\end{array}$ & $\begin{array}{l}11.9 \\
11.2 \\
11.2 \\
15.7 \\
18.7 \\
20.1 \\
20.8 \\
19.4\end{array}$ & $\begin{array}{r}6.0 \\
6.0 \\
6.5 \\
9.1 \\
10.8 \\
11.4 \\
11.3 \\
11.5\end{array}$ & $\begin{array}{l}12.1 \\
11.5 \\
11.4 \\
16.4 \\
20.5 \\
21.8 \\
21.4 \\
19.9\end{array}$ & $\begin{array}{r}6.0 \\
6.1 \\
6.5 \\
9.5 \\
11.2 \\
12.0 \\
111.9 \\
12.1\end{array}$ & $\begin{array}{l}12.3 \\
11.5 \\
11: 5 \\
17: 1 \\
21: 1 \\
22.7 \\
21.08 \\
20.0\end{array}$ & $\begin{array}{r}6.2 \\
6.1 \\
6.5 \\
9.5 \\
11.6 \\
17.2 \\
11.7 \\
11.9\end{array}$ & $\begin{array}{l}7.1 \\
6: 9 \\
6.9 \\
8.1 \\
9.5 \\
8.8\end{array}$ & & $\begin{array}{r}9.0 \\
11.7 \\
16.0 \\
15.1 \\
12.9 \\
7.6 \\
7.0 \\
13.8\end{array}$ & $\begin{array}{r}10.1 \\
13.0 \\
17.2 \\
16.4 \\
14.3 \\
8.9 \\
8.2 \\
15.3\end{array}$ & $\begin{array}{r}11.3 \\
14.3 \\
18.7 \\
18.3 \\
16.2 \\
10.9 \\
9.5 \\
17.1\end{array}$ & $\begin{array}{l}13.6 \\
16.6 \\
20.5 \\
20.1 \\
17.6 \\
12.0 \\
11.5 \\
19.2\end{array}$ \\
\hline $\begin{array}{l}5 \\
5 \\
5 \\
5 \\
5 \\
5 \\
5 \\
5\end{array}$ & $\begin{array}{r}0 \\
3 \\
6 \\
9 \\
12 \\
15 \\
18 \\
21\end{array}$ & $\begin{array}{l}17.1 \\
13.0 \\
12.1 \\
12.5 \\
13.6 \\
17.6 \\
15.1 \\
14.4\end{array}$ & $\begin{array}{l}11.5 \\
10.8 \\
11.03 \\
11.9 \\
13.0 \\
15.0 \\
14.1 \\
12.6\end{array}$ & $\begin{array}{l}17.1 \\
12.4 \\
11.8 \\
12.4 \\
13.0 \\
17.0 \\
14.9 \\
14.5\end{array}$ & $\begin{array}{l}11.6 \\
10.7 \\
10.8\end{array}$ & $\begin{array}{l}17.6 \\
12.9 \\
12.1 \\
12.7 \\
13.6 \\
17.5 \\
15.1 \\
15.4\end{array}$ & $\begin{array}{l}11.9 \\
11: 0 \\
11.03 \\
12: 0 \\
13.1 \\
14.8 \\
14.1 \\
12.8\end{array}$ & $\begin{array}{l}17.7 \\
13.0 \\
12.3 \\
12.7 \\
13.5 \\
17.1 \\
15.1 \\
15.8\end{array}$ & $\begin{array}{l}11.8 \\
10.9 \\
11.4 \\
12.0 \\
12.9 \\
14.6 \\
14.0 \\
12.8\end{array}$ & & & $\begin{array}{r}18.0 \\
15.7 \\
17.8 \\
15.7 \\
13.8 \\
10.8 \\
9.0 \\
3.9\end{array}$ & $\begin{array}{r}19.7 \\
17.0 \\
19.9 \\
17.2 \\
15.4 \\
12.3 \\
10.7 \\
5.2\end{array}$ & $\begin{array}{r}21.5 \\
18.9 \\
21.3 \\
18.9 \\
17.0 \\
13.5 \\
12.4 \\
6.5\end{array}$ & $\begin{array}{r}24.3 \\
21.0 \\
24: 1 \\
21.5 \\
19.3 \\
15.4 \\
14.9 \\
7.9\end{array}$ \\
\hline $\begin{array}{l}6 \\
6 \\
6 \\
6 \\
6 \\
6 \\
6 \\
6\end{array}$ & $\begin{array}{r}0 \\
3 \\
6 \\
9 \\
12 \\
15 \\
18 \\
21\end{array}$ & $\begin{array}{l}12.2 \\
11.4 \\
10.8 \\
12.7 \\
14.6 \\
13.4 \\
11.6 \\
10.5\end{array}$ & $\begin{array}{r}11.6 \\
10.8 \\
10.1 \\
10.0 \\
10.4 \\
9.97 \\
9.3 \\
8.8\end{array}$ & $\begin{array}{l}11.9 \\
11.0 \\
10: 4 \\
12.0 \\
13.7 \\
12.8 \\
11.3 \\
10.4\end{array}$ & $\begin{array}{r}9.8 \\
10.0 \\
9.6 \\
9.1 \\
8.8\end{array}$ & $\begin{array}{l}12.4 \\
11.2 \\
10.4 \\
12.2 \\
13.7 \\
13.0 \\
11.6 \\
10.6\end{array}$ & $\begin{array}{r}11.9 \\
10.6 \\
9.7 \\
9.6 \\
9.8 \\
9.5 \\
0.1 \\
8.7\end{array}$ & $\begin{array}{l}12.5 \\
11 . ? \\
10.5 \\
12.2 \\
13.6 \\
13.0 \\
11.5 \\
10.6\end{array}$ & $\begin{array}{r}11.9 \\
10.5 \\
9.8 \\
9.3 \\
9.6 \\
9.3 \\
8.9 \\
8.6\end{array}$ & & & $\begin{array}{r}7.1 \\
8.5 \\
7.0 \\
8.8 \\
10.9 \\
10.3 \\
9.6 \\
8.5\end{array}$ & $\begin{array}{r}8.5 \\
10.6 \\
8.8 \\
10.6 \\
13.0 \\
12.4 \\
11.4 \\
10.2\end{array}$ & $\begin{array}{r}8.8 \\
14.7 \\
11.9 \\
14.6 \\
16.3 \\
15.1 \\
13.2 \\
11.8\end{array}$ & $\begin{array}{l}12.6 \\
14.9 \\
12.0 \\
15.3 \\
16.8 \\
15.3 \\
13.5 \\
12.2\end{array}$ \\
\hline $\begin{array}{l}7 \\
7 \\
7 \\
7 \\
7 \\
7 \\
7 \\
7\end{array}$ & $\begin{array}{r}0 \\
3 \\
6 \\
9 \\
12 \\
15 \\
18 \\
21\end{array}$ & $\begin{array}{r}8.3 \\
6.5 \\
7.0 \\
11.0 \\
12.6 \\
12.3 \\
9.8 \\
8.2\end{array}$ & $\begin{array}{l}7.3 \\
5.8 \\
5.9 \\
6.3 \\
6.9 \\
6.1 \\
4.4 \\
3.6\end{array}$ & $\begin{array}{r}8.2 \\
6.3 \\
5.8 \\
10.2 \\
11.6 \\
11.8 \\
9.6 \\
8.0\end{array}$ & $\begin{array}{l}7.2 \\
6.1 \\
6.0 \\
5.9 \\
6.3 \\
5.6 \\
4.1 \\
3.4\end{array}$ & $\begin{array}{r}8.3 \\
6.5 \\
7.2 \\
10.3 \\
11.5 \\
11.7 \\
9.7 \\
8.1\end{array}$ & $\begin{array}{l}7 \cdot 1 \\
5.7 \\
5 \cdot 7 \\
5.7 \\
5.2 \\
5.4 \\
3.9 \\
3.4\end{array}$ & $\begin{array}{r}8.2 \\
6.4 \\
7.3 \\
10.1 \\
11.2 \\
11.5 \\
9.5 \\
8.0\end{array}$ & $\begin{array}{l}7.0 \\
5.5 \\
5.5 \\
5.4 \\
5.9 \\
5.1 \\
3.8 \\
3.3\end{array}$ & & & $\begin{array}{r}7.2 \\
7.6 \\
12.0 \\
16.1 \\
14.2 \\
12.5 \\
7.4 \\
6.7\end{array}$ & $\begin{array}{r}8.7 \\
9.3 \\
14.1 \\
18.0 \\
16.5 \\
14.9 \\
9.5 \\
7.7\end{array}$ & $\begin{array}{l}12.1 \\
12.4 \\
16.0 \\
20.8 \\
19.6 \\
19.8 \\
12.3 \\
11.0\end{array}$ & $\begin{array}{l}11.9 \\
12.7 \\
16.6 \\
21.2 \\
20.2 \\
20.3 \\
14.1 \\
10.9\end{array}$ \\
\hline $\begin{array}{l}8 \\
8 \\
8 \\
8 \\
8 \\
8 \\
8 \\
8\end{array}$ & $\begin{array}{r}0 \\
3 \\
6 \\
9 \\
12 \\
15 \\
18 \\
21\end{array}$ & $\begin{array}{r}6.0 \\
4.7 \\
6.1 \\
10.4 \\
13.4 \\
14.5 \\
10.9 \\
7.9\end{array}$ & $\begin{array}{l}2.6 \\
1.9 \\
2.3 \\
3.9 \\
5.3 \\
9.5 \\
3.3 \\
3.1\end{array}$ & $\begin{array}{r}6.1 \\
4.7 \\
5.9 \\
9.7 \\
12.6 \\
13.9 \\
10.8 \\
8.1\end{array}$ & $\begin{array}{l}2.6 \\
1.9 \\
2.1 \\
3.6 \\
5.3 \\
5.8 \\
3.8 \\
3.0\end{array}$ & $\begin{array}{r}6.1 \\
4.7 \\
5.9 \\
9.5 \\
12.5 \\
14.0 \\
11.0 \\
8.2\end{array}$ & $\begin{array}{l}2.5 \\
1.7 \\
1.9 \\
3.3 \\
5.0 \\
5.7 \\
3.7 \\
3.0\end{array}$ & $\begin{array}{r}6.0 \\
4.5 \\
5.0 \\
9.4 \\
12.3 \\
13.8 \\
11.2 \\
8.2\end{array}$ & $\begin{array}{l}2 \cdot 3 \\
1.4 \\
1.7 \\
3.0 \\
4.7 \\
5.5 \\
3.7 \\
2.7\end{array}$ & $\begin{array}{l}6.1 \\
6.0 \\
6.7 \\
8.1 \\
9.1 \\
8.5 \\
7.9 \\
7.7\end{array}$ & & $\begin{array}{r}5.7 \\
10.5 \\
11.3 \\
12.0 \\
12.6 \\
11.3 \\
4.7 \\
3.6\end{array}$ & $\begin{array}{r}6.6 \\
11.8 \\
12.8 \\
14.6 \\
15.1 \\
23.8 \\
5.9 \\
4.1\end{array}$ & $\begin{array}{r}4.6 \\
13.7 \\
15.3 \\
18.6 \\
18.6 \\
18.0 \\
7.3 \\
4.2\end{array}$ & $\begin{array}{r}8.6 \\
13.1 \\
16.8 \\
22.0 \\
21.2 \\
19.7 \\
8.6 \\
6.2\end{array}$ \\
\hline $\begin{array}{l}9 \\
9 \\
9 \\
9 \\
9 \\
9 \\
9 \\
9\end{array}$ & $\begin{array}{r}0 \\
3 \\
6 \\
9 \\
12 \\
15 \\
18 \\
21\end{array}$ & $\begin{array}{r}7.0 \\
6.0 \\
6.6 \\
13.3 \\
15.7 \\
17.2 \\
13.2 \\
9.0\end{array}$ & $\begin{array}{l}3.2 \\
2.5 \\
2.6\end{array}$ & $\begin{array}{r}6.8 \\
6.0 \\
6.6 \\
12.2 \\
15.2 \\
16.5 \\
13.3 \\
9.7\end{array}$ & $\begin{array}{l}2.8 \\
2.1 \\
2.2 \\
4.6 \\
5.6 \\
5.5 \\
4.9 \\
3.4\end{array}$ & $\begin{array}{r}6.7 \\
5.9 \\
6.7 \\
11.9 \\
14.8 \\
16.4 \\
13.9 \\
10.3\end{array}$ & $\begin{array}{l}2.8 \\
1.7 \\
2.0 \\
4.2 \\
5.3 \\
5.3 \\
5.2 \\
3.9\end{array}$ & $\begin{array}{r}6.9 \\
5.7 \\
6.6 \\
11.9 \\
14.6 \\
16.3 \\
14.5 \\
11.2\end{array}$ & $\begin{array}{l}2.5 \\
1.5 \\
1.7 \\
4.7 \\
5.4 \\
6.4 \\
5.6 \\
4.3\end{array}$ & $\begin{array}{r}6.7 \\
6.7 \\
6.9 \\
9.7 \\
10.9 \\
8.7 \\
7.4 \\
7.8\end{array}$ & & $\begin{array}{l}6.8 \\
8.3 \\
7.8 \\
7.9 \\
9.1 \\
8.8 \\
3.8 \\
4.2\end{array}$ & $\begin{array}{r}7.4 \\
9.1 \\
9.0 \\
9.2 \\
10.7 \\
10.2 \\
4.9 \\
5.6\end{array}$ & $\begin{array}{r}8.7 \\
9.8 \\
10.2 \\
10.8 \\
12.8 \\
11.9 \\
6.5 \\
7.7\end{array}$ & $\begin{array}{r}8.7 \\
10.6 \\
11.3 \\
13.4 \\
14.0 \\
12.2 \\
8.2 \\
10.4\end{array}$ \\
\hline $\begin{array}{l}10 \\
10 \\
10 \\
10 \\
10 \\
10 \\
10 \\
10\end{array}$ & $\begin{array}{r}0 \\
3 \\
6 \\
9 \\
12 \\
15 \\
18 \\
21\end{array}$ & $\begin{array}{r}6.2 \\
6.7 \\
7.4 \\
11.7 \\
13.6 \\
8.0 \\
5.8 \\
5.1\end{array}$ & $\begin{array}{l}4 \cdot 9 \\
4.9 \\
5.0 \\
6.7 \\
8.2 \\
6.0 \\
4.9 \\
4 \cdot 0\end{array}$ & $\begin{array}{r}7.4 \\
6.8 \\
7.2 \\
11.5 \\
13.9 \\
7.7 \\
5.7 \\
5.0\end{array}$ & $\begin{array}{l}4 \cdot 5 \\
4.8 \\
4.9 \\
6.8 \\
8.0 \\
6.0 \\
4.7 \\
3.9\end{array}$ & $\begin{array}{r}7.7 \\
6.8 \\
7.2 \\
11.5 \\
13.6 \\
7.5 \\
5.77 \\
4.9\end{array}$ & $\begin{array}{l}4.7 \\
4.8 \\
4.8 \\
6.7 \\
7.9 \\
5.7 \\
4.8 \\
3.8\end{array}$ & $\begin{array}{r}7.6 \\
6.8 \\
7.3 \\
11.3 \\
13.2 \\
7.2 \\
5.7 \\
4.8\end{array}$ & $\begin{array}{l}4.8 \\
4.8 \\
5.0 \\
6.6 \\
7.5 \\
5.7 \\
4.8 \\
3.7\end{array}$ & $\begin{array}{l}7.6 \\
7.2 \\
8.0 \\
8.3 \\
9.3 \\
7.9 \\
6.7 \\
5.5\end{array}$ & & $\begin{array}{r}7.0 \\
6.3 \\
8.9 \\
9.6 \\
12.5 \\
17.3 \\
17.3 \\
16.5\end{array}$ & $\begin{array}{r}8.1 \\
7.5 \\
9.8 \\
11.2 \\
16.6 \\
20.3 \\
18.9 \\
18.4\end{array}$ & $\begin{array}{r}9.3 \\
8.8 \\
11.4 \\
13.4 \\
18.7 \\
23.3 \\
22.2 \\
20.9\end{array}$ & $\begin{array}{l}11.5 \\
10.7 \\
13.1 \\
14.7 \\
18.9 \\
22.0 \\
22.6 \\
22.0\end{array}$ \\
\hline
\end{tabular}


Table 10. - Three-hour averages of air and water-surface temperatures and wind directions and speed, April 1950-August 1951, Lake Hefner - Continued

STATION 3 THREE-HOURLY AVERAGES

APRIL, 1951

\begin{tabular}{|c|c|c|c|c|c|c|c|c|c|c|c|c|c|c|c|}
\hline \multirow{3}{*}{ 岳 } & \multirow{3}{*}{ 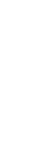 } & \multicolumn{8}{|c|}{ Average air temperature $\left({ }^{\circ} \mathrm{C}\right)$ at indicated height } & \multirow{3}{*}{$\begin{array}{l}\text { Average } \\
\text { water- } \\
\text { surface } \\
\text { tempera- } \\
\text { ture } \\
\left({ }^{\circ} \mathrm{C}\right)\end{array}$} & \multirow{3}{*}{$\begin{array}{l}\text { A verage } \\
\text { wind } \\
\text { direction } \\
\text { (coded) }\end{array}$} & \multirow{2}{*}{\multicolumn{4}{|c|}{$\begin{array}{l}\text { Average wind speed (knots) } \\
\text { at indicated height }\end{array}$}} \\
\hline & & \multicolumn{2}{|c|}{$\begin{array}{c}2 \\
\text { meters }\end{array}$} & \multicolumn{2}{|c|}{$\begin{array}{c}4 \\
\text { meters }\end{array}$} & \multicolumn{2}{|c|}{$\begin{array}{c}8 \\
\text { meters }\end{array}$} & \multicolumn{2}{|c|}{$\begin{array}{c}16 \\
\text { meters }\end{array}$} & & & & & & \\
\hline & & $\begin{array}{l}\text { Dry } \\
\text { bulb }\end{array}$ & $\begin{array}{l}\text { Wet } \\
\text { bulb }\end{array}$ & $\begin{array}{l}\text { Dry } \\
\text { bulb }\end{array}$ & $\begin{array}{l}\text { Wet } \\
\text { bulb }\end{array}$ & $\begin{array}{l}\text { Dry } \\
\text { bulb }\end{array}$ & $\begin{array}{l}\text { Wet } \\
\text { bulb }\end{array}$ & $\begin{array}{l}\text { Dry } \\
\text { bulb }\end{array}$ & $\begin{array}{l}\text { Wet } \\
\text { bulb }\end{array}$ & & & meters & meters & meters & meters \\
\hline $\begin{array}{l}11 \\
11 \\
11 \\
11 \\
11 \\
11 \\
11 \\
11\end{array}$ & $\begin{array}{r}0 \\
3 \\
6 \\
9 \\
12 \\
15 \\
18 \\
21\end{array}$ & $\begin{array}{l}4.3 \\
2.8 \\
2.5\end{array}$ & $\begin{array}{l}3.3 \\
1.6 \\
1.2\end{array}$ & $\begin{array}{l}4.2 \\
2.9 \\
2.6\end{array}$ & $\begin{array}{l}3.0 \\
1.6 \\
1.2\end{array}$ & $\begin{array}{l}4.2 \\
? .8 \\
2.6\end{array}$ & $\begin{array}{l}2.1 \\
1.4 \\
0.6\end{array}$ & $\begin{array}{l}6.0 \\
4.8 \\
2.8\end{array}$ & $\begin{array}{l}3.1 \\
1.4 \\
0.6\end{array}$ & $\begin{array}{l}8.0 \\
7.0 \\
6.4\end{array}$ & & $\begin{array}{r}10.6 \\
7.5 \\
11.7 \\
17.6 \\
16.0 \\
16.3 \\
8.2 \\
8.6\end{array}$ & $\begin{array}{r}12.2 \\
9.6 \\
14.6 \\
31.0 \\
19.1 \\
19.5 \\
9.9 \\
9.2\end{array}$ & $\begin{array}{l}13.9 \\
13.4 \\
19.8 \\
25.7 \\
23.5 \\
23.8 \\
13.0\end{array}$ & $\begin{array}{l}14.7 \\
12.9 \\
20.0 \\
26.1 \\
25.0 \\
24.6 \\
13.5 \\
11.8\end{array}$ \\
\hline $\begin{array}{l}12 \\
12 \\
12 \\
12 \\
12 \\
12 \\
12 \\
12\end{array}$ & $\begin{array}{r}0 \\
3 \\
6 \\
9 \\
12 \\
15 \\
18 \\
21\end{array}$ & $\begin{array}{r}2.0 \\
1.0 \\
2.5 \\
5.0 \\
8.2 \\
11.1 \\
9.5 \\
6.6\end{array}$ & $\begin{array}{r}-0.9 \\
-0.5 \\
1.4 \\
3.6 \\
5.4 \\
4.6 \\
3.2\end{array}$ & $\begin{array}{r}1.8 \\
0.9 \\
2.5 \\
4.5 \\
7.7 \\
10.6 \\
9.4 \\
6.6\end{array}$ & $\begin{array}{r}-0.3 \\
-0.8 \\
-0.2 \\
1.9 \\
3.2 \\
5.0 \\
4.5 \\
3.1\end{array}$ & $\begin{array}{r}1.5 \\
0.8 \\
2.3 \\
4.1 \\
7.3 \\
30.5 \\
4.4 \\
6.6\end{array}$ & $\begin{array}{l}1.1 \\
3.0 \\
4.8 \\
4.4 \\
3.0\end{array}$ & $\begin{array}{r}1.5 \\
0.5 \\
2.0 \\
3.8 \\
7.1 \\
10.3 \\
9.2 \\
6.5\end{array}$ & $\begin{array}{l}1.1 \\
3.4 \\
5.3 \\
4.5 \\
2.9\end{array}$ & $\begin{array}{l}6.6 \\
6.5 \\
7.1 \\
8.3 \\
8.9 \\
8.5 \\
7.0 \\
6.4\end{array}$ & & $\begin{array}{r}10.7 \\
11.44 \\
14.2 \\
15.5 \\
13.2 \\
11.0 \\
6.1 \\
7.1\end{array}$ & $\begin{array}{r}11.8 \\
12.0 \\
17.1 \\
19.0 \\
16.0 \\
14.8 \\
7.5 \\
7.7\end{array}$ & $\begin{array}{l}12.7 \\
20.7 \\
24.9 \\
21.0 \\
10.5 \\
13.0\end{array}$ & $\begin{array}{l}14.6 \\
17.5 \\
25.2 \\
26.3 \\
22.4 \\
20.5 \\
11.4 \\
10.4\end{array}$ \\
\hline $\begin{array}{l}13 \\
13 \\
13 \\
13 \\
13 \\
13 \\
13 \\
13\end{array}$ & $\begin{array}{r}0 \\
3 \\
6 \\
9 \\
12 \\
15 \\
18 \\
21\end{array}$ & $\begin{array}{r}5.1 \\
3.2 \\
4.4 \\
10.2 \\
13.9 \\
16.1 \\
14.0 \\
10.5\end{array}$ & $\begin{array}{l}2.0 \\
0.4 \\
1.5 \\
4.5 \\
5.7 \\
6.9 \\
5.9 \\
5.4\end{array}$ & $\begin{array}{r}5.0 \\
3.2 \\
4.9 \\
9.8 \\
13.0 \\
15.6 \\
14.3 \\
10.9\end{array}$ & $\begin{array}{l}1.7 \\
0.3 \\
1.5 \\
4.1 \\
5.2 \\
6.4 \\
6.4 \\
5.0\end{array}$ & $\begin{array}{r}4.9 \\
3.1 \\
4.9 \\
9.5 \\
12.8 \\
16.0 \\
15.7 \\
11.3\end{array}$ & $\begin{array}{l}1.5 \\
0.2 \\
1.5 \\
3.9 \\
4.8 \\
6.2 \\
6.3 \\
5.1\end{array}$ & 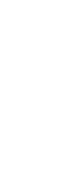 & $\begin{array}{l}1.5 \\
0.2 \\
1.3 \\
3.8 \\
4.6 \\
6.2 \\
6.4 \\
5.0\end{array}$ & $\begin{array}{r}6.1 \\
5.9 \\
6.7 \\
9.1 \\
10.8 \\
9.8 \\
8.2 \\
7.7\end{array}$ & & $\begin{array}{r}7.0 \\
8.2 \\
8.5 \\
10.0 \\
0.5 \\
5.8 \\
2.0 \\
6.1\end{array}$ & $\begin{array}{r}7.8 \\
6.7 \\
9.6 \\
12.0 \\
10.6 \\
6.6 \\
2.5 \\
6.7\end{array}$ & $\begin{array}{r}15.2 \\
14.9 \\
17.0 \\
6.9 \\
3.6 \\
8.4\end{array}$ & $\begin{array}{r}2.7 \\
9.4 \\
13.3 \\
17.4 \\
14.6 \\
8.9 \\
4.4 \\
10.7\end{array}$ \\
\hline $\begin{array}{l}14 \\
14 \\
14 \\
14 \\
14 \\
14 \\
14 \\
14\end{array}$ & $\begin{array}{r}0 \\
3 \\
6 \\
9 \\
12 \\
15 \\
18 \\
21\end{array}$ & $\begin{array}{l}10.7 \\
10.7 \\
12.9 \\
18.4 \\
22.2 \\
20.8 \\
16.4 \\
11.7\end{array}$ & $\begin{array}{r}5.7 \\
5.8 \\
6.4 \\
8.9 \\
11.4 \\
11.3 \\
9.2 \\
6.9\end{array}$ & $\begin{array}{l}10.9 \\
10.8 \\
13.0 \\
18.8 \\
22.4 \\
20.2 \\
16.4 \\
11.7\end{array}$ & $\begin{array}{r}5.4 \\
5.5 \\
6.0 \\
8.6 \\
10.9 \\
10.8 \\
8.9 \\
6.8\end{array}$ & $\begin{array}{l}11.1 \\
10.8 \\
13.6 \\
19.7 \\
22.5 \\
20.1 \\
16.4 \\
11.8\end{array}$ & $\begin{array}{r}5.3 \\
5.2 \\
6.0 \\
8.9 \\
10.9 \\
10.8 \\
9.0 \\
6.8\end{array}$ & $\begin{array}{l}11.7 \\
11 .: 7 \\
13.8 \\
20.5 \\
22.6 \\
20.1 \\
16.2 \\
11.7\end{array}$ & $\begin{array}{r}5.1 \\
5.1 \\
5.9 \\
8.8 \\
10.9 \\
10.8 \\
0.0 \\
6.8\end{array}$ & $\begin{array}{r}6.9 \\
6.8 \\
7.5 \\
9.4 \\
10.4 \\
0.2 \\
8.1 \\
7.8\end{array}$ & & $\begin{array}{r}13.3 \\
15.4 \\
19.3 \\
12.2 \\
9.7 \\
15.4 \\
11.8 \\
6.3\end{array}$ & $\begin{array}{r}14.2 \\
16.7 \\
20.5 \\
13.0 \\
11.5 \\
17.7 \\
13.2 \\
8.3\end{array}$ & $\begin{array}{l}15.5 \\
18.1 \\
23.5 \\
15.1 \\
13.5 \\
20.0 \\
15.4 \\
10.0\end{array}$ & $\begin{array}{l}17.2 \\
19.6 \\
24.1 \\
16.0 \\
14.1 \\
20.8 \\
15.6 \\
10.2\end{array}$ \\
\hline $\begin{array}{l}15 \\
15 \\
15 \\
15 \\
15 \\
15 \\
15 \\
15\end{array}$ & $\begin{array}{r}0 \\
3 \\
6 \\
9 \\
12 \\
15 \\
18 \\
21\end{array}$ & $\begin{array}{r}8.8 \\
6.9 \\
6.4 \\
10.1 \\
12.0 \\
11.2 \\
7.7 \\
4.3\end{array}$ & $\begin{array}{l}5.2 \\
3.4 \\
2.0 \\
3.6 \\
4.3 \\
3.9 \\
2.0 \\
0.6\end{array}$ & $\begin{array}{r}8.8 \\
6.8 \\
6.3 \\
9.3 \\
11.2 \\
10.6 \\
7.5 \\
4.4\end{array}$ & $\begin{array}{l}5.1 \\
3.2 \\
1.9 \\
3.3 \\
3.7 \\
3.5 \\
1.8 \\
0.6\end{array}$ & $\begin{array}{r}8.8 \\
6.8 \\
6.3 \\
9.1 \\
11.1 \\
10.4 \\
7.3 \\
4.7\end{array}$ & $\begin{array}{l}5.2 \\
3.2 \\
1.8 \\
3.3 \\
3.5 \\
3.4 \\
1.7 \\
0.5\end{array}$ & $\begin{array}{r}9.0 \\
6.6 \\
6 . ? \\
8: 9 \\
10.4 \\
10.0 \\
7.1 \\
4.8\end{array}$ & $\begin{array}{l}5.2 \\
3.0 \\
1.8 \\
3.1 \\
3.2 \\
3.2 \\
1.7 \\
0.6\end{array}$ & $\begin{array}{r}7.4 \\
7.5 \\
7.9 \\
9.4 \\
10.2 \\
9.6 \\
8.0 \\
7.8\end{array}$ & & $\begin{array}{r}4.9 \\
10.2 \\
11.6 \\
14.8 \\
13.9 \\
13.8 \\
9.9 \\
2.3\end{array}$ & $\begin{array}{r}6.3 \\
12.6 \\
14.6 \\
17.2 \\
16.4 \\
15.5 \\
10.9 \\
2.6\end{array}$ & $\begin{array}{r}7.7 \\
14.8 \\
16.9 \\
19.6 \\
19.8 \\
17.6 \\
12.4 \\
3.6\end{array}$ & $\begin{array}{r}9.1 \\
10.4\end{array}$ \\
\hline $\begin{array}{l}16 \\
16 \\
16 \\
16 \\
16 \\
16 \\
16 \\
16\end{array}$ & $\begin{array}{r}0 \\
3 \\
6 \\
9 \\
12 \\
15 \\
18 \\
21\end{array}$ & $\begin{array}{r}5.4 \\
3.9 \\
3.6 \\
6.9 \\
9.6 \\
12.1 \\
9.0 \\
4.9\end{array}$ & $\begin{array}{r}1.6 \\
-0.4 \\
-0.3 \\
1.4 \\
3.2 \\
4.0 \\
2.6 \\
0.5\end{array}$ & $\begin{array}{r}5.4 \\
3.9 \\
3.5 \\
6.5 \\
10.0 \\
11.7 \\
9.1 \\
5.7\end{array}$ & $\begin{array}{l}1.5 \\
0.4 \\
1.0 \\
2.6 \\
3.4 \\
2.4 \\
0.7\end{array}$ & $\begin{array}{r}5.5 \\
3.9 \\
3.6 \\
6.4 \\
9.6 \\
11.3 \\
9.5 \\
6.6\end{array}$ & $\begin{array}{r}-0.6 \\
0.6 \\
2.4 \\
3.4 \\
2.6 \\
1.2\end{array}$ & $\begin{array}{r}5.5 \\
3.8 \\
3.5 \\
6.5 \\
9.8 \\
11.3 \\
9.8 \\
7.1\end{array}$ & $\begin{array}{l}1.4 \\
0.2 \\
0.2 \\
0.8 \\
2.7 \\
3.8 \\
3.0 \\
1.6\end{array}$ & $\begin{array}{r}7.5 \\
7.2 \\
7.9 \\
9.7 \\
11.5 \\
10.6 \\
8.8 \\
8.1\end{array}$ & & $\begin{array}{l}3.1 \\
5.3 \\
4.6 \\
8.1 \\
8.9 \\
6.8 \\
3.2 \\
4.4\end{array}$ & $\begin{array}{l}3.7 \\
6.5 \\
5.2 \\
9.1 \\
9.9 \\
7.5 \\
3.9 \\
5.7\end{array}$ & $\begin{array}{r}4.3 \\
7.5 \\
6.2 \\
10.3 \\
11.3 \\
8.6 \\
5.0 \\
7.6\end{array}$ & $\begin{array}{l}8.0 \\
9.8\end{array}$ \\
\hline $\begin{array}{l}17 \\
17 \\
17 \\
17 \\
17 \\
17 \\
17 \\
17\end{array}$ & $\begin{array}{r}0 \\
3 \\
6 \\
9 \\
12 \\
15 \\
18 \\
21\end{array}$ & $\begin{array}{r}5.3 \\
6.0 \\
6.7 \\
13.2 \\
17.6 \\
16.9 \\
17.3 \\
15.8\end{array}$ & $\begin{array}{l}2.3 \\
1.8 \\
2.6 \\
6.1 \\
8.8 \\
9.7 \\
9.4 \\
8.9\end{array}$ & $\begin{array}{r}5.5 \\
6.1 \\
6.9 \\
13.3 \\
17.8 \\
18.8 \\
17.6 \\
16.0\end{array}$ & $\begin{array}{l}1.2 \\
1.6 \\
2.4 \\
5.6 \\
8.3 \\
9.2 \\
8.8 \\
8.4\end{array}$ & $\begin{array}{r}5.6 \\
6.0 \\
7.1 \\
13.6 \\
17.9 \\
19.1 \\
17.9 \\
16.3\end{array}$ & $\begin{array}{l}1.0 \\
1.2 \\
2.3 \\
5.5 \\
8.0 \\
9.1 \\
8.8 \\
8.4\end{array}$ & $\begin{array}{r}5.9 \\
5.9 \\
7.2 \\
14.0 \\
18.4 \\
19.7 \\
18.1 \\
16.4\end{array}$ & $\begin{array}{l}1.3 \\
1.4 \\
2.3 \\
5.7 \\
8.2 \\
0.3 \\
9.7 \\
8.7\end{array}$ & $\begin{array}{r}7.5 \\
7.1 \\
7.6 \\
10.4 \\
12.3 \\
11.3 \\
9.6 \\
8.9\end{array}$ & & $\begin{array}{r}5.9 \\
12.1 \\
14.8 \\
18.7 \\
18.1 \\
19.4 \\
14.9 \\
20.4\end{array}$ & $\begin{array}{r}6.8 \\
13.0 \\
15.9 \\
20.1 \\
19.5 \\
21.0 \\
16.3 \\
22.0\end{array}$ & $\begin{array}{r}8.1 \\
13.9 \\
16.9 \\
22.0 \\
21.6 \\
23.3 \\
18.2 \\
24.0\end{array}$ & $\begin{array}{l}10.5 \\
15.5 \\
18.0 \\
23.6 \\
23.4 \\
25.4 \\
20.5 \\
26.8\end{array}$ \\
\hline $\begin{array}{l}18 \\
18 \\
18 \\
18 \\
18 \\
18 \\
18 \\
18\end{array}$ & $\begin{array}{r}0 \\
3 \\
6 \\
9 \\
12 \\
15 \\
18 \\
21\end{array}$ & $\begin{array}{l}14.9 \\
14 \cdot 1 \\
14.5 \\
18.4 \\
22.2 \\
24.6 \\
28.9 \\
15.2\end{array}$ & $\begin{array}{r}9.1 \\
9.7 \\
11.0 \\
12.9 \\
13.4 \\
13.7 \\
12.7 \\
10.7\end{array}$ & $\begin{array}{l}15.1 \\
14.4 \\
14.7 \\
19.3 \\
24.9 \\
24.5 \\
18.8 \\
15.3\end{array}$ & $\begin{array}{r}8.8 \\
9.4 \\
11.0 \\
13.1 \\
13.3 \\
13.3 \\
12.5 \\
10.5\end{array}$ & $\begin{array}{l}15.4 \\
14.6 \\
15.0 \\
20.0 \\
76.1 \\
25.4 \\
18.9 \\
15.4\end{array}$ & $\begin{array}{r}8.8 \\
9.6 \\
11.2 \\
13.3 \\
13.5 \\
13.7 \\
12.5 \\
10.5\end{array}$ & $\begin{array}{l}15.6 \\
14.7 \\
15.4 \\
20.9 \\
26.9 \\
25.0 \\
18.0 \\
15.5\end{array}$ & $\begin{array}{r}9.0 \\
9.6 \\
11.4 \\
13.7 \\
13.8 \\
13.7 \\
12.5 \\
10.5\end{array}$ & $\begin{array}{r}8.3 \\
8.1 \\
8.8 \\
11.7 \\
14.1 \\
11.5 \\
9.5 \\
9.9\end{array}$ & & $\begin{array}{r}22.0 \\
21.9 \\
21.2 \\
15.1 \\
7.2 \\
7.2 \\
11.2 \\
9.0\end{array}$ & $\begin{array}{r}23.5 \\
23.6 \\
22.6 \\
16.6 \\
8.5 \\
8.5 \\
13.5 \\
10.6\end{array}$ & $\begin{array}{l}25.9 \\
25.7 \\
25.1 \\
19.1 \\
10.2 \\
10.2 \\
15.3 \\
12.0\end{array}$ & $\begin{array}{l}27.5 \\
27.9 \\
26.7 \\
20.0 \\
10.6 \\
11.5 \\
16.5 \\
13.2\end{array}$ \\
\hline $\begin{array}{l}19 \\
19 \\
19 \\
19 \\
19 \\
19 \\
19 \\
19\end{array}$ & $\begin{array}{r}0 \\
3 \\
6 \\
9 \\
12 \\
15 \\
18 \\
21\end{array}$ & $\begin{array}{r}12.2 \\
9.9 \\
10.9 \\
17.1 \\
22.4 \\
24.1 \\
19.8 \\
16.5\end{array}$ & $\begin{array}{r}9.2 \\
7.8 \\
8.2 \\
11.5 \\
14.4 \\
14.9 \\
13.6 \\
12.2\end{array}$ & $\begin{array}{l}12.4 \\
10.1 \\
11.1 \\
16.9 \\
22.0 \\
23.5 \\
19.9 \\
16.6\end{array}$ & $\begin{array}{r}9.1 \\
7.8 \\
7.9 \\
11: 1 \\
14: 0 \\
14: 6 \\
13.3 \\
12.0\end{array}$ & $\begin{array}{l}12.5 \\
10.2 \\
11.00 \\
16.7 \\
21.8 \\
23.2 \\
19.9 \\
16.9\end{array}$ & $\begin{array}{r}9.1 \\
7.8 \\
7.8 \\
11.1 \\
13.8 \\
14.4 \\
13.3 \\
12.1\end{array}$ & $\begin{array}{l}12.5 \\
10.4 \\
11.0 \\
16.6 \\
21.5 \\
23.0 \\
20.1 \\
17.0\end{array}$ & $\begin{array}{r}9.2 \\
7.8 \\
7.8 \\
11.1 \\
13.8 \\
14.4 \\
13.4 \\
12.2\end{array}$ & $\begin{array}{r}9.2 \\
8.5 \\
9.0 \\
10.9 \\
10.5 \\
9.1 \\
8.2 \\
8.2\end{array}$ & & $\begin{array}{l}6.0 \\
4.3 \\
6.2 \\
6.9 \\
7.0 \\
7.5 \\
5.4 \\
6.1\end{array}$ & $\begin{array}{l}7.0 \\
5.4 \\
7.6 \\
7.8 \\
7.9 \\
8.6 \\
6.5 \\
7.3\end{array}$ & $\begin{array}{l}8.3 \\
6.8 \\
8.7 \\
8.6 \\
8.8 \\
9.7 \\
8.1 \\
8.8\end{array}$ & $\begin{array}{r}7.8 \\
7.2 \\
9.8 \\
9.3 \\
10.0 \\
10.9 \\
10.3 \\
11.5\end{array}$ \\
\hline $\begin{array}{l}20 \\
20 \\
20 \\
20 \\
20 \\
20 \\
20 \\
20\end{array}$ & $\begin{array}{r}0 \\
3 \\
6 \\
9 \\
12 \\
15 \\
18 \\
21\end{array}$ & $\begin{array}{l}16 \cdot 6 \\
27 \cdot 5 \\
15.3 \\
23.2 \\
14.2\end{array}$ & $\begin{array}{l}11.5 \\
14.4 \\
14.9 \\
15.4 \\
15.9 \\
14.0 \\
12.6 \\
12.6\end{array}$ & $\begin{array}{l}14 \cdot 9 \\
16 \cdot 7 \\
16 \cdot 3 \\
16 \cdot 7 \\
17 \cdot 6 \\
15.1 \\
13.4 \\
14.2\end{array}$ & $\begin{array}{l}11.5 \\
14.3 \\
15.0 \\
15.2 \\
15.8 \\
13.9 \\
12.4 \\
12.5\end{array}$ & $\begin{array}{l}15.3 \\
16.8 \\
16.4 \\
16.7 \\
17.8 \\
15.5\end{array}$ & $\begin{array}{l}11: 7 \\
14: 5 \\
15.0 \\
15.2 \\
15.9 \\
14.3\end{array}$ & $\begin{array}{l}15.4 \\
16.9 \\
16.4 \\
16.6 \\
17.7 \\
15.4 \\
13.9 \\
14.7\end{array}$ & $\begin{array}{l}11.8 \\
14.6 \\
15.0 \\
15.2 \\
15.9 \\
14.3 \\
12.9 \\
12.8\end{array}$ & $\begin{array}{l}8.2 \\
7.7\end{array}$ & & $\begin{array}{r}6.7 \\
11.6 \\
9.6 \\
15.9 \\
17.3 \\
11.6 \\
7.0 \\
13.6\end{array}$ & $\begin{array}{r}8.0 \\
13.1 \\
11.4 \\
17.7 \\
19.3 \\
12.8 \\
7.7 \\
14.8\end{array}$ & $\begin{array}{r}9.6 \\
14.4 \\
12.6 \\
19.4 \\
21.2 \\
14.4 \\
9.1 \\
16.4\end{array}$ & $\begin{array}{r}12 \cdot 1 \\
17.0 \\
14 \cdot 8 \\
22.3 \\
24.2 \\
15.9 \\
8.2 \\
18.4\end{array}$ \\
\hline
\end{tabular}


TABLE 10

Table 10. - Three-hour averages of air and water-surface temperatures and wind directions and speed, April 1950-August 1951, Lake Hefner-Continued

STATION 3

THREE-HOURLY AVERAGES

APRIL, 1951

\begin{tabular}{|c|c|c|c|c|c|c|c|c|c|c|c|c|c|c|c|}
\hline \multirow{4}{*}{ 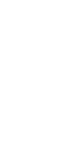 } & \multirow{4}{*}{ 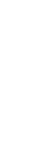 } & \multicolumn{8}{|c|}{ Average air temperature $\left({ }^{\circ} \mathrm{C}\right)$ at indicated height } & \multirow{4}{*}{\begin{tabular}{|c|} 
Average \\
water- \\
surface \\
tempera- \\
ture \\
$\left({ }^{\circ} \mathrm{C}\right)$
\end{tabular}} & \multirow{4}{*}{$\begin{array}{c}\text { Average } \\
\text { wind } \\
\text { direction } \\
\text { (coded) }\end{array}$} & \multirow{2}{*}{\multicolumn{4}{|c|}{$\begin{array}{l}\text { Average wind speed (knots) } \\
\text { at indicated height }\end{array}$}} \\
\hline & & \multirow{2}{*}{\multicolumn{2}{|c|}{$\begin{array}{c}2 \\
\text { meters }\end{array}$}} & \multirow{2}{*}{\multicolumn{2}{|c|}{$\begin{array}{c}4 \\
\text { meters }\end{array}$}} & \multirow{2}{*}{\multicolumn{2}{|c|}{$\begin{array}{c}8 \\
\text { meters }\end{array}$}} & \multirow{2}{*}{\multicolumn{2}{|c|}{$\begin{array}{c}16 \\
\text { meters }\end{array}$}} & & & & & & \\
\hline & & & & & & & & & & & & 2 & 4 & 8 & 16 \\
\hline & & $\begin{array}{l}\text { Dry } \\
\text { bulb }\end{array}$ & $\begin{array}{l}\text { Wet } \\
\text { bulb }\end{array}$ & $\begin{array}{l}\text { Dry } \\
\text { bulb }\end{array}$ & $\begin{array}{l}\text { Wet } \\
\text { bulb }\end{array}$ & $\begin{array}{l}\text { Dry } \\
\text { bulb }\end{array}$ & $\begin{array}{l}\text { Wet } \\
\text { bulb }\end{array}$ & $\begin{array}{l}\text { Dry } \\
\text { bulb }\end{array}$ & $\begin{array}{l}\text { Wet } \\
\text { bulb }\end{array}$ & & & meters & meters & meters & meters \\
\hline $\begin{array}{l}21 \\
21 \\
21 \\
21 \\
21 \\
21 \\
21 \\
21\end{array}$ & $\begin{array}{r}0 \\
3 \\
6 \\
5 \\
12 \\
15 \\
18 \\
21\end{array}$ & $\begin{array}{r}13.4 \\
12.1 \\
8.6 \\
8.5 \\
12.0 \\
15.2 \\
13.9 \\
10.0\end{array}$ & $\begin{array}{r}12.2 \\
11.7 \\
7.8 \\
6.9 \\
9.2 \\
11.1 \\
10.7 \\
8.2\end{array}$ & $\begin{array}{l}13.1 \\
12.8\end{array}$ & $\begin{array}{r}12.3 \\
11.6 \\
7.5 \\
6.6 \\
8.6 \\
10.6 \\
10.3 \\
8.0\end{array}$ & $\begin{array}{r}13.6 \\
12.4 \\
8.3 \\
8.1 \\
11.4 \\
14.8 \\
14.1 \\
9.9\end{array}$ & $\begin{array}{r}12.4 \\
11.8 \\
7.3 \\
6.4 \\
8.4 \\
10.2 \\
10.2 \\
8.0\end{array}$ & $\begin{array}{r}13.7 \\
12.5 \\
8.1 \\
8.0 \\
11.3 \\
14.8 \\
14.3 \\
9.9\end{array}$ & $\begin{array}{r}12.5 \\
11.9 \\
6.9 \\
6.2 \\
8.4 \\
10.0 \\
10.1 \\
7.9\end{array}$ & $\begin{array}{r}7.9 \\
9.3 \\
11.3 \\
10.9 \\
9.0 \\
8.1\end{array}$ & & $\begin{array}{r}13.5 \\
3.8 \\
10.0 \\
10.6 \\
8.1 \\
6.4 \\
3.7 \\
7.6\end{array}$ & $\begin{array}{r}14.6 \\
4.8 \\
12.7 \\
13.1 \\
9.7 \\
7.7 \\
4.6 \\
10.0\end{array}$ & $\begin{array}{r}16.2 \\
5.9 \\
18.4 \\
17.0 \\
12.3 \\
10.0 \\
5.5 \\
11.6\end{array}$ & $\begin{array}{r}17.9 \\
6.7 \\
18.4 \\
18.7 \\
13.3 \\
10.7 \\
6.2 \\
9.7\end{array}$ \\
\hline $\begin{array}{l}22 \\
22 \\
22 \\
22 \\
22 \\
22 \\
22 \\
22\end{array}$ & $\begin{array}{r}0 \\
3 \\
6 \\
9 \\
12 \\
15 \\
18 \\
21\end{array}$ & $\begin{array}{r}7.8 \\
6.9 \\
4 \cdot 3 \\
6.6 \\
10.3 \\
12.6 \\
10.5 \\
8.4\end{array}$ & $\begin{array}{l}6.7 \\
5.3 \\
2.2 \\
3.1 \\
5.1 \\
6.4 \\
5.8 \\
5.2\end{array}$ & $\begin{array}{l}4.8 \\
3.8 \\
6.1 \\
9.7\end{array}$ & $\begin{array}{l}6.6 \\
5.0 \\
2.1 \\
2.8 \\
4.5 \\
5.6 \\
5.5 \\
4.9\end{array}$ & $\begin{array}{r}7.9 \\
6.5 \\
4.0 \\
6.3 \\
9.9 \\
17.2 \\
10.8 \\
9.6\end{array}$ & $\begin{array}{l}6.6 \\
4.8 \\
2.0 \\
2.6 \\
4.2 \\
5.5 \\
5.5 \\
5.0\end{array}$ & $\begin{array}{r}7.9 \\
6.4 \\
3.8 \\
6.0 \\
9.9 \\
12.2 \\
11.1 \\
10.1\end{array}$ & $\begin{array}{l}6.5 \\
4 \cdot 9 \\
1.6 \\
2.3 \\
4.2 \\
5.4 \\
5.5 \\
4.9\end{array}$ & $\begin{array}{r}7.6 \\
7.8 \\
8.2 \\
9.6 \\
10.8 \\
9.6 \\
8.1 \\
8.0\end{array}$ & & $\begin{array}{r}10.9 \\
15.7 \\
15.6 \\
16.3 \\
12.5 \\
8.4 \\
2.3 \\
1.3\end{array}$ & $\begin{array}{r}12.8 \\
17.4 \\
17.3 \\
18.3 \\
14.6 \\
10.2 \\
2.9\end{array}$ & $\begin{array}{r}14.9 \\
20.0 \\
19.9 \\
20.9 \\
16.6 \\
11.7 \\
4.2 \\
2.1\end{array}$ & $\begin{array}{l}15.6 \\
20.6 \\
21.0 \\
22.8\end{array}$ \\
\hline $\begin{array}{l}23 \\
23 \\
23 \\
23 \\
23 \\
23 \\
23 \\
23\end{array}$ & $\begin{array}{r}0 \\
3 \\
6 \\
9 \\
12 \\
15 \\
18 \\
21\end{array}$ & $\begin{array}{r}7.1 \\
6.0 \\
8.3 \\
13.8 \\
17.1 \\
19.6 \\
17.3 \\
16.4\end{array}$ & $\begin{array}{r}4.6 \\
4.1 \\
5.1 \\
8.1 \\
11.1 \\
12.6 \\
11.9 \\
10.8\end{array}$ & $\begin{array}{r}7.4 \\
6.2 \\
8.5 \\
13.3 \\
16.7\end{array}$ & $\begin{array}{l}4 \cdot 5 \\
4 \cdot 0\end{array}$ & $\begin{array}{r}8.2 \\
6.4 \\
9.0 \\
13.6 \\
17.3 \\
20.1 \\
18.7 \\
16.7\end{array}$ & $\begin{array}{r}4.5 \\
3.9 \\
4.8 \\
8.0 \\
10.5 \\
12.1 \\
1.1 .5 \\
10.4\end{array}$ & $\begin{array}{r}8.5 \\
6.7 \\
8.8 \\
13.4 \\
17.5 \\
20.2 \\
19.0 \\
16.8\end{array}$ & $\begin{array}{r}4.9 \\
3.9 \\
5.0 \\
7.7 \\
10.5 \\
12.2 \\
11.5 \\
10.5\end{array}$ & 10.5 & & $\begin{array}{r}1.4 \\
3.4 \\
7.0 \\
13.7 \\
14.2 \\
16.6 \\
13.6 \\
16.2\end{array}$ & $\begin{array}{r}1.5 \\
3.9 \\
7.7 \\
14.6 \\
15.7 \\
18.0 \\
14.7 \\
17.7\end{array}$ & $\begin{array}{r}1.7 \\
4.7 \\
8.5 \\
16.0 \\
17.3 \\
20.0 \\
16.5 \\
19.3\end{array}$ & $\begin{array}{r}2.2 \\
6.3 \\
10.1 \\
17.1 \\
18.8 \\
22.1 \\
18.5 \\
21.8\end{array}$ \\
\hline $\begin{array}{l}24 \\
24 \\
24 \\
24 \\
24 \\
24 \\
24 \\
24\end{array}$ & $\begin{array}{r}0 \\
3 \\
6 \\
9 \\
12 \\
15 \\
18 \\
21\end{array}$ & $\begin{array}{l}15 \cdot 1 \\
14 \cdot 2 \\
14.8 \\
19 \cdot 2 \\
23 \cdot 8 \\
25.4 \\
23.4 \\
22.9\end{array}$ & $\begin{array}{l}10.7 \\
10.2 \\
11.5 \\
14.4 \\
15.5 \\
16.0 \\
15.7 \\
15.7\end{array}$ & $\begin{array}{l}15.0 \\
14.0 \\
14.8 \\
18.7\end{array}$ & & $\begin{array}{l}15.4 \\
14.4 \\
15.3 \\
20.3 \\
24.7 \\
26.6 \\
25.1 \\
23.5\end{array}$ & $\begin{array}{r}10.1 \\
9.9 \\
11.5 \\
14.3 \\
15.7 \\
16.0 \\
15.9 \\
15.6\end{array}$ & $\begin{array}{l}15 \cdot 5 \\
14: 5 \\
15: 5 \\
20: 7 \\
25: 4 \\
27.4 \\
25.5 \\
24 \cdot 0\end{array}$ & $\begin{array}{r}10.1 \\
9.9 \\
11.5 \\
14.5 \\
15.8\end{array}$ & & & $\begin{array}{l}20.5 \\
20.3 \\
24.0 \\
23.3 \\
25.3 \\
22.8 \\
16.1 \\
24.3\end{array}$ & $\begin{array}{l}22.0 \\
21.5 \\
25.7 \\
25.2 \\
27.2 \\
24.6 \\
17.9 \\
26.0\end{array}$ & $\begin{array}{l}24.1 \\
23.3 \\
28.0 \\
28.0 \\
30.5 \\
27.7 \\
20.2 \\
29.3\end{array}$ & $\begin{array}{l}26.6 \\
25.6 \\
30.2 \\
30.5 \\
33.0 \\
30.4 \\
22.5 \\
32.1\end{array}$ \\
\hline $\begin{array}{l}25 \\
25 \\
25 \\
25 \\
25 \\
25 \\
25 \\
25\end{array}$ & $\begin{array}{r}0 \\
3 \\
6 \\
9 \\
12 \\
15 \\
18 \\
21\end{array}$ & $\begin{array}{l}20.5 \\
16.3 \\
12.0 \\
15.8 \\
18.1 \\
17.5 \\
16.7 \\
15.2\end{array}$ & $\begin{array}{l}15.5 \\
13.5 \\
10.1 \\
11.9 \\
12.9 \\
12.9 \\
12.9 \\
12.0\end{array}$ & $11 \cdot ?$ & $\begin{array}{l}15 \cdot 6 \\
12 \cdot 8 \\
10 \bullet 1 \\
11 \cdot 9 \\
12 \cdot 9 \\
12 \bullet 8 \\
12 \bullet 9 \\
11.9\end{array}$ & $\begin{array}{l}21.0 \\
15.7 \\
11.6 \\
15.1 \\
17.2 \\
17.3 \\
16.9 \\
15.2\end{array}$ & $\begin{array}{r}15.6 \\
12.8 \\
9.9 \\
11.6 \\
12.6 \\
12.7 \\
12.9 \\
11.8\end{array}$ & $\begin{array}{l}21.5 \\
15.0 \\
11.5 \\
15.0 \\
17.0 \\
17.7 \\
16.8 \\
15.1\end{array}$ & $\begin{array}{l}12.04 \\
12.6 \\
12.8 \\
11.8\end{array}$ & & & $\begin{array}{r}21.3 \\
13.3 \\
10.7 \\
8.6 \\
7.7 \\
7.2 \\
3.7 \\
4.8\end{array}$ & $\begin{array}{r}23.0 \\
15.2 \\
12.8 \\
9.7 \\
8.8 \\
8.9 \\
4.6 \\
5.6\end{array}$ & $\begin{array}{r}25.4 \\
17.7 \\
15.4 \\
11.1 \\
10.2 \\
10.2 \\
5.7 \\
6.6\end{array}$ & $\begin{array}{r}27.6 \\
19.9 \\
15.5 \\
11.0 \\
9.8 \\
9.0 \\
6.1 \\
7.5\end{array}$ \\
\hline $\begin{array}{l}26 \\
26 \\
26 \\
26 \\
26 \\
26 \\
26 \\
26\end{array}$ & $\begin{array}{r}0 \\
3 \\
6 \\
9 \\
12 \\
15 \\
18 \\
21\end{array}$ & $\begin{array}{r}12.2 \\
3.8 \\
11.5 \\
18.9 \\
23.7 \\
24.4 \\
22.4 \\
20.6\end{array}$ & $\begin{array}{r}10.3 \\
9.1 \\
10.0 \\
14.2 \\
17.3 \\
17.0 \\
18.0 \\
18.2\end{array}$ & & $\begin{array}{r}10.3 \\
9.1 \\
9.9 \\
14.1 \\
17.2 \\
17.7 \\
18.0 \\
18.2\end{array}$ & $\begin{array}{r}12.1 \\
9.8 \\
11.6 \\
18.0 \\
23.3 \\
25.1 \\
22.7 \\
20.9\end{array}$ & $\begin{array}{r}10.2 \\
9.0 \\
10.1 \\
14 \cdot 3 \\
17.1 \\
17.9 \\
18.1 \\
18.3\end{array}$ & $\begin{array}{r}12.2 \\
9.9 \\
11.6 \\
17.8 \\
23.1 \\
24.9 \\
22.7 \\
21.0\end{array}$ & $\begin{array}{r}10.2 \\
9.0 \\
10.1 \\
14.2 \\
17.1 \\
17.9 \\
18.2 \\
18.4\end{array}$ & $\begin{array}{l}12.3 \\
13.8 \\
14.8 \\
14.0 \\
13.2 \\
12.9\end{array}$ & & $\begin{array}{r}3.0 \\
3.4 \\
5.0 \\
5.5 \\
7.1 \\
12.1 \\
11.9 \\
13.8\end{array}$ & $\begin{array}{r}3.7 \\
4.0 \\
5.8 \\
6.1 \\
7.7 \\
13.5 \\
13.2 \\
15.3\end{array}$ & $\begin{array}{r}4.9 \\
4.9 \\
6.6 \\
6.7 \\
8.5 \\
14.8 \\
14.7 \\
17.0\end{array}$ & $\begin{array}{r}6.3 \\
5.9 \\
7.3 \\
7.3 \\
9.3 \\
17.0 \\
16.8 \\
10.4\end{array}$ \\
\hline $\begin{array}{l}27 \\
27 \\
27 \\
27 \\
27 \\
27 \\
27 \\
27\end{array}$ & $\begin{array}{r}0 \\
3 \\
6 \\
9 \\
12 \\
15 \\
18 \\
21\end{array}$ & $\begin{array}{l}19 \cdot 3 \\
17.9 \\
18 \cdot 1 \\
21.2 \\
24 \cdot 3 \\
25.5 \\
23.6 \\
21.3\end{array}$ & $\begin{array}{l}17.5 \\
16.4 \\
16.3 \\
17.5 \\
17.5 \\
17.8 \\
17.9 \\
17.3\end{array}$ & $\begin{array}{l}18.3 \\
21.4 \\
24.7 \\
25.9 \\
24.0 \\
21.7\end{array}$ & $\begin{array}{l}17.4 \\
16.5 \\
16.5 \\
17.6 \\
17.5 \\
17.8 \\
17.8 \\
17.2\end{array}$ & $\begin{array}{l}19.6 \\
18.4 \\
18.5 \\
22.0 \\
25.4 \\
26.7 \\
24.8 \\
22.0\end{array}$ & $\begin{array}{l}17.6 \\
16.8 \\
16.5 \\
17.7 \\
17.6 \\
17.9 \\
17.9 \\
17.3\end{array}$ & $\begin{array}{l}19 \cdot 7 \\
18.7 \\
18 \cdot 7 \\
22 \cdot 6 \\
26 \cdot 4 \\
27 \cdot 3 \\
25 \cdot 2 \\
22.2\end{array}$ & $\begin{array}{l}17.7 \\
17.0 \\
16.7 \\
17.9 \\
18.0 \\
18.2 \\
18.1 \\
17.6\end{array}$ & $\begin{array}{l}14.2 \\
13.8 \\
12.7 \\
12.2\end{array}$ & & $\begin{array}{l}18.5 \\
14.1 \\
18.4 \\
17.3 \\
14.4 \\
16.4 \\
12.4 \\
14.4\end{array}$ & $\begin{array}{l}20.1 \\
15.3 \\
20.0 \\
18.7 \\
15.8 \\
17.8 \\
13.7 \\
15.7\end{array}$ & $\begin{array}{l}22.1 \\
17.3 \\
22.0 \\
21.0 \\
18.2 \\
20.3 \\
15.8 \\
17.6\end{array}$ & $\begin{array}{l}24.5 \\
19.2 \\
24.2 \\
23.0 \\
19.6 \\
22.3 \\
17.7 \\
19.5\end{array}$ \\
\hline $\begin{array}{l}28 \\
28 \\
28 \\
28 \\
28 \\
28 \\
28 \\
28\end{array}$ & $\begin{array}{r}0 \\
3 \\
6 \\
9 \\
12 \\
15 \\
18 \\
21\end{array}$ & $\begin{array}{l}19.5 \\
18.6 \\
18.7 \\
22.3 \\
25.1 \\
26.3 \\
23.9 \\
21.2\end{array}$ & $\begin{array}{l}16.9 \\
16.5 \\
16.8 \\
18.2 \\
18.4 \\
18.3 \\
18.6 \\
17.3\end{array}$ & $\begin{array}{l}19.7 \\
18.8 \\
19.0 \\
22.7 \\
25.5 \\
26.5 \\
24 \cdot 1 \\
21.4\end{array}$ & $\begin{array}{l}16.9 \\
16.4 \\
16.8 \\
18.4 \\
18.3 \\
18.2 \\
18.5 \\
17.2\end{array}$ & $\begin{array}{l}20.1 \\
19.1 \\
19.3 \\
23.2 \\
26.1 \\
27.0 \\
24.2 \\
21.6\end{array}$ & $\begin{array}{l}16.9 \\
16.5 \\
16.9 \\
18.3 \\
18.4 \\
18.4 \\
18.5 \\
17.2\end{array}$ & $\begin{array}{l}20.3 \\
19.3 \\
19.5 \\
23.6 \\
27.1 \\
27.6 \\
24.4 \\
21.03\end{array}$ & $\begin{array}{l}17.0 \\
16.5 \\
17.0 \\
18.6 \\
18.7 \\
18.6 \\
18.6 \\
17.2\end{array}$ & $\begin{array}{l}12.1 \\
11.5 \\
11.9 \\
13.8 \\
15.2 \\
14.9 \\
13.9 \\
13.7\end{array}$ & & $\begin{array}{l}12.1 \\
12.9 \\
16.2 \\
13.3 \\
15.0 \\
17.4 \\
18.9 \\
15.5\end{array}$ & $\begin{array}{l}13.2 \\
13.9 \\
17.5 \\
14.5 \\
17.1 \\
19.2 \\
20.7 \\
16.8\end{array}$ & $\begin{array}{l}14.9 \\
15.6 \\
19.4 \\
16.2 \\
18.9 \\
21.7 \\
23.0 \\
18.8\end{array}$ & $\begin{array}{l}26.7 \\
17.3 \\
21.2 \\
27.8 \\
20.3 \\
24.0 \\
25.7 \\
20.8\end{array}$ \\
\hline $\begin{array}{l}29 \\
29 \\
29 \\
29 \\
29 \\
29 \\
29 \\
29\end{array}$ & $\begin{array}{r}0 \\
3 \\
6 \\
9 \\
12 \\
15 \\
18 \\
21\end{array}$ & $\begin{array}{l}19.8 \\
19.3 \\
18.9 \\
19.4 \\
17.9 \\
20.7 \\
18.9 \\
19.6\end{array}$ & $\begin{array}{l}17.1 \\
17.1 \\
16.6 \\
16.3 \\
15.9 \\
17.2 \\
16.3 \\
17.5\end{array}$ & $\begin{array}{l}20.0 \\
19.5 \\
19.0 \\
19.4 \\
18.8 \\
21.6\end{array}$ & $\begin{array}{l}17.2 \\
17.1 \\
16.6 \\
16.0 \\
16.5 \\
17.3 \\
16.1 \\
17.5\end{array}$ & $\begin{array}{l}20.0 \\
19.7 \\
19.1 \\
19.4 \\
18.1 \\
21.1 \\
19.6 \\
19.8\end{array}$ & $\begin{array}{l}17.2 \\
17.1 \\
16.6 \\
15.9 \\
15.8 \\
17.2 \\
16.8 \\
17.7\end{array}$ & $\begin{array}{l}20.1 \\
19.6 \\
19.1 \\
19.2 \\
18.1 \\
21.1 \\
19.6 \\
19.8\end{array}$ & $\begin{array}{l}17.2 \\
17.1 \\
16.6 \\
15.5 \\
15.7 \\
17.3 \\
16.7 \\
17.8\end{array}$ & $\begin{array}{l}13.0 \\
12.5 \\
12.6\end{array}$ & & $\begin{array}{l}15.4 \\
14.5 \\
20.2 \\
19.1 \\
15.2 \\
15.5 \\
13.1 \\
19.6\end{array}$ & $\begin{array}{l}16.6 \\
15.9 \\
21.8 \\
20.9 \\
16.6 \\
17.1 \\
14.2 \\
21.4\end{array}$ & $\begin{array}{l}18.2 \\
17.3 \\
24.0 \\
22.6 \\
18.0 \\
18.8 \\
16.2 \\
23.6\end{array}$ & $\begin{array}{l}20.2 \\
19.4 \\
25.8 \\
24.6 \\
20.1 \\
21.2 \\
18.7 \\
26.2\end{array}$ \\
\hline $\begin{array}{l}30 \\
30 \\
30 \\
30 \\
30 \\
30 \\
30 \\
30\end{array}$ & $\begin{array}{r}0 \\
3 \\
6 \\
9 \\
12 \\
15 \\
18 \\
21\end{array}$ & $\begin{array}{l}19.6 \\
19.1 \\
18.3 \\
15.4 \\
15.8 \\
16.7 \\
13.9 \\
14.0\end{array}$ & $\begin{array}{l}17.7 \\
17.0 \\
16.6 \\
13.6 \\
13.6 \\
14.5 \\
13.8 \\
13.7\end{array}$ & $\begin{array}{l}15 \cdot 8 \\
16 \cdot 7 \\
14 \cdot 3 \\
14 \cdot 2\end{array}$ & $\begin{array}{l}17.6 \\
17.0 \\
16.8\end{array}$ & $\begin{array}{l}19.9 \\
19.4 \\
18.8 \\
15.7 \\
15.8 \\
16.7 \\
14.3 \\
14.1\end{array}$ & $\begin{array}{l}17.8 \\
17.1 \\
16.5 \\
13.8 \\
13.3 \\
14.3 \\
13.9 \\
13.9\end{array}$ & $\begin{array}{l}19.9 \\
19.2 \\
18.5 \\
15.5 \\
15.5 \\
16.7 \\
14.3 \\
13.9\end{array}$ & $\begin{array}{l}17.7 \\
17.1 \\
16.7 \\
13.5 \\
13.4 \\
14.2 \\
13.8 \\
13.5\end{array}$ & 16.0 & & $\begin{array}{r}21.6 \\
22.5 \\
18.3 \\
8.2 \\
5.1 \\
4.7 \\
4.3 \\
7.4\end{array}$ & $\begin{array}{r}23.3 \\
24.4 \\
19.4 \\
8.7 \\
5.4 \\
5.2 \\
4.9 \\
8.6\end{array}$ & $\begin{array}{r}25.5 \\
26.8 \\
21.6 \\
9.6 \\
5.8 \\
6.0 \\
5.7 \\
9.5\end{array}$ & $\begin{array}{r}27.6 \\
29.6 \\
23.7 \\
9.8 \\
6.2 \\
6.7 \\
6.4 \\
10.9\end{array}$ \\
\hline
\end{tabular}


Table 10. - Three-hour averages of air and water-surface temperatures and wind directions and speed, April 1950-August 1951, Lake Hefner-Continued

STATION 3

THREE-HOURLY AVERAGES

MAY, 1951

\begin{tabular}{|c|c|c|c|c|c|c|c|c|c|c|c|c|c|c|c|}
\hline \multirow{4}{*}{ 秃 } & \multirow{4}{*}{ 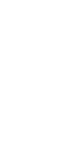 } & \multicolumn{8}{|c|}{ Average air temperature $\left({ }^{\circ} \mathrm{C}\right)$ at indicated height } & \multirow{4}{*}{$\begin{array}{c}\text { Average } \\
\text { water- } \\
\text { surface } \\
\text { tempera- } \\
\text { ture } \\
\left({ }^{\circ} \mathrm{C}\right)\end{array}$} & \multirow{4}{*}{$\begin{array}{c}\text { Average } \\
\text { wind } \\
\text { direction } \\
\text { (coded) }\end{array}$} & \multirow{2}{*}{\multicolumn{4}{|c|}{$\begin{array}{l}\text { Average wind speed (knots) } \\
\text { at indicated he ight }\end{array}$}} \\
\hline & & \multirow{2}{*}{\multicolumn{2}{|c|}{$\begin{array}{c}2 \\
\text { meters }\end{array}$}} & \multirow{2}{*}{\multicolumn{2}{|c|}{$\begin{array}{c}4 \\
\text { meters }\end{array}$}} & \multirow{2}{*}{\multicolumn{2}{|c|}{$\begin{array}{c}8 \\
\text { meters } \\
\end{array}$}} & \multirow{2}{*}{\multicolumn{2}{|c|}{$\begin{array}{c}16 \\
\text { meters }\end{array}$}} & & & & & & \\
\hline & & & & & & & & & & & & 2 & 4 & 8 & 16 \\
\hline & & $\begin{array}{l}\text { Dry } \\
\text { bulb }\end{array}$ & $\begin{array}{l}\text { Wet } \\
\text { bulb }\end{array}$ & $\begin{array}{l}\text { Dry } \\
\text { bulb }\end{array}$ & $\begin{array}{l}\text { Wet } \\
\text { bulb }\end{array}$ & $\begin{array}{l}\text { Dry } \\
\text { bulb }\end{array}$ & $\begin{array}{l}\text { Wet } \\
\text { bulb }\end{array}$ & $\begin{array}{l}\text { Dry } \\
\text { bulb }\end{array}$ & $\begin{array}{l}\text { Wet } \\
\text { bulb }\end{array}$ & & & meters & meters & meters & meters \\
\hline $\begin{array}{l}1 \\
1 \\
1 \\
1 \\
1 \\
1 \\
1 \\
1\end{array}$ & $\begin{array}{r}0 \\
3 \\
6 \\
9 \\
12 \\
15 \\
18 \\
21\end{array}$ & $\begin{array}{l}21.2 \\
11.6 \\
12.8 \\
15.7 \\
17.9 \\
19.7 \\
18.6 \\
26.6\end{array}$ & $\begin{array}{l}10.3 \\
10.5 \\
11.3 \\
10.7 \\
11.5 \\
12.0 \\
11.5 \\
10.9\end{array}$ & $\begin{array}{l}11.8 \\
12.1 \\
12.9 \\
15.9 \\
18.1 \\
20.0 \\
18.7 \\
16.7\end{array}$ & $\begin{array}{l}9.7 \\
10.3 \\
10.4 \\
11.3 \\
11.4 \\
11.4 \\
10.8\end{array}$ & $\begin{array}{l}11.5 \\
12.3 \\
13.0 \\
15.8 \\
18.2 \\
20.3 \\
18.8 \\
16.7\end{array}$ & $\begin{array}{r}9.3 \\
10.7 \\
10.9 \\
10.3 \\
10.7 \\
11.2 \\
11.1 \\
10.5\end{array}$ & $\begin{array}{l}11.4 \\
12.3 \\
13.0 \\
15.9 \\
18.2 \\
20.5 \\
19.0 \\
16.6\end{array}$ & $\begin{array}{r}11.1 \\
10.8 \\
10.8 \\
9.8 \\
10.6 \\
11.2 \\
11.1 \\
10.5\end{array}$ & $\begin{array}{l}18.7 \\
17.7 \\
15.8 \\
14.8\end{array}$ & & $\begin{array}{r}6.3 \\
4.9 \\
12.7 \\
19.6 \\
19.8 \\
18.8 \\
13.0 \\
14.3\end{array}$ & $\begin{array}{r}7.3 \\
5.5 \\
13.4 \\
21.6 \\
21.2 \\
20.2 \\
13.9 \\
15.3\end{array}$ & $\begin{array}{r}7.0 \\
5.7 \\
14.5 \\
24.5 \\
23.7 \\
22.6 \\
15.6 \\
16.8\end{array}$ & $\begin{array}{r}9.6 \\
8.6 \\
14.8 \\
24.7 \\
24.3 \\
23.4 \\
17.1 \\
18.1\end{array}$ \\
\hline $\begin{array}{l}2 \\
2 \\
2 \\
2 \\
2 \\
2 \\
2 \\
2\end{array}$ & $\begin{array}{r}0 \\
3 \\
6 \\
9 \\
12 \\
15 \\
18 \\
21\end{array}$ & $\begin{array}{l}14.5 \\
12.4 \\
13.5 \\
18.0 \\
21.9 \\
22.8 \\
19.8 \\
17.1\end{array}$ & $\begin{array}{r}10.8 \\
9.8 \\
10.3 \\
12.3 \\
12.4 \\
13.4 \\
13.8 \\
12.7\end{array}$ & $\begin{array}{l}14.5 \\
12.2 \\
13.4 \\
18.2 \\
22.1 \\
23.2 \\
20.0 \\
17.2\end{array}$ & $\begin{array}{r}10.7 \\
9.6 \\
10.1 \\
11.9 \\
12.0 \\
12.5 \\
13.5 \\
12.3\end{array}$ & $\begin{array}{l}14.4 \\
12.2 \\
13.4 \\
18.6 \\
22.5 \\
23.5 \\
20.7 \\
17.3\end{array}$ & $\begin{array}{r}10.3 \\
9.5 \\
9.9 \\
11.5 \\
11.8 \\
12.5 \\
13.2 \\
12.1\end{array}$ & $\begin{array}{l}14.4 \\
12.0 \\
13.5 \\
19.7 \\
23.0 \\
23.0 \\
21.1 \\
17.4\end{array}$ & $\begin{array}{r}10.3 \\
9.4 \\
10.1 \\
11.7 \\
11.5 \\
12.1 \\
13.0 \\
11.8\end{array}$ & $\begin{array}{l}13.9 \\
13.5 \\
14.3 \\
17.7 \\
19.1 \\
18.4 \\
16.6 \\
15.2\end{array}$ & & $\begin{array}{r}13.7 \\
11.0 \\
15.04 \\
16.7 \\
18.0 \\
16.6 \\
9.0 \\
10.0\end{array}$ & $\begin{array}{l}14.6 \\
11.7 \\
16.3 \\
17.8 \\
19.4 \\
18.0 \\
10.0 \\
10.6\end{array}$ & $\begin{array}{l}16.0 \\
12.6 \\
17.6 \\
19.6 \\
21.0 \\
20.6 \\
12.0 \\
12.2\end{array}$ & $\begin{array}{l}17.0 \\
13.7 \\
18.4 \\
21.0 \\
22.9 \\
21.5 \\
13.9 \\
13.7\end{array}$ \\
\hline $\begin{array}{l}3 \\
3 \\
3 \\
3 \\
3 \\
3 \\
3 \\
3 \\
3\end{array}$ & $\begin{array}{r}0 \\
3 \\
6 \\
9 \\
12 \\
15 \\
18 \\
21\end{array}$ & $\begin{array}{l}15.1 \\
14.8 \\
14.0 \\
20.4 \\
24.4 \\
24.7 \\
21.0 \\
16.2\end{array}$ & $\begin{array}{l}11.7 \\
11.4 \\
10.4 \\
12.9 \\
13.2 \\
12.4 \\
12.4 \\
10.9\end{array}$ & $\begin{array}{l}15.2 \\
15.1 \\
14.2 \\
20.2 \\
24.1 \\
24.2 \\
21.1 \\
17.6\end{array}$ & $\begin{array}{l}11.4 \\
11.2 \\
10.4 \\
12.5 \\
12.4 \\
11.8 \\
12.1 \\
11.1\end{array}$ & $\begin{array}{l}15.4 \\
14.9 \\
14.4 \\
20.1 \\
23.7 \\
24.3 \\
21.0 \\
19.0\end{array}$ & $\begin{array}{l}11.3 \\
11.0 \\
10.5 \\
12.4 \\
12.2 \\
11.8 \\
12.4 \\
11.3\end{array}$ & $\begin{array}{l}15.4 \\
14.7 \\
14.9 \\
20.2 \\
23.8 \\
24.3 \\
22.0 \\
19.8\end{array}$ & $\begin{array}{l}11.0 \\
10.4 \\
10.1 \\
12.1 \\
11.9 \\
11.8 \\
12.1 \\
11.1\end{array}$ & $\begin{array}{l}14.7 \\
14.4 \\
15.5 \\
18.0 \\
18.9 \\
17.5 \\
16.0 \\
15.7\end{array}$ & & $\begin{array}{l}9.6 \\
8.6 \\
4.9 \\
7.6 \\
8.7 \\
6.9 \\
2.2 \\
2.2\end{array}$ & $\begin{array}{r}10.1 \\
9.2 \\
5.7 \\
8.6 \\
9.7 \\
7.9 \\
2.6 \\
2.6\end{array}$ & $\begin{array}{r}11.2 \\
10.4 \\
6.8 \\
9.8 \\
11.2 \\
9.1 \\
4.1 \\
4.4\end{array}$ & $\begin{array}{r}12.4 \\
11.3 \\
7.5 \\
10.2 \\
11.4 \\
9.1 \\
5.3 \\
6.2\end{array}$ \\
\hline $\begin{array}{l}4 \\
4 \\
4 \\
4 \\
4 \\
4 \\
4 \\
4\end{array}$ & $\begin{array}{r}0 \\
3 \\
6 \\
9 \\
12 \\
15 \\
18 \\
21\end{array}$ & $\begin{array}{l}15.4 \\
13.9 \\
15.1 \\
19.4 \\
22.6 \\
22.9 \\
19.6 \\
15.9\end{array}$ & $\begin{array}{l}12.2 \\
10.7 \\
10.6 \\
12.6 \\
15.2 \\
13.7 \\
12.7 \\
11.9\end{array}$ & $\begin{array}{l}15.6 \\
14.1 \\
15.1 \\
18.9 \\
22.2 \\
22.5 \\
19.5 \\
16.3\end{array}$ & $\begin{array}{l}12.1 \\
10.2 \\
10.2 \\
12.2 \\
13.8 \\
13.1 \\
12.6 \\
12.1\end{array}$ & $\begin{array}{l}16.0 \\
14.1 \\
14.8 \\
18.7 \\
21.8 \\
22.5 \\
19.6 \\
16.8\end{array}$ & $\begin{array}{l}21.5 \\
10.3 \\
10.4 \\
12.0 \\
12.6 \\
13.1 \\
12.7 \\
12.4\end{array}$ & $\begin{array}{l}17.0 \\
14.4 \\
14.9 \\
18.9 \\
21.7 \\
22.4 \\
20.0 \\
17.7\end{array}$ & $\begin{array}{l}10.9 \\
10.0 \\
10.3 \\
11.8 \\
12.6 \\
12.9 \\
12.5 \\
12.0\end{array}$ & $\begin{array}{l}15.5 \\
15.2 \\
16.0 \\
18.3 \\
19.6 \\
18.4 \\
16.0 \\
15.6\end{array}$ & & $\begin{array}{r}5.0 \\
5.8 \\
5.1 \\
9.5 \\
11.6 \\
12.2 \\
4.8 \\
2.3\end{array}$ & $\begin{array}{r}5.1 \\
6.3 \\
5.8 \\
10.9 \\
13.5 \\
13.7 \\
5.5 \\
2.7\end{array}$ & $\begin{array}{r}6.1 \\
7.5 \\
7.6 \\
12.7 \\
16.1 \\
15.7 \\
6.9 \\
3.8\end{array}$ & $\begin{array}{r}7.3 \\
8.1 \\
8.8 \\
14.5 \\
15.6 \\
16.2 \\
7.0 \\
5.4\end{array}$ \\
\hline $\begin{array}{l}5 \\
5 \\
5 \\
5 \\
5 \\
5 \\
5 \\
5\end{array}$ & $\begin{array}{r}0 \\
3 \\
6 \\
9 \\
12 \\
15 \\
18 \\
21\end{array}$ & $\begin{array}{l}14.7 \\
14.5 \\
16.0 \\
21.5 \\
24.4 \\
25.0 \\
21.1 \\
17.8\end{array}$ & $\begin{array}{l}12.8 \\
12.3 \\
12.4 \\
14.2 \\
14.8 \\
14.9 \\
13.8 \\
12.6\end{array}$ & $\begin{array}{l}15.3 \\
14.5 \\
16.0 \\
21.7 \\
23.8 \\
24.7 \\
21.3 \\
18.0\end{array}$ & $\begin{array}{l}12.5 \\
12.1 \\
12.4 \\
14.1 \\
14.4 \\
14.3 \\
13.7 \\
12.5\end{array}$ & $\begin{array}{l}15.7 \\
14.5 \\
16.03 \\
22.4 \\
23.8 \\
24.7 \\
21.6 \\
18.1\end{array}$ & $\begin{array}{l}12.3 \\
12.1 \\
12,3 \\
15.0 \\
14.7 \\
14.6 \\
13.9 \\
12.7\end{array}$ & $\begin{array}{l}17.7 \\
14.5 \\
16.2 \\
21.8 \\
23.6 \\
24.5 \\
21.8 \\
18.3\end{array}$ & $\begin{array}{l}11.4 \\
11.7 \\
12.2 \\
14.1 \\
14.2 \\
14.0 \\
13.6 \\
12.6\end{array}$ & $\begin{array}{l}25.9 \\
15.7 \\
16.9 \\
20.3 \\
20.9 \\
20.2 \\
18.0 \\
16.9\end{array}$ & & $\begin{array}{l}2.2 \\
6.5 \\
2.6 \\
3.7 \\
4.8 \\
5.1 \\
5.4 \\
6.9\end{array}$ & $\begin{array}{l}2.0 \\
5.8 \\
2.3 \\
3.1 \\
5.1 \\
5.7 \\
6.4 \\
8.1\end{array}$ & $\begin{array}{l}2.6 \\
6.5 \\
2.8 \\
3.4 \\
5.7 \\
6.3 \\
8.0 \\
9.7\end{array}$ & $\begin{array}{r}3.9 \\
6.6 \\
2.7 \\
3.6 \\
6.3 \\
7.1 \\
10.6 \\
11.9\end{array}$ \\
\hline $\begin{array}{l}0 \\
6 \\
6 \\
6 \\
6 \\
6 \\
6 \\
6\end{array}$ & $\begin{array}{r}0 \\
3 \\
6 \\
9 \\
12 \\
15 \\
18 \\
21\end{array}$ & $\begin{array}{l}15.1 \\
13.6 \\
11.4 \\
11.8 \\
11.5 \\
12.7 \\
12.7 \\
11.3\end{array}$ & $\begin{array}{r}11.6 \\
10.5 \\
8.5 \\
7.5 \\
6.6 \\
7.3 \\
7.9 \\
7.9\end{array}$ & $\begin{array}{l}15.3 \\
13.6 \\
11.4 \\
11.4 \\
11.3 \\
12.3 \\
12.7 \\
11.2\end{array}$ & $\begin{array}{r}11.7 \\
10.3 \\
8.3 \\
7.0 \\
6.4 \\
6.9 \\
7.8 \\
7.8\end{array}$ & $\begin{array}{l}15.4 \\
13.6 \\
11.3 \\
11.03 \\
11.2 \\
12.1 \\
12.7 \\
11.2\end{array}$ & $\begin{array}{r}11.7 \\
10.3 \\
8.0 \\
7.0 \\
6.3 \\
6.9 \\
7.7 \\
7.7\end{array}$ & $\begin{array}{l}15.7 \\
13.4 \\
11.1 \\
11.2 \\
10.9 \\
12.0 \\
12.5 \\
11.2\end{array}$ & $\begin{array}{r}11.7 \\
10.1 \\
7.8 \\
6.8 \\
6.2 \\
6.8 \\
7.6 \\
7.6\end{array}$ & $\begin{array}{l}16.3 \\
16.2 \\
16.0 \\
15.9 \\
15.9 \\
15.6 \\
14.9 \\
14.6\end{array}$ & & $\begin{array}{r}4.4 \\
11.6 \\
13.9 \\
13.8 \\
12.0 \\
12.2 \\
9.8 \\
5.7\end{array}$ & $\begin{array}{r}5.3 \\
14.3 \\
16.7 \\
17.7 \\
14.4 \\
14.2 \\
10.8 \\
6.4\end{array}$ & $\begin{array}{r}6.7 \\
16.4 \\
19.1 \\
20.2 \\
15.3 \\
16.4 \\
12.5 \\
7.7\end{array}$ & $\begin{array}{r}8.8 \\
17.7 \\
22.4 \\
24.4\end{array}$ \\
\hline $\begin{array}{l}? \\
? \\
7 \\
7 \\
? \\
? \\
7 \\
7\end{array}$ & $\begin{array}{r}0 \\
3 \\
6 \\
9 \\
12 \\
15 \\
18 \\
21\end{array}$ & $\begin{array}{r}8.9 \\
8.2 \\
9.5 \\
13.7 \\
17.9 \\
18.5 \\
15.4 \\
12.2\end{array}$ & $\begin{array}{r}7.0 \\
6.8 \\
7.0 \\
8.5 \\
9.9 \\
10.8 \\
9.6 \\
8.7\end{array}$ & $\begin{array}{r}8.9 \\
8.1 \\
9.8 \\
13.5 \\
16.8 \\
18.1 \\
16.0 \\
13.2\end{array}$ & $\begin{array}{l}6 \cdot 9 \\
5 \cdot 8 \\
7: 0 \\
8: 1 \\
9.6 \\
9 \cdot 9 \\
9 \cdot 5 \\
9.1\end{array}$ & $\begin{array}{r}9.0 \\
8.2 \\
9.6 \\
13.4 \\
17.0 \\
18.0 \\
16.3 \\
13.9\end{array}$ & $\begin{array}{r}6.9 \\
6.7 \\
6.9 \\
8.0 \\
9.5 \\
10.3 \\
9.6 \\
9.2\end{array}$ & $\begin{array}{r}9.0 \\
8: 2 \\
9.5 \\
13.5 \\
17.3 \\
17.8 \\
16.5 \\
14.4\end{array}$ & $\begin{array}{r}6.8 \\
6.7 \\
6.7 \\
8.0 \\
9.3 \\
10.0 \\
9.5 \\
9.0\end{array}$ & $\begin{array}{l}14.5 \\
14.7 \\
15.5 \\
17.8 \\
19.2 \\
19.5 \\
17.2 \\
16.3\end{array}$ & & $\begin{array}{l}4.3 \\
2.3 \\
5.4 \\
6.1 \\
3.0 \\
3.1 \\
3.1 \\
2.9\end{array}$ & $\begin{array}{l}4.9 \\
2.6 \\
5.0 \\
7.2 \\
3.3 \\
3.0 \\
4.0 \\
3.5\end{array}$ & $\begin{array}{l}6.0 \\
3.6 \\
6.9 \\
9.2 \\
4.0 \\
3.5 \\
5.2 \\
4.9\end{array}$ & $\begin{array}{l}6.8 \\
4.5 \\
7.6 \\
9.1 \\
4.1 \\
3.8 \\
6.3 \\
6.4\end{array}$ \\
\hline $\begin{array}{l}8 \\
8 \\
8 \\
8 \\
8 \\
8 \\
8 \\
8\end{array}$ & $\begin{array}{r}0 \\
3 \\
6 \\
9 \\
12 \\
15 \\
18 \\
21\end{array}$ & $\begin{array}{l}12.0 \\
12.5 \\
23.9 \\
17.3 \\
20.2 \\
20.8 \\
20.0 \\
18.4\end{array}$ & $\begin{array}{r}9.2 \\
10.3 \\
11.7 \\
12.8 \\
15.0 \\
16.1 \\
15.5 \\
14.9\end{array}$ & $\begin{array}{l}12.3 \\
12.5 \\
14.0 \\
17.1 \\
20.0 \\
20.8 \\
20.0 \\
18.5\end{array}$ & $\begin{array}{r}9.1 \\
10.2 \\
11.5 \\
12.7 \\
14.8 \\
16.0 \\
15.5 \\
14.8\end{array}$ & $\begin{array}{l}12.6 \\
12.4 \\
14.0 \\
17.02 \\
19.9 \\
21.0 \\
20.2 \\
18.5\end{array}$ & $\begin{array}{r}9.1 \\
10.0 \\
11.4 \\
12.5 \\
14.8 \\
16.1 \\
15.4 \\
14.7\end{array}$ & $\begin{array}{l}12.9 \\
12.2 \\
14: 0 \\
17.2 \\
20.0 \\
21.0 \\
20.3 \\
18.5\end{array}$ & $\begin{array}{r}8.9 \\
9.9 \\
11.3 \\
12.5 \\
14.6 \\
15.8 \\
15.2 \\
14.6\end{array}$ & $\begin{array}{l}16.0 \\
15.1 \\
15.6 \\
18.7 \\
20.3 \\
18.9 \\
17.5 \\
16.6\end{array}$ & & $\begin{array}{r}5.0 \\
8.11 \\
10.5 \\
15.5 \\
16.0 \\
16.1 \\
12.7 \\
15.1\end{array}$ & $\begin{array}{r}5.6 \\
8.3 \\
11.1 \\
16.4 \\
17.1 \\
17.3 \\
13.8 \\
16.2\end{array}$ & $\begin{array}{r}6.5 \\
8.7 \\
12.0 \\
17.09 \\
13.8 \\
19.4 \\
15.3 \\
17.8\end{array}$ & $\begin{array}{r}8.0 \\
9.0 \\
12.6 \\
19.0 \\
20.1 \\
20.6 \\
16.8 \\
19.5\end{array}$ \\
\hline $\begin{array}{l}9 \\
9 \\
9 \\
9 \\
9 \\
9 \\
9 \\
9\end{array}$ & $\begin{array}{r}0 \\
3 \\
6 \\
9 \\
12 \\
15 \\
18 \\
21\end{array}$ & $\begin{array}{l}16.8 \\
16.0 \\
16.9 \\
19.8 \\
22.3 \\
23.2 \\
16.3 \\
16.0\end{array}$ & $\begin{array}{l}14.5 \\
14.9 \\
15: 9 \\
17.0 \\
17.7 \\
18.3 \\
15.1 \\
14.7\end{array}$ & $\begin{array}{l}16.9 \\
16.1 \\
17.1 \\
20.0 \\
22.4 \\
23.2 \\
16.3 \\
16.0\end{array}$ & $\begin{array}{l}14.4 \\
14.9 \\
15.8 \\
17.0 \\
17.8 \\
18.2 \\
14.6 \\
14.6\end{array}$ & $\begin{array}{l}17.0 \\
16.3 \\
16.3 \\
20.2 \\
22.7 \\
23.8 \\
16.3 \\
16.0\end{array}$ & $\begin{array}{l}14.4 \\
15.0 \\
15: 8 \\
17.0 \\
17.8 \\
18.3 \\
14.9 \\
14.5\end{array}$ & $\begin{array}{l}16.7 \\
16.1 \\
17.1 \\
20.5 \\
23.8 \\
24.0 \\
16.5 \\
16.3\end{array}$ & $\begin{array}{l}14.3 \\
14.8 \\
15.8 \\
17.1 \\
17.8 \\
18.3 \\
13.8 \\
14.3\end{array}$ & $\begin{array}{l}15.9 \\
14.8 \\
14.4 \\
17.2 \\
18.8 \\
18.9 \\
17.9 \\
17.3\end{array}$ & & $\begin{array}{r}16.1 \\
13.4 \\
12.0 \\
17.0 \\
15.6 \\
13.4 \\
8.00 \\
4.5\end{array}$ & $\begin{array}{r}17.4 \\
14.3 \\
13.4 \\
18.3 \\
16.8 \\
14.6 \\
8.8 \\
5.4\end{array}$ & $\begin{array}{r}19.2 \\
15.7 \\
14.8 \\
20.2 \\
19.9 \\
15.5 \\
10.0 \\
6.5\end{array}$ & $\begin{array}{r}20.5 \\
17.0 \\
15.6 \\
21.3 \\
20.3 \\
15.0 \\
10.9 \\
8.9\end{array}$ \\
\hline $\begin{array}{l}10 \\
10 \\
10 \\
10 \\
10 \\
10 \\
10 \\
10\end{array}$ & $\begin{array}{r}0 \\
3 \\
6 \\
9 \\
12 \\
15 \\
18 \\
21\end{array}$ & $\begin{array}{l}14.7 \\
12.5 \\
12.6 \\
14.4 \\
16.2 \\
18.0 \\
15.7 \\
12.3\end{array}$ & $\begin{array}{l}13.0 \\
10.6 \\
10.5 \\
12.5 \\
13.4 \\
13.7 \\
13.0 \\
11.1\end{array}$ & $\begin{array}{l}14.7 \\
12.5 \\
12.7 \\
14.4 \\
16.0 \\
17.8 \\
15.7 \\
12.4\end{array}$ & $\begin{array}{l}13.0 \\
10.5 \\
10.4 \\
12.4 \\
13.1 \\
13.4 \\
12.9 \\
11.1\end{array}$ & $\begin{array}{l}14.7 \\
12.5 \\
12.5 \\
14.2 \\
15.8 \\
17.6 \\
15.6 \\
12.5\end{array}$ & $\begin{array}{l}12.9 \\
10.3 \\
10.3 \\
12.3 \\
13.0 \\
13.4 \\
12.8 \\
10.9\end{array}$ & $\begin{array}{l}14 \cdot 8 \\
12: 3 \\
12.4 \\
14 \cdot 1 \\
15.8 \\
17.6 \\
15.5 \\
12.4\end{array}$ & $\begin{array}{l}12.7 \\
10.0 \\
10.1 \\
12.1 \\
12.7 \\
13.1 \\
12.6 \\
10.9\end{array}$ & $\begin{array}{l}15.9 \\
15.2 \\
15.5 \\
15.8 \\
15.6 \\
17.0 \\
15.7 \\
15.3\end{array}$ & & $\begin{array}{r}7.7 \\
9.1 \\
7.5 \\
9.8 \\
10.7 \\
11.5 \\
7.00 \\
4.3\end{array}$ & $\begin{array}{r}9.5 \\
11.2 \\
9.2 \\
11.7 \\
12.9 \\
13.4 \\
7.7 \\
5.4\end{array}$ & $\begin{array}{r}12.2 \\
14.5 \\
11.0 \\
15.2 \\
16.9 \\
16.0 \\
4.1 \\
6.4\end{array}$ & $\begin{array}{r}13.1 \\
14.2 \\
13.6 \\
15.0 \\
16.6 \\
16.3 \\
0.6 \\
6.0\end{array}$ \\
\hline
\end{tabular}


TABLE 10

Table 10. - Three-hour averages of air and water-surface temperatures and wind directions and speed, April 1950-August 1951, Lake Hefner-Continued

STATION 3

THREE-HOURLY AVERAGES

MAY, 1951

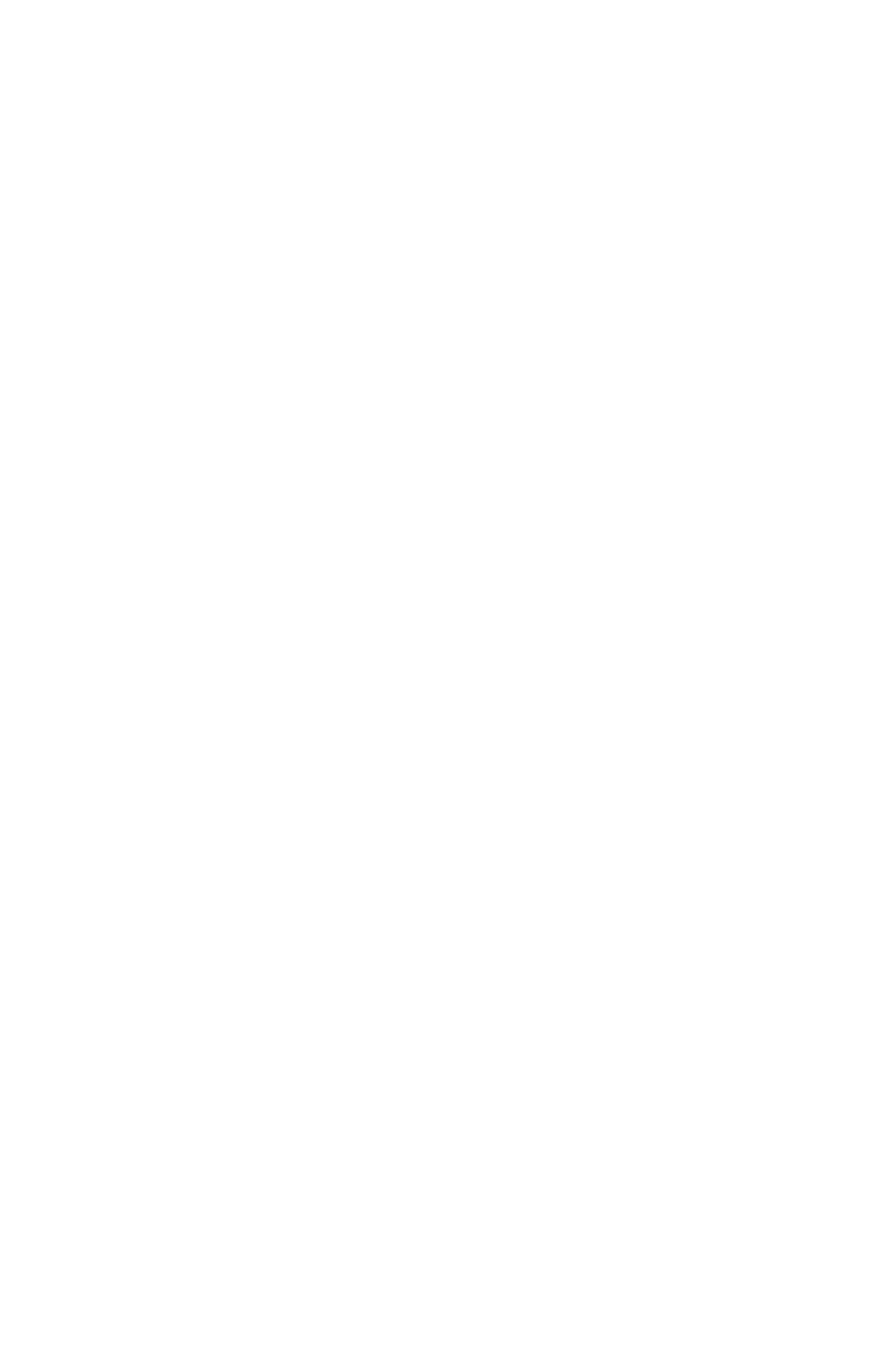


Table 10. - Three-hour averages of air and water-surface temperatures and wind directions and speed, April 1950-August 951, Lake Hefner-Continue

STATION 3

THREE-HOURLY AVERAGES

MAY, 1951

\begin{tabular}{|c|c|c|c|c|c|c|c|c|c|c|c|c|c|c|c|}
\hline \multirow{4}{*}{ 吉 } & \multirow{4}{*}{ 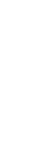 } & \multicolumn{8}{|c|}{ Average air temperature $\left({ }^{\circ} \mathrm{C}\right)$ at indicated height } & \multirow{4}{*}{$\begin{array}{c}\text { Average } \\
\text { water- } \\
\text { surface } \\
\text { tempera- } \\
\text { ture } \\
\text { (ㄷ) }\end{array}$} & \multirow{4}{*}{$\begin{array}{c}\text { Average } \\
\text { wind } \\
\text { direction } \\
\text { (coded) }\end{array}$} & \multirow{2}{*}{\multicolumn{4}{|c|}{$\begin{array}{l}\text { Average wind speed (knots) } \\
\text { at indicated height }\end{array}$}} \\
\hline & & \multirow{2}{*}{\multicolumn{2}{|c|}{$\begin{array}{c}2 \\
\text { meters }\end{array}$}} & \multirow{2}{*}{\multicolumn{2}{|c|}{$\begin{array}{c}4 \\
\text { meters }\end{array}$}} & \multirow{2}{*}{\multicolumn{2}{|c|}{$\begin{array}{c}8 \\
\text { meters }\end{array}$}} & \multirow{2}{*}{\multicolumn{2}{|c|}{$\begin{array}{c}16 \\
\text { meters }\end{array}$}} & & & & & & \\
\hline & & & & & & & & & & & & 2 & 4 & 8 & 16 \\
\hline & & $\begin{array}{l}\text { Dry } \\
\text { bulb }\end{array}$ & $\begin{array}{l}\text { Wet } \\
\text { bulb }\end{array}$ & $\begin{array}{l}\text { Dry } \\
\text { bulb }\end{array}$ & $\begin{array}{l}\text { Wet } \\
\text { bulb }\end{array}$ & $\begin{array}{l}\text { Dry } \\
\text { bulb }\end{array}$ & $\begin{array}{l}\text { Wet } \\
\text { bulb }\end{array}$ & $\begin{array}{l}\text { Dry } \\
\text { bulb }\end{array}$ & $\begin{array}{l}\text { Wet } \\
\text { bulb }\end{array}$ & & & & & & \\
\hline
\end{tabular}

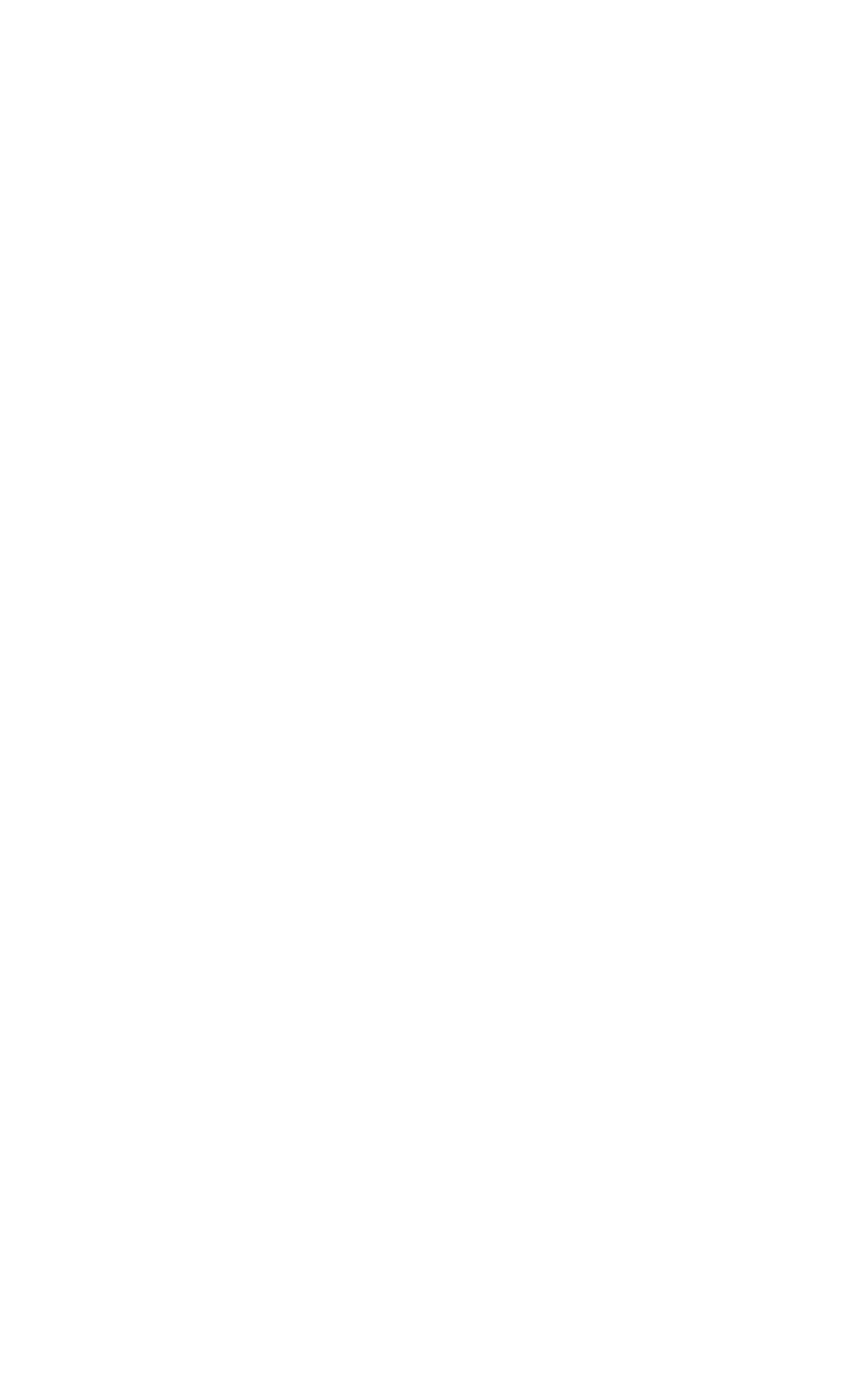


TABLE 10

Table 10. - Three-hour averages of air and water-surface temperatures and wind directions and speed, April 1950-August 951. Lake Hefner-Continued

STATION 3 THREE-HOURLY AVERAGES

JUNE, 1951

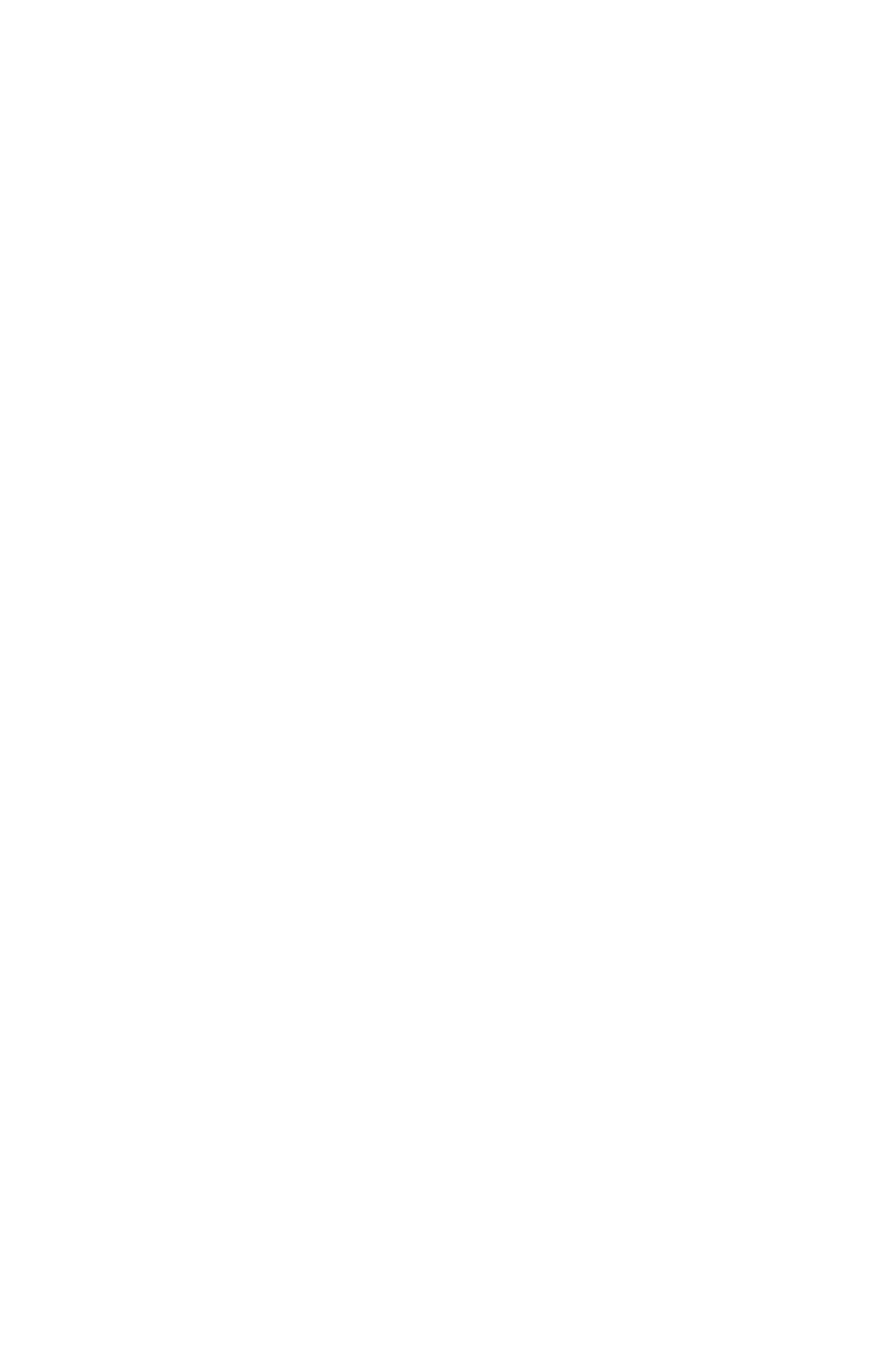


TABLE 10

\begin{tabular}{|c|c|c|c|c|c|c|c|c|c|c|c|c|c|c|c|}
\hline \multicolumn{2}{|c|}{ STATION } & 3 & \multicolumn{11}{|c|}{ THREE-HOURLY AVERAGES } & \multirow{2}{*}{\multicolumn{2}{|c|}{$\begin{array}{l}\text { JUNE, } 1951 \\
\text { speed (knots) } \\
\text { ted height }\end{array}$}} \\
\hline \multirow{3}{*}{ 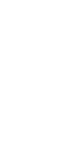 } & \multirow{3}{*}{ 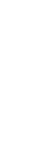 } & \multicolumn{8}{|c|}{ Average air temperature $\left({ }^{\circ} \mathrm{C}\right)$ at indicated height } & \multirow{3}{*}{\begin{tabular}{|l} 
Average \\
water- \\
surface \\
tempera- \\
ture \\
('C)
\end{tabular}} & \multirow{3}{*}{$\begin{array}{l}\text { Average } \\
\text { wind } \\
\text { direction } \\
\text { (coded) }\end{array}$} & \multicolumn{2}{|c|}{$\begin{array}{l}\text { Average wind speed (knots) } \\
\text { at indicated height }\end{array}$} & & \\
\hline & & \multicolumn{2}{|c|}{$\begin{array}{c}2 \\
\text { meters }\end{array}$} & \multicolumn{2}{|c|}{$\begin{array}{c}4 \\
\text { meters }\end{array}$} & \multicolumn{2}{|c|}{$\begin{array}{c}8 \\
\text { meters }\end{array}$} & \multicolumn{2}{|c|}{$\begin{array}{c}16 \\
\text { meters }\end{array}$} & & & 2 & 4 & 8 & 16 \\
\hline & & $\begin{array}{l}\text { Dry } \\
\text { bulb }\end{array}$ & $\begin{array}{l}\text { Wet } \\
\text { bulb }\end{array}$ & $\begin{array}{l}\text { Dry } \\
\text { bulb }\end{array}$ & $\begin{array}{l}\text { Wet } \\
\text { bulb }\end{array}$ & $\begin{array}{l}\text { Dry } \\
\text { bulb }\end{array}$ & $\begin{array}{l}\text { Wet } \\
\text { bulb }\end{array}$ & $\begin{array}{l}\text { Dry } \\
\text { bulb }\end{array}$ & $\begin{array}{l}\text { Wet } \\
\text { bulb }\end{array}$ & & & meters & meters & meters & meters \\
\hline $\begin{array}{l}11 \\
11 \\
11 \\
11 \\
11 \\
11 \\
11 \\
11\end{array}$ & $\begin{array}{r}0 \\
3 \\
6 \\
9 \\
12 \\
15 \\
18 \\
21\end{array}$ & $\begin{array}{l}18.5 \\
18.6 \\
17.5 \\
18.6 \\
20.4 \\
21.8 \\
21.0 \\
19.9\end{array}$ & $\begin{array}{l}17.9 \\
17.7 \\
17.4 \\
18.0 \\
18.1 \\
19.0 \\
19.1 \\
18.7\end{array}$ & $\begin{array}{l}18.6 \\
18.6 \\
17.6 \\
18.6 \\
20.4 \\
21.9 \\
21.0 \\
19.9\end{array}$ & $\begin{array}{l}17.7 \\
17.5 \\
16.9 \\
17.5 \\
17.8 \\
18.8 \\
19.0 \\
18.6\end{array}$ & $\begin{array}{l}18.5 \\
18.6 \\
17.7 \\
18.6 \\
20.4 \\
21.9 \\
20.9 \\
19.9\end{array}$ & $\begin{array}{l}17.7 \\
17.4 \\
17.5 \\
17.5 \\
17.7 \\
18.8 \\
19.0 \\
18.7\end{array}$ & $\begin{array}{l}18.6 \\
18.4 \\
17.6 \\
18.5 \\
20.3 \\
21.6 \\
20.7 \\
19.9\end{array}$ & $\begin{array}{l}18.0 \\
17.7 \\
17.4 \\
17.6 \\
17.6 \\
19.2 \\
19.3 \\
18.8\end{array}$ & $\begin{array}{l}20.9 \\
20.8 \\
20.8 \\
21.5 \\
22.2 \\
23.1 \\
21.6\end{array}$ & & $\begin{array}{r}3.9 \\
10.5 \\
6.8 \\
7.5 \\
9.3 \\
3.3 \\
6.1 \\
5.0\end{array}$ & $\begin{array}{r}4.4 \\
11.5 \\
7.9 \\
9.0 \\
10.0 \\
3.6 \\
6.3 \\
5.1\end{array}$ & $\begin{array}{r}5.2 \\
12.3 \\
9.0 \\
10.3 \\
10.4 \\
3.6 \\
6.5 \\
5.2\end{array}$ & $\begin{array}{r}5.6 \\
13.2 \\
10.1 \\
11.4 \\
11.4 \\
3.8 \\
6.9 \\
5.4\end{array}$ \\
\hline $\begin{array}{l}12 \\
12 \\
12 \\
12 \\
12 \\
12 \\
12 \\
12\end{array}$ & $\begin{array}{r}0 \\
3 \\
6 \\
9 \\
12 \\
15 \\
18 \\
21\end{array}$ & $\begin{array}{l}18.9 \\
17.5 \\
18.5 \\
20.0 \\
23.0 \\
23.5 \\
22.6 \\
18.9\end{array}$ & $\begin{array}{l}18.1 \\
17.0 \\
17.5 \\
18.4 \\
18.9 \\
18.3 \\
18.4 \\
17.7\end{array}$ & $\begin{array}{l}18.8 \\
17.6 \\
18.5 \\
20.4 \\
22.7 \\
23.2 \\
22.5 \\
19.3\end{array}$ & $\begin{array}{l}17.9 \\
16.8 \\
17.4 \\
18.2 \\
18.3 \\
18.0 \\
18.4 \\
17.5\end{array}$ & $\begin{array}{l}18.7 \\
17.7 \\
18.5 \\
20.2 \\
22.4 \\
23.0 \\
22.6 \\
19.6\end{array}$ & $\begin{array}{l}18.0 \\
17.0 \\
17.3 \\
18.3 \\
18.1 \\
17.8 \\
20.0 \\
17.5\end{array}$ & $\begin{array}{l}18.5 \\
17.7 \\
18.3 \\
19.8 \\
22.3 \\
22.9 \\
22.7 \\
20.1\end{array}$ & $\begin{array}{l}18.4 \\
17.0 \\
18.2 \\
18.6 \\
18.4 \\
18.4 \\
1.6\end{array}$ & $\begin{array}{l}21.6 \\
21.4 \\
21.5 \\
22.8 \\
21.4 \\
21.1\end{array}$ & & $\begin{array}{l}7.9 \\
4.2 \\
8.2 \\
5.9 \\
6.03 \\
4.06 \\
2.3 \\
2.9\end{array}$ & $\begin{array}{l}8.3 \\
4.6 \\
8.5 \\
6.2 \\
7.6 \\
5.4 \\
2.9 \\
3.7\end{array}$ & $\begin{array}{l}8.5 \\
4.8 \\
9.2 \\
6.8 \\
9.2 \\
6.2 \\
3.5 \\
5.3\end{array}$ & $\begin{array}{r}9.1 \\
5.5 \\
9.0 \\
7.1 \\
10.3 \\
6.5 \\
4.8 \\
7.5\end{array}$ \\
\hline $\begin{array}{l}13 \\
13 \\
13 \\
13 \\
13 \\
13 \\
13 \\
13\end{array}$ & $\begin{array}{r}0 \\
3 \\
6 \\
9 \\
12 \\
15 \\
18 \\
21\end{array}$ & $\begin{array}{l}17.9 \\
18.7 \\
20.9 \\
23.7 \\
25.5 \\
25.6 \\
20.8 \\
22.0\end{array}$ & $\begin{array}{l}16.8 \\
17.8 \\
19.4 \\
19.9 \\
20.4 \\
20.1 \\
17.2 \\
18.8\end{array}$ & $\begin{array}{l}18.4 \\
18.8 \\
20.8 \\
23.8 \\
25.7 \\
25.6 \\
20.9 \\
22.0\end{array}$ & $\begin{array}{l}16.7 \\
17.6 \\
19.1 \\
19.7 \\
20.2 \\
19.8 \\
17.0 \\
18.6\end{array}$ & $\begin{array}{l}19.1 \\
18.9 \\
21.1 \\
24.1 \\
25.9 \\
25.2 \\
20.9 \\
22.9\end{array}$ & $\begin{array}{l}16.8 \\
17.6 \\
19.3 \\
19.5 \\
20.0 \\
1.3 .5 \\
17.1 \\
18.6\end{array}$ & $\begin{array}{l}19.7 \\
19.0 \\
21.1 \\
23.8 \\
25.9 \\
24.8 \\
21.3 \\
21.9\end{array}$ & $\begin{array}{l}19.2 \\
17.5\end{array}$ & $\begin{array}{l}23.7 \\
23.6 \\
22.7\end{array}$ & & $\begin{array}{r}2.3 \\
5.3 \\
6.0 \\
7.4 \\
8.2 \\
9.1 \\
9.5 \\
12.9\end{array}$ & $\begin{array}{r}4.1 \\
5.6 \\
6.2 \\
8.0 \\
8.9 \\
10.5 \\
11.5 \\
13.6\end{array}$ & $\begin{array}{r}5.2 \\
6.0 \\
6.3 \\
8.8 \\
9.6 \\
11.8 \\
13.1 \\
14.4\end{array}$ & $\begin{array}{r}7.2 \\
6.8 \\
6.8 \\
9.0 \\
10.2 \\
13.5 \\
15.6 \\
15.5\end{array}$ \\
\hline $\begin{array}{l}14 \\
14 \\
14 \\
14 \\
14 \\
14 \\
14 \\
14\end{array}$ & $\begin{array}{r}0 \\
3 \\
6 \\
9 \\
12 \\
15 \\
18 \\
21\end{array}$ & $\begin{array}{l}19.8 \\
17.8 \\
18.7 \\
22.5 \\
24.5\end{array}$ & $\begin{array}{l}17.4 \\
16.6 \\
17.3 \\
19.2 \\
20.1\end{array}$ & $\begin{array}{l}19.8 \\
17.8 \\
18.7 \\
22.4 \\
24.5\end{array}$ & $\begin{array}{l}17.4 \\
16.4 \\
16.9 \\
19.0 \\
19.8\end{array}$ & $\begin{array}{l}19.5 \\
18.1 \\
19.7 \\
22.4 \\
24.6\end{array}$ & $\begin{array}{l}17.2 \\
16.5 \\
17.0 \\
18.8 \\
19.8\end{array}$ & $\begin{array}{l}19.2 \\
18.1 \\
18.7 \\
22.2 \\
24.7\end{array}$ & $\begin{array}{l}17.2 \\
17.0 \\
17.2 \\
19.1 \\
20.3\end{array}$ & $\begin{array}{l}21.6 \\
21.8 \\
22.5 \\
22.5 \\
23.9\end{array}$ & & $\begin{array}{l}7.0 \\
5.9 \\
7.3 \\
8.6 \\
5.6 \\
3.9 \\
3.03 \\
7.1\end{array}$ & $\begin{array}{l}8.2 \\
6.0 \\
8.3 \\
9.9 \\
6.0 \\
4.3 \\
4.3 \\
8.0\end{array}$ & $\begin{array}{r}7.6 \\
7.3 \\
8.8 \\
10.5 \\
6.2 \\
4.5 \\
5.5 \\
8.8\end{array}$ & $\begin{array}{r}10.9 \\
8.3 \\
10.0 \\
11.9 \\
6.8 \\
5.3 \\
6.8 \\
10.5\end{array}$ \\
\hline $\begin{array}{l}15 \\
15 \\
15 \\
15 \\
15 \\
15 \\
15 \\
15\end{array}$ & $\begin{array}{r}0 \\
3 \\
6 \\
9 \\
12 \\
15 \\
18 \\
21\end{array}$ & $\begin{array}{l}19.5 \\
21.6 \\
25.1 \\
27.1 \\
26.2 \\
24.0\end{array}$ & $\begin{array}{l}17.7 \\
18.5 \\
20.1 \\
21.2 \\
21.9 \\
20.9\end{array}$ & $\begin{array}{l}19.4 \\
21.6 \\
25.1 \\
27.1 \\
26.1 \\
23.9\end{array}$ & $\begin{array}{l}17.2 \\
18.4 \\
19.9 \\
20.9 \\
22.2 \\
20.6\end{array}$ & $\begin{array}{l}19.5 \\
21.9 \\
25.8 \\
27.3 \\
26.1 \\
23.8\end{array}$ & $\begin{array}{l}17.7 \\
18.5 \\
20.0 \\
20.6 \\
21.2 \\
20.5\end{array}$ & $\begin{array}{l}18.9 \\
21.8 \\
25.4 \\
27.3 \\
26.1 \\
23.7\end{array}$ & $\begin{array}{l}18.5 \\
18.8 \\
20.1 \\
20.7 \\
20.8 \\
20.3\end{array}$ & $\begin{array}{l}21.1 \\
24.5 \\
29.2 \\
29.1 \\
27.2 \\
25.7\end{array}$ & & $\begin{array}{l}9.1 \\
9.1 \\
6.2 \\
6.2 \\
3.2 \\
4.4 \\
5.9 \\
8.1\end{array}$ & $\begin{array}{r}9.8 \\
10.7 \\
6.5 \\
6.4 \\
3.3 \\
4.8 \\
6.2 \\
8.3\end{array}$ & $\begin{array}{r}10.4 \\
12.0 \\
6.7 \\
6.9 \\
3.4 \\
5.2 \\
6.7 \\
8.8\end{array}$ & $\begin{array}{r}11.7 \\
12.9 \\
6.8 \\
6.8 \\
3.6 \\
5.4 \\
7.5 \\
9.4\end{array}$ \\
\hline $\begin{array}{l}16 \\
16 \\
16 \\
16 \\
16 \\
16 \\
16 \\
16\end{array}$ & $\begin{array}{r}0 \\
3 \\
6 \\
9 \\
12 \\
15 \\
18 \\
21\end{array}$ & $\begin{array}{l}22.7 \\
21.7 \\
22.1 \\
24.9 \\
27.5 \\
28.7 \\
27.4 \\
24.9\end{array}$ & $\begin{array}{l}20.4 \\
19.3 \\
19.4 \\
20.6 \\
21.4 \\
21.0 \\
22.4 \\
21.8\end{array}$ & $\begin{array}{l}22.7 \\
21.7 \\
22.2 \\
25.2 \\
27.8 \\
29.0 \\
27.4 \\
24.8\end{array}$ & $\begin{array}{l}20.3 \\
20.7 \\
19.0 \\
20.2 \\
20.7 \\
20.5 \\
21.8 \\
21.5\end{array}$ & $\begin{array}{l}22.5 \\
21.6 \\
22.1 \\
25.3 \\
28.0 \\
29.1 \\
27.5 \\
74.7\end{array}$ & $\begin{array}{l}20.2 \\
18.7 \\
18.8 \\
20.0 \\
20.4 \\
20.4 \\
21.5 \\
21.3\end{array}$ & $\begin{array}{l}22.4 \\
21.3 \\
22.1 \\
25.2 \\
28.0 \\
29.2 \\
27.7 \\
24.7\end{array}$ & $\begin{array}{l}20.2 \\
10.1 \\
19.2 \\
20.1 \\
20.3 \\
20.1 \\
21.0 \\
21.2\end{array}$ & $\begin{array}{l}25.0 \\
22.8 \\
25.1 \\
27.3 \\
30.1 \\
30.9 \\
29.3 \\
27.0\end{array}$ & & $\begin{array}{r}7.5 \\
6.7 \\
10.0 \\
8.4 \\
4.8\end{array}$ & $\begin{array}{r}7.8 \\
7.0 \\
10.4 \\
8.9 \\
5.4\end{array}$ & $\begin{array}{r}8.0 \\
7.3 \\
11.5 \\
9.8 \\
6.0\end{array}$ & $\begin{array}{r}8.2 \\
7.6 \\
11.4 \\
9.8 \\
6.1\end{array}$ \\
\hline $\begin{array}{l}17 \\
17 \\
17 \\
17 \\
17 \\
17 \\
17 \\
17\end{array}$ & $\begin{array}{r}0 \\
3 \\
6 \\
9 \\
12 \\
15 \\
18 \\
21\end{array}$ & $\begin{array}{l}23.0 \\
22.1 \\
24.1 \\
27.8 \\
31.1 \\
30.6 \\
27.0 \\
23.6\end{array}$ & $\begin{array}{l}21.0 \\
20.3 \\
20.7 \\
21.9 \\
23.6 \\
23.1 \\
22.8 \\
21.9\end{array}$ & $\begin{array}{l}23.0 \\
22.3 \\
24.2 \\
27.7 \\
30.7 \\
30.4 \\
27.2 \\
24.0\end{array}$ & $\begin{array}{l}21.1 \\
20.1 \\
20.4 \\
22.0 \\
22.5 \\
23.0 \\
22.7 \\
21.9\end{array}$ & $\begin{array}{l}22.9 \\
22.5 \\
24.2 \\
27.7 \\
31.0 \\
30.1 \\
27.4 \\
74.3\end{array}$ & $\begin{array}{l}20.9 \\
20.1 \\
20.4 \\
21.8 \\
22.5 \\
23.0 \\
22.7 \\
22.0\end{array}$ & $\begin{array}{l}22.7 \\
22.9 \\
24.2 \\
27.5 \\
30.5 \\
29.9 \\
27.5 \\
24.7\end{array}$ & $\begin{array}{l}21.1 \\
20.6 \\
20.4 \\
21.5 \\
22.5 \\
22.6 \\
22.5 \\
22.0\end{array}$ & $\begin{array}{l}26.2 \\
25.4 \\
26.3 \\
27.8 \\
29.4 \\
27.4 \\
24.7 \\
23.6\end{array}$ & & $\begin{array}{l}4.6 \\
3.3 \\
3.5 \\
2.6 \\
4.9 \\
4.6 \\
3.7\end{array}$ & $\begin{array}{l}6.0 \\
3.7 \\
4.1 \\
3.0 \\
5.8 \\
6.0 \\
4.9\end{array}$ & $\begin{array}{l}5.2 \\
3.8 \\
4.5 \\
3.0 \\
6.4 \\
7.5 \\
6.3\end{array}$ & $\begin{array}{l}6.0 \\
4.2 \\
5.1 \\
3.6 \\
7.4 \\
9.6 \\
8.5\end{array}$ \\
\hline $\begin{array}{l}18 \\
18 \\
18 \\
18 \\
18 \\
18 \\
18 \\
18\end{array}$ & $\begin{array}{r}0 \\
3 \\
6 \\
9 \\
12 \\
15 \\
18 \\
21\end{array}$ & $\begin{array}{l}22.7 \\
21.8 \\
24.0 \\
26.4 \\
24.5 \\
27.8 \\
25.0 \\
22.6\end{array}$ & $\begin{array}{l}21.4 \\
21.1 \\
21.6 \\
21.6 \\
22.4 \\
21.5 \\
21.7 \\
21.0\end{array}$ & $\begin{array}{l}22.8 \\
21.0 \\
24.1 \\
26.5 \\
24.6 \\
27.4 \\
25.3 \\
22.0\end{array}$ & $\begin{array}{l}21.3 \\
21.1 \\
21.3 \\
21.4 \\
21.9 \\
21.0 \\
21.4 \\
20.9\end{array}$ & $\begin{array}{l}3.8 \\
21.9 \\
24.1 \\
26.0 \\
24.7 \\
27.5 \\
25.6 \\
23.2\end{array}$ & $\begin{array}{l}21.4 \\
21.0 \\
21.0 \\
21.1 \\
21.7 \\
20.8 \\
21.3 \\
20.0\end{array}$ & $\begin{array}{l}23.1 \\
21.0 \\
24.2 \\
25.0 \\
24.4 \\
27.3 \\
25.0 \\
23.4\end{array}$ & $\begin{array}{l}21.6 \\
21.2 \\
21.0 \\
21.0 \\
21.0 \\
20.5 \\
21.2 \\
20.9\end{array}$ & $\begin{array}{l}24.5 \\
24.8 \\
24.5 \\
25.3 \\
26.2 \\
25.8 \\
24.3 \\
24.1\end{array}$ & & $\begin{array}{r}4.2 \\
6.3 \\
11.9 \\
9.1 \\
5.9 \\
5.0 \\
2.4 \\
2.9\end{array}$ & $\begin{array}{r}5.3 \\
7.0 \\
13.2 \\
11.7 \\
7.6 \\
6.2 \\
3.7 \\
3.9\end{array}$ & $\begin{array}{r}6.2 \\
7.7 \\
14.1 \\
13.4 \\
8.6 \\
6.8 \\
4.8 \\
5.0\end{array}$ & $\begin{array}{r}7.6 \\
8.5 \\
15.1 \\
14.3 \\
7.9 \\
7.9 \\
6.5 \\
6.9\end{array}$ \\
\hline $\begin{array}{l}19 \\
19 \\
19 \\
19 \\
19 \\
19 \\
19 \\
19\end{array}$ & $\begin{array}{r}0 \\
3 \\
6 \\
9 \\
12 \\
15 \\
18 \\
21\end{array}$ & $\begin{array}{l}21.8 \\
20.4 \\
22.6 \\
26.1 \\
28.6 \\
30.5 \\
28.0 \\
26.4\end{array}$ & $\begin{array}{l}20.3 \\
19.0 \\
19.8 \\
2.08 \\
2.2 .5 \\
23.7 \\
23.3 \\
23.2\end{array}$ & $\begin{array}{l}21.8 \\
20.3 \\
22.8 \\
26.4 \\
29.2 \\
30.5 \\
28.1 \\
26.4\end{array}$ & $\begin{array}{l}20.3 \\
18.8 \\
19.3 \\
20.4 \\
22.1 \\
23.0 \\
23.2 \\
23.0\end{array}$ & $\begin{array}{l}21.8 \\
20.3 \\
22.7 \\
26.5 \\
29.3 \\
30.7 \\
28.1 \\
26.4\end{array}$ & $\begin{array}{l}20.2 \\
18.8 \\
19.3 \\
20.4 \\
22.1 \\
22.9 \\
23.1 \\
22.9\end{array}$ & $\begin{array}{l}22.0 \\
20.1 \\
23.9 \\
26.5 \\
29.4 \\
30.8 \\
28.2 \\
26.4\end{array}$ & $\begin{array}{l}20.1 \\
19.1 \\
12.9 \\
19.8 \\
21.4 \\
22.1 \\
27.7 \\
27.3\end{array}$ & $\begin{array}{l}24.2 \\
23.9 \\
24.7 \\
27.2 \\
30.7 \\
30.0 \\
27.9 \\
26.7\end{array}$ & & $\begin{array}{r}3.6 \\
10.6 \\
10.0 \\
8.0 \\
4.2 \\
6.0 \\
6.5 \\
7.8\end{array}$ & $\begin{array}{r}4.6 \\
11.6 \\
11.1 \\
8.7 \\
7.0 \\
7.7 \\
7.5 \\
8.3\end{array}$ & $\begin{array}{r}5.6 \\
12.5 \\
12.0 \\
9.8 \\
5.1 \\
7.0 \\
8.4 \\
8.9\end{array}$ & $\begin{array}{r}7.4 \\
13.2 \\
12.4 \\
9.8 \\
5.2 \\
7.6 \\
10.0 \\
10.1\end{array}$ \\
\hline $\begin{array}{l}20 \\
20 \\
20 \\
20 \\
20 \\
20 \\
20 \\
20\end{array}$ & $\begin{array}{r}0 \\
3 \\
6 \\
9 \\
12 \\
15 \\
18 \\
21\end{array}$ & $\begin{array}{l}24.9 \\
33.0 \\
23.4 \\
76.1 \\
28.1 \\
28.8 \\
27.2 \\
25.6\end{array}$ & $\begin{array}{l}19.6 \\
20.5 \\
21.3 \\
24.0 \\
24.5 \\
25.0 \\
23.8 \\
23.0\end{array}$ & $\begin{array}{l}24.9 \\
22.8 \\
23.3 \\
25.9 \\
28.0 \\
28.7 \\
27.3 \\
25.8\end{array}$ & $\begin{array}{l}19.6 \\
20.3 \\
21.3 \\
23.7 \\
74.2 \\
24.8 \\
23.6 \\
23.0\end{array}$ & $\begin{array}{l}24.1 \\
22.7 \\
23.4 \\
25.9 \\
28.1 \\
29.0 \\
27.5 \\
25.6\end{array}$ & $\begin{array}{l}19.3 \\
20.3 \\
21.2 \\
23.5 \\
24.2 \\
24.8 \\
23.6 \\
23.0\end{array}$ & $\begin{array}{l}24.4 \\
22.5 \\
23.3 \\
25.0 \\
28.0 \\
29.0 \\
27.4 \\
25.0\end{array}$ & $\begin{array}{l}18.5 \\
19.3 \\
20.7 \\
23.1 \\
24.0 \\
24.6 \\
23.5 \\
27.9\end{array}$ & $\begin{array}{l}25.5 \\
24.8 \\
25.5 \\
25.8 \\
27.3 \\
27.5 \\
25.8 \\
25.1\end{array}$ & & $\begin{array}{r}14.2 \\
9.6 \\
5.3 \\
8.6 \\
11.8 \\
12.2 \\
9.4 \\
11.4\end{array}$ & $\begin{array}{r}15.3 \\
10.3 \\
6.5 \\
10.4 \\
13.4 \\
13.3 \\
11.0 \\
13.5\end{array}$ & $\begin{array}{l}16 \cdot 9 \\
11 \cdot 1 \\
7.5 \\
11.5 \\
14.4 \\
14.4 \\
12.0 \\
14.8\end{array}$ & $\begin{array}{r}18.4 \\
12.5 \\
8.9 \\
13.2 \\
16.7 \\
16.1 \\
14.0 \\
17.2\end{array}$ \\
\hline
\end{tabular}


TABLE 10

167

Table 10. - Three-hour averages of air and water-surface temperatures and wind directions and speed, April 1950-August 1951. Lake Heiner-Continued

STATION 3 THREE-HOURLY AVERAGES

JUNE, 1951

\begin{tabular}{|c|c|c|c|c|c|c|c|c|c|c|c|c|c|c|c|}
\hline \multirow{4}{*}{ 至 } & \multirow{4}{*}{ 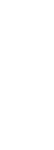 } & \multicolumn{8}{|c|}{ Average air temperature $\left({ }^{\circ} \mathrm{C}\right)$ at indicated height } & \multirow{4}{*}{$\begin{array}{l}\text { Average } \\
\text { water- } \\
\text { surface } \\
\text { tempera- } \\
\text { ture } \\
\left({ }^{\circ} \mathrm{C}\right)\end{array}$} & \multirow{4}{*}{$\begin{array}{c}\text { Average } \\
\text { wind } \\
\text { direction } \\
\text { (coded) }\end{array}$} & \multirow{2}{*}{\multicolumn{4}{|c|}{$\begin{array}{l}\text { Average wind speed (knots) } \\
\text { at indicated height }\end{array}$}} \\
\hline & & \multirow{2}{*}{\multicolumn{2}{|c|}{$\begin{array}{c}2 \\
\text { meters }\end{array}$}} & \multirow{2}{*}{\multicolumn{2}{|c|}{$\begin{array}{c}4 \\
\text { meters }\end{array}$}} & \multirow{2}{*}{\multicolumn{2}{|c|}{$\begin{array}{c}8 \\
\text { meters } \\
\end{array}$}} & \multirow{2}{*}{\multicolumn{2}{|c|}{$\begin{array}{c}16 \\
\text { meters }\end{array}$}} & & & & & & \\
\hline & & & & & & & & & & & & 2 & 4 & 8 & 16 \\
\hline & & $\begin{array}{l}\text { Dry } \\
\text { bulb }\end{array}$ & $\begin{array}{l}\text { Wet } \\
\text { bulb }\end{array}$ & $\begin{array}{l}\text { Dry } \\
\text { bulb }\end{array}$ & $\begin{array}{l}\text { Wet } \\
\text { bulb }\end{array}$ & $\begin{array}{l}\text { Dry } \\
\text { bulb }\end{array}$ & $\begin{array}{l}\text { Wet } \\
\text { bulb }\end{array}$ & $\begin{array}{l}\text { Dry } \\
\text { bulb }\end{array}$ & $\begin{array}{l}\text { Wet } \\
\text { bulb }\end{array}$ & & & meters & meters & meters & meters \\
\hline $\begin{array}{l}21 \\
21 \\
21 \\
21 \\
21 \\
21 \\
21 \\
21\end{array}$ & $\begin{array}{r}0 \\
3 \\
6 \\
9 \\
12 \\
15 \\
18 \\
21\end{array}$ & $\begin{array}{l}24 \cdot 3 \\
24 \cdot 2 \\
23 . \varepsilon\end{array}$ & $\begin{array}{l}22.4 \\
22.5 \\
22.4\end{array}$ & $\begin{array}{l}24.5 \\
24.3 \\
24.0\end{array}$ & $\begin{array}{l}22.4 \\
22.3 \\
22.2\end{array}$ & $\begin{array}{l}24.7 \\
24.3 \\
23.9 \\
25.0 \\
26.6\end{array}$ & $\begin{array}{l}22.5 \\
22.4 \\
22.1 \\
22.4 \\
22.8\end{array}$ & $\begin{array}{l}24 \cdot 9 \\
24 \cdot 3 \\
23 \cdot 9 \\
25 \cdot 1 \\
26 \cdot 6\end{array}$ & $\begin{array}{l}22 \cdot 2 \\
22 \cdot 1 \\
21 \cdot 9\end{array}$ & $\begin{array}{l}24.7 \\
24.5 \\
24.8 \\
25.2 \\
26.5\end{array}$ & & $\begin{array}{r}8.7 \\
13.7 \\
5.5 \\
10.5 \\
9.5 \\
7.0 \\
3.9 \\
10.1\end{array}$ & $\begin{array}{r}10.3 \\
15.2 \\
6.2 \\
11.3 \\
10.1 \\
7.7 \\
4.7 \\
10.9\end{array}$ & $\begin{array}{r}11.7 \\
16.5 \\
6.7 \\
11.8 \\
10.9 \\
8.5 \\
5.2 \\
11.9\end{array}$ & $\begin{array}{r}12.3 \\
17.3 \\
8.4 \\
13.1 \\
11.6 \\
9.3 \\
6.4 \\
15.3\end{array}$ \\
\hline $\begin{array}{l}22 \\
22 \\
22 \\
22 \\
22 \\
22 \\
22 \\
22\end{array}$ & $\begin{array}{r}0 \\
3 \\
6 \\
9 \\
12 \\
15 \\
13 \\
21\end{array}$ & $\begin{array}{l}24 \cdot 4 \\
26.2 \\
27.9 \\
28.6 \\
27 \cdot 3 \\
24 \cdot 8\end{array}$ & $\begin{array}{l}21 \cdot 9 \\
22.5 \\
23.3 \\
23.5 \\
23.4 \\
22.9 \\
22.3\end{array}$ & $\begin{array}{l}23.9 \\
24.6 \\
26.3 \\
28.3 \\
28.8 \\
27.4 \\
24.8\end{array}$ & $\begin{array}{l}22.0 \\
22.3 \\
23.0 \\
23.2 \\
23.1 \\
22.5 \\
22.2\end{array}$ & $\begin{array}{l}24.0 \\
24.6 \\
26.4 \\
28.4 \\
28.9 \\
27.6 \\
25.0\end{array}$ & $\begin{array}{l}22.0 \\
22.3 \\
23.0 \\
23.1 \\
23.0 \\
22.4 \\
22.3\end{array}$ & $\begin{array}{l}23 \cdot 8 \\
24 \cdot 7 \\
26 \cdot 4 \\
28 \cdot 4 \\
29 \cdot 0 \\
27 \cdot 8 \\
25.3\end{array}$ & $\begin{array}{l}20.5 \\
20.0 \\
21.5 \\
21.8 \\
22.1 \\
21.6 \\
21.7\end{array}$ & $\begin{array}{l}24.7 \\
25.2 \\
26.5 \\
28.3 \\
27.1 \\
26.6 \\
26.0\end{array}$ & & $\begin{array}{r}4.7 \\
15.6 \\
10.1 \\
9.0 \\
9.1 \\
10.9 \\
7.0 \\
3.2\end{array}$ & $\begin{array}{r}5.9 \\
16.8 \\
11.0 \\
9.6 \\
9.8 \\
11.8 \\
7.9 \\
4.0\end{array}$ & $\begin{array}{r}6.6 \\
17.9 \\
11.9 \\
10.3 \\
10.6 \\
12.6 \\
8.7 \\
5.1\end{array}$ & $\begin{array}{r}8.3 \\
20.1 \\
12.7 \\
11.1 \\
11.4 \\
14.1 \\
10.3 \\
6.5\end{array}$ \\
\hline $\begin{array}{l}23 \\
23 \\
23 \\
23 \\
23 \\
23 \\
23 \\
23\end{array}$ & $\begin{array}{r}0 \\
3 \\
5 \\
9 \\
12 \\
15 \\
19 \\
21\end{array}$ & $\begin{array}{l}22 \cdot 3 \\
23 \cdot 9 \\
24 \cdot 1 \\
2.6 \cdot 2 \\
37 \cdot 0 \\
26 \cdot 7 \\
26 \cdot 7 \\
25 \cdot 3\end{array}$ & $\begin{array}{l}21.2 \\
21.6 \\
21.6 \\
21.4 \\
21.6 \\
23.5 \\
22.9 \\
21.9\end{array}$ & $\begin{array}{l}22.5 \\
23.9 \\
24 \cdot 2 \\
25 \cdot 3 \\
27 \cdot 3 \\
26.7 \\
27.1 \\
25.8\end{array}$ & $\begin{array}{l}21.1 \\
21.4 \\
21.4 \\
21.0 \\
21.2 \\
-2.1 \\
22.8 \\
21.8\end{array}$ & $\begin{array}{l}23.1 \\
23.8 \\
24.3 \\
26.4 \\
27.2 \\
26.8 \\
27.2 \\
26.1\end{array}$ & $\begin{array}{l}21.3 \\
21.2 \\
21.2 \\
21.0 \\
21.4 \\
22.0 \\
22.7 \\
21.8\end{array}$ & $\begin{array}{l}23.5 \\
23.8 \\
24.3 \\
26 \cdot 5 \\
27 \cdot 3 \\
26: 9 \\
27.4 \\
26.4\end{array}$ & $\begin{array}{l}21.0 \\
20.6 \\
20.3 \\
20.2 \\
20.7 \\
21.6 \\
22.3 \\
21.4\end{array}$ & $\begin{array}{l}25.6 \\
24 \cdot 9 \\
25 \cdot 3 \\
26 \cdot 1 \\
26.9 \\
26.6 \\
25 \cdot 7 \\
25.3\end{array}$ & & $\begin{array}{r}3.2 \\
12.4 \\
16.6 \\
18.3 \\
17.9 \\
14.7 \\
4.7 \\
5.4\end{array}$ & $\begin{array}{r}4.1 \\
13.2 \\
18.0 \\
19.4 \\
19.3 \\
15.8 \\
5.3 \\
6.9\end{array}$ & $\begin{array}{r}5.0 \\
14.0 \\
19.0 \\
21.0 \\
20.7 \\
17.0 \\
5.8 \\
9.0\end{array}$ & $\begin{array}{r}6.5 \\
15.5 \\
20.1 \\
22.3 \\
22.3 \\
18.0 \\
6.4 \\
9.8\end{array}$ \\
\hline $\begin{array}{l}24 \\
24 \\
24 \\
24 \\
24 \\
34 \\
24 \\
24\end{array}$ & $\begin{array}{r}0 \\
3 \\
6 \\
9 \\
12 \\
15 \\
18 \\
21\end{array}$ & $\begin{array}{l}23.6 \\
21.4 \\
20.4 \\
24.9 \\
27.3 \\
27.7 \\
25.8 \\
24.5\end{array}$ & $\begin{array}{l}20.6 \\
19.7 \\
16.8 \\
19.6 \\
22.0 \\
22.1 \\
22.1 \\
22.1\end{array}$ & $\begin{array}{l}23.6 \\
21.5 \\
20.4 \\
24.8 \\
27.0 \\
27.9 \\
26.0 \\
74.7\end{array}$ & $\begin{array}{l}20.5 \\
19.6 \\
16.6 \\
19.4 \\
21.6 \\
21.4 \\
22.0 \\
22.0\end{array}$ & $\begin{array}{l}23.8 \\
21.6 \\
20.4 \\
24.5 \\
27.4 \\
28.1 \\
26.3 \\
24.0\end{array}$ & $\begin{array}{l}20.5 \\
19.7 \\
16.7 \\
19.4 \\
21.7 \\
21.5 \\
22.0 \\
2 ? .0\end{array}$ & $\begin{array}{l}24 \cdot 1 \\
21: 5 \\
20.3 \\
24: 3 \\
27 \cdot 2 \\
28.0 \\
26.5 \\
25.0\end{array}$ & $\begin{array}{l}20.2 \\
19.5 \\
16.3 \\
28.8 \\
20.9 \\
20.9 \\
21.6 \\
21.7\end{array}$ & $\begin{array}{l}24.6 \\
24.3 \\
24.3 \\
25.7 \\
26.1 \\
26.3 \\
25.7 \\
25.0\end{array}$ & & $\begin{array}{r}6.0 \\
5.4 \\
8.5 \\
10.8 \\
10.0 \\
8.7 \\
4.0 \\
9.2\end{array}$ & $\begin{array}{r}7.4 \\
6.8 \\
10.3 \\
13.3 \\
11.5 \\
10.0 \\
4.9 \\
10.5\end{array}$ & $\begin{array}{r}8.4 \\
8.1 \\
12.5 \\
15.4 \\
12.6 \\
10.8 \\
5.9 \\
11.4\end{array}$ & $\begin{array}{r}10.3 \\
9.5 \\
13.8 \\
18.0 \\
14.4 \\
12.3 \\
7.4 \\
13.6\end{array}$ \\
\hline $\begin{array}{l}25 \\
25 \\
25 \\
25 \\
25 \\
25 \\
25 \\
25\end{array}$ & $\begin{array}{r}0 \\
3 \\
6 \\
9 \\
12 \\
15 \\
18 \\
21\end{array}$ & $\begin{array}{l}23.9 \\
23.0 \\
23.5 \\
25.3 \\
26.7 \\
27.7 \\
27.4 \\
26.1\end{array}$ & $\begin{array}{l}22.4 \\
22.0 \\
22.1 \\
22.7 \\
23.3 \\
23.6 \\
23.8 \\
23.4\end{array}$ & $\begin{array}{l}24.0 \\
22.9 \\
23.5 \\
25.3 \\
25.9 \\
28.0 \\
27.6 \\
26.2\end{array}$ & $\begin{array}{l}22.2 \\
21.8 \\
21.9 \\
22.5 \\
23.0 \\
23.4 \\
23.6 \\
23.2\end{array}$ & $\begin{array}{l}23.9 \\
22.9 \\
23.6 \\
25.4 \\
27.0 \\
28.1 \\
27.7 \\
26.2\end{array}$ & $\begin{array}{l}22 \cdot 1 \\
21 \cdot 1 \\
21.9 \\
22 \cdot 0 \\
23 \cdot 0 \\
23 \cdot 0 \\
23 \cdot 5 \\
23 \cdot 2\end{array}$ & $\begin{array}{l}23.8 \\
22.8 \\
23.7 \\
25.4 \\
27.2 \\
28.3 \\
27.6 \\
2.6 \cdot 1\end{array}$ & $\begin{array}{l}21.7 \\
21.3 \\
21.4 \\
23.0 \\
22.0 \\
23.0 \\
23.3 \\
22.7\end{array}$ & $\begin{array}{l}24 \cdot 6 \\
24 \cdot 5 \\
24 \cdot 8 \\
25.7 \\
27.0 \\
27 \cdot 5 \\
26.4 \\
25.5\end{array}$ & & $\begin{array}{l}13.8 \\
16.6 \\
14.6 \\
10.7 \\
11.6 \\
13.3 \\
11.7 \\
14.8\end{array}$ & $\begin{array}{l}14.8 \\
17.8 \\
15.5 \\
11.4 \\
12.4 \\
14.3 \\
12.5 \\
15.8\end{array}$ & $\begin{array}{l}15.5 \\
18.9 \\
16.5 \\
19.1 \\
13.2 \\
15.5 \\
13.4 \\
16.7\end{array}$ & $\begin{array}{l}16.7 \\
20.6 \\
17.2 \\
12.7 \\
14.2 \\
16.6 \\
14.7 \\
18.2\end{array}$ \\
\hline $\begin{array}{l}26 \\
26 \\
26 \\
26 \\
26 \\
26 \\
26 \\
26\end{array}$ & $\begin{array}{r}0 \\
3 \\
6 \\
9 \\
12 \\
15 \\
18 \\
21\end{array}$ & $\begin{array}{l}25 \cdot 1 \\
24 \cdot 2 \\
24 \cdot 3 \\
26 \cdot 5 \\
28 \cdot 8 \\
29 \cdot 7 \\
28 \cdot 4 \\
26 \cdot 3\end{array}$ & $\begin{array}{l}22.0 \\
21.2 \\
21 \cdot 6 \\
22.6 \\
23.3 \\
23 \cdot 3 \\
22 \cdot 4 \\
21.6\end{array}$ & $\begin{array}{l}25.1 \\
24 \cdot 7 \\
24.5 \\
26.8 \\
29.1 \\
30.0 \\
28.8 \\
2.0 .4\end{array}$ & $\begin{array}{l}21 \cdot 7 \\
20.9 \\
21.4 \\
22.2 \\
23 \cdot 2 \\
32.9 \\
22.0 \\
21.2\end{array}$ & $\begin{array}{l}25.1 \\
24.2 \\
24.5 \\
27.1 \\
29.3 \\
30.3 \\
28.8 \\
26.5\end{array}$ & $\begin{array}{l}21.5 \\
20.8 \\
21.3 \\
22.1 \\
23.1 \\
23.1 \\
22.0 \\
21.1\end{array}$ & $\begin{array}{l}25.1 \\
24: 3 \\
34: 5 \\
27: 0 \\
29.4 \\
30.4 \\
28.0 \\
26.3\end{array}$ & $\begin{array}{l}21.3 \\
20.7 \\
21.0 \\
21.7 \\
22.7 \\
27.6 \\
21.4 \\
21.5\end{array}$ & $\begin{array}{l}24 \cdot 8 \\
24 \cdot 3 \\
24 \cdot 8 \\
26.7 \\
28.1 \\
27.8 \\
26.2 \\
25.1\end{array}$ & & $\begin{array}{l}17.7 \\
16.4 \\
16.0 \\
15.5 \\
17.4 \\
19.6 \\
16.2 \\
17.2\end{array}$ & $\begin{array}{l}18.9 \\
17.4 \\
17.1 \\
16.7 \\
18.7 \\
21.1 \\
17.4 \\
18.5\end{array}$ & $\begin{array}{l}20.2 \\
18.5 \\
18.4 \\
18.6 \\
20.7 \\
23.1 \\
18.9 \\
19.7\end{array}$ & $\begin{array}{l}21.4 \\
19.4 \\
19.0 \\
18.9 \\
21.8 \\
24.6 \\
20.4 \\
21.3\end{array}$ \\
\hline $\begin{array}{l}27 \\
27 \\
27 \\
27 \\
27 \\
27 \\
27 \\
27\end{array}$ & $\begin{array}{r}0 \\
3 \\
6 \\
9 \\
12 \\
15 \\
18 \\
21\end{array}$ & $\begin{array}{l}25 \cdot 3 \\
24 \cdot 5 \\
24 \cdot 7 \\
26.9 \\
29 \cdot 1 \\
29.8 \\
28.1 \\
26.2\end{array}$ & $\begin{array}{l}21 \cdot 0 \\
20.8 \\
21.0 \\
21 \cdot 8 \\
22.5 \\
21.9 \\
21.9 \\
22 \cdot 0\end{array}$ & $\begin{array}{l}25.4 \\
24 \cdot 5 \\
24 \cdot 9 \\
27 \cdot 1 \\
29 \cdot 5 \\
30 \cdot 0 \\
28 \cdot 3 \\
26 \cdot 4\end{array}$ & $\begin{array}{l}20.8 \\
20.4 \\
20.8 \\
21.7 \\
22.2 \\
21.3 \\
21.6 \\
21.8\end{array}$ & $\begin{array}{l}25.5 \\
24.5 \\
24.9 \\
27.4 \\
29.7 \\
30.2 \\
28.4 \\
26.4\end{array}$ & $\begin{array}{l}20.8 \\
20.4 \\
20.8 \\
22.5\end{array}$ & $\begin{array}{l}25.4 \\
24.4 \\
24.9 \\
27.5 \\
29.9 \\
30.6 \\
28.5 \\
26.3\end{array}$ & $\begin{array}{l}20.3 \\
20.0 \\
20.3 \\
21.1 \\
21.7 \\
20.8 \\
21.1 \\
21.2\end{array}$ & $\begin{array}{l}24.5 \\
24.0 \\
24.4 \\
26.1 \\
27.4 \\
27.2 \\
25.7 \\
24.9\end{array}$ & & $\begin{array}{l}17.3 \\
15.8 \\
15.1 \\
18.3 \\
18.0 \\
16.9 \\
14.5 \\
15.3\end{array}$ & $\begin{array}{l}18.5 \\
16.8 \\
16.1 \\
19.7 \\
19.3 \\
18.2 \\
15.4 \\
16.4\end{array}$ & $\begin{array}{l}19.8 \\
18.2 \\
17.2 \\
21.7 \\
21.4 \\
19.8 \\
16.7 \\
17.4\end{array}$ & $\begin{array}{l}21.0 \\
18.5 \\
17.9 \\
22.6 \\
22.8 \\
21.2 \\
18.2 \\
19.0\end{array}$ \\
\hline $\begin{array}{l}28 \\
28 \\
28 \\
28 \\
28 \\
28 \\
28 \\
28\end{array}$ & $\begin{array}{r}0 \\
3 \\
6 \\
9 \\
12 \\
15 \\
18 \\
21\end{array}$ & $\begin{array}{l}25.0 \\
23.6 \\
24.0 \\
27.1\end{array}$ & $\begin{array}{l}21.6 \\
21.0 \\
21.4 \\
27.6\end{array}$ & $\begin{array}{l}25.0 \\
23.7 \\
24.2 \\
27.7\end{array}$ & $\begin{array}{l}2.1 \cdot 3 \\
20 \cdot 8 \\
21 \cdot 3 \\
22 \cdot 3\end{array}$ & $\begin{array}{l}25.0 \\
23.6 \\
74.3 \\
27.3\end{array}$ & & $\begin{array}{l}24 \cdot 9 \\
23 \cdot 5 \\
24 \cdot 0 \\
27 \cdot 2\end{array}$ & $\begin{array}{l}20.9 \\
20.4 \\
20.9 \\
21.7\end{array}$ & $\begin{array}{l}24 \cdot 3 \\
23.9 \\
24 \cdot 2 \\
26 \cdot 1\end{array}$ & & $\begin{array}{r}16.8 \\
11.4 \\
10.3 \\
4.3 \\
5.7 \\
9.9 \\
10.0 \\
12.1\end{array}$ & $\begin{array}{r}17.8 \\
12.0 \\
11.0 \\
5.0 \\
6.1 \\
10.6 \\
10.8 \\
12.9\end{array}$ & $\begin{array}{r}13.8 \\
12.6 \\
11.8 \\
5.1 \\
6.5 \\
1.1 .5 \\
11.6 \\
13.6\end{array}$ & $\begin{array}{r}20.3 \\
13.2 \\
12.0 \\
5.2 \\
7.0 \\
12.8 \\
13.0 \\
15.2\end{array}$ \\
\hline $\begin{array}{l}29 \\
29 \\
29 \\
29 \\
29 \\
29 \\
29 \\
29\end{array}$ & $\begin{array}{r}0 \\
3 \\
6 \\
9 \\
12 \\
15 \\
18 \\
21\end{array}$ & $\begin{array}{l}25.6 \\
28.7 \\
29.7 \\
28.4 \\
76.8\end{array}$ & $\begin{array}{l}22 \cdot 6 \\
23 \cdot 5 \\
23 \cdot 2 \\
22.7 \\
21.9\end{array}$ & $\begin{array}{l}25 \cdot 9 \\
28 \cdot 9 \\
29 \cdot 9 \\
28 \cdot 5 \\
26 \cdot 8\end{array}$ & $\begin{array}{l}22.6 \\
23.2 \\
23.0 \\
22.4 \\
21.7\end{array}$ & $\begin{array}{l}25.9 \\
29.5 \\
30.1 \\
28.8 \\
26.9\end{array}$ & & $\begin{array}{l}25.9 \\
29 \cdot 3 \\
30.3 \\
28.8 \\
26.9\end{array}$ & $\begin{array}{r}20.7 \\
22.3 \\
22.2 \\
21.4 \\
-21.1\end{array}$ & $\begin{array}{l}24 \cdot 7 \\
27 \cdot 0 \\
27 \cdot 5 \\
26 \cdot 3 \\
25 \cdot 2\end{array}$ & & $\begin{array}{r}16.2 \\
13.0 \\
15.4 \\
7.4 \\
8.8 \\
14.5 \\
12.2 \\
14.7\end{array}$ & $\begin{array}{r}17.3 \\
13.7 \\
16.4 \\
8.1 \\
9.6 \\
15.7 \\
13.1 \\
15.9\end{array}$ & $\begin{array}{r}18.2 \\
14.4 \\
17.6 \\
8.9 \\
10.3 \\
17.0 \\
14.3 \\
16.8\end{array}$ & $\begin{array}{r}19.4 \\
15.2 \\
18.2 \\
9.7 \\
11.4 \\
18.7 \\
15.9 \\
18.9\end{array}$ \\
\hline $\begin{array}{l}30 \\
30 \\
30 \\
30 \\
30 \\
30 \\
30 \\
30\end{array}$ & $\begin{array}{r}0 \\
3 \\
6 \\
9 \\
12 \\
15 \\
18 \\
21\end{array}$ & $\begin{array}{l}24 \cdot 2 \\
19.8 \\
19.3 \\
20.6 \\
20.6 \\
21.7 \\
20.6 \\
17.8\end{array}$ & $\begin{array}{l}21.0 \\
18.3 \\
17.9 \\
19.0 \\
18.3 \\
17.1 \\
16.1 \\
15.5\end{array}$ & $\begin{array}{l}24.1 \\
19.8 \\
19.4 \\
20.7 \\
20.3 \\
21.5 \\
20.4 \\
17.9\end{array}$ & $\begin{array}{l}20.8 \\
18.3 \\
17.9 \\
18.6 \\
18.1 \\
17.0 \\
15.8 \\
15.4\end{array}$ & $\begin{array}{l}24 \cdot 0 \\
19.8 \\
19.3 \\
20.4 \\
20.2 \\
210.4 \\
20.4 \\
18.0\end{array}$ & $\begin{array}{l}27.5 \\
18.7 \\
18.0 \\
16.8 \\
15.8 \\
15.6\end{array}$ & $\begin{array}{l}23.3 \\
19.7 \\
19.2 \\
20.2 \\
19.7 \\
21.1 \\
20.3 \\
18.2\end{array}$ & $\begin{array}{l}19.5 \\
17.5 \\
17.2 \\
17.0 \\
16.1 \\
16.9 \\
15.5 \\
14.9\end{array}$ & $\begin{array}{l}24 \cdot 2 \\
24.0 \\
24.0 \\
24.2 \\
23.7 \\
23.7 \\
22.5 \\
22.0\end{array}$ & & $\begin{array}{r}12.5 \\
6.7 \\
7.4 \\
7.1 \\
10.8 \\
9.1 \\
5.4 \\
2.5\end{array}$ & $\begin{array}{r}14.4 \\
8.6 \\
8.8 \\
8.5 \\
13.5 \\
11.8 \\
6.6 \\
3.1\end{array}$ & $\begin{array}{r}15.8 \\
10.2 \\
10.3 \\
9.8 \\
15.3 \\
14.0 \\
8.1 \\
4.2\end{array}$ & $\begin{array}{l}15.8 \\
10.5 \\
12.0 \\
10.4\end{array}$ \\
\hline
\end{tabular}


TABLE 10

Table 10. - Three-hour averages of air and water-surface temperatures and wind directions and speed, April 1950-August 1951, Lake Hefner-Continued

STATION 3

THREE-HOURLY AVERAGES

JULY, 1951

\begin{tabular}{|c|c|c|c|c|c|c|c|c|c|c|c|c|c|c|c|}
\hline \multirow{4}{*}{ 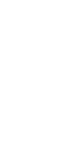 } & \multirow{4}{*}{ 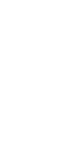 } & \multicolumn{8}{|c|}{ Average air temperature $\left({ }^{\circ} \mathrm{C}\right)$ at indicated he ight } & \multirow{4}{*}{$\begin{array}{l}\text { Average } \\
\text { water- } \\
\text { surface } \\
\text { tempera- } \\
\text { ture } \\
\text { ("C) }\end{array}$} & \multirow{4}{*}{$\begin{array}{c}\text { Average } \\
\text { wind } \\
\text { direction } \\
\text { (coded) }\end{array}$} & \multirow{2}{*}{\multicolumn{4}{|c|}{$\begin{array}{l}\text { Average wind speed (knots) } \\
\text { at indicated height }\end{array}$}} \\
\hline & & \multirow{2}{*}{\multicolumn{2}{|c|}{$\stackrel{2}{2}$ meters }} & \multirow{2}{*}{\multicolumn{2}{|c|}{$\begin{array}{c}4 \\
\text { meters }\end{array}$}} & \multirow{2}{*}{\multicolumn{2}{|c|}{$\begin{array}{c}8 \\
\text { meters }\end{array}$}} & \multirow{2}{*}{\multicolumn{2}{|c|}{$\begin{array}{c}16 \\
\text { meters. }\end{array}$}} & & & & & & \\
\hline & & & & & & & & & & & & 2 & 4 & 8 & 16 \\
\hline & & $\begin{array}{l}\text { Dry } \\
\text { bulb }\end{array}$ & $\begin{array}{l}\text { Wet } \\
\text { bulb }\end{array}$ & $\begin{array}{l}\text { Dry } \\
\text { bulb }\end{array}$ & $\begin{array}{l}\text { Wet } \\
\text { bulb }\end{array}$ & $\begin{array}{l}\text { Dry } \\
\text { bulb }\end{array}$ & $\begin{array}{l}\text { Wet } \\
\text { bulb }\end{array}$ & $\begin{array}{l}\text { Dry } \\
\text { butb }\end{array}$ & $\begin{array}{l}\text { Wet } \\
\text { bulb }\end{array}$ & & & meters & meters & meters & meters \\
\hline $\begin{array}{l}1 \\
1 \\
1 \\
1 \\
1 \\
1 \\
1 \\
1\end{array}$ & $\begin{array}{r}0 \\
3 \\
6 \\
9 \\
12 \\
15 \\
18 \\
21\end{array}$ & $\begin{array}{l}16.9 \\
16.9 \\
16.5 \\
14.8 \\
16.3 \\
18.4 \\
17.8 \\
17.1\end{array}$ & $\begin{array}{l}15.5 \\
15.4 \\
14.6 \\
13.9 \\
14.8 \\
16.6 \\
17.0 \\
17.0\end{array}$ & $\begin{array}{l}17.0 \\
17.0 \\
16.2 \\
14.7 \\
15.9 \\
18.5 \\
18.0 \\
17.5\end{array}$ & $\begin{array}{l}15.5 \\
15.3 \\
14.4 \\
13.4 \\
16.9 \\
17.1 \\
16.9\end{array}$ & $\begin{array}{l}17.2 \\
17.1 \\
16.6 \\
14.9 \\
16.3 \\
18.2 \\
18.0 \\
17.8\end{array}$ & $\begin{array}{l}15.6 \\
15.3 \\
14.7 \\
13.7 \\
14.9 \\
16.6 \\
17.1 \\
17.0\end{array}$ & $\begin{array}{l}17.4 \\
17.12 \\
16.5 \\
14.8 \\
16.2 \\
17.8 \\
17.8 \\
17.7\end{array}$ & $\begin{array}{l}13.9 \\
13.3\end{array}$ & $\begin{array}{l}22.9 \\
22.7 \\
23.2 \\
23.1 \\
23.4 \\
23.1 \\
22.3 \\
22.5\end{array}$ & & $\begin{array}{l}2.0 \\
2.4 \\
5.7 \\
7.8 \\
6.9 \\
7.4 \\
5.6 \\
2.9\end{array}$ & $\begin{array}{l}2.3 \\
3.2 \\
7.0 \\
9.4 \\
8.3 \\
9.1 \\
6.9 \\
3.8\end{array}$ & $\begin{array}{r}3.0 \\
3.9 \\
8.1 \\
10.9 \\
9.6 \\
10.8 \\
8.0 \\
4.7\end{array}$ & $\begin{array}{r}4.5 \\
5.2 \\
9.2 \\
12.4 \\
10.3 \\
12.4 \\
9.6 \\
5.9\end{array}$ \\
\hline $\begin{array}{l}2 \\
2 \\
2 \\
2 \\
2 \\
2 \\
2 \\
2\end{array}$ & $\begin{array}{r}0 \\
3 \\
6 \\
9 \\
12 \\
15 \\
18 \\
21\end{array}$ & $\begin{array}{l}17.3 \\
16.0 \\
17.3 \\
22.4 \\
25.1 \\
26.2 \\
25.3 \\
23.1\end{array}$ & $\begin{array}{l}18.1 \\
18.6 \\
20.3 \\
21.7 \\
21.7 \\
21.5\end{array}$ & $\begin{array}{l}23.6 \\
24.7 \\
26.1 \\
25.1 \\
27.9\end{array}$ & $\begin{array}{l}19.0 \\
20.4 \\
21.6 \\
21.6 \\
21.4\end{array}$ & $\begin{array}{l}17.9 \\
28.5 \\
19.1 \\
23.8 \\
25.0 \\
26.2 \\
25.2 \\
23.0\end{array}$ & $\begin{array}{l}17.3 \\
17.8 \\
18.0 \\
19.3 \\
20.5 \\
21.3 \\
21.4 \\
21.2\end{array}$ & $\begin{array}{l}17.8 \\
18.3 \\
18.9 \\
23.3 \\
24.8 \\
26.1 \\
25.0 \\
22.8\end{array}$ & $\begin{array}{l}18.5 \\
29.6 \\
20.8 \\
20.5 \\
19.7\end{array}$ & $\begin{array}{l}22.7 \\
22.6 \\
22.7 \\
20.3 \\
21.7 \\
25.1 \\
23.4 \\
23.4\end{array}$ & & $\begin{array}{r}5.0 \\
10.4 \\
4.5 \\
2.9 \\
8.3 \\
10.5 \\
11.1 \\
12.9\end{array}$ & $\begin{array}{r}6.0 \\
13.0 \\
6.0 \\
3.2 \\
8.8 \\
11.4 \\
11.8 \\
13.8\end{array}$ & $\begin{array}{r}6.6 \\
14.6 \\
6.6 \\
3.4 \\
9.2 \\
12.0 \\
12.5 \\
14.5\end{array}$ & $\begin{array}{r}7.9 \\
16.2 \\
7.4 \\
3.7 \\
10.1 \\
13.1 \\
13.8 \\
16.2\end{array}$ \\
\hline $\begin{array}{l}3 \\
3 \\
3 \\
3 \\
3 \\
3 \\
3 \\
3\end{array}$ & $\begin{array}{r}0 \\
3 \\
6 \\
9 \\
12 \\
15 \\
18 \\
21\end{array}$ & $\begin{array}{l}22.0 \\
22.4 \\
23.7 \\
26.3 \\
27.8 \\
28.8 \\
28.1 \\
26.8\end{array}$ & $\begin{array}{l}21.6 \\
21.8 \\
21.9 \\
23.2 \\
24.0 \\
24.4 \\
24.5 \\
23.6\end{array}$ & $\begin{array}{l}21.9 \\
22.2 \\
23.8 \\
26.4 \\
28.0 \\
29.1 \\
28.3 \\
26.8\end{array}$ & $\begin{array}{l}2.1 .3 \\
21.5 \\
22.0 \\
23.4 \\
24.0 \\
24.4 \\
24.6 \\
23.7\end{array}$ & $\begin{array}{l}27.3 \\
23.0 \\
24.2 \\
26.9 \\
28.4 \\
29.5 \\
28.9 \\
26.7\end{array}$ & $\begin{array}{l}21.3 \\
21.4 \\
22.01 \\
23.5 \\
24.1 \\
24.4 \\
24.7 \\
22.9\end{array}$ & $\begin{array}{l}22.1 \\
22.8 \\
24.2 \\
26.9 \\
28.6 \\
29.8 \\
28.9 \\
26.6\end{array}$ & & $\begin{array}{l}23.1 \\
22.06 \\
21.5 \\
22.2 \\
22.9 \\
23.6 \\
24.0 \\
23.5\end{array}$ & & $\begin{array}{l}13.3 \\
15.6 \\
14.6 \\
17.9 \\
13.5 \\
13.4 \\
10.7 \\
10.0\end{array}$ & $\begin{array}{l}14.3 \\
16.6 \\
15.5 \\
19.3 \\
14.6 \\
14.6 \\
11.6 \\
11.1\end{array}$ & $\begin{array}{l}15.1 \\
17.5 \\
16.5 \\
21.0 \\
16.0 \\
16.0 \\
12.8 \\
12.2\end{array}$ & $\begin{array}{l}16.7 \\
18.8 \\
17.5 \\
22.3 \\
17.2 \\
17.2 \\
14.4 \\
14.2\end{array}$ \\
\hline $\begin{array}{l}4 \\
4 \\
4 \\
4 \\
4 \\
4 \\
4 \\
4\end{array}$ & $\begin{array}{r}0 \\
3 \\
6 \\
9 \\
17 \\
15 \\
18 \\
23\end{array}$ & $\begin{array}{l}20.7 \\
26.9 \\
28.0 \\
24.8 \\
24.0\end{array}$ & $\begin{array}{l}17.6 \\
19.6 \\
22.1 \\
21.9 \\
22.6\end{array}$ & $\begin{array}{l}20.8 \\
27.1 \\
27.8 \\
25.1 \\
24.4\end{array}$ & $\begin{array}{l}18.7 \\
21: 0 \\
22.5 \\
32.4 \\
? 2.9\end{array}$ & $\begin{array}{l}21.9 \\
27.0 \\
27.7 \\
25.5 \\
24.8\end{array}$ & $\begin{array}{l}18.9 \\
21.1 \\
22.5 \\
22.5 \\
23.1\end{array}$ & $\begin{array}{l}22.2 \\
27.2 \\
27.0 \\
25.5 \\
24.9\end{array}$ & $\begin{array}{l}17.5 \\
19.7 \\
21.1 \\
21.6 \\
22.1\end{array}$ & $\begin{array}{l}23.8 \\
23.3 \\
29.9 \\
20.7 \\
21.5 \\
21.5\end{array}$ & & $\begin{array}{r}9.1 \\
8.9 \\
9.2 \\
10.7 \\
2.0 \\
5.5 \\
4.6 \\
5.4\end{array}$ & $\begin{array}{r}11.1 \\
10.7 \\
10.0 \\
11.7 \\
3.04 \\
6.9 \\
5.8 \\
6.6\end{array}$ & $\begin{array}{r}12.6 \\
12.6 \\
10.6 \\
12.6 \\
3.6 \\
8.0 \\
7.1 \\
7.8\end{array}$ & $\begin{array}{r}15.0 \\
13.1 \\
11.8 \\
13.5 \\
3.8 \\
9.2 \\
8.9 \\
9.4\end{array}$ \\
\hline $\begin{array}{l}5 \\
5 \\
5 \\
5 \\
5 \\
5 \\
5 \\
5\end{array}$ & $\begin{array}{r}0 \\
3 \\
6 \\
9 \\
17 \\
15 \\
18 \\
21\end{array}$ & $\begin{array}{l}23.6 \\
23.3 \\
23.8 \\
26.7 \\
28.5\end{array}$ & $\begin{array}{l}21.8 \\
21.0 \\
21.2 \\
22.7 \\
23.4\end{array}$ & $\begin{array}{l}24.0 \\
23.0 \\
24.1 \\
27 . ? \\
29.9\end{array}$ & $\begin{array}{l}22.0 \\
21.1 \\
21.5 \\
22.9 \\
23.1\end{array}$ & $\begin{array}{l}24.4 \\
23.8 \\
24.7 \\
27.6 \\
79.4\end{array}$ & $\begin{array}{l}22.1 \\
21.2 \\
21.4 \\
22.9 \\
23.0\end{array}$ & $\begin{array}{l}24.4 \\
23.7 \\
24.4 \\
27.7 \\
29.4\end{array}$ & & $\begin{array}{l}21.8 \\
21.9 \\
21.6\end{array}$ & & $\begin{array}{r}8.3 \\
12.5 \\
15.6 \\
13.7 \\
11.9 \\
14.0 \\
12.2 \\
14.4\end{array}$ & $\begin{array}{r}9.4 \\
13.3 \\
16.6 \\
14.9 \\
12.9 \\
15.2 \\
13.2 \\
15.4\end{array}$ & $\begin{array}{l}10.03 \\
14.1 \\
17.9 \\
16.4 \\
14.1 \\
16.5 \\
14.2 \\
16.3\end{array}$ & $\begin{array}{l}12.3 \\
15.4 \\
18.8 \\
17.1 \\
15.3 \\
18.3 \\
15.8 \\
18.3\end{array}$ \\
\hline $\begin{array}{l}6 \\
6 \\
6 \\
6 \\
6 \\
6 \\
6 \\
6\end{array}$ & $\begin{array}{r}0 \\
3 \\
5 \\
9 \\
12 \\
15 \\
18 \\
21\end{array}$ & $\begin{array}{l}25 \cdot 3 \\
27.4 \\
28.9 \\
29.5 \\
28.02 \\
26.2\end{array}$ & $\begin{array}{l}21.3 \\
22.0 \\
22.8 \\
23.2 \\
22.8 \\
22.0\end{array}$ & $\begin{array}{l}25.5 \\
27.8 \\
29.3 \\
29.8 \\
28.4 \\
25.3\end{array}$ & $\begin{array}{l}21 \cdot 1 \\
21 \cdot 9 \\
22 \cdot 6 \\
23 \cdot 0 \\
22 \cdot 0 \\
21 \bullet 9\end{array}$ & $\begin{array}{l}25.9 \\
28.2 \\
29.5 \\
30.1 \\
28.5 \\
26.4\end{array}$ & $\begin{array}{l}21.2 \\
21.8 \\
22.6 \\
22.9 \\
22.5 \\
21.9\end{array}$ & $\begin{array}{l}25.9 \\
28.2 \\
29.8 \\
30.2 \\
28.6 \\
26.3\end{array}$ & $\begin{array}{l}20.3 \\
20.8 \\
21.5 \\
22.0 \\
21.0 \\
21.0\end{array}$ & $\begin{array}{l}23 \cdot 9 \\
24 \cdot 0 \\
23 \cdot 3\end{array}$ & & $\begin{array}{l}16.9 \\
16.00 \\
17.5 \\
15.6 \\
14.3 \\
12.9 \\
11.04 \\
12.8\end{array}$ & $\begin{array}{l}18.1 \\
17.0 \\
18.7 \\
16.8 \\
15.5 \\
14.0 \\
12.4 \\
13.6\end{array}$ & $\begin{array}{l}19.0 \\
18.1 \\
20.1 \\
18.5 \\
17.1 \\
15.1 \\
13.3 \\
14.6\end{array}$ & $\begin{array}{l}20.6 \\
19.3 \\
21.1 \\
19.2 \\
18.2 \\
16.6 \\
15.2 \\
16.5\end{array}$ \\
\hline $\begin{array}{l}7 \\
7 \\
7 \\
7 \\
7 \\
7 \\
7 \\
7\end{array}$ & $\begin{array}{r}0 \\
3 \\
6 \\
9 \\
12 \\
15 \\
18 \\
>1\end{array}$ & $\begin{array}{l}24.6 \\
3.3 .2 \\
? 4.1 \\
37.8 \\
29.05 \\
29.8 \\
38.2 \\
25.0\end{array}$ & $\begin{array}{l}21.7 \\
20.7 \\
21.02 \\
23.6 \\
23.0 \\
23.1 \\
22.0 \\
21.03\end{array}$ & $\begin{array}{l}24.7 \\
23.3 \\
24.2 \\
28.1 \\
29.8 \\
30.2 \\
28.4 \\
25.2\end{array}$ & $\begin{array}{l}21.7 \\
20.9 \\
21.1 \\
22.3 \\
22.7 \\
22.8 \\
21.6 \\
21.0\end{array}$ & $\begin{array}{l}24.7 \\
23.3 \\
24.5 \\
28.4 \\
30.2 \\
30.4 \\
28.5 \\
25.2\end{array}$ & $\begin{array}{l}21.7 \\
21.0 \\
20.8 \\
22.2 \\
22.6 \\
22.4 \\
21.5 \\
20.8\end{array}$ & $\begin{array}{l}24.6 \\
23.0 \\
24.5 \\
28.6 \\
30.4 \\
30.6 \\
28.4 \\
26.2\end{array}$ & $\begin{array}{l}21.9 \\
22.0 \\
20.8 \\
20.2\end{array}$ & $\begin{array}{l}23.0 \\
22.5 \\
23.7 \\
25.5 \\
27.3 \\
27.4 \\
26.0 \\
24.8\end{array}$ & & $\begin{array}{l}15.6 \\
15.8 \\
13.7 \\
14.6 \\
16.0 \\
16.6 \\
13.2 \\
15.1\end{array}$ & $\begin{array}{l}16.7 \\
16.7 \\
14.6 \\
15.7 \\
17.4 \\
17.9 \\
14.2 \\
16.2\end{array}$ & $\begin{array}{l}17.5 \\
17.6 \\
15.3 \\
17.2 \\
19.0 \\
19.5 \\
15.0 \\
17.2\end{array}$ & $\begin{array}{l}19.2 \\
18.7 \\
16.4 \\
18.2 \\
20.3 \\
21.0 \\
16.4 \\
18.6\end{array}$ \\
\hline $\begin{array}{l}8 \\
8 \\
8 \\
8 \\
8 \\
8 \\
6 \\
8\end{array}$ & $\begin{array}{r}0 \\
3 \\
6 \\
9 \\
12 \\
15 \\
18 \\
71\end{array}$ & $\begin{array}{l}24.7 \\
23.8 \\
25.1 \\
27.7 \\
29.6 \\
20.9 \\
? 9.8 \\
26.6\end{array}$ & $\begin{array}{l}21.0 \\
20.3 \\
21.1 \\
22.2 \\
22.5 \\
22.7 \\
22.4 \\
27.2\end{array}$ & $\begin{array}{l}24.7 \\
23.8 \\
25.3 \\
23.2 \\
30.0 \\
30.3 \\
29.0 \\
26.7\end{array}$ & $\begin{array}{l}20.9 \\
20.2 \\
20.9 \\
22.0 \\
22.1 \\
22.4 \\
? 2 . ? \\
? ? .0\end{array}$ & $\begin{array}{l}24.6 \\
23.8 \\
25.5 \\
28.5 \\
30.4 \\
30.5 \\
20.1 \\
26.8\end{array}$ & $\begin{array}{l}20.7 \\
20.0 \\
20.9 \\
21.9 \\
22.1 \\
27.4 \\
27.0 \\
21.9\end{array}$ & $\begin{array}{l}24.5 \\
23.7 \\
25.7 \\
28.7 \\
30.6 \\
30.8 \\
29.3 \\
26.9\end{array}$ & $\begin{array}{l}20 \cdot 0 \\
19 \cdot 3 \\
20.4 \\
21 \cdot 3 \\
21.5 \\
21.9 \\
21.5 \\
21.4\end{array}$ & $\begin{array}{l}24.0 \\
23.5 \\
24.0 \\
25.8 \\
25.9 \\
27.3 \\
26.3 \\
74.8\end{array}$ & & $\begin{array}{l}17.5 \\
16.1 \\
17.3 \\
19.2 \\
19.03 \\
16.3 \\
14.6 \\
16.2\end{array}$ & $\begin{array}{l}18.8 \\
17.1 \\
18.5 \\
20.7 \\
20.8 \\
17.6 \\
15.7 \\
17.4\end{array}$ & $\begin{array}{l}19.7 \\
18.0 \\
19.8 \\
22.9 \\
23.1 \\
19.3 \\
16.9 \\
18.5\end{array}$ & $\begin{array}{l}21.4 \\
19.2 \\
20.8 \\
23.8 \\
24.1 \\
20.8 \\
18.4 \\
19.9\end{array}$ \\
\hline $\begin{array}{l}9 \\
9 \\
9 \\
9 \\
9 \\
9 \\
9 \\
9\end{array}$ & $\begin{array}{r}0 \\
3 \\
6 \\
0 \\
12 \\
15 \\
18 \\
? 1\end{array}$ & $\begin{array}{l}24.7 \\
23.1 \\
24.0 \\
27.3 \\
29.5 \\
30.0 \\
78.6 \\
26.4\end{array}$ & $\begin{array}{l}71.9 \\
20.7 \\
20.9 \\
22.2 \\
23.1 \\
23.4 \\
27.7 \\
22.1\end{array}$ & $\begin{array}{l}24.7 \\
23.7 \\
24 . ? \\
27.7 \\
29.8 \\
30.1 \\
78.8 \\
26.8\end{array}$ & $\begin{array}{l}21.7 \\
20.5 \\
20.8 \\
22.1 \\
22.9 \\
23.1 \\
22.5 \\
21.9\end{array}$ & $\begin{array}{l}24.7 \\
33.7 \\
24.4 \\
28.1 \\
30.1 \\
30.4 \\
78.8 \\
25.8\end{array}$ & $\begin{array}{l}21.2 \\
20.5 \\
20.7 \\
22.0 \\
22.9 \\
23.0 \\
22.5 \\
22.0\end{array}$ & $\begin{array}{l}24.5 \\
23.1 \\
24.5 \\
28.1 \\
30.4 \\
30.5 \\
27.0 \\
26.0\end{array}$ & $\begin{array}{l}20.6 \\
19.9 \\
20.4 \\
21.4 \\
22.3 \\
22.4 \\
27.0 \\
21.5\end{array}$ & $\begin{array}{l}24.0 \\
23.9 \\
24.3 \\
25.3 \\
26.8 \\
27.03 \\
25.0 \\
24.9\end{array}$ & & $\begin{array}{r}13.4 \\
8.1 \\
12.8 \\
14.6 \\
13.5 \\
12.4 \\
10.7 \\
13.0\end{array}$ & $\begin{array}{r}14.2 \\
8.4 \\
13.6 \\
15.7 \\
14.6 \\
13.5 \\
11.7 \\
14.0\end{array}$ & $\begin{array}{r}15.1 \\
8.6 \\
14.5 \\
17.1 \\
15.9 \\
14.7 \\
12.7 \\
14.9\end{array}$ & $\begin{array}{r}16.2 \\
9.4 \\
15.2 \\
18.1 \\
17.0 \\
16.4 \\
14.6 \\
16.9\end{array}$ \\
\hline $\begin{array}{l}10 \\
10 \\
10 \\
10 \\
10 \\
10 \\
10 \\
10\end{array}$ & $\begin{array}{r}0 \\
3 \\
6 \\
9 \\
1 ? \\
15 \\
18 \\
? 1\end{array}$ & $\begin{array}{l}25.4 \\
34.5 \\
24.5 \\
77.7 \\
29.0 \\
29.7 \\
38.6 \\
26.6\end{array}$ & $\begin{array}{l}21.7 \\
21.4 \\
21.2 \\
23.6 \\
23.1 \\
33.6 \\
23.6 \\
23.7\end{array}$ & $\begin{array}{l}25.5 \\
24.6 \\
24.5 \\
27.6 \\
29.4 \\
29.8 \\
28.7 \\
26.7\end{array}$ & $\begin{array}{l}21.8 \\
? \geqslant .3 \\
? 1.3 \\
? 2.4 \\
2 ? .9 \\
? 3.4 \\
23.1 \\
? ? .6\end{array}$ & $\begin{array}{l}35.6 \\
24.6 \\
24.8 \\
28.0 \\
20.6 \\
30.0 \\
28.8 \\
76.6\end{array}$ & $\begin{array}{l}21.8 \\
21.2 \\
21.3 \\
22.4 \\
33.0 \\
23.5 \\
23.0 \\
22.6\end{array}$ & $\begin{array}{l}25.5 \\
24.4 \\
24.7 \\
28.0 \\
29.8 \\
30.0 \\
28.7 \\
26.5\end{array}$ & $21 \cdot ?$ & $\begin{array}{l}24.1 \\
23.7 \\
23.9 \\
25.6 \\
27.7 \\
28.6 \\
26.9 \\
25.7\end{array}$ & & $\begin{array}{l}15.2 \\
15.6 \\
12.0 \\
12.3 \\
13.8 \\
16.0 \\
10.8 \\
10.2\end{array}$ & $\begin{array}{l}16.4 \\
16.6 \\
13.6 \\
13.2 \\
14.9 \\
17.2 \\
11.8 \\
11.2\end{array}$ & $\begin{array}{l}17.3 \\
17.5 \\
14.3 \\
14.0 \\
15.9 \\
18.3 \\
12.7 \\
12.0\end{array}$ & $\begin{array}{l}19.3 \\
19.0 \\
15.2 \\
15.2 \\
17.5 \\
19.7 \\
14.6 \\
14.0\end{array}$ \\
\hline
\end{tabular}


TABLE 10

Table 10. - Three-hour averages of air and water-surface temperatures and wind directions and speed, April 1950-August 1951, Lake Hefner-Continued

STATION 3

THREE-HOURLY AVERAGES

JULY, 1951

\begin{tabular}{|c|c|c|c|c|c|c|c|c|c|c|c|c|c|c|}
\hline & & Ave & rage ai & tempe & rature & $\left({ }^{\circ} \mathrm{C}\right)$ at & indicat & ed heig & & Average & Average & Avera & age wind & speed ( \\
\hline$>$ 듈 & 至 & 2 & & 4 & & 8 & & 10 & & water- & wind & & 100 & \\
\hline ดั & $\left|2, \frac{5}{b 0}\right|$ & meter & & met & & met & & met & & tempera- & & 2 & 4 & 8 \\
\hline ๘ั & م. & $\begin{array}{l}\text { Dry } \\
\text { bulb }\end{array}$ & $\begin{array}{l}\text { Wet } \\
\text { bulb }\end{array}$ & $\begin{array}{l}\text { Dry } \\
\text { bulb }\end{array}$ & $\begin{array}{l}\text { Wet } \\
\text { bulb }\end{array}$ & $\begin{array}{l}\text { Dry } \\
\text { bulb }\end{array}$ & $\begin{array}{l}\text { Wet } \\
\text { bulb }\end{array}$ & $\begin{array}{l}\text { Dry } \\
\text { bulb }\end{array}$ & $\begin{array}{l}\text { Wet } \\
\text { bulb }\end{array}$ & $\begin{array}{l}\text { ture } \\
\left({ }^{\circ} \mathrm{C}\right)\end{array}$ & (coded) & meters & meters & meters \\
\hline 11 & 0 & 25.6 & $22 \cdot 1$ & 25.7 & 22.1 & 25.8 & 22.1 & 25.7 & & 24.9 & & 11.5 & 12.5 & 13.3 \\
\hline II & 3 & $24 \cdot 6$ & 21.9 & 24.6 & $? 1 \bullet 8$ & 24.6 & 21.7 & $24 \cdot 4$ & & $24 \cdot 1$ & & 16.1 & 17.2 & 18.2 \\
\hline 11 & 6 & 24.4 & 21.9 & 24.5 & 21.9 & 24.5 & 21.8 & 24.5 & & 24.7 & & 16.9 & 18.0 & 19.1 \\
\hline 11 & 9 & 27.8 & $22 \cdot 6$ & 28.0 & $22 \cdot 2$ & 28.2 & 21.9 & 28.4 & & $26 \cdot 2$ & & 13.7 & 14.7 & 16.1 \\
\hline 11 & 12 & 29.4 & 22.7 & 29.7 & $2 \geq 05$ & 29.9 & 21.9 & 29.9 & & 28.4 & & 11.4 & 12.3 & 13.3 \\
\hline 11 & 15 & 29.9 & 23.2 & 30.2 & 22.7 & 30.1 & 22.4 & 30,3 & & 28.5 & & 13.6 & 14.6 & 15.8 \\
\hline 11 & 18 & 28.3 & 23.2 & 28.3 & 32.9 & 28.3 & 22.8 & 28.3 & & 27.1 & & 11.3 & 12.0 & 12.8 \\
\hline 11 & 21. & 25.7 & $22 \cdot 3$ & 25.7 & $22 \cdot 3$ & 25.8 & 22.2 & 25.0 & & $26 \cdot 1$ & & 4.9 & 6.1 & 7.0 \\
\hline 12 & 0 & 24.2 & 21.7 & 24.4 & 2.1 .7 & 24.5 & 21.6 & 24.4 & & 25.4 & & 9.3 & 10.1 & 10.8 \\
\hline 12 & 3 & 23.7 & 21.5 & 23.7 & 21.6 & .3 .7 & 21.2 & 23.6 & & 24.6 & & 14.0 & 14.8 & 15.5 \\
\hline $1 ?$ & 6 & 34.5 & 21.9 & 24.7 & $>1.7$ & 25.1 & 21.6 & $\geq 5.1$ & 22.0 & $25 \cdot 3$ & & 14.8 & 15.6 & 16.8 \\
\hline 12 & o & 28.2 & 22.7 & 28.6 & $? 2.4$ & 29.0 & 22.0 & 29.1 & 22.0 & 27.3 & & 14.3 & 15.4 & 17.0 \\
\hline 12 & 12 & 30.0 & 23.1 & 30.4 & $\geqslant 2.6$ & 30.8 & 27.5 & 30.9 & 23.2 & 29.3 & & 9.1 & 9.8 & 10.9 \\
\hline $1 ?$ & 25 & 30.7 & 25.1 & 30.0 & $? 2.8$ & 31.4 & 22.5 & 31.6 & 27.2 & 20.1 & & 12.0 & 12.0 & 13.1 \\
\hline 12 & 18 & 29.3 & $23 \cdot 6$ & 29.6 & 73.1 & 29.8 & 23.0 & 29.9 & 27.6 & 28.0 & & 9.0 & 9.8 & 10.6 \\
\hline 12 & 21 & 27.6 & $23 \cdot 2$ & 27.6 & $22 \cdot 9$ & 27.7 & 22.7 & 27.6 & 27.5 & 26.7 & & 9.2 & 9.8 & 10.4 \\
\hline 13 & 0 & 25.0 & 21.9 & 25.0 & 21.8 & 25.1 & 21.7 & 25.1 & 21.6 & 26.0 & & 4.8 & 5.5 & 6.3 \\
\hline 13 & 3 & 21.5 & 20.2 & 21.5 & 20.3 & 21.6 & 20.2 & $>1,6$ & 20.2 & 25.6 & & 5.3 & 6.5 & 7.6 \\
\hline 13 & 6 & 23.9 & 21.4 & 23.8 & 21.3 & 23.8 & 21.3 & 23.8 & 21.2 & 26.1 & & 3.5 & 4.2 & 4.4 \\
\hline 13 & 9 & 26.6 & 22.6 & 26.4 & 22.5 & 25.8 & 22.4 & 25.7 & 22.3 & 26.7 & & 6.7 & 8.3 & 9.6 \\
\hline 13 & 12 & 38.4 & 23.1 & 77.8 & $24 \cdot 2$ & 27.8 & 22.8 & 27.6 & 22.5 & $27 \cdot 4$ & & 5.7 & 6.8 & 8.0 \\
\hline 13 & 15 & 30.6 & 23.7 & 30.2 & 23.5 & 29.7 & 23.4 & 20.5 & 23.3 & 27.7 & & 3.8 & 4.6 & 5.3 \\
\hline 13 & 18 & 25.6 & 27.6 & $25 \cdot 3$ & 22.6 & 25.2 & 27.6 & 24.0 & 22.5 & 25.4 & & 6.4 & 7.9 & 0.3 \\
\hline 13 & 21 & .22 .7 & 21.1 & 22.8 & 21.1 & $2 ? .8$ & 21.1 & 22.6 & 21.0 & $25 \cdot 1$ & & $4 \cdot 2$ & 5.2 & 6.0 \\
\hline 14 & 0 & 21.0 & 20.5 & $21 \cdot 2$ & 20.4 & 21.3 & 20.5 & 21.4 & 20.5 & 25.0 & & 1.8 & & 2.9 \\
\hline 14 & 3 & 20.1 & 20.1 & 20.3 & 20.0 & 20.3 & 20.0 & 20.2 & 20.0 & $25 \cdot 1$ & & 2.0 & 2.7 & 3.3 \\
\hline 14 & 6 & 21.9 & 20.2 & $21 \cdot 2$ & 20.8 & 21.4 & 20.8 & $22 \cdot 1$ & 20.3 & 25.5 & & 6.7 & 8.4 & 9.9 \\
\hline 14 & 9 & 21.8 & 20.3 & $? 1.3$ & 30.6 & 21.4 & 20.7 & 22.0 & & 25.3 & & 8.0 & $9 \cdot 9$ & 11.4 \\
\hline 14 & 12 & 34.2 & $? 1.7$ & 23.7 & 21.4 & $? 3.4$ & 21.2 & 24.2 & 21.2 & 26.4 & & 8.3 & 10.0 & 11.4 \\
\hline 14 & 15 & 27.3 & $23 \cdot 1$ & 27.2 & 22.8 & 77.3 & 22.9 & 27.1 & 22.4 & 26.5 & & 8.4 & 9.5 & 10.2 \\
\hline 14 & 18 & 26.2 & 22.9 & 25.4 & 22.7 & 26.4 & $22 \cdot 8$ & 26.3 & $2>05$ & 26.2 & & $4 \cdot 4$ & 5.6 & 6.9 \\
\hline 14 & 21 & 23.3 & 21.7 & 23.4 & 23.7 & 73.5 & 21.8 & 23.5 & 21.6 & 25.4 & & 4.6 & 5.8 & 6.8 \\
\hline 25 & ? & 23.1 & $2 ? .1$ & 23.2 & $? ? 1$ & 2.3 .2 & 20.1 & 23.2 & 22.0 & 25.3 & & 5.8 & 6.6 & 7.2 \\
\hline 15 & 3 & 22.7 & 21.4 & 23.6 & $2.1 \cdot 3$ & 20.7 & 21.3 & 22.7 & 21.0 & 25.0 & & 5.7 & $6 . ?$ & 6.5 \\
\hline 15 & 6 & 33.6 & $22 \cdot 2$ & 23.5 & 22.2 & 23.3 & $22 \cdot 1$ & 23.2 & 21.9 & 25.8 & & 4.5 & 5.5 & 6.3 \\
\hline 15 & 9 & 25.9 & 22.3 & 25.6 & 22.0 & 25.8 & 22.0 & 25.0 & 21.4 & 26.5 & & $8 . ?$ & 9.9 & 11.3 \\
\hline 15 & 12 & 29.4 & 23.4 & 29.3 & 27.8 & $>9.5$ & 22.9 & 29.3 & 22.6 & 27.8 & & 10.6 & 11.6 & $12 \cdot 4$ \\
\hline 15 & 15 & 29.9 & 23.8 & 29.8 & 23.6 & 30.0 & 23.4 & 29.7 & 23.0 & 28.5 & & 11.0 & 12.2 & 13.1 \\
\hline 15 & 18 & 27.4 & 22.6 & 27.4 & $22 \cdot 2$ & 27.4 & $2 ? .1$ & 27.2 & 21.8 & 26.8 & & 10.9 & 11.6 & 12.3 \\
\hline 15 & 21 & 34.8 & $\gg .2$ & 24.7 & 21.9 & 24.7 & 21.8 & 24.7 & $>3.5$ & 25.8 & & 11.3 & 12.0 & $12 \cdot 4$ \\
\hline 16 & 0 & 23.4 & 21.4 & 23.4 & 21.2 & 23.3 & 21.1 & 23.2 & 20.9 & 25.1 & & 8.7 & 9.1 & 9.3 \\
\hline 16 & 3 & 22.5 & 20.8 & 22.4 & 20.7 & 32.6 & 20.6 & 22.3 & 20.4 & 25.1 & & $7 \cdot 2$ & 7.4 & 7.6 \\
\hline 16 & 6 & 74.2 & 21.7 & 24.4 & 21.5 & 74.5 & 21.1 & 24.4 & 20.0 & 23.0 & & 10.0 & 10.4 & 10.9 \\
\hline 16 & 9 & $28.4^{\circ}$ & 27.9 & 28.0 & 22.3 & 29.2 & 21.8 & 29.7 & 21.3 & 25.0 & & 7.9 & 8.5 & 9.3 \\
\hline 16 & $1 ?$ & 30.5 & 33.3 & 30.8 & 32.1 & 31.3 & $>2.2$ & 31.3 & 21.2 & 28.8 & & 5.9 & 6.4 & 6.9 \\
\hline 16 & 15 & 31.3 & 29.8 & 37.6 & 73.6 & 31.9 & 21.9 & 31.9 & 21.1 & 28.8 & & 7.2 & 7.9 & 8.5 \\
\hline in & 18 & 29.5 & 23.6 & 20.7 & 22.3 & 29.9 & 32.1 & 30.1 & 21.5 & 27.4 & & 5.0 & 5.6 & 6.6 \\
\hline 16 & 21 & 26.5 & 22.8 & 26.7 & 22.6 & 26.7 & 22.4 & 26.8 & 21.8 & 26.2 & & 6.0 & 6.4 & 7.1 \\
\hline 17 & 0 & 24.9 & 22.3 & 24.0 & 22.0 & 24.8 & 22.0 & 24.6 & 21.4 & 25.7 & & 7.2 & 7.5 & 7.6 \\
\hline 17 & 3 & 73.6 & $>1.5$ & 23.5 & 21.2 & 23.4 & $21 \cdot 1$ & 23.2 & 20.4 & 24 & & 8.4 & B. & 9.0 \\
\hline 17 & 6 & 24.0 & 21.4 & 24.1 & 21.0 & $24 \cdot 3$ & 20.9 & $24 \cdot 2$ & 20.4 & 23.5 & & 6.5 & 6. & 7.1 \\
\hline 17 & 9 & 28.5 & 22.9 & 28.7 & 22.7 & 28.9 & 22.7 & 29.2 & 22.2 & 27.0 & & 3.8 & 4. & 4.1 \\
\hline 17 & 12 & 32.0 & 22.7 & 31.8 & 72.2 & 37.0 & 22.1 & 31.7 & 21.6 & 30.6 & & 3.8 & 4.0 & 4.2 \\
\hline 17 & 15 & 32.4 & 22.6 & 32.3 & $? ?, 1$ & 30.4 & $2 ? \cdot 3$ & 32.2 & 21.7 & 31.1 & & 5.3 & 5.9 & 6.2 \\
\hline 17 & 18 & 30.2 & 22.9 & 30.0 & 22.4 & 30.3 & 22.5 & 30.3 & 21.7 & 28.9 & & 3.1 & 3.8 & $4 \cdot 7$ \\
\hline 17 & 21 & 26.8 & 23.2 & 26.9 & 23.0 & 27.1 & 22.9 & 27.1 & 22.1 & 27.6 & & 405 & 4.9 & 5.4 \\
\hline 18 & 0 & 25.6 & 22.0 & 25.6 & $? 1.6$ & 25.5 & 21.5 & 25.4 & 20.9 & 27.0 & & 8.2 & 8.4 & 8.5 \\
\hline 18 & 3 & 24.6 & 21.1 & $\geqslant 4.5$ & 20.0 & 24.5 & 20.9 & $24 \cdot 3$ & 20.3 & 25 & & 7.6 & & 8.0 \\
\hline 18 & 6 & 25.3 & 21.5 & 25.5 & 21.0 & 25.6 & 21.1 & 25.6 & 20.4 & 25 & & 9.1 & 9. & 9.9 \\
\hline 18 & 9 & 29.2 & 32.4 & 20.5 & 21.8 & 30.1 & 21.9 & 30.7 & 21.8 & 29.2 & & 5.0 & & 5.9 \\
\hline 18 & 12 & 33.5 & 21.7 & 33.2 & 20.8 & 33.7 & 20.8 & 33.5 & 20.0 & 32.5 & & 2.8 & 3.0 & 3.0 \\
\hline 18 & 15 & 33.9 & 22.3 & 33.5 & 21.7 & 33.1 & 21.6 & 33.0 & 21.2 & 31.7 & & 5.0 & 5.7 & 6.1 \\
\hline 18 & 18 & 30.5 & 22.0 & 30.4 & 21.8 & 30.6 & 21.8 & 30.6 & 21.5 & 28.8 & & 5.5 & 6.4 & 7.5 \\
\hline 18 & 21 & 27.6 & 21.9 & 27.7 & 21.7 & 27.9 & 21.6 & 27.9 & 21.2 & 27.9 & & 5.7 & 6.4 & 7.0 \\
\hline 19 & 0 & 25.3 & 21.6 & 25,3 & $? .1 .3$ & 25.3 & 21.2 & 25.3 & 20.0 & 27.1 & & 4.7 & 5.0 & 5.3 \\
\hline 19 & 3 & 22.7 & 20.5 & 2.2 .7 & & 22.7 & 20.6 & 23.0 & & & & & & \\
\hline 19 & 6 & 24.4 & 22.6 & 24.4 & 22.4 & 24.2 & 22.5 & 24.4 & 22.2 & 27.4 & & 2.6 & 3.1 & 3.4 \\
\hline 19 & 9 & 28.2 & 23.2 & 28.2 & 22.2 & 73.5 & 22.4 & 28.4 & 21.8 & $29 \cdot 3$ & & 2.7 & 2.9 & 3.0 \\
\hline 19 & 12 & 33.2 & 23.6 & 32.1 & 2304 & 32.3 & $22 \cdot 3$ & 32.3 & 21.9 & 32 & & 3.2 & & 3 \\
\hline 19 & 15 & 33.8 & 32.8 & 33.5 & 22.6 & 33.2 & 72.7 & 33.0 & $2 ?$. & 30 & & 5. & & \\
\hline 19 & 18 & 30.2 & 23.1 & 30.3 & 23.1 & 30.6 & 23.3 & 30.7 & 23.1 & 27.8 & & 3.6 & 4.8 & 6.1 \\
\hline 19 & 21 & 36.2 & 22.8 & 26.5 & 22.9 & 27.0 & 22.9 & 27.4 & $2 ? .8$ & 27.2 & & 3.8 & 5.0 & 6.4 \\
\hline 20 & 0 & 26.0 & 22.9 & 25.0 & 22.7 & 26.1 & 22.6 & 26.0 & & 26.9 & & 7.6 & 8.2 & 8.7 \\
\hline 20 & 3 & 25.0 & 27.7 & 25.0 & 22.4 & 25.0 & 22.4 & 25.0 & & 26.7 & & & & 10.0 \\
\hline 20 & 6 & 25.7 & 22.9 & 25.8 & 22.6 & 26.0 & 22.6 & 26.0 & 21.2 & 26.1 & & 11.6 & 12.3 & \\
\hline 20 & 9 & 28.9 & 23.4 & 29.1 & 23.0 & 29.4 & 23.0 & 29.6 & 21.9 & 21. & & 12. & 13 & $14 \cdot 3$ \\
\hline 20 & 12 & 31.8 & 22.8 & 32.1 & 22.2 & 32.5 & 22.3 & 32.5 & 21.1 & 24.5 & & 12.1 & 13.0 & 14.0 \\
\hline 20 & 15 & 32.3 & 22.9 & 32.5 & 22.5 & 32.8 & 22.5 & 33.0 & 21.8 & 25.6 & & 13.7 & 14.8 & 16.1 \\
\hline 20 & 18 & 30.8 & 22.6 & 31.0 & 22.3 & 31.2 & $2 \geq .3$ & 31.3 & 21.3 & 25.0 & & 9.5 & 10.4 & 11.4 \\
\hline 20 & 21 & 28.4 & 22.8 & 28.5 & 22.7 & 28.5 & 22.8 & 28.4 & 22.0 & 24.8 & & 13.6 & 14.8 & 15.6 \\
\hline
\end{tabular}


Table 10. - Three-hour averages of air and water-surface temperatures and wind directions and speed, April 1950-August STATION 3

THREE-HOURLY AVERAGES

JULY, 1951

\begin{tabular}{|c|c|c|c|c|c|c|c|c|c|c|c|c|c|c|c|}
\hline \multirow{4}{*}{ 施 } & \multirow{4}{*}{ 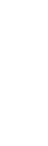 } & \multicolumn{8}{|c|}{ Average air temperature $\left({ }^{\circ} \mathrm{C}\right)$ at indicated height } & \multirow{4}{*}{$\begin{array}{l}\text { Average } \\
\text { water- } \\
\text { surface } \\
\text { tempera- } \\
\text { ture } \\
\text { (ㄷ) }\end{array}$} & \multirow{4}{*}{$\begin{array}{c}\text { Average } \\
\text { wind } \\
\text { direction } \\
\text { (coded) }\end{array}$} & \multirow{2}{*}{\multicolumn{4}{|c|}{$\begin{array}{l}\text { Average wind speed (knots) } \\
\text { at indicated height }\end{array}$}} \\
\hline & & \multirow{2}{*}{\multicolumn{2}{|c|}{$\begin{array}{c}2 \\
\text { meters }\end{array}$}} & \multirow{2}{*}{\multicolumn{2}{|c|}{$\begin{array}{c}4 \\
\text { meters }\end{array}$}} & \multirow{2}{*}{\multicolumn{2}{|c|}{$\begin{array}{c}8 \\
\text { meters }\end{array}$}} & \multirow{2}{*}{\multicolumn{2}{|c|}{$\begin{array}{c}16 \\
\text { meters }\end{array}$}} & & & & & & \\
\hline & & & & & & & & & & & & & & 8 & 16 \\
\hline & & $\begin{array}{l}\text { Dry } \\
\text { bulb }\end{array}$ & $\begin{array}{l}\text { Wet } \\
\text { bulb }\end{array}$ & $\begin{array}{l}\text { Dry } \\
\text { bulb }\end{array}$ & $\begin{array}{l}\text { Wet } \\
\text { bulb }\end{array}$ & $\begin{array}{l}\text { Dry } \\
\text { bulb }\end{array}$ & $\begin{array}{l}\text { Wet } \\
\text { bulb }\end{array}$ & $\begin{array}{l}\text { Dry } \\
\text { bulb }\end{array}$ & $\begin{array}{l}\text { Wet } \\
\text { bulb }\end{array}$ & & & & & & \\
\hline
\end{tabular}

\begin{tabular}{l|l|l|l|l|l|l|l|l|l|}
21 & 0 & 26.5 & 22.5 & 26.5 & 22.2 & 26.6 & 22.2 & 26.4 & 21.3 \\
21 & 3 & 25.6 & 22.0 & 25.5 & 21.7 & 25.7 & 21.6 & 25.6 & 20.7
\end{tabular}

\begin{tabular}{l|l|l|l|l|l|l|l|l|l|}
21 & 6 & 27.1 & 21.9 & 27.3 & 21.8 & 27.4 & 21.8 & 27.5 & 21.2 \\
21 & 9 & 30.2 & 27.9 & 30.5 & 22.4 & 31.1 & 22.8 & 31.4 & 27.0
\end{tabular}

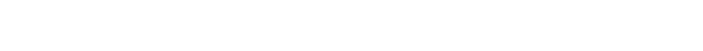

\begin{tabular}{l|l|l|l|l|l|l|l|l|l|}
21 & 15 & 32.7 & 23.6 & 33.1 & 23.4 & 33.8 & 23.4 & 34.2 & 23.1 \\
21 & 18 & 31.0 & 23.3 & 31.5 & 23.3 & 32.0 & 23.3 & 32.1 & 22.6 \\
21 & 21 & 28.9 & 22.3 & 29.0 & 22.2 & 29.1 & 22.2 & 29.2 & 21.6
\end{tabular}

\begin{tabular}{ll|l|l|l|l|l|l|l|l|l|}
22 & 0 & 26.3 & 21.6 & 26.5 & 21.4 & 26.5 & 21.4 & 26.4 & 21.0 \\
\hline & 3 & 25.3 & 21.2 & 25.2 & 21.0 & 25.2 & 20.9 & 25.3 & 20.6
\end{tabular}

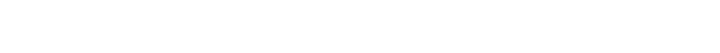

\begin{tabular}{l|r|r|r|r|r|r|r|r|r|}
22 & 9 & 28.8 & 23.1 & 29.1 & 22.8 & 29.3 & 22.9 & 29.4 & 22.6 \\
22 & 12 & 31.2 & 23.8 & 31.5 & 23.4 & 31.9 & 23.2 & 32.2 & 27.8 \\
22 & 15 & 32.1 & 23.7 & 32.5 & 23.1 & 32.9 & 23.0 & 32.9 & 22.2
\end{tabular}

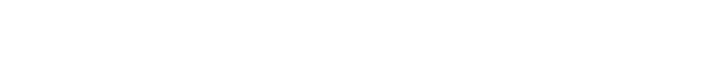

24.5
24.3

25.4

28.7

28.8
27.2

26.0

25.4
25.3

26.1
27.7

29.7

230

38.1
28.7

24

\begin{tabular}{|l|l|l|l|l|l|l|l|}
24.9 & 22.3 & 24.7 & 22.4 & 24.7 & 22.0 & 25.0 & 21.6 \\
28.5 & 23.0 & 28.6 & 22.9 & 38.2 & 22.9 & 28.6 & 22.1
\end{tabular}

\begin{tabular}{l|l|l|l|l|l|l|l}
30.9 & 23.2 & 30.1 & 23.0 & 29.8 & 22.7 & 30.2 & 27.0
\end{tabular}

\begin{tabular}{l|l|l|l|l|l|l|l|}
27.3 & 22.3 & 27.1 & 22.3 & 27.1 & 22.1 & 27.3 & 21.7 \\
22.4 & 20.9 & 22.4 & 21.1 & 22.6 & 21.4 & 22.6 & 21.0
\end{tabular}

\begin{tabular}{l|l|l|l|l|l|l|l|}
21.2 & 20.7 & 21.3 & 20.8 & 21.4 & 20.9 & 21.6 & 20.7 \\
20.7 & 20.5 & 20.9 & 20.7 & 21.4 & 20.9 & 22.0 & 20.8
\end{tabular}

\begin{tabular}{ll|l|l|l|l|l|l|l|l|}
25 & 3 & 20.7 & 20.6 & 20.9 & 20.7 & 21.4 & 20.9 & 22.0 & 20.8 \\
25 & 6 & 23.1 & 22.2 & 23.0 & 22.1 & 23.4 & 22.4 & 23.1 & 2.2 .0
\end{tabular}

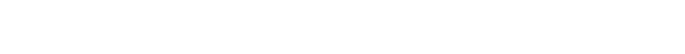

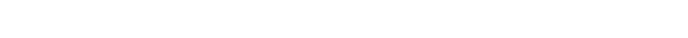

\begin{tabular}{l|l|l|l|l|l|l|l|l|l|}
25 & 18 & 27.9 & 22.8 & 27.9 & 23.2 & 28.3 & 23.3 & 28.7 & 23.0 \\
25 & 21 & 25.1 & 22.8 & 25.3 & 22.7 & 25.6 & 20.9 & 2500 & 37.7
\end{tabular}

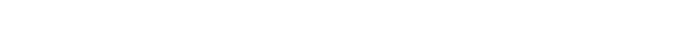

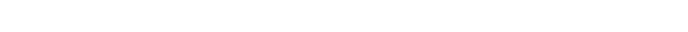

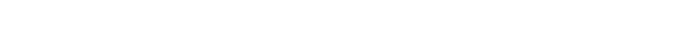

\begin{tabular}{l|l|l|l|l|l|l|l|}
28.3 & 23.6 & 28.2 & 23.1 & 28.5 & 23.3 & 28.2 & 23.1 \\
30.4 & 23.9 & 30.5 & 23.3 & 30.2 & 23.3 & 29.1 & 23.0
\end{tabular}

26

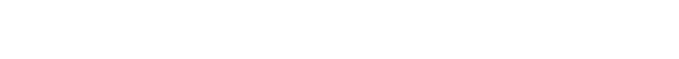

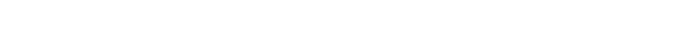
\begin{tabular}{l|l|l|l|l|l|l|l|l|l|}
27 & 15 & 32.5 & 23.7 & 31.8 & 24.1 & 31.8 & 24.2 & 31.3 & 23.2
\end{tabular} \begin{tabular}{l|l|l|l|l|l|l|l|l|l|}
27 & 21 & 28.3 & 23.8 & 28.2 & 24.0 & 28.4 & 24.3 & 28.4 & 23.5 \\
& 24.4 & 22.5 & 74.7 & 72.6 & 25.5 & 32.7 & 29.2 & 22.2
\end{tabular}

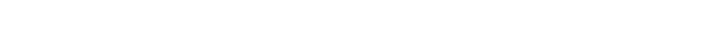

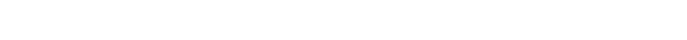
\begin{tabular}{l|r|r|r|r|r|r|r|r|r|}
28 & 9 & 29.6 & 23.4 & 29.4 & 23.2 & 39.8 & 23.2 & 79.7 & 23.6 \\
28 & 12 & 32.4 & 23.2 & 32.5 & 23.2 & 31.7 & 23.3 & 31.0 & 27.9
\end{tabular}

$$
2
$$$$
\begin{aligned}
& 29 \\
& 29 \\
& >9
\end{aligned}
$$$$
\text { 29 }
$$$$
\begin{aligned}
& 29 \\
& 29
\end{aligned}
$$$$
300
$$$$
\begin{aligned}
& 30 \\
& 30 \\
& 30
\end{aligned}
$$$$
\begin{aligned}
& 30 \\
& 30 \\
& 30
\end{aligned}
$$

\begin{tabular}{|c|c|c|c|}
\hline $\begin{array}{l}15.0 \\
16.7 \\
18.2 \\
17.2 \\
15.9 \\
16.1 \\
13.7 \\
14.7\end{array}$ & $\begin{array}{l}16.1 \\
17: 7 \\
19.0 \\
18.4 \\
17.2 \\
17.1 \\
14: 8 \\
15.7\end{array}$ & $\begin{array}{l}17.0 \\
18.8 \\
20.9 \\
20.3 \\
19.1 \\
18.6 \\
15.9 \\
16.6\end{array}$ & $\begin{array}{l}18.8 \\
19.8 \\
21.4 \\
21.0 \\
20.02 \\
20.0 \\
17.4 \\
18.3\end{array}$ \\
\hline $\begin{array}{r}11.7 \\
11.8 \\
10.2 \\
10.6 \\
9.0 \\
8.2 \\
9.3 \\
9.3\end{array}$ & $\begin{array}{r}12.5 \\
12.5 \\
10.8 \\
11.3 \\
10.7 \\
8.9 \\
10.4 \\
10.1\end{array}$ & $\begin{array}{l}13.0 \\
13.0 \\
11.3 \\
12: 1 \\
11.5 \\
0.8 \\
11.4 \\
10.6\end{array}$ & $\begin{array}{l}14.4 \\
14.0 \\
12.0 \\
12.0 \\
12.3 \\
130.0 \\
13.2 \\
12.2\end{array}$ \\
\hline $\begin{array}{l}7.3 \\
6.4 \\
7.7 \\
4.5 \\
4.8 \\
4.9 \\
2.9 \\
3.9\end{array}$ & $\begin{array}{l}7.9 \\
7.7 \\
9.4 \\
5.3 \\
5.7 \\
6.3 \\
3.7 \\
4.3\end{array}$ & $\begin{array}{r}8.5 \\
9.0 \\
10.8 \\
5.9 \\
6.3 \\
7.5 \\
4.1 \\
4.5\end{array}$ & $\begin{array}{r}10.1 \\
9.4 \\
11.8 \\
6.5 \\
7.8 \\
8.9 \\
4.8 \\
4.8\end{array}$ \\
\hline $\begin{array}{l}5.0 \\
2.1 \\
1.5 \\
3.4 \\
3.4 \\
3.0 \\
3.1 \\
7.6\end{array}$ & $\begin{array}{l}6.1 \\
2.6 \\
1.9 \\
4.1 \\
3.9 \\
3.6 \\
3.3 \\
9.1\end{array}$ & $\begin{array}{r}7.0 \\
3.6 \\
2.1 \\
4.7 \\
4.2 \\
4.1 \\
4.9 \\
10.5\end{array}$ & $\begin{array}{r}7.8 \\
4.5 \\
2.2 \\
5.0 \\
4.7 \\
3.0 \\
6.4 \\
12.6\end{array}$ \\
\hline $\begin{array}{l}2.0 \\
1.6 \\
3.6 \\
3.7 \\
4.0 \\
4.6 \\
3.5 \\
3.8\end{array}$ & $\begin{array}{l}2.4 \\
2.3 \\
4 . ? \\
4.0 \\
4.3 \\
5.4 \\
4.7 \\
5.0\end{array}$ & $\begin{array}{l}2.5 \\
3.0 \\
4.5 \\
4.1 \\
4.6 \\
6.3 \\
5.9 \\
6.4\end{array}$ & $\begin{array}{l}3.1 \\
3.4 \\
4.8 \\
4.4 \\
4.9 \\
7.02 \\
7.3 \\
8.2\end{array}$ \\
\hline $\begin{array}{l}7: 3 \\
7.8 \\
9: 0 \\
8.2 \\
5.8 \\
8: 3 \\
7: 7 \\
6.2\end{array}$ & $\begin{array}{r}7.9 \\
8.4 \\
10.5 \\
8.5 \\
6.7 \\
5.9 \\
9.6 \\
7.6\end{array}$ & $\begin{array}{r}8.3 \\
8.8 \\
10.6 \\
0.1 \\
7.3 \\
10.8 \\
11.1 \\
8.4\end{array}$ & $\begin{array}{r}9.9 \\
10.4 \\
11.2 \\
9.05 \\
8.4 \\
12.2 \\
13.2 \\
9.0\end{array}$ \\
\hline $\begin{array}{l}5.7 \\
9.1 \\
4.0 \\
2.5 \\
3.2 \\
5.4 \\
3.5 \\
2.4\end{array}$ & $\begin{array}{l}6.6 \\
9.8 \\
4.1 \\
2.7 \\
3.7 \\
5.6 \\
4.5 \\
3.5\end{array}$ & $\begin{array}{r}7.3 \\
10.3 \\
4: 2 \\
7.6 \\
4: 1 \\
7.6 \\
5.8 \\
5.0\end{array}$ & $\begin{array}{r}8.0 \\
11.0 \\
4.3 \\
2.2 \\
4.3 \\
8.5 \\
7.4 \\
6.7\end{array}$ \\
\hline $\begin{array}{l}2.0 \\
3.6 \\
3.6 \\
2.6 \\
4.1 \\
4.8 \\
2.3 \\
2.9\end{array}$ & $\begin{array}{l}2.5 \\
3.7 \\
3.8 \\
2.8 \\
4.8 \\
6.1 \\
2.9 \\
3.9\end{array}$ & $\begin{array}{l}3.1 \\
3.7 \\
3.9 \\
3.1 \\
5.3 \\
7.0 \\
3.0 \\
5.4\end{array}$ & $\begin{array}{l}4.0 \\
3: 7 \\
3.9 \\
4: 6 \\
5: 7 \\
7: 2 \\
4.2 \\
7.2\end{array}$ \\
\hline $\begin{array}{l}2.2 \\
0.9 \\
2: 4 \\
3.0 \\
4.8 \\
4.7 \\
3.1 \\
2.7\end{array}$ & $\begin{array}{l}3.3 \\
1.2 \\
3.0 \\
3.6 \\
5.8 \\
5.6 \\
4.3 \\
4.1\end{array}$ & $\begin{array}{l}4.7 \\
1.6 \\
3.4 \\
4.2 \\
6.6 \\
6.8 \\
5.7 \\
5.8\end{array}$ & $\begin{array}{l}0.6 \\
2: 3 \\
3: 0 \\
4.6 \\
7.4 \\
7.4 \\
7: 0 \\
7.0\end{array}$ \\
\hline $\begin{array}{l}3.3 \\
6.5 \\
9.6 \\
9.2 \\
4.5 \\
4.1 \\
3.0 \\
2.8\end{array}$ & $\begin{array}{r}4.5 \\
7: 1 \\
10: 1 \\
9.6 \\
5 . ? 2 \\
4.7 \\
4: ? \\
4.1\end{array}$ & $\begin{array}{r}6.1 \\
7.7 \\
10.5 \\
10.0 \\
5.4 \\
5.1 \\
5.3 \\
5.8\end{array}$ & $\begin{array}{r}a .2 \\
0.5 \\
10.7 \\
10.0 \\
5.5 \\
5.5 \\
5.0 \\
7.5\end{array}$ \\
\hline $\begin{array}{l}3.1 \\
6.6 \\
7.2 \\
6.0 \\
5.2 \\
4.0 \\
2.1 \\
1.7\end{array}$ & $\begin{array}{l}4.0 \\
6.8 \\
7.5 \\
8.1 \\
6.3 \\
5.0 \\
2.5 \\
2.4\end{array}$ & $\begin{array}{l}5: 3 \\
5: 9 \\
7: 9 \\
0: 0 \\
7: 3 \\
5.8 \\
3.0 \\
3.0\end{array}$ & $\begin{array}{l}7: 2 \\
7: 3 \\
5: 3 \\
8: 3 \\
7: 0 \\
6: 2 \\
4: 5 \\
3.4\end{array}$ \\
\hline
\end{tabular}


TABLE 10

171

Table 10. - Three-hour averages of air and water-surface temperatures and wind directions and speed, April 1950-August 1951, Lake Hefner-Continued

STATION 3

THREE-HOURLY AVERAGES

AUGUST, 1951

\begin{tabular}{|c|c|c|c|c|c|c|c|c|c|c|c|c|c|c|c|}
\hline \multirow{3}{*}{ 点 } & \multirow{3}{*}{ 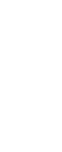 } & \multicolumn{8}{|c|}{ Average air temperature $\left({ }^{\circ} \mathrm{C}\right)$ at indicated height } & \multirow{3}{*}{$\begin{array}{c}\text { Average } \\
\text { water- } \\
\text { surface } \\
\text { tempera- } \\
\text { ture } \\
\text { ("C) }\end{array}$} & \multirow{3}{*}{$\begin{array}{c}\text { Average } \\
\text { wind } \\
\text { direction } \\
\text { (coded) }\end{array}$} & \multirow{2}{*}{\multicolumn{4}{|c|}{$\begin{array}{l}\text { Average wind speed (knots) } \\
\text { at indicated height }\end{array}$}} \\
\hline & & \multicolumn{2}{|c|}{$\begin{array}{c}2 \\
\text { meters }\end{array}$} & \multicolumn{2}{|c|}{$\begin{array}{c}4 \\
\text { meters }\end{array}$} & \multicolumn{2}{|c|}{$\begin{array}{c}8 \\
\text { meters }\end{array}$} & \multicolumn{2}{|c|}{$\begin{array}{c}16 \\
\text { meters }\end{array}$} & & & & & & \\
\hline & & $\begin{array}{l}\text { Dry } \\
\text { bulb }\end{array}$ & $\begin{array}{l}\text { Wet } \\
\text { bulb }\end{array}$ & $\begin{array}{l}\text { Dry } \\
\text { bulb }\end{array}$ & $\begin{array}{l}\text { Wet } \\
\text { bulb }\end{array}$ & $\begin{array}{l}\text { Dry } \\
\text { bulb }\end{array}$ & $\begin{array}{l}\text { Wet } \\
\text { bulb }\end{array}$ & $\begin{array}{l}\text { Dry } \\
\text { bulb }\end{array}$ & $\begin{array}{l}\text { Wet } \\
\text { bulb }\end{array}$ & & & meters & $\begin{array}{c}4 \\
\text { meters }\end{array}$ & $\begin{array}{c}0 \\
\text { meters }\end{array}$ & $\begin{array}{c}16 \\
\text { meters }\end{array}$ \\
\hline $\begin{array}{l}1 \\
1 \\
1 \\
1 \\
1 \\
1 \\
1 \\
1\end{array}$ & $\begin{array}{r}0 \\
3 \\
6 \\
9 \\
12 \\
15 \\
18 \\
21\end{array}$ & $\begin{array}{l}21.6 \\
21.8 \\
25.2 \\
29.0 \\
31.4 \\
32.8 \\
29.1 \\
25.7\end{array}$ & $\begin{array}{l}20.8 \\
21.0 \\
22.5 \\
23.4 \\
23.6 \\
23.1 \\
22.7 \\
21.6\end{array}$ & $\begin{array}{l}22.0 \\
22.2 \\
25.1 \\
28.1 \\
30.7 \\
31.0 \\
29.1 \\
26.1\end{array}$ & $\begin{array}{l}30.8 \\
? 1.2 \\
? 2.5 \\
32.6 \\
2 ? .8 \\
32.7 \\
22.7 \\
21.6\end{array}$ & $\begin{array}{l}27.4 \\
2 ? .7 \\
25.3 \\
23.5 \\
31.4 \\
32.0 \\
29.4 \\
26.6\end{array}$ & 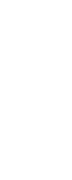 & $\begin{array}{l}23.1 \\
22: 9 \\
25.4 \\
28.4 \\
31.1 \\
31.5 \\
29.5 \\
26.8\end{array}$ & 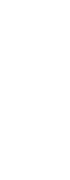 & $\begin{array}{l}23.4 \\
27.2 \\
27.9 \\
2 ? .9 \\
24.2 \\
22.2 \\
21.6 \\
22.7\end{array}$ & & $\begin{array}{l}1.7 \\
1.5 \\
0.9 \\
2.1 \\
2.2\end{array}$ & $\begin{array}{l}2.4 \\
2.0 \\
1.0 \\
2.9 \\
3.0 \\
4.5 \\
4.0 \\
3.9\end{array}$ & $\begin{array}{l}3.1 \\
2.2 \\
1.0 \\
2.6 \\
2.7 \\
5: 1 \\
5.3 \\
6.2\end{array}$ & $\begin{array}{l}4.4 \\
2.6 \\
2.8 \\
3.0 \\
3.2 \\
5.7 \\
6.8 \\
8.1\end{array}$ \\
\hline $\begin{array}{l}2 \\
2 \\
2 \\
2 \\
2 \\
2 \\
2 \\
2\end{array}$ & $\begin{array}{r}0 \\
3 \\
6 \\
9 \\
12 \\
15 \\
18 \\
21\end{array}$ & $\begin{array}{l}23.9 \\
23.9 \\
24.8\end{array}$ & $\begin{array}{l}21 \cdot 1 \\
21.9 \\
22.2\end{array}$ & $\begin{array}{l}24.2 \\
24.1 \\
24.6\end{array}$ & $\begin{array}{l}21 \cdot 3 \\
21 \cdot 8 \\
21: 0\end{array}$ & $\begin{array}{l}24.7 \\
24.1 \\
24.9\end{array}$ & $\begin{array}{l}21.5 \\
21.7 \\
22.0\end{array}$ & $\begin{array}{l}24.9 \\
24.1 \\
24.8\end{array}$ & $\begin{array}{l}21 \cdot 1 \\
21,3 \\
21 \cdot 3\end{array}$ & $\begin{array}{l}23 \cdot 5 \\
23 \cdot 2 \\
24 \cdot 2\end{array}$ & $\cdot$ & $\begin{array}{r}6.3 \\
11.8 \\
8.6 \\
8.3 \\
5.2 \\
4.3\end{array}$ & $\begin{array}{r}2.9 \\
4.7 \\
8.6 \\
12.1 \\
9.1 \\
8.0 \\
5.9 \\
4.9\end{array}$ & $\begin{array}{r}4.4 \\
4.4 \\
7.4 \\
13.0 \\
0.0 \\
9.9 \\
7.0 \\
6.1\end{array}$ & $\begin{array}{r}6.0 \\
6.5 \\
3.4 \\
13.2 \\
10.3 \\
10.4 \\
8.8 \\
8.0\end{array}$ \\
\hline $\begin{array}{l}3 \\
3 \\
3 \\
3 \\
3 \\
3 \\
3 \\
3\end{array}$ & $\begin{array}{r}0 \\
3 \\
6 \\
9 \\
12 \\
15 \\
18 \\
21\end{array}$ & $\begin{array}{l}31.2 \\
34.2 \\
36.8 \\
31.0 \\
27.8\end{array}$ & $\begin{array}{l}23.6 \\
23.8 \\
22.3 \\
23.6 \\
22.3\end{array}$ & $\begin{array}{l}31.8 \\
34.2 \\
36.2 \\
31.2 \\
28.3\end{array}$ & $\begin{array}{l}22.8 \\
22.8 \\
22.0 \\
23.1 \\
22.1\end{array}$ & $\begin{array}{l}32.2 \\
35.0 \\
36.2 \\
31.9 \\
28.9\end{array}$ & & $\begin{array}{l}32.0 \\
35.1 \\
35.8 \\
32.4 \\
29.5\end{array}$ & $\begin{array}{l}21.3 \\
21.1 \\
21.8 \\
21.6 \\
21.3\end{array}$ & & & $\begin{array}{r}9.7 \\
10.1 \\
7.0 \\
4.3 \\
5.1 \\
6.0 \\
3.6 \\
2.5\end{array}$ & $\begin{array}{r}10.3 \\
10.5 \\
7.4 \\
5.0 \\
5.8 \\
7.4 \\
4.4 \\
3.3\end{array}$ & $\begin{array}{r}10.7 \\
10.9 \\
7.8 \\
5.5 \\
7.7 \\
8.5 \\
5.5 \\
4.6\end{array}$ & $\begin{array}{r}11.4 \\
11.2 \\
7.0 \\
5.6 \\
6.9 \\
9.9 \\
6.9 \\
6.7\end{array}$ \\
\hline $\begin{array}{l}4 \\
4 \\
4 \\
4 \\
4 \\
4 \\
4 \\
4\end{array}$ & $\begin{array}{r}0 \\
3 \\
6 \\
9 \\
12 \\
15 \\
18 \\
21\end{array}$ & $\begin{array}{l}25.7 \\
22.8 \\
24.6 \\
31.0 \\
36.2 \\
36.3 \\
32.0 \\
27.9\end{array}$ & $\begin{array}{l}21.9 \\
21.5 \\
22.8 \\
25.1 \\
25.0 \\
23.3 \\
22.9 \\
22.5\end{array}$ & $\begin{array}{l}26 \cdot 1 \\
22: 8 \\
24: 4 \\
31.0 \\
35 \cdot 4 \\
35.5 \\
31 \cdot 8 \\
28.2\end{array}$ & $\begin{array}{l}21.8 \\
21.06 \\
22.9 \\
24.3 \\
23.9 \\
22.8 \\
22.8 \\
32.3\end{array}$ & $\begin{array}{l}26.2 \\
22.9 \\
24.6 \\
31.6 \\
36.4 \\
35.6 \\
31.07 \\
28.5\end{array}$ & & $\begin{array}{l}26.5 \\
21.8 \\
23.3 \\
31.2 \\
35.4 \\
35.9 \\
31.7 \\
28.9\end{array}$ & $\begin{array}{l}21.0 \\
20.5 \\
20.9 \\
23.8 \\
23.0 \\
22.5 \\
22.9 \\
22.1\end{array}$ & $\begin{array}{l}30.9 \\
27.8 \\
27.7\end{array}$ & & $\begin{array}{l}2.8 \\
2.6 \\
3.7 \\
2.6 \\
2.0 \\
6.0 \\
5.6 \\
4.0\end{array}$ & $\begin{array}{l}3.6 \\
3.3 \\
4.6 \\
2.9 \\
2.1 \\
7.3 \\
7.1 \\
5.3\end{array}$ & $\begin{array}{l}4.8 \\
4.4 \\
5.3 \\
3.1 \\
2.3 \\
3.1 \\
9.6 \\
6.7\end{array}$ & $\begin{array}{r}6.9 \\
6.0 \\
6.2 \\
3.6 \\
2.4 \\
0.2 \\
10.5 \\
3.9\end{array}$ \\
\hline $\begin{array}{l}5 \\
5 \\
5 \\
5 \\
5 \\
5 \\
5 \\
5\end{array}$ & $\begin{array}{r}0 \\
3 \\
6 \\
9 \\
12 \\
15 \\
18 \\
21\end{array}$ & $\begin{array}{l}27.5 \\
26.0 \\
26.3 \\
29.8 \\
32.7 \\
33.6 \\
32.6 \\
30.5\end{array}$ & $\begin{array}{l}22.8 \\
23.4 \\
24.1 \\
24.5 \\
24.2 \\
24.1 \\
23.8 \\
23.7\end{array}$ & $\begin{array}{l}27.6 \\
25.9 \\
26.3 \\
30.1 \\
33.4 \\
34.1 \\
33.0 \\
30.6\end{array}$ & $\begin{array}{l}22.8 \\
33.2 \\
23.8 \\
24.2 \\
23.4 \\
23.3 \\
23.4 \\
23.5\end{array}$ & $\begin{array}{l}27.6 \\
25.09 \\
26.4 \\
30.5 \\
33.9 \\
34.7 \\
33.0 \\
30.5\end{array}$ & & $\begin{array}{l}27.7 \\
25.3 \\
26.3 \\
30.8 \\
34 \cdot 2 \\
35.4 \\
33.5 \\
30.6\end{array}$ & $\begin{array}{l}22.5 \\
23.0 \\
23.3 \\
23.4 \\
27.7 \\
2 ? .3 \\
27.9 \\
23.3\end{array}$ & $\begin{array}{l}27.0 \\
25.9 \\
25.0 \\
24.0 \\
20.6 \\
29.7 \\
23.4 \\
27.4\end{array}$ & & $\begin{array}{r}7.9 \\
11.1 \\
15.4 \\
13.5 \\
11.4 \\
9.3 \\
9.4 \\
13.6\end{array}$ & $\begin{array}{r}8.8 \\
11.7 \\
16.3 \\
14.5 \\
12.4 \\
10.2 \\
10.2 \\
14.5\end{array}$ & $\begin{array}{r}c .6 \\
12.3 \\
17 \cdot 1 \\
15.7 \\
13.9 \\
11.5 \\
11.2 \\
15.5\end{array}$ & $\begin{array}{l}11.6 \\
14.0 \\
18.3 \\
16.4 \\
14.5 \\
12.5 \\
13.2 \\
17.6\end{array}$ \\
\hline $\begin{array}{l}6 \\
6 \\
6 \\
6 \\
6 \\
6 \\
6 \\
6\end{array}$ & $\begin{array}{r}0 \\
3 \\
6 \\
9 \\
12 \\
15 \\
18 \\
21\end{array}$ & $\begin{array}{l}28.4 \\
26.8 \\
26.7 \\
32.2 \\
34.5 \\
35.5 \\
33.2 \\
31.4\end{array}$ & $\begin{array}{l}24.1 \\
23.6 \\
23.4 \\
24.6 \\
24.7 \\
25.4 \\
24.8 \\
23.8\end{array}$ & $\begin{array}{l}28.4 \\
26.8 \\
26.7 \\
32.8 \\
35.4 \\
36.5 \\
33.6 \\
31.7\end{array}$ & $\begin{array}{l}23.8 \\
? 3.3 \\
23.3 \\
23.6 \\
24.1 \\
24.1 \\
24.2 \\
? 3.1\end{array}$ & $\begin{array}{l}28.5 \\
26.7 \\
26.9 \\
33.6 \\
35.0 \\
37.8 \\
34.2 \\
31.8\end{array}$ & 23.5 & $\begin{array}{l}28.4 \\
26.5 \\
25.0 \\
33.5 \\
35.0 \\
38.5 \\
35.5 \\
31.9\end{array}$ & $\begin{array}{l}23.4 \\
22.9 \\
22.8 \\
23.1 \\
23.4 \\
23.4 \\
23.4 \\
73.3\end{array}$ & $\begin{array}{l}26.0 \\
24.5 \\
25.4 \\
30.0 \\
31.0 \\
32.1 \\
30.3 \\
29.1\end{array}$ & & $\begin{array}{r}17.6 \\
16.1 \\
14.6 \\
10.7 \\
8.5 \\
7.3 \\
5.8 \\
11.2\end{array}$ & $\begin{array}{r}18.8 \\
17.1 \\
15.5 \\
11.5 \\
9.5 \\
8.4 \\
5.5 \\
12.0\end{array}$ & $\begin{array}{r}10.9 \\
19.0 \\
16.6 \\
12.8 \\
10.9 \\
7.9 \\
10.2 \\
10.9\end{array}$ & $\begin{array}{l}21.5 \\
19.0 \\
17.3 \\
13.1 \\
11.4 \\
10.7 \\
10.3 \\
14.2\end{array}$ \\
\hline $\begin{array}{l}7 \\
7 \\
7 \\
7 \\
7 \\
7 \\
7 \\
7\end{array}$ & $\begin{array}{r}0 \\
3 \\
6 \\
9 \\
12 \\
15 \\
18 \\
21\end{array}$ & $\begin{array}{l}30.1 \\
29.3 \\
28.3 \\
32.6 \\
35.6 \\
36.1 \\
34.4 \\
31.6\end{array}$ & $\begin{array}{l}22.9 \\
22.0 \\
21.7 \\
23.1 \\
24.0 \\
24.6 \\
23.8 \\
22.7\end{array}$ & $\begin{array}{l}30.2 \\
29.4 \\
28.5 \\
33.2 \\
37.0 \\
37.1 \\
34.4 \\
32.0\end{array}$ & $\begin{array}{l}22.2 \\
? 1.5 \\
? 1.3 \\
22.8 \\
23.3 \\
23.4 \\
23.2 \\
22.0\end{array}$ & $\begin{array}{l}30.2 \\
29.4 \\
28.5 \\
33.7 \\
37.0 \\
37.5 \\
34.5 \\
37.1\end{array}$ & $\begin{array}{l}22.6 \\
22.5 \\
23.2 \\
22.4 \\
21.6\end{array}$ & $\begin{array}{l}30.4 \\
29.3 \\
28.5 \\
34.4 \\
37.9 \\
38.1 \\
35.0 \\
32.1\end{array}$ & $\begin{array}{l}21.4 \\
20.7 \\
20.6 \\
21.9 \\
22.1 \\
23.6 \\
23.3 \\
21.04\end{array}$ & $\begin{array}{l}28.0 \\
27.3 \\
27.8 \\
29.6 \\
31.3 \\
31.1 \\
29.4 \\
27.9\end{array}$ & & $\begin{array}{l}13.7 \\
14.9 \\
10.9 \\
12.5 \\
10.5 \\
12.5 \\
12.6 \\
16.7\end{array}$ & $\begin{array}{l}14.4 \\
15.8 \\
11.4 \\
13.5 \\
11.7 \\
13.6 \\
13.6 \\
17.7\end{array}$ & $\begin{array}{l}15.4 \\
17.0 \\
12.2 \\
15.0 \\
13.4 \\
15.3 \\
15.1 \\
18.9\end{array}$ & $\begin{array}{l}16.5 \\
17.5 \\
12.4 \\
15.4 \\
13.9 \\
16.5 \\
16.8 \\
20.2\end{array}$ \\
\hline $\begin{array}{l}8 \\
8 \\
8 \\
8 \\
8 \\
8 \\
8 \\
8\end{array}$ & $\begin{array}{r}0 \\
3 \\
6 \\
9 \\
12 \\
15 \\
18 \\
21\end{array}$ & $\begin{array}{l}30.0 \\
28.5 \\
26.7 \\
30.1 \\
33.3 \\
35.6\end{array}$ & $\begin{array}{l}21.5 \\
20.9 \\
22.3 \\
22.9 \\
23.5 \\
24.0\end{array}$ & $\begin{array}{l}30.2 \\
28.8 \\
26.5 \\
30.1 \\
33.2 \\
34.2\end{array}$ & $\begin{array}{l}20.9 \\
20.7 \\
22.1 \\
22.3 \\
23.3 \\
73.4\end{array}$ & $\begin{array}{l}30.3 \\
28.0 \\
26.5 \\
30.4 \\
33.6 \\
34.0\end{array}$ & $\begin{array}{l}20.4 \\
20.5 \\
27.2 \\
22.0 \\
23.5\end{array}$ & $\begin{array}{l}28.6 \\
28.4 \\
26.4 \\
30.5 \\
34.0\end{array}$ & $\begin{array}{l}20.3 \\
20.5 \\
2 ? .2 \\
22.0 \\
2.3 .4\end{array}$ & $\begin{array}{l}20.8 \\
26.9 \\
27.3 \\
27.9 \\
28.9\end{array}$ & & $\begin{array}{r}15.6 \\
7.7 \\
4.1 \\
7.3 \\
2.2 \\
4.2 \\
6.3 \\
14.5\end{array}$ & $\begin{array}{r}16.6 \\
8.9 \\
5.1 \\
8.2 \\
2.7 \\
4.7 \\
7.0 \\
15.6\end{array}$ & $\begin{array}{r}17.6 \\
0.9 \\
5.9 \\
8.8 \\
3.1 \\
5.7 \\
8.3 \\
16.6\end{array}$ & $\begin{array}{r}18.6 \\
10.7 \\
6.4 \\
9.8 \\
3.4 \\
6.9 \\
10.4 \\
17.9\end{array}$ \\
\hline $\begin{array}{l}9 \\
9 \\
9 \\
9 \\
9 \\
9 \\
9 \\
9\end{array}$ & $\begin{array}{r}0 \\
3 \\
6 \\
9 \\
12 \\
15 \\
18 \\
21\end{array}$ & $\begin{array}{l}22.3 \\
21.8 \\
24 \cdot 1 \\
26.0 \\
24.0 \\
22.3\end{array}$ & $\begin{array}{l}19.4 \\
19.9 \\
21.4 \\
22.7 \\
22.5 \\
21.6\end{array}$ & $\begin{array}{l}22.4 \\
21.8 \\
34.1 \\
25.9 \\
24.1 \\
22.4\end{array}$ & $\begin{array}{l}19.4 \\
20.2 \\
21.9 \\
22.9 \\
22.6 \\
21.8\end{array}$ & $\begin{array}{l}27.3 \\
21: 9 \\
24.1 \\
25: 8 \\
24: 1 \\
22.6\end{array}$ & $\begin{array}{l}19 \cdot 3 \\
20.1 \\
21 \cdot 8 \\
22 \cdot 9 \\
22 \cdot 4 \\
21.6\end{array}$ & $\begin{array}{l}22.2 \\
21.9 \\
24.3 \\
25.7 \\
24.1 \\
22.6\end{array}$ & $\begin{array}{l}19 \cdot 3 \\
20.1 \\
21.7 \\
22.8 \\
22.5 \\
21.7\end{array}$ & $\begin{array}{l}25.5 \\
25.4 \\
25.3 \\
24.8 \\
24.5 \\
25.3\end{array}$ & & $\begin{array}{r}12.8 \\
10.1 \\
6.9 \\
6.5 \\
5.1 \\
3.8 \\
3.3 \\
1.7\end{array}$ & $\begin{array}{r}13.7 \\
11.4 \\
8.5 \\
8.1 \\
6.1 \\
4.8 \\
4.0 \\
2.4\end{array}$ & $\begin{array}{r}14.4 \\
13.0 \\
10.0 \\
9.7 \\
7.7 \\
5.6 \\
4.9 \\
3.2\end{array}$ & 17.8 \\
\hline $\begin{array}{l}10 \\
10 \\
10 \\
10 \\
10 \\
10 \\
10 \\
10\end{array}$ & $\begin{array}{r}0 \\
3 \\
6 \\
9 \\
12 \\
15 \\
18 \\
21\end{array}$ & $\begin{array}{l}28.1 \\
28.8\end{array}$ & $\begin{array}{l}23.7 \\
23.5\end{array}$ & $\begin{array}{l}28.2 \\
28.4\end{array}$ & $\begin{array}{l}21 \cdot 1 \\
22 \cdot 8 \\
23 \cdot 1 \\
22.8\end{array}$ & $\begin{array}{l}21.2 \\
24.9 \\
27.3 \\
28.0\end{array}$ & $\begin{array}{l}22.2 \\
22.6 \\
23.2\end{array}$ & $\begin{array}{l}27.7 \\
28.9\end{array}$ & $\begin{array}{l}20.5 \\
22.5 \\
22.6 \\
23.2\end{array}$ & $\begin{array}{l}27 \cdot 2 \\
26.9\end{array}$ & & $\begin{array}{l}1.7 \\
3.0 \\
2.9 \\
2.8 \\
7.4 \\
7.9 \\
3.4 \\
2.6\end{array}$ & $\begin{array}{l}2.2 \\
3.8 \\
3.7 \\
3.6 \\
9.1 \\
9.1 \\
4.3 \\
3.4\end{array}$ & $\begin{array}{r}2.9 \\
4.7 \\
3.8 \\
4.8 \\
0.16 \\
10.7 \\
5.3 \\
4.4\end{array}$ & $\begin{array}{r}15.6 \\
10.1 \\
5.9 \\
5.7\end{array}$ \\
\hline
\end{tabular}


Table 10. - Three-hour averages of air and water-surface temperatures and wind directions and speed, April 1950-August STATION THREE-HOURLY AVERAGES

AUGUSI, 1951

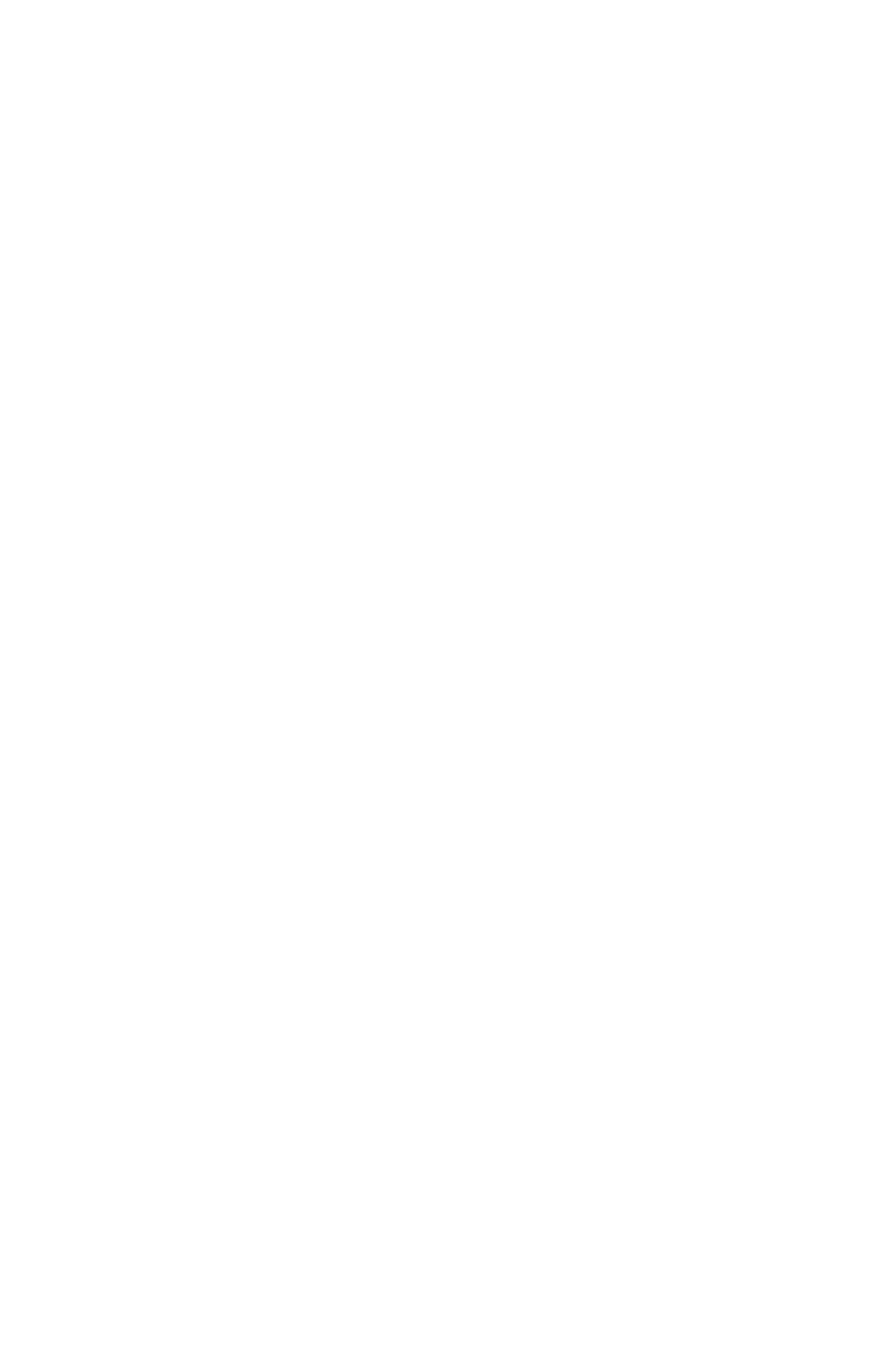


TABLE 1.0

173

Table 10. -Three-hour averages of air and water-surface temperatures and wind directions and speed, April 1950-August 1951, Lake Hefner-Continued

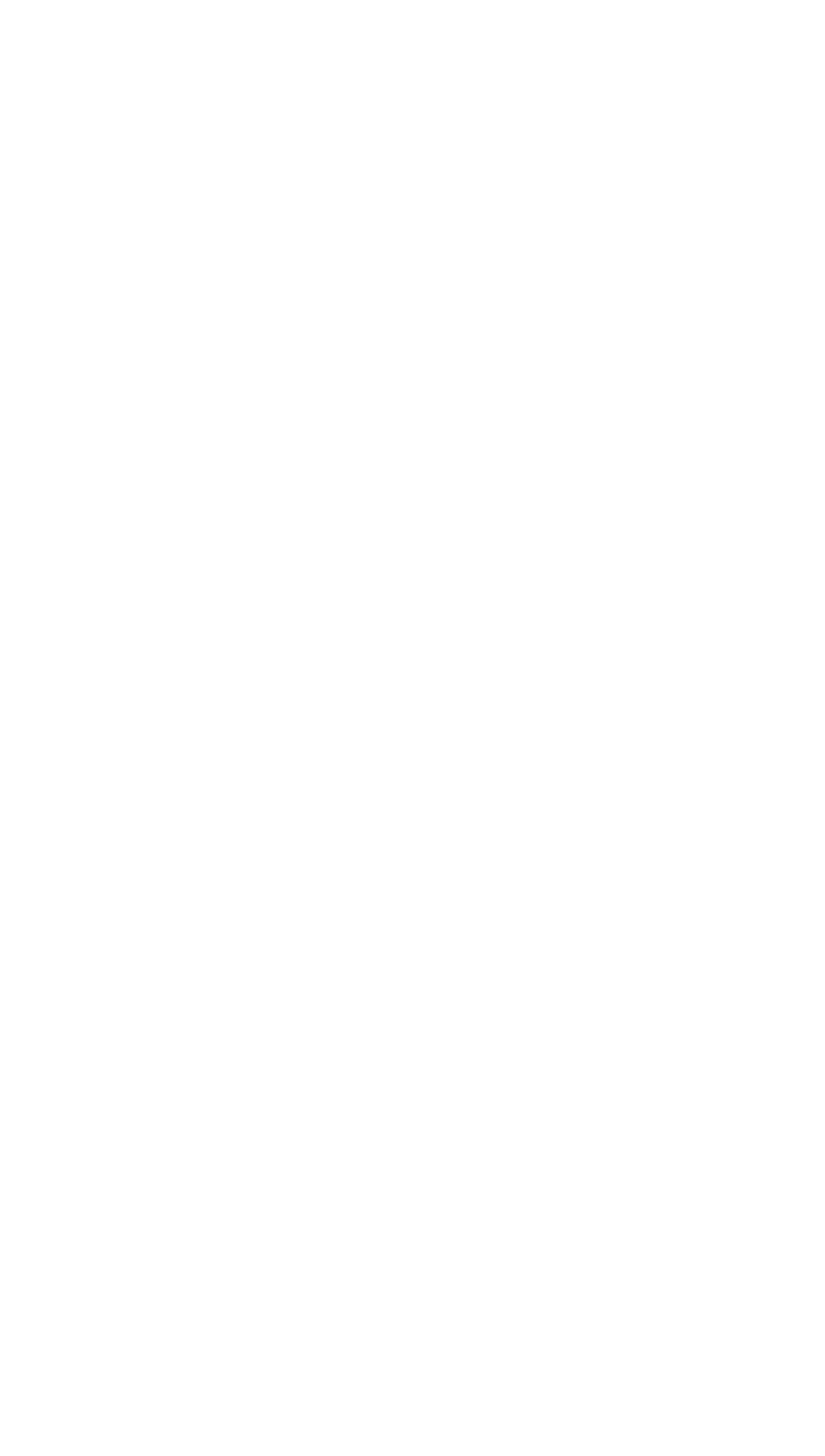


TABLE 10

Table 10. -Three-hour averages of air and water-surface temperatures and wind directions and speed, April 1950-August 1951, Lake Hefner-Continued

STATION 4

THREE-HOURLY AVERAGES

APRIL, 1950

\begin{tabular}{|c|c|c|c|c|c|c|c|c|c|c|c|c|c|c|c|}
\hline \multirow{3}{*}{ 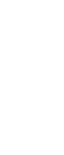 } & \multirow{3}{*}{ 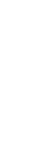 } & \multicolumn{8}{|c|}{ Average air temperature $\left({ }^{\circ} \mathrm{C}\right)$ at indicated height } & \multirow{3}{*}{$\begin{array}{l}\text { Average } \\
\text { water- } \\
\text { surface } \\
\text { tempera- } \\
\text { ture } \\
\text { ("C) }\end{array}$} & \multirow{3}{*}{$\begin{array}{c}\text { Average } \\
\text { wind } \\
\text { direction } \\
\text { (coded) }\end{array}$} & \multicolumn{4}{|c|}{$\begin{array}{l}\text { Average wind speed (knots) } \\
\text { at indicated height }\end{array}$} \\
\hline & & \multicolumn{2}{|c|}{$\begin{array}{c}2 \\
\text { meters }\end{array}$} & \multicolumn{2}{|c|}{$\begin{array}{c}4 \\
\text { meters }\end{array}$} & \multicolumn{2}{|c|}{$\begin{array}{c}8 \\
\text { meters }\end{array}$} & \multicolumn{2}{|c|}{$\begin{array}{c}16 \\
\text { meters }\end{array}$} & & & 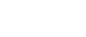 & & & \\
\hline & & $\begin{array}{l}\text { Dry } \\
\text { bulb }\end{array}$ & $\begin{array}{l}\text { Wet } \\
\text { bulb }\end{array}$ & $\begin{array}{l}\text { Dry } \\
\text { bulb }\end{array}$ & $\begin{array}{l}\text { Wet } \\
\text { bulb }\end{array}$ & $\begin{array}{l}\text { Dry } \\
\text { buib }\end{array}$ & $\begin{array}{l}\text { Wet } \\
\text { bulb }\end{array}$ & $\begin{array}{l}\text { Dry } \\
\text { bulb }\end{array}$ & $\begin{array}{l}\text { Wet } \\
\text { bulb }\end{array}$ & & & meters & meters & meters & meters \\
\hline $\begin{array}{l}25 \\
25 \\
25 \\
25 \\
25 \\
25 \\
25 \\
25\end{array}$ & $\begin{array}{r}0 \\
3 \\
6 \\
9 \\
12 \\
15 \\
18 \\
21\end{array}$ & $\begin{array}{r}10.5 \\
8.0 \\
8.2 \\
11.5 \\
14.8 \\
16.6 \\
15.7 \\
13.0\end{array}$ & $\begin{array}{l}5.6 \\
4.1 \\
4.2 \\
5.1 \\
6.2 \\
6.2 \\
8.5 \\
7.6\end{array}$ & $\begin{array}{r}10.3 \\
7.8 \\
8.5 \\
11.8 \\
15.1 \\
16.6 \\
15.7 \\
13.0\end{array}$ & $\begin{array}{l}5.5 \\
3.8 \\
4.2 \\
5.0 \\
5.6 \\
7.0 \\
8.5 \\
7.3\end{array}$ & $\begin{array}{r}10.2 \\
7.7 \\
8.1 \\
11.7 \\
15.2 \\
16.6 \\
15.8 \\
12.9\end{array}$ & $\begin{array}{l}5.3 \\
3.5 \\
3.5 \\
4.4 \\
6.3 \\
6.7 \\
8.3 \\
7.0\end{array}$ & $\begin{array}{r}10.0 \\
7.5 \\
7.5 \\
10.7 \\
14.7 \\
16.3 \\
15.4 \\
12.7\end{array}$ & $\begin{array}{l}5.5 \\
3.6 \\
3.3 \\
4.6 \\
6.4 \\
6.3 \\
7.0 \\
6.5\end{array}$ & $\begin{array}{l}15.4 \\
15.3 \\
15.3 \\
15.5 \\
15.8 \\
15.4 \\
15.2 \\
15.1\end{array}$ & & $\begin{array}{l}3.2 \\
3.2 \\
2.2 \\
5.0 \\
5.4 \\
5.4 \\
2.4 \\
6.2\end{array}$ & $\begin{array}{l}4.4 \\
5.8 \\
5.4 \\
1.8 \\
7.4\end{array}$ & $\begin{array}{r}4.6 \\
10.0 \\
6.0 \\
10.2 \\
10.2 \\
8.0 \\
3.0 \\
8.8\end{array}$ & $\begin{array}{r}16.8 \\
17.2 \\
8.4 \\
13.8 \\
13.0 \\
8.8 \\
3.6 \\
9.2\end{array}$ \\
\hline $\begin{array}{l}26 \\
26 \\
26 \\
26 \\
26 \\
26 \\
26 \\
26\end{array}$ & $\begin{array}{r}0 \\
3 \\
6 \\
9 \\
12 \\
15 \\
18 \\
21\end{array}$ & $\begin{array}{l}17 \cdot 3 \\
19 \cdot 3 \\
20.8 \\
19 \cdot 1 \\
17 \cdot 3\end{array}$ & $\begin{array}{l}10.0 \\
11.0 \\
12.4 \\
13.7 \\
12.1\end{array}$ & $\begin{array}{l}17.8 \\
19.6 \\
19.5 \\
19.4 \\
17.5\end{array}$ & $\begin{array}{r}9.8 \\
10.7 \\
12.4 \\
12.7 \\
11.7\end{array}$ & $\begin{array}{l}18.2 \\
20.1 \\
21.4 \\
20.1 \\
17.7\end{array}$ & $\begin{array}{r}9.3 \\
10.6 \\
12.0 \\
12.2 \\
11.4\end{array}$ & $\begin{array}{l}16 \cdot 0 \\
20 \cdot 3 \\
21 \cdot 9 \\
20 \cdot 5 \\
17 \cdot 7\end{array}$ & $\begin{array}{r}9.1 \\
10.6 \\
11.8 \\
11.8 \\
11.1\end{array}$ & $\begin{array}{l}15 \cdot 1 \\
15 \cdot 3 \\
16.0 \\
16 \cdot 1 \\
15.4\end{array}$ & & $\begin{array}{r}9.4 \\
12.0 \\
13.0 \\
16.2 \\
13.8 \\
8.8 \\
6.6 \\
8.4\end{array}$ & $\begin{array}{r}10.6 \\
13.6 \\
15.2 \\
18.6 \\
15.6 \\
11.4 \\
8.2 \\
9.8\end{array}$ & $\begin{array}{l}12.0 \\
15.8 \\
17.8 \\
22.4 \\
16.6 \\
13.0 \\
10.8 \\
12.2\end{array}$ & $\begin{array}{l}13.2 \\
17.0 \\
19.0 \\
23.6 \\
18.0 \\
15.4 \\
12.2 \\
13.0\end{array}$ \\
\hline $\begin{array}{l}27 \\
27 \\
27 \\
27 \\
27 \\
27 \\
27 \\
27\end{array}$ & $\begin{array}{r}0 \\
3 \\
6 \\
9 \\
12 \\
15 \\
18 \\
21\end{array}$ & $\begin{array}{r}16.3 \\
11.8 \\
9.9 \\
11.6 \\
13.6 \\
14.3 \\
13.4 \\
11.3\end{array}$ & $\begin{array}{r}11.6 \\
8.2 \\
4.9 \\
6.0 \\
7.9 \\
8.7 \\
8.1 \\
6.6\end{array}$ & $\begin{array}{l}16.2 \\
11.6 \\
10.0 \\
11.6 \\
13.5 \\
14.3 \\
13.3 \\
11.0\end{array}$ & $\begin{array}{r}11.4 \\
7.8 \\
4.8 \\
6.0 \\
7.8 \\
8.6 \\
8.0 \\
6.5\end{array}$ & $\begin{array}{l}16.0 \\
11.5 \\
10.0 \\
11.7 \\
13.5 \\
14.3 \\
13.2 \\
10.9\end{array}$ & $\begin{array}{r}11.1 \\
7.7 \\
4.8 \\
5.9 \\
7.8 \\
8.5 \\
7.8 \\
6.4\end{array}$ & 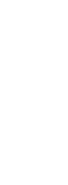 & $\begin{array}{r}10.9 \\
7.2 \\
4.4 \\
5.7 \\
7.4 \\
8.2 \\
7.5 \\
6.2\end{array}$ & $\begin{array}{l}15.1 \\
15.0 \\
15.0 \\
14.9 \\
14.9 \\
14.8 \\
14.7 \\
14.7\end{array}$ & & $\begin{array}{r}7.4 \\
10.2 \\
13.6 \\
12.6 \\
11.04 \\
10.2 \\
8.0 \\
7.0\end{array}$ & $\begin{array}{r}8 . ? \\
11.6 \\
14.4 \\
13.4 \\
12.2 \\
10.8 \\
8.6 \\
7.4\end{array}$ & $\begin{array}{r}9.8 \\
13.2 \\
15.6 \\
14.6 \\
13.0 \\
11.8 \\
9.4 \\
7.8\end{array}$ & $\begin{array}{r}10.8 \\
16.4 \\
18.2 \\
17.2 \\
15.0 \\
13.6 \\
11.6 \\
8.8\end{array}$ \\
\hline $\begin{array}{l}28 \\
28 \\
28 \\
28 \\
28 \\
28 \\
28 \\
28\end{array}$ & $\begin{array}{r}0 \\
3 \\
6 \\
9 \\
12 \\
15 \\
18 \\
21\end{array}$ & $\begin{array}{l}10.7 \\
13.4 \\
13.1 \\
16.4 \\
20.7 \\
21.3 \\
18.5 \\
18.9\end{array}$ & $\begin{array}{r}6.7 \\
7.5 \\
10.5 \\
16.4 \\
17.7 \\
18.0 \\
16.3 \\
17.0\end{array}$ & $\begin{array}{l}10.7 \\
11.04 \\
13.3 \\
17.4 \\
21.6 \\
21.9 \\
18.9 \\
19.2\end{array}$ & $\begin{array}{r}6.6 \\
7.6 \\
10.6 \\
17.2 \\
18.2 \\
18.2 \\
16.5 \\
17.0\end{array}$ & $\begin{array}{l}10.7 \\
11.4 \\
13.4 \\
17.1 \\
22.1 \\
23.1 \\
19.2 \\
19.4\end{array}$ & $\begin{array}{r}6.5 \\
7.4 \\
10.8 \\
16.9 \\
18.2 \\
18.7 \\
16.5 \\
17.0\end{array}$ & $\begin{array}{l}10.5 \\
111.2 \\
13.4 \\
17.2 \\
22.9 \\
23.8 \\
19.1 \\
19.3\end{array}$ & $\begin{array}{r}6.4 \\
7.2 \\
20.9 \\
17.1 \\
18.5 \\
10.0 \\
16.5 \\
16.8\end{array}$ & & & $\begin{array}{r}4.4 \\
2.8 \\
4.8 \\
7.4 \\
13.0 \\
7.8 \\
8.0 \\
10.2\end{array}$ & $\begin{array}{r}4.8 \\
3.0 \\
5.2 \\
8.0 \\
15.0 \\
7.8 \\
9.8 \\
13.2\end{array}$ & $\begin{array}{r}5.2 \\
3.4 \\
6.2 \\
10.6 \\
17.8 \\
10.2 \\
11.8 \\
16.0\end{array}$ & $\begin{array}{r}6.4 \\
4.6 \\
6.4 \\
11.8 \\
20.2 \\
12.0 \\
13.8 \\
17.4\end{array}$ \\
\hline $\begin{array}{l}29 \\
29 \\
29 \\
29 \\
29 \\
29 \\
29 \\
29\end{array}$ & $\begin{array}{r}0 \\
3 \\
6 \\
9 \\
12 \\
15 \\
18 \\
21\end{array}$ & $\begin{array}{r}16.8 \\
16.1 \\
17.3 \\
17.5 \\
11.1 \\
10.1 \\
10.1 \\
8.1\end{array}$ & $\begin{array}{r}14.2 \\
14.0 \\
15.7 \\
15.8 \\
9.2 \\
8.2 \\
7.8 \\
6.2\end{array}$ & $\begin{array}{r}16.9 \\
16.3 \\
17.6 \\
16.9 \\
11.1 \\
10.2 \\
10.1 \\
8.0\end{array}$ & $\begin{array}{r}14.1 \\
1.400 \\
15.8 \\
14.8 \\
9.0 \\
8.2 \\
7.7 \\
6.0\end{array}$ & $\begin{array}{r}17.0 \\
16.4 \\
17.8 \\
17.1 \\
10.8 \\
10.0 \\
10.0 \\
7.8\end{array}$ & $\begin{array}{r}14.0 \\
13.9 \\
15.9 \\
14.9 \\
9.0 \\
8.1 \\
7.5 \\
5.8\end{array}$ & $\begin{array}{r}16.8 \\
16.3 \\
17.0 \\
17.2 \\
10.3 \\
9.5 \\
9.5 \\
7.5\end{array}$ & $\begin{array}{r}13.9 \\
13.8 \\
15.9 \\
14.9 \\
8.5 \\
7.7 \\
7.3 \\
5.5\end{array}$ & $\begin{array}{l}15.0 \\
14.09 \\
15.01 \\
15.4 \\
14.9 \\
14.9 \\
14.8 \\
14.7\end{array}$ & & $\begin{array}{r}9.0 \\
12.2 \\
12.0 \\
9.8 \\
9.4 \\
4.8 \\
3.4 \\
4.4\end{array}$ & $\begin{array}{r}11.4 \\
15.0 \\
14.4 \\
11.6 \\
9.6 \\
6.4 \\
6.8 \\
7.0\end{array}$ & $\begin{array}{l}13.2 \\
18.2 \\
17.4 \\
14.2 \\
16.2 \\
14.4 \\
14.0 \\
14.4\end{array}$ & $\begin{array}{l}14.4 \\
19.2 \\
19.6 \\
15.4 \\
19.6 \\
22.8 \\
20.8 \\
22.2\end{array}$ \\
\hline $\begin{array}{l}30 \\
30 \\
30 \\
30 \\
30 \\
30 \\
30 \\
30\end{array}$ & $\begin{array}{r}0 \\
3 \\
6 \\
9 \\
12 \\
15 \\
18 \\
21\end{array}$ & $\begin{array}{r}5.9 \\
4.6 \\
4.2 \\
7.4 \\
11.8 \\
14.7 \\
12.8 \\
11.1\end{array}$ & $\begin{array}{l}4.4 \\
3.2 \\
2.8 \\
4.6 \\
7.2 \\
9.3 \\
9.2 \\
8.8\end{array}$ & $\begin{array}{r}5.9 \\
4.5 \\
4.02 \\
7.5 \\
11.8 \\
14.2 \\
12.7 \\
11.1\end{array}$ & $\begin{array}{l}4 \cdot 3 \\
3.0 \\
2.7 \\
4.5 \\
7.4 \\
9.2 \\
9.1 \\
8.7\end{array}$ & $\begin{array}{r}5.6 \\
4.3 \\
4.1 \\
7.7 \\
12.00 \\
14.2 \\
12.5 \\
10.9\end{array}$ & $\begin{array}{l}3.9 \\
2.8 \\
2.4 \\
4.5 \\
7.4 \\
9.2 \\
9.0 \\
8.6\end{array}$ & $\begin{array}{r}5.2 \\
3.9 \\
3.5 \\
6.0 \\
11.4 \\
13.0 \\
12.4 \\
10.7\end{array}$ & $\begin{array}{l}3.6 \\
2.4 \\
3.1 \\
4.1 \\
7.1 \\
9.0 \\
8.8 \\
8.3\end{array}$ & $\begin{array}{l}14.6 \\
14.5 \\
14.3 \\
14.4 \\
14.4 \\
14.5 \\
14.2 \\
14.1\end{array}$ & & $\begin{array}{l}5.0 \\
2.8 \\
4.6 \\
5.8 \\
4.6 \\
6.6 \\
8.2 \\
6.0\end{array}$ & $\begin{array}{l}6.6 \\
6.4 \\
6.6 \\
7.2 \\
6.0 \\
7.0 \\
9.0 \\
6.8\end{array}$ & $\begin{array}{r}14.2 \\
12.6 \\
11.6 \\
9.4 \\
7.2 \\
7.6 \\
9.8 \\
7.6\end{array}$ & $\begin{array}{r}21.6 \\
19.0 \\
18.4 \\
13.6 \\
10.6 \\
8.4 \\
10.2 \\
7.4\end{array}$ \\
\hline
\end{tabular}


TABLE 10

Table 10. - Three-hour averages of air and water-surface temperatures and wind directions and speed, April 1950-August 1951, Lake Hefner-Continued

STATION 4

THREE-HOURLY AVERAGES

MAY, 1950

\begin{tabular}{|c|c|c|c|c|c|c|c|c|c|c|c|c|c|c|c|}
\hline \multirow{3}{*}{ 突 } & \multirow{3}{*}{ 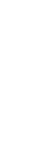 } & \multicolumn{8}{|c|}{ Average air temperature $\left({ }^{\circ} \mathrm{C}\right)$ at indicated height } & \multirow{3}{*}{$\begin{array}{l}\text { Average } \\
\text { water- } \\
\text { surface } \\
\text { tempera- } \\
\text { ture } \\
\left({ }^{\circ} \mathrm{C}\right)\end{array}$} & \multirow{3}{*}{$\begin{array}{c}\text { Average } \\
\text { wind } \\
\text { direction } \\
\text { (coded) }\end{array}$} & \multicolumn{4}{|c|}{$\begin{array}{l}\text { Average wind speed (knots) } \\
\text { at indicated height }\end{array}$} \\
\hline & & \multicolumn{2}{|c|}{$\begin{array}{c}2 \\
\text { meters }\end{array}$} & \multicolumn{2}{|c|}{$\begin{array}{c}4 \\
\text { meters }\end{array}$} & \multicolumn{2}{|c|}{$\begin{array}{c}\mathbf{8} \\
\text { meters }\end{array}$} & \multicolumn{2}{|c|}{$\begin{array}{c}16 \\
\text { meters }\end{array}$} & & & & & & \\
\hline & & $\begin{array}{l}\text { Dry } \\
\text { bulb }\end{array}$ & $\begin{array}{l}\text { Wet } \\
\text { bulb }\end{array}$ & $\begin{array}{l}\text { Dry } \\
\text { bulb }\end{array}$ & $\begin{array}{l}\text { Wet } \\
\text { bulb }\end{array}$ & $\begin{array}{l}\text { Dry } \\
\text { bulb }\end{array}$ & $\begin{array}{l}\text { Wet } \\
\text { bulb }\end{array}$ & $\begin{array}{l}\text { Dry } \\
\text { bulb }\end{array}$ & $\begin{array}{l}\text { Wet } \\
\text { bulb }\end{array}$ & & & meters & meters & meters & meters \\
\hline $\begin{array}{l}1 \\
1 \\
1 \\
1 \\
1 \\
1 \\
1 \\
1\end{array}$ & $\begin{array}{r}0 \\
3 \\
6 \\
9 \\
12 \\
15 \\
18 \\
21\end{array}$ & $\begin{array}{r}10.2 \\
9.8 \\
9.4 \\
12.1 \\
13.6 \\
14.9 \\
13.9 \\
12.9\end{array}$ & $\begin{array}{r}8.6 \\
8.5 \\
7.7 \\
9.5 \\
11.2 \\
12.4 \\
12.1 \\
12.2\end{array}$ & $\begin{array}{r}10.2 \\
9.8 \\
9.5 \\
12.5 \\
13.7 \\
15.0 \\
13.9 \\
12.9\end{array}$ & $\begin{array}{r}8.5 \\
8.4 \\
7.7 \\
9.5 \\
11.1 \\
12.3 \\
12.0 \\
12.2\end{array}$ & $\begin{array}{r}10.1 \\
9.7 \\
9.5 \\
12.4 \\
13.5 \\
14.9 \\
13.9 \\
12.9\end{array}$ & $\begin{array}{r}8.4 \\
8.2 \\
7.7 \\
9.6 \\
11.1 \\
12.3 \\
12.0 \\
12.1\end{array}$ & $\begin{array}{r}9.9 \\
9.3 \\
9.2 \\
11.9 \\
13.5 \\
14.8 \\
13.7 \\
12.8\end{array}$ & $\begin{array}{r}8.1 \\
7.9 \\
7.3 \\
9.3 \\
11.0 \\
12.2 \\
11.9 \\
12.0\end{array}$ & $\begin{array}{l}14.1 \\
14.0 \\
14.2 \\
14.5 \\
14.7 \\
14.8 \\
14.5 \\
14.3\end{array}$ & & $\begin{array}{l}4.44 \\
4.4 \\
4.8 \\
4.4 \\
6.8 \\
5.8 \\
7.8 \\
4.4\end{array}$ & $\begin{array}{l}4.6 \\
5.4 \\
5.4 \\
5.0 \\
7.2 \\
6.0 \\
7.8 \\
4.6\end{array}$ & $\begin{array}{l}5.2 \\
6.4 \\
6.8 \\
5.4 \\
8.2 \\
6.8 \\
9.2 \\
5.4\end{array}$ & $\begin{array}{l}7.4 \\
9.6 \\
9.4 \\
6.6 \\
8.0 \\
6.8 \\
9.0 \\
5.4\end{array}$ \\
\hline $\begin{array}{l}2 \\
2 \\
2 \\
2 \\
2 \\
2 \\
2 \\
2 \\
2\end{array}$ & $\begin{array}{r}0 \\
3 \\
6 \\
9 \\
12 \\
15 \\
18 \\
21\end{array}$ & $\begin{array}{l}11.6 \\
10.8 \\
11.0 \\
14.1 \\
18.2 \\
20.4 \\
20.0 \\
19.0\end{array}$ & $\begin{array}{l}11.4 \\
10.8 \\
11.0 \\
13.3 \\
15.3 \\
16.4 \\
17.2 \\
18.0\end{array}$ & $\begin{array}{l}11.7 \\
10.8 \\
11.3 \\
14.5 \\
18.6 \\
21.1 \\
20.4 \\
19.2\end{array}$ & $\begin{array}{l}11.3 \\
10.8 \\
11.3 \\
13.4 \\
15.3 \\
16.4 \\
17.3 \\
18.2\end{array}$ & $\begin{array}{l}11.6 \\
10.8 \\
11.1 \\
14.5 \\
18.8 \\
21.5 \\
20.7 \\
19.5\end{array}$ & $\begin{array}{l}11.2 \\
10.7 \\
11.0 \\
13.3 \\
15.5 \\
16.5 \\
17.5 \\
18.4\end{array}$ & $\begin{array}{l}11.4 \\
10.7 \\
10.9 \\
14.4 \\
19.3 \\
21.8 \\
21.2 \\
19.7\end{array}$ & $\begin{array}{l}11.1 \\
10.7 \\
10.9 \\
13.3 \\
15.3 \\
16.6 \\
17.5 \\
18.6\end{array}$ & $\begin{array}{l}14.2 \\
14.1 \\
13.6 \\
14.4 \\
15.3 \\
16.3 \\
16.2 \\
15.6\end{array}$ & & $\begin{array}{r}4.4 \\
4.0 \\
6.6 \\
11.2 \\
12.4 \\
12.4 \\
12.2 \\
16.4\end{array}$ & $\begin{array}{r}5.2 \\
4.2 \\
7.2 \\
13.2 \\
14.6 \\
15.0 \\
15.2 \\
20.8\end{array}$ & $\begin{array}{r}5.6 \\
4.8 \\
3.6 \\
15.4 \\
17.2 \\
18.0 \\
18.6 \\
24.8\end{array}$ & $\begin{array}{r}6.2 \\
5.0 \\
8.8 \\
17.2 \\
19.4 \\
20.6 \\
21.2 \\
27.8\end{array}$ \\
\hline $\begin{array}{l}3 \\
3 \\
3 \\
3 \\
3 \\
3 \\
3 \\
3 \\
3\end{array}$ & $\begin{array}{r}0 \\
3 \\
6 \\
9 \\
12 \\
15 \\
18 \\
21\end{array}$ & $\begin{array}{l}19.0 \\
19.6 \\
20.9 \\
23.5 \\
26.4 \\
26.5 \\
23.1 \\
21.5\end{array}$ & $\begin{array}{l}18.5 \\
18.9 \\
19.4 \\
19.6 \\
18.6 \\
19.9 \\
20.7 \\
19.9\end{array}$ & $\begin{array}{l}19.3 \\
20.1 \\
21.5 \\
24.2 \\
27.4 \\
27.0 \\
23.7 \\
21.9\end{array}$ & $\begin{array}{l}18.8 \\
19.1 \\
19.8 \\
19.8 \\
18.9 \\
20.4 \\
21.1 \\
20.1\end{array}$ & $\begin{array}{l}19.7 \\
20.3 \\
22.0 \\
25.2 \\
28.4 \\
28.0 \\
24.3 \\
22.3\end{array}$ & $\begin{array}{l}18.9 \\
19.5 \\
20.0 \\
19.9 \\
18.9 \\
20.4 \\
21.2 \\
20.4\end{array}$ & $\begin{array}{l}19.9 \\
20.5 \\
22.3 \\
25.3 \\
28.9 \\
28.6 \\
24.5 \\
22.4\end{array}$ & $\begin{array}{l}19.1 \\
19.8 \\
20.1 \\
20.1 \\
19.0 \\
20.6 \\
21.6 \\
20.7\end{array}$ & $\begin{array}{l}15.8 \\
15.7 \\
15.9 \\
16.9 \\
17.8 \\
18.8 \\
18.4 \\
18.0\end{array}$ & & $\begin{array}{l}16.2 \\
14.6 \\
17.6 \\
19.6 \\
15.6 \\
13.6 \\
14.6 \\
15.8\end{array}$ & $\begin{array}{l}19.0 \\
17.2 \\
20.6 \\
22.5 \\
18.0 \\
16.2 \\
17.2 \\
17.8\end{array}$ & $\begin{array}{l}21.8 \\
19.0 \\
22.8 \\
24.2 \\
19.8 \\
10.2 \\
21.0 \\
21.4\end{array}$ & $\begin{array}{l}25.0 \\
22.2 \\
26.4 \\
19.0 \\
24.0 \\
22.8 \\
23.8 \\
24.4\end{array}$ \\
\hline $\begin{array}{l}4 \\
4 \\
4 \\
4 \\
4 \\
4 \\
4 \\
4\end{array}$ & $\begin{array}{r}0 \\
3 \\
6 \\
9 \\
12 \\
15 \\
18 \\
21\end{array}$ & $\begin{array}{l}20.6 \\
20.5 \\
21 \cdot 2 \\
22 \cdot 3 \\
23.5 \\
23.3 \\
23.1 \\
22 \cdot 7\end{array}$ & $\begin{array}{l}19.9 \\
19.7 \\
19.9 \\
20.0 \\
20.2 \\
20.1 \\
20.0 \\
19.4\end{array}$ & $\begin{array}{l}21.1 \\
20.9 \\
21.5 \\
22.5 \\
24 \cdot 0 \\
23.7 \\
23.4 \\
23.0\end{array}$ & $\begin{array}{l}20.1 \\
20.0 \\
20.2 \\
20.2 \\
20.5 \\
20.3 \\
20.2 \\
19.5\end{array}$ & $\begin{array}{l}21 \cdot 3 \\
21 \cdot 2 \\
21 \cdot 9 \\
23 \cdot 2 \\
24 \cdot 3 \\
24 \cdot 3 \\
23.6 \\
23.4\end{array}$ & $\begin{array}{l}20.3 \\
20.4 \\
20.6 \\
20.6 \\
20.8 \\
20.6 \\
20.3 \\
19.7\end{array}$ & $\begin{array}{l}21 \cdot 6 \\
21.6 \\
22.1 \\
23.5 \\
24.7 \\
24 \cdot 3 \\
23.9 \\
23.4\end{array}$ & $\begin{array}{l}20.6 \\
20.7 \\
20.8 \\
20.7 \\
20.9 \\
20.8 \\
20.4 \\
19.4\end{array}$ & $\begin{array}{l}17.9 \\
17.7 \\
17.7 \\
18.4 \\
18.6 \\
18.8 \\
18.4 \\
18.0\end{array}$ & & $\begin{array}{l}13.8 \\
11.2 \\
13.2 \\
13.4 \\
14.0 \\
16.6 \\
19.2 \\
23.2\end{array}$ & $\begin{array}{l}16.8 \\
13.2 \\
15.4 \\
15.8 \\
16.2 \\
19.0 \\
22.0 \\
26.4\end{array}$ & $\begin{array}{l}20.0 \\
15.4 \\
17.4 \\
18.2 \\
19.0 \\
23.2 \\
26.6 \\
30.8\end{array}$ & $\begin{array}{l}23.0 \\
18.0 \\
20.6 \\
21.4 \\
22.0 \\
26.4 \\
29.6 \\
35.0\end{array}$ \\
\hline $\begin{array}{l}5 \\
5 \\
5 \\
5 \\
5 \\
5 \\
5 \\
5\end{array}$ & $\begin{array}{r}0 \\
3 \\
6 \\
9 \\
12 \\
15 \\
18 \\
21\end{array}$ & $\begin{array}{l}17 \cdot 3 \\
15.8 \\
14.3 \\
15.3 \\
19.1 \\
21.2 \\
18.4 \\
15.9\end{array}$ & $\begin{array}{r}13.4 \\
9.1 \\
8.3 \\
8.2 \\
9.2 \\
10.2 \\
10.4 \\
9.5\end{array}$ & $\begin{array}{l}17 \cdot 2 \\
15.7 \\
14 \cdot 2 \\
15 \cdot 5 \\
19.2 \\
21.1 \\
18 \cdot 3 \\
15.7\end{array}$ & $\begin{array}{r}13.2 \\
8.7 \\
8.0 \\
8.0 \\
9.0 \\
9.7 \\
10.1 \\
9.4\end{array}$ & $\begin{array}{l}17.1 \\
15.6 \\
14.3 \\
15.5 \\
19.2 \\
21.0 \\
18.4 \\
15.8\end{array}$ & $\begin{array}{r}12.8 \\
8.2 \\
7.7 \\
7.0 \\
8.9 \\
9.7 \\
9.5 \\
9.0\end{array}$ & $\begin{array}{l}16.9 \\
15.3 \\
1400 \\
15.4 \\
18.9 \\
20.7 \\
18.7 \\
15.5\end{array}$ & $\begin{array}{r}12.1 \\
7.7 \\
7.4 \\
7.8 \\
8.6 \\
9.2 \\
0.2 \\
8.9\end{array}$ & $\begin{array}{l}17.3 \\
17.0 \\
16.6 \\
16.8 \\
16.9 \\
17.0 \\
17.0 \\
16.9\end{array}$ & & $\begin{array}{r}17.4 \\
21.6 \\
21.2 \\
15.2 \\
11.6 \\
3.6 \\
5.6 \\
7.4\end{array}$ & $\begin{array}{r}19.0 \\
23.0 \\
21.8 \\
16.0 \\
12.0 \\
3.8 \\
6.0 \\
8.0\end{array}$ & $\begin{array}{r}18.4 \\
22.2 \\
21.2 \\
17.0 \\
14.4 \\
5.8 \\
7.8 \\
9.0\end{array}$ & $\begin{array}{r}21.4 \\
25.4 \\
23.4 \\
18.0 \\
15.0 \\
7.0 \\
9.0 \\
10.6\end{array}$ \\
\hline $\begin{array}{l}5 \\
6 \\
5 \\
6 \\
6 \\
5 \\
6 \\
6\end{array}$ & $\begin{array}{r}0 \\
3 \\
5 \\
9 \\
12 \\
15 \\
18 \\
21\end{array}$ & $\begin{array}{l}15.1 \\
14.5 \\
15.0 \\
19.5 \\
23.2 \\
23.6 \\
70.7 \\
17.5\end{array}$ & $\begin{array}{r}9.4 \\
0.3 \\
10.0 \\
12.5 \\
13.9 \\
15.0 \\
15.8 \\
16.0\end{array}$ & $\begin{array}{l}15.0 \\
14.3 \\
15.1 \\
19.7 \\
23.6 \\
24.2 \\
20.7 \\
17.5\end{array}$ & $\begin{array}{r}9.2 \\
8.8 \\
9.9 \\
12.0 \\
13.4 \\
14.6 \\
15.7 \\
16.0\end{array}$ & $\begin{array}{l}15 \cdot 0 \\
14 \cdot 2 \\
15 \cdot 2 \\
20.3 \\
24 \cdot 1 \\
24 \cdot 3 \\
20 \cdot 9 \\
17.5\end{array}$ & $\begin{array}{r}8.8 \\
8.7 \\
9.6 \\
11.9 \\
13.2 \\
14.3 \\
15.4 \\
15.9\end{array}$ & $\begin{array}{l}14.9 \\
13.0 \\
15.2 \\
20.5 \\
24.4 \\
24.5 \\
20.8 \\
17.3\end{array}$ & $\begin{array}{r}8.7 \\
8.6 \\
9.5 \\
11.9\end{array}$ & $\begin{array}{l}16.6 \\
16.5 \\
16.6 \\
17.1 \\
18.9 \\
19.0 \\
18.8 \\
17.9\end{array}$ & & $\begin{array}{l}8.0 \\
9.2 \\
9.0 \\
8.0 \\
5.4 \\
9.2 \\
8.8 \\
6.6\end{array}$ & $\begin{array}{r}8.8 \\
10.0 \\
10.0 \\
9.4 \\
6.2 \\
10.4 \\
9.6 \\
7.6\end{array}$ & $\begin{array}{r}10.4 \\
12.0 \\
11.8 \\
10.6 \\
7.4 \\
13.0 \\
12.4 \\
9.2\end{array}$ & $\begin{array}{r}11.2 \\
12.8 \\
12.8 \\
12.0 \\
8.2 \\
14.2 \\
13.4 \\
9.6\end{array}$ \\
\hline $\begin{array}{l}7 \\
7 \\
7 \\
7 \\
7 \\
7 \\
7 \\
7\end{array}$ & $\begin{array}{r}0 \\
3 \\
5 \\
9 \\
12 \\
15 \\
18 \\
21\end{array}$ & $\begin{array}{l}17.0 \\
17.4 \\
18.3 \\
20.5 \\
21.1 \\
22.2 \\
21.3 \\
21.4\end{array}$ & $\begin{array}{l}15.2 \\
16.9 \\
18.1 \\
19.2 \\
20.0 \\
20.7 \\
20.4 \\
19.9\end{array}$ & $\begin{array}{l}17 \cdot 1 \\
17: 6 \\
18: 7 \\
21 \cdot 7 \\
21 \cdot 9 \\
22.4 \\
21.8 \\
22.0\end{array}$ & $\begin{array}{l}16.2 \\
17.0 \\
18.5 \\
19.7 \\
20.3 \\
20.9 \\
20.7 \\
20.0\end{array}$ & $\begin{array}{l}17.1 \\
17.7 \\
18.8 \\
21.2 \\
22.2 \\
22.7 \\
22.3 \\
22.6\end{array}$ & $\begin{array}{l}16.2 \\
17.2 \\
18.4 \\
19.8 \\
20.6 \\
21.0 \\
20.8 \\
20.1\end{array}$ & $\begin{array}{l}37.1 \\
17.6 \\
19.8 \\
21.8 \\
22.5 \\
22.7 \\
22.1 \\
? 2.4\end{array}$ & $\begin{array}{l}19.2 \\
20.0 \\
20.6 \\
21.0 \\
20.8 \\
19.9\end{array}$ & $\begin{array}{l}17.7 \\
17.6 \\
17.3 \\
17.7 \\
18.0 \\
17.9 \\
17.4\end{array}$ & & $\begin{array}{r}7.8 \\
8.6 \\
8.2 \\
0.6 \\
6.0 \\
12.2 \\
12.2 \\
13.2\end{array}$ & $\begin{array}{r}8.6 \\
9.8 \\
9.7 \\
7.8 \\
7.0 \\
14.0 \\
13.6 \\
19.6\end{array}$ & $\begin{array}{r}10.0 \\
11.6 \\
11.2 \\
0.6 \\
8.6 \\
16.6 \\
16.2 \\
24.0\end{array}$ & $\begin{array}{l}10.4 \\
12.2 \\
12.0 \\
11.2 \\
10.0 \\
17.0 \\
17.0 \\
26.4\end{array}$ \\
\hline $\begin{array}{l}8 \\
8 \\
8 \\
8 \\
8 \\
8 \\
8 \\
8\end{array}$ & $\begin{array}{r}0 \\
3 \\
6 \\
9 \\
12 \\
15 \\
18 \\
21\end{array}$ & $\begin{array}{l}21.0 \\
19.6 \\
19.9 \\
21.9 \\
23.0 \\
24.0 \\
23.1 \\
21.8\end{array}$ & $\begin{array}{l}19.0 \\
18.3 \\
18.6 \\
19.4 \\
19.9 \\
20.3 \\
19.9 \\
18.9\end{array}$ & $\begin{array}{l}21.3 \\
20.0 \\
20.2 \\
22.2 \\
23.4 \\
24.3 \\
23.5 \\
22.0\end{array}$ & $\begin{array}{l}1 \varsigma \cdot 2 \\
18.4 \\
18.8 \\
19.6 \\
20.1 \\
20.5 \\
20.0 \\
18.9\end{array}$ & $\begin{array}{l}21.5 \\
20.1 \\
20.4 \\
22.5 \\
23.8 \\
24.5 \\
23.7 \\
22.2\end{array}$ & $\begin{array}{l}19.1 \\
18.4 \\
18.8 \\
19.6 \\
20.1 \\
20.6 \\
20.0 \\
18.9\end{array}$ & $\begin{array}{l}21.5 \\
20.0 \\
20.4 \\
22.7 \\
24 \cdot 7 \\
25 \cdot 0 \\
23.8 \\
22.2\end{array}$ & $\begin{array}{l}18.8 \\
18.3 \\
18.8 \\
19.7 \\
20.2 \\
20.6 \\
20.0 \\
18.8\end{array}$ & $\begin{array}{l}17.7 \\
17.1 \\
17.0 \\
17.7 \\
18.4 \\
18.6 \\
18.7 \\
18.3\end{array}$ & & $\begin{array}{l}20.8 \\
15.4 \\
14.8 \\
17.6 \\
14.6 \\
15.2 \\
18.2 \\
18.2\end{array}$ & $\begin{array}{l}23.6 \\
17.8 \\
16.8 \\
20.6 \\
17.6 \\
18.4 \\
20.8 \\
20.8\end{array}$ & $\begin{array}{l}28.8 \\
21.2 \\
20.0 \\
23.4 \\
20.4 \\
22.4 \\
25.0 \\
24.8\end{array}$ & $\begin{array}{l}32.0 \\
23.5 \\
22.2 \\
27.2 \\
23.5 \\
24.4 \\
28.4 \\
27.6\end{array}$ \\
\hline $\begin{array}{l}9 \\
9 \\
9 \\
9 \\
9 \\
9 \\
9 \\
9\end{array}$ & $\begin{array}{r}0 \\
3 \\
6 \\
9 \\
12 \\
15 \\
18 \\
21\end{array}$ & $\begin{array}{l}21 \cdot 3 \\
20.1 \\
18 \cdot 6 \\
15: 4 \\
17.1 \\
16.9 \\
15.3 \\
14.7\end{array}$ & $\begin{array}{l}18.4 \\
18.1 \\
17.3 \\
14.0 \\
14.3 \\
15.1 \\
14.8 \\
14.6\end{array}$ & $\begin{array}{l}21.5 \\
20.3 \\
18.7 \\
15.7 \\
17.5 \\
16.7 \\
15.4 \\
14.8\end{array}$ & $\begin{array}{l}18 \cdot 4 \\
18 \cdot 2 \\
17 \cdot 3 \\
14 \cdot 1 \\
14 \cdot 3 \\
15 \cdot 0 \\
14 \cdot 8 \\
14 \cdot 8\end{array}$ & $\begin{array}{l}21.6 \\
20.5 \\
18.5 \\
15.5 \\
17.4 \\
15.8 \\
15.3 \\
14.8\end{array}$ & $\begin{array}{l}18.4 \\
18.2 \\
17.2 \\
13.9 \\
14.3 \\
15.0 \\
14.6 \\
14.4\end{array}$ & $\begin{array}{l}21.7 \\
20.5 \\
18.6 \\
15.1 \\
16.8 \\
16.5 \\
15.2 \\
14.5\end{array}$ & $\begin{array}{l}18.3 \\
18.1 \\
16.8 \\
13.4 \\
14.0 \\
14.8 \\
14.5 \\
14.5\end{array}$ & $\begin{array}{l}18.2 \\
13.0 \\
17.6 \\
17.4 \\
18.0 \\
17.5 \\
17.1 \\
16.7\end{array}$ & & $\begin{array}{r}17.4 \\
16.0 \\
8.4 \\
3.2 \\
4.4 \\
3.2 \\
7.4 \\
3.0\end{array}$ & $\begin{array}{r}20.2 \\
18.6 \\
9.2 \\
3.8 \\
5.4 \\
5.2 \\
7.6 \\
5.0\end{array}$ & $\begin{array}{r}22.2 \\
20.2 \\
10.8 \\
9.4 \\
7.6 \\
6.2 \\
9.6 \\
6.2\end{array}$ & $\begin{array}{r}25.4 \\
23.6 \\
12.0 \\
12.6 \\
11.4 \\
9.0 \\
10.6 \\
7.6\end{array}$ \\
\hline $\begin{array}{l}10 \\
10 \\
10 \\
10 \\
10 \\
10 \\
10 \\
10\end{array}$ & $\begin{array}{r}0 \\
3 \\
6 \\
9 \\
12 \\
15 \\
18 \\
21\end{array}$ & & & & & & & & & & & $\begin{array}{l}2.44 \\
7.8 \\
4.06 \\
7.8 \\
4.8 \\
6.2 \\
4.2 \\
7.0\end{array}$ & $\begin{array}{l}3.2 \\
7.6 \\
6.0 \\
8.2 \\
5.8 \\
7.4 \\
5.2 \\
8.0\end{array}$ & $\begin{array}{l}5.4 \\
9.2 \\
7.6 \\
9.2 \\
6.8 \\
9.2 \\
6.4 \\
8.8\end{array}$ & $\begin{array}{r}7.8 \\
10.4 \\
9.8 \\
11.2 \\
9.4 \\
12.4 \\
7.8 \\
9.8\end{array}$ \\
\hline
\end{tabular}



Table 10. -Three-hour averages of air and water-surface temperatures and wind directions and speed, April 1950-August
1951, Lake Hefner-Continued

MAY, 1950

\begin{tabular}{|c|c|c|c|c|c|c|c|c|c|c|c|c|c|c|c|}
\hline \multirow{4}{*}{ 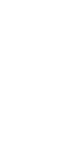 } & \multirow{4}{*}{ 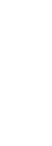 } & \multicolumn{8}{|c|}{ Average air temperature $\left({ }^{\circ} \mathrm{C}\right)$ at indicated height } & \multirow{4}{*}{$\begin{array}{l}\text { Average } \\
\text { water- } \\
\text { surface } \\
\text { tempera- } \\
\text { ture } \\
\text { ('C) }\end{array}$} & \multirow{4}{*}{$\begin{array}{c}\text { Average } \\
\text { wind } \\
\text { direction } \\
\text { (coded) }\end{array}$} & \multirow{2}{*}{\multicolumn{4}{|c|}{$\begin{array}{l}\text { Average wind speed (knots) } \\
\text { at indicated height }\end{array}$}} \\
\hline & & \multirow{2}{*}{\multicolumn{2}{|c|}{$\begin{array}{c}2 \\
\text { meters }\end{array}$}} & \multirow{2}{*}{\multicolumn{2}{|c|}{$\begin{array}{c}4 \\
\text { meters }\end{array}$}} & \multirow{2}{*}{\multicolumn{2}{|c|}{$\begin{array}{c}8 \\
\text { meters }\end{array}$}} & \multirow{2}{*}{\multicolumn{2}{|c|}{$\begin{array}{c}16 \\
\text { meters }\end{array}$}} & & & & & & \\
\hline & & & & & & & & & & & & 2 & & 8 & 16 \\
\hline & & $\begin{array}{l}\text { Dry } \\
\text { bulb }\end{array}$ & $\begin{array}{l}\text { Wet } \\
\text { bulb }\end{array}$ & $\begin{array}{l}\text { Dry } \\
\text { bulb }\end{array}$ & $\begin{array}{l}\text { Wet } \\
\text { bulb }\end{array}$ & $\begin{array}{l}\text { Dry } \\
\text { bulb }\end{array}$ & $\begin{array}{l}\text { Wet } \\
\text { bulb }\end{array}$ & $\begin{array}{l}\text { Dry } \\
\text { bulb }\end{array}$ & $\begin{array}{l}\text { Wet } \\
\text { bulb }\end{array}$ & & & & meters & meters & \\
\hline
\end{tabular}

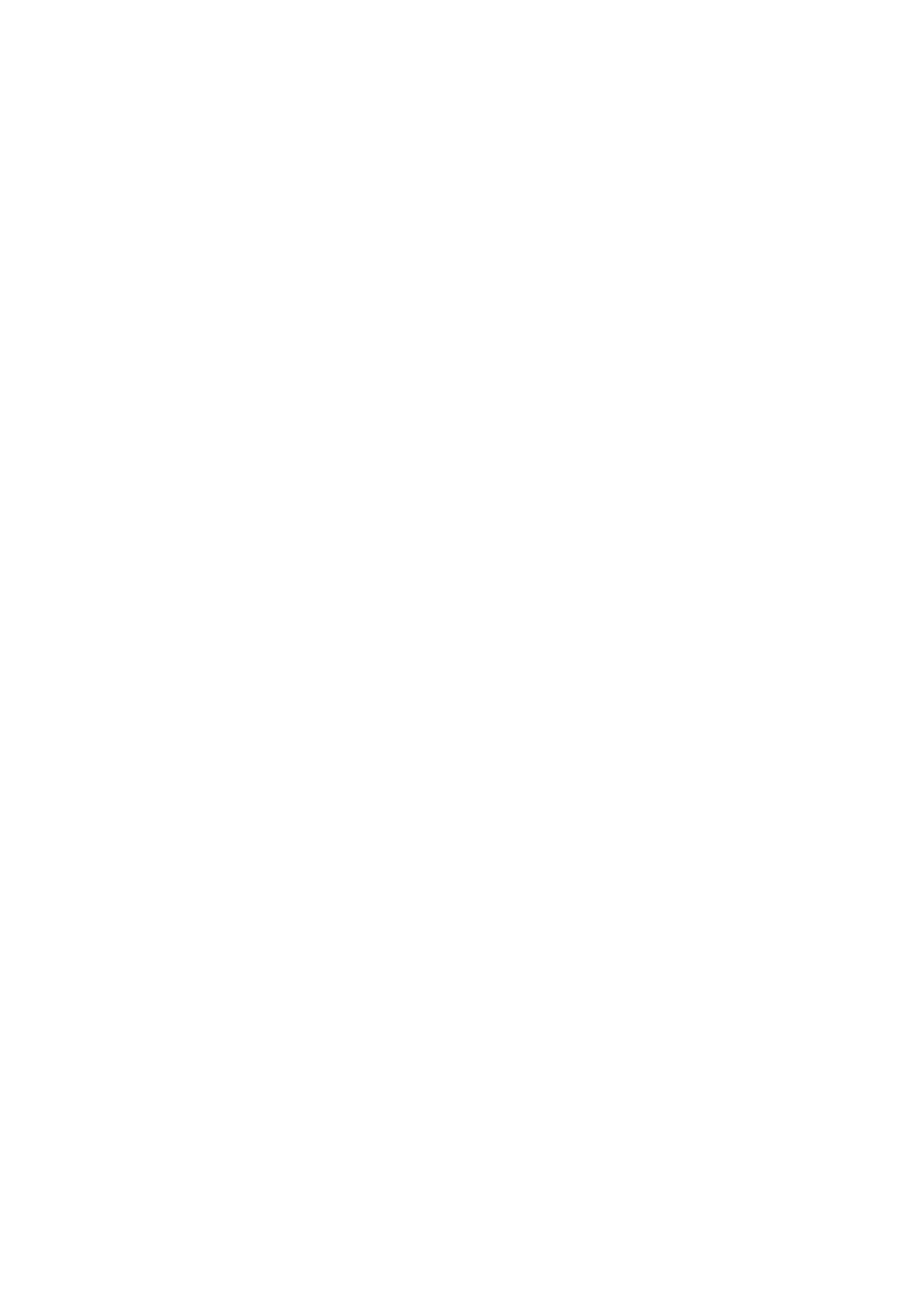


TABLE 10

Cable 10. - Three-hour averages of air and water-surface temperatures and wind directions and speed, April 1950-August 1951, Lake Hefner-Continued

STATION 4

THREE-HOURLY AVERAGES

MAY, 1950

\begin{tabular}{|c|c|c|c|c|c|c|c|c|c|c|c|}
\hline & 0 & Aver & rage air & tempe & rature & $\left({ }^{\circ} \mathrm{C}\right)$ at & indicate & ed heigh & & $\begin{array}{c}\text { Average } \\
\text { water- }\end{array}$ & $\begin{array}{c}\text { Average } \\
\text { wind }\end{array}$ \\
\hline बे & $\Phi$ & $\begin{array}{c}2 \\
\text { meter }\end{array}$ & & $\begin{array}{r}4 \\
\text { mete }\end{array}$ & ers & $\begin{array}{r}8 \\
\text { mete }\end{array}$ & & $\begin{array}{r}16 \\
\text { mete }\end{array}$ & & surface & direction \\
\hline$\ddot{0}$ & 先 & $\begin{array}{l}\text { Dry } \\
\text { bulb }\end{array}$ & $\begin{array}{l}\text { Wet } \\
\text { bulb }\end{array}$ & $\begin{array}{l}\text { Dry } \\
\text { bulb }\end{array}$ & $\begin{array}{l}\text { Wet } \\
\text { bulb }\end{array}$ & $\begin{array}{l}\text { Dry } \\
\text { bulb }\end{array}$ & $\begin{array}{l}\text { Wet } \\
\text { bulb }\end{array}$ & $\begin{array}{l}\text { Dry } \\
\text { bulb }\end{array}$ & $\begin{array}{l}\text { Wet } \\
\text { bulb }\end{array}$ & $\begin{array}{l}\text { ture } \\
\left({ }^{\circ} \mathrm{C}\right)\end{array}$ & (coded) \\
\hline 21 & 0 & 15.0 & 14.8 & 14.9 & 14.7 & 14.7 & 14.6 & 14.7 & 14.5 & 19.8 & \\
\hline 21 & 3 & 13.4 & 13.3 & 13.3 & 13.1 & 13.1 & 12.0 & 13.1 & 12.9 & 19.5 & \\
\hline 21 & 6 & 15.0 & 13.7 & 14.7 & 13.7 & 15.0 & 13.5 & 15.0 & 13.4 & 19.6 & \\
\hline 21 & 9 & 20.1 & 14.2 & 20.3 & 14.4 & 20.1 & 14.0 & 19.6 & 13.5 & 20.4 & \\
\hline 21 & 12 & 22.8 & 14.0 & 23.0 & 13.9 & 3.3 & 13.9 & $22 \cdot 6$ & 13.7 & 21.2 & \\
\hline 21 & 15 & 23.7 & 14.9 & $24 \cdot 1$ & 14.3 & 34.0 & 14.5 & $24: 0$ & 14.1 & 21.4 & \\
\hline 21 & 18 & 22.5 & 16,3 & $2 ? \cdot 6$ & 15.8 & $22 \cdot 8$ & 15.1 & 22.5 & 14.9 & $21 \cdot 2$ & \\
\hline 21 & 21 & 20.8 & $15 \cdot 8$ & 20.7 & 15.0 & 20.7 & $15 \cdot 1$ & 20.5 & 14.8 & 21.1 & \\
\hline $\begin{array}{l}22 \\
22\end{array}$ & $\begin{array}{l}0 \\
3\end{array}$ & & & & & & & & & & \\
\hline 22 & 6 & & & & & & & & & & \\
\hline 22 & 9 & & & & & & & & & & \\
\hline 22 & 12 & 25.1 & 15.5 & 25.0 & 15.8 & 25.4 & 15.7 & 25.5 & 15.6 & $21 \cdot 2$ & \\
\hline 22 & 15 & $25 \cdot 1$ & 16.3 & $25 \cdot 6$ & 16.1 & 25.7 & 15.7 & 26.0 & 15.0 & $21 \cdot 2$ & \\
\hline $\begin{array}{l}22 \\
22\end{array}$ & $\begin{array}{l}18 \\
21\end{array}$ & & & & & & & & & & \\
\hline 23 & 0 & & & & & & & & & & \\
\hline 23 & 3 & & & & & & & & & & \\
\hline 23 & $\begin{array}{l}6 \\
0 \\
0\end{array}$ & & & & & & & & & & \\
\hline 23 & 9 & 24.8 & 19.0 & 25.0 & 18.5 & 25.7 & 18.3 & $25 \cdot 3$ & $18 \cdot 8$ & 21.0 & \\
\hline 23 & 12 & $25 \cdot 8$ & $18 \cdot 4$ & $26 \cdot 2$ & $18 \cdot 2$ & 26.7 & 18.0 & 26.8 & 17.8 & 21.0 & \\
\hline $\begin{array}{l}23 \\
23\end{array}$ & $\begin{array}{l}15 \\
18\end{array}$ & & & & & & & & & & \\
\hline 23 & 21 & & & & & & & & & & \\
\hline 24 & 0 & & & & & & & & & & \\
\hline 24 & 3 & & & & & & & & & & \\
\hline$? 4$ & 6 & $21 \cdot 2$ & 18.0 & 21.2 & 18.0 & $21 \cdot 1$ & 17.5 & $21 \cdot 1$ & 17.6 & 20.0 & \\
\hline 24 & 9 & 23.0 & 18.7 & 23.5 & 18.7 & 23.7 & 18.5 & 2401 & 18.5 & 20.0 & \\
\hline 74 & 12 & 26.6 & 19.0 & 26.8 & 19.2 & 27.0 & 19.0 & 27.2 & 10.1 & $21 \cdot 1$ & \\
\hline 24 & 15 & 26.1 & 18.9 & 26.5 & 19.0 & 25.8 & 18.8 & 27.1 & 18.8 & $21 \cdot 1$ & \\
\hline 24 & 18 & 24.6 & 19.4 & 24.8 & 19.3 & $=5.1$ & 10.2 & $25 . ?$ & 10.0 & 20.9 & \\
\hline 24 & 21 & 23.1 & 18.9 & $23 \cdot 3$ & 18.7 & 23.4 & 18.5 & 23.4 & 18.5 & 20.6 & \\
\hline 25 & 0 & $22 \cdot 1$ & $18 \cdot 6$ & $22 \cdot 2$ & 18.4 & 22.2 & 18.1 & 22.2 & 19.0 & 20.5 & \\
\hline 25 & 3 & $21 \cdot 2$ & 18.4 & 21.7 & 18.3 & 21.7 & 18.2 & 21.7 & 18.1 & 20.3 & \\
\hline 25 & 6 & 21.7 & $18 . \circ$ & 21.9 & 18.9 & 22.0 & 18.8 & 22.1 & 18.8 & 20.5 & \\
\hline $\begin{array}{l}25 \\
35\end{array}$ & 9 & 24.1 & 19.9 & 24.4 & 19.9 & 24.9 & 19.8 & 24.7 & 19.8 & $21 \cdot 2$ & \\
\hline 25 & 12 & 25.0 & 20.3 & 25.5 & 20.3 & 25.5 & 20.3 & 25.3 & 20.0 & 22.1 & \\
\hline 25 & 15 & 21.4 & 18.0 & 21.4 & 17.8 & $21 \cdot 1$ & 17.5 & 20.8 & 17.5 & 20.4 & \\
\hline $\begin{array}{l}25 \\
25\end{array}$ & $\begin{array}{l}18 \\
21\end{array}$ & $\begin{array}{l}18.7 \\
15.5\end{array}$ & $\begin{array}{l}16.5 \\
14.5\end{array}$ & $\begin{array}{l}18.6 \\
15.4\end{array}$ & $\begin{array}{l}16 \cdot 3 \\
14.2\end{array}$ & 18.5 & 16.2 & $18 . ?$ & 16.0 & 20.1 & \\
\hline 25 & & & 14.5 & 15.4 & 14.2 & 15.1 & 14.0 & 14.8 & 13.9 & 20.1 & \\
\hline 26 & 0 & 13.2 & 13.0 & 13.0 & 12.9 & 12.9 & 12.8 & 12,8 & 12.8 & 19.8 & \\
\hline 26 & 3 & 11.9 & 11.8 & 11.7 & 11.5 & 11.5 & $11 \cdot 3$ & $11 \cdot 3$ & 11.1 & 19.4 & \\
\hline 26 & $\begin{array}{l}6 \\
9\end{array}$ & 11.2 & 10.6 & 11.0 & 10.3 & 10.6 & 10.0 & 10.3 & 9.8 & 19.4 & \\
\hline 26 & 9 & 12.0 & 10.7 & $11 \cdot 8$ & 10.5 & 11.6 & 10.4 & 11.5 & 10.2 & 20.0 & \\
\hline 26 & 1? & 12.7 & 11.7 & 12.5 & 11.4 & $12 \cdot 1$ & 11.1 & 12.0 & 11.0 & 19.4 & \\
\hline 26 & 15 & 13.0 & 12.1 & 12.8 & 11.8 & 12.6 & 11.6 & 12.5 & 11.4 & $19 \cdot 3$ & \\
\hline $\begin{array}{l}26 \\
26\end{array}$ & $\begin{array}{l}18 \\
21\end{array}$ & $\begin{array}{l}13.4 \\
13.2\end{array}$ & $\begin{array}{l}12.2 \\
12.0\end{array}$ & $\begin{array}{l}13.2 \\
13.1\end{array}$ & $\begin{array}{l}11.9 \\
12.0\end{array}$ & $\begin{array}{l}13.0 \\
12.9\end{array}$ & $\begin{array}{l}11.6 \\
11.7\end{array}$ & 13.0 & 11.5 & 19.4 & \\
\hline & & & & & & the & 11.7 & $12 \cdot 8$ & 11.5 & 19.6 & \\
\hline $\begin{array}{l}27 \\
27\end{array}$ & 0 & 12.6 & 11.5 & 12.5 & 11.2 & 12.3 & 11.0 & $12 \cdot 1$ & 10.8 & 19.4 & \\
\hline $\begin{array}{l}27 \\
27\end{array}$ & $\begin{array}{l}3 \\
6\end{array}$ & 11.4 & $\begin{array}{l}10.5 \\
8.0\end{array}$ & 11.3 & 10.3 & 11.1 & 10.0 & 10.7 & $9 \cdot 8$ & 19.3 & \\
\hline 27 & $\begin{array}{l}6 \\
9\end{array}$ & 9.7 & 8.9 & 9.5 & 8.7 & 9.1 & 8.4 & $8 \bullet 9$ & 8.1 & 19.5 & \\
\hline 27 & 12 & $\begin{array}{l}10.3 \\
15.2\end{array}$ & $\begin{array}{r}9.5 \\
12.5\end{array}$ & 10.3 & $\begin{array}{r}9.2 \\
13.2\end{array}$ & 10.1 & 9.3 & 10,1 & $9 \cdot 1$ & 19.7 & \\
\hline 27 & 15 & & $\begin{array}{l}12.5 \\
14.0\end{array}$ & $\begin{array}{l}15.7 \\
18.4\end{array}$ & 12.2 & $\begin{array}{l}15.4 \\
18.3\end{array}$ & 12.2 & $15 \cdot 2$ & 12.1 & 20.3 & \\
\hline 27 & 18 & 18.6 & $\begin{array}{l}14.0 \\
14.9\end{array}$ & $\begin{array}{l}18.4 \\
18.6\end{array}$ & $\begin{array}{l}13.8 \\
14.6\end{array}$ & $\begin{array}{l}18.3 \\
18.5\end{array}$ & $\begin{array}{l}13.8 \\
14.3\end{array}$ & $18 \cdot 1$ & 13.7 & 20.7 & \\
\hline 27 & 21 & 16.1 & $14 \cdot 3$ & 16.1 & 14.1 & 15.9 & $\begin{array}{l}14.3 \\
13.9\end{array}$ & $\begin{array}{l}18 \cdot 3 \\
15 \cdot 9\end{array}$ & $\begin{array}{l}14.2 \\
13.6\end{array}$ & $\begin{array}{l}20.2 \\
20.1\end{array}$ & \\
\hline 28 & 0 & 15.0 & 13.9 & 14.9 & 13.6 & $14 \cdot 8$ & 13.4 & $14 \cdot 7$ & 13.2 & 19.4 & \\
\hline 78 & 3 & & & & & & & & & & \\
\hline 28 & 6 & 16.1 & 14.7 & 15.9 & 14.4 & 15.7 & 14.3 & 15.4 & 14.0 & 18.6 & \\
\hline 28 & 9 & 17.6 & 16.1 & 17.7 & 15.6 & 17.6 & 15.6 & 17.6 & $15 \cdot 4$ & 19.6 & \\
\hline 28 & 12 & 19.4 & 17.5 & 19.5 & 17.4 & 29.6 & 17.2 & 19.5 & 17.2 & 19 & \\
\hline 28 & 15 & 20.5 & 18.5 & 20.6 & 18.4 & 20.7 & $18 \cdot 3$ & 20.6 & 18.3 & & \\
\hline 28 & 18 & 21.0 & 19.2 & 21.1 & 19.1 & 21.2 & 19.1 & 21.2 & 10.0 & 20.3 & \\
\hline 28 & 21 & 20.4 & 19.1 & 20.5 & 19.0 & 20.5 & 19.0 & 20.4 & 18.9 & 19.9 & \\
\hline 29 & 0 & 19.3 & 18.4 & 19.3 & 18.3 & 19.3 & 18.2 & 19.1 & $18 \cdot 1$ & $19 \bullet 8$ & \\
\hline 29 & & & 18.6 & 19.0 & 18.4 & & & 18.0 & 18.4 & 19.3 & \\
\hline 29 & 6 & 20.4 & 19.4 & 20.5 & 19.4 & 20.3 & 19.3 & 20.3 & 10. & 19.5 & \\
\hline 29 & 9 & 23.4 & 20.3 & 23.8 & $20 \cdot 3$ & $24 \cdot 3$ & 20. & 24.3 & 20.4 & 200 & \\
\hline 29 & 12 & 24.8 & 20.3 & 24.9 & 20.3 & $24 \cdot 7$ & $20 . ?$ & 24.5 & 19.9 & 20.2 & \\
\hline 29 & 15 & 31.9 & $17 \cdot 7$ & 21.9 & 17.3 & 21.7 & $17 . ?$ & 21.5 & 17.0 & 19.9 & \\
\hline $\begin{array}{l}29 \\
29\end{array}$ & 18 & $\begin{array}{r}20.4 \\
18.5\end{array}$ & 15.9 & $\begin{array}{l}20.5 \\
18.6\end{array}$ & 15.8 & 20.4 & 15.6 & 20.6 & 15.5 & 19.7 & \\
\hline 29 & 21 & 18.5 & 15.8 & 18.6 & 15.7 & 13.5 & 15.6 & 18.8 & 15.6 & 19.8 & \\
\hline 30 & 0 & 16.8 & $1 b \cdot 1$ & 17.0 & 15.0 & 16.9 & 14.7 & 16.7 & 14.2 & 19.9 & \\
\hline 30 & 3 & $14 \cdot 5$ & & & $12 \cdot 1$ & 14.3 & 12.0 & 14.4 & 11.9 & 19. & \\
\hline 30 & 6 & 16.6 & $13 \cdot 6$ & 16.8 & 13.5 & 16.6 & 13.4 & 16.7 & 13. & 19 & \\
\hline 30 & 9 & $21 \cdot 3$ & 15.9 & 21.5 & 15.9 & & & 21.3 & $15 \cdot 3$ & 20.1 & \\
\hline 30 & 12 & 25.1 & 16.9 & $25 \cdot 4$ & $16 \bullet 8$ & $25 \cdot 3$ & 16.6 & 24.9 & 16.1 & 21.0 & \\
\hline $\begin{array}{l}30 \\
30\end{array}$ & $\begin{array}{l}15 \\
18\end{array}$ & 26.2 & $17 \cdot 1$ & 26.6 & $16 \bullet 6$ & 25.7 & 16.6 & 25.4 & 16.5 & $21 \cdot 1$ & \\
\hline $\begin{array}{l}30 \\
30\end{array}$ & 18 & $\begin{array}{l}23.4 \\
21.0\end{array}$ & $19 \cdot 3$ & $24 \cdot ?$ & 18.1 & 24.7 & 17.7 & 25.0 & 16.9 & & \\
\hline 30 & & 21.0 & 18.2 & 21.1 & 17.8 & $21 \cdot 2$ & $17 . ?$ & 21.4 & 16.9 & 20.8 & \\
\hline $\begin{array}{l}31 \\
31\end{array}$ & 0 & 19.9 & 17.2 & 20.0 & 17.0 & 19.9 & 16.9 & 19.9 & 16.5 & 20.8 & \\
\hline $\begin{array}{l}31 \\
31\end{array}$ & 3 & 1801 & 16.1 & 17.9 & 16. & & & & & & \\
\hline $\begin{array}{l}31 \\
31\end{array}$ & 6 & 17.8 & 15.7 & 13.0 & 15. & 17. & 15. & 17.7 & 15.3. & 20. & \\
\hline $\begin{array}{l}31 \\
31\end{array}$ & 9 & 20.8 & 15.1 & 21.0 & 15.0 & 21.0 & 14.9 & 20.9 & 14.7 & & \\
\hline 31 & 12 & 22.4 & $15 \cdot 4$ & $22 \cdot 3$ & 15.3 & 22.3 & $15 \cdot 1$ & 22.2 & 14. & 20.8 & \\
\hline 31 & 15 & 22.6 & 15.9 & $22 \cdot 9$ & 15.6 & 2.8 & 15.4 & 22.8 & 15.4 & 20.8 & \\
\hline 31 & 18 & 19.6 & 15.5 & 19.5 & 15.3 & 13.4 & 15.2 & $19 \cdot 0$ & 15.0 & 20.7 & \\
\hline 31 & 22 & 16.2 & 14.0 & $15 . ?$ & 13.0 & 26.0 & 13.8 & 15.8 & 13.6 & 20.6 & \\
\hline
\end{tabular}


TABLE 10

Table 10. - Three-hour averages of air and water-surface temperatures and wind directions and speed, April 1950-August 1951, Lake Hefner-Continued

STATION 4 THREE-HOURLY AVERAGES

JUNE, 1950

\begin{tabular}{|c|c|c|c|c|c|c|c|c|c|c|c|c|c|c|c|}
\hline \multirow{3}{*}{ वึ } & \multirow{3}{*}{ 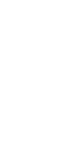 } & \multicolumn{8}{|c|}{ Average air temperature $\left({ }^{\circ} \mathrm{C}\right)$ at indicated height } & \multirow{3}{*}{$\begin{array}{l}\text { Average } \\
\text { water- } \\
\text { surface } \\
\text { tempera- } \\
\text { ture } \\
\left({ }^{\circ} \mathrm{C}\right)\end{array}$} & \multirow{3}{*}{$\begin{array}{l}\text { Average } \\
\text { wind } \\
\text { direction } \\
\text { (coded) }\end{array}$} & \multirow{2}{*}{\multicolumn{4}{|c|}{$\begin{array}{l}\text { Average wind speed (knots) } \\
\text { at indicated height }\end{array}$}} \\
\hline & & \multicolumn{2}{|c|}{$\begin{array}{c}2 \\
\text { meters }\end{array}$} & \multicolumn{2}{|c|}{$\begin{array}{c}4 \\
\text { meters }\end{array}$} & \multicolumn{2}{|c|}{$\begin{array}{c}8 \\
\text { meters }\end{array}$} & \multicolumn{2}{|c|}{$\begin{array}{c}16 \\
\text { meters }\end{array}$} & & & & & & \\
\hline & & $\begin{array}{l}\text { Dry } \\
\text { bulb }\end{array}$ & $\begin{array}{l}\text { Wet } \\
\text { bulb }\end{array}$ & $\begin{array}{l}\text { Dry } \\
\text { bulb }\end{array}$ & $\begin{array}{l}\text { Wet } \\
\text { bulb }\end{array}$ & $\begin{array}{l}\text { Dry } \\
\text { bulb }\end{array}$ & $\begin{array}{l}\text { Wet } \\
\text { bulb }\end{array}$ & $\begin{array}{l}\text { Dry } \\
\text { bulb }\end{array}$ & $\begin{array}{l}\text { Wet } \\
\text { bulb }\end{array}$ & & & meters & meters & meters & meters \\
\hline $\begin{array}{l}1 \\
1 \\
1 \\
1 \\
1 \\
1 \\
1 \\
1\end{array}$ & $\begin{array}{r}0 \\
3 \\
6 \\
9 \\
12 \\
15 \\
18 \\
21\end{array}$ & $\begin{array}{l}14.3 \\
13.7 \\
15.1 \\
20.6 \\
19.5 \\
23.6 \\
22.1 \\
20.6\end{array}$ & $\begin{array}{l}12.9 \\
12.7 \\
13.9 \\
18.2 \\
16.5 \\
19.8 \\
18.9 \\
19.5\end{array}$ & $\begin{array}{l}14.2 \\
13.7 \\
15.4 \\
20.9 \\
19.7 \\
24.0 \\
22.2 \\
20.7\end{array}$ & $\begin{array}{l}12.8 \\
12.6 \\
13.9 \\
18.2 \\
16.4 \\
19.7 \\
18.8 \\
19.3\end{array}$ & $\begin{array}{l}14.1 \\
13.5 \\
15.4 \\
21.1 \\
19.7 \\
24.1 \\
23.12 \\
20.6\end{array}$ & $\begin{array}{l}12.8 \\
17.4 \\
13.8 \\
18.1 \\
16.4 \\
19.5 \\
18.8 \\
19.2\end{array}$ & $\begin{array}{l}13.9 \\
13.3 \\
15.4 \\
21.7 \\
19.9 \\
24.2 \\
22.1 \\
20.5\end{array}$ & $\begin{array}{l}12.5 \\
12.3 \\
13.9 \\
18.1 \\
16.4 \\
10.3 \\
18.7 \\
19.0\end{array}$ & $\begin{array}{l}20.5 \\
20.4 \\
20.4 \\
21.1 \\
17.8 \\
21.3 \\
20.8 \\
20.9\end{array}$ & & $\begin{array}{l}3.4 \\
3.6 \\
4.6 \\
7.4 \\
7.8 \\
10.8 \\
12.0 \\
12.8\end{array}$ & $\begin{array}{r}3.8 \\
3.8 \\
5.2 \\
8.2 \\
9.2 \\
12.6 \\
13.8 \\
14.6\end{array}$ & $\begin{array}{r}4.2 \\
4.4 \\
5.8 \\
9.8 \\
11.2 \\
15.0 \\
16.6 \\
17.0\end{array}$ & $\begin{array}{l}5.2 \\
5.0 \\
6.0 \\
10.2 \\
12.4 \\
17.4 \\
18.4 \\
18.8\end{array}$ \\
\hline $\begin{array}{l}2 \\
2 \\
2 \\
2 \\
2 \\
2 \\
2 \\
2\end{array}$ & $\begin{array}{r}0 \\
3 \\
6 \\
9 \\
12 \\
15 \\
18 \\
21\end{array}$ & $\begin{array}{l}19.5 \\
18.9 \\
19.6 \\
21.2 \\
21.6 \\
22.1 \\
22.1 \\
17.8\end{array}$ & $\begin{array}{l}18.7 \\
18.5 \\
18.6 \\
18.6 \\
19.0 \\
20.0 \\
20.2 \\
17.3\end{array}$ & $\begin{array}{l}19.5 \\
18.9 \\
19.6 \\
21.03 \\
21.7 \\
22.03 \\
22.1 \\
17.3\end{array}$ & $\begin{array}{l}18.6 \\
18.3 \\
18.5 \\
18.5 \\
19.2 \\
19.9 \\
20.1 \\
16.8\end{array}$ & $\begin{array}{l}19.3 \\
18.8 \\
19.7 \\
21.3 \\
21.8 \\
22.4 \\
22.1 \\
17.2\end{array}$ & $\begin{array}{l}18.4 \\
18.2 \\
18.3 \\
18.4 \\
19.1 \\
20.0 \\
20.0 \\
16.8\end{array}$ & $\begin{array}{l}19.2 \\
18.6 \\
19.7 \\
21.2 \\
21.7 \\
22.4 \\
22.2 \\
17.1\end{array}$ & $\begin{array}{l}18.3 \\
18.1 \\
18.3 \\
18.4 \\
10.0 \\
19.9 \\
20.0 \\
16.8\end{array}$ & $\begin{array}{l}21.1 \\
20.7 \\
20.8 \\
20.9 \\
21.1 \\
21.0 \\
20.9 \\
19.7\end{array}$ & & $\begin{array}{r}10.0 \\
10.4 \\
23.0 \\
12.0 \\
12.8 \\
10.0 \\
6.4 \\
7.0\end{array}$ & $\begin{array}{l}11.6 \\
11.8 \\
15.2 \\
13.8 \\
14.8 \\
11.8 \\
7.6 \\
7.8\end{array}$ & $\begin{array}{r}13.0 \\
13.0 \\
17.00 \\
15.4 \\
17.0 \\
14.0 \\
0.0 \\
9.2\end{array}$ & $\begin{array}{l}14.4 \\
15.0 \\
19.0 \\
17.4 \\
19.4 \\
15.6 \\
10.4 \\
12.0\end{array}$ \\
\hline $\begin{array}{l}3 \\
3 \\
3 \\
3 \\
3 \\
3 \\
3 \\
3\end{array}$ & $\begin{array}{r}0 \\
3 \\
6 \\
9 \\
12 \\
15 \\
18 \\
21\end{array}$ & $\begin{array}{l}16.8 \\
15.3 \\
14.6 \\
17.7 \\
20.0 \\
20.5 \\
18.2 \\
14.3\end{array}$ & $\begin{array}{l}16.7 \\
14.09 \\
13.0 \\
13.5 \\
14.1 \\
14.00 \\
13.0 \\
12.5\end{array}$ & $\begin{array}{l}16.6 \\
15.0 \\
14.7 \\
17.7 \\
20.1 \\
20.5 \\
18.1 \\
14.1\end{array}$ & $\begin{array}{l}16.4 \\
14.5 \\
12.9 \\
13.7 \\
14.2 \\
14.0 \\
13.8 \\
12.3\end{array}$ & $\begin{array}{l}10.5 \\
14.9 \\
14.6 \\
17.7 \\
19.9 \\
20.4 \\
17.8 \\
13.8\end{array}$ & $\begin{array}{l}16.3 \\
14.04 \\
12.7 \\
13.4 \\
13.8 \\
13.9 \\
13.06 \\
12.0\end{array}$ & $\begin{array}{l}16.4 \\
14.7 \\
14.3 \\
17.2 \\
19.4 \\
20.0 \\
17.7 \\
14.2\end{array}$ & $\begin{array}{l}16.3 \\
14.1 \\
12.4 \\
13.1 \\
13.6 \\
13.5 \\
13.2 \\
11.9\end{array}$ & $\begin{array}{l}19.0 \\
19.02 \\
20.1 \\
20.0 \\
20.7 \\
20.0 \\
20.02 \\
20.2\end{array}$ & & $\begin{array}{l}2.4 \\
5.02 \\
6.4 \\
8.0 \\
7.2 \\
6.02 \\
3.22 \\
1.0\end{array}$ & $\begin{array}{r}3.4 \\
6.8 \\
8.6 \\
10.0 \\
9.6 \\
8.0 \\
4.4 \\
1.8\end{array}$ & $\begin{array}{r}8.2 \\
13.2 \\
13.0 \\
13.6 \\
14.6 \\
12.6 \\
7.2 \\
4.8\end{array}$ & $\begin{array}{r}11.6 \\
19.0 \\
19.6 \\
20.2 \\
21.2 \\
19.2 \\
11.2 \\
7.6\end{array}$ \\
\hline $\begin{array}{l}4 \\
4 \\
4 \\
4 \\
4 \\
4 \\
4 \\
4\end{array}$ & $\begin{array}{r}0 \\
3 \\
6 \\
9 \\
12 \\
15 \\
18 \\
21\end{array}$ & $\begin{array}{l}12.4 \\
10.8 \\
13.5 \\
17.8 \\
20.0 \\
20.8 \\
19.5 \\
16.9\end{array}$ & $\begin{array}{l}11.5 \\
10.0 \\
11.4 \\
12.0 \\
12.9 \\
13.5 \\
13.8 \\
13.7\end{array}$ & $\begin{array}{l}12.7 \\
10.6 \\
13.8 \\
17.6 \\
20.2 \\
20.8 \\
19.8 \\
17.1\end{array}$ & $\begin{array}{r}11.3 \\
9.9 \\
11.4 \\
12.2 \\
12.8 \\
13.2 \\
13.6 \\
13.6\end{array}$ & $\begin{array}{l}11.9 \\
10.3 \\
13.4 \\
17.7 \\
20.0 \\
20.8 \\
19.1 \\
10.0\end{array}$ & $\begin{array}{r}10.9 \\
9.5 \\
11.1 \\
12.0 \\
12.6 \\
13.0 \\
13.6 \\
13.3\end{array}$ & $\begin{array}{l}12.2 \\
10.5 \\
12.7 \\
17.7 \\
19.4 \\
20.2 \\
19.0 \\
16.9\end{array}$ & $\begin{array}{r}10.8 \\
9.3 \\
10.7 \\
11.8 \\
12.1 \\
12.7 \\
13.2 \\
13.0\end{array}$ & $\begin{array}{l}20.2 \\
20.1 \\
20.3 \\
20.9 \\
21.5 \\
20.9 \\
20.9 \\
20.1\end{array}$ & & $\begin{array}{l}1.06 \\
2.6 \\
2.44 \\
2.6 \\
3.0 \\
2.06 \\
2.00 \\
4.22\end{array}$ & $\begin{array}{l}2.2 \\
2.8 \\
3.0 \\
2.8 \\
3.6 \\
3.0 \\
2.2 \\
5.2\end{array}$ & $\begin{array}{l}4.22 \\
4.0 \\
4.44 \\
3.8 \\
5.6 \\
3.6 \\
2.44 \\
5.2\end{array}$ & $\begin{array}{l}0.4 \\
4.6 \\
6.4 \\
5.0 \\
7.6 \\
4.8 \\
2.8 \\
6.8\end{array}$ \\
\hline $\begin{array}{l}5 \\
5 \\
5 \\
5 \\
5 \\
5 \\
5 \\
5\end{array}$ & $\begin{array}{r}0 \\
3 \\
6 \\
9 \\
12 \\
15 \\
18 \\
21\end{array}$ & $\begin{array}{l}16.8 \\
16.1 \\
16.4 \\
18.9 \\
20.0 \\
20.0 \\
18.8 \\
17.0\end{array}$ & $\begin{array}{l}14.0 \\
13.9 \\
14 \bullet ? \\
14.7 \\
14.5 \\
14.6 \\
15.8 \\
16.1\end{array}$ & $\begin{array}{l}16.6 \\
15.9 \\
16.5 \\
18.9 \\
19.0 \\
20.0 \\
18.0 \\
16.9\end{array}$ & $\begin{array}{l}13.6 \\
13.8 \\
14.1 \\
14.5 \\
14.4 \\
14.1 \\
15.6 \\
15.8\end{array}$ & $\begin{array}{l}16.5 \\
15.8 \\
16.3 \\
18.8 \\
19.8 \\
19.8 \\
18.6 \\
16.7\end{array}$ & $\begin{array}{l}13.5 \\
13.6 \\
14.0 \\
14.4 \\
14.0 \\
13.9 \\
15.4 \\
15.7\end{array}$ & $\begin{array}{l}16.4 \\
15.6 \\
16.3 \\
18.6 \\
19.7 \\
19.6 \\
18.3 \\
16.5\end{array}$ & $\begin{array}{l}13.3 \\
13.5 \\
14.0 \\
14.4 \\
14.1 \\
13.8 \\
15.3 \\
15.6\end{array}$ & $\begin{array}{l}20.3 \\
20.4 \\
20.7 \\
21.1 \\
21.8 \\
21.8 \\
21.3 \\
21.3\end{array}$ & & $\begin{array}{l}6.0 \\
5.22 \\
3.2 \\
2.2 \\
2.8 \\
5.8 \\
7.02 \\
7.22\end{array}$ & $\begin{array}{l}6.6 \\
5.8 \\
3.4 \\
2.4 \\
3.2 \\
6.2 \\
7.8 \\
7.8\end{array}$ & $\begin{array}{l}7.6 \\
6.2 \\
3.2 \\
2.6 \\
3.6 \\
7.2 \\
9.0 \\
9.2\end{array}$ & $\begin{array}{l}8.0 \\
6.8 \\
3.6 \\
2.8 \\
3.6 \\
7.4 \\
9.2 \\
9.6\end{array}$ \\
\hline $\begin{array}{l}6 \\
6 \\
6 \\
6 \\
6 \\
6 \\
6 \\
6\end{array}$ & $\begin{array}{r}0 \\
3 \\
6 \\
0 \\
12 \\
15 \\
18 \\
21\end{array}$ & $\begin{array}{l}16.1 \\
15.9 \\
16.3 \\
18.4 \\
19.7 \\
20.5 \\
19.9 \\
18.3\end{array}$ & $\begin{array}{l}16.0 \\
15.7 \\
15.8 \\
16.2 \\
16.6 \\
17.3 \\
17.3 \\
16.8\end{array}$ & $\begin{array}{l}16.1 \\
15.8 \\
16.3 \\
18.3 \\
19.8 \\
20.5 \\
19.9 \\
18.3\end{array}$ & $\begin{array}{l}15.9 \\
15.4 \\
15.5 \\
16.1 \\
16.2 \\
17.0 \\
17.0 \\
16.5\end{array}$ & $\begin{array}{l}15.9 \\
15.6 \\
16.7 \\
18.3 \\
19.8 \\
20.4 \\
19.8 \\
18.1\end{array}$ & $\begin{array}{l}15.7 \\
15.2 \\
15.4 \\
15.9 \\
15.2 \\
16.7 \\
16.7 \\
16.4\end{array}$ & $\begin{array}{l}15.9 \\
15.5 \\
16.1 \\
18.2 \\
10.7 \\
20.4 \\
19.6 \\
17.9\end{array}$ & $\begin{array}{l}15.6 \\
15.2 \\
15.4 \\
15.8 \\
16.0 \\
16.5 \\
16.5 \\
16.3\end{array}$ & $\begin{array}{l}20.6 \\
20.6 \\
20.6 \\
20.9 \\
21.5 \\
22.0 \\
21.4 \\
21.1\end{array}$ & & $\begin{array}{l}8.8 \\
8.0 \\
7.4 \\
6.8 \\
8.0 \\
9.2 \\
9.2 \\
8.4\end{array}$ & $\begin{array}{r}9.6 \\
9.0 \\
8.2 \\
7.6 \\
9.0 \\
10.4 \\
10.6 \\
0.4\end{array}$ & $\begin{array}{r}10.6 \\
9.6 \\
8.6 \\
8.2 \\
10.0 \\
12.2 \\
12.0 \\
10.8\end{array}$ & $\begin{array}{r}11.6 \\
10.6 \\
9.6 \\
9.2 \\
11.2 \\
13.2 \\
13.4 \\
11.4\end{array}$ \\
\hline $\begin{array}{l}7 \\
7 \\
7 \\
7 \\
7 \\
7 \\
7 \\
7\end{array}$ & $\begin{array}{r}0 \\
3 \\
6 \\
9 \\
12 \\
15 \\
18 \\
21\end{array}$ & $\begin{array}{l}17.4 \\
17.3 \\
18.1 \\
21.0 \\
23.4 \\
24.3 \\
23.5 \\
21.0\end{array}$ & $\begin{array}{l}16.8 \\
16.3 \\
16.4 \\
17.0 \\
19.4 \\
19.2 \\
10.5 \\
18.9\end{array}$ & $\begin{array}{l}17.3 \\
17.1 \\
18.1 \\
21.7 \\
23.7 \\
24.7 \\
23.0 \\
22.0\end{array}$ & $\begin{array}{l}16.5 \\
16.0 \\
16.3 \\
17.7 \\
18.3 \\
19.0 \\
10.4 \\
18.9\end{array}$ & $\begin{array}{l}17.2 \\
17.0 \\
18.0 \\
31.0 \\
23.8 \\
24.9 \\
23.8 \\
22.0\end{array}$ & $\begin{array}{l}16.4 \\
15.8 \\
16.0 \\
17.4 \\
17.9 \\
18.9 \\
19.1 \\
18.7\end{array}$ & $\begin{array}{l}17.0 \\
16.9 \\
18.0 \\
21.2 \\
24.1 \\
25.1 \\
23.0 \\
21.0\end{array}$ & $\begin{array}{l}16.3 \\
15.5 \\
15.0 \\
17.3 \\
18.0 \\
18.8 \\
10.0 \\
18.06\end{array}$ & $\begin{array}{l}20.7 \\
20.6 \\
20.7 \\
21.0 \\
21.0 \\
21.03 \\
21.1 \\
20.8\end{array}$ & & $\begin{array}{r}8.6 \\
10.0 \\
11.02 \\
12.0 \\
12.4 \\
13.8 \\
13.2 \\
12.2\end{array}$ & $\begin{array}{r}9.8 \\
11.00 \\
12.6 \\
14.0 \\
14.2 \\
15.8 \\
15.0 \\
14.0\end{array}$ & $\begin{array}{l}11.2 \\
13.00 \\
14.44 \\
16.2 \\
17.2 \\
19.6 \\
18.2 \\
16.8\end{array}$ & $\begin{array}{l}12.4 \\
14.0 \\
15.8 \\
18.2 \\
19.2 \\
21.8 \\
20.0 \\
18.8\end{array}$ \\
\hline $\begin{array}{l}8 \\
9 \\
8 \\
8 \\
8 \\
8 \\
8 \\
8\end{array}$ & $\begin{array}{r}0 \\
3 \\
6 \\
9 \\
12 \\
15 \\
18 \\
21\end{array}$ & $\begin{array}{l}20.4 \\
20.7 \\
20.7 \\
23.8 \\
25.0 \\
26.1 \\
25.3 \\
23.9\end{array}$ & $\begin{array}{l}18.7 \\
18.6 \\
19.1 \\
21.3 \\
22.1 \\
22.7 \\
22.4 \\
21.9\end{array}$ & $\begin{array}{l}20.5 \\
20.0 \\
20.9 \\
24.2 \\
25.4 \\
25.5 \\
25.8 \\
24.8\end{array}$ & $\begin{array}{l}18.6 \\
18.5 \\
19.1 \\
? 1.03 \\
? 2.2 \\
22.8 \\
? 2.04 \\
21.9\end{array}$ & $\begin{array}{l}20.4 \\
20.2 \\
21.0 \\
24.4 \\
25.7 \\
27.0 \\
26.1 \\
24.3\end{array}$ & $\begin{array}{l}18.4 \\
18.4 \\
19.0 \\
21.5 \\
22.02 \\
22.0 \\
22.4 \\
21.9\end{array}$ & $\begin{array}{l}20.4 \\
20.2 \\
21.1 \\
24.9 \\
25.9 \\
27.4 \\
25.3 \\
24.4\end{array}$ & $\begin{array}{l}18.3 \\
18.4 \\
19.1 \\
21.6 \\
22.3 \\
23.0 \\
22.6 \\
21.9\end{array}$ & $\begin{array}{l}20.5 \\
20.5 \\
20.4 \\
21.0 \\
21.0 \\
22.3 \\
27.1 \\
21.08\end{array}$ & & $\begin{array}{l}12.6 \\
12.0 \\
14.0 \\
14.0 \\
12.6 \\
12.4 \\
11.8 \\
13.4\end{array}$ & $\begin{array}{l}14.0 \\
13.6 \\
16.0 \\
16.2 \\
14.6 \\
14.8 \\
13.6 \\
15.4\end{array}$ & $\begin{array}{l}17.2 \\
16.00 \\
18.8 \\
28.2 \\
16.8 \\
17.0 \\
17.4 \\
18.6\end{array}$ & $\begin{array}{l}18.8 \\
18.0 \\
20.8 \\
21.2 \\
19.2 \\
20.0 \\
18.8 \\
21.0\end{array}$ \\
\hline $\begin{array}{l}9 \\
9 \\
9 \\
9 \\
9 \\
9 \\
9 \\
9\end{array}$ & $\begin{array}{r}0 \\
3 \\
6 \\
0 \\
12 \\
15 \\
18 \\
21\end{array}$ & $\begin{array}{l}22.8 \\
21.9 \\
23.2 \\
25.7 \\
27.3 \\
27.3 \\
25.8 \\
24.3\end{array}$ & $\begin{array}{l}21.0 \\
20.8 \\
21.7 \\
23.0 \\
23.0 \\
23.03 \\
23.1 \\
22.7\end{array}$ & $\begin{array}{l}22.9 \\
22.00 \\
23.6 \\
26.3 \\
27.8 \\
28.1 \\
26.7 \\
24.7\end{array}$ & $\begin{array}{l}20.9 \\
20.8 \\
21.9 \\
23.1 \\
23.4 \\
23.4 \\
23.1 \\
? 3.6\end{array}$ & $\begin{array}{l}23.0 \\
23.1 \\
23.8 \\
26.5 \\
78.2 \\
28.3 \\
26.6 \\
24.9\end{array}$ & $\begin{array}{l}20.9 \\
20.7 \\
21.9 \\
23.1 \\
23.3 \\
23.6 \\
23.2 \\
22.6\end{array}$ & $\begin{array}{l}23.1 \\
22.1 \\
23.9 \\
26.9 \\
28.8 \\
28.8 \\
26.8 \\
25.0\end{array}$ & $\begin{array}{l}20.9 \\
20.9 \\
22.1 \\
23.2 \\
23.5 \\
23.9 \\
23.9 \\
22.7\end{array}$ & $\begin{array}{l}21.4 \\
21.1 \\
21.5 \\
22.2 \\
22.5 \\
23.2 \\
23.4 \\
22.9\end{array}$ & & $\begin{array}{r}13.8 \\
11.8 \\
14.0 \\
12.2 \\
9.8 \\
9.4 \\
8.8 \\
7.4\end{array}$ & $\begin{array}{r}16.2 \\
13.6 \\
16.0 \\
14.0 \\
10.6 \\
11.4 \\
10.6 \\
8.6\end{array}$ & $\begin{array}{l}18.8 \\
15.06 \\
17.4 \\
14.8 \\
12.0 \\
13.4 \\
12.6 \\
10.4\end{array}$ & $\begin{array}{l}21.0 \\
17.8 \\
20.8 \\
17.8 \\
14.4 \\
16.0 \\
14.8 \\
12.4\end{array}$ \\
\hline $\begin{array}{l}10 \\
10 \\
10 \\
10 \\
10 \\
10 \\
10 \\
10\end{array}$ & $\begin{array}{r}0 \\
3 \\
6 \\
9 \\
12 \\
15 \\
18 \\
21\end{array}$ & $\begin{array}{l}22.8 \\
21.7 \\
? 2.8 \\
26.3 \\
28.4 \\
20.1 \\
20.2 \\
20.5\end{array}$ & $\begin{array}{l}22.0 \\
21.3 \\
71.9 \\
23.3 \\
22.7 \\
18.5 \\
17.4 \\
18.3\end{array}$ & $\begin{array}{l}23 \cdot 1 \\
21.8 \\
23.2 \\
27: 0 \\
28 \cdot 3 \\
20.2 \\
20.2 \\
20.5\end{array}$ & $\begin{array}{l}22.1 \\
? 3.3 \\
21.9 \\
23.0 \\
22.6 \\
18.3 \\
17.2 \\
18.1\end{array}$ & $\begin{array}{l}23.1 \\
71.8 \\
23.3 \\
27.5 \\
28.9 \\
20.0 \\
20.1 \\
20.4\end{array}$ & $\begin{array}{l}22.0 \\
22.3 \\
21.9 \\
23.1 \\
22.7 \\
18.2 \\
17.1 \\
17.9\end{array}$ & $\begin{array}{l}23.3 \\
22.3 \\
23.5 \\
27.6 \\
28.7 \\
19.5 \\
20.2 \\
20.3\end{array}$ & $\begin{array}{l}27.3 \\
21 \cdot 4 \\
2 ? .0 \\
23.0 \\
22.3 \\
18.1 \\
16.0 \\
17.9\end{array}$ & $\begin{array}{l}22.3 \\
21.9 \\
22.4 \\
24.4 \\
26.3 \\
23.2 \\
211.1 \\
21.7\end{array}$ & & $\begin{array}{r}1.8 \\
3.6 \\
3.2 \\
3.4 \\
5.8 \\
9.8 \\
12.2 \\
10.0\end{array}$ & $\begin{array}{r}2.2 \\
4.2 \\
3.6 \\
4.2 \\
6.6 \\
11.4 \\
13.4 \\
11.2\end{array}$ & $\begin{array}{r}2.8 \\
5.2 \\
4.4 \\
5.0 \\
8.2 \\
15.4 \\
15.8 \\
12.8\end{array}$ & $\begin{array}{r}4.2 \\
6.4 \\
5.0 \\
5.8 \\
9.4 \\
20.4 \\
16.6 \\
14.0\end{array}$ \\
\hline
\end{tabular}


TABLE 10

Table 10. - Three-hour averagea of air and water-surface temperatures and wind directions and speed, April 1950-August 1951, Lake Hefner-Continued

THREE-HOURLY AVERAGES

JUNE, $\cdot 1950$

\begin{tabular}{|c|c|c|c|c|c|c|c|c|c|c|c|c|c|c|c|}
\hline \multirow{4}{*}{ 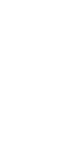 } & \multirow{4}{*}{ 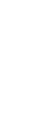 } & \multicolumn{8}{|c|}{ Average air temperature $\left({ }^{\circ} \mathrm{C}\right)$ at indicated height } & \multirow{4}{*}{$\begin{array}{l}\text { Average } \\
\text { water- } \\
\text { surface } \\
\text { tempera- } \\
\text { ture } \\
\text { (ㄷ) }\end{array}$} & \multirow{4}{*}{$\begin{array}{c}\text { Average } \\
\text { wind } \\
\text { direction } \\
\text { (coded) }\end{array}$} & \multirow{2}{*}{\multicolumn{4}{|c|}{$\begin{array}{l}\text { Average wind speed (knots) } \\
\text { at indicated height }\end{array}$}} \\
\hline & & \multirow{2}{*}{\multicolumn{2}{|c|}{$\begin{array}{c}2 \\
\text { meters }\end{array}$}} & \multirow{2}{*}{\multicolumn{2}{|c|}{$\begin{array}{c}4 \\
\text { meters }\end{array}$}} & \multirow{2}{*}{\multicolumn{2}{|c|}{$\begin{array}{c}8 \\
\text { meters }\end{array}$}} & \multirow{2}{*}{\multicolumn{2}{|c|}{$\begin{array}{c}16 \\
\text { meters }\end{array}$}} & & & & & & \\
\hline & & & & & & & & & & & & 2 & 4 & 8 & 16 \\
\hline & & $\begin{array}{l}\text { Dry } \\
\text { bulb }\end{array}$ & $\begin{array}{l}\text { Wet } \\
\text { bulb }\end{array}$ & & $\begin{array}{l}\text { Wet } \\
\text { bulb }\end{array}$ & & & & & & & & & & \\
\hline
\end{tabular}

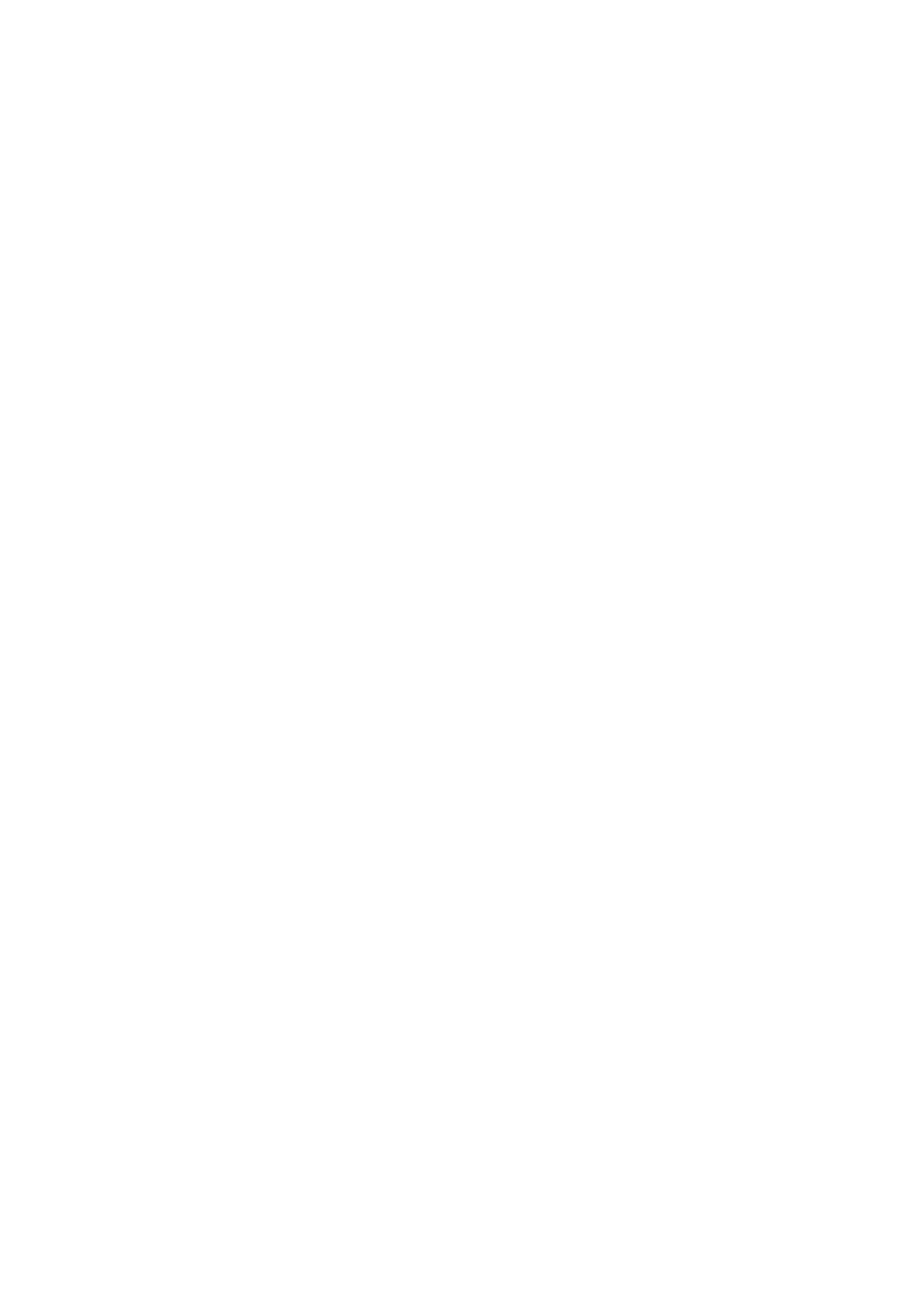


Table 10. - Three-hour averages of air and water-surface temperatures and wind directions and speed, April 1950-August 1951, Lake Hefner-Continued

STATION 4 THREE-HOURLY AVERAGES

JUNE, $1950^{\circ}$

\begin{tabular}{|c|c|c|c|c|c|c|c|c|c|c|c|c|c|c|c|}
\hline \multirow{4}{*}{ 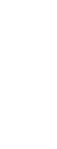 } & \multirow{4}{*}{ 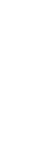 } & \multicolumn{8}{|c|}{ Average air temperature $\left({ }^{\circ} \mathrm{C}\right)$ at indicated height } & \multirow{4}{*}{$\begin{array}{l}\text { Average } \\
\text { water- } \\
\text { surface } \\
\text { tempera- } \\
\text { ture } \\
\left.\text { ( }{ }^{\circ} \mathrm{C}\right)\end{array}$} & \multirow{4}{*}{$\begin{array}{l}\text { Average } \\
\text { wind } \\
\text { direction } \\
\text { (coded) }\end{array}$} & \multirow{2}{*}{\multicolumn{4}{|c|}{$\begin{array}{l}\text { Average wind speed (knots) } \\
\text { at indicated height }\end{array}$}} \\
\hline & & \multirow{2}{*}{\multicolumn{2}{|c|}{$\begin{array}{c}2 \\
\text { meters }\end{array}$}} & \multirow{2}{*}{\multicolumn{2}{|c|}{$\begin{array}{c}4 \\
\text { meters }\end{array}$}} & \multirow{2}{*}{\multicolumn{2}{|c|}{$\begin{array}{c}8 \\
\text { meters }\end{array}$}} & \multirow{2}{*}{\multicolumn{2}{|c|}{$\begin{array}{c}16 \\
\text { meters }\end{array}$}} & & & & & & \\
\hline & & & & & & & & & & & & 2 & 4 & 8 & 16 \\
\hline & & bulb & bulb & & & $\begin{array}{l}\text { Dry } \\
\text { bulb }\end{array}$ & bulb & $\begin{array}{l}\text { Dry } \\
\text { bulb }\end{array}$ & $\begin{array}{l}\text { Wet } \\
\text { bulb }\end{array}$ & & & meters & meters & meters & meters \\
\hline
\end{tabular}

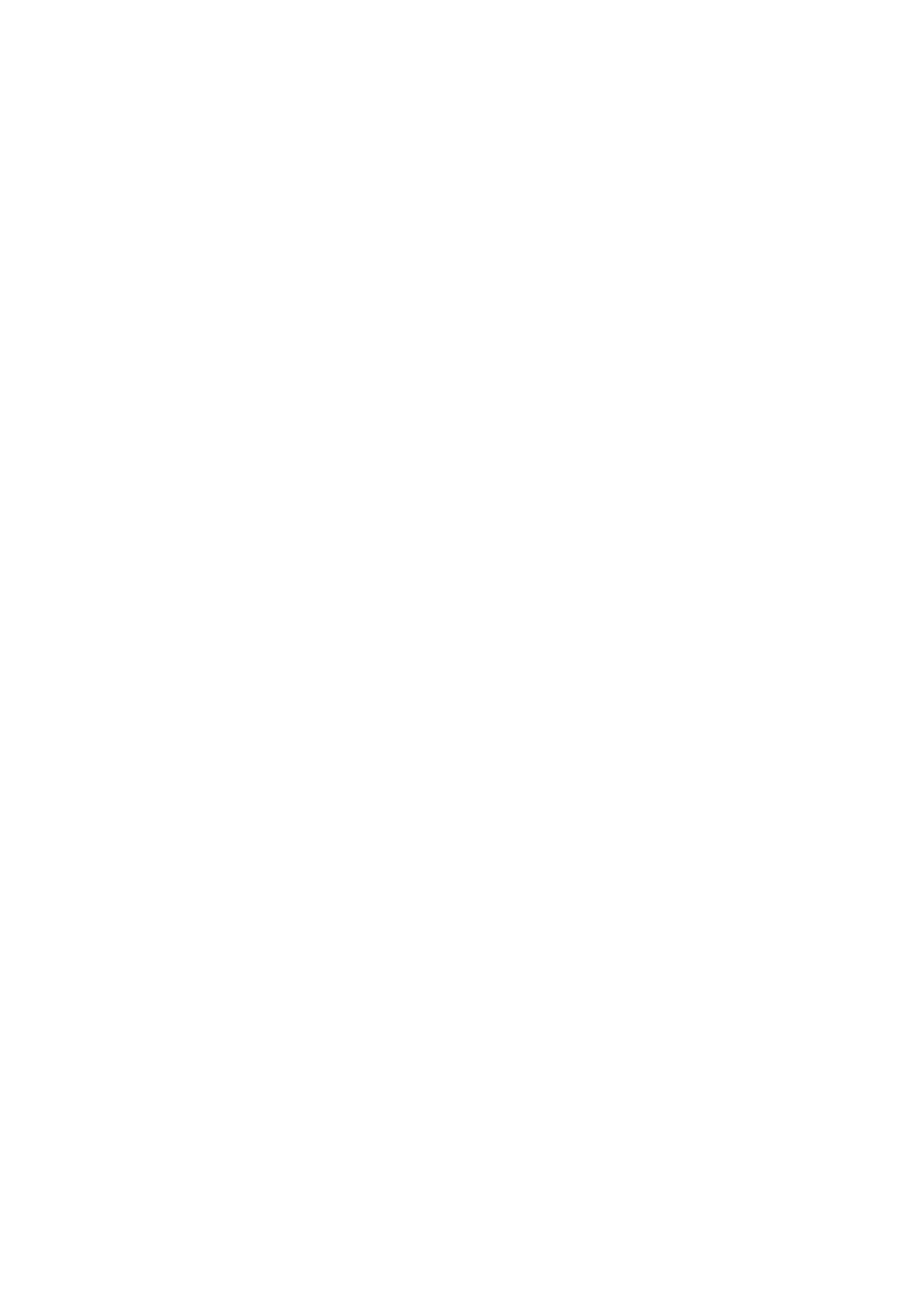


TABLE 10

181

Table 10. -Three-hour averages of air and water-surface temperatures and wind directions and speed, April 1950-August 1951, Lake Hefner-Continued

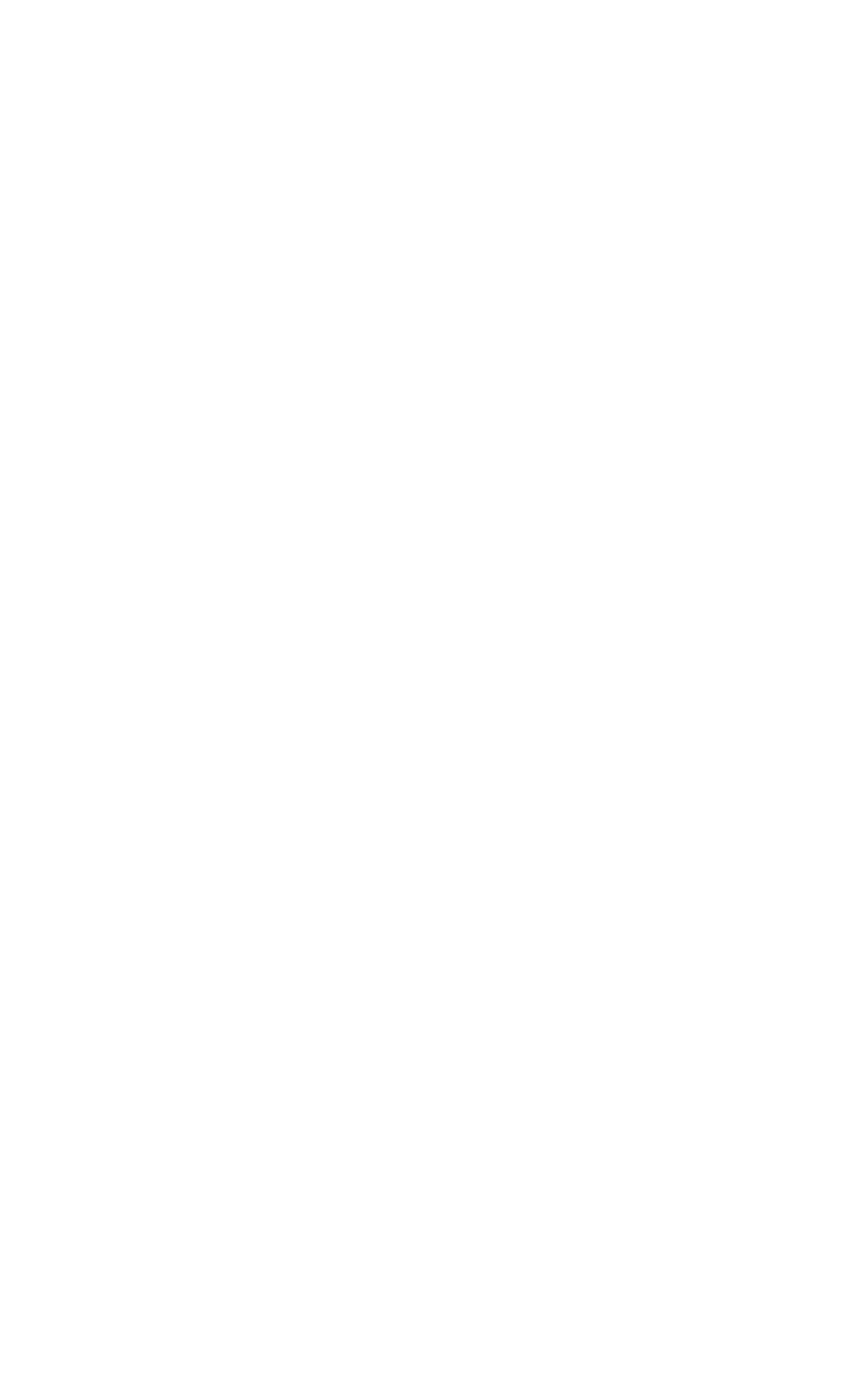


Table 10. - Three-hour averages of air and water-surface temperatures and wind directions and speed, April 1950-August 1951, Lake Hefner-Continued

STATION

THREE-HOURLY AVERAGES

JULY, 1950

\begin{tabular}{|c|c|c|c|c|c|c|c|c|c|c|c|c|c|c|c|}
\hline \multirow{3}{*}{ 息 } & \multirow{3}{*}{ 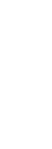 } & \multicolumn{8}{|c|}{ Aversge air tempersture $\left({ }^{\circ} \mathrm{C}\right)$ at indicsted height } & \multirow{3}{*}{$\begin{array}{l}\text { Average } \\
\text { water- } \\
\text { surface } \\
\text { tempera- } \\
\text { ture } \\
\text { ("C) }\end{array}$} & \multirow{3}{*}{$\begin{array}{c}\text { Average } \\
\text { wind } \\
\text { direction } \\
\text { (coded) }\end{array}$} & \multicolumn{4}{|c|}{$\begin{array}{l}\text { Average wind speed (knots) } \\
\text { at indicated height }\end{array}$} \\
\hline & & \multicolumn{2}{|c|}{$\begin{array}{c}2 \\
\text { meters }\end{array}$} & \multicolumn{2}{|c|}{$\begin{array}{c}4 \\
\text { meters }\end{array}$} & \multicolumn{2}{|c|}{$\begin{array}{c}B \\
\text { meters }\end{array}$} & \multicolumn{2}{|c|}{$\begin{array}{c}16 \\
\text { meters }\end{array}$} & & & r & & - & 16 \\
\hline & & $\begin{array}{l}\text { Dry } \\
\text { bulb }\end{array}$ & $\begin{array}{l}\text { Wet } \\
\text { bulb }\end{array}$ & $\begin{array}{l}\text { Dry } \\
\text { bulb }\end{array}$ & $\begin{array}{l}\text { Wet } \\
\text { bulb }\end{array}$ & $\begin{array}{l}\text { Dry } \\
\text { bulb }\end{array}$ & $\begin{array}{l}\text { Wet } \\
\text { bulb }\end{array}$ & $\begin{array}{l}\text { Dry } \\
\text { bulb }\end{array}$ & $\begin{array}{l}\text { Wet } \\
\text { bulb }\end{array}$ & & & meters & meters & meters & \\
\hline $\begin{array}{l}11 \\
11 \\
11 \\
11 \\
11 \\
11 \\
11 \\
11\end{array}$ & $\begin{array}{r}0 \\
3 \\
6 \\
9 \\
12 \\
15 \\
18 \\
21\end{array}$ & $\begin{array}{l}21.6 \\
21.2 \\
21.2 \\
22.6 \\
24.4 \\
25.2 \\
24.8 \\
23.4\end{array}$ & $\begin{array}{l}20.9 \\
20.6 \\
20.4 \\
20.7 \\
21.4 \\
22.1 \\
22.0 \\
21.5\end{array}$ & $\begin{array}{l}21.5 \\
21.01 \\
21.01 \\
22.7 \\
24.6 \\
25.1 \\
24.8 \\
23.4\end{array}$ & $\begin{array}{l}20.7 \\
20.4 \\
20: 2 \\
20.5 \\
21.3 \\
21.9 \\
21.8 \\
21.3\end{array}$ & $\begin{array}{l}21.03 \\
21.00 \\
21.00 \\
22.7 \\
24.6 \\
25.01 \\
24.07 \\
23.3\end{array}$ & $\begin{array}{l}20.5 \\
20.03 \\
20.1 \\
20.5 \\
21.1 \\
21.07 \\
21.07 \\
21.03\end{array}$ & $\begin{array}{l}21.03 \\
21.00 \\
20.9 \\
22.6 \\
24 \cdot 3 \\
25.02 \\
24.06 \\
23.2\end{array}$ & $\begin{array}{l}20.6 \\
20.3 \\
20.0 \\
20.5 \\
21.0 \\
21.6 \\
21.6 \\
21.1\end{array}$ & $\begin{array}{l}24.5 \\
24.3 \\
24.6 \\
24.8 \\
25.2 \\
25.5 \\
25.0 \\
24.8\end{array}$ & & $\begin{array}{l}5.9 \\
6.0 \\
6.9 \\
7.5 \\
6.1 \\
7.1 \\
8.0 \\
6.6\end{array}$ & $\begin{array}{l}5.6 \\
6.6 \\
7.6 \\
8.0 \\
6.8 \\
8.0 \\
8.5 \\
7.2\end{array}$ & $\begin{array}{r}7.7 \\
7.8 \\
8.9 \\
9.7 \\
7.7 \\
9.6 \\
10.0 \\
8.7\end{array}$ & $\begin{array}{r}8.1 \\
7.9 \\
9.1 \\
10.3\end{array}$ \\
\hline $\begin{array}{l}12 \\
12 \\
12 \\
12 \\
12 \\
12 \\
12 \\
12\end{array}$ & $\begin{array}{r}0 \\
3 \\
6 \\
9 \\
12 \\
15 \\
18 \\
21\end{array}$ & $\begin{array}{l}22.7 \\
21.8 \\
22.4 \\
25.2 \\
26.3 \\
26.5 \\
23.0 \\
19.0\end{array}$ & $\begin{array}{l}20.8 \\
20.1 \\
20.5 \\
21.0 \\
21.7 \\
22.4 \\
21.1 \\
19.5\end{array}$ & $\begin{array}{l}22.7 \\
21.8 \\
22.6 \\
25.6 \\
26.3 \\
26.7 \\
23.1 \\
19.7\end{array}$ & $\begin{array}{l}20.6 \\
20.0 \\
20.4 \\
20.9 \\
21.6 \\
22.1 \\
20.9 \\
19.5\end{array}$ & $\begin{array}{l}22.5 \\
21.7 \\
22.3 \\
25.5 \\
26.4 \\
26.9 \\
23.1 \\
19.6\end{array}$ & $\begin{array}{l}20.5 \\
19.9 \\
20.3 \\
20.7 \\
21.4 \\
21.8 \\
20.8 \\
19.3\end{array}$ & $\begin{array}{l}22.5 \\
21.6 \\
22.6 \\
25.5 \\
26.3 \\
26.9 \\
22.04 \\
19.7\end{array}$ & $\begin{array}{l}20.4 \\
19.9 \\
20.1 \\
20.5 \\
21.2 \\
21.5 \\
20.1 \\
19.3\end{array}$ & $\begin{array}{l}24.7 \\
24.44 \\
24.7 \\
25.5 \\
25.9 \\
26.1 \\
25.4 \\
24.9\end{array}$ & & $\begin{array}{l}6.1 \\
6.8 \\
6.5 \\
5.4 \\
5.7 \\
4.9 \\
4.1 \\
1.0\end{array}$ & $\begin{array}{l}6.8 \\
7.5 \\
7.3 \\
6.2 \\
6.3 \\
5.5 \\
4.7 \\
1.0\end{array}$ & $\begin{array}{l}8.0 \\
8.8 \\
8.5 \\
7.1 \\
7.3 \\
6.7 \\
6.8 \\
2.6\end{array}$ & $\begin{array}{l}9.0 \\
4.4\end{array}$ \\
\hline $\begin{array}{l}13 \\
13 \\
13 \\
13 \\
13 \\
13 \\
13 \\
13\end{array}$ & $\begin{array}{r}0 \\
3 \\
6 \\
9 \\
12 \\
15 \\
18 \\
21\end{array}$ & $\begin{array}{l}20.1 \\
19.5 \\
18.6 \\
21.0 \\
22.7 \\
23.7 \\
22.1 \\
18.2\end{array}$ & $\begin{array}{l}19.9 \\
18.6 \\
16.5 \\
16.8 \\
16.9 \\
16.9 \\
17.0 \\
16.1\end{array}$ & $\begin{array}{l}20.1 \\
19.5 \\
18.6 \\
21.1 \\
22.9 \\
23.9 \\
22.1 \\
18.1\end{array}$ & $\begin{array}{l}19.8 \\
18.5 \\
16.5 \\
16.8 \\
16.9 \\
16.9 \\
16.9 \\
16.0\end{array}$ & $\begin{array}{l}20.1 \\
19.5 \\
18.5 \\
21.3 \\
23.0 \\
23.8 \\
22.0 \\
18.0\end{array}$ & $\begin{array}{l}19.7 \\
18.3 \\
16.4 \\
16.5 \\
16.9 \\
16.8 \\
16.8 \\
16.0\end{array}$ & $\begin{array}{l}20.1 \\
19.4 \\
18.3 \\
20.7 \\
22.6 \\
23.2 \\
21.8 \\
18.2\end{array}$ & $\begin{array}{l}19.7 \\
18.1 \\
16.2 \\
16.1 \\
16.3 \\
16.4 \\
16.5 \\
15.6\end{array}$ & $\begin{array}{l}24.7 \\
24.02 \\
24.02 \\
24.7 \\
24.9 \\
25.0 \\
24.4 \\
24.3\end{array}$ & & $\begin{array}{l}3.3 \\
4.6 \\
6.9 \\
8.7 \\
6.3 \\
6.1 \\
4.2 \\
2.5\end{array}$ & $\begin{array}{l}4.0 \\
5.7 \\
7.9 \\
9.7 \\
7.1 \\
6.6 \\
4.3 \\
2.5\end{array}$ & $\begin{array}{r}6.2 \\
7.9 \\
11.0 \\
11.7 \\
8.4 \\
7.5 \\
5.1 \\
3.4\end{array}$ & $\begin{array}{l}8.2 \\
10.3 \\
14.1 \\
14.1\end{array}$ \\
\hline $\begin{array}{l}14 \\
14 \\
14 \\
14 \\
14 \\
14 \\
14 \\
14\end{array}$ & $\begin{array}{r}0 \\
3 \\
6 \\
9 \\
12 \\
15 \\
18 \\
21\end{array}$ & $\begin{array}{l}16.2 \\
15.0 \\
17.2 \\
21.6 \\
24.5 \\
26.6 \\
26.0 \\
23.9\end{array}$ & $\begin{array}{l}15.1 \\
14.6 \\
15.3 \\
16.7 \\
18.6 \\
20.2 \\
21.4 \\
22.0\end{array}$ & $\begin{array}{l}16.0 \\
14.9 \\
17.3 \\
21.7 \\
24.8 \\
26.7 \\
26.0 \\
23.9\end{array}$ & $\begin{array}{l}14.9 \\
14.2 \\
15.2 \\
16.7 \\
18.5 \\
19.9 \\
21.3 \\
21.8\end{array}$ & $\begin{array}{l}15.8 \\
14.3 \\
17.2 \\
21.5 \\
25.3 \\
26.7 \\
25.8 \\
23.7\end{array}$ & $\begin{array}{l}14.7 \\
13.7 \\
15.0 \\
16.5 \\
18.5 \\
19.8 \\
21.1 \\
21.7\end{array}$ & $\begin{array}{l}15.0 \\
14.4 \\
17.2 \\
21.5 \\
24.0 \\
26.5 \\
25.7 \\
23.4\end{array}$ & $\begin{array}{l}14.7 \\
13.7 \\
15.0 \\
16.4 \\
18.4 \\
19.5 \\
20.8 \\
21.6\end{array}$ & $\begin{array}{l}24.2 \\
24.2 \\
24.6 \\
25.6 \\
27.6 \\
28.4 \\
27.7 \\
26.9\end{array}$ & & $\begin{array}{l}1.8 \\
0.8 \\
5.1 \\
3.6 \\
2.1 \\
4.0 \\
5.9 \\
7.5\end{array}$ & $\begin{array}{l}1.7 \\
0.8 \\
6.3 \\
3.8 \\
2.9 \\
4.4 \\
6.6 \\
8.5\end{array}$ & $\begin{array}{r}2.5 \\
1.7 \\
5.4 \\
4.5 \\
3.2 \\
5.3 \\
7.6 \\
10.0\end{array}$ & $\begin{array}{r}2.6 \\
2.7 \\
5.0 \\
3.3 \\
2.4 \\
5.8 \\
8.2 \\
10.2\end{array}$ \\
\hline $\begin{array}{l}15 \\
15 \\
15 \\
15 \\
15 \\
15 \\
15 \\
15\end{array}$ & $\begin{array}{r}0 \\
3 \\
6 \\
9 \\
12 \\
15 \\
18 \\
21\end{array}$ & $\begin{array}{l}22.7 \\
22.0 \\
23.4 \\
25.2 \\
27.5 \\
28.7 \\
27.7 \\
26.2\end{array}$ & $\begin{array}{l}21 \cdot 9 \\
21 \\
21.3 \\
22: 8 \\
23.1 \\
23.2 \\
23.5 \\
23.1\end{array}$ & $\begin{array}{l}22.6 \\
21.9 \\
23.5 \\
25.4 \\
27.8 \\
29.0 \\
28.0 \\
26.2\end{array}$ & $\begin{array}{l}21.7 \\
21.1 \\
21.7 \\
22.4 \\
23.1 \\
23.0 \\
23.4 \\
22.8\end{array}$ & $\begin{array}{l}23.5 \\
21.8 \\
23.6 \\
25.4 \\
28.0 \\
29.1 \\
>8.0 \\
>6.2\end{array}$ & $\begin{array}{l}21.5 \\
20.9 \\
21.6 \\
23.4 \\
22.8 \\
22.8 \\
23.2 \\
22.7\end{array}$ & $\begin{array}{l}22.0 \\
21.5 \\
23.5 \\
25.4 \\
28.0 \\
29.1 \\
28.0 \\
26.0\end{array}$ & $\begin{array}{l}21.2 \\
20.7 \\
21.2 \\
23.0 \\
27.7 \\
22.6 \\
23.0 \\
23.4\end{array}$ & $\begin{array}{l}26.5 \\
26.0 \\
26.0 \\
26.8 \\
27.5 \\
27.1 \\
26.4 \\
26.2\end{array}$ & & $\begin{array}{r}9.1 \\
10.8 \\
10.0 \\
10.8 \\
13.3 \\
13.9 \\
12.4 \\
14.1\end{array}$ & $\begin{array}{l}10.3 \\
12.1 \\
13.5 \\
12.4 \\
15.3 \\
16.0 \\
14.2 \\
16.2\end{array}$ & $\begin{array}{l}12.0 \\
13.7 \\
12.1 \\
13.6 \\
17.0 \\
17.5 \\
16.5 \\
10.4\end{array}$ & $\begin{array}{l}13.6 \\
15.3 \\
19.6 \\
20.4 \\
18.4 \\
21.2\end{array}$ \\
\hline $\begin{array}{l}16 \\
16 \\
16 \\
16 \\
16 \\
16 \\
16 \\
16\end{array}$ & $\begin{array}{r}0 \\
3 \\
6 \\
9 \\
12 \\
15 \\
18 \\
21\end{array}$ & $\begin{array}{l}25.0 \\
23.0 \\
24.4 \\
26.3 \\
28.2 \\
28.3 \\
27.4 \\
26.5\end{array}$ & $\begin{array}{l}21.9 \\
21.9 \\
22.3 \\
22.5 \\
23.0 \\
23.1 \\
22.7 \\
27.4\end{array}$ & $\begin{array}{l}25.0 \\
23.9 \\
24.6 \\
26.5 \\
28.5 \\
28.5 \\
27.6 \\
26.7\end{array}$ & $\begin{array}{l}21 \cdot .7 \\
21.08 \\
22.02 \\
22.44 \\
23.0 \\
23.09 \\
22.06 \\
22.4\end{array}$ & $\begin{array}{l}25.0 \\
23.9 \\
24.6 \\
36.7 \\
28.7 \\
28.6 \\
27.7 \\
26.7\end{array}$ & $\begin{array}{l}21.5 \\
21 \cdot 5 \\
22 \cdot 5 \\
22 \cdot 3 \\
22 \cdot 8 \\
22.8 \\
22.4 \\
22.3\end{array}$ & $\begin{array}{l}24 \cdot 7 \\
23.7 \\
24 \cdot 4 \\
26.1 \\
28.0 \\
28.5 \\
27.7 \\
26.7\end{array}$ & $\begin{array}{ll}21 & \cdot 2 \\
21 & .3 \\
21 & .9 \\
22 & .1 \\
22 & \cdot 7 \\
22 & .5 \\
22 & .1 \\
22 & .0\end{array}$ & $\begin{array}{l}25.9 \\
25.6 \\
25.5 \\
25.7 \\
26.0 \\
26.1 \\
25.1 \\
24.9\end{array}$ & & $\begin{array}{l}15.7 \\
15.5 \\
17.4 \\
15.4 \\
14.2 \\
16.9 \\
14.2 \\
16.0\end{array}$ & $\begin{array}{l}18.1 \\
17.9 \\
20.2 \\
17.5 \\
16.4 \\
19.7 \\
16.5 \\
18.4\end{array}$ & $\begin{array}{l}21.2 \\
19.9 \\
22.02 \\
12.03 \\
18.03 \\
22.03 \\
19.4 \\
22.0\end{array}$ & $\begin{array}{l}23.4 \\
22.5 \\
25.3 \\
21.06 \\
21.0 \\
25.7 \\
21.8 \\
23.5\end{array}$ \\
\hline $\begin{array}{l}17 \\
17 \\
17 \\
17 \\
17 \\
17 \\
17 \\
17\end{array}$ & $\begin{array}{r}0 \\
3 \\
6 \\
9 \\
12 \\
15 \\
18 \\
21\end{array}$ & $\begin{array}{l}25.5 \\
23.8 \\
20.5 \\
20.2 \\
19.7 \\
22.7 \\
22.5 \\
21.1\end{array}$ & $\begin{array}{l}22.1 \\
21.4 \\
19.6 \\
19.7 \\
19: 4 \\
21.0 \\
21.4 \\
20.8\end{array}$ & $\begin{array}{l}25.6 \\
23.8 \\
20.0 \\
20.2 \\
19.8 \\
22.8 \\
22.3 \\
21.1\end{array}$ & $\begin{array}{l}27.00 \\
21.00 \\
19.03 \\
19.04 \\
19.04 \\
21.00 \\
31.03 \\
20.06\end{array}$ & $\begin{array}{l}25.7 \\
33.6 \\
20.0 \\
20.0 \\
10.7 \\
23.0 \\
33.0 \\
20.9\end{array}$ & $\begin{array}{l}21.0 \\
20.9 \\
19.1 \\
19.3 \\
19.4 \\
20.8 \\
21.3 \\
20.6\end{array}$ & $\begin{array}{l}25.5 \\
23.4 \\
20.0 \\
20.2 \\
20.0 \\
22.8 \\
22.0 \\
21.2\end{array}$ & $\begin{array}{l}21.7 \\
20.7 \\
10.3 \\
10.6 \\
10.4 \\
20.7 \\
21.7 \\
20.6\end{array}$ & $\begin{array}{l}24.7 \\
24.6 \\
24.5 \\
24.5 \\
24.8 \\
25.1 \\
24.8 \\
24.6\end{array}$ & & $\begin{array}{r}16.2 \\
12.9 \\
9.8 \\
1.8 \\
7.6 \\
5.2 \\
7.0 \\
8.8\end{array}$ & $\begin{array}{r}18.8 \\
14.7 \\
10.8 \\
2.6 \\
8.2 \\
6.7 \\
7.4 \\
9.5\end{array}$ & $\begin{array}{r}22.2 \\
15.5 \\
11.4 \\
2.3 \\
9.6 \\
7.9 \\
8.1 \\
10.8\end{array}$ & $\begin{array}{r}23.5 \\
18.3 \\
12.5 \\
3.1 \\
20.5 \\
8.0 \\
8.2 \\
10.8\end{array}$ \\
\hline $\begin{array}{l}18 \\
18 \\
18 \\
18 \\
18 \\
18 \\
18 \\
18\end{array}$ & $\begin{array}{r}0 \\
3 \\
6 \\
9 \\
12 \\
15 \\
18 \\
71\end{array}$ & $\begin{array}{l}25 \cdot 3 \\
26 \cdot 4 \\
26 \cdot 3 \\
25 \cdot 1\end{array}$ & $\begin{array}{l}23.0 \\
23.0 \\
22.7 \\
27.8\end{array}$ & $\begin{array}{l}25 \cdot 5 \\
25 \cdot 6 \\
25 \cdot 5 \\
75 \cdot 1\end{array}$ & $\begin{array}{l}? 2.9 \\
? ? .0 \\
? ? \cdot 4 \\
? 1.4\end{array}$ & $\begin{array}{l}25.4 \\
25.7 \\
26.6 \\
25.4\end{array}$ & $\begin{array}{l}22.0 \\
2 ? \cdot 7 \\
27.3 \\
27.7\end{array}$ & $\begin{array}{l}25.5 \\
26.7 \\
2 F .5 \\
25.2\end{array}$ & $\begin{array}{l}20.2 \\
21.3 \\
21.8 \\
29.5 \\
29.5 \\
29.0 \\
70.0\end{array}$ & $\begin{array}{l}24.4 \\
34.3 \\
24.3 \\
24.8 \\
24.9 \\
24.7 \\
24.4\end{array}$ & & $\begin{array}{r}7.9 \\
8.7 \\
4.7 \\
3.8 \\
9.3 \\
10.1 \\
8.6 \\
11.6\end{array}$ & $\begin{array}{r}8.4 \\
9.7 \\
5.3 \\
4.2 \\
10.5 \\
11.5 \\
10.0 \\
13.1\end{array}$ & $\begin{array}{r}9.8 \\
11.4 \\
6.9 \\
5.4 \\
11.9 \\
12.9 \\
12.0 \\
15.0\end{array}$ & $\begin{array}{r}9.8 \\
12.1 \\
6.6 \\
5.9 \\
15.7 \\
14.7 \\
14.0 \\
14.6\end{array}$ \\
\hline $\begin{array}{l}19 \\
19 \\
19 \\
19 \\
19 \\
19 \\
19 \\
19\end{array}$ & $\begin{array}{r}0 \\
3 \\
6 \\
9 \\
12 \\
15 \\
18 \\
21\end{array}$ & $\begin{array}{l}22.3 \\
22.4 \\
21.7 \\
22.2 \\
24.8 \\
26.5 \\
22.0 \\
21.0\end{array}$ & $\begin{array}{l}20.2 \\
20.5 \\
20.8 \\
21.2 \\
22.6 \\
23.7 \\
21.5 \\
20.4\end{array}$ & $\begin{array}{l}22.3 \\
22.4 \\
22.0 \\
2 ?: ? \\
25: 1 \\
26.8 \\
2 ? .4 \\
21.8\end{array}$ & $\begin{array}{l}1^{c} .5 \\
20.3 \\
20.7 \\
20.7 \\
27.5 \\
23.5 \\
20.3 \\
20.1\end{array}$ & 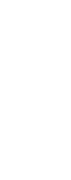 & $\begin{array}{l}19.5 \\
20.1 \\
20.7 \\
20.8 \\
27.5 \\
23.5 \\
20.7 \\
10.9\end{array}$ & $\begin{array}{l}22: 0 \\
22: 01 \\
23: ? \\
21: 0 \\
25: 2 \\
27: 5 \\
22: 5 \\
2102\end{array}$ & $\begin{array}{l}10.7 \\
20.1 \\
20.6 \\
20.5 \\
2 ? .3 \\
23.4 \\
? 0.4 \\
17.8\end{array}$ & $\begin{array}{l}2 / .2 \\
24.1 \\
24.1 \\
24.1 \\
35: 3 \\
25.2 \\
24.7 \\
24.3\end{array}$ & & $\begin{array}{r}10.7 \\
5.0 \\
5.2 \\
11.5 \\
9.9 \\
6.3 \\
7.0 \\
7.7\end{array}$ & $\begin{array}{r}11.6 \\
5.6 \\
5.8 \\
13.1 \\
11.6 \\
7.4 \\
9.0 \\
8.7\end{array}$ & $\begin{array}{r}11.9 \\
5.6 \\
6.2 \\
13.0 \\
13.8 \\
0.6 \\
11.2 \\
0.7\end{array}$ & $\begin{array}{r}13.7 \\
3.5 \\
8.4 \\
12.6 \\
14.4 \\
7.4 \\
10.2\end{array}$ \\
\hline $\begin{array}{l}20 \\
20 \\
20 \\
20 \\
20 \\
20 \\
20 \\
20\end{array}$ & $\begin{array}{r}0 \\
3 \\
6 \\
0 \\
12 \\
15 \\
18 \\
21\end{array}$ & $\begin{array}{l}20.9 \\
21.1 \\
20.5 \\
32.1 \\
25.1 \\
25.3 \\
24.6 \\
23.0\end{array}$ & $\begin{array}{l}10.7 \\
10: 07 \\
19.9 \\
20: ? \\
21: 1 \\
? 1: ? \\
? ?: ? \\
? 2: 0\end{array}$ & $\begin{array}{l}21.1 \\
20: 8 \\
20: 1 \\
22.3 \\
25: 5 \\
26: 2 \\
24: 7 \\
23.0\end{array}$ & $\begin{array}{l}10.3 \\
19.3 \\
19.5 \\
20.1 \\
71.1 \\
21.0 \\
22: 1 \\
71.8\end{array}$ & $\begin{array}{l}20.9 \\
20.8 \\
20.0 \\
27.5 \\
25.4 \\
25.0 \\
24.0 \\
23.0\end{array}$ & 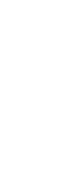 & 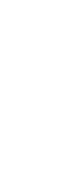 & $\begin{array}{l}19.5 \\
120.8 \\
10.5 \\
20.0 \\
20.0 \\
21.0 \\
31.0 \\
21.6\end{array}$ & $\begin{array}{l}24.1 \\
23.0 \\
23.9 \\
25.0 \\
27.1 \\
27.8 \\
26.3 \\
35.2\end{array}$ & & $\begin{array}{r}13.1 \\
9.3 \\
4.1 \\
1.9 \\
1.7 \\
1.0 \\
4.4 \\
5.8\end{array}$ & $\begin{array}{r}15.1 \\
10.5 \\
4.5 \\
3.1 \\
2.2 \\
2.0 \\
4.8 \\
6.3\end{array}$ & $\begin{array}{r}25.2 \\
11.3 \\
5.2 \\
2.4 \\
2.7 \\
2.04 \\
5.4 \\
7.4\end{array}$ & $\begin{array}{r}20.3 \\
12.6 \\
5.3\end{array}$ \\
\hline
\end{tabular}


TABLE 10

183

Table 10. -Three-hour averages of air and water-surface temperatures and wind directions and speed, April 1950—August 1951, Lake Hefner-Continued

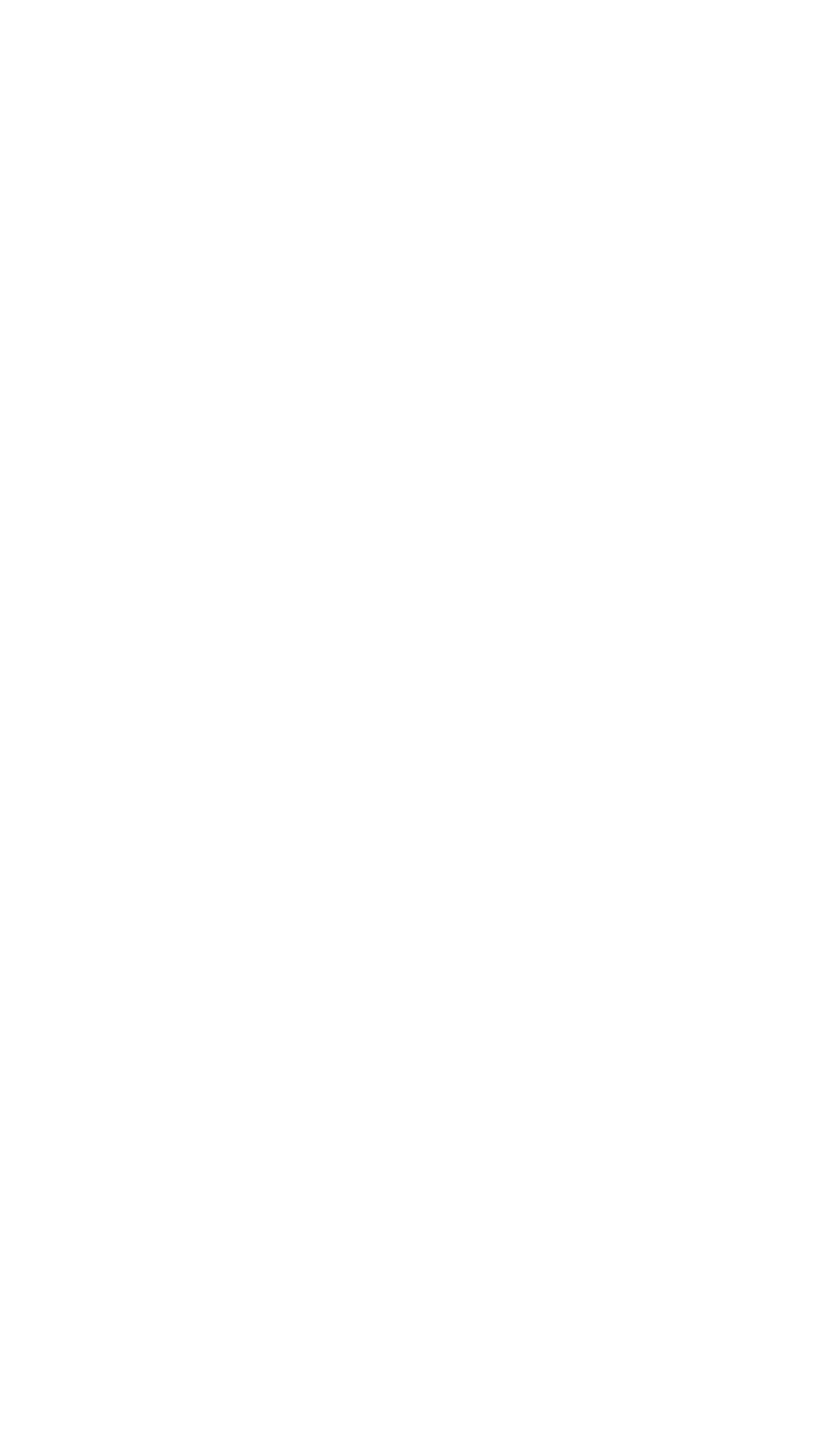


Table 10. - Three-hour averages of air and water-surface temperatures and wind directions and speed, April 1950-August 195L, Lake Hefner-Continued

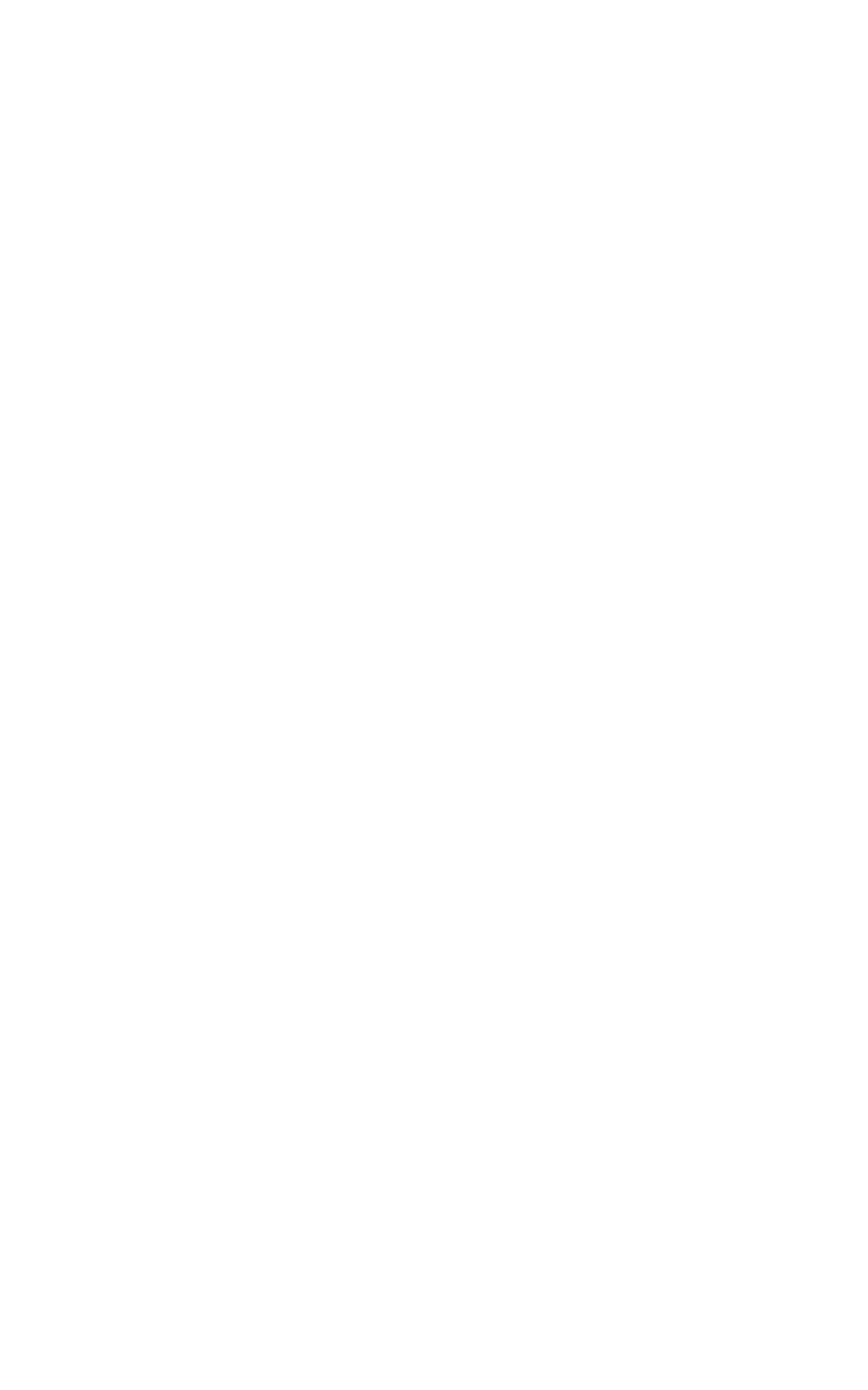


TABLE 10

Table 10. - Three-hour averages of air and water-surface temperatures and wind directions and speed, April 1950-August 951, Lake Hefner-Continued

STATION 4

THREE-HOURLY AVERAGES

AUGUST, 1950

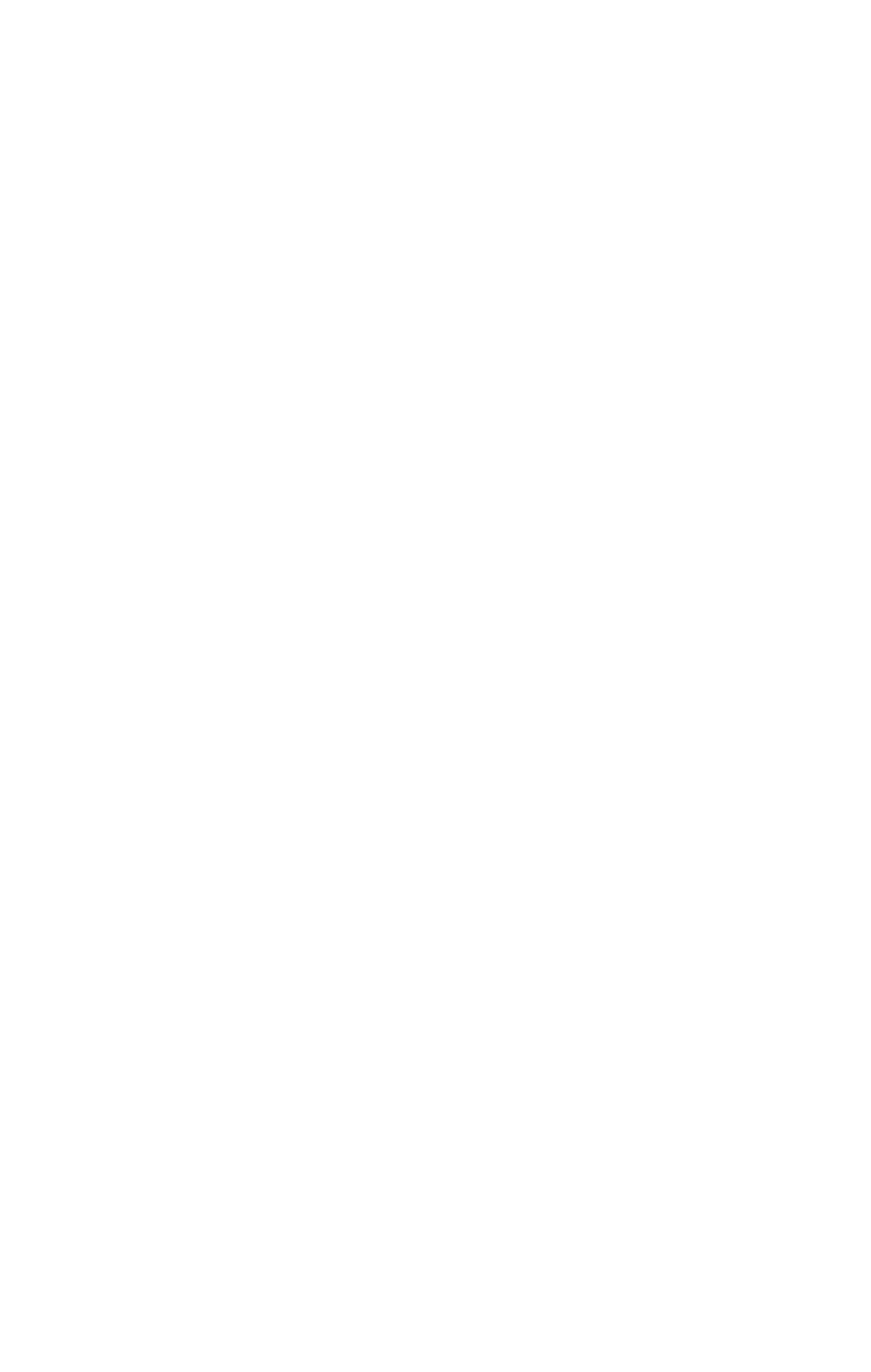


Table 10. - Three-hour averages of air and water-surface temperatures and wind directions and speed, April 1950-August 1951, Lake Hefner-Continued

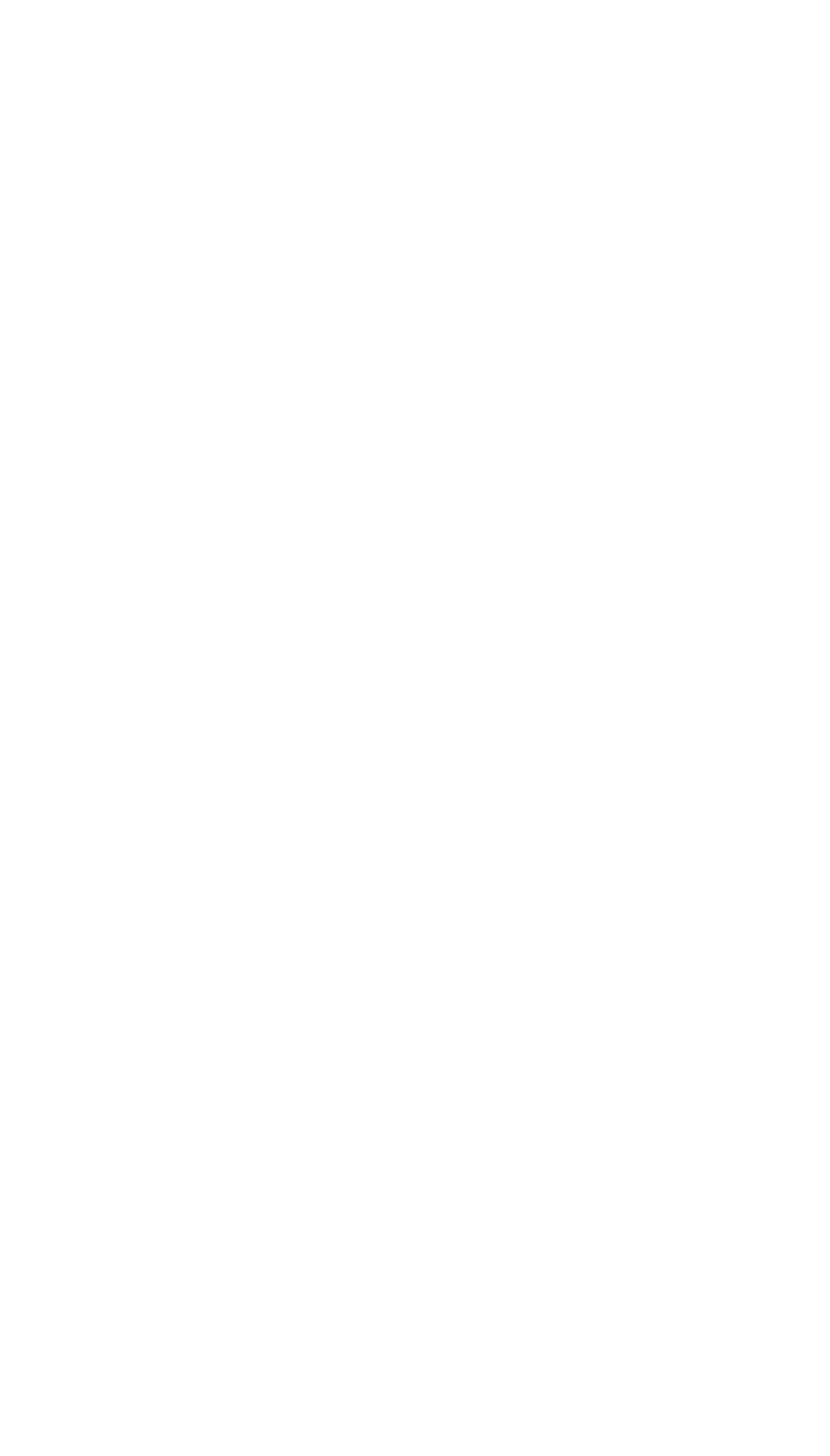


TABLE 10

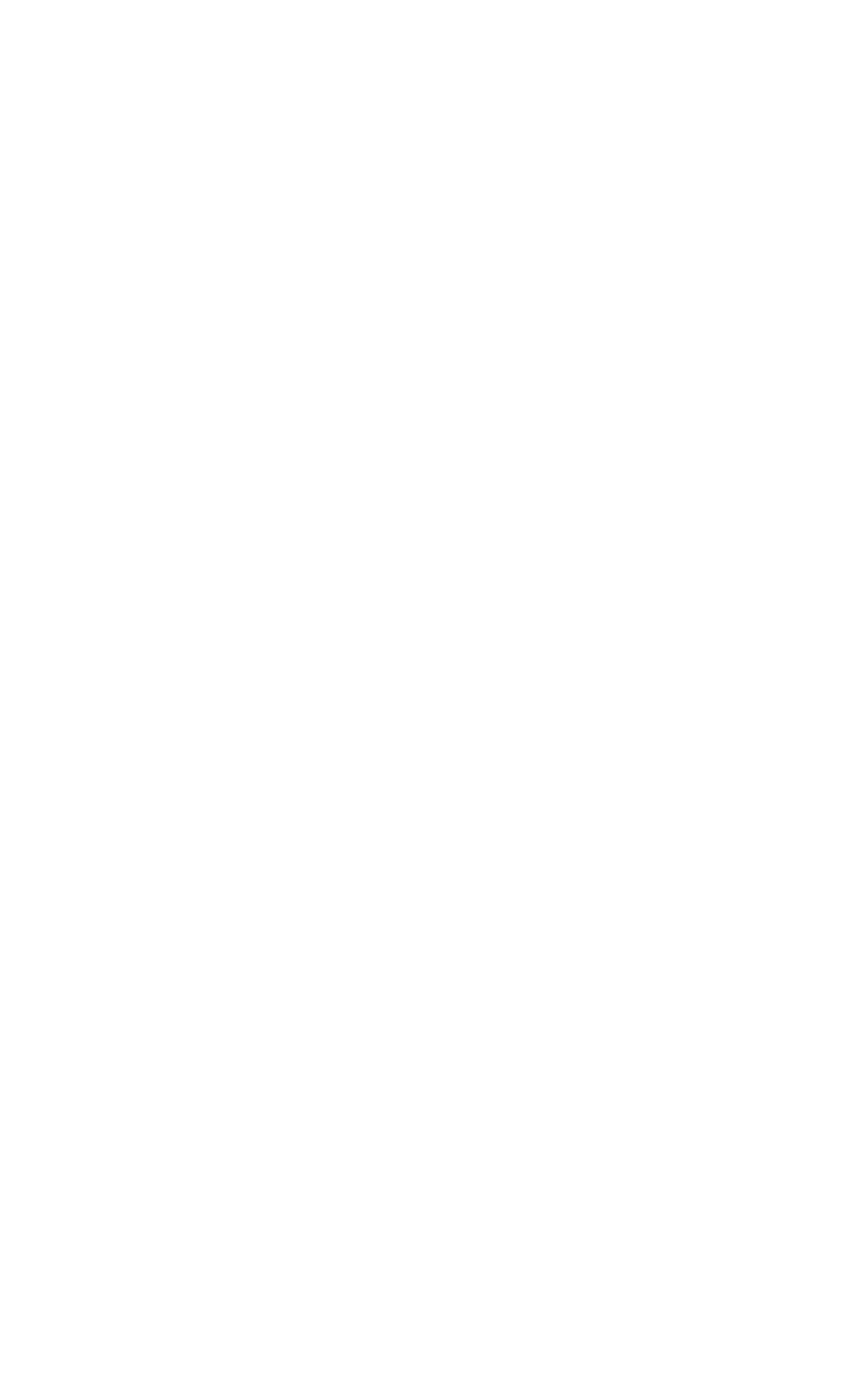



Table 10. -Three-hour averages of air and kater-surface temperatures and wind directions and speed, April 1950-August

THREE-HOURLY AVERAGES

SEPTEMBER, 1950

\begin{tabular}{|c|c|c|c|c|c|c|c|c|c|c|c|c|c|c|c|}
\hline \multirow{3}{*}{ 喿 } & \multirow{3}{*}{ 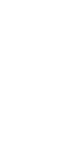 } & \multicolumn{8}{|c|}{ Average air temperature $\left({ }^{\circ} \mathrm{C}\right)$ at indicated height } & \multirow{3}{*}{$\begin{array}{l}\text { Average } \\
\text { water- } \\
\text { surface } \\
\text { tempera- } \\
\text { ture } \\
\text { ("C) }\end{array}$} & \multirow{3}{*}{$\begin{array}{l}\text { Average } \\
\text { wind } \\
\text { direction } \\
\text { (coded) }\end{array}$} & \multirow{2}{*}{\multicolumn{4}{|c|}{$\begin{array}{c}\text { Average wind speed (knots) } \\
\text { at indicated height }\end{array}$}} \\
\hline & & \multicolumn{2}{|c|}{$\begin{array}{c}2 \\
\text { meters }\end{array}$} & \multicolumn{2}{|c|}{$\frac{4}{\text { meters }}$} & \multicolumn{2}{|c|}{$\begin{array}{c}8 \\
\text { meters }\end{array}$} & \multicolumn{2}{|c|}{$\begin{array}{c}16 \\
\text { meters }\end{array}$} & & & & & & \\
\hline & & $\begin{array}{l}\text { Dry } \\
\text { bulb }\end{array}$ & $\begin{array}{l}\text { Wet } \\
\text { bulb }\end{array}$ & $\begin{array}{l}\text { Dry } \\
\text { bulb }\end{array}$ & $\begin{array}{l}\text { Wet } \\
\text { bulb }\end{array}$ & $\begin{array}{l}\text { Dry } \\
\text { bulb }\end{array}$ & $\begin{array}{l}\text { Wet } \\
\text { bulb }\end{array}$ & $\begin{array}{l}\text { Dry } \\
\text { bulb }\end{array}$ & $\begin{array}{l}\text { Wet } \\
\text { bulb }\end{array}$ & & & $\begin{array}{c}2 \\
\text { meters }\end{array}$ & $\begin{array}{c}4 \\
\text { meters }\end{array}$ & $\begin{array}{c}8 \\
\text { meters }\end{array}$ & meters \\
\hline
\end{tabular}

\begin{tabular}{|c|c|c|c|c|c|c|c|c|c|}
\hline $\begin{array}{l}11 \\
11 \\
11 \\
11 \\
11 \\
11 \\
11 \\
11\end{array}$ & $\begin{array}{r}0 \\
3 \\
6 \\
9 \\
12 \\
15 \\
18 \\
21\end{array}$ & $\begin{array}{l}20.8 \\
16.7 \\
15.3 \\
15.9 \\
18.5 \\
21.6 \\
19.1 \\
16.2\end{array}$ & $\begin{array}{l}18.0 \\
14.1 \\
12.7 \\
13.5 \\
14.3 \\
16.0 \\
15.3 \\
14.3\end{array}$ & $\begin{array}{l}20.5 \\
16.5 \\
15.1 \\
15.8 \\
18.6 \\
21.5 \\
18.8 \\
15.9\end{array}$ & $\begin{array}{l}17.5 \\
13.9 \\
12.6 \\
13.3 \\
14.4 \\
16.1 \\
15.2 \\
14.1\end{array}$ & $\begin{array}{l}20.0 \\
16.3 \\
15.0 \\
15.6 \\
18.7 \\
21.6 \\
18.6 \\
15.8\end{array}$ & $\begin{array}{l}17.4 \\
13.6 \\
12.5 \\
12.4 \\
1402 \\
16.1 \\
15.0 \\
13.8\end{array}$ & $\begin{array}{l}20.0 \\
16.0 \\
14: 8 \\
15.2 \\
17.8 \\
21.0 \\
18.8 \\
15.9\end{array}$ & $\begin{array}{l}17.2 \\
13.4 \\
12.3 \\
12.2 \\
13.8 \\
15.8 \\
14.9 \\
13.7\end{array}$ \\
\hline $\begin{array}{l}12 \\
12 \\
12 \\
12 \\
12 \\
12 \\
12 \\
12\end{array}$ & $\begin{array}{r}0 \\
3 \\
6 \\
9 \\
12 \\
15 \\
18 \\
21\end{array}$ & $\begin{array}{l}14.3 \\
14.2 \\
15.2 \\
17.1 \\
17.7 \\
19.5 \\
18.0 \\
17.7\end{array}$ & $\begin{array}{l}13.1 \\
13.2 \\
14.0 \\
15.6 \\
16.7 \\
18.2 \\
17.7 \\
17.2\end{array}$ & $\begin{array}{l}14.0 \\
14.1 \\
15.2 \\
17.2 \\
17.5 \\
19.4 \\
17.9 \\
17.7\end{array}$ & $\begin{array}{l}12.9 \\
13.0 \\
14.0 \\
15.5 \\
16.5 \\
18.1 \\
17.6 \\
17.1\end{array}$ & $\begin{array}{l}13.5 \\
13.8 \\
15.0 \\
17.0 \\
17.6 \\
19.4 \\
17.9 \\
17.5\end{array}$ & $\begin{array}{l}12.6 \\
12.9 \\
13.8 \\
15.3 \\
16.5 \\
18.0 \\
17.6 \\
17.0\end{array}$ & $\begin{array}{l}13.6 \\
13.7 \\
14.8 \\
16.9 \\
17.3 \\
19.2 \\
17.6 \\
17.2\end{array}$ & $\begin{array}{l}12.5 \\
12.7 \\
13.0 \\
15.1 \\
16.3 \\
17.9 \\
17.3 \\
16.9\end{array}$ \\
\hline $\begin{array}{l}13 \\
13 \\
13 \\
13 \\
13 \\
13 \\
13 \\
13\end{array}$ & $\begin{array}{r}0 \\
3 \\
6 \\
9 \\
12 \\
15 \\
18 \\
21\end{array}$ & $\begin{array}{l}17 \cdot 3 \\
16.7 \\
16.4 \\
17.3 \\
19.5 \\
21.6 \\
20.4 \\
19.9\end{array}$ & $\begin{array}{l}17.0 \\
16.3 \\
15.7 \\
16.7 \\
18.6 \\
19.6 \\
19.2 \\
19.0\end{array}$ & $\begin{array}{l}17.3 \\
16.4 \\
16.4 \\
17.4 \\
19.5 \\
21.8 \\
20.4 \\
19.8\end{array}$ & $\begin{array}{l}17.0 \\
16.1 \\
15.6 \\
16.6 \\
18.6 \\
19.6 \\
19.2 \\
18.9\end{array}$ & $\begin{array}{l}17.3 \\
16.4 \\
16.2 \\
17.5 \\
19.6 \\
21.7 \\
20.3 \\
19.7\end{array}$ & $\begin{array}{l}16.8 \\
16.0 \\
15.4 \\
16.7 \\
18.5 \\
19.6 \\
19.1 \\
18.8\end{array}$ & $\begin{array}{l}16.8 \\
16.0 \\
16.0 \\
17.2 \\
19.3 \\
21.7 \\
20.2 \\
19.4\end{array}$ & $\begin{array}{l}16.7 \\
15.7 \\
15.2 \\
16.5 \\
18.3 \\
19.5 \\
18.9 \\
18.8\end{array}$ \\
\hline $\begin{array}{l}24 \\
14 \\
14 \\
14 \\
14 \\
14 \\
14 \\
14\end{array}$ & $\begin{array}{r}0 \\
3 \\
6 \\
9 \\
12 \\
15 \\
18 \\
21\end{array}$ & $\begin{array}{l}13.5 \\
16.1 \\
15.9 \\
27.9 \\
18.8 \\
20.1 \\
19.7 \\
19.6\end{array}$ & $\begin{array}{l}18.0 \\
15.3 \\
15.3 \\
16.6 \\
17.6 \\
18.7 \\
18.8 \\
19.0\end{array}$ & $\begin{array}{l}18.2 \\
15.8 \\
16.0 \\
17.8 \\
18.8 \\
20.1 \\
19.7 \\
19.2\end{array}$ & $\begin{array}{l}27.9 \\
15.2 \\
15.2 \\
16.6 \\
17.5 \\
18.6 \\
18.8 \\
19.2\end{array}$ & $\begin{array}{l}18.1 \\
15.9 \\
15.9 \\
17.9 \\
18.8 \\
20.1 \\
19.6 \\
19.1\end{array}$ & $\begin{array}{l}17.8 \\
15.0 \\
15.2 \\
16.6 \\
17.5 \\
18.6 \\
18.7 \\
19.0\end{array}$ & $\begin{array}{l}27.8 \\
15.3 \\
15.7 \\
17.7 \\
18.9 \\
20.0 \\
19.4 \\
18.9\end{array}$ & $\begin{array}{l}17.4 \\
14.8 \\
15.1 \\
16.4 \\
17.4 \\
18.6 \\
18.6 \\
18.8\end{array}$ \\
\hline $\begin{array}{l}15 \\
15 \\
15 \\
15 \\
15 \\
15 \\
15 \\
15\end{array}$ & $\begin{array}{r}0 \\
3 \\
6 \\
9 \\
12 \\
15 \\
18 \\
21\end{array}$ & $\begin{array}{l}20.9 \\
20.9 \\
19.9 \\
21.1 \\
25.0 \\
26.8 \\
24.0 \\
20.7\end{array}$ & $\begin{array}{l}19.6 \\
19.4 \\
19.5 \\
20.3 \\
22.3 \\
22.8 \\
22.4 \\
19.7\end{array}$ & $\begin{array}{l}20.4 \\
20.0 \\
19.8 \\
21.1 \\
25.6 \\
27.4 \\
23.7 \\
20.7\end{array}$ & $\begin{array}{l}19.7 \\
19.2 \\
19.3 \\
20.2 \\
72.4 \\
22.8 \\
22.2 \\
19.6\end{array}$ & $\begin{array}{l}20.4 \\
19.9 \\
19.6 \\
21.1 \\
25.5 \\
27.6 \\
23.6 \\
20.5\end{array}$ & $\begin{array}{l}19.6 \\
19.3 \\
19.4 \\
20.3 \\
22 \cdot 3 \\
22.9 \\
22.1 \\
19.4\end{array}$ & $\begin{array}{l}29.9 \\
20.0 \\
19.3 \\
21.1 \\
25.5 \\
28.1 \\
23.5 \\
20.5\end{array}$ & $\begin{array}{l}19.1 \\
19.0 \\
19.0 \\
20.1 \\
22.3 \\
22.8 \\
22.0 \\
19.3\end{array}$ \\
\hline $\begin{array}{l}16 \\
16 \\
16 \\
16 \\
16 \\
16 \\
16 \\
16\end{array}$ & $\begin{array}{r}0 \\
3 \\
6 \\
9 \\
12 \\
15 \\
18 \\
21\end{array}$ & $\begin{array}{l}20.5 \\
20.0 \\
19.9 \\
20.2 \\
21.9 \\
23.5 \\
21.7 \\
20.6\end{array}$ & $\begin{array}{l}19.3 \\
19.2 \\
19.0 \\
10.3 \\
20.0 \\
20.4 \\
20.1 \\
20.0\end{array}$ & $\begin{array}{l}20.5 \\
20.0 \\
19.9 \\
20.2 \\
22.0 \\
23.6 \\
21.7 \\
20.5\end{array}$ & $\begin{array}{l}29.1 \\
19.0 \\
18.9 \\
19.1 \\
20.0 \\
20.5 \\
20.0 \\
19.8\end{array}$ & $\begin{array}{l}20.4 \\
19.9 \\
19.8 \\
20.1 \\
22.0 \\
23.5 \\
21.7 \\
20.7\end{array}$ & $\begin{array}{l}19.0 \\
18.9 \\
18.8 \\
19.0 \\
19.8 \\
20.4 \\
20.0 \\
19.8\end{array}$ & $\begin{array}{l}20.4 \\
19.0 \\
29.0 \\
20.2 \\
22.1 \\
23.5 \\
21.6 \\
20.7\end{array}$ & $\begin{array}{l}19.0 \\
18.8 \\
18.7 \\
19.2 \\
19.9 \\
20.3 \\
20.0 \\
19.7\end{array}$ \\
\hline $\begin{array}{l}17 \\
17 \\
17 \\
17 \\
27 \\
17 \\
17 \\
17\end{array}$ & $\begin{array}{r}0 \\
3 \\
6 \\
9 \\
12 \\
15 \\
18 \\
21\end{array}$ & $\begin{array}{l}19.7 \\
20.1 \\
19.9 \\
22.6 \\
24.6 \\
25.5 \\
24.0 \\
23.2\end{array}$ & $\begin{array}{l}19.1 \\
18.9 \\
19.2 \\
19.7 \\
20.1 \\
20.9 \\
21.4 \\
20.7\end{array}$ & $\begin{array}{l}19.8 \\
20.1 \\
19.0 \\
23.1 \\
24.9 \\
25.9 \\
24.2 \\
23.0\end{array}$ & $\begin{array}{l}19.2 \\
18.8 \\
19.0 \\
19.7 \\
19.9 \\
20.8 \\
21.0 \\
20.5\end{array}$ & $\begin{array}{l}19.7 \\
19.9 \\
19.0 \\
22.9 \\
25.0 \\
25.9 \\
24.2 \\
22.9\end{array}$ & $\begin{array}{l}19.3 \\
18.7 \\
15.9 \\
19.4 \\
19.8 \\
20.6 \\
20.8 \\
20.2\end{array}$ & $\begin{array}{l}19.6 \\
20.0 \\
19.0 \\
22.8 \\
24: 0 \\
26.1 \\
24.5 \\
22.9\end{array}$ & $\begin{array}{l}19.0 \\
18.7 \\
19.0 \\
19.5 \\
19.7 \\
20.4 \\
20.4 \\
20.1\end{array}$ \\
\hline $\begin{array}{l}18 \\
18 \\
18 \\
18 \\
18 \\
18 \\
18 \\
18\end{array}$ & $\begin{array}{r}0 \\
3 \\
6 \\
9 \\
12 \\
15 \\
18 \\
21\end{array}$ & $\begin{array}{l}21.6 \\
21.0 \\
20.9 \\
24.4 \\
26.1 \\
26.7 \\
24.9 \\
23.1\end{array}$ & $\begin{array}{l}20.1 \\
19.8 \\
20.0 \\
21.1 \\
21.2 \\
21.2 \\
21.7 \\
21.3\end{array}$ & $\begin{array}{l}21.6 \\
20.9 \\
20.9 \\
24.6 \\
26.5 \\
26.8 \\
24.9 \\
22.9\end{array}$ & $\begin{array}{l}19.9 \\
19.8 \\
20.0 \\
21.0 \\
21.9 \\
21.3 \\
21.6 \\
21.2\end{array}$ & $\begin{array}{l}21.5 \\
20.9 \\
21.1 \\
24.8 \\
26.6 \\
27.2 \\
25.0 \\
22.9\end{array}$ & $\begin{array}{l}19.8 \\
19.7 \\
20.0 \\
21.0 \\
20.7 \\
20.8 \\
21.2 \\
21.1\end{array}$ & $\begin{array}{l}22.4 \\
20.0 \\
21.0 \\
25.0 \\
26.7 \\
27.5 \\
25.1 \\
22.0\end{array}$ & $\begin{array}{l}10.7 \\
19.6 \\
19.9 \\
20.9 \\
20.6 \\
20.8 \\
21.0 \\
21.0\end{array}$ \\
\hline $\begin{array}{l}19 \\
19 \\
19 \\
19 \\
19 \\
19 \\
19 \\
19\end{array}$ & $\begin{array}{r}0 \\
3 \\
6 \\
9 \\
12 \\
15 \\
18 \\
21 .\end{array}$ & $\begin{array}{l}22.4 \\
31.4 \\
21.3 \\
34.4 \\
24.9 \\
24: 7 \\
23.1 \\
22.2\end{array}$ & $\begin{array}{l}20.9 \\
20.5 \\
20.6 \\
22.1 \\
22.3 \\
21.5 \\
21.0 \\
21.3\end{array}$ & $\begin{array}{l}22.4 \\
21.4 \\
21.4 \\
24.6 \\
25.1 \\
24.8 \\
23.1 \\
22.1\end{array}$ & $\begin{array}{l}20.9 \\
20.4 \\
20.5 \\
22.1 \\
22.2 \\
21.4 \\
21.0 \\
21.2\end{array}$ & $\begin{array}{l}22.4 \\
21.3 \\
21.4 \\
24.6 \\
25.7 \\
24.8 \\
22.9 \\
72.1\end{array}$ & $\begin{array}{l}20.8 \\
20.4 \\
20.5 \\
22.0 \\
22.2 \\
21.2 \\
20.9 \\
21.1\end{array}$ & $\begin{array}{l}22 \cdot 2 \\
21 \cdot 2 \\
21 \cdot 3 \\
24 \cdot 6 \\
25 \cdot 3 \\
24: 7 \\
22.8 \\
22.1\end{array}$ & $\begin{array}{l}20.7 \\
20.2 \\
20.3 \\
21.9 \\
22.1 \\
22.0 \\
20.7 \\
21.0\end{array}$ \\
\hline $\begin{array}{l}20 \\
20 \\
20 \\
20 \\
20 \\
20 \\
20 \\
20\end{array}$ & $\begin{array}{r}0 \\
3 \\
6 \\
9 \\
12 \\
15 \\
18 \\
21\end{array}$ & $\begin{array}{l}22.1 \\
21.3 \\
21.1 \\
23.9 \\
28.0 \\
29.0 \\
27.4 \\
25.4\end{array}$ & $\begin{array}{l}21.4 \\
20.8 \\
20.5 \\
21.6 \\
22.8 \\
23.0 \\
23.0 \\
22.7\end{array}$ & $\begin{array}{l}22.1 \\
21.2 \\
21.2 \\
24.3 \\
28.5 \\
29.5 \\
27.8 \\
25.5\end{array}$ & $\begin{array}{l}21.4 \\
20.7 \\
20.4 \\
21.6 \\
22.8 \\
23.0 \\
23.0 \\
22.6\end{array}$ & $\begin{array}{l}21.9 \\
21.2 \\
21.3 \\
34.4 \\
29.0 \\
29.8 \\
77.9 \\
25.6\end{array}$ & $\begin{array}{l}21.2 \\
20.5 \\
20.3 \\
21.0 \\
22.5 \\
22.9 \\
22.8 \\
22.4\end{array}$ & $\begin{array}{l}21.0 \\
21.0 \\
21.3 \\
24: 7 \\
29: 2 \\
30.5 \\
28.5 \\
25.7\end{array}$ & $\begin{array}{l}21.0 \\
20.5 \\
20.3 \\
21.5 \\
22.6 \\
22.9 \\
27.8 \\
27.4\end{array}$ \\
\hline
\end{tabular}

\begin{tabular}{|c|c|c|c|c|}
\hline $\begin{array}{l}23.9 \\
23.4 \\
23.0 \\
23.0 \\
23.4 \\
23.4 \\
22.9 \\
22.9\end{array}$ & $\begin{array}{l}5.8 \\
5.6 \\
5.4 \\
3.9 \\
3.9 \\
2.9 \\
2.0 \\
1.5\end{array}$ & $\begin{array}{l}7.4 \\
5.8 \\
6.0 \\
5.3\end{array}$ & $\begin{array}{r}6.3 \\
10.0 \\
10.3 \\
6.4 \\
4.6 \\
1.7\end{array}$ & $\begin{array}{l}6.8 \\
4.6\end{array}$ \\
\hline $\begin{array}{l}22 \bullet 9 \\
22 \bullet 9 \\
22 \bullet 9 \\
22 \bullet 9 \\
23 \bullet 0 \\
22 \bullet 9 \\
22 \bullet 8 \\
22 \bullet 8\end{array}$ & $\begin{array}{l}1.7 \\
2.0 \\
4.7 \\
8.3 \\
4.3 \\
4.6 \\
5.4\end{array}$ & $\begin{array}{l}2.0 \\
1.5 \\
2.7 \\
3.0 \\
5.2 \\
4.6 \\
6.2\end{array}$ & $\begin{array}{l}1.8 \\
2.0 \\
5.2 \\
9.5 \\
6.7 \\
5.8 \\
6.4\end{array}$ & $\begin{array}{l}2.6 \\
2.5 \\
3.2 \\
6.7 \\
9.4 \\
8.8 \\
6.0 \\
7.0\end{array}$ \\
\hline $\begin{array}{l}22.7 \\
22.6 \\
22.6 \\
22.8 \\
23.0 \\
23.3 \\
22.8 \\
22.6\end{array}$ & $\begin{array}{l}3.7 \\
4.6 \\
4.6 \\
8.4 \\
6.4 \\
5.6 \\
7.7 \\
5.7\end{array}$ & $\begin{array}{l}4.8 \\
5.0 \\
5.1 \\
8.0 \\
8.6 \\
5.6 \\
8.2 \\
7.0\end{array}$ & $\begin{array}{l}7.1 \\
5.4 \\
9.6\end{array}$ & $\begin{aligned} 7.4 \\
9.4 \\
7.7 \\
21.3 \\
7.6 \\
7.2 \\
10.1 \\
8.2\end{aligned}$ \\
\hline $\begin{array}{l}22.5 \\
22 . \bullet 2 \\
22.22 \\
22.4 \\
22.3 \\
22.2 \\
22.1 \\
22.1\end{array}$ & $\begin{array}{l}8.4 \\
6.0 \\
6.1 \\
7.4 \\
5.8 \\
6.3 \\
4.0\end{array}$ & $\begin{array}{r}9.4 \\
11.2 \\
7.5 \\
7.6 \\
6.2 \\
6.8 \\
5.0\end{array}$ & $\begin{array}{r}10.4 \\
6.3 \\
7.0 \\
8.3 \\
6.9 \\
7.4 \\
5.5\end{array}$ & $\begin{array}{r}13.6 \\
13.5 \\
6.6 \\
8.7 \\
7.8 \\
6.7 \\
7.7 \\
5.6\end{array}$ \\
\hline $\begin{array}{l}22.0 \\
22.0 \\
22.0 \\
22.3 \\
23.2 \\
23.7 \\
23.0 \\
22.7\end{array}$ & $\begin{array}{r}5.9 \\
8.0 \\
7.7 \\
11.3 \\
7.0 \\
4.4 \\
6.5 \\
6.3\end{array}$ & $\begin{array}{r}6.5 \\
8.7 \\
8.5 \\
13.0 \\
8.3 \\
5.6 \\
6.9 \\
6.8\end{array}$ & $\begin{array}{r}7.4 \\
9.9 \\
9.9 \\
15.0 \\
9.5 \\
5.3 \\
7.9 \\
7.5\end{array}$ & $\begin{array}{r}7.8 \\
10.3 \\
10.3 \\
16.2 \\
10.7 \\
7.5 \\
8.7 \\
7.7\end{array}$ \\
\hline $\begin{array}{l}22.6 \\
22.3 \\
22.2 \\
22.2 \\
22.4 \\
22.3 \\
22.1 \\
22.1\end{array}$ & $\begin{array}{r}10.2 \\
12.5 \\
10.1 \\
9.3 \\
13.8 \\
8.5 \\
8.9 \\
5.6\end{array}$ & $\begin{array}{r}11.3 \\
13.8 \\
11.2 \\
10.2 \\
15.5 \\
9.4 \\
9.6 \\
6.0\end{array}$ & $\begin{array}{r}13.2 \\
16.0 \\
12.7 \\
11.2 \\
17.3 \\
11.5 \\
10.0 \\
6.1\end{array}$ & $\begin{array}{r}13.8 \\
16.7 \\
13.2 \\
11.3 \\
19.4 \\
11.0 \\
10.7 \\
7.2\end{array}$ \\
\hline $\begin{array}{l}22.2 \\
22.22 \\
22.2 \\
22.7 \\
24.1 \\
25.0 \\
24.4 \\
23.8\end{array}$ & $\begin{array}{l}5.0 \\
5.2 \\
6.8 \\
3.9 \\
4.9 \\
4.3 \\
3.4\end{array}$ & $\begin{array}{l}5.5 \\
5.8 \\
7.6 \\
5.0 \\
5.7 \\
5.2 \\
3.7 \\
6.8\end{array}$ & $\begin{array}{l}6.6 \\
4.6 \\
7.2\end{array}$ & $\begin{array}{l}6.7 \\
7.0 \\
9.0 \\
6.7 \\
7.3 \\
6.9 \\
5.9 \\
8.9\end{array}$ \\
\hline $\begin{array}{l}23.5 \\
23.02 \\
23.0 \\
23.6 \\
24.1 \\
24.5 \\
24.0 \\
23.7\end{array}$ & $\begin{array}{l}6.0 \\
7.3 \\
5.7 \\
6.1\end{array}$ & $\begin{array}{r}6.8 \\
8.1 \\
9.6 \\
11.1 \\
7.6 \\
8.6 \\
6.8 \\
7.0\end{array}$ & $\begin{array}{r}7.6 \\
9.3 \\
10.4 \\
11.3 \\
8.7 \\
10.0 \\
8.0 \\
8.0\end{array}$ & $\begin{array}{r}8.3 \\
9.9 \\
11.7 \\
13.2 \\
10.0 \\
11.6 \\
9.5 \\
9.1\end{array}$ \\
\hline $\begin{array}{l}23.3 \\
23.1 \\
23.1 \\
23.7 \\
24.5 \\
24.7 \\
24.0 \\
23.7\end{array}$ & $\begin{array}{r}7.0 \\
4.9 \\
5.5 \\
6.1 \\
11.2 \\
10.9 \\
8.4 \\
8.8\end{array}$ & $\begin{array}{r}8.0 \\
5.6 \\
6.2 \\
7.2 \\
12.9 \\
12.6 \\
9.6 \\
10.0\end{array}$ & $\begin{array}{r}8.5 \\
5.9 \\
6.9 \\
8.2 \\
14.0 \\
13.6 \\
10.8 \\
11.4\end{array}$ & $\begin{array}{r}9.7 \\
6.6 \\
7.5 \\
9.2 \\
16.1 \\
15.6 \\
11.09 \\
12.4\end{array}$ \\
\hline $\begin{array}{l}23.6 \\
23.4 \\
23.3 \\
23.7 \\
24.3 \\
24.0 \\
23.8 \\
23.8\end{array}$ & $\begin{array}{r}10.0 \\
7.7 \\
11.8 \\
12.0 \\
10.7 \\
11.4 \\
9.3 \\
7.3\end{array}$ & $\begin{array}{r}11.6 \\
3.8 \\
13.4 \\
13.6 \\
12.2 \\
13.1 \\
10.9 \\
8.5\end{array}$ & $\begin{array}{r}12.6 \\
0.4 \\
14.2 \\
13.9 \\
13.0 \\
13.6 \\
11.8 \\
0.1\end{array}$ & $\begin{array}{l}14.1 \\
10.3 \\
15.8 \\
16.3 \\
15.3 \\
16.5 \\
14.2 \\
11.0\end{array}$ \\
\hline
\end{tabular}


TABLE 10

Table 10. - Three-hour averages of air and water-surface temperatures and wind directions and speed, April 1950-August 1951, Lake Hefner Continued

STATION 4 THREE-MOURLY AVERAGES

SEPTEMBER, 1950

\begin{tabular}{|c|c|c|c|c|c|c|c|c|c|c|c|c|c|c|c|}
\hline \multirow{3}{*}{ 咅 } & \multirow{3}{*}{ 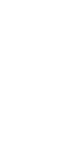 } & \multicolumn{8}{|c|}{ Average air temperature $\left({ }^{\circ} \mathrm{C}\right)$ at indicated height } & \multirow{3}{*}{$\begin{array}{l}\text { Average } \\
\text { water- } \\
\text { súrface } \\
\text { tempera- } \\
\text { ture } \\
\left({ }^{\circ} \mathrm{C}\right)\end{array}$} & \multirow{3}{*}{$\begin{array}{c}\text { Average } \\
\text { wind } \\
\text { direction } \\
\text { (coded) }\end{array}$} & \multicolumn{4}{|c|}{$\begin{array}{l}\text { Average wind speed (knots) } \\
\text { at indicated height }\end{array}$} \\
\hline & & \multicolumn{2}{|c|}{$\begin{array}{c}2 \\
\text { meters }\end{array}$} & \multicolumn{2}{|c|}{$\begin{array}{c}4 \\
\text { meters }\end{array}$} & \multicolumn{2}{|c|}{$\begin{array}{c}8 \\
\text { meters }\end{array}$} & \multicolumn{2}{|c|}{$\begin{array}{c}16 \\
\text { meters }\end{array}$} & & & & & & \\
\hline & & $\begin{array}{l}\text { Dry } \\
\text { bulb }\end{array}$ & $\begin{array}{l}\text { Wet } \\
\text { bulb }\end{array}$ & $\begin{array}{l}\text { Dry } \\
\text { bulb }\end{array}$ & $\begin{array}{l}\text { Wet } \\
\text { bulb }\end{array}$ & $\begin{array}{l}\text { Dry } \\
\text { bulb }\end{array}$ & $\begin{array}{l}\text { Wet } \\
\text { bulb }\end{array}$ & $\begin{array}{l}\text { Dry } \\
\text { bulb }\end{array}$ & $\begin{array}{l}\text { Wet } \\
\text { bulb }\end{array}$ & & & meters & meters & meters & meters \\
\hline $\begin{array}{l}21 \\
21 \\
21 \\
21 \\
21 \\
21 \\
21 \\
21\end{array}$ & $\begin{array}{r}0 \\
3 \\
6 \\
9 \\
12 \\
15 \\
18 \\
21\end{array}$ & $\begin{array}{l}23.8 \\
21.7 \\
20.0 \\
22.3 \\
24.8 \\
26.0 \\
22.8 \\
18.0\end{array}$ & $\begin{array}{l}22.4 \\
19.0 \\
15.3 \\
15.5 \\
17.7 \\
17.1 \\
16.4 \\
14.7\end{array}$ & $\begin{array}{l}23.8 \\
21.5 \\
20.6 \\
22.5 \\
25.0 \\
26.0 \\
22.6 \\
17.9\end{array}$ & $\begin{array}{l}22.3 \\
18.8 \\
15.1 \\
15.5 \\
17.6 \\
17.1 \\
16.2 \\
14.6\end{array}$ & $\begin{array}{l}23.7 \\
21.5 \\
20.3 \\
22.2 \\
24.7 \\
25.8 \\
22.4 \\
17.6\end{array}$ & $\begin{array}{l}22.2 \\
18.4 \\
14.7 \\
15.2 \\
17 \cdot 3 \\
16.8 \\
15.9 \\
14.4\end{array}$ & $\begin{array}{l}23.6 \\
21: 5 \\
20: 1 \\
21.6 \\
24.4 \\
25,4 \\
22: 3 \\
17.7\end{array}$ & $\begin{array}{l}22.2 \\
18.2 \\
14.5 \\
14.8 \\
17.2 \\
16.6 \\
15.8 \\
14.3\end{array}$ & $\begin{array}{l}23.8 \\
23.4 \\
23.2 \\
23.2 \\
23.6 \\
23.2 \\
22.9 \\
22.9\end{array}$ & & $\begin{array}{l}4.7 \\
4.7 \\
3.6 \\
4.1 \\
4.8 \\
4.1 \\
2.6 \\
2.1\end{array}$ & $\begin{array}{l}5.2 \\
5.3 \\
5.4 \\
5.8 \\
5.8 \\
5.0 \\
4.7 \\
3.9\end{array}$ & $\begin{array}{r}5.4 \\
8.2 \\
10.9 \\
10.8 \\
10.7 \\
9.7 \\
8.3 \\
4.9\end{array}$ & $\begin{array}{r}0.6 \\
9.3 \\
12.6 \\
13.2 \\
11.9 \\
10.5 \\
11.9 \\
9.5\end{array}$ \\
\hline $\begin{array}{l}22 \\
22 \\
22 \\
22 \\
22 \\
22 \\
22 \\
22\end{array}$ & $\begin{array}{r}0 \\
3 \\
6 \\
9 \\
12 \\
15 \\
18 \\
21\end{array}$ & $\begin{array}{l}15.6 \\
14.8 \\
1,5.6 \\
19.9 \\
22.1 \\
23.1 \\
20.1 \\
19.2\end{array}$ & $\begin{array}{l}14.1 \\
13.9 \\
14.4 \\
15.6 \\
15.6 \\
15.9 \\
15.2 \\
14.6\end{array}$ & $\begin{array}{l}15.4 \\
14.6 \\
15.6 \\
19.8 \\
22.2 \\
23.3 \\
19.9 \\
19.0\end{array}$ & $\begin{array}{l}13.9 \\
13.7 \\
14.2 \\
15.6 \\
15.5 \\
15.6 \\
14.9 \\
14.3\end{array}$ & $\begin{array}{l}15.2 \\
14.4 \\
15.3 \\
19.9 \\
22.2 \\
23.3 \\
19.9 \\
18.9\end{array}$ & $\begin{array}{l}13.7 \\
13.4 \\
13.9 \\
15.3 \\
15.4 \\
15.6 \\
14 \cdot 8 \\
14.3\end{array}$ & $\begin{array}{l}15.2 \\
14 \cdot 3 \\
15.0 \\
19.3 \\
21.2 \\
22.3 \\
20.2 \\
18.9\end{array}$ & $\begin{array}{l}13.8 \\
13.3 \\
13.7 \\
14.9 \\
14.9 \\
15.2 \\
14.5 \\
13.9\end{array}$ & $\begin{array}{l}22.7 \\
22.7 \\
22.7 \\
23.7 \\
23.5 \\
23.1 \\
22.5 \\
22.4\end{array}$ & & $\begin{array}{l}2.3 \\
2.09 \\
2.06 \\
3.7 \\
4.11 \\
3.5 \\
0.8 \\
0.6\end{array}$ & $\begin{array}{l}2.7 \\
2.8 \\
4.4 \\
5.1 \\
5.5 \\
4.4 \\
1.2 \\
0.8\end{array}$ & $\begin{array}{l}5.6 \\
6.3 \\
7.2 \\
7.0 \\
7.7 \\
5.6 \\
2.3 \\
0.8\end{array}$ & $\begin{array}{r}8.1 \\
7.1 \\
10.7 \\
10.6 \\
10.1 \\
7.7 \\
3.9 \\
1.2\end{array}$ \\
\hline $\begin{array}{l}23 \\
23 \\
23 \\
23 \\
23 \\
23 \\
23 \\
23\end{array}$ & $\begin{array}{r}0 \\
3 \\
6 \\
9 \\
12 \\
15 \\
18 \\
21\end{array}$ & $\begin{array}{l}17.8 \\
17.5 \\
18.4 \\
24.3 \\
26.1 \\
26.1 \\
23.3 \\
20.1\end{array}$ & $\begin{array}{l}15.0 \\
15.0 \\
15.1 \\
16.0 \\
15.7 \\
16.4 \\
16.9 \\
16.3\end{array}$ & $\begin{array}{l}17.6 \\
17.3 \\
18.5 \\
24.5 \\
26.3 \\
26.4 \\
23.3 \\
19.6\end{array}$ & $\begin{array}{l}14.5 \\
14.7 \\
14.9 \\
15.9 \\
15.9 \\
16.3 \\
16.8 \\
16.1\end{array}$ & $\begin{array}{l}27.5 \\
17 \cdot 2 \\
18.7 \\
24.2 \\
26.4 \\
26.6 \\
23.4 \\
19.9\end{array}$ & $\begin{array}{l}14.4 \\
14.7 \\
14.8 \\
15.7 \\
15.8 \\
16.3 \\
16.7 \\
16.1\end{array}$ & $\begin{array}{l}17 \cdot 5 \\
17 \cdot 2 \\
18.7 \\
24 \cdot 5 \\
25.9 \\
26.0 \\
23.7 \\
20.7\end{array}$ & $\begin{array}{l}14.4 \\
14.6 \\
14.7 \\
15.7 \\
15.4 \\
16.0 \\
16.3 \\
16.1\end{array}$ & $\begin{array}{l}22.3 \\
22.4 \\
22.5 \\
23.5 \\
24.4 \\
23.4 \\
22.5 \\
22.3\end{array}$ & & $\begin{array}{l}2.0 \\
6.7 \\
6.9 \\
3.2 \\
3.4 \\
4.2 \\
2.6 \\
1.5\end{array}$ & $\begin{array}{l}2.1 \\
7.0 \\
7.2 \\
3.5 \\
3.8 \\
4.6 \\
3.0 \\
1.8\end{array}$ & $\begin{array}{l}1.8 \\
5.3 \\
4.5 \\
4.3 \\
5.2 \\
4.0\end{array}$ & $\begin{array}{l}2.03 \\
7.0 \\
7.04 \\
4.7 \\
5.1 \\
6.4 \\
4.8 \\
3.0\end{array}$ \\
\hline $\begin{array}{l}24 \\
24 \\
24 \\
24 \\
24 \\
24 \\
24 \\
24\end{array}$ & $\begin{array}{r}0 \\
3 \\
6 \\
9 \\
12 \\
15 \\
18 . \\
21\end{array}$ & $\begin{array}{l}18.5 \\
16.1 \\
16.2 \\
21.6 \\
24.1 \\
24.4 \\
20.9 \\
18.0\end{array}$ & $\begin{array}{l}15.4 \\
14.6 \\
14.6 \\
15.3 \\
15.8 \\
16.3 \\
16.6 \\
16.3\end{array}$ & $\begin{array}{l}17.3 \\
16: 3 \\
17.0 \\
21.9 \\
24.4 \\
24.5 \\
20.8 \\
17.9\end{array}$ & $\begin{array}{l}15.0 \\
14.5 \\
14.7 \\
15.0 \\
15.5 \\
16.0 \\
16.5 \\
16.2\end{array}$ & $\begin{array}{l}17.6 \\
16.0 \\
16.6 \\
22.0 \\
24.3 \\
24.5 \\
20.5 \\
17.8\end{array}$ & $\begin{array}{l}15.0 \\
14.1 \\
14.5 \\
14.9 \\
15.4 \\
15.9 \\
16.2 \\
15.9\end{array}$ & $\begin{array}{l}18 \cdot 2 \\
16.0 \\
16.4 \\
22.1 \\
24 \cdot 2 \\
24 \cdot 3 \\
20.5 \\
17.6\end{array}$ & $\begin{array}{l}14.8 \\
13.9 \\
14.3 \\
14.7 \\
15.2 \\
15.7 \\
16.1 \\
15.8\end{array}$ & $\begin{array}{l}22.4 \\
22.4 \\
22.7 \\
23.9 \\
24.7 \\
24.0 \\
23.3 \\
23.1\end{array}$ & & $\begin{array}{l}3.0 \\
2.1 \\
1.7 \\
3.9 \\
5.8 \\
7.0 \\
6.7 \\
7.0\end{array}$ & $\begin{array}{l}3.9 \\
2.6 \\
2.0 \\
4.4 \\
6.3 \\
7.2 \\
7.3 \\
7.5\end{array}$ & $\begin{array}{l}4.3 \\
4.8 \\
7.3 \\
7.6\end{array}$ & $\begin{array}{l}5.3 \\
3.9 \\
2.3 \\
4.8 \\
6.7 \\
8.0 \\
8.9 \\
8.9\end{array}$ \\
\hline $\begin{array}{l}25 \\
25 \\
25 \\
25 \\
25 \\
25 \\
25 \\
25\end{array}$ & $\begin{array}{r}0 \\
3 \\
6 \\
9 \\
12 \\
15 \\
18 \\
21\end{array}$ & $\begin{array}{l}16.5 \\
15.7 \\
16.4 \\
18.3 \\
20.5 \\
20.9 \\
19.3 \\
18.6\end{array}$ & $\begin{array}{l}15.3 \\
15.1 \\
14.7 \\
14.4 \\
15.7 \\
16.4 \\
16.0 \\
16.0\end{array}$ & $\begin{array}{l}16.3 \\
15.6 \\
16.2 \\
18.5 \\
20.7 \\
20.8 \\
19.2 \\
18.5\end{array}$ & $\begin{array}{l}15.2 \\
14.9 \\
14.4 \\
14.4 \\
15.4 \\
16 \cdot 0 \\
15.8 \\
15.7\end{array}$ & $\begin{array}{l}16.1 \\
15.5 \\
16.1 \\
18.4 \\
20.5 \\
20.8 \\
19.0 \\
18.5\end{array}$ & $\begin{array}{l}15.0 \\
14.9 \\
14.1 \\
14.3 \\
15.1 \\
15.8 \\
15.6 \\
15.7\end{array}$ & $\begin{array}{l}15.9 \\
15.4 \\
15.9 \\
18.2 \\
20.5 \\
20.5 \\
18.0 \\
18.2\end{array}$ & $\begin{array}{l}14.8 \\
14.6 \\
13.8 \\
13.9 \\
15.1 \\
15.6 \\
15.4 \\
15.4\end{array}$ & $\begin{array}{l}23.0 \\
22.8 \\
22.9 \\
23.5 \\
23.9 \\
23.2 \\
22.9 \\
22.8\end{array}$ & & $\begin{array}{r}6.0 \\
6.5 \\
10.5 \\
8.3 \\
7.2 \\
8.2 \\
7.1 \\
8.9\end{array}$ & $\begin{array}{r}6.5 \\
7.1 \\
11.9 \\
9.3 \\
8.1 \\
9.1 \\
7.7 \\
9.9\end{array}$ & $\begin{array}{r}11.1 \\
14.5 \\
10.6 \\
9.2 \\
10.7 \\
9.2 \\
11.4\end{array}$ & $\begin{array}{r}7.4 \\
8.3 \\
24.4 \\
11.3 \\
9.8 \\
10.9 \\
9.0 \\
11.9\end{array}$ \\
\hline $\begin{array}{l}26 \\
26 \\
25 \\
26 \\
26 \\
26 \\
26 \\
26\end{array}$ & $\begin{array}{r}0 \\
3 \\
6 \\
9 \\
12 \\
15 \\
18 \\
21\end{array}$ & $\begin{array}{l}17.4 \\
16.1 \\
15.8 \\
16.4 \\
19.5 \\
20.9 \\
20.0 \\
18.5\end{array}$ & $\begin{array}{l}15.6 \\
14.5 \\
14.0 \\
15.5 \\
16.8 \\
17.1 \\
17.3 \\
16.2\end{array}$ & $\begin{array}{l}17.2 \\
15.8 \\
15.6 \\
16.1 \\
19.5 \\
20.9 \\
19.9 \\
18.3\end{array}$ & $\begin{array}{l}15.3 \\
14.4 \\
13.8 \\
15.3 \\
16.5 \\
16.9 \\
17.0 \\
15.8\end{array}$ & $\begin{array}{l}17.1 \\
15.7 \\
15.3 \\
15.1 \\
19.4 \\
20.8 \\
19.8 \\
18.1\end{array}$ & $\begin{array}{l}15.0 \\
14.2 \\
13.5 \\
15.0 \\
16.2 \\
16.9 \\
16.8 \\
15.6\end{array}$ & $\begin{array}{l}16.8 \\
15.3 \\
15.2 \\
15.0 \\
19.4 \\
20.7 \\
19.5 \\
17.9\end{array}$ & $\begin{array}{l}14.9 \\
13.9 \\
13.3 \\
14.7 \\
16.0 \\
16.4 \\
16.7 \\
15.4\end{array}$ & $\begin{array}{l}22.6 \\
22.3 \\
22.2 \\
22.6 \\
22.9 \\
22.6 \\
22.1 \\
22.0\end{array}$ & & $\begin{array}{r}8.6 \\
8.1 \\
10.3 \\
11.5 \\
12.0 \\
10.5 \\
9.8 \\
12.7\end{array}$ & $\begin{array}{r}9.7 \\
9.0 \\
21.4 \\
13.0 \\
13.7 \\
12.0 \\
11.0 \\
14.4\end{array}$ & $\begin{array}{l}11.0 \\
10.3 \\
13.2 \\
14.9 \\
15.4 \\
13.5 \\
12.6 \\
16.6\end{array}$ & $\begin{array}{l}11.6 \\
10.7 \\
13.8 \\
15.9 \\
16.8 \\
14.8 \\
13.5 \\
17.8\end{array}$ \\
\hline $\begin{array}{l}27 \\
27 \\
27 \\
27 \\
27 \\
27 \\
27 \\
27\end{array}$ & $\begin{array}{r}0 \\
3 \\
6 \\
9 \\
12 \\
15 \\
18 \\
21\end{array}$ & $\begin{array}{l}17.2 \\
18.2 \\
18.4 \\
19.7 \\
22.5 \\
23.9 \\
22.5 \\
20.7\end{array}$ & $\begin{array}{l}16.5 \\
17.7 \\
18.0 \\
18.5 \\
10.8 \\
20.3 \\
20.0 \\
19.5\end{array}$ & $\begin{array}{l}17.0 \\
18.1 \\
18.3 \\
19.8 \\
23.1 \\
24.1 \\
22.5 \\
20.7\end{array}$ & $\begin{array}{l}16.4 \\
17.5 \\
17.8 \\
18.5 \\
19.7 \\
20.2 \\
19.8 \\
19.2\end{array}$ & $\begin{array}{l}10.9 \\
17.9 \\
18.2 \\
10.7 \\
23.2 \\
24.1 \\
22.5 \\
20.6\end{array}$ & $\begin{array}{l}16.3 . \\
17.4 \\
17.7 \\
18.5 \\
19.7 \\
20.1 \\
19.7 \\
19.2\end{array}$ & $\begin{array}{l}15.7 \\
17.8 \\
17.9 \\
19.7 \\
23.3 \\
24.2 \\
22.4 \\
20.5\end{array}$ & $\begin{array}{l}26.1 \\
17.1 \\
17.4 \\
18.3 \\
19.5 \\
20.0 \\
19.6 \\
19.0\end{array}$ & $\begin{array}{l}21.9 \\
21.8 \\
21.8 \\
22.5 \\
23.0 \\
22.7 \\
21.8 \\
21.6\end{array}$ & & $\begin{array}{l}14.2 \\
11.8 \\
12.7 \\
12.9 \\
12.5 \\
13.9 \\
11.7 \\
13.3\end{array}$ & $\begin{array}{l}16.2 \\
13.4 \\
14.6 \\
14.8 \\
14.3 \\
16.0 \\
13.4 \\
15.1\end{array}$ & $\begin{array}{l}18.4 \\
15.0 \\
15.2 \\
16.7 \\
16.6 \\
18.8 \\
15.6 \\
17.6\end{array}$ & $\begin{array}{l}19.9 \\
16.3 \\
17.7 \\
19.2 \\
18.2 \\
21.0 \\
17.3 \\
19.9\end{array}$ \\
\hline $\begin{array}{l}28 \\
28 \\
28 \\
28 \\
28 \\
28 \\
28 \\
28\end{array}$ & $\begin{array}{r}0 \\
3 \\
6 \\
9 \\
12 \\
15 \\
18 \\
21\end{array}$ & $\begin{array}{l}19.9 \\
19.8 \\
19.9 \\
21.5 \\
24.1 \\
24.8 \\
22.5 \\
21.0\end{array}$ & $\begin{array}{l}19.0 \\
18.8 \\
18.9 \\
19.5 \\
20.2 \\
20.6 \\
20.0 \\
19.2\end{array}$ & $\begin{array}{l}19.9 \\
19: 7 \\
19.9 \\
21.0 \\
24.4 \\
25.1 \\
22.6 \\
21.0\end{array}$ & $\begin{array}{l}18.8 \\
18.7 \\
18.6 \\
29.5 \\
20.1 \\
20.6 \\
19.9 \\
10.0\end{array}$ & $\begin{array}{l}19.8 \\
19.6 \\
19.9 \\
21.7 \\
24.5 \\
25.1 \\
22.5 \\
21.0\end{array}$ & $\begin{array}{l}18.8 \\
18.6 \\
18.6 \\
19.4 \\
20.1 \\
20.6 \\
19.7 \\
29.0\end{array}$ & $\begin{array}{l}19.6 \\
19.5 \\
19.7 \\
21.0 \\
24.7 \\
25.3 \\
22.4 \\
20.9\end{array}$ & $\begin{array}{l}18.7 \\
19.4 \\
18.5 \\
19.4 \\
20.1 \\
20.5 \\
19.6 \\
18.9\end{array}$ & $\begin{array}{l}21.6 \\
21.6 \\
21.7 \\
22.4 \\
22.8 \\
22.5 \\
21.8 \\
21.7\end{array}$ & & $\begin{array}{l}14.2 \\
12.2 \\
13.5 \\
14.6 \\
13.9 \\
13.7 \\
12.6 \\
12.4\end{array}$ & $\begin{array}{l}16.7 \\
13.8 \\
15.4 \\
16.8 \\
15.3 \\
15.9 \\
14.3 \\
14.1\end{array}$ & $\begin{array}{l}18.6 \\
15.9 \\
17.7 \\
19.1 \\
17.8 \\
18.6 \\
16.7 \\
16.2\end{array}$ & $\begin{array}{l}20.4 \\
17.3 \\
19.3 \\
21.3 \\
19.9 \\
20.7 \\
18.3 \\
17.7\end{array}$ \\
\hline $\begin{array}{l}29 \\
29 \\
29 \\
29 \\
29 \\
29 \\
29 \\
29\end{array}$ & $\begin{array}{r}0 \\
3 \\
6 \\
9 \\
12 \\
15 \\
18 \\
21\end{array}$ & $\begin{array}{l}20.2 \\
20 \cdot 6 \\
21 \cdot 2 \\
22 \cdot 8 \\
25.3 \\
25.9 \\
>4 \cdot 1 \\
72.2\end{array}$ & $\begin{array}{l}19.3 \\
12.9 \\
20.1 \\
20.7 \\
21.0 \\
22.0 \\
20.5 \\
20.6\end{array}$ & $\begin{array}{l}20.2 \\
20.6 \\
21: ? \\
23.0 \\
25.6 \\
26.0 \\
24.2 \\
22.2\end{array}$ & $\begin{array}{l}19.2 \\
10.9 \\
20.1 \\
20.6 \\
21.0 \\
21.0 \\
20.4 \\
20.5\end{array}$ & $\begin{array}{l}20.1 \\
20.6 \\
21.2 \\
23.2 \\
25.9 \\
26.2 \\
24.2 \\
72.2\end{array}$ & $\begin{array}{l}19.2 \\
19.9 \\
20.1 \\
20.5 \\
20.9 \\
20.8 \\
20.2 \\
20.4\end{array}$ & $\begin{array}{l}20.0 \\
20.5 \\
21.3 \\
23.3 \\
26.2 \\
26.5 \\
24.2 \\
22.2\end{array}$ & $\begin{array}{l}19.0 \\
19.8 \\
20.0 \\
20.5 \\
21.0 \\
20.8 \\
20.2 \\
20.5\end{array}$ & $\begin{array}{l}21.6 \\
21.6 \\
21.8 \\
22.5 \\
23.0 \\
22.7 \\
22.1 \\
22.0\end{array}$ & & $\begin{array}{l}12.2 \\
12.8 \\
13.2 \\
12.5 \\
10.8 \\
11.5 \\
10.3 \\
12.8\end{array}$ & $\begin{array}{l}14.0 \\
14.0 \\
15.2 \\
14.5 \\
12.0 \\
13.4 \\
11.8 \\
14.7\end{array}$ & $\begin{array}{l}15.7 \\
16.6 \\
17.1 \\
16.0 \\
14.3 \\
15.9 \\
14.0 \\
17.1\end{array}$ & $\begin{array}{l}17.1 \\
18.3 \\
18.9 \\
18.1 \\
16.4 \\
17.9 \\
15.6 \\
18.8\end{array}$ \\
\hline $\begin{array}{l}30 \\
30 \\
30 \\
30 \\
30 \\
30 \\
30 \\
30\end{array}$ & $\begin{array}{r}0 \\
3 \\
6 \\
9 \\
12 \\
15 \\
18 \\
21\end{array}$ & $\begin{array}{l}22.0 \\
21.1 \\
21.2 \\
2.2 .7 \\
24.0 \\
24.9 \\
73.5 \\
21.1\end{array}$ & $\begin{array}{l}20.8 \\
20.1 \\
20.3 \\
21.0 \\
21.1 \\
21.2 \\
20.8 \\
19.9\end{array}$ & $\begin{array}{l}22 \cdot 1 \\
21.3 \\
21.3 \\
22.7 \\
24.3 \\
25.11 \\
23.6 \\
21.00\end{array}$ & $\begin{array}{l}20.7 \\
20.0 \\
20.3 \\
21.0 \\
21.1 \\
21.11 \\
20.8 \\
19.7\end{array}$ & $\begin{array}{l}22.0 \\
21.1 \\
21.3 \\
22.9 \\
24.5 \\
25.2 \\
23.5 \\
20.8\end{array}$ & $\begin{array}{l}20.6 \\
20.0 \\
20.2 \\
20.9 \\
21.0 \\
21.0 \\
20.6 \\
19.8\end{array}$ & $\begin{array}{l}22.0 \\
21.0 \\
21.3 \\
23.0 \\
24.5 \\
25.2 \\
23.5 \\
20.7\end{array}$ & $\begin{array}{l}20.5 \\
19.9 \\
20.2 \\
20.9 \\
21.0 \\
21.0 \\
20.5 \\
19.4\end{array}$ & $\begin{array}{l}21.9 \\
21.8 \\
21.9 \\
22.3 \\
23.0 \\
22.8 \\
22.3 \\
22.0\end{array}$ & & $\begin{array}{l}14.4 \\
12.9 \\
11.5 \\
11.4 \\
12.8 \\
12.8 \\
12.1 \\
13.9\end{array}$ & $\begin{array}{l}16.6 \\
14.8 \\
13.2 \\
13.2 \\
15.0 \\
14.8 \\
13.8 \\
15.9\end{array}$ & $\begin{array}{l}19.0 \\
16.9 \\
15.1 \\
15.1 \\
17.4\end{array}$ & $\begin{array}{l}20.9 \\
18.5 \\
16.5 \\
16.7 \\
19.4 \\
19.1 \\
17.9 \\
20.1\end{array}$ \\
\hline
\end{tabular}




\begin{tabular}{|c|c|c|c|c|c|c|c|c|c|c|c|c|c|c|c|}
\hline \multicolumn{2}{|c|}{ STATION } & \multicolumn{5}{|l|}{4} & \multicolumn{7}{|c|}{ THREE-HOURLY AVERAGES } & \multirow{2}{*}{\multicolumn{2}{|c|}{$\begin{array}{l}\text { OCTOBER, } 2950 \\
\text { d speed (knots) } \\
\text { ated height }\end{array}$}} \\
\hline \multirow{3}{*}{ 兵 } & \multirow{3}{*}{ 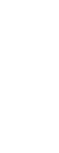 } & \multicolumn{8}{|c|}{ Average air temperature $\left({ }^{\circ} \mathrm{C}\right)$ at indicated height } & \multirow{3}{*}{$\begin{array}{l}\text { Average } \\
\text { water- } \\
\text { surface } \\
\text { tempera- } \\
\text { ture } \\
\text { ("C) }\end{array}$} & \multirow{3}{*}{$\begin{array}{c}\begin{array}{c}\text { Average } \\
\text { wind } \\
\text { direction } \\
\text { (coded) }\end{array} \\
\text { (c) }\end{array}$} & \multicolumn{2}{|c|}{$\begin{array}{l}\text { Average wind speed (knots) } \\
\text { at indicated height }\end{array}$} & & \\
\hline & & \multicolumn{2}{|c|}{$\begin{array}{c}2 \\
\text { meters }\end{array}$} & \multicolumn{2}{|c|}{$\stackrel{4}{\text { meters }}$} & \multicolumn{2}{|c|}{$\begin{array}{c}8 \\
\text { meters }\end{array}$} & \multicolumn{2}{|c|}{$\begin{array}{c}18 \\
\text { meters }\end{array}$} & & & 2 & 4 & 8 & 18 \\
\hline & & $\begin{array}{l}\text { Dry } \\
\text { bulb }\end{array}$ & $\begin{array}{l}\text { Wet } \\
\text { bulb }\end{array}$ & $\begin{array}{l}\text { Dry } \\
\text { bulb }\end{array}$ & $\begin{array}{l}\text { Wet } \\
\text { bulb }\end{array}$ & $\begin{array}{l}\text { Dry } \\
\text { bulb }\end{array}$ & $\begin{array}{l}\text { Wet } \\
\text { bulb }\end{array}$ & $\begin{array}{l}\text { Dry } \\
\text { bulb }\end{array}$ & $\begin{array}{l}\text { Wet } \\
\text { bulb }\end{array}$ & & & meters & meters & meters & meters \\
\hline $\begin{array}{l}1 \\
1 \\
1 \\
1 \\
1 \\
1 \\
2 \\
1\end{array}$ & $\begin{array}{r}0 \\
3 \\
6 \\
9 \\
12 \\
15 \\
18 \\
21\end{array}$ & $\begin{array}{l}19.9 \\
19.9 \\
20.4 \\
21.9 \\
23.6 \\
24.9 \\
23.6 \\
21.7\end{array}$ & $\begin{array}{l}18.9 \\
19.0 \\
19.5 \\
19.9 \\
20.1 \\
20.3 \\
20.2 \\
20.0\end{array}$ & $\begin{array}{l}19.9 \\
19.8 \\
20.5 \\
22.0 \\
23.9 \\
25.1 \\
23.7 \\
21.7\end{array}$ & $\begin{array}{l}18.8 \\
18.9 \\
19.4 \\
19.8 \\
20.0 \\
20.2 \\
20.1 \\
19.9\end{array}$ & $\begin{array}{l}19.8 \\
19.8 \\
20.4 \\
22.1 \\
24.0 \\
25.2 \\
23.0 \\
21.6\end{array}$ & $\begin{array}{l}18.6 \\
18.8 \\
19.3 \\
19.8 \\
19.9 \\
20.0 \\
19.9 \\
19.9\end{array}$ & $\begin{array}{l}19.6 \\
19.6 \\
20.3 \\
22.1 \\
24.0 \\
25.4 \\
23.5 \\
21.5\end{array}$ & $\begin{array}{l}18.4 \\
18.8 \\
19.2 \\
19.6 \\
19.8 \\
20.0 \\
19.9 \\
19.7\end{array}$ & $\begin{array}{l}21 \cdot 8 \\
21 \cdot 8 \\
21.8 \\
22 \cdot 3 \\
22 \cdot 7 \\
22.4 \\
22.0 \\
21.9\end{array}$ & & $\begin{array}{l}14.3 \\
14.6 \\
14.1 \\
13.9 \\
13.7 \\
13.8 \\
13.2 \\
14.4\end{array}$ & $\begin{array}{l}16.5 \\
17.4 \\
16.5 \\
16.2 \\
15.8 \\
16.0 \\
15.2 \\
16.7\end{array}$ & $\begin{array}{l}18.8 \\
19.1 \\
18.4 \\
18.2 \\
18.4 \\
18.6 \\
17.8 \\
19.1\end{array}$ & $\begin{array}{l}20.5 \\
20.7 \\
20.7 \\
20.2 \\
20.3 \\
20.6 \\
19.6 \\
21.0\end{array}$ \\
\hline $\begin{array}{l}2 \\
2 \\
2 \\
2 \\
2 \\
2 \\
2 \\
2\end{array}$ & $\begin{array}{r}0 \\
3 \\
6 \\
9 \\
12 \\
15 \\
18 \\
21\end{array}$ & $\begin{array}{l}20.8 \\
20.2 \\
20.6 \\
23 \cdot 5 \\
18 \cdot 6 \\
14 \cdot 2 \\
13 \cdot 9 \\
13.1\end{array}$ & $\begin{array}{l}19.9 \\
19.7 \\
19.9 \\
20.4 \\
17.4 \\
13.8 \\
13.5 \\
13.0\end{array}$ & $\begin{array}{l}20.8 \\
20.7 \\
20.7 \\
23.8 \\
18.5 \\
14.7 \\
13.7 \\
13.1\end{array}$ & $\begin{array}{l}19.8 \\
19.7 \\
19.8 \\
20.3 \\
17.1 \\
13.6 \\
13.1 \\
12.9\end{array}$ & $\begin{array}{l}20.7 \\
20.1 \\
20.7 \\
23.7 \\
18.5 \\
14.1 \\
13.7 \\
13.3\end{array}$ & $\begin{array}{l}19.7 \\
19.6 \\
19.8 \\
20.2 \\
16.9 \\
13.5 \\
13.4 \\
12.9\end{array}$ & $\begin{array}{l}20.5 \\
20.0 \\
20.7 \\
23.9 \\
18.2 \\
13.8 \\
13.3 \\
12.9\end{array}$ & $\begin{array}{l}19.6 \\
19.3 \\
19.7 \\
20.2 \\
16.2 \\
13.2 \\
12.9 \\
12.6\end{array}$ & $\begin{array}{l}21.8 \\
21.8 \\
21.9 \\
22.1 \\
21.9 \\
21.8 \\
21.6 \\
21.5\end{array}$ & & $\begin{array}{l}14.4 \\
12.1 \\
11.4 \\
13.8 \\
4.6 \\
4.4 \\
4.2 \\
5.5\end{array}$ & $\begin{array}{r}16.6 \\
13.9 \\
13.2 \\
15.7 \\
6.5 \\
7.0 \\
6.2 \\
6.5\end{array}$ & $\begin{array}{r}18.8 \\
15.4 \\
14.5 \\
16.5 \\
11.6 \\
10.8 \\
8.7 \\
7.5\end{array}$ & $\begin{array}{l}20.7 \\
17.3 \\
16.0 \\
18.7 \\
13.4 \\
15.4 \\
12.8 \\
10.5\end{array}$ \\
\hline $\begin{array}{l}3 \\
3 \\
3 \\
3 \\
3 \\
3 \\
3 \\
3\end{array}$ & $\begin{array}{r}0 \\
3 \\
6 \\
9 \\
17 \\
15 \\
18 \\
21\end{array}$ & $\begin{array}{l}13.1 \\
12.1 \\
10.8 \\
10.6 \\
14.1 \\
17.02 \\
14.1 \\
11.03\end{array}$ & $\begin{array}{r}12.5 \\
11.0 \\
9.7 \\
9.5 \\
11.7 \\
13.2 \\
12.1 \\
10.3\end{array}$ & $\begin{array}{l}13.0 \\
12.0 \\
10.7 \\
10.6 \\
14.4 \\
17.2 \\
13.8 \\
11.0\end{array}$ & $\begin{array}{r}12.3 \\
10.7 \\
9.5 \\
9.3 \\
11.6 \\
13.1 \\
11.8 \\
9.9\end{array}$ & $\begin{array}{l}13.1 \\
12.0 \\
10.5 \\
10.5 \\
14.4 \\
17.0 \\
13.5 \\
10.7\end{array}$ & $\begin{array}{r}12.4 \\
10.7 \\
9.3 \\
9.2 \\
11.6 \\
12.9 \\
11.5 \\
9.6\end{array}$ & $\begin{array}{l}12.8 \\
11.6 \\
10.1 \\
9.9 \\
13.5 \\
16.5 \\
13.5 \\
10.7\end{array}$ & $\begin{array}{r}12.1 \\
10.3 \\
8.9 \\
8.9 \\
11.2 \\
12.7 \\
11.3 \\
9.5\end{array}$ & $\begin{array}{l}21.5 \\
21.4 \\
21.3 \\
21.5 \\
21.9 \\
21.4 \\
20.9 \\
20.9\end{array}$ & & $\begin{array}{l}5.7 \\
6.0 \\
5.6 \\
4.0 \\
3.9 \\
4.0 \\
1.1 \\
1.3\end{array}$ & $\begin{array}{l}6.7 \\
7.3 \\
7.3 \\
5.6 \\
5.1 \\
5.2 \\
2.4 \\
2.3\end{array}$ & $\begin{array}{l}7.9 \\
8.7 \\
8.8 \\
7.8 \\
6.5 \\
6.5 \\
4.0 \\
3.7\end{array}$ & $\begin{array}{r}10.8 \\
12.5 \\
12.9 \\
11.4 \\
9.0 \\
9.5 \\
7.5 \\
6.2\end{array}$ \\
\hline $\begin{array}{l}4 \\
4 \\
4 \\
4 \\
4 \\
4 \\
4 \\
4\end{array}$ & $\begin{array}{r}0 \\
3 \\
6 \\
9 \\
12 \\
15 \\
18 \\
21\end{array}$ & $\begin{array}{r}9.5 \\
7.6 \\
8.0 \\
12.6 \\
15.3 \\
16.1 \\
14.8 \\
13.4\end{array}$ & $\begin{array}{r}8.6 \\
7.0 \\
6.9 \\
8.4 \\
9.4 \\
9.8 \\
10.1 \\
10.1\end{array}$ & $\begin{array}{r}9.3 \\
7.5 \\
8.0 \\
12.5 \\
15.2 \\
16.1 \\
14.8 \\
13.3\end{array}$ & $\begin{array}{l}8.4 \\
6.9 \\
6.7 \\
8.2 \\
9.1 \\
9.9 \\
9.9 \\
9.9\end{array}$ & $\begin{array}{r}9.0 \\
7.4 \\
8.0 \\
12.6 \\
15.4 \\
16.1 \\
14.7 \\
13.3\end{array}$ & $\begin{array}{l}8.2 \\
6.7 \\
6.5 \\
8.1 \\
9.0 \\
9.5 \\
9.6 \\
9.8\end{array}$ & $\begin{array}{r}8.9 \\
7.2 \\
7.8 \\
12.3 \\
15.0 \\
15.9 \\
14.4 \\
13.0\end{array}$ & $\begin{array}{l}7.9 \\
6.5 \\
6.1 \\
7.8 \\
9.0 \\
9.3 \\
9.4 \\
9.7\end{array}$ & $\begin{array}{l}20.7 \\
20.6 \\
20.7 \\
21.0 \\
21.2 \\
20.8 \\
20.5 \\
20.3\end{array}$ & & $\begin{array}{l}2.6 \\
5.9 \\
6.0 \\
8.5 \\
5.8 \\
5.8 \\
4.9 \\
6.8\end{array}$ & $\begin{array}{l}3.9 \\
7.2 \\
6.8 \\
9.3 \\
6.2 \\
6.2 \\
5.2 \\
7.4\end{array}$ & $\begin{array}{l}5.2 \\
8.4 \\
7.5 \\
9.8 \\
6.8 \\
6.8 \\
5.9 \\
8.5\end{array}$ & $\begin{array}{r}6.5 \\
11.7 \\
9.9 \\
10.8 \\
7.1 \\
6.8 \\
5.9 \\
8.6\end{array}$ \\
\hline $\begin{array}{l}5 \\
5 \\
5 \\
5 \\
5 \\
5 \\
5 \\
5\end{array}$ & $\begin{array}{r}0 \\
3 \\
6 \\
9 \\
12 \\
15 \\
18 \\
21\end{array}$ & $\begin{array}{l}13.1 \\
13.0 \\
13.04 \\
17.02 \\
20.0 \\
21.06 \\
19.7 \\
17.9\end{array}$ & $\begin{array}{r}10.0 \\
9.8 \\
11.3 \\
14.5 \\
16.2 \\
17.1 \\
16.4 \\
15.2\end{array}$ & $\begin{array}{l}13.0 \\
12.9 \\
13.2 \\
17.3 \\
20.2 \\
21.7 \\
19.7 \\
17.8\end{array}$ & $\begin{array}{r}9.8 \\
9.6 \\
10.9 \\
14.5 \\
15.9 \\
17.0 \\
16.3 \\
14.8\end{array}$ & $\begin{array}{l}13.0 \\
12.7 \\
12.9 \\
17.3 \\
20.2 \\
21.7 \\
19.6 \\
17.7\end{array}$ & $\begin{array}{r}9.4 \\
9.3 \\
10.8 \\
14.2 \\
15.7 \\
17.8 \\
16.0 \\
14.5\end{array}$ & $\begin{array}{l}12.8 \\
12.5 \\
12.9 \\
17.1 \\
20.2 \\
21.7 \\
19.4 \\
17.4\end{array}$ & $\begin{array}{r}9.2 \\
9.2 \\
10.6 \\
14.1 \\
15.8 \\
17.5 \\
15.7 \\
14.4\end{array}$ & $\begin{array}{l}20.3 \\
20.02 \\
20.4 \\
20.5 \\
20.9 \\
20.4 \\
20.1 \\
20.0\end{array}$ & & $\begin{array}{r}8.7 \\
8.7 \\
12.2 \\
13.8 \\
13.3 \\
10.8 \\
10.5 \\
11.4\end{array}$ & $\begin{array}{r}9.6 \\
9.8 \\
13.9 \\
15.9 \\
15.4 \\
12.6 \\
12.0 \\
12.9\end{array}$ & $\begin{array}{l}11.1 \\
11.1 \\
15.5 \\
17.0 \\
17.0 \\
13.9 \\
13.7 \\
14.7\end{array}$ & $\begin{array}{l}11.4 \\
12.7 \\
16.7 \\
18.1 \\
19.0 \\
15.8 \\
15.0 \\
16.0\end{array}$ \\
\hline $\begin{array}{l}6 \\
6 \\
6 \\
6 \\
6 \\
6 \\
6 \\
6\end{array}$ & $\begin{array}{r}0 \\
3 \\
6 \\
9 \\
12 \\
15 \\
18 \\
21\end{array}$ & $\begin{array}{l}16.3 \\
15.3 \\
15.9 \\
20.3 \\
23.9 \\
24.0 \\
23.2 \\
22.1\end{array}$ & $\begin{array}{l}13.9 \\
13.4 \\
14.2 \\
17.2 \\
19.2 \\
19.9 \\
19.6 \\
18.8\end{array}$ & $\begin{array}{l}16.2 \\
15.0 \\
15.9 \\
20.5 \\
24.3 \\
24.9 \\
23.4 \\
22.2\end{array}$ & $\begin{array}{l}13.6 \\
13.1 \\
14.0 \\
17.0 \\
19.2 \\
19.9 \\
19.6 \\
18.7\end{array}$ & $\begin{array}{l}15.9 \\
15.0 \\
15.9 \\
20.7 \\
24.5 \\
25.1 \\
23.04 \\
22.3\end{array}$ & $\begin{array}{l}13.2 \\
12.8 \\
13.8 \\
16.9 \\
19.1 \\
19.8 \\
19.4 \\
18.5\end{array}$ & $\begin{array}{l}15.6 \\
14.8 \\
15.8 \\
20.8 \\
24.8 \\
25.4 \\
23.6 \\
22.4\end{array}$ & $\begin{array}{l}13.1 \\
12.6 \\
13.7 \\
17.0 \\
19.1 \\
19.9 \\
19.4 \\
18.4\end{array}$ & $\begin{array}{l}19.9 \\
19.8 \\
19.9 \\
20.1 \\
20.4 \\
20.1 \\
20.0 \\
19.9\end{array}$ & & $\begin{array}{l}12.5 \\
14.7 \\
15.3 \\
15.1 \\
17.0 \\
17.4 \\
16.7 \\
18.0\end{array}$ & $\begin{array}{l}14.4 \\
16.7 \\
17.6 \\
27.5 \\
20.4 \\
20.3 \\
19.4 \\
20.9\end{array}$ & $\begin{array}{l}16.3 \\
18.4 \\
19.5 \\
19.4 \\
22.8 \\
23.4 \\
22.5 \\
23.7\end{array}$ & $\begin{array}{l}17.6 \\
20.3 \\
21.6 \\
21.6 \\
25.8 \\
26.4 \\
25.0 \\
26.8\end{array}$ \\
\hline $\begin{array}{l}7 \\
7 \\
7 \\
7 \\
7 \\
7 \\
7 \\
7\end{array}$ & $\begin{array}{r}0 \\
3 \\
6 \\
9 \\
12 \\
15 \\
18 \\
21\end{array}$ & $\begin{array}{l}21 \cdot 1 \\
20.2 \\
17.0 \\
17.4 \\
22.4 \\
23.0 \\
17.9 \\
16 \cdot 1\end{array}$ & $\begin{array}{r}18.3 \\
17.9 \\
15.2 \\
15.4 \\
13.2 \\
12.6 \\
10.3 \\
8.9\end{array}$ & $\begin{array}{l}21.3 \\
20.3 \\
17.0 \\
17.5 \\
22.8 \\
22.9 \\
17.8 \\
16.1\end{array}$ & $\begin{array}{r}18.2 \\
17.8 \\
15.1 \\
15.3 \\
13.0 \\
12.4 \\
9.7 \\
8.5\end{array}$ & $\begin{array}{l}21.3 \\
20.3 \\
16.9 \\
17.7 \\
22.8 \\
22.7 \\
18.0 \\
15.7\end{array}$ & $\begin{array}{r}18.1 \\
17.7 \\
14.8 \\
15.3 \\
12.9 \\
11.9 \\
9.4 \\
8.1\end{array}$ & $\begin{array}{l}21.2 \\
20.3 \\
16.1 \\
17.6 \\
22.3 \\
22.4 \\
18.7 \\
16.0\end{array}$ & $\begin{array}{r}18.0 \\
17.7 \\
14.6 \\
15.0 \\
12.4 \\
11.6 \\
9.4 \\
8.1\end{array}$ & $\begin{array}{l}19.9 \\
19.8 \\
19.8 \\
20.1 \\
20.7 \\
19.9 \\
19.7 \\
19.6\end{array}$ & & $\begin{array}{r}17.2 \\
9.8 \\
8.4 \\
7.0 \\
6.4 \\
3.2 \\
1.5 \\
4.8\end{array}$ & $\begin{array}{r}18.9 \\
10.3 \\
9.5 \\
8.2 \\
8.1 \\
4.7 \\
2.02 \\
5.4\end{array}$ & $\begin{array}{r}22.2 \\
12.3 \\
13.1 \\
9.4 \\
9.8 \\
7.1 \\
3.3 \\
5.4\end{array}$ & $\begin{array}{r}23.1 \\
13.9 \\
13.3 \\
12.6 \\
14.4 \\
11.3 \\
5.5 \\
6.9\end{array}$ \\
\hline $\begin{array}{l}8 \\
8 \\
8 \\
8 \\
8 \\
8 \\
8 \\
8\end{array}$ & $\begin{array}{r}0 \\
3 \\
6 \\
9 \\
12 \\
15 \\
18 \\
21\end{array}$ & $\begin{array}{l}13 \cdot 2 \\
12.2 \\
12.7 \\
18 \cdot 8 \\
21 \cdot 3 \\
21.6 \\
16 \cdot 2 \\
14.2\end{array}$ & $\begin{array}{r}7.4 \\
6.9 \\
7.7 \\
11.3 \\
12.2 \\
12.5 \\
10.9 \\
10.3\end{array}$ & $\begin{array}{l}13.0 \\
12.0 \\
12.7 \\
19.2 \\
21.8 \\
21.6 \\
16.1 \\
14.1\end{array}$ & $\begin{array}{r}7.2 \\
6.6 \\
7.5 \\
11.5 \\
12.1 \\
12.3 \\
10.07 \\
10.1\end{array}$ & $\begin{array}{l}12.88 \\
11.09 \\
12.44 \\
19.11 \\
21.05 \\
21.03 \\
16.0 \\
14.0\end{array}$ & $\begin{array}{r}6.9 \\
6.4 \\
7.2 \\
10.7 \\
11.7 \\
11.9 \\
10.5 \\
9.9\end{array}$ & $\begin{array}{l}13.0 \\
12.0 \\
12.0 \\
18.7 \\
20.9 \\
20.8 \\
16.7 \\
14.1\end{array}$ & $\begin{array}{r}6.8 \\
6.3 \\
7.4 \\
10.6 \\
11.5 \\
11.8 \\
10.6 \\
9.8\end{array}$ & $\begin{array}{l}19.5 \\
19.5 \\
19.6 \\
20.1 \\
19.9 \\
19.6 \\
19.3 \\
19.2\end{array}$ & & $\begin{array}{l}2.3 \\
3.1 \\
2.8 \\
4.4 \\
6.2 \\
3.8 \\
4.5 \\
5.1\end{array}$ & $\begin{array}{l}2.5 \\
3.2 \\
3.1 \\
6.3 \\
7.4 \\
5.8 \\
5.0 \\
5.5\end{array}$ & $\begin{array}{r}3.6 \\
4.0 \\
5.0 \\
11.0 \\
13.1 \\
-9.0 \\
5.8 \\
6.2\end{array}$ & $\begin{array}{r}409 \\
409 \\
50.8 \\
14.7 \\
1504 \\
1309 \\
80.1 \\
6.9\end{array}$ \\
\hline $\begin{array}{l}9 \\
9 \\
9 \\
9 \\
9 \\
9 \\
9 \\
9\end{array}$ & $\begin{array}{r}0 \\
3 \\
6 \\
9 \\
12 \\
15 \\
18 \\
21\end{array}$ & $\begin{array}{l}14.0 \\
13.8 \\
13.2 \\
16.9 \\
20.3 \\
21.7 \\
19.3 \\
17.4\end{array}$ & $\begin{array}{r}10.1 \\
10.1 \\
9.9 \\
12.0 \\
13.8 \\
14.9 \\
14.6 \\
13.6\end{array}$ & $\begin{array}{l}13.9 \\
13.7 \\
13.2 \\
17.0 \\
20.4 \\
21.8 \\
19.3 \\
17.4\end{array}$ & $\begin{array}{r}10.0 \\
9.9 \\
9.8 \\
11.8 \\
13.5 \\
14.6 \\
14.2 \\
13.3\end{array}$ & $\begin{array}{l}13.8 \\
13.5 \\
13.2 \\
17.1 \\
20.8 \\
21.9 \\
19.2 \\
17.3\end{array}$ & $\begin{array}{r}9.8 \\
9.7 \\
9.4 \\
11.6 \\
13.0 \\
14.4 \\
14.1 \\
13.0\end{array}$ & $\begin{array}{l}13.7 \\
13.2 \\
12.9 \\
17.2 \\
20.7 \\
21.9 \\
19.1 \\
17.0\end{array}$ & $\begin{array}{r}9.7 \\
9.6 \\
9.4 \\
11.4 \\
13.0 \\
13.9 \\
13.6 \\
12.8\end{array}$ & $\begin{array}{l}19.2 \\
19.1 \\
19.3 \\
19.7 \\
20.1 \\
19.9 \\
19.7 \\
19.3\end{array}$ & & $\begin{array}{r}5.1 \\
5.2 \\
6.5 \\
7.5 \\
8.1 \\
9.1 \\
8.2 \\
11.5\end{array}$ & $\begin{array}{r}5.5 \\
5.8 \\
7.3 \\
8.5 \\
9.3 \\
10.8 \\
9.5 \\
13.1\end{array}$ & $\begin{array}{r}6.4 \\
6.6 \\
7.7 \\
9.4 \\
10.5 \\
12.1 \\
10.8 \\
14.9\end{array}$ & $\begin{array}{r}6.7 \\
6.8 \\
8.3 \\
10.2 \\
12.4 \\
13.7 \\
12.1 \\
15.4\end{array}$ \\
\hline $\begin{array}{l}10 \\
10 \\
10 \\
10 \\
10 \\
10 \\
10 \\
10\end{array}$ & $\begin{array}{r}0 \\
3 \\
6 \\
9 \\
12 \\
15 \\
18 \\
21\end{array}$ & $\begin{array}{l}15.9 \\
14.5 \\
14.7 \\
19.3 \\
22.9 \\
23.8 \\
19.4 \\
18.5\end{array}$ & $\begin{array}{l}12.7 \\
12.1 \\
12.0 \\
14.3 \\
16.0 \\
16.4 \\
15.0 \\
15.4\end{array}$ & $\left|\begin{array}{l}15.7 \\
14.3 \\
14.6 \\
19.4 \\
23.4 \\
23.9 \\
19.4 \\
18.5\end{array}\right|$ & $\begin{array}{l}12.4 \\
11.7 \\
11.8 \\
14.0 \\
15.6 \\
16.1 \\
15.0 \\
15.1\end{array}$ & $\begin{array}{l}15.5 \\
14.2 \\
14.7 \\
19.6 \\
23.5 \\
23.7 \\
19.4 \\
18.6\end{array}$ & $\begin{array}{l}12.2 \\
11.6 \\
11.5 \\
13.7 \\
14.8 \\
15.6 \\
14.8 \\
15.0\end{array}$ & $\begin{array}{l}15.2 \\
13.9 \\
140.5 \\
19.9 \\
23.8 \\
23.3 \\
20.3 \\
18.9\end{array}$ & $\begin{array}{l}11.9 \\
11.04 \\
11.03 \\
13.8 \\
14.8 \\
15.5 \\
14.2 \\
14.04\end{array}$ & $\begin{array}{l}19.0 \\
18.9 \\
19.0 \\
19.4 \\
20.0 \\
19.9 \\
19.3 \\
19.1\end{array}$ & & $\begin{array}{r}12.8 \\
13.02 \\
11.01 \\
7.0 \\
5.5 \\
5.0 \\
2.02 \\
2.5\end{array}$ & $\begin{array}{r}14.6 \\
15.2 \\
12.7 \\
8.0 \\
7.6 \\
6.4 \\
2.6 \\
2.8\end{array}$ & $\begin{array}{r}16.4 \\
16.7 \\
13.7 \\
8.9 \\
9.0 \\
8.0 \\
3.3 \\
3.3\end{array}$ & $\begin{array}{r}17.8 \\
18.0 \\
15.0 \\
9.9 \\
10.1 \\
10.5 \\
5.1 \\
4.1\end{array}$ \\
\hline
\end{tabular}


TABLE 10

\begin{tabular}{|c|c|c|c|c|c|c|c|c|c|c|c|c|c|c|c|}
\hline \multicolumn{2}{|c|}{ STATION } & \multicolumn{4}{|l|}{4} & \multicolumn{6}{|c|}{ THREE-HOURLY AVERAGES } & \multirow{3}{*}{\multicolumn{4}{|c|}{$\begin{array}{l}\text { OCTOBER, } 1950 \\
\text { dind speed (knots) } \\
\text { dicated height }\end{array}$}} \\
\hline \multirow{3}{*}{ 总 } & \multirow{3}{*}{ 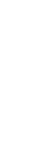 } & \multicolumn{8}{|c|}{ Average air temperature $\left({ }^{\circ} \mathrm{C}\right)$ at indicated height } & \multirow{3}{*}{$\begin{array}{l}\text { Average } \\
\text { water- } \\
\text { surface } \\
\text { tempera- } \\
\text { ture } \\
\text { () }\end{array}$} & \multirow{3}{*}{ 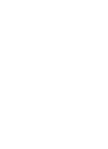 } & & & & \\
\hline & & \multicolumn{2}{|c|}{$\begin{array}{c}2 \\
\text { meters }\end{array}$} & \multicolumn{2}{|c|}{$\begin{array}{c}4 \\
\text { meters }\end{array}$} & \multicolumn{2}{|c|}{$\begin{array}{c}8 \\
\text { meters }\end{array}$} & \multicolumn{2}{|c|}{$\begin{array}{c}16 \\
\text { meters }\end{array}$} & & & & & & \\
\hline & & $\begin{array}{l}\text { Dry } \\
\text { bulb }\end{array}$ & $\begin{array}{l}\text { Wet } \\
\text { bulb }\end{array}$ & $\begin{array}{l}\text { Dry } \\
\text { bulb }\end{array}$ & $\begin{array}{l}\text { Wet } \\
\text { bulb }\end{array}$ & $\begin{array}{l}\text { Dry } \\
\text { bulb }\end{array}$ & $\begin{array}{l}\text { Wet } \\
\text { bulb }\end{array}$ & $\begin{array}{l}\text { Dry } \\
\text { bulb }\end{array}$ & $\begin{array}{l}\text { Wet } \\
\text { bulb }\end{array}$ & & & meters & meters & meters & meters \\
\hline $\begin{array}{l}11 \\
11 \\
11 \\
11 \\
11 \\
11 \\
11 \\
11\end{array}$ & $\begin{array}{r}0 \\
3 \\
6 \\
9 \\
12 \\
15 \\
18 \\
21\end{array}$ & $\begin{array}{l}17.1 \\
15.6 \\
15.1 \\
20.2 \\
25.9 \\
29.4 \\
23.5 \\
20.1\end{array}$ & $\begin{array}{l}14.1 \\
13.2 \\
13.0 \\
15.7 \\
17.5 \\
18.0 \\
17.1 \\
14.6\end{array}$ & $\begin{array}{l}17.2 \\
15.6 \\
15.4 \\
20.7 \\
26.5 \\
29.7 \\
23.7 \\
20.0\end{array}$ & $\begin{array}{l}14.0 \\
13.2 \\
12.9 \\
15.6 \\
17.0 \\
17.5 \\
16.7 \\
14.4\end{array}$ & $\begin{array}{l}17.2 \\
15.7 \\
14.6 \\
21.2 \\
26.9 \\
29.8 \\
23.9 \\
20.1\end{array}$ & $\begin{array}{l}13.9 \\
13.1 \\
12.6 \\
15.3 \\
16.5 \\
17.5 \\
16.2 \\
14.2\end{array}$ & $\begin{array}{l}17 \cdot 3 \\
15.6 \\
15.2 \\
21.6 \\
27 \cdot 3 \\
29 \cdot 5 \\
24 \cdot 6 \\
20.3\end{array}$ & $\begin{array}{l}14.0 \\
13.2 \\
12.7 \\
15.4 \\
16.7 \\
17.0 \\
16.2 \\
14.2\end{array}$ & $\begin{array}{l}19.0 \\
19.0 \\
19.1 \\
20.2 \\
22.4 \\
23.0 \\
21.9 \\
20.3\end{array}$ & & $\begin{array}{l}2.2 \\
2.7 \\
2.4 \\
1.9 \\
2.9 \\
1.9 \\
2.06 \\
4.6\end{array}$ & $\begin{array}{l}2.5 \\
3.0 \\
2.0 \\
2.0 \\
3.1 \\
2.0 \\
3.1 \\
5.3\end{array}$ & $\begin{array}{l}2.7 \\
3.1 \\
2.8 \\
? .7 \\
3.1 \\
2.0 \\
3.7 \\
6.1\end{array}$ & $\begin{array}{l}3.12 \\
3.6 \\
3.2 \\
2.2 \\
3.4 \\
6.6 \\
5.2 \\
8.4\end{array}$ \\
\hline $\begin{array}{l}12 \\
12 \\
12 \\
12 \\
12 \\
12 \\
12 \\
12\end{array}$ & $\begin{array}{r}0 \\
3 \\
6 \\
9 \\
12 \\
15 \\
18 \\
21\end{array}$ & $\begin{array}{l}16.8 \\
15.2 \\
15.3 \\
21.2 \\
24.1 \\
24.1 \\
20.3 \\
18.3\end{array}$ & $\begin{array}{l}13.1 \\
11.5 \\
12.1 \\
14.0 \\
15.0 \\
16.5 \\
15.4 \\
14.0\end{array}$ & $\begin{array}{l}16.8 \\
15.1 \\
15.5 \\
21.5 \\
24.6 \\
24.6 \\
20.3 \\
18.2\end{array}$ & $\begin{array}{l}12.9 \\
11.3 \\
11.8 \\
13.6 \\
14.5 \\
15.8 \\
14.9 \\
13.8\end{array}$ & $\begin{array}{l}16.8 \\
15.3 \\
15.3 \\
21.6 \\
24.9 \\
25.2 \\
20.4 \\
18.2\end{array}$ & $\begin{array}{l}12.7 \\
11.1 \\
11.3 \\
13.0 \\
13.8 \\
14.9 \\
14.1 \\
13.5\end{array}$ & $\begin{array}{l}17.3 \\
15: 5 \\
15: 7 \\
21: 8 \\
25: 2 \\
25.7 \\
20.8 \\
18.1\end{array}$ & $\begin{array}{l}19.7 \\
11.1 \\
11.4 \\
12.7 \\
13.8 \\
14.6 \\
13.7 \\
13.1\end{array}$ & $\begin{array}{l}18.9 \\
18.8 \\
19.2 \\
19.9 \\
20.8 \\
20.6 \\
20.1 \\
20.0\end{array}$ & & $\begin{array}{l}1.0 \\
1.7 \\
1.7 \\
6.1 \\
4.7 \\
4.4 \\
4.8 \\
7.5\end{array}$ & $\begin{array}{l}1.4 \\
1.9 \\
1.09 \\
7.3 \\
5.6 \\
6.0 \\
5.5 \\
8.5\end{array}$ & $\begin{array}{l}1.9 \\
? .7 \\
2.7 \\
8.6 \\
6.7 \\
7.4 \\
6.6 \\
3.5\end{array}$ & $\begin{array}{r}2.6 \\
3.2 \\
3.5 \\
9.2 \\
7.3 \\
8.8 \\
8.2 \\
10.8\end{array}$ \\
\hline $\begin{array}{l}13 \\
13 \\
13 \\
13 \\
13 \\
13 \\
13 \\
13\end{array}$ & $\begin{array}{r}0 \\
3 \\
6 \\
9 \\
12 \\
15 \\
18 \\
21\end{array}$ & $\begin{array}{l}17.9 \\
16.8 \\
17.2 \\
21.9 \\
25.5 \\
26.1 \\
22.9 \\
20.4\end{array}$ & $\begin{array}{l}13.7 \\
12.9 \\
13.2 \\
16.1 \\
18.2 \\
18.9 \\
18.1 \\
16.6\end{array}$ & $\begin{array}{l}17.8 \\
16.8 \\
17.1 \\
22.2 \\
25.1 \\
26.6 \\
23.1 \\
70.5\end{array}$ & $\begin{array}{l}13.3 \\
12.7 \\
12.9 \\
15.7 \\
18.2 \\
18.9 \\
17.9 \\
16.5\end{array}$ & $\begin{array}{l}17.7 \\
16.8 \\
17.2 \\
22.7 \\
26.6 \\
27.2 \\
23.4 \\
20.5\end{array}$ & $\begin{array}{l}13.0 \\
12.3 \\
12.5 \\
15.7 \\
18.0 \\
18.5 \\
17.5 \\
16.2\end{array}$ & $\begin{array}{l}17.5 \\
16: 5 \\
17: 5 \\
22.0 \\
27.1 \\
27.7 \\
22: 9 \\
20.4\end{array}$ & $\begin{array}{l}12.9 \\
12.1 \\
17.5 \\
15.7 \\
13.0 \\
18.6 \\
17.4 \\
16.1\end{array}$ & $\begin{array}{l}20.0 \\
19.9 \\
20.0 \\
20.2 \\
20.7 \\
20.5 \\
20.1 \\
20.0\end{array}$ & . & $\begin{array}{r}9.1 \\
9.8 \\
10.8 \\
12.3 \\
11.1 \\
9.7 \\
9.5 \\
12.6\end{array}$ & $\begin{array}{r}9.1 \\
11.0 \\
12.3 \\
14.2 \\
13.2 \\
11.6 \\
11.2 \\
14.6\end{array}$ & $\begin{array}{l}10.2 \\
11.3 \\
13.0 \\
15.5 \\
14.2 \\
13.2 \\
13.2 \\
15.9\end{array}$ & $\begin{array}{l}11.3 \\
13.7 \\
14.5 \\
17.3 \\
16.6 \\
15.7 \\
15.3 \\
18.4\end{array}$ \\
\hline $\begin{array}{l}14 \\
14 \\
14 \\
14 \\
14 \\
14 \\
14 \\
14\end{array}$ & $\begin{array}{r}0 \\
3 \\
6 \\
9 \\
12 \\
15 \\
18 \\
21\end{array}$ & $\begin{array}{l}19.1 \\
19.1 \\
19.3 \\
23.2 \\
77.4 \\
27.2 \\
22.8 \\
71.4\end{array}$ & $\begin{array}{l}15.8 \\
15.4 \\
15.7 \\
17.3 \\
18.4 \\
19.7 \\
17.7 \\
16.9\end{array}$ & $\begin{array}{l}19.1 \\
19.1 \\
10.4 \\
23.9 \\
28.5 \\
28.7 \\
23.4 \\
21.5\end{array}$ & $\begin{array}{l}15.5 \\
15.1 \\
15.5 \\
17.4 \\
18.3 \\
18.6 \\
17.4 \\
16.7\end{array}$ & $\begin{array}{l}10.1 \\
19.1 \\
10.5 \\
24.3 \\
39.2 \\
20.0 \\
23.8 \\
21.6\end{array}$ & $\begin{array}{l}15.3 \\
15.0 \\
15.5 \\
17.2 \\
18.3 \\
18.3 \\
17.0 \\
16.6\end{array}$ & $\begin{array}{l}19.1 \\
19.1 \\
10.7 \\
24.8 \\
29.9 \\
30.1 \\
24.6 \\
21.7\end{array}$ & $\begin{array}{l}15.2 \\
15.0 \\
15.4 \\
17.3 \\
32.4 \\
18.4 \\
16.9 \\
16.4\end{array}$ & $\begin{array}{l}19.7 \\
19.4 \\
19.4 \\
20.0 \\
19.9 \\
19.8 \\
19.5 \\
19.7\end{array}$ & & $\begin{array}{r}9.7 \\
12.6 \\
14.5 \\
12.2 \\
10.7 \\
8.8 \\
6.5 \\
10.1\end{array}$ & $\begin{array}{r}11.2 \\
14.2 \\
16.3 \\
13.4 \\
12.1 \\
10.5 \\
8.1 \\
11.7\end{array}$ & $\begin{array}{r}12.1 \\
14.5 \\
16.0 \\
13.2 \\
13.2 \\
11.2 \\
9.8 \\
13.0\end{array}$ & $\begin{array}{l}13.8 \\
16.8 \\
18.6 \\
15.5 \\
14.3 \\
13.8 \\
12.6 \\
15.2\end{array}$ \\
\hline $\begin{array}{l}15 \\
15 \\
15 \\
15 \\
15 \\
15 \\
15 \\
15\end{array}$ & $\begin{array}{r}0 \\
3 \\
6 \\
9 \\
12 \\
15 \\
18 \\
21\end{array}$ & $\begin{array}{l}19.3 \\
18.1 \\
17.8 \\
22.5 \\
25.5 \\
28.0 \\
23.3 \\
21.2\end{array}$ & $\begin{array}{l}16.3 \\
15.0 \\
14.6 \\
17.0 \\
17.9 \\
18.4 \\
17.8 \\
16.3\end{array}$ & $\begin{array}{l}19.3 \\
18.1 \\
17.8 \\
23.0 \\
26.4 \\
26.6 \\
23.7 \\
21.4\end{array}$ & $\begin{array}{l}15.0 \\
14.7 \\
14.5 \\
17.1 \\
17.8 \\
18.2 \\
17.5 \\
16.0\end{array}$ & $\begin{array}{l}19.2 \\
19.0 \\
17.9 \\
23.4 \\
26.7 \\
26.9 \\
24.0 \\
21.3\end{array}$ & $\begin{array}{l}15.8 \\
14.5 \\
14.3 \\
15.7 \\
17.7 \\
18.1 \\
17.4 \\
15.7\end{array}$ & $\begin{array}{l}19.1 \\
17.0 \\
17: 0 \\
33: 6 \\
27: 0 \\
27.4 \\
24: 4 \\
? 1.4\end{array}$ & $\begin{array}{l}15.6 \\
14.3 \\
14.2 \\
16 \cdot 8 \\
17.7 \\
10.7 \\
17.3 \\
15.5\end{array}$ & $\begin{array}{l}19.5 \\
19.3 \\
10.4 \\
90.0 \\
20.3 \\
20.3 \\
19.8 \\
19.2\end{array}$ & & $\begin{array}{r}9.2 \\
10.2 \\
10.1 \\
8.4 \\
10.0 \\
10.7 \\
9.2 \\
12.0\end{array}$ & $\begin{array}{r}10.6 \\
11.7 \\
11.5 \\
9.6 \\
12.0 \\
12.8 \\
10.0 \\
13.9\end{array}$ & $\begin{array}{l}11.5 \\
13.0 \\
19.2 \\
10.5 \\
14.2 \\
14.9 \\
13.0 \\
15.0\end{array}$ & $\begin{array}{l}13.2 \\
14.4 \\
13.7 \\
12.2 \\
16.7 \\
17.4 \\
15.1 \\
17.0\end{array}$ \\
\hline $\begin{array}{l}16 \\
16 \\
16 \\
16 \\
16 \\
16 \\
16 \\
16\end{array}$ & $\begin{array}{r}0 \\
3 \\
6 \\
9 \\
12 \\
15 \\
18 \\
21\end{array}$ & $\begin{array}{l}19.5 \\
17.8 \\
17.6 \\
22.4 \\
25.1 \\
25.0 \\
22.4 \\
19.0\end{array}$ & $\begin{array}{l}15.2 \\
14.9 \\
15.0 \\
17.2 \\
16.9 \\
16.8 \\
15.8 \\
15.3\end{array}$ & $\begin{array}{l}19.5 \\
17.7 \\
17.6 \\
22.0 \\
25.7 \\
75.4 \\
22.5 \\
19.0\end{array}$ & $\begin{array}{l}15.0 \\
14.7 \\
14.8 \\
17.0 \\
16.8 \\
16.5 \\
15.5 \\
15.1\end{array}$ & $\begin{array}{l}10.4 \\
17.7 \\
17.7 \\
23.1 \\
25.9 \\
25.8 \\
37.5 \\
10.0\end{array}$ & $\begin{array}{l}14.8 \\
14.6 \\
14.7 \\
15.8 \\
16.6 \\
16.3 \\
15.2 \\
14.8\end{array}$ & $\begin{array}{l}12,3 \\
17: 5 \\
17: 7 \\
23: 5 \\
26: 5 \\
26: 1 \\
27.5 \\
18.0\end{array}$ & $\begin{array}{l}14.7 \\
14.4 \\
14.7 \\
16.8 \\
15.7 \\
15.1 \\
15.0 \\
14.6\end{array}$ & $\begin{array}{l}13.9 \\
10.0 \\
10.1 \\
30.5 \\
10.8 \\
10.7 \\
10.1 \\
13.9\end{array}$ & & $\begin{array}{r}11.7 \\
9.8 \\
10.9 \\
14.5 \\
12.5 \\
10.9 \\
9.2 \\
7.0\end{array}$ & $\begin{array}{c}13.5 \\
11.9 \\
12.4 \\
16.7 \\
14.5 \\
12.07 \\
10.8 \\
8.1\end{array}$ & $\begin{array}{r}11 . ? \\
1 ? \cdot 4 \\
13.2 \\
17.3 \\
15.4 \\
15.7 \\
12.5 \\
7.1\end{array}$ & $\begin{array}{l}15.8 \\
13.7 \\
14.8 \\
20.4 \\
13.1 \\
17.3 \\
14.4 \\
10.6\end{array}$ \\
\hline $\begin{array}{l}17 \\
17 \\
17 \\
17 \\
17 \\
17 \\
17 \\
17\end{array}$ & $\begin{array}{r}0 \\
3 \\
6 \\
9 \\
12 \\
15 \\
18 \\
21\end{array}$ & $\begin{array}{l}17.9 \\
17.4 \\
17.3 \\
22.1 \\
25.3 \\
24.9 \\
21.1 \\
20.0\end{array}$ & $\begin{array}{l}14.8 \\
14.8 \\
14.8 \\
16.8 \\
18.0 \\
18.3 \\
17.6 \\
16.8\end{array}$ & $\begin{array}{l}17.9 \\
17.3 \\
17.4 \\
22.2 \\
25.3 \\
25.1 \\
21.6 \\
20.2\end{array}$ & $\begin{array}{l}14.7 \\
14.6 \\
14.6 \\
16.8 \\
17.9 \\
18.0 \\
17.2 \\
16.5\end{array}$ & $\begin{array}{l}17.9 \\
17.3 \\
17.5 \\
2 ? .9 \\
26.0 \\
26.4 \\
27.3 \\
20.4\end{array}$ & $\begin{array}{l}14.5 \\
14.5 \\
14.5 \\
16.7 \\
17.5 \\
17.5 \\
16.7 \\
16.0\end{array}$ & $\begin{array}{l}17.0 \\
17.9 \\
17.5 \\
23.5 \\
26.5 \\
27.0 \\
23.0 \\
20.6\end{array}$ & $\begin{array}{l}14.2 \\
14.3 \\
14.4 \\
16.8 \\
17.7 \\
17.6 \\
16.4 \\
15.7\end{array}$ & $\begin{array}{l}18.9 \\
18.9 \\
18.9 \\
19.7 \\
21.6 \\
20.1 \\
19.9 \\
10.6\end{array}$ & & $\begin{array}{r}8.5 \\
9.5 \\
10.1 \\
9.5 \\
7.4 \\
5.1 \\
3.9 \\
5.4\end{array}$ & $\begin{array}{r}0.6 \\
10.2 \\
11.5 \\
11.0 \\
8.6 \\
6.6 \\
5.7 \\
0.3\end{array}$ & $\begin{array}{r}12.6 \\
11.4 \\
6.6 \\
7.0 \\
7.0 \\
7.4\end{array}$ & $\begin{array}{r}12.0 \\
12.3 \\
14.6 \\
13.5 \\
10.7 \\
9.4 \\
0.1 \\
9.1\end{array}$ \\
\hline $\begin{array}{l}18 \\
18 \\
18 \\
18 \\
18 \\
18 \\
18 \\
18\end{array}$ & $\begin{array}{r}0 \\
3 \\
6 \\
9 \\
12 \\
15 \\
18 \\
21\end{array}$ & $\begin{array}{l}18.3 \\
17.3 \\
17.6 \\
21.9 \\
23.4 \\
22.4 \\
19.8 \\
18.5\end{array}$ & $\begin{array}{r}15.6 \\
14.9 \\
15.5 \\
17.5 \\
17.2 \\
17.7 \\
17.1 \\
16.4\end{array}$ & $\begin{array}{l}18.3 \\
17.2 \\
17.6 \\
22.3 \\
24.1 \\
22.7 \\
19.8 \\
18.4\end{array}$ & $\begin{array}{l}15.4 \\
14.9 \\
15.3 \\
17.3 \\
17.1 \\
17.6 \\
16.9 \\
16.3\end{array}$ & $\begin{array}{l}18 \cdot 2 \\
17.3 \\
17.7 \\
23: 2 \\
24.7 \\
22.9 \\
10.8 \\
18.4\end{array}$ & $\begin{array}{l}15.1 \\
14.6 \\
15.2 \\
16.9 \\
15.3 \\
17.2 \\
16.5 \\
16 . ?\end{array}$ & $\begin{array}{l}18.2 \\
17.2 \\
17.9 \\
22.5 \\
24.8 \\
23.1 \\
20.1 \\
18.4\end{array}$ & $\begin{array}{l}15.1 \\
14.6 \\
15.4 \\
16.9 \\
15.3 \\
17.0 \\
16.2 \\
16.2\end{array}$ & $\begin{array}{l}19.1 \\
19.1 \\
19.3 \\
20.3 \\
21.3 \\
20.7 \\
20.1 \\
10.8\end{array}$ & & $\begin{array}{l}6.2 \\
4.8 \\
4.8 \\
3.4 \\
3.8 \\
5.0 \\
2.0 \\
2.6\end{array}$ & $\begin{array}{l}7.1 \\
5.3 \\
5.4 \\
4.1 \\
4.6 \\
7.1 \\
3.4 \\
2.9\end{array}$ & $\begin{array}{l}7.9 \\
5.9 \\
5.9 \\
4.4 \\
5.5 \\
3.8 \\
3.9 \\
3.0\end{array}$ & $\begin{array}{r}9.2 \\
6.4 \\
6.7 \\
5.4 \\
6.1 \\
10.0 \\
5.2 \\
3.6\end{array}$ \\
\hline $\begin{array}{l}19 \\
19 \\
19 \\
19 \\
19 \\
19 \\
19 \\
19\end{array}$ & $\begin{array}{r}0 \\
3 \\
6 \\
9 \\
12 \\
15 \\
18 \\
21\end{array}$ & $\begin{array}{l}18.1 \\
18.2 \\
16.2 \\
18.6 \\
22.5 \\
23.3 \\
20.3 \\
18.1\end{array}$ & $\begin{array}{l}16.1 \\
15.9 \\
14.5 \\
15.4 \\
16.2 \\
15.8 \\
15.2 \\
14.0\end{array}$ & $\begin{array}{l}18.1 \\
18.1 \\
15.9 \\
18.9 \\
22.6 \\
23.3 \\
20.3 \\
10.1\end{array}$ & $\begin{array}{l}16.1 \\
15.9 \\
14.3 \\
15.5 \\
15.9 \\
15.6 \\
15.1 \\
13.8\end{array}$ & $\begin{array}{l}17.0 \\
13.0 \\
15.6 \\
10.9 \\
22.5 \\
23.3 \\
20.5 \\
18.0\end{array}$ & $\begin{array}{l}15.0 \\
15.8 \\
14.1 \\
15.4 \\
15.8 \\
15.5 \\
14.8 \\
13.6\end{array}$ & $\begin{array}{l}17.0 \\
13.0 \\
15.6 \\
18.8 \\
22.4 \\
23.5 \\
21.1 \\
18.3\end{array}$ & $\begin{array}{l}15.9 \\
15.7 \\
14.1 \\
15.3 \\
15.5 \\
15.5 \\
14.9 \\
13.6\end{array}$ & $\begin{array}{l}19.8 \\
19.7 \\
13.6 \\
10.9 \\
30.0 \\
18.2 \\
18.8 \\
18.7\end{array}$ & & $\begin{array}{l}2.03 \\
2.09 \\
1.8 \\
1.9 \\
2.1 \\
2.0 \\
0.5 \\
1.3\end{array}$ & $\begin{array}{l}2.5 \\
3.3 \\
2.1 \\
2.0 \\
2.3 \\
2.7 \\
1.1 \\
1.4\end{array}$ & $\begin{array}{l}2.7 \\
3.4 \\
3.3 \\
4.0 \\
4.7 \\
4.0 \\
2.0 \\
2.0\end{array}$ & $\begin{array}{l}3.0 \\
3.0 \\
3.6 \\
4.0 \\
6.3 \\
6.3 \\
5.4 \\
3.9\end{array}$ \\
\hline $\begin{array}{l}20 \\
20 \\
20 \\
20 \\
20 \\
20 \\
20 \\
20\end{array}$ & $\begin{array}{r}0 \\
3 \\
6 \\
9 \\
12 \\
15 \\
18 \\
21\end{array}$ & $\begin{array}{l}16.3 \\
14.5 \\
14.5 \\
17.6 \\
21.6 \\
20.9 \\
17.9 \\
15.6\end{array}$ & $\begin{array}{l}12.7 \\
12.3 \\
12.8 \\
14.0 \\
15.5 \\
15.0 \\
14.4 \\
12.0\end{array}$ & $\begin{array}{l}16.3 \\
14: 4 \\
14.6 \\
17.0 \\
21.0 \\
20.0 \\
17.7 \\
15.4\end{array}$ & $\begin{array}{l}12.7 \\
12: 1 \\
12: 6 \\
14: 1 \\
15: 5 \\
14: 9 \\
14 \cdot 2 \\
11.7\end{array}$ & $\begin{array}{l}15.3 \\
14.3 \\
14.4 \\
77.8 \\
21.9 \\
21.0 \\
17.6 \\
15.4\end{array}$ & $\begin{array}{l}12.4 \\
11.9 \\
12.4 \\
13.0 \\
15.4 \\
14.7 \\
23.2 \\
11.5\end{array}$ & $\begin{array}{l}16.7 \\
14: 7 \\
14: 4 \\
17: 7 \\
21: 6 \\
21.2 \\
18.6 \\
15.9\end{array}$ & $\begin{array}{l}12.4 \\
13.0 \\
12.0 \\
13.0 \\
15.3 \\
14.6 \\
13.0 \\
11.04\end{array}$ & $\begin{array}{l}18.8 \\
13.7 \\
13.7 \\
19.1 \\
19.1 \\
13.8 \\
18.7 \\
19.6\end{array}$ & & $\begin{array}{l}2.1 \\
1.09 \\
1.3 \\
1.8 \\
1.0 \\
3.1 \\
0.8 \\
0.7\end{array}$ & $\begin{array}{l}2.3 \\
1.9 \\
1.0 \\
3.0 \\
3.4 \\
3.4 \\
1.1 \\
1.0\end{array}$ & $\begin{array}{l}3.1 \\
3.0 \\
3.7 \\
3.9 \\
4.0 \\
4.1 \\
? .1 \\
1.9\end{array}$ & $\begin{array}{l}3.1 \\
3.4 \\
4.5 \\
5.4 \\
6.6 \\
6.2 \\
4.5 \\
3.4\end{array}$ \\
\hline
\end{tabular}




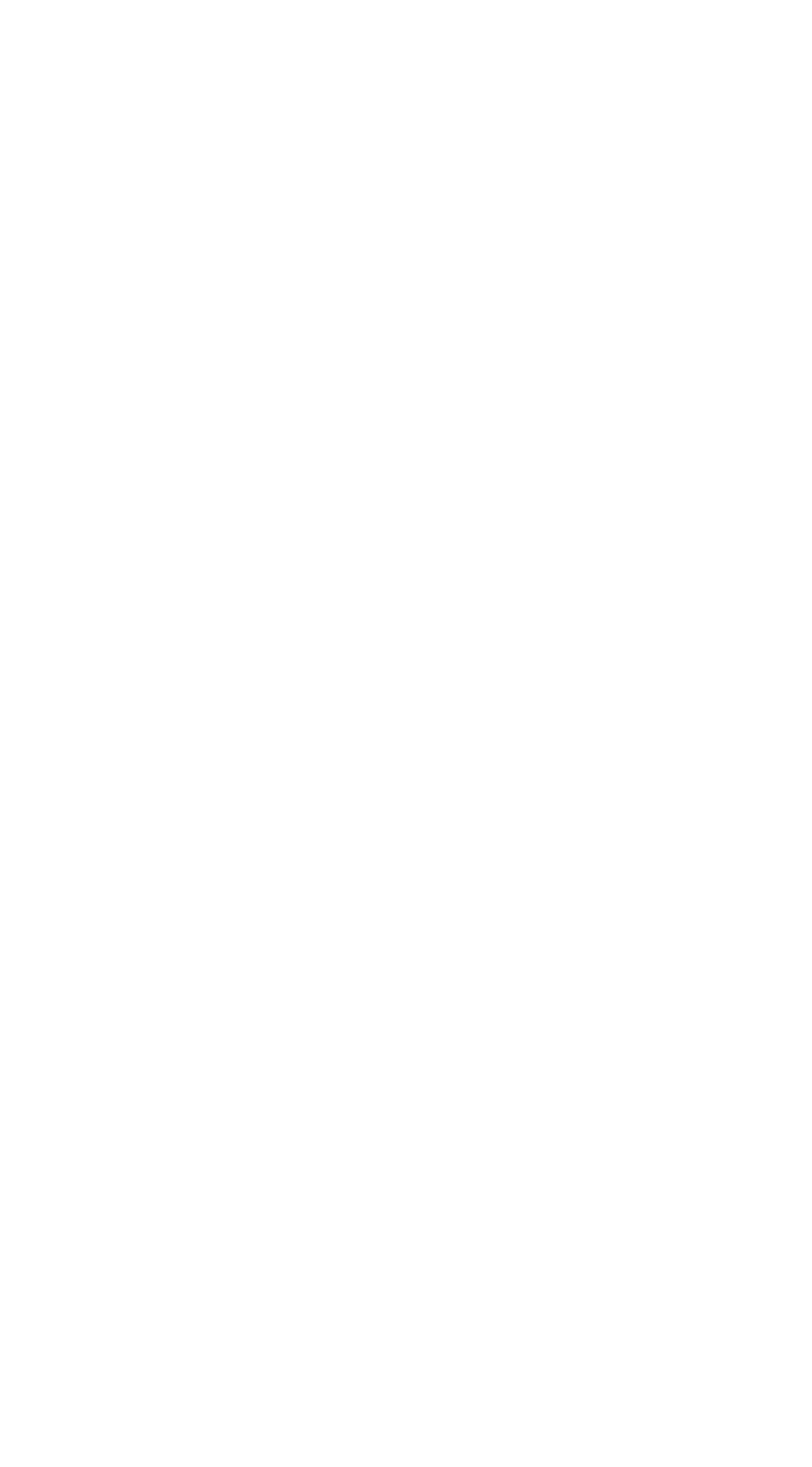


TABLE 10

Table 10. - Three-hour averages of air and water-surface temperatures and wind directions and speed, April 1950-August 1951, Lake Hetner-Continued

STATION 4 THREE-HOURLY AVERAGES

NOVEMBER, 1950

\begin{tabular}{|c|c|c|c|c|c|c|c|c|c|c|c|c|c|c|c|}
\hline \multirow{3}{*}{ 吉 } & \multirow{3}{*}{ 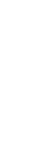 } & \multicolumn{8}{|c|}{ Average air temperature $\left({ }^{\circ} \mathrm{C}\right)$ at indicated height } & \multirow{3}{*}{$\begin{array}{l}\text { Average } \\
\text { water- } \\
\text { surface } \\
\text { tempera- } \\
\text { ture } \\
\text { (C) }\end{array}$} & \multirow{3}{*}{$\begin{array}{c}\text { A verage } \\
\text { wind } \\
\text { direction } \\
\text { (coded) }\end{array}$} & \multirow{2}{*}{\multicolumn{4}{|c|}{$\begin{array}{c}\text { Average wind speed (knots) } \\
\text { at indicated height }\end{array}$}} \\
\hline & & \multicolumn{2}{|c|}{$\begin{array}{c}2 \\
\text { meters }\end{array}$} & \multicolumn{2}{|c|}{$\begin{array}{c}4 \\
\text { meters }\end{array}$} & \multicolumn{2}{|c|}{$\begin{array}{c}8 \\
\text { meters }\end{array}$} & \multicolumn{2}{|c|}{$\begin{array}{c}16 \\
\text { meters }\end{array}$} & & & & & & \\
\hline & & $\begin{array}{l}\text { Dry } \\
\text { bulb }\end{array}$ & $\begin{array}{l}\text { Wet } \\
\text { bulb }\end{array}$ & $\begin{array}{l}\text { Dry } \\
\text { bulb }\end{array}$ & $\begin{array}{l}\text { Wet } \\
\text { bulb }\end{array}$ & $\begin{array}{l}\text { Dry } \\
\text { buib }\end{array}$ & $\begin{array}{l}\text { Wet } \\
\text { bulb }\end{array}$ & $\begin{array}{l}\text { Dry } \\
\text { bulb }\end{array}$ & $\begin{array}{l}\text { Wet } \\
\text { bulb }\end{array}$ & & & $\begin{array}{c}2 \\
\text { meters }\end{array}$ & $\begin{array}{c}4 \\
\text { meters }\end{array}$ & $\begin{array}{c}8 \\
\text { meters }\end{array}$ & $\begin{array}{c}16 \\
\text { meters }\end{array}$ \\
\hline $\begin{array}{l}1 \\
1 \\
1 \\
1 \\
1 \\
1 \\
1 \\
1\end{array}$ & $\begin{array}{r}0 \\
3 \\
6 \\
9 \\
12 \\
15 \\
18 \\
21\end{array}$ & $\begin{array}{l}17.7 \\
18.0 \\
18.2 \\
13.4 \\
10.3\end{array}$ & $\begin{array}{r}10.7 \\
10.6 \\
10.5 \\
7.7 \\
6.2\end{array}$ & $\begin{array}{l}17.9 \\
18.2 \\
18.2 \\
13.0 \\
10.0\end{array}$ & $\begin{array}{r}10.5 \\
10.2 \\
10.2 \\
7.4 \\
5.9\end{array}$ & $\begin{array}{r}17.4 \\
18.0 \\
18.0 \\
12.9 \\
0.8\end{array}$ & $\begin{array}{r}10.2 \\
10.0 \\
9.9 \\
7.0 \\
5.5\end{array}$ & $\begin{array}{l}17.1 \\
17.4 \\
17.5 \\
13.4 \\
10.2\end{array}$ & $\begin{array}{l}9.9 \\
9.7 \\
2.7 \\
7.1 \\
5.5\end{array}$ & $\begin{array}{l}18.0 \\
18.0 \\
17.6 \\
17.5 \\
17.3\end{array}$ & & $\begin{array}{r}17.2 \\
16.7 \\
14.3 \\
7.2 \\
4.9 \\
3.7 \\
1.4 \\
1.4\end{array}$ & $\begin{array}{r}19.6 \\
18.9 \\
15.7 \\
8.6 \\
7.2 \\
6.0 \\
2.9 \\
3.0\end{array}$ & $\begin{array}{l}20.1 \\
19.1 \\
15.4 \\
14.1 \\
17.3 \\
10.3 \\
5.4 \\
5.3\end{array}$ & $\begin{array}{r}23.7 \\
22.4 \\
17.8 \\
17.4 \\
17.5 \\
15.8 \\
9.6 \\
9.2\end{array}$ \\
\hline $\begin{array}{l}2 \\
2 \\
2 \\
2 \\
2 \\
2 \\
2 \\
2\end{array}$ & $\begin{array}{r}0 \\
3 \\
6 \\
9 \\
12 \\
15 \\
18 \\
21\end{array}$ & $\begin{array}{r}8.0 \\
6.4 \\
5.7 \\
10.1 \\
13.1 \\
12.8 \\
11.4 \\
8.9\end{array}$ & $\begin{array}{l}5.3 \\
4.5 \\
4.2 \\
7.0 \\
8.2 \\
7.7 \\
7.4 \\
7.7\end{array}$ & $\begin{array}{r}7 \cdot 7 \\
6.2 \\
5.4 \\
10.2 \\
13.2 \\
12.7 \\
11.2 \\
8.9\end{array}$ & $\begin{array}{l}4.8 \\
4.3 \\
4.2 \\
5.9 \\
8.9 \\
7.6 \\
7.3 \\
7.6\end{array}$ & $\begin{array}{r}7.3 \\
5.9 \\
5.4 \\
10.2 \\
13.1 \\
12.5 \\
11.2 \\
8.7\end{array}$ & $\begin{array}{l}4.4 \\
4.0 \\
4.0 \\
6.7 \\
8.1 \\
7.5 \\
7.1 \\
7.5\end{array}$ & $\begin{array}{r}7.8 \\
6.1 \\
5.5 \\
10.0 \\
12.8 \\
12.4 \\
11.2 \\
8.4\end{array}$ & $\begin{array}{l}4.5 \\
4.0 \\
3.0 \\
6.7 \\
7.9 \\
7.3 \\
7.0 \\
7.2\end{array}$ & $\begin{array}{l}17.3 \\
17: 2 \\
17: 0 \\
17.4 \\
17.2 \\
17.09 \\
16.9 \\
16.8\end{array}$ & & $\begin{array}{l}1.0 \\
1.8 \\
3.04 \\
2.44 \\
4.1 \\
5.4 \\
2.7 \\
3.4\end{array}$ & $\begin{array}{l}1.8 \\
2.0 \\
2.4 \\
3.0 \\
4.6 \\
6.2 \\
4.1 \\
4.8\end{array}$ & $\begin{array}{l}3.7 \\
3.1 \\
3.5 \\
3.9 \\
5.0 \\
7.2 \\
6.0 \\
7.3\end{array}$ & $\begin{array}{r}7.1 \\
4.3 \\
4.2 \\
4.8 \\
6.7 \\
10.1 \\
9.0 \\
10.1\end{array}$ \\
\hline $\begin{array}{l}3 \\
3 \\
3 \\
3 \\
3 \\
3 \\
3 \\
3 \\
3\end{array}$ & $\begin{array}{r}0 \\
3 \\
6 \\
9 \\
12 \\
15 \\
18 \\
21\end{array}$ & $\begin{array}{l}7.2 \\
3.8 \\
3.4 \\
2.3 \\
2.8 \\
3.7 \\
2.4 \\
0.3\end{array}$ & $\begin{array}{r}7.1 \\
3.6 \\
2.9 \\
2.0 \\
2.03 \\
1.9 \\
0.9 \\
-0.1\end{array}$ & $\begin{array}{l}7.1 \\
3.7 \\
3.7 \\
2.1 \\
2.6 \\
3.4 \\
2.0 \\
0.1\end{array}$ & $\begin{array}{r}7.0 \\
3.5 \\
2.6 \\
1.0 \\
2.1 \\
1.7 \\
0.5 \\
-0.6\end{array}$ & $\begin{array}{r}7.0 \\
3.5 \\
2.9 \\
1.9 \\
2.6 \\
3.1 \\
3.7 \\
-0.2\end{array}$ & $\begin{array}{r}6.7 \\
3.1 \\
2.2 \\
1.6 \\
1.0 \\
1.04 \\
0.22 \\
-0.9\end{array}$ & $\begin{array}{r}6.7 \\
3.4 \\
2.8 \\
1.0 \\
2.5 \\
3.0 \\
1.6 \\
-0.3\end{array}$ & $\begin{array}{r}6.4 \\
2.9 \\
1.9 \\
1.4 \\
1.8 \\
1.3 \\
0.1 \\
-0.9\end{array}$ & $\begin{array}{l}16.8 \\
16.6 \\
16.5 \\
16.0 \\
15.8 \\
15.7 \\
15.5 \\
15.4\end{array}$ & & $\begin{array}{l}3.8 \\
6.1 \\
7.4 \\
6.9 \\
5.7 \\
5.7 \\
3.2 \\
2.9\end{array}$ & $\begin{array}{r}5.8 \\
9.4 \\
11.4 \\
10.7 \\
10.3 \\
9.4 \\
5.3 \\
3.0\end{array}$ & $\begin{array}{r}10.4 \\
17.6 \\
21.0 \\
20.2 \\
10.6 \\
15.6 \\
0.1 \\
5.5\end{array}$ & $\begin{array}{r}14.9 \\
24.8 \\
28.8 \\
28.8 \\
27.8 \\
23.7 \\
13.5 \\
5.7\end{array}$ \\
\hline $\begin{array}{l}4 \\
4 \\
4 \\
4 \\
4 \\
4 \\
4 \\
4\end{array}$ & $\begin{array}{r}0 \\
3 \\
6 \\
9 \\
22 \\
15 \\
18 \\
21\end{array}$ & $\begin{array}{r}-0.4 \\
-0.7 \\
-0.3 \\
5.3 \\
7.7 \\
9.9 \\
9.0 \\
7.9\end{array}$ & $\begin{array}{r}-0.8 \\
-1.4 \\
-1.3 \\
1.3 \\
3.1 \\
5.0 \\
5.0 \\
4.3\end{array}$ & $\begin{array}{l}0.8 \\
1.1 \\
0.5 \\
5.7 \\
7.6 \\
9.8 \\
8.5 \\
7.7\end{array}$ & $\mid \begin{array}{r}-1.3 \\
-1.8 \\
-1.4 \\
1.8 \\
3.2 \\
4.7 \\
4.7 \\
4.1\end{array}$ & $\begin{array}{r}-1.0 \\
=1.3 \\
-0.6 \\
5.0 \\
7.6 \\
9.7 \\
8.4 \\
7.8\end{array}$ & $\begin{array}{r}-1.5 \\
-2.0 \\
-1.3 \\
2.1 \\
3.3 \\
4.4 \\
4.2 \\
3.5\end{array}$ & $\left|\begin{array}{r}-1.1 \\
-1.6 \\
-0.5 \\
5.5 \\
7.5 \\
9.5 \\
8.0 \\
7.3\end{array}\right|$ & {$\left[\begin{array}{r}-1.7 \\
-1.9 \\
1.7 \\
3.0 \\
4.3 \\
4.0 \\
3.1\end{array}\right.$} & $\begin{array}{l}15.3 \\
15.1 \\
15.0 \\
15.4 \\
15.7 \\
15.1 \\
14.9 \\
14.8\end{array}$ & & $\begin{array}{r}2.7 \\
3.6 \\
4.4 \\
2.2 \\
4.6 \\
6.8 \\
0.7 \\
13.4\end{array}$ & $\begin{array}{r}2.8 \\
3.7 \\
4.7 \\
2.3 \\
4.9 \\
7.6 \\
10.7 \\
15.0\end{array}$ & $\begin{array}{r}4 . ? \\
4.4 \\
4.8 \\
2.9 \\
4.7 \\
7.8 \\
11.9 \\
15.4\end{array}$ & $\begin{array}{r}4.8 \\
5.1 \\
5.4 \\
3.0 \\
5.3 \\
8.4 \\
12.7 \\
17.2\end{array}$ \\
\hline $\begin{array}{l}5 \\
5 \\
5 \\
5 \\
5 \\
5 \\
5 \\
5\end{array}$ & $\begin{array}{r}0 \\
3 \\
6 \\
9 \\
12 \\
15 \\
18 \\
21\end{array}$ & $\begin{array}{r}7.8 \\
7.1 \\
6.7 \\
22.0 \\
18.5 \\
21.4 \\
17.1 \\
13.8\end{array}$ & $\begin{array}{r}4.4 \\
3.9 \\
3.8 \\
7.5 \\
11.0 \\
12.4 \\
10.8 \\
9.3\end{array}$ & $\begin{array}{r}7.5 \\
6.9 \\
6.4 \\
12.2 \\
19.1 \\
22.1 \\
17.2 \\
13.7\end{array}$ & $\begin{array}{r}3.9 \\
3.6 \\
3.6 \\
7.3 \\
11.01 \\
12.4 \\
10.8 \\
0.1\end{array}$ & $\begin{array}{r}7.3 \\
6.5 \\
6.1 \\
12.5 \\
10.6 \\
22.6 \\
17.0 \\
13.7\end{array}$ & $\begin{array}{r}3.1 \\
2.9 \\
3.1 \\
7.1 \\
10.6 \\
11.8 \\
10.2 \\
8.7\end{array}$ & $\begin{array}{r}6.0 \\
6.0 \\
6.0 \\
12.5 \\
10.0 \\
23.1 \\
17.0 \\
13.5\end{array}$ & $\begin{array}{r}3.0 \\
2.8 \\
2.8 \\
6.8 \\
10.2 \\
11.5 \\
9.8 \\
2.3\end{array}$ & $\begin{array}{l}14.7 \\
14.6 \\
14.5 \\
14.6 \\
14.9 \\
14.6 \\
14.4 \\
14.1\end{array}$ & & $\begin{array}{l}15.4 \\
14 . ? \\
12.7 \\
10.9 \\
12.4 \\
12.0 \\
12.1 \\
12.7\end{array}$ & $\begin{array}{l}17.3 \\
16.5 \\
14.4 \\
12.3 \\
14.5 \\
13.9 \\
14.1 \\
14.5\end{array}$ & $\begin{array}{l}17.4 \\
15.9 \\
15.0 \\
13.1 \\
15.3 \\
15.3 \\
16.0 \\
15.4\end{array}$ & $\begin{array}{l}19.5 \\
19.8 \\
15.5 \\
14.6 \\
13.0 \\
18.1 \\
18.8 \\
17.7\end{array}$ \\
\hline $\begin{array}{l}6 \\
6 \\
6 \\
6 \\
6 \\
6 \\
6 \\
6\end{array}$ & $\begin{array}{r}0 \\
3 \\
6 \\
9 \\
12 \\
15 \\
18 \\
21\end{array}$ & $\begin{array}{l}13.9 \\
12.1 \\
10.5 \\
13.7 \\
16.1 \\
18.5 \\
14.3 \\
11.0\end{array}$ & $\begin{array}{r}8.5 \\
7.3 \\
6.4 \\
7.2 \\
9.2 \\
10.1 \\
8.9 \\
7.4\end{array}$ & $\begin{array}{l}13.9 \\
12.0 \\
10.4 \\
13.7 \\
16.3 \\
18.7 \\
14.1 \\
10.8\end{array}$ & $\begin{array}{r}8.5 \\
7.2 \\
6.3 \\
7.4 \\
0.0 \\
10.2 \\
8.6 \\
7.0\end{array}$ & $\begin{array}{l}14.0 \\
11.8 \\
10.4 \\
13.8 \\
16.5 \\
18.8 \\
14.0 \\
10.5\end{array}$ & $\begin{array}{r}8.1 \\
6.6 \\
5.7 \\
7.1 \\
8.4 \\
10.3 \\
8.4 \\
6.8\end{array}$ & $\begin{array}{l}14: 0 \\
11: 7 \\
10.1 \\
13.9 \\
16 \cdot 7 \\
18: 8 \\
14 \cdot 7 \\
11.4\end{array}$ & $\begin{array}{l}7.6 \\
6.3 \\
5.6 \\
7.0 \\
8.2 \\
0.5 \\
8.1 \\
6.8\end{array}$ & $\begin{array}{l}14.0 \\
14: 0 \\
14.1 \\
14: 7 \\
15.6 \\
15.0 \\
14 \cdot 2 \\
14.1\end{array}$ & & $\begin{array}{r}13.6 \\
10.2 \\
8.1 \\
4.1 \\
1.6 \\
0.8 \\
1.4\end{array}$ & $\begin{array}{r}15.3 \\
11.5 \\
9.1 \\
4.4 \\
2.5 \\
1.1 \\
1.8 \\
0.9\end{array}$ & $\begin{array}{r}15.9 \\
12.3 \\
0.7 \\
4.2 \\
2.5 \\
1.3 \\
2.4 \\
2.0\end{array}$ & $\begin{array}{r}13.4 \\
13.9 \\
10.7 \\
4.6 \\
2.5 \\
2.4 \\
4.0 \\
2.3\end{array}$ \\
\hline $\begin{array}{l}7 \\
7 \\
7 \\
7 \\
7 \\
7 \\
7 \\
7\end{array}$ & $\begin{array}{r}0 \\
3 \\
6 \\
9 \\
12 \\
15 \\
18 \\
21\end{array}$ & $\begin{array}{r}9.9 \\
8.9 \\
6.3 \\
9.4 \\
16.1 \\
17.5 \\
13.4 \\
12.2\end{array}$ & $\begin{array}{r}7.0 \\
7.2 \\
5.4 \\
7.3 \\
10.7 \\
11.6 \\
11.9 \\
10.6\end{array}$ & $\begin{array}{r}9.9 \\
8.8 \\
6 \cdot 2 \\
10.0 \\
16 \cdot 2 \\
17.9 \\
13.4 \\
12.3\end{array}$ & $\begin{array}{r}7.0 \\
7: 3 \\
5: 4 \\
7.4 \\
11.0 \\
11.7 \\
11.7 \\
10.7\end{array}$ & $\begin{array}{r}10.0 \\
8.7 \\
6.1 \\
9.8 \\
16.4 \\
17.7 \\
13.8 \\
12.6\end{array}$ & $\begin{array}{r}6.8 \\
7.2 \\
5: 3 \\
7.2 \\
10.7 \\
11.3 \\
11.0 \\
10.3\end{array}$ & $\begin{array}{r}10.5 \\
8.8 \\
6.1 \\
10.0 \\
16.0 \\
17.4 \\
14.5 \\
13.0\end{array}$ & $\begin{array}{r}7.0 \\
7.3 \\
5.2 \\
7.1 \\
10.5 \\
10.9 \\
10.2 \\
0.7\end{array}$ & $\begin{array}{l}14.0 \\
13.9 \\
13.9 \\
14.1 \\
14.9 \\
14.5 \\
14.0 \\
13.9\end{array}$ & & $\begin{array}{l}1.4 \\
1.5 \\
3.2 \\
3.4 \\
2.5 \\
2.1 \\
0.6 \\
0.7\end{array}$ & $\begin{array}{l}1.5 \\
2.1 \\
3.7 \\
3.4 \\
2.9 \\
2.1 \\
0.8 \\
0.6\end{array}$ & $\begin{array}{l}2.8 \\
3.3 \\
4.2 \\
5.1 \\
4.0 \\
3.1 \\
0.9 \\
1.4\end{array}$ & $\begin{array}{l}2.85 \\
3.6 \\
4.6 \\
5.2 \\
4.7 \\
3.6 \\
0.8 \\
1.3\end{array}$ \\
\hline $\begin{array}{l}8 \\
8 \\
8 \\
8 \\
8 \\
8 \\
8 \\
8\end{array}$ & $\begin{array}{r}0 \\
3 \\
6 \\
9 \\
12 \\
15 \\
18 \\
21 .\end{array}$ & $\begin{array}{r}11.0 \\
11.4 \\
11.00 \\
13.8 \\
17.3 \\
10.5 \\
5.0 \\
3.4\end{array}$ & $\begin{array}{r}9.2 \\
9.5 \\
9.7 \\
11.2 \\
11.9 \\
6.8 \\
2.3 \\
0.7\end{array}$ & $\begin{array}{r}11.01 \\
31.01 \\
11.0 \\
13.9 \\
17.6 \\
9.9 \\
4.8 \\
3.2\end{array}$ & $\begin{array}{r}9.2 \\
9.6 \\
9.8 \\
11.4 \\
12.0 \\
6.6 \\
2.02 \\
0.7\end{array}$ & $\begin{array}{r}10.9 \\
11.00 \\
11.01 \\
14.0 \\
17.0 \\
9.3 \\
4.6 \\
3.1\end{array}$ & $\begin{array}{r}9.0 \\
9.5 \\
9.7 \\
11.0 \\
11.7 \\
6.0 \\
1.9 \\
0.4\end{array}$ & $\begin{array}{r}11.3 \\
10.0 \\
11.0 \\
14.2 \\
17.6 \\
8.6 \\
4.02 \\
2.7\end{array}$ & $\begin{array}{r}9.0 \\
0.4 \\
9.5 \\
11.0 \\
13.2 \\
5.3 \\
1.5 \\
0.1\end{array}$ & $\begin{array}{l}13.8 \\
13.7 \\
13.7 \\
14.1 \\
14.6 \\
14.0 \\
13.7 \\
13.8\end{array}$ & & $\begin{array}{l}4.4 \\
5.9 \\
5.6 \\
6.0 \\
4.4 \\
7.3 \\
7.7 \\
7.1\end{array}$ & $\begin{array}{l}4.9 \\
6.6 \\
6.2 \\
8.7 \\
5.2 \\
21.8 \\
12.4 \\
10.8\end{array}$ & $\begin{array}{r}5.9 \\
7.4 \\
6.5 \\
7.0 \\
6.9 \\
21.2 \\
10.9 \\
15.9\end{array}$ & $\begin{array}{r}6.9 \\
3.1 \\
7.3 \\
7.8 \\
9.2 \\
30.7 \\
30.6 \\
25.3\end{array}$ \\
\hline $\begin{array}{l}9 \\
9 \\
9 \\
9 \\
9 \\
9 \\
9 \\
9\end{array}$ & $\begin{array}{r}0 \\
3 \\
6 \\
9 \\
12 \\
15 \\
18 \\
21 .\end{array}$ & $\begin{array}{r}1.8 \\
0.2 \\
0.1 \\
1.2 \\
2.4 \\
2.4 \\
0.1 \\
-\quad 1.0\end{array}$ & $\begin{array}{l}-0.5 \\
-1.8\end{array}$ & $\begin{array}{l}1.5 \\
0.1 \\
0.3 \\
1.2 \\
2.4 \\
2.2 \\
0.0 \\
2.3\end{array}$ & -0.7 & $\begin{array}{r}1.3 \\
-0.3 \\
-0.5 \\
1.0 \\
2.2 \\
1.7 \\
-0.2 \\
-1.5\end{array} \mid$ & -1.7 & $\begin{array}{r}1.0 \\
-0.5 \\
-0.09 \\
0.2 \\
1.5 \\
1.2 \\
-0.6 \\
-1.7\end{array} \mid$ & -0.9 & $\begin{array}{l}13.6 \\
13.4 \\
13.3 \\
13.4 \\
13.1 \\
12.8 \\
12.5 \\
12.3\end{array}$ & & $\begin{array}{l}5.4 \\
3.0 \\
5.0 \\
7.1 \\
5.9 \\
5.4 \\
4.4 \\
4.4\end{array}$ & $\begin{array}{r}8.6 \\
6.7 \\
7.9 \\
10.6 \\
10.3 \\
8.8 \\
7.3 \\
7.1\end{array}$ & $\begin{array}{l}13.2 \\
11.5 \\
12.6 \\
16.1 \\
15.6 \\
13.7 \\
12.6 \\
12.0\end{array}$ & $\begin{array}{l}20.1 \\
17.5 \\
19.5 \\
24.9 \\
24.0 \\
21.3 \\
19.5 \\
18.4\end{array}$ \\
\hline $\begin{array}{l}10 \\
10 \\
10 \\
10 \\
10 \\
10 \\
10 \\
10\end{array}$ & $\begin{array}{r}0 \\
3 \\
6 \\
9 \\
12 \\
15 \\
18 \\
21\end{array}$ & $\begin{array}{r}-2.6 \\
=3.5 \\
=-4.8 \\
=2.7 \\
=0.77 \\
0.9 \\
0.1 \\
-0.4\end{array}$ & & $\begin{array}{l}2.9 \\
3.8 \\
5.1 \\
2.7 \\
0.7 \\
0.6 \\
0.0 \\
0.0\end{array}$ & & $\begin{array}{l}-3.2 \\
-\quad 4.2 \\
-5.5 \\
-3.3 \\
-1.0 \\
0.5 \\
0.0 \\
-0.8\end{array}$ & ' & $\begin{array}{l}-3.7 \\
=4.5 \\
-6.0 \\
-0.7 \\
-0.1 \\
-1.1\end{array} \mid$ & - & $\begin{array}{l}12.1 \\
12.0 \\
12.0 \\
12.1 \\
12.0 \\
11.0 \\
11.4 \\
11.2\end{array}$ & & $\begin{array}{l}4.2 \\
4.5 \\
3.9 \\
3.7 \\
4.5 \\
3.4 \\
4.1 \\
9.6\end{array}$ & $\begin{array}{l}7.1 \\
6.5 \\
5.4 \\
4.7 \\
5.0 \\
3.5 \\
4.5 \\
9.5\end{array}$ & $\begin{array}{r}12.1 \\
13.0 \\
10.8 \\
7.9 \\
8.1 \\
4.8 \\
40.6 \\
10.0\end{array}$ & $\begin{array}{r}18.2 \\
17.5 \\
13.2 \\
9.8 \\
9.1 \\
5.2 \\
4.9 \\
10.6\end{array}$ \\
\hline
\end{tabular}




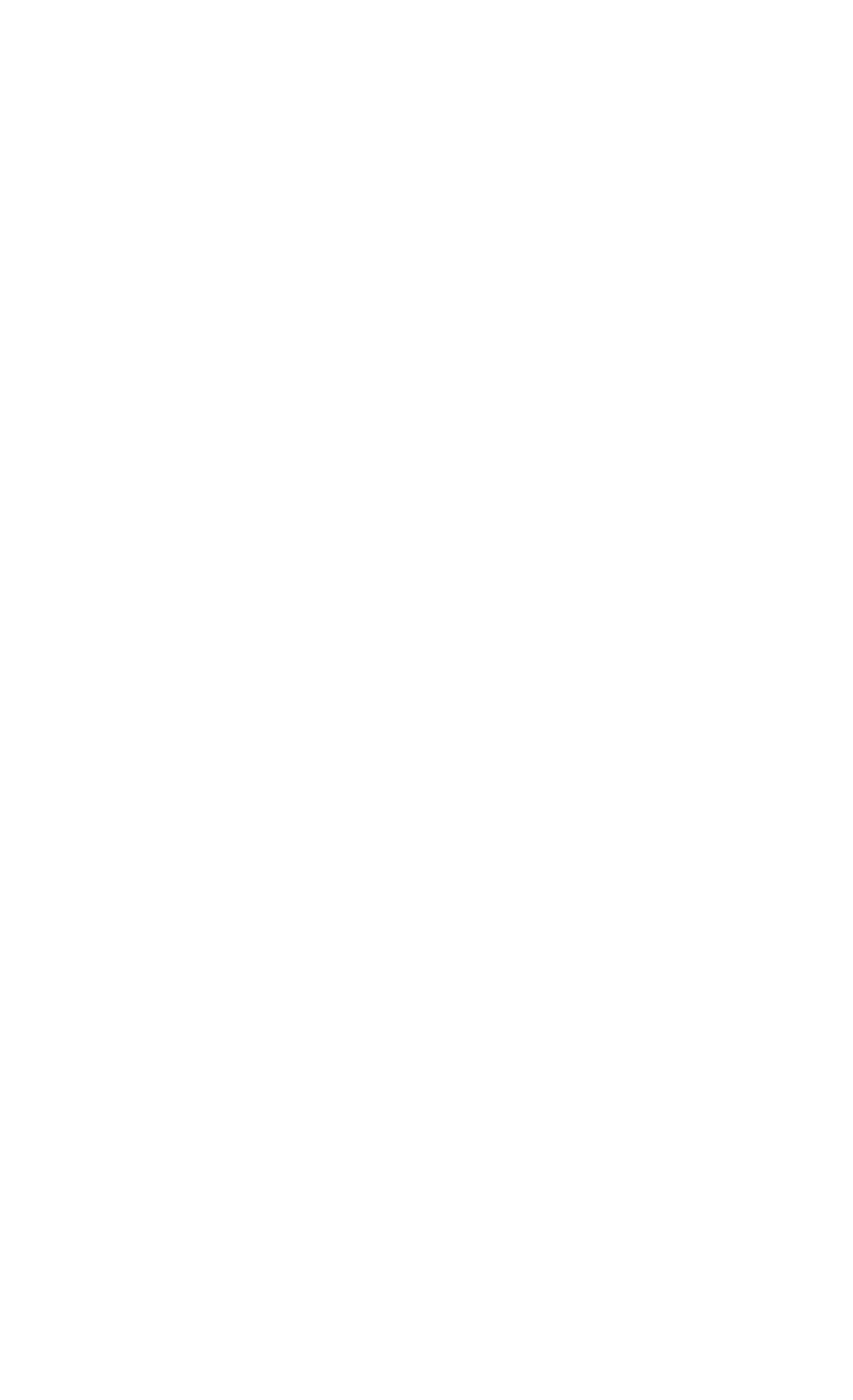


TABLE 10 Table 10. - Three-hour averages of air and water-surface temperatures and wind directions and speed, April 1950-Auguat
1951, Lake Hefner-Continued

STATION 4 THREE-HOURLY AVERAGES NOVEMBER, 1950

\begin{tabular}{|c|c|c|c|c|c|c|c|c|c|c|c|c|c|c|c|}
\hline \multirow{4}{*}{ 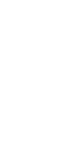 } & \multirow{4}{*}{ 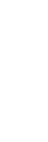 } & \multicolumn{8}{|c|}{ Average air temperature $\left({ }^{\circ} \mathrm{C}\right)$ at indicated height } & \multirow{4}{*}{$\begin{array}{l}\text { Average } \\
\text { water- } \\
\text { surface } \\
\text { tempera- } \\
\text { ture } \\
\text { ('C) }\end{array}$} & \multirow{4}{*}{$\begin{array}{l}\text { Average } \\
\text { wind } \\
\text { direction } \\
\text { (coded) }\end{array}$} & \multirow{2}{*}{\multicolumn{4}{|c|}{$\begin{array}{l}\text { Average wind speed (knots) } \\
\text { at indicated height }\end{array}$}} \\
\hline & & \multirow{2}{*}{\multicolumn{2}{|c|}{$\begin{array}{c}2 \\
\text { meters }\end{array}$}} & \multirow{2}{*}{\multicolumn{2}{|c|}{$\begin{array}{c}4 \\
\text { meters }\end{array}$}} & \multirow{2}{*}{\multicolumn{2}{|c|}{$\begin{array}{c}8 \\
\text { meters }\end{array}$}} & \multirow{2}{*}{\multicolumn{2}{|c|}{$\begin{array}{c}16 \\
\text { meters }\end{array}$}} & & & & & & \\
\hline & & & & & & & & & & & & 2 & 4 & 8 & 16 \\
\hline & & $\begin{array}{l}\text { Dry } \\
\text { bulb }\end{array}$ & $\begin{array}{l}\text { Wet } \\
\text { bulb }\end{array}$ & $\begin{array}{l}\text { Dry } \\
\text { bulb }\end{array}$ & $\begin{array}{l}\text { Wet } \\
\text { bulb }\end{array}$ & $\begin{array}{l}\text { Dry } \\
\text { bulb }\end{array}$ & $\begin{array}{l}\text { Wet } \\
\text { bulb }\end{array}$ & $\begin{array}{l}\text { Dry } \\
\text { bulb }\end{array}$ & $\begin{array}{l}\text { Wet } \\
\text { bulb }\end{array}$ & & & & & & \\
\hline
\end{tabular}

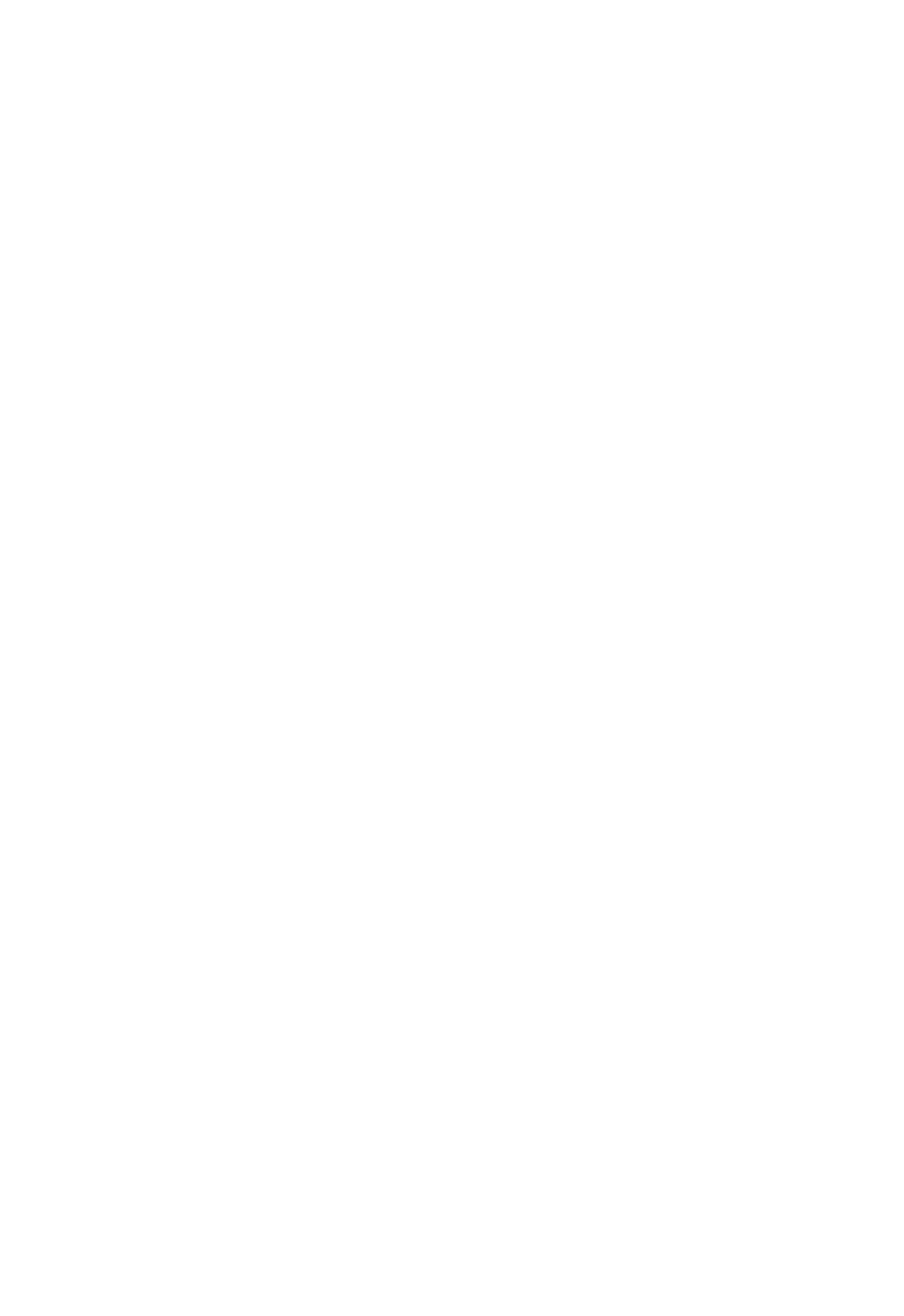


TABLE 10

Table 10. - Three-hour averages of air and water-surface temperatures and wind directions and speed, April 1950-August 1851, Lake Fefner-Continued

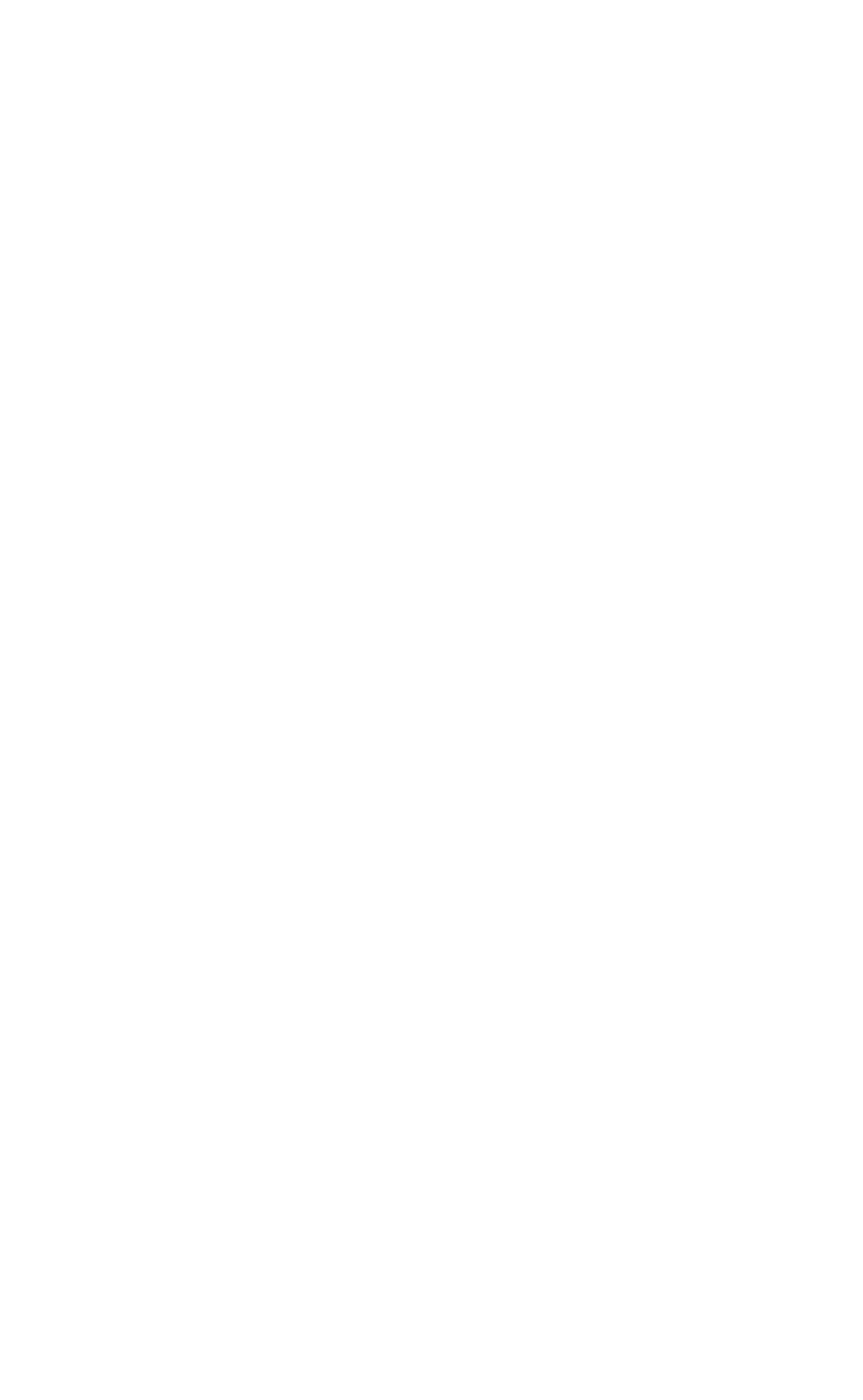


TABLE 10

Table 10. -Three-hour averages of alr and water-surface temperatures and wind directions and speed, April 1950-August 1951, Lake Hefner-Continued

STATION 4

THREE-HOURLY AVERAGES

DECEMBER, 1950

\begin{tabular}{|c|c|c|c|c|c|c|c|c|c|c|c|c|c|c|c|}
\hline \multirow{3}{*}{ 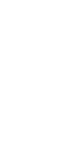 } & \multirow{3}{*}{ 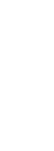 } & \multicolumn{8}{|c|}{ Average air temperature $\left({ }^{\circ} \mathrm{C}\right)$ at indicated height } & \multirow{3}{*}{$\begin{array}{c}\text { Average } \\
\text { water- } \\
\text { surface } \\
\text { tempera- } \\
\text { ture } \\
\left.{ }^{\circ} \mathrm{C}\right)\end{array}$} & \multirow{3}{*}{$\begin{array}{c}\begin{array}{c}\text { Average } \\
\text { wind } \\
\text { direction }\end{array} \\
\text { (coded) }\end{array}$} & \multicolumn{4}{|c|}{$\begin{array}{l}\text { Average wind speed (knots) } \\
\text { at indicated height }\end{array}$} \\
\hline & & \multicolumn{2}{|c|}{$\begin{array}{c}2 \\
\text { meters }\end{array}$} & \multicolumn{2}{|c|}{$\begin{array}{c}4 \\
\text { meters }\end{array}$} & \multicolumn{2}{|c|}{$\begin{array}{c}8 \\
\text { meters }\end{array}$} & \multicolumn{2}{|c|}{$\begin{array}{c}16 \\
\text { meters }\end{array}$} & & & & & & \\
\hline & & $\begin{array}{l}\text { Dry } \\
\text { bulb }\end{array}$ & $\begin{array}{l}\text { Wet } \\
\text { bulb }\end{array}$ & $\begin{array}{l}\text { Dry } \\
\text { bulb }\end{array}$ & $\begin{array}{l}\text { Wet } \\
\text { bulb }\end{array}$ & $\begin{array}{l}\text { Dry } \\
\text { bulb }\end{array}$ & $\begin{array}{l}\text { Wet } \\
\text { bulb }\end{array}$ & $\begin{array}{l}\text { Dry } \\
\text { bulb }\end{array}$ & $\begin{array}{l}\text { Wet } \\
\text { bulb }\end{array}$ & & & meters & meters & meters & meters \\
\hline $\begin{array}{l}11 \\
11 \\
11 \\
11 \\
11 \\
11 \\
11 \\
11\end{array}$ & $\begin{array}{r}0 \\
3 \\
6 \\
9 \\
12 \\
15 \\
18 \\
21\end{array}$ & $\begin{array}{r}4.6 \\
4.0 \\
3.7 \\
10.0 \\
15.7 \\
15.7 \\
8.7 \\
6.6\end{array}$ & $\begin{array}{l}1.7 \\
1.4 \\
1.4 \\
5.4 \\
8.7 \\
8.9 \\
5.1 \\
4.2\end{array}$ & $\begin{array}{r}4.7 \\
3.9 \\
3.9 \\
10.5 \\
15.7 \\
15.7 \\
8.8 \\
7.2\end{array}$ & & $\begin{array}{r}4.8 \\
3.9 \\
4.1 \\
10.7 \\
15.8 \\
15.5 \\
9.0 \\
8.4\end{array}$ & $\begin{array}{l}1.2 \\
0.9 \\
1.3 \\
5.5 \\
8.4 \\
8.2 \\
4.8 \\
4.5\end{array}$ & $\begin{array}{r}4.8 \\
3.7 \\
4.5 \\
10.7 \\
15.7 \\
15.5 \\
10.6 \\
9.2\end{array}$ & $\begin{array}{l}1.2 \\
0.7 \\
1.4 \\
5.5 \\
8.3 \\
8.3 \\
5.7 \\
4.9\end{array}$ & $\begin{array}{l}3.8 \\
3.8 \\
3.8 \\
4.4 \\
4.6 \\
4.5 \\
4.3 \\
4.2\end{array}$ & & $\begin{array}{l}8.9 \\
7.1 \\
6.8 \\
5.9 \\
5.3 \\
3.8 \\
1.7 \\
2.1\end{array}$ & $\begin{array}{r}10.3 \\
7.99 \\
7.2 \\
6.3 \\
6.5 \\
4.8 \\
1.8 \\
2.6\end{array}$ & $\begin{array}{r}11.1 \\
7.9 \\
7.9 \\
11.9 \\
12.7 \\
10.2 \\
3.1 \\
3.1\end{array}$ & $\begin{array}{r}13.1 \\
9.5 \\
9.7 \\
13.3 \\
16.4 \\
14.3 \\
5.0 \\
4.5\end{array}$ \\
\hline $\begin{array}{l}12 \\
12 \\
12 \\
12 \\
12 \\
12 \\
12 \\
12\end{array}$ & $\begin{array}{r}c \\
3 \\
6 \\
9 \\
12 \\
15 \\
18 \\
21\end{array}$ & $\begin{array}{l}3.7 \\
2.6 \\
0.9 \\
2.7 \\
5.7 \\
6.1 \\
2.9 \\
1.5\end{array}$ & $\begin{array}{r}2.9 \\
1.0 \\
-0.4 \\
1.00 \\
2.6 \\
2.5 \\
-0.7 \\
-0.1\end{array}$ & $\begin{array}{l}3.8 \\
2.5 \\
0.7 \\
2.8 \\
5.8 \\
6.1 \\
2.8 \\
1.2\end{array}$ & $\begin{array}{r}2.9 \\
\\
2.4 \\
0.07 \\
-0.2\end{array}$ & $\begin{array}{l}4.5 \\
2.4 \\
0.5 \\
2.8 \\
6.0 \\
6.0 \\
2.9 \\
1.1\end{array}$ & $\begin{array}{r}2.7 \\
0.77 \\
-0.7 \\
0.9 \\
2.3 \\
2.02 \\
0.5 \\
-0.3\end{array}$ & $\begin{array}{l}6.3 \\
3.1 \\
0.7 \\
2.8 \\
5.8 \\
6.0 \\
3.01 \\
1.2\end{array}$ & $\begin{array}{r}3.5 \\
1.1 \\
-0.5 \\
0.9 \\
2.2 \\
2.0 \\
0.4 \\
-0.4\end{array} \mid$ & $\begin{array}{l}4.0 \\
3.8 \\
3.9 \\
4.1 \\
4.2 \\
4.1 \\
3.9 \\
3.9\end{array}$ & & $\begin{array}{l}0.8 \\
1.7 \\
0.7 \\
2.4 \\
4.5 \\
5.4 \\
3.8 \\
3.1\end{array}$ & $\begin{array}{l}1.1 \\
2.2 \\
1.0 \\
2.7 \\
4.9 \\
6.1 \\
4.4 \\
3.5\end{array}$ & $\begin{array}{l}1.5 \\
3.0 \\
1.8 \\
3.2 \\
5.5 \\
6.8 \\
5.4 \\
4.3\end{array}$ & $\begin{array}{l}3.0 \\
5.9 \\
3.0 \\
3.5 \\
5.7 \\
7.5 \\
6.8 \\
5.5\end{array}$ \\
\hline $\begin{array}{l}13 \\
13 \\
13 \\
13 \\
13 \\
13 \\
13 \\
13\end{array}$ & $\begin{array}{r}0 \\
3 \\
6 \\
9 \\
12 \\
15 \\
18 \\
21\end{array}$ & $\begin{array}{r}0.0 \\
-3.4 \\
-1.4 \\
2.2 \\
6.9 \\
8.3 \\
4.4 \\
2.9\end{array}$ & $\left|\begin{array}{r}-1.1 \\
-3.4 \\
0.7 \\
3.0 \\
3.8 \\
2.4 \\
1.9\end{array}\right|$ & $\begin{array}{l}0.0 \\
3.8 \\
1.7 \\
2.4 \\
7.1 \\
8.8 \\
4.9 \\
2.9\end{array}$ & $\begin{array}{l}0.8 \\
3.2 \\
4.0 \\
2.3 \\
1.7\end{array}$ & $\begin{array}{r}0.1 \\
-4.2 \\
-\quad 1.7 \\
2.5 \\
7.3 \\
9.2 \\
5.1 \\
3.2\end{array}$ & $\begin{array}{l}0.9 \\
3.1 \\
3.7 \\
2.2 \\
1.1\end{array}$ & $\begin{array}{r}0.1 \\
-3.8 \\
-1.4 \\
2.1 \\
7.3 \\
9.1 \\
6.3 \\
3.9\end{array}$ & $\begin{array}{l}0.7 \\
2.9 \\
3.6 \\
2.5 \\
1.4\end{array}$ & $\begin{array}{l}3.7 \\
3.7 \\
3.8 \\
4.2 \\
4.3 \\
4.2 \\
3.9 \\
3.9\end{array}$ & & $\begin{array}{l}2.1 \\
0.9 \\
2.2 \\
3.1 \\
5.5 \\
4.2 \\
1.3 \\
0.9\end{array}$ & $\begin{array}{l}2.5 \\
1.2 \\
2.5 \\
4.0 \\
6.0 \\
4.8 \\
1.8 \\
1.2\end{array}$ & $\begin{array}{l}3.0 \\
2.8 \\
3.4 \\
5.4 \\
6.5 \\
5.3 \\
2.4 \\
1.2\end{array}$ & $\begin{array}{l}3.6 \\
4.6 \\
3.8 \\
7.5 \\
7.0 \\
6.3 \\
3.3 \\
1.4\end{array}$ \\
\hline $\begin{array}{l}14 \\
14 \\
14 \\
14 \\
14 \\
14 \\
14 \\
14\end{array}$ & $\begin{array}{r}0 \\
3 \\
6 \\
9 \\
12 \\
15 \\
18 \\
21\end{array}$ & $\begin{array}{r}1.7 \\
0.9 \\
1.5 \\
4.9 \\
9.9 \\
11.5 \\
5.4 \\
4.8\end{array}$ & $\begin{array}{l}0.7 \\
0.2 \\
0.7 \\
3.6 \\
6.1 \\
7.1 \\
4.2 \\
3.9\end{array}$ & $\begin{array}{r}1.6 \\
0.8 \\
1.6 \\
5.2 \\
10.4 \\
11.5 \\
6.5 \\
5.6\end{array}$ & $\begin{array}{l}0.7 \\
0.0 \\
0.8 \\
3.8 \\
6.5 \\
7.3 \\
4.7 \\
4.1\end{array}$ & $\begin{array}{r}1.7 \\
0.8 \\
1.6 \\
5.2 \\
10.7 \\
11.8 \\
7.5 \\
6.5\end{array}$ & $\begin{array}{r}0.6 \\
-0.1 \\
0.7 \\
3.5 \\
6.8 \\
7.4 \\
5.0 \\
4.4\end{array}$ & $\begin{array}{r}2.5 \\
1.0 \\
1.5 \\
5.3 \\
10.1 \\
11.2 \\
9.4 \\
7.4\end{array}$ & $\begin{array}{l}0.7 \\
0.7 \\
0.6 \\
3.7 \\
6.3 \\
0.8 \\
5.9 \\
5.0\end{array}$ & $\begin{array}{l}3.8 \\
3.7 \\
3.9 \\
4.2 \\
6.2 \\
5.0 \\
4.5 \\
4.4\end{array}$ & & $\begin{array}{l}1.9 \\
1.6 \\
3.0 \\
4.0 \\
0.7 \\
0.4 \\
1.9 \\
2.3\end{array}$ & $\begin{array}{l}2.2 \\
1.9 \\
3.4 \\
4.7 \\
0.9 \\
0.4 \\
2.4 \\
3.4\end{array}$ & $\begin{array}{l}2.6 \\
2.3 \\
3.6 \\
5.4 \\
0.8 \\
0.4 \\
3.1 \\
4.3\end{array}$ & $\begin{array}{l}2.6 \\
2.2 \\
4.2 \\
6.3 \\
1.0 \\
0.5 \\
4.0 \\
5.5\end{array}$ \\
\hline $\begin{array}{l}15 \\
15 \\
15 \\
15 \\
15 \\
15 \\
15 \\
15\end{array}$ & $\begin{array}{r}0 \\
3 \\
6 \\
9 \\
12 \\
15 \\
18 \\
21\end{array}$ & $\begin{array}{r}3.4 \\
0.8 \\
-1.1 \\
3.7 \\
7.3 \\
6.6 \\
2.2 \\
1.1\end{array}$ & $\left|\begin{array}{r}2.5 \\
0.1 \\
-2.0 \\
0.5 \\
2.0 \\
1.5 \\
-1.2 \\
-1.6\end{array}\right|$ & $\begin{array}{l}3.4 \\
0.6 \\
1.2 \\
3.8 \\
7.3 \\
6.6 \\
2.0 \\
1.0\end{array}$ & $\begin{array}{r}2.6 \\
0.0 \\
-1.44 \\
1.00 \\
2.06 \\
2.00 \\
-0.66 \\
-1.7\end{array}$ & $\begin{array}{r}3.4 \\
0.6 \\
-1.4 \\
4.0 \\
7.5 \\
6.55 \\
2.00 \\
0.8\end{array}$ & $\begin{array}{r}2.3 \\
-0.1 \\
-1.9 \\
0.8 \\
2.2 \\
1.3 \\
-0.9 \\
-2.2\end{array} \mid$ & $\begin{array}{r}4.3 \\
1.0 \\
-1.2 \\
3.8 \\
7.2 \\
6.3 \\
2.4 \\
1.2\end{array}$ & $\begin{array}{r}3.1 \\
0.1 \\
-1.7 \\
0.4 \\
1.8 \\
1.2 \\
-0.8 \\
-2.2\end{array}$ & $\begin{array}{l}4.0 \\
3.9 \\
4.0 \\
4.1 \\
4.3 \\
4.1 \\
4.0 \\
3.9\end{array}$ & & $\begin{array}{l}2.3 \\
2.0 \\
0.9 \\
7.7 \\
5.6 \\
3.1 \\
1.3 \\
0.9\end{array}$ & $\begin{array}{l}1.4 \\
2.3 \\
1.6 \\
8.5 \\
6.0 \\
3.8 \\
1.7 \\
1.1\end{array}$ & $\begin{array}{l}2.4 \\
3.5 \\
3.3 \\
9.3 \\
6.0 \\
4.9 \\
2.6 \\
2.0\end{array}$ & $\begin{array}{r}3.1 \\
4.1 \\
6.5 \\
11.3 \\
8.5 \\
8.4 \\
5.4 \\
3.2\end{array}$ \\
\hline $\begin{array}{l}16 \\
16 \\
16 \\
16 \\
16 \\
16 \\
16 \\
16\end{array}$ & $\begin{array}{r}0 \\
3 \\
6 \\
9 \\
12 \\
15 \\
18 \\
21\end{array}$ & $\begin{array}{r}-0.3 \\
-0.5 \\
0.0 \\
2.1 \\
5.0 \\
7.4 \\
5.2 \\
5.3\end{array}$ & $\left|\begin{array}{r}-3.0 \\
-3.0 \\
-2.4 \\
-0.3 \\
2.7 \\
5.0 \\
3.2 \\
3.3\end{array}\right|$ & $\begin{array}{l}0.8 \\
1.0 \\
0.3 \\
2.2 \\
5.5 \\
8.7 \\
5.6 \\
5.5\end{array}$ & $\left|\begin{array}{r}-2.9 \\
-3.0 \\
-2.4 \\
-0.1 \\
2.9 \\
5.5 \\
3.5 \\
3.5\end{array}\right|$ & $\mid \begin{array}{r}-0.9 \\
-1.22 \\
-0.4 \\
2.1 \\
5.8 \\
9.2 \\
6.0 \\
5.6\end{array}$ & $\mid \begin{array}{r}-3.2 \\
=3.3 \\
-2.7 \\
-0.4 \\
2.5 \\
4.9 \\
3.0 \\
3.0\end{array}$ & $\begin{array}{r}-0.4 \\
-0.9 \\
-0.4 \\
2.1 \\
6.0 \\
9.4 \\
6.5 \\
5.9\end{array}$ & $\left|\begin{array}{r}-3.2 \\
-3.3 \\
-2.7 \\
-0.3 \\
2.7 \\
5.2 \\
3.4 \\
3.2\end{array}\right|$ & $\begin{array}{l}3.9 \\
3.9 \\
3.9 \\
4.0 \\
4.5 \\
4.7 \\
4.1 \\
4.0\end{array}$ & & $\begin{array}{l}0.9 \\
0.9 \\
1.8 \\
3.4 \\
3.1 \\
3.3 \\
5.7 \\
8.4\end{array}$ & $\begin{array}{l}1.3 \\
1.1 \\
2.0 \\
3.7 \\
3.7 \\
4.5 \\
6.7 \\
9.1\end{array}$ & $\begin{array}{l}2.1 \\
2.1 \\
1.6 \\
3.6 \\
3.9 \\
5.0 \\
7.5 \\
9.2\end{array}$ & $\begin{array}{r}3.6 \\
2.8 \\
2.6 \\
4.2 \\
4.5 \\
6.0 \\
10.3 \\
11.5\end{array}$ \\
\hline $\begin{array}{l}17 \\
17 \\
17 \\
17 \\
17 \\
17 \\
17 \\
17\end{array}$ & $\begin{array}{r}0 \\
3 \\
6 \\
9 \\
12 \\
15 \\
18 \\
21\end{array}$ & $\begin{array}{r}3.8 \\
1.2 \\
-1.7 \\
1.1 \\
4.8 \\
4.7 \\
1.0 \\
-0.4\end{array}$ & $\begin{array}{r}1.09 \\
-0.5 \\
-2.8 \\
-0.9 \\
1.0 \\
1.00 \\
-1.4 \\
-2.6\end{array}$ & $\begin{array}{l}3.7 \\
0.6 \\
1.7 \\
1.1 \\
4.8 \\
4.5 \\
0.8 \\
0.8\end{array}$ & $\begin{array}{r}2.0 \\
-0.6 \\
-2.3 \\
-0.8 \\
1.3\end{array}$ & $\begin{array}{r}3.7 \\
0.3 \\
-2.3 \\
1.4 \\
5.0 \\
4.5 \\
0.7 \\
-1.0\end{array}$ & $\begin{array}{r}1.6 \\
-1.1 \\
-3.2 \\
-0.7 \\
1.2 \\
0.8 \\
-1.77 \\
-3.0\end{array} \mid$ & $\begin{array}{r}3.9 \\
0.6 \\
-2.5 \\
1.6 \\
4.4 \\
4.2 \\
1.0 \\
-1.1\end{array}$ & $\begin{array}{r}1.7 \\
-0.7 \\
-3.3 \\
-1.1 \\
0.7 \\
0.7 \\
-1.7 \\
-2.7\end{array}$ & $\begin{array}{l}4.0 \\
3.9 \\
3.9 \\
4.1 \\
4.5 \\
4.1 \\
3.9 \\
3.9\end{array}$ & & $\begin{array}{l}3.8 \\
3.2 \\
1.5 \\
3.9 \\
3.0 \\
3.5 \\
3.7 \\
4.9\end{array}$ & $\begin{array}{l}4.4 \\
3.3 \\
2.0 \\
4.7 \\
3.7 \\
4.0 \\
4.2 \\
5.5\end{array}$ & $\begin{array}{l}4.6 \\
5.1 \\
4.5 \\
5.5 \\
4.6 \\
5.0 \\
4.8 \\
6.1\end{array}$ & $\begin{array}{l}6.2 \\
6.5 \\
6.6 \\
7.6 \\
6.6 \\
6.0 \\
7.0 \\
7.03\end{array}$ \\
\hline $\begin{array}{l}18 \\
18 \\
18 \\
18 \\
16 \\
16 \\
16 \\
18\end{array}$ & $\begin{array}{r}0 \\
3 \\
6 \\
9 \\
12 \\
15 \\
18 \\
21\end{array}$ & $\begin{array}{r}-2.7 \\
=2.9 \\
=3.2 \\
-0.6 \\
4.1 \\
5.4 \\
3.8 \\
3.1\end{array}$ & $\begin{array}{l}2.0 \\
2.6 \\
2.7 \\
0.9\end{array}$ & $\begin{array}{l}3.0 \\
3.0 \\
3.4 \\
0.4 \\
4.1 \\
5.6 \\
3.8 \\
3.1\end{array}$ & $\left|\begin{array}{r}-3.7 \\
0.6 \\
2.3\end{array}\right|$ & $\begin{array}{r}-3.1 \\
-3.2 \\
=3.4 \\
-0.4 \\
4.4 \\
5.8 \\
3.8 \\
3.0\end{array}$ & $\left|\begin{array}{r}-3.5 \\
\\
1.1 \\
2.3 \\
1.1 \\
0.5\end{array}\right|$ & $\begin{array}{r}-3.3 \\
-3.3 \\
-3.6 \\
-0.3 \\
3.9 \\
5.9 \\
4.0 \\
3.0\end{array}$ & $\begin{array}{l}0.0 \\
2.1 \\
1.0 \\
0.4\end{array}$ & $\begin{array}{l}3.8 \\
3.8 \\
3.7 \\
3.9 \\
4.6 \\
4.4 \\
4.1 \\
4.0\end{array}$ & & $\begin{array}{l}4.7 \\
4.6 \\
2.5 \\
2.9 \\
2.2 \\
5.0 \\
4.1 \\
5.5\end{array}$ & $\begin{array}{l}5.3 \\
5.1 \\
2.8 \\
3.4 \\
2.5 \\
5.8 \\
4.9 \\
6.2\end{array}$ & $\begin{array}{l}5.9 \\
5.6 \\
3.1 \\
3.9 \\
2.7 \\
6.3 \\
5.5 \\
6.8\end{array}$ & $\begin{array}{l}6.05 \\
5.7 \\
3.2 \\
4.2 \\
3.0 \\
7.6 \\
7.8 \\
8.1\end{array}$ \\
\hline $\begin{array}{l}19 \\
19 \\
19 \\
19 \\
19 \\
19 \\
19 \\
19\end{array}$ & $\begin{array}{r}0 \\
3 \\
6 \\
9 \\
12 \\
15 \\
18 \\
21\end{array}$ & $\begin{array}{l}2.9 \\
1.4 \\
0.2 \\
3.3 \\
8.0 \\
8.0 \\
4.9 \\
1.4\end{array}$ & $\begin{array}{r}0.7 \\
-0.2 \\
-1.0 \\
1.4 \\
3.7 \\
3.7 \\
1.9 \\
-0.5\end{array}$ & $\begin{array}{l}2.8 \\
1.3 \\
0.1 \\
3.7 \\
8.1 \\
8.1 \\
4.7 \\
1.2\end{array}$ & $\begin{array}{r}1.0 \\
0.0 \\
-0.9 \\
0.2 \\
\end{array}$ & $\begin{array}{l}2.7 \\
1.1 \\
0.0 \\
4.0 \\
8.4 \\
8.1 \\
4.6 \\
1.1\end{array}$ & $\begin{array}{r}0.2 \\
-0.6 \\
-1.3 \\
1.6 \\
3.7 \\
3.5 \\
1.5 \\
-0.8\end{array}$ & $\begin{array}{r}2.6 \\
1.0 \\
-0.2 \\
3.9 \\
8.2 \\
8.2 \\
5.2 \\
1.7\end{array}$ & $\begin{array}{r}0.3 \\
-0.5 \\
-1.4 \\
1.4 \\
3.8 \\
3.7 \\
2.0 \\
-0.5\end{array}$ & $\begin{array}{l}4.0 \\
3.8 \\
3.8 \\
4.0 \\
4.4 \\
4.1 \\
4.0 \\
3.9\end{array}$ & & $\begin{array}{l}7.3 \\
6.3 \\
6.5 \\
3.2 \\
3.5 \\
4.5 \\
3.1 \\
2.5\end{array}$ & $\begin{array}{l}6.1 \\
7.2 \\
7.3 \\
3.8 \\
3.9 \\
4.8 \\
3.4 \\
3.3\end{array}$ & $\begin{array}{l}8.4 \\
7.6 \\
8.0 \\
3.2 \\
4.6 \\
5.2 \\
4.2 \\
4.1\end{array}$ & $\begin{array}{l}9.9 \\
6.5 \\
8.7 \\
3.8 \\
6.5 \\
6.9 \\
6.4 \\
6.7\end{array}$ \\
\hline $\begin{array}{l}20 \\
20 \\
20 \\
20 \\
20 \\
20 \\
20 \\
20\end{array}$ & $\begin{array}{r}0 \\
3 \\
6 \\
9 \\
12 \\
15 \\
18 \\
21\end{array}$ & $\begin{array}{r}0.0 \\
-0.9 \\
-2.5 \\
0.2 \\
4.5 \\
5.6 \\
4.6 \\
4.0\end{array}$ & $\begin{array}{l}1.3 \\
1.9 \\
1.6 \\
1.3\end{array}$ & $\begin{array}{l}0.4 \\
1.2 \\
2.6 \\
0.4 \\
4.7 \\
5.5 \\
4.6 \\
4.0\end{array}$ & $=1.06$ & $\mid \begin{array}{r}-0.5 \\
-1.4 \\
-2.6 \\
0.7 \\
4.6 \\
5.5 \\
4.5 \\
4.0\end{array}$ & $\begin{array}{l}1.1 \\
1.7 \\
1.3 \\
0.9\end{array}$ & $\begin{array}{r}-0.5 \\
-1.5 \\
-2.9 \\
0.3 \\
4.5 \\
5.4 \\
4.6 \\
4.0\end{array}$ & $\begin{array}{l}1.2 \\
1.01 \\
1.2 \\
0.9\end{array}$ & $\begin{array}{l}3.8 \\
3.9 \\
3.8 \\
4.1 \\
4.2 \\
4.0 \\
4.0 \\
3.9\end{array}$ & & $\begin{array}{l}3.3 \\
4.8 \\
1.9 \\
4.1 \\
3.5 \\
3.5 \\
1.7 \\
0.6\end{array}$ & $\begin{array}{l}3.9 \\
5.2 \\
2.3 \\
4.5 \\
4.2 \\
4.0 \\
2.1 \\
1.2\end{array}$ & $\begin{array}{l}4.8 \\
5.6 \\
2.8 \\
4.9 \\
5.1 \\
4.6 \\
2.6 \\
2.4\end{array}$ & $\begin{array}{l}6.7 \\
6.8 \\
5.1 \\
6.2 \\
7.0 \\
6.2 \\
3.3 \\
3.3\end{array}$ \\
\hline
\end{tabular}


Table 10. -Three-hour averagea of air and water-surface temperatures and wind directions and speed, April 1950-August STATION 4 THREE-HOURLY AVERAGES

DECEMBER, 1930

\begin{tabular}{|c|c|c|c|c|c|c|c|c|c|c|c|c|c|c|c|}
\hline \multirow{3}{*}{ 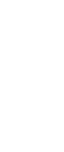 } & \multirow{3}{*}{ 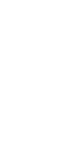 } & \multicolumn{8}{|c|}{ Average air temperature $\left({ }^{\circ} \mathrm{C}\right)$ at indicated height } & \multirow{3}{*}{$\begin{array}{l}\text { Aversge } \\
\text { water- } \\
\text { surface } \\
\text { tempera- } \\
\text { ture } \\
\text { ('C) }\end{array}$} & \multirow{3}{*}{$\begin{array}{c}\text { Average } \\
\text { wind } \\
\text { direction } \\
\text { (coded) }\end{array}$} & \multicolumn{4}{|c|}{$\begin{array}{l}\text { Average wind speed (knots) } \\
\text { at indicated height }\end{array}$} \\
\hline & & \multicolumn{2}{|c|}{$\begin{array}{c}2 \\
\text { meters }\end{array}$} & \multicolumn{2}{|c|}{$\stackrel{4}{\text { meters }}$} & \multicolumn{2}{|c|}{$\begin{array}{c}8 \\
\text { meters }\end{array}$} & \multicolumn{2}{|c|}{$\begin{array}{c}16 \\
\text { meters }\end{array}$} & & & & & 8 & 16 \\
\hline & & $\begin{array}{l}\text { Dry } \\
\text { bulb }\end{array}$ & $\begin{array}{l}\text { Wet } \\
\text { butb }\end{array}$ & $\begin{array}{l}\text { Dry } \\
\text { bulb }\end{array}$ & $\begin{array}{l}\text { Wet } \\
\text { bulb }\end{array}$ & $\begin{array}{l}\text { Dry } \\
\text { bulb }\end{array}$ & $\begin{array}{l}\text { Wet } \\
\text { bulb }\end{array}$ & $\begin{array}{l}\text { Dry } \\
\text { bulb }\end{array}$ & $\begin{array}{l}\text { Wet } \\
\text { bulb }\end{array}$ & & & meters & meters & metere & meters \\
\hline $\begin{array}{l}22 \\
21 \\
21 \\
21 \\
21 \\
21 \\
21 \\
21\end{array}$ & $\begin{array}{r}0 \\
3 \\
6 \\
9 \\
12 \\
15 \\
18 \\
21\end{array}$ & $\begin{array}{l}3.9 \\
3.9 \\
3.4 \\
5.7 \\
7.6 \\
7.7 \\
5.0 \\
4.3\end{array}$ & $\begin{array}{l}1.8 \\
1.4 \\
1.1 \\
3.5 \\
5.1 \\
5.7 \\
4.2 \\
3.2\end{array}$ & $\begin{array}{l}4.0 \\
3.9 \\
3.4 \\
6.3 \\
8.2 \\
8.5 \\
5.3 \\
4.2\end{array}$ & $\begin{array}{l}2.0 \\
1.6 \\
1.1 \\
4.7 \\
6.1 \\
8.1 \\
4.3 \\
3.3\end{array}$ & $\begin{array}{l}4.0 \\
3.8 \\
3.4 \\
6.3 \\
8.5 \\
9.0 \\
6.3 \\
4.2\end{array}$ & $\begin{array}{l}1.4 \\
1.2 \\
1.0 \\
3.6 \\
5.5 \\
8.1 \\
4.5 \\
3.0\end{array}$ & $\begin{array}{l}3.9 \\
3.8 \\
3.3 \\
6.7 \\
8.7 \\
9.4 \\
5.6 \\
4.2\end{array}$ & $\begin{array}{l}1.1 \\
1.0 \\
0.9 \\
3.6 \\
5.5 \\
3.2 \\
4.6 \\
2.9\end{array}$ & $\begin{array}{l}3.9 \\
3.9 \\
3.9 \\
4.4 \\
4.9 \\
4.8 \\
4.3 \\
4.0\end{array}$ & & $\begin{array}{l}1.0 \\
0.9 \\
1.4 \\
3.5 \\
5.2 \\
4.7 \\
3.5 \\
6.6\end{array}$ & $\begin{array}{l}1.4 \\
1.2 \\
1.9 \\
4.0 \\
6.1 \\
6.0 \\
4.7 \\
7.5\end{array}$ & $\begin{array}{l}1.9 \\
2.0 \\
2.3 \\
4.3 \\
6.3 \\
6.6 \\
6.2 \\
8.5\end{array}$ & $\begin{array}{r}2.3 \\
2.2 \\
2.6 \\
5.1 \\
7.3 \\
8.0 \\
7.8 \\
10.3\end{array}$ \\
\hline $\begin{array}{l}22 \\
22 \\
22 \\
22 \\
22 \\
22 \\
22 \\
22\end{array}$ & $\begin{array}{r}0 \\
3 \\
8 \\
9 \\
12 \\
15 \\
18 \\
21\end{array}$ & $\begin{array}{r}3.5 \\
3.4 \\
2.3 \\
5.7 \\
9.8 \\
10.4 \\
7.8 \\
5.9\end{array}$ & $\begin{array}{l}2.8 \\
2.8 \\
1.9 \\
4.7 \\
6.7 \\
7.1 \\
5.8 \\
4.9\end{array}$ & $\begin{array}{r}3.5 \\
3.3 \\
2.3 \\
6.6 \\
11.0 \\
11.7 \\
8.0 \\
5.1\end{array}$ & $\begin{array}{l}2.9 \\
2.9 \\
2.1 \\
5.0 \\
8.0 \\
8.1 \\
6.0 \\
5.2\end{array}$ & $\begin{array}{r}3.5 \\
3.2 \\
2.3 \\
6.9 \\
11.1 \\
12.9 \\
8.5 \\
6.4\end{array}$ & $\begin{array}{l}2.8 \\
2.7 \\
1.9 \\
5.3 \\
7.5 \\
7.9 \\
6.1 \\
5.1\end{array}$ & $\begin{array}{r}3.5 \\
3.2 \\
2.2 \\
7.2 \\
12.0 \\
13.0 \\
9.5 \\
7.3\end{array}$ & $\begin{array}{l}2.7 \\
2.7 \\
1.8 \\
5.0 \\
7.8 \\
8.2 \\
6.7 \\
5.6\end{array}$ & $\begin{array}{l}4.3 \\
4.1 \\
4.0 \\
4.5 \\
4.8 \\
4.9 \\
5.0 \\
4.9\end{array}$ & & $\begin{array}{l}7.7 \\
8.5 \\
6.6 \\
5.0 \\
8.5 \\
5.6 \\
5.8 \\
6.1\end{array}$ & $\begin{array}{r}8.6 \\
9.4 \\
7.2 \\
6.0 \\
10.0 \\
7.1 \\
7.2 \\
7.4\end{array}$ & $\begin{array}{r}9.0 \\
9.6 \\
7.0 \\
6.2 \\
12.6 \\
8.1 \\
8.7 \\
9.0\end{array}$ & $\begin{array}{r}10.7 \\
11.1 \\
8.1 \\
7.6 \\
12.7 \\
9.4 \\
11.2 \\
11.9\end{array}$ \\
\hline $\begin{array}{l}23 \\
23 \\
23 \\
23 \\
23 \\
23 \\
23 \\
23\end{array}$ & $\begin{array}{r}0 \\
3 \\
6 \\
9 \\
12 \\
15 \\
18 \\
21\end{array}$ & $\begin{array}{r}5.7 \\
5.0 \\
4.8 \\
7.0 \\
10.2 \\
10.2 \\
7.7 \\
6.8\end{array}$ & $\begin{array}{l}5.0 \\
4.8 \\
4.6 \\
6.0 \\
7.1 \\
7.2 \\
6.2 \\
5.1\end{array}$ & $\begin{array}{r}5.7 \\
5.1 \\
4.9 \\
7.5 \\
10.9 \\
11.0 \\
8.2 \\
7.0\end{array}$ & $\begin{array}{l}5.1 \\
4.8 \\
4.7 \\
6.3 \\
7.3 \\
7.8 \\
6.7\end{array}$ & $\begin{array}{r}5.8 \\
5.1 \\
4.9 \\
7.9 \\
11.7 \\
11.9 \\
8.6 \\
7.5\end{array}$ & $\begin{array}{l}5.0 \\
4.8 \\
4.6 \\
6.4 \\
7.7 \\
7.9 \\
6.3 \\
5.2\end{array}$ & $\begin{array}{r}5.9 \\
5.2 \\
5.0 \\
8.3 \\
12.1 \\
12.6 \\
9.1 \\
8.2\end{array}$ & $\begin{array}{l}5.0 \\
4.9 \\
4.7 \\
6.5 \\
7.9 \\
8.3 \\
5.7 \\
5.6\end{array}$ & $\begin{array}{l}4.8 \\
4.5 \\
4.5 \\
4.8 \\
5.0 \\
5.2 \\
5.1 \\
5.0\end{array}$ & & $\begin{array}{r}6.4 \\
8.5 \\
12.2 \\
9.9 \\
10.3 \\
7.9 \\
5.5 \\
8.7\end{array}$ & $\begin{array}{r}7.3 \\
9.8 \\
13.8 \\
11.4 \\
12.0 \\
9.6 \\
7.2 \\
9.8\end{array}$ & $\begin{array}{r}8.1 \\
10.8 \\
14.4 \\
12.1 \\
12.8 \\
10.6 \\
8.3 \\
10.3\end{array}$ & $\begin{array}{l}10.1 \\
12.8 \\
17.1 \\
14.1 \\
15.5 \\
12.9 \\
11.0 \\
13.4\end{array}$ \\
\hline $\begin{array}{l}24 \\
24 \\
24 \\
24 \\
24 \\
24 \\
24 \\
24\end{array}$ & $\begin{array}{r}0 \\
3 \\
6 \\
9 \\
12 \\
15 \\
18 \\
21\end{array}$ & $\begin{array}{r}6.0 \\
3.8 \\
1.8 \\
7.1 \\
12.2 \\
14.9 \\
9.0 \\
7.0\end{array}$ & $\begin{array}{r}4.1 \\
1.7 \\
-0.2 \\
3.5 \\
6.5 \\
7.8 \\
5.4 \\
4.4\end{array}$ & $\begin{array}{r}6.0 \\
3.5 \\
1.9 \\
7.5 \\
13.5 \\
15.5 \\
10.7 \\
7.5\end{array}$ & & $\begin{array}{r}0.1 \\
3.5 \\
1.5 \\
7.5 \\
14.5 \\
16.0 \\
11.5 \\
8.4\end{array}$ & $\begin{array}{r}4.0 \\
1.4 \\
-0.6 \\
3.4 \\
7.5 \\
8.0 \\
5.6 \\
4.2\end{array}$ & $\begin{array}{r}6.6 \\
4.3 \\
2.2 \\
7.0 \\
14.4 \\
16.2 \\
13.0 \\
9.3\end{array}$ & $\begin{array}{r}4.2 \\
1.5 \\
-0.4 \\
3.3 \\
7.3 \\
8.0 \\
5.3 \\
4.6\end{array}$ & $\begin{array}{l}4.0 \\
4.2 \\
4.2 \\
4.9 \\
6.0 \\
6.0 \\
5.5 \\
5.0\end{array}$ & & $\begin{array}{l}5.5 \\
3.2 \\
2.5 \\
0.9 \\
2.1 \\
1.2 \\
2.7 \\
4.6\end{array}$ & $\begin{array}{l}7.2 \\
3.4 \\
2.9 \\
2.0 \\
2.3 \\
1.7 \\
3.7 \\
6.0\end{array}$ & $\begin{array}{l}7.5 \\
4.4 \\
4.1 \\
2.9 \\
2.1 \\
2.3 \\
4.6 \\
7.8\end{array}$ & $\begin{array}{r}9.4 \\
5.8 \\
4.9 \\
4.0 \\
2.5 \\
3.2 \\
6.0 \\
10.1\end{array}$ \\
\hline $\begin{array}{l}25 \\
25 \\
25 \\
25 \\
25 \\
25 \\
25 \\
25\end{array}$ & $\begin{array}{r}0 \\
3 \\
6 \\
9 \\
12 \\
15 \\
18 \\
21\end{array}$ & $\begin{array}{r}6.8 \\
6.4 \\
6.1 \\
9.6 \\
15.1 \\
15.8 \\
13.2 \\
11.0\end{array}$ & $\begin{array}{l}4.1 \\
4.0 \\
4.0 \\
5.6 \\
7.0 \\
8.2 \\
7.0 \\
6.2\end{array}$ & $\begin{array}{r}7.0 \\
8.5 \\
6.3 \\
10.4 \\
16.2 \\
16.9 \\
13.8 \\
11.6\end{array}$ & & $\begin{array}{r}7.5 \\
6.8 \\
8.3 \\
11.0 \\
16.9 \\
17.7 \\
14.6 \\
12.2\end{array}$ & $\begin{array}{l}3.9 \\
3.8 \\
3.7 \\
5.8 \\
7.5 \\
7.6 \\
6.5 \\
5.7\end{array}$ & $\begin{array}{r}8.2 \\
7.0 \\
6.4 \\
11.7 \\
18.0 \\
18.9 \\
15.7 \\
13.1\end{array}$ & $\begin{array}{l}3.9 \\
3.8 \\
3.6 \\
5.8 \\
7.9 \\
8.0 \\
6.8 \\
6.0\end{array}$ & $\begin{array}{l}4.7 \\
4.7 \\
4.6 \\
4.9 \\
5.3 \\
5.5 \\
5.4 \\
5.2\end{array}$ & & $\begin{array}{r}6.7 \\
8.0 \\
8.4 \\
9.4 \\
16.5 \\
13.7 \\
12.0 \\
10.4\end{array}$ & $\begin{array}{r}8.3 \\
9: 2 \\
9.7 \\
11.0 \\
18.4 \\
15.8 \\
14.0 \\
12.3\end{array}$ & $\begin{array}{l}10.1 \\
10.1 \\
10.6 \\
12.2 \\
18.9 \\
17.0 \\
15.4 \\
13.5\end{array}$ & $\begin{array}{l}12.7 \\
12.8 \\
13.2 \\
14.5 \\
22.8 \\
21.0 \\
18.9 \\
17.1\end{array}$ \\
\hline $\begin{array}{l}26 \\
26 \\
26 \\
26 \\
26 \\
26 \\
26 \\
26\end{array}$ & $\begin{array}{r}0 \\
3 \\
6 \\
9 \\
12 \\
15 \\
18 \\
21\end{array}$ & 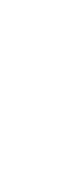 & $\begin{array}{r}4.5 \\
1.1 \\
-3.1 \\
\end{array}$ & $\begin{array}{l}8.7 \\
3.5 \\
2.0 \\
1.3 \\
0.1 \\
1.4 \\
4.1 \\
6.2\end{array}$ & & $\begin{array}{r}8.9 \\
3.2 \\
-2.2 \\
=-1.3 \\
=0.3 \\
=1.6 \\
=-4.4 \\
-5.4\end{array}$ & $\begin{array}{r}3.9 \\
0.3 \\
-\quad 2.9\end{array}$ & $\begin{array}{r}9.3 \\
2.7 \\
-2.4 \\
=1.9 \\
=1.1 \\
=2.2 \\
-4.6 \\
-\quad 6.6\end{array}$ & $\begin{array}{r}4.0 \\
-0.0 \\
-2.6\end{array}$ & $\begin{array}{l}5.0 \\
4.6 \\
4.5 \\
4.6 \\
4.7 \\
4.3 \\
4 \cdot 2 \\
4.0\end{array}$ & & $\begin{array}{r}7.5 \\
8.6 \\
20.6 \\
11.1 \\
8.9 \\
8.4 \\
8.7 \\
8.0\end{array}$ & $\begin{array}{r}8.8 \\
11.6 \\
12.9 \\
12.9 \\
11.4 \\
10.4 \\
10.3 \\
9.4\end{array}$ & $\begin{array}{l}10.7 \\
16.2 \\
16.0 \\
15.7 \\
15.2 \\
14.0 \\
12.0 \\
11.2\end{array}$ & $\begin{array}{l}14.2 \\
26.0 \\
25.7 \\
23.0 \\
23.0 \\
22.1 \\
17.6 \\
15.7\end{array}$ \\
\hline $\begin{array}{l}27 \\
27 \\
27 \\
27 \\
27 \\
27 \\
27 \\
27\end{array}$ & $\begin{array}{r}0 \\
3 \\
6 \\
9 \\
12 \\
15 \\
18 \\
21\end{array}$ & $\begin{array}{l}=7.5 \\
=6.0 \\
=6.0 \\
=4.3 \\
=2.5 \\
=1.8 \\
=4.3 \\
=3.6\end{array}$ & & $\begin{array}{l}7.7 \\
6.1 \\
6.0 \\
4.4 \\
2.3 \\
2.1 \\
4.6 \\
3.9\end{array}$ & & $\begin{array}{l}-7.9 \\
-6.1 \\
=6.1 \\
=4.3 \\
=2.6 \\
=2.2 \\
=4.6 \\
-4.0\end{array}$ & & $\begin{array}{l}-8.0 \\
-6.5 \\
-6.5 \\
-5.1 \\
-3.1 \\
-2.8 \\
-4.5 \\
-4.1\end{array}$ & & $\begin{array}{l}4.0 \\
4.0 \\
4.0 \\
4.2 \\
4.4 \\
4.0 \\
3.9 \\
3.9\end{array}$ & $=$ & $\begin{array}{l}4.1 \\
6.2 \\
5.4 \\
2.8 \\
2.9 \\
2.1 \\
3.4 \\
5.4\end{array}$ & $\begin{array}{l}5.1 \\
7.1 \\
5.9 \\
3.4 \\
3.7 \\
2.8 \\
3.7 \\
5.8\end{array}$ & $\begin{array}{l}6.7 \\
8.5 \\
6.6 \\
4.1 \\
4.9 \\
3.8 \\
4.3 \\
6.7\end{array}$ & $\begin{array}{r}10.4 \\
12.0 \\
8.5 \\
5.3 \\
6.6 \\
6.5 \\
6.5 \\
6.8\end{array}$ \\
\hline $\begin{array}{l}28 \\
28 \\
28 \\
28 \\
28 \\
28 \\
28 \\
28\end{array}$ & $\begin{array}{r}0 \\
3 \\
6 \\
9 \\
12 \\
15 \\
18 \\
21\end{array}$ & $\begin{array}{r}-3.7 \\
=4.0 \\
=4.2 \\
-0.9 \\
3.4 \\
5.3 \\
3.3 \\
2.8\end{array}$ & $\begin{array}{r} \\
0.5 \\
1.9 \\
0.8 \\
-0.4\end{array}$ & $\begin{array}{l}3.9 \\
4.3 \\
4.3 \\
0.8 \\
3.5 \\
5.5 \\
3.2 \\
1.7\end{array}$ & -0.2 & $\begin{array}{r}-4.0 \\
-4.3 \\
-4.4 \\
-\quad 0.7 \\
3.7 \\
5.9 \\
3.3 \\
1.07\end{array}$ & $\begin{array}{r}0.5 \\
1.2 \\
-0.1 \\
-\quad 1.3\end{array}$ & $\begin{array}{r}-4.1 \\
-4.6 \\
-4.6 \\
-0.7 \\
3.8 \\
6.0 \\
3.7 \\
1.6\end{array}$ & $\begin{array}{r} \\
\\
\\
0.7 \\
0.8 \\
-0.8 \\
-1.5\end{array}$ & $\begin{array}{l}3.9 \\
3.6 \\
3.4 \\
3.5 \\
3.7 \\
3.9 \\
3.8 \\
3.8\end{array}$ & & $\begin{array}{l}6.3 \\
7.3 \\
6.3 \\
7.7 \\
6.4 \\
4.1 \\
3.8 \\
5.4\end{array}$ & $\begin{array}{l}6.9 \\
8.0 \\
7.0 \\
8.3 \\
6.8 \\
5.0 \\
4.5 \\
6.1\end{array}$ & $\begin{array}{l}8.0 \\
8.5 \\
7.1 \\
7.6 \\
6.8 \\
5.8 \\
5.6 \\
6.8\end{array}$ & $\begin{array}{l}8.2 \\
9.2 \\
7.8 \\
9.0 \\
7.7 \\
6.9 \\
7.03 \\
7.5\end{array}$ \\
\hline $\begin{array}{l}29 \\
29 \\
29 \\
29 \\
29 \\
29 \\
29 \\
29\end{array}$ & $\begin{array}{r}0 \\
3 \\
6 \\
9 \\
12 \\
15 \\
18 \\
21\end{array}$ & $\begin{array}{l}0.8 \\
1.1 \\
0.6 \\
1.6 \\
3.8 \\
3.8 \\
2.02 \\
1.6\end{array}$ & $\begin{array}{l}0.3 \\
1.1 \\
1.2 \\
1.3\end{array}$ & $\begin{array}{l}0.8 \\
0.9 \\
0.5 \\
1.6 \\
3.7 \\
3.8 \\
2.0 \\
1.4\end{array}$ & $\begin{array}{l}1.2 \\
1.6\end{array}$ & $\begin{array}{l}0.8 \\
0.9 \\
0.7 \\
1.7 \\
3.8 \\
3.8 \\
2.00 \\
1.5\end{array}$ & $\begin{array}{l}0.4 \\
0.0 \\
0.9 \\
1.1 \\
1.2\end{array}$ & $\begin{array}{l}0.6 \\
0.8 \\
0.7 \\
1.4 \\
3.3 \\
3.6 \\
1.9 \\
1.4\end{array}$ & 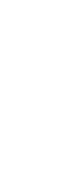 & $\begin{array}{l}3.7 \\
3.3 \\
3.4 \\
3.5 \\
3.8 \\
3.7 \\
3.6 \\
3.6\end{array}$ & & $\begin{array}{l}4.7 \\
3.9 \\
2.2 \\
1.2 \\
1.7 \\
4.0 \\
3.7 \\
4.9\end{array}$ & $\begin{array}{l}5.2 \\
4.5 \\
2.3 \\
1.1 \\
2.4 \\
4.3 \\
4.0 \\
5.4\end{array}$ & $\begin{array}{l}5.7 \\
5.0 \\
2.7 \\
1.9 \\
4.1 \\
5.1 \\
4.6 \\
5.9\end{array}$ & $\begin{array}{l}6.4 \\
5.4 \\
2.4 \\
1.8 \\
5.6 \\
5.4 \\
3.8 \\
6.5 .5\end{array}$ \\
\hline $\begin{array}{l}30 \\
30 \\
30 \\
30 \\
30 \\
30 \\
30 \\
30\end{array}$ & $\begin{array}{r}0 \\
3 \\
6 \\
9 \\
12 \\
15 \\
18 \\
21\end{array}$ & $\begin{array}{r}0.4 \\
-0.2 \\
0.0 \\
2.0 \\
6.0 \\
8.0 \\
3.8 \\
3.2\end{array}$ & $\left\{\begin{array}{r}0.3 \\
-0.4 \\
-0.1 \\
1.1 \\
4.2 \\
4.2 \\
2.05 \\
1.0\end{array}\right.$ & $\begin{array}{l}0.3 \\
0.4 \\
0.0 \\
2.2 \\
7.3 \\
8.6 \\
4.0 \\
3.2\end{array}$ & $\begin{array}{r}0.3 \\
-0.5 \\
-0.2\end{array}$ & $\begin{array}{r}0.2 \\
-0.24 \\
-0.2 \\
2.03 \\
7.01 \\
8.6 \\
4.5 \\
3.1\end{array}$ & $\begin{array}{r}0.1 \\
-0.6 \\
-0.2 \\
1.4 \\
4.2 \\
4.1 \\
2.3 \\
1.9\end{array}$ & $\begin{array}{r}0.1 \\
-0.4 \\
-0.2 \\
2.5 \\
7.2 \\
8.5 \\
5.2 \\
3.2\end{array}$ & $\begin{array}{r}0.0 \\
-0.0 \\
-0.3 \\
1.6 \\
4.0 \\
4.03 \\
2.6 \\
1.6\end{array}$ & $\begin{array}{l}3.4 \\
3.4 \\
3.3 \\
3.6 \\
3.9 \\
3.9 \\
3.5 \\
3.5\end{array}$ & & $\begin{array}{l}6.6 \\
6.0 \\
6.6 \\
5.0 \\
4.2 \\
3.2 \\
4.3 \\
9.8\end{array}$ & $\begin{array}{r}7.2 \\
6.5 \\
7.4 \\
5.0 \\
4.5 \\
3.5 \\
5.2 \\
11.3\end{array}$ & $\begin{array}{r}7.2 \\
6.3 \\
7.1 \\
5.7 \\
5.2 \\
3.8 \\
6.8 \\
12.9\end{array}$ & $\begin{array}{r}8.0 \\
7.1 \\
7.8 \\
6.4 \\
5.5 \\
5.3 \\
8.7 \\
14.7\end{array}$ \\
\hline $\begin{array}{l}31 \\
31 \\
31 \\
31 \\
31 \\
31 \\
31 \\
31\end{array}$ & $\begin{array}{r}0 \\
3 \\
6 \\
9 \\
12 \\
15 \\
18 \\
21\end{array}$ & $\begin{array}{r}2.8 \\
2.7 \\
2.9 \\
6.2 \\
10.4 \\
10.9 \\
9.0 \\
7.6\end{array}$ & $\begin{array}{l}1.4 \\
1.2 \\
1.0 \\
3.0 \\
5.1 \\
5.6 \\
4.8 \\
4.4\end{array}$ & $\begin{array}{r}2.7 \\
2.8 \\
2.8 \\
6.7 \\
10.9 \\
11.03 \\
0.3 \\
7.9\end{array}$ & & $\begin{array}{r}2.7 \\
2.6 \\
2.8 \\
6.8 \\
11.3 \\
11.6 \\
9.5 \\
8.0\end{array}$ & $\begin{array}{l}1.1 \\
0.9 \\
0.9 \\
3.7 \\
0.6 \\
7.0 \\
6.0 \\
5.4\end{array}$ & $\begin{array}{r}2.6 \\
2.5 \\
2.7 \\
7.1 \\
11.6 \\
12.0 \\
9.7 \\
8.3\end{array}$ & $\begin{array}{l}1.2 \\
0.8 \\
0.9 \\
3.8 \\
6.8 \\
7.1 \\
6.2 \\
5.2\end{array}$ & $\begin{array}{l}3.5 \\
3.4 \\
3.3 \\
3.7 \\
4.2 \\
4.1 \\
4.0 \\
3.9\end{array}$ & & $\begin{array}{l}12.5 \\
14.3 \\
15.6 \\
17.7 \\
19.5 \\
17.6 \\
17.8 \\
18.4\end{array}$ & $\begin{array}{l}14.4 \\
16.3 \\
17.9 \\
20.6 \\
22.8 \\
20.1 \\
20.8 \\
21.4\end{array}$ & $\begin{array}{l}16.3 \\
18.5 \\
20.5 \\
23.3 \\
24.9 \\
23.4 \\
24.3 \\
24.7\end{array}$ & $\begin{array}{l}18.3 \\
20.8 \\
22.8 \\
26.6 \\
29.2 \\
26.7 \\
27.6 \\
28.1\end{array}$ \\
\hline
\end{tabular}


TABLE 10

Table 10. -Three-hour averages of air and water-surface temperatures and wind directions and speed, April 1950-August 1951, Lake Hefner-Continued

STATION 4 THREE-HOURLY AVERAGES

JANUARY, 1951

\begin{tabular}{|c|c|c|c|c|c|c|c|c|c|c|c|c|c|c|c|}
\hline \multirow{3}{*}{ 吉 } & \multirow{3}{*}{ 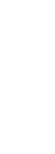 } & \multicolumn{8}{|c|}{ Average air temperature $\left({ }^{\circ} \mathrm{C}\right)$ at indicated height } & \multirow{3}{*}{$\mid \begin{array}{c}\text { Average } \\
\text { water- } \\
\text { surface } \\
\text { tempera- } \\
\text { ture } \\
\text { ("C) }\end{array}$} & \multirow{3}{*}{$\begin{array}{c}\text { Average } \\
\text { wind } \\
\text { direction } \\
\text { (coded) }\end{array}$} & \multirow{2}{*}{\multicolumn{4}{|c|}{$\begin{array}{c}\text { Average wind speed (knots) } \\
\text { at indicated height }\end{array}$}} \\
\hline & & \multicolumn{2}{|c|}{$\begin{array}{c}2 \\
\text { meters }\end{array}$} & \multicolumn{2}{|c|}{$\begin{array}{c}4 \\
\text { meters }\end{array}$} & \multicolumn{2}{|c|}{$\begin{array}{c}8 \\
\text { meters }\end{array}$} & \multicolumn{2}{|c|}{$\begin{array}{c}16 \\
\text { meters }\end{array}$} & & & & & & \\
\hline & & $\begin{array}{l}\text { Dry } \\
\text { bulb }\end{array}$ & $\begin{array}{l}\text { Wet } \\
\text { bulb }\end{array}$ & $\begin{array}{l}\text { Dry } \\
\text { bulb }\end{array}$ & $\begin{array}{l}\text { Wet } \\
\text { bulb }\end{array}$ & $\begin{array}{l}\text { Dry } \\
\text { bulb }\end{array}$ & $\begin{array}{l}\text { Wet } \\
\text { bulb }\end{array}$ & $\begin{array}{l}\text { Dry } \\
\text { bulb }\end{array}$ & $\begin{array}{l}\text { Wet } \\
\text { bulb }\end{array}$ & & & meters & $\begin{array}{c}4 \\
\text { meters }\end{array}$ & $\begin{array}{c}8 \\
\text { meters }\end{array}$ & $\begin{array}{c}16 \\
\text { meters }\end{array}$ \\
\hline $\begin{array}{l}1 \\
1 \\
1 \\
1 \\
1 \\
1 \\
1 \\
1\end{array}$ & $\begin{array}{r}0 \\
3 \\
6 \\
9 \\
12 \\
15 \\
18 \\
21\end{array}$ & $\begin{array}{l}6.9 \\
7.1 \\
7.7 \\
8.0 \\
8.2 \\
8.6 \\
8.4\end{array}$ & $\begin{array}{l}4.7 \\
6.1 \\
7.1 \\
7.5 \\
8.0 \\
8.3 \\
8.3\end{array}$ & $\begin{array}{l}7.0 \\
7.2 \\
7.9 \\
8.2 \\
8.9 \\
9.0 \\
8.8\end{array}$ & & $\begin{array}{l}7.0 \\
7.5 \\
8.1 \\
8.5 \\
9.3 \\
9.9 \\
9.4\end{array}$ & $\begin{array}{l}5.5 \\
6.8 \\
7.7 \\
8.2 \\
8.9 \\
9.5 \\
9.5\end{array}$ & $\begin{array}{r}7.2 \\
7.8 \\
8.4 \\
8.8 \\
9.9 \\
10.4 \\
9.7\end{array}$ & $\begin{array}{r}5.3 \\
6.9 \\
7.8 \\
8.3 \\
9.4 \\
10.0 \\
9.6\end{array}$ & $\begin{array}{l}3.9 \\
4.0 \\
4.0 \\
4.2 \\
4.4 \\
4.3 \\
4.8 \\
4.2\end{array}$ & & $\begin{array}{r}16.4 \\
15.0 \\
14.1 \\
12.0 \\
9.8 \\
6.9 \\
5.9 \\
6.7\end{array}$ & $\begin{array}{r}19.1 \\
17.4 \\
16.4 \\
13.9 \\
11.7 \\
8.5 \\
6.9 \\
7.9\end{array}$ & $\begin{array}{r}22.0 \\
20.3 \\
19.4 \\
16.8 \\
14.2 \\
11.0 \\
8.3 \\
11.1\end{array}$ & $\begin{array}{r}24.9 \\
23.4 \\
22.1 \\
19.0 \\
16.3 \\
12.5 \\
8.8 \\
10.4\end{array}$ \\
\hline $\begin{array}{l}2 \\
2 \\
2 \\
2 \\
2 \\
2 \\
2 \\
2 \\
2\end{array}$ & $\begin{array}{r}0 \\
3 \\
6 \\
9 \\
12 \\
15 \\
18 \\
21\end{array}$ & $\begin{array}{r}1.0 \\
0.8 \\
1.7 \\
0.6 \\
-0.2\end{array}$ & $\begin{array}{r}0.7 \\
0.2 \\
1.0 \\
0.1 \\
-0.6\end{array}$ & $\begin{array}{l}1.0 \\
0.6 \\
1.7 \\
0.5 \\
0.3\end{array}$ & & $\begin{array}{r}1.3 \\
1.5 \\
0.6 \\
-0.3\end{array}$ & $\begin{array}{r}0.7 \\
0.8 \\
0.2 \\
-0.1\end{array}$ & $\begin{array}{r}1.0 \\
1.3 \\
0.3 \\
-0.5\end{array}$ & $\begin{array}{r}0.3 \\
0.6 \\
-0.4 \\
-0.8\end{array}$ & $\begin{array}{l}4.1 \\
4 \bullet 3 \\
4 \bullet 0 \\
3 \bullet 9 \\
4 \bullet 0 \\
3 \bullet 9 \\
3 \bullet 9 \\
3 \bullet 9\end{array}$ & & $\begin{array}{l}7.1 \\
6.5 \\
5.7 \\
6.0 \\
6.0 \\
4.3 \\
3.4 \\
5.7\end{array}$ & $\begin{array}{l}8.6 \\
6.4 \\
6.3 \\
7.1 \\
7.4 \\
0.3 \\
4.7 \\
5.6\end{array}$ & $\begin{array}{r}10.8 \\
9.9 \\
10.5 \\
14.6 \\
15.1 \\
11.9 \\
8.8 \\
8.0\end{array}$ & $\begin{array}{r}12.7 \\
10.7 \\
11.8 \\
17.9 \\
22.1 \\
18.4 \\
12.3 \\
8.6\end{array}$ \\
\hline $\begin{array}{l}3 \\
3 \\
3 \\
3 \\
3 \\
3 \\
3 \\
3\end{array}$ & $\begin{array}{r}0 \\
3 \\
6 \\
9 \\
12 \\
15 \\
18 \\
21\end{array}$ & $\begin{array}{r}-0.2 \\
=0.6 \\
-0.6 \\
0.9 \\
4.7 \\
6.7 \\
4.3 \\
3.4\end{array}$ & $\begin{array}{l}0.5 \\
1.9 \\
3.1 \\
2.6 \\
2.1\end{array}$ & $\begin{array}{l}0.5 \\
0.8 \\
0.9 \\
1.1 \\
4.9 \\
6.8 \\
4.3 \\
3.4\end{array}$ & & $\begin{array}{r}-0.6 \\
-0.9 \\
-0.9 \\
1.1 \\
5.0 \\
7.1 \\
4.5 \\
3.4\end{array}$ & $\begin{array}{l}0.6 \\
1.8 \\
2.8 \\
2.2 \\
1.9\end{array}$ & $\mid \begin{array}{r}-0.7 \\
-\quad 1.0 \\
-0.9 \\
1.2 \\
5.1 \\
7.3 \\
4.6 \\
3.5\end{array}$ & $\begin{array}{l}0.8 \\
1.8 \\
3.4 \\
2.6 \\
2.1\end{array}$ & $\begin{array}{l}3.9 \\
3.8 \\
3.8 \\
3.9 \\
4.1 \\
4.1 \\
3.9 \\
3.9\end{array}$ & & $\begin{array}{r}4.5 \\
3.9 \\
7.3 \\
6.2 \\
20.9 \\
8.6 \\
4.2 \\
5.3\end{array}$ & $\begin{array}{r}4.4 \\
4.1 \\
7.6 \\
6.8 \\
12.3 \\
9.9 \\
4.7 \\
5.7\end{array}$ & $\begin{array}{r}7.4 \\
4.5 \\
7.1 \\
12.8 \\
10.6 \\
5.0 \\
5.6\end{array}$ & $\begin{array}{r}7.8 \\
5.2 \\
7.6 \\
7.6 \\
14.6 \\
12.6 \\
7.0 \\
7.4\end{array}$ \\
\hline $\begin{array}{l}4 \\
4 \\
4 \\
4 \\
4 \\
4 \\
4 \\
4\end{array}$ & $\begin{array}{r}0 \\
3 \\
6 \\
9 \\
12 \\
15 \\
18 \\
21\end{array}$ & $\begin{array}{r}3.0 \\
2.9 \\
1.7 \\
4.0 \\
6.7 \\
20.9 \\
6.4 \\
7.1\end{array}$ & $\begin{array}{l}2.4 \\
1.0 \\
0.1 \\
1.6 \\
3.5 \\
5.9 \\
4.2 \\
4.1\end{array}$ & $\begin{array}{r}3.1 \\
2.8 \\
1.8 \\
4.4 \\
7.0 \\
10.9 \\
7.2 \\
7.3\end{array}$ & & $\begin{array}{r}3.0 \\
3.0 \\
1.8 \\
4.0 \\
7.2 \\
11.0 \\
8.2 \\
7.6\end{array}$ & $\begin{array}{r}1.1 \\
0.0 \\
-0.1 \\
1.03 \\
3.9 \\
5.8 \\
4.4 \\
4.1\end{array}$ & $\begin{array}{r}3.1 \\
3.2 \\
2.3 \\
3.7 \\
7.6 \\
11.2 \\
9.3 \\
8.0\end{array}$ & $\begin{array}{l}1.7 \\
1.4 \\
0.5 \\
1.3 \\
4.0 \\
6.1 \\
5.1 \\
4.7\end{array}$ & $\begin{array}{l}3.8 \\
3.7 \\
3.7 \\
4.2 \\
4.8 \\
5.3 \\
4.5 \\
4.2\end{array}$ & & $\begin{array}{l}4.9 \\
3.8 \\
2.6 \\
2.0 \\
1.7 \\
1.06 \\
5.5 \\
8.9\end{array}$ & $\begin{array}{r}5.2 \\
4.0 \\
2.6 \\
2.5 \\
1.9 \\
2.4 \\
7.0 \\
10.5\end{array}$ & $\begin{array}{r}5.7 \\
5.0 \\
4.0 \\
4.5 \\
2.0 \\
3.2 \\
9.4 \\
12.8\end{array}$ & $\begin{array}{r}7.1 \\
6.4 \\
5.4 \\
5.1 \\
2.0 \\
3.9 \\
12.2 \\
15.3\end{array}$ \\
\hline $\begin{array}{l}5 \\
5 \\
5 \\
5 \\
5 \\
5 \\
5 \\
5\end{array}$ & $\begin{array}{r}0 \\
3 \\
6 \\
9 \\
12 \\
15 \\
18 \\
21\end{array}$ & $\begin{array}{r}6.5 \\
5.0 \\
4.9 \\
7.5 \\
10.4 \\
10.1 \\
-1.2 \\
-0.4\end{array}$ & $\begin{array}{r}3.9 \\
3.0 \\
2.7 \\
3.9 \\
5.9 \\
6.2 \\
0.5 \\
-1.1\end{array}$ & $\begin{array}{r}6.7 \\
5.0 \\
5.1 \\
7.8 \\
10.8 \\
10.0 \\
1.0 \\
0.7\end{array}$ & & $\begin{array}{r}6.0 \\
5.0 \\
5.2 \\
8.2 \\
10.6 \\
9.4 \\
0.7 \\
-0.9\end{array}$ & $\begin{array}{r}3.9 \\
2.8 \\
2.7 \\
4.0 \\
5.8 \\
5.5 \\
0.1 \\
-1.4\end{array}$ & $\begin{array}{r}7.2 \\
5.1 \\
5.3 \\
8.5 \\
30.6 \\
8.7 \\
0.55 \\
-1.2\end{array}$ & $\begin{array}{r}4.3 \\
3.1 \\
3.0 \\
4.7 \\
5.0 \\
3.4 \\
-1.5\end{array} \mid$ & $\begin{array}{l}4.1 \\
3.9 \\
3.8 \\
4.02 \\
4.6 \\
4.5 \\
3.9 \\
3.8\end{array}$ & & $\begin{array}{l}1106 \\
12.1 \\
10.7\end{array}$ & $\begin{array}{l}13.5 \\
13.9 \\
12.3\end{array}$ & $\begin{array}{l}16.2 \\
16.0 \\
13.9\end{array}$ & $\begin{array}{l}19.2 \\
18.4 \\
16.2\end{array}$ \\
\hline $\begin{array}{l}6 \\
6 \\
5 \\
6 \\
5 \\
6 \\
5 \\
6\end{array}$ & $\begin{array}{r}0 \\
3 \\
6 \\
9 \\
12 \\
15 \\
18 \\
21\end{array}$ & $\begin{array}{l}=2.1 \\
=3.2 \\
=5.0 \\
=3.6 \\
=0.6 \\
=0.3 \\
=2.09 \\
=4.8\end{array}$ & & $\begin{array}{l}2.3 \\
3.5 \\
5.1 \\
3.5 \\
0.6 \\
0.5 \\
3.1 \\
5.0\end{array}$ & & $\begin{array}{l}-2.4 \\
=3.6 \\
=5.3 \\
-3.7 \\
-0.9 \\
-0.9 \\
-3.4 \\
-5.2\end{array}$ & & $\left|\begin{array}{l}-2.6 \\
=4.0 \\
=5.6 \\
=4.2 \\
=1.4 \\
=1.3 \\
=3.5 \\
-5.3\end{array}\right|$ & & $\begin{array}{l}3.8 \\
3.8 \\
3.8 \\
4.0 \\
3.9 \\
3.6 \\
3.4 \\
3.3\end{array}$ & & $\begin{array}{l}6.4 \\
6.6 \\
4.7 \\
2.9 \\
2.8\end{array}$ & $\begin{array}{l}9.7 \\
9.7 \\
7.0 \\
4.4 \\
3.6\end{array}$ & $\begin{array}{r}16.6 \\
17.8 \\
13.7 \\
9.2 \\
8.3\end{array}$ & $\begin{array}{l}24.9 \\
27.9 \\
21.9 \\
14.9 \\
11.7\end{array}$ \\
\hline $\begin{array}{l}7 \\
7 \\
7 \\
7 \\
7 \\
7 \\
7 \\
7\end{array}$ & $\begin{array}{r}0 \\
3 \\
6 \\
9 \\
12 \\
15 \\
18 \\
21\end{array}$ & $\begin{array}{r}-6.0 \\
=7.0 \\
=5.5 \\
-1.4 \\
4.5 \\
5.4 \\
1.2 \\
-1.2\end{array}$ & $\begin{array}{r}0.7 \\
0.6 \\
-0.65\end{array}$ & $\begin{array}{l}6.2 \\
7.2 \\
5.6 \\
1.3 \\
4.03 \\
5.5 \\
0.9 \\
1.3\end{array}$ & & $\begin{array}{r}-6.4 \\
-7.5 \\
-5.4 \\
-1.2 \\
4.8 \\
5.1 \\
0.8 \\
-1.3\end{array}$ & $\begin{array}{l}0.6 \\
0.3\end{array}$ & $\left|\begin{array}{r}-6.5 \\
-7.5 \\
-5.5 \\
-\quad 1.1 \\
4.8 \\
4.8 \\
0.9 \\
-1.1\end{array}\right|$ & $\begin{array}{r}0.7 \\
0.5 \\
-1.7 \\
-3.0\end{array}$ & $\begin{array}{l}3.1 \\
3.0 \\
3.2 \\
3.7 \\
3.5 \\
3.4 \\
3.1 \\
3.1\end{array}$ & & $\begin{array}{r}2.7 \\
2.6 \\
7.3 \\
7.7 \\
10.6 \\
3.9 \\
3.0 \\
3.4\end{array}$ & $\begin{array}{r}2.9 \\
2.7 \\
7.6 \\
8.1 \\
10.9 \\
4.1 \\
3.2 \\
3.5\end{array}$ & $\begin{array}{r}6.4 \\
3.8 \\
7.7 \\
12.3 \\
7.5 \\
3.4 \\
4.3\end{array}$ & $\begin{array}{r}6.8 \\
5.2 \\
8.4 \\
8.7 \\
13.7 \\
9.1 \\
5.0 \\
5.6\end{array}$ \\
\hline $\begin{array}{l}5 \\
0 \\
0 \\
0 \\
8 \\
8 \\
8 \\
8\end{array}$ & $\begin{array}{r}0 \\
3 \\
5 \\
0 \\
12 \\
15 \\
13 \\
21\end{array}$ & $\begin{array}{r}-2.2 \\
-2.0 \\
-2.00 \\
1.8 \\
6.5 \\
8.4 \\
5.1 \\
3.0\end{array}$ & $\begin{array}{l}0.8 \\
2.5 \\
3.4 \\
2.4 \\
0.5\end{array}$ & $\begin{array}{l}2.22 \\
2.1 \\
2.1 \\
2.2 \\
6.8 \\
8.8 \\
5.2 \\
3.7\end{array}$ & & $\begin{array}{r}-2.3 \\
-2.02 \\
-2.3 \\
2.4 \\
7.2 \\
9.3 \\
5.3 \\
3.7\end{array}$ & $\begin{array}{ll} & \\
0.7 & \\
2.3 & 3 \\
3.1 \\
1.4 \\
0.1\end{array}$ & $\left|\begin{array}{r}-2.3 \\
-2.3 \\
-2.2 \\
2.5 \\
7.4 \\
9.5 \\
5.9 \\
3.5\end{array}\right|$ & $\begin{array}{r}-3.8 \\
1.3 \\
2.3\end{array}$ & $\begin{array}{l}3.0 \\
3.0 \\
3.1 \\
3.3 \\
3.5 \\
3.7 \\
3.1 \\
2.9\end{array}$ & & $\begin{array}{r}3.5 \\
5.4 \\
5.2 \\
8.9 \\
12.7 \\
10.2 \\
9.1 \\
10.5\end{array}$ & $\begin{array}{r}3.5 \\
5.6 \\
5.5 \\
9.4 \\
14.0 \\
11.5 \\
10.6 \\
12.1\end{array}$ & $\begin{array}{l}14.0 \\
12.0 \\
12.0 \\
13.6\end{array}$ & $\begin{array}{r}5.0 \\
6.4 \\
5.7 \\
10.6 \\
16.4 \\
14.7 \\
14.8 \\
15.5\end{array}$ \\
\hline $\begin{array}{l}9 \\
9 \\
9 \\
9 \\
9 \\
9 \\
9 \\
9\end{array}$ & $\begin{array}{r}0 \\
3 \\
6 \\
9 \\
12 \\
15 \\
18 \\
21\end{array}$ & $\begin{array}{l}3.1 \\
1.00 \\
1.02 \\
2.05 \\
7.00 \\
9.06 \\
8.0 \\
6.7\end{array}$ & $\begin{array}{r}0.0 \\
-1.0 \\
-0.8 \\
0.5 \\
2.5 \\
4.5 \\
4.4 \\
4.5\end{array}$ & $\begin{array}{r}3.1 \\
1.7 \\
1.2 \\
2.8 \\
7.2 \\
10.3 \\
8.4 \\
7.0\end{array}$ & & $\begin{array}{r}3.2 \\
1.5 \\
1.2 \\
2.9 \\
7.6 \\
10.6 \\
3.6 \\
7.2\end{array}$ & $\left|\begin{array}{r}-0.3 \\
-1.5 \\
-1.8 \\
0.3 \\
2.5 \\
4.6 \\
4.6 \\
4.9\end{array}\right|$ & $\begin{array}{r}3.3 \\
1.4 \\
1.1 \\
3.2 \\
8.1 \\
11.0 \\
9.2 \\
7.4\end{array}$ & & $\begin{array}{l}2.9 \\
2.6 \\
2.6 \\
2.8 \\
3.3 \\
3.5 \\
3.3 \\
3.2\end{array}$ & & $\begin{array}{l}11.8 \\
12.4 \\
12.7 \\
13.7 \\
15.3 \\
13.8 \\
11.9 \\
10.9\end{array}$ & $\begin{array}{l}13.2 \\
14.0 \\
14.4 \\
15.7 \\
17.8 \\
16.1 \\
14.0 \\
12.6\end{array}$ & $\begin{array}{l}14.2 \\
14.8 \\
15.5 \\
17.4 \\
19.6 \\
18.2 \\
16.6 \\
14.1\end{array}$ & $\begin{array}{l}16.3 \\
17.0 \\
17.6 \\
19.4 \\
22.9 \\
21.2 \\
19.5 \\
16.7\end{array}$ \\
\hline $\begin{array}{l}10 \\
10 \\
10 \\
10 \\
10 \\
10 \\
10 \\
10\end{array}$ & $\begin{array}{r}0 \\
3 \\
5 \\
9 \\
12 \\
15 \\
18 \\
21\end{array}$ & $\begin{array}{l}1.0 \\
0.2 \\
0.5 \\
2.6 \\
6.5 \\
7.5 \\
3.3 \\
1.4\end{array}$ & $\mid \begin{array}{r}-0.9 \\
=1.7 \\
=-1.3 \\
-0.1 \\
1.7 \\
1.9 \\
0.00 \\
-0.1\end{array}$ & $\begin{array}{l}0.5 \\
0.1 \\
0.4 \\
2.09 \\
0.7 \\
7.6 \\
3.4 \\
1.5\end{array}$ & & $\begin{array}{l}0.5 \\
0.1 \\
0.7 \\
3.0 \\
6.7 \\
7.3 \\
3.5 \\
1.7\end{array}$ & 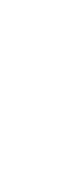 & $\begin{array}{l}0.2 \\
0.2 \\
0.2 \\
2.9 \\
6.5 \\
7.1 \\
4.2 \\
2.8\end{array}$ & & $\begin{array}{l}2.09 \\
2.99 \\
2.9 \\
3.2 \\
3.0 \\
3.1 \\
2.6 \\
2.6\end{array}$ & & $\begin{array}{r}9.1 \\
10.3 \\
8.2 \\
9.2 \\
7.8 \\
4.6 \\
1.0 \\
2.0\end{array}$ & $\begin{array}{r}9.9 \\
10.4 \\
8.3 \\
9.3 \\
8.1 \\
4.9 \\
1.1 \\
2.4\end{array}$ & $\begin{array}{r}10.7 \\
16.4 \\
15.2 \\
15.9 \\
14.3 \\
9.4 \\
2.0 \\
2.5\end{array}$ & $\begin{array}{r}12.5 \\
18.9 \\
14.8 \\
16.5 \\
15.8 \\
10.5 \\
3.6 \\
4.7\end{array}$ \\
\hline
\end{tabular}


TABLE 10

Table 10. -Three-hour averages of air and water-surface temperatures and wind directions and speed, April 1950-August 1951, Lake Hefner-Continued

THREE-HOURLY AVERAGES

JANUARY, 1951

\begin{tabular}{|c|c|c|c|c|c|c|c|c|c|c|c|c|c|c|c|}
\hline \multirow{3}{*}{ कृ } & \multirow{3}{*}{ 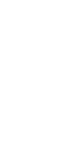 } & \multicolumn{8}{|c|}{ Average air temperature $\left({ }^{\circ} \mathrm{C}\right)$ at indicated height } & \multirow{3}{*}{$\begin{array}{l}\text { Average } \\
\text { water- } \\
\text { surface } \\
\text { tempera- } \\
\text { ture } \\
\text { ("C) }\end{array}$} & \multirow{3}{*}{$\begin{array}{c}\begin{array}{c}\text { Average } \\
\text { wind } \\
\text { direction } \\
\text { (coded) }\end{array} \\
\text { (a) }\end{array}$} & \multicolumn{4}{|c|}{$\begin{array}{l}\text { Average wind speed (knots) } \\
\text { at indicated height }\end{array}$} \\
\hline & & \multicolumn{2}{|c|}{$\begin{array}{c}2 \\
\text { meters }\end{array}$} & \multicolumn{2}{|c|}{$\begin{array}{c}4 \\
\text { meters }\end{array}$} & \multicolumn{2}{|c|}{$\begin{array}{c}8 \\
\text { meters }\end{array}$} & \multicolumn{2}{|c|}{$\begin{array}{c}16 \\
\text { meters }\end{array}$} & & & & & & \\
\hline & & $\begin{array}{l}\text { Dry } \\
\text { bulb }\end{array}$ & $\begin{array}{l}\text { Wet } \\
\text { bulb }\end{array}$ & $\begin{array}{l}\text { Dry } \\
\text { bulb }\end{array}$ & $\begin{array}{l}\text { Wet } \\
\text { bulb }\end{array}$ & $\begin{array}{l}\text { Dry } \\
\text { bulb }\end{array}$ & $\begin{array}{l}\text { Wet } \\
\text { bulb }\end{array}$ & $\begin{array}{l}\text { Dry } \\
\text { bulb }\end{array}$ & $\begin{array}{l}\text { Wet } \\
\text { bulb }\end{array}$ & & & meters & meters & meters & meters \\
\hline $\begin{array}{l}11 \\
11 \\
11 \\
11 \\
11 \\
11 \\
11 \\
11\end{array}$ & $\begin{array}{r}0 \\
3 \\
6 \\
9 \\
12 \\
15 \\
18 \\
21\end{array}$ & $\begin{array}{l}0.8 \\
0.8 \\
0.6 \\
2.8 \\
5.0 \\
7.2 \\
6.5 \\
5.8\end{array}$ & $\begin{array}{r}-1.1 \\
=1.2 \\
-1.7 \\
0.0 \\
1.4 \\
2.5 \\
2.4 \\
2.2\end{array}$ & $\begin{array}{l}0.8 \\
0.6 \\
0.5 \\
2.8 \\
5.3 \\
7.5 \\
6.7 \\
6.0\end{array}$ & & $\begin{array}{l}0.9 \\
0.4 \\
0.5 \\
2.8 \\
5.6 \\
7.7 \\
6.8 \\
6.0\end{array}$ & $\mid \begin{array}{rr}- & 2.03 \\
-2.00 \\
-2.00 \\
-0.02 \\
1.04 \\
2.05 \\
2.04 \\
2.2\end{array}$ & $\begin{array}{l}1 \cdot 1 \\
0: 3 \\
0.3 \\
2 \cdot 9 \\
5 \cdot 7 \\
8 \cdot 0 \\
7 \cdot 1 \\
6 \cdot 2\end{array}$ & 3.1 & $\begin{array}{l}2.7 \\
2.5 \\
2.6 \\
2.9 \\
2.9 \\
3.1 \\
3.1 \\
3.0\end{array}$ & & $\begin{array}{r}3.7 \\
7.8 \\
8.4 \\
11.4 \\
9.8 \\
14.0 \\
10.4 \\
14.6\end{array}$ & $\begin{array}{r}4.1 \\
8.6 \\
9.7 \\
13.0 \\
11.5 \\
16.1 \\
12.0 \\
16.8\end{array}$ & $\begin{array}{r}4.6 \\
10.0 \\
11.2 \\
14.9 \\
13.7 \\
19.5 \\
14.7 \\
20.0\end{array}$ & $\begin{array}{r}5.6 \\
11.0 \\
12.2 \\
17.1 \\
15.5 \\
21.8 \\
16.6 \\
22.4\end{array}$ \\
\hline $\begin{array}{l}12 \\
12 \\
12 \\
12 \\
12 \\
12 \\
12 \\
12\end{array}$ & $\begin{array}{r}0 \\
3 \\
6 \\
9 \\
12 \\
15 \\
18 \\
21\end{array}$ & $\begin{array}{r}5.3 \\
4.4 \\
4.0 \\
5.3 \\
9.0 \\
10.8 \\
7.5 \\
4.8\end{array}$ & $\begin{array}{l}2.5 \\
2.7 \\
3.3 \\
4.8 \\
6.6 \\
7.8 \\
6.4 \\
4.6\end{array}$ & $\begin{array}{r}5.4 \\
4.4 \\
4.0 \\
5.8 \\
9.0 \\
12.0 \\
8.3 \\
5.1\end{array}$ & & $\begin{array}{r}5.4 \\
4.5 \\
4.0 \\
5.9 \\
10.8 \\
12.1 \\
8.5 \\
5.4\end{array}$ & $\begin{array}{l}2.4 \\
2.7 \\
3.4 \\
5.2 \\
7.4 \\
3.3 \\
7.0 \\
5.1\end{array}$ & $\begin{array}{r}5.6 \\
4.6 \\
4.0 \\
6.4 \\
11.3 \\
12.3 \\
8.7 \\
5.7\end{array}$ & & $\begin{array}{l}3.0 \\
3.0 \\
3.0 \\
3.2 \\
3.7 \\
3.0 \\
3.4 \\
3.2\end{array}$ & & $\begin{array}{r}15.2 \\
14.0 \\
10.6 \\
9.4 \\
4.1 \\
2.5 \\
5.9 \\
2.3\end{array}$ & $\begin{array}{r}17.6 \\
16.1 \\
12.1 \\
10.9 \\
5.3 \\
3.5 \\
7.0 \\
3.3\end{array}$ & $\begin{array}{r}20.3 \\
18.3 \\
14.0 \\
12.0 \\
6.3 \\
4.2 \\
8.4 \\
4.2\end{array}$ & $\begin{array}{r}23.1 \\
21.1 \\
15.8 \\
13.9 \\
7.2 \\
4.7 \\
9.4 \\
4.8\end{array}$ \\
\hline $\begin{array}{l}13 \\
13 \\
13 \\
13 \\
13 \\
13 \\
13 \\
13\end{array}$ & $\begin{array}{r}0 \\
3 \\
6 \\
9 \\
12 \\
15 \\
18 \\
21\end{array}$ & $\begin{array}{l}3.8 \\
4 \cdot 2 \\
4 \cdot 5 \\
5.9 \\
6.3 \\
5.7 \\
5.5 \\
4.3\end{array}$ & $\begin{array}{l}3 \cdot 7 \\
4 \cdot 3 \\
4 \cdot 5 \\
5 \cdot 9 \\
6 \cdot 3 \\
5 \cdot 7 \\
5.5 \\
4 \cdot ?\end{array}$ & $\begin{array}{l}3.8 \\
4.3 \\
4.5 \\
5.9 \\
6.3 \\
5.8 \\
5.5 \\
4.2\end{array}$ & $\begin{array}{l}3.7 \\
4.3 \\
4.5 \\
5.9 \\
6.3 \\
5.8 \\
5.5 \\
4.3\end{array}$ & $\begin{array}{l}3.8 \\
4.4 \\
4.6 \\
5.9 \\
6.4 \\
5.8 \\
5.5 \\
4.3\end{array}$ & $\begin{array}{l}3.8 \\
4.4 \\
4.5 \\
5.9 \\
6.4 \\
5.8 \\
5.5 \\
4.1\end{array}$ & $\begin{array}{l}3.9 \\
4.5 \\
4.8 \\
6.2 \\
6.6 \\
5.0 \\
5.7 \\
4.1\end{array}$ & $\begin{array}{l}3.8 \\
4.5 \\
4.8 \\
5.2 \\
6.5 \\
5.9 \\
5.6 \\
4.0\end{array}$ & $\begin{array}{l}3.2 \\
3.2 \\
3.3 \\
3.5 \\
3.5 \\
3.6 \\
3.4 \\
3.2\end{array}$ & & $\begin{array}{l}1.7 \\
1.9 \\
1.9 \\
8.1 \\
8.0 \\
3.3 \\
5.2 \\
4.8\end{array}$ & $\begin{array}{l}2.5 \\
2.5 \\
2.5 \\
8.7 \\
8.6 \\
5.1 \\
6.5 \\
6.1\end{array}$ & $\begin{array}{l}2.9 \\
3.1 \\
3.4 \\
9.5 \\
9.7 \\
8.5 \\
8.5 \\
9.4\end{array}$ & $\begin{array}{r}3.3 \\
3.5 \\
4.7 \\
10.5 \\
11.9 \\
13.4 \\
13.2 \\
13.6\end{array}$ \\
\hline $\begin{array}{l}14 \\
14 \\
14 \\
14 \\
14 \\
14 \\
14 \\
14\end{array}$ & $\begin{array}{r}0 \\
3 \\
6 \\
9 \\
12 \\
15 \\
18 \\
21\end{array}$ & $\begin{array}{l}2.0 \\
1.0 \\
0.2 \\
1.3 \\
4.6 \\
6.8 \\
3.7 \\
3.4\end{array}$ & $\begin{array}{l}1.9 \\
0.8 \\
0.2 \\
1.1 \\
3.3 \\
3.8 \\
1.8 \\
1.6\end{array}$ & $\begin{array}{l}2.0 \\
0.9 \\
0.1 \\
1.2 \\
4.9 \\
6.7 \\
3.6 \\
3.5\end{array}$ & $\begin{array}{l}1.9 \\
0.7 \\
0.1 \\
1.1 \\
3.1 \\
3.8 \\
1.6 \\
1.4\end{array}$ & $\begin{array}{l}2.0 \\
0.8 \\
0.1 \\
1.3 \\
5.0 \\
6.7 \\
3.5 \\
3.5\end{array}$ & $\begin{array}{l}1.2 \\
3.1 \\
3.7 \\
1.5 \\
1.2\end{array}$ & $\begin{array}{l}2.0 \\
0.7 \\
1.2 \\
5.0 \\
6.7 \\
3.8 \\
3.4\end{array}$ & $\begin{array}{l}1.7 \\
0.5 \\
0.8 \\
2.8 \\
3.4 \\
1.5 \\
1.3\end{array}$ & $\begin{array}{l}3.0 \\
2.9 \\
2.7 \\
3.1 \\
3.0 \\
3.4 \\
3.0 \\
3.0\end{array}$ & & $\begin{array}{r}4.5 \\
5.4 \\
3.9 \\
5.3 \\
8.7 \\
8.2 \\
10.1 \\
11.1\end{array}$ & $\begin{array}{r}6.3 \\
7.1 \\
6.4 \\
5.4 \\
8.5 \\
8.8 \\
10.7 \\
12.2\end{array}$ & $\begin{array}{r}11.3 \\
13.7 \\
12.3 \\
8.4 \\
11.6 \\
9.8 \\
9.7 \\
11.6\end{array}$ & $\begin{array}{l}17.7 \\
18.9 \\
18.3 \\
11.3 \\
13.7 \\
11.4 \\
12.5 \\
13.2\end{array}$ \\
\hline $\begin{array}{l}15 \\
15 \\
15 \\
15 \\
15 \\
15 \\
15 \\
15\end{array}$ & $\begin{array}{r}0 \\
3 \\
6 \\
0 \\
12 \\
15 \\
13 \\
21\end{array}$ & $\begin{array}{r}3.7 \\
3.5 \\
1.7 \\
5.5 \\
10.1 \\
11.6 \\
4.2 \\
3.7\end{array}$ & $\begin{array}{l}1.8 \\
1.4 \\
0.3 \\
3.0 \\
5.0 \\
6.1 \\
3.2 \\
2.7\end{array}$ & $\begin{array}{r}3.9 \\
3.3 \\
1.7 \\
5.7 \\
10.3 \\
11.6 \\
4.8 \\
4.2\end{array}$ & $\begin{array}{l}1.7 \\
1.2 \\
0.2 \\
3.2 \\
5.1 \\
6.2 \\
3.4 \\
2.7\end{array}$ & $\begin{array}{r}3.8 \\
3.3 \\
1.7 \\
5.9 \\
10.3 \\
11.9 \\
7.5 \\
4.7\end{array}$ & $\begin{array}{l}3.5 \\
1.1 \\
0.3 \\
3.2 \\
4.7 \\
5.0 \\
3.9 \\
2.7\end{array}$ & $\begin{array}{r}4.0 \\
3.5 \\
1.9 \\
6.0 \\
10.3 \\
11.2 \\
10.1 \\
5.9\end{array}$ & & $\begin{array}{l}3.0 \\
3.0 \\
2.9 \\
3.4 \\
3.8 \\
3.6 \\
3.1 \\
3.1\end{array}$ & & $\begin{array}{r}10.0 \\
5.1 \\
3.8 \\
5.3 \\
4.4 \\
2.5 \\
1.6 \\
2.9\end{array}$ & $\begin{array}{r}10.6 \\
5.2 \\
3.9 \\
5.4 \\
5.0 \\
2.8 \\
2.3 \\
3.7\end{array}$ & $\begin{array}{r}10.5 \\
9.6 \\
5.0 \\
7.0 \\
8.9 \\
4.6 \\
3.4 \\
4.8\end{array}$ & $\begin{array}{r}12.3 \\
10.4 \\
6.3 \\
7.5 \\
10.8 \\
5.4 \\
4.2 \\
7.5\end{array}$ \\
\hline $\begin{array}{l}16 \\
16 \\
16 \\
16 \\
16 \\
16 \\
16 \\
16\end{array}$ & $\begin{array}{r}0 \\
3 \\
6 \\
9 \\
12 \\
15 \\
18 \\
21\end{array}$ & $\begin{array}{r}3.4 \\
3.9 \\
3.8 \\
7.6 \\
12.5 \\
14.0 \\
11.5 \\
10.0\end{array}$ & $\begin{array}{l}2.4 \\
2 \cdot 1 \\
1.9 \\
4.3 \\
6.1 \\
6.9 \\
5.6 \\
5.4\end{array}$ & $\begin{array}{r}3.5 \\
4.0 \\
3.9 \\
8.2 \\
12.8 \\
14.5 \\
11.5 \\
10.3\end{array}$ & $\begin{array}{l}2.3 \\
2.0 \\
1.8 \\
4.4 \\
6.1 \\
6.6 \\
5.3 \\
4.9\end{array}$ & $\begin{array}{r}3.8 \\
4.0 \\
4.1 \\
8.6 \\
13.5 \\
13.7 \\
11.9 \\
10.9\end{array}$ & $\begin{array}{l}2.1 \\
1.9 \\
1.7 \\
4.4 \\
6.2 \\
6.8 \\
5.3 \\
5.0\end{array}$ & $\begin{array}{r}4 \cdot 5 \\
4 \cdot 2 \\
4 \cdot 1 \\
9.0 \\
14 \cdot 3 \\
16.2 \\
13.0 \\
11.5\end{array}$ & & $\begin{array}{l}3.0 \\
3.0 \\
3.1 \\
3.8 \\
4 \cdot 1 \\
4 \cdot 2 \\
4.1 \\
4 \cdot 2\end{array}$ & & $\begin{array}{r}4.4 \\
9.8 \\
13.2 \\
16.4 \\
16.3 \\
14.5 \\
12.8 \\
16.1\end{array}$ & $\begin{array}{r}5.4 \\
11.1 \\
15.1 \\
18.8 \\
18.3 \\
16.9 \\
15.3 \\
18.7\end{array}$ & $\begin{array}{r}6.5 \\
12.6 \\
17.0 \\
20.3 \\
18.7 \\
18.6 \\
17.5 \\
20.8\end{array}$ & $\begin{array}{r}8.3 \\
24.6 \\
19.5 \\
23.4 \\
22.42 \\
22.4 \\
21.4 \\
25.1\end{array}$ \\
\hline $\begin{array}{l}17 \\
17 \\
17 \\
17 \\
17 \\
17 \\
17 \\
17\end{array}$ & $\begin{array}{r}0 \\
3 \\
6 \\
9 \\
12 \\
15 \\
18 \\
21\end{array}$ & $\begin{array}{r}10.7 \\
9.0 \\
6.9 \\
7.7 \\
12.2 \\
15.0 \\
8.3 \\
6.2\end{array}$ & $\begin{array}{l}5.7 \\
4.9 \\
3.7 \\
4.2 \\
6.6 \\
7.8 \\
5.0 \\
3.8\end{array}$ & $\begin{array}{r}11.0 \\
9.3 \\
7.0 \\
7.9 \\
13.1 \\
16.3 \\
9.9 \\
6.7\end{array}$ & $\begin{array}{l}5.0 \\
4.3 \\
3.0 \\
3.7 \\
6.0 \\
7.3 \\
4.7 \\
3.3\end{array}$ & $\begin{array}{r}11.6 \\
9.4 \\
7.2 \\
8.2 \\
13.7 \\
17.2 \\
11.6 \\
7.4\end{array}$ & $\begin{array}{l}5.0 \\
4.2 \\
3.0 \\
3.7 \\
6.01 \\
7.7 \\
5.0 \\
3.4\end{array}$ & $\begin{array}{r}12.1 \\
9.8 \\
7.4 \\
9.0 \\
14 \cdot 5 \\
17.5 \\
13.3 \\
9.8\end{array}$ & & $\begin{array}{l}4.0 \\
4.0 \\
3.9 \\
4.0 \\
4.3 \\
4.6 \\
4.3 \\
4.1\end{array}$ & & $\begin{array}{r}17.8 \\
17.6 \\
15.2 \\
9.0 \\
8.0 \\
6.4 \\
4.9 \\
3.9\end{array}$ & $\begin{array}{r}20.4 \\
19.5 \\
16.5 \\
10.0 \\
8.9 \\
7.7 \\
8.2 \\
5.4\end{array}$ & $\begin{array}{r}21.4 \\
19.8 \\
16.6 \\
9.7 \\
9.7 \\
8.1 \\
7.9 \\
6.7\end{array}$ & $\begin{array}{r}25.4 \\
23.5 \\
19.4 \\
12.4 \\
9.8 \\
9.0 \\
12.1 \\
10.4\end{array}$ \\
\hline $\begin{array}{l}18 \\
18 \\
18 \\
18 \\
18 \\
18 \\
18 \\
18\end{array}$ & $\begin{array}{r}0 \\
3 \\
6 \\
9 \\
12 \\
15 \\
18 \\
21\end{array}$ & $\begin{array}{r}6.0 \\
5.0 \\
5.0 \\
7.9 \\
15.5 \\
15.8\end{array}$ & $\begin{array}{l}3.6 \\
2.9 \\
2.8 \\
4.5 \\
8.4 \\
9.0\end{array}$ & $\begin{array}{r}6.5 \\
5.2 \\
5.2 \\
8.9 \\
16.2 \\
18.3\end{array}$ & $\begin{array}{l}3.0 \\
2.5 \\
2.3 \\
4.6 \\
8.0 \\
8.5\end{array}$ & $\begin{array}{r}7.5 \\
5.7 \\
5.6 \\
9.6 \\
17.2 \\
19.6\end{array}$ & $\begin{array}{l}3.0 \\
2.3 \\
2.2 \\
4.6 \\
8.2 \\
9.0\end{array}$ & $\begin{array}{r}8.9 \\
6.4 \\
6.4 \\
10.3 \\
17.6 \\
19.9\end{array}$ & & $\begin{array}{l}4.2 \\
4.1 \\
3.9 \\
5.1 \\
7.1 \\
7.7\end{array}$ & & $\begin{array}{l}4.0 \\
4.5 \\
4.2 \\
2.8 \\
1.9 \\
4.9 \\
5.2 \\
6.4\end{array}$ & $\begin{array}{l}5.6 \\
6.0 \\
5.1 \\
3.6 \\
2.8 \\
6.1 \\
6.9 \\
8.2\end{array}$ & $\begin{array}{r}7.0 \\
7.1 \\
6.1 \\
4.0 \\
3.1 \\
6.5 \\
8.6 \\
10.5\end{array}$ & $\begin{array}{r}9.9 \\
9.6 \\
7.7 \\
4.9 \\
3.7 \\
7.5 \\
11.9 \\
13.5\end{array}$ \\
\hline $\begin{array}{l}19 \\
19 \\
19 \\
19 \\
19 \\
19 \\
19 \\
19\end{array}$ & $\begin{array}{r}0 \\
3 \\
6 \\
9 \\
12 \\
15 \\
18 \\
21\end{array}$ & $\begin{array}{l}11.0 \\
14.2 \\
16.1 \\
13.9 \\
12.8\end{array}$ & $\begin{array}{l}6.4 \\
8.3 \\
9.5 \\
8.4 \\
7.8\end{array}$ & $\begin{array}{l}11.2 \\
15.7 \\
16.8 \\
14.8 \\
13.6\end{array}$ & $\begin{array}{l}5.4 \\
7.0 \\
7.8 \\
6.7 \\
6.2\end{array}$ & $\begin{array}{l}12.4 \\
16.9 \\
18.1 \\
16.0 \\
34.6\end{array}$ & $\begin{array}{l}5.4 \\
7.1 \\
7.8 \\
6.7 \\
6.2\end{array}$ & $\begin{array}{l}13.3 \\
18.1 \\
19.3 \\
16.9 \\
15.5\end{array}$ & & $\begin{array}{l}4.7 \\
5.0 \\
5.4 \\
5.6 \\
5.4\end{array}$ & & $\begin{array}{r}5.8 \\
10.0 \\
9.7 \\
9.2 \\
12.6 \\
13.7 \\
12.9 \\
10.8\end{array}$ & $\begin{array}{r}7.0 \\
11.1 \\
10.7 \\
10.7 \\
14.4 \\
15.7 \\
15.7 \\
12.7\end{array}$ & $\begin{array}{r}8.0 \\
11.2 \\
10.9 \\
11.3 \\
15.5 \\
17.0 \\
16.6 \\
14.1\end{array}$ & $\begin{array}{r}9.1 \\
13.7 \\
13.6 \\
13.7 \\
18.9 \\
21.0 \\
20.4 \\
17.5\end{array}$ \\
\hline $\begin{array}{l}20 \\
20 \\
20 \\
20 \\
20 \\
20 \\
20 \\
20\end{array}$ & $\begin{array}{r}0 \\
3 \\
6 \\
9 \\
12 \\
15 \\
18 \\
21\end{array}$ & $\begin{array}{r}5.9 \\
-0.5 \\
-1.5 \\
-0.9 \\
1.2 \\
4.4 \\
1.2 \\
-2.0\end{array}$ & $\begin{array}{l}-0.1 \\
1.4 \\
-0.8 \\
-3.0\end{array}$ & $\begin{array}{l}6.7 \\
0.8 \\
1.7 \\
0.9 \\
1.2 \\
4.4 \\
1.0 \\
2.4\end{array}$ & $\begin{array}{r}2.6 \\
-2.1 \\
\\
\\
0.1 \\
-1.03 \\
-3.2\end{array}$ & $\begin{array}{r}7.0 \\
-1.0 \\
-1.0 \\
-1.1 \\
1.3 \\
4.1 \\
0.9 \\
-2.6\end{array}$ & $\begin{array}{r}2.3 \\
-1.9 \\
\\
0.3 \\
-1.5 \\
-2.9\end{array} \mid$ & $\begin{array}{r}6.6 \\
-1.2 \\
-2.1 \\
-1.4 \\
1.1 \\
3.9 \\
0.9 \\
-2.7\end{array} \mid$ & & $\begin{array}{l}4.9 \\
4.0 \\
4.0 \\
4.1 \\
4.2 \\
4.1 \\
3.8 \\
3.7\end{array}$ & & $\begin{array}{l}9.1 \\
7.3 \\
5.7 \\
4.5 \\
4.9 \\
3.9 \\
3.0 \\
2.03\end{array}$ & $\begin{array}{l}9.9 \\
7.7 \\
6.4 \\
5.1 \\
5.1 \\
4.9 \\
4.7 \\
3.8\end{array}$ & $\begin{array}{r}15.4 \\
16.4 \\
13.4 \\
10.0 \\
8.7 \\
9.02 \\
8.03 \\
7.0\end{array}$ & $\begin{array}{r}15.6 \\
19.7 \\
17.5 \\
12.1 \\
9.3 \\
13.0 \\
13.5 \\
11.8\end{array}$ \\
\hline
\end{tabular}


TABLE 10

201

Table 10. - Three-hour averages of air and water-surface temperatures and wind directions and speed, April 1950-August 1951, Lake Hefner-Continued

STATION 4 THREE-HOURLY AVERAGES

JANUARY, 1951

\begin{tabular}{|c|c|c|c|c|c|c|c|c|c|c|c|c|c|c|c|}
\hline \multirow{3}{*}{ 害嘉 } & \multirow{3}{*}{ 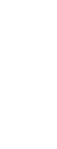 } & \multicolumn{8}{|c|}{ Average air temperature $\left({ }^{\circ} \mathrm{C}\right)$ at indicated height } & \multirow{3}{*}{$\begin{array}{l}\text { Average } \\
\text { water- } \\
\text { surface } \\
\text { tempera- } \\
\text { ture } \\
\text { ("C) }\end{array}$} & \multirow{3}{*}{$\begin{array}{c}\text { A verage } \\
\text { wind } \\
\text { direction } \\
\text { (coded) }\end{array}$} & \multicolumn{4}{|c|}{$\begin{array}{l}\text { Average wind speed (knots) } \\
\text { at indicated height }\end{array}$} \\
\hline & & \multicolumn{2}{|c|}{$\begin{array}{c}2 \\
\text { meters }\end{array}$} & \multicolumn{2}{|c|}{ meters } & \multicolumn{2}{|c|}{$\begin{array}{c}8 \\
\text { meters }\end{array}$} & \multicolumn{2}{|c|}{$\begin{array}{c}16 \\
\text { meters }\end{array}$} & & & & & & \\
\hline & & $\begin{array}{l}\text { Dry } \\
\text { bulb }\end{array}$ & $\begin{array}{l}\text { Wet } \\
\text { bulb }\end{array}$ & $\begin{array}{l}\text { Dry } \\
\text { bulb }\end{array}$ & $\begin{array}{l}\text { Wet } \\
\text { bulb }\end{array}$ & $\begin{array}{l}\text { Dry } \\
\text { bulb }\end{array}$ & $\begin{array}{l}\text { Wet } \\
\text { bulb }\end{array}$ & $\begin{array}{l}\text { Dry } \\
\text { bulb }\end{array}$ & $\begin{array}{l}\text { Wet } \\
\text { bulb }\end{array}$ & & & meters & meters & meters & $\begin{array}{c}16 \\
\text { meters }\end{array}$ \\
\hline $\begin{array}{l}21 \\
21 \\
21 \\
21 \\
21 \\
21 \\
21 \\
21\end{array}$ & $\begin{array}{r}0 \\
3 \\
6 \\
9 \\
12 \\
15 \\
18 \\
21\end{array}$ & $\begin{array}{r}=4.7 \\
=6.3 \\
=6.7 \\
=4.9 \\
=0.7 \\
3.5 \\
1.06 \\
0.2\end{array}$ & & $\begin{array}{l}4.9 \\
6.5 \\
6.8 \\
4.7 \\
0.5 \\
3.5 \\
1.5 \\
0.0\end{array}$ & & $\begin{array}{r}-5.2 \\
-6.8 \\
-7.0 \\
-4.9 \\
0.1 \\
3.4 \\
1.4 \\
0.0\end{array}$ & & $\mid \begin{array}{r}-5.3 \\
-7.0 \\
-7.4 \\
-5.3 \\
-0.3 \\
3.2 \\
1.02 \\
-0.1\end{array}$ & & $\begin{array}{l}3.6 \\
3.6 \\
3.6 \\
4.0 \\
4.0 \\
4.1 \\
3.7 \\
3.7\end{array}$ & & $\begin{array}{l}2.09 \\
2.03 \\
1.04 \\
1.09 \\
1.01 \\
4.03 \\
7.1 \\
9.8\end{array}$ & $\begin{array}{r}3.3 \\
2.2 \\
2.4 \\
2.5 \\
1.9 \\
5.0 \\
7.9 \\
11.1\end{array}$ & $\begin{array}{r}5.7 \\
5.0 \\
4.5 \\
3.2 \\
2.1 \\
5.4 \\
8.9 \\
12.2\end{array}$ & $\begin{array}{r}9.4 \\
7.9 \\
7.1 \\
4.5 \\
2.1 \\
5.9 \\
9.6 \\
13.4\end{array}$ \\
\hline $\begin{array}{l}22 \\
22 \\
22 \\
22 \\
22 \\
22 \\
22 \\
22\end{array}$ & $\begin{array}{r}0 \\
3 \\
6 \\
9 \\
12 \\
15 \\
18 \\
21\end{array}$ & $\begin{array}{r}-0.1 \\
0.0 \\
0.8 \\
2.9 \\
7.2 \\
9.1 \\
7.8 \\
6.7\end{array}$ & $\begin{array}{l}1.3 \\
3.4 \\
4.7 \\
4.0 \\
3.5\end{array}$ & $\begin{array}{l}0.2 \\
0.0 \\
0.8 \\
3.1 \\
7.4 \\
0.6 \\
8.1 \\
6.9\end{array}$ & $\begin{array}{l}1.1 \\
2.7\end{array}$ & $\begin{array}{r}-0.3 \\
-0.2 \\
0.6 \\
3.2 \\
7.6 \\
10.1 \\
8.4 \\
7.1\end{array}$ & $\begin{array}{l}0.7 \\
2.4 \\
3.9 \\
3.3 \\
3.1\end{array}$ & $\mid \begin{array}{r}-0.5 \\
-0.04 \\
0.4 \\
3.2 \\
7.8 \\
10.5 \\
8.8 \\
7.2\end{array}$ & & $\begin{array}{l}3.2 \\
3.0 \\
2.9 \\
3.1 \\
3.8 \\
3.9 \\
3.8 \\
3.8\end{array}$ & & $\begin{array}{l}12.3 \\
16.2 \\
17.4 \\
18.9 \\
17.2 \\
14.1 \\
12.7 \\
13.3\end{array}$ & $\begin{array}{l}13.9 \\
18.5 \\
19.9 \\
21.6 \\
19.7 \\
16.4 \\
14.3 \\
15.2\end{array}$ & $\begin{array}{l}15.2 \\
20.6 \\
22.4 \\
24.5 \\
20.8 \\
18.0 \\
17.2 \\
18.0\end{array}$ & $\begin{array}{l}16.8 \\
22.8 \\
24.6 \\
27.4 \\
24.4 \\
21.2 \\
19.6 \\
20.5\end{array}$ \\
\hline $\begin{array}{l}23 \\
23 \\
23 \\
23 \\
23 \\
23 \\
23 \\
23\end{array}$ & $\begin{array}{r}0 \\
3 \\
6 \\
9 \\
12 \\
15 \\
18 \\
21\end{array}$ & $\begin{array}{l}3.4 \\
0.3 \\
0.6 \\
3.9\end{array}$ & $\begin{array}{r}1.0 \\
-1.3 \\
-0.9 \\
2.5\end{array}$ & $\begin{array}{l}3.2 \\
0.2 \\
0.4 \\
4.4\end{array}$ & $\begin{array}{r}0.9 \\
-1.4 \\
-0.8 \\
2.6\end{array}$ & $\begin{array}{l}3.0 \\
0.2 \\
0.7 \\
4.2\end{array}$ & $\begin{array}{r}0.5 \\
-1.5 \\
-0.9 \\
2.4\end{array}$ & $\begin{array}{l}2.9 \\
0.3 \\
0.7 \\
4.0\end{array}$ & & $\begin{array}{l}3.3 \\
3.2 \\
3.4 \\
3.8\end{array}$ & & $\begin{array}{l}2.6 \\
2.8 \\
2.7 \\
3.9 \\
3.3 \\
2.06 \\
1.5 \\
2.2\end{array}$ & $\begin{array}{l}3.5 \\
4.1 \\
3.6 \\
5.8 \\
4.8 \\
3.5 \\
2.00 \\
2.6\end{array}$ & $\begin{array}{r}6.5 \\
8.2 \\
7.9 \\
10.0 \\
9.1 \\
6.9 \\
2.5 \\
3.2\end{array}$ & $\begin{array}{r}10.3 \\
9.2 \\
11.7 \\
15.7 \\
13.2 \\
10.4 \\
3.7 \\
5.1\end{array}$ \\
\hline $\begin{array}{l}24 \\
24 \\
24 \\
24 \\
24 \\
24 \\
24 \\
24\end{array}$ & $\begin{array}{r}0 \\
3 \\
6 \\
9 \\
12 \\
15 \\
18 \\
21\end{array}$ & $\begin{array}{l}5.1 \\
9.6 \\
8.7 \\
2.8 \\
0.0\end{array}$ & $\begin{array}{r}1.6 \\
3.8 \\
3.2 \\
-0.4 \\
-2.0\end{array}$ & $\begin{array}{l}5.4 \\
9.9 \\
8.6 \\
2.6 \\
0.3\end{array}$ & $\begin{array}{r}0.9 \\
1.6 \\
3.9 \\
3.2 \\
-0.5 \\
-\quad 2.2\end{array}$ & $\begin{array}{r}3.2 \\
5.5 \\
10.2 \\
8.5 \\
2.5 \\
-0.3\end{array}$ & $\begin{array}{r}0.1 \\
1.5 \\
3.8 \\
2.9 \\
-0.6 \\
-2.3\end{array}$ & $\begin{array}{r}2.9 \\
5.6 \\
10.4 \\
8.3 \\
3.0 \\
0.1\end{array}$ & & $\begin{array}{l}3.4 \\
3.8 \\
4.0 \\
3.9 \\
3.2 \\
3.1\end{array}$ & & $\begin{array}{r}3.9 \\
5.9 \\
4.1 \\
8.9 \\
14.7 \\
5.7 \\
2.6 \\
1.6\end{array}$ & $\begin{array}{r}4.3 \\
5.6 \\
4.6 \\
9.6 \\
15.6 \\
7.1 \\
3.5 \\
2.3\end{array}$ & $\begin{array}{r}4.4 \\
5.1 \\
4.1 \\
9.2 \\
15.6 \\
12.2 \\
5.2 \\
3.3\end{array}$ & $\begin{array}{r}5.8 \\
8.0 \\
5.5 \\
10.6 \\
18.0 \\
18.0 \\
8.7 \\
6.1\end{array}$ \\
\hline $\begin{array}{l}25 \\
25 \\
25 \\
25 \\
25 \\
25 \\
25 \\
25\end{array}$ & $\begin{array}{r}0 \\
3 \\
6 \\
9 \\
12 \\
15 \\
18 \\
21\end{array}$ & $\begin{array}{r}-1.0 \\
0.1 \\
0.0 \\
1.05 \\
5.1 \\
6.6 \\
4.5 \\
3.7\end{array}$ & $\begin{array}{r}-3.1 \\
=2.2 \\
=1.9 \\
-1.1 \\
1.3 \\
2.5 \\
1.4 \\
0.5\end{array}$ & $\begin{array}{l}1.3 \\
0.0 \\
0.2 \\
1.6 \\
5.03 \\
7.00 \\
4.5 \\
3.7\end{array}$ & $\begin{array}{r}-3.1 \\
=2.3 \\
=1.9 \\
-1.1 \\
1.4 \\
2.4 \\
1.3 \\
0.5\end{array}$ & $\mid \begin{array}{r}-1.2 \\
-0.1 \\
-0.1 \\
1.06 \\
5.5 \\
7.1 \\
4.6 \\
3.7\end{array}$ & $\begin{array}{r}-3.3 \\
-2.06 \\
=2.1 \\
-1.2 \\
1.1 \\
2.1 \\
0.0 .1 \\
0.0\end{array}$ & $\left|\begin{array}{r}-0.8 \\
0.1 \\
-0.72 \\
1.5 \\
5.6 \\
7.2 \\
5.00 \\
3.6\end{array}\right|$ & & $\begin{array}{l}3.3 \\
3.3 \\
3.3 \\
3.7 \\
3.8 \\
3.9 \\
3.7 \\
3.6\end{array}$ & & $\begin{array}{r}5.2 \\
3.6 \\
2.4 \\
8.3 \\
9.6 \\
9.7 \\
5.5 \\
11.0\end{array}$ & $\begin{array}{r}5.7 \\
3.9 \\
2.7 \\
9.3 \\
10.8 \\
11.0 \\
6.7 \\
12.6\end{array}$ & $\begin{array}{r}6.5 \\
4.4 \\
3.0 \\
10.1 \\
11.2 \\
11.8 \\
8.0 \\
14.2\end{array}$ & $\begin{array}{r}8.8 \\
4.6 \\
3.4 \\
11.3 \\
13.1 \\
13.9 \\
10.2 \\
16.4\end{array}$ \\
\hline $\begin{array}{l}26 \\
26 \\
26 \\
26 \\
26 \\
26 \\
26 \\
26\end{array}$ & $\begin{array}{r}0 \\
3 \\
6 \\
9 \\
12 \\
15 \\
18 \\
21\end{array}$ & $\begin{array}{r}2.7 \\
2.7 \\
2.0 \\
6.9 \\
12.8 \\
15.5 \\
13.1 \\
12.9\end{array}$ & {$\left[\begin{array}{r}0.1 \\
-0.1 \\
-0.2 \\
-0.5 \\
2.8 \\
6.2 \\
7.5 \\
7.2 \\
7.8\end{array}\right.$} & $\begin{array}{r}2.6 \\
2.6 \\
2.0 \\
7.4 \\
13.4 \\
15.8 \\
13.8 \\
13.5\end{array}$ & $\begin{array}{r}0.0 \\
-0.2 \\
-0.4 \\
3.3 \\
6.8 \\
8.2 \\
7.8 \\
8.2\end{array}$ & $\begin{array}{r}2.7 \\
2.6 \\
2.0 \\
7.9 \\
34.2 \\
16.9 \\
14.7 \\
14.1\end{array}$ & $\begin{array}{r}-0.4 \\
-0.07 \\
-0.0 \\
3.1 \\
6.5 \\
7.8 \\
7.7 \\
0.11\end{array}$ & $\begin{array}{r}2.8 \\
2.5 \\
1.9 \\
8.3 \\
15.2 \\
17.5 \\
15.6 \\
14.8\end{array}$ & , & $\begin{array}{l}3.4 \\
3.2 \\
3.2 \\
3.8 \\
4.1 \\
4.5 \\
4.3 \\
4.3\end{array}$ & & $\begin{array}{l}10.7 \\
10.3 \\
10.7 \\
13.2 \\
14.3 \\
17.3 \\
14.3 \\
18.6\end{array}$ & $\begin{array}{l}12.6 \\
11.7 \\
12.1 \\
15.2 \\
16.5 \\
20.0 \\
16.6 \\
21.3\end{array}$ & $\begin{array}{l}13.9 \\
13.1 \\
13.5 \\
10.1 \\
17.9 \\
21.5 \\
18.6 \\
22.7\end{array}$ & $\begin{array}{l}16.1 \\
14.8 \\
15.1 \\
19.3 \\
21.2 \\
26.0 \\
22.0 \\
27.5\end{array}$ \\
\hline $\begin{array}{l}27 \\
27 \\
27 \\
27 \\
27 \\
27 \\
27 \\
27\end{array}$ & $\begin{array}{r}0 \\
3 \\
6 \\
9 \\
12 \\
15 \\
18 \\
21\end{array}$ & $\begin{array}{r}12.3 \\
3.3 \\
-2.0 \\
=3.4 \\
=4.0 \\
=4.5 \\
=4.7 \\
-409\end{array}$ & $\begin{array}{r}7.2 \\
0.9 \\
-3.3 \\
\end{array}$ & $\begin{array}{r}12.9 \\
3.2 \\
2.4 \\
3.6 \\
4.1 \\
4.7 \\
4.8 \\
5.0\end{array}$ & $\begin{array}{r}7.5 \\
0.8 \\
-\quad 3.3\end{array}$ & $\begin{array}{r}13.7 \\
-3.1 \\
-2.6 \\
-3.8 \\
-4.4 \\
-4.8 \\
-4.9 \\
-5.1\end{array}$ & $\begin{array}{r}7.5 \\
-0.5 \\
-3.6\end{array}$ & $\begin{array}{r}14.2 \\
2.2 \\
-3.0 \\
-4.5 \\
-5.0 \\
-5.0 \\
-5.1 \\
-5.4\end{array}$ & & $\begin{array}{l}4.4 \\
3.9 \\
3.9 \\
4.0 \\
3.8 \\
3.6 \\
3.5 \\
3.3\end{array}$ & & $\begin{array}{r}15.5 \\
4.7 \\
4.8 \\
6.2 \\
5.2 \\
5.5 \\
5.4 \\
4.8\end{array}$ & $\begin{array}{r}17.5 \\
6.4 \\
7.4 \\
9.0 \\
7.5 \\
7.5 \\
7.1 \\
7.0\end{array}$ & $\begin{array}{l}18.0 \\
11.7 \\
12.8 \\
14.2 \\
14.1 \\
11.4 \\
10.7 \\
10.6\end{array}$ & $\begin{array}{l}21.9 \\
17.4 \\
21.1 \\
23.0 \\
21.0 \\
18.5 \\
17.5 \\
17.4\end{array}$ \\
\hline $\begin{array}{l}28 \\
28 \\
28 \\
28 \\
28 \\
28 \\
28 \\
28\end{array}$ & $\begin{array}{r}0 \\
3 \\
6 \\
9 \\
12 \\
15 \\
18 \\
21\end{array}$ & $\begin{array}{r}-6.6 \\
-10.3 \\
-11.0 \\
-10.7 \\
-9.4 \\
-8.8 \\
-10.2 \\
-11.4\end{array}$ & & $\begin{array}{r}6.9 \\
10.5 \\
11.2 \\
10.9 \\
9.4 \\
9.0 \\
10.4 \\
11.6\end{array}$ & & $\begin{array}{l}-7.3 \\
-10.9 \\
-11.5 \\
-11.2 \\
-10.00 \\
-9.93 \\
-10.6 \\
-11.8\end{array}$ & & $\left|\begin{array}{r}-7.8 \\
-11 . .2 \\
-11.9 \\
-11.7 \\
-10.6 \\
-9.8 \\
-10.8 \\
-12.2\end{array}\right|$ & & $\begin{array}{l}3.2 \\
3.1 \\
3.0 \\
3.1 \\
3.0 \\
2.8 \\
2.5 \\
2.5\end{array}$ & & $\begin{array}{l}5.4 \\
5.4 \\
4.4 \\
5.5 \\
4.9 \\
5.5 \\
6.02 \\
5.3\end{array}$ & $\begin{array}{l}7.09 \\
7.09 \\
6.5 \\
8.1 \\
7.0 \\
7.7 \\
7.09 \\
7.5\end{array}$ & $\begin{array}{l}13.7 \\
12.8 \\
11.4 \\
13.0 \\
12.5 \\
11.8 \\
11.1 \\
11.4\end{array}$ & $\begin{array}{l}22.2 \\
21.3 \\
19.2 \\
21.3 \\
19.5 \\
19.7 \\
18.2 \\
18.9\end{array}$ \\
\hline $\begin{array}{l}29 \\
29 \\
29 \\
29 \\
29 \\
29 \\
29 \\
29\end{array}$ & $\begin{array}{r}0 \\
3 \\
6 \\
9 \\
12 \\
15 \\
18 \\
21\end{array}$ & $\begin{array}{l}-12.4 \\
-13.6 \\
-14.6 \\
-13.6 \\
-10.3 \\
-8.5 \\
-8.9 \\
-10.6\end{array}$ & & $\begin{array}{r}12.5 \\
13.9 \\
14.8 \\
13.2 \\
10.6 \\
8.9 \\
9.9 \\
10.7\end{array}$ & & $\begin{array}{l}-12.9 \\
-14.2 \\
-15.1 \\
-13.6 \\
-10.4 \\
-9.0 \\
-10.1 \\
-10.8\end{array}$ & & $\begin{array}{l}-13.02 \\
-14.5 \\
-15.7 \\
-14.5 \\
-11.02 \\
-9.9 \\
-10.0 \\
-11.0\end{array}$ & & $\begin{array}{l}2.5 \\
2.5 \\
2.6 \\
2.8 \\
2.7 \\
2.04 \\
2.11 \\
2.0\end{array}$ & & $\begin{array}{l}5.8 \\
5.5 \\
5.8 \\
6.8 \\
7.1 \\
7.6 \\
5.2 \\
8.0\end{array}$ & $\begin{array}{l}7.9 \\
7.7 \\
8.1 \\
8.7 \\
8.8 \\
9.2 \\
6.6 \\
8.7\end{array}$ & $\begin{array}{r}11.2 \\
11.1 \\
12.0 \\
12.2 \\
11.4 \\
11.5 \\
8.5 \\
11.1\end{array}$ & $\begin{array}{l}18.7 \\
18.7 \\
20.1 \\
19.3 \\
17.5 \\
17.6 \\
13.2 \\
15.6\end{array}$ \\
\hline $\begin{array}{l}30 \\
30 \\
30 \\
30 \\
30 \\
30 \\
30 \\
30\end{array}$ & $\begin{array}{r}0 \\
3 \\
6 \\
9 \\
12 \\
15 \\
18 \\
21\end{array}$ & $\begin{array}{l}-11.3 \\
-12.3 \\
-12.9 \\
-11.7 \\
-9.2 \\
-8.2 \\
-10.1 \\
-11.2\end{array}$ & & $\begin{array}{r}11.4 \\
12.6 \\
13.0 \\
11.8 \\
9.2 \\
8.4 \\
10.4 \\
11.4\end{array}$ & & 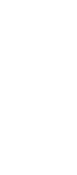 & & $\begin{array}{r}-12.0 \\
-13.0 \\
-13.7 \\
-12.5 \\
-10.5 \\
-9.2 \\
-10.8 \\
-11.8\end{array}$ & & $\begin{array}{l}1.9 \\
1.5 \\
1.5 \\
1.6 \\
1.8 \\
1.5 \\
1.2 \\
1.3\end{array}$ & & $\begin{array}{l}7.6 \\
6.1 \\
5.8 \\
4.8 \\
4.8 \\
5.3 \\
4.3 \\
4.3\end{array}$ & $\begin{array}{l}8.9 \\
7.3 \\
7.02 \\
6.0 \\
5.2 \\
6.3 \\
5.4 \\
5.9\end{array}$ & $\begin{array}{r}10.9 \\
9.5 \\
8.8 \\
7.6 \\
8.5 \\
7.8 \\
7.6 \\
8.0\end{array}$ & $\begin{array}{l}16.1 \\
14.9 \\
14.0 \\
11.6 \\
12.8 \\
11.7 \\
12.6 \\
13.2\end{array}$ \\
\hline $\begin{array}{l}31 \\
31 \\
31 \\
31 \\
31 \\
31 \\
31 \\
31\end{array}$ & $\begin{array}{r}0 \\
3 \\
6 \\
9 \\
12 \\
15 \\
18 \\
21\end{array}$ & $\begin{array}{l}-11.7 \\
-11.9 \\
-12.2 \\
-11.3 \\
-9.6 \\
-90.2 \\
-10.4 \\
-12.2\end{array}$ & & $\begin{array}{r}11.8 \\
12.0 \\
12.4 \\
11.4 \\
9.9 \\
9.3 \\
10.5 \\
12.4\end{array}$ & & $\mid \begin{array}{l}-12.00 \\
-12.0 \\
-12.6 \\
-11.08 \\
-10.2 \\
-9.9 \\
-10.98 \\
-12.7\end{array}$ & & $\begin{array}{l}-12 \cdot 0 \\
-12.6 \\
-13 \cdot 0 \\
-12 \cdot 2 \\
-10.07 \\
-10.0 \\
-11 \cdot 0 \\
-12.0\end{array}$ & & $\begin{array}{l}1.3 \\
1.11 \\
1.1 \\
1.3 \\
1.5 \\
0.09 \\
0.8 \\
0.6\end{array}$ & & $\begin{array}{l}4.0 \\
4.0 \\
3.7 \\
3.8 \\
4.9 \\
4.7 \\
4.8 \\
4.0\end{array}$ & $\begin{array}{l}5.2 \\
5.6 \\
5.5 \\
6.1 \\
6.4 \\
7.0 \\
7.0 \\
6.1\end{array}$ & $\begin{array}{r}7.7 \\
8.5 \\
7.2 \\
10.3 \\
12.7 \\
13.1 \\
14.2 \\
11.5\end{array}$ & $\begin{array}{l}12.4 \\
13.6 \\
15.3 \\
17.1 \\
20.4 \\
21.1 \\
21.0 \\
19.2\end{array}$ \\
\hline
\end{tabular}


Table 10. - Three-hour averages of air and water-surface temperatures and wind directions and speed. April 1950-August 1851, Lake Hefner-Continued

STATION 4 THREE-HOURLY.AVERAGES

FEBRUARY, 1951

\begin{tabular}{|c|c|c|c|c|c|c|c|c|c|c|c|c|c|c|c|}
\hline \multirow{3}{*}{ 题 } & \multirow{3}{*}{ 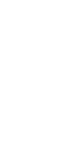 } & \multicolumn{8}{|c|}{ Average air temperature $\left({ }^{\circ} \mathrm{C}\right)$ at indicated height } & \multirow{3}{*}{$\begin{array}{l}\text { Average } \\
\text { water- } \\
\text { surface } \\
\text { tempera- } \\
\text { ture } \\
\left({ }^{\circ} \mathrm{C}\right)\end{array}$} & \multirow{3}{*}{$\begin{array}{c}\text { Average } \\
\text { wind } \\
\text { direction } \\
\text { (coded) }\end{array}$} & \multirow{2}{*}{\multicolumn{4}{|c|}{$\begin{array}{l}\text { Average wind speed (knotal } \\
\text { at indicated height }\end{array}$}} \\
\hline & & \multicolumn{2}{|c|}{$\begin{array}{c}2 \\
\text { meters }\end{array}$} & \multicolumn{2}{|c|}{$\begin{array}{c}4 \\
\text { meters }\end{array}$} & \multicolumn{2}{|c|}{$\begin{array}{c} \\
\text { meters }\end{array}$} & \multicolumn{2}{|c|}{$\begin{array}{c}16 \\
\text { meters }\end{array}$} & & & & & & \\
\hline & & $\begin{array}{l}\text { Dry } \\
\text { bulb }\end{array}$ & $\begin{array}{l}\text { Wet } \\
\text { bulb }\end{array}$ & $\begin{array}{l}\text { Dry } \\
\text { bulb }\end{array}$ & $\begin{array}{l}\text { Wet } \\
\text { bulb }\end{array}$ & $\begin{array}{l}\text { Dry } \\
\text { bulb }\end{array}$ & $\begin{array}{l}\text { Wet } \\
\text { bulb }\end{array}$ & $\begin{array}{l}\text { Dry } \\
\text { bulb }\end{array}$ & $\begin{array}{l}\text { Wet } \\
\text { bulb }\end{array}$ & & & $\begin{array}{c}2 \\
\text { meters }\end{array}$ & $\begin{array}{c}4 \\
\text { meters }\end{array}$ & $\begin{array}{c}8 \\
\text { meters }\end{array}$ & $\begin{array}{c}16 \\
\text { meters }\end{array}$ \\
\hline $\begin{array}{l}1 \\
1 \\
1 \\
1 \\
1 \\
1 \\
1 \\
1\end{array}$ & $\begin{array}{r}0 \\
3 \\
6 \\
9 \\
12 \\
15 \\
18 \\
21\end{array}$ & $\begin{array}{r}-13.7 \\
-15.7 \\
49.3 \\
-14.9 \\
-11.3 \\
=7.9 \\
=8.3 \\
-8.8\end{array}$ & & $\begin{array}{r}13.9 \\
16.0 \\
49.2 \\
14.7 \\
9.7 \\
7.8 \\
8.4 \\
9.1\end{array}$ & & $\begin{array}{r}-14.2 \\
-16.3 \\
48.8 \\
-15.2 \\
-21.3 \\
-8.02 \\
-8.6 \\
-9.2\end{array}$ & & $\begin{array}{l}-14.4 \\
-16.06 \\
-17.9 \\
-15.6 \\
-11.06 \\
-8.04 \\
-8.07 \\
-9.5\end{array}$ & & $\begin{array}{l}0.7 \\
0.5 \\
0.3 \\
0.5 \\
0.6 \\
0.3 \\
0.1\end{array}$ & & $\begin{array}{l}4.6 \\
4.2 \\
5.6 \\
5.8 \\
8.1 \\
5.6 \\
2.0 \\
6.8\end{array}$ & $\begin{array}{l}5.4 \\
4.5 \\
5.1 \\
6.3 \\
7.8 \\
4.8 \\
2.1 \\
7.2\end{array}$ & $\begin{array}{r}11.7 \\
9.2 \\
10.1 \\
12.0 \\
11.2 \\
8.5 \\
2.4 \\
7.8\end{array}$ & $\begin{array}{r}16.4 \\
14.5 \\
10.7 \\
14.3 \\
12.6 \\
9.3 \\
3.3 \\
7.7\end{array}$ \\
\hline $\begin{array}{l}2 \\
2 \\
2 \\
2 \\
2 \\
2 \\
2 \\
2\end{array}$ & $\begin{array}{r}0 \\
3 \\
6 \\
9 \\
12 \\
15 \\
18 \\
21\end{array}$ & $\begin{array}{l}-10.3 \\
=-10.7 \\
=10.4 \\
=5.7 \\
=1.0 \\
=0.7 \\
=0.5 \\
-1.5\end{array}$ & & $\begin{array}{r}10.5 \\
11.0 \\
10.5 \\
5.8 \\
1.2 \\
0.7 \\
0.5 \\
1.7\end{array}$ & & $\begin{array}{l}-10.6 \\
-11.1 \\
-10.5 \\
-5.9 \\
-1.2 \\
-0.9 \\
-0.5 \\
-1.7\end{array}$ & & $\begin{array}{l}-10.8 \\
-11.03 \\
-10.44 \\
-5.0 \\
-1.2 \\
-0.09 \\
-0.5 \\
-1.8\end{array}$ & & $\begin{array}{l}0.2 \\
0.2\end{array}$ & & $\begin{array}{r}9.3 \\
11.0 \\
11.2 \\
15.2 \\
15.2 \\
12.4 \\
8.0 \\
13.9\end{array}$ & $\begin{array}{r}9.8 \\
12.1 \\
11.7 \\
16.3 \\
16.5 \\
13.7 \\
9.4 \\
15.3\end{array}$ & $\begin{array}{l}10.6 \\
16.9\end{array}$ & $\begin{array}{l}10.4 \\
12.8 \\
12.4 \\
17.6 \\
18.2 \\
15.9 \\
12.5 \\
19.2\end{array}$ \\
\hline $\begin{array}{l}3 \\
3 \\
3 \\
3 \\
3 \\
3 \\
3 \\
3\end{array}$ & $\begin{array}{r}6 \\
3 \\
6 \\
9 \\
12 \\
15 \\
18 \\
21\end{array}$ & $\begin{array}{r}-3.6 \\
=4.1 \\
=4.7 \\
=0.9 \\
3.2 \\
4.4 \\
1.5 \\
-0.3\end{array}$ & $\begin{array}{r} \\
0.3 \\
0.5 \\
-0.7\end{array}$ & $\begin{array}{l}3.7 \\
4.2 \\
4.8 \\
0.8 \\
3.4 \\
4.8 \\
1.7 \\
0.4\end{array}$ & $\begin{array}{r} \\
\\
0.4 \\
0.6 \\
-0.9 \\
-\quad 2.0\end{array}$ & $\begin{array}{r}-3.8 \\
-\quad 4.3 \\
-4.9 \\
-0.7 \\
3.8 \\
5.2 \\
2.4 \\
-0.6\end{array}$ & $\begin{array}{r} \\
\\
0.3 \\
0.8 \\
-0.8 \\
-\quad 2.1\end{array}$ & $\begin{array}{r}-3.9 \\
-\quad 4.5 \\
-5.0 \\
-0.6 \\
4.0 \\
5.5 \\
2.9 \\
-0.5\end{array}$ & & $\begin{array}{l}0.2 \\
0.2 \\
0.2\end{array}$ & & $\begin{array}{r}12.4 \\
12.7 \\
12.9 \\
14.4 \\
9.9 \\
7.4 \\
6.0 \\
8.2\end{array}$ & $\begin{array}{r}13.9 \\
14.2 \\
14.3 \\
16.3 \\
11.4 \\
8.9 \\
7.3 \\
9.3\end{array}$ & $\begin{array}{r}15.5 \\
15.7 \\
15.7 \\
17.7 \\
12.3 \\
9.9 \\
9.2 \\
10.3\end{array}$ & $\begin{array}{l}17.2 \\
17.2 \\
17.4 \\
19.7 \\
14.0 \\
11.9 \\
11.2 \\
12.0\end{array}$ \\
\hline $\begin{array}{l}4 \\
4 \\
4 \\
4 \\
4 \\
4 \\
4 \\
4\end{array}$ & $\begin{array}{r}0 \\
3 \\
6 \\
9 \\
12 \\
15 \\
18 \\
21\end{array}$ & $\begin{array}{r}=1.0 \\
=0.8 \\
-1.1 \\
4.5 \\
10.0 \\
8.1 \\
5.3 \\
3.9\end{array}$ & $\begin{array}{l}1.4 \\
4.1 \\
3.2 \\
1.5 \\
1.3\end{array}$ & $\begin{array}{r}1.0 \\
0.8 \\
1.2 \\
5.0 \\
10.1 \\
9.5 \\
7.6 \\
4.8\end{array}$ & $\begin{array}{l}1.6 \\
4.2 \\
3.6 \\
1.8 \\
1.4\end{array}$ & $\begin{array}{r}-2.2 \\
-0.9 \\
-1.3 \\
5.0 \\
10.5 \\
10.5 \\
8.2 \\
5.8\end{array}$ & $\begin{array}{l}1.8 \\
4.7 \\
4.4 \\
2.9 \\
2.2\end{array}$ & $\mid \begin{array}{r}-1.3 \\
-0.7 \\
-0.8 \\
4.9 \\
10.4 \\
10.7 \\
9.4 \\
6.7\end{array}$ & & $\begin{array}{l}0.5 \\
0.4 \\
0.2 \\
0.2 \\
0.1\end{array}$ & & $\begin{array}{l}7.1 \\
5.4 \\
5.1 \\
3.1 \\
1.7 \\
1.5 \\
3.6 \\
6.2\end{array}$ & $\begin{array}{l}8.1 \\
6.0 \\
5.0 \\
3.0 \\
2.2 \\
2.3 \\
4.3 \\
7.8\end{array}$ & $\begin{array}{r}8.2 \\
6.2 \\
5.1 \\
5.0 \\
3.1 \\
2.8 \\
5.7 \\
10.0\end{array}$ & $\begin{array}{r}9.9 \\
7.9 \\
7.6 \\
6.1 \\
3.7 \\
7.4 \\
12.4\end{array}$ \\
\hline $\begin{array}{l}5 \\
5 \\
5 \\
5 \\
5 \\
5 \\
5 \\
5\end{array}$ & $\begin{array}{r}0 \\
3 \\
6 \\
9 \\
22 \\
15 \\
18 \\
21\end{array}$ & $\begin{array}{l}4.1 \\
4.0 \\
3.3 \\
4.0 \\
8.4 \\
9.9 \\
8.3 \\
8.2\end{array}$ & $\begin{array}{l}1.9 \\
1.05 \\
1.6 \\
4.2 \\
6.1 \\
7.3 \\
7.7 \\
7.5\end{array}$ & $\begin{array}{r}4.6 \\
4.2 \\
3.7 \\
5.4 \\
9.1 \\
10.7 \\
9.0 \\
8.8\end{array}$ & $\begin{array}{l}1.9 \\
1.4 \\
1.5 \\
4.2 \\
7.2 \\
7.6 \\
8.1 \\
7.9\end{array}$ & $\begin{array}{r}5.1 \\
4.6 \\
3.8 \\
5.8 \\
9.7 \\
11.4 \\
9.7 \\
9.3\end{array}$ & $\begin{array}{l}2.5 \\
1.9 \\
2.0 \\
4.8 \\
7.8 \\
8.3 \\
8.6 \\
8.3\end{array}$ & $\begin{array}{r}5.9 \\
5.0 \\
4.0 \\
6.1 \\
10.3 \\
11.8 \\
10.04 \\
10.3\end{array}$ & & $\begin{array}{l}0.1 \\
0.1 \\
0.6 \\
1.0\end{array}$ & & $\begin{array}{r}7.5 \\
10.6 \\
12.4 \\
16.0 \\
17.5 \\
15.2 \\
14.9 \\
15.5\end{array}$ & $\begin{array}{r}9.2 \\
12.5 \\
14.2 \\
18.6 \\
20.3 \\
17.6 \\
17.9 \\
18.3\end{array}$ & $\begin{array}{l}11.4 \\
15.2 \\
17.3 \\
21.8 \\
23.8 \\
21.1 \\
21.6 \\
21.6\end{array}$ & $\begin{array}{l}13.4 \\
17.2 \\
19.0 \\
24.2 \\
26.8 \\
24.4 \\
24.7 \\
25.3\end{array}$ \\
\hline $\begin{array}{l}6 \\
6 \\
6 \\
6 \\
6 \\
6 \\
6 \\
6\end{array}$ & $\begin{array}{r}0 \\
3 \\
6 \\
9 \\
12 \\
15 \\
18 \\
21\end{array}$ & $\begin{array}{r}6.6 \\
7.8 \\
-2.8 \\
-0.3\end{array}$ & $\begin{array}{r}4.2 \\
3.7 \\
-\quad 0.1 \\
-\quad 2.6\end{array}$ & $\begin{array}{l}6.8 \\
7.8 \\
2.7 \\
0.8\end{array}$ & $\begin{array}{r}4.2 \\
3.7 \\
-\quad 0.4 \\
-\quad 3.0\end{array}$ & $\begin{array}{r}6.9 \\
7.6 \\
2.6 \\
-0.9\end{array}$ & $\begin{array}{r}4.3 \\
3.7 \\
-\quad 0.4 \\
-\quad 3.0\end{array}$ & $\left|\begin{array}{r}5.4 \\
7.2 \\
2.8 \\
-0.7\end{array}\right|$ & & & & $\begin{array}{r}10.5 \\
6.9 \\
8.2 \\
6.8 \\
7.1 \\
5.5 \\
3.4 \\
4.0\end{array}$ & $\begin{array}{r}12.5 \\
6.9 \\
7.6 \\
8.9 \\
8.9 \\
7.8 \\
5.1 \\
5.0\end{array}$ & $\begin{array}{r}14.8 \\
9.7 \\
12.8 \\
17.4 \\
18.1 \\
13.8 \\
7.7 \\
6.8\end{array}$ & $\begin{array}{l}17.9 \\
10.8 \\
13.6 \\
25.6 \\
27.1 \\
22.4 \\
13.2 \\
11.1\end{array}$ \\
\hline $\begin{array}{l}7 \\
7 \\
7 \\
7 \\
7 \\
7 \\
7 \\
7\end{array}$ & $\begin{array}{r}0 \\
3 \\
6 \\
9 \\
12 \\
15 \\
18 \\
21\end{array}$ & $\begin{array}{l}-3.0 \\
-5.5 \\
-\quad 6.5 \\
-\quad 4.9 \\
-1.5 \\
-0.2 \\
-0.5 \\
-2.1\end{array}$ & $-4 \cdot 1$ & $\begin{array}{l}3.4 \\
5.5 \\
6.7 \\
4.8 \\
1.4 \\
0.3 \\
0.7 \\
2.3\end{array}$ & -4.2 & $\begin{array}{r}-3.6 \\
-5.7 \\
-6.9 \\
-4.7 \\
-1.4 \\
0.02 \\
-0.8 \\
-2.5\end{array}$ & & $\left|\begin{array}{l}-3.5 \\
-5.8 \\
-7.2 \\
-5.3 \\
-2.6 \\
-0.3 \\
-0.9 \\
-2.6\end{array}\right|$ & & $\begin{array}{l}1.8 \\
1.7 \\
1.3 \\
2.2\end{array}$ & & $\begin{array}{l}2.0 \\
1.9 \\
3.6 \\
6.5 \\
5.0 \\
5.8 \\
5.5 \\
6.7\end{array}$ & $\begin{array}{l}3.6 \\
3.1 \\
4.8 \\
7.4 \\
5.5 \\
6.7 \\
6.1 \\
7.3\end{array}$ & $\begin{array}{l}5.8 \\
5.7 \\
6.7 \\
8.8 \\
6.0 \\
7.0 \\
7.2 \\
8.5\end{array}$ & $\begin{array}{r}10.3 \\
10.0 \\
11.0 \\
11.8 \\
7.6 \\
7.1 \\
7.8 \\
8.9\end{array}$ \\
\hline $\begin{array}{l}8 \\
8 \\
8 \\
8 \\
8 \\
8 \\
8 \\
8\end{array}$ & $\begin{array}{r}0 \\
3 \\
6 \\
9 \\
12 \\
15 \\
18 \\
21\end{array}$ & $\begin{array}{r}-2.6 \\
=1.6 \\
-\quad 0.3 \\
4.6 \\
9.5 \\
9.7 \\
8.0 \\
4.5\end{array}$ & $\begin{array}{l}2.8 \\
4.8 \\
5.2 \\
3.9 \\
1.7\end{array}$ & $\begin{array}{r}2.7 \\
1.7 \\
0.3 \\
5.1 \\
10.1 \\
11.3 \\
7.9 \\
4.7\end{array}$ & $\begin{array}{l}2.8 \\
4.9 \\
5.7 \\
3.6 \\
1.6\end{array}$ & $\begin{array}{r}-2.9 \\
-1.8 \\
-0.3 \\
6.1 \\
11.4 \\
13.0 \\
8.7 \\
4.8\end{array}$ & $\begin{array}{l}3.3 \\
5.9 \\
6.8 \\
4.2 \\
1.8\end{array}$ & $\mid \begin{array}{r}-3.0 \\
-1.0 \\
-0.3 \\
6.1 \\
11.7 \\
13.6 \\
9.5 \\
5.5\end{array}$ & $\begin{array}{l}5 \cdot 1 \\
8 \cdot 2 \\
9 \cdot 8 \\
6 \cdot 1 \\
3 \cdot 3\end{array}$ & $\begin{array}{l}2.03 \\
2.03 \\
2.02 \\
1.8 \\
2.03 \\
2.11 \\
2.00 \\
1.8\end{array}$ & & $\begin{array}{r}9.9 \\
12.0 \\
14.6 \\
16.2 \\
13.5 \\
5.8 \\
1.6 \\
3.0\end{array}$ & $\begin{array}{r}10.8 \\
13.5 \\
16.5 \\
18.5 \\
15.4 \\
7.6 \\
2.5 \\
4.0\end{array}$ & $\begin{array}{r}12.5 \\
15.6 \\
18.8 \\
19.6 \\
16.1 \\
8.0 \\
3.0 \\
6.0\end{array}$ & $\begin{array}{r}13.0 \\
17.0 \\
20.7 \\
23.1 \\
19.3 \\
9.6 \\
5.7 \\
9.5\end{array}$ \\
\hline $\begin{array}{l}9 \\
9 \\
9 \\
9 \\
9 \\
9 \\
9 \\
9\end{array}$ & $\begin{array}{r}0 \\
3 \\
6 \\
9 \\
12 \\
15 \\
18 \\
21\end{array}$ & $\begin{array}{r}2.3 \\
-\quad 2.5 \\
-4.8 \\
-2.5 \\
0.6\end{array}$ & $=1.3$ & $\begin{array}{l}1.0 \\
3.0 \\
4.9 \\
2.4 \\
0.8\end{array}$ & $=1.6$ & $\begin{array}{r}0.8 \\
-3.2 \\
=-5.2 \\
= \\
-2.0 \\
0.8\end{array}$ & -1.5 & $\begin{array}{r}0.6 \\
-3.3 \\
-5.6 \\
-2.6 \\
0.9\end{array}$ & & $\begin{array}{l}1.4 \\
1.3 \\
1.2 \\
1.8 \\
2.0\end{array}$ & & $\begin{array}{l}2.7 \\
3.5 \\
2.8 \\
3.7 \\
2.7 \\
2.0 \\
5.1 \\
9.5\end{array}$ & $\begin{array}{r}3.9 \\
5.3 \\
4.4 \\
4.7 \\
3.0 \\
2.7 \\
6.4 \\
11.0\end{array}$ & $\begin{array}{r}7.9 \\
9.4 \\
7.6 \\
6.2 \\
3.1 \\
3.1 \\
8.4 \\
13.3\end{array}$ & $\begin{array}{r}13.0 \\
15.4 \\
12.5 \\
9.5 \\
3.4 \\
3.7 \\
10.1 \\
15.3\end{array}$ \\
\hline $\begin{array}{l}10 \\
10 \\
10 \\
10 \\
10 \\
10 \\
10 \\
10\end{array}$ & $\begin{array}{r}0 \\
3 \\
6 \\
9 \\
12 \\
15 \\
18 \\
21\end{array}$ & $\begin{array}{r}12.1 \\
13.8 \\
11.4 \\
9.2\end{array}$ & $\begin{array}{l}7.4 \\
8.3 \\
7.0 \\
8.0\end{array}$ & $\begin{array}{l}13.7 \\
16.0 \\
15.0 \\
10.2\end{array}$ & $\begin{array}{l}8.2 \\
9.4 \\
9.0 \\
8.7\end{array}$ & $\begin{array}{l}14.8 \\
18.5 \\
16.2 \\
11.0\end{array}$ & $\begin{array}{r}8.0 \\
9.4 \\
11.4 \\
10.2 \\
9.8\end{array}$ & $\begin{array}{l}15.1 \\
16.3 \\
20.1 \\
17.1 \\
12.8\end{array}$ & & $\begin{array}{l}2.5 \\
2.7 \\
2.8 \\
2.4 \\
2.5\end{array}$ & & $\begin{array}{r}12.4 \\
11.8 \\
12.9 \\
13.0 \\
11.7 \\
7.1 \\
4.8 \\
10.2\end{array}$ & $\begin{array}{r}14.2 \\
13.5 \\
14.7 \\
14.7 \\
13.6 \\
8.9 \\
6.1 \\
12.4\end{array}$ & $\begin{array}{r}16.0 \\
15.4 \\
16.0 \\
15.7 \\
14.4 \\
9.9 \\
7.3 \\
15.6\end{array}$ & $\begin{array}{r}18.6 \\
17.7 \\
18.5 \\
19.0 \\
17.0 \\
12.1 \\
9.0 \\
18.3\end{array}$ \\
\hline
\end{tabular}


TABLE 10

Table 10. -Three-hour averages of air and water-surface temperatures and wind directions and speed, April 1950-August 1951, Lake Hefner-Continued

STATION 4

THREE-HOURLY AVERAGES

FEBRUARY, 3951

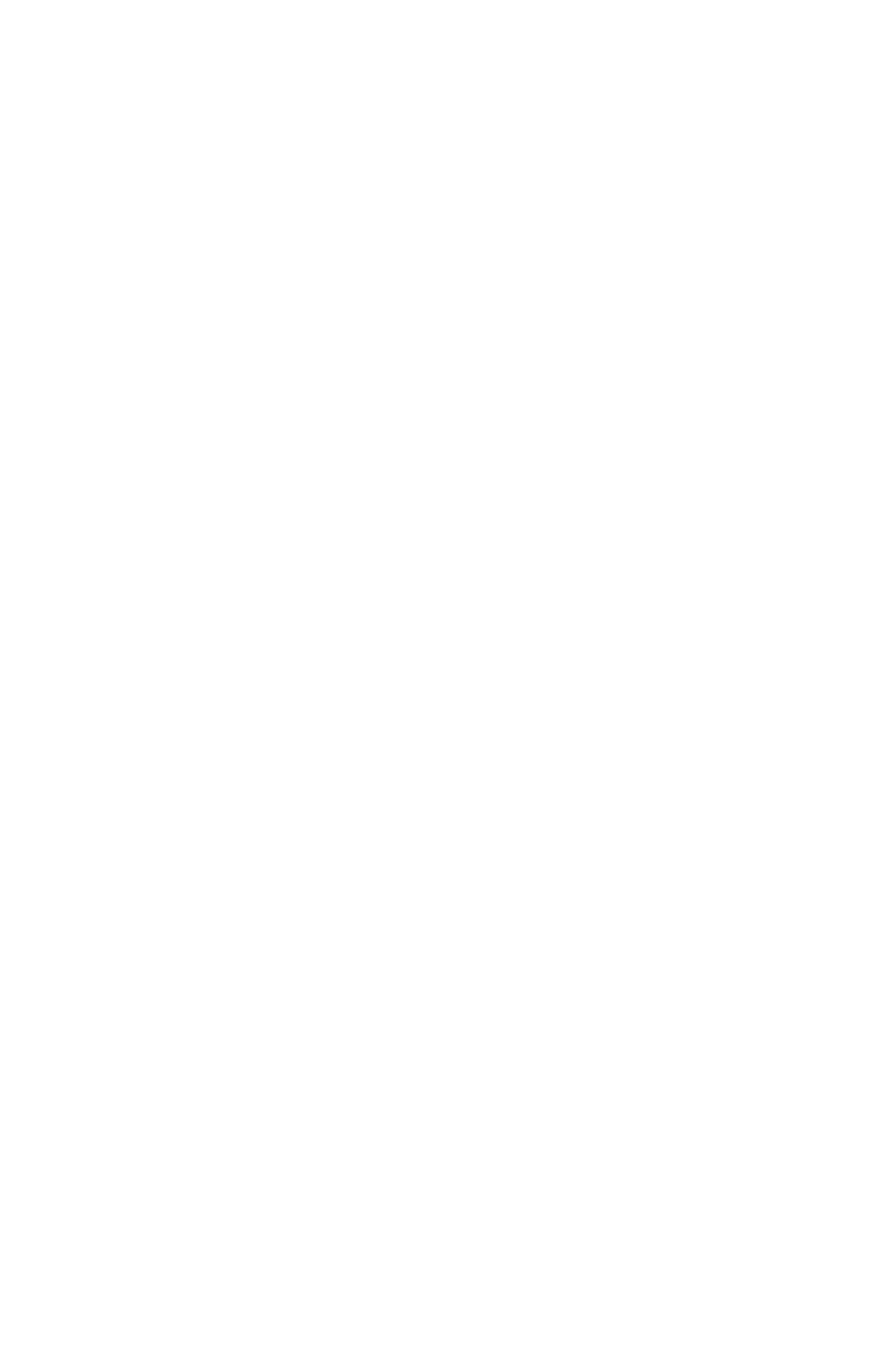


TABLE 10

Table 10. -Three-hour averages of air and water-surface temperatures and wind directions and speed, April 1950-August 1951, Lake Hefner-Continued

STATION 4

THREE-HOURLY AVERAGES

FEBRUARY, 2951

\begin{tabular}{|c|c|c|c|c|c|c|c|c|c|c|c|c|c|c|c|}
\hline \multirow{3}{*}{ 超 } & \multirow{3}{*}{ 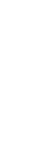 } & \multicolumn{8}{|c|}{ Average air temperature $\left({ }^{\circ} \mathrm{C}\right)$ at indicated height } & \multirow{3}{*}{$\begin{array}{l}\text { Average } \\
\text { water- } \\
\text { surface } \\
\text { tempera- } \\
\text { ture } \\
\text { (ㄷ) }\end{array}$} & \multirow{3}{*}{$\begin{array}{c}\text { Average } \\
\text { wind } \\
\text { direction } \\
\text { (coded) }\end{array}$} & \multirow{2}{*}{\multicolumn{4}{|c|}{$\begin{array}{l}\text { Average wind speed (knots) } \\
\text { at indicated height }\end{array}$}} \\
\hline & & \multicolumn{2}{|c|}{$\begin{array}{c}2 \\
\text { meters }\end{array}$} & \multicolumn{2}{|c|}{$\begin{array}{c}4 \\
\text { meters }\end{array}$} & \multicolumn{2}{|c|}{$\begin{array}{c}\mathbf{8} \\
\text { meters }\end{array}$} & \multicolumn{2}{|c|}{$\begin{array}{c}16 \\
\text { meters }\end{array}$} & & & & & & \\
\hline & & $\begin{array}{l}\text { Dry } \\
\text { bulb }\end{array}$ & $\begin{array}{l}\text { Wet } \\
\text { bulb }\end{array}$ & $\begin{array}{l}\text { Dry } \\
\text { bulb }\end{array}$ & $\begin{array}{l}\text { Wet } \\
\text { bulb }\end{array}$ & $\begin{array}{l}\text { Dry } \\
\text { bulh }\end{array}$ & $\begin{array}{l}\text { Wet } \\
\text { bulb }\end{array}$ & $\begin{array}{l}\text { Dry } \\
\text { bulb }\end{array}$ & $\begin{array}{l}\text { Wet } \\
\text { bulb }\end{array}$ & & & $\begin{array}{c}2 \\
\text { meters }\end{array}$ & $\begin{array}{c}4 \\
\text { meters }\end{array}$ & $\begin{array}{c}8 \\
\text { meters }\end{array}$ & $\begin{array}{c}16 \\
\text { meters }\end{array}$ \\
\hline $\begin{array}{l}21 \\
21 \\
21 \\
21 \\
21 \\
21 \\
21 \\
21\end{array}$ & $\begin{array}{r}0 \\
3 \\
5 \\
9 \\
12 \\
15 \\
19 \\
21\end{array}$ & $\begin{array}{l}1.7 \\
1.9 \\
2.7 \\
4.4 \\
8.1 \\
6.0 \\
4.5 \\
3.6\end{array}$ & $\begin{array}{l}1.7 \\
1.4 \\
2.7 \\
4.1 \\
6.3 \\
5.4 \\
4.4 \\
3.6\end{array}$ & $\begin{array}{l}1.6 \\
2.0 \\
2.7 \\
4.0 \\
8.7 \\
5.1 \\
4.8 \\
3.8\end{array}$ & $\begin{array}{l}1.6 \\
2.0 \\
2.5 \\
4.2 \\
6.5 \\
5.4 \\
4.6 \\
3.8\end{array}$ & $\begin{array}{l}1.7 \\
1.9 \\
2.0 \\
4.6 \\
3.7 \\
5.2 \\
4.9 \\
4.3\end{array}$ & $\begin{array}{l}1.6 \\
1.08 \\
2.06 \\
4.2 \\
6.8 \\
5.6 \\
4.8 \\
4.2\end{array}$ & $\begin{array}{l}2.0 \\
1.0 \\
1.9 \\
4.3 \\
9.0 \\
6.4 \\
5.0 \\
4.5\end{array}$ & $\begin{array}{l}1.9 \\
1.8 \\
2.2 \\
3.8 \\
6.9 \\
5.7 \\
4.9 \\
4.3\end{array}$ & $\begin{array}{l}2.9 \\
3.0 \\
3.0 \\
3.5 \\
4.1 \\
3.9 \\
4.5 \\
4.3\end{array}$ & & $\begin{array}{l}0.09 \\
1.6 \\
1.22 \\
2.5 \\
2.7 \\
7.6 \\
4.2 \\
1.9\end{array}$ & $\begin{array}{l}1.3 \\
2.8 \\
1.8 \\
3.0 \\
4.3 \\
9.1 \\
5.0 \\
2.9\end{array}$ & $\begin{array}{r}2.5 \\
2.8 \\
2.2 \\
3.5 \\
4.9 \\
10.3 \\
6.4 \\
3.9\end{array}$ & $\begin{array}{r}3.5 \\
4.5 \\
1.8 \\
3.8 \\
5.8 \\
12.1 \\
7.5 \\
5.4\end{array}$ \\
\hline $\begin{array}{l}22 \\
22 \\
22 \\
22 \\
22 \\
22 \\
22 \\
22\end{array}$ & $\begin{array}{r}0 \\
3 \\
6 \\
9 \\
12 \\
15 \\
13 \\
21\end{array}$ & $\begin{array}{r}3.4 \\
3.6 \\
4.6 \\
8.7 \\
11.5 \\
12.1 \\
10.1 \\
8.6\end{array}$ & $\begin{array}{l}3.4 \\
3.6 \\
4.4 \\
6.6 \\
8.3 \\
7.4 \\
7.8 \\
6.7\end{array}$ & $\begin{array}{r}3.5 \\
3.8 \\
5.1 \\
9.4 \\
13.5 \\
12.9 \\
11.5 \\
9.8\end{array}$ & $\begin{array}{l}3.5 \\
3.8 \\
4.7 \\
7.0 \\
0.0 \\
9.1 \\
8.4 \\
7.6\end{array}$ & $\begin{array}{r}3.8 \\
4.1 \\
5.6 \\
10.3 \\
13.7 \\
14.8 \\
12.7 \\
11.1\end{array}$ & $\begin{array}{l}3.7 \\
4.0 \\
5.0 \\
7.3 \\
9.5 \\
9.5 \\
2.0 \\
7.0\end{array}$ & $\begin{array}{r}4.2 \\
4.6 \\
5.2 \\
10.9 \\
14.5 \\
15.8 \\
13.0 \\
11.7\end{array}$ & $\begin{array}{r}4.0 \\
4.4 \\
5.3 \\
7.5 \\
9.7 \\
10.0 \\
4.5 \\
8.2\end{array}$ & $\begin{array}{l}3.6 \\
3.2 \\
3.4 \\
4.3 \\
5.4 \\
5.0 \\
5.0 \\
5.3\end{array}$ & & $\begin{array}{l}1.7 \\
1.03 \\
5.0 \\
8.5 \\
7.6 \\
7.7 \\
6.8 \\
6.7\end{array}$ & $\begin{array}{r}2.6 \\
2.2 \\
6.4 \\
10.4 \\
9.6 \\
9.9 \\
8.8 \\
8.3\end{array}$ & $\begin{array}{r}3.5 \\
3.2 \\
8.2 \\
12.8 \\
11.7 \\
12.4 \\
11.6 \\
11.1\end{array}$ & $\begin{array}{r}5.0 \\
4.7 \\
10.2 \\
15.0 \\
13.7 \\
14.8 \\
13.8 \\
12.9\end{array}$ \\
\hline $\begin{array}{l}23 \\
23 \\
23 \\
23 \\
23 \\
23 \\
23 \\
23\end{array}$ & $\begin{array}{r}0 \\
3 \\
6 \\
9 \\
12 \\
15 \\
18 \\
21\end{array}$ & $\begin{array}{r}8.7 \\
8.5 \\
8.2 \\
9.6 \\
11.6 \\
11.1 \\
10.5 \\
8.4\end{array}$ & $\begin{array}{l}6.1 \\
5.6 \\
5.2 \\
6.3 \\
7.7 \\
7.6 \\
7.0 \\
7.0\end{array}$ & $\begin{array}{r}7.4 \\
8.9 \\
8.5 \\
0.8 \\
12.5 \\
12.1 \\
11.4 \\
8.3\end{array}$ & $\begin{array}{l}6.5 \\
6.0 \\
5.6 \\
6.7 \\
8.4 \\
8.1 \\
7.5 \\
7.3\end{array}$ & $\begin{array}{r}10.0 \\
9.3 \\
8.8 \\
11.1 \\
13.4 \\
13.0 \\
12.1 \\
8.7\end{array}$ & $\begin{array}{l}5.5 \\
5.8 \\
5.5 \\
7.0 \\
8.5 \\
3.2 \\
7.5 \\
7.3\end{array}$ & $\begin{array}{r}10.5 \\
9.6 \\
9.1 \\
11.8 \\
14.6 \\
14.5 \\
12.6 \\
9.4\end{array}$ & $\begin{array}{l}6.7 \\
6.0 \\
5.5\end{array}$ & $\begin{array}{l}5.2 \\
4.9 \\
5.1 \\
5.5 \\
6.2 \\
5.6 \\
6.0 \\
5.7\end{array}$ & & $\begin{array}{r}8.5 \\
10.9 \\
10.5 \\
8.4 \\
8.7 \\
8.2 \\
8.3 \\
7.6\end{array}$ & $\begin{array}{r}10.1 \\
12.6 \\
12.3 \\
10.2 \\
10.7 \\
10.2 \\
9.9 \\
9.1\end{array}$ & $\begin{array}{l}12.6 \\
15.6 \\
15.0 \\
12.7 \\
13.2 \\
13.6 \\
12.3 \\
11.3\end{array}$ & $\begin{array}{l}14.3 \\
17.4 \\
16.7 \\
14.6 \\
15.5 \\
15.2 \\
13.8 \\
13.1\end{array}$ \\
\hline $\begin{array}{l}24 \\
24 \\
24 \\
24 \\
24 \\
24 \\
24 \\
24\end{array}$ & $\begin{array}{r}0 \\
3 \\
6 \\
9 \\
12 \\
15 \\
18 \\
21\end{array}$ & $\begin{array}{r}7.8 \\
7.8 \\
8.0 \\
8.3 \\
10.2 \\
13.0 \\
11.2 \\
10.9\end{array}$ & $\begin{array}{r}7.0 \\
6.5 \\
5.9 \\
6.2 \\
8.2 \\
10.6 \\
9.0 \\
7.9\end{array}$ & $\begin{array}{r}8.0 \\
9.1 \\
8.3 \\
8.8 \\
10.8 \\
13.6 \\
12.0 \\
11.4\end{array}$ & $\begin{array}{r}7.1 \\
6.6 \\
6.0 \\
6.3 \\
8.3 \\
10.9 \\
9.4 \\
8.1\end{array}$ & $\begin{array}{r}8.2 \\
8.4 \\
8.5 \\
9.0 \\
10.9 \\
14.5 \\
12.6 \\
11.6\end{array}$ & $\begin{array}{r}7.2 \\
6.7 \\
5.0 \\
6.3 \\
3.7 \\
11.2 \\
9.5 \\
8.1\end{array}$ & $\begin{array}{r}9.4 \\
9.7 \\
9.1 \\
9.6 \\
11.8 \\
15.4 \\
13.4 \\
12.3\end{array}$ & & $\begin{array}{l}5.7 \\
5.4 \\
5.3 \\
5.5 \\
5.5 \\
6.5 \\
5.5 \\
5.9\end{array}$ & & $\begin{array}{r}7.3 \\
7.5 \\
10.1 \\
11.8 \\
11.4 \\
10.6 \\
12.1 \\
12.6\end{array}$ & $\begin{array}{r}8.4 \\
8.7 \\
11.7 \\
13.8 \\
23.8 \\
22.8 \\
14.2 \\
15.2\end{array}$ & $\begin{array}{l}10.6 \\
10.6 \\
14.3 \\
16.7 \\
16.9 \\
15.7 \\
17.6 \\
17.4\end{array}$ & $\begin{array}{l}11.3 \\
11.5 \\
16.2 \\
18.8 \\
19.5 \\
18.6 \\
20.2 \\
20.4\end{array}$ \\
\hline $\begin{array}{l}25 \\
25 \\
25 \\
25 \\
25 \\
25 \\
25 \\
25\end{array}$ & $\begin{array}{r}0 \\
3 \\
6 \\
9 \\
12 \\
15 \\
18 \\
21\end{array}$ & $\begin{array}{r}10.4 \\
10.0 \\
9.7 \\
11.1 \\
12.0\end{array}$ & $\begin{array}{r}8.1 \\
7.8 \\
8.6 \\
10.4 \\
11.1\end{array}$ & $\begin{array}{l}10.8 \\
10.4 \\
10.1 \\
11.5 \\
12.4\end{array}$ & $\begin{array}{r}8.2 \\
7.9 \\
9.0 \\
10.9 \\
11.7\end{array}$ & $\begin{array}{l}21.2 \\
10.7 \\
10.7 \\
12.7 \\
13.3\end{array}$ & $\begin{array}{r}8.3 \\
8.0 \\
9.2 \\
11.5 \\
12.0\end{array}$ & $\begin{array}{l}11.8 \\
11.2 \\
11.2 \\
13.1 \\
14.0\end{array}$ & & $\begin{array}{l}5.7 \\
6.0 \\
5.6 \\
6.0 \\
6.2\end{array}$ & & $\begin{array}{r}12.5 \\
11.9 \\
9.9 \\
10.0 \\
12.2 \\
8.3 \\
5.1 \\
6.8\end{array}$ & $\begin{array}{r}14.7 \\
13.9 \\
11.9 \\
12.0 \\
14.5 \\
8.8 \\
6.5 \\
8.2\end{array}$ & $\begin{array}{r}18.0 \\
16.8 \\
14.4 \\
14.2 \\
17.1 \\
10.4 \\
7.7 \\
9.4\end{array}$ & $\begin{array}{l}20.8 \\
19.6 \\
17.0 \\
16.8 \\
20.1 \\
14.2 \\
10.1 \\
11.9\end{array}$ \\
\hline $\begin{array}{l}26 \\
26 \\
26 \\
26 \\
26 \\
26 \\
26 \\
26\end{array}$ & $\begin{array}{r}0 \\
3 \\
6 \\
9 \\
12 \\
15 \\
12 \\
21\end{array}$ & $\begin{array}{r}9.8 \\
10.3\end{array}$ & $\begin{array}{l}7.8 \\
7.7\end{array}$ & $\begin{array}{r}9.9 \\
10.5\end{array}$ & 7.6 & $\begin{array}{l}10.0 \\
10.9\end{array}$ & $\begin{array}{l}7.8 \\
8.4\end{array}$ & $\begin{array}{r}8.9 \\
10.6\end{array}$ & $\begin{array}{l}7.1 \\
8.0\end{array}$ & & & $\begin{array}{l}6.6 \\
5.8 \\
2.1 \\
2.3 \\
1.9 \\
1.5 \\
0.3 \\
0.5\end{array}$ & $\begin{array}{l}7.4 \\
5.9 \\
3.0 \\
3.2 \\
2.4 \\
1.9 \\
0.3 \\
0.8\end{array}$ & $\begin{array}{l}7.6 \\
8.03 \\
6.00 \\
4.7 \\
2.8 \\
2.0 \\
1.02 \\
1.6\end{array}$ & $\begin{array}{r}10.5 \\
9.7 \\
9.0 \\
6.7 \\
3.3 \\
1.8 \\
2.3 \\
2.7\end{array}$ \\
\hline $\begin{array}{l}27 \\
27 \\
27 \\
27 \\
27 \\
27 \\
27 \\
27\end{array}$ & $\begin{array}{r}0 \\
3 \\
6 \\
9 \\
12 \\
15 \\
18 \\
21\end{array}$ & & & & & & & & & & & $\begin{array}{r}2.1 \\
3.4 \\
5.2 \\
8.4 \\
20.1 \\
12.5 \\
9.9 \\
11.7\end{array}$ & $\begin{array}{r}2.8 \\
4.0 \\
6.0 \\
10.2 \\
12.1 \\
14.9 \\
11.8 \\
13.9\end{array}$ & $\begin{array}{r}3.7 \\
5.2 \\
7.4 \\
12.2 \\
15.0 \\
18.4 \\
14.7 \\
17.2\end{array}$ & $\begin{array}{r}5.1 \\
6.8 \\
8.6 \\
13.1 \\
17.1 \\
21.3 \\
16.5 \\
19.8\end{array}$ \\
\hline $\begin{array}{l}28 \\
28 \\
28 \\
28 \\
28 \\
28 \\
28 \\
28\end{array}$ & $\begin{array}{r}0 \\
3 \\
6 \\
9 \\
12 \\
15 \\
18 \\
21\end{array}$ & $\begin{array}{r}12.7 \\
13.4 \\
23.3 \\
8.7 \\
6.2\end{array}$ & $\begin{array}{l}5.0 \\
5.4 \\
6.3 \\
4.9 \\
3.9\end{array}$ & $\begin{array}{r}12.8 \\
13.4 \\
13.4 \\
8.5 \\
6.3\end{array}$ & $\begin{array}{l}5.0 \\
5.5 \\
6.3 \\
4.8 \\
3.8\end{array}$ & $\begin{array}{r}12.9 \\
13.3 \\
13.3 \\
8.4 \\
6.2\end{array}$ & $\begin{array}{l}4 \cdot 9 \\
5 \cdot 3 \\
6 \cdot 2 \\
4 \cdot 6 \\
3.7\end{array}$ & $\begin{array}{r}12.9 \\
13.4 \\
13.2 \\
9.0 \\
6.6\end{array}$ & $\begin{array}{l}4.9 \\
5.4 \\
6.1 \\
4.8 \\
3.8\end{array}$ & $\begin{array}{l}6.9 \\
6.9 \\
6.9 \\
5.4 \\
5.3\end{array}$ & & $\begin{array}{r}14.2 \\
12.1 \\
15.0 \\
17.7 \\
14.6 \\
9.0 \\
1.9 \\
0.8\end{array}$ & $\begin{array}{r}16.6 \\
14.3 \\
16.3 \\
18.5 \\
15.3 \\
9.5 \\
2.7 \\
1.5\end{array}$ & $\begin{array}{r}19.8 \\
16.2 \\
16.6 \\
20.0 \\
15.9 \\
11.9 \\
4.8 \\
1.9\end{array}$ & $\begin{array}{r}23.1 \\
19.0 \\
18.8 \\
19.6 \\
17.9 \\
13.5 \\
9.2 \\
3.5\end{array}$ \\
\hline
\end{tabular}


TABLE 10

Table 10. - Three-hour averages of air and water-surface temperatures and wind directions and speed, April 1950-August 1951, Lake Hefner-Continued

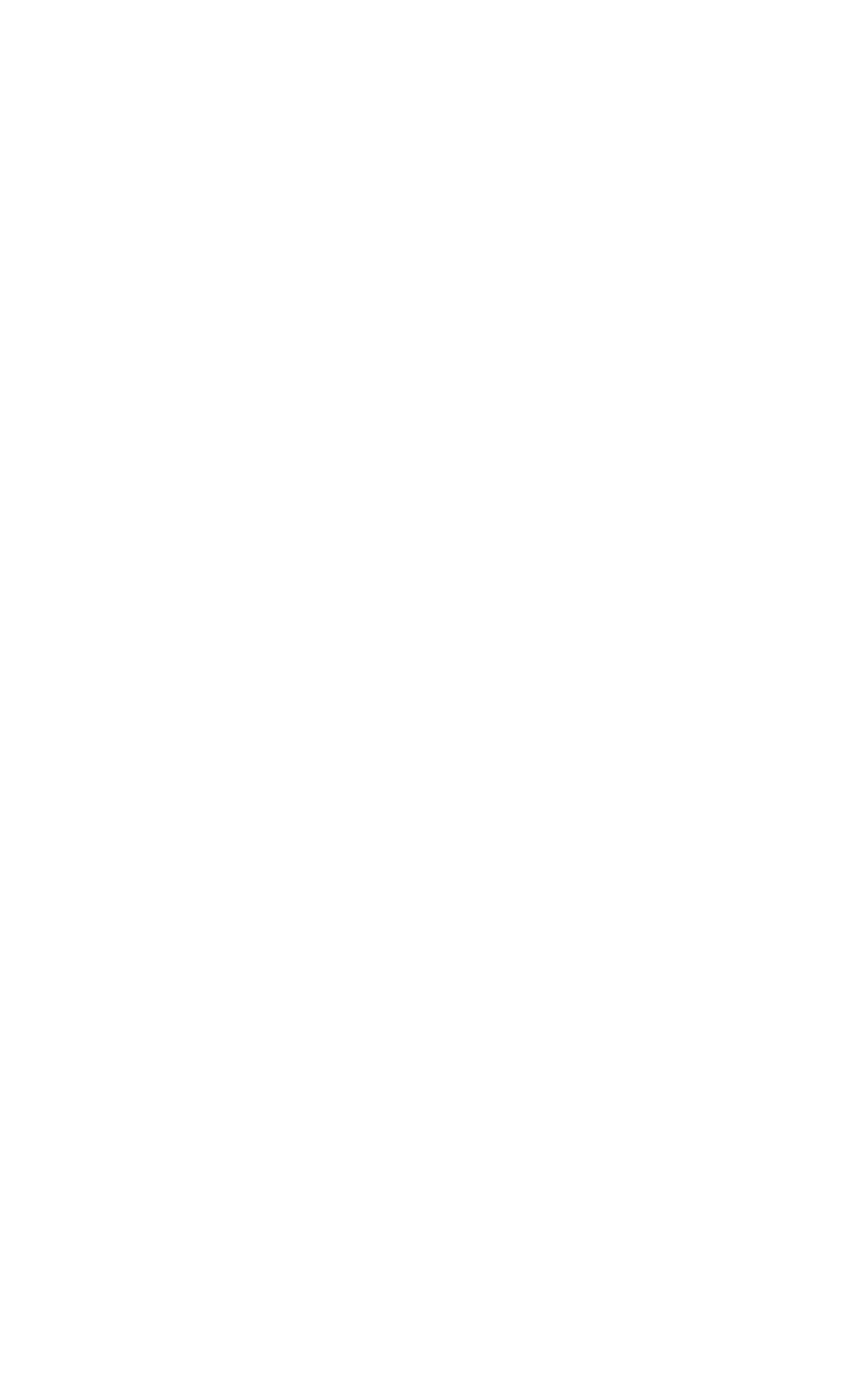


TABLE 10

Table 10. -Three-hour averages of air and water-surface temperatures and wind directions and speed, April 1950-August 1951, Lake Hefner-Continued

STATION 4 THREE-HOURLY AVERAGES

MARCH, 1951

\begin{tabular}{|c|c|c|c|c|c|c|c|c|c|c|c|c|c|c|c|}
\hline \multirow{4}{*}{ 总 } & \multirow{4}{*}{ 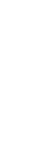 } & \multicolumn{8}{|c|}{ Average air temperature $\left({ }^{\circ} \mathrm{C}\right)$ at indicated height } & \multirow{4}{*}{$\begin{array}{l}\text { Average } \\
\text { water- } \\
\text { surface } \\
\text { tempera- } \\
\text { ture } \\
\text { () }\end{array}$} & \multirow{4}{*}{$\begin{array}{c}\text { Average } \\
\text { wind } \\
\text { direction } \\
\text { (coded) }\end{array}$} & \multirow{2}{*}{\multicolumn{4}{|c|}{$\begin{array}{c}\text { Average wind speed (knots) } \\
\text { at indicated height }\end{array}$}} \\
\hline & & \multirow{2}{*}{\multicolumn{2}{|c|}{$\begin{array}{c}2 \\
\text { meters }\end{array}$}} & \multirow{2}{*}{\multicolumn{2}{|c|}{$\begin{array}{c}4 \\
\text { meters }\end{array}$}} & \multirow{2}{*}{\multicolumn{2}{|c|}{$\begin{array}{c}8 \\
\text { meters }\end{array}$}} & \multirow{2}{*}{\multicolumn{2}{|c|}{$\begin{array}{c}16 \\
\text { meters }\end{array}$}} & & & & & & \\
\hline & & & & & & & & & & & & 2 & 4 & 8 & 16 \\
\hline & & $\begin{array}{l}\text { Dry } \\
\text { bulb }\end{array}$ & & & & & & & & & & & & & \\
\hline
\end{tabular}

\begin{tabular}{|c|c|c|c|c|c|c|c|c|c|c|c|c|c|c|}
\hline $\begin{array}{l}11 \\
11 \\
11 \\
11 \\
11 \\
11 \\
11 \\
11\end{array}$ & $\begin{array}{r}0 \\
3 \\
6 \\
9 \\
12 \\
15 \\
28 \\
21\end{array}$ & $\begin{array}{r}3.5 \\
-0.6 \\
-1.7 \\
-1.7 \\
0.00 \\
0.07 \\
-0.8 \\
-2.0\end{array}$ & $\begin{array}{l}3.4 \\
0.7\end{array}$ & $\begin{array}{l}3.5 \\
0.4 \\
1.9 \\
1.8 \\
0.0 \\
0.5 \\
1.0 \\
2.2\end{array}$ & $\begin{array}{l}3.3 \\
0.4\end{array}$ & $\begin{array}{r}3.3 \\
0.2 \\
-2.2 \\
-2.0 \\
-0.1 \\
0.4 \\
-1.1 \\
-2.4\end{array}$ & $\begin{array}{l}3.1 \\
0.1\end{array}$ & $\begin{array}{r}3.1 \\
0.0 \\
-2.8 \\
-2.3 \\
-0.4 \\
-0.1 \\
-1.3 \\
-2.6\end{array}$ & $\mid \begin{array}{r}2.9 \\
-0.2 \\
\end{array}$ & $\begin{array}{l}6.9 \\
6.9 \\
6.8 \\
6.8 \\
6.8 \\
6.5 \\
6.3 \\
6.2\end{array}$ & $\begin{array}{l}6.5 \\
9.0 \\
7.0 \\
7.0 \\
8.0 \\
6.2 \\
6.2 \\
6.8\end{array}$ & $\begin{array}{l}7.1 \\
9.1 \\
7.9 \\
7.4 \\
8.1 \\
7.8 \\
8.1 \\
8 . ?\end{array}$ & $\begin{array}{l}14.8 \\
19.1 \\
17.1 \\
16.1 \\
17.5 \\
17.5 \\
17.7 \\
18.3\end{array}$ & $\begin{array}{l}18.8 \\
23.2 \\
22.2 \\
22.4 \\
23.0 \\
27.0 \\
28.3 \\
27.9\end{array}$ \\
\hline $\begin{array}{l}12 \\
12 \\
12 \\
12 \\
12 \\
12 \\
12 \\
12\end{array}$ & $\begin{array}{r}0 \\
3 \\
6 \\
9 \\
12 \\
15 \\
18 \\
21\end{array}$ & $\begin{array}{l}=3.1 \\
=4.2 \\
=5.0 \\
=3.9 \\
=0.5 \\
0.6 \\
=0.4 \\
=2.0\end{array}$ & & $\begin{array}{l}3.2 \\
4.3 \\
5.2 \\
4.0 \\
0.4 \\
0.7 \\
0.6 \\
2.2\end{array}$ & & $\begin{array}{l}3.5 \\
-4.6 \\
-5.4 \\
-4.2 \\
-0.5 \\
0.6 \\
-0.7 \\
-7.4\end{array}$ & & $\begin{array}{r}-3.7 \\
=-4.8 \\
=-4.7 \\
=\quad 4.5 \\
-0.8 \\
0.03 \\
-0.9 \\
-2.6\end{array}$ & & $\begin{array}{l}6.1 \\
5.9 \\
5.8 \\
5.9 \\
5.9 \\
5.0 \\
5.2 \\
5.2\end{array}$ & $\begin{array}{l}6.5 \\
7.4 \\
8.0 \\
9.0 \\
8.8 \\
7.0 \\
5.0 \\
4.5\end{array}$ & $\begin{array}{l}7.5 \\
8.0 \\
8.4 \\
9.1 \\
9.3 \\
9.0 \\
6.1 \\
5.0\end{array}$ & $\begin{array}{l}17.1 \\
17.5 \\
18.2 \\
18.5 \\
19.8 \\
20.1 \\
13.5 \\
11.5\end{array}$ & $\begin{array}{l}25.7 \\
25.6 \\
24.8 \\
21.8 \\
27.1 \\
29.4 \\
20.4 \\
16.6\end{array}$ \\
\hline $\begin{array}{l}13 \\
13 \\
13 \\
13 \\
13 \\
13 \\
13 \\
13\end{array}$ & $\begin{array}{r}0 \\
3 \\
6 \\
9 \\
12 \\
15 \\
18 \\
21\end{array}$ & $\begin{array}{r}-3.5 \\
=4.8 \\
=4.9 \\
-1.9 \\
1.4 \\
3.5 \\
0.5 \\
-1.3\end{array}$ & -0.3 & $\begin{array}{l}3.6 \\
5.0 \\
5.0 \\
1.0 \\
1.6 \\
3.5 \\
0.0 \\
1.6\end{array}$ & & $\begin{array}{r}-3.9 \\
-5.1 \\
-5.2 \\
-1.9 \\
1.5 \\
3.5 \\
-0.2 \\
-1.7\end{array}$ & 1.3 & $\begin{array}{l}-4.0 \\
-5.3 \\
-5.4 \\
-2.3 \\
1.0 \\
3.3 \\
-0.1 \\
-\quad 1.4\end{array}$ & & $\begin{array}{l}5.2 \\
5.0 \\
5.1 \\
5.0 \\
5.4 \\
5.1 \\
4.9 \\
4.9\end{array}$ & $\begin{array}{l}5.6 \\
6.8 \\
8.2 \\
9.1 \\
9.0 \\
8.0 \\
2.7 \\
1.2\end{array}$ & $\begin{array}{l}5.7 \\
6.9 \\
8.7 \\
9.0 \\
9.4 \\
8.4 \\
2.3 \\
1.7\end{array}$ & $\begin{array}{r}13.0 \\
13.9 \\
14.0 \\
17.1 \\
17.4 \\
15.3 \\
7.1 \\
4.2\end{array}$ & $\begin{array}{r}17.0 \\
14.8 \\
15.0 \\
18.9 \\
19.4 \\
16.5 \\
10.7 \\
7.2\end{array}$ \\
\hline $\begin{array}{l}14 \\
14 \\
14 \\
14 \\
14 \\
14 \\
14 \\
14\end{array}$ & $\begin{array}{r}0 \\
3 \\
6 \\
9 \\
12 \\
15 \\
18 \\
21\end{array}$ & $\begin{array}{r}-2.6 \\
=3.3 \\
-2.9 \\
0.4 \\
5.0 \\
7.9 \\
6.0 \\
2.7\end{array}$ & $\begin{array}{r}-0.2 \\
0.5 \\
2.3 \\
2.8 \\
0.4\end{array}$ & $\begin{array}{l}2.8 \\
3.4 \\
2.9 \\
0.5 \\
5.3 \\
8.2 \\
5.9 \\
2.6\end{array}$ & $\begin{array}{l}0.1 \\
0.8 \\
2.5 \\
2.9 \\
0.3\end{array}$ & $\begin{array}{r}2.9 \\
-3.5 \\
-3.1 \\
0.6 \\
5.3 \\
7.8 \\
6.0 \\
2.07\end{array}$ & $\begin{array}{l} \\
0.4 \\
2.0 \\
? .5 \\
0.1\end{array}$ & $\begin{array}{r}-2.8 \\
-3.7 \\
=3.3 \\
-0.1 \\
5.0 \\
7.0 \\
5.3 \\
3.0\end{array}$ & $\begin{array}{l}0.5 \\
1.7 \\
1.7\end{array}$ & $\begin{array}{l}4 \cdot 09 \\
4 \cdot 8 \\
4 \cdot 8 \\
5.2 \\
5 \cdot 5 \\
5.4 \\
4.9 \\
4.8\end{array}$ & $\begin{array}{l}3.3 \\
4.4 \\
5.4 \\
5.9 \\
5.4 \\
4.3 \\
0.8 \\
1.6\end{array}$ & $\begin{array}{l}3.5 \\
4.5 \\
5.5 \\
6.0 \\
6.7 \\
4.4 \\
1.1 \\
1.9\end{array}$ & $\begin{array}{l}4.5 \\
6.2 \\
9.1 \\
9.8 \\
9.3 \\
6.8 \\
1.5 \\
2.4\end{array}$ & $\begin{array}{r}5.6 \\
7.3 \\
9.9 \\
10.2 \\
10.1 \\
7.8 \\
2.9 \\
3.2\end{array}$ \\
\hline $\begin{array}{l}15 \\
15 \\
15 \\
15 \\
15 \\
15 \\
15 \\
15\end{array}$ & $\begin{array}{r}0 \\
3 \\
6 \\
9 \\
12 \\
15 \\
11 \\
21\end{array}$ & $\begin{array}{r}0.8 \\
-0.8 \\
-0.7 \\
3.2 \\
7.0 \\
7.9 \\
6.0 \\
3.1\end{array}$ & $\begin{array}{r}-1.1 \\
-2.0 \\
-1.3 \\
0.9 \\
2.7 \\
3.4 \\
3.2 \\
1.4\end{array}$ & $\begin{array}{l}0.4 \\
1.2 \\
1.0 \\
3.3 \\
6.9 \\
8.0 \\
6.2 \\
3.1\end{array}$ & $\begin{array}{r}-1.2 \\
-2.1 \\
-1.0 \\
1.3 \\
3.0 \\
3.7 \\
3.1 \\
1.5\end{array}$ & $\begin{array}{r}0.3 \\
-1.02 \\
-1.1 \\
4.0 \\
7.4 \\
8.1 \\
6.4 \\
3.0\end{array}$ & {$\left[\begin{array}{r}1.5 \\
-2.4 \\
1.7 \\
1.0 \\
2.9 \\
3.2 \\
2.6 \\
1.1\end{array}\right.$} & $\begin{array}{r}0.8 \\
-1.0 \\
-0.8 \\
3.3 \\
6.0 \\
8.2 \\
6.7 \\
3.3\end{array}$ & $\left|\begin{array}{r}-1.4 \\
-2.3 \\
-1.7 \\
0.6 \\
2.6 \\
3.3 \\
2.7 \\
1.1\end{array}\right|$ & $\begin{array}{l}4.8 \\
4.8 \\
4.9 \\
5.6 \\
6.1 \\
5.7 \\
5.3 \\
5.2\end{array}$ & $\begin{array}{l}1.6 \\
0.8 \\
1.2 \\
5.2 \\
3.9 \\
5.5 \\
3.5 \\
6.1\end{array}$ & $\begin{array}{l}1.7 \\
1.2 \\
1.6 \\
5.4 \\
4.3 \\
6.1 \\
4.2 \\
6.7\end{array}$ & $\begin{array}{l}2.5 \\
1.9 \\
2.6 \\
6.4 \\
4.7 \\
6.6 \\
5.4 \\
8.0\end{array}$ & $\begin{array}{l}3.3 \\
2.7 \\
2.9 \\
7.2 \\
6.0 \\
7.0 \\
6.6 \\
9.4\end{array}$ \\
\hline $\begin{array}{l}16 \\
16 \\
16 \\
16 \\
16 \\
16 \\
16 \\
16\end{array}$ & $\begin{array}{r}0 \\
3 \\
6 \\
9 \\
12 \\
15 \\
18 \\
21\end{array}$ & $\begin{array}{r}2.3 \\
2.4 \\
2.9 \\
8.0 \\
13.7 \\
16.8 \\
13.9 \\
11.8\end{array}$ & $\begin{array}{r}0.8 \\
0.8 \\
1.5 \\
6.3 \\
9.7 \\
10.2 \\
8.8 \\
8.0\end{array}$ & $\begin{array}{r}2.2 \\
2.3 \\
3.0 \\
8.4 \\
14.3 \\
18.4 \\
15.6 \\
12.7\end{array}$ & $\begin{array}{l}0.9 \\
0.8 \\
1.6 \\
6.9 \\
9.9\end{array}$ & $\begin{array}{r}2.2 \\
2.2 \\
3.0 \\
8.8 \\
14.9 \\
19.9 \\
18.7 \\
14.1\end{array}$ & $\begin{array}{r}0.6 \\
0.5 \\
1.4 \\
6.8 \\
10.4 \\
11.0 \\
10.2 \\
8.7\end{array}$ & $\begin{array}{r}2.1 \\
2.0 \\
3.1 \\
9.2 \\
15.7 \\
21.4 \\
20.3 \\
15.7\end{array}$ & $\begin{array}{r}0.4 \\
0.2 \\
1.3 \\
7.1 \\
10.9 \\
11.6 \\
10.7 \\
9.2\end{array}$ & $\begin{array}{l}5.0 \\
4.9 \\
5.0 \\
5.5 \\
6.0 \\
6.6 \\
6.8 \\
6.6\end{array}$ & $\begin{array}{r}7.8 \\
9.5 \\
12.3 \\
13.5 \\
12.4 \\
11.0 \\
7.3 \\
8.2\end{array}$ & $\begin{array}{r}8.6 \\
10.4 \\
13.7 \\
15.6 \\
14.9 \\
13.5 \\
9.8 \\
10.7\end{array}$ & $\begin{array}{l}10.2 \\
12.2 \\
16.3 \\
10.2 \\
10.3 \\
15.6 \\
13.3 \\
14.0\end{array}$ & $\begin{array}{l}10.9 \\
12.7 \\
17.2 \\
21.2 \\
21.2 \\
20.0 \\
15.8 \\
17.3\end{array}$ \\
\hline $\begin{array}{l}17 \\
17 \\
17 \\
17 \\
17 \\
17 \\
17 \\
17\end{array}$ & $\begin{array}{r}0 \\
3 \\
6 \\
9 \\
12 \\
15 \\
18 \\
21\end{array}$ & $\begin{array}{r}12.0 \\
9.0 \\
5.8 \\
5.1 \\
8.8 \\
8.6 \\
5.8 \\
1.3\end{array}$ & $\begin{array}{r}7.2 \\
6.2 \\
5.1 \\
4.0 \\
5.6 \\
5.0 \\
-0.9 \\
-0.4\end{array}$ & $\begin{array}{r}12.7 \\
8.4 \\
5.7 \\
5.1 \\
9.0 \\
8.8 \\
5.6 \\
1.1\end{array}$ & $\begin{array}{l}5.9 \\
5.2 \\
4.0\end{array}$ & $\begin{array}{r}13.5 \\
8.7 \\
5.6 \\
5.0 \\
9.0 \\
8.6 \\
5.4 \\
0.9\end{array}$ & $\begin{array}{r}7.5 \\
5.3 \\
5.0 \\
4.0 \\
5.5 \\
4.8 \\
2.5 \\
-\quad 0.8\end{array}$ & $\begin{array}{r}14.4 \\
9.0 \\
5.5 \\
4.8 \\
3.5 \\
8.5 \\
5.3 \\
0.6\end{array}$ & $\begin{array}{r}7.7 \\
6.3 \\
4.7 \\
3.7 \\
5.1 \\
4.6 \\
2.4 \\
-1.0\end{array} \mid$ & $\begin{array}{l}6.4 \\
6.0 \\
5.6 \\
5.8 \\
6.4 \\
5.9 \\
5.6 \\
5.6\end{array}$ & $\begin{array}{r}12.2 \\
10.1 \\
8.8 \\
6.1 \\
5.9 \\
6.7 \\
7.7 \\
9.4\end{array}$ & $\begin{array}{r}14.7 \\
10.8 \\
7.7 \\
5.0 \\
5.3 \\
5.8 \\
9.0\end{array}$ & $\begin{array}{l}17.9 \\
12.8 \\
13.6 \\
17.7 \\
12.1 \\
14.2 \\
15.03 \\
19.0\end{array}$ & $\begin{array}{l}21.5 \\
15.0 \\
14.8 \\
14.4 \\
15.1 \\
18.3 \\
17.1 \\
19.8\end{array}$ \\
\hline $\begin{array}{l}18 \\
18 \\
18 \\
18 \\
18 \\
18 \\
18 \\
18\end{array}$ & $\begin{array}{r}0 \\
3 \\
6 \\
9 \\
12 \\
15 \\
18 \\
21\end{array}$ & $\begin{array}{r}-0.8 \\
-1.8 . \\
-1.0 \\
1.4 \\
4.5 \\
5.6\end{array}$ & $\mid \begin{array}{l}-1.8 \\
-0.1 \\
0.6\end{array}$ & $\begin{array}{l}1.1 \\
1.9 \\
2.0 \\
1.5 \\
4.7 \\
5.7\end{array}$ & -1.8 & $=\begin{array}{r}1.3 \\
-2.0 \\
-2.2 \\
1.6 \\
4.6 \\
5.5\end{array}$ & $\begin{array}{c}-2.0 \\
0.3 \\
0.1\end{array}$ & $\begin{array}{r}-1.5 \\
-2.2 \\
-2.5 \\
1.1 \\
3.7 \\
4.8\end{array}$ & -1.5 & $\begin{array}{l}5.6 \\
5.5 \\
5.5 \\
5.8 \\
6.1 \\
5.8\end{array}$ & $\begin{array}{l}7.0 \\
4.4 \\
4.7 \\
7.0 \\
5.3 \\
5.7 \\
1.8 \\
1.5\end{array}$ & $\begin{array}{l}7.8 \\
5.1 \\
6.5 \\
9.2 \\
8.2 \\
7.5 \\
2.7 \\
2.0\end{array}$ & $\begin{array}{r}17.2 \\
11.8 \\
12.1 \\
14.3 \\
14.4 \\
12.1 \\
5.1 \\
2.6\end{array}$ & $\begin{array}{r}24.4 \\
19.4 \\
19.8 \\
23.5 \\
23.0 \\
19.9 \\
9.6 \\
5.5\end{array}$ \\
\hline $\begin{array}{l}19 \\
19 \\
19 \\
19 \\
19 \\
19 \\
19 \\
19\end{array}$ & $\begin{array}{r}0 \\
3 \\
6 \\
9 \\
12 \\
15 \\
18 \\
21\end{array}$ & $\begin{array}{l}0.5 \\
3.4 \\
7.3 \\
8.6\end{array}$ & $\begin{array}{r}-2.2 \\
-\quad 1.5 \\
0.9 \\
2.2 \\
2.8\end{array}$ & $\begin{array}{l}0.5 \\
0.2 \\
3.4 \\
7.4 \\
8.9\end{array}$ & {$\left[\begin{array}{l}-2.0 \\
-2\end{array} \mid .1\right.$} & $\begin{array}{r}-0.5 \\
0.2 \\
3.5 \\
7.4 \\
8.7\end{array}$ & {$\left[\begin{array}{l}2.7 \\
1.9 \\
0.7 \\
2.1 \\
2.7\end{array} \mid\right.$} & $-\begin{array}{r}0.5 \\
0.1 \\
3.5 \\
7.1 \\
8.7\end{array}$ & $\begin{array}{l}1.0 \\
1.3 \\
2.5\end{array}$ & $\begin{array}{l}5.0 \\
5.3 \\
6.0 \\
6.1 \\
5.9\end{array}$ & $\begin{array}{l}1.5 \\
0.8 \\
7.8 \\
8.6 \\
8.7 \\
6.9 \\
1.8 \\
3.4\end{array}$ & $\begin{array}{l}2.0 \\
1.00 \\
8.5 \\
9.1 \\
9.0 \\
7.2 \\
2.02 \\
3.9\end{array}$ & $\begin{array}{r}2.2 \\
3.2 \\
4.8 \\
12.1 \\
11.6 \\
8.3 \\
2.9 \\
4.8\end{array}$ & $\begin{array}{r}2.6 \\
4.4 \\
8.9 \\
12.0 \\
12.7 \\
9.0 \\
4.2 \\
6.2\end{array}$ \\
\hline $\begin{array}{l}20 \\
20 \\
20 \\
20 \\
20 \\
20 \\
20 \\
20\end{array}$ & $\begin{array}{r}0 \\
3 \\
6 \\
9 \\
12 \\
15 \\
18 \\
21\end{array}$ & $\begin{array}{r}5.6 \\
8.2 \\
11.5 \\
12.5 \\
7.2 \\
2.1\end{array}$ & $\begin{array}{r}2.1 \\
3.1 \\
4.6 \\
5.6 \\
2.8 \\
-0.5\end{array}$ & $\begin{array}{r}5.8 \\
8.5 \\
12.0 \\
13.8 \\
7.7 \\
1.9\end{array}$ & 1.9 & $\begin{array}{r}5.9 \\
8.8 \\
12.7 \\
14.5 \\
7.0 \\
1.7\end{array}$ & $\left|\begin{array}{r}1.5 \\
2.9 \\
4.5 \\
5.5 \\
2.4 \\
-0.8\end{array}\right|$ & $\begin{array}{r}5.2 \\
9.1 \\
12.8 \\
15.0 \\
6.7 \\
1.4\end{array}$ & $\begin{array}{r}1.2 \\
2.8 \\
4.3 \\
5.3 \\
2.0 \\
-\quad 0.9\end{array}$ & $\begin{array}{l}5.5 \\
5.9 \\
6.5 \\
6.5 \\
5.9 \\
5.4\end{array}$ & $\begin{array}{r}8.0 \\
9.8 \\
11.2 \\
17.6 \\
15.1 \\
9.3 \\
6.1 \\
8.2\end{array}$ & $\begin{array}{r}9.1 \\
11.1 \\
13.0 \\
19.5 \\
16.9 \\
10.5 \\
7.9 \\
9.1\end{array}$ & $\begin{array}{l}10.5 \\
12.5 \\
13.0 \\
19.5 \\
17.4 \\
11.1 \\
11.5 \\
11.2\end{array}$ & $\begin{array}{l}11.7 \\
14.0 \\
15.9 \\
22.8 \\
20.4 \\
13.2 \\
18.0 \\
16.7\end{array}$ \\
\hline
\end{tabular}


TABLE 10

207

Table 10. - Three-hour averages of air and water-surface temperatures and wind directions and speed, Aprn 1950-August 1951, Lake Hefrier-Continued

STATION 4 THREE-HOURLY AVERAGES

MARCH, 2951

\begin{tabular}{|c|c|c|c|c|c|c|c|c|c|c|c|c|c|c|c|}
\hline \multirow{4}{*}{ 它吉 } & \multirow{4}{*}{ 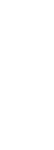 } & \multicolumn{8}{|c|}{ Average air temperature $\left({ }^{\circ} \mathrm{C}\right)$ at indicated height } & \multirow{4}{*}{\begin{tabular}{|l} 
Average \\
water- \\
surface \\
tempera- \\
ture \\
$\left.{ }^{\circ} \mathrm{C}\right)$
\end{tabular}} & \multirow{4}{*}{$\begin{array}{c}\text { Average } \\
\text { wind } \\
\text { diręction } \\
\text { (coded) }\end{array}$} & \multirow{2}{*}{\multicolumn{4}{|c|}{$\begin{array}{l}\text { Average wind speed (knots) } \\
\text { at indicated height }\end{array}$}} \\
\hline & & \multirow{2}{*}{\multicolumn{2}{|c|}{$\begin{array}{c}2 \\
\text { meters }\end{array}$}} & \multirow{2}{*}{\multicolumn{2}{|c|}{$\begin{array}{c}4 \\
\text { meters } \\
\end{array}$}} & \multirow{2}{*}{\multicolumn{2}{|c|}{$\begin{array}{c}8 \\
\text { meters }\end{array}$}} & \multirow{2}{*}{\multicolumn{2}{|c|}{$\begin{array}{c}16 \\
\text { meters }\end{array}$}} & & & & & & \\
\hline & & & & & & & & & & & & $\mathbf{2}$ & 4 & 8 & 16 \\
\hline & & $\begin{array}{l}\text { Dry } \\
\text { bulb }\end{array}$ & $\begin{array}{l}\text { Wet } \\
\text { bulb }\end{array}$ & $\begin{array}{l}\text { Dry } \\
\text { bulb }\end{array}$ & $\begin{array}{l}\text { Wet } \\
\text { bulb }\end{array}$ & $\begin{array}{l}\text { Dry } \\
\text { bulb }\end{array}$ & $\begin{array}{l}\text { Wet } \\
\text { bulb }\end{array}$ & $\begin{array}{l}\text { Dry } \\
\text { bulb }\end{array}$ & $\begin{array}{l}\text { Wet } \\
\text { bulb }\end{array}$ & & & meters & meters & meters & meters \\
\hline $\begin{array}{l}21 \\
21 \\
21 \\
21 \\
21 \\
21 \\
21 \\
21\end{array}$ & $\begin{array}{r}0 \\
3 \\
6 \\
9 \\
12 \\
15 \\
18 \\
21\end{array}$ & $\begin{array}{r}=1.3 \\
=3.4 \\
-2.1 \\
2.2 \\
8.1 \\
10.8 \\
9.7 \\
7.2\end{array}$ & $\begin{array}{r}-2.9 \\
-3.8 \\
0.1 \\
2.9 \\
5.2 \\
5.3 \\
4.7\end{array}$ & $\begin{array}{r}1.8 \\
3.7 \\
2.2 \\
2.3 \\
8.3 \\
11.5 \\
10.3 \\
7.7\end{array}$ & $=3.6$ & $\mid \begin{array}{r}1.09 \\
-3.7 \\
-2.2 \\
2.4 \\
8.05 \\
12.0 \\
12.7 \\
8.8\end{array}$ & $\mid \begin{array}{r}3.2 \\
-3.7 \\
2.6 \\
5.00 \\
4.09 \\
4.0\end{array}$ & $\mid \begin{array}{r}-2.3 \\
-3.8 \\
-2.0 \\
2.3 \\
8.6 \\
12.2 \\
12.2 \\
9.5\end{array}$ & $\begin{array}{r}-3.1 \\
-3.7 \\
0.1 \\
2.5 \\
4.9 \\
4.9 \\
4.1\end{array}$ & $\begin{array}{l}5: 1 \\
5: 1 \\
5: 3 \\
6.0 \\
7.9 \\
7: 9 \\
7.6 \\
6.9\end{array}$ & & $\begin{array}{l}3.4 \\
1.05 \\
5.03 \\
5.8 \\
2.5 \\
5.1 \\
3.9 \\
4.6\end{array}$ & $\begin{array}{l}4.0 \\
2.0 \\
5.6 \\
6.4 \\
3.0 \\
6.03 \\
5.2 \\
5.6\end{array}$ & $\begin{array}{l}5.2 \\
2.6 \\
6.5 \\
7.4 \\
3.6 \\
7.6 \\
7.2 \\
7.0\end{array}$ & $\begin{array}{r}8.8 \\
4.5 \\
6.7 \\
7.8 \\
4.1 \\
9.3 \\
8.7 \\
10.1\end{array}$ \\
\hline $\begin{array}{l}22 \\
22 \\
22 \\
22 \\
22 \\
22 \\
22 \\
22\end{array}$ & $\begin{array}{r}0 \\
3 \\
6 \\
9 \\
12 \\
15 \\
18 \\
21\end{array}$ & $\begin{array}{r}7.9 \\
8.1 \\
8.0 \\
14.4 \\
18.3 \\
21.8 \\
18.9 \\
16.6\end{array}$ & $\begin{array}{l}5.1 \\
5.7 \\
6.0 \\
7.5 \\
9.3 \\
9.9 \\
9.0 \\
9.3\end{array}$ & $\begin{array}{r}8.2 \\
8.1 \\
8.2 \\
15.1 \\
19.8 \\
23.5 \\
20.5 \\
17.5\end{array}$ & & $\begin{array}{r}8.6 \\
8.2 \\
8.5 \\
16.2 \\
21.3 \\
24.9 \\
22.5 \\
19.1\end{array}$ & $\begin{array}{r}4.9 \\
5.7 \\
6.1 \\
7.8 \\
9.9 \\
10.4 \\
9.7 \\
9.6\end{array}$ & $\begin{array}{r}9.1 \\
8.3 \\
8.8 \\
16.8 \\
22.5 \\
26.0 \\
24.3 \\
20.5\end{array}$ & $\begin{array}{r}4.8 \\
5.7 \\
5.9 \\
8.0 \\
10.1 \\
10.7 \\
10.1 \\
10.3\end{array}$ & $\begin{array}{l}6.8 \\
6.4 \\
5.4 \\
7.2 \\
7.09 \\
8.00 \\
8.2 \\
7.8\end{array}$ & & $\begin{array}{r}7.3 \\
10.5 \\
11.0 \\
13.6 \\
13.9 \\
16.8 \\
10.2 \\
11.4\end{array}$ & $\begin{array}{r}8.6 \\
12.1 \\
12.6 \\
15.4 \\
16.2 \\
19.1 \\
12.6 \\
13.7\end{array}$ & $\begin{array}{l}11.0 \\
15.0 \\
14.7 \\
16.5 \\
17.5 \\
20.3 \\
14.9 \\
16.2\end{array}$ & $\begin{array}{l}13.2 \\
16.9 \\
16.6 \\
20.0 \\
21.2 \\
24.6 \\
18.5 \\
20.0\end{array}$ \\
\hline $\begin{array}{l}23 \\
23 \\
23 \\
23 \\
23 \\
23 \\
23 \\
23\end{array}$ & $\begin{array}{r}0 \\
3 \\
6 \\
9 \\
12 \\
15 \\
18 \\
21\end{array}$ & $\begin{array}{r}15.7 \\
13.4 \\
10.4 \\
12.8 \\
14.4 \\
14.4 \\
9.7 \\
6.1\end{array}$ & $\begin{array}{l}8 \cdot 3 \\
7.0 \\
5.4 \\
4 \cdot 5 \\
6.1 \\
6.2 \\
4.6 \\
2.2\end{array}$ & $\begin{array}{r}16.2 \\
13.5 \\
10.4 \\
13.0 \\
14.7 \\
14.6 \\
9.6 \\
6.0\end{array}$ & & $\begin{array}{r}17.2 \\
13.9 \\
10.6 \\
13.2 \\
14.6 \\
14.5 \\
9.5 \\
6.1\end{array}$ & $\begin{array}{l}8.6 \\
7.1 \\
5.2 \\
4.5 \\
6.00 \\
5.9 \\
4.03 \\
2.0\end{array}$ & $\begin{array}{r}17.4 \\
13.0 \\
10.5 \\
13.2 \\
14.2 \\
13.9 \\
9.6 \\
6.3\end{array}$ & $\begin{array}{l}8.7 \\
7.2 \\
5.0 \\
4.4 \\
5.5 \\
5.5 \\
4.3 \\
2.1\end{array}$ & $\begin{array}{l}7.4 \\
6.9 \\
6.3 \\
7.1 \\
7.02 \\
7.0 \\
6.7 \\
6.5\end{array}$ & & $\begin{array}{r}14.3 \\
8.5 \\
8.9 \\
10.6 \\
9.1 \\
6.7 \\
4.8 \\
3.7\end{array}$ & $\begin{array}{r}16.2 \\
8.9 \\
9.0 \\
10.6 \\
9.6 \\
7.7 \\
5.9 \\
4.2\end{array}$ & $\begin{array}{r}17.4 \\
12.3 \\
16.2 \\
20.6 \\
10.6 \\
16.1 \\
8.1 \\
5.0\end{array}$ & $\begin{array}{l}21.1 \\
14: 0 \\
17.7 \\
24.8 \\
24.8 \\
23.6 \\
13.1 \\
7: 1\end{array}$ \\
\hline $\begin{array}{l}24 \\
24 \\
24 \\
24 \\
24 \\
24 \\
24 \\
24\end{array}$ & $\begin{array}{r}0 \\
3 \\
6 \\
9 \\
12 \\
15 \\
18 \\
21\end{array}$ & $\begin{array}{r}4.2 \\
2.0 \\
2.4 \\
6.9 \\
11.7 \\
12.8 \\
10.6 \\
9.8\end{array}$ & $\begin{array}{l}1.4 \\
0.0 \\
0.5 \\
3.1 \\
5.7 \\
6.3 \\
5.9 \\
4.8\end{array}$ & $\begin{array}{r}4.1 \\
1.8 \\
2.4 \\
7.5 \\
11.9 \\
13.1 \\
10.9 \\
9.8\end{array}$ & -0.4 & $\begin{array}{r}4.0 \\
1.8 \\
2.6 \\
7.4 \\
11.9 \\
13.4 \\
11.5 \\
20.0\end{array}$ & $\begin{array}{r}0.8 \\
-0.5 \\
0.2 \\
2.9 \\
4.7 \\
5.4 \\
4.9 \\
3.9\end{array}$ & $\begin{array}{r}4.2 \\
2.0 \\
2.6 \\
7.7 \\
12.0 \\
13.9 \\
12.2 \\
10.0\end{array}$ & $\begin{array}{r}0.8 \\
-0.4 \\
0.2 \\
2.7 \\
4.6 \\
5.2 \\
4.7 \\
3.9\end{array}$ & $\begin{array}{r}6.5 \\
6.4 \\
6.5 \\
7.7 \\
10.4 \\
10.0 \\
8.8 \\
8.1\end{array}$ & & $\begin{array}{l}3.7 \\
2.0 \\
2.0 \\
2.0 \\
4.03 \\
6.3 \\
4.7 \\
8.9\end{array}$ & $\begin{array}{l}4 \cdot 0 \\
2.2 \\
2.9 \\
3.2 \\
4 \cdot 9 \\
7.3 \\
5.8 \\
9.9\end{array}$ & $\begin{array}{r}4.8 \\
2.7 \\
3.2 \\
3.4 \\
5.1 \\
7.9 \\
6.6 \\
10.3\end{array}$ & $\begin{array}{r}5.9 \\
3.7 \\
3.5 \\
3.7 \\
5.9 \\
9.3 \\
9.0 \\
12.8\end{array}$ \\
\hline $\begin{array}{l}25 \\
25 \\
25 \\
25 \\
25 \\
25 \\
25 \\
25\end{array}$ & $\begin{array}{r}0 \\
3 \\
6 \\
9 \\
12 \\
15 \\
18 \\
21\end{array}$ & $\begin{array}{r}7.6 \\
6.0 \\
7.0 \\
13.7 \\
18.4 \\
17.2 \\
13.8 \\
11.9\end{array}$ & $\begin{array}{l}3.6 \\
2.4 \\
2.7 \\
6.0 \\
7.6 \\
8.1 \\
7.4 \\
6.6\end{array}$ & $\begin{array}{r}7.6 \\
6.3 \\
7.1 \\
14.6 \\
18.7 \\
18.5 \\
14.4 \\
12.4\end{array}$ & & $\begin{array}{r}7.4 \\
6.2 \\
7.1 \\
15.3 \\
19.4 \\
19.8 \\
16.0 \\
13.4\end{array}$ & $\begin{array}{l}2 \cdot 8 \\
1 \cdot \bullet \\
2 \cdot 5 \\
5.9 \\
7.4 \\
7 \cdot 7 \\
6 \cdot 3 \\
6 \cdot 0\end{array}$ & $\begin{array}{r}7.8 \\
6.1 \\
7.3 \\
15.8 \\
19.6 \\
19.1 \\
17.0 \\
14.3\end{array}$ & $\begin{array}{l}2.8 \\
1.7 \\
2.4 \\
6.0 \\
7.4 \\
7.8 \\
6.9 \\
5.8\end{array}$ & $\begin{array}{l}7.9 \\
7.6 \\
7.4 \\
8.2 \\
8.6 \\
8.4 \\
8.1 \\
8.5\end{array}$ & & $\begin{array}{r}9.8 \\
5.8 \\
8.0 \\
10.2 \\
7.3 \\
7.2 \\
6.1 \\
5.9\end{array}$ & $\begin{array}{r}10.7 \\
6.6 \\
8.6 \\
11.4 \\
8.1 \\
8.8 \\
7.7 \\
7.5\end{array}$ & $\begin{array}{r}10.8 \\
7.0 \\
8.5 \\
21.5 \\
7.9 \\
9.5 \\
9.5 \\
9.3\end{array}$ & $\begin{array}{r}13.0 \\
8.4 \\
9.1 \\
12.9 \\
8.8 \\
11.1 \\
12.5 \\
12.1\end{array}$ \\
\hline $\begin{array}{l}26 \\
26 \\
26 \\
26 \\
26 \\
26 \\
26 \\
26\end{array}$ & $\begin{array}{r}0 \\
3 \\
6 \\
9 \\
12 \\
15 \\
18 \\
21\end{array}$ & $\begin{array}{r}11.5 \\
10.0 \\
9.0 \\
12.5 \\
14.0 \\
13.5 \\
9.4 \\
8.5\end{array}$ & $\begin{array}{l}6 \cdot 1 \\
5.6 \\
5.3 \\
6.7 \\
7.9 \\
7.4 \\
8.2 \\
8.2\end{array}$ & $\begin{array}{r}11.8 \\
10.1 \\
9.2 \\
12.9 \\
14.2 \\
14.1 \\
9.4 \\
8.6\end{array}$ & $\begin{array}{l}8.6 \\
8.4 \\
8.4 \\
8.3\end{array}$ & $\begin{array}{r}12.2 \\
10.3 \\
9.3 \\
13.6 \\
15.1 \\
14.4 \\
9.3 \\
8.6\end{array}$ & $\begin{array}{l}5.6 \\
5.0 \\
4.8 \\
6.6 \\
7.7 \\
7.1 \\
8.3 \\
8.3\end{array}$ & $\begin{array}{r}12.5 \\
10.5 \\
9.5 \\
14.3 \\
15.7 \\
14.8 \\
9.3 \\
8.5\end{array}$ & $\begin{array}{l}5.4 \\
4.9 \\
4.6 \\
6.5 \\
7.6 \\
7.1 \\
8.3 \\
8.2\end{array}$ & $\begin{array}{l}8.9 \\
8.5 \\
8.2 \\
8.6 \\
8.7 \\
8.6 \\
8.3 \\
8.1\end{array}$ & & $\begin{array}{r}10.0 \\
7.3 \\
7.2 \\
10.8 \\
11.8 \\
11.4 \\
12.8 \\
16.8\end{array}$ & $\begin{array}{r}11.7 \\
8.3 \\
8.4 \\
12.9 \\
14.0 \\
13.8 \\
14.4 \\
19.4\end{array}$ & $\begin{array}{r}13.1 \\
9.1 \\
9.8 \\
15.6 \\
17.0 \\
16.9 \\
17.5 \\
23.3\end{array}$ & $\begin{array}{l}16.0 \\
11.7 \\
12.2 \\
18.1 \\
19.7 \\
19.1 \\
19.8 \\
25.7\end{array}$ \\
\hline $\begin{array}{l}27 \\
27 \\
27 \\
27 \\
27 \\
27 \\
27 \\
27\end{array}$ & $\begin{array}{r}0 \\
3 \\
6 \\
9 \\
12 \\
15 \\
18 \\
21\end{array}$ & $\begin{array}{l}8.1 \\
7.8 \\
7.9 \\
8.7\end{array}$ & $\begin{array}{l}7.8 \\
7.6 \\
7.9 \\
8.5\end{array}$ & $\begin{array}{r}8.1 \\
7.7 \\
8.0 \\
9.8 \\
13.5 \\
15.3 \\
14.7 \\
13.5\end{array}$ & $\begin{array}{r}7.9 \\
7.7 \\
7.9 \\
9.5 \\
11.9 \\
13.3 \\
13.0 \\
12.2\end{array}$ & $\begin{array}{r}8.0 \\
7.7 \\
8.0 \\
9.9 \\
14.1 \\
15.8 \\
14.9 \\
13.8\end{array}$ & $\begin{array}{r}7.9 \\
7.7 \\
7.9 \\
9.5 \\
12.0 \\
13.2 \\
12.9 \\
12.2\end{array}$ & $\begin{array}{r}8.0 \\
7.7 \\
8.0 \\
10.1 \\
14.7 \\
16.2 \\
15.4 \\
14.2\end{array}$ & $\begin{array}{r}7.8 \\
7.7 \\
7.9 \\
9.7 \\
12.4 \\
13.6 \\
13.3 \\
12.5\end{array}$ & $\begin{array}{r}7.8 \\
7.7 \\
7.8 \\
8.3 \\
9.5 \\
10.0 \\
9.7 \\
9.5\end{array}$ & & $\begin{array}{l}15.1 \\
13.6 \\
12.7 \\
14.7 \\
13.4 \\
13.5 \\
14.1 \\
15.9\end{array}$ & $\begin{array}{l}17.5 \\
15.7 \\
14.6 \\
17.2 \\
15.8 \\
15.9 \\
16.5 \\
18.6\end{array}$ & $\begin{array}{l}20.4 \\
18.3 \\
17.0 \\
20.0 \\
18.8 \\
10.6 \\
20.4 \\
22.2\end{array}$ & $\begin{array}{l}22.8 \\
20.5 \\
19.0 \\
22.8 \\
21.6 \\
22.5 \\
23.3 \\
25.4\end{array}$ \\
\hline $\begin{array}{l}28 \\
28 \\
28 \\
28 \\
28 \\
28 \\
28 \\
28\end{array}$ & $\begin{array}{r}0 \\
3 \\
6 \\
9 \\
12 \\
15 \\
18 \\
21\end{array}$ & & & $\begin{array}{r}12.6 \\
11.6 \\
10.9 \\
9.8 \\
6.6 \\
3.8 \\
2.4 \\
2.8\end{array}$ & $\begin{array}{r}12.8 \\
10.8 \\
9.1 \\
9.0 \\
5.7 \\
3.8 \\
2.3 \\
2.4\end{array}$ & $\begin{array}{r}13.1 \\
11.9 \\
11.0 \\
9.9 \\
6.2 \\
3.6 \\
2.2 \\
2.5\end{array}$ & $\begin{array}{r}11.9 \\
10.8 \\
8.8 \\
8.9 \\
5.5 \\
3.3 \\
2.1 \\
2.2\end{array}$ & $\begin{array}{r}13.5 \\
12.2 \\
11.2 \\
9.8 \\
6.0 \\
3.4 \\
2.1 \\
2.5\end{array}$ & $\begin{array}{r}12.3 \\
10.9 \\
8.9 \\
8.9 \\
5.3 \\
3.0 \\
1.8 \\
2.0\end{array}$ & $\begin{array}{l}9.6 \\
9.1 \\
8.9 \\
8.8 \\
8.3 \\
8.2 \\
8.0 \\
7.9\end{array}$ & & $\begin{array}{r}11.7 \\
11.1 \\
14.9 \\
15.0 \\
13.8 \\
12.2 \\
10.1 \\
9.6\end{array}$ & $\begin{array}{r}13.8 \\
13.2 \\
16.8 \\
15.9 \\
13.9 \\
11.3 \\
10.2 \\
9.7\end{array}$ & $\begin{array}{l}16.4 \\
15.8 \\
18.0 \\
14.8 \\
17.7 \\
19.0 \\
17.0 \\
18.8\end{array}$ & $\begin{array}{l}19.7 \\
18.5 \\
20.7 \\
16.9 \\
19.9 \\
20.1 \\
17.9 \\
22.8\end{array}$ \\
\hline $\begin{array}{l}29 \\
29 \\
29 \\
29 \\
29 \\
29 \\
29 \\
29\end{array}$ & $\begin{array}{r}0 \\
3 \\
6 \\
9 \\
22 \\
15 \\
18 \\
21\end{array}$ & & & $\begin{array}{l}3.1 \\
3.1 \\
3.1 \\
5.03 \\
7.7 \\
7.8 \\
6.0 \\
5.1\end{array}$ & $\begin{array}{l}2.2 \\
1.9 \\
1.02 \\
2.11 \\
2.77 \\
2.8 \\
1.9 \\
1.8\end{array}$ & $\begin{array}{l}2.8 \\
2.7 \\
2.7 \\
4.9 \\
7.5 \\
7.5 \\
5.4 \\
4.6\end{array}$ & $\begin{array}{l}2.00 \\
1.06 \\
0.9 \\
1.03 \\
1.0 \\
2.00 \\
1.2 \\
1.4\end{array}$ & $\begin{array}{l}2.7 \\
2.6 \\
2.6 \\
4.7 \\
7.2 \\
7.44 \\
5.3 \\
4.9\end{array}$ & 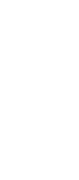 & $\begin{array}{l}7.8 \\
7.6 \\
7.7 \\
8.1 \\
8.1 \\
7.09 \\
7.5 \\
7.6\end{array}$ & & $\begin{array}{r}7.8 \\
7.1 \\
12.0 \\
13.0 \\
13.4 \\
11.5 \\
4.1 \\
3.7\end{array}$ & $\begin{array}{r}8.8 \\
7.5 \\
11.8 \\
12.4\end{array}$ & $\begin{array}{r}19.8 \\
14.5 \\
16.5 \\
21.0 \\
21.5 \\
18.7 \\
6.5 \\
3.9\end{array}$ & $\begin{array}{r}29.5 \\
19.0 \\
18.8 \\
23.1 \\
23.6 \\
20.4 \\
7.3 \\
4.6\end{array}$ \\
\hline $\begin{array}{l}30 \\
30 \\
30 \\
30 \\
30 \\
30 \\
30 \\
30\end{array}$ & $\begin{array}{r}0 \\
3 \\
6 \\
9 \\
12 \\
15 \\
18 \\
21\end{array}$ & & & $\begin{array}{r}3.9 \\
3.4 \\
4.3 \\
9.8 \\
13.7 \\
15.8 \\
14.7 \\
12.2\end{array}$ & $\begin{array}{l}1.6 \\
0.9 \\
1.7\end{array}$ & $\begin{array}{r}3.5 \\
2.8 \\
4.5 \\
10.0 \\
14.2 \\
16.5 \\
15.7 \\
12.7\end{array}$ & $\begin{array}{l}1.0 \\
0.6 \\
1.6 \\
3.8 \\
5.1 \\
7.0 \\
7.1 \\
5.5\end{array}$ & $\begin{array}{r}3.4 \\
2.8 \\
4.4 \\
10.2 \\
14 \cdot 3 \\
16.8 \\
16.2 \\
13.2\end{array}$ & $\begin{array}{l}0.8 \\
0.3 \\
1.7 \\
3.7 \\
5.1 \\
7.0 \\
7.3 \\
4.5\end{array}$ & $\begin{array}{l}7.5 \\
7.4 \\
7.5 \\
8.5 \\
9.5 \\
9.0 \\
9.2 \\
9.2\end{array}$ & & $\begin{array}{r}8.5 \\
11.1 \\
12.3 \\
7.8 \\
6.2 \\
7.0 \\
4.2 \\
7.2\end{array}$ & $\begin{array}{r}9.1 \\
11.8 \\
13.4 \\
8.8 \\
7.3 \\
8.3 \\
5.4 \\
8.4\end{array}$ & $\begin{array}{r}8.6 \\
11.5 \\
12.9 \\
8.8 \\
7.2 \\
8.8 \\
6.7 \\
10.7\end{array}$ & $\begin{array}{r}9.9 \\
12.8 \\
14.5 \\
10.2 \\
8.3 \\
10.7 \\
7.7 \\
12.3\end{array}$ \\
\hline $\begin{array}{l}31 \\
31 \\
31 \\
31 \\
31 \\
31 \\
31 \\
31\end{array}$ & $\begin{array}{r}0 \\
3 \\
6 \\
9 \\
12 \\
15 \\
18 \\
21\end{array}$ & & & $\begin{array}{r}11.0 \\
12.5 \\
12.7 \\
14: 2 \\
18.3 \\
18.6 \\
12.9 \\
9.9\end{array}$ & & $\begin{array}{r}11.2 \\
12: 9 \\
11.9 \\
14.7 \\
19.6 \\
19.6 \\
12: 7 \\
9.9\end{array}$ & $\begin{array}{r}6.2 \\
7.0 \\
7.7 \\
9.2 \\
10.7 \\
10.0 \\
7.0 \\
5.0\end{array}$ & $\begin{array}{r}12.6 \\
13.3 \\
12.2 \\
15.0 \\
18.6 \\
17.9 \\
12.7 \\
9.9\end{array}$ & $\begin{array}{r}6.1 \\
6.9 \\
7.7 \\
0.1 \\
10.8 \\
9.7 \\
5.9 \\
9.0\end{array}$ & $\begin{array}{r}8.8 \\
8.6 \\
8.6 \\
0.4 \\
11.1 \\
9.7 \\
8.3 \\
8.1\end{array}$ & & $\begin{array}{r}8.9 \\
12.0 \\
9.8 \\
8.2 \\
2.1 \\
6.4 \\
4.0 \\
4.8\end{array}$ & $\begin{array}{r}10.3 \\
14.2 \\
11.4 \\
0.4 \\
2.2 \\
7.4 \\
5.0 \\
5.7\end{array}$ & $\begin{array}{r}12.6 \\
16.0 \\
12.8 \\
0.6 \\
2.5 \\
9.3 \\
7.1 \\
7.9\end{array}$ & $\begin{array}{r}14.9 \\
19: 1 \\
14: 9 \\
11: 2 \\
2.7 \\
14.1 \\
11.8 \\
12.2\end{array}$ \\
\hline
\end{tabular}




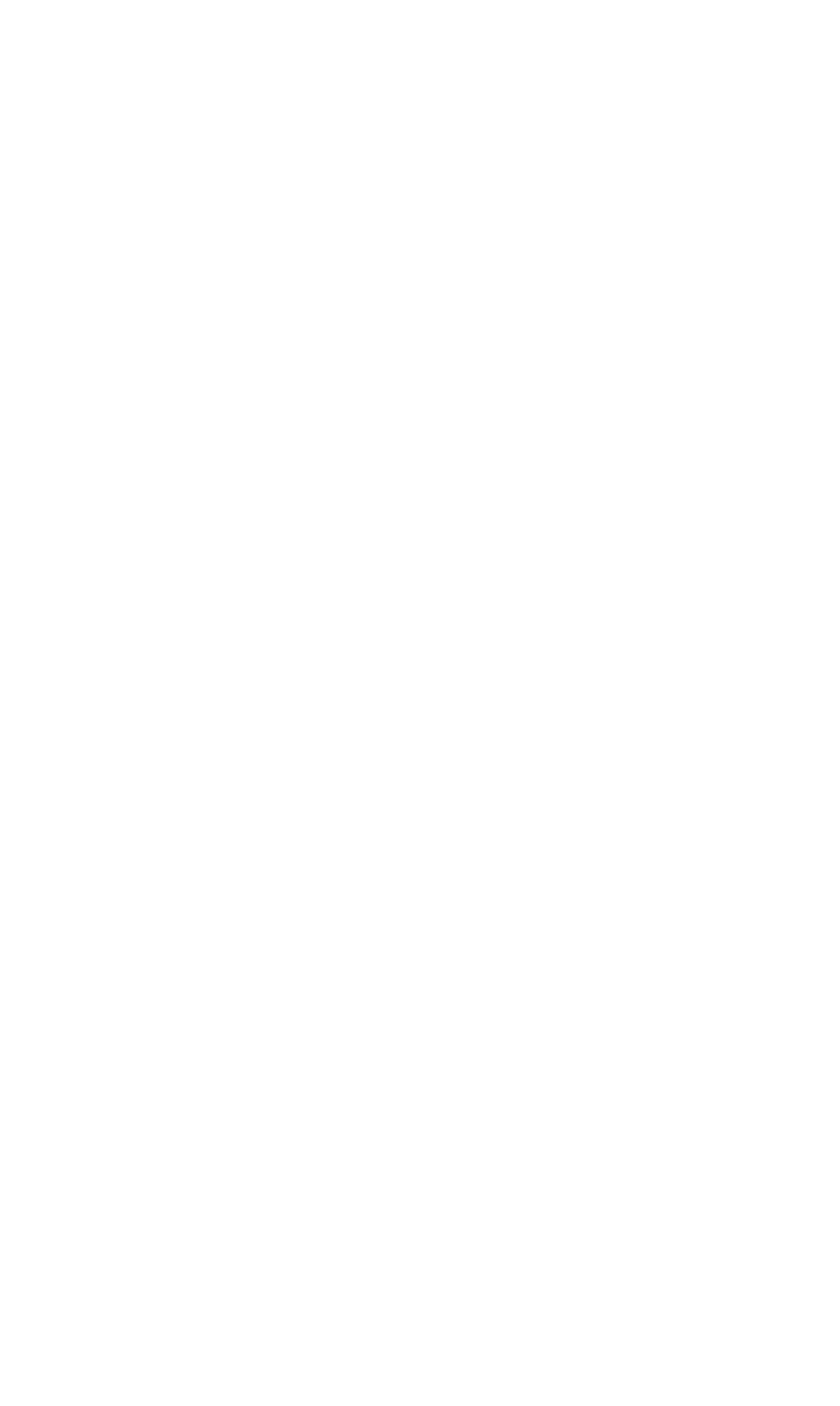


TABLE 10

Table 10. - Three-hour averages of air and water-surface temperatures and wind directions and speed, April 1950-August 1951, Lake Hefner-Continued

STATION 4 THREE-HOURLY AVERAGES

APRIL, 1951

\begin{tabular}{|c|c|c|c|c|c|c|c|c|c|c|c|c|c|c|c|}
\hline \multirow{4}{*}{ 秀 } & \multirow{4}{*}{ 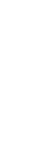 } & \multicolumn{8}{|c|}{ Average air temperature $\left({ }^{\circ} \mathrm{C}\right)$ at indicated height } & \multirow{4}{*}{$\begin{array}{l}\text { Average } \\
\text { water- } \\
\text { surface } \\
\text { tempera- } \\
\text { ture } \\
\left({ }^{\circ} \mathrm{C}\right)\end{array}$} & \multirow{4}{*}{$\begin{array}{l}\text { Average } \\
\text { wind } \\
\text { direction } \\
\text { (coded) }\end{array}$} & \multirow{2}{*}{\multicolumn{4}{|c|}{$\begin{array}{l}\text { Average wind speed (knots) } \\
\text { at indicated height }\end{array}$}} \\
\hline & & \multicolumn{2}{|c|}{$\begin{array}{c}2 \\
\text { meters }\end{array}$} & \multirow{2}{*}{\multicolumn{2}{|c|}{$\begin{array}{c}4 \\
\text { meters }\end{array}$}} & \multirow{2}{*}{\multicolumn{2}{|c|}{$\begin{array}{c}8 \\
\text { meters }\end{array}$}} & \multirow{2}{*}{\multicolumn{2}{|c|}{$\begin{array}{c}16 \\
\text { meters }\end{array}$}} & & & & & & \\
\hline & & & & & & & & & & & & 2 & 4 & 8 & 16 \\
\hline & & $\begin{array}{l}\text { Dry } \\
\text { bulb }\end{array}$ & $\begin{array}{l}\text { Wet } \\
\text { bulb }\end{array}$ & & & & & & $\begin{array}{l}\text { Wet } \\
\text { bulb }\end{array}$ & & & & & & \\
\hline
\end{tabular}

\begin{tabular}{|c|c|c|c|c|c|c|c|c|c|c|c|c|c|c|}
\hline $\begin{array}{l}11 \\
11 \\
11 \\
11 \\
11 \\
11 \\
11 \\
11\end{array}$ & $\begin{array}{r}0 \\
3 \\
6 \\
9 \\
12 \\
15 \\
18 \\
21\end{array}$ & & $\begin{array}{l}4.6 \\
2.9 \\
3.4 \\
6.8 \\
7.7 \\
7.7 \\
5.2 \\
2.5\end{array}$ & $\begin{array}{l}3.4 \\
1.5 \\
1.5 \\
2.6 \\
3.0 \\
2.8 \\
1.5 \\
0.1\end{array}$ & $\begin{array}{l}4.3 \\
2.6 \\
3.2 \\
6.6 \\
7.5 \\
7.2 \\
4.8 \\
2.1\end{array}$ & $\begin{array}{r}3.1 \\
1.03 \\
1.2 \\
2.1 \\
2.2 \\
2.5 \\
1.02 \\
-0.2\end{array} \mid$ & $\begin{array}{l}4 \cdot 2 \\
2.6 \\
3.1 \\
6: 2 \\
7.1 \\
7.1 \\
4: 1 \\
2.0\end{array}$ & $\begin{array}{r}2.8 \\
1.1 \\
0.9 \\
1.6 \\
3.0 \\
1.09 \\
1.00 \\
-0.4\end{array} \mid$ & $\begin{array}{r}10.0 \\
10.0 \\
10.1 \\
10.4 \\
10.1 \\
10.0 \\
9.8 \\
9.7\end{array}$ & & $\begin{array}{r}5.0 \\
6.6 \\
9.7 \\
11.4 \\
11.6 \\
11.7 \\
7.2 \\
6.5\end{array}$ & $\begin{array}{r}4.9 \\
6.6 \\
8.4 \\
11.6 \\
12.0 \\
11.4 \\
7.4 \\
6.1\end{array}$ & $\begin{array}{r}10.6 \\
10.5 \\
14.6 \\
10.1 \\
18.6 \\
10.7 \\
10.6 \\
6.4\end{array}$ & $\begin{array}{r}12.9 \\
11.3 \\
15.9 \\
21.0 \\
20.7 \\
21.1 \\
12.3 \\
8.5\end{array}$ \\
\hline $\begin{array}{l}12 \\
12 \\
12 \\
12 \\
12 \\
12 \\
12 \\
12\end{array}$ & $\begin{array}{r}0 \\
3 \\
6 \\
9 \\
12 \\
15 \\
18 \\
21\end{array}$ & & $\begin{array}{r}1.0 \\
0.3 \\
1.8 \\
4.6 \\
8.2 \\
11.2 \\
9.6 \\
6.3\end{array}$ & $\left|\begin{array}{r}-1.1 \\
-0.5 \\
0.8 \\
1.0 \\
3.44 \\
5.6 \\
4.6 \\
2.7\end{array}\right|$ & $\begin{array}{r}0.6 \\
1.9 \\
4.6 \\
8.1 \\
11.1 \\
9.3 \\
6.1\end{array}$ & $\left|\begin{array}{r}-1.3 \\
-0.8 \\
1.0 \\
0.7 \\
3.3 \\
5.1 \\
4.2 \\
2.5\end{array}\right|$ & $\begin{array}{r}0.5 \\
0.0 \\
1.7 \\
4.1 \\
7.7 \\
10.8 \\
9.3 \\
6.1\end{array}$ & $\begin{array}{r}-1.5 \\
-0.5 \\
1.2 \\
0.4 \\
2.3 \\
4.8 \\
4.0 \\
2.0\end{array}$ & $\begin{array}{l}9.6 \\
9.4 \\
9.5 \\
9.8 \\
9.8 \\
0.7 \\
9.4 \\
9.3\end{array}$ & & $\begin{array}{r}9.2 \\
10.6 \\
14.2 \\
13.1 \\
11.3 \\
10.5 \\
5.8 \\
5.8\end{array}$ & $\begin{array}{r}9.4 \\
10.8 \\
14.5 \\
13.4 \\
11.4 \\
10.7 \\
5.7 \\
5.8\end{array}$ & $\begin{array}{r}10.0 \\
12.2 \\
19.8 \\
20.1 \\
16.9 \\
15.9 \\
8.2 \\
6.4\end{array}$ & $\begin{array}{r}11.3 \\
14.0 \\
22.0 \\
22.1 \\
18.4 \\
17.5 \\
9.6 \\
8.6\end{array}$ \\
\hline $\begin{array}{l}13 \\
13 \\
13 \\
13 \\
13 \\
13 \\
13 \\
13\end{array}$ & $\begin{array}{r}0 \\
3 \\
6 \\
9 \\
12 \\
15 \\
18 \\
>1\end{array}$ & & $\begin{array}{r}4.4 \\
2.8 \\
5.0 \\
10.4 \\
13.4 \\
16.3 \\
14.7 \\
11.3\end{array}$ & $\begin{array}{r}1.1 \\
-0.1 \\
1.1 \\
4.3 \\
5.0 \\
6.3 \\
6.9 \\
6.1\end{array} \mid$ & $\begin{array}{r}4.0 \\
2.4 \\
4.9 \\
10.3 \\
14.0 \\
16.4 \\
14.9 \\
11.5\end{array}$ & $\begin{array}{r}0.7 \\
-0.3 \\
1.1 \\
3.0 \\
5.0 \\
5.0 \\
6.4 \\
5.2\end{array}$ & $\begin{array}{r}4.0 \\
2.4 \\
4.9 \\
10.0 \\
13.7 \\
16.6 \\
16.7 \\
12.2\end{array}$ & $\begin{array}{r}0.5 \\
-0.5 \\
0.9 \\
3.7 \\
4.5 \\
5.9 \\
6.0 \\
4.9\end{array}$ & $\begin{array}{l}9 \cdot 1 \\
9 \cdot 0 \\
9 \cdot 3 \\
9.09 \\
9.09 \\
9.9 \\
9.6 \\
9.6\end{array}$ & & $\begin{array}{r}5.1 \\
4.3 \\
7.7 \\
9.7 \\
10.3 \\
7.3 \\
1.9 \\
5.8\end{array}$ & $\begin{array}{r}5.2 \\
4.4 \\
8.0 \\
9.8 \\
10.8 \\
8.2 \\
3.1 \\
7.0\end{array}$ & $\begin{array}{r}5.5 \\
5.5 \\
9.3 \\
13.6 \\
12.4 \\
0.1 \\
3.9 \\
9.1\end{array}$ & $\begin{array}{r}7.0 \\
7.00 \\
11.2 \\
15.00 \\
13.03 \\
8.05 \\
7.4 \\
11.2\end{array}$ \\
\hline $\begin{array}{l}14 \\
14 \\
14 \\
14 \\
14 \\
14 \\
14 \\
14\end{array}$ & $\begin{array}{r}0 \\
3 \\
6 \\
9 \\
12 \\
15 \\
18 \\
21\end{array}$ & & $\begin{array}{l}11.1 \\
11.1 \\
12.6 \\
20.0 \\
23.4 \\
20.7 \\
16.2 \\
11.7\end{array}$ & $\begin{array}{r}5.7 \\
5.7 \\
6.1 \\
8.8 \\
11.3 \\
11.4 \\
9.3 \\
7.1\end{array}$ & $\begin{array}{l}11.3 \\
11.2 \\
13.1 \\
20.6 \\
23.4 \\
20.7 \\
16.2 \\
11.7\end{array}$ & $\begin{array}{r}5.4 \\
5.0 \\
5.9 \\
8.6 \\
11.0 \\
11.0 \\
9.0 \\
6.8\end{array}$ & 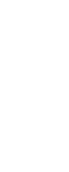 & $\begin{array}{r}5.0 \\
5.1 \\
5.7 \\
8.6 \\
10.8 \\
10.7 \\
9.0 \\
6.9\end{array}$ & $\begin{array}{r}9.4 \\
9.5 \\
9.7 \\
10.2 \\
10.9 \\
10.6 \\
9.7 \\
9.6\end{array}$ & & $\begin{array}{r}10.5 \\
13.5 \\
17.2 \\
13.5 \\
7.4 \\
5.6 \\
4.5 \\
5.0\end{array}$ & $\begin{array}{r}12.5 \\
25.2 \\
19.0 \\
15.1 \\
8.0 \\
7.2 \\
6.3 \\
5.8\end{array}$ & $\begin{array}{r}13.7 \\
15.9 \\
19.3 \\
15.1 \\
11.4 \\
13.9 \\
10.4 \\
7.9\end{array}$ & $\begin{array}{l}16.4 \\
10.9 \\
22.8 \\
16.8 \\
13.6 \\
22.87 \\
17.8 \\
12.9\end{array}$ \\
\hline $\begin{array}{l}15 \\
15 \\
15 \\
15 \\
15 \\
15 \\
15 \\
15\end{array}$ & $\begin{array}{r}0 \\
3 \\
6 \\
9 \\
12 \\
15 \\
18 \\
21\end{array}$ & & $\begin{array}{r}8.9 \\
6.9 \\
6.8 \\
9.8 \\
11.5 \\
11.1 \\
7.8 \\
5.0\end{array}$ & $\begin{array}{l}5.5 \\
3.5 \\
2.3 \\
3.9 \\
4.4 \\
4.3 \\
2.3 \\
1.3\end{array}$ & $\begin{array}{r}8.7 \\
6.5 \\
6.5 \\
9.7 \\
11.5 \\
10.9 \\
7.4 \\
4.7\end{array}$ & $\begin{array}{l}5.1 \\
3.1 \\
2.0 \\
3.5 \\
4.0 \\
3.8 \\
1.8 \\
0.7\end{array}$ & $\begin{array}{r}8.8 \\
6.5 \\
6.2 \\
8.7 \\
10.3 \\
10.2 \\
7.1 \\
40.9\end{array}$ & $\begin{array}{l}5.1 \\
3.1 \\
1.7 \\
3.0 \\
3.4 \\
3.2 \\
1.6 \\
0.5\end{array}$ & $\begin{array}{r}9.8 \\
9.7 \\
9.8 \\
10.0 \\
10.2 \\
10.0 \\
9.7 \\
9.6\end{array}$ & & $\begin{array}{l}3.2 \\
6.8 \\
8.9 \\
8.3 \\
7.9 \\
6.5 \\
3.0 \\
0.6\end{array}$ & $\begin{array}{r}3.8 \\
8.1 \\
10.3 \\
10.1 \\
9.5 \\
8.1 \\
4.6 \\
1.3\end{array}$ & $\begin{array}{r}5.2 \\
11.1 \\
13.4 \\
14.3 \\
13.3 \\
21.2 \\
8.7 \\
3.0\end{array}$ & $\begin{array}{r}8.4 \\
17.6 \\
20.7 \\
22.7 \\
21.2 \\
19.9 \\
15.6 \\
5.4\end{array}$ \\
\hline $\begin{array}{l}16 \\
16 \\
16 \\
16 \\
16 \\
16 \\
16 \\
16\end{array}$ & $\begin{array}{r}0 \\
3 \\
6 \\
9 \\
12 \\
15 \\
18 \\
21\end{array}$ & & $\begin{array}{r}5.8 \\
4.2 \\
4.3 \\
7.7 \\
10.4 \\
12.3 \\
10.4 \\
7.7\end{array}$ & $\begin{array}{l}1.8 \\
0.5 \\
1.6 \\
3.0 \\
4.5 \\
3.7 \\
2.6\end{array}$ & $\begin{array}{r}5.4 \\
3.8 \\
3.9 \\
7.3 \\
10.7 \\
12.7 \\
10.0 \\
7.4\end{array}$ & $\begin{array}{r}1.4 \\
0.3 \\
-0.7 \\
1.2 \\
2.7 \\
3.9 \\
3.2 \\
2.2\end{array}$ & $\begin{array}{r}5.4 \\
3.0 \\
3.6 \\
6.3 \\
9.7 \\
110.5 \\
10.0 \\
7.4\end{array}$ & $\begin{array}{l}1.0 \\
0.2 \\
1.1 \\
0.8 \\
3.3 \\
3.4 \\
3.0 \\
1.8\end{array}$ & $\begin{array}{r}9.7 \\
9.6 \\
9.8 \\
10.4 \\
11.5 \\
10.5 \\
9.8 \\
9.7\end{array}$ & & $\begin{array}{l}1.9 \\
3.1 \\
2.0 \\
3.9 \\
4.4 \\
3.6 \\
3.1 \\
6.5\end{array}$ & $\begin{array}{l}1.8 \\
3.5 \\
2.5 \\
4.8 \\
5.2 \\
4.2 \\
3.6 \\
7.1\end{array}$ & $\begin{array}{l}2.9 \\
5.2 \\
4.2 \\
7.6 \\
9.7 \\
6.5 \\
4.6 \\
8.5\end{array}$ & $\begin{array}{r}3.5 \\
8.3 \\
6.3 \\
11.5 \\
11.8 \\
9.1 \\
6.7 \\
9.8\end{array}$ \\
\hline $\begin{array}{l}17 \\
17 \\
17 \\
17 \\
17 \\
17 \\
17 \\
17\end{array}$ & $\begin{array}{r}0 \\
3 \\
6 \\
9 \\
12 \\
15 \\
18 \\
21\end{array}$ & & $\begin{array}{r}7.2 \\
6.6 \\
7.3 \\
13.2 \\
17.3 \\
18.3 \\
17.02 \\
15.5\end{array}$ & $\begin{array}{r}2.5 \\
2.3 \\
2.9 \\
5.2 \\
8.9 \\
10.0 \\
10.0 \\
9.4\end{array}$ & $\begin{array}{r}6.9 \\
5.3 \\
\cdot 7.3 \\
73.4 \\
17.6 \\
18.7 \\
17.5 \\
15.8\end{array}$ & $\begin{array}{l}1.9 \\
1.8 \\
2.5 \\
5.6 \\
8.0 \\
9.2 \\
9.3 \\
8.5\end{array}$ & $\begin{array}{r}6.8 \\
6.2 \\
7.3 \\
13.8 \\
18.0 \\
19.01 \\
18.0 \\
16.0\end{array}$ & $\begin{array}{l}1.0 \\
1.5 \\
2.1 \\
5.4 \\
8.0 \\
9.2 \\
9.2 \\
8.5\end{array}$ & $\begin{array}{r}9.7 \\
9.5 \\
9.7 \\
10.0 \\
10.7 \\
11.0 \\
10.9 \\
10.3\end{array}$ & : & $\begin{array}{r}8.3 \\
11.4 \\
12.6 \\
15.1 \\
14.3 \\
15.0 \\
12.0 \\
16.5\end{array}$ & $\begin{array}{r}9.2 \\
12.8 \\
14.4 \\
17.4 \\
16.7 \\
17.7 \\
14.0 \\
19.4\end{array}$ & $\begin{array}{l}10.9 \\
15.0 \\
16.2 \\
19.5 \\
19.0 \\
20.4 \\
17.0 \\
22.7\end{array}$ & $\begin{array}{l}11.5 \\
16.3 \\
18.0 \\
22.7 \\
22.0 \\
23.8 \\
19.6 \\
25.8\end{array}$ \\
\hline $\begin{array}{l}18 \\
18 \\
18 \\
18 \\
18 \\
18 \\
18 \\
18\end{array}$ & $\begin{array}{r}0 \\
3 \\
6 \\
9 \\
12 \\
15 \\
18 \\
21\end{array}$ & & $\begin{array}{l}14.8 \\
14.0 \\
14.7 \\
19.3 \\
25.5 \\
26.1 \\
19.0 \\
15.1\end{array}$ & $\begin{array}{r}9.7 \\
10.1 \\
11.5 \\
13.8 \\
14.4 \\
14.7 \\
13.3 \\
11.0\end{array}$ & $\begin{array}{l}15.0 \\
14.4 \\
14.0 \\
19.9 \\
25.9 \\
26.3 \\
19.0 \\
15.2\end{array}$ & $\begin{array}{r}9.0 \\
9.7 \\
11.3 \\
13.4 \\
13.7 \\
13.8 \\
12.7 \\
10.5\end{array}$ & $\begin{array}{l}15.3 \\
14.5 \\
15.2 \\
20.6 \\
27.0 \\
25.8 \\
19.0 \\
15.4\end{array}$ & $\begin{array}{r}8.9 \\
9.6 \\
11.4 \\
13.6 \\
13.7 \\
13.9 \\
12.0 \\
10.5\end{array}$ & $\begin{array}{l}10.1 \\
10.0 \\
10.4 \\
11.3 \\
12.2 \\
11.5 \\
11.1 \\
10.5\end{array}$ & & $\begin{array}{l}17.1 \\
17.1 \\
17.4\end{array}$ & $\begin{array}{l}19.8 \\
20.0 \\
20.0\end{array}$ & $\begin{array}{l}22.6 \\
23.0 \\
21.9\end{array}$ & $\begin{array}{l}26.1 \\
26.2 \\
25.5\end{array}$ \\
\hline $\begin{array}{l}19 \\
19 \\
19 \\
19 \\
19 \\
19 \\
19 \\
19\end{array}$ & $\begin{array}{r}0 \\
3 \\
6 \\
9 \\
12 \\
15 \\
18 \\
21\end{array}$ & & $\begin{array}{r}12.0 \\
9.7 \\
11.1 \\
16.3 \\
20.1 \\
21.9 \\
19.5 \\
16.7\end{array}$ & $\begin{array}{r}9.2 \\
7.7 \\
8.2 \\
11.3 \\
13.8 \\
14.5 \\
13.7 \\
12.5\end{array}$ & $\begin{array}{r}12.1 \\
9.5 \\
11.1 \\
16.5 \\
20.6 \\
22.6 \\
20.1 \\
17.0\end{array}$ & $\begin{array}{r}8.9 \\
7.5 \\
8.0 \\
11.1 \\
13.3 \\
14.0 \\
13.4 \\
12.3\end{array}$ & $\begin{array}{l}12.5 \\
10.2 \\
10.8 \\
16.1 \\
20.6 \\
22.5 \\
20.2 \\
17.2\end{array}$ & $\begin{array}{r}9.0 \\
7.7 \\
7.0 \\
10.0 \\
13.3 \\
14.0 \\
13.4 \\
12.3\end{array}$ & $\begin{array}{l}10.2 \\
10.2 \\
10.6 \\
11.6 \\
12.4 \\
12.4 \\
11.8 \\
11.6\end{array}$ & & $\begin{array}{l}7.4 \\
6.5 \\
7.5 \\
8.5 \\
7.2 \\
7.8\end{array}$ & $\begin{array}{l}8.0 \\
7.1 \\
8.3 \\
9.5 \\
8.4 \\
8.7\end{array}$ & $\begin{array}{r}8.2 \\
7.7 \\
9.04 \\
11.0 \\
9.9 \\
10.0\end{array}$ & $\begin{array}{r}9.4 \\
8.8 \\
10.0 \\
11.4 \\
10.9 \\
11.2\end{array}$ \\
\hline $\begin{array}{l}20 \\
20 \\
20 \\
20 \\
20 \\
20 \\
20 \\
20\end{array}$ & $\begin{array}{r}0 \\
3 \\
6 \\
9 \\
12 \\
15 \\
18 \\
21\end{array}$ & & $\begin{array}{l}14.9 \\
16.1 \\
15.8 \\
16.0 \\
16.8 \\
15.3 \\
13.6 \\
14.5\end{array}$ & $\begin{array}{l}11.9 \\
14: 2 \\
14: 7 \\
15.0 \\
155: 5 \\
1402 \\
12.8 \\
12.9\end{array}$ & $\begin{array}{l}15.2 \\
16.6 \\
15.8 \\
16.3 \\
17.2 \\
15.3 \\
13.8 \\
14.5\end{array}$ & $\begin{array}{l}11.8 \\
14: 5 \\
14: 6 \\
15.0 \\
15.5 \\
14.3 \\
13.0 \\
12.8\end{array}$ & $\begin{array}{l}15.5 \\
16.7 \\
16.2 \\
16.5 \\
17.4 \\
15.5 \\
14.0 \\
14.6\end{array}$ & $\begin{array}{l}11.8 \\
14.5 \\
14.7 \\
15.3 \\
15.7 \\
140 . \\
13.1 \\
12.8\end{array}$ & $\begin{array}{l}11.3 \\
11.5 \\
11.5 \\
11.5 \\
11.8 \\
11.9 \\
12.2 \\
12.1\end{array}$ & & $\begin{array}{r}8.3 \\
11.9 \\
11.0 \\
15.9 \\
16.4 \\
11.3 \\
6.9 \\
11.2\end{array}$ & $\begin{array}{r}9.5 \\
13.5 \\
12.8 \\
18.0 \\
19.1 \\
12.8 \\
7.7 \\
12.9\end{array}$ & $\begin{array}{r}11.7 \\
16.9 \\
15.6 \\
22.3 \\
23.4 \\
17.4 \\
7.2 \\
15.3\end{array}$ & $\begin{array}{r}13.1 \\
18.6 \\
17.0 \\
24.1 \\
25.0 \\
-16.6 \\
14.02 \\
17.3\end{array}$ \\
\hline
\end{tabular}


Table 10. -Three-hour averages of air and water-surface temperatures and wind directions and speed, April 1950-August 1951, Lake Hefner-Continued

STATION 4

THREE-HOURLY AVERAGES

APRIL, 1951

\begin{tabular}{|c|c|c|c|c|c|c|c|c|c|c|c|c|c|c|c|}
\hline \multirow{4}{*}{ 宽 } & \multirow{4}{*}{ 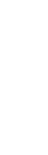 } & \multicolumn{8}{|c|}{ Average air temperature $\left({ }^{\circ} \mathrm{C}\right)$ at indicated height } & \multirow{4}{*}{$\begin{array}{l}\text { Average } \\
\text { water- } \\
\text { surface } \\
\text { tempera- } \\
\text { ture } \\
\text { ("C) }\end{array}$} & \multirow{4}{*}{$\begin{array}{c}\text { Average } \\
\text { wind } \\
\text { direction } \\
\text { (coded) }\end{array}$} & \multirow{2}{*}{\multicolumn{4}{|c|}{$\begin{array}{l}\text { Average wind speed (knots) } \\
\text { at indicated height }\end{array}$}} \\
\hline & & \multirow{2}{*}{\multicolumn{2}{|c|}{$\begin{array}{c}2 \\
\text { meters }\end{array}$}} & \multirow{2}{*}{\multicolumn{2}{|c|}{$\begin{array}{c}4 \\
\text { meters }\end{array}$}} & \multirow{2}{*}{\multicolumn{2}{|c|}{$\begin{array}{c}8 \\
\text { metera }\end{array}$}} & \multirow{2}{*}{\multicolumn{2}{|c|}{$\begin{array}{c}16 \\
\text { meters }\end{array}$}} & & & & & & \\
\hline & & & & & & & & & & & & 2 & 4 & 8 & 16 \\
\hline & & $\begin{array}{l}\text { Dry } \\
\text { bulb }\end{array}$ & $\begin{array}{l}\text { Wet } \\
\text { bulb }\end{array}$ & $\begin{array}{l}\text { Dry } \\
\text { bulb }\end{array}$ & $\begin{array}{l}\text { Wet } \\
\text { bulb }\end{array}$ & $\begin{array}{l}\text { Dry } \\
\text { bulb }\end{array}$ & $\begin{array}{l}\text { Wet } \\
\text { bulb }\end{array}$ & $\begin{array}{l}\text { Dry } \\
\text { bulb }\end{array}$ & $\begin{array}{l}\text { Wet } \\
\text { bulb }\end{array}$ & & & meters & meters & meters & meters \\
\hline $\begin{array}{l}21 \\
21 \\
21 \\
21 \\
21 \\
21 \\
21 \\
21\end{array}$ & $\begin{array}{r}0 \\
3 \\
6 \\
9 \\
12 \\
15 \\
18 \\
21\end{array}$ & & & $\begin{array}{r}13.5 \\
12.6 \\
8.9 \\
8.9 \\
12.4 \\
15.8 \\
14.5 \\
10.5\end{array}$ & $\begin{array}{r}12.6 \\
12.1 \\
7.8 \\
7.1 \\
9.6 \\
11.4 \\
11.2 \\
8.6\end{array}$ & $\begin{array}{r}13.6 \\
12.6 \\
8.8 \\
8.7 \\
12.1 \\
15.6 \\
14.3 \\
10.3\end{array}$ & $\begin{array}{r}12.6 \\
12.0 \\
7.6 \\
5.9 \\
9.5 \\
10.9 \\
10.7 \\
8.4\end{array}$ & $\begin{array}{r}13.7 \\
12.5 \\
8.3 \\
8.4 \\
12.1 \\
15.4 \\
14.5 \\
10.3\end{array}$ & $\begin{array}{r}12.6 \\
12.0 \\
7.3 \\
6.5 \\
8.9 \\
10.6 \\
10.4 \\
8 . ?\end{array}$ & $\begin{array}{l}12.0 \\
12.0 \\
11.8 \\
12.0 \\
12.3 \\
12.3 \\
11.8 \\
11.8\end{array}$ & & $\begin{array}{r}11.1 \\
2.9 \\
8.9 \\
9.6 \\
6.6 \\
4.8 \\
1.5 \\
6.6\end{array}$ & $\begin{array}{r}12.9 \\
3.3 \\
8.7 \\
9.7 \\
6.9 \\
5.0 \\
2.0 \\
7.5\end{array}$ & $\begin{array}{r}15.3 \\
3.6 \\
12.8 \\
14.1 \\
10.6 \\
8.4 \\
3.8 \\
0.7\end{array}$ & $\begin{array}{r}17.7 \\
3.9 \\
14.0 \\
15.4 \\
11.4 \\
9.3 \\
6.4 \\
13.3\end{array}$ \\
\hline $\begin{array}{l}22 \\
22 \\
22 \\
22 \\
22 \\
22 \\
22 \\
22\end{array}$ & $\begin{array}{r}0 \\
3 \\
6 \\
9 \\
17 \\
15 \\
18 \\
21\end{array}$ & & & $\begin{array}{r}8.4 \\
7.4 \\
4.5 \\
6.9 \\
10.4 \\
12.6 \\
11.6 \\
10.4\end{array}$ & $\begin{array}{l}5.9 \\
5.7 \\
2.4 \\
3.1 \\
4.9 \\
5.1 \\
0.2 \\
5.8\end{array}$ & $\begin{array}{r}8.2 \\
6.8 \\
4.0 \\
6.0 \\
10.4 \\
12.9 \\
11.2 \\
10.1\end{array}$ & $\begin{array}{l}6.8 \\
5.0 \\
2.3 \\
3.0 \\
4.9 \\
5.9 \\
5.0 \\
5.6\end{array}$ & $\begin{array}{r}8.1 \\
6.3 \\
3.8 \\
6.0 \\
9.8 \\
12.2 \\
11.4 \\
10.3\end{array}$ & $\begin{array}{l}6.7 \\
4.7 \\
1.8 \\
2.5 \\
4.1 \\
5.4 \\
5.7 \\
5.4\end{array}$ & $\begin{array}{l}11.6 \\
11.4 \\
11.6 \\
11.9 \\
12.2 \\
11.9 \\
11.7 \\
11.7\end{array}$ & & $\begin{array}{l}6.44 \\
6.0 \\
5.3 \\
7.8 \\
8.2 \\
7.2 \\
2.8 \\
1.1\end{array}$ & $\begin{array}{l}8.2 \\
8.4 \\
7.9 \\
9.7 \\
9.7 \\
8.1 \\
3.0 \\
1.3\end{array}$ & $\begin{array}{r}11.4 \\
13.8 \\
13.2 \\
14.5 \\
12.7 \\
10.0 \\
3.9 \\
2.0\end{array}$ & $\begin{array}{r}17.4 \\
22.5 \\
21.8 \\
23.3 \\
19.0 \\
14.2 \\
6.4 \\
2.0\end{array}$ \\
\hline $\begin{array}{l}23 \\
23 \\
23 \\
23 \\
23 \\
23 \\
23 \\
23\end{array}$ & $\begin{array}{r}0 \\
3 \\
6 \\
9 \\
12 \\
15 \\
18 \\
21\end{array}$ & & & $\begin{array}{r}9.0 \\
8.5 \\
9.4 \\
13.2 \\
16.4 \\
19.1 \\
18.1 \\
16.4\end{array}$ & $\begin{array}{r}5.8 \\
5.1 \\
5.4 \\
8.1 \\
10.8 \\
12.2 \\
12.1 \\
11.0\end{array}$ & $\begin{array}{r}8.7 \\
8.2 \\
9.1 \\
13.2 \\
17.2 \\
19.5 \\
18.5 \\
16.6\end{array}$ & $\begin{array}{r}5.7 \\
4.9 \\
5.1 \\
7.7 \\
10.6 \\
12.1 \\
11.6 \\
10.7\end{array}$ & $\begin{array}{r}9.1 \\
8.0 \\
9.2 \\
13.4 \\
17.3 \\
19.9 \\
19.1 \\
16.7\end{array}$ & $\begin{array}{r}5.7 \\
4.7 \\
4.8 \\
7.7 \\
10.5 \\
12.1 \\
11.5 \\
10.6\end{array}$ & $\begin{array}{l}11.5 \\
11.5 \\
11.8 \\
12.4 \\
12.8 \\
13.6 \\
13.2 \\
12.7\end{array}$ & & $\begin{array}{r}2.1 \\
5.0 \\
7.4 \\
8.0 \\
10.0 \\
13.8\end{array}$ & $\begin{array}{r}1.3 \\
5.5 \\
8.1 \\
11.4 \\
13.4 \\
14.7 \\
13.7 \\
16.3\end{array}$ & $\begin{array}{r}1.3 \\
0.3 \\
9.7 \\
12.0 \\
15.5 \\
17.7 \\
15.7 \\
18.7\end{array}$ & $\begin{array}{r}1.8 \\
6.7 \\
10.3 \\
15.2 \\
17.3 \\
20.4 \\
18.0 \\
21.0\end{array}$ \\
\hline $\begin{array}{l}24 \\
24 \\
24 \\
24 \\
24 \\
24 \\
24 \\
24\end{array}$ & $\begin{array}{r}0 \\
3 \\
6 \\
9 \\
12 \\
15 \\
18 \\
21\end{array}$ & & & $\begin{array}{l}15.2 \\
14.3 \\
14.8 \\
19.5 \\
23.6 \\
25.0 \\
23.6 \\
22.7\end{array}$ & $\begin{array}{l}10.6 \\
10.2 \\
11.5 \\
14.3 \\
15.6 \\
15.9 \\
15.8 \\
15.7\end{array}$ & $\begin{array}{l}15.3 \\
14.3 \\
14.9 \\
20.0 \\
24.4 \\
26.0 \\
24 \cdot 3 \\
23.3\end{array}$ & $\begin{array}{l}10.2 \\
10.0 \\
11.5 \\
14.3 \\
15.6 \\
15.9 \\
15.8 \\
15.6\end{array}$ & $\begin{array}{l}15.4 \\
14.3 \\
15.1 \\
20.5 \\
25.0 \\
26.6 \\
25.5 \\
23.8\end{array}$ & $\begin{array}{r}10.1 \\
0.0 \\
11.5 \\
14.4 \\
15.8 \\
16.0 \\
16.0 \\
15.8\end{array}$ & $\begin{array}{l}12.4 \\
1 ?: 1 \\
12.3 \\
12.9 \\
14 \cdot 2 \\
14 \cdot 5 \\
14.0 \\
13.4\end{array}$ & & $\begin{array}{l}16.6 \\
14.8\end{array}$ & $\begin{array}{l}19.4 \\
18.4 \\
21.3 \\
21.9 \\
23.1 \\
20.9 \\
14.4 \\
21.8\end{array}$ & $\begin{array}{l}22.8 \\
21.8 \\
24.6 \\
24.8 \\
26.1 \\
24.0 \\
17.3 \\
26.4\end{array}$ & $\begin{array}{l}25.8 \\
24.3 \\
28.0 \\
28.7 \\
30.8 \\
28.4 \\
20.6 \\
30.3\end{array}$ \\
\hline $\begin{array}{l}25 \\
25 \\
25 \\
25 \\
25 \\
25 \\
25 \\
25\end{array}$ & $\begin{array}{r}0 \\
3 \\
6 \\
9 \\
12 \\
15 \\
18 \\
21\end{array}$ & & & $\begin{array}{l}20.5 \\
16.7 \\
12.4 \\
15.9 \\
18.0 \\
17.8 \\
16.9 \\
15.5\end{array}$ & $\begin{array}{l}15.5 \\
13.6 \\
10.4 \\
12.1 \\
13.1 \\
13.0 \\
13.1 \\
12.3\end{array}$ & $\begin{array}{l}21.0 \\
16.2 \\
12.1 \\
15.5 \\
17.8 \\
17.8 \\
17.0 \\
15.4\end{array}$ & $\begin{array}{l}15.5 \\
13.1 \\
10.2 \\
12.0 \\
13.0 \\
13.0 \\
13.0 \\
12.2\end{array}$ & $\begin{array}{l}21.3 \\
16.7 \\
11.5 \\
15.2 \\
17.3 \\
17.6 \\
17.2 \\
15.4\end{array}$ & $\begin{array}{l}15.7 \\
13.4 \\
10.0 \\
11.8 \\
12.7 \\
13.0 \\
13.1 \\
12.7\end{array}$ & $\begin{array}{l}13.8 \\
13.5 \\
13.0 \\
14.3 \\
13.6 \\
13.2 \\
13.0 \\
12.8\end{array}$ & & $\begin{array}{l}3.6 \\
3.3 \\
4.7\end{array}$ & $\begin{array}{r}19.3 \\
13.0 \\
6.0 \\
4.0 \\
4.3 \\
6.3 \\
3.2 \\
2.9\end{array}$ & $\begin{array}{r}22.5 \\
15.2 \\
11.6 \\
8.2 \\
7.3 \\
9.2 \\
4.2 \\
4.6\end{array}$ & $\begin{array}{r}25.9 \\
17.7 \\
13.6 \\
11.9 \\
10.8 \\
11.9 \\
7.2 \\
7.4\end{array}$ \\
\hline $\begin{array}{l}26 \\
26 \\
26 \\
26 \\
26 \\
26 \\
26 \\
26\end{array}$ & $\begin{array}{r}0 \\
3 \\
6 \\
9 \\
12 \\
15 \\
18 \\
21\end{array}$ & & & $\begin{array}{l}12.7 \\
10.2 \\
11.9 \\
16.9 \\
21.6 \\
23.0 \\
22.0 \\
20.3\end{array}$ & $\begin{array}{r}10.8 \\
9.3 \\
10.3 \\
13.8 \\
16.8 \\
17.3 \\
17.9 \\
18.1\end{array}$ & $\begin{array}{r}12.5 \\
9.9 \\
11.8 \\
17.0 \\
22.3 \\
23.7 \\
22.4 \\
20.7\end{array}$ & $\begin{array}{r}10.7 \\
9.1 \\
10.3 \\
13.9 \\
15.9 \\
17.5 \\
18.1 \\
18.3\end{array}$ & $\begin{array}{l}12: 8 \\
10: 1 \\
11: 7 \\
17: 6 \\
22: 6 \\
24: 6 \\
22.9 \\
20.9\end{array}$ & $\begin{array}{r}10.7 \\
0.2 \\
10.3 \\
14.0 \\
17.0 \\
17.8 \\
18.4 \\
18.5\end{array}$ & $\begin{array}{l}12.8 \\
12.8 \\
12.9 \\
14.1 \\
15.9 \\
15.3 \\
14.9 \\
14.9\end{array}$ & & $\begin{array}{r}7.0 \\
10.1 \\
11.3 \\
12.9\end{array}$ & $\begin{array}{r}2.1 \\
3.5 \\
4.1 \\
5.7 \\
5.1 \\
12.0 \\
13.2 \\
15.3\end{array}$ & $\begin{array}{l}3.2 \\
2.9 \\
5.1 \\
6.8 \\
7.8 \\
15.3 \\
16.6 \\
18.5\end{array}$ & $\begin{array}{r}6.1 \\
5.6 \\
6.6 \\
6.8 \\
8.4 \\
17.3 \\
18.4 \\
20.5\end{array}$ \\
\hline $\begin{array}{l}27 \\
27 \\
27 \\
27 \\
27 \\
27 \\
27 \\
27\end{array}$ & $\begin{array}{r}0 \\
3 \\
6 \\
9 \\
12 \\
15 \\
18 \\
21\end{array}$ & & & $\begin{array}{l}19.2 \\
18.4 \\
18.2 \\
21.3 \\
25.1 \\
26.0 \\
23.8 \\
21.4\end{array}$ & $\begin{array}{l}17.7 \\
17.0 \\
16.7 \\
17.7 \\
18.2 \\
18.1 \\
18.1 \\
17.6\end{array}$ & $\begin{array}{l}19.5 \\
18.6 \\
18.4 \\
22.2 \\
25.5 \\
26.6 \\
24.5 \\
21.8\end{array}$ & $\begin{array}{l}17.8 \\
17.1 \\
16.8 \\
17.9 \\
19.2 \\
18.0 \\
18.0 \\
17.4\end{array}$ & $\begin{array}{l}19.8 \\
18.0 \\
18.7 \\
22.7 \\
26.9 \\
27.6 \\
25: 5 \\
22.3\end{array}$ & $\begin{array}{l}17.9 \\
17.4 \\
16.0 \\
18.0 \\
18.3 \\
18.2 \\
18.3 \\
17.6\end{array}$ & $\begin{array}{l}15.0 \\
15.3 \\
16.0 \\
16.6 \\
17.2 \\
16.7 \\
17.3 \\
16.1\end{array}$ & & $\begin{array}{r}14.7 \\
10.9 \\
14.2 \\
13.4 \\
12.0 \\
12.9 \\
9.7 \\
11.4\end{array}$ & $\begin{array}{l}17.1 \\
12.9 \\
16.4 \\
15.9 \\
14.0 \\
15.4 \\
11.8 \\
13.5\end{array}$ & $\begin{array}{l}20.3 \\
15.4 \\
19.6 \\
18.5 \\
15.5 \\
18.1 \\
14.7 \\
16.4\end{array}$ & $\begin{array}{l}23.2 \\
18.1 \\
22.5 \\
21.6 \\
18.4 \\
21.2 \\
17.4 \\
18.9\end{array}$ \\
\hline $\begin{array}{l}28 \\
28 \\
28 \\
28 \\
28 \\
28 \\
28 \\
28\end{array}$ & $\begin{array}{r}0 \\
3 \\
6 \\
9 \\
12 \\
15 \\
18 \\
21\end{array}$ & & & $\begin{array}{l}10.7 \\
18.7 \\
18.9 \\
22.5 \\
24.7 \\
26.7 \\
23.5 \\
21.5\end{array}$ & $\begin{array}{l}17.1 \\
16.7 \\
16.9 \\
18.4 \\
18.7 \\
18.8 \\
18.9 \\
17.8\end{array}$ & $\begin{array}{l}20.1 \\
19.1 \\
19.1 \\
23.0 \\
25.3 \\
27.0 \\
24 \bullet 0 \\
21.6\end{array}$ & $\begin{array}{l}17.0 \\
16.6 \\
16.9 \\
18.4 \\
18.5 \\
18.3 \\
18.5 \\
17.4\end{array}$ & $\begin{array}{l}20.5 \\
19.4 \\
19.5 \\
23.8 \\
26.1 \\
27.7 \\
24.7 \\
21.9\end{array}$ & $\begin{array}{l}17.2 \\
16.8 \\
17.1 \\
18.6 \\
18.7 \\
18.5 \\
18.7 \\
17.5\end{array}$ & $\begin{array}{l}16.1 \\
15.7 \\
15.8 \\
16.9 \\
17.5 \\
18.1 \\
17.6 \\
17.0\end{array}$ & & $\begin{array}{r}9.4 \\
10.2 \\
13.4 \\
10.5 \\
12.0 \\
13.5 \\
14.8 \\
12.9\end{array}$ & $\begin{array}{l}11.1 \\
12.0 \\
15.6 \\
12.5 \\
14.0 \\
16.0 \\
17.4 \\
15.1\end{array}$ & $\begin{array}{l}13.5 \\
14.2 \\
17.8 \\
14.4 \\
15.8 \\
19.0 \\
21.1 \\
18.2\end{array}$ & $\begin{array}{l}15.4 \\
16.3 \\
20.6 \\
16.5 \\
18.6 \\
21.8 \\
23.5 \\
20.9\end{array}$ \\
\hline $\begin{array}{l}29 \\
29 \\
29 \\
29 \\
29 \\
29 \\
29 \\
29\end{array}$ & $\begin{array}{r}0 \\
3 \\
6 \\
9 \\
12 \\
15 \\
18 \\
21\end{array}$ & & & $\begin{array}{l}19.9 \\
19.3 \\
19.0 \\
19.1 \\
17.9 \\
20.2 \\
19.5 \\
19.7\end{array}$ & $\begin{array}{l}17.6 \\
17.6 \\
16.9 \\
16.5 \\
16.2 \\
17.6 \\
16.8 \\
17.7\end{array}$ & $\begin{array}{l}20.1 \\
19.5 \\
19.1 \\
19.1 \\
18.0 \\
20.6 \\
19.3 \\
19.9\end{array}$ & $\begin{array}{l}17.3 \\
17.3 \\
16.7 \\
16.0 \\
16.0 \\
17.0 \\
16.7 \\
17.7\end{array}$ & $\begin{array}{l}20.3 \\
19.7 \\
19.1 \\
19.2 \\
18.3 \\
20.9 \\
19.3 \\
20.0\end{array}$ & $\begin{array}{l}17.4 \\
17.4 \\
16.8 \\
16.0 \\
15.0 \\
17.2 \\
16.6 \\
18.1\end{array}$ & $\begin{array}{l}16.7 \\
16.6 \\
16.5 \\
16.4 \\
16.5 \\
16.7 \\
16.2 \\
16.3\end{array}$ & & $\begin{array}{l}12.7 \\
12.7 \\
16.9 \\
15.6 \\
13.3 \\
14.4 \\
14.0 \\
17.8\end{array}$ & $\begin{array}{l}14.5 \\
14.6 \\
19.2 \\
18.0 \\
15.3 \\
16.5 \\
15.5 \\
20.0\end{array}$ & $\begin{array}{l}17.8 \\
17.7 \\
21.0 \\
21.4 \\
18.6 \\
19.9 \\
18.8 \\
24.7\end{array}$ & $\begin{array}{l}19.0 \\
19.7 \\
24.3 \\
23.8 \\
19.9 \\
22.0 \\
20.8 \\
27.1\end{array}$ \\
\hline $\begin{array}{l}30 \\
30 \\
30 \\
30 \\
30 \\
30 \\
30 \\
30\end{array}$ & $\begin{array}{r}0 \\
3 \\
6 \\
9 \\
12 \\
15 \\
18 \\
21\end{array}$ & & & $\begin{array}{l}19.7 \\
19.2 \\
18.6 \\
16.0 \\
15.6 \\
17.0 \\
15.0 \\
14.3\end{array}$ & $\begin{array}{l}18.0 \\
17.5 \\
17.2 \\
14.6 \\
13.7 \\
14.7 \\
14.4 \\
14.0\end{array}$ & $\begin{array}{l}19.8 \\
19.2 \\
18.8 \\
15.8 \\
15.6 \\
16.9 \\
14.9 \\
14.1\end{array}$ & $\begin{array}{l}18.0 \\
17.4 \\
17.2 \\
14.5 \\
13.6 \\
14.4 \\
14.1 \\
13.7\end{array}$ & $\begin{array}{l}19.9 \\
19.5 \\
18.9 \\
15.8 \\
15.5 \\
16.7 \\
14.7 \\
13.9\end{array}$ & $\begin{array}{l}18.1 \\
17.5 \\
17.2 \\
14.4 \\
13.4 \\
14.3 \\
14.1 \\
13.7\end{array}$ & $\begin{array}{l}16.3 \\
16.2 \\
16.3 \\
16.2 \\
16.6 \\
16.6 \\
16.3 \\
16.1\end{array}$ & & $\begin{array}{r}18.2 \\
19.5 \\
16.8 \\
7.1 \\
4.9 \\
5.0 \\
4.2 \\
5.6\end{array}$ & $\begin{array}{r}20.9 \\
22.6 \\
19.3 \\
7.8 \\
5.3 \\
5.8 \\
4.6 \\
6.1\end{array}$ & $\begin{array}{r}25.2 \\
26.3 \\
23.1 \\
8.0 \\
6.1 \\
6.7 \\
5.5 \\
7.9\end{array}$ & $\begin{array}{r}27.9 \\
30.1 \\
25.4 \\
8.9 \\
6.5 \\
7.1 \\
6.2 \\
9.6\end{array}$ \\
\hline
\end{tabular}


TABLE 10

211

Table 10. - Three-hour averages of air and water-surface temperatures and wind directions and speed, April 1950-August 1951, Lake Hefner-Continued

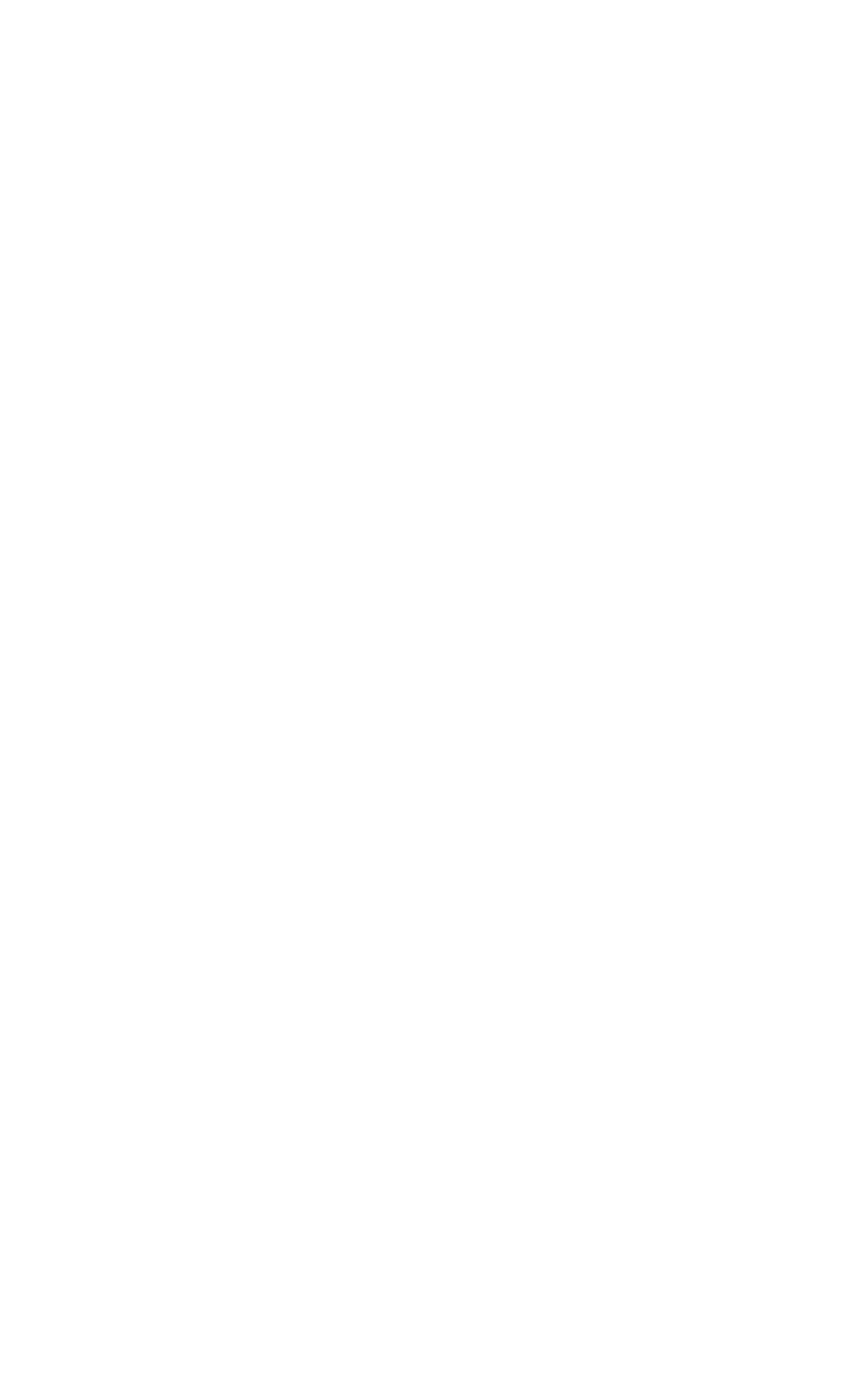


Table 10. -Three-hour averages of air and watsr-surface temperatures and wind directions and speed, April 1950-August
1851, Lake Hefner-Continued STATION 4 THREE-HOURLY AVERAGES

MAY, 1951

\begin{tabular}{|c|c|c|c|c|c|c|c|c|c|c|c|c|c|c|c|}
\hline \multirow{4}{*}{ 害 } & \multirow{4}{*}{ 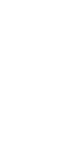 } & \multicolumn{8}{|c|}{ Average air temperature $\left({ }^{\circ} \mathrm{C}\right)$ at indicated height } & \multirow{4}{*}{$\begin{array}{l}\text { Average } \\
\text { water- } \\
\text { surface } \\
\text { tempera- } \\
\text { ture } \\
\text { ("C) }\end{array}$} & \multirow{4}{*}{$\begin{array}{l}\text { Average } \\
\text { wind } \\
\text { diredtion } \\
\text { (coded) }\end{array}$} & \multirow{2}{*}{\multicolumn{4}{|c|}{$\begin{array}{l}\text { Average wind speed (knots) } \\
\text { at indicated height }\end{array}$}} \\
\hline & & \multirow{2}{*}{\multicolumn{2}{|c|}{$\begin{array}{c}2 \\
\text { meters }\end{array}$}} & \multirow{2}{*}{\multicolumn{2}{|c|}{$\begin{array}{c}4 \\
\text { meters }\end{array}$}} & \multirow{2}{*}{\multicolumn{2}{|c|}{$\begin{array}{c}8 \\
\text { meters }\end{array}$}} & \multirow{2}{*}{\multicolumn{2}{|c|}{$\begin{array}{c}16 \\
\text { meters }\end{array}$}} & & & & & & \\
\hline & & & & & & & & & & & & 2 & 4 & 8 & 16 \\
\hline & & $\begin{array}{l}\text { Dry } \\
\text { bulbr. }\end{array}$ & $\begin{array}{l}\text { Wet } \\
\text { bulb }\end{array}$ & $\begin{array}{l}\text { Dry } \\
\text { bulb }\end{array}$ & $\begin{array}{l}\text { Wet } \\
\text { bulb }\end{array}$ & $\begin{array}{l}\text { Dry } \\
\text { bulb }\end{array}$ & $\begin{array}{l}\text { Wet } \\
\text { bulb }\end{array}$ & $\begin{array}{l}\text { Dry } \\
\text { bulb }\end{array}$ & $\begin{array}{l}\text { Wet } \\
\text { bulb }\end{array}$ & & & & & & meters \\
\hline
\end{tabular}

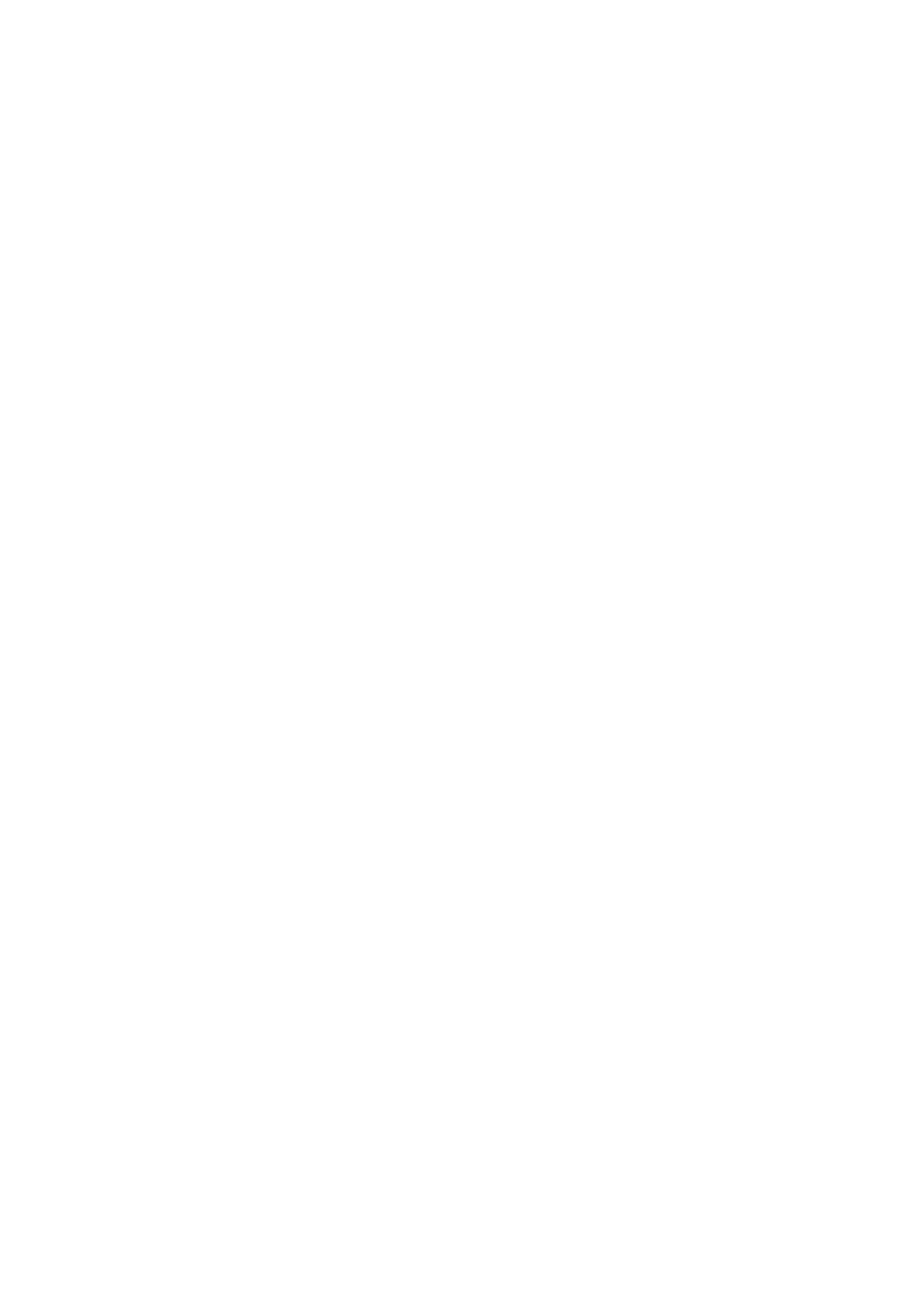


TABLE 10

Table 10. -Three-hour averages of air and water-surface temperatures and wind directions and speed, April 1950-August 1951, Lake Hefner-Continued

STATION 4 THREE-HOURLY AVERAGES

NiAY, 1G51

\begin{tabular}{|c|c|c|c|c|c|c|c|c|c|c|c|c|c|c|c|}
\hline \multirow{3}{*}{ 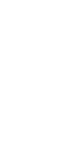 } & \multirow{3}{*}{ 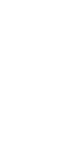 } & \multicolumn{8}{|c|}{ Average air temperature $\left({ }^{\circ} \mathrm{C}\right)$ at indicated height } & \multirow{3}{*}{$\begin{array}{c}\text { Average } \\
\text { water- } \\
\text { surface } \\
\text { tempera- } \\
\text { ture } \\
\left({ }^{\circ} \mathrm{C}\right)\end{array}$} & \multirow{3}{*}{$\begin{array}{c}\text { Average } \\
\text { wind } \\
\text { direction } \\
\text { (coded) }\end{array}$} & \multirow{2}{*}{\multicolumn{4}{|c|}{$\begin{array}{c}\text { Average wind speed (knots) } \\
\text { at indicated height }\end{array}$}} \\
\hline & & \multicolumn{2}{|c|}{$\begin{array}{c}2 \\
\text { meters } \\
\end{array}$} & \multicolumn{2}{|c|}{$\begin{array}{c}4 \\
\text { meters }\end{array}$} & \multicolumn{2}{|c|}{$\begin{array}{c}8 \\
\text { meters }\end{array}$} & \multicolumn{2}{|c|}{$\begin{array}{c}16 \\
\text { meters }\end{array}$} & & & & & & \\
\hline & & $\begin{array}{c}\text { Dry } \\
\text { bulb }\end{array}$ & $\begin{array}{l}\text { Wet } \\
\text { bulb }\end{array}$ & 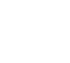 & \begin{tabular}{|l|}
$\begin{array}{l}\text { Wet } \\
\text { bulb }\end{array}$ \\
\end{tabular} & $\begin{array}{l}\text { Dry } \\
\text { bulb }\end{array}$ & \begin{tabular}{|c|} 
Wet \\
bulb \\
\end{tabular} & \begin{tabular}{|l|} 
Dry \\
bulb
\end{tabular} & \begin{tabular}{|l|} 
Wet \\
bulb
\end{tabular} & & & meters & meters & & \\
\hline $\begin{array}{l}21 \\
21\end{array}$ & 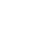 & & & $\begin{array}{l}20.8 \\
19.6\end{array}$ & $\begin{array}{l}19: 1 \\
10.5\end{array}$ & 20.5 & $\begin{array}{l}18 \cdot 9 \\
1: 0\end{array}$ & $\begin{array}{l}20: ? \\
1 \subseteq:\end{array}$ & & $\begin{array}{ll}21 \\
2: 0\end{array}$ & & $\begin{array}{l}4: 4 \\
1.2\end{array}$ & $\begin{array}{l}4: 2 \\
2: 4\end{array}$ & $\begin{array}{l}\because 08 \\
3: 7\end{array}$ & $\begin{array}{r}7: 2 \\
4: 7\end{array}$ \\
\hline $\begin{array}{l}21 \\
21\end{array}$ & 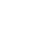 & & & 23.6 & $\begin{array}{l}18: 8 \\
20: 0\end{array}-10-10$ & $\begin{array}{l}20.7 \\
24.1\end{array}$ & $\begin{array}{l}18.8 \\
19.3\end{array}$ & $24: 1$ & $\begin{array}{l}10.5 \\
10.9\end{array}$ & 2: 20.2 & & $\begin{array}{l}3.2 \\
3.6\end{array}$ & $\begin{array}{l}4.4 \\
3.3\end{array}$ & $\begin{array}{r}5.9 \\
7.2\end{array}$ & $\begin{array}{l}6.1 \\
8.5\end{array}$ \\
\hline 21. & 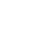 & & & 25.6 .3 & $\begin{array}{l}20.7 \\
20.4\end{array}$ & \begin{tabular}{|l}
26.1 \\
25.5
\end{tabular} & $\begin{array}{l}20.5 \\
20.2 \\
20.2\end{array}$ & $\begin{array}{l}25.5 \\
25.3\end{array}$ & $\begin{array}{l}20.4 \\
20.0\end{array}$ & $\begin{array}{l}23.5 \\
2.05\end{array}$ & & $\begin{array}{c}5.7 \\
13.3\end{array}$ & $\begin{array}{l}11.0 \\
16.7\end{array}$ & $\begin{array}{l}13.7 \\
20.4\end{array}$ & \\
\hline $\begin{array}{l}21 \\
21\end{array}$ & $\begin{array}{l}18 \\
21\end{array}$ & & & $\begin{array}{l}21.3 \\
27: 4\end{array}$ & $\begin{array}{l}10.4 \\
25.9\end{array}$ & $\begin{array}{l}21.1 \\
16.7\end{array}$ & $\begin{array}{l}18.2 \\
15.9\end{array}$ & $\begin{array}{l}21.1 \\
16.5\end{array}$ & $\begin{array}{l}18: 0 \\
15: 6\end{array}$ & $\begin{array}{l}21.7 \\
20.6\end{array}$ & & $\begin{array}{l}9.3 \\
9.1\end{array}$ & $\begin{array}{l}10.9 \\
10.2\end{array}$ & $\begin{array}{l}13.4 \\
22.3\end{array}$ & 22.0 \\
\hline $\begin{array}{l}22 \\
22\end{array}$ & $\begin{array}{c}2 \\
3\end{array}$ & & & $15: 0$ & 15.3 & 15.7 & 15.0 & 15.5 & 14.9 & 19.0 & & 6.3 & 7.0 & 8.5 & 7.5 \\
\hline 22 & $\begin{array}{c}6 \\
6 \\
a\end{array}$ & & & $\begin{array}{lll}17.8 \\
170\end{array}$ & 15.8 & (17.6 & $\begin{array}{ll}1409 \\
15.6\end{array}$ & 17.5 & 15.3 & 19.07 & & $\begin{array}{l}3.88 \\
8.1\end{array}$ & $\begin{array}{r}4.5 \\
10.0\end{array}$ & & \\
\hline 22 & 12 & & & 19.4 & 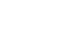 & $19: 0$ & $\begin{array}{l}16.2 \\
15.1\end{array}$ & 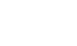 & $\begin{array}{l}10.4 \\
16.0\end{array}-190$ & 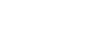 & & $\begin{array}{l}1011 \\
10.5\end{array}$ & $\begin{array}{l}12.0 \\
11.2\end{array}$ & $\begin{array}{l}14: 6 \\
17.07\end{array}$ & \\
\hline $\begin{array}{l}22 \\
22\end{array}$ & $\begin{array}{ll}18 \\
31\end{array}$ & & & 16.8 & $\begin{array}{r}15.0 \\
14: 0\end{array}-100$ & 16.2 & $\begin{array}{ll}34.8 \\
13.7\end{array}$ & $\begin{array}{l}15.0 \\
150\end{array}$ & 14.7 & 19.0 & & $\begin{array}{l}4.60 \\
1.5\end{array}$ & 3.8 & 8.9 & 12.2 \\
\hline & & & & 1303 & 1207 & 120 & 12.5 & 100 & & 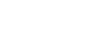 & & 0 & & & \\
\hline & & & & 13.2 & 12.5 & 12.8 & $12 \cdot 2$ & 12.7 & 12.1 & 18.0 & & $\begin{array}{l}2.0 \\
2.4\end{array}$ & $\begin{array}{l}104 \\
2.0\end{array}$ & $\begin{array}{l}3.0 \\
3.1\end{array}$ & $\begin{array}{l}2.7 \\
3.2\end{array}$ \\
\hline 23 & & & & 18.4 & 13.6 & $12: 0$ & 13.3 & 18.0 & 13.2 & $\begin{array}{l}19.44 \\
21.02\end{array}$ & & $\begin{array}{l}0.6 \\
0.5\end{array}$ & $\begin{array}{l}1.6 \\
1.6\end{array}$ & $\begin{array}{l}207 \\
1.6\end{array}$ & $\begin{array}{l}2.4 \\
1.08\end{array}$ \\
\hline $\begin{array}{l}23 \\
23\end{array}$ & 15 & & & 20.9 & $1<.5$ & 300 & $14 \cdot 2$ & 70.6 & 14.1 & $\begin{array}{l}24.9 \\
240.8\end{array}$ & & $\begin{array}{l}0.8 \\
3.1\end{array}$ & $\begin{array}{l}1.5 \\
4.6\end{array}$ & $\begin{array}{l}106 \\
5.4\end{array}$ & $\begin{array}{l}100 \\
5.04\end{array}$ \\
\hline 23 & 21 & & & 13.7 & 14.9 & 13.5 & 14.5 & 18.2 & $14: 2$ & 22.2 & & 5.0 & $\begin{array}{l}01 \\
6.6\end{array}$ & $\begin{array}{l}0.8 \\
7.8\end{array}$ & 8.9 \\
\hline $\begin{array}{l}24 \\
24\end{array}$ & 3 & & & $\begin{array}{ll}18.0 \\
17\end{array}$ & $\begin{array}{l}14: 0 \\
13: 0\end{array}$ & $\begin{array}{r}27.5 \\
17.0\end{array}$ & $\begin{array}{r}13.7 \\
13.5\end{array}$ & $\begin{array}{lll}17 & 2 \\
10 & 2\end{array}$ & 13.4 & 21.6 & & 8.0 & 9.3 & 11.0 & 11.3 \\
\hline $\begin{array}{l}24 \\
24\end{array}$ & $\begin{array}{c}6 \\
0\end{array}$ & & & $\begin{array}{lll}170 \\
10\end{array}$ & $\begin{array}{ll}1<01 \\
140\end{array}$ & $\begin{array}{l}17.0 \\
17.6\end{array}$ & $\begin{array}{l}13.7 \\
14.6\end{array}$ & 16.8 & 13.3 & 20.6 & & 1102 & $\begin{array}{l}13.4 \\
13.4\end{array}$ & $\begin{array}{l}16.0 \\
15.0\end{array}$ & \\
\hline $\begin{array}{l}24 \\
24\end{array}$ & $\begin{array}{l}17 \\
15\end{array}$ & & & $\begin{array}{l}16 \cdot 6 \\
15 \cdot 3\end{array}$ & $\begin{array}{r}15.3 \\
154\end{array}$ & $\begin{array}{l}15.1 \\
15.2\end{array}$ & $\begin{array}{l}15: 0 \\
15: 1\end{array}$ & $\begin{array}{l}150 \\
150\end{array}$ & $\begin{array}{ll}140 \\
15: 0\end{array}$ & $\begin{array}{l}19.8 \\
1908\end{array}$ & & $\begin{array}{l}110^{3} \\
11.22 \\
50\end{array}$ & $\begin{array}{l}100 \\
10.5 \\
0.5\end{array}$ & $\begin{array}{r}150 \\
12.2 \\
10.2\end{array}$ & \\
\hline $\begin{array}{l}\frac{24}{24} \\
24\end{array}$ & $\begin{array}{l}19 \\
21 \\
21\end{array}$ & & & $\begin{array}{l}15.0 \\
150\end{array}$ & $\begin{array}{l}15.2 \\
140\end{array}$ & $\begin{array}{l}15.5 \\
15.5\end{array}$ & $\begin{array}{l}15.0 \\
14.0\end{array}$ & $\begin{array}{l}15.2 \\
15.2\end{array}$ & $\begin{array}{l}14: 3 \\
14: 0\end{array}$ & $\begin{array}{l}18.7 \\
18.5\end{array}$ & & $\begin{array}{l}4.0 \\
4.0\end{array}$ & $\begin{array}{l}6.8 \\
6.1 \\
6.1\end{array}$ & $\begin{array}{l}7.6 \\
7.1\end{array}$ & 8104 \\
\hline 25 & 2 & & & 15.5 & 13.9 & 14.9 & 13.9 & 14.06 & 13.5 & 18.5 & & 3.0 & 4.5 & & 5.2 \\
\hline $\begin{array}{l}25 \\
25 \\
25\end{array}$ & $\frac{3}{6}$ & & & $\begin{array}{l}14.5 \\
10: 0\end{array}$ & $\begin{array}{r}12: 8 \\
14: 1\end{array}$ & $\begin{array}{l}14: 0 \\
15: 0\end{array}$ & $\begin{array}{l}13.7 \\
14.0\end{array}$ & $\begin{array}{l}13.0 \\
15 \%\end{array}$ & $\begin{array}{l}13.3 \\
13.3\end{array}$ & $\begin{array}{l}18.6 \\
19.0\end{array}$ & & $\begin{array}{l}3.5 \\
40.5\end{array}$ & $\begin{array}{l}4.4 \\
6.4\end{array}$ & $\begin{array}{l}5.1 \\
5.2 .\end{array}$ & 10.2 \\
\hline $\begin{array}{l}25 \\
25 \\
25\end{array}$ & 12 & & & $\begin{array}{l}17.8 \\
19: 1\end{array}$ & $\begin{array}{l}15.3 \\
16.4\end{array}$ & $\begin{array}{ll}17.6 \\
19: 0\end{array}$ & $\begin{array}{l}15 \cdot 0 \\
16: 3\end{array}$ & $\begin{array}{ll}17: 4 \\
18: 0\end{array}$ & $\begin{array}{l}14.8 \\
16.8\end{array}$ & $\begin{array}{l}19.7 \\
20.97\end{array}$ & & & 7.6 & & $\begin{array}{r}9: 9 \\
9: 0\end{array}$ \\
\hline 25 & $\begin{array}{l}13 \\
13\end{array}$ & & & $\begin{array}{r}20.5 \\
20.0 \\
20.0\end{array}$ & $\begin{array}{l}17.11 \\
17.06\end{array}$ & $\begin{array}{l}20.5 \\
19.9\end{array}$ & $\begin{array}{l}16 \cdot 9 \\
17\end{array}$ & $\begin{array}{l}20.6 \\
190\end{array}$ & $\begin{array}{l}16.8 \\
17: 1\end{array}$ & $\begin{array}{l}\begin{array}{l}0.5 \\
20.5\end{array} \\
20.0\end{array}$ & & & $\begin{array}{l}9.0 \\
8.4\end{array}$ & $\begin{array}{l}9.3 \\
8.1\end{array}$ & $\begin{array}{l}10.0 \\
10.0\end{array}$ \\
\hline & & & & 18.5 & & 1302 & $15_{\bullet} 5$ & 13.1 & 16.6 & 19.9 & & & 7.5 & 8.1 & 9.5 \\
\hline 26 & 3 & & & $\begin{array}{ll}17: 9 \\
16: 3\end{array}$ & $\begin{array}{l}16.0 \\
16.1\end{array}$ & $\begin{array}{l}1709 \\
16.4\end{array}$ & $\begin{array}{lll}16.5 & 16.9\end{array}$ & $\begin{array}{l}17: 5 \\
1606\end{array}$ & $\begin{array}{l}36: 4 \\
16: 0\end{array}$ & $\begin{array}{l}2000 \\
19.9\end{array}$ & & & $\begin{array}{l}6.9 \\
2.04\end{array}$ & $\begin{array}{l}7.2 \\
4 \cdot 3\end{array}$ & $\begin{array}{l}8.2 \\
7.7\end{array}$ \\
\hline 26 & & & & $\begin{array}{l}11: 9 \\
21.06\end{array}$ & $\begin{array}{l}1328 \\
12.8\end{array}$ & $\begin{array}{l}170 \\
21.8\end{array}$ & $\begin{array}{l}15: 0 \\
1\end{array}$ & $\begin{array}{ll}17: 6 \\
21104\end{array}$ & $\begin{array}{l}14 \cdot 7 \\
12\end{array}$ & $\begin{array}{l}19.8 \\
20.1\end{array}$ & & & $\begin{array}{l}7.2 \\
9.3\end{array}$ & $\begin{array}{r}8 \cdot 3 \\
10.2\end{array}$ & $\begin{array}{l}10.7 \\
12.4\end{array}$ \\
\hline $\begin{array}{l}25 \\
26 \\
26\end{array}$ & $\begin{array}{l}12 \\
15 \\
\end{array}$ & & & $\begin{array}{l}23.3 \\
24.03 \\
24\end{array}$ & $\begin{array}{l}1330 \\
13.4 \\
13.4\end{array}$ & $\begin{array}{l}23.8 \\
24.4\end{array}$ & $\begin{array}{l}13.8 \\
13.8\end{array}$ & $\begin{array}{l}23.0 \\
230\end{array}$ & $\begin{array}{l}13.6 \\
13: 0\end{array}$ & $\begin{array}{l}20.2 \\
20.6\end{array}$ & & 305 & $\begin{array}{l}5.9 \\
4.1\end{array}$ & $\begin{array}{l}6.6 \\
4.7\end{array}$ & $\begin{array}{l}8.5 \\
6.4 \\
6.4\end{array}$ \\
\hline 26 & 21 & & & $\begin{array}{l}210.7 \\
18.7\end{array}$ & $\begin{array}{l}140 \\
1304\end{array}$ & $\begin{array}{l}21000 \\
18.0\end{array}$ & $\begin{array}{l}14: 1 \\
13.01\end{array}$ & $\begin{array}{l}21801 \\
190: 1\end{array}$ & $\begin{array}{l}13.4 \\
12.4\end{array}$ & $\begin{array}{l}20: 0 \\
20: 0\end{array}$ & & $\begin{array}{l}1.77 \\
3.9\end{array}$ & $\begin{array}{l}2.6 \\
4.6\end{array}$ & $\begin{array}{l}3.6 \\
5.5 \\
5.5\end{array}$ & $\begin{array}{l}5.7 \\
7.1\end{array}$ \\
\hline 27 & $\begin{array}{l}0 \\
3 \\
3\end{array}$ & & & 13.0 & 12.9 & $17: 6$ & 12.4 & 1707 & 12.2 & 19.8 & & 3.4 & 5.0 & 6.0 & 6.5 \\
\hline $\begin{array}{l}27 \\
27\end{array}$ & $\begin{array}{l}6 \\
0 \\
0\end{array}$ & & & 18.8 & 13.4 & 15.5 & 13.00 & 18.5 & 12.7 & $\begin{array}{l}19.9 \\
1909\end{array}$ & & & 7.99 & 9.3 & $10 \%$ \\
\hline $\begin{array}{l}27 \\
27\end{array}$ & $\begin{array}{l}12 \\
15\end{array}$ & & & & & & & & & & & & $\begin{array}{l}1400 \\
9.5 \\
3.5\end{array}$ & $\begin{array}{l}1302 \\
10.7\end{array}$ & $\begin{array}{l}17.1 \\
11.0\end{array}$ \\
\hline $\begin{array}{l}27 \\
27\end{array}$ & $\begin{array}{l}18 \\
22\end{array}$ & & & & & & & & & & & & $\begin{array}{l}5.3 \\
4.7\end{array}$ & $\begin{array}{l}6.45 \\
6.5 \\
5.5\end{array}$ & $\begin{array}{l}4.0 \\
5.9 \\
5.9\end{array}$ \\
\hline $\begin{array}{l}28 \\
28\end{array}$ & $\begin{array}{l}0 \\
3 \\
3\end{array}$ & & & & & & & & & & & & 6.0 & 7.8 & 8.3 \\
\hline $\begin{array}{l}28 \\
28 \\
28\end{array}$ & $\begin{array}{l}6 \\
9 \\
\end{array}$ & & & & 20.2 & $16 \cdot 3$ & 20.4 & 16.1 & 20.5 & & & & 11.8 & $\begin{array}{r}13.8 \\
33.8\end{array}$ & $\begin{array}{l}30 \cdot 0 \\
14.04\end{array}$ \\
\hline 28 & 12 & & & $\begin{array}{ll}2482 \\
2403\end{array}$ & 1406 & $=4.4$ & 19.6 & 2404 & 19.7 & 21.1 & & $\begin{array}{l}9.5 \\
8.1\end{array}$ & 9.8 & $\begin{array}{l}130.0 \\
11.1\end{array}$ & $\begin{array}{l}13.7 \\
11.06\end{array}$ \\
\hline $\begin{array}{l}28 \\
28 \\
28\end{array}$ & $\begin{array}{l}18 \\
21 \\
21\end{array}$ & & & $\begin{array}{l}24.0 \\
2.0 \\
2.0\end{array}$ & $\begin{array}{lll}2103 \\
20.9\end{array}$ & $\begin{array}{l}24.4 \\
230\end{array}$ & $\begin{aligned} 21.03 \\
20.3\end{aligned}$ & $\begin{array}{ll}240 \\
230\end{array}$ & $\begin{array}{l}1104 \\
210.4\end{array}$ & $\begin{array}{l}21.00 \\
200\end{array}$ & & $\begin{array}{l}5.7 \\
883\end{array}$ & 7.0 & 8.99 & 10.3 \\
\hline & & & & & & & & & 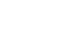 & (2) & & & & & \\
\hline 29 & 3 & & & $\begin{array}{l}21.0 \\
21\end{array}$ & $\begin{array}{l}1807 \\
118\end{array}$ & $\begin{array}{l}21.0 \\
21.0\end{array}$ & $\begin{array}{l}18.5 \\
185\end{array}$ & $\begin{array}{l}1190 \\
21100\end{array}$ & 18.3 & $\begin{array}{l}20.6 \\
20.1\end{array}$ & & 110.3 & $\begin{array}{l}13.4 \\
3.2\end{array}$ & 15.4 & 17.2 \\
\hline 20 & . & & & $\begin{array}{l}25: 0 \\
250 \\
27\end{array}$ & $\begin{array}{l}20: 3 \\
20 \\
203\end{array}$ & $\begin{array}{ll}1500 \\
2500\end{array}$ & 1099 & $\begin{array}{l}2108 \\
260 \\
28.6\end{array}$ & $\begin{array}{l}180 \\
20\end{array}$ & 2103 & & $\begin{array}{r}12.77 \\
954\end{array}$ & $\begin{array}{l}15.2 \\
11.04\end{array}$ & $\begin{array}{l}16.4 \\
11.09\end{array}$ & $\begin{array}{l}18.4 \\
14.3\end{array}$ \\
\hline $\begin{array}{l}29 \\
29\end{array}$ & $\begin{array}{l}15 \\
10 \\
10\end{array}$ & & & 29.0 & $\begin{array}{r}22.5 \\
33\end{array}$ & 2009 & $\begin{array}{l}22 \cdot 1 \\
23.2\end{array}$ & $\begin{array}{c}3003 \\
2703\end{array}$ & $\begin{array}{l}22.0 \\
23\end{array}$ & $\begin{array}{l}2409 \\
2402\end{array}$ & & $\begin{array}{l}0.7 \\
3.3\end{array}$ & $\begin{array}{l}0.9 \\
5.6\end{array}$ & $7: 00$ & $8 \% 6$ \\
\hline 29 & 21 & & & 23.3 & $2 \pi .2$ & 23.4 & 22.2 & 23.6 & 22.02 & 21.8 & & & 3.8 & $\begin{array}{l}3.9 \\
3.4\end{array}$ & 3.6 \\
\hline $\begin{array}{l}3 ? \\
30\end{array}$ & 3 & & & 20.0 & 19.8 & 20.0 & 19,7 & & 19,0 & & & 0.7 & $\frac{1}{2} .12$ & 2.3 & $\begin{array}{l}3.7 \\
6.07\end{array}$ \\
\hline $\begin{array}{l}\begin{array}{l}30 \\
30\end{array} \\
30\end{array}$ & $\begin{array}{l}6 \\
9 \\
9\end{array}$ & & & $\begin{array}{l}20.8 \\
24.6\end{array}$ & $\begin{array}{lll}20 & 1 \\
22 & 0\end{array}$ & $\begin{array}{l}21.1 \\
2400\end{array}$ & $\begin{array}{l}20: 1 \\
218\end{array}$ & $\begin{array}{l}20.7 \\
250\end{array}$ & $\begin{array}{l}20.9 \\
21: 9\end{array}$ & $\begin{aligned} 20.9 \\
22.9\end{aligned}$ & & $\begin{array}{l}2.5 \\
1.9\end{array}$ & $\begin{array}{l}4.11 \\
3.2\end{array}$ & $\begin{array}{r}4.8 \\
4.8\end{array}$ & 6.2 \\
\hline $\begin{array}{l}30 \\
30\end{array}$ & $\begin{array}{l}12 \\
15\end{array}$ & & & $\begin{array}{l}28.4 \\
28.6\end{array}$ & $\begin{array}{l}23.7 \\
24.3\end{array}$ & $\begin{array}{l}28.7 \\
20.0\end{array}$ & $\begin{array}{l}23.4 \\
24.0\end{array}$ & $\begin{array}{r}29.11 \\
30.4\end{array}$ & $\begin{array}{l}23.2 \\
24.2\end{array}$ & $\begin{array}{l}26.7 \\
28.7\end{array}$ & & $\begin{array}{l}2.3 \\
3.3\end{array}$ & $\begin{array}{l}4.2 \\
5.7\end{array}$ & 5.1 & 404 \\
\hline $3 j$ & $\begin{array}{l}18 \\
21\end{array}$ & & & $\begin{array}{l}27.5 \\
25.4\end{array}$ & $\begin{array}{l}23.6 \\
21.5\end{array}$ & $\begin{array}{l}28.01 \\
25.6\end{array}$ & $\begin{array}{r}23.4 \\
21.0\end{array}$ & $\begin{array}{l}29.0 \\
25.6\end{array}$ & $\begin{array}{l}23.11 \\
20.8\end{array}$ & $\begin{array}{l}25.8 \\
23.8\end{array}$ & & 4.7 & $\begin{array}{r}6.4 \\
11.8\end{array}$ & $\begin{array}{r}8.5 \\
13.7\end{array}$ & $\begin{array}{l}31.4 \\
37.8\end{array}$ \\
\hline 31 & : & & & & & & & & & & & & 13.0 & 1404 & \\
\hline $\begin{array}{l}31 \\
31\end{array}$ & & & & $\begin{array}{l}21.0 \\
22.0\end{array}$ & $\begin{array}{l}19.4 \\
20.3\end{array}$ & $\begin{aligned} 21.99 \\
22.8\end{aligned}$ & $\begin{array}{l}19 \cdot 5 \\
20.2\end{array}$ & $\begin{array}{l}21.8 \\
23.0\end{array}$ & $\begin{array}{l}19 \cdot 2 \\
20.2\end{array}$ & $\begin{array}{l}\begin{array}{l}24: 1 \\
24: 0\end{array}\end{array}$ & & $\begin{array}{l}12.4 \\
120\end{array}$ & $\begin{array}{l}13.3 \\
13.3\end{array}$ & $\begin{array}{lll}14.6 \\
14.3\end{array}$ & 16.8 \\
\hline 31 & & & & $\begin{array}{l}25.7 \\
27.5\end{array}$ & 20.7 & $\begin{array}{l}26.0 \\
27.8\end{array}$ & $20 \cdot 3$ & $26 \cdot 2$ & $\begin{array}{l}21.7 \\
100\end{array}$ & $\begin{array}{l}\begin{array}{l}24.4 \\
24.8\end{array}\end{array}$ & & 12,8 & 15.5 & $17.0^{\circ}$ & 19.6 \\
\hline $\begin{array}{l}31 \\
31 \\
31\end{array}$ & 18 & & & $\begin{array}{l}28.5 \\
27.5\end{array}$ & 20.6 & 29.0 & $20 \cdot 1$ & 29.2 & 10.9 & 2408 & & 12.4 & 16.2 & 18.8 & 2101 \\
\hline 31 & 21 & & & 25.5 & 21.5 & 25.0 & $z 1.0$ & 25.7 & 20.8 & 24.1 & & & 11.03 & $\begin{array}{l}14.0 \\
13.5\end{array}$ & 15.3 \\
\hline
\end{tabular}


Table 10. -Three-hour averages of air and water-surface temperatures and wind directions and speed, April 1950-August 1951, Lake Hefner-Continued

STATION 4 TIIREE-HOIRLY AVERAGES

JUNE, 1951

\begin{tabular}{|c|c|c|c|c|c|c|c|c|c|c|c|c|c|c|c|}
\hline \multirow{3}{*}{ 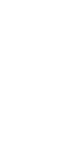 } & \multirow{3}{*}{ 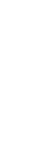 } & \multicolumn{8}{|c|}{ Average air temperature $\left({ }^{\circ} \mathrm{C}\right)$ at indicated height } & \multirow{3}{*}{$\begin{array}{c}\text { Average } \\
\text { water- } \\
\text { surface } \\
\text { tempera- } \\
\text { ture } \\
\left({ }^{\circ} \mathrm{C}\right)\end{array}$} & \multirow{3}{*}{$\begin{array}{c}\begin{array}{c}\text { Average } \\
\text { wind } \\
\text { direction }\end{array} \\
\text { (coded) }\end{array}$} & \multirow{2}{*}{\multicolumn{4}{|c|}{$\begin{array}{l}\text { Average wind speed (knots) } \\
\text { at indicated height }\end{array}$}} \\
\hline & & \multicolumn{2}{|c|}{$\begin{array}{c}2 \\
\text { meters }\end{array}$} & \multicolumn{2}{|c|}{$\begin{array}{c}4 \\
\text { meters }\end{array}$} & \multicolumn{2}{|c|}{\begin{tabular}{|c|}
8 \\
meters
\end{tabular}} & \multicolumn{2}{|c|}{$\begin{array}{c}16 \\
\text { meters }\end{array}$} & & & & & & \\
\hline & & $\begin{array}{l}\text { Dry } \\
\text { butb }\end{array}$ & $\begin{array}{l}\text { Wet } \\
\text { bulb }\end{array}$ & $\begin{array}{l}\text { Dry } \\
\text { bulb }\end{array}$ & $\begin{array}{l}\text { Wet } \\
\text { bulb }\end{array}$ & $\begin{array}{l}\text { Dry } \\
\text { bulb }\end{array}$ & $\begin{array}{l}\text { Wet } \\
\text { bulb }\end{array}$ & $\begin{array}{l}\text { Dry } \\
\text { bulb }\end{array}$ & $\begin{array}{l}\text { Wet } \\
\text { bulb }\end{array}$ & & & meters & meters & meters & meters \\
\hline $\begin{array}{l}1 \\
1 \\
1 \\
1 \\
1 \\
1 \\
1 \\
1\end{array}$ & $\begin{array}{r}2 \\
3 \\
6 \\
9 \\
17 \\
15 \\
19 \\
21\end{array}$ & & & $\begin{array}{l}24.1 \\
22.5 \\
22.7 \\
24.3 \\
25.4 \\
24.2 \\
23.3 \\
24.4\end{array}$ & $\begin{array}{l}21.0 \\
20.3 \\
20.0 \\
20.7 \\
21.8 \\
21.0 \\
21.8 \\
21.2\end{array}$ & $\begin{array}{l}24.2 \\
22.6 \\
22.8 \\
24.6 \\
20.5 \\
24.2 \\
23.5 \\
24.6\end{array}$ & $\begin{array}{l}20.5 \\
20.0 \\
19.7 \\
20.4 \\
21.5 \\
20.5 \\
21.5 \\
20.8\end{array}$ & $\begin{array}{l}24.9 \\
22.4 \\
22.8 \\
24 \cdot 6 \\
25.8 \\
24.5 \\
23.8 \\
24.6\end{array}$ & $\begin{array}{l}20.4 \\
19.9 \\
19.3 \\
20.2 \\
21.3 \\
19 \cdot 3 \\
21.3 \\
20.5\end{array}$ & $\begin{array}{l}23.7 \\
23.4 \\
23.4 \\
23.6 \\
23.0 \\
23.3 \\
23.0 \\
22.6\end{array}$ & & $\begin{array}{r}5.6 \\
13.4\end{array}$ & $\begin{array}{l}15.1 \\
10.04 \\
15.9 \\
19.7 \\
18.2 \\
16.7 \\
9.2 \\
15.5\end{array}$ & $\begin{array}{l}17.2 \\
11.06 \\
15: 2 \\
22.03 \\
20.0 \\
18.3 \\
11.1 \\
18.4\end{array}$ & $\begin{array}{l}19.9 \\
13.2 \\
20.1 \\
25.3 \\
23.4 \\
21.1 \\
12.7 \\
20.7\end{array}$ \\
\hline $\begin{array}{l}2 \\
2 \\
2 \\
2 \\
2 \\
2 \\
2 \\
2\end{array}$ & $\begin{array}{r}0 \\
3 \\
6 \\
.7 \\
12 \\
15 \\
18 \\
31\end{array}$ & & & $\begin{array}{l}23.6 \\
22.6 \\
22.1 \\
17.3 \\
16.1 \\
15.0 \\
15.6 \\
15.1\end{array}$ & $\begin{array}{l}20.2 \\
17.9 \\
19.3 \\
15.3 \\
13.7 \\
13.8 \\
13.7 \\
33.5\end{array}$ & $\begin{array}{l}23.7 \\
22.7 \\
21.4 \\
15.5 \\
15.2 \\
15.1 \\
14.5 \\
14.5\end{array}$ & $\begin{array}{l}19.8 \\
19.4 \\
19.8 \\
14.7 \\
13.0 \\
13.2 \\
13 . ? \\
13.1\end{array}$ & $\begin{array}{l}23 \cdot 7 \\
22: 6 \\
21: 3 \\
16: ? \\
14 \bullet 5 \\
14 \bullet 5 \\
14: 3 \\
14 \cdot ?\end{array}$ & $\begin{array}{l}19.5 \\
1=.2 \\
18.6 \\
14.3 \\
12.7 \\
12.7 \\
13.0 \\
12.9\end{array}$ & $\begin{array}{l}22.3 \\
22.1 \\
22.1 \\
21.7 \\
21.3 \\
21.0 \\
21.0 \\
20.9\end{array}$ & & $\begin{array}{r}13.2 \\
5.7 \\
4.6 \\
3.7 \\
6.6\end{array}$ & $\begin{array}{r}15.8 \\
12.8 \\
9.2 \\
4.8 \\
5.7 \\
5.8 \\
5.7 \\
5.0\end{array}$ & $\begin{array}{r}10.4 \\
1.4 .4 \\
10.6 \\
8.9 \\
10.3 \\
10.2 \\
7.9 \\
7.0\end{array}$ & $\begin{array}{r}20.6 \\
16.4 \\
11.8 \\
9.4 \\
14.6 \\
13.5 \\
12.1 \\
9.7\end{array}$ \\
\hline $\begin{array}{l}3 \\
3 \\
3 \\
3 \\
3 \\
3 \\
3 \\
3\end{array}$ & $\begin{array}{r}0 \\
3 \\
5 \\
9 \\
12 \\
15 \\
13 \\
21\end{array}$ & & & $\begin{array}{l}14.1 \\
13.4 \\
13: 1 \\
14: 5 \\
16.2 \\
17: 0 \\
15.5 \\
13.3\end{array}$ & $\begin{array}{l}12.9 \\
12.5 \\
11.5 \\
10.8 \\
12.1 \\
12.7 \\
12.6 \\
11.9\end{array}$ & $\begin{array}{l}13.7 \\
13.2 \\
12.7 \\
13.8 \\
15.6 \\
15.6 \\
15.0 \\
10.0\end{array}$ & $\begin{array}{l}12.0 \\
12.5 \\
11.2 \\
10.2 \\
17.0 \\
12.5 \\
12.5 \\
11.7\end{array}$ & $\begin{array}{l}13.3 \\
12.3 \\
12.4 \\
13.1 \\
14.8 \\
15.9 \\
14.5 \\
12.7\end{array}$ & $\begin{array}{l}12.4 \\
11.9 \\
10.9 \\
10.2 \\
11.5 \\
12.0 \\
12.1 \\
11.5\end{array}$ & $\begin{array}{l}20.8 \\
20.8 \\
20.6 \\
20.9 \\
21.02 \\
21.01 \\
20.5 \\
20.5\end{array}$ & & $\begin{array}{l}6.2 \\
3.2 \\
6.4 \\
6.2 \\
6.4 \\
4.9 \\
7.2 \\
1.8\end{array}$ & $\begin{array}{l}5.6 \\
5.2 \\
8.1 \\
8.8 \\
7.8 \\
7.1 \\
5.8 \\
2.5\end{array}$ & $\begin{array}{r}9.0 \\
8.5 \\
11.7 \\
12.3 \\
10.5 \\
0.3 \\
7.6 \\
3.0\end{array}$ & $\begin{array}{l}13.1 \\
12.6 \\
17.6 \\
18.2 \\
14.9 \\
13.0 \\
9.0 \\
4.3\end{array}$ \\
\hline $\begin{array}{l}4 \\
4 \\
4 \\
4 \\
4 \\
4 \\
4 \\
4\end{array}$ & $\begin{array}{r}0 \\
3 \\
6 \\
9 \\
12 \\
15 \\
18 \\
21\end{array}$ & & & $\begin{array}{l}12.0 \\
11.5 \\
11.8 \\
15.7 \\
18.2 \\
19.9 \\
19.4 \\
17.5\end{array}$ & $\begin{array}{l}11 \cdot 3 \\
11: 08 \\
10.0 \\
11: 7 \\
12 \bullet 8 \\
14 \cdot 1 \\
14: 9 \\
15.2\end{array}$ & $\begin{array}{l}11.4 \\
11.0 \\
11.7 \\
15.5 \\
13.2 \\
19.0 \\
19.1 \\
17.1\end{array}$ & $\begin{array}{l}10.0 \\
10.5 \\
10.0 \\
11.7 \\
12.7 \\
13.9 \\
14.7 \\
15.1\end{array}$ & $\begin{array}{l}11 . ? \\
10.9 \\
11: 3 \\
15: 0 \\
17.5 \\
19: 5 \\
19.0 \\
15.9\end{array}$ & $\begin{array}{r}10.7 \\
10.2 \\
9.7 \\
13.7 \\
12.0 \\
13.9 \\
14.6 \\
15.0\end{array}$ & $\begin{array}{l}20.4 \\
20.4 \\
20.4 \\
21.1 \\
21.7 \\
21.4 \\
20.9 \\
20.5\end{array}$ & & $\begin{array}{l}5.5 \\
4.7 \\
4.2 \\
3.6 \\
4.4 \\
5.2\end{array}$ & $\begin{array}{l}1.5 \\
4.7 \\
7.5 \\
5.4 \\
4.6 \\
3.9 \\
4.8 \\
5.7\end{array}$ & $\begin{array}{l}2.8 \\
5.4 \\
8.2 \\
6.3 \\
5.0 \\
4.4 \\
5.3 \\
6.7\end{array}$ & $\begin{array}{r}5.1 \\
9.7 \\
10.3 \\
8.0 \\
5.9 \\
4.0 \\
5.6 \\
7.1\end{array}$ \\
\hline $\begin{array}{l}5 \\
5 \\
5 \\
5 \\
5 \\
5 \\
5 \\
5\end{array}$ & $\begin{array}{r}6 \\
3 \\
6 \\
3 \\
17 \\
15 \\
18 \\
21\end{array}$ & & & $\begin{array}{l}16.5 \\
16.2\end{array}$ & $\begin{array}{l}14.8 \\
15.0\end{array}$ & $\begin{array}{l}15.7 \\
15.6\end{array}$ & $\begin{array}{l}14.5 \\
14.0 \\
16.3\end{array}$ & $\begin{array}{l}16.0 \\
15.5 \\
19.7\end{array}$ & $\begin{array}{l}14 \cdot 7 \\
14 \cdot 9 \\
16 \cdot 1\end{array}$ & $\begin{array}{l}20.7 \\
20.7 \\
21.1\end{array}$ & & $\begin{array}{l}3.3 \\
3.6 \\
4.1 \\
6.3 \\
6.5 \\
9.0\end{array}$ & $\begin{array}{l}3.6 \\
5.2 \\
4.5 \\
6.8 \\
8.5 \\
8.9 \\
8.3 \\
9.1\end{array}$ & $\begin{array}{r}4.2 \\
5.2 \\
5.0 \\
7.9 \\
9.9 \\
10.4 \\
9.8 \\
10.4\end{array}$ & $\begin{array}{r}4.4 \\
5.4 \\
5.8 \\
9.1 \\
10.4 \\
11.8 \\
10.8 \\
13.2\end{array}$ \\
\hline $\begin{array}{l}6 \\
6 \\
6 \\
6 \\
6 \\
6 \\
6 \\
6\end{array}$ & $\begin{array}{r}0 \\
3 \\
6 \\
9 \\
12 \\
15 \\
13 \\
21\end{array}$ & & & $\begin{array}{l}22 \cdot 1 \\
21 \cdot 0 \\
23 \cdot 5 \\
23 \cdot 3 \\
22.3\end{array}$ & $\begin{array}{l}19.9 \\
19.0 \\
20.6 \\
20.5 \\
20.0\end{array}$ & $\begin{array}{l}22.2 \\
21.0 \\
23.3 \\
23.5 \\
2 ? .4\end{array}$ & $\begin{array}{l}12.9 \\
19.0 \\
20.6 \\
20.4 \\
20.0\end{array}$ & $\begin{array}{l}20.4 \\
23.0 \\
21.0 \\
24.0 \\
23.4 \\
22.4\end{array}$ & $\begin{array}{l}13.4 \\
10.5 \\
12.6 \\
20.5 \\
20.3 \\
10.5\end{array}$ & $\begin{array}{l}21.3 \\
21.3 \\
21.6 \\
21.4 \\
21.2 \\
20.8\end{array}$ & & $12 \cdot 8$ & $\begin{array}{l}13.2 \\
13.1 \\
13.9 \\
12.4 \\
10.6 \\
15.0 \\
16.2\end{array}$ & $\begin{array}{l}19.1 \\
17.7 \\
11.6 \\
14.4 \\
14.0 \\
17.8 \\
17.4 \\
17.3\end{array}$ & $\begin{array}{l}19.6 \\
19.3 \\
13.0 \\
17.2 \\
14.8 \\
14.1 \\
19.8 \\
19.6\end{array}$ \\
\hline $\begin{array}{l}7 \\
? \\
? \\
? \\
? \\
? \\
? \\
7\end{array}$ & $\begin{array}{r}0 \\
3 \\
6 \\
9 \\
12 \\
15 \\
18 \\
21\end{array}$ & & & $\begin{array}{l}20.5 \\
19.1 \\
18.5 \\
20.5 \\
25.7\end{array}$ & $\begin{array}{l}17.0 \\
15.4 \\
15.5 \\
18.8 \\
22.0\end{array}$ & $\begin{array}{l}20.7 \\
13.7 \\
17.8 \\
20.5 \\
25.4\end{array}$ & $\begin{array}{l}15.8 \\
16.1 \\
16.4 \\
19.0 \\
20.2\end{array}$ & $\begin{array}{l}20.4 \\
13.7 \\
17.5 \\
20.7 \\
23.6\end{array}$ & $\begin{array}{l}16.1 \\
15.8 \\
16.0 \\
19.0 \\
22.0\end{array}$ & $\begin{array}{l}20.7 \\
20.5 \\
20.5 \\
20.9 \\
22.2\end{array}$ & & $\begin{array}{c}10.8 \\
10.4 \\
8.4 \\
7.4 \\
9.0\end{array}$ & $\begin{array}{r}13.3 \\
11.0 \\
6.3 \\
11.2 \\
10.3 \\
10.5 \\
10.1 \\
10.5\end{array}$ & $\begin{array}{r}16.4 \\
12.8 \\
7.9 \\
11.0 \\
11.0 \\
12.7 \\
12.1 \\
12.2\end{array}$ & $\begin{array}{r}18.7 \\
13.7 \\
8.6 \\
11.1 \\
13.9 \\
14.7 \\
14.0 \\
12.8\end{array}$ \\
\hline $\begin{array}{l}8 \\
8 \\
8 \\
8 \\
8 \\
8 \\
8 \\
8\end{array}$ & $\begin{array}{r}0 \\
3 \\
6 \\
9 \\
12 \\
15 \\
18 \\
21\end{array}$ & & & & & & & & & & & $\begin{array}{l}16.4 \\
14.4 \\
10.9\end{array}$ & $\begin{array}{r}8.6 \\
11.7 \\
17.8 \\
20.4 \\
17.4 \\
16.0 \\
13.03 \\
11.8\end{array}$ & $\begin{array}{l}10.4 \\
13.8 \\
19.6 \\
21.2 \\
18.3 \\
12.9 \\
13.7\end{array}$ & $\begin{array}{l}11.5 \\
17.2 \\
18.4 \\
25.1 \\
22.3 \\
21.02 \\
16.8 \\
15.6\end{array}$ \\
\hline $\begin{array}{l}9 \\
9 \\
9 \\
9 \\
9 \\
9 \\
9 \\
9\end{array}$ & $\begin{array}{r}0 \\
3 \\
6 \\
9 \\
12 \\
15 \\
18 \\
21\end{array}$ & & & $\begin{array}{l}19.4 \\
22.8 \\
25.3 \\
25.0 \\
23.5 \\
20.4\end{array}$ & $\begin{array}{l}17.3 \\
18.7 \\
19.6 \\
19.9 \\
19.3 \\
18.6\end{array}$ & $\begin{array}{l}19.1 \\
23.2 \\
25.8 \\
26.2 \\
23.7 \\
20.1\end{array}$ & $\begin{array}{l}17.1 \\
18.8 \\
19.5 \\
19.5 \\
19.1 \\
18.5\end{array}$ & $\begin{array}{l}18.0 \\
22.5 \\
24.8 \\
25.8 \\
23.5 \\
20.1\end{array}$ & $\begin{array}{l}16.9 \\
18.4 \\
19.2 \\
19.2 \\
19.0 \\
18.4\end{array}$ & $\begin{array}{l}21.7 \\
22.6 \\
22.8 \\
22.1 \\
21.5 \\
21.8\end{array}$ & & $\begin{array}{l}6.1 \\
8.8\end{array}$ & $\begin{array}{l}3.7 \\
4.4 \\
4.5 \\
5.3 \\
6.8 \\
8.3 \\
6.6 \\
4.9\end{array}$ & $\begin{array}{r}4.3 \\
5.6 \\
6.0 \\
6.3 \\
7.5 \\
10.1 \\
6.19 \\
5.5\end{array}$ & $\begin{array}{r}5.1 \\
6.1 \\
7.8 \\
8.2 \\
8.9 \\
12.2 \\
7.0 \\
6.3\end{array}$ \\
\hline $\begin{array}{l}10 \\
10 \\
10 \\
10 \\
10 \\
10 \\
10 \\
10\end{array}$ & $\begin{array}{r}0 \\
3 \\
6 \\
9 \\
12 \\
15 \\
18 \\
21\end{array}$ & & & $\begin{array}{l}18.8 \\
18.02 \\
17.8 \\
18.8 \\
23.1 \\
22.8 \\
21.9 \\
19.9\end{array}$ & $\begin{array}{l}17.9 \\
17.5 \\
17.02 \\
16.7 \\
18.7 \\
19.1 \\
19.8 \\
18.4\end{array}$ & $\begin{array}{l}18.6 \\
17.9 \\
37.5 \\
18.6 \\
23.3 \\
22.09 \\
22.0 \\
19.5\end{array}$ & $\begin{array}{l}17.7 \\
17.3 \\
17.1 \\
16.7 \\
18.9 \\
18.9 \\
19.6 \\
18.1\end{array}$ & $\begin{array}{l}18.5 \\
17.0 \\
17.5 \\
18.5 \\
22.9 \\
22.7 \\
21.8 \\
19.4\end{array}$ & $\begin{array}{l}17.5 \\
17.2 \\
16.8 \\
16.2 \\
18.4 \\
18.7 \\
19.4 \\
18.0\end{array}$ & $\begin{array}{l}21.9 \\
21.6 \\
21.2 \\
21.2 \\
23.3 \\
22.7 \\
22.2 \\
22.1\end{array}$ & & $\begin{array}{r}0.4 \\
2.7 \\
7.17 \\
11.7 \\
2.3 \\
5.7 \\
2.9 \\
5.1\end{array}$ & $\begin{array}{r}1.3 \\
.5 .4 \\
12.0 \\
17.2 \\
3.2 \\
8.1 \\
4.6 \\
5.6\end{array}$ & $\begin{array}{r}2.4 \\
5.8 \\
13.8 \\
17.1 \\
5.7 \\
9.6 \\
4.5 \\
8.0\end{array}$ & $\begin{array}{r}3.4 \\
6.0 \\
18.5 \\
17.9 \\
6.6 \\
9.6 \\
5.9 \\
9.0\end{array}$ \\
\hline
\end{tabular}


TABLE 10

Table 10. -Three-hour averages of air and water-surface temperatures and wind directions and apeed, April 1950-August 1951, Lake Hefner-Continued

STATION 4

THREE-HOURLY AVERAGES

JUNE, 1951

\begin{tabular}{|c|c|c|c|c|c|c|c|c|c|c|c|c|c|c|c|}
\hline \multirow{4}{*}{ 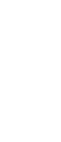 } & \multirow{4}{*}{ 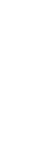 } & \multicolumn{8}{|c|}{ Average air temperature $\left({ }^{\circ} \mathrm{C}\right)$ at indicated height } & \multirow{4}{*}{$\begin{array}{l}\text { Average } \\
\text { water- } \\
\text { surface } \\
\text { tempera- } \\
\text { ture } \\
\left.{ }^{\circ} \mathrm{C}\right)\end{array}$} & \multirow{4}{*}{$\begin{array}{l}\text { Average } \\
\text { wind } \\
\text { direction } \\
\text { (coded) }\end{array}$} & \multirow{2}{*}{\multicolumn{4}{|c|}{$\begin{array}{l}\text { Average wind speed (knots) } \\
\text { at indicated height }\end{array}$}} \\
\hline & & \multirow{2}{*}{\multicolumn{2}{|c|}{$\stackrel{2}{\text { meters }}$}} & \multirow{2}{*}{\multicolumn{2}{|c|}{$\begin{array}{c}4 \\
\text { meters }\end{array}$}} & \multirow{2}{*}{\multicolumn{2}{|c|}{$\begin{array}{c}8 \\
\text { meters }\end{array}$}} & \multirow{2}{*}{\multicolumn{2}{|c|}{$\begin{array}{c}16 \\
\text { meters }\end{array}$}} & & & & & & \\
\hline & & & & & & & & & & & & 2 & 4 & 8 & 16 \\
\hline & & $\begin{array}{l}\text { Dry } \\
\text { bulb }\end{array}$ & $\begin{array}{l}\text { Wet } \\
\text { bulb }\end{array}$ & $\begin{array}{l}\text { Dry } \\
\text { bulb }\end{array}$ & $\begin{array}{l}\text { Wet } \\
\text { bulb }\end{array}$ & $\begin{array}{l}\text { Dry } \\
\text { bulb }\end{array}$ & $\begin{array}{l}\text { Wet } \\
\text { bulb }\end{array}$ & $\begin{array}{l}\text { Dry } \\
\text { bulb }\end{array}$ & $\begin{array}{l}\text { Wet } \\
\text { bulb }\end{array}$ & & & & & & \\
\hline
\end{tabular}

\begin{tabular}{|c|c|c|c|c|c|c|c|c|c|c|c|c|}
\hline $\begin{array}{l}11 \\
11 \\
11 \\
11 \\
11 \\
11 \\
11 \\
11\end{array}$ & $\begin{array}{r}0 \\
3 \\
6 \\
9 \\
12 \\
15 \\
18 \\
21\end{array}$ & $\begin{array}{l}19.1 \\
18.9 \\
17.6 \\
18.4 \\
20.3 \\
21.4 \\
21.0 \\
20.0\end{array}$ & $\begin{array}{l}18.0 \\
17.7 \\
17.5 \\
17.4 \\
17.7 \\
18.6 \\
18.9 \\
18.8\end{array}$ & $\begin{array}{l}18.8 \\
18.6 \\
17.5 \\
18.3 \\
20.1 \\
21.3 \\
20.8 \\
19.7\end{array}$ & $\begin{array}{l}17.9 \\
17.6 \\
17.3 \\
17.4 \\
17.6 \\
18.6 \\
18.8 \\
18.6\end{array}$ & $\begin{array}{l}18.8 \\
18.2 \\
17.3 \\
18.1 \\
19.0 \\
22.1 \\
20.6 \\
19.5\end{array}$ & $\begin{array}{l}17 \cdot 7 \\
16 \cdot 9 \\
17: 1 \\
17: 0 \\
17 \cdot 3 \\
18 \cdot 3 \\
18 \cdot 5 \\
18 \cdot 4\end{array}$ & $\begin{array}{l}21.9 \\
22.0 \\
21.9 \\
22.0 \\
22.1 \\
22.7 \\
22.5 \\
22.4\end{array}$ & $\begin{array}{l}3.6 \\
6.2 \\
4.3 \\
7.3 \\
6.3 \\
3.7 \\
4.3 \\
3.9\end{array}$ & $\begin{array}{l}5.2 \\
9.2 \\
5.9 \\
8.6 \\
8.1 \\
2.0 \\
5.9 \\
4.3\end{array}$ & $\begin{array}{r}6.4 \\
11.2 \\
7.6 \\
9.1 \\
9.5 \\
4.3 \\
6.5 \\
4.9\end{array}$ & $\begin{array}{r}6.2 \\
11.0 \\
9.2 \\
11.9 \\
11.0 \\
4.7 \\
6.8 \\
4.8\end{array}$ \\
\hline $\begin{array}{l}12 \\
12 \\
12 \\
12 \\
12 \\
12 \\
12 \\
12\end{array}$ & $\begin{array}{r}0 \\
3 \\
6 \\
9 \\
12 \\
15 \\
18 \\
21\end{array}$ & $\begin{array}{l}19.0 \\
18.2 \\
18.6 \\
20.7 \\
22.9 \\
24.6 \\
22.9 \\
20.5\end{array}$ & $\begin{array}{l}18.1 \\
17.2 \\
17.5 \\
18.5 \\
18.5 \\
18.5 \\
18.5 \\
18.1\end{array}$ & $\begin{array}{l}13.8 \\
18.0 \\
18.4 \\
20.2 \\
22.8 \\
24.3 \\
22.7 \\
20.2\end{array}$ & $\begin{array}{l}18.0 \\
17.3 \\
17.4 \\
18.4 \\
18.5 \\
18.0 \\
18.4 \\
17.8\end{array}$ & $\begin{array}{l}18.5 \\
17.8 \\
18.3 \\
20.2 \\
22.5 \\
23.8 \\
22.4 \\
20.1\end{array}$ & $\begin{array}{l}17.6 \\
16.8 \\
17.2 \\
18.0 \\
17.8 \\
17.6 \\
17.9 \\
17.6\end{array}$ & $\begin{array}{l}22 \cdot 3 \\
22 \cdot 0 \\
22 \cdot 0 \\
22 \cdot 5 \\
23.0 \\
23.0 \\
21 \cdot 7 \\
21.5\end{array}$ & $\begin{array}{l}5.8 \\
3.7 \\
6.2 \\
3.8 \\
3.1 \\
0.9 \\
1.6 \\
3.7\end{array}$ & $\begin{array}{l}7.8 \\
4.6 \\
8.6 \\
6.6 \\
4.2 \\
2.1 \\
2.06 \\
5.0\end{array}$ & $\begin{array}{l}8.9 \\
5.3 \\
9.0 \\
5.1 \\
6.6 \\
4.0 \\
3.3 \\
6.5\end{array}$ & $\begin{array}{l}6.3 \\
8.3 \\
5.1 \\
4.5 \\
7.4\end{array}$ \\
\hline $\begin{array}{l}13 \\
13 \\
13 \\
13 \\
13 \\
13 \\
13 \\
13\end{array}$ & $\begin{array}{r}0 \\
3 \\
6 \\
9 \\
12 \\
15 \\
18 \\
21\end{array}$ & $\begin{array}{l}20.1 \\
19.4 \\
20.9 \\
23.6 \\
25.3 \\
25.0 \\
21.2 \\
21.8\end{array}$ & $\begin{array}{l}27.6 \\
17.8 \\
19.3 \\
19.7 \\
20.0 \\
19.6 \\
17.5 \\
18.8\end{array}$ & $\begin{array}{l}19.7 \\
19.1 \\
21.0 \\
23.9 \\
25.5 \\
24.5 \\
21.2 \\
21.8\end{array}$ & $\begin{array}{l}17.3 \\
17.7 \\
19.2 \\
19.5 \\
19.9 \\
19.2 \\
17.3 \\
18.5\end{array}$ & $\begin{array}{l}19.6 \\
18.9 \\
20.9 \\
23.8 \\
25.7 \\
24.5 \\
20.9 \\
21.6\end{array}$ & $\begin{array}{l}17.0 \\
17.5 \\
19.1 \\
19.1 \\
19.4 \\
18.9 \\
17.1 \\
18.3\end{array}$ & $\begin{array}{l}21.7 \\
21.7 \\
21.9 \\
23.3 \\
24.0 \\
24.8 \\
23.5 \\
23.1\end{array}$ & $\begin{array}{r}4.6 \\
4.6 \\
4.2 \\
5.9 \\
14.1 \\
10.2\end{array}$ & $\begin{array}{r}5.0 \\
5.3 \\
5.3 \\
8.2 \\
14.6 \\
12.0\end{array}$ & $\begin{array}{r}6.4 \\
5.7 \\
5.8 \\
8.0 \\
8.4 \\
10.9 \\
16.0 \\
13.3\end{array}$ & $\begin{array}{r}6.4 \\
6.4 \\
5.7 \\
9.6 \\
9.8 \\
14.8 \\
14.8 \\
15.6\end{array}$ \\
\hline $\begin{array}{l}14 \\
14 \\
14 \\
14 \\
14 \\
14 \\
14 \\
14\end{array}$ & $\begin{array}{r}0 \\
3 \\
6 \\
9 \\
12 \\
15 \\
18 \\
21\end{array}$ & $\begin{array}{l}19.4 \\
18.7 \\
29.2 \\
21.8 \\
24.0 \\
25.3 \\
24.5 \\
22.6\end{array}$ & $\begin{array}{l}17.2 \\
16.8 \\
17.3 \\
18.7 \\
20.0 \\
21.0 \\
21.3 \\
21.3\end{array}$ & $\begin{array}{l}19.0 \\
18.3 \\
18.7 \\
21.9 \\
24.3 \\
25.6 \\
24.6 \\
22.7\end{array}$ & $\begin{array}{l}16.8 \\
16.9 \\
17.1 \\
18.6 \\
19.4 \\
20.8 \\
21.1 \\
21.1\end{array}$ & $\begin{array}{l}18.7 \\
18.1 \\
18.5 \\
23 \cdot 7 \\
24 \cdot 2 \\
25.5 \\
24.4 \\
22.4\end{array}$ & $\begin{array}{l}16.5 \\
16.3 \\
16.9 \\
13.4 \\
19.5 \\
20.5 \\
20.9 \\
21.1\end{array}$ & $\begin{array}{l}22.9 \\
22.6 \\
22.5 \\
23.0 \\
24.1 \\
24 \cdot 8 \\
24.3 \\
23.8\end{array}$ & $\begin{array}{l}3.3 \\
4.6 \\
8.0 \\
3.3 \\
3.6 \\
8.5\end{array}$ & $\begin{array}{r}5.2 \\
6.9 \\
7.7 \\
10.0 \\
3.2 \\
4.6 \\
4.4 \\
9.5\end{array}$ & $\begin{array}{r}6.5 \\
6.9 \\
9.2 \\
13.6 \\
5.7 \\
4.8 \\
5.8\end{array}$ & $\begin{array}{r}6.2 \\
5.4 \\
14.0 \\
12.2 \\
6.4 \\
5.1 \\
11.2\end{array}$ \\
\hline $\begin{array}{l}15 \\
15 \\
15 \\
15 \\
15 \\
15 \\
15 \\
15\end{array}$ & $\begin{array}{r}0 \\
3 \\
6 \\
9 \\
12 \\
15 \\
18 \\
21\end{array}$ & $\begin{array}{l}21.5 \\
17.8 \\
19.4 \\
22.0 \\
24.8 \\
27.2 \\
25.6 \\
23.7\end{array}$ & $\begin{array}{l}20.7 \\
16.8 \\
17.8 \\
18.8 \\
20.0 \\
20.8 \\
21.8 \\
20.7\end{array}$ & $\begin{array}{l}21.4 \\
17.4 \\
18.8 \\
21.9 \\
25.1 \\
27.3 \\
25.7 \\
23.7\end{array}$ & $\begin{array}{l}20.3 \\
16.7 \\
17.5 \\
18.7 \\
19.9 \\
20.7 \\
21.3 \\
20.4\end{array}$ & $\begin{array}{l}21.3 \\
17: 0 \\
18 \cdot 7 \\
21 \cdot 8 \\
25: 0 \\
27 \cdot 4 \\
25 \cdot 9 \\
23.5\end{array}$ & $\begin{array}{l}20.0 \\
16.0 \\
17.4 \\
18.6 \\
19.9 \\
20.8 \\
20.9 \\
20.4\end{array}$ & $\begin{array}{l}23.5 \\
23.1 \\
23.6 \\
24.6 \\
26.3 \\
26.1 \\
25.2 \\
26.0\end{array}$ & $\begin{array}{r}10.1 \\
2.8 \\
5.2 \\
6.7 \\
2.8 \\
3.3 \\
2.8 \\
5.8\end{array}$ & $\begin{array}{l}7.4 \\
9.8 \\
5.4 \\
7.1 \\
3.2 \\
5.1 \\
7.4\end{array}$ & $\begin{array}{r}14.5 \\
9.2 \\
6.2 \\
6.0 \\
3.7 \\
4.9 \\
5.6 \\
6.7\end{array}$ & $\begin{array}{r}14: 2 \\
17: 0 \\
5: 9 \\
7: 9 \\
4: 0 \\
5.1 \\
6.9 \\
8.0\end{array}$ \\
\hline $\begin{array}{l}16 \\
16 \\
16 \\
16 \\
16 \\
16 \\
16 \\
16\end{array}$ & $\begin{array}{r}0 \\
3 \\
6 \\
9 \\
12 \\
15 \\
28 \\
21\end{array}$ & $\begin{array}{l}22.6 \\
21.8 \\
22.2 \\
25.3 \\
28.0 \\
29.0 \\
27.4 \\
24.9\end{array}$ & $\begin{array}{l}20.5 \\
19.2 \\
19.3 \\
20.8 \\
20.9 \\
21.1 \\
22.4 \\
21.9\end{array}$ & $\begin{array}{l}22.4 \\
21.6 \\
22.2 \\
25.4 \\
28.1 \\
29.3 \\
27.5 \\
24.9\end{array}$ & $\begin{array}{l}20.3 \\
19.0 \\
19.1 \\
20.3 \\
20.3 \\
20.2 \\
21.8 \\
21.7\end{array}$ & $\begin{array}{l}22,0 \\
22,4 \\
22: 2 \\
25: 4 \\
28,4 \\
29 \cdot 6 \\
27,9 \\
24,7\end{array}$ & $\begin{array}{l}20.2 \\
19.1 \\
19.1 \\
20.5 \\
20.4 \\
20.7 \\
21.4 \\
21.6\end{array}$ & $\begin{array}{l}25 \cdot 2 \\
25 \cdot 0 \\
25: 3 \\
26 \cdot 0 \\
27 \cdot 4 \\
27 \cdot 2 \\
28 \cdot 3 \\
27 \cdot 1\end{array}$ & $\begin{array}{l}5.9 \\
9.7 \\
8.5 \\
5.0 \\
6.8 \\
3.2 \\
6.0\end{array}$ & $\begin{array}{l}6.4 \\
6.2 \\
9.5 \\
8.0 \\
5.2 \\
7.0 \\
5.2 \\
6.6\end{array}$ & $\begin{array}{r}7.3 \\
10.2 \\
8.5 \\
5.6 \\
7.2 \\
5.4\end{array}$ & $\begin{array}{r}6.9 \\
8.4 \\
11.8 \\
9.0 \\
6.0 \\
9.2 \\
7.00 \\
8.2\end{array}$ \\
\hline $\begin{array}{l}27 \\
17 \\
17 \\
17 \\
17 \\
17 \\
17 \\
17\end{array}$ & $\begin{array}{r}0 \\
3 \\
6 \\
9 \\
12 \\
15 \\
13 \\
21\end{array}$ & $\begin{array}{l}22.7 \\
22.5 \\
24.4 \\
26.8 \\
29.8 \\
29.7 \\
27.5 \\
24.9\end{array}$ & $\begin{array}{l}20.9 \\
20.4 \\
20.9 \\
21.9 \\
22.6 \\
23.4 \\
23.3 \\
22.9\end{array}$ & $\begin{array}{l}22.4 \\
22.4 \\
24.4 \\
27.2 \\
30.4 \\
29.7 \\
27.7 \\
24.8\end{array}$ & $\begin{array}{l}20.8 \\
20.2 \\
20.8 \\
21.8 \\
22.4 \\
23.0 \\
23.0 \\
22.0\end{array}$ & $\begin{array}{l}22.4 \\
22.6 \\
24.4 \\
27.2 \\
30.4 \\
29.6 \\
27.8 \\
24.8\end{array}$ & $\begin{array}{l}20.7 \\
20.4 \\
21.0 \\
22.1 \\
22.6 \\
23.2 \\
23.2 \\
22.5\end{array}$ & $\begin{array}{l}26 \cdot 6 \\
26 \cdot 1 \\
26 \cdot 3 \\
27 \cdot 5 \\
30.2 \\
30.3 \\
28 \cdot 3 \\
26.8\end{array}$ & $\begin{array}{l}2.1 \\
1.8 \\
2.5 \\
2.7 \\
1.6 \\
4.1 \\
5.5 \\
4.8\end{array}$ & $\begin{array}{l}3.7 \\
2.1 \\
3.4 \\
4.4 \\
2.3 \\
6.0 \\
6.0 \\
5.7\end{array}$ & $\begin{array}{l}4.2 \\
1.9 \\
3.4 \\
4.7 \\
2.5 \\
6.8 \\
7.4 \\
6.8\end{array}$ & $\begin{array}{l}4.8 \\
2.8 \\
3.9 \\
3.6 \\
2.3 \\
7.3 \\
9.8 \\
8.2\end{array}$ \\
\hline $\begin{array}{l}18 \\
18 \\
18 \\
18 \\
18 \\
18 \\
13 \\
18\end{array}$ & $\begin{array}{r}0 \\
3 \\
6 \\
9 \\
12 \\
15 \\
18 \\
21\end{array}$ & $\begin{array}{l}23.5 \\
22.3 \\
24.5 \\
26.5 \\
24.5 \\
27.2 \\
26.2 \\
24.2\end{array}$ & $\begin{array}{l}22 \cdot 2 \\
21: 6 \\
22.1 \\
21.9 \\
20.6 \\
21.5 \\
22.5 \\
21.9\end{array}$ & $\begin{array}{l}23 \cdot 3 \\
2 ? \cdot 3 \\
24 \cdot 3 \\
26 \cdot 4 \\
24 \cdot 5 \\
27 \cdot 5 \\
26 \cdot 1 \\
24 \cdot 1\end{array}$ & $\begin{array}{l}22.0 \\
21 \cdot 5 \\
21.5 \\
21 \cdot 7 \\
20.5 \\
20.7 \\
22 \cdot 3 \\
21.5\end{array}$ & $\begin{array}{l}22 \cdot 9 \\
22 \cdot 2 \\
24: 6 \\
25 \cdot 9 \\
24 \cdot 4 \\
27.6 \\
26 \cdot 1 \\
23.9\end{array}$ & 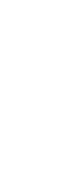 & $\begin{array}{l}26.8 \\
26.7 \\
26.3 \\
26.7 \\
26.3 \\
26.3 \\
25.5 \\
25.5\end{array}$ & $\begin{array}{l}3.8 \\
3.7 \\
9.5 \\
9.5 \\
6.7 \\
5.9 \\
4.4 \\
4.7\end{array}$ & $\begin{array}{r}4.0 \\
5.8 \\
12.1 \\
7.5 \\
6.6 \\
4.9 \\
5.3\end{array}$ & $\begin{array}{r}5.5 \\
2.5 \\
12.8 \\
14.8 \\
8.5 \\
7.7 \\
5.7 \\
6.1\end{array}$ & $\begin{array}{r}8.1 \\
6.0 \\
13.3 \\
16.7 \\
9.9 \\
8.1 \\
6.0 \\
7.2\end{array}$ \\
\hline $\begin{array}{l}19 \\
19 \\
19 \\
19 \\
19 \\
19 \\
19 \\
19\end{array}$ & $\begin{array}{r}0 \\
3 \\
6 \\
9 \\
12 \\
15 \\
18 \\
21\end{array}$ & $\begin{array}{l}22.6 \\
22 \cdot 3 \\
23.3 \\
26.5 \\
29 \cdot 0 \\
30.2 \\
28.7 \\
27.1\end{array}$ & $\begin{array}{l}20.9 \\
19.8 \\
19.9 \\
20.8 \\
22.4 \\
23.6 \\
24.1 \\
23.7\end{array}$ & $\begin{array}{l}29.4 \\
21.0 \\
23.2 \\
26.7 \\
29.3 \\
30.5 \\
23.7 \\
27.0\end{array}$ & $\begin{array}{l}20.8 \\
19.7 \\
19.7 \\
20.7 \\
22.3 \\
23.2 \\
23.8 \\
23.5\end{array}$ & $\begin{array}{l}22.4 \\
20.9 \\
23.2 \\
26.9 \\
29.5 \\
30.8 \\
23.8 \\
27.1\end{array}$ & $\begin{array}{l}20.8 \\
19.1 \\
19.5 \\
20.8 \\
22.2 \\
23.0 \\
23.5 \\
23.6\end{array}$ & $\begin{array}{l}25.3 \\
25.1 \\
25.6 \\
26.5 \\
27.3 \\
29.4 \\
23.4 \\
27.2\end{array}$ & $\begin{array}{r}5.3 \\
10.3 \\
10.6 \\
8.5 \\
4.6 \\
4.6 \\
6.4 \\
6.7\end{array}$ & $\begin{array}{r}5.8 \\
11.5 \\
11.4 \\
9.1 \\
5.7 \\
5.7 \\
7.5 \\
7.6\end{array}$ & $\begin{array}{r}6.5 \\
11.9 \\
11.3 \\
8.8 \\
5.4 \\
6.8 \\
9.2 \\
3.7\end{array}$ & $\begin{array}{r}7.2 \\
13.3 \\
12.4 \\
9.8 \\
5.9 \\
7.8 \\
10.3 \\
10.0\end{array}$ \\
\hline $\begin{array}{l}20 \\
20 \\
20 \\
20 \\
20 \\
20 \\
20 \\
20\end{array}$ & $\begin{array}{r}0 \\
3 \\
6 \\
9 \\
12 \\
15 \\
18 \\
21\end{array}$ & $\begin{array}{l}24 \cdot 9 \\
23.9 \\
24 \cdot 0 \\
26 \cdot 3 \\
27 \cdot 7 \\
28.5 \\
27.5 \\
25.0\end{array}$ & $\begin{array}{l}20 \cdot 5 \\
21 \bullet 4 \\
22 \bullet 0 \\
24 \bullet 2 \\
24 \bullet 1 \\
24 \bullet 1 \\
24 \bullet 0 \\
23.3\end{array}$ & $\begin{array}{l}24.5 \\
23.7 \\
24 \cdot 2 \\
26.7 \\
27.7 \\
23.7 \\
27.5 \\
26.0\end{array}$ & $\begin{array}{l}29.0 \\
21.3 \\
22.1 \\
24.0 \\
24.0 \\
24.0 \\
23.9 \\
23.4\end{array}$ & $\begin{array}{l}24.0 \\
24: 0 \\
24.3 \\
26: 4 \\
27.9 \\
28.3 \\
27.6 \\
26.0\end{array}$ & $\begin{array}{l}19.4 \\
20.0 \\
22 \cdot 0 \\
24 \cdot 1 \\
24 \cdot 0 \\
24.1 \\
23.9 \\
23.5\end{array}$ & $\begin{array}{l}27.1 \\
25.6 \\
26.8 \\
27.4 \\
27.7 \\
27.0 \\
26.0 \\
24.7\end{array}$ & $\begin{array}{r}13.3 \\
8.7 \\
7.1 \\
9.9 \\
11.8 \\
10.3 \\
9.7 \\
12.8\end{array}$ & $\begin{array}{r}14.6 \\
9.8 \\
7.8 \\
11.2 \\
13.6 \\
12.1 \\
11.1 \\
14.6\end{array}$ & $\begin{array}{r}15.1 \\
10.5 \\
4.0 \\
13.3 \\
16.6 \\
14.5 \\
13.5 \\
17.7\end{array}$ & $\begin{array}{r}17.3 \\
12.3 \\
9.4 \\
14.0 \\
18.0 \\
16.0 \\
14.8 \\
19.3\end{array}$ \\
\hline
\end{tabular}


Table 10. - Three-hour averages of air and water-surface temperatures and wind directions and speed, April 1950-Auguet 1951, Lake Hefner-Continued

STATION 4 THREE-HOURLY AVERAGES

JUNE, 2951

\begin{tabular}{|c|c|c|c|c|c|c|c|c|c|c|c|c|c|c|c|}
\hline \multirow{4}{*}{ 害点 } & \multirow{4}{*}{ 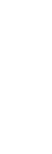 } & \multicolumn{8}{|c|}{ Average air temperature $\left({ }^{\circ} \mathrm{C}\right)$ at indicated height } & \multirow{4}{*}{$\begin{array}{c}\text { Average } \\
\text { water- } \\
\text { surface } \\
\text { tempera- } \\
\text { ture } \\
\left.{ }^{\circ} \mathrm{C}\right)\end{array}$} & \multirow{4}{*}{$\begin{array}{c}\text { Average } \\
\text { wind } \\
\text { direction } \\
\text { (coded) }\end{array}$} & \multirow{2}{*}{\multicolumn{4}{|c|}{$\begin{array}{l}\text { Average wind speed (knots) } \\
\text { at indicated height }\end{array}$}} \\
\hline & & \multirow{2}{*}{\multicolumn{2}{|c|}{$\begin{array}{c}2 \\
\text { meters }\end{array}$}} & \multirow{2}{*}{\multicolumn{2}{|c|}{$\begin{array}{c}4 \\
\text { meters }\end{array}$}} & \multirow{2}{*}{\multicolumn{2}{|c|}{$\begin{array}{c}8 \\
\text { meters }\end{array}$}} & \multirow{2}{*}{\multicolumn{2}{|c|}{$\begin{array}{c}16 \\
\text { meters }\end{array}$}} & & & & & & \\
\hline & & & & & & & & & & & & 2 & 4 & 8 & 16 \\
\hline & & $\begin{array}{l}\text { Dry } \\
\text { bulb }\end{array}$ & $\begin{array}{l}\text { Wet } \\
\text { bulb }\end{array}$ & $\begin{array}{l}\text { Dry } \\
\text { bulb }\end{array}$ & $\begin{array}{l}\text { Wet } \\
\text { bulb }\end{array}$ & $\begin{array}{l}\text { Dry } \\
\text { bulb }\end{array}$ & $\begin{array}{l}\text { Wet } \\
\text { bulb }\end{array}$ & $\begin{array}{l}\text { Dry } \\
\text { bulb }\end{array}$ & $\begin{array}{l}\text { Wet } \\
\text { bulb }\end{array}$ & & & meters & meters & meters & meters \\
\hline $\begin{array}{l}21 \\
21 \\
21 \\
21 \\
21 \\
21 \\
21 \\
21\end{array}$ & $\begin{array}{r}0 \\
3 \\
6 \\
9 \\
12 \\
15 \\
18 \\
21\end{array}$ & & & $\begin{array}{l}24.8 \\
24: 6 \\
24: 3 \\
24.8 \\
26.7 \\
28: 1 \\
27: 4 \\
25.6\end{array}$ & $\begin{array}{l}22.9 \\
22.8 \\
22.6 \\
22.7 \\
23.4 \\
24.0 \\
24 \cdot 8 \\
24.3\end{array}$ & $\begin{array}{l}24 \cdot 9 \\
24 \cdot 5 \\
24 \cdot 3 \\
24 \cdot 8 \\
26.7 \\
28 \cdot 0 \\
27.4 \\
26.5\end{array}$ & $\begin{array}{l}22 \cdot 8 \\
22.8 \\
22.5 \\
22.5 \\
23.0 \\
23.9 \\
24 \cdot 5 \\
23.9\end{array}$ & $\begin{array}{l}25 \cdot 1 \\
24: 4 \\
24 \cdot 2 \\
24 \cdot 6 \\
26 \cdot 9 \\
28 \cdot 2 \\
27 \cdot 5 \\
26 \cdot 7\end{array}$ & $\begin{array}{l}22.4 \\
22.4 \\
22.0 \\
22.3 \\
22.8 \\
23.8 \\
24.4 \\
24.1\end{array}$ & $\begin{array}{l}25.8 \\
25.8 \\
25.8 \\
26.3 \\
27.3 \\
27.7 \\
27.3 \\
26.9\end{array}$ & & $\begin{array}{r}9.4 \\
12.5 \\
5.7 \\
8.7 \\
7.5 \\
5.6 \\
4.2 \\
8.7\end{array}$ & $\begin{array}{r}10.7 \\
13.9 \\
6.4 \\
10.0 \\
8.6 \\
6.6 \\
4.8 \\
10.1\end{array}$ & $\begin{array}{r}13.2 \\
17.0 \\
7.6 \\
11.7 \\
9.6 \\
8.0 \\
5.8 \\
12.0\end{array}$ & $\begin{array}{r}14.6 \\
18.6 \\
8.1 \\
12.7 \\
10.9 \\
9.1 \\
6.6 \\
13.5\end{array}$ \\
\hline $\begin{array}{l}22 \\
22 \\
22 \\
22 \\
22 \\
22 \\
22 \\
22\end{array}$ & $\begin{array}{r}0 \\
3 \\
6 \\
9 \\
17 \\
15 \\
10 \\
21\end{array}$ & & & $\begin{array}{l}25.2 \\
24 \cdot 9 \\
24: 6 \\
26: 2 \\
23: 2 \\
28.6 \\
27: 5 \\
25.4\end{array}$ & $\begin{array}{l}23.4 \\
22.8 \\
22.6 \\
23.1 \\
23.3 \\
23.5 \\
23.0 \\
22.3\end{array}$ & $\begin{array}{l}24.9 \\
24.8 \\
24.6 \\
25.3 \\
20.5 \\
211.0 \\
27.6 \\
25.4\end{array}$ & $\begin{array}{l}23 \cdot 2 \\
22.7 \\
22.4 \\
23.0 \\
23.0 \\
23.1 \\
22.7 \\
22.6\end{array}$ & $\begin{array}{l}25 \cdot 3 \\
24 \cdot 7 \\
24 \cdot 3 \\
26 \cdot 3 \\
28 \cdot 4 \\
23 \cdot 8 \\
27 \cdot 5 \\
25 \cdot 4\end{array}$ & $\begin{array}{l}23 \cdot 1 \\
22.04 \\
23 .-2 \\
23.9 \\
23.9 \\
22.03 \\
2 ? .4 \\
22.5\end{array}$ & $\begin{array}{l}26.2 \\
25.9 \\
26.0 \\
26.6 \\
27.5 \\
27.9 \\
27.2 \\
26.7\end{array}$ & & $\begin{array}{r}4.7 \\
14.2 \\
7: 4 \\
7: 0 \\
7.4 \\
8.6 \\
6.7 \\
4: 4\end{array}$ & $\begin{array}{r}5.3 \\
16.4 \\
8.7 \\
8.4 \\
8.5 \\
10.2 \\
7.7 \\
5.0\end{array}$ & $\begin{array}{r}7.6 \\
19.2 \\
10.2 \\
9.1 \\
9.3 \\
12.2 \\
9.3 \\
6.0\end{array}$ & $\begin{array}{r}7.9 \\
19.6 \\
11.6 \\
10.1 \\
10.7 \\
13.8 \\
10.7 \\
6.4\end{array}$ \\
\hline $\begin{array}{l}23 \\
23 \\
23 \\
23 \\
23 \\
23 \\
23 \\
23\end{array}$ & $\begin{array}{r}0 \\
3 \\
6 \\
9 \\
13 \\
15 \\
13 \\
21\end{array}$ & & & $\begin{array}{l}24 \cdot ? \\
26 \cdot 3 \\
27 \cdot 1 \\
26 \cdot 5 \\
27 \cdot 0 \\
26.2\end{array}$ & $\begin{array}{l}21.6 \\
21.04 \\
21.7 \\
22.2 \\
33.0 \\
32.5\end{array}$ & $\begin{array}{l}23.6 \\
24.2 \\
26.4 \\
27.3 \\
27.0 \\
27.4 \\
26.4\end{array}$ & 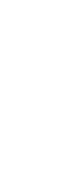 & $\begin{array}{l}23.4 \\
24 \cdot 2 \\
26 \cdot 3 \\
27 \cdot 2 \\
25 \cdot 9 \\
27.4 \\
25.5\end{array}$ & $\begin{array}{l}21 \cdot 3 \\
21 \cdot 2 \\
20.8 \\
21.2 \\
22 \cdot 1 \\
22 \cdot 8 \\
22 \cdot 1\end{array}$ & $\begin{array}{l}26.1 \\
26.2 \\
26.5 \\
26.9 \\
2 \ldots .7 \\
25.1 \\
25.5\end{array}$ & & $\begin{array}{r}4.9 \\
10.6 \\
13.6 \\
14.6 \\
14.2 \\
12.1 \\
4.3 \\
7.2\end{array}$ & $\begin{array}{r}5.3 \\
12.2 \\
15.8 \\
16.9 \\
16.6 \\
14.0 \\
5.0 \\
8.3\end{array}$ & $\begin{array}{r}6.2 \\
14.2 \\
17.6 \\
10.6 \\
1.06 \\
15.4 \\
5.6 \\
10.0\end{array}$ & $\begin{array}{r}6.9 \\
15.4 \\
19.8 \\
21.2 \\
21.2 \\
17.5 \\
6.3 \\
11.0\end{array}$ \\
\hline $\begin{array}{l}24 \\
24 \\
24 \\
24 \\
24 \\
24 \\
34 \\
24\end{array}$ & $\begin{array}{r}0 \\
3 \\
6 \\
1 \\
12 \\
15 \\
15 \\
21\end{array}$ & & & $\begin{array}{l}24.4 \\
22.1 \\
20.7 \\
23.9 \\
26.5 \\
27.5 \\
26.0 \\
25.0\end{array}$ & $\begin{array}{l}21.5 \\
20: 0 \\
16.9 \\
10.5 \\
21.5 \\
21.7 \\
22: 7 \\
22.6\end{array}$ & $\begin{array}{l}? .4 .4 \\
? 1 \cdot 8 \\
70.5 \\
? 4.0 \\
? 6.5 \\
? 7.9 \\
? 6.3 \\
? 5.0\end{array}$ & $\begin{array}{l}21 \cdot 0 \\
20: 0 \\
15: 0 \\
19.4 \\
21.5 \\
21.5 \\
22.4 \\
22.3\end{array}$ & 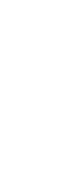 & $\begin{array}{l}21.7 \\
19.9 \\
16.8 \\
10.4 \\
21.4 \\
21.5 \\
22.1 \\
27.2\end{array}$ & $\begin{array}{l}25.2 \\
25.0 \\
25.0 \\
25.7 \\
25.9 \\
25.8 \\
25.3 \\
25.1\end{array}$ & & $\begin{array}{r}7.7 \\
7.3 \\
11.1 \\
13.8 \\
9.9 \\
8.1 \\
4.5 \\
10.2\end{array}$ & $\begin{array}{r}8.7 \\
8.0 \\
12.3 \\
15.6 \\
11.3 \\
9.6 \\
5.2 \\
11.8\end{array}$ & $\begin{array}{r}10.1 \\
9.8 \\
13.7 \\
17.9 \\
13.6 \\
11.2 \\
5.3 \\
14.0\end{array}$ & $\begin{array}{r}11.1 \\
10.5 \\
15.1 \\
18.4 \\
14.8 \\
12.6 \\
7.2 \\
15.3\end{array}$ \\
\hline $\begin{array}{l}25 \\
25 \\
25 \\
25 \\
25 \\
25 \\
25 \\
25 \\
25\end{array}$ & $\begin{array}{c}0 \\
2 \\
0 \\
i \\
12 \\
15 \\
1 \\
21\end{array}$ & & & $\begin{array}{l}24.1 \\
23.1 \\
23.7 \\
25.3 \\
26.0 \\
29.0 \\
27.5 \\
25.1\end{array}$ & $\begin{array}{l}22.5 \\
22.2 \\
22.2 \\
22.0 \\
23.3 \\
23.7 \\
23.7 \\
23.4\end{array}$ & $\begin{array}{l}23.0 \\
33.0 \\
23.0 \\
25.4 \\
27.0 \\
37.1 \\
27.3 \\
25.1\end{array}$ & $\begin{array}{l}22.5 \\
22: 0 \\
22: 0 \\
22 \cdot 0 \\
23.0 \\
23.5 \\
23.7 \\
23.3\end{array}$ & $\begin{array}{l}23.7 \\
22: 8 \\
23: 5 \\
25: 7 \\
27: 0 \\
28: 2 \\
27: 7 \\
25: 9\end{array}$ & $\begin{array}{ll}22 & .2 \\
21.9 \\
21.9 \\
29 & .5 \\
23 & .0 \\
23 & .3 \\
23.5 \\
23.1\end{array}$ & $\begin{array}{l}25.1 \\
24.9 \\
25.0 \\
25.5 \\
26.5 \\
26.6 \\
26.1 \\
25.5\end{array}$ & & $\begin{array}{r}11.3 \\
13.7 \\
11.7 \\
8.9 \\
8.6 \\
10.5 \\
9.3 \\
11.4\end{array}$ & $\begin{array}{l}12.9 \\
15.9 \\
13.3 \\
10.2 \\
10.6 \\
12.4 \\
10.9 \\
13.2\end{array}$ & $\begin{array}{l}14.4 \\
1.8 .4 \\
14.3 \\
10.9 \\
11.9 \\
14.1 \\
12.7 \\
15.2\end{array}$ & $\begin{array}{l}15.9 \\
20.2 \\
16.1 \\
12.4 \\
13.5 \\
16.1 \\
14.6 \\
17.0\end{array}$ \\
\hline $\begin{array}{l}26 \\
26 \\
26 \\
36 \\
25 \\
25 \\
25 \\
-6 \\
26\end{array}$ & $\begin{array}{r}0 \\
3 \\
5 \\
8 \\
12 \\
12 \\
13 \\
21\end{array}$ & & & $\begin{array}{l}25.2 \\
24.4 \\
24.7 \\
26.8 \\
28.8 \\
29.8 \\
27.7 \\
25.1\end{array}$ & $\begin{array}{l}-2.0 \\
21.2 \\
21.7 \\
22.4 \\
23.0 \\
23.2 \\
22.4 \\
21.3\end{array}$ & $\begin{array}{l}25.1 \\
24.2 \\
24.3 \\
25.7 \\
25.1 \\
30.1 \\
27.8 \\
26.1\end{array}$ & $\begin{array}{l}21.7 \\
21.0 \\
21.0 \\
22.0 \\
23.0 \\
23.0 \\
22.0 \\
21.0\end{array}$ & $\begin{array}{l}25.0 \\
24: 0 \\
24: 7 \\
27.0 \\
29.1 \\
30.1 \\
27.8 \\
26.0\end{array}$ & $\begin{array}{l}21 .-4 \\
20.8 \\
21.4 \\
2 ? \cdot 1 \\
22.8 \\
22.8 \\
21.8 \\
20.8\end{array}$ & $\begin{array}{l}25.2 \\
24.9 \\
25.3 \\
20.1 \\
26.3 \\
26.7 \\
26.3 \\
25.1\end{array}$ & & $\begin{array}{l}14.5 \\
13.4 \\
13.6 \\
14.7 \\
14.5 \\
15.5 \\
12.5 \\
14.0\end{array}$ & $\begin{array}{l}16.8 \\
15.0 \\
15.3 \\
16.0 \\
16.7 \\
18.1 \\
14.7 \\
16.0\end{array}$ & $\begin{array}{l}18.4 \\
16.0 \\
15.7 \\
15.9 \\
17.6 \\
10.7 \\
16.9 \\
18.2\end{array}$ & $\begin{array}{l}20.7 \\
18.3 \\
18.2 \\
18.7 \\
20.1 \\
23.0 \\
29.4 \\
20.5\end{array}$ \\
\hline $\begin{array}{l}27 \\
27 \\
27 \\
27 \\
27 \\
27 \\
27 \\
27\end{array}$ & $\begin{array}{l}? \\
2 \\
5 \\
8 \\
13 \\
15 \\
15 \\
? 1\end{array}$ & & & $\begin{array}{l}25 . ? \\
24: 6 \\
24: 7 \\
25: 9 \\
20: 1 \\
20: 7 \\
28 \cdot 0 \\
2 \epsilon: ?\end{array}$ & $\begin{array}{l}2 . .7 \\
20.5 \\
20.7 \\
21.7 \\
22.1 \\
21.5 \\
21.8 \\
22.0\end{array}$ & $\begin{array}{l}25.2 \\
24.5 \\
24.6 \\
27.1 \\
20.2 \\
30.0 \\
? 8.2 \\
20.3\end{array}$ & $\begin{array}{l}20.5 \\
20.4 \\
20.4 \\
21.5 \\
21.0 \\
21.5 \\
21.5 \\
21.8\end{array}$ & $\begin{array}{l}25 \cdot 1 \\
24 \cdot 3 \\
24: 5 \\
27: 3 \\
29 \cdot 6 \\
30 \cdot 2 \\
28 \cdot 3 \\
26 \cdot 2\end{array}$ & $\begin{array}{l}20.5 \\
20.5 \\
20.4 \\
21.3 \\
21.7 \\
21.1 \\
21.4 \\
21.6\end{array}$ & $\begin{array}{l}24.9 \\
24.8 \\
25.1 \\
25.5 \\
25.1 \\
26.5 \\
25.6 \\
25.0\end{array}$ & & $\begin{array}{l}14.0 \\
13.6 \\
13.3 \\
16.3 \\
15.4 \\
13.7 \\
11.2 \\
12.1\end{array}$ & $\begin{array}{l}16.1 \\
15.3 \\
15.0 \\
18.4 \\
17.6 \\
16.2 \\
13.4 \\
14.2\end{array}$ & $\begin{array}{l}17.6 \\
15.6 \\
15.3 \\
1.8 \\
1.0 .5 \\
12.0 \\
15.2 \\
10.3\end{array}$ & $\begin{array}{l}20.0 \\
17: 9 \\
27: 6 \\
22: 0 \\
21.6 \\
20: 9 \\
17.4 \\
18.3\end{array}$ \\
\hline $\begin{array}{l}28 \\
28 \\
28 \\
29 \\
38 \\
28 \\
78 \\
28\end{array}$ & $\begin{array}{l}0 \\
0 \\
12 \\
15 \\
19 \\
21\end{array}$ & & & $\begin{array}{l}24 \cdot 9 \\
24.1 \\
24 \cdot 5 \\
26.7 \\
20.4 \\
20.0 \\
28.3 \\
27.0\end{array}$ & $\begin{array}{l}21.5 \\
20.9 \\
21.4 \\
22.3 \\
2209 \\
22.9 \\
23.4 \\
22.4\end{array}$ & $\begin{array}{l}24.7 \\
23.0 \\
24.5 \\
26.7 \\
27.7 \\
30.2 \\
27.5 \\
27.1\end{array}$ & $\begin{array}{l}21.3 \\
20.3 \\
21.3 \\
23.0 \\
22.5 \\
22.7 \\
23.0 \\
22.1\end{array}$ & $\begin{array}{l}24.7 \\
23.7 \\
24.4 \\
26.7 \\
29.5 \\
30.4 \\
28.6 \\
27.0\end{array}$ & 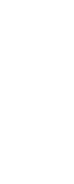 & $\begin{array}{l}24.7 \\
24.7 \\
25.0 \\
26.0 \\
28.0 \\
23.6 \\
27.7 \\
26.7\end{array}$ & & $\begin{array}{r}13.2 \\
9.5 \\
9.7 \\
4.6 \\
3.8 \\
7.2 \\
7.7 \\
10.1\end{array}$ & $\begin{array}{r}15.3 \\
10.9 \\
10.5 \\
5.2 \\
4.7 \\
8.6 \\
9.1 \\
11.8\end{array}$ & $\begin{array}{r}17.6 \\
11.5 \\
11.6 \\
5.1 \\
5.4 \\
0.8 \\
10.6 \\
13.6\end{array}$ & $\begin{array}{r}19.6 \\
13.0 \\
11.8 \\
5.9 \\
6.3 \\
11.5 \\
12.4 \\
15.3\end{array}$ \\
\hline $\begin{array}{l}=1 \\
29 \\
29 \\
20 \\
29 \\
29 \\
29 \\
29\end{array}$ & $\begin{array}{r}5 \\
3 \\
6 \\
n \\
12 \\
15 \\
15 \\
31\end{array}$ & & & $\begin{array}{l}25 \cdot 5 \\
24 \cdot 3 \\
25 \cdot 0 \\
25.0 \\
22.7 \\
20.5 \\
20.5 \\
26.0\end{array}$ & $\begin{array}{l}22.1 \\
21: 9 \\
22: 3 \\
29: 3 \\
23.5 \\
23.5 \\
23: 8 \\
22.3\end{array}$ & 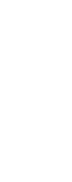 & 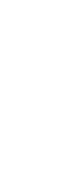 & $\begin{array}{l}25.0 \\
23 .: \\
25.0 \\
25.0 \\
23: 2 \\
30.1 \\
20: \\
26.7\end{array}$ & 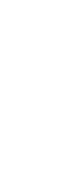 & $\begin{array}{l}26.4 \\
26.1 \\
26.0 \\
25.9 \\
27.3 \\
27.3 \\
26.8 \\
26.6\end{array}$ & & $\begin{array}{r}13.1 \\
10.4 \\
12.7 \\
6.6 \\
6.8 \\
10.8 \\
9.0 \\
12.7\end{array}$ & $\begin{array}{r}15.2 \\
11.7 \\
14.4 \\
7.5 \\
8.2 \\
13.2 \\
11.5 \\
14.0\end{array}$ & $\begin{array}{r}17.0 \\
12.5 \\
15.1 \\
15.1 \\
9.6 \\
15.6 \\
13.2 \\
17.3\end{array}$ & $\begin{array}{r}19.0 \\
14: 1 \\
17.3 \\
9.3 \\
11.0 \\
17.8 \\
15.2 \\
19.3\end{array}$ \\
\hline $\begin{array}{l}30 \\
30 \\
30 \\
30 \\
30 \\
30 \\
50 \\
30\end{array}$ & $\begin{array}{r}5 \\
3 \\
5 \\
5 \\
17 \\
15 \\
15 \\
21\end{array}$ & & & $\begin{array}{l}24 \cdot 3 \\
20.2 \\
10: 0 \\
21.2 \\
20.7 \\
21.7 \\
20 . c \\
10 . ?\end{array}$ & $\begin{array}{l}21 \cdot 1 \\
10 \cdot 9 \\
10 \cdot 5 \\
19 \cdot 0 \\
17 \cdot 3 \\
17 \cdot 0 \\
16 \cdot 3 \\
10 \cdot 3\end{array}$ & $\begin{array}{l}23.9 \\
13.9 \\
13.5 \\
20.5 \\
20.3 \\
21.4 \\
20.4 \\
1-.7\end{array}$ & $\begin{array}{l}20 \cdot 7 \\
15: 5 \\
17: 5 \\
13: 7 \\
15: ? \\
17: 5 \\
15: 5 \\
1600\end{array}$ & $\begin{array}{l}23.3 \\
10.7 \\
19.2 \\
20.2 \\
19.5 \\
20.5 \\
20.2 \\
19.5\end{array}$ & $\begin{array}{l}20.5 \\
13.5 \\
10.1 \\
18.6 \\
15.0 \\
17.0 \\
15.9 \\
15.9\end{array}$ & $\begin{array}{l}25.4 \\
25.2 \\
24.9 \\
23.1 \\
25.0 \\
24.8 \\
24.6 \\
24.7\end{array}$ & & $\begin{array}{l}9.7 \\
7.00 \\
9.03 \\
5.5 \\
7.09 \\
9.0 \\
5.6 \\
4.5\end{array}$ & $\begin{array}{r}11.1 \\
7.7 \\
10.2 \\
6.8 \\
9.8 \\
10.4 \\
6.6 \\
5.1\end{array}$ & $\begin{array}{r}13.4 \\
6.8 \\
11.0 \\
1.44 \\
12.2 \\
12.1 \\
7.1 \\
5.7\end{array}$ & $\begin{array}{r}16.6 \\
11.6 \\
12.1 \\
11.0 \\
17.5 \\
16.7 \\
8.9 \\
6.3\end{array}$ \\
\hline
\end{tabular}


TABLE 10

Table 10. - Three-hour averages of air and water-surface temperatures and wind directions and speed, April 1950-August 1951, Lake Hefner-Continued

STATION 4 THREE-HOURLY AVERAGES

JULY, 1951

\begin{tabular}{|c|c|c|c|c|c|c|c|c|c|c|c|c|c|c|c|}
\hline \multirow{4}{*}{ 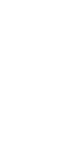 } & \multirow{4}{*}{ 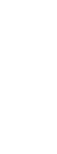 } & \multicolumn{8}{|c|}{ Average air temperature $\left({ }^{\circ} \mathrm{C}\right)$ at indicated height } & \multirow{4}{*}{$\begin{array}{l}\text { Average } \\
\text { water- } \\
\text { surface } \\
\text { tempera- } \\
\text { ture } \\
\left({ }^{\circ} \mathrm{C}\right)\end{array}$} & \multirow{4}{*}{$\begin{array}{c}\text { Average } \\
\text { wind } \\
\text { direction } \\
\text { (coded) }\end{array}$} & \multirow{2}{*}{\multicolumn{4}{|c|}{$\begin{array}{l}\text { Average wind speed (knots) } \\
\text { at indicated height }\end{array}$}} \\
\hline & & \multirow{2}{*}{\multicolumn{2}{|c|}{$\begin{array}{c}2 \\
\text { meters }\end{array}$}} & \multirow{2}{*}{\multicolumn{2}{|c|}{$\begin{array}{c}4 \\
\text { meters }\end{array}$}} & \multirow{2}{*}{\multicolumn{2}{|c|}{$\begin{array}{c}8 \\
\text { meters }\end{array}$}} & \multirow{2}{*}{\multicolumn{2}{|c|}{$\begin{array}{c}16 \\
\text { meters }\end{array}$}} & & & & & & \\
\hline & & & & & & & & & & & & 2 & 4 & 8 & 16 \\
\hline & & $\begin{array}{l}\text { Dry } \\
\text { bulb }\end{array}$ & $\begin{array}{l}\text { Wet } \\
\text { bulb }\end{array}$ & $\begin{array}{l}\text { Dry } \\
\text { bulb }\end{array}$ & $\begin{array}{l}\text { Wet } \\
\text { bulb }\end{array}$ & $\begin{array}{l}\text { Dry } \\
\text { bulb }\end{array}$ & $\begin{array}{l}\text { Wet } \\
\text { bulb }\end{array}$ & $\begin{array}{l}\text { Dry } \\
\text { bulb }\end{array}$ & $\begin{array}{l}\text { Wet } \\
\text { bulb }\end{array}$ & & & meters & meters & meters & meters \\
\hline $\begin{array}{l}1 \\
1 \\
1 \\
1 \\
1 \\
1 \\
1 \\
1\end{array}$ & $\begin{array}{r}0 \\
3 \\
6 \\
9 \\
12 \\
15 \\
13 \\
21\end{array}$ & & & $\begin{array}{l}18.1 \\
18.0 \\
17 . ? \\
15.5 \\
16.0 \\
18.5 \\
18.6 \\
18.7\end{array}$ & $\begin{array}{l}16.0 \\
15: 9 \\
15: 2 \\
14: 6 \\
15.4 \\
17.2 \\
17: 9 \\
18.1\end{array}$ & $\begin{array}{l}17.6 \\
17.5 \\
16.6 \\
15.3 \\
16.5 \\
18.1 \\
18.3 \\
12.3\end{array}$ & $\begin{array}{l}15.9 \\
15: 7 \\
14: 9 \\
14: 4 \\
15.3 \\
17.0 \\
17.3 \\
17.9\end{array}$ & $\begin{array}{l}17.5 \\
17.4 \\
16: 3 \\
14.9 \\
16.3 \\
17.9 \\
18: 1 \\
18.1\end{array}$ & $\begin{array}{l}15.8 \\
15.5 \\
14.5 \\
13.8 \\
15.0 \\
16.6 \\
17.5 \\
17.8\end{array}$ & $\begin{array}{l}24.4 \\
24.4 \\
24.4 \\
24.1 \\
24.7 \\
24.4 \\
23.9 \\
23.9\end{array}$ & & $\begin{array}{l}3.5 \\
3.5 \\
5.6 \\
5.9\end{array}$ & $\begin{array}{r}3.9 \\
4.5 \\
7.0 \\
10.1 \\
8.0 \\
11.4 \\
9.2 \\
5.9\end{array}$ & $\begin{array}{r}4.3 \\
5.1 \\
3.3 \\
11.6 \\
3.4 \\
12.8 \\
10.5 \\
5.7\end{array}$ & $\begin{array}{r}5.3 \\
5.2 \\
10.3 \\
12.9 \\
11.1 \\
13.3 \\
11.2 \\
6.6\end{array}$ \\
\hline $\begin{array}{l}2 \\
2 \\
2 \\
2 \\
2 \\
2 \\
2 \\
2 \\
2\end{array}$ & $\begin{array}{r}0 \\
3 \\
0 \\
0 \\
12 \\
15 \\
13 \\
21\end{array}$ & & & $\begin{array}{l}18.7 \\
19.8 \\
19.5 \\
22.9 \\
24.8 \\
25.0 \\
25.3 \\
23.3\end{array}$ & $\begin{array}{l}18.4 \\
18.5 \\
18.8 \\
10.7 \\
20.7 \\
21.3 \\
22.0 \\
21.9\end{array}$ & $\begin{array}{l}18.2 \\
19.1 \\
19.5 \\
27.8 \\
24.8 \\
25.0 \\
25.2 \\
23.2\end{array}$ & $\begin{array}{l}13.0 \\
18.8 \\
18.7 \\
19.3 \\
20.4 \\
21.5 \\
21.8 \\
21.3\end{array}$ & $\begin{array}{l}18.3 \\
18.9 \\
19 \cdot 2 \\
22.7 \\
24.7 \\
26.0 \\
25.1 \\
22.9\end{array}$ & $\begin{array}{l}17.9 \\
18.1 \\
18.2 \\
19.3 \\
20.3 \\
21.3 \\
21.6 \\
21.6\end{array}$ & $\begin{array}{l}24 \cdot 1 \\
23.2 \\
23 \cdot 9 \\
25 \cdot 1 \\
27 \cdot 1 \\
27 \cdot 1 \\
25 \cdot 1 \\
25.3\end{array}$ & & $\begin{array}{r}0.3 \\
8 \cdot 3 \\
9 \cdot 5 \\
11.3\end{array}$ & $\begin{array}{r}7.5 \\
13.0 \\
6.0 \\
2.7 \\
7.1 \\
9.7 \\
11.0 \\
13.1\end{array}$ & $\begin{array}{r}3.8 \\
15.3 \\
7.0 \\
3.4 \\
3.0 \\
11.3 \\
12.7 \\
15.3\end{array}$ & $\begin{array}{r}9.1 \\
17.2 \\
7.5 \\
3.4 \\
9.0 \\
12.5 \\
14.1 \\
16.5\end{array}$ \\
\hline $\begin{array}{l}3 \\
3 \\
3 \\
3 \\
3 \\
3 \\
3 \\
3\end{array}$ & $\begin{array}{r}0 \\
3 \\
6 \\
9 \\
12 \\
15 \\
18 \\
21\end{array}$ & & & $\begin{array}{l}23.1 \\
23.5 \\
24.7 \\
26.8 \\
28.3 \\
29.1 \\
28.2 \\
26.5\end{array}$ & $\begin{array}{l}22.3 \\
22.4 \\
22.9 \\
23.8 \\
24.4 \\
24.8 \\
24.9 \\
23.3\end{array}$ & $\begin{array}{l}23.0 \\
23.3 \\
24.8 \\
27.1 \\
22.7 \\
29.5 \\
28.5 \\
26.5\end{array}$ & $\begin{array}{l}22 \cdot 2 \\
22 \cdot 3 \\
22 \cdot 9 \\
23 \cdot 2 \\
24 \cdot 3 \\
24 \cdot 7 \\
24 \cdot 9 \\
23.2\end{array}$ & $\begin{array}{l}22.7 \\
23: 1 \\
24: 8 \\
27: 2 \\
28: 1 \\
29: 1 \\
28: 7 \\
25: 7\end{array}$ & $\begin{array}{l}21.9 \\
21.0 \\
22.8 \\
23.7 \\
24.7 \\
24.7 \\
24.8 \\
23.0\end{array}$ & $\begin{array}{l}24.9 \\
24.4 \\
24.8 \\
2=.5 \\
25.3 \\
26.4 \\
26.0 \\
25.8\end{array}$ & & $\begin{array}{r}11.9 \\
12.4 \\
11.8 \\
14.3 \\
10.9 \\
10.3 \\
8.3 \\
9.7\end{array}$ & $\begin{array}{l}13.8 \\
14.4 \\
13.5 \\
16.7 \\
12.8 \\
12.2 \\
10.0 \\
11.1\end{array}$ & $\begin{array}{l}15.8 \\
15.0 \\
14.5 \\
11.04 \\
14.2 \\
13.5 \\
11.9 \\
13.1\end{array}$ & $\begin{array}{l}17.3 \\
17.9 \\
16.5 \\
21.3 \\
16.8 \\
15.9 \\
14 \cdot 1 \\
14.8\end{array}$ \\
\hline $\begin{array}{l}4 \\
4 \\
4 \\
4 \\
4 \\
4 \\
4 \\
4\end{array}$ & $\begin{array}{r}0 \\
3 \\
6 \\
9 \\
12 \\
15 \\
18 \\
21\end{array}$ & & & $\begin{array}{l}21.2 \\
20.0 \\
20.1 \\
22.2 \\
27.2 \\
27.1 \\
25.3 \\
44.8\end{array}$ & $\begin{array}{l}18.9 \\
18.3 \\
18.5 \\
19.1 \\
21.2 \\
22.5 \\
2 ? .7 \\
2.3 .4\end{array}$ & $\begin{array}{l}20.7 \\
19.5 \\
19.8 \\
27.1 \\
27.4 \\
27.2 \\
25.03 \\
24.09\end{array}$ & $\begin{array}{l}19.7 \\
17.8 \\
18.3 \\
19.2 \\
21.2 \\
22.5 \\
32.7 \\
23.4\end{array}$ & $\begin{array}{l}20.3 \\
19.3 \\
19.5 \\
21.0 \\
27.4 \\
27.0 \\
25.2 \\
24.0\end{array}$ & $\begin{array}{l}19.4 \\
17.5 \\
18.0 \\
19.0 \\
21.3 \\
22.2 \\
22.5 \\
23.2\end{array}$ & $\begin{array}{l}24.7 \\
24.4 \\
24 \cdot 1 \\
24 \cdot 3 \\
26 \cdot 5 \\
25 \cdot 2 \\
24.5 \\
24.2\end{array}$ & & $\begin{array}{r}12.3 \\
9.4 \\
9.3 \\
9.0 \\
1.7 \\
7.4 \\
6.5 \\
6.3\end{array}$ & $\begin{array}{r}13.5 \\
10.7 \\
10.5 \\
10.2 \\
2.2 \\
8.4 \\
7.4 \\
7.4\end{array}$ & $\begin{array}{r}15.5 \\
12.3 \\
11.6 \\
11.3 \\
2.5 \\
9.5 \\
8.8 \\
0.1\end{array}$ & $\begin{array}{r}16.2 \\
14.3 \\
12.9 \\
12.8 \\
3.1 \\
9.8 \\
9.6 \\
10.4\end{array}$ \\
\hline $\begin{array}{l}5 \\
5 \\
5 \\
5 \\
5 \\
5 \\
5 \\
5\end{array}$ & $\begin{array}{r}0 \\
3 \\
6 \\
9 \\
12 \\
15 \\
18 \\
21\end{array}$ & & & $\begin{array}{l}24.4 \\
23.9 \\
24: 5 \\
27.4 \\
28.7 \\
29.3 \\
27.7 \\
25.0\end{array}$ & $\begin{array}{l}22.6 \\
21: 8 \\
21: 9 \\
23.2 \\
23.5 \\
23.1 \\
23.0 \\
22.8\end{array}$ & $\begin{array}{l}24.6 \\
23.8 \\
24.6 \\
27.7 \\
29.1 \\
29.6 \\
27.9 \\
26.1\end{array}$ & $\begin{array}{l}22.5 \\
21.6 \\
21.7 \\
23.0 \\
23.2 \\
22.7 \\
23.8 \\
22.7\end{array}$ & $\begin{array}{l}24.5 \\
23.5 \\
24: 6 \\
27.8 \\
29.3 \\
29.9 \\
27.9 \\
25.0\end{array}$ & $\begin{array}{l}22.2 \\
21.4 \\
21.7 \\
23.0 \\
23.0 \\
22.4 \\
22.7 \\
22.4\end{array}$ & $\begin{array}{l}24.6 \\
24.9 \\
25.3 \\
26.1 \\
25.9 \\
27.2 \\
26.0 \\
25.2\end{array}$ & & $\begin{array}{r}8.7 \\
10.7 \\
13.4 \\
11.5 \\
9.0 \\
10.8 \\
9.8 \\
12.2\end{array}$ & $\begin{array}{l}10.1 \\
12.3 \\
15.2 \\
13.3 \\
10.7 \\
12.8 \\
11.6 \\
14.2\end{array}$ & $\begin{array}{l}11.9 \\
13.9 \\
15.8 \\
13.8 \\
12.4 \\
15.2 \\
13.6 \\
16.5\end{array}$ & $\begin{array}{l}13.2 \\
15.4 \\
18.2 \\
16.2 \\
14.3 \\
17.4 \\
15.5 \\
18.5\end{array}$ \\
\hline $\begin{array}{l}6 \\
5 \\
6 \\
6 \\
6 \\
6 \\
6 \\
6\end{array}$ & $\begin{array}{r}0 \\
3 \\
5 \\
9 \\
12 \\
15 \\
15 \\
21\end{array}$ & & & $\begin{array}{l}24.8 \\
23.8 \\
24.8 \\
27.7 \\
29.3 \\
29.7 \\
28.4 \\
26.4\end{array}$ & $\begin{array}{l}22.2 \\
21.4 \\
21.4 \\
27.2 \\
22.9 \\
23.2 \\
23.8 \\
22.5\end{array}$ & $\begin{array}{l}24.6 \\
23.5 \\
24.3 \\
23.0 \\
29.8 \\
30.0 \\
28.4 \\
26.4\end{array}$ & $\begin{array}{l}21: 0 \\
21: 01 \\
21: 2 \\
22: 0 \\
22: 0 \\
23: 0 \\
23: 0 \\
22: 4\end{array}$ & $\begin{array}{l}24.5 \\
23.3 \\
24.9 \\
28.2 \\
29.8 \\
30.3 \\
28.6 \\
35.3\end{array}$ & $\begin{array}{l}21.8 \\
20: 9 \\
20.9 \\
21.8 \\
22.5 \\
22.7 \\
22.8 \\
22.1\end{array}$ & $\begin{array}{l}24.9 \\
24.7 \\
25.1 \\
26.0 \\
26.6 \\
26.8 \\
26.4 \\
25.6\end{array}$ & & $\begin{array}{r}13.3 \\
12.4 \\
14.4 \\
13.2 \\
12.6 \\
10.1 \\
9.2 \\
10.9\end{array}$ & $\begin{array}{l}16.2 \\
14.4 \\
16.6 \\
15.0 \\
13.5 \\
12.0 \\
10.9 \\
12.7\end{array}$ & $\begin{array}{l}18.4 \\
16.2 \\
17.6 \\
15.0 \\
14.6 \\
13.7 \\
13.0 \\
14.9\end{array}$ & $\begin{array}{l}20.5 \\
18.1 \\
20.1 \\
18.2 \\
17.2 \\
16.0 \\
14.7 \\
16.6\end{array}$ \\
\hline $\begin{array}{l}7 \\
7 \\
7 \\
7 \\
7 \\
7 \\
7 \\
7\end{array}$ & $\begin{array}{r}0 \\
3 \\
6 \\
9 \\
12 \\
15 \\
18 \\
31\end{array}$ & & & $\begin{array}{l}25.0 \\
23.7 \\
24.7 \\
28.1 \\
29.8 \\
30.1 \\
28.3 \\
76.3\end{array}$ & $\begin{array}{l}22.2 \\
21.4 \\
21.5 \\
22.4 \\
22.8 \\
23.0 \\
22.0 \\
=1.5\end{array}$ & $\begin{array}{l}24.7 \\
23.4 \\
2.07 \\
2.0 .5 \\
30.2 \\
30.4 \\
20.4 \\
35 . ?\end{array}$ & $\begin{array}{l}32.0 \\
21.1 \\
21.4 \\
22 \cdot 2 \\
22 \cdot 7 \\
22.3 \\
21.3 \\
21.1\end{array}$ & $\begin{array}{l}24.5 \\
23.3 \\
24.5 \\
28.7 \\
30.5 \\
30.5 \\
29.5 \\
26.2\end{array}$ & $\begin{array}{l}21 \cdot 8 \\
20 \cdot 9 \\
21 \cdot 2 \\
22 \cdot 2 \\
22 \cdot 5 \\
22 \cdot 4 \\
21.5 \\
20 \cdot 5\end{array}$ & $\begin{array}{l}25.2 \\
25.0 \\
25.3 \\
25.1 \\
25.5 \\
27.0 \\
20.5 \\
25.3\end{array}$ & & $\begin{array}{l}12.9 \\
12.5 \\
10.9 \\
12.8 \\
13.2 \\
13.1 \\
10.2 \\
11.9\end{array}$ & $\begin{array}{l}15.0 \\
14.4 \\
12.6 \\
14.5 \\
15.2 \\
15.4 \\
12.0 \\
13.9\end{array}$ & $\begin{array}{l}17.3 \\
15.0 \\
14.0 \\
15.0 \\
16.2 \\
17.1 \\
14.0 \\
15.9\end{array}$ & $\begin{array}{l}19.1 \\
17.8 \\
15.5 \\
17.5 \\
19.1 \\
20.0 \\
15.8 \\
17.9\end{array}$ \\
\hline $\begin{array}{l}8 \\
8 \\
6 \\
8 \\
8 \\
8 \\
8 \\
3\end{array}$ & $\begin{array}{r}0 \\
3 \\
0 \\
0 \\
12 \\
15 \\
12 \\
21\end{array}$ & & & $\begin{array}{l}24.0 \\
24.2 \\
25.7 \\
28.0 \\
20.9 \\
30.4 \\
28.9 \\
26.7\end{array}$ & $\begin{array}{l}21.2 \\
20.7 \\
21.4 \\
22.1 \\
27 \cdot 3 \\
22 \cdot 7 \\
22 \cdot 7 \\
22 \cdot 5\end{array}$ & $\begin{array}{l}24.5 \\
23.9 \\
25.7 \\
28.3 \\
30.3 \\
30.6 \\
29.0 \\
26.7\end{array}$ & 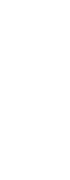 & $\begin{array}{l}3.9 \\
23.0 \\
26.0 \\
28.4 \\
30.5 \\
31.0 \\
29.0 \\
26.3\end{array}$ & $\begin{array}{l}20 \cdot 8 \\
20.2 \\
21.1 \\
21: 4 \\
2201 \\
29.5 \\
22.1 \\
22.0\end{array}$ & $\begin{array}{l}25.0 \\
25.0 \\
25.2 \\
25.6 \\
25.4 \\
26.7 \\
25.0 \\
25.3\end{array}$ & & $\begin{array}{l}14.1 \\
12.6 \\
14.1 \\
16.2 \\
16.6 \\
12.8 \\
11.4 \\
12.7\end{array}$ & $\begin{array}{l}16.4 \\
14.6 \\
16.2 \\
18.3 \\
19.0 \\
15.0 \\
13.4 \\
14.8\end{array}$ & $\begin{array}{l}18.7 \\
15.4 \\
17.1 \\
19.2 \\
10.8 \\
10.5 \\
15.4 \\
16.7\end{array}$ & $\begin{array}{l}20.8 \\
18.2 \\
19.7 \\
22.2 \\
23.3 \\
19.2 \\
18.0 \\
19.1\end{array}$ \\
\hline $\begin{array}{l}9 \\
9 \\
9 \\
9 \\
9 \\
9 \\
9 \\
9\end{array}$ & $\begin{array}{r}0 \\
3 \\
6 \\
9 \\
12 \\
15 \\
12 \\
21\end{array}$ & & & $\begin{array}{l}25.0 \\
23.7 \\
24.9 \\
27.7 \\
20.6 \\
30.0 \\
23.5 \\
26.0\end{array}$ & $\begin{array}{l}21.7 \\
20.9 \\
21.3 \\
22.3 \\
23.2 \\
23.4 \\
23.2 \\
22.8\end{array}$ & $\begin{array}{l}24.8 \\
23.4 \\
24.9 \\
28.1 \\
30.2 \\
30.2 \\
23.8 \\
27.0\end{array}$ & $\begin{array}{l}21.4 \\
20.9 \\
21.1 \\
22: 2 \\
22: 0 \\
23.3 \\
27.9 \\
22.6\end{array}$ & $\begin{array}{l}24 \cdot 6 \\
23.2 \\
240 \\
28.3 \\
30.5 \\
30.6 \\
28.9 \\
26.2\end{array}$ & $\begin{array}{l}21 \cdot 3 \\
20.7 \\
20 \cdot 9 \\
27 \cdot 2 \\
22 \cdot 7 \\
23 \cdot 1 \\
22 \cdot 7 \\
22 \cdot 4\end{array}$ & $\begin{array}{l}25.0 \\
24.8 \\
25.1 \\
25.7 \\
25.9 \\
27.2 \\
25.2 \\
25.7\end{array}$ & & $\begin{array}{r}10.6 \\
6.6 \\
10.9 \\
12.1 \\
10.6 \\
10.1 \\
9.4 \\
11.2\end{array}$ & $\begin{array}{r}12.2 \\
7.5 \\
12.3 \\
13.8 \\
12.5 \\
12.0 \\
11.0 \\
13.0\end{array}$ & $\begin{array}{r}13.2 \\
8.4 \\
13.1 \\
14.7 \\
14.0 \\
14.3 \\
13.2 \\
15.2\end{array}$ & $\begin{array}{r}15.0 \\
9.2 \\
15.0 \\
17.0 \\
16.2 \\
16.4 \\
15.0 \\
17.0\end{array}$ \\
\hline $\begin{array}{l}10 \\
10 \\
10 \\
10 \\
10 \\
10 \\
10 \\
10\end{array}$ & $\begin{array}{r}0 \\
3 \\
6 \\
9 \\
12 \\
15 \\
18 \\
21\end{array}$ & & & $\begin{array}{l}25.9 \\
25.1 \\
25.4 \\
27.6 \\
29.1 \\
29.5 \\
28.5 \\
26.7\end{array}$ & $\begin{array}{l}22.5 \\
22.0 \\
22.0 \\
22.9 \\
23.2 \\
23.4 \\
23.4 \\
23.1\end{array}$ & $\begin{array}{l}25.9 \\
24.8 \\
25.3 \\
27.8 \\
29.4 \\
27.6 \\
28.6 \\
26.7\end{array}$ & $\begin{array}{l}22.2 \\
21.9 \\
21.9 \\
22.5 \\
22.9 \\
23.3 \\
23.2 \\
22.8\end{array}$ & $\begin{array}{l}25.8 \\
24 \cdot 7 \\
25 \cdot 4 \\
23 \cdot 1 \\
29 \cdot 5 \\
29.5 \\
23.7 \\
25.7\end{array}$ & $\begin{array}{l}22.1 \\
21.7 \\
219.8 \\
22.5 \\
22.8 \\
23.1 \\
23.0 \\
22.07\end{array}$ & $\begin{array}{l}25.5 \\
25.3 \\
25: 5 \\
26.0 \\
26.9 \\
27.1 \\
26.5 \\
25.9\end{array}$ & & $\begin{array}{r}13.0 \\
12.7 \\
10.1 \\
9.6 \\
10.6 \\
12.6 \\
10.0 \\
9.8\end{array}$ & $\begin{array}{l}15.1 \\
14.7 \\
11.7 \\
11.2 \\
12.4 \\
14.8 \\
11.5 \\
11.3\end{array}$ & $\begin{array}{l}17.8 \\
16.4 \\
13.1 \\
13.0 \\
14.6 \\
17.3 \\
13.8 \\
13.4\end{array}$ & $\begin{array}{l}19.5 \\
18.3 \\
14.5 \\
14.6 \\
16.5 \\
19.5 \\
15.5 \\
14.7\end{array}$ \\
\hline
\end{tabular}


TABLE 10

\begin{tabular}{|c|c|c|c|c|c|c|c|c|c|c|c|c|c|c|c|}
\hline \multicolumn{2}{|c|}{ STATIOII } & \multicolumn{4}{|l|}{4} & \multicolumn{8}{|c|}{ THREE-HOURLY AVERAGES } & \multirow{2}{*}{\multicolumn{2}{|c|}{$\frac{\text { JULY, } 1951}{\text { speed (knots) }}$}} \\
\hline \multirow{3}{*}{ 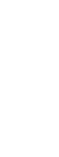 } & \multirow{3}{*}{ 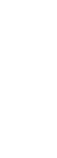 } & \multicolumn{8}{|c|}{ Average air temperature $\left({ }^{\circ} \mathrm{C}\right)$ at indicated height } & \multirow{3}{*}{$\begin{array}{l}\text { Average } \\
\text { water- } \\
\text { surface } \\
\text { tempera- } \\
\text { ture } \\
\left({ }^{\circ} \mathrm{C}\right)\end{array}$} & \multirow{3}{*}{$\begin{array}{c}\text { Average } \\
\text { wind } \\
\text { direction } \\
\text { (coded) }\end{array}$} & \multirow{2}{*}{\multicolumn{4}{|c|}{$\begin{array}{l}\text { Average wind speed (knots) } \\
\text { at indicated height }\end{array}$}} \\
\hline & & \multicolumn{2}{|c|}{$\begin{array}{c}2 \\
\text { meters }\end{array}$} & \multicolumn{2}{|c|}{$\begin{array}{c}4 \\
\text { meters }\end{array}$} & \multicolumn{2}{|c|}{$\begin{array}{c}8 \\
\text { meters }\end{array}$} & \multicolumn{2}{|c|}{$\begin{array}{c}16 \\
\text { meters }\end{array}$} & & & & & & \\
\hline & & $\begin{array}{l}\text { Dry } \\
\text { bulb }\end{array}$ & $\begin{array}{l}\text { Wet } \\
\text { bulb }\end{array}$ & $\begin{array}{l}\text { Dry } \\
\text { bulb }\end{array}$ & $\begin{array}{l}\text { Wet } \\
\text { bulb }\end{array}$ & $\begin{array}{l}\text { Dry } \\
\text { bulb }\end{array}$ & $\begin{array}{l}\text { Wet } \\
\text { bulb }\end{array}$ & $\begin{array}{l}\text { Dry } \\
\text { bulb }\end{array}$ & $\begin{array}{l}\text { Wet } \\
\text { bulb }\end{array}$ & & & meters & meters & meters & meters \\
\hline $\begin{array}{l}11 \\
11 \\
11 \\
11 \\
11 \\
11 \\
11 \\
11\end{array}$ & \begin{tabular}{r|}
0 \\
3 \\
6 \\
9 \\
17 \\
15 \\
19 \\
21
\end{tabular} & & & $\begin{array}{l}25.8 \\
24.7 \\
24.7 \\
27.6 \\
29.4 \\
29.8 \\
28.0 \\
26.2\end{array}$ & $\begin{array}{l}22.5 \\
22.0 \\
22.1 \\
22.3 \\
22.4 \\
23.0 \\
23.3 \\
23.0\end{array}$ & $\begin{array}{l}25.8 \\
24.5 \\
24.6 \\
27.9 \\
29.6 \\
20.0 \\
28.1 \\
26.1\end{array}$ & $\begin{array}{l}2 ? .2 \\
21.8 \\
21: 0 \\
21.9 \\
27.0 \\
22.5 \\
23.0 \\
22.7\end{array}$ & $\begin{array}{l}25.6 \\
24 \cdot 3 \\
24 \cdot 6 \\
23.1 \\
29.0 \\
30.1 \\
28.1 \\
26.1\end{array}$ & 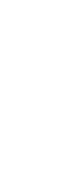 & $\begin{array}{l}25.5 \\
25.02 \\
25.2 \\
26.0 \\
26.4 \\
27.6 \\
26.0 \\
26.1\end{array}$ & & $\begin{array}{r}10.9 \\
13.0 \\
13.4 \\
10.6 \\
9.2 \\
10.1 \\
9.0 \\
6.6\end{array}$ & $\begin{array}{l}12.6 \\
15.1 \\
15.4 \\
12.1 \\
10.3 \\
11.9 \\
10.5 \\
7.5\end{array}$ & $\begin{array}{r}15.0 \\
17.1 \\
16.8 \\
12.7 \\
12.1 \\
14.0 \\
12.3 \\
8.9\end{array}$ & $\begin{array}{r}16.3 \\
19.0 \\
18.9 \\
14.8 \\
13.8 \\
16.0 \\
13.9 \\
9.6\end{array}$ \\
\hline $\begin{array}{l}12 \\
12 \\
12 \\
12 \\
12 \\
12 \\
12 \\
13\end{array}$ & $\begin{array}{r}0 \\
3 \\
6 \\
9 \\
12 \\
35 \\
18 \\
21\end{array}$ & & & $\begin{array}{l}25.0 \\
24.04 \\
25.3 \\
28.6 \\
30.7 \\
31.0 \\
29.6 \\
27.6\end{array}$ & $\begin{array}{l}22.3 \\
22.0 \\
22.4 \\
23.0 \\
23.0 \\
23.5 \\
23.9 \\
23.4\end{array}$ & $\begin{array}{l}24.9 \\
23.9 \\
25.2 \\
22.8 \\
31.0 \\
31.2 \\
29.8 \\
27.7\end{array}$ & $\begin{array}{l}22.1 \\
21.9 \\
27.1 \\
22.7 \\
22.7 \\
22.9 \\
23.4 \\
23.2\end{array}$ & $\begin{array}{l}24 \cdot 7 \\
23.7 \\
25: 0 \\
29 \cdot 1 \\
32 \cdot 2 \\
31: 5 \\
30.0 \\
27.7\end{array}$ & $\begin{array}{l}22.0 \\
21.8 \\
22.00 \\
22.07 \\
22.8 \\
23.0 \\
23.1 \\
23.0\end{array}$ & $\begin{array}{l}25.9 \\
25.8 \\
25.9 \\
26.5 \\
27.5 \\
28.2 \\
27.8 \\
27.0\end{array}$ & & $\begin{array}{r}9.2 \\
11.5 \\
12.5 \\
12.6 \\
7.9 \\
8.1 \\
7.2 \\
7.7\end{array}$ & $\begin{array}{r}10.4 \\
13.0 \\
14.1 \\
14.0 \\
9.0 \\
9.7 \\
8.6 \\
8.9\end{array}$ & $\begin{array}{l}12.04 \\
15.0 \\
14.6 \\
13.4 \\
0.7 \\
11.03 \\
10.1 \\
10.3\end{array}$ & $\begin{array}{l}13.4 \\
16.5 \\
16.8 \\
16.4 \\
11.0 \\
13.2 \\
11.7 \\
11.7\end{array}$ \\
\hline $\begin{array}{l}13 \\
13 \\
13 \\
13 \\
13 \\
13 \\
13 \\
13\end{array}$ & $\begin{array}{r}0 \\
3 \\
6 \\
9 \\
12 \\
15 \\
18 \\
21\end{array}$ & & & $\begin{array}{l}25.4 \\
22.06 \\
24.04 \\
26.0 \\
27.4 \\
30.0 \\
25.09 \\
23.0\end{array}$ & $\begin{array}{l}22.4 \\
21.0 \\
21.8 \\
22.9 \\
23.0 \\
23.9 \\
23.1 \\
21.8\end{array}$ & $\begin{array}{l}25.3 \\
22.2 \\
24.2 \\
25.4 \\
27.6 \\
30.6 \\
25.5 \\
23.2\end{array}$ & $\begin{array}{l}22.3 \\
20.9 \\
21.8 \\
22.8 \\
23.0 \\
24.0 \\
23.1 \\
21.7\end{array}$ & $\begin{array}{l}25 \cdot 1 \\
22.0 \\
23 \cdot 8 \\
25.5 \\
27 \cdot 6 \\
30 \cdot 3 \\
25 \cdot 1 \\
23.0\end{array}$ & $\begin{array}{l}22.2 \\
20.8 \\
21.7 \\
22.6 \\
23.0 \\
23.8 \\
22.8 \\
21.4\end{array}$ & $\begin{array}{l}26.6 \\
26.2 \\
26.5 \\
27.0 \\
27.2 \\
28.2 \\
26.8 \\
76.7\end{array}$ & & $\begin{array}{l}4.7 \\
7.9 \\
3.4 \\
6.6 \\
6.5 \\
3.4 \\
7.5 \\
4.9\end{array}$ & $\begin{array}{l}5.4 \\
8.7 \\
3.9 \\
7.4 \\
7.2 \\
3.9 \\
8.2 \\
5.4\end{array}$ & $\begin{array}{l}5.3 \\
9.9 \\
4.2 \\
8.4 \\
8.1 \\
4.4 \\
9.1 \\
5.9\end{array}$ & $\begin{array}{r}7.4 \\
10.1 \\
4.5 \\
11.1 \\
8.3 \\
5.2 \\
11.1 \\
6.8\end{array}$ \\
\hline $\begin{array}{l}1.4 \\
1.4 \\
14 \\
1.4 \\
14 \\
14 \\
14 \\
14\end{array}$ & $\begin{array}{r}2 \\
3 \\
6 \\
9 \\
12 \\
15 \\
18 \\
21\end{array}$ & & & $\begin{array}{l}22.5 \\
21.0 \\
22.2 \\
22.0 \\
23.2 \\
27.0 \\
26.8 \\
24.4\end{array}$ & $\begin{array}{l}21.2 \\
20.6 \\
21.5 \\
21.5 \\
21.7 \\
23.4 \\
23.6 \\
22.6\end{array}$ & $\begin{array}{l}21.9 \\
20.8 \\
21.8 \\
21.9 \\
23.2 \\
27.1 \\
26.8 \\
24.0\end{array}$ & $\begin{array}{l}21.0 \\
20.4 \\
21.4 \\
21.4 \\
21.6 \\
23.2 \\
23.3 \\
22.4\end{array}$ & $\begin{array}{l}21.6 \\
20.6 \\
21.6 \\
21.6 \\
22.9 \\
27.1 \\
26.7 \\
23.9\end{array}$ & $\begin{array}{l}20.9 \\
20.2 \\
21.1 \\
21.2 \\
21.5 \\
23.0 \\
23.2 \\
22.2\end{array}$ & $\begin{array}{l}26.5 \\
26.6 \\
26.3 \\
26.0 \\
25.9 \\
25.8 \\
26.04 \\
26.3\end{array}$ & & $\begin{array}{r}2.6 \\
2.1 \\
9.9 \\
11.1 \\
10.2 \\
7.8 \\
6.5 \\
7.0\end{array}$ & $\begin{array}{r}2.9 \\
2.4 \\
10.7 \\
12.1 \\
11.3 \\
8.9 \\
7.4 \\
7.7\end{array}$ & $\begin{array}{r}3.3 \\
2.8 \\
11.9 \\
13.4 \\
12.8 \\
10.7 \\
8.5 \\
8.9\end{array}$ & $\begin{array}{r}3.5 \\
3.8 \\
5.2 \\
13.8 \\
13.1 \\
11.6 \\
9.0 \\
9.2\end{array}$ \\
\hline $\begin{array}{l}15 \\
15 \\
15 \\
15 \\
15 \\
15 \\
15 \\
15\end{array}$ & $\begin{array}{r}0 \\
3 \\
6 \\
9 \\
12 \\
15 \\
18 \\
? 1\end{array}$ & & & $\begin{array}{l}24.1 \\
23.0 \\
23.7 \\
25.5 \\
29.7 \\
29.4 \\
27.05 \\
25.4\end{array}$ & $\begin{array}{l}22.9 \\
22.0 \\
22.4 \\
22.6 \\
23.3 \\
24.0 \\
23.1 \\
22.5\end{array}$ & $\begin{array}{l}23.7 \\
23.02 \\
23.4 \\
25.4 \\
29.0 \\
29.7 \\
27.6 \\
24.9\end{array}$ & $\begin{array}{l}22.7 \\
21.9 \\
22.5 \\
22.4 \\
23.2 \\
23.9 \\
22.9 \\
22.3\end{array}$ & $\begin{array}{l}23.6 \\
23.0 \\
23.4 \\
25.5 \\
29.1 \\
29.7 \\
27.5 \\
34.7\end{array}$ & $\begin{array}{l}22.5 \\
21 . \cdot 8 \\
22.44 \\
22.02 \\
23.0 \\
23.4 \\
22.5 \\
22.1\end{array}$ & $\begin{array}{l}26.2 \\
26.00 \\
25.03 \\
26.0 \\
27.03 \\
27.5 \\
26.8 \\
26.4\end{array}$ & & $\begin{array}{r}6.9 \\
6.2 \\
6.3 \\
10.2 \\
8.9 \\
9.5 \\
9.5 \\
9.8\end{array}$ & $\begin{array}{r}7.8 \\
7.11 \\
6.09 \\
11.02 \\
10.4 \\
11.1 \\
11.0 \\
11.0\end{array}$ & $\begin{array}{r}9.1 \\
7.09 \\
7.7 \\
12.8 \\
12.4 \\
13.4 \\
13.1 \\
12.4\end{array}$ & $\begin{array}{r}9.6 \\
8.4 \\
7.9 \\
13.4 \\
13.6 \\
14.9 \\
14.3 \\
13.9\end{array}$ \\
\hline $\begin{array}{l}16 \\
16 \\
16 \\
16 \\
16 \\
16 \\
16 \\
16\end{array}$ & $\begin{array}{r}2 \\
3 \\
6 \\
9 \\
12 \\
15 \\
18 \\
21\end{array}$ & & & $\begin{array}{l}24.1 \\
23.2 \\
24.7 \\
28.9 \\
30.8 \\
31.3 \\
29.8 \\
27.0\end{array}$ & $\begin{array}{l}21.5 \\
21 \cdot 1 \\
21: 9 \\
22: 7 \\
22: 5 \\
22: 9 \\
23 \cdot 7 \\
23.3\end{array}$ & $\begin{array}{l}23.7 \\
22.7 \\
24.5 \\
29.02 \\
31.02 \\
31.06 \\
29.9 \\
26.9\end{array}$ & $\begin{array}{l}21.5 \\
20.9 \\
21.3 \\
22.5 \\
22.4 \\
22.3 \\
23.3 \\
23.3\end{array}$ & $\begin{array}{l}23.5 \\
22.5 \\
24.6 \\
29: 2 \\
31.4 \\
31.0 \\
30.2 \\
26.8\end{array}$ & $\begin{array}{l}21.4 \\
20.8 \\
21.6 \\
22.1 \\
21.8 \\
21.7 \\
22.6 \\
27.9\end{array}$ & $\begin{array}{l}26.4 \\
26.03 \\
26.04 \\
27.13 \\
28.7 \\
29.8 \\
29.02 \\
28.0\end{array}$ & & $\begin{array}{l}7.5 \\
5.1 \\
9.4 \\
7.4 \\
5.1 \\
5.1 \\
4.6 \\
5.3\end{array}$ & $\begin{array}{r}8.5 \\
6.7 \\
10.4 \\
8.4 \\
5.9 \\
6.4 \\
5.3 \\
6.0\end{array}$ & $\begin{array}{r}0.4 \\
7.4 \\
10.7 \\
8.6 \\
6.5 \\
7.5 \\
6.8 \\
6.7\end{array}$ & $\begin{array}{r}10.1 \\
7.8 \\
12.0 \\
9.9 \\
7.3 \\
8.5 \\
8.2 \\
7.4\end{array}$ \\
\hline $\begin{array}{l}17 \\
17 \\
17 \\
17 \\
17 \\
17 \\
17 \\
17\end{array}$ & $\begin{array}{r}0 \\
3 \\
6 \\
9 \\
12 \\
15 \\
18 \\
21\end{array}$ & & & $\begin{array}{l}25 \cdot 3 \\
24 \cdot 3 \\
24 \cdot 7 \\
27.8\end{array}$ & $\begin{array}{r}27 \cdot 7 \\
22.0 \\
21.8 \\
-22.5 \\
21.5 \\
21.8\end{array}$ & $\begin{array}{l}25.1 \\
23.99 \\
24.05 \\
22.5 \\
31.5 \\
32.0 \\
30.6 \\
27.5\end{array}$ & $\begin{array}{l}22.4 \\
21 . \bullet 8 \\
21.07 \\
22.5 \\
21.09 \\
22.3 \\
23.1 \\
23.0\end{array}$ & $\begin{array}{l}24.9 \\
23.7 \\
24.5 \\
28.6 \\
31.5 \\
31.9 \\
30.5 \\
27.4\end{array}$ & $\begin{array}{l}22 \cdot 3 \\
21 \cdot 6 \\
21.6 \\
22 \cdot 6 \\
21 \cdot 9 \\
23.2 \\
22.6 \\
23.1\end{array}$ & $\begin{array}{l}27.5 \\
27.02 \\
27.3 \\
28.5 \\
31.0 \\
31.4 \\
30.6 \\
29.6\end{array}$ & & $\begin{array}{l}6.5 \\
7.0 \\
6.0 \\
3.4 \\
2.5 \\
3.6 \\
3.8 \\
5.1\end{array}$ & $\begin{array}{l}7.4 \\
7.8 \\
6.3 \\
3.7 \\
3.0 \\
4.4 \\
4.3 \\
5.7\end{array}$ & $\begin{array}{l}8.2 \\
8.1 \\
6.0 \\
3.9 \\
3.3 \\
5.1 \\
5.2 \\
6.5\end{array}$ & $\begin{array}{l}9.1 \\
9.0 \\
6.6 \\
4 \cdot 2 \\
3.0 \\
5.6 \\
5.7 \\
7.1\end{array}$ \\
\hline $\begin{array}{l}18 \\
18 \\
18 \\
18 \\
18 \\
18 \\
18 \\
18\end{array}$ & $\begin{array}{r}0 \\
3 \\
6 \\
9 \\
12 \\
15 \\
18 \\
? 1\end{array}$ & & & $\begin{array}{l}25.7 \\
29.0 \\
31.7 \\
32.3 \\
30.4 \\
28.0\end{array}$ & $\begin{array}{l}21 \cdot 3 \\
22 \cdot 0 \\
20: 7 \\
22 \cdot 1 \\
22 \cdot 8 \\
22 \cdot 4\end{array}$ & $\begin{array}{l}25.7 \\
22.55 \\
25.6 \\
29.1 \\
31.9 \\
3.01 \\
30.03 \\
27.9\end{array}$ & $\begin{array}{l}21.8 \\
20.8 \\
21.1 \\
21.03 \\
20.5 \\
21.7 \\
22.4 \\
22.2\end{array}$ & $\begin{array}{l}25.6 \\
24.2 \\
25.5 \\
29.2 \\
32.1 \\
32.3 \\
30.4 \\
27.8\end{array}$ & $\begin{array}{l}21.5 \\
20.7 \\
21.0 \\
21.2 \\
20.2 \\
21.4 \\
21.8 \\
22.0\end{array}$ & $\begin{array}{l}29.2 \\
28.7 \\
28.6 \\
2.71 \\
30.9 \\
31.2 \\
30.0 \\
28.9\end{array}$ & & $\begin{array}{l}6.8 \\
6.9 \\
8.5 \\
4.3 \\
2.4 \\
4.3 \\
7.0 \\
6.4\end{array}$ & $\begin{array}{l}7.5 \\
7.4 \\
9.3 \\
6.0 \\
3.0 \\
5.3 \\
8.0 \\
7.1\end{array}$ & $\begin{array}{l}7.6 \\
7.3 \\
9.1 \\
5.8 \\
3.2 \\
7.2 \\
9.6 \\
8.4\end{array}$ & $\begin{array}{r}8.6 \\
8.3 \\
10.2 \\
6.4 \\
3.3 \\
6.3 \\
10.5 \\
9.1\end{array}$ \\
\hline $\begin{array}{l}19 \\
19 \\
19 \\
19 \\
19 \\
19 \\
19 \\
19\end{array}$ & $\begin{array}{r}0 \\
3 \\
6 \\
9 \\
12 \\
15 \\
18 \\
21\end{array}$ & & & $\begin{array}{l}25.8 \\
23.7 \\
24.5 \\
27.08 \\
31.4 \\
32.4 \\
30.5 \\
27.6\end{array}$ & $\begin{array}{l}21 \cdot 7 \\
21 \cdot 1 \\
22 \cdot 5 \\
22: 2 \\
21: 0 \\
23 \cdot 0 \\
24 \cdot 2 \\
23: 7\end{array}$ & $\begin{array}{l}25.0 \\
23.00 \\
24.0 \\
27.9 \\
31.7 \\
32.06 \\
30.7 \\
27.5\end{array}$ & $\begin{array}{l}21.6 \\
21.02 \\
22.05 \\
22.11 \\
22.0 \\
22.6 \\
23.8 \\
23.5\end{array}$ & $\begin{array}{l}25.4 \\
23.1 \\
23.0 \\
27.9 \\
31.8 \\
32.5 \\
30.7 \\
27.4\end{array}$ & $\begin{array}{l}21 \cdot 3 \\
21.0 \\
22.2 \\
22.0 \\
21.8 \\
22.3 \\
23.5 \\
23.3\end{array}$ & $\begin{array}{l}28.4 \\
28.3 \\
28.4 \\
28 \% 9 \\
31.5 \\
31.4 \\
29.7 \\
29.0\end{array}$ & & $\begin{array}{l}5.0 \\
3.9 \\
3.1 \\
1.8 \\
2.5 \\
6.6 \\
5.3 \\
6.2\end{array}$ & $\begin{array}{l}7.4 \\
6.0 \\
6.9\end{array}$ & $\begin{array}{l}6.1 \\
4.7 \\
3.7 \\
2.9 \\
2.7 \\
8.6 \\
7.2 \\
7.8\end{array}$ & $\begin{array}{l}6.5 \\
5.6 \\
3.9 \\
2.7 \\
2.7 \\
8.9 \\
8.1 \\
9.3\end{array}$ \\
\hline $\begin{array}{l}20 \\
20 \\
20 \\
20 \\
20 \\
20 \\
20 \\
20\end{array}$ & $\begin{array}{r}0 \\
3 \\
6 \\
9 \\
12 \\
15 \\
18 \\
21\end{array}$ & & & $\begin{array}{l}26.5 \\
25.3 \\
26.0 \\
29.3 \\
32.1 \\
32.7 \\
31.6 \\
29.0\end{array}$ & $\begin{array}{l}23.1 \\
22.8 \\
23.2 \\
23.7 \\
23.0 \\
23.1 \\
23.5 \\
23.6\end{array}$ & $\begin{array}{l}25.5 \\
25.0 \\
26.0 \\
29.5 \\
32.03 \\
32.8 \\
31.6 \\
28.9\end{array}$ & $\begin{array}{l}23.0 \\
22.9 \\
23.0 \\
23.4 \\
22.7 \\
23.0 \\
23.1 \\
23.4\end{array}$ & $\begin{array}{l}26.2 \\
24.9 \\
25.9 \\
29.7 \\
32.5 \\
33.0 \\
31.6 \\
28.7\end{array}$ & $\begin{array}{l}22.7 \\
22.6 \\
22.8 \\
23.0 \\
22 \cdot 3 \\
22.5 \\
22.6 \\
23.1\end{array}$ & $\begin{array}{l}28.9 \\
28.7 \\
28.8 \\
29.3 \\
30.0 \\
29.9 \\
29.5 \\
29.0\end{array}$ & & $\begin{array}{r}7.6 \\
9.0 \\
9.4 \\
9.9 \\
9.1 \\
10.7 \\
8.2 \\
12.6\end{array}$ & $\begin{array}{r}8.5 \\
10.03 \\
10.6 \\
11.5 \\
10.6 \\
12.5 \\
9.5 \\
14.5\end{array}$ & $\begin{array}{r}9.7 \\
11.7 \\
11.8 \\
12.9 \\
12.5 \\
14.6 \\
11.4 \\
17.1\end{array}$ & $\begin{array}{l}10.5 \\
12.6 \\
12.8 \\
14.6 \\
14.1 \\
16.7 \\
13.0 \\
18.8\end{array}$ \\
\hline
\end{tabular}


TABLE 10

Table 10. -Three-hour averages of air and water-surface temperatures and wind directions and speed, April 1950-August 1951, Lake Hefner-Continued

STATION 4

THREE-HOURLY AVERAGES

JULY, 1951

\begin{tabular}{|c|c|c|c|c|c|c|c|c|c|c|c|c|c|c|c|}
\hline \multirow{3}{*}{ 宽 } & \multirow{3}{*}{ 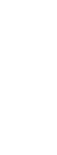 } & \multicolumn{8}{|c|}{ Average air temperature $\left({ }^{\circ} \mathrm{C}\right)$ at indicated height } & \multirow{3}{*}{$\begin{array}{c}\text { Average } \\
\text { water- } \\
\text { surface } \\
\text { tempera- } \\
\text { ture } \\
\left({ }^{\circ} \mathrm{C}\right)\end{array}$} & \multirow{3}{*}{$\begin{array}{c}\text { Average } \\
\text { wind } \\
\text { direction } \\
\text { (coded) }\end{array}$} & \multirow{2}{*}{\multicolumn{4}{|c|}{$\begin{array}{l}\text { Average wind speed (knots) } \\
\text { at indicated height }\end{array}$}} \\
\hline & & \multicolumn{2}{|c|}{$\begin{array}{c}2 \\
\text { meters }\end{array}$} & \multicolumn{2}{|c|}{$\begin{array}{c}4 \\
\text { meters }\end{array}$} & \multicolumn{2}{|c|}{$\begin{array}{c}8 \\
\text { meters }\end{array}$} & \multicolumn{2}{|c|}{$\begin{array}{c}16 \\
\text { meters }\end{array}$} & & & & & & \\
\hline & & $\begin{array}{l}\text { Dry } \\
\text { bulb }\end{array}$ & $\begin{array}{l}\text { Wet } \\
\text { bulb }\end{array}$ & $\begin{array}{l}\text { Dry } \\
\text { bulb }\end{array}$ & $\begin{array}{l}\text { Wet } \\
\text { bulb }\end{array}$ & $\begin{array}{l}\text { Dry } \\
\text { bulb }\end{array}$ & $\begin{array}{l}\text { Wet } \\
\text { bulb }\end{array}$ & $\begin{array}{l}\text { Dry } \\
\text { bulb }\end{array}$ & $\begin{array}{l}\text { Wet } \\
\text { bulb }\end{array}$ & & & meters & meters & meters & $\begin{array}{c}16 \\
\text { meters }\end{array}$ \\
\hline $\begin{array}{l}21 \\
21 \\
21 \\
21 \\
21 \\
21 \\
21 \\
21\end{array}$ & $\begin{array}{r}0 \\
3 \\
6 \\
9 \\
12 \\
15 \\
18 \\
21\end{array}$ & & & $\begin{array}{l}26.0 \\
26.0 \\
27.7 \\
31.1 \\
33.0 \\
33.7 \\
32.0 \\
29.4\end{array}$ & $\begin{array}{l}23.0 \\
22.4 \\
22.3 \\
23.0 \\
23.6 \\
23.9 \\
23.9 \\
22.6\end{array}$ & $\begin{array}{l}26.9 \\
25.9 \\
28.1 \\
31.5 \\
33.5 \\
34.1 \\
32.1 \\
29.4\end{array}$ & $\begin{array}{l}22.8 \\
22: 0 \\
21: 0 \\
22 \cdot 0 \\
23.1 \\
23.4 \\
23 \cdot 3 \\
22.03\end{array}$ & $\begin{array}{l}26.7 \\
25: 8 \\
28: 1 \\
31: 6 \\
33: 9 \\
34: 3 \\
32: 3 \\
29.3\end{array}$ & $\begin{array}{l}22.4 \\
21.9 \\
21.7 \\
22.6 \\
22.9 \\
23.2 \\
23.0 \\
22.0\end{array}$ & $\begin{array}{l}28.5 \\
28.7 \\
28.3 \\
28.6 \\
28.6 \\
28.5 \\
23.1 \\
27.9\end{array}$ & & $\begin{array}{l}12.9 \\
13 . ? \\
16.1 \\
14.9 \\
13.6 \\
12.4 \\
11.2 \\
11.9\end{array}$ & $\begin{array}{l}14.3 \\
15.1 \\
17.8 \\
16.6 \\
15.4 \\
14.4 \\
13.2 \\
13.9\end{array}$ & $\begin{array}{l}17.0 \\
17.0 \\
18.2 \\
17.0 \\
16.2 \\
15.9 \\
15.2 \\
15.0\end{array}$ & $\begin{array}{l}13.8 \\
18.8 \\
21.0 \\
19.8 \\
18.7 \\
18.4 \\
17.4 \\
17.9\end{array}$ \\
\hline $\begin{array}{l}22 \\
22 \\
22 \\
22 \\
22 \\
22 \\
22 \\
22\end{array}$ & $\begin{array}{r}0 \\
3 \\
6 \\
9 \\
12 \\
15 \\
18 \\
21\end{array}$ & & & $\begin{array}{l}27.0 \\
25: 0 \\
26.3 \\
29.4 \\
31.7 \\
32.6 \\
31.3 \\
29.1\end{array}$ & $\begin{array}{l}21.9 \\
? 1.5 \\
? 1.9 \\
23.3 \\
23.9 \\
23.5 \\
23.9 \\
23.2\end{array}$ & $\begin{array}{l}27.0 \\
25.6 \\
26.3 \\
27.6 \\
32.1 \\
33.1 \\
31.6 \\
29.1\end{array}$ & $\begin{array}{l}21.05 \\
31.03 \\
? 1.0 \\
23.0 \\
23.4 \\
23.2 \\
23.5 \\
? ? .0\end{array}$ & $\begin{array}{l}26.8 \\
25.5 \\
25.3 \\
29.7 \\
32.4 \\
33.2 \\
31.7 \\
29.1\end{array}$ & $\begin{array}{l}21.4 \\
21.0 \\
21.7 \\
23.07 \\
23.2 \\
29.9 \\
23.3 \\
29.7\end{array}$ & $\begin{array}{l}27.6 \\
27.4 \\
27.3 \\
27.9 \\
28.8 \\
39.3 \\
39.0 \\
28.2\end{array}$ & & $\begin{array}{r}10.0 \\
0.7 \\
8.1 \\
9.1 \\
7.7 \\
6.7 \\
8.7 \\
8.3\end{array}$ & $\begin{array}{r}11.4 \\
11.0 \\
9.7 \\
10.7 \\
9.0 \\
7.4 \\
10.1 \\
0.5\end{array}$ & $\begin{array}{r}13.1 \\
12.2 \\
0.8 \\
10.7 \\
0.9 \\
8.5 \\
12.3 \\
11.1\end{array}$ & $\begin{array}{r}14.4 \\
13.5 \\
11.0 \\
12.3 \\
11.3 \\
9.8 \\
13.8 \\
12.4\end{array}$ \\
\hline $\begin{array}{l}23 \\
23 \\
23 \\
23 \\
23 \\
23 \\
23 \\
23\end{array}$ & $\begin{array}{r}0 \\
3 \\
6 \\
9 \\
12 \\
15 \\
18 \\
21\end{array}$ & & & $\begin{array}{l}27.1 \\
24.9 \\
24.0 \\
27.1 \\
30.6 \\
27.1 \\
25.0 \\
24.6\end{array}$ & $\begin{array}{l}22 \cdot 1 \\
21 .: 5 \\
21: 17 \\
22.7 \\
23.6 \\
22.7 \\
22.9 \\
22.8\end{array}$ & $\begin{array}{l}27.2 \\
24.4 \\
23.4 \\
27.2 \\
30.7 \\
27.0 \\
24.6 \\
24.3\end{array}$ & $\begin{array}{l}21.9 \\
21.2 \\
20.8 \\
22.5 \\
23.4 \\
22.6 \\
22.7 \\
23.6\end{array}$ & $\begin{array}{l}26.9 \\
33.0 \\
23.1 \\
27.2 \\
30.4 \\
25.0 \\
24.3 \\
24 . ?\end{array}$ & $\begin{array}{l}21.7 \\
21.0 \\
20.8 \\
22.7 \\
23.2 \\
22.6 \\
22.6 \\
2 ? .5\end{array}$ & $\begin{array}{l}27.8 \\
27.4 \\
27.3 \\
23.1 \\
20.5 \\
27.9 \\
27.2 \\
27.4\end{array}$ & & $\begin{array}{l}7.5 \\
4.2 \\
6.6 \\
5.0 \\
3.3 \\
6.7 \\
4.3 \\
3.7\end{array}$ & $\begin{array}{l}8.5 \\
5.5 \\
7.5 \\
6.4 \\
6.5 \\
7.3 \\
6.6 \\
5.6\end{array}$ & $\begin{array}{l}0.8 \\
7.5 \\
0.5 \\
6.3 \\
2.9 \\
0.1 \\
5.4 \\
2.7\end{array}$ & $\begin{array}{r}10.7 \\
9.8 \\
11.8 \\
6.3 \\
7.6 \\
9.6 \\
5.5 \\
4.4\end{array}$ \\
\hline $\begin{array}{l}24 \\
24 \\
24 \\
24 \\
24 \\
24 \\
24 \\
24\end{array}$ & $\begin{array}{r}0 \\
3 \\
5 \\
9 \\
12 \\
15 \\
18 \\
21\end{array}$ & & & $\begin{array}{l}22.4 \\
21.9 \\
22.7 \\
24.9 \\
26.9 \\
29.3 \\
27.9 \\
23.7\end{array}$ & $\begin{array}{l}21.4 \\
20.09 \\
21.04 \\
22.5 \\
22.9 \\
22.9 \\
22.09 \\
21.8\end{array}$ & $\begin{array}{l}21.9 \\
21.5 \\
27.3 \\
24.4 \\
27.0 \\
29.4 \\
27.8 \\
23.4\end{array}$ & $\begin{array}{l}21.2 \\
20.8 \\
21.6 \\
22.4 \\
22.6 \\
22.8 \\
22.7 \\
21.7\end{array}$ & $\begin{array}{l}21.5 \\
21.3 \\
22.0 \\
24.1 \\
27.0 \\
29.3 \\
27.5 \\
23.1\end{array}$ & $\begin{array}{l}20.3 \\
20.2 \\
29.1 \\
23.0 \\
22.6 \\
23.6 \\
2 ? .6 \\
21.9\end{array}$ & $\begin{array}{l}27.7 \\
26.7 \\
26.8 \\
27.2 \\
28.5 \\
39.4 \\
28.6 \\
27.6\end{array}$ & & $\begin{array}{r}2.0 \\
3.0 \\
1 . ? \\
5.4 \\
3.3 \\
3 . ? \\
4.1 \\
10.1\end{array}$ & $\begin{array}{l}3.2 \\
4.8 \\
2.0 \\
7.0 \\
5.0 \\
4.7 \\
11.2\end{array}$ & $\begin{array}{r}5.1 \\
4.6 \\
1.8 \\
5.1 \\
4.12 \\
3.8 \\
5.3 \\
13.1\end{array}$ & $\begin{array}{r}7.0 \\
5.2 \\
1.2 \\
6.2 \\
4.2 \\
4.5 \\
5.3 \\
13.7\end{array}$ \\
\hline $\begin{array}{l}25 \\
25 \\
25 \\
25 \\
25 \\
25 \\
25 \\
25\end{array}$ & $\begin{array}{r}0 \\
3 \\
6 \\
9 \\
12 \\
15 \\
18 \\
21\end{array}$ & & & $\begin{array}{l}22.4 \\
22.2 \\
23.2 \\
26.2 \\
29.2 \\
29.8 \\
28.7 \\
26.4\end{array}$ & $\begin{array}{l}21 \cdot 4 \\
21 \cdot 4 \\
22 \cdot 3 \\
22 \cdot 9 \\
22 \cdot 9 \\
23 \cdot 0 \\
23 \cdot 0 \\
23.7\end{array}$ & $\begin{array}{l}22.1 \\
22.1 \\
22.8 \\
25.9 \\
29.0 \\
29.9 \\
28.7 \\
26.4\end{array}$ & $\begin{array}{l}21.4 \\
21.3 \\
22: 3 \\
22.6 \\
22: 1 \\
22: 8 \\
23.4 \\
23.4\end{array}$ & $\begin{array}{l}22.0 \\
22.0 \\
22: 0 \\
25: 0 \\
20.0 \\
29.8 \\
28.5 \\
26.3\end{array}$ & $\begin{array}{l}21.0 \\
20.0 \\
22.7 \\
22.5 \\
21.9 \\
22.5 \\
23.4 \\
23.2\end{array}$ & $\begin{array}{l}26.9 \\
26.8 \\
26.7 \\
27.7 \\
20.5 \\
29.8 \\
29.1 \\
28.8\end{array}$ & & $\begin{array}{l}1.7 \\
2.0 \\
4.5 \\
2.7 \\
2.7 \\
5.3 \\
5.0 \\
6.6\end{array}$ & $\begin{array}{l}3.8 \\
5.6 \\
5.0 \\
4.4 \\
7.0 \\
6.5 \\
7 . ?\end{array}$ & $\begin{array}{l}2.6 \\
3.5 \\
3.0 \\
4.0 \\
3.3 \\
8.9 \\
7.3 \\
7.4\end{array}$ & $\begin{array}{l}3.0 \\
3.7 \\
6: 0 \\
4: 2 \\
4: 2 \\
7: 1 \\
7.9 \\
8.9\end{array}$ \\
\hline $\begin{array}{l}26 \\
26 \\
26 \\
26 \\
26 \\
26 \\
26 \\
26\end{array}$ & $\begin{array}{r}0 \\
3 \\
6 \\
9 \\
12 \\
15 \\
18 \\
21\end{array}$ & & & $\begin{array}{l}26.0 \\
25.0 \\
25.3 \\
28.4 \\
28.0 \\
26.9 \\
25.2 \\
22.9\end{array}$ & $\begin{array}{l}23.3 \\
22.8 \\
22.4 \\
23.4 \\
22.7 \\
22.9 \\
21.9 \\
20.5\end{array}$ & $\begin{array}{l}25.8 \\
24.7 \\
25.1 \\
28.5 \\
27.5 \\
26.7 \\
24.6 \\
22.0\end{array}$ & $\begin{array}{l}23.1 \\
22.4 \\
22.2 \\
23.1 \\
22.5 \\
22.7 \\
21.7 \\
20.4\end{array}$ & $\begin{array}{l}25.6 \\
24.5 \\
25.0 \\
28.5 \\
27.5 \\
26.5 \\
34.3 \\
2 ? .0\end{array}$ & $\begin{array}{l}23.0 \\
22.3 \\
22.2 \\
23.0 \\
21.8 \\
22.6 \\
21.3 \\
20.4\end{array}$ & $\begin{array}{l}28.5 \\
28.0 \\
28.0 \\
28.7 \\
28.9 \\
29.9 \\
28.3 \\
27.8\end{array}$ & & $\begin{array}{r}7.5 \\
8.2 \\
8.5 \\
6.2 \\
6.2 \\
9.1 \\
11.2 \\
8.8\end{array}$ & $\begin{array}{r}8.5 \\
9.5 \\
9.5 \\
7.0 \\
8 . ? \\
10.3 \\
12.3 \\
9.3\end{array}$ & $\begin{array}{r}-.9 \\
10.8 \\
10.8 \\
7.6 \\
7.8 \\
13.0 \\
14.0 \\
11.5\end{array}$ & $\begin{array}{r}10.6 \\
11.5 \\
11.06 \\
3.5 \\
8.9 \\
12.5 \\
14.4 \\
11.9\end{array}$ \\
\hline $\begin{array}{l}27 \\
27 \\
27 \\
27 \\
27 \\
27 \\
27 \\
27\end{array}$ & $\begin{array}{r}0 \\
3 \\
6 \\
9 \\
12 \\
15 \\
18 \\
21\end{array}$ & & & $\begin{array}{l}22.8 \\
23: 5 \\
24.2 \\
27.7 \\
31.8 \\
31.7 \\
29.1 \\
26.7\end{array}$ & $\begin{array}{l}20.4 \\
20.8 \\
22.2 \\
23.5 \\
23.8 \\
23.9 \\
24.5 \\
23.6\end{array}$ & $\begin{array}{l}22.3 \\
23.2 \\
23.5 \\
27.9 \\
32.4 \\
31.6 \\
29.1 \\
26.6\end{array}$ & $\begin{array}{l}20.3 \\
20.8 \\
21.8 \\
23.5 \\
23.8 \\
23.7 \\
24.3 \\
23.4\end{array}$ & $\begin{array}{l}22.0 \\
22: 7 \\
24: 0 \\
28.0 \\
31.8 \\
31.6 \\
29.0 \\
26.5\end{array}$ & $\begin{array}{l}20.1 \\
20.5 \\
22.0 \\
23.5 \\
23.7 \\
23.7 \\
24.7 \\
23.1\end{array}$ & $\begin{array}{l}27.5 \\
27.5 \\
28.0 \\
29.5 \\
31.8 \\
29.9 \\
28.4 \\
28.0\end{array}$ & & $\begin{array}{l}7.8 \\
8.7 \\
3.3 \\
1.3 \\
1.8 \\
7.2 \\
6.1 \\
4.7\end{array}$ & $\begin{array}{l}3 . ? \\
8.4 \\
6.8 \\
5.3\end{array}$ & $\begin{array}{r}10.1 \\
10.8 \\
3.9 \\
2.4 \\
3.3 \\
8.7 \\
7.7 \\
6.1\end{array}$ & $\begin{array}{r}10.5 \\
12.0 \\
4.2 \\
2.3 \\
3.6 \\
8.6 \\
8.2 \\
6.7\end{array}$ \\
\hline $\begin{array}{l}28 \\
28 \\
28 \\
28 \\
28 \\
28 \\
28 \\
28\end{array}$ & $\begin{array}{r}0 \\
3 \\
6 \\
9 \\
12 \\
15 \\
18 \\
21\end{array}$ & & & $\begin{array}{l}25.7 \\
25.1 \\
25.9 \\
29.5 \\
32.0 \\
31.9 \\
28.4 \\
26.5\end{array}$ & $\begin{array}{l}22.8 \\
22.8 \\
23.1 \\
23.1 \\
23.4 \\
23.5 \\
23.7 \\
23.5\end{array}$ & $\begin{array}{l}25.1 \\
25.0 \\
25.5 \\
30.0 \\
32.0 \\
32.1 \\
28.3 \\
26.5\end{array}$ & $\begin{array}{l}22.8 \\
22.7 \\
23.0 \\
23.0 \\
23.3 \\
23.3 \\
23.5 \\
23.4\end{array}$ & $\begin{array}{l}25.2 \\
24.8 \\
25.6 \\
20.9 \\
31.7 \\
31.9 \\
28.4 \\
26.4\end{array}$ & $\begin{array}{l}22.9 \\
22.6 \\
23.0 \\
22.9 \\
23.1 \\
23.2 \\
23.3 \\
23.2\end{array}$ & $\begin{array}{l}28.0 \\
27.9 \\
28.3 \\
30.2 \\
31.2 \\
29.8 \\
28.9 \\
28.7\end{array}$ & & $\begin{array}{l}3.0 \\
3.3 \\
3.5 \\
2.1 \\
4.2 \\
5.7 \\
1.3 \\
5.7\end{array}$ & $\begin{array}{l}4.8 \\
3.6 \\
3.8 \\
4.6 \\
6.4 \\
1.7 \\
6.2\end{array}$ & $\begin{array}{l}4.1 \\
3.6 \\
3.6 \\
2.5 \\
5.0 \\
7.2 \\
2.5 \\
6.9\end{array}$ & $\begin{array}{l}4.5 \\
3.8 \\
3.8 \\
2.6 \\
5.5 \\
8.5 \\
4.7 \\
8.0\end{array}$ \\
\hline $\begin{array}{l}29 \\
29 \\
29 \\
29 \\
29 \\
29 \\
29 \\
29\end{array}$ & $\begin{array}{r}0 \\
3 \\
6 \\
9 \\
12 \\
15 \\
18 \\
21\end{array}$ & & & $\begin{array}{l}25.1 \\
23.3 \\
24: 5 \\
27 \cdot 1 \\
30.1 \\
30.8 \\
29.0 \\
26.4\end{array}$ & $\begin{array}{l}22.4 \\
21.7 \\
21: 9 \\
21.7 \\
21.3 \\
21.7 \\
23.3 \\
22.6\end{array}$ & $\begin{array}{l}24.8 \\
23.1 \\
24.4 \\
27.2 \\
30.3 \\
30.9 \\
29.0 \\
26.3\end{array}$ & 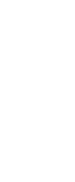 & $\begin{array}{l}24.7 \\
23.0 \\
24.03 \\
27.0 \\
30.2 \\
30.8 \\
29.1 \\
26.5\end{array}$ & $\begin{array}{l}22 \cdot 1 \\
21 \\
21.2 \\
21.05 \\
21.2 \\
21.8 \\
22.4 \\
22.2\end{array}$ & $\begin{array}{l}28.2 \\
28.2 \\
28.7 \\
29.04 \\
30.7 \\
30.0 \\
29.0 \\
28.0\end{array}$ & & $\begin{array}{l}4.6 \\
0.8 \\
2.5 \\
3.3 \\
5.5 \\
5.8 \\
4.8 \\
5.8\end{array}$ & $\begin{array}{l}5.0 \\
3.3 \\
3.7 \\
6.4 \\
6.4 \\
5.9 \\
6.3\end{array}$ & $\begin{array}{l}5.6 \\
1.6 \\
3.3 \\
4.2 \\
7.1 \\
7.4 \\
6.6 \\
7.3\end{array}$ & $\begin{array}{l}6.4 \\
2.0 \\
3.5 \\
4.2 \\
7.2 \\
7.4 \\
7.4 \\
8.3\end{array}$ \\
\hline $\begin{array}{l}30 \\
30 \\
30 \\
30 \\
30 \\
30 \\
30 \\
30\end{array}$ & $\begin{array}{r}0 \\
3 \\
6 \\
9 \\
12 \\
15 \\
18 \\
21\end{array}$ & & & $\begin{array}{l}25.2 \\
25.4 \\
25.5 \\
27.8 \\
29.7 \\
31.4 \\
30.0 \\
27.0\end{array}$ & $\begin{array}{l}22.9 \\
23.0 \\
23.1 \\
23.5 \\
23.3 \\
23.0 \\
23.4 \\
23.4\end{array}$ & $\begin{array}{l}24.9 \\
25.1 \\
25: 3 \\
27.9 \\
29.9 \\
31.5 \\
30.0 \\
26.9\end{array}$ & $\begin{array}{l}22.8 \\
22.8 \\
22.8 \\
22.9 \\
23.1 \\
22.5 \\
23.4 \\
23.1\end{array}$ & $\begin{array}{l}24.8 \\
24.7 \\
25.2 \\
27.0 \\
29.8 \\
31.4 \\
29.9 \\
26.8\end{array}$ & $\begin{array}{l}22.6 \\
22.6 \\
22.7 \\
23.0 \\
23.1 \\
22.8 \\
23.1 \\
23.0\end{array}$ & $\begin{array}{l}28.7 \\
28.5 \\
28.9 \\
29.4 \\
31.2 \\
31.5 \\
30.2 \\
29.4\end{array}$ & & $\begin{array}{l}6.4 \\
7.2 \\
9.0 \\
7.6 \\
4.0 \\
3.8 \\
5.0 \\
5.8\end{array}$ & $\begin{array}{r}7.1 \\
8.2 \\
10.0 \\
8.5 \\
4.5 \\
4.3 \\
5.6 \\
6.4\end{array}$ & $\begin{array}{r}8.1 \\
9.4 \\
10.0 \\
8.9 \\
4.8 \\
5.0 \\
6.4 \\
7.4\end{array}$ & $\begin{array}{r}8.6 \\
10.0 \\
11.2 \\
10.0 \\
5.3 \\
5.1 \\
7.1 \\
8.1\end{array}$ \\
\hline $\begin{array}{l}31 \\
31 \\
31 \\
31 \\
31 \\
31 \\
31 \\
31\end{array}$ & $\begin{array}{r}0 \\
3 \\
6 \\
9 \\
12 \\
15 \\
18 \\
21\end{array}$ & & & $\begin{array}{l}26.3 \\
25.3 \\
25.9 \\
26.8 \\
25.6 \\
26.0 \\
25.1 \\
24.2\end{array}$ & $\begin{array}{l}22.2 \\
21.8 \\
22.0 \\
22.7 \\
22.5 \\
22.7 \\
23.1 \\
22.3\end{array}$ & $\begin{array}{l}26.3 \\
24.9 \\
25.8 \\
26.7 \\
25.4 \\
27.1 \\
25.9 \\
23.8\end{array}$ & $\begin{array}{l}22.1 \\
21.5 \\
21.9 \\
22: 4 \\
22.6 \\
22.9 \\
23.0 \\
32.1\end{array}$ & $\begin{array}{l}25.1 \\
24.7 \\
25.8 \\
26.4 \\
25.0 \\
26.7 \\
? 5.8 \\
3.3 .8\end{array}$ & $\begin{array}{l}22.0 \\
21.04 \\
21.9 \\
22.3 \\
22.4 \\
22.5 \\
23.1 \\
22.1\end{array}$ & $\begin{array}{l}29.0 \\
29.0 \\
29.0 \\
29.2 \\
28.6 \\
28.3 \\
27.9 \\
27.8\end{array}$ & & $\begin{array}{l}5.6 \\
5.8 \\
7.2 \\
6.0 \\
2.5 \\
4.1 \\
3.8 \\
1.9\end{array}$ & $\begin{array}{l}6.2 \\
6.5 \\
7.6 \\
6.8 \\
3.9 \\
4.6 \\
4.1 \\
2.3\end{array}$ & $\begin{array}{l}7.2 \\
6.8 \\
8.0 \\
3.0 \\
5.4 \\
5.1 \\
4.6 \\
2.9\end{array}$ & $\begin{array}{r}7.6 \\
7.5 \\
7.9 \\
10.0 \\
7.8 \\
6.6 \\
4.7 \\
3.4\end{array}$ \\
\hline
\end{tabular}


Table 10. - Three-hour averages of air and water-surface temperatures and wind directions and speed, April 1950-August 1951, Lake Hefner-Continued

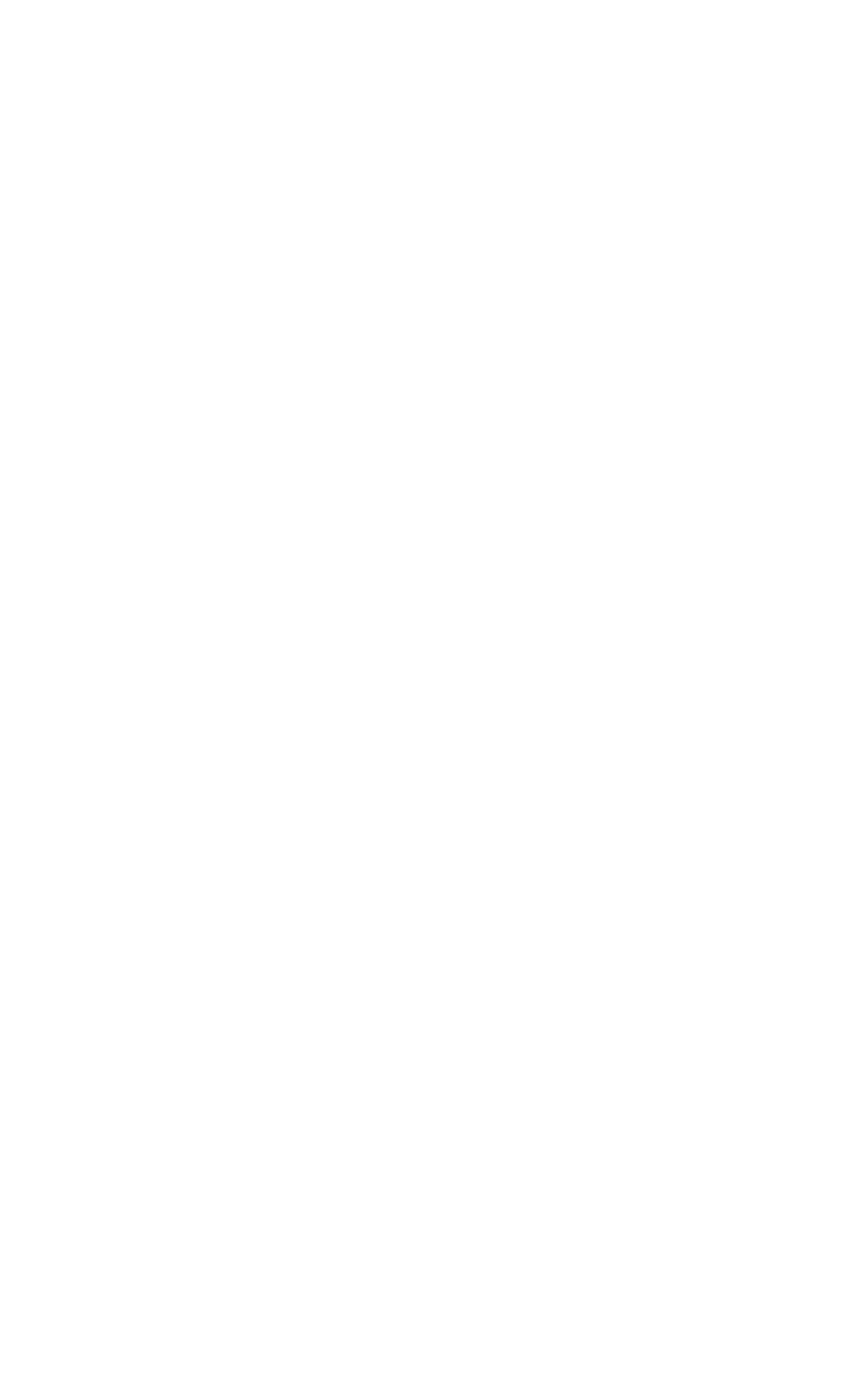


TABLE 10

Table 10. - Three-hour averages of air and water-surface temperatures and wind directions and speed, April 1950-August 1951, Lake Hefner-Continued

STATION 4 THREE-HOURLY AVERAGES

AUGUST, 1951

\begin{tabular}{|c|c|c|c|c|c|c|c|c|c|c|c|c|c|c|c|}
\hline \multirow{3}{*}{ 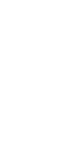 } & \multirow{3}{*}{ 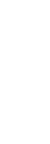 } & \multicolumn{8}{|c|}{ Average air temperature $\left({ }^{\circ} \mathrm{C}\right)$ at indicated height } & \multirow{3}{*}{$\begin{array}{l}\text { Average } \\
\text { water- } \\
\text { surface } \\
\text { tempera- } \\
\text { ture } \\
\left({ }^{\circ} \mathrm{C}\right)\end{array}$} & \multirow{3}{*}{$\begin{array}{l}\text { Average } \\
\text { wind } \\
\text { direction } \\
\text { (coded) }\end{array}$} & \multirow{2}{*}{\multicolumn{4}{|c|}{$\begin{array}{l}\text { Average wind speed (knots) } \\
\text { at indicated height }\end{array}$}} \\
\hline & & \multicolumn{2}{|c|}{$\begin{array}{c}2 \\
\text { meters }\end{array}$} & \multicolumn{2}{|c|}{$\begin{array}{c}4 \\
\text { meters }\end{array}$} & \multicolumn{2}{|c|}{$\begin{array}{c}8 \\
\text { meters }\end{array}$} & \multicolumn{2}{|c|}{$\begin{array}{c}16 \\
\text { meters }\end{array}$} & & & & & & \\
\hline & & $\begin{array}{l}\text { Dry } \\
\text { bulb }\end{array}$ & $\begin{array}{l}\text { Wet } \\
\text { bulb }\end{array}$ & $\begin{array}{l}\text { Dry } \\
\text { bulb }\end{array}$ & $\begin{array}{l}\text { Wet } \\
\text { bulb }\end{array}$ & 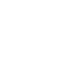 & $\begin{array}{l}\text { Wet } \\
\text { bulb }\end{array}$ & $\begin{array}{l}\text { Dry } \\
\text { bulb }\end{array}$ & $\begin{array}{l}\text { Wet } \\
\text { bulb }\end{array}$ & & & $\begin{array}{c}2 \\
\text { meters }\end{array}$ & $\begin{array}{c}4 \\
\text { meters }\end{array}$ & $\begin{array}{c}8 \\
\text { meter }\end{array}$ & \\
\hline
\end{tabular}

\begin{tabular}{|c|c|c|c|c|c|c|c|c|c|c|c|c|c|c|}
\hline & & & & & & & & & & & meters & meters & meters & \\
\hline $\begin{array}{l}11 \\
11 \\
11 \\
11 \\
11 \\
11 \\
11 \\
11\end{array}$ & $\begin{array}{r}0 \\
3 \\
6 \\
0 \\
12 \\
15 \\
18 \\
21\end{array}$ & & & $\begin{array}{l}20.2 \\
18.6 \\
20.3 \\
22.9 \\
25: 2 \\
27.1 \\
26.3 \\
24.5\end{array}$ & $\begin{array}{l}18.9 \\
18.5 \\
10.1 \\
20.7 \\
21.9 \\
22.3 \\
22.7 \\
22.3\end{array}$ & $\begin{array}{l}19.7 \\
18.5 \\
20.2 \\
22.6 \\
24.8 \\
27.1 \\
26.0 \\
24.1\end{array}$ & $\begin{array}{l}13.7 \\
18.3 \\
19.1 \\
20.6 \\
21.9 \\
22.2 \\
22.5 \\
22.2\end{array}$ & $\begin{array}{l}19 \cdot: \\
13: 3 \\
19: 7 \\
22: 5 \\
24 \cdot 8 \\
27 \cdot 0 \\
25: 0 \\
2401\end{array}$ & $\begin{array}{l}18.7 \\
18.2 \\
19.0 \\
20.7 \\
21.9 \\
22.4 \\
22.7 \\
22.2\end{array}$ & $\begin{array}{l}26.3 \\
25.2 \\
26.4 \\
27.1 \\
28.5 \\
28.8 \\
28.0 \\
27.8\end{array}$ & $\begin{array}{l}3.0 \\
3.4 \\
2.6 \\
4.1 \\
4.5 \\
4.6 \\
4.8 \\
5.5\end{array}$ & $\begin{array}{l}3.5 \\
3.8 \\
2.9 \\
4.2 \\
5.0 \\
5.1 \\
5.2 \\
5.0\end{array}$ & $\begin{array}{l}4.3 \\
4.6 \\
3.7 \\
4.5 \\
5.6 \\
5.8 \\
5.9 \\
6.8\end{array}$ & $\begin{array}{l}5.2 \\
6.1 \\
3.8 \\
4: 7 \\
6.0 \\
5.8 \\
6.3 \\
7.4\end{array}$ \\
\hline $\begin{array}{l}12 \\
12 \\
12 \\
12 \\
12 \\
12 \\
12 \\
12\end{array}$ & $\begin{array}{r}0 . \\
3 \\
6 \\
9 \\
12 \\
15 \\
18 \\
21\end{array}$ & & & $\begin{array}{l}23.4 \\
22: 9 \\
23.7 \\
26: 9 \\
30.7 \\
31.8 \\
29.1 \\
27.1\end{array}$ & $\begin{array}{l}21.9 \\
21.6 \\
21.6 \\
22.1 \\
23.1 \\
23.4 \\
24.1 \\
23.3\end{array}$ & $\begin{array}{r}22.9 \\
22.6 \\
23.3 \\
26.7 \\
31.2 \\
31.2 \\
29.0 \\
27.1\end{array}$ & 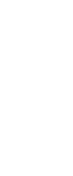 & $\begin{array}{l}22.8 \\
22.8 \\
23.4 \\
27 \cdot 0 \\
31 \cdot 0 \\
31 \cdot 0 \\
28 \cdot 9 \\
26.9\end{array}$ & $\begin{array}{l}21.8 \\
21.6 \\
21.5 \\
23.4 \\
23.3 \\
23.7 \\
24.0 \\
23.3\end{array}$ & $\begin{array}{l}27.5 \\
27.3 \\
27.4 \\
28.9 \\
31.9 \\
37.1 \\
29.5 \\
28.6\end{array}$ & $\begin{array}{l}5.5 \\
5.4 \\
4.1 \\
1.9 \\
1.1 \\
4.1 \\
6.2 \\
7.5\end{array}$ & $\begin{array}{l}6.1 \\
5.1 \\
4.6 \\
2.1 \\
1.5 \\
4.5 \\
6.8 \\
3.4\end{array}$ & $\begin{array}{l}7.0 \\
7.0 \\
5.4 \\
? .4 \\
1.6 \\
5.1 \\
7.9 \\
9.9\end{array}$ & $\begin{array}{r}7.4 \\
7.3 \\
5.5 \\
2.4 \\
1.8 \\
6.5 \\
8.6 \\
10.7\end{array}$ \\
\hline $\begin{array}{l}13 \\
13 \\
13 \\
13 \\
13 \\
13 \\
13 \\
13\end{array}$ & $\begin{array}{r}0 \\
3 \\
6 \\
9 \\
12 \\
15 \\
18 \\
21\end{array}$ & $\cdot$ & & $\begin{array}{l}25.8 \\
24.5 \\
24.4 \\
25.8 \\
30.8 \\
33.7 \\
30.9 \\
28.8\end{array}$ & $\begin{array}{l}22.7 \\
21.7 \\
21.4 \\
21.7 \\
22.4 \\
22.3 \\
23.2 \\
? ? .1\end{array}$ & $\begin{array}{l}25.5 \\
24.2 \\
23.9 \\
25 \cdot 7 \\
31 \cdot 2 \\
34 \cdot 0 \\
31 \cdot 3 \\
29.8\end{array}$ & $\begin{array}{l}22 \cdot 5 \\
21 \cdot 7 \\
21: 3 \\
21: 7 \\
22: 3 \\
21 \cdot 7 \\
22 \cdot 5 \\
21 \cdot 3\end{array}$ & $\begin{array}{l}25.3 \\
23: 0 \\
23 \cdot 5 \\
25.7 \\
31 \cdot 3 \\
34 \cdot 2 \\
31 \cdot 3 \\
29.0\end{array}$ & 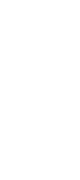 & $\begin{array}{l}28.4 \\
28.3 \\
27.9 \\
27.9 \\
29.1 \\
29.9 \\
28.8 \\
38.1\end{array}$ & $\begin{array}{r}8.3 \\
8.7 \\
7.8 \\
10.2 \\
8.3 \\
4.2 \\
4.0 \\
8.0\end{array}$ & $\begin{array}{r}9.4 \\
9.8 \\
8.6 \\
11.4 \\
9.5 \\
4.8 \\
4.9 \\
9.3\end{array}$ & $\begin{array}{r}10.7 \\
10.8 \\
0.5 \\
13.1 \\
10.3 \\
5.0 \\
7.0 \\
10.6\end{array}$ & $\begin{array}{r}11.6 \\
11.8 \\
10.7 \\
13.4 \\
11.8 \\
6.0 \\
7.9 \\
17.1\end{array}$ \\
\hline $\begin{array}{l}14 \\
14 \\
14 \\
14 \\
14 \\
14 \\
14 \\
14\end{array}$ & $\begin{array}{r}0 \\
3 \\
6 \\
9 \\
12 \\
15 \\
18 \\
21\end{array}$ & & & $\begin{array}{l}27.3 \\
25.6 \\
25.3 \\
30.9 \\
33.6 \\
34: 2 \\
31.5 \\
29.5\end{array}$ & $\begin{array}{l}21 \cdot 0 \\
23 \cdot 7 \\
21: 3 \\
21: 4 \\
21: 6 \\
22: 3 \\
22: 8 \\
22: 3\end{array}$ & $\begin{array}{l}27 \cdot 3 \\
25: 5 \\
25: 2 \\
32: 2 \\
24: 0 \\
34: 4 \\
32: 1 \\
39: 7\end{array}$ & 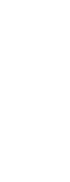 & $\begin{array}{l}27.0 \\
26.5 \\
35: 7 \\
31.6 \\
34: 0 \\
35.0 \\
32.0 \\
29.0\end{array}$ & 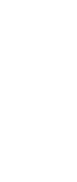 & $\begin{array}{l}77: 6 \\
77: 3 \\
77: 2 \\
27: 0 \\
28: 0 \\
70: 2 \\
27.7 \\
77.6\end{array}$ & $\begin{array}{r}11.5 \\
11.3 \\
9.6 \\
12.9 \\
12.1 \\
10.1 \\
6.4 \\
9.7\end{array}$ & $\begin{array}{r}13.2 \\
13.0 \\
10.8 \\
14.0 \\
13.4 \\
11.6 \\
7.8 \\
11.2\end{array}$ & $\begin{array}{r}15.0 \\
14.4 \\
11.7 \\
13.5 \\
13.4 \\
12.5 \\
0.5 \\
13.0\end{array}$ & $\begin{array}{l}16.7 \\
16.1 \\
12.7 \\
16.0 \\
15.6 \\
14.9 \\
11.3 \\
15.1\end{array}$ \\
\hline $\begin{array}{l}15 \\
15 \\
15 \\
15 \\
15 \\
15 \\
15 \\
15\end{array}$ & $\begin{array}{r}0 \\
3 \\
5 \\
9 \\
12 \\
15 \\
10 \\
21\end{array}$ & - & & $\begin{array}{l}27.7 \\
25.8 \\
26.4 \\
30.6 \\
20.8 \\
30.0 \\
26.7 \\
22.9\end{array}$ & $\begin{array}{l}21.8 \\
21: 0 \\
21: 9 \\
22: 3 \\
21: 8 \\
21 \cdot 2 \\
19: 5 \\
18: 1\end{array}$ & $\begin{array}{l}27.6 \\
25.5 \\
25.6 \\
30.6 \\
29.9 \\
30.2 \\
26.4 \\
7 ? .3\end{array}$ & $\begin{array}{l}21.4 \\
20.8 \\
22 \cdot 1 \\
22 \cdot 1 \\
21.6 \\
21.1 \\
19 \cdot 3 \\
18.0\end{array}$ & $\begin{array}{l}27.4 \\
25.5 \\
26.5 \\
30.2 \\
20.2 \\
29.5 \\
26.0 \\
22.2\end{array}$ & $\begin{array}{l}21.7 \\
20: 7 \\
21.3 \\
22.5 \\
21.9 \\
21.6 \\
19.9 \\
18.3\end{array}$ & $\begin{array}{l}27.3 \\
27.0 \\
27.1 \\
28.4 \\
28.0 \\
27.6 \\
26.8 \\
26.8\end{array}$ & $\begin{array}{r}10.1 \\
6.1 \\
3.4 \\
3.2 \\
7.0 \\
6.4 \\
6.9 \\
3.8\end{array}$ & $\begin{array}{r}11.5 \\
6.6 \\
4.4 \\
4.6 \\
8.0 \\
7.3 \\
7.7 \\
4.2\end{array}$ & $\begin{array}{r}13.0 \\
7.0 \\
4.4 \\
6.1 \\
0.1 \\
7.4 \\
0.3 \\
4.9\end{array}$ & $\begin{array}{r}14.6 \\
7.3 \\
4.9 \\
8.2 \\
12.7 \\
11.5 \\
13.0 \\
7.2\end{array}$ \\
\hline $\begin{array}{l}16 \\
15 \\
16 \\
16 \\
16 \\
16 \\
16 \\
16\end{array}$ & $\begin{array}{r}\hat{3} \\
3 \\
6 \\
9 \\
12 \\
15 \\
18 \\
21\end{array}$ & & & $\begin{array}{l}21.0 \\
19.6 \\
20.7 \\
24.7 \\
27.9 \\
30.9 \\
29.6 \\
25.8\end{array}$ & $\begin{array}{l}17.9 \\
17: 0 \\
18: 1 \\
18: 8 \\
20: 0 \\
22.0 \\
23.8 \\
32.9\end{array}$ & $\begin{array}{l}20.3 \\
20.8 \\
20.3 \\
24.5 \\
28.0 \\
31.2 \\
20.7 \\
26.8\end{array}$ & $\begin{array}{l}17.7 \\
17.4 \\
18: 0 \\
18.3 \\
19.7 \\
21.7 \\
33.5 \\
20.5\end{array}$ & $\begin{array}{l}20.2 \\
18.6 \\
20.2 \\
24 \cdot 5 \\
28.1 \\
31.3 \\
30.0 \\
? 7.0\end{array}$ & $\begin{array}{l}17 \cdot 7 \\
17 \cdot 3 \\
17 \cdot 9 \\
18 \cdot 3 \\
29 \cdot 8 \\
2 ? .0 \\
23.3 \\
2 ? .4\end{array}$ & $\begin{array}{l}26.9 \\
26.5 \\
26.5 \\
27.1 \\
27.9 \\
28.0 \\
27.3 \\
77.0\end{array}$ & $\begin{array}{l}1.6 \\
0.0 \\
4.8 \\
8.2 \\
6.8 \\
5.9 \\
4.2 \\
6.9\end{array}$ & $\begin{array}{l}1.7 \\
1.5 \\
5.3 \\
8.9 \\
7.7 \\
5.6 \\
4.9 \\
7.7\end{array}$ & $\begin{array}{l}0.4 \\
2.6 \\
5.8 \\
9.9 \\
0.9 \\
7.6 \\
5.8 \\
0.1\end{array}$ & $\begin{array}{r}4.4 \\
4.8 \\
6.6 \\
10.3 \\
9.3 \\
7.7 \\
7.0 \\
10.6\end{array}$ \\
\hline $\begin{array}{l}17 \\
17 \\
17 \\
17 \\
17 \\
17 \\
17 \\
17\end{array}$ & $\begin{array}{r}0 \\
3 \\
6 \\
9 \\
12 \\
15 \\
18 \\
21\end{array}$ & & & $\begin{array}{l}26.9 \\
26.5 \\
28.4 \\
32.0 \\
35.7 \\
36.2 \\
30.6 \\
26.6\end{array}$ & $\begin{array}{l}23.0 \\
22.1 \\
21.1 \\
21.8 \\
22.1 \\
22.5 \\
20.6 \\
19.5\end{array}$ & $\begin{array}{l}26.9 \\
26.5 \\
20.5 \\
3.2 \cdot 5 \\
36.3 \\
37.3 \\
31.2 \\
26.7\end{array}$ & $\begin{array}{lll}2 & 2 & 0 \\
2 & 1 & 0 \\
2 & 0 & 0 \\
2 & 1 & 2 \\
21 & 0 \\
22 & 0 \\
20 & 0 \\
1 & 0 & 1\end{array}$ & 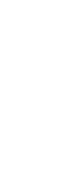 & 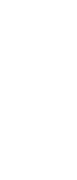 & $\begin{array}{l}26.9 \\
26.9 \\
27.1 \\
27.7 \\
27.9 \\
27.9 \\
27.2 \\
26.9\end{array}$ & $\begin{array}{r}7.0 \\
8.5 \\
14.8 \\
16.5 \\
14.3 \\
11.1 \\
5.9 \\
2.8\end{array}$ & $\begin{array}{r}7.9 \\
9.5 \\
15.3 \\
18.1 \\
15.8 \\
12.7 \\
7.5 \\
3.7\end{array}$ & $\begin{array}{r}9.2 \\
10.0 \\
15.3 \\
17.6 \\
15.7 \\
13.3 \\
11.5 \\
5.3\end{array}$ & $\begin{array}{r}10.1 \\
11.5 \\
17.5 \\
20.4 \\
18.2 \\
16.0 \\
14.1 \\
7.0\end{array}$ \\
\hline $\begin{array}{l}19 \\
18 \\
18 \\
18 \\
18 \\
18 \\
18 \\
18\end{array}$ & $\begin{array}{r}0 \\
3 \\
6 \\
9 \\
12 \\
15 \\
18 \\
21\end{array}$ & & $\therefore$ & $\begin{array}{l}26.2 \\
24.6 \\
23.5 \\
26.4 \\
29.0 \\
30.2 \\
28.8 \\
26.1\end{array}$ & $\begin{array}{l}21.4 \\
22.8 \\
22.0 \\
23.1 \\
24.1 \\
23.7 \\
23.4 \\
? 2.6\end{array}$ & $\left|\begin{array}{l}25.0 \\
24.3 \\
23.1 \\
25.1 \\
20.2 \\
30.5 \\
29.3 \\
25.9\end{array}\right|$ & 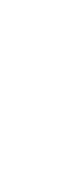 & $\begin{array}{l}25.0 \\
24.1 \\
23.0 \\
26.3 \\
27.8 \\
30.5 \\
28.5 \\
25.5\end{array}$ & $\begin{array}{l}21.3 \\
22.6 \\
22.0 \\
23.2 \\
24.2 \\
23.0 \\
23.5 \\
22.4\end{array}$ & $\begin{array}{l}76.8 \\
76.7 \\
26.8 \\
27.5 \\
23.5 \\
73.6 \\
37.9 \\
77.0\end{array}$ & $\begin{array}{l}4.0 \\
2.5 \\
2.8 \\
4.8 \\
3.3 \\
2.0 \\
5.4 \\
6.2\end{array}$ & $\begin{array}{l}5.6 \\
2.6 \\
4.0 \\
5.2 \\
3.2 \\
2.3 \\
5.0 \\
5 . ?\end{array}$ & $\begin{array}{l}6.6 \\
3.2 \\
6.5 \\
5.7 \\
4.8 \\
2.4 \\
6.7 \\
2.0\end{array}$ & $\begin{array}{l}8.6 \\
3.3 \\
8.9 \\
5.7 \\
5.9 \\
2.6 \\
7.3 \\
3.9\end{array}$ \\
\hline $\begin{array}{l}19 \\
19 \\
19 \\
19 \\
19 \\
19 \\
19 \\
19\end{array}$ & $\begin{array}{r}0 \\
3 \\
6 \\
9 \\
12 \\
15 \\
18 \\
21\end{array}$ & & & $\begin{array}{l}25 \cdot 4 \\
24 \cdot 0 \\
24.5 \\
28.7 \\
31.5\end{array}$ & $\begin{array}{l}21 \cdot 3 \\
21 \cdot 0 \\
21: 3 \\
22.5 \\
22.5\end{array}$ & $\begin{array}{l}24.0 \\
23.5 \\
24.1 \\
28.0 \\
31.8\end{array}$ & $\begin{array}{l}21.8 \\
20.3 \\
21.2 \\
2 ? .1 \\
22.5\end{array}$ & $\begin{array}{l}24 \cdot 5 \\
23.3 \\
24.1 \\
29.0 \\
31.5\end{array}$ & $\begin{array}{l}21.7 \\
20.9 \\
21.4 \\
22: 07 \\
23.7\end{array}$ & $\begin{array}{l}26.9 \\
27.0 \\
27.1 \\
23.2 \\
29.8\end{array}$ & $\begin{array}{l}4.9 \\
2.1 \\
3.3 \\
3.8 \\
3.6 \\
3.6 \\
4.3 \\
7.7\end{array}$ & $\begin{array}{l}5.5 \\
9.0 \\
9.3 \\
4 . ? \\
4.2 \\
4.3 \\
5.1 \\
8.7\end{array}$ & $\begin{array}{r}5.2 \\
17.4 \\
\because .8 \\
4.6 \\
4.5 \\
4.7 \\
6.2 \\
0.8\end{array}$ & $\begin{array}{r}6.8 \\
11.1 \\
10.8 \\
5.2 \\
5.1 \\
5.5 \\
7.8 \\
11.2\end{array}$ \\
\hline $\begin{array}{l}20 \\
20 \\
20 \\
20 \\
20 \\
20 \\
20 \\
20\end{array}$ & $\begin{array}{r}0 \\
3 \\
6 \\
9 \\
12 \\
15 \\
18 \\
21\end{array}$ & & & $\begin{array}{l}25.6 \\
27: 9 \\
30: 8 \\
32.0 \\
30.0 \\
27.6\end{array}$ & $\begin{array}{l}21.5 \\
22.2 \\
22.1 \\
23.0 \\
23.3 \\
22.6\end{array}$ & $\begin{array}{l}24.9 \\
28.0 \\
31.0 \\
32.1 \\
30.0 \\
27.7\end{array}$ & $\begin{array}{l}21 \cdot 2 \\
21 \cdot 9 \\
21 \cdot 5 \\
27 \cdot 3 \\
24 \cdot 3 \\
27.5\end{array}$ & $\begin{array}{l}24 \cdot 0 \\
28.0 \\
31.0 \\
32 \cdot 2 \\
30.5 \\
27.8\end{array}$ & 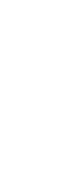 & $\begin{array}{l}28.3 \\
29.5 \\
28.9 \\
28.8 \\
28.3 \\
77.9\end{array}$ & $\begin{array}{r}10.1 \\
9.6 \\
9.1 \\
13.0 \\
11.8 \\
9.4 \\
4.4 \\
5.1\end{array}$ & $\begin{array}{r}19.2 \\
10.5 \\
10.0 \\
14.3 \\
13.1 \\
0.6 \\
5.6 \\
5.9\end{array}$ & $\begin{array}{r}11.5 \\
10: 5 \\
14.8 \\
13: 3 \\
13: 1 \\
10: 5 \\
6.5 \\
6.6\end{array}$ & $\begin{array}{r}13.0 \\
11.9 \\
11.0 \\
16.5 \\
15.3 \\
11.0 \\
8.5 \\
3.0\end{array}$ \\
\hline
\end{tabular}


Table 10. - Three-hour averages of air and water-surface temperatures and wind directions and speed, Apri1 1950-August 1951, Lake Hefner - Continued

STATION 4

THREE-HOURLY AVERAGES

AUGUST, 1951

\begin{tabular}{|c|c|c|c|c|c|c|c|c|c|c|c|c|c|c|c|}
\hline \multirow{4}{*}{ 密菩 } & \multirow{4}{*}{ 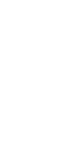 } & \multicolumn{8}{|c|}{ Average air temperature $\left({ }^{\circ} \mathrm{C}\right)$ at indicated height } & \multirow{4}{*}{$\begin{array}{l}\text { Average } \\
\text { water- } \\
\text { surface } \\
\text { tempera- } \\
\text { ture } \\
\text { (ㄷ) }\end{array}$} & \multirow{4}{*}{$\begin{array}{c}\text { Average } \\
\text { wind } \\
\text { direction } \\
\text { (coded) }\end{array}$} & \multirow{2}{*}{\multicolumn{4}{|c|}{$\begin{array}{l}\text { Average wind speed (knots) } \\
\text { at indicated height }\end{array}$}} \\
\hline & & \multirow{2}{*}{\multicolumn{2}{|c|}{$\stackrel{2}{\text { meters }}$}} & \multirow{2}{*}{\multicolumn{2}{|c|}{$\stackrel{\text { A }}{\text { meters }}$}} & \multirow{2}{*}{\multicolumn{2}{|c|}{$\begin{array}{c}8 \\
\text { meters }\end{array}$}} & \multirow{2}{*}{\multicolumn{2}{|c|}{$\begin{array}{c}16 \\
\text { meters }\end{array}$}} & & & & & & \\
\hline & & & & & & & & & & & & 2 & 4 & 8 & 16 \\
\hline & & $\begin{array}{l}\text { Dry } \\
\text { bulb }\end{array}$ & $\begin{array}{l}\text { Wet } \\
\text { bulb }\end{array}$ & $\begin{array}{l}\text { Dry } \\
\text { bnIb }\end{array}$ & $\begin{array}{l}\text { Wet } \\
\text { bulb }\end{array}$ & $\begin{array}{l}\text { Dry } \\
\text { bulb }\end{array}$ & $\begin{array}{l}\text { Wet } \\
\text { bulb }\end{array}$ & $\begin{array}{l}\text { Dry } \\
\text { bulb }\end{array}$ & $\begin{array}{l}\text { Wet } \\
\text { bulb }\end{array}$ & & & meters & meters & meters & meters \\
\hline $\begin{array}{l}21 \\
21 \\
21 \\
21 \\
21 \\
21 \\
21 \\
21\end{array}$ & $\begin{array}{r}0 \\
3 \\
6 \\
9 \\
12 \\
15 \\
18 \\
21\end{array}$ & & & $\begin{array}{l}26.5 \\
23.9 \\
21.2 \\
21.3 \\
22.6 \\
23.5 \\
22.0 \\
20.4\end{array}$ & $\begin{array}{l}21.5 \\
21: 0 \\
20.1 \\
20.3 \\
21.3 \\
21.2 \\
19.7 \\
18.1\end{array}$ & $\begin{array}{l}26.4 \\
23.3 \\
20.7 \\
20.8 \\
22.4 \\
23.0 \\
21.5 \\
19.7\end{array}$ & $\begin{array}{l}21.2 \\
21: 1 \\
19: 9 \\
20.1 \\
21.3 \\
20.0 \\
19.5 \\
17.3\end{array}$ & $\begin{array}{l}26 \cdot 1 \\
23.1 \\
20.4 \\
20.6 \\
22.2 \\
22.7 \\
21.3 \\
19.5\end{array}$ & $\begin{array}{l}21.0 \\
21.1 \\
19.7 \\
20.0 \\
20.8 \\
20.9 \\
19.3 \\
17.6\end{array}$ & $\begin{array}{l}27.7 \\
27.2 \\
26.8 \\
26.4 \\
26.7 \\
26.6 \\
26.02 \\
26.1\end{array}$ & & $\begin{array}{l}6.9 \\
3.0 \\
7.5 \\
6.1 \\
6.7 \\
6.6 \\
6.7 \\
4.0\end{array}$ & $\begin{array}{l}7.5 \\
3.9 \\
8.4 \\
6.6 \\
7.3 \\
8.0 \\
7.3 \\
4.6\end{array}$ & $\begin{array}{l}7.7 \\
5.9 \\
9.4 \\
7.1 \\
7.8 \\
9.8 \\
7.7 \\
5.2\end{array}$ & $\begin{array}{r}8.9 \\
8.5 \\
12.1 \\
8.1 \\
10.4 \\
12.3 \\
10.2 \\
7.3\end{array}$ \\
\hline $\begin{array}{l}22 \\
22 \\
22 \\
22 \\
22 \\
22 \\
22 \\
22\end{array}$ & $\begin{array}{r}0 \\
3 \\
6 \\
9 \\
12 \\
15 \\
18 \\
21\end{array}$ & & & $\begin{array}{l}19.1 \\
18.9 \\
19.0 \\
19.0 \\
22.1 \\
22.7 \\
22.6 \\
21.7\end{array}$ & $\begin{array}{l}16.9 \\
16.5 \\
16.6 \\
17.5 \\
20.0 \\
21.0 \\
21.0 \\
20.8\end{array}$ & $\begin{array}{l}18.5 \\
18.1 \\
18.2 \\
18.7 \\
21.8 \\
22.2 \\
22.1 \\
21.3\end{array}$ & $\begin{array}{l}16.6 \\
16.2 \\
16.2 \\
17.2 \\
19.9 \\
20.9 \\
20.8 \\
20.6\end{array}$ & $\begin{array}{l}18 \cdot 3 \\
17.0 \\
18 \cdot 0 \\
18 \cdot 5 \\
21.7 \\
22.0 \\
21: 9 \\
21.0\end{array}$ & $\begin{array}{l}16.3 \\
15.8 \\
16.0 \\
17.2 \\
10.9 \\
20.8 \\
20.6 \\
20.2\end{array}$ & $\begin{array}{l}26.2 \\
25.0 \\
26.1 \\
26.2 \\
25.7 \\
26.5 \\
25.0 \\
25.9\end{array}$ & & $\begin{array}{l}2.9 \\
1.7 \\
2.8 \\
7.3 \\
4.3 \\
5.5 \\
6.7 \\
5.4\end{array}$ & $\begin{array}{l}3.3 \\
2.2 \\
3.4 \\
7.8 \\
4.6 \\
5.0 \\
7.3 \\
5.9\end{array}$ & $\begin{array}{l}3.8 \\
? .7 \\
4.0 \\
0.7 \\
5.3 \\
8.5 \\
6.4 \\
6.6\end{array}$ & $\begin{array}{l}5.2 \\
4.1 \\
5.4 \\
8.0 \\
5.2 \\
6.4 \\
3.5 \\
6.9\end{array}$ \\
\hline $\begin{array}{l}23 \\
23 \\
23 \\
23 \\
23 \\
23 \\
23 \\
23\end{array}$ & $\begin{array}{r}0 \\
3 \\
6 \\
9 \\
12 \\
15 \\
18 \\
21\end{array}$ & & & $\begin{array}{l}21.6 \\
21.9 \\
21.9 \\
22.7 \\
25.9 \\
27.4 \\
27.0 \\
25.8\end{array}$ & $\begin{array}{l}20.5 \\
21.01 \\
21.02 \\
21.06 \\
23.0 \\
23.5 \\
23.6 \\
23.1\end{array}$ & $\begin{array}{l}21.2 \\
21.4 \\
21.6 \\
22.3 \\
25.8 \\
27.6 \\
26.9 \\
25.6\end{array}$ & $\begin{array}{l}20.6 \\
20.5 \\
20.6 \\
21.2 \\
22.6 \\
23.1 \\
23.4 \\
22.8\end{array}$ & $\begin{array}{l}21 \cdot 1 \\
21: 3 \\
21: 4 \\
22 \cdot 3 \\
25: 7 \\
27: 7 \\
27: 0 \\
25 \cdot 4\end{array}$ & $\begin{array}{l}20.2 \\
20.8 \\
21.0 \\
21.5 \\
22.6 \\
23.1 \\
23.2 \\
22.7\end{array}$ & $\begin{array}{l}25.9 \\
25.9 \\
25.7 \\
25.8 \\
26.1 \\
26.5 \\
26.2 \\
25.9\end{array}$ & & $\begin{array}{r}5.9 \\
10.0 \\
8.0 \\
9.5 \\
8.0 \\
7.0 \\
6.5 \\
10.9\end{array}$ & $\begin{array}{r}6.6 \\
11.2 \\
8.9 \\
10.6 \\
9.0 \\
8.8 \\
7.4 \\
12.4\end{array}$ & $\begin{array}{r}7.0 \\
12: 9 \\
10.0 \\
12.6 \\
9.8 \\
10.5 \\
8.8 \\
14.7\end{array}$ & $\begin{array}{r}7.0 \\
13.3 \\
11.1 \\
10.9 \\
11.6 \\
9.8 \\
15.8\end{array}$ \\
\hline $\begin{array}{l}24 \\
24 \\
24 \\
24 \\
24 \\
24 \\
24 \\
24\end{array}$ & $\begin{array}{r}0 \\
3 \\
6 \\
9 \\
12 \\
15 \\
18 \\
21\end{array}$ & & & $\begin{array}{l}25.2 \\
23.9 \\
23.7 \\
26.3 \\
29.6 \\
30.7 \\
29.0 \\
27.7\end{array}$ & $\begin{array}{l}22.5 \\
21.9 \\
21.9 \\
23.0 \\
23.0 \\
24.0 \\
24.3 \\
23.4\end{array}$ & $\begin{array}{l}24.7 \\
23.4 \\
23.2 \\
26.4 \\
30.1 \\
31.1 \\
29.3 \\
27.7\end{array}$ & $\begin{array}{l}22.01 \\
21: 7 \\
21.7 \\
22.7 \\
23.0 \\
23.5 \\
23.8 \\
23.0\end{array}$ & $\begin{array}{l}24 \cdot 5 \\
23 \cdot 1 \\
23 \cdot 1 \\
26 \cdot 4 \\
30 \cdot 0 \\
31 \cdot 3 \\
29 \cdot 6 \\
27.6\end{array}$ & $\begin{array}{l}22.0 \\
21.6 \\
21.5 \\
22.6 \\
22.9 \\
23.3 \\
23.6 \\
22.9\end{array}$ & $\begin{array}{l}25.8 \\
25.7 \\
25.9 \\
26.7 \\
27.9 \\
27.2 \\
26.8 \\
26.5\end{array}$ & & $\begin{array}{r}11.7 \\
11.0 \\
12.4 \\
11.9 \\
10.4 \\
9.6 \\
6.4 \\
10.7\end{array}$ & $\begin{array}{r}13.4 \\
12.7 \\
14.6 \\
13.6 \\
11.6 \\
11.2 \\
7.6 \\
12.4\end{array}$ & $\begin{array}{r}15.5 \\
14.3 \\
16.5 \\
14.8 \\
12.1 \\
12.0 \\
9.4 \\
14.6\end{array}$ & $\begin{array}{l}17.0 \\
15: 6 \\
17: 9 \\
16: 9 \\
14.0 \\
14: 1 \\
11.3 \\
16.2\end{array}$ \\
\hline $\begin{array}{l}25 \\
25 \\
25 \\
25 \\
25 \\
25 \\
25 \\
25\end{array}$ & $\begin{array}{r}0 \\
3 \\
6 \\
9 \\
12 \\
15 \\
18 \\
21\end{array}$ & & & $\begin{array}{l}26.1 \\
25.3 \\
25.2 \\
28.0 \\
30.7 \\
31.7 \\
29.1 \\
28.5\end{array}$ & $\begin{array}{l}22.7 \\
21.9 \\
21.8 \\
22.8 \\
23.7 \\
24.1 \\
24.3 \\
23.1\end{array}$ & $\begin{array}{l}25.9 \\
24.7 \\
25.1 \\
28.2 \\
31.1 \\
32.0 \\
29.7 \\
28.5\end{array}$ & $\begin{array}{l}22.4 \\
21.6 \\
21.3 \\
22.3 \\
23.2 \\
23.5 \\
23.7 \\
22.5\end{array}$ & $\begin{array}{l}25.7 \\
24 \cdot 6 \\
25: 0 \\
23 \cdot 3 \\
31 \cdot 2 \\
32.5 \\
30.4 \\
78.8\end{array}$ & $\begin{array}{l}22.2 \\
21.5 \\
21.5 \\
22.4 \\
23.1 \\
23.5 \\
23.3 \\
22.5\end{array}$ & $\begin{array}{l}26.0 \\
25.9 \\
26.0 \\
27.0 \\
23.0 \\
27.3 \\
27.0 \\
26.6\end{array}$ & & $\begin{array}{r}11.9 \\
12.0 \\
14.7 \\
11.1 \\
12.0 \\
8.7 \\
4.2 \\
9.6\end{array}$ & $\begin{array}{r}13.7 \\
13.8 \\
16.3 \\
12.7 \\
13.5 \\
10.1 \\
5.0 \\
11.1\end{array}$ & $\begin{array}{r}15.6 \\
15.8 \\
18.1 \\
13.9 \\
13.8 \\
11.1 \\
6.9 \\
13.1\end{array}$ & $\begin{array}{r}17.3 \\
17.3 \\
20.2 \\
15.8 \\
16.2 \\
13.1 \\
8.9 \\
14.9\end{array}$ \\
\hline $\begin{array}{l}26 \\
26 \\
26 \\
26 \\
26 \\
26 \\
26 \\
25\end{array}$ & $\begin{array}{r}0 \\
3 \\
6 \\
9 \\
12 \\
15 \\
18 \\
21\end{array}$ & & & $\begin{array}{l}26.9 \\
25.9 \\
25.6 \\
29.2 \\
31.6 \\
32.0 \\
27.0 \\
26.9\end{array}$ & $\begin{array}{l}22.1 \\
21.7 \\
21.4 \\
22.9 \\
23.2 \\
23.5 \\
23.2 \\
23.4\end{array}$ & $\begin{array}{l}26.0 \\
25.8 \\
25.5 \\
20.7 \\
32.1 \\
37.5 \\
26.8 \\
27.0\end{array}$ & $\begin{array}{l}21.6 \\
21.1 \\
21.2 \\
22.7 \\
23.0 \\
23.0 \\
23.0 \\
23.0\end{array}$ & $\begin{array}{l}25.8 \\
25,5 \\
2505 \\
20.5 \\
32.7 \\
32.5 \\
26.6 \\
27,1\end{array}$ & $\begin{array}{l}21 \cdot 6 \\
21 \cdot 01 \\
21 \cdot 1 \\
22.6 \\
22.7 \\
23.2 \\
23.0 \\
23.0\end{array}$ & $\begin{array}{l}26.1 \\
25.8 \\
25.1 \\
27.4 \\
27.7 \\
27.2 \\
28.3 \\
26.3\end{array}$ & & $\begin{array}{r}10.9 \\
11.9 \\
9.7 \\
10.8 \\
10.8 \\
7.1 \\
7.3 \\
7.2\end{array}$ & $\begin{array}{r}12.5 \\
13.7 \\
10.9 \\
11.9 \\
12.0 \\
8.0 \\
8.0 \\
8 . ?\end{array}$ & $\begin{array}{r}14.6 \\
15.4 \\
11.5 \\
11.7 \\
12.1 \\
8.2 \\
8.9 \\
9.5\end{array}$ & $\begin{array}{r}16.2 \\
17.4 \\
13.0 \\
13.5 \\
14.0 \\
9.8 \\
9.8 \\
10.9\end{array}$ \\
\hline $\begin{array}{l}27 \\
27 \\
27 \\
27 \\
27 \\
27 \\
27 \\
27\end{array}$ & $\begin{array}{r}0 \\
3 \\
6 \\
9 \\
12 \\
15 \\
19 \\
21\end{array}$ & & & $\begin{array}{l}26.8 \\
25.7 \\
26.2 \\
29.6 \\
32.0 \\
32.9 \\
30.8 \\
29.6\end{array}$ & $\begin{array}{l}22.3 \\
21.6 \\
21.6 \\
22.1 \\
22.5 \\
27.5 \\
23.2 \\
21.8\end{array}$ & $\begin{array}{l}26.7 \\
25.3 \\
26.2 \\
29.8 \\
32.7 \\
33.6 \\
31.3 \\
29.7\end{array}$ & $\begin{array}{l}21 \cdot 8 \\
21 \cdot 2 \\
21: 2 \\
21.8 \\
22.1 \\
22.5 \\
22.7 \\
? 1.5\end{array}$ & $\begin{array}{l}26 \cdot 6 \\
25: 2 \\
26: 3 \\
30: 0 \\
32.8 \\
33.6 \\
32: 1 \\
29.0\end{array}$ & $\begin{array}{l}21.7 \\
21.2 \\
21.2 \\
21.5 \\
22.0 \\
23.5 \\
3 ? \cdot 3 \\
21.4\end{array}$ & $\begin{array}{l}26.2 \\
26.0 \\
26.2 \\
27.2 \\
27.7 \\
27.1 \\
28.8 \\
26.5\end{array}$ & & $\begin{array}{r}9.8 \\
10.0 \\
12.0 \\
15.2 \\
11.8 \\
10.9 \\
6.4 \\
13.0\end{array}$ & $\begin{array}{l}11.2 \\
11.3 \\
13.6 \\
16.6 \\
13.1 \\
12.6 \\
7.9 \\
15.0\end{array}$ & $\begin{array}{r}12.5 \\
12.1 \\
14.0 \\
16.4 \\
13.4 \\
13.5 \\
9.7 \\
17.6\end{array}$ & $\begin{array}{l}14.2 \\
13.7 \\
16.2 \\
19.0 \\
15.7 \\
15.7 \\
11.7 \\
19.6\end{array}$ \\
\hline $\begin{array}{l}28 \\
28 \\
28 \\
28 \\
28 \\
28 \\
28 \\
28\end{array}$ & $\begin{array}{r}0 \\
3 \\
6 \\
9 \\
27 \\
15 \\
18 \\
21\end{array}$ & & & $\begin{array}{l}27.6 \\
27.7 \\
27.4 \\
30.0 \\
33.2 \\
34.5 \\
32.1 \\
29.7\end{array}$ & $\begin{array}{l}20.9 \\
20.4 \\
21.0 \\
22 \cdot 2 \\
23.0 \\
23.5 \\
23.5 \\
22.3\end{array}$ & $\begin{array}{l}27.8 \\
27.7 \\
27.5 \\
30.4 \\
33.8 \\
34.9 \\
37.4 \\
29.9\end{array}$ & $\begin{array}{l}20.4 \\
20.2 \\
20.8 \\
22.0 \\
22.8 \\
23.1 \\
23.0 \\
21.9\end{array}$ & $\begin{array}{l}27.7 \\
27: 7 \\
27: 5 \\
30.7 \\
34: 2 \\
35: 3 \\
33.2 \\
30.0\end{array}$ & $\begin{array}{l}20.3 \\
20.2 \\
20.8 \\
22.3 \\
23.2 \\
23.3 \\
23.3 \\
22.4\end{array}$ & $\begin{array}{l}25.9 \\
25.8 \\
26.2 \\
27.0 \\
27.3 \\
26.9 \\
26.4 \\
26.1\end{array}$ & & $\begin{array}{r}12.7 \\
12.0 \\
13.9 \\
15.1 \\
15.1 \\
13.5 \\
8.7 \\
13.5\end{array}$ & $\begin{array}{l}14.6 \\
13.7 \\
15.7 \\
16.8 \\
16.8 \\
15.5 \\
10.4 \\
15.7\end{array}$ & $\begin{array}{l}16.4 \\
15.0 \\
16.5 \\
17.2 \\
17.6 \\
16.4 \\
12.2 \\
17.8\end{array}$ & $\begin{array}{l}18.5 \\
17.0 \\
19.0 \\
20.1 \\
20.3 \\
19.5 \\
14.9 \\
20.2\end{array}$ \\
\hline $\begin{array}{l}29 \\
29 \\
29 \\
29 \\
29 \\
29 \\
29 \\
29\end{array}$ & $\begin{array}{r}0 \\
3 \\
6 \\
9 \\
12 \\
15 \\
18 \\
21\end{array}$ & & & $\begin{array}{l}27.9 \\
26.6 \\
26.9 \\
30.5 \\
33.5 \\
34.1 \\
30.4 \\
28.8\end{array}$ & $\begin{array}{l}20.8 \\
20.1 \\
20.6 \\
22.2 \\
23.0 \\
23.3 \\
23.1 \\
21.8\end{array}$ & $\begin{array}{l}27.9 \\
26.6 \\
27.1 \\
30.0 \\
34.3 \\
34.9 \\
31.6 \\
20.0\end{array}$ & $\begin{array}{l}20.5 \\
19.7 \\
20.3 \\
22.0 \\
22.7 \\
22.9 \\
22.4 \\
21.5\end{array}$ & $\begin{array}{l}27 \cdot 9 \\
25 \cdot 6 \\
27: 1 \\
31 \cdot 3 \\
34 \cdot 7 \\
35: 4 \\
37: 5 \\
20: 1\end{array}$ & & $\begin{array}{l}25.6 \\
25.5 \\
26.0 \\
26.5 \\
26.9 \\
25.4 \\
26.1 \\
25.9\end{array}$ & & $\begin{array}{r}12.6 \\
10.5 \\
13.9 \\
15.6 \\
13.6 \\
10.4 \\
5.5 \\
10.5\end{array}$ & $\begin{array}{r}14.5 \\
11.9 \\
15.5 \\
17.0 \\
15.1 \\
12.2 \\
7.0 \\
12.2\end{array}$ & $\begin{array}{r}16.2 \\
12.7 \\
16.0 \\
17.0 \\
15.4 \\
13.3 \\
8.9 \\
14.0\end{array}$ & $\begin{array}{l}18.4 \\
14.7 \\
18.3 \\
19.8 \\
18.3 \\
15.8 \\
11.4 \\
16.4\end{array}$ \\
\hline $\begin{array}{l}30 \\
30 \\
30 \\
30 \\
30 \\
30 \\
30 \\
30\end{array}$ & $\begin{array}{r}0 \\
3 \\
6 \\
9 \\
12 \\
15 \\
18 \\
21\end{array}$ & & & $\begin{array}{l}26.7 \\
25.4 \\
26.6 \\
31.1 \\
33.6 \\
34.3\end{array}$ & $\begin{array}{l}21.0 \\
20.9 \\
21.4 \\
22.2 \\
22.8 \\
22.4\end{array}$ & $\begin{array}{l}26.6 \\
25.2 \\
26.8 \\
31.7 \\
34.2 \\
35.0\end{array}$ & $\begin{array}{l}20.6 \\
20.6 \\
21.1 \\
27.0 \\
22.3 \\
27.0\end{array}$ & $\begin{array}{l}26.0 \\
25.0 \\
27: 1 \\
32.0 \\
34.7 \\
35.5\end{array}$ & & $\begin{array}{l}25.6 \\
25.3 \\
25.8 \\
26.7 \\
27.1 \\
26.7\end{array}$ & & $\begin{array}{r}9.3 \\
10.6 \\
13.3 \\
14.8 \\
11.6 \\
11.0 \\
5.6 \\
8.8\end{array}$ & $\begin{array}{r}11.3 \\
11.2 \\
14.6 \\
16.2 \\
13.1 \\
12.3 \\
7.0 \\
10 . ?\end{array}$ & $\begin{array}{r}12.8 \\
11.9 \\
14.9 \\
15.9 \\
13.7 \\
13.2 \\
8.7 \\
12.0\end{array}$ & $\begin{array}{l}14.6 \\
13.8 \\
17.2 \\
18.7 \\
16.2 \\
15.7 \\
11.4 \\
14.1\end{array}$ \\
\hline $\begin{array}{l}31 \\
31 \\
31 \\
31 \\
31 \\
31 \\
31 \\
31 \\
\end{array}$ & $\begin{array}{r}0 \\
3 \\
6 \\
9 \\
12 \\
15 \\
18 \\
21 \\
\end{array}$ & & & $\begin{array}{l}31 \cdot 2 \\
33: 7 \\
34: 7 \\
31: 2 \\
28.7\end{array}$ & $\begin{array}{l}22.4 \\
22.5 \\
22.7 \\
22.0 \\
22.2\end{array}$ & $\begin{array}{l}31.8 \\
35.0 \\
35.4 \\
31.6 \\
20.1\end{array}$ & $\begin{array}{l}21.8 \\
21.4 \\
21.7 \\
21.4 \\
21.5\end{array}$ & $\begin{array}{l}31.0 \\
35.5 \\
35 . i_{r} \\
33.0 \\
30.0\end{array}$ & $\begin{array}{l}21.1 \\
21.0\end{array}$ & $\begin{array}{l}26.9 \\
27.5 \\
27.4 \\
26.9 \\
26.7\end{array}$ & & $\begin{array}{r}9.1 \\
8.8 \\
11.1 \\
10.5 \\
9.6 \\
7.2 \\
3.8 \\
4.8 \\
\end{array}$ & $\begin{array}{r}10.4 \\
10.0 \\
12.3 \\
11.7 \\
10.8 \\
8.7 \\
5.1 \\
5 . ? \\
\end{array}$ & $\begin{array}{r}11.5 \\
10.7 \\
12.7 \\
12.0 \\
11.3 \\
9.6 \\
6.4 \\
7.0 \\
\end{array}$ & $\begin{array}{r}13.3 \\
12.4 \\
14.6 \\
14: 1 \\
13.3 \\
11.3 \\
8.0 \\
8.1 \\
\end{array}$ \\
\hline
\end{tabular}


TABLE 11

Table 11.-Daily averages of air and water temperatures and wind speeds, July 1950-August 1951, Lake Hefner

\begin{tabular}{|c|c|c|c|c|c|c|c|c|c|c|c|c|c|}
\hline \multicolumn{2}{|c|}{ STATION 1} & \multicolumn{7}{|c|}{ DAILY AVERAGES } & \multirow{4}{*}{$\begin{array}{c}\text { Average } \\
\text { water- } \\
\text { surface } \\
\text { temperature }\end{array}$} & \multicolumn{4}{|r|}{1950} \\
\hline \multirow{4}{*}{ 急 } & \multicolumn{8}{|c|}{ Average air temperature $\left({ }^{\circ} \mathrm{C}\right)$ at indicated height } & & \multirow{2}{*}{\multicolumn{4}{|c|}{$\begin{array}{l}\text { Average wind speed (knots) } \\
\text { at indicated height }\end{array}$}} \\
\hline & \multirow{2}{*}{\multicolumn{2}{|c|}{$\begin{array}{c}2 \\
\text { meters }\end{array}$}} & \multirow{2}{*}{\multicolumn{2}{|c|}{$\stackrel{4}{\text { meters }}$}} & \multirow{2}{*}{\multicolumn{2}{|c|}{$\stackrel{8}{\text { meters }}$}} & \multirow{2}{*}{\multicolumn{2}{|c|}{$\begin{array}{c}116 \\
\text { meters }\end{array}$}} & & & & & \\
\hline & & & & & & & & & & & & & \\
\hline & $\begin{array}{c}\text { Dry } \\
\text { bulb }\end{array}$ & $\begin{array}{l}\text { Wet } \\
\text { bulb }\end{array}$ & $\begin{array}{l}\text { Dry } \\
\text { bulb }\end{array}$ & $\begin{array}{l}\text { Wet } \\
\text { bulb }\end{array}$ & $\begin{array}{l}\text { Dry } \\
\text { bulb }\end{array}$ & $\begin{array}{l}\text { Wet } \\
\text { bulb }\end{array}$ & $\begin{array}{l}\text { Dry } \\
\text { bulb }\end{array}$ & $\begin{array}{l}\text { Wet } \\
\text { bulb }\end{array}$ & $\left.{ }^{\circ} \mathrm{C}\right)$ & $\begin{array}{c}2 \\
\text { meters }\end{array}$ & $\stackrel{4}{\text { meters }}$ & $\begin{array}{c}-8 \\
\text { meters }\end{array}$ & $\begin{array}{c}16 \\
\text { meters }\end{array}$ \\
\hline \multicolumn{14}{|c|}{ JULY } \\
\hline $\begin{array}{l}1 \\
2 \\
3 \\
4 \\
5\end{array}$ & $\begin{array}{l}25.0 \\
25.9 \\
25.8 \\
23.0 \\
24.9\end{array}$ & $\begin{array}{l}19.6 \\
20.6 \\
21.7 \\
20.8 \\
21.7\end{array}$ & $\begin{array}{l}25.0 \\
25.9 \\
25.8 \\
22.9 \\
24.9\end{array}$ & $\begin{array}{l}19.3 \\
20.3 \\
21.5 \\
20.7 \\
21.5\end{array}$ & $\begin{array}{l}25.2 \\
26.1 \\
26.0 \\
22.9 \\
25.0\end{array}$ & $\begin{array}{l}19.2 \\
20.2 \\
21.4 \\
20.7 \\
21.5\end{array}$ & $\begin{array}{l}25.4 \\
26.4 \\
26.2 . \\
23.1 \\
24.9\end{array}$ & $\begin{array}{l}19.6 \\
20.8 \\
21.8 \\
20.8 \\
21.7\end{array}$ & $\begin{array}{l}26.1 \\
26.0 \\
26.5 \\
26.2 \\
26.5\end{array}$ & $\begin{array}{r}10.5 \\
10.9 \\
6.4 \\
4.9 \\
4.5\end{array}$ & $\begin{array}{r}11.6 \\
12.0 \\
6.9 \\
5.4 \\
4.5\end{array}$ & $\begin{array}{r}12.8 \\
13.2 \\
7.6 \\
5.3 \\
5.1\end{array}$ & $\begin{array}{r}13.2 \\
13.6 \\
7.7 \\
5.4 \\
5.2\end{array}$ \\
\hline $\begin{array}{r}6 \\
7 \\
8 \\
9 \\
10\end{array}$ & $\begin{array}{l}24.1 \\
2404 \\
2409\end{array}$ & $\begin{array}{l}21 \cdot 1 \\
21.3 \\
22 \cdot 1\end{array}$ & $\begin{array}{l}23.9 \\
24.4 \\
24.8\end{array}$ & $\begin{array}{l}20.8 \\
21.1 \\
22.0\end{array}$ & $\begin{array}{l}24 \cdot 0 \\
24.4\end{array}$ & $\begin{array}{l}20.9 \\
21.1\end{array}$ & $\begin{array}{l}24 \cdot 1 \\
24.6\end{array}$ & $\begin{array}{l}21.1 \\
21.4\end{array}$ & $\begin{array}{l}26.4 \\
26.6\end{array}$ & $\begin{array}{r}5.1 \\
7.0 \\
11.1 \\
15.1 \\
11.7\end{array}$ & $\begin{array}{r}5.4 \\
7.6 \\
12.3 \\
16.6 \\
12.7\end{array}$ & $\begin{array}{r}5.7 \\
8.0 \\
13.2 \\
28.0 \\
23.0\end{array}$ & $\begin{array}{r}5.8 \\
8.0 \\
13.7 \\
28.7 \\
14.0\end{array}$ \\
\hline $\begin{array}{l}11 \\
12 \\
13 \\
14 \\
15\end{array}$ & $\begin{array}{l}23.5 \\
24.1 \\
21.7 \\
22.2 \\
25.9\end{array}$ & $\begin{array}{l}21.3 \\
21.2 \\
18.2 \\
18.3 \\
22.6\end{array}$ & $\begin{array}{l}23.5 \\
24.2 \\
21.4 \\
22.1 \\
26.0\end{array}$ & $\begin{array}{l}21.3 \\
21.0 \\
17.6 \\
18.2 \\
22.5\end{array}$ & $\begin{array}{l}23 \cdot 6 \\
24 \cdot 3 \\
21.4 \\
22 \cdot 3 \\
26.1\end{array}$ & $\begin{array}{l}21.4 \\
21.1 \\
17.6 \\
18.2 \\
22.6\end{array}$ & $\begin{array}{l}23.8 \\
24.5 \\
21.5 \\
27.4 \\
26.3\end{array}$ & $\begin{array}{l}21.5 \\
21.2 \\
17.7 \\
18.5 \\
22.8\end{array}$ & $\begin{array}{l}25.5 \\
25.7 \\
25.5 \\
25.9 \\
25.5\end{array}$ & $\begin{array}{r}7.4 \\
6.1 \\
9.6 \\
5.3 \\
13.5\end{array}$ & $\begin{array}{r}8.1 \\
6.9 \\
10.6 \\
5.5 \\
14.9\end{array}$ & $\begin{array}{r}8.6 \\
7.4 \\
10.9 \\
5.8 \\
16.3\end{array}$ & $\begin{array}{r}8.8 \\
7.7 \\
11.6 \\
5.9 \\
16.8\end{array}$ \\
\hline $\begin{array}{l}16 \\
17 \\
18 \\
19 \\
20\end{array}$ & 26.9 & 22.7 & 27.0 & 22.6 & $27 \cdot 2$ & 22.6 & 27.6 & 22.8 & 25.5 & $\begin{array}{r}18.3 \\
10.0 \\
9.4 \\
9.3 \\
5.7\end{array}$ & $\begin{array}{r}20.2 \\
10.8 \\
10.2 \\
10.1 \\
6.1\end{array}$ & $\begin{array}{r}22.3 \\
11.5 \\
10.9 \\
11.0 \\
6.5\end{array}$ & $\begin{array}{r}23.2 \\
11.9 \\
11.3 \\
11.4 \\
6.6\end{array}$ \\
\hline $\begin{array}{l}21 \\
22\end{array}$ & & & & & & & & & & 8.0 & 8.3 & 8.6 & 8.7 \\
\hline $\begin{array}{l}23 \\
24 \\
25\end{array}$ & $\begin{array}{l}24.5 \\
24.4 \\
23.2\end{array}$ & $\begin{array}{l}20.2 \\
21.8 \\
21.8\end{array}$ & $\begin{array}{l}24.2 \\
24.4 \\
23.1\end{array}$ & $\begin{array}{l}20.1 \\
21.6 \\
21.6\end{array}$ & $\begin{array}{l}24.5 \\
24.4 \\
23.2\end{array}$ & $\begin{array}{l}20.2 \\
21.7 \\
21.7\end{array}$ & $\begin{array}{l}24.3 \\
24.7 \\
23.4\end{array}$ & $\begin{array}{l}20.3 \\
22.0 \\
21.8\end{array}$ & $\begin{array}{l}26.1 \\
26.2 \\
25.8\end{array}$ & $\begin{array}{l}4.0 \\
5.8\end{array}$ & $\begin{array}{l}4.5 \\
6.6\end{array}$ & $\begin{array}{l}4.7 \\
7.1\end{array}$ & \\
\hline $\begin{array}{l}26 \\
27 \\
28\end{array}$ & $\begin{array}{l}22.2 \\
24.1\end{array}$ & $\begin{array}{l}20.1 \\
20.7\end{array}$ & $\begin{array}{l}21.9 \\
24.0\end{array}$ & $\begin{array}{l}19.7 \\
20.7\end{array}$ & $\begin{array}{l}22.1 \\
24.0\end{array}$ & $\begin{array}{l}19.9 \\
20.9\end{array}$ & $\begin{array}{l}22.3 \\
24.1\end{array}$ & $\begin{array}{l}20.0 \\
20.9\end{array}$ & $\begin{array}{l}25.9 \\
26.7\end{array}$ & $\begin{array}{l}5.0 \\
4.7 \\
6.8\end{array}$ & $\begin{array}{l}5.8 \\
5.1 \\
7.4\end{array}$ & $\begin{array}{l}5.9 \\
5.3 \\
7.7\end{array}$ & 8.0 \\
\hline $\begin{array}{l}29 \\
30\end{array}$ & $\begin{array}{l}24 * 1 \\
24 * 9\end{array}$ & $\begin{array}{l}22.4 \\
22.8\end{array}$ & $\begin{array}{l}24.1 \\
24.9\end{array}$ & $\begin{array}{l}22.3 \\
22.6\end{array}$ & $\begin{array}{l}24 . ? \\
25.0\end{array}$ & $\begin{array}{l}22.4 \\
22.7\end{array}$ & $\begin{array}{l}24 \cdot 3 \\
25.3\end{array}$ & $\begin{array}{l}22.4 \\
2.2 .9\end{array}$ & $\begin{array}{l}25.4 \\
25.3\end{array}$ & $\begin{array}{l}10.0 \\
10.3\end{array}$ & $\begin{array}{l}11.1 \\
11.6\end{array}$ & $\begin{array}{l}11.8 \\
12.5\end{array}$ & $\begin{array}{l}12.4 \\
13.2\end{array}$ \\
\hline 31 & 25.9 & 22.5 & 25.9 & 22.4 & $26 \cdot 0$ & 22.4 & 26.3 & 22.6 & 26.1 & 9.8 & 11.0 & 11.9 & $12 \cdot 6$ \\
\hline
\end{tabular}

AUGUST

\begin{tabular}{|c|c|c|c|c|c|c|c|c|c|c|c|c|c|}
\hline $\begin{array}{l}1 \\
2 \\
3 \\
4 \\
5\end{array}$ & $\begin{array}{l}21.1 \\
24.0 \\
23.7\end{array}$ & $\begin{array}{l}20.1 \\
19.3 \\
19.6\end{array}$ & $\begin{array}{l}20.8 \\
23.5 \\
23.5\end{array}$ & $\begin{array}{l}19.8 \\
18.9 \\
19.3\end{array}$ & $\begin{array}{l}20.8 \\
23.7 \\
23.7\end{array}$ & $\begin{array}{l}19.8 \\
18.9 \\
19.3\end{array}$ & $\begin{array}{l}21.1 \\
23.9 \\
23.9\end{array}$ & $\begin{array}{l}20.1 \\
19.1 \\
19.5\end{array}$ & $\begin{array}{l}25.4 \\
26.2 \\
25.8\end{array}$ & $\begin{array}{r}7.1 \\
4.1 \\
8.5 \\
11.8 \\
9.1\end{array}$ & $\begin{array}{r}7.7 \\
4.3 \\
9.4 \\
13.1 \\
9.9\end{array}$ & $\begin{array}{r}7.9 \\
4.6 \\
10.0 \\
14.0 \\
10.4\end{array}$ & $\begin{array}{r}8.1 \\
5.1 \\
10.5 \\
14.7 \\
10.9\end{array}$ \\
\hline $\begin{array}{r}6 \\
7 \\
8 \\
9 \\
10\end{array}$ & $\begin{array}{l}24.5 \\
26.2 \\
26.1 \\
25.7\end{array}$ & $\begin{array}{l}22.6 \\
22.4 \\
22.1 \\
21.7\end{array}$ & $\begin{array}{l}24.4 \\
26.3 \\
26.1 \\
25.6\end{array}$ & $\begin{array}{l}22.4 \\
22.1 \\
21.8 \\
21.4\end{array}$ & $\begin{array}{l}24.5 \\
26.5 \\
26.3 \\
25.8\end{array}$ & $\begin{array}{l}22.5 \\
22.0 \\
21.9 \\
21.5\end{array}$ & $\begin{array}{l}24.7 \\
26.8 \\
26.5 \\
26.0\end{array}$ & $\begin{array}{l}22.7 \\
22.2 \\
22.0 \\
21.7\end{array}$ & $\begin{array}{l}25.7 \\
26.2 \\
26.5 \\
27.3\end{array}$ & $\begin{array}{r}10.0 \\
9.9 \\
5.5 \\
5.2 \\
5.6\end{array}$ & $\begin{array}{r}10.9 \\
11.2 \\
6.2 \\
5.6 \\
6.2\end{array}$ & $\begin{array}{r}11.6 \\
12.1 \\
6.5 \\
5.9 \\
6.5\end{array}$ & $\begin{array}{r}12.1 \\
13.1 \\
7.1 \\
6.2 \\
6.9\end{array}$ \\
\hline $\begin{array}{l}11 \\
12 \\
13 \\
14 \\
15\end{array}$ & $\begin{array}{l}27.0 \\
27.4\end{array}$ & $\begin{array}{l}23.1 \\
22.0\end{array}$ & $\begin{array}{l}27.1 \\
27.4\end{array}$ & $\begin{array}{l}22.9 \\
21.6\end{array}$ & $\begin{array}{l}27.2 \\
27.6\end{array}$ & $\begin{array}{l}22.9 \\
21.4\end{array}$ & $\begin{array}{l}27.5 \\
28.0\end{array}$ & $\begin{array}{l}23.1 \\
21.6\end{array}$ & $\begin{array}{l}26.9 \\
27.3\end{array}$ & $\begin{array}{r}9.3 \\
10.6 \\
8.7 \\
6.0 \\
9.8\end{array}$ & $\begin{array}{r}10.4 \\
11.9 \\
9.7 \\
6.6 \\
10.9\end{array}$ & $\begin{array}{r}11.2 \\
12.9 \\
10.6 \\
7.1 \\
11.7\end{array}$ & $\begin{array}{r}11.8 \\
13.8 \\
11.2 \\
7.7 \\
12.4\end{array}$ \\
\hline $\begin{array}{l}16 \\
17 \\
18 \\
19 \\
20\end{array}$ & $\begin{array}{l}23.9 \\
22.5 \\
22.3 \\
15.2\end{array}$ & $\begin{array}{l}21.5 \\
20.6 \\
18.4 \\
13.1\end{array}$ & $\begin{array}{l}23.8 \\
22.4 \\
22.0\end{array}$ & $\begin{array}{l}21.3 \\
20.1 \\
18.0 \\
12.5\end{array}$ & $\begin{array}{l}23.9 \\
22.4 \\
22.0\end{array}$ & $\begin{array}{l}21.3 \\
20.1 \\
17.7 \\
12.2\end{array}$ & $\begin{array}{l}24.0 \\
22.5 \\
22.3 \\
14.7\end{array}$ & $\begin{array}{l}21.6 \\
20.4 \\
18.0 \\
12.4\end{array}$ & $\begin{array}{l}26.6 \\
26.7 \\
26.4 \\
25.1\end{array}$ & $\begin{array}{l}5.5 \\
8.2 \\
8.1 \\
4.3\end{array}$ & $\begin{array}{l}6.0 \\
9.0 \\
9.0 \\
4.6\end{array}$ & $\begin{array}{l}6.3 \\
9.7 \\
9.6 \\
4.8\end{array}$ & $\begin{array}{r}6.5 \\
10.1 \\
10.0 \\
4.9\end{array}$ \\
\hline $\begin{array}{l}21 \\
22 \\
23 \\
24 \\
25\end{array}$ & $\begin{array}{l}19.4 \\
23.4 \\
22.1 \\
25.6 \\
27.1\end{array}$ & $\begin{array}{l}16.6 \\
20.1 \\
19.8 \\
22.4 \\
22.4\end{array}$ & $\begin{array}{l}19.4 \\
23.3 \\
22.0 \\
25.8 \\
27.2\end{array}$ & $\begin{array}{l}16.4 \\
19.9 \\
19.6 \\
22.3 \\
22.2\end{array}$ & $\begin{array}{l}19.4 \\
23.4 \\
22.0 \\
26.0 \\
27.4\end{array}$ & $\begin{array}{l}16.3 \\
19.9 \\
19.6 \\
22.3 \\
22.2\end{array}$ & $\begin{array}{l}19.5 \\
23.5 \\
22.3 \\
26.3 \\
27.7\end{array}$ & $\begin{array}{l}16.8 \\
20.3 \\
19.9 \\
22.6 \\
22.5\end{array}$ & $\begin{array}{l}25.5 \\
25.5 \\
25.3 \\
25.4 \\
25.7\end{array}$ & $\begin{array}{r}5.7 \\
7.2 \\
10.1 \\
8.4\end{array}$ & $\begin{array}{r}6.3 \\
7.9 \\
11.3 \\
9.5\end{array}$ & $\begin{array}{r}6.6 \\
8.3 \\
12.2 \\
10.4\end{array}$ & $\begin{array}{r}7.1 \\
8.7 \\
13.0 \\
11.2\end{array}$ \\
\hline $\begin{array}{l}26 \\
27 \\
28 \\
29 \\
30\end{array}$ & $\begin{array}{l}26.3 \\
23.6 \\
20.9\end{array}$ & $\begin{array}{l}22.1 \\
20.4\end{array}$ & $\begin{array}{l}26.4 \\
23.4\end{array}$ & $\begin{array}{l}21.8 \\
20.2 \\
17.7\end{array}$ & $\begin{array}{l}26.5 \\
23.4\end{array}$ & $\begin{array}{l}21.7 \\
20.2 \\
17.6\end{array}$ & $\begin{array}{l}26.8 \\
23.6 \\
20.7\end{array}$ & $\begin{array}{l}22.0 \\
20.5 \\
17.8\end{array}$ & $\begin{array}{l}25.9 \\
26.2 \\
26.0\end{array}$ & $\begin{array}{l}9.0 \\
4.5 \\
5.4 \\
5.0 \\
9.7\end{array}$ & $\begin{array}{r}10.0 \\
4.9 \\
5.8 \\
5.6 \\
10.9\end{array}$ & $\begin{array}{r}10.9 \\
5.1 \\
6.1 \\
5.9 \\
11.8\end{array}$ & $\begin{array}{r}11.6 \\
5.2 \\
6.5 \\
5.12 \\
12.2\end{array}$ \\
\hline 31 & $19 \cdot 8$ & 17.1 & 19.6 & 16.8 & $19 \cdot 6$ & 16.6 & 19.9 & 16.7 & 25.3 & 10.3 & 11.4 & 12.5 & 13.0 \\
\hline
\end{tabular}


Table 11. -Daily averages of air and water temperatures and wind speeds, July 1950-August 1951, Lake Hefner-Con. STATION 1 DAILY AVERAGES

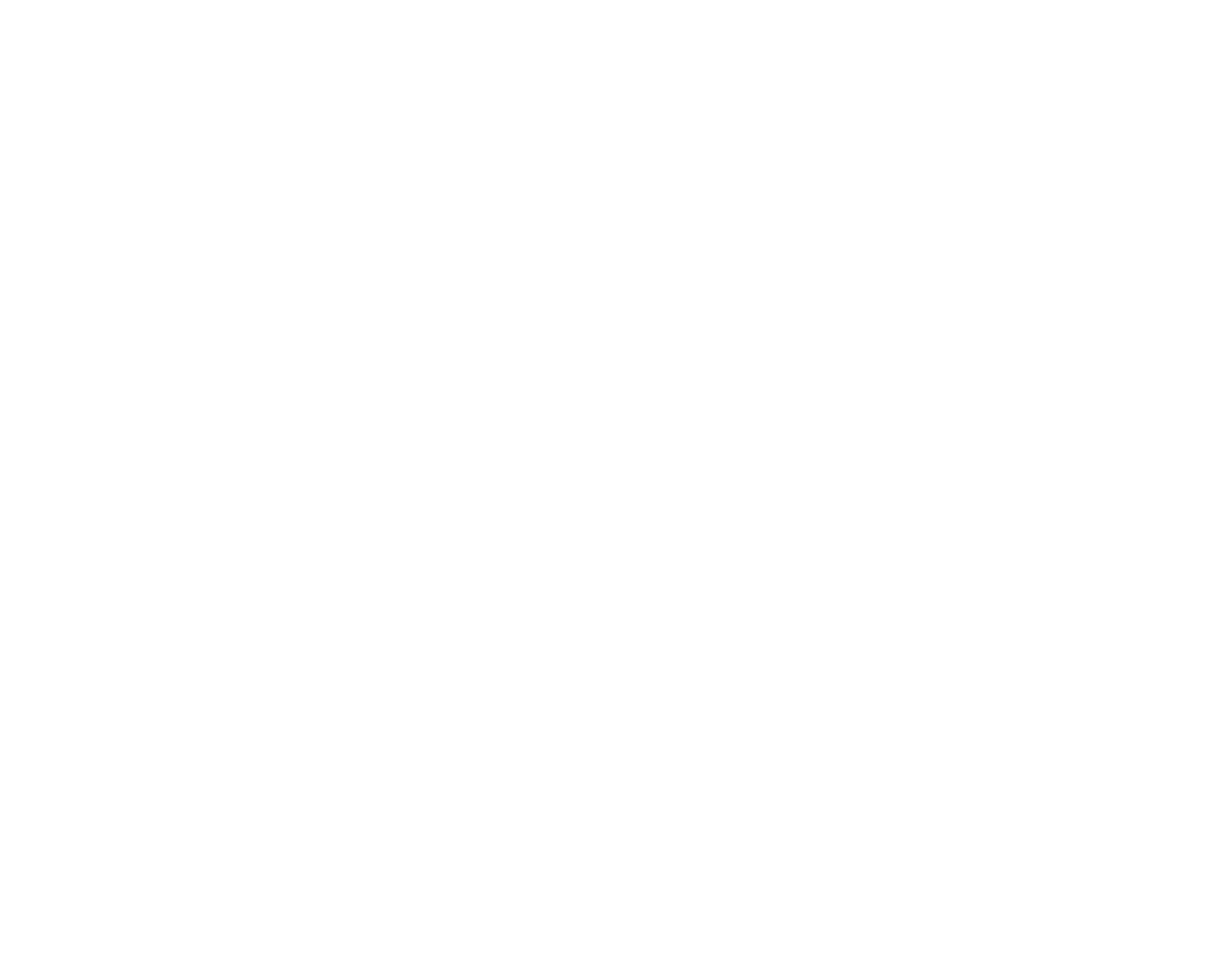

OCTORE?

\begin{tabular}{|c|c|c|c|c|c|c|c|c|c|c|c|c|c|}
\hline $\begin{array}{r}1 \\
2 \\
3 \\
4 \\
5 \\
6 \\
7 \\
8 \\
9 \\
10\end{array}$ & $\begin{array}{l}15.4 \\
16.4 \\
18.2\end{array}$ & $\begin{array}{l}10.8 \\
11.8 \\
13.8\end{array}$ & $\begin{array}{l}16.3 \\
16.4 \\
18.3\end{array}$ & $\begin{array}{l}10.3 \\
11.4 \\
13.4\end{array}$ & $\begin{array}{l}16.2 \\
16.4 \\
18.2\end{array}$ & $\begin{array}{l}11.2 \\
13.3\end{array}$ & $\begin{array}{l}16.1 \\
16.4 \\
18.6\end{array}$ & $\begin{array}{l}10.2 \\
11.2 \\
12.9\end{array}$ & $\begin{array}{l}19.4 \\
19.1 \\
19.1\end{array}$ & $\begin{array}{l}7.8 \\
8.1\end{array}$ & $\begin{array}{l}8.8 \\
9.3\end{array}$ & $\begin{array}{r}9.4 \\
10.4\end{array}$ & $\begin{array}{l}10.1 \\
11.1\end{array}$ \\
\hline $\begin{array}{l}11 \\
12 \\
13 \\
14 \\
15\end{array}$ & $\begin{array}{l}20.8 \\
19.8 \\
21.0 \\
22.7 \\
21.8\end{array}$ & $\begin{array}{l}15.5 \\
13.8 \\
15.4 \\
15.6 \\
16.2\end{array}$ & $\begin{array}{l}20.8 \\
19.9 \\
21.3 \\
23.1 \\
22.1\end{array}$ & $\begin{array}{l}14.8 \\
13.3 \\
15.1 \\
16.4 \\
15.9\end{array}$ & $\begin{array}{l}21 \cdot 1 \\
20 \cdot 1 \\
21.4 \\
23.3 \\
22.2\end{array}$ & $\begin{array}{l}14.8 \\
13.1 \\
15: 1 \\
16: 3 \\
15.8\end{array}$ & $\begin{array}{l}21.4 \\
20.2 \\
21.6 \\
23.5 \\
22.4\end{array}$ & $\begin{array}{l}15.4 \\
16.7 \\
16.1\end{array}$ & $\begin{array}{l}20.3 \\
19.5 \\
19.3 \\
19.4 \\
19.4\end{array}$ & $\begin{array}{r}2.6 \\
4.5 \\
11.4 \\
11.0 \\
11.1\end{array}$ & $\begin{array}{r}3.0 \\
5.2 \\
13.1 \\
12.5 \\
12.8\end{array}$ & $\begin{array}{r}5.6 \\
14.6 \\
14.3 \\
14.2\end{array}$ & $\begin{array}{r}6.5 \\
15.7 \\
15.4 \\
15.3\end{array}$ \\
\hline $\begin{array}{l}16 \\
17 \\
18 \\
19 \\
20\end{array}$ & $\begin{array}{l}21.3 \\
20.8 \\
19.8 \\
19.2 \\
17.8\end{array}$ & $\begin{array}{l}15.5 \\
16.0 \\
16.0 \\
15.0 \\
14.1\end{array}$ & $\begin{array}{l}21.3 \\
21.2 \\
20.0 \\
19.4 \\
17.9\end{array}$ & $\begin{array}{l}15.1 \\
15.5 \\
15.6 \\
15.2 \\
13.6\end{array}$ & $\begin{array}{l}21.5 \\
21.4 \\
20.1 \\
19.5 \\
18.0\end{array}$ & $\begin{array}{l}14.9 \\
15.5 \\
15.5 \\
15.0 \\
13.4\end{array}$ & $\begin{array}{l}21.6 \\
21.7 \\
20.2 \\
19.7 \\
18.0\end{array}$ & $\begin{array}{l}15.2 \\
15.8 \\
15.7 \\
15.0 \\
13.5\end{array}$ & $\begin{array}{l}19.3 \\
19.4 \\
19.4 \\
19.4 \\
19.0\end{array}$ & $\begin{array}{r}11.7 \\
7.7 \\
4.4 \\
3.0 \\
3.9\end{array}$ & $\begin{array}{r}13.3 \\
8.9 \\
5.1 \\
3.8 \\
4.5\end{array}$ & $\begin{array}{r}14.9 \\
10.0 \\
5.7 \\
4.4 \\
5.2\end{array}$ & $\begin{array}{r}16.0 \\
11: 1 \\
5: 5 \\
5.2 \\
5.7\end{array}$ \\
\hline $\begin{array}{l}21 \\
22 \\
23 \\
24 \\
25\end{array}$ & $\begin{array}{l}17.3 \\
15.2 \\
12.7 \\
19.1 \\
16.3\end{array}$ & $\begin{array}{l}11.9 \\
11.0 \\
10.0 \\
13.9 \\
13.6\end{array}$ & $\begin{array}{l}17.1 \\
14.9 \\
12.3 \\
19.4 \\
16.2\end{array}$ & $\begin{array}{r}11.3 \\
10.3 \\
9.4 \\
13.5 \\
13.2\end{array}$ & $\begin{array}{l}17.2 \\
14: 8 \\
12.2 \\
19.5 \\
16.4\end{array}$ & $\begin{array}{r}11.0 \\
10.1 \\
9.2 \\
13.4 \\
13.0\end{array}$ & $\begin{array}{l}17.3 \\
14.8 \\
12.1 \\
19.6 \\
16.4\end{array}$ & $\begin{array}{r}11.2 \\
10.3 \\
9.4 \\
13.6 \\
13.1\end{array}$ & $\begin{array}{l}19.0 \\
18.8 \\
18.7 \\
18.3 \\
18.5\end{array}$ & $\begin{array}{l}4.4 \\
9.2 \\
5.7 \\
9.7 \\
5.5\end{array}$ & $\begin{array}{r}4.5 \\
10.3 \\
6.5 \\
11.1 \\
6.1\end{array}$ & $\begin{array}{r}5.3 \\
11.2 \\
6.8 \\
12.5 \\
6.8\end{array}$ & $\begin{array}{r}7.2 \\
13.4 \\
7.3\end{array}$ \\
\hline $\begin{array}{l}26 \\
27 \\
28 \\
29 \\
30\end{array}$ & $\begin{array}{l}22.7 \\
20.5 \\
20.1 \\
20.9 \\
21.4\end{array}$ & $\begin{array}{l}14.6 \\
13.3 \\
15.1 \\
15.3 \\
16.3\end{array}$ & $\begin{array}{l}23.1 \\
20.7 \\
20.3 \\
21.2 \\
21.7\end{array}$ & $\begin{array}{l}14.0 \\
12.5 \\
14.5 \\
14.0 \\
16.1\end{array}$ & $\begin{array}{l}23.4 \\
20.9 \\
20.7 \\
21.4 \\
21.9\end{array}$ & $\begin{array}{l}13.9 \\
12.3 \\
14.3\end{array}$ & $\begin{array}{l}23.7 \\
21.2 \\
21.2 \\
21.9 \\
22.0\end{array}$ & $\begin{array}{l}14.3 \\
12.0 \\
14.6 \\
15.1 \\
16.2\end{array}$ & $\begin{array}{l}18.1 \\
18.2 \\
18.0 \\
18.0 \\
18.0\end{array}$ & $\begin{array}{r}14.0 \\
8.2 \\
6.4 \\
9.3 \\
12.3\end{array}$ & $\begin{array}{r}16.1 \\
9.4 \\
7.3 \\
10.7 \\
14.2\end{array}$ & $\begin{array}{r}13.2 \\
10.8 \\
8.0 \\
12.3 \\
16.0\end{array}$ & $\begin{array}{r}19.5 \\
11.9 \\
8.7 \\
13.6 \\
17.1\end{array}$ \\
\hline 31 & 22.0 & 17.1 & 22.2 & 16.8 & 22.4 & 16.7 & 22.7 & 16.0 & $18, ?$ & 14.4 & 16.5 & 1887 & 10.9 \\
\hline
\end{tabular}


TABLE 11

Table 11. -Daily averages of air and water temperatures and wind speeds, July 1950-August 1951, Lake Hefner-Con. STATION 1 DAILY AVERAGES

\begin{tabular}{|c|c|c|c|c|c|c|c|c|c|c|c|c|c|}
\hline \multirow{4}{*}{ 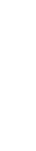 } & \multicolumn{8}{|c|}{ Average air temperature $\left({ }^{\circ} \mathrm{C}\right)$ at indicated height } & \multirow{4}{*}{$\begin{array}{c}\text { water- } \\
\text { surface } \\
\text { temperature } \\
\left({ }^{\circ} \mathrm{C}\right)\end{array}$} & \multirow{2}{*}{\multicolumn{4}{|c|}{$\begin{array}{l}\text { Average wind speed (knots) } \\
\text { at indicated height }\end{array}$}} \\
\hline & \multirow{2}{*}{\multicolumn{2}{|c|}{$\begin{array}{c}2 \\
\text { meters }\end{array}$}} & \multirow{2}{*}{\multicolumn{2}{|c|}{$\begin{array}{c}4 \\
\text { meters }\end{array}$}} & \multirow{2}{*}{\multicolumn{2}{|c|}{$\begin{array}{c}8 \\
\text { meters } \\
\end{array}$}} & \multirow{2}{*}{\multicolumn{2}{|c|}{$\begin{array}{c}16 \\
\text { meters }\end{array}$}} & & & & & \\
\hline & & & & & & & & & & \multirow[b]{2}{*}{$\begin{array}{c}2 \\
\text { meters }\end{array}$} & \multirow[b]{2}{*}{$\begin{array}{c}4 \\
\text { meters }\end{array}$} & \multirow[b]{2}{*}{$\begin{array}{c}8 \\
\text { meters }\end{array}$} & \multirow[b]{2}{*}{$\begin{array}{c}16 \\
\text { meters }\end{array}$} \\
\hline & $\begin{array}{l}\text { Dry } \\
\text { bulb }\end{array}$ & $\begin{array}{l}\text { Wet } \\
\text { bulb }\end{array}$ & $\begin{array}{l}\text { Dry } \\
\text { bulb }\end{array}$ & $\begin{array}{l}\text { Wet } \\
\text { bulb }\end{array}$ & $\begin{array}{l}\text { Dry } \\
\text { bulb }\end{array}$ & $\begin{array}{l}\text { Wet } \\
\text { bulb }\end{array}$ & $\begin{array}{l}\text { Dry } \\
\text { bulb }\end{array}$ & $\begin{array}{l}\text { Wet } \\
\text { bulb }\end{array}$ & & & & & \\
\hline
\end{tabular}

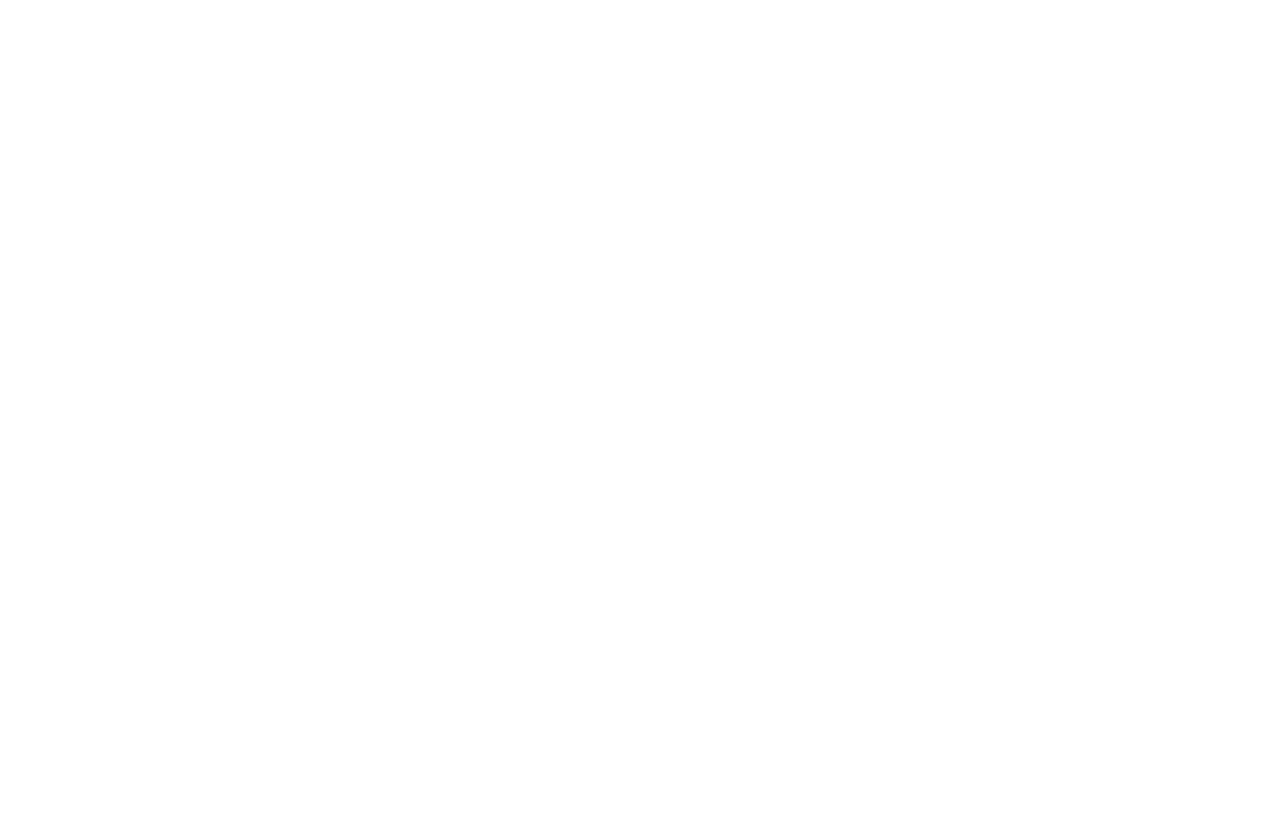

DECEMBER

\begin{tabular}{|c|c|c|c|c|c|c|c|c|c|c|c|c|c|}
\hline $\begin{array}{l}1 \\
2 \\
3 \\
4 \\
5\end{array}$ & $\begin{array}{r}12.5 \\
8.3 \\
2.0 \\
7.2\end{array}$ & $\begin{array}{l}7.5 \\
4.2 \\
2.8\end{array}$ & $\begin{array}{r}13.2 \\
8.2 \\
1.8 \\
7.1\end{array}$ & $\begin{array}{l}7.7 \\
3.8 \\
2.3\end{array}$ & $\begin{array}{r}13.7 \\
8.2 \\
1.8 \\
7.1\end{array}$ & $\begin{array}{l}7.8 \\
3.6 \\
2.0\end{array}$ & $\begin{array}{r}14.1 \\
8.1 \\
1.7 \\
7.0\end{array}$ & & $\begin{array}{r}8.1 \\
8.1 \\
7.8 \\
7.4 \\
\end{array}$ & $\begin{array}{r}10.7 \\
11.8 \\
7.0 \\
13.8 \\
20.2\end{array}$ & $\begin{array}{r}12.5 \\
13.3 \\
7.7 \\
15.5 \\
25.0\end{array}$ & $\begin{array}{r}14.6 \\
15.1 \\
8.2 \\
16.9 \\
27.8\end{array}$ & $\begin{array}{r}15.8 \\
15.8 \\
8.8 \\
17.8 \\
28.8\end{array}$ \\
\hline $\begin{array}{r}6 \\
7 \\
8 \\
9 \\
10\end{array}$ & $\begin{array}{r}-0.2 \\
5.6 \\
3.8\end{array}$ & $\begin{array}{l}2.5 \\
0.8\end{array}$ & $\begin{array}{r}0.0 \\
5.9 \\
3.9\end{array}$ & $\begin{array}{l}2.2 \\
0.4\end{array}$ & $\begin{array}{l}0.2 \\
4.1\end{array}$ & $\begin{array}{l}2.1 \\
0.3\end{array}$ & $\begin{array}{l}0.3 \\
5.5 \\
4.3\end{array}$ & & $\begin{array}{l}3.9 \\
4.1 \\
4.3\end{array}$ & $\begin{array}{r}11.4 \\
7.7 \\
5.7 \\
6.6 \\
6.3\end{array}$ & $\begin{array}{r}13.9 \\
8.1 \\
6.2 \\
7.1\end{array}$ & $\begin{array}{r}14.7 \\
8.7 \\
7.2 \\
8.8 \\
8.0\end{array}$ & $\begin{array}{r}15.3 \\
8.8 \\
7.8 \\
10.5\end{array}$ \\
\hline $\begin{array}{l}12 \\
12 \\
13 \\
14 \\
15\end{array}$ & $\begin{array}{l}2.7 \\
4.8 \\
3.8\end{array}$ & $\begin{array}{l}0.9 \\
2.9 \\
1.1\end{array}$ & $\begin{array}{l}2.7 \\
5.0 \\
3.6\end{array}$ & $\begin{array}{l}0.6 \\
3.0 \\
0.7\end{array}$ & $\begin{array}{l}2.9 \\
5.7 \\
3.6\end{array}$ & $\begin{array}{l}0.6 \\
3.3 \\
0.7\end{array}$ & $\begin{array}{l}3.2 \\
6.4 \\
3.7\end{array}$ & & $\begin{array}{l}4.2 \\
4.6 \\
4.5\end{array}$ & $\begin{array}{l}7.8 \\
3.3 \\
3.6 \\
1.8 \\
4.9\end{array}$ & $\begin{array}{l}9.3 \\
3.7 \\
4.2 \\
2.5 \\
5.6\end{array}$ & $\begin{array}{r}10.7 \\
4.2 \\
4.5 \\
6.0\end{array}$ & $\begin{array}{r}22.3 \\
4.9 \\
4.8 \\
6.5\end{array}$ \\
\hline $\begin{array}{l}16 \\
17 \\
18 \\
19 \\
20\end{array}$ & $\begin{array}{l}3.5 \\
2.3\end{array}$ & $\begin{array}{c}0.9 \\
1.3\end{array}$ & $\begin{array}{l}3.5 \\
1.9\end{array}$ & 0.9 & $\begin{array}{l}3.5 \\
1.9\end{array}$ & $\begin{array}{l}0.7 \\
2.0\end{array}$ & $\begin{array}{l}3.6 \\
2.9\end{array}$ & $\cdot$ & $\begin{array}{l}4.1 \\
4.0\end{array}$ & $\begin{array}{l}4.0 \\
6.2 \\
4.8 \\
5.2 \\
5.2\end{array}$ & $\begin{array}{l}4.7 \\
6.8 \\
5.3 \\
6.0 \\
5.8\end{array}$ & $\begin{array}{l}5.3 . \\
7.3 \\
5.7 \\
6.8 \\
6.1\end{array}$ & $\begin{array}{l}6.1 \\
7.9 \\
5.4 \\
7.5 \\
6.4\end{array}$ \\
\hline $\begin{array}{l}21 \\
22 \\
23 \\
24 \\
25\end{array}$ & $\begin{array}{r}5.5 \\
6.2 \\
7.4 \\
7.4 \\
11.0\end{array}$ & $\begin{array}{l}3.3 \\
4.6 \\
5.5 \\
4 \cdot 0 \\
5.5\end{array}$ & $\begin{array}{r}5.6 \\
5.6 \\
7.6 \\
7.8 \\
11.6\end{array}$ & $\begin{array}{l}3.2 \\
4.7 \\
5.9 \\
4.0 \\
5.3\end{array}$ & $\begin{array}{r}5.8 \\
6.9 \\
8.0 \\
8.4 \\
12.0\end{array}$ & $\begin{array}{l}3.2 \\
4.3 \\
6.0 \\
4.1 \\
5.3\end{array}$ & $\begin{array}{r}5.9 \\
7.2 \\
8.2 \\
8.8 \\
12.3\end{array}$ & & $\begin{array}{l}4.4 \\
4: 5 \\
4: 7 \\
5.0 \\
4.0\end{array}$ & $\begin{array}{r}3.6 \\
6.4 \\
9.6 \\
3.4 \\
11.7\end{array}$ & $\begin{array}{r}.4 .4 \\
7.6 \\
12.3 \\
4.0 \\
13.8\end{array}$ & $\begin{array}{r}5.0 \\
8.9 \\
13.1 \\
4.9 \\
16.0\end{array}$ & $\begin{array}{r}5.6 \\
9.9 \\
14.2 \\
17.3\end{array}$ \\
\hline $\begin{array}{l}26 \\
27 \\
28 \\
29 \\
30\end{array}$ & $\begin{array}{r}0.3 \\
-\quad 3.6 \\
-0.3 \\
1.5\end{array}$ & -0.3 & $\begin{array}{r}-0.1 \\
-4.5 \\
-0.4 \\
1.5\end{array}$ & -0.4 & $\begin{array}{r}-0.5 \\
=-4.7 \\
-0.4 \\
1.4\end{array}$ & & $\begin{aligned}- & 0.7 \\
= & 4.9 \\
- & 0.3 \\
& 1.4\end{aligned}$ & & $\begin{array}{l}4.7 \\
4: 1 \\
3.8 \\
3.3\end{array}$ & $\begin{array}{r}16.5 \\
7.0 \\
5.7 \\
3.6 \\
5.4\end{array}$ & $\begin{array}{r}19.0 \\
7.8 \\
6.5 \\
4.1 \\
5.9\end{array}$ & $\begin{array}{r}20.6 \\
8.1 \\
7.3 \\
4.4 \\
6.7\end{array}$ & $\begin{array}{r}21.7 \\
8.3 \\
4.6 \\
7.4\end{array}$ \\
\hline 31 & & & & & & & & & & 17.9 & 20.6 & 23.2 & 24.9 \\
\hline
\end{tabular}


Table 11.-Daily averages of air and water temperatures and wind speeds, July 1950—August 1951, Lake Hefner-Con. STATION 1 DAILY AVERAGES

\begin{tabular}{|c|c|c|c|c|c|c|c|c|c|c|c|c|c|}
\hline \multirow{4}{*}{ 亗 } & \multicolumn{8}{|c|}{ Average atr temperature $\left({ }^{\circ} \mathrm{C}\right)$ at indicated height } & \multirow{4}{*}{$\begin{array}{c}\text { water- } \\
\text { surface } \\
\text { temperature } \\
\text { ('C) }\end{array}$} & \multirow{2}{*}{\multicolumn{4}{|c|}{$\begin{array}{l}\text { Average wind speed (knots) } \\
\text { at indicated height }\end{array}$}} \\
\hline & \multirow{2}{*}{\multicolumn{2}{|c|}{$\begin{array}{c}2 \\
\text { meters }\end{array}$}} & \multirow{2}{*}{\multicolumn{2}{|c|}{$\begin{array}{c}4 \\
\text { meters }\end{array}$}} & \multirow{2}{*}{\multicolumn{2}{|c|}{$\begin{array}{c}8 \\
\text { meters }\end{array}$}} & \multirow{2}{*}{\multicolumn{2}{|c|}{$\begin{array}{c}16 \\
\text { meters } \\
\end{array}$}} & & & & & \\
\hline & & & & & & & & & & \multirow{2}{*}{$\begin{array}{c}2 \\
\text { meters }\end{array}$} & \multirow{2}{*}{$\begin{array}{c}4 \\
\text { meters }\end{array}$} & \multirow{2}{*}{$\begin{array}{c}8 \\
\text { meters }\end{array}$} & \multirow{2}{*}{$\begin{array}{c}16 \\
\text { meters }\end{array}$} \\
\hline & $\begin{array}{l}\text { Dry } \\
\text { bulb }\end{array}$ & $\begin{array}{l}\text { Wet } \\
\text { bulb }\end{array}$ & $\begin{array}{l}\text { Dry } \\
\text { bulb }\end{array}$ & $\begin{array}{l}\text { Wet } \\
\text { bulb }\end{array}$ & $\begin{array}{l}\text { Dry } \\
\text { bulb }\end{array}$ & $\begin{array}{l}\text { Wet } \\
\text { bulb }\end{array}$ & $\begin{array}{l}\text { Dry } \\
\text { bulb }\end{array}$ & $\begin{array}{l}\text { Wet } \\
\text { bulb }\end{array}$ & & & & & \\
\hline
\end{tabular}

\begin{tabular}{|c|c|c|c|c|c|c|c|c|c|c|c|c|c|}
\hline $\begin{array}{l}\frac{1}{2} \\
3 \\
4 \\
5\end{array}$ & $\begin{array}{l}2.1 \\
5.7 \\
5.4\end{array}$ & $\begin{array}{l}3.0 \\
2.9\end{array}$ & $\begin{array}{l}2.1 \\
5.8 \\
5.5\end{array}$ & $\begin{array}{l}2.8 \\
2.9\end{array}$ & $\begin{array}{l}2.2 \\
6.1 \\
5.5\end{array}$ & $\begin{array}{l}2.6 \\
2.7\end{array}$ & $\begin{array}{l}2.2 \\
6.2 \\
5.5\end{array}$ & & $\begin{array}{l}4.0 \\
4.2 \\
4.2\end{array}$ & $\begin{array}{r}11.9 \\
12.2 \\
7.0 \\
5.4 \\
11.0\end{array}$ & $\begin{array}{r}13.9 \\
13.8 \\
6.3 \\
13.2\end{array}$ & $\begin{array}{r}15.7 \\
15.6 \\
8.8 \\
7.5 \\
15.4\end{array}$ & $\begin{array}{r}16.7 \\
16.0 \\
9.5 \\
16.2\end{array}$ \\
\hline $\begin{array}{r}6 \\
7 \\
8 \\
9 \\
10\end{array}$ & $\begin{array}{r}-2.5 \\
-0.8 \\
2.8\end{array}$ & & $\begin{array}{r}2.8 \\
-0.9 \\
2.7\end{array}$ & & $\begin{array}{r}3.0 \\
-0.9 \\
2.7\end{array}$ & & $\begin{array}{r}3.3 \\
-1.0 \\
2.9\end{array}$ & & $\begin{array}{l}3.8 \\
3.4 \\
3.4\end{array}$ & $\begin{array}{r}16.0 \\
7.5 \\
8.5 \\
14.0 \\
11.4\end{array}$ & $\begin{array}{r}18.2 \\
8.0 \\
9.8 \\
16.1 \\
11.8\end{array}$ & $\begin{array}{r}20.5 \\
8.8 \\
10.8 \\
18.2 \\
15.0\end{array}$ & $\begin{array}{l}21.2 \\
11.7 \\
19.5\end{array}$ \\
\hline $\begin{array}{l}11 \\
12 \\
13 \\
14 \\
15\end{array}$ & 5.0 & 2.8 & 5.6 & 2.8 & 6.2 & 2.8 & 6.8 & 3.2 & 3.5 & $\begin{array}{r}10.9 \\
8.0 \\
7.3 \\
12.0 \\
6.5\end{array}$ & $\begin{array}{r}12.4 \\
9.4 \\
8.5 \\
13.3 \\
7.1\end{array}$ & $\begin{array}{r}13.7 \\
10.6 \\
9.5 \\
14.9 \\
8.7\end{array}$ & $\begin{array}{r}14.8 \\
11.5 \\
10.0 \\
9.6\end{array}$ \\
\hline $\begin{array}{l}16 \\
17 \\
18 \\
19 \\
20\end{array}$ & $\begin{array}{r}8.7 \\
10.0 \\
9.7 \\
11.7 \\
0.6\end{array}$ & $\begin{array}{l}4.2 \\
4.8 \\
5.2 \\
6.0\end{array}$ & $\begin{array}{r}9.1 \\
10.8 \\
10.5 \\
12.6 \\
1.0\end{array}$ & $\begin{array}{l}4.1 \\
4.6 \\
4.9 \\
5.4\end{array}$ & $\begin{array}{r}9.5 \\
11.5 \\
11.1 \\
13.1 \\
0.8\end{array}$ & $\begin{array}{l}4.2 \\
4.8 \\
5.0 \\
5.5\end{array}$ & $\begin{array}{r}9.9 \\
12.1 \\
11.7 \\
13.6 \\
0.6\end{array}$ & & $\begin{array}{l}3.9 \\
4.2 \\
4.5 \\
4.6 \\
4.1\end{array}$ & $\begin{array}{r}14.2 \\
10.0 \\
4.2 \\
10.8 \\
12.6\end{array}$ & $\begin{array}{r}16.5 \\
11.8 \\
5.4 \\
12.7 \\
14.3\end{array}$ & $\begin{array}{r}18.9 \\
13.8 \\
6.8 \\
14.7 \\
16.2\end{array}$ & $\begin{array}{r}20.5 \\
15.3 \\
8.1 \\
16.0 \\
16.9\end{array}$ \\
\hline $\begin{array}{l}21 \\
22 \\
23 \\
24 \\
25\end{array}$ & $\begin{array}{r}-2.1 \\
3.9 \\
4.0 \\
2.7\end{array}$ & $\begin{array}{r}1.4 \\
-0.9 \\
-\quad 0.2\end{array}$ & $\begin{array}{r}-2.4 \\
4.1 \\
4.2 \\
2.7\end{array}$ & $\begin{array}{r}1.1 \\
-0.6 \\
-\quad 0.5\end{array}$ & $\begin{array}{r}-2.5 \\
4.4 \\
4.3 \\
2.6\end{array}$ & $\begin{array}{r}0.9 \\
0.6 \\
-\quad 0.7\end{array}$ & $\begin{array}{r}-2.6 \\
4.6 \\
4.4 \\
2.7\end{array}$ & & $\begin{array}{l}3.8 \\
3.5 \\
3.6 \\
3.7\end{array}$ & $\begin{array}{r}6.2 \\
16.1 \\
7.6 \\
7.3 \\
7.5\end{array}$ & $\begin{array}{r}7.0 \\
18.5 \\
8.9 \\
8.0 \\
8.5\end{array}$ & $\begin{array}{r}7.6 \\
20.7 \\
10.1 \\
9.4 \\
9.5\end{array}$ & $\begin{array}{r}8.1 \\
21.9 \\
11.1 \\
10.3 \\
10.2\end{array}$ \\
\hline $\begin{array}{l}26 \\
27 \\
28 \\
29 \\
30\end{array}$ & 9.0 & 4.0 & 9.3 & 3.9 & 9.6 & 3.9 & 10.0 & & & $\begin{array}{l}14.4 \\
15.5 \\
15.8 \\
14.2 \\
11.2\end{array}$ & $\begin{array}{l}16.8 \\
17.4 \\
18.0 \\
16.5 \\
12.7\end{array}$ & $\begin{array}{l}19.3 \\
19.7 \\
20.0 \\
17.7 \\
13.5\end{array}$ & $\begin{array}{l}20.6 \\
20.6 \\
20.7 \\
18.3 \\
13.8\end{array}$ \\
\hline 31 & -10.2 & & -10.8 & & $-11 \cdot 3$ & & -11.6 & & 0.6 & 14.2 & 15.8 & 17.7 & 18.2 \\
\hline
\end{tabular}

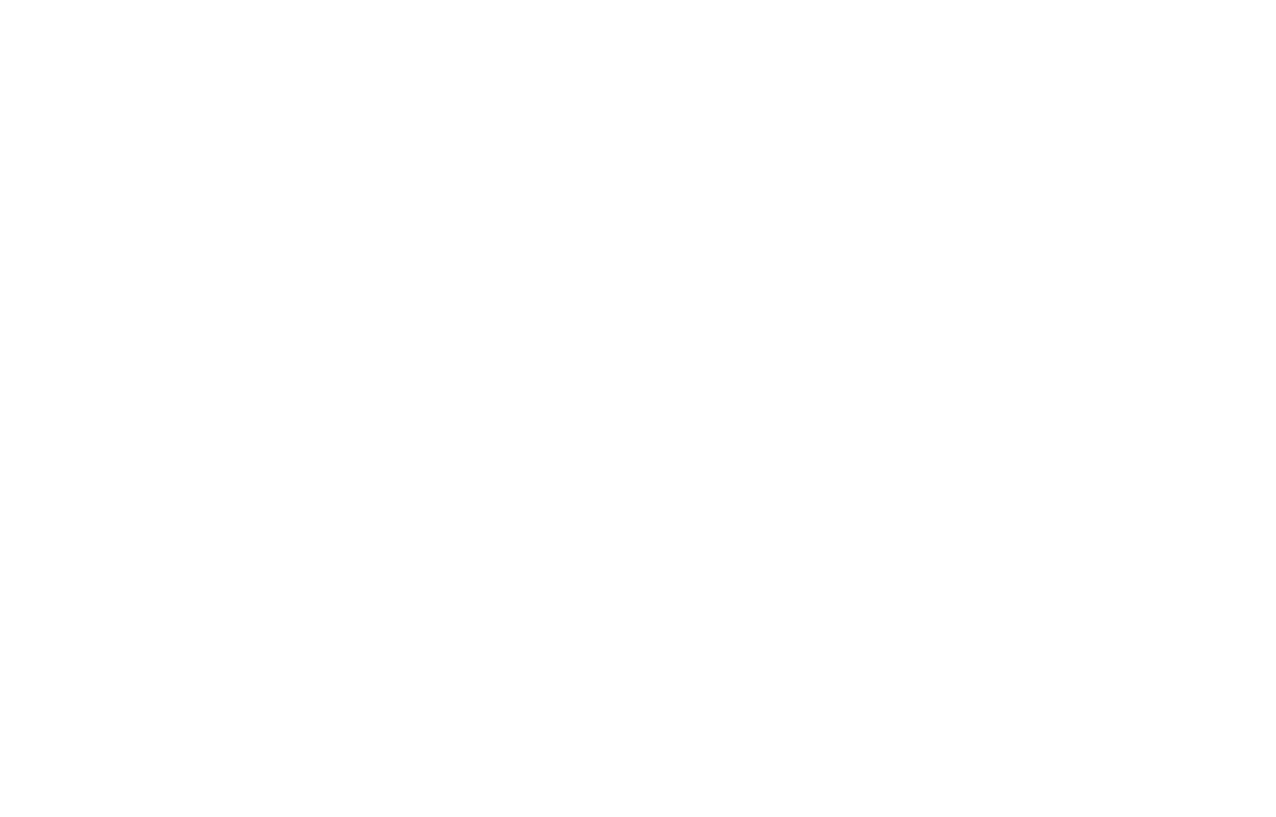


TABLE 11

Table 11. -Daily averages of air and water temperatures and wind speeds, July 1950-August 1951, Lake Hefner-Con. STATION 1 DAILY AVERAGES

1951

\begin{tabular}{|c|c|c|c|c|c|c|c|c|c|c|c|c|c|}
\hline \multirow{4}{*}{ Фัّ } & \multicolumn{8}{|c|}{ Average air temperature $\left({ }^{\circ} \mathrm{C}\right)$ at indicated height } & \multirow{4}{*}{$\begin{array}{c}\text { Average } \\
\text { water- } \\
\text { surface } \\
\text { temperature } \\
\left.\text { ( }{ }^{\circ} \mathrm{C}\right)\end{array}$} & \multirow{2}{*}{\multicolumn{4}{|c|}{$\begin{array}{l}\text { Average wind speed (knots) } \\
\text { at indica ted height }\end{array}$}} \\
\hline & \multirow{2}{*}{\multicolumn{2}{|c|}{$\begin{array}{c}2 \\
\text { meters }\end{array}$}} & \multirow{2}{*}{\multicolumn{2}{|c|}{$\begin{array}{c}4 \\
\text { meters }\end{array}$}} & \multirow{2}{*}{\multicolumn{2}{|c|}{$\begin{array}{c}8 \\
\text { meters }\end{array}$}} & \multirow{2}{*}{\multicolumn{2}{|c|}{$\begin{array}{c}16 \\
\text { meters }\end{array}$}} & & & & & \\
\hline & & & & & & & & & & \multirow{2}{*}{$\begin{array}{c}2 \\
\text { meters }\end{array}$} & \multirow{2}{*}{$\begin{array}{c}4 \\
\text { meters }\end{array}$} & \multirow[b]{2}{*}{$\begin{array}{c}8 \\
\text { meters }\end{array}$} & \multirow[b]{2}{*}{$\begin{array}{c}16 \\
\text { meters }\end{array}$} \\
\hline & $\begin{array}{l}\text { Dry } \\
\text { bulb }\end{array}$ & $\begin{array}{l}\text { Wet } \\
\text { bulb }\end{array}$ & $\begin{array}{l}\text { Dry } \\
\text { bulb }\end{array}$ & $\begin{array}{l}\text { Wet } \\
\text { bulb }\end{array}$ & $\begin{array}{l}\text { Dry } \\
\text { bulb }\end{array}$ & $\begin{array}{l}\text { Wet } \\
\text { bulb }\end{array}$ & $\begin{array}{l}\text { Dry } \\
\text { bulb }\end{array}$ & $\begin{array}{l}\text { Wet } \\
\text { bulb }\end{array}$ & & & & & \\
\hline \multicolumn{14}{|c|}{ MARCH } \\
\hline $\begin{array}{l}1 \\
2 \\
3 \\
4 \\
5\end{array}$ & $\begin{array}{r}8.7 \\
16.3 \\
7.2 \\
6.4 \\
12.8\end{array}$ & $\begin{array}{r}5.1 \\
12.4 \\
3.1 \\
2.8 \\
5.8\end{array}$ & $\begin{array}{r}9.0 \\
27.3 \\
7.1 \\
6.2 \\
13.3\end{array}$ & $\begin{array}{r}5.1 \\
12.9 \\
2.9 \\
2.5 \\
5.7\end{array}$ & $\begin{array}{r}9.3 \\
17.9 \\
7.1 \\
6.2 \\
13.8\end{array}$ & $\begin{array}{l}5.1 \\
2.0 \\
2.5 \\
5.3\end{array}$ & $\begin{array}{r}9.5 \\
17.8 \\
7.0 \\
6.4 \\
13.0\end{array}$ & 3.3 & $\begin{array}{l}6.9 \\
7.5 \\
7.5 \\
8.0 \\
7.9\end{array}$ & $\begin{array}{r}9.8 \\
6.6 \\
14.8\end{array}$ & $\begin{array}{r}10.9 \\
7.4 \\
17.1\end{array}$ & $\begin{array}{r}11.7 \\
8.2 \\
19.4\end{array}$ & $\begin{array}{r}12.5 \\
8.5 \\
20.7\end{array}$ \\
\hline $\begin{array}{r}6 \\
7 \\
8 \\
9 \\
20\end{array}$ & $\begin{array}{r}12.9 \\
5.4 \\
4.5 \\
-0.0 \\
6.5\end{array}$ & 1.8 & $\begin{array}{r}13.4 \\
5.3 \\
4.1 \\
-0.5 \\
5.4\end{array}$ & $\begin{array}{l}9.1 \\
2.4 \\
1.4\end{array}$ & $\begin{array}{r}13.9 \\
5.3 \\
3.8 \\
-0.6 \\
6.2\end{array}$ & $\begin{array}{l}2.3 \\
1.2\end{array}$ & $\begin{array}{r}14.2 \\
5.3 \\
3.6 \\
-0.8 \\
6.5\end{array}$ & & $\begin{array}{l}8.0 \\
8.1 \\
8.1 \\
7.1 \\
7.3\end{array}$ & $\begin{array}{r}10.5 \\
6.5 \\
11.9 \\
8.2 \\
7.8\end{array}$ & $\begin{array}{r}12.2 \\
7.6 \\
13.3 \\
9.0 \\
9.4\end{array}$ & $\begin{array}{r}14.4 \\
8.1 \\
14.5 \\
9.6 \\
10.4\end{array}$ & $\begin{array}{r}15.5 \\
8.9 \\
15.2 \\
10.0 \\
11.0\end{array}$ \\
\hline $\begin{array}{l}12 \\
12 \\
13 \\
14 \\
15\end{array}$ & 400 & 2.6 & 3.5 & 2.4 & 3.5 & 1.1 & 3.6 & 1.5 & $\begin{array}{l}6.9 \\
6.4 \\
5.8 \\
5.6 \\
5.6\end{array}$ & $\begin{array}{r}19.6 \\
19.0 \\
14.3 \\
7.3 \\
4.1\end{array}$ & $\begin{array}{r}23.1 \\
23.0 \\
17.2 \\
7.6\end{array}$ & $\begin{array}{r}25.0 \\
24.5 \\
18.7 \\
8.9 \\
4.9\end{array}$ & $\begin{array}{r}26.2 \\
25.8 \\
19.8 \\
5.5\end{array}$ \\
\hline $\begin{array}{l}16 \\
17 \\
28 \\
19 \\
25\end{array}$ & $\begin{array}{l}3.8 \\
7.3\end{array}$ & $\begin{array}{l}0.8 \\
2.8\end{array}$ & $\begin{array}{r}10.7 \\
7.2 \\
1.4 \\
3.7 \\
7.4\end{array}$ & 5.8 & $\begin{array}{r}11.1 \\
7.2 \\
1.3 \\
3.8 \\
7.4\end{array}$ & $\begin{array}{l}0.7 \\
4.6 \\
0.5 \\
2.4\end{array}$ & $\begin{array}{r}11.6 \\
7.3 \\
1.2 \\
4.0 \\
7.4\end{array}$ & & $\begin{array}{l}5.8 \\
6.2 \\
6.0 \\
5.8 \\
6 . ?\end{array}$ & $\begin{array}{r}11.7 \\
14.7 \\
13.9 \\
3.9 \\
12.6\end{array}$ & $\begin{array}{r}13.6 \\
17.5 \\
15.7 \\
6.2 \\
14.4\end{array}$ & $\begin{array}{r}15.4 \\
19.5 \\
17.6 \\
6.9 \\
15.9\end{array}$ & $\begin{array}{l}16.5 \\
21.3 \\
18.4 \\
17.0\end{array}$ \\
\hline $\begin{array}{l}21 \\
22 \\
23 \\
24 \\
25\end{array}$ & $\begin{array}{r}4.6 \\
25.6 \\
11.0 \\
7.3 \\
22.3\end{array}$ & $\begin{array}{l}8.0 \\
5.3 \\
3.2\end{array}$ & $\begin{array}{r}4.7 \\
16.5 \\
12.8 \\
7.8 \\
12.9\end{array}$ & & $\begin{array}{r}5.0 \\
17: 1 \\
11: 0 \\
8: 0 \\
13.3\end{array}$ & $\begin{array}{l}3.5 \\
5.9 \\
3.1 \\
5.3\end{array}$ & $\begin{array}{r}5.2 \\
27.6 \\
22.3 \\
8.2 \\
13.6\end{array}$ & & $\begin{array}{l}6.4 \\
6.9 \\
7.9 \\
7.4 \\
7.7\end{array}$ & $\begin{array}{r}5.6 \\
13.1 \\
14.2 \\
5.3 \\
7.7\end{array}$ & $\begin{array}{r}6.3 \\
15.2 \\
15.8 \\
5.8 \\
3.9\end{array}$ & $\begin{array}{r}7.1 \\
18.1 \\
18.8 \\
6.7 \\
20.2\end{array}$ & $\begin{array}{r}8.1 \\
20.7 \\
7.0 \\
11.5\end{array}$ \\
\hline $\begin{array}{l}26 \\
27 \\
28 \\
29 \\
30\end{array}$ & 9.0 & 4.1 & 12.9 & & $\exists .7$ & 3.8 & 22.3 & & $\begin{array}{l}7.6 \\
8.2 \\
8.4 \\
8.2 \\
8.1\end{array}$ & $\begin{array}{r}12.8 \\
16.3 \\
17.2 \\
16.5 \\
7.8\end{array}$ & $\begin{array}{r}14.9 \\
18.7 \\
18.1 \\
19.1 \\
8.8\end{array}$ & $\begin{array}{r}16.9 \\
21.1 \\
22.5 \\
20.8 \\
9.9\end{array}$ & $\begin{array}{l}12 \cdot 0 \\
22.3\end{array}$ \\
\hline 31 & 23.0 & 7.9 & 13.2 & & & & 13.7 & & 8.5 & 9.1 & 10.9 & 22.3 & 13.2 \\
\hline
\end{tabular}

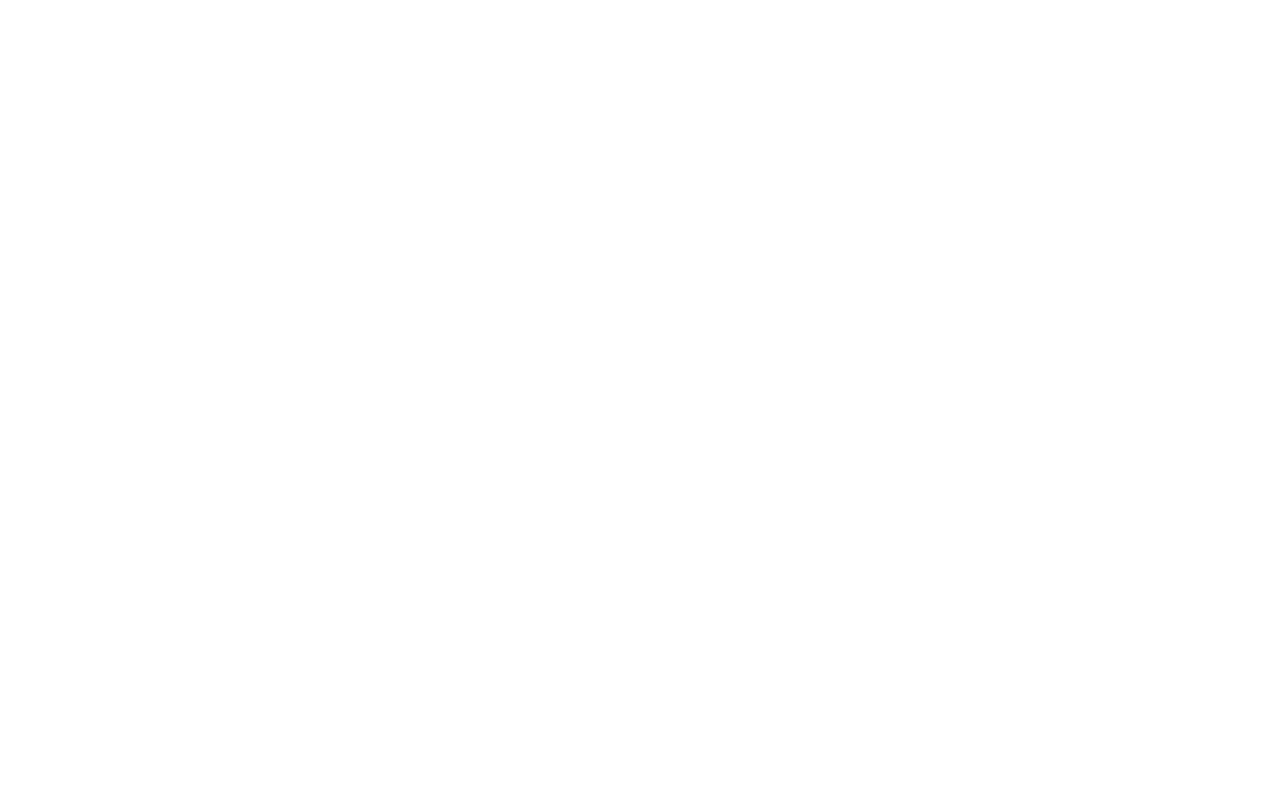


Table 11. -Daily averages of air and water temperatures and wind speeds, July 1950-August 1951, Lake Hefner-Con. STATION 1 DAILY AVERAGES

\begin{tabular}{|c|c|c|c|c|c|c|c|c|c|c|c|c|c|}
\hline \multirow{4}{*}{ ڤ̆ } & \multicolumn{8}{|c|}{ Average air temperature $\left({ }^{\circ} \mathrm{C}\right)$ at indicated height } & \multirow{4}{*}{$\begin{array}{c}\text { Average } \\
\text { water- } \\
\text { surface } \\
\text { temperature } \\
\left({ }^{\circ} \mathrm{C}\right)\end{array}$} & \multirow{2}{*}{\multicolumn{4}{|c|}{$\begin{array}{l}\text { Average wind speed (knots) } \\
\text { at indicated height }\end{array}$}} \\
\hline & \multirow{2}{*}{\multicolumn{2}{|c|}{$\stackrel{2}{2}$}} & \multirow{2}{*}{\multicolumn{2}{|c|}{$\stackrel{4}{\text { meters }}$}} & \multirow{2}{*}{\multicolumn{2}{|c|}{$\begin{array}{c}8 \\
\text { meters }\end{array}$}} & \multirow{2}{*}{\multicolumn{2}{|c|}{$\begin{array}{c}16 \\
\text { meters }\end{array}$}} & & & & & \\
\hline & & & & & & & & & & & & & \\
\hline & $\begin{array}{l}\text { Dry } \\
\text { bulb }\end{array}$ & $\begin{array}{l}\text { Wet } \\
\text { bulb }\end{array}$ & $\begin{array}{l}\text { Dry } \\
\text { bulb }\end{array}$ & $\begin{array}{l}\text { Wet } \\
\text { bulb }\end{array}$ & $\begin{array}{l}\text { Dry } \\
\text { bulb }\end{array}$ & $\begin{array}{l}\text { Wet } \\
\text { bulb }\end{array}$ & $\begin{array}{l}\text { Dry } \\
\text { bulb }\end{array}$ & $\begin{array}{l}\text { Wet } \\
\text { bulb }\end{array}$ & & ${ }_{\text {meters }}^{2}$ & $\begin{array}{c}4 \\
\text { meters }\end{array}$ & $\begin{array}{c}8 \\
\text { meters }\end{array}$ & $\begin{array}{c}16 \\
\text { meters }\end{array}$ \\
\hline
\end{tabular}

\begin{tabular}{|c|c|c|c|c|c|c|c|c|c|c|c|c|c|}
\hline \multicolumn{14}{|c|}{ MAY } \\
\hline $\begin{array}{l}1 \\
2 \\
3 \\
4 \\
5\end{array}$ & $\begin{array}{l}17.8 \\
18.5 \\
17.7 \\
13.9\end{array}$ & $\begin{array}{l}12.1 \\
12.6 \\
12.8 \\
13.7\end{array}$ & $\begin{array}{l}18.0 \\
18.7 \\
17.8 \\
18.9\end{array}$ & $\begin{array}{l}11.8 \\
12.0 \\
12.3 \\
13.3\end{array}$ & $\begin{array}{l}13.2 \\
19.0 \\
19.1 \\
19.2\end{array}$ & $\begin{array}{l}11.6 \\
11.6 \\
11.9 \\
13.1\end{array}$ & $\begin{array}{l}17.9 \\
18.9 \\
18.2 \\
10.3\end{array}$ & $\begin{array}{l}11.6 \\
11.8 \\
11.9 \\
13.0\end{array}$ & $\begin{array}{l}15.7 \\
15.9 \\
16.3 \\
17.0 \\
17.5\end{array}$ & $\begin{array}{r}12.5 \\
12.5 \\
5.9 \\
7.5 \\
4.9\end{array}$ & $\begin{array}{r}14.3 \\
14.2 \\
6.9 \\
8.7 \\
5.5\end{array}$ & $\begin{array}{r}15.9 \\
16.0 \\
8.1 \\
10.1 \\
6.1\end{array}$ & $\begin{array}{r}16.8 \\
17.1 \\
9.3 \\
11.3 \\
6.7\end{array}$ \\
\hline $\begin{array}{r}5 \\
7 \\
8 \\
9 \\
10\end{array}$ & $\begin{array}{l}13.1 \\
13.7 \\
16.9\end{array}$ & $\begin{array}{r}9.6 \\
9.4 \\
13.2\end{array}$ & $\begin{array}{l}12.8 \\
13.3 \\
17.0\end{array}$ & $\begin{array}{r}8.9 \\
9.0 \\
13.2\end{array}$ & $\begin{array}{l}12.6 \\
13.2 \\
17.1\end{array}$ & $\begin{array}{r}8.5 \\
8.7 \\
13.2\end{array}$ & $\begin{array}{l}12.3 \\
13.0 \\
17.0\end{array}$ & $\begin{array}{r}5.4 \\
8.6 \\
13.0\end{array}$ & $\begin{array}{l}16.1 \\
16.5 \\
16.5\end{array}$ & $\begin{array}{r}13.5 \\
5.0 \\
11.4 \\
11.9 \\
11.2\end{array}$ & $\begin{array}{r}15.3 \\
5.4 \\
12.9 \\
12.3\end{array}$ & $\begin{array}{r}15.9 \\
5.7 \\
14.3 \\
15.3 \\
14.3\end{array}$ & $\begin{array}{r}17.1 \\
5.9 \\
15.0\end{array}$ \\
\hline $\begin{array}{l}11 \\
12 \\
13 \\
14 \\
15\end{array}$ & $\begin{array}{l}15.3 \\
17.3 \\
18.8 \\
20.8 \\
20.1\end{array}$ & $\begin{array}{l}14.1 \\
15.4 \\
16.5 \\
18.7\end{array}$ & $\begin{array}{l}15.2 \\
17.2 \\
19.0 \\
21.1 \\
20.1\end{array}$ & $\begin{array}{l}11.8 \\
12: 0 \\
14: 0 \\
16.0 \\
18.4\end{array}$ & $\begin{array}{l}15.2 \\
17.4 \\
10.1 \\
31.3 \\
20.1\end{array}$ & $\begin{array}{l}11.6 \\
12.6 \\
13.6 \\
15.4 \\
13.2\end{array}$ & $\begin{array}{l}17.0 \\
18.8 \\
21.0 \\
20.2\end{array}$ & 18.5 & $\begin{array}{l}18.0 \\
17: 1 \\
17.5 \\
17: 7 \\
17.7\end{array}$ & $\begin{array}{r}3.6 \\
10.6 \\
15.8 \\
17.0 \\
14.4\end{array}$ & $\begin{array}{r}4.0 \\
11.8 \\
17.8 \\
19.2 \\
16.3\end{array}$ & $\begin{array}{r}4.2 \\
12.9 \\
19.6 \\
21.3 \\
18.0\end{array}$ & $\begin{array}{r}4.5 \\
13.4 \\
20.6 \\
22.4 \\
19.0\end{array}$ \\
\hline $\begin{array}{l}16 \\
17\end{array}$ & 20.3 & 18.4 & 20.4 & 18.0 & 20.5 & 18.0 & 20.5 & 17.9 & 18.0 & $\begin{array}{l}13.0 \\
11.9\end{array}$ & $\begin{array}{l}14.8 \\
13.2\end{array}$ & $\begin{array}{l}15.4 \\
14.5\end{array}$ & $\begin{array}{l}17.3 \\
15.0\end{array}$ \\
\hline $\begin{array}{l}18 \\
19 \\
20\end{array}$ & $\begin{array}{l}17.2 \\
20.4\end{array}$ & $\begin{array}{l}16.3 \\
18.3\end{array}$ & & $\begin{array}{l}15.7 \\
18.1\end{array}$ & $\begin{array}{l}17.3 \\
20.7\end{array}$ & $\begin{array}{l}15.5 \\
18.0\end{array}$ & $\begin{array}{l}16.9 \\
20 . ?\end{array}$ & & $\begin{array}{l}17.8 \\
18 . ?\end{array}$ & $\begin{array}{r}32.6 \\
11.9 \\
5.6\end{array}$ & $\begin{array}{r}14.1 \\
13.6 \\
6.7\end{array}$ & $\begin{array}{r}15.6 \\
15.5 \\
7.4\end{array}$ & $\begin{array}{r}16.2 \\
16.2 \\
7.9\end{array}$ \\
\hline $\begin{array}{l}21 \\
22 \\
23 \\
24 \\
25\end{array}$ & $\begin{array}{r}17.1 \\
27.5\end{array}$ & $\begin{array}{l}15.5 \\
15.6\end{array}$ & $\begin{array}{l}17.1 \\
17.5\end{array}$ & $\begin{array}{l}15.4 \\
15.4\end{array}$ & $\begin{array}{r}17.1 \\
17.6\end{array}$ & $\begin{array}{l}15.3 \\
15.4\end{array}$ & $\begin{array}{l}15.5 \\
17.4\end{array}$ & $\begin{array}{l}15.3 \\
15.4\end{array}$ & $\begin{array}{l}19.9 \\
19.4\end{array}$ & $\begin{array}{r}9.2 \\
11.1 \\
3.8 \\
9.2 \\
6.5\end{array}$ & $\begin{array}{r}10.5 \\
12.0 \\
4.2 \\
10.1 \\
7.1\end{array}$ & $\begin{array}{r}12.0 \\
13.7 \\
4.5 \\
11.0 \\
7.8\end{array}$ & $\begin{array}{r}12.6 \\
4.6 \\
11.3 \\
8.1\end{array}$ \\
\hline $\begin{array}{l}25 \\
27 \\
23 \\
29 \\
30\end{array}$ & $\begin{array}{l}20.5 \\
18.1 \\
21.0 \\
24.0\end{array}$ & $\begin{array}{l}15.4 \\
15.4 \\
18.6 \\
20.6\end{array}$ & $\begin{array}{l}20.0 \\
17.0 \\
21.3 \\
24.4\end{array}$ & $\begin{array}{l}14.6 \\
15.0 \\
18.5 \\
20.5\end{array}$ & $\begin{array}{l}20.0 \\
19.0 \\
21.5 \\
24.7\end{array}$ & $\begin{array}{l}14.5 \\
15.0 \\
13.5 \\
20.5\end{array}$ & $\begin{array}{l}19.8 \\
17.1 \\
21.6 \\
24.8\end{array}$ & $\begin{array}{l}14.1 \\
14.9 \\
1 \geqslant .5 \\
20.6\end{array}$ & $\begin{array}{l}20.0 \\
19.5 \\
19.8 \\
21.0\end{array}$ & $\begin{array}{r}6.2 \\
5.5 \\
3.7 \\
5.1 \\
5.5 \\
13.0\end{array}$ & $\begin{array}{r}7.2 \\
7.2 \\
9.5 \\
9.6 \\
6.5 \\
15.2 \\
\end{array}$ & $\begin{array}{r}7.7 \\
7.8 \\
10.4 \\
11.4 \\
7.5\end{array}$ & $\begin{array}{r}8.3 \\
8.3 \\
11.1 \\
12.1 \\
8.3\end{array}$ \\
\hline
\end{tabular}

\begin{tabular}{|c|c|c|c|c|c|c|c|c|c|c|c|c|c|}
\hline \multicolumn{14}{|c|}{ JUNE } \\
\hline $\begin{array}{l}1 \\
2 \\
3 \\
4 \\
5\end{array}$ & $\begin{array}{l}23.9 \\
18.1 \\
14.7 \\
16.0 \\
18.7\end{array}$ & $\begin{array}{l}20.5 \\
15.9 \\
12.6 \\
13.1 \\
16.8\end{array}$ & $\begin{array}{l}24.2 \\
17.9 \\
14: 1 \\
15.4 \\
18.7\end{array}$ & $\begin{array}{l}20.4 \\
15.6 \\
12.0 \\
12.5 \\
16.6\end{array}$ & $\begin{array}{l}24.3 \\
17.8 \\
13.7 \\
15.3 \\
18.7\end{array}$ & $\begin{array}{l}20.2 \\
15.2 \\
11.7 \\
12.3 \\
16.5\end{array}$ & $\begin{array}{l}24.5 \\
17.6 \\
13.7 \\
15.2 \\
18.6\end{array}$ & $\begin{array}{l}20.3 \\
15.1 \\
11.5 \\
12.3 \\
16.4\end{array}$ & $\begin{array}{l}21.4 \\
21.03 \\
20.7 \\
20.6 \\
20.6\end{array}$ & $\begin{array}{r}14.6 \\
11.5 \\
11.3 \\
6.5 \\
6.5\end{array}$ & $\begin{array}{r}16.5 \\
12.9 \\
12.4 \\
7.1 \\
7.2\end{array}$ & $\begin{array}{r}18.7 \\
14.4 \\
12.9 \\
7.6 \\
7.8\end{array}$ & $\begin{array}{r}20.0 \\
15.0 \\
14.0 \\
7.7 \\
8.1\end{array}$ \\
\hline $\begin{array}{r}6 \\
7 \\
8 \\
9 \\
10\end{array}$ & $\begin{array}{l}21 \cdot 0 \\
21.7 \\
23.9 \\
21 \cdot 5 \\
20.3\end{array}$ & $\begin{array}{l}19.3 \\
19: 0 \\
21.1 \\
18.8 \\
18.4\end{array}$ & $\begin{array}{l}21.0 \\
21.9 \\
24.3 \\
21.2 \\
20.1\end{array}$ & $\begin{array}{l}19.0 \\
18.6 \\
20.8 \\
18.2 \\
18.2\end{array}$ & $\begin{array}{l}20.9 \\
21: 9 \\
24.4 \\
21.3 \\
20.2\end{array}$ & $\begin{array}{l}19.0 \\
18: 9 \\
21.0 \\
18.1 \\
18.0\end{array}$ & $\begin{array}{l}21.1 \\
21.9 \\
24.5 \\
21.2 \\
20.0\end{array}$ & $\begin{array}{l}19.0 \\
18.4 \\
20.8 \\
18.0 \\
17.9\end{array}$ & $\begin{array}{l}20.7 \\
20.7 \\
21.3 \\
21.8 \\
22.2\end{array}$ & $\begin{array}{l}6.9 \\
8.4\end{array}$ & 14.8 & $\begin{array}{l}8.1 \\
9.5\end{array}$ & $\begin{array}{r}8.5 \\
10.1\end{array}$ \\
\hline $\begin{array}{l}11 \\
12 \\
13 \\
14 \\
15\end{array}$ & $\begin{array}{l}19.5 \\
20.6 \\
22.1 \\
23.0 \\
23.5\end{array}$ & $\begin{array}{l}18.1 \\
18: 1 \\
18: 9 \\
19.4 \\
19.6\end{array}$ & $\begin{array}{l}19.5 \\
20.4 \\
22.1 \\
22.0 \\
22.5\end{array}$ & $\begin{array}{l}17.9 \\
17: 9 \\
18.0 \\
19.1 \\
19.2\end{array}$ & $\begin{array}{l}19.4 \\
20.5 \\
22: 5 \\
21.8 \\
22.5\end{array}$ & $\begin{array}{l}17.5 \\
17.8 \\
18.5 \\
19.0 \\
19.1\end{array}$ & $\begin{array}{l}19.3 \\
20.4 \\
22.1 \\
22.0 \\
22.5\end{array}$ & $\begin{array}{l}17.8 \\
17.7 \\
13.5 \\
19.0 \\
19.1\end{array}$ & $\begin{array}{l}21.9 \\
22.4 \\
23.0 \\
23.0 \\
23.7\end{array}$ & $\begin{array}{l}6.9 \\
5.9 \\
8.4 \\
7.3 \\
6.4\end{array}$ & $\begin{array}{l}6.4 \\
9.2 \\
7.9 \\
7.0\end{array}$ & $\begin{array}{l}8.6 \\
5.9 \\
9.8 \\
8.6 \\
7.5\end{array}$ & $\begin{array}{r}8.7 \\
7.4 \\
20.4 \\
8.2 \\
8.1\end{array}$ \\
\hline $\begin{array}{l}16 \\
17 \\
13 \\
19 \\
20\end{array}$ & $\begin{array}{l}24.5 \\
25.8 \\
24.4 \\
25.5\end{array}$ & $\begin{array}{l}20.3 \\
21.8 \\
21.5 \\
21.5\end{array}$ & $\begin{array}{l}24.4 \\
25.6 \\
24.4 \\
25.5\end{array}$ & $\begin{array}{l}20.0 \\
21.5 \\
21.3 \\
21.4\end{array}$ & $\begin{array}{l}24.7 \\
25.7 \\
24.4 \\
25.7\end{array}$ & $\begin{array}{l}19.8 \\
21: 5 \\
21: 1 \\
21.2\end{array}$ & $\begin{array}{l}24.7 \\
25.7 \\
24.4 \\
25.7\end{array}$ & $\begin{array}{l}19.7 \\
? 1.5 \\
? 1.1 \\
=1.2\end{array}$ & $\begin{array}{l}24.3 \\
25.5 \\
24.4 \\
25.3\end{array}$ & $\begin{array}{r}6.2 \\
4.6 \\
7.1 \\
7.2 \\
11.6\end{array}$ & $\begin{array}{r}6.8 \\
5.2 \\
8.0 \\
8.0 \\
12.8\end{array}$ & $\begin{array}{r}7.6 \\
5.5 \\
8.6 \\
8.6 \\
14.1\end{array}$ & $\begin{array}{r}8.2 \\
6.0 \\
9.2 \\
9.2 \\
14.7\end{array}$ \\
\hline $\begin{array}{l}21 \\
22 \\
23 \\
24 \\
25\end{array}$ & $\begin{array}{l}25.8 \\
25.4 \\
34.5 \\
25.3\end{array}$ & $\begin{array}{l}22.7 \\
21.8 \\
20.9 \\
22.7\end{array}$ & $\begin{array}{l}25.9 \\
25.5 \\
24: 5 \\
25.3\end{array}$ & $\begin{array}{l}22.5 \\
21.6 \\
20.6 \\
22.6\end{array}$ & $\begin{array}{l}25.0 \\
25.6 \\
24.5 \\
25.4\end{array}$ & $\begin{array}{l}32.4 \\
21.5 \\
20.5 \\
22.5\end{array}$ & $\begin{array}{l}26.1 \\
25.6 \\
24.5 \\
25.4\end{array}$ & $\begin{array}{l}22.4 \\
21.4 \\
20.4 \\
22.5\end{array}$ & $\begin{array}{l}25.1 \\
25.1 \\
25.2 \\
25.0\end{array}$ & $\begin{array}{r}8.9 \\
8.7 \\
11.4 \\
10.3 \\
11.8\end{array}$ & $\begin{array}{l}10.2 \\
10.0 \\
12.8 \\
11.3 \\
13.3\end{array}$ & $\begin{array}{l}11.2 \\
11.1 \\
14.2 \\
12.1 \\
14.9\end{array}$ & $\begin{array}{l}11.0 \\
11.7 \\
15.0 \\
12.7 \\
15.5\end{array}$ \\
\hline $\begin{array}{l}26 \\
27 \\
28 \\
29 \\
30\end{array}$ & $\begin{array}{r}35.7 \\
36.5 \\
36.2 \\
26.4 \\
20.9\end{array}$ & $\begin{array}{l}? 1.9 \\
? 1.2 \\
31: 7 \\
22.3 \\
18.7\end{array}$ & $\begin{array}{l}36.7 \\
26.7 \\
25.3 \\
26.6 \\
32.6\end{array}$ & $\begin{array}{l}21.7 \\
21.0 \\
21.5 \\
22.1 \\
18.3\end{array}$ & $\begin{array}{l}26.8 \\
26.8 \\
26.5 \\
26.7 \\
20.4\end{array}$ & $\begin{array}{l}21.5 \\
20.8 \\
21.3 \\
22.0 \\
18.0\end{array}$ & $\begin{array}{l}75.7 \\
26.9 \\
26.4 \\
26.7 \\
20.2\end{array}$ & $\begin{array}{l}21.6 \\
30.7 \\
21.2 \\
21.9 \\
17.8\end{array}$ & $\begin{array}{l}25.2 \\
24.8 \\
25.1 \\
25.0 \\
24.5\end{array}$ & $\begin{array}{r}14.9 \\
14.5 \\
9.1 \\
11.7 \\
11.0\end{array}$ & $\begin{array}{l}16.8 \\
16.4 \\
10.2 \\
13.2 \\
12.5\end{array}$ & $\begin{array}{l}18.8 \\
18.6 \\
11.4 \\
14.7 \\
13.0\end{array}$ & $\begin{array}{l}19.7 \\
19.5 \\
12.0 \\
15.5 \\
13.8\end{array}$ \\
\hline
\end{tabular}


TABLE 11

Table 11.-Daily averages of air and water temperatures and wind speeds, July 1950—August 1951, Lake Hefnẹm-Con. STATION 1 DAILY AVERAGES

1951

\begin{tabular}{|c|c|c|c|c|c|c|c|c|c|c|c|c|c|}
\hline \multirow{3}{*}{ 亗 } & \multicolumn{8}{|c|}{ Average air temperature $\left({ }^{\circ} \mathrm{C}\right)$ at indicated he ight } & \multirow{3}{*}{$\begin{array}{c}\text { Average } \\
\text { water- } \\
\text { surface } \\
\text { temperature } \\
\left.\text { ( }{ }^{\circ} \mathrm{C}\right)\end{array}$} & \multirow{2}{*}{\multicolumn{4}{|c|}{$\begin{array}{l}\text { Average wind speed (knots) } \\
\text { at indicated height }\end{array}$}} \\
\hline & \multicolumn{2}{|c|}{$\begin{array}{c}2 \\
\text { meters }\end{array}$} & \multicolumn{2}{|c|}{$\begin{array}{c}4 \\
\text { meters }\end{array}$} & \multicolumn{2}{|c|}{$\begin{array}{c}8 \\
\text { meters }\end{array}$} & \multicolumn{2}{|c|}{$\begin{array}{c}16 \\
\text { meters }\end{array}$} & & & & & \\
\hline & $\begin{array}{l}\text { Dry } \\
\text { bulb }\end{array}$ & $\begin{array}{l}\text { Wet } \\
\text { bulb }\end{array}$ & $\begin{array}{l}\text { Dry } \\
\text { bulb }\end{array}$ & $\begin{array}{l}\text { Wet } \\
\text { bulb }\end{array}$ & $\begin{array}{l}\text { Dry } \\
\text { bulb }\end{array}$ & $\begin{array}{l}\text { Wet } \\
\text { bulb }\end{array}$ & $\begin{array}{l}\text { Dry } \\
\text { bulb }\end{array}$ & $\begin{array}{l}\text { Wet } \\
\text { bulb }\end{array}$ & & $\begin{array}{c}2 \\
\text { meters }\end{array}$ & $\begin{array}{c}4 \\
\text { meters }\end{array}$ & $\begin{array}{c}8 \\
\text { meters }\end{array}$ & $\begin{array}{c}16 \\
\text { meters }\end{array}$ \\
\hline \multicolumn{14}{|c|}{ JULY } \\
\hline $\begin{array}{l}1 \\
2 \\
3 \\
4 \\
5\end{array}$ & $\begin{array}{l}26.0 \\
23.4 \\
26.2\end{array}$ & $\begin{array}{l}23.5 \\
20.6 \\
22.4\end{array}$ & $\begin{array}{l}26.2 \\
23.2 \\
26.4\end{array}$ & $\begin{array}{l}23.3 \\
20.4 \\
22.3\end{array}$ & $\begin{array}{l}26.3 \\
23.3 \\
26.5\end{array}$ & $\begin{array}{l}23.3 \\
20.1 \\
22.3\end{array}$ & $\begin{array}{l}26.4 \\
23.1 \\
26.6\end{array}$ & $\begin{array}{l}23.3 \\
20.1 \\
22.1\end{array}$ & $\begin{array}{l}24.6 \\
24.4 \\
24.7\end{array}$ & $\begin{array}{r}8.5 \\
0.9 \\
12.5 \\
8.7 \\
12.0\end{array}$ & $\begin{array}{r}9.2 \\
9.8 \\
14.2 \\
9.6 \\
13.6\end{array}$ & $\begin{array}{r}9.4 \\
10.7 \\
16.0 \\
10.3 \\
15.1\end{array}$ & $\begin{array}{r}9.5 \\
11.0 \\
16.8 \\
10.9 \\
15.9\end{array}$ \\
\hline $\begin{array}{r}6 \\
7 \\
8 \\
0 \\
10\end{array}$ & $\begin{array}{l}26.5 \\
26.7 \\
27.2 \\
26.8 \\
27.1\end{array}$ & $\begin{array}{l}22.0 \\
21.9 \\
21.7 \\
22.2 \\
22.7\end{array}$ & $\begin{array}{l}26.7 \\
26.0 \\
27.3 \\
27.0 \\
27.5\end{array}$ & $\begin{array}{l}21.9 \\
21.7 \\
21.5 \\
22: 0 \\
22.5\end{array}$ & $\begin{array}{l}26.8 \\
25.0 \\
27.5 \\
25.9 \\
77.3\end{array}$ & $\begin{array}{l}21.8 \\
21.5 \\
21.4 \\
21.9 \\
22.4\end{array}$ & $\begin{array}{l}25.8 \\
26.9 \\
27.5 \\
27.0 \\
37.0\end{array}$ & $\begin{array}{l}11.7 \\
? 1.5 \\
? 1.5 \\
? ? .0 \\
? .3\end{array}$ & $\begin{array}{l}25.0 \\
25.3 \\
25.4 \\
25.5 \\
25.8\end{array}$ & $\begin{array}{l}13.2 \\
13.4 \\
15.0 \\
11.7 \\
12.6\end{array}$ & $\begin{array}{l}15.0 \\
15.1 \\
17.0 \\
12.0 \\
14.2\end{array}$ & $\begin{array}{l}16.7 \\
16.9 \\
19.1 \\
14.3 \\
15.7\end{array}$ & $\begin{array}{l}17.5 \\
17: 7 \\
20.0 \\
15.3 \\
16.5\end{array}$ \\
\hline $\begin{array}{l}11 \\
12 \\
13 \\
14 \\
15\end{array}$ & $\begin{array}{l}26.9 \\
27.5 \\
25.6 \\
23.6 \\
25.7\end{array}$ & $\begin{array}{l}22.4 \\
22.6 \\
22.6 \\
22.1 \\
22.5\end{array}$ & $\begin{array}{l}27.1 \\
27.6 \\
25.4 \\
23.5 \\
25.7\end{array}$ & $\begin{array}{l}22.2 \\
22: 3 \\
22: 4 \\
21 \cdot 8 \\
27.4\end{array}$ & $\begin{array}{l}27 .: \\
27: 8 \\
25: 3 \\
23.5 \\
25.7\end{array}$ & $\begin{array}{l}22: 1 \\
22: 2 \\
22: 3 \\
21: 7 \\
2 ?: 2\end{array}$ & $\begin{array}{l}27 . ? \\
27.3 \\
25.2 \\
25.2\end{array}$ & $\begin{array}{rl}7 & 1.9 \\
-2 & 1 \\
22.2 & 1\end{array}$ & $\begin{array}{l}25.7 \\
26.2 \\
25.6 \\
26.2 \\
26.2\end{array}$ & $\begin{array}{r}11.7 \\
10.5 \\
7.0 \\
8.7 \\
9.4\end{array}$ & $\begin{array}{r}13.1 \\
11.8 \\
7.7 \\
9.4 \\
10.4\end{array}$ & $\begin{array}{r}14.5 \\
13.2 \\
8.2 \\
9.7 \\
11.2\end{array}$ & $\begin{array}{r}15.4 \\
13.8 \\
8.9 \\
9.9 \\
11.7\end{array}$ \\
\hline $\begin{array}{l}16 \\
17 \\
18 \\
19 \\
20\end{array}$ & $\begin{array}{l}27.0 \\
27.7 \\
25.3\end{array}$ & $\begin{array}{l}22.2 \\
22.5 \\
22.0\end{array}$ & $\begin{array}{l}27 . ? \\
26.9 \\
28.4\end{array}$ & $\begin{array}{l}21.9 \\
22: 3 \\
21.7\end{array}$ & $\begin{array}{l}27.3 \\
27.6 \\
28.4\end{array}$ & $\begin{array}{l}21.8 \\
22.2 \\
21.4\end{array}$ & $\begin{array}{l}27.0 \\
27.6 \\
23.3\end{array}$ & $21 \cdot 3$ & $\begin{array}{l}27.0 \\
28.1 \\
28.2\end{array}$ & $\begin{array}{r}6.4 \\
4.7 \\
5.6 \\
4.4 \\
18.4\end{array}$ & $\begin{array}{l}7.2 \\
4: 8 \\
5.9\end{array}$ & $\begin{array}{r}8.1 \\
5.8 \\
7.0 \\
5.1 \\
13.0\end{array}$ & $\begin{array}{l}8.7 \\
7.6\end{array}$ \\
\hline $\begin{array}{l}21 \\
22 \\
23 \\
24 \\
25\end{array}$ & $\begin{array}{l}35.2 \\
70.3\end{array}$ & $\begin{array}{l}22: 4 \\
22: 3\end{array}$ & $\begin{array}{l}25.0 \\
25.3\end{array}$ & $\begin{array}{l}22.1 \\
22.6\end{array}$ & $\begin{array}{l}24.9 \\
26.2\end{array}$ & $\begin{array}{l}21: 9 \\
22: 4\end{array}$ & 30.3 & 22.3 & $\begin{array}{l}27 \cdot 8 \\
28.2\end{array}$ & $\begin{array}{r}14.2 \\
9.1 \\
6.6 \\
5.5 \\
4.3\end{array}$ & $\begin{array}{r}16.0 \\
10.3 \\
7.3 \\
5.8 \\
4.6\end{array}$ & $\begin{array}{r}18.0 \\
11.4 \\
7.7 \\
6.1 \\
4.8\end{array}$ & $\begin{array}{r}18.8 \\
12.2 \\
8.4 \\
6.4 \\
5.0\end{array}$ \\
\hline $\begin{array}{l}26 \\
27 \\
28 \\
29 \\
30\end{array}$ & & & & & & & & & & $\begin{array}{l}2.7 \\
5.5 \\
3.9 \\
4.8 \\
6.2\end{array}$ & $\begin{array}{l}9.5 \\
6.0 \\
4.2 \\
4.9 \\
6.6\end{array}$ & $\begin{array}{l}9.9 \\
6.3 \\
4.4 \\
7.3\end{array}$ & $\begin{array}{r}10.6 \\
6.7 \\
4.7 \\
5.4 \\
7.5\end{array}$ \\
\hline 31 & 25.9 & 22.8 & 25.8 & 23.4 & $25 \cdot 7$ & $22 . ?$ & 25.6 & $3,7.1$ & $28 \cdot 3$ & 5.6 & 6.1 & 6.3 & 6.6 \\
\hline
\end{tabular}

AUGUST

\begin{tabular}{|c|c|c|c|c|c|c|c|c|c|c|c|c|c|}
\hline $\begin{array}{l}1 \\
2 \\
3 \\
4 \\
5\end{array}$ & $\begin{array}{l}27.6 \\
23.0 \\
29.5 \\
29.5 \\
30.1\end{array}$ & $\begin{array}{l}23.1 \\
22.5 \\
22.6 \\
24.1 \\
24.3\end{array}$ & $\begin{array}{l}27.5 \\
28.1 \\
29.7 \\
25.4 \\
30.3\end{array}$ & $\begin{array}{l}2 ? .7 \\
22.0 \\
22.1 \\
23.5 \\
23.5\end{array}$ & $\begin{array}{l}77.6 \\
29.3 \\
29.7 \\
29.5 \\
30.5\end{array}$ & $\begin{array}{l}22.7 \\
21.7 \\
21.6 \\
23.2 \\
23.2\end{array}$ & $\begin{array}{l}27.6 \\
23.4 \\
2.48 \\
2.0 .4 \\
30.5\end{array}$ & $\begin{array}{r}7.6 \\
7.6 \\
1.4 \\
3.1 \\
3.3\end{array}$ & $\begin{array}{l}29.0 \\
23.3 \\
28.6 \\
29.3 \\
28.3\end{array}$ & $\begin{array}{r}3.3 \\
6.7 \\
6.0 \\
5.4 \\
10.6\end{array}$ & $\begin{array}{r}3.5 \\
7.4 \\
6.6 \\
5.7 \\
12.0\end{array}$ & $\begin{array}{r}3.7 \\
2.3 \\
7.3 \\
6.1 \\
13.4\end{array}$ & $\begin{array}{r}3.9 \\
8.8 \\
7.9 \\
6.5 \\
14.2\end{array}$ \\
\hline $\begin{array}{r}6 \\
7 \\
9 \\
9 \\
10\end{array}$ & 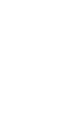 & $\begin{array}{r}23.9 \\
32.7 \\
22.1 \\
2 ? .4 \\
21.3\end{array}$ & $\begin{array}{l}31.4 \\
22.7 \\
30.5 \\
25.0 \\
22.5\end{array}$ & $\begin{array}{l}23.3 \\
21.7 \\
22.5 \\
21.5 \\
20.5\end{array}$ & $\begin{array}{l}31.0 \\
37.0 \\
30.7 \\
24.5 \\
22.3\end{array}$ & $\begin{array}{l}23.0 \\
21.5 \\
22.0 \\
21.7 \\
20.3\end{array}$ & $\begin{array}{l}21.3 \\
33.1 \\
30.9 \\
24.7 \\
22.2\end{array}$ & $\begin{array}{r}2.7 \\
71.3 \\
71.9 \\
71.6 \\
=0.7\end{array}$ & $\begin{array}{l}23.5 \\
29.6 \\
28.4 \\
27.4 \\
27.0\end{array}$ & $\begin{array}{r}10.2 \\
11.4 \\
7.4 \\
8.6 \\
6.5\end{array}$ & $\begin{array}{r}11.7 \\
12.9 \\
8.6 \\
9.3 \\
7.1\end{array}$ & $\begin{array}{r}13.3 \\
14.7 \\
9.8 \\
9.8 \\
7.6\end{array}$ & $\begin{array}{r}14.3 \\
15.5 \\
10.4 \\
10.4 \\
7.7\end{array}$ \\
\hline $\begin{array}{l}11 \\
12 \\
13 \\
14 \\
15\end{array}$ & $\begin{array}{l}23.1 \\
77.0 \\
77.6 \\
30.0 \\
27.2\end{array}$ & $\begin{array}{l}20.0 \\
22.7 \\
22.7 \\
21.8 \\
21.6\end{array}$ & $\begin{array}{l}22 . \\
26: 7 \\
370 \\
370 \\
270\end{array}$ & $\begin{array}{l}20.15 \\
22.4 \\
21.0 \\
21.2 \\
20.0\end{array}$ & $\begin{array}{l}22.0 \\
26.7 \\
27.5 \\
30.4 \\
27.0\end{array}$ & $\begin{array}{l}20.6 \\
22.3 \\
21.4 \\
20.9 \\
20.6\end{array}$ & $\begin{array}{l}22.7 \\
26.6 \\
25.0 \\
30.6 \\
27.0\end{array}$ & $\begin{array}{r}0.6 \\
2.3 \\
-1.1 \\
\because 0.7 \\
0.5\end{array}$ & $\begin{array}{l}27.0 \\
27.7 \\
27.2 \\
27: 1 \\
27: 1\end{array}$ & $\begin{array}{r}5.0 \\
4.6 \\
8.0 \\
10.7 \\
7.7\end{array}$ & $\begin{array}{r}5.3 \\
4.0 \\
9.0 \\
12.0 \\
8.7\end{array}$ & $\begin{array}{r}5.4 \\
5.2 \\
9.9 \\
13.0 \\
9.4\end{array}$ & $\begin{array}{r}5.8 \\
5.5 \\
10.5 \\
14.5 \\
10.1\end{array}$ \\
\hline $\begin{array}{l}16 \\
17 \\
19 \\
19 \\
20\end{array}$ & $\begin{array}{l}25 \cdot 2 \\
30.7\end{array}$ & $\begin{array}{l}20.8 \\
31.8\end{array}$ & $\begin{array}{l}25 . ? \\
20.6\end{array}$ & $\begin{array}{l}20.1 \\
21.2\end{array}$ & $\begin{array}{l}25.2 \\
30.5\end{array}$ & $\begin{array}{l}20.0 \\
20.9\end{array}$ & $\begin{array}{l}25.3 \\
31.0\end{array}$ & $\begin{array}{l}19.0 \\
20.7\end{array}$ & $\begin{array}{l}26.7 \\
26.8 \\
26.5\end{array}$ & $\begin{array}{r}6.2 \\
21.4 \\
5.1 \\
5.7 \\
8.8\end{array}$ & $\begin{array}{r}6.8 \\
12.8 \\
5.7 \\
6.4 \\
9.8\end{array}$ & $\begin{array}{r}7.0 \\
14.2 \\
6.0 \\
7.2 \\
11.2\end{array}$ & $\begin{array}{r}7.6 \\
15.3 \\
0.3 \\
7.7 \\
11.5\end{array}$ \\
\hline $\begin{array}{l}21 \\
23 \\
23 \\
24 \\
25\end{array}$ & $\begin{array}{l}2.0 \\
2: 08 \\
240.8 \\
26.7 \\
27.8\end{array}$ & 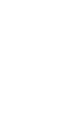 & 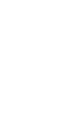 & 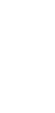 & $\begin{array}{r}29.4 \\
32.5 \\
2.0 \\
7.0 \\
7.00 \\
=.3\end{array}$ & $\begin{array}{l}20.3 \\
18: 4 \\
21.7 \\
2: 4 \\
3: 3\end{array}$ & $\begin{array}{r}27.3 \\
20.4 \\
25.0 \\
27.0 \\
27.07\end{array}$ & $\begin{array}{r}0.1 \\
1 \cong .4 \\
-1.6 \\
=2.2 \\
9.1\end{array}$ & $\begin{array}{l}25.7 \\
26.2 \\
25.8 \\
25.9 \\
25.9\end{array}$ & $\begin{array}{r}0.0 \\
6.2 \\
5.9 \\
11.3 \\
11.1\end{array}$ & $\begin{array}{r}\because .9 \\
6.6 \\
12.8 \\
12.8 \\
1=0\end{array}$ & $\begin{array}{r}10.5 \\
6.8 \\
10.7 \\
14.2 \\
14.2\end{array}$ & $\begin{array}{r}10.8 \\
6.9 \\
14.9 \\
15.0\end{array}$ \\
\hline $\begin{array}{l}25 \\
27 \\
23 \\
26 \\
30\end{array}$ & $\begin{array}{l}23: 1 \\
2: 0 \\
30: 2 \\
30.2\end{array}$ & $\begin{array}{l}22.6 \\
22.1 \\
2.1 \\
22.1\end{array}$ & $\begin{array}{l}20.2 \\
20: 3 \\
30.7 \\
20.6\end{array}$ & $\begin{array}{l}2201 \\
? 1: 0 \\
210 \% \\
2106\end{array}$ & $\begin{array}{l}23.4 \\
30: 5 \\
30 .\end{array}$ & $\begin{array}{l}23: 1 \\
21: 5 \\
21: 0 \\
21.6\end{array}$ & $\begin{array}{l}23.4 \\
2.6 \\
30.9 \\
31 . ?\end{array}$ & $\begin{array}{r}1.9 \\
1.3 \\
1.4 \\
31.4\end{array}$ & $\begin{array}{l}26.1 \\
26.0 \\
20.1 \\
25.9\end{array}$ & $\begin{array}{r}.7 \\
11.5 \\
13.6 \\
12.0 \\
10.3\end{array}$ & $\begin{array}{l}10.8 \\
1=: 9 \\
15.4 \\
13.7 \\
12.3\end{array}$ & $\begin{array}{l}12.0 \\
14.0 \\
17.5 \\
15.0 \\
14.0\end{array}$ & $\begin{array}{l}12.5 \\
15.3 \\
12.4 \\
16.5 \\
14.5\end{array}$ \\
\hline$=i$ & 25.4 & $\therefore 1 . ?$ & $z \leqslant \cdot 0$ & $21 . ?$ & 30.1 & 26.9 & 20.4 & $\because-8$ & $250=$ & {$[\cdot E$} & 5.7 & 11.2 & 11.3 \\
\hline
\end{tabular}


Table 11.-Daily averages of air and water temperatures and wind speeds, July 1950-August 1951, Lake Hefner-Con.

\begin{tabular}{|c|c|c|c|c|c|c|c|c|c|c|c|c|c|}
\hline \multicolumn{3}{|c|}{ STATION 2} & \multicolumn{6}{|c|}{ DAILY AVERAGES } & \multirow{4}{*}{$\begin{array}{c}\text { Average } \\
\text { water- } \\
\text { surface } \\
\text { temperature }\end{array}$} & \multicolumn{4}{|r|}{1950} \\
\hline \multirow{4}{*}{ कू } & \multicolumn{8}{|c|}{ Average air temperature $\left({ }^{\circ} \mathrm{C}\right)$ at indicated height } & & \multirow{2}{*}{\multicolumn{4}{|c|}{$\begin{array}{l}\text { Average wind speed (knots) } \\
\text { at indicated height }\end{array}$}} \\
\hline & \multirow{2}{*}{\multicolumn{2}{|c|}{$\begin{array}{c}2 \\
\text { meters }\end{array}$}} & \multirow{2}{*}{\multicolumn{2}{|c|}{$\begin{array}{c}4 \\
\text { meters }\end{array}$}} & \multirow{2}{*}{\multicolumn{2}{|c|}{$\begin{array}{c}\mathbf{8} \\
\text { meters }\end{array}$}} & \multirow{2}{*}{\multicolumn{2}{|c|}{$\begin{array}{c}16 \\
\text { meters }\end{array}$}} & & & & & \\
\hline & & & & & & & & & & & & & \\
\hline & $\begin{array}{l}\text { Dry } \\
\text { bulb }\end{array}$ & $\begin{array}{l}\text { Wet } \\
\text { bulb }\end{array}$ & $\begin{array}{l}\text { Dry } \\
\text { bulb }\end{array}$ & $\begin{array}{l}\text { Wet } \\
\text { bulb }\end{array}$ & $\begin{array}{l}\text { Dry } \\
\text { bulb }\end{array}$ & $\begin{array}{l}\text { Wet } \\
\text { bulb }\end{array}$ & $\begin{array}{l}\text { Dry } \\
\text { bulb }\end{array}$ & $\begin{array}{l}\text { Wet } \\
\text { bulb }\end{array}$ & & meters & meters & meters & meters \\
\hline
\end{tabular}

\begin{tabular}{|c|c|c|c|c|c|c|c|c|c|c|c|c|c|}
\hline \multicolumn{14}{|c|}{ JULY } \\
\hline 1 & 24.8 & 18.8 & 24.7 & 18.7 & 24.7 & 18.7 & 24.7 & 18.6 & & 8.1 & 9.4 & 10.9 & $12 \cdot 3$ \\
\hline $\begin{array}{l}2 \\
3 \\
4 \\
5\end{array}$ & $\begin{array}{l}25.8 \\
22.5 \\
24.2\end{array}$ & $\begin{array}{l}21.4 \\
20.7 \\
21.5\end{array}$ & $\begin{array}{l}25.7 \\
22.5 \\
24.2\end{array}$ & $\begin{array}{l}21.3 \\
20.6 \\
21.4\end{array}$ & $\begin{array}{l}25.6 \\
22.4 \\
24.4\end{array}$ & $\begin{array}{l}21.3 \\
20.6 \\
21.5\end{array}$ & $\begin{array}{l}25.6 \\
22.4 \\
24.6\end{array}$ & $\begin{array}{l}21.2 \\
20.5 \\
21.3\end{array}$ & & $\begin{array}{l}8.5 \\
4.5 \\
2.5\end{array}$ & $\begin{array}{l}5.8 \\
3.8 \\
3.6 \\
3.5\end{array}$ & 6.8 & $\begin{array}{r}7.4 \\
7.6 \\
4.7 \\
5.0\end{array}$ \\
\hline $\begin{array}{r}6 \\
7 \\
8 \\
9 \\
10\end{array}$ & 23.9 & 21.0 & 23.8 & 20.0 & 23.8 & 20.8 & 22.9 & 20.7 & $\begin{array}{l}25.9 \\
22.6\end{array}$ & $\begin{array}{r}8.4 \\
11.4 \\
8.2\end{array}$ & $\begin{array}{r}3.7 \\
5.6 \\
9.8 \\
13.2 \\
9.9\end{array}$ & $\begin{array}{r}4.3 \\
6.6 \\
11.1 \\
15.1\end{array}$ & $\begin{array}{r}5.1 \\
7.5 \\
12.4 \\
16.7 \\
12.7\end{array}$ \\
\hline $\begin{array}{l}11 \\
12 \\
13 \\
14 \\
15\end{array}$ & 26.2 & $\begin{array}{l}18.0 \\
22.4\end{array}$ & $\begin{array}{l}22.1 \\
26.2\end{array}$ & $\begin{array}{l}13.0 \\
22.4\end{array}$ & $\begin{array}{l}21.9 \\
26.1\end{array}$ & $\begin{array}{l}17.8 \\
22.3\end{array}$ & $\begin{array}{l}21.8 \\
26.0\end{array}$ & $\begin{array}{r}17.9 \\
? 2.3\end{array}$ & $\begin{array}{l}26.2 \\
25.9\end{array}$ & $\begin{array}{r}5.1 \\
4.6 \\
6.1 \\
3.3 \\
10.6\end{array}$ & $\begin{array}{r}6.2 \\
5.5 \\
7.2 \\
4.0 \\
12.3\end{array}$ & $\begin{array}{r}7.1 \\
6.5 \\
7.9 \\
4.7 \\
13.9\end{array}$ & $\begin{array}{r}8.0 \\
7.3 \\
9.9 \\
5.4 \\
15.3\end{array}$ \\
\hline $\begin{array}{l}16 \\
17 \\
18 \\
19 \\
20\end{array}$ & $\begin{array}{l}27 \cdot 3 \\
22 \cdot 2 \\
23.3 \\
22: 9 \\
22.8\end{array}$ & $\begin{array}{l}22.3 \\
20.7 \\
21.4 \\
21.2 \\
20.5\end{array}$ & $\begin{array}{l}37.4 \\
22.2 \\
23.4 \\
22.9 \\
22.7\end{array}$ & $\begin{array}{l}22.4 \\
20.7 \\
21.4 \\
21.1 \\
20.6\end{array}$ & $\begin{array}{l}27.3 \\
22: 1 \\
23.6 \\
22.0 \\
22.3\end{array}$ & $\begin{array}{l}22.3 \\
20.6 \\
21.4 \\
21.0 \\
20.4\end{array}$ & $\begin{array}{l}27.2 \\
22.2 \\
23.7 \\
23.0 \\
22.7\end{array}$ & $\begin{array}{l}22.3 \\
30.7 \\
21.4 \\
21.1 \\
30.3\end{array}$ & $\begin{array}{l}26.1 \\
24.7 \\
24.7 \\
25.6\end{array}$ & $\begin{array}{r}14.7 \\
6.9 \\
6.6 \\
6.7\end{array}$ & $\begin{array}{r}16.8 \\
8.4 \\
8.0 \\
7.9\end{array}$ & $\begin{array}{r}19.0 \\
9.6 \\
9.2 \\
9.1\end{array}$ & $\begin{array}{l}21.0 \\
10.7 \\
10.4 \\
10.4\end{array}$ \\
\hline $\begin{array}{l}21 \\
22 \\
23 \\
24 \\
25\end{array}$ & 21.3 & 20.4 & 21.4 & 20.3 & 21.2 & 20.2 & 21.3 & 20.2 & 25.7 & & $\begin{array}{l}3.6 \\
4.6\end{array}$ & $\begin{array}{l}4.2 \\
5.5\end{array}$ & $\begin{array}{l}4.8 \\
6.4\end{array}$ \\
\hline $\begin{array}{l}26 \\
27 \\
28 \\
29 \\
30\end{array}$ & $\begin{array}{l}23.7 \\
24.5\end{array}$ & $\begin{array}{l}22.2 \\
22.6\end{array}$ & $\begin{array}{l}23.7 \\
24.6\end{array}$ & $\begin{array}{l}22.1 \\
22.5\end{array}$ & $\begin{array}{l}23.6 \\
24.5\end{array}$ & $\begin{array}{l}22.0 \\
22.5\end{array}$ & $\begin{array}{l}23.6 \\
24.6\end{array}$ & $\begin{array}{r}22.0 \\
22.5\end{array}$ & $\begin{array}{l}24.0 \\
23.0\end{array}$ & $\begin{array}{l}3.5 \\
3.0 \\
4.4 \\
6.9 \\
7.7\end{array}$ & $\begin{array}{l}4.0 \\
3.6 \\
5.4 \\
8.3 \\
9.1\end{array}$ & $\begin{array}{l}4.3 \\
6.3 \\
9.6\end{array}$ & $\begin{array}{r}5.5 \\
5.1 \\
7.3 \\
70.9 \\
11.9\end{array}$ \\
\hline 31 & & & & & & & & & & 7.5 & 8.8 & 10.3 & 21.6 \\
\hline
\end{tabular}

\begin{tabular}{|c|c|c|c|c|c|c|c|c|c|c|c|c|c|}
\hline \multicolumn{14}{|c|}{ AUGUST } \\
\hline $\begin{array}{l}1 \\
2 \\
3 \\
4 \\
5\end{array}$ & $\begin{array}{l}22.9 \\
23.3 \\
24.4\end{array}$ & $\begin{array}{l}19.1 \\
20.6 \\
22.5\end{array}$ & $\begin{array}{l}23.1 \\
23.4 \\
24.4\end{array}$ & $\begin{array}{l}18.9 \\
20.5 \\
22.4\end{array}$ & $\begin{array}{l}23.1 \\
23.3 \\
24.3\end{array}$ & $\begin{array}{l}18.9 \\
20.4 \\
22.3\end{array}$ & $\begin{array}{l}23.3 \\
23.3 \\
24.2\end{array}$ & $\begin{array}{l}18.9 \\
20.4 \\
72.3\end{array}$ & $\begin{array}{l}23.7 \\
22.3 \\
23.2\end{array}$ & $\begin{array}{l}4.2 \\
2.3 \\
5.7 \\
8.9 \\
5.9\end{array}$ & $\begin{array}{r}5.1 \\
2.9 \\
7.0 \\
10.7 \\
7.5\end{array}$ & $\begin{array}{r}5.9 \\
3.6 \\
8.2 \\
12.3 \\
8.7\end{array}$ & $\begin{array}{r}7.1 \\
4.2 \\
9.6 \\
13.8 \\
9.8\end{array}$ \\
\hline $\begin{array}{r}6 \\
7 \\
8 \\
9 \\
10\end{array}$ & $\begin{array}{l}24.3 \\
26.2 \\
26.0 \\
23.8 \\
25.0\end{array}$ & $\begin{array}{l}22.3 \\
21.9 \\
21.7 \\
19.9 \\
21.0\end{array}$ & $\begin{array}{l}24.3 \\
26.2 \\
26.0 \\
24.0 \\
25.0\end{array}$ & $\begin{array}{l}22.3 \\
21.8 \\
21.8 \\
20.0 \\
21.0\end{array}$ & $\begin{array}{l}24 \cdot 1 \\
26 \cdot ? \\
26 \cdot 1 \\
24 \cdot 1 \\
25.1\end{array}$ & $\begin{array}{l}22.1 \\
21.7 \\
21.6 \\
19.8 \\
20.9\end{array}$ & $\begin{array}{l}24.1 \\
26.3 \\
26.2 \\
24.3 \\
25.3\end{array}$ & $\begin{array}{l}22.1 \\
21.7 \\
21.6 \\
19.8 \\
21.0\end{array}$ & $\begin{array}{l}22.8 \\
22.8 \\
25.4 \\
25.5 \\
24.2\end{array}$ & $\begin{array}{l}3.0 \\
2.8\end{array}$ & $\begin{array}{l}4.1 \\
4.5\end{array}$ & $\begin{array}{l}5.0 \\
5.3\end{array}$ & 5.8 \\
\hline $\begin{array}{l}11 \\
12 \\
13 \\
14 \\
15\end{array}$ & $\begin{array}{l}27.2 \\
27.6 \\
27.4\end{array}$ & $\begin{array}{l}22.8 \\
21.2 \\
21.3\end{array}$ & $\begin{array}{l}27.2 \\
27.6 \\
27.4\end{array}$ & $\begin{array}{l}22.7 \\
21.2 \\
21.3\end{array}$ & $\begin{array}{l}27.0 \\
27.5 \\
27.3\end{array}$ & $\begin{array}{l}22.6 \\
21.1 \\
21.2\end{array}$ & $\begin{array}{l}27.1 \\
27.6 \\
27.3\end{array}$ & $\begin{array}{l}22.6 \\
21.1 \\
71.2\end{array}$ & $\begin{array}{l}23.9 \\
23.8 \\
24.4\end{array}$ & $\begin{array}{l}6.6 \\
7.9 \\
6.3 \\
4.2 \\
6.9\end{array}$ & $\begin{array}{l}8.1 \\
9.3 \\
7.5 \\
5.0 \\
8.2\end{array}$ & $\begin{array}{r}9.4 \\
10.8 \\
8.8 \\
6.2 \\
9.5\end{array}$ & $\begin{array}{r}10.2 \\
7.3 \\
10.8\end{array}$ \\
\hline $\begin{array}{l}16 \\
17 \\
18 \\
19 \\
20\end{array}$ & $\begin{array}{l}23.1 \\
21.9 \\
21.5 \\
21.8\end{array}$ & $\begin{array}{l}21.1 \\
20.1 \\
17.8 \\
16.6\end{array}$ & $\begin{array}{l}23.2 \\
21.9 \\
21.7 \\
22.0\end{array}$ & $\begin{array}{l}21.1 \\
20.1 \\
17.7 \\
16.6\end{array}$ & $\begin{array}{l}23.2 \\
21.8 \\
21.7 \\
22.3\end{array}$ & $\begin{array}{l}20.9 \\
19.8 \\
17.5 \\
16.5\end{array}$ & $\begin{array}{l}23.2 \\
21.8 \\
21.7 \\
22.6\end{array}$ & $\begin{array}{l}20.9 \\
19.8 \\
17.3 \\
16.6\end{array}$ & $\begin{array}{l}26.7 \\
26.8 \\
26.5 \\
27.7\end{array}$ & $\begin{array}{l}3.2 \\
5.5 \\
5.3 \\
2.7 \\
5.5\end{array}$ & $\begin{array}{l}3.9 \\
6.6 \\
6.6 \\
3.3 \\
6.3\end{array}$ & $\begin{array}{l}4 \cdot 7 \\
8.3 \\
8.2 \\
4.0 \\
7.2\end{array}$ & $\begin{array}{l}5.7 \\
8.7 \\
4.6 \\
8.4\end{array}$ \\
\hline $\begin{array}{l}21 \\
22 \\
23 \\
24 \\
25\end{array}$ & $\begin{array}{l}22.7 \\
21.4\end{array}$ & $\begin{array}{l}19.5 \\
19.3\end{array}$ & $\begin{array}{r}22.7 \\
21.4\end{array}$ & $\begin{array}{l}19.5 \\
19.2\end{array}$ & $\begin{array}{l}22.6 \\
21.3\end{array}$ & $\begin{array}{l}19.4 \\
19.1\end{array}$ & $\begin{array}{l}22.6 \\
21.4\end{array}$ & $\begin{array}{l}19.5 \\
19.1\end{array}$ & $\begin{array}{l}26.3 \\
25.4\end{array}$ & $\begin{array}{l}2.5 \\
3.6 \\
4.6 \\
7.3 \\
6.3\end{array}$ & $\begin{array}{l}3.0 \\
4.5 \\
5.7 \\
8.8 \\
7.5\end{array}$ & $\begin{array}{r}3.7 \\
5.2 \\
6.7 \\
10.2 \\
9.0\end{array}$ & $\begin{array}{r}4.0 \\
6.0 \\
7.7 \\
11.6 \\
10.4\end{array}$ \\
\hline $\begin{array}{l}26 \\
27\end{array}$ & 26.4 & 21.6 & 26.3 & 21.5 & 26.2 & 21.3 & 26.3 & 21.5 & 26.0 & $\begin{array}{l}6.6 \\
2.8\end{array}$ & $\begin{array}{l}8.0 \\
3.6\end{array}$ & $\begin{array}{l}9.5 \\
4.5\end{array}$ & $\begin{array}{r}10.6 \\
4.8\end{array}$ \\
\hline $\begin{array}{l}28 \\
29 \\
30\end{array}$ & $\begin{array}{l}24.2 \\
22.8 \\
20.5\end{array}$ & $\begin{array}{l}21.0 \\
19.9 \\
17.7\end{array}$ & $\begin{array}{l}24.3 \\
23.0 \\
20.4\end{array}$ & $\begin{array}{l}21.0 \\
19.9 \\
17.7\end{array}$ & $\begin{array}{l}24.2 \\
22.9 \\
20.1\end{array}$ & $\begin{array}{l}21.0 \\
19.8 \\
17.4\end{array}$ & $\begin{array}{l}24.3 \\
22.9 \\
20.1\end{array}$ & $\begin{array}{l}21.1 \\
19.8 \\
17.3\end{array}$ & $\begin{array}{l}27.7 \\
26.9 \\
26.6\end{array}$ & $\begin{array}{l}3.2 \\
3.5 \\
6.9\end{array}$ & $\begin{array}{l}4.0 \\
4.5 \\
8.2\end{array}$ & $\begin{array}{r}4.9 \\
5.5 \\
10.0\end{array}$ & $\begin{array}{r}5.7 \\
5.7 \\
10.2\end{array}$ \\
\hline 31 & 19.8 & 17.0 & 19.8 & 16.0 & 19.6 & 16.7 & 19.5 & 16.6 & 25.2 & 7.4 & 8.8 & 11.3 & \\
\hline
\end{tabular}


TABLE 11

Table 11. -Daily averages of air and water temperatures and wind speeds, July 1950-August 1951, Lake Hefner-Con. STATION 2 DAILY AVERAGES

\begin{tabular}{|c|c|c|c|c|c|c|c|c|c|c|c|c|c|}
\hline \multirow{4}{*}{ وّ } & \multicolumn{8}{|c|}{ Average air temperature $\left({ }^{\circ} \mathrm{C}\right)$ at indicated height } & \multirow{4}{*}{ 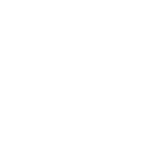 } & \multirow{2}{*}{\multicolumn{4}{|c|}{$\begin{array}{l}\text { Average wind speed (knots) } \\
\text { at indicated height }\end{array}$}} \\
\hline & \multirow{2}{*}{\multicolumn{2}{|c|}{$\begin{array}{c}2 \\
\text { meters }\end{array}$}} & \multirow{2}{*}{\multicolumn{2}{|c|}{$\begin{array}{c}4 \\
\text { meters }\end{array}$}} & \multirow{2}{*}{\multicolumn{2}{|c|}{$\begin{array}{c}8 \\
\text { meters }\end{array}$}} & \multirow{2}{*}{\multicolumn{2}{|c|}{$\begin{array}{c}16 \\
\text { meters }\end{array}$}} & & & & & \\
\hline & & & & & & & & & & \multirow[b]{2}{*}{$\begin{array}{c}2 \\
\text { meters }\end{array}$} & \multirow[b]{2}{*}{$\begin{array}{c}4 \\
\text { meters }\end{array}$} & \multirow[b]{2}{*}{$\begin{array}{c}8 \\
\text { meters }\end{array}$} & \multirow[b]{2}{*}{$\begin{array}{c}16 \\
\text { meters }\end{array}$} \\
\hline & $\begin{array}{l}\text { Dry } \\
\text { bulb }\end{array}$ & $\begin{array}{l}\text { Wet } \\
\text { bulb }\end{array}$ & $\begin{array}{l}\text { Dry } \\
\text { bulb }\end{array}$ & $\begin{array}{l}\text { Wet } \\
\text { bulb }\end{array}$ & $\begin{array}{l}\text { Dry } \\
\text { bulb }\end{array}$ & $\begin{array}{l}\text { Wet } \\
\text { bulb }\end{array}$ & $\begin{array}{l}\text { Dry } \\
\text { bulb }\end{array}$ & $\begin{array}{l}\text { Wet } \\
\text { bulb }\end{array}$ & & & & & \\
\hline \multicolumn{14}{|c|}{ SEPTEMBER } \\
\hline $\begin{array}{l}1 \\
2 \\
3 \\
4 \\
5\end{array}$ & $\begin{array}{l}21.7 \\
22.1\end{array}$ & $\begin{array}{l}17.4 \\
18.5\end{array}$ & $\begin{array}{l}21.7 \\
22.2\end{array}$ & $\begin{array}{l}17.3 \\
18.4\end{array}$ & 21.7 & $\begin{array}{l}17.1 \\
18.3\end{array}$ & $\begin{array}{l}21.7 \\
22.2\end{array}$ & $\begin{array}{l}17.1 \\
18.4\end{array}$ & $\begin{array}{l}25.3 \\
25.6\end{array}$ & $\begin{array}{l}6.2 \\
5.7 \\
4.4 \\
3.0 \\
4.5\end{array}$ & $\begin{array}{l}7.8 \\
7.0 \\
5.4 \\
3.8 \\
5.7\end{array}$ & $\begin{array}{l}8.9 \\
8.4 \\
6.5 \\
4.5 \\
6.7\end{array}$ & $\begin{array}{r}10.5 \\
10.4 \\
8.1 \\
5.4 \\
7.8\end{array}$ \\
\hline $\begin{array}{r}6 \\
7 \\
8 \\
9 \\
10\end{array}$ & $\begin{array}{l}16.9 \\
17.6 \\
18.7\end{array}$ & $\begin{array}{l}13.6 \\
13.7 \\
14.6\end{array}$ & $\begin{array}{l}16.9 \\
18.3 \\
18.9\end{array}$ & $\begin{array}{l}13.4 \\
13.9 \\
14.5\end{array}$ & $\begin{array}{l}16.9 \\
13.7 \\
19.1\end{array}$ & $\begin{array}{l}13.3 \\
13.9 \\
14.6\end{array}$ & $\begin{array}{l}16.8 \\
18.9 \\
19.4\end{array}$ & $\begin{array}{l}13.4 \\
14.1 \\
14.6\end{array}$ & $\begin{array}{l}24.6 \\
24.9 \\
23.7\end{array}$ & $\begin{array}{l}3.0 \\
1.7 \\
2.9 \\
2.3 \\
2.5\end{array}$ & $\begin{array}{l}3.8 \\
2.2 \\
3.5 \\
2.9 \\
3.2\end{array}$ & $\begin{array}{l}4.5 \\
2.5 \\
4.3 \\
3.4 \\
4.1\end{array}$ & $\begin{array}{l}5.4 \\
5.3 \\
4.3 \\
5.0\end{array}$ \\
\hline $\begin{array}{l}11 \\
12 \\
13 \\
14 \\
15\end{array}$ & $\begin{array}{l}17.7 \\
16.5 \\
18.4 \\
18.0 \\
22.3\end{array}$ & $\begin{array}{l}14.7 \\
15.5 \\
17.5 \\
17.2 \\
20.6\end{array}$ & $\begin{array}{l}17.5 \\
16.5 \\
18.3 \\
17.9 \\
22.4\end{array}$ & $\begin{array}{l}14.7 \\
15.5 \\
17.4 \\
17.1 \\
20.5\end{array}$ & $\begin{array}{l}17.4 \\
16.4 \\
18.1 \\
17.8 \\
22.2\end{array}$ & $\begin{array}{l}14.5 \\
15.5 \\
17.4 \\
17.1 \\
20.4\end{array}$ & $\begin{array}{l}17.3 \\
16.4 \\
18.2 \\
17.8 \\
22.2\end{array}$ & $\begin{array}{l}14.2 \\
15.3 \\
17.2 \\
17.0 \\
20.5\end{array}$ & $\begin{array}{l}21.9 \\
20: 9 \\
21: 4 \\
21.1 \\
21.7\end{array}$ & $\begin{array}{l}6.3 \\
3.7 \\
4.0 \\
4.4 \\
5.0\end{array}$ & $\begin{array}{l}7.6 \\
4.6 \\
5.3 \\
5.6 \\
6.5\end{array}$ & $\begin{array}{l}9.0 \\
5.3 \\
5.7 \\
7.6\end{array}$ & $\begin{array}{r}10.3 \\
6.2 \\
7.0 \\
7.0 \\
8.8\end{array}$ \\
\hline $\begin{array}{l}16 \\
17 \\
18 \\
19 \\
20\end{array}$ & $\begin{array}{l}22.9 \\
25.2\end{array}$ & $\begin{array}{l}20.8 \\
21.6\end{array}$ & $\begin{array}{l}22.8 \\
25.2\end{array}$ & $\begin{array}{l}20.8 \\
21.5\end{array}$ & $\begin{array}{l}22.9 \\
25.2\end{array}$ & $\begin{array}{l}20.7 \\
21.5\end{array}$ & $\begin{array}{l}22.7 \\
25.0\end{array}$ & $\begin{array}{l}20.7 \\
21.4\end{array}$ & $\begin{array}{l}21 . ? \\
22: 0\end{array}$ & $\begin{array}{l}6.3 \\
3.7 \\
5.7 \\
6.2 \\
8.3\end{array}$ & $\begin{array}{l}8.2 \\
4.6 \\
6.9 \\
7.4 \\
9.7\end{array}$ & $\begin{array}{r}9.4 \\
5.5 \\
8.1 \\
8.6 \\
11.2\end{array}$ & $\begin{array}{r}10.9 \\
6.4 \\
9.5 \\
10.0 \\
12.8\end{array}$ \\
\hline $\begin{array}{l}21 \\
22 \\
23 \\
24 \\
25\end{array}$ & $17 \cdot 4$ & $14 \cdot 3$ & 17.3 & $14 \cdot 2$ & $17 \cdot 3$ & $14 \cdot 1$ & $17 \cdot 3$ & 14.2 & $22 \cdot 2$ & $\begin{array}{l}7.2 \\
5.1 \\
2.1 \\
2.6 \\
4.5\end{array}$ & $\begin{array}{l}9.1 \\
6.4 \\
2.7 \\
3.6 \\
6.2\end{array}$ & $\begin{array}{r}10.5 \\
3.5 \\
4.3 \\
7.3\end{array}$ & $\begin{array}{r}21.9 \\
4.3 \\
5.2 \\
8.5\end{array}$ \\
\hline $\begin{array}{l}26 \\
27 \\
28 \\
29 \\
30\end{array}$ & $\begin{array}{l}20.2 \\
21.7 \\
22.9 \\
22.5\end{array}$ & $\begin{array}{l}18.1 \\
19.0 \\
19.9 \\
20.0\end{array}$ & $\begin{array}{l}20.2 \\
21.7 \\
22 \cdot 9 \\
22.4\end{array}$ & $\begin{array}{l}18.0 \\
18.9 \\
19.9 \\
10.9\end{array}$ & $\begin{array}{l}20.1 \\
21.5 \\
22.9 \\
22.3\end{array}$ & $\begin{array}{l}18.0 \\
18.8 \\
19.9 \\
19.9\end{array}$ & $\begin{array}{l}20.0 \\
21.5 \\
22.8 \\
22.1\end{array}$ & $\begin{array}{l}18.0 \\
18.9 \\
19.9 \\
19.8\end{array}$ & $\begin{array}{l}20.4 \\
21.0 \\
21.4 \\
20.7\end{array}$ & $\begin{array}{r}6.7 \\
10.3 \\
10.6 \\
9.5 \\
9.8\end{array}$ & $\begin{array}{r}8.4 \\
12.4 \\
13.0 \\
12.4 \\
12.1\end{array}$ & $\begin{array}{r}9.9 \\
14.2 \\
14.8 \\
13.1 \\
13.8\end{array}$ & $\begin{array}{l}11.4 \\
15.9 \\
16.7 \\
14.8 \\
15.5\end{array}$ \\
\hline
\end{tabular}

OCTOBER

\begin{tabular}{|c|c|c|c|c|c|c|c|c|c|c|c|c|c|}
\hline $\begin{array}{l}1 \\
2 \\
3 \\
4 \\
5\end{array}$ & $\begin{array}{l}11.9 \\
16.3\end{array}$ & $\begin{array}{r}8.6 \\
12.6\end{array}$ & $\begin{array}{l}11.8 \\
16.3\end{array}$ & $\begin{array}{r}8.3 \\
12.4\end{array}$ & $\begin{array}{l}21.7 \\
11.8 \\
16.3\end{array}$ & $\begin{array}{r}18.7 \\
8.2 \\
12.3\end{array}$ & $\begin{array}{l}11.5 \\
16.1\end{array}$ & $\begin{array}{r}7.9 \\
12.2\end{array}$ & $\begin{array}{l}17.5 \\
17.4\end{array}$ & $\begin{array}{r}10.9 \\
9.0 \\
6.0 \\
4.6\end{array}$ & $\begin{array}{r}13.4 \\
11.0 \\
5.9 \\
5.7\end{array}$ & $\begin{array}{r}15.3 \\
12.4 \\
7.8 \\
6.8\end{array}$ & $\begin{array}{r}17.2 \\
13.9 \\
8.9 \\
8.1\end{array}$ \\
\hline $\begin{array}{r}6 \\
7 \\
8 \\
9 \\
10\end{array}$ & $\begin{array}{l}20.2 \\
18.4 \\
15.1 \\
15.3 \\
17.4\end{array}$ & $\begin{array}{r}16.1 \\
13.7 \\
9.7 \\
12.5 \\
12.6\end{array}$ & $\begin{array}{l}20.2 \\
18.4 \\
15.2 \\
15.5 \\
17.7\end{array}$ & $\begin{array}{r}16.0 \\
13.6 \\
9.5 \\
10.5 \\
12.5\end{array}$ & $\begin{array}{l}20.3 \\
18.7 \\
15.4 \\
25.8 \\
17.9\end{array}$ & $\begin{array}{r}16.1 \\
13.5 \\
9.4 \\
10.6 \\
12.6\end{array}$ & $\begin{array}{l}20.2 \\
18.7 \\
15.5 \\
15.9 \\
18.1\end{array}$ & $\begin{array}{r}16.0 \\
13.0 \\
9.2 \\
10.6 \\
12.6\end{array}$ & $\begin{array}{l}18.0 \\
17.6 \\
16.1 \\
16.1 \\
15.7\end{array}$ & $\begin{array}{l}0.3 \\
5.2 \\
5.2 \\
5.1\end{array}$ & $\begin{array}{l}7.9 \\
6.7 \\
6.2 \\
7.5\end{array}$ & $\begin{array}{l}9.2 \\
8.2 \\
7.5 \\
8.7\end{array}$ & $\begin{array}{r}11.1 \\
9.6 \\
9.1 \\
10.2\end{array}$ \\
\hline $\begin{array}{l}11 \\
12 \\
13 \\
14 \\
15\end{array}$ & $\begin{array}{l}20.6 \\
19.4 \\
21.4 \\
23.3 \\
22.3\end{array}$ & $\begin{array}{l}14.6 \\
12.5 \\
14.7 \\
16.1 \\
15.6\end{array}$ & $\begin{array}{l}20.8 \\
19.5 \\
21.3 \\
23.4 \\
22.3\end{array}$ & $\begin{array}{l}14.6 \\
12.3 \\
14.5\end{array}$ & $\begin{array}{l}21.1 \\
19.8 \\
21.3 \\
23.9 \\
22.4\end{array}$ & $\begin{array}{l}14.6 \\
12.5 \\
14.5 \\
15.9 \\
15.4\end{array}$ & $\begin{array}{l}21.2 \\
19.8 \\
21.2 \\
23.3 \\
22.3\end{array}$ & $\begin{array}{l}14.6 \\
12.4 \\
14.6 \\
16.2 \\
15.7\end{array}$ & $\begin{array}{l}17.5 \\
16.2 \\
16.3 \\
17.1 \\
17.0\end{array}$ & $\begin{array}{l}3.2 \\
9.4 \\
9.1 \\
8.9\end{array}$ & $\begin{array}{r}2.4 \\
4.2 \\
11.0 \\
10.5 \\
10.6\end{array}$ & $\begin{array}{r}2.9 \\
5.2 \\
12.7 \\
12.3 \\
12.1\end{array}$ & $\begin{array}{l}14.1 \\
13.8\end{array}$ \\
\hline $\begin{array}{l}16 \\
17 \\
18 \\
19 \\
20\end{array}$ & $\begin{array}{l}21.4 \\
21.0 \\
19.5 \\
18.5 \\
17.3\end{array}$ & $\begin{array}{l}14.6 \\
15.2 \\
15.2 \\
15.4 \\
13.7\end{array}$ & $\begin{array}{l}21.4 \\
21.3 \\
19.8 \\
18.8 \\
17.5\end{array}$ & $\begin{array}{l}14.4 \\
15.1 \\
15.1 \\
15.2 \\
13.6\end{array}$ & $\begin{array}{l}21.5 \\
21.5 \\
20.0 \\
19.1 \\
17.6\end{array}$ & $\begin{array}{l}14.5 \\
15.2 \\
15.8 \\
15.1 \\
13.5\end{array}$ & $\begin{array}{l}21.3 \\
21.6 \\
20.3 \\
19.3 \\
17.6\end{array}$ & $\begin{array}{l}15.0 \\
15.8 \\
15.7 \\
15.2 \\
13.5\end{array}$ & $\begin{array}{l}17.5 \\
17.9 \\
18.4 \\
17.8 \\
17.6\end{array}$ & $\begin{array}{l}9.3 \\
6.1 \\
3.4 \\
1.7 \\
2.4\end{array}$ & $\begin{array}{r}11.0 \\
7.5 \\
4.3 \\
2.4 \\
3.1\end{array}$ & $\begin{array}{r}22.6 \\
8.9 \\
5.4 \\
3.2 \\
3.9\end{array}$ & $\begin{array}{r}14.5 \\
10.5 \\
6.6 \\
3.8 \\
4.5\end{array}$ \\
\hline $\begin{array}{l}21 \\
22 \\
23 \\
24 \\
25\end{array}$ & $\begin{array}{l}15.7 \\
14.5 \\
11.7 \\
18.9\end{array}$ & $\begin{array}{r}10.7 \\
10.6 \\
9.0 \\
12.9\end{array}$ & $\begin{array}{l}16.0 \\
14.4 \\
11.8 \\
18.9\end{array}$ & $\begin{array}{r}10.8 \\
10.3 \\
8.8 \\
12.7\end{array}$ & $\begin{array}{l}16.3 \\
14.5 \\
11.8 \\
19.0\end{array}$ & $\begin{array}{r}10.7 \\
10.1 \\
8.7 \\
12.7\end{array}$ & $\begin{array}{l}16.7 \\
14.5 \\
11.7 \\
19.1\end{array}$ & $\begin{array}{r}11.0 \\
10.2 \\
3.8 \\
12.9\end{array}$ & $\begin{array}{l}18.4 \\
17.9 \\
17.0 \\
17.0\end{array}$ & $\begin{array}{l}2.4 \\
6.3 \\
4.4 \\
7.7 \\
4.3\end{array}$ & $\begin{array}{l}2.8 \\
8.1 \\
5.7 \\
9.0 \\
5.3\end{array}$ & $\begin{array}{r}3.6 \\
9.1 \\
6.5 \\
20.5 \\
6.2\end{array}$ & $\begin{array}{r}10.0 \\
7.5 \\
12.0\end{array}$ \\
\hline $\begin{array}{l}26 \\
27 \\
29 \\
29 \\
30\end{array}$ & $\begin{array}{l}23.1 \\
20.8 \\
19.7 \\
21.1 \\
22.2\end{array}$ & $\begin{array}{l}13.8 \\
12.2 \\
14.3 \\
14.5 \\
16.2\end{array}$ & $\begin{array}{l}23.1 \\
20.8 \\
20.2 \\
21.4 \\
22.2\end{array}$ & $\begin{array}{l}13.2 \\
11.7 \\
14.2 \\
14.3 \\
16.0\end{array}$ & $\begin{array}{l}23.1 \\
21.0 \\
20.6 \\
21.6 \\
22.2\end{array}$ & $\begin{array}{l}13.2 \\
11.9 \\
14.3 \\
14.5 \\
16.0\end{array}$ & $\begin{array}{l}23.1 \\
21.2 \\
20.9 \\
21.9 \\
22.2\end{array}$ & $\begin{array}{l}14.4 \\
12.4 \\
14.6 \\
15.0 \\
16.5\end{array}$ & $\begin{array}{l}16.2 \\
16.4 \\
17.8 \\
17.5 \\
17.8\end{array}$ & $\begin{array}{r}11.1 \\
6.8 \\
4.5 \\
7.7 \\
10.1\end{array}$ & $\begin{array}{r}12.8 \\
7.9 \\
5.4 \\
9.0 \\
11.6\end{array}$ & $\begin{array}{r}14.7 \\
9.4 \\
6.6 \\
10.5 \\
13.3\end{array}$ & $\begin{array}{r}16.8 \\
11.1 \\
8.3 \\
12.3 \\
15.4\end{array}$ \\
\hline 31 & 22.8 & 17.0 & 22.0 & 16.3 & 22.5 & 16.8 & 22.3 & 17.2 & 18.5 & 12.0 & 13.8 & 15.7 & 17.8 \\
\hline
\end{tabular}


TABLE 1 .

Table 11. -Daily averages of air and water temperatures and wind speeds, July 1950-August 1951, Lake Hefner-Con. STATION 2 DAILY AVERAGES

\begin{tabular}{|c|c|c|c|c|c|c|c|c|c|c|c|c|c|}
\hline \multirow{4}{*}{ פूّ } & \multicolumn{8}{|c|}{ A verage air temperature $\left({ }^{\circ} \mathrm{C}\right)$ at indicated height } & \multirow{4}{*}{$\begin{array}{c}\text { Average } \\
\text { water- } \\
\text { surface } \\
\text { temperature } \\
\left({ }^{\circ} \mathrm{C}\right)\end{array}$} & \multirow{2}{*}{\multicolumn{4}{|c|}{$\begin{array}{l}\text { Average wind speed (knots) } \\
\text { at indicated height }\end{array}$}} \\
\hline & \multirow{2}{*}{\multicolumn{2}{|c|}{$\begin{array}{c}2 \\
\text { meters }\end{array}$}} & \multirow{2}{*}{\multicolumn{2}{|c|}{$\stackrel{4}{4}$}} & \multirow{2}{*}{\multicolumn{2}{|c|}{$\begin{array}{c}8 \\
\text { meters }\end{array}$}} & \multirow{2}{*}{\multicolumn{2}{|c|}{$\begin{array}{c}16 \\
\text { meters }\end{array}$}} & & & & & \\
\hline & & & & & & & & & & & & & \\
\hline & $\begin{array}{l}\text { Dry } \\
\text { bulb }\end{array}$ & $\begin{array}{l}\text { Wet } \\
\text { bulb }\end{array}$ & $\begin{array}{l}\text { Dry } \\
\text { bulb }\end{array}$ & $\begin{array}{l}\text { Wet } \\
\text { bulb }\end{array}$ & $\begin{array}{l}\text { Dry } \\
\text { bulb }\end{array}$ & $\begin{array}{l}\text { Wet } \\
\text { bulb }\end{array}$ & $\begin{array}{l}\text { Dry } \\
\text { bulb }\end{array}$ & $\begin{array}{l}\text { Wet } \\
\text { bulb }\end{array}$ & & ${ }^{2}$ & $\begin{array}{c}4 \\
\text { meters }\end{array}$ & $\begin{array}{c}8 \\
\text { meters }\end{array}$ & $\begin{array}{c}16 \\
\text { meters }\end{array}$ \\
\hline
\end{tabular}

NOVEMBE?

\begin{tabular}{|c|c|c|c|c|c|c|c|c|c|c|c|c|c|}
\hline $\begin{array}{l}1 \\
2 \\
3 \\
4 \\
5\end{array}$ & $\begin{array}{l}17.2 \\
10.6\end{array}$ & $\begin{array}{r}11.8 \\
7.3\end{array}$ & $\begin{array}{l}17.2 \\
10.6\end{array}$ & $\begin{array}{r}11.5 \\
7.1\end{array}$ & $\begin{array}{l}17.0 \\
10.4\end{array}$ & $\begin{array}{r}17.2 \\
7.0\end{array}$ & $\begin{array}{l}16.9 \\
10.3 \\
13.0\end{array}$ & $\begin{array}{r}11.3 \\
6.9\end{array}$ & 13.9 & $\begin{array}{r}10.2 \\
4.0 \\
15.6 \\
5.3 \\
10.6\end{array}$ & $\begin{array}{r}12.2 \\
5.8 \\
19.1 \\
6.2 \\
12.3\end{array}$ & $\begin{array}{r}13.5 \\
6.5 \\
20.2 \\
7.4 \\
14.1\end{array}$ & $\begin{array}{r}15.4 \\
7.4 \\
21.8 \\
8.4 \\
16.3\end{array}$ \\
\hline $\begin{array}{r}6 \\
7 \\
8 \\
9 \\
10\end{array}$ & $\begin{array}{l}12.7 \\
10.3\end{array}$ & $\begin{array}{l}7.3 \\
7.7\end{array}$ & $\begin{array}{l}13.1 \\
11.0\end{array}$ & $\begin{array}{l}7.2 \\
7.9\end{array}$ & $\begin{array}{l}13 \cdot 3 \\
11.2\end{array}$ & $\begin{array}{l}7.2 \\
8.0\end{array}$ & $\begin{array}{l}13.5 \\
11.7\end{array}$ & $\begin{array}{r}3.3 \\
\end{array}$ & $\begin{array}{r}14.4 \\
14.5 \\
9.8\end{array}$ & $\begin{array}{r}3.9 \\
2.2 \\
9.3 \\
14.4 \\
7.7\end{array}$ & $\begin{array}{r}4.5 \\
2.4 \\
10.7 \\
15.8 \\
9.6\end{array}$ & $\begin{array}{r}5.4 \\
3.0 \\
11.9 \\
16.8 \\
10.8\end{array}$ & $\begin{array}{r}6.4 \\
3.4 \\
17.5 \\
11.9\end{array}$ \\
\hline $\begin{array}{l}12 \\
12 \\
13 \\
14 \\
15\end{array}$ & $\begin{array}{r}1.4 \\
6.0 \\
9.2 \\
16.4 \\
19.5\end{array}$ & $\begin{array}{r}1.4 \\
5.1 \\
13.7 \\
14.7\end{array}$ & $\begin{array}{r}1.4 \\
6.0 \\
9.2 \\
16.5 \\
19.6\end{array}$ & $\begin{array}{r}0.2 \\
4.6 \\
13.6 \\
14.4\end{array}$ & $\begin{array}{r}1.4 \\
6.0 \\
9.3 \\
16.5 \\
19.7\end{array}$ & $\begin{array}{r}0.7 \\
4.7 \\
13.5 \\
14.3\end{array}$ & $\begin{array}{r}1.4 \\
6.0 \\
9.3 \\
16.5 \\
19.9\end{array}$ & & $\begin{array}{r}9.5 \\
9.5 \\
9.3 \\
11.1 \\
12.6\end{array}$ & $\begin{array}{l}8.1 \\
9.3\end{array}$ & $\begin{array}{r}9.5 \\
11.0\end{array}$ & $\begin{array}{l}11.0 \\
12.6 \\
14.0\end{array}$ & $\begin{array}{l}12.7 \\
14.4\end{array}$ \\
\hline $\begin{array}{l}16 \\
17 \\
18\end{array}$ & 8.4 & 3.8 & 8.5 & 3.5 & 8.5 & 3.3 & 8.4 & 3.4 & 11.4 & $\begin{array}{r}5.2 \\
6.9 \\
10.9\end{array}$ & $\begin{array}{r}6.0 \\
8.2 \\
12.6\end{array}$ & $\begin{array}{r}9.3 \\
14.3\end{array}$ & $\begin{array}{r}7.2 \\
10.6 \\
10.3\end{array}$ \\
\hline $\begin{array}{l}19 \\
20\end{array}$ & $\begin{array}{r}14.2 \\
1.4\end{array}$ & 11.3 & $\begin{array}{r}14 \cdot 1 \\
1.5\end{array}$ & 10.5 & $\begin{array}{r}13.9 \\
1.7\end{array}$ & 10.6 & $\begin{array}{r}13.8 \\
1.7\end{array}$ & 10.5 & $\begin{array}{r}11.9 \\
9.8\end{array}$ & $\begin{array}{r}12.8 \\
7.8\end{array}$ & $\begin{array}{r}15.3 \\
8.8\end{array}$ & $\begin{array}{r}17.4 \\
9.5\end{array}$ & $\begin{array}{l}19.3 \\
10.6\end{array}$ \\
\hline $\begin{array}{l}21 \\
22 \\
23 \\
24 \\
25\end{array}$ & $\begin{array}{r}3.0 \\
10.8 \\
1.6 \\
-3.6 \\
4.3\end{array}$ & $\begin{array}{l}2.5 \\
5.8\end{array}$ & $\begin{array}{r}8.2 \\
11.3 \\
1.4 \\
-3.4 \\
4.5\end{array}$ & $\begin{array}{l}2.4 \\
5.9\end{array}$ & $\begin{array}{r}8.5 \\
11.9 \\
1.3 \\
-3.3 \\
4.7\end{array}$ & $\begin{array}{l}2.5 \\
6.2\end{array}$ & $\begin{array}{r}8.7 \\
12.5 \\
1.1 \\
-3.1 \\
4.9\end{array}$ & & $\begin{array}{r}9.6 \\
10.9 \\
8.4 \\
5.4 \\
6.6\end{array}$ & $\begin{array}{r}7.4 \\
3.1 \\
12.3 \\
7.7 \\
5.8\end{array}$ & $\begin{array}{r}8.7 \\
4.0 \\
13.9 \\
9.5 \\
7.0\end{array}$ & $\begin{array}{r}10.2 \\
5.0 \\
15.4 \\
10.8 \\
E .3\end{array}$ & $\begin{array}{r}11.9 \\
6.2 \\
11.4 \\
9.6\end{array}$ \\
\hline $\begin{array}{l}25 \\
27 \\
23 \\
29 \\
30\end{array}$ & $\begin{array}{l}3.1 \\
3.9 \\
6.3 \\
5.2 \\
7.5\end{array}$ & $\begin{array}{l}0.3 \\
1.9 \\
1.5 \\
1.3 \\
4.7\end{array}$ & $\begin{array}{l}3.4 \\
6.6 \\
6.7 \\
5.8 \\
3.1\end{array}$ & $\begin{array}{l}0.4 \\
2.2 \\
1.5 \\
1.5 \\
5.1\end{array}$ & $\begin{array}{l}3.4 \\
7.3 \\
7.0 \\
5.2 \\
5.3\end{array}$ & $\begin{array}{l}0.4 \\
2.3 \\
1.5 \\
1.7 \\
5.3\end{array}$ & $\begin{array}{l}3.6 \\
8.0 \\
7.3 \\
6.8 \\
3.7\end{array}$ & 5.5 & $\begin{array}{l}7.2 \\
8.6 \\
8.3 \\
7.2 \\
7.5\end{array}$ & $\begin{array}{l}5.2 \\
1.7 \\
3.1 \\
3.0 \\
2.9\end{array}$ & $\begin{array}{l}6.3 \\
2.6 \\
3.8 \\
3.8 \\
3.6\end{array}$ & $\begin{array}{l}2.7 \\
4.6 \\
4.4\end{array}$ & $\begin{array}{l}3.3 \\
6.1 \\
5.4 \\
5: 6\end{array}$ \\
\hline
\end{tabular}

\begin{tabular}{|c|c|c|c|c|c|c|c|c|c|c|c|c|c|}
\hline \multicolumn{14}{|c|}{ DECEMRER } \\
\hline $\begin{array}{l}1 \\
2 \\
3 \\
4 \\
5\end{array}$ & $\begin{array}{r}13.4 \\
2.5 \\
1.9 \\
7.0 \\
-\quad 5.0\end{array}$ & $\begin{array}{l}7.6 \\
4.3 \\
2.2\end{array}$ & $\begin{array}{r}13.0 \\
8.3 \\
1.8 \\
7.0 \\
-5.3\end{array}$ & $\begin{array}{l}7.6 \\
3.9 \\
1.7\end{array}$ & $\begin{array}{r}14.0 \\
8.2 \\
1.9 \\
7.0 \\
-5.7\end{array}$ & $\begin{array}{l}7.8 \\
3.7 \\
2.4\end{array}$ & $\begin{array}{r}14.4 \\
8.1 \\
1.8 \\
6.9 \\
-\quad 6.1\end{array}$ & & $\begin{array}{l}7.7 \\
7.7 \\
5.6 \\
6.3 \\
4.1\end{array}$ & $\begin{array}{l}9.5 \\
9.8\end{array}$ & $\begin{array}{l}11.0 \\
12.0\end{array}$ & $\begin{array}{l}13.0 \\
13.7 \\
\\
25.3\end{array}$ & $\begin{array}{l}14.9 \\
15.2 \\
27.3\end{array}$ \\
\hline $\begin{array}{r}6 \\
7 \\
8 \\
9 \\
12\end{array}$ & $\begin{array}{r}-9.8 \\
-\quad 8.5 \\
-0.9 \\
5.0 \\
3.6\end{array}$ & $\begin{array}{l}2.1 \\
0.5\end{array}$ & $\begin{array}{r}-10.1 \\
-\quad 8.5 \\
-0.5 \\
5.5 \\
3.8\end{array}$ & $\begin{array}{l}2.0 \\
0.3\end{array}$ & $\begin{array}{r}-10.4 \\
-8.4 \\
-8.1 \\
6.0 \\
4.0\end{array}$ & $\begin{array}{l}2.2 \\
0.4\end{array}$ & $\begin{array}{r}-10.6 \\
-8.3 \\
0.2 \\
6.6 \\
4.2\end{array}$ & $\begin{array}{l}2.7 \\
0.8\end{array}$ & $\begin{array}{l}0.4 \\
2.1\end{array}$ & $\begin{array}{r}10.9 \\
4.7 \\
3.6 \\
4.4 \\
4.7\end{array}$ & $\begin{array}{r}13.1 \\
5.8 \\
4.4 \\
5.6 \\
5.8\end{array}$ & $\begin{array}{r}14.6 \\
6.8 \\
5.6 \\
8.0 \\
7.8\end{array}$ & $\begin{array}{r}15.4 \\
7.9 \\
6.7 \\
9.7 \\
9.0\end{array}$ \\
\hline $\begin{array}{l}12 \\
12 \\
13 \\
14 \\
15\end{array}$ & $\begin{array}{l}6.9 \\
2.9 \\
1.9 \\
4.1 \\
3.2\end{array}$ & $\begin{array}{l}3.6 \\
0.8 \\
2.1 \\
0.8\end{array}$ & $\begin{array}{l}7.5 \\
3.2 \\
2.3 \\
4.5 \\
3.3\end{array}$ & $\begin{array}{l}3.7 \\
0.9 \\
0.0 \\
2.6 \\
0.7\end{array}$ & $\begin{array}{l}8.0 \\
3.0 \\
2.6 \\
5.4 \\
3.5\end{array}$ & $\begin{array}{l}3.8 \\
1.1 \\
0.2 \\
3.1 \\
0.7\end{array}$ & $\begin{array}{l}9.0 \\
4.0 \\
3.1 \\
6.2 \\
3.5\end{array}$ & $\begin{array}{l}4.4 \\
1.4 \\
0.6 \\
3.6 \\
0.6\end{array}$ & $\begin{array}{l}3.8 \\
3.9 \\
4.1 \\
5.3 \\
4.6\end{array}$ & $\begin{array}{l}5.9 \\
2.3 \\
7.4 \\
1.7 \\
3.0\end{array}$ & $\begin{array}{l}7.5 \\
2.8 \\
3.1 \\
2.2 \\
3.7\end{array}$ & $\begin{array}{l}0.4 \\
3.6 \\
3.6 \\
2.8 \\
4.7\end{array}$ & $\begin{array}{r}10.9 \\
4.7 \\
4.5 \\
3.5 \\
5.5\end{array}$ \\
\hline $\begin{array}{l}16 \\
17 \\
10 \\
19 \\
20\end{array}$ & $\begin{array}{l}3.5 \\
2.0 \\
0.2 \\
3.4 \\
2.3\end{array}$ & $\begin{array}{r}0.7 \\
-0.1 \\
0.8 \\
0.0\end{array}$ & $\begin{array}{l}3.7 \\
1.9 \\
0.8 \\
3.3 \\
2.2\end{array}$ & $\begin{array}{r}0.7 \\
-0.3\end{array}$ & $\begin{array}{l}3.9 \\
1.9 \\
0.9 \\
3.5 \\
2.0\end{array}$ & $\begin{array}{r}0.8 \\
-0.4 \\
-0.8 \\
-0.0\end{array}$ & $\begin{array}{l}4.0 \\
1.8 \\
1.0 \\
3.6 \\
2.0\end{array}$ & $\begin{array}{r}0.9 \\
-0.5 \\
-0.9 \\
-0.3\end{array}$ & $\begin{array}{l}3.9 \\
4.2 \\
3.8 \\
4.4 \\
4.0\end{array}$ & $\begin{array}{l}3.0 \\
4.2 \\
3.1 \\
3.6 \\
3.1\end{array}$ & $\begin{array}{l}3.6 \\
5.2 \\
3.9 \\
4.4 \\
3.9\end{array}$ & $\begin{array}{l}4.5 \\
6.2 \\
4.8 \\
5.6 \\
4.7\end{array}$ & $\begin{array}{l}5.4 \\
7.2 \\
5.7 \\
6.9 \\
5.5\end{array}$ \\
\hline $\begin{array}{l}21 \\
22 \\
23 \\
24 \\
25\end{array}$ & $\begin{array}{r}6.1 \\
6.3 \\
8.3 \\
7.9 \\
12.1\end{array}$ & $\begin{array}{l}3.4 \\
4.6 \\
6.1 \\
3.9 \\
5.3\end{array}$ & $\begin{array}{r}6.1 \\
6.9 \\
8.3 \\
8.4 \\
12.3\end{array}$ & $\begin{array}{l}3.4 \\
4.7 \\
6.2 \\
4.0 \\
5.4\end{array}$ & $\begin{array}{r}6.3 \\
7.1 \\
3.5 \\
8.3 \\
12.4\end{array}$ & $\begin{array}{l}3.4 \\
4 \cdot 8 \\
5 \cdot 1 \\
4 \cdot 2 \\
5.2\end{array}$ & $\begin{array}{r}6.3 \\
7.3 \\
8.5 \\
9.3 \\
12.7\end{array}$ & $\begin{array}{l}3.5 \\
5.0 \\
6.3 \\
4.6\end{array}$ & $\begin{array}{l}4.5 \\
4: 5 \\
5.0 \\
6.0 \\
5.4\end{array}$ & $\begin{array}{r}3.2 \\
5.5 \\
0.5 \\
3.0 \\
10.4\end{array}$ & $\begin{array}{r}4.0 \\
6.4 \\
9.9 \\
3.8 \\
11.9\end{array}$ & $\begin{array}{r}4.8 \\
7.8 \\
11.7 \\
4.9 \\
14.0\end{array}$ & $\begin{array}{r}14.1 \\
6.2 \\
16.6\end{array}$ \\
\hline $\begin{array}{l}26 \\
27 \\
20 \\
20 \\
30\end{array}$ & $\begin{array}{r}2.0 \\
-\quad 4.9 \\
-1.6 \\
1.2 \\
2.8\end{array}$ & 1.3 & $\begin{array}{r}-0.1 \\
-\quad 4.9 \\
-1.1 \\
1.2 \\
3.0\end{array}$ & 1.3 & $\begin{array}{r}-0.2 \\
-\quad 4.8 \\
-0.7 \\
1.3 \\
3.1\end{array}$ & 1.4 & $\begin{array}{r}-0.5 \\
-\quad 4.9 \\
-\quad 0.3 \\
1.5 \\
3.1\end{array}$ & & $\begin{array}{l}3.7 \\
1.9 \\
2.2 \\
1.6 \\
4.0\end{array}$ & $\begin{array}{r}11.9 \\
4.6 \\
3.5 \\
1.5 \\
4.7\end{array}$ & $\begin{array}{r}13.4 \\
5.4 \\
4.8 \\
2.7 \\
5.0\end{array}$ & $\begin{array}{r}16.2 \\
6.4 \\
5.8 \\
3.4 \\
6.2\end{array}$ & $\begin{array}{r}18 \cdot 0 \\
7 \cdot 4 \\
7 \cdot 3 \\
4 \cdot 3 \\
7 \cdot 4\end{array}$ \\
\hline 31 & 7.5 & 2.8 & 7.6 & 2.9 & 7.6 & 2.8 & 7.6 & & 3.9 & 15.4 & 17.8 & 20.2 & 22.8 \\
\hline
\end{tabular}


TABLE 11

Table 11. -Daily averages of air and water temperatures and wind speeds, July 1950-August 1951, Lake Hefner-Con.

\begin{tabular}{|c|c|c|c|c|c|c|c|c|c|c|c|c|c|}
\hline \multicolumn{3}{|c|}{ CTATIOL 2} & \multicolumn{6}{|c|}{ DAILV AVERAGES } & & & & & 1951 \\
\hline \multirow{4}{*}{ 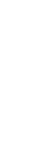 } & \multicolumn{8}{|c|}{ Average air temperature $\left({ }^{\circ} \mathrm{C}\right)$ at indicated height } & \multirow{4}{*}{$\begin{array}{c}\text { Average } \\
\text { water- } \\
\text { surface } \\
\text { temperature } \\
\left({ }^{\circ} \mathrm{C}\right)\end{array}$} & \multirow{2}{*}{\multicolumn{4}{|c|}{$\begin{array}{l}\text { Average wind speed (knots) } \\
\text { at indicated height }\end{array}$}} \\
\hline & \multirow{2}{*}{\multicolumn{2}{|c|}{$\begin{array}{c}2 \\
\text { meters }\end{array}$}} & \multirow{2}{*}{\multicolumn{2}{|c|}{$\begin{array}{c}4 \\
\text { meters }\end{array}$}} & \multirow{2}{*}{\multicolumn{2}{|c|}{$\begin{array}{c}8 \\
\text { meters } \\
\end{array}$}} & \multirow{2}{*}{\multicolumn{2}{|c|}{$\begin{array}{c}16 \\
\text { meters } \\
\end{array}$}} & & & & & \\
\hline & & & & & & & & & & \multirow{2}{*}{$\begin{array}{c}2 \\
\text { meters }\end{array}$} & \multirow[b]{2}{*}{$\begin{array}{c}4 \\
\text { meters }\end{array}$} & \multirow[b]{2}{*}{$\begin{array}{c}8 \\
\text { meters }\end{array}$} & \multirow[b]{2}{*}{$\begin{array}{c}16 \\
\text { meters }\end{array}$} \\
\hline & $\begin{array}{l}\text { Dry } \\
\text { bulb }\end{array}$ & $\begin{array}{l}\text { Wet } \\
\text { bulb }\end{array}$ & $\begin{array}{l}\text { Dry } \\
\text { buib }\end{array}$ & $\begin{array}{l}\text { Wet } \\
\text { bulb }\end{array}$ & $\begin{array}{l}\text { Dry } \\
\text { bulb }\end{array}$ & $\begin{array}{l}\text { Wet } \\
\text { bulb }\end{array}$ & $\begin{array}{l}\text { Dry } \\
\text { bulb }\end{array}$ & $\begin{array}{l}\text { Wet } \\
\text { bulb }\end{array}$ & & & & & \\
\hline \multicolumn{14}{|c|}{ JAIIUARY } \\
\hline 2 & -.5 & $\therefore 0$ & 9.6 & 8.6 & 0.5 & 3.6 & & & 4.8 & 10.1 & $11 \cdot 8$ & 13.4 & 15.1 \\
\hline$?$ & $3 \cdot 0$ & 3.6 & 2.5 & $? \cdot 4$ & $2 \cdot 7$ & $2 \cdot 3$ & & $2 \cdot 2$ & 405 & 20.0 & $12 \cdot 2$ & 14.1 & 15.3 \\
\hline $\begin{array}{l}3 \\
4\end{array}$ & $\begin{array}{ll}0.1 \\
5.5\end{array}$ & $2 . E$ & $\begin{array}{l}2.2 \\
\Xi: 0\end{array}$ & 7.6 & $\begin{array}{ll}2.4 \\
6.1\end{array}$ & 7.6 & $\begin{array}{l}3.5 \\
5.3\end{array}$ & .0 & & $\begin{array}{l}5 \cdot 3 \\
4.4\end{array}$ & $\begin{array}{l}6.4 \\
5.4\end{array}$ & $\begin{array}{l}7.8 \\
6.7\end{array}$ & $\begin{array}{l}9.1 \\
8.2\end{array}$ \\
\hline 5 & 5.8 & 3.0 & 5.0 & $\because$ & 5.5 & $\therefore 6$ & 5.7 & 2.9 & & 9.6 & 11.6 & & 14.7 \\
\hline 6 & -2.5 & & -2.7 & & -2.0 & & -3.1 & & $2 \cdot 2$ & $14 \cdot 3$ & 16.3 & 16.5 & 17.7 \\
\hline $\begin{array}{l}7 \\
8\end{array}$ & & & & & & & & & & $\begin{array}{r}5.4 \\
6.0\end{array}$ & $\begin{array}{l}6.5 \\
7.0\end{array}$ & $\begin{array}{l}7.7 \\
8.2\end{array}$ & $\begin{array}{l}8.9 \\
9.7\end{array}$ \\
\hline 0 & 5.5 & 1.0 & 5.5 & $1 \cdot ?$ & 5.6 & & 5.8 & & $2 \cdot ?$ & 11.8 & 13.7 & 15.8 & 18.2 \\
\hline 10 & 2.5 & -0.4 & 2.5 & -9.5 & 2.8 & -0.4 & 3.0 & & 3.2 & 8.7 & 10.2 & 14.1 & 15.5 \\
\hline 11 & 3.5 & & 3.7 & & $4 . ?$ & & 4.4 & & 2.9 & 5.5 & 10.4 & $12 . ?$ & 14.2 \\
\hline $\begin{array}{l}12 \\
13\end{array}$ & 7.5 & 5.3 & 7.7 & 5.4 & 7.7 & $5 \cdot ?$ & $7 .=$ & & & 6.9 & 8.3 & 9.9 & 11.1 \\
\hline 14 &. .5 & 1.5 & 2.7 & 1.5 & -.7 & 1.3 & $\therefore 7$ & 1.3 & .2 & 10.0 & 11.6 & 13.5 & 14.6 \\
\hline 15 & 5.7 & 3.0 & 6.0 & 20 & 6.5 & 3.0 & 6.8 & 3.2 & 3.5 & 4.9 & 6.1 & 8.0 & 9.4 \\
\hline 10 & $3 \cdot 6$ & $4 \cdot 3$ & 0.7 & $4 \cdot 3$ & c. 9 & 4.2 & $10 . ?$ & & $3 \cdot 3$ & 12.5 & $14 \cdot 4$ & 16.7 & 19.5 \\
\hline 17 & 11.7 & 5.1 & $11 . c$ & 5.7 & $12 \cdot 3$ & 5.0 & 12.6 & & 4.0 & $8 . ?$ & 10. & 12. & $14 \cdot 3$ \\
\hline 19 & 10.9 & $5 \cdot 1$ & 11.3 & $5 . \div$ & 11.0 & 5.0 & $1\urcorner . ?$ & & $4 \cdot 7$ & 4.4 & 5 & 6.8 & 8.7 \\
\hline $\begin{array}{l}19 \\
20\end{array}$ & $\begin{array}{r}1.3 .8 \\
1.5\end{array}$ & 6.0 & $\begin{array}{r}1400 \\
1.3\end{array}$ & 5.8 & $\begin{array}{r}14.2 \\
1.2\end{array}$ & 5.7 & $14 . ?$ & & $\begin{array}{ll}4 \cdot 6 \\
3\end{array}$ & $\begin{array}{r}0.8 \\
10.9\end{array}$ & 11. & 13.1 & 15.4 \\
\hline & & & & & & & & & & & & & \\
\hline 21 & -2.4 & & -2.5 & & -204 & & -2.4 & & & 5.1 & 5.9 & 6.4 & 7.2 \\
\hline $\begin{array}{l}32 \\
23\end{array}$ & $\begin{array}{l}4.7 \\
3.8\end{array}$ & 1,1 & $\begin{array}{l}408 \\
4.1\end{array}$ & & $\begin{array}{l}40 \\
4: 4\end{array}$ & 1.0 & 405 & & 301 & $13 \cdot 7$ & 15.8 & 18.1 & 20.4 \\
\hline 24 & 4.0 & $\therefore 5$ & $40 ?$ & 0.3 & 4.4 & 0.4 & $\begin{array}{l}4.8 \\
4.8\end{array}$ & 0.7 & 3.9 & 5.4 & 6. & 8.1 & 9.8 \\
\hline 25 & 2.7 & & 2.8 & $-0 . E$ & 2.9 & -0.8 & 3.0 & -0.6 & 3.2 & $6 . ?$ & 7.2 & 8.4 & 10.0 \\
\hline '5 & 10.4 & $4 \cdot 5$ & 10.5 & $\angle \cdot I$ & 10.5 & $4 \cdot 1$ & 10.6 & 404 & 3.9 & 13.7 & 15.6 & 17.8 & 20.6 \\
\hline$\geq 7$ & -0.7 & & -0.0 & & -1.2 & & -1.4 & & 2.5 & 12.3 & 14.4 & & 16.1 \\
\hline $\begin{array}{l}23 \\
20\end{array}$ & -9.5 & & -9.9 & & $-10 \cdot ?$ & & -10.4 & & & 12.7 & 14.5 & 25.3 & \\
\hline $\begin{array}{l}29 \\
30\end{array}$ & -10.8 & & -11.0 & & $-11 \cdot 2$ & & -11.4 & & & $\begin{array}{r}10.7 \\
7.9\end{array}$ & $\begin{array}{r}12.0 \\
9.1\end{array}$ & $\begin{array}{l}14 \cdot 2 \\
10.7\end{array}$ & $\begin{array}{l}14.7 \\
11.7\end{array}$ \\
\hline 31 & -10.8 & & -10.9 & & -11.1 & & $-11 \cdot 3$ & & & 11.7 & $14 \cdot 1$ & 14.5 & 15.4 \\
\hline
\end{tabular}

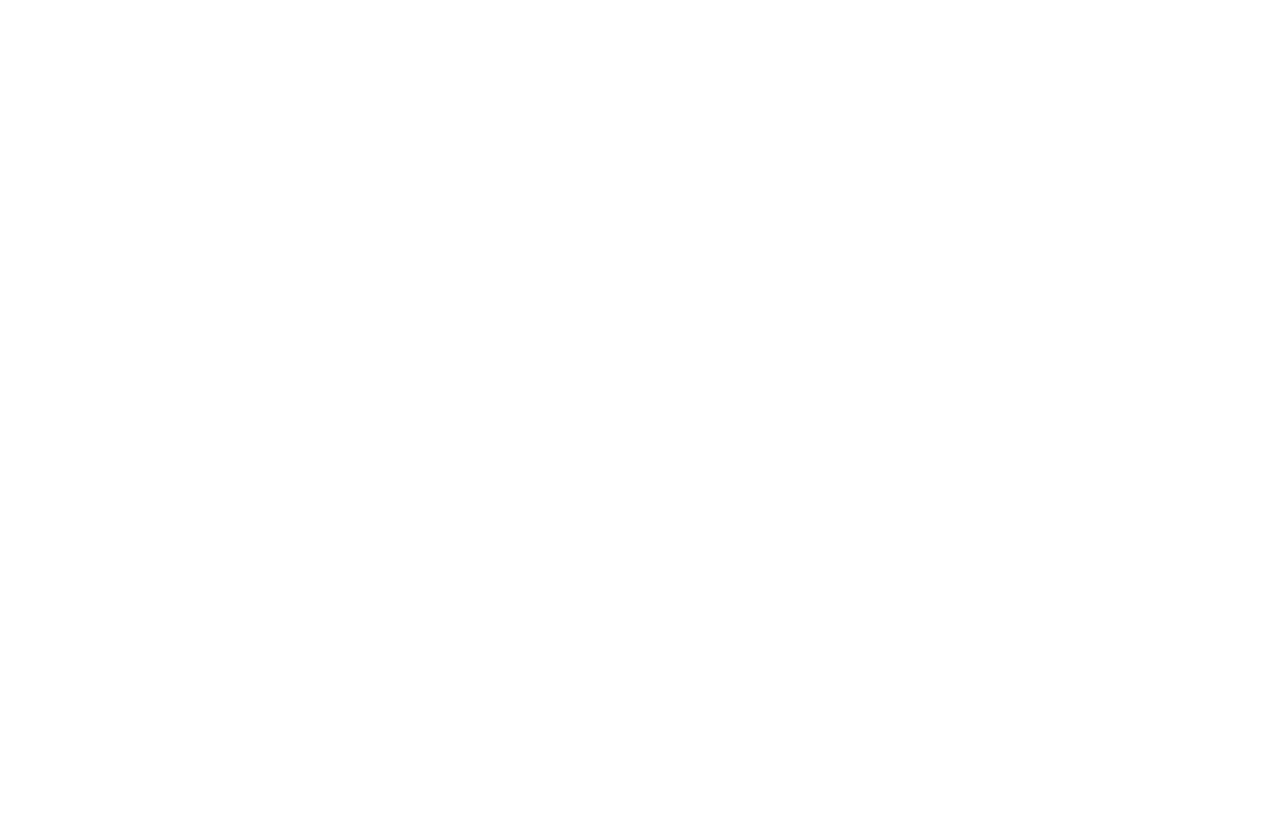


Table 11. -Daily averages of air and water temperatures and wind speeds, July 1950-August 1951, Lake Hefner-Con. STATION 2 DAILY AVERAGES

\begin{tabular}{|c|c|c|c|c|c|c|c|c|c|c|c|c|c|}
\hline \multirow{4}{*}{ ڤั } & \multicolumn{8}{|c|}{ Average air temperature $\left({ }^{\circ} \mathrm{C}\right)$ at indicated height } & \multirow{4}{*}{$\begin{array}{c}\text { Average } \\
\text { water- } \\
\text { surface } \\
\text { temperature } \\
\text { ('C) }\end{array}$} & \multirow{2}{*}{\multicolumn{4}{|c|}{$\begin{array}{l}\text { Average wind speed (knots) } \\
\text { at indicated height }\end{array}$}} \\
\hline & \multirow{2}{*}{\multicolumn{2}{|c|}{$\begin{array}{c}2 \\
\text { meters }\end{array}$}} & \multirow{2}{*}{\multicolumn{2}{|c|}{$\begin{array}{c}4 \\
\text { meters }\end{array}$}} & \multirow{2}{*}{\multicolumn{2}{|c|}{$\begin{array}{c}\mathbf{8} \\
\text { meters }\end{array}$}} & \multirow{2}{*}{\multicolumn{2}{|c|}{$\begin{array}{c}16 \\
\text { meters }\end{array}$}} & & & & & \\
\hline & & & & & & & & & & \multirow[b]{2}{*}{$\begin{array}{c}2 \\
\text { meters }\end{array}$} & \multirow{2}{*}{$\begin{array}{c}4 \\
\text { meters }\end{array}$} & \multirow[b]{2}{*}{$\begin{array}{c}8 \\
\text { meters }\end{array}$} & \multirow[b]{2}{*}{$\begin{array}{c}16 \\
\text { meters }\end{array}$} \\
\hline & $\begin{array}{l}\text { Dry } \\
\text { bulb }\end{array}$ & $\begin{array}{l}\text { Wet } \\
\text { bulb }\end{array}$ & $\begin{array}{l}\text { Dry } \\
\text { bulb }\end{array}$ & $\begin{array}{l}\text { Wet } \\
\text { bulb }\end{array}$ & $\begin{array}{l}\text { Dry } \\
\text { bulb }\end{array}$ & $\begin{array}{l}\text { Wet } \\
\text { bulb }\end{array}$ & $\begin{array}{l}\text { Dry } \\
\text { butb }\end{array}$ & $\begin{array}{l}\text { Wet } \\
\text { bulb }\end{array}$ & & & & & \\
\hline \multicolumn{14}{|c|}{ MARCH } \\
\hline $\begin{array}{l}1 \\
2 \\
3 \\
4 \\
5\end{array}$ & $\begin{array}{r}8.0 \\
6.9 \\
14.4\end{array}$ & $\begin{array}{l}3.1 \\
2.4 \\
5.8\end{array}$ & $\begin{array}{r}7.7 \\
6.9 \\
14.5\end{array}$ & $\begin{array}{l}2.8 \\
2.4 \\
5.8\end{array}$ & $\begin{array}{r}7.5 \\
7.0 \\
14.5\end{array}$ & $\begin{array}{l}2.5 \\
2.5\end{array}$ & $\begin{array}{r}7.5 \\
7.0 \\
14.6\end{array}$ & $\begin{array}{l}2.4 \\
6.0\end{array}$ & $\begin{array}{l}9.2 \\
7.3\end{array}$ & $\begin{array}{r}6.3 \\
12.2 \\
7.5 \\
5.4 \\
13.6\end{array}$ & $\begin{array}{r}7.5 \\
14.3 \\
8.9 \\
6.3 \\
15.9\end{array}$ & $\begin{array}{r}8.7 \\
16.3 \\
10.1 \\
7.3 \\
18.0\end{array}$ & $\begin{array}{r}9.9 \\
19.4 \\
21.3 \\
8.2 \\
20.4\end{array}$ \\
\hline $\begin{array}{r}6 \\
7 \\
8 \\
9 \\
10\end{array}$ & $\begin{array}{r}14.1 \\
5.2 \\
4.3 \\
-0.3 \\
7.2\end{array}$ & $\begin{array}{l}9.6 \\
2.7 \\
1.6 \\
6.6\end{array}$ & $\begin{array}{r}14.5 \\
5.5 \\
4.2 \\
-0.4 \\
7.2\end{array}$ & $\begin{array}{l}9.6 \\
2.6 \\
1.4 \\
5.4\end{array}$ & $\begin{array}{r}14.6 \\
5.6 \\
4.0 \\
-0.0 \\
7.0\end{array}$ & $\begin{array}{l}0.4 \\
2.2 \\
1.2\end{array}$ & $\begin{array}{r}14.7 \\
5.6 \\
3.0 \\
-0.7 \\
6.8\end{array}$ & $\begin{array}{l}2.4 \\
1.1\end{array}$ & $\begin{array}{l}4.7 \\
7.4\end{array}$ & $\begin{array}{l}9.7 \\
5.5 \\
8.1 \\
5.9 \\
7.2\end{array}$ & $\begin{array}{r}11.4 \\
6.5 \\
9.5 \\
7.1 \\
8.6\end{array}$ & $\begin{array}{r}7.9 \\
11.5\end{array}$ & $\begin{array}{r}14.5 \\
8.6 \\
13.7 \\
8.03 \\
10.6\end{array}$ \\
\hline $\begin{array}{l}11 \\
12 \\
13 \\
14 \\
15\end{array}$ & $\begin{array}{r}0.2 \\
-1.6 \\
2.0 \\
3.0\end{array}$ & 0.9 & $\begin{array}{r}0.0 \\
-1.8 \\
2.0 \\
3.8\end{array}$ & 0.9 & $\begin{array}{r}-0.2 \\
-2.0 \\
2.0 \\
3.0\end{array}$ & & $\begin{array}{r}-0.7 \\
-2.2 \\
2.1 \\
4.2\end{array}$ & 1.3 & & $\begin{array}{r}18.2 \\
18.5 \\
12.7 \\
6.3 \\
2.8\end{array}$ & $\begin{array}{r}22.0 \\
22.1 \\
14.0 \\
6.7 \\
3.7\end{array}$ & $\begin{array}{r}23.8 \\
18.4 \\
8.7 \\
4.2\end{array}$ & $\begin{array}{r}25.1 \\
19.5 \\
9.3 \\
5.0\end{array}$ \\
\hline $\begin{array}{l}16 \\
17 \\
18 \\
19 \\
20\end{array}$ & $\begin{array}{r}11.6 \\
7.8 \\
1.8 \\
3.3 \\
7.8\end{array}$ & $\begin{array}{l}6.8 \\
4.9\end{array}$ & $\begin{array}{r}11.8 \\
7.5 \\
1.5 \\
3.8 \\
7.9\end{array}$ & $\begin{array}{l}6.8 \\
4.7\end{array}$ & $\begin{array}{r}11.8 \\
7.4 \\
1.4 \\
3.9 \\
7.8\end{array}$ & $\begin{array}{r}6.5 \\
4.5 \\
-0.1 \\
2.1\end{array}$ & $\begin{array}{r}12.1 \\
7.4 \\
1.2 \\
4.3 \\
7.7\end{array}$ & $\begin{array}{l}0.2 \\
2.2\end{array}$ & $\begin{array}{l}6.9 \\
4.9 \\
6.2 \\
6.1\end{array}$ & $\begin{array}{r}9.8 \\
12.8 \\
10.9 \\
4.7 \\
10.0\end{array}$ & $\begin{array}{r}11.6 \\
14.1 \\
13.3 \\
5.6 \\
11.6\end{array}$ & $\begin{array}{r}13.4 \\
18.7 \\
14.3 \\
6.8 \\
13.6\end{array}$ & $\begin{array}{r}15.44 \\
20.3 \\
7.7 \\
15.6\end{array}$ \\
\hline $\begin{array}{l}21 \\
22 \\
23 \\
24 \\
25\end{array}$ & $\begin{array}{r}5.4 \\
18.0 \\
12.3 \\
8.4 \\
13.7\end{array}$ & $\begin{array}{l}8.6 \\
5.9 \\
3.1 \\
5.1\end{array}$ & $\begin{array}{r}5.4 \\
18.2 \\
12.3 \\
8.6 \\
13.8\end{array}$ & $\begin{array}{l}1.0 \\
8.5 \\
5.6 \\
3.0 \\
4.9\end{array}$ & $\begin{array}{r}5.6 \\
18.2 \\
12.4 \\
8.7 \\
13.8\end{array}$ & $\begin{array}{l}8.6 \\
5.5 \\
3.0 \\
5.0\end{array}$ & $\begin{array}{r}5.7 \\
18.3 \\
12.6 \\
8.8 \\
14.0\end{array}$ & $\begin{array}{l}1.3 \\
8.9 \\
5.5 \\
3.0 \\
5.0\end{array}$ & $\begin{array}{l}4.9 \\
5.7 \\
7.8 \\
6.6 \\
7.5\end{array}$ & $\begin{array}{r}11.6 \\
11.8 \\
4.1 \\
6.9\end{array}$ & $\begin{array}{r}5.4 \\
13.5 \\
13.8 \\
4.7 \\
7.9\end{array}$ & $\begin{array}{r}6.5 \\
15.8 \\
17.2 \\
5.6 \\
9.4\end{array}$ & $\begin{array}{r}7.6 \\
18.1 \\
19.0 \\
6.7 \\
11.0\end{array}$ \\
\hline $\begin{array}{l}26 \\
27 \\
28 \\
29 \\
30\end{array}$ & $\begin{array}{r}12.5 \\
12.9 \\
8.5 \\
5.2 \\
10.4\end{array}$ & $\begin{array}{r}6.8 \\
11.6 \\
7.6 \\
1.6 \\
4.1\end{array}$ & $\begin{array}{r}12.5 \\
12.9 \\
8.4 \\
5.1 \\
10.7\end{array}$ & $\begin{array}{r}6.7 \\
11.5 \\
7.5\end{array}$ & $\begin{array}{r}12.4 \\
12.7 \\
8.3 \\
5.2 \\
11.0\end{array}$ & $\begin{array}{r}6.6 \\
11.2 \\
7.2\end{array}$ & $\begin{array}{r}12.5 \\
12.4 \\
8.3 \\
5.3 \\
11.2\end{array}$ & $\begin{array}{l}6.6 \\
7.1 \\
1.4 \\
4.2\end{array}$ & $\begin{array}{l}7.6 \\
8.6 \\
8.7 \\
6.9 \\
7.2\end{array}$ & $\begin{array}{r}11.0 \\
14.5 \\
14.4 \\
13.9 \\
5.7\end{array}$ & $\begin{array}{r}12.8 \\
16.6 \\
16.2 \\
15.9 \\
6.9\end{array}$ & $\begin{array}{r}14.6 \\
18.5 \\
20.3 \\
20.3 \\
8.2\end{array}$ & $\begin{array}{r}26.7 \\
20.6 \\
22.4 \\
21.9 \\
9.5\end{array}$ \\
\hline 31 & 14.8 & 8.6 & 14.7 & 8.4 & $14 \cdot 7$ & 8.4 & 14.8 & 8.2 & 9.5 & 7.5 & 8.6 & 10.5 & $12 \cdot 5$ \\
\hline
\end{tabular}

APR IL

\begin{tabular}{|c|c|c|c|c|c|c|c|c|c|c|c|c|c|}
\hline $\begin{array}{l}1 \\
2 \\
3 \\
4 \\
5\end{array}$ & $\begin{array}{r}7.0 \\
6.3 \\
10.6 \\
17.8 \\
14.9\end{array}$ & $\begin{array}{r}4.2 \\
3.7 \\
5.2 \\
9.5 \\
12.8\end{array}$ & $\begin{array}{r}6.9 \\
6.3 \\
11.0 \\
17.9 \\
14.8\end{array}$ & $\begin{array}{r}4.0 \\
3.5 \\
5.2 \\
9.4 \\
12.7\end{array}$ & $\begin{array}{r}6.8 \\
6.2 \\
11.2 \\
17.9 \\
14.7\end{array}$ & $\begin{array}{r}3.7 \\
3.4 \\
5.2 \\
9.4 \\
12.6\end{array}$ & $\begin{array}{r}6.6 \\
6.3 \\
11.5 \\
17.8 \\
14.8\end{array}$ & $\begin{array}{r}3.6 \\
3.3 \\
5.3 \\
9.5 \\
12.7\end{array}$ & $\begin{array}{l}7.8 \\
8.3 \\
9.2 \\
8.2\end{array}$ & $\begin{array}{r}9.4 \\
7.6 \\
3.9 \\
10.1 \\
10.2\end{array}$ & $\begin{array}{r}12.0 \\
9.2 \\
4.7 \\
12.1 \\
12.7\end{array}$ & $\begin{array}{r}13.2 \\
5.5 \\
13.8 \\
14.4\end{array}$ & $\begin{array}{r}14.3 \\
11.2 \\
6.4 \\
15.5 \\
16.1\end{array}$ \\
\hline $\begin{array}{r}6 \\
7 \\
8 \\
9 \\
10\end{array}$ & $\begin{array}{r}12.2 \\
9.6 \\
8.7 \\
9.6 \\
8.5\end{array}$ & $\begin{array}{r}10.4 \\
6.1 \\
3.6 \\
3.8 \\
5.9\end{array}$ & $\begin{array}{r}12.0 \\
9.4 \\
8.8 \\
9.9 \\
8.4\end{array}$ & $\begin{array}{r}10.2 \\
5.8 \\
3.4 \\
3.6 \\
5.7\end{array}$ & $\begin{array}{r}11.8 \\
9.1 \\
8.7 \\
10.1 \\
8.2\end{array}$ & $\begin{array}{l}9.7 \\
5.3 \\
3.2 \\
3.4 \\
5.5\end{array}$ & $\begin{array}{r}11.9 \\
9.1 \\
9.0 \\
10.6 \\
8.2\end{array}$ & $\begin{array}{l}9.9 \\
5.4 \\
3.1 \\
3.5 \\
5.5\end{array}$ & $\begin{array}{l}11.3 \\
10.3 \\
10.5 \\
11.0 \\
10.0\end{array}$ & $\begin{array}{r}8.5 \\
10.5 \\
8.6 \\
5.8 \\
10.3\end{array}$ & $\begin{array}{r}9.9 \\
12.6 \\
10.2 \\
7.1 \\
12.6\end{array}$ & $\begin{array}{r}13.4 \\
15.5 \\
12.7 \\
8.8 \\
14.2\end{array}$ & $\begin{array}{l}14.7 \\
16.5 \\
14.3 \\
10.3 \\
15.8\end{array}$ \\
\hline $\begin{array}{l}11 \\
12 \\
13 \\
14 \\
15\end{array}$ & $\begin{array}{r}5.1 \\
5.3 \\
9.6 \\
15.7 \\
8.4\end{array}$ & $\begin{array}{l}2.4 \\
2.0 \\
3.7 \\
7.9 \\
3.9\end{array}$ & $\begin{array}{r}5.0 \\
5.3 \\
9.9 \\
15.7 \\
8.2\end{array}$ & $\begin{array}{l}2.1 \\
3.5 \\
7.7 \\
3.7\end{array}$ & $\begin{array}{r}4.9 \\
5.2 \\
20.0 \\
15.5 \\
8.1\end{array}$ & $\begin{array}{l}1.9 \\
1.7 \\
3.4 \\
7.6 \\
3.4\end{array}$ & $\begin{array}{r}4.9 \\
5.3 \\
10.1 \\
15.6 \\
7.9\end{array}$ & $\begin{array}{l}3.3 \\
7.6 \\
3.2\end{array}$ & $\begin{array}{r}7.8 \\
7.0 \\
9.5 \\
10.7 \\
9.7\end{array}$ & $\begin{array}{r}12.6 \\
12.2 \\
7.5 \\
10.1 \\
8.8\end{array}$ & $\begin{array}{r}14.0 \\
13.7 \\
8.7 \\
11.8 \\
10.2\end{array}$ & $\begin{array}{l}18.7 \\
17.7 \\
10.8 \\
13.8 \\
12.3\end{array}$ & $\begin{array}{l}20.1 \\
29.3 \\
12.0 \\
15.7 \\
13.5\end{array}$ \\
\hline $\begin{array}{l}16 \\
17 \\
18 \\
19 \\
20\end{array}$ & $\begin{array}{l}16.9 \\
15.7\end{array}$ & $\begin{array}{l}11.9 \\
14.3\end{array}$ & $\begin{array}{l}16.9 \\
15.6\end{array}$ & $\begin{array}{r}1.8 \\
5.4 \\
11.8 \\
14.2\end{array}$ & $\begin{array}{r}6.9 \\
13.4 \\
15.7 \\
15.7\end{array}$ & $\begin{array}{r}1.8 \\
12.2 \\
11.6 \\
14.2\end{array}$ & $\begin{array}{r}6.9 \\
13.5 \\
19.7 \\
16.7 \\
15.9\end{array}$ & $\begin{array}{r}1.6 \\
5.5 \\
11.9 \\
11.5 \\
14.3\end{array}$ & $\begin{array}{r}10.7 \\
9.7 \\
11.0 \\
17.6 \\
10.8\end{array}$ & $\begin{array}{r}5.0 \\
12.5 \\
11.9 \\
5.4 \\
10.0\end{array}$ & $\begin{array}{r}6.0 \\
14.5 \\
14.0 \\
6.6 \\
11.9\end{array}$ & $\begin{array}{r}6.3 \\
16.5 \\
16.0 \\
7.8 \\
13.5\end{array}$ & $\begin{array}{r}7.5 \\
18.7 \\
18.0 \\
9.0 \\
15.3\end{array}$ \\
\hline $\begin{array}{l}21 \\
22 \\
23 \\
24 \\
25\end{array}$ & $\begin{array}{r}11.8 \\
8.5 \\
13.7 \\
21.6 \\
16.3\end{array}$ & $\begin{array}{r}10.0 \\
5.3 \\
8.2 \\
13.9 \\
13.0\end{array}$ & $\begin{array}{r}11.5 \\
8.5 \\
13.8 \\
21.7 \\
16.2\end{array}$ & $\begin{array}{r}9.8 \\
5.1 \\
8.1 \\
13.9 \\
12.9\end{array}$ & $\begin{array}{r}11.6 \\
8.5 \\
14.1 \\
21.5 \\
16.2\end{array}$ & $\begin{array}{r}9.6 \\
4.8 \\
8.1 \\
13.8 \\
12.7\end{array}$ & $\begin{array}{r}11.7 \\
8.4 \\
14.3 \\
21.4 \\
16.2\end{array}$ & $\begin{array}{l}3.5 \\
4.7 \\
8.2\end{array}$ & $\begin{array}{l}11.7 \\
10.7 \\
11.1 \\
12: 0 \\
14.5\end{array}$ & $\begin{array}{r}7.4 \\
8.8 \\
8.7 \\
17.5 \\
7.7\end{array}$ & $\begin{array}{r}8.5 \\
10.0 \\
10.2 \\
20.1 \\
9.2\end{array}$ & $\begin{array}{l}11.2 \\
10.9 \\
11.7 \\
22.6 \\
10.6\end{array}$ & $\begin{array}{l}12.6 \\
12.2 \\
13.3 \\
25.2 \\
12.3\end{array}$ \\
\hline $\begin{array}{l}26 \\
27 \\
28 \\
29 \\
30\end{array}$ & $\begin{array}{l}18.6 \\
23.4 \\
23.8 \\
19.7 \\
16.6\end{array}$ & $\begin{array}{l}15.1 \\
18.2 \\
18.3 \\
17.1 \\
15.1\end{array}$ & $\begin{array}{l}18.6 \\
23.4 \\
23.9\end{array}$ & $\begin{array}{l}15.0 \\
18.1 \\
18.3 \\
17.1 \\
15.1\end{array}$ & $\begin{array}{l}18.5 \\
23.3 \\
23.7 \\
19.8 \\
16.6\end{array}$ & $\begin{array}{l}14.9 \\
18.0 \\
18.2 \\
17.0 \\
15.1\end{array}$ & $\begin{array}{l}18.4 \\
23.2 \\
23.6 \\
19.0 \\
16.7\end{array}$ & $\begin{array}{l}14.8 \\
17.9 \\
18.1 \\
17.0 \\
14.8\end{array}$ & $\begin{array}{l}13.0 \\
12.1 \\
13.2 \\
14.1 \\
14 . ?\end{array}$ & $\begin{array}{r}6.9 \\
13.2 \\
12.7 \\
13.0 \\
8.9\end{array}$ & $\begin{array}{r}8.1 \\
15.1 \\
14.7 \\
15.2 \\
10.3\end{array}$ & $\begin{array}{r}9.2 \\
17.0 \\
16.5 \\
17.2 \\
11.6\end{array}$ & $\begin{array}{l}10.4 \\
18.8 \\
18.2 \\
19.1 \\
12.9\end{array}$ \\
\hline
\end{tabular}


TABLE 11

Table 11. -Daily averages of air and water temperatures and wind speeds, July 1950—August 1951, Lake Hefner-Con.

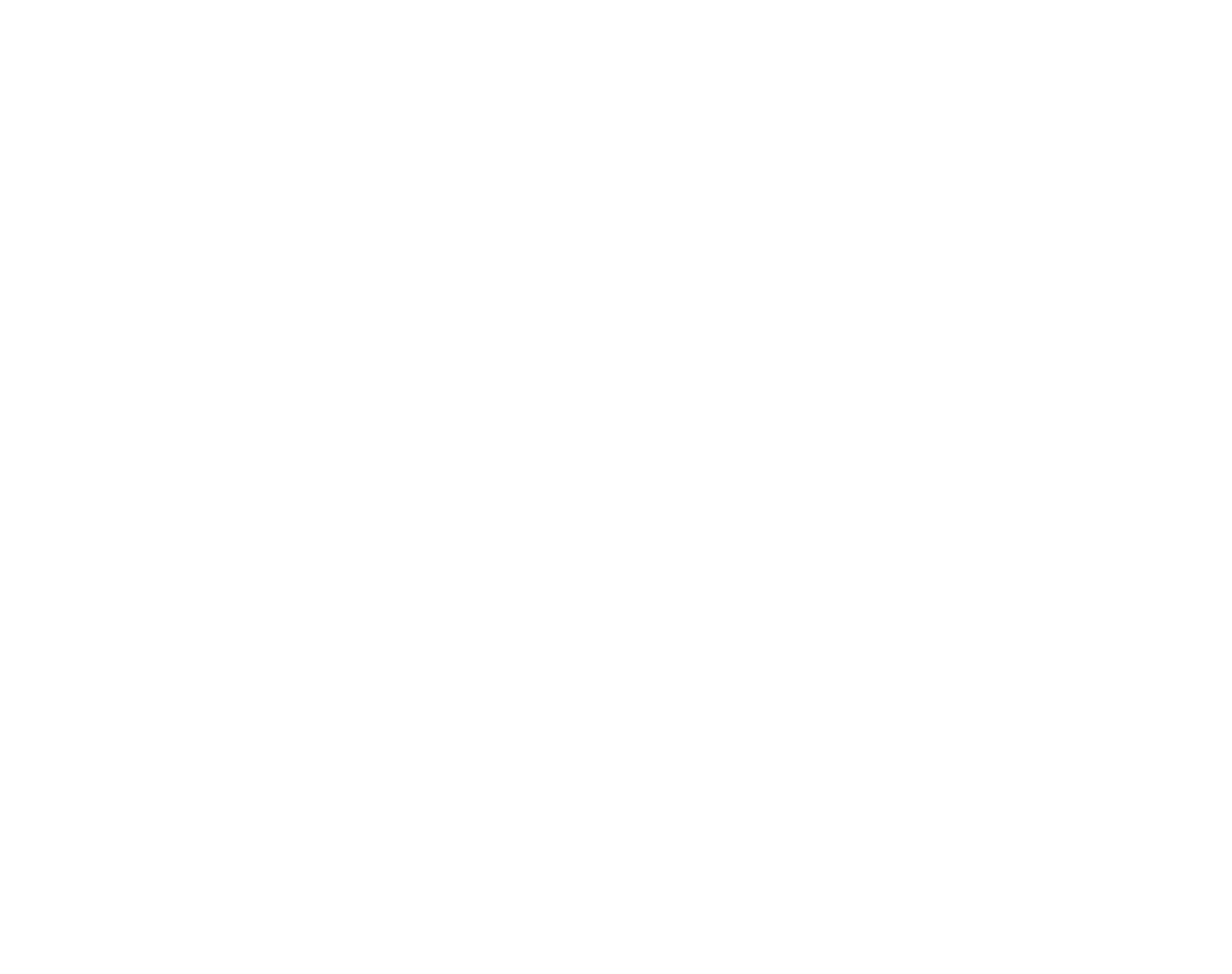

\begin{tabular}{|c|c|c|c|c|c|c|c|c|c|c|c|c|c|}
\hline $\begin{array}{l}1 \\
2 \\
3 \\
4 \\
5\end{array}$ & $\begin{array}{l}24.9 \\
18.7 \\
14.9 \\
16.2 \\
19.3\end{array}$ & $\begin{array}{l}21.1 \\
16.1 \\
12.5 \\
13.0 \\
16.9\end{array}$ & $\begin{array}{l}25.0 \\
18.6 \\
14.7 \\
16.1 \\
19.2\end{array}$ & $\begin{array}{l}20.9 \\
15.9 \\
12.3 \\
12.9 \\
16.7\end{array}$ & $\begin{array}{l}25.0 \\
18.4 \\
14.5 \\
16.1 \\
19.2\end{array}$ & $\begin{array}{l}20.8 \\
15.7 \\
12.1 \\
12.7 \\
16.7\end{array}$ & $\begin{array}{l}24.9 \\
18.3 \\
14.3 \\
15.9 \\
19.1\end{array}$ & $\begin{array}{l}20.7 \\
15.5 \\
11.8 \\
12.6 \\
16.6\end{array}$ & $\begin{array}{l}21.7 \\
20.7 \\
20.0 \\
21.0 \\
20.3\end{array}$ & $\begin{array}{r}11.9 \\
8.5 \\
7.9 \\
4.1 \\
4.6\end{array}$ & $\begin{array}{r}13.8 \\
10.4 \\
9.9 \\
4.9 \\
5.6\end{array}$ & $\begin{array}{r}15.7 \\
11.6 \\
9.8 \\
5.6 \\
6.4\end{array}$ & $\begin{array}{r}17.7 \\
12.9 \\
10.6 \\
8.7 \\
7.3\end{array}$ \\
\hline $\begin{array}{r}6 \\
7 \\
8 \\
9 \\
10\end{array}$ & $\begin{array}{l}22.4 \\
20.9\end{array}$ & $\begin{array}{l}18.9 \\
18.7\end{array}$ & $\begin{array}{l}22.3 \\
20.8\end{array}$ & $\begin{array}{l}18.7 \\
18.5\end{array}$ & $\begin{array}{l}22.1 \\
20.7\end{array}$ & $\begin{array}{l}18.5 \\
18.4\end{array}$ & $\begin{array}{l}22.0 \\
20.7\end{array}$ & $\begin{array}{l}18.4 \\
18.3\end{array}$ & $\begin{array}{l}23.1 \\
23.8\end{array}$ & $\begin{array}{r}9.9 \\
7.5 \\
11.2 \\
4.3 \\
5.6\end{array}$ & $\begin{array}{r}12.1 \\
9.1 \\
13.0 \\
5.3 \\
6.4\end{array}$ & $\begin{array}{r}13.4 \\
10.4 \\
14.8 \\
6.0 \\
7.0\end{array}$ & $\begin{array}{r}15.1 \\
21.8 \\
16.0 \\
7.4 \\
8.2\end{array}$ \\
\hline $\begin{array}{l}11 \\
12 \\
13 \\
14 \\
15\end{array}$ & $\begin{array}{l}19.9 \\
21.0 \\
22.8 \\
23.0\end{array}$ & $\begin{array}{l}18.4 \\
18.3 \\
19.0 \\
19.7\end{array}$ & $\begin{array}{l}19.9 \\
20.9 \\
22.9 \\
22.9\end{array}$ & $\begin{array}{l}18.3 \\
18.1 \\
18.8 \\
19.5\end{array}$ & $\begin{array}{l}19.8 \\
20.9 \\
22.8 \\
22.8\end{array}$ & $\begin{array}{l}18.1 \\
18.0 \\
18.7 \\
19.4\end{array}$ & $\begin{array}{l}19.7 \\
20.9 \\
22.8 \\
22.8\end{array}$ & $\begin{array}{l}18.1 \\
17.8 \\
18.7 \\
19.3\end{array}$ & $\begin{array}{l}18.8 \\
22.0 \\
22.5\end{array}$ & $\begin{array}{l}4.7 \\
3.8 \\
5.9 \\
5.3 \\
4.8\end{array}$ & $\begin{array}{l}5.8 \\
4.6 \\
7.0 \\
6.3 \\
5.6\end{array}$ & $\begin{array}{l}6.6 \\
5.6 \\
8.0 \\
7.3 \\
6.7\end{array}$ & $\begin{array}{l}7.6 \\
8.8 \\
9.3 \\
8.3 \\
8.7\end{array}$ \\
\hline $\begin{array}{l}16 \\
17 \\
18 \\
19 \\
20\end{array}$ & $\begin{array}{l}26.0 \\
25.9\end{array}$ & $\begin{array}{l}21.8 \\
22.7\end{array}$ & $\begin{array}{l}26.0 \\
25.9\end{array}$ & $\begin{array}{l}21.6 \\
22.5\end{array}$ & $\begin{array}{l}26.0 \\
25.8\end{array}$ & $\begin{array}{l}21 \cdot 3 \\
22.4\end{array}$ & $\begin{array}{l}25.8 \\
25.9\end{array}$ & $\begin{array}{l}21.2 \\
22.2\end{array}$ & $\begin{array}{l}23.6 \\
22.4\end{array}$ & $\begin{array}{l}4.5 \\
2.9 \\
4.6 \\
4.9 \\
7.5\end{array}$ & $\begin{array}{r}5.2 \\
3.9 \\
5.1 \\
5.9 \\
10.1\end{array}$ & $\begin{array}{r}6.3 \\
4.6 \\
7.2 \\
7.0 \\
11.6\end{array}$ & $\begin{array}{r}7.5 \\
9.8 \\
13.2\end{array}$ \\
\hline $\begin{array}{l}21 \\
22 \\
23 \\
24 \\
25\end{array}$ & $\begin{array}{l}25.5 \\
26.1 \\
25.4 \\
24.7 \\
25.9\end{array}$ & $\begin{array}{l}22.9 \\
22.7 \\
21.6 \\
20.6 \\
22.8\end{array}$ & $\begin{array}{l}25.6 \\
25.2 \\
25.6 \\
24.7 \\
25.9\end{array}$ & $\begin{array}{l}22.8 \\
22.6 \\
21.5 \\
20.5 \\
22.8\end{array}$ & $\begin{array}{l}25.6 \\
26.2 \\
25.6 \\
24.6 \\
25.8\end{array}$ & $\begin{array}{l}22.7 \\
22.4 \\
21.4 \\
20.5 \\
22.6\end{array}$ & $\begin{array}{l}25.6 \\
26.3 \\
25.6 \\
24.6 \\
25.7\end{array}$ & $\begin{array}{l}22.6 \\
22.4 \\
21.4 \\
20.5 \\
22.7\end{array}$ & $\begin{array}{l}20.1 \\
21.7 \\
22.6 \\
22.6 \\
22.6\end{array}$ & $\begin{array}{l}6.8 \\
6.8 \\
8.8 \\
6.5 \\
9.1\end{array}$ & $\begin{array}{r}8.2 \\
7.9 \\
10.3 \\
8.4 \\
10.7\end{array}$ & $\begin{array}{r}9.5 \\
9.3 \\
11.8 \\
9.6 \\
12.1\end{array}$ & $\begin{array}{r}10.6 \\
10.7 \\
13.4 \\
11.0 \\
13.8\end{array}$ \\
\hline $\begin{array}{l}26 \\
27 \\
28 \\
29 \\
30\end{array}$ & $\begin{array}{l}27.5 \\
27.5 \\
27.5\end{array}$ & $\begin{array}{l}22.0 \\
21.2 \\
21.9\end{array}$ & $\begin{array}{l}27.4 \\
27.6 \\
27.4\end{array}$ & $\begin{array}{l}21.9 \\
21: 1 \\
21.8\end{array}$ & $\begin{array}{l}27.3 \\
27.4 \\
27.3\end{array}$ & $\begin{array}{l}21.8 \\
21: 1 \\
21: 7\end{array}$ & $\begin{array}{l}27.3 \\
27.4 \\
27.3\end{array}$ & $\begin{array}{l}22.0 \\
21.6 \\
21.8\end{array}$ & $\begin{array}{l}24.8 \\
25.0 \\
24.9\end{array}$ & $\begin{array}{r}11.4 \\
11.1 \\
7.1 \\
8.7 \\
6.8\end{array}$ & $\begin{array}{r}13.1 \\
12.9 \\
8.2 \\
10.3 \\
8.0\end{array}$ & $\begin{array}{r}14.9 \\
14.7 \\
9.4 \\
11.8 \\
9.3\end{array}$ & $\begin{array}{l}16.8 \\
16.7 \\
10.7 \\
13.4 \\
11.2\end{array}$ \\
\hline
\end{tabular}


Table 11.-Daily averages of air and water temperatures and wind speeds, July 1950-August 1951, Lake Hefner-Con. STATION 2 DATLY AVERAGES

1951

\begin{tabular}{|c|c|c|c|c|c|c|c|c|c|c|c|c|c|}
\hline \multirow{4}{*}{ 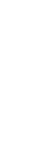 } & \multicolumn{8}{|c|}{ Average air temperature $\left({ }^{\circ} \mathrm{C}\right)$ at indicated height } & \multirow{4}{*}{$\begin{array}{c}\text { Average } \\
\text { water- } \\
\text { surface } \\
\text { temperature } \\
\text { (ㄷ) }\end{array}$} & \multirow{2}{*}{\multicolumn{4}{|c|}{$\begin{array}{l}\text { Average wind speed (knots) } \\
\text { at indicated height }\end{array}$}} \\
\hline & \multirow{2}{*}{\multicolumn{2}{|c|}{$\begin{array}{c}2 \\
\text { meters }\end{array}$}} & \multirow{2}{*}{\multicolumn{2}{|c|}{$\begin{array}{c}4 \\
\text { meters }\end{array}$}} & \multirow{2}{*}{\multicolumn{2}{|c|}{$\begin{array}{c}\mathbf{8} \\
\text { meters } \\
\end{array}$}} & \multirow{2}{*}{\multicolumn{2}{|c|}{$\begin{array}{c}16 \\
\text { meters }\end{array}$}} & & & & & \\
\hline & & & & & & & & & & & & & \\
\hline & $\begin{array}{c}\text { Dry } \\
\text { bulb }\end{array}$ & $\begin{array}{l}\text { Wet } \\
\text { bulb }\end{array}$ & $\begin{array}{l}\text { Dry } \\
\text { bulb }\end{array}$ & $\begin{array}{l}\text { Wet } \\
\text { bulb }\end{array}$ & $\begin{array}{l}\text { Dry } \\
\text { bulb }\end{array}$ & $\begin{array}{l}\text { Wet } \\
\text { bulb }\end{array}$ & $\begin{array}{l}\text { Dry } \\
\text { bulb }\end{array}$ & $\begin{array}{l}\text { Wet } \\
\text { bulb }\end{array}$ & & meters & meters & meters & meters \\
\hline
\end{tabular}

\begin{tabular}{|c|c|c|c|c|c|c|c|c|c|c|c|c|c|}
\hline \multicolumn{14}{|c|}{ JULY } \\
\hline $\begin{array}{l}1 \\
2 \\
3 \\
4 \\
5\end{array}$ & $\begin{array}{l}17.5 \\
23.4 \\
27.4 \\
23.4 \\
27.5\end{array}$ & $\begin{array}{l}16.2 \\
20.5 \\
24.0 \\
20.8 \\
23.0\end{array}$ & $\begin{array}{l}17.5 \\
23.2 \\
27.4 \\
23.4 \\
27.5\end{array}$ & $\begin{array}{l}16.1 \\
20.2 \\
23.8 \\
20.6 \\
22.9\end{array}$ & $\begin{array}{l}17.4 \\
23.0 \\
27.2 \\
23.5 \\
27.4\end{array}$ & $\begin{array}{r}26.0 \\
20.1 \\
23.8 \\
-20.6 \\
22.8\end{array}$ & $\begin{array}{l}17.3 \\
22.9 \\
27.1 \\
23.6 \\
27.4\end{array}$ & $\begin{array}{l}25.9 \\
20.1 \\
23.8 \\
20.5 \\
22.8\end{array}$ & $\begin{array}{l}21.7 \\
18 \cdot 2 \\
23 \cdot 3 \\
23 \cdot 2\end{array}$ & $\begin{array}{l}4.5 \\
6.4 \\
9.6 \\
5.1 \\
9.1\end{array}$ & $\begin{array}{r}6.0 \\
7.8 \\
11.4 \\
6.9 \\
10.8\end{array}$ & $\begin{array}{r}7.1 \\
8.6 \\
12.9 \\
8.2 \\
12.3\end{array}$ & $\begin{array}{r}8.1 \\
9.7 \\
14.6 \\
9.4 \\
14.1\end{array}$ \\
\hline $\begin{array}{r}6 \\
7 \\
8 \\
9 \\
10\end{array}$ & $\begin{array}{l}27.9 \\
27.8 \\
28.3 \\
28.2 \\
28.4\end{array}$ & $\begin{array}{l}22.6 \\
22.0 \\
21.9 \\
22.4 \\
22.9\end{array}$ & $\begin{array}{l}27.9 \\
27.8 \\
28.2 \\
28.1 \\
28.4\end{array}$ & $\begin{array}{l}22.4 \\
22.0 \\
21.8 \\
22.3 \\
22.8\end{array}$ & $\begin{array}{l}27.7 \\
27.7 \\
28.2 \\
28.0 \\
28.2\end{array}$ & $\begin{array}{l}22.2 \\
21: 9 \\
21: 7 \\
22: 3 \\
22: 7\end{array}$ & $\begin{array}{l}27.8 \\
27.7 \\
28 . ? \\
28.0 \\
28.1\end{array}$ & $\begin{array}{r}22.5 \\
20.2\end{array}$ & $\begin{array}{l}24 \cdot 3 \\
24.4 \\
24 \cdot 1 \\
25.2 \\
25.4\end{array}$ & $\begin{array}{r}10.0 \\
10.5 \\
11.6 \\
9.1 \\
9.7\end{array}$ & $\begin{array}{l}11.8 \\
12.2 \\
13.4 \\
10.6 \\
11.4\end{array}$ & $\begin{array}{l}13.4 \\
13.8 \\
15.2 \\
12.1 \\
12.9\end{array}$ & $\begin{array}{l}15.1 \\
15.6 \\
17.2 \\
13.7 \\
14.4\end{array}$ \\
\hline $\begin{array}{l}11 \\
12 \\
13 \\
14 \\
15\end{array}$ & $\begin{array}{l}28.3 \\
28.8 \\
26.1 \\
23.9 \\
26.4\end{array}$ & $\begin{array}{l}22.5 \\
22.7 \\
22.7 \\
22.0 \\
22.9\end{array}$ & $\begin{array}{l}28.2 \\
28.7 \\
25.8 \\
23.7 \\
26.2\end{array}$ & $\begin{array}{l}22.5 \\
22.5 \\
22.6 \\
21.9 \\
22.7\end{array}$ & $\begin{array}{l}28.0 \\
28.5 \\
25.7 \\
23.6 \\
26.0\end{array}$ & $\begin{array}{l}22.4 \\
22.5 \\
22.5 \\
21.9 \\
22.6\end{array}$ & $\begin{array}{l}27.9 \\
23.4 \\
25.6 \\
23.5 \\
26.0\end{array}$ & $\begin{array}{l}32.0 \\
33.0 \\
32.5 \\
? 1.0\end{array}$ & $\begin{array}{l}25.6 \\
25.4 \\
27.1 \\
24.7 \\
23.5\end{array}$ & $\begin{array}{l}8.7 \\
7 \cdot 3 \\
4.7 \\
4 \cdot 7 \\
6.6\end{array}$ & $\begin{array}{r}10.4 \\
9.2 \\
5.4 \\
6.3 \\
8.0\end{array}$ & $\begin{array}{r}11.8 \\
10.5 \\
6.3 \\
7.5 \\
9.3\end{array}$ & $\begin{array}{r}13.2 \\
12.0 \\
7.4 \\
8.6 \\
10.8\end{array}$ \\
\hline $\begin{array}{l}16 \\
17 \\
18 \\
19 \\
20\end{array}$ & $\begin{array}{l}27.9 \\
28.4 \\
28.8\end{array}$ & $\begin{array}{l}22.1 \\
22: 3 \\
21.6\end{array}$ & $\begin{array}{l}27.9 \\
28.3 \\
28.8\end{array}$ & $\begin{array}{l}21.9 \\
22.0 \\
21.2\end{array}$ & $\begin{array}{l}27.8 \\
29.3 \\
28.8\end{array}$ & $\begin{array}{l}21.8 \\
22.0 \\
21.1\end{array}$ & $\begin{array}{l}27.8 \\
29.4 \\
28.8\end{array}$ & $\begin{array}{l}32,1 \\
32: 1 \\
71.3\end{array}$ & $\begin{array}{l}25.6 \\
26.3 \\
26.7\end{array}$ & $\begin{array}{l}4.9 \\
3.6 \\
4.2 \\
2.9 \\
7.8\end{array}$ & $\begin{array}{l}5.9 \\
4.3 \\
5.1 \\
3.5 \\
9.4\end{array}$ & $\begin{array}{r}6.9 \\
5.2 \\
6.1 \\
4.3 \\
10.7\end{array}$ & $\begin{array}{r}8.1 \\
6.3 \\
7: 4 \\
5: 1 \\
12.1\end{array}$ \\
\hline $\begin{array}{l}21 \\
22 \\
23 \\
24 \\
25\end{array}$ & $\begin{array}{l}31.4 \\
30.4 \\
26.6 \\
25.7\end{array}$ & $\begin{array}{l}23.1 \\
22.9 \\
22.7 \\
22.5\end{array}$ & $\begin{array}{l}31.3 \\
30.2 \\
25.5\end{array}$ & $\begin{array}{l}22.4 \\
22 . ? \\
22.4\end{array}$ & $\begin{array}{l}31.0 \\
30.1 \\
25.5\end{array}$ & $\begin{array}{l}22.3 \\
22.4 \\
22.4 \\
22.2\end{array}$ & $\begin{array}{l}31.0 \\
30.0 \\
26.2 \\
25.1\end{array}$ & $\begin{array}{r}22.5 \\
32.1\end{array}$ & $\begin{array}{l}25.9 \\
26.3 \\
28.0 \\
27.8\end{array}$ & $\begin{array}{r}12.2 \\
7.3 \\
4.2 \\
3.2 \\
7.8\end{array}$ & $\begin{array}{r}12.7 \\
8.4 \\
5.5 \\
4.3 \\
3.4\end{array}$ & $\begin{array}{r}14.4 \\
0.6 \\
6.3 \\
4.7 \\
4.0\end{array}$ & $\begin{array}{r}16.2 \\
10.9 \\
7.2 \\
5.4 \\
4.7\end{array}$ \\
\hline $\begin{array}{l}26 \\
27 \\
28 \\
29 \\
30\end{array}$ & $\begin{array}{l}27.2 \\
27.8 \\
27.0 \\
27.8\end{array}$ & $\begin{array}{l}22.9 \\
23.3 \\
22.2 \\
23.0\end{array}$ & $\begin{array}{l}27.1 \\
27.8 \\
27.0 \\
27.9\end{array}$ & $\begin{array}{l}22.7 \\
23.2 \\
22.1 \\
22.9\end{array}$ & $\begin{array}{l}27.4 \\
28.1 \\
27.1 \\
28.0\end{array}$ & $\begin{array}{l}22.7 \\
23.1 \\
22.0 \\
22.7\end{array}$ & $\begin{array}{l}27.3 \\
28.1 \\
27.2 \\
28.0\end{array}$ & $\begin{array}{l}37.6 \\
33: 1 \\
37.0 \\
33.7\end{array}$ & $\begin{array}{l}2 \varepsilon \cdot 3 \\
28.3 \\
25.8 \\
27.7\end{array}$ & $\begin{array}{l}5.8 \\
3.4 \\
2.1 \\
2.4 \\
4.0\end{array}$ & $\begin{array}{l}7.3 \\
4.3 \\
2.9 \\
3.2 \\
4.8\end{array}$ & $\begin{array}{l}8.5 \\
5.1 \\
3.4 \\
3.9 \\
5.8\end{array}$ & $\begin{array}{l}9.8 \\
5.9 \\
4 \cdot 2 \\
4 \cdot 8 \\
6.9\end{array}$ \\
\hline 31 & 24.9 & 22.2 & 25.1 & 22.1 & 25.2 & 27.1 & 25.3 & 21.9 & 26.3 & 3.7 & 4.1 & 4.6 & 5.8 \\
\hline
\end{tabular}

AUGUST

\begin{tabular}{|c|c|c|c|c|c|c|c|c|c|c|c|c|c|}
\hline $\begin{array}{l}1 \\
2 \\
3 \\
4 \\
5\end{array}$ & $\begin{array}{l}27.1 \\
28.1 \\
29.8 \\
29.5 \\
31.1\end{array}$ & $\begin{array}{l}22.7 \\
21.5 \\
21.7 \\
23.4 \\
23.5\end{array}$ & $\begin{array}{l}27.0 \\
28.3 \\
29.8 \\
29.5 \\
31.1\end{array}$ & $\begin{array}{l}22.7 \\
21.4 \\
21.6 \\
23.3 \\
23.3\end{array}$ & $\begin{array}{l}27.0 \\
28.4 \\
30.0 \\
29.5 \\
31.0\end{array}$ & $\begin{array}{l}22.7 \\
21.4 \\
21.4 \\
23.3 \\
23.2\end{array}$ & $\begin{array}{l}27.1 \\
23.6 \\
30.2 \\
29.7 \\
31.0\end{array}$ & $\begin{array}{l}? 2.5 \\
? 1.44 \\
? 1.5 \\
33.3 \\
33.4\end{array}$ & $\begin{array}{l}26.0 \\
25.0 \\
27.2 \\
28.4 \\
26.5\end{array}$ & $\begin{array}{l}1.7 \\
4.5 \\
4.2 \\
2.6 \\
7.9\end{array}$ & $\begin{array}{l}2.7 \\
5.8 \\
5.3 \\
4.0 \\
9.4\end{array}$ & $\begin{array}{r}3.2 \\
7.0 \\
6.3 \\
4.9 \\
27.9\end{array}$ & $\begin{array}{r}3.9 \\
8.4 \\
7.6 \\
5.9 \\
12.3\end{array}$ \\
\hline $\begin{array}{r}6 \\
7 \\
8 \\
9 \\
10\end{array}$ & 32.7 & 23.5 & 32.7 & 23.2 & 21.9 & 23.1 & 32.6 & $? 3.4$ & 26.7 & $\begin{array}{l}8.1 \\
8.7 \\
5.6 \\
5.0 \\
3.5\end{array}$ & $\begin{array}{r}9.5 \\
10.0 \\
6.8 \\
6.2 \\
4.5\end{array}$ & $\begin{array}{r}22.8 \\
11.6 \\
7.8 \\
7.2 \\
5.6\end{array}$ & $\begin{array}{r}12.4 \\
13.2 \\
9.1 \\
2.5 \\
6.6\end{array}$ \\
\hline $\begin{array}{l}11 \\
12 \\
13 \\
14 \\
15\end{array}$ & $\begin{array}{l}27.6 \\
30.0 \\
25.9\end{array}$ & $\begin{array}{l}20.9 \\
20.3 \\
20.4\end{array}$ & $\begin{array}{l}27.6 \\
30.0 \\
26.9\end{array}$ & $\begin{array}{l}20.8 \\
20.2 \\
20.3\end{array}$ & $\begin{array}{l}27.6 \\
30.0 \\
27.0\end{array}$ & $\begin{array}{l}20.7 \\
20.2 \\
20.2\end{array}$ & $\begin{array}{l}27.8 \\
30.0 \\
26.5\end{array}$ & & $\begin{array}{l}25.5 \\
24.7 \\
25.8\end{array}$ & $\begin{array}{l}2.5 \\
2.8 \\
5.2 \\
7.8 \\
4.7\end{array}$ & $\begin{array}{l}3.4 \\
3.5 \\
6.7 \\
9.2 \\
5.5\end{array}$ & $\begin{array}{r}4.0 \\
4.3 \\
7.9 \\
10.7 \\
6.6\end{array}$ & $\begin{array}{r}4.7 \\
5.3 \\
9.3 \\
12.3 \\
0.6\end{array}$ \\
\hline $\begin{array}{l}16 \\
17 \\
18 \\
19 \\
20\end{array}$ & $\begin{array}{l}25.1 \\
30.5 \\
26.0 \\
27.2 \\
27.6\end{array}$ & $\begin{array}{l}19.6 \\
20.7 \\
22.2 \\
20.4 \\
20.5\end{array}$ & $\begin{array}{l}24.9 \\
30.4 \\
26.1 \\
27.4 \\
27.7\end{array}$ & $\begin{array}{l}10.4 \\
20.4 \\
22.1 \\
20.2 \\
20.4\end{array}$ & $\begin{array}{l}25.0 \\
30.7 \\
26.2 \\
27.5 \\
27.8\end{array}$ & $\begin{array}{l}19.3 \\
20,3 \\
22.0 \\
20.2 \\
20.4\end{array}$ & $\begin{array}{l}25.1 \\
30.7 \\
26.2 \\
27.5 \\
27.5\end{array}$ & $\begin{array}{l}19.6 \\
20.3 \\
21.9 \\
20.4 \\
20.6\end{array}$ & $\begin{array}{l}25.5 \\
24.6 \\
25.5 \\
23.5 \\
24.1\end{array}$ & $\begin{array}{l}3.3 \\
8.5 \\
3.5 \\
4.1 \\
6.4\end{array}$ & $\begin{array}{l}4.6 \\
9.6 \\
4.2 \\
5.1 \\
7.8\end{array}$ & $\begin{array}{r}5.7 \\
11.6 \\
5.0 \\
6.0 \\
9.1\end{array}$ & $\begin{array}{r}6.8 \\
13.2 \\
5.8 \\
7.2 \\
10.6\end{array}$ \\
\hline $\begin{array}{l}21 \\
22 \\
23 \\
24 \\
25\end{array}$ & $\begin{array}{l}21.6 \\
19.7 \\
23.0 \\
26.4 \\
27.5\end{array}$ & $\begin{array}{l}19 \cdot 7 \\
17: 9 \\
21: 0 \\
21.7 \\
21 \cdot 3\end{array}$ & $\begin{array}{l}21.6 \\
19.7 \\
23.0 \\
26.4 \\
27.5\end{array}$ & $\begin{array}{l}19.6 \\
17.8 \\
20.8 \\
21.5 \\
21.1\end{array}$ & $\begin{array}{l}21.5 \\
13.7 \\
23.1 \\
26.5 \\
27.6\end{array}$ & $\begin{array}{l}19.0 \\
17.8 \\
20.9 \\
21.5 \\
21.1\end{array}$ & $\begin{array}{l}21.5 \\
19.6 \\
23.0 \\
26.2 \\
27.4\end{array}$ & $\begin{array}{l}19.5 \\
17.7 \\
20.8 \\
21.4 \\
71.0\end{array}$ & $\begin{array}{l}23.8 \\
22.5\end{array}$ & $\begin{array}{l}4.6 \\
3.8 \\
5.4 \\
8.4 \\
7.2\end{array}$ & $\begin{array}{l}0.0 \\
4.1 \\
7.2 \\
9.9 \\
3.0\end{array}$ & $\begin{array}{r}7.4 \\
5.0 \\
3.4 \\
11.3 \\
11.3\end{array}$ & $\begin{array}{r}9.6 \\
5.9 \\
9.8 \\
12.8 \\
12.9\end{array}$ \\
\hline $\begin{array}{l}26 \\
27 \\
28 \\
29 \\
30\end{array}$ & $\begin{array}{r}27.5 \\
28.9 \\
30.3 \\
30.3 \\
.29 .8\end{array}$ & $\begin{array}{l}21.0 \\
20.5 \\
20.3 \\
20.3 \\
20.3\end{array}$ & $\begin{array}{l}27.5 \\
38.9 \\
30.2 \\
30.2 \\
29.8\end{array}$ & $\begin{array}{l}20.8 \\
20.3 \\
20.2 \\
20.2 \\
20.2\end{array}$ & $\begin{array}{l}27.5 \\
28.9 \\
30.2 \\
30.3 \\
29.9\end{array}$ & $\begin{array}{l}20.8 \\
20.3 \\
20.2 \\
20.2\end{array}$ & $\begin{array}{l}27.3 \\
23.7 \\
29.9 \\
30.0 \\
29.6\end{array}$ & $\begin{array}{l}20.3 \\
=0.5 \\
20.5 \\
>0.3 \\
20.3\end{array}$ & & $\begin{array}{r}5.7 \\
3.5 \\
10.4 \\
0.2 \\
8.3\end{array}$ & $\begin{array}{r}8.0 \\
10.0 \\
12.2 \\
10.8 \\
9.9\end{array}$ & $\begin{array}{r}9.3 \\
11.5 \\
13,0 \\
12.5 \\
11.3\end{array}$ & $\begin{array}{l}16.7 \\
13.2 \\
15.7 \\
1+.3 \\
13.1\end{array}$ \\
\hline 31 & 29.4 & 20.0 & 29.5 & 10.8 & 29.6 & 19.8 & 29.5 & $=0.1$ & & 6.5 & 7.0 & $0_{n} 3$ & 10.0 \\
\hline
\end{tabular}


TABLE 11

Table 11. -Daily averages of air and water temperatures and wind speeds, July 1950-August 1951, Lake Hefner-Con. DAILY AVERAGES

1950

\begin{tabular}{|c|c|c|c|c|c|c|c|c|c|c|c|c|c|}
\hline \multirow{4}{*}{ 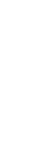 } & \multicolumn{8}{|c|}{ Average air temperature $\left({ }^{\circ} \mathrm{C}\right)$-at indicated height } & \multirow{4}{*}{$\begin{array}{c}\text { Average } \\
\text { water- } \\
\text { surface } \\
\text { temperature } \\
\left({ }^{\circ} \mathrm{C}\right)\end{array}$} & \multirow{2}{*}{\multicolumn{4}{|c|}{$\begin{array}{l}\text { Average wind speed (knots) } \\
\text { at indicated height }\end{array}$}} \\
\hline & \multirow{2}{*}{\multicolumn{2}{|c|}{$\begin{array}{c}2 \\
\text { meters } \\
\end{array}$}} & \multirow{2}{*}{\multicolumn{2}{|c|}{$\begin{array}{c}4 \\
\text { meters }\end{array}$}} & \multirow{2}{*}{\multicolumn{2}{|c|}{$\begin{array}{c}8 \\
\text { meters } \\
\end{array}$}} & \multirow{2}{*}{\multicolumn{2}{|c|}{$\begin{array}{c}16 \\
\text { meters }\end{array}$}} & & & & & \\
\hline & & & & & & & & & & \multirow[b]{2}{*}{$\begin{array}{c}2 \\
\text { meters }\end{array}$} & \multirow[b]{2}{*}{$\begin{array}{c}4 \\
\text { meters }\end{array}$} & \multirow[b]{2}{*}{$\begin{array}{c}\mathbf{8} \\
\text { meters }\end{array}$} & \multirow{2}{*}{$\begin{array}{c}16 \\
\text { meters }\end{array}$} \\
\hline & $\begin{array}{l}\text { Dry } \\
\text { bulb }\end{array}$ & $\begin{array}{l}\text { Wet } \\
\text { bulb }\end{array}$ & $\begin{array}{l}\text { Dry } \\
\text { bulb }\end{array}$ & $\begin{array}{l}\text { Wet } \\
\text { bulb }\end{array}$ & $\begin{array}{l}\text { Dry } \\
\text { bulb }\end{array}$ & $\begin{array}{l}\text { Wet } \\
\text { bulb }\end{array}$ & $\begin{array}{l}\text { Dry } \\
\text { bulb }\end{array}$ & $\begin{array}{l}\text { Wet } \\
\text { bulb }\end{array}$ & & & & & \\
\hline \multicolumn{14}{|c|}{ JULY } \\
\hline $\begin{array}{l}1 \\
2 \\
3 \\
4 \\
5\end{array}$ & $\begin{array}{l}25.5 \\
22.0 \\
23.7\end{array}$ & $\begin{array}{l}20 \cdot 3 \\
21.2\end{array}$ & $\begin{array}{l}25.4 \\
22.0 \\
23.8\end{array}$ & $\begin{array}{l}21.1 \\
20.0 \\
20.8\end{array}$ & $\begin{array}{l}25.5 \\
22.1 \\
23.9\end{array}$ & $\begin{array}{l}21.1 \\
20.1 \\
20.9\end{array}$ & $\begin{array}{l}25.3 \\
21.9 \\
23.9\end{array}$ & $\begin{array}{l}20.9 \\
19.9 \\
20.8\end{array}$ & $\begin{array}{l}25.0 \\
24.3 \\
24.6\end{array}$ & $\begin{array}{r}10.8 \\
10.6 \\
5.5 \\
3.3 \\
3.4\end{array}$ & $\begin{array}{r}12.2 \\
12.3 \\
6.6 \\
4.3 \\
4.1\end{array}$ & $\begin{array}{r}13.2 \\
13.4 \\
7.3 \\
5.0 \\
5.0\end{array}$ & $\begin{array}{r}13.8 \\
14.5 \\
8.1 \\
5.8 \\
5.5\end{array}$ \\
\hline $\begin{array}{l}6 \\
7 \\
8 \\
9\end{array}$ & $\begin{array}{l}23.0 \\
23.0\end{array}$ & $\begin{array}{l}20.3 \\
20.4\end{array}$ & $\begin{array}{l}23.0 \\
23.1\end{array}$ & $\begin{array}{l}20.1 \\
20.2\end{array}$ & $\begin{array}{l}23 \cdot 2 \\
33 \cdot 3\end{array}$ & $\begin{array}{l}20.2 \\
20.3\end{array}$ & $\begin{array}{l}23.1 \\
23.2\end{array}$ & $\begin{array}{l}20.1 \\
20.2\end{array}$ & $\begin{array}{l}24.1 \\
25.0\end{array}$ & $\begin{array}{l}2.9 \\
4.5 \\
8.4\end{array}$ & $\begin{array}{r}3.9 \\
6.0 \\
10.7\end{array}$ & $\begin{array}{r}4.7 \\
7.0 \\
12.3\end{array}$ & $\begin{array}{r}5.7 \\
8.2 \\
24.0\end{array}$ \\
\hline 10 & 22.6 & 20.2 & $2 \approx .5$ & 20.1 & $22 \cdot 6$ & 20.1 & 22.3 & 20.0 & $23 \cdot 1$ & 7.8 & 10.0 & 11.7 & 13.4 \\
\hline $\begin{array}{l}11 \\
12 \\
13 \\
14 \\
15\end{array}$ & $\begin{array}{l}22.8 \\
23.3 \\
20.4 \\
21.4 \\
25.3\end{array}$ & $\begin{array}{l}20.7 \\
20.7 \\
17.2 \\
17.7 \\
72.3\end{array}$ & $\begin{array}{l}22.7 \\
23.3 \\
20.4 \\
21.2 \\
25.3\end{array}$ & $\begin{array}{l}20.7 \\
20.5 \\
16.9 \\
17.5 \\
22.1\end{array}$ & $\begin{array}{l}22.8 \\
23.4 \\
20.4 \\
21.4 \\
25.4\end{array}$ & $\begin{array}{l}20.6 \\
20.4 \\
16.8 \\
17.6 \\
22.1\end{array}$ & $\begin{array}{l}22.6 \\
23.2 \\
20.4 \\
21.2 \\
25 . ?\end{array}$ & $\begin{array}{l}20.6 \\
20.2 \\
16.7 \\
17.6 \\
11.0\end{array}$ & $\begin{array}{l}23.4 \\
24 \cdot 0 \\
23.1 \\
24.8 \\
24.7\end{array}$ & $\begin{array}{r}4.8 \\
4.4 \\
5.9 \\
3.3 \\
12.1\end{array}$ & $\begin{array}{r}6.3 \\
5.6 \\
7.5 \\
4.4 \\
14.5\end{array}$ & $\begin{array}{r}7.2 \\
6.5 \\
9.0 \\
5.2 \\
16.0\end{array}$ & $\begin{array}{r}8.4 \\
7.2 \\
10.5 \\
6.1 \\
17.4\end{array}$ \\
\hline $\begin{array}{l}16 \\
17 \\
18\end{array}$ & $\begin{array}{l}26.3 \\
21.7\end{array}$ & $\begin{array}{l}22 \cdot 2 \\
2 c \cdot 3\end{array}$ & $\begin{array}{l}26.4 \\
21.6\end{array}$ & $\begin{array}{l}22.1 \\
20.1\end{array}$ & $\begin{array}{l}26.6 \\
21.7\end{array}$ & $\begin{array}{l}22.2 \\
20.2\end{array}$ & $\begin{array}{l}26.4 \\
21.5\end{array}$ & $\begin{array}{l}21.9 \\
20.0\end{array}$ & $\begin{array}{l}23.3 \\
22.4\end{array}$ & $\begin{array}{r}16.7 \\
7.3\end{array}$ & $\begin{array}{r}20.1 \\
9.6 \\
9.1\end{array}$ & $\begin{array}{l}22.1 \\
10.8 \\
10.5\end{array}$ & $\begin{array}{l}2401 \\
12: 0 \\
12: 7\end{array}$ \\
\hline $\begin{array}{l}19 \\
20\end{array}$ & 22.5 & 20.8 & 22.4 & $20 \cdot 6$ & 22.6 & 20.7 & 22.5 & 20.5 & $22 \cdot 9$ & $\begin{array}{l}8.3 \\
4 \cdot 7\end{array}$ & 9.9 & $\begin{array}{r}10.9 \\
6.2\end{array}$ & $11 \cdot \varepsilon$ \\
\hline $\begin{array}{l}21 \\
22 \\
23 \\
24 \\
25\end{array}$ & & & & & & & & & & $\begin{array}{l}4.7 \\
3.4 \\
2.0 \\
3.8 \\
6.2\end{array}$ & 7.0 & $\begin{array}{l}5.7 \\
5.1 \\
2.8 \\
4.5 \\
7.4\end{array}$ & $\begin{array}{l}7: 9 \\
5: 6 \\
3: 6 \\
5.0 \\
7.8\end{array}$ \\
\hline $\begin{array}{l}26 \\
27 \\
28 \\
29 \\
30\end{array}$ & $\begin{array}{l}22.9 \\
22.3 \\
23.3 \\
23.9\end{array}$ & $\begin{array}{l}20.2 \\
21.1 \\
21.8 \\
22.2\end{array}$ & $\begin{array}{l}22.9 \\
22.2 \\
23.2 \\
24.0\end{array}$ & $\begin{array}{l}19.0 \\
20.8 \\
21.7 \\
22.1\end{array}$ & $\begin{array}{l}23 \cdot 2 \\
22 \cdot 3 \\
23 \cdot 2 \\
24 \cdot 2\end{array}$ & $\begin{array}{l}20.0 \\
20.8 \\
21.6 \\
22.1\end{array}$ & $\begin{array}{l}23.0 \\
22.1 \\
23.2 \\
24.2\end{array}$ & $\begin{array}{l}20.0 \\
20.7 \\
21.6 \\
22.0\end{array}$ & $\begin{array}{l}25 \cdot 3 \\
24 \cdot ?\end{array}$ & $\begin{array}{l}3.4 \\
3.4 \\
5.3 \\
7.0 \\
0.4\end{array}$ & $\begin{array}{r}4.2 \\
4.1 \\
6.3 \\
3.8 \\
10.8\end{array}$ & $\begin{array}{r}5.0 \\
4.8 \\
7.0 \\
10.0 \\
12.0\end{array}$ & $\begin{array}{r}5.8 \\
5.6 \\
8.1 \\
11 \% 6 \\
13.4\end{array}$ \\
\hline 31 & & & & & & & & & & 8.9 & 10.1 & 11.3 & 12.6 \\
\hline
\end{tabular}

AUGUST

\begin{tabular}{|c|c|c|c|c|c|c|c|c|c|c|c|c|c|}
\hline $\begin{array}{l}1 \\
2 \\
3 \\
4 \\
5\end{array}$ & 25.0 & 23.0 & 25.0 & 23.0 & $24 \cdot 6$ & 22.0 & 24.6 & 22.6 & 25.4 & $\begin{array}{l}3.9 \\
2.8 \\
6.7 \\
9.5 \\
6.0\end{array}$ & $\begin{array}{r}4.9 \\
3.6 \\
7.9 \\
11.4 \\
7.5\end{array}$ & $\begin{array}{r}5.9 \\
8.9 \\
12.6 \\
8.7\end{array}$ & $\begin{array}{r}7.1 \\
5.3 \\
10.4 \\
14.5 \\
10.2\end{array}$ \\
\hline $\begin{array}{r}6 \\
7 \\
8 \\
9 \\
10\end{array}$ & $\begin{array}{l}24.5 \\
25.7 \\
26.0 \\
24.1 \\
25.2\end{array}$ & $\begin{array}{l}22.6 \\
22.5 \\
22.1 \\
20.3 \\
21.6\end{array}$ & $\begin{array}{l}24.5 \\
25.9 \\
26.3 \\
24 \cdot 3 \\
25.3\end{array}$ & $\begin{array}{l}22.6 \\
22.3 \\
22.0 \\
20.1 \\
21.4\end{array}$ & $\begin{array}{l}24 \cdot ? \\
26 \cdot 0 \\
26 \cdot 2 \\
24 \cdot 2 \\
25 \cdot 3\end{array}$ & $\begin{array}{l}22 \cdot 3 \\
21: 3 \\
21: 7 \\
10: 9 \\
21: 2\end{array}$ & $\begin{array}{l}24.2 \\
26.1 \\
26.5 \\
24.4 \\
25.6\end{array}$ & $\begin{array}{l}22.3 \\
21.9 \\
21.9 \\
20.1 \\
21.4\end{array}$ & $\begin{array}{l}25.4 \\
26 . ? \\
25.9 \\
27.0 \\
27.9\end{array}$ & $\begin{array}{l}6.4 \\
3.9 \\
3.8 \\
3.2 \\
3.6\end{array}$ & $\begin{array}{r}8.2 \\
10.3 \\
4.7 \\
4.3 \\
4.6\end{array}$ & $\begin{array}{r}9.5 \\
11.5 \\
5.8 \\
5.2\end{array}$ & $\begin{array}{r}11.1 \\
12.9 \\
6.9 \\
6.5 \\
7.1\end{array}$ \\
\hline $\begin{array}{l}11 \\
12 \\
13 \\
14 \\
15\end{array}$ & $\begin{array}{l}27.4 \\
27.3 \\
27.3 \\
26.6 \\
26.4\end{array}$ & $\begin{array}{l}23.4 \\
22.6 \\
22.5 \\
22.4 \\
22.6\end{array}$ & $\begin{array}{l}27.3 \\
27.5 \\
27.5 \\
20.7 \\
25.5\end{array}$ & $\begin{array}{l}23.2 \\
22.1 \\
22.1 \\
22.2 \\
22.2\end{array}$ & $\begin{array}{l}27.1 \\
27.4 \\
27.3 \\
26.5 \\
26.4\end{array}$ & $\begin{array}{l}27.8 \\
21: 6 \\
21: 7 \\
21.8 \\
21.7\end{array}$ & $\begin{array}{l}27.1 \\
27.5 \\
27.3 \\
26.4 \\
26.5\end{array}$ & $\begin{array}{l}22.8 \\
21: 6 \\
21.6 \\
21.7 \\
21.6\end{array}$ & $\begin{array}{l}27.2 \\
27.2 \\
27.9 \\
28.6 \\
29.5\end{array}$ & $\begin{array}{r}7.4 \\
10.6 \\
8.8 \\
5.7 \\
9.3\end{array}$ & $\begin{array}{r}9.1 \\
11.9 \\
9.9 \\
6.5 \\
10.7\end{array}$ & $\begin{array}{r}10.3 \\
13.0 \\
10.7 \\
7.2 \\
11.7\end{array}$ & $\begin{array}{r}11.8 \\
14.3 \\
11.5 \\
7.8 \\
12.6\end{array}$ \\
\hline $\begin{array}{l}16 \\
17 \\
18 \\
19 \\
20\end{array}$ & $\begin{array}{l}23.68 \\
22.3 \\
21 \cdot 7 \\
22: 1 \\
14.5\end{array}$ & $\begin{array}{l}21: 6 \\
20: 3 \\
17: 8 \\
17: 0 \\
12.1\end{array}$ & $\begin{array}{l}23.8 \\
22.2 \\
21.0 \\
22.2 \\
14.4\end{array}$ & $\begin{array}{l}21.4 \\
20.1 \\
17.7 \\
16.9 \\
12.0\end{array}$ & $\begin{array}{l}23 \cdot 6 \\
21: 9 \\
21: 7 \\
22: 3 \\
14 \cdot 0\end{array}$ & $\begin{array}{l}21.2 \\
19.7 \\
17.3 \\
15.7 \\
11.6\end{array}$ & $\begin{array}{l}23.6 \\
21.9 \\
21.8 \\
22.6 \\
13.9\end{array}$ & $\begin{array}{l}11.2 \\
19.7 \\
17.3 \\
16.3 \\
11.6\end{array}$ & $\begin{array}{l}27.0 \\
26.3 \\
25.8 \\
26.4 \\
24.9\end{array}$ & $\begin{array}{l}4.9 \\
6.2 \\
5.4 \\
2.9 \\
5.3\end{array}$ & $\begin{array}{l}5.7 \\
7.7 \\
6.8 \\
3.5 \\
6.7\end{array}$ & $\begin{array}{l}6.2 \\
8.8 \\
8.3 \\
4.1 \\
8.0\end{array}$ & $\begin{array}{l}6.8 \\
9.5 \\
9.1 \\
5.1 \\
8.9\end{array}$ \\
\hline $\begin{array}{l}21 \\
22 \\
23 \\
24 \\
25\end{array}$ & $\begin{array}{l}18.9 \\
22.9 \\
21.8 \\
25.4 \\
26.6\end{array}$ & $\begin{array}{l}16.4 \\
20.1 \\
19.8 \\
22.4 \\
22.8\end{array}$ & $\begin{array}{l}18.9 \\
22.9 \\
21.8 \\
25.5 \\
26.9\end{array}$ & $\begin{array}{l}16.3 \\
19.8 \\
19.6 \\
22.4 \\
22.5\end{array}$ & $\begin{array}{l}18.8 \\
22.8 \\
21.6 \\
25.4 \\
26.9\end{array}$ & $\begin{array}{l}16.1 \\
16.6 \\
19.3 \\
22: 1 \\
22.0\end{array}$ & $\begin{array}{l}12.8 \\
22.9 \\
21.0 \\
25.0 \\
27.1\end{array}$ & $\begin{array}{l}16.2 \\
19.7 \\
19.4 \\
22.2 \\
22.1\end{array}$ & $\begin{array}{r}25.9 \\
26.2 \\
25.3 \\
25.6 \\
26.0\end{array}$ & $\begin{array}{l}2.7 \\
4.5 \\
5.7 \\
8.5 \\
8.5\end{array}$ & $\begin{array}{r}3.2 \\
5.5 \\
6.8 \\
10.0 \\
9.6\end{array}$ & $\begin{array}{r}3.6 \\
6.2 \\
7.6 \\
11.1 \\
10.8\end{array}$ & $\begin{array}{r}4.2 \\
7.0 \\
8.5 \\
12.7 \\
11.7\end{array}$ \\
\hline $\begin{array}{l}26 \\
27 \\
28 \\
29 \\
30\end{array}$ & $\begin{array}{l}25 \cdot 7 \\
23 \cdot 0 \\
24 \cdot 5 \\
22 \cdot 8 \\
20 \cdot 3\end{array}$ & $\begin{array}{l}22.0 \\
20.2 \\
21.5 \\
20.2 \\
17.6\end{array}$ & $\begin{array}{l}26.0 \\
23.0 \\
24.5 \\
22.3 \\
20.2\end{array}$ & $\begin{array}{l}21.8 \\
20.1 \\
21.3 \\
19.9 \\
17.5\end{array}$ & $\begin{array}{l}26.0 \\
22.8 \\
24.3 \\
22.6 \\
19.8\end{array}$ & $\begin{array}{l}21.5 \\
19.9 \\
21.0 \\
13.6 \\
17.0\end{array}$ & $\begin{array}{l}26.2 \\
22.9 \\
24.3 \\
22.6 \\
19.8\end{array}$ & $\begin{array}{l}21.6 \\
20.0 \\
21.2 \\
19.7 \\
17.0\end{array}$ & $\begin{array}{l}26.3 \\
26.3 \\
26.3 \\
25.8 \\
24.7\end{array}$ & $\begin{array}{l}3.0 \\
2.7 \\
4.1\end{array}$ & $\begin{array}{l}9.2 \\
3.4 \\
5.0 \\
4.5 \\
8.3\end{array}$ & $\begin{array}{r}10.5 \\
3.8 \\
5.6 \\
5.2 \\
10.0\end{array}$ & $\begin{array}{r}11.4 \\
4.6 \\
6.5 \\
5.7 \\
11.0\end{array}$ \\
\hline 31 & 18.9 & 16.3 & 18.9 & 16.3 & 18.7 & 16.0 & 18.8 & 15.9 & 23.9 & & 8.5 & 10.1 & 11.5 \\
\hline
\end{tabular}


Table 11. - Daily averages of air and water temperatures and wind speeds, July 1950—August 1951, Lake Hefner-Con. STATION 3 OAILY AVERAGES

\begin{tabular}{|c|c|c|c|c|c|c|c|c|c|c|c|c|c|}
\hline \multirow{4}{*}{ ตัّ } & \multicolumn{8}{|c|}{ Average air temperature $\left({ }^{\circ} \mathrm{C}\right)$ at indicated height } & \multirow{4}{*}{ 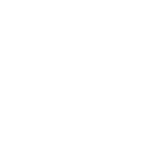 } & \multirow{2}{*}{\multicolumn{4}{|c|}{$\begin{array}{l}\text { Average wind speed (knots) } \\
\text { at indicated height }\end{array}$}} \\
\hline & \multirow{2}{*}{\multicolumn{2}{|c|}{$\stackrel{2}{2}$}} & \multirow{2}{*}{\multicolumn{2}{|c|}{$\stackrel{4}{4}$}} & \multirow{2}{*}{\multicolumn{2}{|c|}{$\begin{array}{c}8 \\
\text { meters }\end{array}$}} & \multirow{2}{*}{\multicolumn{2}{|c|}{$\begin{array}{c}16 \\
\text { meters }\end{array}$}} & & & & & \\
\hline & & & & & & & & & & \multirow{2}{*}{$\begin{array}{c}2 \\
\text { meters }\end{array}$} & \multirow[b]{2}{*}{$\begin{array}{c}4 \\
\text { meters }\end{array}$} & \multirow[b]{2}{*}{$\begin{array}{c}8 \\
\text { meters }\end{array}$} & \multirow[b]{2}{*}{$\begin{array}{c}16 \\
\text { meters }\end{array}$} \\
\hline & $\begin{array}{l}\text { Dry } \\
\text { hulb }\end{array}$ & $\begin{array}{l}\text { Wet } \\
\text { bulb }\end{array}$ & $\begin{array}{l}\text { Dry } \\
\text { bulb }\end{array}$ & $\begin{array}{l}\text { Wet } \\
\text { bulb }\end{array}$ & $\begin{array}{l}\text { Dry } \\
\text { bulb }\end{array}$ & $\begin{array}{l}\text { Wet } \\
\text { bulb }\end{array}$ & $\begin{array}{l}\text { Dry } \\
\text { bulb }\end{array}$ & $\begin{array}{l}\text { Wet } \\
\text { bulb }\end{array}$ & & & & & \\
\hline \multicolumn{14}{|c|}{ SEPTEQMBER } \\
\hline $\begin{array}{l}1 \\
2 \\
3 \\
4 \\
5\end{array}$ & $\begin{array}{l}21.6 \\
22.4 \\
21.4 \\
22.2 \\
18.8\end{array}$ & $\begin{array}{l}17.1 \\
18.5 \\
19.9 \\
20.8 \\
16.6\end{array}$ & $\begin{array}{l}21.5 \\
22.4 \\
21.3 \\
22.1 \\
18.7\end{array}$ & $\begin{array}{l}17.1 \\
18.6 \\
19.9 \\
20.7 \\
16.5\end{array}$ & $\begin{array}{l}21.4 \\
22.2 \\
21.1 \\
21.9 \\
18.5\end{array}$ & $\begin{array}{l}16.8 \\
18.2 \\
19.7 \\
20.6 \\
16.2\end{array}$ & $\begin{array}{l}21.4 \\
22.1 \\
21.2\end{array}$ & $\begin{array}{l}16.8 \\
18.3 \\
19.8\end{array}$ & $\begin{array}{l}24 \cdot 2 \\
24 \cdot 1 \\
23 \cdot 3\end{array}$ & $\begin{array}{l}5.9 \\
6.0 \\
4.7 \\
3.0 \\
4.5\end{array}$ & $\begin{array}{l}7.6 \\
7.5 \\
5.8 \\
3.7 \\
5.5\end{array}$ & $\begin{array}{l}9.5 \\
9.5 \\
7.1 \\
4.8 \\
6.6\end{array}$ & $\begin{array}{r}10.7 \\
10.8 \\
9.4 \\
5.7 \\
8.2\end{array}$ \\
\hline $\begin{array}{r}6 \\
7 \\
8 \\
9 \\
10\end{array}$ & $\begin{array}{l}16.7 \\
18.4 \\
19.1 \\
20.3 \\
22.4\end{array}$ & $\begin{array}{l}13.5 \\
14.2 \\
14.7 \\
15.7 \\
18.2\end{array}$ & $\begin{array}{l}16.7 \\
18.8 \\
19.2 \\
20.3 \\
22.4\end{array}$ & $\begin{array}{l}13.4 \\
14.1 \\
14.6 \\
15.6 \\
18.1\end{array}$ & $\begin{array}{l}16.5 \\
18.9 \\
19.2 \\
20.3 \\
22.6\end{array}$ & $\begin{array}{l}13.1 \\
14.1 \\
14.6 \\
15.5 \\
18.0\end{array}$ & $\begin{array}{l}16.8 \\
19.3 \\
19.4 \\
20.3 \\
22.7\end{array}$ & $\begin{array}{l}13.1 \\
14.3 \\
14.4 \\
15.3 \\
18.0\end{array}$ & $\begin{array}{l}23.6 \\
23.5 \\
22.1 \\
22.2 \\
22.9\end{array}$ & $\begin{array}{l}3.4 \\
2.2 \\
3.5 \\
2.9 \\
3.7\end{array}$ & $\begin{array}{l}4.3 \\
2.7 \\
4.4 \\
3.6 \\
4.4\end{array}$ & $\begin{array}{l}5.3 \\
3.4 \\
5.6 \\
4.5 \\
5.1\end{array}$ & $\begin{array}{l}6.6 \\
3.7 \\
6.4 \\
5.0 \\
5.6\end{array}$ \\
\hline 11 & 17.6 & 14.6 & 17.4 & 14.5 & $17 \cdot 3$ & $14 \cdot 3$ & 17.2 & 14.1 & 21.5 & $\begin{array}{l}5.2 \\
3.8\end{array}$ & $\begin{array}{l}8.0 \\
4.7\end{array}$ & $\begin{array}{l}9.8 \\
5.7\end{array}$ & $\begin{array}{r}10.7 \\
6.5\end{array}$ \\
\hline $\begin{array}{l}13 \\
14 \\
15\end{array}$ & $\begin{array}{l}18.2 \\
17.8 \\
21.4\end{array}$ & $\begin{array}{l}17.3 \\
17.0 \\
20.3\end{array}$ & $\begin{array}{l}18.1 \\
17.8 \\
21.7\end{array}$ & $\begin{array}{l}17.2 \\
17.0 \\
20.2\end{array}$ & $\begin{array}{l}10.1 \\
17.8 \\
21.9\end{array}$ & $\begin{array}{l}17.1 \\
16.9 \\
20.2\end{array}$ & $\begin{array}{l}18.0 \\
17.7 \\
21.9\end{array}$ & $\begin{array}{l}17.0 \\
16.8 \\
20.2\end{array}$ & $21 \cdot 2$ & $\begin{array}{l}4.4 \\
4.8 \\
5.5\end{array}$ & $\begin{array}{l}5.5 \\
6.1 \\
6.8\end{array}$ & $\begin{array}{l}6.6 \\
7.2\end{array}$ & $\begin{array}{l}7.7 \\
8.4 \\
9.4\end{array}$ \\
\hline $\begin{array}{l}16 \\
17 \\
18 \\
19 \\
20\end{array}$ & $\begin{array}{l}20.5 \\
21.8 \\
23.1 \\
22.6 \\
24.0\end{array}$ & $\begin{array}{l}19.2 \\
19.5 \\
20.5 \\
21.1 \\
21.5\end{array}$ & $\begin{array}{l}20.6 \\
22.0 \\
23.2 \\
22.6 \\
24.3\end{array}$ & $\begin{array}{l}19.1 \\
19.4 \\
20.3 \\
20.9 \\
21.4\end{array}$ & $\begin{array}{l}20.5 \\
22.0 \\
23.3 \\
22.6 \\
24.5\end{array}$ & $\begin{array}{l}19.1 \\
19.3 \\
20.2 \\
20.8 \\
21.3\end{array}$ & $\begin{array}{l}20.5 \\
22.1 \\
23.3 \\
22.5 \\
24.6\end{array}$ & $\begin{array}{l}19.0 \\
19.2 \\
20.2 \\
20.7 \\
21.2\end{array}$ & $\begin{array}{l}20.6 \\
21.5 \\
22.8 \\
22.2\end{array}$ & $\begin{array}{r}6.4 \\
4.4 \\
7.2 \\
8.2 \\
11 . ?\end{array}$ & $\begin{array}{r}8.2 \\
5.2 \\
8.2 \\
9.3 \\
12.4\end{array}$ & $\begin{array}{r}10.0 \\
6.0 \\
9.2 \\
10.1 \\
13.7\end{array}$ & $\begin{array}{r}11.7 \\
7: 0 \\
10.3 \\
11.2 \\
14.8\end{array}$ \\
\hline $\begin{array}{l}21 \\
22 \\
23 \\
24 \\
25\end{array}$ & $\begin{array}{l}21.7 \\
18.1 \\
21.0 \\
19.1\end{array}$ & $\begin{array}{l}17.1 \\
14.7 \\
15.4 \\
14.6\end{array}$ & $\begin{array}{l}21.7 \\
18.1 \\
21.1 \\
19.2\end{array}$ & $\begin{array}{l}16.8 \\
14.5 \\
15.3 \\
14.6\end{array}$ & $\begin{array}{l}21.4 \\
18.0 \\
21.2 \\
19.3\end{array}$ & $\begin{array}{l}16.4 \\
14.3 \\
15.1 \\
14.7\end{array}$ & $\begin{array}{l}21.4 \\
17.9 \\
21.4 \\
19.7\end{array}$ & $\begin{array}{l}16.3 \\
14.2 \\
15.2 \\
14.7\end{array}$ & $\begin{array}{l}22.3 \\
21.6 \\
22.1 \\
22.1\end{array}$ & $\begin{array}{l}7.0 \\
4.6 \\
3.5 \\
3.1 \\
5.5\end{array}$ & $\begin{array}{l}8.9 \\
4.1 \\
4.1 \\
6.8\end{array}$ & $\begin{array}{r}10.9 \\
7.1 \\
4.9 \\
5.2 \\
7.9\end{array}$ & $\begin{array}{l}5.2 \\
6.6 \\
9.3\end{array}$ \\
\hline $\begin{array}{l}26 \\
27 \\
28 \\
29 \\
30\end{array}$ & $\begin{array}{l}21.4 \\
22.5\end{array}$ & $\begin{array}{l}19.1 \\
20.0\end{array}$ & $\begin{array}{l}21.5 \\
22.6\end{array}$ & $\begin{array}{l}19.1 \\
20.0\end{array}$ & $\begin{array}{l}21: 5 \\
22: 7\end{array}$ & $\begin{array}{l}19.0 \\
20.0\end{array}$ & $\begin{array}{l}21.4 \\
22.7\end{array}$ & $\begin{array}{l}18.9 \\
20.0\end{array}$ & 19.8 & $\begin{array}{r}8.7 \\
13.1 \\
13.7 \\
12.3 \\
12.8\end{array}$ & $\begin{array}{l}10.4 \\
14.9 \\
15.4 \\
14.1 \\
24.7\end{array}$ & $\begin{array}{l}11.4 \\
16.2 \\
16.9 \\
15.5 \\
16.1\end{array}$ & $\begin{array}{l}12.9 \\
19.1 \\
19.0 \\
17.4 \\
18.1\end{array}$ \\
\hline
\end{tabular}

OCTOPER

\begin{tabular}{|c|c|c|c|c|c|c|c|c|c|c|c|c|c|}
\hline $\begin{array}{l}1 \\
2 \\
3 \\
4 \\
5\end{array}$ & $\begin{array}{l}21.8 \\
17.6 \\
12.4 \\
11.7 \\
16.5\end{array}$ & $\begin{array}{r}19.3 \\
16.8 \\
10.9 \\
8.4 \\
13.4\end{array}$ & $\begin{array}{l}21.9 \\
17.7 \\
12.3 \\
11.6 \\
16.5\end{array}$ & $\begin{array}{r}19.2 \\
16.7 \\
10.7 \\
8.2 \\
13.2\end{array}$ & $\begin{array}{l}21.9 \\
17.9 \\
12.2 \\
11.6 \\
16.4\end{array}$ & $\begin{array}{r}10.2 \\
16.7 \\
10.6 \\
8.0 \\
13.0\end{array}$ & $\begin{array}{l}? 1.8 \\
17.6 \\
12.0 \\
11.4 \\
16.4\end{array}$ & $\begin{array}{r}19.1 \\
16.4 \\
10.3 \\
7.8 \\
12.8\end{array}$ & $\begin{array}{l}10.2 \\
16.1 \\
17.6 \\
18.6 \\
17.7\end{array}$ & $\begin{array}{r}14.4 \\
11.3 \\
5.7 \\
4.8 \\
11.5\end{array}$ & $\begin{array}{r}16.3 \\
13.0 \\
7.1 \\
5.0 \\
12.7\end{array}$ & $\begin{array}{r}17.7 \\
14.6 \\
8.4 \\
7.2 \\
13.8\end{array}$ & $\begin{array}{r}19.9 \\
15.5 \\
9.4 \\
8.4 \\
15.1\end{array}$ \\
\hline $\begin{array}{r}6 \\
7 \\
8 \\
9 \\
10\end{array}$ & $\begin{array}{l}20.2 \\
19.1 \\
15.5 \\
15.9 \\
17.9\end{array}$ & $\begin{array}{r}16.8 \\
14.2 \\
9.6 \\
11.9 \\
13.7\end{array}$ & $\begin{array}{l}20.4 \\
19.1 \\
15.6 \\
16.1 \\
18.1\end{array}$ & $\begin{array}{r}16.7 \\
14.0 \\
9.5 \\
11.8 \\
13.5\end{array}$ & $\begin{array}{l}20.4 \\
19.2 \\
15.7 \\
16.3 \\
18.4\end{array}$ & $\begin{array}{r}16.5 \\
13.5 \\
9.3 \\
11.5 \\
13.2\end{array}$ & $\begin{array}{l}20.5 \\
19.2 \\
15.9 \\
16.3 \\
18.5\end{array}$ & $\begin{array}{r}16.5 \\
13.5 \\
9.3 \\
11.3 \\
13.1\end{array}$ & $\begin{array}{l}16.4 \\
16.8 \\
18.7 \\
18.9 \\
18.0\end{array}$ & $\begin{array}{r}18.5 \\
8.3 \\
5.5 \\
7.6 \\
8.5\end{array}$ & $\begin{array}{r}20.0 \\
10.3 \\
7.1 \\
8.4 \\
9.4\end{array}$ & 22.0 & $\begin{array}{r}24.0 \\
12.8 \\
9.8 \\
10.4 \\
11.5\end{array}$ \\
\hline $\begin{array}{l}11 \\
12 \\
13 \\
14 \\
15\end{array}$ & $\begin{array}{l}20.6 \\
19.4 \\
20.7 \\
22.0 \\
21.5\end{array}$ & $\begin{array}{l}15.1 \\
13.2 \\
15.4 \\
16.7 \\
16.2\end{array}$ & $\begin{array}{l}20.9 \\
19.5 \\
21.0 \\
22.5 \\
21.8\end{array}$ & $\begin{array}{l}15.0 \\
13.2 \\
15.3 \\
16.6 \\
16.1\end{array}$ & $\begin{array}{l}21.3 \\
19.8 \\
21.2 \\
22.9 \\
22.1\end{array}$ & $\begin{array}{l}15.0 \\
12.9 \\
15.1 \\
16.4 \\
15.9\end{array}$ & $\begin{array}{l}21.4 \\
20.0 \\
21.4 \\
23.3 \\
22.2\end{array}$ & $\begin{array}{l}15.1 \\
12.8 \\
15.0 \\
16.2 \\
15.7\end{array}$ & $\begin{array}{l}19.3 \\
18.9 \\
19.2 \\
19.3 \\
19.2\end{array}$ & $\begin{array}{l}11.4 \\
11.5\end{array}$ & $\begin{array}{r}2.6 \\
4.8 \\
13.1 \\
12.6 \\
12.7\end{array}$ & $\begin{array}{r}2.9 \\
5.5 \\
14.4 \\
14.3 \\
14.1\end{array}$ & $\begin{array}{r}3.9 \\
6.7 \\
25.9 \\
15.5 \\
15.6\end{array}$ \\
\hline $\begin{array}{l}16 \\
17 \\
18\end{array}$ & 20.9 & 15.3 & 21.1 & 15.2 & 21.3 & 15.1 & 21.4 & 14.8 & 18.7 & $\begin{array}{r}12.2 \\
7.5 \\
4.5\end{array}$ & $\begin{array}{r}13.3 \\
8.4 \\
5.1\end{array}$ & $\begin{array}{r}14.8 \\
9.7 \\
5.6\end{array}$ & $\begin{array}{r}16.5 \\
11.1 \\
6.6\end{array}$ \\
\hline $\begin{array}{l}19 \\
20\end{array}$ & $\begin{array}{l}19.3 \\
17.3\end{array}$ & $\begin{array}{l}15.3 \\
13.2\end{array}$ & $\begin{array}{l}19.4 \\
17.4\end{array}$ & $\begin{array}{l}15.1 \\
13.1\end{array}$ & $\begin{array}{l}19.5 \\
17.4\end{array}$ & $\begin{array}{l}14.9 \\
13.0\end{array}$ & $\begin{array}{l}19.6 \\
17.6\end{array}$ & $\begin{array}{l}14.8 \\
12.8\end{array}$ & $\begin{array}{l}19.0 \\
18.3\end{array}$ & $\begin{array}{l}2.8 \\
2.7\end{array}$ & $\begin{array}{l}3.5 \\
3.6\end{array}$ & $\begin{array}{l}4.3 \\
4.5\end{array}$ & $\begin{array}{l}4.8 \\
5.3\end{array}$ \\
\hline $\begin{array}{l}21 \\
22 \\
23 \\
24 \\
25\end{array}$ & $\begin{array}{l}16.4 \\
14.5 \\
12.0 \\
18.4 \\
15.7\end{array}$ & $\begin{array}{r}10.6 \\
9.9 \\
9.5 \\
13.7 \\
13.0\end{array}$ & $\begin{array}{l}16.5 \\
14.3 \\
11.8 \\
18.7 \\
15.9\end{array}$ & $\begin{array}{r}10.5 \\
9.8 \\
9.4 \\
13.5 \\
12.0\end{array}$ & $\begin{array}{l}16.5 \\
14.2 \\
11.0 \\
19.0 \\
16.0\end{array}$ & $\begin{array}{r}10.3 \\
9.6 \\
0.2 \\
13.3 \\
12.8\end{array}$ & $\begin{array}{l}16.8 \\
14.2 \\
11.8 \\
19.2 \\
16.1\end{array}$ & $\begin{array}{r}10.2 \\
9.4 \\
9.1 \\
13.2 \\
12.8\end{array}$ & $\begin{array}{l}18.2 \\
17.6 \\
17.7 \\
17.8 \\
17.8\end{array}$ & $\begin{array}{l}2.8 \\
6.6 \\
4.6 \\
9.6\end{array}$ & $\begin{array}{r}3.8 \\
8.1 \\
5.5 \\
10.7\end{array}$ & $\begin{array}{r}4.9 \\
10.0 \\
6.2 \\
12.2 \\
6.6\end{array}$ & $\begin{array}{r}5.4 \\
10.7 \\
5.8 \\
13.1 \\
7.4\end{array}$ \\
\hline $\begin{array}{l}26 \\
27 \\
28 \\
29 \\
30\end{array}$ & $\begin{array}{l}22.2 \\
20.1 \\
20.6 \\
20.1 \\
20.9\end{array}$ & $\begin{array}{l}14.5 \\
13.6 \\
14.9 \\
15.3 \\
16.2\end{array}$ & $\begin{array}{l}22.7 \\
20.4 \\
20.8 \\
20.6 \\
21.2\end{array}$ & $\begin{array}{l}14.6 \\
13.3 \\
14.9 \\
15.3 \\
16.2\end{array}$ & $\begin{array}{l}23.1 \\
20.7 \\
21.0 \\
21.1 \\
21.6\end{array}$ & $\begin{array}{l}14.2 \\
12.8 \\
14: 5 \\
15.0 \\
16.0\end{array}$ & $\begin{array}{l}23.4 \\
21.0 \\
21.3 \\
21.6 \\
21.8\end{array}$ & $\begin{array}{l}13.9 \\
12.5 \\
14.4 \\
14.9 \\
15.9\end{array}$ & $\begin{array}{l}17.7 \\
18.3 \\
17.5 \\
17.9 \\
18.0\end{array}$ & $\begin{array}{r}15.6 \\
8.7 \\
6.1 \\
9.6 \\
12.8\end{array}$ & $\begin{array}{r}17.0 \\
9.7 \\
7.1 \\
10.9 \\
13.9\end{array}$ & $\begin{array}{r}19.1 \\
11.0 \\
8.2 \\
12.1 \\
15.7\end{array}$ & $\begin{array}{l}13.6 \\
16.9\end{array}$ \\
\hline 31 & 21.5 & 16.9 & 21.6 & 16.9 & 22.0 & 16.7 & $22 . ?$ & 16.7 & 18.0 & 15.4 & 16.7 & 18.7 & 20.1 \\
\hline
\end{tabular}


TABLE 11

Table 11.-Daily averages of air and water temperatures and wind speeds, July 1950-August 1951, Lake Hefner-Con.

\begin{tabular}{|c|c|c|c|c|c|c|c|c|c|c|c|c|c|}
\hline \multicolumn{2}{|c|}{ STATION 3} & \multicolumn{7}{|c|}{ DAILY AVERAGES } & \multirow{4}{*}{$\begin{array}{c}\text { Average } \\
\text { water- } \\
\text { surface } \\
\text { temperature }\end{array}$} & \multirow{3}{*}{\multicolumn{4}{|c|}{$\begin{array}{c}1950 \\
\begin{array}{c}\text { Average wind speed (knots) } \\
\text { at indicated height }\end{array}\end{array}$}} \\
\hline \multirow{4}{*}{ 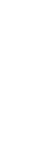 } & \multicolumn{8}{|c|}{ Average air temperature $\left({ }^{\circ} \mathrm{C}\right)$ at indicated height } & & & & & \\
\hline & \multirow{2}{*}{\multicolumn{2}{|c|}{$\begin{array}{c}2 \\
\text { meters } \\
\end{array}$}} & \multirow{2}{*}{\multicolumn{2}{|c|}{$\begin{array}{c}4 \\
\text { meters } \\
\end{array}$}} & \multirow{2}{*}{\multicolumn{2}{|c|}{$\begin{array}{c}8 \\
\text { meters }\end{array}$}} & \multirow{2}{*}{\multicolumn{2}{|c|}{$\begin{array}{c}16 \\
\text { meters }\end{array}$}} & & & & & \\
\hline & & & & & & & & & & \multirow{2}{*}{$\begin{array}{c}2 \\
\text { meters }\end{array}$} & \multirow[b]{2}{*}{$\begin{array}{c}4 \\
\text { meters }\end{array}$} & \multirow[b]{2}{*}{$\begin{array}{c}8 \\
\text { meters }\end{array}$} & \multirow[b]{2}{*}{$\begin{array}{c}16 \\
\text { meters }\end{array}$} \\
\hline & $\begin{array}{l}\text { Dry } \\
\text { bulb }\end{array}$ & $\begin{array}{l}\text { Wet } \\
\text { bulb }\end{array}$ & $\begin{array}{l}\text { Dry } \\
\text { bulb }\end{array}$ & $\begin{array}{l}\text { Wet } \\
\text { bulb }\end{array}$ & $\begin{array}{l}\text { Dry } \\
\text { bulb }\end{array}$ & $\begin{array}{l}\text { Wet } \\
\text { bulb }\end{array}$ & $\begin{array}{l}\text { Dry } \\
\text { bulb }\end{array}$ & $\begin{array}{l}\text { Wet } \\
\text { bulb }\end{array}$ & $\left({ }^{\circ} \mathrm{C}\right)$ & & & & \\
\hline \multicolumn{14}{|c|}{ NOVEMPER } \\
\hline $\begin{array}{l}1 \\
2 \\
3 \\
4 \\
5\end{array}$ & $\begin{array}{r}15.0 \\
9.5 \\
3.3 \\
4.8 \\
12.8\end{array}$ & $\begin{array}{r}11.4 \\
5.3 \\
2.7 \\
2.0 \\
7.5\end{array}$ & $\begin{array}{r}15.8 \\
9.5 \\
3.2 \\
4.6 \\
12.9\end{array}$ & $\begin{array}{r}11 \cdot 3 \\
6: 3 \\
2.6 \\
7.2\end{array}$ & $\begin{array}{r}10.7 \\
9.4 \\
3.0 \\
4.6 \\
12.9\end{array}$ & $\begin{array}{r}10.9 \\
6.2 \\
2.2 \\
2.7\end{array}$ & $\begin{array}{r}16.5 \\
9.4 \\
2.9 \\
4.4 \\
13.0\end{array}$ & $\begin{array}{r}10.7 \\
6.0 \\
1.9 \\
1.4 \\
5.7\end{array}$ & $\begin{array}{l}17: 1 \\
15: 9 \\
12: 6 \\
14: 0 \\
13 \cdot 3\end{array}$ & $\begin{array}{r}12.2 \\
4.4 \\
14.7 \\
5.6 \\
14.9\end{array}$ & $\begin{array}{r}13.9 \\
5.4 \\
17.3 \\
7.4 \\
16.1\end{array}$ & $\begin{array}{r}16.0 \\
6.6 \\
19.8 \\
7.8 \\
17.5\end{array}$ & $\begin{array}{r}17: 0 \\
6: 6 \\
20.9 \\
3: 9 \\
18.6\end{array}$ \\
\hline $\begin{array}{r}6 \\
7 \\
9 \\
9 \\
10\end{array}$ & $\begin{array}{r}13.3 \\
11.4 \\
9.9 \\
0.9 \\
-1.8\end{array}$ & $\begin{array}{l}7.0 \\
8.0 \\
7.4\end{array}$ & $\begin{array}{r}13.4 \\
11.5 \\
9.0 \\
0.6 \\
-2.0\end{array}$ & $\begin{array}{l}7.6 \\
2: 8 \\
7.2\end{array}$ & $\begin{array}{r}13.5 \\
11.7 \\
9.3 \\
0.4 \\
-2.3\end{array}$ & & $\begin{array}{r}13.7 \\
11.0 \\
9.9 \\
0.2 \\
-2.5\end{array}$ & $\begin{array}{l}7.4 \\
2.2 \\
6.8\end{array}$ & $\begin{array}{r}14.1 \\
13.8 \\
13.5 \\
11.5 \\
9.9\end{array}$ & $\begin{array}{r}14.2 \\
3.2\end{array}$ & $\begin{array}{r}6.1 \\
2.8 \\
12.9 \\
16.4 \\
0.5\end{array}$ & $\begin{array}{r}6.7 \\
3.2 \\
14.2 \\
18.9 \\
10.8\end{array}$ & $\begin{array}{r}7.3 \\
16.5 \\
19.7 \\
11.4\end{array}$ \\
\hline $\begin{array}{l}11 \\
12 \\
13 \\
14 \\
15\end{array}$ & $\begin{array}{r}2.5 \\
6.0 \\
8.4 \\
15.1 \\
17.4\end{array}$ & $\begin{array}{r}1.2 \\
4.7 \\
12.8 \\
13.2\end{array}$ & $\begin{array}{r}2.3 \\
6.0 \\
8.6 \\
15.3 \\
18.0\end{array}$ & $\begin{array}{r}1.2 \\
5.0 \\
13.4 \\
13.5\end{array}$ & $\begin{array}{r}2.2 \\
5.9 \\
8.7 \\
15.6 \\
17.6\end{array}$ & $\begin{array}{l}13.2 \\
13.6\end{array}$ & $\begin{array}{r}2.0 \\
5.9 \\
8.9 \\
15.0 \\
10.0\end{array}$ & $\begin{array}{r}0.7 \\
4.7 \\
13.3 \\
13.7\end{array}$ & $\begin{array}{r}3.9 \\
3.5 \\
8.9 \\
10.9 \\
11.7\end{array}$ & $\begin{array}{r}12.0 \\
11.6 \\
0.2 \\
17.0 \\
12.0\end{array}$ & $\begin{array}{l}13.8 \\
12.9 \\
10.4 \\
18.5 \\
14.7\end{array}$ & $\begin{array}{l}14.6 \\
14.0 \\
11.7 \\
20.8 \\
17.0\end{array}$ & $\begin{array}{l}15.6 \\
15.8 \\
13.7 \\
23.3 \\
18.8\end{array}$ \\
\hline $\begin{array}{l}16 \\
17 \\
18 \\
19 \\
20\end{array}$ & $2 \cdot 2$ & & 2.0 & - & 1.8 & & 1.8 & & $8 \cdot 9$ & $\begin{array}{r}4.9 \\
8.9 \\
13.8 \\
14 . ? \\
7.9\end{array}$ & $\begin{array}{r}6.0 \\
9.7 \\
15.1 \\
16.2 \\
9.1\end{array}$ & $\begin{array}{r}7.2 \\
10.7 \\
16.7 \\
18.8 \\
10.5\end{array}$ & $\begin{array}{r}7.0 \\
11.9 \\
18.7 \\
20.0 \\
11.0\end{array}$ \\
\hline $\begin{array}{l}21 \\
22 \\
23 \\
2.4 \\
25\end{array}$ & $\begin{array}{r}7.9 \\
11.0\end{array}$ & $\begin{array}{l}3.7 \\
5.7\end{array}$ & $\begin{array}{r}8.1 \\
11.2 \\
4.9\end{array}$ & $\begin{array}{l}3.6 \\
6.7\end{array}$ & $\begin{array}{r}8.5 \\
11.5 \\
5.0\end{array}$ & $\begin{array}{l}3.4 \\
6.5\end{array}$ & $\begin{array}{r}9.5 \\
12.1 \\
5.1\end{array}$ & $\begin{array}{l}3.1 \\
6.4\end{array}$ & $\begin{array}{l}8.8 \\
0.8\end{array}$ & $\begin{array}{r}3.9 \\
12.7 \\
6.5 \\
8.2\end{array}$ & $\begin{array}{r}11.2 \\
4.8 \\
14.7 \\
8.0 \\
9.2\end{array}$ & $\begin{array}{r}12.4 \\
6.1 \\
17.1 \\
9.3 \\
10.4\end{array}$ & $\begin{array}{r}13.4 \\
6.8 \\
17.5 \\
9.6 \\
11.0\end{array}$ \\
\hline $\begin{array}{l}26 \\
27 \\
28 \\
29 \\
30\end{array}$ & $\begin{array}{l}3.4 \\
6.6 \\
5.2 \\
5.2 \\
7.6\end{array}$ & $\begin{array}{l}0.7 \\
2.0 \\
1.3 \\
1.5 \\
4.8\end{array}$ & $\begin{array}{l}3.3 \\
5.9 \\
5 . ? \\
5.6 \\
7.8\end{array}$ & $\begin{array}{l}0.7 \\
2.7 \\
1.4 \\
1.07 \\
5.0\end{array}$ & $\begin{array}{l}3.2 \\
7.5 \\
6.6 \\
6.1 \\
8.3\end{array}$ & $\begin{array}{l}0.5 \\
3: 0 \\
1.6 \\
1.0 \\
5.1\end{array}$ & $\begin{array}{r}3.3 \\
8.2 \\
7.1 \\
-6.4 \\
5.7\end{array}$ & $\begin{array}{l}0.2 \\
3.0 \\
1.6 \\
1.9 \\
E .4\end{array}$ & $\begin{array}{l}5 \cdot 7 \\
7: 7 \\
7.2 \\
7 \cdot 1 \\
7 \cdot 2\end{array}$ & $\begin{array}{l}4.5 \\
2.0 \\
3.5 \\
3.4 \\
3.7\end{array}$ & $\begin{array}{l}5.4 \\
2.7 \\
4.4 \\
4.2 \\
4.5\end{array}$ & $\begin{array}{l}5.5 \\
3.3 \\
5.6 \\
5.1 \\
5.5\end{array}$ & $\begin{array}{l}7.0 \\
7.3 \\
6.0 \\
7.1\end{array}$ \\
\hline
\end{tabular}

DECFMDER

\begin{tabular}{|c|c|c|c|c|c|c|c|c|c|c|c|c|c|}
\hline $\begin{array}{r}1 \\
2 \\
3 \\
4 \\
5 \\
5 \\
7 \\
8 \\
9 \\
10\end{array}$ & $\begin{array}{r}11.8 \\
7.7 \\
1.5 \\
6.0 \\
-5.6 \\
-6.8\end{array}$ & $\begin{array}{l}7.8 \\
3.8\end{array}$ & $\begin{array}{r}12.5 \\
7.7 \\
1.5 \\
5.9 \\
-5.7 \\
-7.0\end{array}$ & $\begin{array}{l}7.8 \\
3.7\end{array}$ & $\begin{array}{r}13.3 \\
7.7 \\
1.5 \\
5.9 \\
-5.0 \\
-7.1 \\
3.8\end{array}$ & $\begin{array}{l}7.7 \\
3.5\end{array}$ & $\begin{array}{r}13.0 \\
7.0 \\
1.3 \\
6.8 \\
-6.2 \\
-7.4 \\
4.0\end{array}$ & $\begin{array}{l}3.0 \\
3.3\end{array}$ & $\begin{array}{r}7.9 \\
7.8 \\
6.8 \\
6.8 \\
4.7 \\
3.0 \\
\\
3.4\end{array}$ & $\begin{array}{r}11.8 \\
10.4 \\
6.1 \\
12.2 \\
19.2 \\
9.3 \\
7.5 \\
5.1 \\
5.1 \\
4.7\end{array}$ & $\begin{array}{r}13.0 \\
12.1 \\
6.9 \\
13.5 \\
27.3 \\
11.0 \\
8.3 \\
6.7 \\
6.3 \\
5.8\end{array}$ & $\begin{array}{r}15.0 \\
14.3 \\
7.7 \\
15.2 \\
25.2 \\
12.4 \\
7.4 \\
8.0 \\
7.4\end{array}$ & $\begin{array}{r}16.5 \\
15.4 \\
3.5 \\
17.5 \\
26.8 \\
13.0 \\
9.3 \\
7.9 \\
9.1 \\
8.6\end{array}$ \\
\hline $\begin{array}{l}11 \\
12 \\
13 \\
14 \\
15\end{array}$ & $\begin{array}{l}7.6 \\
0.6 \\
0.6 \\
4.7 \\
3.0\end{array}$ & $\begin{array}{r}4.2 \\
-1.3 \\
3.1 \\
0.6\end{array}$ & $\begin{array}{l}7.8 \\
0.6 \\
0.7 \\
5.2 \\
3.1\end{array}$ & $\begin{array}{r}3.7 \\
-1.5 \\
3.2 \\
0.3\end{array}$ & $\begin{array}{l}8.2 \\
0.8 \\
0.9 \\
5.7 \\
3.1\end{array}$ & $\begin{array}{r}3.8 \\
-1.5 \\
3.4 \\
0.2\end{array}$ & $\begin{array}{l}8.7 \\
1.4 \\
1.3 \\
6.3 \\
3.4\end{array}$ & $\begin{array}{r}4.3 \\
-0.9 \\
4.0 \\
0.5\end{array}$ & $\begin{array}{l}3.8 \\
\\
4.5 \\
4.4\end{array}$ & $\begin{array}{l}7.3 \\
2.3 \\
2.7 \\
2.3 \\
3.4\end{array}$ & $\begin{array}{l}9.6 \\
3.0 \\
3.3 \\
2.7 \\
4.3\end{array}$ & $\begin{array}{r}10.4 \\
3.8 \\
4.0 \\
3.1 \\
5.2\end{array}$ & $\begin{array}{r}11.5 \\
5.2 \\
4.0 \\
6.0\end{array}$ \\
\hline $\begin{array}{l}16 \\
17 \\
18 \\
19 \\
20\end{array}$ & $\begin{array}{l}2.8 \\
1.7 \\
0.8 \\
3.6 \\
2.0\end{array}$ & $\begin{array}{r}0.8 \\
-0.2 \\
1.2\end{array}$ & $\begin{array}{l}3.0 \\
1.5 \\
0.7 \\
3.5 \\
1.8\end{array}$ & $\begin{array}{r}-0.6 \\
0.0\end{array}$ & $\begin{array}{l}3.3 \\
1.4 \\
0.7 \\
3.6 \\
1.7\end{array}$ & $\begin{array}{r}0.5 \\
-0.7 \\
-0.5 \\
-0.5\end{array}$ & $\begin{array}{l}3.5 \\
1.5 \\
0.7 \\
3.8 \\
1.7\end{array}$ & $\begin{array}{r}0.8 \\
-0.7 \\
-0.3\end{array}$ & $\begin{array}{l}4.1 \\
3.7 \\
3.9 \\
3.4 \\
3.7\end{array}$ & $\begin{array}{l}3.4 \\
4.1 \\
4.1 \\
5.3 \\
3.5\end{array}$ & $\begin{array}{l}4.0 \\
5.1 \\
4.6 \\
5.0 \\
4.3\end{array}$ & $\begin{array}{l}4.8 \\
6.2 \\
5.2 \\
6.7 \\
5.0\end{array}$ & $\begin{array}{l}5.5 \\
6.0 \\
7.9 \\
5.7\end{array}$ \\
\hline $\begin{array}{l}21 \\
22 \\
23 \\
24 \\
25\end{array}$ & $\begin{array}{l}5.2 \\
5.9\end{array}$ & $\begin{array}{l}3.1 \\
4.4\end{array}$ & $\begin{array}{l}5.5 \\
6.3\end{array}$ & $\begin{array}{l}3.1 \\
4.6\end{array}$ & $\begin{array}{l}5.7 \\
6.7\end{array}$ & $\begin{array}{l}3.1 \\
4.7\end{array}$ & $\begin{array}{l}5.8 \\
7.1\end{array}$ & 5.0 & $\begin{array}{l}4.9 \\
5.0\end{array}$ & $\begin{array}{r}3.7 \\
7.9 \\
10.0 \\
3.1 \\
12.5\end{array}$ & $\begin{array}{r}4.2 \\
8.7 \\
11.0 \\
3.8 \\
13.8\end{array}$ & $\begin{array}{r}5.1 \\
10.1 \\
12.7 \\
4.6 \\
16.1\end{array}$ & $\begin{array}{r}5.6 \\
11.1 \\
14.1 \\
5.9 \\
27.7\end{array}$ \\
\hline $\begin{array}{l}26 \\
27 \\
28 \\
29 \\
30\end{array}$ & $\begin{array}{r}-0.3 \\
-0.0 \\
-0.5 \\
1.06 \\
3.2\end{array}$ & $\begin{array}{r}-0.5 \\
1.7\end{array}$ & $\begin{array}{r}-0.5 \\
-5.2 \\
-0.3 \\
1.5 \\
3.2\end{array}$ & $\begin{array}{r}-0.6 \\
1.7\end{array}$ & $\begin{array}{r}-0.6 \\
=-5.2 \\
-0.2 \\
1.5 \\
3.3\end{array}$ & $\begin{array}{r}-0.6 \\
1.6\end{array}$ & $\begin{array}{r}-0.7 \\
=-5.1 \\
-0.0 \\
1.5 \\
3.5\end{array}$ & $\begin{array}{r}-0.4 \\
1.7\end{array}$ & $\begin{array}{l}4.4 \\
3.2 \\
2.8 \\
2.4 \\
3.3\end{array}$ & $\begin{array}{r}12.5 \\
4.3 \\
6.2 \\
3.2 \\
5.6\end{array}$ & $\begin{array}{r}15.3 \\
5.4 \\
6.8 \\
3.8 \\
6.3\end{array}$ & $\begin{array}{r}18.0 \\
6.4 \\
7.4 \\
4.1 \\
7.1\end{array}$ & $\begin{array}{l}8.2 \\
4.7 \\
7.9\end{array}$ \\
\hline 31 & 6.7 & 2.7 & 6.8 & 2.8 & 7.0 & 2.8 & 7.2 & 3.2 & 3.6 & 19.8 & 21.3 & 23.5 & 25.9 \\
\hline
\end{tabular}


Table 11. -Daily averages of air and water temperatures and wind speeds, Juty 1950-August 1951, Lake Hefner-Con.

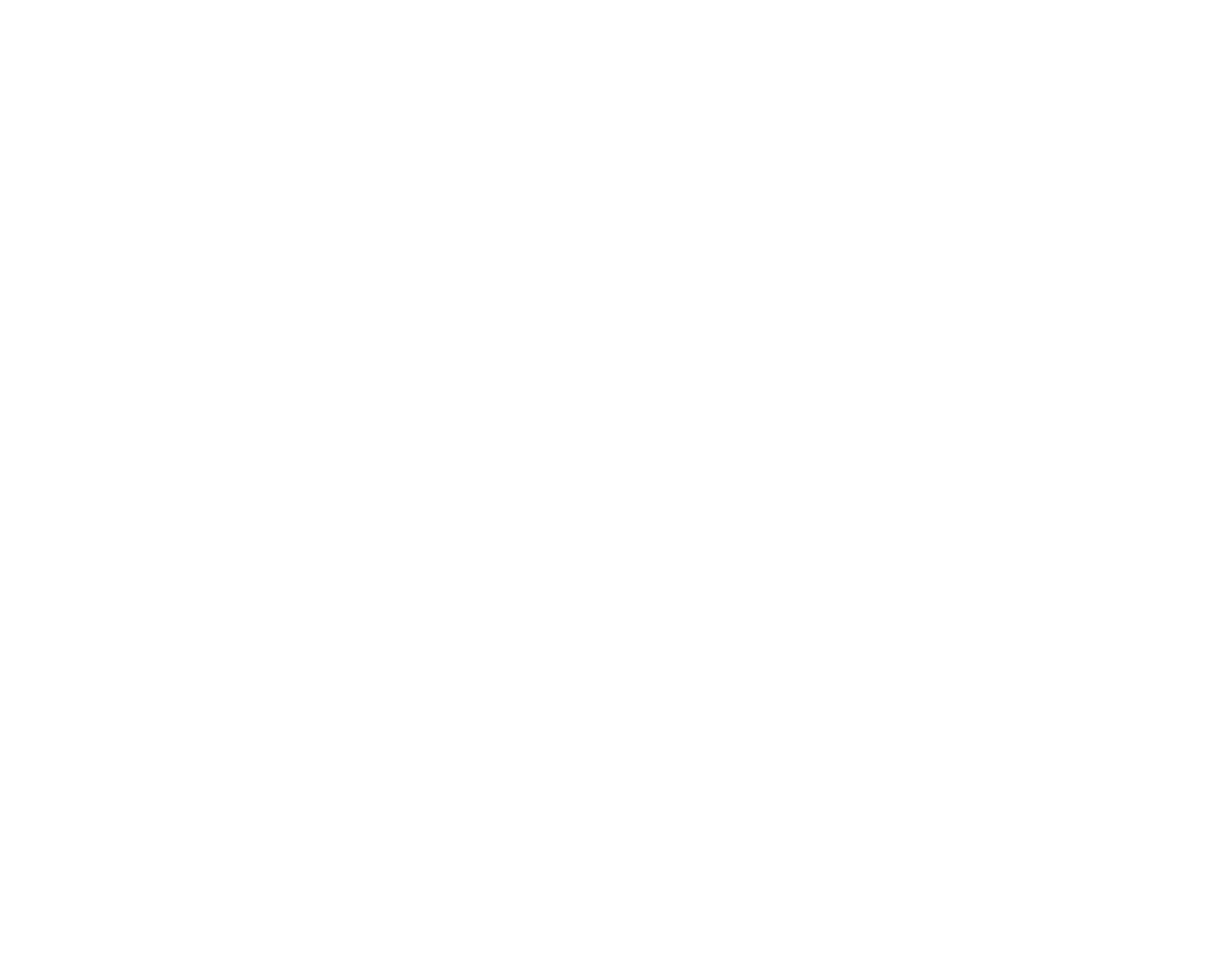

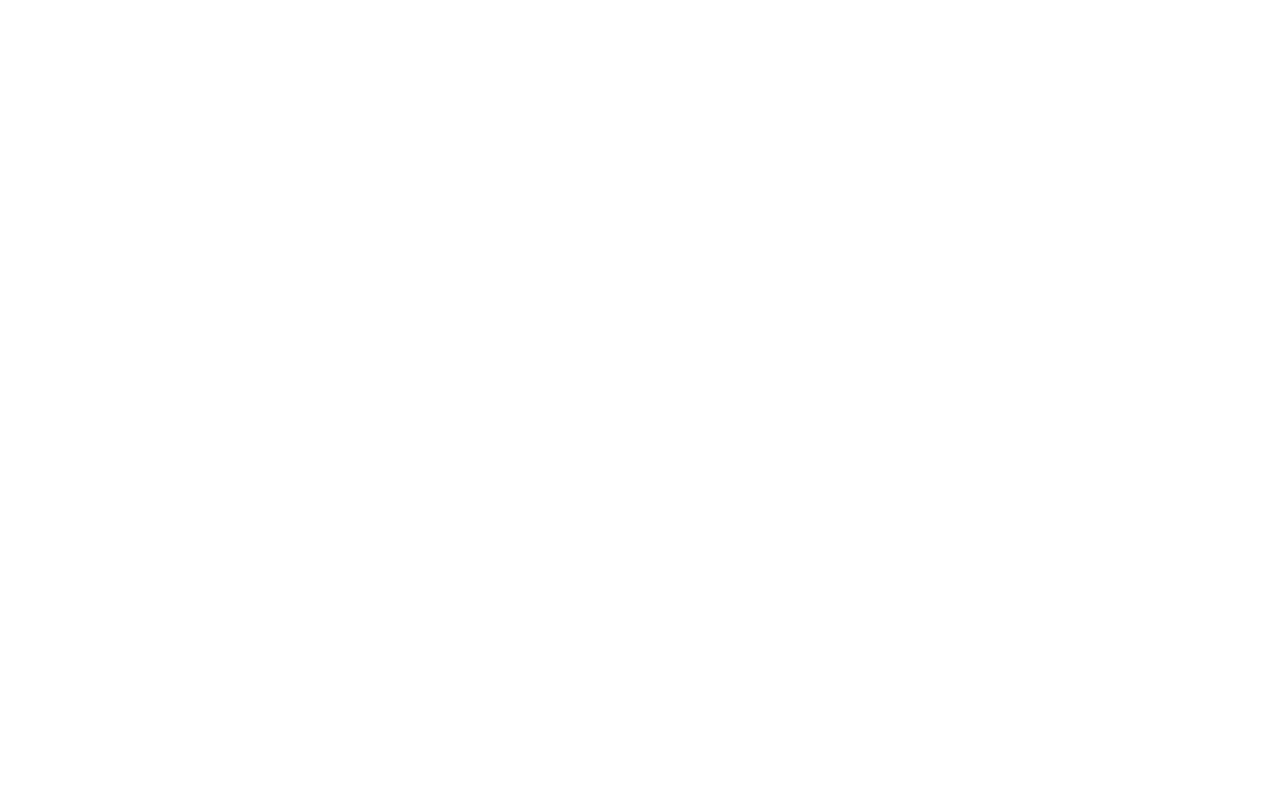


TABLE 11

241

Table 11.-Daily averages of air and water temperatures and wind speeds, July 1950-August 1951, Lake Hefner-Con. STATION 3

DAILY AVERAGE

1951

\begin{tabular}{|c|c|c|c|c|c|c|c|c|c|c|c|c|c|}
\hline \multirow{4}{*}{ ڤึّ } & \multicolumn{8}{|c|}{ Average air temperature $\left({ }^{\circ} \mathrm{C}\right)$ at indicated height } & \multirow{4}{*}{$\begin{array}{c}\text { Average } \\
\text { water- } \\
\text { surface } \\
\text { temperature } \\
\text { ('C) }\end{array}$} & \multirow{2}{*}{\multicolumn{4}{|c|}{$\begin{array}{l}\text { Average wind apeed (knots) } \\
\text { at indicated height }\end{array}$}} \\
\hline & \multirow{2}{*}{\multicolumn{2}{|c|}{$\stackrel{2}{\text { meters }}$}} & \multirow{2}{*}{\multicolumn{2}{|c|}{ meters }} & \multirow{2}{*}{\multicolumn{2}{|c|}{$\begin{array}{c}8 \\
\text { meters }\end{array}$}} & \multirow{2}{*}{\multicolumn{2}{|c|}{$\begin{array}{c}16 \\
\text { meters }\end{array}$}} & & & & & \\
\hline & & & & & & & & & & \multirow{2}{*}{$\begin{array}{c}2 \\
\text { meters }\end{array}$} & \multirow{2}{*}{$\begin{array}{c}4 \\
\text { meters }\end{array}$} & \multirow{2}{*}{$\begin{array}{c}8 \\
\text { meters }\end{array}$} & \multirow{2}{*}{$\begin{array}{c}18 \\
\text { meters }\end{array}$} \\
\hline & $\begin{array}{l}\text { Dry } \\
\text { bulb }\end{array}$ & $\begin{array}{l}\text { Wet } \\
\text { bulh }\end{array}$ & $\begin{array}{l}\text { Dry } \\
\text { bulb }\end{array}$ & $\begin{array}{l}\text { Wet } \\
\text { bulb }\end{array}$ & $\begin{array}{l}\text { Dry } \\
\text { bulb }\end{array}$ & $\begin{array}{l}\text { Wet } \\
\text { bulb }\end{array}$ & $\begin{array}{l}\text { Dry } \\
\text { bulb }\end{array}$ & $\begin{array}{l}\text { Wet } \\
\text { bulb }\end{array}$ & & & & & \\
\hline \multicolumn{14}{|c|}{ MARCH } \\
\hline $\begin{array}{l}1 \\
2 \\
3 \\
4 \\
5\end{array}$ & $\begin{array}{r}9.1 \\
15.9 \\
7.2 \\
6.1 \\
12.6\end{array}$ & $\begin{array}{r}4.9 \\
12.2 \\
2.9 \\
2.8 \\
6.0\end{array}$ & $\begin{array}{r}7.2 \\
6.1 \\
13.1\end{array}$ & $\begin{array}{l}4.9 \\
2.8 \\
2.4 \\
6.0\end{array}$ & $\begin{array}{r}9.4 \\
17.4 \\
7.0 \\
6.2 \\
13.6\end{array}$ & $\begin{array}{r}5.0 \\
22.9 \\
2.4 \\
2.3 \\
5.9\end{array}$ & $\begin{array}{r}9.0 \\
18.0 \\
7.0 \\
0.4 \\
14.0\end{array}$ & $\begin{array}{r}5.1 \\
13.3 \\
2.5 \\
2.3 \\
6.0\end{array}$ & $\begin{array}{l}0.1 \\
7.8 \\
7.1 \\
7.9 \\
7.6\end{array}$ & $\begin{array}{r}0.7 \\
8.8 \\
5.9 \\
16.5\end{array}$ & $\begin{array}{r}7.8 \\
16.5 \\
10.0 \\
6.8 \\
17.9\end{array}$ & $\begin{array}{r}9.1 \\
18.9 \\
11.7 \\
7.8 \\
20.2\end{array}$ & $\begin{array}{r}21.2 \\
2100 \\
12.6 \\
8.9 \\
21.9\end{array}$ \\
\hline 6 & 12.6 & 8.7 & 13.1 & 8.8 & 13.5 & 9.0 & 13.9 & 9.1 & $7 \cdot 9$ & $\begin{array}{r}10.3 \\
5.4\end{array}$ & $\begin{array}{r}11.7 \\
6.4\end{array}$ & $\begin{array}{r}13.7 \\
7.4\end{array}$ & $\begin{array}{r}15.4 \\
8.4\end{array}$ \\
\hline $\begin{array}{r}8 \\
9 \\
10\end{array}$ & $\begin{array}{r}3.6 \\
-0.5 \\
6.5\end{array}$ & $\begin{array}{l}0.9 \\
0.0\end{array}$ & $\begin{array}{r}3.5 \\
-0.5\end{array}$ & 0.9 & $\begin{array}{r}3.4 \\
-0.7 \\
0.7\end{array}$ & $\begin{array}{l}0.6 \\
6.1\end{array}$ & $\begin{array}{r}3.3 \\
-0.8 \\
6.8\end{array}$ & $\begin{array}{l}0.6 \\
0.0\end{array}$ & $\begin{array}{l}6.9 \\
5.5\end{array}$ & $\begin{array}{l}9.1 \\
6.3 \\
7.1\end{array}$ & $\begin{array}{r}10.8 \\
7.5 \\
8.6\end{array}$ & $\begin{array}{r}12.8 \\
8.5 \\
9.5\end{array}$ & $\begin{array}{r}8.8 \\
10.3\end{array}$ \\
\hline $\begin{array}{l}11 \\
12 \\
13 \\
14 \\
15\end{array}$ & $\begin{array}{l}1.9 \\
3.3\end{array}$ & 0.8 & -0.2 & 0.8 & $\begin{array}{l}1.8 \\
3.5\end{array}$ & 0.7 & $\begin{array}{l}1.8 \\
3.6\end{array}$ & 0.8 & $\begin{array}{l}4.6 \\
4.6\end{array}$ & $\begin{array}{r}18.1 \\
17.5 \\
12.1 \\
5.2 \\
3.3\end{array}$ & $\begin{array}{r}20.8 \\
20.1 \\
14.3 \\
0.2 \\
4.0\end{array}$ & $\begin{array}{r}23.1 \\
22.3 \\
16.7 \\
7.7 \\
4.8\end{array}$ & $\begin{array}{r}24.2 \\
23.5 \\
17.4 \\
8.5 \\
5.5\end{array}$ \\
\hline $\begin{array}{l}16 \\
17 \\
18 \\
19 \\
20\end{array}$ & $\begin{array}{l}9.6 \\
1.1 \\
3.9\end{array}$ & 6.0 & $\begin{array}{r}10.0 \\
1.1 \\
3.9\end{array}$ & 5.8 & $\begin{array}{r}10.8 \\
1.0 \\
4.1\end{array}$ & 0.6 & $\begin{array}{r}11.4 \\
1.0 \\
4.2\end{array}$ & 6.5 & $\begin{array}{l}5.9 \\
4.9 \\
5.9\end{array}$ & $\begin{array}{r}10.9 \\
13.3 \\
11.9 \\
5.0 \\
12.3\end{array}$ & $\begin{array}{r}12.3 \\
15.7 \\
13.5 \\
5.8 \\
13.7\end{array}$ & $\begin{array}{r}14.4 \\
18.5 \\
15.6 \\
6.6 \\
15.5\end{array}$ & $\begin{array}{l}16.7 \\
19.7 \\
16.2 \\
16.3\end{array}$ \\
\hline $\begin{array}{l}21 \\
22 \\
23 \\
24 \\
25\end{array}$ & $\begin{array}{r}4.3 \\
14.6 \\
12.2 \\
7.5 \\
11.8\end{array}$ & $\begin{array}{l}7.8 \\
5.6 \\
3.2 \\
5.7\end{array}$ & $\begin{array}{r}4.7 \\
15.4 \\
12.1 \\
7.8 \\
12.3\end{array}$ & $\begin{array}{l}7.7 \\
5.3 \\
2.9 \\
5.5\end{array}$ & $\begin{array}{r}4.9 \\
16.5 \\
12.4 \\
8.1 \\
13.3\end{array}$ & 3.1 & $\begin{array}{r}5.1 \\
17.4 \\
12.6 \\
8.4 \\
13.6\end{array}$ & 8.6 & $\begin{array}{l}7.0 \\
6.7 \\
7.0 \\
7.8 \\
8.2\end{array}$ & $\begin{array}{r}4.5 \\
13.7 \\
13.2 \\
4.6 \\
7.5\end{array}$ & $\begin{array}{r}5.5 \\
15.2 \\
15.5 \\
5.2 \\
8.5\end{array}$ & $\begin{array}{r}0.5 \\
17.8 \\
18.1 \\
6.2 \\
10.1\end{array}$ & $\begin{array}{r}7.6 \\
19.7 \\
19.4 \\
7.1 \\
11.0\end{array}$ \\
\hline $\begin{array}{l}26 \\
27 \\
28 \\
29 \\
30\end{array}$ & 9.4 & 4.3 & & & 10.0 & & 10.2 & 4.0 & 6.5 & $\begin{array}{r}13.3 \\
17.6 \\
15.4 \\
13.4 \\
9.0\end{array}$ & $\begin{array}{r}14.4 \\
19.0 \\
17.7 \\
16.0 \\
8.9\end{array}$ & $\begin{array}{l}26.1 \\
20.9 \\
21.0 \\
19.4 \\
10.1\end{array}$ & $\begin{array}{l}18.1 \\
23.1 \\
22.4 \\
20.8\end{array}$ \\
\hline 31 & 13.8 & 8.1 & $13.0^{\circ}$ & 7.9 & 14.0 & & 14.0 & 7.9 & 7.2 & 9.0 & 10.1 & 11.6 & \\
\hline
\end{tabular}

\begin{tabular}{|c|c|c|c|c|c|c|c|c|c|c|c|c|c|}
\hline \multicolumn{14}{|c|}{ APRIL } \\
\hline $\begin{array}{l}1 \\
2 \\
3 \\
4 \\
5\end{array}$ & $\begin{array}{r}6.5 \\
6.4 \\
10.6 \\
16.1 \\
14.4\end{array}$ & $\begin{array}{r}3.7 \\
3.5 \\
5.8 \\
9.1 \\
12.5\end{array}$ & $\begin{array}{r}6.5 \\
6.2 \\
10.5 \\
16.1 \\
14.1\end{array}$ & $\begin{array}{l}3.5 \\
3.3 \\
5.6 \\
9.0\end{array}$ & $\begin{array}{r}6.4 \\
6.1 \\
10.9 \\
16.8 \\
14.6\end{array}$ & $\begin{array}{r}5.5 \\
9.3 \\
12.6\end{array}$ & $\begin{array}{r}6 \cdot 3 \\
6.1 \\
11 \cdot 2 \\
17.2 \\
14.6\end{array}$ & $\begin{array}{r}3.4 \\
3.2 \\
5.8 \\
9.4 \\
12.5\end{array}$ & $\begin{array}{l}6.2 \\
6.6 \\
8.6\end{array}$ & $\begin{array}{r}0.6 \\
8.1 \\
4.4 \\
11.0 \\
13.0\end{array}$ & $\begin{array}{r}11.5 \\
9.6 \\
4.6 \\
12.9 \\
14.6\end{array}$ & $\begin{array}{r}13.3 \\
11.2 \\
5.4 \\
14.5 \\
16.2\end{array}$ & $\begin{array}{r}13.6 \\
11.6 \\
6.0 \\
16.3 \\
18.5\end{array}$ \\
\hline $\begin{array}{r}6 \\
7 \\
8 \\
.9 \\
10\end{array}$ & $\begin{array}{r}12.1 \\
9.4 \\
9.2 \\
11.0 \\
8.0\end{array}$ & $\begin{array}{r}10.0 \\
5.7 \\
3.9\end{array}$ & $\begin{array}{r}11.6 \\
9.0 \\
8.9 \\
10.7 \\
8.1\end{array}$ & $\begin{array}{l}5.5 \\
3.5 \\
4.0 \\
5.4\end{array}$ & $\begin{array}{r}11.8 \\
9.1 \\
8.9 \\
10.8 \\
8.1\end{array}$ & $\begin{array}{l}0.8 \\
5.3 \\
3.3 \\
3.9 \\
5.4\end{array}$ & $\begin{array}{r}11.8 \\
9.0 \\
8.9 \\
10.9 \\
7.9\end{array}$ & $\begin{array}{l}9.7 \\
5.1 \\
3.1 \\
3.9 \\
5.3\end{array}$ & $\begin{array}{l}7.5 \\
8.1 \\
7.5\end{array}$ & $\begin{array}{r}5.8 \\
10.4 \\
8.9 \\
7.0 \\
11.9\end{array}$ & $\begin{array}{r}10.6 \\
12.3 \\
10.5 \\
8.2 \\
13.8\end{array}$ & $\begin{array}{r}13.3 \\
15.5 \\
12.5 \\
9.8 \\
15.9\end{array}$ & $\begin{array}{l}14.0 \\
15.9 \\
14.5 \\
11.1 \\
16.9\end{array}$ \\
\hline $\begin{array}{l}12 \\
12 \\
13 \\
14 \\
15\end{array}$ & $\begin{array}{r}5.7 \\
9.6 \\
15.4 \\
8.4\end{array}$ & $\begin{array}{l}2.1 \\
4 \cdot 0 \\
8 \cdot 2 \\
3.1\end{array}$ & $\begin{array}{r}5.4 \\
9.5 \\
15.5 \\
8.1\end{array}$ & $\begin{array}{l}2.0 \\
3.8 \\
7.8 \\
2.9\end{array}$ & $\begin{array}{r}5.3 \\
9.7 \\
15.7 \\
8.0\end{array}$ & $\begin{array}{l}3.5 \\
7.8 \\
2.8\end{array}$ & $\begin{array}{r}5.1 \\
9.8 \\
15.9 \\
7.8\end{array}$ & $\begin{array}{l}3.6 \\
7.8 \\
2.7\end{array}$ & $\begin{array}{l}7.4 \\
8.0 \\
8.2 \\
8.4\end{array}$ & $\begin{array}{r}12.0 \\
11.2 \\
6.8 \\
12.9 \\
90.1\end{array}$ & $\begin{array}{r}14.3 \\
13.3 \\
7.8 \\
14.5 \\
12.0\end{array}$ & $\begin{array}{l}16.5 \\
13.9\end{array}$ & $\begin{array}{l}18.5 \\
18.5 \\
11.0 \\
17.3\end{array}$ \\
\hline $\begin{array}{l}16 \\
17 \\
18 \\
19 \\
20\end{array}$ & $\begin{array}{r}6.9 \\
12.3 \\
17.8 \\
16.6\end{array}$ & $\begin{array}{r}1.6 \\
6.0 \\
11.6 \\
11.4 \\
13.9\end{array}$ & $\begin{array}{r}6.9 \\
12.7 \\
18.3 \\
16.5 \\
15.6\end{array}$ & $\begin{array}{r}1.5 \\
5.6 \\
11.4 \\
11.2 \\
13.8\end{array}$ & $\begin{array}{r}7.0 \\
12.9 \\
18.8 \\
16.5\end{array}$ & $\begin{array}{r}1.4 \\
5.5 \\
11.6 \\
11.1\end{array}$ & $\begin{array}{r}7.1 \\
13.2 \\
19.1 \\
16.5 \\
15.8\end{array}$ & $\begin{array}{r}1.7 \\
5.7 \\
11.7 \\
11.2 \\
14.0\end{array}$ & $\begin{array}{r}9.9 \\
9.3 \\
20.3 \\
9.2\end{array}$ & $\begin{array}{r}5.5 \\
15.5 \\
14.3 \\
6.1 \\
11.6\end{array}$ & $\begin{array}{r}6.4 \\
16.8 \\
15.8 \\
7.2 \\
13.1\end{array}$ & $\begin{array}{r}7.6 \\
13.5 \\
17.8 \\
8.4 \\
14.8\end{array}$ & $\begin{array}{r}20.4 \\
19.2 \\
9.6 \\
16.6\end{array}$ \\
\hline $\begin{array}{l}21 \\
22 \\
23 \\
24 \\
25\end{array}$ & $\begin{array}{r}11.7 \\
8.4 \\
13.2 \\
19.8 \\
16.5\end{array}$ & $\begin{array}{r}9.7 \\
4.9 \\
8.5 \\
13.7 \\
12.7\end{array}$ & & $\begin{array}{l}9.4 \\
4.6\end{array}$ & $\begin{array}{r}11.5 \\
8.4 \\
13.7 \\
20.6 \\
16.2\end{array}$ & $\begin{array}{r}9.3 \\
4.5 \\
3.2 \\
13.6 \\
12.4\end{array}$ & $\begin{array}{r}11.5 \\
8.4 \\
13.8 \\
21.0 \\
16 . ?\end{array}$ & $\begin{array}{l}9 . ? \\
4 \cdot 4 \\
8.2\end{array}$ & 8.7 & $\begin{array}{r}7.9 \\
10.3 \\
10.7 \\
22.0 \\
3.6\end{array}$ & $\begin{array}{r}9.6 \\
11.7 \\
23.7 \\
11.0\end{array}$ & $\begin{array}{l}12.1 \\
13.7 \\
13.0 \\
26.3 \\
12.7\end{array}$ & $\begin{array}{l}12.7 \\
14.6 \\
28.8 \\
13.3\end{array}$ \\
\hline $\begin{array}{l}26 \\
27 \\
28 \\
29 \\
30\end{array}$ & $\begin{array}{l}17.9 \\
21.4 \\
21.9 \\
19.3 \\
16.6\end{array}$ & $\begin{array}{l}14.3 \\
17.2 \\
17.6 \\
16.7 \\
15.0\end{array}$ & 22.2 & $\begin{array}{l}14.3 \\
17.2 \\
17.5 \\
16.7\end{array}$ & $\begin{array}{l}17.9 \\
22.1 \\
22.5 \\
19.6 \\
16.8\end{array}$ & $\begin{array}{l}14.3 \\
17.4 \\
17.6 \\
16.7 \\
15.0\end{array}$ & $\begin{array}{l}17.9 \\
22.6 \\
22.9 \\
19.5 \\
16.7\end{array}$ & $\begin{array}{l}14.3 \\
17.6 \\
17.7 \\
16.7 \\
15.0\end{array}$ & 13.3 & $\begin{array}{r}7.7 \\
15.7 \\
15.1 \\
16.5 \\
11.5\end{array}$ & $\begin{array}{r}8.6 \\
17.1 \\
16.5 \\
18.0 \\
12.4\end{array}$ & $\begin{array}{r}9.7 \\
19.2 \\
18.5 \\
19.8 \\
13.8\end{array}$ & $\begin{array}{l}11.1 \\
21.2 \\
20.4 \\
22.0 \\
15.1\end{array}$ \\
\hline
\end{tabular}


Table 11. -Daily averages of air and water temperatures and wind speeds, July 1950—August 1951, Lake Hefnen—Con. STATION 3 DAILY AVERAGES

\begin{tabular}{|c|c|c|c|c|c|c|c|c|c|c|c|c|c|}
\hline \multirow{4}{*}{ 苂 } & \multicolumn{8}{|c|}{ Average air temperature $\left({ }^{\circ} \mathrm{C}\right)$ at indicated height } & \multirow{4}{*}{ 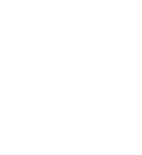 } & \multirow{2}{*}{\multicolumn{4}{|c|}{$\begin{array}{l}\text { Average wind speed (knots) } \\
\text { at indicated height }\end{array}$}} \\
\hline & \multirow{2}{*}{\multicolumn{2}{|c|}{$\begin{array}{c}2 \\
\text { meters }\end{array}$}} & \multirow{2}{*}{\multicolumn{2}{|c|}{$\begin{array}{c}4 \\
\text { meters } \\
\end{array}$}} & \multirow{2}{*}{\multicolumn{2}{|c|}{$\begin{array}{c}8 \\
\text { meters } \\
\end{array}$}} & \multirow{2}{*}{\multicolumn{2}{|c|}{$\begin{array}{c}16 \\
\text { meters }\end{array}$}} & & & & & \\
\hline & & & & & & & & & & \multirow{2}{*}{$\begin{array}{c}2 \\
\text { meters }\end{array}$} & \multirow{2}{*}{$\begin{array}{c}4 \\
\text { meters }\end{array}$} & \multirow{2}{*}{$\begin{array}{c}8 \\
\text { meters }\end{array}$} & \multirow{2}{*}{$\begin{array}{c}16 \\
\text { meters }\end{array}$} \\
\hline & $\begin{array}{l}\text { Dry } \\
\text { bulb }\end{array}$ & $\begin{array}{l}\text { Wet } \\
\text { bulb }\end{array}$ & $\begin{array}{l}\text { Dry } \\
\text { bulb }\end{array}$ & $\begin{array}{l}\text { Wet } \\
\text { bulb }\end{array}$ & $\begin{array}{l}\text { Dry } \\
\text { bulb }\end{array}$ & $\begin{array}{l}\text { Wet } \\
\text { bulb }\end{array}$ & $\begin{array}{l}\text { Dry } \\
\text { bulb }\end{array}$ & $\begin{array}{l}\text { Wet } \\
\text { bulb }\end{array}$ & & & & & \\
\hline \multicolumn{14}{|c|}{ MAY } \\
\hline $\begin{array}{l}1 \\
2 \\
3 \\
4 \\
5\end{array}$ & $\begin{array}{l}15.5 \\
17.5 \\
18.8 \\
18.1 \\
19.3\end{array}$ & $\begin{array}{l}111: 0 \\
11: 9 \\
11: 9 \\
12: 4 \\
13.4\end{array}$ & $\begin{array}{l}15.7 \\
17.6 \\
18.9 \\
18.0 \\
19.4\end{array}$ & $\begin{array}{l}11.5 \\
11.6 \\
12.0 \\
13.2\end{array}$ & $\begin{array}{l}15.8 \\
17.8 \\
19.1 \\
13.0 \\
19.6\end{array}$ & $\begin{array}{l}10.5 \\
11.3 \\
11.6 \\
11.8 \\
13.4\end{array}$ & $\begin{array}{l}15.8 \\
18.1 \\
19.3 \\
19.3 \\
19.8\end{array}$ & $\begin{array}{l}10.7 \\
11.2 \\
11.3 \\
11.6 \\
12.0\end{array}$ & $\begin{array}{l}16.0 \\
16.3 \\
16.8 \\
18.1\end{array}$ & $\begin{array}{r}13.6 \\
13.8 \\
6.3 \\
7.0 \\
4.6\end{array}$ & $\begin{array}{r}14.8 \\
14: 8 \\
7.0 \\
7.9 \\
4.8\end{array}$ & $\begin{array}{r}16.2 \\
16.5 \\
8.3 \\
9.5 \\
5.6\end{array}$ & $\begin{array}{r}17.5 \\
17.7 \\
9.1 \\
10.4 \\
6.5\end{array}$ \\
\hline $\begin{array}{r}6 \\
7 \\
8 \\
9 \\
10\end{array}$ & $\begin{array}{l}12.5 \\
13.0 \\
16.8 \\
18.4 \\
14.5\end{array}$ & $\begin{array}{r}8.4 \\
8.5 \\
13.1 \\
16.0 \\
12.2\end{array}$ & $\begin{array}{l}12.4 \\
13.0 \\
16.9 \\
18.5 \\
14.5\end{array}$ & $\begin{array}{r}9.2 \\
8.3 \\
13.0 \\
15.0 \\
12.1\end{array}$ & $\begin{array}{l}12.3 \\
13.1 \\
16.0 \\
19.5 \\
14.4\end{array}$ & $\begin{array}{r}8.2 \\
8.3 \\
13.0 \\
15.9 \\
11.9\end{array}$ & $\begin{array}{l}12.2 \\
13.2 \\
17.0 \\
18.8 \\
14.3\end{array}$ & $\begin{array}{r}8.0 \\
8.2 \\
12.8 \\
15.7 \\
11.7\end{array}$ & $\begin{array}{l}15.6 \\
16.8 \\
17.3 \\
16.9 \\
15.8\end{array}$ & $\begin{array}{r}10.4 \\
3.7 \\
12.3 \\
12.5 \\
3.4\end{array}$ & $\begin{array}{r}12.4 \\
4.3 \\
13.2 \\
13.8 \\
10.1\end{array}$ & $\begin{array}{r}14.4 \\
5.2 \\
14.5 \\
15.2 \\
12.6\end{array}$ & $\begin{array}{r}5.9 \\
15.7 \\
16.5 \\
13.0\end{array}$ \\
\hline $\begin{array}{l}11 \\
12 \\
13 \\
14 \\
15\end{array}$ & $\begin{array}{l}14.5 \\
17.2 \\
18.8 \\
20.6 \\
20.3\end{array}$ & $\begin{array}{l}11.4 \\
12.8 \\
13.7 \\
15.5 \\
18.5\end{array}$ & $\begin{array}{l}14.6 \\
17.2 \\
19.9 \\
20.7 \\
20.3\end{array}$ & $\begin{array}{l}11.3 \\
12.7 \\
13.5 \\
15.4 \\
18.4\end{array}$ & $\begin{array}{l}14.6 \\
17.2 \\
19.0 \\
20.8 \\
20.3\end{array}$ & $\begin{array}{l}11.4 \\
12.6 \\
13.4 \\
15.4 \\
18.4\end{array}$ & $\begin{array}{l}14.7 \\
17.2 \\
18.0 \\
20.9 \\
20.4\end{array}$ & $\begin{array}{l}11.01 \\
12.3 \\
13.2 \\
15.3 \\
18.2\end{array}$ & $\begin{array}{l}16.0 \\
15.8 \\
16.7 \\
16.7\end{array}$ & $\begin{array}{r}2.7 \\
9.2 \\
15.5 \\
16.9 \\
14.6\end{array}$ & $\begin{array}{r}3.1 \\
10.3 \\
16.9 \\
18.4 \\
16.0\end{array}$ & $\begin{array}{r}4.0 \\
11.4 \\
18.6 \\
20.3 \\
17.5\end{array}$ & $\begin{array}{r}4.7 \\
13.1 \\
20.7 \\
22.3 \\
19.5\end{array}$ \\
\hline $\begin{array}{l}16 \\
17 \\
18 \\
19 \\
20\end{array}$ & $21.3^{\circ}$ & 18.3 & 20.5 & 18.0 & 20.6 & 18.1 & 20.7 & 18.0 & & $\begin{array}{r}13.1 \\
10.8 \\
12.6 \\
12.5 \\
6.0\end{array}$ & $\begin{array}{r}14.3 \\
12.0 \\
13.7 \\
13.5 \\
6.6\end{array}$ & $\begin{array}{r}5.8 \\
3.3 \\
15.2 \\
15.2 \\
7.3\end{array}$ & $\begin{array}{r}17.6 \\
15.0 \\
16.6 \\
16.2 \\
8.1\end{array}$ \\
\hline $\begin{array}{l}21 \\
22 \\
23 \\
24 \\
25\end{array}$ & $\begin{array}{l}21.8 \\
17.1 \\
17.7 \\
16.7 \\
17.4\end{array}$ & $\begin{array}{l}19.0 \\
15.4 \\
14.1 \\
14.6 \\
15.6\end{array}$ & $\begin{array}{l}22.0 \\
17.3 \\
17.8 \\
16.7 \\
17.5\end{array}$ & $\begin{array}{l}19.0 \\
15.0 \\
13.7 \\
14.4 \\
15.4\end{array}$ & $\begin{array}{l}22.2 \\
17.0 \\
17.5 \\
16.6 \\
17.5\end{array}$ & $\begin{array}{l}19.0 \\
15.2 \\
13.8 \\
14.3 \\
15.5\end{array}$ & $\begin{array}{l}22.4 \\
16.8 \\
17.7 \\
16.6 \\
17.4\end{array}$ & $\begin{array}{l}18.9 \\
15.0 \\
13.7 \\
14.1 \\
15.1\end{array}$ & $\begin{array}{l}19.6 \\
21.5 \\
17.7\end{array}$ & $\begin{array}{l}9.0 \\
9.0 \\
3.1 \\
8.9 \\
6.9\end{array}$ & $\begin{array}{r}10.0 \\
10.5 \\
3.9 \\
9.7 \\
7.3\end{array}$ & $\begin{array}{r}11.4 \\
12.1 \\
4.2 \\
10.2 \\
8.3\end{array}$ & $\begin{array}{r}13.0 \\
13.3 \\
4.8 \\
21.5 \\
8.5\end{array}$ \\
\hline $\begin{array}{l}26 \\
27 \\
28 \\
29 \\
30\end{array}$ & $\begin{array}{l}20.0 \\
17.7 \\
21.8 \\
24.3 \\
25.1\end{array}$ & $\begin{array}{l}14.6 \\
15.2 \\
18.9 \\
20.8 \\
22.3\end{array}$ & $\begin{array}{l}20.1 \\
17.9 \\
21.8 \\
24.6 \\
25.2\end{array}$ & $\begin{array}{l}14.3 \\
14.9 \\
18.7 \\
20.8 \\
22.1\end{array}$ & $\begin{array}{l}20.2 \\
18.1 \\
22.0 \\
25.0 \\
25.5\end{array}$ & $\begin{array}{l}14.4 \\
15.0 \\
18.8 \\
20.9 \\
22.1\end{array}$ & $\begin{array}{l}20.3 \\
18.3 \\
22.0 \\
25.3 \\
25.5\end{array}$ & $\begin{array}{l}13.9 \\
14.9 \\
18.6 \\
20.7 \\
22.0\end{array}$ & $\begin{array}{l}18.7 \\
19.7 \\
20.7 \\
22.2 \\
23.9\end{array}$ & $\begin{array}{l}5.4 \\
5.4 \\
7.2 \\
8.5 \\
5.7\end{array}$ & $\begin{array}{l}6.4 \\
6.3 \\
8.4 \\
9.5 \\
6.5\end{array}$ & $\begin{array}{r}7.3 \\
7.3 \\
9.4 \\
10.9 \\
7.3\end{array}$ & $\begin{array}{r}8.1 \\
8.6 \\
11.1 \\
12.0 \\
8.3\end{array}$ \\
\hline 31 & 25.4 & 21.2 & 25.5 & 20.2 & 25.8 & 20.3 & 26.0 & 20.0 & 23.4 & 14.4 & 15.5 & 17.0 & 18.6 \\
\hline
\end{tabular}

\begin{tabular}{|c|c|c|c|c|c|c|c|c|c|c|c|c|c|}
\hline \multicolumn{14}{|c|}{ JUNE } \\
\hline \begin{tabular}{l|}
1 \\
2 \\
3 \\
4 \\
5
\end{tabular} & 18.5 & 16.6 & 18.6 & 16.6 & 18.7 & 20.5 & 18.8 & 16.4 & 21.0 & $\begin{array}{r}15.8 \\
10.9 \\
8.7 \\
4.5 \\
5.9\end{array}$ & $\begin{array}{r}17.1 \\
12.3 \\
10.1 \\
5.3 \\
6.5\end{array}$ & $\begin{array}{r}18.6 \\
13.6 \\
11.5 \\
6.1 \\
7.1\end{array}$ & $\begin{array}{r}20.5 \\
14.4 \\
12.2 \\
8.1\end{array}$ \\
\hline \begin{tabular}{r|}
6 \\
7 \\
8 \\
9 \\
10
\end{tabular} & 19.9 & 18.2 & 20.0 & 17.9 & 20.1 & 19.2 & 20.1 & 18.0 & 21.4 & $\begin{array}{r}14.1 \\
9.7 \\
24.4 \\
5.1 \\
5.8\end{array}$ & $\begin{array}{r}15.3 \\
10.8 \\
15.7 \\
6.1 \\
6.7\end{array}$ & $\begin{array}{r}16.4 \\
12.0 \\
17.7 \\
7.1 \\
7.9\end{array}$ & $\begin{array}{r}17.8 \\
13.5 \\
19.2 \\
7.9 \\
9.2\end{array}$ \\
\hline $\begin{array}{l}11 \\
12 \\
13 \\
14 \\
15\end{array}$ & $\begin{array}{l}19.5 \\
20.3 \\
21.8\end{array}$ & $\begin{array}{l}18.2 \\
18.0 \\
18.8\end{array}$ & $\begin{array}{l}19.5 \\
20.3 \\
22.0\end{array}$ & $\begin{array}{l}17.9 \\
17.8 \\
18.5\end{array}$ & $\begin{array}{l}19 \cdot 5 \\
20.3 \\
22.1\end{array}$ & $\begin{array}{l}18.0 \\
18.0 \\
18.5\end{array}$ & $\begin{array}{l}19 \cdot 4 \\
20.2 \\
22.1\end{array}$ & 18.2 & & $\begin{array}{l}6.5 \\
5.2 \\
7.5 \\
6.0 \\
6.5\end{array}$ & $\begin{array}{l}7.2 \\
5.9 \\
8.5 \\
6.9 \\
7.0\end{array}$ & $\begin{array}{l}7.8 \\
6.6 \\
9.4 \\
7.4 \\
7.5\end{array}$ & $\begin{array}{r}8.4 \\
7.4 \\
10.5 \\
8.8 \\
8.0\end{array}$ \\
\hline $\begin{array}{l}16 \\
17 \\
18 \\
19 \\
20\end{array}$ & $\begin{array}{l}24.9 \\
26.1 \\
24.3 \\
25.5 \\
25.8\end{array}$ & $\begin{array}{l}20.7 \\
21.9 \\
21.5 \\
21.5 \\
22.7\end{array}$ & $\begin{array}{l}25.1 \\
26.1 \\
24.4 \\
25.6 \\
25.8\end{array}$ & $\begin{array}{l}20.5 \\
21 \cdot 7 \\
21 \cdot 2 \\
21 \cdot 2 \\
22.5\end{array}$ & $\begin{array}{l}25 \cdot 1 \\
26 \cdot 2 \\
24 \cdot 4 \\
25 \cdot 7 \\
25.8\end{array}$ & $\begin{array}{l}20.1 \\
21.6 \\
21.1 \\
21.2 \\
22.4\end{array}$ & $\begin{array}{l}25.0 \\
26.0 \\
24.5 \\
25.7 \\
25.7\end{array}$ & $\begin{array}{l}20.1 \\
21.6 \\
21.1 \\
20.8 \\
22.0\end{array}$ & $\begin{array}{l}27.1 \\
26.3 \\
24.9 \\
26.9 \\
25.9\end{array}$ & $\begin{array}{r}5.9 \\
7: 0 \\
10.3\end{array}$ & $\begin{array}{r}7.3 \\
8.3 \\
11.7\end{array}$ & $\begin{array}{r}8.3 \\
8.6 \\
22.8\end{array}$ & $\begin{array}{r}9.3 \\
9.4 \\
14.6\end{array}$ \\
\hline $\begin{array}{l}21 \\
22 \\
23 \\
24 \\
25\end{array}$ & $\begin{array}{l}25.2 \\
24.4 \\
25.4\end{array}$ & $\begin{array}{l}2.1 .8 \\
20.6 \\
22.9\end{array}$ & $\begin{array}{l}25.4 \\
24.4 \\
25.5\end{array}$ & $\begin{array}{l}21.6 \\
20.3 \\
22.7\end{array}$ & $\begin{array}{l}25.6 \\
24.6 \\
25.6\end{array}$ & $\begin{array}{l}21.5 \\
20.4 \\
22.6\end{array}$ & $\begin{array}{l}25.7 \\
24.6 \\
25.6\end{array}$ & $\begin{array}{l}21.0 \\
19.0 \\
22.2\end{array}$ & $\begin{array}{l}25.8 \\
25.2 \\
25.7\end{array}$ & $\begin{array}{r}8.6 \\
8.7 \\
11.6 \\
7.8 \\
13.3\end{array}$ & $\begin{array}{r}9.5 \\
9.6 \\
12.7 \\
9.3 \\
14.3\end{array}$ & $\begin{array}{l}10.4 \\
10.4 \\
13.8 \\
10.6 \\
15.2\end{array}$ & $\begin{array}{l}11.7 \\
11.8 \\
15.1 \\
12.4 \\
16.3\end{array}$ \\
\hline $\begin{array}{l}26 \\
27 \\
28 \\
29 \\
30\end{array}$ & $\begin{array}{l}26.6 \\
26.8 \\
20.5\end{array}$ & $\begin{array}{l}22.2 \\
21.6\end{array}$ & $\begin{array}{l}26.8 \\
27.0 \\
20.5\end{array}$ & $\begin{array}{l}21.9 \\
21.3 \\
17.7\end{array}$ & $\begin{array}{l}26.9 \\
27.1 \\
20.4\end{array}$ & 21.8 & $\begin{array}{l}26.8 \\
27.1 \\
20.2\end{array}$ & $\begin{array}{l}21.6 \\
20.8 \\
16.8\end{array}$ & $\begin{array}{l}25.9 \\
25.5 \\
23.5\end{array}$ & $\begin{array}{r}17.0 \\
16.4 \\
10.0 \\
12.7 \\
7.6\end{array}$ & $\begin{array}{r}18.2 \\
17.5 \\
10.7 \\
13.7 \\
9.4\end{array}$ & $\begin{array}{l}19.7 \\
19.0 \\
11.4 \\
14.6 \\
10.9\end{array}$ & $\begin{array}{l}20.8 \\
20.1 \\
12.3 \\
15.9\end{array}$ \\
\hline
\end{tabular}


TABLE 11

Table 11. - Daily averages of air and water temperatures and wind speeds, July 1950-August 1951, Lake Hefner-Con.

\begin{tabular}{|c|c|c|c|c|c|c|c|c|c|c|c|c|c|}
\hline \multicolumn{2}{|c|}{ STATION 3} & \multicolumn{7}{|c|}{ DAILY AVERAGES } & \multirow{5}{*}{\begin{tabular}{|c|} 
Average \\
water- \\
surface \\
temperature \\
$\left({ }^{\circ} \mathrm{C}\right)$
\end{tabular}} & \multirow{3}{*}{\multicolumn{4}{|c|}{$\frac{1951}{\text { knots) }}$}} \\
\hline \multirow{4}{*}{ 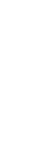 } & \multicolumn{8}{|c|}{ Average air temperature $\left({ }^{\circ} \mathrm{C}\right)$ at indicated height } & & & & & \\
\hline & \multirow{2}{*}{\multicolumn{2}{|c|}{$\begin{array}{c}2 \\
\text { meters }\end{array}$}} & \multirow{2}{*}{\multicolumn{2}{|c|}{$\begin{array}{c}4 \\
\text { meters }\end{array}$}} & \multirow{2}{*}{\multicolumn{2}{|c|}{$\begin{array}{c}8 \\
\text { meters }\end{array}$}} & \multirow{2}{*}{\multicolumn{2}{|c|}{$\begin{array}{c}16 \\
\text { meters }\end{array}$}} & & & & & \\
\hline & & & & & & & & & & \multirow[b]{2}{*}{$\begin{array}{c}2 \\
\text { meters }\end{array}$} & \multirow[b]{2}{*}{$\begin{array}{c}4 \\
\text { meters }\end{array}$} & \multirow[b]{2}{*}{$\begin{array}{c}8 \\
\text { meters }\end{array}$} & \multirow[b]{2}{*}{$\begin{array}{c}16 \\
\text { meters }\end{array}$} \\
\hline & $\begin{array}{l}\text { Dry } \\
\text { bulb }\end{array}$ & $\begin{array}{l}\text { Wet } \\
\text { bulb }\end{array}$ & $\begin{array}{l}\text { Dry } \\
\text { bulb }\end{array}$ & $\begin{array}{l}\text { Wet } \\
\text { bulb }\end{array}$ & $\begin{array}{l}\text { Dry } \\
\text { bulb }\end{array}$ & $\begin{array}{l}\text { Wet } \\
\text { bulb }\end{array}$ & $\begin{array}{l}\text { Dry } \\
\text { bulb }\end{array}$ & $\begin{array}{l}\text { Wet } \\
\text { bulb }\end{array}$ & & & & & \\
\hline \multicolumn{14}{|c|}{ JULY } \\
\hline $\begin{array}{l}1 \\
2 \\
3 \\
4 \\
5\end{array}$ & $\begin{array}{l}16.8 \\
21.5 \\
25.7\end{array}$ & $\begin{array}{l}15.6 \\
23.1\end{array}$ & $\begin{array}{l}16.8 \\
25.8\end{array}$ & 23.1 & $\begin{array}{l}17.0 \\
22.3 \\
26.2\end{array}$ & $\begin{array}{l}15.6 \\
19.6 \\
23.0\end{array}$ & $\begin{array}{l}16.9 \\
22.1 \\
26 . ?\end{array}$ & & $\begin{array}{l}22.9 \\
22.7 \\
22.9\end{array}$ & $\begin{array}{r}5.0 \\
8.2 \\
13.6 \\
7.0 \\
12.8\end{array}$ & $\begin{array}{r}6.2 \\
9.2 \\
14.7 \\
8.2 \\
13.8\end{array}$ & $\begin{array}{r}7.3 \\
9.9 \\
15.8 \\
9.3 \\
14.9\end{array}$ & $\begin{array}{r}8.6 \\
11.0 \\
17.2 \\
10.5 \\
16.4\end{array}$ \\
\hline $\begin{array}{r}6 \\
7 \\
8 \\
9 \\
10\end{array}$ & $\begin{array}{l}26.6 \\
27.0 \\
26.7 \\
27.0\end{array}$ & $\begin{array}{l}21.9 \\
21.8 \\
22.1 \\
22.4\end{array}$ & $\begin{array}{l}26.8 \\
27.2 \\
26.9 \\
27.1\end{array}$ & $\begin{array}{l}21.7 \\
21: 5 \\
21: 0 \\
22.3\end{array}$ & $\begin{array}{l}27.0 \\
27.4 \\
27.0 \\
27.2\end{array}$ & $\begin{array}{l}21.6 \\
21.4 \\
21.8 \\
22.3\end{array}$ & $\begin{array}{l}27.0 \\
27.5 \\
26.9 \\
27 . ?\end{array}$ & $\begin{array}{l}? 0.9 \\
: 1.3\end{array}$ & $\begin{array}{l}25.0 \\
25.3 \\
25.3 \\
25.7\end{array}$ & $\begin{array}{l}14.6 \\
15.0 \\
17.0 \\
12.3 \\
13.3\end{array}$ & $\begin{array}{l}15.7 \\
16.1 \\
18.3 \\
13.2 \\
14.03\end{array}$ & $\begin{array}{l}16.9 \\
17.2 \\
19.8 \\
14.1 \\
15.2\end{array}$ & $\begin{array}{l}18.3 \\
13.6 \\
21.0 \\
15.4 \\
16.8\end{array}$ \\
\hline $\begin{array}{l}11 \\
12 \\
13 \\
14 \\
15\end{array}$ & $\begin{array}{l}26.9 \\
27.2 \\
25.5 \\
23.2 \\
25.8\end{array}$ & $\begin{array}{l}22.4 \\
22.8 \\
22.0 \\
21.3 \\
22.5\end{array}$ & $\begin{array}{l}27.0 \\
27.4 \\
25.3 \\
23.0 \\
25.7\end{array}$ & $\begin{array}{l}22 \cdot 3 \\
22: 3 \\
22: 1 \\
21: 3 \\
22: ?\end{array}$ & $\begin{array}{l}27.1 \\
27: 7 \\
25: 2 \\
23: 1 \\
25.9\end{array}$ & $\begin{array}{l}22 \cdot 1 \\
22: 1 \\
21: 9 \\
21 \cdot 3 \\
22.2\end{array}$ & $\begin{array}{l}27.1 \\
27.7 \\
25.1 \\
23.4 \\
25.7\end{array}$ & $\begin{array}{l}? 1.8 \\
21.8\end{array}$ & $\begin{array}{l}26.2 \\
26.9 \\
26.2 \\
25.6 \\
26.4\end{array}$ & $\begin{array}{r}12.4 \\
11.3 \\
5.0 \\
5.5 \\
8.5\end{array}$ & $\begin{array}{r}13.4 \\
12.1 \\
6.1 \\
6.7 \\
9.4\end{array}$ & $\begin{array}{r}14.4 \\
13.1 \\
7.0 \\
7.8 \\
10.1\end{array}$ & $\begin{array}{r}15.7 \\
14.1 \\
8.6 \\
9.2 \\
11.5\end{array}$ \\
\hline $\begin{array}{l}16 \\
17 \\
18 \\
19 \\
20\end{array}$ & $\begin{array}{l}27.0 \\
27.7 \\
20.7 \\
29.0 \\
28.6\end{array}$ & $\begin{array}{l}22.2 \\
22.4 \\
21.8 \\
22.5 \\
22.8\end{array}$ & $\begin{array}{l}27.2 \\
27.7 \\
22.7 \\
27.8 \\
23.7\end{array}$ & $\begin{array}{l}21.7 \\
22.0 \\
21.4 \\
22.1 \\
22.5\end{array}$ & $\begin{array}{l}27.4 \\
27.0 \\
28: 9 \\
27.9 \\
28.9\end{array}$ & $\begin{array}{l}21.5 \\
22.0 \\
21.4 \\
22.2 \\
22.5\end{array}$ & $\begin{array}{l}27.3 \\
27 \cdot 3 \\
23.9 \\
23.0 \\
28.9\end{array}$ & $\begin{array}{l}21.0 \\
21.4 \\
20.9 \\
21.9\end{array}$ & $\begin{array}{l}26 \cdot 1 \\
27 \cdot 3 \\
28.5 \\
28.4 \\
25 \cdot 1\end{array}$ & $\begin{array}{r}7.2 \\
5.3 \\
6.1 \\
3.5 \\
11.2\end{array}$ & $\begin{array}{r}7.7 \\
5.7 \\
6.6 \\
4.3 \\
12.1\end{array}$ & $\begin{array}{r}8.2 \\
6.0 \\
6.9 \\
4.9 \\
12.3\end{array}$ & $\begin{array}{r}9.0 \\
6.5 \\
7.8 \\
5.8 \\
14.1\end{array}$ \\
\hline $\begin{array}{l}21 \\
22 \\
23 \\
24 \\
25\end{array}$ & $\begin{array}{l}29 \cdot 3 \\
28 \cdot 5\end{array}$ & $\begin{array}{l}22.7 \\
22.4\end{array}$ & $\begin{array}{l}20.5 \\
23.7\end{array}$ & $\begin{array}{l}22.5 \\
22.2\end{array}$ & $\begin{array}{l}20.8 \\
28.3\end{array}$ & $\begin{array}{l}22.5 \\
22.2\end{array}$ & $\begin{array}{l}30.0 \\
28.9\end{array}$ & $\begin{array}{l}21.9 \\
21.7\end{array}$ & $\begin{array}{l}26.5 \\
27 \cdot 3\end{array}$ & $\begin{array}{r}15.9 \\
10.1 \\
5.3 \\
3.6 \\
3.3\end{array}$ & $\begin{array}{r}17.0 \\
10.9 \\
6.2 \\
4.4 \\
4.0\end{array}$ & $\begin{array}{r}18.4 \\
11.5 \\
7.0 \\
5.1 \\
4.6\end{array}$ & $\begin{array}{r}19.6 \\
12.6 \\
7.9 \\
5.9 \\
5.4\end{array}$ \\
\hline $\begin{array}{l}26 \\
27 \\
28 \\
29 \\
30\end{array}$ & & & & & & & & & & $\begin{array}{l}7.6 \\
4.4 \\
3.7 \\
2.9 \\
5.3\end{array}$ & $\begin{array}{l}8.6 \\
5.1 \\
3.8 \\
3.8 \\
6.1\end{array}$ & $\begin{array}{l}9.3 \\
5.8 \\
4.3 \\
4.8 \\
6.9\end{array}$ & $\begin{array}{r}10.5 \\
6.5 \\
5.1 \\
5.8 \\
8.0\end{array}$ \\
\hline 31 & & & & & & & & & & 4.6 & 5.3 & 6.0 & 6.6 \\
\hline
\end{tabular}

\begin{tabular}{|c|c|c|c|c|c|c|c|c|c|c|c|c|c|}
\hline \multicolumn{14}{|c|}{ AUGUST } \\
\hline $\begin{array}{l}1 \\
2 \\
3 \\
4 \\
5\end{array}$ & $\begin{array}{l}27.0 \\
29.5 \\
29.8\end{array}$ & $\begin{array}{l}22.3 \\
23.1 \\
23.8\end{array}$ & $\begin{array}{l}26.9 \\
29.4 \\
30.1\end{array}$ & $\begin{array}{l}22.8 \\
23.4\end{array}$ & $\begin{array}{l}27.2 \\
29.6 \\
30.3\end{array}$ & 22.2 & $\begin{array}{l}29.2 \\
30.5\end{array}$ & $\begin{array}{l}21.9 \\
? 2.0 \\
? 2.9\end{array}$ & 22.7 & $\begin{array}{r}6.0 \\
3.6 \\
21.4\end{array}$ & $\begin{array}{r}2.9 \\
7.1 \\
6.7 \\
4.5 \\
12.3\end{array}$ & $\begin{array}{r}3.5 \\
7.7 \\
7.6 \\
5.4 \\
13.3\end{array}$ & $\begin{array}{r}4.5 \\
9.1 \\
8.3 \\
6.7 \\
14.7\end{array}$ \\
\hline $\begin{array}{r}6 \\
7 \\
8 \\
9 \\
10\end{array}$ & $\begin{array}{l}31 \cdot 0 \\
32.2\end{array}$ & $\begin{array}{l}24.3 \\
23.1\end{array}$ & $\begin{array}{l}31.4 \\
32.7\end{array}$ & $\begin{array}{l}23.6 \\
22.4\end{array}$ & $\begin{array}{l}31.9 \\
32.9\end{array}$ & & $\begin{array}{l}32.0 \\
33.2\end{array}$ & $\begin{array}{l}22.8 \\
21.6\end{array}$ & $\begin{array}{l}28.6 \\
29.0\end{array}$ & $\begin{array}{r}11.4 \\
13.0 \\
7.7 \\
6.2 \\
3.9\end{array}$ & $\begin{array}{r}12.4 \\
13.9 \\
8.6 \\
7.3 \\
4.9\end{array}$ & $\begin{array}{r}13.6 \\
15.2 \\
9.4 \\
8.5 \\
5.6\end{array}$ & $\begin{array}{l}14.6 \\
16.1 \\
10.5\end{array}$ \\
\hline $\begin{array}{l}11 \\
12 \\
13 \\
14 \\
15\end{array}$ & & & & & & & & & & $\begin{array}{r}3.0 \\
3.2 \\
7.3 \\
11.9\end{array}$ & $\begin{array}{r}3.7 \\
4.0 \\
8.2 \\
22.8 \\
7.6\end{array}$ & $\begin{array}{r}4.6 \\
4.7 \\
9.2 \\
13.9 \\
8.8\end{array}$ & $\begin{array}{r}5.4 \\
5.7 \\
10.6 \\
15.1 \\
9.1\end{array}$ \\
\hline $\begin{array}{l}16 \\
17 \\
18 \\
19 \\
20\end{array}$ & $\begin{array}{l}25.6 \\
29.8 \\
27.0 \\
28.1 \\
27.9\end{array}$ & $\begin{array}{l}19.9 \\
21.7 \\
22.9 \\
22.4 \\
22.2\end{array}$ & $\begin{array}{l}25.5 \\
30.4 \\
27.1 \\
28.3 \\
28.0\end{array}$ & $\begin{array}{l}19.7 \\
21.3 \\
22.7 \\
21.8 \\
21.8\end{array}$ & $\begin{array}{l}25.3 \\
30.8 \\
27.1 \\
28.4 \\
28.1\end{array}$ & $\begin{array}{l}19.6 \\
21.0 \\
22.7 \\
21.5 \\
21.4\end{array}$ & $\begin{array}{l}25.6 \\
31.3 \\
27.0 \\
28.6 \\
28.2\end{array}$ & $\begin{array}{l}19.3 \\
20.7 \\
22.6 \\
21.3 \\
21.1\end{array}$ & $\begin{array}{l}27.6 \\
28.7 \\
28.2\end{array}$ & $\begin{array}{r}10.8 \\
3.8 \\
5.8 \\
10.0\end{array}$ & $\begin{array}{r}5.3 \\
12.0 \\
4.7 \\
6.3 \\
10.6\end{array}$ & $\begin{array}{r}6.4 \\
13.7 \\
5.6 \\
7.2 \\
11.5\end{array}$ & $\begin{array}{r}7.7 \\
14.6 \\
6.3 \\
8.0 \\
12.1\end{array}$ \\
\hline $\begin{array}{l}21 \\
22 \\
23 \\
24 \\
25\end{array}$ & $\begin{array}{l}22.2 \\
20.2 \\
23.7 \\
27.0 \\
28.0\end{array}$ & $\begin{array}{l}20.2 \\
18.1 \\
21.7 \\
22.9 \\
22.7\end{array}$ & $\begin{array}{l}22.2 \\
20.2 \\
23.9 \\
27.2 \\
28.2\end{array}$ & $\begin{array}{l}20.0 \\
18.0 \\
21.5 \\
22.7 \\
22.4\end{array}$ & $\begin{array}{l}22.2 \\
20.1 \\
24.1 \\
27.3 \\
28.4\end{array}$ & $\begin{array}{l}19.9 \\
18.0 \\
21.6 \\
22.5 \\
22.2\end{array}$ & $\begin{array}{l}22.1 \\
20.1 \\
24.1 \\
27.3 \\
28.6\end{array}$ & 19.8 & $\begin{array}{l}26.3 \\
25.5 \\
26.1 \\
26.8\end{array}$ & $\begin{array}{r}5.9 \\
3.5 \\
7.3 \\
12.2 \\
12.1\end{array}$ & $\begin{array}{r}7.3 \\
4.4 \\
8.5 \\
13.0 \\
13.1\end{array}$ & $\begin{array}{r}8.7 \\
5.5 \\
9.3 \\
24.0 \\
14.1\end{array}$ & $\begin{array}{r}9.5 \\
5.9 \\
10.7 \\
15.3 \\
15.5\end{array}$ \\
\hline $\begin{array}{l}26 \\
27 \\
28 \\
29 \\
30\end{array}$ & $\begin{array}{l}28.0 \\
29.1 \\
30.2 \\
29.9 \\
29.5\end{array}$ & $\begin{array}{l}22.4 \\
22.2 \\
22.4 \\
22.4 \\
22.2\end{array}$ & $\begin{array}{l}28.2 \\
29.4 \\
30.6 \\
30.4 \\
29.9\end{array}$ & $\begin{array}{l}22.1 \\
21.9 \\
21.9 \\
21 \bullet 9 \\
21.8\end{array}$ & $\begin{array}{l}28.4 \\
29.7 \\
30.9 \\
30.9 \\
30.3\end{array}$ & $\begin{array}{l}21.9 \\
21.6 \\
21.5 \\
21.5 \\
21.6\end{array}$ & $\begin{array}{l}28.4 \\
29.9 \\
31.2 \\
31.2 \\
30.7\end{array}$ & $\begin{array}{l}21.9 \\
21.5 \\
21.6 \\
21.3 \\
21.4\end{array}$ & $\begin{array}{l}26.8 \\
26.0 \\
25.9\end{array}$ & $\begin{array}{r}9.7 \\
13.0 \\
15.3 \\
13.5 \\
12.0\end{array}$ & $\begin{array}{l}10.7 \\
13.9 \\
16.5 \\
14.4 \\
13.1\end{array}$ & $\begin{array}{l}11.7 \\
15.0 \\
18.1 \\
15.9 \\
14.3\end{array}$ & $\begin{array}{l}12.8 \\
16.2 \\
19.3 \\
17.1 \\
15.5\end{array}$ \\
\hline 31 & 29.3 & 22.1 & 29.8 & 21.6 & 30.4 & 21.9 & 30.8 & 21.3 & & & 10.0 & 11.2 & 12.2 \\
\hline
\end{tabular}


Table 11. -Daily averages of air and water temperatures and wind speeds, July 1950—August 1951, Lake Hefner-Con. STATION 4 DAILY AVERAGES

\begin{tabular}{|c|c|c|c|c|c|c|c|c|c|c|c|c|c|}
\hline \multirow{4}{*}{$\stackrel{\mathscr{Z}}{\sharp}$} & \multicolumn{8}{|c|}{ Average air temperature $\left({ }^{\circ} \mathrm{C}\right)$ at indicated height } & \multirow{4}{*}{$\mid \begin{array}{c}\text { Average } \\
\text { water- } \\
\text { surface } \\
\text { temperature } \\
\left.{ }^{\circ} \mathrm{C}\right)\end{array}$} & \multirow{2}{*}{\multicolumn{4}{|c|}{$\begin{array}{l}\text { Average wind speed (knots) } \\
\text { at indicated height }\end{array}$}} \\
\hline & \multirow{2}{*}{\multicolumn{2}{|c|}{$\begin{array}{c}2 \\
\text { meters }\end{array}$}} & \multirow{2}{*}{\multicolumn{2}{|c|}{$\begin{array}{c}4 \\
\text { meters }\end{array}$}} & \multirow{2}{*}{\multicolumn{2}{|c|}{$\begin{array}{c}8 \\
\text { meters } \\
\end{array}$}} & \multirow{2}{*}{\multicolumn{2}{|c|}{$\begin{array}{c}16 \\
\text { meters }\end{array}$}} & & & & & \\
\hline & & & & & & & & & & \multirow{2}{*}{$\begin{array}{c}2 \\
\text { meters }\end{array}$} & \multirow{2}{*}{$\begin{array}{c}4 \\
\text { meters }\end{array}$} & \multirow{2}{*}{$\begin{array}{c}8 \\
\text { meters }\end{array}$} & \multirow{2}{*}{$\begin{array}{c}16 \\
\text { meters }\end{array}$} \\
\hline & $\begin{array}{l}\text { Dry } \\
\text { bulb }\end{array}$ & $\begin{array}{l}\text { Wet } \\
\text { bulb }\end{array}$ & $\begin{array}{l}\text { Dry } \\
\text { bulb }\end{array}$ & $\begin{array}{l}\text { Wet } \\
\text { bulb }\end{array}$ & $\begin{array}{l}\text { Dry } \\
\text { bulb }\end{array}$ & $\begin{array}{l}\text { Wet } \\
\text { bulb }\end{array}$ & $\begin{array}{l}\text { Dry } \\
\text { bulb }\end{array}$ & $\begin{array}{l}\text { Wet } \\
\text { bulb }\end{array}$ & & & & & \\
\hline
\end{tabular}

\begin{tabular}{|c|c|c|c|c|c|c|c|c|c|c|c|c|c|}
\hline \multicolumn{14}{|c|}{ JULY } \\
\hline $\begin{array}{l}1 \\
2 \\
3 \\
4 \\
5\end{array}$ & $24 \cdot 3$ & 19.7 & 24.5 & 19.5 & 24.6 & 19.3 & 24.4 & 18.9 & 24.8 & $\begin{array}{l}9.7 \\
9.5 \\
5.8 \\
3.1\end{array}$ & $\begin{array}{r}10.9 \\
10.9 \\
6.5 \\
3.5\end{array}$ & $\begin{array}{r}11.5 \\
12.1 \\
7.2 \\
4.5\end{array}$ & $\begin{array}{r}13.2 \\
13.7 \\
7.9 \\
5.2\end{array}$ \\
\hline $\begin{array}{r}6 \\
7 \\
8 \\
9 \\
10\end{array}$ & $\begin{array}{l}23.7 \\
24.4 \\
23.7\end{array}$ & $\begin{array}{l}21.0 \\
22.1 \\
21.8\end{array}$ & $\begin{array}{l}23.8 \\
24.5 \\
23.7\end{array}$ & $\begin{array}{l}20.8 \\
21.9 \\
21.5\end{array}$ & $\begin{array}{l}23.8 \\
24.5 \\
23.6\end{array}$ & $\begin{array}{l}20.7 \\
21.8 \\
21.4\end{array}$ & $\begin{array}{l}23.6 \\
24.3 \\
23.5\end{array}$ & $\begin{array}{l}20.5 \\
21.5 \\
21.1\end{array}$ & $\begin{array}{l}26.3 \\
26.0 \\
25.3\end{array}$ & $\begin{array}{r}6.3 \\
10.1 \\
13.2 \\
10.3\end{array}$ & $\begin{array}{r}6.9 \\
11.4 \\
15.0 \\
11.5\end{array}$ & $\begin{array}{r}8.1 \\
13.5 \\
17.8 \\
13.6\end{array}$ & $\begin{array}{r}8.5 \\
14.5 \\
19.3 \\
14.4\end{array}$ \\
\hline $\begin{array}{l}11 \\
12 \\
13 \\
14 \\
15\end{array}$ & $\begin{array}{l}23.0 \\
23.4 \\
20.7 \\
21.3 \\
25.4\end{array}$ & $\begin{array}{l}21.2 \\
20.8 \\
17.3 \\
17.9 \\
22.5\end{array}$ & $\begin{array}{l}23.0 \\
23.5 \\
20.7 \\
21.4 \\
25.5\end{array}$ & $\begin{array}{l}21.0 \\
20.7 \\
17.2 \\
17.8 \\
22.4\end{array}$ & $\begin{array}{l}22.9 \\
23.5 \\
20.7 \\
21.2 \\
25.5\end{array}$ & $\begin{array}{l}20.9 \\
20.5 \\
17.1 \\
17.6 \\
22.2\end{array}$ & $\begin{array}{l}22.0 \\
23.4 \\
20.5 \\
21.1 \\
25.4\end{array}$ & $\begin{array}{l}20.8 \\
20.3 \\
16.8 \\
17.5 \\
21.9\end{array}$ & $\begin{array}{l}24.8 \\
25.2 \\
24.5 \\
26.1 \\
26.5\end{array}$ & $\begin{array}{r}6.7 \\
5.0 \\
5.3 \\
3.8 \\
11.8\end{array}$ & $\begin{array}{r}7.4 \\
5.6 \\
5.9 \\
4.3 \\
13.5\end{array}$ & $\begin{array}{r}8.7 \\
6.9 \\
7.6 \\
5.0 \\
15.2\end{array}$ & 5.0 \\
\hline $\begin{array}{l}16 \\
17 \\
18\end{array}$ & $\begin{array}{l}26.2 \\
22.0\end{array}$ & $\begin{array}{l}22.4 \\
20.5\end{array}$ & $\begin{array}{l}26.4 \\
21.9\end{array}$ & $\begin{array}{l}22.5 \\
20.5\end{array}$ & $\begin{array}{l}26.4 \\
21.8\end{array}$ & $\begin{array}{l}22.2 \\
20.4\end{array}$ & $\begin{array}{l}26.4 \\
21.9\end{array}$ & $\begin{array}{l}21.9 \\
20.4\end{array}$ & $\begin{array}{l}25.6 \\
24.7\end{array}$ & $\begin{array}{r}15.6 \\
8.7 \\
8.0\end{array}$ & $\begin{array}{r}28.0 \\
9.7 \\
9.0\end{array}$ & $\begin{array}{l}20.4 \\
11.1 \\
10.6\end{array}$ & $\begin{array}{l}23.1 \\
11.8 \\
11.6\end{array}$ \\
\hline $\begin{array}{l}19 \\
20\end{array}$ & $\begin{array}{l}22.9 \\
22.9\end{array}$ & $\begin{array}{l}21.3 \\
20.7\end{array}$ & $\begin{array}{l}23.1 \\
22.9\end{array}$ & $\begin{array}{l}21.0 \\
20.5\end{array}$ & $\begin{array}{l}22.9 \\
22.9\end{array}$ & $\begin{array}{l}20.9 \\
20.5\end{array}$ & $\begin{array}{l}23.0 \\
22.8\end{array}$ & $\begin{array}{l}20.7 \\
20.2\end{array}$ & $\begin{array}{l}24.5 \\
25.4\end{array}$ & $\begin{array}{l}8.0 \\
5.2\end{array}$ & $\begin{array}{l}9.1 \\
6.1\end{array}$ & $\begin{array}{r}30.1 \\
8.6\end{array}$ & \\
\hline $\begin{array}{l}21 \\
22 \\
23 \\
24 \\
25\end{array}$ & & & & & & & & & & $\begin{array}{l}6.2 \\
2.3\end{array}$ & $\begin{array}{l}6.8 \\
2.8 \\
6.8\end{array}$ & $\begin{array}{l}7.4 \\
4.0 \\
7.3\end{array}$ & 4.7 \\
\hline $\begin{array}{l}26 \\
27 \\
38\end{array}$ & & & & & & & & & & $\begin{array}{l}3.5 \\
4.4 \\
6.4\end{array}$ & $\begin{array}{l}3.9 \\
4.9 \\
7.2\end{array}$ & $\begin{array}{l}4.8 \\
5.5 \\
8.2\end{array}$ & \\
\hline $\begin{array}{l}29 \\
30\end{array}$ & 24.6 & 22.0 & 24.6 & 22.6 & 24.5 & 22.5 & 24.5 & 22.3 & $25 \cdot 2$ & $\begin{array}{l}8.6 \\
8.9\end{array}$ & $\begin{array}{r}9.8 \\
10.3\end{array}$ & $\begin{array}{l}11.5 \\
11.9\end{array}$ & 13.2 \\
\hline 31 & 25.2 & $22 \cdot 3$ & 25.3 & 22.2 & 25.4 & 22.0 & 25.2 & 21.8 & 25.6 & 7.80 & 9.1 & 10.2 & 11.9 \\
\hline
\end{tabular}

\begin{tabular}{|c|c|c|c|c|c|c|c|c|c|c|c|c|c|}
\hline \multicolumn{14}{|c|}{ AUGUST } \\
\hline $\begin{array}{l}1 \\
2 \\
3 \\
4 \\
5\end{array}$ & $\begin{array}{l}20.4 \\
23.0 \\
23.1 \\
23.2 \\
24.0\end{array}$ & $\begin{array}{l}19.7 \\
18.7 \\
19.5 \\
20.9 \\
22.4\end{array}$ & $\begin{array}{l}20.3 \\
23.0 \\
23.1 \\
23.2 \\
24.1\end{array}$ & $\begin{array}{l}19.5 \\
18.5 \\
19.3 \\
20.6 \\
22.3\end{array}$ & $\begin{array}{l}20.1 \\
23.0 \\
23.1 \\
23.0 \\
24.0\end{array}$ & $\begin{array}{l}19.4 \\
18.3 \\
18.9 \\
20.5 \\
22.2\end{array}$ & $\begin{array}{l}20.0 \\
22.7 \\
22.9 \\
22.9 \\
24.0\end{array}$ & $\begin{array}{l}19.4 \\
18.1 \\
18.7 \\
20.3 \\
22.1\end{array}$ & $\begin{array}{l}24.8 \\
25.0 \\
25.5 \\
25.0 \\
25.0\end{array}$ & $\begin{array}{r}4.1 \\
2.9 \\
7.6 \\
10.5 \\
8.3\end{array}$ & $\begin{array}{r}3.1 \\
8.7 \\
12.1 \\
9.2\end{array}$ & $\begin{array}{r}5.5 \\
4.2 \\
10.0 \\
14.1 \\
10.5\end{array}$ & 10.9 \\
\hline $\begin{array}{r}6 \\
7 \\
8 \\
9 \\
10\end{array}$ & 23.9 & 22.4 & 23.9 & $22 \cdot 2$ & 23.9 & 22.1 & 23.3 & 22.0 & 25.3 & $\begin{array}{l}8.8 \\
8.9 \\
5.1 \\
4.2 \\
4.5\end{array}$ & $\begin{array}{r}10.1 \\
10.4 \\
5.8 \\
5.2 \\
6.0\end{array}$ & $\begin{array}{r}11.9 \\
11.6 \\
6.3 \\
6.2 \\
7.0\end{array}$ & 12.5 \\
\hline $\begin{array}{l}11 \\
12 \\
13 \\
14 \\
15\end{array}$ & $\begin{array}{r}26.9 \\
26.2\end{array}$ & $\begin{array}{l}22.1 \\
22: 0\end{array}$ & $\begin{array}{l}27.0 \\
26: 3\end{array}$ & $\begin{array}{l}21.8 \\
21.8\end{array}$ & $\begin{array}{l}27.0 \\
26.2\end{array}$ & $\begin{array}{l}21.4 \\
21.4\end{array}$ & $\begin{array}{l}27.0 \\
26.2\end{array}$ & $\begin{array}{ll}21.2 \\
21.2\end{array}$ & $\begin{array}{l}27.4 \\
27.6\end{array}$ & 9.5 & $\begin{array}{r}10.0 \\
11.1 \\
9.3 \\
6.7 \\
10.6\end{array}$ & $\begin{array}{r}11.7 \\
12.3 \\
10.0 \\
7.2 \\
11.4\end{array}$ & \\
\hline $\begin{array}{l}16 \\
17 \\
18 \\
19 \\
20\end{array}$ & 22.0 & 20.0 & 22.0 & 19.9 & 21.8 & 19,6 & 21.5 & 19.6 & 26.0 & $\begin{array}{l}4.6 \\
3.0\end{array}$ & $\begin{array}{l}5.6 \\
5.8 \\
4.9 . \\
5.5\end{array}$ & $\begin{array}{l}6.4 \\
7.0 \\
0.0\end{array}$ & \\
\hline $\begin{array}{l}21 \\
22 \\
23 \\
24 \\
25\end{array}$ & $\begin{array}{l}18.8 \\
22.8\end{array}$ & $\begin{array}{l}16.3 \\
20.0\end{array}$ & $\begin{array}{l}18.8 \\
22.8\end{array}$ & $\begin{array}{l}16.1 \\
19.8\end{array}$ & $\begin{array}{l}18.5 \\
22.6\end{array}$ & $\begin{array}{l}15.9 \\
19.5\end{array}$ & $\begin{array}{l}18.4 \\
22.7\end{array}$ & $\begin{array}{l}15.8 \\
19.5\end{array}$ & $\begin{array}{l}25.1 \\
25.4\end{array}$ & 5.1 & $\begin{array}{r}2.6 \\
6.0 \\
7.3 \\
10.4 \\
9.8\end{array}$ & $\begin{array}{r}3.3 \\
6.9 \\
8.5 \\
11.8 \\
10.4\end{array}$ & 12.4 \\
\hline $\begin{array}{l}26 \\
27 \\
28 \\
29 \\
30\end{array}$ & 22.3 & 19.6 & 22.3 & 19.4 & 22.3 & 19.3 & 22.0 & 19.2 & 26.0 & $\begin{array}{l}6.4 \\
5.4 \\
3.6 \\
3.7\end{array}$ & $\begin{array}{l}8.2 \\
2.9 \\
6.1 \\
4.0 \\
5.2\end{array}$ & $\begin{array}{l}9.4 \\
3.9 \\
6.7 \\
5.1 \\
7.5\end{array}$ & $\begin{array}{r}10.7 \\
4.6 \\
7.1 \\
6.0 \\
10.9\end{array}$ \\
\hline 31 & & & & & & & & & & & 4.4 & 7.4 & 10.2 \\
\hline
\end{tabular}


TABLE 11

Table 11.-Daily averagea of air and water temperatures and wind speeds, July 1950-August 1951, Lake Hefner-Con.

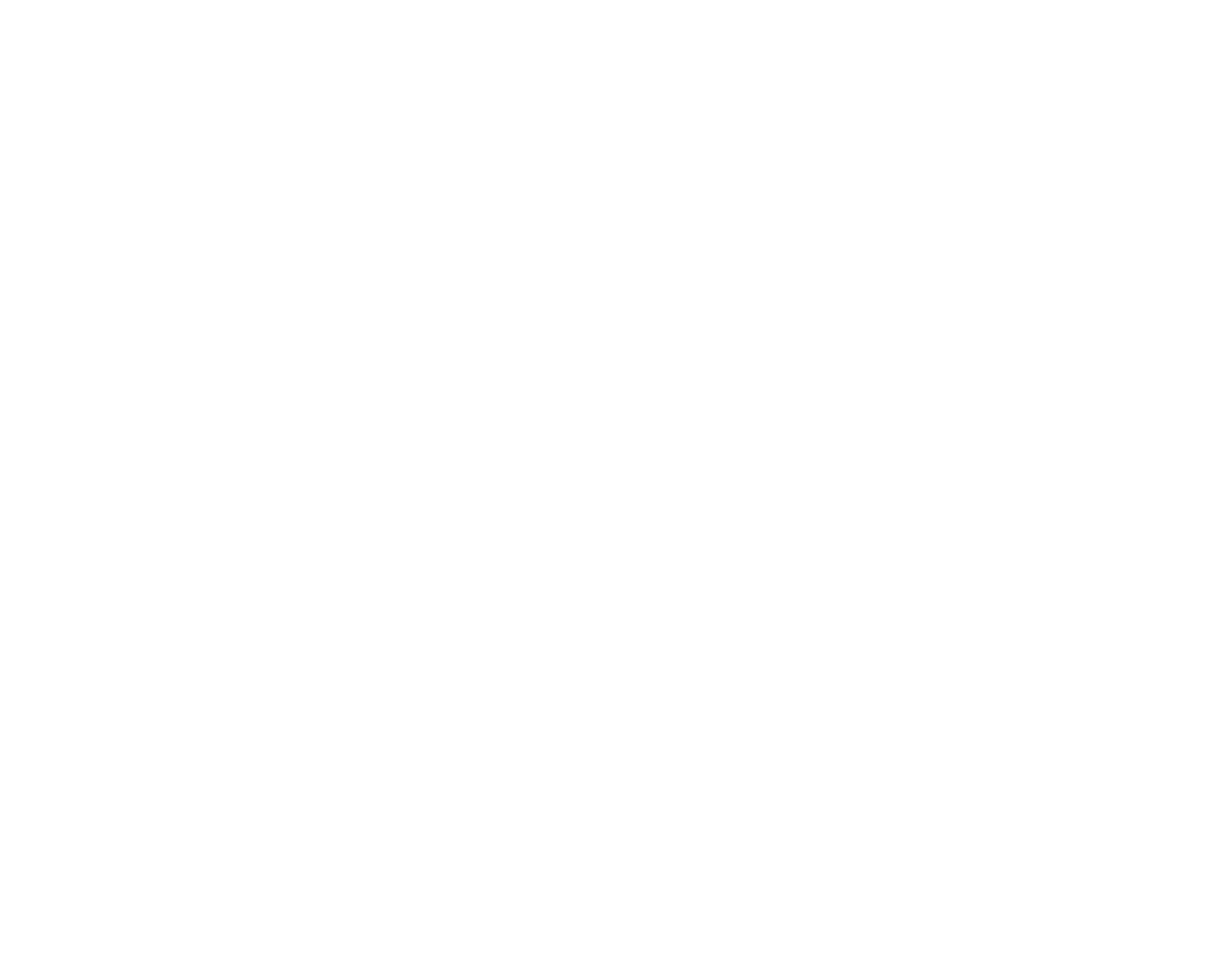

OCTOBER

\begin{tabular}{|c|c|c|c|c|c|c|c|c|c|c|c|c|c|}
\hline $\begin{array}{l}1 \\
2 \\
3 \\
4 \\
5\end{array}$ & $\begin{array}{l}21.9 \\
18.1 \\
12.9 \\
12.1 \\
16.9\end{array}$ & $\begin{array}{r}19.7 \\
17.2 \\
11.2 \\
8.7 \\
13.8\end{array}$ & $\begin{array}{l}22.0 \\
18.1 \\
12.8 \\
12.0 \\
16.8\end{array}$ & $\begin{array}{r}19.6 \\
17.0 \\
11.0 \\
8.6 \\
13.6\end{array}$ & $\begin{array}{l}22.0 \\
18.1 \\
12.7 \\
12.0 \\
16.8\end{array}$ & $\begin{array}{r}19.5 \\
17.0 \\
10.9 \\
8.4 \\
13.4\end{array}$ & $\begin{array}{l}22.0 \\
17.9 \\
12.3 \\
11.8 \\
16.7\end{array}$ & $\begin{array}{r}19.4 \\
16.7 \\
10.6 \\
8.2 \\
13.3\end{array}$ & $\begin{array}{l}22.0 \\
21.8 \\
21.3 \\
20.7 \\
20.3\end{array}$ & $\begin{array}{r}14.0 \\
8.8 \\
3.9 \\
5.7 \\
11.1\end{array}$ & $\begin{array}{r}16.2 \\
10.7 \\
5.2 \\
6.5 \\
12.7\end{array}$ & $\begin{array}{r}18.5 \\
12.9 \\
6.7 \\
7.3 \\
14.2\end{array}$ & $\begin{array}{r}20.4 \\
15.6 \\
9.9 \\
8.6 \\
15.5\end{array}$ \\
\hline $\begin{array}{r}6 \\
7 \\
8 \\
9 \\
10\end{array}$ & $\begin{array}{l}20.2 \\
19.3 \\
16.2 \\
17.0 \\
18.6\end{array}$ & $\begin{array}{r}17.0 \\
13.9 \\
9.9 \\
12.3 \\
14.2\end{array}$ & $\begin{array}{l}20.3 \\
19.4 \\
16.3 \\
17.0 \\
19.6\end{array}$ & $\begin{array}{r}16.8 \\
13.7 \\
9.7 \\
12.1 \\
13.9\end{array}$ & $\begin{array}{l}20.3 \\
19.4 \\
16.1 \\
17.1 \\
18.6\end{array}$ & $\begin{array}{r}16.6 \\
13.5 \\
9.4 \\
11.8 \\
13.6\end{array}$ & $\begin{array}{l}20.4 \\
12.3 \\
16.1 \\
16.9 \\
13.7\end{array}$ & $\begin{array}{r}16.6 \\
13.3 \\
9.3 \\
11.6 \\
13.4\end{array}$ & $\begin{array}{l}20.0 \\
19.9 \\
19.5 \\
19.5 \\
19.3\end{array}$ & $\begin{array}{r}15.8 \\
7.2 \\
4.0 \\
7.6 \\
7.5\end{array}$ & $\begin{array}{r}18.4 \\
8.4 \\
4.8 \\
8.7 \\
8.7\end{array}$ & $\begin{array}{r}20.7 \\
10.3 \\
7.2 \\
9.8 \\
9.9\end{array}$ & $\begin{array}{r}23.1 \\
12.6 \\
9.3 \\
10.5 \\
11.3\end{array}$ \\
\hline $\begin{array}{l}11 \\
12 \\
13 \\
14 \\
15\end{array}$ & $\begin{array}{l}20.8 \\
19.4 \\
21.0 \\
22.4 \\
21.7\end{array}$ & $\begin{array}{l}15.4 \\
13.9 \\
15.9 \\
16.9 \\
16.6\end{array}$ & $\begin{array}{l}21.1 \\
19.5 \\
21.2 \\
22.0 \\
22.0\end{array}$ & $\begin{array}{l}15.1 \\
13.5 \\
15.7 \\
16.8 \\
16.4\end{array}$ & $\begin{array}{l}21.1 \\
19.7 \\
21.5 \\
23.7 \\
22.1\end{array}$ & $\begin{array}{l}14.9 \\
13.0 \\
15.4 \\
16.5 \\
16.2\end{array}$ & $\begin{array}{l}? 1.4 \\
20.0 \\
21.5 \\
23.6 \\
? ? .3\end{array}$ & $\begin{array}{l}14.9 \\
12.8 \\
15.4 \\
16.6 \\
16.1\end{array}$ & $\begin{array}{l}20.6 \\
19.7 \\
20.1 \\
19.6 \\
19.7\end{array}$ & $\begin{array}{r}2.6 \\
3.9 \\
10.4 \\
10.6 \\
10.0\end{array}$ & $\begin{array}{r}2.9 \\
4.7 \\
12.1 \\
12.1 \\
11.7\end{array}$ & $\begin{array}{r}3.2 \\
5.7 \\
13.3 \\
12.7 \\
13.1\end{array}$ & $\begin{array}{r}4.4 \\
6.7 \\
15.3 \\
15.0 \\
15.0\end{array}$ \\
\hline $\begin{array}{l}16 \\
17 \\
18 \\
19 \\
20\end{array}$ & $\begin{array}{l}21.1 \\
20.7 \\
19.9 \\
19.4 \\
17.3\end{array}$ & $\begin{array}{l}15.8 \\
16.4 \\
15.4 \\
15.3 \\
13.5\end{array}$ & $\begin{array}{l}21.2 \\
20.8 \\
20.0 \\
19.4 \\
17.3\end{array}$ & $\begin{array}{l}15.6 \\
16.2 \\
16.3 \\
15.2 \\
13.4\end{array}$ & $\begin{array}{l}21.3 \\
21.3 \\
20.1 \\
19.3 \\
17.3\end{array}$ & $\begin{array}{l}15.4 \\
15.0 \\
16.0 \\
15.1 \\
13.1\end{array}$ & $\begin{array}{l}21.4 \\
21.6 \\
20.2 \\
19.4 \\
17.5\end{array}$ & $\begin{array}{l}15.3 \\
15.8 \\
15.9 \\
15.0 \\
13.1\end{array}$ & $\begin{array}{l}19.3 \\
19.7 \\
19.9 \\
19.4 \\
18.8\end{array}$ & $\begin{array}{r}10.8 \\
7.3 \\
4.3 \\
1.8 \\
1.7\end{array}$ & $\begin{array}{r}12.5 \\
8.6 \\
4.9 \\
2.2 \\
2.2\end{array}$ & $\begin{array}{r}13.7 \\
5.5 \\
3.4 \\
3.3\end{array}$ & $\begin{array}{r}15.7 \\
12.4 \\
6.5 \\
4.5 \\
4.6\end{array}$ \\
\hline $\begin{array}{l}21 \\
22 \\
23 \\
24 \\
25\end{array}$ & $\begin{array}{l}16.3 \\
14.3 \\
12.2 \\
18.6 \\
15.5\end{array}$ & $\begin{array}{r}10.6 \\
9.9 \\
9.6 \\
13.9 \\
13.2\end{array}$ & $\begin{array}{l}10.3 \\
14.2 \\
12.2 \\
18.8 \\
15.7\end{array}$ & $\begin{array}{r}10.4 \\
9.7 \\
9.4 \\
13.9 \\
13.1\end{array}$ & $\begin{array}{l}16.4 \\
14.0 \\
12.0 \\
10.0 \\
15.7\end{array}$ & $\begin{array}{r}10.2 \\
9.6 \\
9.1 \\
13.3 \\
12.8\end{array}$ & $\begin{array}{l}16.5 \\
14.0 \\
11.8 \\
10.3 \\
15.8\end{array}$ & $\begin{array}{r}10.2 \\
9.4 \\
9.0 \\
13.4 \\
12.8\end{array}$ & $\begin{array}{l}18.7 \\
18.4 \\
18.3 \\
18.1 \\
18.2\end{array}$ & $\begin{array}{r}2.6 \\
3.1 \\
3.4 \\
18.7 \\
3.2\end{array}$ & $\begin{array}{l}3.0 \\
4.5 \\
4.0 \\
9.9 \\
3.7\end{array}$ & $\begin{array}{r}4.1 \\
7.2 \\
5.5 \\
10.4 \\
5.1\end{array}$ & $\begin{array}{r}5.4 \\
9.9 \\
6.4 \\
12.2 \\
5.9\end{array}$ \\
\hline $\begin{array}{l}26 \\
27 \\
29 \\
29 \\
30\end{array}$ & $\begin{array}{l}22.1 \\
20.1 \\
20.7\end{array}$ & $\begin{array}{l}15.0 \\
13.9 \\
15.2\end{array}$ & $\begin{array}{l}22.5 \\
20.4 \\
21.0 \\
21.5\end{array}$ & $\begin{array}{l}15.3 \\
13.8 \\
15.0 \\
16.8\end{array}$ & $\begin{array}{l}22.8 \\
20.7 \\
21.1 \\
21.6\end{array}$ & $\begin{array}{l}14.2 \\
13.1 \\
14.8 \\
16.5\end{array}$ & $\begin{array}{l}23.1 \\
20.9 \\
21.4 \\
21.8\end{array}$ & $\begin{array}{l}14.3 \\
13.0 \\
14.6 \\
16.6\end{array}$ & $\begin{array}{l}17.9 \\
18.3 \\
13.2 \\
18.1\end{array}$ & $\begin{array}{r}13.8 \\
8.1 \\
5.9 \\
8.4 \\
11.4\end{array}$ & $\begin{array}{r}15.7 \\
9.2 \\
6.6 \\
9.8 \\
13.0\end{array}$ & $\begin{array}{r}16.4 \\
9.7 \\
7.3 \\
10.8 \\
13.6\end{array}$ & $\begin{array}{r}19.4 \\
11.4 \\
8.9 \\
12.7 \\
16.1\end{array}$ \\
\hline 31 & 21.4 & 17.4 & $21 \cdot 6$ & & & & & & & 13.4 & 15.4 & 16.3 & 19.0 \\
\hline
\end{tabular}


Table 11. -Daily averages of air and water temperatures and wind speeds, July 1950-August 1951, Lake Hefner-Con STATION 4 DALY AVERAGES

\begin{tabular}{|c|c|c|c|c|c|c|c|c|c|c|c|c|c|}
\hline \multirow{4}{*}{ 竎 } & \multicolumn{8}{|c|}{ Average air temperature $\left({ }^{\circ} \mathrm{C}\right)$ at indicated height } & \multirow{4}{*}{$\begin{array}{c}\text { Average } \\
\text { water- } \\
\text { surface } \\
\text { temperature } \\
\left({ }^{\circ} \mathrm{C}\right)\end{array}$} & \multirow{2}{*}{\multicolumn{4}{|c|}{$\begin{array}{l}\text { Average wind speed (knots) } \\
\text { at indicated height }\end{array}$}} \\
\hline & \multirow{2}{*}{\multicolumn{2}{|c|}{$\begin{array}{c}2 \\
\text { meters }\end{array}$}} & \multirow{2}{*}{\multicolumn{2}{|c|}{$\begin{array}{c}4 \\
\text { meters }\end{array}$}} & \multirow{2}{*}{\multicolumn{2}{|c|}{$\begin{array}{c}8 \\
\text { meters }\end{array}$}} & \multirow{2}{*}{\multicolumn{2}{|c|}{$\begin{array}{c}16 \\
\text { meters } \\
\end{array}$}} & & & & & \\
\hline & & & & & & & & & & & & & \\
\hline & $\begin{array}{l}\text { Dry } \\
\text { bulb }\end{array}$ & $\begin{array}{l}\text { Wet } \\
\text { bulb }\end{array}$ & $\begin{array}{l}\text { Dry } \\
\text { bulb }\end{array}$ & $\begin{array}{l}\text { Wet } \\
\text { bulb }\end{array}$ & $\begin{array}{l}\text { Dry } \\
\text { bulb }\end{array}$ & $\begin{array}{l}\text { Wet } \\
\text { bulb }\end{array}$ & $\begin{array}{l}\text { Dry } \\
\text { bulb }\end{array}$ & $\begin{array}{l}\text { Wet } \\
\text { bulb }\end{array}$ & & ${ }_{\text {meters }}^{2}$ & $\begin{array}{c}4 \\
\text { meters }\end{array}$ & $\begin{array}{c}8 \\
\text { meters }\end{array}$ & $\begin{array}{c}16 \\
\text { meters }\end{array}$ \\
\hline
\end{tabular}

\begin{tabular}{|c|c|c|c|c|c|c|c|c|c|c|c|c|c|}
\hline $\begin{array}{l}1 \\
2 \\
3 \\
4 \\
5\end{array}$ & $\begin{array}{r}9.5 \\
3.2 \\
4.7 \\
13.0\end{array}$ & $\begin{array}{l}6.5 \\
2.5 \\
1.5 \\
7.8\end{array}$ & $\begin{array}{r}9.4 \\
3.0 \\
4.6 \\
13.1\end{array}$ & $\begin{array}{l}6.2 \\
2.3 \\
1.7 \\
7.7\end{array}$ & $\begin{array}{r}0.2 \\
2.2 \\
4.4 \\
13.1\end{array}$ & $\begin{array}{l}6.1 \\
2.0 \\
1.6 \\
7.1\end{array}$ & $\begin{array}{r}9.2 \\
2.7 \\
4.3 \\
12.1\end{array}$ & $\begin{array}{l}0.0 \\
1.03\end{array}$ & $\begin{array}{l}17.1 \\
16.0 \\
15.1 \\
14.5\end{array}$ & $\begin{array}{r}3.3 \\
2.9 \\
5.3 \\
5.9 \\
12.8\end{array}$ & $\begin{array}{r}10.2 \\
3.6 \\
3.1 \\
6.4 \\
14.6\end{array}$ & $\begin{array}{r}12.7 \\
4.5 \\
14.8 \\
7.0 \\
15.5\end{array}$ & $\begin{aligned} 16.0 \\
7.0 \\
20.9 \\
7.7 \\
17.7\end{aligned}$ \\
\hline $\begin{array}{r}6 \\
7 \\
8 \\
9 \\
10\end{array}$ & $\begin{array}{r}13.7 \\
11.7 \\
10.4 \\
0.9 \\
-1.7\end{array}$ & $\begin{array}{l}8.1 \\
8.0 \\
7.6\end{array}$ & $\begin{array}{r}13.6 \\
11.8 \\
1.03 \\
0.7 \\
-1.9\end{array}$ & $\begin{array}{l}5.0 \\
3.0 \\
7.6\end{array}$ & $\begin{array}{r}13.7 \\
11.5 \\
10.2 \\
0.4 \\
-2.1\end{array}$ & $\begin{array}{l}7.6 \\
8.7 \\
7.4\end{array}$ & $\begin{array}{r}1: 9 \\
1: 0 \\
10.0 \\
0.0\end{array}$ & $\begin{array}{l}7.2 \\
7.2\end{array}$ & $\begin{array}{l}14.5 \\
14.1 \\
13.0 \\
13.0 \\
11.8\end{array}$ & $\begin{array}{l}1.9 \\
6.0 \\
5.3 \\
4.6\end{array}$ & $\begin{array}{l}5.0 \\
2.1 \\
15.0 \\
8.4 \\
5.7\end{array}$ & $\begin{array}{r}6.2 \\
3.1 \\
11.3 \\
23.4 \\
0.9\end{array}$ & $\begin{array}{r}7.3 \\
3.3 \\
15.6 \\
20.0 \\
11.0\end{array}$ \\
\hline $\begin{array}{l}11 \\
12 \\
13 \\
14 \\
15\end{array}$ & $\begin{array}{l}2.8 \\
5.4 \\
8.9\end{array}$ & $\begin{array}{l}2.4 \\
6.0\end{array}$ & $\begin{array}{l}2.5 \\
5.3 \\
9.0\end{array}$ & $\begin{array}{l}2: 1 \\
5: 6\end{array}$ & $\begin{array}{l}2.4 \\
0.3 \\
9.0\end{array}$ & $\begin{array}{l}1.4 \\
5.2\end{array}$ & $\begin{array}{l}2 . ? \\
5.1 \\
.1\end{array}$ & 0.5 & $\begin{array}{l}10.8 \\
10.3 \\
10.0\end{array}$ & $\begin{array}{r}11.8 \\
12.0 \\
1.7 \\
14.7 \\
11.6\end{array}$ & $\begin{array}{l}13.3 \\
13.6 \\
11.1 \\
17.2 \\
15.2\end{array}$ & $\begin{array}{l}14.1 \\
15.5 \\
13.8 \\
19.7 \\
14.8\end{array}$ & $\begin{array}{l}15.6 \\
16.8 \\
14.1 \\
22.7 \\
17.4\end{array}$ \\
\hline $\begin{array}{l}16 \\
17 \\
18 \\
19 \\
20\end{array}$ & $\begin{array}{r}12.3 \\
2.4\end{array}$ & 3.0 & $\begin{array}{r}7.5 \\
12.2 \\
2.1\end{array}$ & 10.2 & $\begin{array}{r}1.20 \\
2.00\end{array}$ & 9.9 & $\begin{array}{r}7.6 \\
12.7 \\
1.6\end{array}$ & 0.9 & $\begin{array}{l}11.0 \\
10.1\end{array}$ & $\begin{array}{r}2.0 \\
8.4 \\
13.1 \\
7.9 \\
3.7\end{array}$ & $\begin{array}{r}2.9 \\
9.5 \\
14.1 \\
11.5 \\
5.2\end{array}$ & $\begin{array}{r}4.8 \\
10.8 \\
15.0 \\
15.3 \\
8.0\end{array}$ & $\begin{array}{r}7.7 \\
11.9 \\
18.4 \\
13.8 \\
11.5\end{array}$ \\
\hline $\begin{array}{l}21 \\
22 \\
23 \\
24 \\
25\end{array}$ & $\begin{array}{r}8.4 \\
11.2 \\
1.3 \\
-3.0 \\
5.0\end{array}$ & $\begin{array}{l}4.5 \\
7.2\end{array}$ & $\begin{array}{r}8.5 \\
11.5 \\
1.2 \\
-3.2 \\
4.9\end{array}$ & $\begin{array}{l}4.1 \\
5.7\end{array}$ & $\begin{array}{r}8.6 \\
11.6 \\
1.0 \\
-3.4 \\
4.9\end{array}$ & $\begin{array}{l}3.8 \\
6.8\end{array}$ & $\begin{array}{r}8.6 \\
12.0 \\
0.7 \\
-\quad 3.7 \\
5.1\end{array}$ & $\begin{array}{l}3.3 \\
5.4\end{array}$ & $\begin{array}{r}9.9 \\
10.1 \\
9.5 \\
8.5 \\
7.8\end{array}$ & $\begin{array}{l}0.1 \\
3.5 \\
7.2 \\
3.0 \\
7.1\end{array}$ & $\begin{array}{r}10.4 \\
4.1 \\
9.7 \\
3.9 \\
8.0\end{array}$ & $\begin{array}{r}11.3 \\
5.1 \\
12.8 \\
6.8\end{array}$ & $\begin{array}{r}13.0 \\
6.3 \\
19.0 \\
3.2 \\
10.9\end{array}$ \\
\hline $\begin{array}{l}26 \\
27 \\
28 \\
29 \\
30\end{array}$ & $\begin{array}{l}3.5 \\
7.3 \\
6.8 \\
5.8 \\
7.7\end{array}$ & $\begin{array}{l}0.6 \\
3.3 \\
2.3 \\
2.3 \\
5.4\end{array}$ & $\begin{array}{l}3.3 \\
7.5 \\
5.8 \\
5.9 \\
8.0\end{array}$ & $\begin{array}{l}0.6 \\
3.1 \\
2.0 \\
2.1 \\
5.4\end{array}$ & $\begin{array}{l}3.1 \\
7.6 \\
6.9 \\
5.8 \\
8.3\end{array}$ & $\begin{array}{l}3.1 \\
1.9 \\
1.9 \\
5.3\end{array}$ & $\begin{array}{l}3.1 \\
8.1 \\
7.1 \\
6.5 \\
8.7\end{array}$ & $\begin{array}{l}0.0 \\
2.9 \\
1.6 \\
1.7 \\
5.5\end{array}$ & $\begin{array}{l}7.6 \\
8.2 \\
8.1 \\
3.1 \\
8.1\end{array}$ & $\begin{array}{l}2.2 \\
2.2 \\
4.4 \\
3.2 \\
4.0\end{array}$ & $\begin{array}{l}2.8 \\
2.5 \\
5.0 \\
3.7 \\
4.7\end{array}$ & $\begin{array}{l}4.8 \\
3.0 \\
5.8 \\
4.9 \\
5.7\end{array}$ & $\begin{array}{l}6.5 \\
3.8 \\
6.8 \\
5.3 \\
6.6\end{array}$ \\
\hline
\end{tabular}

\begin{tabular}{|c|c|c|c|c|c|c|c|c|c|c|c|c|c|}
\hline $\begin{array}{l}1 \\
2 \\
3 \\
4 \\
5\end{array}$ & $\begin{array}{r}11.9 \\
7.7 \\
1.5 \\
7.0 \\
-6.0\end{array}$ & $\begin{array}{l}7.8 \\
3.8\end{array}$ & $\begin{array}{r}12.4 \\
7.8 \\
1.4 \\
7.0 \\
-6.1\end{array}$ & $\begin{array}{l}7.9 \\
3.3\end{array}$ & $\begin{array}{r}13.0 \\
7.7 \\
1.2 \\
6.9 \\
-6.4\end{array}$ & $\begin{array}{l}7.9 \\
3.4 \\
2.1\end{array}$ & $\begin{array}{r}14.0 \\
7.8 \\
1.2 \\
6.9 \\
-6.9\end{array}$ & 3.4 & $\begin{array}{l}8.1 \\
7.9 \\
7.3 \\
6.4\end{array}$ & $\begin{array}{r}9.8 \\
6.5 \\
4.7 \\
12.5 \\
6.0\end{array}$ & $\begin{array}{r}11.5 \\
7.7 \\
5.4 \\
14.2 \\
9.2\end{array}$ & $\begin{array}{r}12.8 \\
11.1 \\
6.8 \\
16.6 \\
18.7\end{array}$ & $\begin{array}{r}15.4 \\
14.1 \\
8.0 \\
18.3 \\
27.8\end{array}$ \\
\hline $\begin{array}{r}6 \\
7 \\
8 \\
9 \\
10\end{array}$ & -10.7 & & -10.9 & & $-11 \cdot 3$ & & -11.8 & & 4.8 & $\begin{array}{l}3.4 \\
7.7 \\
5.6 \\
4.1 \\
3.7\end{array}$ & $\begin{array}{l}4.5 \\
8.5 \\
6.3 \\
4.5 \\
4.2\end{array}$ & $\begin{array}{l}9.2 \\
8.6 \\
6.5 \\
6.4\end{array}$ & $\begin{array}{r}11.4 \\
9.2 \\
7.9 \\
8.0 \\
7.6\end{array}$ \\
\hline $\begin{array}{l}11 \\
12 \\
13 \\
14 \\
15\end{array}$ & $\begin{array}{l}8.6 \\
3.2 \\
2.4 \\
5.0 \\
3.0\end{array}$ & $\begin{array}{l}4.6 \\
1.2 \\
3.3 \\
0.2\end{array}$ & $\begin{array}{l}8.8 \\
3.2 \\
2.5 \\
5.4 \\
2.9\end{array}$ & $\begin{array}{l}3.4 \\
0.5\end{array}$ & $\begin{array}{l}9.0 \\
3.2 \\
2.6 \\
5.7 \\
2.9\end{array}$ & $\begin{array}{l}4.3 \\
1.0 \\
3.5 \\
0.1\end{array}$ & $\begin{array}{l}9.3 \\
3.6 \\
2.9 \\
6.0 \\
3.1\end{array}$ & $\begin{array}{l}4.5 \\
1.1 \\
3.6 \\
0.2\end{array}$ & $\begin{array}{l}4.1 \\
3.9 \\
3.9 \\
4.4 \\
4.0\end{array}$ & $\begin{array}{l}5.2 \\
2.8 \\
2.5 \\
1.9 \\
2.8\end{array}$ & $\begin{array}{l}5.9 \\
3.2 \\
3.0 \\
2.4 \\
3.3\end{array}$ & $\begin{array}{l}8.4 \\
3.9 \\
3.7 \\
2.8 \\
4.3\end{array}$ & $\begin{array}{r}10.7 \\
5.1 \\
4.6 \\
3.2 \\
6.3\end{array}$ \\
\hline $\begin{array}{l}16 \\
17 \\
18 \\
19 \\
20\end{array}$ & $\begin{array}{l}3.0 \\
1.8 \\
0.8 \\
3.7 \\
1.9\end{array}$ & $\begin{array}{r}0.6 \\
-0.5 \\
1.2\end{array}$ & $\begin{array}{l}3.1 \\
1.6 \\
0.8 \\
3.7 \\
1.8\end{array}$ & 0.8 & $\begin{array}{l}3.2 \\
1.5 \\
0.8 \\
3.7 \\
1.8\end{array}$ & $\begin{array}{r}0.4 \\
-0.7 \\
0.9\end{array}$ & $\begin{array}{l}3.5 \\
1.5 \\
0.7 \\
3.8 \\
1.7\end{array}$ & $\begin{array}{r}0.6 \\
-0.7 \\
1.0\end{array}$ & $\begin{array}{l}4.1 \\
4.0 \\
4.0 \\
4.0 \\
3.9\end{array}$ & $\begin{array}{l}3.4 \\
3.4 \\
3.9 \\
4.5 \\
2.9\end{array}$ & $\begin{array}{l}4.0 \\
3.9 \\
4.5 \\
5.2 \\
3.4\end{array}$ & $\begin{array}{l}4.3 \\
5.0 \\
5.0 \\
5.6 \\
4.1\end{array}$ & $\begin{array}{l}5.6 \\
7.0 \\
5.7 \\
7.1 \\
5.5\end{array}$ \\
\hline $\begin{array}{l}21 \\
22 \\
23 \\
24 \\
25\end{array}$ & $\begin{array}{r}5.1 \\
6.1 \\
7.1 \\
7.7 \\
10.5\end{array}$ & $\begin{array}{l}3.2 \\
4.5 \\
5.7 \\
4.1 \\
5.8\end{array}$ & $\begin{array}{r}5.4 \\
5.5 \\
7.5 \\
8.2 \\
11.0\end{array}$ & $\begin{array}{l}3.6 \\
5.0\end{array}$ & $\begin{array}{r}5.6 \\
6.8 \\
7.9 \\
8.6 \\
11.6\end{array}$ & $\begin{array}{l}3.2 \\
4.9 \\
5.9 \\
4.1 \\
5.5\end{array}$ & $\begin{array}{r}5.8 \\
7.2 \\
8.3 \\
9.1 \\
12.3\end{array}$ & $\begin{array}{l}3.2 \\
5.0 \\
6.2 \\
4.3 \\
5.7\end{array}$ & $\begin{array}{l}4.2 \\
4.5 \\
4.8 \\
5.1 \\
5.0\end{array}$ & $\begin{array}{r}3.3 \\
6.7 \\
8.6 \\
2.9 \\
10.6\end{array}$ & $\begin{array}{r}4.1 \\
7.8 \\
10.1 \\
3.6 \\
12.3\end{array}$ & $\begin{array}{r}4.7 \\
8.5 \\
10.9 \\
4.4 \\
13.4\end{array}$ & $\begin{array}{r}5.7 \\
10.3 \\
13.3 \\
5.7 \\
16.6\end{array}$ \\
\hline $\begin{array}{l}26 \\
27 \\
28 \\
29 \\
30\end{array}$ & $\begin{array}{r}-0.2 \\
-4.5 \\
0.1 \\
1.9 \\
3.0\end{array}$ & 1.7 & $\begin{array}{r}-0.3 \\
-4.6 \\
0.0 \\
1.8 \\
3.1\end{array}$ & & $\begin{array}{r}-0.5 \\
-\quad 4.7 \\
0.1 \\
1.9 \\
3.1\end{array}$ & 1.6 & $\begin{array}{r}-0.8 \\
-5.0 \\
0.1 \\
1.7 \\
3.7\end{array}$ & $\begin{array}{r}-0.4 \\
1.6\end{array}$ & $\begin{array}{l}4.4 \\
4.0 \\
3.7 \\
3.5 \\
3.5\end{array}$ & $\begin{array}{l}8.9 \\
4.0 \\
5.9 \\
3.2 \\
5.7\end{array}$ & $\begin{array}{r}10.9 \\
4.6 \\
6.5 \\
3.6 \\
6.3\end{array}$ & $\begin{array}{r}13.9 \\
5.7 \\
7.0 \\
4.3 \\
6.8\end{array}$ & $\begin{array}{r}20.9 \\
7.8 \\
7.9 \\
4.6 \\
7.9\end{array}$ \\
\hline 31 & 6.5 & 3.3 & 6.8 & & 6.9 & 3.9 & 7.0 & 3.9 & 3.7 & 16.6 & 19.2 & 21.9 & 25.0 \\
\hline
\end{tabular}


TABLE 11

Table 11. -Daily averages of air and water temperatures and wind speeds, July 1950-August 1951, Lake Hefner-Con. DAILY AVERAGES

2952

\begin{tabular}{|c|c|c|c|c|c|c|c|c|c|c|c|c|c|}
\hline \multirow{4}{*}{$\stackrel{\sharp}{\text { म̆ }}$} & \multicolumn{8}{|c|}{ Average air temperature $\left({ }^{\circ} \mathrm{C}\right)$ at indicated height } & \multirow{4}{*}{$\begin{array}{c}\text { Average } \\
\text { water- } \\
\text { surface } \\
\text { temperature } \\
\left({ }^{\circ} \mathrm{C}\right)\end{array}$} & \multirow{2}{*}{\multicolumn{4}{|c|}{$\begin{array}{l}\text { Average wind speed (knots) } \\
\text { at indicated height }\end{array}$}} \\
\hline & \multirow{2}{*}{\multicolumn{2}{|c|}{$\begin{array}{c}2 \\
\text { meters }\end{array}$}} & \multirow{2}{*}{\multicolumn{2}{|c|}{$\begin{array}{c}4 \\
\text { meters }\end{array}$}} & \multirow{2}{*}{\multicolumn{2}{|c|}{$\begin{array}{c}8 \\
\text { meters } \\
\end{array}$}} & \multirow{2}{*}{\multicolumn{2}{|c|}{$\begin{array}{c}16 \\
\text { meters } \\
\end{array}$}} & & & & & \\
\hline & & & & & & & & & & & & & \\
\hline & $\begin{array}{l}\text { Dry } \\
\text { bulb }\end{array}$ & $\begin{array}{l}\text { Wet } \\
\text { bulb }\end{array}$ & $\begin{array}{l}\text { Dry } \\
\text { bulb }\end{array}$ & $\begin{array}{l}\text { Wet } \\
\text { bulb }\end{array}$ & $\begin{array}{l}\text { Dry } \\
\text { bulb }\end{array}$ & $\begin{array}{l}\text { Wet } \\
\text { bulb }\end{array}$ & $\begin{array}{l}\text { Dry } \\
\text { bulb }\end{array}$ & $\begin{array}{l}\text { Wet } \\
\text { bulb }\end{array}$ & & meters & meters & meters & meters \\
\hline
\end{tabular}

JANUARY

\begin{tabular}{|c|c|c|c|c|c|c|c|c|c|c|c|c|c|}
\hline $\begin{array}{l}1 \\
2 \\
3 \\
4 \\
5 \\
6 \\
7 \\
8 \\
9 \\
10\end{array}$ & $\begin{array}{r}2.3 \\
5.3 \\
5.6 \\
-2.8 \\
-2.8 \\
1.2 \\
2.4 \\
5.0 \\
2.8\end{array}$ & $\begin{array}{r}1.8 \\
-0.0\end{array}$ & $\begin{array}{r}2.2 \\
5.5 \\
5.7 \\
-\quad 2.9 \\
-1.3 \\
2.5 \\
5.2 \\
2.0\end{array}$ & & $\begin{array}{r}2.3 \\
5.7 \\
3.0 \\
-3.1 \\
-3.1 \\
-1.3 \\
2.6 \\
5.3 \\
2.8\end{array}$ & 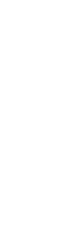 & $\begin{array}{r}2.3 \\
5.0 \\
5.5 \\
-3.4 \\
-1.4 \\
2.7 \\
5.5 \\
3.0\end{array}$ & $\begin{array}{l}3.1 \\
3.1\end{array}$ & $\begin{array}{l}4.2 \\
4.0 \\
3.9 \\
4.2 \\
4.1 \\
3.7 \\
3.2 \\
3.2 \\
3.0 \\
2.9\end{array}$ & $\begin{array}{r}10.8 \\
5.5 \\
5.3 \\
3.8 \\
\\
5.1 \\
9.1 \\
12.8 \\
6.5\end{array}$ & $\begin{array}{r}12.7 \\
6.5 \\
5.9 \\
4.5 \\
\\
5.3 \\
9.0 \\
14.7 \\
6.8\end{array}$ & $\begin{array}{r}15.3 \\
11.2 \\
5.8\end{array}$ & $\begin{array}{r}17.1 \\
14.1 \\
8.7 \\
7.1 \\
\\
7.8 \\
11.1 \\
18.8 \\
12.2\end{array}$ \\
\hline $\begin{array}{l}11 \\
12 \\
13 \\
14 \\
15\end{array}$ & $\begin{array}{l}3.6 \\
5.3 \\
5.0 \\
2.0 \\
5.5\end{array}$ & $\begin{array}{l}0.5 \\
4.8 \\
5.0 \\
1.0 \\
2.0\end{array}$ & $\begin{array}{l}3.7 \\
0.8 \\
5.0 \\
2.8 \\
5.6\end{array}$ & $\begin{array}{l}5.0 \\
3.7 \\
2.9\end{array}$ & $\begin{array}{l}3.8 \\
7.01 \\
5.1 \\
? .0 \\
6.2\end{array}$ & $\begin{array}{l}0.3 \\
5.1 \\
5.0 \\
1.6 \\
2.9\end{array}$ & $\begin{array}{l}3.9 \\
7.3 \\
5.7 \\
2.8 \\
6.5\end{array}$ & $\begin{array}{l}5.1 \\
1.5\end{array}$ & $\begin{array}{l}2.8 \\
3.2 \\
3.3 \\
3.0 \\
3.2\end{array}$ & $\begin{array}{r}10.0 \\
8.0 \\
4.3 \\
7.1 \\
4.4\end{array}$ & $\begin{array}{r}11.4 \\
9.4 \\
5.3 \\
8.1 \\
4.8\end{array}$ & $\begin{array}{r}13.5 \\
10.9 \\
6.8 \\
11.0 \\
6.7\end{array}$ & $\begin{array}{r}15.2 \\
12.5 \\
9.2 \\
14.6 \\
8.0\end{array}$ \\
\hline $\begin{array}{l}16 \\
17 \\
18 \\
19 \\
21\end{array}$ & 0.9 & $\begin{array}{l}4.3 \\
5.2\end{array}$ & $\begin{array}{r}3.5 \\
10.1 \\
0.9\end{array}$ & $\begin{array}{l}4.1 \\
4.5\end{array}$ & $\begin{array}{r}2.3 \\
10.7 \\
0.2\end{array}$ & $\begin{array}{l}4.1 \\
4.7\end{array}$ & $\begin{array}{r}9.6 \\
11.6 \\
0.6\end{array}$ & & $\begin{array}{l}3.6 \\
4.1 \\
4.1\end{array}$ & $\begin{array}{r}12.9 \\
10.3 \\
4.2 \\
10.5 \\
5.0\end{array}$ & $\begin{array}{r}14.9 \\
12.0 \\
5.5 \\
22.1 \\
5.9\end{array}$ & $\begin{array}{r}16.5 \\
12.4 \\
6.5 \\
13.0 \\
11.0\end{array}$ & $\begin{array}{r}19.6 \\
25.2 \\
8.5 \\
15.9 \\
14.0\end{array}$ \\
\hline $\begin{array}{l}21 \\
22 \\
23 \\
24 \\
25\end{array}$ & $\begin{array}{r}-2.2 \\
4.3\end{array}$ & $=0.3$ & $\begin{array}{r}2.3 \\
4.4\end{array}$ & -0.3 & $\begin{array}{r}-2.3 \\
4.5 \\
2.6\end{array}$ & -0.6 & $\begin{array}{r}-2.6 \\
4.6 \\
2.7\end{array}$ & & $\begin{array}{l}3.8 \\
3.4 \\
3.5\end{array}$ & $\begin{array}{r}3.6 \\
15.2 \\
2.7 \\
5.8 \\
6.9\end{array}$ & $\begin{array}{r}4.5 \\
17.4 \\
3.7 \\
6.5 \\
7.8\end{array}$ & $\begin{array}{r}5.8 \\
29.5 \\
6.7 \\
7.5 \\
8.6\end{array}$ & $\begin{array}{r}7.4 \\
22.1 \\
9.9 \\
10.0 \\
20.2\end{array}$ \\
\hline $\begin{array}{l}26 \\
27 \\
23 \\
29 \\
32\end{array}$ & $\begin{array}{r}3.5 \\
-0.0 \\
-9.0 \\
-11.6 \\
-10.8\end{array}$ & 3.8 & 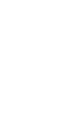 & 4.2 & $\begin{array}{r}9.3 \\
-1.1 \\
-10.3 \\
-12.0 \\
-11.1\end{array}$ & 3.9 & $\begin{array}{r}9.8 \\
-1.4 \\
-10.7 \\
-12.5 \\
-11.7\end{array}$ & & $\begin{array}{l}3.8 \\
3.8 \\
2.9 \\
2.4 \\
2.5\end{array}$ & $\begin{array}{r}13.6 \\
6.5 \\
5.3 \\
6.4 \\
5.3\end{array}$ & $\begin{array}{r}15.7 \\
8.5 \\
7.5 \\
8.2 \\
6.6\end{array}$ & $\begin{array}{r}17.1 \\
12.9 \\
12.2 \\
11.2 \\
8.5\end{array}$ & $\begin{array}{l}20.3 \\
19.7 \\
20.0 \\
17.5 \\
13.3\end{array}$ \\
\hline 31 & $-11 \cdot 0$ & & -11.2 & & $-11 \cdot 4$ & & $-11 \cdot 8$ & & 1.0 & $4 \cdot 2$ & 5.1 & 10.8 & 17.5 \\
\hline
\end{tabular}

FEBRUARY

\begin{tabular}{|c|c|c|c|c|c|c|c|c|c|c|c|c|c|}
\hline $\begin{array}{r}1 \\
2 \\
3 \\
4 \\
5 \\
\\
5 \\
7 \\
8 \\
9 \\
10\end{array}$ & $\begin{array}{r}-12.2 \\
-5.1 \\
-0.5 \\
3.6 \\
6.3 \\
-\quad 2.9 \\
3.9\end{array}$ & 4.7 & $\begin{array}{r}-12.2 \\
-5.0 \\
-0.5 \\
4.2 \\
6.0 \\
-3.0 \\
4.3\end{array}$ & 4.9 & $\begin{array}{r}-12.6 \\
-5.3 \\
-0.3 \\
4.5 \\
7.4 \\
-\quad 3.1 \\
4.8\end{array}$ & 5.5 & $\begin{array}{r}-12.8 \\
-5.3 \\
-\quad 0.2 \\
4.9 \\
7.9 \\
\\
-\quad 3.3 \\
5.1\end{array}$ & & 1.7 & $\begin{array}{r}5.3 \\
12.1 \\
10.4 \\
4.2 \\
13.7 \\
\\
6.5 \\
4.7 \\
9.5 \\
4.0 \\
10.4\end{array}$ & $\begin{array}{r}5.4 \\
13.1 \\
11.9 \\
4.8 \\
16.0 \\
7.8 \\
7.8 \\
5.5 \\
11.1 \\
5.1 \\
12.2\end{array}$ & $\begin{array}{r}9.1 \\
13.2 \\
5.7 \\
19.2 \\
12.6 \\
6.9 \\
12.4 \\
7.3 \\
13.7\end{array}$ & $\begin{array}{r}11.1 \\
14.8 \\
15.0 \\
21.8 \\
17.7 \\
9.3 \\
14.7 \\
10.3 \\
16.3\end{array}$ \\
\hline $\begin{array}{l}11 \\
12 \\
13 \\
14 \\
15\end{array}$ & $\begin{array}{r}11.9 \\
-8.1 \\
-6.9 \\
-7.4 \\
-\quad 5.0\end{array}$ & 9.4 & $\begin{array}{r}12.7 \\
-8.3 \\
-7.0 \\
-7.5 \\
-5.1\end{array}$ & C. & $\begin{array}{r}13.6 \\
-3.3 \\
-7.1 \\
-7.7 \\
-\quad 5.2\end{array}$ & 10.6 & $\begin{array}{r}15.1 \\
-8.5 \\
-7.5 \\
-\quad 8.0 \\
-5.4\end{array}$ & & $\begin{array}{l}3.2 \\
3.9 \\
2.9 \\
2.0 \\
1.6\end{array}$ & $\begin{array}{r}13.0 \\
12.4 \\
5.2 \\
4.7 \\
4.3\end{array}$ & $\begin{array}{r}15.5 \\
14.7 \\
8.9 \\
6.6 \\
4.5\end{array}$ & $\begin{array}{r}18.2 \\
18.9 \\
15.3 \\
11.9 \\
7.0\end{array}$ & $\begin{array}{r}21.9 \\
24.4 \\
24.2 \\
19.3 \\
8.6\end{array}$ \\
\hline $\begin{array}{l}16 \\
17 \\
18 \\
19 \\
20\end{array}$ & $\begin{array}{r}-0.4 \\
4.2\end{array}$ & 3,0 & $\begin{array}{r}-0.4 \\
4.4\end{array}$ & 3.1 & $\begin{array}{r}-0.3 \\
4.6\end{array}$ & 3.3 & $\begin{array}{r}-0.3 \\
4.9\end{array}$ & & $\begin{array}{l}1.3 \\
1.9\end{array}$ & $\begin{array}{r}7.3 \\
11.4 \\
8.6 \\
7.0 \\
6.5\end{array}$ & $\begin{array}{r}8.3 \\
13.2 \\
20.3 \\
8.7 \\
7.2\end{array}$ & $\begin{array}{l}15.4 \\
11.8 \\
10.8 \\
12.0\end{array}$ & $\begin{array}{l}10.4 \\
17.8 \\
14.4 \\
13.3 \\
13.9\end{array}$ \\
\hline $\begin{array}{l}21 \\
22 \\
23 \\
? 4 \\
25\end{array}$ & $\begin{array}{l}4.1 \\
7.8 \\
9.5 \\
9.6\end{array}$ & $\begin{array}{l}3.7 \\
6.0 \\
6.5 \\
7.6\end{array}$ & $\begin{array}{r}4.2 \\
8.6 \\
10.1 \\
10.1\end{array}$ & $\begin{array}{l}3.8 \\
6.6 \\
7.0 \\
7.8\end{array}$ & $\begin{array}{r}4.3 \\
9.5 \\
10.8 \\
10.4\end{array}$ & $\begin{array}{l}3.9 \\
6.9 \\
7.0 \\
7.9\end{array}$ & $\begin{array}{r}4.2 \\
10.2 \\
11.5 \\
11.3\end{array}$ & $\begin{array}{l}3.9 \\
7.3\end{array}$ & $\begin{array}{l}3.6 \\
4.6 \\
5.6 \\
5.7\end{array}$ & $\begin{array}{r}2.8 \\
5.8 \\
8.9 \\
10.4 \\
9.5\end{array}$ & $\begin{array}{r}3.7 \\
7.2 \\
20.8 \\
12.3 \\
12.3\end{array}$ & $\begin{array}{r}4.5 \\
9.3 \\
13.2 \\
14.9 \\
13.5\end{array}$ & $\begin{array}{r}5.5 \\
21.2 \\
15.0 \\
17.0 \\
16.3\end{array}$ \\
\hline $\begin{array}{l}26 \\
27 \\
? 8\end{array}$ & & & & & & & & & & $\begin{array}{r}2.6 \\
7.9 \\
10.6\end{array}$ & $\begin{array}{r}3.1 \\
9.4 \\
11.8\end{array}$ & $\begin{array}{r}4.2 \\
11.7 \\
13.3\end{array}$ & $\begin{array}{r}5.7 \\
13.5 \\
15.5\end{array}$ \\
\hline
\end{tabular}


Table 11. -Daily averages of air and water temperatures and wind speeds, July 1950-August 1951, Lake Hefner-Con. STATION 4 DAILY AVERAGES

\begin{tabular}{|c|c|c|c|c|c|c|c|c|c|c|c|c|c|}
\hline \multirow{4}{*}{$\stackrel{\Xi}{\square}$} & \multicolumn{8}{|c|}{ A verage air temperature $\left({ }^{\circ} \mathrm{C}\right)$ at indicated height } & \multirow{4}{*}{$\begin{array}{c}\text { Average } \\
\text { water- } \\
\text { surface } \\
\text { temperature } \\
\left({ }^{\circ} \mathrm{C}\right) \\
\end{array}$} & \multirow{2}{*}{\multicolumn{4}{|c|}{$\begin{array}{l}\text { Average wind speed (knots) } \\
\text { at indicated height }\end{array}$}} \\
\hline & \multirow{2}{*}{\multicolumn{2}{|c|}{$\begin{array}{c}2 \\
\text { meters }\end{array}$}} & \multirow{2}{*}{\multicolumn{2}{|c|}{$\begin{array}{c}4 \\
\text { meters }\end{array}$}} & \multirow{2}{*}{\multicolumn{2}{|c|}{$\begin{array}{c}8 \\
\text { meters }\end{array}$}} & \multirow{2}{*}{\multicolumn{2}{|c|}{$\begin{array}{c}16 \\
\text { meters }\end{array}$}} & & & & & \\
\hline & & & & & & & & & & & & & \\
\hline & $\begin{array}{l}\text { Dry } \\
\text { bulb }\end{array}$ & $\begin{array}{l}\text { Wet } \\
\text { bulb }\end{array}$ & $\begin{array}{l}\text { Dry } \\
\text { bulb }\end{array}$ & $\begin{array}{l}\text { Wet } \\
\text { bulb }\end{array}$ & $\begin{array}{l}\text { Dry } \\
\text { bulb }\end{array}$ & $\begin{array}{l}\text { Wet } \\
\text { bulb }\end{array}$ & $\begin{array}{l}\text { Dry } \\
\text { bulb }\end{array}$ & $\begin{array}{l}\text { Wet } \\
\text { butb }\end{array}$ & & meters & meters & meters & meters \\
\hline \multicolumn{14}{|c|}{ MARCH } \\
\hline $\begin{array}{l}1 \\
2 \\
3 \\
4 \\
5\end{array}$ & $\begin{array}{r}15.3 \\
7.4 \\
5.8 \\
12.2\end{array}$ & $\begin{array}{r}11.9 \\
2.9 \\
2.6 \\
6.0\end{array}$ & $\begin{array}{r}16.1 \\
7.4 \\
5.8 \\
12.6\end{array}$ & $\begin{array}{r}12.2 \\
2.8 \\
2.4 \\
5.9\end{array}$ & $\begin{array}{r}17.1 \\
7.3 \\
6.0 \\
13.1\end{array}$ & $\begin{array}{r}12.6 \\
2.5 \\
2.2 \\
5.8\end{array}$ & $\begin{array}{r}17.8 \\
7.0 \\
5.9 \\
13.5\end{array}$ & $\begin{array}{l}2.2 \\
2.1 \\
5.7\end{array}$ & $\begin{array}{l}8.2 \\
7.3 \\
8: 1 \\
7.8\end{array}$ & $\begin{array}{r}7.5 \\
13.3 \\
7.7 \\
5.1 \\
14.0\end{array}$ & $\begin{array}{r}8.5 \\
15.4 \\
8.5 \\
6.1 \\
16.0\end{array}$ & $\begin{array}{r}10.4 \\
17.0 \\
10.0 \\
7.1 \\
17.9\end{array}$ & $\begin{array}{r}11.5 \\
20.7 \\
12.1 \\
8.5 \\
20.8\end{array}$ \\
\hline $\begin{array}{r}6 \\
7 \\
8 \\
9 \\
10\end{array}$ & $\begin{array}{r}12.2 \\
5.2 \\
3.4 \\
-0.3 \\
6.4\end{array}$ & $\begin{array}{l}8.6 \\
2.3 \\
0.9 \\
5.9\end{array}$ & $\begin{array}{r}12.5 \\
5.2 \\
3.4 \\
-0.5 \\
6.5\end{array}$ & $\begin{array}{l}3.7 \\
2.2 \\
0.8 \\
6.0\end{array}$ & $\begin{array}{r}13.2 \\
5.1 \\
3.3 \\
-0.6 \\
6.5\end{array}$ & $\begin{array}{l}8.8 \\
2.1 \\
0.7 \\
6.0\end{array}$ & $\begin{array}{r}13.5 \\
5.1 \\
3.0 \\
-0.9 \\
6.6\end{array}$ & $\begin{array}{l}8.9 \\
1.8 \\
0.4 \\
6.0\end{array}$ & $\begin{array}{l}8.0 \\
7.5 \\
7.3 \\
7.0 \\
7.2\end{array}$ & $\begin{array}{l}7.5 \\
3.4 \\
5.1 \\
3.6 \\
5.9\end{array}$ & $\begin{array}{l}4.3 \\
6.0\end{array}$ & $\begin{array}{r}11.4 \\
6.1 \\
9.1 \\
0.4 \\
8.6\end{array}$ & $\begin{array}{r}9.7 \\
10.2\end{array}$ \\
\hline $\begin{array}{l}11 \\
12 \\
13 \\
14 \\
15\end{array}$ & $\begin{array}{r}-0.1 \\
=2.3 \\
= \\
1.3 \\
1.6 \\
3.3\end{array}$ & 0.9 & $\begin{array}{r}-0.3 \\
-2.4 \\
-1.4 \\
1.5 \\
3.2\end{array}$ & 0.9 & $\begin{array}{r}-0.4 \\
=2.5 \\
-1.6 \\
1.6 \\
3.3\end{array}$ & 0.6 & $\begin{array}{r}-0.7 \\
-2.8 \\
-1.7 \\
1.5 \\
3.4\end{array}$ & 0.6 & $\begin{array}{l}6.6 \\
5.7 \\
5.1 \\
5.0 \\
5.2\end{array}$ & $\begin{array}{l}7.0 \\
7.1 \\
6.4 \\
4.0 \\
3.4\end{array}$ & $\begin{array}{l}7.9 \\
7.0 \\
6.5 \\
4.2 \\
3.9\end{array}$ & $\begin{array}{r}17.2 \\
17.0 \\
12.7 \\
6.2 \\
4.7\end{array}$ & $\begin{array}{r}24.1 \\
23.9 \\
15.0 \\
7.1 \\
5.0\end{array}$ \\
\hline $\begin{array}{l}16 \\
17 \\
18 \\
19 \\
20\end{array}$ & $\begin{array}{l}8.9 \\
7.0\end{array}$ & $\begin{array}{l}5.7 \\
4.4\end{array}$ & $\begin{array}{l}9.5 \\
7.0\end{array}$ & & $\begin{array}{r}10.4 \\
7.0\end{array}$ & $\begin{array}{l}5.2 \\
4.3\end{array}$ & $\begin{array}{r}11.1 \\
7.0\end{array}$ & $\begin{array}{l}6.4 \\
4.1\end{array}$ & $\begin{array}{l}5.8 \\
5.9\end{array}$ & $\begin{array}{r}10.2 \\
3.3 \\
4.8 \\
4.9 \\
10.6\end{array}$ & $\begin{array}{r}12.1 \\
6.2 \\
5.3 \\
12.1\end{array}$ & $\begin{array}{r}15.0 \\
14.6 \\
11.2 \\
6.2 \\
13.4\end{array}$ & $\begin{array}{r}17.0 \\
17.0 \\
18.1 \\
7.5 \\
16.5\end{array}$ \\
\hline $\begin{array}{l}21 \\
22 \\
23 \\
24 \\
25\end{array}$ & $\begin{array}{r}3.9 \\
14 . ? \\
12.1 \\
7.5 \\
11.9\end{array}$ & $\begin{array}{l}7.7 \\
5.5 \\
3.4 \\
5.5\end{array}$ & $\begin{array}{r}4.0 \\
15.1 \\
12.2 \\
7.6 \\
12.4\end{array}$ & & $\begin{array}{r}4.4 \\
15.1 \\
12.4 \\
7.8 \\
13.0\end{array}$ & $\begin{array}{l}9.0 \\
5.4 \\
2.7 \\
5.1\end{array}$ & $\begin{array}{r}4.5 \\
17.0 \\
12.3 \\
8.0 \\
13.3\end{array}$ & $\begin{array}{l}9.2 \\
5.3 \\
2.7 \\
5.1\end{array}$ & $\begin{array}{l}6.4 \\
7.3 \\
6.9 \\
8.0 \\
8.0\end{array}$ & $\begin{array}{r}4.0 \\
11.8 \\
8.3 \\
4.4 \\
7.5\end{array}$ & $\begin{array}{r}4.7 \\
13.7 \\
9.0 \\
5.0 \\
8.6\end{array}$ & $\begin{array}{r}6.0 \\
15.7 \\
14.4 \\
5.5 \\
9.2\end{array}$ & $\begin{array}{r}7.5 \\
28.8 \\
18.2 \\
6.7 \\
10.9\end{array}$ \\
\hline $\begin{array}{l}26 \\
27 \\
28 \\
29 \\
30\end{array}$ & 11.0 & 6.9 & $\begin{array}{r}11.2 \\
11.3 \\
7.5 \\
5.1 \\
9.7\end{array}$ & $\begin{array}{r}10.4 \\
6.8 \\
2.0\end{array}$ & $\begin{array}{r}11.0 \\
11.5 \\
7.5 \\
4.7 \\
9.0\end{array}$ & $\begin{array}{r}5.6 \\
10.4 \\
6.0 \\
1.5 \\
3.9\end{array}$ & $\begin{array}{r}11.9 \\
11.7 \\
7.5 \\
4.6 \\
10.1\end{array}$ & $\begin{array}{r}5.5 \\
10.6 \\
6.6 \\
1.1 \\
3.7\end{array}$ & $\begin{array}{l}9.4 \\
8.7 \\
3.6 \\
7.7 \\
8.4\end{array}$ & $\begin{array}{r}10.9 \\
14.1 \\
12.3 \\
9.0 \\
8.0\end{array}$ & $\begin{array}{r}12.8 \\
16.4 \\
13.1 \\
9.0\end{array}$ & $\begin{array}{r}15.2 \\
19.5 \\
17.2 \\
15.3 \\
9.4\end{array}$ & $\begin{array}{l}17.7 \\
22.2 \\
19.5 \\
18.2 \\
10.8\end{array}$ \\
\hline 31 & & & 13.6 & & 13.8 & 7.8 & 14.0 & 7.7 & 9.0 & 7.0 & 8.2 & 9.7 & 12.6 \\
\hline
\end{tabular}

\begin{tabular}{l|l|r|r|r|r|r|r|r|r|r|r|r}
\hline 1 \\
\hline 2 \\
3 \\
4 \\
5
\end{tabular}


TABLE 11

Table 11. -Daily averages of air and water temperatures and wind speeds, July 1950-August i951, Lake Hefner-Con.

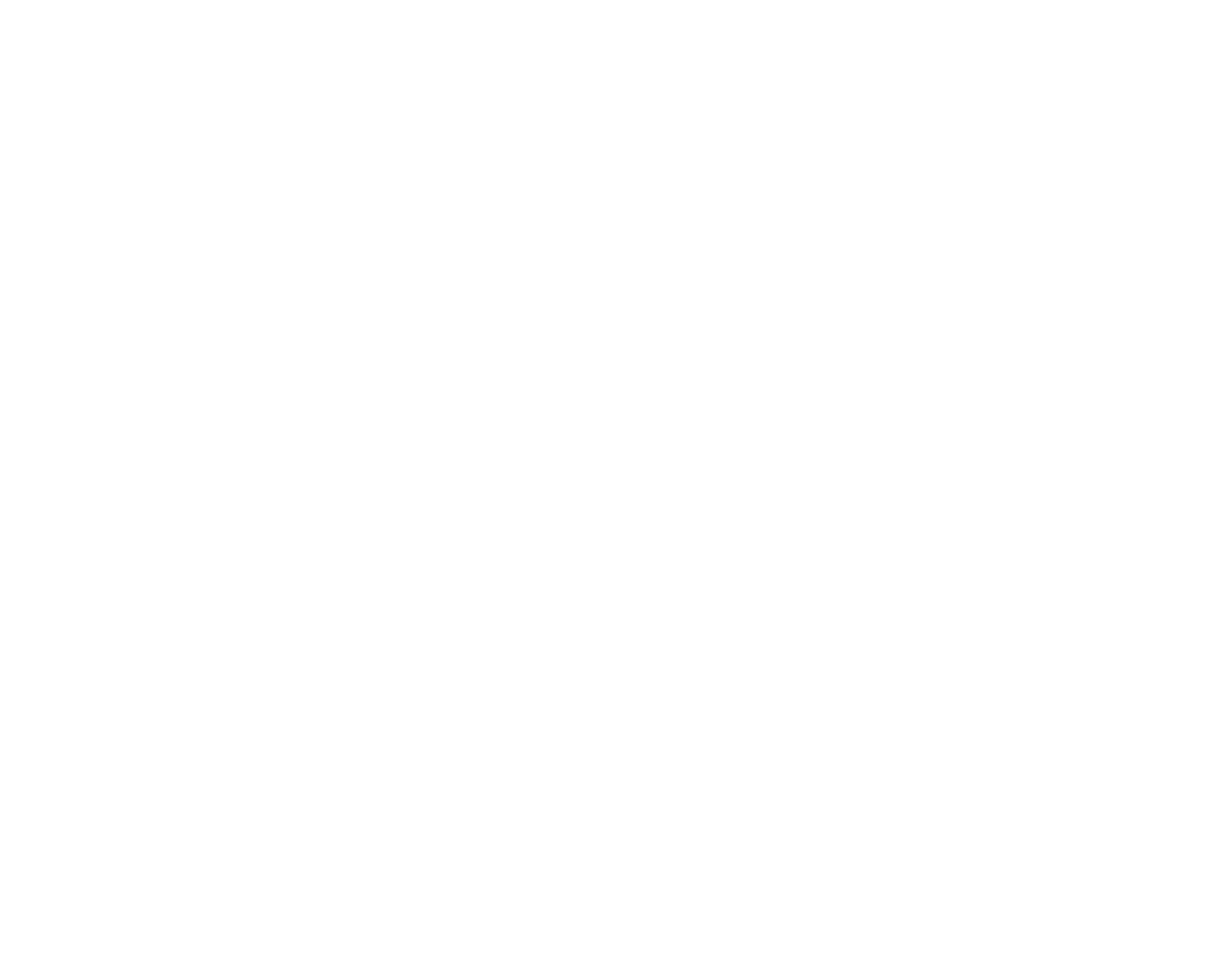

\begin{tabular}{r|r|r|r|r|r|r|r|r|r|r|r|r}
\hline 1 \\
2 \\
3 \\
4 \\
5
\end{tabular}


Table 11. -Daily averages of air and water temperaturts and wind speeds, July 1950-August 1951, Lake Hefner-Con. STATION 4 DAILY AVERAGES

\begin{tabular}{|c|c|c|c|c|c|c|c|c|c|c|c|c|c|}
\hline \multirow{4}{*}{$\stackrel{\Xi}{5}$} & \multicolumn{8}{|c|}{ Average air temperature $\left({ }^{\circ} \mathrm{C}\right)$ at indicated height } & \multirow{4}{*}{$\begin{array}{c}\text { Average } \\
\text { water- } \\
\text { surface } \\
\text { temperature } \\
\left({ }^{\circ} \mathrm{C}\right)\end{array}$} & \multirow{2}{*}{\multicolumn{4}{|c|}{$\begin{array}{l}\text { Average wind speed (knots) } \\
\text { at indicated height }\end{array}$}} \\
\hline & \multirow{2}{*}{\multicolumn{2}{|c|}{$\begin{array}{c}2 \\
\text { meters }\end{array}$}} & \multirow{2}{*}{\multicolumn{2}{|c|}{$\begin{array}{c}4 \\
\text { meters } \\
\end{array}$}} & \multirow{2}{*}{\multicolumn{2}{|c|}{$\begin{array}{c}8 \\
\text { meters }\end{array}$}} & \multirow{2}{*}{\multicolumn{2}{|c|}{$\begin{array}{c}16 \\
\text { meters }\end{array}$}} & & & & & \\
\hline & & & & & & & & & & & & & \\
\hline & $\begin{array}{l}\text { Dry } \\
\text { bulb }\end{array}$ & $\begin{array}{l}\text { Wet } \\
\text { bulb }\end{array}$ & $\begin{array}{l}\text { Dry } \\
\text { bulb }\end{array}$ & $\begin{array}{l}\text { Wet } \\
\text { bulb }\end{array}$ & $\begin{array}{l}\text { Dry } \\
\text { bulb }\end{array}$ & $\begin{array}{l}\text { Wet } \\
\text { bulb }\end{array}$ & $\begin{array}{l}\text { Dry } \\
\text { butb }\end{array}$ & $\begin{array}{l}\text { Wet } \\
\text { bulb }\end{array}$ & & $\stackrel{2}{2}_{\text {meters }}$ & $\begin{array}{c}4 \\
\text { meters }\end{array}$ & $\begin{array}{c}8 \\
\text { meters }\end{array}$ & $\begin{array}{c}16 \\
\text { meters }\end{array}$ \\
\hline \multicolumn{14}{|c|}{ JULY } \\
\hline $\begin{array}{l}1 \\
2 \\
3 \\
4 \\
5\end{array}$ & & & $\begin{array}{l}17.6 \\
22.4 \\
26.2 \\
23.4 \\
26.4\end{array}$ & $\begin{array}{l}16.7 \\
20.2 \\
23.6 \\
20.5 \\
22.8\end{array}$ & $\begin{array}{l}17 . ? \\
22 \cdot 3 \\
26.4 \\
23.3 \\
26.6\end{array}$ & $\begin{array}{l}16.1 \\
20.0 \\
23.5 \\
20.4 \\
22.6\end{array}$ & $\begin{array}{l}17.0 \\
22.2 \\
26.5 \\
23.2 \\
26.6\end{array}$ & $\begin{array}{l}15.8 \\
19.7 \\
23.3 \\
20.2 \\
? .3\end{array}$ & $\begin{array}{l}24 . ? \\
25.2 \\
25.5 \\
24.7 \\
25.7\end{array}$ & $\begin{array}{r}11.2 \\
7.7 \\
10.7\end{array}$ & $\begin{array}{r}7.5 \\
8.7 \\
13.0 \\
8.8 \\
12.5\end{array}$ & $\begin{array}{r}8.5 \\
10.2 \\
14.6 \\
10.0 \\
14.1\end{array}$ & $\begin{array}{r}9.4 \\
11.1 \\
16.8 \\
11.1 \\
16.0\end{array}$ \\
\hline $\begin{array}{r}6 \\
7 \\
8 \\
9 \\
10\end{array}$ & & & $\begin{array}{l}26.8 \\
27.0 \\
27.3 \\
27.0 \\
27.2\end{array}$ & $\begin{array}{l}27.4 \\
22.1 \\
21.9 \\
22.3 \\
? 2.8\end{array}$ & $\begin{array}{l}26.9 \\
77.0 \\
27.3 \\
27.1 \\
77.2\end{array}$ & $\begin{array}{l}22.1 \\
21.8 \\
21: 7 \\
22.1 \\
72.5\end{array}$ & $\begin{array}{l}26.5 \\
27.1 \\
27.4 \\
27.2 \\
77.3\end{array}$ & $\begin{array}{l}-1.9 \\
? 1.0 \\
? 1.5 \\
? ? .0 \\
? ? .4\end{array}$ & $\begin{array}{l}25.7 \\
25.8 \\
25.6 \\
25.8 \\
25.0\end{array}$ & $\begin{array}{l}11.9 \\
12.1 \\
13.8 \\
10.1 \\
11.0\end{array}$ & $\begin{array}{l}13.9 \\
14.1 \\
15.9 \\
11.7 \\
12.8\end{array}$ & $\begin{array}{l}15.4 \\
15.6 \\
17.4 \\
13.2 \\
14.9\end{array}$ & $\begin{array}{l}17.6 \\
17.8 \\
20.0 \\
15.1 \\
16.6\end{array}$ \\
\hline $\begin{array}{l}11 \\
12 \\
13 \\
14 \\
15\end{array}$ & & & $\begin{array}{l}27.0 \\
27.7 \\
25.7 \\
23.5 \\
26.0\end{array}$ & $\begin{array}{l}22.5 \\
22.0 \\
23.4 \\
23.0 \\
22.8\end{array}$ & $\begin{array}{l}27.0 \\
77.8 \\
25.6 \\
23.4 \\
25.8\end{array}$ & $\begin{array}{l}22.2 \\
22.6 \\
22.4 \\
21.8 \\
22.7\end{array}$ & $\begin{array}{l}27.0 \\
27.8 \\
25.3 \\
23.2 \\
25.0\end{array}$ & $\begin{array}{l}32.2 \\
32.5 \\
32.2 \\
21.6 \\
22.4\end{array}$ & $\begin{array}{l}26.0 \\
26.8 \\
26.9 \\
26.4 \\
26.6\end{array}$ & $\begin{array}{r}10.3 \\
9.5 \\
5.6 \\
7.1 \\
8.4\end{array}$ & $\begin{array}{r}11.9 \\
11.0 \\
6.2 \\
7.9 \\
9.5\end{array}$ & $\begin{array}{r}13.6 \\
12.1 \\
7.0 \\
9.0 \\
11.1\end{array}$ & $\begin{array}{r}15.2 \\
13.8 \\
8.0 \\
8.6 \\
12.0\end{array}$ \\
\hline $\begin{array}{l}16 \\
17 \\
18 \\
19 \\
20\end{array}$ & & & $\begin{array}{l}27.4 \\
27.9 \\
29.0\end{array}$ & $\begin{array}{l}22.5 \\
23.2\end{array}$ & $\begin{array}{l}27.4 \\
27.9 \\
28.3 \\
27.8 \\
29.0\end{array}$ & $\begin{array}{l}22.2 \\
22.3 \\
21.4 \\
22.4 \\
23.0\end{array}$ & $\begin{array}{l}27.5 \\
27.8 \\
28.3 \\
27.8 \\
29.0\end{array}$ & $\begin{array}{l}21.8 \\
22.2 \\
21 . ? \\
22.1 \\
22.7\end{array}$ & $\begin{array}{l}27.7 \\
29.1 \\
29.5 \\
29.4 \\
29.2\end{array}$ & $\begin{array}{l}6.3 \\
4.7 \\
5.8 \\
4.3 \\
9.5\end{array}$ & $\begin{array}{r}7.2 \\
5.3 \\
6.7 \\
11.0\end{array}$ & $\begin{array}{r}7.9 \\
5.7 \\
7.2 \\
5.4 \\
12.7\end{array}$ & $\begin{array}{r}8.9 \\
6.3 \\
7.8 \\
5.9 \\
14.1\end{array}$ \\
\hline $\begin{array}{l}21 \\
22 \\
23 \\
24 \\
25\end{array}$ & & & $\begin{array}{l}30.0 \\
29 \cdot 1 \\
26.3 \\
24.9 \\
26.0\end{array}$ & $\begin{array}{l}23.0 \\
22.8 \\
22.4 \\
22.0 \\
22.6\end{array}$ & $\begin{array}{l}30.1 \\
29.3 \\
26.1 \\
24.7 \\
25.8\end{array}$ & $\begin{array}{l}22 \cdot 7 \\
22: 6 \\
22.2 \\
21.9 \\
22.4\end{array}$ & $\begin{array}{l}30.2 \\
29.3 \\
25.8 \\
24.4 \\
25.8\end{array}$ & $\begin{array}{l}22.4 \\
? 2.3 \\
22.1 \\
21.7 \\
32.1\end{array}$ & $\begin{array}{l}28.3 \\
28.1 \\
27.8 \\
27.7 \\
28.1\end{array}$ & $\begin{array}{r}13.2 \\
8.4 \\
5.1 \\
4.2 \\
4.0\end{array}$ & $\begin{array}{r}25.1 \\
9.7 \\
6.8\end{array}$ & $\begin{array}{r}16.5 \\
10.9 \\
6.8 \\
5.5 \\
5.2\end{array}$ & $\begin{array}{r}18.8 \\
12.3 \\
8.2 \\
6.0 \\
5.6\end{array}$ \\
\hline $\begin{array}{l}26 \\
27 \\
28 \\
29 \\
30\end{array}$ & & & $\begin{array}{l}25.9 \\
27.1 \\
28.1 \\
27.0 \\
27.7\end{array}$ & $\begin{array}{l}22.4 \\
22.8 \\
23.2 \\
22.0 \\
23.2\end{array}$ & $\begin{array}{l}25.6 \\
27.0 \\
28.0 \\
27.0 \\
27.6\end{array}$ & $\begin{array}{l}22 \cdot 2 \\
22.7 \\
23.1 \\
21.0 \\
2 ? .9\end{array}$ & $\begin{array}{l}25.5 \\
26.9 \\
27.9 \\
26.9 \\
27.5\end{array}$ & $\begin{array}{l}32.0 \\
23.6 \\
23.0 \\
21.7 \\
22.8\end{array}$ & $\begin{array}{l}28.3 \\
28.8 \\
29.1 \\
29.1 \\
29.7\end{array}$ & $\begin{array}{l}8.2 \\
5.2 \\
3.6 \\
4.1 \\
6.1\end{array}$ & 9.4 & $\begin{array}{r}10.5 \\
6.6 \\
4.4 \\
5.3 \\
7.5\end{array}$ & $\begin{array}{r}11.2 \\
7.0 \\
5.1 \\
5.8 \\
8.1\end{array}$ \\
\hline 31 & & & 25.8 & 27,4 & 25.7 & 22.3 & 25.5 & 23.2 & 29.6 & 4.6 & 5.2 & 6.0 & 6.9 \\
\hline
\end{tabular}

AUGUST

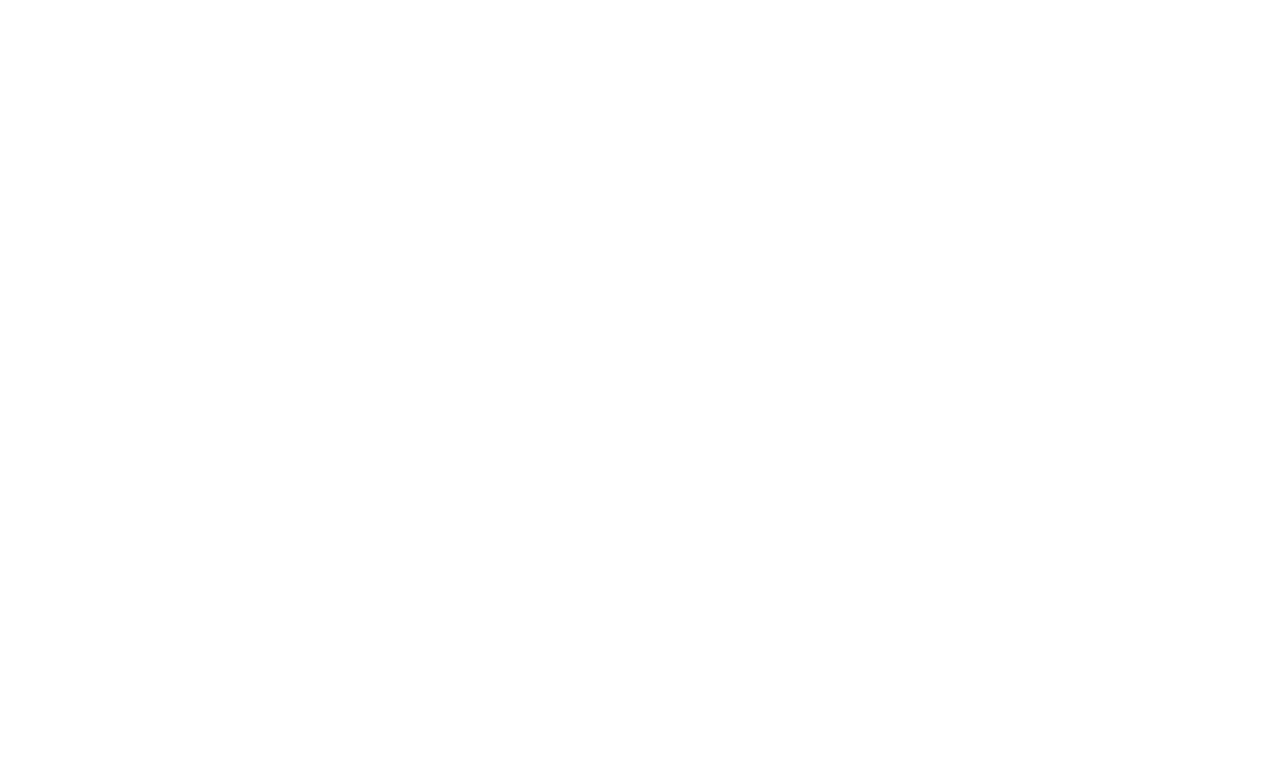


TABLE 12

Table 12.-Daily mean solar radiation, in calories per square centimeter per day

[* indicates questionable or missing data]

\begin{tabular}{|c|c|c|c|c|c|c|c|c|c|c|c|c|c|c|c|c|}
\hline \multirow{2}{*}{ Day } & \multicolumn{8}{|c|}{1950} & \multicolumn{8}{|c|}{1951} \\
\hline & May & June & July & Aug. & Sept. & Oct. & Nov. & Dec. & Jan. & Feb. & Mar. & Apr. & May & June & July & Aug. \\
\hline 1 & 321 & * & 691 & * & 622 & * & 343 & 283 & * & 391 & 447 & 133 & * & * & * & 665 \\
\hline 2 & $*$ & * & 657 & * & 511 & * & 165 & 262 & * & 386 & 174 & 651 & 730 & $*$ & 630 & 679 \\
\hline 3 & * & * & 488 & * & 188 & * & 61 & 293 & 320 & 348 & 490 & * & 727 & 564 & 637 & 612 \\
\hline 4 & * & * & * & * & * & 472 & 376 & * & 253 & 327 & 503 & 461 & 714 & 680 & 461 & 668 \\
\hline 5 & * & * & 510 & * & * & * & 366 & 94 & 292 & 234 & * & * & 589 & 464 & * & 675 \\
\hline 6 & * & * & * & 444 & * & 402 & 340 & 316 & 276 & * & 288 & 363 & 271 & * & 734 & 663 \\
\hline 7 & * & * & * & 595 & 608 & $*$ & 283 & 128 & 313 & * & 442 & * & 693 & * & 726 & 646 \\
\hline 8 & * & * & * & 656 & 596 & 483 & 272 & 289 & 327 & * & 323 & 671 & 627 & 726 & * & 364 \\
\hline 9 & * & * & 241 & 660 & $*$ & $*$ & 358 & 276 & * & 379 & $*$ & 681 & $*$ & * & * & * \\
\hline 10 & * & * & * & 557 & 387 & 356 & 357 & * & 324 & 372 & 213 & 300 & 341 & * & * & * \\
\hline 11 & * & $*$ & * & 581 & 293 & $*$ & 336 & * & 171 & 380 & 136 & 521 & 720 & * & * & * \\
\hline 12 & 622 & 673 & * & 627 & $*$ & 456 & 338 & * & 219 & 332 & 348 & 561 & 493 & * & 731 & * \\
\hline 13 & 643 & 719 & 682 & 648 & * & * & 325 & 247 & * & 37 & 560 & 682 & * & 702 & * & 664 \\
\hline 14 & * & * & $*$ & * & 173 & 429 & * & 233 & * & 115 & 539 & 667 & * & 642 & * & 662 \\
\hline 15 & 714 & * & * & * & 377 & 410 & 268 & 258 & 325 & 216 & 387 & 660 & 211 & 672 & 644 & 641 \\
\hline 16 & * & 717 & * & * & 155 & 417 & 322 & * & 331 & 435 & * & 613 & 375 & 735 & * & 643 \\
\hline 17 & * & * & 250 & * & * & * & 215 & * & 272 & 372 & 340 & 581 & 180 & 723 & * & 648 \\
\hline 18 & 574 & * & 188 & 637 & 420 & 352 & 239 & * & 337 & * & 542 & 559 & 436 & 417 & 677 & 473 \\
\hline 19 & * & * & 359 & 658 & 404 & 160 & 265 & * & 340 & 341 & * & 610 & * & * & 621 & 640 \\
\hline 20 & * & * & * & 193 & 516 & 176 & 323 & 171 & 192 & * & 494 & * & * & * & 696 & $65 \mathrm{C}$ \\
\hline 21 & * & * & * & * & 505 & * & 302 & 255 & 293 & * & 577 & 524 & 618 & * & 689 & $18 \varepsilon$ \\
\hline 22 & * & * & * & * & 487 & 422 & 304 & * & 282 & 437 & 528 & 636 & * & * & 706 & $27 i$ \\
\hline 23 & * & 545 & * & * & 523 & 400 & 217 & * & 304 & 299 & 534 & 668 & * & 596 & 512 & $34 ؟$ \\
\hline 24 & * & 718 & 568 & * & 499 & 401 & 329 & 273 & 282 & 259 & 513 & 558 & * & 646 & 487 & 623 \\
\hline 25 & * & 736 & * & * & 421 & 345 & 288 & 259 & 331 & 60 & 562 & 410 & * & 474 & 670 & 612 \\
\hline 26 & 171 & * & * & * & $*$ & 396 & 295 & 282 & 353 & 459 & 271 & 580 & $*$ & 722 & * & 616 \\
\hline 27 & 542 & * & * & * & * & 400 & 288 & 240 & 152 & 410 & * & 615 & 335 & 715 & 679 & 628 \\
\hline 28 & 435 & 531 & * & * & * & 382 & 282 & 290 & 213 & 400 & * & 609 & 654 & 640 & 634 & 619 \\
\hline 29 & * & 320 & * & * & * & * & 264 & 67 & 337 & & 550 & * & 700 & 483 & 572 & 622 \\
\hline 30 & * & 673 & * & * & * & * & 271 & * & 292 & & 612 & * & * & 239 & 671 & 632 \\
\hline 31 & * & & * & 485 & & 362 & & 268 & 219 & & 485 & & * & & 271 & 619 \\
\hline
\end{tabular}


Table 13. -Daily mean reflected solar radiation, in calories per square centimeter per day

[* indicates questionable or missing data]

\begin{tabular}{|c|c|c|c|c|c|c|c|c|c|c|c|c|c|c|c|c|}
\hline \multirow{2}{*}{ Day } & \multicolumn{8}{|c|}{1950} & \multicolumn{8}{|c|}{1951} \\
\hline & M ay & June & July & Aug. & Sept. & Oct. & Nov. & Dec. & Jan. & Feb. & Mar. & Apr. & May & June & July & Aug. \\
\hline 1 & 26 & * & 44 & * & 38 & * & 24 & 23 & * & 32 & 30 & 9 & * & * & 13 & 37 \\
\hline 2 & * & * & 47 & * & 29 & * & 10 & 24 & * & 47 & 8 & 46 & 34 & * & * & 38 \\
\hline 3 & * & * & 34 & * & 13 & $*$ & 4 & 31 & 32 & 30 & 40 & * & 43 & * & 37 & 32 \\
\hline 4 & * & * & * & * & * & 21 & 32 & * & 30 & 22 & 37 & 23 & 39 & * & 21 & 30 \\
\hline 5 & * & * & 34 & * & * & * & 26 & 9 & 31 & 11 & 30 & * & 29 & * & 35 & 34 \\
\hline 6 & * & * & * & 34 & * & 21 & 25 & 36 & 25 & * & 21 & 22 & 17 & * & 38 & 33 \\
\hline 7 & * & * & * & 38 & 36 & 19 & 20 & 13 & 36 & * & 30 & 34 & 37 & * & 41 & 33 \\
\hline 8 & * & * & * & 46 & 34 & 27 & 18 & 32 & 33 & * & 22 & 43 & 25 & * & * & 21 \\
\hline 9 & * & * & 21 & 42 & * & $*$ & 31 & 30 & * & * & * & 45 & 17 & * & 38 & * \\
\hline 10 & * & * & * & 37 & 22 & 18 & 31 & * & 33 & * & 15 & 15 & * & * & * & * \\
\hline 11 & $*$ & * & * & 32 & 19 & * & 28 & * & 14 & * & 8 & 42 & 41 & * & * & * \\
\hline 12 & 43 & 55 & * & 40 & 8 & 23 & 28 & * & 19 & * & 25 & 40 & 29 & * & 38 & 28 \\
\hline 13 & 36 & 55 & 47 & 41 & * & * & 29 & 26 & * & * & 41 & 45 & * & 38 & * & 28 \\
\hline 14 & * & $*$ & * & * & 11 & 19 & * & 22 & * & * & 41 & 41 & * & 30 & * & 28 \\
\hline 15 & 51 & $*$ & * & * & 20 & 20 & 17 & 26 & 32 & * & 29 & 44 & 6 & 36 & 32 & 27 \\
\hline 16 & * & 55 & * & * & 10 & 22 & 28 & * & 26 & * & * & 43 & 17 & 39 & * & 27 \\
\hline 17 & * & * & 21 & * & $*$ & 25 & 17 & * & 23 & * & 22 & 33 & 7 & 39 & * & 36 \\
\hline 18 & 35 & * & 18 & 50 & 27 & 15 & 16 & * & 33 & * & 38 & 32 & * & * & 31 & 31 \\
\hline 19 & * & * & 24 & 51 & 28 & 9 & 22 & * & 30 & * & 39 & 40 & * & * & 24 & 38 \\
\hline 20 & * & * & * & 17 & 29 & 9 & 35 & 17 & 20 & * & 34 & 4 & * & * & 31 & 37 \\
\hline 21 & * & * & * & * & 31 & 27 & 30 & 26 & 29 & * & 38 & 37 & * & * & 32 & 14 \\
\hline 22 & * & * & * & * & 35 & 31 & 30 & * & 24 & * & 30 & 43 & * & * & 34 & 20 \\
\hline 23 & * & 48 & * & * & 32 & 32 & 17 & * & 31 & * & 37 & 41 & * & 32 & $2 \mathrm{C}$ & 25 \\
\hline 24 & * & 53 & 36 & * & 31 & 28 & 34 & * & 22 & 15 & 34 & 31 & 3 & 28 & 22 & 34 \\
\hline 25 & 29 & 54 & * & * & 27 & 21 & 29 & 23 & 31 & 1 & 33 & 25 & * & 27 & 31 & 32 \\
\hline 26 & 16 & 51 & * & * & * & 27 & 30 & 28 & 28 & 28 & 20 & 31 & * & 40 & * & 32 \\
\hline 27 & 40 & * & * & * & $*$ & 27 & 32 & 26 & 12 & 25 & 30 & 31 & * & 37 & 32 & 34 \\
\hline 28 & 35 & 37 & * & * & * & 27 & 29 & 33 & 16 & 28 & $*$ & 30 & * & 35 & 31 & 33 \\
\hline 29 & * & 25 & * & * & * & * & 25 & 6 & 28 & & 37 & * & * & 27 & $3 \tilde{4}$ & 32 \\
\hline 30 & * & 45 & * & $*$ & * & * & 26 & * & 26 & & 36 & * & * & 16 & $3 f$ & 34 \\
\hline 31 & * & & * & 30 & & 23 & & 20 & 16 & & 32 & & * & & 20 & 30 \\
\hline
\end{tabular}


TABLE 14

Table 14. -Daily mean atmospheric radiation, in calories per square centimeter per day

[* indicates questionable or missing data]

\begin{tabular}{|c|c|c|c|c|c|c|c|c|c|c|c|c|c|c|c|c|}
\hline \multirow{2}{*}{ Day } & \multicolumn{8}{|c|}{1950} & \multicolumn{8}{|c|}{1951} \\
\hline & May & June & July & Aug. & Sept. & Oct. & Nov. & Dec. & Jan. & Feb. & Mar. & Apr. & May & June & July & Aug. \\
\hline 1 & 733 & * & 740 & * & 640 & * & 631 & 607 & * & 369 & 615 & 697 & * & * & 773 & 830 \\
\hline 2 & * & * & 765 & * & 459 & * & 524 & 608 & * & 426 & 769 & * & 595 & * & $*$ & 834 \\
\hline 3 & * & * & 797 & * & * & * & 592 & 496 & 557 & 495 & 613 & 588 & 621 & 689 & 826 & 835 \\
\hline 4 & * & * & 779 & * & * & 622 & 488 & * & 570 & 538 & 558 & 673 & 624 & 659 & * & 843 \\
\hline 5 & * & * & 772 & * & 680 & 693 & 588 & 526 & 594 & 666 & 601 & * & 650 & * & * & 853 \\
\hline 6 & * & * & 774 & 896 & * & 666 & 592 & 414 & 557 & $*$ & 608 & 679 & 701 & * & 804 & 869 \\
\hline 7 & * & * & 753 & 847 & 658 & 655 & 602 & 446 & 473 & * & 550 & 595 & 631 & * & 791 & 868 \\
\hline 8 & * & * & 768 & 806 & 643 & 610 & 608 & 516 & 504 & 543 & 608 & 527 & 665 & * & * & 883 \\
\hline 9 & * & * & 819 & 764 & 656 & 625 & 521 & 546 & 526 & 521 & * & 547 & * & * & * & 825 \\
\hline 10 & * & * & * & 798 & 731 & 659 & 485 & $*$ & $*$ & 587 & * & 636 & * & 744 & * & 852 \\
\hline 11 & * & * & * & 811 & 737 & 667 & 479 & * & 559 & 632 & * & 535 & 597 & * & * & * \\
\hline 12 & 693 & 705 & * & 779 & * & * & 516 & * & * & 651 & 516 & 515 & 683 & * & 821 & $*$ \\
\hline 13 & 741 & 755 & 755 & 802 & * & * & 568 & 537 & * & 592 & 476 & * & 661 & 750 & * & 785 \\
\hline 14 & 733 & 734 & 684 & * & 807 & 692 & $*$ & 556 & * & 572 & 494 & 598 & 736 & 773 & * & 787 \\
\hline 15 & 692 & 721 & * & * & * & 687 & 650 & 551 & 545 & 577 & 519 & 594 & * & * & 799 & 756 \\
\hline 16 & * & 779 & * & * & * & * & 551 & 579 & 584 & 506 & 605 & 572 & * & 791 & * & 747 \\
\hline 17 & * & 784 & 779 & * & * & * & 574 & * & 626 & 576 & 600 & 597 & * & * & * & 819 \\
\hline 18 & * & * & 789 & 767 & * & 685 & 647 & * & 593 & 606 & 522 & 665 & * & 790 & 806 & 838 \\
\hline 19 & * & * & * & 737 & 797 & $*$ & 651 & * & 582 & $*$ & 503 & 653 & * & 847 & 828 & 825 \\
\hline 20 & 759 & * & * & 743 & 813 & * & 547 & 626 & 532 & * & 537 & 686 & * & $*$ & 826 & 818 \\
\hline 21 & 688 & * & * & $*$ & 740 & * & 599 & 633 & 491 & 597 & 526 & 616 & * & * & 823 & 831 \\
\hline 22 & * & $*$ & * & * & 679 & 601 & 606 & 548 & 567 & 584 & 651 & 626 & * & * & 826 & 798 \\
\hline 23 & * & 850 & * & * & 725 & $*$ & 560 & $*$ & 548 & $*$ & 603 & 587 & * & 821 & 840 & 846 \\
\hline 24 & * & 828 & 737 & * & 783 & * & 463 & 580 & 548 & 694 & 543 & 721 & * & 812 & * & 831 \\
\hline 25 & * & 805 & * & * & 700 & 647 & 523 & 601 & 575 & $*$ & 595 & 734 & * & 833 & 822 & 826 \\
\hline 26 & * & 811 & * & * & $*$ & $*$ & 522 & 520 & 591 & 558 & 611 & 692 & * & 806 & 822 & 829 \\
\hline 27 & 723 & 790 & * & * & * & $*$ & 555 & 500 & 574 & 647 & 603 & 721 & 729 & 790 & $*$ & 825 \\
\hline 28 & * & 795 & * & * & $*$ & 665 & 547 & 501 & 509 & 629 & * & 761 & 786 & 810 & * & 822 \\
\hline 29 & * & 763 & * & * & * & $*$ & 541 & * & 441 & & * & $*$ & * & 825 & 791 & 812 \\
\hline 30 & * & 753 & * & * & * & * & 567 & * & 485 & & 585 & * & * & 813 & 823 & 793 \\
\hline 31 & * & & & 602 & & * & & 535 & 495 & & 686 & & * & & 826 & 809 \\
\hline
\end{tabular}


TABLE 15

\begin{tabular}{|c|c|c|}
\hline \multirow{2}{*}{ : } & \multirow{2}{*}{ 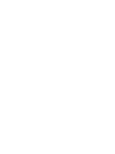 } & 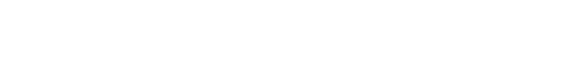 \\
\hline & & 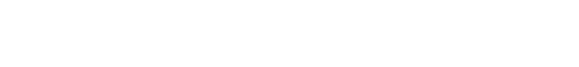 \\
\hline \multirow{2}{*}{ 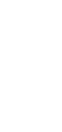 } & $\left|\begin{array}{ll}0 & 0 \\
0 & 8\end{array}\right|$ & 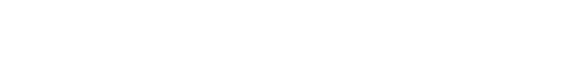 \\
\hline & $\stackrel{\infty}{\stackrel{0}{g}}$ & 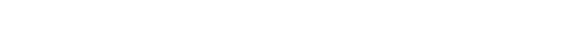 \\
\hline \multirow{2}{*}{ 萬 } & $\stackrel{2}{\stackrel{0}{0}}$ & 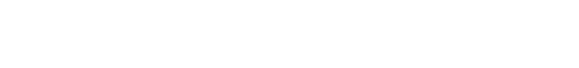 \\
\hline & 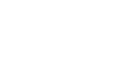 & 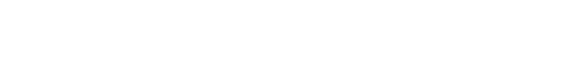 \\
\hline 害同 & ส & 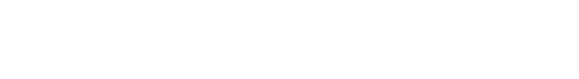 \\
\hline 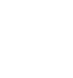 & - & 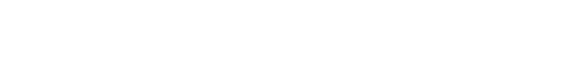 \\
\hline 逽 & $\begin{array}{lll} & 9 \\
\end{array}$ & 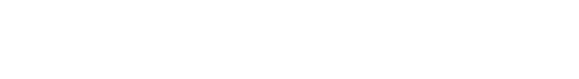 \\
\hline 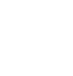 & 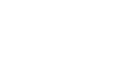 & 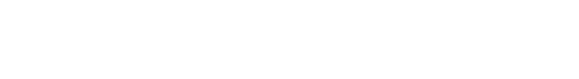 \\
\hline & 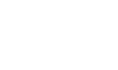 & 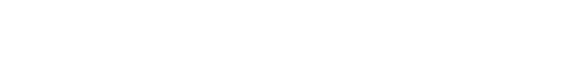 \\
\hline \multirow{6}{*}{ 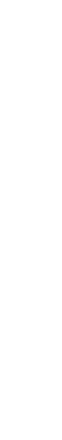 } & 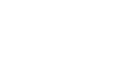 & 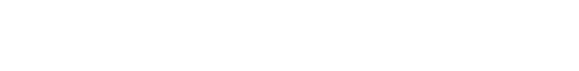 \\
\hline & $r \begin{array}{r}\infty \\
\mathbb{E}_{0}\end{array}$ & 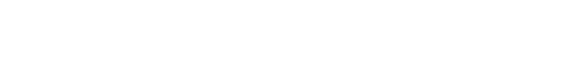 \\
\hline & $\begin{array}{ll}\infty & \infty \\
& 0 \\
0 & 0\end{array}$ & की \\
\hline & 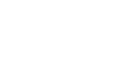 & 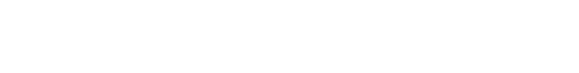 \\
\hline & 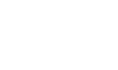 & " \\
\hline & $\rightarrow$ 星 & 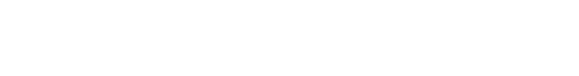 \\
\hline \multirow{4}{*}{ 怘 } & $\therefore$ & 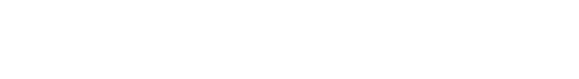 \\
\hline & 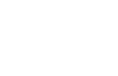 & 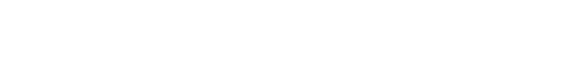 \\
\hline & 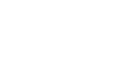 & 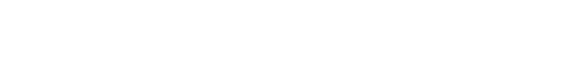 \\
\hline & ష & 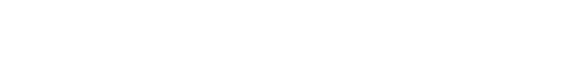 \\
\hline 密 & 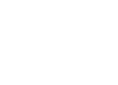 & 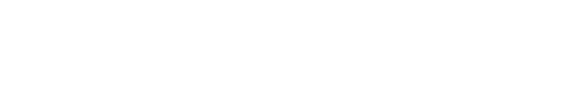 \\
\hline 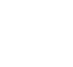 & 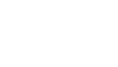 & 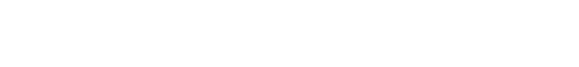 \\
\hline & 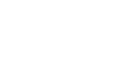 & 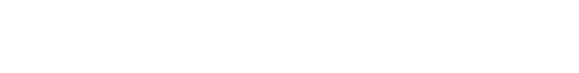 \\
\hline \multirow{2}{*}{ 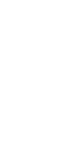 } & $\vec{N}$ & I. \\
\hline & 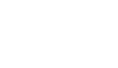 & มี่ \\
\hline \multirow{2}{*}{ 密 } & 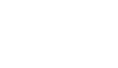 & 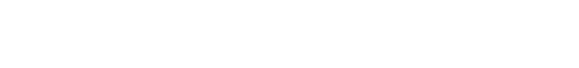 \\
\hline & $\cong$ 怘 & 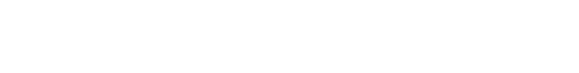 \\
\hline & 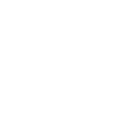 & 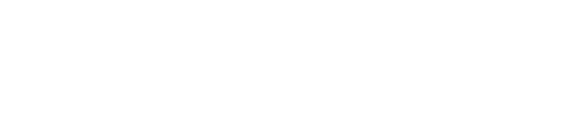 \\
\hline
\end{tabular}




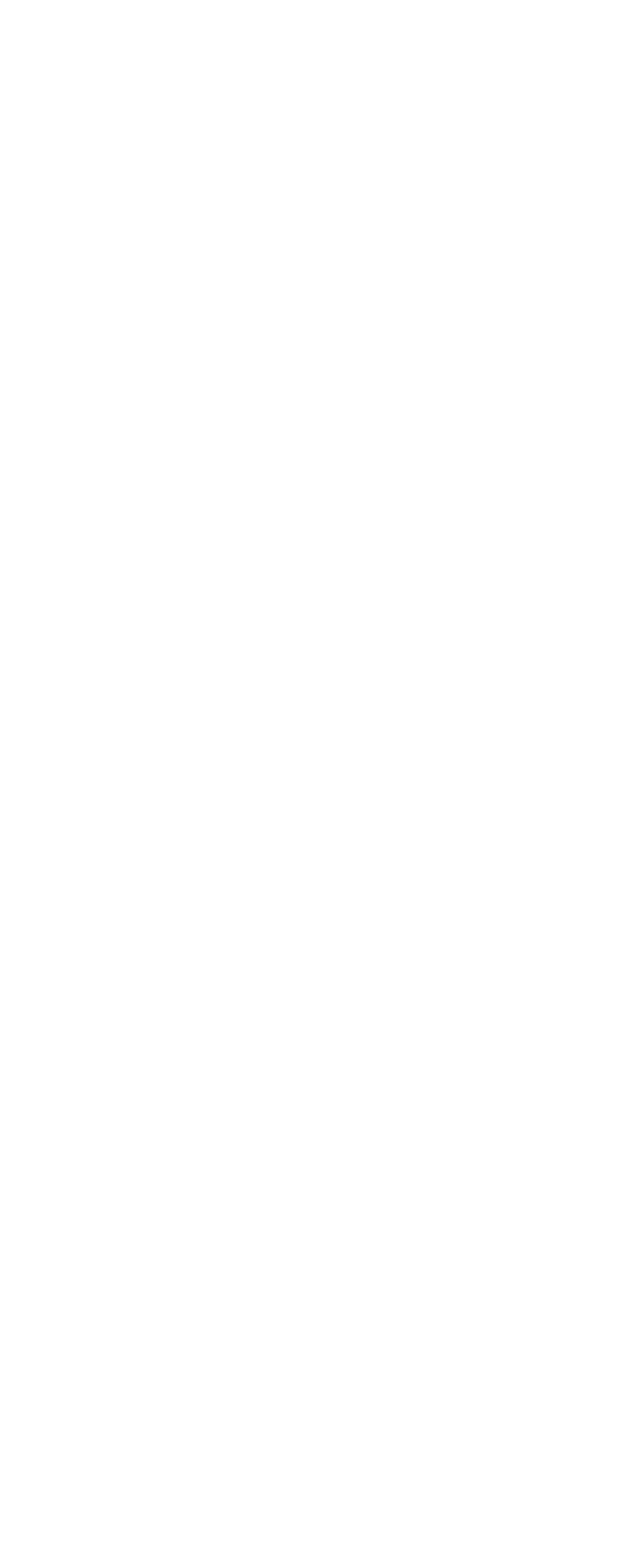


TABLE 15

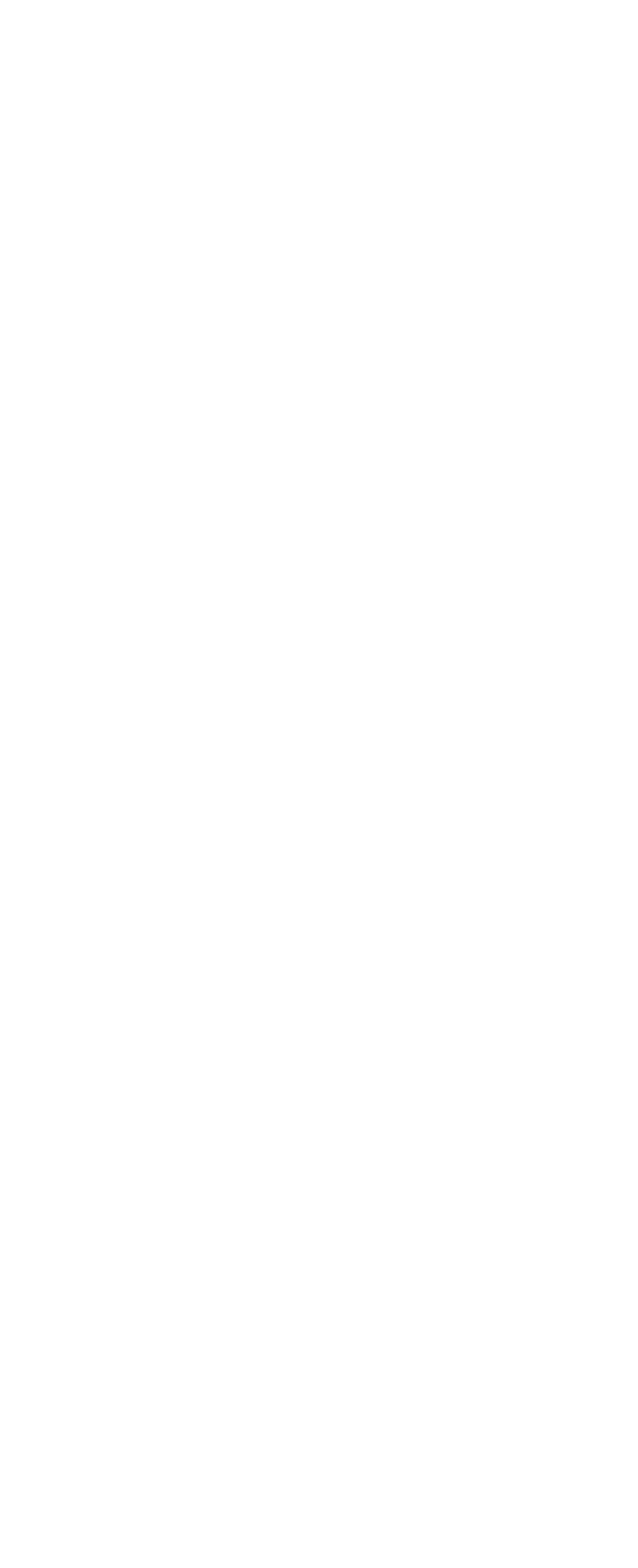




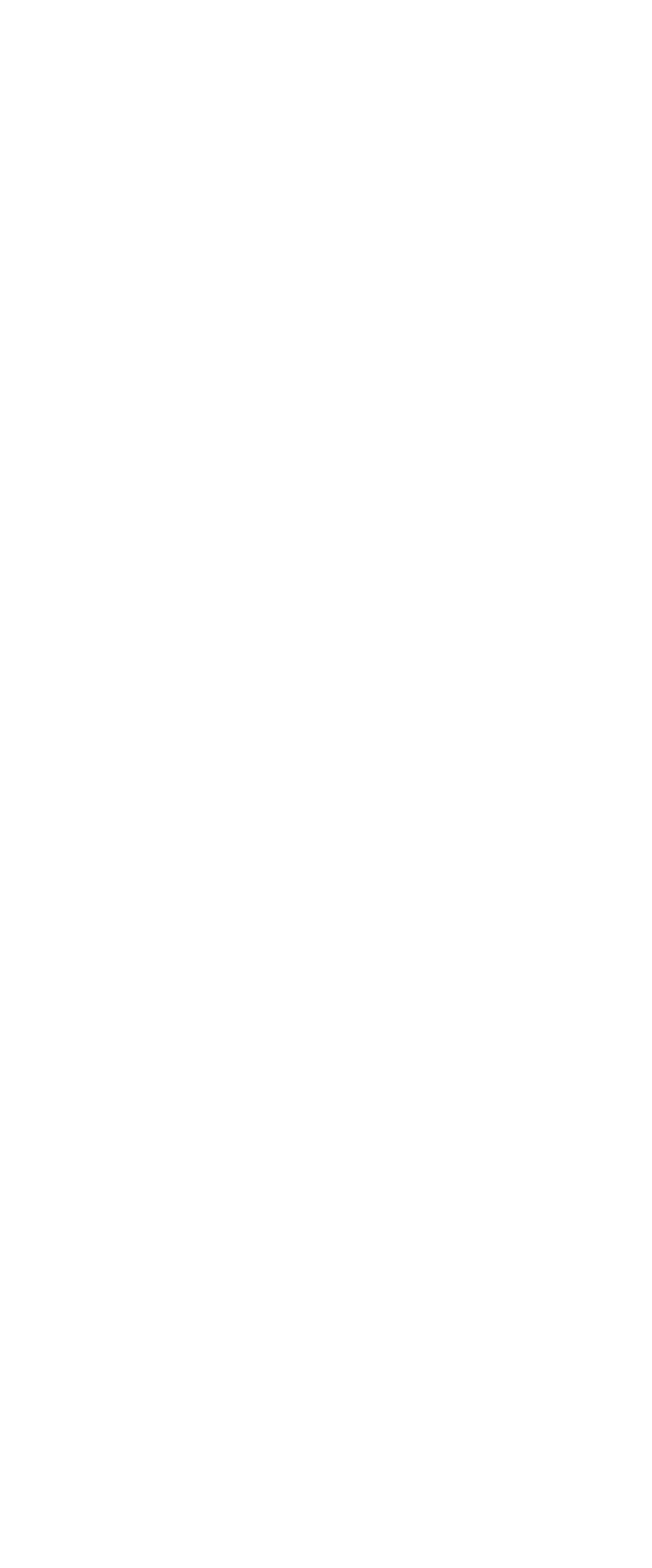




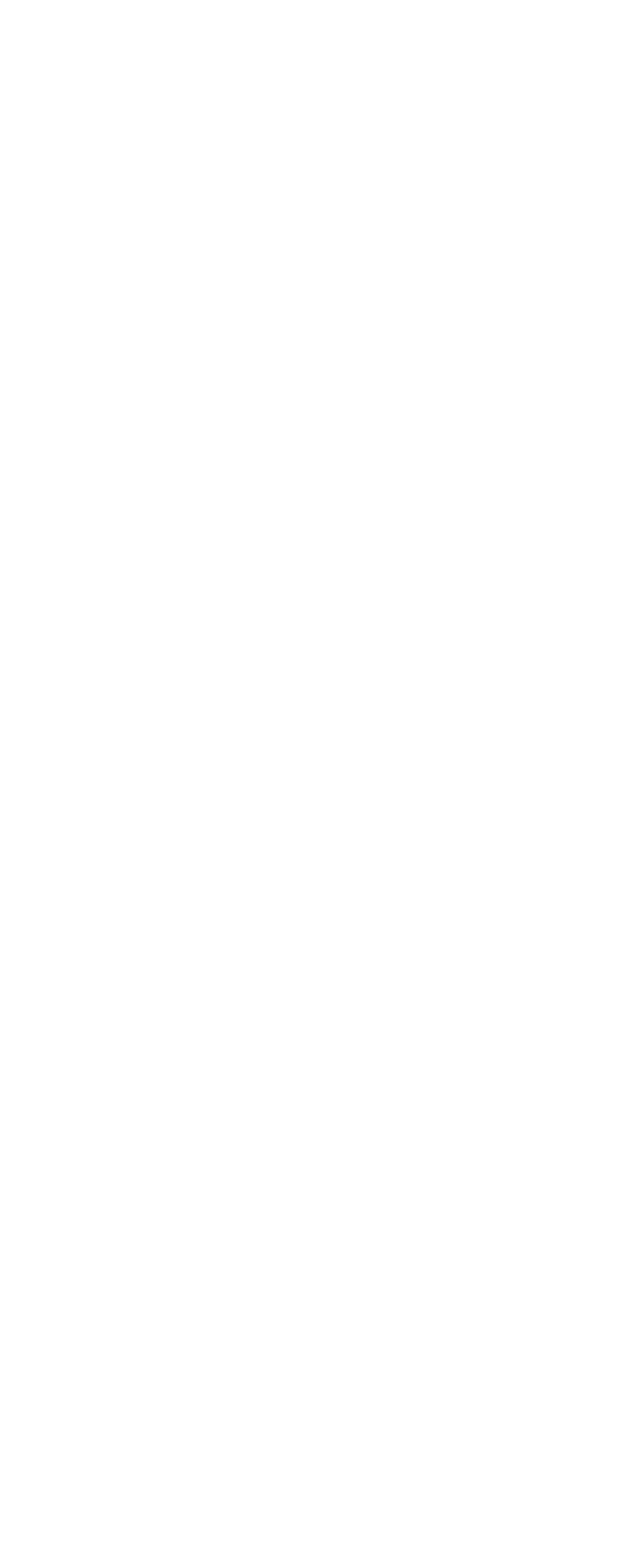




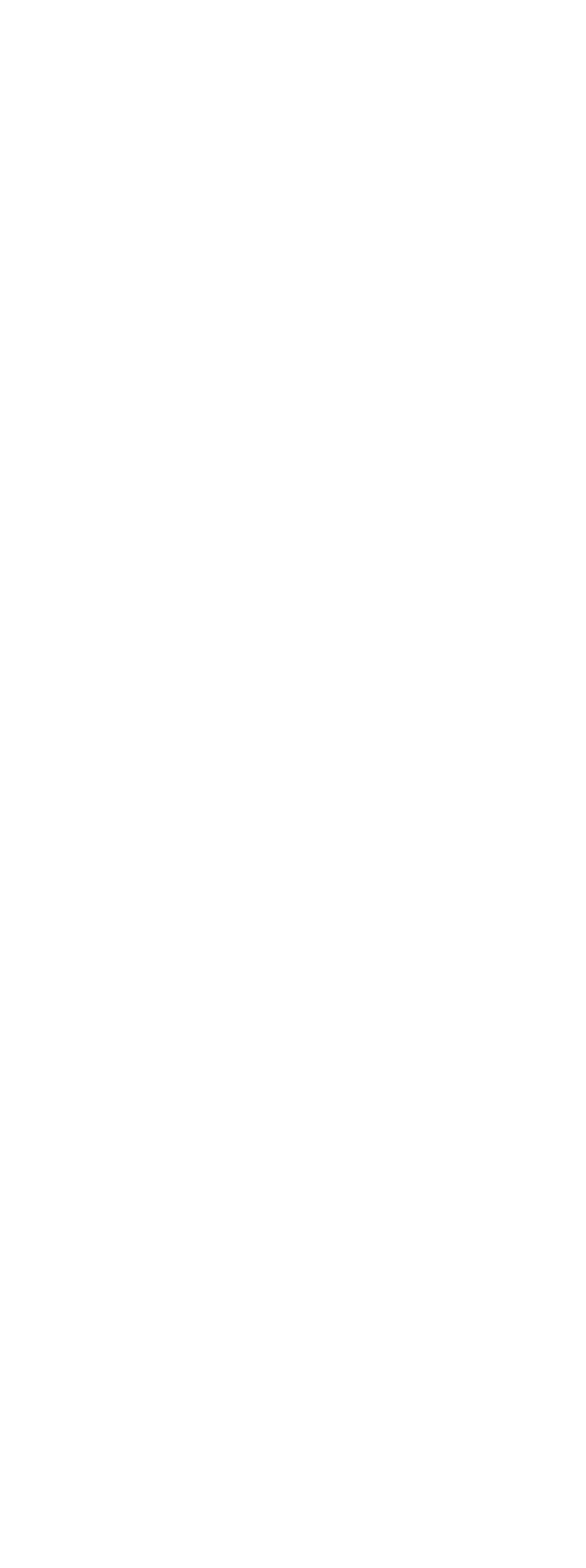




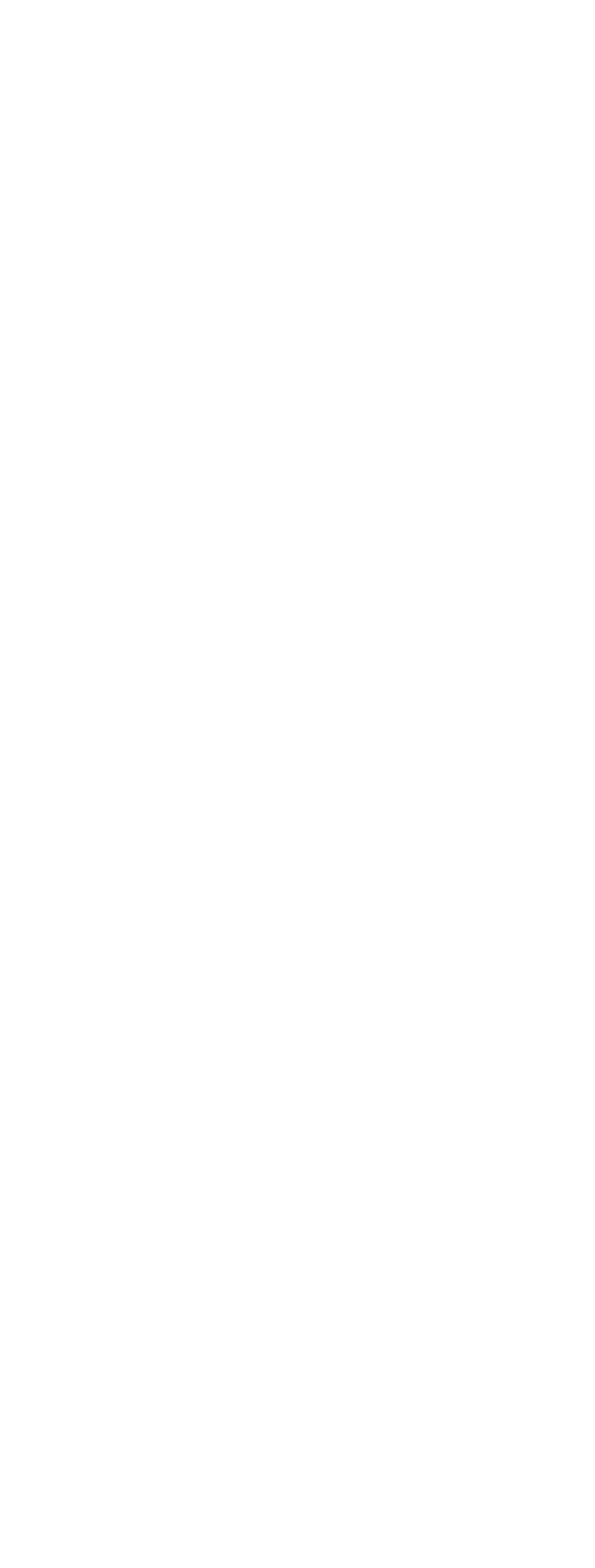




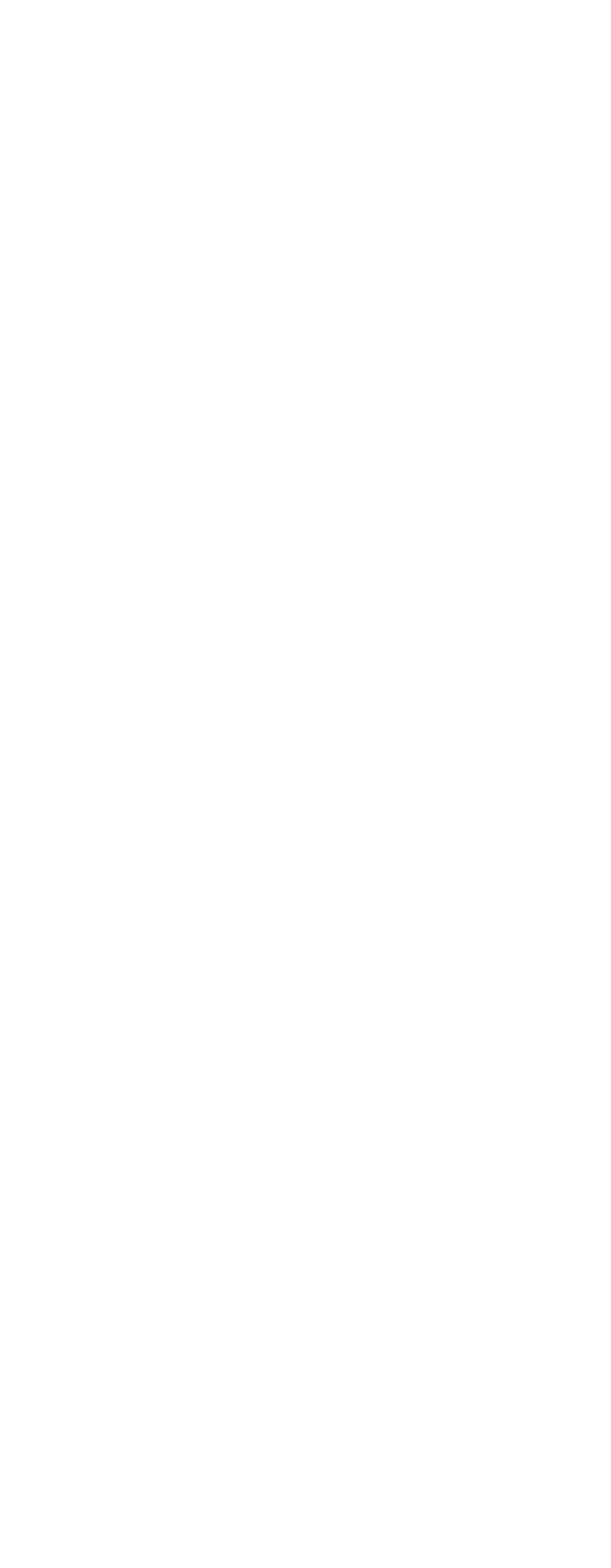




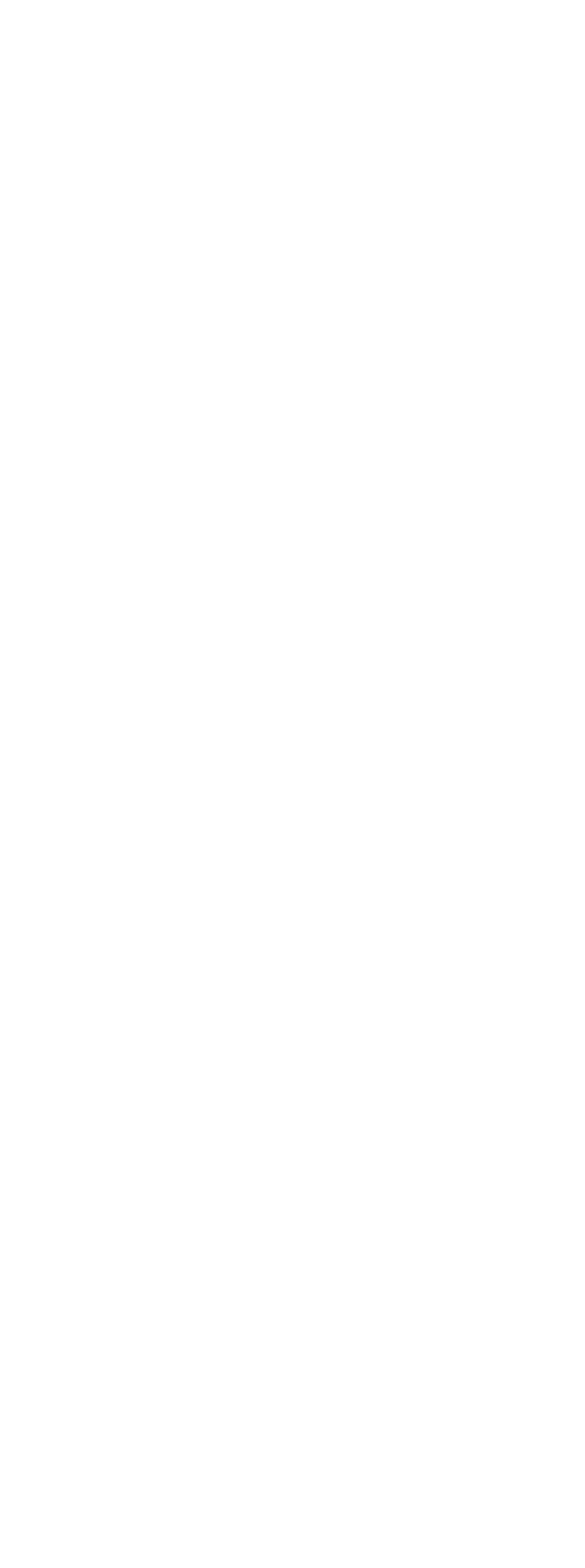




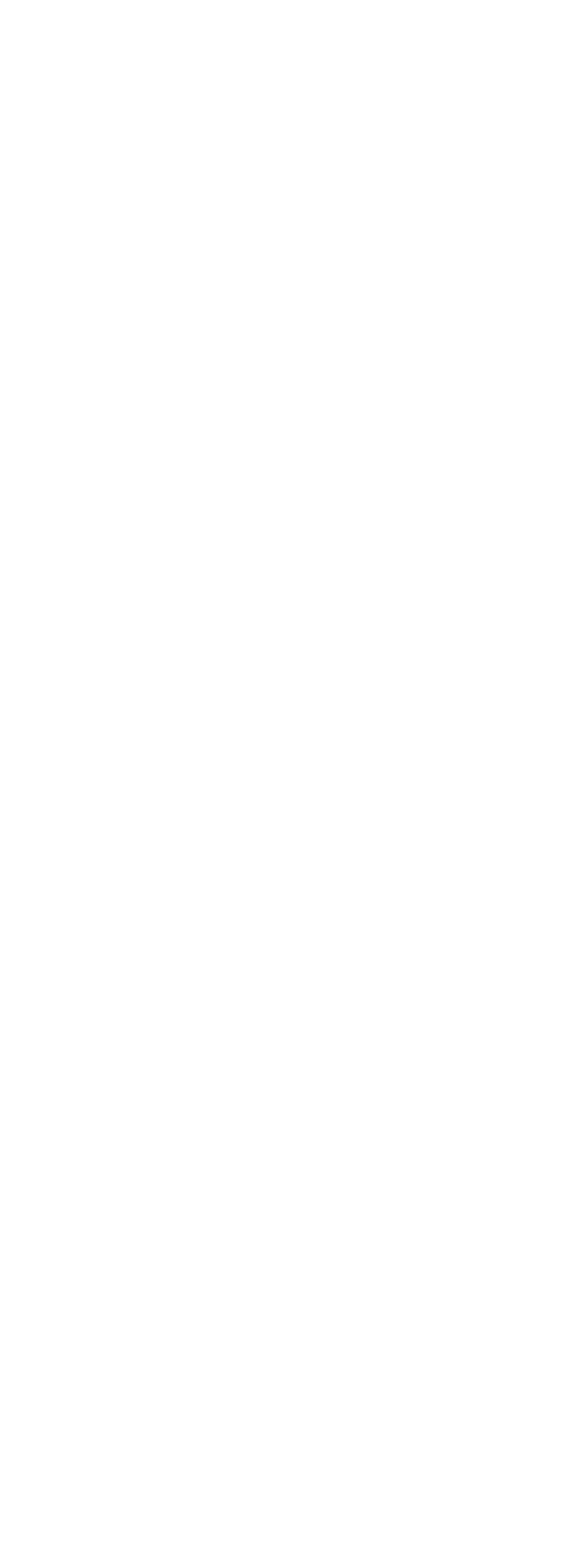




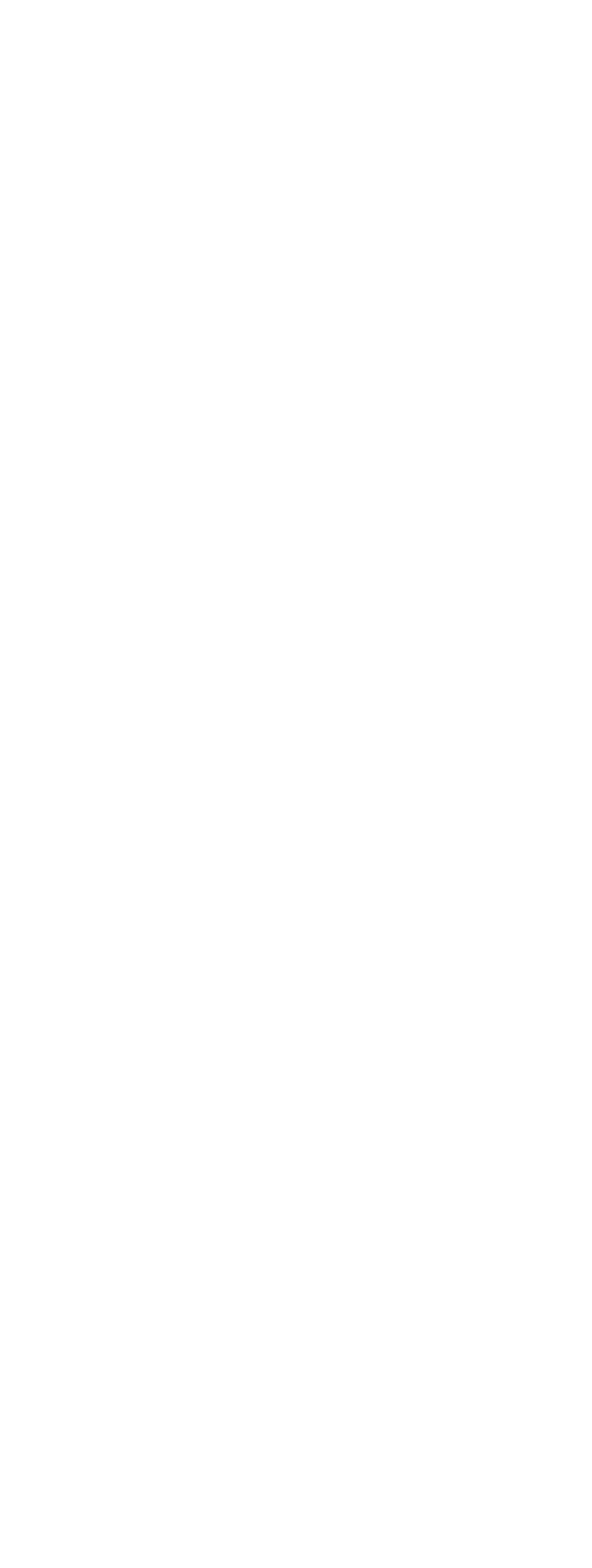




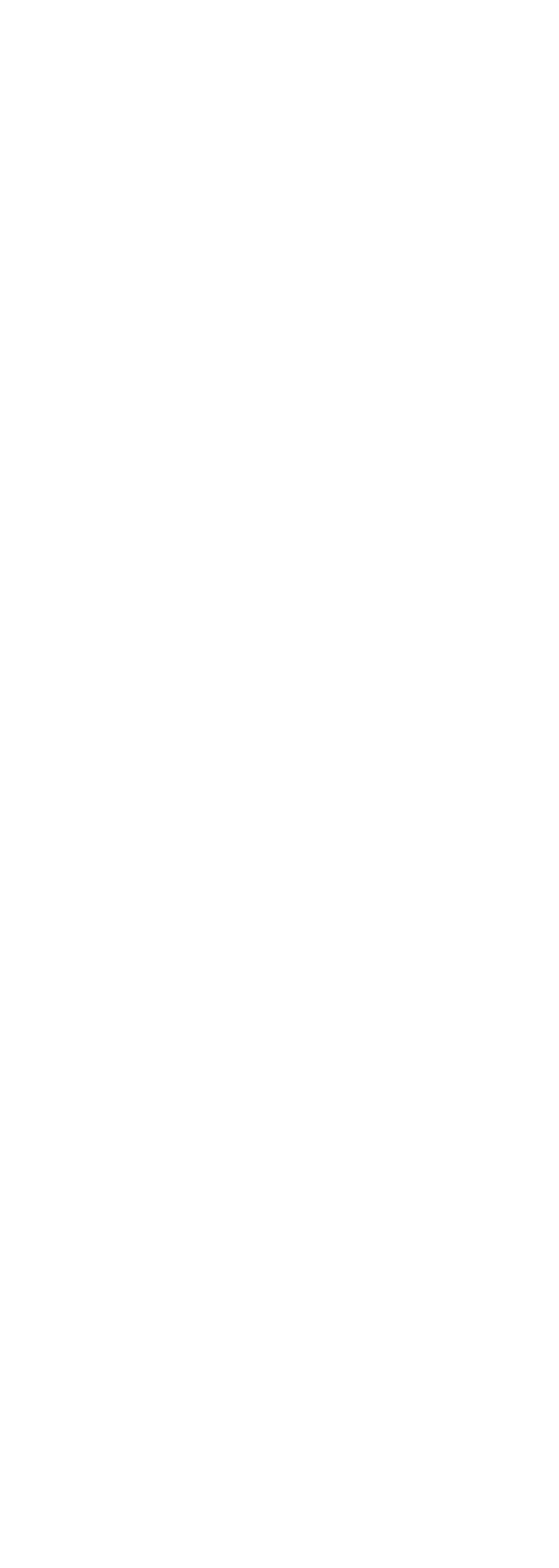




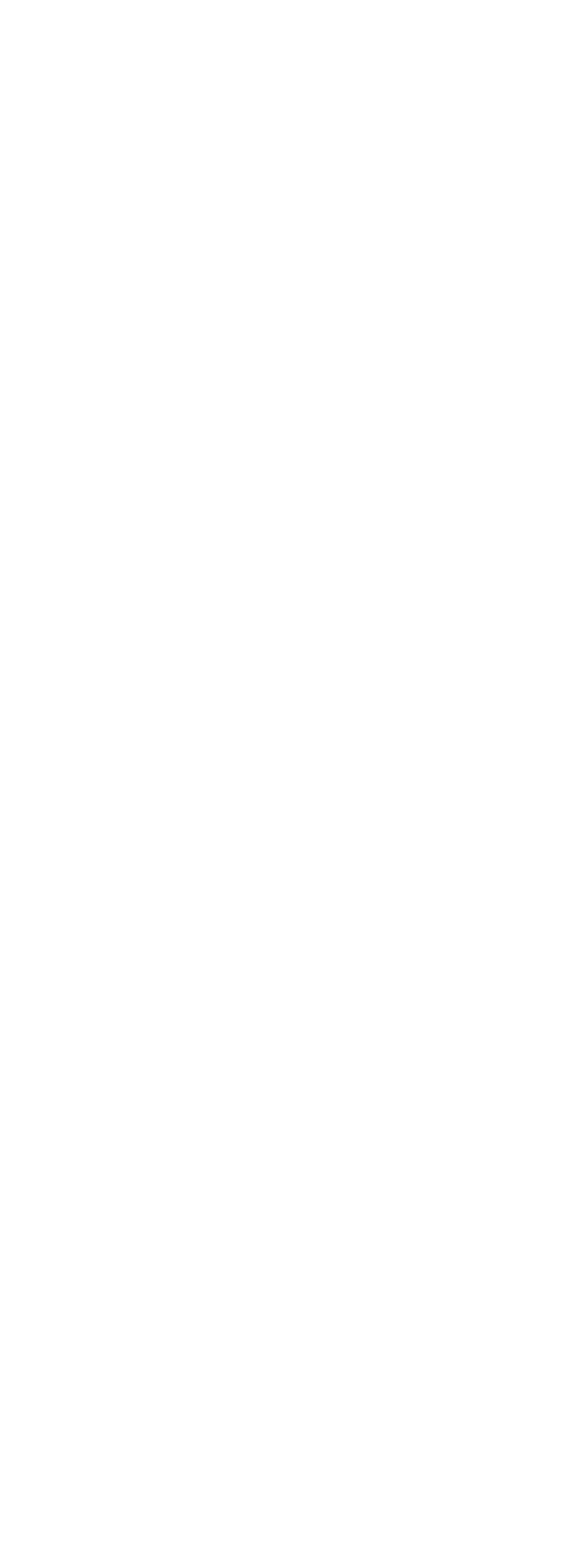


TABLE 16

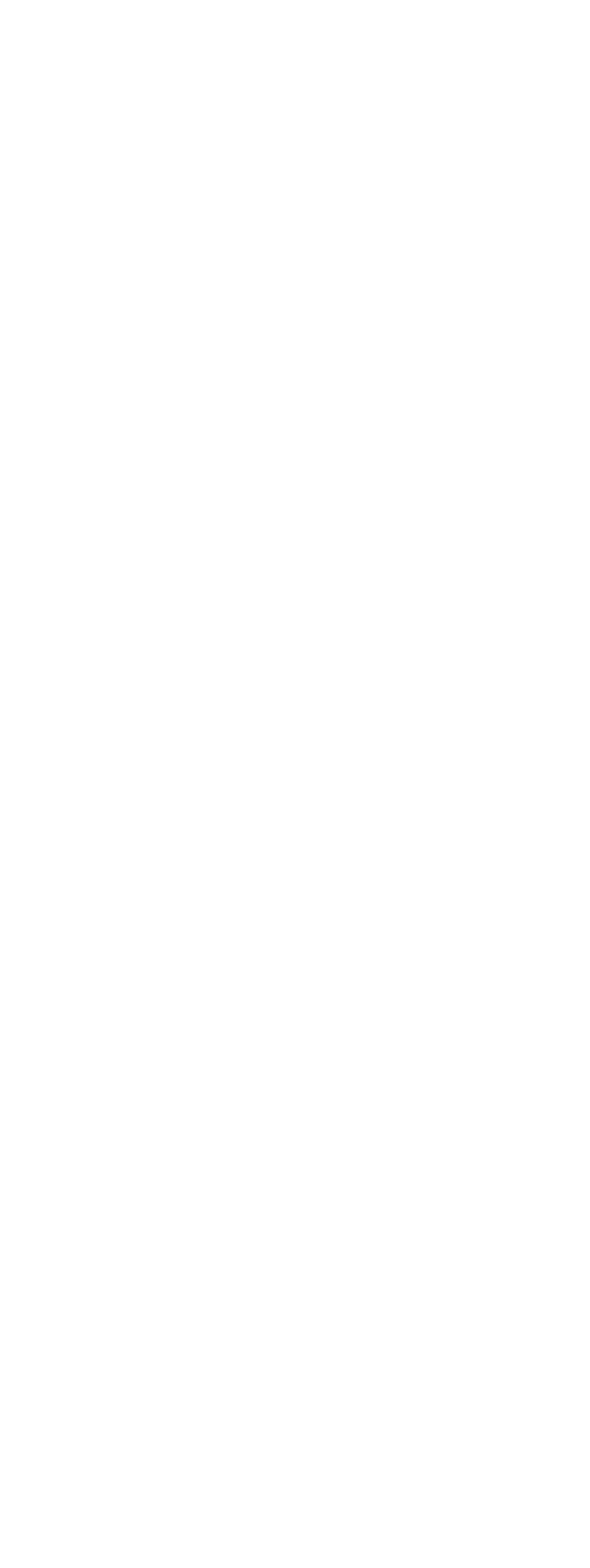

$2948710-54-19$ 


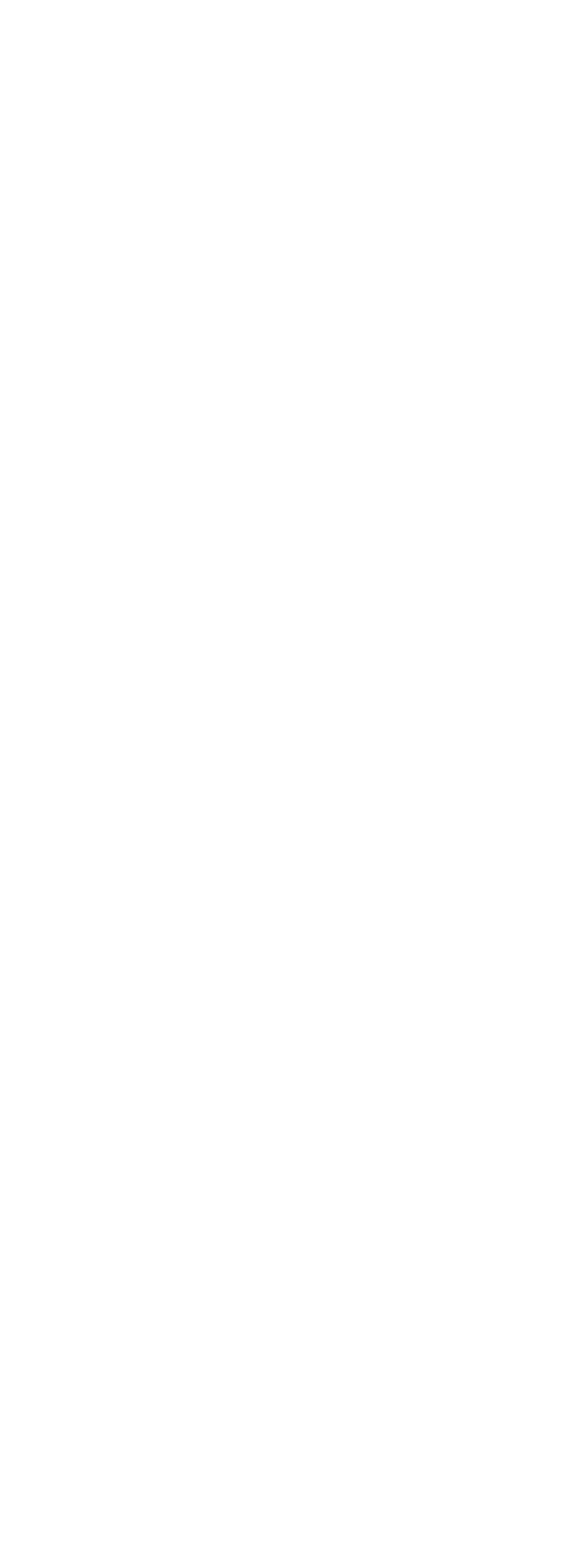




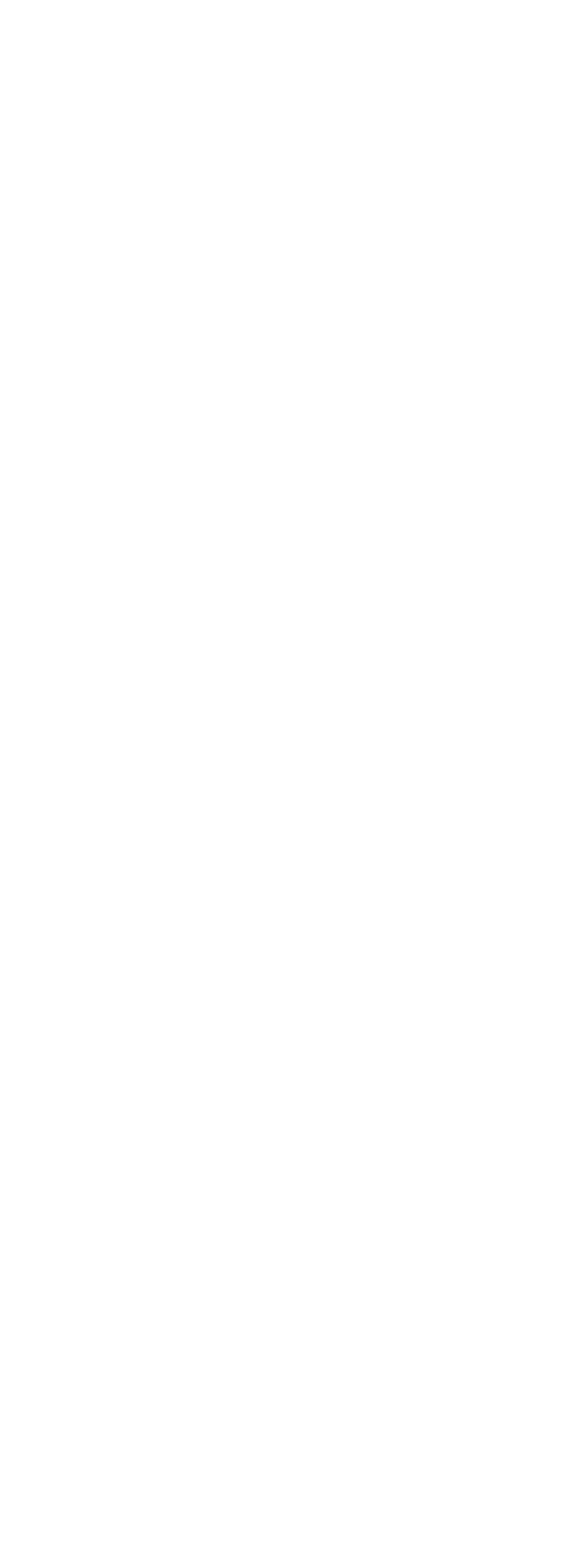




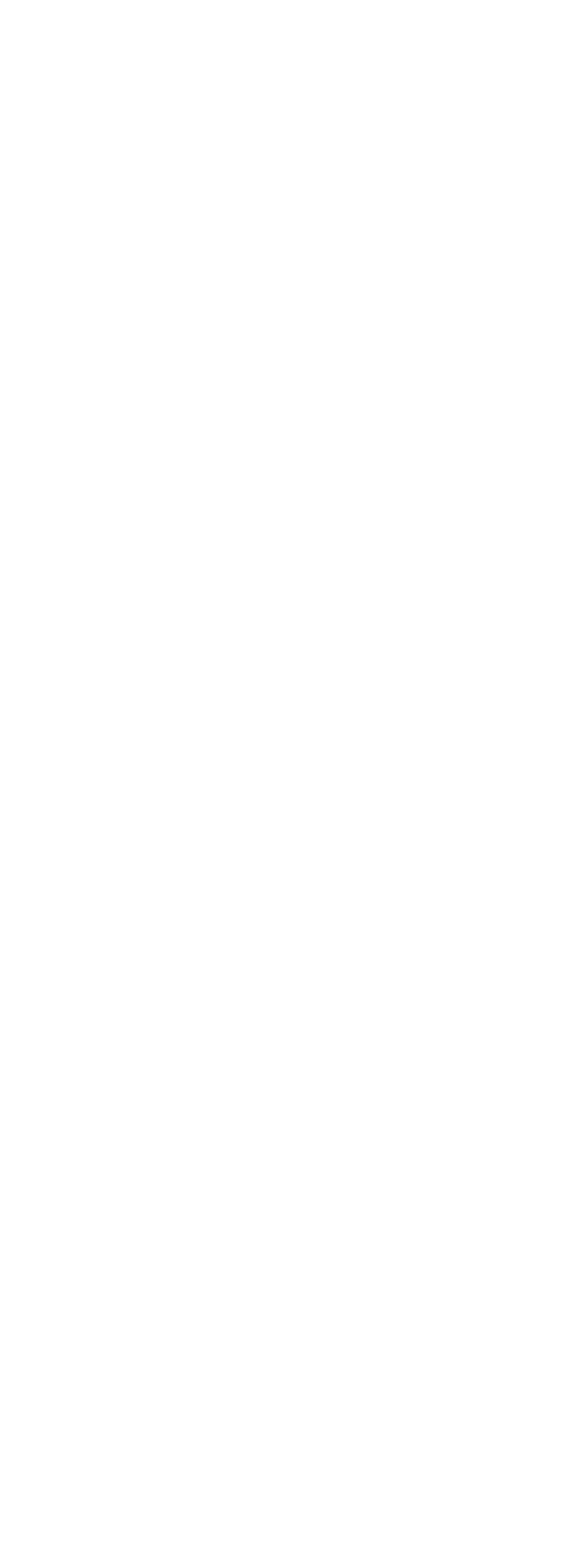




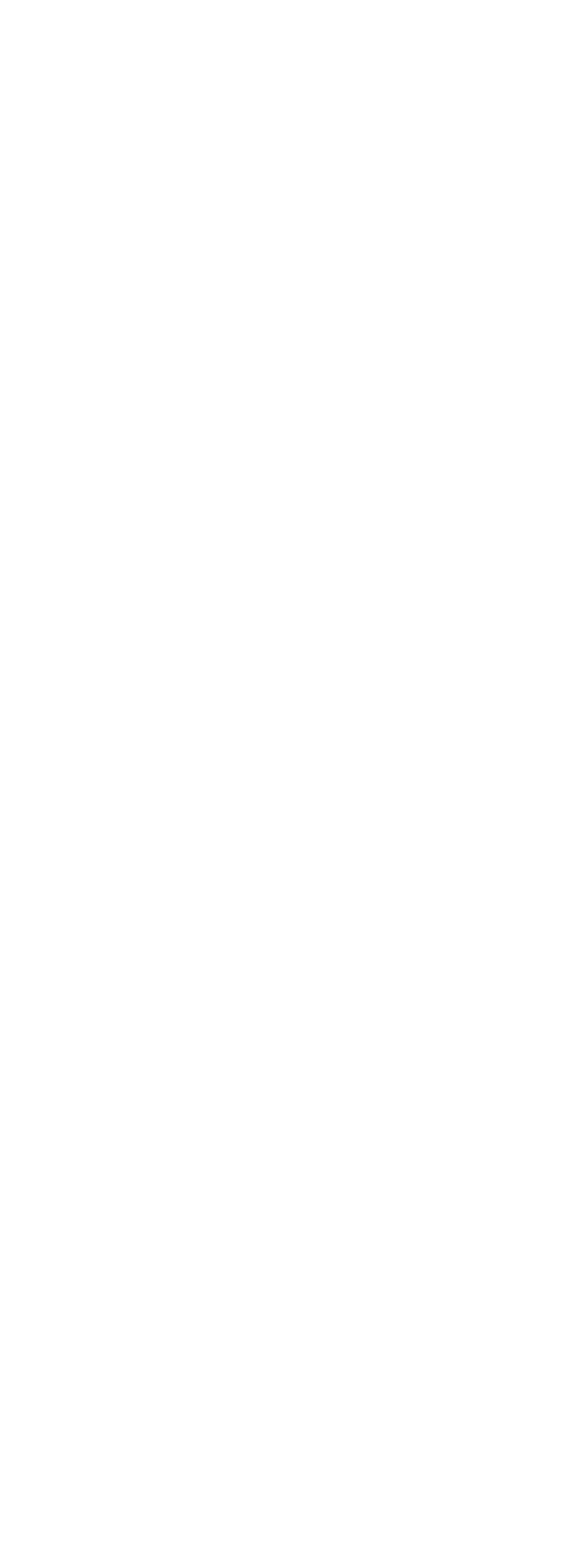




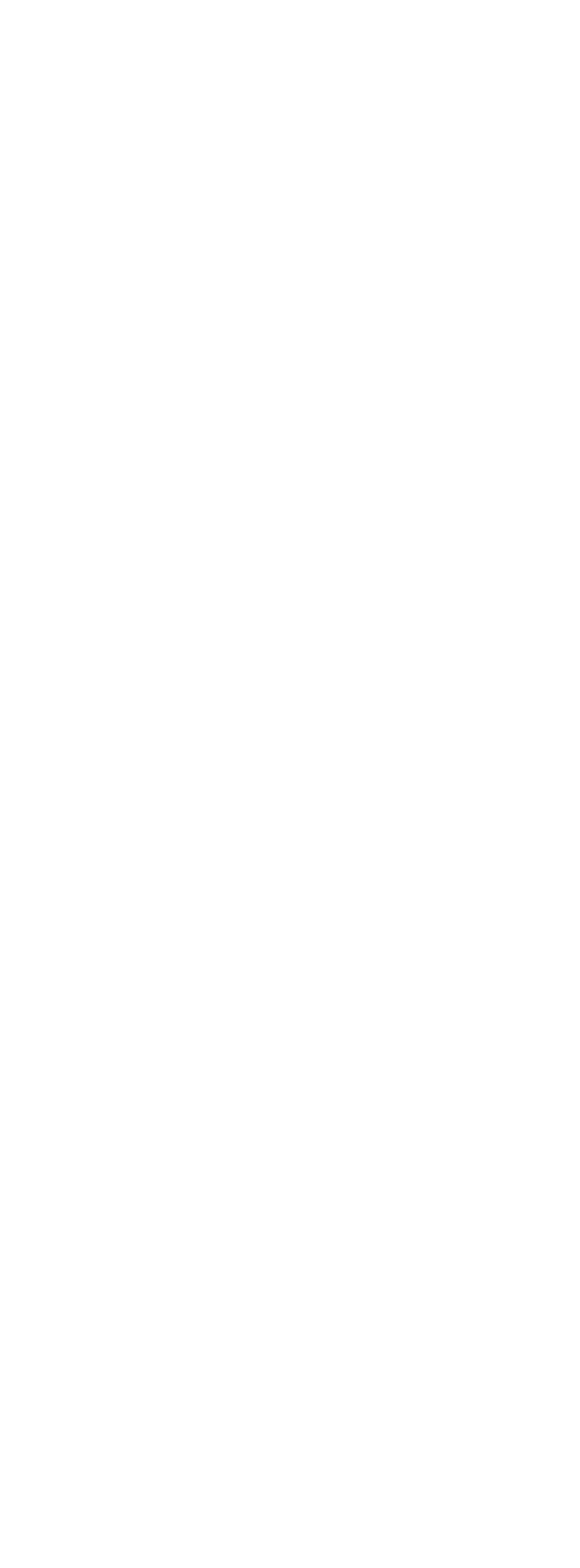




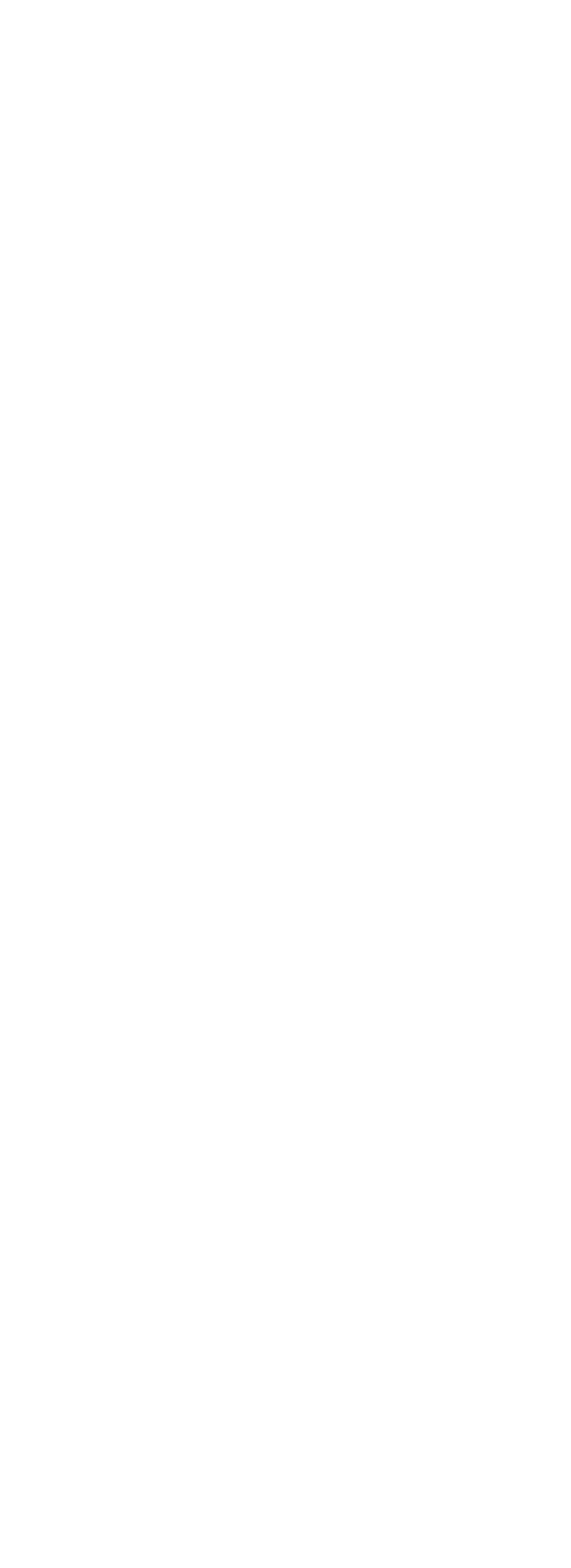




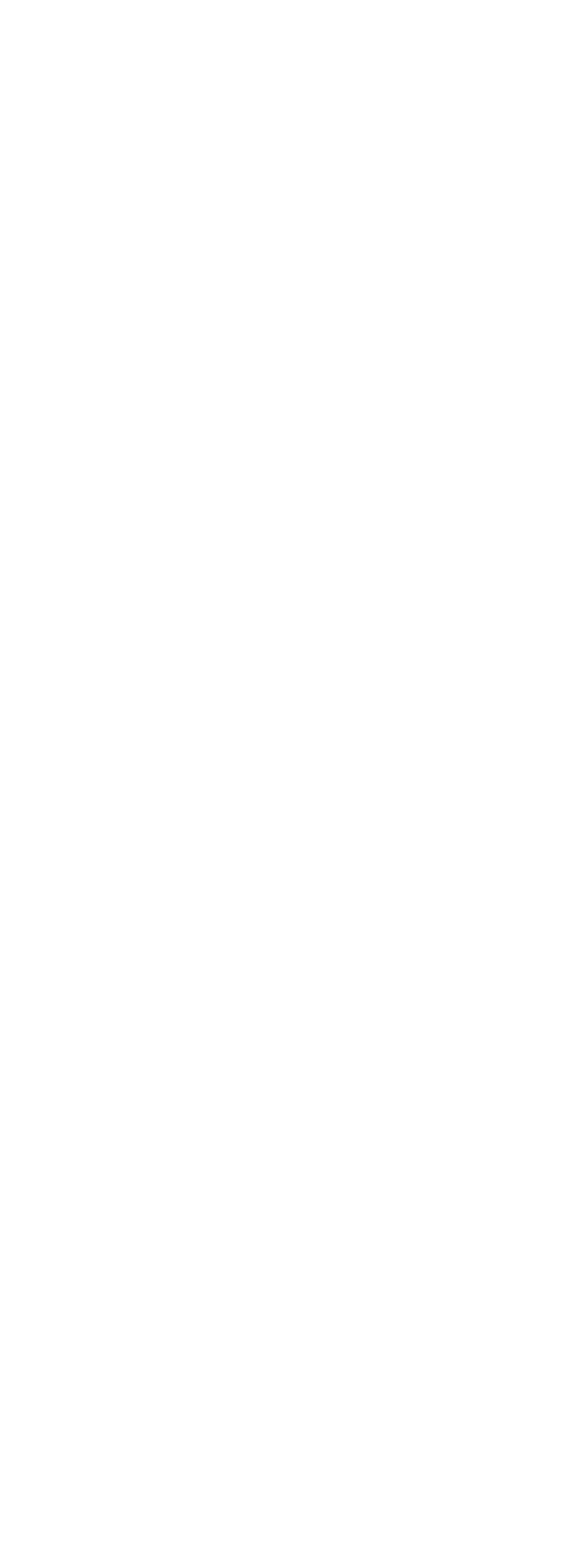




\begin{tabular}{|c|c|c|c|}
\hline$\infty$ & & ఫ્త్ & 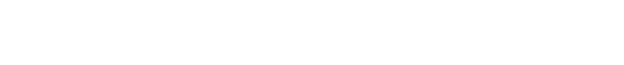 \\
\hline$\infty$ & & & 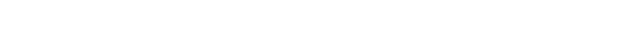 \\
\hline$\sigma$ & & & 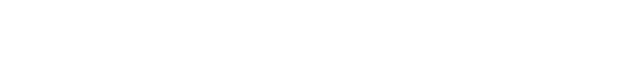 \\
\hline 6 & & 䔽 & 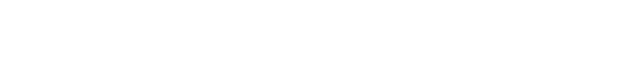 \\
\hline एक & a] & 용 & के $\left.5{ }^{\infty}\right)_{\infty}^{\infty}$ \\
\hline 7 & & 罗 & 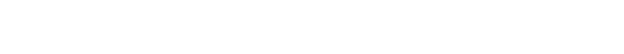 \\
\hline ) & & 要 & 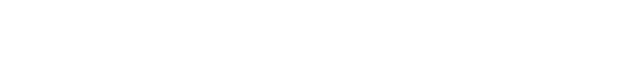 \\
\hline ब & & 部 & 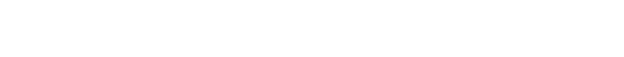 \\
\hline 7 & & 莙 & 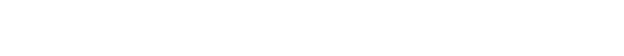 \\
\hline $\mathscr{7}$ & & 용 & - \\
\hline 20 & & & 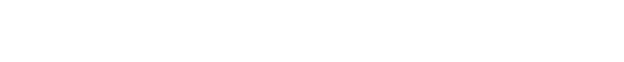 \\
\hline$\nexists$ & & & 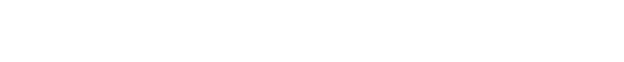 \\
\hline$\Phi$ & & 윻 & 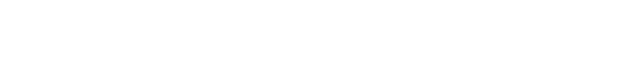 \\
\hline F & & \% & 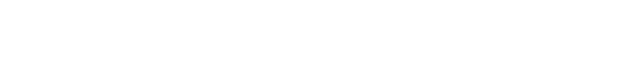 \\
\hline $\bar{F}$ & & 象 & 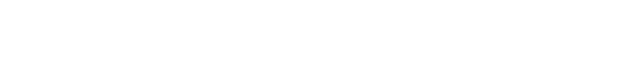 \\
\hline ㅇ & & (2) & 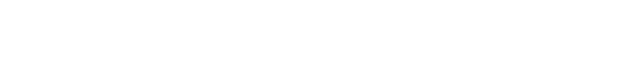 \\
\hline$\sigma$ & 离 & 홍 & 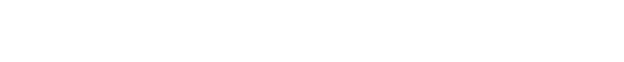 \\
\hline$\infty$ & : & 禺 & 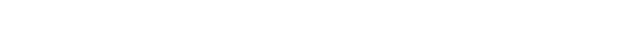 \\
\hline$\sigma$ & & 要 & 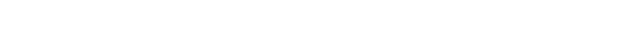 \\
\hline 6 & & क्ष्ठ: & 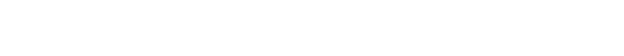 \\
\hline 6 & & 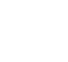 & 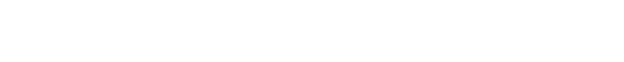 \\
\hline 7 & & 舜 & 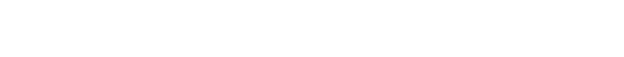 \\
\hline$m$ & & ד্ষ & 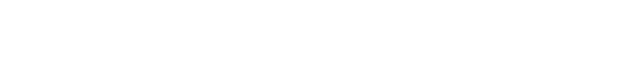 \\
\hline$\alpha$ & & 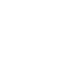 & 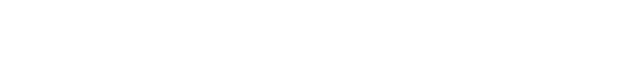 \\
\hline$F$ & & 产 & 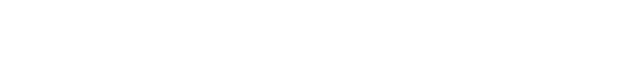 \\
\hline$\Phi$ & & 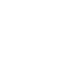 & 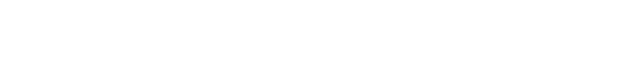 \\
\hline 20 & & 중 & 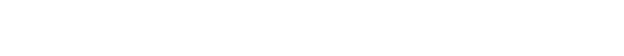 \\
\hline I & is & क्ष & 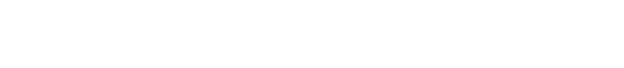 \\
\hline $\mathscr{\pi}$ & & Г్ & 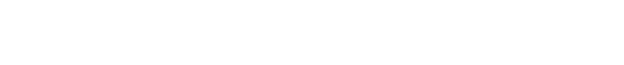 \\
\hline I्न & 部 & $\bar{D}$ & 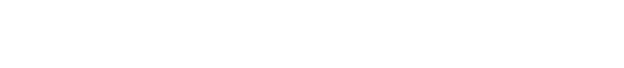 \\
\hline$\overline{7}$ & & $\begin{array}{c}\text { No } \\
\text { g }\end{array}$ & 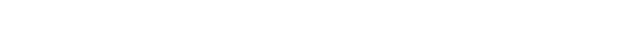 \\
\hline 요 & & : & 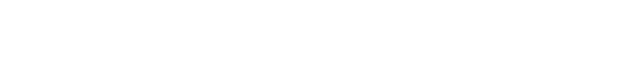 \\
\hline & & 领 & 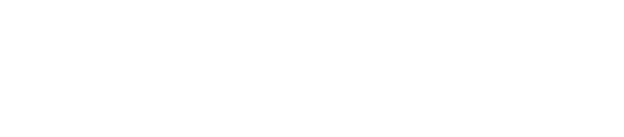 \\
\hline
\end{tabular}




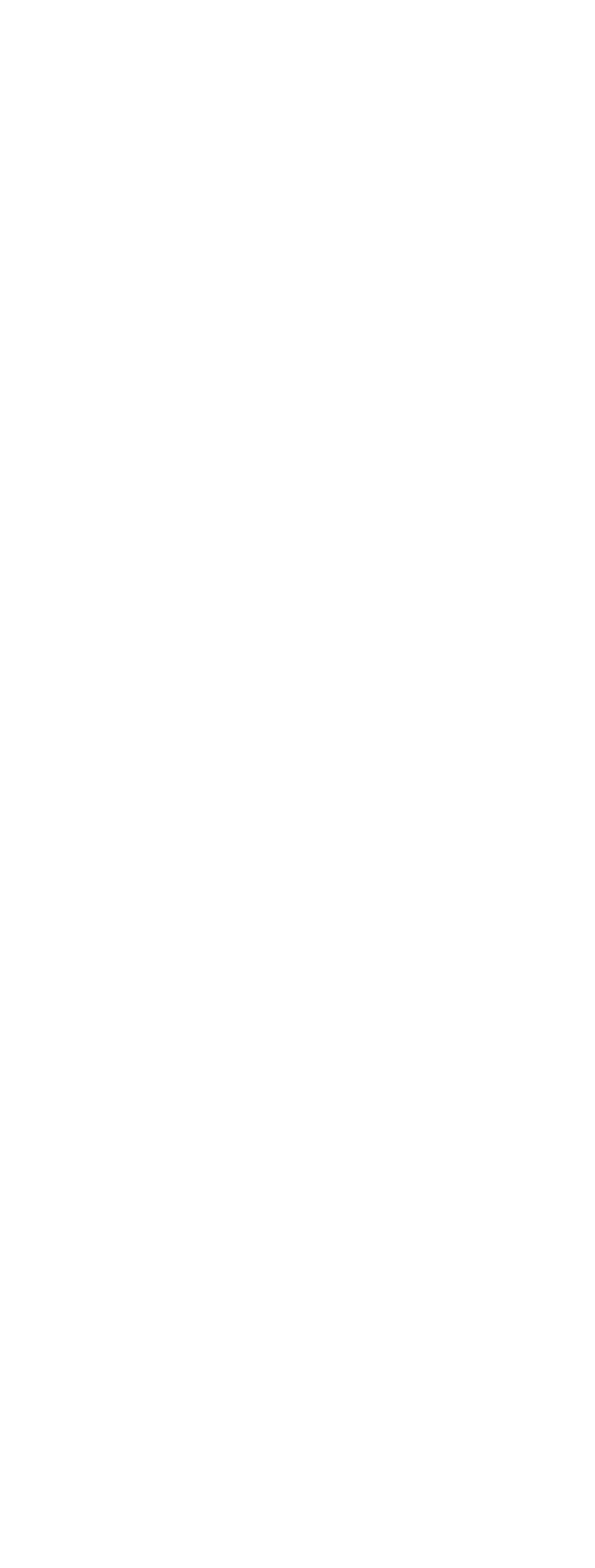




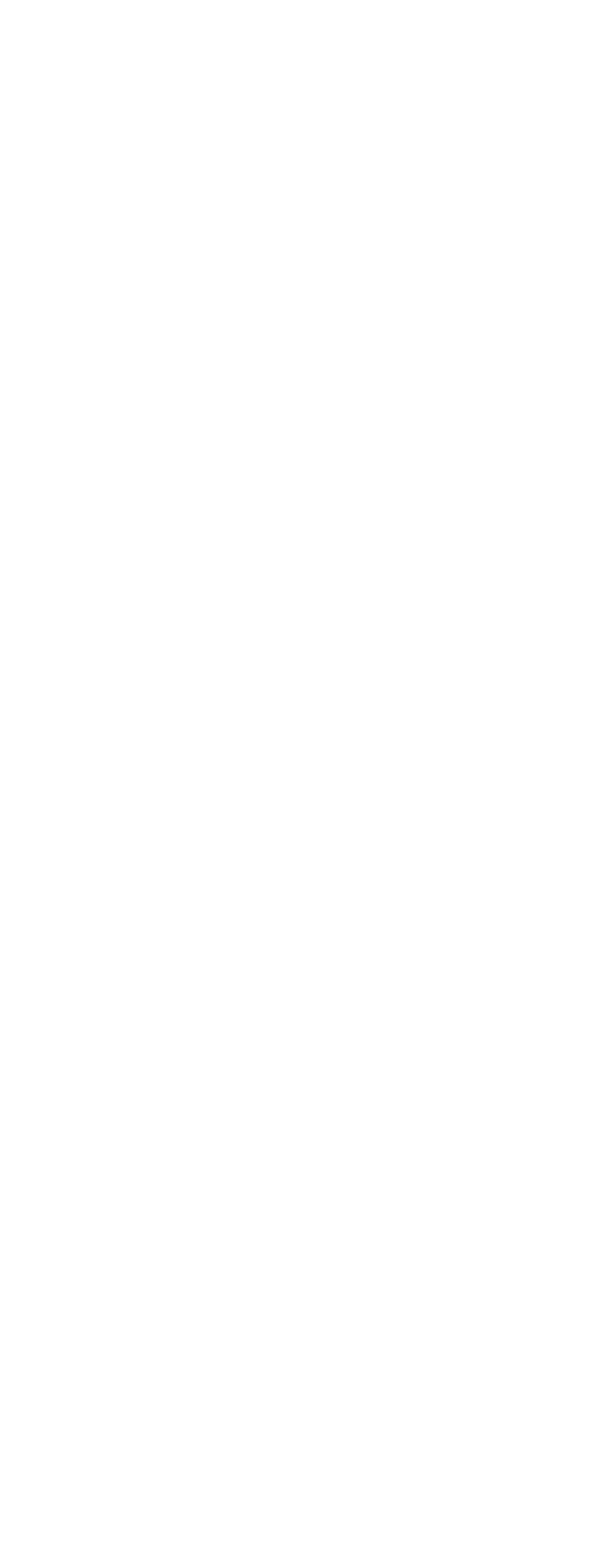




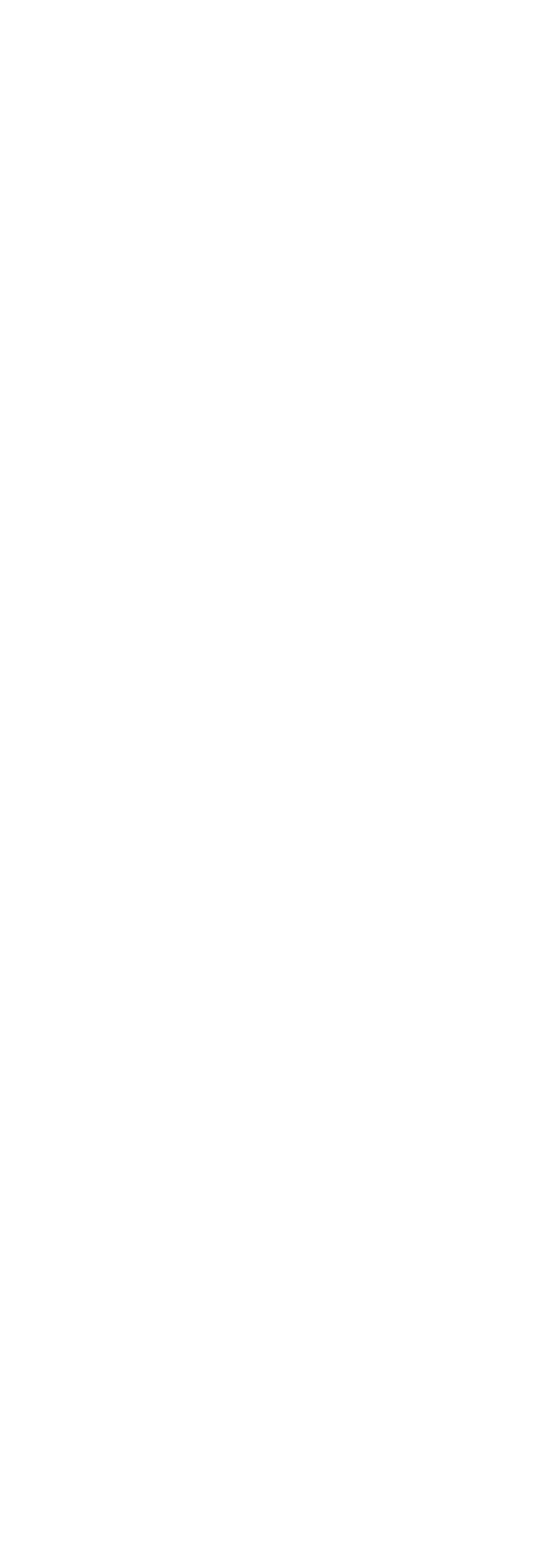




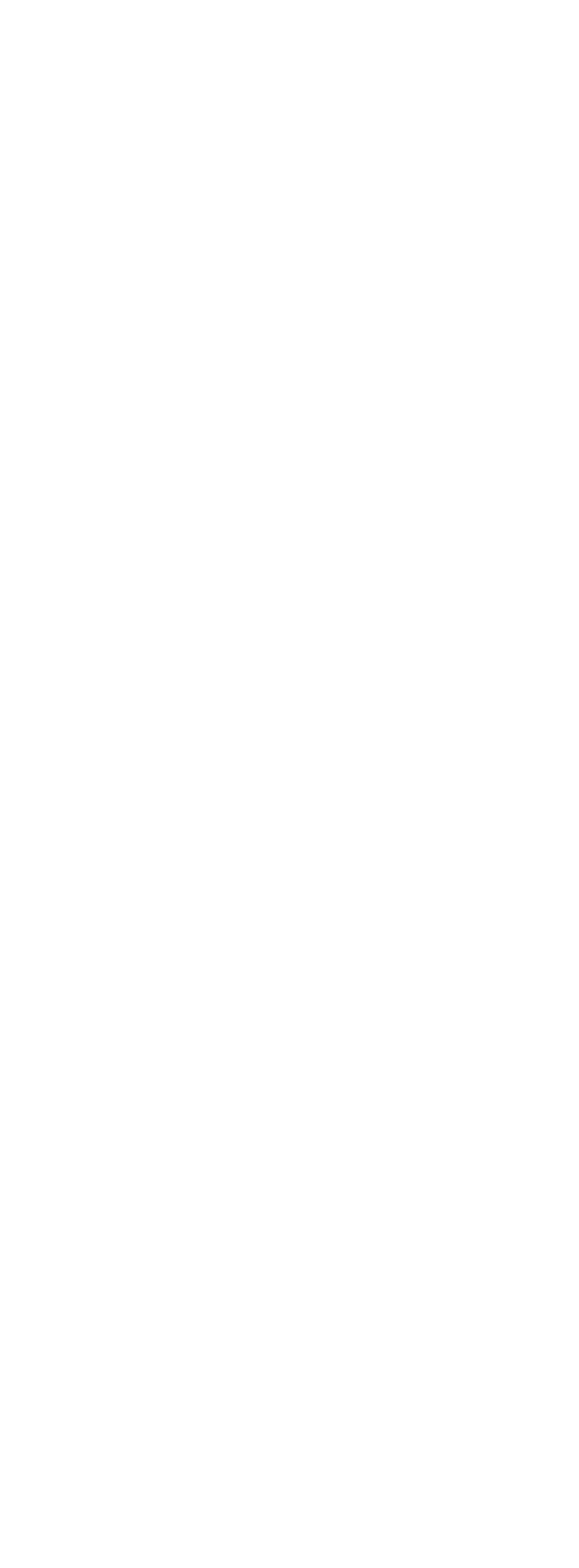




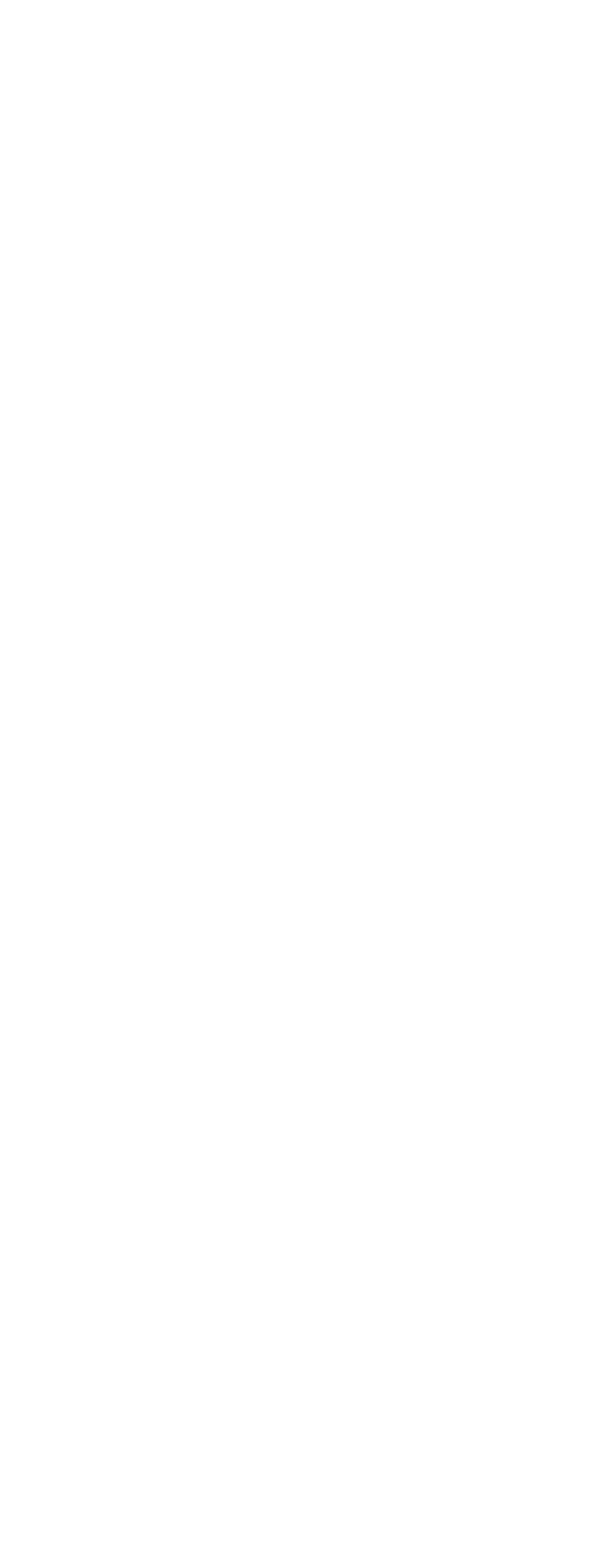


TABLE 17

Table 17. -Energy-storage data for Cummings radiation integrator

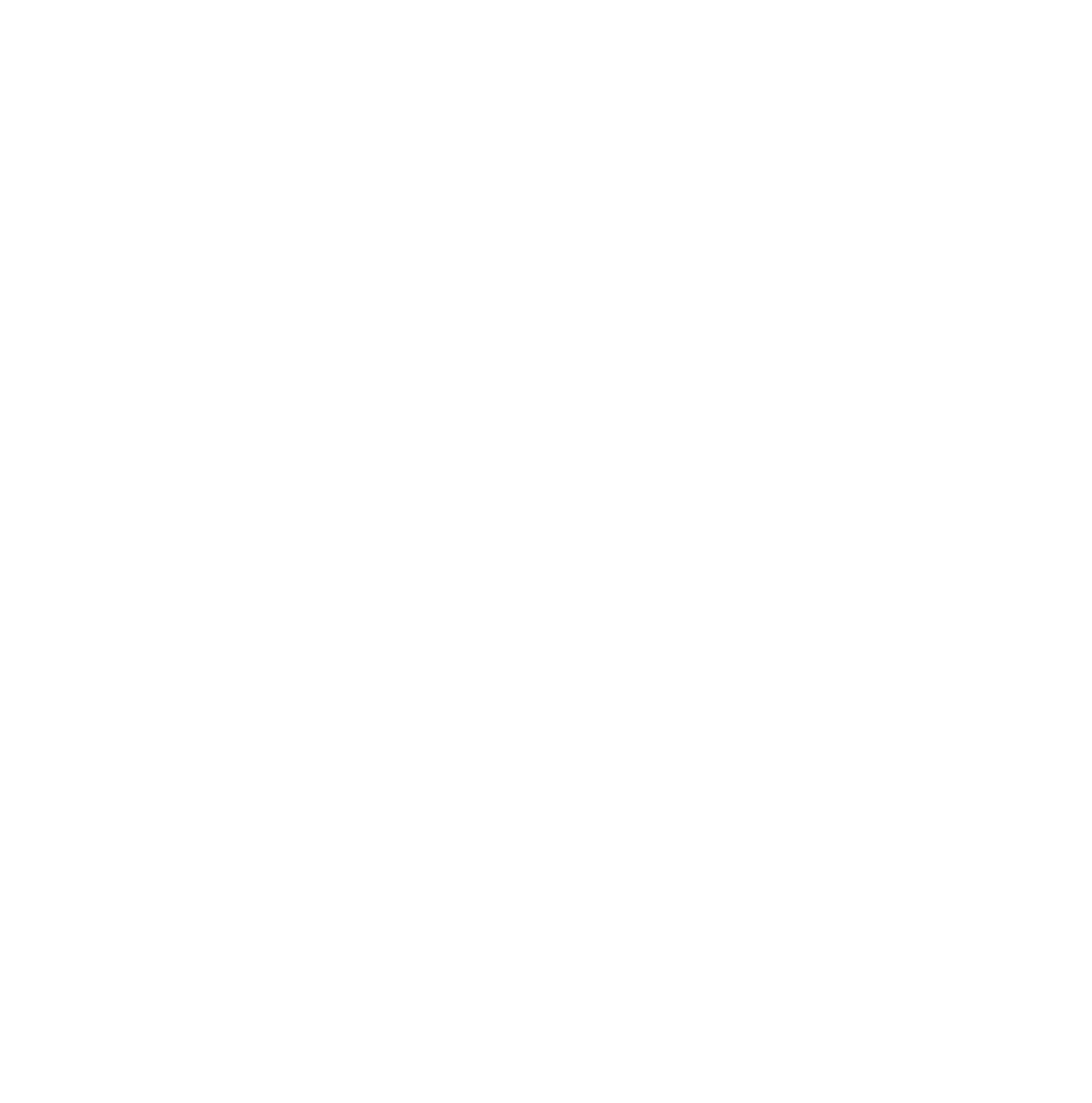

a Content at point of fixed hook gage $605,000 \mathrm{~cm}^{3}$. Minus sign indicates water removed. 
284

Table 18.-Evaporation and

[Cummings radiation integra*

\section{Feriod}

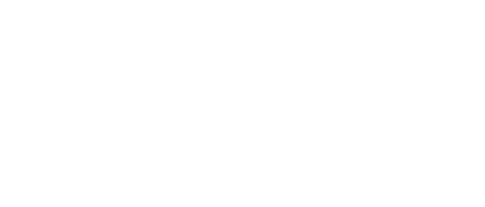


TABLE 19
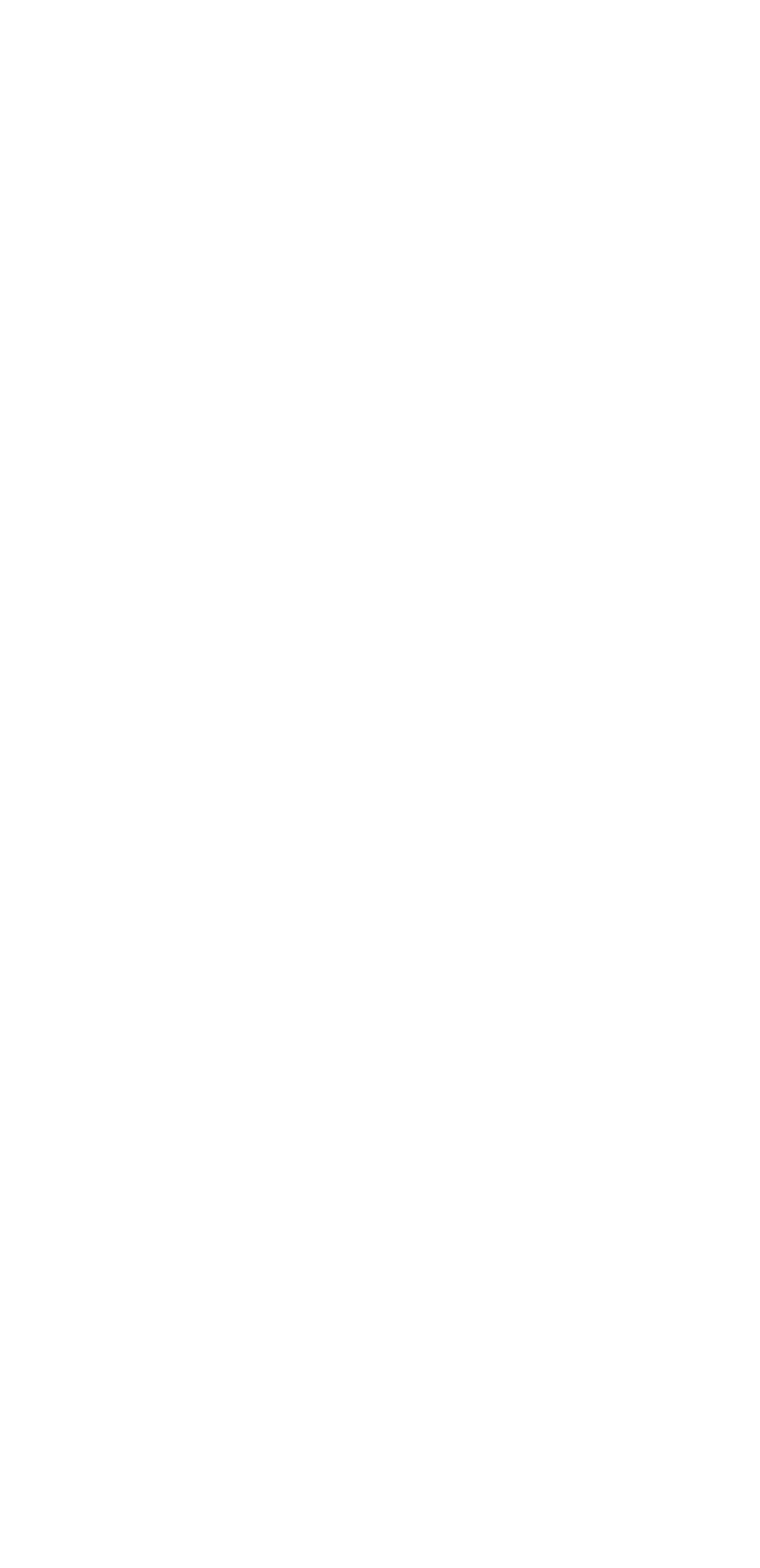


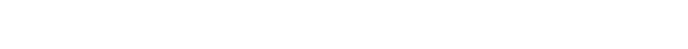
$0.7 .4)^{\circ}$ ฉ

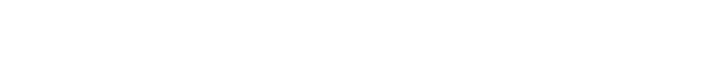

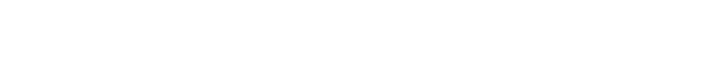
乩员

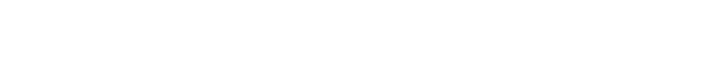

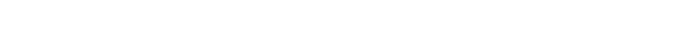
……

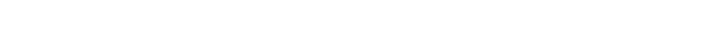

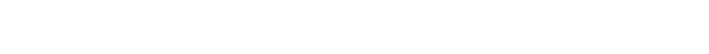

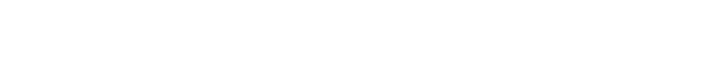

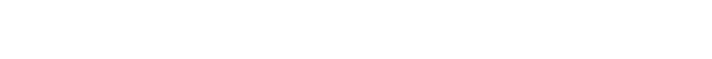

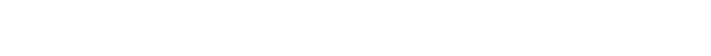
覀

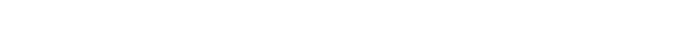
7 我里

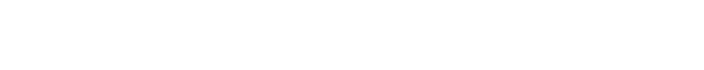
ஈかゅ

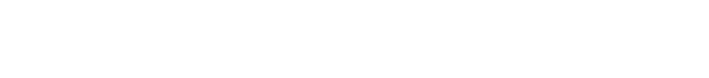

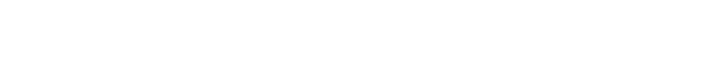

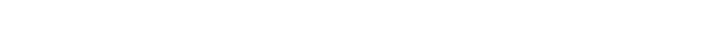

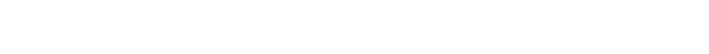

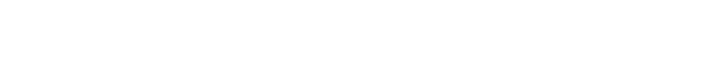

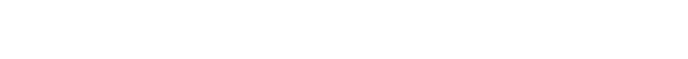

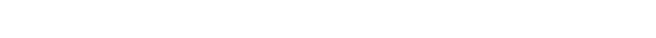

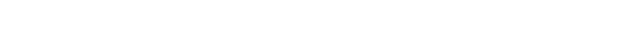

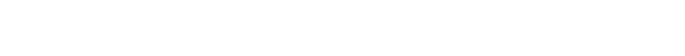

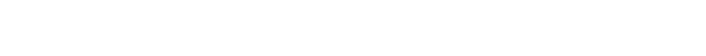

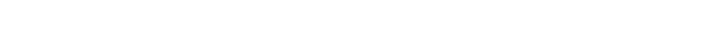

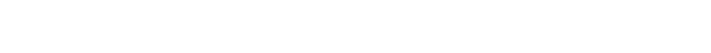

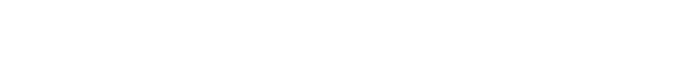
०

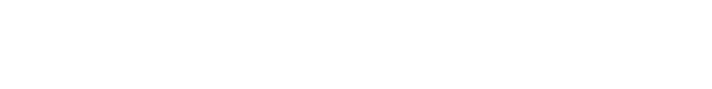


TABLE 19

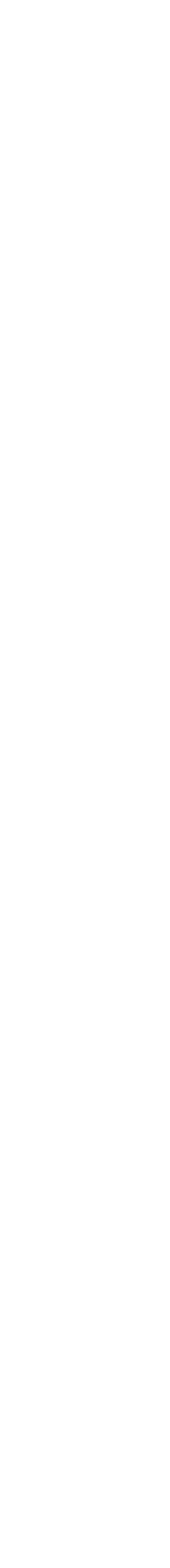

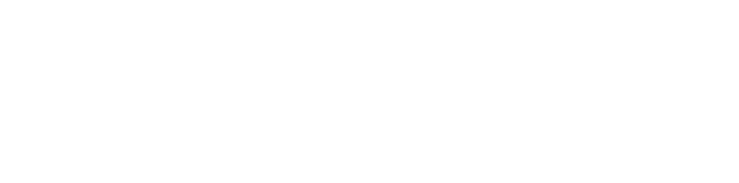

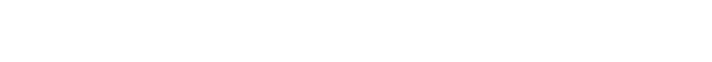

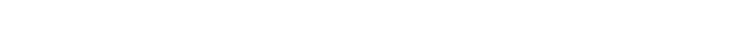

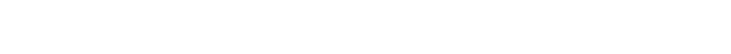

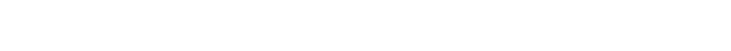

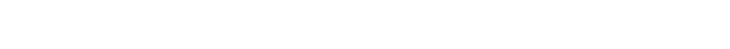

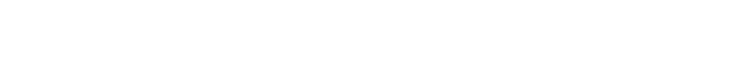

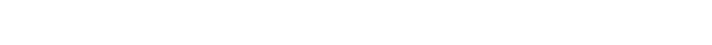

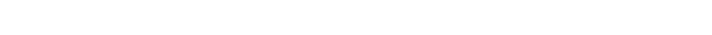

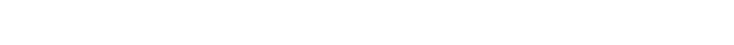

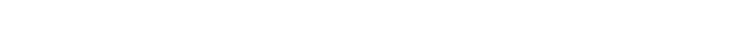

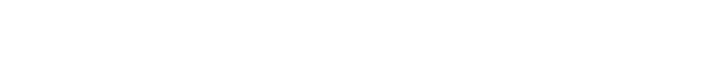

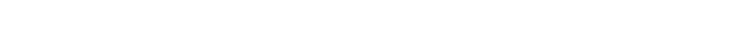

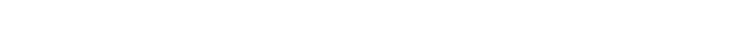

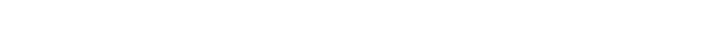
$0^{\circ}$

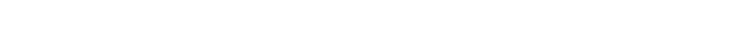

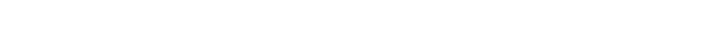

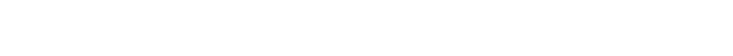

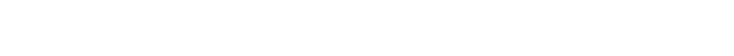

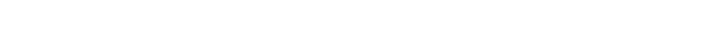

๑.

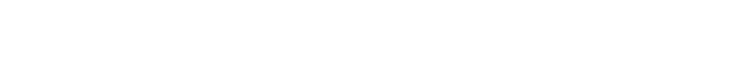

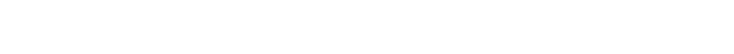

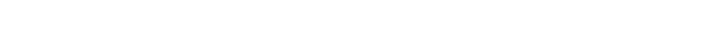

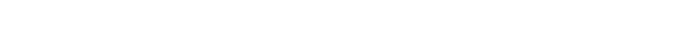

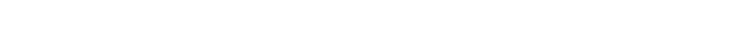

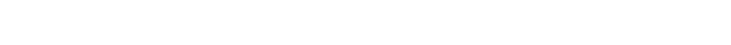

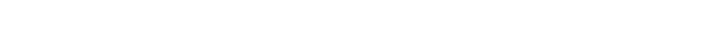

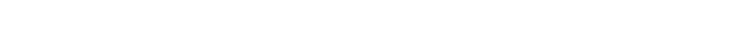

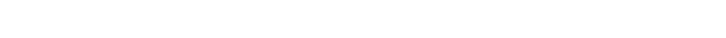

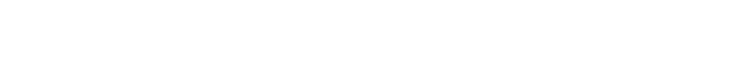

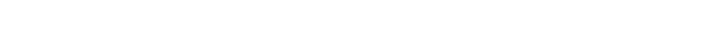
…ำ ПNッナம

$2948710-54-20$ 


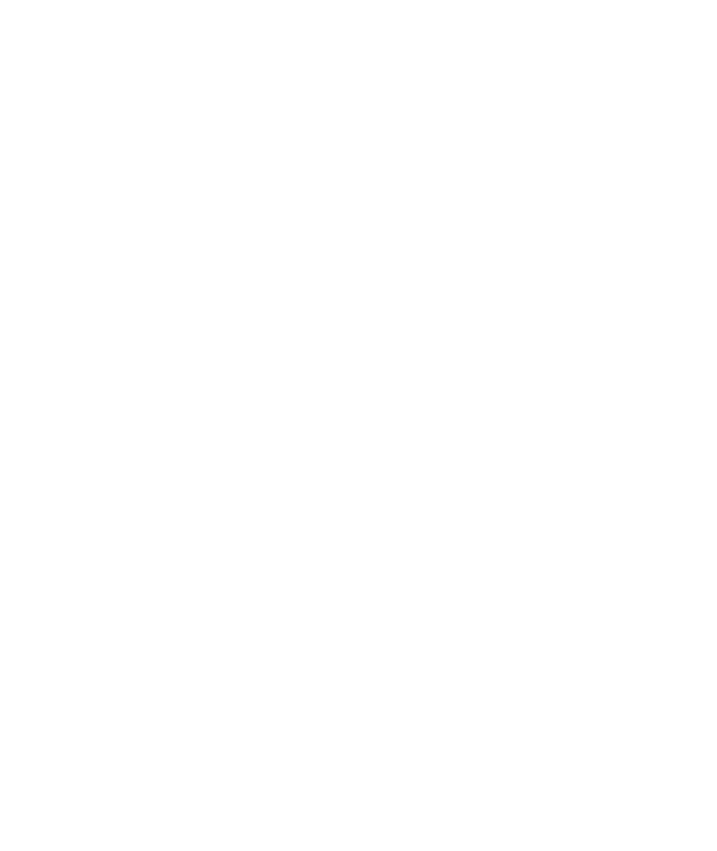

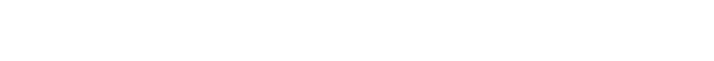

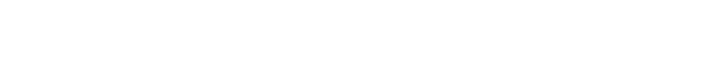

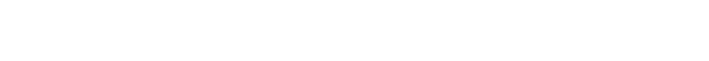

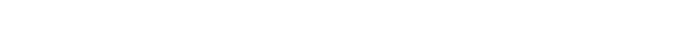

品

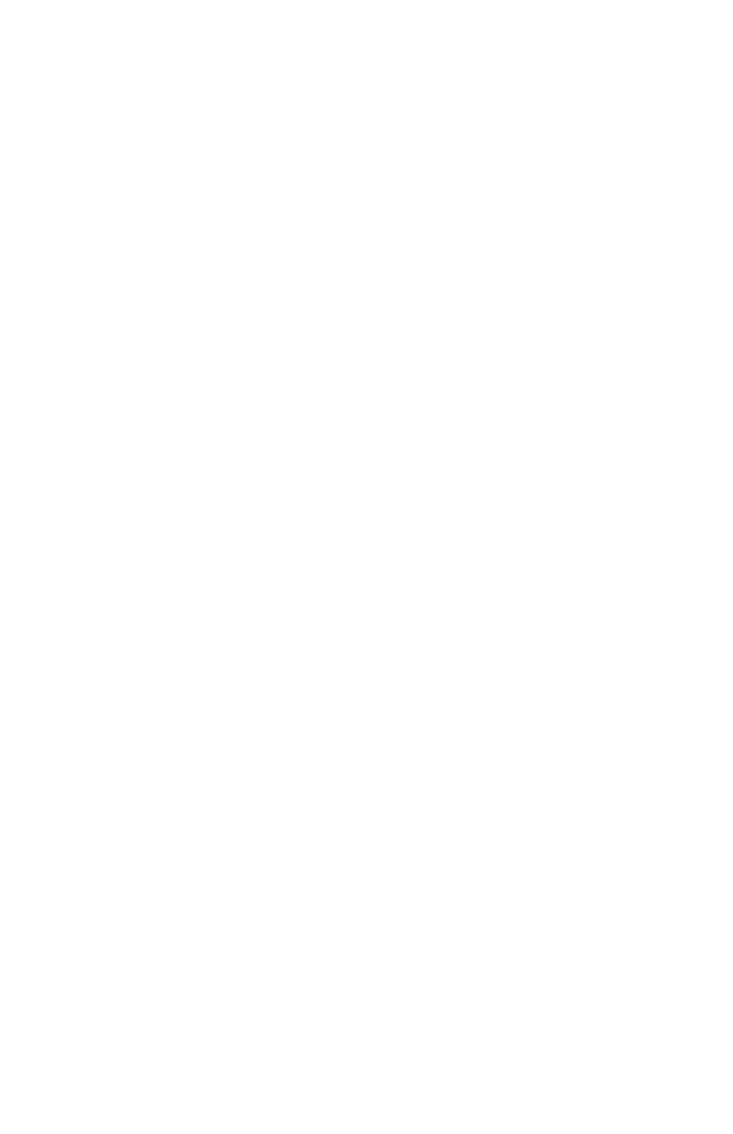




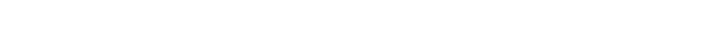

0.

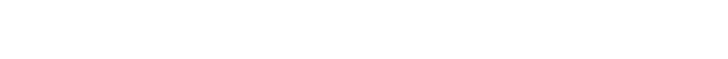

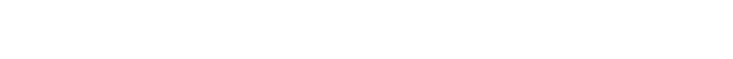

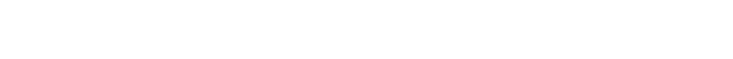

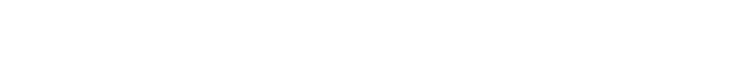

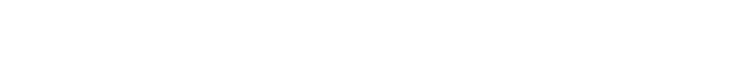

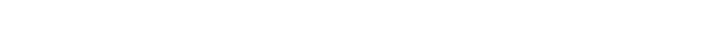
○.

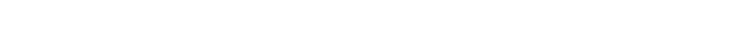

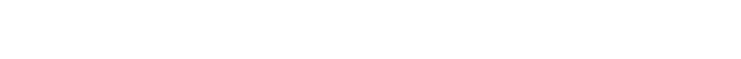

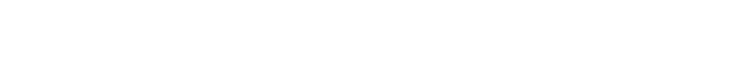

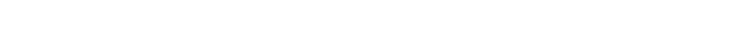

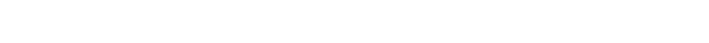

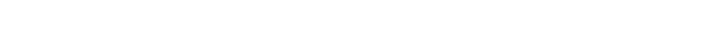

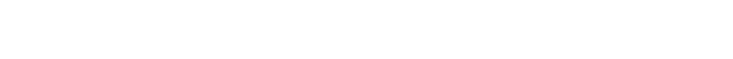

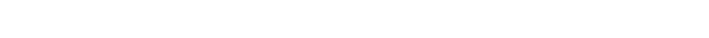

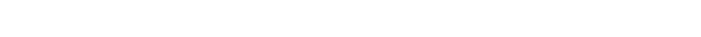

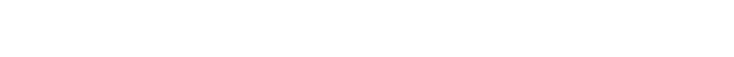

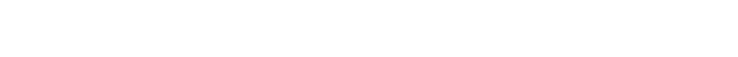

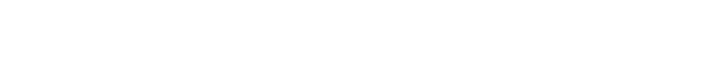

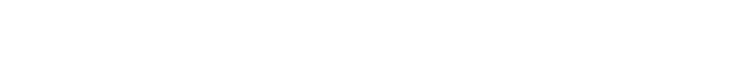

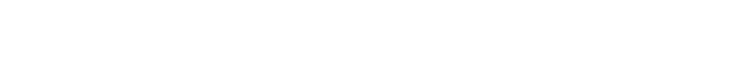

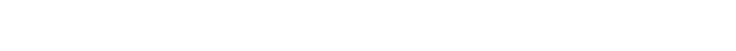

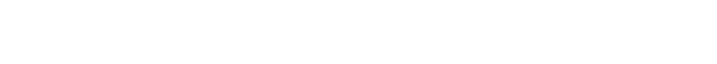

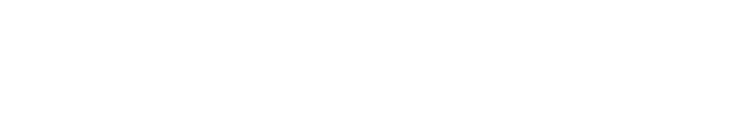


TABLE 19

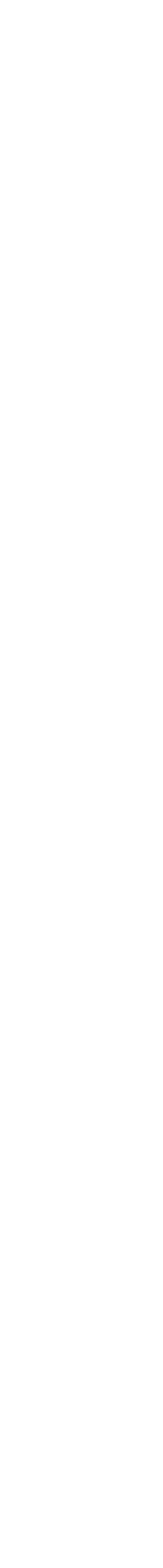

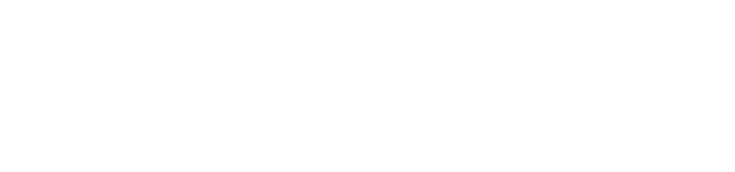

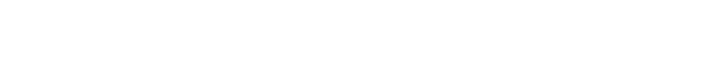

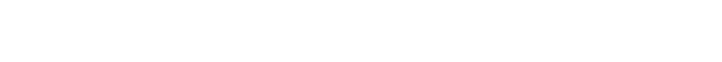

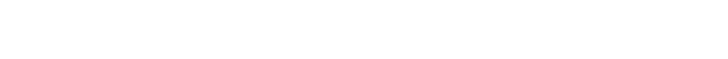

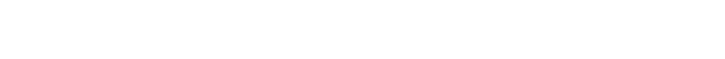

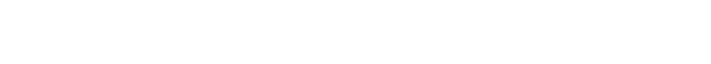

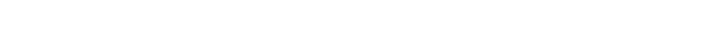

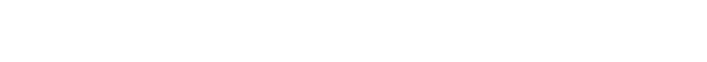

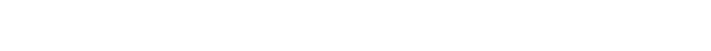

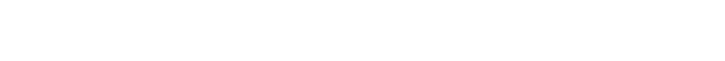

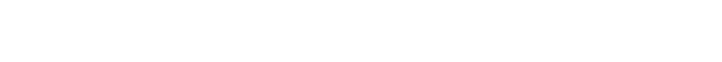

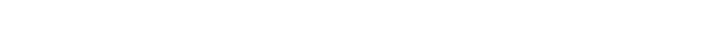

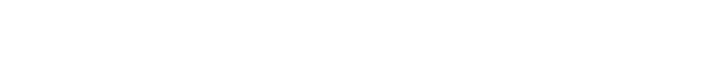

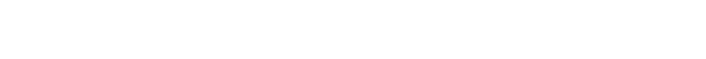
号

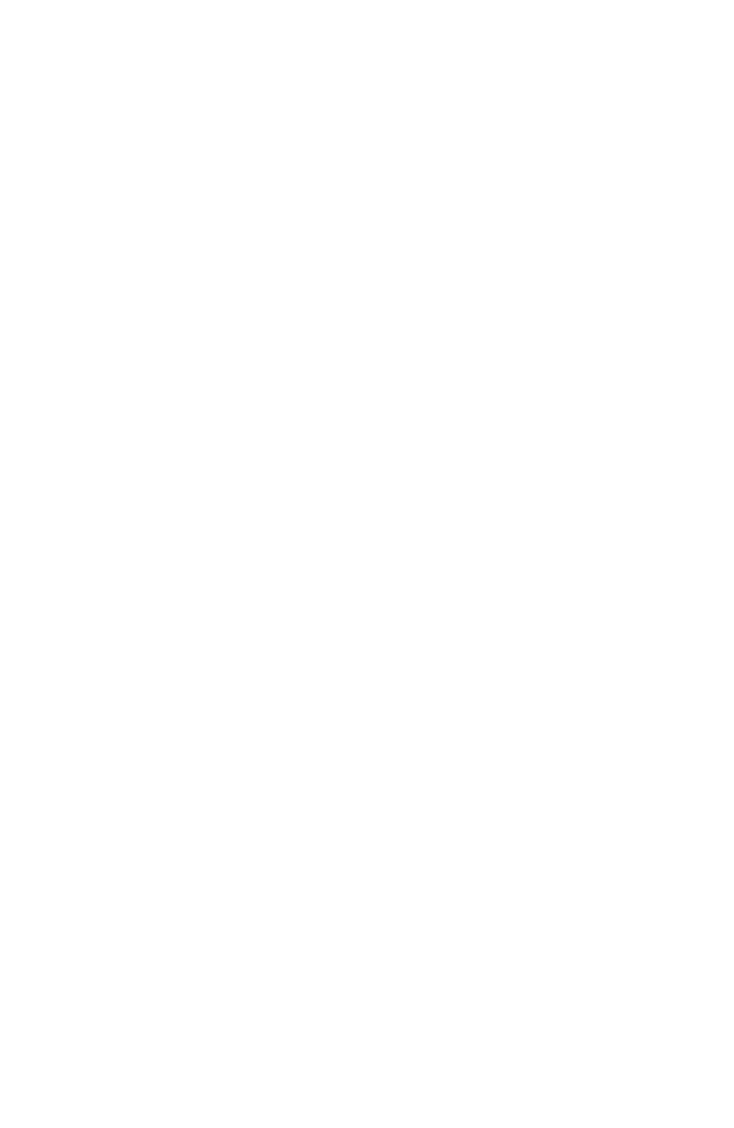




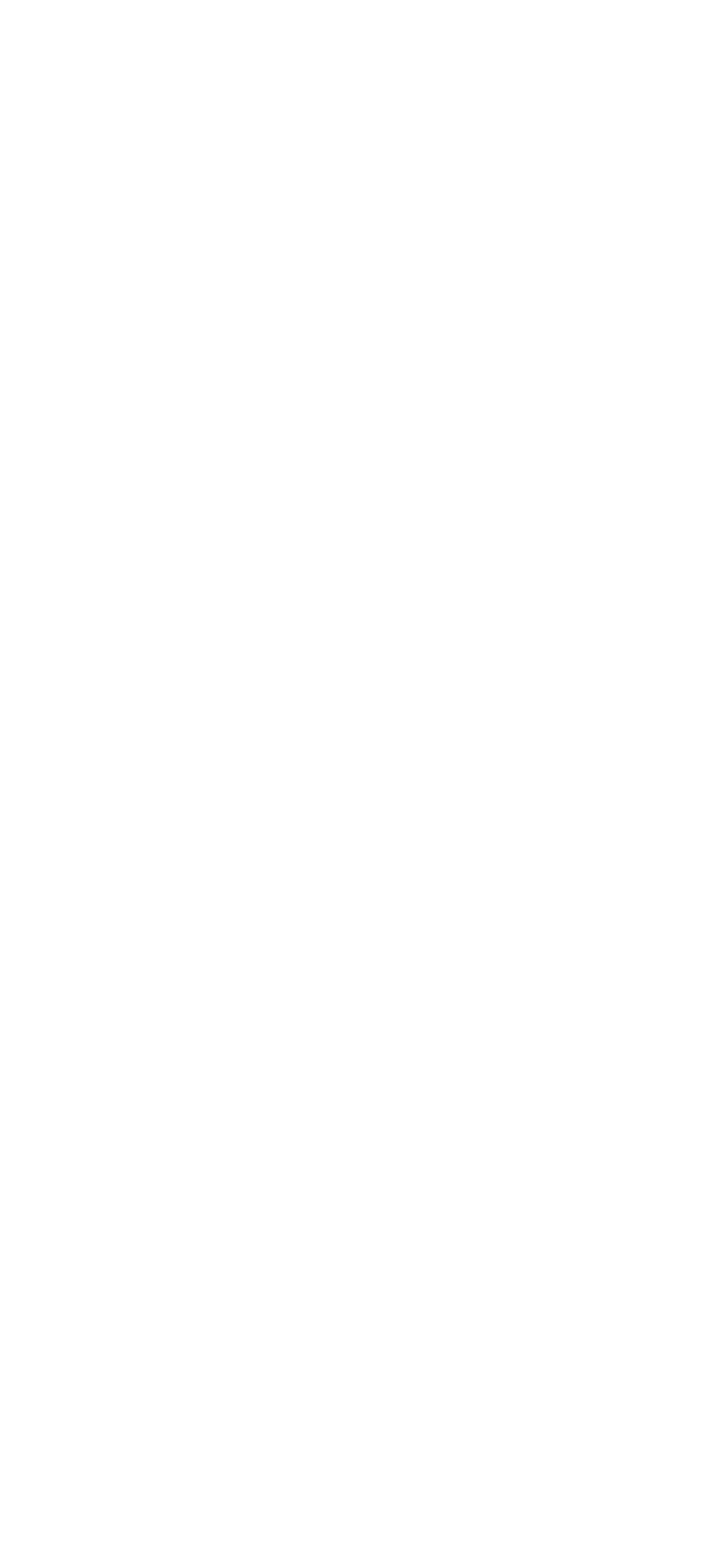


TABLE 19

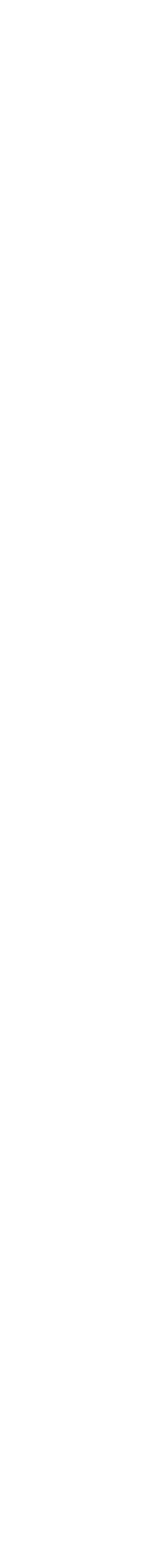

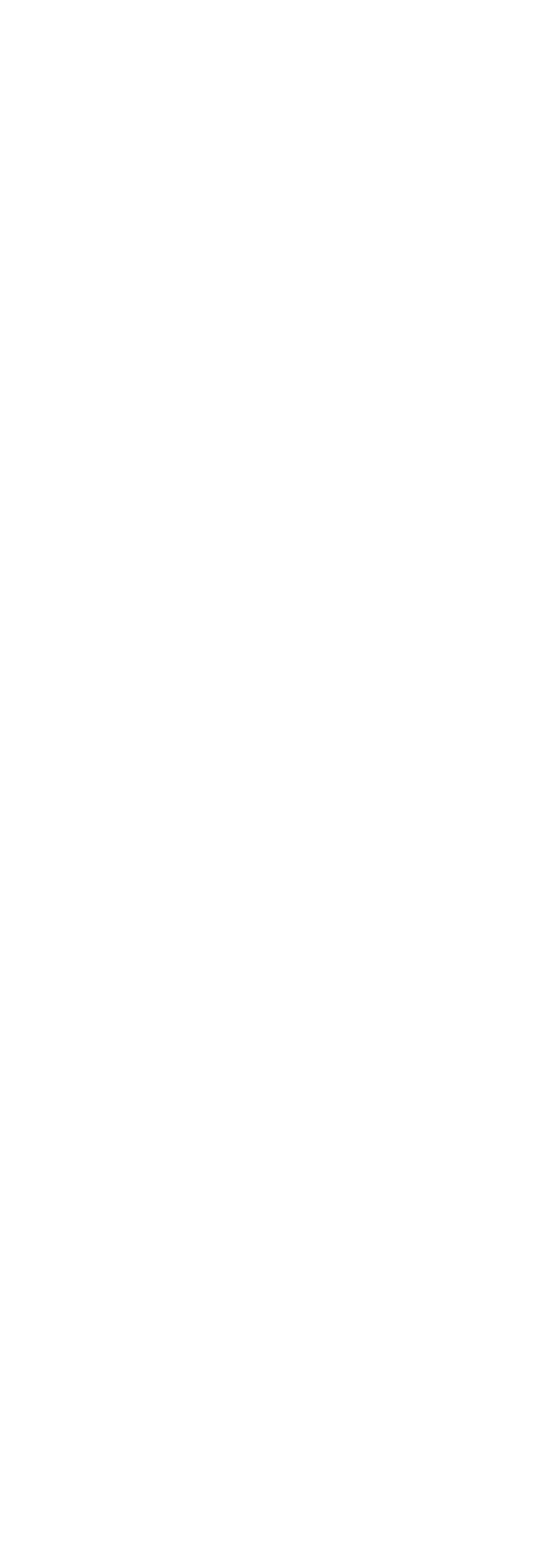




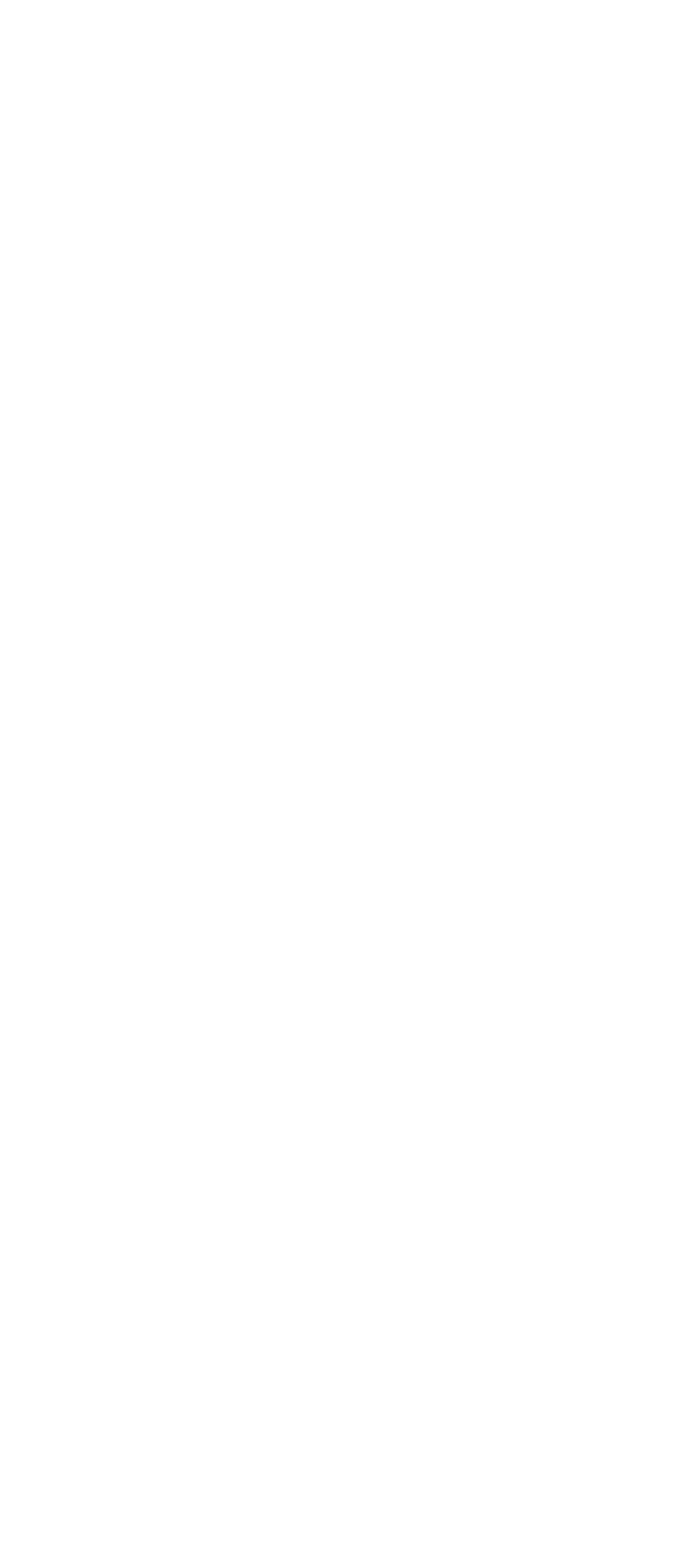




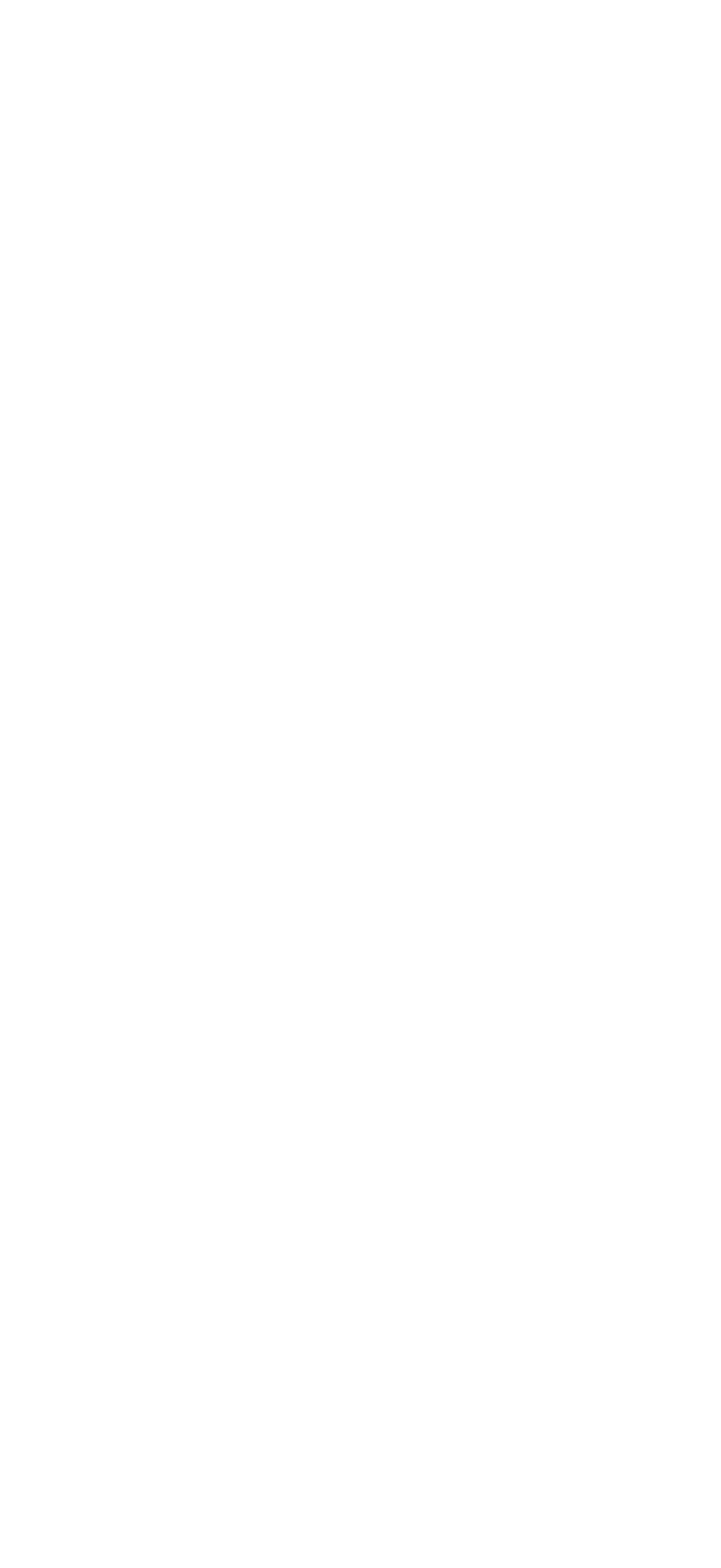




\begin{tabular}{|c|c|c|c|}
\hline \multirow{10}{*}{ 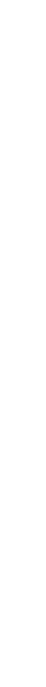 } & & 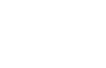 & 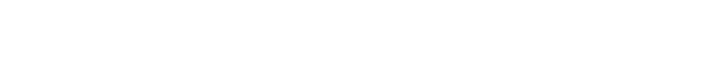 \\
\hline & & \multirow{2}{*}{ 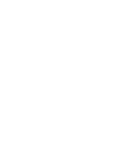 } & 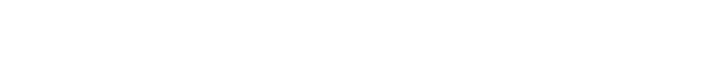 \\
\hline & & & 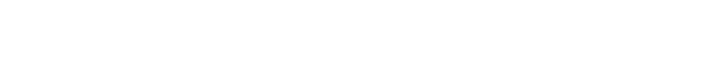 \\
\hline & & 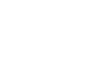 & 本赵 \\
\hline & & & 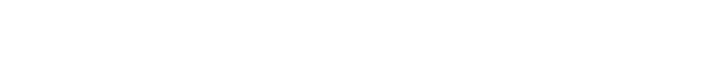 \\
\hline & & & 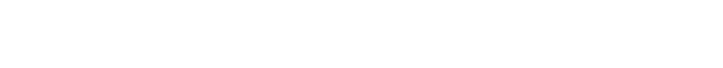 \\
\hline & & 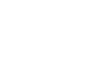 & 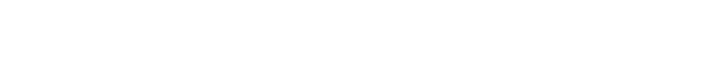 \\
\hline & & & 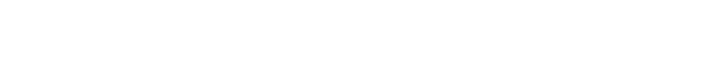 \\
\hline & & & 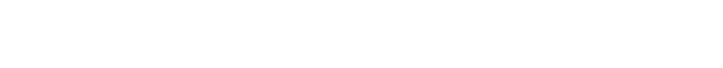 \\
\hline & & : & م్ \\
\hline \multirow{6}{*}{ 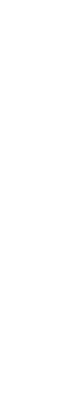 } & \multirow{6}{*}{$\begin{array}{l}4 \\
\text { 胥 }\end{array}$} & \multirow{2}{*}{ 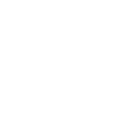 } & 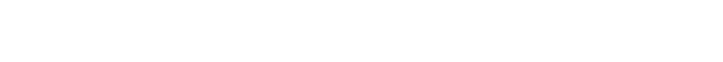 \\
\hline & & & 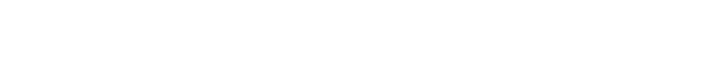 \\
\hline & & & 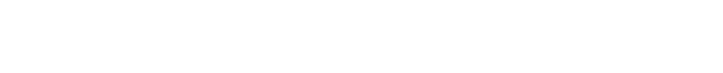 \\
\hline & & & 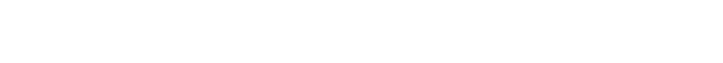 \\
\hline & & & 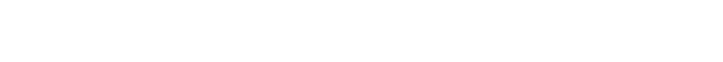 \\
\hline & & & 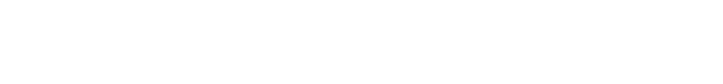 \\
\hline \multirow{15}{*}{ 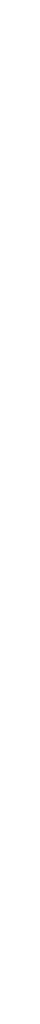 } & \multirow{5}{*}{ 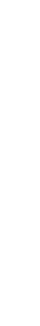 } & \multirow{2}{*}{ 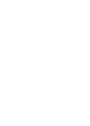 } & 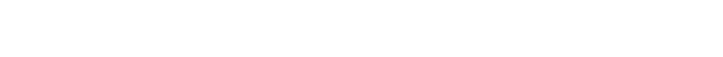 \\
\hline & & & 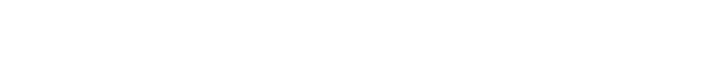 \\
\hline & & \multirow{2}{*}{ 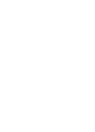 } & 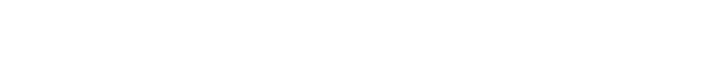 \\
\hline & & & 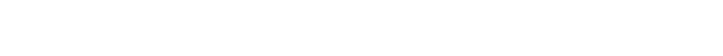 \\
\hline & & & 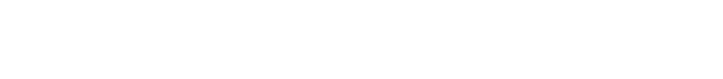 \\
\hline & \multirow{3}{*}{ 递 } & & 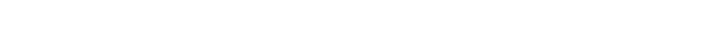 \\
\hline & & 3 & 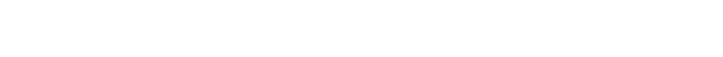 \\
\hline & & & 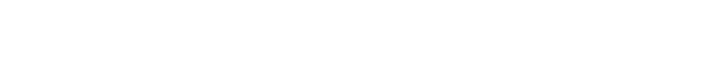 \\
\hline & \multirow{3}{*}{ 六 } & \multirow{2}{*}{ 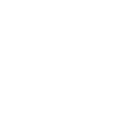 } & 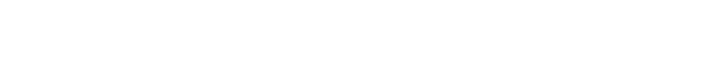 \\
\hline & & & 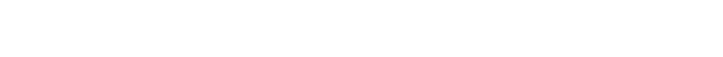 \\
\hline & & 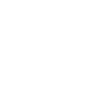 & 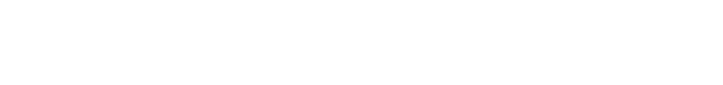 \\
\hline & \multirow{4}{*}{$\begin{array}{l}4 \\
\text { s. } \\
\text { uै }\end{array}$} & 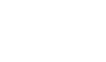 & 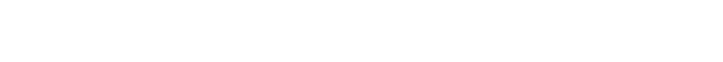 \\
\hline & & \multirow{2}{*}{ 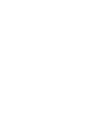 } & 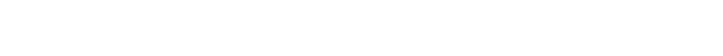 \\
\hline & & & 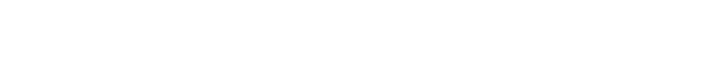 \\
\hline & & 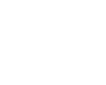 & 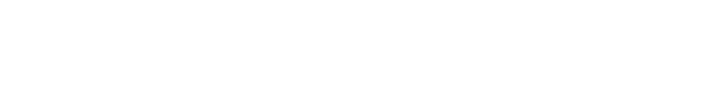 \\
\hline & & & 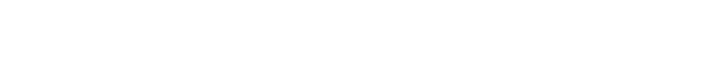 \\
\hline
\end{tabular}




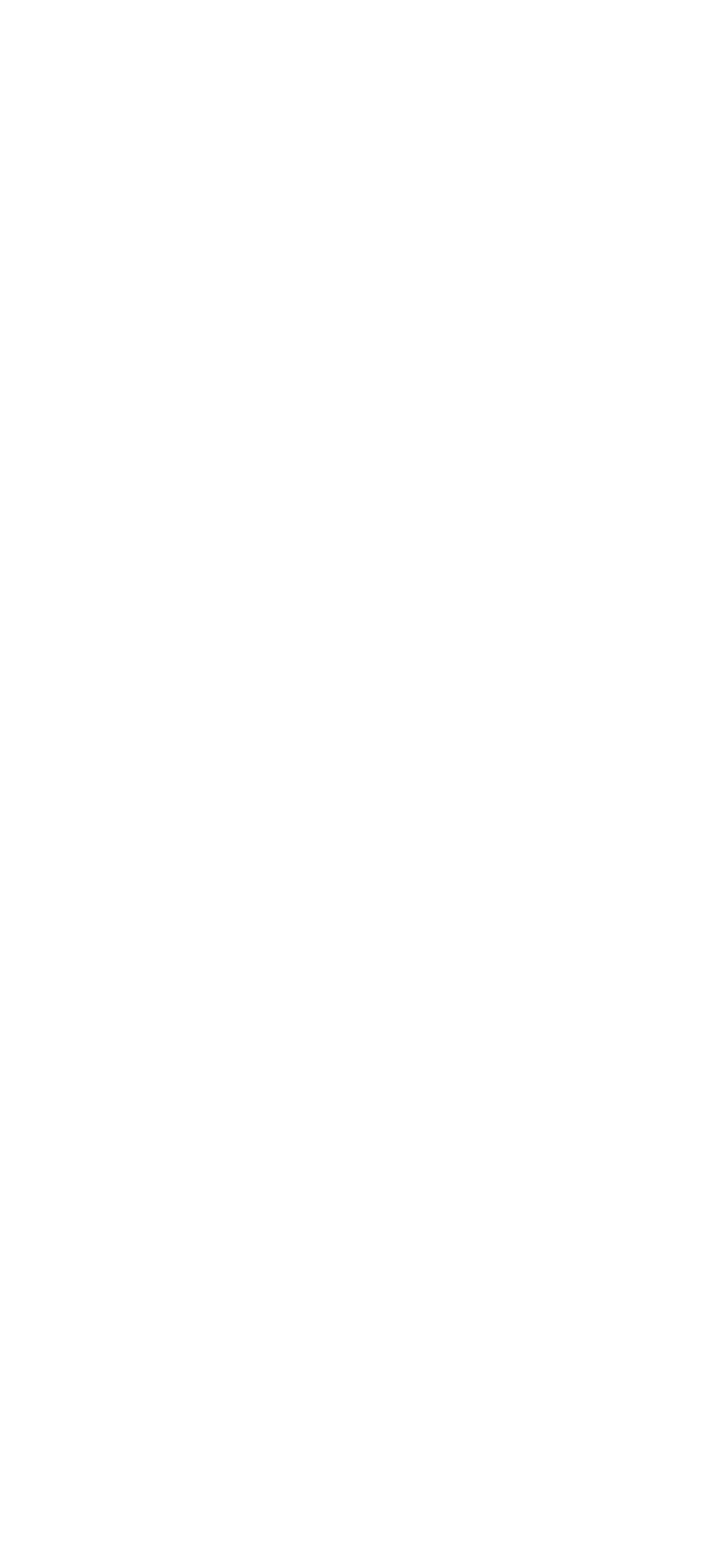




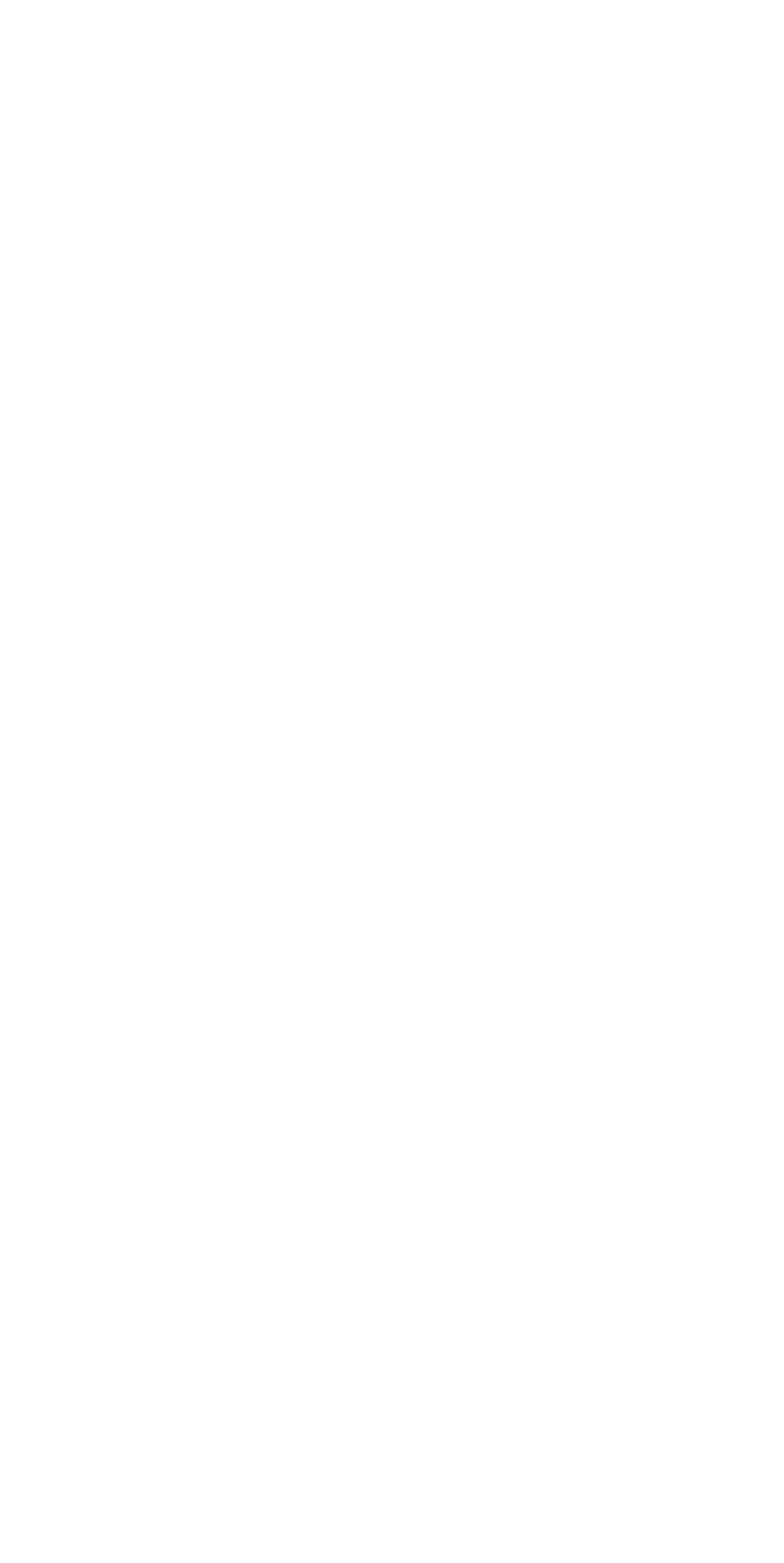

